\title{
Evaluation of Ultra Clean Fuels from Natural Gas
}

\section{Final Report}

September 1999 - February 2006 Volume 1: Final Report

Robert Abbott, Edward Casey, Etop Esen, Douglas Smith ConocoPhillips

Bruce Burke, Binh Nguyen, Samuel Tam, Paul Worhach Nexant, Inc.

Mahabubul Alam, Juhun Song, James Szybist, Ragini Acharya, Vince Zello, David Morris, Patrick Flynn, Stephen Kirby, Krishan Bhatia, Jeff Gonder, Yun Wang, Wenpeng Liu, Hua Meng, Subramani Velu, Jian-Ping Shen, Weidong Gu, Elise Bickford, Chunshan Song, Chao-Yang Wang, André Boehman Pennsylvania State University

February 28, 2006

Co-operative Agreement DE-FC26-01NT41098

\section{ConocoPhillips}

600 North Dairy Ashford Houston, TX 77079-1175

\section{(NNexant}

$1012^{\text {nd }}$ St, 10 ${ }^{\text {th }}$ Floor

San Francisco, CA 94105

Pennsylvania State University The Energy Institute University Park, PA 16802 


\section{Disclaimer}

This report was prepared as an account of work sponsored by an agency of the United States Government. Neither the United States Government nor any agency thereof, nor any of their employees, makes any warranty, express or implied, or assumes and legal liability or responsibility for the accuracy, completeness, or usefulness of any information, apparatus, product, or process disclosed, or represents that its use would not infringe privately owned rights. Reference herein to any specific commercial product, process or service by trade name, trademark, manufacturer, or otherwise does not necessarily constitute or imply its endorsement, recommendation, or favoring by the United States Government or any agency thereof. The views and opinions of authors expressed herein do not necessarily state or reflect those of the United States Government or any agency thereof. 
VOLUME 1

Section 1 UCF Project Overview .....................................................................

1.1 Introduction ………………...................................................................... $1-1$

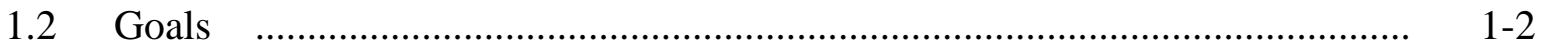

$1.3 \quad$ Structure of the Final Report ........................................................................ 1-2

$1.4 \quad$ Project Deliverables ...................................................................................... 1-3

1.5 Overall Project Approach and Methodology...................................................... 1-4

Section 2 Ultra Clean Fuels Life Cycle Assessment ........................................................ 2 2-1

2.1 Introduction ....................................................................................... 2-1

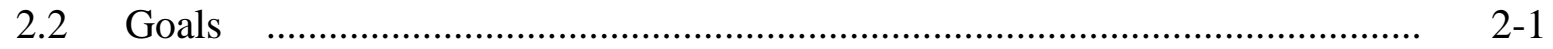

2.2.1 Audience ............................................................................. 2-2

2.2.2 Objectives ................................................................................ 2

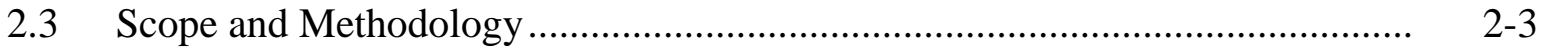

2.4 LCA Models ........................................................................................ 2- 2-4

2.5 Aspen Plus Models .............................................................................. 2-5

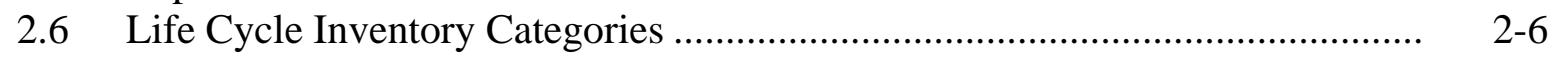

2.7 Life Cycle Impact Assessment Indicators ............................................................. 2- 2-7

2.8 Results from the Life Cycle Inventory …………............................................... 2- 2-7

2.9 Sensitivity Analysis of the LCI ....................................................................... 2-9

2.10 Results and conclusions from the Life Cycle Impact Assessment ..................... 2-10

Section 3 UCF Market Study ……………………................................................. 3-1

3.1 Introduction ..............................................................................................

3.2 Conventional Fuels Market Overview ……………………………………..... 3-2

3.2.1 Macroeconomic Assumptions............................................................. 3-2

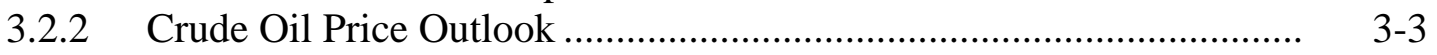

3.2.3 Environmental Regulations.............................................................. 3-3

3.2.4 Trends in Global and Regional Refinery Capacity ………………........ 3 3-3

3.2.5 Global Trade of Primary Refined Products .......................................... 3 3-3

3.3 Ethylene Industry Overview............................................................................. 3-4

3.3.1 Alternate Markets for FT Naphtha........................................................ 3 3-5

3.3.2 FT Diesel - Technical Suitability as an Ethylene Feedstock................. 3 3-5

3.3.3 FT Naphtha - Technical Suitability as an Ethylene Feedstock ............ 3 3-5

3.3.4 FT Diesel - Economics as an Ethylene Cracker Feedstock.................... 3 3-6

3.3.5 FT Naphtha - Economics as an Ethylene Cracker Feedstock .............. 3 3-6

3.4 Methanol Conventional Markets ........................................................................... 3-6

3.5 United States Regional Fuels Markets …………................................................ 3-7

3.5.1 Refined Product Production ................................................................... 3-8

3.5.2 Crude Oil Quality Trends................................................................... 3 3-8

3.5.3 Petroleum Trade......................................................................... 
3.6 Technology Evaluation of Selected Alternative Fuels ...................................... 3-10

3.6.1 GTL FT Liquid Products ................................................................. 3-10

3.6.2 Methanol ................................................................................ $\quad 3-10$

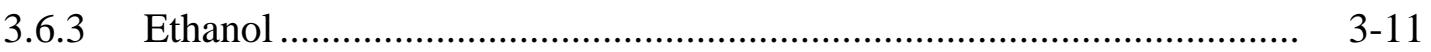

3.6.4 Syngas/Hydrogen................................................................................ 3-11

3.7 Technical Issues for UCF Use in Transport ........................................................ 3-11

3.7.1 Key Developments in Conventional Vehicle Technology..................... 3-11

3.7.2 FT Diesel as a Vehicle Fuel - Conventional Engines............................ 3 3-12

3.7.3 FT Diesel for Fuel Cells....................................................................... 3-13

3.7.4 FT Naphtha as a Vehicle Fuel.............................................................. 3-13

3.7.5 FT Naphtha Fuel Cells ..................................................................... 3-13

3.7.6 Methanol as a Vehicle Fuel - Conventional .......................................... 3-13

3.7.7 Methanol Fuel Cells ....................................................................

3.8 Methanol Infrastructure Issues ..................................................................... 3-15

3.8.1 Neat Fuel Supplied for Internal Combustion Engine Vehicles.............. 3-15

3.8.2 Methanol Blended with Conventional Gasoline .................................... 3-15

3.8.3 Methanol Use in Fuel Cell Vehicles ................................................... 3-15

3.8.4 Methanol Distribution Infrastructure ……………………………….. $\quad 3-15$

3.9 Impact of FT Diesel on U.S. Refineries ........................................................... 3-16

3.9.1 Impact of FT Diesel on Refinery Operations........................................ 3-17

3.9.2 Value of FT Diesel Relative to Market Value ....................................... 3-17

3.9.3 FT Diesel Absolute Value............................................................. 3-18

3.10 Conventional Fuel Price Outlook .............................................................. 3-18

3.11 UCF Market Potential ……………………........................................... 3-19

3.11.1 FT Diesel...............................................................................

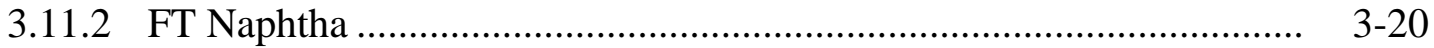

3.11.3 Methanol .................................................................................. $\quad 3-20$

Section 4 Engine Testing ………….......................................................................

4.1 Introduction ……......................................................................................... 4

4.2 Task 3.1, Database Compilation and Definition of Testing Needs .................... 4 4-1

4.3 Task 3.2, Direct and Indirect Methanol Fuel Cell Testing .................................. . 4-2

4.3.1 Task 3.2.1 Methanol Fuel Cell Testing.................................................. 4. 4-2

4.3.2 Task 3.2.2 Methanol Reformer ............................................................. 4. 4

4.3.3 Task 3.3.3 Compression Ignition Engine Studies ................................... 4 4-6

4.3.4 Outcomes ................................................................................ 4-8

Section 5 Recommendations and Conclusions ……………………............................ $5-1$

5.1 Lifecycle Assessment ................................................................................. 5

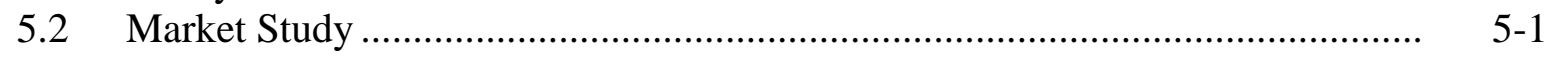

5.3 Engine Testing ............................................................................................ 
VOLUME 2

Appendix A

Papers, Theses and Patents

A-1

Appendix B

UCF Life Cycle Assessment Final Report

B-1

Appendix C

GTL Industry LCA Synthesis Report

VOLUME 3

Appendix D

Market Study Reports

D-1

Section I: Conventional Fuels-Market Overview

Section II: $\quad$ Ethylene Industry Overview

Section III: Methanol Conventional Markets

Section IV: United States Regional Fuel Markets

VOLUME 4

Appendix D

Market Study Reports (Continued)

Section V: Technology Evaluation of Selected Alternative Fuels

VOLUME 5

Appendix D Market Study Reports (Continued)

Section VI: Technical Issues for UCF Use in Transport

Section VII: Methanol Distribution Infrastructure Issues

Section VIII: Impact of FT Diesel on U.S. Refineries

Section IX: UCF Values and Market Potential

Section X: $\quad$ Ultra Clean Fuels Market Assessment-Executive Summary

VOLUME 6

Appendix E

Engine Testing Final Technical Report

E-1 


\section{Figures and Tables}

$\begin{array}{lll}\text { Figure Page } & \end{array}$

2-1 Aspen Plus Process Simulation Flow Diagram for Syngas Generation ........................ 2 2-6

2-2 Global Warming Potential, 2006 ................................................................................ 2-. 2

2-3 Global Warming Potential, 2015 .............................................................................. 2-9

2-4 Total Photochemical Smog, 2006 ...................................................................... 2-12

2-5 Total Photochemical Smog, 2015 ........................................................................... 2-13

2-6 Crude Oil Consumption, 2015 ……………………............................................. 2-13

$\begin{array}{lll}\text { Table Page } & \end{array}$

1-1 Project Deliverables and Completion Date.................................................................. 1-3

2-1 Important Fuel Properties for FT Diesel................................................................... 2- 2-10

2-2 FTD, ULSD, and FRFG Fuel Properties .................................................................... 2-11 
Executive Summary 


\section{Executive Summary}

\section{OVERVIEW}

ConocoPhillips, in conjunction with Nexant Inc., Penn State University, and Cummins Engine Co., joined with the U.S. Department of Energy (DOE) National Energy Technology Laboratory (NETL) in a cooperative agreement to perform a comprehensive study of new ultra clean fuels (UCFs) produced from remote sources of natural gas. The project study consists of three primary tasks: an environmental Life Cycle Assessment (LCA), a Market Study, and a series of Engine Tests to evaluate the potential markets for Ultra Clean Fuels.

The overall objective of DOE's Ultra Clean Transportation Fuels Initiative is to develop and deploy technologies that will produce ultra-clean burning transportation fuels for the $21^{\text {st }}$ century from both petroleum and non-petroleum resources. These fuels will:

- Enable vehicles to comply with future emission requirements;

- Be compatible with the existing liquid fuels infrastructure;

- Enable vehicle efficiencies to be significantly increased, with concomitantly reduced $\mathrm{CO}_{2}$ emissions;

- Be obtainable from a fossil resource, alone or in combination with other hydrocarbon materials such as refinery wastes, municipal wastes, biomass, and coal;

- Be competitive with current petroleum fuels

The objectives of the ConocoPhillips Ultra Clean Fuels Project are to perform a comprehensive life cycle analysis and to conduct a market study on ultra clean fuels of commercial interest produced from natural gas, and, in addition, perform engine tests for Fisher-Tropsch diesel and methanol in neat, blended or special formulations to obtain data on emissions. This resulting data will be used to optimize fuel compositions and engine operation in order to minimize the release of atmospheric pollutants resulting from the fuel combustion. Development and testing of both direct and indirect methanol fuel cells was to be conducted and the optimum properties of a suitable fuel-grade methanol was to be defined.

The results of the study are also applicable to coal-derived FT liquid fuels. After different gas clean up processes steps, the coal-derived syngas will produce FT liquid fuels that have similar properties to natural gas derived FT liquids.

\section{TASK 1: LIFE CYCLE ASSESSMENT}

ConocoPhillips and Nexant Inc. conducted the Ultra Clean Fuels Life Cycle Assessment (UCF LCA), consisting of a Life Cycle Inventory (LCI) and a Life Cycle Impact Assessment (LCIA) for GTL transportation fuels.

The UCF LCA study was conducted according to the requirements of the ISO 14040 International Standard for Life Cycle Assessment, which included a critical review conducted by an outside independent panel. The study was certified as being fully compliant with ISO 
standards for LCA by the panel. A novel methodology for considering co-products in the analysis was also developed.

The UCF LCA is based on three successive analyses:

- A detailed engineering analysis of the process efficiencies of current and future commercial technologies for GTL production.

- A Co-product Function Expansion (CFE) for the petroleum and GTL systems based on detailed modeling of petroleum and GTL fuel processing. This is a novel methodology for considering the impacts of co-products.

- Sensitivity analysis that considers future heavy crude input slates for petroleum refiningand flared gas used in the production of GTL products. In addition, a comprehensive parametric sensitivity analysis is performed for all key study parameters.

The UCF LCA utilizes the scope and results from the Market Study to examine likely future commercial recovery, processing, and fuel distribution operating scenarios for GTL fuels and methanol. In establishing the baseline scenarios for conventional transportation fuels, a detailed assessment was performed for two Petroleum Administration Defense Districts (PADDs), due to the fact that refinery location is an important factor in determining the likely changes in petroleum product slates.

The LCA results showed that the well-to-wheel global warming potential (GWP) of GTL fuels (Fischer-Tropsch diesel and FT naphtha ) is roughly equivalent to that of petroleum-based transportation fuels in light duty vehicles. Criteria pollutants $\left(\mathrm{NO}_{\mathrm{x}}, \mathrm{SO}_{\mathrm{x}}\right.$, and particulates) for total and urban emissions demonstrated lower values for GTL fuels. The Life Cycle Impact Assessment indicators for acidification, eutrophication, and human health (criteria, cancer, and non-cancer) impact categories are consistently lower for GTL fuels, while ecotoxicity results are varied.

A GTL industry synthesis LCA report was also developed as a result of this project. Independent studies from Shell, SasolChevron and ConocoPhillips were compared, and a synthesized set of conclusions applicable to all three studies were developed. The GTL LCA synthesis report is included in the appendices to this final report.

\section{TASK 2: MARKET STUDY}

The objective of the Ultra Clean Fuels Market Study was to assess the potential markets through 2015 for FT diesel, FT naphtha and methanol as transportation fuels, and FT naphtha as a petrochemical feedstock. Coverage was global, with primary focus on the United States market. The study was conducted in 2001-2002 and completed at the end of 2002. The study is based upon then current market conditions and forecasts, which Nexant believes to be consistent with long term market dynamics.

The study consists of nine focused topical reports on the market for UCFs: 
- Conventional Fuels Market Overview

- Ethylene Industry Overview

- Methanol Conventional Markets

- United States Regional Fuel Markets

- Technology Evaluation of Selected Alternative Fuels

- Technical Issues for UCF Use in Transport

- Methanol Distribution Infrastructure Issues

- Impact of FT Diesel on U.S. Refineries

- UCF Values and Market Potential

The key findings of the market study are summarized below.

\section{FT Diesel}

- FT diesel is expected to be an acceptable fuel to help meet low sulfur requirements in vehicle engines and systems that will be developed over the coming decade.

- FT diesel is expected to be an acceptable diesel blendstock for United States refineries. Blends containing up to 15-20 percent FT diesel are expected to be economically attractive to produce for domestic refiners.

- The United States market for diesel/gas oil fuel is expected to increase by about 1.4 percent per year, representing an absolute increase of about 730,000 barrels per day between 2001 and 2015. Globally, the market for diesel/gas oil fuel is expected to increase about 2.3 percent per year or about 5 million barrels per day by 2015 . Approximately 60 percent of these volumes are consumed as on-road diesel fuel. A typical worldscale GTL facility is expected to produce about 50,000 barrels per day of FT diesel. This study concludes that the global market for diesel fuel is sufficiently large and robust to absorb the industry's ability to build GTL facilities over the next 15 years.

\section{FT Naphtha}

The potential market for naphtha as an ethylene feedstock was evaluated in the Market Study. The United States market for naphtha is expected to increase about 2.2 percent per year, or by about 150,000 barrels per day. Global demand for petrochemical-grade naphtha is forecast to increase by 3.6 percent annually, or about 2.3 million barrels per day by 2015 . A typical worldscale GTL facility is expected to produce about 18,000 barrels per day of FT naphtha. The study concludes that the global market for naphtha as an ethylene feedstock is sufficiently large and robust to absorb the industry's ability to build GTL facilities over the next 15 years.

\section{Methanol}

The theoretical market for methanol as a transportation fuel is enormous. The current demand for chemical methanol in the United States is about 3 billion gallons per year. Achieving a 20 
percent market penetration in the United States gasoline market, the minimum level required to achieve a self-sustaining infrastructure, would result in slightly more than tripling the amount of methanol consumed in the country. The transport market represents a very large area of potential new demand for methanol. However, based on the analysis performed in Market Report Section VI, methanol faces a number of critical barriers to successful commercialization and use as a transportation fuel over the next 15 years. The study concludes that methanol will not become a significant fuel for conventional motor vehicles over the next 15 years.

In contrast to its limitations for use in conventional motor vehicles, methanol appears to be hypothetically more attractive as a fuel for fuel cells. However, the analysis concluded that the technology for fuel cells is still too immature to achieve significant commercialization within the next 15 years. The study concludes that methanol will not achieve significant demand as a transportation fuel over the next 15 years.

\section{TASK 3: ENGINE TESTING}

Penn State University and Cummins Engine Company collaborated to evaluate the performance of ultra-clean fuels in fuel cells and compression ignition engines. The key task areas were:

- Task 3.1: Database Compilation and Definition of Testing Needs

- Task 3.2: Indirect and Direct Methanol Fuel Cell Testing

- Task 3.3: Compression Ignition Engine (FT Liquids) Studies

\section{Task 3.1}

The Database Compilation and Definition of Testing Needs task includes a detailed literature review in several major subject areas including impacts of diesel fuel formulation, alternative diesel fuels (especially Fischer-Tropsch fuels), methanol reforming for fuel cell applications and the development of PEM fuel cell technologies. This literature review helped to guide the development of the research plans for the engine testing program.

Also under this task, fuel property characterization provided essential information on the differences in fuel injection behavior for fuels ranging from methyl esters to pure normal paraffins (e.g., spanning the range from biodiesel to Fischer-Tropsch diesel). The chemical structure of a fuel substantially alters the injection timing, retarding or advancing injection timing by as much as 1 crank angle degree relative to conventional diesel fuel, and therefore the combustion phasing and emissions formation.

\section{Task 3.2}

Under Task 3.2.1, indirect and direct methanol fuels cell experiments and simulation showed how carbon monoxide generated in the reforming of methanol influences the operation and efficiency of an IDMFC and how cycling of the methanol federate can serve to enhance the efficiency of a DMFC.

Under Task 3.2.2, a novel "tri-reforming” approach based on commercially available catalyst formulation demonstrated an ability to produce reformate gas with between 50-60 vol.\% 
hydrogen but less than 30 ppmv CO during methanol reforming. Together the outcomes from Task 3.2.1 and Task 3.2.2 demonstrated the practicality of combining a methanol reformer and PEM fuel cell.

\section{Task 3.3}

Under this task, observations were made of injection, combustion, emissions formation and emissions control with fuels of substantially different formulation provided important insights into how to interpret the performance of a turbodiesel engine operated on different fuel formulations and how fuel formulation can impact the characteristics of the emissions. A key observation was that variations in the bulk modulus of compressibility between fuels leads to shifts in injection timing, shifts in combustion phasing and emissions formation. Even with the electronic control present on the Cummins, ISB test engine, shifts in injection timing of as much as 0.5 crank angle degrees were observed, although the trends were not consistent with the bulk modulus of compressibility because the fuel system control is dictated by the settings in the electronic control module. Since the cetane number, calorific value and compressibility varied between the low sulfur diesel, ultra low sulfur diesel, biodiesel blends and GTL diesel fuel, the throttle position to achieve a particular speed and load setting with the engine required different throttle positions, and thereby shifted the engine to different parts of the control parameter map. This observation has substantial significance for Fischer-Tropsch fuels, which possess substantially different bulk modulus than low or ultra low sulfur diesel fuels. Nonetheless, the neat GTL diesel fuel demonstrated reduced emissions relative to low sulfur diesel fuel of $17 \%$ for hydrocarbons, 31\% for NOx and 12\% for particulate matter. Another key observation was that the nanostructure of diesel soot and the corresponding oxidative reactivity of diesel soot can shift significantly as fuel formulation changes. Biodiesel derived soots from a Cummins turbodiesel engine showed much less ordered structure in the primary soot particles and 2.5 times higher rate of oxidation than soot derived from conventional diesel fuel, which has significant implications for the regeneration of diesel particulate filters. Making the particulate easier to oxidize from the filter will enhance the effectiveness of the operation of the filter and may lower the fuel economy penalty that arises from the operation of the filter. 
Section 1

\section{UCF Project Overview}




\section{$1.1 \quad$ INTRODUCTION}

Throughout the world, there are large proven reserves of natural gas that are "stranded" because their remote locations render them incapable of being economically brought to market. ConocoPhillips is developing proprietary gas-to-liquids (GTL) technology to economically convert this natural gas to GTL products, primarily diesel, for use as a transportation fuel. Another significant product of the GTL process is naphtha, which may be used for a number of applications, such as petrochemical feedstock or as a fuel for fuel cell vehicles. In this study, GTL diesel and naphtha together are referred to as GTL products.

GTL technology is not the only means available to gas reserve owners or technology developers for the utilization of remote gas. Methanol and liquefied natural gas (LNG) are the two primary alternatives. Methanol has the technical potential to be used in fuel cell vehicles; LNG has been used commercially for decades for power generation. ConocoPhillips believes that those interested in developing and monetizing remote gas fields may consider methanol and LNG as alternative competing options.

ConocoPhillips, in conjunction with Nexant Inc., Penn State University, and Cummins Engine Co., joined with the U.S. Department of Energy (DOE) National Energy Technology Laboratory (NETL) in a cooperative agreement to perform a comprehensive study of new ultra clean fuels (UCFs) produced from remote sources of natural gas. The project study consists of three primary tasks areas: an environmental Life Cycle Assessment (LCA), a Market Study, and a series of Engine Tests, to evaluate the potential markets for Ultra Clean Fuels.

The overall objective of DOE's Ultra Clean Transportation Fuels Initiative is to develop and deploy technologies that will produce ultra-clean burning transportation fuels for the $21^{\text {st }}$ century from both petroleum and non-petroleum resources. These fuels will:

- Enable vehicles to comply with future emission requirement

- Be compatible with the existing liquid fuels infrastructure

- Enable vehicle efficiencies to be significantly increased, with concomitantly reduced $\mathrm{CO}_{2}$ emissions

- Be obtainable from a fossil resource, alone or in combination with other hydrocarbon materials such as refinery wastes, municipal wastes, and biomass

- Be cost competitive with current fuels

The results from the Ultra Clean Fuels Project's LCA, Market Study and Engine Tests will be used to optimize fuel compositions and engine operation required for optimal engine performance and to minimize the release of atmospheric pollutants resulting from the fuel combustion. Conoco's Fisher-Tropsch diesel, as well as methanol, was be tested in engines, in neat, blended or special formulations, to obtain data on emissions. Development and testing of both direct and indirect methanol fuel cells was also conducted and the optimum properties of a suitable fuel-grade methanol were defined. 


\subsection{GOALS}

ConocoPhillips undertook this study to help ensure that its investment in and development of GTL technology will be sustainable into the future. ConocoPhillips believes that GTL fuelsFischer-Tropsch diesel (FTD) and FT naphtha-are competitive options in the development and monetization of remote natural gas fields. These natural-gas-sourced fuels are assumed to displace or offset conventional petroleum fuels for transportation end uses. ${ }^{1}$

In accordance with ConocoPhillips's business planning and its corporate commitment to sustainable development, it is important and necessary to understand potential life cycle environmental and human health impacts of GTL products in comparison with alternatives. Therefore the LCA study is designed to estimate, with available data and within available study resources, the energy utilization and emissions life cycle profiles of ConocoPhillips GTL fuels and selected competitive fuels in the future.

Successful results in this project will encourage ConocoPhillips and others in the energy industry to make the large investments necessary to develop infrastructure and markets for FischerTropsch ultra clean diesel and/or methanol. Use of these alternative clean fuels will reduce the reliance of the United States on foreign petroleum as a primary energy source while also reducing transportation-related emissions.

The UCF Project will be used to help educate and inform stakeholders involved in gas development projects. The audience includes:

- National oil companies (gas reserve owners)

- Government energy and environmental agencies

- Peer group of refiners and GTL technology developers

The results of the study will be made available to:

- Environmental non-government organizations

- Transportation and power industry trade and market associations

- The general public

ConocoPhillips also intends to use the study internally to assess, improve, and complement the environmental programs (e.g., Product Stewardship and environmental impact assessment) used to manage the life cycle impacts of ConocoPhillips's GTL products.

\subsection{STRUCTURE OF THE FINAL REPORT}

This final report of the Ultra Clean Fuels project summarizes the results of each of the task areas. Section 2 of this report provides an overview and key results of the Ultra Clean Fuels Life Cycle Assessment. Section 3 reviews the results of the UCF Market Assessment, and Section 4

1 Because of the clean combustion properties of GTL fuels, ConocoPhillips believes that GTL transportation fuels (such as FTD) will substitute for or directly displace traditional petroleum transportation fuels (such as conventional or ultra-low sulfur diesel), in neat or blended formulations. It is assumed that over the time frame of the study, newer transport energy alternatives (such as hydrogen, biodiesel, and electric vehicles) may be introduced over and above the mix of fossil fuels in use. 
reviews the key findings of the Engine Testing activities. Section 5 reviews the key findings of each task, and presents a set of recommendations focused on next steps for the commercialization of UCF fuels.

\subsection{PROJECT DELIVERABLES}

Table 1-1 provides a list of the UCF Project deliverables as presented in the Project Management Plan of September, 2001.

The Ultra Clean Fuels Life Cycle Assessment Final Report for Task 1 was issued in draft form to ConocoPhillips and to the DOE in November 2003, and presented in final form at NETL in April 2004. A final presentation of the results of the Market Study for Task 2 was presented to DOE in October 2002, and the Ultra Clean Fuels Market Assessment report was issued in January 2003. The Literature Survey of Fuel Composition and Its Relation to Performance of CI Engines, Fuel Cells and Reformers for Task 3 was issued in January 2002. An Interim Technical Progress Report, Evaluation of Ultra Clean Fuels from Natural Gas was issued for Task 3 in April 2004. A final report for Task 3 was issued in February, 2006.

Each of these reports is included in the Appendix to this final report.

Table 1-1 Project Deliverables and Completion Dates

\begin{tabular}{|c|c|c|}
\hline & Tasks & Task/Deliverable Completion Date \\
\hline Phase I Project Manage & nt Plan & October 2001 \\
\hline Task 1 Life Cycle Analy & & May 2004 \\
\hline Subtask 1.1 Envir & nental LCA & \\
\hline Subtask 1.2 Engir & ring LCA (as part of the Market Assessment) & \\
\hline Task 2 Fuel Market Ass & ment & January 2003 \\
\hline Subtask 2.1 Fuel & larket Study & \\
\hline Subtask 2.2 Infra & ucture & \\
\hline Task 3 Engine Testing & & February 2006 \\
\hline Subtask $3.1 \quad \mathrm{Li}$ & ature Review and Data Compilation & \\
\hline Subtask 3.2.1 M & anol Fuel Cell Testing & \\
\hline Subtask 3.2.2 M & anol Reformer Testing & \\
\hline Subtask $3.3 \quad \mathrm{C}$ & pression Ignition/FT Liquids Engine Testing & \\
\hline Project Management an & eporting & Ongoing through February 2006 \\
\hline Deliverables: Topical F & orts \& Test Plans & \\
\hline Task 1 Topical Report & Ultra Clean Fuels LCA & November 2003 Draft, April 2004 Final \\
\hline Task 2 Topical Report & Ultra Clean Fuels Market Assessment & November 2002 \\
\hline Task 3 Topical Reports & Literature Review Data Compilation & Jan 2002 \\
\hline & Methanol Fuel cell Tests & September 2004 \\
\hline & IC Engine Tests on FT liquids Final Report & January 2006 \\
\hline Task 3 Test Plans & Methanol Fuel cell Tests & May 2003 \\
\hline & IC Engine Tests on FT liquids & July 2003 \\
\hline
\end{tabular}




\subsection{OVERALL PROJECT APPROACH AND METHODOLOGY}

The overall objective the Ultra Clean Fuels Project was to address the suitability of UCFs specifically Fischer-Tropsch diesel, Fischer Tropsch naphtha, and methanol produced from remote sources of natural gas - for use as transportation fuels. Three key dimensions were addressed: environmental, economic, and end-use performance. The UCF LCA, Market Study and Engine Tests were coordinated to examine comparable scenarios of production and use over similar time frames to evaluate the potential market for GTL fuels, from both the perspective of the producer and the consumer. Where appropriate, data and results were shared and used by the individual project teams.

The methodology used in the UCF LCA was based upon internationally accepted standards. ISO 14040 standards were used in the development of the LCA scope, data collection, and in the documentation and verification of the results. The study was reviewed by an independent peer review panel, and the study was certified by the panel as being compliant with the ISO standards. It is the only GTL industry LCA that has been ISO 14040 certified by a third party peer review panel. In order to enhance transparency, the UCF LCA used two publicly available models, the Greenhouse Gases, Regulated Emissions and Energy Use in Transportation (GREET) model from Argonne National Laboratory and the Tool for the Reduction and Assessment of Chemical and other Impacts (TRACI) model from the U.S. EPA, in addition to two commercial process modeling systems, AspenPlus and the Process Industries Modeling System (PIMS).

The Market Study drew upon Nexant's extensive experience in the petroleum and petrochemical industries. Nexant regularly provides market assessments, competitive analysis, data analysis, data forecasting, and profitability analysis for the global petroleum and petrochemical industries. The Market Study was based upon Nexant's in-house data as well as publicly available data and data that were provided by ConocoPhillips.

The Engine Testing task drew upon and supported the research facilities of Prof. Boehman and Prof. Song at the Penn State Energy Institute, where they supervise the Diesel Combustion and Emissions Laboratory and the Clean Fuels and Catalysis Laboratory, respectively. Prof. Wang heads the Electrochemical Engine Center.

The Diesel Combustion and Emissions Laboratory is home to seven engine test stands and supporting instrumentation for fuel characterization, particulate and gaseous emissions measurements, in-cylinder digital imaging of combustion and detailed combustion analysis. The engines range in capacity from single-cylinder to $\mathrm{V}-8$ and include a highly instrumented 2.5L common rail diesel engine, a Ricardo Hydra single-cylinder research engine, a Cummins ISB turbodiesel and a 7.3L International V-8 turbodiesel.

The Clean Fuels and Catalysis laboratory includes instrumentation for detailed fuel characterization, catalyst synthesis facilities and catalyst characterization facilities. Catalyst characterization includes High-Temperature/High-Pressure CIR FT-IR System, a Tapered Element Oscillating microscope (TEOM) and Pulse Chemisorption and TPD/TPR Apparatus. Fuel characterization includes Low-Level Sulfur Analyzers, GC-SimDist, GC, GC-MS and HPLC. 
The Electrochemical Engine Center includes experimental and numerical modeling facilities. The experimental facilities for fuel cell and battery research include the capabilities to measure current density distribution with high temporal and spatial resolution, species distribution including water and $\mathrm{CO}$ with on-line gas chromatography, gas diffusion layer characterization, hydrophobic/hydrophilic quantification for gas diffusion layer water transport characterization and to fabricate membrane-electrode assemblies. The numerical capabilities include fuel cell modeling using CFD Packages, Fluent and Star-CD, in-house, high performance algorithm development for fuel cells and advanced battery systems, a 50-node Beowulf cluster and a 32node high-performance Beowulf cluster. 
Section 2

\section{Ultra Clean Fuels Life Cycle Assessment}




\section{$2.1 \quad$ INTRODUCTION}

ConocoPhillips, in conjunction with Nexant Inc., conducted a comprehensive environmental lifecycle study of ultra clean fuels (UCFs) produced from remote sources of natural gas. The Ultra Clean Fuels Life Cycle Assessment (UCF LCA) consists of a Life Cycle Inventory (LCI) and a Life Cycle Impact Assessment (LCIA) for Gas-to-Liquids (GTL) transportation fuels, namely, Fischer-Tropsch diesel (FTD) and FT naphtha. The complete LCA report is included as an appendix to this final report.

ConocoPhillips sought to address the following question: with respect to cost and environmental impact, how do UCFs (FTD and FT naphtha) compare with conventional fuels-federal reformulated gasoline (FRFG), conventional diesel, and ultra-low sulfur diesel (ULSD)_and how do they compare with methanol? (Liquefied national gas was not considered a transportation fuel in this study.)

To address this question, ConocoPhillips and Nexant conducted a comprehensive LCA of UCFs and a separately published market study that focuses on the commercial feasibility and engineering lifecycle of these UCFs. The UCF LCA uses the market study to examine likely future commercial recovery, processing, and fuel distribution operating scenarios for GTL fuels and methanol. A study of GTL fuels for use in power generation and an air quality modeling study of GTL fuels in the Houston area were also conducted, and are included as appendices to the full LCA report.

For comparison purposes, the environmental lifecycle of conventional transportation fuels were also modeled in detail in the ConocoPhillips UCF LCA study. Since refinery location is an important factor in determining the likely changes in petroleum product slates, a detailed assessment was performed for two Petroleum Administration Defense Districts (PADDs): PADD III and PADD I. PADD III is representative of a U.S. national average crude slate; PADD I is representative of a lighter crude slate. A significant feature of the UCF LCA is that the coproducts from petroleum refining, including petroleum coke and heavy residual oil, were explicitly included in the lifecycle assessment. Other studies have used "allocation" methodologies, in which such co-products have been placed outside of the system boundary of the study.

\section{$2.2 \quad$ GOALS}

ConocoPhillips undertook this study to help ensure that its investment in and development of GTL technology would be sustainable into the future. ConocoPhillips believes that GTL fuelsFTD and FT naphtha-are competitive options in the development and monetization of remote natural gas fields. These natural-gas-sourced fuels are assumed to displace or offset conventional petroleum fuels for transportation end uses.

In accordance with its business planning and corporate commitment to sustainable development, ConocoPhillips believes that it is important and necessary to understand life cycle environmental 
and human health potential impacts of GTL products in comparison with alternatives. Therefore, this LCA study is designed to estimate, with available data and within available study resources, the energy utilization and emissions life cycle profiles of ConocoPhillips GTL fuels and selected competitive fuels in the future.

This study is also part of the U.S. Department of Energy (DOE) Ultra Clean Fuels initiative, which aims to develop and deploy technologies that will produce ultra-clean-burning transportation fuels for the 21st century from both petroleum and non-petroleum resources. ConocoPhillips's goals are in accord with those of DOE, namely, to produce fuels that will:

- Enable vehicles to comply with future emission requirements

- Be compatible with the existing liquid fuels infrastructure

- Enable vehicle efficiencies to be significantly increased, with concomitantly reduced $\mathrm{CO}_{2}$ emissions

- Be obtainable from a fossil resource, alone or in combination with other hydrocarbon materials such as refinery wastes, municipal wastes, and biomass

- Be cost-competitive with current fuels

\subsubsection{Audience}

The UCF LCA will be used to help educate and inform stakeholders in gas development projects. The audience includes:

- National oil companies (gas reserve owners)

- Government energy and environmental agencies

- Peer group of refiners and GTL technology developers

The results of the study will be made available to:

- Environmental non-government organizations

- Transportation and power industry trade and market associations

- The general public

ConocoPhillips also intends to use the study internally to assess, improve, and complement the environmental programs (e.g., Product Stewardship and environmental impact assessment) used to manage the life cycle impacts of ConocoPhillips’s GTL products.

\subsubsection{Objectives}

The specific objectives for the UCF LCA are:

- For the Life Cycle Inventory:

- Quantification of the energy use and selected emissions inventory associated with the production and use of GTL fuels. Although there are significant markets for these fuels around the world, this study focuses on the use of GTL products in the United 
States, where significant fuel use and refining baseline data exists. In addition, the study assumes that GTL fuels are produced near stranded gas reserves in remote areas in the Middle East.

- Comparison of the energy use and emissions inventory for the production and use of GTL products on an equivalent basis with refined petroleum products predominantly in use today. For example, FTD may be compared with petroleum diesel in application as a transportation fuel

- Comparison of methanol (as an alternative natural gas utilization option) for use in fuel cell vehicles with GTL and petroleum fuels

- For the Life Cycle Impact Assessment:

- Quantification of potential life cycle impacts associated with the production and use of GTL fuels, in comparison with the potential life cycle impacts of petroleum fuels and competing natural gas utilization options in transportation applications

The life cycle inventory categories considered are total energy, greenhouse gases $\left(\mathrm{CO}_{2}, \mathrm{CH}_{4}\right.$, and $\mathrm{N}_{2} \mathrm{O}$ ), criteria pollutants ( $\mathrm{NO}_{\mathrm{X}}, \mathrm{SO}_{\mathrm{X}}, \mathrm{CO}, \mathrm{PM} 10$, and VOC), total petroleum fuel use, total fossil fuel use, solid waste, and wastewater.

The life cycle impact indicators considered are global warming potential, acidification, photochemical smog, eutrophication, human health (criteria, cancer, and non-cancer), ecotoxicity, resource depletion, land use, and water use.

The functional unit for the UCF LCA is light duty (LD) vehicle miles. LD vehicles are defined as passenger vehicles with gross weights of less than 6,000 pounds.

The study was conducted according to the requirements of the ISO 14040 International Standard for Life Cycle Assessment, which included a critical review conducted by an outside independent panel. The outside peer review panel certified the UCF LCA study as conforming to the ISO standards. The report of the peer review panel is included as an appendix to the full UCF LCA report.

\subsection{SCOPE AND METHODOLOGY}

The UCF LCA develops a set of near-term (2006) and long-term (2015) scenarios, in coordination with the market study task of the UCF project, to assess the potential impacts associated with likely commercial scenarios for these time frames. The years 2006 and 2015 were selected to represent the likely times of the emergence of the GTL fuels production technologies represented in the scenarios. The vehicle technologies considered in each scenario are representative of the technologies that are likely to be technologically feasible and may be commercially available. The vehicles modeled are theoretical and are not average representations of actual in-use vehicle fleets.

The UCF LCA builds on three successive analyses: 
- A detailed engineering analysis of the process efficiencies of current and future commercial technologies for GTL production

- An analysis of energy and emissions due to the production and downstream use of petroleum and GTL system co-products. A novel methodology for considering coproducts was developed in this study, and is described in detail in Section 5 of the full UCF LCA report. The methodology is referred to at the Co-product Function Expansion (CFE).

- Sensitivity analysis that considers future heavy crude input slates for petroleum refining, 3 ppm ultra-low sulfur petroleum diesel, and flared gas used in the production of GTL products. In addition, a comprehensive parametric sensitivity analysis was performed for all key study parameters

The study scenarios consider the following fuels and vehicle configurations:

For transportation fuels:

- Current and future petroleum fuels—federal reformulated gasoline (FRFG), conventional diesel, and ULSD

- A 20\% FTD/80\% ULSD blend (FTD20), 100\% FTD (FTD100), methanol, and FT naphtha, all produced from remote natural gas

For vehicles:

- Vehicle configurations include conventional spark ignition (SI) engines for FRFG, advanced spark ignition direction injection (SIDI) engines for FRFG, compression ignition direct injection (CIDI) diesel engines, hybrid electric vehicles (HEVs) with SIDI and CIDI engines, and fuel processor fuel cell vehicles (FCVs). The vehicles modeled are representative of theoretical vehicle configurations and performances

\section{$2.4 \quad$ LCA MODELS}

The GREET (Greenhouse Gases, Regulated Emissions, and Energy Use in Transportation) model, Version 1.6, from Argonne National Laboratory served as the primary modeling tool for the UCF LCA. GREET has become a standard tool for conducting and benchmarking fuel-cycle studies in the United States, and its use worldwide is growing.

GREET is not an LCA tool per se, but rather a fuel cycle, or input-output, model. In the UCF LCA, GREET is paired with two process simulation tools (PIMS and Aspen Plus) for detailed data development and validation.

GREET was chosen primarily because:

- It has become a standard tool and reference for fuel cycle modeling in the United States for transportation and has been extensively peer-reviewed.

- It is a spreadsheet model that is easily extensible. Moreover, the Argonne team is interested in helping to validate and further develop the model. 
In the course of selecting and using the model in the UCF LCA analysis, the model was examined and validated with respect to both the well-to-tank (fuel extraction, production, transportation and distribution) and the tank-to-wheel (fuel end-use) life cycle stages, and the literature, the technology assumptions, and all input data were reviewed. To address specific questions in the study relating to ConocoPhillips technology or scenarios, data was independently developed.

The Tool for the Reduction and Assessment of Chemical and other Impacts (TRACI) model is the LCIA tool used in this study. Developed by the U.S. EPA National Risk Management Research Laboratory (NRMRL), TRACI was recently released for public use. TRACI can identify the potential for impacts, in relative terms, and provide consistent comparisons given scenarios for fuel use in selected metropolitan areas. The approach and outputs of TRACI conform to current industry-standard methods and ongoing international work in LCIA.

\subsection{ASPEN PLUS MODELS}

The modeling tool used to estimate thermal efficiency for GTL and methanol production was Aspen Plus. Aspen Plus is a process simulator employed extensively by the chemical industry to model heat and material balances, thermodynamic equilibrium, optimization of process design, and operation of chemical plants. Aspen Plus was used to model the thermodynamic efficiency of GTL and methanol production in order to determine achievable efficiencies and to establish theoretical upper limits on efficiency.

Figure 2-1 shows an example of the Aspen process flow simulation model of the two-stage reforming process for synthesis gas (syngas) generation for GTL and methanol.

Simulation models of idealized systems in Aspen were developed to estimate the upper limits of thermal efficiency for GLT and methanol production. The assumptions used for the maximum thermodynamic efficiency models include an equilibrium approach temperature of zero for all reactors; $100 \%$ efficiency for all pumps, compressors, and expanders; and a low-level heat dissipation to atmospheric air (meaning that power required for cooling water pumps and air cooling fans is zero). The effect of these assumptions is that energy losses within the system are ignored.

The upper bound efficiency estimates for GTL and methanol were then used to validate the efficiency values for each process, and to ensure that the final values were well below the upper limit efficiencies. 


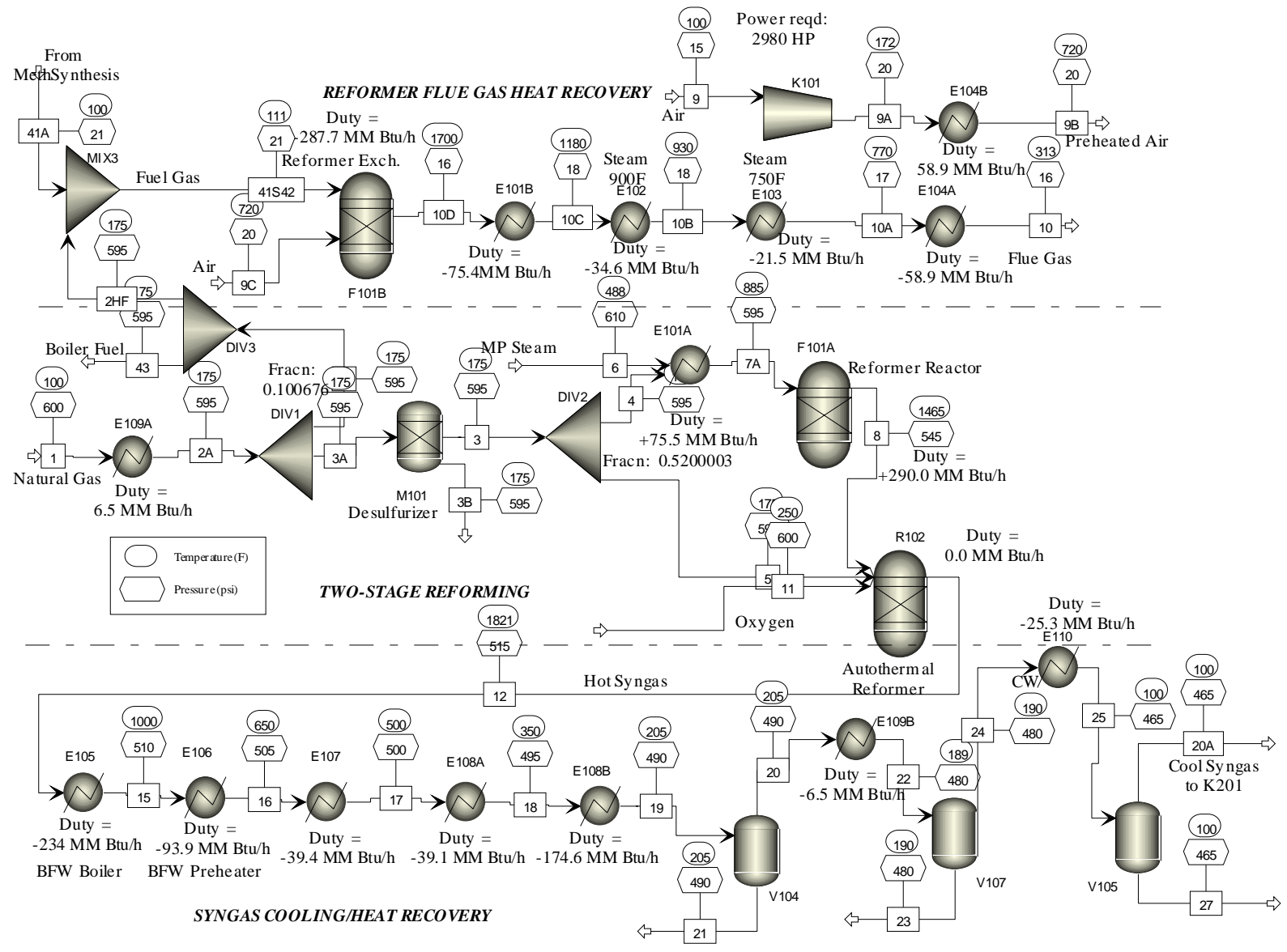

Figure 2-1 Aspen Plus Process Simulation Flow Diagram for Syngas Generation

\subsection{LIFE CYCLE INVENTORY CATEGORIES}

The LCI categories considered are total energy, greenhouse gases $\left(\mathrm{CO}_{2}, \mathrm{CH}_{4}\right.$, and $\left.\mathrm{N}_{2} \mathrm{O}\right)$, and criteria pollutants $\left(\mathrm{NO}_{\mathrm{X}}, \mathrm{SO}_{\mathrm{X}}, \mathrm{CO}, \mathrm{PM} 10\right.$, and VOC). GHG emissions are reported as global warming potential (GWP), which is a weighted aggregate of $\mathrm{CO}_{2}, \mathrm{CH}_{4}$, and $\mathrm{N}_{2} \mathrm{O}$ expressed as $\mathrm{CO}_{2}$-equivalents over a 100-year time horizon. The UCF LCA uses GWP factors from the International Panel on Climate Change Third Assessment Report on climate change.

The primary goals of the UCF LCA are: (1) to ensure that ConocoPhillips's GTL business is sustainable into the future and (2) to support the DOE Ultra Clean Fuels project objectives.

The LCI categories are comprehensive and support these primary goals. The LCI also provides data for the LCIA stage of the UCF LCA. The LCIA impact indicators fully address the stated goals of the UCF LCA. 


\subsection{LIFE CYCLE IMPACT ASSESSMENT INDICATORS}

ConocoPhillips has conducted an LCIA to compare potential environmental impacts resulting from the use of GTL products, petroleum fuels, and alternative fuels for transportation

Results from the Life Cycle Inventory phase of the UCF LCA were entered into TRACI to determine the relative potential life cycle impacts of the fuel alternatives. The results are expressed as comparisons employing the set of impact categories from TRACI: global warming potential, acidification, photochemical smog, eutrophication, human health (criteria, cancer, and non-cancer), ecotoxicity, resource depletion, land use, and water use. Supplementary toxics emissions data was collected for the LCIA for the human health and ecotoxic categories.

The LCIA impact categories and characterization models are comprehensive, are based upon ongoing international potential impact modeling research, and support the stated goals of the UCF LCA.

\subsection{RESULTS FROM THE LIFE CYCLE INVENTORY}

The goal of the UCF LCA is to examine the potential life cycle environmental and human health impacts of GTL products in comparison with competing alternatives. The LCI phase of this assessment demonstrates that on the basis of GHG and criteria pollutant emissions measured on the functional unit basis of light duty vehicle miles, there are no significant disparities between GTL and competing fuels.

Critics of GTL transportation fuels have suggested that these fuels contribute significantly more $\mathrm{CO}_{2}$ (and hence, GHG) emissions than conventional petroleum-derived fuels. Technological advances in GTL production have narrowed this gap to the extent that full well-to-wheel GHG emissions from neat FTD (FTD100) produced from stranded natural gas compared with ULSD are equivalent. If $10 \%$ or more of the feed gas comes from gas that is otherwise flared, the FTD100 demonstrates a significant reduction in GHG emissions. FT100 also exhibits lower GHG emissions than FRFG.

This study also demonstrates a reduction in criteria pollutants when FTD100 fuel is used in light duty vehicles. The reduced emissions observed in the LCI are likely to result in corresponding reductions in potential health and environmental impacts. At a minimum, the increased consumption of GTL fuels in the marketplace should not have greater impacts than petroleumderived transportation fuels.

With regard to overall energy efficiency, default assumptions in the GREET showed FTD100 to be approximately 44\% less energy-efficient than ULSD. Projections of GTL process energy efficiency factors for future commercial operations as used in the UCF LCA reduce this gap to approximately $25 \%$.

The conclusions below are presented in the context of the data quality and sensitivity analysis as discussed earlier. Comparative results between fuels for total energy and GWP within 10\% are considered to be equivalent. For criteria emissions inventories, results within $15 \%$ are considered to be equivalent. 


\section{FT Diesel}

- FTD20 and FTD100 are equivalent to ULSD in GWP in the 2006 and 2015 scenarios.

- FTD20 and FTD100 have lower GWPs than FRFG in the 2006 and 2015 scenarios.

- FTD20 (2006) is equivalent to ULSD in VOC, CO, NO $\mathrm{X}_{\mathrm{X}}$, and PM10 emissions. FTD20 has lower $\mathrm{SO}_{\mathrm{X}}$ emissions than ULSD.

- FTD100 (2015) has lower inventories of total and urban criteria emissions than ULSD.

- FTD100 (2015) has lower inventories of total and urban criteria emissions than FRFG.

- FTD100 (2015) is 25\% less energy-efficient than ULSD, and equivalent in life cycle energy efficiency to FRFG, based on ConocoPhillips's projected GTL process energy efficiency. (GREET, based on default data, estimates that FTD100 is $44 \%$ less energy efficient than ULSD.)

- FTD100 (2015) sourced from 10\% flared gas performs better with regard to GWP than ULSD. The aggressive FTD100 CIDI (2015) case, with a 5\% improvement in vehicle efficiency, has 7\% lower GWP than the comparable ULSD case. However, this difference in GWP is considered equivalent with respect to data quality.

- GTL products consume only small amounts of petroleum fuel in the feedstock and fuel stages.

\section{FT Naphtha}

- FT naphtha used in FCVs is equivalent to FRFG and to methanol for GWP (2015).

- For both total and urban criteria emissions, FT naphtha FCV has lower emissions of VOC, $\mathrm{NO}_{\mathrm{X}}$, and $\mathrm{SO}_{\mathrm{X}}$ than methanol and FRFG (2015).

Figures 2-2 and 2-3 summarize the results for GWP for the 2006 and 2015 cases. Detailed graphical comparisons for all LCI categories are presented in the full UCF LCA report.

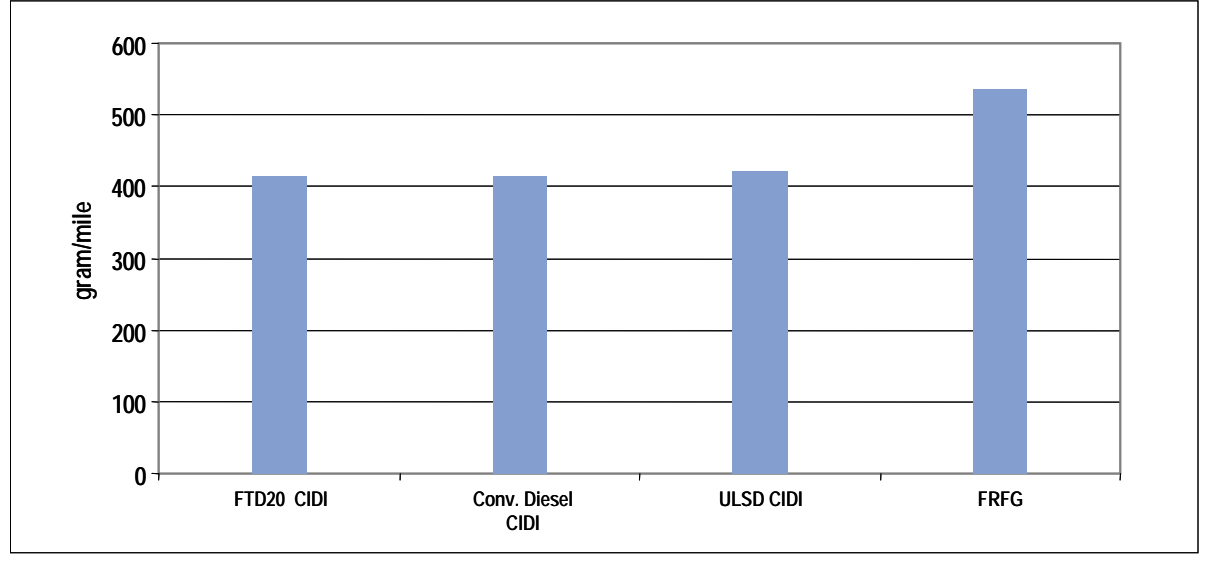

Figure 2-2 Global Warming Potential, 2006 


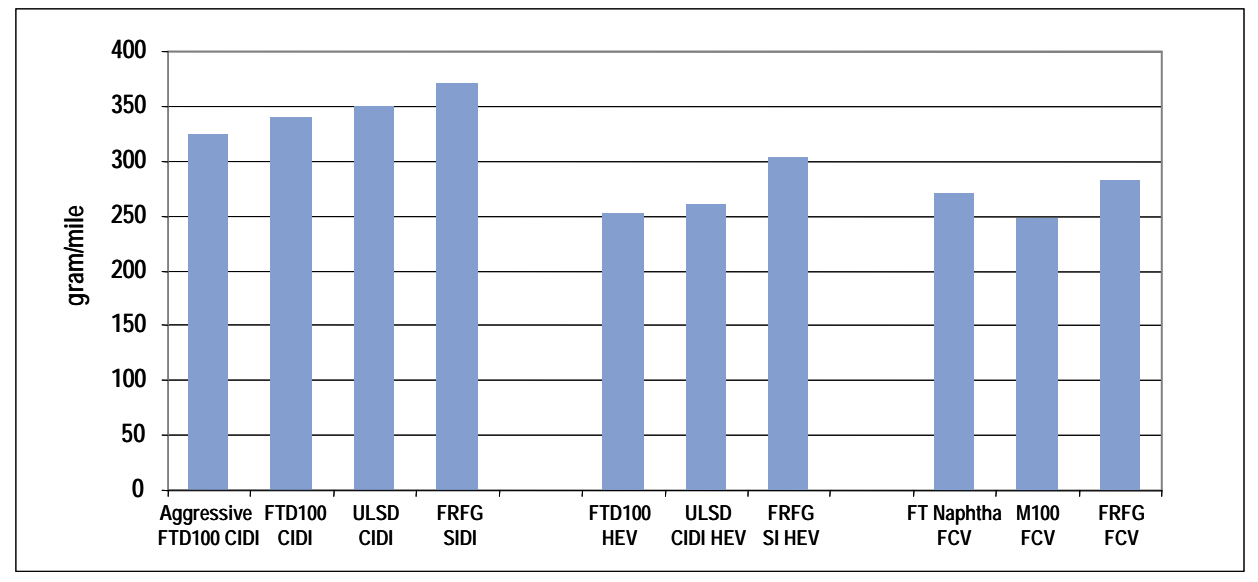

Figure 2-3 Global Warming Potential, 2015

\subsection{SENSITIVITY ANALYSIS OF THE LCI}

The sensitivity analysis of the LCI considers the following cases:

- Changes in the petroleum refining crude slate due to the refining of heavier and higher sulfur concentration crude oil

- A reduction of sulfur concentrations in ULSD from 10 ppm to 3 ppm

- ULSD refined from $100 \%$ imported crude oil from the Middle East

- The use of flared gas for GTL production

- A parametric sensitivity analysis for key study parameters

For the crude slate sensitivity, crude density and sulfur concentration are increased. In the future, as lighter and "sweeter" (i.e., lower sulfur) crude oil resources are depleted, the refining industry will need to rely increasingly on a heavier and more sulfurous crude slate. As a consequence, the industry will produce greater quantities of heavy co-products such as petroleum coke and residual oil; the heavy crude slate case includes effects of petroleum coke and heavy residual oil through the application of the Co-product Function Expansion (CFE) methodology. GTL and other petroleum fuel alternatives, as new entrants to the transportation fuel market, will compete with these heavy crude slate petroleum fuels on the margin. For the purpose of comparison, a light, sweet crude slate is also assessed.

ULSD on the order of 3 ppm sulfur or lower is also examined in the sensitivity analysis. Analysis of diesel sulfur concentrations at this level provides a closer equivalent comparison with zerosulfur FTD. It is uncertain, however, if the industry will be able to economically produce diesel with these sulfur levels.

The production of natural gas is often "associated" with the production of crude oil. This gas is sometimes flared, particularly in developing countries and in the Middle East. If this gas were captured and used for GTL production, FTD and FT naphtha could be credited for the avoided 
$\mathrm{CO}_{2}$ emissions from flaring. This case is modeled in the flared gas sensitivity for GTL production.

A comprehensive parametric sensitivity was carried out for all significant study parameters for each life cycle stage for the GTL and petroleum fuels.

Each of these sensitivity cases demonstrated small, but quantifiable, changes in the LCA profiles of the baseline petroleum fuels and the GTL fuels. Refer to Section 6 of the full UCF LCA report for details.

\subsection{RESULTS AND CONCLUSIONS FROM THE LIFE CYCLE IMPACT ASSESSMENT}

The assessment of the sustainability of GTL fuels was a primary goal of ConocoPhillips in undertaking this UCF LCA study. The Department of Energy’s Ultra Clean Fuels Program specifically seeks to ensure that fossil-resource-fueled vehicles will comply with future emissions standards and reduce $\mathrm{CO}_{2}$ emissions.

Conclusions for the LCIA are drawn on the basis of a 10\% range of error for GWP, a 15\% range of error for solid waste, wastewater, and resource depletion, and a $100 \%$ range for all other categories. The choice of the $100 \%$ error range is a commonly used LCIA rule-of-thumb that considers results to be different only if differing by a factor of two, taking into account the inherently uncertainty in the LCIA characterization models. These ranges were established using best professional judgment that took into account the data gaps and data quality. Refer to Section 7 of the full UCF LCA for a complete discussion.

Tables 2-1 and 2-2 provide details on the properties of the FTD and petroleum fuels considered in the study. These fuel properties have a significant effect on end-use emissions, and consequently the life cycle impacts.

Table 2-1 Important Fuel Properties for FT Diesel

\begin{tabular}{|l|l|}
\hline \multicolumn{1}{|c|}{ Property } & \multicolumn{1}{c|}{ Description } \\
\hline Zero sulfur & $\begin{array}{l}\text { Lower sulfur leads directly to lower SOx emissions and lower particulate emissions } \\
\text { Ultra-low sulfur fuels can permit advanced exhaust after-treatment devices }\end{array}$ \\
\hline High cetane number & High-cetane fuels may reduce exhaust emissions of NOx and particulate matter (PM) \\
\hline High paraffin content & $\begin{array}{l}\text { Paraffins readily combust in diesel engines, and normal paraffins are responsible for the high } \\
\text { cetane number of FTD }\end{array}$ \\
\hline High normal paraffin content & The higher the normal paraffin content, the higher the cetane number of the fuel \\
\hline Low aromatic content & $\begin{array}{l}\text { Aromatic compounds in diesel fuel do not combust as readily as paraffin compounds, leading to } \\
\text { increased exhaust emissions of NOx and PM and toxics emissions }\end{array}$ \\
\hline Low PAH content & Lower PAH emissions relative to petroleum diesel \\
\hline Density and heating value & $\begin{array}{l}\text { FTD has a lower density than petroleum diesel. FTD has a lower volumetric energy content, but } \\
\text { a higher heating content on mass basis; a ton of FTD has greater energy content than a ton of } \\
\text { crude-oil-derived diesel, but a barrel of FTD has less energy than a barrel of crude-oil-derived } \\
\text { diesel. }\end{array}$ \\
\hline
\end{tabular}


Table 2-2 FTD, ULSD, and FRFG Fuel Properties

\begin{tabular}{|l|c|c|c|}
\multicolumn{1}{|c|}{ Property } & FTD & ULSD & $\begin{array}{c}\text { Reformulate } \\
\text { d Gasoline }\end{array}$ \\
\hline Cetane number & 70 & 50 & - \\
\hline Octane number & - & - & 87 \\
\hline Sulfur (ppm) & 0 & 15 & 30 \\
\hline Aromatics (vol\%) & $<1$ & 10 & 23 \\
\hline Density (g/cm ${ }^{3}$ ) & 0.77 & 0.85 & 0.74 \\
\hline Heating value, LHV (Btu/gal) & 118,800 & 128,000 & 112,793 \\
\hline
\end{tabular}

The following is a summary of the results from the LCIA:

- In light duty vehicles, for both the near-term and long-term scenarios, FTD and ULSD have equivalent GWPs. This is an important conclusion as previous studies have concluded that GTL fuels have larger GWPs than petroleum diesel fuels, largely due to an assumed increase in $\mathrm{CO}_{2}$ emissions in the fuel production stage. When ConocoPhillips estimates for carbon and energy process efficiencies are used, this disparity in GWP does not appear to exist.

- For the acidification, eutrophication, and human health criteria impact categories, FTD consistently exhibits indicator values that are 5\% to 98\% lower than those of both ULSD and FRFG. The application of a 100\% differential error range precludes any comparative assertions that FTD or FT naphtha have less potential for environmental impact for these indicators, but it is apparent that these fuels are probably not at a disadvantage with respect to conventional petroleum-derived transportation fuels.

- For the human health cancer and non-cancer impact categories, both FTD and ULSD exhibit significantly lower potential impacts than FRFG. These results, however, are based on the comparison of actual emissions testing for FTD and ULSD and proposed regulatory standards for FRFG. The results indicate only that toxics emissions for FTD and ULSD are well within the proposed Tier 2 regulatory standards set for FRFG light duty vehicles.

- Both FTD and ULSD have ecotoxicity indicator values that are greater than those of FRFG, but the differences are within the error threshold. The indicator value differences are due to the small quantities of formaldehyde emitted in the vehicle stage for diesel fuels. FTD, however, has a lower indicator value for ecotoxicity than ULSD.

- The production of GTL fuels generates less solid waste than the production of ULSD and FRFG. GTL production generates less wastewater than does the production of FRFG and a quantity of wastewater within $15 \%$ of that resulting from the production of ULSD.

- There are currently large, proven and potentially large, unproven reserves of stranded gas. Given forecasts of the rate of development of stranded gas projects, of which 
GTL is only a small portion, the production of products from these gas reserves will continue for some 40 years after global crude oil reserves have been depleted. FTD and FT naphtha are substantially non-petroleum fuels. The FTD- and FT-naphthafueled vehicles consume only small amounts of petroleum resources per mile. This is due exclusively to upstream production and transportation of the fuels.

- Currently, petroleum reserves contain about twice the energy content on a Btu basis as stranded gas reserves. However, given projections of resource use, the Btu contents of the two resources will be equal in about 2015. Although a non-renewable resource, stranded gas will continue to provide energy to the global market for a long time in a manner that is at least comparable to petroleum reserves with respect to the broad set of environmental indicators examined in this study.

Figures 2-4 and 2-5 are examples of graphic presentations of the LCIA results, which are presented in some detail in Section 7 of the UCF LCA report. The figures shown here compare the photochemical smog potentials for the 2006 and 2015 scenarios, segmenting the impact potential by the feedstock extraction, fuel production, and vehicle use life cycle stages.

Figure 2-6 compares the resource consumption of crude oil on a per-mile basis for the various fuels and vehicle scenarios. A complete set of resource indicators are also graphically presented in Section 7 of the full UCF LCA report.

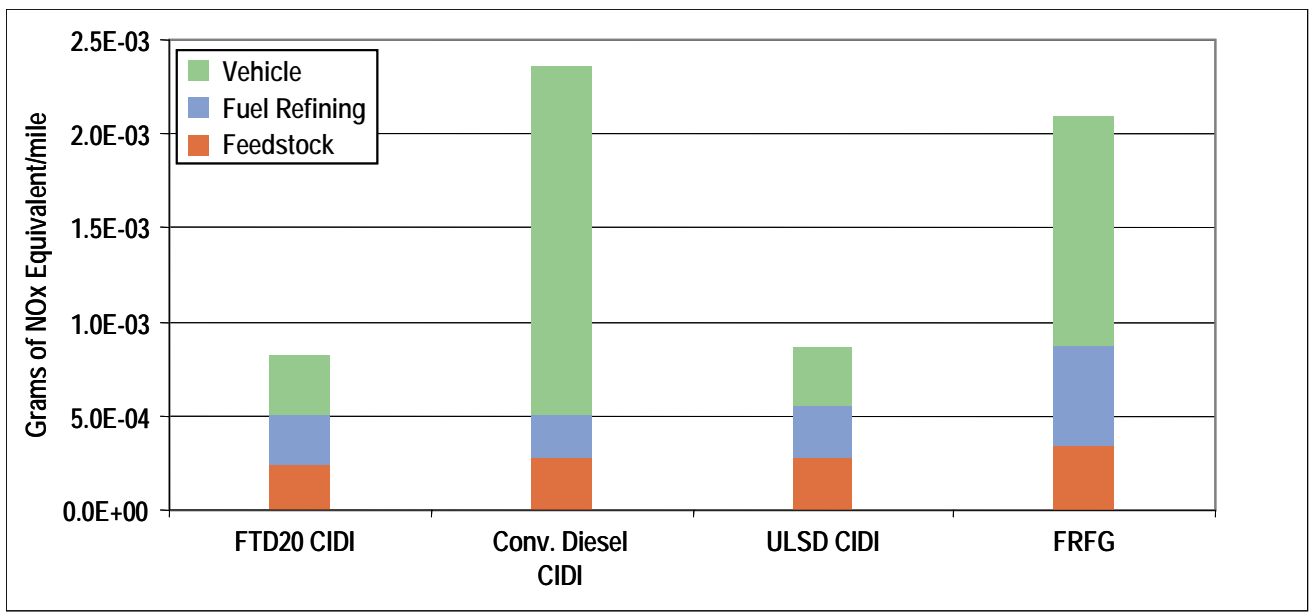

Figure 2-4 Total Photochemical Smog, 2006 


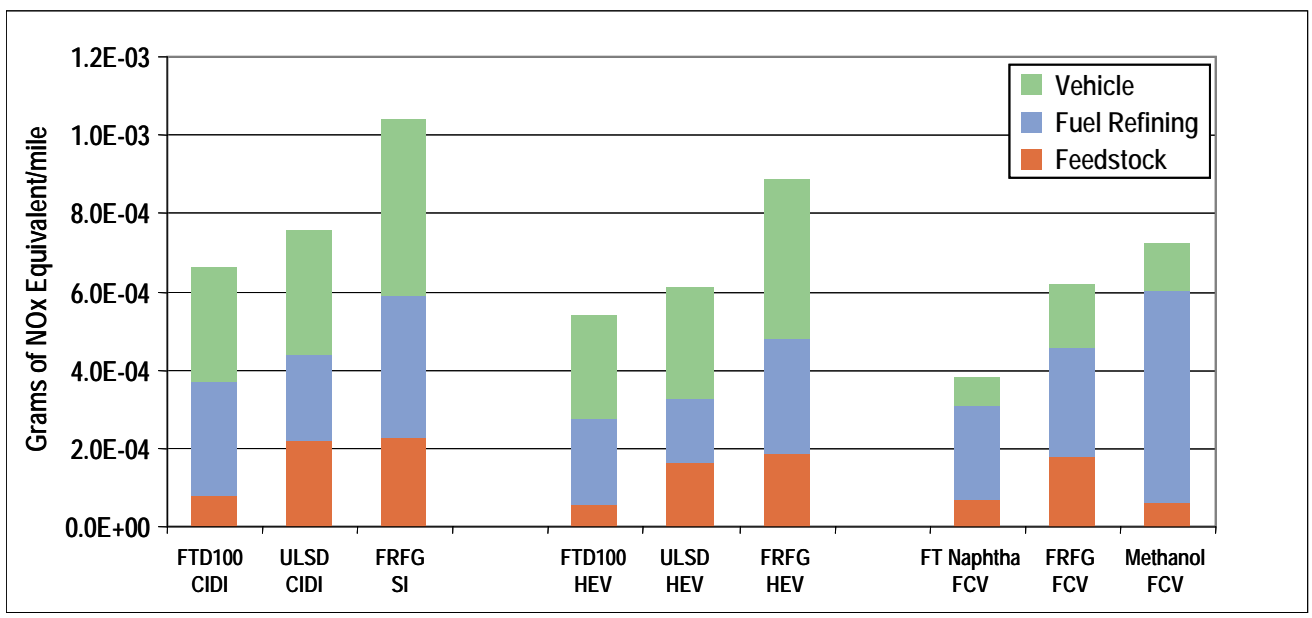

Figure 2-5 Total Photochemical Smog, 2015

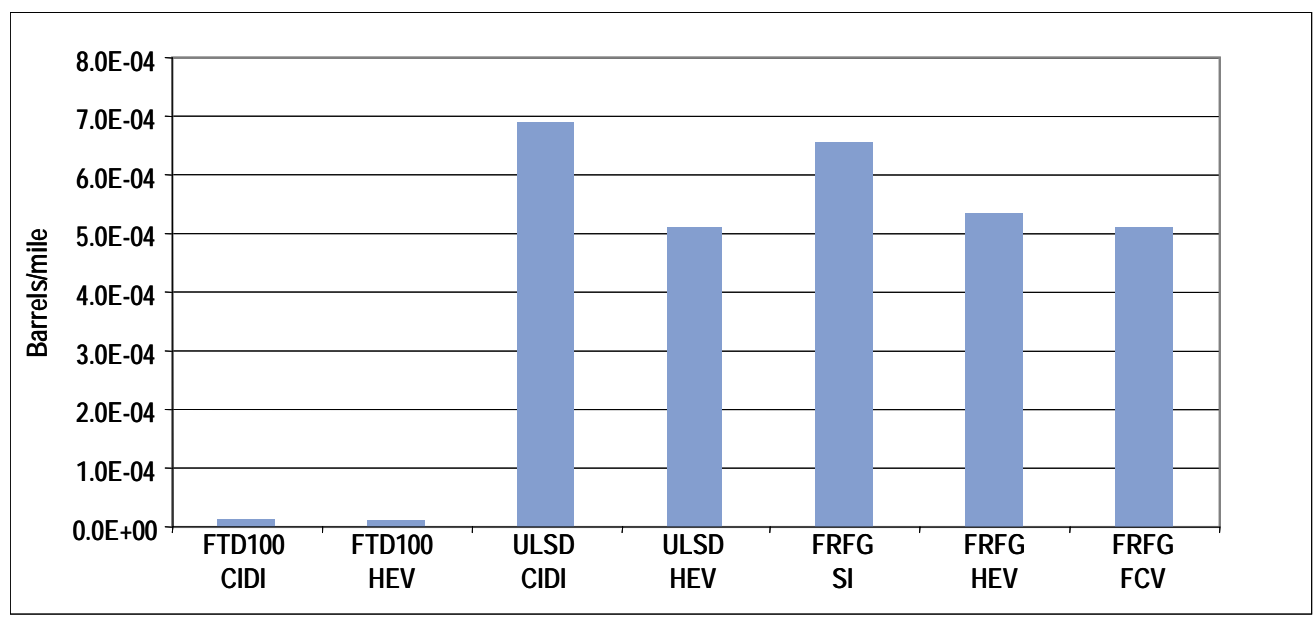

Figure 2-6 Crude Oil Consumption, 2015 
Section 3

UCF Market Study 


\subsection{INTRODUCTION}

The objective of the Ultra Clean Fuels Market Study was to assess the potential markets through 2015 for FT diesel, FT naphtha and methanol as transportation fuels. Coverage was global, with primary focus on the United States market. The analysis and report were completed in November 2002, and the baseline data for crude oil prices and forecasts reflect then-current market conditions.

The following key activities were undertaken to meet this objective:

- Conventional Fuels Market Overview: an overview of major trends that will define the global and regional markets for conventional petroleum-based fuels. Specific elements addressed are a characterization of expected developments in the worldwide and regional economy, future environmental regulations that will impact the quality of gasoline and diesel fuel, trends in global and regional refinery capacity, and trends in global trade of primary refined products

- Ethylene Industry Overview: an evaluation of the potential market for FT diesel and FT naphtha as feedstocks for ethylene production, including an overview of the global and United States ethylene industry with an emphasis on identifying the size of future demand for naphtha and diesel/gasoils as feedstocks, an evaluation of alternative markets for FT naphtha and of the technical suitability of FT naphtha and FT diesel as ethylene feedstocks, and a comparative analysis of the economics for FT diesel and FT naphtha versus conventional cracking feedstocks

- Methanol Conventional Markets: an overview of the current and projected future global demand for methanol in established conventional markets, a projection of methanol supply in the context of conventional uses, an assessment of the potential for methanol as a neat transportation fuel or as a blending component for producing transportation fuels, and an analysis of the traditional uses and sources of methanol and supply and demand projections through the year 2015. The existing methanol markets and producers are also profiled.

- United States Regional Fuel Markets: a definition of historical and forecast profiles of supply, demand and trade for refined petroleum products by major region within the United States, and an evaluation of historical and forecast trends of crude oil quality by region. Five regions, based on the Department of Defense Petroleum Administration for Defense Districts (PADD) were evaluated.

- Technology Evaluation of Selected Alternative Fuels: a comparison of competing technologies' production costs and performance with that of FT liquids and methanol over the period from 2006 to 2015. The 2006 analysis was based on the current stateof-the-art technologies (i.e., recently or currently announced projects) that are expected to be on-stream in the 2006 timeframe. The 2015 economics included learning curve effects, economies of scale and selection of future technologies. 
- Technical Issues for UCF Use in Transport: a definition of the technical issues, status and potential for Ultra Clean Fuels (UCFs) in the vehicle transportation sector. The timeframe considered is from the current period to 2015. Where appropriate, longer-term issues were addressed where they were believed to impact short-term developments.

- Methanol Distribution Infrastructure Issues: an evaluation of issues related to methanol distribution infrastructure that impact its potential as a transportation or stationary power fuel, and of strategies to overcome any hurdles to its use. There is an existing methanol distribution infrastructure for serving current conventional methanol markets (chemical uses and MTBE feedstock). However, a much larger distribution infrastructure will be required if methanol becomes a significant transportation fuel.

- Impact of FT Diesel on U.S. Refineries: development of a linear programming model for different PADDs, a determination of the volumes of FT Diesel that can be economically blended with petroleum-derived fuels, and evaluations of the modifications that may be required in existing refineries to process FT Diesel and the value of FT Diesel to refiners

- UCF Values and Market Potential: development of a basis for valuing FT-diesel, FT naphtha and methanol over the period 2002-2015, and to provide a view on potential markets for UCF over the 2002-2015 period

This section of the final report is organized to highlight the findings of each of these activities. The full market study report is attached as an appendix to this final report.

\subsection{CONVENTIONAL FUELS MARKET OVERVIEW}

\subsubsection{Macroeconomic Assumptions}

The following economic assumptions were used in the market assessment.

The world economy was projected to grow only modestly in 2002 with GDP rising by 1.9 percent over 2001. Overall economic activity is expected to benefit from low inflationary pressures and relatively low and stable crude oil prices. The global economy is predicted to grow at an average rate of 3.1 percent over the next decade, roughly in line with historical trendline performance.

The GDP deflator is the broadest measure of inflation, reflecting the combined experience of government (federal, state and local), businesses, and consumers. Nexant utilizes the U.S. GDP deflator as the basis for converting financials between current U.S. dollar (inflated) and constant U.S. dollar (non-inflated) financial data. The U.S. GDP deflator has declined significantly over the past 30 years, averaging 7 percent annually during the 1970s, 4.3 percent during the 1980s, and 2.2 percent during the 1990s. Nexant forecasts that inflationary pressures will remain at the low end of historical values, with a forecast trendline value of 2.5 percent annually. 


\subsubsection{Crude Oil Price Outlook}

Recognizing the uncertainty associated with forecasting crude oil prices, Nexant forecasted a future range of crude oil prices that were designed to capture the likely range of actual prices. It should be noted that forecast prices are trendline in nature, and no attempt has been made to try to capture short-term volatility of crude oil pricing. Reflecting these factors, Nexant's envelope of prices (all in constant 2001 dollars) for FOB Brent crude oil is:

- A "High Oil” case at \$22.0 per barrel in 2003, declining to \$20.5 in 2015

- A “Medium Oil” case at \$18.0 per barrel in 2003, declining to \$16.8 in 2015

- A "Low Oil” case at \$ 14.0 per barrel in 2003, declining to \$13.0 per barrel in 2015

After 2003, crude oil prices were projected to decline at 1.0 percent per year in real terms until 2010, after which prices are forecast to stabilize in real terms. This decline in price reflects trends in other commodities, which continue to show reductions in real prices due to continuing gains in production efficiency. Stabilization of real prices after 2010 reflects the increased potential for a tightening of petroleum availability on a global basis by that time.

\subsubsection{Environmental Regulations}

Current and future environmental regulations that will impact the quality of gasoline and diesel fuels have been reviewed and forecast in the body of the report. The primary trend that will impact gasoline and diesel quality is continued reductions in sulfur content of gasoline and diesel that will continue in all regions of the world. By 2015 about 50 percent of global diesel is forecast to have a sulfur content of 15 ppm or less

\subsubsection{Trends in Global and Regional Refinery Capacity}

The global and regional refining industry has been profiled within the main report. A key finding is that each region's refining industry is unique, with different characteristics and capabilities to meet local product requirements (mix of products as well as quality). Indicative of this range of capabilities is a profile of global refining complexity, higher values indicating straonger capabilities for refiners to producer higher yields of high value products, and to produce higher quality (e.g. lower sulfur content) products

\subsubsection{Global Trade of Primary Refined Products}

Production and consumption of each major refined product has been evaluated for the major regions of the world. An analysis of the resulting regional trade balances indicates the following key product trade trends:

- The gasoline deficit in the United States will continue to be met by exports from Canada, Latin America and Western Europe, and reduced U.S. exports to Mexico following the completion of major refinery investments in Mexico.

- Demand growth for middle distillates in East Asia and Europe is expected to exceed increases in local production. The increased deficits will be met by increasing exports from the Middle East and the FSU. 
- Growing residual fuel oil deficits in East Asia will primarily be met by increased exports from the Middle East and a shift in Western Europe's trade position from a deficit to roughly a balanced position.

- Naphtha deficits in Western Europe and East Asia are projected to increase, met by growing supply from Africa and the Middle East

\subsection{ETHYLENE INDUSTRY OVERVIEW}

Ethylene is used to produce a wide variety of petrochemicals, but demand is driven by polyethylene. Greater than 50 percent of the ethylene consumed on a global basis is used to produce polyethylene. This is expected to increase to over 60 percent by 2015. Global ethylene demand and production are forecast to grow at an average annual rate of 4.3 percent through 2015. In developed regions such as the United States, Western Europe, and Japan, the industry is mature and demand growth is expected to be moderate, with growth over the forecast period ranging from 0.1 percent in Japan to 2.2 percent in the United States. In developing regions such as most of Asia, Latin America, and the Middle East, growth will continue to be strong, ranging from 6.1 percent in Asia to 9.8 percent in the Middle East.

In 2000, the United States (28 percent), Western Europe (22 percent), Asia (20 percent), and Japan (9 percent) were the four largest producers of ethylene. This pattern is expected to shift significantly in the future. By 2015, the leading producers will be Asia (25 percent), the United States (20 percent), the Middle East (16 percent), and Western Europe (15 percent).

About fifty percent of global ethylene production is naphtha-based. The portion of naphthabased production varies significantly by region. In terms of percent of feedstock, the leading naphtha-based regions are Japan, Eastern Europe, Western Europe, and Asia. Ethane is the next largest feedstock, with more than 25 percent of global production. The leading ethane-based regions are the Middle East/Africa, Canada, Latin America, and the United States.

Driven by demand for polyethylene, ethylene production is expected to show good growth on a global basis. Naphtha will continue to be a major feedstock for ethylene production, accounting for approximately 45 percent by 2015. Based on the ethylene production forecast, the amount of naphtha required in 2015 will be approximately 70 percent greater than what was required in 2000, an increase of 106 million metric tons.

This represents a large market requiring a significant increase in feedstock supply, thus presenting an opportunity for FT naphtha. FT naphtha can be used in any cracker that uses conventional naphtha. The best opportunities would exist in countries where naphtha is already used as an ethylene feedstock since these countries generally already have established markets for the co-products. Given the high quality of FT naphtha, Nexant believes that it can readily be placed in any market. The projected market for naphtha is expected to increase about 2.7 million BPD by 2015 - well in excess of potential supply from GTL facilities. 


\subsubsection{Alternate Markets for FT Naphtha}

Alternatives to producing ethylene are not considered viable for FT naphtha. These alternatives include:

- Uses as a refinery feedstock which would require too much high cost processing

- Specialty markets are too small with high barriers to entry

- Use as a fuel cell fuel is considered unlikely by 2015.

The most likely target market for FT naphtha produced in a Mideast GTL plant is the Asian ethylene industry due to the high growth in this region and the region being a major naphtha importer.

\subsubsection{FT Diesel - Technical Suitability as an Ethylene Feedstock}

Typical FT diesel properties were supplied to four of the top ethylene technology licensors (Kellogg Brown \& Root, Linde AG, ABB Lummus and Stone \& Webster) to obtain yield data for steam cracking of FT diesel. The data obtained from the licensors was compared to typical yields that are obtained from cracking conventional gas oils. This data comparison covered a range of operating severities. In this case, the severity of the operation is measured by the overall propylene to ethylene ratio (of ethane and propane to extinction). A low severity operation has a high propylene to ethylene ratio and conversely a high severity operation has a low propylene to ethylene ratio.

The results of this analysis indicates that FT diesel potentially is a very good cracker feed, with the following characteristics:

- Propylene to ethylene yield ratios are shown graphically in Figure 6.2 and indicate that FT diesel feedstocks have similar yields to conventional feeds at equivalent operating severities.

- Combined ethylene and propylene yields are shown in Figure 6.3 and indicate that FT diesel yields will, on average, have measurably superior combined yields of ethylene and propylene at the equivalent operating severity compared to conventional feedstocks.

- The ethylene product to gasoil feed ratio indicates that less feed is required to produce the equivalent amount of ethylene product when employing an FT feedstock.

\subsubsection{FT Naphtha - Technical Suitability as an Ethylene Feedstock}

Typical FT naphtha properties were supplied to four ethylene plant licensors (Kellogg Brown \& Root, Linde AG, ABB Lummus and Stone \& Webster) to obtain yield data for steam cracking to ethylene and other chemicals. The licensors indicated that the paraffinic nature of the FT naphtha allows for a higher severity operation than might be normally considered when compared to conventional naphtha cracking. 
Similar to FT diesel, the analysis of this data indicates that FT naphtha has the potential to be a very good cracker feed, with the following characteristics:

- The propylene-to-ethylene ratios for conventional and FT naphtha feedstocks indicate similar yield structure for both feedstocks at equivalent operating severity

- Combined ethylene and propylene yields indicate better combined yields for FT naphtha at equivalent operating severity

- The ethylene product to naphtha feed ratio indicates that in all cases less of the FT feed is needed to produce the same amount of ethylene.

The overall conclusion of this analysis is that FT naphthas can be expected to be excellent steam cracker feedstocks for the production of ethylene.

\subsubsection{FT Diesel - Economics as an Ethylene Cracker Feedstock}

The economics for cracking FT diesel are superior to conventional gas oils as an ethylene feedstock with a projected premium of between \$11 and 31 per ton. However, a gas oil cracker requires higher capital investment (+25\% compared to naphtha or NGLs), making this option less likely. In addition no gas oil crackers are being built at this time.

\subsubsection{FT Naphtha - Economics as an Ethylene Cracker Feedstock}

The higher quality for FT naphtha is expected to result in a price premium of \$19-24 per ton versus conventional naphtha based on superior yields and cracking economics.

\subsection{METHANOL CONVENTIONAL MARKETS}

Nexant forecast that conventional global methanol demand would grow from 29.9 million metric tons in 2001 to 32.6 million metric tons in 2006. Global demand was projected to decline to 31.2 million metric tons in 2007 due to the phase out of MTBE in the United States. Thereafter, conventional methanol demand will resume growth, reaching 40.1 million metric tons by 2015 .

United States conventional methanol demand is forecast to decline from 8.7 million metric tons in 2001 to 7.15 million metric tons in 2015, primarily due to a drop in MTBE production to minimal levels.

Methanol capacity worldwide was 37.7 million metric tons per year at the end of 2001. The uncertainty about the future demand for MTBE has made the development of new methanol capacity difficult at present. There has been a trend towards larger methanol plants. In 1990, a world scale plant had a capacity of 660 thousand metric tons per year. Currently, a world scale plant is about 1 million metric tons per year, and new projects are being developed with capacities of over 2 million metric tons per year.

In 2001 and 2002 several methanol methanol plants closed down due to:

- Recent additions of new capacity in low cost feedstock regions

- A slowing global economy 
- Fly-up in the price of North American natural gas feedstock

Nexant expects further permanent plant closures as operators of older plant in North America and Western Europe conclude they are not competitive with larger plants in gas-rich countries. Global methanol supply and demand will continue to be in oversupply until the latter part of this decade. This surplus supply will provide a potential driving force for development of new fuel methanol markets over the next five to ten years.

\subsection{UNITED STATES REGIONAL FUELS MARKETS}

Total U.S. refined product demand is forecast to increase by 1.1 percent annually over the 20012015 period. This is somewhat lower than the 10 year historical average of 1.3 percent, and reflects the somewhat lower outlook for economic growth as well as potentially higher pricing of crude oil and products that is expected for the forecast period. Key drivers and assumptions behind these demand projections include:

- High gasoline demand growth during the 1990 s was driven by a number of "stepchange" factors, including the rapid growth in lower mileage Sport Utility Vehicles (SUVs) and the very strong economic expansion experienced in the United States during this period. The projected growth rate in gasoline demand of 1.1 percent annually assumes that there will be a modest increase in average vehicle fleet efficiency, but that alternatively-powered vehicles will not materially impact gasoline demand during the next 10 years

- Jet fuel consumption is expected to grow 0.8 percent per year, reflecting expected continuing gains in engine efficiency in the commercial air fleet as well as a negative step-change in use that has occurred due to the impact of September 11 attacks

- Limited growth in off-highway uses of middle distillates, in particular due to continued loss of the residential heating market to natural gas, will offset continued growth in on-highway diesel fuel. Combined growth in on-highway and off-highway uses is expected to average 1.3 percent annually

- Residual fuel oil use, after suffering a step-change reduction in demand between 1994 and 1995, has achieved demand in the 850-950 thousand barrels per day (KBPD) range through 2001. Future consumption is forecast to decline about 0.4 percent annually

- "Other products" consists of a wide range of relatively minor products, including gas liquids (ethane, propane, normal and iso-butane, and pentanes plus), asphalt, chemical feedstocks, petroleum coke, lubricants, waxes, kerosene and miscellaneous products. A number of these products, such as lubricants, and waxes, are very mature with limited growth potential. Others, in particular feedstock for chemical production, are expected to have high growth rates. On balance, this category of products is expected in grow about 1.4 percent annually, somewhat higher than overall petroleum demand growth 
PADD 1 has the highest level of petroleum consumption, with about 36 percent of the national total. This is followed by PADD 2 with about 27 percent, and PADDs 3 and 5, each with about 16-17 percent. PADD 4, reflecting its very sparse population, accounts for about 3.5 percent of national demand. This distribution of demand is very similar to the distribution of population within the United States, indicating a similar level of per capita consumption across the nation.

\subsubsection{Refined Product Production}

Total domestic production of refined products in the United States will increase throughout the forecast period, with an average growth rate of about 1.1 percent per year, in line with average growth achieved over the previous 10 years. By 2015, refined product output is expected to reach 20.2 million bpd, up 16 percent from 17.3 million bpd in 2001. Consistent with the outlook for consumption, distillates and other products are expected to have the highest annual rate of production growth through 2015.

PADD 3 has the highest level of petroleum production, with about 46 percent of the national total. This is followed by PADD 2 with about 21 percent, PADD 5 with 17.5 percent, and PADD 1 with 12 percent. PADD 4, reflecting its very sparse population, accounts for about 3.3 percent of national production.

Future distribution of demand for refined petroleum products in the United States is expected to remain relatively stable, similar to historical performance.

\subsubsection{Crude Oil Quality Trends}

The gravity of domestic and imported crude oils along with the composite average underwent a steady deterioration of quality over this period 1980 to 2001.

The average composite crude oil sulfur levels rose from about 0.8 weight percent in 1980 to over 1.3 weight percent in 2001. Increased imports of heavy Canadian, Mexican and Venezuelan crudes have been the major underlying factors driving the long-term increase in crude oil sulfur levels.

Average crude oil quality in the United States is forecast to continue to decline, becoming heavier and higher in sulfur content. Key assumptions behind this outlook include:

- Increased heavy offshore Gulf of Mexico crude production will contribute to a gradual decline in domestic crude oil quality, somewhat offset by a slowing in the rate of decline in Alaskan crude production

- Increased heavy, sour crude oil imports from Venezuela and Canada will be primarily responsible for the forecast heavying up of the crude oil import barrel and the resultant decline in composite crude oil slate quality

Crude oil quality by PADD varies considerably relative to the national averages. Crude oil quality in all PADDs is expected to follow national trends, i.e. average crude oil will become heavier and higher in sulfur content in all regions. It is expected that crude oil quality in PADD 3 will decline somewhat faster than in the other regions, reflecting the assumption that a 
disproportionate percentage of new investment in the United States refining industry will take place in expanding and enhancing the already dominant refining industry at the USGC. Such new investment will tend to allow processing of poorer quality crude oils, and the resulting crude oil slate that the USGC will thus decline somewhat faster than elsewhere in the country.

The U.S. refining industry consists of about 150 operable refineries. Average processing capabilities have been on the rise since the 1980s. The number of operating refineries in the United States has steadily decreased during the 1990s, reflecting the combined impacts of generally low refining margins as well as industry consolidation. The average refinery size has increased steadily over the last 40 years, as the need to achieve economies of scale has reduced the competitiveness of smaller facilities.

Crude oil distillation capacity is forecast to increase by about 2.5 million barrels per day between 2001 and 2015, reflecting a 1 percent annual growth rate, which is considered a sustainable range of capacity creep for the domestic industry. Investment in downstream refining facilities, in particular hydrotreating, hydrocraking and coking, is expected to result in an increase in the percent of each of these units expressed as a percentage of crude oil distillation capacity. MTBE capacity in the United States is expected to be completely shut down by 2015.

Refining capacity is highly concentrated in PADD 3, with about 46 percent of the national total. PADD 2 (21 percent) and PADD 5 (19 percent) have substantial refining industries. PADD 1 has relatively limited refining capacity relative to its level of consumption, and as a result is the country's primary importer of refined products. PADD 4, reflecting its sparse population and isolation, has limited refining capacity of about 3.5 percent of the national total, roughly in line with its consumption share.

\subsubsection{Petroleum Trade}

The United States has historically been a significant importer of petroleum products. Total product imports have averaged about 2 million barrels per day between 1970 and 1998, or about 12 percent of consumption of total refined products. Product imports are expected to increase only marginally over the next 20 years, reflecting the combined impact of the following factors:

- U.S. refining capacity is expected to increase about 1 percent per year, via capacity creep of existing refineries

- Projected demand for U.S. refined products is expected to grow about 1.1 percent per year, only slightly higher than the rate of growth in domestic refining capacity

- Availability of suitable quality refined products from outside the United States may become constrained as U.S. quality standards become increasingly more stringent

PADD 1 receives over 80 percent of total foreign-sourced product imports, with about 9 percent each coming into PADDs 3 and 5. The interior of the country, PADDs 2 and 4, receives very little foreign-sourced product imports.

PADD 1 receives about 70 percent of product imports, most of which is supplied from PADD 3. PADD 2 receives about 25 percent of domestically sourced supplies, also supplied largely from 
PADD 3. PADDs 4 and 5, reflecting their geographic isolation, have limited supply links to the rest of the country. PADD 3, reflecting its major production surplus position, receives very little supply from other parts of the country.

\subsection{TECHNOLOGY EVALUATION OF SELECTED ALTERNATIVE FUELS}

\subsubsection{GTL FT Liquid Products}

For 2006, the full cost of production plus 10 percent ROI for FT liquids produced at a 75,000 barrels per day facility in a Middle East remote location will be about $\$ 27.58$ per barrel if natural gas cost is $\$ 1.00$ per million BTU. Taking into account transportation costs and tariff, the total delivered cost of FT liquids will be \$30.72, \$29.88, and \$29.67 per barrel at the USGC, Western European, and Japanese markets, respectively.

Based on Nexant's 2006 medium crude price outlook and the weighted average naphtha/diesel market prices of \$24.5, \$24.5 and \$28.2 per barrel at the USGC, Western Europe, and Japanese markets, respectively, the GTL process with natural gas price at \$1.00 per million BTU can deliver FT products at a return on investment of 1.2, 2.3, and 7.9 percent to the above markets respectively.

For 2015, the full cost of production plus 10 percent ROI for FT Liquids produced at a 150,000 barrels per day facility in a remote Middle East location will be about $\$ 24.54$ per barrel if natural gas cost is $\$ 1.25$ per million BTU. Taking into account transportation costs and tariff, the total delivered cost of FT liquids will be \$28.09, \$27.15, and \$26.91 per barrel at the USGC, Western European, and Japanese markets, respectively.

Based on Nexant's 2015 medium crude price outlook and the weighted average naphtha/diesel market prices of \$29.1, \$29.4 and \$33.3 per barrel at the USGC, Western European, and Japanese markets, respectively, the GTL process with natural gas price at \$1.25 per million BTU can deliver FT products at a return on investment of 12.2, 14.5, and 22.8 percent to the above markets respectively.

The above GTL full costs of production plus 10 percent ROI are compared favorably with the costs of production of a USGC conventional coking refinery at \$29.11 and \$35.06 per barrel of refined products for 2006 and 2015, respectively. The USGC delivered cost of FT liquid product also shows a better profit margin than the conventional refinery products.

\subsubsection{Methanol}

For 2006, the full cost of production plus 10 percent ROI for methanol produced at a 5,000 metric tons per day facility in a Middle East remote location will be about $\$ 0.285$ per gallon if natural gas cost is $\$ 1$ per million BTU. Taking into account transportation costs and tariff, the total delivered cost of methanol will be $\$ 0.364$, \$0.359, and \$0.340 per gallon at the USGC, Western European, and Japanese markets, respectively.

Based on Nexant's 2006 medium crude price outlook, the Mega Methanol Process with natural gas price at \$1.00 per million BTU can deliver methanol at a return on investment of 5.9, 19.0, 
and 26.0 percent based on USGC gasoline, CARB gasoline, and USGC chemical grade methanol, respectively.

For 2015, the full cost of production plus 10 percent ROI for methanol produced at a 15,000 metric tons per day facility in a Middle East remote location will be about $\$ 0.277$ per gallon if natural gas cost is $\$ 1.25$ per million BTU. Taking into account transportation costs and tariff, the total delivered cost of methanol will be \$0.367, \$0.346, and \$0.339 per gallon at the USGC, Western European, and Japanese markets, respectively.

Based on Nexant's 2006 medium crude price outlook, the Mega Methanol Process with natural gas at \$1.25 per million BTU can deliver methanol at a return on investment of 13.6, 25.8, and 41.6 percent based on USGC gasoline, CARB gasoline, and USGC chemical grade methanol, respectively.

In general, the ROI for methanol is higher than that of FT liquid products. While both methanol and GTL ROIs improve significantly from 2006 to 2015, the improvement for methanol is more pronounced than that of GTL.

\subsubsection{Ethanol}

For 2006, the full cost of production plus 10 percent ROI for ethanol produced at a 50 million gallon per year facility in a U.S. Midwest location will be about \$1.12 and \$1.88 per gallon from corn and biomass, respectively. These costs compare unfavorably to ethanol blending value of $\$ 0.80$ per gallon and unleaded regular gasoline of $\$ 0.61$ per gallon.

For 2015, the full cost of production plus 10 percent ROI for ethanol produced at a 150 million gallons per year facility in a U.S. Midwest location will be about \$1.06 and \$1.30 per gallon from corn and biomass, respectively. These costs compare unfavorably to ethanol blending value of \$0.93 per gallon and unleaded regular gasoline of \$0.73 per gallon.

\subsubsection{Syngas/Hydrogen}

The economics for syngas production are driven by the underlying cost of natural gas. Natural gas feedstock makes up about $50 \%$ of the cost of production hydrogen.

Comparing steam methane reforming (SMR) with partial oxidation (POX) economics, SMR has lower costs for producing hydrogen since it produces less carbon monoxide. Thus, SMR is the logical choice for hydrogen production based on the optimal syngas composition.

\subsection{TECHNICAL ISSUES FOR UCF USE IN TRANSPORT}

\subsubsection{Key Developments in Conventional Vehicle Technology}

The primary drivers for the potential development of methanol and FT naphtha or diesel as UCFs are:

- Requirements for refiners to drastically reduce the sulfur content of diesel fuel to enable use of particulate traps and catalytic converters to achieve significant reductions in fine particulate (PM or soot) and NOx emissions. The recent and 
anticipated technical development of these emission after-treatment devices has prompted the U.S. and the European Union to adopt emission standards that are designed to force the use of these devices on heavy-duty diesel engines.

- The desire among vehicle manufacturers to begin early development and demonstration of technical and market approaches to cope with the expected eventual decline of petroleum supplies for fueling vehicles in the longer term, along with:

- Increasing levels of sulfur in crude oil supplies in the near term

- The greater abundance of natural gas supplies, including "stranded gas"

- These drivers have led the manufacturers of gasoline engine passenger automobiles for the North American market, along with government agencies and other stakeholders, to focus on developing gasoline-electric hybrids for the short term and fuel cell vehicles and auxiliary power units (APUs) for the long term. In addition to the need for cab amenities in long-haul trucks, auxiliary (non-propulsion) power requirements, including many systems that in the past were manual or mechanically linked to the engine, are increasing in proportion to propulsion power in conventional trucks and automobiles.

- Manufacturers of heavy-duty diesel engines have focused on fundamental internal engine design modifications, primarily in fuel injection and combustion configurations, to achieve lower NOx and PM emissions, in addition to add-on particulate traps and catalytic converters. APUs are also of great interest in these vehicles.

- Despite tremendous on-going development efforts, Nexant does not expect FCVs to achieve significant commercial market share within the next 10-20 years. Hybrid gasoline-electric or diesel-electric automobiles will strongly compete with FCVs, especially if more stringent fuel economy standards are mandated or encouraged via tax credits, or other incentives and subsidies.

- The most popular ICE hybrid-electric vehicle models are initially likely to follow current preferences and be gasoline-fueled in the U.S. and diesel-fueled in Europe. These hybrid vehicles will not necessarily require the use of fuels with radically more stringent quality requirements

\subsubsection{FT Diesel as a Vehicle Fuel - Conventional Engines}

- Nexant believes that there are minimal impediments presented by engine technology issues for FT diesel use as a supplement to, or replacement for, conventional petroleum derived diesel fuel in conventional diesel engines

- Nexant believes that the impediments are no greater for FT diesel use in the advanced technology engines being developed

- FT diesel appears to have its greatest potential as a blendstock to achieve the ultra low sulfur levels needed to meet emerging regulations for NOx and PM and enable emissions controls in future diesel fuel in North America, Europe, Japan and 
elsewhere (in either hybrid or conventional vehicle configurations). Significant market penetration could be achieved by 2015 .

- Based on their technical qualities, market penetration already achieved and their growth rates, CNG/LNG and biodiesel could compete with FT diesel, but methanol is not a serious contender as a fuel for ICE vehicles. Biodiesel will always be limited in its production volume potential, but can be advantageously blended to enhance FT diesel's lubricity.

- The EPA and other stakeholders need to collaborate to set specifications for FT diesel because lack of standards is a key objection of engine providers. The stakeholders that must collaborate are:

- Engine providers

- Regulators (federal and state)

- Fuel makers

- Customers (fleet owners)

\subsubsection{FT Diesel for Fuel Cells}

FT diesel offers no technical advantages versus, say, ultra low sulfur gasoline, CNG, or alcohols for reforming to hydrogen for use with lower temperature vehicle fuel cells (e.g., PEMs) or for potential direct in use in SOFCs. Neither the introduction of hybrid vehicles or fuel cell vehicles is expected to result in major increases in the demand for FT diesel as a fuel during the next 10-15 years

\subsubsection{FT Naphtha as a Vehicle Fuel}

FT naphtha has insufficient octane to be useful in spark-ignited gasoline internal combustion engines (ICEs). However, because it is paraffinic and essentially sulfur-free, it may be attractive to use it in fuel cells with reformer systems, potentially directly in SOFCs applied in APUs and/or in hybrid propulsion systems. Developers of fuel processing systems (reformers, etc.) are testing FT naphtha for vehicle fuel cells.

\subsubsection{FT Naphtha Fuel Cells}

FT naphtha has some potential for use with reformers in lower temperature vehicle fuel cell propulsion systems or in SOFCs for APUs. In competition with methanol, naphtha has even less infrastructure, but is potentially more compatible chemically with the hydrocarbon fuel infrastructure.

\subsubsection{Methanol as a Vehicle Fuel - Conventional}

As a conventional ICE vehicle fuel, methanol is technically demonstrated but is not market attractive.

- Despite extensive support from the California and federal governments, methanol interests, auto and diesel engine companies, and the cooperation of the petroleum 
industry, there are very few ICE vehicles currently running on methanol in the U.S. today (fewer than for any other salient alternative fuel)

- Methanol was tested for many years as an ICE fuel in California as a strategy to reduce air pollutant emissions and reduce dependence on petroleum liquids. Despite these efforts, methanol was not a commercial success.

- Methanol fuel has not found enthusiastic consumer acceptance because it:

- Has challenges in materials compatibility, and because of this, it is impractical to retrofit an auto for its use and new cars designed for dual fuel would cost more than gasoline-only engines, unless subsidized

- Offers no real advantages in price, convenience or performance

- Has not been subsidized as has ethanol, and lacking comparable political support, is unlikely to receive required subsidies in the future

- Methanol's relatively low energy density (roughly half of that of gasoline) has been a real impediment to acceptance in terms of vehicle range, and there are concerns over its toxicity and other health, safety and environmental issues

- The neat methanol (M100) option is not practical for cars primarily because of cold start problems

- The option of using gasoline-blended methanol (M85) in flexible fuel vehicles currently seems to have little potential for light duty gasoline-type passenger automobiles in the U.S. because it requires special, more expensive car designs without a significant savings in fuel cost or other advantages to the consumer

- Neither M100 nor M85 has been seen as attractive to date for heavy duty diesel transit vehicles and trucks because it has a very low cetane rating, incompatible with diesel engines, and has no advantages for the owner/operator

- Despite all the demonstrations and its status as a commercial commodity, there appears to be a low little probability of its widespread commercialization for any methanol ICE fuel in the U.S. or Europe. Methanol is not expected to gain any share of the conventional vehicle fuel market in the timeframe of this report.

- Japan currently seems to have a greater interest in fuel methanol in general.

- The methanol industry has largely abandoned its support of methanol in ICEs for the reasons listed above, but the industry is now instead championing methanol use in fuel cells, especially for vehicle and portable power applications

\subsubsection{Methanol Fuel Cells}

- The preferred fuel for initial fuel cell vehicle models has not been determined, but if technical advantages weigh heavily in the determination, then it is more likely that methanol (because of its lead in DMFCs and its higher efficiency in reforming), rather than ultra clean hydrocarbon fuels such as FT naphtha or naphtha, will be selected for this purpose. 
- Even if DMFC fuel cells were to be widely commercialized for consumer small electronics, such as cell phones and laptops despite the regulatory and corporate risk challenges, their methanol demands would be relatively small.

\subsection{METHANOL INFRASTRUCTURE ISSUES}

The following options for fuel methanol uses have been analyzed from the perspective of required infrastructure to support:

\subsubsection{Neat fuel supplied for internal combustion engine vehicles}

Neat or near-neat (M85) methanol was demonstrated in California in the 1990s as a fuel for fuelflexible vehicles capable of using either M85 or gasoline. At its peak, there were about fifteen thousand flexible fuel vehicles and over fifty public service stations operating on methanol. However, the program was a commercial failure. Methanol could not economically compete with gasoline because its energy density is only one-half that of gasoline, and thermal efficiency of methanol in an internal combustion engine is similar to that of gasoline.

\subsubsection{Methanol blended with conventional gasoline}

Methanol blends in gasoline and neat methanol in internal combustion engines are not projected to be commercialized in the future. Methanol blends were commercially demonstrated in the early 1980s. ARCO and Sunoco both marketed a blend of about 5 percent methanol and 5 percent tertiary-butyl alcohol with a total oxygen content of 9.6 percent (comparable oxygen content as ethanol blends) in the northeast U.S. out of refineries in Philadelphia. However, the products were abandoned in the mid-1980s due to the sensitivity of methanol to water present in the conventional gasoline distribution system.

\subsubsection{Methanol use in fuel cell vehicles}

Methanol fuel cell vehicles are projected to have a lower fuel cost per mile than hybrid vehicles operating on gasoline. However, the economic incentive to the consumer is only about 100 dollars per year per vehicle. Penetration of methanol fuel cell vehicles is projected to be less than 2 percent of the total light vehicle transportation fuel market through 2015. Initial commercialization is projected to be in the state of California followed by one other major metropolitan area, possibly the New York area.

\subsubsection{Methanol distribution infrastructure}

\subsubsection{Requirements for Significant Market Penetration}

Methanol distribution infrastructure investment costs in the U.S. could total as much as $\$ 6.5$ billion dollars for methanol to capture 20 percent of the light vehicle transportation market.

However, this investment could be phased in over time as an extension to the existing methanol distribution infrastructure. It is likely to involve the companies that represent the independent fuel distributors as well as existing methanol suppliers and the major integrated oil companies 


\subsubsection{Comparison of Methanol Distribution Infrastructure Requirements with Other Alternative Fuels}

The capital investment for retail service stations designed to dispense methanol, CNG, LNG and hydrogen were compared. Methanol retail outlets cost a fraction of those for the other clean fuel alternatives.

There are over 240 CNG stations currently operating in California. Over 100 offer full or partial public access. CNG stations cost approximately ten times the cost of a methanol station.

There are over 140 LNG stations operating in California. LNG storage requires double walled, stainless steel, "superinsulated" storage tanks. Because of the higher cost, LNG has primarily been used for buses and other heavy fleet vehicles to ensure maximum throughput. The operating costs are lower than for CNG, since no compressor is required. However, training costs are higher and maintenance costs have been estimated at 3 to 6 cents per gallon ${ }^{1}$. LNG stations must meet similar standards and codes as CNG stations.

Some LNG stations are designed to also supply CNG. Such systems consist of a conventional LNG station with the addition of high-pressure cryogenic pumps that compress the LNG to 4 to 5 thousand psi, and then vaporize the compressed liquid. The advantages of these combined stations (L/CNG systems) is that the cryogenic pumps consume much less energy than the compressors used at conventional CNG stations and require less maintenance. Second, L/CNG is delivered to the vehicle at ambient temperature, facilitating complete filling of the vehicle storage tank and eliminating the need for temperature compensation systems. Furthermore, since LNG is nearly pure methane, $\mathrm{L} / \mathrm{CNG}$ is delivered to the vehicle with virtually no contaminants or undesirable fuel elements such as oil carryover, moisture, and higher hydrocarbons.

There is less commercial experience with hydrogen stations. Only a few hand-built first generation stations have been built, including two different systems in California used by Sunline Transit to fuel its direct-hydrogen fuel cell bus in the Coachella Valley. For this reason, the capital costs for hydrogen stations are not fully known at this time. Station designs are only conceptual at this stage, and few hydrogen-specific codes and standards exist. Capital cost will depend, in part, on whether a liquefied hydrogen or compressed form of hydrogen will be stored and/or produced at the station by reforming natural gas. In either case, costly fire and safety requirements are likely to be the norm, especially in the early years of deployment. Recent estimates for first-generation stations being built in Sacramento and other areas under the California Fuel Cell Partnership indicate that they can cost between 2 and 3 million dollars each.

\subsection{IMPACT OF FT DIESEL ON U.S. REFINERIES}

The analysis performed in this section has examined the potential impact of FT diesel fuel on U.S. refining operations.

The study analysis was structured to evaluate refinery configurations that were deemed to be representative of average refining industry operation and structure in key regions of the United

${ }^{1}$ Jim Harger, Vice President of Marketing, Pickens Fuel Corporation, 12/6/00. 
States. Therefore, the results of this analysis should be considered from this perspective, as average representative values for FT diesel. However, it should be recognized that the value of FT diesel for some specific refineries, especially those producing diesel with a cetane number close to the minimum specified level, may be higher than those estimated in this analysis.

Key findings include the following:

\subsubsection{Impact of FT Diesel on Refinery Operations}

- Using FT diesel as a diesel blendstock, in small volumes, is expected to have little impact on refinery process unit operations in 2006 and beyond. The primary reason for this conclusion is that FT diesel quality is very close to finished ULSD product quality specs (i.e., 15 ppm sulfur specification) and, the stream can be used directly as a blendstock without processing by refinery unit

- The primary processing impact on refining operations of blending of FT Diesel was a reduction in required Distillate Hydrotreater desulfurization severity, which resulted in lower hydrogen usage and lower catalyst and utilities costs

- For each refinery operation considered, the initial volumes of FT diesel blended generate the highest value to the refiner. As the volume of FT diesel blended increases, the refinery must begin to make processing adjustments in order to make on-specification diesel product. These adjustments are required to compensate for the low density of FT diesel, and the value of the FT diesel declines at these higher blend rates

- For each region considered, FT diesel value to refineries is attractive only at relatively low blending levels, typically in the range of 4-5 percent of crude oil processed. Thereafter FT diesel values decline rapidly and eventually fall below the value of conventional diesel fuels

\subsubsection{Value of FT Diesel Relative to Market Value}

- Even though there is currently little commercially available, FT diesel, primarily due to its very low sulfur content, would command a premium value to conventional 500 ppm diesel fuel. There will continue to be a premium value over the next 15 years, but the size of the premium will decline as the quality differential between FT diesel and conventional diesel declines

- Based on the analysis performed for this study, PADD 3 (USGC), due to the highly competitive nature of the region, achieved the lowest values in major markets for FT diesel relative to conventional diesel fuels. For blending up to 4-5 percent, the value of FT diesel was estimated to be about $\$ .40 /$ bbl above the market price of diesel

- PADDs 1 (East Coast) and 2 (Midwest) achieved somewhat higher values for FT diesel than PADD 3. For blending up to 4-5 percent, the value of FT diesel was estimated to be about $\$ .40-0.50 / \mathrm{bbl}$ above the market price of diesel

- The California market achieved the highest value for FT diesel, reflecting the value associated with FT diesel's high cetane rating, which is a premium quality in the 
California market. For blending up to 2 percent, the value of FT diesel was estimated to be over $\$ 3.00 / \mathrm{bbl}$ above the market price of diesel. This premium declined to about $\$ 1.00 / \mathrm{bbl}$ at a blending level of 5 percent of crude processed

\subsubsection{FT Diesel Absolute Value}

- The value of FT diesel in absolute terms will reflect the price of conventional diesel plus the premium value of FT diesel to each region's refining industry

- The lowest absolute value for FT diesel is expected in PADD 3 (USGC), primarily reflecting the low market price for conventional diesel as well as low estimated premium for FT diesel

- Somewhat higher absolute values for FT diesel are expected for PADDs 2 and 3, largely reflecting the higher market price for conventional diesel that these markets command

- FT diesel is expected to have the highest absolute value in California due to the generally higher level of product prices in California and the more stringent quality requirements of CARB diesel. In particular, the CARB requirement for a lower aromatics content/higher cetane number necessitates the use of expensive cetane number improver by many California refineries. The use of high cetane number FT diesel as a California refinery blendstock would help to alleviate this constraint

- Due to the high cost of shipping FT diesel to PADD 4 (Rocky Mountain region), it was estimated that the netback value at the USGC of FT diesel on an absolute \$/bbl basis would be less than the market price of conventional diesel

\subsection{CONVENTIONAL FUEL PRICE OUTLOOK}

The methodology utilized in this analysis for forecasting refined product prices can be simplified and broken down into several principal steps:

- Identifying the refinery configuration most representative of a region's incremental producer of refined products

- Forecasting the variable margin for the incremental refinery configuration

- Forecasting price differentials between major refined products

Given the crude oil price outlook and these variable margin and price differential forecasts, the individual refined product prices can be calculated algebraically.

Nexant utilizes a cost-based approach to forecast refined product prices, which is comprised of a projection of the global economic environment (real economic growth and price inflation), the projected underlying international crude oil price, and the business environment for each key refined product. The outlook for each product's price on the U.S. Gulf Coast reflects the industry's expected supply/demand balance and refinery operating rates that determine the price relationships between key products, refinery margins and profitability. The trendline outlook for 
refinery profitability is expected to be in line with historical performance. Profitability margins are expected to decline in real terms due to the commodity nature of the refining business.

Diesel fuel pricing will track underlying prices of crude oil, but, due to expected strong growth and tightening quality specifications, will be at the high end of historical relationships to crude oil price. Thus, diesel fuel will average about $\$ 3.60$ per barrel premium over WTI crude oil over the next 10 years, as compared to an average of about $\$ 2.70$ per barrel over the previous decade.

Conventional naphtha that is suitable as a feedstock to produce ethylene and other basic chemicals is forecast to track pricing of unleaded regular gasoline. On average, conventional naphtha is expected to sell at about 10-12 cents per gallon less than unleaded regular gasoline. This discount reflects naphtha's poor quality as a gasoline blendstock (i.e. low octane and relatively high vapor pressure).

Pricing for methanol in the U.S. market has historically been closely linked to the underlying cost of natural gas, such that leader methanol plants operating in the United States have achieved a modest, but acceptable, level of profitability. Methanol is a feedstock for MTBE production, so that methanol demand in the U.S. will be severely reduced over the next 5-10 years due to the anticipated elimination of MTBE use in U.S. motor gasoline. As a result of this change, most of the methanol facilities currently operating in the United States are expected to shut down, with only 1-2 relatively large facilities still in operation by 2015. Future methanol pricing will be sufficient to provide a modest return for these remaining plants.

\subsection{UCF MARKET POTENTIAL}

\subsubsection{FT Diesel}

The potential for FT diesel to serve as a transportation fuel has been assessed from a number of perspectives in this Market Study Report. Specifically the following has been concluded:

- FT diesel is expected to be an acceptable fuel to help meet low sulfur requirements in vehicle engines and systems that will be developed over the coming decade. There may be a need for lubricity additives due to the very low sulfur content of FT diesels. Details of this analysis are provided in Market Study Report Section VI

- FT diesel is expected to be an acceptable diesel blendstock for United States refineries. Blends containing up to 15-20 percent FT diesel are expected to be economically attractive to produce for domestic refiners. Details of this analysis are provided in Market Study Report Section VIII

- As presented in Market Study Report Section I, the United States market for diesel/gas oil fuel is expected to increase by about 1.4 percent per year, representing an absolute increase of about 730,000 barrels per day between 2001 and 2015. Globally, the market for diesel/gas oil fuel is expected to increase about 2.3 percent per year, or about 5 million barrels per day by 2015. Approximately 60 percent of these volumes are consumed as on-road diesel fuel. A typical worldscale GTL facility is expected to produce about 50,000 barrels per day of FT diesel. Thus, to achieve a 10 percent market share of new U.S. demand by 2015, a total of about 9 
new GTL plants would need to be built and in operation. To achieve the same level on a global basis, approximately 60 new plants would be needed. Realistic projects for GTL capacity construction call for at most 20-25 plants to be built by 2015. As a result, this study concludes that the global market for diesel fuel is sufficiently large and robust to absorb the industry's ability to build GTL facilities over the next 15 years.

\subsubsection{FT Naphtha}

The potential market for naphtha as an ethylene feedstock was evaluated in Market Study Report II. The United States market for naphtha is expected to increase about 2.2 percent per year, or by about 150,000 barrels per day. Global demand for petrochemical-grade naphtha is forecast to increase by 3.6 percent annually, or about 2.3 million barrels per day by 2015. A typical worldscale GTL facility is expected to produce about 18,000 barrels per day of FT naphtha. Thus, to achieve a 10 percent market share of new U.S. demand by 2015, a total of about 9 new GTL plants would need to be built and in operation. To achieve the same level on a global basis, approximately 130 new plants would be needed. Realistic projects for GTL capacity construction call for at most 20-25 plants to be built by 2015 . Therefore, similar to the result for FT diesel, this study concludes that the global market for naphtha as an ethylene feedstock is sufficiently large and robust to absorb the industry's ability to build GTL facilities over the next 15 years.

\subsubsection{Methanol}

As defined in Market Study Report Section VII, the theoretical market for methanol as a transportation fuel is enormous. To put this into perspective, the current demand for chemical methanol in the United States is about 3 billion gallons per year. Achieving a 20 percent market penetration in the United States gasoline market, the minimum level required to achieve a selfsustaining infrastructure, would result in slightly more than tripling the amount of methanol consumed in the country. Substantially larger consumption numbers would apply on a global basis. Thus, the transport market represents a very large area of potential new demand for methanol. However, based on the analysis performed in Market Report Section VI, methanol faces a number of critical barriers to successful commercialization and use as a transportation fuel over the next 15 years. Although many of these problems can be addressed at a technical level, ultimately the key issue comes down to making methanol acceptable to the consuming public. Thus, despite considerable effort and expense, methanol has failed as a transportation fuel due to its low energy density (resulting in limited vehicle range), requirement for subsidies (both for vehicles and fuel) to be economically neutral to consumers, and its potentially significant issues of health/toxicity. As a result of these issues, this study concludes that methanol will not become a significant fuel for conventional motor vehicles over the next 15 years.

In contrast to its limitations for use in conventional motor vehicles, methanol appears to be hypothetically more attractive as a fuel for fuel cells. This potential was also examined in Market Report Section VI. The analysis concluded that the technology for fuel cells is still too immature to achieve significant commercialization within the next 15 years. Fundamental issues 
such as high cost, feedstock limits due to the need to improve fuel reforming technology, limited infrastructure and the long lead-time to commercialize such a fundamentally different transport technology for vehicles has all contributed to this conclusion. Of the fuel cell fuels considered, methanol has some strong advantages. However, they are not sufficient to overcome the more fundamental issues that must first be addressed to commercialize fuel cell technology.

In summary, this study concludes that methanol will not achieve significant demand as a transportation fuel over the next 15 years. 
Section 4

Engine Testing 


\subsection{INTRODUCTION}

Under the Conoco-Phillips - DOE Ultra Clean Fuels Project, Penn State University and Cummins Engine Company were tasked with the duty to perform "Engine Testing" activities under Task 3 of the program. The work performed under Task 3 was organized into three subtasks: Database Compilation and Definition of Testing Needs, which included supporting fuel property analyses and a comprehensive literature survey; Indirect Methanol Fuel Cell (IDMFC) and Direct Methanol Fuel Cell (DMFC) Testing, including IDMFC, DMFC and methanol reformer studies; and Compression Ignition Engine Studies.

\subsection{TASK 3.1, DATABASE COMPILATION AND DEFINITION OF TESTING NEEDS}

The Database Compilation and Definition of Testing Needs task included a detailed literature review in several major subject areas including impacts of diesel fuel formulation, alternative diesel fuels (especially Fischer-Tropsch fuels), methanol reforming for fuel cell applications and the development of PEM fuel cell technologies. This literature review helped to guide the development of the research plans for Task 3. The fuels considered in Tasks 3.1 and 3.3 included a progression of fuels with regard to sulfur content, ranging from conventional low sulfur diesel fuel to ultra low sulfur diesel fuel to various sulfur-free fuels, including GTL diesel. Among the key observations from the literature review were that the compressibility of diesel fuel can significantly alter the injection characteristics of the fuel and alter the timing of injection in a pump-line-nozzle (PLN) type injection system. Another key observation was that fuel composition can have a significant impact on the NOx emissions from diesel engines. This is particularly true for Fischer-Tropsch diesel fuel, which is observed to have a simultaneous beneficial effect on NOx emissions and particulate emissions. This is also true for biodiesel (e.g., soybean oil methyl esters, referred to as "SME" or "biodiesel”) which was selected as an oxygenate to include in the test matrix for this program and is observed to cause an increase in NOx emissions under certain conditions. On this basis, the Penn State activities were expanded to include consideration of the injection and ignition characteristics of various types of fuels and fuel blends.

Also under Task 3.1, fuel property characterization provided essential information on the differences in fuel injection behavior for fuels ranging from methyl esters to pure normal paraffins (e.g., spanning the range from biodiesel to Fischer-Tropsch diesel). The measurements helped to show that the chemical structure of a fuel substantially alters the injection timing and therefore the combustion phasing and emissions formation. These measurements included unique measurements of the bulk modulus of compressibility for a range of fuel samples from purely paraffinic hydrocarbons to vegetable oil methyl esters to complex fuel mixtures. The measurements relied on an experimental apparatus that permits examination of the change in volume of a liquid sample as the pressure applied to the sample is increased. These direct measurements of the compressibility of fuel samples complement similar but less extensive measurements reported by Van Gerpen and colleagues wherein they measured the speed of sound within a fuel sample. Agreement was observed between the two techniques for soybean oil methyl ester and the present work accomplished both an extension of such measurements to 
paraffinic fuels and fuel blends and a direct linkage to behavior of the fuel samples in a diesel fuel injection system.

Injection timing measurements were made in two types of "pump-line-nozzle" fuel systems, one on a single-cylinder DI diesel engine with purely mechanical control (cam driven) of injection timing and one on a 6 cylinder Cummins engine with a rotary fuel pump. In both engines, clear trends were observed wherein fuels with less compressibility led to advanced injection timing (and higher NOx emissions) and fuels with higher compressibility led to retarded injection timing (and reduced NOx emissions). On the Cummins engine, which included electronic control of injection timing, the results were less distinct because in some cases, the differences in calorific value or the cetane number of a fuel sample required a change in the throttle position to achieve the same speed and load from the engine, thereby shifting the engine to a different part of the control map. Nonetheless, the experiments in the single-cylinder DI engine gave a clear indication of the impact of bulk modulus of compressibility on fuel injection timing and emissions, and assisted with the interpretation of results from the Cummins engine. In addition, these results on the impact of fuel formulation on NOx emissions formed the basis of an invention disclosure on a fuel formulation strategy to combat the "biodiesel NOx effect."

Ignition measurements were performed in a modified octane rating engine which had been adapted to permit fuel vaporization and premixing with air and diluents prior to entry to the engine, essentially allowing the octane rating engine to operate as a rapid compression machine. Thus, fuel samples in the lighter end of the diesel boiling range could be mixed with air and compression ignited (with the spark disabled) at various compression ratios. This strategy permits gradual increase of compression ratio from a preignition regime through first stage and finally second stage ignition, during which time the stable exhaust species can be characterized by FTIR spectrometry and collected for GC-MS analysis. Key observations were that GTL diesel behaves much like n-heptane and low sulfur diesel fuel during the ignition process, with regard to the intermediate species through which ignition proceeds. However, methyl decanoate (used as a model for the methyl esters that comprise biodiesel) undergoes a decarboxylation reaction leading to release of $\mathrm{CO}_{2}$ at much lower extents of reaction than other diesel fuels.

\subsection{TASK 3.2, DIRECT AND INDIRECT METHANOL FUEL CELL TESTING}

Under Task 3.2, the activities were organized into two major subtasks: Task 3.2.1 Methanol Fuel Cell Testing, which involved experimental and numerical studies of direct and indirect methanol fuel cells, and Task 3.2.2 Methanol Reformer, which involved the development of a methanol reforming strategy, a supported catalyst to accomplish continuous reforming of methanol and a reformer reactor system to implement the catalyst during operation of a PEM fuel cell (e.g., an "indirect" methanol fuel cell). The two subtasks are linked in that the deliverable from subtask 3.2.2 was essential to the completion of subtask 3.2.1.

\subsubsection{Task 3.2.1 Methanol Fuel Cell Testing}

Under Task 3.2.1, indirect and direct methanol fuels cell experiments and simulation showed how CO generated in the reforming of methanol influences the operation and efficiency of an IDMFC and how cycling of the methanol feed rate can serve to enhance the efficiency of a 
DMFC. Key observations included the enhancement of the $\mathrm{CO}$ poisoning effect when dilute hydrogen (e.g., from a reformer) is fed to the IDMFC and the remediation of this poisoning effect when air bleed into the anode is used to oxidize CO from the catalyst. These studies included both experimental and numerical investigations.

Numerical simulations of a double-path flowfield Proton Exchange Fuel Cell (PEFC) with thirtysix channels were carried out to study the complex flow phenomena and water transport in PEFCs. The simulation results reveal that the effect of internal humidification induced by diffusion promoted by making the two neighboring channels in counter flow is significant, but is in reality offset by the opposed gas bypass flow induced also by the same flow configuration. In addition, the bypass phenomenon leads to significant leakage of gas, substantially reducing the reactant utilization. To decrease the effect of bypass, small permeability of Gas Diffusion Layers (GDLs) was recommended for the double-path, counter-flow PEFCs. In addition, a transient model of PEFCs was developed to study the intricate dynamic response to step changes in operating conditions. Time constants for electrochemical double-layer, gas transport, and water accumulation in the membrane were estimated to identify the dominant effects of membrane water uptake and gas transport processes on the transient performance of PEFCs. Numerical simulations were carried out to study the transience of a singe-channel PEFC with N112 membrane. Results indicate that after the step change, the transition takes place on the order of 10 seconds, and the membrane hydration was the controlling process in the transient analyses. In addition, overshoot or undershoot in the current density was found in certain cases. Detailed species distributions within the cell were provided to explain the physics underlying the transient phenomena and to indicate that under low-humidity operation membrane water accumulation is responsible, while under high-humidity operation oxygen transport dictates the dynamic response of PEFCs. The dynamic behaviors of PEFCs captured herein for the first time, including undershoot and overshoot in the current output, are expected to be useful for the design of power electronics and control algorithms for fuel cell engines.

The numerical studies also included consideration of DMFCs. A comprehensive "M2" model for DMFCs was developed and several simulations were studied in order to understand the experimental results. With the different practical physical parameters and operating conditions implemented in the numerical simulations, the methanol and liquid water distributions in the DMFC can be investigated in detail. The methanol concentration distribution plays a very important role in the local current density profile and thus impacts overall performance of the DMFC. The liquid water profile affects the effective methanol transport and oxygen transport in both anode backing and cathode backing layers. These complicated relationships depend strongly on physical parameters and cell operating conditions. In order to produce better performance in DMFC systems, all these relationships must be optimized, including material characteristics and operating conditions. In this respect, the proposed two-phase M2 model is believed to provide insight into the governing physical phenomena and electrochemical kinetics, and thus offers very useful information for the optimization of overall DMFC performance.

In the experimental studies, the impact of $\mathrm{CO}$ poisoning was an area of significant interest. The transient polarization of a PEM fuel cell undergoing the $\mathrm{CO}$ poisoning process was experimentally measured. This process was observed under variable $\mathrm{CO}$ and hydrogen dilution 
levels. The transient poisoning model developed by Springer et al. (2001), which was modified and solved here, agrees well with the experimentally observed results of transient CO poisoning for both pure and dilute hydrogen feed streams. It was found that while hydrogen dilution alone lowers the fractional coverage on the catalyst surface, it is only when $\mathrm{CO}$ is present that the coverage is lowered to a degree that affects cell voltage. Under this condition, the addition of hydrogen dilution will compound the low surface coverage problem even further, and thus cause very poor cell performance. Even with low CO levels normally considered safe for cell operation (i.e. 10ppm), hydrogen dilution can cause an extremely severe loss of cell polarization. These results are easily explainable by the hydrogen and CO adsorption, desorption, and electrooxidation model developed.

An essential consideration for use of methanol in PEFCs is the combination of fuel reforming with PEM fuel cell operation. Thus, for this program a methanol reformer, completely designed, developed, and built under the efforts of Task 3.1 and 3.2.2, was integrated into a hydrogen fuel cell test stand. The reformer was fed a methanol/water solution and air for the oxidative steam reforming and CO clean-up reactions. The reformer produced an effluent containing roughly 50$60 \%$ hydrogen and less than 30ppm of carbon monoxide. This reformer effluent was fed directly into a hydrogen PEM fuel cell. The system also utilized the anode air injection method, outlined in the previous section, to deal with the CO levels. With a dry cathode feed gas, only $44 \%$ of the power is obtainable. This is as opposed to a fully humidified cathode stream, where $76 \%$ of the pure hydrogen anode feed power is obtainable. Thus, combining low cathode relative humidity levels with a reformer fed anode greatly reduces overall cell power density. However, at certain mid-range humidity levels, this drop in cell power density may be offset by an increase in system efficiency due to the need to no longer fully humidify the cathode air stream.

Experimental studies of DMFC performance yielded a number of important observations. DMFC steady-state performance will include a negative contribution from diffusion-driven methanol crossover, which exists as a result of the stable methanol concentration gradient established across the PEM. DMFC transient response to a step reduction in load illustrates this phenomenon. Following an initial voltage overshoot, cell performance gradually decreases as the elevated concentration gradient stabilizes at the reduced level of cell loading. In a similar fashion, cell performance may be temporarily increased at a constant current draw by reducing the anode methanol concentration. This may be achieved by shutting off the anode inlet, so that as the reaction continues to consume methanol, the solution contained within the chamber becomes increasingly diluted. Another means of improving performance is to operate at a higher methanol concentration (e.g., $4 \mathrm{M}$ solution rather than $1 \mathrm{M}$ solution), but combining this with periodic fuel injection. Following a brief upward spike in performance, cell voltage then gradually drops for a period long after the injection valve has re-closed. The minima in performance generally corresponds to a point halfway through the pause between injections. At these points, the methanol concentration gradient across the PEM has reaches a maximum, resulting in the largest presence of diffusion-driven crossover. From this point forward the concentration gradient is reduced, as no new methanol enters the cell to replace that being consumed by the current draw. As the cell voltage again approaches a maxima, crossover reaches a minimum, but the catalyst layer methanol concentration begins to near levels low 
enough to adversely affect the anode reaction kinetics. Before this occurs, methanol is again injected and the cycle begins again.

The impact of methanol composition was considered as well, to assess the potential differences between using research grade methanol and practical fuel grade methanol. The testing results with a fuel-grade "M-100" (100\% methanol) sample from California indicate that operation using this particular batch of fuel-grade M-100 has no adverse effect on DMFC performance as compared to chemical-grade methanol operation. Test results using chloride, methylene chloride and 2-butanone as model contaminants show no performance loss and no escalation in the rate of performance degradation from using elevated levels of the three tested contaminants.

Finally, a side-by-side comparison was performed between the DMFC and IDMFC (using the methanol reformer developed in Task 3.2.2). The end result was a comparison of the total efficiency for both systems. The "Conversion Efficiency" represents the actual measured cell power output divided by the power available in the methanol feed stream to each system. The DMFC system was only $1.75 \%$ efficient in converting methanol to electricity. This is in sharp contrast to the IDMFC system, which was $21.23 \%$ efficient. However, looking at the breakdown of losses, it is clear that the low efficiency is the result of low DMFC fuel utilization. This low fuel utilization is due the DMFC running at a high anode stoichiometry of 27. In practical applications, the remaining methanol, not reacted in the fuel cell, would be simply re-circulated back into the system. During re-circulation, a small amount of pure methanol would be added to maintain a constant concentration level. Therefore, a much higher practical DMFC efficiency than $1.75 \%$ is possible due to increased fuel utilization. For the IDMFC system, an anode stoichiometry of 1.5 was used. This led to an IDMFC fuel utilization efficiency of only 66.67\%. Like the DMFC, in practical applications, this number would be nearly $90 \%$. Thus, for both systems, a projected efficiency employing a realistic fuel utilization figure in the mid to high $20 \%$ range is easily possible. The IDMFC resulted in a slightly higher efficiency than the DMFC, with an overall effectiveness of $28.67 \%$ in converting methanol to electricity.

\subsubsection{Task 3.2.2 Methanol Reformer}

Under Task 3.2.2, a novel "tri-reforming” approach based on commercially available catalyst formulation demonstrated an ability to produce reformate gas with between 50-60 vol.\% hydrogen but less than 30 ppmv CO during methanol reforming. This highly effective methanol reformer strategy was incorporated into a reactor system that was connected to the IDMFC fuel cell experiment in Task 3.2.1. The combined reformer and fuel cell experiment for the IDMFC was compared against the DMFC and showed a much higher efficiency for the IDMFC and an efficiency of over $70 \%$ of that obtained with pure hydrogen. Together the outcomes from Task 3.2.1 and Task 3.2.2 demonstrated the practicality of combining a methanol reformer and PEM fuel cell.

At the outset of the reformer studies, it was decided that the catalyst would be based on commercially available formulations based on specific request from the research and management team at ConocoPhillips. The methanol reforming reactions are reversible reactions. Therefore, the commercially available catalysts that are designed for water-gas-shift reactions in stationary plants and that are designed for methanol synthesis can also used for methanol steam 
reforming. Thus, some commercially available copper and noble metal based catalysts were selected for evaluation.

Screening studies were performed to clarify the effect of catalyst type and reaction conditions on methanol steam reforming and oxidative steam reforming, to further optimize the reaction conditions and to achieve high hydrogen production and elimination of carbon monoxide yield. Results indicated that $\mathrm{Cu} / \mathrm{Zn} / \mathrm{Al}$ catalysts have high activity for low-temperature steam reforming and oxidative steam reforming of methanol. As the reaction temperature increased, the activity of catalysts is increased. When the reaction temperature reached $275^{\circ} \mathrm{C}$, methanol is totally converted over any one of the four commercial catalysts. But CO formation can be significantly different. Lower temperature also helps to minimize CO formation. Sud-Chemie catalysts are superior to Synetix, and Sud-Chemie C18HA and C18-7-01 have the best performance according the methanol conversion and $\mathrm{CO}$ concentration in reformate gas. Pt catalysts are not effective for methanol reforming. At the optimal reaction conditions: $230^{\circ} \mathrm{C}$ reforming temperature ; $\mathrm{O} 2 / \mathrm{CH} 3 \mathrm{OH}$ ratio as 0.3 ; WHSV as $5.2 \mathrm{~h}-1$; methanol water mole ratio as 1:1.4, methanol oxidative steam reforming over commercial catalyst C18HA has high methanol conversion $(>97 \%)$ and low CO concentration in products stream $(<0.5 \%)$ and hydrogen concentration is about 55\%. Thus, a combination of commercial water-gas-shift and preferential oxidation catalysts can effectively reduce the $\mathrm{CO}$ outlet concentration of reformed gas.

It has also been determined that the bed position of the catalysts can play a large role in the CO conversion levels that are achieved. Based on these results, a two zone reactor was configured and delivered for use in Task 3.2.1. The two zone reformer with one zone for reforming and another for CO clean up has simple and compact features. The methanol reforming over the two zone integrated reformer in which the first zone is held at $230^{\circ} \mathrm{C}$ over $\mathrm{C} 18 \mathrm{HA}$ and the second zone is held at $150^{\circ} \mathrm{C}$ over $1 \% \mathrm{Pt} / \mathrm{Al} 2 \mathrm{O} 3$ reveals that the final $\mathrm{CO}$ concentration in outlet stream is able to reach about 30ppm.

\subsubsection{Task 3.3.3 Compression Ignition Engine Studies}

Under Task 3.3, observations of injection, combustion, emissions formation and emissions control with fuels of substantially different formulation provided important insights into how to interpret the performance of a turbodiesel engine operated on different fuel formulations and how fuel formulation can impact the characteristics of the emissions. Two base fuels were used for the evaluations, a conventional low sulfur diesel fuel (325 ppm sulfur) and an ultra low sulfur diesel fuel (15 ppm sulfur). These base fuels were blended with soybean oil-derived biodiesel and GTL diesel fuel. Emissions and performance measurements were obtained over the AVL 8mode steady state test protocol, using the Cummins ISB 6-cylinder turbodiesel engine on an eddy current dynamometer. Gaseous and particulate mass emissions were measured and combustion analyses were performed using in-cylinder pressure sensing. In the AVL 8-Mode tests with the two base fuels and 20 wt.\% biodiesel blends with the base fuels, weighted mode average emissions show that all the gaseous and PM emissions are reduced with ultra low sulfur diesel fuel. Blending biodiesel provides further reduction in emissions (with the exception of NOx), but in either case exhaust aftertreatment is needed to attain future PM and NOx emissions targets. Neat GTL diesel showed consistent reductions in CO, HC, NOx and PM emissions relative to the base diesel fuels. However, with the second of the two batches of GTL diesel 
studied (which was available in sufficient quantity to permit AVL 8-mode tests), excessive compressibility of the fuel led to operational problems with the Cummins engine, including rough idling and stall at lighter loads.

The Cummins test engine was also equipped with an engine videoscope to permit in-cylinder observation of spray and combustion. A key observation was that variations in the bulk modulus of compressibility between fuels leads to shifts in injection timing and shifts in combustion phasing, which consequently impact emissions. Experiments were conducted with base fuels BP-325 (low sulfur) and BP-15 (ultra low sulfur) diesel fuels, an oxygenated blend (diethylene glycol dimethyl ether), FT-100 and its blends and some biodiesel blends with BP-15. In-cylinder visualization of spray and combustion was performed with these test fuels with 0.1 crank angle degree resolution. For both the B-20 and O-20 blended fuels, the start of injection event occurs at the same time. A 0.2 deg crank angle advance of fuel injection timing is observed with the blended fuels relative to the base BP-15 diesel fuel. Among the test fuels, the lowest premixed burn peak is observed with the O-20 blend, after that with the B-20 blend and the highest is with base diesel fuel. This trend is consistent with the cetane number of the test fuels, wherein the highest cetane number fuel should show the lowest premixed burn peak. The O-20 blend has the highest cetane number compared to B-20 and the base diesel fuel. For the biodiesel blended fuels, the start of injection event occurs earlier compared to the base fuel. Almost one deg crank angle advance of fuel injection timing is observed with the B-80 blended fuel relative to the base diesel fuel. Among the biodiesel blends, B-20 shows the earliest end of injection, while B-80 shows the longest injection duration. The start of injection event was retarded with FT-100 and its blends compared to the base diesel fuels and B-20 blend. The FT-100 and FT-80 B-20 blend show identical start of injection and 0.2 CAD retarded SOI compared to base BP-15 fuel. Among the FT-100 and its blends and BP-15, the highest premixed burn peak is observed with the base BP-15 fuel, which is consistent with the cetane number of the fuels. The change in start of injection event and injection duration might be an effect of the density variation and the variation in calorific value among the test fuels.

The Cummins test engine was equipped with a diesel particulate filter (DPF) for control of particulate matter emissions and a twin-reactor urea-selective catalytic reduction (urea-SCR) system for control of NOx emissions. The impact of fuel formulation on performance of these devices was examined in much detail. With regard to the DPF system, fuels of different sulfur content including Fischer-Tropsch diesel and biodiesel are considered to reduce the regeneration temperature of a catalytic DPF, since both F-T and biodiesel have no sulfur content that can inhibit catalyst activity. Furthermore, biodiesel is known to suppress soot and increase the soluble organic fraction (SOF) in particulate matter due to its high oxygen content and its distinct property effects on in-cylinder combustion. Thus, biodiesel and biodiesel fuel blends are good candidates to explore the effects of particulate composition and SOF content on particulate reactivity during oxidation on the catalytic surface of a DPF.

Two types of tests were performed to assess the impact of fuel on DPF regeneration, a high temperature regeneration by snapping to a high load after the DPF was filled with particulate and a "break even temperature" test, wherein load is increased gradually after the DPF is filled until pressure drop across the DPF filter begins to fall. Two effects were considered with this fuel 
matrix, the impact of sulfur and the impact of particulate composition and reactivity. Enhanced regeneration with decreasing fuel sulfur is due to the sole effect of reduced sulfur inhibition on catalyst activity, with no difference in intrinsic particulate reactivity. Blending with biodiesel reduced the temperature required to achieve regeneration of the DPF and increased the rate of oxidation of the particulate from the filter. A key observation was that the nanostructure of diesel soot and the corresponding oxidative reactivity of diesel soot can shift significantly as fuel formulation changes. Biodiesel derived soots from the Cummins turbodiesel engine showed much less ordered structure in the primary soot particles in the case of B20 soot, a much different oxidation process for B100 soot and a greater rate of oxidation than for diesel and F-T diesel soot, which has significant implications for the regeneration of diesel particulate filters.

The examination of NOx control by urea-SCR also showed significant fuel composition effects. The objectives of these tests were to examine the effect of fuel sulfur on NOx reduction efficiency of the urea- SCR system and to determine the effect of urea dosing rate on NOx reduction efficiency and NH3 slip. The urea-SCR system was located downstream of the DPF. Due to the presence of the oxidizing DPF filter before the urea-SCR reactor, the composition of NOx going into the urea-SCR reactor changed depending upon whether the DPF was undergoing regeneration or not. The DPF reactor oxidized some of the exhaust NO into NO2, making it a major constituent in the NOx at the inlet to the urea-SCR reactor. So the urea- SCR system was characterized for NOx reduction efficiency, urea dosing rate and NH3 slip with four test fuels, i.e., BP15, BP325 and their 20\% w/w blends with biodiesel, in the exhaust with enhanced NO2. The SCR catalyst activity was not affected directly by fuel sulfur and showed NOx conversion efficiencies of more than $90 \%$ under certain operating conditions. The SCR catalyst is more selective for NO2 than NO in the NOx reduction reaction. The NO2 content in the NOx inlet to the SCR reactor depends upon the DPF activity, which is affected by the fuel sulfur content and temperature. So, it can be concluded that in this work, the fuel sulfur content indirectly affects the urea-SCR catalyst performance through the coupling with the DPF.

\subsubsection{Outcomes}

A number of journal articles and conference papers have been produced from the work performed under this Ultra Clean Fuels project. Although the totals will increase since there are papers in preparation, at the date of the preparation of this report, stemming from work under this project, 19 journals articles have appeared in print, 3 journal articles are presently in preparation, 16 conference papers have been presented, 3 presentations were made at DOE-sponsored Diesel Engine Emissions Reduction (DEER) conferences, 3 MS theses have been completed and 3 doctoral theses have been completed. An invention conception record and two provisional patents were filed based on data obtained during the course of the project. 
Section 5

Recommendations and Conclusions 


\subsection{LIFECYCLE ASSESSMENT}

- GTL fuels have lower levels of criteria pollutant emissions at the same level of GHG emissions when compared with conventional and ultra-low sulfur petroleum diesel fuels. GTL fuels have the potential to reduce GHG emissions when used in light duty vehicles as a replacement for gasoline, due to greater engine efficiencies. GTL fuels are substantially non-petroleum, offering additional energy diversity and security benefits.

- The aggressive FTD100 CIDI case, which is an FTD optimized engine with a 5\% improvement in vehicle efficiency, has 7\% lower GHG emissions than the comparable ULSD case

- The use of flared gas in GTL production offers an opportunity for additional GHG emissions reductions. GTL producers should examine opportunities for the use of flared gas. GTL sourced from $10 \%$ flared gas/90\% natural gas shows improved performance with regard energy efficiency and to GHG impacts, with an additional 10\% GHG emissions reduction

- Lifecycle $\mathrm{CO}_{2}$ emissions of GTL fuels are sensitive to the thermal and carbon efficiencies of the GTL production process. Fuel producers should maintain a focus on process efficiencies within the constraints of the process economics.

- The design of diesel engines to take advantage of the superior specifications of GTL fuels offers the opportunity for further efficiency gains and emissions reductions. Where possible, the fuels and engines industries should work cooperatively as the market for GTL fuels emerges.

- The assessment of the sustainability of GTL fuels was a primary goal of ConocoPhillips in undertaking this UCF LCA study. The Department of Energy's Ultra Clean Fuels Program specifically seeks to ensure that vehicles fueled with fossil resources will comply with future emissions standards and reduce CO2 emissions. The results of the LCA indicate that GTL fuels meet these objectives

- The lifecyle impact categories examined (global warming potential, acidification, smog, eutrophication, human health, etc.) trend toward favoring GTL fuels compared to ultra low sulfur diesel and federal reformulated gasoline used in light duty passenger vehicles.

\subsection{MARKET STUDY}

- GTL transportation fuels will provide superior performance and solid competitive returns in the marketplace, while offering the potential for significant environmental and energy security benefits. FT Diesel will find a ready home in global diesel markets, with small price premiums over conventional ultra low sulfur diesel. FT distillate appears to have its greatest potential as blend stock to achieve the ultra low 
sulfur levels needed to meet emerging regulations for NOx and PM and enable advanced emissions controls in future diesel fuel in North America, Europe, Japan and elsewhere (in either hybrid or conventional vehicle configurations) that require the use of ultra-low sulfur fuels. Significant market penetration could be achieved by 2015.

- FT diesel is expected to have the highest absolute value in California due to the generally higher level of product prices in California and the more stringent quality requirements of CARB diesel. In particular, the CARB requirement for a lower aromatics content/higher cetane number necessitates the use of expensive cetane number improver by many California refineries. The use of high cetane number FT diesel as a California refinery blendstock would help to alleviate this constraint

- The US EPA, state regulators, and other stakeholders need to collaborate to set fuel specifications for FT diesel when used as a neat fuel. Key stakeholders include engine manufacturers, regulators, fuel producers, and customers.

- FT Naphtha will be an excellent ethylene feedstock, and will achieve \$5-10/mt premium over conventional naphthas. The best opportunities would exist in countries where naphtha is already used as an ethylene feedstock since these countries generally already have established markets for the co-products. Given the high quality of FT naphtha, Nexant believes that it can readily be placed in any market.

- Methanol does not appear to have significant potential as a UCF

- Methanol as an ICE fuel has been tried and failed

- The use of fuel cells for transportation still faces significant technical barriers, although mega-methanol-based supplies would be competitive. Future potential may be limited by solid oxide fuel cell development

- Direct methanol fuel cell applications are small in volume, and face technical, regulatory and legal hurdles

- The commercialization and widespread use of fuel cell vehicles is not likely to occur during the next 10-15 years, especially if more stringent fuel economy standards are mandated or encouraged via tax credits, or other incentives and subsidies.

- It is not expected that either methanol or FT naphtha will be significantly used in fuel cells for stationary power or CHP generation in the U.S. in the near future

- The introduction of GTL fuels to the marketplace not be impeded by state and federal authorities. GTL fuels should receive recognition as "Alternative Fuels" by state and federal authorities, due to the following characteristics of GTL fuels:

- The CO2 and criteria pollutant emissions from GTL fuels used in light duty vehicles compared with gasoline are substantially lower

- Criteria pollutant emissions GTL fuels compared with petroleum diesel fuels are lower 
- GTL fuels are substantially non-petroleum.

- GTL fuel producers should work with state agencies to certify their GTL products for demonstration and commercial use

- More real-world experience in the use of GTL fuels, particularly in large commercial and transit fleets, is required. The fuels and engine industry, and where appropriate the government, should work with fleets in demonstration programs as sufficient volumes of GTL fuels become available from commercial operations.

\subsection{ENGINE TESTING}

Task 3.1

- Fuels of different chemical composition can have very different compressibility, which is related to the speed of sound of pressure waves traveling within the fuel injection system and which can substantially alter the injection timing of the fuel. Paraffinic fuels such as Fischer-Tropsch (F-T) diesel fuel produced from gas-toliquids (GTL) processes has a lower bulk modulus of compressibility than conventional diesel fuel leading to retarded injection timing, because the pressure wave initiated by the fuel injection pump takes longer to reach the fuel injector, and thereby lower levels of NOx emissions.

- Biodiesel fuels have a higher bulk modulus of compressibility leading to advanced injection timing, because the pressure wave initiated by the fuel injection pump takes longer to reach the fuel injector, and thereby higher levels of NOx emissions.

- Fischer-Tropsch diesel fuel has a higher intensity of low temperature heat release during the first stage of ignition than conventional diesel fuel, but proceeds to ignition through the same intermediate species.

- More work is needed to understand whether highly compressible fuels such as F-T diesel will perform well in current and future fuel injection systems in terms of injection timing and quantity.

- Optimization of engine control parameters may be needed to obtain all the potential benefits of the high cetane number offered by F-T diesel.

\section{Task 3.2.1}

- An enhancement of the CO poisoning effect on fuel cell performance occurs when dilute hydrogen (e.g., from a reformer) is fed to the anode of a polymer electrolyte fuel cell (PEFC)

- Remediation of this CO poisoning effect can be achieved when air bleed into the anode is used to oxidize $\mathrm{CO}$ from the catalyst

- Cyclic feed of high concentration methanol solutions provides improvements in DMFC efficiency and performance

- Performance modeling of both indirect and direct methanol fuel cells has reached a leading level in the industry 
- There is ample room for further improvement in performance of both indirect and direct methanol fuel cells. Future work should direct towards these as the jury is still out whether the future transportation fuel should be hydrogen or methanol considering that hydrogen storage may be a science hurdle that cannot be overcome in many decades to come.

\section{Task 3.2.2}

- The two-zone reactor with a combination of oxidative steam reforming (OSRM) of methanol over $\mathrm{Cu}-\mathrm{ZnO} / \mathrm{Al}_{2} \mathrm{O}_{3}$ catalyst and preferential oxidation (PrOX) of carbon monoxide over $\mathrm{Pt} / \mathrm{Al}_{2} \mathrm{O}_{3}$ catalyst can lead to an effective reformer for $\mathrm{H}_{2}$ production from methanol

- The integrated OSRM and OWGS/PrOX reaction in a two-zone is the best option to produce fuel cell-grade hydrogen in a single reactor

- The methanol oxidative steam reforming over $\mathrm{C} 18 \mathrm{HA} \mathrm{Cu}-\mathrm{Zn} / \mathrm{Al}_{2} \mathrm{O}_{3}$ at $230^{\circ} \mathrm{C}$ coupled with $\mathrm{CO}$ OWGS/PrOX over $0.5 \% \mathrm{Pt} / \mathrm{Al}_{2} \mathrm{O}_{3}$ at $150^{\circ} \mathrm{C}$ can produce $\mathrm{H}_{2}$-rich gas with lower than 30ppm CO

- Need to identify better catalysts and reaction conditions for more effective and more selective conversion of $\mathrm{CO}$ (selective CO oxidation)

Task 3.3

- Weighted mode average emissions show that all the gaseous and PM emissions are reduced with ultra low sulfur diesel BP15 fuel. Blending biodiesel provides further reduction in emissions. GTL diesel fuel leads to reductions in all measured emissions, neat and in blends.

- US 2006 ultra low sulfur diesel fuel BP15 has emissions reduction potential, however, more reduction is necessary to attain future emissions standards. Therefore, ultra low sulfur diesel fuel along with emissions reduction technology clearly is necessary to attain stringent future emission regulations.

- In-cylinder imaging within a Cummins ISB engine operating on low sulfur diesel fuel, ultra low sulfur diesel fuel, biodiesel blends and GTl diesel fuel shows that there are shifts injection timing and duration, but that there is little difference in flame structure and luminosity.

- The nanostructure of diesel soot can vary with the composition of fuel burned, which combined with variations in the surface oxygen content of the soot, can yield substantial differences in the oxidative reactivity of the soot. More reactive soot will make it easier to burn particulate off of a diesel particulate filter, enhancing the effectiveness of diesel particulate filter operation and potentially lowering the fuel consumption associated with regenerating the particulate filter.

- The effectiveness of urea-selective catalytic reduction of NOx is not directly affected by fuel sulfur content, but can be indirectly affected because of coupling with the 
diesel particulate filter, since the DPF may alter the ratio of $\mathrm{NO}_{2} / \mathrm{NO}$ depending on whether the DPF is regenerating or not.

- The compressibility of GTL diesel fuel may interfere with the operation of the fuel injection process on pump-line-nozzle fuel systems, and may require changes in the engine control parameters to maintain engine performance and efficiency.

- More work is needed to assess the impact of GTL diesel fuel on the behavior of fuel injection systems due to its large compressibility (low bulk modulus of compressibility) and its high cetane number. There may be options for making use of the high cetane number of GTL diesel fuel in advanced "low temperature" combustion modes.

- More work is needed to determine the impact of GTL diesel on the operation and effectiveness of diesel particulate filters under real-world operating conditions and duty-cycles. 


\section{A.1 INTRODUCTION}

This Appendix provides a list of all papers, presentations, graduated students and their theses, and patents that resulted from the Ultra Clean Fuels project. The list is organized by project task.

\section{A.2 UCF LIFE CYCLE ASSESSMENT}

\section{A.2.1 Conference Papers}

1. Life Cycle Analysis of GTL Fuels, AICHe Spring National Meeting, , Robert Abbott, Etop Esen, Paul Worhach, Binh Nguyen, New Orleans, LA,March11, 2002

2. Co-Product Function Expansion, A Method for Incrementally Considering the Effects of Co-Products in Multi-Product Systems, Paul Worhach and Robert Abbott , International Conference on Life Cycle Assessment and Life Cycle Management, Seattle, WA, September 22, 2003,

3. A Life Cycle Assessment Comparing Select Gas-to-Liquid Fuels with Conventional Fuels in the Transportation Sector, Robert Abbott and Paul Worhach, Energy Frontiers International Members Conference, San Francisco, October 15-17, 2003

4. A Lifecycle Assessment of Ultra Clean Fuels, Paul Worhach, EPA Millennium Lecture Series, May 27, 2004

5. A Life Cycle Assessment Comparing Select Gas-to-Liquid Fuels with Conventional Fuels in the Transportation Sector, Robert Abbott and Paul Worhach, Diesel Engines Emission Reduction Conference, Coronado, CA, September 1, 2004

6. Gas to Liquids Life Cycle Assessment Report, Charlene Pretorius, Robert Abbott and Douglas Smith, Presentation to the California Energy Commission, Sacramento, CA, March 14, 2005

\section{A.2.2 Papers}

1. Gas to Liquids Industry Life Cycle Assessment Synthesis Report, ConocoPhillips, SasolChevron, Shell Oil, August 2004

\section{A.3 UCF ENGINE TESTING}

\section{A.3.1 Conference Papers}

1. Acharya, R., M. Alam and A. L. Boehman, Fuel and System Interaction Effects on UreaSCR Control of NOx in Diesel Exhaust Aftertreatment, Submitted to Society of Automotive Engineers for presentation at the 2006 SAE International Congress and Exposition. 
2. Alam, M., J. Song and A. Boehman, In-cylinder Combustion Visualization of Ultra Low Sulfur, Neat Biodiesel and Biodiesel Blended Fuels, In ACS Fuel Chemistry Division Preprints, 50(1), 412-414 (2005).

3. Boehman, A.L., J. P. Szybist, J. Song, V. Zello, M. Alam, K. Miller, Combustion Characterization Of GTL Diesel Fue, In ACS Fuel Chemistry Division Preprints, 49(2), 714-716 (2004).

4. Song, J., M. Alam, A. L. Boehman and K. Miller, Characterization of Diesel and Biodiesel Soot, In ACS Fuel Chemistry Division Preprints, 49(2), 767-769 (2004).

5. Boehman, A., J. Song, M. Alam, V. Zello and K. Miller, Fuel Formulation Effects on Diesel Particulate Filter Regeneration, In ACS Fuel Chemistry Division Preprints, 48(2), 634-635 (2003).

6. Song, J., M. Alam, V. Zello, A.L. Boehman, B. Bishop and F. Walton. Fuel Sulfur Effect on Membrane Coated Diesel Particulate Filter,. Society of Automotive Engineers Technical Paper No. 2002-01-2788, Presented at the SAE Powertrain \& Fluid Systems Conference \& Exhibition, San Diego, CA, October 2002.

7. Szybist, J.P. and A.L. Boehman, Auto-Ignition Behavior of Methyl Decanoate, In ACS Fuel Chemistry Division Preprints, 50(2), 730-731 (2005).

8. Boehman, A.L., J. P. Szybist, J. Song, V. Zello, M. Alam, K. Miller, Combustion Characterization of GTL Diesel Fuel, In ACS Fuel Chemistry Division Preprints, 49(2), 714-716 (2004).

9. Szybist J., D. Morris, A.L. Boehman and E. Esen, Diesel Fuel Formulation Effects on Injection Timing and Emissions, In ACS Fuel Chemistry Division Preprints, 48(1), 428429 (2003).

10. C.Y. Wang, Computational fuel cell research at Penn State,” invited talk at NASA SOFC Workshop, NASA - Glenn Research Center, April 2003.

11. U. Pasaogullari and C.Y. Wang, Flooding prediction in polymer electrolyte fuel cells, 203rd Electrochemical Soc. Meeting, Paris, France, April 2003.

12. X.G. Yang, N. Burke, Q.L. Dong, M.M. Mench and C.Y. Wang, Simultaneous measurement of current and species distributions in polymer electrolyte fuel cells, 203rd Electrochemical Soc. Meeting, Paris, France, April 2003.

13. H. Meng and C.Y. Wang, Large-scale modeling of PEM fuel cells by parallel computations, 203rd Electrochemical Soc. Meeting, Paris, France, April 2003.

14. C.Y. Wang, Transport issues in polymer electrolyte fuel cells, in Proc of Heat Transfer 75th Celebration, Purdue University, April 2003. 
15. C.Y. Wang, Micro- and meso-scale phenomena in polymer electrolyte fuel cells, invited talk at Nanotech 2003, San Francisco, Feb. 2003.

16. Gu, W., J.-P. Shen and C. Song, Hydrogen Production from Integrated Methanol Reforming over Cu-ZnO/Al2O3 and Pt/Al2O3 Catalysts for PEM Fuel Cells, Am. Chem. Soc. Div. Fuel Chem. Prepr., 2003, 48 (2), 804-807.

\section{A.3.2 Journal Articles and Book Chapters}

1. Boehman, A.L., J. Song, and M. Alam, Impact of Biodiesel Blending on Diesel Soot and the Regeneration of Particulate Filters,. Energy \& Fuels, 19, 1857-1864 (2005).

2. Alam, M., J. Song, R. Acharya A. Boehman and K. Miller, Combustion and Emissions Performance of Low Sulfur, Ultra Low Sulfur and Biodiesel Blends in a DI Diesel Engine, Society of Automotive Engineers Technical Paper No. 2004-01-3024. SAE Transactions: Journal of Fuels and Lubricants, 113:4, 1986-1997 (2004).

3. Szybist, J. P., A.L. Boehman, J.D. Taylor and R.L. McCormick, Evaluation of Formulation Strategies to Eliminate the Biodiesel NOx Effect, Fuel Processing Technology, 86, 1109-1126 (2005).

4. Szybist, J. P., S.R. Kirby and A.L. Boehman, NOx Emissions of Alternative Diesel Fuels: A Comparative Analysis of Biodiesel and FT Diesel, Energy \& Fuels, 19, 1484-1492 (2005).

5. Boehman, A.L., D. Morris, J. Szybist and E. Esen, The Impact of Bulk Modulus of Diesel Fuels on Fuel Injection Timing, Energy \& Fuels, 18, 1877-1882 (2004).

6. C.Y. Wang, "Two-phase flow and transport in polymer electrolyte fuel cells," in Handbook of Fuel Cells, eds. by W. Vielstich, A. Lamm, and H. Gasteiger, Wiley-VCH, 2003, pp.337-348.

7. C.Y. Wang, "Fundamental Models for Fuel Cell Engineering,” Chemical Reviews, Vol.104, pp.4727-4766, 2004.

8. G. Lu and C.Y. Wang, "Two-phase microfluidics, heat and mass transport in direct methanol fuel cells,” Chapter 9 in Transport Phenomena in Fuel Cells, Eds. B. Sunder and M. Faghri, WIT Press, pp.317-358 (2005).

9. C. Lim and C.Y. Wang, Development of high-power electrodes for a liquid-feed direct methanol fuel cell, J of Power Sources, Vol.113, pp.145-150, 2003.

10. Z.H. Wang and C.Y. Wang, Mathematical modeling of liquid-feed direct methanol fuel cells, J of Electrochem. Soc., Vol.150, pp.A508-A519, 2003.

11. M.M. Mench, C.Y. Wang and M. Ishikawa, In-situ current distribution measurements in polymer electrolyte fuel cells, J of Electrochem. Soc., Vol.150, pp.A1052-A1059, 2003. 
12. M.M. Mench, Q.L. Dong, C.Y. Wang, In-situ water distribution measurements in a polymer electrolyte fuel cell, J of Power Sources, Vol.124, pp.90-98, 2003.

13. H. Meng and C.Y. Wang, Large-scale simulation of polymer electrolyte fuel cells by parallel computing, Chemical Engineering Science, Vol.59, 3331-3343, 2004.

14. H. Meng and C.Y. Wang, Electron transport in polymer electrolyte fuel cells, J. Electrochem. Soc., Vol.151, pp.A358-A367, 2004.

15. K.K. Bhatia and C.Y. Wang, Transient carbon monoxide poisoning of a polymer electrolyte fuel cell operating on diluted hydrogen feed, Electrochim. Acta, Vol.49, pp.2333-2341, 2004.

16. C. Lim and C.Y. Wang, Effects of hydrophobic polymer content in GDL on power performance of a PEM fuel cell, Electrochim. Acta, Vol.49, pp.4149-4156, 2004.

17. Y. Wang and C.Y. Wang, Modeling polymer electrolyte fuel cells with large density and velocity changes, J. Electrochem. Soc., Vol.152, pp.A445-A453, 2005.

18. Y. Wang and C.Y. Wang, Simulation of flow and transport phenomena in a polymer electrolyte fuel cell under low-humidity operation, J. Power Sources, Vol.147, pp.148161, 2005.

19. Y. Wang and C.Y. Wang, Transient analysis of polymer electrolyte fuel cells, Electrochimica Acta, Vol.50, 1307-1315, 2005.

\section{A.3.3 Journal Articles in Preparation or Submitted}

1. Alam. M., J. Song, V. Zello, and A.L. Boehman, Spray and Combustion Visualization of a Direct Injection Diesel Engine Operated with Various Fuel Blends, Submitted to the International Journal of Engine Research (2005).

2. Szybist, J. P., A.L. Boehman, H. Koga and D.C. Haworth, Premixed Ignition Behavior of Alternative Diesel Fuel-Relevant Compounds in a Motored Engine Experiment,. Submitted to Combustion \& Flame (2005).

3. Song, J., M. Alam and A.L. Boehman, Impact of Alternative Fuels on Soot Properties and DPF Regeneration, In preparation for submission to Combustion Science and Technology (2006).

\section{A.3.4 Patents}

1. Jeffrey Gonder and C.Y. Wang, Method of using concentrated fuel in direct methanol fuel cells by periodic anode injection, Provisional U.S. Patent 60/462,720, April 2003.

2. David Morris, André L. Boehman and Etop Esen,. Invention Conception Record submitted to ConocoPhillips under DOE Contract \#DE-FC26-01NT41098 on "Biodiesel - Paraffinic Fuel Blend Ratios to Offset the Biodiesel NOx Effect,” 2004. 


\section{A.3.5 Theses}

1. Jeffrey Gonder, "Direct Methanol Fuel Cells for Automotive Applications: Experimental Analysis of transient characteristics, periodic fuel injection and fuel quality requirements,” (M.S.)

2. Ragini Acharya, "Impact of Ultra Clean Fuel on Selective Catalytic Reduction of NOx with Urea,” (M.S.)

3. Weidong $\mathrm{Gu}$, "New Processing Scheme of MeOH Reforming for Hydrogen Production for Proton-Exchange Membrane Fuel Cell Application,” (M.S.)

4. James Szybist, "Fuel Composition Impacts on Processes in Compression Ignition Engines,“(Ph.D.)

5. Juhun Song, "Effect of Fuel Formulation on Soot Properties and Regeneration of Diesel Particulate Filters," (Ph.D.)

6. Krishan Bhatia, "Study of a Methanol Reforming Polymer Electrolyte Fuel Cell System," (Ph.D.) 
Submitted To:

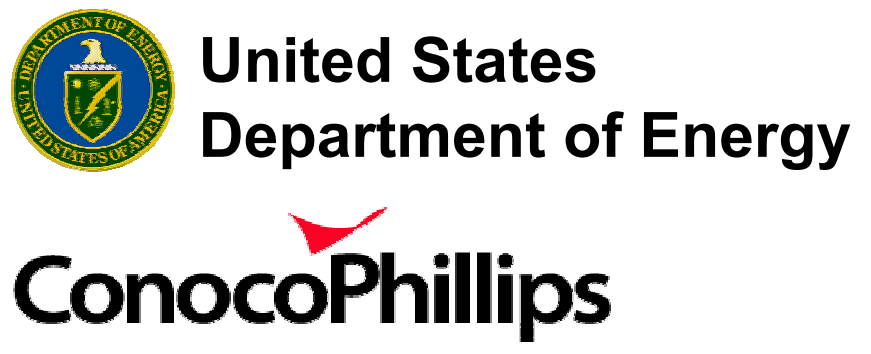

Ultra Clean Fuels

Life Cycle Assessment Final Report

Co-operative Agreement DE-FC26-01NT41098

Submitted By:

cNexant

NOVEMBER 2003 


\section{Abstract}

Throughout the world, there are large proven reserves of natural gas that are "stranded" because their remote locations render them incapable of being economically brought to market.

ConocoPhillips is developing proprietary gas-to-liquids (GTL) technology to economically convert this natural gas to GTL products, primarily diesel, for use as a transportation fuel. Another significant product of the GTL process is naphtha, which may be used for a number of applications, such as petrochemical feedstock or as a fuel for fuel cell vehicles.

ConocoPhillips, in conjunction with Nexant Inc., Penn State University, and Cummins Engine Co., has joined with the U.S. Department of Energy (DOE) National Energy Technology Laboratory (NETL) in a cooperative agreement to perform a comprehensive study of new ultra clean fuels (UCFs) produced from remote sources of natural gas. This study, called the Ultra Clean Fuels Life Cycle Assessment (UCF LCA), consists of a Life Cycle Inventory (LCI) and Life Cycle Impact Assessment (LCIA) for GTL transportation fuels, namely, Fischer-Tropsch diesel (FTD) and FT naphtha.

ConocoPhillips undertook this study to help ensure that its investment in and development of GTL technology would be sustainable into the future. ConocoPhillips believes that GTL fuelsFTD and FT naphtha - are competitive options in the development and monetization of remote natural gas fields. These natural-gas-sourced fuels are assumed to displace or offset conventional petroleum fuels for transportation end uses.

In accordance with ConocoPhillips's business planning and its corporate commitment to sustainable development, it is important and necessary to understand life cycle environmental and human health potential impacts of GTL products in comparison with alternatives. Therefore, this LCA study is designed to estimate, with available data and within available study resources, the future energy utilization and emissions life cycle profiles of ConocoPhillips GTL fuels and selected competitive fuels.

The UCF LCA study was conducted according to the requirements of the ISO 14040 International Standard for Life Cycle Assessment, which included a critical review conducted by an outside independent panel.

The LCA results showed that the well-to-wheel energy efficiency of petroleum-based transportation fuels (ultra-low sulfur diesel and federally reformulated gasoline) in light duty vehicles is approximately $25 \%$ higher than that of GTL transportation fuel (Fischer-Tropsch diesel and FT naphtha) using ConocoPhillips's expected GTL carbon and energy process efficiencies. The global warming potential (GWP) of these two groups of fuels is roughly equivalent. Almost every inventory conducted on total and urban criteria pollutant emissions demonstrated lower values for GTL fuels. These inventories were input into the EPA's TRACI model, along with additional supplemental data, to perform the Life Cycle Impact Assessment. The impact indicator values for acidification, eutrophication, and human health (criteria, cancer, and non-cancer) impact categories are consistently lower for GTL fuels, while ecotoxicity results are varied. 
$\begin{array}{lll}\text { Section } & \text { Page }\end{array}$

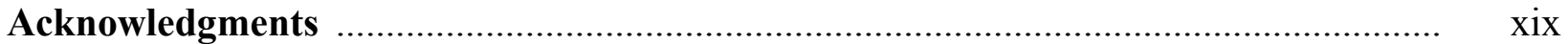

Acronyms and Abbreviations ............................................................................ $\mathrm{xx}$

Glossary

Executive Summary ……………………………….............................................. ES-1

1 UCF LCA Goals and Scope

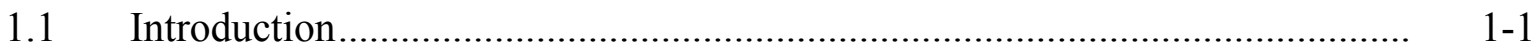

$1.2 \quad$ Goals and Scope of a Life Cycle Assessment.................................................. 1-1

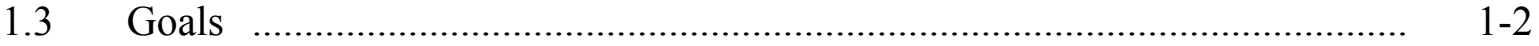

1.3.1 Intended Application and Audience …………................................. 1-3

1.3.2 Objectives .............................................................................

$1.4 \quad$ Study Approach ...............................................................................

1.4.1 GTL Engineering Analysis ............................................................. 1-4

1.4.2 Co-product Function Expansion .......................................................... 1-4

1.4.3 Sensitivity Analysis ...................................................................... 1-5

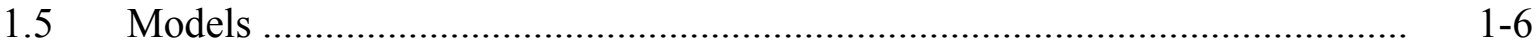

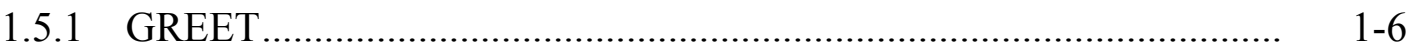

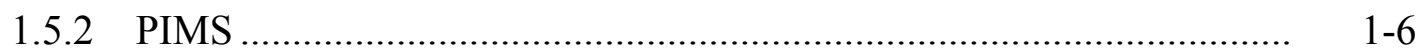

1.5.3 Aspen Plus ................................................................................. 1-7

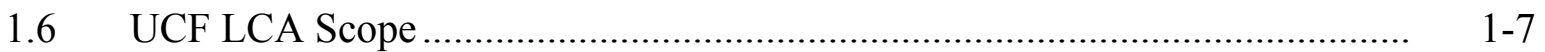

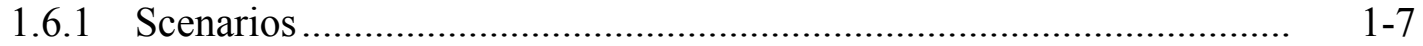

1.6.2 Functional Unit .................................................................. $1-10$

1.6.3 System Boundaries................................................................... $1-10$

1.6.4 Study Assumptions ................................................................... $\quad 1-20$

1.6.5 Geographic Considerations............................................................. 1-21

1.6.6 Life Cycle Inventory Categories .......................................................... 1-21

1.6.7 Life Cycle Impact Assessment.......................................................... 1-21

$1.7 \quad$ Data Requirements, Sources, and Quality ................................................ $1-25$

1.8 Uncertainty Analysis......................................................................... 1-25

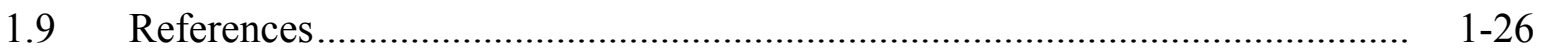


Section Page

$2 \quad$ Literature Survey ................................................................................... 2

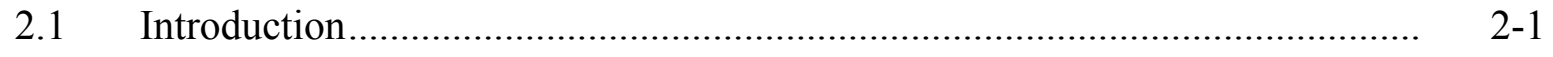

2.2 General Motors (GM) Well-to-Wheel Analysis ............................................ 2-2

2.2.1 Pathways .............................................................................. 2-2

2.2.2 Scope and Methodology ……………………………………..... 2-3

2.2.3 Assumptions and Data ............................................................... 2-3

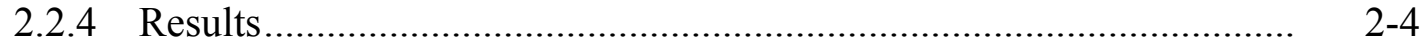

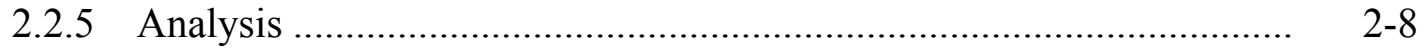

$2.3 \quad$ MIT Fuel Cycle Study ……………………….................................. 2-8

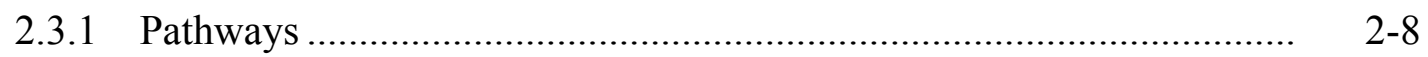

2.3.2 Assumptions and Data ................................................................... 2-9

2.3.3 Results................................................................................... 2

2.3.4 Analysis .............................................................................. 2-11

2.4 Argonne National Laboratory (ANL) Natural Gas Fuels .................................. 2-11

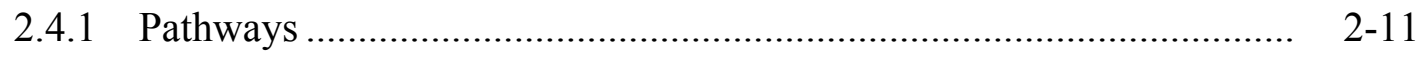

2.4.2 Assumptions and Data .................................................................... 2-11

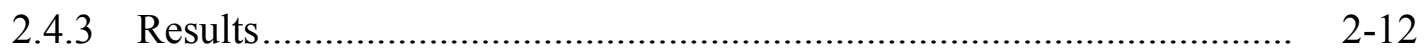

2.4.4 Analysis ............................................................................... 2-14

$2.5 \quad$ Australian Fuels Study ...................................................................... 2-14

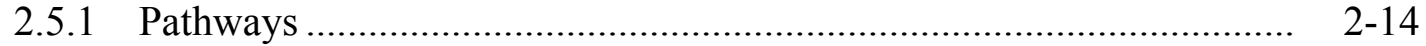

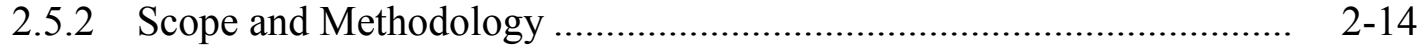

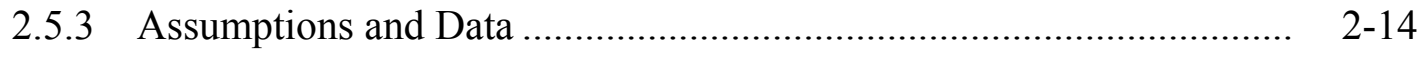

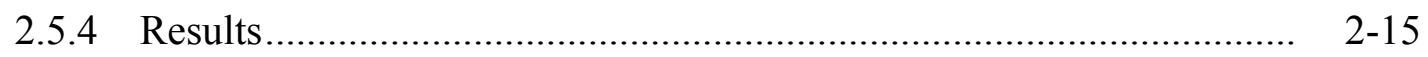

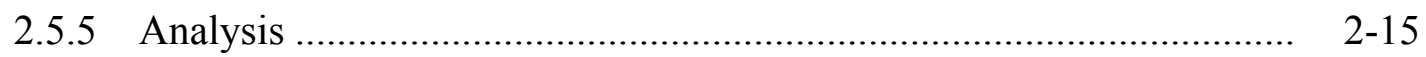

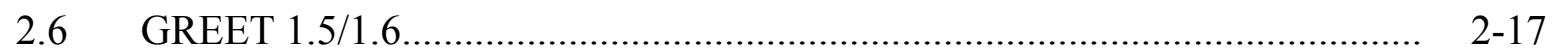

2.6.1 Pathways ………..................................................................... 2-17

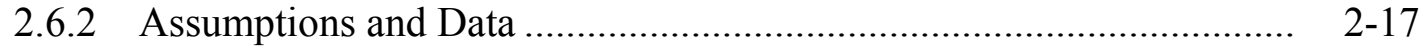

2.6 .3 Results............................................................................... 2-18

2.7 National Energy Technology Laboratory (NETL) Gasification Study ............ 2- 2-18

2.7.1 Pathways ……....................................................................... 2-18

2.7.2 Assumptions, Data, Results, and Analysis .......................................... 2 2-19

$2.8 \quad$ National Renewable Energy Laboratory (NREL) Biomass.............................. 2 2-19

2.8.1 Pathways ……..................................................................... 2-19

2.8.2 Scope, Methodology, Assumptions, and Data …………………….... 2 2-20 


\section{Section}

2.8.3 Results and Analysis

$2-20$

$2.9 \quad$ Summaries and Needs for Further Research................................................ 2-22

2.9.1 Summary — GREET-Based Studies .................................................. 2-22

2.9.2 Summary—Non-GREET-Based Studies ........................................... 2-22

2.9.3 Research Needs ............................................................................... 2-22

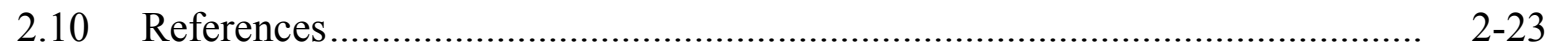

$3 \quad$ GREET Review and Validation ...................................................................

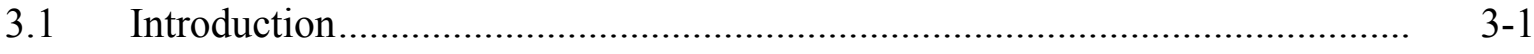

3.1.1 Literature Review …………………………............................ 3-1

3.1.2 Technology Review ................................................................ 3-2

3.1.3 Allocation Methodology in GREET ……………….......................... 3-2

3.1.4 Data Review and Development ...................................................... 3-2

3.2 GREET Model Structure, Key Parameters, and Model Outputs ...................... 3-3

3.2.1 Unit Processes in GREET ………………………........................... 3-3

3.2.2 Thermal Efficiency .................................................................... 3-3

3.2.3 Process Fuel and Combustion Technology Shares ................................ 3-4

3.2.4 Emission Factors ........................................................................... 3-4

3.2.5 Greenhouse Gas Emissions............................................................... 3-6

3.2.6 Criteria Pollutant Emissions ............................................................... 3-6

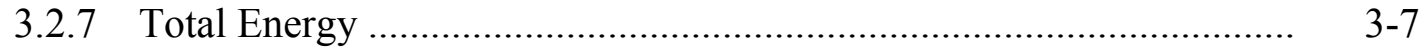

$3.3 \quad$ Well-to-Tank Validation........................................................................

3.3.1 Feedstock Production....................................................................

3.3.2 Transportation and Distribution........................................................... 3-8

3.3.3 Petroleum Refining ..................................................................... 3-9

3.3.4 GTL and Methanol Production ............................................................ 3-11

3.3.5 Data Sources ............................................................................ $\quad 3-12$

$3.4 \quad$ Tank-to-Wheels Validation..................................................................... 3-13

3.4.1 GREET Default Vehicle Data......................................................... 3-14

3.4.2 Federal Reformulated Gasoline Vehicles ……………………............ 3-14

3.4.3 Ultra-Low Sulfur Diesel Vehicles ...................................................... 3-15

3.4.4 FT Diesel Vehicles........................................................................ 3-16

3.4.5 Methanol Vehicles ..................................................................... 3-17

3.4.6 FT Naphtha Vehicles ………….................................................. 3-18

3.4.7 Data Sources ........................................................................ 3-19 


\section{Section}

3.5 Model and Data Development ................................................................. 3-19

3.5.1 Petroleum Refining Efficiencies ......................................................... 3-19

3.5.2 GTL Fuels and Methanol Efficiencies ............................................... 3-20

3.5.3 Wastewater and Solid Waste ......................................................... $3-20$

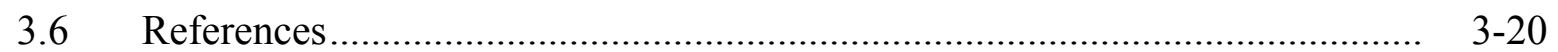

4 GTL and Methanol Process Validation .............................................................. 4-1

$4.1 \quad$ Introduction................................................................................. 4-

4.2 Aspen Plus Models ............................................................................. 4- 4

4.3 GTL Production ..............................................................................

4.3.1 GREET Assumptions ................................................................. 4-2

4.3.2 Technology Assumptions for the UCF LCA ......................................

4.3.3 Theoretical Limits............................................................................. 4.

4.3.4 UCF Final GTL Technology and Data .............................................. 4 4-6

4.4 Methanol ...........................................................................................

4.4.1 GREET Assumptions ................................................................... 4. 4-6

4.4.2 Technology Assumptions for the UCF LCA ....................................... 4. 4-8

4.4.3 Methanol Data Development ............................................................. 4. 4

4.4.4 Theoretical Limits........................................................................... 4... 4

4.4.5 UCF Final Methanol Technology and Data.......................................... 4-11

$4.5 \quad$ References........................................................................... 4-11

$5 \quad$ Co-product Function Expansion ……………..............................................

$5.1 \quad$ Introduction................................................................................... $5-1$

5.1.1 Primary Products and Co-products .................................................... 5-1

5.1.2 Allocation vs. System Boundary Expansion........................................... 5-1

$5.2 \quad$ CFE Methodology .............................................................................. 5-2

5.3 Scope Definition for the CFE Application to the Petroleum System ............... 5-3

5.3.1 CFE System Boundaries for Petroleum Coke and Heavy Residual Oil 5-3

5.3.2 CFE Sensitivity: Lower and Upper Ranges ........................................ 5 5-4

5.3.3 The CFE Functional Unit................................................................. 5-4

5.3.4 CFE Petroleum Cases ...................................................................... 5

$5.4 \quad$ Application of CFE to Petroleum ............................................................... 5-5

5.4.1 Fuel Production Stage ....................................................................... 5-6

5.4.2 Downstream Co-product Stages ………………................................ 5-7

5.4.3 CFE Methodology Summary for the Petroleum System ...................... 5-7 
Section Page

$5.5 \quad$ Refinery Co-products................................................................... $5-8$

5.5.1 Petroleum Coke........................................................................... 5-8

5.5.2 Heavy Residual Oil ................................................................... 5

5.5.3 Petroleum Coke and Heavy Residual Oil as Waste Products............... 5-11

5.6 GTL Products ........................................................................................ 5

$5.7 \quad$ CFE Application and Results ................................................................. 5-12

5.7.1 Step 1: Allocation of Co-product Energy and Emissions ..................... 5-12

5.7.2 Step 2: Downstream Function Comparisons......................................... 5-14

$5.8 \quad$ Final CFE Results ............................................................................ 5

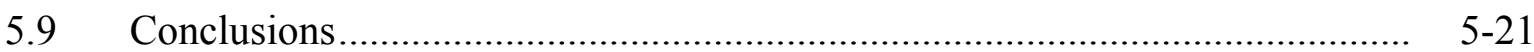

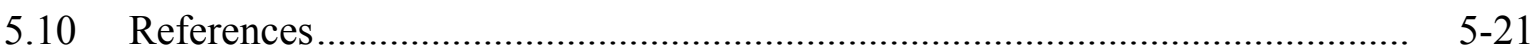

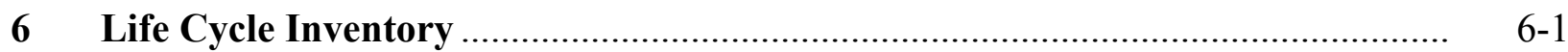

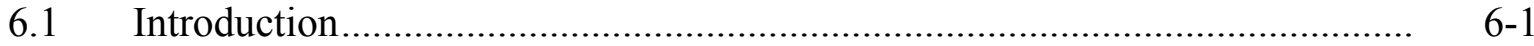

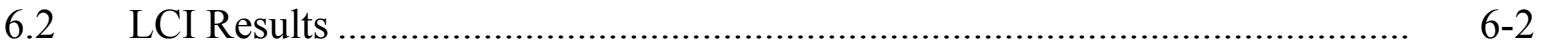

6.2.1 Near-Term Results of the LCI ...................................................... 6-3

6.2.2 Long-Term Results of the LCI............................................................. 6-7

6.3 Solid Waste and Wastewater .................................................................. 6-14

6.4 Sensitivity Analysis of the LCI................................................................ 6-16

6.4.1 Heavy and Light Crude Oil............................................................ 6-17

6.4.2 3 ppm LS Diesel..................................................................

6.4.3 Imported Crude Oil ................................................................... 6-21

6.4.4 Flared Gas in GTL Production........................................................ 6-22

6.4.5 Parametric Sensitivity .................................................................. $\quad 6-22$

6.5 Unit Process LCI Results ..................................................................... 6-25

6.6 Sensitivity Analysis Conclusions............................................................... 6- 6-30

6.7 LCI Results Summary and Conclusions ……………................................... 6-31

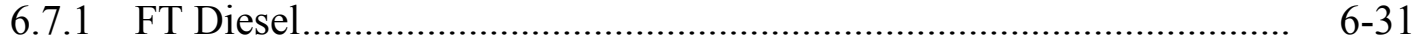

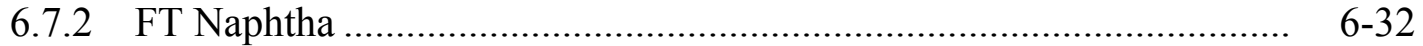

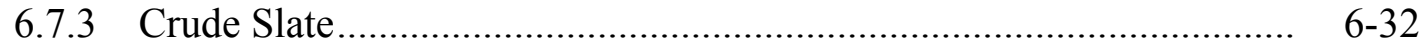

6.7.4 Solid Waste and Wastewater ……………………............................ $\quad$ 6-32 


\section{Section}

Page

7 Life Cycle Impact Assessment

$7-1$

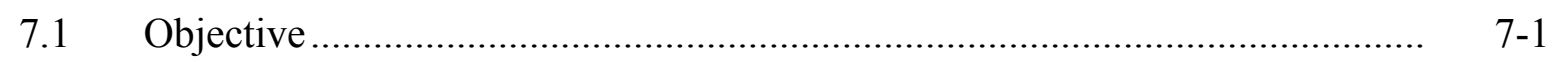

7.2 Scope and Overview …………………….........................................

7.3 The TRACI Model ......................................................................................

7.4 Impact Categories ............................................................................

7.5 Classification, Impact Indicators, and Characterizations Models .................... 7-4

7.5.1 Global Warming Potential ............................................................... 7-4

7.5.2 Acidification ..............................................................................

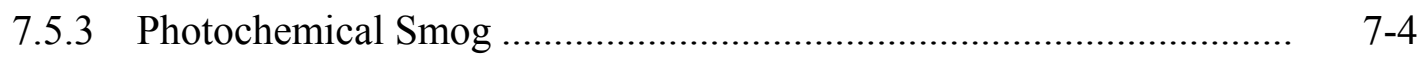

7.5.4 Eutrophication...........................................................................

7.5.5 Human Health Criteria ...................................................................

7.5.6 Human Health, Cancer (HHC); Human Health, Non-Cancer (HHNC) 7-5

7.5.7 Ecotoxicity ..............................................................................

7.5.8 Petroleum Use and Natural Gas Consumption .................................... 7 7-6

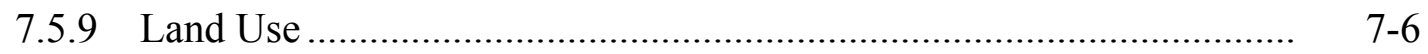

7.5.10 Water Use................................................................................

7.6 Supplementary Data Collection for the LCIA ................................................. 7-6

7.6.1 GTL and Conventional Petroleum Fuel Properties................................ 7-7

7.6.2 Toxic Emissions from GTL Production................................................. 7. 7-9

7.6.3 Toxic Emissions Data Collection …………………............................

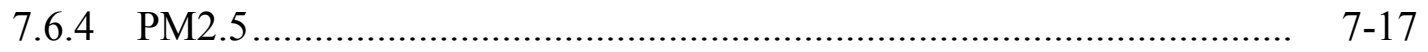

7.6.5 Remote Gas Reserves and Crude Oil Reserves ................................... 7-18

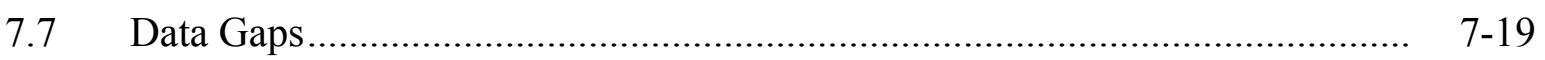

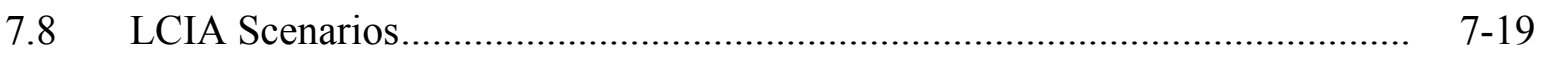

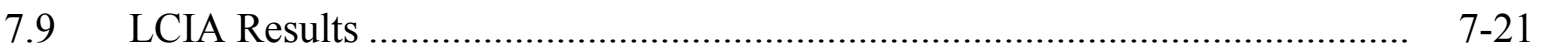

7.9.1 Global Warming Potential ………………….................................... 7-22

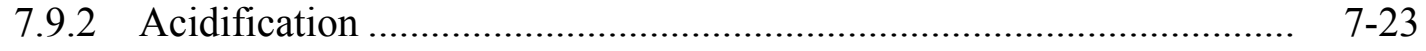

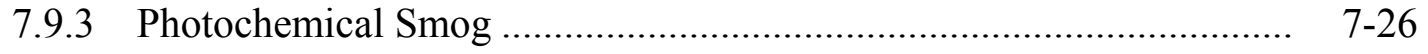

7.9.4 Eutrophication.........................................................................

7.9.5 Human Health Criteria ................................................................... $\quad$ 7-30

7.9.6 Human Health, Cancer and Human Health, Non-Cancer ..................... 7-32

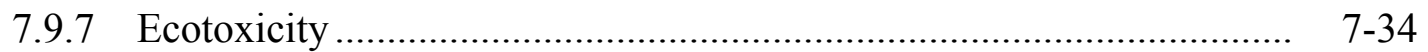

7.9.8 Petroleum Use and Natural Gas Consumption ..................................... 7-35

7.9.9 Land Use and Water Use .............................................................. 
$\begin{array}{lll}\text { Section } & \text { Page }\end{array}$

7.10 Conclusions

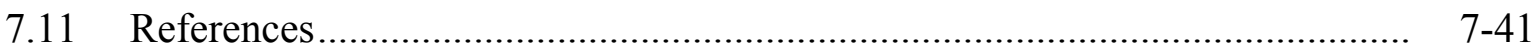

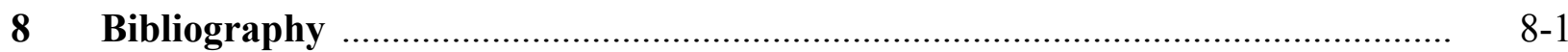

Appendix A Petroleum Refining and Co-product Function Expansion Data .......... A-1

Appendix B Complete Life Cycle Inventory Results............................................... B-1

Appendix C Uncertainty Analysis ………..................................................... C-1

Appendix D $\quad$ LCIA Input Data and Results ..................................................... D-1

Appendix E $\quad$ Power Generation Fuel Cycle Study ……………………………........ E- E-1

Appendix F $\quad$ Mobile6 Air Quality Modeling ………............................................ F- F-1

Appendix G $\quad$ Peer Review Panel Report …………........................................... G- G-1 


\section{FIGURES AND TABLES}

Figure

1-1 Global Crude Oil Production .................................................................... $1-11$

1-2 Middle Eastern Crude Oil Production ............................................................... 1-11

1-3 Ultra-Low Sulfur Diesel Production ............................................................ $1-12$

$1-4 \quad$ FRFG Production ................................................................................ $1-12$

1-5 Conventional Diesel Production ................................................................... $1-12$

1-6 Petroleum Coke CFE …......................................................................... 1-13

1-7 Heavy Residual Oil CFE............................................................................. $1-13$

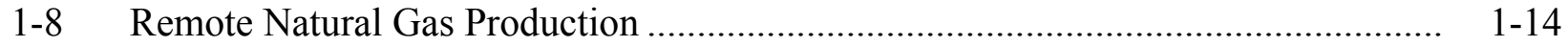

1-9 Remote Natural Gas and Flared Gas Production .............................................. 1-14

$1-10 \quad$ FT Diesel Production .................................................................................... $1-15$

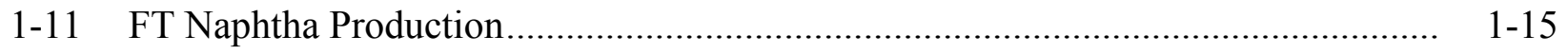

1-12 Methanol Production.............................................................................. $1-15$

1-13 Scenario 1 System Boundary …....................................................................... $\quad 1-16$

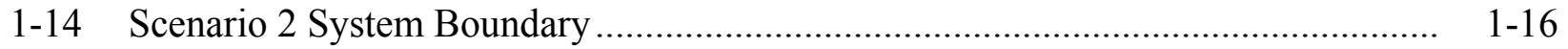

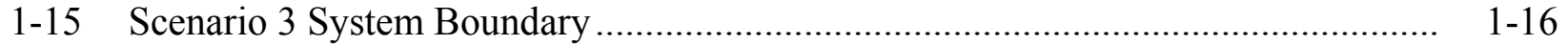

1-16 Scenario 4 System Boundary ....................................................................... $1-16$

1-17 Scenario 5 System Boundary .................................................................... $1-16$

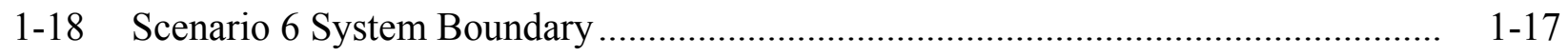

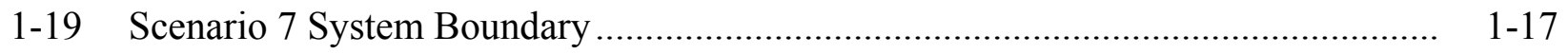

1-20 Scenario 8 System Boundary ......................................................................... $1-17$

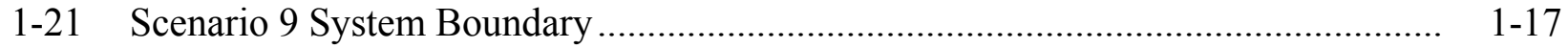

1-22 Scenario 10 System Boundary .................................................................... $1-17$

1-23 Scenario 11 System Boundary ….............................................................. $1-18$

1-24 Scenario 12 System Boundary .................................................................. $1-18$

1-25 Scenario 13 System Boundary .................................................................... $1-18$

1-26 Scenario 14 System Boundary ................................................................... $1-18$

1-27 Scenario 15 System Boundary ................................................................... $1-18$

1-28 Scenario 16 System Boundary ...................................................................... 1-19

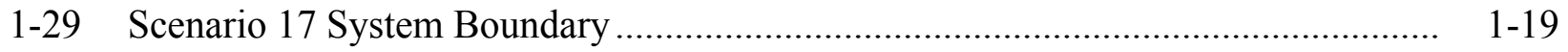

1-30 Scenario 18 System Boundary ....................................................................... $1-19$

1-31 Scenario 19 System Boundary .......................................................................... $1-19$

1-32 Scenario 20 System Boundary .................................................................. $1-19$ 
Figure

2-1 WTW Total System Energy Use for Conventional and Hybrid Fuel/

Vehicle Pathways (SI and CIDI) ....................................................................... 2-4

2-2 WTW $\mathrm{CO}_{2}$ Emissions for Conventional and Hybrid Fuel/Vehicle Pathways........... 2-5

2-3 WTW Total System Energy for Hybrid Fuel/FCV Pathways .................................. 2-6

2-4 WTW $\mathrm{CO}_{2}$ Emissions for Hybrid Fuel/FCV Pathways .............................................. 2- 2-7

3-1 Petroleum Administration for Defense Districts ................................................... 3-9

4-1 Aspen Plus Process Simulation Flow Diagram for Syngas Generation ................... 4 4-2

5-1 CFE System Boundary for Petroleum Coke ……………………………………...... 5-3

5-2 CFE System Boundary for Heavy Residual Oil ........................................................ 5-4

5-3 $\quad \mathrm{CO}_{2}$ CFE Allocation Well-to-Tank................................................................ 5-17

5-4 $\quad \mathrm{SO}_{\mathrm{X}}$ CFE Allocation Well-to-Tank …………….............................................. 5-18

5-5 $\quad \mathrm{NO}_{\mathrm{X}}$ CFE Allocation Well-to-Tank ................................................................ 5-18

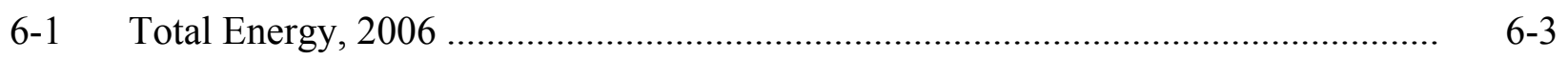

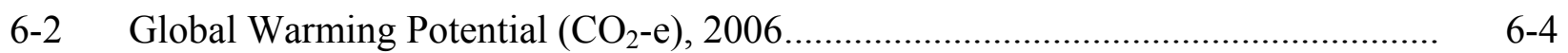

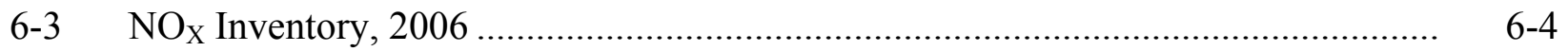

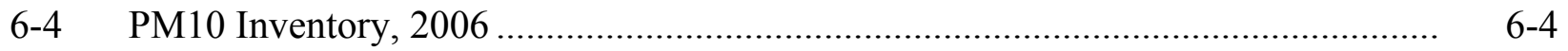

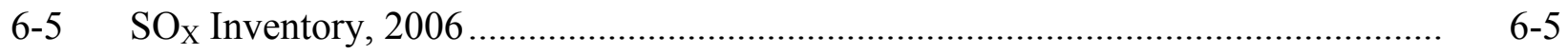

6-6 Long-Term Total Energy, 2015 ........................................................................ 6

6-7 Global Warming Potential, 2015 ......................................................................... 6-9

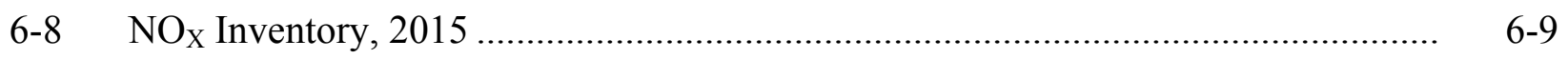

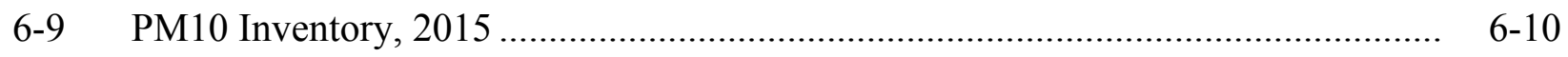

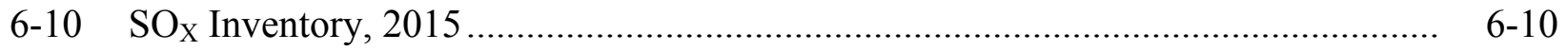

6-11 FTD100 CIDI and ULSD CIDI WTT Process Unit Total Energy, 2015 .................. 6-25

6-12 FTD100 CIDI and ULSD CIDI TTW Process Unit Total Energy, 2015 .................. 6-25

6-13 FTD100 CIDI and ULSD CIDI WTT Process Unit GWP, 2015 ............................ 6-26

6-14 FTD100 CIDI and ULSD CIDI TTW Process Unit GWP, 2015 ............................. 6-26

6-15 FTD100 CIDI and ULSD CIDI WTT Process Unit $\mathrm{NO}_{\mathrm{X}}$ Inventory, $2015 \ldots \ldots \ldots \ldots \ldots . . . . .6-26$

6-16 FTD100 CIDI and ULSD CIDI TTW Process Unit $\mathrm{NO}_{\mathrm{X}}$ Inventory, 2015 ............... 6-27

6-17 FTD100 CIDI and ULSD CIDI WTT Process Unit PM10 Inventory, 2015 ............. 6-27

6-18 FTD100 CIDI and ULSD CIDI TTW Process Unit PM10 Inventory, 2015 ............. 6-27

6-19 FTD100 CIDI and ULSD CIDI WTT Process Unit SO $_{X}$ Inventory, 2015 ............... 6-28

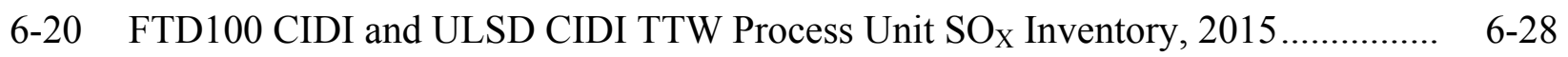


$\begin{array}{ll}\text { Figure } & \text { Page }\end{array}$

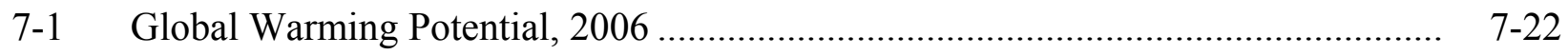

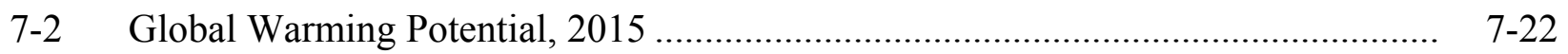

7-3 Total Acidification, 2006 ....................................................................

7-4 Total Acidification, 2015 .............................................................................

7-5 Urban Acidification, Houston, 2006 .............................................................. $\quad$ 7-24

7-6 Urban Acidification, Houston, 2015 ……………........................................ 7-24

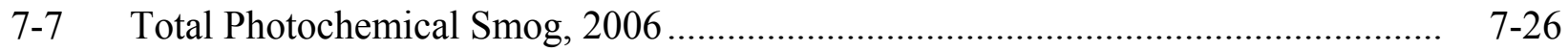

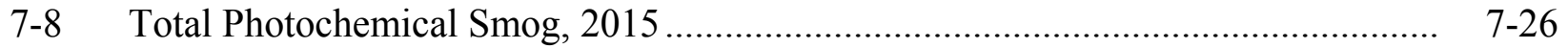

7-9 Urban Photochemical Smog, Houston, 2006 ………………………………..... 7-27

7-10 Urban Photochemical Smog, Houston, 2015 …………………………………...... 7-27

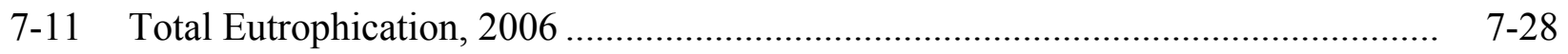

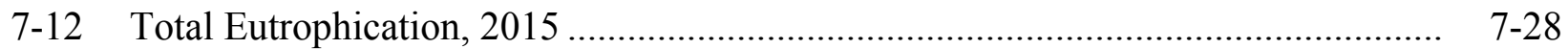

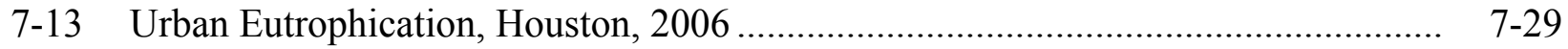

7-14 Urban Eutrophication, Houston, 2015 ………............................................. 7-29

7-15 Total Human Health Criteria, 2006 ................................................................ 7-30

7-16 Total Human Health Criteria, 2015 .................................................................. 7-30

7-17 Urban Human Health Criteria, Houston, 2006 .................................................... 7-31

7-18 Urban Human Health Criteria, Houston, 2015 ........................................................ 7-31

7-19 Human Health, Cancer, 2015 ........................................................................ 7-32

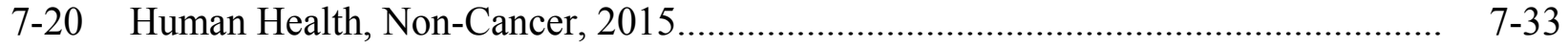

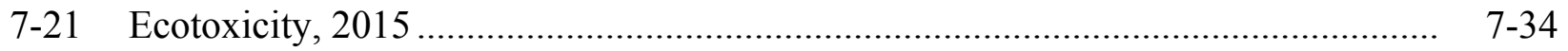

7-22 Crude Oil Consumption, 2006 ........................................................................ $\quad$ 7-35

7-23 Crude Oil Consumption, 2015 ............................................................... $\quad$ 7-35

7-24 Natural Gas and Stranded Natural Gas Consumption, 2006 .................................. 7-36

7-25 Natural Gas and Stranded Natural Gas Consumption, 2015 ................................... 7 7-36

7-26 Depletion of Crude Oil Reserves ................................................................ $\quad$ 7-37

7-27 Depletion of Stranded Gas Reserves ............................................................... $\quad$ 7-37

7-28 Stranded Gas Consumption by Project Type ....................................................... 7-38

7-29 Depletion of Crude Oil and Stranded Gas Reserves, Btu Equivalents ...................... 7 7-38

C-1 Uncertainty Analysis: Total Energy, 2006 ....................................................... C-3

C-2 Uncertainty Analysis: Global Warming Potentials, 2006...................................... C-3

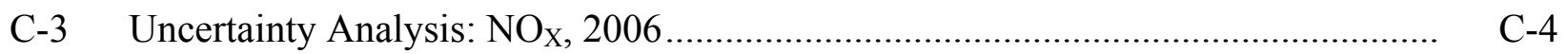

C-4 Uncertainty Analysis: PM10, 2006...................................................................... C-4 
Figure $\quad$ Page

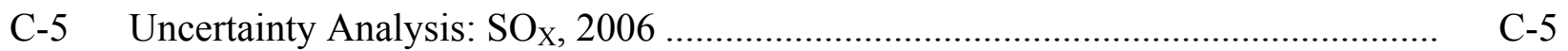

C-6 Uncertainty Analysis: Total Energy, 2015 .................................................... C-6

C-7 Uncertainty Analysis: Global Warming Potentials, 2015 ................................... C-6

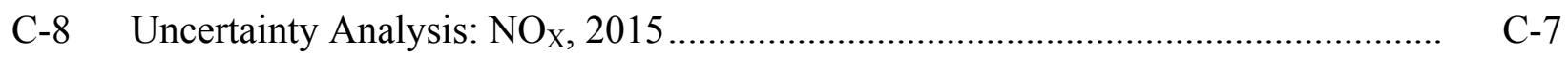

C-9 Uncertainty Analysis: PM10, 2015 ............................................................. C-7

C-10 Uncertainty Analysis: $\mathrm{SO}_{\mathrm{X}}, 2015$..................................................................... C-8

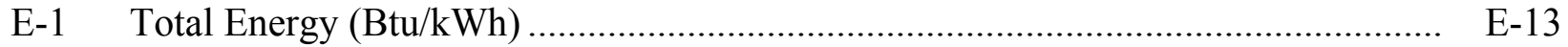

E-2 Global Warming Potential $\left(\mathrm{CO}_{2}\right.$ Equivalents/kWh) ....................................... E-14

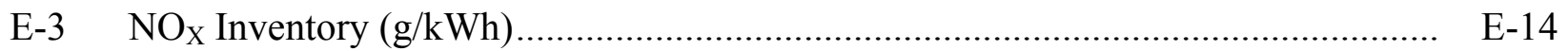

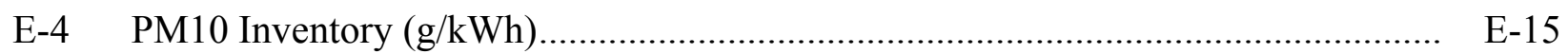

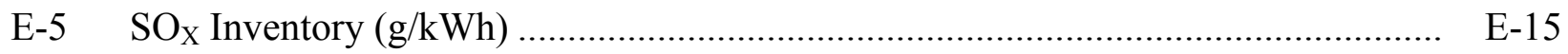


1-1 UCF LCA Petroleum Fuels Systems …………............................................... 1-8

1-2 UCF LCA GTL and Methanol Systems.............................................................. 1-8

1-3 Short-Term Transportation Scenarios........................................................................ 1-9

1-4 Long-Term Transportation Scenarios ...................................................................... 1-9

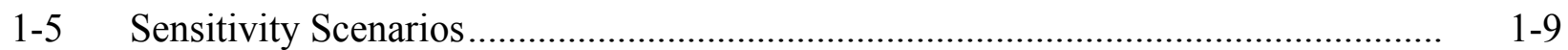

1-6 Life Cycle Stages and Unit Processes in the UCF LCA........................................ 1-10

1-7 TRACI Impact Categories, Indicators, Characterization Models, and Input Parameters for the UCF LCIA ........................................................... 1-24

2-1 GM WTW Fuel Pathways............................................................................... 2-2

2-2 WTW Total System Energy for
Conventional and Hybrid Fuel/Vehicle Pathways (SI and CIDI).............................. 2-4

2-3 WTW $\mathrm{CO}_{2}$ Emissions for Conventional and Hybrid Fuel/Vehicle Pathways (SI and CIDI)............................. 2 2-5

2-4 WTW Total System Energy for Hybrid Fuel/FCV Pathways ................................... 2 2-6

2-5 WTW $\mathrm{CO}_{2}$ Emissions for Hybrid Fuel/FCV Pathways ........................................... 2- 2-7

2-6 MIT Study Vehicle Efficiency Assumptions ................................................................. 2- 2-9

2-7 MIT Study Results ..................................................................................... 2-10

2-8 Selected GM WTW Results.................................................................. 2-10

2-9 Argonne Natural Gas Process Energy Efficiencies ............................................... 2-12

2-10 GHG Impact Reductions Relative to Conventional Gasoline ................................. 2-13

2-11 Long-Term Electric Vehicle and Fuel Cell Vehicle Technologies: GHG Emission Changes Relative to Conventional Gasoline................................... 2 2-13

2-12 Long-Term CIDI Engine Technologies:

Total $\mathrm{SO}_{\mathrm{X}}$ Emission Changes Relative to Conventional Gasoline ............................ 2-13

2-13 Results for Low-Sulfur and Ultra-Low Sulfur Diesel and FT Diesel....................... 2 2-16

2-14 GTL Efficiencies Assumed in GREET 1.6 ……………………………............ 2-17

2-15 GREET 1.6 Results from Default Data: Percentage Reductions

Relative to Conventional Gasoline ……........................................................... 2-18

2-16 GHG Emissions from the NETL Study ............................................................ 2-19

2-17 NREL Results for Allocation of Emissions to FRFG for the 2000 Case.................. 2-20

2-18 NREL Study Results for Allocation of Emissions to FRFG from Co-products ........ 2-21

3-1 GREET 1.6 Results: Percentage Reduction Relative to Reformulated Gasoline in Conventional Engines................................................... 3-. 3-1

3-2 Shares of Combustion Technologies by Process Unit ............................................... 3-5

3-3 Shares of Process Fuel by Process Unit...................................................................... 3-6 
3-4 Global Warming Potentials of Greenhouse Gases, $\mathrm{CO}_{2}$ Equivalents, 100-Year Time Period.................................................................................... 3-6

3-5 GREET 1.6 and UCF LCA Urban Emission Shares for Criteria Pollutants.............. 3-7

3-6 Feedstock Stage Thermal Efficiencies................................................................ 3-8

3-7 Transportation Distances per Transportation Mode for Petroleum Fuels ................. 3-8

3-8 Transportation Distances per Transportation Mode for Methanol and GTL Fuels ... 3-8

3-9 Shares by Transportation Mode....................................................................... 3-9

3-10 GREET 1.6 Default and UCF LCA Petroleum Refining Efficiencies....................... 3-11

3-11 Default and Revised FT Diesel, FT Naphtha, and Methanol Process Efficiencies ... 3-11

3-12 Data Sources for the Petroleum Fuel Production System...................................... 3-12

3-13 Data Sources for the GTL Fuel Production System …………….......................... 3-12

3-14 FRFG, GREET 1.6 Default Data and UCF LCA Revisions................................... 3-15

3-15 Ultra-Low Sulfur Diesel, GREET 1.6 Default Data and UCF LCA Revisions......... 3-16

3-16 FT Diesel, GREET 1.6 Default Data and UCF LCA Revisions ............................... 3-17

3-17 Methanol, GREET 1.6 Default Data and UCF LCA Revisions ............................... 3-18

3-18 FT Naphtha, GREET 1.6 Default Data and UCF LCA Revisions............................ 3-18

3-19 Data Sources for Vehicle Use .......................................................................... 3-19

4-1 Energy and Carbon Efficiencies for GTL Production Technologies......................... 4 4-3

4-2 GREET 1.5 Efficiencies for GTL Production.......................................................... 4-3

4-3 GREET 1.6 Default Efficiencies for GTL Production................................................ 4. 4-4

4-4 UCF LCA Efficiencies for GTL Production............................................................. 4- 4-6

4-5 GREET 1.6 Efficiencies for Methanol Production..................................................... 4- 4

4-6 UCF LCA Efficiencies for Methanol Production .................................................. 4-11

5-1 UCF LCA Cases .................................................................................

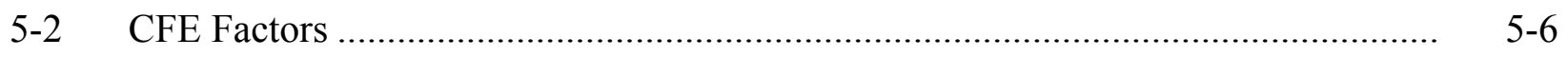

5-3 Downstream Applications and Alternative Products................................................. 5 5-7

5-4 Petroleum-Coke-to-Power Parameters ……………………………………............. 5-9

5-5 Coal-to-Power Parameters .................................................................................... 5-9

5-6 Natural-Gas-to-Power Parameters ……………….................................................. 5-9

5-7 Petroleum-Coke-to-Cement Parameters ……….............................................. $\quad$ 5-10

5-8 Heavy Residual Oil-to-Power and to-Heat/Steam Parameters, U.S. ....................... 5-11

5-9 Natural-Gas-to-Power and to-Heat/Steam Parameters, U.S. .................................. 5-11

5-10 PADD III 2006 - Co-product Energy and Emissions Well-to-Tank

Allocations to Gasoline (Btu/MMBtu or g/MMBtu) ............................................... 5 5-13 
Table

5-11 PADD III 2006-Co-product Energy and Emissions Well-to-Tank

Allocations to Diesel (Btu/MMBtu or g/MMBtu)

5-12 PADD III 2015-Co-product Energy and Emissions Well-to-Tank Allocations to Gasoline (Btu/MMBtu or g/MMBtu).

5-13 PADD III 2015-Co-product Energy and Emissions Well-to-Tank Allocations to Diesel (Btu/MMBtu or g/MMBtu)

5-14 Coke-to-Power (Global), PADD III 2006 and 2015.

5-15 Coke-to-Cement (Global), PADD III 2006 and 2015.

5-16 Heavy Residual Oil-to-Power/Heat vs. Natural Gas-to-Power/Heat, PADD III 2006.

5-17 Heavy Residual Oil-to-Power/Heat vs. Natural Gas-to-Power/Heat, PADD III 2015.

5-18 CFE Allocations for Gasoline, Increases over PADD III 2006 Case (GREET Default) (g/MMBtu of Gasoline).

5-19 CFE for Gasoline, Increases over PADD III 2015 Case (GREET Default) (g/MMBtu)

5-20 CFE for ULSD, Increases over PADD III 2006 Case (GREET Default), (g/MMBtu)

5-21 CFE for ULSD, Increases over PADD III 2015 Case (GREET Default), (g/MMBtu)

6-1 FTD20 CIDI Comparison with Conventional Diesel CIDI, 2006 (Btu/mi or g/mi)..

6-2 FTD20 CIDI Comparison with Ultra-Low Sulfur Diesel CIDI, 2006 (Btu/mi or $\mathrm{g} / \mathrm{mi})$

6-3 FTD20 CIDI Comparison with FRFG, 2006 (Btu/mi or g/mi).

6-4 FTD100 CIDI Comparison with ULSD CIDI and FRFG SIDI (Btu/mi or g/mi) .....

6-5 Aggressive FTD100 CIDI Comparison with ULSD CIDI and FRFG SIDI (Btu/mi or $\mathrm{g} / \mathrm{mi}$ )

6-6 FTD100 CIDI HEV Comparison with ULSD CIDI HEV and FRFG SIDI HEV (Btu/mi or $\mathrm{g} / \mathrm{mi}$ )

6-7 FT Naphtha FCV Comparison with Methanol FCV and FRFG FCV (Btu/mi or $\mathrm{g} / \mathrm{mi}$ )

6-8 GTL Wastewater (gal/MMBtu) and Solid Waste (g/MMBtu) for FTD and FT Naphtha...

6-9 Petroleum System Wastewater (WW) (gal/MMBtu).

6-10 Petroleum System Solid Waste (SW) (g/MMBtu)................................................ 6-16

6-11 Solid Waste and Wastewater Comparison of FTD with ULSD and FRFG (g/MMBtu and gal/MMBtu) 
Table

Page

6-12 FTD100 CIDI Comparison with ULSD CIDI and FRFG, PADD III Heavy, 2015 (Btu/mi or g/mi) ................................................................................ 6-18

6-13 FTD100 CIDI Comparison with ULSD, PADD I 2015 (Btu/mi or g/mi) ................. 6-19

6-14 FTD100 CIDI Comparison with ULSD 3 ppm Sulfur, PADD III 2015 (Btu/mi or $\mathrm{g} / \mathrm{mi})$

6-15 FTD100 CIDI Comparison with ULSD CIDI from Partial and 100\% Middle East Crude Import, 2015 (Btu/mi or g/mi).

6-16 FTD100 CIDI 10\% Flared Gas and 90\% NG Comparison with ULSD CIDI 2015 (Btu/mi or g/mi)

6-17 ULSD CIDI 2015 Parametric Sensitivity Results:

Percentage Change in Outputs Due to Percentage Reduction in Parameters

6-18 FTD100 CIDI 2015 Parametric Sensitivity Results:

Percentage Change in Outputs Due to Percentage Reduction in Parameters

6-19 ULSD CIDI Process Unit Inventory

6-20 FTD100 CIDI Process Unit Inventory.....

6-30

7-1 UCF LCIA Impact Categories, Classification, Category Indicators, and Characterization Models

7-2 Important Fuel Properties for FT Diesel

$7-8$

7-3 FTD, ULSD, and FRFG Fuel Properties

$7-8$

7-4 BTEX Emissions for Crude Oil Production.

$7-11$

7-5 BTEX Emissions for Natural Gas Processing

$7-11$

7-6 TRI Emissions for Gasoline Refining (g/MMBtu)

$7-12$

7-7 TRI Emissions for Diesel Refining (g/MMBtu)

$7-14$

7-8 ULS Diesel and FT Diesel Air Toxics Emissions (g/mi)

7-9 Tier 2 Toxics Emissions Standards for Light Duty Gasoline Vehicles (g/mi)...

7-10 Stranded Gas Reserve Parameter Assumptions... $7-18$

7-11 Crude Oil Reserve Assumptions. $7-18$

7-12 Near-Term LCIA Scenarios

$7-20$

7-13 Long-Term LCIA Scenarios...

$7-20$

7-14 LCIA Total Emissions and Urban Emissions Scenarios

$7-20$

7-15 Wastewater and Solid Waste Comparison of FTD with ULSD and FRFG (gal/MMBtu and g/MMBtu)

A-1 Crude Slates Used in PIMS Models

A-2 Product Slates from PIMS Models …………………………………………..... A-2

A-3 Receipts of Petroleum Coke by Electric Utilities, $2000 \ldots \ldots \ldots \ldots \ldots \ldots \ldots \ldots \ldots \ldots \ldots \ldots \ldots \ldots \ldots \ldots . . . \quad$ A-3 
Table

Page

A-4 1998 U.S. Exports of Fuel Grade Petroleum Coke for Power .................................. A-3

A-5 U.S. Exports of Petroleum Coke for Cement Production ......................................... A-4

A-6 U.S. Sales of Residual Fuel Oil for End Use, Year 2000 (Thousand Gallons) ......... A A-4

A-7 $\quad \mathrm{SO}_{\mathrm{X}}$ and $\mathrm{NO}_{\mathrm{X}}$ Emissions Factors for the CFE .......................................................... A-4

A-8 CFE for Coke-to-Power, PADD III 2006 ………………....................................... A-5

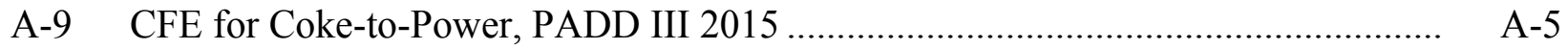

A-10 CFE for Coke-to-Power, PADD III Heavy ……………………………….......... A-6

A-11 PADD III Heavy — Co-Product Energy and Emissions Well-to-Tank Allocations to Gasoline (Btu/MMBtu or g/MMBtu) ............................................... A-6

A-12 PADD III Heavy—Co-Product Energy and Emissions Well-to-Tank Allocations to Diesel (Btu/MMBtu or g/MMBtu) .................................................. A-7

A-13 CFE for Gasoline and Diesel for Coke to Power, PADD III Heavy .......................... A-7

A-14 CFE for Petroleum Coke to Cement, PADD III Heavy ……………………................ A-7

A-15 CFE for Heavy Residual Oil-to-Power/Heat vs. Natural Gas-to-Power/Heat, PADD III Heavy ………......................................... A- A

A-16 CFE for Gasoline, PADD III Heavy Case ………............................................... A-8

A-17 CFE for ULSD, PADD III Heavy Case ………………………............................... A-8

B-1 Near Term Conventional Diesel, ULS Diesel, and FRFG PADD III 2006 ............... B B-2

B-2 Long-Term FRFG PADD III 2015 ………….............................................. B-3

B-3 Long-Term ULS Diesel, PADD III 2015 ……………………............................ B-4

B-4 Long-Term PADD III Heavy 2015, PADD I 2015 .............................................. B-5

B-5 Long-Term Methanol FCV ………………................................................. B-6

C-1 Normal Distribution Ranges for UCF Fuel Production Energy Efficiency ............... C-2

C-2 Normal Distribution Ranges for Petroleum Refining Energy Efficiency ................... C-2

C-3 Weibull Distribution Ranges for Vehicle Efficiency Improvement Relative to Baseline Vehicle................................................................................ C-2

D-1 2006 Total LCIA Results .............................................................................. D-1

D-2 2015 Total FTD, ULSD, and FRFG LCIA Results ................................................ D-1

D-3 2015 Total HEV LCIA Results....................................................................... D-1

D-4 2015 Total FCV LCIA Results …………………………………………......... D-2

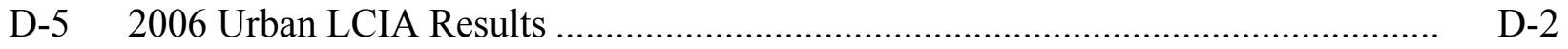

D-6 2015 Urban FTD, ULSD, and FRFG LCIA Results................................................. D-2

D-7 2015 Urban HEV LCIA Results …………………………………………….... D-2

D-8 2015 Urban FCV LCIA Results.......................................................................... D-3 
Table

D-9 Total LCIA Results for All Scenarios................................................................ D-3

D-10 Houston Urban LCIA Results for All Scenarios ................................................... D-4

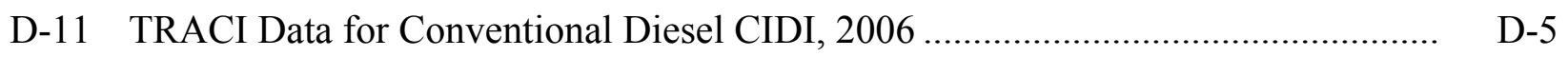

D-12 TRACI Data for FTD20, 2006 .............................................................................. D-9

D-13 TRACI Data for ULSD CIDI, 2006 ............................................................... D-10

D-14 TRACI Data for FRFG SI, 2006 ............................................................... D-15

D-15 TRACI Data for FTD100 CIDI, 2015 ................................................................. D-19

D-16 TRACI Data for FTD100 HEV, 2015 .......................................................... D-21

D-17 TRACI Data for ULSD CIDI, 2015 ................................................................ D-22

D-18 TRACI Data for ULSD HEV, 2015 .................................................................... D-26

D-19 TRACI Data for FRFG SI, 2015 .................................................................. D-30

D-20 TRACI Data for FRFG HEV, 2015 ............................................................... D-35

D-21 TRACI Data for FT Naphtha FCV, 2015 ......................................................... D-39

D-22 TRACI Data for FRFG FCV, 2015 ............................................................... D-40

D-23 TRACI Data for Methanol FCV, 2015 .......................................................... D-44

E-1 GTL-Fired Combined-Cycle Gas Turbine Emissions Factors ................................. E-4

E-2 Methanol-Fired Combined-Cycle Gas Turbine Emissions Factors ............................ E- E

E-3 Coal-Fired Power Plant Emissions Factors (Btu/kWh or g/kWh) ........................... E-7

E-4 Natural-Gas-Fired Combined-Cycle Gas Turbine Emissions Factors $(\mathrm{Btu} / \mathrm{kWh}$ or $\mathrm{g} / \mathrm{kWh})$

E-5 LNG-Fired Combined-Cycle Gas Turbine Emissions Factors

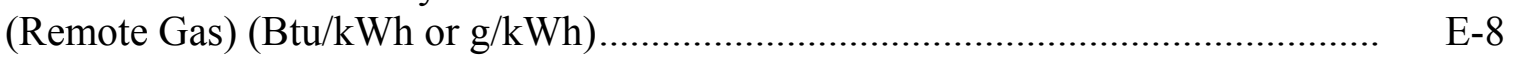

E-6 Regional Electricity Generation Mixes................................................................... E-8

E-7 Regional Electricity Generation Emissions Factors (Btu/kWh or $\mathrm{g} / \mathrm{kWh}) \ldots \ldots \ldots \ldots \ldots \ldots . . \quad$ E-8

E-8 GTL vs. Power Options, Comparison of Combustion Emissions,

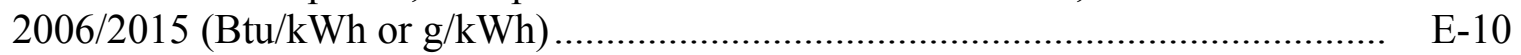

E-9 GTL vs. Power Options, Comparison of Full Fuel Cycle Emissions, $2006(\mathrm{Btu} / \mathrm{kWh}$ or $\mathrm{g} / \mathrm{kWh})$

E-10 GTL vs. Power Options, Comparison of Full Fuel Cycle Emissions, $2015(\mathrm{Btu} / \mathrm{kWh}$ or $\mathrm{g} / \mathrm{kWh})$.

E-11 Methanol vs. Power Options, Comparisons of Combustion Emissions, 2006/2015 (Btu/kWh or $\mathrm{g} / \mathrm{kWh})$

E-12 Methanol vs. Power Options, Comparisons of Full Fuel Cycle Emissions, $2006(\mathrm{Btu} / \mathrm{kWh}$ or $\mathrm{g} / \mathrm{kWh})$. 
Table $\quad$ Page

E-13 Methanol vs. Power Options, Comparison of Full Fuel Cycle Emissions, $2015(\mathrm{Btu} / \mathrm{kWh}$ or $\mathrm{g} / \mathrm{kWh})$

E-13

F-1 $\quad \mathrm{NO}_{\mathrm{X}}$ Emissions Comparisons, FTD vs. HGAC SIP

Base Case for August 302007 SIP Scenario (tons of $\mathrm{NO}_{\mathrm{X}} /$ day).

F-2 


\section{ACKNOWLEDGMENTS}

The ConocoPhillips Ultra Clean Fuels Life Cycle Assessment study benefited greatly from the input of colleagues from ConocoPhillips and Nexant, as well as several other organizations.

Thomas Ryan from the Southwest Research Institute conducted a review of vehicle efficiency and emissions. Michael Wang from Argonne National Laboratory assisted in the development of co-product modeling in GREET. The peer review panel, chaired by Steven Young of the University of Waterloo with members Rita Schenk of the Institute for Environmental Research and Education, Margaret Mann of the National Rewewable Energy Laboratory, and Ferry Van Dijk of Shell International Gas Ltd., provided an extensive and valuable critical review of the study. 


\section{ACRONYMS AND ABBREVIATIONS}

\begin{tabular}{|c|c|}
\hline $\mathrm{AGC}$ & Advanced Gas Conversion \\
\hline ANL & Argonne National Laboratory \\
\hline ATR & auto-thermal reforming \\
\hline CAFE & combined average fleet efficiency \\
\hline CARFG & California reformulated gasoline \\
\hline CD & conventional diesel \\
\hline CFE & Co-product Function Expansion \\
\hline $\mathrm{CH}_{4}$ & methane \\
\hline CIDI & compression ignition direct injection \\
\hline $\mathrm{CNG}$ & compressed natural gas \\
\hline CNGV & compressed natural gas vehicle \\
\hline $\mathrm{CO}$ & carbon monoxide \\
\hline $\mathrm{CO}_{2}$ & carbon dioxide \\
\hline $\mathrm{CP}$ & co-products \\
\hline DOE & Department of Energy \\
\hline EIA & Energy Information Agency \\
\hline EPA & Environmental Protection Agency \\
\hline EPA AP-42 & Environmental Protection Agency Emissions Factors reference \\
\hline EPRI & Electric Power Research Institute \\
\hline FCV & fuel cell vehicle \\
\hline FG & flared gas \\
\hline FO & No. 2 fuel oil \\
\hline FP & fuel-processor \\
\hline FRFG & federal reformulated gasoline \\
\hline FT & Fischer-Tropsch \\
\hline FTD & Fischer-Tropsch diesel \\
\hline FTD20 & $\begin{array}{l}\text { mixture of } 20 \% \text { Fischer-Tropsch diesel and } 80 \% \text { ultra-low sulfur diesel (by } \\
\text { volume) }\end{array}$ \\
\hline FTD100 & $100 \%$ Fischer-Tropsch diesel \\
\hline GHG & greenhouse gases \\
\hline GM & General Motors \\
\hline GREET & Greenhouse Gases, Regulated Emissions, and Energy Use in Transportation \\
\hline GTL & gas-to-liquid \\
\hline GWP & global warming potential \\
\hline $\mathrm{HEV}$ & hybrid electric vehicle \\
\hline HHV & high heating value \\
\hline HRSG & heat recovery and steam generator system \\
\hline ICE & internal combustion engine \\
\hline ISO & International Standards Organization \\
\hline LCA & Life Cycle Assessment \\
\hline LCI & Life Cycle Inventory \\
\hline LCIA & Life Cycle Impact Assessment \\
\hline LHV & low heating value \\
\hline
\end{tabular}




$\begin{array}{ll}\text { LNG } & \text { liquefied natural gas } \\ \text { LPG } & \text { liquefied petroleum gas } \\ \text { M100 } & \text { 100\% methanol by volume (pure methanol) } \\ \text { MOGD } & \text { Mobil Olefins to Gasoline and Distillates } \\ \text { MPG } & \text { miles per gallon } \\ \text { MWh } & \text { megawatt hour } \\ \text { N}_{2} \mathrm{O} & \text { nitrous oxide } \\ \text { NETL } & \text { National Energy Technology Laboratory } \\ \text { NG } & \text { natural gas } \\ \text { NNA NG } & \text { Non-North American natural gas } \\ \text { NOX } & \text { nitrogen oxides } \\ \text { NREL } & \text { National Renewable Energy Laboratory } \\ \text { P20/50/80 } & \text { 20\%/50\%/80\% probability } \\ \text { PADD } & \text { Petroleum Administration Defense District } \\ \text { PADD I } & \text { Petroleum Administration Defense District I (East Coast states) } \\ \text { PADD III } & \text { Petroleum Administration Defense District III (Gulf Coast states) } \\ \text { PIMS } & \text { Process Industries Modeling System } \\ \text { PM10 } & \text { particulate matter with diameter of 10 microns or less } \\ \text { POX } & \text { partial oxidation process for syngas production } \\ \text { RFG } & \text { reformulated gasoline } \\ \text { RO } & \text { residual oil } \\ \text { SBE } & \text { system boundary expansion } \\ \text { SI } & \text { spark ignition } \\ \text { SMDS } & \text { Shell Middle Distillate Synthesis } \\ \text { SMR } & \text { steam reforming } \\ \text { SOX } & \text { sulfur oxides } \\ \text { SPD } & \text { slurry phase distillate } \\ \text { TRACI } & \text { Tool for the Reduction and Assessment of Chemical and other Impacts } \\ \text { TRI } & \text { toxic release inventory } \\ \text { UCF } & \text { ultra clean fuel } \\ \text { ULSD } & \text { ultra-low sulfur diesel } \\ \text { USEA } & \text { U.S. Energy Association } \\ \text { USAID } & \text { U.S. Agency for International Development } \\ \text { VOC } & \text { volatile organic compound } \\ \text { WTT } & \text { well-to-tank } \\ \text { WTW } & \text { well-to-wheel } \\ \text { WW } & \text { wastewater } \\ & \end{array}$




\section{GLOSSARY}

Aggressive FTD Engine. A diesel engine that is optimized to take advantage of the beneficial characteristics of FT diesel (FTD). This opportunity comes about mostly as a result of the high cetane number of FTD, allowing for injection timing changes. It is estimated that a 5\% improvement in fuel consumption is possible at the same $\mathrm{NO}_{\mathrm{X}}$ level.

Allocation. Allocation is a method whereby energy and emissions at the production stage are divided among various products and co-products on the basis of mass, energy content, or economic value. Typically, the upstream and downstream lifecycle effects of co-products produced in multi-product systems are placed outside of the system boundary by via allocation.

Co-Products. Co-products are those outputs produced along with the primary product that may have economic value, but are not the primary economic drivers of the system. In the petroleum refining industry, petroleum coke, heavy residual oil, asphalt, fuel oil, naphtha, kerosene/jet fuel, and liquid petroleum gas are co-products. For gas-to-liquids (GTL) production systems, there are no significant co-products. For the conversion of natural gas to methanol, there are no significant co-products.

Co-product Function Expansion. CFE is a methodology developed in the UCF LCA study that incrementally considers functions associated with system co-products, including these functions within the system boundary.

Full Fuel System. A full fuel system is one that incorporates every life cycle fuel production and use stage and takes into account all products and co-products.

Global Warming Potential. An indicator for global warming, GWP is a function of greenhouse gas (GHG) emissions. GWP is a weighted aggregate of $\mathrm{CO}_{2}, \mathrm{CH}_{4}$, and $\mathrm{N}_{2} \mathrm{O}$ expressed as $\mathrm{CO}_{2}-$ equivalents over a 100-year time horizon. The UCF LCA uses GWP factors from the International Panel on Climate Change third report on climate change (IPCC, 2001).

Inventory. A life cycle inventory for a specified emission is a complete accounting of the emission from each life cycle stage associated with a fuel pathway.

Pathway. A fuel pathway is defined by the specific lifecycle stages, production technologies, and end-use technologies associated with the pathway. An example of a complete fuel pathway is as follows: the Fischer-Tropsch diesel (FTD) compression ignition, direct injection (CIDI) vehicle, with FTD sourced from a remote source of natural gas, with a specified fuel production efficiency, with FTD transported over a specified number of ocean miles from the remote site, and with specified fuel efficiency and emissions factors for the FTD CIDI vehicle.

Primary Products. Primary products are those outputs of a production system that are the primary economic drivers of the system or industry. In the petroleum refining industry, gasoline and diesel motor fuels are the primary products. For GTL production systems, FTD and FT 
naphtha are primary products. For the conversion of natural gas to methanol, methanol is the primary product.

System Boundary Expansion (SBE). SBE is a method whereby all products and co-products and product functions are including in the system boundary. In comparative assessments, the coproducts are considered relative to alternative products in downstream functions (e.g., petroleum coke versus coal for power generation), and the net emissions inventories are assigned as either credits or debits to the primary products.

Tank-to-Wheel. Tank-to-wheel refers to the end-use stages of a transportation fuel pathway, which includes only the operation of the vehicle.

Well-to-Tank. Well-to-tank refers to the stages of a fuel pathway from fuel extraction and fuel production to the delivery of the fuel to the vehicle tank. 


\section{Executive Summary}

\section{OVERVIEW}

Throughout the world, there are large proven reserves of natural gas that are "stranded" because their remote locations render them incapable of being economically brought to market. ConocoPhillips is developing proprietary gas-to-liquids (GTL) technology to economically convert this natural gas to GTL products, primarily diesel, for use as a transportation fuel. Another significant product of the GTL process is naphtha, which may be used for a number of applications, such as petrochemical feedstock or as a fuel for fuel cell vehicles. In this study, GTL diesel and naphtha together are referred to as GTL products.

GTL technology is not the only means available to gas reserve owners or technology developers for the utilization of remote gas. Methanol and liquefied natural gas (LNG) are the two primary alternatives. Methanol has the technical potential to be used in fuel cell vehicles; LNG has been used commercially for decades for power generation. ConocoPhillips believes that those interested in developing and monetizing remote gas fields may consider methanol and LNG as alternative competing options. It is therefore important and necessary to study and understand the potential environmental and human health impacts of these alternatives in comparison with GTL products.

ConocoPhillips, in conjunction with Nexant Inc., Penn State University, and Cummins Engine Co., has joined with the U.S. Department of Energy (DOE) National Energy Technology Laboratory (NETL) in a cooperative agreement to perform a comprehensive study of new ultra clean fuels (UCFs) produced from remote sources of natural gas. This study, called the Ultra Clean Fuels Life Cycle Assessment (UCF LCA), consists of a Life Cycle Inventory (LCI) and a Life Cycle Impact Assessment (LCIA) for GTL transportation fuels, namely, Fischer-Tropsch diesel (FTD) and FT naphtha.

The question arises: With respect to cost and environmental impact, how do these UCFs compare with conventional fuels - federal reformulated gasoline (FRFG), conventional diesel, and ultralow sulfur diesel (ULSD) — and how do they compare with methanol? (LNG is not considered a transportation fuel in this study.)

To address this question, ConocoPhillips and Nexant conducted a comprehensive LCA of UCFs and a separately published market study that focuses on the commercial feasibility of these UCFs. The UCF LCA uses this market study to examine likely future commercial recovery, processing, and fuel distribution operating scenarios for GTL fuels and methanol. This report contains the results of the LCA. A study of GTL fuels for use in power generation and an air quality modeling study of GTL fuels in the Houston area were also conducted, and are included as appendices to this report.

For comparison purposes, ConocoPhillips and Nexant included conventional transportation fuels in the study. Since refinery location is an important factor in determining the likely changes in petroleum product slates, a detailed assessment was performed for two Petroleum Administration 
Defense Districts (PADDs): PADD III and PADD I. PADD III is representative of a U.S. national average crude slate; PADD I is representative of a lighter crude slate.

\section{GOALS}

ConocoPhillips undertook this study to help ensure that its investment in and development of GTL technology would be sustainable into the future. ConocoPhillips believes that GTL fuelsFTD and FT naphtha - are competitive options in the development and monetization of remote natural gas fields. These natural-gas-sourced fuels are assumed to displace or offset conventional petroleum fuels for transportation end uses.

In accordance with its business planning and corporate commitment to sustainable development, ConocoPhillips believes that it is important and necessary to understand life cycle environmental and human health potential impacts of GTL products in comparison with alternatives. Therefore, this LCA study is designed to estimate, with available data and within available study resources, the energy utilization and emissions life cycle profiles of ConocoPhillips GTL fuels and selected competitive fuels in the future.

This study is also part of the U.S. Department of Energy (DOE) Ultra Clean Fuels initiative, which aims to develop and deploy technologies that will produce ultra-clean-burning transportation fuels for the 21 st century from both petroleum and non-petroleum resources. ConocoPhillips's goals are in accord with those of DOE, namely, to produce fuels that will:

- Enable vehicles to comply with future emission requirements

- Be compatible with the existing liquid fuels infrastructure

- Enable vehicle efficiencies to be significantly increased, with concomitantly reduced $\mathrm{CO}_{2}$ emissions

- Be obtainable from a fossil resource, alone or in combination with other hydrocarbon materials such as refinery wastes, municipal wastes, and biomass

- Be cost-competitive with current fuels

\section{Audience}

The UCF LCA will be used to help educate and inform stakeholders in gas development projects. The audience includes:

- National oil companies (gas reserve owners)

- Government energy and environmental agencies

- Peer group of refiners and GTL technology developers

The results of the study will be made available to:

- Environmental non-government organizations

- Transportation and power industry trade and market associations

- The general public 
ConocoPhillips also intends to use the study internally to assess, improve, and complement the environmental programs (e.g., Product Stewardship and environmental impact assessment) used to manage the life cycle impacts of ConocoPhillips's GTL products.

\section{Objectives}

The specific objectives for the UCF LCA are:

- For the LCI:

- Quantification of the energy use and selected emissions inventory associated with the production and use of GTL fuels. Although there are significant markets for these fuels around the world, this study focuses on the use of GTL products in the United States, where significant fuel use and refining baseline data exists. In addition, the study assumes that GTL fuels are produced near stranded gas reserves in remote areas in the Middle East.

- Comparison of the energy use and emissions inventory for the production and use of GTL products on an equivalent basis with refined petroleum products predominantly in use today. For example, FTD may be compared with petroleum diesel in application as a transportation fuel

- Comparison of methanol (as an alternative natural gas utilization option) for use in fuel cell vehicles with GTL and petroleum fuels

- For the LCIA:

- Quantification of potential life cycle impacts associated with the production and use of GTL fuels, in comparison with the potential life cycle impacts of petroleum fuels and competing natural gas utilization options in transportation applications

The life cycle inventory categories considered are total energy, greenhouse gases $\left(\mathrm{CO}_{2}, \mathrm{CH}_{4}\right.$, and $\mathrm{N}_{2} \mathrm{O}$ ), criteria pollutants $\left(\mathrm{NO}_{\mathrm{X}}, \mathrm{SO}_{\mathrm{X}}, \mathrm{CO}, \mathrm{PM} 10\right.$, and $\left.\mathrm{VOC}\right)$, total petroleum fuel use, total fossil fuel use, solid waste, and wastewater.

The functional unit for the UCF LCA is light duty (LD) vehicle miles. LD vehicles are defined as passenger vehicles with gross weights of less than 6,000 pounds.

The study was conducted according to the requirements of the ISO 14040 International Standard for Life Cycle Assessment, which included a critical review conducted by an outside independent panel.

\section{SCOPE AND METHODOLOGY}

The UCF LCA develops a set of near-term (2006) and long-term (2015) scenarios, in coordination with the market study task of the UCF project, to assess the potential impacts associated with likely commercial scenarios for these time frames. The years 2006 and 2015 were selected to represent the likely times of the emergence of the GTL fuels production technologies represented in the scenarios. The vehicle technologies considered in each scenario are representative of the technologies that are likely to be technologically feasible and may be 
commercially available. The vehicles modeled are theoretical and are not average representations of actual in-use vehicle fleets.

The UCF LCA builds on three successive analyses:

- A detailed engineering analysis of the process efficiencies of current and future commercial technologies for GTL production

- An analysis of energy and emissions due to the production and downstream use of petroleum and GTL system co-products. A novel methodology for considering coproducts was developed in this study, and is described in detail in Section 5 of this report

- Sensitivity analysis that considers future heavy crude input slates for petroleum refining, 3 ppm ultra-low sulfur petroleum diesel, and flared gas used in the production of GTL products. In addition, a comprehensive parametric sensitivity analysis was performed for all key study parameters

The study scenarios consider the following fuels and vehicle configurations:

For transportation fuels:

- Current and future petroleum fuels - federal reformulated gasoline (FRFG), conventional diesel, and ULSD

- A 20\% FTD/80\% ULSD blend (FTD20), 100\% FTD (FTD100), methanol, and FT naphtha, all produced from remote natural gas

For vehicles:

- Vehicle configurations include conventional spark ignition (SI) engines for FRFG, advanced spark ignition direction injection (SIDI) engines for FRFG, compression ignition direct injection (CIDI) diesel engines, hybrid electric vehicles (HEVs) with SIDI and CIDI engines, and fuel processor fuel cell vehicles (FCVs). The vehicles modeled are representative of theoretical vehicle configurations and performances

\section{MODEL}

The GREET (Greenhouse Gases, Regulated Emissions, and Energy Use in Transportation) model, Version 1.6, from Argonne National Laboratory served as the primary modeling tool for the UCF LCA. GREET has become a standard tool for conducting and benchmarking fuel-cycle studies in the United States, and its use worldwide is growing.

GREET is not an LCA tool per se, but rather a fuel cycle, or input-output, model. In the UCF LCA, GREET is paired with two process simulation tools (PIMS and Aspen Plus) for detailed data development and validation.

The Tool for the Reduction and Assessment of Chemical and other Impacts (TRACI) model is the LCIA tool used in this study. Developed by the U.S. EPA National Risk Management Research Laboratory (NRMRL), TRACI was recently released for public use. TRACI can identify the potential for impacts, in relative terms, and provide consistent comparisons given 
scenarios for fuel use in selected metropolitan areas. The approach and outputs of TRACI conform to current industry-standard methods and ongoing international work in LCIA.

\section{LIFE CYCLE INVENTORY CATEGORIES}

The LCI categories considered are total energy, greenhouse gases $\left(\mathrm{CO}_{2}, \mathrm{CH}_{4}\right.$, and $\left.\mathrm{N}_{2} \mathrm{O}\right)$, and criteria pollutants $\left(\mathrm{NO}_{\mathrm{X}}, \mathrm{SO}_{\mathrm{X}}, \mathrm{CO}, \mathrm{PM} 10\right.$, and $\left.\mathrm{VOC}\right)$. GHG emissions are reported as global warming potential (GWP), which is a weighted aggregate of $\mathrm{CO}_{2}, \mathrm{CH}_{4}$, and $\mathrm{N}_{2} \mathrm{O}$ expressed as $\mathrm{CO}_{2}$-equivalents over a 100-year time horizon. The UCF LCA uses GWP factors from the International Panel on Climate Change Third Assessment Report on climate change.

The primary goals of the UCF LCA are: (1) to ensure that ConocoPhillips's GTL business is sustainable into the future and (2) to support the DOE Ultra Clean Fuels project objectives.

The LCI categories are comprehensive and support these primary goals. The LCI also provides data for the LCIA stage of the UCF LCA. The LCIA impact indicators fully address the stated goals of the UCF LCA.

\section{LIFE CYCLE IMPACT ASSESSMENT INDICATORS}

ConocoPhillips has conducted an LCIA to compare potential environmental impacts resulting from the use of GTL products, petroleum fuels, and alternative fuels for transportation

Results from the Life Cycle Inventory phase of the UCF LCA were entered into TRACI to determine the relative potential life cycle impacts of the fuel alternatives. The results are expressed as comparisons employing the set of impact categories from TRACI: global warming potential, acidification, photochemical smog, eutrophication, human health (criteria, cancer, and non-cancer), ecotoxicity, resource depletion, land use, and water use. Supplementary toxics emissions data was collected for the LCIA for the human health and ecotoxic categories.

The LCIA impact categories and characterization models are comprehensive, are based upon ongoing international potential impact modeling research, and support the stated goals of the UCF LCA.

\section{RESULTS FROM THE LIFE CYCLE INVENTORY}

The goal of the UCF LCA is to examine the potential life cycle environmental and human health impacts of GTL products in comparison with competing alternatives. The LCI phase of this assessment demonstrates that on the basis of GHG and criteria pollutant emissions measured on the functional unit basis of light duty vehicle miles, there are no significant disparities between GTL and competing fuels.

Critics of GTL transportation fuels have suggested that these fuels contribute significantly more $\mathrm{CO}_{2}$ (and hence, GHG) emissions than conventional petroleum-derived fuels. Technological advances in GTL production have narrowed this gap to the extent that full well-to-wheel GHG emissions from neat FTD (FTD100) produced from stranded natural gas compared with ULSD are equivalent. If $10 \%$ or more of the feed gas comes from gas that is otherwise flared, the 
FTD100 demonstrates a significant reduction in GHG emissions. FT100 also exhibits lower GHG emissions than FRFG.

This study also demonstrates a reduction in criteria pollutants when FTD100 fuel is used in light duty vehicles. The reduced emissions observed in the LCI are likely to result in corresponding reductions in potential health and environmental impacts. At a minimum, the increased consumption of GTL fuels in the marketplace should not have greater impacts than petroleumderived transportation fuels.

With regard to overall energy efficiency, default assumptions in the GREET showed FTD100 to be approximately 44\% less energy-efficient than ULSD. Projections of GTL process energy efficiency factors for future commercial operations as used in the UCF LCA reduce this gap to approximately $25 \%$.

The conclusions below are presented in the context of the data quality and sensitivity analysis as discussed earlier. Comparative results between fuels for total energy and GWP within 10\% are considered to be equivalent. For criteria emissions inventories, results within $15 \%$ are considered to be equivalent.

\section{FT Diesel}

- FTD20 and FTD100 are equivalent to ULSD in GWP in the 2006 and 2015 scenarios.

- FTD20 and FTD100 have lower GWPs than FRFG in the 2006 and 2015 scenarios.

- FTD20 (2006) is equivalent to ULSD in VOC, CO, NO has lower $\mathrm{SO}_{\mathrm{X}}$ emissions than ULSD.

- FTD100 (2015) has lower inventories of total and urban criteria emissions than ULSD.

- FTD100 (2015) has lower inventories of total and urban criteria emissions than FRFG.

- FTD100 (2015) is 25\% less energy-efficient than ULSD, and equivalent in life cycle energy efficiency to FRFG, based on ConocoPhillips's projected GTL process energy efficiency. (GREET, based on default data, estimates that FTD100 is $44 \%$ less energy efficient than ULSD.)

- FTD100 (2015) sourced from 10\% flared gas performs better with regard to GWP than ULSD. The aggressive FTD100 CIDI (2015) case, with a 5\% improvement in vehicle efficiency, has 7\% lower GWP than the comparable ULSD case. However, this difference in GWP is considered equivalent with respect to data quality.

- GTL products consume only small amounts of petroleum fuel in the feedstock and fuel stages.

\section{FT Naphtha}

- FT naphtha used in FCVs is equivalent to FRFG and to methanol for GWP (2015).

- For both total and urban criteria emissions, FT naphtha FCV has lower emissions of VOC, $\mathrm{NO}_{\mathrm{X}}$, and $\mathrm{SO}_{\mathrm{X}}$ than methanol and FRFG (2015). 


\section{RESULTS FROM THE LIFE CYCLE IMPACT ASSESSMENT}

The assessment of the sustainability of GTL fuels was a primary goal of ConocoPhillips in undertaking this UCF LCA study. The Department of Energy's Ultra Clean Fuels Program specifically seeks to ensure that fossil-resource-fueled vehicles will comply with future emissions standards and reduce $\mathrm{CO}_{2}$ emissions.

Conclusions for the LCIA are drawn on the basis of a 10\% range of error for GWP, a $15 \%$ range of error for solid waste, wastewater, and resource depletion, and a 100\% range for all other categories. These ranges were established using best professional judgment that took into account the data gaps and data quality.

From the results of the LCIA, it can be concluded that in light duty vehicles, in both the nearterm and long-term scenarios, FTD and ULSD have equivalent GWPs. This is an important conclusion as previous studies have concluded that GTL fuels have larger GWPs than petroleum diesel fuels, largely due to an assumed increase in $\mathrm{CO}_{2}$ emissions in the fuel production stage. When ConocoPhillips estimates for carbon and energy process efficiencies are used, this disparity in GWP does not appear to exist.

For the acidification, eutrophication, and human health criteria impact categories, FTD consistently exhibits indicator values that are 5\% to $98 \%$ lower than those of both ULSD and FRFG. The application of a 100\% differential error range precludes any comparative assertions that FTD or FT naphtha have less potential for environmental impact for these indicators, but it is apparent that these fuels are probably not at a disadvantage with respect to conventional petroleum-derived transportation fuels.

For the human health cancer and non-cancer impact categories, both FTD and ULSD exhibit significantly lower potential impacts than FRFG. These results, however, are based on the comparison of actual emissions testing for FTD and ULSD and proposed regulatory standards for FRFG. The results indicate only that toxics emissions for FTD and ULSD are well within the proposed Tier 2 regulatory standards set for FRFG light duty vehicles.

Both FTD and ULSD have ecotoxicity indicator values that are greater than those of FRFG, but the differences are within the error threshold. The indicator value differences are due to the small quantities of formaldehyde emitted in the vehicle stage for diesel fuels. FTD, however, has a lower indicator value for ecotoxicity than ULSD.

The production of GTL fuels generates less solid waste than the production of ULSD and FRFG. GTL production generates less wastewater than does the production of FRFG and a quantity of wastewater within $15 \%$ of that resulting from the production of ULSD.

There are currently large, proven and potentially large, unproven reserves of stranded gas. Given forecasts of the rate of development of stranded gas projects, of which GTL is only a small portion, the production of products from these gas reserves will continue for some 40 years after global crude oil reserves have been depleted. 
FTD and FT naphtha are substantially non-petroleum fuels. The FTD- and FT-naphtha-fueled vehicles consume only small amounts of petroleum resources per mile. This is due exclusively to upstream production and transportation of the fuels.

Currently, petroleum reserves contain about twice the energy content on a Btu basis as stranded gas reserves. However, given projections of resource use, the Btu contents of the two resources will be equal in about 2015. Although a non-renewable resource, stranded gas will continue to provide energy to the global market for a long time in a manner that is at least comparable to petroleum reserves with respect to the broad set of environmental indicators examined in this study. 


\section{$1.1 \quad$ INTRODUCTION}

Throughout the world, there are large proven reserves of natural gas that are "stranded" because their remote locations render them incapable of being economically brought to market. ConocoPhillips is developing proprietary gas-to-liquids (GTL) technology to economically convert this natural gas to GTL products, primarily diesel, for use as a transportation fuel. Another significant product of the GTL process is naphtha, which may be used for a number of applications, such as petrochemical cracker feed or as a fuel for fuel cell vehicles. ${ }^{1,2}$ In this study, GTL diesel and naphtha together are referred to as GTL products.

GTL technology is not the only means available to gas reserve owners or technology developers for the utilization of remote gas. Methanol and liquefied natural gas (LNG) are the two primary alternatives. Methanol has the technical potential to be used in fuel cell vehicles; LNG has been used commercially for decades for power generation. ConocoPhillips believes that those interested in developing and monetizing remote gas fields may consider methanol and LNG as alternative competing options. It is therefore important and necessary to study and understand the environmental and human health impacts of these alternatives in comparison with GTL products.

This study, called the Ultra Clean Fuels Life Cycle Assessment (UCF LCA), consists of a Life Cycle Inventory (LCI) and a Life Cycle Impact Assessment (LCIA) for transportation fuels produced from remote natural gas. The goals and scope of the UCF LCA are defined in this section.

The UCF LCA scope was developed in coordination with a UCF market study (ConocoPhillips, 2003). The UCF LCA considers the most likely commercial operations, technologies, and markets for ultra clean fuels as identified in the market study.

A review and an assessment of results from LCA studies in the literature were also conducted in order to establish comparative scenarios, to determine the assumptions and parameters that most influence comparative assertions made in the literature, and to gather and analyze data.

\subsection{GOALS AND SCOPE OF A LIFE CYCLE ASSESSMENT}

The context and foundation of an LCA are defined by its goals and scope definition. The scope of an LCA defines the system boundaries, assumptions, limitations, methodologies, data sources, and data categories, all of which must be clearly stated, comprehensible, and transparent.

The ISO 14040 standards for LCAs (International Standards Organization, 1997, 1998, 1999) establish the following requirements for the scope definition:

\footnotetext{
1 Moncrieff, I., T. Partridge, and J. Thijssen, “Gas-to-Liquids Conversion - Ready for the 21st Century,” Arthur D. Little, Inc., 1998.

2 Peckham, J., "Sasol, Chevron Form Worldwide Gas-to-Liquids Joint Venture," Octane Week, Vol. 14, No. 24, Phillips Business Information, Inc., 1999.
} 
- The goal of an LCA must unambiguously state the intended application, the reasons for carrying out the study, and the intended audience.

- The functions of the system must be clearly defined, and relevant functional units (e.g., light duty passenger vehicle miles) must be established.

- System boundaries must be stated and justified.

- Data requirements and sources must be defined.

ISO 14040 establishes two general standards governing the way in which the results of an LCA can be used. First, if the study is intended to make a comparative assertion that is to be disclosed to the public, a critical review must be conducted. This review was carried out, and the report from the review panel is appended to this report. Second, results from an inventory analysis, because they refer to input and output data and not to environmental impacts, must be interpreted with caution, and must not be used to make comparative environmental assertions. In particular, ISO 14040 states that an LCIA must be conducted in order to make comparative environmental claims. This LCIA was carried out and is described in Section 7 of this report.

\subsection{GOALS}

ConocoPhillips undertook this study to help ensure that its investment in and development of GTL technology will be sustainable into the future. ConocoPhillips believes that GTL fuelsFischer-Tropsch diesel (FTD) and FT naphtha - are competitive options in the development and monetization of remote natural gas fields. These natural-gas-sourced fuels are assumed to displace or offset conventional petroleum fuels for transportation end uses. ${ }^{3}$

In accordance with ConocoPhillips's business planning and its corporate commitment to sustainable development, it is important and necessary to understand potential life cycle environmental and human health impacts of GTL products in comparison with alternatives. Therefore this LCA study is designed to estimate, with available data and within available study resources, the energy utilization and emissions life cycle profiles of ConocoPhillips GTL fuels and selected competitive fuels in the future.

This study is also part of the U.S. Department of Energy (DOE) Ultra Clean Fuels Initiative, which aims to develop and deploy technologies that will produce ultra-clean-burning transportation fuels for the 21 st century from both petroleum and non-petroleum resources. ConocoPhillips's goals are in accord with those of DOE, namely, to produce fuels that will:

- Enable vehicles to comply with future emission requirements

- Be compatible with the existing liquid fuels infrastructure

\footnotetext{
${ }^{3}$ Because of the clean combustion properties of GTL fuels, ConocoPhillips believes that GTL transportation fuels (such as FTD) will substitute for or directly displace traditional petroleum transportation fuels (such as conventional or ultra-low sulfur diesel), in neat or blended formulations. It is assumed that over the time frame of the study, newer transport energy alternatives (such as hydrogen, biodiesel, and electric vehicles) may be introduced over and above the mix of fossil fuels in use.
} 
- Enable vehicle efficiencies to be significantly increased, with concomitantly reduced $\mathrm{CO}_{2}$ emissions

- Be obtainable from a fossil resource, alone or in combination with other hydrocarbon materials such as refinery wastes, municipal wastes, and biomass

- Be cost-competitive with current fuels

\subsubsection{Intended Application and Audience}

The UCF LCA will be used to help educate and inform stakeholders involved in gas development projects. The audience includes:

- National oil companies (gas reserve owners)

- Government energy and environmental agencies

- Peer group of refiners and GTL technology developers

The results of the study will be made available to:

- Environmental non-government organizations

- Transportation and power industry trade and market associations

- The general public

ConocoPhillips also intends to use the study internally to assess, improve, and complement the environmental programs (e.g., Product Stewardship and environmental impact assessment) used to manage the life cycle impacts of ConocoPhillips's GTL products.

\subsubsection{Objectives}

The specific objectives for the UCF LCA are:

- For the LCI:

- Quantification of the energy use and selected emissions inventory associated with the production and use of GTL fuels. Although there are significant markets for these fuels around the world, this study focuses on the use of GTL products in the United States, where significant amount of fuel use and refining baseline data exists. In addition, the study assumes that GTL fuels are produced near stranded gas reserves in remote areas in the Middle East.

- Comparison of the energy use and emissions inventory for the production and use of GTL products on an equivalent basis with refined petroleum products predominantly in use today. For example, FTD may be compared with petroleum diesel in application as a transportation fuel

- Comparison of methanol (as an alternative natural gas utilization option) for use in fuel cell vehicles with GTL and petroleum fuels

- For the LCIA: 
- Quantification of potential life cycle impacts associated with the production and use of GTL fuels, in comparison with the potential life cycle impacts of petroleum fuels in transportation applications

The study was conducted according to the requirements of the ISO 14040 International Standard for Life Cycle Assessment, which includes a critical review conducted by an outside independent panel. The report from the review panel is included in Appendix $\mathrm{G}$ of this report.

\subsection{STUDY APPROACH}

The UCF LCA is based on three successive analyses:

- A detailed engineering analysis of the process efficiencies of current and future commercial technologies for GTL production

- A Co-product Function Expansion (CFE) for the petroleum and GTL systems based on detailed modeling of petroleum and GTL fuel processing. This is a novel methodology for considering the impacts of co-products, and is described in detail in Section 5 of this report

- Sensitivity analysis that considers future heavy crude input slates for petroleum refining, 3 ppm ultra-low sulfur petroleum diesel, and flared gas used in the production of GTL products. In addition, a comprehensive parametric sensitivity analysis is performed for all key study parameters

\subsubsection{GTL Engineering Analysis}

An up-to-date engineering analysis was conducted for GTL production in order to model current and the likely future commercial technologies for UCF production. These technologies were assessed in conjunction with the market study component of this UCF project. The key output of this analysis - process efficiency for GTL and methanol production - is an important factor for both the economic and environmental performance of the technologies. This analysis is detailed in Section 4 of this report.

\subsubsection{Co-product Function Expansion}

Most transportation fuel LCA studies in the literature have used an allocation approach for dealing with multiple products from a production system. Fuel systems such as petroleum refining produce primary products, co-products, and by-products. In the resource extraction, transportation, production, and product distribution stages, energy use and emissions are allocated among the system products on the basis of measures such as mass or energy content. Once this allocation has been performed, the upstream and downstream impacts of co-products (such as petroleum coke and heavy residual oil in the petroleum system) are not reflected in the results for the primary products (e.g., gasoline and diesel).

For petroleum refining, typically $30 \%$ to $40 \%$ of emissions (including upstream emissions from extraction and transportation of crude oil) are allocated to products other than gasoline and diesel fuels. With an allocation-based method, all downstream impacts of co-products are set outside of the system boundaries of the study. 
Refining co-products, such as petroleum coke and heavy residual oil, can have significant environmental impacts associated with their production and use (e.g., combustion of petroleum coke and heavy fuel oils for power generation). As growth in demand for petroleum-based transportation fuels is reduced as a result of the introduction of alternative fuels, the growth in production of co-products will be reduced as well.

The CFE methodology as developed in this study accounts for the downstream energy and emissions inventories of co-products of the production system. First, co-product emissions are attributed to the primary product or products in the fuel production stage. For example, in the petroleum refining process, emissions from the petroleum coking equipment are attributed to gasoline and diesel. The co-products are then compared with alternative products in downstream applications (e.g., petroleum coke vs. coal for power production), and the net emissions inventories are assigned as either credits or debits to the primary products.

The co-products examined in the UCF LCA are petroleum coke and heavy residual oil. The CFE methodology was used to develop the scenarios for the UCF LCA gasoline and diesel pathways, and is detailed in Section 5 of this report.

The GM Wheel to Wheels study (General Motors et al., 2001) makes reference to the general issue of co-products, and acknowledges that this issue may be significant when comparing petroleum fuel cycles with natural-gas fuel cycles. The study, however, does not quantify the impacts.

\subsubsection{Sensitivity Analysis}

The sensitivity analysis considers the effects of changes in the petroleum refining crude input slates, the effects of reducing sulfur concentrations in ultra-low sulfur diesel (ULSD) from 10 ppm to $3 \mathrm{ppm}$, the effect of refining ULSD from 100\% imported crude oil from the Middle East, and the use of flared gas in the production of GTL products. In addition, a comprehensive parametric sensitivity analysis was performed for all key study parameters.

For the crude slate, crude density and sulfur concentration are increased. In the future, as lighter and "sweeter" (i.e., lower sulfur) crude oil resources are depleted, the refining industry will come to rely more on a heavier and more sulfurous crude slate for producing gasoline and diesel fuels, and as a consequence will also produce greater quantities of heavy co-products such as petroleum coke and heavy residual oil. GTL and other petroleum fuel alternatives, as new entrants to the transportation fuel market, will be competing with petroleum fuels on this margin. For comparison, a light, sweet crude slate was also assessed.

ULSD on the order of $3 \mathrm{ppm}$ sulfur or lower was also examined in the sensitivity analysis. Analysis of diesel sulfur concentrations at this level provides a closer equivalent comparison with zero-sulfur FTD.

Natural gas often exists as "associated gas" along with the production of crude oil. This gas is sometimes flared, particularly in developing countries and in the Middle East. If this gas were 
captured and used in the production of GTL products, a credit would be given for the averted $\mathrm{CO}_{2}$ emissions from flaring. This case is captured in the flared gas sensitivity.

Finally, a comprehensive sensitivity was carried out for all significant study parameters for each life cycle stage.

\subsection{MODELS}

Three primary modeling tools were used in the UCF LCA: GREET, PIMS, and Aspen Plus. GREET is the primary modeling, analysis, and reporting tool for the study; PIMS and Aspen Plus are process modeling systems that were employed to model and validate the petroleum refining and GTL production systems.

\subsubsection{GREET}

The GREET (Greenhouse Gases, Regulated Emissions, and Energy Use in Transportation) model, Version 1.6, from Argonne National Laboratory served as the primary modeling tool for the UCF LCA (Argonne National Laboratory, 1999, 2001). GREET has become a standard tool for conducting and benchmarking fuel-cycle studies in the United States, and its use worldwide is growing. GREET is currently being employed by DOE for policy analysis under the Energy Policy Act of 1992. GREET was also used in the General Motors Well-to-Wheels study.

GREET is not an LCA tool per se, but rather a fuel cycle, or input-output, model. In the UCF LCA, GREET is paired with two process simulation tools (PIMS and Aspen Plus) for detailed data development and validation. GREET itself is based upon strong and mature data-(1) from current best sources from the Energy Information Agency along with other sources and (2) from primary data supplied by vehicle manufacturers and petroleum companies for modeling resource extraction, fuel production, fuel transport, and fuel use. The UCF LCA also reviewed all GREET data and modeling assumptions.

\subsubsection{PIMS}

The Process Industries Modeling System (PIMS) is a linear-programming-based tool that models the operation of petroleum refineries, taking into consideration crude slates, desired product slates, and refinery configuration. For a given crude and product slate, PIMS determines required process fuels, electricity, and heat/steam inputs.

PIMS was used in the UCF LCA to validate the data employed in GREET for petroleum refining, to model different crude input slates, and to model the production of co-products for the CFE.

PIMS was used to benchmark refining efficiencies and to determine efficiencies for the different crude slate scenarios. This was performed in coordination with the market study task of the UCF project. The market study used PIMS to develop detailed optimization models of notional refineries in each of the Petroleum Administration Defense Districts (PADDs). The UCF LCA petroleum scenarios for PADD III and PADD I are based on two of these models. 


\subsubsection{Aspen Plus}

Aspen Plus is a process simulator used extensively by the chemical industry to model heat and material balances, thermodynamic equilibrium, optimization of process design, and the operation of chemical plants. Nexant used Aspen Plus to model the thermodynamic efficiency of GTL and methanol production in order to determine achievable efficiencies and to establish theoretical upper limits on efficiency. The use of Aspen Plus is discussed further in Section 4 of this report.

\subsection{UCF LCA SCOPE}

The fuel pathways, life cycle stages, assumptions, methodologies, functional units, and geographic and temporal boundaries define the scope of an LCA. These elements in turn determine data requirements for the analysis. This section defines the scope of the UCF LCA with respect to these parameters

\subsubsection{Scenarios}

This study compares GTL fuels (FTD and FT naphtha) and methanol with conventional fuels (federal reformulated gasoline [FRFG], conventional diesel [CD], and ULSD) in transportation.

The UCF LCA develops a set of near-term (2006) and long-term (2015) scenarios, in coordination with the market study task of the UCF project, to assess impacts associated with likely commercial scenarios for these years. The years 2006 and 2015 were selected to represent the likely times of the emergence of the GTL fuels technologies represented in the scenarios. The vehicle technologies considered in each scenario are representative of the technologies that are likely to be technologically feasible and may be commercially available. The vehicles modeled are theoretical, and are not average representations of actual in-use vehicle fleets.

Refinery location is an important factor in determining the likely changes in petroleum-based product slates. As part of the development of the petroleum fuel scenarios, an assessment was performed in detail for two Petroleum Administration Defense Districts (PADDs): PADD III and PADD I. PADD III is representative of a U.S. national average crude slate; PADD I is representative of a lighter crude slate.

The study scenarios consist of the petroleum and UCF natural-gas-based fuel scenarios and the vehicle configurations listed below.

For transportation fuels:

- Current and future petroleum fuels-FRFG, CD, and ULSD

- A 20\% FTD/80\% ULSD blend (FTD20), 100\% FTD (FTD100), methanol, and FT naphtha, all produced from remote natural gas.

For vehicles:

- Vehicle configurations include conventional spark ignition (SI) engines, advanced spark ignition direction injection (SIDI) engines, compression ignition direct injection (CIDI) diesel engines, FTD optimized CIDI engines (5\% improved fuel efficiency), hybrid 
electric vehicles (HEVs) with spark ignition direct injection (SIDI) and CIDI engines, and fuel processor fuel cell vehicles (FCVs). The vehicles modeled are representative of theoretical vehicle configurations and performances

Tables 1-1 and 1-2 provide a general description of the fuel pathways and associated key parameters. Tables 1-3, 1-4, and 1-5 provide a detailed listing of all specific scenarios.

\section{Table 1-1 UCF LCA Petroleum Fuels Systems}

\begin{tabular}{|c|c|c|c|c|c|c|}
\hline Case & Fuel Input & Location & Year & Other Scenario Parameters & Product & $\begin{array}{l}\text { Transportation } \\
\text { End Use }\end{array}$ \\
\hline $\begin{array}{l}\text { Near-term } \\
\text { typical } \\
\text { refinery }\end{array}$ & $\begin{array}{l}\text { PADD III } \\
\text { average } \\
\text { crude slate } \\
\text { (API density } \\
=31.2 \text { ) }\end{array}$ & PADD III & 2006 & & $\begin{array}{l}\text { FRFG, CD, ULSD (10 } \\
\text { ppm sulfur), petroleum } \\
\text { coke, and heavy residual } \\
\text { oil }\end{array}$ & $\begin{array}{l}\mathrm{SI}, \mathrm{CIDI} \\
\text { engines }\end{array}$ \\
\hline $\begin{array}{l}\text { Future } \\
\text { typical } \\
\text { refinery }\end{array}$ & $\begin{array}{l}\text { PADD III } \\
2015 \\
\text { average } \\
\text { crude slate } \\
\text { (API density } \\
=29.9 \text { ) }\end{array}$ & PADD III & 2015 & $\begin{array}{l}\text { PADD III heavy crude slate } \\
\text { (API density = } 25.4 \text { ) } \\
\text { PADD I light crude slate } \\
\text { (API density = 32.9) } \\
\text { ULSD (3 ppm sulfur) }\end{array}$ & $\begin{array}{l}\text { FRFG, ULSD (10 ppm } \\
\text { sulfur, 3ppm sulfur), } \\
\text { petroleum coke, and } \\
\text { heavy residual oil }\end{array}$ & $\begin{array}{l}\text { SIDI, CIDI } \\
\text { engines, HEV, } \\
\text { FCV }\end{array}$ \\
\hline
\end{tabular}

Table 1-2 UCF LCA GTL and Methanol Systems

\begin{tabular}{|c|c|c|c|c|c|c|c|c|}
\hline Case & $\begin{array}{l}\text { Fuel } \\
\text { Input }\end{array}$ & Location & Year & Technology & $\begin{array}{l}\text { Process } \\
\text { Parameters }\end{array}$ & $\begin{array}{c}\text { Other } \\
\text { Scenario } \\
\text { Parameters }\end{array}$ & Product & $\begin{array}{l}\text { Transportation } \\
\text { End Use }\end{array}$ \\
\hline $\begin{array}{l}\text { GTL fuel } \\
\text { blending }\end{array}$ & $\begin{array}{l}\text { FTD from } \\
\text { remote } \\
\text { gas, } \\
\text { PADD III } \\
\text { ULSD }\end{array}$ & $\begin{array}{l}\text { Middle } \\
\text { East } \\
\text { natural } \\
\text { gas (NG); } \\
\text { blending } \\
\text { in PADD } \\
\text { III; ULSD } \\
\text { refining in } \\
\text { PADD III }\end{array}$ & 2006 & $\begin{array}{l}\text { GTL: } 75,000 \\
\text { bpd single } \\
\text { train } \\
\text { Refinery: } \\
\text { near-term }\end{array}$ & $\begin{array}{l}\text { No electricity or } \\
\text { steam } \\
\text { FT thermal } \\
\text { efficiency = } \\
67 \% \\
\text { Carbon } \\
\text { efficiency = } \\
85 \%\end{array}$ & & $\begin{array}{l}20 \% \\
\text { FTD, } \\
80 \% \\
\text { ULSD } \\
\text { blend }\end{array}$ & CIDI engine \\
\hline \multirow[t]{2}{*}{$\begin{array}{l}100 \% \\
\text { GTL } \\
\text { fuels }\end{array}$} & \multirow[t]{2}{*}{$\begin{array}{l}\text { FTD from } \\
\text { remote } \\
\text { gas }\end{array}$} & \multirow[t]{2}{*}{$\begin{array}{l}\text { Middle } \\
\text { East }\end{array}$} & \multirow[t]{2}{*}{2015} & \multirow[t]{2}{*}{$\begin{array}{l}150,000 \mathrm{bpd} \\
\text { two trains }\end{array}$} & \multirow{2}{*}{$\begin{array}{l}\text { No electricity or } \\
\text { steam } \\
\text { FT thermal } \\
\text { efficiency = } \\
70 \% \\
\text { Carbon } \\
\text { efficiency = } \\
85 \%\end{array}$} & \multirow[t]{2}{*}{$\begin{array}{l}10 \% \text { FG } \\
\text { sensitivity }\end{array}$} & FTD100 & $\begin{array}{l}\text { CIDI engine, } \\
\text { FTD100- } \\
\text { optimized CIDI } \\
\text { engine, HEV }\end{array}$ \\
\hline & & & & & & & $\begin{array}{l}\text { FT } \\
\text { naphtha }\end{array}$ & FCV \\
\hline Methanol & $\begin{array}{l}\text { Methanol } \\
\text { from } \\
\text { remote } \\
\text { gas }\end{array}$ & $\begin{array}{l}\text { Middle } \\
\text { East }\end{array}$ & 2015 & $\begin{array}{l}\text { Lurgi } 10,000 \\
\text { tonne/day } \\
\text { mega } \\
\text { methanol, } \\
\text { single train }\end{array}$ & $\begin{array}{l}\text { No electricity or } \\
\text { steam } \\
\text { Thermal } \\
\text { efficiency = } \\
71 \%\end{array}$ & & M100 & FCV \\
\hline
\end{tabular}




\section{Table 1-3 Short-Term Transportation Scenarios}

\begin{tabular}{|l|l|l|l|}
$\begin{array}{l}\text { Scenario } \\
\text { Number }\end{array}$ & \multicolumn{1}{|c|}{ Scenario Name } & \multicolumn{1}{|c|}{ Fuel } & \multicolumn{1}{c|}{ Vehicle } \\
\hline 1 & PADD III FTD20 CIDI & $\begin{array}{l}\text { Blend of 20\% remotely produced GTL } \\
\text { diesel and 80\% PADD III ULSD }\end{array}$ & $\begin{array}{l}\text { Light duty (LD) passenger } \\
\text { vehicle with CIDI engine }\end{array}$ \\
\hline 2 & PADD III CD CIDI & PADD III CD & LD vehicle with CIDI engine \\
\hline 3 & PADD III ULSD CIDI & PADD III ULSD with CFE & LD vehicle with CIDI engine \\
\hline 4 & PADD III FRFG & PADD III FRFG with CFE & $\begin{array}{l}\text { LD passenger vehicle with SI } \\
\text { engine }\end{array}$ \\
\hline
\end{tabular}

Table 1-4 Long-Term Transportation Scenarios

\begin{tabular}{|l|l|l|l|}
$\begin{array}{l}\text { Scenario } \\
\text { Number }\end{array}$ & \multicolumn{1}{|c|}{ Scenario Name } & \multicolumn{1}{c|}{ Fuel } & \multicolumn{1}{c|}{ Vehicle } \\
\hline 5 & FTD100 CIDI & $100 \%$ remotely produced GTL diesel & LD passenger, CIDI engine \\
\hline 6 & Aggressive FTD100 CIDI & $100 \%$ remotely produced GTL diesel & $\begin{array}{l}\text { LD passenger, with FTD- } \\
\text { optimized CIDI engine, 5\% } \\
\text { improved fuel efficiency }\end{array}$ \\
\hline 7 & PADD III ULSD CIDI & PADD III ULSD with CFE & LD passenger, CIDI engine \\
\hline 8 & PADD III FRFG & PADD III FRFG with CFE & LD passenger, SIDI engine \\
\hline 9 & FTD100 HEV & $100 \%$ remotely produced GTL diesel & $\begin{array}{l}\text { LD passenger, HEV with CIDI } \\
\text { engine }\end{array}$ \\
\hline 10 & Aggressive FTD100 HEV & $100 \%$ remotely produced GTL diesel & $\begin{array}{l}\text { LD passenger, HEV with FTD- } \\
\text { optimized CIDI engine, 5\% } \\
\text { improved fuel efficiency }\end{array}$ \\
\hline 11 & PADD III ULSD HEV & PADD III ULSD with CFE & LD HEV with CIDI engine \\
\hline 12 & PADD III FRFG HEV & PADD III FRFG with CFE & $\begin{array}{l}\text { LD passenger, HEV with SIDI } \\
\text { engine }\end{array}$ \\
\hline 13 & Methanol FCV & $100 \%$ remotely produced methanol & FCV with methanol reformer \\
\hline 14 & PADD III FRFG FCV & PADD III FRFG with CFE & FCV with gasoline reformer \\
\hline 15 & FT naphtha FCV & $100 \%$ remotely produced FT naphtha & $\begin{array}{l}\text { FCV with FT naphtha } \\
\text { reformer }\end{array}$ \\
\hline
\end{tabular}

Table 1-5 Sensitivity Scenarios

\begin{tabular}{|l|l|l|l|}
\hline $\begin{array}{l}\text { Scenario } \\
\text { Number }\end{array}$ & \multicolumn{1}{|c|}{ Scenario Name } & \multicolumn{1}{c|}{ Fuel } & \multicolumn{1}{c|}{ Vehicle } \\
\hline 16 & PADD III heavy ULSD CIDI & ULSD produced from heavy crude & LD passenger, CIDI engine \\
\hline 17 & PADD I light ULSD CIDI & ULSD produced from light crude & LD passenger, CIDI engine \\
\hline 18 & PADD III ULSD (3 ppm) CIDI & ULSD with 3 ppm sulfur & LD passenger, CIDI engine \\
\hline 19 & $\begin{array}{l}\text { PADD III ULSD CIDI 100\% } \\
\text { Middle East crude }\end{array}$ & $\begin{array}{l}\text { ULSD refined in PADD III from 100\% } \\
\text { imported Middle East crude }\end{array}$ & LD passenger, CIDI engine \\
\hline 20 & FTD100 FG/NG CIDI & FTD100 produced from 10\% FG /90\% NG & LD passenger, CIDI engine \\
\hline
\end{tabular}




\subsubsection{Functional Unit}

The functional unit for the UCF LCA is light duty (LD) vehicle miles. LD vehicles are defined as passenger vehicles with gross weights of less than 6,000 pounds. This functional unit is chosen for the following reasons:

- It is assumed that over the next 10 to 15 years, GTL diesel has the potential to significantly penetrate the LD passenger vehicle market and compete directly with LD gasoline-powered vehicles. Although the number of such vehicles on U.S. roads today is relatively small, recent trends indicate that the use of LD diesel passenger vehicles is gaining acceptance in the United States as it has in Western Europe. ${ }^{4,5}$

- LD vehicle miles as the functional unit for both the short and long term was selected in order to demonstrate of the effects of expected improvements in GTL production efficiency.

- The choice of LD vehicle miles greatly facilitates comparison of numerous fuel-vehicle combinations for GTL and the other transportation fuels selected for analysis.

- There are reductions in criteria emissions for FTD in both light duty and heavy duty vehicles, although the reductions in emissions for FTD compared with ULSD in heavy duty vehicles may be somewhat smaller than in light duty vehicles. LD vehicles serve as a reasonable proxy for all vehicles classes, to the extent that there are emissions reductions in all vehicle classes, although the reductions may be expected to be less for heavy duty vehicles.

Light duty vehicle miles is the functional unit used in each of the study scenarios. It is also the functional unit employed in the petroleum fuel scenarios constructed using the CFE methodology. This subject is discussed in detail Section 5 of this report.

\subsubsection{System Boundaries}

The life cycle stages and unit processes considered in the UCF LCA are shown in Table 1-6. In addition, the study addresses a selected set of co-products in the CFE methodology. Figures 1-1 through 1-32 show the complete system boundaries for the study.

Table 1-6 Life Cycle Stages and Unit Processes in the UCF LCA

\begin{tabular}{|l|l|l|}
\multicolumn{1}{|c|}{ Feedstock Stage } & \multicolumn{1}{c|}{ Fuel Stage } & \multicolumn{1}{c|}{ Vehicle Stage } \\
\hline Recovery & Production & Fuel use \\
\hline Processing & Transportation & \\
\hline Transportation & Distribution & \\
\hline
\end{tabular}

\footnotetext{
${ }^{4}$ Peckham, J., "Rising Gasoline Prices, CAFE Standards Likely to Spur Diesels: Size Matters," Diesel Fuel News, Vol. 5, No. 12, Phillips Business Information Inc., 2001.

${ }^{5}$ Hart, R., "The Thing Before the Next Big Thing, Parts 1 and 2: Long Before Fuel Cells Are Ready, You Could Find a New Powerplant in Your Performance Car: A Diesel," Auto Week, Crain Communications Inc., December 23, 2002.
} 


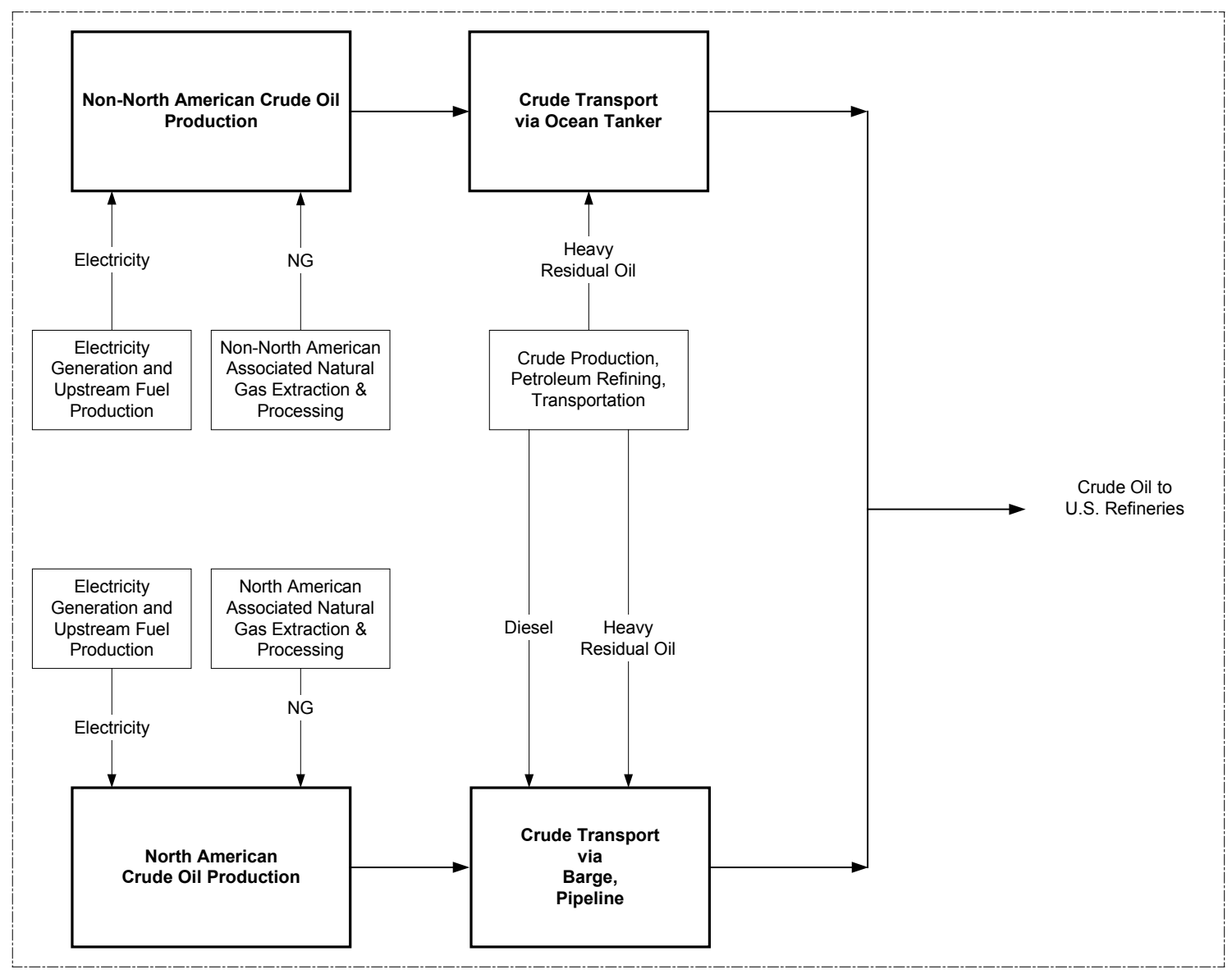

Figure 1-1 Global Crude Oil Production

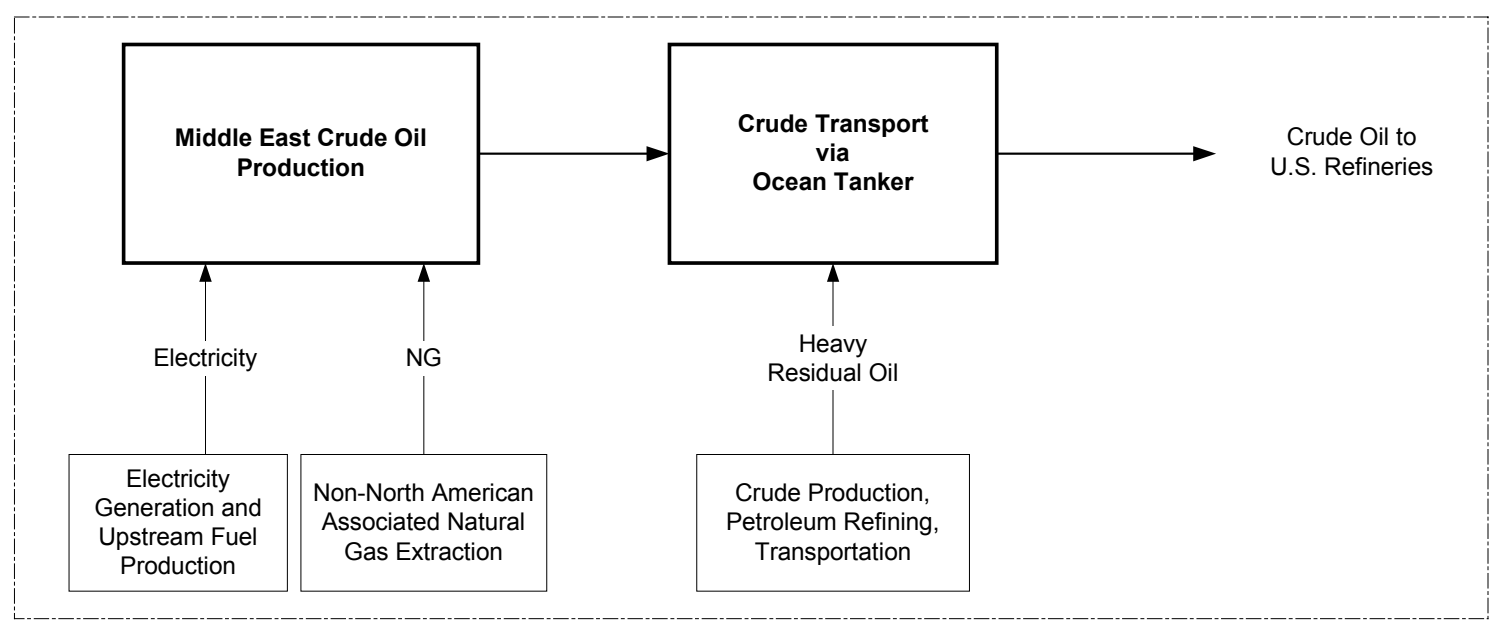

Figure 1-2 Middle Eastern Crude Oil Production 


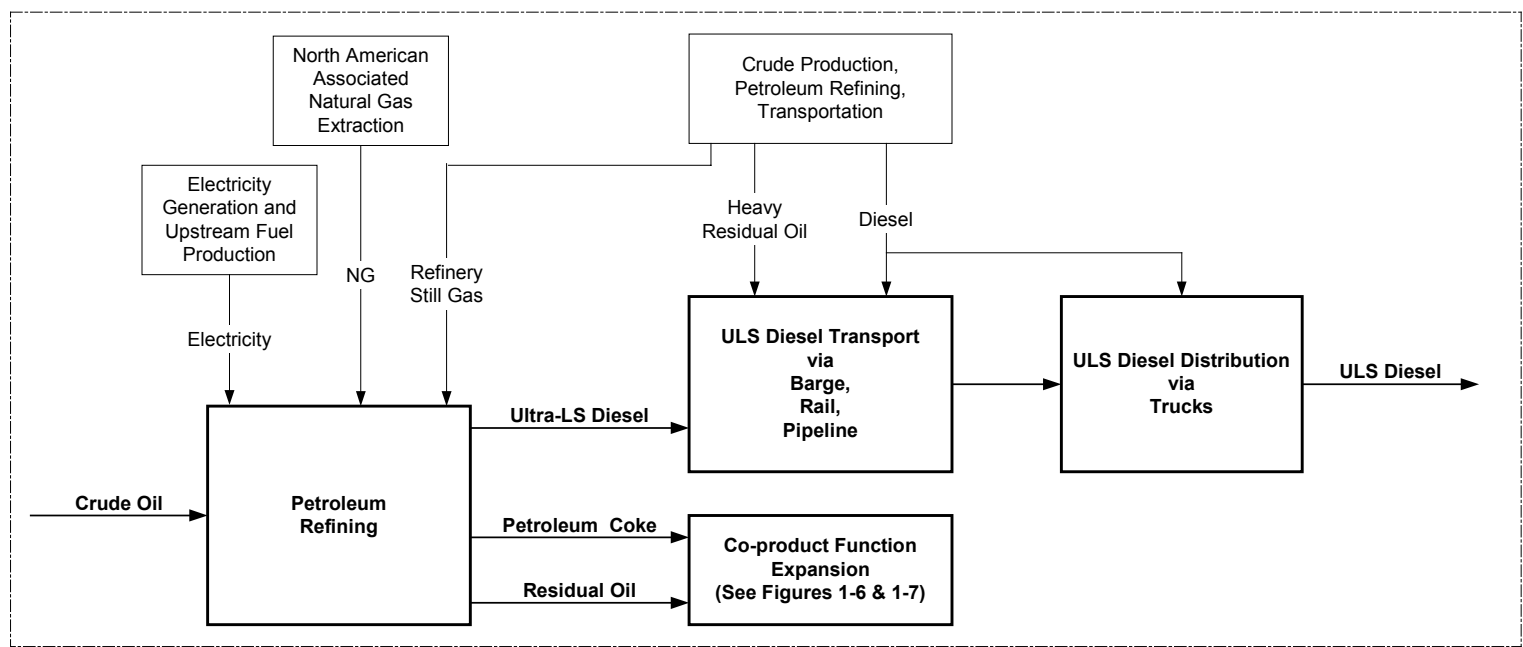

Figure 1-3 Ultra-low Sulfur Diesel Production

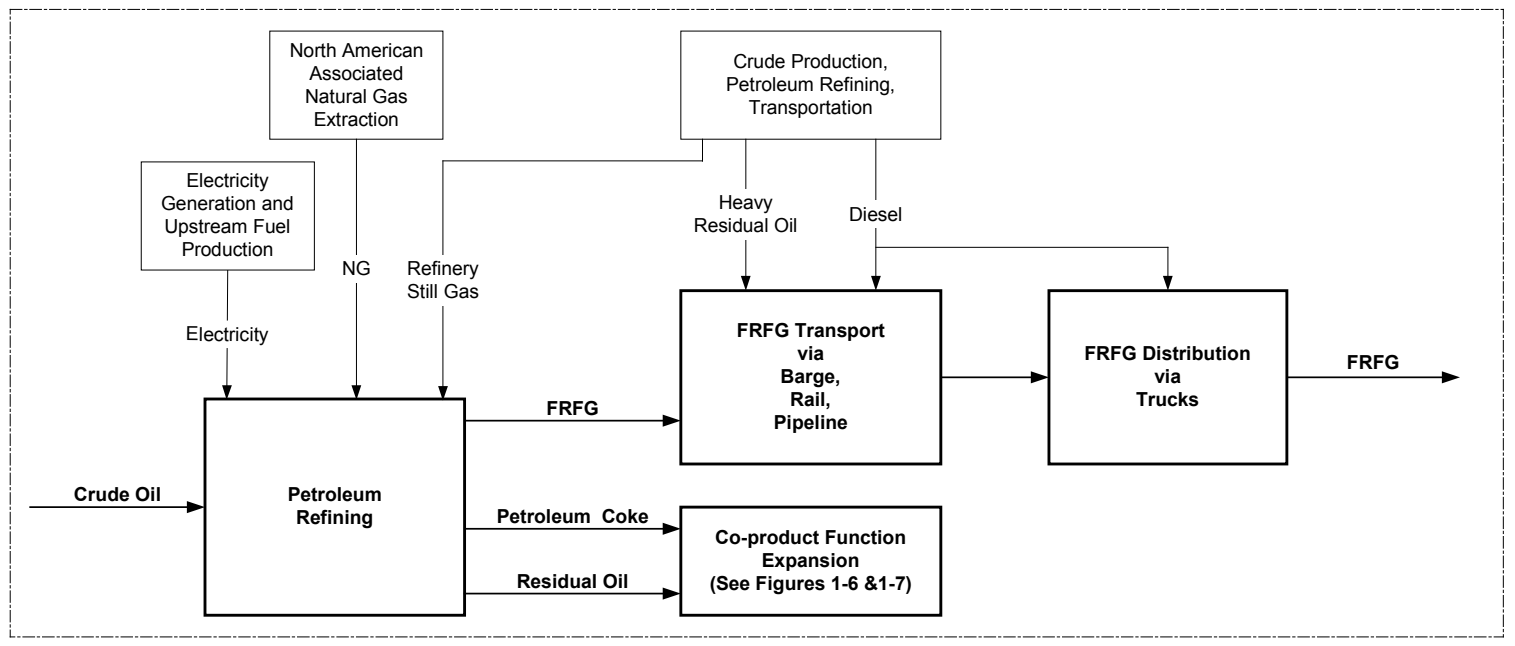

Figure 1-4 FRFG Production

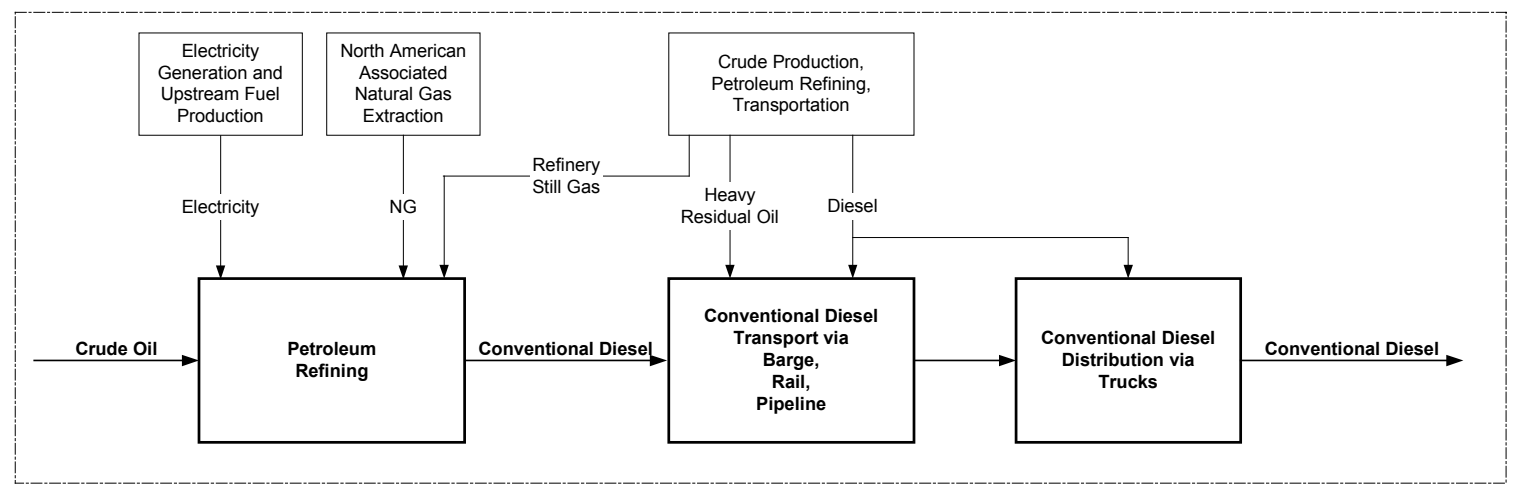

Figure 1-5 Conventional Diesel Production 


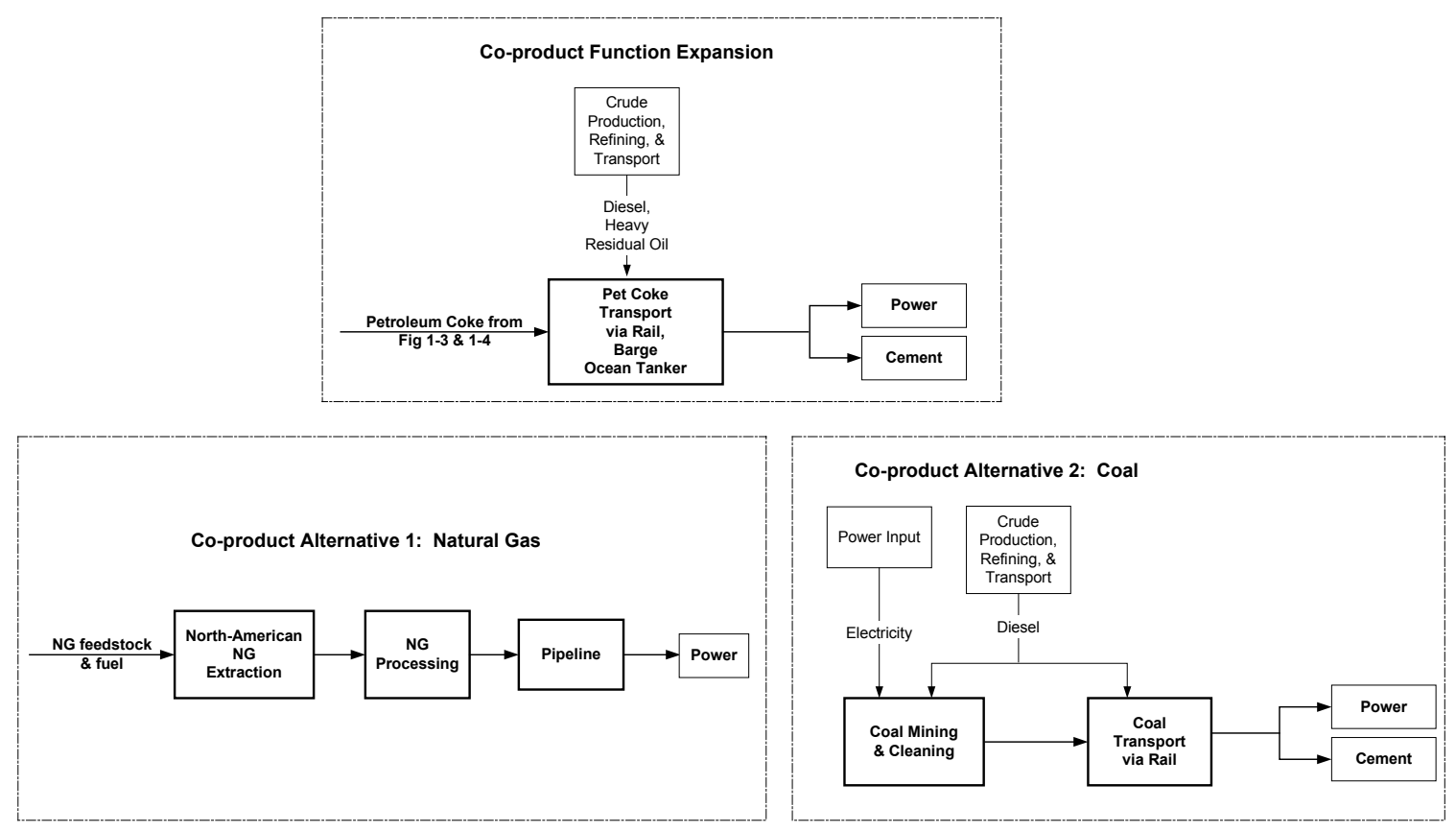

Figure 1-6 Petroleum Coke CFE
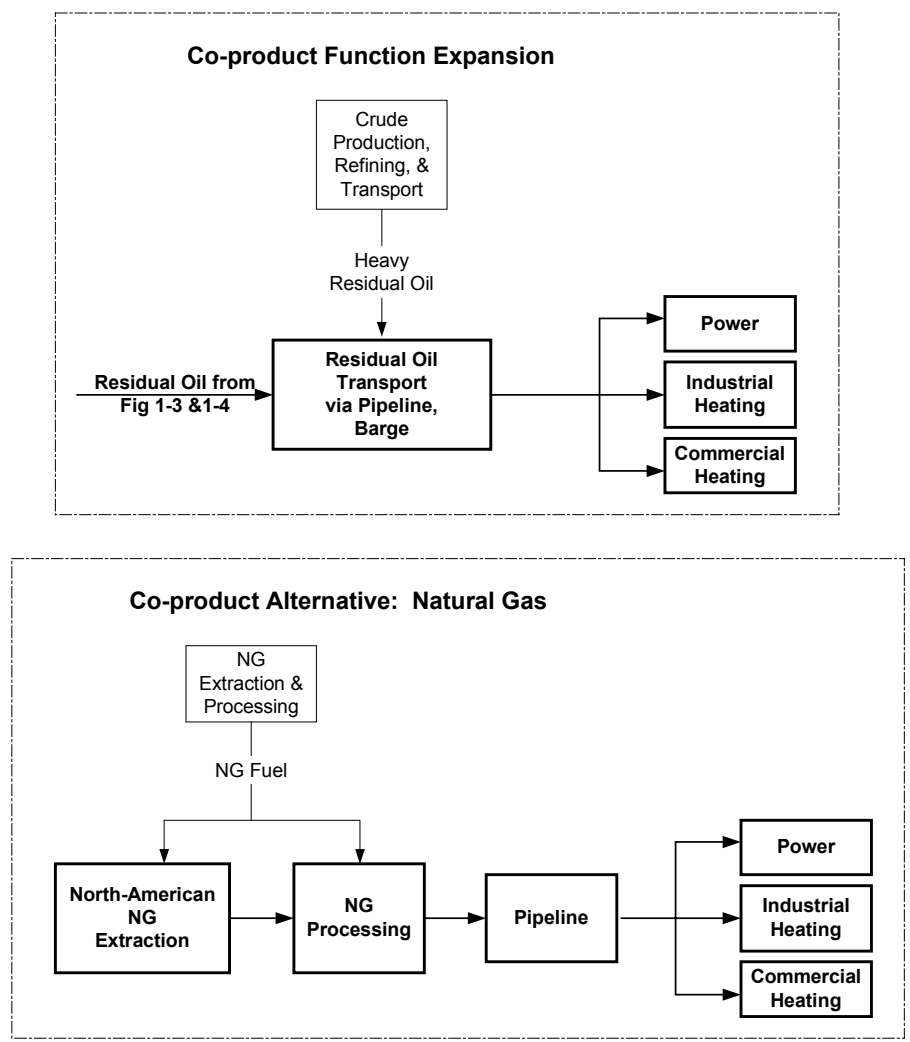

Figure 1-7 Heavy Residual Oil CFE 


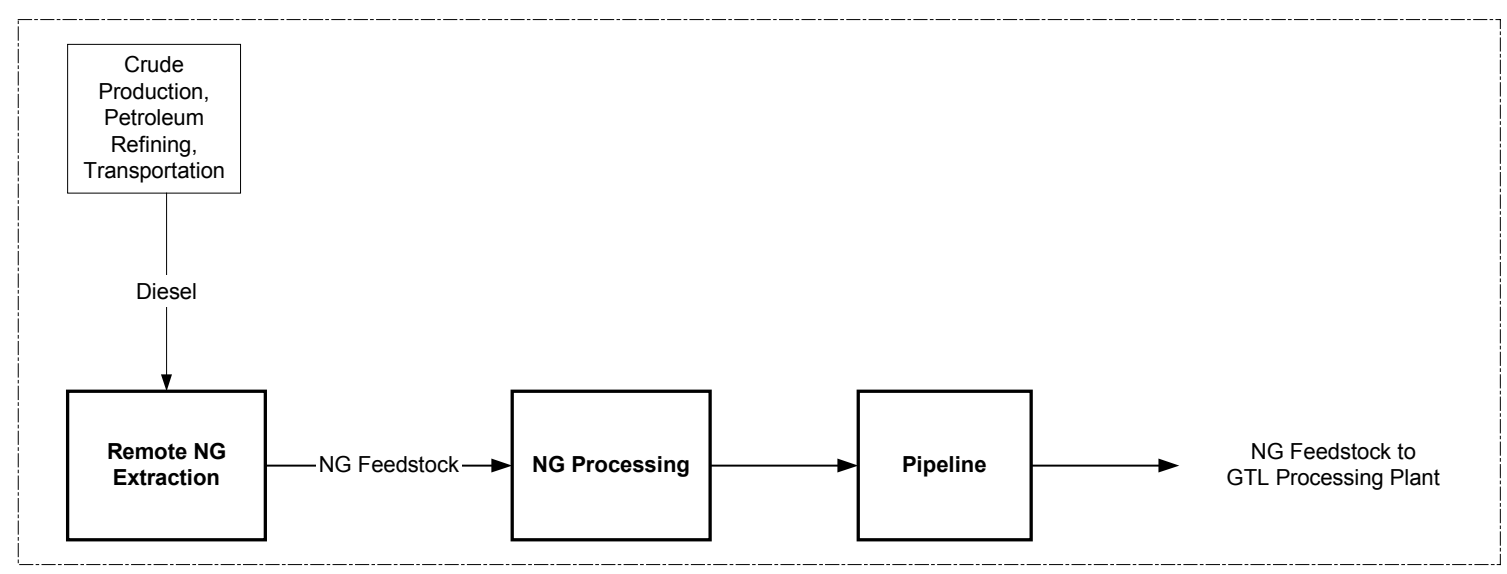

Figure 1-8 Remote Natural Gas Production

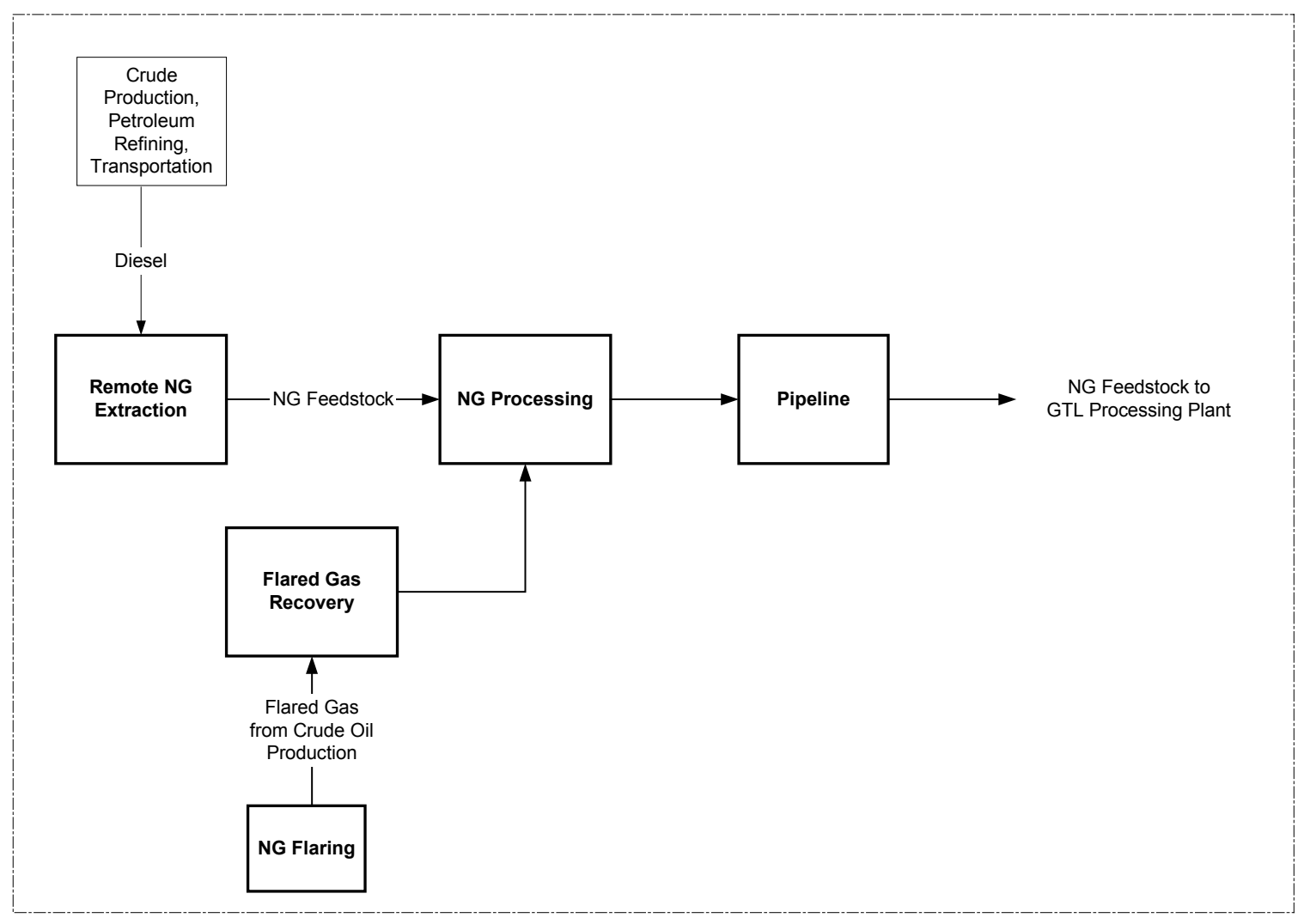

Figure 1-9 Remote Natural Gas and Flared Gas Production 


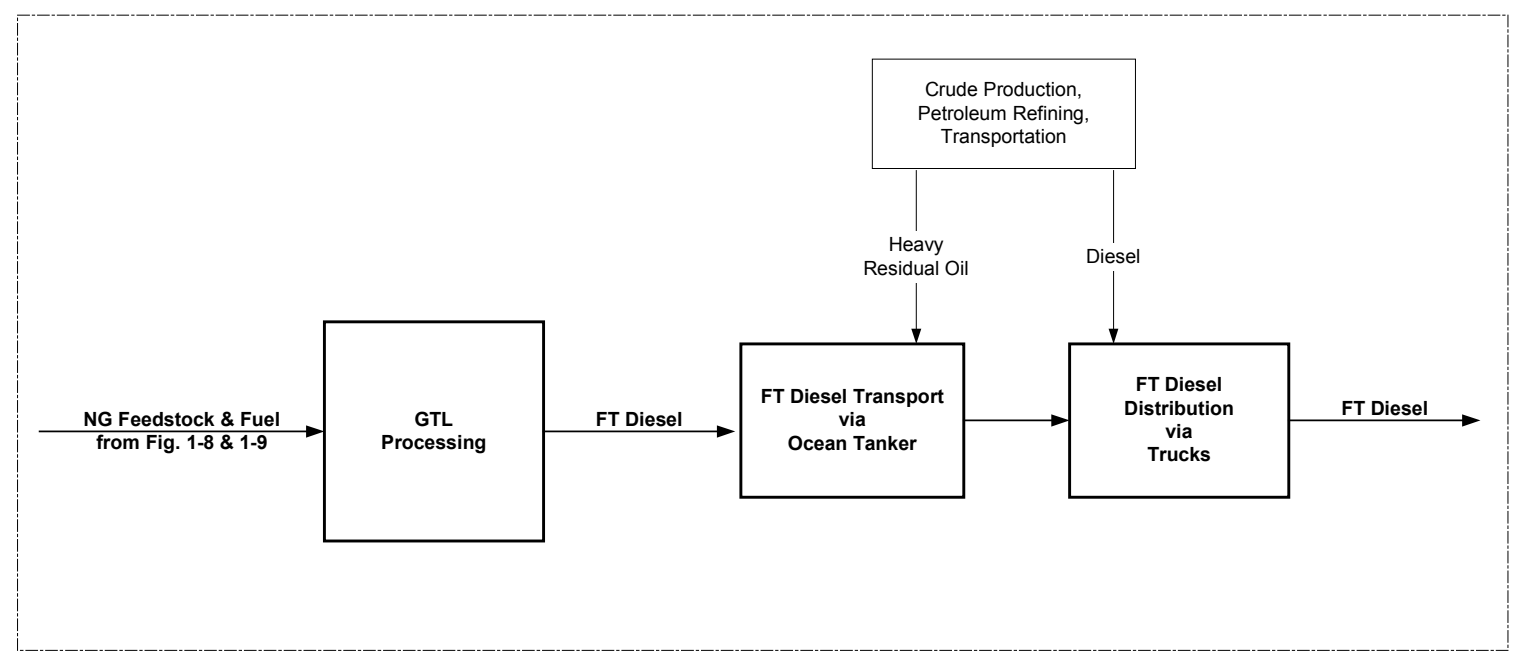

Figure 1-10 FT Diesel Production

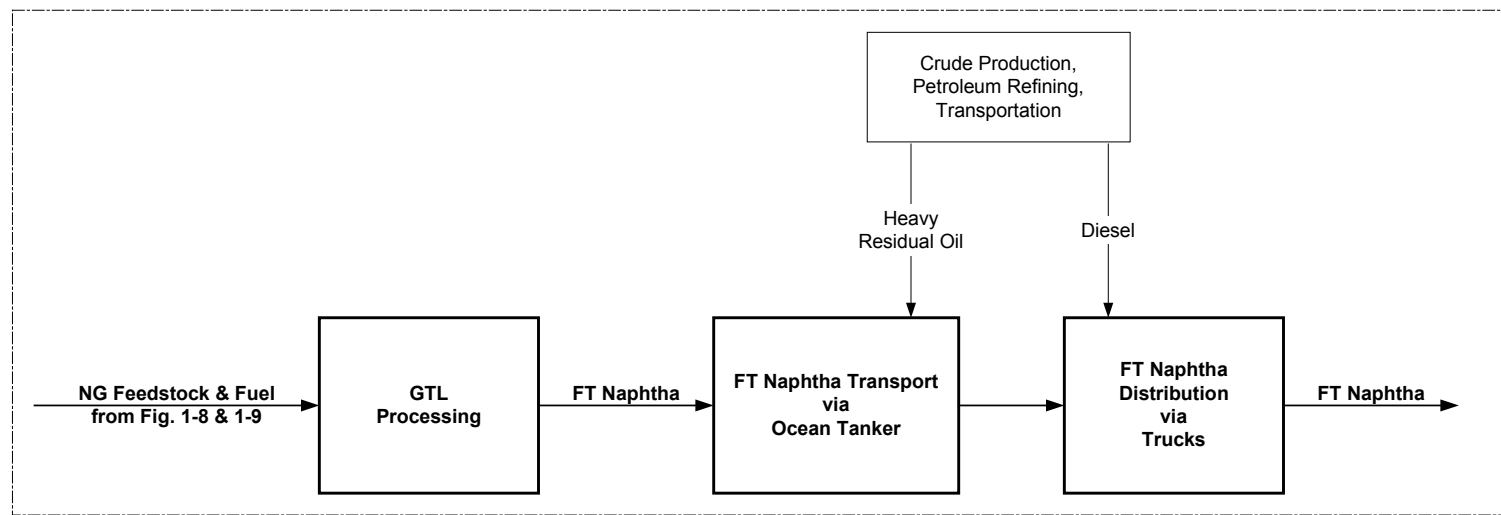

Figure 1-11 FT Naphtha Production

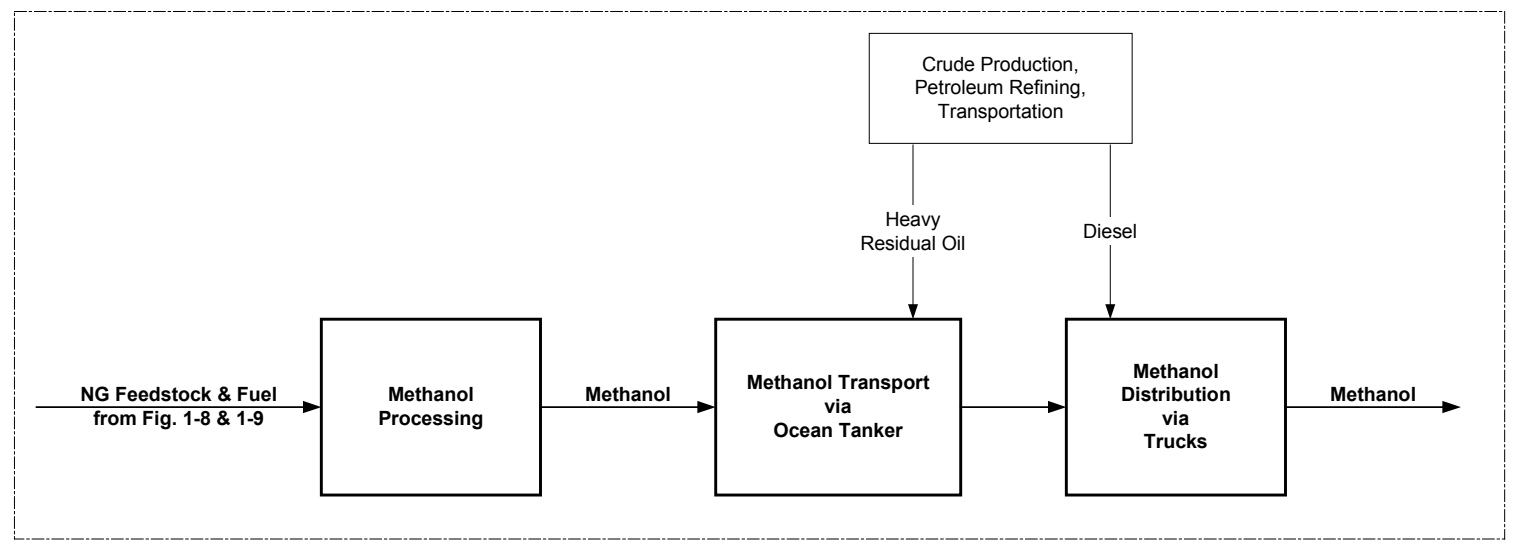

Figure 1-12 Methanol Production 
Scenario 1:

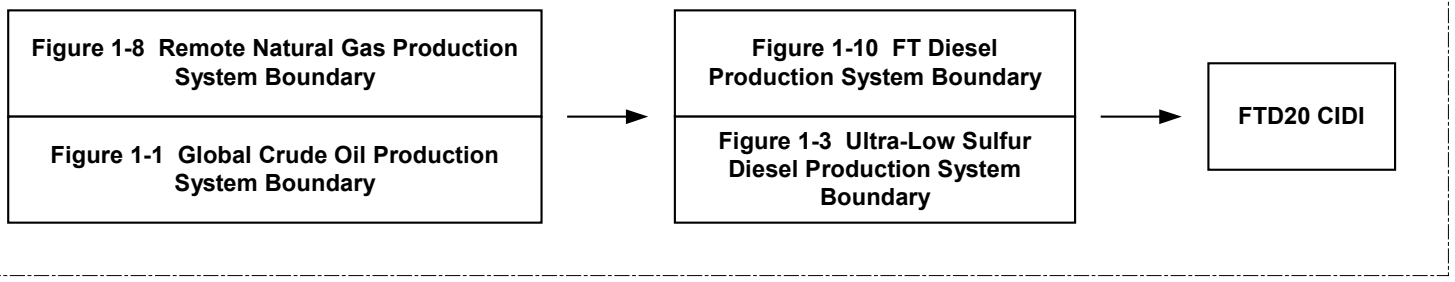

Figure 1-13 Scenario 1 System Boundary

Scenario 2

\begin{tabular}{|c|c|c|c|}
\hline Figure 1-1 Global Crude Oil Production \\
System Boundary
\end{tabular}$\longrightarrow \begin{gathered}\text { Figure 1-5 Conventional Diesel Production } \\
\text { System Boundary }\end{gathered} \rightarrow \begin{gathered}\text { Conventional Diesel } \\
\text { CIDI }\end{gathered}$

Figure 1-14 Scenario 2 System Boundary

Scenario 3

Figure 1-1 Global Crude Oil Production System Boundary

\section{Figure 1-3 Ultra-Low Sulfur \\ Diesel Production System Boundary}

Figure 1-6 Petroleum Coke CFE System Boundary

(coke vs. coal)

Figure 1-7 Residual Oil CFE System Boundary

Figure 1-15 Scenario 3 System Boundary

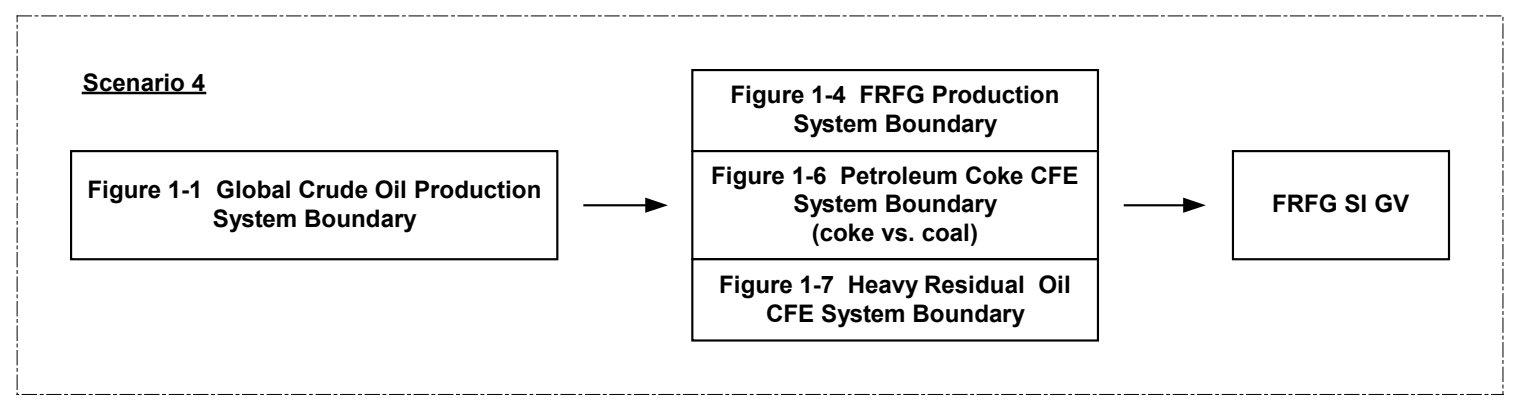

Figure 1-16 Scenario 4 System Boundary

Scenario 5

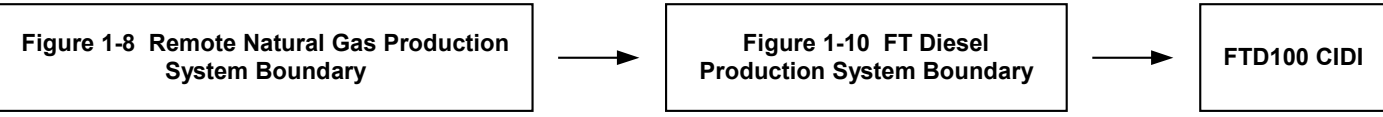

Figure 1-17 Scenario 5 System Boundary 


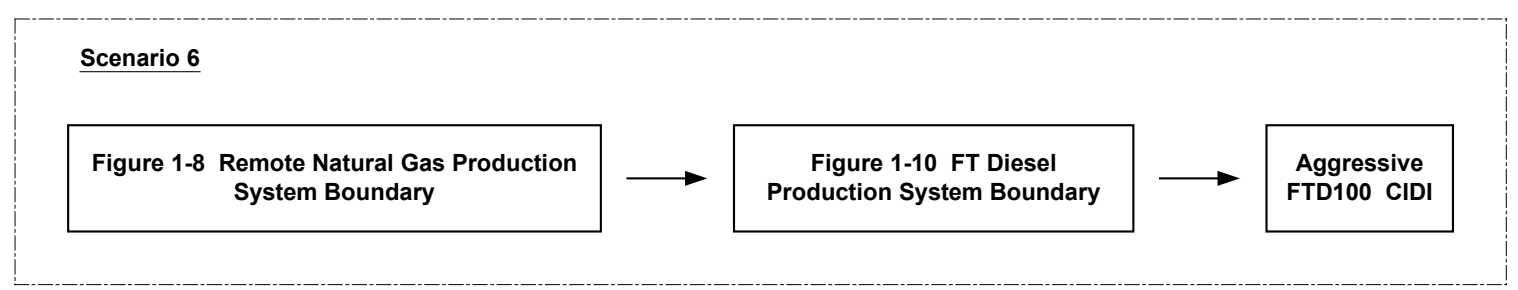

Figure 1-18 Scenario 6 System Boundary

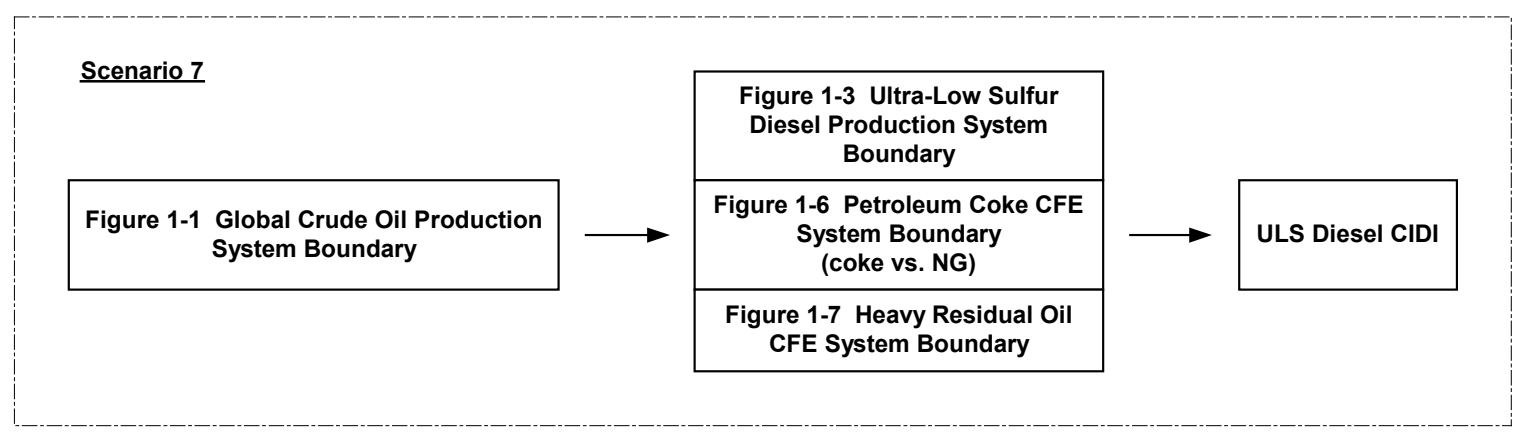

Figure 1-19 Scenario 7 System Boundary

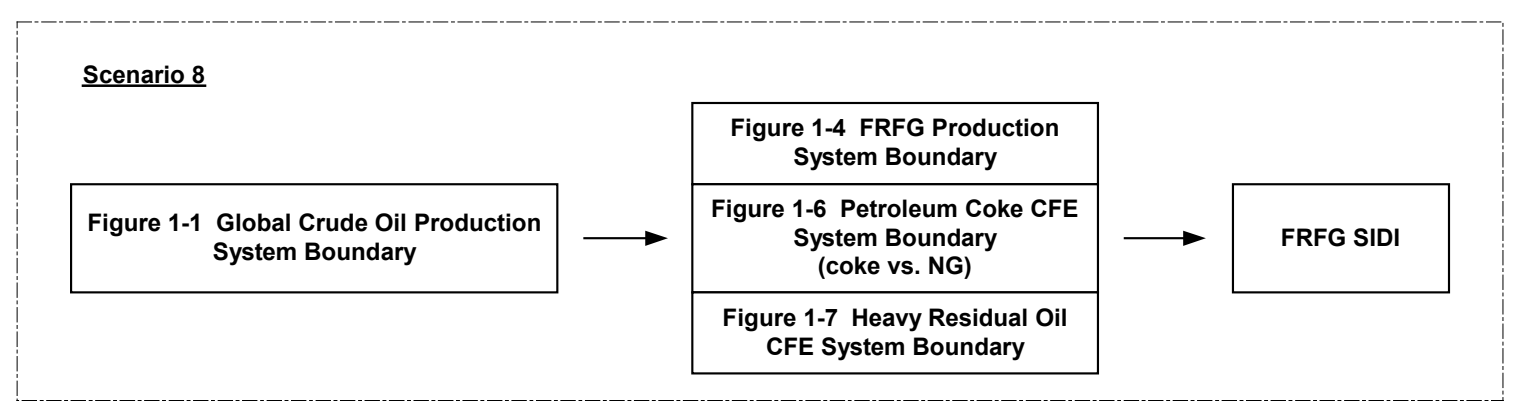

Figure 1-20 Scenario 8 System Boundary

Scenario 9

Figure 1-8 Remote Natural Gas Production System Boundary

Figure 1-21 Scenario 9 System Boundary

Scenario 10

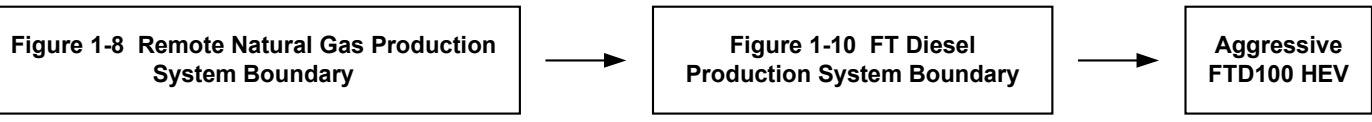

Figure 1-22 Scenario 10 System Boundary 


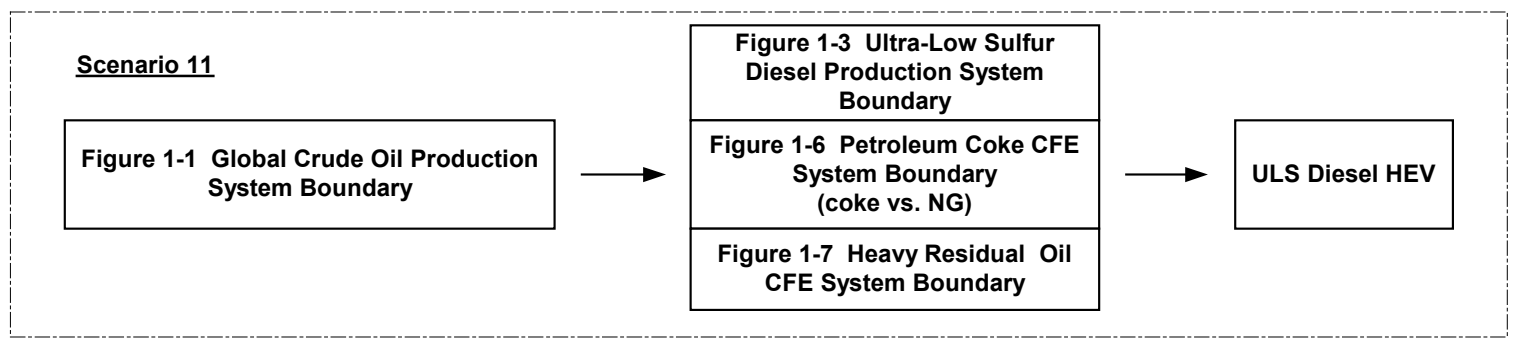

Figure 1-23 Scenario 11 System Boundary

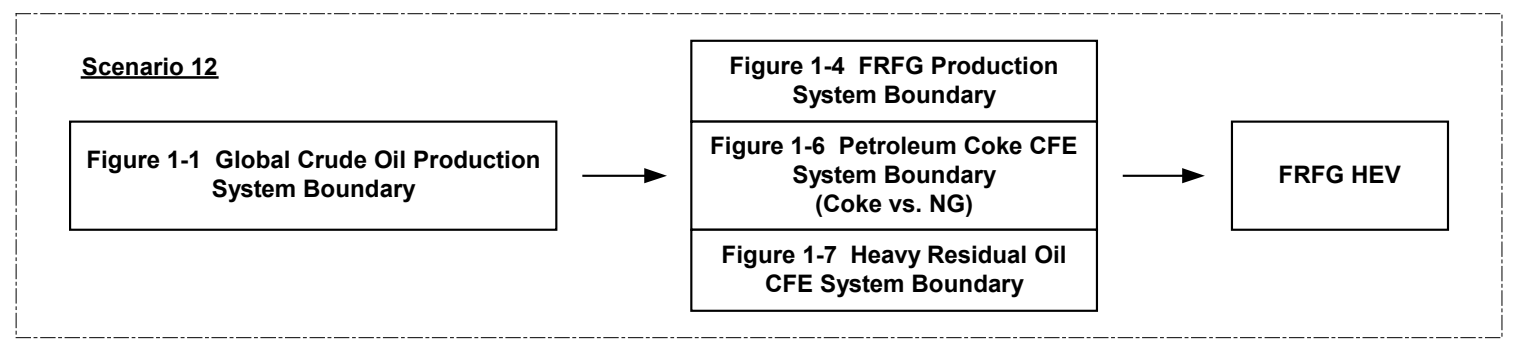

Figure 1-24 Scenario 12 System Boundary

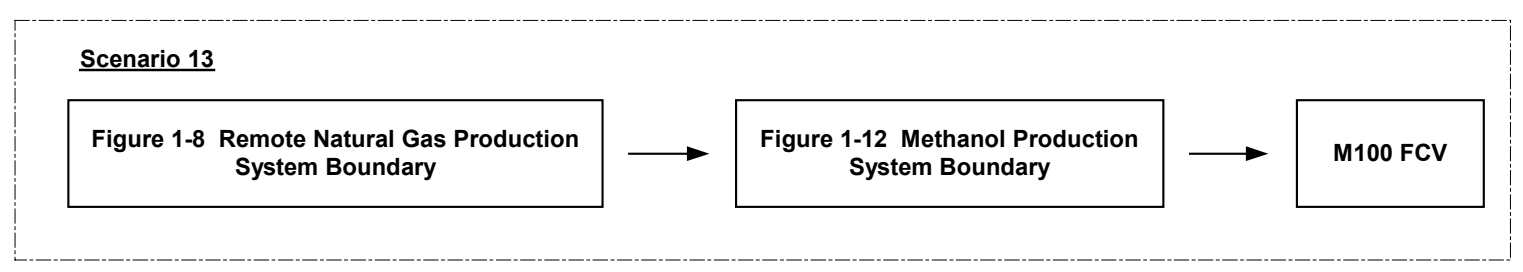

Figure 1-25 Scenario 13 System Boundary

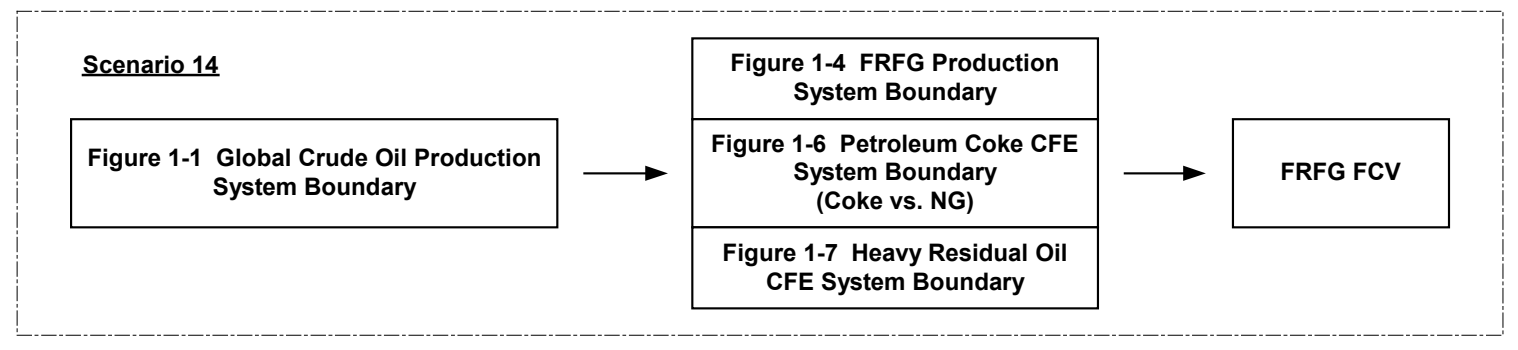

Figure 1-26 Scenario 14 System Boundary

Scenario 15

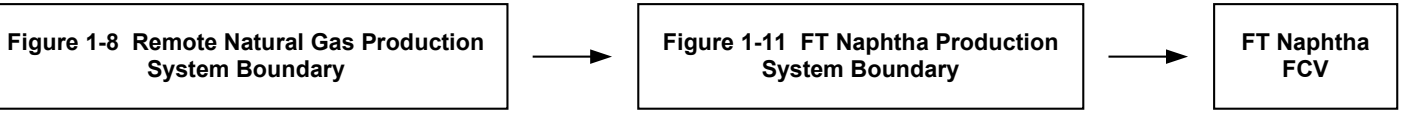

Figure 1-27 Scenario 15 System Boundary 


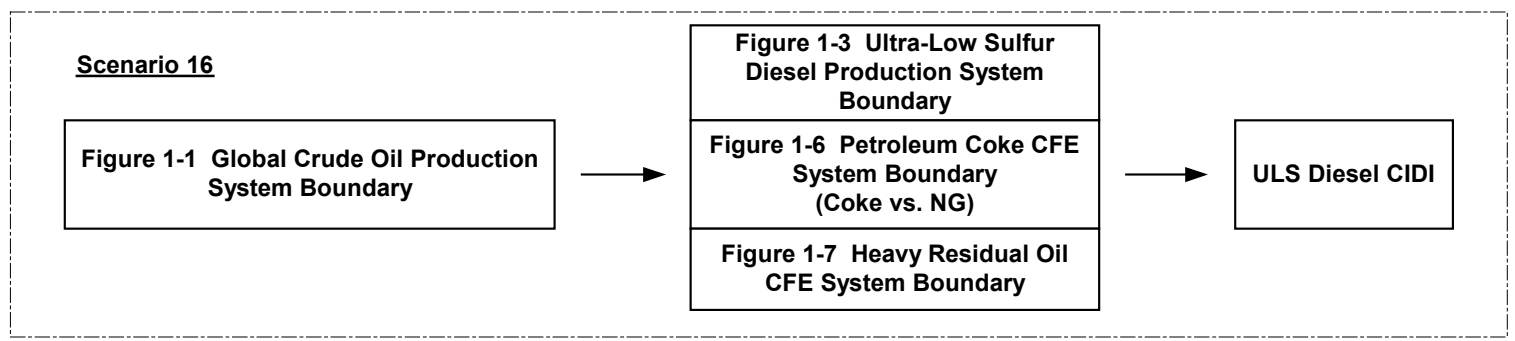

Figure 1-28 Scenario 16 System Boundary

Scenario 17

Figure 1-1 Global Crude Oil Production System Boundary

Figure 1-3 ULS Diesel Production System Boundary

Figure 1-29 Scenario 17 System Boundary

Scenario 18

Figure 1-1 Global Crude Oil Production System Boundary

Figure 1-3 ULS Diese Production System Boundary

ULS Diesel CIDI

Figure 1-30 Scenario 18 System Boundary

Scenario 19

Figure 1-2 Middle East Crude Oil Production System Boundary

Figure 1-3 ULS Diesel Production System Boundary

Figure 1-31 Scenario 19 System Boundary

Scenario 20

Figure 1-9 Remote Natural Gas \& Flared Gas Production System Boundary

Figure 1-10 FT Diesel Production System Boundary

FTD100 CIDI

Figure 1-32 Scenario 20 System Boundary 


\subsubsection{Study Assumptions}

This section describes the primary assumptions used in this study.

\subsubsection{Feedstock Recovery and Processing}

- GREET default data for crude recovery and natural gas recovery and processing is used in this study. GREET default data and data sources are documented in Section 3 of this report.

- Remote natural gas sites are assumed to be in the Middle East. Transport mileages to the United States reflect these distances.

- The remote gas sites are in non-urban locations.

- Some portion of natural gas feedstock for GTL and methanol production can be sourced from flared associated gas (up to $10 \%$ ). This assumption is used in the flared gas sensitivity scenarios.

\subsubsection{Fuel Production}

- GTL and methanol fuels are produced through leading-edge commercial technologies. The data representing GTL production is based on ConocoPhillips engineering estimates, lab-scale experiments, and targets that have been validated by Nexant, but is not representative of currently operating commercial facilities.

- Petroleum fuel slates, heavy crude slates, and CFE cases are based on models of notional PADD I and PADD III refineries, rather than on actual refineries.

- Emissions data for petroleum refining and fuels transport is based on AP-42 data from the U.S. EPA.

- Petroleum refining efficiencies are based on GREET defaults, as validated by Nexant. Refining efficiencies for the sensitivity cases were developed from PIMS model runs from the notional PADD III and PADD I refineries.

\subsubsection{Co-product Function Expansion}

- The lower heating value (LHV) of petroleum and GTL products is used in the CFE analysis.

\subsubsection{Fuel Distribution}

- GREET default data for fuel distribution in the United States is used. This data includes distances, modes, and emissions factors by transport mode.

\subsubsection{Vehicles}

- Vehicle miles-per-gallons (mpg) and emissions performance are based on theoretical representative vehicle configurations for each engine type and each fuel. The vehicles are not representative of the average U.S. fleet for the time horizons studied. 


\subsubsection{Geographic Considerations}

The study considers only remote natural gas for the production of GTL products and methanol.

Natural gas will be recovered as associated gas, flared gas, and primary gas from the Middle East, and the GTL facilities are located in remote sites in the Middle East. The conversion facilities are located near the wellhead. There will not be a significant potential for co-located petrochemical facilities that can use steam and co-generated electricity from the fuel production facilities.

For the LCIA, the metropolitan area of Houston was selected for specific evaluation. This region is a non-attainment area for photochemical smog under the Clean Air Act and the National Ambient Air Quality Standards (NAAQS), and is representative of regions in which emissions reductions are of a high priority.

Urban and non-urban emissions of criteria pollutants and their associated impact indicators were evaluated separately in the LCIA. Most upstream stages for both the petroleum and GTL systems occur in non-urban areas. Some portion of petroleum refining occurs in urban areas, but no GTL processing takes place in urban areas. Most vehicle miles traveled occur in urban areas. These assumptions are documented in Section 3 of this report.

\subsubsection{Life Cycle Inventory Categories}

The life cycle inventory categories considered are total energy, emissions of greenhouse gases $\left(\mathrm{CO}_{2}, \mathrm{CH}_{4}\right.$, and $\left.\mathrm{N}_{2} \mathrm{O}\right)$ and criteria pollutants $\left(\mathrm{NO}_{\mathrm{X}}, \mathrm{SO}, \mathrm{CO}, \mathrm{PM} 10\right.$, and $\left.\mathrm{VOC}\right)$. In addition, the inventory categories for total petroleum fuel use, total fossil fuel use, solid waste, and wastewater are reported in the context of the life cycle impact assessment.

The primary goals of the UCF LCA are: (1) to ensure that ConocoPhillips GTL business is sustainable into the future and (2) to support the DOE Ultra Clean Fuels project objectives. The LCI categories are comprehensive and support these primary goals and provide data for the LCIA stage of the UC LCA.

\subsubsection{Life Cycle Impact Assessment}

ConocoPhillips has conducted an LCIA to compare potential environmental impacts resulting from the use of GTL products, petroleum fuels, and alternative fuels for transportation

Results from the life cycle inventory phase of the UCF LCA were entered into the U.S. EPA's Tool for the Reduction and Assessment of Chemical and other Impacts (TRACI) model to determine the relative life cycle impacts of the fuel alternatives. The results are expressed as comparisons employing the set of impact categories from TRACI: global warming potential, acidification, photochemical smog, eutrophication, human health (criteria, cancer, and noncancer), ecotoxicity, resource depletion, land use, and water use. Supplementary toxics emissions data was collected for the LCIA for the human health and ecotoxic categories. The LCIA impact categories are comprehensive and support the stated goals of the UCF LCA. The indicators cover four significant issues of concern related to the study goals: global warming, air and water 
quality, direct impact on human and ecosystem health, and resource depletion. When these four issues are considered, conclusions can be drawn with respect to the primary study goals: assessment of the sustainability of GTL fuels, and, more specifically, the assessment of the effects of GTL fuels on global warming and air quality.

\subsubsection{Model}

The TRACI model is the Life Cycle Impact Assessment tool used in this study. Developed by the U.S. EPA National Risk Management Research Laboratory (NRMRL), TRACI was recently released for public use. TRACI can identify the potential for impacts, in relative terms, and provide consistent comparisons given scenarios for fuel use in selected metropolitan areas. The approach and outputs of TRACI conform to current industry-standard methods for an LCIA.

\subsubsection{Scope}

The LCIA considers the life cycle potential impacts associated with extraction, transportation, production, distribution, storage, and use of the fuels considered in the LCI. Scenarios defined in the LCI scope are evaluated in the LCIA for both the near term (2006) and long term (2015). A complete listing of these scenarios is provided above.

\subsubsection{Indicators}

The LCIA involves the calculation of indicators of potential impact on the environment. TRACI assigns the inventory results $\left(\mathrm{CO}_{2}, \mathrm{CH}_{4}, \mathrm{~N}_{2} \mathrm{O}, \mathrm{SO}_{\mathrm{X}}, \mathrm{NO}_{\mathrm{X}}\right.$, particulates, etc., normalized to the functional unit of LD vehicle miles) from the LCI to impact categories and applies weighting factors to each flow. This characterization determines the proportional contribution of the various flows to each impact category.

Emissions of primary concern, and the associated impact categories, are:

- $\mathrm{CO}_{2}, \mathrm{~N}_{2} \mathrm{O}$, and $\mathrm{CH}_{4}$ as they contribute to climate change (Global Warming Potential)

- $\mathrm{NO}_{\mathrm{X}}$ and $\mathrm{SO}_{\mathrm{X}}$ as they contribute to air acidification (Acidification)

- $\mathrm{NO}_{\mathrm{X}}$ and VOCs as they contribute to formation of ground level ozone (Photochemical Smog)

- $\mathrm{NO}_{\mathrm{X}}$ as it contributes to eutrophication (Eutrophication)

- Criteria pollutants $\left(\mathrm{CO}, \mathrm{SO}_{\mathrm{X}}, \mathrm{NO}_{\mathrm{X}}\right.$, and PM10 and PM2.5) as they impact human health (Human Health Criteria)

- Toxics as they impact human health (Human Health, Cancer)

- Toxics as they impact human health (Human Health, Non-Cancer)

- Toxics as they impact ecosystems (Ecotoxicity)

- Petroleum and natural gas use (Resource Depletion)

- Solid waste as it requires landfill space (Land Use)

- Consumption of water (Water Use) 
Impact categories have either a global or a specific local impact. Global warming is a global phenomenon. The indicator for global warming is global warming potential (GWP), as a function of greenhouse gas (GHG) emissions. GWP is a weighted aggregate of $\mathrm{CO}_{2}, \mathrm{CH}_{4}$, and $\mathrm{N}_{2} \mathrm{O}$, expressed as $\mathrm{CO}_{2}$-equivalents over a 100-year time horizon. This impact must be considered over the full life cycle of the fuels because the global warming phenomenon is independent of the specific location of the GHG emissions.

However, some potential impacts (e.g., photochemical smog formation and human health criteria) are affected by localized background levels of pollutants. These impacts occur primarily in urban regions where emissions are more concentrated. For this reason, the LCI examines these emissions through both their full life cycle and on a localized (urban) basis. The TRACI model utilizes the urban emission data and factors in specific local or regional conditions (e.g., background emission levels and climatology) to predict a given pollutant's potential to affect each of the impact categories.

The Houston Metropolitan Area was selected for more specific evaluation of urban impacts. Houston is designated as a non-attainment area for photochemical smog under the Clean Air Act and the National Ambient Air Quality Standards (NAAQS), and is representative of regions in which emissions reductions are of a high priority.

Most upstream stages for both the petroleum and GTL systems occur in non-urban areas. Emissions occurring in urban areas will be assessed separately from the non-urban emissions, and the regional urban factor for Houston from TRACI are applied to these emissions.

Table 1-7 lists the impacts categories, category indicators, characterization models, and the assignment of LCI results to impact categories.

\subsubsection{Data Requirements}

Most data for the LCIA - including GHG emissions, criteria pollutants, and energy and petroleum fuel use - comes directly from the LCI and the GREET model. Additional data for the LCIA, specific to several of the impact categories, was developed. This includes:

- Air toxics

- PM2.5

- Ecologically toxic emissions, including heavy metals and alcohols

There are several issues related to the development of data for these categories. High-quality data for vehicle air toxic emissions from GTL fuels is not currently available. This lack of data is due to the limited number of engine tests that have been performed and the limited availability of end use GTL fuel. However, such tests are currently being conducted as part of the petition to DOE on classification of GTL fuels as an alternative fuel under the Energy Policy Act of 1992. ${ }^{6}$ This data will be included as a proxy for a more complete data set. It is expected that because of the

${ }^{6}$ http://www.ott.doe.gov/epact/fuel_pet.shtml 
very low aromatics content in FTD, specifically low polyaromatic hydrocarbons, GTL fuels will very likely demonstrate benefits in air toxic emissions relative to conventional fuels.

Because the PM2.5 regulation is still in a proposed status, good data does not currently exist. However, a general relationship between the concentrations of PM2.5 and PM10 can serve as a proxy.

Table 1-7 TRACI Impact Categories, Indicators, Characterization Models and Input Parameters for the UCF LCIA

\begin{tabular}{|c|c|c|c|c|}
\hline Impact Category & $\begin{array}{l}\text { Classification: } \\
\text { LCI Inputs to } \\
\text { LCIA }\end{array}$ & Category Indicator & Characterization Models & $\begin{array}{l}\text { Is Indicator } \\
\text { Used in Urban } \\
\text { Analysis? }\end{array}$ \\
\hline Global warming & $\begin{array}{l}\mathrm{CO}_{2}, \mathrm{CH}_{4} \text {, and } \\
\mathrm{N}_{2} \mathrm{O} \text { for full life } \\
\text { cycle }\end{array}$ & $\begin{array}{l}\text { 100-year } \mathrm{CO}_{2} \text { gram- } \\
\text { equivalent }\left(\mathrm{CO}_{2} \mathrm{e}\right) \\
\text { GWP }\end{array}$ & IPCC global warming index & No \\
\hline Acidification & $\mathrm{SO}_{2}, \mathrm{NOx}$ & $\begin{array}{c}\text { Moles of } \mathrm{H}+ \\
\text { equivalent }\end{array}$ & $\begin{array}{c}\text { (Norris, 2002), } \\
\text { (Shannon, 1992), } \\
\text { (Carter, 2000) }\end{array}$ & Yes \\
\hline Photochemical smog & VOCs, NOx & $\begin{array}{l}\text { Grams of } \mathrm{NOx} \\
\text { equivalent }\end{array}$ & $\begin{array}{c}\text { (Carter, 2000), (Cardelino, 1995), } \\
\text { (Rabl, 1997), (Sepalla, 1997) }\end{array}$ & Yes \\
\hline Eutrophication & $\mathrm{NOx}$ & Kilograms of nitrogen & (Norris, 2002) & Yes \\
\hline Human health criteria & $\begin{array}{c}\text { Criteria } \\
\text { pollutants } \\
\text { (PM10 and } \\
\text { PM2.5, SOx, } \\
\text { NOx, CO) }\end{array}$ & $\begin{array}{l}\text { Total disability } \\
\text { adjusted life years } \\
\text { (DALYs) }\end{array}$ & $\begin{array}{c}\text { (U.S. EPA, 1999), (Levy, 2000), } \\
\text { (Nishioka, 2002) }\end{array}$ & Yes \\
\hline Human health (cancer) & $\begin{array}{l}\text { Toxics, } \\
\text { carcinogens }\end{array}$ & $\begin{array}{c}\text { Human toxicity } \\
\text { potential (HTP), } \mathrm{C}_{6} \mathrm{H}_{6} \\
\text { (benzene) pounds } \\
\text { equivalent }\end{array}$ & $\begin{array}{c}\text { (Hertwich, 2001) } \\
\text { CalTOX, California EPA }\end{array}$ & No \\
\hline $\begin{array}{l}\text { Human health (non- } \\
\text { cancer) }\end{array}$ & $\begin{array}{l}\text { Toxics, non- } \\
\text { carcinogen }\end{array}$ & $\begin{array}{c}\text { Human toxicity } \\
\text { potential (HTP), } \mathrm{C}_{6} \mathrm{H}_{6} \\
\text { pounds equivalent }\end{array}$ & $\begin{array}{c}\text { (Hertwich, 2001) } \\
\text { CalTOX, California EPA }\end{array}$ & No \\
\hline Ecotoxicity & $\begin{array}{l}\text { Ecotoxic } \\
\text { elements and } \\
\text { compounds }\end{array}$ & $\begin{array}{l}\text { Pounds of 2,4- } \\
\text { dichlorophenoxyacetic } \\
\text { acid (2,4-D) equivalent }\end{array}$ & (Hertwich, 2001) & No \\
\hline Land use & Solid waste & $\begin{array}{l}\text { Mass of solid waste } \\
\text { produced }\end{array}$ & & No \\
\hline Water use & $\begin{array}{l}\text { Intake or use, } \\
\text { in gallons }\end{array}$ & $\begin{array}{l}\text { Intake or use, in } \\
\text { gallons }\end{array}$ & & No \\
\hline Petroleum fuel use & $\begin{array}{l}\text { Energy input } \\
\text { from crude oil }\end{array}$ & Barrels of crude oil & & No \\
\hline Natural gas use & $\begin{array}{l}\text { Energy input } \\
\text { from natural } \\
\text { gas and } \\
\text { stranded NG }\end{array}$ & SCF of gas & & No \\
\hline
\end{tabular}




\subsection{DATA REQUIREMENTS, SOURCES, AND QUALITY}

Data for this study was collected from sources published in the LCA literature (including the GM Well-to-Wheels study and many of the references included at the end of this report), from ConocoPhillips for GTL production, from the US EPA and the Energy Information Agency (EIA) of the Department of Energy, from the GREET model, and from the expertise of Nexant process engineers.

Emissions factors were derived from the U.S. EPA AP-42 (EPA, 1999) document on emissions from petroleum refining and power generation. GREET is also based on this data. In addition, emissions factors by fuel type for $\mathrm{CO}_{2}$ from the EIA are used (EIA, 2001).

A validation of the GREET model data was also conducted. For each fuel pathway under study, at least three other studies were reviewed. The data from these studies was compared with data generated from the GREET model. Nexant process engineers reviewed all sources of data to develop the final data sets.

All data sources used in this study are documented in Sections 3 and 4 of this report.

\subsection{UNCERTAINTY ANALYSIS}

Uncertainty analysis can be performed using GREET 1.6. However, it is unusual to perform a formal uncertainty analysis in LCA studies. Rather, parametric sensitivities studies are commonly performed. This is the primary methodology used in this study.

GREET employs simulation software known as Crystal Ball to carry out Monte Carlo simulations based on probability distributions that are specified for the key model parameters: energy and carbon efficiency of fuel processing and energy efficiency of vehicle use. Once the distributions have been input to GREET, Crystal Ball develops statistical ranges for each of the model outputs, e.g., total energy, GWP, $\mathrm{NO}_{\mathrm{X}}$, and $\mathrm{SO}_{\mathrm{X}}$.

Uncertainty analysis in GREET makes use of expert judgment to develop subjective probability distribution functions for the key model parameters. On the basis of the range of values for the parameter from published sources, the upper, middle, and lower range values for the input parameter are specified as the lower, midpoint, and upper tail ranges corresponding to the $20 \%$, $50 \%$, and $80 \%$ points on a normal or triangular probability distribution.

In developing the lower and upper ranges for model parameters, GREET considers such factors as status of technology development, variability in existing operations, uncertainty in business decisions for promoting certain technologies, and the regulatory uncertainty in developing and operating facilities. As comprehensive as these considerations are, the uncertainty approximations are rough, since they are based not on actual data sets but on subjective judgment.

Uncertainty estimates can provide a valuable perspective on model robustness, but ultimately are only as good as the probability distributions used to model the uncertainty. GREET also 
performs only a limited uncertainty analysis on the energy efficiency parameters. For reference, the uncertainty analysis generated by GREET is presented in an appendix of this report.

\subsection{REFERENCES}

Argonne National Laboratory, "GREET 1.5 - Transportation Fuel-Cycle Model (Vol. 1), Methodology, Development, Use and Results," August 1999.

Argonne National Laboratory, “GREET 1.5 - Transportation Fuel-Cycle Model (Vol. 2), Appendices of Data and Results," August 1999.

Argonne National Laboratory, "Development and Use of the GREET 1.6 Fuel-Cycle Model for Transportation Fuels and Vehicle Technologies," June 2001.

ConocoPhillips, "Ultra Clean Fuels Market Assessment," Submitted to DOE, and to be published, February 2003.

Energy Information Agency, "Voluntary Reporting of Greenhouse Gases 1999," DOE/EIA0608(99), January 2001.

General Motors, Argonne National Laboratory, ExxonMobil, Shell, "Well-to-Wheel Energy Use and Greenhouse Gas Emissions of Advanced Fuel/Vehicle Systems - North American Analysis," April 2001.

International Standards Organization, ISO 14040, "Environmental Management - Life Cycle Assessment - Principles and Framework," 1997

International Standards Organization, ISO 14041, "Environmental Management - Life Cycle Assessment - Goal and Scope Definition and Inventory Analysis," 1998.

International Standards Organization, ISO 14042, "Environmental Management - Life Cycle Assessment - Life Cycle Impact Assessment," 1999.

U.S. EPA, Compilation of Air Pollutant Emission Factors, AP-42, Fifth Edition, Vol. I:

Stationary Point and Area Sources, Office of Air Quality Planning and Standards, 1999. 


\section{$2.1 \quad$ INTRODUCTION}

There is an extensive body of LCA literature for transportation systems. Much of the research has come from U.S. national laboratories, including the National Renewable Energy Laboratory, the National Energy Technology Laboratory, Oak Ridge National Laboratory, and the Argonne National Laboratory, as well as from international agencies, including the International Energy Agency and governmental environmental organizations such as the Australian EPA. Studies have also come directly from fuel and vehicle companies, including General Motors and Shell.

Argonne National Laboratory (ANL), through its Transportation Technology R\&D Center, has produced a significant body of research in this area and has developed a fuel cycle model-the Greenhouse gases, Regulated Emissions, and Energy Use in Transportation (GREET) model (Argonne National Laboratory, 1999, 2001) — that has become a standard in the field. GREET is widely used in the United States. for fuel cycle studies. ANL studies based on GREET have covered a range of transport fuels for conventional and advanced vehicles. Other studies, such as one from the MIT Energy Laboratory, have used GREET to analyze portions of the fuel cycle (in the MIT case, the well-to-tank stage) and have focused further research on other segments (vehicle use in the MIT study). GREET is also currently being used for policy analysis by the U.S. Department of Energy (DOE) for rule making under the Energy Policy Act (EPACT) of 1992.

This section classifies the literature into GREET-based and non-GREET-based studies. Since the UCF LCA employs GREET as a primary modeling tool, it is useful to compare results generated from GREET with results from other studies, and this has been done here. GREET has also been extensively validated for and adapted to the UCF LCA to address specific study questions.

This section also addresses the question of system co-products. There are two approaches: the allocation approach and the system boundary expansion (SBE) approach.

In the allocation approach, used in most studies, energy and emissions are shared among the primary products and co-products of a system, and the co-products are thus placed outside of the system boundary of the primary transportation fuel products, such as gasoline and diesel. In the SBE approach, the system boundaries expand to include the functions and associated energy and emissions of all system products. Both methods are acceptable under the ISO 14040 standards for LCA. The allocation methodology is often used because of the significant amount of data required for a fully expanded system analysis. It has been frequently suggested in the literature (but not verified or quantified) that the two approaches yield comparable results. This is likely to be true if the co-products of the system do not have significant environmental downstream impacts.

Each of the studies discussed in this section employs an allocation-based methodology. However, two of the studies do consider an SBE, either qualitatively or quantitatively.

At the end of this section, areas in which further research needs to be conducted are identified. 


\subsection{GENERAL MOTORS (GM) WELL-TO-WHEEL ANALYSIS}

"Well-to-Wheel Energy Use and Greenhouse Gas Emissions of Advanced Fuel/Vehicle Systems - North American Analysis," General Motors, Argonne National Laboratory, ExxonMobil, Shell, April 2001.

\subsubsection{Pathways}

The GM Well-to-Wheel (WTW) study examines 15 vehicle configurations, including conventional gasoline and diesel engine vehicles, hybrid electric vehicles, fuel cell and hybrid fuel cell electric vehicles. It examines 75 complete fuel-vehicle pathways, including conventional gasoline and diesel, low-sulfur gasoline and diesel, crude-oil-based naphtha, Fischer-Tropsch (FT) naphtha, FT diesel (FTD), methanol, and hydrogen.

The study, carried out in conjunction with Argonne National Laboratory, Shell, and ExxonMobil, is based on the GREET model for the well-to-tank (WTT) fuels stages. GM conducted the tankto-wheel portion of the analysis using proprietary engine simulation software and engine testing.

Several fuel pathways were eliminated from final consideration on the basis of technical, economic, or practical considerations. For example, in the natural gas pathways for FTD and methanol, no flared gas scenarios were considered, nor was any share of flared gas $(5 \%-20 \%$, for example, which is the estimate of total natural gas that is flared in the Middle East). The capture and use of flared gas can provide significant global warming potential (GWP) impact reduction benefits. Table 2-1 lists the pathways considered in the final GM analysis.

Table 2-1 GM WTW Fuel Pathways

\begin{tabular}{|l|l|l|l|}
\hline \multicolumn{1}{|c|}{ Petroleum } & \multicolumn{1}{c|}{ Natural Gas (NG) } & \multicolumn{1}{c|}{ Ethanol } \\
\hline Conventional gasoline & $\begin{array}{l}\text { Compressed natural gas (CNG): non- } \\
\text { North American (NNA) natural gas (NG) }\end{array}$ & $\begin{array}{l}\text { E100, E85 } \\
\text { herbaceous }\end{array}$ & $\begin{array}{l}\text { Hydrogen produced } \\
\text { from NG }\end{array}$ \\
\hline Reformulated gasoline & Methanol: NNA NG & $\begin{array}{l}\text { E100, E85 woody } \\
\text { biomass }\end{array}$ & $\begin{array}{l}\text { Hydrogen produced } \\
\text { via electrolysis }\end{array}$ \\
\hline Low-sulfur diesel & FT naphtha: NNA NG & & \\
\hline Crude naphtha & FT diesel: NNA NG & & \\
\hline
\end{tabular}

The GM study focuses on the comparison of fuel cell vehicles (FCVs), fueled by hydrogen and gasoline, with other conventional and advanced vehicles. The gasoline is reformed on-board into hydrogen. These FCVs are compared with conventional and hybrid electric vehicles (HEVs) fueled with gasoline, methanol, low-sulfur diesel (LSD), and FTD. The low-sulfur gasoline and diesel in the GM study are assumed to be no lower than $10 \mathrm{ppm}$ sulfur, which, while meeting EPA standards for conventional engines, poses technical challenges for use in FCVs, since the fuel must be desulfurized before being reformed into hydrogen. Use of zero-sulfur methanol in FCVs reformed to hydrogen does not pose this problem. 


\subsubsection{Scope and Methodology}

GREET models feedstock and fuel production and transportation using such factors as the thermal efficiency of production, transportation mode efficiencies, shares of process fuel inputs, and combustion technologies, and takes into account both combustion and non-combustion emissions. GREET uses factors from the U.S. EPA AP-42 (EPA, 1999) for emissions from petroleum refining to calculate final WTT emissions for criteria pollutants. $\mathrm{CO}_{2}$ emissions are calculated on the basis of carbon balances. GREET models emissions and energy use for only the primary fuel products (e.g., gasoline and diesel). The functions and associated energy and emissions for co-products, such as petroleum coke, are placed outside the system boundary.

The GM study covers the WTW fuel cycle, from feedstock extraction and production, transportation, fuel processing, fuel distribution, to fuel end use. The study does not consider the impacts of infrastructure or manufacturing of vehicles; such study boundaries are customarily used in the literature and are acceptable under the ISO 14040 standards for LCAs.

\subsubsection{Assumptions and Data}

WTT energy and emissions results in GREET are largely a function of the thermal and carbon efficiency parameters for fuel production; the thermal efficiencies chosen for petroleum and natural-gas-based fuels are key drivers of comparative results. The process efficiency factors are developed outside GREET through engineering analysis.

The GM study assumes thermal efficiencies for GTL fuels in the range 55\%-63\%. These efficiencies are representative of designs from the early to mid 1990s and are used in both the near-term and long-term scenarios, with no provision for process improvements. The GREET 1.5 manual and the GM WTW report document the specific technology assumptions.

All flared-gas scenarios are excluded from the final WTW analysis, but are included in the WTT analysis. The study also does not include energy and emission inventories associated with petroleum co-products; that is to say, the study uses an allocation approach for dealing with coproducts rather than the SBE methodology.

The GM study does not model the effect of heavier crude slates for petroleum refining or higher sulfur concentration in crude oil for future scenarios. Future petroleum refining efficiencies are not lowered to reflect the increase in energy and emissions that would be associated with refining heavier crude slates. Since thermal efficiency is a key parameter for the fuel processing stage, this could have a potentially significant effect on the results. 


\subsubsection{Results}

The results of the GM study are summarized below. The error bars in the charts reflect results from an uncertainty analysis for key parameters, including thermal and carbon efficiencies.

As shown in Figure 2-1 and Table 2-2, FTD requires 35\% more energy per mile than crudebased diesel and $14 \%$ more energy than gasoline.

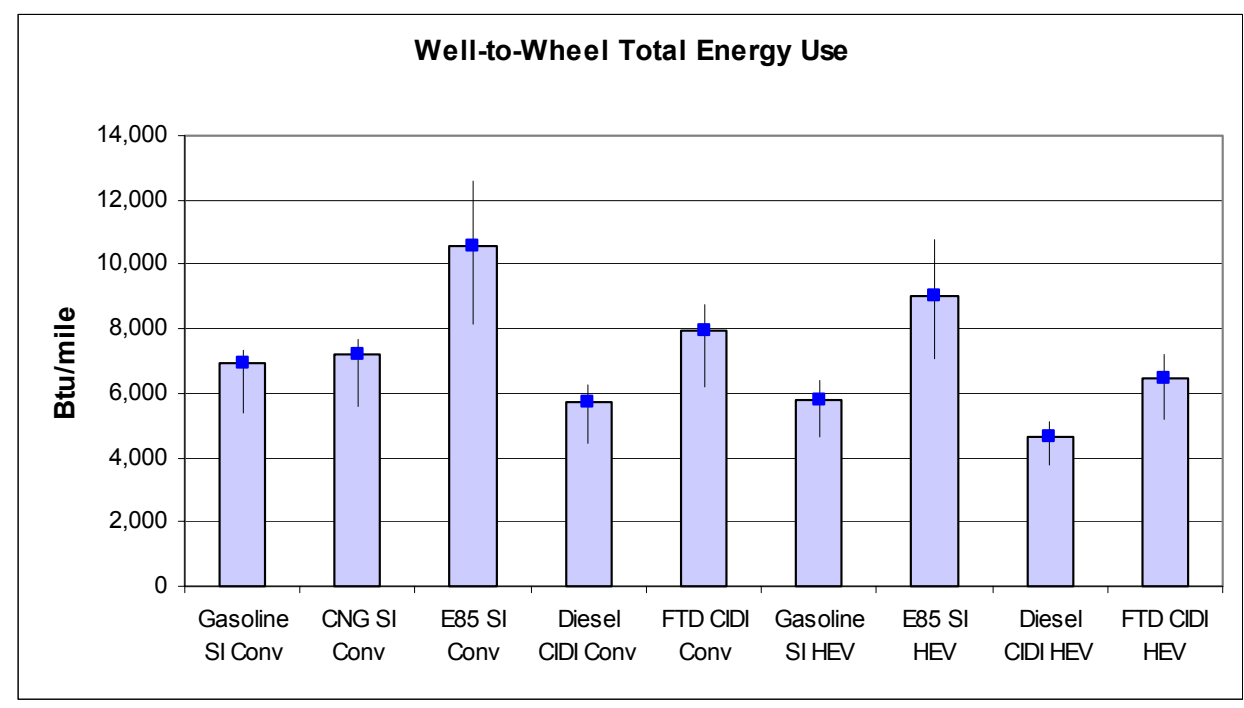

Figure 2-1 WTW Total System Energy Use for Conventional and Hybrid Fuel/ Vehicle Pathways (SI and CIDI)

Table 2-2 WTW Total System Energy for Conventional and Hybrid Fuel/Vehicle Pathways (SI and CIDI)

\begin{tabular}{|l|c|c|c|c|c|c|c|c|c|c|}
\hline \multicolumn{1}{|c|}{ Btu/mi } & $\begin{array}{c}\text { Gasoline } \\
\text { SI Conv }\end{array}$ & $\begin{array}{c}\text { CNG } \\
\text { SI Conv }\end{array}$ & $\begin{array}{c}\text { E85 } \\
\text { SI Conv }\end{array}$ & $\begin{array}{c}\text { Diesel } \\
\text { CIDI Conv }\end{array}$ & $\begin{array}{c}\text { FTD } \\
\text { CIDI Conv }\end{array}$ & $\begin{array}{c}\text { Gasoline } \\
\text { SI HEV }\end{array}$ & $\begin{array}{c}\text { E85 } \\
\text { SI HEV }\end{array}$ & $\begin{array}{c}\text { Diesel } \\
\text { CIDI HEV }\end{array}$ & $\begin{array}{c}\text { FTD } \\
\text { CIDI HEV }\end{array}$ \\
\hline Midpoint & 6,949 & 7,224 & 10,579 & 5,735 & 7,945 & 5,788 & 9,000 & 4,650 & 6,471 \\
\hline Low & 5,388 & 5,566 & 8,170 & 4,462 & 6,191 & 4,617 & 7,097 & 3,741 & 5,209 \\
\hline High & 7,365 & 7,644 & 12,582 & 6,232 & 8,718 & 6,362 & 10,771 & 5,126 & 7,169 \\
\hline
\end{tabular}


FTD compression ignition direct injection (CIDI) vehicles and CIDI HEVs have 2\% and 1\% higher $\mathrm{CO}_{2}$ emissions than the LSD pathway, respectively, but are better than conventional gasoline (-14\% for CIDI, and $-16 \%$ for CIDI HEVs), as shown in Figure 2-2 and Table 2-3.

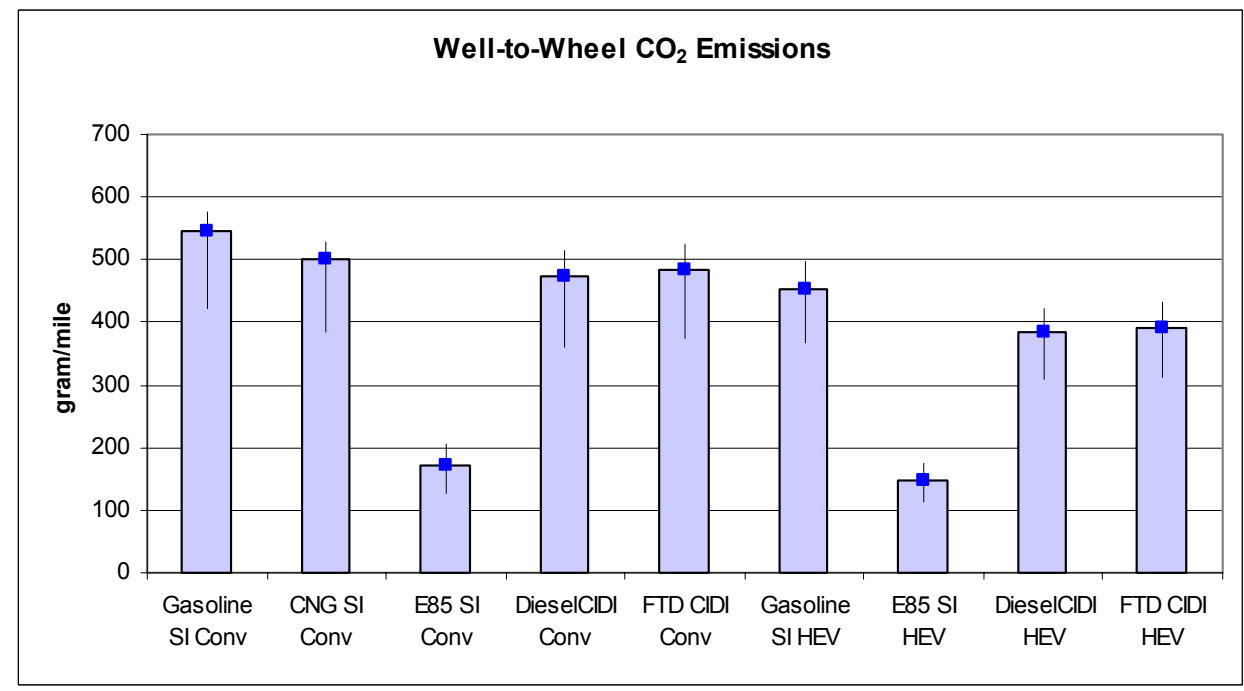

Figure 2-2 WTW $\mathrm{CO}_{2}$ Emissions for Conventional and Hybrid Fuel/Vehicle Pathways (SI and CIDI)

Table 2-3 WTW $\mathrm{CO}_{2}$ Emissions for Conventional and Hybrid Fuel/Vehicle Pathways (SI and CIDI)

\begin{tabular}{|l|c|c|c|c|c|c|c|c|c|}
\hline \multicolumn{1}{|c|}{ g/mi } & $\begin{array}{c}\text { Gasoline } \\
\text { SI Conv }\end{array}$ & $\begin{array}{c}\text { CNG } \\
\text { SI Conv }\end{array}$ & $\begin{array}{c}\text { E85 } \\
\text { SI Conv }\end{array}$ & $\begin{array}{c}\text { Diesel } \\
\text { CIDI Conv }\end{array}$ & $\begin{array}{c}\text { FTD } \\
\text { CIDI Conv }\end{array}$ & $\begin{array}{c}\text { Gasoline } \\
\text { SI HEV }\end{array}$ & $\begin{array}{c}\text { E85 } \\
\text { SI HEV }\end{array}$ & $\begin{array}{c}\text { Diesel } \\
\text { CIDI HEV }\end{array}$ & $\begin{array}{c}\text { FTD } \\
\text { CIDI HEV }\end{array}$ \\
\hline Midpoint & 544 & 500 & 172 & 472 & 484 & 454 & 146 & 384 & 392 \\
\hline Low & 422 & 385 & 128 & 362 & 375 & 366 & 113 & 309 & 313 \\
\hline High & 577 & 530 & 205 & 513 & 524 & 498 & 174 & 423 & 432 \\
\hline
\end{tabular}


The gasoline and the petroleum naphtha fuel processor fuel cell vehicles (FP-FCVs) consume less total well-to-wheel energy per mile than all other fuel pathways and vehicle options. However, the results for the methanol FCV are very close to that for gasoline and naphtha, with error ranges that overlap significantly, as seen in Figure 2-3 and Table 2-4.

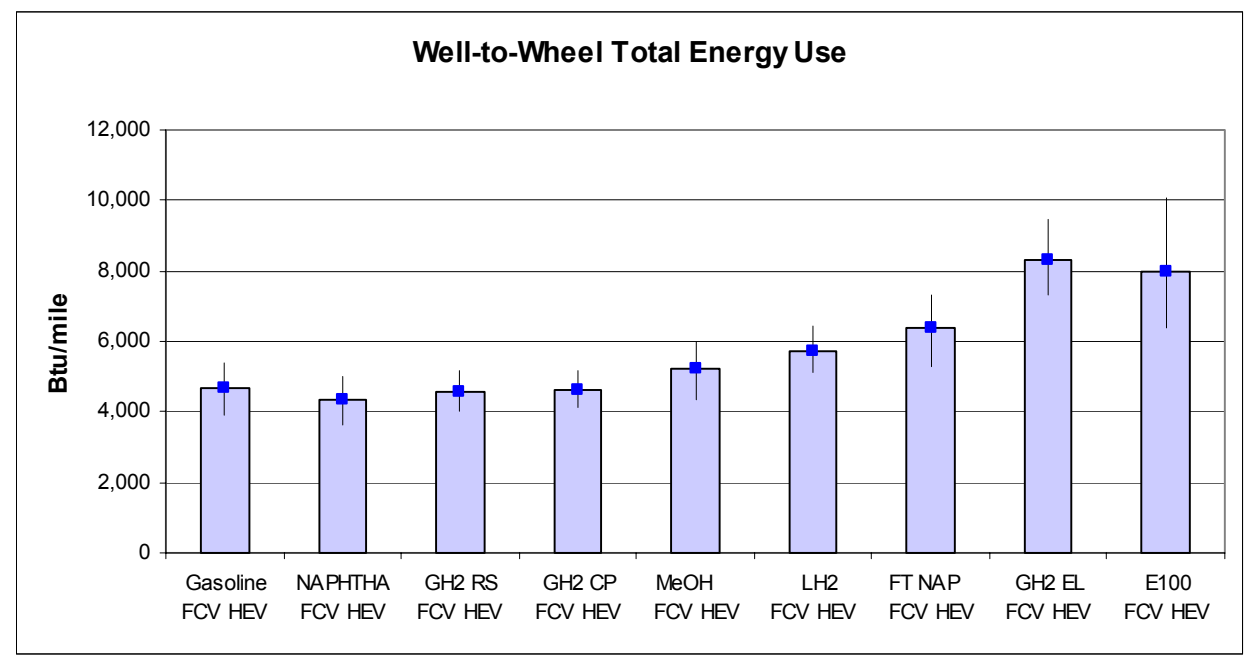

Figure 2-3 WTW Total System Energy for Hybrid Fuel/FCV Pathways

Table 2-4 WTW Total System Energy for Hybrid Fuel/FCV Pathways

\begin{tabular}{|c|c|c|c|c|c|c|c|c|c|}
\hline Btu/mi & $\begin{array}{l}\text { Gas } \\
\text { FCV } \\
\text { HEV }\end{array}$ & $\begin{array}{l}\text { NAP } \\
\text { FCV } \\
\text { HEV }\end{array}$ & $\begin{array}{c}\text { GH2 RS } \\
\text { FCV } \\
\text { HEV }\end{array}$ & $\begin{array}{c}\text { GH2 CP } \\
\text { FCV } \\
\text { HEV }\end{array}$ & $\begin{array}{l}\text { Methanol } \\
\text { FCV HEV }\end{array}$ & $\begin{array}{l}\text { LH2 } \\
\text { FCV } \\
\text { HEV }\end{array}$ & $\begin{array}{l}\text { FT NAP } \\
\text { FCV } \\
\text { HEV }\end{array}$ & $\begin{array}{c}\text { GH2 EL } \\
\text { FCV } \\
\text { HEV }\end{array}$ & $\begin{array}{l}\text { E100 } \\
\text { FCV } \\
\text { HEV }\end{array}$ \\
\hline Midpoint & 4,675 & 4,357 & 4,549 & 4,625 & 5,224 & 5,718 & 6,362 & 8,289 & 7,979 \\
\hline Low & 3,912 & 3,621 & 4,022 & 4,122 & 4,341 & 5,101 & 5,272 & 7,294 & 6,358 \\
\hline High & 5,398 & 5,035 & 5,159 & 5,178 & 6,000 & 6,427 & 7,346 & 9,463 & 10,052 \\
\hline
\end{tabular}


Figure 2-4 and Table 2-5 show $\mathrm{CO}_{2}$ results for FCVs and HEV/FCVs. Because of the carbon cycling associated with biomass production, herbaceous E100 (neat ethanol) FCV HEV produces the lowest level of $\mathrm{CO}_{2}$ emissions. This result is driven by changes in land use that assumes net carbon sequestration in the well-to-tank (to be precise, farm-to-tank) stage that offsets $\mathrm{CO}_{2}$ from the vehicle use stage.

The gaseous hydrogen FCV has the second lowest $\mathrm{CO}_{2}$ emissions rate; petroleum naphtha and methanol are a close third ( 350 and $320 \mathrm{~g} / \mathrm{mi} \mathrm{GHG}$ emissions, respectively); and the gasoline FCV HEV is fourth (360 g/mi). However, as discussed above, the sulfur petroleum fuelsgasoline, diesel, and naphtha- have sulfur concentrations in the 15-30 ppm range. These concentrations are likely to exceed requirements for use in FCVs even with on-board desulfurization.

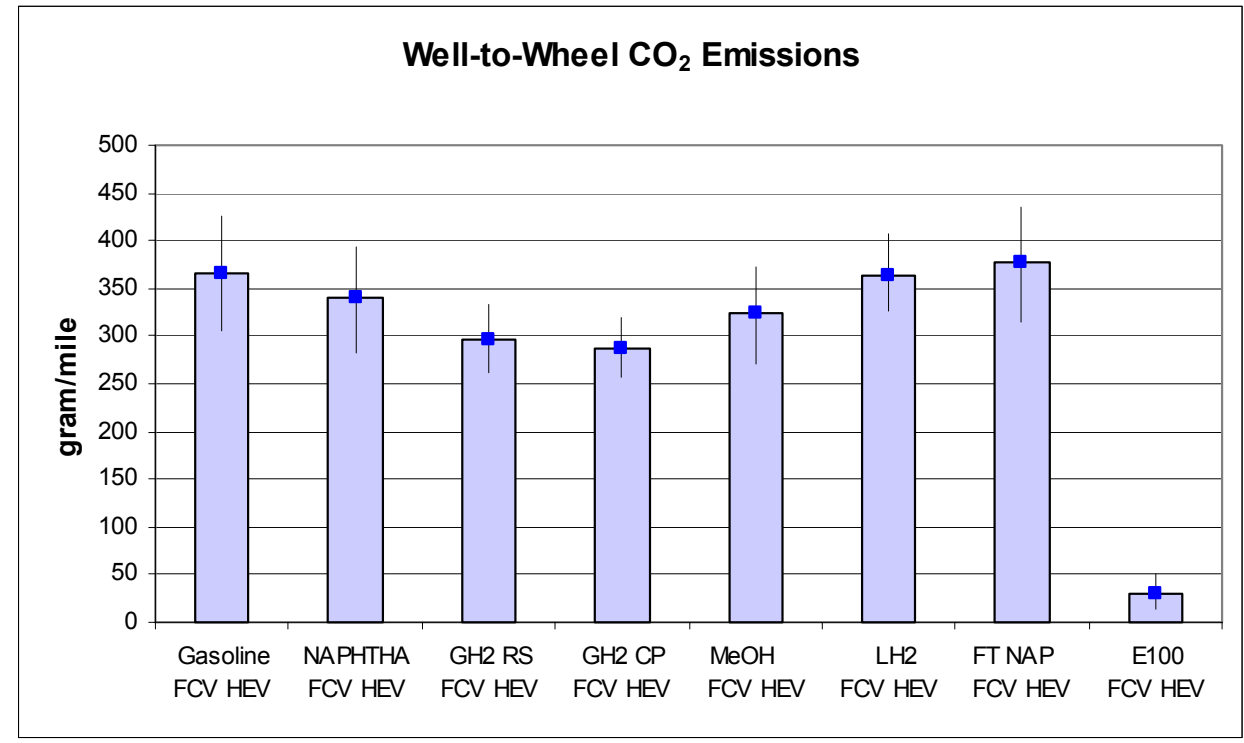

Figure 2-4 WTW $\mathrm{CO}_{2}$ Emissions for Hybrid Fuel/FCV Pathways

Table 2-5 WTW $\mathrm{CO}_{2}$ Emissions for Hybrid Fuel/FCV Pathways

\begin{tabular}{|l|c|c|c|c|c|c|c|c|}
\multicolumn{1}{|c|}{$\begin{array}{c}\text { Gasoline } \\
\text { FCV } \\
\text { FEV }\end{array}$} & $\begin{array}{c}\text { NAP } \\
\text { FCV } \\
\text { HEV }\end{array}$ & $\begin{array}{c}\text { GH2 RS } \\
\text { FCV } \\
\text { HEV }\end{array}$ & $\begin{array}{c}\text { GH2 CP } \\
\text { FCV HEV }\end{array}$ & $\begin{array}{l}\text { Methanol } \\
\text { FCV HEV }\end{array}$ & $\begin{array}{c}\text { LH2 } \\
\text { FCV } \\
\text { HEV }\end{array}$ & $\begin{array}{c}\text { FT NAP } \\
\text { FCV } \\
\text { HEV }\end{array}$ & $\begin{array}{c}\text { E100 FP } \\
\text { FCV } \\
\text { HEV }\end{array}$ \\
\hline Midpoint & 366 & 340 & 296 & 286 & 324 & 364 & 377 & 31 \\
\hline Low & 305 & 283 & 262 & 256 & 270 & 326 & 315 & 13 \\
\hline High & 425 & 394 & 333 & 319 & 373 & 407 & 436 & 51 \\
\hline
\end{tabular}




\subsubsection{Analysis}

The GM study concludes that FTD is inferior to conventional diesel and LSD with respect to total energy and just slightly inferior with respect to $\mathrm{CO}_{2}$ emissions. Because the study places great emphasis on energy use and energy efficiency of fuel pathways, irrespective of potential environmental impact (such as from $\mathrm{CO}_{2}$ emissions), FTD is eliminated from the final set of scenarios. The study does not model criteria pollutant emissions $-\mathrm{SO}_{\mathrm{X}}, \mathrm{NO}_{\mathrm{X}}, \mathrm{VOC}, \mathrm{CO}$, and PM10 - and for these emission inventories, natural-gas-based fuels have distinct advantages over petroleum fuels. GM is addressing these criteria emissions in a second study phase.

The GM study assumes process GTL and methanol production efficiencies that are representative of older technology, in a lower range relative to current and future technologies. Since the efficiency parameters are a key driver of GREET model outputs, these assumptions have a significant impact on the comparative results of petroleum and natural gas fuels.

Despite the fact that methanol FCVs perform very well, the study dismisses methanol as "having no significant energy use or emissions reduction advantages over the crude oil-based pathways," even though the methanol FCV shows a $12 \%$ reduction in GHG impacts relative to the gasoline FCV. Furthermore, there are inherently greater technical challenges for the gasoline FCV than the methanol FCV.

The GM analysis excludes neat methanol and M90 (90\% methanol, 10\% gasoline) fuel blends used in internal combustion engines. However, a previous study from Argonne National Laboratory (Wang, 1999) shows M90 to be roughly equivalent to reformulated gasoline with regard to energy and GHG emissions, and better with regard to criteria emissions inventories.

Petroleum co-products are not accounted for in the GM study. The allocation methodology employed in the study, while compliant with ISO 14040 standards, may understate the energy and emissions inventories of petroleum-based fuels.

\subsection{MIT FUEL CYCLE STUDY}

"On the Road in 2020: A Life-Cycle Analysis of New Automobile Technologies," Energy Laboratory, MIT, October 2000.

\subsubsection{Pathways}

The MIT LCA study considers the potential for future advanced transportation technologies to significantly reduce GHG emissions from passenger vehicles. MIT used an advanced simulation system to estimate overall vehicle driving cycle performance and also evaluated the potential for the use of advanced materials in automobiles. MIT did not conduct an original well-to-tank analysis, but relied on results from previous GREET-based studies from Argonne National Laboratory. However, fuel production efficiencies for gasoline and diesel were increased to represent European refineries. Vehicle efficiency and emission reduction assumptions were much more aggressive than those considered in the GM and other GREET studies. Since vehicle use contributes up to $80 \%$ of energy and emissions over the full fuel cycle, these assumptions have a significant impact on the results. 


\subsubsection{Assumptions and Data}

All data for the well-to-tank portion of this analysis is based on existing data from the literature - in particular from Argonne National Laboratory (Argonne National Laboratory, 1999). Because the MIT study used GREET to model WTT stages, the WTT results are similar to those reported in other GREET-based studies. But because MIT carried out original vehicle simulations based on models of specific vehicle configurations and driving cycle characteristics, the total fuel cycle emissions are different from those reported in these studies.

The MIT study also estimated energy and emissions from the vehicle life cycle, including raw material extraction, manufacturing, recycling, and disposal. The results indicate that all vehicle types are essentially equivalent with respect to life cycle inventories of material consumption and emissions, and ultimately have no differential impact in the final comparative WTW results.

The MIT study uses the same process efficiencies assumed in GREET for the GTL and methanol pathways $-53 \%$ for GTL and $68 \%$ for methanol. However, the 53\% assumed for GTL fuels is from an earlier version of GREET (GREET 1.5) than the one used in the GM study. The current version of GREET (Version 1.6) assumes an efficiency in the mid 60\% range. By comparison, the thermal efficiency for diesel production in GREET is $87 \%-89 \%$.

The vehicle efficiencies used in the study are listed in Table 2-6.

Table 2-6 MIT Study Vehicle Efficiency Assumptions

\begin{tabular}{|l|c|}
\hline \multicolumn{1}{|c|}{ Vehicle } & mpg \\
\hline Base case spark ignition (SI) internal combustion engine (ICE) & 43.2 \\
\hline Advanced SI ICE & 49.1 \\
\hline Advanced CIDI ICE & 56 \\
\hline Advanced gasoline SI ICE hybrid & 70.8 \\
\hline Advanced CNG SI hybrid & 73.4 \\
\hline Advanced diesel CI ICE hybrid & 82.3 \\
\hline Gasoline reformer fuel cell & 42.3 \\
\hline Methanol reformer fuel cell & 56.9 \\
\hline Hydrogen gas FCV & 94.1 \\
\hline
\end{tabular}




\subsubsection{Results}

Table 2-7 presents the key results of the MIT study for gasoline, diesel, FTD, and methanol vehicles over the 1996-2020 time frame. The results are similar to the results of the GM study (Table 2-8) with regard to the relative rankings of alternatives. Variations are due to the different assumptions made for vehicle characteristics and performance. FTD as a neat fuel consumes $61 \%$ more energy and generates $17 \%$ more $\mathrm{CO}_{2}$ emissions than the comparable petroleum diesel pathway, assuming a process efficiency of $53 \%$ for GTL production.

Table 2-7 MIT Study Results

\begin{tabular}{|l|c|c|c|c|}
\hline \multicolumn{1}{|c|}{ Fuel/Vehicle } & MJ / km & $\begin{array}{c}\text { Percent of } 1996 \\
\text { Baseline }\end{array}$ & $\begin{array}{c}\text { Grams Carbon / } \\
\text { km }\end{array}$ & $\begin{array}{c}\text { Percent of } 1996 \\
\text { Baseline }\end{array}$ \\
\hline 1996 current gasoline & 3.57 & $100 \%$ & 71.8 & $100 \%$ \\
\hline 2020 baseline gasoline & 2.34 & $65 \%$ & 47.2 & $65 \%$ \\
\hline 2020 advanced gasoline & 2.08 & $58 \%$ & 41.9 & $58 \%$ \\
\hline 2020 advanced diesel & 1.77 & $49 \%$ & 37.0 & $51 \%$ \\
\hline 2020 advanced FT diesel & 2.86 & $80 \%$ & 43.4 & $60 \%$ \\
\hline 2020 advanced HEV gasoline & 1.53 & $42 \%$ & 29.8 & $41 \%$ \\
\hline Advanced HEV diesel & 1.28 & $35 \%$ & 26.5 & $36 \%$ \\
\hline Advanced HEV FT diesel & 2.02 & $56 \%$ & 31.0 & $43 \%$ \\
\hline Advanced gasoline direct fuel cell & 2.44 & $68 \%$ & 49.0 & $68 \%$ \\
\hline Advanced methanol direct fuel cell & 2.32 & $65 \%$ & 37.6 & $52 \%$ \\
\hline
\end{tabular}

Table 2-8 Selected GM WTW Results

\begin{tabular}{|l|c|c|c|c|}
\multicolumn{1}{c|}{ Fuel/Vehicle } & Btu/mi & $\%$ of Baseline & g/mi & $\begin{array}{c}\% \text { of } \\
\text { Baseline }\end{array}$ \\
\hline Gasoline conventional & 7,000 & $100 \%$ & 550 & $100 \%$ \\
\hline Diesel conventional & 5,900 & $84 \%$ & 475 & $86 \%$ \\
\hline FT conventional diesel & 8,000 & $114 \%$ & 480 & $87 \%$ \\
\hline Methanol FC HEV & 5,500 & $79 \%$ & 325 & $59 \%$ \\
\hline Gas FC HEV & 4,800 & $68 \%$ & 375 & $68 \%$ \\
\hline
\end{tabular}

Vehicles with hybrid electric propulsion systems using either internal combustion engines or fuel cells were the most efficient and lowest emitting technologies assessed. In general, internal combustion engine hybrids appear to have advantages over fuel cell hybrids with respect to life cycle GHG impacts and energy efficiency, but the differences are within the uncertainty ranges of the results and depend on the source of fuel.

The study draws the following final conclusion: if automobile systems with drastically lower GHG impacts are required in the distant future (perhaps in 30 to 50 years or more), hydrogen and electrical energy are the only options that can meet these aggressive targets, but only if both are 
produced from non-fossil sources of primary energy (such as nuclear or solar) or from fossil primary energy with carbon sequestration.

\subsubsection{Analysis}

The results of the MIT study are similar to those of the GM study. However, the results for FTD are significantly different because a much lower GTL efficiency is assumed than in the GM study and in the current GREET 1.6. Results for gasoline FCVs are also significantly different owing to vehicle technology assumptions.

The MIT study assumes that all vehicles will meet regulatory requirements. Like the GM study, the MIT study does not consider criteria pollutants, and thus the comparative advantages of the sulfur-free GTL fuels with respect to $\mathrm{SO}_{\mathrm{X}}, \mathrm{NO}_{\mathrm{X}}$, and PM10 are not accounted for.

The MIT study contains a considerable amount of analysis on the life cycle inventory of vehicle manufacturing, from raw material extraction to disposal. However, the results across vehicle systems - e.g., internal combustion engines vs. fuel cell engines - are essentially equivalent. This suggests that it is permissible to exclude vehicles from the comparative analysis.

\subsection{ARGONNE NATIONAL LABORATORY (ANL) NATURAL GAS FUELS}

M. Wang, "A Full Fuel-Cycle Analysis of Energy and Emissions Impacts of Transportation Fuels Produced from Natural Gas,” Argonne National Laboratory, December 1999.

\subsubsection{Pathways}

ANL has conducted fuel cycle studies for a range of conventional and alternative transport fuels. The ANL study discussed below focuses on fuels from natural gas and employs an earlier version of GREET than the GM study. The end use fuels considered are compressed natural gas $(\mathrm{CNG})$, liquefied natural gas (LNG), liquid petroleum gas, electricity via combined-cycle gas turbines and regional average electricity mixes, methanol, gaseous and liquid hydrogen, dimethyl ether, and FTD. The study considers scenarios in which flared natural gas is used and also includes a much wider range of scenarios and process options for natural gas than the GM study, which eliminated many of the scenarios from final consideration.

\subsubsection{Assumptions and Data}

The GTL and methanol thermal efficiencies are based on published reports from the mid 1990s. The methanol process, based on an auto-thermal two-step reforming technology, is assumed to have an efficiency of $65 \%$ for the near-term case and $67 \%$ for the long-term case. These estimates are somewhat higher than the efficiencies assumed in the GM study.

Several studies are considered for GTL fuels:

- A Syntroleum design, with steam cogeneration: thermal efficiency of $66 \%$, carbon efficiency of $76 \%$

- A Syntroleum case without steam cogeneration: $49 \%$ for thermal efficiency, carbon efficiency of $76 \%$ 
- A Bechtel/Shell design, without steam cogeneration: thermal efficiency of $57 \%$ and carbon efficiency of $73 \%$.

- A simple average is used for the final GTL efficiencies: $57 \%$ thermal and $75 \%$ carbon.

Table 2-9 shows the fuel production efficiency assumptions used in the ANL study. Different efficiencies are assumed for two time frames and technology advancement scenarios: a near-term "incremental" case and a long-term "leap-forward" case.

The study also examines a number of flared gas scenarios. Worldwide, about $5 \%$ of associated natural gas produced from oil wells is flared; in the Middle East, an estimated $20 \%$ of associated natural gas is flared. The capture of natural gas that is otherwise flared provides a significant opportunity to reduce potential global warming impacts.

Table 2-9 Argonne Natural Gas Process Energy Efficiencies

\begin{tabular}{|l|c|c|}
\hline \multicolumn{1}{|c|}{ Process } & $\begin{array}{c}\text { Leap-Forward } \\
\text { Incremental Scenario } \\
\text { Energy Efficiency, \% }\end{array}$ & $\begin{array}{c}\text { Scenario Energy } \\
\text { Efficiency, \% }\end{array}$ \\
\hline NG to LNG: NG liquefaction & 90 & 90 \\
\hline NG to electricity: combined cycle & 58 & 60 \\
\hline NG to methanol & 65 & 67 \\
\hline NG to gaseous H2: central plants & 73 & 73 \\
Without steam co-production & 71 & 71 \\
With steam co-production & & 57 \\
\hline NG to FT diesel & 55 & 49 \\
Without steam co-production & 49 & 67 \\
\hline With steam co-production & 65 & 57 \\
\hline FG to methanol & 55 & \\
\hline FG to FT diesel & & \\
\hline
\end{tabular}

\subsubsection{Results}

Except for the near-term flexible fuel methanol vehicle, GHG emissions and total and urban VOCs, $\mathrm{NO}_{\mathrm{X}}, \mathrm{SO}_{\mathrm{X}}$, and PM10 emissions are reduced for all $\mathrm{NG}$ pathways vehicle compared with conventional petroleum fuels. The use of flared gas results in significant additional benefits for GHG impacts. Table 2-10 shows the percentage orders of reduction. Because of the low process efficiencies assumed for GTL, FTD shows only a $0 \%-20 \%$ reduction relative to conventional gasoline, while LSD in an advanced CIDI engine shows a $20 \%-40 \%$ reduction.

Tables 2-11 and 2-12 show the results for long-term vehicle technologies. FTD HEV vehicles and methanol fuel cell vehicles are among the best options for the HEV and fuel cell cases, particularly when the use of flared gas is considered. With respect to $\mathrm{SO}_{\mathrm{X}}$ emissions, FTD shows clear advantages over the LSD cases. 


\section{Table 2-10 GHG Impact Reductions Relative to Conventional Gasoline}

\begin{tabular}{|l|c|}
\hline \multicolumn{1}{|c|}{ Vehicle Configuration } & GHG Emission Reductions \\
\hline Compressed NG & $0-20 \%$ \\
\hline M90 & $0-20 \%$ \\
\hline SIDI RFG & $20-40 \%$ \\
\hline SIDI HEV RFG & $40-60 \%$ \\
\hline CIDI LS diesel & $20-40 \%$ \\
\hline CIDI FT diesel & $0-20 \%$ \\
\hline CIDI HEV LS diesel & $40-60 \%$ \\
\hline CIDI HEV FT diesel & $40-60 \%$ \\
\hline FCV methanol & $40-60 \%$ \\
\hline FCV RFG & $40-60 \%$ \\
\hline CIDI FT diesel, FG & $88 \%$ \\
\hline CIDI HEV FT diesel, FG & $>80 \%$ \\
\hline Methanol FCV, FG & $>80 \%$ \\
\hline
\end{tabular}

Table 2-11 Long-Term Electric Vehicle and Fuel Cell Vehicle Technologies: GHG Emission Changes Relative to Conventional Gasoline

\begin{tabular}{|l|c|}
\multicolumn{1}{|c|}{ Vehicle Configuration } & GHG Emission Reductions \\
\hline LPG FCV & $58 \%-67 \%$ \\
\hline LNG FCV, FG & $94 \%-96 \%$ \\
\hline LNG FCV, NG & $53 \%-63 \%$ \\
\hline CNG FCV & $53 \%-64 \%$ \\
\hline RFG FCV & $44 \%-56 \%$ \\
\hline Methanol FCV, FG & $95 \%-96 \%$ \\
\hline Methanol FCV, NG & $51 \%-61 \%$ \\
\hline Liquid $\mathrm{H}_{2}$ FCV, FG & $86 \%-89 \%$ \\
\hline Liquid $\mathrm{H}_{2}$ FCV, NG & $54 \%-61 \%$ \\
\hline Gaseous $\mathrm{H}_{2}$ FCV, regional station & $56 \%-61 \%$ \\
\hline Gaseous $\mathrm{H}_{2}$ FCV central & $64 \%-68 \%$ \\
\hline EV & $59.5 \%-70.5 \%$ \\
\hline
\end{tabular}

Table 2-12 Long-Term CIDI Engine Technologies: Total SOx Emission Changes Relative to Conventional Gasoline

\begin{tabular}{|l|c|}
\hline \multicolumn{1}{|c|}{ Vehicle Configuration } & SOx Emission Reductions \\
\hline CIDI HEV FT diesel, FG & $87.5 \%-89.5 \%$ \\
\hline CIDI HEV FT diesel, NG & $87 \%-89 \%$ \\
\hline CIDI HEV LS diesel & $47 \%-55 \%$ \\
\hline CIDI FT diesel, FG & $82 \%-84 \%$ \\
\hline CIDI FT diesel, NG & $81 \%-83 \%$ \\
\hline CIDI LS diesel & $23 \%-30 \%$ \\
\hline
\end{tabular}




\subsubsection{Analysis}

As in the GM and the MIT GREET-based studies, the results are sensitive to assumptions regarding process efficiency for GTL and methanol. Although the vehicle use stage contributes the largest share of life cycle energy and emissions, vehicle performance is similar with regard to efficiency and emissions across similar fuels, e.g., LSD and FTD. Upstream fuel production, transportation, and processing account for the primary differences in the WTW fuel performance.

Unlike the GM study, cases for flared associated gas are considered. The use of flared gas significantly reduces GHG impacts. Furthermore, the inclusion of criteria pollutant emissions demonstrates benefits of natural-gas-based fuels that are not included in the GM study.

\subsection{AUSTRALIAN FUELS STUDY}

"Life Cycle Emissions Analysis of Alternate Fuels," Commonwealth Industrial and Scientific Research Organisation, Atmospheric Research Report C/0411/1.1/F2, Australian Greenhouse Office, March 2000.

\subsubsection{Pathways}

The Australian study examines available information from the literature for low- and ultra-low sulfur diesel and alternative fuels for heavy vehicles for GHG and criteria pollutant emission inventories. Ultra LSD (ULSD), FTD, biodiesel, ethanol, methanol, CNG, LNG, and liquefied petroleum gas (LPG) are considered for use in urban buses and trucks. Although the study is tailored for Australia, the upstream fuel cycle data is from the United States and Europe, and thus serves as a good comparative reference. The functional unit used in this study is brakehorsepower-hours, relevant for heavy vehicles and trucks.

\subsubsection{Scope and Methodology}

The Australian study takes an allocation-based approach, with no accounting for co-products from the petroleum or natural gas systems. The methodology employed is comparable to the one used in the GREET-based studies.

A distinguishing feature of the Australian study, however, is that the issue of co-products and the allocation versus the SBE approach is acknowledged. The study points out that the ISO 14040 standards for life cycle assessment state a preference for the SBE method, but does not carry out the full analysis, leaving this for future research.

\subsubsection{Assumptions and Data}

The WTT data in this study for the petroleum pathways is derived, in part, from Argonne National Laboratory studies and the GREET model, as well as from a series of European studies on petroleum and natural gas fuels. Based on an independent review of the technology, the study assumes a higher thermal efficiency and carbon efficiency for the GTL process- $63 \%$ for thermal and $80 \%$ for carbon. Use of this higher efficiency is reflected in the comparative results between LSD to FTD relative to the GM and Argonne studies. 


\subsubsection{Results}

Results of the analysis for energy, GHG emissions, and criteria pollutant emissions for diesel, LSD, and FTD are shown in Table 2-13. The report draws the following conclusions.

- A properly tuned engine using FTD or LSD will lead to lower particle exhaust emissions, and the emissions control systems will operate at maximum efficiency, compared with conventional diesel.

- The existing diesel infrastructure can be used for FTD, unchanged.

- FTD can be employed in existing diesel engines.

- An FT plant does not produce any of the less desirable co-products from a refinery, such as heavy fuel oil or coke. This is an acknowledgment of the co-products issue.

- When FT plants use an oxygen rather than air-based feed, a pure $\mathrm{CO}_{2}$ stream is produced that provides an option for the collection and sequestration of $\mathrm{CO}_{2}$.

Because of the relative energy inefficiency of FTD production, the primary disadvantage of FTD identified in the study is the production of more embodied GHG emissions than any of the fuels studied in the report. The magnitude of this difference depends on technology and process efficiency assumptions for the GTL process.

\subsubsection{Analysis}

Because this study assumes a higher energy efficiency for GTL production than that used in the GM and GREET studies, GHG emissions from FTD are closer to those of LSD. For criteria emissions inventories, the study shows FTD to have clear advantages over petroleum diesel. The study further segments criteria pollutant emissions into urban and non-urban emissions, which show FTD to have even greater benefits relative to LSD.

The study also suggests that an analysis of petroleum refining co-products is relevant, and that an SBE approach would be the means of addressing the issue. 
Table 2-13 Results for Low-Sulfur and Ultra-Low Sulfur Diesel and FT Diesel (g/km or MJ/km)

\begin{tabular}{|c|c|c|c|c|c|}
\hline Emissions & Stage & LS Diesel & $\begin{array}{c}\text { Ultra } \\
\text { LS Diesel }\end{array}$ & FT Diesel & $\begin{array}{l}\text { FT Diesel } \\
\text { Relative to } \\
\text { LS Diesel }\end{array}$ \\
\hline \multirow{3}{*}{ GHG } & Fuel processing & 0.02 & 0.02 & 0.03 & \multirow[b]{3}{*}{$11 \%$} \\
\hline & Vehicle operation & 0.07 & 0.07 & 0.07 & \\
\hline & Total & 0.09 & 0.09 & 0.10 & \\
\hline \multirow{3}{*}{ VOC total } & Fuel processing & 0.06 & 0.06 & 0.04 & \multirow[b]{3}{*}{$-40 \%$} \\
\hline & Vehicle operation & 0.09 & 0.07 & 0.05 & \\
\hline & Total & 0.15 & 0.13 & 0.09 & \\
\hline \multirow{3}{*}{ VOC urban } & Fuel processing & 0.03 & 0.03 & 0.00 & \multirow[b]{3}{*}{$-58 \%$} \\
\hline & Vehicle operation & 0.09 & 0.07 & 0.05 & \\
\hline & Total & 0.12 & 0.10 & 0.05 & \\
\hline \multirow{3}{*}{ NOx total } & Fuel processing & 0.11 & 0.11 & 0.14 & \multirow[b]{3}{*}{$-9 \%$} \\
\hline & Vehicle operation & 1.00 & 0.85 & 0.87 & \\
\hline & Total & 1.11 & 0.96 & 1.01 & \\
\hline \multirow{3}{*}{ NOx urban } & Fuel processing & 0.05 & 0.05 & 0.01 & \multirow[b]{3}{*}{$-16 \%$} \\
\hline & Vehicle operation & 1.00 & 0.85 & 0.87 & \\
\hline & Total & 1.05 & 0.90 & 0.88 & \\
\hline \multirow{3}{*}{ CO total } & Fuel processing & 0.02 & 0.02 & 0.03 & \multirow[b]{3}{*}{$-15 \%$} \\
\hline & Vehicle operation & 0.24 & 0.31 & 0.20 & \\
\hline & Total & 0.27 & 0.33 & 0.23 & \\
\hline \multirow{3}{*}{ CO urban } & Fuel processing & 0.01 & 0.01 & 0.00 & \multirow[b]{3}{*}{$-23 \%$} \\
\hline & Vehicle operation & 0.24 & 0.31 & 0.20 & \\
\hline & Total & 0.26 & 0.32 & 0.20 & \\
\hline \multirow{3}{*}{ PM10 total } & Fuel processing & 5.74 & 5.81 & 2.00 & \multirow[b]{3}{*}{$-39 \%$} \\
\hline & Vehicle operation & 37.38 & 27.94 & 24.18 & \\
\hline & Total & 43.12 & 33.75 & 26.18 & \\
\hline \multirow{3}{*}{ PM10 urban } & Fuel processing & 4.24 & 4.29 & 0.07 & \multirow{4}{*}{$\begin{array}{c}-42 \% \\
34 \%\end{array}$} \\
\hline & Vehicle operation & 37.38 & 27.94 & 24.18 & \\
\hline & Total & 41.62 & 32.23 & 24.25 & \\
\hline Total energy & Total & 1.25 & 1.27 & 1.68 & \\
\hline
\end{tabular}




\subsection{GREET $1.5 / 1.6$}

“GREET 1.5 - Transportation Fuel-Cycle Model," Vol. 1, Methodology, Development, Use and Results, Argonne National Laboratory, August 1999.

"Development and Use of the GREET 1.6 Fuel-Cycle Model for Transportation Fuels and Vehicle Technologies," Argonne National Laboratory, June 2001.

\subsubsection{Pathways}

GREET 1.6 is a recent model release that incorporates several additional fuels: crude naphtha, FT naphtha, and gaseous and liquid hydrogen produced via electrolysis. GREET 1.6 is the version used in the UCF LCA study.

Reformulated gasoline (RFG) in GREET 1.6 now includes California Phase 3 RFG with ethanol as the oxygenate, Phase 2 federal RFG (FRFG), and the new low-sulfur gasoline (30 ppm) in the EPA Tier 2 standards. For diesel fuels, GREET 1.6 includes LSD with a sulfur content of 10 ppm. This is the lowest sulfur concentration modeled for petroleum diesel fuels.

Vehicle technologies in GREET 1.6 include conventional spark-ignition (SI) engines; sparkignition, direct-injection (SIDI) engines; compression-ignition, direct-injection (CIDI) engines; grid-independent (GI) hybrid electric vehicles (HEVs) powered by SI engines, grid-connected (GC) HEVs powered by SI engines; GI HEVs powered by CIDI engines; diesel HEVs powered by CIDI engines; battery-powered electric vehicles (EVs); and fuel processor (FP) fuel-cell vehicles (FCVs). Direct methanol fuel cell vehicles, which have the potential to reduce criteria emissions further compared with methanol FP FCVs, are not modeled.

\subsubsection{Assumptions and Data}

In GREET 1.6, somewhat higher efficiencies are assumed for the GTL process and for methanol than in previous GREET versions. Table 2-14 lists the technologies referenced for the development of the GTL efficiency, and the default values assumed in GREET. For methanol, GREET 1.6 assumes an efficiency of $68 \%$ based on a 2,000 tonne/day design.

Table 2-14 GTL Efficiencies Assumed in GREET 1.6

\begin{tabular}{|l|c|c|}
\hline \multicolumn{1}{|c|}{ GTL Production Technology } & Energy Efficiency, \% & Carbon Efficiency, \% \\
\hline ANL assessment of FT production, excess steam exported & & 71 \\
\hline Partial oxidation (POX) design & 55 & 78 \\
\hline Sasol, Shell, Exxon design & 62 & 72 \\
\hline Syntroleum & 75 & \\
\hline Syntroleum analysis & & 75 \\
\hline Excess steam not recovered & 53 & 75 \\
\hline Excess steam recovered & 67 & 75 \\
\hline GREET default values & & 75 \\
\hline FT, no steam credit & 53 & \\
\hline FT, steam credit & 67 & \\
\hline
\end{tabular}




\subsubsection{Results}

On the basis of the default data in GREET 1.6, the GREET documentation compares all fuels and vehicle configurations available in the model. The results for GHG emissions and total energy are shown Table 2-15. The results are presented in terms of percentage reductions relative to conventional gasoline.

A comparison of FTD with LSD with respect to GHG emissions shows that the two fuels are very similar, more so than in any previous GREET-based study. This similarity is due primarily to the increased process efficiency default for the GTL production in GREET 1.6. For the case in which GTL is given credit for electricity or steam production, FTD shows lower GHG emissions of about $4 \%$ relative to LSD. For the case of flared gas, FTD is significantly lower in GHG emissions than LSD.

Methanol FCVs are among the best fuel-vehicle options with respect to GHG emissions, and are lower in GHG emissions than reformulated gasoline in FCVs.

Table 2-15 GREET 1.6 Results from Default Data: Percentage Reductions Relative to Conventional Gasoline

\begin{tabular}{|l|c|c|}
\hline \multicolumn{1}{|c|}{ Vehicle Configuration } & Total Energy & GHG Emissions \\
\hline CNG NNA NG & $-0.4 \%$ & $-17.1 \%$ \\
\hline Ethanol from corn, E90 & $12.3 \%$ & $-37.1 \%$ \\
\hline CIDI LS diesel & $-24.4 \%$ & $-20.9 \%$ \\
\hline CIDI FT diesel, NNA NG & $4.7 \%$ & $-16.5 \%$ \\
\hline CIDI FT diesel, NNA FG & $-95.5 \%$ & $-95.1 \%$ \\
\hline CIDI FTD, NNA, NG, electricity & $11.9 \%$ & $-20.3 \%$ \\
\hline CARFG HEV & $-34.7 \%$ & $-33.8 \%$ \\
\hline LS diesel HEV & $-44.2 \%$ & $-40.9 \%$ \\
\hline FTD HEV, NNA NG & $-27.0 \%$ & $-42.0 \%$ \\
\hline FTD HEV, NNA NG electricity & $-21.7 \%$ & $-44.6 \%$ \\
\hline Methanol FCV, NNA NG & $-29.9 \%$ & $-44.9 \%$ \\
\hline RFG FCV & $-36.6 \%$ & $-37.5 \%$ \\
\hline Crude naphtha FCV & $-39.5 \%$ & $-43.0 \%$ \\
\hline FT naphtha FCV, NNA NG & $-12.5 \%$ & $-34.5 \%$ \\
\hline
\end{tabular}

\subsection{ENERGY TECHNOLOGY LABORATORY (NETL) GASIFICATION}

Moreno, J.J. and J.P. Ciferno, "Life Cycle Greenhouse Gas Emissions Inventory for FischerTropsch Fuels," U.S. Department of Energy, National Energy Technology Laboratory, June 2001.

\subsubsection{Pathways}

The NETL study models the production of FT liquids from coal, biomass, and natural gas. Scenarios from the literature for petroleum diesel are reported. The petroleum cases were developed from a source other than GREET (McCann and Magee, 1999), thereby providing an 
additional point of reference and comparison. Both heavy crude and light crude slates are considered.

The gas feedstock in this study is obtained through gasification of coal and biomass. The study estimates GHG emissions for a number of conceptual gasification/GTL designs. Sport utility vehicles serve as the basis for the vehicle use stage, rather than the light duty vehicles used in the Argonne and GM studies; thus, the total emissions are greater than those reported in the Argonne GREET-based studies and in the GM study.

As in the Argonne study, and unlike the GM study, the NETL study considers the use of captured flared gas, as well as options for carbon sequestration at the GTL plant.

The NETL study also makes reference to the issue of petroleum co-products and SBE, and identifies this issue as an important topic for future research. However, it does not quantitatively consider co-product emissions and downstream impacts.

\subsubsection{Assumptions, Data, Results, and Analysis}

Results for FTD and petroleum diesel are shown in Table 2-16. A thermal efficiency of 59\% for GTL was assumed. This figure is somewhat higher than the default value used in the GM report, even though the assumptions are based on similar technologies from the early 1990s.

The results are similar to those reported in other studies. On a WTW basis, FTD produces about 9\% more GHG emissions than petroleum diesel, based on an average of the light and heavy crude slates for petroleum diesel. The study also considers a case with credit given to GTL fuels for flared gas, in which GHG emissions are reduced by 17\% for FTD.

Table 2-16 GHG Emissions from the NETL Study

\begin{tabular}{|l|c|c|}
\hline \multicolumn{1}{|c|}{ Fuel and Vehicle Pathways } & Efficiencies & GHG Emissions, g/mi \\
\hline FT diesel, NNA NG & $59 \%$ thermal & 562 \\
\hline FT diesel with flaring credit & $59 \%$ thermal & 496 \\
\hline Diesel from light crude (API 38) & NA & 509 \\
\hline Diesel from heavy crude (API 24) & NA & 534 \\
\hline
\end{tabular}

\subsection{NATIONAL RENEWABLE ENERGY LABORATORY (NREL) BIOMASS}

Tyson, K.S., C.J. Riley, and K.K. Humphreys, "Fuel Cycle Evaluations of Biomass - Ethanol and Reformulated Gasoline," Vol. 1, National Renewable Energy Laboratory, Oak Ridge National Laboratory, and Pacific Northwest Laboratory, NREL/TP-463-4950, November 1993.

\subsubsection{Pathways}

The NREL study focuses on renewable sources of liquid fuels produced from corn, wood, and herbaceous biomass. Ethanol is the primary final product, and is used in $10 \%$ and $95 \%$ ethanol/gasoline blends. Scenarios for reformulated gasoline served as comparative cases. 


\subsubsection{Scope, Methodology, Assumptions, and Data}

In addition to examining criteria pollutant and GHG emissions, the NREL study is thorough in that it also estimates solid waste and wastewater from ethanol and petroleum fuels production. The study is also notable for its quantitative examination of co-products in the gasoline fuel cycle. The study is unique in the literature in two ways: (1) it quantifies the effects of coproducts in the petroleum fuel pathways and uses these co-product allocations as alternatives for comparison, and (2) it models the effects of heavier and more sulfurous future crude oil slates.

In the cases for reformulated gasoline (without considering co-products), emissions are allocated on a Btu-fuel-equivalent basis relative to the total refinery output. In the 2000 case, $35 \%$ of total refinery emissions (as well as upstream emissions from feedstock extraction and transportation) is allocated to gasoline. In the 2010 case, only $30 \%$ of emissions is allocated to RFG because of the heavier crude slates and the corresponding production of heavier co-products, such as residual fuel oil and petroleum coke.

The study also examines future scenarios in which an increasing share of crude oil is imported from foreign sources. This assumption increases the transportation-related (e.g., ocean tanker) emissions for the petroleum fuels. Neither the GM study nor the ANL study considers this effect.

\subsubsection{Results and Analysis}

For the co-product case, in which all petroleum refinery energy and emissions are allocated to the reformulated gasoline pathway, GHG emissions for FRFG at the refinery stage increase $180 \%$ for the year 2000 scenario and $230 \%$ for the year 2010 scenario. (The cases differ only in the density of the crude slates, becoming heavier over time). Transportation emissions due to importing crude oil increase $400 \%$ in 2000 and 500\% in 2010, but the absolute increases in these emissions are small.

The ethanol biomass fuels perform extremely well compared with these cases. Table 2-17 shows the total life cycle emissions increases for FRFG with the inclusion of co-products. The study justifies comparison with this case by suggesting that since gasoline and diesel are the driving economic force of petroleum refining, then co-products such as petroleum coke and heavy residual oil can be regarded as emission-free in their upstream feedstock and fuel stages. However, this is clearly an extreme case, in that useful fuel products, such as diesel, jet fuel, and kerosene are not allocated any share of the emissions and energy at the fuel production stage.

Table 2-17 NREL Results for Allocation of Emissions to FRFG for the 2000 Case

\begin{tabular}{|c|c|}
\hline Emission & $\begin{array}{c}\text { Percentage Increase for FRFG Life } \\
\text { Cycle Under 100\% Allocation }\end{array}$ \\
\hline NOx & $66 \%$ \\
\hline $\mathrm{PM} 10$ & $198 \%$ \\
\hline $\mathrm{SO} \times$ & $95 \%$ \\
\hline $\mathrm{CO}_{2}$ & $33 \%$ \\
\hline $\mathrm{VOC}$ & $21 \%$ \\
\hline
\end{tabular}


An alternative case could be developed in which the emissions associated only with co-products such as petroleum coke, heavy residual oil, and asphalt are allocated to FRFG. Table 2-18 shows the percentage of emissions contributed by each refinery product and the increase in emissions resulting from allocation of the co-products to the primary refinery products. (The percentages are calculated on an LHV basis.) Gasoline alone accounts for $44 \%$ of the total refinery emissions. Allocation of emissions from petroleum coke and heavy residual oil increases this to $52.6 \%$ for gasoline.

\section{Table 2-18 NREL Study Results for Allocation of Emissions to FRFG from Co-products}

\begin{tabular}{|l|c|c|}
\multicolumn{1}{|c|}{ Refinery Products } & $\begin{array}{c}\text { Base Case } \\
\text { (\% emission contribution from } \\
\text { each product) }\end{array}$ & $\begin{array}{c}\text { Co-products Allocation to } \\
\text { Primary Products }\end{array}$ \\
\hline Primary products & $13.4 \%$ & $16.0 \%$ \\
\hline Diesel <5\% sulfur & $10.1 \%$ & $12.1 \%$ \\
\hline Diesel > 5\% sulfur & $44.0 \%$ & $52.6 \%$ \\
\hline Gasoline & $10.0 \%$ & $11.9 \%$ \\
\hline Jet fuel & $0.4 \%$ & $0.5 \%$ \\
\hline Kerosene & $0.7 \%$ & $0.8 \%$ \\
\hline LPG & $1.3 \%$ & $1.6 \%$ \\
\hline Lubes & $3.2 \%$ & $3.8 \%$ \\
\hline Refinery gases & $0.2 \%$ & $0.2 \%$ \\
\hline Petroleum waxes & $0.4 \%$ & $0.5 \%$ \\
\hline Naphtha & & \\
\hline Co-products & $6.0 \%$ & $100 \%$ \\
\hline Petroleum coke & $3.8 \%$ & \\
\hline Asphalt & $6.2 \%$ & \\
\hline Heavy residual oil & $0.4 \%$ & \\
\hline Miscellaneous & $100 \%$ & \\
\hline Total & & \\
\hline
\end{tabular}

When a heavy crude slate is considered, an interesting outcome is observed as a result of the allocation methodology, in which FRFG is allocated only a share of overall refinery emissions. In the 2000 case, $35 \%$ of total refinery emissions is allocated to FRFG. In the 2010 case, only $30 \%$ of emissions is allocated to FRFG, because in the heavier crude slate case a greater quantity of heavy co-products, such as fuel oil and coke, are produced. This methodology gives an undue advantage to FRFG and diesel relative to other fuels. What is actually occurring is that more coproducts and by-products are being produced, not that gasoline is becoming inherently less emission-intensive. 


\subsection{SUMMARIES AND NEEDS FOR FURTHER RESEARCH}

\subsubsection{Summary-GREET-Based Studies}

The key features of the GREET-based studies are as follows:

- The studies use GTL efficiencies of 53\%-63\% and methanol efficiencies of $67 \%-68 \%$.

- Based on these efficiencies, the studies conclude that FTD is less energy-efficient than petroleum diesel, but has comparable GHG emissions and much lower $\mathrm{SO}_{\mathrm{X}}, \mathrm{PM} 10$, and VOC emissions.

- The GM study does not take criteria pollutant inventories into consideration and reaches conclusions based only on energy and GHG emissions.

- The GM study concludes that GTL is comparable to petroleum fuels for energy and GHG emissions, and hence the status quo is preferred.

- In long-term scenarios, methanol fuel cell vehicles are identified as the best option for reducing GHG and criteria pollutant emissions.

- All of the studies use the allocation approach in considering co-products; none use the SBE approach. GM does acknowledge the issue, but does not quantify the boundary expansion impacts of co-products.

\subsubsection{Summary-Non-GREET-Based Studies}

The key features of the non-GREET-based studies are as follows:

- Each of the studies considers the issue of co-products, either qualitatively or quantitatively.

- The Australian study discusses methodologies for modeling co-products.

- The NREL study quantifies co-product energy and emissions.

- Energy use and emissions of production and use of all co-products (including diesel) are allocated to RFG.

- WTW emissions for RFG increase 33\% for GHG emissions, $100 \%$ for $\mathrm{SO}_{\mathrm{X}}$, and $190 \%$ for PM10

- The study results are comparable to those of GREET when using similar thermal efficiencies for FTD and methanol

- NETL quantifies the benefits of using flared gas for GTL and methanol production.

\subsubsection{Research Needs}

Based on a survey of the literature, the following conclusions are drawn, and a set of research needs are identified:

- Most studies do not quantify co-product impacts. This is an important area of research and should be addressed. 
- NREL's full co-product allocation to RFG is useful in establishing an upper bound.

- NETL, NREL, and the Australian EPA study identify co-products as an important issue for research

- GTL thermal efficiency data needs to be updated to represent future commercial technologies. The range $53 \%-63 \%$ assumed in previous studies is outdated.

- Criteria pollutants should be considered through inventory and impact assessments. The GM WTW study does not consider criteria emissions.

- Impacts of future heavy crude slates are not considered in the literature.

- Crude slates will on average become heavier in the future.

- As new entrants to the market, GTL fuels and methanol will compete on the margin with these heavier crude slates in order to serve the "last mile" of transportation.

\subsection{REFERENCES}

Argonne National Laboratory, "Methodology, Development, Use and Results," Vol. 1., GREET 1.5 - Transportation Fuel-Cycle Model, August 1999.

Argonne National Laboratory, “Appendices of Data and Results," Vol. 2, GREET 1.5 Transportation Fuel-Cycle Model Vol. 2, August 1999.

Argonne National Laboratory, "Development and Use of the GREET 1.6 Fuel-Cycle Model for Transportation Fuels and Vehicle Technologies," June 2001.

Commonwealth Industrial and Scientific Research Organisation, "Life Cycle Emissions Analysis of Alternate Fuels," Atmospheric Research Report C/0411/1.1/F2 to the Australian Greenhouse Office, March 2000.

General Motors, Argonne National Laboratory, ExxonMobil, Shell, "Well-to-Wheel Energy Use and Greenhouse Gas Emissions of Advanced Fuel/Vehicle Systems - North American Analysis," April 2001.

Massachusetts Institute of Technology Energy Laboratory, "On the Road in 2020: A Life-Cycle Analysis of New Automobile Technologies," October 2000.

McCann, T., and P. Magee, "Crude Oil Greenhouse Gas Life Cycle Analysis Helps Assign Values for $\mathrm{CO}_{2}$ Emissions Trading," Oil \& Gas Journal, February 22, 1999.

Moreno, J.J. and J.P. Ciferno, "Life Cycle Greenhouse Gas Emissions Inventory for FischerTropsch Fuels," U.S. Department of Energy, National Energy Technology Laboratory, June 2001.

Tyson, K.S., C.J. Riley, and K.K. Humphreys, "Fuel Cycle Evaluations of Biomass - Ethanol and Reformulated Gasoline," Vol. 1, National Renewable Energy Laboratory, Oak Ridge National Laboratory, and Pacific Northwest Laboratory, NREL/TP-463-4950, November 1993. 
U.S. EPA, "Compilation of Air Pollutant Emission Factors," AP-42, Fifth Edition, Vol. I: Stationary Point and Area Sources, Office of Air Quality Planning and Standards, 1999.

Wang, M., "A Full Fuel-Cycle Analysis of Energy and Emissions Impacts of Transportation Fuels Produced from Natural Gas," Argonne National Laboratory, December 1999. 


\subsection{INTRODUCTION}

GREET 1.6, from Argonne National Laboratory, was selected as the primary modeling tool for the Ultra Clean Fuels (UCF) LCA project. The UCF LCA uses the most recent release of the model, and the project team has worked closely with the developers of GREET to review, debug, and add required features to this version in order to meet the modeling objectives of the project, as described in the project scope.

GREET was chosen primarily because:

- It has become a standard tool and reference for fuel cycle modeling in the United States for transportation and has been extensively peer-reviewed.

- It is a spreadsheet model that is easily extensible. Moreover, the Argonne team is interested in helping to validate and further develop the model.

In the course of selecting and using the model in the UCF LCA analysis, the model was examined and validated with respect to both the well-to-tank and the tank-to-wheel life cycle stages, and the literature, the technology assumptions, and all input data were reviewed. To address specific questions in the study, data was independently developed.

\subsubsection{Literature Review}

A detailed review of fuel cycle studies is presented in Section 2 of this report. The review covers studies that used GREET as the primary modeling tool, as well as studies that used other models or independently developed data and calculation methods. In addition, a large body of literature was examined that included data on petroleum fuel refining and crude production. These studies, as referenced in Section 8, were used to benchmark GREET results.

Table 3-1 presents a summary of relevant well-to-wheels results from GREET 1.6, based on GREET default data, showing the performance of GTL and methanol pathways relative to reformulated gasoline used in conventional engines.

Table 3-1 GREET 1.6 Results:

Percentage Reduction Relative to Reformulated Gasoline in Conventional Engines

\begin{tabular}{|l|c|c|c|c|}
\multicolumn{1}{|c|}{ Vehicle/Fuel Pathway } & $\begin{array}{c}\text { Total } \\
\text { Energy }\end{array}$ & $\begin{array}{c}\text { Fossil } \\
\text { Energy }\end{array}$ & $\begin{array}{c}\text { Petroleum } \\
\text { Fuel }\end{array}$ & GWP \\
\hline Compression ignition, direct injection (CIDI) low-Sulfur (LS) diesel & -18 & -18 & -6.8 & -14.6 \\
\hline CIDI FT diesel & 16 & 16.3 & -98 & -10.6 \\
\hline CIDI FT diesel, 100\% flared gas & -90.3 & -90.3 & -97.9 & -90.5 \\
\hline Methanol fuel cell vehicle (FCV) & -25.3 & -25.1 & -97.7 & -41.8 \\
\hline Methanol FCVs, no steam or electricity credits & -92.4 & -92.4 & -97 & -93.3 \\
\hline
\end{tabular}




\subsubsection{Technology Review}

GREET embeds technology assumptions through data parameters into the fuel pathways. For example, thermal efficiency of fuel production is a key driver of model results, and is derived by models users through engineering analysis of fuel production systems. The GREET documentation references the studies from which the parameters were developed, but it was necessary to validate the suitability of the technologies chosen (particularly for GTL and methanol) and to independently develop parameters if these technologies were not representative of ConocoPhillips future commercial processes.

Vehicle end use technologies and data were also reviewed and validated, including vehicle efficiency and emissions. The technical feasibility of future vehicle configurations, such as the use of gasoline in fuel processor fuel cell vehicles, was also considered.

\subsubsection{Allocation Methodology in GREET}

GREET employs an allocation approach to deal with multiple products and multiple functions of the fuel product systems. Although the direct upstream and downstream energy and emissions of the primary products (e.g., gasoline and diesel) are accounted for, the upstream and downstream impacts of co-products (such as petroleum coke and heavy residual oil) are not reflected in the results for the primary products. This aspect of the model was of particular concern to ConocoPhillips, and was also acknowledged as a limitation of GREET in the General Motors Well-to-Wheel study.

In GREET, allocation is performed for the well-to-tank stages based upon the energy content (lower heating value basis, or LHV) of the products. Thus, each end use fuel includes only a portion of the full upstream system energy and emissions. For petroleum refining, GREET allocates $30 \%-40 \%$ of well-to-tank energy and emissions to products other than gasoline and diesel fuels. With an allocation-based method, all downstream impacts of co-products are thus set outside of the system boundaries of the study.

There are potential differences in energy use and emissions that could result from considering functional equivalence between GTL plants and conventional petroleum refineries. These differences are of interest. For this reason, the UCF LCA study addresses the question, How does the inclusion of co-products (and corresponding downstream functions of the products) affect the energy and emission results? To answer this question, a novel methodology, called Co-product Function Expansion (CFE), was developed to examine two "undesirable" refinery co-products: petroleum coke and heavy residual oil. These co-products have potentially significant upstream and downstream environmental impacts. GTL production has no such corresponding undesirable co-products. Section 5 of this report details the methodology.

\subsubsection{Data Review and Development}

A review of GREET was completed that examined all input data for conventional and LS gasoline and diesel, GTL fuels, and methanol. The data reviewed covered process efficiencies, shares of process fuel inputs for fuel production, transportation and distribution distances and modes, emissions factors, fuel specifications, upstream life cycle emissions and energy 
efficiency data for crude and natural gas extraction, and efficiency and emissions factors for electricity production.

As a standard in the field, GREET has been frequently applied in fuel cycle analyses and has undergone extensive peer review. The UCF LCA review was conducted in this context. However, while the data sources are in general well documented in the GREET manual, much of the actual data is embedded in the model, in tables, and in some instances in cells of the spreadsheets, and sometimes is hard to find. Consequently, a thorough review was required to fully document and understand the data that drives GREET results.

In the following sections, relevant default data from the GREET spreadsheets has been extracted to serve as a central reference. For cases in which GREET 1.6 default data was changed for the UCF LCA, these changes are documented. Section 4 contains a detailed discussion of the methodology used in the UCF LCA to develop parameters for the GTL and methanol pathways.

GREET is a publicly available model. ${ }^{1}$ The model is very well structured and relatively transparent. The default and revised data provided in this section will allow full replication of the UCF LCA study results.

\subsection{GREET MODEL STRUCTURE, KEY PARAMETERS, AND MODEL OUTPUTS}

\subsubsection{Unit Processes in GREET}

The GREET model is structured around a set of unit processes, which are aggregated into feedstock stages, fuel stages, and vehicle stages. All reporting in GREET is done at the feedstock, fuel, and vehicle, level, although the more detailed unit process data can be extracted from the model.

The feedstock stage includes unit processes for crude oil recovery, crude transportation, crude storage, natural gas recovery, natural gas processing, and natural gas transmission and distribution.

The fuel stage includes unit processes for petroleum fuel refining, petroleum fuel transportation, and petroleum fuel storage, GTL and methanol production, GTL and methanol transportation, and GTL and methanol storage.

The vehicle stage includes a single unit process for vehicle use.

\subsubsection{Thermal Efficiency}

A key parameter in the GREET model for each feedstock recovery and fuel production unit process is thermal efficiency. In GREET, the overall thermal efficiency for each such unit process is required as an input. Based on this parameter, the total required energy input to the process is then calculated as 1/(Efficiency).

1 http://www.anl.gov/GREET/ 
Although the vehicle use stage typically comprises between $70 \%$ and $80 \%$ of the total life cycle energy use and emissions, vehicle emissions tend to be similar within a similar fuel pathway and vehicle class - e.g., petroleum diesel CIDI and FTD CIDI vehicles. Thus, the fuel processing and upstream feedstock extraction stages tend to be the primary differentiators between similar pathways. Upstream stages are especially important for electric vehicles and fuel cell vehicles.

For each unit process, the share of various processes fuels and electricity input is specified, as are the combustion technologies by process fuel. Finally, emissions factors from the U.S. EPA AP-42 document (U.S. EPA, 1999) are used to compute total combustion emissions, as a function of process fuel throughput through each combustion technology type. Non-combustion emissions are also computed from AP-42 as a function of MMBtu of fuel throughput at a unit process.

$\mathrm{CO}_{2}$ and $\mathrm{SO}_{\mathrm{X}}$ emissions are calculated by means of a carbon balance approach and a sulfur balance approach, respectively, as a function of the process fuels and associated control technologies (for $\mathrm{SO}_{\mathrm{X}}$ ) used at each stage.

\subsubsection{Process Fuel and Combustion Technology Shares}

As mentioned, for each unit process unit, the share of process fuels and combustion technologies used are specified in GREET. Tables 3-2 and 3-3 provide the GREET default data as used in the UCF LCA.

\subsubsection{Emission Factors}

Emissions factors in GREET for the feedstock production and fuel processing unit processes are based on AP-42 emissions factors. Emissions factors are provided for specific combustion technologies (e.g., large natural gas turbines, natural gas boilers, diesel stationary engines, and coal industrial boilers), as indicated in the previous section.

AP-42 factors are also used for emissions for fuel transportation in ocean tanker, rail, and truck. The transportation unit processes are described in more detail in Section 3.3.2. 
Table 3-2 Shares of Combustion Technologies by Process Unit

\begin{tabular}{|c|c|c|c|c|c|c|c|c|}
\hline Combustion Unit & $\begin{array}{c}\text { Crude } \\
\text { Recovery }\end{array}$ & $\begin{array}{l}\text { Gasoline } \\
\text { Refining }\end{array}$ & $\begin{array}{c}\text { Diesel Fuel } \\
\text { Refining }\end{array}$ & $\begin{array}{l}\text { Natural } \\
\text { Gas (NG) } \\
\text { Recovery }\end{array}$ & $\begin{array}{c}\text { NG } \\
\text { Processing }\end{array}$ & $\begin{array}{c}\text { Methanol } \\
\text { Production }\end{array}$ & $\begin{array}{l}\text { FT Diesel } \\
\text { Production }\end{array}$ & $\begin{array}{l}\text { FT Naphtha } \\
\text { Production }\end{array}$ \\
\hline $\begin{array}{l}\text { Heavy residual oil } \\
\text { industrial boiler: } \\
\text { current }\end{array}$ & $0 \%$ & $0 \%$ & $0 \%$ & $0 \%$ & $0 \%$ & $0 \%$ & $0 \%$ & $0 \%$ \\
\hline $\begin{array}{l}\text { Heavy residual oil } \\
\text { industrial boiler: } \\
\text { future }\end{array}$ & $100 \%$ & $100 \%$ & $100 \%$ & $100 \%$ & $100 \%$ & $100.0 \%$ & $100 \%$ & $100 \%$ \\
\hline $\begin{array}{l}\text { Diesel comm. boiler: } \\
\text { current }\end{array}$ & $0 \%$ & $0 \%$ & $0 \%$ & $0 \%$ & $0 \%$ & $0 \%$ & $0 \%$ & $0 \%$ \\
\hline $\begin{array}{l}\text { Diesel comm. boiler: } \\
\text { future }\end{array}$ & $33 \%$ & $33 \%$ & $33 \%$ & $33 \%$ & $33 \%$ & $33 \%$ & $33 \%$ & $33 \%$ \\
\hline $\begin{array}{l}\text { Diesel stationary } \\
\text { engine }\end{array}$ & $33 \%$ & $33 \%$ & $33 \%$ & $33 \%$ & $33 \%$ & $33 \%$ & $33 \%$ & $33 \%$ \\
\hline Diesel turbine & $34 \%$ & $34 \%$ & $34 \%$ & $34 \%$ & $34 \%$ & $34 \%$ & $34 \%$ & $34 \%$ \\
\hline Diesel train & $0 \%$ & $0 \%$ & $0 \%$ & $0 \%$ & $0 \%$ & $0 \%$ & $0 \%$ & $0 \%$ \\
\hline Diesel HDE trucks & $0 \%$ & $0 \%$ & $0 \%$ & $0 \%$ & $0 \%$ & $0 \%$ & $0 \%$ & $0 \%$ \\
\hline NG engine: current & $0 \%$ & $0 \%$ & $0 \%$ & $0 \%$ & $0 \%$ & $0 \%$ & $0 \%$ & $0 \%$ \\
\hline NG engine: future & $25 \%$ & & & $25 \%$ & $0 \%$ & $0 \%$ & $0 \%$ & $0 \%$ \\
\hline $\begin{array}{l}\text { NG large turbine: } \\
\text { current }\end{array}$ & $0 \%$ & $0 \%$ & $0 \%$ & $0 \%$ & $0 \%$ & $0 \%$ & $0 \%$ & $0 \%$ \\
\hline $\begin{array}{l}\text { NG large turbine: } \\
\text { future }\end{array}$ & $25 \%$ & $25 \%$ & $25 \%$ & $50 \%$ & $50 \%$ & $0 \%$ & $0 \%$ & $0 \%$ \\
\hline $\begin{array}{l}\text { NG industrial boiler: } \\
\text { current }\end{array}$ & $0 \%$ & $0 \%$ & $0 \%$ & $0 \%$ & $0 \%$ & $0 \%$ & $0 \%$ & $0 \%$ \\
\hline $\begin{array}{l}\text { NG industrial boiler: } \\
\text { future }\end{array}$ & $25 \%$ & $60 \%$ & $60 \%$ & $0 \%$ & $50 \%$ & $100 \%$ & $100 \%$ & $100 \%$ \\
\hline $\begin{array}{l}\text { NG small industrial } \\
\text { boiler: current }\end{array}$ & $0 \%$ & $0 \%$ & $0 \%$ & $0 \%$ & $0 \%$ & $0 \%$ & $0 \%$ & $0 \%$ \\
\hline $\begin{array}{l}\text { NG small industrial } \\
\text { boiler: future }\end{array}$ & $25 \%$ & $15 \%$ & $15 \%$ & $25 \%$ & $0 \%$ & $0 \%$ & $0 \%$ & $0 \%$ \\
\hline NG pipeline turbine & $0 \%$ & $0 \%$ & $0 \%$ & $0 \%$ & $0 \%$ & $0 \%$ & $0 \%$ & $0 \%$ \\
\hline $\begin{array}{l}\text { Coal industrial } \\
\text { boiler: current }\end{array}$ & $0 \%$ & $0 \%$ & $0 \%$ & $0 \%$ & $0 \%$ & $0 \%$ & $0 \%$ & $0 \%$ \\
\hline $\begin{array}{l}\text { Coal industrial } \\
\text { boiler: future }\end{array}$ & $0 \%$ & $100 \%$ & $100 \%$ & $0 \%$ & $0 \%$ & $0 \%$ & $0 \%$ & $0 \%$ \\
\hline $\begin{array}{l}\text { Coal } \\
\text { Gasification/turbine }\end{array}$ & $0 \%$ & $0 \%$ & $0 \%$ & $0 \%$ & $0 \%$ & $0 \%$ & $0 \%$ & $0 \%$ \\
\hline
\end{tabular}


Table 3-3 Shares of Process Fuel by Process Unit

\begin{tabular}{|l|c|c|c|c|c|c|c|}
\multicolumn{1}{c|}{ Fuel } & $\begin{array}{c}\text { Crude } \\
\text { Recovery }\end{array}$ & $\begin{array}{c}\text { Gasoline } \\
\text { Refining }\end{array}$ & $\begin{array}{c}\text { LS Diesel } \\
\text { Refining }\end{array}$ & $\begin{array}{c}\text { NG } \\
\text { Recovery }\end{array}$ & $\begin{array}{c}\text { NG } \\
\text { Processing }\end{array}$ & $\begin{array}{c}\text { MeOH } \\
\text { Production }\end{array}$ & $\begin{array}{c}\text { FT Diesel } \\
\text { Production }\end{array}$ \\
\hline Crude oil & $1 \%$ & $0 \%$ & $0 \%$ & $0 \%$ & $0 \%$ & $0 \%$ & $0 \%$ \\
\hline Heavy residual oil & $1 \%$ & $3 \%$ & $3 \%$ & $0.9 \%$ & $0 \%$ & $0 \%$ & $0 \%$ \\
\hline Diesel fuel & $15 \%$ & $0 \%$ & $0 \%$ & $9.6 \%$ & $0.9 \%$ & $0 \%$ & $0 \%$ \\
\hline Gasoline & $2 \%$ & $0 \%$ & $0 \%$ & $0.9 \%$ & $0 \%$ & $0 \%$ & $0 \%$ \\
\hline Natural gas & $62 \%$ & $30 \%$ & $30 \%$ & $75.1 \%$ & $90.7 \%$ & $99.8 \%$ & $99.7 \%$ \\
\hline Coal & $0 \%$ & $13 \%$ & $13 \%$ & $0 \%$ & $0 \%$ & $0 \%$ & $0 \%$ \\
\hline N-butane & $0 \%$ & $0 \%$ & $0 \%$ & $0 \%$ & $0 \%$ & $0 \%$ & $0.3 \%$ \\
\hline Electricity & $19 \%$ & $4 \%$ & $4 \%$ & $0.9 \%$ & $2.8 \%$ & $0.2 \%$ & $0 \%$ \\
\hline Refinery still gas & $0 \%$ & $50 \%$ & $50 \%$ & $0 \%$ & $0 \%$ & $0 \%$ & $0 \%$ \\
\hline
\end{tabular}

\subsubsection{Greenhouse Gas Emissions}

GREET uses the International Panel on Climate Change (IPCC) weighting factors for assessing global warming potential (GWP) from $\mathrm{CO}_{2}, \mathrm{CH}_{4}$, and $\mathrm{N}_{2} \mathrm{O}$ emissions based on $\mathrm{CO}_{2}$ equivalents over a 100-year time frame. GREET reports $\mathrm{CO}_{2}, \mathrm{CH}_{4}$, and $\mathrm{N}_{2} \mathrm{O}$ inventories and the aggregated GWP from these three emissions. Previous GREET studies are based on GWP weighting factors from the second report from the IPCC (IPCC, 1996). The UCF LCA is based on updated GWP factors from the IPCC's third report on climate change (IPCC, 2001).

The updated IPCC factors are shown in Table 3-4.

Table 3-4 Global Warming Potentials of Greenhouse Gases, $\mathrm{CO}_{2}$ Equivalents, 100-Year Time Period

\begin{tabular}{|l|c|}
\hline \multicolumn{1}{|c|}{ Emission } & $\begin{array}{c}\mathrm{CO}_{2} \text {-Equivalent Global } \\
\text { Warming Factor }\end{array}$ \\
\hline $\mathrm{CO}_{2}$ & 1 \\
\hline $\mathrm{CH}_{4}$ & 23 \\
\hline $\mathrm{N}_{2} \mathrm{O}$ & 296 \\
\hline
\end{tabular}

Source: IPCC 2001

\subsubsection{Criteria Pollutant Emissions}

GREET contains emissions factors for criteria pollutants $\left(\mathrm{SO}_{\mathrm{X}}, \mathrm{NO}_{\mathrm{X}}, \mathrm{CO}, \mathrm{VOC}\right.$, and PM10) that are used in process units for fuel transportation (ocean, rail, truck, etc.), combustion technology/fuel combinations for the fuel production stage, non-combustion emissions for fuel production, power generation, and vehicle use. The emissions factors for the industrial processes and fuel transportation are derived from AP-42. Emissions factors for vehicle use were developed based on the U.S. EPA Mobile5 model and associated EPA regulations and on engine testing conducted by General Motors. 
GREET segments criteria pollutants between urban and non-urban emissions. For the purposes of conducting a Life Cycle Impact Assessment (LCIA), non-urban and urban emissions are considered separately. (See the LCIA scope in Section 1 for more details.)

Table 3-5 shows the GREET 1.6 assumptions for urban/non-urban emissions and the changes made to these assumptions in the UCF LCA. Since it is assumed that the natural gas is sourced from remote sites, the urban share for GTL and methanol production was changed from $10 \%$ to $0 \%$. (This was the only change made.)

Table 3-5 GREET 1.6 and UCF LCA Urban Emission Shares for Criteria Pollutants

\begin{tabular}{|l|c|c|}
\hline \multicolumn{1}{|c|}{ Stage } & $\begin{array}{c}\text { GREET 1.6 Default } \\
\text { Urban Share }\end{array}$ & $\begin{array}{c}\text { UCF LCA Urban } \\
\text { Share }\end{array}$ \\
\hline Ocean tanker & $0 \%$ & $0 \%$ \\
\hline Truck & $50 \%$ & $50 \%$ \\
\hline Rail & $0 \%$ & $0 \%$ \\
\hline Barge & $0 \%$ & $0 \%$ \\
\hline Petroleum refining & $65 \%$ & $65 \%$ \\
\hline LNG/CNG production & $0 \%$ & $0 \%$ \\
\hline Methanol production & $10 \%$ & $0 \%$ \\
\hline GTL production & $10 \%$ & $0 \%$ \\
\hline Vehicle use & $100 \%$ & $100 \%$ \\
\hline
\end{tabular}

\subsubsection{Total Energy}

GREET computes total required energy, total petroleum fuel use, and total fossil fuel use, based on the thermal efficiency parameters for the recovery and production unit processes and on fuel efficiency parameters for the transportation stages, as described below.

\subsection{WELL-TO-TANK VALIDATION}

This section presents an overview of the key well-to-tank unit processes and parameters in GREET, and provides tables showing the GREET defaults and the changes made to GREET 1.6 for the UCF LCA.

Details are given on data and parameter development for crude oil and natural gas production, fuel transportation, and petroleum refining efficiency; data development for solid waste and wastewater is discussed. Solid waste and wastewater are not part of GREET, and data needed to be developed independently. Details for the engineering analysis and data development for FTD and methanol are presented in Section 4 of this report.

\subsubsection{Feedstock Production}

Table 3-6 shows the energy efficiencies of crude oil recovery, natural gas recovery, and natural gas processing assumed as defaults in GREET 1.6 and used in this study. 
Table 3-6 Feedstock Stage Thermal Efficiencies

\begin{tabular}{|l|l|c|}
\multicolumn{1}{|c|}{ Stage } & \multicolumn{1}{|c|}{ Unit Process } & Thermal Efficiency \\
\hline Feedstock & Crude recovery & $97.7 \%$ \\
\hline & Natural gas recovery & $97.5 \%$ \\
\hline & Natural gas processing & $97.5 \%$ \\
\hline
\end{tabular}

\subsubsection{Transportation and Distribution}

Tables 3-7 and 3-8 show the transportation distance assumptions for each transportation mode used in GREET 1.6 for petroleum fuels and methanol and GTL fuels (FTD and FT naphtha), respectively. The only change made for the UCF LCA was to the methanol pathway for remote natural gas. The ocean tanker distance was increased from 3,000 to 5,000 miles to reflect sourcing from remote natural gas in the Middle East.

Table 3-7 Transportation Distances per Transportation Mode for Petroleum Fuels

\begin{tabular}{|l|c|c|c|c|c|}
\hline & \multicolumn{5}{|c|}{ Distance, mi } \\
\hline Transport Mode & $\begin{array}{c}\text { Foreign Crude Oil to } \\
\text { U.S. }\end{array}$ & $\begin{array}{c}\text { Gasoline (CG } \\
\text { and FRFG) }\end{array}$ & Diesel & LS Diesel & $\begin{array}{c}\text { Heavy } \\
\text { Residual Oil }\end{array}$ \\
\hline Ocean tanker & 5,000 & 1,700 & 1,450 & 1,450 & 3,000 \\
\hline Barge & 500 & 520 & 520 & 520 & 340 \\
\hline Pipeline & 750 & 400 & 400 & 400 & 400 \\
\hline Rail & 800 & 800 & 800 & 800 & 800 \\
\hline Truck for distribution & 30 & 30 & 30 & 30 & 30 \\
\hline
\end{tabular}

Table 3-8 Transportation Distances per Transportation Mode for Methanol and GTL Fuels

\begin{tabular}{|l|c|c|c|}
\hline \multicolumn{3}{|c|}{ Transport Mode } & \multicolumn{3}{c|}{ Dethanol } & FT Diesel & FT Naphtha \\
\hline Ocean tanker & $\begin{array}{c}3,000 \text { (GREET 1.6 default) } \\
5,000 \text { (UCF LCA) }\end{array}$ & 5,000 & 5,000 \\
\hline Barge & 520 & 520 & 520 \\
\hline Pipeline & 600 & 400 & 400 \\
\hline Rail & 700 & 800 & 800 \\
\hline Truck for distribution & 30 & 30 & 30 \\
\hline
\end{tabular}

Table 3-9 shows the shares of transportation modes for crude oil, petroleum fuels, GTL fuels, and methanol. "Trans" indicates the bulk transportation of the fuel from production to bulk storage terminals, and "Dist" indicates distribution from bulk storage to retail locations. The percentage in each column refers to the percentage of each fuel that is carried by a specific mode at any stage in the fuel cycle. For example, $57 \%$ of crude oil is carried by ocean tanker, indicating that $57 \%$ of crude is imported from foreign sources. $100 \%$ of crude oil (both domestic and foreign crude) is transported via pipeline, once the crude is produced in the United States or transported to the United States. For FRFG and low-sulfur diesel (LSD), 16\% and 24\% of the 
fuels, respectively, are transported via ocean tanker. This indicates that the fuels were produced in foreign refineries and transported to the U.S.

Table 3-9 Shares by Transportation Mode

\begin{tabular}{|c|c|c|c|c|c|c|c|c|c|c|c|c|c|}
\hline \multirow[t]{2}{*}{ Mode } & \multirow{2}{*}{$\begin{array}{c}\begin{array}{c}\text { Crude Oil } \\
\text { to U.S. } \\
\text { Refineries } \\
\text { Trans }\end{array} \\
\end{array}$} & \multicolumn{2}{|c|}{ FRFG } & \multicolumn{2}{|c|}{ LS Diesel } & \multirow{2}{*}{$\begin{array}{c}\text { Heavy } \\
\text { Residual } \\
\text { Oil } \\
\text { Trans }\end{array}$} & \multirow{2}{*}{$\begin{array}{l}\text { Coke } \\
\text { Trans }\end{array}$} & \multicolumn{2}{|c|}{ Methanol } & \multicolumn{2}{|c|}{ FT Diesel } & \multicolumn{2}{|c|}{ FT Naphtha } \\
\hline & & Trans & Dist & Trans & Dist & & & Trans & Dist & Trans & Dist & Trans & Dist \\
\hline $\begin{array}{l}\text { Ocean } \\
\text { tanker }\end{array}$ & $57 \%$ & $20 \%$ & & $16 \%$ & & $24 \%$ & $24 \%$ & $100 \%$ & & $100 \%$ & & $100 \%$ & \\
\hline Barge & $1 \%$ & $4 \%$ & & $6 \%$ & & $40 \%$ & $40 \%$ & $40 \%$ & & $33 \%$ & & $33 \%$ & \\
\hline Pipeline & $100 \%$ & $73 \%$ & & $75 \%$ & & $60 \%$ & $0 \%$ & $0 \%$ & & $60 \%$ & & $60 \%$ & \\
\hline Rail & $0 \%$ & $7 \%$ & & $7 \%$ & & $5 \%$ & $65 \%$ & $40 \%$ & & $7 \%$ & & $7 \%$ & \\
\hline Truck & $0 \%$ & & $100 \%$ & & $100 \%$ & $0 \%$ & $0 \%$ & $100 \%$ & $90 \%$ & & $100 \%$ & & $100 \%$ \\
\hline
\end{tabular}

\subsubsection{Petroleum Refining}

The Process Industries Modeling System (PIMS) was used in the UCF LCA to model the operations of PADD III and PADD I refineries in order to validate GREET data and to model coproduct production in the refinery and sensitivity scenarios for petroleum refining. Figure 3-1 shows the distribution of U.S. states within the PADDs.

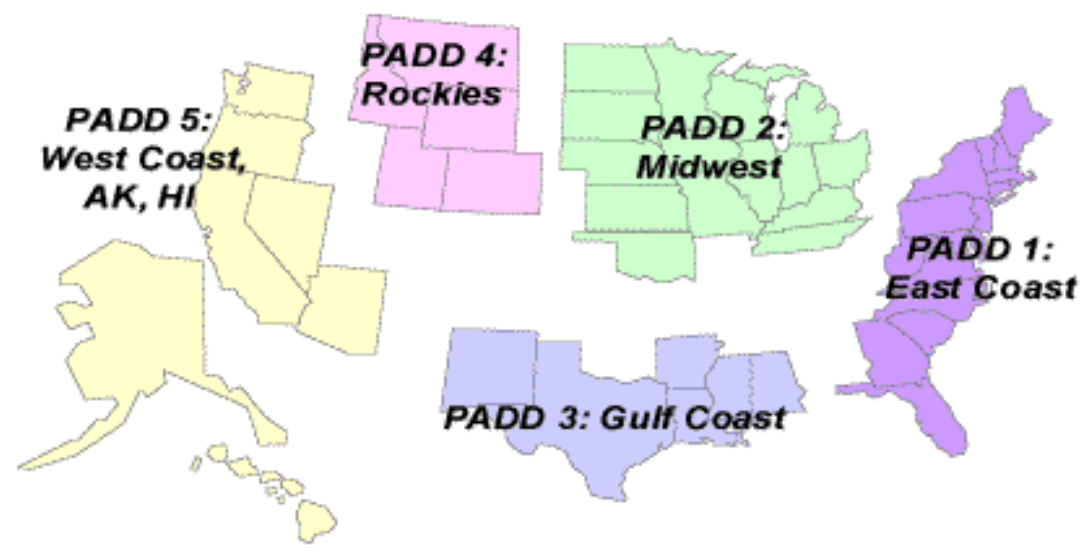

Figure 3-1 Petroleum Administration for Defense Districts 
States within each PADD are defined as follows:

- PAD District I (East Coast)

- New England: Connecticut, Maine, Massachusetts, New Hampshire, Rhode Island, Vermont

- Central Atlantic: Delaware, District of Columbia, Maryland, New Jersey, New York, Pennsylvania

- Lower Atlantic: Florida, Georgia, North Carolina, South Carolina, Virginia, West Virginia

- PAD District II (Midwest): Illinois, Indiana, Iowa, Kansas, Kentucky, Michigan, Minnesota, Missouri, Nebraska, North Dakota, South Dakota, Ohio, Oklahoma, Tennessee, Wisconsin

- PAD District III (Gulf Coast): Alabama, Arkansas, Louisiana, Mississippi, New Mexico, Texas

- PAD District IV (Rocky Mountain): Colorado Idaho, Montana, Utah, Wyoming

- PAD District V (West Coast): Alaska, Arizona, California, Hawaii, Nevada, Oregon, Washington

The sensitivity scenarios examined are:

- A heavy crude input slate case for PADD III, based on a crude slate API of 25.4

- A light crude input slate case for PADD I, based on a crude slate of 33.1 API

- Production of ultra-low sulfur petroleum diesel (less than 3 ppm sulfur) from a PADD III average crude slate

Details of the PIMS modeling and methodologies are provided in Section 3.5. The GREET 1.6 default refining efficiencies and UCF changes are documented in Table 3-10. The data in columns 3 through 6 is the result of runs of the PIMS model. The UCF LCA petroleum scenario data in column 4 was chosen to correspond to GREET defaults in column 3. Efficiencies for other cases were determined by the changes in efficiencies as generated by the PIMS model. 
Table 3-10 GREET 1.6 Default and UCF LCA Petroleum Refining Efficiencies

\begin{tabular}{|c|c|c|c|c|c|c|}
\hline Fuel & $\begin{array}{l}\text { Sulfur Level, } \\
\text { ppm }\end{array}$ & $\begin{array}{l}\text { GREET } 1.6 \\
\text { Default } \\
\text { Refining } \\
\text { Efficiency }\end{array}$ & $\begin{array}{l}\text { UCF LCA } \\
\text { Refining } \\
\text { Efficiency } \\
\text { PADD III }\end{array}$ & $\begin{array}{l}\text { UCF LCA } \\
\text { Refining } \\
\text { Efficiency } \\
\text { Heavy Crude }\end{array}$ & $\begin{array}{l}\text { UCF LCA } \\
\text { Refining } \\
\text { Efficiency } \\
\text { Light Crude }\end{array}$ & $\begin{array}{l}\text { UCF LCA } \\
\text { Efficiency LS } \\
\text { Fuels }\end{array}$ \\
\hline $\begin{array}{l}\text { Conventional } \\
\text { gasoline }\end{array}$ & 340 & $85.5 \%$ & $85.5 \%$ & $84.5 \%$ & $85.83 \%$ & $\mathrm{~N} / \mathrm{A}$ \\
\hline \multirow{4}{*}{$\begin{array}{l}\text { Federal reformulated } \\
\text { gasoline, with MTBE }\end{array}$} & 150 & $86.0 \%$ & $86.0 \%$ & $85 \%$ & $86.33 \%$ & N/A \\
\hline & 30 & $85.5 \%$ & $85.5 \%$ & $84.5 \%$ & $85.83 \%$ & N/A \\
\hline & 15 & $85.5 \%$ & $85.5 \%$ & $84.5 \%$ & $85.83 \%$ & N/A \\
\hline & 5 & $85.5 \%$ & $85.5 \%$ & $84.5 \%$ & $85.83 \%$ & $N / A$ \\
\hline Conventional diesel & 350 & $89.0 \%$ & $89.0 \%$ & $88 \%$ & $89.33 \%$ & $\mathrm{~N} / \mathrm{A}$ \\
\hline \multirow[t]{4}{*}{ LS diesel } & 30 & $87.0 \%$ & $87.0 \%$ & $86 \%$ & $87.33 \%$ & N/A \\
\hline & 15 & $87.0 \%$ & $87.0 \%$ & $86 \%$ & $87.33 \%$ & $\mathrm{~N} / \mathrm{A}$ \\
\hline & 5 & $87.0 \%$ & $87.0 \%$ & $86 \%$ & $87.33 \%$ & $\mathrm{~N} / \mathrm{A}$ \\
\hline & 3 & $\mathrm{~N} / \mathrm{A}$ & $\mathrm{N} / \mathrm{A}$ & $\mathrm{N} / \mathrm{A}$ & $\mathrm{N} / \mathrm{A}$ & $86.78 \%$ \\
\hline Crude naphtha & 1 & $91.0 \%$ & $91.0 \%$ & $90 \%$ & $91.33 \%$ & $N / A$ \\
\hline
\end{tabular}

\subsubsection{GTL and Methanol Production}

The default and revised energy and carbon efficiencies for GTL fuels and methanol are shown in Table 3-11. The UCF LCA considers only cases of plant designs with no steam or electricity cogeneration. Section 4 describes in detail the GREET 1.6 defaults and the analysis used to revise the efficiencies.

Table 3-11 Default and Revised FT Diesel, FT Naphtha, and Methanol Process Efficiencies

\begin{tabular}{|l|c|c|c|c|}
\multicolumn{1}{c}{$\begin{array}{c}\text { Efficiencies for NNA NG and FG, No } \\
\text { Steam/Electricity Cogeneration }\end{array}$} & $\begin{array}{c}\text { Near-Term } \\
\text { GREET 1.6 } \\
\text { Default }\end{array}$ & $\begin{array}{c}\text { Long-Term } \\
\text { GREET 1.6 } \\
\text { Default }\end{array}$ & $\begin{array}{c}\text { Near-Term UCF } \\
\text { LCA }\end{array}$ & $\begin{array}{c}\text { Long-Term UCF } \\
\text { LCA }\end{array}$ \\
\hline FT diesel energy efficiency & $63 \%$ & $63 \%$ & $67 \%$ & $70 \%$ \\
\hline FT naphtha energy efficiency & $63 \%$ & $63 \%$ & $67 \%$ & $70 \%$ \\
\hline FT diesel carbon efficiency & $80 \%$ & $80 \%$ & $85 \%$ & $85 \%$ \\
\hline FT naphtha carbon efficiency & $80 \%$ & $80 \%$ & $85 \%$ & $85 \%$ \\
\hline Methanol energy efficiency & $67.8 \%$ & $67.8 \%$ & $68 \%$ & $71 \%$ \\
\hline
\end{tabular}

GREET 1.6 assumes an air-based syngas generation process for the production of FTD. GREET uses an emissions factor of $17.6 \mathrm{~g} / \mathrm{MMBtu}$ for $\mathrm{NO}_{\mathrm{X}}$ at the fuel processing stage.

$\mathrm{NO}_{\mathrm{X}}$ at the syngas unit comes from two sources: (1) the nitrogen in the feed gas and (2) the nitrogen in the oxidant. The oxidant is either air, as in GREET, or oxygen. For an air-based process, a significant amount of $\mathrm{NO}_{\mathrm{X}}$ is generated in the syngas unit because of the presence of nitrogen from the air in the stream at high temperatures. However, for oxygen-based processes, there should be no $\mathrm{NO}_{\mathrm{X}}$ generated in this fashion; the only $\mathrm{NO}_{\mathrm{X}}$ comes from nitrogen in the gas 
stream. Even with the presence of nitrogen in the gas, for the oxygen-based syngas process the $\mathrm{NO}_{\mathrm{X}}$ generation should be very small.

An oxygen-based syngas generation process is assumed in the UCF LCA study, and an emission factor of zero is used for $\mathrm{NO}_{\mathrm{X}}$ generation at the fuel conversion stage.

\subsubsection{Data Sources}

Tables 3-12 and 3-13 document the sources of data for each of the GREET well-to-tank unit processes, and indicate where primary/secondary sources and data from Nexant analyses were used.

\section{Table 3-12 Data Sources for the Petroleum Fuel Production System}

\begin{tabular}{|l|l|l|l|l|l|}
\multicolumn{1}{|c|}{ Stage } & \multicolumn{2}{|c|}{ Data Source } & \multicolumn{1}{c|}{$\begin{array}{c}\text { Primaryl } \\
\text { Secondary }\end{array}$} & \multicolumn{1}{c|}{ Parameter } & Notes \\
\hline $\begin{array}{l}\text { Crude oil } \\
\text { recovery }\end{array}$ & $\begin{array}{l}\text { Energy Information } \\
\text { Agency (EIA) } \\
\text { EPA }\end{array}$ & $\begin{array}{l}\text { Secondary, } \\
\text { GREET defaults }\end{array}$ & $\begin{array}{l}\text { Energy efficiency } \\
\text { Shares of process fuels and } \\
\text { combustion processes } \\
\text { AP-42 emissions factors }\end{array}$ & \\
\hline $\begin{array}{l}\text { Crude transport } \\
\text { via ocean } \\
\text { tanker }\end{array}$ & $\begin{array}{l}\text { EIA } \\
\text { American } \\
\text { Petroleum Institute } \\
\text { (API) }\end{array}$ & $\begin{array}{l}\text { Secondary, } \\
\text { GREET defaults }\end{array}$ & $\begin{array}{l}\text { Distance } \\
\text { Emissions factors }\end{array}$ & \\
\hline $\begin{array}{l}\text { Crude transport } \\
\text { via truck, rail, } \\
\text { pipeline, barge }\end{array}$ & EIA & $\begin{array}{l}\text { Secondary, } \\
\text { GREET defaults }\end{array}$ & $\begin{array}{l}\text { Distances } \\
\text { Emissions factors }\end{array}$ & \\
\hline Refining & $\begin{array}{l}\text { EIA } \\
\text { Nexant analysis }\end{array}$ & $\begin{array}{l}\text { Primary and } \\
\text { secondary }\end{array}$ & $\begin{array}{l}\text { Energy efficiency } \\
\text { Shares of process fuels and } \\
\text { combustion processes } \\
\text { AP-42 emissions factors }\end{array}$ & $\begin{array}{l}\text { GREET energy efficiency } \\
\text { defaults for gasoline and } \\
\text { diesel validated for PADD III } \\
\text { and PADD I with PIMS }\end{array}$ \\
\hline
\end{tabular}

Table 3-13 Data Sources for the GTL Fuel Production System

\begin{tabular}{|l|l|l|l|l|l|}
\multicolumn{1}{|c|}{ Stage } & \multicolumn{1}{c|}{ Data Source } & \multicolumn{1}{c|}{$\begin{array}{c}\text { Primaryl } \\
\text { Secondary }\end{array}$} & \multicolumn{1}{c|}{ Parameter } \\
\hline NG recovery & EIA & $\begin{array}{l}\text { Secondary, } \\
\text { GREET defaults }\end{array}$ & $\begin{array}{l}\text { Efficiency } \\
\text { Emissions factors }\end{array}$ & \begin{tabular}{l} 
Notes \\
\hline GTL production
\end{tabular} \\
& $\begin{array}{l}\text { ConocoPhillips } \\
\text { Nexant analysis }\end{array}$ & Primary & $\begin{array}{l}\text { Energy efficiency } \\
\text { Carbon efficiency } \\
\text { Emissions factors }\end{array}$ & $\begin{array}{l}\text { On pilot-scale plants and } \\
\text { efficiency targets } \\
\text { Nexant developed Aspen } \\
\text { Plus models for validation } \\
\text { and theoretical limits }\end{array}$ \\
\hline $\begin{array}{l}\text { GTL } \\
\text { transportation }\end{array}$ & $\begin{array}{l}\text { ConocoPhillips } \\
\text { EIA }\end{array}$ & $\begin{array}{l}\text { Primary, } \\
\text { secondary }\end{array}$ & $\begin{array}{l}\text { Distance } \\
\text { Emissions factors }\end{array}$ & $\begin{array}{l}\text { Distances based on } \\
\text { ConocoPhillips future } \\
\text { operations }\end{array}$ \\
\hline
\end{tabular}




\subsection{TANK-TO-WHEELS VALIDATION}

This section reviews the tank-to-wheels stage in GREET, including vehicle end use fuel efficiency, emissions, and technology assumptions for various vehicle configurations from GREET 1.6. The data is examined at two levels: first, the absolute values of the data are verified; second, relative differences between vehicle types are examined and verified. The goal of this assessment is to examine the data, ensure that it is reasonable and consistent, that it agrees in general with comparable data in the literature, and that, in particular, it reflects the most current vehicle engineering, research, and development.

Of the full well-to-wheels fuel cycle, the vehicle stage (or tank-to-wheels) typically accounts for between $70 \%$ and $80 \%$ of the total life cycle energy use and emissions. However, vehicle emissions tend to be similar within similar fuel pathways and vehicle classes, e.g., petroleum diesel CIDI and FT diesel CIDI vehicles. Thus, the fuel processing and upstream feedstock extraction stages tend to be the source of differences between pathways.

Twelve different pathways were identified for evaluation in the UCF LCA. The target vehicle, as well as the corresponding functional unit for the UCF LCA, is a light duty passenger vehicle, defined as a vehicle of less than 6,000 pounds. Organized by fuel type, the vehicle configurations are:

- Federal reformulated gasoline (FRFG):

- Spark ignition, direct injection (SIDI) engine

- Grid-independent (GI) hybrid electric vehicle (HEV)

- Fuel processor fuel cell vehicle (FCV)

- ULSD

- Compression ignition, direct injection (CIDI) engine

- CIDI GI HEV

- FTD

- CIDI

- CIDI GI HEV

- Advanced, FT-optimized CIDI and CIDI HEV engines

- $\quad$ FT naphtha

- FCV

- Methanol

- FCV

Emissions data in GREET is derived from the Mobile5 model from the U.S. EPA, as well as from engine and vehicle tests performed by General Motors. 
This review reflects a detailed validation of the data in GREET 1.6, and was conducted in collaboration with experts from the Southwest Research Institute.

\subsubsection{GREET Default Vehicle Data}

For the most part, the GREET default data appears to be reasonable, if somewhat on the conservative side, in terms of the emissions and fuel economy estimates. The fuel consumption estimates for the HEV technology from the literature are in agreement with the GREET data, reflecting 35\%-45\% improvement in fuel economy compared with corresponding conventional drive trains. Some recent modeling work at the Southwest Research Institute and other organizations indicates that the improvements can be as high as $100 \%$, depending on the selection of individual components and design of the vehicle control system.

The emissions estimates are generally consistent with light duty vehicles that will be in compliance with the EPA TIER II emissions standards. There are some discrepancies, and these are detailed in the next section.

Fuel and vehicle configurations are discussed below. The analyses are based on comparisons with published data. Much of the available information in the literature is generated and/or reported by the Center for Transportation Research at Argonne National Laboratory.

\subsubsection{Federal Reformulated Gasoline Vehicles}

The fuel economy of the FRFG in light passenger vehicles in GREET 1.6 is assumed to be $27.4 \mathrm{mpg}$. This is consistent with the combined average fleet efficiency (CAFE) requirement for this class of vehicle. Within EPA, there are ongoing discussions regarding future changes in these CAFE requirements, but the details have not been officially released. It has been speculated that the standard for passenger cars could be raised to $40 \mathrm{mpg}$, but this is a politically contentious issue.

The CO emissions in GREET 1.6 are somewhat high relative to the TIER II limits, but are still within the TIER II limits. All other criteria emissions correspond to TIER II limits.

The hybrid electric vehicle (HEV) configuration for FRFG in GREET 1.6 reflects a 42\% improvement in fuel economy versus the conventional power train. The latest reference (Santini, 2002) indicates that average fuel economy improvements for production and prototype gridindependent HEVs are $29 \%$, with a two-standard-deviation range of $13 \%-45 \%$.

However, current production HEVs (Honda Insight and Toyota Prius) have demonstrated fuel economy improvements over conventional but comparable vehicles of $66 \%$ and $53 \%$, respectively, and prototype HEVs have demonstrated improvements of $166 \%-205 \%$ (Feng, 2001).

The significant improvement in fuel economy estimated for the HEVs, along with the opportunity to optimize performance and emissions in hybrid applications, means that reductions in emissions relative to the corresponding conventional power train are likely. It is estimated that these reductions should be around 15\%-20\% for PM10 and $\mathrm{NO}_{\mathrm{X}}$. 
Because the engines in HEVs typically have very narrow operating ranges relative to engines in conventional vehicles, there are additionally significant opportunities for optimizing the engine for low emissions and high efficiency.

The fuel cell fuel economy improvement in GREET 1.6 over conventional power trains is $50 \%$, an estimate that appears to reflect a combined reformer plus fuel cell efficiency of $45 \%$. This level of efficiency would require over $65 \%$ efficiencies from both the reformer and the fuel cell. Although these combined efficiencies have not yet been demonstrated, they do reflect the estimates that have been cited in the literature (Argonne National Laboratory, 2001).

Table 3-14 shows the GREET 1.6 and UCF LCA data for the FRFG pathways. The columns headed by the term "UCF LCA" contain the data used in the UCF LCA.

Table 3-14 Federal Reformulated Gasoline, GREET 1.6 Default Data and UCF LCA Revisions

\begin{tabular}{|l|c|c|c|c|c|c|}
\multicolumn{1}{c|}{$\begin{array}{c}\text { Vehicle Configuration } \\
\text { FRFG }\end{array}$} & $\begin{array}{c}\text { UCF LCA } \\
\text { FRFG }\end{array}$ & $\begin{array}{c}\text { GREET 1.6 } \\
\text { GI SI HEV }\end{array}$ & $\begin{array}{c}\text { UCF LCA GI } \\
\text { SI HEV }\end{array}$ & $\begin{array}{c}\text { GREET } 1.6 \\
\text { Fuel Cell }\end{array}$ & $\begin{array}{c}\text { UCF LCA } \\
\text { Fuel Cell }\end{array}$ \\
\hline mpg (per gasoline equivalent gallon) & 27.4 & 27.4 & 39.1 & 39.1 & 41.0 & 41.0 \\
\hline Emissions, g/mi & & & & & & \\
\hline VOC: exhaust & 0.062 & 0.062 & 0.062 & 0.062 & 0.012 & 0.012 \\
\hline VOC: evaporation & 0.063 & 0.063 & 0.044 & 0.044 & 0.044 & 0.044 \\
\hline CO & 2.759 & 2.759 & 2.759 & 2.759 & 0.552 & 0.552 \\
\hline NOx & 0.036 & 0.036 & 0.036 & 0.029 & 0.007 & 0.007 \\
\hline PM10: exhaust & 0.010 & 0.010 & 0.012 & 0.010 & 0.000 & 0.000 \\
\hline PM10: brake and tire wearing & 0.021 & 0.021 & 0.021 & 0.021 & 0.021 & 0.021 \\
\hline SOx & 0.031 & 0.005 & 0.021 & 0.004 & 0.000 & 0.000 \\
\hline
\end{tabular}

\subsubsection{Ultra-Low Sulfur Diesel Vehicles}

ULSD fuel offers significant opportunity for fuel economy improvement through the use of highefficiency CIDI engine technology. The estimated improvement in GREET 1.6 over SIDI technology is $21 \%$, as shown in Table $3-13$. This appears to be conservative, because the CAFE standard for current vehicles specifies a $75 \%$ and $58 \%$ improvement, respectively, for city and highway CAFE for diesel vehicles. (See www.fueleconomy.gov for the comparative mpg's of VW Golf diesel and gasoline models.) However, because these figures are not reported on the basis of gasoline-equivalent-gallons, the actual improvements are likely to be smaller.

The CO reported in GREET 1.6 appears to be reasonable.

The CIDI HEV vehicles in GREET are estimated to provide a 35\% improvement in fuel economy over conventional CIDIs. As discussed above, the latest reference (Santini, 2002) indicates that the average fuel economy improvements for production and prototype gridindependent HEVs is $29 \%$, with a two-standard-deviation range of $13 \%-45 \%$, and current production and prototype vehicles demonstrate 53\%-205\% improvements. These figures are also not reported on the basis of gasoline-equivalent gallons, and the actual improvements are probably smaller. 
As is the case with the FRFG HEV vehicle, there should be reductions in emissions for ULSD HEVs compared with the corresponding conventional power train. It is estimated that these reductions should be about $15 \%-20 \%$ for $\mathrm{PM} 10$ and $\mathrm{NO}_{\mathrm{X}}$.

Emissions reductions of $52 \%$ and $18 \%$ for $\mathrm{NO}_{\mathrm{X}}$ and PM10, respectively, were reported in the literature (Uematsu et al., 2002) through optimization of a CIDI HEV.

Table 3-15 shows the GREET 1.6, and UCF LCA data for the ULSD pathways. The columns headed by the term "UCF LCA" contain the data used in the UCF LCA. The UCF LCA has adopted the GREET 1.6 default data for vehicle fuel efficiency.

Table 3-15 Ultra-Low Sulfur Diesel, GREET 1.6 Default Data and UCF LCA Revisions

\begin{tabular}{|l|c|c|c|c|}
\multicolumn{1}{|c|}{ Vehicle Configuration } & $\begin{array}{c}\text { GREET 1.6 } \\
\text { CIDI }\end{array}$ & $\begin{array}{c}\text { UCF LCA } \\
\text { CIDI }\end{array}$ & $\begin{array}{c}\text { GREET 1.6 GI } \\
\text { CIDI HEV }\end{array}$ & $\begin{array}{c}\text { UCF LCA GI } \\
\text { CIDI HEV }\end{array}$ \\
\hline mpg (per gasoline equivalent gallon) & 33.2 & 33.2 & 44.8 & 44.8 \\
\hline Emissions, g/mi & & & & \\
\hline VOC: exhaust & 0.049 & 0.049 & 0.049 & 0.049 \\
\hline VOC: evaporation & 0.000 & 0.000 & 0.000 & 0.000 \\
\hline CO & 1.070 & 1.070 & 1.070 & 1.070 \\
\hline NOx & 0.063 & 0.063 & 0.063 & 0.050 \\
\hline PM10: exhaust & 0.010 & 0.010 & 0.010 & 0.008 \\
\hline PM10: brake and tire wearing & 0.021 & 0.021 & 0.021 & 0.021 \\
\hline SOx & 0.005 & 0.003 & 0.004 & 0.002 \\
\hline
\end{tabular}

\subsubsection{FT Diesel Vehicles}

In GREET 1.6, the FTD CIDI data is identical to the ULSD CIDI data. GREET thus assumes that engines have not been optimized for use of the FTD. Recent data indicates that there are emissions-fuel economy tradeoffs that might be different for FTD, as discussed in the following references: (Ryan and Montalvo, 1997), (Schaberg et al., 1998), (Norton et al., 1998), (Atkinson et al., 1999), (Sirman and Owens, 1998), and (Ryan and Leet, 1997).

With no optimization of the CIDI for the high cetane number and high hydrogen content of FTD, literature data indicates that on average the $\mathrm{NO}_{\mathrm{X}}$ emissions are reduced by $15 \%$ and the PM10 emissions are reduced by $30 \%$ when switching to the FTD. These averages are based on both light and heavy duty engine data.

The emissions estimates in GREET 1.6 should reflect these differences between the ULSD CIDI and the FTD CIDI. The paper by Ryan and Montalvo (Ryan and Montalvo, 1997) may be the best source of data for this modification, where the $\mathrm{NO}_{\mathrm{X}}$ and $\mathrm{PM} 10$ reductions are $15 \%$ and $30 \%$, respectively.

Recent data (Ryan and Leet, 1997 and May et al., 2001) indicates that the engine can be optimized for the beneficial characteristics of the FTD. This opportunity comes about mostly as a 
result of the high cetane number of the FT diesel, allowing for injection timing changes that bring about either fuel economy improvement or further $\mathrm{NO}_{\mathrm{X}}$ reductions at the same fuel economy. It is estimated that a 5\% improvement in fuel consumption is possible at the same $\mathrm{NO}_{\mathrm{X}}$ level. This case is referred to as the "Aggressive FTD" in the UCF LCA.

The FTD HEV is estimated in GREET 1.6 to provide a 35\% improvement in fuel economy compared with the conventional FTD CIDI. The observations for HEV for ULSD and FRFG also apply to FTD.

Table 3-16 shows the GREET 1.6 and UCF LCA data for the FTD pathways. The columns headed by the term "UCF LCA" contain the data used in the UCF LCA. The columns headed by the words "UCF LCA Aggressive" represent cases for FTD-optimized CIDI and CIDI HEV engines that are likely to be technically achievable (but may not be commercially available,) with a $5 \%$ improvement in fuel efficiency.

Table 3-16 FT Diesel, GREET 1.6 Default Data and UCF LCA Revisions

\begin{tabular}{|c|c|c|c|c|c|c|}
\hline Vehicle Configuration & $\begin{array}{l}\text { GREET } 1.6 \\
\text { FTD CIDI }\end{array}$ & $\begin{array}{l}\text { UCF LCA } \\
\text { FTD CIDI }\end{array}$ & $\begin{array}{l}\text { UCF LCA } \\
\text { Aggressive } \\
\text { FTD CIDI }\end{array}$ & $\begin{array}{c}\text { GREET } 1.6 \\
\text { GI FTD CIDI } \\
\text { HEV }\end{array}$ & $\begin{array}{l}\text { UCF LCA GI } \\
\text { FTD CIDI } \\
\text { HEV }\end{array}$ & $\begin{array}{c}\text { UCF LCA } \\
\text { Aggressive } \\
\text { GI FTD CIDI } \\
\text { HEV }\end{array}$ \\
\hline mpg (per gasoline equivalent gallon) & 33.2 & 33.2 & 34.8 & 44.8 & 44.8 & 47.0 \\
\hline \multicolumn{7}{|l|}{ Emissions, g/mi } \\
\hline VOC: exhaust & 0.049 & 0.049 & 0.049 & 0.049 & 0.049 & 0.049 \\
\hline VOC: evaporation & 0.000 & 0.000 & 0.000 & 0.000 & 0.000 & 0.000 \\
\hline $\mathrm{CO}$ & 1.070 & 1.070 & 1.070 & 1.070 & 1.070 & 1.070 \\
\hline $\mathrm{NO} x$ & 0.063 & 0.053 & 0.053 & 0.063 & 0.045 & 0.045 \\
\hline PM10: exhaust & 0.008 & 0.007 & 0.007 & 0.008 & 0.006 & 0.006 \\
\hline PM10: brake and tire wearing & 0.021 & 0.021 & 0.021 & 0.021 & 0.021 & 0.021 \\
\hline $\mathrm{SO} x$ & 0.000 & 0.000 & 0.000 & 0.000 & 0.000 & 0.000 \\
\hline
\end{tabular}

\subsubsection{Methanol Vehicles}

The methanol fuel cell vehicle assumes a relatively minor 7\% improvement in fuel economy compared with the equivalent FRFG pathway, reflecting the differences in reformer efficiencies for FRFG and methanol. This appears to be acceptable, but the assumption could not be verified at this time.

Table 3-17 shows the GREET 1.6 and UCF LCA data for the methanol fuel cell vehicle. 


\section{Table 3-17 Methanol, GREET 1.6 Default Data and UCF LCA Revisions}

\begin{tabular}{|l|c|c|}
\multicolumn{1}{|c|}{ Vehicle Configuration } & $\begin{array}{c}\text { GREET 1.6 } \\
\text { Fuel Cell }\end{array}$ & $\begin{array}{c}\text { UCF LCA } \\
\text { Fuel Cell }\end{array}$ \\
\hline mpg (per gasoline equivalent gallon) & 44.0 & 44.0 \\
\hline Emissions, g/mi & & \\
\hline VOC: exhaust & 0.012 & 0.012 \\
\hline VOC: evaporation & 0.025 & 0.025 \\
\hline CO & 0.552 & 0.552 \\
\hline NOx & 0.007 & 0.007 \\
\hline PM10: exhaust & 0.000 & 0.000 \\
\hline PM10: brake and tire wearing & 0.021 & 0.021 \\
\hline SOx & 0.000 & 0.000 \\
\hline
\end{tabular}

\subsubsection{FT Naphtha Vehicles}

For the FT naphtha fuel cell vehicle, the combined efficiencies of the reformer and the fuel cell assumed in GREET are identical to the corresponding FRFG fuel cell pathway. This is probably a good estimate.

Recent data at the Southwest Research Institute indicates another possible pathway for the FT naphtha in which this material is used directly as a fuel in homogeneous charge compression ignition (HCCI) engines (Stanglmaier and Ryan, 2001). This engine offers an alternative to diesel engines, with very high efficiency and low $\mathrm{NO}_{\mathrm{X}}$ and PM10. This vehicle was not modeled in the UCF LCA, since the required estimates are beyond the scope of this analysis.

Table 3-18 shows the GREET 1.6 and UCF LCA data for the FT naphtha fuel cell vehicle.

Table 3-18 FT Naphtha, GREET 1.6 Default Data and UCF LCA Revisions

\begin{tabular}{|l|c|c|}
\multicolumn{1}{|c|}{ Vehicle Configuration } & GREET 1.6 Fuel Cell & UCF LCA Fuel Cell \\
\hline mpg (per gasoline equivalent gallon) & 41.0 & 41.0 \\
\hline Emissions, g/mi & & \\
\hline VOC: exhaust & 0.012 & 0.012 \\
\hline VOC: evaporation & 0.003 & 0.003 \\
\hline CO & 0.552 & 0.552 \\
\hline NOx & 0.007 & 0.007 \\
\hline PM10: exhaust & 0.000 & 0.000 \\
\hline PM10: brake and tire wearing & 0.021 & 0.021 \\
\hline SOx & 0.000 & 0.000 \\
\hline
\end{tabular}




\subsubsection{Data Sources}

Table 3-19 lists the data sources for the tank-to-wheels stages in GREET.

Table 3-19 Data Sources for Vehicle Use

\begin{tabular}{|c|c|c|c|c|}
\hline Stage & Data Source & Primary/Secondary & Parameter & Notes \\
\hline Fuel storage & EPA & Secondary & Emissions factors & \\
\hline Vehicle use & $\begin{array}{l}\text { EPA } \\
\text { General Motors } \\
\text { Southwest } \\
\text { Research Institute } \\
\text { (SWRI) }\end{array}$ & $\begin{array}{l}\text { Primary and } \\
\text { secondary }\end{array}$ & $\begin{array}{l}\text { Vehicle efficiency } \\
\text { Emissions factors }\end{array}$ & $\begin{array}{l}\text { GREET default data is based upon } \\
\text { CAFE standards } \\
\text { Default data is supplemented with } \\
\text { General Motors data for future vehicles } \\
\text { SWRI was engaged by ConocoPhillips } \\
\text { to review and validate the data }\end{array}$ \\
\hline
\end{tabular}

\subsection{MODEL AND DATA DEVELOPMENT}

This section documents the features of GREET 1.6 for which data was independently developed or the GREET model was extended in modeling capability for the UCF LCA. These are:

- Co-product Function Expansion modeling for petroleum coke and heavy residual oil

- Petroleum refining efficiencies for heavy crude, light crude, and ultra-LS fuel

- GTL and methanol efficiencies

- Solid waste and wastewater data

\subsubsection{Petroleum Refining Efficiencies}

The default refinery efficiencies used in GREET 1.6 were calculated by Argonne National Laboratory using MathPro, a linear programming application that optimizes the product slate of a refinery for a specified set of economic and production objectives. The Process Industries Modeling System (PIMS), also a linear programming (LP) application, was used in the UCF LCA to determine modifications to the refinery efficiencies used in this study for heavy crude slates, light crude slates, and LS petroleum fuels.

In both applications, the optimization calculation was based on the inputs of crude oil, electricity and process fuels, and the product yield and capacity of each refinery unit. The thermal efficiency of the refinery was calculated from the LP output, which includes product flow rates and utility consumption rates. A calibration between results from MathPro and PIMS was carried out in order to obtain a consistent case. The PIMS-based efficiencies were calculated for PADD III crude slates $\left(31.2^{\circ} \mathrm{API}\right)$, a PADD III heavy crude slate case $\left(25.4^{\circ} \mathrm{API}\right)$, and a PADD I lighter crude case $\left(33.1^{\circ} \mathrm{API}\right)$. The PADD III case was set as the comparable scenario for the default GREET 1.6 refinery case.

The UCF LCA efficiencies for petroleum refining were chosen to correspond to GREET defaults (as shown in Table 3-10 above.) Efficiencies for other cases were determined by the changes in efficiencies as generated by the PIMS model. 
In PIMS, the PADD III case efficiency was found to be one percentage point higher than the heavy crude efficiency; the PADD III heavy crude case efficiency was thus reduced by one percentage point. The PADD I light crude case was found to be $0.33 \%$ more efficient than the PADD III case, and the efficiency was increased accordingly in the GREET model.

\subsubsection{GTL Fuels and Methanol Efficiencies}

Data revisions are listed in Table 3-11 above. Details are given in Section 4 of this report.

\subsubsection{Wastewater and Solid Waste}

Wastewater and solid waste for petroleum refining were calculated based on the NREL report, "Fuel Cycle Evaluations of Biomass - Ethanol and Reformulated Gasoline," and from a report from the American Petroleum Institute (API, 2001). These reports cite DOE, EPA, and industry data on national average petroleum waste. Wastewater includes treated and untreated process water sources from all unit operations as well as from onshore crude oil production. Similarly, the solid waste factors account for solid wastes generated from crude production and refining.

\subsection{REFERENCES}

American Petroleum Institute, "Protecting Our Environment," 2001.

Argonne National Laboratory, "Methodology, Development, Use and Results," Vol. 1, GREET 1.5 - Transportation Fuel-Cycle Model, August 1999, and GREET 1.6 October 2001

Atkinson, C., G.J. Thompson, M.L. Traver, and N.N. Clark, "In-cylinder Combustion Pressure Characteristics of Fischer Tropsch and Conventional Diesel Fuels in a Heavy Duty Diesel Engine," SAE Paper 1999-01-1472, May 1999.

"Climate Change 1995: The Science of Climate Change," Intergovernmental Panel on Climate Change, Cambridge, United Kingdom, Cambridge University Press, 1996.

"Climate Change 2001: The Scientific Basis," Intergovernmental Panel on Climate Change, Cambridge, United Kingdom, Cambridge University Press, 2001.

Feng, A., A. Vyas, J. Anderson, and D. Santini, "Evaluating Commercial and Prototype HEVs," SAE Paper No. 2001-01-0951

Kadam, K., "Environmental Life Cycle Implications of Fuel Oxygenate Production from California Biomass," NREL NREL/TP-580-25688, May 1999.

May, M.P., K. Vertin, S. Ren, X. Gui, I. Myburgh, and P. Schaberg, "Development of Truck Engine Technologies for Use with Fischer-Tropsch Fuels," SAE Paper No. 2001-01-3520, Reprinted from SI and Diesel Engine Performance and Fuel Effects (SP-1645).

Norton, P., K. Vertin, B. Bailey, N.N. Clark, D.W. Lyons, S. Goguen, and J. Eberhardt, "Emissions from Trucks Using Fischer-Tropsch Diesel Fuel," SAE Paper 982526, October 1998. 
Ryan, T. W. III and D. Montalvo, "Emissions and Performance of Fischer Tropsch Diesel Fuels in a Modern Heavy Duty Diesel Engine," AICHE, Houston, March 1997.

Ryan, T.W. III and J. Leet, "Natural Gas Vehicle Options: CNG/LNG/DME/Fischer Tropsch or ???," Presentation at Energy Frontiers International Meeting, Tucson, 1997.

Santini, D. J., A.D. Vyas, and J.L. Anderson, "Fuel Economy Improvement via Hybridization vs. Vehicle Performance Level," SAE Paper No. 2002-01-1901, Reprinted from Proceedings of the 2002 Future Car Congress on CD-ROM (FCC2002CD), 2002.

Schaberg, P.W., I.S. Myburgh, J.J. Botha, P.N. Roets, C.L. Vijoen, L.P. Dancuart, and M. Starr, "Diesel Exhaust Emissions Using Sasol Slurry Phase Distillate Process Fuels," SAE 972898, October 1998.

Sirman, M. and E. Owens, "DOE/PNGV Project for Emissions Comparisons of Alternative Fuels in an Advanced Automotive Diesel Engine," DOE Fuels Workshop, Tucson, September 1998.

Stanglmaier, R., T.W. Ryan, and J. Souder, "HCCI Operation of a Dual-Fuel Natural Gas Engine for Improved Fuel Efficiency and Ultra-Low $\mathrm{NO}_{\mathrm{X}}$ Emissions at Low to Moderate Engine Loads," SAE Paper 2001-02-1897, Reprinted from: HCCI Combustion (SP-1627).

Tyson, K.S., C.J. Riley, and K.K. Humphreys, "Fuel Cycle Evaluations of Biomass - Ethanol and Reformulated Gasoline," Volume 1, National Renewable Energy Laboratory, Oak Ridge National Laboratory, and Pacific Northwest Laboratory, NREL/TP-463-4950, November 1993.

Uematsu, Y., T. Nakada, L. Zhang, H. Ichikawa, and W.H. Haverdink, "High Fuel Economy CIDI Engine for G PNGV Program," SAE Paper No. 2002-01-1084, Reprinted from Advanced Hybrid Vehicle Powertrain Technology (SP-1697), 2002.

U.S. EPA, "Compilation of Air Pollutant Emission Factors," AP-42, Fifth Edition, Vol. I, Stationary Point and Area Sources, Office of Air Quality Planning and Standards, 1999.

Wang, M., GREET 1.5a: Changes from GREET 1.5, Center for Transportation Research, Argonne National Laboratory, January 2000.

Web site: FuelEconomy.gov (www.fueleconomy.gov/feg/findacar.htm) 


\subsection{INTRODUCTION}

The LCA studies (reviewed in Section 2) and GREET 1.6 (reviewed in Section 3) consider GTL and methanol production technologies that were largely based on conceptual process designs from several studies published in the early to mid 1990s. These studies generally employed efficiencies in the lower range for current and future commercial process technologies. Such efficiencies are appropriate representations of current industry averages, but not of future commercial processes, the great majority of whose capacity has yet to be constructed and put into operation.

A focus of the UCF LCA is to calculate thermal efficiencies of the commercial technologiesover the near term (2006) and long term (2015) - that will be best representative of ConocoPhillips processes.

This section reviews the process data for GTL fuels and methanol in GREET, reviews other commercial GTL and methanol technologies, calculates thermal and carbon efficiencies for the technologies chosen to be representative of current and future ConocoPhillips processes, and calculates theoretical limits for thermal efficiencies for these processes.

\subsection{ASPEN PLUS MODELS}

The modeling tool used to estimate thermal efficiency for GTL and methanol production was Aspen Plus. Aspen Plus is a process simulator employed extensively by the chemical industry to model heat and material balances, thermodynamic equilibrium, optimization of process design, and operation of chemical plants. Aspen Plus was used to model the thermodynamic efficiency of GTL and methanol production in order to determine achievable efficiencies and to establish theoretical upper limits on efficiency.

Figure 4-1 shows an example of the Aspen process flow simulation model of the two-stage reforming process for synthesis gas (syngas) generation for GTL and methanol.

Simulation models of idealized systems in Aspen were developed to estimate the upper limits of thermal efficiency for GLT and methanol production. The assumptions used for the maximum thermodynamic efficiency models include an equilibrium approach temperature of zero for all reactors; $100 \%$ efficiency for all pumps, compressors, and expanders; and a low-level heat dissipation to atmospheric air (meaning that power required for cooling water pumps and air cooling fans is zero). The effect of these assumptions is that energy losses within the system are ignored.

The upper bound efficiency estimates for GTL and methanol were then used to validate the efficiency values for each process, and to ensure that the final values were well below the upper limit efficiencies. 


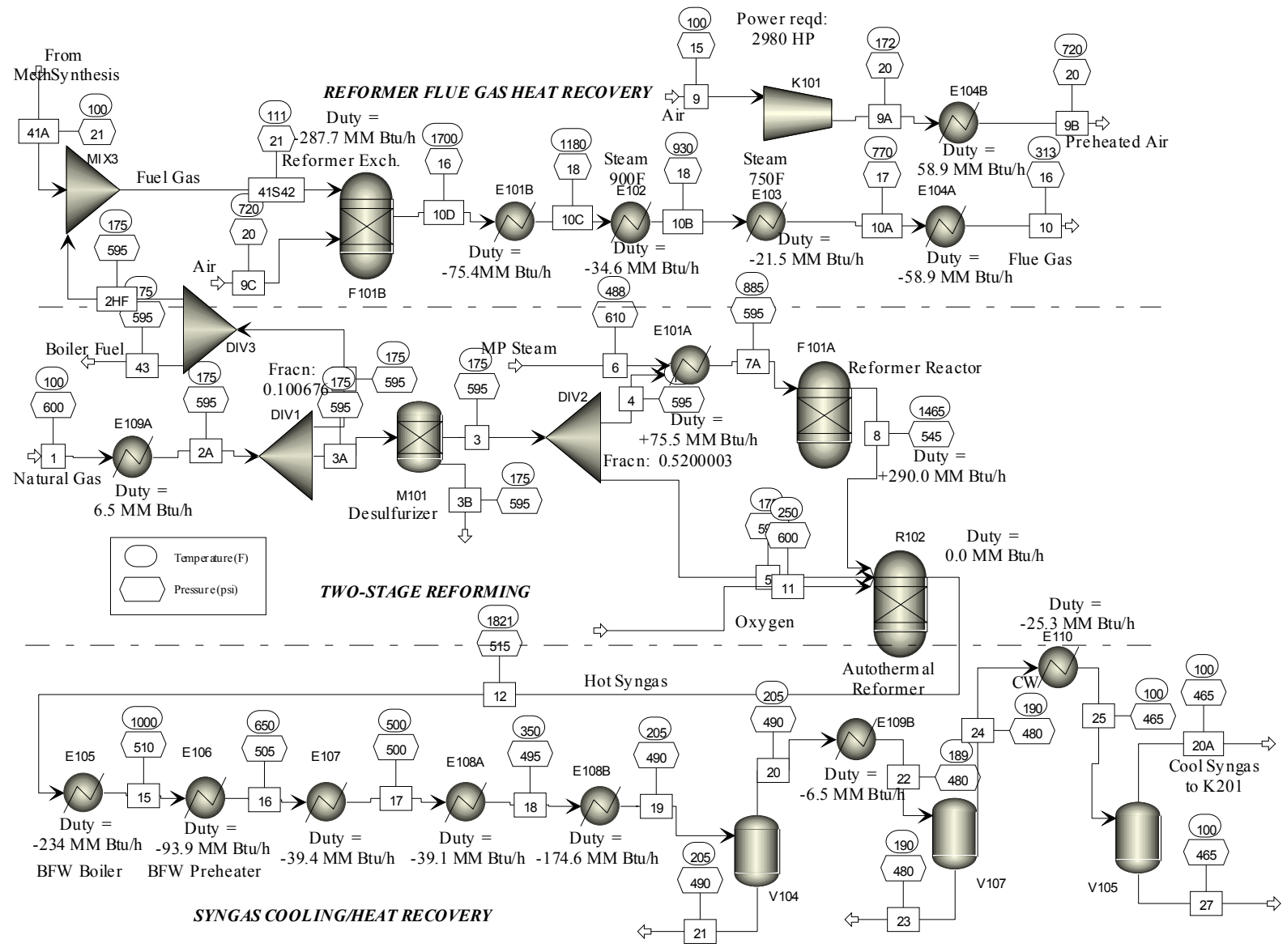

Figure 4-1 Aspen Plus Process Simulation Flow Diagram for Syngas Generation

\subsection{GTL PRODUCTION}

\subsubsection{GREET Assumptions}

The UCF LCA assumes that because of the remote location of the GTL plant, neither electricity nor steam can be exported. For this case, GREET uses an average process efficiency based on two plant designs: a Bechtel conceptual design, and a Syntroleum commercial design. GREET assumes that half the GTL plants will be of the Bechtel design and the other half of the Syntroleum design.

GREET 1.6 assumes an air-based syngas generation process for the production of FTD, reflected in an emissions factor of $17.6 \mathrm{~g} / \mathrm{MMBtu}$ for $\mathrm{NO}_{\mathrm{X}}$ at the fuel processing stage.

$\mathrm{NO}_{\mathrm{X}}$ at the syngas unit comes from two sources: (1) the nitrogen in the feed gas and (2) the nitrogen in the oxidant. For an oxygen-based process, there should be no $\mathrm{NO}_{\mathrm{X}}$ generated from the oxidant, with the only $\mathrm{NO}_{\mathrm{X}}$ coming from nitrogen in the gas stream. For the oxygen-based 
syngas process, even with the presence of nitrogen in the natural gas, the $\mathrm{NO}_{\mathrm{X}}$ generation should be very small.

\subsubsection{Energy Efficiency Calculation}

Choi (Choi, 1997) includes a material balance for the GTL plant that uses a partial oxidation (POX) design and co-produces power for export. May (May, 2001) and Bennethum (Bennethum, 1991) provide energy content data for GTL products, which are used in GREET 1.5 to develop the energy efficiency data for the GTL plant, which is calculated to be $55 \%$. This number takes into account the net power produced.

\subsubsection{Efficiencies in GREET Documentation}

GREET references data used to calculate the default energy efficiency and carbon efficiency for GTL production based on the following designs: POX, Sasol, Shell, Exxon, and Syntroleum. Table 4-1 summarizes the efficiencies of these plant designs, as reported in GREET documentation. The top two sets of efficiencies are based on an Argonne National Laboratory (Argonne National Laboratory, 1999) study. The bottom two sets were provided to ANL by Syntroleum. On the basis of the information summarized in Table 4-3, GREET 1.5 (an earlier version than the one used in the UCF LCA) assumes GTL production energy efficiencies as given in Table 4-2. In Table 4-2, the energy efficiency for GTL plants with cogeneration is lower because the steam and heat that would otherwise be used in the process is used instead to generate electricity. An emissions credit is given for cogeneration, assuming that there is a ready market for the power and that other sources of electricity are displaced.

Table 4-1 Energy and Carbon Efficiencies for GTL Production Technologies

\begin{tabular}{|l|c|c|}
\hline \multicolumn{1}{|c|}{ GTL Process Design } & Energy Efficiency & Carbon Efficiency \\
\hline ANL's FT assessment, excess steam exported & & \\
\hline POX design & $55 \%$ & $71 \%$ \\
\hline Sasol, Shell, Exxon design & $62 \%$ & $78 \%$ \\
\hline Syntroleum design & & \\
\hline Excess steam not recovered & $53 \%$ & $75 \%$ \\
\hline Excess steam recovered & $67 \%$ & $75 \%$ \\
\hline
\end{tabular}

Table 4-2 GREET 1.5 Efficiencies for GTL Production

\begin{tabular}{|l|c|}
\multicolumn{1}{|c|}{ GTL Process Design } & Energy Efficiency \\
\hline FT plant, without cogeneration & $55 \%$ \\
\hline FT plant, with cogeneration & $53 \%$ \\
\hline
\end{tabular}

In GREET 1.6, the efficiencies are different from those used in GREET 1.5, as documented in the GREET 1.5 manuals. However, GREET 1.6 has not been fully documented. Table 4-3 shows the default values assumed in GREET 1.6. 
Table 4-3 GREET 1.6 Default Efficiencies for GTL Production

\begin{tabular}{|l|c|}
\hline \multicolumn{1}{|c|}{ GTL Process Design } & Energy Efficiency \\
\hline GTL plant, with cogeneration & $55 \%$ \\
\hline GTL plant, without cogeneration & $63 \%$ \\
\hline
\end{tabular}

\subsubsection{Technology Assumptions for the UCF LCA}

To realize economies of scale and to improve the thermal efficiency by greater heat integration, plants producing 150,000 barrels per day (bpd) of FT liquids will be in operation by the year 2015. To produce 150,000 bpd of FT liquids before 2015 , two trains each of 75,000 bpd capacity will be required.

In the GTL process, natural gas is converted to syngas by the partial oxidation method, in which the following reaction takes place:

$$
\mathrm{CH}_{4}+1 / 2 \mathrm{O}_{2} \rightarrow \mathrm{CO}+2 \mathrm{H}_{2}+\text { Heat }
$$

The syngas produced is converted to hydrocarbons of varying chain length by passing over a suitable catalyst. The following reaction occurs in the FT unit:

$$
(2 \mathrm{n}+1) \mathrm{H}_{2}+\mathrm{nCO} \rightarrow \mathrm{C}_{\mathrm{n}} \mathrm{H}_{2 \mathrm{n}+2}+\mathrm{nH}_{2} \mathrm{O}+\text { Heat }
$$

Five major processes are under development: one by ConocoPhillips, two by ExxonMobil, one by Rentech, and one by Syntroleum. Three commercial FT processes-from Sasol, Shell, and ExxonMobil—currently exist. These processes are briefly described below.

\subsubsection{ConocoPhillips}

The ConocoPhillips process produces syngas by a catalytic partial oxidation step in which natural gas reacts with oxygen. The hot syngas is cooled by raising steam, which is then used to produce power. The cooled syngas is passed over cobalt catalysts to produce FT liquids, which are mostly normal paraffins and unreacted syngas. The unreacted syngas is recycled, and the liquids are fractionated to produce diesel, naphtha, and kerosene/jet fuel.

An oxygen-based syngas generation process is assumed in the UCF LCA, representative of the ConocoPhillips process, and an emission factor of zero is used for $\mathrm{NO}_{\mathrm{X}}$ generation at GTL production. The thermal efficiency factor for this design includes energy use for the air separation unit.

\subsubsection{ExxonMobil AGC}

ExxonMobil has two processes under development: Advanced Gas Conversion (AGC), and Mobil Olefins to Gasoline and Distillates (MOGD). In the AGC process, natural gas is partially oxidized in a fluidized-bed reactor with oxygen. The syngas from the fluidized reactor is sent to the bubble-column-type FT reactor. The FT reactor effluent is hydrocracked and then fractionated to produce naphtha, diesel, and waxes. 


\subsubsection{Rentech}

In the Rentech process, natural gas is converted to syngas by any one of the methods for converting natural gas to syngas. The syngas is then passed over an iron-based catalyst in the FT reactor, where it is converted to FT liquids, which are fractionated to $70 \%$ middle distillates and $30 \%$ naphtha. In one conceptual design, Rentech carbon efficiency was calculated as $77 \%$ (Yakobson, 2000).

\subsubsection{Syntroleum}

In the Syntroleum process, natural gas is converted to syngas by an air-based steam reforming process (instead of oxygen, as in other processes). The syngas is fed to the FT reactor, which can be tubular or a slurry type using a proprietary catalyst. The reactor products are light paraffins and heavy paraffins. The light paraffins are condensed and the heavy paraffins are hydrocracked. The light paraffins and hydrocracked paraffins are combined and subjected to fractionation to produce the final products.

\subsubsection{Sasol}

In the Sasol Slurry Phase Distillate (SSPD) process (a commercial process), natural gas is converted to syngas by a Haldor Topsoe's auto-thermal reforming step. The synthesis gas is then converted to GTL products in the Sasol slurry phase FT reactor, which produces waxy synthetic crude. The waxy crude is then hydro-isomerized to produce diesel and naphtha.

\subsubsection{Shell}

In the Shell Middle Distillate Synthesis (SMDS) process (a commercial process), natural gas is reformed in a non-catalytic partial oxidation step. The syngas is fed to the FT reactor, which uses Shell's proprietary zirconium-promoted cobalt catalyst packed in tubes. The gas phase flows inside the tube, and boiler feedwater flows outside the tubes to remove the reaction heat. The reactor effluent contains wax and condensable hydrocarbons. The hydrocarbons produce naphtha, kerosene, and diesel.

Shell indicates that the SMDS process has a thermal efficiency range of $60 \%-65 \%$ and a carbon conversion efficiency of $75 \%-80 \%$. This is consistent with the GREET 1.6 default values of $63 \%$ thermal efficiency and $80 \%$ carbon efficiency for GTL plants that do not export electricity or steam.

\subsubsection{ExxonMobil MOGD}

No information was available regarding the ExxonMobil MOGD commercial process.

\subsubsection{Theoretical Limits}

In all the GTL production processing, natural gas is first converted to syngas constituents, which are then subjected to the FT synthesis. The following reaction may be used to chemically represent the whole GTL process:

$$
n \mathrm{CH}_{4}+1 / 2 n \mathrm{O}_{2} \rightarrow\left(\mathrm{CH}_{2}\right)_{n}+n \mathrm{H}_{2} \mathrm{O}
$$


Based on the stoichiometry of the above reaction, the maximum thermal efficiency of the FT process is calculated to be $77 \%$.

Clarke of Foster Wheeler (Clarke, 2002) calculated the maximum theoretical efficiency of GTL by means of the following equation:

$$
\text { Maximum theoretical efficiency }=100\left(\mathrm{LHV} \text { of }-\mathrm{CH}_{2}-\right) /\left(\mathrm{LHV} \text { of } \mathrm{CH}_{4}\right)
$$

Where $-\mathrm{CH}_{2}$ - is a unit group of a hydrocarbon chain.

This calculation yields a maximum thermal efficiency of $78 \%$.

\subsubsection{UCF Final GTL Technology and Data}

Nexant developed the data shown in Table 4-4 for future GTL efficiencies with respect to the above analysis and review of commercial technologies. The efficiencies for the years 2000-2001 and 2006 are representative of the ConocoPhillips commercial technologies for 2006 and 2015, as reported to Nexant by ConocoPhillips. The efficiencies for the year 2015 are projected forecasts, with a $0.55 \%$ efficiency improvement per year from 2006 to 2015 . For the year 2015, efficiency is assumed to be seven percentage points lower than the maximum thermal efficiency $(77 \%)$.

The ConocoPhillips technology estimates were derived from engineering analysis and lab-scale demonstrations, and not from commercial operation.

An oxygen-based syngas generation process is assumed in the UCF LCA, and an emission factor of zero is used for $\mathrm{NO}_{\mathrm{X}}$ generation at GTL production. The energy efficiency calculation includes energy required for the air separation unit.

Table 4-4 UCF LCA Efficiencies for GTL Production

\begin{tabular}{|l|c|c|c|}
\hline \multicolumn{1}{|c|}{ Parameter } & $\mathbf{2 0 0 0 - 2 0 0 1}$ & $\mathbf{2 0 0 6}$ & $\mathbf{2 0 1 5}$ \\
\hline Gas consumption & & & \\
\hline MMBtu (HHV)/bbl & 8.7 & 8.3413 & 7.9838 \\
\hline MMBtu (LHV)/bbl & 7.8 & 7.507 & 7.1854 \\
\hline bbl/100MMScf & 11,700 & 12,110 & 12,650 \\
\hline Energy efficiency, \% & $65 \%$ & $67 \%$ & $70 \%$ \\
\hline Carbon efficiency, \% & $85 \%$ & $85 \%$ & $85 \%$ \\
\hline
\end{tabular}

\subsection{METHANOL}

\subsubsection{GREET Assumptions}

GREET bases its analysis of methanol production on steam reforming (SMR) and auto-thermal reforming (ATR) for the production of syngas. Natural gas is reformed to produce syngas, and the components of syngas then undergo a synthesis reaction to produce methanol. Reforming is energy consuming and has a significant impact on the overall process efficiency. GREET 
assumes that most of the existing plants are SMR type, and that future plants will rely on ATR or two-stage reforming technologies that yield higher efficiencies. GREET uses a thermal efficiency of $67.8 \%$ for both the near-term and long-term cases.

\subsubsection{Natural Gas Composition}

GREET assumes that natural gas contains $74 \%$ carbon by weight; pure methane contains $75 \%$ carbon. GREET assumes an HHV and LHV for natural gas of 1,031 Btu/SCF and $928 \mathrm{Btu} / \mathrm{SCF}$, respectively

\subsubsection{Natural Gas Reforming and Excess Hydrogen}

The GREET documentation for methanol does not clearly state how excess hydrogen is handled in the production of syngas. However, in the GREET documentation for GTL production, it is stated that in the production of syngas, natural gas is reformed in an SMR, and the excess hydrogen is used as fuel. This same assumption is assumed to apply for syngas production for methanol.

\subsubsection{Natural Gas for Feed and Fuel}

In methanol production, natural gas is used as both a feedstock and a process fuel. The GREET default proportion for the amount of natural gas fed to the methanol process is $83 \%$, and $17 \%$ of the natural gas is combusted to generate process heat.

In a paper describing the Lurgi process (Gohna, 1997) for a 5,000 tonne/day (tpd) plant, a feed of $90 \%$ for process and $10 \%$ for fuel is cited, with no import/export of steam or electricity.

\subsubsection{Methanol Plant Efficiencies}

The GREET default efficiency values for various methanol plant designs are listed in Table 4-5.

Table 4-5 GREET 1.6 Efficiencies for Methanol Production

\begin{tabular}{|l|c|}
\hline \multicolumn{1}{|c|}{ Methanol Plant Configuration } & Value \\
\hline $\begin{array}{l}\text { Energy efficiency of methanol plants: remote natural gas as feedstock, without steam or } \\
\text { electricity export }\end{array}$ & $67.8 \%$ \\
\hline $\begin{array}{l}\text { Energy efficiency of methanol plants: remote natural gas as feedstock, with steam or } \\
\text { electricity export }\end{array}$ & $64.0 \%$ \\
\hline $\begin{array}{l}\text { Energy efficiency of methanol plants, remote flared gas as feedstock, without steam or } \\
\text { electricity export }\end{array}$ & $67.8 \%$ \\
\hline $\begin{array}{l}\text { Energy efficiency of methanol plants: remote flared gas as feedstock, with steam or } \\
\text { electricity export }\end{array}$ & $64.0 \%$ \\
\hline
\end{tabular}

The Lurgi methanol plant efficiency as quoted in an SRI report (Apanel, 2000) is 69.9\%, on an LHV basis. The SRI-calculated $69.9 \%$ value is for future, rather than current, Lurgi plants. 


\subsubsection{Technology Assumptions for the UCF LCA}

This section provides an overview of the process configuration for methanol production assumed in the UCF LCA, based on the Lurgi process.

Lurgi (Lurgi, 2001) completed a single-train 2,500 tpd methanol plant in Point Lisas, Trinidad, in September 2000, and will build a single-train 5,000 tpd methanol plant in Point Lisas and a single-train 5,000 tpd methanol plant in Bandar Assaluye, Iran. Both 5,000 tpd plants are scheduled for completion by 2004. To realize economies of scale and to increase the thermal efficiency by greater heat integration, plants of 10,000 tpd capacities may be offered by the year 2015. To produce 10,000 tpd of methanol before 2015 , two trains each of 5,000 tpd capacity will have to be built. A 10,000 tpd plant consisting of two 5,000 tpd trains will have the advantage of operational flexibility.

The Lurgi methanol process is divided into three parts: syngas generation, methanol synthesis, and methanol purification.

\subsubsection{Syngas Generation}

Natural gas passes through a zinc oxide bed and is desulfurized. The desulfurized natural gas is then split into two roughly equal feed streams for each of the two reforming stages. The first feed stream is combined with steam, heated to about $850^{\circ} \mathrm{F}$, and then fed to the primary reformer. The primary reformer is a natural-gas-fired furnace which houses tubes packed with nickel-based catalyst. The reforming reactions take place in these tubes. Most of the packed tubes are located in the radiant section of the furnace. Additional tubes are located in the convection section of the reformer furnace to preheat the natural gas feed, and to raise steam from waste heat in flue gas. About two-thirds of the methane in the feed gas is converted to syngas in this primary reformer. Syngas exits the primary reformer at about $1,450^{\circ} \mathrm{F}$ and $530 \mathrm{psig}$.

The primary reformer effluent, the other half of the desulfurized natural gas feed, and oxygen are fed to the secondary ATR reformer. The secondary reformer is a refractory-lined, fixed-bed adiabatic reactor packed with a nickel-based catalyst. Because the oxidation reactions are exothermic, the temperature of the ATR effluent (syngas product) increases to $1,760^{\circ} \mathrm{F}$. The hot syngas, which is cooled before compression for methanol synthesis, represents substantial potential for waste heat energy recovery.

\subsubsection{Methanol Synthesis}

The cooled syngas is compressed to 1,335 psig, combined with recycle gas from the recycle compressor, preheated, and then fed to the methanol synthesis reactor. The Lurgi methanol synthesis reactor consists of a serial configuration of two shell-and-tube reactors with a copperbased catalyst inside the tubes. The first-stage reactor is cooled by boiler feedwater on the shell side to produce steam. The second-stage reactor, which operates at a lower temperature, is cooled by the syngas feed on the tube side.

The product gas exits the second-stage reactor at $450^{\circ} \mathrm{F}$. The gas is cooled partly by preheating the feed and partly by an air-cooled heat exchanger and water-cooled condenser. The condensate 
is the crude methanol, and the non-condensable gases are recycled to the reactor, with a small purge gas that is used as fuel. The pressure in the exiting crude methanol liquid stream is reduced to 20 psig by passing it through a hydraulic power-recovery turbine. Any vapor released during the pressure letdown is used as purge gas fuel. The crude methanol stream is sent to the methanol purification section.

\subsubsection{Methanol Purification}

The crude methanol stream from the methanol synthesis section contains water, higher alcohols, and light ends, all of which must be removed in order to meet the chemical grade product specification. Purification of the stream is accomplished by a two-column distillation system. The crude methanol is preheated by heat exchange with hot methanol distillate product and then fed to the light-ends column, where light ends are stripped overhead. The recovered light ends are sent to the purge gas header. The bottoms product from this column is then fed to the methanol product column. A side draw-off from the product column contains the higher alcohol by-product. Methanol is recovered overhead while water is rejected from the column bottoms.

The Lurgi methanol process is self-sufficient in meeting its power requirements. It neither exports nor imports power.

\subsubsection{Methanol Data Development}

The Lurgi methanol plant efficiency was calculated from an article published by Lurgi (Gohna, 1997 ) to be $66.6 \%$ (LHV basis). The assumed plant capacity was 5,000 tpd. An SRI report (Apanel, 2000) analyzed heat and material balances for a Lurgi plant producing 2,500 tpd of methanol and determined the thermal efficiency to be $66.9 \%$ (LHV basis). SRI subsequently revised its calculation to $69.9 \%$ efficiency after incorporating comments from Lurgi. The reason for this improvement was that while the distillation section in the SRI plant configuration consists of two columns (light-ends column and methanol product column), the revised Lurgi scheme contains three distillation columns, which results in heat savings.

\subsubsection{Theoretical Limits}

Assumptions were made on future process efficiencies arising from technology or operational improvements. To ensure the validity of these assumptions, two calculations were performed to estimate the theoretical maximum efficiency values of the methanol process. One calculation was based on the reaction stoichiometry, the other on the thermodynamic equilibrium state.

\subsubsection{Stoichiometric Efficiency Calculation}

With this method, the thermal and carbon efficiencies were calculated from the following hypothetical reaction:

$$
\mathrm{CH}_{4}+1 / 2 \mathrm{O}_{2} \rightarrow \mathrm{CH}_{3} \mathrm{OH}
$$

In this calculation, thermal efficiency is the ratio of the methanol LHV to methane LHV. This calculation gives a thermal efficiency of $80 \%$ (LHV basis) and a carbon efficiency of $100 \%$. Both efficiencies are idealized. The thermal efficiency is high because the energy released in the 
reaction, along with any energy required in bringing about the reaction, is not taken into account. The carbon efficiency is high because of the reaction stoichiometry.

\subsubsection{Thermodynamic Equilibrium State Efficiency}

With this method, the thermal efficiency of the Lurgi methanol plant was calculated using the thermodynamic equilibrium compositions of the reactor effluents under plant operating conditions. This was done with the process simulation software, Aspen Plus 11.0. In the simulation, the operating conditions of various reactors and unit operations given in the SRI report (Apanel, 2000) for the Lurgi methanol plant were used as the input to Aspen Plus.

The simulation input included the following specifications and idealized assumptions:

- The equilibrium approach temperature for all the reactors (i.e., natural gas steam reformer, auto-thermal reformer, and methanol synthesis reactors) is zero.

- The isentropic efficiency of all the compressors, pumps, and expanders is $100 \%$.

- By-products such as dimethyl ether and higher alcohols are not formed.

- No power is required (for the cooling water circulation pumps, cooling tower fans, or aircooling fans) to dissipate the low-temperature heat.

- The reflux ratio in the methanol distillation columns is equal to the minimum reflux ratio.

- No power is required to separate oxygen from atmospheric air.

From the Aspen Plus output obtained under the above specifications/assumptions, heat and material balances were prepared and thermal and carbon efficiencies were calculated. With the above specifications/assumptions, the maximum (thermodynamic equilibrium) thermal efficiency of the Lurgi methanol process was found to be $73 \%$ and the corresponding carbon efficiency $81.5 \%$.

It could be argued that by changing the operating conditions, one might be able to obtain a higher efficiency for a different equilibrium state, even though the plant might not be economical and the technology might be different from Lurgi's. In principle, the argument is correct. However, variations in the operating temperatures and pressures of the methanol synthesis reactors did not increase methanol production. A closer look at the simulation output showed that whereas the $\mathrm{CO}_{2}$ and $\mathrm{H}_{2}$ conversions were $30 \%-35 \%$, the $\mathrm{CO}$ conversion was $91 \%$, indicating that not much reactant was left in the system to produce additional methanol even by moving to another equilibrium state. Assuming that the equilibrium-based efficiency calculation did not use the best equilibrium state to give the maximum efficiency, the above findings suggest that the thermodynamic equilibrium state used in the efficiency calculation is quite close to the ideal equilibrium state (even if a technology other than the Lurgi technology is used). Thus, the 73\% thermal efficiency is near the maximum value. For the $73 \%$ thermal efficiency plant, the carbon efficiency is $81 \%$.

The maximum thermal efficiency determined by the thermodynamic equilibrium calculation $(73 \%)$ is lower than that determined by the stoichiometric calculation $(80 \%)$. There are two 
reasons for this: (1) the utilities required are ignored in the stoichiometric calculation; and (2) since the equilibrium composition of the reactor effluent is always less than the composition of the stoichiometric reactor, the product formed in an equilibrium state is always less than that formed by the reaction stoichiometry.

From the above discussion, it was concluded that for any methanol plant the maximum thermal efficiency is $73 \%$ and the maximum carbon efficiency is $81 \%$.

\subsubsection{UCF Final Methanol Technology and Data}

Table 4-6 shows the final methanol thermal and carbon efficiencies assumed for the UCF LCA. In this table, the efficiency for the year 2001 is based on the efficiency of currently operating methanol plants. The efficiency for the year 2006 is for the methanol plants cited above whose construction will be completed after 2004. A rate of improvement in thermal efficiency of $0.45 \%$ per year is assumed (a relatively modest growth for a mature technology), but is still two percentage points lower than the thermodynamic maximum for methanol process technologies (73\%). After 2015, this efficiency would be expected to plateau.

Based on a Lurgi paper (Gohna, 1997) for a 5,000 tpd plant, the UCF LCA uses 90\% natural gas for process feed and $10 \%$ for heat generation, with no import/export of steam or electricity.

\section{Table 4-6 UCF LCA Efficiencies for Methanol Production}

\begin{tabular}{|l|c|c|c|}
\multicolumn{1}{|c|}{ Parameter } & $\mathbf{2 0 0 0 - 2 0 0 1}$ & $\mathbf{2 0 0 6}$ & $\mathbf{2 0 1 5}$ \\
\hline Gas consumption & & & \\
\hline MMBtu (HHV)/gal & 0.0945 & 0.0928 & 0.0889 \\
\hline MMBtu (LHV)/gal & 0.0853 & 0.0836 & 0.0800 \\
\hline GJ (HHV)/tonne & 33.1 & 32.52 & 31.15 \\
\hline GJ (LHV)/tonne & 29.9 & 29.29 & 28.03 \\
\hline Energy efficiency, \% & $67 \%$ & $68 \%$ & $71 \%$ \\
\hline Carbon efficiency, \% & $84 \%$ & $86 \%$ & $89 \%$ \\
\hline
\end{tabular}

\subsection{REFERENCES}

Apanel, G. J., "Report No. 43C, Methanol Supplement C, A Private Report by the Process Economics Program,” SRI Consulting, Menlo Park, California, 2000.

Argonne National Laboratory, “Methodology, Development, Use and Results," Vol. 1, GREET 1.5 - Transportation Fuel-Cycle Model, August 1999.

Bennethum, J.E. and R.E. Winsor, "Towards Improved Diesel Fuels," International Fall Fuels and Lubricants Meeting and Exposition, Toronto, Canada, October 7-10, 1991.

Choi GN., S.J. Kramer, S. S. Tam, J.M., Fox, N.L. Carr, and G.R. Wilson, "Design/Economics of a Once-Through Natural Gas Fischer-Tropsch Plant with Power Co-production," 1997 Coal Liquefaction and Solid Fuels Contractors Review Conference, Pittsburgh, Pennsylvania, September 3-4, 1997. 
Clarke, S., "Developments in GTL Technology," Presentation to the Subject Group for Oil and Natural Gas, Institution of Chemical Engineers, March 12, 2002.

General Motors, Argonne National Laboratory, ExxonMobil, Shell, "Well-to-Wheel Energy Use and Greenhouse Gas Emissions of Advanced Fuel/Vehicle Systems - North American Analysis," April 2001.

Gohna, H., "Concepts for Modern Methanol Plants," presented at the 1997 World Methanol Conference, Tampa, Florida, December 8-10, 1997.

Lurgi, "Lurgi AG: Major Contracts Consolidate World Market Position,” 2001

May, M.P., K. Vertin, S. Ren, X. Gui, I. Myburgh, and P. Schaberg, "Development of Truck Engine Technologies for Use with Fischer-Tropsch Fuels," International Fall Fuels and Lubricants Meeting and Exposition, San Antonio, Texas, September 24 -27, 2001.

Yakobson, D.L., "Fischer-Tropsch Technology, GTL's Place in the Drive Towards Cleaner Fuels," GasTech 2000 Conference, Houston, Texas, November 15, 2000. 


\section{$5.1 \quad$ INTRODUCTION}

An important component of a Life Cycle Assessment (LCA) is the methodology by which energy and emissions in multiproduct production systems, such as petroleum refining, are attributed to the production of the various products. The ISO 14040 standards for LCAs specify two methodologies for dealing with multiproduct systems: the allocation approach and the system boundary expansion (SBE) approach. Regardless of the approach taken, the key question is how to attribute the emissions inventory and environmental burdens to the system outputs. Before this question can be addressed, the terms "primary product" and "co-product" need to be clearly defined.

\subsubsection{Primary Products and Co-products}

In this study, the term "primary product" is defined as those outputs of a production system that are the primary economic drivers of the system or industry. The term "co-products" is defined as those outputs that are produced along with the primary products, and that may have economic value, but that would not be produced if not for the production of the primary products. In a system such as petroleum refining, although a wide range of useful products is produced, the primary economic drivers of the system are transportation fuels for motor vehicles. If it were not for these primary drivers, other products, such as petroleum coke, would not be produced.

This study makes use of the following classifications of primary products and co-products:

- Gasoline and diesel motor fuels are primary products of petroleum refining.

- Petroleum coke, heavy residual oil, asphalt, fuel oil, naphtha, kerosene/jet fuel, and liquefied petroleum gas (LPG) are co-products of the system.

- Fischer-Tropsch (FT) diesel and FT naphtha are primary products in gas-to-liquids (GTL) production systems. For the configuration studied in this report, FT diesel (FTD) makes up $70 \%$ of the product slate by mass, and FT naphtha makes up 30\%.

- There are no significant co-products produced from the GTL process.

- Methanol is a primary product of natural-gas-to-methanol conversion; there are no co-products in the system.

\subsubsection{Allocation vs. System Boundary Expansion}

ISO 14040 states that allocation is acceptable if data or resources are limited. Most fuel cycle studies in the literature, including those using the GREET model, take an allocation approach. In this approach, all products, except for the primary products under study, are placed outside the system boundary; energy and emissions are allocated on the basis of mass, energy content, or economic value of the products; and all downstream applications of the excluded products are also excluded from the system boundary. Specifically, for the systems discussed here, gasoline and diesel, the primary system products for petroleum refining, are each allocated a share of full refinery emissions based on their energy contents relative the energy contents of all system 
products. The downstream energy and emissions of the primary products are analyzed and accounted for. The energy and emissions due to production and downstream use of co-products are not considered; that is, the co-products are placed outside of the system boundary. This considerably reduces the data collection and analysis effort required in the LCA.

ISO 14040 expresses a preference for the SBE methodology (International Standards Organization, 1997, 1998, 1999). In this approach, all co-product emissions at the production stage are accounted for in the system, and the downstream co-products functions and associated energy and emissions are included in the system as well. When used in a comparative assessment, the downstream functions of the co-products are compared with alternative products serving the same functions, and the net energy and emissions are credited or debited to the primary system.

The UCF LCA develops a novel methodology, known as Co-product Function Expansion (CFE). CFE expands the system boundary based on the functions of individual co-products in order to assess the effects of incrementally including co-products within the system boundary.

ISO 14040 states that SBE is applicable only when alternative products can serve the functions served by the co-products, and assumptions about what is actually displaced by the co-products must be reasonable and documented. An example in petroleum refining in which this condition can be satisfied is the use of petroleum coke for power generation. If petroleum coke is not burned for fuel, the electricity it would have generated will be replaced by electricity generated by coal, natural gas, a regional electricity mix, or perhaps even conservation.

Two examples in petroleum refining in which the SBE condition cannot be satisfied - thereby making allocation mandatory - are heavy residual oil to marine transportation, and petroleum jet fuel to air transportation. In marine transportation, although there are alternatives such as diesel fuel or other lighter distillate fuels, the replacement of bunker fuel by other fuels in ocean tankers is not a reasonable assumption, owing largely to economics. Over the near term, the same argument holds for jet fuel. (Over the long term, however, GTL fuels have the technical and economic potential to replace petroleum jet fuels.)

The CFE methodology conforms to these ISO requirements for SBE.

\subsection{CFE METHODOLOGY}

CFE is a comparative methodology, in which the downstream functions of the co-products are assessed relative to products that would replace the functions of the co-products if they were not produced. The specific alternative product comparisons must be explicitly stated in the CFE scenario definition.

Generically, the CFE methodology is carried out as follows:

- Co-product emissions are attributed to the primary product or products in the fuel production stage. For example, in petroleum refining, emissions from petroleum coke are attributed to gasoline and diesel. The allocation to gasoline and diesel is based upon the energy content of each product. 
- Energy and emissions for only the portion of the co-products (on an energy content, lower heating value [LHV] basis) that are used in the specified downstream functions are attributed to the primary products. Market data and or market assumptions are used to determine these proportions.

- The co-products are then compared with alternative products in downstream applications (e.g., petroleum coke vs. coal for power production), and the net energy and emissions inventories are assigned as either credits or debits to the primary products.

\subsection{SCOPE DEFINITION FOR THE CFE APPLICATION TO THE PETROLEUM SYSTEM}

\subsubsection{CFE System Boundaries for Petroleum Coke and Heavy Residual Oil}

In this study, the CFE methodology was applied to two petroleum system co-products: petroleum coke and heavy residual oil, which are "less desirable" co-products of the petroleum refining system. Petroleum coke and heavy residual oil have relatively low economic value, and have considerable potential environmental impact in downstream applications.

Figures 5-1 and 5-2 show the CFE system boundaries for petroleum coke and heavy residual oil. The system boundary encompasses the full upstream systems for the alternative products (e.g., coal and natural gas.) When the CFE system boundary is coupled with the primary product system boundary, the full upstream system for coke and heavy residual oil are included as well, so that there is a full equivalent comparison between systems.

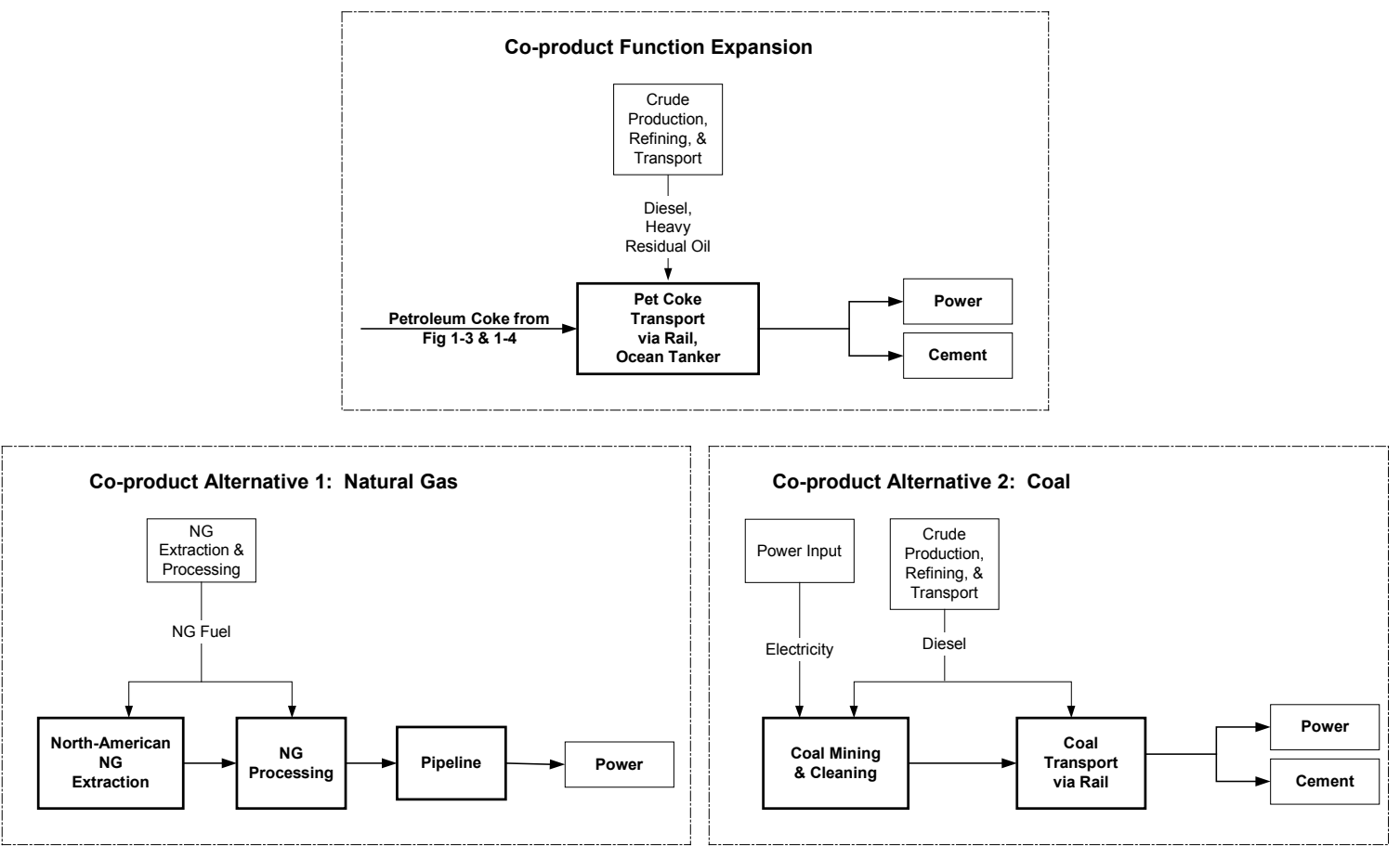

Figure 5-1 CFE System Boundary for Petroleum Coke 

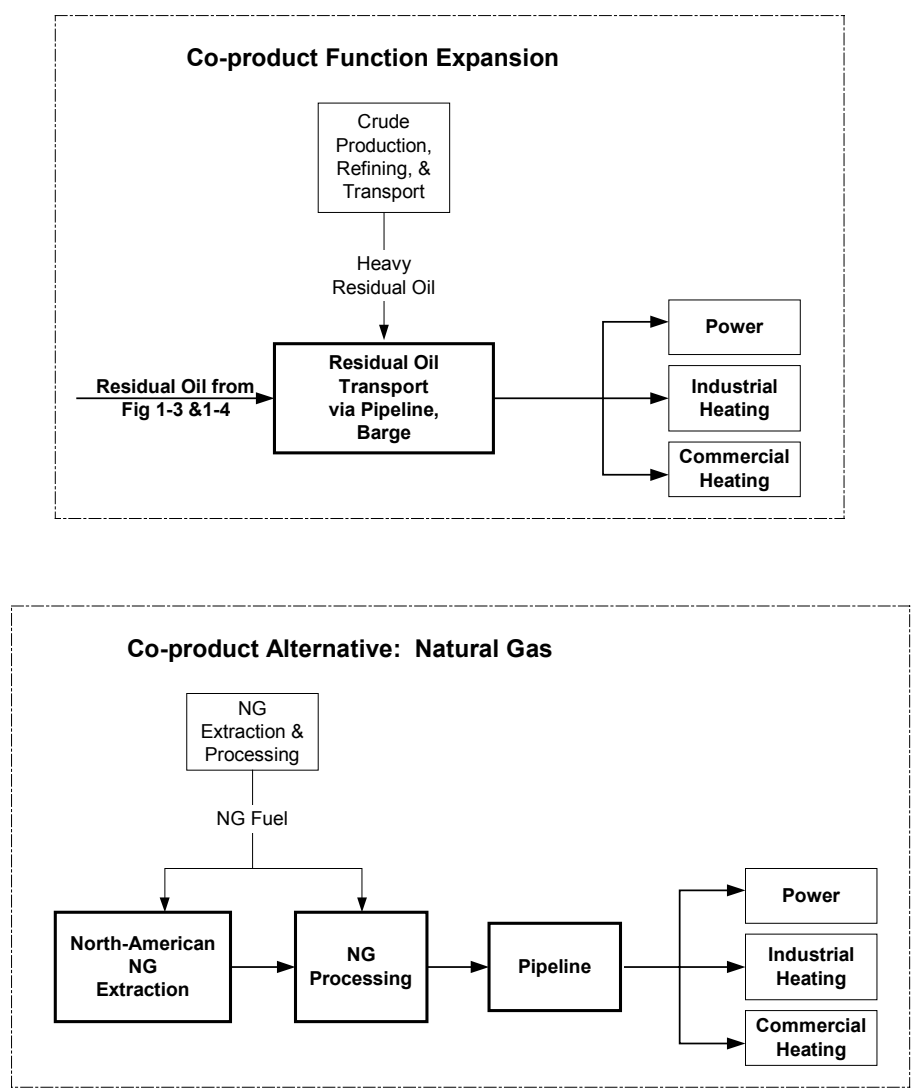

Figure 5-2 CFE System Boundary for Heavy Residual Oil

\subsubsection{CFE Sensitivity: Lower and Upper Ranges}

Two limiting cases were calculated in order to characterize the lower and upper ranges on the CFE, if more or fewer co-products were included in the analysis.

The lower range for the CFE is defined as the case in which no co-product energy or emissions are allocated to the primary product results. This is the default result from the GREET model.

The upper range for the CFE is defined as the case in which all refinery and upstream feedstock stage co-product energy and emissions are allocated to gasoline and diesel. However, no downstream co-product functions are included in the system boundary, as is done in the CFE. Assuming that there are no significant net benefits from downstream function comparisons credited to the primary products, this upper range is at least as great as a full system boundary expansion.

\subsubsection{The CFE Functional Unit}

The functional unit used for the full fuel cycle (well-to-wheels, or WTW) for the CFE scenarios is light duty vehicle miles, as used throughout the UCF LCA. 
Expanded co-product functions are considered within the analysis (coke-to-power, coke-tocement, heavy residual oil-to-power, and heavy residual oil-to-heat/steam). These functions are considered on a net basis relative to product alternatives serving the same functions. In the wellto-tank (WTT) analysis considered in this section, net energy and emissions inventories are allocated to the primary fuels, gasoline and diesel, per MMBtu of primary fuel. These results are then converted to the WTW functional unit, light duty vehicle miles, by taking into account the quantity of fuel, in MMBtu's, required to serve the functional unit.

\subsubsection{CFE Petroleum Cases}

Table 5-1 shows the set of petroleum fuel cases used in this study. Lower range, upper range, and CFE cases are developed for PADD III 2006 and 2015. PADD III heavy is a sensitivity case for a higher density crude slate.

The CFE cases are the primary petroleum fuel scenarios used in the Life Cycle Inventory (LCI) results presented in Section 6 of this report. The lower and upper range cases are presented only in this section (Section 5) to provide some context for the results.

Table 5-1 UCF LCA Cases

\begin{tabular}{|c|c|c|c|c|}
\hline PADD & Description & $\begin{array}{c}\text { Gasoline } \\
\text { Efficiency } \\
(\%)\end{array}$ & $\begin{array}{l}\text { LS Diesel } \\
\text { Efficiency } \\
(\%)\end{array}$ & $\begin{array}{c}\text { LS } \\
\text { Diesel } \\
\text { (ppm) }\end{array}$ \\
\hline \multirow{3}{*}{ PADD III 2006} & Lower range: no-co-product allocation & \multirow{3}{*}{85.5} & \multirow{3}{*}{87.0} & \multirow{3}{*}{10} \\
\hline & $\begin{array}{l}\text { Upper range: full co-product slate allocation: coke, RO, naphtha, } \\
\text { kerosene, jet fuel, fuel oil, asphalt }\end{array}$ & & & \\
\hline & CFE: power (coke vs. coal, RO vs. NG), and cement (coke vs. coal) & & & \\
\hline \multirow{3}{*}{ PADD III 2015} & Lower range: no co-product allocation & \multirow{3}{*}{85.3} & \multirow{3}{*}{86.8} & \multirow{3}{*}{7} \\
\hline & $\begin{array}{l}\text { Upper range: full co-product slate allocation: coke, RO, naphtha, } \\
\text { kerosene, jet fuel, fuel oil, asphalt }\end{array}$ & & & \\
\hline & CFE: power (coke vs. coal, RO vs. NG), and cement (coke vs. coal) & & & \\
\hline \multirow{3}{*}{$\begin{array}{l}\text { PADD III heavy } \\
2015\end{array}$} & Lower range: no co-product allocation & \multirow{3}{*}{85.1} & \multirow{3}{*}{86.6} & \multirow{3}{*}{7} \\
\hline & $\begin{array}{l}\text { Upper range: full co-product slate allocation: coke, RO, naphtha, } \\
\text { kerosene, jet fuel, fuel oil, asphalt }\end{array}$ & & & \\
\hline & CFE: power (coke vs. NG,RO vs. NG), and cement (coke vs. coal) & & & \\
\hline
\end{tabular}

CFE $=$ Co-product Function Expansion $\mathrm{RO}=$ Heavy residual oil $\mathrm{NG}=$ Natural gas

\subsection{APPLICATION OF CFE TO PETROLEUM}

In this study, the CFE methodology was applied to the federal reformulated gasoline (FRFG) and ultra-low sulfur diesel (ULSD) cases. PADD III is used to represent the product slate for which the function expansion for petroleum coke and heavy residual oil is performed. (Refer to Tables A-1 and A-2 in Appendix A for crude slate and product slate data for the PADD III case.) PADD III is representative of the average crude input slate and product output slate in the United States.

There are two steps in performing CFE. These steps are discussed in Sections 5.3.1 and 5.3.2. 


\subsubsection{Fuel Production Stage}

The first step in performing CFE for petroleum coke and heavy residual oil is to determine the refining energy and emissions of each co-product and then attribute these emissions to gasoline and diesel.

GREET calculates energy and emissions for several individual refinery products and coproducts: gasoline, diesel, petroleum naphtha, heavy residual oil, and LPG. GREET does not calculate emissions for petroleum coke, kerosene/jet fuel, asphalt, and No. 2 fuel oil (Argonne National Laboratory, 1999).

As mentioned earlier, the energy and emissions inventories attributable to co-products must be calculated with respect to a specific representative product slate, with primary product and coproduct volumes, calculated on an LHV basis for each product. PIMS was run to obtain the product slate energy content of given product slates, with cases for PADD III 2006, PADD III 2015, and PADD III heavy, and then used to calculate factors for the co-product energy/emissions shares.

Table 5-2 summarizes the CFE factors, which represent the energy content of each co-product relative to the total energy content for gasoline and diesel for that case. The proportions are based on the total Btu content of the product slate.

Table 5-2 CFE Factors

\begin{tabular}{|l|c|c|c|}
\multicolumn{1}{|c|}{ Co-Product } & PADD II 2006 & PADD II 2015 & PADD III Heavy \\
\hline Coke & 0.0575 & 0.0741 & 0.1249 \\
\hline Heavy residual oil & 0.0810 & 0.0699 & 0.0800 \\
\hline LPG & 0.0544 & 0.0561 & 0.0599 \\
\hline Kerosene/jet fuel, naphtha & 0.2086 & 0.2014 & 0.2059 \\
\hline No. 2 fuel oil & 0.1408 & 0.1269 & 0.1351 \\
\hline Asphalt & None & None & 0.0261 \\
\hline
\end{tabular}

For a given product slate, the CFE factors are calculated as:

$$
\text { Co-product } i \text { factor }=\frac{\text { Total co-product } i \text { Btu }}{(\text { Total gasoline Btu }+ \text { Total diesel Btu })}
$$

The total co-product Btus is for only the portion of the co-product included in the CFE system boundary.

The next step is then to allocate co-product $i$ energy and emissions to gasoline and diesel.

The total refining energy for PADD III FRFG 2006 is then modified as follows:

$$
\mathrm{B}=\mathrm{A}(1+0.0575)
$$

Where, 
$\mathrm{A}=$ total refining energy for gasoline

$\mathrm{B}=$ total refining energy for gasoline adjusted for petroleum coke

Emissions from other co-products are allocated to gasoline and diesel in a similar fashion.

Not all petroleum coke or heavy residual oil that is produced in the PADD III refinery is employed for the functional uses specified in the CFE system boundary. For example, market data for petroleum coke indicates that $14 \%$ of U.S. domestic coke produced is used in power production globally, and $40 \%$ of this coke is used in cement production. Thus, $54 \%$ of the coke from the PADD III case is included in the system boundary in the CFE, and $46 \%$ of petroleum coke remains outside of the system boundary through application of the allocation methodology. Market data and assumptions are presented in detail below for coke and heavy residual oil.

\subsubsection{Downstream Co-product Stages}

The second step in the CFE method is to calculate emissions from downstream functional uses of petroleum coke and heavy residual oil. The functions considered in this study for petroleum coke are power generation and cement production, and for heavy residual oil are power generation and heat/steam production. Downstream energy and emissions also include transportation of the co-products. Table 5-3 lists the functions and alternatives selected for the 2006 and 2015 scenarios.

Energy and emissions from the co-product uses are then compared with energy and emissions generated by alternative products in the same function, e.g., power generation from coal or natural gas, and cement production from coal.

A positive net difference between energy and emissions from coke versus alternative products places an additional burden on gasoline and diesel; a negative net difference provides a credit.

Table 5-3 Downstream Applications and Alternative Products

\begin{tabular}{|c|c|c|c|}
\multirow{2}{*}{ Co-product } & & \multicolumn{2}{|c|}{ Alternative Products } \\
\hline \multirow{2}{*}{ Petroleum coke } & Application & 2006 & 2015 \\
\cline { 2 - 4 } & Power & Coal & Natural gas \\
\hline \multirow{2}{*}{ Heavy residual oil } & Cement & Coal & Coal \\
\cline { 2 - 4 } & Heat/steam & Natural gas & Natural gas \\
\cline { 2 - 4 } & Heatural gas & Natural gas \\
\hline
\end{tabular}

\subsubsection{CFE Methodology Summary for the Petroleum System}

- Choose a reference product slate (such as PADD III 2006).

- Allocate the selected co-product energy and emissions to gasoline and diesel on the basis of the energy content (LHV basis) of gasoline and diesel.

- Select a set of downstream applications for the co-product, perhaps based on the ISO $14040 \mathrm{SBE}$ requirement that there be alternative products that can serve the same function. 
- Using appropriate market data, determine what portion of the co-product is employed in the downstream application.

- Calculate the downstream emissions for the co-product in the specific applications.

- Calculate the downstream emissions of alternative products for the same functional use (e.g., energy and emissions per kWh of power produced). The energy and emissions must include the full life cycle inventories for the alternatives, from feedstock to fuel production.

- Calculate the net difference in energy and emissions between the co-product and the alternative.

- Assign the net difference to gasoline and diesel for a specific product slate case (e.g., the PADD III 2006 case). The emissions are allocated on the basis of the energy content (LHV basis) of gasoline and diesel.

\subsection{REFINERY CO-PRODUCTS}

This section presents the complete set of market and emissions data used in the CFE for petroleum coke, heavy residual oil, and petroleum naphtha. Tables A-3 through A-6 in Appendix A provide the market data used in the CFE for coke and heavy residual oil. Tables A- 8 through A-10 show details on the regional allocations used within the CFE.

\subsubsection{Petroleum Coke}

Petroleum coke is employed in downstream applications such as power generation and cement production. A description of these applications follows.

\subsubsection{Coke-to-Power}

In 1999, a total of 48 millions tonnes of petroleum coke was produced globally (Energy Information Agency, 2001), 14\% of which was used for power generation, $40 \%$ for cement production, $22 \%$ for anodes and other high-grade coke products by calcination, and $24 \%$ for other uses such as metallurgy, heating, and process heat generation. The United States produces $75 \%$ of fuel grade coke used globally, and exports $55 \%$ of its domestic production.

In the United States, less than 5\% of power generation comes from petroleum coke or a coke/coal mixture and a very small amount from coke gasification. In developing countries, particularly in Asia, petroleum coke is more commonly used in power generation because of less stringent $\mathrm{SO}_{\mathrm{X}}$ emission standards. Petroleum coke has a high sulfur content, upwards of $6 \%$. Of the 20 million tonnes of fuel grade petroleum coke that the United States exported in 1998, 3.4 million tonnes went to Japan, and 0.62 million tonnes went to the rest of Asia. Electric utilities in the United States burn about 1.6 million tonnes of petroleum coke per year (Energy Information Agency, 1998). (Refer to Tables A-3 and A-4 in Appendix A for data on petroleum coke consumption for power generation.)

Emissions factors from the Energy Information Agency (EIA) and the U.S. EPA AP-42 were used to estimate emissions from coke-based power production. In the United States and Europe, 90\% desulfurization efficiency is assumed; in Asia and Latin America, 10\% desulfurization 
efficiency is assumed. Tables 5-4 and 5-5 show that per MMBtu of energy produced, coke is more carbon-intensive than coal in generating power. For comparison, Table 5-6 shows the relevant data for the natural-gas-to-power pathway. Emissions from ocean transportation for coke exports are accounted for in the analysis.

Table 5-4 Petroleum-Coke-to-Power Parameters

\begin{tabular}{|l|c|c|c|}
\multicolumn{1}{|c|}{ Parameter } & U.S. & Japan, Europe, Canada & Asia and Latin America \\
\hline Sulfur content, \% & 6 & 6 & 6 \\
\hline Power generation efficiency, \% & $35.0 \%$ & $35.0 \%$ & $30.0 \%$ \\
\hline Fuel heating value, Btu/lb & 13,337 & 13,337 & 13,337 \\
\hline SOx emission factor constant, Ib/tonne (uncontrolled) & 234 & 234 & 234 \\
\hline SOx reduction factor (desulfurization efficiency), \% & $90.0 \%$ & $90.0 \%$ & $10.0 \%$ \\
\hline NOx emission factor, Ib/tonne & 21 & 21 & 21 \\
\hline $\mathrm{NO}_{x}$ reduction factor, \% & $30 \%$ & $30 \%$ & $0 \%$ \\
\hline $\mathrm{CO}_{2}$ emission factor, Ib/MMBtu & 225 & 225 & 225 \\
\hline
\end{tabular}

Source: EIA, US EPA AP-42 Emissions Factors

Table 5-5 Coal-to-Power Parameters

\begin{tabular}{|l|c|c|c|}
\multicolumn{1}{|c|}{ Parameter } & U.S. & $\begin{array}{c}\text { Japan, Europe, } \\
\text { Canada }\end{array}$ & $\begin{array}{c}\text { Asia and Latin } \\
\text { America }\end{array}$ \\
\hline Sulfur content, \% & 3 & 3 & 3 \\
\hline Desulfurization efficiency, \% & $90.0 \%$ & $90.0 \%$ & $10.0 \%$ \\
\hline Power generation efficiency, \% & $35.0 \%$ & $35.0 \%$ & $30.0 \%$ \\
\hline Fuel heating value, Btu/lb & 10,825 & 10,825 & 10,825 \\
\hline SOx emission factor constant, Ib/tonne & 114 & 114 & 114 \\
\hline SOx reduction factor (desulfurization efficiency), \% & $90.0 \%$ & $90.0 \%$ & $10.0 \%$ \\
\hline NOx emission factor, Ib/tonne & 63 & 63 & 63 \\
\hline $\mathrm{NO}_{x}$ reduction factor, \% & $30 \%$ & $30 \%$ & $0 \%$ \\
\hline $\mathrm{CO}_{2}$ emission factor, Ib/MMBtu & 205 & 205 & 205 \\
\hline
\end{tabular}

Source: EIA, US EPA AP-42 Emissions Factors

Table 5-6 Natural-Gas-to-Power Parameters

\begin{tabular}{|l|c|c|c|}
\multicolumn{1}{|c|}{ Parameter } & U.S. & $\begin{array}{c}\text { Japan, Europe, } \\
\text { Canada }\end{array}$ & $\begin{array}{c}\text { Asia and Latin } \\
\text { America }\end{array}$ \\
\hline Sulfur content, \% & 0.05 & 0.05 & 0.05 \\
\hline Power generation efficiency, \% & $50.0 \%$ & $50.0 \%$ & $45.0 \%$ \\
\hline Fuel heating value, Btu/cu ft & 1,031 & 1,031 & 1,031 \\
\hline SOx emission factor constant, Ib/106 cu ft & 0.6 & 0.6 & 0.6 \\
\hline $\mathrm{NOx}$ emission factor, lb/106 cu ft & 170 & 170 & 170 \\
\hline $\mathrm{NO}$ reduction factor, \% & $30 \%$ & $30 \%$ & $0 \%$ \\
\hline $\mathrm{CO}_{2}$ emission factor, Ib/MMBtu & 116 & 116 & 116 \\
\hline
\end{tabular}

Source: EIA, US EPA AP-42 Emissions Factors 


\subsubsection{Coke-to-Cement}

The cement industry uses $40 \%$ of the fuel-grade petroleum coke produced globally for fuel in cement kilns, and most of the coke produced in the United States is exported to Europe and Latin America for this purpose (EIA, 1998). (Refer to Table A-5 in the Appendix A for market data for petroleum coke demand in various regions for cement production.) Coal is an alternative to petroleum coke for use as a fuel in cement kilns. Table 5-7 shows the emissions factors assumed for coke used in cement production. Since no fuel-specific data for cement production was available, the same factors used for power generation are assumed here. Coke is desulfurized as an inherent part of the cement production process, and thus sulfur emissions are similar across regions regardless of control technology.

Table 5-7 Petroleum-Coke-to-Cement Parameters

\begin{tabular}{|l|c|c|c|c|}
\multicolumn{1}{|c|}{ Parameter } & \multicolumn{3}{c|}{ Petroleum Coke } & Coal \\
\hline & Asia & Europe & Latin America & Average \\
\hline Sulfur content, \% & 6 & 6 & 6 & 6 \\
\hline Fuel heating value, Btu/lb (HHV) & 13,337 & 13,337 & 13,337 & 12,000 \\
\hline SOx emission factor, kg/tonne of cement & 4.9 & 4.9 & 4.9 & 4.8 \\
\hline SOx reduction factor (desulfurization efficiency), \% & $90.0 \%$ & $90.0 \%$ & $90.0 \%$ & $90.0 \%$ \\
\hline NOx emission factor, kg/tonne of cement & 3 & 3 & 3 & 3 \\
\hline Total $\mathrm{CO}_{2}$ emission factor, kg/tonne of cement & 900 & 900 & 900 & 820 \\
\hline Energy requirement, MMBtu/tonne of cement & 4.336 & 4.336 & 4.336 & 4.336 \\
\hline
\end{tabular}

Source: EIA, US EPA AP-42 Emissions Factors

\subsubsection{Heavy Residual Oil}

One-third of the residual fuel oil produced in the United States is used in electricity generation, and another $17 \%$ in industrial applications for electricity and process heat generation. The other major use (49\%) is in marine transportation. (Refer to Table A-6 in Appendix A for data on heavy residual oil consumption in the United States.)

Heavy residual oil is used to generate about $1.5 \%$ of the power produced in the United States. Heavy residual oil is often co-fired with natural gas when gas inventory or price necessitates an alternative (EIA, 2001). Hence, natural gas is a valid alternative for direct comparison. In industrial heat and steam applications, natural gas is also a valid basis for comparison, although the price differential between gas and oil typically makes oil more economical. Lighter distillate fuels, such as fuel oil No. 2, may also be a valid alternative.

Since heavy residual oil employed in marine transportation does not have a viable economic alternative, marine transportation is not considered in the CFE analysis. The $49 \%$ of heavy residual oil used in marine transportation is placed outside the CFE system boundary.

Tables 5-8 and 5-9 show efficiencies, desulfurization efficiency, $\mathrm{NO}_{\mathrm{X}}$ reduction factors, and emissions factors for the heavy residual oil-to-power and natural-gas-to-power pathways. 
Table 5-8 Heavy Residual Oil-to-Power and to-Heat/Steam Parameters, U.S.

\begin{tabular}{|l|c|c|c|}
\multicolumn{1}{|c|}{ Parameter } & Electric Utilities & $\begin{array}{c}\text { Industrial } \\
\text { Heat/Steam }\end{array}$ & $\begin{array}{c}\text { Commercial } \\
\text { Heat/Steam }\end{array}$ \\
\hline Sulfur content, \% & 3 & 3 & 3 \\
\hline Desulfurization efficiency, \% & $90.0 \%$ & $0.0 \%$ & $0.0 \%$ \\
\hline Power or steam generation efficiency, \% & $38.0 \%$ & $80.0 \%$ & $85.0 \%$ \\
\hline Fuel heating value, Btu/gal & 151,470 & 151,470 & 151,470 \\
\hline SOx emission factor constant, lb/103 gal & 157 & 157 & 157 \\
\hline SOx reduction factor (desulfurization efficiency), \% & $90.0 \%$ & $0.0 \%$ & $0.0 \%$ \\
\hline NOx emission factor, Ib/103 gal & 32 & 32 & 32 \\
\hline $\mathrm{NO}_{2}$ reduction factor, \% & $30 \%$ & $30 \%$ & $0 \%$ \\
\hline $\mathrm{CO}_{2}$ emission factor, Ib/MMBtu & 174 & 174 & 174 \\
\hline
\end{tabular}

Source: EIA, US EPA AP-42 Emissions Factors

Table 5-9 Natural-Gas-to-Power and to-Heat/Steam Parameters, U.S.

\begin{tabular}{|l|c|c|c|}
\multicolumn{1}{|c|}{ Parameter } & Electric Utilities & $\begin{array}{c}\text { Industrial } \\
\text { Heat/Steam }\end{array}$ & $\begin{array}{c}\text { Commercial } \\
\text { Heat/Steam }\end{array}$ \\
\hline Sulfur content, \% & .05 & .05 & .05 \\
\hline Power generation efficiency, \% & $50.0 \%$ & $85.0 \%$ & $90.0 \%$ \\
\hline Fuel heating value, Btu/cu ft & 928 & 928 & 928 \\
\hline SOx emission factor constant, lb/106 cu ft & 0.6 & 0.6 & 0.6 \\
\hline SOx reduction factor (desulfurization efficiency), \% & $0.0 \%$ & $0.0 \%$ & $0.0 \%$ \\
\hline NOx emission factor, Ib/106 cu ft & 170 & 170 & 170 \\
\hline NOx reduction factor, \% & $30 \%$ & $30 \%$ & $0 \%$ \\
\hline $\mathrm{CO}_{2}$ emission factor, Ib/MMBtu & 116 & 116 & 116 \\
\hline
\end{tabular}

Source: EIA, US EPA AP-42 Emissions Factors

\subsubsection{Petroleum Coke and Heavy Residual Oil as Waste Products}

A research paper from the Energy Information Agency (EIA, 1998) discussed the diminishing market for residual fuel and petroleum coke in the United States. This diminishing market is due largely to environmental restrictions; heavier crude slates produce lower quality coke and heavy residual oils. According to this paper:

Refiners have been using a greater quantity of higher sulfur crude oil and more crude oil with high heavy metal content. Most of the sulfur, metals, and inert material found in the crude oil are not removed as the oil is processed, but are concentrated in the residual fuel oil. Coking has been a standard process used to convert residual fuel with high sulfur and heavy metals content; however, coking further concentrates the sulfur and metals in the petroleum coke.

Metals content can be an even greater problem than sulfur content. Burning either residual fuel or coke containing higher sulfur in a boiler can be handled with standard emissions control devices, but heavy metals content can result in hazardous airborne pollution and higher metal content ash, which can become a disposal problem. In the future, high sulfur, high-metals residual fuels and coke may even become "wastes" to be disposed of rather than fuels to be sold. 
This observation has implications for both the allocation and the CFE methodologies. Under the allocation methodology, the associated refining energy and emissions for coke and heavy residual oil should be allocated to gasoline and diesel if coke and heavy residual oil are considered to be waste products. Thus, the high heavy metals and sulfur content and any associated potential environmental impacts from the waste products should be accounted for and attributed to gasoline and diesel.

For the CFE methodology, if coke and heavy residual oil with high concentrations of sulfur and heavy metals continue to be produced as salable products for power or heat, then the downstream inventories and impacts of metals and sulfur emissions associated with the use of these products should be accounted for in the gasoline and diesel pathways. As suggested in the EIA study, these impacts and inventories may be significant.

Thus, the general conclusion is that under either the allocation methodology or the CFE methodology, the inventories and impacts of heavier crude slates should be accounted for in the gasoline and diesel pathways. To date, no other study has addressed this issue.

\subsection{GTL PRODUCTS}

As was indicated at the beginning this section, the GTL has two primary products - FTD and FT naphtha - and no significant co-products. Furthermore, GTL has no "undesirable" co-products comparable to petroleum coke and heavy residual oil. For these reasons, the CFE methodology as such cannot be applied to the GTL system.

\subsection{CFE APPLICATION AND RESULTS}

This section presents the step-by-step application of CFE and the results for the petroleum cases for gasoline, ULSD, and GTL fuels.

\subsubsection{Step 1: Allocation of Co-product Energy and Emissions}

The results of the first CFE step are presented below. In Tables 5-10 through 5-13, the lower range case (no co-product allocation to gasoline or diesel) is shown in the second column from the left. The incremental (delta) allocation of refinery stage energy and emissions due to coke and heavy residual oil is shown the adjoining column to the right, followed by the upper range case, in which all refinery co-products are allocated to gasoline and diesel.

\subsubsection{Gasoline and Diesel}

Tables 5-10 through 5-13 show the allocation of co-products to gasoline and diesel for the petroleum cases for PADD III 2006 and 2015.

Table 5-10 shows that the allocation of coke and heavy residual oil to gasoline adds $3 \%$ (i.e., $7,635 / 266,490)$ to total energy, $3 \%$ to $\mathrm{CO}_{2}, 5 \%$ to $\mathrm{NO}_{\mathrm{X}}, 4 \%$ to $\mathrm{PM} 10$, and $3.6 \%$ to $\mathrm{SO}_{\mathrm{X}}$ for the WTT of the fuel cycle. This case would be relevant by itself if coke and heavy residual oil were treated as waste products, as suggested in Section 5.4.3. 
The upper range full co-product slate case adds $20 \%$ to total energy, $19 \%$ to $\mathrm{CO}_{2}, 14 \%$ to $\mathrm{NO}_{\mathrm{X}}$, $19 \%$ to $\mathrm{PM} 10,20 \%$ to $\mathrm{SO}_{\mathrm{X}}$ for the well-to-tank portion of the gasoline fuel cycle.

\section{Table 5-10 PADD III 2006-Co-product Energy and Emissions Well-to-Tank Allocations to Gasoline (Btu/MMBtu or g/MMBtu)}

\begin{tabular}{|l|c|c|c|}
\multicolumn{1}{|c|}{ Output } & $\begin{array}{c}\text { Lower Range: } \\
\text { No Co-products }\end{array}$ & Coke and RO & $\begin{array}{c}\text { Upper Range: } \\
\text { Full Co-product Slate }\end{array}$ \\
\hline Total energy & 266,490 & 7,635 & 53,680 \\
\hline $\mathrm{CO}_{2}$ & 20,111 & 566 & 3,794 \\
\hline $\mathrm{NO}_{\mathrm{X}}$ & 46.76 & 2.08 & 6.62 \\
\hline $\mathrm{PM} 10$ & 3.40 & 0.13 & 0.65 \\
\hline $\mathrm{SO}_{\mathrm{X}}$ & 22.60 & 0.81 & 4.59 \\
\hline
\end{tabular}

Table 5-11 shows that for ULSD, the allocation of coke and heavy residual oil adds 4\%, 4\%, 5\%, $5 \%$, and $4 \%$ to total energy, $\mathrm{CO}_{2}, \mathrm{NO}_{\mathrm{X}}, \mathrm{PM} 10$, and $\mathrm{SO}_{\mathrm{X}}$, respectively. The upper range full co-product slate case adds $21 \%, 20 \%, 20 \%, 23 \%$, and $22 \%$ to total energy, $\mathrm{CO}_{2}, \mathrm{NO}_{\mathrm{X}}, \mathrm{PM} 10$, and $\mathrm{SO}_{\mathrm{X}}$, respectively.

\section{Table 5-11 PADD III 2006-Co-product Energy and Emissions Well-to-Tank Allocations to Diesel (Btu/MMBtu or g/MMBtu)}

\begin{tabular}{|l|c|c|c|}
\hline \multicolumn{1}{|c|}{ Output } & $\begin{array}{c}\text { Lower Range: } \\
\text { No Co-products }\end{array}$ & Delta Energy and Emissions to Diesel from: \\
\hline Total energy & 214,562 & 8,499 & $\begin{array}{c}\text { Upper Range: } \\
\text { Full Co-product Slate }\end{array}$ \\
\hline $\mathrm{CO}_{2}$ & 16,544 & 626 & 45,800 \\
\hline $\mathrm{NO} x$ & 39.83 & 2.32 & 3,352 \\
\hline PM10 & 3.07 & 0.15 & 7.92 \\
\hline SOx & 20.68 & 0.90 & 0.71 \\
\hline
\end{tabular}

Table 5-12 shows that for the allocation of coke and heavy residual oil to PADD III 2015 gasoline adds $3 \%, 3 \%, 5 \%, 4 \%$, and $4 \%$ to total energy, $\mathrm{CO}_{2}, \mathrm{NO}_{\mathrm{X}}, \mathrm{PM} 10$, and $\mathrm{SO}_{\mathrm{X}}$, respectively, while the upper range full co-product slate adds $13 \%, 13 \%, 15 \%, 16 \%$, and $16 \%$ to total energy, $\mathrm{CO}_{2}, \mathrm{NO}_{\mathrm{X}}, \mathrm{PM} 10$, and $\mathrm{SO}_{\mathrm{X}}$, respectively.

Table 5-13 shows that for the ULSD pathway, total energy, $\mathrm{CO}_{2}, \mathrm{NO}_{\mathrm{X}}, \mathrm{PM} 10$, and $\mathrm{SO}_{\mathrm{X}}$ are increased by $4 \%, 4 \%, 7 \%, 5 \%$, and $5 \%$, respectively, as a result of coke and heavy residual oil allocations. The upper range full co-product slate case adds $21 \%, 20 \%, 20 \%, 23 \%$, and $22.5 \%$ to total energy, $\mathrm{CO}_{2}, \mathrm{NO}_{\mathrm{X}}, \mathrm{PM} 10$, and $\mathrm{SO}_{\mathrm{X}}$, respectively. 
Table 5-12 PADD III 2015-Co-product Energy and Emissions Well-to-Tank Allocations to Gasoline (Btu/MMBtu or g/MMBtu)

\begin{tabular}{|l|c|c|c|}
\hline \multicolumn{1}{|c|}{ Output } & $\begin{array}{c}\text { Lower Range: } \\
\text { No-Co-products }\end{array}$ & Coke and RO & $\begin{array}{c}\text { Upper Range: } \\
\text { Full Co- product Slate }\end{array}$ \\
\hline Total energy & 268,328 & 8,128 & 34,377 \\
\hline $\mathrm{CO}_{2}$ & 20,206 & 603 & 2,535 \\
\hline $\mathrm{NO} x$ & 43.92 & 2.23 & 6.36 \\
\hline $\mathrm{PM} 10$ & 3.38 & 0.14 & 0.55 \\
\hline $\mathrm{SO}$ & 18.76 & 0.74 & 2.99 \\
\hline
\end{tabular}

Table 5-13 PADD III 2015-Co-product Energy and Emissions Well-to-Tank Allocations to Diesel (Btu/MMBtu or g/MMBtu)

\begin{tabular}{|l|c|c|c|}
\hline \multicolumn{1}{|c|}{ Output } & $\begin{array}{c}\text { Lower Range: } \\
\text { No-Co-products }\end{array}$ & Coke and RO & $\begin{array}{c}\text { Upper Range: } \\
\text { Full Co- product Slate }\end{array}$ \\
\hline Total energy & 216,692 & 9,048 & 45,810 \\
\hline $\mathrm{CO}_{2}$ & 16,667 & 669 & 3,349 \\
\hline $\mathrm{NOx}$ & 37.51 & 2.48 & 7.54 \\
\hline $\mathrm{PM} 10$ & 3.06 & 0.16 & 0.70 \\
\hline $\mathrm{SO}$ & 17.20 & 0.82 & 3.87 \\
\hline
\end{tabular}

Results for the PADD III 2015 heavy case are shown in Tables A-11 through A-17 in Appendix A. The larger observed increases for the heavy case are due to the larger quantity of petroleum coke in the heavy product slate.

\subsubsection{Step 2: Downstream Function Comparisons}

Tables 5-14 through 5-17 show the net energy and emissions differences of petroleum coke and heavy residual oil compared with alternatives in downstream applications. (Refer again to Table 5-3 above for the comparisons considered.). Positive numbers indicate net inventory burdens, and negative numbers indicate net inventory credits that are allocated to the primary products.

For example, the $\mathrm{CFE}$ for $\mathrm{CO}_{2}$ emission for PADD III 2006 gasoline is calculated as follows:

Total $\mathrm{CO}_{2}=\mathrm{CO}_{2}$ from PADD III gasoline lower range (Table 5-9)

$+\mathrm{CO}_{2}$ from coke and heavy residual oil allocations (Table 5-9)

$+\mathrm{CO}_{2}$ from CFE of coke vs. coal-to-power (Table 5-13)

$+\mathrm{CO}_{2}$ from CFE of coke vs. coal-to-cement (Table 5-14)

$+\mathrm{CO}_{2}$ from CFE of heavy residual oil vs. NG-to-power (Table 5-15)

or, Total $\mathrm{CO}_{2}=20,111+566+43.4+126+2,097=22,943 \mathrm{~g} / \mathrm{MMBtu}$ 
This final CFE calculation results in a $14.5 \%$ increase in $\mathrm{CO}_{2}$ to the WTT portion for PADD III 2006 gasoline. Coke and heavy residual oil refinery emissions allocation accounts for 3.0\% of this total, net coke-to-power $0.2 \%$, net coke-to-cement $0.6 \%$, and net heavy residual oil-to-power and heat $10.7 \%$.

The CFE analysis includes only $\mathrm{CO}_{2}, \mathrm{SO}_{\mathrm{X}}$, and $\mathrm{NO}_{\mathrm{X}}$ emissions since data for particulate emissions was not available for all downstream pathways. As a rule, particulate emissions are correlated with $\mathrm{SO}_{\mathrm{X}}$ emissions, and thus should exhibit a similar order of effect.

\subsubsection{Petroleum Coke}

\section{Power}

Table 5-14 shows the net results for coke-to-power for PADD III 2006 and 2015 versus alternatives. (Refer to Table A-10 in Appendix A for the PADD III heavy case.) For the 2006 case, coke generates 43.4 more grams of $\mathrm{CO}_{2}$ per $\mathrm{MMBtu}$ of gasoline than coal; for the 2015 case, it generates 424.0 more grams of $\mathrm{CO}_{2}$ per $\mathrm{MMBtu}$ than natural gas. The results are allocated to gasoline and diesel based on the energy content (LHV basis) of each fuel. $\mathrm{NO}_{\mathrm{X}}$ emissions for coke are decreased slightly relative to coal. (See Table A-7 for the emissions factors for coke and coal used in the analysis.)

Table 5-14 Coke-to-Power (Global), PADD III 2006 and 2015

\begin{tabular}{|l|c|c|}
\hline \multicolumn{1}{|c|}{ Emissions Allocated } & 2006 & 2015 \\
\hline To gasoline, g/MMBtu of gasoline & Coke vs. Coal & Coke vs. NG \\
\hline $\mathrm{SO}_{\mathrm{X}}$ & & \\
\hline $\mathrm{NO}$ & 1.391 & 4.852 \\
\hline $\mathrm{CO}_{2}$ & -0.362 & 1.378 \\
\hline $\mathrm{To} \mathrm{diesel,} \mathrm{g/MMBtu} \mathrm{of} \mathrm{diesel}_{1}$ & 43.4 & 424.0 \\
\hline $\mathrm{SO}$ & & \\
\hline $\mathrm{NO}_{\mathrm{x}}$ & 0.426 & 1.756 \\
\hline $\mathrm{CO}_{2}$ & -0.111 & 0.499 \\
\hline
\end{tabular}

\section{Cement}

Table 5-15 shows the net results for coke-to-cement for PADD III 2006 and 2015 relative to alternatives. (Refer to Table A-14 in Appendix A for results for the PADD III heavy case.) For gasoline, $\mathrm{CO}_{2}$ emissions increase by 126 and $155 \mathrm{gm} / \mathrm{MMBtu}$ of gasoline and by 38 and 56 gm/MMBtu of ULSD. 
Table 5-15 Coke-to-Cement (Global), PADD III 2006 and 2015

\begin{tabular}{|l|c|c|}
\hline \multicolumn{1}{|c|}{ Emissions Allocated } & 2006 & 2015 \\
\hline To gasoline, g/MMBtu of gasoline & Coke vs. Coal & Coke vs. Coal \\
\hline $\mathrm{SO}$ & & \\
\hline $\mathrm{NO}$ & 2.236 & 2.766 \\
\hline $\mathrm{CO}_{2}$ & -0.908 & -1.123 \\
\hline $\mathrm{To}$ diesel, g/MMBtu of diesel & 126 & 155 \\
\hline $\mathrm{SO}$ & & \\
\hline $\mathrm{NO}_{\mathrm{x}}$ & 0.684 & 1.001 \\
\hline $\mathrm{CO}_{2}$ & -0.278 & -0.406 \\
\hline
\end{tabular}

\subsubsection{Heavy Residual Oil}

Tables 5-16 and 5-17 compare heavy residual oil-to-power and -heat with natural gas-to-power and -heat for PADD III 2006 and 2015, respectively. It can be seen that heavy residual oil adds a considerable burden to the gasoline and diesel pathways. The net residual-oil-to-power allocation increases $\mathrm{CO}_{2}, \mathrm{SO}_{\mathrm{X}}$, and $\mathrm{NO}_{\mathrm{X}}$ emissions significantly as compared with the natural gas-topower. This is due to the zero desulfurization and the zero $\mathrm{NO}_{\mathrm{X}}$ reduction in commercial and industrial heat applications. Some care must be taken in interpreting these results, since the industrial and commercial uses are on a smaller scale and are more dispersed than those of a central power station. (Refer to Table A-15 in Appendix A for the PADD III heavy case.)

Table 5-16 Heavy Residual Oil-to-Power/Heat vs. Natural Gas-to-Power/Heat, PADD III 2006

\begin{tabular}{|l|c|c|c|c|}
\hline \multicolumn{1}{|c|}{ Emissions Allocated } & Electric Utilities & Industrial & Commercial & Total \\
\hline To gasoline, g/MMBtu of gasoline & & & & \\
\hline $\mathrm{SO} x$ & 7.226 & 10.608 & 4.420 & 22.254 \\
\hline $\mathrm{NO} x$ & 0.999 & 0.058 & 0.047 & 1.104 \\
\hline $\mathrm{CO}_{2}$ & 1,833 & 186 & 77.1 & 2,097 \\
\hline To diesel, g/MMBtu of diesel & & & & \\
\hline $\mathrm{SO} x$ & 2.211 & 3.246 & 1.352 & 6.809 \\
\hline $\mathrm{NO} x$ & 0.306 & 0.018 & 0.014 & 0.338 \\
\hline $\mathrm{CO}_{2}$ & 561 & 57.1 & 23.6 & 642 \\
\hline
\end{tabular}


Table 5-17 Heavy Residual Oil-to-Power/Heat vs. Natural Gas-to-Power/Heat, PADD III 2015

\begin{tabular}{|l|c|c|c|c|}
\hline \multicolumn{1}{|c|}{ Emissions Allocated } & Electric Utilities & Industrial & Commercial & Total \\
\hline To gasoline, g/MMBtu of gasoline & & & & \\
\hline $\mathrm{SO} x$ & 5.958 & 8.746 & 3.644 & 18.349 \\
\hline $\mathrm{NOx}$ & 0.823 & 0.048 & 0.039 & 0.910 \\
\hline $\mathrm{CO}_{2}$ & 1,512 & 154 & 63.6 & 1,729 \\
\hline To diesel, g/MMBtu of diesel & & & & \\
\hline $\mathrm{SO}$ & 0.156 & 3.165 & 1.319 & 6.640 \\
\hline $\mathrm{NO}$ & 0.298 & 0.017 & 0.014 & 0.329 \\
\hline $\mathrm{CO}_{2}$ & 547 & 55.6 & 23.0 & 626 \\
\hline
\end{tabular}

\subsection{FINAL CFE RESULTS}

Figure 5-3 through 5-5 and Tables 5-18 through 5-21 present the WTT CFE results for gasoline and ULSD for the PADD III 2006 and 2015 cases. The bottom row of each table shows the percentage increase over the base "No Co-products Allocation" PADD III cases, which are also the GREET default cases for gasoline and diesel.

The WTT $\mathrm{CO}_{2}$ inventory for PADD III is increased by $14.0 \%$ over the base for 2006 (Table 5-18) and 14\% over the base for 2015 (Table 5-23). For $\mathrm{SO}_{\mathrm{X}}$, the CFE increases the base for 2006 by $118 \%$ (Table 5-18) and by $139 \%$ over the base for 2015 (Table 5-19). For $\mathrm{NO}_{\mathrm{X}}$, the comparable figures range from $4 \%$ over the base for 2006 (Table 5-18) and $8 \%$ for 2015. In the figures below, it can be seen that credits are given to gasoline and diesel for lower $\mathrm{NO}_{\mathrm{X}}$ emissions for the coke-to-power and coke-to-cement functions.

Since the WTT stages contribute about $20 \%$ of the energy and emissions from the full fuel cycle, increases in $\mathrm{CO}_{2}$ emissions would be expected to range from $2 \%$ to $4 \%$. For $\mathrm{SO}_{\mathrm{X}}$, this would be from $12 \%$ to $40 \%$, and from $1 \%$ to $3 \%$ for $\mathrm{NO}_{\mathrm{X}}$. (See Section 6 for the complete WTW results.)

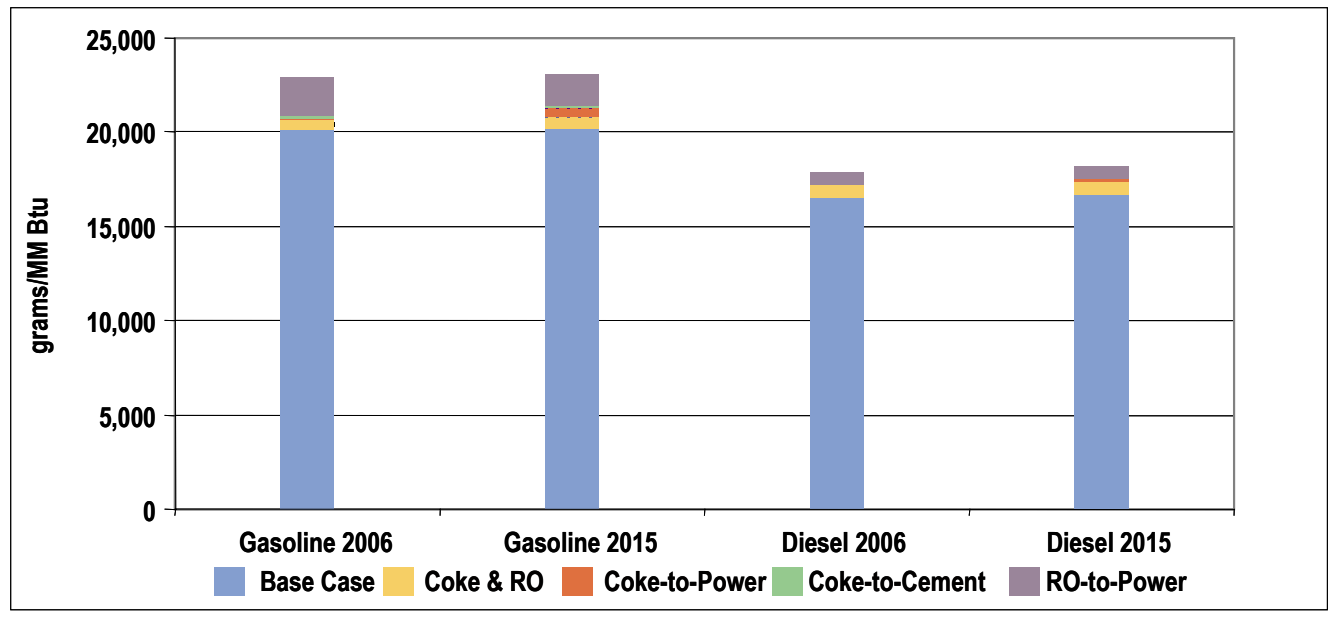

Figure 5-3 Well-to-Tank $\mathrm{CO}_{2}$ CFE Allocation 


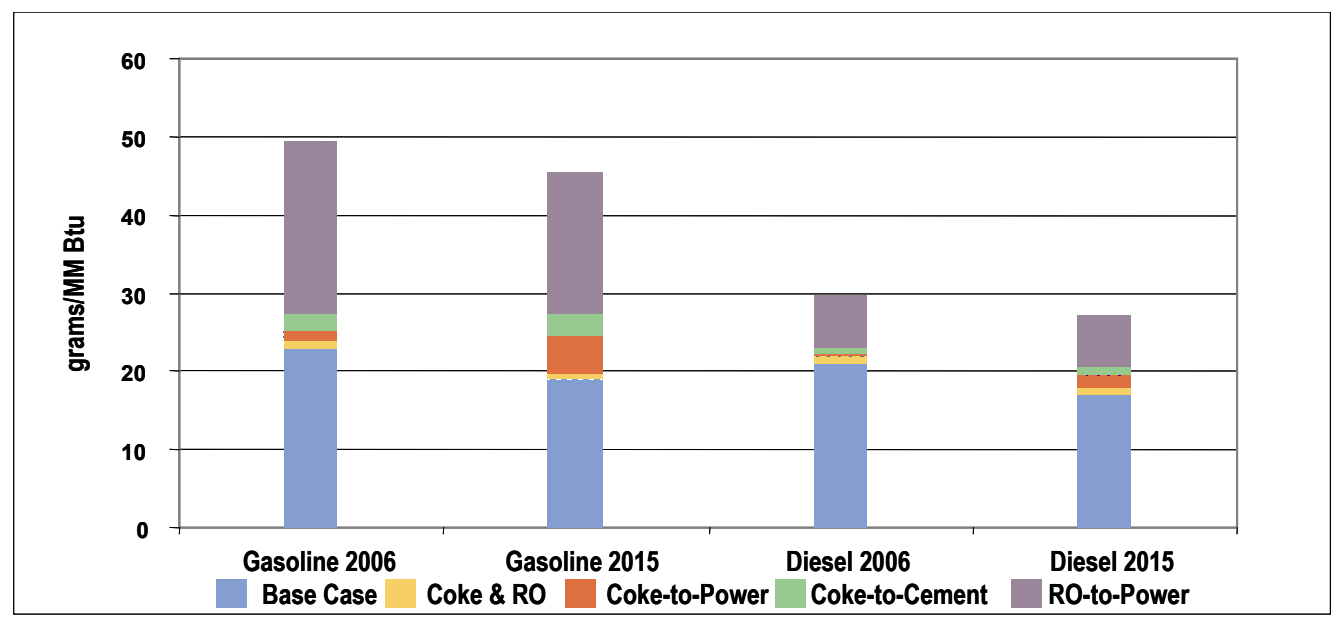

Figure 5-4 Well-to-Tank $\mathrm{SO}_{x}$ CFE Allocation

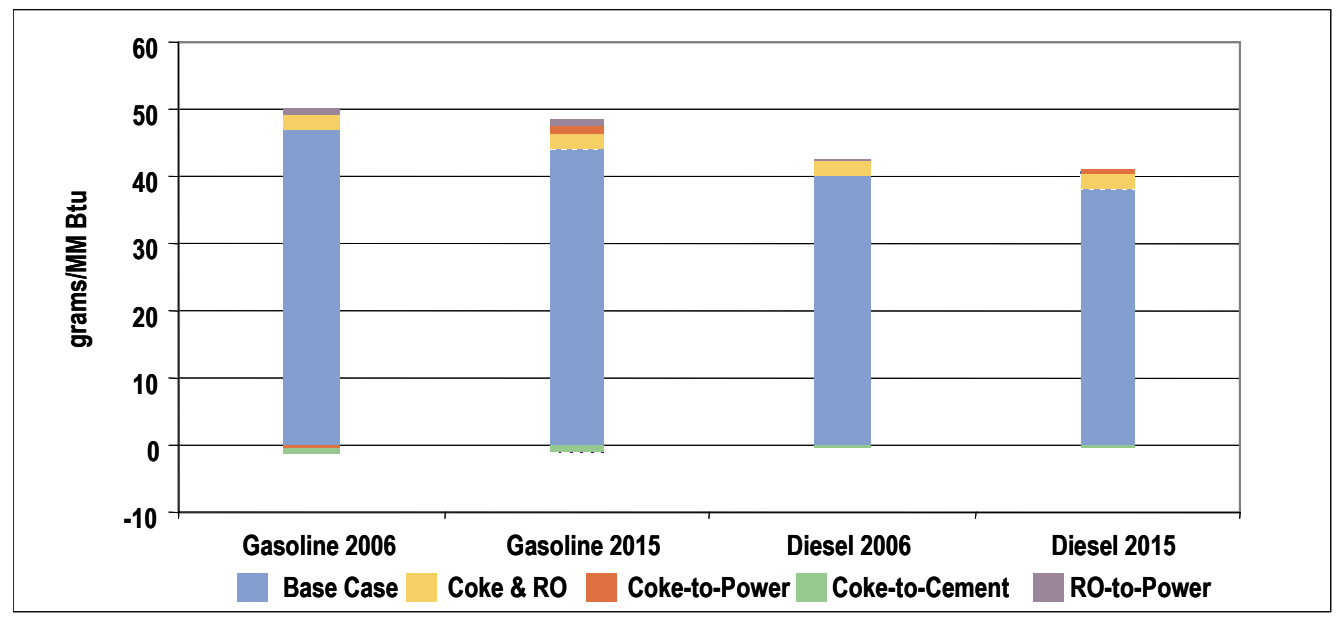

Figure 5-5 Well-to-Tank NOx CFE Allocation

Table 5-18 CFE Allocations for Gasoline, Increases over PADD III 2006 Case (GREET Default) (g/MMBtu of Gasoline)

\begin{tabular}{|l|c|c|c|}
\hline \multicolumn{1}{|c|}{ CFE Allocations } & $\mathrm{CO}_{2}$ & SO $_{x}$ & $\mathrm{NO}_{x}$ \\
\hline Base & 20,111 & 23 & 47 \\
\hline Coke and RO allocations & 566 & 0.8 & 2.1 \\
\hline Coke-to-power (vs. coal) & 43 & 1.4 & -0.4 \\
\hline Coke-to-cement (vs. coal) & 126 & 2.2 & -0.9 \\
\hline RO-to-power (vs. NG) & 2097 & 22 & 1.1 \\
\hline Total CFE & 22,943 & 49 & 49 \\
\hline Increase over base, \% & $14.0 \%$ & $118.6 \%$ & $4.0 \%$ \\
\hline
\end{tabular}




\section{Table 5-19 CFE for Gasoline, Increases over PADD III 2015 Case} (GREET Default) (g/MMBtu)

\begin{tabular}{|l|c|c|c|}
\hline \multicolumn{1}{|c|}{ CFE Allocations } & $\mathrm{CO}_{2}$ & $\mathrm{SO}_{x}$ & $\mathrm{NO}_{x}$ \\
\hline Base & 20,206 & 19 & 44 \\
\hline Coke and RO allocations & 602 & 0.7 & 2.3 \\
\hline Coke-to-power (vs. NG) & 424 & 4.9 & 1.4 \\
\hline Coke-to-cement (vs. coal) & 155 & 2.8 & -1.1 \\
\hline RO-to-power (vs. NG) & 1,729 & 18 & 0.9 \\
\hline Total CFE & 23,116 & 45 & 48 \\
\hline Increase over base, $\%$ & $14.4 \%$ & $139 \%$ & $8.0 \%$ \\
\hline
\end{tabular}

The diesel pathways show similar, but somewhat lower, increases for the CFE (Tables 5-20 and 5-21).

The WTT $\mathrm{CO}_{2}$ CFE inventory for PADD III ULSD is increased by $8.0 \%$ over the base for 2006

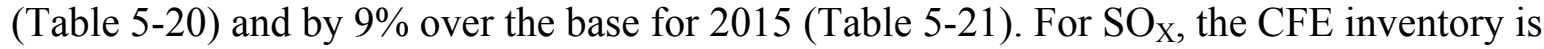
increased by $43 \%$ over the base for 2006 (Table 5-20) and by 59\% over the base for 2015 (Table $5-21$ ). For $\mathrm{NO}_{\mathrm{X}}$, the comparable figures are by $6 \%$ over the base for 2006 (Table 5-20) and 8\% for 2015 (Table 5-21).

Table 5-20 CFE for ULSD, Increases over PADD III 2006 Case (GREET Default), (g/MMBtu)

\begin{tabular}{|l|c|c|c|}
\hline \multicolumn{1}{|c|}{ CFE Allocations } & $\mathrm{CO}_{2}$ & $\mathrm{SO}_{x}$ & $\mathrm{NO}_{x}$ \\
\hline Base & 16,544 & 21 & 40 \\
\hline Coke and RO allocations & 627 & 0.9 & 2.3 \\
\hline Coke-to-power (vs. coal) & 13 & 0.4 & -0.1 \\
\hline Coke-to-cement (vs. coal) & 38 & 0.7 & -0.3 \\
\hline RO-to-power (vs. NG) & 642 & 6.8 & 0.3 \\
\hline Total CFE & 17,865 & 29 & 42 \\
\hline Increase over base, \% & $8.0 \%$ & $42.6 \%$ & $5.7 \%$ \\
\hline
\end{tabular}

Table 5-21 CFE for ULSD, Increases over PADD III 2015 Case (GREET Default), (g/MMBtu)

\begin{tabular}{|l|c|c|c|}
\hline \multicolumn{1}{|c|}{ CFE Allocations } & $\mathrm{CO}_{2}$ & $\mathrm{SO}_{x}$ & $\mathrm{NO}$ \\
\hline Base & 16,667 & 17 & 38 \\
\hline Coke and RO allocations & 668 & 0.8 & 2.5 \\
\hline Coke-to-power (vs. NG) & 153 & 1.8 & 0.5 \\
\hline Coke-to-cement (vs. coal) & 56 & 1.0 & -0.4 \\
\hline RO-to-power (vs. NG) & 626 & 6.6 & 0.3 \\
\hline Total CFE & 18,170 & 27.4 & 40.4 \\
\hline Increase over base, \% & $9.0 \%$ & $59.3 \%$ & $7.7 \%$ \\
\hline
\end{tabular}




\subsection{CONCLUSIONS}

The analysis in this section indicates that for the WTT life cycle stages, there is a quantifiable difference when co-product functions for petroleum coke and heavy residual oil are included in the inventory results for primary system products through the application of the CFE methodology. The magnitude of the differences depends upon the assumptions of the CFE for markets and alternatives for the co-products in downstream applications. Only a portion of total refinery production of petroleum coke and heavy residual oil was included in this analysis. This was done on the basis of market data and assumptions for the use of these products.

$\mathrm{SO}_{\mathrm{X}}$ emissions are the most sensitive to these assumptions, while $\mathrm{CO}_{2}$ and $\mathrm{NO}_{\mathrm{X}}$ are relatively insensitive. For $\mathrm{SO}_{\mathrm{X}}$, a system comparison with natural gas used in downstream functions shows larger differences, and a comparison with coal shows smaller differences.

This section has presented cases only for the WTT life cycle stages. The WTT stages constitute only about $20 \%$ of the energy and emissions from the full fuel cycle. The full WTW results are presented in Section 6.

\subsection{REFERENCES}

American Petroleum Institute, "Protecting Our Environment," 2001.

Argonne National Laboratory, Vol. 1, "Methodology, Development, Use and Results," GREET 1.5 Manual, Transportation Fuel-Cycle Model, August 1999.

Energy Information Agency, "Challenges of Electric Power Industry Restructuring for Fuel Suppliers," Office of Coal, Nuclear, Electric and Alternative Fuels, September 1998.

International Energy Agency, "The Use of Petroleum Coke in Coal-fired Plants," November 2001 .

International Standards Organization, ISO 14040, "Environmental Management - Life Cycle Assessment - Principles and Framework,” 1997

International Standards Organization, ISO 14041, "Environmental Management - Life Cycle Assessment - Goal and Scope Definition and Inventory Analysis," 1998.

International Standards Organization, ISO 14042, "Environmental Management - Life Cycle Assessment - Life Cycle Impact Assessment,” 1999.

Tyson, K.S., C.J. Riley, and K.K. Humphreys, "Fuel Cycle Evaluations of Biomass - Ethanol and Reformulated Gasoline," Volume 1, National Renewable Energy Laboratory, Oak Ridge National Laboratory, and Pacific Northwest Laboratory, NREL/TP-463-4950, November 1993. 


\subsection{INTRODUCTION}

This section presents the well-to-wheels transportation Life Cycle Inventory (LCI) results for Fischer-Tropsch (FT) diesel (FTD), FT naphtha, methanol, and the federal reformulated gasoline (FRFG) and ultra-low sulfur diesel (ULSD) 2006 and 2015 PADD III cases.

The following vehicles and fuels are considered for the near term:

- A $20 \% \mathrm{FTD} / 80 \%$ ULSD blend in compression injection direction injection (CIDI) engines

- A conventional diesel compression ignition direction injection (CIDI) engine

- A conventional FRFG spark ignition (SI) engine

- A ULSD CIDI

The following vehicles and fuels are considered for the long term:

- A ULSD CIDI

- An FTD100 CIDI

- An "aggressive" FTD optimized CIDI engine, with a 5\% improvement in fuel efficiency

- An FTD CIDI hybrid electric (HEV)

- An "aggressive" FTD optimized CIDI HEV, also with a 5\% improvement in fuel efficiency

- A ULSD CIDI HEV

- An FRFG spark ignition direction injection (SIDI) engine

- An FRFG SIDI HEV

- An FT naphtha fuel cell vehicle (FCV)

- An FRFG FCV

- A methanol (M100) FCV

The PADD III 2006 and 2015 cases for gasoline and diesel include the Co-product Function Expansion (CFE), as developed in Section 5. The CFE results have been included in order to model the effects of co-products (petroleum coke and heavy residual oil) in the petroleum production system.

Tables 1-3 through 1-5 in Section 1.6 give a complete listing of the scenarios. 


\section{$6.2 \quad$ LCI RESULTS}

Section 6.2.1 presents the near-term comparisons of the FTD20 blend with the PADD III 2006 cases for gasoline and diesel.

Section 6.2.2 presents the long-term comparisons of FTD, FT naphtha, and methanol with gasoline and diesel.

In the figures below, urban and total emissions of $\mathrm{NO}_{\mathrm{X}}, \mathrm{SO}_{\mathrm{X}}$, and PM10 emissions are shown. Total emissions (the total of urban and non-urban emissions) are shown in blue, and urban emissions in red.

Greenhouse gas $(\mathrm{GHG})$ emissions are reported in terms of global warming potential (GWP). GWP is a weighted aggregate of $\mathrm{CO}_{2}, \mathrm{CH}_{4}$, and $\mathrm{N}_{2} \mathrm{O}$ expressed as $\mathrm{CO}_{2}$-equivalents over a 100year time horizon. (See Table 3-3.)

In the tables below, energy and emissions are shown for reference separately for the feedstock, fuel, and vehicles stages for each scenario. In the figures, only the total life cycle energy and emissions are shown.

In addition to the life cycle inventory categories for total energy, GHG emissions, and criteria pollutant emissions, the tables also show the individual constituents of $\mathrm{GHG}$ emissions $\left(\mathrm{CO}_{2}\right.$, $\mathrm{CH}_{4}$, and $\mathrm{N}_{2} \mathrm{O}$ ). Total fossil and petroleum fuels, considered in Section 7 of this report, are shown in the tables as well. These indicators are used in the LCIA as indicators of resource depletion.

Appendix B contains the complete LCI results for all fuels. This section presents the LCI results for FTD and FT naphtha. The results for other fuels are reported relative to FTD and FT naphtha.

The comparisons of the energy and emissions inventories of fuels must be placed within the larger context of data quality. As discussed in Sections 1 and 3, the data in GREET for total energy and $\mathrm{CO}_{2}$ emissions from the feedstock and fuels stages is of high quality and mature, and from the best sources. The data for upstream criteria emissions for petroleum production, based on AP-42 emissions factors, is of lower quality. The data for GTL and methanol production, as primary data, is of good quality, though representative of ConocoPhillips targets and theoretical efficiency, and not of commercially operating GTL plants. The data for efficiency and emissions from the representative theoretical vehicles is of high quality.

The significance of comparative results can be assessed in two ways: through a parametric sensitivity analysis, presented below in this section, or through a formal uncertainty analysis, presented in Appendix C. Many LCA studies also take a rule of thumb approach, in which only percentage differences above a certain threshold are considered to be significant. The UCF LCA takes this approach, with threshold values based on sensitivity analysis, uncertainty analysis, and expert judgment. 
Total energy and GWP of $10 \%$ or greater in difference is considered to be significant. Criteria emissions greater than $15 \%$ in difference are considered to be significant. The selection of these thresholds is discussed in the sensitivity analysis section below.

\subsubsection{Near-Term Results of the LCI}

Figures 6-1 through 6-5 compare FTD20 with PADD III conventional diesel, PADD III ULSD, and PADD III FRFG. Tables 6-1 through 6-3 provide numerical comparisons of these options with FTD20. Figures 6-3 through 6-5 show total emissions in blue and urban emissions in red.

It should be kept in mind that a total energy and GWP of $10 \%$ or greater in difference is considered to be significant. Criteria emissions greater than $15 \%$ in difference are considered to be significant. The summary of conclusions in the last section reflects these thresholds.

The FTD20, blended with ULSD, performs well compared with conventional diesel. FTD20 is equivalent in GWP, $71 \%$ lower in $\mathrm{NO}_{\mathrm{X}}, 71 \%$ lower in $\mathrm{PM} 10$, and $49 \%$ lower in $\mathrm{SO}_{\mathrm{X}}$ than conventional diesel. FTD20 consumes $6 \%$ more total energy than conventional diesel. FTD20 VOCs are reduced by $28 \%$, and $\mathrm{CO}$ is equivalent.

Owing to increasingly stringent environmental regulations, conventional diesel will not be permitted as a commercial fuel by 2006. Conventional diesel is included only as a point of reference.

Compared with ULSD, FTD20 again is essentially equivalent in GWP ( $2 \%$ lower), $6 \%$ lower in $\mathrm{NO}_{\mathrm{X}}, 12 \%$ lower in PM10, and $38 \%$ lower in $\mathrm{SO}_{\mathrm{X}}$. FTD20 consumes $5 \%$ more total energy than ULSD. FTD 20 VOCs are reduced by $4 \%$, and $\mathrm{CO}$ is equivalent.

Compared with the conventional FRFG SI, FTD20 CIDI is 23\% lower in GWP, 57\% lower in $\mathrm{NO}_{\mathrm{X}}, 23 \%$ lower in PM10, and $71 \%$ lower in $\mathrm{SO}_{\mathrm{X}}$. FTD20 consumes $20 \%$ less total energy than FRFG. VOCs are reduced by $67 \%$ for FTD20 CIDI, and CO is reduced by $75 \%$.

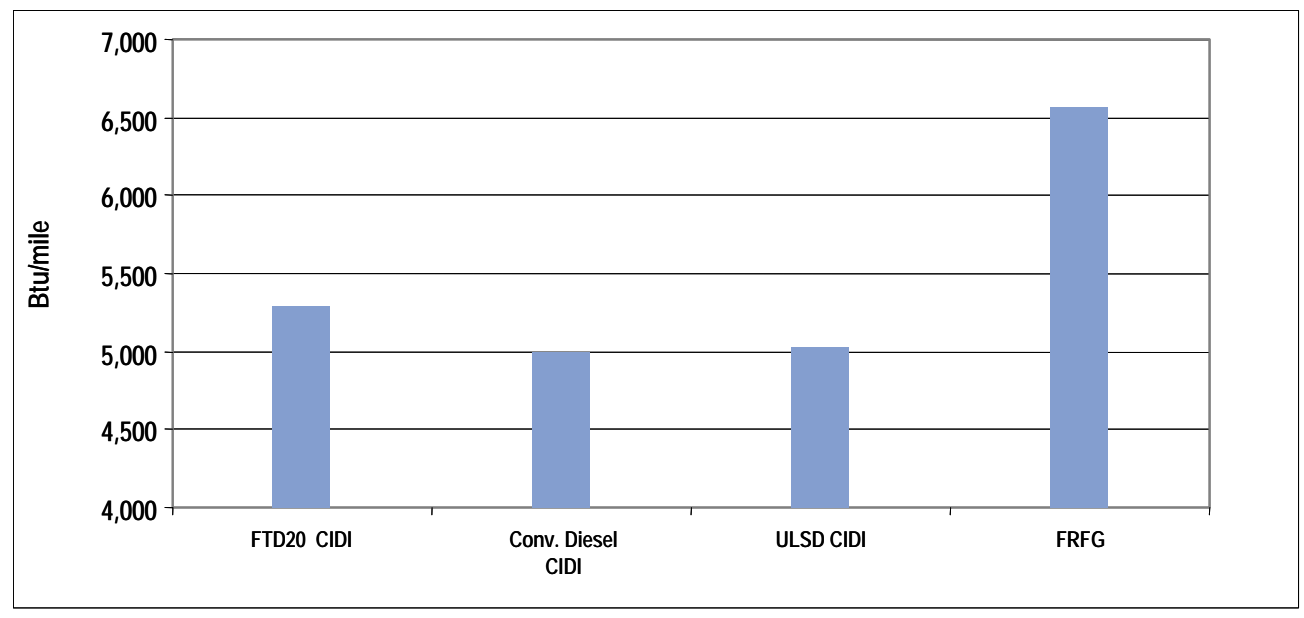

Figure 6-1 Total Energy, 2006 


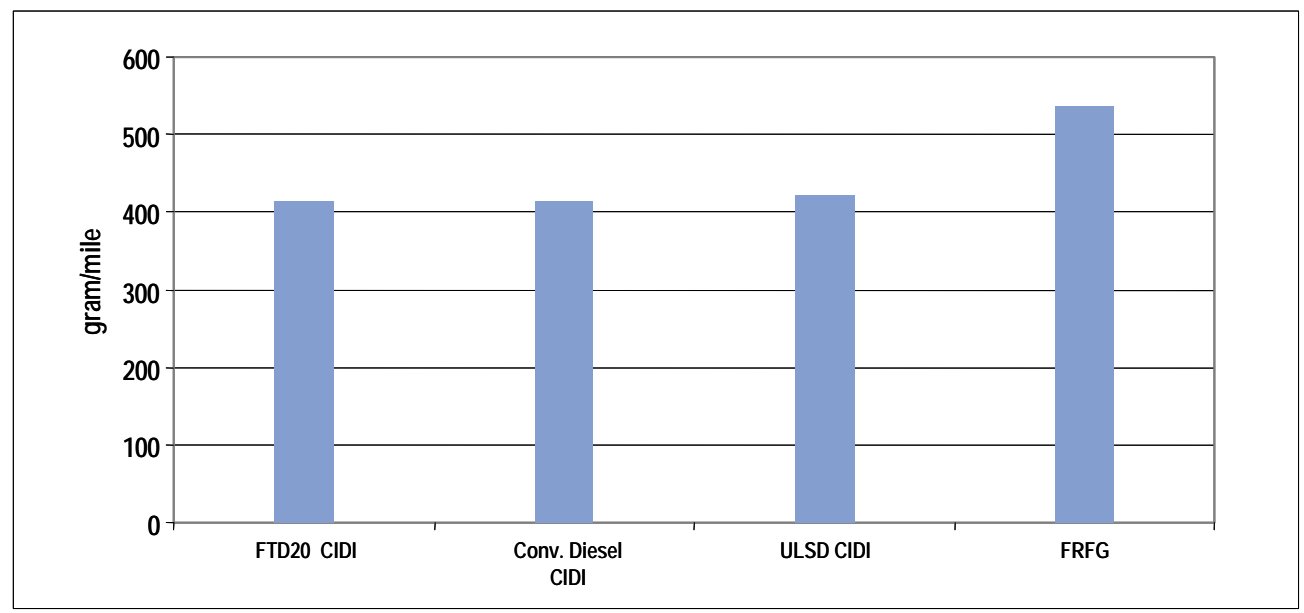

Figure 6-2 Global Warming Potential ( $\left.\mathrm{CO}_{2}-\mathrm{e}\right), 2006$

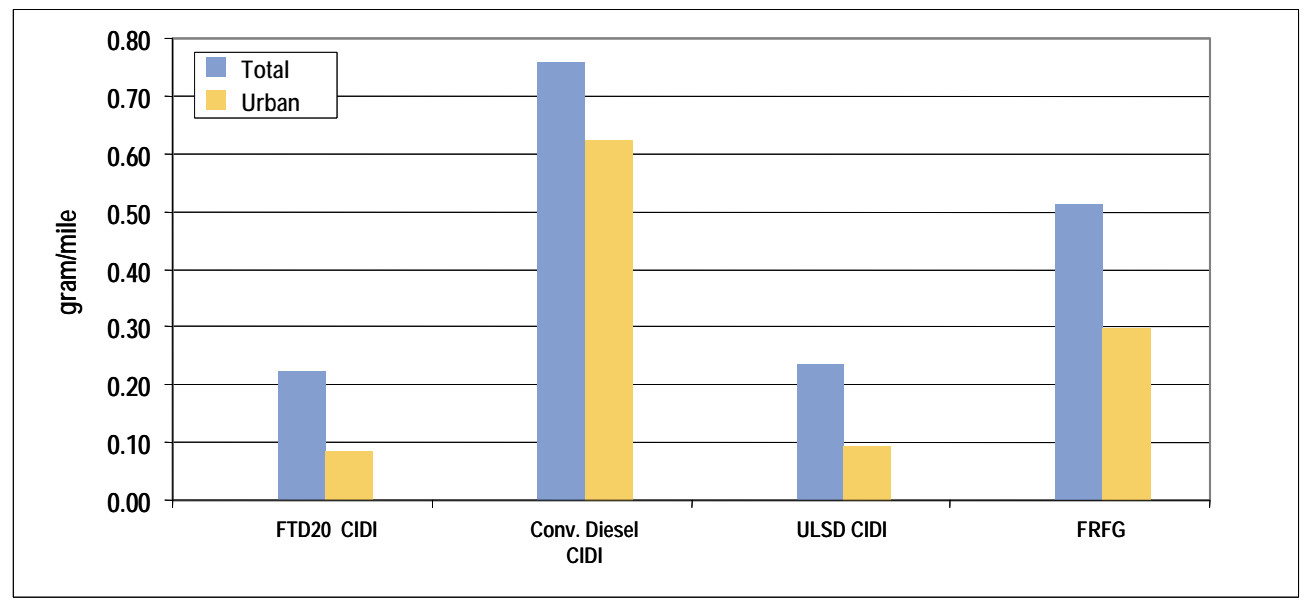

Figure 6-3 NOx Inventory, 2006

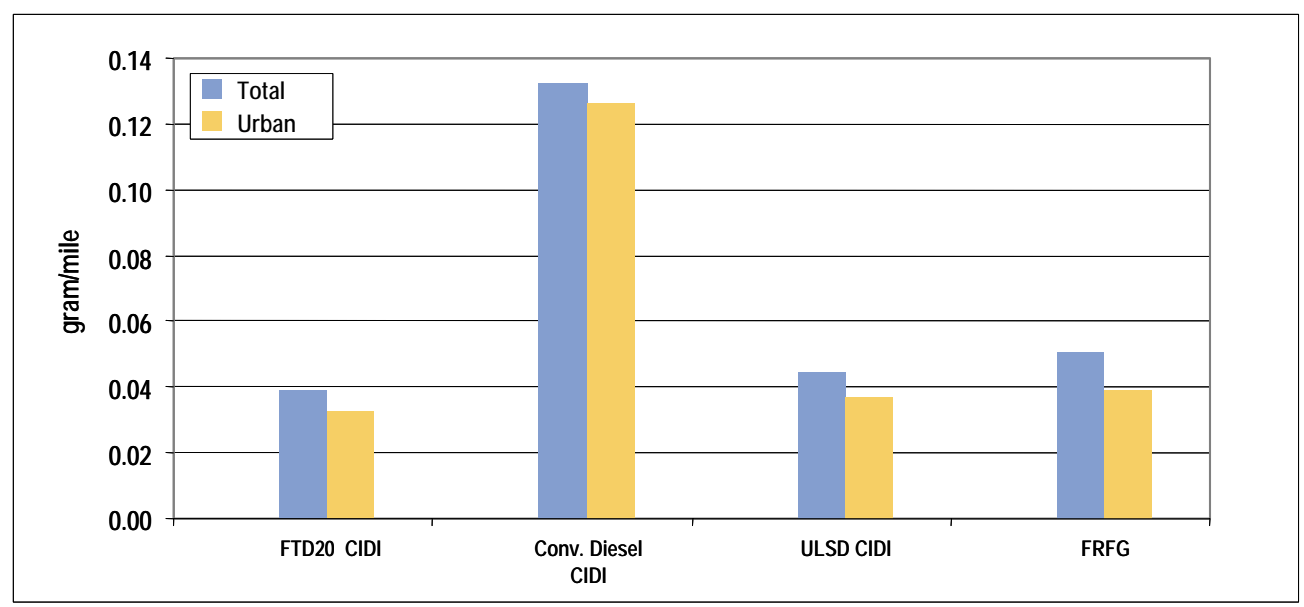

Figure 6-4 PM10 Inventory, 2006 


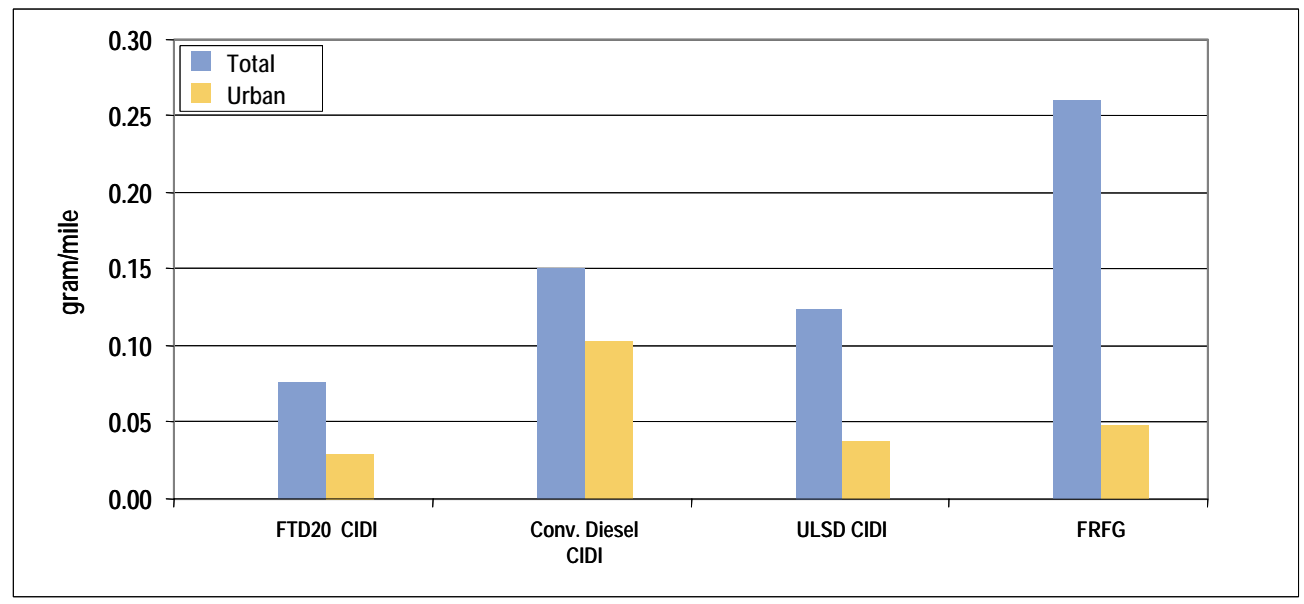

Figure 6-5 SOx Inventory, 2006

Table 6-1 FTD20 CIDI Comparison with Conventional Diesel CIDI, 2006 (Btu/mi or g/mi)

\begin{tabular}{|l|c|c|c|c|c|c|c|c|}
\hline \multicolumn{1}{|c|}{ Outputs } & \multicolumn{4}{|c|}{ FTD20 CIDI } & \multicolumn{3}{c|}{ Comparison with Conventional Diesel CIDI } \\
(FTD20 \% Difference)
\end{tabular}


Table 6-2 FTD20 CIDI Comparison with Ultra-Low Sulfur Diesel CIDI, 2006 (Btu/mi or g/mi)

\begin{tabular}{|l|c|c|c|c|c|c|c|c|}
\hline \multicolumn{1}{|c|}{ Outputs } & \multicolumn{4}{|c|}{} & \multicolumn{4}{c|}{ Comparison with ULSD CIDI } \\
\hline Total energy & Feedstock & Fuel & Vehicle & Total & Feedstock & Fuel & Vehicle & Total \\
\hline Fossil fuels & 185 & 989 & 4,111 & 5,285 & $6 \%$ & $33 \%$ & $0 \%$ & $5 \%$ \\
\hline Petroleum & 179 & 982 & 4,108 & 5,269 & $7 \%$ & $34 \%$ & $0 \%$ & $5 \%$ \\
\hline CO $_{2}$ & 45 & 301 & 3,336 & 3,683 & $-13 \%$ & $-20 \%$ & $-19 \%$ & $-19 \%$ \\
\hline $\mathrm{CH}_{4}$ & 17 & 53 & 329 & 399 & $2 \%$ & $-6 \%$ & $-1 \%$ & $-1 \%$ \\
\hline $\mathrm{N}_{2} \mathrm{O}$ & 0.384 & 0.046 & 0.011 & 0.441 & $3 \%$ & $-21 \%$ & $0 \%$ & $0 \%$ \\
\hline GWP & 0.000 & 0.001 & 0.016 & 0.017 & $-2 \%$ & $-20 \%$ & $0 \%$ & $-1 \%$ \\
\hline VOC & 26 & 54 & 334 & 415 & $54 \%$ & $-19 \%$ & $-1 \%$ & $-2 \%$ \\
\hline CO & 0.011 & 0.022 & 0.049 & 0.082 & $-17 \%$ & $-4 \%$ & $0 \%$ & $-4 \%$ \\
\hline NOx & 0.031 & 0.046 & 1.070 & 1.147 & $-6 \%$ & $69 \%$ & $0 \%$ & $1 \%$ \\
\hline PM10 & 0.080 & 0.080 & 0.062 & 0.222 & $-11 \%$ & $-4 \%$ & $-2 \%$ & $-6 \%$ \\
\hline SOx & 0.002 & 0.009 & 0.028 & 0.039 & $-11 \%$ & $-19 \%$ & $-10 \%$ & $-12 \%$ \\
\hline VOC: urban & 0.017 & 0.057 & 0.003 & 0.077 & $-6 \%$ & $-45 \%$ & $-2 \%$ & $-38 \%$ \\
\hline CO: urban & 0.001 & 0.008 & 0.049 & 0.058 & $-18 \%$ & $-17 \%$ & $0 \%$ & $-3 \%$ \\
\hline NOx: urban & 0.001 & 0.010 & 1.070 & 1.081 & $-11 \%$ & $-18 \%$ & $0 \%$ & $0 \%$ \\
\hline PM10: urban & 0.001 & 0.023 & 0.062 & 0.086 & $-11 \%$ & $-19 \%$ & $-2 \%$ & $-7 \%$ \\
\hline SOx: urban & 0.000 & 0.004 & 0.028 & 0.032 & $-12 \%$ & $-21 \%$ & $-10 \%$ & $-11 \%$ \\
\hline & 0.001 & 0.027 & 0.003 & 0.030 & $-12 \%$ & $-20 \%$ & $-2 \%$ & $-19 \%$ \\
\hline
\end{tabular}


Table 6-3 FTD20 CIDI Comparison with FRFG, 2006 (Btu/mi or g/mi)

\begin{tabular}{|l|c|c|c|c|c|c|c|c|}
\multicolumn{1}{|c|}{} & \multicolumn{4}{|c|}{ FTD20 CIDI } & \multicolumn{3}{c|}{ Comparison with FRFG Gasoline Vehicle } \\
\hline \multicolumn{1}{|c|}{ Outputs } & Feedstock & Fuel & Vehicle & Total & Feedstock & Fuel & Vehicle & Total \\
\hline Total energy & 185 & 989 & 4,111 & 5,285 & $-16 \%$ & $-17 \%$ & $-20 \%$ & $-20 \%$ \\
\hline Fossil fuels & 179 & 982 & 4,108 & 5,269 & $-15 \%$ & $-17 \%$ & $-20 \%$ & $-20 \%$ \\
\hline Petroleum & 45 & 301 & 3,336 & 3,683 & $-31 \%$ & $-39 \%$ & $-28 \%$ & $-29 \%$ \\
\hline $\mathrm{CO}_{2}$ & 17 & 53 & 329 & 399 & $-19 \%$ & $-45 \%$ & $-16 \%$ & $-21 \%$ \\
\hline $\mathrm{CH}_{4}$ & 0.384 & 0.046 & 0.011 & 0.441 & $-18 \%$ & $-79 \%$ & $-86 \%$ & $-42 \%$ \\
\hline $\mathrm{N}_{2} \mathrm{O}$ & 0.000 & 0.001 & 0.016 & 0.017 & $-22 \%$ & $-50 \%$ & $-43 \%$ & $-43 \%$ \\
\hline GWP & 26 & 54 & 334 & 415 & $23 \%$ & $-52 \%$ & $-17 \%$ & $-23 \%$ \\
\hline VOC & 0.011 & 0.022 & 0.049 & 0.082 & $-34 \%$ & $-69 \%$ & $-70 \%$ & $-67 \%$ \\
\hline CO & 0.031 & 0.046 & 1.070 & 1.147 & $-25 \%$ & $-7 \%$ & $-76 \%$ & $-75 \%$ \\
\hline NOx & 0.080 & 0.080 & 0.062 & 0.222 & $-29 \%$ & $-42 \%$ & $-76 \%$ & $-57 \%$ \\
\hline PM10 & 0.002 & 0.009 & 0.028 & 0.039 & $-29 \%$ & $-42 \%$ & $-14 \%$ & $-23 \%$ \\
\hline SOx & 0.017 & 0.057 & 0.003 & 0.077 & $-25 \%$ & $-75 \%$ & $-60 \%$ & $-71 \%$ \\
\hline VOC: urban & 0.001 & 0.008 & 0.049 & 0.058 & $-34 \%$ & $-71 \%$ & $-70 \%$ & $-70 \%$ \\
\hline CO: urban & 0.001 & 0.010 & 1.070 & 1.081 & $-29 \%$ & $-41 \%$ & $-76 \%$ & $-76 \%$ \\
\hline NOx: urban & 0.001 & 0.023 & 0.062 & 0.086 & $-29 \%$ & $-38 \%$ & $-76 \%$ & $-71 \%$ \\
\hline PM10: urban & 0.000 & 0.004 & 0.028 & 0.032 & $-30 \%$ & $-39 \%$ & $-14 \%$ & $-18 \%$ \\
\hline SOx: urban & 0.001 & 0.027 & 0.003 & 0.030 & $-29 \%$ & $-38 \%$ & $-60 \%$ & $-41 \%$ \\
\hline
\end{tabular}

\subsubsection{Long-Term Results of the $\mathrm{LCl}$}

Figures 6-6 through 6-10 compare FTD100 CIDI, FTD100 CIDI HEV, aggressive FTD100 CIDI and aggressive FTD100 CIDI HEV (FTD optimized engines, with a 5\% improvement in fuel efficiency) with PADD III ULSD CIDI, PADD III FRFG SIDI, PADD III ULSD HEV, and PADD III FRFG HEV. FT naphtha FCV is compared with methanol FCVs and FRFG FCVs.

Tables 6-4 through 6-7 provide numerical comparisons for these cases.

It should be kept in mind that a total energy and GWP of $10 \%$ or greater in difference is considered to be significant. Criteria emissions greater than $15 \%$ in difference are considered to be significant. The summary of conclusions in the last section reflects these thresholds.

In comparison with the ULSD CIDI PADD III 2015 (Table 6-4), FTD100 CIDI is 3\% lower in GWP, $15 \%$ lower in total $\mathrm{NO}_{\mathrm{X}}, 26 \%$ lower in total PM10, and 78\% lower in $\mathrm{SO}_{\mathrm{X}}$. FTD100 consumes $25 \%$ more total energy than ULSD. For urban criteria emissions, FTD100 CIDI is $35 \%$ lower in $\mathrm{NO}_{\mathrm{X}}, 21 \%$ lower in PM10, and 99\% lower in $\mathrm{SO}_{\mathrm{X}}$. Total VOCs are reduced by $11 \%$ for FTD100 CIDI, and total CO is increased by 7\%, although urban CO is decreased by $1 \%$. 
The urban emissions comparisons show the effect of segmenting urban and non-urban emissions. For the GTL pathways in this report, a significant portion of the criteria pollutant emissions is generated in upstream stages, at remote wellhead sites or from ocean tankers.

Compared with the PADD III FRFG SIDI (Table 6-4), FTD100 CIDI also shows improvements: $8 \%$ lower in GWP, $16 \%$ lower in $\mathrm{NO}_{\mathrm{X}}\left(8 \%\right.$ lower in urban $\left.\mathrm{NO}_{\mathrm{X}}\right), 34 \%$ lower in PM10 $(30 \%$ lower in urban PM10), and 87\% lower in $\mathrm{SO}_{\mathrm{X}}\left(99 \%\right.$ lower in urban $\mathrm{SO}_{\mathrm{X}}$ ). FTD100 consumes $15 \%$ more total energy than FRFG SIDI. VOCs are reduced by $61 \%$ for FTD100 CIDI, and CO is reduced by $58 \%$.

In comparison with the ULSD CIDI PADD III 2015 (Table 6-5), the aggressive FTD100 CIDI (with a 5\% improvement in fuel efficiency, due to optimization of the engine for FTD) is 7\% lower in GWP, $18 \%$ lower in total $\mathrm{NO}_{\mathrm{X}}, 26 \%$ lower in total PM10, and $79 \%$ lower in $\mathrm{SO}_{\mathrm{X}}$. For urban criteria emissions, the aggressive FTD100 CIDI is $35 \%$ lower in $\mathrm{NO}_{\mathrm{x}}, 21 \%$ lower in PM10, and 99\% lower in $\mathrm{SO}_{\mathrm{x}}$. The aggressive FTD100 consumes 19\% more total energy than ULSD. VOCs are reduced by $7 \%$, and total $\mathrm{CO}$ is increased by $7 \%$.

Compared with the PADD III FRFG SIDI (Table 6-5), the aggressive FTD100 CIDI is $13 \%$ lower in GWP, $19 \%$ lower in $\mathrm{NO}_{\mathrm{X}}\left(8 \%\right.$ lower in urban $\left.\mathrm{NO}_{\mathrm{X}}\right), 35 \%$ lower in PM10 $(30 \%$ lower in urban $\mathrm{PM} 10)$, and $88 \%$ lower in $\mathrm{SO}_{\mathrm{X}}\left(99 \%\right.$ lower in urban $\left.\mathrm{SO}_{\mathrm{X}}\right)$. The aggressive FTD100 consumes $9 \%$ more total energy than FRFG SIDI. VOCs are reduced by $61 \%$, and CO is reduced by $58 \%$.

In comparison with the ULSD CIDI HEV PADD III 2015 (Table 6-6), the FTD100 CIDI HEV is $3 \%$ lower in GWP, $13 \%$ lower in total $\mathrm{NO}_{\mathrm{X}}, 21 \%$ lower in total PM10, and $78 \%$ lower in $\mathrm{SO}_{\mathrm{X}}$. For urban criteria emissions, the FTD100 CIDI HEV is $30 \%$ lower in $\mathrm{NO}_{\mathrm{X}}, 17 \%$ lower in PM10, and $99 \%$ lower in $\mathrm{SO}_{\mathrm{X}}$. The FTD100 CIDI HEV consumes $24 \%$ more total energy than the comparable ULSD. VOCs are reduced by $9 \%$, and total CO is increased by $5 \%$.

Compared with the PADD III FRFG SIDI HEV (Table 6-6), the FTD100 CIDI HEV is $17 \%$ lower in GWP, 20\% lower in $\mathrm{NO}_{\mathrm{X}}\left(3 \%\right.$ lower in urban $\left.\mathrm{NO}_{\mathrm{X}}\right), 29 \%$ lower in PM10 (23\% lower in urban PM10), and 88\% lower in $\mathrm{SO}_{\mathrm{X}}\left(99 \%\right.$ lower in urban $\left.\mathrm{SO}_{\mathrm{X}}\right)$. FTD100 HEV consumes $4 \%$ more total energy than the FRFG HEV. VOCs are reduced by $58 \%$, and CO is reduced by $59 \%$.

Table 6-7 compares the FT naphtha FCV with the methanol and FRFG FCVs. FT naphtha has $4 \%$ lower in GWP than FRFG and has 9\% more GWP than methanol. FT naphtha has lower total and urban criteria emissions than both fuels, except for $\mathrm{CO}$, which is increased. The FT naphtha FCV consumes $26 \%$ and $13 \%$ more total energy than then FRFG and methanol FCVs, respectively. 


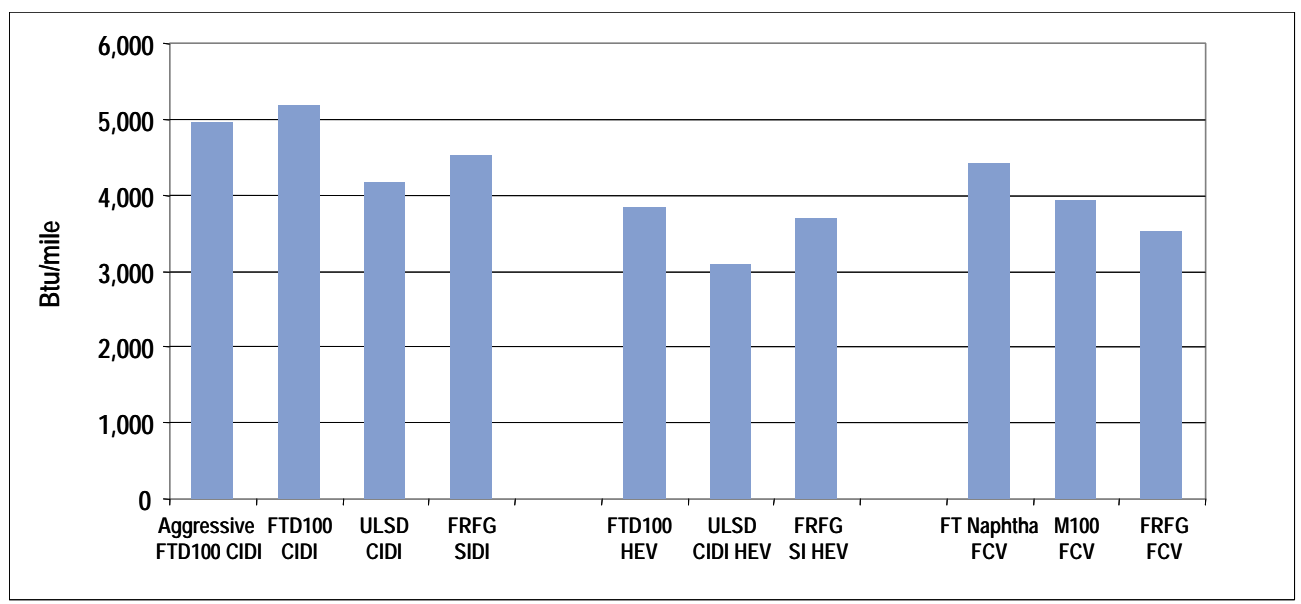

Figure 6-6 Total Energy, 2015

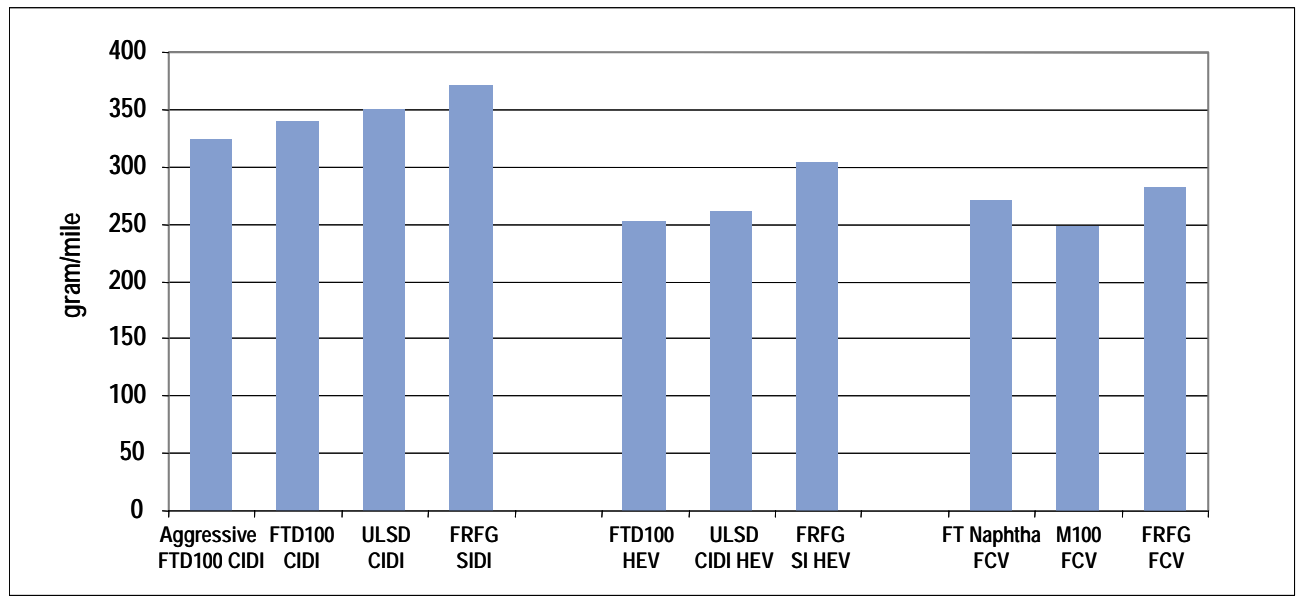

Figure 6-7 Global Warming Potential, 2015

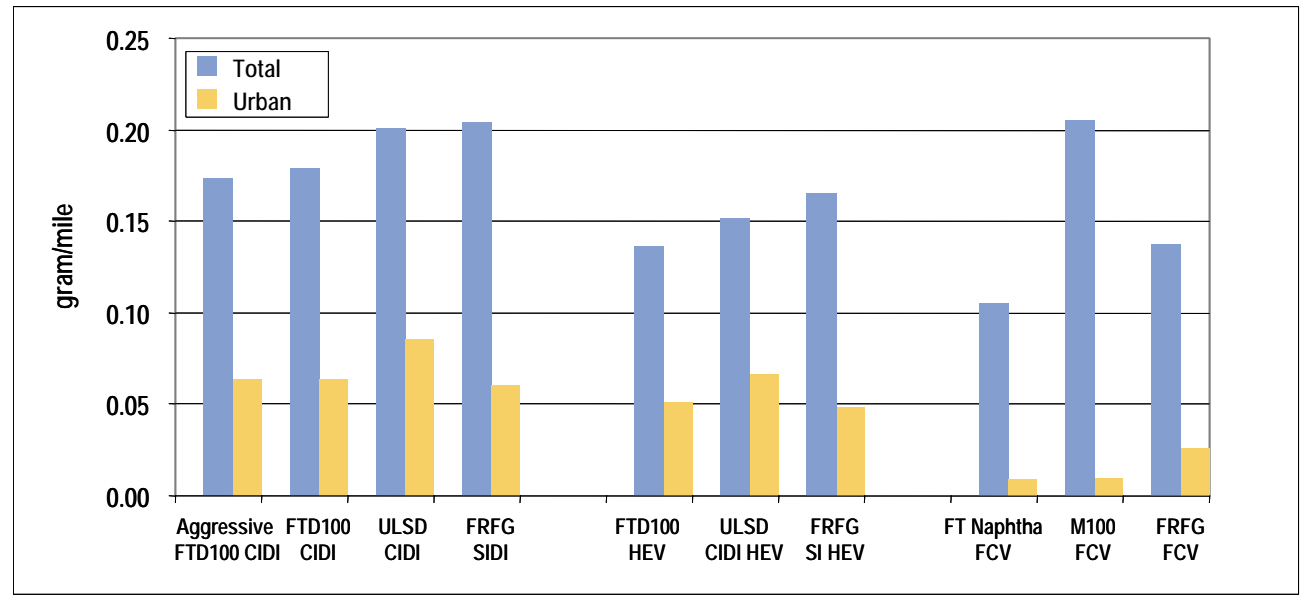

Figure 6-8 NOx Inventory, 2015 


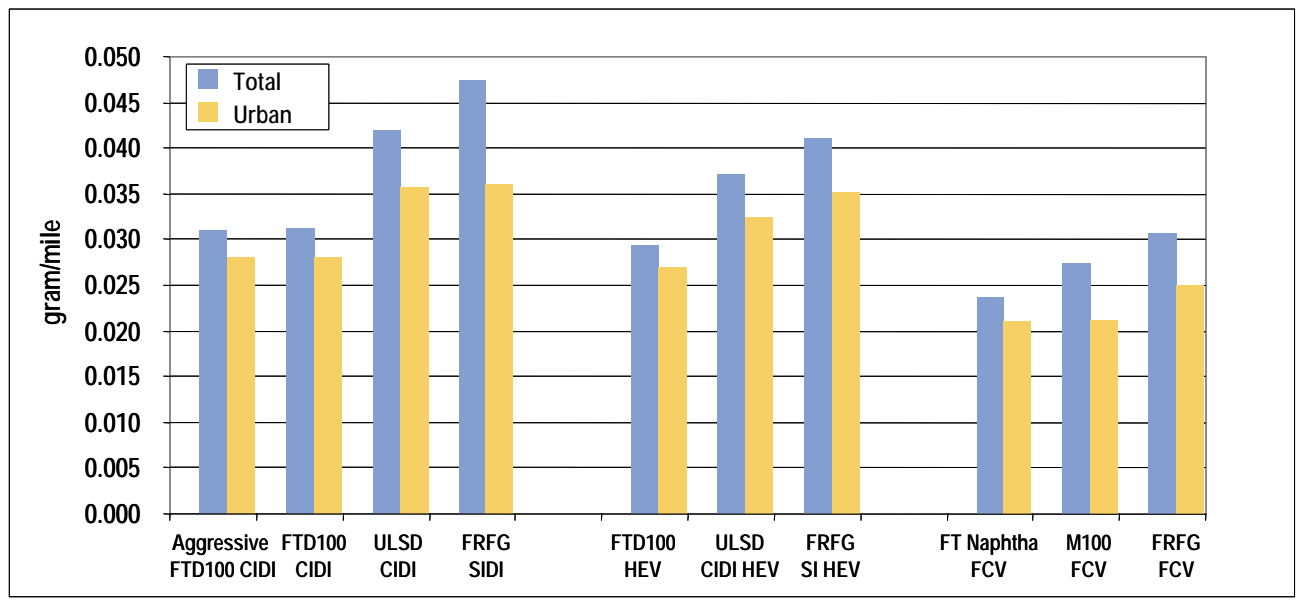

Figure 6-9 PM10 Inventory, 2015

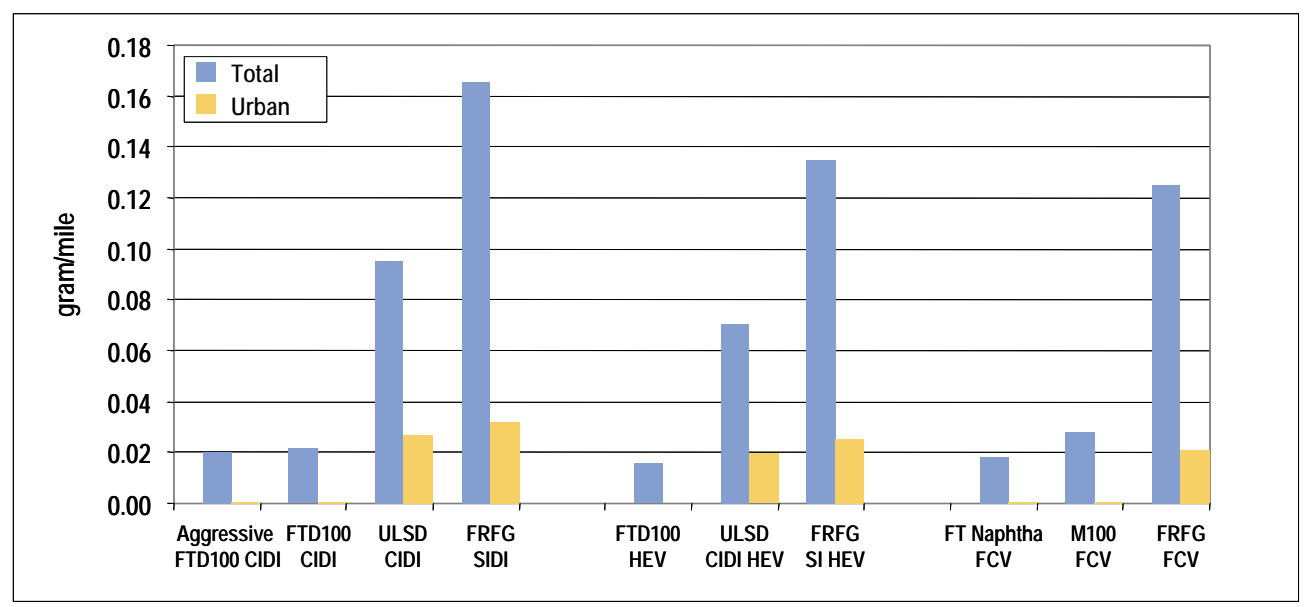

Figure 6-10 SOx Inventory, 2015 
Table 6-4 FTD100 CIDI Comparison with ULSD CIDI and FRFG SIDI (Btu/mi or g/mi)

\begin{tabular}{|c|c|c|c|c|c|c|c|c|c|c|c|c|}
\hline \multirow[b]{2}{*}{ Outputs } & \multicolumn{4}{|c|}{ FTD100 CIDI } & \multicolumn{4}{|c|}{$\begin{array}{l}\text { Comparison with ULSD CIDI } \\
\text { (FTD100 \% Difference) }\end{array}$} & \multicolumn{4}{|c|}{$\begin{array}{l}\text { Comparison with FRFG SIDI } \\
\text { (FTD100\% Difference) }\end{array}$} \\
\hline & $\begin{array}{l}\text { Feed- } \\
\text { stock }\end{array}$ & Fuel & Vehicle & Total & $\begin{array}{l}\text { Feed- } \\
\text { stock }\end{array}$ & Fuel & Vehicle & Total & $\begin{array}{l}\text { Feed- } \\
\text { stock }\end{array}$ & Fuel & Vehicle & Total \\
\hline Total energy & 189 & 1,600 & 3,399 & 5,188 & $32 \%$ & $156 \%$ & $0 \%$ & $25 \%$ & $27 \%$ & $92 \%$ & $-4 \%$ & $15 \%$ \\
\hline Fossil fuels & 188 & 1,599 & 3,399 & 5,186 & $37 \%$ & $159 \%$ & $0 \%$ & $25 \%$ & $31 \%$ & $95 \%$ & $-4 \%$ & $15 \%$ \\
\hline Petroleum & 12 & 56 & 0 & 68 & $-71 \%$ & $-82 \%$ & $-100 \%$ & $-98 \%$ & $-73 \%$ & $-84 \%$ & $-100 \%$ & $-98 \%$ \\
\hline $\mathrm{CO}_{2}$ & 15 & 49 & 263 & 327 & $10 \%$ & $1 \%$ & $-4 \%$ & $-3 \%$ & $6 \%$ & $-28 \%$ & $-2 \%$ & $-7 \%$ \\
\hline $\mathrm{CH}_{4}$ & 0.353 & 0.006 & 0.011 & 0.369 & $14 \%$ & $-88 \%$ & $0 \%$ & $0 \%$ & $9 \%$ & $-96 \%$ & $-83 \%$ & $-31 \%$ \\
\hline $\mathrm{N}_{2} \mathrm{O}$ & 0.000 & 0.000 & 0.016 & 0.016 & $-16 \%$ & $-84 \%$ & $0 \%$ & $-4 \%$ & $-19 \%$ & $-88 \%$ & $-43 \%$ & $-44 \%$ \\
\hline GWP & 23 & 49 & 268 & 340 & $15 \%$ & $-3 \%$ & $-4 \%$ & $-3 \%$ & $10 \%$ & $-32 \%$ & $-4 \%$ & $-8 \%$ \\
\hline VOC: total & 0.001 & 0.020 & 0.049 & 0.071 & $-89 \%$ & $6 \%$ & $0 \%$ & $-11 \%$ & $-89 \%$ & $-58 \%$ & $-59 \%$ & $-61 \%$ \\
\hline CO: total & 0.017 & 0.111 & 1.070 & 1.198 & $-33 \%$ & $390 \%$ & $0 \%$ & $7 \%$ & $-35 \%$ & $229 \%$ & $-61 \%$ & $-58 \%$ \\
\hline NOx: total & 0.028 & 0.089 & 0.054 & 0.171 & $-61 \%$ & $35 \%$ & $-15 \%$ & $-15 \%$ & $-63 \%$ & $-4 \%$ & $49 \%$ & $-16 \%$ \\
\hline PM10: total & 0.001 & 0.002 & 0.028 & 0.031 & $-57 \%$ & $-75 \%$ & $-10 \%$ & $-26 \%$ & $-59 \%$ & $-78 \%$ & $-20 \%$ & $-34 \%$ \\
\hline SOx: Total & 0.009 & 0.012 & 0.000 & 0.021 & $-22 \%$ & $-85 \%$ & $-100 \%$ & $-78 \%$ & $-25 \%$ & $-92 \%$ & $-100 \%$ & $-87 \%$ \\
\hline VOC: urban & 0.000 & 0.002 & 0.049 & 0.051 & $-94 \%$ & $-69 \%$ & $0 \%$ & $-11 \%$ & $-94 \%$ & $-87 \%$ & $-59 \%$ & $-63 \%$ \\
\hline co: urban & 0.000 & 0.000 & 1.070 & 1.071 & $-59 \%$ & $-96 \%$ & $0 \%$ & $-1 \%$ & $-61 \%$ & $-96 \%$ & $-61 \%$ & $-61 \%$ \\
\hline NOx: urban & 0.000 & 0.002 & 0.054 & 0.056 & $-60 \%$ & $-92 \%$ & $-15 \%$ & $-35 \%$ & $-61 \%$ & $-93 \%$ & $49 \%$ & $-8 \%$ \\
\hline PM10: urban & 0.000 & 0.000 & 0.028 & 0.028 & $-64 \%$ & $-99 \%$ & $-10 \%$ & $-21 \%$ & $-66 \%$ & $-99 \%$ & $-20 \%$ & $-30 \%$ \\
\hline SOx: urban & 0.000 & 0.000 & 0.000 & 0.000 & $-55 \%$ & $-99 \%$ & $-100 \%$ & $-99 \%$ & $-57 \%$ & $-99 \%$ & $-100 \%$ & $-99 \%$ \\
\hline
\end{tabular}


Table 6-5 Aggressive FTD100 CIDI Comparison with ULSD CIDI and FRFG SIDI (Btu/mi or g/mi)

\begin{tabular}{|c|c|c|c|c|c|c|c|c|c|c|c|c|}
\hline \multirow[b]{2}{*}{ Outputs } & \multicolumn{4}{|c|}{ Aggressive FTD100 CIDI } & \multicolumn{4}{|c|}{$\begin{array}{l}\text { Comparison with ULSD CIDI } \\
\text { (FTD100\% Difference) }\end{array}$} & \multicolumn{4}{|c|}{$\begin{array}{l}\text { Comparison with FRFG SIDI } \\
\text { FTD100 \% Difference) }\end{array}$} \\
\hline & $\begin{array}{l}\text { Feed- } \\
\text { stock }\end{array}$ & Fuel & Vehicle & Total & $\begin{array}{l}\text { Feed- } \\
\text { stock }\end{array}$ & Fuel & Vehicle & Total & $\begin{array}{l}\text { Feed- } \\
\text { stock }\end{array}$ & Fuel & Vehicle & Total \\
\hline Total energy & 180 & 1,524 & 3,239 & 4,943 & $26 \%$ & $144 \%$ & $-5 \%$ & $19 \%$ & $21 \%$ & $83 \%$ & $-9 \%$ & $9 \%$ \\
\hline Fossil fuels & 179 & 1,523 & 3,239 & 4,941 & $30 \%$ & $147 \%$ & $-5 \%$ & $19 \%$ & $25 \%$ & $85 \%$ & $-9 \%$ & $10 \%$ \\
\hline Petroleum & 12 & 53 & 0 & 65 & $-73 \%$ & $-83 \%$ & $-100 \%$ & $-98 \%$ & $-74 \%$ & $-85 \%$ & $-100 \%$ & $-98 \%$ \\
\hline $\mathrm{CO}_{2}$ & 14 & 46 & 251 & 311 & $5 \%$ & $-4 \%$ & $-9 \%$ & $-7 \%$ & $1 \%$ & $-32 \%$ & $-7 \%$ & $-11 \%$ \\
\hline $\mathrm{CH}_{4}$ & 0.336 & 0.005 & 0.011 & 0.352 & $9 \%$ & $-89 \%$ & $0 \%$ & $-5 \%$ & $4 \%$ & $-96 \%$ & $-83 \%$ & $-35 \%$ \\
\hline $\mathrm{N}_{2} \mathrm{O}$ & 0.000 & 0.000 & 0.016 & 0.016 & $-20 \%$ & $-85 \%$ & $0 \%$ & $-4 \%$ & $-23 \%$ & $-89 \%$ & $-43 \%$ & $-44 \%$ \\
\hline GWP & 22 & 46 & 256 & 324 & $9 \%$ & $-7 \%$ & $-9 \%$ & $-7 \%$ & $5 \%$ & $-36 \%$ & $-8 \%$ & $-13 \%$ \\
\hline VOC: total & 0.001 & 0.019 & 0.049 & 0.070 & $-89 \%$ & $1 \%$ & $0 \%$ & $-12 \%$ & $-90 \%$ & $-60 \%$ & $-59 \%$ & $-61 \%$ \\
\hline CO: total & 0.017 & 0.105 & 1.070 & 1.192 & $-36 \%$ & $366 \%$ & $0 \%$ & $7 \%$ & $-39 \%$ & $213 \%$ & $-61 \%$ & $-58 \%$ \\
\hline NOx: total & 0.027 & 0.085 & 0.054 & 0.165 & $-63 \%$ & $29 \%$ & $-15 \%$ & $-18 \%$ & $-64 \%$ & $-9 \%$ & $49 \%$ & $-19 \%$ \\
\hline PM10: total & 0.001 & 0.002 & 0.028 & 0.031 & $-59 \%$ & $-76 \%$ & $-10 \%$ & $-26 \%$ & $-61 \%$ & $-79 \%$ & $-20 \%$ & $-35 \%$ \\
\hline $\mathrm{SO}_{\mathrm{x}}$ : total & 0.009 & 0.011 & 0.000 & 0.020 & $-25 \%$ & $-86 \%$ & $-100 \%$ & $-79 \%$ & $-28 \%$ & $-92 \%$ & $-100 \%$ & $-88 \%$ \\
\hline VOC: urban & 0.000 & 0.002 & 0.049 & 0.051 & $-94 \%$ & $-71 \%$ & $0 \%$ & $-11 \%$ & $-95 \%$ & $-88 \%$ & $-59 \%$ & $-63 \%$ \\
\hline CO: urban & 0.000 & 0.000 & 1.070 & 1.071 & $-61 \%$ & $-96 \%$ & $0 \%$ & $-1 \%$ & $-63 \%$ & $-97 \%$ & $-61 \%$ & $-61 \%$ \\
\hline NOx: urban & 0.000 & 0.002 & 0.054 & 0.055 & $-62 \%$ & $-93 \%$ & $-15 \%$ & $-35 \%$ & $-63 \%$ & $-93 \%$ & $49 \%$ & $-8 \%$ \\
\hline PM10: urban & 0.000 & 0.000 & 0.028 & 0.028 & $-66 \%$ & $-99 \%$ & $-10 \%$ & $-21 \%$ & $-67 \%$ & $-99 \%$ & $-20 \%$ & $-30 \%$ \\
\hline SOx: urban & 0.000 & 0.000 & 0.000 & 0.000 & $-57 \%$ & $-99 \%$ & $-100 \%$ & $-99 \%$ & $-59 \%$ & $-99 \%$ & $-100 \%$ & $-99 \%$ \\
\hline
\end{tabular}


Table 6-6 FTD100 CIDI HEV Comparison with ULSD CIDI HEV and FRFG SIDI HEV (Btu/mi or $\mathrm{g} / \mathrm{mi}$ )

\begin{tabular}{|c|c|c|c|c|c|c|c|c|c|c|c|c|}
\hline \multirow[b]{2}{*}{ Outputs } & \multicolumn{4}{|c|}{ FTD100 CIDI HEV } & \multicolumn{4}{|c|}{$\begin{array}{l}\text { Comparison with ULSD CIDI HEV } \\
\text { (FTD100 \% Difference) }\end{array}$} & \multicolumn{4}{|c|}{$\begin{array}{l}\text { Comparison with FRFG SI HEV } \\
\text { (FTD100 \% Difference) }\end{array}$} \\
\hline & $\begin{array}{l}\text { Feed- } \\
\text { stock }\end{array}$ & Fuel & Vehicle & Total & $\begin{array}{l}\text { Feed- } \\
\text { stock }\end{array}$ & Fuel & Vehicle & Total & $\begin{array}{l}\text { Feed- } \\
\text { stock }\end{array}$ & Fuel & Vehicle & Total \\
\hline Total energy & 140 & 1,185 & 2,519 & 3,844 & $32 \%$ & $156 \%$ & $0 \%$ & $24 \%$ & $15 \%$ & $75 \%$ & $-13 \%$ & $4 \%$ \\
\hline Fossil fuels & 139 & 1,184 & 2,519 & 3,842 & $36 \%$ & $159 \%$ & $0 \%$ & $25 \%$ & $19 \%$ & $77 \%$ & $-13 \%$ & $5 \%$ \\
\hline Petroleum & 9 & 41 & 0 & 50 & $-71 \%$ & $-82 \%$ & $-100 \%$ & $-98 \%$ & $-75 \%$ & $-85 \%$ & $-100 \%$ & $-98 \%$ \\
\hline $\mathrm{CO}_{2}$ & 11 & 36 & 195 & 242 & $10 \%$ & $1 \%$ & $-4 \%$ & $-3 \%$ & $-4 \%$ & $-35 \%$ & $-11 \%$ & $-15 \%$ \\
\hline $\mathrm{CH}_{4}$ & 0.261 & 0.004 & 0.011 & 0.276 & $14 \%$ & $-88 \%$ & $0 \%$ & $0 \%$ & $-1 \%$ & $-97 \%$ & $-83 \%$ & $-39 \%$ \\
\hline $\mathrm{N}_{2} \mathrm{O}$ & 0.000 & 0.000 & 0.016 & 0.016 & $-16 \%$ & $-84 \%$ & $0 \%$ & $-3 \%$ & $-27 \%$ & $-89 \%$ & $-43 \%$ & $-44 \%$ \\
\hline GWP & 17 & 36 & 200 & 253 & $11 \%$ & $-3 \%$ & $-4 \%$ & $-3 \%$ & $-3 \%$ & $-38 \%$ & $-12 \%$ & $-17 \%$ \\
\hline VOC: total & 0.001 & 0.015 & 0.049 & 0.065 & $-89 \%$ & $6 \%$ & $0 \%$ & $-9 \%$ & $-90 \%$ & $-62 \%$ & $-54 \%$ & $-58 \%$ \\
\hline CO: total & 0.013 & 0.082 & 1.070 & 1.165 & $-33 \%$ & $390 \%$ & $0 \%$ & $5 \%$ & $-41 \%$ & $199 \%$ & $-61 \%$ & $-59 \%$ \\
\hline NOx: total & 0.021 & 0.066 & 0.046 & 0.132 & $-61 \%$ & $35 \%$ & $-10 \%$ & $-13 \%$ & $-66 \%$ & $-13 \%$ & $58 \%$ & $-20 \%$ \\
\hline PM10: total & 0.001 & 0.002 & 0.027 & 0.029 & $-57 \%$ & $-75 \%$ & $-7 \%$ & $-21 \%$ & $-63 \%$ & $-80 \%$ & $-13 \%$ & $-29 \%$ \\
\hline SOx: total & 0.007 & 0.009 & 0.000 & 0.016 & $-22 \%$ & $-85 \%$ & $-100 \%$ & $-78 \%$ & $-32 \%$ & $-93 \%$ & $-100 \%$ & $-88 \%$ \\
\hline VOC: urban & 0.000 & 0.002 & 0.049 & 0.051 & $-94 \%$ & $-69 \%$ & $0 \%$ & $-8 \%$ & $-95 \%$ & $-88 \%$ & $-54 \%$ & $-58 \%$ \\
\hline CO: urban & 0.000 & 0.000 & 1.070 & 1.070 & $-59 \%$ & $-96 \%$ & $0 \%$ & $-1 \%$ & $-65 \%$ & $-97 \%$ & $-61 \%$ & $-61 \%$ \\
\hline NOx: urban & 0.000 & 0.001 & 0.046 & 0.047 & $-60 \%$ & $-92 \%$ & $-10 \%$ & $-30 \%$ & $-65 \%$ & $-94 \%$ & $58 \%$ & $-3 \%$ \\
\hline PM10: urban & 0.000 & 0.000 & 0.027 & 0.027 & $-65 \%$ & $-99 \%$ & $-7 \%$ & $-17 \%$ & $-69 \%$ & $-99 \%$ & $-13 \%$ & $-23 \%$ \\
\hline SOx: urban & 0.000 & 0.000 & 0.000 & 0.000 & $-56 \%$ & $-99 \%$ & $-100 \%$ & $-99 \%$ & $-62 \%$ & $-99 \%$ & $-100 \%$ & $-99 \%$ \\
\hline
\end{tabular}




\section{Table 6-7 FT Naphtha FCV Comparison with Methanol FCV and FRFG FCV} (Btu/mi or $\mathrm{g} / \mathrm{mi}$ )

\begin{tabular}{|l|c|c|c|c|c|c|c|c|c|c|c|c|}
\hline & \multicolumn{4}{|c|}{} & \multicolumn{3}{|c|}{ FT Naphtha FCV } & \multicolumn{3}{c|}{$\begin{array}{c}\text { Comparison with FRFG FCV } \\
\text { (FT Naphtha \% Difference) }\end{array}$} & \multicolumn{3}{c|}{$\begin{array}{c}\text { Comparison with Methanol FCV } \\
\text { (FT Naphtha \% Difference) }\end{array}$} \\
\hline & $\begin{array}{l}\text { Feed- } \\
\text { stock }\end{array}$ & Fuel & Vehicle & Total & $\begin{array}{c}\text { Feed- } \\
\text { stock }\end{array}$ & Fuel & Vehicle & Total & $\begin{array}{c}\text { Feed- } \\
\text { stock }\end{array}$ & Fuel & Vehicle & Total \\
\hline Total energy & 161 & 1,362 & 2,897 & 4,420 & $39 \%$ & $111 \%$ & $5 \%$ & $26 \%$ & $13 \%$ & $12 \%$ & $13 \%$ & $13 \%$ \\
\hline Fossil fuels & 160 & 1,361 & 2,897 & 4,419 & $44 \%$ & $113 \%$ & $5 \%$ & $26 \%$ & $13 \%$ & $12 \%$ & $13 \%$ & $13 \%$ \\
\hline Petroleum & 11 & 50 & 0 & 61 & $-70 \%$ & $-81 \%$ & $-100 \%$ & $-98 \%$ & $13 \%$ & $-52 \%$ & $0 \%$ & $-47 \%$ \\
\hline $\mathrm{CO}_{2}$ & 13 & 41 & 207 & 261 & $16 \%$ & $-22 \%$ & $0 \%$ & $-4 \%$ & $13 \%$ & $-2 \%$ & $12 \%$ & $10 \%$ \\
\hline $\mathrm{CH}_{4}$ & 0.301 & 0.005 & 0.013 & 0.318 & $20 \%$ & $-96 \%$ & $0 \%$ & $-16 \%$ & $13 \%$ & $-90 \%$ & $0 \%$ & $-3 \%$ \\
\hline $\mathrm{N}_{2} \mathrm{O}$ & 0.000 & 0.000 & 0.006 & 0.006 & $-11 \%$ & $-87 \%$ & $0 \%$ & $-11 \%$ & $13 \%$ & $-85 \%$ & $0 \%$ & $-8 \%$ \\
\hline GWP & 20 & 41 & 209 & 270 & $21 \%$ & $-26 \%$ & $0 \%$ & $-4 \%$ & $13 \%$ & $-4 \%$ & $12 \%$ & $9 \%$ \\
\hline VOC: total & 0.001 & 0.017 & 0.016 & 0.034 & $-88 \%$ & $-55 \%$ & $-72 \%$ & $-68 \%$ & $13 \%$ & $-37 \%$ & $-59 \%$ & $-49 \%$ \\
\hline CO: total & 0.015 & 0.094 & 0.552 & 0.661 & $-29 \%$ & $260 \%$ & $0 \%$ & $10 \%$ & $13 \%$ & $162 \%$ & $0 \%$ & $10 \%$ \\
\hline NOx: total & 0.024 & 0.074 & 0.007 & 0.105 & $-59 \%$ & $2 \%$ & $0 \%$ & $-24 \%$ & $13 \%$ & $-58 \%$ & $0 \%$ & $-49 \%$ \\
\hline PM10: total & 0.001 & 0.002 & 0.021 & 0.024 & $-55 \%$ & $-77 \%$ & $0 \%$ & $-23 \%$ & $13 \%$ & $-68 \%$ & $0 \%$ & $-14 \%$ \\
\hline SOx: total & 0.008 & 0.010 & 0.000 & 0.018 & $-17 \%$ & $-91 \%$ & $0 \%$ & $-86 \%$ & $13 \%$ & $-53 \%$ & $0 \%$ & $-36 \%$ \\
\hline VOC: urban & 0.000 & 0.002 & 0.016 & 0.018 & $-94 \%$ & $-83 \%$ & $-72 \%$ & $-75 \%$ & $13 \%$ & $-38 \%$ & $-59 \%$ & $-57 \%$ \\
\hline CO: urban & 0.000 & 0.000 & 0.552 & 0.552 & $-57 \%$ & $-96 \%$ & $0 \%$ & $-2 \%$ & $13 \%$ & $-43 \%$ & $0 \%$ & $0 \%$ \\
\hline NOx: urban & 0.000 & 0.002 & 0.007 & 0.009 & $-58 \%$ & $-91 \%$ & $0 \%$ & $-65 \%$ & $13 \%$ & $-40 \%$ & $0 \%$ & $-10 \%$ \\
\hline PM10: urban & 0.000 & 0.000 & 0.021 & 0.021 & $-62 \%$ & $-99 \%$ & $0 \%$ & $-15 \%$ & $13 \%$ & $-52 \%$ & $0 \%$ & $0 \%$ \\
\hline SOx: urban & 0.000 & 0.000 & 0.000 & 0.000 & $-53 \%$ & $-99 \%$ & $0 \%$ & $-98 \%$ & $13 \%$ & $-59 \%$ & $0 \%$ & $-41 \%$ \\
\hline
\end{tabular}

\subsection{SOLID WASTE AND WASTEWATER}

Wastewater and solid waste data for petroleum and GTL products was gathered from studies from the National Renewable Energy Laboratory (NREL, 1993), the American Petroleum Institute (API, 2002), and the U.S. EPA Toxics Release Inventory (TRI). Wastewater and solid waste for the petroleum and GTL fuels were estimated on a well-to-tank basis, since all the relevant waste for both pathways is generated during these stages. Most wastewater and solid waste are generated during the refining stages for both petroleum and GTL fuels. For petroleum, refining accounts for about $80 \%$ of wastewater generation and about $75 \%$ of solid waste generation.

Because the waste streams are an aggregation of both treated and untreated waste, caution must be taken in the interpretation these results. No specific data is available on the composition of the waste streams. Very limited information is provided in a comparison based only on total quantity of waste.

A comparison of toxic emissions, based on EPA Toxics Release Inventory data would be more comprehensive and consistent. However, since no commercial-scale GTL plants currently operate in the United States, TRI data for such plants is not yet available. 
With these caveats in mind, the total quantities of solid waste and wastewater were estimated for the petroleum and GTL fuels.

The production of FTD generates about 5.9 gal/MMBtu of wastewater, and between 4.3 and 13.6 grams of solid waste per MMBtu of fuel, depending on whether or not the spent catalyst is recycled (Table 6-8). For the full GTL product slate (70\% FTD, 30\% FT naphtha), the figures are $8.4 \mathrm{gal} / \mathrm{MMBtu}$ for wastewater and between 6.2 and $19.4 \mathrm{~g} / \mathrm{MMBtu}$ for solid waste.

\section{Table 6-8 GTL Wastewater (gal/MMBtu) and Solid Waste (g/MMBtu)} for FTD and FT Naphtha

\begin{tabular}{|l|c|c|}
\multicolumn{1}{|c|}{ Case } & FTD & FT Naphtha \\
\hline Total wastewater discharge, treated and untreated & 5.9 & 2.5 \\
\hline Total solid waste assuming that all used catalyst is waste & 13.6 & 5.8 \\
\hline Solid waste assuming that the FT catalyst is recoverable & 4.3 & 1.9 \\
\hline
\end{tabular}

Source: Nexant/Bechtel Analysis

Tables 6-9 and 6-10 present inventory data for the petroleum system. Lower and upper ranges on the inventories were calculated. The lower range is an allocation of wastewater and solid waste among all system products. The upper range is an allocation of all waste only to the primary system products. The allocations were made on the basis of the PADD III 2015 product slate as modeled in PIMS.

For the lower range, the total wastewater for FRFG is $20.3 \mathrm{~g} / \mathrm{MMBtu}$ and for solid waste is $168.9 \mathrm{~g} / \mathrm{MMBtu}$. For ULSD, the figures are 6.2 gal/MMBtu and $51.7 \mathrm{~g} / \mathrm{MMBtu}$.

For the upper range case, FRFG generates $44.3 \mathrm{gal} / \mathrm{MMBtu}$ and $369 \mathrm{~g} / \mathrm{MMBtu}$ of solid waste and wastewater, respectively; ULSD generates $13.5 \mathrm{gal} / \mathrm{MMBtu}$ and $112.9 \mathrm{~g} / \mathrm{MMBtu}$ of solid waste and wastewater.

Table 6-9 Petroleum System Wastewater (WW) (gal/MMBtu)

\begin{tabular}{|c|c|c|c|c|c|c|c|c|c|}
\hline \multirow{2}{*}{\multicolumn{2}{|c|}{ Product }} & \multicolumn{4}{|c|}{ Lower Range: Allocated to the Full Product Slate } & \multicolumn{4}{|c|}{ Upper Range: Allocated to Gasoline and ULSD Only } \\
\hline & & $\begin{array}{l}\text { WW from } \\
\text { Crude } \\
\text { Production }\end{array}$ & $\begin{array}{l}\text { Untreated } \\
\text { WW from } \\
\text { Crude } \\
\text { Refining }\end{array}$ & $\begin{array}{c}\text { Treated } \\
\text { WW from } \\
\text { Crude } \\
\text { Refining }\end{array}$ & Total WW & $\begin{array}{l}\text { WW from } \\
\text { Crude } \\
\text { Production }\end{array}$ & $\begin{array}{l}\text { Untreated Wh } \\
\text { from Crude } \\
\text { Refining }\end{array}$ & $\begin{array}{l}\text { Treated WW } \\
\text { from Crude } \\
\text { Refining }\end{array}$ & Total WW \\
\hline \multirow{4}{*}{$\begin{array}{c}\text { Co- } \\
\text { products }\end{array}$} & RO & 1.52 & 10.0 & 1.27 & 12.8 & & & & \\
\hline & LPG & 0.37 & 2.5 & 0.31 & 3.1 & & & & \\
\hline & Naphtha & 1.43 & 9.4 & 1.19 & 12.1 & & & & \\
\hline & Coke & 0.39 & 2.6 & 0.33 & 3.3 & & & & \\
\hline \multirow{2}{*}{$\begin{array}{l}\text { Primary } \\
\text { products }\end{array}$} & FRFG & 2.40 & 15.9 & 2.00 & 20.3 & 5.24 & 34.65 & 4.37 & 44.3 \\
\hline & ULSD & 0.73 & 4.9 & 0.61 & 6.2 & 1.60 & 10.60 & 1.34 & 13.5 \\
\hline
\end{tabular}

Source: NREL Report "Fuel Cycle Evaluations of Biomass-Ethanol and Reformulated Gasoline," American Petroleum Institute, U.S. EPA 
Table 6-10 Petroleum System Solid Waste (SW) (g/MMBtu)

\begin{tabular}{|c|c|c|c|c|c|c|c|c|c|}
\hline \multirow{2}{*}{\multicolumn{2}{|c|}{ Product }} & \multicolumn{4}{|c|}{ Lower Range: Allocated to the Full Product Slate } & \multicolumn{4}{|c|}{ Upper Range: Allocated to Gasoline and ULSD Only } \\
\hline & & $\begin{array}{l}\text { SW from } \\
\text { Crude } \\
\text { Production }\end{array}$ & $\begin{array}{l}\text { Hazardous } \\
\text { SW from } \\
\text { Crude } \\
\text { Refining }\end{array}$ & $\begin{array}{c}\text { Non- } \\
\text { Hazardous } \\
\text { SW from } \\
\text { Crude } \\
\text { Refining }\end{array}$ & $\begin{array}{l}\text { Total Solid } \\
\text { Waste }\end{array}$ & $\begin{array}{l}\text { SW from } \\
\text { Crude } \\
\text { Production }\end{array}$ & $\begin{array}{l}\text { Hazardous } \\
\text { SW from } \\
\text { Crude } \\
\text { Refining }\end{array}$ & $\begin{array}{l}\text { Non- } \\
\text { Hazardous } \\
\text { SW from } \\
\text { Crude } \\
\text { Refining }\end{array}$ & $\begin{array}{l}\text { Total Solid } \\
\text { Waste }\end{array}$ \\
\hline \multirow{4}{*}{ Co-products } & RO & 25.6 & 30.3 & 51.0 & 106.9 & & & & \\
\hline & LPG & 6.3 & 7.4 & 12.5 & 26.2 & & & & \\
\hline & Naphtha & 24.1 & 28.4 & 48.0 & 100.5 & & & & \\
\hline & Coke & 6.6 & 7.8 & 13.2 & 27.7 & & & & \\
\hline \multirow{2}{*}{$\begin{array}{l}\text { Primary } \\
\text { products }\end{array}$} & FRFG & 40.5 & 47.8 & 80.6 & 168.9 & 88.4 & 104.5 & 176.2 & 369 \\
\hline & ULSD & 12.4 & 14.6 & 24.7 & 51.7 & 27.1 & 32.0 & 53.9 & 112.9 \\
\hline
\end{tabular}

Source: NREL Report "Fuel Cycle Evaluations of Biomass-Ethanol and Reformulated Gasoline," American Petroleum Institute, U.S. EPA

Table 6-11 summarizes the comparisons of the petroleum and GTL fuels. These quantitative estimates, though limited as described above, indicate that the petroleum fuels generate significantly greater quantities of solid waste and wastewater than do the GTL fuels. This issue is further considered in Section 7 of this report.

Table 6-11 Solid Waste and Wastewater Comparison of FTD with ULSD and FRFG (g/MMBtu and gal/MMBtu)

\begin{tabular}{|l|c|c|c|c|c|c|}
\hline \multicolumn{1}{|c|}{ Item } & FRFG & ULSD & FTD & $\begin{array}{c}\text { FRFG, All Co- } \\
\text { products }\end{array}$ & $\begin{array}{c}\text { ULSD, All Co- } \\
\text { products }\end{array}$ & $\begin{array}{c}\text { FTD with FT } \\
\text { Naphtha }\end{array}$ \\
\hline Wastewater, gal/MMBtu & 20.3 & 6.2 & 5.9 & 44.3 & 13.5 & 8.4 \\
\hline Solid waste, g/MMBtu & 168.9 & 51.7 & $4.3-13.6$ & 369 & 112.9 & $6.2-9.4$ \\
\hline
\end{tabular}

Source: NREL, U.S. EPA, American Petroleum Institute

\subsection{SENSITIVITY ANALYSIS OF THE LCI}

The sensitivity analysis of the LCI considers the following cases:

- Changes in the petroleum refining crude slate

- A reduction of sulfur concentrations in ULSD from $10 \mathrm{ppm}$ to $3 \mathrm{ppm}$

- ULSD refined from 100\% imported crude oil from the Middle East

- The use of flared gas for GTL production

- A parametric sensitivity analysis for key study parameters

For the crude slate sensitivity, crude density and sulfur concentration are increased. In the future, as lighter and "sweeter" (i.e., lower sulfur) crude oil resources are depleted, the refining industry will need to rely increasingly on a heavier and more sulfurous crude slate. As a consequence, the industry will produce greater quantities of heavy co-products such as petroleum coke and residual oil; the heavy crude slate case includes effects of petroleum coke and heavy residual oil 
through the application of the CFE methodology. GTL and other petroleum fuel alternatives, as new entrants to the transportation fuel market, will compete with these heavy crude slate petroleum fuels on the margin. For the purpose of comparison, a light, sweet crude slate is also assessed.

ULSD on the order of $3 \mathrm{ppm}$ sulfur or lower is also examined in the sensitivity analysis. Analysis of diesel sulfur concentrations at this level provides a closer equivalent comparison with zerosulfur FTD. It is uncertain, however, if the industry will be able to economically produce diesel with these sulfur levels.

The production of natural gas is often "associated" with the production of crude oil. This gas is sometimes flared, particularly in developing countries and in the Middle East. If this gas were captured and used for GTL production, FTD and FT naphtha could be credited for the avoided $\mathrm{CO}_{2}$ emissions from flaring. This case is modeled in the flared gas sensitivity for GTL production.

A comprehensive parametric sensitivity was carried out for all significant study parameters for each life cycle stage for the GTL and petroleum fuels.

\subsubsection{Heavy and Light Crude Oil}

As shown in Table 6-12, FTD100 CIDI requires 23\% more total energy and has 4\% lower GWP than ULSD CIDI PADD III heavy. This can be compared with 25\% more total energy and a $3 \%$ reduction in GWP for FTD100 CIDI relative to the PADD III ULSD CIDI case. This small additional benefit for FTD is due to the greater quantity of heavier co-products and the lower process efficiency associated with the PADD III heavy crude slate. 
Table 6-12 FTD100 CIDI Comparison with ULSD CIDI and FRFG, PADD III Heavy, 2015 (Btu/mi or $\mathrm{g} / \mathrm{mi}$ )

\begin{tabular}{|l|c|c|c|c|c|c|c|c|}
\hline & \multicolumn{4}{|c|}{ FTD100 CIDI } & \multicolumn{3}{c|}{ Comparison with PADD III Heavy ULSD CIDI } \\
\hline \multicolumn{1}{|c|}{ Outputs } & Feedstock & Fuel & Vehicle & Total & Feedstock & Fuel & Vehicle & Total \\
\hline Total energy & 189 & 1,600 & 3,399 & 5,188 & $32 \%$ & $135 \%$ & $0 \%$ & $23 \%$ \\
\hline Fossil fuels & 188 & 1,599 & 3,399 & 5,186 & $37 \%$ & $138 \%$ & $0 \%$ & $23 \%$ \\
\hline Petroleum & 12 & 56 & 0 & 68 & $-71 \%$ & $-84 \%$ & $-100 \%$ & $-98 \%$ \\
\hline $\mathrm{CO}_{2}$ & 15 & 49 & 263 & 327 & $10 \%$ & $-7 \%$ & $-4 \%$ & $-4 \%$ \\
\hline $\mathrm{CH}_{4}$ & 0.353 & 0.006 & 0.011 & 0.369 & $14 \%$ & $-89 \%$ & $0 \%$ & $-1 \%$ \\
\hline $\mathrm{N}_{2} \mathrm{O}$ & 0.000 & 0.000 & 0.016 & 0.016 & $-16 \%$ & $-86 \%$ & $0 \%$ & $-4 \%$ \\
\hline GWP & 23 & 49 & 268 & 340 & $15 \%$ & $-10 \%$ & $-4 \%$ & $-4 \%$ \\
\hline VOC: total & 0.001 & 0.020 & 0.049 & 0.071 & $-89 \%$ & $4 \%$ & $0 \%$ & $-11 \%$ \\
\hline CO: total & 0.017 & 0.111 & 1.070 & 1.198 & $-33 \%$ & $351 \%$ & $0 \%$ & $7 \%$ \\
\hline NOx: total & 0.028 & 0.089 & 0.062 & 0.179 & $-61 \%$ & $24 \%$ & $-2 \%$ & $-13 \%$ \\
\hline PM10: total & 0.001 & 0.002 & 0.028 & 0.031 & $-57 \%$ & $-76 \%$ & $-10 \%$ & $-27 \%$ \\
\hline SOx: total & 0.009 & 0.012 & 0.000 & 0.021 & $-22 \%$ & $-87 \%$ & $-100 \%$ & $-80 \%$ \\
\hline VOC: urban & 0.000 & 0.002 & 0.049 & 0.051 & $-94 \%$ & $-70 \%$ & $0 \%$ & $-11 \%$ \\
\hline CO: urban & 0.000 & 0.000 & 1.070 & 1.071 & $-60 \%$ & $-96 \%$ & $0 \%$ & $-1 \%$ \\
\hline NOx: urban & 0.000 & 0.002 & 0.062 & 0.064 & $-60 \%$ & $-93 \%$ & $-2 \%$ & $-26 \%$ \\
\hline PM10: urban & 0.000 & 0.000 & 0.028 & 0.028 & $-65 \%$ & $-99 \%$ & $-10 \%$ & $-22 \%$ \\
\hline SOx: urban & 0.000 & 0.000 & 0.000 & 0.000 & $-56 \%$ & $-99 \%$ & $-100 \%$ & $-99 \%$ \\
\hline
\end{tabular}


Table 6-13 shows the sensitivity of the production of ULSD to a decrease in the density of the crude slate. FTD100 CIDI requires 26\% more total energy and has 1\% lower GWP than ULSD CIDI PADD I from a light crude slate. This is a $1 \%$ change in energy and a $2 \%$ change in GWP relative to the PADD III crude slate.

Table 6-13 FTD100 CIDI Comparison with ULSD, PADD I 2015 (Btu/mi or $\mathrm{g} / \mathrm{mi})$

\begin{tabular}{|l|c|c|c|c|c|c|c|c|}
\hline & \multicolumn{4}{|c|}{ FTD100 CIDI } & \multicolumn{3}{c|}{ Comparison with PADD I Light ULSD CIDI } \\
\hline \multicolumn{1}{|c|}{ Outputs } & Feedstock & Fuel & Vehicle & Total & Feedstock & Fuel & Vehicle & Total \\
\hline Total energy & 189 & 1,600 & 3,399 & 5,188 & $32 \%$ & $182 \%$ & $0 \%$ & $26 \%$ \\
\hline Fossil fuels & 188 & 1,599 & 3,399 & 5,186 & $37 \%$ & $185 \%$ & $0 \%$ & $27 \%$ \\
\hline Petroleum & 12 & 56 & 0 & 68 & $-71 \%$ & $-81 \%$ & $-100 \%$ & $-98 \%$ \\
\hline $\mathrm{CO}_{2}$ & 15 & 49 & 263 & 327 & $10 \%$ & $18 \%$ & $-4 \%$ & $-1 \%$ \\
\hline $\mathrm{CH}_{4}$ & 0.353 & 0.006 & 0.011 & 0.369 & $14 \%$ & $-87 \%$ & $0 \%$ & $1 \%$ \\
\hline $\mathrm{N}_{2} \mathrm{O}$ & 0.000 & 0.000 & 0.016 & 0.016 & $-16 \%$ & $-83 \%$ & $0 \%$ & $-4 \%$ \\
\hline GWP & 23 & 49 & 268 & 340 & $11 \%$ & $15 \%$ & $-4 \%$ & $-1 \%$ \\
\hline VOC: total & 0.001 & 0.020 & 0.049 & 0.071 & $-89 \%$ & $14 \%$ & $0 \%$ & $-9 \%$ \\
\hline CO: total & 0.017 & 0.111 & 1.070 & 1.198 & $-33 \%$ & $446 \%$ & $0 \%$ & $7 \%$ \\
\hline NOx: total & 0.028 & 0.089 & 0.062 & 0.179 & $-61 \%$ & $62 \%$ & $-2 \%$ & $-6 \%$ \\
\hline PM10: total & 0.001 & 0.002 & 0.028 & 0.031 & $-57 \%$ & $-73 \%$ & $-10 \%$ & $-24 \%$ \\
\hline SOx: total & 0.009 & 0.012 & 0.000 & 0.021 & $-21 \%$ & $-74 \%$ & $-100 \%$ & $-64 \%$ \\
\hline VOC: urban & 0.000 & 0.002 & 0.049 & 0.051 & $-94 \%$ & $-68 \%$ & $0 \%$ & $-10 \%$ \\
\hline CO: urban & 0.000 & 0.000 & 1.070 & 1.071 & $-59 \%$ & $-96 \%$ & $0 \%$ & $-1 \%$ \\
\hline NOx: urban & 0.000 & 0.002 & 0.062 & 0.064 & $-60 \%$ & $-92 \%$ & $-2 \%$ & $-24 \%$ \\
\hline PM10: urban & 0.000 & 0.000 & 0.028 & 0.028 & $-64 \%$ & $-99 \%$ & $-10 \%$ & $-21 \%$ \\
\hline SOx: urban & 0.000 & 0.000 & 0.000 & 0.000 & $-55 \%$ & $-99 \%$ & $-100 \%$ & $-99 \%$ \\
\hline
\end{tabular}

\subsubsection{3 ppm ULSD}

This sensitivity case is based on the PIMS model for the PADD III 2015 case, modified to produce $3 \mathrm{ppm}$ sulfur ULSD. The analysis indicated that the thermal efficiency of producing ULSD is $86.8 \%$, a loss of $0.2 \%$ from the $87 \%$ efficiency for producing ULSD.

This slight penalty in efficiency does not significantly alter the diesel energy and emissions results, as seen in Table 6-14. On a well-to-wheel basis, the absolute total grams of $\mathrm{SO}_{\mathrm{X}}$ emissions per light duty vehicle mile values for 3 and 10 ppm ULSD are 0.094 and 0.095, respectively. However, it is not foreseen that diesel fuels of $3 \mathrm{ppm}$ sulfur will be produced in 2015 since there are not likely to be such stringent regulatory requirements by that time. There are also issues with regard to contamination within the fuel infrastructure that would make this sulfur level difficult to achieve in practice. 
Table 6-14 FTD100 CIDI Comparison with ULSD 3 ppm Sulfur, PADD III 2015 (Btu/mi or $\mathrm{g} / \mathrm{mi}$ )

\begin{tabular}{|l|c|c|c|c|c|c|c|c|}
\hline & \multicolumn{4}{|c|}{ FTD100 CIDI } & \multicolumn{4}{c|}{ Comparison with 3 ppm ULSD CIDI } \\
\hline \multicolumn{1}{|c|}{ Outputs } & Feedstock & Fuel & Vehicle & Total & Feedstock & Fuel & Vehicle & Total \\
\hline Total energy & 189 & 1,600 & 3,399 & 5,188 & $32 \%$ & $156 \%$ & $0 \%$ & $25 \%$ \\
\hline Fossil fuels & 188 & 1,599 & 3,399 & 5,186 & $37 \%$ & $159 \%$ & $0 \%$ & $25 \%$ \\
\hline Petroleum & 12 & 56 & 0 & 68 & $-71 \%$ & $-82 \%$ & $-100 \%$ & $-98 \%$ \\
\hline $\mathrm{CO}_{2}$ & 15 & 49 & 263 & 327 & $10 \%$ & $1 \%$ & $-4 \%$ & $-3 \%$ \\
\hline $\mathrm{CH}_{4}$ & 0.353 & 0.006 & 0.011 & 0.369 & $14 \%$ & $-88 \%$ & $0 \%$ & $0 \%$ \\
\hline $\mathrm{N}_{2} \mathrm{O}$ & 0.000 & 0.000 & 0.016 & 0.016 & $-16 \%$ & $-84 \%$ & $0 \%$ & $-4 \%$ \\
\hline GWP & 23 & 49 & 268 & 340 & $15 \%$ & $-3 \%$ & $-4 \%$ & $-3 \%$ \\
\hline VOC: total & 0.001 & 0.020 & 0.049 & 0.071 & $-89 \%$ & $6 \%$ & $0 \%$ & $-11 \%$ \\
\hline CO: total & 0.017 & 0.111 & 1.070 & 1.198 & $-33 \%$ & $390 \%$ & $0 \%$ & $7 \%$ \\
\hline NOx: total & 0.028 & 0.089 & 0.054 & 0.171 & $-61 \%$ & $35 \%$ & $-15 \%$ & $-15 \%$ \\
\hline PM10: total & 0.001 & 0.002 & 0.028 & 0.031 & $-57 \%$ & $-75 \%$ & $-10 \%$ & $-26 \%$ \\
\hline SOx: total & 0.009 & 0.012 & 0.000 & 0.021 & $-22 \%$ & $-85 \%$ & $-100 \%$ & $-77 \%$ \\
\hline VOC: urban & 0.000 & 0.002 & 0.049 & 0.051 & $-94 \%$ & $-69 \%$ & $0 \%$ & $-11 \%$ \\
\hline CO: urban & 0.000 & 0.000 & 1.070 & 1.071 & $-59 \%$ & $-96 \%$ & $0 \%$ & $-1 \%$ \\
\hline NOx: urban & 0.000 & 0.002 & 0.054 & 0.056 & $-60 \%$ & $-92 \%$ & $-15 \%$ & $-35 \%$ \\
\hline PM10: urban & 0.000 & 0.000 & 0.028 & 0.028 & $-64 \%$ & $-99 \%$ & $-10 \%$ & $-21 \%$ \\
\hline SOx: urban & 0.000 & 0.000 & 0.000 & 0.000 & $-55 \%$ & $-99 \%$ & $-100 \%$ & $-99 \%$ \\
\hline
\end{tabular}




\subsubsection{Imported Crude Oil}

Table 6-15 compares FTD100 with ULSD that is refined from 100\% imported crude oil from the Middle East. The ULSD CIDI case reflects the use of a mix of foreign and domestic crude oil, and is the same as used for all petroleum fuels in the LCI. The primary difference in results is due to the transportation of all crude oil via ocean tanker over the same distance as FTD, which is imported from remote NG sites in the Middle East.

The most significant change for ULSD is the increase in $\mathrm{NO}_{\mathrm{X}}$ emissions due to the added ocean tanker transportation for the crude oil. FTD100 CIDI is $22 \%$ lower in total $\mathrm{NO}_{\mathrm{X}}$ inventory than ULSD CIDI for crude oil that is 100\% imported from the Middle East and is $15 \%$ lower in total $\mathrm{NO}_{\mathrm{X}}$ inventory than ULSD CIDI for the partial crude import case.

Table 6-15 FTD100 CIDI Comparison with ULSD CIDI from Partial and 100\% Middle East Crude Import, 2015 (Btu/mi or g/mi)

\begin{tabular}{|c|c|c|c|c|c|c|c|c|c|c|c|c|}
\hline \multirow[b]{2}{*}{ Outputs } & \multicolumn{4}{|c|}{ FTD100 CIDI } & \multicolumn{4}{|c|}{$\begin{array}{l}\text { Comparison with } 100 \% \text { Middle } \\
\text { East Crude Import ULSD CIDI } \\
\text { (FTD100\% Difference) }\end{array}$} & \multicolumn{4}{|c|}{$\begin{array}{l}\text { Comparison with ULSD CIDI } \\
\text { (FTD100 \% Difference) }\end{array}$} \\
\hline & $\begin{array}{l}\text { Feed- } \\
\text { stock }\end{array}$ & Fuel & Vehicle & Total & $\begin{array}{l}\text { Feed- } \\
\text { stock }\end{array}$ & Fuel & Vehicle & Total & $\begin{array}{l}\text { Feed- } \\
\text { stock }\end{array}$ & Fuel & Vehicle & Total \\
\hline Total energy & 189 & 1,600 & 3,399 & 5,188 & $24 \%$ & $156 \%$ & $0 \%$ & $24 \%$ & $32 \%$ & $156 \%$ & $0 \%$ & $25 \%$ \\
\hline Fossil fuels & 188 & 1,599 & 3,399 & 5,186 & $28 \%$ & $159 \%$ & $0 \%$ & $25 \%$ & $37 \%$ & $159 \%$ & $0 \%$ & $25 \%$ \\
\hline Petroleum & 12 & 56 & 0 & 68 & $-76 \%$ & $-82 \%$ & $-100 \%$ & $-98 \%$ & $-71 \%$ & $-82 \%$ & $-100 \%$ & $-98 \%$ \\
\hline $\mathrm{CO}_{2}$ & 15 & 49 & 263 & 327 & $4 \%$ & $1 \%$ & $-4 \%$ & $-3 \%$ & $10 \%$ & $1 \%$ & $-4 \%$ & $-3 \%$ \\
\hline $\mathrm{CH}_{4}$ & 0.353 & 0.006 & 0.011 & 0.369 & $14 \%$ & $-88 \%$ & $0 \%$ & $0 \%$ & $14 \%$ & $-88 \%$ & $0 \%$ & $0 \%$ \\
\hline $\mathrm{N}_{2} \mathrm{O}$ & 0.000 & 0.000 & 0.016 & 0.016 & $-21 \%$ & $-84 \%$ & $0 \%$ & $-4 \%$ & $-16 \%$ & $-84 \%$ & $0 \%$ & $-4 \%$ \\
\hline GWP & 23 & 49 & 268 & 340 & $10 \%$ & $-3 \%$ & $-4 \%$ & $-3 \%$ & $15 \%$ & $-3 \%$ & $-4 \%$ & $-3 \%$ \\
\hline VOC: total & 0.001 & 0.020 & 0.049 & 0.071 & $-89 \%$ & $6 \%$ & $0 \%$ & $-11 \%$ & $-89 \%$ & $6 \%$ & $0 \%$ & $-11 \%$ \\
\hline CO: total & 0.017 & 0.111 & 1.070 & 1.198 & $-38 \%$ & $389 \%$ & $0 \%$ & $7 \%$ & $-33 \%$ & $390 \%$ & $0 \%$ & $7 \%$ \\
\hline NOx: total & 0.028 & 0.089 & 0.054 & 0.171 & $-69 \%$ & $35 \%$ & $-15 \%$ & $-22 \%$ & $-61 \%$ & $35 \%$ & $-15 \%$ & $-15 \%$ \\
\hline PM10: total & 0.001 & 0.002 & 0.028 & 0.031 & $-65 \%$ & $-75 \%$ & $-10 \%$ & $-27 \%$ & $-57 \%$ & $-75 \%$ & $-10 \%$ & $-26 \%$ \\
\hline SOx : total & 0.009 & 0.012 & 0.000 & 0.021 & $-34 \%$ & $-85 \%$ & $-100 \%$ & $-78 \%$ & $-22 \%$ & $-85 \%$ & $-100 \%$ & $-78 \%$ \\
\hline VOC: urban & 0.000 & 0.002 & 0.049 & 0.051 & $-94 \%$ & $-69 \%$ & $0 \%$ & $-11 \%$ & $-94 \%$ & $-69 \%$ & $0 \%$ & $-11 \%$ \\
\hline CO: urban & 0.000 & 0.000 & 1.070 & 1.071 & $-60 \%$ & $-96 \%$ & $0 \%$ & $-1 \%$ & $-59 \%$ & $-96 \%$ & $0 \%$ & $-1 \%$ \\
\hline NOx: urban & 0.000 & 0.002 & 0.054 & 0.056 & $-61 \%$ & $-92 \%$ & $-15 \%$ & $-35 \%$ & $-60 \%$ & $-92 \%$ & $-15 \%$ & $-35 \%$ \\
\hline PM10: urban & 0.000 & 0.000 & 0.028 & 0.028 & $-66 \%$ & $-99 \%$ & $-10 \%$ & $-21 \%$ & $-64 \%$ & $-99 \%$ & $-10 \%$ & $-21 \%$ \\
\hline SOx: urban & 0.000 & 0.000 & 0.000 & 0.000 & $-57 \%$ & $-99 \%$ & $-100 \%$ & $-99 \%$ & $-55 \%$ & $-99 \%$ & $-100 \%$ & $-99 \%$ \\
\hline
\end{tabular}




\subsubsection{Flared Gas in GTL Production}

Table 6-16 shows the effects of including 10\% flared gas in the production of FTD. FTD100 CIDI with 10\% flared gas has $12 \%$ lower GWP than the comparable ULSD CIDI. This can be compared with the $3 \%$ lower GWP for the FTD 100 CIDI without flared gas relative to ULSD CIDI. Total energy consumption is also reduced relative to ULSD CIDI, from $25 \%$ greater (FTD100 without flared gas) to $13 \%$ greater (FTD100 with flared gas).

Table 6-16 FTD100 CIDI 10\% Flared Gas and 90\% NG Comparison with ULSD CIDI 2015 (Btu/mi or g/mi)

\begin{tabular}{|l|c|c|c|c|c|c|c|c|}
\hline & \multicolumn{4}{|c|}{ FTD100 CIDI with FG } & \multicolumn{3}{c|}{$\begin{array}{c}\text { Comparison with ULSD CIDI } \\
\text { (FTD100 \% Difference) }\end{array}$} \\
\hline \multicolumn{1}{|c|}{ Outputs } & Feedstock & Fuel & Vehicle & Total & Feedstock & Fuel & Vehicle & Total \\
\hline Total energy & 189 & 1,117 & 3,399 & 4,706 & $32 \%$ & $79 \%$ & $0 \%$ & $13 \%$ \\
\hline Fossil fuels & 188 & 1,116 & 3,399 & 4,703 & $37 \%$ & $81 \%$ & $0 \%$ & $13 \%$ \\
\hline Petroleum & 12 & 56 & 0 & 68 & $-71 \%$ & $-82 \%$ & $-100 \%$ & $-98 \%$ \\
\hline $\mathrm{CO}_{2}$ & 15 & 18 & 263 & 297 & $10 \%$ & $-62 \%$ & $-4 \%$ & $-12 \%$ \\
\hline $\mathrm{CH}_{4}$ & 0.353 & -0.021 & 0.011 & 0.343 & $14 \%$ & $-142 \%$ & $0 \%$ & $-7 \%$ \\
\hline $\mathrm{N}_{2} \mathrm{O}$ & 0.000 & 0.000 & 0.016 & 0.016 & $-16 \%$ & $-164 \%$ & $0 \%$ & $-7 \%$ \\
\hline GWP & 23 & 18 & 268 & 309 & $15 \%$ & $-64 \%$ & $-4 \%$ & $-12 \%$ \\
\hline VOC: total & 0.001 & 0.019 & 0.049 & 0.069 & $-89 \%$ & $-1 \%$ & $0 \%$ & $-12 \%$ \\
\hline CO: total & 0.017 & 0.097 & 1.070 & 1.184 & $-33 \%$ & $327 \%$ & $0 \%$ & $6 \%$ \\
\hline NOx: total & 0.028 & 0.069 & 0.062 & 0.158 & $-61 \%$ & $4 \%$ & $-2 \%$ & $-21 \%$ \\
\hline PM10: total & 0.001 & 0.000 & 0.028 & 0.029 & $-57 \%$ & $-98 \%$ & $-10 \%$ & $-30 \%$ \\
\hline SOx: total & 0.009 & 0.012 & 0.000 & 0.021 & $-22 \%$ & $-86 \%$ & $-100 \%$ & $-78 \%$ \\
\hline VOC: urban & 0.000 & 0.002 & 0.049 & 0.051 & $-94 \%$ & $-70 \%$ & $0 \%$ & $-11 \%$ \\
\hline CO: urban & 0.000 & 0.000 & 1.070 & 1.071 & $-59 \%$ & $-96 \%$ & $0 \%$ & $-1 \%$ \\
\hline NOx: urban & 0.000 & 0.002 & 0.062 & 0.064 & $-60 \%$ & $-92 \%$ & $-2 \%$ & $-25 \%$ \\
\hline PM10: urban & 0.000 & 0.000 & 0.028 & 0.028 & $-64 \%$ & $-99 \%$ & $-10 \%$ & $-21 \%$ \\
\hline SOx: urban & 0.000 & 0.000 & 0.000 & 0.000 & $-55 \%$ & $-99 \%$ & $-100 \%$ & $-99 \%$ \\
\hline
\end{tabular}

\subsubsection{Parametric Sensitivity}

Tables 6-17 and 6-18 show the effects on the WTW LCI results due to changes in key study parameters; Table 6-17 shows the results for ULSD; and Table 6-18 shows the results for FTD. The parameters are organized by life cycle stage: feedstock, fuel production, and vehicle use. The parameters varied were energy efficiency (for feedstock production, fuel production, and vehicle use); carbon efficiency (for GTL production); emissions factors for fuel combustion at the feedstock and fuel stages and for ocean tanker transport (factors for VOC, $\mathrm{CO}, \mathrm{NO}_{\mathrm{X}}, \mathrm{PM10}$, and $\mathrm{SO}_{\mathrm{X}}$ ); and ocean tanker transportation distance. The "Parameter \% Reduction" row of the tables indicates the percentage by which each parameter or set of parameters was reduced corresponding to the percentage change in outputs reported in the table. 
Only changes of $1 \%$ or greater in the outputs are reported in the table.

For both ULSD and FTD, the LCI results are (1) most sensitive to changes in the energy efficiency parameters, namely, feedstock recovery, fuel production, and vehicle efficiency; (2) least sensitive to changes in emissions factors for feedstock recovery, ocean transport, and fuel production; and (3) sensitive to changes in emissions factors for vehicle use.

\section{Table 6-17 ULSD CIDI 2015 Parametric Sensitivity Results : Percentage Change in Outputs Due to Percentage Reduction in Parameters}

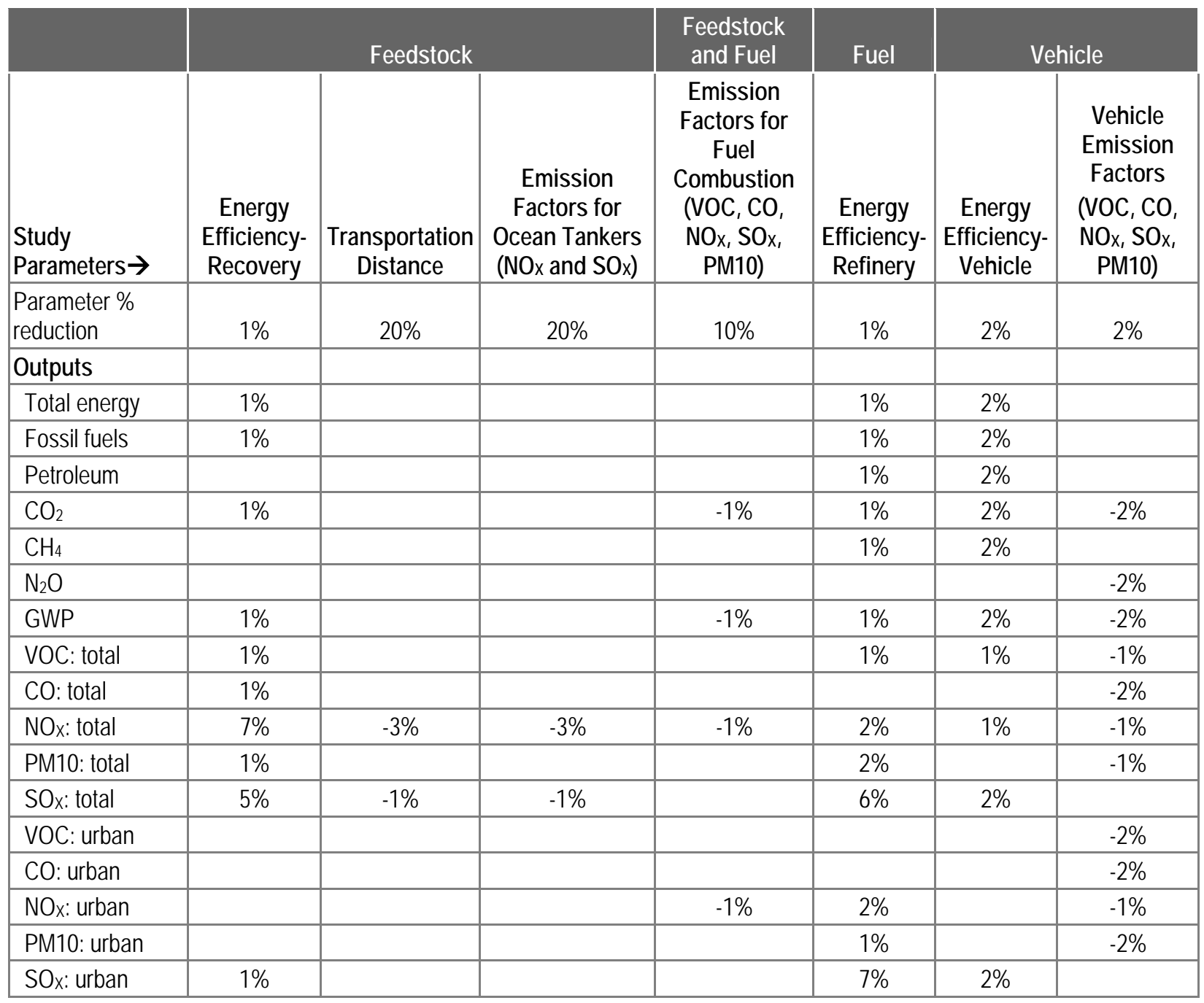


Table 6-18 FTD100 CIDI 2015 Parametric Sensitivity Results: Percentage Change in Outputs Due to Percentage Reduction in Parameters

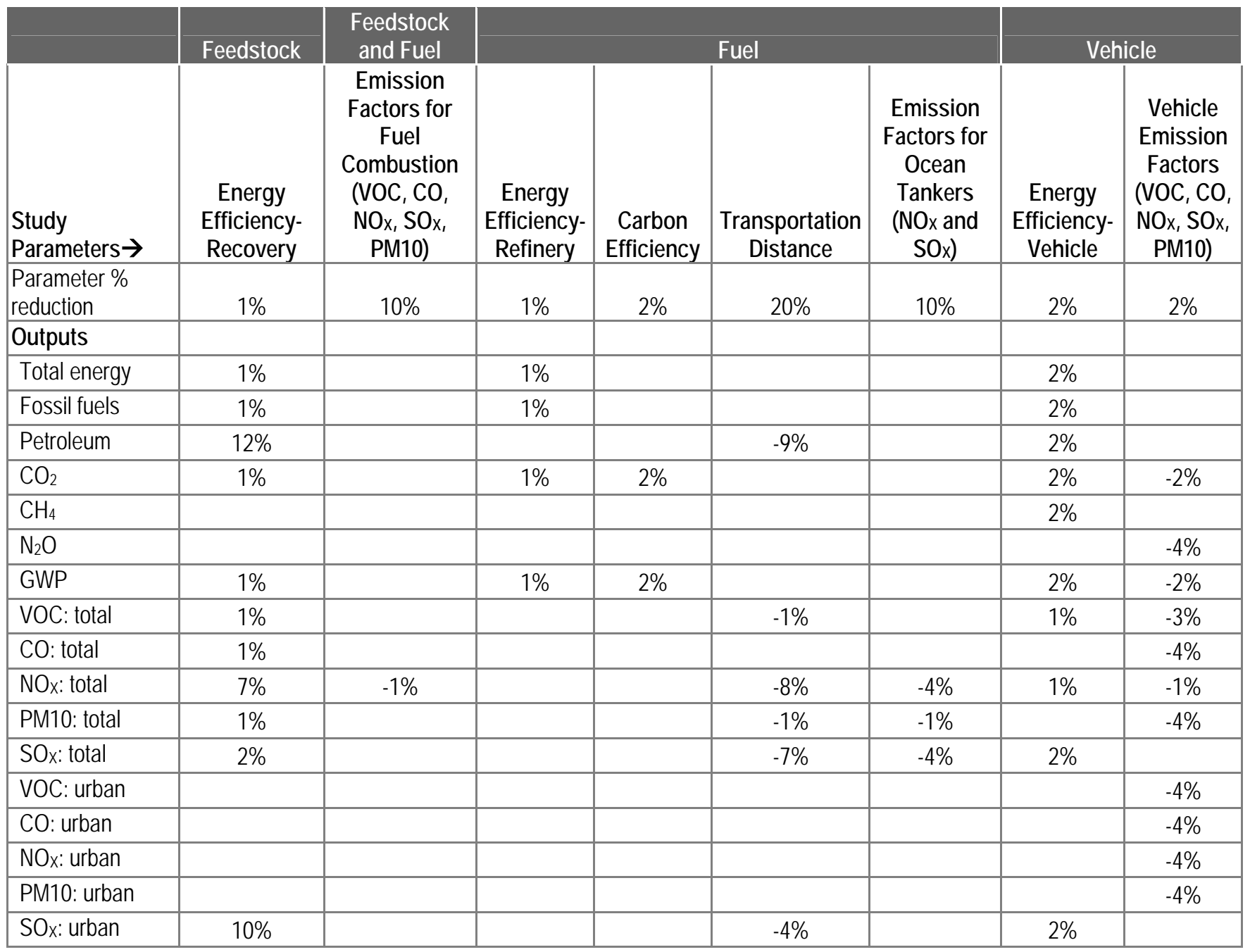




\subsection{UNIT PROCESS LCI RESULTS}

This section presents life cycle energy and emissions inventory data by unit process for the longterm FTD100 CIDI and ULSD CIDI scenarios. Unit processes correspond to the basic life cycle stage components as defined in the system boundaries presented in Section 1 of this report: feedstock recovery, feedstock processing and transportation, fuel refining, fuel transportation, and vehicle use. Figures 6-11 through 6-20 show the comparative unit process inventory results for FTD and ULSD. Tables 6-19 and 6-20 provide the numerical data for each process unit.

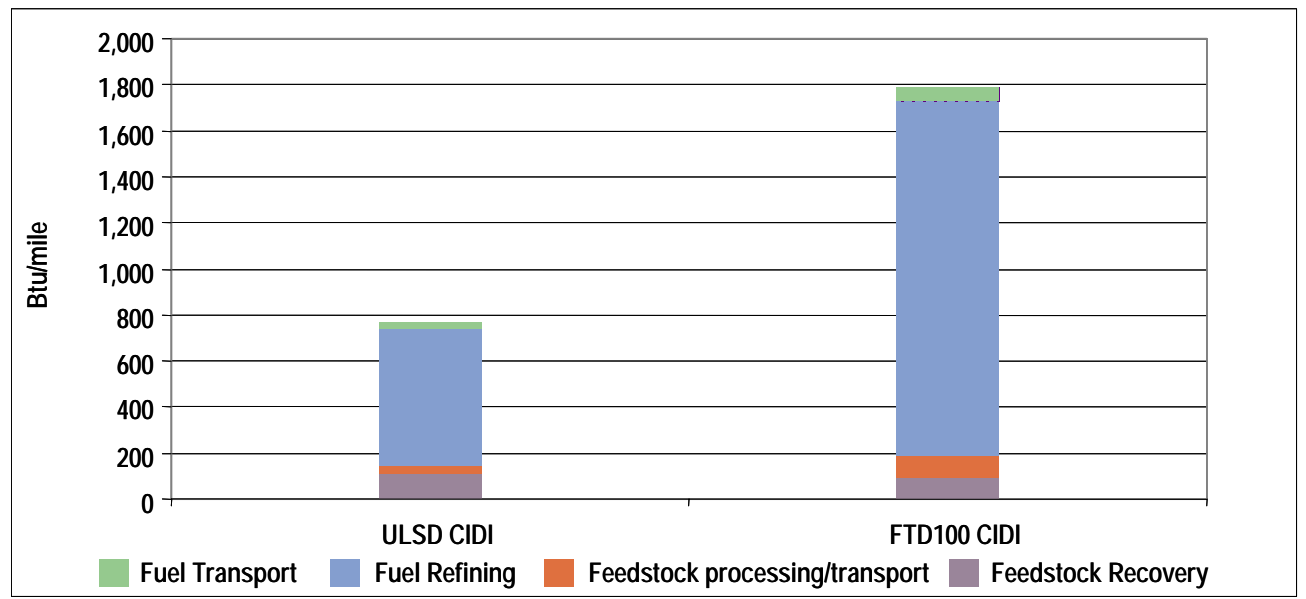

Figure 6-11 FTD100 CIDI and ULSD CIDI Well-to-Tank Process Unit Total Energy, 2015

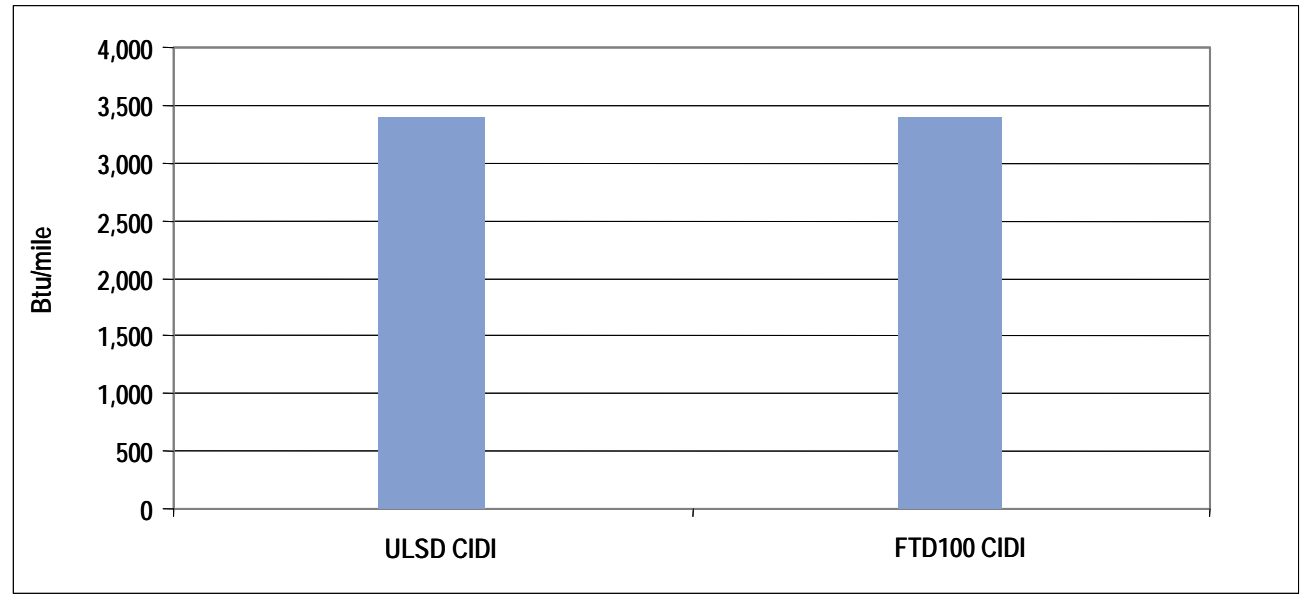

Figure 6-12 FTD100 CIDI and ULSD CIDI Tank-to-Wheels (Vehicle) Process Unit Total Energy, 2015 


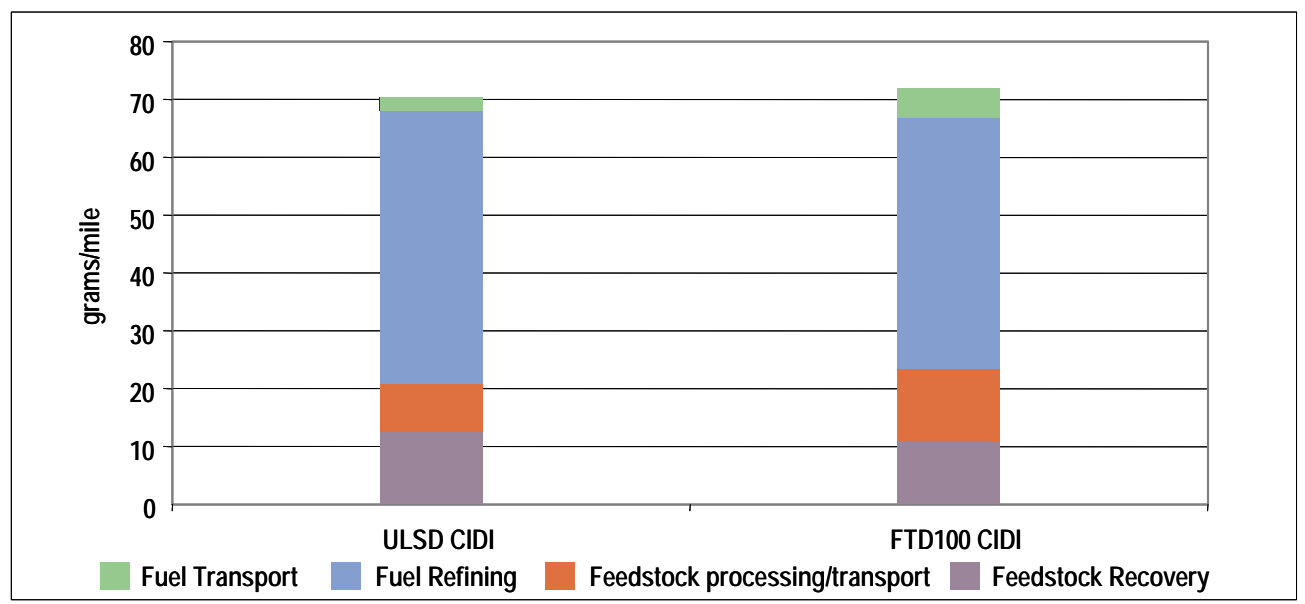

Figure 6-13 FTD100 CIDI and ULSD CIDI Well-to-Tank Process Unit GWP, 2015

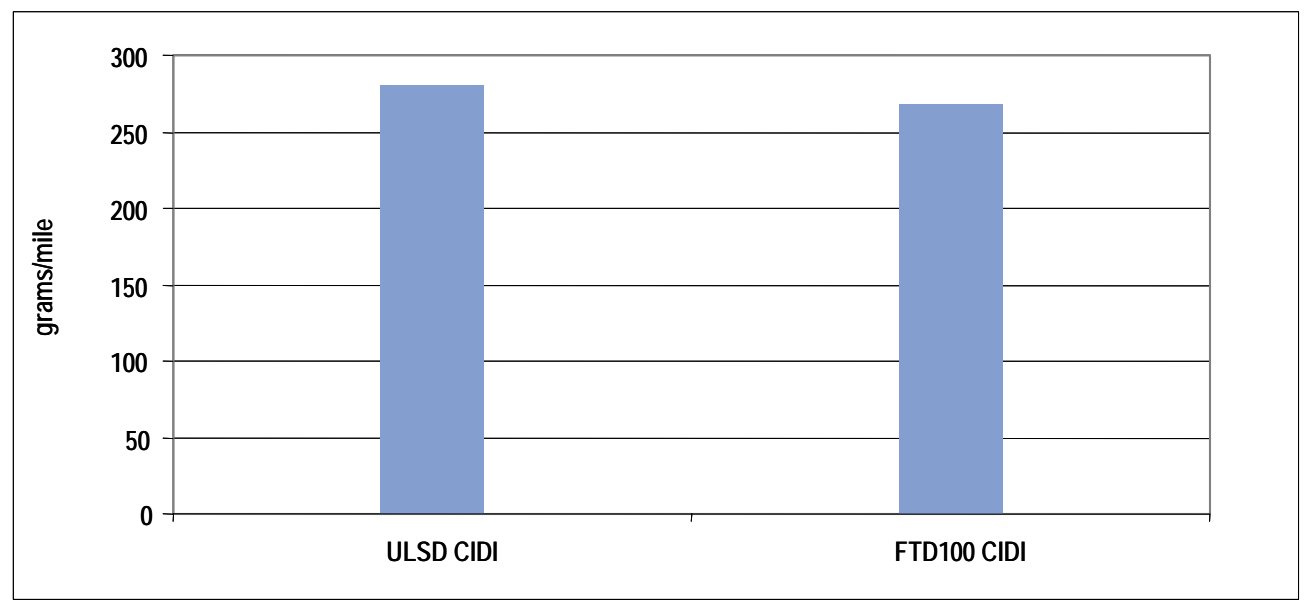

Figure 6-14 FTD100 CIDI and ULSD CIDI Tank-to-Wheels (Vehicle) Process Unit GWP, 2015

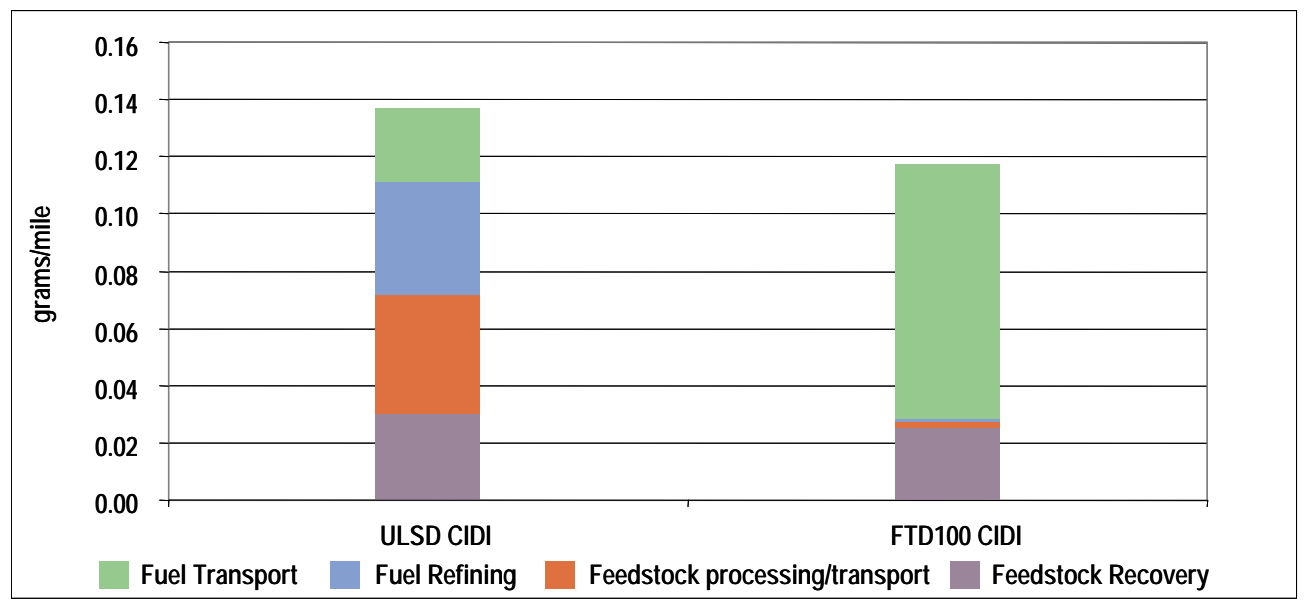

Figure 6-15 FTD100 CIDI and ULSD CIDI Well-to-Tank Process Unit NOx Inventory, 2015 


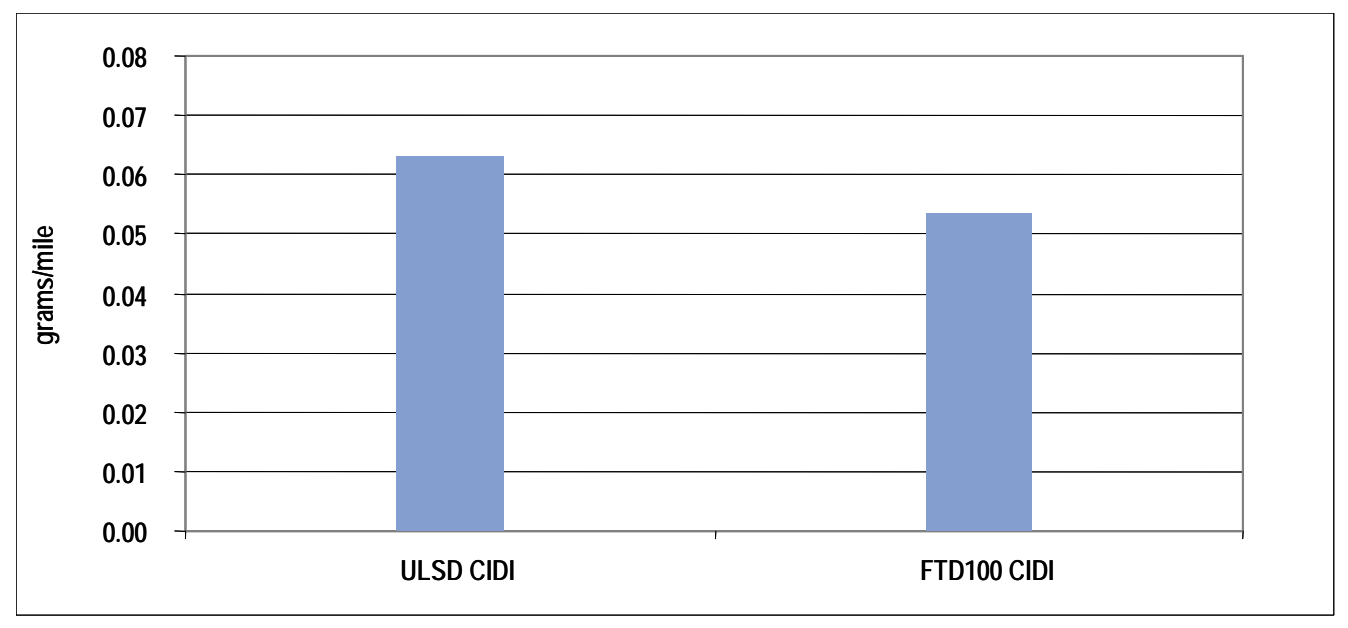

Figure 6-16 FTD100 CIDI and ULSD CIDI Tank-to-Wheels (Vehicle) Process Unit NOx Inventory, 2015

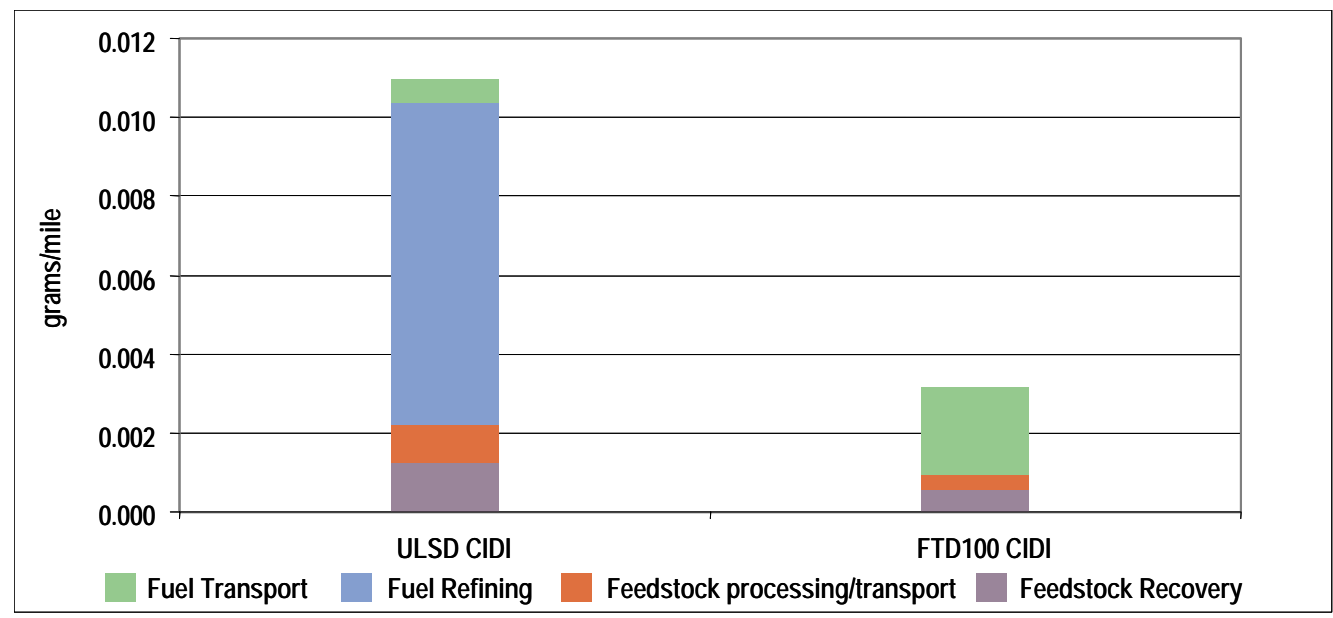

Figure 6-17 FTD100 CIDI and ULSD CIDI Well-to-Tank Process Unit PM10 Inventory, 2015

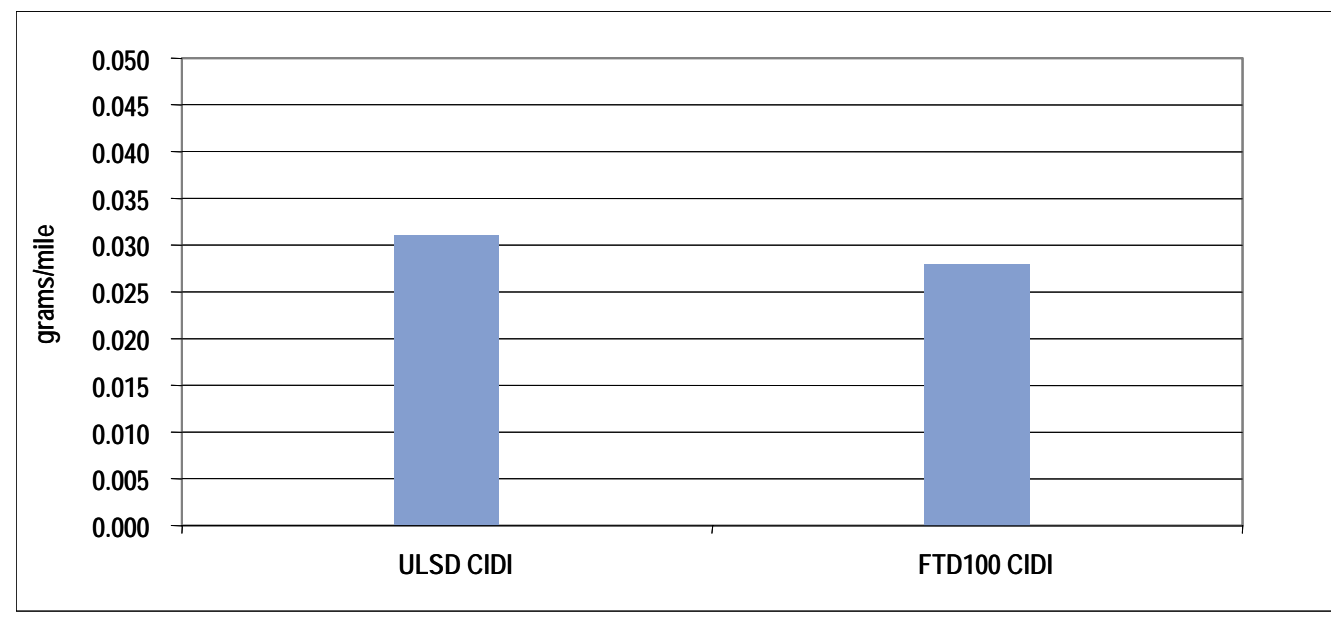

Figure 6-18 FTD100 CIDI and ULSD CIDI Tank-to-Wheels Process (Vehicle) Unit PM10 Inventory, 2015 


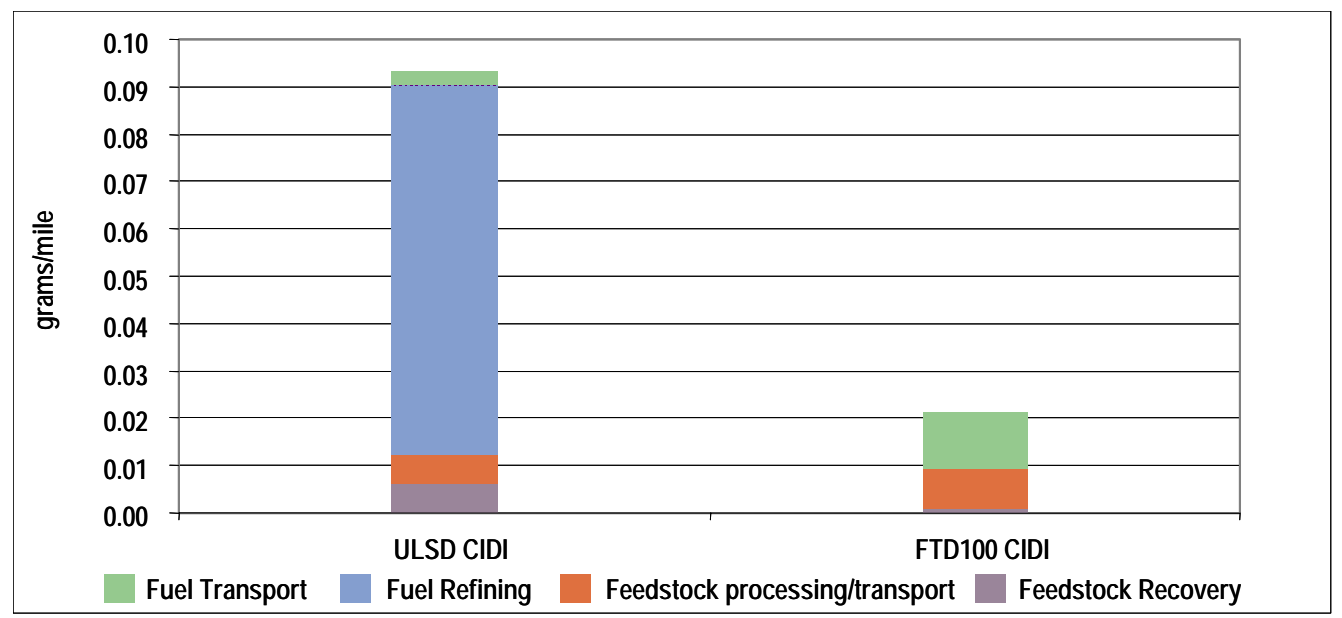

Figure 6-19 FTD100 CIDI and ULSD CIDI Well-to-Tank Process Unit SOX Inventory, 2015

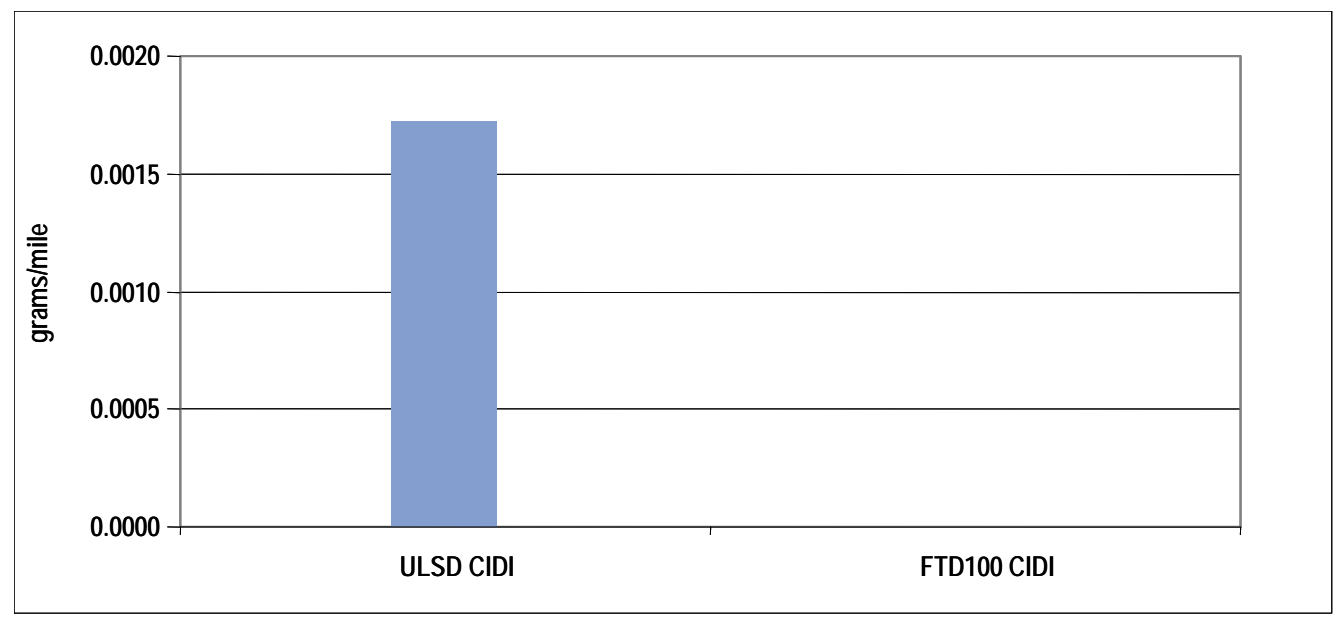

Figure 6-20 FTD100 CIDI and ULSD CIDI Tank-to-Wheels (Vehicle) Process Unit SOx Inventory, 2015 
Table 6-19 ULSD CIDI Process Unit Inventory

\begin{tabular}{|l|c|c|c|c|c|}
\hline \multicolumn{1}{|c|}{ Outputs } & \multicolumn{2}{c|}{ Feedstock } & \multicolumn{2}{c|}{ Fuel } & Vehicle \\
\hline Total energy & 109 & 34 & 597 & 27 & 3,399 \\
\hline Fossil fuels & 104 & 33 & 590 & 27 & $3,399$. \\
\hline Petroleum & 18 & 25 & 294 & 22 & 3,399 \\
\hline $\mathrm{CO}_{2}$ & 11 & 3 & 46 & 2 & 274 \\
\hline $\mathrm{CH}_{4}$ & 0.069 & 0.240 & 0.046 & 0.003 & 0.011 \\
\hline $\mathrm{N}_{2} \mathrm{O}$ & 0.000 & 0.000 & 0.001 & 0.000 & 0.016 \\
\hline GWP & 13 & 8 & 47 & 2 & 279 \\
\hline VOC: total & 0.004 & 0.007 & 0.005 & 0.014 & 0.049 \\
\hline CO: total & 0.019 & 0.006 & 0.018 & 0.004 & 1.070 \\
\hline NOx: total & 0.030 & 0.041 & 0.040 & 0.026 & 0.063 \\
\hline PM10: total & 0.001 & 0.001 & 0.008 & 0.001 & 0.031 \\
\hline SOx: total & 0.006 & 0.006 & 0.078 & 0.003 & 0.002 \\
\hline VOC: urban & 0.000 & 0.001 & 0.003 & 0.005 & 0.049 \\
\hline CO: urban & 0.000 & 0.000 & 0.010 & 0.000 & 1.070 \\
\hline NOx: urban & 0.001 & 0.000 & 0.020 & 0.002 & 0.063 \\
\hline PM10: urban & 0.000 & 0.000 & 0.005 & 0.000 & 0.031 \\
\hline SOx: urban & 0.000 & 0.000 & 0.025 & 0.000 & 0.002 \\
\hline
\end{tabular}


Table 6-20 FTD100 CIDI Process Unit Inventory

\begin{tabular}{|l|c|c|c|c|c|}
\hline \multicolumn{1}{|c|}{ Outputs } & \multicolumn{2}{c|}{ Feedstock } & \multicolumn{2}{c|}{ Fuel } & Vehicle \\
\hline Total energy & 94 & 95 & 1,538 & 62 & 3,399 \\
\hline Fossil fuels & 94 & 94 & 1,537 & 61 & 3,399 \\
\hline Petroleum & 11 & 1 & 5 & 50 & 0 \\
\hline $\mathrm{CO}_{2}$ & 5 & 10 & 43 & 5 & 263 \\
\hline $\mathrm{CH}_{4}$ & 0.247 & 0.106 & 0.000 & 0.006 & 0.011 \\
\hline $\mathrm{N}_{2} \mathrm{O}$ & 0.000 & 0.000 & 0.000 & 0.000 & 0.016 \\
\hline GWP & 11 & 12 & 43 & 5 & 268 \\
\hline VOC: total & 0.001 & 0.000 & 0.005 & 0.015 & 0.049 \\
\hline CO: total & 0.015 & 0.003 & 0.100 & 0.011 & 1.070 \\
\hline NOx: total & 0.025 & 0.003 & 0.000 & 0.089 & 0.054 \\
\hline PM10: total & 0.001 & 0.000 & 0.000 & 0.002 & 0.028 \\
\hline SOx: total & 0.001 & 0.009 & 0.000 & 0.012 & 0.000 \\
\hline VOC: urban & 0.000 & 0.000 & 0.000 & 0.002 & 0.049 \\
\hline CO: urban & 0.000 & 0.000 & 0.000 & 0.000 & 1.070 \\
\hline NOx: urban & 0.000 & 0.000 & 0.000 & 0.002 & 0.054 \\
\hline PM10: urban & 0.000 & 0.000 & 0.000 & 0.000 & 0.028 \\
\hline SOx: urban & 0.000 & 0.000 & 0.000 & 0.000 & 0.000 \\
\hline
\end{tabular}

\subsection{SENSITIVITY ANALYSIS CONCLUSIONS}

The parameters that are the most certain - energy efficiency and criteria emissions for vehicle use - have the greatest sensitivity effects on the LCI results. The parameters that are the least certain - criteria emissions factors for feedstock and fuel production — have the smallest sensitivity effects on the LCI results.

Appendix $\mathrm{C}$ of this report presents the Monte Carlo uncertainty analysis from GREET. Based on probability distributions for fuel production and vehicle use energy efficiency, the Crystal Ball simulation develops a set of error ranges for the LCI results. The error ranges for the results generally do not overlap if the differences in results are at least $10 \%$.

On the basis of these results, an error range of 10\% was selected for total energy and GWP. Life cycle criteria emissions are less certain for upstream stages and more certain for vehicle use. Because vehicle use contributes a greater share to total life cycle emissions, however, the effects of upstream data quality are mitigated. A $15 \%$ error range was thus selected for criteria emissions. 


\subsection{LCI RESULTS SUMMARY AND CONCLUSIONS}

The goal of to the UCF LCA is to examine the potential life cycle environmental and human health impacts of GTL products in comparison with competing alternatives. The LCI phase of this assessment demonstrates that on the basis of GHG emissions and criteria pollutant emissions measured on the functional unit basis of light duty vehicle miles, there are no significant disparities between GTL and competing fuels.

Critics of GTL transportation fuels have suggested that these fuels contribute significantly more $\mathrm{CO}_{2}$ (and hence, GHG) emissions than conventional petroleum-derived fuels. Technological advances in GTL production have narrowed this gap to the extent that full well-to-wheel GHG emissions from neat FTD (FTD100) produced from stranded natural gas compared with ULSD are equivalent. If $10 \%$ or more of the feed gas comes from gas that is otherwise flared, the FTD100 demonstrates a significant reduction in GWP. FT100 also exhibits lower GWP than FRFG.

The study also demonstrates a reduction in criteria pollutants when FTD100 fuel is used in light duty vehicles. The LCIA phase of this study, reported in the next section, deals with the potential environmental impacts from criteria emissions. At a minimum, it can be concluded here that the increased consumption of GTL fuels in the marketplace should not lead to increased impacts compared with petroleum-derived transportation fuels.

With regard to overall energy efficiency, default assumptions in the GREET model showed FTD100 to be approximately 44\% less energy efficient than ULSD. Projections of GTL process energy efficiency factors for future commercial operations as used in the UCF LCA reduce this gap to approximately $25 \%$.

The conclusions below are presented in the context of the data quality and sensitivity analysis as discussed earlier. Comparative results between fuels for total energy and GWP within $10 \%$ are considered to be equivalent. For criteria emissions inventories, results within $15 \%$ are considered to be equivalent.

\subsubsection{FT Diesel}

- FTD20 and FTD100 are equivalent to ULSD in GWP in the 2006 and 2015 scenarios.

- FTD20 and FTD100 have lower GWP than FRFG in the 2006 and 2015 scenarios.

- FTD20 (2006) is equivalent to ULSD in VOC, CO, NO ${ }_{\mathrm{X}}$, and PM10 emissions. FTD20 has lower $\mathrm{SO}_{\mathrm{X}}$ emissions than ULSD.

- FTD100 (2015) has lower inventories of total and urban criteria emissions than ULSD.

- FTD100 (2015) has lower inventories of total and urban criteria emissions than FRFG.

- FTD100 (2015) is 25\% less energy-efficient than ULSD, and equivalent in life cycle energy efficiency to FRFG, based on ConocoPhillips's projected GTL process energy efficiency. (GREET, based on default data, estimates that FTD100 is 44\% less energy efficient than ULSD.) 
- FTD100 (2015) sourced from $10 \%$ flared gas performs better with regard to GWP than ULSD.

- The aggressive FTD100 CIDI (2015) case, with a 5\% improvement in vehicle efficiency, has 7\% lower GWP than the comparable ULSD case. However, this difference in GWP is equivalent with respect to data quality.

- GTL products consume only small amounts of petroleum fuel in the feedstock and fuel stages.

\subsubsection{FT Naphtha}

- FT naphtha used in FCVs is equivalent to FRFG and to methanol for GWP (2015).

- For both total and urban criteria emissions, FT naphtha FCV has lower emissions of VOC, $\mathrm{NO}_{\mathrm{X}}$ and $\mathrm{SO}_{\mathrm{X}}$ than methanol and FRFG (2015).

\subsubsection{Crude Slate}

- Compared with the PADD III cases, heavy and light crude slates show a $1 \%$ increase in total energy and GWP for the heavy crude slate and -1\% in total energy and GWP for the light crude slate. These changes are not significant given the limits in data quality.

- Criteria pollutant inventories are more sensitive to changes in the crude slate, but are still within the limits of data quality.

\subsubsection{Solid Waste and Wastewater}

- The petroleum system generates much greater quantities of solid waste than the GTL system on an MMBtu basis.

- Volumes (gal/MMBtu) of wastewater generated by the GTL system are essentially comparable to that of the petroleum diesel pathway. 


\subsection{OBJECTIVE}

ConocoPhillips undertook the UCF LCA study to help ensure that its investment in and development of GTL technology would be sustainable into the future. In accordance with ConocoPhillips's business planning and its corporate commitment to sustainable development, one must understand the potential life cycle environmental and human health impacts of gas-toliquid (GTL) products in comparison with alternatives. To accomplish these specific ends, a Life Cycle Impact Assessment (LCIA) was conducted to quantify, with available data and within available study resources, the potential life cycle impacts associated with the production and use of GTL fuels in comparison with the potential life cycle impacts of petroleum fuels and competing natural gas utilization options.

\subsection{SCOPE AND OVERVIEW}

The LCIA discussed in this section considers the potential life cycle impacts associated with extraction, transportation, production, distribution, storage, and use of the fuels identified in the Life Cycle Inventory (LCI) (see Sections 1 through 6). Data from the LCI, with supplementary data for toxics emissions, is used to model potential environmental impacts in the LCIA for a focused subset of scenarios from the LCI for both near-term (2006) and long-term (2015) cases. System boundaries for the scenarios are defined in Section 1 of this report.

A comprehensive set of impact indicators that covers impacts both global and local in nature are examined. Categories with a global effect include global warming and resource depletion. The category indicator for global warming is global warming potential (GWP), which is a function of greenhouse gas (GHG) emissions. This impact is considered over the full life cycle of the fuels in all locations because the global warming phenomenon is independent of the specific location of emissions.

Categories with specific location effects include photochemical smog formation, acidification, and eutrophication. Since these indicators are affected by local background levels of pollutants, potential impacts may differ depending on where the emissions occur. For this reason, the LCIA examines these potential impacts both through their full life cycle and on a localized (urban) basis. The model used in the LCIA to conduct the impact assessment uses characterization factors adjusted for local or regional conditions (e.g., background emission levels and climatology) for the United States to predict a given pollutant's potential impact. Most upstream emissions (extraction, transportation, and production) for both the petroleum and GTL systems occur in non-urban areas. Some portion of petroleum refining occurs in urban areas, but no GTL production from remote natural gas takes place in urban areas. Most vehicle miles traveled occur in urban areas. As a result, the largest share of urban impact is attributable to vehicle use, the second largest to petroleum fuel refining.

The Houston Metropolitan Area was selected for more specific evaluation of urban impacts. Houston is designated as a non-attainment area for photochemical smog under the Clean Air Act and the National Ambient Air Quality Standards (NAAQS), and is representative of regions in 
which emissions reductions are of a high priority. As such, this selection could be considered to be a worst-case scenario, and thus is appropriate for the LCIA as a conservative characterization of potential urban impacts.

\subsection{THE TRACI MODEL}

The Tool for the Reduction and Assessment of Chemical and other Impacts (TRACI) was used in this study. Developed by the U.S. EPA National Risk Management Research Laboratory, TRACI was released for public use in January 2003. TRACI estimates potential life cycle impacts and provides consistent comparisons for the impact indicators defined in the model. The results are useful for relative comparisons between alternative scenarios (Bare, 2002).

TRACI contains regionalized factors to reflect background levels of pollutants and the geographical, meteorological, and climatological characteristics of local regions that affect the potential impacts of specific emissions. The approach and outputs of TRACI conform to ISO 14040 standards for LCIA. TRACI includes impact categories for ozone depletion, global warming, acidification, eutrophication, photochemical smog, human health - cancer (HHC), human health - non-cancer (HHNC), human health criteria, ecotoxicity, resource depletion, land use, and water use. The characterization models used for each impact category are documented below.

\subsection{IMPACT CATEGORIES}

Impact categories in LCIA are intended to describe known environmental issues and phenomena. The physical, chemical, or biological mechanisms that link a system output or activity to a discernible environmental impact constitute the basis for the definition of each impact category. These environmental mechanisms include the effects on ecosystems and human health and the depletion of natural resources.

The TRACI model has a set of standard impact categories. The impact categories in TRACI were selected because of their consistency with U.S. EPA regulations and policies. Ozone depletion, global warming, human toxicology, ecotoxicology, photochemical smog formation, acidification, and eutrophication were included in TRACI because U.S. EPA specifically addresses these issues and they are of interest to the public. Human toxicology (human health) was subdivided into cancer, non-cancer, and health impacts of criteria air pollutants (with an initial focus on particulates) to reflect the focus of U.S. EPA regulations.

The full set of TRACI impact categories were used in the UCF LCIA, with two exceptions:

- Neither petroleum nor GTL fuel production generates ozone-depleting substances; therefore, the impact category for ozone depletion from TRACI is not used in the UCF LCIA.

- TRACI has one resource-use category for fossil fuels. Stranded natural gas is the primary resource employed for the production of GTL fuels, and is distinct from both petroleum and commercially produced natural gas because of its remote location. A resource-use category for remote/stranded gas was added in the UCF LCIA and was modeled outside 
of TRACI. The volume of gas used per light duty vehicle mile is reported. The depletion rate of stranded gas is also considered.

Table 7-1 lists the full set of impact categories considered in this study as well as the classification of LCI results and the characterization models used in the study. Classification and characterization models are discussed in more detail below.

\section{Table 7-1 UCF LCIA Impact Categories, Classification, Category Indicators, and Characterization Models}

\begin{tabular}{|c|c|c|c|c|}
\hline Impact Category & $\begin{array}{l}\text { Classification: } \\
\text { LCI Inputs to } \\
\text { LCIA }\end{array}$ & Category Indicator & Characterization Models & $\begin{array}{l}\text { Is Indicator Used } \\
\text { in Urban } \\
\text { Analysis? }\end{array}$ \\
\hline Global warming & $\begin{array}{l}\mathrm{CO}_{2}, \mathrm{CH}_{4} \text {, and } \\
\mathrm{N}_{2} \mathrm{O} \text { for full life } \\
\text { cycle. }\end{array}$ & $\begin{array}{l}\text { 100-year } \mathrm{CO}_{2} \text { gram- } \\
\text { equivalent }\left(\mathrm{CO}_{2} \mathrm{e}\right) \\
\text { GWP }\end{array}$ & $\begin{array}{l}\text { IPCC global warming index } \\
\text { (IPCC 2001) }\end{array}$ & No \\
\hline Acidification & $\mathrm{SO}_{2}, \mathrm{NOx}$ & $\begin{array}{l}\text { Moles of } \mathrm{H}+ \\
\text { equivalent }\end{array}$ & $\begin{array}{c}\text { (Norris, 2002), } \\
\text { (Shannon, 1992), } \\
\text { (Carter, 2000) }\end{array}$ & Yes \\
\hline $\begin{array}{l}\text { Photochemical } \\
\text { smog }\end{array}$ & VOCs, $\mathrm{NOx}$ & $\begin{array}{l}\text { Grams of } \mathrm{NOx} \\
\text { equivalent }\end{array}$ & $\begin{array}{l}\text { (Carter, 2000), (Cardelino, } \\
\text { 1995), (Rabl, 1997), } \\
\text { (Sepalla, 1997) }\end{array}$ & Yes \\
\hline Eutrophication & $\mathrm{NOx}$ & Kilograms of nitrogen & (Norris, 2002) & Yes \\
\hline $\begin{array}{l}\text { Human health } \\
\text { criteria }\end{array}$ & $\begin{array}{c}\text { Criteria } \\
\text { pollutants } \\
\text { (PM10 and } \\
\text { PM2.5, SOx, } \\
\text { NOx, CO) }\end{array}$ & $\begin{array}{c}\text { Total disability } \\
\text { adjusted life years } \\
\text { (DALYs) }\end{array}$ & $\begin{array}{l}\text { (U.S. EPA, 1999), (Nishioka, } \\
\text { 2002) }\end{array}$ & Yes \\
\hline $\begin{array}{l}\text { Human health } \\
\text { (cancer) }\end{array}$ & $\begin{array}{l}\text { Toxics, } \\
\text { carcinogens }\end{array}$ & $\begin{array}{l}\text { Human toxicity } \\
\text { potential (HTP), } \mathrm{C}_{6} \mathrm{H}_{6} \\
\text { (benzene) pounds } \\
\text { equivalent }\end{array}$ & $\begin{array}{c}\text { (Hertwich, 2001) } \\
\text { CalTOX, California EPA }\end{array}$ & No \\
\hline $\begin{array}{l}\text { Human health } \\
\text { (non-cancer) }\end{array}$ & $\begin{array}{l}\text { Toxics, non- } \\
\text { carcinogen }\end{array}$ & $\begin{array}{l}\text { Human toxicity } \\
\text { potential (HTP), } \mathrm{C}_{6} \mathrm{H}_{6} \\
\text { pounds equivalent }\end{array}$ & $\begin{array}{c}\text { (Hertwich, 2001) } \\
\text { CalTOX, California EPA }\end{array}$ & No \\
\hline Ecotoxicity & $\begin{array}{c}\text { Ecotoxic } \\
\text { elements and } \\
\text { compounds }\end{array}$ & $\begin{array}{c}\text { Pounds of 2,4- } \\
\text { dichlorophenoxyacetic } \\
\text { acid (2,4-D) equivalent }\end{array}$ & (Hertwich, 2001) & No \\
\hline Land use & Solid waste & $\begin{array}{l}\text { Mass of solid waste } \\
\text { produced }\end{array}$ & & No \\
\hline Water use & $\begin{array}{l}\text { Intake or use, } \\
\text { in gallons }\end{array}$ & $\begin{array}{l}\text { Intake or use, in } \\
\text { gallons }\end{array}$ & & No \\
\hline $\begin{array}{c}\text { Petroleum fuel } \\
\text { use }\end{array}$ & $\begin{array}{l}\text { Energy input } \\
\text { from crude oil }\end{array}$ & Barrels of crude oil & & No \\
\hline Natural gas use & $\begin{array}{l}\text { Energy input } \\
\text { from natural } \\
\text { gas and } \\
\text { stranded NG }\end{array}$ & SCF of gas & & No \\
\hline
\end{tabular}




\subsection{CLASSIFICATION, CHARACTERIZATION MODELS, AND CATEGORY INDICATORS FOR THE IMPACT CATEGORIES}

Table 7-1 above lists the classification of LCI results, characterization models, and the category indicators for each impact category used in the study. Details are presented below.

\subsubsection{Global Warming Potential}

Emissions of $\mathrm{CO}_{2}, \mathrm{~N}_{2} \mathrm{O}$, and $\mathrm{CH}_{4}$ are assigned to the GWP impact category.

TRACI uses 100-year GWPs as defined by the Intergovernmental Panel on Climate Change (IPCC 2001). GREET uses the same characterization model (see Section 3 of this report). The category indicator is grams of $\mathrm{CO}_{2}$ equivalents $\left(\mathrm{CO}_{2}-\mathrm{e}\right)$.

\subsubsection{Acidification}

Emissions of $\mathrm{NO}_{\mathrm{X}}$ and $\mathrm{SO}_{\mathrm{X}}$ are assigned to the acidification impact category.

The methods developed in TRACI for acidification, photochemical smog, and eutrophication take into account region-specific differential influences on fate, transport, and expected effects , with U.S.-specific modeling. Acidification refers to processes that increase the acidity (hydrogen ion concentration) of water and soil systems. The major acidifying emissions are $\mathrm{NO}_{\mathrm{X}}$ and $\mathrm{SO}_{\mathrm{X}}$.

The acidification model in TRACI (Norris, 2002) makes use of the results of an empirically calibrated atmospheric chemistry and transport model to estimate total North American terrestrial deposition of expected $\mathrm{H}+$ equivalents due to atmospheric emissions of $\mathrm{NO}_{\mathrm{X}}$ and $\mathrm{SO}_{\mathrm{X}}$, as a function of the emissions location. The characterization model takes into account expected differences in total deposition as a result of the pollutant release location. Factors for acidification are available for each U.S. state and for four U.S. regions. The category indicator for acidification is mole equivalents of $\mathrm{H}+$.

\subsubsection{Photochemical Smog}

Emissions of $\mathrm{NO}_{\mathrm{X}}$ and VOCs are assigned to the photochemical smog impact category.

Ozone $\left(\mathrm{O}_{3}\right)$ is a reactive oxidant gas produced naturally in the atmosphere. $\mathrm{O}_{3}$ in the lower atmosphere can lead to harmful effects on human health and ecosystems. The rate of $\mathrm{O}_{3}$ formation in the lower atmosphere is governed by complex chemical reactions that are influenced by background levels of $\mathrm{NO}_{\mathrm{X}}$ and VOCs and by atmospheric conditions, including temperature, sunlight, and convective flows.

As with the acidification characterization model, TRACI provides characterization factors that take into account regional differences in atmospheric conditions and levels of background pollutants for each U.S. state and for four regions. The category indicator for photochemical smog is grams of $\mathrm{NO}_{\mathrm{X}}$ equivalents.

\subsubsection{Eutrophication}

Emissions of $\mathrm{NO}_{\mathrm{X}}$ are assigned to the eutrophication impact category. 
Eutrophication is the process by which excessive nutrients, e.g., phosphorus and nitrogen, accumulate in surface waters and degrade the water quality. Surface waters in the United States are impacted by excessive inputs of phosphorus and nitrogen. The TRACI characterization factors for eutrophication (Norris, 2002) take into account both nutrients and their transport through the environment. The nutrient factor characterizes the relative potency of emissions on algae growth. Transport affects the probability that the release arrives in an aquatic environment directly or transported via water or air. The category indicator for eutrophication is kilograms of nitrogen equivalent.

\subsubsection{Human Health Criteria}

Emissions of criteria pollutants $\left(\mathrm{CO}, \mathrm{SO}_{\mathrm{X}}, \mathrm{NO}_{\mathrm{X}}, \mathrm{PM} 10\right.$, and $\left.\mathrm{PM} 2.5\right)$ are assigned to the human health criteria impact category.

The characterization model used in TRACI for human health criteria takes into account both fate and transport (reflecting atmospheric reactions and transport as well as regional populations densities), and epidemiological studies to provide dose-response relationships for individual pollutants. The methodology conforms to guidelines from the U.S. EPA: U.S. EPA Risk Assessment Guidance for Superfund (U.S. EPA, 1989) and the EPA's Exposure Factors Handbook (U.S. EPA, 1989).

The category indicator for human health criteria is disability-adjusted life-years (DALYs). DALYs is the summation of healthy life years lost due to disability and mortality. Life years lost due to disability are computed by adjusting age-specific life expectancy for loss of healthy life due to disability. The value of a year of life at each age is weighted, as are decrements to health from disability from specific diseases and injuries, and future life years are discounted.

DALYs have seen growing international use as a measure of "burden of disease," but has not been widely used in the United States for policy making. DALYs have been criticized as being based on value judgments rather than on science and for not sufficiently dealing with uncertainty (Anand and Hansen, 1997).

\subsubsection{Human Health, Cancer (HHC); Human Health, Non-Cancer (HHNC)}

Emissions of air and water toxics are assigned to the HHC and HHNC impact categories.

The methodology developed for TRACI is based on a multimedia fate, multi-pathway human exposure, and toxicological potency approach using the CalTOX model from the California Environmental Protection Agency. CalTOX is a multimedia fate and multiple-exposure pathway model with generic parameters for the United States. The relative toxicological potential of an emission is calculated in TRACI, based on human toxicity potentials (HTPs) (Hertwich, 2001). To estimate exposure doses, HTPs were calculated for TRACI using CalTOX linked with human exposure correlations for 23 human health pathways, including cancer, non-cancer, and criteria pollutant related health effects. The doses were then compared with effect data for dermal contact, ingestion, and inhalation, referenced to acceptable daily intakes (for non-carcinogens) and carcinogenic risk factors, and normalized to an equivalent basis with benzene. The category indicator, human toxicity potential (HTP), is pounds of $\mathrm{C}_{6} \mathrm{H}_{6}$ (benzene) equivalent. 


\subsubsection{Ecotoxicity}

Emissions of toxics and heavy metals to air, water, and land are assigned to the ecotoxicity impact category. An ecological toxicity potential (ETP) was developed in TRACI as a measure of potential ecological harm of a chemical released into an environment. ETP estimates are also based on CalTOX (Hertwich, 2001). The category indicator for ecotoxicity is pounds of dichlorophenoxyacetic acid (2,4-D) equivalent.

\subsubsection{Petroleum Use and Natural Gas Consumption}

The use of crude oil, U.S. domestic natural gas, and stranded natural gas are assigned to the resource depletion impact category.

Two measures are used for this indicator:

- Crude oil, natural gas, and stranded gas are reported in volume used per light duty vehicle mile.

- The depletion rates of crude oil and stranded gas reserves are projected on the basis of consumption rates and the rate at which new reserves are proven. These depletion rates are used to place the per-function-unit consumption rates in context. The depletion rates are expressed in barrels of oil, standard cubic feet (SCF) of stranded gas, and Btu's of energy.

\subsubsection{Land Use}

The total mass of solid waste is assigned to the land use impact category.

\subsubsection{Water Use}

The total volume of water use (treated water and total wastewater generation) is assigned the water use impact category.

\subsection{SUPPLEMENTARY DATA COLLECTION FOR THE LCIA}

The majority of data used in the LCIA was generated in the LCI phase of the study and is presented in Section 6 of this report. This data includes emissions of criteria pollutants, GHG emissions, petroleum and fossil fuel use, and solid waste and wastewater generation. The GREET model, as validated in the UCF LCA, served as the primary modeling tool for managing the LCI data and calculating the life cycle results. Data for GTL production was independently developed (refer to Sections 3 and 4 of this report for details). Solid waste and wastewater data is not contained in GREET; thus, this data was developed outside of the model.

GREET does not consider air toxics or ecotoxic emissions, and these inventory categories were not included in the LCI portion of the study. This section documents the data collection for air and water toxic emissions that was conducted for the LCIA.

This section begins with an overview of GTL fuel properties and a discussion of toxics emissions in GTL production, and then specifically addresses the additional data collection for the LCIA 
toxics in GTL and petroleum production, PM2.5, toxic emissions in vehicle use, and resource depletion data for stranded gas and crude oil.

\subsubsection{GTL and Conventional Petroleum Fuel Properties}

The properties of any given fuel have a significant effect on the toxicology of their respective emissions. Because GTL fuels are new to the market and have yet to be introduced commercially in the United States, relatively few toxic emission engine test studies of these fuels have been conducted. The studies that have been conducted have considered a limited range of vehicles. A larger number of studies have compared criteria emissions from Fischer-Tropsch diesel (FTD) with ultra-low sulfur diesel (ULSD) for both heavy and light duty vehicles (Atkinson, 1999, May 2001; Norton, 1998; Ryan, 1997; Schaberg, 1998). Only three studies were identified that evaluated air toxic emissions (Lev-On, 2002; Alleman; 2003, and Frame, 2003). The Lev-On study compares FTD with ULSD in school buses. The Alleman study evaluates heavy duty vehicles, light duty trucks, and light duty vehicles. The ongoing Frame study at the Department of Energy is evaluating criteria and toxic air pollutant emissions from clean diesel fuels.

Even without a large number of studies of a full range of vehicle types, there are inherent properties of FTD that can be considered for evaluation of potential environmental impacts relative to conventional fuels, particularly with respect to air toxics emissions.

FTD has the following characteristics:

- It has a very low aromatic content, and a particularly low polycyclic-aromatic hydrocarbons (PAH) content relative to petroleum-based ULSD. PAHs are toxic compounds, some carcinogenic, and hence are of particular concern with regard to human health. (PAHs are a group of approximately 10,000 compounds, including benzo(a)pyrene, benzanthracene, benzo(b)fluoranthene, and fluoranthene, and are related to petroleum refining and to the combustion of petroleum and other organic compounds.) In Southern California, vehicular emissions are a significant or even dominant contributor to emissions of certain air toxics, including benzene and PAHs (Cohen, 2003).

- The hydrocarbons produced by FT synthesis are predominantly straight-chained. Impurities normally present in products derived from petroleum, such as metals and nitrogen compounds, are entirely absent from FT products. FTD is virtually free of sulfur and does not contain measurable olefins or alcohols.

- FTD has a high cetane number because it consists almost entirely of paraffins.

- Owing to their higher hydrogen/carbon $(\mathrm{H} / \mathrm{C})$ ratio, paraffins have a lower density than other hydrocarbon types. Consequently, the density of the FTD $\left(0.77 \mathrm{~g} / \mathrm{cm}^{3}\right)$ is significantly lower than that of conventional crude-oil-derived diesel fuels, which generally have a significantly higher aromatic content and densities in the range of 0.83 to $0.85 \mathrm{~g} / \mathrm{cm}^{3}$.

- Because of their high $\mathrm{H} / \mathrm{C}$ ratio, paraffins have a higher energy content (on a mass basis) than the other hydrocarbon types. The heating value of FTD is $4-5 \%$ higher than the typical value for a crude-oil-derived diesel fuel. However, because of their low density, 
paraffinic fuels usually have a lower volumetric energy content than fuels with a significant aromatic content. Thus, a ton of FTD has a greater energy content than a ton of crude-oil-derived diesel, but a barrel of FTD has less energy than a barrel of crude-oilderived diesel.

The high cetane number, low aromatic content, and ultra-low sulfur content of FTD fuels lead generally to lower emissions of particulates, $\mathrm{NO}_{\mathrm{X}}$, and air toxics. Table 7-2 lists the most important properties from an environmental standpoint. Emission reductions from FTD are expected to be even greater on newer model engines than on current-generation engines, because new emissions standards will require the use of exhaust control technologies on virtually all new on-highway engines. It is important to note that a fuel with a very low or zero sulfur content, such as FTD, is required by exhaust control technologies since sulfur levels in fuels at ppm levels can contaminate the catalysts used in these systems.

Table 7-2 Important Fuel Properties for FT Diesel

\begin{tabular}{|c|c|}
\hline Property & Description \\
\hline Zero sulfur & $\begin{array}{l}\text { Lower sulfur leads directly to lower SOx emissions and lower particulate emissions } \\
\text { Ultra-low sulfur fuels can permit advanced exhaust after-treatment devices }\end{array}$ \\
\hline High cetane number & High-cetane fuels may reduce exhaust emissions of $\mathrm{NOx}$ and particulate matter (PM) \\
\hline High paraffin content & $\begin{array}{l}\text { Paraffins readily combust in diesel engines, and normal paraffins are responsible for the high } \\
\text { cetane number of FTD }\end{array}$ \\
\hline High normal paraffin content & The higher the normal paraffin content, the higher the cetane number of the fuel \\
\hline Low aromatic content & $\begin{array}{l}\text { Aromatic compounds in diesel fuel do not combust as readily as paraffin compounds, leading to } \\
\text { increased exhaust emissions of } \mathrm{NOx} \text { and PM and toxics emissions }\end{array}$ \\
\hline Low PAH content & Lower PAH emissions relative to petroleum diesel \\
\hline Density and heating value & $\begin{array}{l}\text { FTD has a lower density than petroleum diesel. FTD has a lower volumetric energy content, but } \\
\text { a higher heating content on mass basis; a ton of FTD has greater energy content than a ton of } \\
\text { crude-oil-derived diesel, but a barrel of FTD has less energy than a barrel of crude-oil-derived } \\
\text { diesel. }\end{array}$ \\
\hline
\end{tabular}

The FTD characteristics considered in the UCF LCA are based primarily on the properties expected for the diesel product to be produced using ConocoPhillips GTL technologies. ConocoPhillips-provided estimated typical qualities for this diesel product are presented in Table 7-3, along with fuel properties for ULSD and reformulated gasoline.

Table 7-3 FTD, ULSD, and FRFG Fuel Properties

\begin{tabular}{|l|c|c|c|}
\hline \multicolumn{1}{|c|}{ Property } & FTD & ULSD & $\begin{array}{c}\text { Reformulated } \\
\text { Gasoline }\end{array}$ \\
\hline Cetane number & 70 & 50 & - \\
\hline Octane number & - & - & 87 \\
\hline Sulfur (ppm) & 0 & 15 & 30 \\
\hline Aromatics (vol\%) & $<1$ & 10 & 23 \\
\hline Density (g/cm $\left.{ }^{3}\right)$ & 0.77 & 0.85 & 0.74 \\
\hline Heating value, LHV (Btu/gal) & 118,800 & 128,000 & 112,793 \\
\hline
\end{tabular}

Source: ConocoPhillips, U.S. EPA 
A study by Shell Oil (Clark, 2003) has assessed the direct ecotoxicity and biodegradation of FTD and has concluded that FTD has considerable benefits over traditional diesel fuels. Aquatic ecotoxicity tests indicate that Shell's GTL product is significantly more biodegradable and less toxic than ULSD. 100\% FTD tested "not harmful" to aquatic organisms by the European Union criteria for such designation. The Shell study extrapolates the aquatic toxicology data to terrestrial systems and concludes that Shell GTL fuels would be less toxic in terrestrial ecosystems as well. Although not directly supported by data, the biodegradation results are directly applicable to spills whether they are on land or water.

\subsubsection{Toxic Emissions from GTL Production}

As discussed in Section 4 of this report, the ConocoPhillips GTL technology integrates three major processes to convert natural gas into ultra clean fuels (FTD and FT naphtha) or chemical feedstocks (FT naphtha). GTL production occurs after the natural gas has been processed to remove the valuable natural gas liquids and impurities such as $\mathrm{CO}_{2}$, sulfur, and water.

The first step in processing the clean methane/ethane is to efficiently convert it to $\mathrm{CO}$ and $\mathrm{H} 2$, or synthesis gas (syngas), through ConocoPhillips's proprietary COPox ${ }^{\circledR}$ technology. The desired reaction is:

$$
\mathrm{CH}_{4}+1 / 2 \mathrm{O}_{2} \rightarrow \mathrm{CO}+2 \mathrm{H}_{2}+\text { Heat }
$$

The syngas is fed to the Fischer-Tropsch unit where the following reaction occurs:

$$
(2 \mathrm{n}+1) \mathrm{H}_{2}+\mathrm{nCO} \rightarrow \mathrm{C}_{\mathrm{n}} \mathrm{H}_{2 \mathrm{n}+2}+\mathrm{nH}_{2} \mathrm{O}+\text { Heat }
$$

During these reactions, some oxygenates (e.g., aldehydes, alcohols, and esters) and polynuclear aromatics may be generated in very small quantities. Olefins are also made in the FT reaction. Most of these compounds will be hydrogenated to the corresponding paraffins and sold as products. The small remaining amount will be incinerated in the plant's flare or biotreated in the wastewater system. Therefore, the amount of oxygenates, polynuclear aromatics, and olefins that actually enters the environment is very small.

\subsubsection{Toxic Emissions Data Collection}

Emissions data for toxics releases to air and water was collected for the feedstock recovery, fuel production, and vehicle use stages for the GTL and petroleum systems. The data comes from industry sources and from the U.S. EPA. Toxics data for the fuel production and vehicle stages is the most complete and comprehensive. ConocoPhillips provided primary data for natural gas processing and GTL production, and data for petroleum refining is from the year 2000 U.S. EPA Toxics Release Inventory (TRI). Vehicle stage emissions data is from several recent enginetesting studies.

Toxics data for the feedstock production for natural gas and crude oil is based on information from the U.S. EPA and from the World Bank. This data is less comprehensive than the data for 
the fuel and vehicle stages. The U.S. EPA TRI does not have a category for crude oil or natural gas recovery. Because toxics emissions from recovery are highly dependent on local conditions and on the composition of the crude oil and natural gas, it is difficult to determine representative average emissions factors. However, this data gap equally affects the crude oil and stranded gas results.

Toxic emissions data was not collected for the transportation and distribution of fuel or for power generation as an input to feedstock or fuel production. These two life cycle stages represent a small portion of the overall life cycle energy use associated with production and enduse of the fuels, and are also likely to represent a small portion of toxics emissions.

\subsubsection{Toxics from Feedstock Recovery}

The main wastes of environmental concern associated with crude oil and natural gas production are drilling fluids and cuttings and produced water. Emissions of volatile organic compounds (VOCs) such as benzene and other aromatic compounds are also associated with feedstock recovery. The total mass of drilling wastes and produced water for feedstock recovery is accounted for in the LCIA in the solid waste and wastewater impact categories, but the composition of the wastes is not specifically identified.

Heavy metals such as chromium, mercury, and cadmium are toxics of concern in hydrocarbon exploration and production activities. These metals occur in drilling fluids and to a much lesser extent in produced water. Historically, chromium was present in certain water-based drilling fluid systems where it was added to control mud properties. Mercury and cadmium are present in certain sources of barite, a natural material (barium sulfate) that is used as a weighting agent in drilling fluids. The metals enter the environment via discharges of drilling mud. However, within the last 10 years, regulations have changed around the world and chromium is no longer allowed as a drilling mud additive. ${ }^{1}$

Drilling waste is predominantly the drilling mud and cuttings generated during the drilling of a well. Whether the well targets crude oil or natural gas, the wastes are essentially equivalent and are regulated as discussed above. Therefore, this study does not differentiate between crude oil and natural gas on the basis of potential heavy metal toxicity.

The production of crude oil typically generates significantly larger volumes of produced water than natural gas production. This water is generally quite high in total dissolved solids and can contain trace amounts of heavy metals. For this reason, discharge of produced water onto the ground surface is not widely practiced and is in fact illegal in many countries. Produced water is discharged offshore, where standards such as those proposed by the Export-Import Bank [10 mg/l total metals (except barite), $0.07 \mathrm{mg} / \mathrm{l} \mathrm{Cd}$ and $0.01 \mathrm{mg} / \mathrm{l} \mathrm{Hg}$ ] may be imposed.

\footnotetext{
${ }^{1}$ The World Bank Oil and Gas Development (Offshore) environmental, health and safety guideline states that barite used as a drilling mud additive must have a mercury limit below $1 \mathrm{mg} / \mathrm{kg}$ and a cadmium limit less than $3 \mathrm{mg} / \mathrm{kg}$ on a dry weight basis. These guidelines are often adopted in the absence of country-specific regulations governing drilling fluid discharges.
} 
Toxic air emissions from feedstock recovery are dependent on the composition of the feedstock, so that generic emissions factors are generally not applicable. The U.S. EPA has issued guidance on the estimation of emissions from crude oil and natural gas recovery, using estimating techniques that are specific to local conditions and oil and gas composition. The World Bank has issued a set of toxic emissions standards for fossil fuel recovery. Toxics emissions for feedstock recovery for the LCIA are based on the World Bank data, as shown in Tables 7-4. The heating values of ULSD and FRFG (LHV basis) were used to allocate the emissions to each fuel, based on the total emissions associated with each barrel of crude oil and SCF of natural gas.

Table 7-4 BTEX Emissions for Crude Oil Production

\begin{tabular}{|l|c|c|c|}
\multicolumn{1}{|c|}{ Chemical } & $\begin{array}{c}\text { Crude Oil } \\
\text { (g/bbl) }\end{array}$ & $\begin{array}{c}\text { Allocation to ULSD } \\
\text { (g/MMBtu) }\end{array}$ & $\begin{array}{c}\text { Allocation to FRFG } \\
\text { (g/MMBtu) }\end{array}$ \\
\hline Benzene & 0.0317 & 0.0014 & 0.0045 \\
\hline Toluene & 0.0198 & 0.0009 & 0.0028 \\
\hline Ethylbenzene & 0.0026 & 0.0001 & 0.0004 \\
\hline Xylene & 0.0112 & 0.0005 & 0.0016 \\
\hline
\end{tabular}

Source: World Bank, U.S. EPA

The primary emissions of concern in natural gas processing are the BTEX compounds: benzene, toluene, ethylbenzene, and xylene. These toxic emissions are produced in the glycol dehydration processing for natural gas, in which all non-methane components of the gas are removed.

Table 7-5 shows the BTEX emissions rates for natural gas recovery and processing, with data from the U.S. EPA (U.S. EPA, 1999) and ConocoPhillips. BTEX emission rates are expressed per standard cubic foot (SCF) of natural gas and per MMBtu of FTD. The emission rate for FTD takes into account GTL production efficiency, and the allocation is carried out in the same manner as described in the LCI sections Section 5 and 6 of this report.

Table 7-5 BTEX Emissions for Natural Gas Processing

\begin{tabular}{|l|c|c|}
\multicolumn{1}{|c|}{ Chemical } & Natural Gas (g/SCF) & $\begin{array}{c}\text { Allocation to } \\
\text { FT Diesel (g/MMBtu) }\end{array}$ \\
\hline Benzene & $7.10 \mathrm{E}-05$ & 0.0546 \\
\hline Toluene & $4.44 \mathrm{E}-05$ & 0.0341 \\
\hline Ethylbenzene & $5.92 \mathrm{E}-06$ & 0.0046 \\
\hline Xylene & $2.51 \mathrm{E}-05$ & 0.0193 \\
\hline
\end{tabular}

Source: ConocoPhillips, U.S. EPA

\subsubsection{Toxics from Fuel Production}

The data source for toxic emissions, effluents, and wastes from petroleum refining was the U.S. EPA TRI (U.S. EPA, 2000). The TRI data set for the year 2000 comprises 71 chemical and metal compounds released to air, water, and land, and transferred off site for disposal.

The TRI also reports reference production data for the petroleum refining industry for 2000, in total barrels of crude oil processed, so that the emissions can be normalized to annual production. 
Tables 7-6 and 7-7 show the emissions of hazardous pollutants for petroleum refining, in $\mathrm{g} / \mathrm{MMBtu}$ of gasoline and diesel produced. These emissions were allocated for gasoline and diesel in the same manner as is reported in Sections 5 and 6 of this report for energy, GHGs, and criteria pollutants based on the 2015 CFE cases.

GTL emissions data from production is described above in Section 7.4.2. As reported by ConocoPhillips, nickel compounds from the GTL catalyst are the primary generated toxic waste of concern, with a generation rate of $0.001 \mathrm{~g} / \mathrm{MMBtu}$. Nickel is transported off site for disposal. Emissions of BTEX compounds from GTL production occur only in trace amounts and are considered to be zero.

Table 7-6 TRI Emissions for Gasoline Refining (g/MMBtu)

\begin{tabular}{|c|c|c|c|c|c|c|c|}
\hline Chemical & $\begin{array}{c}\text { Total Air } \\
\text { Emissions }\end{array}$ & $\begin{array}{c}\text { Surface Water } \\
\text { Discharges }\end{array}$ & $\begin{array}{l}\text { Underground } \\
\text { Injection }\end{array}$ & $\begin{array}{l}\text { Releases to } \\
\text { Land }\end{array}$ & $\begin{array}{c}\text { Total Onsite } \\
\text { Releases }\end{array}$ & $\begin{array}{l}\text { Total Offsite } \\
\text { Transfers }\end{array}$ & $\begin{array}{c}\text { Total Onsite } \\
\text { and Offsite } \\
\text { Releases }\end{array}$ \\
\hline 1,1,1-Trichloroethane & 2.01E-05 & $0.00 \mathrm{E}+00$ & $0.00 \mathrm{E}+00$ & $0.00 \mathrm{E}+00$ & 2.01E-05 & $0.00 \mathrm{E}+00$ & 2.01E-05 \\
\hline 1,2,4-Trichlorobenzene & $2.56 \mathrm{E}-05$ & $5.27 \mathrm{E}-08$ & $0.00 \mathrm{E}+00$ & $0.00 \mathrm{E}+00$ & $2.57 \mathrm{E}-05$ & $0.00 \mathrm{E}+00$ & $2.57 \mathrm{E}-05$ \\
\hline 1,2-Dibromoethane & 1.72E-04 & 1.05E-07 & $0.00 \mathrm{E}+00$ & $0.00 \mathrm{E}+00$ & $1.72 \mathrm{E}-04$ & $8.78 \mathrm{E}-08$ & 1.72E-04 \\
\hline 1,2-Dichloroethane & 2.63E-04 & $5.41 \mathrm{E}-06$ & $0.00 \mathrm{E}+00$ & $0.00 \mathrm{E}+00$ & $2.68 \mathrm{E}-04$ & $2.46 \mathrm{E}-07$ & 2.69E-04 \\
\hline 1,3-Butadiene & $1.35 \mathrm{E}-03$ & $1.29 \mathrm{E}-05$ & $0.00 \mathrm{E}+00$ & $7.02 \mathrm{E}-08$ & $1.37 \mathrm{E}-03$ & $1.58 \mathrm{E}-07$ & $1.37 \mathrm{E}-03$ \\
\hline Acetaldehyde & 1.02E-05 & $0.00 \mathrm{E}+00$ & $0.00 \mathrm{E}+00$ & $0.00 \mathrm{E}+00$ & $1.02 \mathrm{E}-05$ & $0.00 \mathrm{E}+00$ & $1.02 \mathrm{E}-05$ \\
\hline Acetonitrile & 1.70E-05 & $1.47 \mathrm{E}-05$ & $0.00 \mathrm{E}+00$ & $0.00 \mathrm{E}+00$ & $3.18 \mathrm{E}-05$ & $0.00 \mathrm{E}+00$ & 3.18E-05 \\
\hline Aniline & 1.76E-07 & $0.00 \mathrm{E}+00$ & $0.00 \mathrm{E}+00$ & $0.00 \mathrm{E}+00$ & 1.76E-07 & $2.63 \mathrm{E}-07$ & 4.39E-07 \\
\hline Antimony compounds & 5.46E-05 & $2.62 \mathrm{E}-05$ & $0.00 \mathrm{E}+00$ & $0.00 \mathrm{E}+00$ & $8.08 \mathrm{E}-05$ & 1.86E-04 & 2.67E-04 \\
\hline Asbestos (friable) & $8.45 \mathrm{E}-06$ & $0.00 \mathrm{E}+00$ & $0.00 \mathrm{E}+00$ & $0.00 \mathrm{E}+00$ & $8.45 \mathrm{E}-06$ & $3.57 \mathrm{E}-03$ & $3.58 \mathrm{E}-03$ \\
\hline Benzene & 3.68E-02 & $2.59 \mathrm{E}-04$ & $4.25 E-03$ & 1.31E-04 & $4.15 \mathrm{E}-02$ & $2.75 \mathrm{E}-04$ & 4.17E-02 \\
\hline Biphenyl & $2.19 \mathrm{E}-04$ & $2.02 \mathrm{E}-06$ & $0.00 \mathrm{E}+00$ & $1.25 \mathrm{E}-06$ & $2.22 \mathrm{E}-04$ & $6.76 \mathrm{E}-06$ & $2.29 \mathrm{E}-04$ \\
\hline Cadmium compounds & $0.00 \mathrm{E}+00$ & $0.00 \mathrm{E}+00$ & $0.00 \mathrm{E}+00$ & $0.00 \mathrm{E}+00$ & $0.00 \mathrm{E}+00$ & $0.00 \mathrm{E}+00$ & $0.00 \mathrm{E}+00$ \\
\hline Carbon disulfide & $5.69 \mathrm{E}-04$ & $0.00 \mathrm{E}+00$ & $0.00 \mathrm{E}+00$ & $0.00 \mathrm{E}+00$ & $5.69 \mathrm{E}-04$ & $0.00 \mathrm{E}+00$ & $5.69 \mathrm{E}-04$ \\
\hline Carbon tetrachloride & 1.14E-04 & $0.00 \mathrm{E}+00$ & $0.00 \mathrm{E}+00$ & $0.00 \mathrm{E}+00$ & $1.14 \mathrm{E}-04$ & $0.00 \mathrm{E}+00$ & $1.14 \mathrm{E}-04$ \\
\hline Carbonyl sulfide & $5.64 \mathrm{E}-03$ & $0.00 \mathrm{E}+00$ & $0.00 \mathrm{E}+00$ & $0.00 \mathrm{E}+00$ & $5.64 \mathrm{E}-03$ & $0.00 \mathrm{E}+00$ & $5.64 \mathrm{E}-03$ \\
\hline Certain glycol ethers & $6.30 \mathrm{E}-04$ & $1.05 \mathrm{E}-05$ & $0.00 \mathrm{E}+00$ & $5.97 \mathrm{E}-05$ & $7.00 \mathrm{E}-04$ & $5.55 \mathrm{E}-05$ & $7.56 \mathrm{E}-04$ \\
\hline Chlorine & $3.48 \mathrm{E}-03$ & $1.88 \mathrm{E}-04$ & 4.74E-07 & $3.51 \mathrm{E}-08$ & $3.66 \mathrm{E}-03$ & $0.00 \mathrm{E}+00$ & $3.66 \mathrm{E}-03$ \\
\hline Chlorobenzene & $0.00 \mathrm{E}+00$ & $0.00 \mathrm{E}+00$ & $0.00 \mathrm{E}+00$ & $0.00 \mathrm{E}+00$ & $0.00 \mathrm{E}+00$ & $0.00 \mathrm{E}+00$ & $0.00 \mathrm{E}+00$ \\
\hline Chloroform & $2.99 \mathrm{E}-04$ & 2.81E-06 & $0.00 \mathrm{E}+00$ & $0.00 \mathrm{E}+00$ & $3.02 \mathrm{E}-04$ & $0.00 \mathrm{E}+00$ & 3.02E-04 \\
\hline Chloromethane & $2.43 \mathrm{E}-05$ & $0.00 \mathrm{E}+00$ & $0.00 \mathrm{E}+00$ & $0.00 \mathrm{E}+00$ & $2.43 E-05$ & $0.00 \mathrm{E}+00$ & $2.43 \mathrm{E}-05$ \\
\hline Chromium compounds & 9.43E-06 & $7.60 \mathrm{E}-05$ & $0.00 \mathrm{E}+00$ & $6.39 \mathrm{E}-04$ & $7.24 \mathrm{E}-04$ & $2.68 \mathrm{E}-04$ & $9.92 \mathrm{E}-04$ \\
\hline Cobalt compounds & $1.21 \mathrm{E}-05$ & 1.17E-05 & $0.00 \mathrm{E}+00$ & $2.59 \mathrm{E}-05$ & 4.97E-05 & 8.88E-04 & 9.37E-04 \\
\hline Cresol (mixed isomers) & $3.65 \mathrm{E}-04$ & $4.31 \mathrm{E}-05$ & $1.35 \mathrm{E}-03$ & $2.81 \mathrm{E}-07$ & $1.76 \mathrm{E}-03$ & $1.57 \mathrm{E}-03$ & 3.33E-03 \\
\hline Cumene & 3.70E-03 & $3.06 \mathrm{E}-06$ & $1.62 \mathrm{E}-06$ & $6.34 \mathrm{E}-06$ & $3.71 \mathrm{E}-03$ & 1.20E-05 & $3.73 \mathrm{E}-03$ \\
\hline Cyanide compounds & 4.82E-04 & 4.39E-06 & $0.00 \mathrm{E}+00$ & $0.00 \mathrm{E}+00$ & 4.87E-04 & $9.02 \mathrm{E}-06$ & 4.96E-04 \\
\hline Di(2-ethylhexyl) phthalate & 1.76E-07 & $0.00 \mathrm{E}+00$ & $0.00 \mathrm{E}+00$ & $0.00 \mathrm{E}+00$ & $1.76 \mathrm{E}-07$ & $2.63 \mathrm{E}-07$ & 4.39E-07 \\
\hline Dibenzofuran & 4.39E-06 & $0.00 \mathrm{E}+00$ & $0.00 \mathrm{E}+00$ & $0.00 \mathrm{E}+00$ & 4.39E-06 & 4.39E-06 & $8.78 \mathrm{E}-06$ \\
\hline Dibutyl phthalate & $5.21 \mathrm{E}-05$ & $0.00 \mathrm{E}+00$ & $0.00 \mathrm{E}+00$ & $0.00 \mathrm{E}+00$ & $5.21 \mathrm{E}-05$ & $0.00 \mathrm{E}+00$ & $5.21 \mathrm{E}-05$ \\
\hline
\end{tabular}




\begin{tabular}{|c|c|c|c|c|c|c|c|}
\hline Chemical & $\begin{array}{c}\text { Total Air } \\
\text { Emissions }\end{array}$ & $\begin{array}{c}\text { Surface Water } \\
\text { Discharges }\end{array}$ & $\begin{array}{l}\text { Underground } \\
\text { Injection }\end{array}$ & $\begin{array}{l}\text { Releases to } \\
\text { Land }\end{array}$ & $\begin{array}{l}\text { Total Onsite } \\
\text { Releases }\end{array}$ & $\begin{array}{l}\text { Total Offsite } \\
\text { Transfers }\end{array}$ & $\begin{array}{l}\text { Total Onsite } \\
\text { and Offsite } \\
\text { Releases }\end{array}$ \\
\hline Dichloromethane & $0.00 \mathrm{E}+00$ & $0.00 \mathrm{E}+00$ & $0.00 \mathrm{E}+00$ & $0.00 \mathrm{E}+00$ & $0.00 \mathrm{E}+00$ & $0.00 \mathrm{E}+00$ & $0.00 \mathrm{E}+00$ \\
\hline Diethanolamine & $2.55 \mathrm{E}-03$ & 8.70E-04 & $0.00 \mathrm{E}+00$ & 1.16E-03 & $4.58 \mathrm{E}-03$ & $1.10 \mathrm{E}-03$ & $5.68 \mathrm{E}-03$ \\
\hline Dimethyl sulfate & $0.00 E+00$ & $0.00 \mathrm{E}+00$ & $0.00 \mathrm{E}+00$ & $0.00 \mathrm{E}+00$ & $0.00 E+00$ & $0.00 E+00$ & $0.00 E+00$ \\
\hline Ethylbenzene & 1.12E-02 & 1.97E-04 & 7.64E-05 & 5.45E-05 & 1.16E-02 & $3.08 \mathrm{E}-04$ & 1.19E-02 \\
\hline Ethylene glycol & 1.34E-03 & 2.71E-05 & $0.00 E+00$ & 8.81E-06 & $1.38 \mathrm{E}-03$ & 2.61E-02 & $2.75 \mathrm{E}-02$ \\
\hline Ethylene oxide & 3.05E-04 & $0.00 \mathrm{E}+00$ & $0.00 \mathrm{E}+00$ & $0.00 \mathrm{E}+00$ & 3.05E-04 & $0.00 \mathrm{E}+00$ & 3.05E-04 \\
\hline Formaldehyde & 2.26E-03 & $0.00 E+00$ & $0.00 \mathrm{E}+00$ & $0.00 \mathrm{E}+00$ & $2.26 \mathrm{E}-03$ & $6.69 \mathrm{E}-06$ & $2.27 \mathrm{E}-03$ \\
\hline Hydrazine & $0.00 \mathrm{E}+00$ & $0.00 \mathrm{E}+00$ & $0.00 \mathrm{E}+00$ & $0.00 \mathrm{E}+00$ & $0.00 \mathrm{E}+00$ & $0.00 \mathrm{E}+00$ & $0.00 \mathrm{E}+00$ \\
\hline Hydrochloric acid & 1.64E-02 & $0.00 \mathrm{E}+00$ & $0.00 \mathrm{E}+00$ & $0.00 \mathrm{E}+00$ & 1.64E-02 & $0.00 \mathrm{E}+00$ & $1.64 \mathrm{E}-02$ \\
\hline Hydrogen fluoride & 4.11E-03 & $5.27 \mathrm{E}-08$ & $0.00 \mathrm{E}+00$ & $0.00 \mathrm{E}+00$ & 4.11E-03 & $0.00 \mathrm{E}+00$ & 4.11E-03 \\
\hline Hydroquinone & $0.00 \mathrm{E}+00$ & $0.00 \mathrm{E}+00$ & $0.00 \mathrm{E}+00$ & $0.00 \mathrm{E}+00$ & $0.00 \mathrm{E}+00$ & $0.00 \mathrm{E}+00$ & $0.00 \mathrm{E}+00$ \\
\hline Lead compounds & $5.70 \mathrm{E}-05$ & $9.88 \mathrm{E}-06$ & $0.00 \mathrm{E}+00$ & $1.69 \mathrm{E}-04$ & $2.36 \mathrm{E}-04$ & $4.11 \mathrm{E}-04$ & $6.47 \mathrm{E}-04$ \\
\hline Maleic anhydride & $6.15 \mathrm{E}-07$ & $0.00 \mathrm{E}+00$ & $0.00 \mathrm{E}+00$ & $0.00 \mathrm{E}+00$ & $6.15 \mathrm{E}-07$ & $0.00 \mathrm{E}+00$ & 6.15E-07 \\
\hline Manganese compounds & 1.50E-05 & $1.81 \mathrm{E}-05$ & $0.00 \mathrm{E}+00$ & $6.29 \mathrm{E}-05$ & 9.59E-05 & 1.07E-04 & 2.03E-04 \\
\hline Mercury compounds & 8.73E-05 & 1.86E-06 & 1.55E-07 & 3.37E-06 & 9.27E-05 & $9.78 \mathrm{E}-05$ & 1.90E-04 \\
\hline Methanol & 8.09E-02 & 1.32E-03 & 3.62E-04 & $2.67 \mathrm{E}-05$ & $8.26 \mathrm{E}-02$ & $9.15 \mathrm{E}-05$ & 8.27E-02 \\
\hline Methyl ethyl ketone & $5.78 \mathrm{E}-02$ & 7.64E-05 & $2.98 \mathrm{E}-04$ & $1.58 \mathrm{E}-05$ & 5.82E-02 & 7.53E-06 & 5.82E-02 \\
\hline Methyl isobutyl ketone & 4.26E-03 & 5.44E-07 & $0.00 \mathrm{E}+00$ & $5.44 \mathrm{E}-07$ & 4.26E-03 & 4.74E-07 & 4.26E-03 \\
\hline Methyl tert-butyl ether & 3.17E-02 & 1.89E-03 & $4.68 \mathrm{E}-05$ & $1.60 \mathrm{E}-05$ & 3.37E-02 & 1.64E-05 & 3.37E-02 \\
\hline Naphthalene & $3.44 \mathrm{E}-03$ & $6.25 \mathrm{E}-05$ & 3.13E-05 & $1.41 \mathrm{E}-04$ & 3.67E-03 & $2.17 \mathrm{E}-04$ & 3.89E-03 \\
\hline Nickel compounds & 3.59E-04 & 1.19E-04 & $0.00 \mathrm{E}+00$ & 2.83E-03 & 3.31E-03 & $7.30 \mathrm{E}-03$ & 1.06E-02 \\
\hline Phenol & 2.22E-03 & $2.25 \mathrm{E}-04$ & $1.53 \mathrm{E}-03$ & $2.58 \mathrm{E}-06$ & 3.97E-03 & 5.85E-04 & 4.56E-03 \\
\hline Polychlorinated biphenyls & $1.76 \mathrm{E}-10$ & $3.51 \mathrm{E}-10$ & $0.00 \mathrm{E}+00$ & $0.00 \mathrm{E}+00$ & $5.27 \mathrm{E}-10$ & $0.00 \mathrm{E}+00$ & $5.27 \mathrm{E}-10$ \\
\hline Polycyclic aromatics & 2.82E-03 & 7.34E-06 & $1.76 \mathrm{E}-04$ & 5.73E-05 & 3.06E-03 & $2.36 \mathrm{E}-03$ & 5.41E-03 \\
\hline Propylene oxide & $0.00 \mathrm{E}+00$ & $0.00 \mathrm{E}+00$ & $0.00 \mathrm{E}+00$ & $0.00 \mathrm{E}+00$ & $0.00 \mathrm{E}+00$ & $0.00 \mathrm{E}+00$ & $0.00 \mathrm{E}+00$ \\
\hline Selenium compounds & 4.48E-06 & $4.21 \mathrm{E}-05$ & $0.00 \mathrm{E}+00$ & $0.00 \mathrm{E}+00$ & 4.66E-05 & $4.65 \mathrm{E}-06$ & 5.13E-05 \\
\hline Styrene & 2.19E-04 & $1.23 E-06$ & $0.00 \mathrm{E}+00$ & $2.00 \mathrm{E}-06$ & $2.22 \mathrm{E}-04$ & $2.98 \mathrm{E}-07$ & $2.22 \mathrm{E}-04$ \\
\hline Tetrachloroethylene & 1.05E-03 & $0.00 \mathrm{E}+00$ & $3.51 \mathrm{E}-07$ & $0.00 \mathrm{E}+00$ & 1.05E-03 & $1.33 \mathrm{E}-06$ & 1.05E-03 \\
\hline Toluene & $8.10 \mathrm{E}-02$ & 4.45E-04 & 1.60E-03 & $1.22 \mathrm{E}-04$ & 8.32E-02 & $1.03 \mathrm{E}-03$ & $8.42 \mathrm{E}-02$ \\
\hline Toluene-2,4-diisocyanate & $5.27 \mathrm{E}-07$ & 8.78E-08 & $0.00 \mathrm{E}+00$ & $0.00 \mathrm{E}+00$ & $6.15 \mathrm{E}-07$ & $3.51 \mathrm{E}-07$ & $9.66 \mathrm{E}-07$ \\
\hline Trichloroethylene & 1.12E-03 & $0.00 \mathrm{E}+00$ & $0.00 \mathrm{E}+00$ & $0.00 \mathrm{E}+00$ & 1.12E-03 & $2.11 \mathrm{E}-07$ & $1.12 \mathrm{E}-03$ \\
\hline Triethylamine & $0.00 \mathrm{E}+00$ & $0.00 \mathrm{E}+00$ & $0.00 \mathrm{E}+00$ & $0.00 \mathrm{E}+00$ & $0.00 \mathrm{E}+00$ & $0.00 \mathrm{E}+00$ & $0.00 \mathrm{E}+00$ \\
\hline Vinyl acetate & $6.25 \mathrm{E}-06$ & $4.92 \mathrm{E}-07$ & $0.00 \mathrm{E}+00$ & $0.00 \mathrm{E}+00$ & $6.74 \mathrm{E}-06$ & $1.05 \mathrm{E}-07$ & $6.85 \mathrm{E}-06$ \\
\hline Xylene (mixed isomers) & 4.95E-02 & $9.04 \mathrm{E}-04$ & $5.54 \mathrm{E}-04$ & $1.90 \mathrm{E}-04$ & $5.11 \mathrm{E}-02$ & 1.50E-03 & 5.26E-02 \\
\hline m-Cresol & $0.00 \mathrm{E}+00$ & $0.00 \mathrm{E}+00$ & $0.00 \mathrm{E}+00$ & $0.00 \mathrm{E}+00$ & $0.00 \mathrm{E}+00$ & 2.19E-06 & $2.19 \mathrm{E}-06$ \\
\hline m-Xylene & $2.22 \mathrm{E}-03$ & $2.07 \mathrm{E}-06$ & $6.24 \mathrm{E}-05$ & $9.02 \mathrm{E}-06$ & $2.29 \mathrm{E}-03$ & $7.58 \mathrm{E}-06$ & $2.30 \mathrm{E}-03$ \\
\hline n-Hexane & $5.88 \mathrm{E}-02$ & $3.57 \mathrm{E}-05$ & 1.36E-05 & $5.71 \mathrm{E}-05$ & 5.89E-02 & $1.18 \mathrm{E}-04$ & $5.90 \mathrm{E}-02$ \\
\hline o-Cresol & $0.00 \mathrm{E}+00$ & $0.00 \mathrm{E}+00$ & $0.00 \mathrm{E}+00$ & $0.00 \mathrm{E}+00$ & $0.00 \mathrm{E}+00$ & $2.81 \mathrm{E}-07$ & $2.81 \mathrm{E}-07$ \\
\hline o-Toluidine & 1.76E-07 & $0.00 \mathrm{E}+00$ & $0.00 \mathrm{E}+00$ & $0.00 \mathrm{E}+00$ & 1.76E-07 & $2.63 \mathrm{E}-07$ & 4.39E-07 \\
\hline o-Xylene & $1.88 \mathrm{E}-03$ & 2.07E-06 & 5.93E-05 & 9.43E-06 & 1.95E-03 & $1.37 \mathrm{E}-05$ & $1.97 \mathrm{E}-03$ \\
\hline $\mathrm{p}$-Cresol & $0.00 \mathrm{E}+00$ & 6.41E-06 & $0.00 \mathrm{E}+00$ & $0.00 \mathrm{E}+00$ & 6.41E-06 & 2.63E-07 & $6.67 \mathrm{E}-06$ \\
\hline
\end{tabular}




\begin{tabular}{|l|c|c|c|c|c|c|c|}
\multicolumn{1}{c|}{\begin{tabular}{c} 
Chemical \\
\cline { 3 - 9 }
\end{tabular}} & $\begin{array}{c}\text { Total Air } \\
\text { Emissions }\end{array}$ & $\begin{array}{c}\text { Surface Water } \\
\text { Discharges }\end{array}$ & $\begin{array}{c}\text { Underground } \\
\text { Injection }\end{array}$ & $\begin{array}{c}\text { Releases to } \\
\text { Land }\end{array}$ & $\begin{array}{c}\text { Total Onsite } \\
\text { Releases }\end{array}$ & $\begin{array}{c}\text { Total Offsite } \\
\text { Transfers }\end{array}$ & $\begin{array}{c}\text { Total Onsite } \\
\text { and Offsite } \\
\text { Releases }\end{array}$ \\
\hline p-Xylene & $2.36 \mathrm{E}-03$ & $2.07 \mathrm{E}-06$ & $6.24 \mathrm{E}-05$ & $1.05 \mathrm{E}-06$ & $2.42 \mathrm{E}-03$ & $1.74 \mathrm{E}-06$ & $2.43 \mathrm{E}-03$ \\
\hline Total & 0.4744 & 0.0069 & 0.0105 & 0.0058 & 0.5071 & 0.0482 & 0.5554 \\
\hline
\end{tabular}


Table 7-7 TRI Emissions for Diesel Refining (g/MMBtu)

\begin{tabular}{|c|c|c|c|c|c|c|c|}
\hline Chemical & $\begin{array}{c}\text { Total Air } \\
\text { Emissions }\end{array}$ & $\begin{array}{c}\text { Surface } \\
\text { Water } \\
\text { Discharges }\end{array}$ & $\begin{array}{l}\text { Underground } \\
\text { Injection }\end{array}$ & $\begin{array}{l}\text { Releases to } \\
\text { Land }\end{array}$ & $\begin{array}{l}\text { Total Onsite } \\
\text { Releases }\end{array}$ & $\begin{array}{l}\text { Total Offsite } \\
\text { Transfers }\end{array}$ & $\begin{array}{l}\text { Total Onsite } \\
\text { and Offsite } \\
\text { Releases }\end{array}$ \\
\hline 1,1,1-Trichloroethane & $6.15 \mathrm{E}-06$ & $0.00 \mathrm{E}+00$ & $0.00 \mathrm{E}+00$ & $0.00 \mathrm{E}+00$ & $6.15 \mathrm{E}-06$ & $0.00 \mathrm{E}+00$ & $6.15 \mathrm{E}-06$ \\
\hline 1,2,4-Trichlorobenzene & 7.84E-06 & 1.61E-08 & $0.00 E+00$ & $0.00 \mathrm{E}+00$ & 7.86E-06 & $0.00 \mathrm{E}+00$ & $7.86 \mathrm{E}-06$ \\
\hline 1,2-Dibromoethane & 5.27E-05 & $3.22 \mathrm{E}-08$ & $0.00 E+00$ & $0.00 \mathrm{E}+00$ & 5.27E-05 & 2.69E-08 & $5.27 \mathrm{E}-05$ \\
\hline 1,2-Dichloroethane & 8.04E-05 & 1.65E-06 & $0.00 E+00$ & $0.00 E+00$ & $8.21 E-05$ & $7.52 \mathrm{E}-08$ & $8.22 \mathrm{E}-05$ \\
\hline 1,3-Butadiene & 4.15E-04 & $3.95 \mathrm{E}-06$ & $0.00 \mathrm{E}+00$ & $2.15 \mathrm{E}-08$ & $4.19 \mathrm{E}-04$ & $4.83 \mathrm{E}-08$ & 4.19E-04 \\
\hline Acetaldehyde & $3.12 \mathrm{E}-06$ & $0.00 \mathrm{E}+00$ & $0.00 \mathrm{E}+00$ & $0.00 \mathrm{E}+00$ & $3.12 \mathrm{E}-06$ & $0.00 \mathrm{E}+00$ & $3.12 \mathrm{E}-06$ \\
\hline Acetonitrile & $5.21 \mathrm{E}-06$ & $4.51 \mathrm{E}-06$ & $0.00 \mathrm{E}+00$ & $0.00 \mathrm{E}+00$ & $9.72 \mathrm{E}-06$ & $0.00 \mathrm{E}+00$ & $9.72 \mathrm{E}-06$ \\
\hline Aniline & 5.37E-08 & $0.00 \mathrm{E}+00$ & $0.00 \mathrm{E}+00$ & $0.00 \mathrm{E}+00$ & $5.37 \mathrm{E}-08$ & $8.06 \mathrm{E}-08$ & $1.34 \mathrm{E}-07$ \\
\hline Antimony compounds & 1.67E-05 & 8.03E-06 & $0.00 \mathrm{E}+00$ & $0.00 \mathrm{E}+00$ & $2.47 \mathrm{E}-05$ & $5.68 \mathrm{E}-05$ & $8.16 \mathrm{E}-05$ \\
\hline Asbestos (friable) & $2.58 \mathrm{E}-06$ & $0.00 \mathrm{E}+00$ & $0.00 \mathrm{E}+00$ & $0.00 \mathrm{E}+00$ & $2.58 \mathrm{E}-06$ & $1.09 \mathrm{E}-03$ & 1.10E-03 \\
\hline Benzene & 1.13E-02 & $7.92 E-05$ & $1.30 \mathrm{E}-03$ & 4.02E-05 & $1.27 \mathrm{E}-02$ & $8.40 \mathrm{E}-05$ & $1.28 \mathrm{E}-02$ \\
\hline Biphenyl & $6.70 \mathrm{E}-05$ & $6.18 \mathrm{E}-07$ & $0.00 \mathrm{E}+00$ & $3.81 \mathrm{E}-07$ & $6.80 \mathrm{E}-05$ & $2.07 \mathrm{E}-06$ & $7.01 \mathrm{E}-05$ \\
\hline Cadmium compounds & $0.00 \mathrm{E}+00$ & $0.00 \mathrm{E}+00$ & $0.00 \mathrm{E}+00$ & $0.00 \mathrm{E}+00$ & $0.00 \mathrm{E}+00$ & $0.00 \mathrm{E}+00$ & $0.00 \mathrm{E}+00$ \\
\hline Carbon disulfide & $1.74 \mathrm{E}-04$ & $0.00 \mathrm{E}+00$ & $0.00 \mathrm{E}+00$ & $0.00 \mathrm{E}+00$ & 1.74E-04 & $0.00 \mathrm{E}+00$ & 1.74E-04 \\
\hline Carbon tetrachloride & $3.49 \mathrm{E}-05$ & $0.00 \mathrm{E}+00$ & $0.00 \mathrm{E}+00$ & $0.00 \mathrm{E}+00$ & $3.49 \mathrm{E}-05$ & $0.00 \mathrm{E}+00$ & $3.49 \mathrm{E}-05$ \\
\hline Carbonyl sulfide & 1.72E-03 & $0.00 \mathrm{E}+00$ & $0.00 \mathrm{E}+00$ & $0.00 \mathrm{E}+00$ & $1.72 \mathrm{E}-03$ & $0.00 \mathrm{E}+00$ & 1.72E-03 \\
\hline Certain glycol ethers & 1.93E-04 & $3.22 \mathrm{E}-06$ & $0.00 \mathrm{E}+00$ & 1.83E-05 & $2.14 \mathrm{E}-04$ & $1.70 \mathrm{E}-05$ & $2.31 \mathrm{E}-04$ \\
\hline Chlorine & 1.06E-03 & $5.76 \mathrm{E}-05$ & $1.45 \mathrm{E}-07$ & 1.07E-08 & $1.12 \mathrm{E}-03$ & $0.00 \mathrm{E}+00$ & $1.12 \mathrm{E}-03$ \\
\hline Chlorobenzene & $0.00 \mathrm{E}+00$ & $0.00 \mathrm{E}+00$ & $0.00 \mathrm{E}+00$ & $0.00 \mathrm{E}+00$ & $0.00 \mathrm{E}+00$ & $0.00 \mathrm{E}+00$ & $0.00 \mathrm{E}+00$ \\
\hline Chloroform & $9.14 \mathrm{E}-05$ & $8.60 \mathrm{E}-07$ & $0.00 \mathrm{E}+00$ & $0.00 \mathrm{E}+00$ & $9.23 \mathrm{E}-05$ & $0.00 \mathrm{E}+00$ & $9.23 \mathrm{E}-05$ \\
\hline Chloromethane & 7.44E-06 & $0.00 \mathrm{E}+00$ & $0.00 \mathrm{E}+00$ & $0.00 \mathrm{E}+00$ & $7.44 \mathrm{E}-06$ & $0.00 \mathrm{E}+00$ & 7.44E-06 \\
\hline Chromium compounds & $2.88 \mathrm{E}-06$ & $2.32 \mathrm{E}-05$ & $0.00 \mathrm{E}+00$ & 1.95E-04 & $2.22 \mathrm{E}-04$ & $8.21 \mathrm{E}-05$ & 3.04E-04 \\
\hline Cobalt compounds & $3.71 \mathrm{E}-06$ & $3.58 \mathrm{E}-06$ & $0.00 \mathrm{E}+00$ & 7.92E-06 & $1.52 \mathrm{E}-05$ & $2.72 \mathrm{E}-04$ & $2.87 \mathrm{E}-04$ \\
\hline Cresol (mixed isomers) & 1.12E-04 & 1.32E-05 & $4.14 \mathrm{E}-04$ & 8.60E-08 & 5.39E-04 & $4.82 \mathrm{E}-04$ & $1.02 \mathrm{E}-03$ \\
\hline Cumene & 1.13E-03 & $9.35 \mathrm{E}-07$ & 4.94E-07 & 1.94E-06 & $1.14 \mathrm{E}-03$ & $3.69 \mathrm{E}-06$ & 1.14E-03 \\
\hline Cyanide compounds & 1.48E-04 & $1.34 \mathrm{E}-06$ & $0.00 \mathrm{E}+00$ & $0.00 \mathrm{E}+00$ & $1.49 \mathrm{E}-04$ & $2.76 \mathrm{E}-06$ & $1.52 \mathrm{E}-04$ \\
\hline Di(2-ethylhexyl) phthalate & 5.37E-08 & $0.00 \mathrm{E}+00$ & $0.00 \mathrm{E}+00$ & $0.00 \mathrm{E}+00$ & $5.37 \mathrm{E}-08$ & $8.06 \mathrm{E}-08$ & 1.34E-07 \\
\hline Dibenzofuran & 1.34E-06 & $0.00 \mathrm{E}+00$ & $0.00 \mathrm{E}+00$ & $0.00 \mathrm{E}+00$ & $1.34 \mathrm{E}-06$ & $1.34 \mathrm{E}-06$ & 2.69E-06 \\
\hline Dibutyl phthalate & 1.59E-05 & $0.00 \mathrm{E}+00$ & $0.00 \mathrm{E}+00$ & $0.00 \mathrm{E}+00$ & $1.59 \mathrm{E}-05$ & $0.00 \mathrm{E}+00$ & 1.59E-05 \\
\hline Dichloromethane & $0.00 \mathrm{E}+00$ & $0.00 \mathrm{E}+00$ & $0.00 \mathrm{E}+00$ & $0.00 \mathrm{E}+00$ & $0.00 \mathrm{E}+00$ & $0.00 \mathrm{E}+00$ & $0.00 \mathrm{E}+00$ \\
\hline Diethanolamine & $7.81 \mathrm{E}-04$ & $2.66 \mathrm{E}-04$ & $0.00 \mathrm{E}+00$ & 3.55E-04 & 1.40E-03 & $3.35 \mathrm{E}-04$ & 1.74E-03 \\
\hline Dimethyl sulfate & $0.00 \mathrm{E}+00$ & $0.00 \mathrm{E}+00$ & $0.00 \mathrm{E}+00$ & $0.00 \mathrm{E}+00$ & $0.00 \mathrm{E}+00$ & $0.00 \mathrm{E}+00$ & $0.00 \mathrm{E}+00$ \\
\hline Ethylbenzene & 3.43E-03 & $6.04 \mathrm{E}-05$ & $2.34 \mathrm{E}-05$ & $1.67 \mathrm{E}-05$ & $3.54 \mathrm{E}-03$ & $9.42 \mathrm{E}-05$ & $3.63 \mathrm{E}-03$ \\
\hline Ethylene glycol & 4.10E-04 & $8.31 \mathrm{E}-06$ & $0.00 \mathrm{E}+00$ & $2.70 \mathrm{E}-06$ & $4.21 \mathrm{E}-04$ & 7.99E-03 & $8.41 \mathrm{E}-03$ \\
\hline Ethylene oxide & 9.33E-05 & $0.00 \mathrm{E}+00$ & $0.00 \mathrm{E}+00$ & $0.00 \mathrm{E}+00$ & $9.33 \mathrm{E}-05$ & $0.00 \mathrm{E}+00$ & 9.33E-05 \\
\hline Formaldehyde & $6.92 \mathrm{E}-04$ & $0.00 \mathrm{E}+00$ & $0.00 \mathrm{E}+00$ & $0.00 \mathrm{E}+00$ & $6.92 \mathrm{E}-04$ & $2.05 \mathrm{E}-06$ & $6.94 \mathrm{E}-04$ \\
\hline Hydrazine & $0.00 \mathrm{E}+00$ & $0.00 \mathrm{E}+00$ & $0.00 \mathrm{E}+00$ & $0.00 \mathrm{E}+00$ & $0.00 \mathrm{E}+00$ & $0.00 \mathrm{E}+00$ & $0.00 \mathrm{E}+00$ \\
\hline Hydrochloric acid & 5.03E-03 & $0.00 \mathrm{E}+00$ & $0.00 \mathrm{E}+00$ & $0.00 \mathrm{E}+00$ & $5.03 \mathrm{E}-03$ & $0.00 \mathrm{E}+00$ & $5.03 \mathrm{E}-03$ \\
\hline Hydrogen fluoride & $1.26 \mathrm{E}-03$ & $1.61 \mathrm{E}-08$ & $0.00 \mathrm{E}+00$ & $0.00 \mathrm{E}+00$ & $1.26 \mathrm{E}-03$ & $0.00 \mathrm{E}+00$ & $1.26 \mathrm{E}-03$ \\
\hline
\end{tabular}




\begin{tabular}{|c|c|c|c|c|c|c|c|}
\hline Chemical & $\begin{array}{l}\text { Total Air } \\
\text { Emissions }\end{array}$ & $\begin{array}{c}\text { Surface } \\
\text { Water } \\
\text { Discharges }\end{array}$ & $\begin{array}{l}\text { Underground } \\
\text { Injection }\end{array}$ & $\begin{array}{l}\text { Releases to } \\
\text { Land }\end{array}$ & $\begin{array}{l}\text { Total Onsite } \\
\text { Releases }\end{array}$ & $\begin{array}{l}\text { Total Offsite } \\
\text { Transfers }\end{array}$ & $\begin{array}{l}\text { Total Onsite } \\
\text { and Offsite } \\
\text { Releases }\end{array}$ \\
\hline Hydroquinone & $0.00 \mathrm{E}+00$ & $0.00 \mathrm{E}+00$ & $0.00 \mathrm{E}+00$ & $0.00 \mathrm{E}+00$ & $0.00 \mathrm{E}+00$ & $0.00 \mathrm{E}+00$ & $0.00 \mathrm{E}+00$ \\
\hline Lead compounds & 1.75E-05 & 3.02E-06 & $0.00 \mathrm{E}+00$ & 5.17E-05 & $7.22 \mathrm{E}-05$ & $1.26 \mathrm{E}-04$ & $1.98 \mathrm{E}-04$ \\
\hline Maleic anhydride & $1.88 \mathrm{E}-07$ & $0.00 \mathrm{E}+00$ & $0.00 \mathrm{E}+00$ & $0.00 \mathrm{E}+00$ & $1.88 \mathrm{E}-07$ & $0.00 \mathrm{E}+00$ & $1.88 \mathrm{E}-07$ \\
\hline Manganese compounds & $4.58 \mathrm{E}-06$ & 5.53E-06 & $0.00 \mathrm{E}+00$ & $1.92 \mathrm{E}-05$ & 2.93E-05 & $3.28 \mathrm{E}-05$ & $6.22 \mathrm{E}-05$ \\
\hline Mercury compounds & 2.67E-05 & 5.71E-07 & 4.73E-08 & 1.03E-06 & 2.84E-05 & 2.99E-05 & $5.83 \mathrm{E}-05$ \\
\hline Methanol & $2.48 \mathrm{E}-02$ & 4.04E-04 & 1.11E-04 & $8.16 \mathrm{E}-06$ & $2.53 \mathrm{E}-02$ & $2.80 \mathrm{E}-05$ & $2.53 \mathrm{E}-02$ \\
\hline Methyl ethyl ketone & 1.77E-02 & 2.34E-05 & $9.13 E-05$ & 4.83E-06 & $1.78 \mathrm{E}-02$ & $2.30 \mathrm{E}-06$ & $1.78 \mathrm{E}-02$ \\
\hline Methyl isobutyl ketone & 1.30E-03 & 1.67E-07 & $0.00 \mathrm{E}+00$ & $1.67 \mathrm{E}-07$ & 1.30E-03 & 1.45E-07 & 1.30E-03 \\
\hline Methyl tert-butyl ether & $9.71 \mathrm{E}-03$ & $5.79 \mathrm{E}-04$ & 1.43E-05 & $4.88 \mathrm{E}-06$ & 1.03E-02 & 5.02E-06 & 1.03E-02 \\
\hline Naphthalene & $1.05 E-03$ & 1.91E-05 & 9.57E-06 & 4.33E-05 & 1.12E-03 & $6.65 \mathrm{E}-05$ & 1.19E-03 \\
\hline Nickel compounds & $1.10 \mathrm{E}-04$ & $3.64 \mathrm{E}-05$ & $0.00 \mathrm{E}+00$ & $8.66 \mathrm{E}-04$ & $1.01 \mathrm{E}-03$ & $2.23 \mathrm{E}-03$ & $3.25 \mathrm{E}-03$ \\
\hline Phenol & $6.78 \mathrm{E}-04$ & $6.88 \mathrm{E}-05$ & 4.67E-04 & $7.90 \mathrm{E}-07$ & $1.22 \mathrm{E}-03$ & 1.79E-04 & 1.39E-03 \\
\hline Polychlorinated biphenyls & $5.37 \mathrm{E}-11$ & 1.07E-10 & $0.00 \mathrm{E}+00$ & $0.00 \mathrm{E}+00$ & $1.61 \mathrm{E}-10$ & $0.00 \mathrm{E}+00$ & $1.61 \mathrm{E}-10$ \\
\hline $\begin{array}{l}\text { Polycyclic aromatic } \\
\text { compounds }\end{array}$ & $8.62 \mathrm{E}-04$ & $2.24 \mathrm{E}-06$ & 5.37E-05 & $1.75 \mathrm{E}-05$ & $9.36 \mathrm{E}-04$ & $7.21 \mathrm{E}-04$ & $1.66 \mathrm{E}-03$ \\
\hline Propylene oxide & $0.00 \mathrm{E}+00$ & $0.00 \mathrm{E}+00$ & $0.00 \mathrm{E}+00$ & $0.00 \mathrm{E}+00$ & $0.00 \mathrm{E}+00$ & $0.00 \mathrm{E}+00$ & $0.00 \mathrm{E}+00$ \\
\hline Selenium compounds & 1.37E-06 & $1.29 \mathrm{E}-05$ & $0.00 \mathrm{E}+00$ & $0.00 \mathrm{E}+00$ & $1.43 \mathrm{E}-05$ & $1.42 \mathrm{E}-06$ & $1.57 \mathrm{E}-05$ \\
\hline Styrene & $6.69 \mathrm{E}-05$ & 3.76E-07 & $0.00 \mathrm{E}+00$ & $6.12 \mathrm{E}-07$ & $6.79 \mathrm{E}-05$ & 9.13E-08 & $6.80 \mathrm{E}-05$ \\
\hline Tetrachloroethylene & $3.21 \mathrm{E}-04$ & $0.00 \mathrm{E}+00$ & $1.07 \mathrm{E}-07$ & $0.00 \mathrm{E}+00$ & $3.21 \mathrm{E}-04$ & 4.08E-07 & $3.21 \mathrm{E}-04$ \\
\hline Toluene & $2.48 \mathrm{E}-02$ & 1.36E-04 & 4.89E-04 & $3.72 \mathrm{E}-05$ & $2.54 \mathrm{E}-02$ & 3.15E-04 & $2.58 \mathrm{E}-02$ \\
\hline Toluene-2,4-diisocyanate & $1.61 \mathrm{E}-07$ & $2.69 \mathrm{E}-08$ & $0.00 \mathrm{E}+00$ & $0.00 \mathrm{E}+00$ & $1.88 \mathrm{E}-07$ & 1.07E-07 & $2.95 \mathrm{E}-07$ \\
\hline Trichloroethylene & 3.43E-04 & $0.00 \mathrm{E}+00$ & $0.00 \mathrm{E}+00$ & $0.00 \mathrm{E}+00$ & $3.43 \mathrm{E}-04$ & $6.45 \mathrm{E}-08$ & 3.43E-04 \\
\hline Triethylamine & $0.00 \mathrm{E}+00$ & $0.00 \mathrm{E}+00$ & $0.00 \mathrm{E}+00$ & $0.00 \mathrm{E}+00$ & $0.00 \mathrm{E}+00$ & $0.00 \mathrm{E}+00$ & $0.00 \mathrm{E}+00$ \\
\hline Vinyl acetate & $1.91 \mathrm{E}-06$ & $1.50 \mathrm{E}-07$ & $0.00 \mathrm{E}+00$ & $0.00 E+00$ & 2.06E-06 & $3.22 \mathrm{E}-08$ & $2.10 \mathrm{E}-06$ \\
\hline Xylene & $1.51 \mathrm{E}-02$ & $2.77 \mathrm{E}-04$ & $1.69 \mathrm{E}-04$ & $5.82 \mathrm{E}-05$ & $1.56 \mathrm{E}-02$ & 4.60E-04 & $1.61 \mathrm{E}-02$ \\
\hline m-Cresol & $0.00 \mathrm{E}+00$ & $0.00 \mathrm{E}+00$ & $0.00 \mathrm{E}+00$ & $0.00 \mathrm{E}+00$ & $0.00 \mathrm{E}+00$ & $6.72 \mathrm{E}-07$ & $6.72 \mathrm{E}-07$ \\
\hline m-Xylene & 6.79E-04 & 6.34E-07 & 1.91E-05 & $2.76 \mathrm{E}-06$ & 7.01E-04 & 2.32E-06 & 7.04E-04 \\
\hline n-Hexane & 1.80E-02 & 1.09E-05 & 4.17E-06 & 1.75E-05 & 1.80E-02 & 3.62E-05 & 1.80E-02 \\
\hline o-Cresol & $0.00 \mathrm{E}+00$ & $0.00 \mathrm{E}+00$ & $0.00 \mathrm{E}+00$ & $0.00 \mathrm{E}+00$ & $0.00 \mathrm{E}+00$ & 8.60E-08 & 8.60E-08 \\
\hline 0-Toluidine & $5.37 \mathrm{E}-08$ & $0.00 \mathrm{E}+00$ & $0.00 \mathrm{E}+00$ & $0.00 \mathrm{E}+00$ & $5.37 \mathrm{E}-08$ & 8.06E-08 & 1.34E-07 \\
\hline o-Xylene & $5.76 \mathrm{E}-04$ & $6.34 \mathrm{E}-07$ & 1.81E-05 & $2.88 \mathrm{E}-06$ & 5.97E-04 & 4.18E-06 & $6.02 \mathrm{E}-04$ \\
\hline p-Cresol & $0.00 \mathrm{E}+00$ & 1.96E-06 & $0.00 \mathrm{E}+00$ & $0.00 \mathrm{E}+00$ & 1.96E-06 & 8.06E-08 & $2.04 \mathrm{E}-06$ \\
\hline p-Xylene & 7.21E-04 & 6.34E-07 & 1.91E-05 & 3.22E-07 & 7.42E-04 & 5.32E-07 & 7.42E-04 \\
\hline Total & 0.1451 & 0.0021 & 0.0032 & 0.0018 & 0.1523 & 0.0148 & 0.1670 \\
\hline
\end{tabular}




\subsubsection{Toxics from Vehicle Use}

As discussed above, three studies (that evaluated air toxic emissions from vehicle use were identified (Lev-On, 2002; Alleman, 2003, and Frame, 2003). The Lev-On study compares FTD with ULSD in school buses; the Alleman study evaluates heavy-duty vehicles, light duty trucks, and light duty vehicles; and the ongoing Frame study at the Department of Energy is evaluating criteria and toxic air pollutant emissions from clean diesel fuels.

No studies were identified that compare FTD or ULSD with FRFG under comparable testing conditions. FRFG toxics emissions used in the LCIA are based on the proposed U.S. EPA Tier 2 standards for light duty gasoline vehicles.

Table 7-8 shows the results from the toxics emissions engine test studies, reported as $\mathrm{g} / \mathrm{vehicle}$ mile traveled (VMT), for benzene, an aggregate of toluene, ethylbenzene, and xylene isomers, 1,3-butadiene, formaldehyde, and acetaldehyde. Although the absolute emissions values cover a wide range, depending on the vehicle tested, it can be observed that the relative differences between ULSD and FTD are within a consistent range. Compared with ULSD, FTD emissions are $50-73 \%$ lower for benzene; $38-50 \%$ lower for the toluene group; $54-75 \%$ lower for $1,3-$ butadiene; $56-80 \%$ lower for formaldehyde; and $50-88 \%$ lower for acetaldehyde.

The UCF LCA functional unit is light duty VMT. However, the only complete data set for toxic emissions from the available studies was for light duty trucks. Data for the light duty passenger diesel vehicle from (Allemann, 2003) is used for the UCF LCA, with a proxy of emissions of 1,3-butadiene from light duty trucks from the same study. This represents a conservative estimate for the light duty vehicle for this emission.

Table 7-9 shows the toxics emissions corresponding to the proposed U.S. EPA Tier 2 standards for gasoline light duty vehicles. These estimated limits are based on a total Tier 2 limit on VOCs of $0.09 \mathrm{~g} / \mathrm{mile}$ and an estimated VOC composition of $0.5 \%$ acetaldehyde, $0.5 \% 1,3$-butadiene, $1 \%$ formaldehyde, $4 \%$ benzene, and $10 \%$ toluene (U.S. EPA, December 2000 ) from light duty gasoline vehicles. It should be emphasized that the comparisons made for the human health and ecotoxicity impact categories are between actual tests of light duty diesel vehicles and proposed standards for light duty gasoline vehicles. 
Table 7-8 ULS Diesel and FT Diesel Air Toxics Emissions (g/mile)

\begin{tabular}{|c|c|c|c|c|c|c|c|c|}
\hline \multirow[b]{3}{*}{ Chemical } & \multirow{2}{*}{\multicolumn{2}{|c|}{$\begin{array}{c}\text { (Lev-On, 2002) } \\
\text { Heavy Duty Vehicle (School } \\
\text { Bus) }\end{array}$}} & \multicolumn{4}{|c|}{ (Allemann, 2003) } & \multirow{2}{*}{\multicolumn{2}{|c|}{$\begin{array}{l}\text { (Frame, 2003) } \\
\text { Heavy Duty Truck }\end{array}$}} \\
\hline & & & \multicolumn{2}{|c|}{$\begin{array}{l}\text { Light Duty Truck (Dodge } \\
\text { Ram) }\end{array}$} & \multicolumn{2}{|c|}{ Light Duty (Volkswagen Golf) } & & \\
\hline & ULSD & FTD & ULSD & FTD & ULSD & FTD & ULSD & FTD \\
\hline Benzene & 0.0023 & 0.0017 & 0.0013 & 0.0009 & 0.00011 & 0.00008 & 0.0050 & 0.0025 \\
\hline \begin{tabular}{|l|} 
Toluene, \\
ethylbenzene, \\
xylene isomers
\end{tabular} & 0.0032 & 0.0013 & 0.0018 & 0.0007 & 0.0002 & 0.0001 & NA & NA \\
\hline 1,3-butadiene & NA & NA & 0.0008 & 0.0006 & NA & NA & 0.0048 & 0.0026 \\
\hline Formaldehyde & NA & NA & 0.0161 & 0.0129 & 0.002 & 0.0015 & 0.3656 & 0.2062 \\
\hline Acetaldehyde & NA & NA & 0.0096 & 0.0055 & 0.0026 & 0.0023 & 0.1484 & 0.0747 \\
\hline
\end{tabular}

\section{Table 7-9 Tier 2 Toxics Emissions Standards for Light Duty Gasoline Vehicles (g/mile)}

\begin{tabular}{|l|c|}
\multicolumn{1}{|c|}{ Chemical } & $\begin{array}{c}\text { FRFG Tier 2 } \\
\text { Emissions Limits }\end{array}$ \\
\hline Benzene & 0.0054 \\
\hline Toluene & 0.0126 \\
\hline 1,3 Butadiene & 0.00045 \\
\hline Formaldehyde & 0.0009 \\
\hline Acetaldehyde & 0.00045 \\
\hline
\end{tabular}

Source: U.S. EPA

\subsubsection{PM2.5}

The indicator value for the human health criteria impact category is a function of criteria pollutant emissions. In TRACI, both PM10 and PM2.5 are assigned to this impact category. Standards for PM2.5 are currently being considered by the U.S. EPA and are widely debated by environmental and industry groups. There are no studies that have directly measured PM2.5 emissions for FTD and ULSD fuels. Only PM10 emissions are reported in the LCI.

A research paper from the U.S. EPA (U.S. EPA, 2001) develops empirical relationships between PM10 and PM2.5 based on testing of background levels of particulates. The relationship varies by geographic location and particulate composition. The ratio of PM2.5 to PM10 generally varies in these measurements between 0.4 and 0.7 . For the purposes of this LCIA, a value of 0.7 for the ratio PM2.5/PM10 was chosen as a conservative, or worst case, estimate. As the proportion of PM2.5 increases, particulate emissions have an increased potential impact on human health. Even though the total mass loading, reported as micrograms of PM10 per cubic

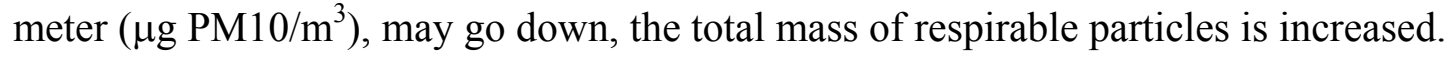




\subsubsection{Remote Gas Reserves and Crude Oil Reserves}

Stranded gas is defined as discovered, but undeveloped, reserves that do not have a readily available market. There is an estimated 3,500 trillion standard cubic feet (TCF) of stranded gas worldwide. A number of countries have stranded gas, with the three largest being Russia, Iran, and Qatar. Stranded gas will eventually be used in pipeline export projects, LNG projects, and other fuel and petrochemical projects as well as in GTL projects, but the volume will be small in the near term when compared with the large amount of stranded gas that exists.

When considering the amount of feed gas required for large export projects, the economy of scale generally necessary to obtain acceptable economics requires very large volumes over a long production period. For example, a large GTL plant would need about 6 TCF to produce 80,000 barrels per day over a 25 -year period. One such plant represents a multibillion-dollar project and would take over 6 years in planning, designing, fabricating, and commissioning.

Table 7-10 shows the parameters used to estimate the rate at which stranded gas projects might be developed over the next 50 years, along with the rate at which new reserves might be proven. These assumptions are used in the impact assessment to estimate the rate at which the reserves might be depleted.

Table 7-10 Stranded Gas Reserve Parameter Assumptions

\begin{tabular}{|l|c|c|c|}
\hline \multicolumn{2}{|c|}{ Parameter } & $\mathbf{2 0 0 0 - 2 0 2 5}$ & $\mathbf{2 0 2 6 - 2 0 5 0}$ \\
\hline Current proven stranded gas reserves & 3,500 TCF & & $1.1 \%$ \\
\hline Reserve growth per year & & $1.75 \%$ & 0.3 \\
\hline Number of GTL projects developed per year & & 0.3 & 6 \\
\hline Stranded gas commitment per GTL project over 25 years & & 6 & 9.7 \\
\hline Number of other projects per year (LNG, pipeline) & & 6 & 20 \\
\hline Stranded gas commitment per other project over 25 years & & 4.7 & \\
\hline
\end{tabular}

Worldwide crude oil reserves have been estimated to be 1.2 trillion barrels (Oil and Gas Journal, 2003), (EIA, 2003), with a total estimated proven and unproven reserve of 1.9 trillion barrels. Table 7-11 shows the assumptions used in the LCIA to estimate the rate of crude oil reserve depletion.

Table 7-11 Crude Oil Reserve Assumptions

\begin{tabular}{|l|c|c|c|c|c|c|}
\hline \multicolumn{1}{|c|}{ Parameter } & \multicolumn{2}{|c|}{$2000-2010$} & $2011-2020$ & $2021-2030$ & $2031-2040$ & $2041-2050$ \\
\hline Current proven reserves & 1.212 billon barrels & & & & & \\
\hline $\begin{array}{l}\text { Percentage increase in } \\
\text { consumption }\end{array}$ & $2 \%$ & & & & & \\
\hline Reserve growth per year & & $1.9 \%$ & $1.5 \%$ & $1.2 \%$ & $0 \%$ & $0 \%$ \\
\hline
\end{tabular}




\subsection{DATA GAPS}

This section summarizes the primary data gaps in the LCIA.

Toxic emissions are the one set of data that is not comprehensively represented for all unit processes and for all scenarios. The data gaps with respect to toxics are:

- Toxic emissions from fuel transportation and distribution for GTL or petroleum fuels are not included. These stages, on an energy basis, represent a small portion of the full fuel life cycles, and are also likely to represent a small portion of toxic emissions.

- Toxic emissions from power generation used in feedstock recovery and fuel production are not included.

- In the production of crude oil and natural gas, toxic wastes are essentially equivalent and are regulated as discussed above. Therefore, this study does not differentiate between crude oil and natural gas feedstock production on the basis of potential heavy metal toxicity.

- Currently available data for toxic emissions for the vehicle use stage is limited. The data used in the UCF LCA is drawn from three recent studies. The data for light duty diesel vehicles is from engine test studies, and the data for light duty gasoline vehicles is based on proposed standards.

- Comparable toxic emissions from fuel cell vehicles and HEVs were not available to this study and are thus not included. However, the emissions from these vehicles are expected to be very low during the operation of the vehicle. Batteries and lead issues may come up as life cycle issues; however, this is yet to be determined.

- Only FTD CIDI, ULSD CIDI, and FRFG SI for the long-term scenarios are compared for the HHC, HHNC, and ecotoxic impact categories.

\subsection{LCIA SCENARIOS}

Tables 7-12 and 7-13 list the near-term and long-term scenarios from the LCI that are considered in the LCIA. (The FTD "aggressive" cases for CIDI and CIDI HEV have been excluded in the LCIA in order to narrow the scope of the analysis.) Table 7-14 lists the indicators and characterization factors considered in the LCIA for the total emissions and the urban emissions impact cases.

Urban potential impacts are calculated for the Houston-Galveston Metropolitan Area for each scenario and for the relevant indicator categories. However, TRACI does not have regional characterization factors for all impact categories. The impact categories for human health (cancer, non-cancer) and ecotoxicity have only average factors for the United States. 
Table 7-12 Near-Term LCIA Scenarios

\begin{tabular}{|c|c|c|c|}
\hline $\begin{array}{c}2006 \\
\text { Scenario } \\
\text { Number }\end{array}$ & Scenario Name & Fuel & Vehicle \\
\hline 1 & PADD III FTD20 CIDI & $\begin{array}{l}\text { Blend of } 20 \% \text { remotely produced GTL } \\
\text { diesel and } 80 \% \text { PADD III ULSD }\end{array}$ & $\begin{array}{l}\text { Light duty (LD) passenger vehicle with } \\
\text { CIDI engine }\end{array}$ \\
\hline 2 & PADD III CD CIDI & PADD III CD & LD vehicle with $\mathrm{CIDI}$ engine \\
\hline 3 & PADD III ULSD CIDI & PADD III ULSD with CFE & LD vehicle with CIDI engine \\
\hline 4 & PADD III FRFG & PADD III FRFG with CFE & LD passenger vehicle with SI engine \\
\hline
\end{tabular}

Table 7-13 Long-Term LCIA Scenarios

\begin{tabular}{|c|c|c|c|}
$\begin{array}{c}2015 \text { Scenario } \\
\text { Number }\end{array}$ & Scenario Name & Fuel & Vehicle \\
\hline 5 & FTD100 CIDI & 100\% remotely produced GTL diesel & LD passenger, CIDI engine \\
\hline 7 & PADD III ULSD CIDI & PADD III ULSD with CFE & LD passenger, CIDI engine \\
\hline 8 & PADD III FRFG & PADD III FRFG with CFE & LD passenger, SIDI engine \\
\hline 9 & FTD100 HEV & $100 \%$ remotely produced GTL diesel & LD passenger, HEV with CIDI engine \\
\hline 11 & PADD III ULSD HEV & PADD III ULSD with CFE & LD HEV with CIDI engine \\
\hline 12 & PADD III FRFG HEV & PADD III FRFG with CFE & LD passenger, HEV with SIDI engine \\
\hline 13 & Methanol FCV & $100 \%$ remotely produced methanol & FCV with methanol reformer \\
\hline 14 & PADD III FRFG FCV & PADD III FRFG with CFE & FCV with gasoline reformer \\
\hline 15 & FT naphtha FCV & $100 \%$ remotely produced FT naphtha & FCV with FT naphtha reformer \\
\hline
\end{tabular}

\section{Table 7-14 LCIA Total Emissions and Urban Emissions Scenarios}

\begin{tabular}{|c|c|c|c|c|}
\hline Emissions Case & $\begin{array}{c}\text { Characterization } \\
\text { Factors }\end{array}$ & Impact categories & Vehicle/Fuels & Comments \\
\hline Total emissions & $\begin{array}{l}\text { U.S. } \\
\text { average/global } \\
\text { factors }\end{array}$ & $\begin{array}{l}\text { GWP, acidification, } \\
\text { photochemical smog, } \\
\text { eutrophication, human health } \\
\text { criteria, land, water, resource } \\
\text { depletion }\end{array}$ & $\begin{array}{l}\text { All vehicles and } \\
\text { fuels }\end{array}$ & $\begin{array}{l}\text { GWP, land, water, and resource } \\
\text { depletion are meaningful only in a } \\
\text { total life cycle analysis and are not } \\
\text { considered in the urban cases }\end{array}$ \\
\hline Total emissions & $\begin{array}{l}\text { U.S. average } \\
\text { factors }\end{array}$ & HHC, HHNC, ecotoxicity & $\begin{array}{l}\text { FTD CIDI, ULSD } \\
\text { CIDI, FRFG SI }\end{array}$ & $\begin{array}{l}\text { Comparable vehicle toxics } \\
\text { emissions data is available only for } \\
\text { FTD CIDI, ULSD CIDI, and FRFG } \\
\text { SI. Regional characterization } \\
\text { factors are not available in TRACI }\end{array}$ \\
\hline $\begin{array}{l}\text { Urban } \\
\text { Emissions }\end{array}$ & Houston & $\begin{array}{l}\text { Human health criteria, } \\
\text { acidification, photochemical } \\
\text { smog, eutrophication }\end{array}$ & $\begin{array}{l}\text { All vehicles and } \\
\text { fuels }\end{array}$ & $\begin{array}{l}\text { Only these impact categories have } \\
\text { regional characterization factors in } \\
\text { TRACI }\end{array}$ \\
\hline
\end{tabular}




\subsection{LCIA RESULTS}

This section presents the full set of results and conclusions for the LCIA impact indicators for the scenarios defined above. Tables D-1 through D-10 in Appendix D show the indicator values for each TRACI impact category for each scenario. Tables D-11 through D-23 provide the complete set of input data to TRACI for the LCIA.

LCIA involves a greater degree of inherent uncertainty than LCI because of the complex environmental mechanisms that are represented by the impact indicators. To capture this uncertainty, broader error ranges than those used in the LCI are generally required to differentiate the results. Professional judgment is used to develop reasonable and conservative ranges of error.

The 10\% threshold used for GWP is considered appropriate because of the high level of certainty of the data and the low sensitivity of the results to changes in the data. A $15 \%$ threshold is used to differentiate the impact category results for solid waste, wastewater, and resource depletion, as in the LCI.

The uncertainty inherent in the acidification, smog, eutrophication, human health, and ecotoxicity impact categories is considerably greater. The variability and uncertainty in the inventory data and the nature of the TRACI characterization models make it very difficult to distinguish potential impacts between the fuels studied unless the results differ considerably. An error range of $100 \%$ was chosen based on the professional judgment of the study authors for these LCIA categories.

Issues related to uncertainty in life cycle assessment are discussed in the paper by Ross (Ross et al., 2002), which also identifies the aggregation of results across life cycle stages and geographic areas as a point of concern. The UCF LCA has attempted to address this issue by considering urban emissions in a specific area, and using characterization factors specific to that region from the TRACI model.

In the sections below, the differences in indicator values between scenarios are detailed for each of the impact categories. Conclusions are then drawn in the final section based on these results and on the appropriate error ranges for each impact category. 


\subsubsection{Global Warming Potential (GWP)}

The category indicator for GWP is grams of $\mathrm{CO}_{2}$ equivalents $\left(\mathrm{CO}_{2}\right.$-e) as defined by the IPCC for a 100-year horizon.

Figures 7-1 and 7-2 show the results for GWP for the 2006 and 2015 cases. These results are identical to those presented in Section 6 of this report. They are included again here for completeness. When a 10\% uncertainty threshold is used, the GWP of FTD100 is comparable to both the GWP impact indicator of ULSD and FRFG. The GWPs of FT naphtha FCV, FRFG FCV, and methanol FCV are comparable. In the near term, FTD20 has a GWP comparable to that of conventional diesel and ULSD and a lower GWP than FRFG.

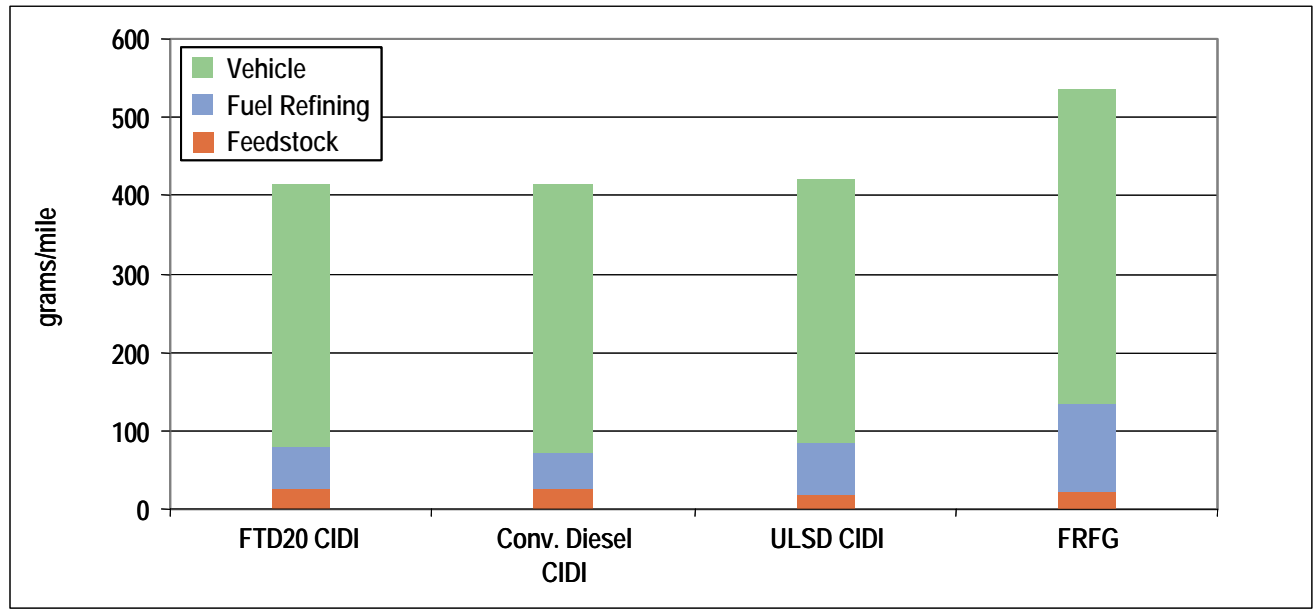

Figure 7-1 Global Warming Potential, 2006

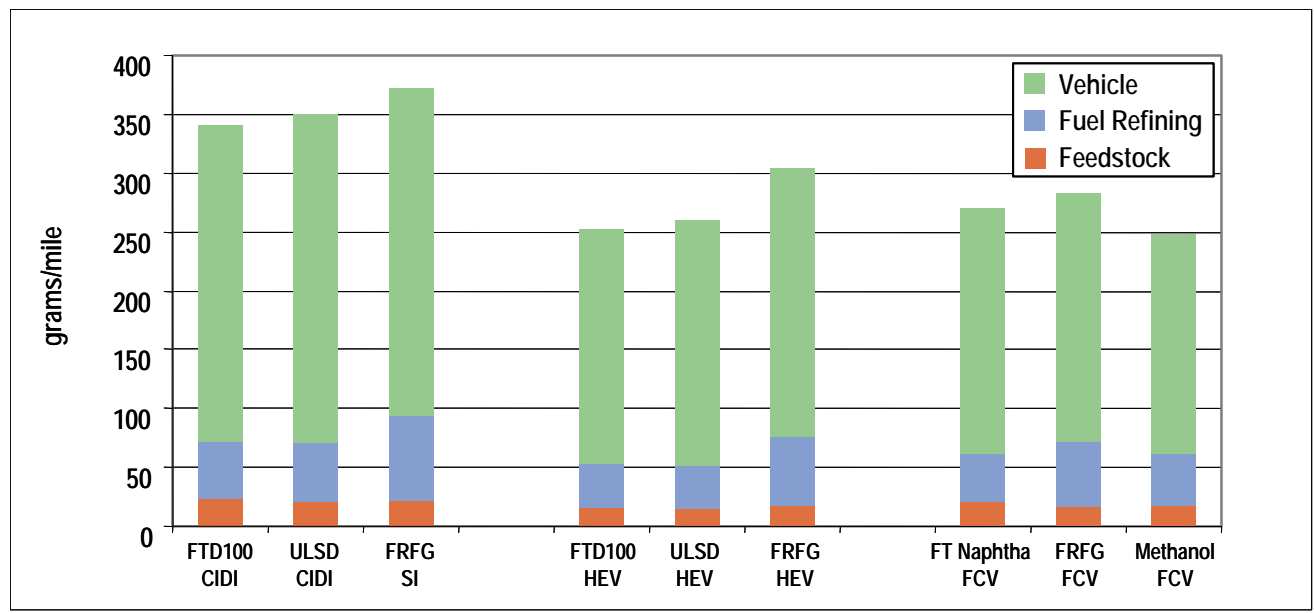

Figure 7-2 Global Warming Potential, 2015 


\subsubsection{Acidification}

The category indicator for acidification is mole equivalents of $\mathrm{H}+$. Acidification refers to processes that increase the acidity of water and soil systems. The major acidifying emissions are $\mathrm{NO}_{\mathrm{X}}$ and $\mathrm{SO}_{\mathrm{X}}$.

Figures 7-3 and 7-4 show the total life cycle acidification impact potential results for the 2006 and 2015 scenarios, respectively. For the 2006 scenarios, FTD20 has an indicator value that is $19 \%$ lower than ULSD, 66\% lower than conventional diesel, and 62\% lower than FRFG. For the 2015 scenarios, FTD CIDI has an indicator value that is 38\% and 52\% lower than ULSD and FRFG, respectively. The results are similar for FTD HEV and FT naphtha FCV compared with similar vehicles. These lower indicator values are due to the reduction of $\mathrm{SO}_{\mathrm{X}}$ and $\mathrm{NO}_{\mathrm{X}}$ emissions in the fuel and vehicle stages for GTL relative to petroleum fuels.

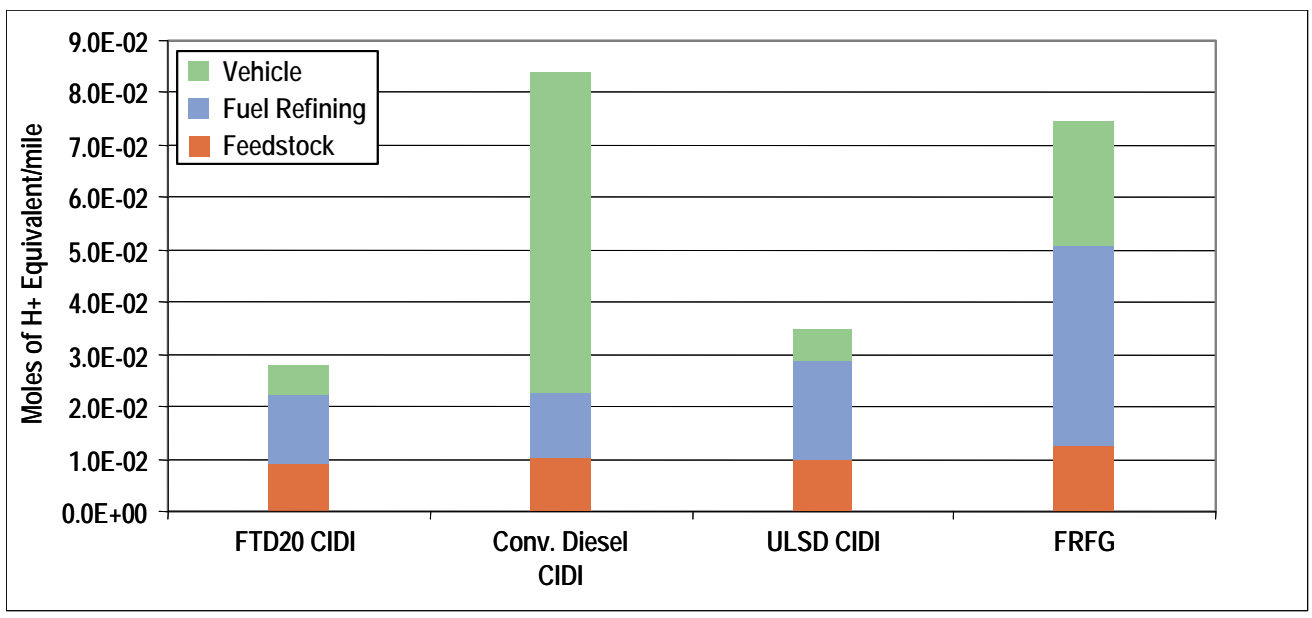

Figure 7-3 Total Acidification, 2006

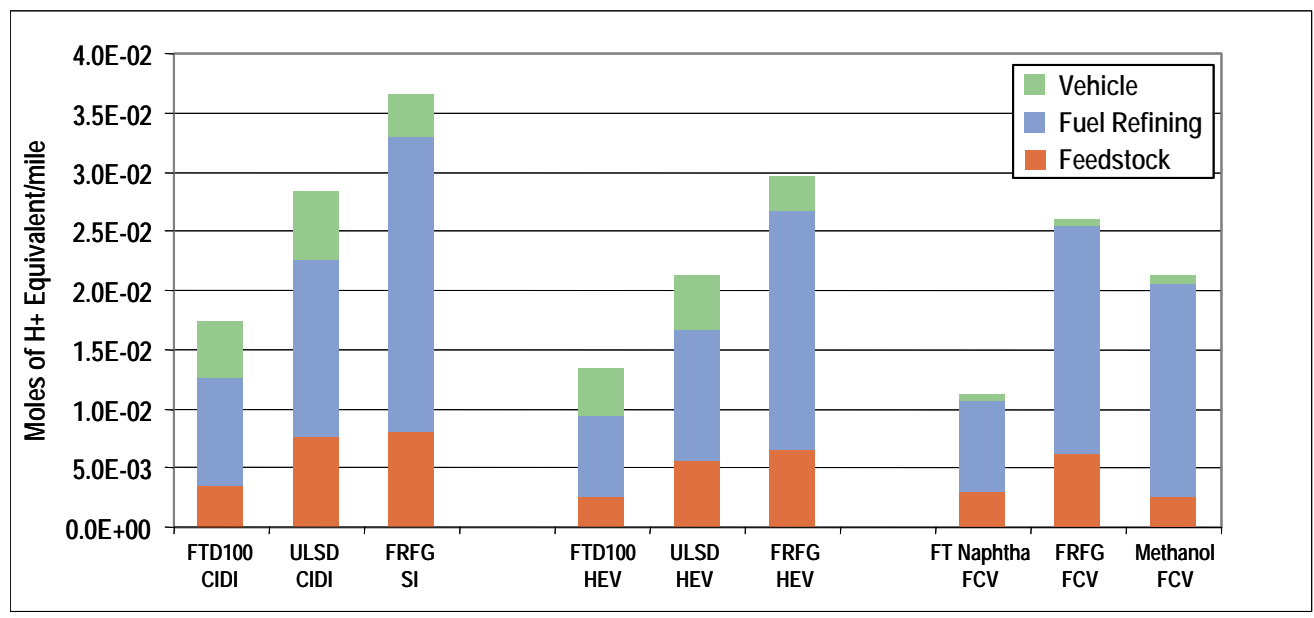

Figure 7-4 Total Acidification, 2015 
Figures 7-5 and 7-6 show the urban acidification impact potentials for Houston for the 2006 and 2015 scenarios, respectively. Both the total urban impact potentials (including potential impacts from the feedstock, fuel, and vehicle stages) and the potential impact due only to vehicle use are shown. The difference between the total urban impact potential and the vehicle stage impact potential is due primarily to that portion of fuel refining that occurs in urban areas. (A U.S. average figure of $20 \%$ of petroleum fuel production occurs in urban areas, and GTL production occurs only in remote areas.) A small portion of feedstock production for petroleum occurs in urban areas.

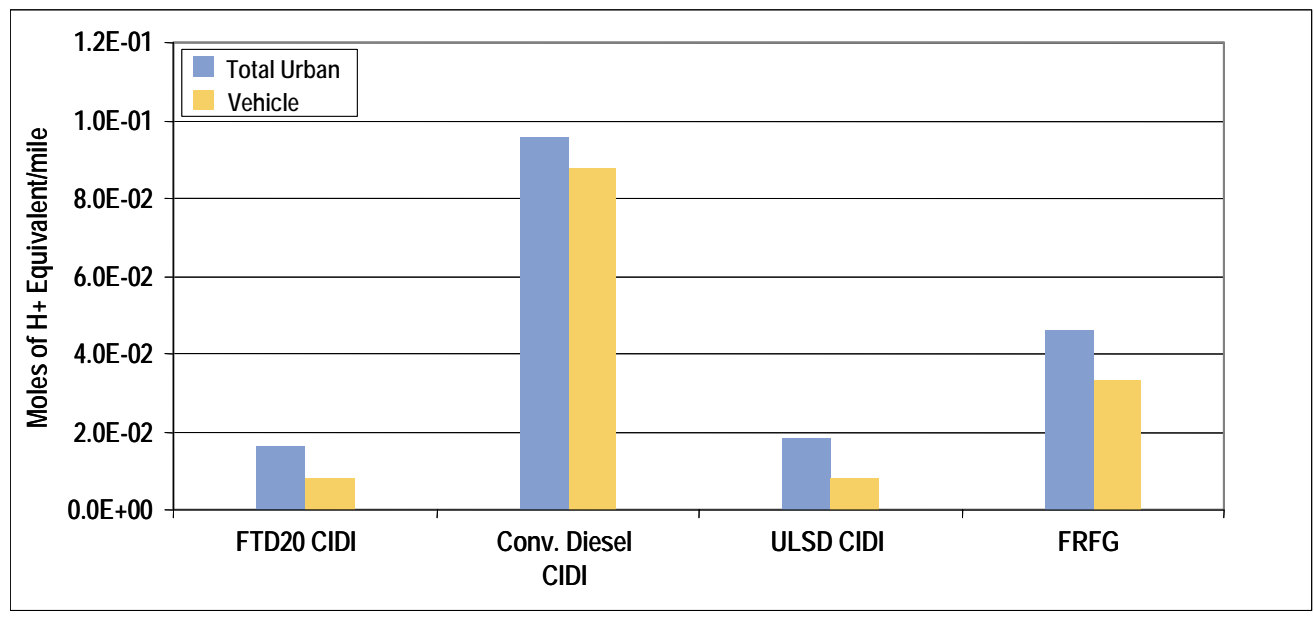

Figure 7-5 Urban Acidification, Houston, 2006

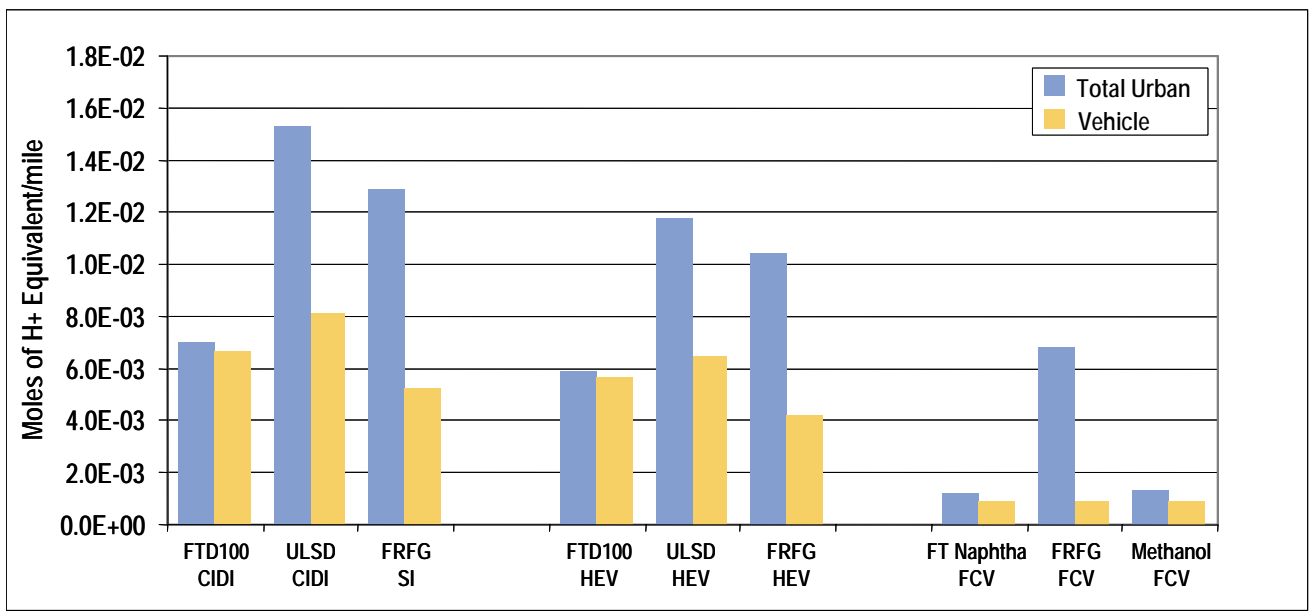

Figure 7-6 Urban Acidification, Houston, 2015 
In the 2006 urban potential impact scenarios, FTD20 has an indicator value that is $12 \%$ lower than ULSD, 82\% lower than conventional diesel, and 65\% lower than FRFG (Figure 7-5). In the 2015 urban potential impact scenarios, FTD CIDI also has lower indicator values than comparable vehicles. FT naphtha has an indicator value that is $82 \%$ and $14 \%$ lower than the FRFG and methanol FCVs, respectively. Most of the differences for the GTL fuels are due to the fuel production, but the indicator value for vehicle use alone is also lower for FTD than for ULSD. On the other hand, FTD has a greater vehicle stage acidification indicator value than FRFG.

In both near- and long-term cases, FTD fuels compare favorably with ULSD and FRFG in terms of both total and urban acidification. However, given the uncertainty of the LCIA, it is considered that these results cannot be differentiated. One can see from these figures that a large portion of the urban indicator for ULSD and FRFG is attributed to fuel production. 


\subsubsection{Photochemical Smog}

The category indicator for photochemical smog is grams of $\mathrm{NO}_{\mathrm{X}}$ equivalents. Ozone formation in the lower atmosphere is governed by complex chemical reactions that are influenced by background levels of $\mathrm{NO}_{\mathrm{X}}$ and VOCs and by atmospheric conditions, including temperature, sunlight, and convective flows. Thus, the rate of smog formation differs significantly by region.

Figures 7-7 and 7-8 show total photochemical smog impact potential for the 2006 and 2015 scenarios, respectively. FTD20 has a photochemical smog indicator value that is 5\% lower than ULSD, 65\% lower than conventional diesel, and 61\% lower than FRFG. FTD100 CIDI has an indicator value 13\% lower than ULSD 2015 and 37\% lower than FRFG. Results are similar for the HEV cases. FT naphtha FCV has an indicator value that is $47 \%$ and $38 \%$ lower than methanol and FRFG, respectively.

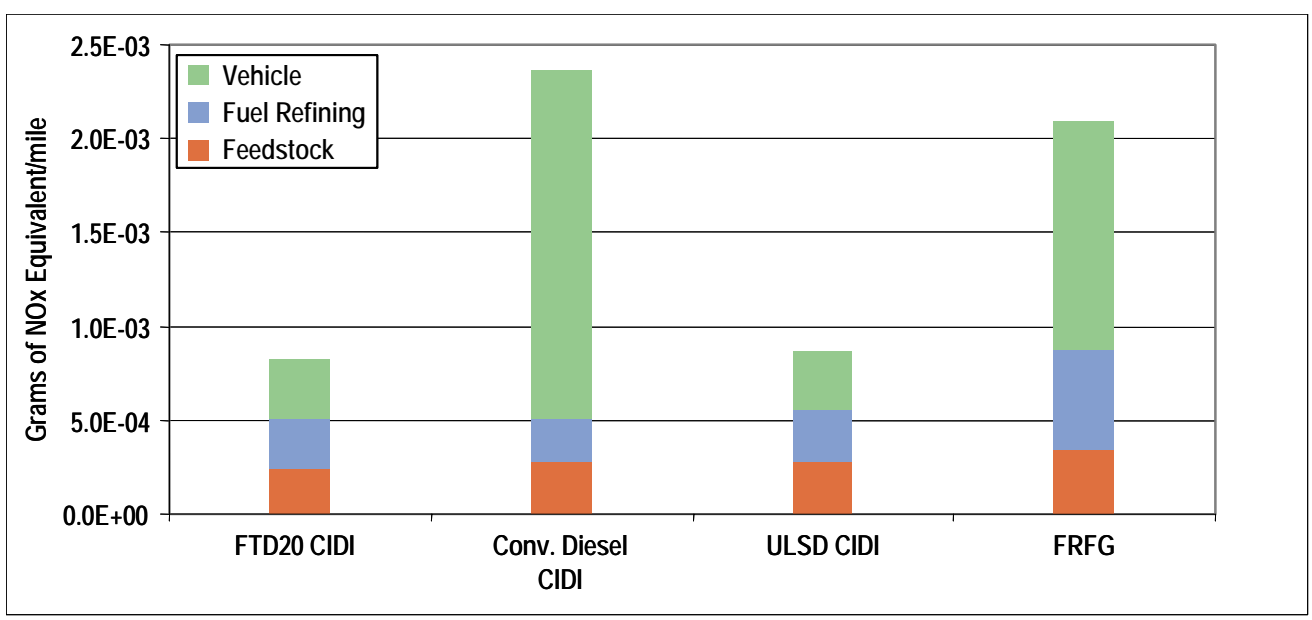

Figure 7-7 Total Photochemical Smog, 2006

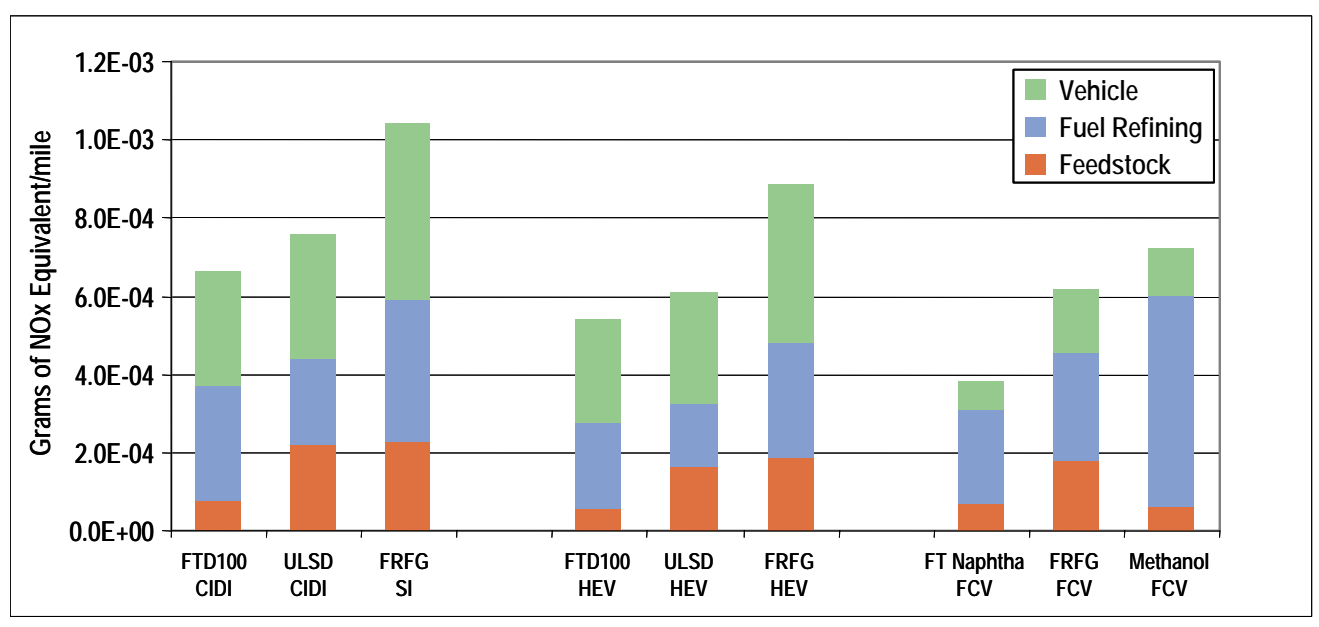

Figure 7-8 Total Photochemical Smog, 2015

The lower indicator values for FTD are due to the reduction of $\mathrm{NO}_{\mathrm{X}}$ and VOC emissions in the fuel and vehicle stages of GTL fuel relative to petroleum fuels. 
For the 2015 urban potential impact scenarios, FTD100 CIDI has an indicator value that is $25 \%$ and 52\% lower than ULSD and FRFG, respectively (Figure 7-10). Results are similar for the HEV cases. As in the acidification cases, the difference is due primarily to fuel production, but the indicator value due to vehicle use alone is also lower for FTD than for ULSD. In the 2006 scenarios, the indicator value for FTD20 is 27\% lower than for ULSD, $80 \%$ lower than for conventional diesel and 71\% lower than for FRFG (Figure 7-9).

As with acidification, the general trend is toward reduced potential impact numbers for GTL fuels. However, these values exhibit insufficient differences to allow discrimination between results.

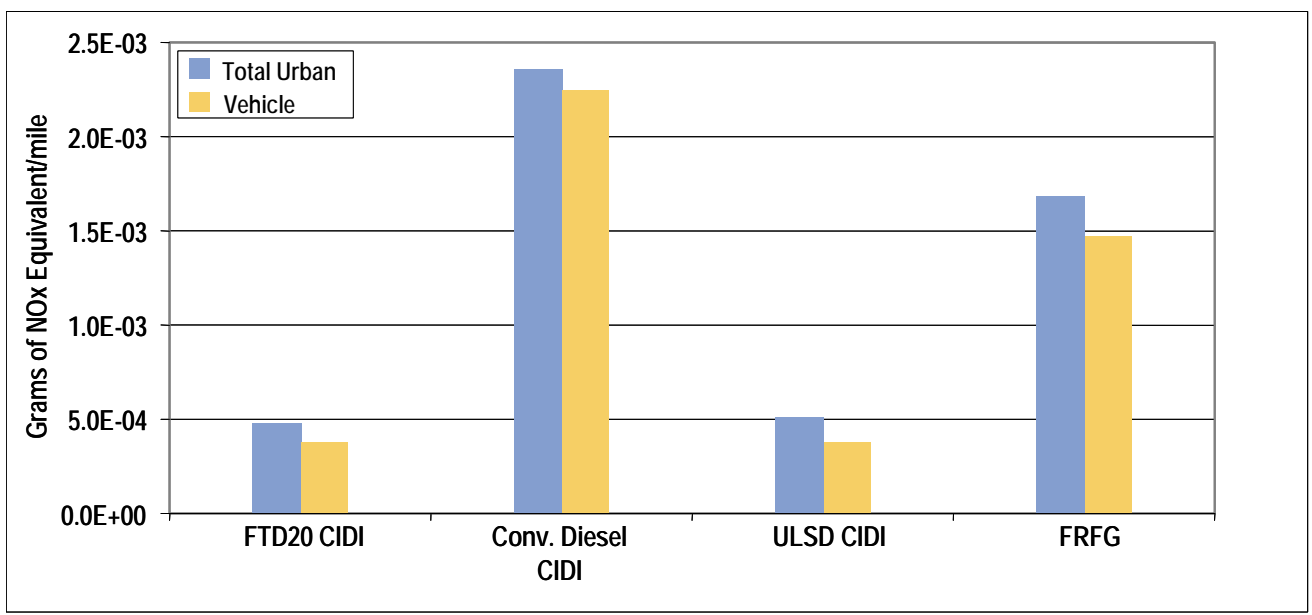

Figure 7-9 Urban Photochemical Smog, Houston, 2006

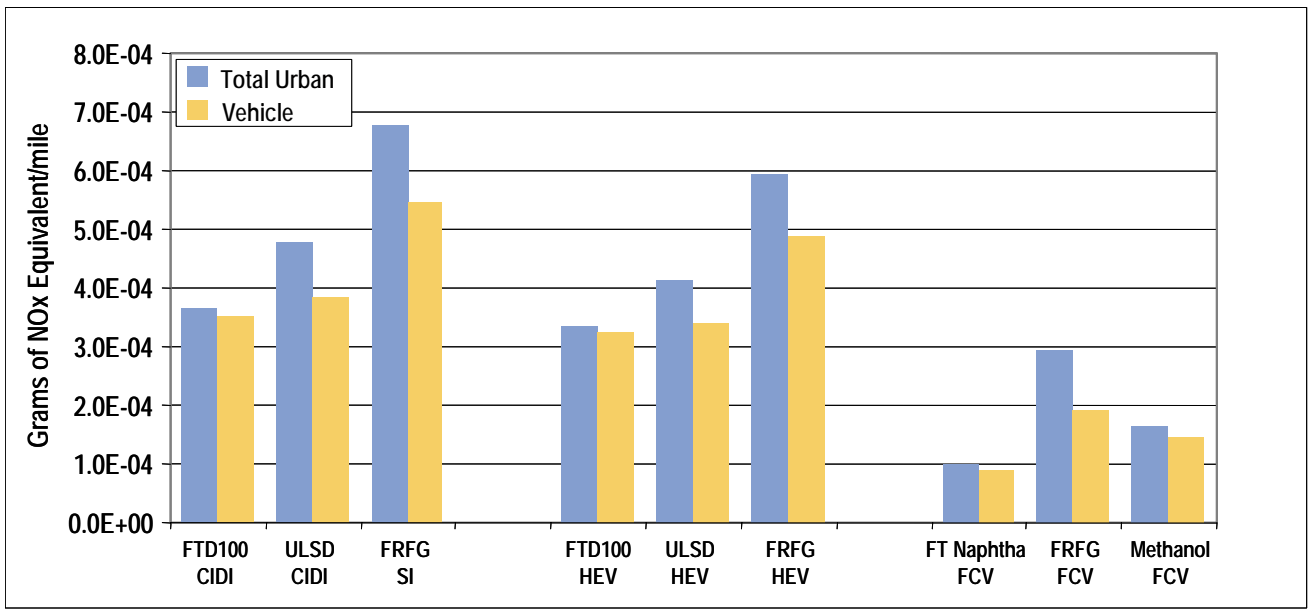

Figure 7-10 Urban Photochemical Smog, Houston, 2015 


\subsubsection{Eutrophication}

The category indicator for eutrophication is kilograms of nitrogen equivalent. Eutrophication is the process by which excessive nutrients accumulate in surface waters and degrade water quality.

Figures 7-11 and 7-12 present total eutrophication impact potentials for 2006 and 2015, respectively. In 2006, FTD20 has an indicator value that is $71 \%$ lower than conventional diesel, $57 \%$ lower than FRFG, and 6\% lower than ULSD. The differences are due to the reduction of $\mathrm{NO}_{\mathrm{X}}$ emissions in the fuel and vehicle stages of GTL relative to the other fuels. In 2015, FTD100 CIDI has an indicator value that is 15\% lower than ULSD and 16\% lower than FRFG. Results are similar for HEVs. FT naphtha has an indicator value that is $49 \%$ and $24 \%$ lower than methanol and FRFG FCVs, respectively.

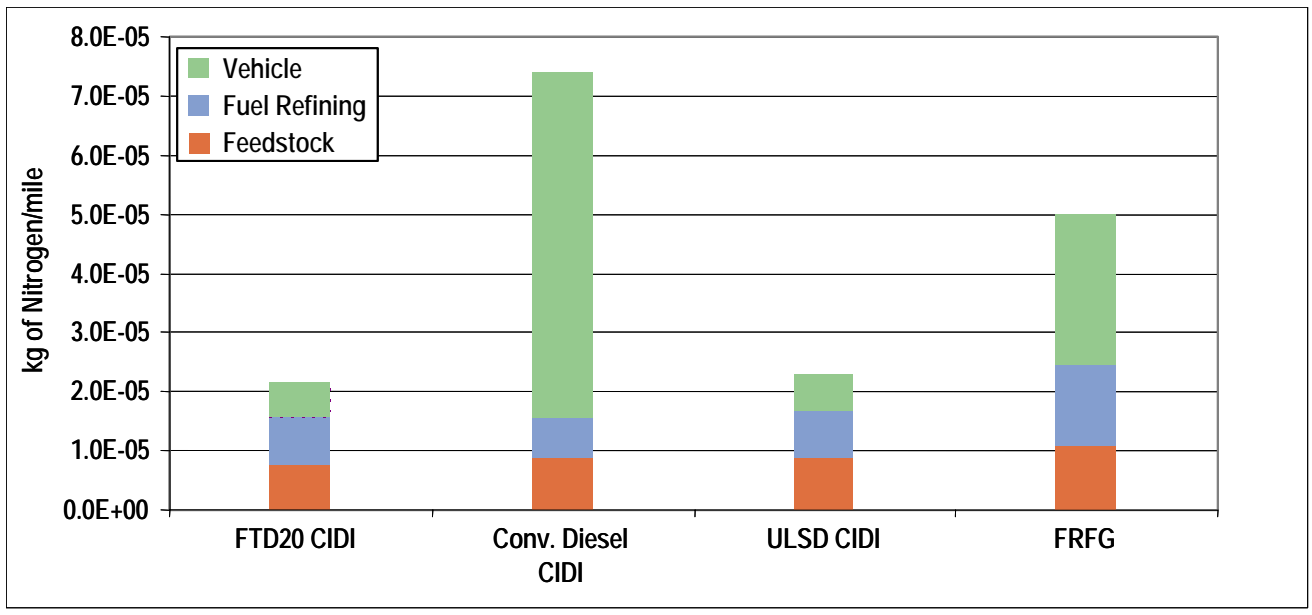

Figure 7-11 Total Eutrophication, 2006

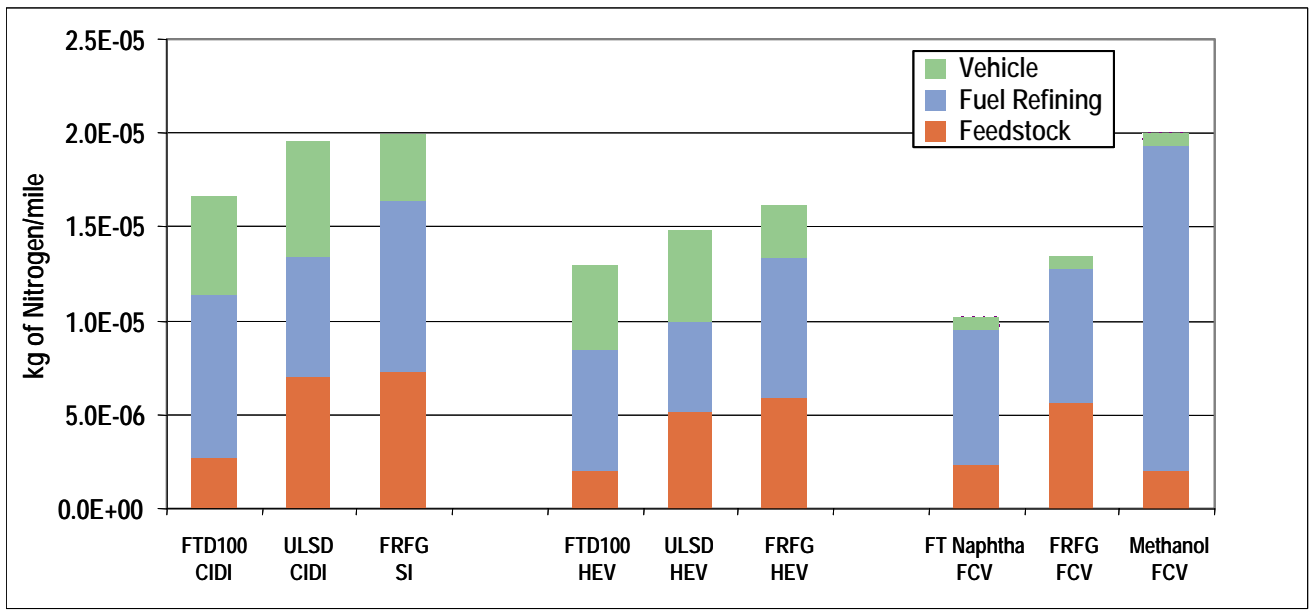

Figure 7-12 Total Eutrophication, 2015 
For the 2015 urban potential impact scenarios, FTD has an indicator value that is $35 \%$ lower than ULSD and 8\% lower than FRFG. However, FTD100 has a larger vehicle stage impact potential (Figure 7-14). In 2006, FTD20 has an indicator value that is $86 \%$ lower than conventional diesel, $7 \%$ lower than ULSD, and 71\% lower than FRFG (Figure 7-13).

In none of the cases are these differences significant with respect to the error range of the results.

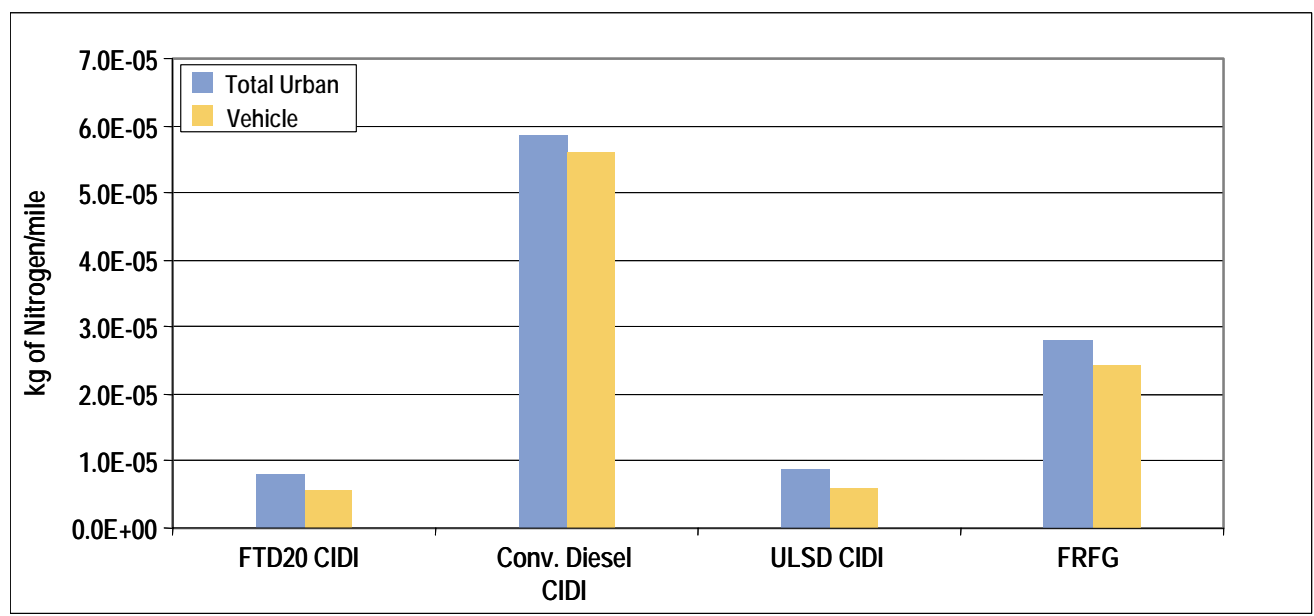

Figure 7-13 Urban Eutrophication, Houston, 2006

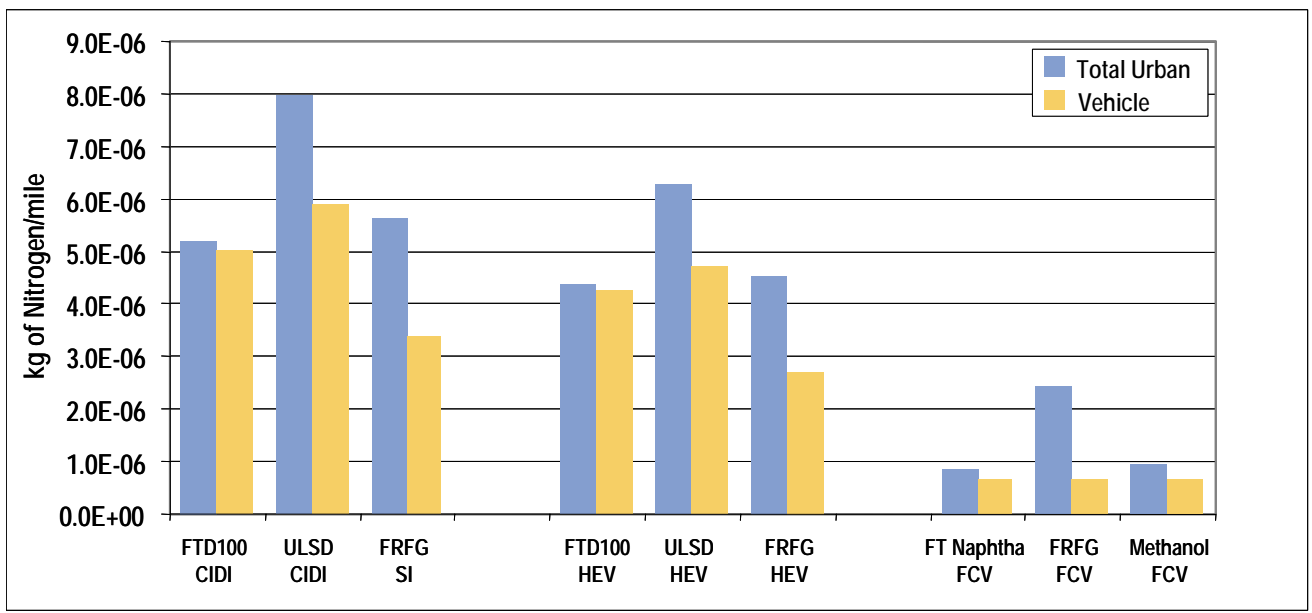

Figure 7-14 Urban Eutrophication, Houston, 2015 


\subsubsection{Human Health Criteria}

The category indicator for human health criteria is disability-adjusted life-years (DALYs). The characterization model used in TRACI for human health criteria takes into account both fate and transport (reflecting atmospheric reactions and transport as well as regional population densities), and epidemiological studies to provide dose-response relationships for individual pollutants.

Figures 7-15 and 7-16 present the total human health criteria impact potential. In 2006, FTD20 has an indicator value that is $71 \%$ lower than conventional diesel, $11 \%$ lower than ULSD, and $27 \%$ lower than FRFG. In 2015, FTD has an indicator value that is $25 \%$ lower than ULSD and $33 \%$ lower than FRFG. The lower indicator values are a result of the reduction of criteria pollutant emissions in the fuel and vehicle stages of GTL relative to the other fuels.

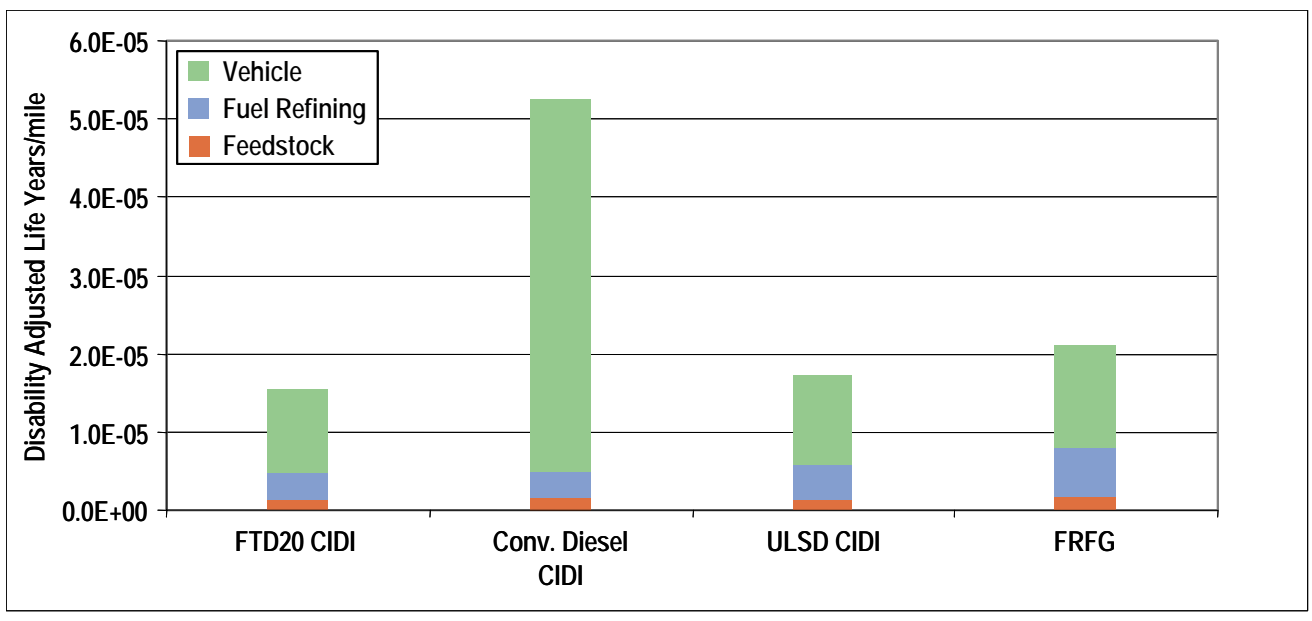

Figure 7-15 Total Human Health Criteria, 2006

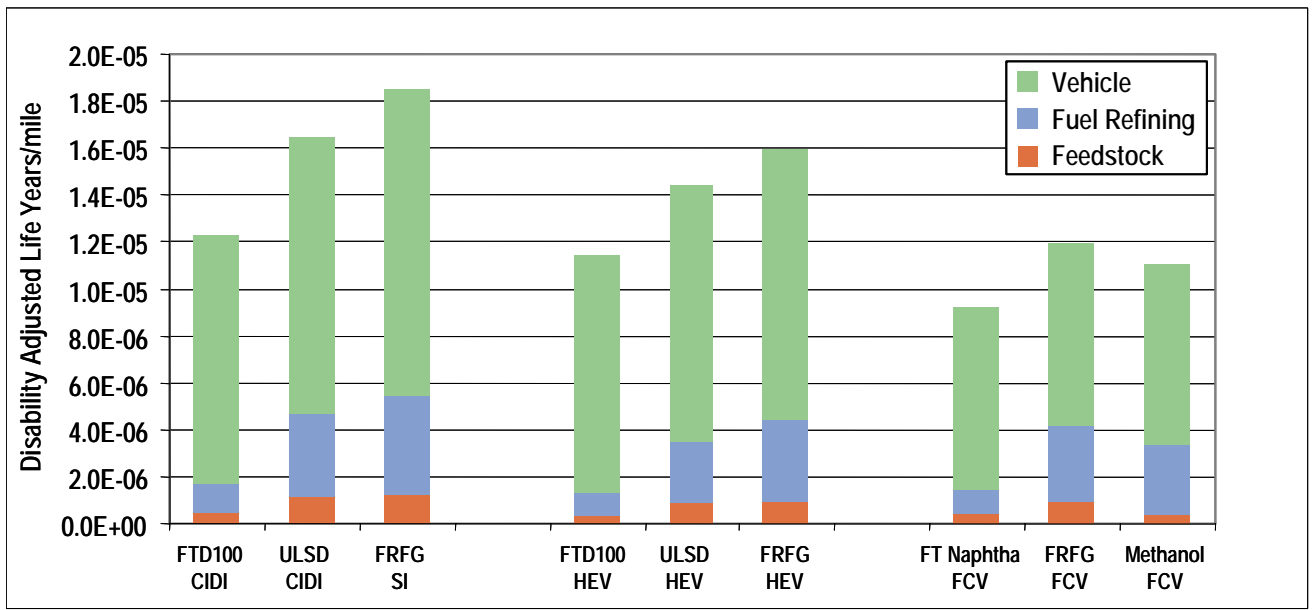

Figure 7-16 Total Human Health Criteria, 2015 
In 2006 for the urban potential impact scenarios, FTD20 has an indicator value that is 11\% lower than ULSD, 74\% lower than conventional diesel, and 20\% lower than FRFG (Figure 7-17). For the 2015 case, FTD 100 is $22 \%$ and $30 \%$ lower than ULSD and FRFG, respectively. FT naphtha is $16 \%$ lower than FRFG and equivalent to the methanol FCV with respect to the indicator value (Figure 7-18).

Once again in both the near-term and long-term scenarios, the GTL fuels show a trend that indicates reduced potential environmental impact, but the differences are not great enough to allow one to draw firm conclusions.

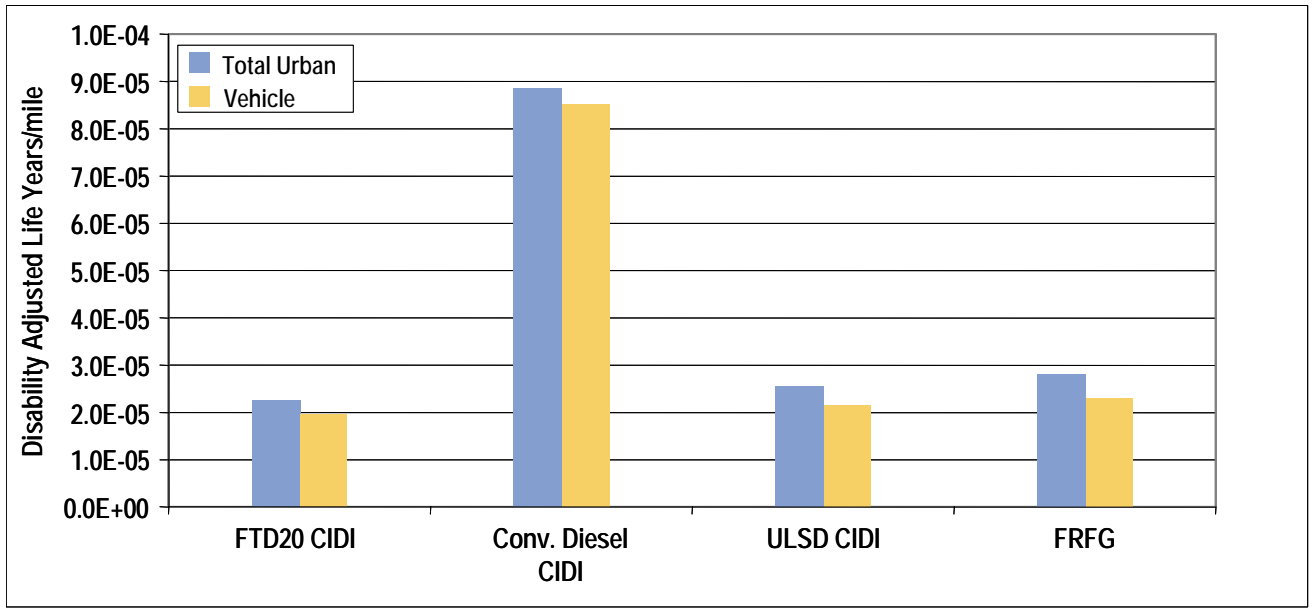

Figure 7-17 Urban Human Health Criteria, Houston, 2006

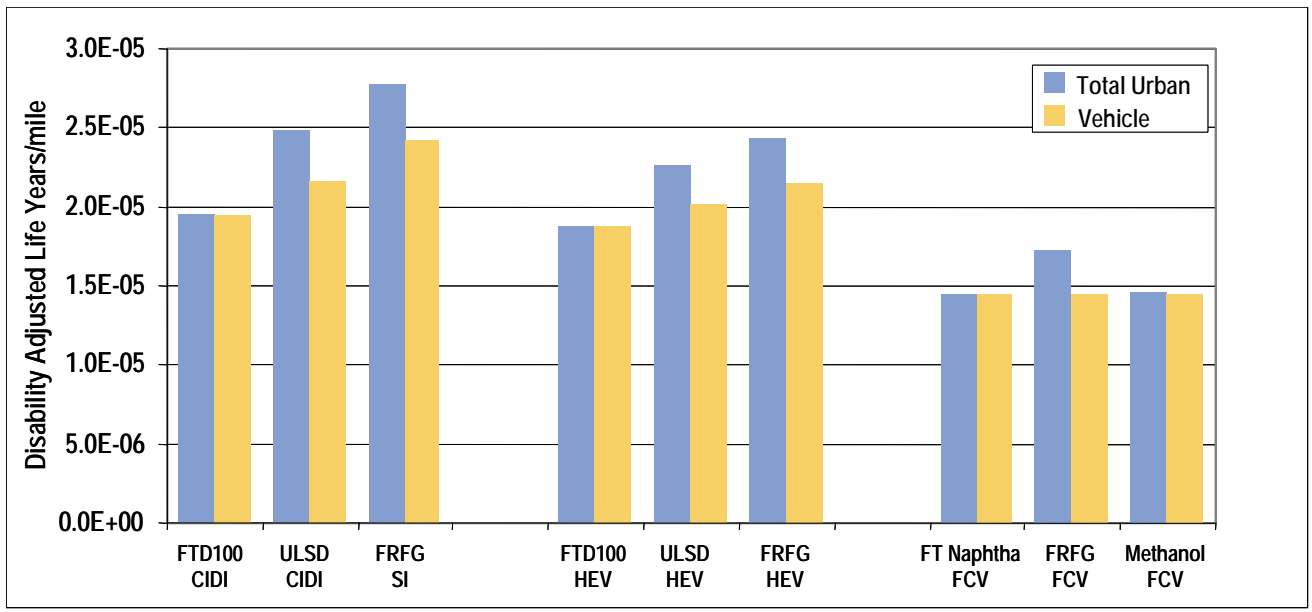

Figure 7-18 Urban Human Health Criteria, Houston, 2015 


\subsubsection{Human Health, Cancer (HHC) and Human Health, Non-Cancer (HHNC)}

The category indicator for cancer and non-cancer human health impact, human toxicity potential (HTP), is based on a $\mathrm{C}_{6} \mathrm{H}_{6}$ (benzene) equivalent factor. The methodology developed for TRACI is based on a multimedia fate, multipathway human exposure, and toxicological potency approach using the CalTOX model from the California Environmental Protection Agency. Emissions of toxics are assigned to the $\mathrm{HHC}$ and $\mathrm{HHNC}$ impact categories.

As discussed above in Section 7.6.1.3, complete and comparable vehicle toxics emissions data was available only for the FTD and ULSD test cases. With a proxy of data for 1,3-butadiene from light duty trucks as a conservative estimate, data from one test of a light duty diesel passenger vehicle was used for ULSD and FTD. Toxic emissions data for FRFG is based on the estimated proposed U.S. EPA Tier 2 standards for light duty gasoline vehicles. Indicator values for these two impact categories are calculated only for the FTD100 CIDI, ULSD CIDI, and FRFG SI vehicle options for the 2015 scenario.

\subsubsection{Human Health, Cancer}

In Figure 7-19, the total HHC indicator value for FTD100 CIDI is $2.5 \%$ greater than for ULSD CIDI, and the total HHC indicator value for FTD100 CIDI is 91\% lower than for FRFG. BTEX compounds are the most significant contributors to the HHC indicator values. Some care must be taken in the interpretation of these values, because the FRFG emissions data are based on proposed Tier 2 standards for toxic emissions and not on actual vehicle tests. The difference in HHC between FTD and FRFG indicates only that FTD will be well below the proposed regulatory standards for light duty vehicles, and not necessarily that FTD is inherently better than a comparable FRFG vehicle.

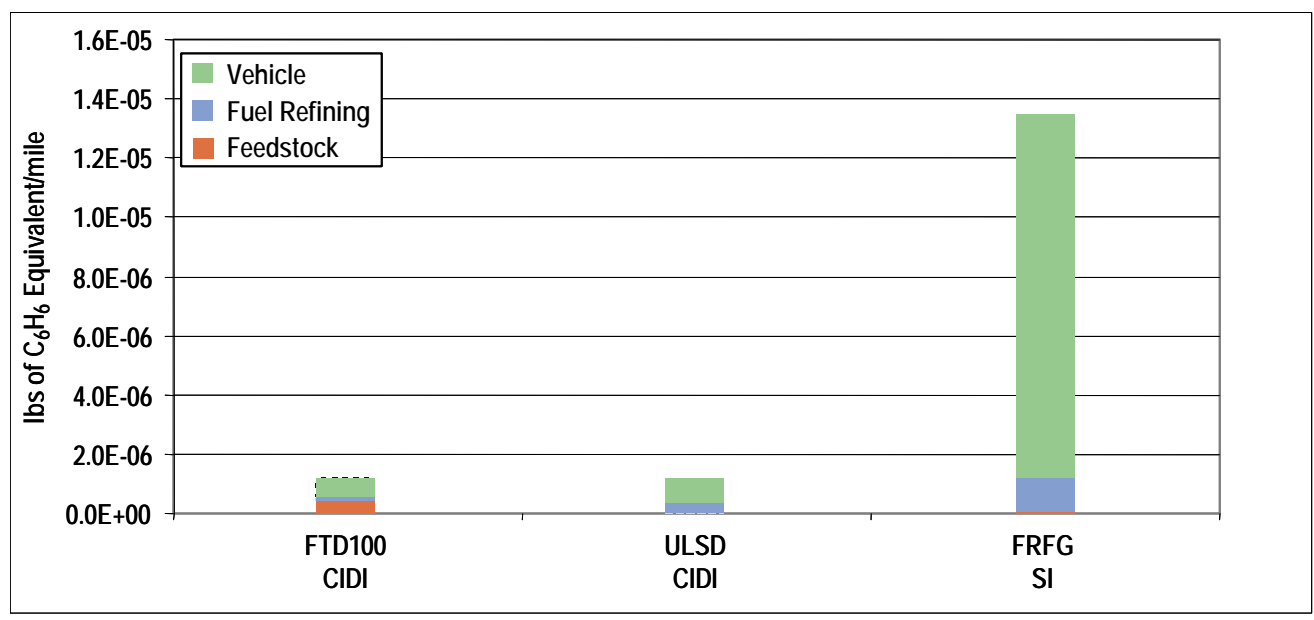

Figure 7-19 Human Health, Cancer, 2015 


\subsubsection{Human Health, Non-Cancer}

As shown in Figure 7-20, the total HHNC indicator value for FTD100 CIDI is 96\% lower than for ULSD CIDI, and the total HHNC indicator value for FTD100 CIDI is $99 \%$ lower than for FRFG. The greatest contributor to the HHNC indicator value for the petroleum fuels occurs in the crude oil refining stage. The release of compounds such as benzene, ethylbenzene, $n$-hexane, and toluene from petroleum refineries is the greatest contributor to this potential impact. (See Tables D-15, D-17, and D-19 for details.) The vehicle stage HHNC value is roughly equivalent for the three fuels. Again, the differences between the diesel fuels and FRFG are based on the proposed standards for FRFG rather than on actual vehicle tests.

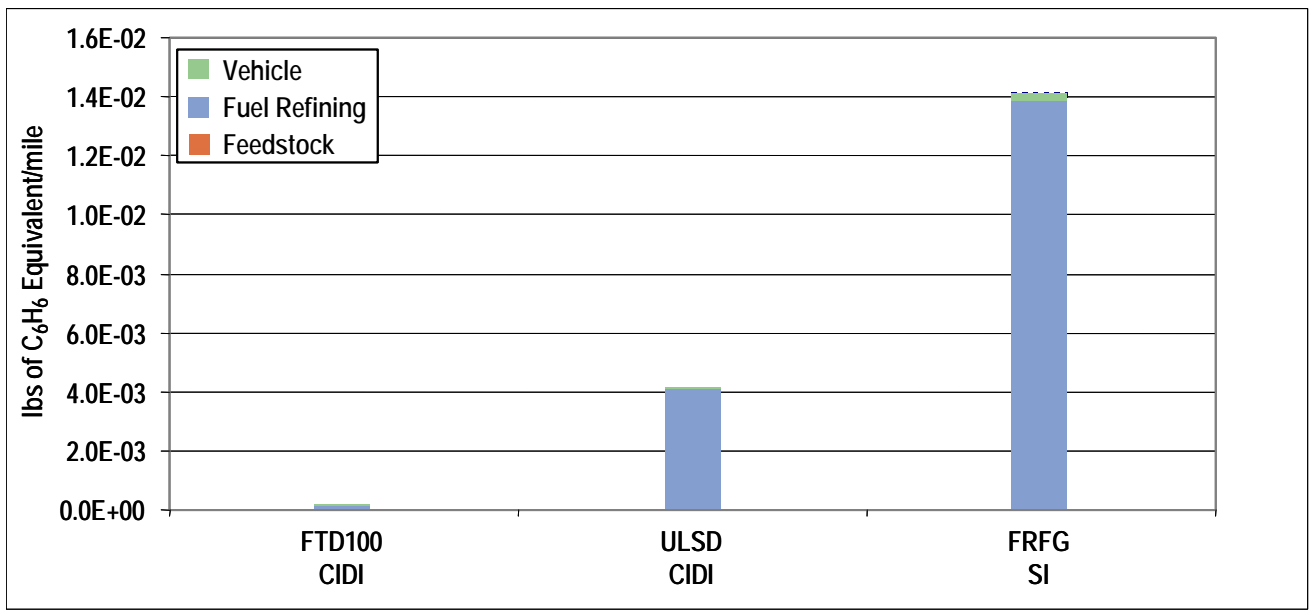

Figure 7-20 Human Health, Non-Cancer, 2015 


\subsubsection{Ecotoxicity}

The category indicator for ecotoxicity is pounds of dichlorophenoxyacetic acid (2,4-D) equivalent. Ecological toxicity potential (ETP) was developed in TRACI as a measure of potential ecological harm of a chemical released into an environment.

Ecotoxic emissions for FTD, ULSD, and FRFG are shown in Figures 7-21. FTD has an ecotoxic indicator value that is $26 \%$ lower than ULSD and $53 \%$ higher than FRFG. The vehicle stage is the greatest contributor to the total indicator value for all three fuels. The emission of formaldehyde in the vehicle stage for FTD and ULSD is the primary source of the difference in their indicator values from that of FRFG.

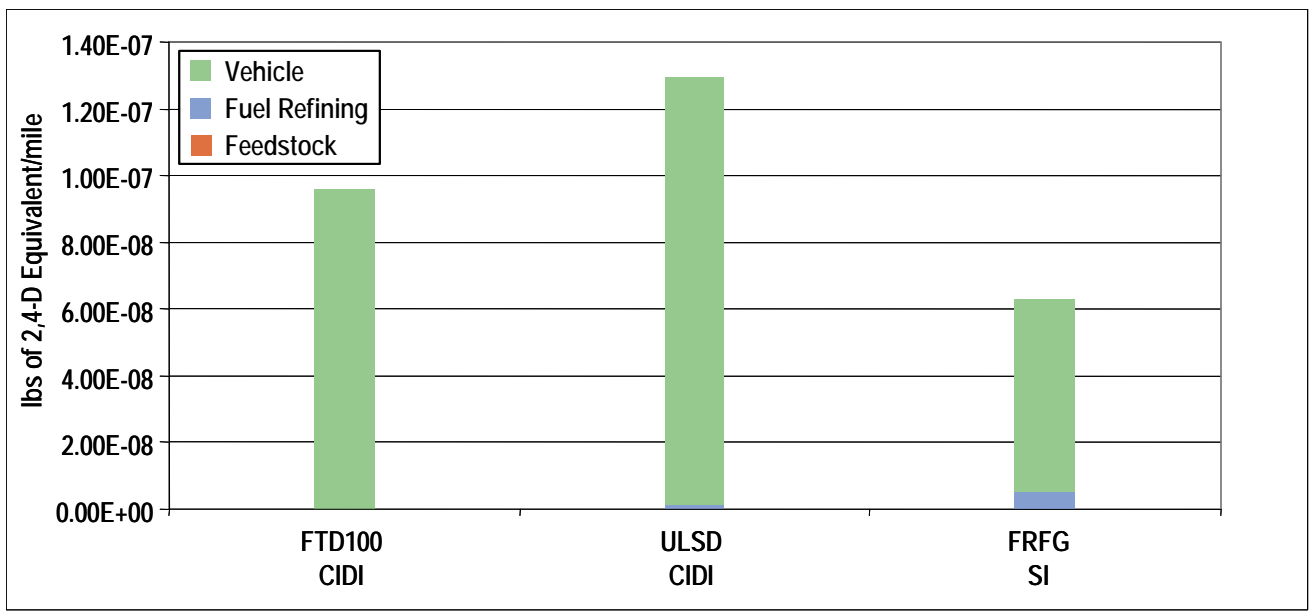

Figure 7-21 Ecotoxicity, 2015 


\subsubsection{Petroleum Use and Natural Gas Consumption}

The use of crude oil, U.S. domestic natural gas, and stranded natural gas is assigned to the resource depletion impact category.

Figures 7-22 and 7-23 show the consumption rates of crude oil for the 2006 and 2015 scenarios, respectively, per light duty VMT. In 2015, the FTD options consume only a small amount of petroleum for the transportation and distribution of the GTL fuel. On the petroleum side, refining consumes a small amount of domestically produced natural gas.

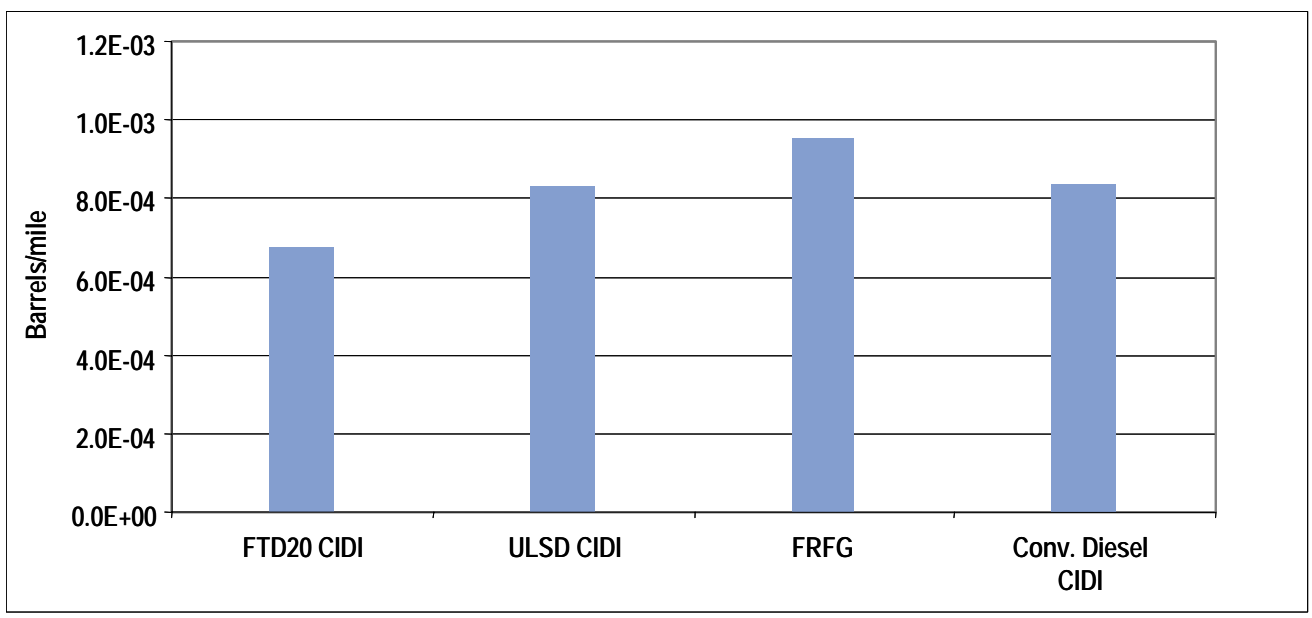

Figure 7-22 Crude Oil Consumption, 2006

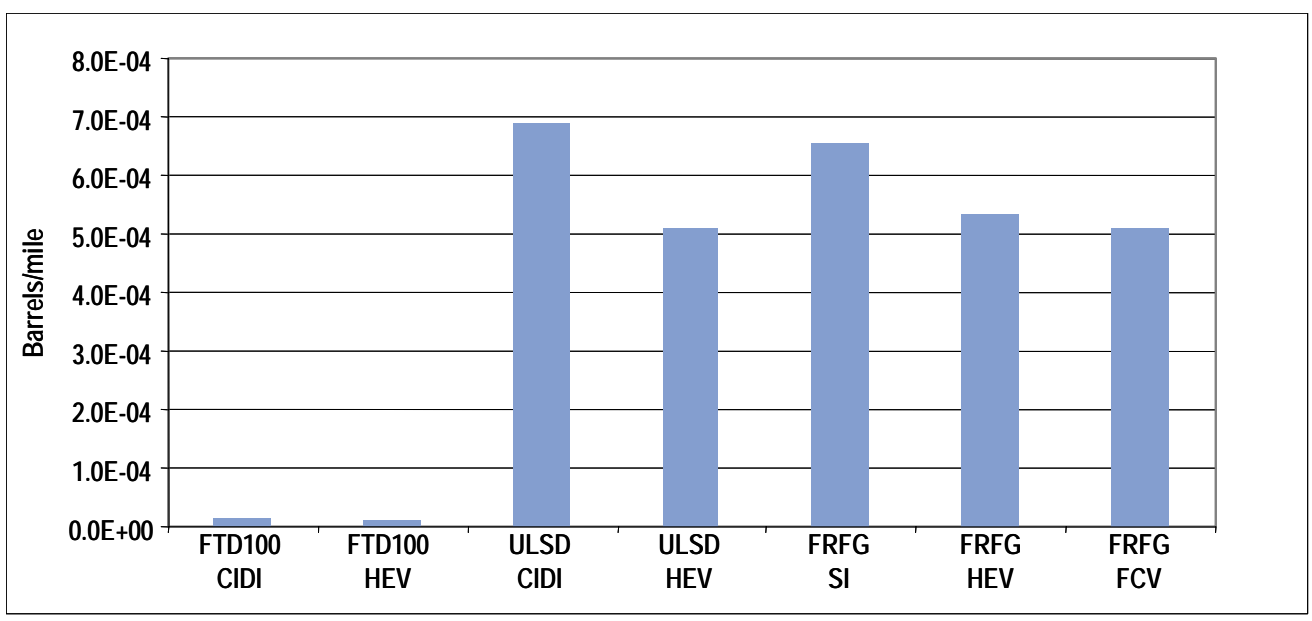

Figure 7-23 Crude Oil Consumption, 2015 
Figures 7-24 and 7-25 show consumption rates of domestic natural gas used in petroleum refining and stranded gas used in the production of GTL fuels for the 2006 and 2015 scenarios, respectively, per light duty VMT. The consumption rates per light duty VMT must be placed in the larger context of the absolute rate of the depletion of crude oil and stranded gas reserves. Section 7.6.3 discusses the key assumptions used to estimate the rate of depletion of these reserves, shown in Figures 7-26 and 7-27.

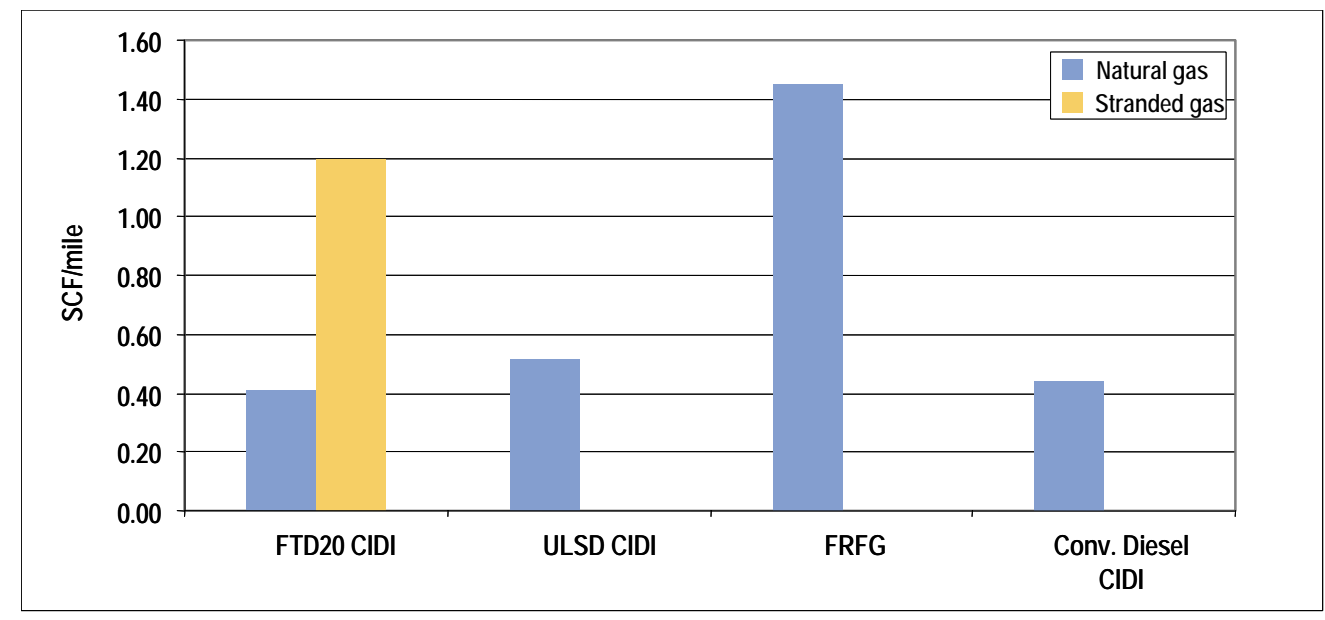

Figure 7-24 Natural Gas and Stranded Natural Gas Consumption, 2006

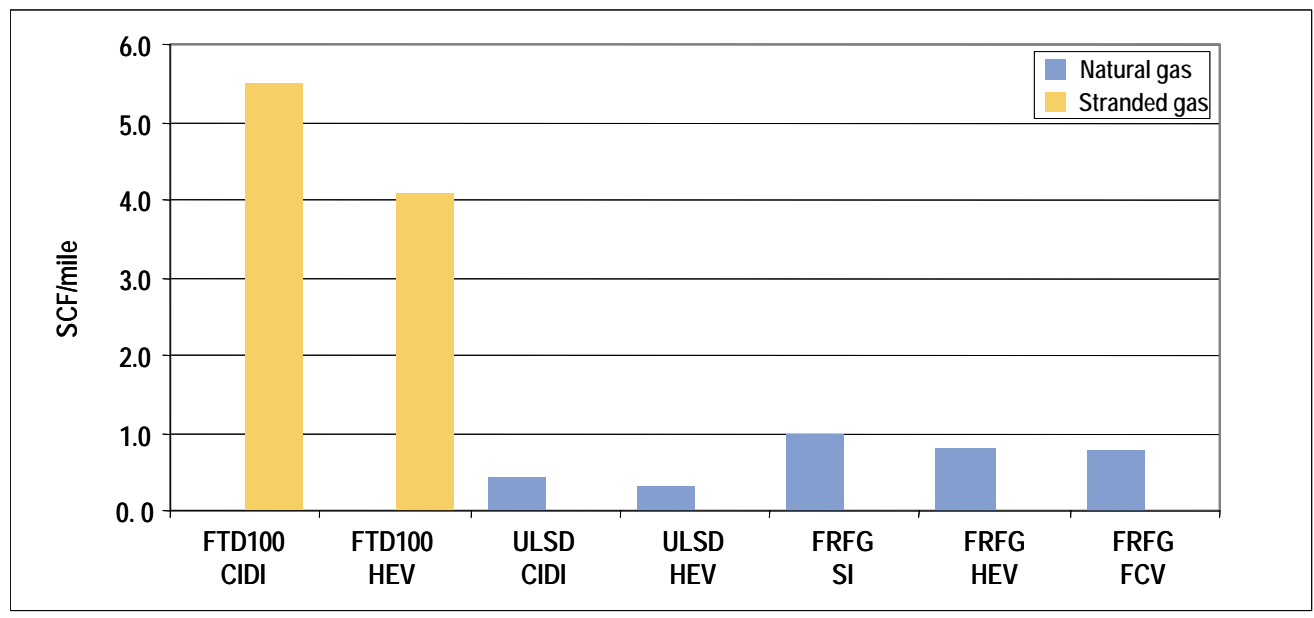

Figure 7-25 Natural Gas and Stranded Natural Gas Consumption, 2015 


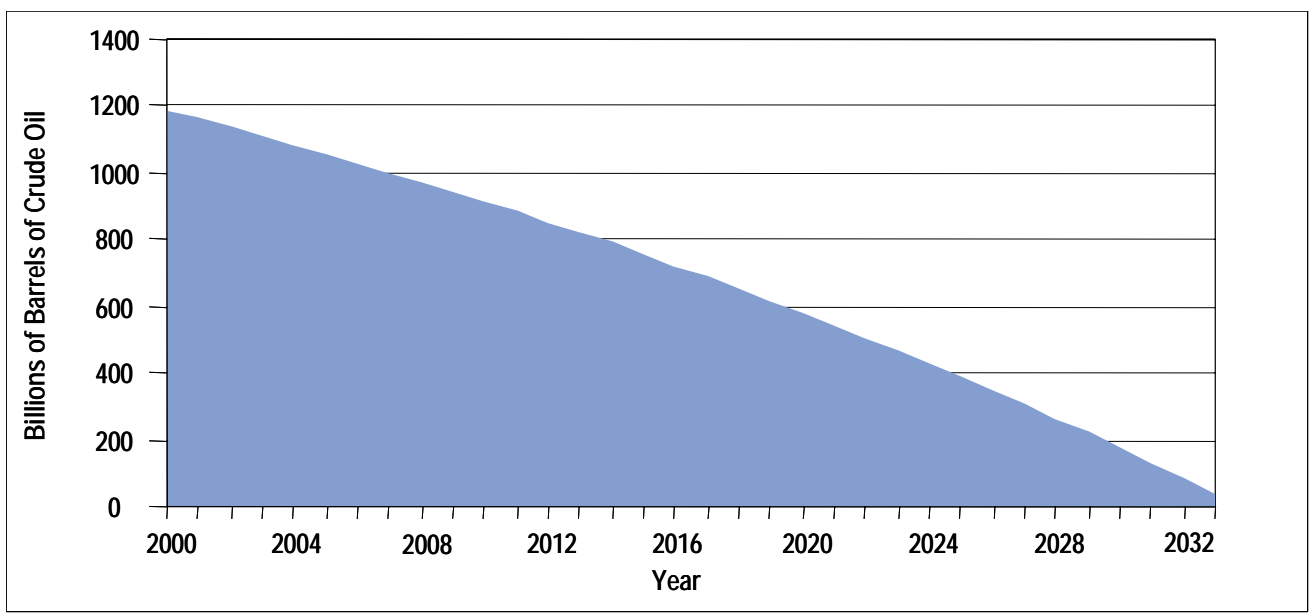

Figure 7-26 Depletion of Crude Oil Reserves (Source: U.S. Geological Survey, ConocoPhillips)

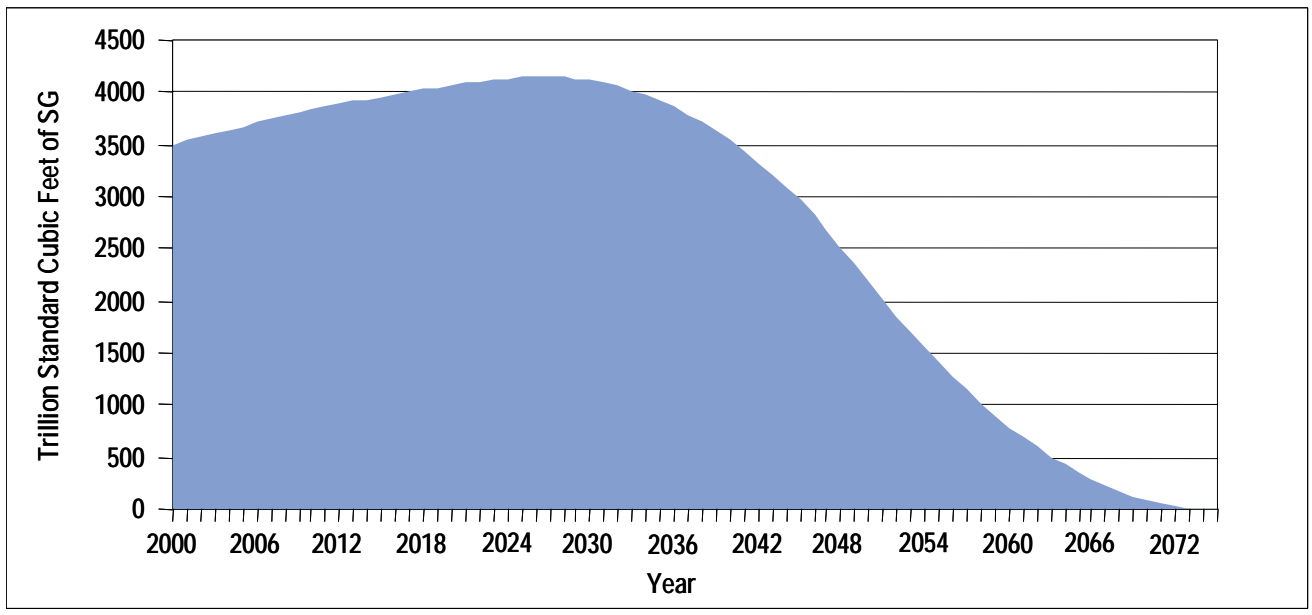

Figure 7-27 Depletion of Stranded Gas Reserves (Source: ConocoPhillips)

U.S. Geological Survey estimates of proven and unproven crude oil reserves (1.9 trillion barrels) were used, along with a current consumption estimate of 67 million barrels of oil per day that is increased over time, to develop an estimate indicating that crude oil reserves might be depleted between the years 2030 and 2040. Stranded gas projects, including GTL, LNG, and pipelines, will slowly be developed from the present until 2025, during which time the total reserve of stranded gas will actually grow as a result of the discovery of new reserves. After 2025, the rate at which stranded gas projects are developed will increase, and it is estimated that the reserves will be depleted sometime after 2070 .

Figure 7-28 shows the total yearly consumption of stranded gas by GTL, LNG, and pipeline projects. It can be seen that the use of stranded gas for GTL is projected to be a small portion of the overall consumption of stranded gas. Gas from LNG and pipeline projects will be primarily used for the production of power. 
Crude oil and natural gas fossil resources will inevitably be depleted over the course of this century. As they are developed, the stranded gas reserves for power and transportation will be one part of what is a more greatly diversified base of energy resources.

Figure 7-29 shows the projected depletion rate of crude oil and stranded gas expressed in Btu's of energy. Presently, world reserves of crude oil are approximately twice the world reserves of stranded gas on an energy basis. In 2018, the two reserves will be equivalent on an energy basis. When crude oil is depleted sometime between 2030 and 2040, the energy content of the reserve of stranded gas will reach its peak and will be depleted after another 40 years.

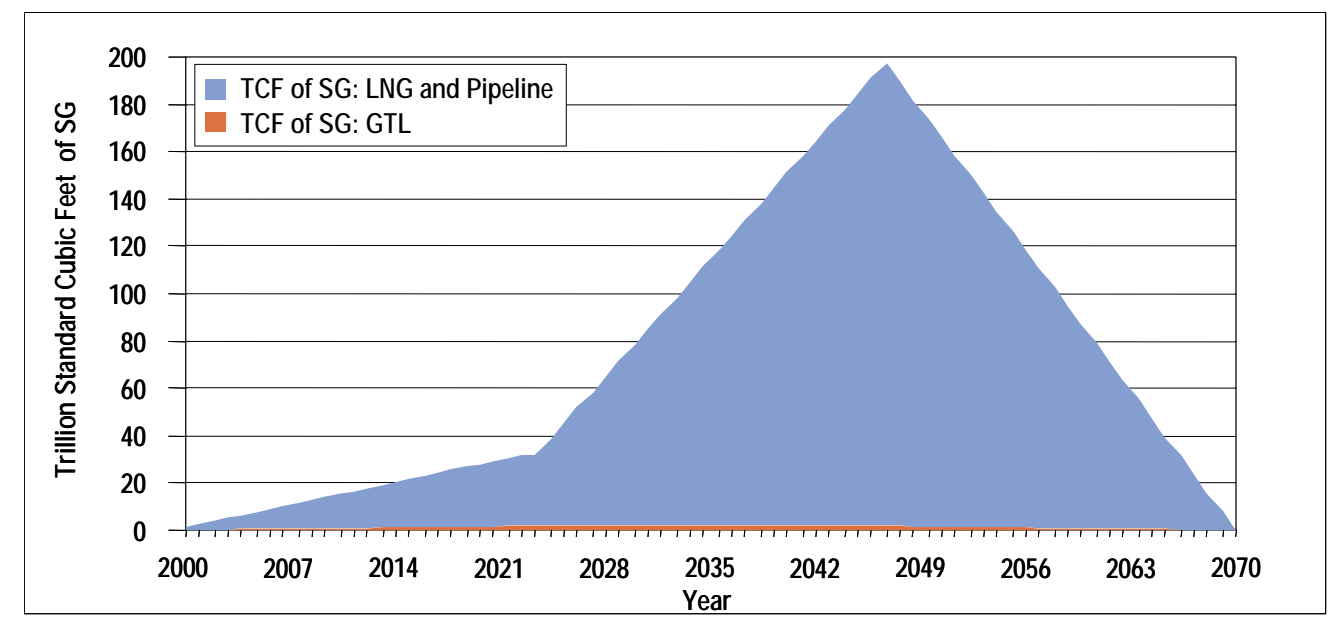

Figure 7-28 Stranded Gas Consumption by Project Type (Source: ConocoPhillips)

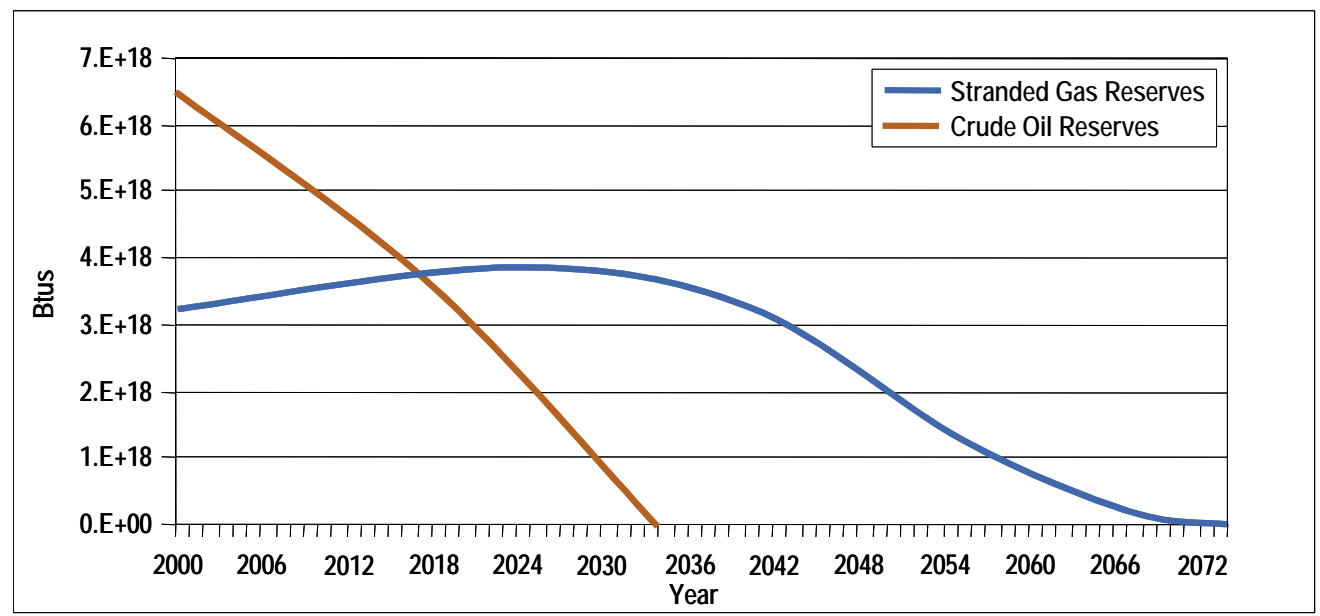

Figure 7-29 Depletion of Crude Oil and Stranded Gas Reserves, Btu Equivalents (Source: ConocoPhilips, U.S. Geological Survey)

Stranded gas reserves will continue to supply energy to the world market for many decades. The production of GTL will be a relatively small part of the use of the stranded gas reserves, with most stranded gas eventually used in LNG and pipeline projects for application in power generation. 


\subsubsection{Land Use and Water Use}

The category indicator for land use is total mass of solid waste. The category indicator for water use is the total volume of water consumed.

Wastewater and solid waste data for petroleum and GTL products was compiled from studies from the National Renewable Energy Laboratory (NREL, 1993), the American Petroleum Institute (API, 2002), and the U.S. EPA Toxics Release Inventory (U.S. EPA, 2000). Wastewater and solid waste generation for petroleum and GTL fuels were estimated on a well-to-tank basis, since all the relevant waste for both pathways is generated during these stages. Most wastewater and solid waste are generated during the refining stages for both petroleum and GTL fuels. For petroleum, refining accounts for about $80 \%$ of reported wastewater generation and about $75 \%$ of solid waste generation.

Because the waste streams are an aggregation of both treated and untreated waste, caution must be exercised in the interpretation these results. No specific data is available on the composition of the waste streams. Very limited information is furnished in a comparison based only on total quantity of waste. The data should be interpreted here only as an aggregate measure of water use, and land use using a proxy measure of solid waste generation.

Table 7-15 provides a summary comparison of FTD with ULSD and FRFG with respect to volumes of wastewater and mass of solid waste produced per MMBtu of product. The production of FTD generates about 5.9 gal/MMBtu of wastewater, and between 4.3 and 13.6 grams of solid waste per MMBtu of fuel, depending on whether or not the spent catalyst is recycled. The wastewater for FRFG is $20.3 \mathrm{~g} / \mathrm{MMBtu}$ and for solid waste is $168.9 \mathrm{~g} / \mathrm{MMBtu}$. For ULSD, the figures are 6.2 gal/MMBtu and $51.7 \mathrm{~g} / \mathrm{MMBtu}$.

Comparatively, FTD production generates 71\% less wastewater than FRFG and 5\% less wastewater than ULSD. For solid waste, FTD generates between 97\% (with catalyst recycling) and $92 \%$ (without catalyst recycling) less solid waste than FRFG and between $92 \%$ (with recycling) and 74\% (without recycling) less solid waste than ULSD.

\section{Table 7-15 Wastewater and Solid Waste Comparison of FTD with ULSD and FRFG (gal/MMBtu and g/MMBtu)}

\begin{tabular}{|l|c|c|c|}
\hline \multicolumn{1}{|c|}{ Item } & FRFG & ULSD & FTD \\
\hline Wastewater, gal/MMBtu & 20.3 & 6.2 & 5.9 \\
\hline Solid waste, g/MMBtu & 168.9 & 51.7 & $4.3-13.6$ \\
\hline
\end{tabular}

Source: NREL, U.S. EPA, American Petroleum Institute 


\subsection{CONCLUSIONS}

The assessment of the sustainability of GTL fuels was a primary goal of ConocoPhillips in undertaking this UCF LCA study. The Department of Energy's Ultra Clean Fuels Program specifically seeks to ensure that vehicles fueled with fossil resources will comply with future emissions standards and reduce $\mathrm{CO}_{2}$ emissions.

Conclusions for the LCIA are drawn on the basis of a 10\% range of error for GWP; a 15\% range of error for solid waste, wastewater, and resource depletion; and a 100\% range for all other categories. These ranges were established using best professional judgment in consideration of the data gaps and data quality.

From the results of the LCIA, it can be concluded that in light duty vehicles, in both the nearterm and long-term scenarios, FTD and ULSD have equivalent GWPs. This is an important conclusion as previous studies have concluded that GTL fuels have larger GWPs than petroleum diesel fuels, owing largely to an assumed increase in $\mathrm{CO}_{2}$ emissions in the fuel production stage. When ConocoPhillips estimates for carbon and energy process efficiencies are used, this disparity in GWP does not appear to exist.

For the acidification, eutrophication, and human health criteria impact categories, FTD consistently exhibits $5 \%$ to $98 \%$ lower indicator values than both ULSD and FRFG. The application of a $100 \%$ differential error range precludes any comparative assertions that FTD or FT naphtha have less potential for environmental impact, but it is apparent that these fuels are not at a disadvantage with respect to conventional petroleum-derived transportation fuels.

For the human health cancer, and non-cancer impact categories, both FTD and ULSD exhibit significantly lower potential impacts than FRFG. These results, however, are based on the comparison of actual emissions testing for FTD and ULSD and proposed regulatory standards for FRFG. The results indicate only that toxics emissions for FTD and ULSD are well within the proposed Tier 2 regulatory standards set for FRFG light duty vehicles.

Both FTD and ULSD have ecotoxicity indicator values that are greater than those of FRFG, but the differences are within the error threshold. The indicator value differences are due to the small quantities of formaldehyde emitted in the vehicle stage for diesel fuels. FTD has a lower indicator value for ecotoxicty than ULSD.

The production of GTL fuels generates less solid waste than the production of ULSD and FRFG. GTL production generates less wastewater than does the production of FRFG, and a quantity of wastewater within $15 \%$ of that resulting from the production of ULSD.

There are currently large, proven and potentially large, unproven reserves of stranded gas. Given forecasts of the rate of development of stranded gas projects, of which GTL is only a small portion, the production of products from these gas reserves will continue for some 40 years after global crude oil reserves have been depleted. 
FTD and FT naphtha are substantially non-petroleum fuels. The FTD and FT-naphtha-fueled vehicles consume only small amounts of petroleum resources per mile. This is due exclusively to upstream production and transportation of the fuels.

Currently, petroleum reserves contain about twice the energy content on a Btu basis as stranded gas reserves. However, given projections of resource use, this difference will be equalized in about 2015. Although a non-renewable resource, stranded gas will continue to supply energy to the global market for a long time in a manner that is at least comparable to petroleum reserves with respect to the broad set of environmental indicators examined in this study.

\subsection{REFERENCES}

Alleman, T., R. McCormick, and K. Vertin, “Assessment of Criteria Pollutant Emissions from Liquid Fuels Derived from Natural Gas,” National Renewal Energy Laboratory, 2003.

Anand, S. and K. Hansen, "Disability-adjusted life years: a critical review," Journal of Health Economics, December 1997.

Atkinson, C., G.J. Thompson, M.L. Traver, and N.N. Clark, "In-cylinder Combustion Pressure Characteristics of Fischer Tropsch and Conventional Diesel Fuels in a Heavy Duty Diesel Engine," SAE Paper 1999-01-1472, May 1999.

Bare, J. "Developing a Consistent Decision-Making Framework by Using the U.S. EPA's TRACI," AICHE, November 2002.

Cardelino, C.A., and W.L. Chameides, “An Observation-based Model for Analyzing Ozone Precursor Relationships in the Urban Atmosphere," Journal of Air \& Waste Management, 45:161-180, 1995.

Carter W., "Updated Maximum Incremental Reactivity Scale for Regulatory Applications," California Air Resources Board, 2000.

Clark, R.H., Battersby, N.S., Louis, J.J.J., Palmer, A.P, Stradling, R.J., and Whale, G.F., "The Environmental Benefits of Shell GTL Diesel," Proceedings of the $4^{\text {th }}$ International Colloquium, Fuels, Tech. Akad. Esslingen, Ostfildern, Germany, January 15-16, 2003.

Cohen, Y., "The Air Toxics Problem," Department of Chemical Engineering, University of California, Los Angeles, www.ioe.ucla.edu/publications/report00/

Frame, E, and D. Yost, "Chemical Characterization of Toxicologically Relevant Compounds From Diesel Emissions," Fuels for Advanced CIDI Engines and Fuel Cells, FY 2000 Progress Report, Office of Transportation Technologies, www.ott.doe.gov.

Hertwich, E.G., S.F. Mateles, W.S. Pease, T.E. McKone, "Human toxicity Potentials for Life Cycle Analysis and Toxics Release Inventory Risk Screening," Environmental Toxicology and Chemistry 20:928-939, 2001. 
International Panel on Climate Change, "IPCC Third Assesssment Report: Climate Change $2001, ” 2001$.

Lev-On, M., C. LeTavec, J. Uihlein, T. Alleman, D. Laswon, K. Vertin, "Chemical Speciation of Exhaust Emission from Trucks and Buses Fueled on Ultra-low Sulfur Diesel and CNG," SAE Technical Paper Series, 2002-01-0432, March 2002.

May, M.P., K. Vertin, S. Ren, X. Gui, I. Myburgh, and P. Schaberg, "Development of Truck Engine Technologies for Use with Fischer-Tropsch Fuels," SAE Paper No. 2001-01-3520, Reprinted from SI and Diesel Engine Performance and Fuel Effects (SP-1645).

Nishioka, Y., G.A. Norris , J. Levy, "The TRACI Midpoint and Endpoint-Based Method for Life Cycle Impact Assessment of Primary and Secondary Particulates,” In Preparation, 2002.

Norris, G., "TRACI Impact Characterization Methods for Acidification, Eutrophication, and Tropospheric Ozone Formation, Submitted for Review to the Journal of Industrial Ecology, 2002.

Norton, P., K. Vertin, B. Bailey, N.N. Clark, D.W. Lyons, S. Goguen, and J. Eberhardt, “Emissions from Trucks Using Fischer-Tropsch Diesel Fuel," SAE Paper 982526, October 1998.

Rabl, A., and N. Eyre, "An Estimate of Regional and Global $\mathrm{O}_{3}$ Damage from Precursor $\mathrm{NO}_{\mathrm{X}}$ and VOC Emissions," Unpublished Manuscript, Ecole des Mines, Paris, 1997.

Ross, S., D. Evans and M. Webber, "How LCA Studies Deal with Uncertainty,” International Journal of Life Cycle Assessment, Volume 7, No. 1, 2002.

Ryan, T. W. III and D. Montalvo, "Emissions and Performance of Fischer Tropsch Diesel Fuels in a Modern Heavy Duty Diesel Engine," AICHE, Houston, March 1997.

Schaberg, P.W., I.S. Myburgh, J.J. Botha, P.N. Roets, C.L. Vijoen, L.P. Dancuart, and M. Starr, "Diesel Exhaust Emissions Using Sasol Slurry Phase Distillate Process Fuels," SAE 972898, October 1998.

Seppala, J., "Decision Analysis as a Tool for Life Cycle Impact Assessment," Finnish Environment Institute, Helsinki, 1997.Ddeposition Trends in North America from 1979 through 1988," Air Pollution Modeling and Its Application IX, Edited by H. van Dop and G. Kallos, Plenum Press, New York, 1992.

U.S. EPA, Exposure Factors Handbook, EPA/600/8-89/043, Office of Health and Environmental Assessment, 1989.

U.S. EPA, Risk Assessment Guidance for Superfund, Volume I: Human Health Evaluation Manual (Part A)," EPA/540/1-89/002, Office of Emergency and Remedial Response, 1989. 
U.S. EPA, "The Benefits and Costs of the Clean Air Act: 1990 to 2010 (EPA-410-R99-001)," Washington, D.C.:, EPA Office of Air and Radiation, 1999.

U.S. EPA, "Preferred and Alternative Methods for Estimating Air Emissions from Oil and Gas Field Production and Processing Operations," Emission Inventory Improvement Program, September 1999.

U.S. EPA Toxics Release Inventory, TRI Explorer, http://www.epa.gov/triexplorer/chemical.htm, 2000.

U.S. EPA, "Technical Support Document: Control of Hazardous Air Pollutants from Motor Vehicles and Motor Vehicle Fuels," EPA420-R-00-023, December 2000.

U.S. EPA, "Review of the National Ambient Air Quality Standards for Particulate Matter: Policy Assessment of Scientific and Technical Information," Office of Air Quality Planning and Standards, June 2001. 
Alleman, T., R. McCormick, and K. Vertin, "Assessment of Criteria Pollutant Emissions from Liquid Fuels Derived from Natural Gas," National Renewal Energy Laboratory, 2003.

American Petroleum Institute, "Protecting Our Environment," 2001.

Anand, S. and K. Hansen, "Disability-Adjusted Life Years: A Critical Review," Journal of Health Economics, December 1997.

Apanel, G. J., "Report No. 43C, Methanol Supplement C, A Private Report by the Process Economics Program,” SRI Consulting, Menlo Park, California, 2000.

Argonne National Laboratory, "Future Restrictions on Diesel Fuel Combustion in California: Energy and Emission Implications for Four Scenarios," September 1999.

Argonne National Laboratory, "GREET 1.5 - Transportation Fuel-Cycle Model (Vol. 1), Methodology, Development, Use and Results," August 1999.

Argonne National Laboratory, “GREET 1.5 - Transportation Fuel-Cycle Model (Vol. 2), Appendices of Data and Results," August 1999.

Argonne National Laboratory, "Development and Use of the GREET 1.6 Fuel-Cycle Model for Transportation Fuels and Vehicle Technologies," June 2001.

Argonne National Laboratory, National Renewable Energy Laboratory, and Pacific Northwest Laboratory, "Total Energy Cycle Assessment of Electric and Conventional Vehicles: An Energy and Environmental Analysis," January 1998.

Atkinson, C., G.J. Thompson, M.L. Traver, and N.N. Clark, "In-cylinder Combustion Pressure Characteristics of Fischer Tropsch and Conventional Diesel Fuels in a Heavy Duty Diesel Engine," SAE Paper 1999-01-1472, May 1999.

Bare, J. "Developing a Consistent Decision-Making Framework by Using the U.S. EPA's TRACI," AICHE, November 2002.

Bennethum, J.E. and R.E. Winsor, "Towards Improved Diesel Fuels," International Fall Fuels and Lubricants Meeting and Exposition, Toronto, Canada, October 7-10, 1991.

Cardelino, C.A., and W.L. Chameides, "An Observation-based Model for Analyzing Ozone Precursor Relationships in the Urban Atmosphere," Journal of Air \& Waste Management, 45:161-180, 1995.

Carter W., "Updated Maximum Incremental Reactivity Scale for Regulatory Applications," California Air Resources Board, 2000. 
Choi G. N., S.J. Kramer, S. S. Tam, J.M. Fox, N. L. Carr, and G. R. Wilson, “Design/Economics of a Once-Through Natural Gas Fischer-Tropsch Plant with Power Co-production," 1997 Coal Liquefaction and Solid Fuels Contractors Review Conference, Pittsburgh, Pennsylvania, September 3-4, 1997.

Clark, R.H., Battersby, N.S., Louis, J.J.J., Palmer, A.P, Stradling, R.J., and Whale, G.F., "The Environmental Benefits of Shell GTL Diesel," Proceedings of the 4th International Colloquium, Fuels, Tech. Akad. Esslingen, Ostfildern, Germany, January 15-16, 2003.

Clarke, S., "Developments in GTL Technology," Presentation to the Subject Group for Oil and Natural Gas, Institution of Chemical Engineers, March 12, 2002.

"Climate Change 1995: The Science of Climate Change," Intergovernmental Panel on Climate Change, Cambridge, United Kingdom, Cambridge University Press, 1996.

“Climate Change 2001: The Scientific Basis,” Intergovernmental Panel on Climate Change, Cambridge, United Kingdom, Cambridge University Press, 2001.

Cohen, Y., "The Air Toxics Problem," Department of Chemical Engineering, University of California, Los Angeles, www.ioe.ucla.edu/publications/report00/

Commonwealth Industrial and Scientific Research Organisation, "Life Cycle Emissions Analysis of Alternate Fuels," Atmospheric Research Report C/0411/1.1/F2 to the Australian Greenhouse Office, March 2000.

ConocoPhillips, "Ultra Clean Fuels Market Assessment," Submitted to DOE, and to be published, February 2003.

DOE National Laboratories, “Technology Opportunities to Reduce US Greenhouse Gas Emissions,” DOE/EE-98004846, October 1997.

Energy Information Agency, "Challenges of Electric Power Industry Restructuring for Fuel Suppliers," Office of Coal, Nuclear, Electric and Alternative Fuels, September 1998.

Energy Information Agency, "Voluntary Reporting of Greenhouse Gases 1999," DOE/EIA0608(99), January 2001.

Frame, E, and D. Yost, "Chemical Characterization of Toxicologically Relevant Compounds From Diesel Emissions," Fuels for Advanced CIDI Engines and Fuel Cells, FY 2000 Progress Report, Office of Transportation Technologies, www.ott.doe.gov.

Feng, A., A. Vyas, J. Anderson, and D. Santini, "Evaluating Commercial and Prototype HEVs," SAE Paper No. 2001-01-0951. 
General Motors, Argonne National Laboratory, ExxonMobil, Shell, "Well-to-Wheel Energy Use and Greenhouse Gas Emissions of Advanced Fuel/Vehicle Systems - North American Analysis," April 2001.

Gohna, H., "Concepts for Modern Methanol Plants," presented at the 1997 World Methanol Conference, Tampa, Florida, December 8-10, 1997.

Greene, D.L., "An Assessment of Energy and Environmental Issues Related to the Use of Gasto-Liquid Fuels in Transportation," Center for Transportation Analysis, Oak Ridge National Laboratory, November 1999.

Hertwich, E.G., S.F. Mateles, W.S. Pease, T.E. McKone, "Human Toxicity Potentials for Life Cycle Analysis and Toxics Release Inventory Risk Screening," Environmental Toxicology and Chemistry 20:928-939, 2001.

International Energy Agency, “The Use of Petroleum Coke in Coal-fired Plants," November 2001.

International Panel on Climate Change, "IPCC Third Assessment Report: Climate Change $2001, " 2001$.

International Standards Organization, ISO 14040, "Environmental Management - Life Cycle Assessment - Principles and Framework,” 1997

International Standards Organization, ISO 14041, "Environmental Management - Life Cycle Assessment - Goal and Scope Definition and Inventory Analysis," 1998.

International Standards Organization, ISO 14042, "Environmental Management - Life Cycle Assessment - Life Cycle Impact Assessment,” 1999.

Kadam, K., "Environmental Life Cycle Implications of Fuel Oxygenate Production from California Biomass,” NREL NREL/TP-580-25688, May 1999.

Lawrence Berkeley National Laboratory, "Real-World Emissions from Model Year 1993, 2000, 2010 Passenger Cars,” LBL-37977 UC-400, November 1995.

Lev-On, M., C. LeTavec, J. Uihlein, T. Alleman, D. Laswon, K. Vertin, "Chemical Speciation of Exhaust Emission from Trucks and Buses Fueled on Ultra-low Sulfur Diesel and CNG," SAE Technical Paper Series, 2002-01-0432, March 2002.

Lurgi, "Lurgi AG: Major Contracts Consolidate World Market Position,” 2001

Massachusetts Institute of Technology Energy Laboratory, "On the Road in 2020: A Life-Cycle Analysis of New Automobile Technologies," October 2000. 
May, M.P., K. Vertin, S. Ren, X. Gui, I. Myburgh, and P. Schaberg, "Development of Truck Engine Technologies for Use with Fischer-Tropsch Fuels," SAE Paper No. 2001-01-3520, Reprinted from SI and Diesel Engine Performance and Fuel Effects (SP-1645).

May, M.P., K. Vertin, S. Ren, X. Gui, I. Myburgh, and P. Schaberg, "Development of Truck Engine Technologies for Use with Fischer-Tropsch Fuels," International Fall Fuels and Lubricants Meeting and Exposition, San Antonio, Texas, September 24 -27, 2001.

McCann, T., and P. Magee, "Crude Oil Greenhouse Gas Life Cycle Analysis Helps Assign Values for $\mathrm{CO}_{2}$ Emissions Trading," Oil \& Gas Journal, February 22, 1999.

Moreno, J.J. and J.P. Ciferno, "Life Cycle Greenhouse Gas Emissions Inventory for FischerTropsch Fuels," U.S. Department of Energy, National Energy Technology Laboratory, February 2001.

Nishioka, Y., G.A. Norris , J. Levy, "The TRACI Midpoint and Endpoint-Based Method for Life Cycle Impact Assessment of Primary and Secondary Particulates," In Preparation, 2002.

Norris, G., "TRACI Impact Characterization Methods for Acidification, Eutrophication, and Tropospheric Ozone Formation, Submitted for Review to the Journal of Industrial Ecology, 2002.

Norton, P., K. Vertin, B. Bailey, N.N. Clark, D.W. Lyons, S. Goguen, and J. Eberhardt, "Emissions from Trucks Using Fischer-Tropsch Diesel Fuel," SAE Paper 982526, October 1998.

Rabl, A., and N. Eyre, "An Estimate of Regional and Global $\mathrm{O}_{3}$ Damage from Precursor $\mathrm{NO}_{\mathrm{X}}$ and VOC Emissions,” Unpublished Manuscript, Ecole des Mines, Paris, 1997.

Ross, S., D. Evans and M. Webber, "How LCA Studies Deal with Uncertainty," International Journal of Life Cycle Assessment, Volume 7, No. 1, 2002.

Ryan, T. W. III and D. Montalvo, "Emissions and Performance of Fischer Tropsch Diesel Fuels in a Modern Heavy Duty Diesel Engine,” AICHE, Houston, March 1997.

Ryan, T.W. III and J. Leet, "Natural Gas Vehicle Options: CNG/LNG/DME/Fischer Tropsch or ???," Presentation at Energy Frontiers International Meeting, Tucson, 1997.

Santini, D. J., A.D. Vyas, and J.L. Anderson, "Fuel Economy Improvement via Hybridization vs. Vehicle Performance Level," SAE Paper No. 2002-01-1901, Reprinted from Proceedings of the 2002 Future Car Congress on CD-ROM (FCC2002CD), 2002.

Schaberg, P.W., I.S. Myburgh, J.J. Botha, P.N. Roets, C.L. Vijoen, L.P. Dancuart, and M. Starr, "Diesel Exhaust Emissions Using Sasol Slurry Phase Distillate Process Fuels," SAE 972898, October 1998. 
Seppala, J., "Decision Analysis as a Tool for Life Cycle Impact Assessment," Finnish Environment Institute, Helsinki, 1997.Ddeposition Trends in North America from 1979 through 1988," Air Pollution Modeling and Its Application IX, Edited by H. van Dop and G. Kallos, Plenum Press, New York, 1992.

Singh, M.K, "Total Energy Cycle Assessment of Electric and Conventional Vehicles: An Energy and Environmental Analysis," Argonne National Laboratory, ANL/ES/CP-98079, March 1998.

Sirman, M. and E. Owens, "DOE/PNGV Project for Emissions Comparisons of Alternative Fuels in an Advanced Automotive Diesel Engine," DOE Fuels Workshop, Tucson, September 1998.

Stanglmaier, R., T.W. Ryan, and J. Souder, "HCCI Operation of a Dual-Fuel Natural Gas Engine for Improved Fuel Efficiency and Ultra-Low $\mathrm{NO}_{\mathrm{X}}$ Emissions at Low to Moderate Engine Loads," SAE Paper 2001-02-1897, Reprinted from: HCCI Combustion (SP-1627).

Tyson, K.S., C.J. Riley, and K.K. Humphreys, "Fuel Cycle Evaluations of Biomass - Ethanol and Reformulated Gasoline," Volume 1, National Renewable Energy Laboratory, Oak Ridge National Laboratory, and Pacific Northwest Laboratory, NREL/TP-463-4950, November 1993.

Uematsu, Y., T. Nakada, L. Zhang, H. Ichikawa, and W.H. Haverdink, "High Fuel Economy CIDI Engine for GM PNGV Program," SAE Paper No. 2002-01-1084, Reprinted from Advanced Hybrid Vehicle Powertrain Technology (SP-1697), 2002.

U.S. Energy Association and the U.S. Agency for International Development, "USEA/USAID Handbook of Climate Change Mitigation Options," June 1999.

U.S. EPA, "Compilation of Air Pollutant Emission Factors," AP-42, Fifth Edition, Vol. I, Stationary Point and Area Sources, Office of Air Quality Planning and Standards, 1999

U.S. EPA, Exposure Factors Handbook, EPA/600/8-89/043, Office of Health and Environmental Assessment, 1989.

U.S. EPA, Risk Assessment Guidance for Superfund, Volume I: Human Health Evaluation Manual (Part A)," EPA/540/1-89/002, Office of Emergency and Remedial Response, 1989.

U.S. EPA, "The Benefits and Costs of the Clean Air Act: 1990 to 2010 (EPA-410-R99-001)," Washington, D.C.:, EPA Office of Air and Radiation, 1999.

U.S. EPA, "Preferred and Alternative Methods for Estimating Air Emissions from Oil and Gas Field Production and Processing Operations," Emission Inventory Improvement Program, September 1999.

U.S. EPA Toxics Release Inventory, TRI Explorer, http://www.epa.gov/triexplorer/chemical.htm, 2000. 
U.S. EPA, "Technical Support Document: Control of Hazardous Air Pollutants from Motor Vehicles and Motor Vehicle Fuels,” EPA420-R-00-023, December 2000.

U.S. EPA, "Review of the National Ambient Air Quality Standards for Particulate Matter: Policy Assessment of Scientific and Technical Information," Office of Air Quality Planning and Standards, June 2001.

Wang, M. A., GREET 1.5a: Changes from GREET 1.5, Center for Transportation Research, Argonne National Laboratory, January 2000.

Wang, M.A., "A Full Fuel-Cycle Analysis of Energy and Emissions Impacts of Transportation Fuels Produced from Natural Gas," Argonne National Laboratory, ANL/ESD-40, December 1999.

Web site: FuelEconomy.gov (www.fueleconomy.gov/feg/findacar.htm)

Yakobson, D.L., "Fischer-Tropsch Technology, GTL's Place in the Drive Towards Cleaner Fuels," GasTech 2000 Conference, Houston, Texas, November 15, 2000. 


\section{Appendices}

The appendices of the UCF LCA contain supporting data for the analysis, additional work that was outside the scope of the main report, and a letter from the peer review panel discussing the review process and the conclusions of the panel.

Appendices A and B provide detailed results for all scenarios for the CFE and LCI, respectively. Appendix C presents an uncertainty analysis of the LCI, and Appendix D provides detailed TRACI input data and TRACI results for the LCIA for all scenarios.

In the course of the work on the UCF LCA, there arose related issues of interest to ConocoPhillips that were outside of the direct scope of the study. After discussion with the UCF LCA peer review panel, it was decided that these topics would be kept separate from the main body of the report. These sections are included as Appendices $\mathrm{E}$ and $\mathrm{F}$ to the report. They have not been reviewed by the panel as part of the ISO 14040 certification process. The work presented in Appendix E, a power generation fuel cycle analysis, has undergone a thorough internal review by Nexant and ConocoPhillips; the work presented in Appendix F, a Mobile6based study of air quality impacts in the Houston-Galveston region, has been reviewed by Nexant, ConocoPhillips, and the Houston-Galveston Area Council.

Appendix G provides a report from the outside peer review panel. 


\section{Appendix A Petroleum Refining and Co-product Function Expansion Data}

This appendix contains crude and product slate data for the baselines, data used in the Coproduct Function Expansions (CFE), and the results of the CFE for the PADD III 2015 heavy case as developed and in Section 5.

\section{A.1 DATA FOR PADD III AND PADD I BASELINES}

Table A-1 Crude Slates Used in PIMS Models

\begin{tabular}{|c|c|c|c|c|}
\hline Crude Slate & PADD III 2006 & PADD III Heavy & PADD III 2015 & PADD I 2015 \\
\hline Average API & 31.2 & 25.4 & 29.9 & 33.1 \\
\hline \multicolumn{5}{|l|}{ Feedstock, bbl/day } \\
\hline Arabian light & 75,000 & 40,648 & 92,006 & 32,380 \\
\hline Nigerian light & 87,500 & 27,099 & 63,697 & 52,930 \\
\hline Bachaquero & 25,000 & 108,396 & 39,633 & \\
\hline Arabian heavy & 62,500 & 94,846 & 87,760 & \\
\hline Alaska North Slope & - & & & 20,540 \\
\hline Kirkuk & - & - & - & 15,800 \\
\hline Minas & - & & - & 36,340 \\
\hline Total crude oils, bbl/day & 250,000 & 270,989 & 283,096 & 157,990 \\
\hline
\end{tabular}


Table A-2 Product Slates from PIMS Models

\begin{tabular}{|c|c|c|c|c|}
\hline Products Slate & PADD III 2006 & PADD III 2015 & PADD III heavy 2015 & PADD I 2015 \\
\hline \multicolumn{5}{|l|}{ Products, bbl/day } \\
\hline Propylene & 0 & 7,698 & 0 & 0 \\
\hline LPG and gases & 13,504 & 23,844 & 15,078 & 9,693 \\
\hline Unleaded regular gasoline & 94,180 & 102,399 & 94,180 & 16,664 \\
\hline Unleaded premium gasoline & 19,970 & 21,713 & 19,970 & 4,348 \\
\hline Total conventional gasoline & 114,150 & 124,112 & 114,150 & 21,012 \\
\hline Reformulated regular gasoline & 21,580 & 23,463 & 21,580 & 50,197 \\
\hline Reformulated premium gasoline & 4,670 & 5,078 & 4,670 & 13,109 \\
\hline Total reformulated gasoline & 26,250 & 28,541 & 26,250 & 63,306 \\
\hline Kero/jet & 34,860 & 38,172 & 34,860 & 11,669 \\
\hline Low-sulfur diesel & 38,595 & 49,628 & 40,740 & 23,316 \\
\hline No. 2 fuel oil & 22,390 & 21,808 & 22,390 & 23,601 \\
\hline Total distillates, bbl/day & 95,845 & 109,608 & 97,990 & 58,586 \\
\hline Residual fuel oil & 12,200 & 11,932 & 12,200 & 8,051 \\
\hline Asphalt & 0 & 0 & 0 & 9,809 \\
\hline Anode coke, short tons & 0 & 0 & 0 & 0 \\
\hline Fuel coke, short tons & 1,696 & 2,481 & 3,943 & 299 \\
\hline Sulfur, long tons & 334 & 341 & 470 & 82 \\
\hline Total misc. products, bbl/day & 2,030 & 2,822 & 4,413 & 10,190 \\
\hline Refinery fuel & 11,367 & 13,856 & 17,215 & 7,038 \\
\hline Cat slurry & 596 & 1,590 & 1,116 & \\
\hline Grand total products, bbl/day & 262,545 & 291,554 & 266,784 & 160,648 \\
\hline
\end{tabular}




\section{A.2 DATA FOR CO-PRODUCT FUNCTION EXPANSION}

Table A-3 Receipts of Petroleum Coke by Electric Utilities, 2000

\begin{tabular}{|l|c|c|c|}
\hline \multicolumn{1}{|c|}{ Electric Utility } & $\begin{array}{c}\text { Receipts } \\
\text { (1000 Short Tons) }\end{array}$ & $\begin{array}{c}\text { Sulfur } \\
(\mathbf{W t} \% \mathbf{t})\end{array}$ & $\begin{array}{c}\text { Cost/Energy } \\
\text { (Cents/MMBtu) }\end{array}$ \\
\hline Jacksonville & 444 & 5.99 & 60.8 \\
\hline Lakeland & 2 & 6.43 & 42.7 \\
\hline Manitowoc & 36 & 5.88 & 46.5 \\
\hline Michigan South Central Power & 2 & 4.9 & 106.9 \\
\hline Northern Indiana & 174 & 4.11 & 65.2 \\
\hline Northern States Power & 220 & 5.34 & 33.4 \\
\hline Ohio Edison & 8 & 3.71 & 73.9 \\
\hline Owensboro & 9 & 5.24 & 53.7 \\
\hline Pennsylvania Power & 203 & 5.62 & 74.3 \\
\hline San Antonio & 9 & 4 & 42 \\
\hline Tampa Electric & 211 & 4.49 & 51.2 \\
\hline Union Electric & 124 & 3.74 & 60.5 \\
\hline Wisconsin Electric Power & 147 & 5.01 & 70.3 \\
\hline Wisconsin Power \& Light & 69 & 5.62 & 46.7 \\
\hline Total & 1,683 & 5.14 (Average) & 58.5 (Average) \\
\hline Data is for electric generating plants with a total steam-electric and combined-cycle nameplate capacity of 50 MW or more. \\
\hline Source: Federal Energy Regulatory Commission, FERC Form 423, "Monthly Report of Cost and Quality of Fue/s for Electric Plants.
\end{tabular}

Table A-4 1998 U.S. Exports of Fuel Grade Petroleum Coke for Power

\begin{tabular}{|l|r|r|}
\hline \multicolumn{1}{|c|}{ Country/Region } & Metric Tons of Coke & Share of U.S. Exports \\
\hline Japan & 858,600 & $21 \%$ \\
\hline Asia & 153,900 & $4 \%$ \\
\hline Europe & $2,413,800$ & $60 \%$ \\
\hline Latin America & 542,700 & $13 \%$ \\
\hline Canada & 81,000 & $2 \%$ \\
\hline Total international power served by U.S. exports & $4,050,000$ & $100 \%$ \\
\hline $\begin{array}{l}\text { Total U.S. power served by U.S. domestic } \\
\text { production }\end{array}$ & $1,600,000$ & \\
\hline
\end{tabular}

Source: International Energy Agency, 2001 
Table A-5 U.S. Exports of Petroleum Coke for Cement Production

\begin{tabular}{|l|r|}
\multicolumn{1}{|c|}{ Region } & $\begin{array}{r}\text { Petroleum Coke, Metric } \\
\text { Tons }\end{array}$ \\
\hline Asia & 216,791 \\
\hline Europe & $3,258,698$ \\
\hline Latin America & 761,535 \\
\hline Total international cement served by U.S. & $4,237,023$ \\
\hline
\end{tabular}

Source: Pace Consultants, 2000

Table A-6 U.S. Sales of Residual Fuel Oil for End Use, Year 2000 (Thousand Gallons)

\begin{tabular}{|l|r|r|}
\multicolumn{1}{|c|}{ End Use } & $\begin{array}{r}\text { Consumption (1,000 } \\
\text { Gallons) }\end{array}$ & \multicolumn{1}{c|}{ Share } \\
\hline Commercial & 664,360 & $5 \%$ \\
\hline Industrial & $1,585,140$ & $12 \%$ \\
\hline Oil company & 153,522 & $1 \%$ \\
\hline Electric utility & $4,362,680$ & $33 \%$ \\
\hline Marine & $6,409,863$ & $49 \%$ \\
\hline Military & 28,427 & $0 \%$ \\
\hline Other & 6,942 & $0 \%$ \\
\hline Total & $13,210,934$ & \\
\hline
\end{tabular}

Source: Energy Information Agency, 2001

Table A-7 SOx and NOx Emissions Factors for the CFE

\begin{tabular}{|l|r|r|}
\hline \multicolumn{1}{|c|}{ Fuel } & \multicolumn{2}{|c|}{ Emission Factors } \\
\hline & Sulfur Dioxide ${ }^{1}$ & Nitrogen Oxides \\
\hline Bituminous coal, Ib/ton & $38.00 \times \mathrm{S}$ & 33.0 \\
\hline Petroleum coke, lb/ton & $39.00 \times \mathrm{S}$ & 21.00 \\
\hline Residual oil, lb/ $10^{3} \mathrm{gal}$ & $157.00 \times \mathrm{S}$ & 32.00 \\
\hline Natural gas, lb/10 $\mathrm{cf}$ & 0.60 & 170.00 \\
\hline
\end{tabular}

Source: Energy Information Agency, 2000

${ }^{1}$ Uncontrolled sulfur dioxide emission factors. "x S" indicates that the constant must be multiplied by the percentage (by weight) of sulfur in the fuel. Sulfur dioxide emission estimates from facilities with flue gas desulfurization equipment are calculated by multiplying uncontrolled emission estimates by one minus the reported sulfur removal efficiencies. Sulfur dioxide emission factors also account for small quantities of sulfur trioxide and gaseous sulfates 


\section{A.3 DETAILED REGIONAL CFE DATA}

Table A-8 CFE for Coke-to-Power, PADD III 2006

\begin{tabular}{|c|c|c|c|c|c|c|c|}
\hline & \multicolumn{3}{|c|}{ U.S } & \multicolumn{2}{|c|}{ Japan, Europe, Canada } & \multicolumn{2}{|c|}{ Asia and Latin America } \\
\hline Emissions Allocated & Coal vs. Coke & NG vs. Coke & $\begin{array}{c}\text { U.S. } \\
\text { Electricity } \\
\text { Mix vs. Coke }\end{array}$ & $\begin{array}{l}\text { Coal vs. } \\
\text { Coke }\end{array}$ & NG vs. Coke & $\begin{array}{l}\text { Coal vs. } \\
\text { Coke }\end{array}$ & NG vs. Coke \\
\hline $\begin{array}{l}\text { To gasoline, g/MMBtu } \\
\text { of gasoline }\end{array}$ & & & & & & & \\
\hline $\mathrm{SO}_{2}$ & 0.213 & 0.556 & 0.258 & 0.451 & 1.172 & 0.727 & 2.194 \\
\hline $\mathrm{NO} x$ & -0.114 & 0.283 & 0.133 & -0.193 & 0.640 & -0.055 & 0.190 \\
\hline $\mathrm{CO}_{2}$ & 11.6 & 96 & 98.5 & 26.3 & 203 & 5.5 & 43.5 \\
\hline $\begin{array}{l}\text { To diesel, g/MMBtu of } \\
\text { diesel }\end{array}$ & & & & & & & \\
\hline $\mathrm{SO}_{2}$ & 0.065 & 0.170 & 0.079 & 0.138 & 0.358 & 0.222 & 0.671 \\
\hline $\mathrm{NOx}$ & -0.035 & 0.087 & 0.041 & -0.059 & 0.196 & -0.017 & 0.058 \\
\hline $\mathrm{CO}_{2}$ & 3.6 & 29.4 & 30.1 & 8.0 & 62.2 & 1.7 & 13.3 \\
\hline
\end{tabular}

Table A-9 CFE for Coke-to-Power, PADD III 2015

\begin{tabular}{|c|c|c|c|c|c|c|c|}
\hline \multirow{2}{*}{$\begin{array}{l}\text { Emissions } \\
\text { Allocated }\end{array}$} & \multicolumn{3}{|c|}{ U.S } & \multicolumn{2}{|c|}{ Japan, Europe, Canada } & \multicolumn{2}{|c|}{ Asia and Latin America } \\
\hline & Coal vs. Coke & NG vs. Coke & $\begin{array}{c}\text { U.S. } \\
\text { Electricity } \\
\text { Mix vs. Coke }\end{array}$ & Coal vs. Coke & NG vs. Coke & $\begin{array}{l}\text { Coal vs. } \\
\text { Coke }\end{array}$ & NG vs. Coke \\
\hline \multicolumn{8}{|l|}{$\begin{array}{l}\text { To gasoline, } \\
\text { g/MMBtu of } \\
\text { gasoline }\end{array}$} \\
\hline $\mathrm{SO}_{2}$ & 0.263 & 0.688 & 0.320 & 0.558 & 1.449 & 0.899 & 2.714 \\
\hline $\mathrm{NOx}$ & -0.141 & 0.350 & 0.164 & -0.238 & 0.792 & -0.068 & 0.235 \\
\hline $\mathrm{CO}_{2}$ & 14.4 & 118.8 & 121.9 & 32.5 & 251.4 & 6.8 & 53.8 \\
\hline \multicolumn{8}{|c|}{$\begin{array}{l}\text { To diesel, } \\
\text { g/MMBtu of diesel }\end{array}$} \\
\hline $\mathrm{SO}_{2}$ & 0.095 & 0.249 & 0.116 & 0.202 & 0.525 & 0.326 & 0.982 \\
\hline $\mathrm{NOx}$ & -0.051 & 0.127 & 0.059 & -0.086 & 0.287 & -0.025 & 0.085 \\
\hline $\mathrm{CO}_{2}$ & 5.2 & 43.0 & 44.1 & 11.8 & 91.0 & 2.4 & 19.5 \\
\hline
\end{tabular}


Table A-10 CFE for Coke-to-Power, PADD III Heavy

\begin{tabular}{|c|c|c|c|c|c|c|c|}
\hline \multirow[b]{2}{*}{ Emissions Allocated } & \multicolumn{3}{|c|}{ U.S } & \multicolumn{2}{|c|}{ Japan, Europe, Canada } & \multicolumn{2}{|c|}{ Asia and Latin America } \\
\hline & $\begin{array}{c}\text { Coal vs. } \\
\text { Coke }\end{array}$ & $\begin{array}{c}\text { NG vs. } \\
\text { Coke }\end{array}$ & $\begin{array}{l}\text { U.S. } \\
\text { Electricity } \\
\text { Mix vs. } \\
\text { Coke }\end{array}$ & $\begin{array}{c}\text { Coal vs. } \\
\text { Coke }\end{array}$ & $\begin{array}{l}\text { NG vs. } \\
\text { Coke }\end{array}$ & $\begin{array}{c}\text { Coal vs. } \\
\text { Coke }\end{array}$ & $\begin{array}{l}\text { NG vs. } \\
\text { Coke }\end{array}$ \\
\hline \multicolumn{8}{|l|}{ To gasoline, g/MMBtu of gasoline } \\
\hline $\mathrm{SO}_{2}$ & 0.456 & 1.194 & 0.555 & 0.968 & 2.514 & 1.560 & 4.707 \\
\hline $\mathrm{NOx}$ & -0.245 & 0.608 & 0.284 & -0.413 & 1.374 & -0.118 & 0.408 \\
\hline $\mathrm{CO}_{2}$ & 25.0 & 206.1 & 211.4 & 56.4 & 436.0 & 11.7 & 93.3 \\
\hline \multicolumn{8}{|l|}{ To diesel, g/MMBtu of diesel } \\
\hline $\mathrm{SO}_{2}$ & 0.147 & 0.386 & 0.179 & 0.313 & 0.812 & 0.504 & 1.520 \\
\hline NOx & -0.079 & 0.196 & 0.092 & -0.133 & 0.444 & -0.038 & 0.132 \\
\hline $\mathrm{CO}_{2}$ & 8.1 & 66.6 & 68.3 & 18.2 & 140.8 & 3.8 & 30.1 \\
\hline
\end{tabular}

\section{A.4 ALLOCATIONS OF CO-PRODUCTS FOR PADD III HEAVY}

Table A-11 PADD III Heavy-Co-Product Energy and Emissions Well-to-Tank Allocations to Gasoline (Btu/MMBtu or g/MMBtu)

\begin{tabular}{|c|c|c|c|}
\hline & & \multicolumn{2}{|c|}{ Delta Energy and Emissions to Gasoline from: } \\
\hline Output & $\begin{array}{c}\text { Lower Bound: No } \\
\text { Co-products }\end{array}$ & Coke and RO & $\begin{array}{l}\text { Upper Bound: } \\
\text { Full Co- product Slate }\end{array}$ \\
\hline Total energy & 273,594 & 26,192 & 65,755 \\
\hline $\mathrm{CO}_{2}$ & 20,549 & 1,825 & 4704 \\
\hline NOx & 47.01 & 4.19 & 10.01 \\
\hline PM10 & 3.40 & 0.30 & 0.88 \\
\hline SOx & 22.83 & 2.08 & 5.87 \\
\hline
\end{tabular}


Table A-12 PADD III Heavy-Co-Product Energy and Emissions Well-to-Tank Allocations to Diesel (Btu/MMBtu or g/MMBtu)

\begin{tabular}{|l|c|c|c|}
\multicolumn{1}{|c|}{ Output } & $\begin{array}{c}\text { Lower Bound: } \\
\text { No Co- } \\
\text { Products }\end{array}$ & \multicolumn{2}{|c|}{$\begin{array}{c}\text { Delta Energy and Emissions to } \\
\text { Gasoline from: }\end{array}$} \\
\hline Cotal energy & 229,550 & 28,707 & $\begin{array}{c}\text { Upper Bound: } \\
\text { Full Co- } \\
\text { product Slate }\end{array}$ \\
\hline $\mathrm{CO}_{2}$ & 17,539 & 1,999 & 73,099 \\
\hline $\mathrm{NO}_{\mathrm{x}}$ & 40.63 & 4.66 & 11.18 \\
\hline $\mathrm{PM} 10$ & 3.17 & 0.34 & 0.98 \\
\hline $\mathrm{SO}$ & 21.60 & 2.31 & 6.56 \\
\hline
\end{tabular}

Table A-13 CFE for Gasoline and Diesel for Coke to Power, PADD III Heavy

\begin{tabular}{|l|c|c|}
\hline \multicolumn{1}{|c|}{ Emissions Allocated } & Coke vs. Coal & Coke vs. NG \\
\hline To gasoline, g/MMBtu of gasoline & & \\
\hline $\mathrm{SO}_{2}$ & & \\
\hline $\mathrm{NO}$ & 2.985 & 8.415 \\
\hline $\mathrm{CO}_{2}$ & -0.777 & 2.390 \\
\hline & 93.1 & 735.4 \\
\hline $\mathrm{To}_{2}$ diesel, g/MMBtu of diesel & & \\
\hline $\mathrm{SO}_{2}$ & & \\
\hline $\mathrm{NO}_{\mathbf{1}}$ & 0.964 & 2.718 \\
\hline $\mathrm{CO}_{2}$ & -0.251 & 0.772 \\
\hline
\end{tabular}

Table A-14 CFE for Petroleum Coke to Cement, PADD III Heavy

\begin{tabular}{|l|c|}
\multicolumn{1}{|c|}{ Emissions Allocated } & Coal vs. Coke \\
\hline To gasoline, g/MMBtu of gasoline & \\
\hline $\mathrm{SO}_{2}$ & 4.797 \\
\hline $\mathrm{NO} x$ & -1.948 \\
\hline $\mathrm{CO}_{2}$ & 269 \\
\hline $\mathrm{To} \mathrm{diesel}_{2}$ g/MMBtu of diesel & \\
\hline $\mathrm{SO}_{2}$ & 1.550 \\
\hline $\mathrm{NO}$ & -0.629 \\
\hline $\mathrm{CO}_{2}$ & 87 \\
\hline
\end{tabular}


Table A-15 CFE for Heavy Residual Oil-to-Power/Heat vs. Natural Gas-to-Power/Heat, PADD III Heavy

\begin{tabular}{|l|c|c|c|c|}
\hline \multicolumn{1}{|c|}{ Emissions Allocated } & Electric Utilities & Industrial & Commercial & Total \\
\hline To gasoline, g/MMBtu of gasoline & & & & \\
\hline $\mathrm{SO}_{2}$ & 7.041 & 10.337 & 4.307 & 22.254 \\
\hline $\mathrm{NO}$ & 0.973 & 0.057 & 0.046 & 1.104 \\
\hline $\mathrm{CO}_{2}$ & 1,786 & 182 & 75 & 2,097 \\
\hline $\mathrm{To}_{\mathrm{Niesel}}$ g/MMBtu of diesel & & & & \\
\hline $\mathrm{SO}_{2}$ & 2.274 & 3.339 & 1.391 & 6.809 \\
\hline $\mathrm{NO}_{x}$ & 0.314 & 0.018 & 0.015 & 0.338 \\
\hline $\mathrm{CO}_{2}$ & 577 & 58.7 & 24.3 & 642 \\
\hline
\end{tabular}

Table A-16 CFE for Gasoline, PADD III Heavy Case

\begin{tabular}{|l|r|r|r|r|r|r|}
\hline & \multicolumn{3}{|c|}{ Coal vs. Coke } & \multicolumn{3}{c|}{ NG vs. Coke } \\
\hline Base & \multicolumn{1}{c|}{$\mathrm{CO}_{2}$} & \multicolumn{1}{c|}{ SOx } & \multicolumn{1}{c|}{ NOx } & \multicolumn{1}{c|}{ CO $_{2}$} & \multicolumn{1}{c|}{ SOx } & \multicolumn{1}{c|}{ NOx } \\
\hline Coke, RO & 20,549 & 22.83 & 47.01 & 20,549 & 22.83 & 47.01 \\
\hline Coke power & 1,825 & 2.08 & 4.19 & 1825 & 2.08 & 4.19 \\
\hline Coke cement & 93.1 & 2.985 & -0.777 & 735.4 & 8.415 & 2.39 \\
\hline RO to power & 269 & 4.797 & -1.948 & 269 & 4.797 & -1.948 \\
\hline Total CFE & $24,833.1$ & 54.946 & 49.579 & 25475.4 & 60.376 & 52.746 \\
\hline $\begin{array}{l}\text { Increase over } \\
\text { base, \% }\end{array}$ & $21 \%$ & $141 \%$ & $6 \%$ & $24 \%$ & $165 \%$ & $12 \%$ \\
\hline
\end{tabular}

Table A-17 CFE for ULSD, PADD III Heavy Case

\begin{tabular}{|l|r|r|r|r|r|r|}
\hline CFE Allocations & \multicolumn{3}{|c|}{ Coal vs. Coke } & \multicolumn{3}{c|}{ NG vs. Coke } \\
\hline Base & $\mathbf{C O}_{2}$ & \multicolumn{1}{c|}{ SOx } & \multicolumn{1}{c|}{ NOx } & \multicolumn{1}{c|}{ C $_{2}$} & \multicolumn{1}{c|}{ SOx } & \multicolumn{1}{c|}{ NOx } \\
\hline Coke, RO & 17,539 & 21.6 & 40.63 & 17,539 & 21.6 & 40.63 \\
\hline Coke power & 1,999 & 2.31 & 4.66 & 1,999 & 2.31 & 4.66 \\
\hline Coke cement & 30.1 & 0.964 & -0.251 & 237.5 & 2.718 & 0.772 \\
\hline RO to power & 87 & 1.55 & -0.629 & 87 & 1.55 & -0.629 \\
\hline Total CFE & $20,297.1$ & 6.809 & 0.338 & 642 & 6.809 & 0.338 \\
\hline $\begin{array}{l}\text { Increase over } \\
\text { base, \% }\end{array}$ & $16 \%$ & $54 \%$ & $10 \%$ & $17 \%$ & $62 \%$ & $13 \%$ \\
\hline
\end{tabular}




\section{Appendix B Complete Life Cycle Inventory Results}

Appendix B contains the complete LCI results for the FRFG, ULSD, and methanol cases. 


\section{B.1 COMPLETE LCI DATA FOR PETROLEUM FUELS}

Table B-1 Near Term: Conventional Diesel, ULS Diesel, and FRFG PADD III 2006

\begin{tabular}{|c|c|c|c|c|c|c|c|c|c|c|c|c|}
\hline \multirow[b]{2}{*}{ Output } & \multicolumn{4}{|c|}{ Conv. Diesel CIDI } & \multicolumn{4}{|c|}{ LS Diesel CIDI } & \multicolumn{4}{|c|}{ FRFG Gasoline Vehicle } \\
\hline & Feedstock & Fuel & Vehicle & Total & Feedstock & Fuel & Vehicle & Total & Feedstock & Fuel & Vehicle & Total \\
\hline Total energy & 179.1 & 603.5 & 4,209 & 4,992 & 174.9 & 742.0 & 4,111 & 5,027 & 219 & 1,194 & 5,156 & 6,570 \\
\hline Fossil fuels & 172.1 & 595.8 & 4,209 & 4,977 & 168.1 & 732.5 & 4,111 & 5,011 & 211 & 1,181 & 5,156 & 6,548 \\
\hline Petroleum & 53 & 305 & 4,209 & 4,568 & 52 & 375 & 4,111 & 4,537 & 66 & 495 & 4,643 & 5,203 \\
\hline $\mathrm{CO}_{2}$ & 17 & 44 & 339 & 400 & 17 & 57 & 332 & 405 & 21 & 97 & 390 & 508.6 \\
\hline $\mathrm{CH}_{4}$ & 0.383 & 0.047 & 0.011 & 0.441 & 0.374 & 0.058 & 0.011 & 0.443 & 0.469 & 0.218 & 0.077 & 0.765 \\
\hline $\mathrm{N}_{2} \mathrm{O}$ & 0.000 & 0.001 & 0.016 & 0.017 & 0.000 & 0.001 & 0.016 & 0.017 & 0.000 & 0.001 & 0.028 & 0.030 \\
\hline GWP & 26.1 & 45.2 & 343.5 & 415 & 16.8 & 66.9 & 337.4 & 421 & 21.1 & 113.5 & 400.6 & 535.2 \\
\hline VOC: total & 0.013 & 0.021 & 0.080 & 0.114 & 0.013 & 0.023 & 0.049 & 0.085 & 0.016 & 0.071 & 0.161 & 0.249 \\
\hline CO: total & 0.034 & 0.022 & 1.070 & 1.126 & 0.033 & 0.027 & 1.070 & 1.130 & 0.041 & 0.049 & 4.414 & 4.504 \\
\hline NOx: total & 0.092 & 0.067 & 0.600 & 0.759 & 0.090 & 0.083 & 0.063 & 0.236 & 0.112 & 0.139 & 0.261 & 0.512 \\
\hline PM10: total & 0.003 & 0.009 & 0.121 & 0.132 & 0.003 & 0.011 & 0.031 & 0.044 & 0.003 & 0.015 & 0.032 & 0.051 \\
\hline SOx: total & 0.019 & 0.057 & 0.074 & 0.151 & 0.018 & 0.103 & 0.003 & 0.124 & 0.023 & 0.231 & 0.006 & 0.261 \\
\hline VOC: urban & 0.001 & 0.009 & 0.080 & 0.090 & 0.001 & 0.010 & 0.049 & 0.059 & 0.001 & 0.027 & 0.161 & 0.189 \\
\hline CO: urban & 0.001 & 0.011 & 1.070 & 1.082 & 0.001 & 0.013 & 1.070 & 1.083 & 0.001 & 0.018 & 4.414 & 4.432 \\
\hline NOx: urban & 0.001 & 0.025 & 0.600 & 0.626 & 0.001 & 0.029 & 0.063 & 0.093 & 0.002 & 0.038 & 0.261 & 0.301 \\
\hline PM10: urban & 0.000 & 0.005 & 0.121 & 0.126 & 0.000 & 0.006 & 0.031 & 0.037 & 0.000 & 0.007 & 0.032 & 0.040 \\
\hline SOx: urban & 0.001 & 0.028 & 0.074 & 0.103 & 0.001 & 0.034 & 0.003 & 0.037 & 0.001 & 0.043 & 0.006 & 0.051 \\
\hline
\end{tabular}


Table B-2 Long-Term FRFG PADD III 2015

\begin{tabular}{|c|c|c|c|c|c|c|c|c|c|c|c|c|}
\hline \multirow[b]{2}{*}{ Output } & \multicolumn{4}{|c|}{ FRFG SIDI } & \multicolumn{4}{|c|}{ FRFG SI HEV } & \multicolumn{4}{|c|}{ FRFG FCV } \\
\hline & Feedstock & Fuel & Vehicle & Total & Feedstock & Fuel & Vehicle & Total & Feedstock & Fuel & Vehicle & Total \\
\hline Total energy & 149 & 831 & 3,546 & 4,526 & 121 & 677 & 2,887 & 3,685 & 116 & 645 & 2,752 & 3,513 \\
\hline Fossil fuels & 143 & 822 & 3,546 & 4,511 & 117 & 669 & 2,887 & 3,672 & 111 & 638 & 2,752 & 3,501 \\
\hline Petroleum & 45 & 346 & 3,193 & 3,585 & 37 & 282 & 2,599 & 2,918 & 35 & 269 & 2,478 & 2,782 \\
\hline $\mathrm{CO}_{2}$ & 14.3 & 67.7 & 268.3 & 350.3 & 11.6 & 55.1 & 218.4 & 285.1 & 11.1 & 52.5 & 208.4 & 272.0 \\
\hline $\mathrm{CH}_{4}$ & 0.323 & 0.151 & 0.065 & 0.538 & 0.263 & 0.123 & 0.065 & 0.450 & 0.250 & 0.117 & 0.013 & 0.380 \\
\hline $\mathrm{N}_{2} \mathrm{O}$ & 0.000 & 0.001 & 0.028 & 0.029 & 0.000 & 0.001 & 0.028 & 0.029 & 0.000 & 0.001 & 0.006 & 0.007 \\
\hline GWP & 21.2 & 72.1 & 278.1 & 371.4 & 17.2 & 58.7 & 228.5 & 304.4 & 16.4 & 55.9 & 210.4 & 282.7 \\
\hline VOC: total & 0.011 & 0.049 & 0.119 & 0.179 & 0.009 & 0.040 & 0.106 & 0.155 & 0.009 & 0.038 & 0.057 & 0.103 \\
\hline CO: total & 0.027 & 0.034 & 2.759 & 2.820 & 0.022 & 0.027 & 2.759 & 2.808 & 0.021 & 0.026 & 0.552 & 0.599 \\
\hline NOx: total & 0.074 & 0.093 & 0.036 & 0.204 & 0.061 & 0.076 & 0.029 & 0.165 & 0.058 & 0.072 & 0.007 & 0.137 \\
\hline PM10: total & 0.002 & 0.010 & 0.035 & 0.048 & 0.002 & 0.008 & 0.031 & 0.041 & 0.002 & 0.008 & 0.021 & 0.031 \\
\hline SOx: total & 0.013 & 0.149 & 0.004 & 0.166 & 0.010 & 0.121 & 0.004 & 0.135 & 0.010 & 0.115 & 0.000 & 0.125 \\
\hline VOC: urban & 0.001 & 0.019 & 0.119 & 0.138 & 0.001 & 0.015 & 0.106 & 0.122 & 0.001 & 0.015 & 0.057 & 0.072 \\
\hline co: urban & 0.001 & 0.012 & 2.759 & 2.772 & 0.000 & 0.010 & 2.759 & 2.769 & 0.000 & 0.010 & 0.552 & 0.562 \\
\hline NOx: urban & 0.001 & 0.023 & 0.036 & 0.060 & 0.001 & 0.019 & 0.029 & 0.048 & 0.001 & 0.018 & 0.007 & 0.026 \\
\hline PM10: urban & 0.000 & 0.005 & 0.035 & 0.040 & 0.000 & 0.004 & 0.031 & 0.035 & 0.000 & 0.004 & 0.021 & 0.025 \\
\hline SO: urban & 0.000 & 0.026 & 0.004 & 0.031 & 0.000 & 0.021 & 0.004 & 0.025 & 0.000 & 0.020 & 0.000 & 0.021 \\
\hline
\end{tabular}


Table B-3 Long-Term ULS Diesel, PADD III 2015

\begin{tabular}{|c|c|c|c|c|c|c|c|c|c|c|c|c|c|c|c|c|}
\hline \multirow[b]{2}{*}{ Output } & \multicolumn{4}{|c|}{ LS Diesel CIDI } & \multicolumn{4}{|c|}{ ULS Diesel CIDI HEV } & \multicolumn{4}{|c|}{3 ppm ULS Diesel CIDI } & \multicolumn{4}{|c|}{$\begin{array}{c}100 \% \text { Middle East Crude Import } \\
\text { ULS Diesel CIDI }\end{array}$} \\
\hline & Feedstock & Fuel & Vehicle & Total & Feedstock & Fuel & Vehicle & Total & Feedstock & Fuel & Vehicle & Total & Feedstock & Fuel & Vehicle & Total \\
\hline Total energy & 143.0 & 624.4 & 3,399 & 4,167 & 106.0 & 462.6 & 2,519 & 3,087 & 143.0 & 624.4 & 3,399 & 4,167 & 152.6 & 625.2 & 3,399 & 4,177 \\
\hline Fossil fuels & 137.4 & 616.3 & 3,399 & 4,153 & 101.8 & 456.7 & 2,519 & 3,077 & 137.4 & 616.3 & 3,399 & 4,153 & 146.9 & 617.2 & 3,399 & 4,164 \\
\hline Petroleum & 43.2 & 316.3 & 3,399 & 3,759 & 32.0 & 234.4 & 2,519 & 2,785 & 43.2 & 316.3 & 3,399 & 3,759 & 52.2 & 317.1 & 3,399 & 3,769 \\
\hline $\mathrm{CO}_{2}$ & 13.7 & 48.1 & 274.5 & 336 & 10.2 & 35.6 & 203.4 & 249 & 13.7 & 48.1 & 274.5 & 336 & 14.5 & 48.1 & 274.5 & 337 \\
\hline $\mathrm{CH} 4$ & 0.309 & 0.049 & 0.011 & 0.369 & 0.229 & 0.036 & 0.011 & 0.276 & 0.309 & 0.049 & 0.011 & 0.369 & 0.310 & 0.049 & 0.011 & 0.370 \\
\hline $\mathrm{N}_{2} \mathrm{O}$ & 0.000 & 0.001 & 0.016 & 0.017 & 0.000 & 0.001 & 0.016 & 0.017 & 0.000 & 0.001 & 0.016 & 0.017 & 0.000 & 0.001 & 0.016 & 0.017 \\
\hline GWP & 20.3 & 50.0 & 279.7 & 350 & 15.0 & 37.1 & 208.6 & 261 & 20.3 & 50.0 & 279.5 & 350 & 21.1 & 50.0 & 279.5 & 351 \\
\hline VOC: total & 0.011 & 0.019 & 0.049 & 0.079 & 0.008 & 0.014 & 0.049 & 0.071 & 0.011 & 0.019 & 0.049 & 0.079 & 0.012 & 0.019 & 0.049 & 0.080 \\
\hline CO: total & 0.026 & 0.023 & 1.070 & 1.119 & 0.019 & 0.017 & 1.070 & 1.106 & 0.026 & 0.023 & 1.070 & 1.119 & 0.028 & 0.023 & 1.070 & 1.121 \\
\hline $\mathrm{NO}_{\mathrm{x}}$ : total & 0.071 & 0.066 & 0.063 & 0.200 & 0.053 & 0.049 & 0.050 & 0.152 & 0.071 & 0.066 & 0.063 & 0.200 & 0.091 & 0.066 & 0.063 & 0.220 \\
\hline PM10: total & 0.002 & 0.009 & 0.031 & 0.042 & 0.002 & 0.006 & 0.029 & 0.037 & 0.002 & 0.009 & 0.031 & 0.042 & 0.003 & 0.009 & 0.031 & 0.042 \\
\hline $\mathrm{SO}_{\mathrm{x}}$ : total & 0.012 & 0.081 & 0.002 & 0.095 & 0.009 & 0.060 & 0.001 & 0.070 & 0.012 & 0.081 & 0.001 & 0.094 & 0.014 & 0.081 & 0.002 & 0.097 \\
\hline VOC: urban & 0.001 & 0.008 & 0.049 & 0.058 & 0.000 & 0.006 & 0.049 & 0.055 & 0.001 & 0.008 & 0.049 & 0.058 & 0.001 & 0.008 & 0.049 & 0.058 \\
\hline CO: urban & 0.001 & 0.011 & 1.070 & 1.081 & 0.000 & 0.008 & 1.070 & 1.078 & 0.001 & 0.011 & 1.070 & 1.081 & 0.001 & 0.011 & 1.070 & 1.081 \\
\hline NOx: urban & 0.001 & 0.021 & 0.063 & 0.085 & 0.001 & 0.016 & 0.050 & 0.067 & 0.001 & 0.021 & 0.063 & 0.085 & 0.001 & 0.021 & 0.063 & 0.085 \\
\hline PM10: urban & 0.000 & 0.005 & 0.031 & 0.036 & 0.000 & 0.003 & 0.029 & 0.032 & 0.000 & 0.005 & 0.031 & 0.036 & 0.000 & 0.005 & 0.031 & 0.036 \\
\hline $\mathrm{SO}_{\mathrm{x}}$ : urban & 0.000 & 0.025 & 0.002 & 0.027 & 0.000 & 0.018 & 0.001 & 0.020 & 0.000 & 0.025 & 0.001 & 0.026 & 0.000 & 0.025 & 0.002 & 0.027 \\
\hline
\end{tabular}


Table B-4 Long-Term PADD III Heavy 2015, PADD I 2015

\begin{tabular}{|c|c|c|c|c|c|c|c|c|}
\hline \multirow[b]{2}{*}{ Output } & \multicolumn{4}{|c|}{ PADD III Heavy ULS Diesel CIDI } & \multicolumn{4}{|c|}{ PADD I ULS Diesel CIDI } \\
\hline & Feedstock & Fuel & Vehicle & Total & Feedstock & Fuel & Vehicle & Total \\
\hline Total energy & 143.3 & 679.5 & 3,399 & 4,222 & 142.9 & 568.2 & 3,399 & 4,111 \\
\hline Fossil fuels & 137.6 & 670.8 & 3,399 & 4,208 & 137.3 & 560.8 & 3,399 & 4,098 \\
\hline Petroleum & 43.3 & 344.4 & 3,399 & 3,787 & 43.1 & 286.7 & 3,399 & 3,729 \\
\hline $\mathrm{CO}_{2}$ & 13.7 & 52.3 & 274.5 & 341 & 13.7 & 41.3 & 274.5 & 329 \\
\hline $\mathrm{CH}_{4}$ & 0.309 & 0.053 & 0.011 & 0.373 & 0.309 & 0.044 & 0.011 & 0.365 \\
\hline $\mathrm{N}_{2} \mathrm{O}$ & 0.000 & 0.001 & 0.016 & 0.017 & 0.000 & 0.001 & 0.016 & 0.017 \\
\hline GWP & 20.3 & 54.4 & 279.7 & 354 & 20.9 & 42.5 & 279.5 & 343 \\
\hline VOC: total & 0.011 & 0.020 & 0.049 & 0.079 & 0.011 & 0.018 & 0.049 & 0.078 \\
\hline CO: total & 0.026 & 0.025 & 1.070 & 1.120 & 0.026 & 0.020 & 1.070 & 1.116 \\
\hline NOx: total & 0.071 & 0.072 & 0.063 & 0.207 & 0.071 & 0.055 & 0.063 & 0.189 \\
\hline PM10: total & 0.002 & 0.009 & 0.031 & 0.042 & 0.002 & 0.008 & 0.031 & 0.041 \\
\hline SOx: total & 0.012 & 0.091 & 0.002 & 0.104 & 0.012 & 0.045 & 0.002 & 0.059 \\
\hline VOC: urban & 0.001 & 0.008 & 0.049 & 0.058 & 0.001 & 0.008 & 0.049 & 0.057 \\
\hline CO: urban & 0.001 & 0.011 & 1.070 & 1.082 & 0.001 & 0.010 & 1.070 & 1.081 \\
\hline $\mathrm{NO}_{\mathrm{x}}$ : urban & 0.001 & 0.022 & 0.063 & 0.086 & 0.001 & 0.020 & 0.063 & 0.084 \\
\hline PM10: urban & 0.000 & 0.005 & 0.031 & 0.036 & 0.000 & 0.004 & 0.031 & 0.036 \\
\hline SOx: urban & 0.000 & 0.026 & 0.002 & 0.028 & 0.000 & 0.024 & 0.002 & 0.026 \\
\hline
\end{tabular}


Table B-5 Long-Term Methanol FCV

\begin{tabular}{|l|r|r|r|r|}
\hline \multicolumn{1}{|c|}{ Output } & \multicolumn{5}{|c|}{ Methanol FCV } \\
\hline Total energy & 143 & 1,217 & 2,566 & 3,925 \\
\hline Fossil fuels & 142 & 1,216 & 2,566 & 3,923 \\
\hline Petroleum & 9 & 105 & 0 & 114 \\
\hline $\mathrm{CO}_{2}$ & 11 & 42 & 185 & 239 \\
\hline $\mathrm{CH}_{4}$ & 0.266 & 0.048 & 0.013 & 0.327 \\
\hline $\mathrm{N}_{2} \mathrm{O}$ & 0.000 & 0.001 & 0.006 & 0.006 \\
\hline GWP & 18 & 43 & 187 & 248 \\
\hline VOC: total & 0.001 & 0.027 & 0.038 & 0.065 \\
\hline CO: total & 0.013 & 0.036 & 0.552 & 0.601 \\
\hline NO: total & 0.021 & 0.177 & 0.007 & 0.205 \\
\hline PM10: total & 0.001 & 0.006 & 0.021 & 0.027 \\
\hline SO: total & 0.007 & 0.021 & 0.000 & 0.028 \\
\hline VOC: urban & 0.000 & 0.004 & 0.038 & 0.042 \\
\hline CO: urban & 0.000 & 0.001 & 0.552 & 0.553 \\
\hline NO: urban & 0.000 & 0.003 & 0.007 & 0.010 \\
\hline PM10: urban & 0.000 & 0.000 & 0.021 & 0.021 \\
\hline SO $:$ urban & 0.000 & 0.000 & 0.000 & 0.001 \\
\hline
\end{tabular}


This section contains the GREET Crystal Ball uncertainty analysis results for the FT Diesel, ULSD, FRFG, FT naphtha, and methanol cases.

GREET 1.6 employs the simulation software Crystal Ball to carry out Monte Carlo analysis based on probability distributions that are specified for the key model parameters: energy and carbon efficiency of fuel processing and energy efficiency of vehicle use, as shown in Tables C-1, C-2, and C-3. Once the distributions have been input to GREET, Crystal Ball develops statistical ranges for the model outputs. Results for total energy, GWP, $\mathrm{NO}_{\mathrm{X}}, \mathrm{PM} 10$, and $\mathrm{SO}_{\mathrm{X}}$ are reported here. Both total and urban emissions are shown for criteria emissions, but uncertainty is reported only for total emissions.

Uncertainty analysis in GREET makes use of expert judgment to develop subjective probability distribution functions for the key model parameters. On the basis of the range of values for the parameters from published sources, the upper, middle, and lower range values for the input parameters are specified as the lower, midpoint, and upper tail ranges corresponding to the $20 \%$, $50 \%$, and $80 \%$ points on a normal or triangular probability distribution.

In developing the lower and upper ranges for model parameters, GREET considers such factors as status of technology development, variability in existing operations, uncertainty in business decisions for promoting certain technologies, and the regulatory uncertainty in developing and operating facilities. As comprehensive as these considerations are, the uncertainty approximations are rough, since they are based not on actual data sets but on subjective judgment.

Future technologies, such as GTL, are assigned greater uncertainties than established and mature technologies, such as petroleum refining. The larger ranges associated with the inventory results for GTL and methanol thus reflect this uncertainty.

Uncertainty estimates can provide a valuable perspective on model robustness, but ultimately are only as good as the probability distributions used to model the uncertainty. GREET also performs only a limited uncertainty analysis on the energy efficiency parameters. For reference, the uncertainty analysis generated by GREET is presented in this appendix. 


\section{C.1 SENSITIVITY RANGES}

Table C-1 Normal Distribution Ranges for UCF Fuel Production Energy Efficiency

\begin{tabular}{|l|c|c|c|}
\hline \multicolumn{1}{|c|}{ UCF Fuel Pathway } & P20 & P50 & P80 \\
\hline FTD near-term & $65 \%$ & $67 \%$ & $69 \%$ \\
\hline FTD long-term & $68 \%$ & $70 \%$ & $72 \%$ \\
\hline Methanol near-term & $66.5 \%$ & $68 \%$ & $69.5 \%$ \\
\hline Methanol long-term & $69.3 \%$ & $70.7 \%$ & $73 \%$ \\
\hline
\end{tabular}

Table C-2 Normal Distribution Ranges for Petroleum Refining Energy Efficiency

\begin{tabular}{|l|c|c|c|}
\multicolumn{1}{|c|}{ Petroleum Fuel Pathway } & P20 & P50 & P80 \\
\hline 340 ppm sulfur conventional gasoline & $85 \%$ & $85.5 \%$ & $86 \%$ \\
\hline 150 ppm sulfur RFG with MTBE & $85 \%$ & $86 \%$ & $87 \%$ \\
\hline 5-30 ppm sulfur RFG with MTBE & $84 \%$ & $85.5 \%$ & $87 \%$ \\
\hline 5-30 ppm sulfur RFG with no oxygenate & $83 \%$ & $84.5 \%$ & $86 \%$ \\
\hline 120-350 ppm sulfur diesel & $88 \%$ & $89 \%$ & $90 \%$ \\
\hline 5-30 ppm sulfur diesel & $85 \%$ & $87 \%$ & $89 \%$ \\
\hline
\end{tabular}

Table C-3 Weibull Distribution Ranges for Vehicle Efficiency Improvement Relative to Baseline Vehicle

\begin{tabular}{|l|c|c|c|}
\multicolumn{1}{|c|}{ Vehicle Efficiency } & P(location) & P50 & P95 \\
\hline Baseline: gasoline vehicle (mpg) & 22 & 27 & 33 \\
\hline SIDI vehicle & $110 \%$ & $115 \%$ & $125 \%$ \\
\hline CIDI vehicle & $115 \%$ & $120 \%$ & $130 \%$ \\
\hline Grid-independent FRFG SI HEV & $120 \%$ & $140 \%$ & $170 \%$ \\
\hline Grid-independent ULSD CIDI HEV & $140 \%$ & $160 \%$ & $195 \%$ \\
\hline FCV: FRFG and FT naphtha & $100 \%$ & $150 \%$ & $170 \%$ \\
\hline FCV: methanol & $130 \%$ & $160 \%$ & $180 \%$ \\
\hline
\end{tabular}




\section{C.2 UNCERTAINTY ANALYIS FOR NEAR-TERM SCENARIOS}

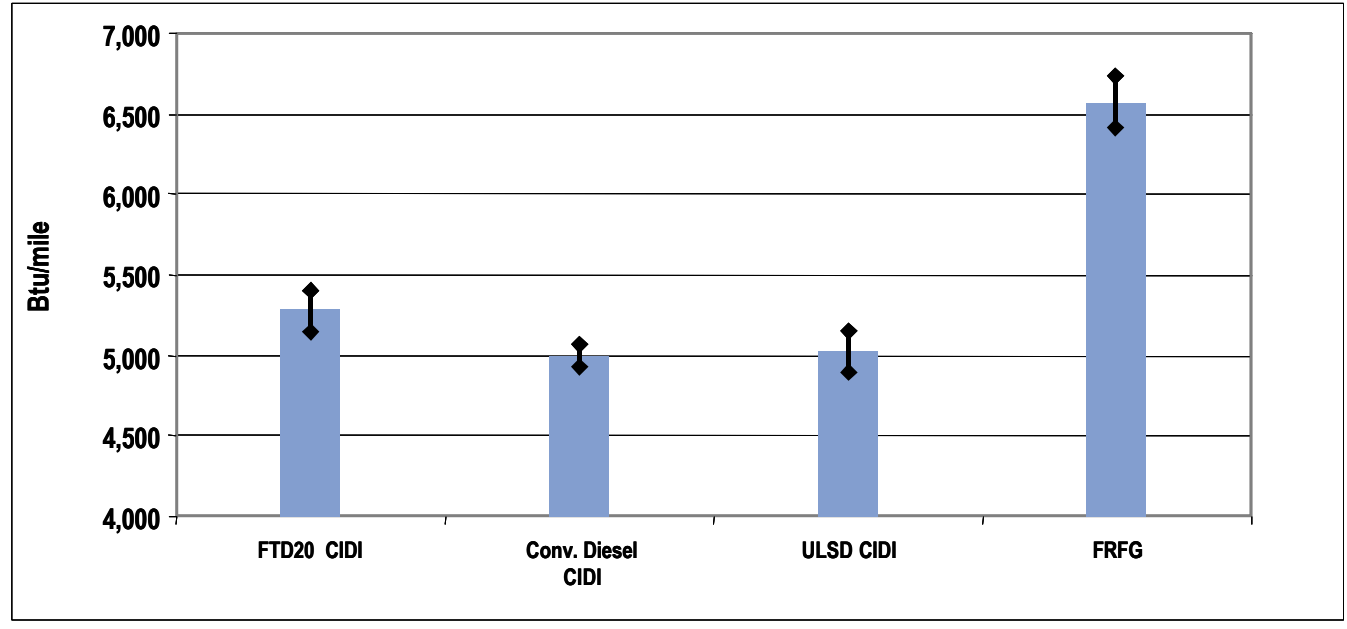

Figure C-1 Uncertainty Analysis: Total Energy, 2006

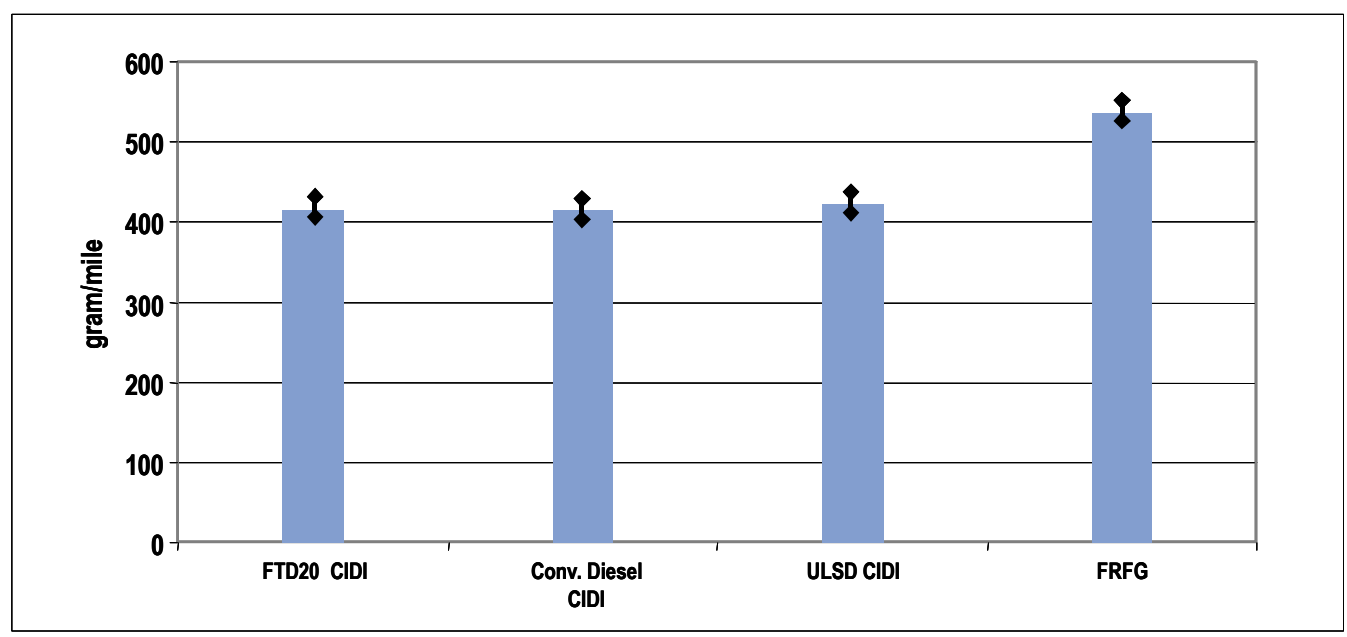

Figure C-2 Uncertainty Analysis: Global Warming Potentials, 2006 


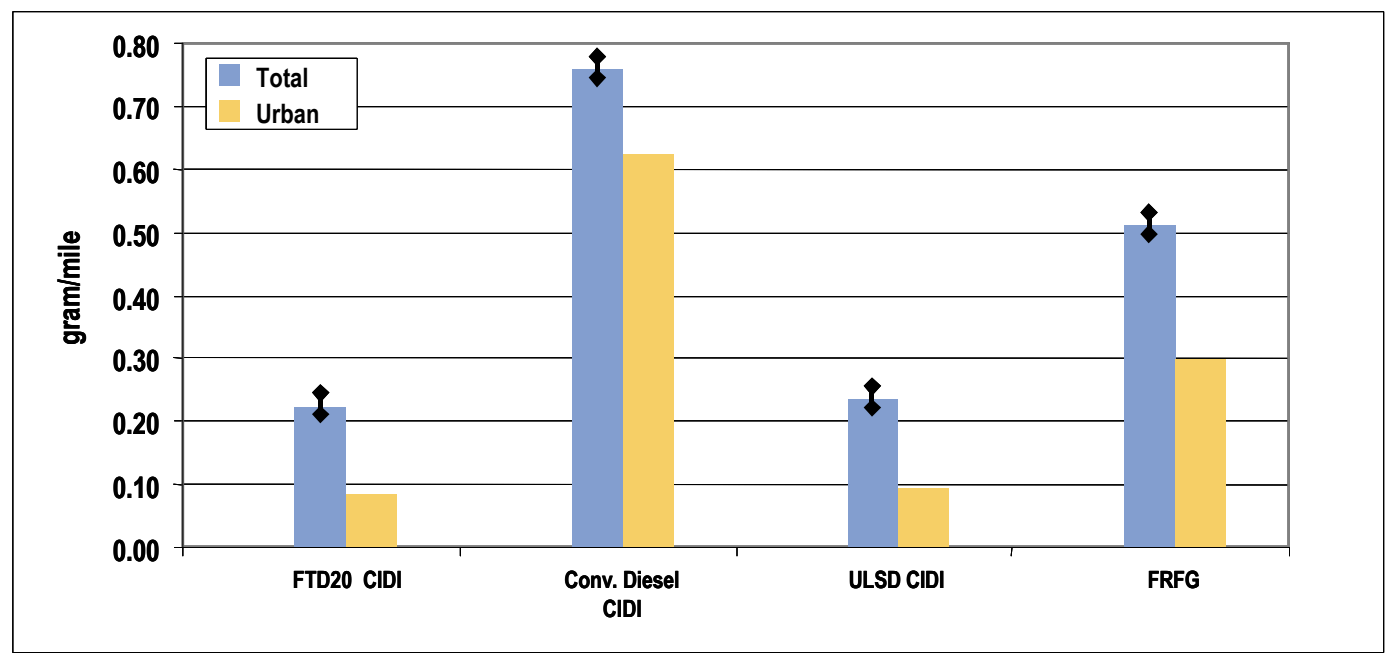

Figure C-3 Uncertainty Analysis: Total and Urban NOx, 2006

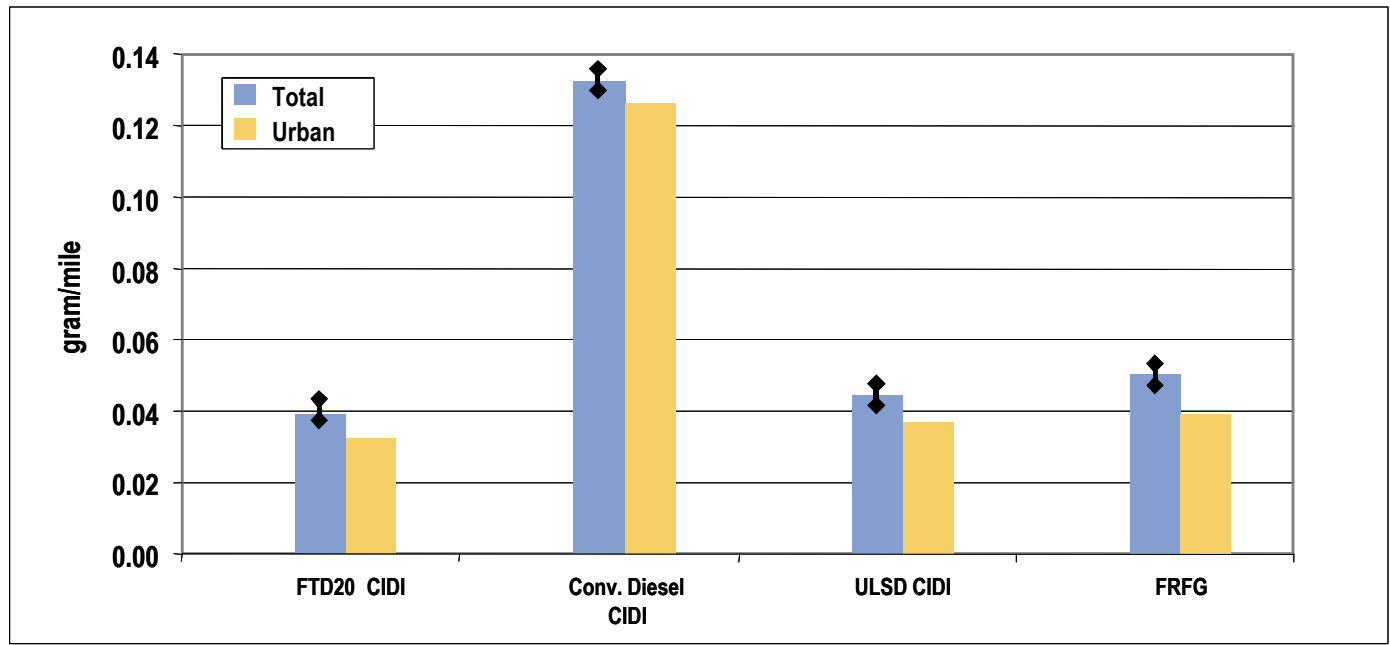

Figure C-4 Uncertainty Analysis: Total and Urban PM10, 2006 


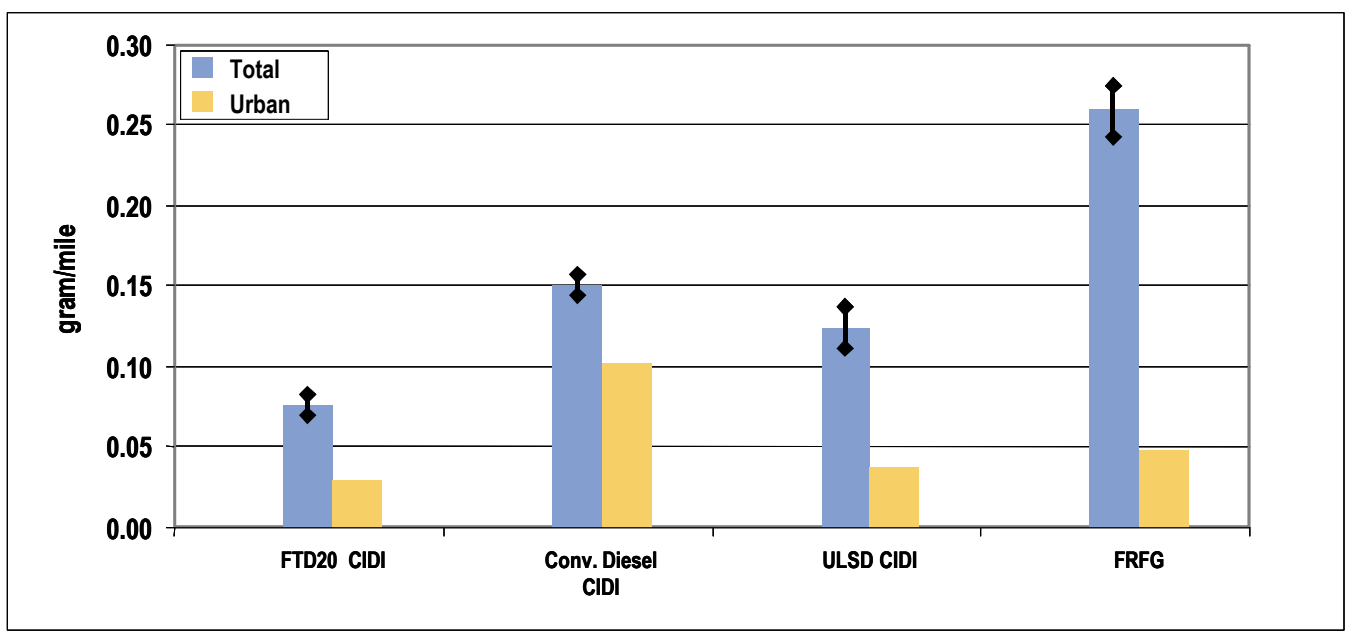

Figure C-5 Uncertainty Analysis: Total and Urban SOX, 2006 


\section{C.3 UNCERTAINTY ANALYIS FOR LONG-TERM SCENARIOS}

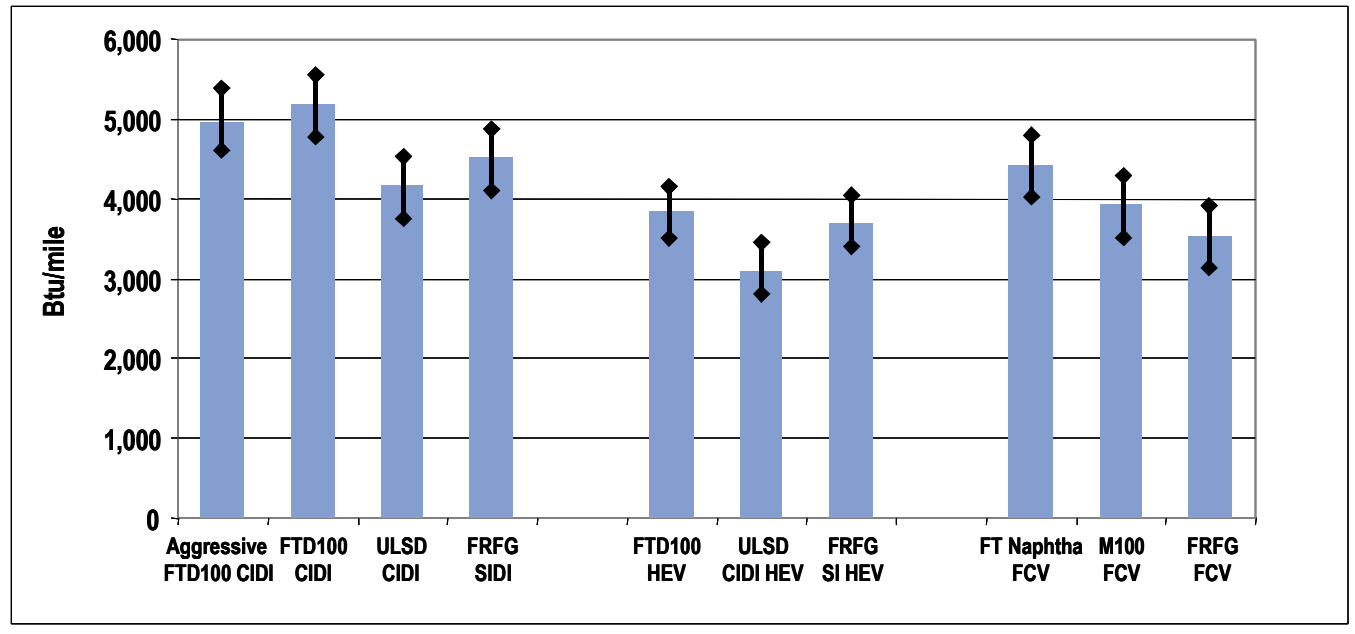

Figure C-6 Uncertainty Analysis: Total Energy, 2015

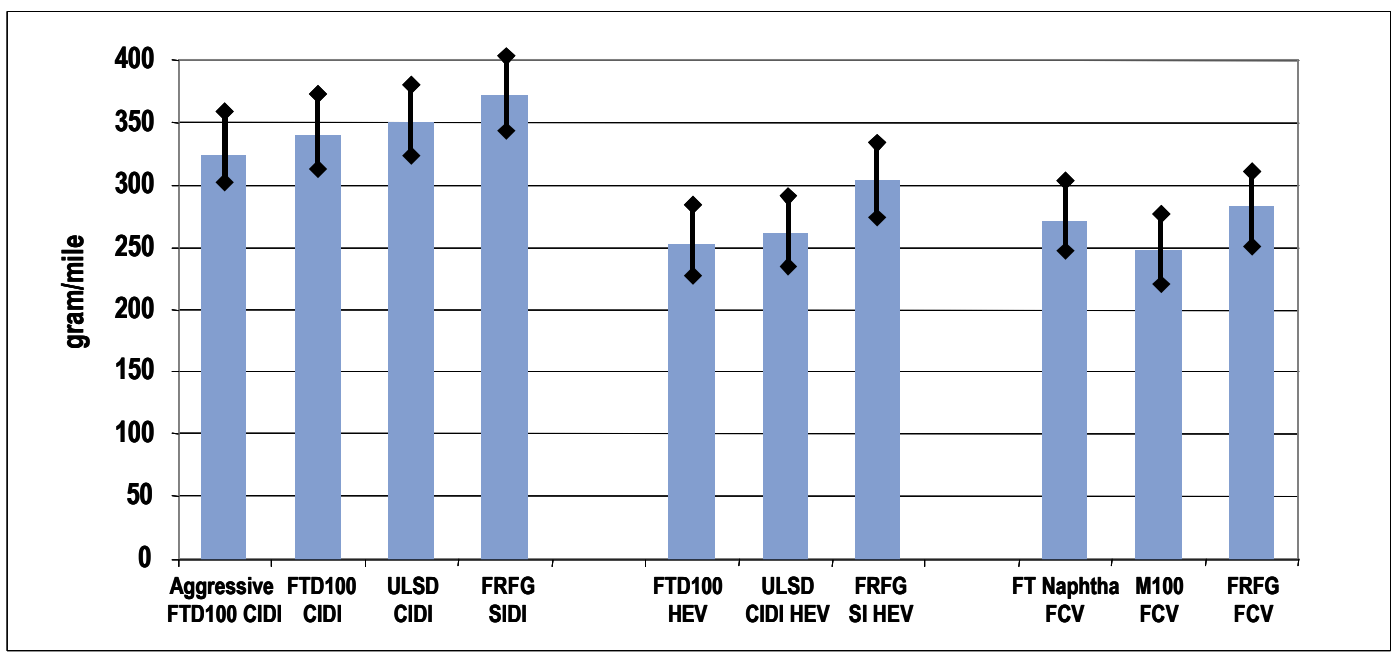

Figure C-7 Uncertainty Analysis: Global Warming Potentials, 2015 


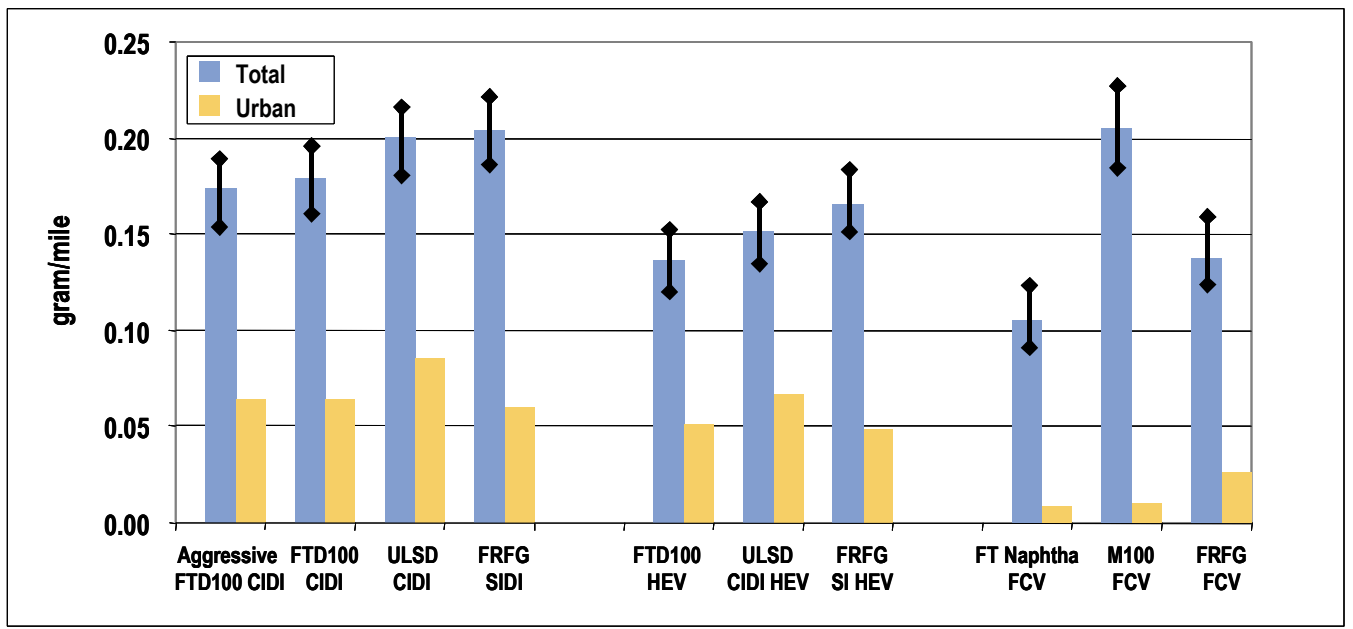

Figure C-8 Uncertainty Analysis: Total and Urban NOX, 2015

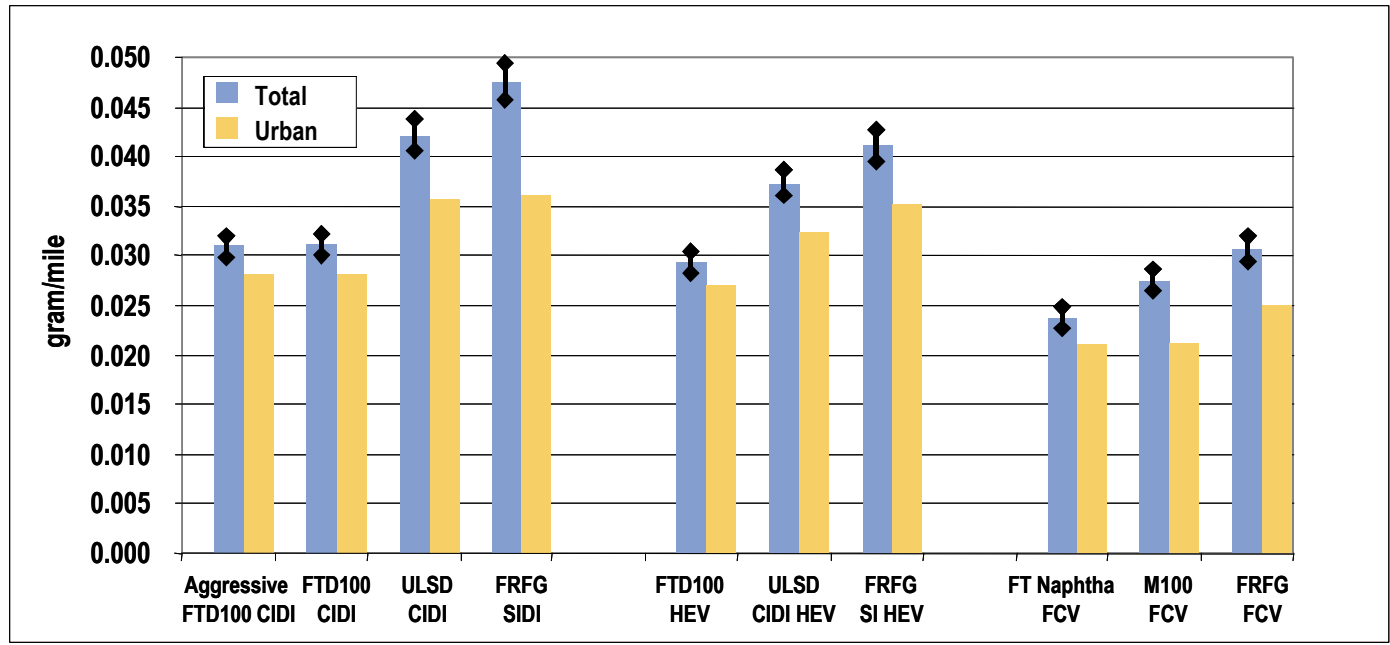

Figure C-9 Uncertainty Analysis: Total and Urban PM10, 2015 


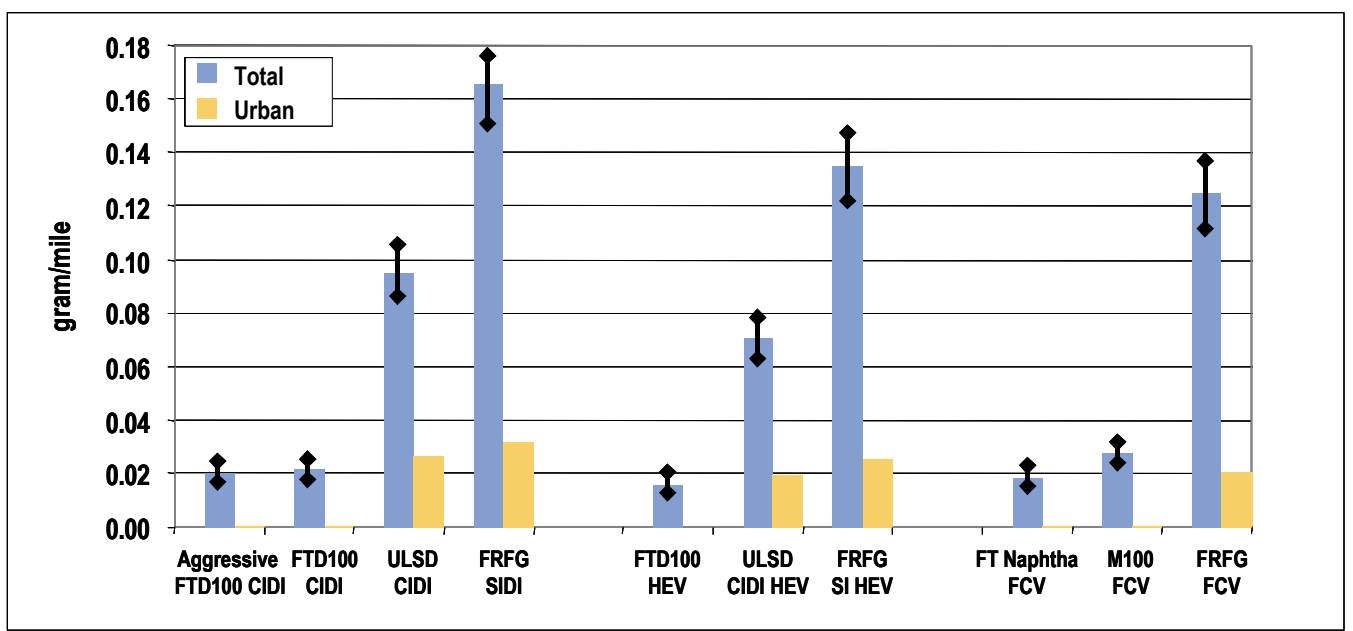

Figure C-10 Uncertainty Analysis: Total and Urban SOx, 2015 


\section{D.1 LCIA RESULTS}

Table D-1 2006 Total LCIA Results

\begin{tabular}{|c|c|c|c|c|}
\hline \multirow[b]{2}{*}{ Indicator Category } & \multirow[b]{2}{*}{ FTD20 CIDI } & \multicolumn{3}{|c|}{ Comparison with FTD20 (FTD20 \% Difference) } \\
\hline & & Conv. Diesel CIDI & ULSD CIDI & FRFG SI \\
\hline GWP & 414.6 & $-0.04 \%$ & $-1.6 \%$ & $-23 \%$ \\
\hline Acidification & $2.8 \mathrm{E}-02$ & $-66 \%$ & $-19 \%$ & $-62 \%$ \\
\hline Smog & $8.2 \mathrm{E}-04$ & $-65 \%$ & $-5 \%$ & $-61 \%$ \\
\hline Eutrophication & 2.2E-05 & $-71 \%$ & $-6 \%$ & $-57 \%$ \\
\hline HH Criteria & 1.5E-05 & $-71 \%$ & $-11 \%$ & $-27 \%$ \\
\hline
\end{tabular}

Table D-2 2015 Total FTD, ULSD and FRFG LCIA Results

\begin{tabular}{|l|r|r|r|}
\hline \multicolumn{1}{|c|}{ Indicator Category } & FTD100 CIDI & \multicolumn{1}{c|}{$\begin{array}{c}\text { ULSD CIDI } \\
\text { \% Difference) }\end{array}$} \\
\hline GWP & 340.1 & $-3 \%$ & \multicolumn{2}{c|}{ FRFG SI } \\
\hline Acidification & $1.7 \mathrm{E}-02$ & $-38 \%$ & $-8 \%$ \\
\hline Smog & $6.6 \mathrm{E}-04$ & $-13 \%$ & $-37 \%$ \\
\hline Eutrophication & $1.7 \mathrm{E}-05$ & $-15 \%$ & $-16 \%$ \\
\hline HH Criteria & $1.2 \mathrm{E}-05$ & $-25 \%$ & $-33 \%$ \\
\hline HH Cancer & $1.23 \mathrm{E}-06$ & $2.5 \%$ & $-96 \%$ \\
\hline HH Non-Cancer & $1.68 \mathrm{E}-06$ & $-96 \%$ & $-99 \%$ \\
\hline Ecotoxicity & $9.59 \mathrm{E}-08$ & $-26 \%$ & $53 \%$ \\
\hline
\end{tabular}

Table D-3 2015 Total HEV LCIA Results

\begin{tabular}{|l|r|r|r|}
\hline \multicolumn{4}{|c|}{$\begin{array}{c}\text { Comparison with FTD100 HEV (FTD100 HEV } \\
\text { \% Difference) }\end{array}$} \\
\hline \multicolumn{1}{|c|}{ Indicator Category } & FTD100 HEV & \multicolumn{1}{c|}{ ULSD HEV } & \multicolumn{1}{c|}{ FRFG HEV } \\
\hline GWP & 252.9 & $-3 \%$ & $-17 \%$ \\
\hline Acidification & $1.3 \mathrm{E}-02$ & $-37 \%$ & $-55 \%$ \\
\hline Smog & $5.4 \mathrm{E}-04$ & $-11 \%$ & $-39 \%$ \\
\hline Eutrophication & $1.3 \mathrm{E}-05$ & $-13 \%$ & $-20 \%$ \\
\hline HH Criteria & $1.1 \mathrm{E}-05$ & $-21 \%$ & $-28 \%$ \\
\hline
\end{tabular}


Table D-4 2015 Total FCV LCIA Results

\begin{tabular}{|l|c|r|r|}
\multicolumn{2}{|c|}{} & \multicolumn{2}{c|}{$\begin{array}{c}\text { Comparison with FT Naphtha FCV (FT } \\
\text { Naphtha FCV \% Difference) }\end{array}$} \\
\hline \multicolumn{1}{|c|}{ Indicator Category } & FT Naphtha FCV & \multicolumn{1}{c|}{ Methanol FCV } & \multicolumn{1}{c|}{ FRFG FCV } \\
\hline GWP & 270.5 & $9 \%$ & $-4 \%$ \\
\hline Acidification & $1.1 \mathrm{E}-02$ & $-47 \%$ & $-57 \%$ \\
\hline Smog & $3.8 \mathrm{E}-04$ & $-47 \%$ & $-38 \%$ \\
\hline Eutrophication & $1.0 \mathrm{E}-05$ & $-49 \%$ & $-24 \%$ \\
\hline HH Criteria & $9.2 \mathrm{E}-06$ & $-17 \%$ & $-23 \%$ \\
\hline
\end{tabular}

Table D-5 2006 Urban LCIA Results

\begin{tabular}{|l|r|r|r|r|r|}
\hline \multicolumn{1}{|c|}{ Indicator Category } & \multicolumn{4}{c|}{ Comparison with FTD20 (FTD20 \% Difference) } \\
\hline Acidification & $1.6 \mathrm{E}-02$ & $-83 \%$ & $-12 \%$ & \multicolumn{1}{c|}{ FRFG SI } \\
\hline Smog & $4.8 \mathrm{E}-04$ & $-80 \%$ & $-27 \%$ & $-71 \%$ \\
\hline Eutrophication & $8.1 \mathrm{E}-06$ & $-86 \%$ & $-7 \%$ & $-71 \%$ \\
\hline HH Criteria & $2.3 \mathrm{E}-05$ & $-74 \%$ & $-11 \%$ & $-20 \%$ \\
\hline
\end{tabular}

Table D-6 2015 Urban FTD, ULSD and FRFG LCIA Results

\begin{tabular}{|l|r|r|r|}
\hline \multicolumn{1}{|c|}{} & \multicolumn{2}{c|}{$\begin{array}{c}\text { Comparison with FTD100 CIDI (FTD100 } \\
\text { CIDI \% Difference) }\end{array}$} \\
\hline Indicator Category & FTD100 CIDI & \multicolumn{1}{|c|}{ ULSD CIDI } & \multicolumn{1}{c|}{ FRFG SI } \\
\hline Acidification & $7.0 \mathrm{E}-03$ & $-54 \%$ & $-46 \%$ \\
\hline Smog & $4.7 \mathrm{E}-04$ & $-25 \%$ & $-52 \%$ \\
\hline Eutrophication & $5.2 \mathrm{E}-06$ & $-35 \%$ & $-8 \%$ \\
\hline HH Criteria & $2.0 \mathrm{E}-05$ & $-22 \%$ & $-30 \%$ \\
\hline
\end{tabular}

Table D-7 2015 Urban HEV LCIA Results

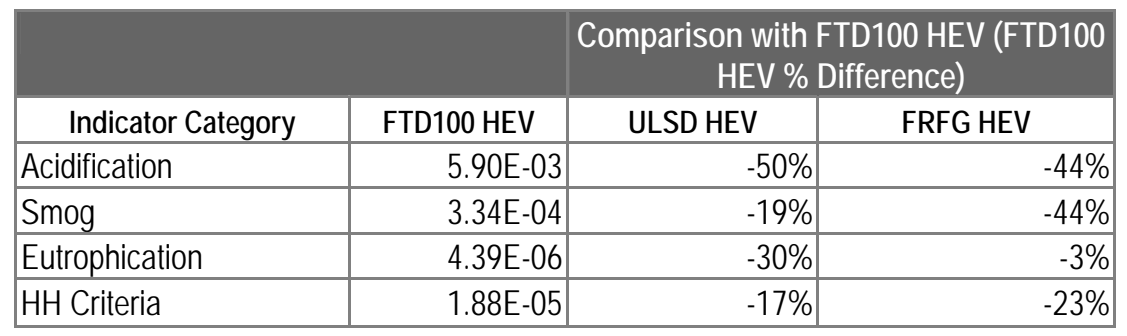


Table D-8 2015 Urban FCV LCIA Results

\begin{tabular}{|l|r|r|r|}
\hline \multicolumn{1}{|c|}{ Indicator Category } & $\begin{array}{c}\text { Comparison with FT Naphtha FCV (FT } \\
\text { Naphtha FCV \% Difference) }\end{array}$ \\
\hline Acidification & FT Naphtha FCV & Methanol FCV & \multicolumn{1}{|c|}{ FRFG FCV } \\
\hline Smog & $1.19 \mathrm{E}-03$ & $-12 \%$ & $-83 \%$ \\
\hline Eutrophication & $1.01 \mathrm{E}-04$ & $-39 \%$ & $-66 \%$ \\
\hline HH Criteria & $8.46 \mathrm{E}-07$ & $-10 \%$ & $-65 \%$ \\
\hline
\end{tabular}

Table D-9 Total LCIA Results for All Scenarios

\begin{tabular}{|c|c|c|c|c|c|c|c|c|}
\hline Vehicle and Fuel & GWP & Acid. & Smog & Eutro. & $\begin{array}{c}\mathrm{HH} \\
\text { Criteria }\end{array}$ & $\begin{array}{c}\mathrm{HH} \\
\text { Cancer }\end{array}$ & $\begin{array}{l}\text { HH Non- } \\
\text { Cancer }\end{array}$ & Ecotox. \\
\hline Conv. Diesel CIDI & 414.7 & $8.4 \mathrm{E}-02$ & $2.4 \mathrm{E}-03$ & 7.4E-05 & $5.2 \mathrm{E}-05$ & NA & NA & NA \\
\hline ULSD CIDI 2006 & 421.2 & $3.5 \mathrm{E}-02$ & 8.7E-04 & 2.3E-05 & 1.7E-05 & NA & NA & NA \\
\hline FRFG SI 2006 & 535.2 & 7.4E-02 & $2.1 \mathrm{E}-03$ & 5.0E-05 & $2.1 \mathrm{E}-05$ & NA & NA & NA \\
\hline FTD20 CIDI 2006 & 414.6 & $2.8 \mathrm{E}-02$ & $8.2 \mathrm{E}-04$ & $2.2 \mathrm{E}-05$ & $1.5 \mathrm{E}-05$ & NA & NA & NA \\
\hline ULSD CIDI 2015 & 350.0 & $2.8 \mathrm{E}-02$ & $7.6 \mathrm{E}-04$ & $2.0 \mathrm{E}-05$ & 4.12E-03 & $1.2 \mathrm{E}-06$ & 4.4E-03 & 1.3E-07 \\
\hline FRFG SI 2015 & 371.4 & 3.7E-02 & $1.0 \mathrm{E}-03$ & $2.0 \mathrm{E}-05$ & $1.8 \mathrm{E}-05$ & 1.35E-05 & 1.41E-02 & $6.27 \mathrm{E}-08$ \\
\hline FTD100 CIDI 2015 & 340.1 & 1.7E-02 & $6.6 \mathrm{E}-04$ & 1.7E-05 & $1.2 \mathrm{E}-05$ & 1.23E-06 & $1.68 \mathrm{E}-04$ & $9.6 \mathrm{E}-08$ \\
\hline ULSD HEV 2015 & 260.6 & $2.1 \mathrm{E}-02$ & $6.1 \mathrm{E}-04$ & $1.5 \mathrm{E}-05$ & $1.4 \mathrm{E}-05$ & NA & NA & NA \\
\hline FRFG HEV 2015 & 304.4 & $3.0 \mathrm{E}-02$ & $8.9 \mathrm{E}-04$ & $1.6 \mathrm{E}-05$ & 1.6E-05 & NA & NA & NA \\
\hline FTD100 HEV 2015 & 252.9 & 1.3E-02 & $5.4 \mathrm{E}-04$ & 1.3E-05 & $1.1 \mathrm{E}-05$ & NA & NA & NA \\
\hline Methanol FCV 2015 & 248.1 & $2.1 \mathrm{E}-02$ & $7.2 \mathrm{E}-04$ & $2.0 \mathrm{E}-05$ & 1.1E-05 & NA & NA & NA \\
\hline FRFG FCV 2015 & 282.7 & $2.6 \mathrm{E}-02$ & $6.2 \mathrm{E}-04$ & $1.3 \mathrm{E}-05$ & $1.2 \mathrm{E}-05$ & NA & NA & NA \\
\hline $\begin{array}{l}\text { FT Naphtha FCV } \\
2015\end{array}$ & 270.5 & $1.1 \mathrm{E}-02$ & $3.8 \mathrm{E}-04$ & 1.0E-05 & $9.2 \mathrm{E}-06$ & NA & NA & NA \\
\hline
\end{tabular}


Table D-10 Houston Urban LCIA Results for All Scenarios

\begin{tabular}{|l|c|c|c|c|c|l|l|}
\multicolumn{1}{|c|}{ Vehicle and Fuel } & Acid. & Smog & Eutro. & $\begin{array}{c}\text { HH } \\
\text { Criteria }\end{array}$ & $\begin{array}{c}\text { HH } \\
\text { Cancer }\end{array}$ & $\begin{array}{c}\text { HH Non- } \\
\text { Cancer }\end{array}$ & Ecotox. \\
\hline Conv. Diesel CIDI & $9.6 \mathrm{E}-02$ & $2.4 \mathrm{E}-03$ & $5.9 \mathrm{E}-05$ & $8.9 \mathrm{E}-05$ & NA & NA & NA \\
\hline ULSD CIDI 2006 & $1.8 \mathrm{E}-02$ & $6.6 \mathrm{E}-04$ & $8.7 \mathrm{E}-06$ & $2.6 \mathrm{E}-05$ & NA & NA & NA \\
\hline FRFG SI 2006 & $4.6 \mathrm{E}-02$ & $1.7 \mathrm{E}-03$ & $2.8 \mathrm{E}-05$ & $2.8 \mathrm{E}-05$ & NA & NA & NA \\
\hline FTD20 CIDI 2006 & $1.6 \mathrm{E}-02$ & $4.8 \mathrm{E}-04$ & $8.1 \mathrm{E}-06$ & $2.3 \mathrm{E}-05$ & NA & NA & NA \\
\hline & & & & & & & \\
\hline ULSD CIDI 2015 & $1.5 \mathrm{E}-02$ & $6.3 \mathrm{E}-04$ & $8.0 \mathrm{E}-06$ & $2.5 \mathrm{E}-05$ & $\mathrm{NA}$ & NA & NA \\
\hline FRFG SI 2015 & $1.3 \mathrm{E}-02$ & $9.9 \mathrm{E}-04$ & $5.6 \mathrm{E}-06$ & $2.8 \mathrm{E}-05$ & NA & NA & NA \\
\hline FTD100 CIDI 2015 & $7.0 \mathrm{E}-03$ & $4.7 \mathrm{E}-04$ & $5.2 \mathrm{E}-06$ & $2.0 \mathrm{E}-05$ & NA & NA & NA \\
\hline & & & & & & & \\
\hline ULSD HEV 2015 & $1.2 \mathrm{E}-02$ & $4.1 \mathrm{E}-04$ & $6.3 \mathrm{E}-06$ & $2.3 \mathrm{E}-05$ & NA & NA & NA \\
\hline FRFG HEV 2015 & $1.0 \mathrm{E}-02$ & $6.0 \mathrm{E}-04$ & $4.5 \mathrm{E}-06$ & $2.4 \mathrm{E}-05$ & NA & NA & NA \\
\hline FTD100 HEV 2015 & $5.9 \mathrm{E}-03$ & $3.3 \mathrm{E}-04$ & $4.4 \mathrm{E}-06$ & $1.9 \mathrm{E}-05$ & NA & NA & NA \\
\hline & & & & & & & \\
\hline Methanol FCV 2015 & $1.4 \mathrm{E}-03$ & $1.6 \mathrm{E}-04$ & $9.4 \mathrm{E}-07$ & $1.5 \mathrm{E}-05$ & NA & NA & NA \\
\hline FRFG FCV 2015 & $6.8 \mathrm{E}-03$ & $3.0 \mathrm{E}-04$ & $2.4 \mathrm{E}-06$ & $1.7 \mathrm{E}-05$ & NA & NA & NA \\
\hline FT Naphtha FCV 2015 & $1.2 \mathrm{E}-03$ & $1.0 \mathrm{E}-04$ & $8.5 \mathrm{E}-07$ & $1.5 \mathrm{E}-05$ & NA & NA & NA \\
\hline
\end{tabular}




\section{D.2 2006 SCENARIOS}

Table D-11 TRACI Data for Conventional Diesel CIDI 2006

\begin{tabular}{|c|c|c|c|c|c|c|}
\hline Impact Category & Stage & Emission & Media & \begin{tabular}{|c|} 
Quantity \\
(grams/mile)
\end{tabular} & $\begin{array}{l}\text { Characterization } \\
\text { Result / mile }\end{array}$ & Factor Measure \\
\hline Acidification & Feedstock & NITROGEN OXIDES & Air & 0.0917 & 0.008095 & moles $\mathrm{H}+$ equiv \\
\hline Acidification & Feedstock & SULFUR OXIDES & Air & 0.0189 & 0.002116 & moles $\mathrm{H}+$ equiv \\
\hline Acidification & Fuel & HYDROGEN FLUORIDE & Air & 5.3E-06 & $9.5 \mathrm{E}-07$ & moles $\mathrm{H}+$ equiv \\
\hline Acidification & Fuel & SULFUR OXIDES & Air & 0.0574 & 0.006427 & moles $\mathrm{H}+$ equiv \\
\hline Acidification & Fuel & NITROGEN OXIDES (NOXO & Air & 0.0672 & 0.005932 & moles $\mathrm{H}+$ equiv \\
\hline Acidification & Fuel & HYDROCHLORIC ACID & Air & 2.12E-05 & 2.09E-06 & moles $\mathrm{H}+$ equiv \\
\hline Acidification & Vehicle & NITROGEN OXIDES & Air & 0.6 & 0.052963 & moles $\mathrm{H}+$ equiv \\
\hline Acidification & Vehicle & SULFUR OXIDES & Air & 0.074 & 0.008286 & moles $\mathrm{H}+$ equiv \\
\hline Ecotoxicity & Feedstock & BENZENE & Air & 5.75E-06 & 3.8E-14 & Ibs 2,4-D equiv \\
\hline Ecotoxicity & Feedstock & ETHYLBENZENE & Air & 4.79E-07 & $4.65 \mathrm{E}-15$ & Ibs 2,4-D equiv \\
\hline Ecotoxicity & Feedstock & NICKEL & Water & 1.02E-05 & 7.19E-08 & Ibs 2,4-D equiv \\
\hline Ecotoxicity & Fuel & TOLUENE & Air & 3.59E-06 & 3.56E-14 & Ibs 2,4-D equiv \\
\hline Ecotoxicity & Fuel & 1,2-DICHLOROETHANE & Air & 3.39E-07 & $4.11 \mathrm{E}-14$ & Ibs 2,4-D equiv \\
\hline Ecotoxicity & Fuel & 1,3-BUTADIENE & Air & 1.74E-06 & 2.03E-16 & Ibs 2,4-D equiv \\
\hline Ecotoxicity & Fuel & BENZENE & Air & 4.74E-05 & 3.13E-13 & Ibs 2,4-D equiv \\
\hline Ecotoxicity & Fuel & CARBON DISULFIDE & Air & 7.33E-07 & $1.78 \mathrm{E}-11$ & Ibs 2,4-D equiv \\
\hline Ecotoxicity & Fuel & CARBON TETRACHLORIDE & Air & 1.47E-07 & 1.07E-12 & Ibs 2,4-D equiv \\
\hline Ecotoxicity & Fuel & DIBUTYL PHTHALATE & Air & 6.71E-08 & 1.01E-09 & Ibs 2,4-D equiv \\
\hline Ecotoxicity & Fuel & ETHYLBENZENE & Air & 1.45E-05 & $1.41 \mathrm{E}-13$ & Ibs 2,4-D equiv \\
\hline Ecotoxicity & Fuel & FORMALDEHYDE & Air & 2.91E-06 & $1.86 \mathrm{E}-10$ & Ibs 2,4-D equiv \\
\hline Ecotoxicity & Fuel & M-XYLENE & Air & 2.86E-06 & 4.54E-15 & Ibs 2,4-D equiv \\
\hline Ecotoxicity & Fuel & NAPHTHALENE & Air & 4.43E-06 & $3.71 \mathrm{E}-10$ & Ibs 2,4-D equiv \\
\hline Ecotoxicity & Fuel & O-XYLENE & Air & 2.42E-06 & $8.54 \mathrm{E}-15$ & Ibs 2,4-D equiv \\
\hline Ecotoxicity & Fuel & P-XYLENE & Air & 3.04E-06 & $6.37 \mathrm{E}-15$ & Ibs 2,4-D equiv \\
\hline Ecotoxicity & Fuel & PHENOL & Air & 2.85E-06 & 2.39E-10 & Ibs 2,4-D equiv \\
\hline Ecotoxicity & Fuel & PROPYLENE OXIDE & Air & 0 & 0 & Ibs 2,4-D equiv \\
\hline Ecotoxicity & Fuel & STYRENE & Air & 2.82E-07 & 7.46E-16 & Ibs 2,4-D equiv \\
\hline Ecotoxicity & Fuel & TETRACHLOROETHYLENE & Air & 1.35E-06 & 1.99E-12 & Ibs 2,4-D equiv \\
\hline Ecotoxicity & Fuel & TOLUENE & Air & 0.000104 & 1.03E-12 & Ibs 2,4-D equiv \\
\hline Ecotoxicity & Fuel & TRICHLOROETHYLENE & Air & 1.44E-06 & 1.27E-14 & Ibs 2,4-D equiv \\
\hline Ecotoxicity & Fuel & CHLOROFORM & Air & 3.85E-07 & 1.02E-13 & Ibs 2,4-D equiv \\
\hline Ecotoxicity & Fuel & 1,1,1-TRICHLOROETHANE & Air & 2.59E-08 & $5.08 \mathrm{E}-14$ & Ibs 2,4-D equiv \\
\hline Eutrophication & Feedstock & NITROGEN OXIDES & Air & 0.0917 & 8.95E-06 & $\mathrm{kg} \mathrm{N}$ \\
\hline Eutrophication & Fuel & NITROGEN OXIDES & Air & 0.0672 & $6.56 \mathrm{E}-06$ & $\mathrm{~kg} \mathrm{~N}$ \\
\hline Eutrophication & Vehicle & NITROGEN OXIDES & Air & 0.6 & 5.86E-05 & $\mathrm{kg} \mathrm{N}$ \\
\hline $\mathrm{HH}$ - Cancer & Feedstock & BENZENE & Air & 5.75E-06 & 1.27E-08 & Ibs $\mathrm{C} 6 \mathrm{H} 6$ equiv \\
\hline $\mathrm{HH}$ - Cancer & Fuel & 1,2-DIBROMOETHANE & Air & 2.22E-07 & 4.12E-09 & Ibs $\mathrm{C} 6 \mathrm{H} 6$ equiv \\
\hline $\mathrm{HH}$ - Cancer & Fuel & 1,2-DICHLOROETHANE & Air & 3.39E-07 & 3.98E-09 & Ibs $\mathrm{C} 6 \mathrm{H} 6$ equiv \\
\hline
\end{tabular}




\begin{tabular}{|c|c|c|c|c|c|c|}
\hline Impact Category & Stage & Emission & Media & \begin{tabular}{|c|} 
Quantity \\
(grams/mile)
\end{tabular} & $\begin{array}{l}\text { Characterization } \\
\text { Result / mile }\end{array}$ & Factor Measure \\
\hline $\mathrm{HH}$ - Cancer & Fuel & 1,3-BUTADIENE & Air & $1.74 \mathrm{E}-06$ & 1.27E-09 & Ibs $\mathrm{C} 6 \mathrm{H} 6$ equiv \\
\hline $\mathrm{HH}$ - Cancer & Fuel & BENZENE & Air & 4.74E-05 & 1.04E-07 & Ibs $\mathrm{C} 6 \mathrm{H} 6$ equiv \\
\hline $\mathrm{HH}$ - Cancer & Fuel & CADMIUM COMPOUNDS & Air & 0 & 0 & Ibs $\mathrm{C} 6 \mathrm{H} 6$ equiv \\
\hline $\mathrm{HH}$ - Cancer & Fuel & CARBON TETRACHLORIDE & Air & $1.47 \mathrm{E}-07$ & 2.66E-07 & Ibs $\mathrm{C} 6 \mathrm{H} 6$ equiv \\
\hline $\mathrm{HH}$ - Cancer & Fuel & CHROMIUM COMPOUNDS & Air & $1.21 \mathrm{E}-08$ & 4.46E-09 & Ibs $\mathrm{C} 6 \mathrm{H} 6$ equiv \\
\hline $\mathrm{HH}$ - Cancer & Fuel & DIMETHYL SULFATE & Air & 0 & 0 & Ibs $\mathrm{C} 6 \mathrm{H} 6$ equiv \\
\hline $\mathrm{HH}$ - Cancer & Fuel & ETHYLENE OXIDE & Air & 3.93E-07 & 2.67E-08 & Ibs C6H6 equiv \\
\hline $\mathrm{HH}$ - Cancer & Fuel & FORMALDEHYDE & Air & 2.91E-06 & $1.94 \mathrm{E}-11$ & Ibs $\mathrm{C} 6 \mathrm{H} 6$ equiv \\
\hline $\mathrm{HH}$ - Cancer & Fuel & HYDRAZINE & Air & 0 & 0 & Ibs $\mathrm{C} 6 \mathrm{H} 6$ equiv \\
\hline $\mathrm{HH}$ - Cancer & Fuel & HYDROQUINONE & Air & 0 & 0 & Ibs $\mathrm{C} 6 \mathrm{H} 6$ equiv \\
\hline $\mathrm{HH}$ - Cancer & Fuel & LEAD COMPOUNDS & Air & 7.35E-08 & 5.75E-09 & Ibs $\mathrm{C} 6 \mathrm{H} 6$ equiv \\
\hline $\mathrm{HH}$ - Cancer & Fuel & NICKEL COMPOUNDS & Air & 4.63E-07 & 3.69E-09 & Ibs C6H6 equiv \\
\hline $\mathrm{HH}$ - Cancer & Fuel & O-TOLUIDINE & Air & 2.26E-10 & $4.53 E-15$ & Ibs $\mathrm{C} 6 \mathrm{H} 6$ equiv \\
\hline $\mathrm{HH}$ - Cancer & Fuel & PROPYLENE OXIDE & Air & 0 & 0 & Ibs $\mathrm{C} 6 \mathrm{H} 6$ equiv \\
\hline $\mathrm{HH}$ - Cancer & Fuel & TETRACHLOROETHYLENE & Air & 1.35E-06 & 5.42E-09 & Ibs $\mathrm{C} 6 \mathrm{H} 6$ equiv \\
\hline $\mathrm{HH}$ - Cancer & Fuel & TRICHLOROETHYLENE & Air & 1.44E-06 & 1.86E-10 & Ibs $\mathrm{C} 6 \mathrm{H} 6$ equiv \\
\hline $\mathrm{HH}$ - Cancer & Fuel & CHLOROMETHANE & Air & 3.13E-08 & $2.43 \mathrm{E}-10$ & Ibs $\mathrm{C} 6 \mathrm{H} 6$ equiv \\
\hline $\mathrm{HH}$ - Cancer & Fuel & CHLOROFORM & Air & 3.85E-07 & 3.88E-09 & Ibs $\mathrm{C} 6 \mathrm{H} 6$ equiv \\
\hline $\mathrm{HH}$ - Cancer & Fuel & ACETALDEHYDE & Air & $1.31 \mathrm{E}-08$ & $1.02 \mathrm{E}-13$ & Ibs $\mathrm{C} 6 \mathrm{H} 6$ equiv \\
\hline $\mathrm{HH}$ - Cancer & Fuel & ANILINE & Air & $2.26 \mathrm{E}-10$ & $1.13 \mathrm{E}-15$ & Ibs $\mathrm{C} 6 \mathrm{H} 6$ equiv \\
\hline $\mathrm{HH}$ - Criteria & Feedstock & NITROGEN OXIDES & Air & 0.0917 & 4.47E-07 & total DALYs \\
\hline $\mathrm{HH}$ - Criteria & Feedstock & PM10 & Air & 0.0028 & 5.15E-07 & total DALYs \\
\hline $\mathrm{HH}$ - Criteria & Feedstock & PM2.5 & Air & 0.00168 & 5.15E-07 & total DALYs \\
\hline $\mathrm{HH}$ - Criteria & Fuel & PM10 & Air & 0.00858 & $1.58 \mathrm{E}-06$ & total DALYs \\
\hline $\mathrm{HH}$ - Criteria & Fuel & PM2.5 & Air & 0.00515 & 1.58E-06 & total DALYs \\
\hline $\mathrm{HH}$ - Criteria & Fuel & NITROGEN OXIDES & Air & 0.0672 & $3.28 \mathrm{E}-07$ & total DALYs \\
\hline $\mathrm{HH}$ - Criteria & Vehicle & NITROGEN OXIDES & Air & 0.6 & 2.93E-06 & total DALYs \\
\hline $\mathrm{HH}$ - Criteria & Vehicle & PM10 & Air & 0.121 & 2.23E-05 & total DALYs \\
\hline $\mathrm{HH}$ - Criteria & Vehicle & PM2.5 & Air & 0.0726 & 2.23E-05 & total DALYs \\
\hline $\mathrm{HH}$ - Non-can & Feedstock & BENZENE & Air & 5.75E-06 & $2.1 \mathrm{E}-07$ & Ibs $\mathrm{C} 6 \mathrm{H} 6$ equiv \\
\hline $\mathrm{HH}$ - Non-can & Feedstock & ETHYLBENZENE & Air & 4.79E-07 & $3.51 \mathrm{E}-10$ & Ibs $\mathrm{C} 6 \mathrm{H} 6$ equiv \\
\hline $\mathrm{HH}$ - Non-can & Feedstock & TOLUENE & Air & 3.59E-06 & 7.92E-09 & Ibs $\mathrm{C} 6 \mathrm{H} 6$ equiv \\
\hline $\mathrm{HH}$ - Non-can & Feedstock & XYLENE & Air & 2.04E-06 & 1.05E-09 & Ibs $\mathrm{C} 6 \mathrm{H} 6$ equiv \\
\hline HH - Non-can & Fuel & 1,1,1-TRICHLOROETHANE & Air & 2.59E-08 & 1.14E-08 & Ibs $\mathrm{C} 6 \mathrm{H} 6$ equiv \\
\hline $\mathrm{HH}$ - Non-can & Fuel & 1,2,4-TRICHLOROBENZENE & Air & 3.3E-08 & 2.19E-09 & Ibs $\mathrm{C} 6 \mathrm{H} 6$ equiv \\
\hline $\mathrm{HH}$ - Non-can & Fuel & 1,2-DIBROMOETHANE & Air & 2.22E-07 & 2E-06 & Ibs $\mathrm{C} 6 \mathrm{H} 6$ equiv \\
\hline $\mathrm{HH}$ - Non-can & Fuel & 1,2-DICHLOROETHANE & Air & 3.39E-07 & $1.41 \mathrm{E}-08$ & Ibs $\mathrm{C} 6 \mathrm{H} 6$ equiv \\
\hline $\mathrm{HH}$ - Non-can & Fuel & 1,3-BUTADIENE & Air & $1.74 \mathrm{E}-06$ & 4.66E-09 & Ibs $\mathrm{C} 6 \mathrm{H} 6$ equiv \\
\hline $\mathrm{HH}$ - Non-can & Fuel & ANTIMONY COMPOUNDS & Air & 7.03E-08 & 3E-06 & Ibs $\mathrm{C} 6 \mathrm{H} 6$ equiv \\
\hline $\mathrm{HH}$ - Non-can & Fuel & BENZENE & Air & 4.74E-05 & 1.73E-06 & Ibs $\mathrm{C} 6 \mathrm{H} 6$ equiv \\
\hline $\mathrm{HH}$ - Non-can & Fuel & BIPHENYL & Air & 2.82E-07 & $4.17 \mathrm{E}-10$ & Ibs $\mathrm{C} 6 \mathrm{H} 6$ equiv \\
\hline HH - Non-can & Fuel & CADMIUM COMPOUNDS & Air & 0 & 0 & Ibs $\mathrm{C} 6 \mathrm{H} 6$ equiv \\
\hline
\end{tabular}




\begin{tabular}{|c|c|c|c|c|c|c|}
\hline Impact Category & Stage & Emission & Media & \begin{tabular}{|c|} 
Quantity \\
(grams/mile)
\end{tabular} & $\begin{array}{l}\text { Characterization } \\
\text { Result / mile }\end{array}$ & Factor Measure \\
\hline $\mathrm{HH}-$ Non-can & Fuel & CARBON DISULFIDE & Air & 7.33E-07 & 7.58E-09 & Ibs C6H6 equiv \\
\hline $\mathrm{HH}$ - Non-can & Fuel & CARBON TETRACHLORIDE & Air & 1.47E-07 & 4.47E-06 & Ibs C6H6 equiv \\
\hline $\mathrm{HH}$ - Non-can & Fuel & CHLOROBENZENE & Air & 0 & 0 & Ibs $\mathrm{C} 6 \mathrm{H} 6$ equiv \\
\hline $\mathrm{HH}$ - Non-can & Fuel & CHROMIUM COMPOUNDS & Air & $1.21 \mathrm{E}-08$ & 1.7E-07 & Ibs $\mathrm{C} 6 \mathrm{H} 6$ equiv \\
\hline HH - Non-can & Fuel & COBALT COMPOUNDS & Air & $1.56 \mathrm{E}-08$ & 2.72E-06 & Ibs $\mathrm{C} 6 \mathrm{H} 6$ equiv \\
\hline HH - Non-can & Fuel & CUMENE & Air & 4.77E-06 & 3.28E-09 & Ibs $\mathrm{C} 6 \mathrm{H} 6$ equiv \\
\hline HH - Non-can & Fuel & DIBUTYL PHTHALATE & Air & 6.71E-08 & 2.99E-09 & Ibs C6H6 equiv \\
\hline $\mathrm{HH}$ - Non-can & Fuel & DIETHANOLAMINE & Air & 3.29E-06 & 1.05E-07 & Ibs C6H6 equiv \\
\hline $\mathrm{HH}$ - Non-can & Fuel & ETHYLBENZENE & Air & $1.45 \mathrm{E}-05$ & 1.06E-08 & Ibs $\mathrm{C} 6 \mathrm{H} 6$ equiv \\
\hline HH - Non-can & Fuel & ETHYLENE GLYCOL & Air & $1.73 \mathrm{E}-06$ & 9.34E-10 & Ibs $\mathrm{C} 6 \mathrm{H} 6$ equiv \\
\hline $\mathrm{HH}$ - Non-can & Fuel & ETHYLENE OXIDE & Air & $3.93 \mathrm{E}-07$ & $1.71 \mathrm{E}-06$ & Ibs $\mathrm{C} 6 \mathrm{H} 6$ equiv \\
\hline HH - Non-can & Fuel & FORMALDEHYDE & Air & 2.91E-06 & 3.06E-08 & Ibs C6H6 equiv \\
\hline $\mathrm{HH}$ - Non-can & Fuel & HYDRAZINE & Air & 0 & 0 & Ibs $\mathrm{C} 6 \mathrm{H} 6$ equiv \\
\hline $\mathrm{HH}$ - Non-can & Fuel & HYDROQUINONE & Air & 0 & 0 & Ibs $\mathrm{C} 6 \mathrm{H} 6$ equiv \\
\hline HH - Non-can & Fuel & LEAD COMPOUNDS & Air & 7.35E-08 & 0.000243 & Ibs $\mathrm{C} 6 \mathrm{H} 6$ equiv \\
\hline $\mathrm{HH}$ - Non-can & Fuel & M-CRESOL & Air & 0 & 0 & Ibs $\mathrm{C} 6 \mathrm{H} 6$ equiv \\
\hline HH - Non-can & Fuel & M-XYLENE & Air & 2.86E-06 & 1.05E-09 & Ibs $\mathrm{C} 6 \mathrm{H} 6$ equiv \\
\hline $\mathrm{HH}$ - Non-can & Fuel & MALEIC ANHYDRIDE & Air & 7.91E-10 & $3.01 \mathrm{E}-10$ & Ibs $\mathrm{C} 6 \mathrm{H} 6$ equiv \\
\hline $\mathrm{HH}$ - Non-can & Fuel & MANGANESE COMPOUNDS & Air & 1.93E-08 & 3.38E-07 & Ibs $\mathrm{C} 6 \mathrm{H} 6$ equiv \\
\hline $\mathrm{HH}$ - Non-can & Fuel & MERCURY COMPOUNDS & Air & 1.12E-07 & 0.004754 & Ibs $\mathrm{C} 6 \mathrm{H} 6$ equiv \\
\hline $\mathrm{HH}$ - Non-can & Fuel & METHANOL & Air & 0.000104 & $2.51 \mathrm{E}-08$ & Ibs $\mathrm{C} 6 \mathrm{H} 6$ equiv \\
\hline $\mathrm{HH}$ - Non-can & Fuel & METHYL ETHYL KETONE & Air & 7.45E-05 & 1.87E-08 & Ibs $\mathrm{C} 6 \mathrm{H} 6$ equiv \\
\hline HH - Non-can & Fuel & METHYL ISOBUTYL KETONE & Air & 5.48E-06 & 8.85E-09 & Ibs $\mathrm{C} 6 \mathrm{H} 6$ equiv \\
\hline $\mathrm{HH}$ - Non-can & Fuel & METHYL TERT-BUTYL ETHER & Air & 4.09E-05 & 8.13E-09 & Ibs $\mathrm{C} 6 \mathrm{H} 6$ equiv \\
\hline $\mathrm{HH}$ - Non-can & Fuel & N-HEXANE & Air & 7.57E-05 & $1.01 \mathrm{E}-07$ & Ibs $\mathrm{C} 6 \mathrm{H} 6$ equiv \\
\hline $\mathrm{HH}$ - Non-can & Fuel & NAPHTHALENE & Air & 4.43E-06 & 1.24E-07 & Ibs $\mathrm{C} 6 \mathrm{H} 6$ equiv \\
\hline HH - Non-can & Fuel & NICKEL COMPOUNDS & Air & 4.63E-07 & 8.43E-06 & Ibs $\mathrm{C} 6 \mathrm{H} 6$ equiv \\
\hline $\mathrm{HH}$ - Non-can & Fuel & O-CRESOL & Air & 0 & 0 & Ibs $\mathrm{C} 6 \mathrm{H} 6$ equiv \\
\hline $\mathrm{HH}$ - Non-can & Fuel & O-XYLENE & Air & 2.42E-06 & 1.5E-09 & Ibs $\mathrm{C} 6 \mathrm{H} 6$ equiv \\
\hline $\mathrm{HH}$ - Non-can & Fuel & P-CRESOL & Air & 0 & 0 & Ibs $\mathrm{C} 6 \mathrm{H} 6$ equiv \\
\hline $\mathrm{HH}$ - Non-can & Fuel & P-XYLENE & Air & 3.04E-06 & $1.8 \mathrm{E}-09$ & Ibs $\mathrm{C} 6 \mathrm{H} 6$ equiv \\
\hline $\mathrm{HH}$ - Non-can & Fuel & PHENOL & Air & 2.85E-06 & $3.59 \mathrm{E}-10$ & Ibs $\mathrm{C} 6 \mathrm{H} 6$ equiv \\
\hline $\mathrm{HH}$ - Non-can & Fuel & PROPYLENE OXIDE & Air & 0 & 0 & Ibs $\mathrm{C} 6 \mathrm{H} 6$ equiv \\
\hline $\mathrm{HH}$ - Non-can & Fuel & SELENIUM COMPOUNDS & Air & 5.77E-09 & 2.69E-07 & Ibs $\mathrm{C} 6 \mathrm{H} 6$ equiv \\
\hline $\mathrm{HH}$ - Non-can & Fuel & STYRENE & Air & 2.82E-07 & 1.79E-11 & Ibs $\mathrm{C} 6 \mathrm{H} 6$ equiv \\
\hline $\mathrm{HH}$ - Non-can & Fuel & TETRACHLOROETHYLENE & Air & 1.35E-06 & $6.42 \mathrm{E}-07$ & Ibs $\mathrm{C} 6 \mathrm{H} 6$ equiv \\
\hline $\mathrm{HH}$ - Non-can & Fuel & TOLUENE & Air & 0.000104 & 2.29E-07 & Ibs $\mathrm{C} 6 \mathrm{H} 6$ equiv \\
\hline $\mathrm{HH}$ - Non-can & Fuel & TRICHLOROETHYLENE & Air & 1.44E-06 & 3.12E-09 & Ibs $\mathrm{C} 6 \mathrm{H} 6$ equiv \\
\hline $\mathrm{HH}$ - Non-can & Fuel & TRIETHYLAMINE & Air & 0 & 0 & Ibs $\mathrm{C} 6 \mathrm{H} 6$ equiv \\
\hline $\mathrm{HH}$ - Non-can & Fuel & VINYL ACETATE & Air & 8.05E-09 & $3.42 \mathrm{E}-11$ & Ibs $\mathrm{C} 6 \mathrm{H} 6$ equiv \\
\hline $\mathrm{HH}$ - Non-can & Fuel & CHLOROMETHANE & Air & 3.13E-08 & 3.72E-08 & Ibs $\mathrm{C} 6 \mathrm{H} 6$ equiv \\
\hline HH - Non-can & Fuel & XYLENE & Air & 6.37E-05 & 3.28E-08 & Ibs $\mathrm{C} 6 \mathrm{H} 6$ equiv \\
\hline
\end{tabular}




\begin{tabular}{|c|c|c|c|c|c|c|}
\hline Impact Category & Stage & Emission & Media & \begin{tabular}{|c||} 
Quantity \\
(grams/mile)
\end{tabular} & $\begin{array}{c}\text { Characterization } \\
\text { Result / mile }\end{array}$ & Factor Measure \\
\hline $\mathrm{HH}$ - Non-can & Fuel & Certain glycol ethers & Air & $8.11 \mathrm{E}-07$ & $6.79 \mathrm{E}-10$ & Ibs C6H6 equiv \\
\hline $\mathrm{HH}$ - Non-can & Fuel & Polychlorinated biphenyls & Air & 2.26E-13 & $2.4 \mathrm{E}-12$ & Ibs $\mathrm{C} 6 \mathrm{H} 6$ equiv \\
\hline $\mathrm{HH}$ - Non-can & Fuel & HYDROCHLORIC ACID & Air & 2.12E-05 & 1.81E-08 & Ibs $\mathrm{C} 6 \mathrm{H} 6$ equiv \\
\hline $\mathrm{HH}$ - Non-can & Fuel & CHLOROFORM & Air & 3.85E-07 & 6.78E-08 & Ibs $\mathrm{C} 6 \mathrm{H} 6$ equiv \\
\hline $\mathrm{HH}$ - Non-can & Fuel & ACETALDEHYDE & Air & $1.31 \mathrm{E}-08$ & 1.13E-10 & Ibs $\mathrm{C} 6 \mathrm{H} 6$ equiv \\
\hline $\mathrm{HH}$ - Non-can & Fuel & ACETONITRILE & Air & $2.19 \mathrm{E}-08$ & 7.61E-09 & Ibs $\mathrm{C} 6 \mathrm{H} 6$ equiv \\
\hline $\mathrm{HH}$ - Non-can & Fuel & ANILINE & Air & 2.26E-10 & 1.98E-11 & Ibs $\mathrm{C} 6 \mathrm{H} 6$ equiv \\
\hline Smog & Feedstock & NITROGEN OXIDES & Air & 0.0917 & 0.000251 & g NOX equiv \\
\hline Smog & Feedstock & BENZENE & Air & 5.75E-06 & 3.12E-09 & g NOX equiv \\
\hline Smog & Feedstock & ETHYLBENZENE & Air & 4.79E-07 & 7.73E-10 & g NOX equiv \\
\hline Smog & Feedstock & TOLUENE & Air & 3.59E-06 & 8.17E-09 & g NOX equiv \\
\hline Smog & Feedstock & VOC & Air & 0.0134 & 2.86E-05 & g NOX equiv \\
\hline Smog & Feedstock & CARBON MONOXIDE & Air & 0.0336 & 1.23E-06 & g NOX equiv \\
\hline Smog & Fuel & 1,1,1-TRICHLOROETHANE & Air & 2.59E-08 & $1.26 \mathrm{E}-12$ & g NOX equiv \\
\hline Smog & Fuel & 1,3-BUTADIENE & Air & 1.74E-06 & 1.24E-08 & g NOX equiv \\
\hline Smog & Fuel & BENZENE & Air & 4.74E-05 & 2.57E-08 & g NOX equiv \\
\hline Smog & Fuel & CHLOROBENZENE & Air & 0 & 0 & g NOX equiv \\
\hline Smog & Fuel & ETHYLBENZENE & Air & 1.45E-05 & 2.34E-08 & g NOX equiv \\
\hline Smog & Fuel & ETHYLENE GLYCOL & Air & 1.73E-06 & 5.32E-09 & g NOX equiv \\
\hline Smog & Fuel & ETHYLENE OXIDE & Air & 3.93E-07 & $1.86 \mathrm{E}-11$ & g NOX equiv \\
\hline Smog & Fuel & FORMALDEHYDE & Air & 2.91E-06 & 1.44E-08 & g NOX equiv \\
\hline Smog & Fuel & M-XYLENE & Air & 2.86E-06 & 1.72E-08 & g NOX equiv \\
\hline Smog & Fuel & METHANOL & Air & 0.000104 & 5.61E-08 & g NOX equiv \\
\hline Smog & Fuel & METHYL ISOBUTYL KETONE & Air & 5.48E-06 & 1.39E-08 & g NOX equiv \\
\hline Smog & Fuel & METHYL TERT-BUTYL ETHER & Air & 4.09E-05 & 2.98E-08 & g NOX equiv \\
\hline Smog & Fuel & N-HEXANE & Air & 7.57E-05 & 6.94E-08 & g NOX equiv \\
\hline Smog & Fuel & NAPHTHALENE & Air & 4.43E-06 & 7.34E-09 & g NOX equiv \\
\hline Smog & Fuel & O-XYLENE & Air & 2.42E-06 & 1.03E-08 & g NOX equiv \\
\hline Smog & Fuel & P-XYLENE & Air & 3.04E-06 & 7.33E-09 & g NOX equiv \\
\hline Smog & Fuel & PHENOL & Air & 2.85E-06 & 5.75E-09 & g NOX equiv \\
\hline Smog & Fuel & PROPYLENE OXIDE & Air & 0 & 0 & g NOX equiv \\
\hline Smog & Fuel & STYRENE & Air & 2.82E-07 & 3.85E-10 & g NOX equiv \\
\hline Smog & Fuel & TETRACHLOROETHYLENE & Air & 1.35E-06 & $8.51 \mathrm{E}-11$ & g NOX equiv \\
\hline Smog & Fuel & TOLUENE & Air & 0.000104 & 2.37E-07 & g NOX equiv \\
\hline Smog & Fuel & TRICHLOROETHYLENE & Air & 1.44E-06 & 8.06E-13 & g NOX equiv \\
\hline Smog & Fuel & VOC & Air & 0.0211 & 4.5E-05 & g NOX equiv \\
\hline Smog & Fuel & CARBON MONOXIDE & Air & 0.022 & 8.05E-07 & g NOX equiv \\
\hline Smog & Fuel & Certain glycol ethers & Air & 8.11E-07 & 1.82E-09 & g NOX equiv \\
\hline Smog & Fuel & NITROGEN OXIDES & Air & 0.0672 & 0.000184 & g NOX equiv \\
\hline Smog & Fuel & ACETALDEHYDE & Air & 1.31E-08 & 5.17E-11 & g NOX equiv \\
\hline Smog & Vehicle & NITROGEN OXIDES & Air & 0.6 & 0.00164 & g NOX equiv \\
\hline Smog & Vehicle & VOC & Air & 0.08 & 0.000171 & g NOX equiv \\
\hline
\end{tabular}




\begin{tabular}{|c|c|c|c|c|c|c|}
\hline Impact Category & Stage & $\begin{array}{l}\text { Emission } \\
\end{array}$ & Media & \begin{tabular}{|c|}
$\begin{array}{c}\text { Quantity } \\
\text { (grams/mile) }\end{array}$ \\
\end{tabular} & $\begin{array}{c}\text { Characterization } \\
\text { Result / mile }\end{array}$ & Factor Measure \\
\hline Smog & Vehicle & CARBON MONOXIDE & Air & 1.07 & 3.92E-05 & g NOX equiv \\
\hline
\end{tabular}

Table D-12 TRACI Data for FTD20 2006

\begin{tabular}{|c|c|c|c|c|c|c|}
\hline Impact Category & Stage & Emission & Media & \begin{tabular}{|c|} 
Mass Flow \\
(grams/mile)
\end{tabular} & $\begin{array}{c}\text { Characterization } \\
\text { Result / mile }\end{array}$ & Factor Measure \\
\hline Acidification & Feedstock & NITROGEN OXIDES & Air & 0.0797 & 0.007035 & moles $\mathrm{H}+$ equiv \\
\hline Acidification & Feedstock & SULFUR OXIDES & Air & 0.0173 & 0.001937 & moles $\mathrm{H}+$ equiv \\
\hline Acidification & Fuel & NITROGEN OXIDES & Air & 0.0805 & 0.007106 & moles $\mathrm{H}+$ equiv \\
\hline Acidification & Fuel & SULFUR OXIDES & Air & 0.0568 & 0.00636 & moles $\mathrm{H}+$ equiv \\
\hline Acidification & Vehicle & NITROGEN OXIDES & Air & 0.0617 & 0.005446 & moles $\mathrm{H}+$ equiv \\
\hline Acidification & Vehicle & SULFUR OXIDES & Air & 0.00253 & 0.000283 & moles $\mathrm{H}+$ equiv \\
\hline Ecotoxicity & Feedstock & BENZENE & Air & 4.16E-05 & $2.75 \mathrm{E}-13$ & Ibs 2,4-D equiv \\
\hline Ecotoxicity & Feedstock & ETHYLBENZENE & Air & 3.47E-06 & 3.37E-14 & Ibs 2,4-D equiv \\
\hline Ecotoxicity & Feedstock & TOLUENE & Air & 0.000026 & $2.58 \mathrm{E}-13$ & Ibs 2,4-D equiv \\
\hline Ecotoxicity & Fuel & BENZENE & Air & 0.00009 & $5.95 \mathrm{E}-13$ & Ibs 2,4-D equiv \\
\hline Eutrophication & Feedstock & NITROGEN OXIDES & Air & 0.0797 & 7.78E-06 & $\mathrm{kg} \mathrm{N}$ \\
\hline Eutrophication & Fuel & NITROGEN OXIDES & Air & 0.0805 & 7.86E-06 & $\mathrm{kg} \mathrm{N}$ \\
\hline Eutrophication & Vehicle & NITROGEN OXIDES & Air & 0.0617 & $6.02 E-06$ & $\mathrm{~kg} \mathrm{~N}$ \\
\hline $\mathrm{HH}$ - Cancer & Feedstock & BENZENE & Air & 4.16E-05 & $9.18 \mathrm{E}-08$ & Ibs $\mathrm{C} 6 \mathrm{H} 6$ equiv \\
\hline $\mathrm{HH}$ - Cancer & Fuel & BENZENE & Air & 0.00009 & $1.98 \mathrm{E}-07$ & Ibs $\mathrm{C} 6 \mathrm{H} 6$ equiv \\
\hline $\mathrm{HH}$ - Cancer & Fuel & NICKEL COMPOUNDS & Water & 0.00099 & 0 & Ibs $\mathrm{C} 6 \mathrm{H} 6$ equiv \\
\hline $\mathrm{HH}$ - Criteria & Feedstock & NITROGEN OXIDES & Air & 0.0797 & 3.89E-07 & total DALYs \\
\hline $\mathrm{HH}$ - Criteria & Feedstock & PM10 & Air & 0.00244 & 4.49E-07 & total DALYs \\
\hline $\mathrm{HH}$ - Criteria & Feedstock & PM2.5 & Air & 0.00146 & 4.48E-07 & total DALYs \\
\hline $\mathrm{HH}$ - Criteria & Fuel & NITROGEN OXIDES & Air & 0.0805 & 3.93E-07 & total DALYs \\
\hline $\mathrm{HH}$ - Criteria & Fuel & PM10 & Air & 0.00853 & $1.57 \mathrm{E}-06$ & total DALYs \\
\hline $\mathrm{HH}$ - Criteria & Fuel & PM2.5 & Air & 0.00512 & 1.57E-06 & total DALYs \\
\hline $\mathrm{HH}$ - Criteria & Vehicle & NITROGEN OXIDES & Air & 0.0617 & 3.01E-07 & total DALYs \\
\hline $\mathrm{HH}$ - Criteria & Vehicle & PM10 & Air & 0.028 & 5.15E-06 & total DALYs \\
\hline $\mathrm{HH}$ - Criteria & Vehicle & PM2.5 & Air & 0.0168 & 5.15E-06 & total DALYs \\
\hline $\mathrm{HH}$ - Non-can & Feedstock & BENZENE & Air & 4.16E-05 & $1.52 \mathrm{E}-06$ & Ibs $\mathrm{C} 6 \mathrm{H} 6$ equiv \\
\hline $\mathrm{HH}$ - Non-can & Feedstock & ETHYLBENZENE & Air & 3.47E-06 & 2.54E-09 & Ibs $\mathrm{C} 6 \mathrm{H} 6$ equiv \\
\hline $\mathrm{HH}$ - Non-can & Feedstock & TOLUENE & Air & 0.000026 & 5.73E-08 & Ibs $\mathrm{C} 6 \mathrm{H} 6$ equiv \\
\hline $\mathrm{HH}$ - Non-can & Feedstock & XYLENE & Air & 1.47E-05 & 7.57E-09 & Ibs $\mathrm{C} 6 \mathrm{H} 6$ equiv \\
\hline $\mathrm{HH}$ - Non-can & Fuel & BENZENE & Air & 0.00009 & 3.29E-06 & Ibs $\mathrm{C} 6 \mathrm{H} 6$ equiv \\
\hline $\mathrm{HH}$ - Non-can & Fuel & NICKEL COMPOUNDS & Water & 0.00099 & 0.000146 & Ibs $\mathrm{C} 6 \mathrm{H} 6$ equiv \\
\hline Smog & Feedstock & NITROGEN OXIDES & Air & 0.0797 & 0.000218 & g NOX equiv \\
\hline Smog & Feedstock & BENZENE & Air & 4.16E-05 & 2.26E-08 & g NOX equiv \\
\hline Smog & Feedstock & ETHYLBENZENE & Air & 3.47E-06 & $5.6 \mathrm{E}-09$ & g NOX equiv \\
\hline Smog & Feedstock & TOLUENE & Air & 0.000026 & 5.92E-08 & g NOX equiv \\
\hline Smog & Feedstock & VOC & Air & 0.0109 & 2.33E-05 & g NOX equiv \\
\hline
\end{tabular}




\begin{tabular}{|l|l|l|l|l|l|l|l|}
\hline Impact Category & \multicolumn{2}{|c|}{ Stage } & \multicolumn{1}{c|}{ Emission } & \multicolumn{1}{c|}{$\begin{array}{c}\text { Mass Flow } \\
\text { (grams/mile) }\end{array}$} & $\begin{array}{l}\text { Characterization } \\
\text { Result / mile }\end{array}$ & Factor Measure \\
\hline Smog & Feedstock & CARBON MONOXIDE & Air & 0.031 & $1.13 \mathrm{E}-06$ & g NOX equiv \\
\hline Smog & Fuel & NITROGEN OXIDES & Air & 0.0805 & 0.00022 & g NOX equiv \\
\hline Smog & Fuel & BENZENE & Air & 0.00009 & $4.89 \mathrm{E}-08$ & g NOX equiv \\
\hline Smog & Fuel & VOC & Air & 0.0222 & $4.74 \mathrm{E}-05$ & g NOX equiv \\
\hline Smog & Fuel & CARBON MONOXIDE & Air & 0.0455 & $1.67 \mathrm{E}-06$ & g NOX equiv \\
\hline Smog & Vehicle & NITROGEN OXIDES & Air & 0.0617 & 0.000169 & g NOX equiv \\
\hline Smog & Vehicle & VOC & Air & 0.049 & 0.000105 & g NOX equiv \\
\hline Smog & Vehicle & CARBON MONOXIDE & Air & 1.07 & $3.92 \mathrm{E}-05$ & g NOX equiv \\
\hline
\end{tabular}

Table D-13 TRACI Data for ULSD CIDI 2006

\begin{tabular}{|c|c|c|c|c|c|c|}
\hline Impact Category & Stage & Emission & Media & \begin{tabular}{|c||} 
Mass Flow \\
(grams/mile)
\end{tabular} & $\begin{array}{c}\text { Characterization } \\
\text { Result / mile }\end{array}$ & Factor Measure \\
\hline Acidification & Feedstock & NITROGEN OXIDES & Air & 0.0896 & 0.007909 & moles $\mathrm{H}+$ equiv \\
\hline Acidification & Feedstock & SULFUR OXIDES & Air & 0.0184 & 0.00206 & moles $\mathrm{H}+$ equiv \\
\hline Acidification & Fuel & NITROGEN OXIDES & Air & 0.0835 & 0.007371 & moles $\mathrm{H}+$ equiv \\
\hline Acidification & Fuel & HYDROCHLORIC ACID & Air & 2.07E-05 & 2.04E-06 & moles $\mathrm{H}+$ equiv \\
\hline Acidification & Fuel & HYDROGEN FLUORIDE & Air & 5.17E-06 & 9.26E-07 & moles $\mathrm{H}+$ equiv \\
\hline Acidification & Fuel & SULFUR OXIDES & Air & 0.103 & 0.011533 & moles $\mathrm{H}+$ equiv \\
\hline Acidification & Vehicle & NITROGEN OXIDES & Air & 0.063 & 0.005561 & moles $\mathrm{H}+$ equiv \\
\hline Acidification & Vehicle & SULFUR OXIDES & Air & 0.00258 & 0.000289 & moles $\mathrm{H}+$ equiv \\
\hline Ecotoxicity & Feedstock & BENZENE & Air & 5.61E-06 & 3.71E-14 & Ibs 2,4-D equiv \\
\hline Ecotoxicity & Feedstock & ETHYLBENZENE & Air & 4.68E-07 & 4.54E-15 & Ibs 2,4-D equiv \\
\hline Ecotoxicity & Feedstock & TOLUENE & Air & $3.51 \mathrm{E}-06$ & 3.48E-14 & Ibs 2,4-D equiv \\
\hline Ecotoxicity & Fuel & CHLOROFORM & Air & 3.76E-07 & 9.95E-14 & Ibs 2,4-D equiv \\
\hline Ecotoxicity & Fuel & 1,1,1-TRICHLOROETHANE & Air & $2.53 \mathrm{E}-08$ & 4.96E-14 & Ibs 2,4-D equiv \\
\hline Ecotoxicity & Fuel & 1,2-DICHLOROETHANE & Air & 3.31E-07 & 4.01E-14 & Ibs 2,4-D equiv \\
\hline Ecotoxicity & Fuel & 1,3-BUTADIENE & Air & $1.7 \mathrm{E}-06$ & 1.99E-16 & Ibs 2,4-D equiv \\
\hline Ecotoxicity & Fuel & BENZENE & Air & 4.63E-05 & 3.06E-13 & Ibs 2,4-D equiv \\
\hline Ecotoxicity & Fuel & CARBON DISULFIDE & Air & 7.16E-07 & 1.74E-11 & Ibs 2,4-D equiv \\
\hline Ecotoxicity & Fuel & CARBON TETRACHLORIDE & Air & 1.43E-07 & 1.04E-12 & Ibs 2,4-D equiv \\
\hline Ecotoxicity & Fuel & DIBUTYL PHTHALATE & Air & $6.55 \mathrm{E}-08$ & 9.82E-10 & Ibs 2,4-D equiv \\
\hline Ecotoxicity & Fuel & ETHYLBENZENE & Air & $1.41 \mathrm{E}-05$ & $1.37 \mathrm{E}-13$ & Ibs 2,4-D equiv \\
\hline Ecotoxicity & Fuel & FORMALDEHYDE & Air & $2.84 \mathrm{E}-06$ & 1.82E-10 & Ibs 2,4-D equiv \\
\hline Ecotoxicity & Fuel & M-XYLENE & Air & 2.79E-06 & 4.43E-15 & Ibs 2,4-D equiv \\
\hline Ecotoxicity & Fuel & NAPHTHALENE & Air & 4.32E-06 & 3.62E-10 & Ibs 2,4-D equiv \\
\hline Ecotoxicity & Fuel & O-XYLENE & Air & 2.37E-06 & 8.36E-15 & Ibs 2,4-D equiv \\
\hline Ecotoxicity & Fuel & P-XYLENE & Air & 2.97E-06 & $6.22 \mathrm{E}-15$ & Ibs 2,4-D equiv \\
\hline Ecotoxicity & Fuel & PHENOL & Air & 2.79E-06 & 2.34E-10 & Ibs 2,4-D equiv \\
\hline Ecotoxicity & Fuel & PROPYLENE OXIDE & Air & 0 & 0 & Ibs 2,4-D equiv \\
\hline Ecotoxicity & Fuel & STYRENE & Air & 2.75E-07 & $7.28 \mathrm{E}-16$ & Ibs 2,4-D equiv \\
\hline Ecotoxicity & Fuel & TETRACHLOROETHYLENE & Air & 1.32E-06 & 1.95E-12 & Ibs 2,4-D equiv \\
\hline
\end{tabular}




\begin{tabular}{|c|c|c|c|c|c|c|}
\hline Impact Category & Stage & Emission & Media & \begin{tabular}{|c||} 
Mass Flow \\
(grams/mile)
\end{tabular} & $\begin{array}{c}\text { Characterization } \\
\text { Result / mile }\end{array}$ & Factor Measure \\
\hline Ecotoxicity & Fuel & TOLUENE & Air & 0.000102 & $1.01 \mathrm{E}-12$ & Ibs 2,4-D equiv \\
\hline Ecotoxicity & Fuel & TRICHLOROETHYLENE & Air & 1.41E-06 & 1.24E-14 & Ibs 2,4-D equiv \\
\hline Ecotoxicity & Vehicle & 1,3-BUTADIENE & Air & 0.0008 & 9.35E-14 & Ibs 2,4-D equiv \\
\hline Ecotoxicity & Vehicle & BENZENE & Air & 0.0013 & $8.6 \mathrm{E}-12$ & Ibs 2,4-D equiv \\
\hline Ecotoxicity & Vehicle & FORMALDEHYDE & Air & 0.0161 & 1.03E-06 & Ibs 2,4-D equiv \\
\hline Ecotoxicity & Vehicle & TOLUENE & Air & 0.0018 & 1.79E-11 & Ibs 2,4-D equiv \\
\hline Eutrophication & Feedstock & NITROGEN OXIDES & Air & 0.0896 & 8.75E-06 & $\mathrm{kg} \mathrm{N}$ \\
\hline Eutrophication & Fuel & NITROGEN OXIDES & Air & 0.0835 & 8.15E-06 & $\mathrm{kg} \mathrm{N}$ \\
\hline Eutrophication & Vehicle & NITROGEN OXIDES & Air & 0.063 & 6.15E-06 & $\mathrm{kg} \mathrm{N}$ \\
\hline $\mathrm{HH}$ - Cancer & Feedstock & BENZENE & Air & 5.61E-06 & 1.24E-08 & Ibs $\mathrm{C} 6 \mathrm{H} 6$ equiv \\
\hline $\mathrm{HH}$ - Cancer & Fuel & CHLOROFORM & Air & 3.76E-07 & 3.79E-09 & Ibs $\mathrm{C} 6 \mathrm{H} 6$ equiv \\
\hline $\mathrm{HH}$ - Cancer & Fuel & ACETALDEHYDE & Air & 1.28E-08 & 9.96E-14 & Ibs $\mathrm{C} 6 \mathrm{H} 6$ equiv \\
\hline $\mathrm{HH}$ - Cancer & Fuel & ANILINE & Air & 2.21E-10 & 1.11E-15 & Ibs $\mathrm{C} 6 \mathrm{H} 6$ equiv \\
\hline $\mathrm{HH}$ - Cancer & Fuel & 1,2-DIBROMOETHANE & Air & 2.16E-07 & 4.01E-09 & Ibs $\mathrm{C} 6 \mathrm{H} 6$ equiv \\
\hline $\mathrm{HH}$ - Cancer & Fuel & 1,2-DICHLOROETHANE & Air & $3.31 \mathrm{E}-07$ & 3.89E-09 & Ibs $\mathrm{C} 6 \mathrm{H} 6$ equiv \\
\hline $\mathrm{HH}$ - Cancer & Fuel & 1,3-BUTADIENE & Air & $1.7 \mathrm{E}-06$ & 1.24E-09 & Ibs $\mathrm{C} 6 \mathrm{H} 6$ equiv \\
\hline $\mathrm{HH}$ - Cancer & Fuel & BENZENE & Air & 4.63E-05 & 1.02E-07 & Ibs $\mathrm{C} 6 \mathrm{H} 6$ equiv \\
\hline $\mathrm{HH}$ - Cancer & Fuel & CADMIUM COMPOUNDS & Air & 0 & 0 & Ibs $\mathrm{C} 6 \mathrm{H} 6$ equiv \\
\hline $\mathrm{HH}$ - Cancer & Fuel & CARBON TETRACHLORIDE & Air & 1.43E-07 & 2.59E-07 & Ibs $\mathrm{C} 6 \mathrm{H} 6$ equiv \\
\hline $\mathrm{HH}$ - Cancer & Fuel & CHROMIUM COMPOUNDS & Air & 1.19E-08 & 4.39E-09 & Ibs $\mathrm{C} 6 \mathrm{H} 6$ equiv \\
\hline HH - Cancer & Fuel & DIMETHYL SULFATE & Air & 0 & 0 & Ibs $\mathrm{C} 6 \mathrm{H} 6$ equiv \\
\hline $\mathrm{HH}$ - Cancer & Fuel & ETHYLENE OXIDE & Air & 3.84E-07 & 2.61E-08 & Ibs $\mathrm{C} 6 \mathrm{H} 6$ equiv \\
\hline $\mathrm{HH}$ - Cancer & Fuel & FORMALDEHYDE & Air & 2.84E-06 & 1.89E-11 & Ibs $\mathrm{C} 6 \mathrm{H} 6$ equiv \\
\hline $\mathrm{HH}$ - Cancer & Fuel & HYDRAZINE & Air & 0 & 0 & Ibs $\mathrm{C} 6 \mathrm{H} 6$ equiv \\
\hline $\mathrm{HH}$ - Cancer & Fuel & HYDROQUINONE & Air & 0 & 0 & Ibs $\mathrm{C} 6 \mathrm{H} 6$ equiv \\
\hline $\mathrm{HH}$ - Cancer & Fuel & LEAD COMPOUNDS & Air & 7.17E-08 & 5.61E-09 & Ibs $\mathrm{C} 6 \mathrm{H} 6$ equiv \\
\hline $\mathrm{HH}$ - Cancer & Fuel & NICKEL COMPOUNDS & Air & 4.52E-07 & $3.6 \mathrm{E}-09$ & Ibs $\mathrm{C} 6 \mathrm{H} 6$ equiv \\
\hline $\mathrm{HH}$ - Cancer & Fuel & O-TOLUIDINE & Air & $2.21 \mathrm{E}-10$ & 4.43E-15 & Ibs $\mathrm{C} 6 \mathrm{H} 6$ equiv \\
\hline $\mathrm{HH}$ - Cancer & Fuel & PROPYLENE OXIDE & Air & 0 & 0 & Ibs $\mathrm{C} 6 \mathrm{H} 6$ equiv \\
\hline $\mathrm{HH}$ - Cancer & Fuel & TETRACHLOROETHYLENE & Air & 1.32E-06 & 5.3E-09 & Ibs $\mathrm{C} 6 \mathrm{H} 6$ equiv \\
\hline $\mathrm{HH}$ - Cancer & Fuel & TRICHLOROETHYLENE & Air & 1.41E-06 & 1.82E-10 & Ibs $\mathrm{C} 6 \mathrm{H} 6$ equiv \\
\hline HH - Cancer & Fuel & CHLOROMETHANE & Air & 3.06E-08 & 2.38E-10 & Ibs $\mathrm{C} 6 \mathrm{H} 6$ equiv \\
\hline $\mathrm{HH}$ - Cancer & Vehicle & ACETALDEHYDE & Air & 0.0096 & 7.47E-08 & Ibs $\mathrm{C} 6 \mathrm{H} 6$ equiv \\
\hline $\mathrm{HH}$ - Cancer & Vehicle & 1,3-BUTADIENE & Air & 0.0008 & 5.86E-07 & Ibs $\mathrm{C} 6 \mathrm{H} 6$ equiv \\
\hline $\mathrm{HH}$ - Cancer & Vehicle & BENZENE & Air & 0.0013 & 2.87E-06 & Ibs $\mathrm{C} 6 \mathrm{H} 6$ equiv \\
\hline $\mathrm{HH}$ - Cancer & Vehicle & FORMALDEHYDE & Air & 0.0161 & 1.07E-07 & Ibs $\mathrm{C} 6 \mathrm{H} 6$ equiv \\
\hline $\mathrm{HH}$ - Criteria & Feedstock & NITROGEN OXIDES & Air & 0.0896 & 4.37E-07 & total DALYs \\
\hline $\mathrm{HH}$ - Criteria & Feedstock & PM10 & Air & 0.00273 & 5.02E-07 & total DALYs \\
\hline $\mathrm{HH}$ - Criteria & Feedstock & PM2.5 & Air & 0.00163 & 5E-07 & total DALYs \\
\hline $\mathrm{HH}$ - Criteria & Fuel & NITROGEN OXIDES & Air & 0.0835 & 4.07E-07 & total DALYs \\
\hline $\mathrm{HH}$ - Criteria & Fuel & PM10 & Air & 0.0105 & 1.93E-06 & total DALYs \\
\hline $\mathrm{HH}$ - Criteria & Fuel & PM2.5 & Air & 0.00631 & 1.93E-06 & total DALYs \\
\hline
\end{tabular}




\begin{tabular}{|c|c|c|c|c|c|c|}
\hline Impact Category & Stage & Emission & Media & \begin{tabular}{|l|} 
Mass Flow \\
(grams/mile)
\end{tabular} & $\begin{array}{l}\text { Characterization } \\
\text { Result / mile }\end{array}$ & Factor Measure \\
\hline $\mathrm{HH}$ - Criteria & Vehicle & NITROGEN OXIDES & Air & 0.063 & 3.07E-07 & total DALYs \\
\hline $\mathrm{HH}$ - Criteria & Vehicle & PM10 & Air & 0.031 & 5.7E-06 & total DALYs \\
\hline $\mathrm{HH}$ - Criteria & Vehicle & PM2.5 & Air & 0.0182 & 5.58E-06 & total DALYs \\
\hline $\mathrm{HH}$ - Non-can & Feedstock & BENZENE & Air & 5.61E-06 & 2.05E-07 & Ibs $\mathrm{C} 6 \mathrm{H} 6$ equiv \\
\hline HH - Non-can & Feedstock & ETHYLBENZENE & Air & 4.68E-07 & 3.42E-10 & Ibs $\mathrm{C} 6 \mathrm{H} 6$ equiv \\
\hline HH - Non-can & Feedstock & TOLUENE & Air & 3.51E-06 & 7.73E-09 & Ibs C6H6 equiv \\
\hline $\mathrm{HH}$ - Non-can & Feedstock & XYLENE & Air & 1.99E-06 & 1.02E-09 & Ibs $\mathrm{C} 6 \mathrm{H} 6$ equiv \\
\hline $\mathrm{HH}$ - Non-can & Fuel & HYDROCHLORIC ACID & Air & 2.07E-05 & 1.77E-08 & Ibs C6H6 equiv \\
\hline $\mathrm{HH}$ - Non-can & Fuel & CHLOROFORM & Air & 3.76E-07 & 6.62E-08 & Ibs $\mathrm{C} 6 \mathrm{H} 6$ equiv \\
\hline HH - Non-can & Fuel & ACETALDEHYDE & Air & $1.28 \mathrm{E}-08$ & $1.1 \mathrm{E}-10$ & Ibs $\mathrm{C} 6 \mathrm{H} 6$ equiv \\
\hline $\mathrm{HH}$ - Non-can & Fuel & ACETONITRILE & Air & $2.14 \mathrm{E}-08$ & 7.44E-09 & Ibs $\mathrm{C} 6 \mathrm{H} 6$ equiv \\
\hline HH - Non-can & Fuel & ANILINE & Air & 2.21E-10 & 1.93E-11 & Ibs C6H6 equiv \\
\hline $\mathrm{HH}$ - Non-can & Fuel & 1,1,1-TRICHLOROETHANE & Air & 2.53E-08 & 1.12E-08 & Ibs $\mathrm{C} 6 \mathrm{H} 6$ equiv \\
\hline $\mathrm{HH}$ - Non-can & Fuel & 1,2,4-TRICHLOROBENZENE & Air & 3.22E-08 & 2.13E-09 & Ibs $\mathrm{C} 6 \mathrm{H} 6$ equiv \\
\hline $\mathrm{HH}$ - Non-can & Fuel & 1,2-DIBROMOETHANE & Air & 2.16E-07 & 1.95E-06 & Ibs $\mathrm{C} 6 \mathrm{H} 6$ equiv \\
\hline HH - Non-can & Fuel & 1,2-DICHLOROETHANE & Air & $3.31 \mathrm{E}-07$ & 1.38E-08 & Ibs $\mathrm{C} 6 \mathrm{H} 6$ equiv \\
\hline $\mathrm{HH}$ - Non-can & Fuel & 1,3-BUTADIENE & Air & $1.7 \mathrm{E}-06$ & 4.55E-09 & Ibs $\mathrm{C} 6 \mathrm{H} 6$ equiv \\
\hline $\mathrm{HH}$ - Non-can & Fuel & ANTIMONY COMPOUNDS & Air & $6.87 \mathrm{E}-08$ & 2.93E-06 & Ibs $\mathrm{C} 6 \mathrm{H} 6$ equiv \\
\hline $\mathrm{HH}$ - Non-can & Fuel & BENZENE & Air & 4.63E-05 & 1.69E-06 & Ibs $\mathrm{C} 6 \mathrm{H} 6$ equiv \\
\hline $\mathrm{HH}$ - Non-can & Fuel & BIPHENYL & Air & 2.76E-07 & $4.08 \mathrm{E}-10$ & Ibs $\mathrm{C} 6 \mathrm{H} 6$ equiv \\
\hline $\mathrm{HH}$ - Non-can & Fuel & CADMIUM COMPOUNDS & Air & 0 & 0 & Ibs $\mathrm{C} 6 \mathrm{H} 6$ equiv \\
\hline $\mathrm{HH}$ - Non-can & Fuel & CARBON DISULFIDE & Air & 7.16E-07 & 7.4E-09 & Ibs $\mathrm{C} 6 \mathrm{H} 6$ equiv \\
\hline HH - Non-can & Fuel & CARBON TETRACHLORIDE & Air & 1.43E-07 & 4.35E-06 & Ibs $\mathrm{C} 6 \mathrm{H} 6$ equiv \\
\hline $\mathrm{HH}$ - Non-can & Fuel & CHLOROBENZENE & Air & 0 & 0 & Ibs $\mathrm{C} 6 \mathrm{H} 6$ equiv \\
\hline $\mathrm{HH}$ - Non-can & Fuel & CHROMIUM COMPOUNDS & Air & 1.19E-08 & 1.67E-07 & Ibs $\mathrm{C} 6 \mathrm{H} 6$ equiv \\
\hline $\mathrm{HH}$ - Non-can & Fuel & COBALT COMPOUNDS & Air & $1.52 \mathrm{E}-08$ & 2.65E-06 & Ibs $\mathrm{C} 6 \mathrm{H} 6$ equiv \\
\hline HH - Non-can & Fuel & CUMENE & Air & $4.66 \mathrm{E}-06$ & 3.21E-09 & Ibs $\mathrm{C} 6 \mathrm{H} 6$ equiv \\
\hline $\mathrm{HH}$ - Non-can & Fuel & DIBUTYL PHTHALATE & Air & $6.55 \mathrm{E}-08$ & 2.92E-09 & Ibs $\mathrm{C} 6 \mathrm{H} 6$ equiv \\
\hline $\mathrm{HH}$ - Non-can & Fuel & DIETHANOLAMINE & Air & 3.21E-06 & 1.02E-07 & Ibs $\mathrm{C} 6 \mathrm{H} 6$ equiv \\
\hline $\mathrm{HH}$ - Non-can & Fuel & ETHYLBENZENE & Air & 1.41E-05 & 1.03E-08 & Ibs $\mathrm{C} 6 \mathrm{H} 6$ equiv \\
\hline $\mathrm{HH}$ - Non-can & Fuel & ETHYLENE GLYCOL & Air & 1.69E-06 & $9.12 \mathrm{E}-10$ & Ibs $\mathrm{C} 6 \mathrm{H} 6$ equiv \\
\hline $\mathrm{HH}$ - Non-can & Fuel & ETHYLENE OXIDE & Air & 3.84E-07 & $1.68 \mathrm{E}-06$ & Ibs $\mathrm{C} 6 \mathrm{H} 6$ equiv \\
\hline $\mathrm{HH}$ - Non-can & Fuel & FORMALDEHYDE & Air & 2.84E-06 & 2.99E-08 & Ibs $\mathrm{C} 6 \mathrm{H} 6$ equiv \\
\hline $\mathrm{HH}$ - Non-can & Fuel & HYDRAZINE & Air & 0 & 0 & Ibs $\mathrm{C} 6 \mathrm{H} 6$ equiv \\
\hline $\mathrm{HH}$ - Non-can & Fuel & HYDROQUINONE & Air & 0 & 0 & Ibs $\mathrm{C} 6 \mathrm{H} 6$ equiv \\
\hline $\mathrm{HH}$ - Non-can & Fuel & LEAD COMPOUNDS & Air & 7.17E-08 & 0.000237 & Ibs $\mathrm{C} 6 \mathrm{H} 6$ equiv \\
\hline $\mathrm{HH}$ - Non-can & Fuel & M-CRESOL & Air & 0 & 0 & Ibs $\mathrm{C} 6 \mathrm{H} 6$ equiv \\
\hline $\mathrm{HH}$ - Non-can & Fuel & M-XYLENE & Air & 2.79E-06 & 1.02E-09 & Ibs $\mathrm{C} 6 \mathrm{H} 6$ equiv \\
\hline $\mathrm{HH}$ - Non-can & Fuel & MALEIC ANHYDRIDE & Air & 7.73E-10 & 2.94E-10 & Ibs $\mathrm{C} 6 \mathrm{H} 6$ equiv \\
\hline $\mathrm{HH}$ - Non-can & Fuel & MANGANESE COMPOUNDS & Air & 1.88E-08 & 3.29E-07 & Ibs $\mathrm{C} 6 \mathrm{H} 6$ equiv \\
\hline $\mathrm{HH}$ - Non-can & Fuel & MERCURY COMPOUNDS & Air & 1.1E-07 & 0.004669 & Ibs $\mathrm{C} 6 \mathrm{H} 6$ equiv \\
\hline HH - Non-can & Fuel & METHANOL & Air & 0.000102 & 2.46E-08 & Ibs $\mathrm{C} 6 \mathrm{H} 6$ equiv \\
\hline
\end{tabular}




\begin{tabular}{|c|c|c|c|c|c|c|}
\hline Impact Category & Stage & Emission & Media & \begin{tabular}{|c||} 
Mass Flow \\
(grams/mile)
\end{tabular} & $\begin{array}{c}\text { Characterization } \\
\text { Result / mile }\end{array}$ & Factor Measure \\
\hline $\mathrm{HH}$ - Non-can & Fuel & METHYL ETHYL KETONE & Air & 7.28E-05 & 1.83E-08 & Ibs C6H6 equiv \\
\hline $\mathrm{HH}$ - Non-can & Fuel & METHYL ISOBUTYL KETONE & Air & 5.35E-06 & 8.64E-09 & Ibs $\mathrm{C} 6 \mathrm{H} 6$ equiv \\
\hline $\mathrm{HH}$ - Non-can & Fuel & METHYL TERT-BUTYL ETHER & Air & 3.99E-05 & 7.93E-09 & Ibs $\mathrm{C} 6 \mathrm{H} 6$ equiv \\
\hline $\mathrm{HH}$ - Non-can & Fuel & N-HEXANE & Air & 7.39E-05 & 9.89E-08 & Ibs $\mathrm{C} 6 \mathrm{H} 6$ equiv \\
\hline $\mathrm{HH}$ - Non-can & Fuel & NAPHTHALENE & Air & $4.32 \mathrm{E}-06$ & 1.21E-07 & Ibs $\mathrm{C} 6 \mathrm{H} 6$ equiv \\
\hline $\mathrm{HH}$ - Non-can & Fuel & NICKEL COMPOUNDS & Air & $4.52 \mathrm{E}-07$ & 8.23E-06 & Ibs $\mathrm{C} 6 \mathrm{H} 6$ equiv \\
\hline $\mathrm{HH}$ - Non-can & Fuel & O-CRESOL & Air & 0 & 0 & Ibs $\mathrm{C} 6 \mathrm{H} 6$ equiv \\
\hline $\mathrm{HH}$ - Non-can & Fuel & O-XYLENE & Air & 2.37E-06 & 1.47E-09 & Ibs $\mathrm{C} 6 \mathrm{H} 6$ equiv \\
\hline $\mathrm{HH}$ - Non-can & Fuel & P-CRESOL & Air & 0 & 0 & Ibs $\mathrm{C} 6 \mathrm{H} 6$ equiv \\
\hline $\mathrm{HH}$ - Non-can & Fuel & P-XYLENE & Air & 2.97E-06 & 1.75E-09 & Ibs $\mathrm{C} 6 \mathrm{H} 6$ equiv \\
\hline $\mathrm{HH}$ - Non-can & Fuel & PHENOL & Air & 2.79E-06 & $3.51 \mathrm{E}-10$ & Ibs $\mathrm{C} 6 \mathrm{H} 6$ equiv \\
\hline $\mathrm{HH}$ - Non-can & Fuel & PROPYLENE OXIDE & Air & 0 & 0 & Ibs $\mathrm{C} 6 \mathrm{H} 6$ equiv \\
\hline $\mathrm{HH}$ - Non-can & Fuel & SELENIUM COMPOUNDS & Air & 5.63E-09 & 2.63E-07 & Ibs $\mathrm{C} 6 \mathrm{H} 6$ equiv \\
\hline $\mathrm{HH}$ - Non-can & Fuel & STYRENE & Air & $2.75 \mathrm{E}-07$ & 1.75E-11 & Ibs $\mathrm{C} 6 \mathrm{H} 6$ equiv \\
\hline $\mathrm{HH}$ - Non-can & Fuel & TETRACHLOROETHYLENE & Air & $1.32 \mathrm{E}-06$ & 6.27E-07 & Ibs $\mathrm{C} 6 \mathrm{H} 6$ equiv \\
\hline $\mathrm{HH}$ - Non-can & Fuel & TOLUENE & Air & 0.000102 & 2.25E-07 & Ibs $\mathrm{C} 6 \mathrm{H} 6$ equiv \\
\hline $\mathrm{HH}$ - Non-can & Fuel & TRICHLOROETHYLENE & Air & 1.41E-06 & 3.05E-09 & Ibs $\mathrm{C} 6 \mathrm{H} 6$ equiv \\
\hline $\mathrm{HH}$ - Non-can & Fuel & TRIETHYLAMINE & Air & 0 & 0 & Ibs $\mathrm{C} 6 \mathrm{H} 6$ equiv \\
\hline $\mathrm{HH}$ - Non-can & Fuel & VINYL ACETATE & Air & 7.86E-09 & 3.34E-11 & Ibs $\mathrm{C} 6 \mathrm{H} 6$ equiv \\
\hline $\mathrm{HH}$ - Non-can & Fuel & CHLOROMETHANE & Air & 3.06E-08 & 3.64E-08 & Ibs $\mathrm{C} 6 \mathrm{H} 6$ equiv \\
\hline $\mathrm{HH}$ - Non-can & Fuel & XYLENE & Air & $6.22 \mathrm{E}-05$ & $3.2 \mathrm{E}-08$ & Ibs $\mathrm{C} 6 \mathrm{H} 6$ equiv \\
\hline $\mathrm{HH}$ - Non-can & Fuel & Certain glycol ethers & Air & $7.92 \mathrm{E}-07$ & 6.63E-10 & Ibs $\mathrm{C} 6 \mathrm{H} 6$ equiv \\
\hline $\mathrm{HH}$ - Non-can & Fuel & Polychlorinated biphenyls & Air & 2.21E-13 & 2.34E-12 & Ibs $\mathrm{C} 6 \mathrm{H} 6$ equiv \\
\hline $\mathrm{HH}$ - Non-can & Vehicle & ACETALDEHYDE & Air & 0.0096 & $8.28 \mathrm{E}-05$ & Ibs $\mathrm{C} 6 \mathrm{H} 6$ equiv \\
\hline $\mathrm{HH}$ - Non-can & Vehicle & 1,3-BUTADIENE & Air & 0.0008 & 2.14E-06 & Ibs $\mathrm{C} 6 \mathrm{H} 6$ equiv \\
\hline HH - Non-can & Vehicle & BENZENE & Air & 0.0013 & 4.75E-05 & Ibs $\mathrm{C} 6 \mathrm{H} 6$ equiv \\
\hline $\mathrm{HH}$ - Non-can & Vehicle & FORMALDEHYDE & Air & 0.0161 & 0.000169 & Ibs $\mathrm{C} 6 \mathrm{H} 6$ equiv \\
\hline HH - Non-can & Vehicle & TOLUENE & Air & 0.0018 & 3.97E-06 & Ibs $\mathrm{C} 6 \mathrm{H} 6$ equiv \\
\hline Smog & Feedstock & NITROGEN OXIDES & Air & 0.0896 & 0.000245 & g NOX equiv \\
\hline Smog & Feedstock & BENZENE & Air & 5.61E-06 & 3.05E-09 & g NOX equiv \\
\hline Smog & Feedstock & ETHYLBENZENE & Air & $4.68 \mathrm{E}-07$ & 7.55E-10 & g NOX equiv \\
\hline Smog & Feedstock & TOLUENE & Air & $3.51 \mathrm{E}-06$ & 7.98E-09 & g NOX equiv \\
\hline Smog & Feedstock & VOC & Air & 0.013 & 2.77E-05 & g NOX equiv \\
\hline Smog & Feedstock & CARBON MONOXIDE & Air & 0.0328 & 1.2E-06 & g NOX equiv \\
\hline Smog & Fuel & NITROGEN OXIDES & Air & 0.0835 & 0.000228 & g NOX equiv \\
\hline Smog & Fuel & ACETALDEHYDE & Air & $1.28 \mathrm{E}-08$ & 5.05E-11 & g NOX equiv \\
\hline Smog & Fuel & 1,1,1-TRICHLOROETHANE & Air & $2.53 \mathrm{E}-08$ & 1.23E-12 & g NOX equiv \\
\hline Smog & Fuel & 1,3-BUTADIENE & Air & 1.7E-06 & 1.21E-08 & g NOX equiv \\
\hline Smog & Fuel & BENZENE & Air & 4.63E-05 & 2.51E-08 & g NOX equiv \\
\hline Smog & Fuel & CHLOROBENZENE & Air & 0 & 0 & g NOX equiv \\
\hline Smog & Fuel & ETHYLBENZENE & Air & 1.41E-05 & 2.28E-08 & g NOX equiv \\
\hline Smog & Fuel & ETHYLENE GLYCOL & Air & 1.69E-06 & $5.2 \mathrm{E}-09$ & g NOX equiv \\
\hline
\end{tabular}




\begin{tabular}{|c|c|c|c|c|c|c|}
\hline Impact Category & Stage & Emission & Media & \begin{tabular}{|l|} 
Mass Flow \\
(grams/mile)
\end{tabular} & $\begin{array}{l}\text { Characterization } \\
\text { Result / mile }\end{array}$ & Factor Measure \\
\hline Smog & Fuel & ETHYLENE OXIDE & Air & 3.84E-07 & $1.81 \mathrm{E}-11$ & g NOX equiv \\
\hline Smog & Fuel & FORMALDEHYDE & Air & 2.84E-06 & 1.41E-08 & g NOX equiv \\
\hline Smog & Fuel & M-XYLENE & Air & 2.79E-06 & 1.68E-08 & g NOX equiv \\
\hline Smog & Fuel & METHANOL & Air & 0.000102 & $5.5 \mathrm{E}-08$ & g NOX equiv \\
\hline Smog & Fuel & METHYL ISOBUTYL KETONE & Air & 5.35E-06 & 1.36E-08 & g NOX equiv \\
\hline Smog & Fuel & METHYL TERT-BUTYL ETHER & Air & 3.99E-05 & 2.91E-08 & g NOX equiv \\
\hline Smog & Fuel & N-HEXANE & Air & 7.39E-05 & 6.78E-08 & g NOX equiv \\
\hline Smog & Fuel & NAPHTHALENE & Air & $4.32 \mathrm{E}-06$ & 7.16E-09 & g NOX equiv \\
\hline Smog & Fuel & O-XYLENE & Air & $2.37 \mathrm{E}-06$ & 1.01E-08 & g NOX equiv \\
\hline Smog & Fuel & P-XYLENE & Air & $2.97 \mathrm{E}-06$ & 7.16E-09 & g NOX equiv \\
\hline Smog & Fuel & PHENOL & Air & 2.79E-06 & 5.63E-09 & g NOX equiv \\
\hline Smog & Fuel & PROPYLENE OXIDE & Air & 0 & 0 & g NOX equiv \\
\hline Smog & Fuel & STYRENE & Air & 2.75E-07 & 3.76E-10 & g NOX equiv \\
\hline Smog & Fuel & TETRACHLOROETHYLENE & Air & 1.32E-06 & 8.32E-11 & g NOX equiv \\
\hline Smog & Fuel & TOLUENE & Air & 0.000102 & 2.32E-07 & g NOX equiv \\
\hline Smog & Fuel & TRICHLOROETHYLENE & Air & 1.41E-06 & $7.89 \mathrm{E}-13$ & g NOX equiv \\
\hline Smog & Fuel & VOC & Air & 0.0232 & 4.95E-05 & g NOX equiv \\
\hline Smog & Fuel & CARBON MONOXIDE & Air & 0.0269 & 9.84E-07 & g NOX equiv \\
\hline Smog & Fuel & Certain glycol ethers & Air & 7.92E-07 & 1.78E-09 & g NOX equiv \\
\hline Smog & Vehicle & NITROGEN OXIDES & Air & 0.063 & 0.000172 & g NOX equiv \\
\hline Smog & Vehicle & ACETALDEHYDE & Air & 0.0096 & 3.79E-05 & g NOX equiv \\
\hline Smog & Vehicle & 1,3-BUTADIENE & Air & 0.0008 & 5.69E-06 & g NOX equiv \\
\hline Smog & Vehicle & BENZENE & Air & 0.0013 & 7.06E-07 & g NOX equiv \\
\hline Smog & Vehicle & FORMALDEHYDE & Air & 0.0161 & 7.98E-05 & g NOX equiv \\
\hline Smog & Vehicle & TOLUENE & Air & 0.0018 & 4.1E-06 & g NOX equiv \\
\hline Smog & Vehicle & VOC & Air & 0.049 & 0.000105 & g NOX equiv \\
\hline Smog & Vehicle & CARBON MONOXIDE & Air & 1.07 & 3.92E-05 & g NOX equiv \\
\hline
\end{tabular}


Table D-14 TRACI Data for FRFG SI 2006

\begin{tabular}{|c|c|c|c|c|c|c|}
\hline Impact Category & Stage & Emission & Media & \begin{tabular}{|c|} 
Mass Flow \\
(grams/mile)
\end{tabular} & $\begin{array}{l}\text { Characterization } \\
\text { Result / mile }\end{array}$ & Factor Measure \\
\hline Acidification & Feedstock & NITROGEN OXIDES & Air & 0.112 & 0.009886 & moles $\mathrm{H}+$ equiv \\
\hline Acidification & Feedstock & SULFUR OXIDES & Air & 0.0231 & 0.002587 & moles $\mathrm{H}+$ equiv \\
\hline Acidification & Fuel & NITROGEN OXIDES & Air & 0.139 & 0.01227 & moles $\mathrm{H}+$ equiv \\
\hline Acidification & Fuel & HYDROCHLORIC ACID & Air & 8.48E-05 & 8.36E-06 & moles $\mathrm{H}+$ equiv \\
\hline Acidification & Fuel & HYDROGEN FLUORIDE & Air & 2.12E-05 & $3.8 \mathrm{E}-06$ & moles $\mathrm{H}+$ equiv \\
\hline Acidification & Fuel & SULFUR OXIDES & Air & 0.231 & 0.025865 & moles $\mathrm{H}+$ equiv \\
\hline Acidification & Vehicle & NITROGEN OXIDES & Air & 0.261 & 0.023039 & moles $\mathrm{H}+$ equiv \\
\hline Acidification & Vehicle & SULFUR OXIDES & Air & 0.00639 & 0.000715 & moles $\mathrm{H}+$ equiv \\
\hline Ecotoxicity & Feedstock & BENZENE & Air & 2.3E-05 & 1.52E-13 & Ibs 2,4-D equiv \\
\hline Ecotoxicity & Feedstock & ETHYLBENZENE & Air & 1.92E-06 & 1.86E-14 & Ibs 2,4-D equiv \\
\hline Ecotoxicity & Feedstock & TOLUENE & Air & 1.44E-05 & $1.43 \mathrm{E}-13$ & Ibs 2,4-D equiv \\
\hline Ecotoxicity & Fuel & CHLOROFORM & Air & $1.54 \mathrm{E}-06$ & 4.07E-13 & Ibs 2,4-D equiv \\
\hline Ecotoxicity & Fuel & 1,1,1-TRICHLOROETHANE & Air & 1.04E-07 & 2.04E-13 & Ibs 2,4-D equiv \\
\hline Ecotoxicity & Fuel & 1,2-DICHLOROETHANE & Air & 1.36E-06 & 1.65E-13 & Ibs 2,4-D equiv \\
\hline Ecotoxicity & Fuel & 1,3-BUTADIENE & Air & 6.99E-06 & 8.17E-16 & Ibs 2,4-D equiv \\
\hline Ecotoxicity & Fuel & BENZENE & Air & 0.00019 & $1.26 \mathrm{E}-12$ & Ibs 2,4-D equiv \\
\hline Ecotoxicity & Fuel & CARBON DISULFIDE & Air & 2.93E-06 & 7.11E-11 & Ibs 2,4-D equiv \\
\hline Ecotoxicity & Fuel & CARBON TETRACHLORIDE & Air & $5.88 \mathrm{E}-07$ & $4.28 \mathrm{E}-12$ & Ibs 2,4-D equiv \\
\hline Ecotoxicity & Fuel & DIBUTYL PHTHALATE & Air & 2.69E-07 & 4.03E-09 & Ibs 2,4-D equiv \\
\hline Ecotoxicity & Fuel & ETHYLBENZENE & Air & 5.79E-05 & $5.62 E-13$ & Ibs 2,4-D equiv \\
\hline Ecotoxicity & Fuel & FORMALDEHYDE & Air & 1.17E-05 & $7.48 \mathrm{E}-10$ & Ibs 2,4-D equiv \\
\hline Ecotoxicity & Fuel & M-XYLENE & Air & 1.14E-05 & $1.81 \mathrm{E}-14$ & Ibs 2,4-D equiv \\
\hline Ecotoxicity & Fuel & NAPHTHALENE & Air & 1.77E-05 & $1.48 \mathrm{E}-09$ & Ibs 2,4-D equiv \\
\hline Ecotoxicity & Fuel & O-XYLENE & Air & 9.7E-06 & $3.42 \mathrm{E}-14$ & Ibs 2,4-D equiv \\
\hline Ecotoxicity & Fuel & P-XYLENE & Air & 1.22E-05 & 2.56E-14 & Ibs 2,4-D equiv \\
\hline Ecotoxicity & Fuel & PHENOL & Air & 1.14E-05 & 9.55E-10 & Ibs 2,4-D equiv \\
\hline Ecotoxicity & Fuel & PROPYLENE OXIDE & Air & 0 & 0 & Ibs 2,4-D equiv \\
\hline Ecotoxicity & Fuel & STYRENE & Air & 1.13E-06 & 2.99E-15 & Ibs 2,4-D equiv \\
\hline Ecotoxicity & Fuel & TETRACHLOROETHYLENE & Air & $5.4 \mathrm{E}-06$ & 7.98E-12 & Ibs 2,4-D equiv \\
\hline Ecotoxicity & Fuel & TOLUENE & Air & 0.000418 & 4.15E-12 & Ibs 2,4-D equiv \\
\hline Ecotoxicity & Fuel & TRICHLOROETHYLENE & Air & 5.79E-06 & 5.11E-14 & Ibs 2,4-D equiv \\
\hline Ecotoxicity & Vehicle & BENZENE & Air & 0.0054 & 3.57145E-11 & Ibs 2,4-D equiv \\
\hline Ecotoxicity & Vehicle & FORMALDEHYDE & Air & 0.0009 & 5.75401E-08 & Ibs 2,4-D equiv \\
\hline Ecotoxicity & Vehicle & TOLUENE & Air & 0.0126 & $1.25001 \mathrm{E}-10$ & Ibs 2,4-D equiv \\
\hline Ecotoxicity & Vehicle & 1,3 Butadiene & Air & 0.00045 & 5.25797E-14 & Ibs 2,4-D equiv \\
\hline Eutrophication & Feedstock & NITROGEN OXIDES & Air & 0.112 & 1.09E-05 & $\mathrm{kg} \mathrm{N}$ \\
\hline Eutrophication & Fuel & NITROGEN OXIDES & Air & 0.139 & 1.36E-05 & $\mathrm{kg} \mathrm{N}$ \\
\hline Eutrophication & Vehicle & NITROGEN OXIDES & Air & 0.261 & 2.55E-05 & $\mathrm{kg} \mathrm{N}$ \\
\hline $\mathrm{HH}$ - Cancer & Feedstock & BENZENE & Air & 2.3E-05 & 5.07E-08 & Ibs $\mathrm{C} 6 \mathrm{H} 6$ equiv \\
\hline $\mathrm{HH}$ - Cancer & Fuel & CHLOROFORM & Air & 1.54E-06 & 1.55E-08 & Ibs $\mathrm{C} 6 \mathrm{H} 6$ equiv \\
\hline
\end{tabular}




\begin{tabular}{|c|c|c|c|c|c|c|}
\hline Impact Category & Stage & Emission & Media & \begin{tabular}{|l|} 
Mass Flow \\
(grams/mile)
\end{tabular} & $\begin{array}{l}\text { Characterization } \\
\text { Result / mile }\end{array}$ & Factor Measure \\
\hline HH - Cancer & Fuel & ACETALDEHYDE & Air & $5.25 \mathrm{E}-08$ & 4.09E-13 & Ibs $\mathrm{C} 6 \mathrm{H} 6$ equiv \\
\hline $\mathrm{HH}$ - Cancer & Fuel & ANILINE & Air & 9.05E-10 & $4.53 E-15$ & Ibs $\mathrm{C} 6 \mathrm{H} 6$ equiv \\
\hline $\mathrm{HH}$ - Cancer & Fuel & 1,2-DIBROMOETHANE & Air & 8.87E-07 & 1.65E-08 & Ibs $\mathrm{C} 6 \mathrm{H} 6$ equiv \\
\hline $\mathrm{HH}$ - Cancer & Fuel & 1,2-DICHLOROETHANE & Air & $1.36 \mathrm{E}-06$ & $1.6 \mathrm{E}-08$ & Ibs $\mathrm{C} 6 \mathrm{H} 6$ equiv \\
\hline $\mathrm{HH}$ - Cancer & Fuel & 1,3-BUTADIENE & Air & 6.99E-06 & 5.12E-09 & Ibs $\mathrm{C} 6 \mathrm{H} 6$ equiv \\
\hline $\mathrm{HH}$ - Cancer & Fuel & BENZENE & Air & 0.00019 & 4.19E-07 & Ibs $\mathrm{C} 6 \mathrm{H} 6$ equiv \\
\hline $\mathrm{HH}$ - Cancer & Fuel & CADMIUM COMPOUNDS & Air & 0 & 0 & Ibs $\mathrm{C} 6 \mathrm{H} 6$ equiv \\
\hline $\mathrm{HH}$ - Cancer & Fuel & CARBON TETRACHLORIDE & Air & 5.88E-07 & 1.07E-06 & Ibs $\mathrm{C} 6 \mathrm{H} 6$ equiv \\
\hline $\mathrm{HH}$ - Cancer & Fuel & CHROMIUM COMPOUNDS & Air & 4.86E-08 & 1.79E-08 & Ibs $\mathrm{C} 6 \mathrm{H} 6$ equiv \\
\hline $\mathrm{HH}$ - Cancer & Fuel & DIMETHYL SULFATE & Air & 0 & 0 & Ibs $\mathrm{C} 6 \mathrm{H} 6$ equiv \\
\hline $\mathrm{HH}$ - Cancer & Fuel & ETHYLENE OXIDE & Air & $1.57 \mathrm{E}-06$ & $1.07 \mathrm{E}-07$ & Ibs $\mathrm{C} 6 \mathrm{H} 6$ equiv \\
\hline $\mathrm{HH}$ - Cancer & Fuel & FORMALDEHYDE & Air & 1.17E-05 & 7.78E-11 & Ibs C6H6 equiv \\
\hline $\mathrm{HH}$ - Cancer & Fuel & HYDRAZINE & Air & 0 & 0 & Ibs $\mathrm{C} 6 \mathrm{H} 6$ equiv \\
\hline $\mathrm{HH}$ - Cancer & Fuel & HYDROQUINONE & Air & 0 & 0 & Ibs $\mathrm{C} 6 \mathrm{H} 6$ equiv \\
\hline $\mathrm{HH}$ - Cancer & Fuel & LEAD COMPOUNDS & Air & 2.94E-07 & 2.3E-08 & Ibs $\mathrm{C} 6 \mathrm{H} 6$ equiv \\
\hline $\mathrm{HH}$ - Cancer & Fuel & NICKEL COMPOUNDS & Air & $1.85 \mathrm{E}-06$ & 1.47E-08 & Ibs $\mathrm{C} 6 \mathrm{H} 6$ equiv \\
\hline $\mathrm{HH}$ - Cancer & Fuel & O-TOLUIDINE & Air & $9.05 \mathrm{E}-10$ & 1.81E-14 & Ibs $\mathrm{C} 6 \mathrm{H} 6$ equiv \\
\hline $\mathrm{HH}$ - Cancer & Fuel & PROPYLENE OXIDE & Air & 0 & 0 & Ibs $\mathrm{C} 6 \mathrm{H} 6$ equiv \\
\hline $\mathrm{HH}$ - Cancer & Fuel & TETRACHLOROETHYLENE & Air & $5.4 \mathrm{E}-06$ & 2.17E-08 & Ibs $\mathrm{C} 6 \mathrm{H} 6$ equiv \\
\hline $\mathrm{HH}$ - Cancer & Fuel & TRICHLOROETHYLENE & Air & $5.79 \mathrm{E}-06$ & $7.48 \mathrm{E}-10$ & Ibs $\mathrm{C} 6 \mathrm{H} 6$ equiv \\
\hline $\mathrm{HH}$ - Cancer & Fuel & CHLOROMETHANE & Air & 1.25E-07 & $9.71 \mathrm{E}-10$ & Ibs $\mathrm{C} 6 \mathrm{H} 6$ equiv \\
\hline $\mathrm{HH}$ - Cancer & Vehicle & ACETALDEHYDE & Air & 0.00045 & 3.50189E-09 & Ibs $\mathrm{C} 6 \mathrm{H} 6$ equiv \\
\hline HH - Cancer & Vehicle & BENZENE & Air & 0.0054 & $1.19048 \mathrm{E}-05$ & Ibs $\mathrm{C} 6 \mathrm{H} 6$ equiv \\
\hline $\mathrm{HH}$ - Cancer & Vehicle & FORMALDEHYDE & Air & 0.0009 & 5.98535E-09 & Ibs $\mathrm{C} 6 \mathrm{H} 6$ equiv \\
\hline $\mathrm{HH}$ - Cancer & Vehicle & 1,3 Butadiene & Air & 0.00045 & 3.29511E-07 & Ibs $\mathrm{C} 6 \mathrm{H} 6$ equiv \\
\hline $\mathrm{HH}$ - Criteria & Feedstock & NITROGEN OXIDES & Air & 0.112 & 5.46E-07 & total DALYs \\
\hline $\mathrm{HH}$ - Criteria & Feedstock & PM10 & Air & 0.00343 & 6.31E-07 & total DALYs \\
\hline $\mathrm{HH}$ - Criteria & Feedstock & PM2.5 & Air & 0.00206 & 6.32E-07 & total DALYs \\
\hline $\mathrm{HH}$ - Criteria & Fuel & NITROGEN OXIDES & Air & 0.139 & 6.78E-07 & total DALYs \\
\hline $\mathrm{HH}$ - Criteria & Fuel & PM10 & Air & 0.0148 & $2.72 \mathrm{E}-06$ & total DALYs \\
\hline $\mathrm{HH}$ - Criteria & Fuel & PM2.5 & Air & 0.00887 & 2.72E-06 & total DALYs \\
\hline $\mathrm{HH}$ - Criteria & Vehicle & NITROGEN OXIDES & Air & 0.261 & $1.27 \mathrm{E}-06$ & total DALYs \\
\hline $\mathrm{HH}$ - Criteria & Vehicle & PM10 & Air & 0.032 & 5.89E-06 & total DALYs \\
\hline $\mathrm{HH}$ - Criteria & Vehicle & PM2.5 & Air & 0.0194 & 5.95E-06 & total DALYs \\
\hline $\mathrm{HH}$ - Non-can & Feedstock & BENZENE & Air & 2.3E-05 & 8.41E-07 & Ibs $\mathrm{C} 6 \mathrm{H} 6$ equiv \\
\hline $\mathrm{HH}$ - Non-can & Feedstock & ETHYLBENZENE & Air & 1.92E-06 & 1.4E-09 & Ibs $\mathrm{C} 6 \mathrm{H} 6$ equiv \\
\hline $\mathrm{HH}$ - Non-can & Feedstock & TOLUENE & Air & 1.44E-05 & 3.17E-08 & Ibs $\mathrm{C} 6 \mathrm{H} 6$ equiv \\
\hline $\mathrm{HH}$ - Non-can & Feedstock & XYLENE & Air & 8.15E-06 & 4.2E-09 & Ibs $\mathrm{C} 6 \mathrm{H} 6$ equiv \\
\hline $\mathrm{HH}$ - Non-can & Fuel & HYDROCHLORIC ACID & Air & 8.48E-05 & 7.26E-08 & Ibs $\mathrm{C} 6 \mathrm{H} 6$ equiv \\
\hline $\mathrm{HH}$ - Non-can & Fuel & CHLOROFORM & Air & $1.54 \mathrm{E}-06$ & 2.71E-07 & Ibs $\mathrm{C} 6 \mathrm{H} 6$ equiv \\
\hline $\mathrm{HH}$ - Non-can & Fuel & ACETALDEHYDE & Air & 5.25E-08 & $4.53 \mathrm{E}-10$ & Ibs $\mathrm{C} 6 \mathrm{H} 6$ equiv \\
\hline HH - Non-can & Fuel & ACETONITRILE & Air & 8.78E-08 & 3.05E-08 & Ibs $\mathrm{C} 6 \mathrm{H} 6$ equiv \\
\hline
\end{tabular}




\begin{tabular}{|c|c|c|c|c|c|c|}
\hline Impact Category & Stage & Emission & Media & \begin{tabular}{||c|c|} 
Mass Flow \\
(grams/mile)
\end{tabular} & $\begin{array}{l}\text { Characterization } \\
\text { Result / mile }\end{array}$ & Factor Measure \\
\hline HH - Non-can & Fuel & ANILINE & Air & $9.05 \mathrm{E}-10$ & 7.91E-11 & Ibs $\mathrm{C} 6 \mathrm{H} 6$ equiv \\
\hline $\mathrm{HH}$ - Non-can & Fuel & 1,1,1-TRICHLOROETHANE & Air & 1.04E-07 & 4.59E-08 & Ibs $\mathrm{C} 6 \mathrm{H} 6$ equiv \\
\hline $\mathrm{HH}$ - Non-can & Fuel & 1,2,4-TRICHLOROBENZENE & Air & $1.32 \mathrm{E}-07$ & 8.75E-09 & Ibs $\mathrm{C} 6 \mathrm{H} 6$ equiv \\
\hline $\mathrm{HH}$ - Non-can & Fuel & 1,2-DIBROMOETHANE & Air & 8.87E-07 & 7.99E-06 & Ibs $\mathrm{C} 6 \mathrm{H} 6$ equiv \\
\hline HH - Non-can & Fuel & 1,2-DICHLOROETHANE & Air & 1.36E-06 & 5.67E-08 & Ibs $\mathrm{C} 6 \mathrm{H} 6$ equiv \\
\hline HH - Non-can & Fuel & 1,3-BUTADIENE & Air & 6.99E-06 & 1.87E-08 & Ibs $\mathrm{C} 6 \mathrm{H} 6$ equiv \\
\hline $\mathrm{HH}$ - Non-can & Fuel & ANTIMONY COMPOUNDS & Air & 2.81E-07 & $1.2 \mathrm{E}-05$ & Ibs $\mathrm{C} 6 \mathrm{H} 6$ equiv \\
\hline $\mathrm{HH}$ - Non-can & Fuel & BENZENE & Air & 0.00019 & 6.94E-06 & Ibs $\mathrm{C} 6 \mathrm{H} 6$ equiv \\
\hline $\mathrm{HH}$ - Non-can & Fuel & BIPHENYL & Air & 1.13E-06 & 1.67E-09 & Ibs $\mathrm{C} 6 \mathrm{H} 6$ equiv \\
\hline HH - Non-can & Fuel & CADMIUM COMPOUNDS & Air & 0 & 0 & Ibs $\mathrm{C} 6 \mathrm{H} 6$ equiv \\
\hline $\mathrm{HH}$ - Non-can & Fuel & CARBON DISULFIDE & Air & $2.93 \mathrm{E}-06$ & 3.03E-08 & Ibs $\mathrm{C} 6 \mathrm{H} 6$ equiv \\
\hline HH - Non-can & Fuel & CARBON TETRACHLORIDE & Air & 5.88E-07 & 1.79E-05 & Ibs C6H6 equiv \\
\hline $\mathrm{HH}$ - Non-can & Fuel & CHLOROBENZENE & Air & 0 & 0 & Ibs $\mathrm{C} 6 \mathrm{H} 6$ equiv \\
\hline $\mathrm{HH}$ - Non-can & Fuel & CHROMIUM COMPOUNDS & Air & 4.86E-08 & $6.82 \mathrm{E}-07$ & Ibs $\mathrm{C} 6 \mathrm{H} 6$ equiv \\
\hline HH - Non-can & Fuel & COBALT COMPOUNDS & Air & $6.25 \mathrm{E}-08$ & 1.09E-05 & Ibs $\mathrm{C} 6 \mathrm{H} 6$ equiv \\
\hline HH - Non-can & Fuel & CUMENE & Air & $1.91 \mathrm{E}-05$ & 1.31E-08 & Ibs $\mathrm{C} 6 \mathrm{H} 6$ equiv \\
\hline HH - Non-can & Fuel & DIBUTYL PHTHALATE & Air & $2.69 \mathrm{E}-07$ & $1.2 \mathrm{E}-08$ & Ibs $\mathrm{C} 6 \mathrm{H} 6$ equiv \\
\hline $\mathrm{HH}$ - Non-can & Fuel & DIETHANOLAMINE & Air & $1.32 \mathrm{E}-05$ & $4.21 \mathrm{E}-07$ & Ibs $\mathrm{C} 6 \mathrm{H} 6$ equiv \\
\hline $\mathrm{HH}$ - Non-can & Fuel & ETHYLBENZENE & Air & 5.79E-05 & $4.24 \mathrm{E}-08$ & Ibs $\mathrm{C} 6 \mathrm{H} 6$ equiv \\
\hline $\mathrm{HH}$ - Non-can & Fuel & ETHYLENE GLYCOL & Air & $6.91 \mathrm{E}-06$ & 3.73E-09 & Ibs $\mathrm{C} 6 \mathrm{H} 6$ equiv \\
\hline $\mathrm{HH}$ - Non-can & Fuel & ETHYLENE OXIDE & Air & $1.57 \mathrm{E}-06$ & $6.85 \mathrm{E}-06$ & Ibs $\mathrm{C} 6 \mathrm{H} 6$ equiv \\
\hline $\mathrm{HH}$ - Non-can & Fuel & FORMALDEHYDE & Air & 1.17E-05 & 1.23E-07 & Ibs $\mathrm{C} 6 \mathrm{H} 6$ equiv \\
\hline $\mathrm{HH}$ - Non-can & Fuel & HYDRAZINE & Air & 0 & 0 & Ibs C6H6 equiv \\
\hline $\mathrm{HH}$ - Non-can & Fuel & HYDROQUINONE & Air & 0 & 0 & Ibs $\mathrm{C} 6 \mathrm{H} 6$ equiv \\
\hline $\mathrm{HH}$ - Non-can & Fuel & LEAD COMPOUNDS & Air & 2.94E-07 & 0.000973 & Ibs $\mathrm{C} 6 \mathrm{H} 6$ equiv \\
\hline $\mathrm{HH}$ - Non-can & Fuel & M-CRESOL & Air & 0 & 0 & Ibs $\mathrm{C} 6 \mathrm{H} 6$ equiv \\
\hline HH - Non-can & Fuel & M-XYLENE & Air & $1.14 \mathrm{E}-05$ & 4.17E-09 & Ibs $\mathrm{C} 6 \mathrm{H} 6$ equiv \\
\hline $\mathrm{HH}$ - Non-can & Fuel & MALEIC ANHYDRIDE & Air & 3.17E-09 & $1.21 \mathrm{E}-09$ & Ibs $\mathrm{C} 6 \mathrm{H} 6$ equiv \\
\hline $\mathrm{HH}$ - Non-can & Fuel & MANGANESE COMPOUNDS & Air & 7.71E-08 & 1.35E-06 & Ibs $\mathrm{C} 6 \mathrm{H} 6$ equiv \\
\hline $\mathrm{HH}$ - Non-can & Fuel & MERCURY COMPOUNDS & Air & 4.5E-07 & 0.019102 & Ibs $\mathrm{C} 6 \mathrm{H} 6$ equiv \\
\hline $\mathrm{HH}$ - Non-can & Fuel & METHANOL & Air & 0.000417 & $1 \mathrm{E}-07$ & Ibs $\mathrm{C} 6 \mathrm{H} 6$ equiv \\
\hline $\mathrm{HH}$ - Non-can & Fuel & METHYL ETHYL KETONE & Air & 0.000298 & 7.49E-08 & Ibs $\mathrm{C} 6 \mathrm{H} 6$ equiv \\
\hline $\mathrm{HH}$ - Non-can & Fuel & METHYL ISOBUTYL KETONE & Air & 2.19E-05 & 3.54E-08 & Ibs $\mathrm{C} 6 \mathrm{H} 6$ equiv \\
\hline $\mathrm{HH}$ - Non-can & Fuel & METHYL TERT-BUTYL ETHER & Air & 0.000164 & 3.26E-08 & Ibs $\mathrm{C} 6 \mathrm{H} 6$ equiv \\
\hline $\mathrm{HH}$ - Non-can & Fuel & N-HEXANE & Air & 0.000303 & 4.05E-07 & Ibs $\mathrm{C} 6 \mathrm{H} 6$ equiv \\
\hline $\mathrm{HH}$ - Non-can & Fuel & NAPHTHALENE & Air & 1.77E-05 & 4.97E-07 & Ibs $\mathrm{C} 6 \mathrm{H} 6$ equiv \\
\hline $\mathrm{HH}$ - Non-can & Fuel & NICKEL COMPOUNDS & Air & 1.85E-06 & 3.37E-05 & Ibs $\mathrm{C} 6 \mathrm{H} 6$ equiv \\
\hline $\mathrm{HH}$ - Non-can & Fuel & O-CRESOL & Air & 0 & 0 & Ibs $\mathrm{C} 6 \mathrm{H} 6$ equiv \\
\hline $\mathrm{HH}$ - Non-can & Fuel & O-XYLENE & Air & $9.7 \mathrm{E}-06$ & $6 \mathrm{E}-09$ & Ibs $\mathrm{C} 6 \mathrm{H} 6$ equiv \\
\hline $\mathrm{HH}$ - Non-can & Fuel & P-CRESOL & Air & 0 & 0 & Ibs $\mathrm{C} 6 \mathrm{H} 6$ equiv \\
\hline $\mathrm{HH}$ - Non-can & Fuel & P-XYLENE & Air & 1.22E-05 & 7.21E-09 & Ibs $\mathrm{C} 6 \mathrm{H} 6$ equiv \\
\hline HH - Non-can & Fuel & PHENOL & Air & 1.14E-05 & 1.44E-09 & Ibs $\mathrm{C} 6 \mathrm{H} 6$ equiv \\
\hline
\end{tabular}




\begin{tabular}{|c|c|c|c|c|c|c|}
\hline Impact Category & Stage & Emission & Media & \begin{tabular}{||c|c|} 
Mass Flow \\
(grams/mile)
\end{tabular} & $\begin{array}{l}\text { Characterization } \\
\text { Result / mile }\end{array}$ & Factor Measure \\
\hline HH - Non-can & Fuel & PROPYLENE OXIDE & Air & 0 & 0 & Ibs $\mathrm{C} 6 \mathrm{H} 6$ equiv \\
\hline $\mathrm{HH}$ - Non-can & Fuel & SELENIUM COMPOUNDS & Air & 2.31E-08 & $1.08 \mathrm{E}-06$ & Ibs $\mathrm{C} 6 \mathrm{H} 6$ equiv \\
\hline $\mathrm{HH}$ - Non-can & Fuel & STYRENE & Air & 1.13E-06 & 7.18E-11 & Ibs $\mathrm{C} 6 \mathrm{H} 6$ equiv \\
\hline $\mathrm{HH}$ - Non-can & Fuel & TETRACHLOROETHYLENE & Air & $5.4 \mathrm{E}-06$ & 2.57E-06 & Ibs $\mathrm{C} 6 \mathrm{H} 6$ equiv \\
\hline HH - Non-can & Fuel & TOLUENE & Air & 0.000418 & 9.22E-07 & Ibs $\mathrm{C} 6 \mathrm{H} 6$ equiv \\
\hline HH - Non-can & Fuel & TRICHLOROETHYLENE & Air & 5.79E-06 & 1.25E-08 & Ibs $\mathrm{C} 6 \mathrm{H} 6$ equiv \\
\hline $\mathrm{HH}$ - Non-can & Fuel & TRIETHYLAMINE & Air & 0 & 0 & Ibs $\mathrm{C} 6 \mathrm{H} 6$ equiv \\
\hline $\mathrm{HH}$ - Non-can & Fuel & VINYL ACETATE & Air & 3.22E-08 & 1.37E-10 & Ibs $\mathrm{C} 6 \mathrm{H} 6$ equiv \\
\hline $\mathrm{HH}$ - Non-can & Fuel & CHLOROMETHANE & Air & 1.25E-07 & 1.49E-07 & Ibs $\mathrm{C} 6 \mathrm{H} 6$ equiv \\
\hline HH - Non-can & Fuel & XYLENE & Air & 0.000255 & 1.31E-07 & Ibs $\mathrm{C} 6 \mathrm{H} 6$ equiv \\
\hline $\mathrm{HH}$ - Non-can & Fuel & Certain glycol ethers & Air & 3.25E-06 & 2.72E-09 & Ibs $\mathrm{C} 6 \mathrm{H} 6$ equiv \\
\hline HH - Non-can & Fuel & Polychlorinated biphenyls & Air & 9.05E-13 & 9.59E-12 & Ibs C6H6 equiv \\
\hline $\mathrm{HH}$ - Non-can & Vehicle & ACETALDEHYDE & & 0.00045 & 3.8833E-06 & Ibs $\mathrm{C} 6 \mathrm{H} 6$ equiv \\
\hline $\mathrm{HH}$ - Non-can & Vehicle & BENZENE & & 0.0054 & 0.000197354 & Ibs $\mathrm{C} 6 \mathrm{H} 6$ equiv \\
\hline $\mathrm{HH}$ - Non-can & Vehicle & FORMALDEHYDE & & 0.0009 & 9.47171E-06 & Ibs $\mathrm{C} 6 \mathrm{H} 6$ equiv \\
\hline HH - Non-can & Vehicle & TOLUENE & & 0.0126 & $2.7778 \mathrm{E}-05$ & Ibs $\mathrm{C} 6 \mathrm{H} 6$ equiv \\
\hline HH - Non-can & Vehicle & 1,3 Butadiene & & 0.00045 & $1.2051 \mathrm{E}-06$ & Ibs C6H6 equiv \\
\hline Smog & Feedstock & NITROGEN OXIDES & Air & 0.112 & 0.000306 & g NOX equiv \\
\hline Smog & Feedstock & BENZENE & Air & 2.3E-05 & 1.25E-08 & g NOX equiv \\
\hline Smog & Feedstock & ETHYLBENZENE & Air & 1.92E-06 & 3.09E-09 & g NOX equiv \\
\hline Smog & Feedstock & TOLUENE & Air & 1.44E-05 & $3.27 \mathrm{E}-08$ & g NOX equiv \\
\hline Smog & Feedstock & VOC & Air & 0.0164 & 3.5E-05 & g NOX equiv \\
\hline Smog & Feedstock & CARBON MONOXIDE & Air & 0.0412 & 1.51E-06 & g NOX equiv \\
\hline Smog & Fuel & NITROGEN OXIDES & Air & 0.139 & 0.00038 & g NOX equiv \\
\hline Smog & Fuel & ACETALDEHYDE & Air & 5.25E-08 & 2.07E-10 & g NOX equiv \\
\hline Smog & Fuel & 1,1,1-TRICHLOROETHANE & Air & 1.04E-07 & $5.07 \mathrm{E}-12$ & g NOX equiv \\
\hline Smog & Fuel & 1,3-BUTADIENE & Air & 6.99E-06 & 4.97E-08 & g NOX equiv \\
\hline Smog & Fuel & BENZENE & Air & 0.00019 & 1.03E-07 & g NOX equiv \\
\hline Smog & Fuel & CHLOROBENZENE & Air & 0 & 0 & g NOX equiv \\
\hline Smog & Fuel & ETHYLBENZENE & Air & 5.79E-05 & 9.34E-08 & g NOX equiv \\
\hline Smog & Fuel & ETHYLENE GLYCOL & Air & $6.91 \mathrm{E}-06$ & 2.13E-08 & g NOX equiv \\
\hline Smog & Fuel & ETHYLENE OXIDE & Air & 1.57E-06 & 7.41E-11 & g NOX equiv \\
\hline Smog & Fuel & FORMALDEHYDE & Air & 1.17E-05 & 5.8E-08 & g NOX equiv \\
\hline Smog & Fuel & M-XYLENE & Air & 1.14E-05 & 6.85E-08 & g NOX equiv \\
\hline Smog & Fuel & METHANOL & Air & 0.000417 & 2.25E-07 & g NOX equiv \\
\hline Smog & Fuel & METHYL ISOBUTYL KETONE & Air & 2.19E-05 & 5.57E-08 & g NOX equiv \\
\hline Smog & Fuel & METHYL TERT-BUTYL ETHER & Air & 0.000164 & 1.19E-07 & g NOX equiv \\
\hline Smog & Fuel & N-HEXANE & Air & 0.000303 & 2.78E-07 & g NOX equiv \\
\hline Smog & Fuel & NAPHTHALENE & Air & 1.77E-05 & 2.93E-08 & g NOX equiv \\
\hline Smog & Fuel & O-XYLENE & Air & $9.7 \mathrm{E}-06$ & 4.13E-08 & g NOX equiv \\
\hline Smog & Fuel & P-XYLENE & Air & 1.22E-05 & 2.94E-08 & g NOX equiv \\
\hline Smog & Fuel & PHENOL & Air & 1.14E-05 & 2.3E-08 & g NOX equiv \\
\hline
\end{tabular}




\begin{tabular}{|l|l|l|l|l|l|l|l|}
\hline Impact Category & \multicolumn{2}{|c|}{ Stage } & \multicolumn{1}{|c|}{ Medission } & \multicolumn{1}{|c|}{$\begin{array}{c}\text { Mass Flow } \\
\text { (grams/mile) }\end{array}$} & \multicolumn{1}{c|}{$\begin{array}{c}\text { Characterization } \\
\text { Result / mile }\end{array}$} & Factor Measure \\
\hline Smog & Fuel & PROPYLENE OXIDE & Air & 0 & 0 & g NOX equiv \\
\hline Smog & Fuel & STYRENE & Air & $1.13 \mathrm{E}-06$ & $1.54 \mathrm{E}-09$ & g NOX equiv \\
\hline Smog & Fuel & TETRACHLOROETHYLENE & Air & $5.4 \mathrm{E}-06$ & $3.4 \mathrm{E}-10$ & g NOX equiv \\
\hline Smog & Fuel & TOLUENE & Air & 0.000418 & $9.51 \mathrm{E}-07$ & g NOX equiv \\
\hline Smog & Fuel & TRICHLOROETHYLENE & Air & $5.79 \mathrm{E}-06$ & $3.24 \mathrm{E}-12$ & g NOX equiv \\
\hline Smog & Fuel & VOC & Air & 0.0714 & 0.000152 & g NOX equiv \\
\hline Smog & Fuel & CARBON MONOXIDE & Air & 0.0491 & $1.8 \mathrm{E}-06$ & g NOX equiv \\
\hline Smog & Fuel & Certain glycol ethers & Air & $3.25 \mathrm{E}-06$ & $7.29 \mathrm{E}-09$ & g NOX equiv \\
\hline Smog & Vehicle & NITROGEN OXIDES & Air & 0.261 & 0.000713 & g NOX equiv \\
\hline Smog & Vehicle & VOC & Air & 0.161 & 0.000344 & g NOX equiv \\
\hline Smog & Vehicle & CARBON MONOXIDE & Air & 4.414 & 0.000162 & g NOX equiv \\
\hline
\end{tabular}

Table D-15 TRACI Data for FTD100 CIDI 2015

\begin{tabular}{|c|c|c|c|c|c|c|}
\hline Impact Category & Stage & Emission & Media & $\begin{array}{c}\text { Mass Flow } \\
\text { (grams/mile) }\end{array}$ & $\begin{array}{l}\text { Characterization } \\
\text { Result / mile }\end{array}$ & Factor Measure \\
\hline Acidification & Feedstock & NITROGEN OXIDES & Air & 0.0278 & 0.002454 & moles $\mathrm{H}+$ equiv \\
\hline Acidification & Feedstock & SULFUR OXIDES & Air & 0.00946 & 0.001059 & moles $\mathrm{H}+$ equiv \\
\hline Acidification & Fuel & NITROGEN OXIDES & Air & 0.0893 & 0.007883 & moles $\mathrm{H}+$ equiv \\
\hline Acidification & Fuel & SULFUR OXIDES & Air & 0.0119 & 0.001332 & moles $\mathrm{H}+$ equiv \\
\hline Acidification & Vehicle & NITROGEN OXIDES & Air & 0.0536 & 0.004731 & moles $\mathrm{H}+$ equiv \\
\hline Acidification & Vehicle & SULFUR OXIDES & Air & 0 & 0 & moles $\mathrm{H}+$ equiv \\
\hline Ecotoxicity & Feedstock & BENZENE & Air & 0.000186 & 1.23017E-12 & Ibs 2,4-D equiv \\
\hline Ecotoxicity & Feedstock & ETHYLBENZENE & Air & 0.0000155 & $1.50354 \mathrm{E}-13$ & Ibs 2,4-D equiv \\
\hline Ecotoxicity & Feedstock & TOLUENE & Air & 0.000116 & 1.1508E-12 & Ibs 2,4-D equiv \\
\hline Ecotoxicity & Feedstock & Phenols & Water & 0.00204 & 4.18257E-06 & Ibs 2,4-D equiv \\
\hline Ecotoxicity & Fuel & BENZENE & Air & 0.00008 & $5.29 \mathrm{E}-13$ & Ibs 2,4-D equiv \\
\hline Ecotoxicity & Vehicle & FORMALDEHYDE & Air & 0.0015 & 9.59E-08 & Ibs 2,4-D equiv \\
\hline Ecotoxicity & Vehicle & TOLUENE & Air & 0.0001 & $9.92 \mathrm{E}-13$ & Ibs 2,4-D equiv \\
\hline Ecotoxicity & Vehicle & BENZENE & Air & 0.00008 & 5.29E-13 & Ibs 2,4-D equiv \\
\hline Ecotoxicity & Vehicle & 1,3-BUTADIENE & Air & 0.0006 & 7.01E-14 & Ibs 2,4-D equiv \\
\hline Eutrophication & Feedstock & NITROGEN OXIDES & Air & 0.0278 & 2.71E-06 & $\mathrm{kg} \mathrm{N}$ \\
\hline Eutrophication & Fuel & NITROGEN OXIDES & Air & 0.0893 & 8.72E-06 & $\mathrm{kg} \mathrm{N}$ \\
\hline Eutrophication & Vehicle & NITROGEN OXIDES & Air & 0.0536 & 5.23E-06 & $\mathrm{kg} \mathrm{N}$ \\
\hline $\mathrm{HH}$ - Cancer & Feedstock & BENZENE & Air & 0.000186 & 4.1E-07 & Ibs $\mathrm{C} 6 \mathrm{H} 6$ equiv \\
\hline $\mathrm{HH}$ - Cancer & Fuel & BENZENE & Air & 0.00008 & 1.76E-07 & Ibs $\mathrm{C} 6 \mathrm{H} 6$ equiv \\
\hline $\mathrm{HH}$ - Cancer & Fuel & NICKEL COMPOUNDS & Water & 0.00082 & 0 & Ibs $\mathrm{C} 6 \mathrm{H} 6$ equiv \\
\hline $\mathrm{HH}$ - Cancer & Vehicle & FORMALDEHYDE & Air & 0.0015 & 9.98E-09 & Ibs $\mathrm{C} 6 \mathrm{H} 6$ equiv \\
\hline $\mathrm{HH}$ - Cancer & Vehicle & BENZENE & Air & 0.00008 & 1.76E-07 & Ibs $\mathrm{C} 6 \mathrm{H} 6$ equiv \\
\hline $\mathrm{HH}$ - Cancer & Vehicle & ACETALDEHYDE & Air & 0.0023 & 1.79E-08 & Ibs $\mathrm{C} 6 \mathrm{H} 6$ equiv \\
\hline $\mathrm{HH}$ - Cancer & Vehicle & 1,3-BUTADIENE & Air & 0.0006 & 4.39E-07 & Ibs $\mathrm{C} 6 \mathrm{H} 6$ equiv \\
\hline $\mathrm{HH}$ - Criteria & Feedstock & NITROGEN OXIDES & Air & 0.0278 & 1.36E-07 & total DALYs \\
\hline
\end{tabular}




\begin{tabular}{|c|c|c|c|c|c|c|}
\hline Impact Category & Stage & Emission & Media & $\begin{array}{l}\text { Mass Flow } \\
\text { (grams/mile) }\end{array}$ & $\begin{array}{l}\text { Characterization } \\
\text { Result / mile }\end{array}$ & Factor Measure \\
\hline $\mathrm{HH}$ - Criteria & Feedstock & PM10 & Air & 0.000954 & 1.76E-07 & total DALYs \\
\hline $\mathrm{HH}$ - Criteria & Feedstock & PM2.5 & Air & 0.000572 & $1.75 \mathrm{E}-07$ & total DALYs \\
\hline $\mathrm{HH}$ - Criteria & Fuel & NITROGEN OXIDES & Air & 0.0893 & 4.36E-07 & total DALYs \\
\hline $\mathrm{HH}$ - Criteria & Fuel & PM10 & Air & 0.00221 & 4.07E-07 & total DALYs \\
\hline $\mathrm{HH}$ - Criteria & Fuel & PM2.5 & Air & 0.00133 & $4.08 \mathrm{E}-07$ & total DALYs \\
\hline $\mathrm{HH}$ - Criteria & Vehicle & NITROGEN OXIDES & Air & 0.0536 & 2.61E-07 & total DALYs \\
\hline $\mathrm{HH}$ - Criteria & Vehicle & PM10 & Air & 0.028 & 5.15E-06 & total DALYs \\
\hline $\mathrm{HH}$ - Criteria & Vehicle & PM2.5 & Air & 0.0168 & 5.15E-06 & total DALYs \\
\hline $\mathrm{HH}$ - Non-can & Feedstock & BENZENE & Air & 0.000186 & 6.79775E-06 & Ibs $\mathrm{C} 6 \mathrm{H} 6$ equiv \\
\hline $\mathrm{HH}$ - Non-can & Feedstock & ETHYLBENZENE & Air & 0.0000155 & 1.13472E-08 & Ibs $\mathrm{C} 6 \mathrm{H} 6$ equiv \\
\hline $\mathrm{HH}$ - Non-can & Feedstock & TOLUENE & Air & 0.000116 & 2.55734E-07 & Ibs $\mathrm{C} 6 \mathrm{H} 6$ equiv \\
\hline HH - Non-can & Feedstock & XYLENE & Air & 0.0000657 & 3.38295E-08 & Ibs $\mathrm{C} 6 \mathrm{H} 6$ equiv \\
\hline $\mathrm{HH}$ - Non-can & Feedstock & Phenols & Water & 0.00204 & 2.41977E-08 & Ibs $\mathrm{C} 6 \mathrm{H} 6$ equiv \\
\hline $\mathrm{HH}$ - Non-can & Fuel & BENZENE & Air & 0.00008 & 2.92E-06 & Ibs $\mathrm{C} 6 \mathrm{H} 6$ equiv \\
\hline $\mathrm{HH}$ - Non-can & Fuel & NICKEL COMPOUNDS & Water & 0.00082 & 0.000121 & Ibs $\mathrm{C} 6 \mathrm{H} 6$ equiv \\
\hline HH - Non-can & Vehicle & FORMALDEHYDE & Air & 0.0015 & $1.58 \mathrm{E}-05$ & Ibs $\mathrm{C} 6 \mathrm{H} 6$ equiv \\
\hline $\mathrm{HH}$ - Non-can & Vehicle & TOLUENE & Air & 0.0001 & 2.20E-07 & Ibs $\mathrm{C} 6 \mathrm{H} 6$ equiv \\
\hline $\mathrm{HH}$ - Non-can & Vehicle & BENZENE & Air & 0.00008 & 2.92E-06 & Ibs $\mathrm{C} 6 \mathrm{H} 6$ equiv \\
\hline HH - Non-can & Vehicle & ACETALDEHYDE & Air & 0.0023 & $1.98 \mathrm{E}-05$ & Ibs $\mathrm{C} 6 \mathrm{H} 6$ equiv \\
\hline $\mathrm{HH}$ - Non-can & Vehicle & 1,3-BUTADIENE & Air & 0.0006 & 1.61E-06 & Ibs $\mathrm{C} 6 \mathrm{H} 6$ equiv \\
\hline Smog & Feedstock & NITROGEN OXIDES & Air & 0.0278 & 7.6E-05 & g NOX equiv \\
\hline Smog & Feedstock & BENZENE & Air & 0.000186 & 1.01E-07 & g NOX equiv \\
\hline Smog & Feedstock & ETHYLBENZENE & Air & 1.55E-05 & $2.5 \mathrm{E}-08$ & g NOX equiv \\
\hline Smog & Feedstock & TOLUENE & Air & 0.000116 & 2.64E-07 & g NOX equiv \\
\hline Smog & Feedstock & VOC & Air & 0.00123 & 2.62E-06 & g NOX equiv \\
\hline Smog & Feedstock & CARBON MONOXIDE & Air & 0.0174 & 6.37E-07 & g NOX equiv \\
\hline Smog & Fuel & NITROGEN OXIDES & Air & 0.0893 & 0.000244 & g NOX equiv \\
\hline Smog & Fuel & BENZENE & Air & 0.00008 & 4.34E-08 & g NOX equiv \\
\hline Smog & Fuel & VOC & Air & 0.0204 & 4.35E-05 & g NOX equiv \\
\hline Smog & Fuel & CARBON MONOXIDE & Air & 0.111 & 4.06E-06 & g NOX equiv \\
\hline Smog & Vehicle & NITROGEN OXIDES & Air & 0.0536 & 0.000147 & g NOX equiv \\
\hline Smog & Vehicle & ACETALDEHYDE & Air & 0.0055 & 2.17E-05 & g NOX equiv \\
\hline Smog & Vehicle & 1,3-BUTADIENE & Air & 0.0006 & 4.27E-06 & g NOX equiv \\
\hline Smog & Vehicle & BENZENE & Air & 0.0009 & 4.89E-07 & g NOX equiv \\
\hline Smog & Vehicle & FORMALDEHYDE & Air & 0.0129 & 6.39E-05 & g NOX equiv \\
\hline Smog & Vehicle & TOLUENE & Air & 0.0007 & 1.59E-06 & g NOX equiv \\
\hline Smog & Vehicle & VOC & Air & 0.049 & 0.000105 & g NOX equiv \\
\hline Smog & Vehicle & CARBON MONOXIDE & Air & 1.07 & 3.92E-05 & g NOX equiv \\
\hline
\end{tabular}




\section{D.3 2015 SCENARIOS}

Table D-16 TRACI Data for FTD100 HEV 2015

\begin{tabular}{|c|c|c|c|c|c|c|}
\hline Impact Category & Stage & Emission & Media & \begin{tabular}{|c|} 
Mass Flow \\
(grams/mile)
\end{tabular} & $\begin{array}{l}\text { Characterization } \\
\text { Result / mile }\end{array}$ & Factor Measure \\
\hline Acidification & Feedstock & NITROGEN OXIDES & Air & 0.0206 & 0.001818 & moles $\mathrm{H}+$ equiv \\
\hline Acidification & Feedstock & SULFUR OXIDES & Air & 0.00694 & 0.000777 & moles $\mathrm{H}+$ equiv \\
\hline Acidification & Fuel & NITROGEN OXIDES & Air & 0.0661 & 0.005835 & moles $\mathrm{H}+$ equiv \\
\hline Acidification & Fuel & SULFUR OXIDES & Air & 0.00881 & 0.000986 & moles $\mathrm{H}+$ equiv \\
\hline Acidification & Vehicle & NITROGEN OXIDES & Air & 0.0455 & 0.004016 & moles $\mathrm{H}+$ equiv \\
\hline Acidification & Vehicle & SULFUR OXIDES & Air & 0 & 0 & moles $\mathrm{H}+$ equiv \\
\hline Ecotoxicity & Feedstock & BENZENE & Air & 0.000138 & $9.13 \mathrm{E}-13$ & Ibs 2,4-D equiv \\
\hline Ecotoxicity & Feedstock & ETHYLBENZENE & Air & 1.15E-05 & $1.12 \mathrm{E}-13$ & Ibs 2,4-D equiv \\
\hline Ecotoxicity & Feedstock & TOLUENE & Air & 0.000086 & $8.53 \mathrm{E}-13$ & Ibs 2,4-D equiv \\
\hline Ecotoxicity & Fuel & BENZENE & Air & 0.00006 & $3.97 \mathrm{E}-13$ & Ibs 2,4-D equiv \\
\hline Eutrophication & Feedstock & NITROGEN OXIDES & Air & 0.0206 & 2.01E-06 & $\mathrm{kg} \mathrm{N}$ \\
\hline Eutrophication & Fuel & NITROGEN OXIDES & Air & 0.0661 & 6.45E-06 & $\mathrm{kg} \mathrm{N}$ \\
\hline Eutrophication & Vehicle & NITROGEN OXIDES & Air & 0.0455 & 4.44E-06 & $\mathrm{kg} \mathrm{N}$ \\
\hline $\mathrm{HH}$ - Cancer & Feedstock & BENZENE & Air & 0.000138 & 3.04E-07 & Ibs $\mathrm{C} 6 \mathrm{H} 6$ equiv \\
\hline $\mathrm{HH}$ - Cancer & Fuel & BENZENE & Air & 0.00006 & 1.32E-07 & Ibs $\mathrm{C} 6 \mathrm{H} 6$ equiv \\
\hline $\mathrm{HH}$ - Cancer & Fuel & NICKEL COMPOUNDS & Water & 0.00061 & 0 & Ibs $\mathrm{C} 6 \mathrm{H} 6$ equiv \\
\hline $\mathrm{HH}$ - Criteria & Feedstock & NITROGEN OXIDES & Air & 0.0206 & $1 \mathrm{E}-07$ & total DALYs \\
\hline $\mathrm{HH}$ - Criteria & Feedstock & PM10 & Air & 0.000701 & 1.29E-07 & total DALYs \\
\hline $\mathrm{HH}$ - Criteria & Feedstock & PM2.5 & Air & 0.000421 & 1.29E-07 & total DALYs \\
\hline $\mathrm{HH}$ - Criteria & Fuel & NITROGEN OXIDES & Air & 0.0661 & 3.22E-07 & total DALYs \\
\hline $\mathrm{HH}$ - Criteria & Fuel & PM10 & Air & 0.00164 & 3.02E-07 & total DALYs \\
\hline $\mathrm{HH}$ - Criteria & Fuel & PM2.5 & Air & 0.000982 & 3.01E-07 & total DALYs \\
\hline $\mathrm{HH}$ - Criteria & Vehicle & NITROGEN OXIDES & Air & 0.0455 & 2.22E-07 & total DALYs \\
\hline $\mathrm{HH}$ - Criteria & Vehicle & PM10 & Air & 0.027 & 4.97E-06 & total DALYs \\
\hline $\mathrm{HH}$ - Criteria & Vehicle & PM2.5 & Air & 0.0162 & 4.97E-06 & total DALYs \\
\hline $\mathrm{HH}$ - Non-can & Feedstock & BENZENE & Air & 0.000138 & 5.04E-06 & Ibs $\mathrm{C} 6 \mathrm{H} 6$ equiv \\
\hline $\mathrm{HH}$ - Non-can & Feedstock & ETHYLBENZENE & Air & 1.15E-05 & 8.42E-09 & Ibs $\mathrm{C} 6 \mathrm{H} 6$ equiv \\
\hline $\mathrm{HH}$ - Non-can & Feedstock & TOLUENE & Air & 0.000086 & $1.9 \mathrm{E}-07$ & Ibs $\mathrm{C} 6 \mathrm{H} 6$ equiv \\
\hline $\mathrm{HH}$ - Non-can & Feedstock & XYLENE & Air & 4.87E-05 & $2.51 \mathrm{E}-08$ & Ibs $\mathrm{C} 6 \mathrm{H} 6$ equiv \\
\hline $\mathrm{HH}$ - Non-can & Fuel & BENZENE & Air & 0.00006 & 2.19E-06 & Ibs $\mathrm{C} 6 \mathrm{H} 6$ equiv \\
\hline $\mathrm{HH}$ - Non-can & Fuel & NICKEL COMPOUNDS & Water & 0.00061 & 8.98E-05 & Ibs $\mathrm{C} 6 \mathrm{H} 6$ equiv \\
\hline Smog & Feedstock & NITROGEN OXIDES & Air & 0.0206 & 5.63E-05 & g NOX equiv \\
\hline Smog & Feedstock & BENZENE & Air & 0.000138 & 7.49E-08 & g NOX equiv \\
\hline Smog & Feedstock & ETHYLBENZENE & Air & 1.15E-05 & 1.86E-08 & g NOX equiv \\
\hline Smog & Feedstock & TOLUENE & Air & 0.000086 & 1.96E-07 & g NOX equiv \\
\hline Smog & Feedstock & VOC & Air & 0.000911 & 1.94E-06 & g NOX equiv \\
\hline Smog & Feedstock & CARBON MONOXIDE & Air & 0.0129 & 4.72E-07 & g NOX equiv \\
\hline Smog & Fuel & NITROGEN OXIDES & Air & 0.0661 & 0.000181 & g NOX equiv \\
\hline Smog & Fuel & BENZENE & Air & 0.00006 & 3.26E-08 & g NOX equiv \\
\hline
\end{tabular}




\begin{tabular}{|c|c|c|c|c|c|c|}
\hline Impact Category & Stage & Emission & Media & \begin{tabular}{|c|} 
Mass Flow \\
(grams/mile)
\end{tabular} & $\begin{array}{l}\text { Characterization } \\
\text { Result / mile }\end{array}$ & Factor Measure \\
\hline Smog & Fuel & VOC & Air & 0.0151 & 3.22E-05 & g NOX equiv \\
\hline Smog & Fuel & CARBON MONOXIDE & Air & 0.0819 & $3 E-06$ & g NOX equiv \\
\hline Smog & Vehicle & NITROGEN OXIDES & Air & 0.0455 & 0.000124 & g NOX equiv \\
\hline Smog & Vehicle & VOC & Air & 0.049 & 0.000105 & g NOX equiv \\
\hline Smog & Vehicle & CARBON MONOXIDE & Air & 1.07 & 3.92E-05 & g NOX equiv \\
\hline
\end{tabular}

Table D-17 TRACI Data for ULSD CIDI 2015

\begin{tabular}{|c|c|c|c|c|c|c|}
\hline Impact Category & Stage & Emission & Media & $\begin{array}{c}\text { Mass Flow } \\
\text { (grams/mile) }\end{array}$ & $\begin{array}{l}\text { Characterization } \\
\text { Result / mile }\end{array}$ & Factor Measure \\
\hline Acidification & Feedstock & NITROGEN OXIDES & Air & 0.0714 & 0.006303 & moles $\mathrm{H}+$ equiv \\
\hline Acidification & Feedstock & SULFUR OXIDES & Air & 0.0121 & 0.001355 & moles $\mathrm{H}+$ equiv \\
\hline Acidification & Fuel & NITROGEN OXIDES & Air & 0.066 & 0.005826 & moles $\mathrm{H}+$ equiv \\
\hline Acidification & Fuel & HYDROCHLORIC ACID & Air & 1.71E-05 & 1.68E-06 & moles $\mathrm{H}+$ equiv \\
\hline Acidification & Fuel & HYDROGEN FLUORIDE & Air & 4.28E-06 & 7.67E-07 & moles $\mathrm{H}+$ equiv \\
\hline Acidification & Fuel & SULFUR OXIDES & Air & 0.0812 & 0.009092 & moles $\mathrm{H}+$ equiv \\
\hline Acidification & Vehicle & NITROGEN OXIDES & Air & 0.063 & 0.005561 & moles $\mathrm{H}+$ equiv \\
\hline Acidification & Vehicle & SULFUR OXIDES & Air & 0.00172 & 0.000193 & moles $\mathrm{H}+$ equiv \\
\hline Ecotoxicity & Feedstock & BENZENE & Air & 4.64E-06 & 3.07E-14 & Ibs 2,4-D equiv \\
\hline Ecotoxicity & Feedstock & ETHYLBENZENE & Air & 3.87E-07 & 3.75E-15 & Ibs 2,4-D equiv \\
\hline Ecotoxicity & Feedstock & TOLUENE & Air & 2.9E-06 & 2.88E-14 & Ibs 2,4-D equiv \\
\hline Ecotoxicity & Fuel & CHLOROFORM & Air & 3.11E-07 & 8.23E-14 & Ibs 2,4-D equiv \\
\hline Ecotoxicity & Fuel & 1,1,1-TRICHLOROETHANE & Air & 2.09E-08 & 4.1E-14 & Ibs 2,4-D equiv \\
\hline Ecotoxicity & Fuel & 1,2-DICHLOROETHANE & Air & 2.73E-07 & 3.31E-14 & Ibs 2,4-D equiv \\
\hline Ecotoxicity & Fuel & 1,3-BUTADIENE & Air & 1.41E-06 & 1.65E-16 & Ibs 2,4-D equiv \\
\hline Ecotoxicity & Fuel & BENZENE & Air & 3.83E-05 & $2.53 \mathrm{E}-13$ & Ibs 2,4-D equiv \\
\hline Ecotoxicity & Fuel & CARBON DISULFIDE & Air & 5.92E-07 & 1.44E-11 & Ibs 2,4-D equiv \\
\hline Ecotoxicity & Fuel & CARBON TETRACHLORIDE & Air & 1.19E-07 & 8.66E-13 & Ibs 2,4-D equiv \\
\hline Ecotoxicity & Fuel & DIBUTYL PHTHALATE & Air & 5.42E-08 & 8.13E-10 & Ibs 2,4-D equiv \\
\hline Ecotoxicity & Fuel & ETHYLBENZENE & Air & 1.17E-05 & 1.13E-13 & Ibs 2,4-D equiv \\
\hline Ecotoxicity & Fuel & FORMALDEHYDE & Air & 2.35E-06 & 1.5E-10 & Ibs 2,4-D equiv \\
\hline Ecotoxicity & Fuel & M-XYLENE & Air & 2.31E-06 & 3.67E-15 & Ibs 2,4-D equiv \\
\hline Ecotoxicity & Fuel & NAPHTHALENE & Air & $3.58 \mathrm{E}-06$ & $3 \mathrm{E}-10$ & Ibs 2,4-D equiv \\
\hline Ecotoxicity & Fuel & O-XYLENE & Air & $1.96 \mathrm{E}-06$ & $6.91 \mathrm{E}-15$ & Ibs 2,4-D equiv \\
\hline Ecotoxicity & Fuel & P-XYLENE & Air & 2.45E-06 & 5.13E-15 & Ibs 2,4-D equiv \\
\hline Ecotoxicity & Fuel & PHENOL & Air & 2.31E-06 & 1.94E-10 & Ibs 2,4-D equiv \\
\hline Ecotoxicity & Fuel & PROPYLENE OXIDE & Air & 0 & 0 & Ibs 2,4-D equiv \\
\hline Ecotoxicity & Fuel & STYRENE & Air & 2.27E-07 & 6.01E-16 & Ibs 2,4-D equiv \\
\hline Ecotoxicity & Fuel & TETRACHLOROETHYLENE & Air & 1.09E-06 & 1.61E-12 & Ibs 2,4-D equiv \\
\hline Ecotoxicity & Fuel & TOLUENE & Air & 8.42E-05 & 8.35E-13 & Ibs 2,4-D equiv \\
\hline Ecotoxicity & Fuel & TRICHLOROETHYLENE & Air & 1.17E-06 & 1.03E-14 & Ibs 2,4-D equiv \\
\hline Ecotoxicity & Vehicle & TOLUENE & Air & 0.0002 & 1.98E-12 & Ibs 2,4-D equiv \\
\hline
\end{tabular}




\begin{tabular}{|c|c|c|c|c|c|c|}
\hline Impact Category & Stage & Emission & Media & $\begin{array}{c}\text { Mass Flow } \\
\text { (grams/mile) }\end{array}$ & $\begin{array}{c}\text { Characterization } \\
\text { Result / mile }\end{array}$ & Factor Measure \\
\hline Ecotoxicity & Vehicle & 1,3-BUTADIENE & Air & 0.0008 & 9.35E-14 & Ibs 2,4-D equiv \\
\hline Ecotoxicity & Vehicle & BENZENE & Air & 0.00011 & 7.28E-13 & Ibs 2,4-D equiv \\
\hline Ecotoxicity & Vehicle & FORMALDEHYDE & Air & 0.002 & 1.28E-07 & Ibs 2,4-D equiv \\
\hline Eutrophication & Feedstock & NITROGEN OXIDES & Air & 0.0714 & 6.97E-06 & $\mathrm{kg} \mathrm{N}$ \\
\hline Eutrophication & Fuel & NITROGEN OXIDES & Air & 0.066 & 6.44E-06 & $\mathrm{kg} \mathrm{N}$ \\
\hline Eutrophication & Vehicle & NITROGEN OXIDES & Air & 0.063 & 6.15E-06 & $\mathrm{kg} \mathrm{N}$ \\
\hline $\mathrm{HH}$ - Cancer & Feedstock & BENZENE & Air & 4.64E-06 & 1.02E-08 & Ibs $\mathrm{C} 6 \mathrm{H} 6$ equiv \\
\hline $\mathrm{HH}$ - Cancer & Fuel & CHLOROFORM & Air & 3.11E-07 & 3.13E-09 & Ibs $\mathrm{C} 6 \mathrm{H} 6$ equiv \\
\hline $\mathrm{HH}$ - Cancer & Fuel & ACETALDEHYDE & Air & 1.06E-08 & 8.25E-14 & Ibs $\mathrm{C} 6 \mathrm{H} 6$ equiv \\
\hline $\mathrm{HH}$ - Cancer & Fuel & ANILINE & Air & 1.83E-10 & 9.17E-16 & Ibs $\mathrm{C} 6 \mathrm{H} 6$ equiv \\
\hline $\mathrm{HH}$ - Cancer & Fuel & 1,2-DIBROMOETHANE & Air & 1.79E-07 & 3.32E-09 & Ibs $\mathrm{C} 6 \mathrm{H} 6$ equiv \\
\hline $\mathrm{HH}$ - Cancer & Fuel & 1,2-DICHLOROETHANE & Air & 2.73E-07 & 3.21E-09 & Ibs $\mathrm{C} 6 \mathrm{H} 6$ equiv \\
\hline $\mathrm{HH}$ - Cancer & Fuel & 1,3-BUTADIENE & Air & 1.41E-06 & 1.03E-09 & Ibs $\mathrm{C} 6 \mathrm{H} 6$ equiv \\
\hline $\mathrm{HH}$ - Cancer & Fuel & BENZENE & Air & 3.83E-05 & 8.44E-08 & Ibs $\mathrm{C} 6 \mathrm{H} 6$ equiv \\
\hline $\mathrm{HH}$ - Cancer & Fuel & CADMIUM COMPOUNDS & Air & 0 & 0 & Ibs $\mathrm{C} 6 \mathrm{H} 6$ equiv \\
\hline $\mathrm{HH}$ - Cancer & Fuel & CARBON TETRACHLORIDE & Air & 1.19E-07 & 2.16E-07 & Ibs $\mathrm{C} 6 \mathrm{H} 6$ equiv \\
\hline $\mathrm{HH}$ - Cancer & Fuel & CHROMIUM COMPOUNDS & Air & 9.81E-09 & 3.62E-09 & Ibs $\mathrm{C} 6 \mathrm{H} 6$ equiv \\
\hline $\mathrm{HH}$ - Cancer & Fuel & DIMETHYL SULFATE & Air & 0 & 0 & Ibs $\mathrm{C} 6 \mathrm{H} 6$ equiv \\
\hline $\mathrm{HH}$ - Cancer & Fuel & ETHYLENE OXIDE & Air & 3.17E-07 & 2.16E-08 & Ibs $\mathrm{C} 6 \mathrm{H} 6$ equiv \\
\hline $\mathrm{HH}$ - Cancer & Fuel & FORMALDEHYDE & Air & 2.35E-06 & $1.56 \mathrm{E}-11$ & Ibs $\mathrm{C} 6 \mathrm{H} 6$ equiv \\
\hline $\mathrm{HH}$ - Cancer & Fuel & HYDRAZINE & Air & 0 & 0 & Ibs $\mathrm{C} 6 \mathrm{H} 6$ equiv \\
\hline $\mathrm{HH}$ - Cancer & Fuel & HYDROQUINONE & Air & 0 & 0 & Ibs $\mathrm{C} 6 \mathrm{H} 6$ equiv \\
\hline $\mathrm{HH}$ - Cancer & Fuel & LEAD COMPOUNDS & Air & 5.93E-08 & 4.64E-09 & Ibs $\mathrm{C} 6 \mathrm{H} 6$ equiv \\
\hline $\mathrm{HH}$ - Cancer & Fuel & NICKEL COMPOUNDS & Air & $3.74 \mathrm{E}-07$ & 2.98E-09 & Ibs $\mathrm{C} 6 \mathrm{H} 6$ equiv \\
\hline $\mathrm{HH}$ - Cancer & Fuel & O-TOLUIDINE & Air & 1.83E-10 & 3.67E-15 & Ibs $\mathrm{C} 6 \mathrm{H} 6$ equiv \\
\hline $\mathrm{HH}$ - Cancer & Fuel & PROPYLENE OXIDE & Air & 0 & 0 & Ibs $\mathrm{C} 6 \mathrm{H} 6$ equiv \\
\hline $\mathrm{HH}$ - Cancer & Fuel & TETRACHLOROETHYLENE & Air & $1.09 \mathrm{E}-06$ & 4.38E-09 & Ibs $\mathrm{C} 6 \mathrm{H} 6$ equiv \\
\hline $\mathrm{HH}$ - Cancer & Fuel & TRICHLOROETHYLENE & Air & 1.17E-06 & 1.51E-10 & Ibs $\mathrm{C} 6 \mathrm{H} 6$ equiv \\
\hline $\mathrm{HH}$ - Cancer & Fuel & CHLOROMETHANE & Air & 2.53E-08 & 1.97E-10 & Ibs $\mathrm{C} 6 \mathrm{H} 6$ equiv \\
\hline $\mathrm{HH}$ - Cancer & Vehicle & ACETALDEHYDE & Air & 0.0026 & 2.02E-08 & Ibs $\mathrm{C} 6 \mathrm{H} 6$ equiv \\
\hline $\mathrm{HH}$ - Cancer & Vehicle & 1,3-BUTADIENE & Air & 0.0008 & 5.86E-07 & Ibs $\mathrm{C} 6 \mathrm{H} 6$ equiv \\
\hline $\mathrm{HH}$ - Cancer & Vehicle & BENZENE & Air & 0.00011 & 2.43E-07 & Ibs $\mathrm{C} 6 \mathrm{H} 6$ equiv \\
\hline $\mathrm{HH}$ - Cancer & Vehicle & FORMALDEHYDE & Air & 0.002 & 1.33E-08 & Ibs $\mathrm{C} 6 \mathrm{H} 6$ equiv \\
\hline $\mathrm{HH}$ - Criteria & Feedstock & NITROGEN OXIDES & Air & 0.0714 & 3.48E-07 & total DALYs \\
\hline $\mathrm{HH}$ - Criteria & Feedstock & PM10 & Air & 0.00222 & 4.08E-07 & total DALYs \\
\hline $\mathrm{HH}$ - Criteria & Feedstock & PM2.5 & Air & 0.00133 & 4.08E-07 & total DALYs \\
\hline $\mathrm{HH}$ - Criteria & Fuel & NITROGEN OXIDES & Air & 0.066 & 3.22E-07 & total DALYs \\
\hline $\mathrm{HH}$ - Criteria & Fuel & PM10 & Air & 0.00874 & 1.61E-06 & total DALYs \\
\hline $\mathrm{HH}$ - Criteria & Fuel & PM2.5 & Air & 0.00525 & 1.61E-06 & total DALYs \\
\hline $\mathrm{HH}$ - Criteria & Vehicle & NITROGEN OXIDES & Air & 0.063 & 3.07E-07 & total DALYs \\
\hline $\mathrm{HH}$ - Criteria & Vehicle & PM10 & Air & 0.031 & 5.7E-06 & total DALYs \\
\hline $\mathrm{HH}$ - Criteria & Vehicle & PM2.5 & Air & 0.0186 & 5.7E-06 & total DALYs \\
\hline
\end{tabular}




\begin{tabular}{|c|c|c|c|c|c|c|}
\hline Impact Category & Stage & Emission & Media & \begin{tabular}{|l|} 
Mass Flow \\
(grams/mile)
\end{tabular} & $\begin{array}{l}\text { Characterization } \\
\text { Result / mile }\end{array}$ & Factor Measure \\
\hline $\mathrm{HH}-$ Non-can & Feedstock & BENZENE & Air & $4.64 \mathrm{E}-06$ & 1.7E-07 & Ibs $\mathrm{C} 6 \mathrm{H} 6$ equiv \\
\hline $\mathrm{HH}$ - Non-can & Feedstock & ETHYLBENZENE & Air & 3.87E-07 & 2.83E-10 & Ibs $\mathrm{C} 6 \mathrm{H} 6$ equiv \\
\hline $\mathrm{HH}$ - Non-can & Feedstock & TOLUENE & Air & 2.9E-06 & 6.4E-09 & Ibs $\mathrm{C} 6 \mathrm{H} 6$ equiv \\
\hline $\mathrm{HH}$ - Non-can & Feedstock & XYLENE & Air & 1.64E-06 & 8.46E-10 & Ibs $\mathrm{C} 6 \mathrm{H} 6$ equiv \\
\hline $\mathrm{HH}$ - Non-can & Fuel & HYDROCHLORIC ACID & Air & $1.71 \mathrm{E}-05$ & 1.46E-08 & Ibs $\mathrm{C} 6 \mathrm{H} 6$ equiv \\
\hline HH - Non-can & Fuel & CHLOROFORM & Air & 3.11E-07 & 5.48E-08 & Ibs $\mathrm{C} 6 \mathrm{H} 6$ equiv \\
\hline $\mathrm{HH}$ - Non-can & Fuel & ACETALDEHYDE & Air & 1.06E-08 & 9.15E-11 & Ibs $\mathrm{C} 6 \mathrm{H} 6$ equiv \\
\hline $\mathrm{HH}$ - Non-can & Fuel & ACETONITRILE & Air & $1.77 \mathrm{E}-08$ & 6.15E-09 & Ibs C6H6 equiv \\
\hline $\mathrm{HH}$ - Non-can & Fuel & ANILINE & Air & $1.83 \mathrm{E}-10$ & $1.6 \mathrm{E}-11$ & Ibs $\mathrm{C} 6 \mathrm{H} 6$ equiv \\
\hline HH - Non-can & Fuel & 1,1,1-TRICHLOROETHANE & Air & $2.09 \mathrm{E}-08$ & 9.22E-09 & Ibs $\mathrm{C} 6 \mathrm{H} 6$ equiv \\
\hline $\mathrm{HH}$ - Non-can & Fuel & 1,2,4-TRICHLOROBENZENE & Air & $2.67 \mathrm{E}-08$ & 1.77E-09 & Ibs $\mathrm{C} 6 \mathrm{H} 6$ equiv \\
\hline HH - Non-can & Fuel & 1,2-DIBROMOETHANE & Air & 1.79E-07 & 1.61E-06 & Ibs C6H6 equiv \\
\hline $\mathrm{HH}$ - Non-can & Fuel & 1,2-DICHLOROETHANE & Air & 2.73E-07 & 1.14E-08 & Ibs $\mathrm{C} 6 \mathrm{H} 6$ equiv \\
\hline $\mathrm{HH}$ - Non-can & Fuel & 1,3-BUTADIENE & Air & $1.41 \mathrm{E}-06$ & 3.78E-09 & Ibs $\mathrm{C} 6 \mathrm{H} 6$ equiv \\
\hline $\mathrm{HH}$ - Non-can & Fuel & ANTIMONY COMPOUNDS & Air & $5.68 \mathrm{E}-08$ & 2.42E-06 & Ibs $\mathrm{C} 6 \mathrm{H} 6$ equiv \\
\hline $\mathrm{HH}$ - Non-can & Fuel & BENZENE & Air & $3.83 \mathrm{E}-05$ & $1.4 \mathrm{E}-06$ & Ibs $\mathrm{C} 6 \mathrm{H} 6$ equiv \\
\hline HH - Non-can & Fuel & BIPHENYL & Air & $2.28 \mathrm{E}-07$ & 3.37E-10 & Ibs $\mathrm{C} 6 \mathrm{H} 6$ equiv \\
\hline $\mathrm{HH}$ - Non-can & Fuel & CADMIUM COMPOUNDS & Air & 0 & 0 & Ibs $\mathrm{C} 6 \mathrm{H} 6$ equiv \\
\hline $\mathrm{HH}$ - Non-can & Fuel & CARBON DISULFIDE & Air & 5.92E-07 & 6.12E-09 & Ibs $\mathrm{C} 6 \mathrm{H} 6$ equiv \\
\hline $\mathrm{HH}$ - Non-can & Fuel & CARBON TETRACHLORIDE & Air & 1.19E-07 & $3.62 \mathrm{E}-06$ & Ibs $\mathrm{C} 6 \mathrm{H} 6$ equiv \\
\hline $\mathrm{HH}$ - Non-can & Fuel & CHLOROBENZENE & Air & 0 & 0 & Ibs $\mathrm{C} 6 \mathrm{H} 6$ equiv \\
\hline $\mathrm{HH}$ - Non-can & Fuel & CHROMIUM COMPOUNDS & Air & $9.81 \mathrm{E}-09$ & 1.38E-07 & Ibs $\mathrm{C} 6 \mathrm{H} 6$ equiv \\
\hline HH - Non-can & Fuel & COBALT COMPOUNDS & Air & $1.26 \mathrm{E}-08$ & 2.19E-06 & Ibs $\mathrm{C} 6 \mathrm{H} 6$ equiv \\
\hline $\mathrm{HH}$ - Non-can & Fuel & CUMENE & Air & 3.85E-06 & 2.65E-09 & Ibs $\mathrm{C} 6 \mathrm{H} 6$ equiv \\
\hline $\mathrm{HH}$ - Non-can & Fuel & DIBUTYL PHTHALATE & Air & $5.42 \mathrm{E}-08$ & $2.41 \mathrm{E}-09$ & Ibs $\mathrm{C} 6 \mathrm{H} 6$ equiv \\
\hline $\mathrm{HH}$ - Non-can & Fuel & DIETHANOLAMINE & Air & $2.65 \mathrm{E}-06$ & 8.45E-08 & Ibs $\mathrm{C} 6 \mathrm{H} 6$ equiv \\
\hline HH - Non-can & Fuel & ETHYLBENZENE & Air & $1.17 \mathrm{E}-05$ & 8.57E-09 & Ibs $\mathrm{C} 6 \mathrm{H} 6$ equiv \\
\hline $\mathrm{HH}$ - Non-can & Fuel & ETHYLENE GLYCOL & Air & 1.39E-06 & $7.51 \mathrm{E}-10$ & Ibs $\mathrm{C} 6 \mathrm{H} 6$ equiv \\
\hline HH - Non-can & Fuel & ETHYLENE OXIDE & Air & 3.17E-07 & 1.38E-06 & Ibs $\mathrm{C} 6 \mathrm{H} 6$ equiv \\
\hline $\mathrm{HH}$ - Non-can & Fuel & FORMALDEHYDE & Air & 2.35E-06 & $2.47 \mathrm{E}-08$ & Ibs $\mathrm{C} 6 \mathrm{H} 6$ equiv \\
\hline $\mathrm{HH}$ - Non-can & Fuel & HYDRAZINE & Air & 0 & 0 & Ibs $\mathrm{C} 6 \mathrm{H} 6$ equiv \\
\hline $\mathrm{HH}$ - Non-can & Fuel & HYDROQUINONE & Air & 0 & 0 & Ibs $\mathrm{C} 6 \mathrm{H} 6$ equiv \\
\hline $\mathrm{HH}$ - Non-can & Fuel & LEAD COMPOUNDS & Air & 5.93E-08 & 0.000196 & Ibs $\mathrm{C} 6 \mathrm{H} 6$ equiv \\
\hline $\mathrm{HH}$ - Non-can & Fuel & M-CRESOL & Air & 0 & 0 & Ibs $\mathrm{C} 6 \mathrm{H} 6$ equiv \\
\hline $\mathrm{HH}$ - Non-can & Fuel & M-XYLENE & Air & 2.31E-06 & $8.45 \mathrm{E}-10$ & Ibs $\mathrm{C} 6 \mathrm{H} 6$ equiv \\
\hline $\mathrm{HH}$ - Non-can & Fuel & MALEIC ANHYDRIDE & Air & 6.39E-10 & $2.43 \mathrm{E}-10$ & Ibs $\mathrm{C} 6 \mathrm{H} 6$ equiv \\
\hline $\mathrm{HH}$ - Non-can & Fuel & MANGANESE COMPOUNDS & Air & $1.56 \mathrm{E}-08$ & 2.73E-07 & Ibs $\mathrm{C} 6 \mathrm{H} 6$ equiv \\
\hline $\mathrm{HH}$ - Non-can & Fuel & MERCURY COMPOUNDS & Air & $9.08 \mathrm{E}-08$ & 0.003854 & Ibs $\mathrm{C} 6 \mathrm{H} 6$ equiv \\
\hline $\mathrm{HH}$ - Non-can & Fuel & METHANOL & Air & 8.42E-05 & 2.03E-08 & Ibs $\mathrm{C} 6 \mathrm{H} 6$ equiv \\
\hline $\mathrm{HH}$ - Non-can & Fuel & METHYL ETHYL KETONE & Air & 6.02E-05 & 1.51E-08 & Ibs $\mathrm{C} 6 \mathrm{H} 6$ equiv \\
\hline $\mathrm{HH}$ - Non-can & Fuel & METHYL ISOBUTYL KETONE & Air & 4.43E-06 & 7.16E-09 & Ibs $\mathrm{C} 6 \mathrm{H} 6$ equiv \\
\hline $\mathrm{HH}$ - Non-can & Fuel & METHYL TERT-BUTYL ETHER & Air & 0.000033 & 6.56E-09 & Ibs $\mathrm{C} 6 \mathrm{H} 6$ equiv \\
\hline
\end{tabular}




\begin{tabular}{|c|c|c|c|c|c|c|}
\hline Impact Category & Stage & Emission & Media & \begin{tabular}{|c||} 
Mass Flow \\
(grams/mile)
\end{tabular} & $\begin{array}{c}\text { Characterization } \\
\text { Result / mile }\end{array}$ & Factor Measure \\
\hline $\mathrm{HH}$ - Non-can & Fuel & N-HEXANE & Air & $6.11 \mathrm{E}-05$ & 8.17E-08 & Ibs C6H6 equiv \\
\hline $\mathrm{HH}$ - Non-can & Fuel & NAPHTHALENE & Air & 3.58E-06 & 1E-07 & Ibs $\mathrm{C} 6 \mathrm{H} 6$ equiv \\
\hline $\mathrm{HH}$ - Non-can & Fuel & NICKEL COMPOUNDS & Air & 3.74E-07 & 6.81E-06 & Ibs $\mathrm{C} 6 \mathrm{H} 6$ equiv \\
\hline $\mathrm{HH}$ - Non-can & Fuel & O-CRESOL & Air & 0 & 0 & Ibs $\mathrm{C} 6 \mathrm{H} 6$ equiv \\
\hline $\mathrm{HH}$ - Non-can & Fuel & O-XYLENE & Air & 1.96E-06 & 1.21E-09 & Ibs $\mathrm{C} 6 \mathrm{H} 6$ equiv \\
\hline $\mathrm{HH}$ - Non-can & Fuel & P-CRESOL & Air & 0 & 0 & Ibs $\mathrm{C} 6 \mathrm{H} 6$ equiv \\
\hline $\mathrm{HH}$ - Non-can & Fuel & P-XYLENE & Air & 2.45E-06 & 1.45E-09 & Ibs $\mathrm{C} 6 \mathrm{H} 6$ equiv \\
\hline HH - Non-can & Fuel & PHENOL & Air & 2.31E-06 & $2.91 \mathrm{E}-10$ & Ibs $\mathrm{C} 6 \mathrm{H} 6$ equiv \\
\hline $\mathrm{HH}$ - Non-can & Fuel & PROPYLENE OXIDE & Air & 0 & 0 & Ibs $\mathrm{C} 6 \mathrm{H} 6$ equiv \\
\hline $\mathrm{HH}$ - Non-can & Fuel & SELENIUM COMPOUNDS & Air & 4.66E-09 & 2.17E-07 & Ibs $\mathrm{C} 6 \mathrm{H} 6$ equiv \\
\hline $\mathrm{HH}$ - Non-can & Fuel & STYRENE & Air & $2.27 \mathrm{E}-07$ & 1.44E-11 & Ibs $\mathrm{C} 6 \mathrm{H} 6$ equiv \\
\hline $\mathrm{HH}$ - Non-can & Fuel & TETRACHLOROETHYLENE & Air & 1.09E-06 & 5.18E-07 & Ibs $\mathrm{C} 6 \mathrm{H} 6$ equiv \\
\hline $\mathrm{HH}$ - Non-can & Fuel & TOLUENE & Air & 8.42E-05 & $1.86 \mathrm{E}-07$ & Ibs $\mathrm{C} 6 \mathrm{H} 6$ equiv \\
\hline $\mathrm{HH}$ - Non-can & Fuel & TRICHLOROETHYLENE & Air & 1.17E-06 & 2.53E-09 & Ibs $\mathrm{C} 6 \mathrm{H} 6$ equiv \\
\hline $\mathrm{HH}$ - Non-can & Fuel & TRIETHYLAMINE & Air & 0 & 0 & Ibs $\mathrm{C} 6 \mathrm{H} 6$ equiv \\
\hline $\mathrm{HH}$ - Non-can & Fuel & VINYL ACETATE & Air & $6.5 \mathrm{E}-09$ & 2.76E-11 & Ibs $\mathrm{C} 6 \mathrm{H} 6$ equiv \\
\hline $\mathrm{HH}$ - Non-can & Fuel & CHLOROMETHANE & Air & 2.53E-08 & 3.01E-08 & Ibs $\mathrm{C} 6 \mathrm{H} 6$ equiv \\
\hline $\mathrm{HH}$ - Non-can & Fuel & XYLENE & Air & 5.14E-05 & 2.65E-08 & Ibs $\mathrm{C} 6 \mathrm{H} 6$ equiv \\
\hline $\mathrm{HH}$ - Non-can & Fuel & Certain glycol ethers & Air & $6.55 \mathrm{E}-07$ & 5.49E-10 & Ibs $\mathrm{C} 6 \mathrm{H} 6$ equiv \\
\hline $\mathrm{HH}$ - Non-can & Fuel & Polychlorinated biphenyls & Air & 1.83E-13 & 1.94E-12 & Ibs $\mathrm{C} 6 \mathrm{H} 6$ equiv \\
\hline $\mathrm{HH}$ - Non-can & Vehicle & TOLUENE & Air & 0.0002 & 4.41E-07 & Ibs $\mathrm{C} 6 \mathrm{H} 6$ equiv \\
\hline $\mathrm{HH}$ - Non-can & Vehicle & 1,3-BUTADIENE & Air & 0.0008 & 2.14E-06 & Ibs $\mathrm{C} 6 \mathrm{H} 6$ equiv \\
\hline $\mathrm{HH}$ - Non-can & Vehicle & BENZENE & Air & 0.00011 & 4.02E-06 & Ibs $\mathrm{C} 6 \mathrm{H} 6$ equiv \\
\hline $\mathrm{HH}$ - Non-can & Vehicle & FORMALDEHYDE & Air & 0.002 & 2.10E-05 & Ibs $\mathrm{C} 6 \mathrm{H} 6$ equiv \\
\hline $\mathrm{HH}$ - Non-can & Vehicle & ACETALDEHYDE & Air & 0.0026 & 2.24E-05 & Ibs $\mathrm{C} 6 \mathrm{H} 6$ equiv \\
\hline Smog & Feedstock & NITROGEN OXIDES & Air & 0.0714 & 0.000195 & g NOX equiv \\
\hline Smog & Feedstock & BENZENE & Air & 4.64E-06 & 2.52E-09 & g NOX equiv \\
\hline Smog & Feedstock & ETHYLBENZENE & Air & 3.87E-07 & 6.24E-10 & g NOX equiv \\
\hline Smog & Feedstock & TOLUENE & Air & $2.9 \mathrm{E}-06$ & $6.6 \mathrm{E}-09$ & g NOX equiv \\
\hline Smog & Feedstock & VOC & Air & 0.0108 & 2.3E-05 & g NOX equiv \\
\hline Smog & Feedstock & CARBON MONOXIDE & Air & 0.0259 & 9.48E-07 & g NOX equiv \\
\hline Smog & Fuel & NITROGEN OXIDES & Air & 0.066 & 0.00018 & g NOX equiv \\
\hline Smog & Fuel & ACETALDEHYDE & Air & 1.06E-08 & 4.19E-11 & g NOX equiv \\
\hline Smog & Fuel & 1,1,1-TRICHLOROETHANE & Air & 2.09E-08 & 1.02E-12 & g NOX equiv \\
\hline Smog & Fuel & 1,3-BUTADIENE & Air & $1.41 \mathrm{E}-06$ & $1 \mathrm{E}-08$ & g NOX equiv \\
\hline Smog & Fuel & BENZENE & Air & 3.83E-05 & 2.08E-08 & g NOX equiv \\
\hline Smog & Fuel & CHLOROBENZENE & Air & 0 & 0 & g NOX equiv \\
\hline Smog & Fuel & ETHYLBENZENE & Air & 1.17E-05 & 1.89E-08 & g NOX equiv \\
\hline Smog & Fuel & ETHYLENE GLYCOL & Air & 1.39E-06 & 4.27E-09 & g NOX equiv \\
\hline Smog & Fuel & ETHYLENE OXIDE & Air & 3.17E-07 & 1.5E-11 & g NOX equiv \\
\hline Smog & Fuel & FORMALDEHYDE & Air & $2.35 \mathrm{E}-06$ & 1.16E-08 & g NOX equiv \\
\hline Smog & Fuel & M-XYLENE & Air & 2.31E-06 & 1.39E-08 & g NOX equiv \\
\hline
\end{tabular}




\begin{tabular}{|c|c|c|c|c|c|c|}
\hline Impact Category & Stage & Emission & Media & \begin{tabular}{|c} 
Mass Flow \\
(grams/mile)
\end{tabular} & $\begin{array}{l}\text { Characterization } \\
\text { Result / mile }\end{array}$ & Factor Measure \\
\hline Smog & Fuel & METHANOL & Air & 8.42E-05 & 4.54E-08 & g NOX equiv \\
\hline Smog & Fuel & METHYL ISOBUTYL KETONE & Air & 4.43E-06 & 1.13E-08 & g NOX equiv \\
\hline Smog & Fuel & METHYL TERT-BUTYL ETHER & Air & 0.000033 & 2.4E-08 & g NOX equiv \\
\hline Smog & Fuel & N-HEXANE & Air & 6.11E-05 & $5.6 \mathrm{E}-08$ & g NOX equiv \\
\hline Smog & Fuel & NAPHTHALENE & Air & $3.58 \mathrm{E}-06$ & 5.94E-09 & g NOX equiv \\
\hline Smog & Fuel & O-XYLENE & Air & 1.96E-06 & 8.34E-09 & g NOX equiv \\
\hline Smog & Fuel & P-XYLENE & Air & $2.45 \mathrm{E}-06$ & 5.91E-09 & g NOX equiv \\
\hline Smog & Fuel & PHENOL & Air & $2.31 \mathrm{E}-06$ & 4.66E-09 & g NOX equiv \\
\hline Smog & Fuel & PROPYLENE OXIDE & Air & 0 & 0 & g NOX equiv \\
\hline Smog & Fuel & STYRENE & Air & 2.27E-07 & $3.1 \mathrm{E}-10$ & g NOX equiv \\
\hline Smog & Fuel & TETRACHLOROETHYLENE & Air & 1.09E-06 & 6.87E-11 & g NOX equiv \\
\hline Smog & Fuel & TOLUENE & Air & 8.42E-05 & 1.92E-07 & g NOX equiv \\
\hline Smog & Fuel & TRICHLOROETHYLENE & Air & 1.17E-06 & 6.55E-13 & g NOX equiv \\
\hline Smog & Fuel & VOC & Air & 0.0191 & 4.08E-05 & g NOX equiv \\
\hline Smog & Fuel & CARBON MONOXIDE & Air & 0.0226 & 8.27E-07 & g NOX equiv \\
\hline Smog & Fuel & Certain glycol ethers & Air & $6.55 \mathrm{E}-07$ & 1.47E-09 & g NOX equiv \\
\hline Smog & Vehicle & NITROGEN OXIDES & Air & 0.063 & 0.000172 & g NOX equiv \\
\hline Smog & Vehicle & ACETALDEHYDE & Air & 0.0096 & 3.79E-05 & g NOX equiv \\
\hline Smog & Vehicle & 1,3-BUTADIENE & Air & 0.0008 & 5.69E-06 & g NOX equiv \\
\hline Smog & Vehicle & BENZENE & Air & 0.0013 & 7.06E-07 & g NOX equiv \\
\hline Smog & Vehicle & FORMALDEHYDE & Air & 0.0161 & 7.98E-05 & g NOX equiv \\
\hline Smog & Vehicle & TOLUENE & Air & 0.0018 & 4.1E-06 & g NOX equiv \\
\hline Smog & Vehicle & VOC & Air & 0.049 & 0.000105 & g NOX equiv \\
\hline Smog & Vehicle & CARBON MONOXIDE & Air & 1.07 & 3.92E-05 & g NOX equiv \\
\hline
\end{tabular}

Table D-18 TRACI Data for ULSD HEV 2015

\begin{tabular}{|c|c|c|c|c|c|c|}
\hline Impact Category & Stage & Emission & Media & \begin{tabular}{|c|} 
Mass Flow \\
(grams/mile)
\end{tabular} & $\begin{array}{l}\text { Characterization } \\
\text { Result / mile }\end{array}$ & Factor Measure \\
\hline Acidification & Feedstock & NITROGEN OXIDES & Air & 0.0529 & 0.00467 & moles $\mathrm{H}+$ equiv \\
\hline Acidification & Feedstock & SULFUR OXIDES & Air & 0.00893 & 0.001 & moles $\mathrm{H}+$ equiv \\
\hline Acidification & Fuel & NITROGEN OXIDES & Air & 0.0489 & 0.004317 & moles $\mathrm{H}+$ equiv \\
\hline Acidification & Fuel & HYDROCHLORIC ACID & Air & $1.27 \mathrm{E}-05$ & $1.25 \mathrm{E}-06$ & moles $\mathrm{H}+$ equiv \\
\hline Acidification & Fuel & HYDROGEN FLUORIDE & Air & $3.17 \mathrm{E}-06$ & $5.68 \mathrm{E}-07$ & moles $\mathrm{H}+$ equiv \\
\hline Acidification & Fuel & SULFUR OXIDES & Air & 0.0601 & 0.006729 & moles $\mathrm{H}+$ equiv \\
\hline Acidification & Vehicle & NITROGEN OXIDES & Air & 0.0504 & 0.004449 & moles $\mathrm{H}+$ equiv \\
\hline Acidification & Vehicle & SULFUR OXIDES & Air & 0.00128 & 0.000143 & moles $\mathrm{H}+$ equiv \\
\hline Ecotoxicity & Feedstock & BENZENE & Air & 3.44E-06 & 2.27E-14 & Ibs 2,4-D equiv \\
\hline Ecotoxicity & Feedstock & ETHYLBENZENE & Air & $2.87 \mathrm{E}-07$ & $2.78 \mathrm{E}-15$ & Ibs 2,4-D equiv \\
\hline Ecotoxicity & Feedstock & TOLUENE & Air & $2.15 \mathrm{E}-06$ & 2.13E-14 & Ibs 2,4-D equiv \\
\hline Ecotoxicity & Fuel & CHLOROFORM & Air & $2.3 \mathrm{E}-07$ & $6.08 \mathrm{E}-14$ & Ibs 2,4-D equiv \\
\hline Ecotoxicity & Fuel & 1,1,1-TRICHLOROETHANE & Air & $1.55 \mathrm{E}-08$ & 3.04E-14 & Ibs 2,4-D equiv \\
\hline
\end{tabular}




\begin{tabular}{|c|c|c|c|c|c|c|}
\hline Impact Category & Stage & Emission & Media & $\begin{array}{l}\text { Mass Flow } \\
\text { (grams/mile) }\end{array}$ & $\begin{array}{l}\text { Characterization } \\
\text { Result / mile }\end{array}$ & Factor Measure \\
\hline Ecotoxicity & Fuel & 1,2-DICHLOROETHANE & Air & 2.03E-07 & $2.46 \mathrm{E}-14$ & Ibs 2,4-D equiv \\
\hline Ecotoxicity & Fuel & 1,3-BUTADIENE & Air & 1.04E-06 & $1.22 \mathrm{E}-16$ & Ibs 2,4-D equiv \\
\hline Ecotoxicity & Fuel & BENZENE & Air & 2.84E-05 & 1.88E-13 & Ibs 2,4-D equiv \\
\hline Ecotoxicity & Fuel & CARBON DISULFIDE & Air & 4.39E-07 & 1.06E-11 & Ibs 2,4-D equiv \\
\hline Ecotoxicity & Fuel & CARBON TETRACHLORIDE & Air & 8.79E-08 & 6.39E-13 & Ibs 2,4-D equiv \\
\hline Ecotoxicity & Fuel & DIBUTYL PHTHALATE & Air & 4.01E-08 & $6.01 \mathrm{E}-10$ & Ibs 2,4-D equiv \\
\hline Ecotoxicity & Fuel & ETHYLBENZENE & Air & 8.65E-06 & 8.39E-14 & Ibs 2,4-D equiv \\
\hline Ecotoxicity & Fuel & FORMALDEHYDE & Air & $1.74 \mathrm{E}-06$ & $1.11 \mathrm{E}-10$ & Ibs 2,4-D equiv \\
\hline Ecotoxicity & Fuel & M-XYLENE & Air & $1.71 \mathrm{E}-06$ & 2.71E-15 & Ibs 2,4-D equiv \\
\hline Ecotoxicity & Fuel & NAPHTHALENE & Air & $2.65 \mathrm{E}-06$ & 2.22E-10 & Ibs 2,4-D equiv \\
\hline Ecotoxicity & Fuel & O-XYLENE & Air & $1.45 \mathrm{E}-06$ & $5.11 \mathrm{E}-15$ & Ibs 2,4-D equiv \\
\hline Ecotoxicity & Fuel & P-XYLENE & Air & 1.82E-06 & 3.81E-15 & Ibs 2,4-D equiv \\
\hline Ecotoxicity & Fuel & PHENOL & Air & 1.71E-06 & 1.43E-10 & Ibs 2,4-D equiv \\
\hline Ecotoxicity & Fuel & PROPYLENE OXIDE & Air & 0 & 0 & Ibs 2,4-D equiv \\
\hline Ecotoxicity & Fuel & STYRENE & Air & 1.69E-07 & $4.47 \mathrm{E}-16$ & Ibs 2,4-D equiv \\
\hline Ecotoxicity & Fuel & TETRACHLOROETHYLENE & Air & $8.08 \mathrm{E}-07$ & 1.19E-12 & Ibs 2,4-D equiv \\
\hline Ecotoxicity & Fuel & TOLUENE & Air & 6.24E-05 & 6.19E-13 & Ibs 2,4-D equiv \\
\hline Ecotoxicity & Fuel & TRICHLOROETHYLENE & Air & 8.65E-07 & $7.63 E-15$ & Ibs 2,4-D equiv \\
\hline Eutrophication & Feedstock & NITROGEN OXIDES & Air & 0.0529 & 5.17E-06 & $\mathrm{kg} \mathrm{N}$ \\
\hline Eutrophication & Fuel & NITROGEN OXIDES & Air & 0.0489 & 4.77E-06 & $\mathrm{kg} \mathrm{N}$ \\
\hline Eutrophication & Vehicle & NITROGEN OXIDES & Air & 0.0504 & 4.92E-06 & $\mathrm{kg} \mathrm{N}$ \\
\hline $\mathrm{HH}$ - Cancer & Feedstock & BENZENE & Air & 3.44E-06 & 7.58E-09 & Ibs $\mathrm{C} 6 \mathrm{H} 6$ equiv \\
\hline HH - Cancer & Fuel & CHLOROFORM & Air & 2.3E-07 & 2.32E-09 & Ibs $\mathrm{C} 6 \mathrm{H} 6$ equiv \\
\hline $\mathrm{HH}$ - Cancer & Fuel & ACETALDEHYDE & Air & 7.85E-09 & $6.11 E-14$ & Ibs C6H6 equiv \\
\hline $\mathrm{HH}$ - Cancer & Fuel & ANILINE & Air & $1.35 \mathrm{E}-10$ & $6.76 \mathrm{E}-16$ & Ibs $\mathrm{C} 6 \mathrm{H} 6$ equiv \\
\hline $\mathrm{HH}$ - Cancer & Fuel & 1,2-DIBROMOETHANE & Air & $1.33 \mathrm{E}-07$ & 2.47E-09 & Ibs $\mathrm{C} 6 \mathrm{H} 6$ equiv \\
\hline $\mathrm{HH}$ - Cancer & Fuel & 1,2-DICHLOROETHANE & Air & $2.03 \mathrm{E}-07$ & 2.38E-09 & Ibs $\mathrm{C} 6 \mathrm{H} 6$ equiv \\
\hline $\mathrm{HH}$ - Cancer & Fuel & 1,3-BUTADIENE & Air & $1.04 \mathrm{E}-06$ & 7.62E-10 & Ibs $\mathrm{C} 6 \mathrm{H} 6$ equiv \\
\hline $\mathrm{HH}$ - Cancer & Fuel & BENZENE & Air & 2.84E-05 & $6.26 \mathrm{E}-08$ & Ibs $\mathrm{C} 6 \mathrm{H} 6$ equiv \\
\hline $\mathrm{HH}$ - Cancer & Fuel & CADMIUM COMPOUNDS & Air & 0 & 0 & Ibs $\mathrm{C} 6 \mathrm{H} 6$ equiv \\
\hline $\mathrm{HH}$ - Cancer & Fuel & CARBON TETRACHLORIDE & Air & 8.79E-08 & 1.59E-07 & Ibs $\mathrm{C} 6 \mathrm{H} 6$ equiv \\
\hline $\mathrm{HH}$ - Cancer & Fuel & CHROMIUM COMPOUNDS & Air & 7.27E-09 & 2.68E-09 & Ibs $\mathrm{C} 6 \mathrm{H} 6$ equiv \\
\hline $\mathrm{HH}$ - Cancer & Fuel & DIMETHYL SULFATE & Air & 0 & 0 & Ibs $\mathrm{C} 6 \mathrm{H} 6$ equiv \\
\hline $\mathrm{HH}$ - Cancer & Fuel & ETHYLENE OXIDE & Air & 2.35E-07 & $1.6 \mathrm{E}-08$ & Ibs $\mathrm{C} 6 \mathrm{H} 6$ equiv \\
\hline $\mathrm{HH}$ - Cancer & Fuel & FORMALDEHYDE & Air & 1.74E-06 & 1.16E-11 & Ibs $\mathrm{C} 6 \mathrm{H} 6$ equiv \\
\hline $\mathrm{HH}$ - Cancer & Fuel & HYDRAZINE & Air & 0 & 0 & Ibs $\mathrm{C} 6 \mathrm{H} 6$ equiv \\
\hline $\mathrm{HH}$ - Cancer & Fuel & HYDROQUINONE & Air & 0 & 0 & Ibs $\mathrm{C} 6 \mathrm{H} 6$ equiv \\
\hline $\mathrm{HH}$ - Cancer & Fuel & LEAD COMPOUNDS & Air & 4.4E-08 & 3.44E-09 & Ibs $\mathrm{C} 6 \mathrm{H} 6$ equiv \\
\hline $\mathrm{HH}$ - Cancer & Fuel & NICKEL COMPOUNDS & Air & 2.77E-07 & 2.2E-09 & Ibs $\mathrm{C} 6 \mathrm{H} 6$ equiv \\
\hline $\mathrm{HH}$ - Cancer & Fuel & O-TOLUIDINE & Air & 1.35E-10 & $2.71 \mathrm{E}-15$ & Ibs $\mathrm{C} 6 \mathrm{H} 6$ equiv \\
\hline $\mathrm{HH}$ - Cancer & Fuel & PROPYLENE OXIDE & Air & 0 & 0 & Ibs $\mathrm{C} 6 \mathrm{H} 6$ equiv \\
\hline $\mathrm{HH}$ - Cancer & Fuel & TETRACHLOROETHYLENE & Air & 8.08E-07 & $3.24 \mathrm{E}-09$ & Ibs $\mathrm{C} 6 \mathrm{H} 6$ equiv \\
\hline
\end{tabular}




\begin{tabular}{|c|c|c|c|c|c|c|}
\hline Impact Category & Stage & Emission & Media & \begin{tabular}{|l|} 
Mass Flow \\
(grams/mile)
\end{tabular} & $\begin{array}{l}\text { Characterization } \\
\text { Result / mile }\end{array}$ & Factor Measure \\
\hline $\mathrm{HH}$ - Cancer & Fuel & TRICHLOROETHYLENE & Air & 8.65E-07 & $1.12 \mathrm{E}-10$ & Ibs $\mathrm{C} 6 \mathrm{H} 6$ equiv \\
\hline $\mathrm{HH}$ - Cancer & Fuel & CHLOROMETHANE & Air & 1.87E-08 & 1.45E-10 & Ibs $\mathrm{C} 6 \mathrm{H} 6$ equiv \\
\hline $\mathrm{HH}$ - Criteria & Feedstock & NITROGEN OXIDES & Air & 0.0529 & 2.58E-07 & total DALYs \\
\hline $\mathrm{HH}$ - Criteria & Feedstock & PM10 & Air & 0.00164 & 3.02E-07 & total DALYs \\
\hline HH - Criteria & Feedstock & PM2.5 & Air & 0.000985 & 3.02E-07 & total DALYs \\
\hline $\mathrm{HH}$ - Criteria & Fuel & NITROGEN OXIDES & Air & 0.0489 & 2.39E-07 & total DALYs \\
\hline $\mathrm{HH}$ - Criteria & Fuel & PM10 & Air & 0.00648 & 1.19E-06 & total DALYs \\
\hline $\mathrm{HH}$ - Criteria & Fuel & PM2.5 & Air & 0.00389 & 1.19E-06 & total DALYs \\
\hline $\mathrm{HH}$ - Criteria & Vehicle & NITROGEN OXIDES & Air & 0.0504 & 2.46E-07 & total DALYs \\
\hline $\mathrm{HH}$ - Criteria & Vehicle & PM10 & Air & 0.029 & 5.34E-06 & total DALYs \\
\hline $\mathrm{HH}$ - Criteria & Vehicle & PM2.5 & Air & 0.0174 & 5.34E-06 & total DALYs \\
\hline HH - Non-can & Feedstock & BENZENE & Air & 3.44E-06 & 1.26E-07 & Ibs C6H6 equiv \\
\hline $\mathrm{HH}$ - Non-can & Feedstock & ETHYLBENZENE & Air & 2.87E-07 & 2.1E-10 & Ibs $\mathrm{C} 6 \mathrm{H} 6$ equiv \\
\hline $\mathrm{HH}$ - Non-can & Feedstock & TOLUENE & Air & 2.15E-06 & 4.74E-09 & Ibs $\mathrm{C} 6 \mathrm{H} 6$ equiv \\
\hline $\mathrm{HH}$ - Non-can & Feedstock & XYLENE & Air & 1.22E-06 & $6.27 \mathrm{E}-10$ & Ibs $\mathrm{C} 6 \mathrm{H} 6$ equiv \\
\hline HH - Non-can & Fuel & HYDROCHLORIC ACID & Air & 1.27E-05 & 1.09E-08 & Ibs $\mathrm{C} 6 \mathrm{H} 6$ equiv \\
\hline $\mathrm{HH}$ - Non-can & Fuel & CHLOROFORM & Air & 2.3E-07 & 4.05E-08 & Ibs $\mathrm{C} 6 \mathrm{H} 6$ equiv \\
\hline $\mathrm{HH}$ - Non-can & Fuel & ACETALDEHYDE & Air & 7.85E-09 & $6.77 \mathrm{E}-11$ & Ibs $\mathrm{C} 6 \mathrm{H} 6$ equiv \\
\hline $\mathrm{HH}$ - Non-can & Fuel & ACETONITRILE & Air & $1.31 \mathrm{E}-08$ & 4.55E-09 & Ibs $\mathrm{C} 6 \mathrm{H} 6$ equiv \\
\hline $\mathrm{HH}$ - Non-can & Fuel & ANILINE & Air & $1.35 \mathrm{E}-10$ & $1.18 \mathrm{E}-11$ & Ibs $\mathrm{C} 6 \mathrm{H} 6$ equiv \\
\hline $\mathrm{HH}$ - Non-can & Fuel & 1,1,1-TRICHLOROETHANE & Air & $1.55 \mathrm{E}-08$ & $6.84 \mathrm{E}-09$ & Ibs $\mathrm{C} 6 \mathrm{H} 6$ equiv \\
\hline $\mathrm{HH}$ - Non-can & Fuel & 1,2,4-TRICHLOROBENZENE & Air & $1.98 \mathrm{E}-08$ & 1.31E-09 & Ibs $\mathrm{C} 6 \mathrm{H} 6$ equiv \\
\hline HH - Non-can & Fuel & 1,2-DIBROMOETHANE & Air & 1.33E-07 & $1.2 \mathrm{E}-06$ & Ibs $\mathrm{C} 6 \mathrm{H} 6$ equiv \\
\hline $\mathrm{HH}$ - Non-can & Fuel & 1,2-DICHLOROETHANE & Air & 2.03E-07 & 8.47E-09 & Ibs $\mathrm{C} 6 \mathrm{H} 6$ equiv \\
\hline $\mathrm{HH}$ - Non-can & Fuel & 1,3-BUTADIENE & Air & $1.04 \mathrm{E}-06$ & 2.79E-09 & Ibs $\mathrm{C} 6 \mathrm{H} 6$ equiv \\
\hline $\mathrm{HH}$ - Non-can & Fuel & ANTIMONY COMPOUNDS & Air & $4.21 \mathrm{E}-08$ & 1.79E-06 & Ibs $\mathrm{C} 6 \mathrm{H} 6$ equiv \\
\hline HH - Non-can & Fuel & BENZENE & Air & $2.84 \mathrm{E}-05$ & 1.04E-06 & Ibs $\mathrm{C} 6 \mathrm{H} 6$ equiv \\
\hline $\mathrm{HH}$ - Non-can & Fuel & BIPHENYL & Air & 1.69E-07 & $2.5 \mathrm{E}-10$ & Ibs $\mathrm{C} 6 \mathrm{H} 6$ equiv \\
\hline $\mathrm{HH}$ - Non-can & Fuel & CADMIUM COMPOUNDS & Air & 0 & 0 & Ibs $\mathrm{C} 6 \mathrm{H} 6$ equiv \\
\hline $\mathrm{HH}$ - Non-can & Fuel & CARBON DISULFIDE & Air & 4.39E-07 & $4.54 \mathrm{E}-09$ & Ibs $\mathrm{C} 6 \mathrm{H} 6$ equiv \\
\hline $\mathrm{HH}$ - Non-can & Fuel & CARBON TETRACHLORIDE & Air & 8.79E-08 & 2.67E-06 & Ibs $\mathrm{C} 6 \mathrm{H} 6$ equiv \\
\hline $\mathrm{HH}$ - Non-can & Fuel & CHLOROBENZENE & Air & 0 & 0 & Ibs $\mathrm{C} 6 \mathrm{H} 6$ equiv \\
\hline $\mathrm{HH}$ - Non-can & Fuel & CHROMIUM COMPOUNDS & Air & 7.27E-09 & 1.02E-07 & Ibs $\mathrm{C} 6 \mathrm{H} 6$ equiv \\
\hline HH - Non-can & Fuel & COBALT COMPOUNDS & Air & 9.34E-09 & $1.63 \mathrm{E}-06$ & Ibs $\mathrm{C} 6 \mathrm{H} 6$ equiv \\
\hline $\mathrm{HH}$ - Non-can & Fuel & CUMENE & Air & 2.85E-06 & 1.96E-09 & Ibs $\mathrm{C} 6 \mathrm{H} 6$ equiv \\
\hline $\mathrm{HH}$ - Non-can & Fuel & DIBUTYL PHTHALATE & Air & 4.01E-08 & 1.78E-09 & Ibs $\mathrm{C} 6 \mathrm{H} 6$ equiv \\
\hline $\mathrm{HH}$ - Non-can & Fuel & DIETHANOLAMINE & Air & 1.97E-06 & $6.28 \mathrm{E}-08$ & Ibs $\mathrm{C} 6 \mathrm{H} 6$ equiv \\
\hline $\mathrm{HH}$ - Non-can & Fuel & ETHYLBENZENE & Air & 8.65E-06 & 6.33E-09 & Ibs $\mathrm{C} 6 \mathrm{H} 6$ equiv \\
\hline $\mathrm{HH}$ - Non-can & Fuel & ETHYLENE GLYCOL & Air & 1.03E-06 & $5.56 \mathrm{E}-10$ & Ibs $\mathrm{C} 6 \mathrm{H} 6$ equiv \\
\hline $\mathrm{HH}$ - Non-can & Fuel & ETHYLENE OXIDE & Air & 2.35E-07 & 1.03E-06 & Ibs $\mathrm{C} 6 \mathrm{H} 6$ equiv \\
\hline HH - Non-can & Fuel & FORMALDEHYDE & Air & $1.74 \mathrm{E}-06$ & 1.83E-08 & Ibs $\mathrm{C} 6 \mathrm{H} 6$ equiv \\
\hline HH - Non-can & Fuel & HYDRAZINE & Air & 0 & 0 & Ibs $\mathrm{C} 6 \mathrm{H} 6$ equiv \\
\hline
\end{tabular}




\begin{tabular}{|c|c|c|c|c|c|c|}
\hline Impact Category & Stage & Emission & Media & $\begin{array}{c}\text { Mass Flow } \\
\text { (grams/mile) }\end{array}$ & $\begin{array}{c}\text { Characterization } \\
\text { Result / mile }\end{array}$ & Factor Measure \\
\hline $\mathrm{HH}$ - Non-can & Fuel & HYDROQUINONE & Air & 0 & 0 & Ibs C6H6 equiv \\
\hline $\mathrm{HH}$ - Non-can & Fuel & LEAD COMPOUNDS & Air & 4.4E-08 & 0.000146 & Ibs $\mathrm{C} 6 \mathrm{H} 6$ equiv \\
\hline $\mathrm{HH}$ - Non-can & Fuel & M-CRESOL & Air & 0 & 0 & Ibs $\mathrm{C} 6 \mathrm{H} 6$ equiv \\
\hline $\mathrm{HH}$ - Non-can & Fuel & M-XYLENE & Air & 1.71E-06 & $6.25 \mathrm{E}-10$ & Ibs $\mathrm{C} 6 \mathrm{H} 6$ equiv \\
\hline $\mathrm{HH}$ - Non-can & Fuel & MALEIC ANHYDRIDE & Air & 4.74E-10 & $1.8 \mathrm{E}-10$ & Ibs $\mathrm{C} 6 \mathrm{H} 6$ equiv \\
\hline $\mathrm{HH}$ - Non-can & Fuel & MANGANESE COMPOUNDS & Air & 1.15E-08 & 2.01E-07 & Ibs $\mathrm{C} 6 \mathrm{H} 6$ equiv \\
\hline $\mathrm{HH}$ - Non-can & Fuel & MERCURY COMPOUNDS & Air & 6.73E-08 & 0.002857 & Ibs $\mathrm{C} 6 \mathrm{H} 6$ equiv \\
\hline HH - Non-can & Fuel & METHANOL & Air & $6.24 \mathrm{E}-05$ & 1.5E-08 & Ibs $\mathrm{C} 6 \mathrm{H} 6$ equiv \\
\hline $\mathrm{HH}$ - Non-can & Fuel & METHYL ETHYL KETONE & Air & 4.46E-05 & 1.12E-08 & Ibs $\mathrm{C} 6 \mathrm{H} 6$ equiv \\
\hline $\mathrm{HH}$ - Non-can & Fuel & METHYL ISOBUTYL KETONE & Air & $3.28 \mathrm{E}-06$ & 5.3E-09 & Ibs $\mathrm{C} 6 \mathrm{H} 6$ equiv \\
\hline $\mathrm{HH}$ - Non-can & Fuel & METHYL TERT-BUTYL ETHER & Air & 2.45E-05 & 4.87E-09 & Ibs $\mathrm{C} 6 \mathrm{H} 6$ equiv \\
\hline $\mathrm{HH}$ - Non-can & Fuel & N-HEXANE & Air & 4.53E-05 & 6.06E-08 & Ibs $\mathrm{C} 6 \mathrm{H} 6$ equiv \\
\hline $\mathrm{HH}$ - Non-can & Fuel & NAPHTHALENE & Air & 2.65E-06 & 7.44E-08 & Ibs $\mathrm{C} 6 \mathrm{H} 6$ equiv \\
\hline $\mathrm{HH}$ - Non-can & Fuel & NICKEL COMPOUNDS & Air & 2.77E-07 & 5.04E-06 & Ibs $\mathrm{C} 6 \mathrm{H} 6$ equiv \\
\hline $\mathrm{HH}$ - Non-can & Fuel & O-CRESOL & Air & 0 & 0 & Ibs $\mathrm{C} 6 \mathrm{H} 6$ equiv \\
\hline $\mathrm{HH}$ - Non-can & Fuel & O-XYLENE & Air & 1.45E-06 & 8.97E-10 & Ibs $\mathrm{C} 6 \mathrm{H} 6$ equiv \\
\hline $\mathrm{HH}$ - Non-can & Fuel & P-CRESOL & Air & 0 & 0 & Ibs $\mathrm{C} 6 \mathrm{H} 6$ equiv \\
\hline $\mathrm{HH}$ - Non-can & Fuel & P-XYLENE & Air & $1.82 \mathrm{E}-06$ & 1.07E-09 & Ibs $\mathrm{C} 6 \mathrm{H} 6$ equiv \\
\hline $\mathrm{HH}$ - Non-can & Fuel & PHENOL & Air & 1.71E-06 & 2.15E-10 & Ibs $\mathrm{C} 6 \mathrm{H} 6$ equiv \\
\hline $\mathrm{HH}$ - Non-can & Fuel & PROPYLENE OXIDE & Air & 0 & 0 & Ibs $\mathrm{C} 6 \mathrm{H} 6$ equiv \\
\hline $\mathrm{HH}$ - Non-can & Fuel & SELENIUM COMPOUNDS & Air & 3.45E-09 & 1.61E-07 & Ibs $\mathrm{C} 6 \mathrm{H} 6$ equiv \\
\hline $\mathrm{HH}$ - Non-can & Fuel & STYRENE & Air & 1.69E-07 & 1.07E-11 & Ibs $\mathrm{C} 6 \mathrm{H} 6$ equiv \\
\hline $\mathrm{HH}$ - Non-can & Fuel & TETRACHLOROETHYLENE & Air & 8.08E-07 & 3.84E-07 & Ibs $\mathrm{C} 6 \mathrm{H} 6$ equiv \\
\hline $\mathrm{HH}$ - Non-can & Fuel & TOLUENE & Air & $6.24 \mathrm{E}-05$ & 1.38E-07 & Ibs $\mathrm{C} 6 \mathrm{H} 6$ equiv \\
\hline $\mathrm{HH}$ - Non-can & Fuel & TRICHLOROETHYLENE & Air & 8.65E-07 & 1.87E-09 & Ibs $\mathrm{C} 6 \mathrm{H} 6$ equiv \\
\hline HH - Non-can & Fuel & TRIETHYLAMINE & Air & 0 & 0 & Ibs $\mathrm{C} 6 \mathrm{H} 6$ equiv \\
\hline $\mathrm{HH}$ - Non-can & Fuel & VINYL ACETATE & Air & 4.82E-09 & 2.05E-11 & Ibs $\mathrm{C} 6 \mathrm{H} 6$ equiv \\
\hline HH - Non-can & Fuel & CHLOROMETHANE & Air & 1.87E-08 & 2.22E-08 & Ibs $\mathrm{C} 6 \mathrm{H} 6$ equiv \\
\hline $\mathrm{HH}$ - Non-can & Fuel & XYLENE & Air & 3.81E-05 & 1.96E-08 & Ibs $\mathrm{C} 6 \mathrm{H} 6$ equiv \\
\hline $\mathrm{HH}$ - Non-can & Fuel & Certain glycol ethers & Air & 4.85E-07 & 4.06E-10 & Ibs $\mathrm{C} 6 \mathrm{H} 6$ equiv \\
\hline $\mathrm{HH}$ - Non-can & Fuel & Polychlorinated biphenyls & Air & 1.35E-13 & 1.43E-12 & Ibs $\mathrm{C} 6 \mathrm{H} 6$ equiv \\
\hline Smog & Feedstock & NITROGEN OXIDES & Air & 0.0529 & 0.000145 & g NOX equiv \\
\hline Smog & Feedstock & BENZENE & Air & 3.44E-06 & 1.87E-09 & g NOX equiv \\
\hline Smog & Feedstock & ETHYLBENZENE & Air & 2.87E-07 & $4.62 \mathrm{E}-10$ & g NOX equiv \\
\hline Smog & Feedstock & TOLUENE & Air & 2.15E-06 & 4.89E-09 & g NOX equiv \\
\hline Smog & Feedstock & VOC & Air & 0.00799 & 1.71E-05 & g NOX equiv \\
\hline Smog & Feedstock & CARBON MONOXIDE & Air & 0.0192 & 7.03E-07 & g NOX equiv \\
\hline Smog & Fuel & NITROGEN OXIDES & Air & 0.0489 & 0.000134 & g NOX equiv \\
\hline Smog & Fuel & ACETALDEHYDE & Air & 7.85E-09 & 3.1E-11 & g NOX equiv \\
\hline Smog & Fuel & 1,1,1-TRICHLOROETHANE & Air & $1.55 \mathrm{E}-08$ & 7.56E-13 & g NOX equiv \\
\hline Smog & Fuel & 1,3-BUTADIENE & Air & 1.04E-06 & 7.39E-09 & g NOX equiv \\
\hline Smog & Fuel & BENZENE & Air & 2.84E-05 & 1.54E-08 & g NOX equiv \\
\hline
\end{tabular}




\begin{tabular}{|c|c|c|c|c|c|c|}
\hline Impact Category & Stage & Emission & Media & \begin{tabular}{|c|}
$\begin{array}{c}\text { Mass Flow } \\
\text { (grams/mile) }\end{array}$ \\
\end{tabular} & $\begin{array}{c}\text { Characterization } \\
\text { Result / mile }\end{array}$ & Factor Measure \\
\hline Smog & Fuel & CHLOROBENZENE & Air & 0 & 0 & g NOX equiv \\
\hline Smog & Fuel & ETHYLBENZENE & Air & 8.65E-06 & 1.4E-08 & g NOX equiv \\
\hline Smog & Fuel & ETHYLENE GLYCOL & Air & 1.03E-06 & 3.17E-09 & g NOX equiv \\
\hline Smog & Fuel & ETHYLENE OXIDE & Air & 2.35E-07 & 1.11E-11 & g NOX equiv \\
\hline Smog & Fuel & FORMALDEHYDE & Air & 1.74E-06 & 8.62E-09 & g NOX equiv \\
\hline Smog & Fuel & M-XYLENE & Air & 1.71E-06 & 1.03E-08 & g NOX equiv \\
\hline Smog & Fuel & METHANOL & Air & 6.24E-05 & 3.36E-08 & g NOX equiv \\
\hline Smog & Fuel & METHYL ISOBUTYL KETONE & Air & 3.28E-06 & 8.34E-09 & g NOX equiv \\
\hline Smog & Fuel & METHYL TERT-BUTYL ETHER & Air & 2.45E-05 & 1.78E-08 & g NOX equiv \\
\hline Smog & Fuel & N-HEXANE & Air & 4.53E-05 & 4.15E-08 & g NOX equiv \\
\hline Smog & Fuel & NAPHTHALENE & Air & 2.65E-06 & 4.39E-09 & g NOX equiv \\
\hline Smog & Fuel & O-XYLENE & Air & 1.45E-06 & 6.17E-09 & g NOX equiv \\
\hline Smog & Fuel & P-XYLENE & Air & 1.82E-06 & 4.39E-09 & g NOX equiv \\
\hline Smog & Fuel & PHENOL & Air & 1.71E-06 & 3.45E-09 & g NOX equiv \\
\hline Smog & Fuel & PROPYLENE OXIDE & Air & 0 & 0 & g NOX equiv \\
\hline Smog & Fuel & STYRENE & Air & 1.69E-07 & $2.31 \mathrm{E}-10$ & g NOX equiv \\
\hline Smog & Fuel & TETRACHLOROETHYLENE & Air & 8.08E-07 & 5.09E-11 & g NOX equiv \\
\hline Smog & Fuel & TOLUENE & Air & 6.24E-05 & 1.42E-07 & g NOX equiv \\
\hline Smog & Fuel & TRICHLOROETHYLENE & Air & 8.65E-07 & $4.84 \mathrm{E}-13$ & g NOX equiv \\
\hline Smog & Fuel & VOC & Air & 0.0142 & 3.03E-05 & g NOX equiv \\
\hline Smog & Fuel & CARBON MONOXIDE & Air & 0.0167 & $6.11 \mathrm{E}-07$ & g NOX equiv \\
\hline Smog & Fuel & Certain glycol ethers & Air & 4.85E-07 & 1.09E-09 & g NOX equiv \\
\hline Smog & Vehicle & NITROGEN OXIDES & Air & 0.0504 & 0.000138 & g NOX equiv \\
\hline Smog & Vehicle & VOC & Air & 0.049 & 0.000105 & g NOX equiv \\
\hline Smog & Vehicle & CARBON MONOXIDE & Air & 1.07 & 3.92E-05 & g NOX equiv \\
\hline
\end{tabular}

Table D-19 TRACI Data for FRFG SI 2015

\begin{tabular}{|c|c|c|c|c|c|c|}
\hline Impact Category & Stage & Emission & Media & $\begin{array}{c}\text { Mass Flow } \\
\text { (grams/mile) }\end{array}$ & $\begin{array}{c}\text { Characterization } \\
\text { Result / mile }\end{array}$ & Factor Measure \\
\hline Acidification & Feedstock & NITROGEN OXIDES & Air & 0.0745 & 0.006576 & moles $\mathrm{H}+$ equiv \\
\hline Acidification & Feedstock & SULFUR OXIDES & Air & 0.0126 & 0.001411 & moles $\mathrm{H}+$ equiv \\
\hline Acidification & Fuel & NITROGEN OXIDES & Air & 0.0933 & 0.008236 & moles $\mathrm{H}+$ equiv \\
\hline Acidification & Fuel & HYDROCHLORIC ACID & Air & $5.83 \mathrm{E}-05$ & 5.74E-06 & moles $\mathrm{H}+$ equiv \\
\hline Acidification & Fuel & HYDROGEN FLUORIDE & Air & 1.46E-05 & $2.62 \mathrm{E}-06$ & moles $\mathrm{H}+$ equiv \\
\hline Acidification & Fuel & SULFUR OXIDES & Air & 0.149 & 0.016684 & moles $\mathrm{H}+$ equiv \\
\hline Acidification & Vehicle & NITROGEN OXIDES & Air & 0.036 & 0.003178 & moles $\mathrm{H}+$ equiv \\
\hline Acidification & Vehicle & SULFUR OXIDES & Air & 0.00439 & 0.000492 & moles $\mathrm{H}+$ equiv \\
\hline Ecotoxicity & Feedstock & BENZENE & Air & $1.58 \mathrm{E}-05$ & 1.05E-13 & Ibs 2,4-D equiv \\
\hline Ecotoxicity & Feedstock & ETHYLBENZENE & Air & $1.32 \mathrm{E}-06$ & 1.28E-14 & Ibs 2,4-D equiv \\
\hline Ecotoxicity & Feedstock & TOLUENE & Air & $9.89 \mathrm{E}-06$ & $9.81 \mathrm{E}-14$ & Ibs 2,4-D equiv \\
\hline Ecotoxicity & Fuel & CHLOROFORM & Air & 1.06E-06 & $2.8 \mathrm{E}-13$ & Ibs 2,4-D equiv \\
\hline
\end{tabular}




\begin{tabular}{|c|c|c|c|c|c|c|}
\hline Impact Category & Stage & Emission & Media & \begin{tabular}{|l|} 
Mass Flow \\
(grams/mile)
\end{tabular} & $\begin{array}{l}\text { Characterization } \\
\text { Result / mile }\end{array}$ & Factor Measure \\
\hline Ecotoxicity & Fuel & 1,1,1-TRICHLOROETHANE & Air & 7.13E-08 & $1.4 \mathrm{E}-13$ & Ibs 2,4-D equiv \\
\hline Ecotoxicity & Fuel & 1,2-DICHLOROETHANE & Air & $9.32 \mathrm{E}-07$ & 1.13E-13 & Ibs 2,4-D equiv \\
\hline Ecotoxicity & Fuel & 1,3-BUTADIENE & Air & $4.8 \mathrm{E}-06$ & 5.61E-16 & Ibs 2,4-D equiv \\
\hline Ecotoxicity & Fuel & BENZENE & Air & 0.000131 & 8.66E-13 & Ibs 2,4-D equiv \\
\hline Ecotoxicity & Fuel & CARBON DISULFIDE & Air & 2.02E-06 & $4.9 \mathrm{E}-11$ & Ibs 2,4-D equiv \\
\hline Ecotoxicity & Fuel & CARBON TETRACHLORIDE & Air & 4.05E-07 & $2.95 \mathrm{E}-12$ & Ibs 2,4-D equiv \\
\hline Ecotoxicity & Fuel & DIBUTYL PHTHALATE & Air & 1.85E-07 & 2.77E-09 & Ibs 2,4-D equiv \\
\hline Ecotoxicity & Fuel & ETHYLBENZENE & Air & 3.98E-05 & $3.86 \mathrm{E}-13$ & Ibs 2,4-D equiv \\
\hline Ecotoxicity & Fuel & FORMALDEHYDE & Air & 8.02E-06 & 5.13E-10 & Ibs 2,4-D equiv \\
\hline Ecotoxicity & Fuel & M-XYLENE & Air & 7.87E-06 & 1.25E-14 & Ibs 2,4-D equiv \\
\hline Ecotoxicity & Fuel & NAPHTHALENE & Air & $1.22 \mathrm{E}-05$ & 1.02E-09 & Ibs 2,4-D equiv \\
\hline Ecotoxicity & Fuel & O-XYLENE & Air & 6.67E-06 & 2.35E-14 & Ibs 2,4-D equiv \\
\hline Ecotoxicity & Fuel & P-XYLENE & Air & 8.36E-06 & 1.75E-14 & Ibs 2,4-D equiv \\
\hline Ecotoxicity & Fuel & PHENOL & Air & 7.86E-06 & $6.58 \mathrm{E}-10$ & Ibs 2,4-D equiv \\
\hline Ecotoxicity & Fuel & PROPYLENE OXIDE & Air & 0 & 0 & Ibs 2,4-D equiv \\
\hline Ecotoxicity & Fuel & STYRENE & Air & 7.76E-07 & 2.05E-15 & Ibs 2,4-D equiv \\
\hline Ecotoxicity & Fuel & TETRACHLOROETHYLENE & Air & $3.72 \mathrm{E}-06$ & 5.49E-12 & Ibs 2,4-D equiv \\
\hline Ecotoxicity & Fuel & TOLUENE & Air & 0.000287 & $2.85 \mathrm{E}-12$ & Ibs 2,4-D equiv \\
\hline Ecotoxicity & Fuel & TRICHLOROETHYLENE & Air & 3.98E-06 & $3.51 \mathrm{E}-14$ & Ibs 2,4-D equiv \\
\hline Ecotoxicity & Vehicle & BENZENE & Air & 0.0054 & 3.57145E-11 & Ibs 2,4-D equiv \\
\hline Ecotoxicity & Vehicle & FORMALDEHYDE & Air & 0.0009 & 5.75401E-08 & Ibs 2,4-D equiv \\
\hline Ecotoxicity & Vehicle & TOLUENE & Air & 0.0126 & $1.25001 \mathrm{E}-10$ & Ibs 2,4-D equiv \\
\hline Ecotoxicity & Vehicle & 1,3 Butadiene & Air & 0.00045 & $5.25797 \mathrm{E}-14$ & Ibs 2,4-D equiv \\
\hline Eutrophication & Feedstock & NITROGEN OXIDES & Air & 0.0745 & 7.27E-06 & $\mathrm{kg} \mathrm{N}$ \\
\hline Eutrophication & Fuel & NITROGEN OXIDES & Air & 0.0933 & 9.11E-06 & $\mathrm{kg} \mathrm{N}$ \\
\hline Eutrophication & Vehicle & NITROGEN OXIDES & Air & 0.036 & 3.52E-06 & $\mathrm{kg} \mathrm{N}$ \\
\hline $\mathrm{HH}$ - Cancer & Feedstock & BENZENE & Air & $1.58 \mathrm{E}-05$ & $3.49 \mathrm{E}-08$ & Ibs $\mathrm{C} 6 \mathrm{H} 6$ equiv \\
\hline HH - Cancer & Fuel & CHLOROFORM & Air & 1.06E-06 & 1.07E-08 & Ibs $\mathrm{C} 6 \mathrm{H} 6$ equiv \\
\hline $\mathrm{HH}$ - Cancer & Fuel & ACETALDEHYDE & Air & $3.61 \mathrm{E}-08$ & $2.81 \mathrm{E}-13$ & Ibs $\mathrm{C} 6 \mathrm{H} 6$ equiv \\
\hline $\mathrm{HH}$ - Cancer & Fuel & ANILINE & Air & $6.23 \mathrm{E}-10$ & $3.12 E-15$ & Ibs $\mathrm{C} 6 \mathrm{H} 6$ equiv \\
\hline $\mathrm{HH}$ - Cancer & Fuel & 1,2-DIBROMOETHANE & Air & $6.1 \mathrm{E}-07$ & 1.13E-08 & Ibs $\mathrm{C} 6 \mathrm{H} 6$ equiv \\
\hline $\mathrm{HH}$ - Cancer & Fuel & 1,2-DICHLOROETHANE & Air & 9.32E-07 & 1.09E-08 & Ibs $\mathrm{C} 6 \mathrm{H} 6$ equiv \\
\hline $\mathrm{HH}$ - Cancer & Fuel & 1,3-BUTADIENE & Air & $4.8 \mathrm{E}-06$ & 3.51E-09 & Ibs $\mathrm{C} 6 \mathrm{H} 6$ equiv \\
\hline HH - Cancer & Fuel & BENZENE & Air & 0.000131 & 2.89E-07 & Ibs $\mathrm{C} 6 \mathrm{H} 6$ equiv \\
\hline $\mathrm{HH}$ - Cancer & Fuel & CADMIUM COMPOUNDS & Air & 0 & 0 & Ibs $\mathrm{C} 6 \mathrm{H} 6$ equiv \\
\hline $\mathrm{HH}$ - Cancer & Fuel & CARBON TETRACHLORIDE & Air & 4.05E-07 & 7.34E-07 & Ibs $\mathrm{C} 6 \mathrm{H} 6$ equiv \\
\hline $\mathrm{HH}$ - Cancer & Fuel & CHROMIUM COMPOUNDS & Air & 3.34E-08 & 1.23E-08 & Ibs $\mathrm{C} 6 \mathrm{H} 6$ equiv \\
\hline $\mathrm{HH}$ - Cancer & Fuel & DIMETHYL SULFATE & Air & 0 & 0 & Ibs $\mathrm{C} 6 \mathrm{H} 6$ equiv \\
\hline $\mathrm{HH}$ - Cancer & Fuel & ETHYLENE OXIDE & Air & 1.08E-06 & 7.34E-08 & Ibs $\mathrm{C} 6 \mathrm{H} 6$ equiv \\
\hline $\mathrm{HH}$ - Cancer & Fuel & FORMALDEHYDE & Air & 8.02E-06 & $5.33 E-11$ & Ibs $\mathrm{C} 6 \mathrm{H} 6$ equiv \\
\hline $\mathrm{HH}$ - Cancer & Fuel & HYDRAZINE & Air & 0 & 0 & Ibs $\mathrm{C} 6 \mathrm{H} 6$ equiv \\
\hline $\mathrm{HH}$ - Cancer & Fuel & HYDROQUINONE & Air & 0 & 0 & Ibs $\mathrm{C} 6 \mathrm{H} 6$ equiv \\
\hline
\end{tabular}




\begin{tabular}{|c|c|c|c|c|c|c|}
\hline Impact Category & Stage & Emission & Media & \begin{tabular}{|l|} 
Mass Flow \\
(grams/mile)
\end{tabular} & $\begin{array}{l}\text { Characterization } \\
\text { Result / mile }\end{array}$ & Factor Measure \\
\hline $\mathrm{HH}$ - Cancer & Fuel & LEAD COMPOUNDS & Air & $2.02 \mathrm{E}-07$ & 1.58E-08 & Ibs $\mathrm{C} 6 \mathrm{H} 6$ equiv \\
\hline $\mathrm{HH}$ - Cancer & Fuel & NICKEL COMPOUNDS & Air & $1.27 \mathrm{E}-06$ & $1.01 \mathrm{E}-08$ & Ibs $\mathrm{C} 6 \mathrm{H} 6$ equiv \\
\hline $\mathrm{HH}$ - Cancer & Fuel & O-TOLUIDINE & Air & $6.23 \mathrm{E}-10$ & $1.25 \mathrm{E}-14$ & Ibs $\mathrm{C} 6 \mathrm{H} 6$ equiv \\
\hline $\mathrm{HH}$ - Cancer & Fuel & PROPYLENE OXIDE & Air & 0 & 0 & Ibs $\mathrm{C} 6 \mathrm{H} 6$ equiv \\
\hline $\mathrm{HH}$ - Cancer & Fuel & TETRACHLOROETHYLENE & Air & 3.72E-06 & 1.49E-08 & Ibs $\mathrm{C} 6 \mathrm{H} 6$ equiv \\
\hline $\mathrm{HH}$ - Cancer & Fuel & TRICHLOROETHYLENE & Air & $3.98 \mathrm{E}-06$ & $5.14 \mathrm{E}-10$ & Ibs C6H6 equiv \\
\hline $\mathrm{HH}$ - Cancer & Fuel & CHLOROMETHANE & Air & $8.62 \mathrm{E}-08$ & $6.7 \mathrm{E}-10$ & Ibs $\mathrm{C} 6 \mathrm{H} 6$ equiv \\
\hline HH - Cancer & Vehicle & ACETALDEHYDE & Air & 0.00045 & 3.50189E-09 & Ibs $\mathrm{C} 6 \mathrm{H} 6$ equiv \\
\hline $\mathrm{HH}$ - Cancer & Vehicle & BENZENE & Air & 0.0054 & 1.19048E-05 & Ibs $\mathrm{C} 6 \mathrm{H} 6$ equiv \\
\hline $\mathrm{HH}$ - Cancer & Vehicle & FORMALDEHYDE & Air & 0.0009 & 5.98535E-09 & Ibs $\mathrm{C} 6 \mathrm{H} 6$ equiv \\
\hline $\mathrm{HH}$ - Cancer & Vehicle & 1,3 Butadiene & Air & 0.00045 & 3.29511E-07 & Ibs $\mathrm{C} 6 \mathrm{H} 6$ equiv \\
\hline $\mathrm{HH}$ - Criteria & Feedstock & NITROGEN OXIDES & Air & 0.0745 & 3.63E-07 & total DALYs \\
\hline $\mathrm{HH}$ - Criteria & Feedstock & PM10 & Air & 0.00231 & 4.25E-07 & total DALYs \\
\hline $\mathrm{HH}$ - Criteria & Feedstock & PM2.5 & Air & 0.00139 & 4.26E-07 & total DALYs \\
\hline $\mathrm{HH}$ - Criteria & Fuel & NITROGEN OXIDES & Air & 0.0933 & 4.55E-07 & total DALYs \\
\hline $\mathrm{HH}$ - Criteria & Fuel & PM10 & Air & 0.0102 & 1.88E-06 & total DALYs \\
\hline $\mathrm{HH}$ - Criteria & Fuel & PM2.5 & Air & 0.00611 & 1.87E-06 & total DALYs \\
\hline $\mathrm{HH}$ - Criteria & Vehicle & NITROGEN OXIDES & Air & 0.036 & 1.76E-07 & total DALYs \\
\hline $\mathrm{HH}$ - Criteria & Vehicle & PM10 & Air & 0.035 & $6.44 \mathrm{E}-06$ & total DALYs \\
\hline $\mathrm{HH}$ - Criteria & Vehicle & PM2.5 & Air & 0.021 & $6.44 \mathrm{E}-06$ & total DALYs \\
\hline $\mathrm{HH}$ - Non-can & Feedstock & BENZENE & Air & $1.58 \mathrm{E}-05$ & 5.78E-07 & Ibs $\mathrm{C} 6 \mathrm{H} 6$ equiv \\
\hline $\mathrm{HH}$ - Non-can & Feedstock & ETHYLBENZENE & Air & $1.32 \mathrm{E}-06$ & 9.65E-10 & Ibs $\mathrm{C} 6 \mathrm{H} 6$ equiv \\
\hline $\mathrm{HH}$ - Non-can & Feedstock & TOLUENE & Air & 9.89E-06 & $2.18 \mathrm{E}-08$ & Ibs $\mathrm{C} 6 \mathrm{H} 6$ equiv \\
\hline $\mathrm{HH}$ - Non-can & Feedstock & XYLENE & Air & $5.6 \mathrm{E}-06$ & 2.89E-09 & Ibs $\mathrm{C} 6 \mathrm{H} 6$ equiv \\
\hline $\mathrm{HH}$ - Non-can & Fuel & HYDROCHLORIC ACID & Air & 5.83E-05 & 4.99E-08 & Ibs $\mathrm{C} 6 \mathrm{H} 6$ equiv \\
\hline $\mathrm{HH}$ - Non-can & Fuel & CHLOROFORM & Air & $1.06 \mathrm{E}-06$ & 1.87E-07 & Ibs $\mathrm{C} 6 \mathrm{H} 6$ equiv \\
\hline $\mathrm{HH}$ - Non-can & Fuel & ACETALDEHYDE & Air & $3.61 \mathrm{E}-08$ & 3.12E-10 & Ibs $\mathrm{C} 6 \mathrm{H} 6$ equiv \\
\hline $\mathrm{HH}$ - Non-can & Fuel & ACETONITRILE & Air & 6.04E-08 & 2.1E-08 & Ibs $\mathrm{C} 6 \mathrm{H} 6$ equiv \\
\hline HH - Non-can & Fuel & ANILINE & Air & $6.23 \mathrm{E}-10$ & $5.45 \mathrm{E}-11$ & Ibs $\mathrm{C} 6 \mathrm{H} 6$ equiv \\
\hline $\mathrm{HH}$ - Non-can & Fuel & 1,1,1-TRICHLOROETHANE & Air & 7.13E-08 & 3.14E-08 & Ibs $\mathrm{C} 6 \mathrm{H} 6$ equiv \\
\hline $\mathrm{HH}$ - Non-can & Fuel & 1,2,4-TRICHLOROBENZENE & Air & $9.09 \mathrm{E}-08$ & 6.03E-09 & Ibs $\mathrm{C} 6 \mathrm{H} 6$ equiv \\
\hline $\mathrm{HH}$ - Non-can & Fuel & 1,2-DIBROMOETHANE & Air & $6.1 \mathrm{E}-07$ & 5.49E-06 & Ibs $\mathrm{C} 6 \mathrm{H} 6$ equiv \\
\hline $\mathrm{HH}$ - Non-can & Fuel & 1,2-DICHLOROETHANE & Air & 9.32E-07 & 3.89E-08 & Ibs $\mathrm{C} 6 \mathrm{H} 6$ equiv \\
\hline $\mathrm{HH}$ - Non-can & Fuel & 1,3-BUTADIENE & Air & $4.8 \mathrm{E}-06$ & 1.29E-08 & Ibs $\mathrm{C} 6 \mathrm{H} 6$ equiv \\
\hline $\mathrm{HH}$ - Non-can & Fuel & ANTIMONY COMPOUNDS & Air & 1.94E-07 & 8.27E-06 & Ibs $\mathrm{C} 6 \mathrm{H} 6$ equiv \\
\hline $\mathrm{HH}$ - Non-can & Fuel & BENZENE & Air & 0.000131 & 4.79E-06 & Ibs $\mathrm{C} 6 \mathrm{H} 6$ equiv \\
\hline $\mathrm{HH}$ - Non-can & Fuel & BIPHENYL & Air & 7.77E-07 & 1.15E-09 & Ibs $\mathrm{C} 6 \mathrm{H} 6$ equiv \\
\hline $\mathrm{HH}$ - Non-can & Fuel & CADMIUM COMPOUNDS & Air & 0 & 0 & Ibs $\mathrm{C} 6 \mathrm{H} 6$ equiv \\
\hline $\mathrm{HH}$ - Non-can & Fuel & CARBON DISULFIDE & Air & 2.02E-06 & 2.09E-08 & Ibs $\mathrm{C} 6 \mathrm{H} 6$ equiv \\
\hline HH - Non-can & Fuel & CARBON TETRACHLORIDE & Air & 4.05E-07 & 1.23E-05 & Ibs $\mathrm{C} 6 \mathrm{H} 6$ equiv \\
\hline $\mathrm{HH}$ - Non-can & Fuel & CHLOROBENZENE & Air & 0 & 0 & Ibs $\mathrm{C} 6 \mathrm{H} 6$ equiv \\
\hline $\mathrm{HH}$ - Non-can & Fuel & CHROMIUM COMPOUNDS & Air & 3.34E-08 & 4.69E-07 & Ibs $\mathrm{C} 6 \mathrm{H} 6$ equiv \\
\hline
\end{tabular}




\begin{tabular}{|c|c|c|c|c|c|c|}
\hline Impact Category & Stage & Emission & Media & \begin{tabular}{|c|} 
Mass Flow \\
(grams/mile)
\end{tabular} & $\begin{array}{l}\text { Characterization } \\
\text { Result / mile }\end{array}$ & Factor Measure \\
\hline $\mathrm{HH}$ - Non-can & Fuel & COBALT COMPOUNDS & Air & 4.3E-08 & 7.48E-06 & Ibs $\mathrm{C} 6 \mathrm{H} 6$ equiv \\
\hline $\mathrm{HH}$ - Non-can & Fuel & CUMENE & Air & 1.31E-05 & 9.02E-09 & Ibs $\mathrm{C} 6 \mathrm{H} 6$ equiv \\
\hline $\mathrm{HH}$ - Non-can & Fuel & DIBUTYL PHTHALATE & Air & $1.85 \mathrm{E}-07$ & 8.23E-09 & Ibs C6H6 equiv \\
\hline $\mathrm{HH}$ - Non-can & Fuel & DIETHANOLAMINE & Air & 9.05E-06 & 2.89E-07 & Ibs $\mathrm{C} 6 \mathrm{H} 6$ equiv \\
\hline $\mathrm{HH}$ - Non-can & Fuel & ETHYLBENZENE & Air & 3.98E-05 & 2.91E-08 & Ibs $\mathrm{C} 6 \mathrm{H} 6$ equiv \\
\hline $\mathrm{HH}$ - Non-can & Fuel & ETHYLENE GLYCOL & Air & 4.75E-06 & 2.56E-09 & Ibs $\mathrm{C} 6 \mathrm{H} 6$ equiv \\
\hline $\mathrm{HH}$ - Non-can & Fuel & ETHYLENE OXIDE & Air & $1.08 \mathrm{E}-06$ & 4.71E-06 & Ibs $\mathrm{C} 6 \mathrm{H} 6$ equiv \\
\hline $\mathrm{HH}$ - Non-can & Fuel & FORMALDEHYDE & Air & 8.02E-06 & 8.44E-08 & Ibs $\mathrm{C} 6 \mathrm{H} 6$ equiv \\
\hline $\mathrm{HH}$ - Non-can & Fuel & HYDRAZINE & Air & 0 & 0 & Ibs $\mathrm{C} 6 \mathrm{H} 6$ equiv \\
\hline $\mathrm{HH}$ - Non-can & Fuel & HYDROQUINONE & Air & 0 & 0 & Ibs $\mathrm{C} 6 \mathrm{H} 6$ equiv \\
\hline $\mathrm{HH}$ - Non-can & Fuel & LEAD COMPOUNDS & Air & 2.02E-07 & 0.000669 & Ibs $\mathrm{C} 6 \mathrm{H} 6$ equiv \\
\hline $\mathrm{HH}$ - Non-can & Fuel & M-CRESOL & Air & 0 & 0 & Ibs $\mathrm{C} 6 \mathrm{H} 6$ equiv \\
\hline $\mathrm{HH}$ - Non-can & Fuel & M-XYLENE & Air & 7.87E-06 & 2.88E-09 & Ibs $\mathrm{C} 6 \mathrm{H} 6$ equiv \\
\hline $\mathrm{HH}$ - Non-can & Fuel & MALEIC ANHYDRIDE & Air & 2.18E-09 & 8.29E-10 & Ibs $\mathrm{C} 6 \mathrm{H} 6$ equiv \\
\hline $\mathrm{HH}$ - Non-can & Fuel & MANGANESE COMPOUNDS & Air & 5.3E-08 & $9.28 \mathrm{E}-07$ & Ibs $\mathrm{C} 6 \mathrm{H} 6$ equiv \\
\hline $\mathrm{HH}$ - Non-can & Fuel & MERCURY COMPOUNDS & Air & $3.1 \mathrm{E}-07$ & 0.013159 & Ibs $\mathrm{C} 6 \mathrm{H} 6$ equiv \\
\hline $\mathrm{HH}$ - Non-can & Fuel & METHANOL & Air & 0.000287 & 6.91E-08 & Ibs $\mathrm{C} 6 \mathrm{H} 6$ equiv \\
\hline $\mathrm{HH}$ - Non-can & Fuel & METHYL ETHYL KETONE & Air & 0.000205 & 5.15E-08 & Ibs $\mathrm{C} 6 \mathrm{H} 6$ equiv \\
\hline $\mathrm{HH}$ - Non-can & Fuel & METHYL ISOBUTYL KETONE & Air & 1.51E-05 & 2.44E-08 & Ibs $\mathrm{C} 6 \mathrm{H} 6$ equiv \\
\hline $\mathrm{HH}$ - Non-can & Fuel & METHYL TERT-BUTYL ETHER & Air & 0.000113 & $2.25 \mathrm{E}-08$ & Ibs $\mathrm{C} 6 \mathrm{H} 6$ equiv \\
\hline $\mathrm{HH}$ - Non-can & Fuel & N-HEXANE & Air & 0.000208 & $2.78 \mathrm{E}-07$ & Ibs $\mathrm{C} 6 \mathrm{H} 6$ equiv \\
\hline $\mathrm{HH}$ - Non-can & Fuel & NAPHTHALENE & Air & 1.22E-05 & 3.42E-07 & Ibs $\mathrm{C} 6 \mathrm{H} 6$ equiv \\
\hline $\mathrm{HH}$ - Non-can & Fuel & NICKEL COMPOUNDS & Air & 1.27E-06 & 2.31E-05 & Ibs $\mathrm{C} 6 \mathrm{H} 6$ equiv \\
\hline $\mathrm{HH}$ - Non-can & Fuel & O-CRESOL & Air & 0 & 0 & Ibs $\mathrm{C} 6 \mathrm{H} 6$ equiv \\
\hline $\mathrm{HH}$ - Non-can & Fuel & O-XYLENE & Air & 6.67E-06 & 4.13E-09 & Ibs $\mathrm{C} 6 \mathrm{H} 6$ equiv \\
\hline $\mathrm{HH}$ - Non-can & Fuel & P-CRESOL & Air & 0 & 0 & Ibs $\mathrm{C} 6 \mathrm{H} 6$ equiv \\
\hline $\mathrm{HH}$ - Non-can & Fuel & P-XYLENE & Air & 8.36E-06 & 4.94E-09 & Ibs $\mathrm{C} 6 \mathrm{H} 6$ equiv \\
\hline $\mathrm{HH}$ - Non-can & Fuel & PHENOL & Air & 7.86E-06 & $9.9 \mathrm{E}-10$ & Ibs $\mathrm{C} 6 \mathrm{H} 6$ equiv \\
\hline $\mathrm{HH}$ - Non-can & Fuel & PROPYLENE OXIDE & Air & 0 & 0 & Ibs $\mathrm{C} 6 \mathrm{H} 6$ equiv \\
\hline HH - Non-can & Fuel & SELENIUM COMPOUNDS & Air & $1.59 \mathrm{E}-08$ & 7.41E-07 & Ibs $\mathrm{C} 6 \mathrm{H} 6$ equiv \\
\hline $\mathrm{HH}$ - Non-can & Fuel & STYRENE & Air & 7.76E-07 & 4.93E-11 & Ibs $\mathrm{C} 6 \mathrm{H} 6$ equiv \\
\hline $\mathrm{HH}$ - Non-can & Fuel & TETRACHLOROETHYLENE & Air & 3.72E-06 & $1.77 \mathrm{E}-06$ & Ibs $\mathrm{C} 6 \mathrm{H} 6$ equiv \\
\hline $\mathrm{HH}$ - Non-can & Fuel & TOLUENE & Air & 0.000287 & 6.33E-07 & Ibs $\mathrm{C} 6 \mathrm{H} 6$ equiv \\
\hline $\mathrm{HH}$ - Non-can & Fuel & TRICHLOROETHYLENE & Air & 3.98E-06 & 8.62E-09 & Ibs $\mathrm{C} 6 \mathrm{H} 6$ equiv \\
\hline $\mathrm{HH}$ - Non-can & Fuel & TRIETHYLAMINE & Air & 0 & 0 & Ibs $\mathrm{C} 6 \mathrm{H} 6$ equiv \\
\hline $\mathrm{HH}$ - Non-can & Fuel & VINYL ACETATE & Air & 2.22E-08 & 9.43E-11 & Ibs $\mathrm{C} 6 \mathrm{H} 6$ equiv \\
\hline $\mathrm{HH}$ - Non-can & Fuel & CHLOROMETHANE & Air & 8.62E-08 & 1.02E-07 & Ibs $\mathrm{C} 6 \mathrm{H} 6$ equiv \\
\hline $\mathrm{HH}$ - Non-can & Fuel & XYLENE & Air & 0.000175 & 9.01E-08 & Ibs $\mathrm{C} 6 \mathrm{H} 6$ equiv \\
\hline $\mathrm{HH}$ - Non-can & Fuel & Certain glycol ethers & Air & 2.23E-06 & 1.87E-09 & Ibs $\mathrm{C} 6 \mathrm{H} 6$ equiv \\
\hline $\mathrm{HH}$ - Non-can & Fuel & Polychlorinated biphenyls & Air & $6.23 \mathrm{E}-13$ & $6.6 \mathrm{E}-12$ & Ibs $\mathrm{C} 6 \mathrm{H} 6$ equiv \\
\hline HH - Non-can & Vehicle & ACETALDEHYDE & Air & 0.00045 & 3.8833E-06 & Ibs $\mathrm{C} 6 \mathrm{H} 6$ equiv \\
\hline $\mathrm{HH}$ - Non-can & Vehicle & BENZENE & Air & 0.0054 & 0.000197354 & Ibs $\mathrm{C} 6 \mathrm{H} 6$ equiv \\
\hline
\end{tabular}




\begin{tabular}{|c|c|c|c|c|c|c|}
\hline Impact Category & Stage & Emission & Media & $\begin{array}{c}\text { Mass Flow } \\
\text { (grams/mile) }\end{array}$ & $\begin{array}{c}\text { Characterization } \\
\text { Result / mile }\end{array}$ & Factor Measure \\
\hline $\mathrm{HH}$ - Non-can & Vehicle & FORMALDEHYDE & Air & 0.0009 & 9.47171E-06 & Ibs C6H6 equiv \\
\hline $\mathrm{HH}$ - Non-can & Vehicle & TOLUENE & Air & 0.0126 & 2.7778E-05 & Ibs $\mathrm{C} 6 \mathrm{H} 6$ equiv \\
\hline $\mathrm{HH}$ - Non-can & Vehicle & 1,3 Butadiene & Air & 0.00045 & 1.2051E-06 & Ibs $\mathrm{C} 6 \mathrm{H} 6$ equiv \\
\hline Smog & Feedstock & NITROGEN OXIDES & Air & 0.0745 & 0.000204 & g NOX equiv \\
\hline Smog & Feedstock & BENZENE & Air & 1.58E-05 & 8.59E-09 & g NOX equiv \\
\hline Smog & Feedstock & ETHYLBENZENE & Air & 1.32E-06 & 2.13E-09 & g NOX equiv \\
\hline Smog & Feedstock & TOLUENE & Air & $9.89 \mathrm{E}-06$ & 2.25E-08 & g NOX equiv \\
\hline Smog & Feedstock & VOC & Air & 0.0112 & 2.39E-05 & g NOX equiv \\
\hline Smog & Feedstock & CARBON MONOXIDE & Air & 0.027 & $9.88 \mathrm{E}-07$ & g NOX equiv \\
\hline Smog & Fuel & NITROGEN OXIDES & Air & 0.0933 & 0.000255 & g NOX equiv \\
\hline Smog & Fuel & ACETALDEHYDE & Air & 3.61E-08 & 1.43E-10 & g NOX equiv \\
\hline Smog & Fuel & 1,1,1-TRICHLOROETHANE & Air & 7.13E-08 & 3.48E-12 & g NOX equiv \\
\hline Smog & Fuel & 1,3-BUTADIENE & Air & 4.8E-06 & 3.41E-08 & g NOX equiv \\
\hline Smog & Fuel & BENZENE & Air & 0.000131 & 7.11E-08 & g NOX equiv \\
\hline Smog & Fuel & CHLOROBENZENE & Air & 0 & 0 & g NOX equiv \\
\hline Smog & Fuel & ETHYLBENZENE & Air & 3.98E-05 & $6.42 \mathrm{E}-08$ & g NOX equiv \\
\hline Smog & Fuel & ETHYLENE GLYCOL & Air & 4.75E-06 & 1.46E-08 & g NOX equiv \\
\hline Smog & Fuel & ETHYLENE OXIDE & Air & 1.08E-06 & $5.1 \mathrm{E}-11$ & g NOX equiv \\
\hline Smog & Fuel & FORMALDEHYDE & Air & 8.02E-06 & 3.97E-08 & g NOX equiv \\
\hline Smog & Fuel & M-XYLENE & Air & 7.87E-06 & 4.73E-08 & g NOX equiv \\
\hline Smog & Fuel & METHANOL & Air & 0.000287 & 1.55E-07 & g NOX equiv \\
\hline Smog & Fuel & METHYL ISOBUTYL KETONE & Air & 1.51E-05 & 3.84E-08 & g NOX equiv \\
\hline Smog & Fuel & METHYL TERT-BUTYL ETHER & Air & 0.000113 & 8.23E-08 & g NOX equiv \\
\hline Smog & Fuel & N-HEXANE & Air & 0.000208 & 1.91E-07 & g NOX equiv \\
\hline Smog & Fuel & NAPHTHALENE & Air & 1.22E-05 & 2.02E-08 & g NOX equiv \\
\hline Smog & Fuel & O-XYLENE & Air & 6.67E-06 & 2.84E-08 & g NOX equiv \\
\hline Smog & Fuel & P-XYLENE & Air & 8.36E-06 & 2.02E-08 & g NOX equiv \\
\hline Smog & Fuel & PHENOL & Air & 7.86E-06 & 1.59E-08 & g NOX equiv \\
\hline Smog & Fuel & PROPYLENE OXIDE & Air & 0 & 0 & g NOX equiv \\
\hline Smog & Fuel & STYRENE & Air & 7.76E-07 & 1.06E-09 & g NOX equiv \\
\hline Smog & Fuel & TETRACHLOROETHYLENE & Air & 3.72E-06 & 2.34E-10 & g NOX equiv \\
\hline Smog & Fuel & TOLUENE & Air & 0.000287 & 6.53E-07 & g NOX equiv \\
\hline Smog & Fuel & TRICHLOROETHYLENE & Air & 3.98E-06 & 2.23E-12 & g NOX equiv \\
\hline Smog & Fuel & VOC & Air & 0.049 & 0.000105 & g NOX equiv \\
\hline Smog & Fuel & CARBON MONOXIDE & Air & 0.0336 & 1.23E-06 & g NOX equiv \\
\hline Smog & Fuel & Certain glycol ethers & Air & 2.23E-06 & 5E-09 & g NOX equiv \\
\hline Smog & Vehicle & NITROGEN OXIDES & Air & 0.036 & 9.84E-05 & g NOX equiv \\
\hline Smog & Vehicle & VOC & Air & 0.119 & 0.000254 & g NOX equiv \\
\hline Smog & Vehicle & CARBON MONOXIDE & Air & 2.759 & 0.000101 & g NOX equiv \\
\hline
\end{tabular}


Table D-20 TRACI Data for FRFG HEV 2015

\begin{tabular}{|c|c|c|c|c|c|c|}
\hline $\begin{array}{l}\text { Impact } \\
\text { Category }\end{array}$ & Stage & Emission & Media & $\begin{array}{l}\text { Mass Flow } \\
\text { (grams/mile) }\end{array}$ & $\begin{array}{l}\text { Characterization } \\
\text { Result/mile }\end{array}$ & Factor Measure \\
\hline Acidification & Feedstock & NITROGEN OXIDES & Air & 0.0606 & 0.005349 & moles $\mathrm{H}+$ equiv \\
\hline Acidification & Feedstock & SULFUR OXIDES & Air & 0.0102 & 0.001142 & moles $\mathrm{H}+$ equiv \\
\hline Acidification & Fuel & HYDROGEN FLUORIDE & Air & 1.19E-05 & 2.13E-06 & moles $\mathrm{H}+$ equiv \\
\hline Acidification & Fuel & SULFUR OXIDES & Air & 0.121 & 0.013549 & moles $\mathrm{H}+$ equiv \\
\hline Acidification & Fuel & NITROGEN OXIDES & Air & 0.0759 & 0.0067 & moles $\mathrm{H}+$ equiv \\
\hline Acidification & Fuel & HYDROCHLORIC ACID & Air & 4.75E-05 & 4.68E-06 & moles $\mathrm{H}+$ equiv \\
\hline Acidification & Vehicle & NITROGEN OXIDES & Air & 0.0288 & 0.002542 & moles $\mathrm{H}+$ equiv \\
\hline Acidification & Vehicle & SULFUR OXIDES & Air & 0.00358 & 0.000401 & moles $\mathrm{H}+$ equiv \\
\hline Ecotoxicity & Feedstock & BENZENE & Air & 1.29E-05 & $8.52 \mathrm{E}-14$ & Ibs 2,4-D equiv \\
\hline Ecotoxicity & Feedstock & ETHYLBENZENE & Air & 1.07E-06 & $1.04 \mathrm{E}-14$ & Ibs 2,4-D equiv \\
\hline Ecotoxicity & Feedstock & TOLUENE & Air & 8.05E-06 & 7.99E-14 & Ibs 2,4-D equiv \\
\hline Ecotoxicity & Fuel & M-XYLENE & Air & $6.4 \mathrm{E}-06$ & 1.02E-14 & Ibs 2,4-D equiv \\
\hline Ecotoxicity & Fuel & NAPHTHALENE & Air & 9.92E-06 & 8.31E-10 & Ibs 2,4-D equiv \\
\hline Ecotoxicity & Fuel & O-XYLENE & Air & 5.43E-06 & 1.92E-14 & Ibs 2,4-D equiv \\
\hline Ecotoxicity & Fuel & P-XYLENE & Air & 6.81E-06 & 1.43E-14 & Ibs 2,4-D equiv \\
\hline Ecotoxicity & Fuel & PHENOL & Air & 6.4E-06 & $5.36 \mathrm{E}-10$ & Ibs 2,4-D equiv \\
\hline Ecotoxicity & Fuel & PROPYLENE OXIDE & Air & 0 & 0 & Ibs 2,4-D equiv \\
\hline Ecotoxicity & Fuel & STYRENE & Air & $6.31 \mathrm{E}-07$ & $1.67 \mathrm{E}-15$ & Ibs 2,4-D equiv \\
\hline Ecotoxicity & Fuel & TETRACHLOROETHYLENE & Air & 3.03E-06 & $4.48 \mathrm{E}-12$ & Ibs 2,4-D equiv \\
\hline Ecotoxicity & Fuel & TOLUENE & Air & 0.000234 & $2.32 \mathrm{E}-12$ & Ibs 2,4-D equiv \\
\hline Ecotoxicity & Fuel & TRICHLOROETHYLENE & Air & 3.24E-06 & 2.86E-14 & Ibs 2,4-D equiv \\
\hline Ecotoxicity & Fuel & CHLOROFORM & Air & 8.63E-07 & $2.28 \mathrm{E}-13$ & Ibs 2,4-D equiv \\
\hline Ecotoxicity & Fuel & 1,1,1-TRICHLOROETHANE & Air & 5.8E-08 & 1.14E-13 & Ibs 2,4-D equiv \\
\hline Ecotoxicity & Fuel & 1,2-DICHLOROETHANE & Air & 7.59E-07 & $9.2 \mathrm{E}-14$ & Ibs 2,4-D equiv \\
\hline Ecotoxicity & Fuel & 1,3-BUTADIENE & Air & 3.91E-06 & $4.57 \mathrm{E}-16$ & Ibs 2,4-D equiv \\
\hline Ecotoxicity & Fuel & BENZENE & Air & 0.000106 & 7.01E-13 & Ibs 2,4-D equiv \\
\hline Ecotoxicity & Fuel & CARBON DISULFIDE & Air & 1.64E-06 & 3.98E-11 & Ibs 2,4-D equiv \\
\hline Ecotoxicity & Fuel & CARBON TETRACHLORIDE & Air & 3.29E-07 & 2.39E-12 & Ibs 2,4-D equiv \\
\hline Ecotoxicity & Fuel & DIBUTYL PHTHALATE & Air & $1.5 \mathrm{E}-07$ & 2.25E-09 & Ibs 2,4-D equiv \\
\hline Ecotoxicity & Fuel & ETHYLBENZENE & Air & 3.24E-05 & 3.14E-13 & Ibs 2,4-D equiv \\
\hline Ecotoxicity & Fuel & FORMALDEHYDE & Air & 6.53E-06 & 4.17E-10 & Ibs 2,4-D equiv \\
\hline Eutrophication & Feedstock & NITROGEN OXIDES & Air & 0.0606 & 5.92E-06 & $\operatorname{kg~N}$ \\
\hline Eutrophication & Fuel & NITROGEN OXIDES & Air & 0.0759 & 7.41E-06 & $\mathrm{kg} \mathrm{N}$ \\
\hline Eutrophication & Vehicle & NITROGEN OXIDES & Air & 0.0288 & 2.81E-06 & $\mathrm{kg} \mathrm{N}$ \\
\hline $\mathrm{HH}$ - Cancer & Feedstock & BENZENE & Air & 1.29E-05 & 2.84E-08 & Ibs $\mathrm{C} 6 \mathrm{H} 6$ equiv \\
\hline $\mathrm{HH}$ - Cancer & Fuel & HYDROQUINONE & Air & 0 & 0 & Ibs $\mathrm{C} 6 \mathrm{H} 6$ equiv \\
\hline $\mathrm{HH}$ - Cancer & Fuel & LEAD COMPOUNDS & Air & 1.65E-07 & 1.29E-08 & Ibs $\mathrm{C} 6 \mathrm{H} 6$ equiv \\
\hline $\mathrm{HH}$ - Cancer & Fuel & NICKEL COMPOUNDS & Air & 1.04E-06 & 8.28E-09 & Ibs $\mathrm{C} 6 \mathrm{H} 6$ equiv \\
\hline $\mathrm{HH}$ - Cancer & Fuel & O-TOLUIDINE & Air & 5.07E-10 & 1.02E-14 & Ibs $\mathrm{C} 6 \mathrm{H} 6$ equiv \\
\hline $\mathrm{HH}$ - Cancer & Fuel & PROPYLENE OXIDE & Air & 0 & 0 & Ibs $\mathrm{C} 6 \mathrm{H} 6$ equiv \\
\hline
\end{tabular}




\begin{tabular}{|c|c|c|c|c|c|c|}
\hline $\begin{array}{l}\text { Impact } \\
\text { Category }\end{array}$ & Stage & Emission & Media & \begin{tabular}{|l|} 
Mass Flow \\
(grams/mile)
\end{tabular} & $\begin{array}{l}\text { Characterization } \\
\text { Result/mile }\end{array}$ & Factor Measure \\
\hline $\mathrm{HH}$ - Cancer & Fuel & TETRACHLOROETHYLENE & Air & 3.03E-06 & $1.22 \mathrm{E}-08$ & Ibs C6H6 equiv \\
\hline $\mathrm{HH}$ - Cancer & Fuel & TRICHLOROETHYLENE & Air & 3.24E-06 & $4.18 \mathrm{E}-10$ & Ibs $\mathrm{C} 6 \mathrm{H} 6$ equiv \\
\hline $\mathrm{HH}$ - Cancer & Fuel & CHLOROMETHANE & Air & $7.02 \mathrm{E}-08$ & $5.45 \mathrm{E}-10$ & Ibs $\mathrm{C} 6 \mathrm{H} 6$ equiv \\
\hline $\mathrm{HH}$ - Cancer & Fuel & CHLOROFORM & Air & 8.63E-07 & 8.69E-09 & Ibs $\mathrm{C} 6 \mathrm{H} 6$ equiv \\
\hline $\mathrm{HH}$ - Cancer & Fuel & ACETALDEHYDE & Air & $2.94 \mathrm{E}-08$ & 2.29E-13 & Ibs $\mathrm{C} 6 \mathrm{H} 6$ equiv \\
\hline $\mathrm{HH}$ - Cancer & Fuel & ANILINE & Air & 5.07E-10 & $2.54 \mathrm{E}-15$ & Ibs $\mathrm{C} 6 \mathrm{H} 6$ equiv \\
\hline $\mathrm{HH}$ - Cancer & Fuel & 1,2-DIBROMOETHANE & Air & 4.97E-07 & 9.23E-09 & Ibs $\mathrm{C} 6 \mathrm{H} 6$ equiv \\
\hline $\mathrm{HH}$ - Cancer & Fuel & 1,2-DICHLOROETHANE & Air & 7.59E-07 & 8.92E-09 & Ibs $\mathrm{C} 6 \mathrm{H} 6$ equiv \\
\hline $\mathrm{HH}$ - Cancer & Fuel & 1,3-BUTADIENE & Air & $3.91 \mathrm{E}-06$ & 2.86E-09 & Ibs $\mathrm{C} 6 \mathrm{H} 6$ equiv \\
\hline $\mathrm{HH}$ - Cancer & Fuel & BENZENE & Air & 0.000106 & 2.34E-07 & Ibs $\mathrm{C} 6 \mathrm{H} 6$ equiv \\
\hline $\mathrm{HH}$ - Cancer & Fuel & CADMIUM COMPOUNDS & Air & 0 & 0 & Ibs $\mathrm{C} 6 \mathrm{H} 6$ equiv \\
\hline $\mathrm{HH}$ - Cancer & Fuel & CARBON TETRACHLORIDE & Air & 3.29E-07 & 5.96E-07 & Ibs C6H6 equiv \\
\hline $\mathrm{HH}$ - Cancer & Fuel & CHROMIUM COMPOUNDS & Air & 2.72E-08 & $1 \mathrm{E}-08$ & Ibs $\mathrm{C} 6 \mathrm{H} 6$ equiv \\
\hline $\mathrm{HH}$ - Cancer & Fuel & DIMETHYL SULFATE & Air & 0 & 0 & Ibs $\mathrm{C} 6 \mathrm{H} 6$ equiv \\
\hline $\mathrm{HH}$ - Cancer & Fuel & ETHYLENE OXIDE & Air & 8.8E-07 & 5.98E-08 & Ibs $\mathrm{C} 6 \mathrm{H} 6$ equiv \\
\hline $\mathrm{HH}$ - Cancer & Fuel & FORMALDEHYDE & Air & $6.53 \mathrm{E}-06$ & 4.34E-11 & Ibs $\mathrm{C} 6 \mathrm{H} 6$ equiv \\
\hline $\mathrm{HH}$ - Cancer & Fuel & HYDRAZINE & Air & 0 & 0 & Ibs $\mathrm{C} 6 \mathrm{H} 6$ equiv \\
\hline $\mathrm{HH}$ - Criteria & Feedstock & NITROGEN OXIDES & Air & 0.0606 & 2.96E-07 & total DALYs \\
\hline $\mathrm{HH}$ - Criteria & Feedstock & PM10 & Air & 0.00188 & 3.46E-07 & total DALYs \\
\hline $\mathrm{HH}$ - Criteria & Feedstock & PM2.5 & Air & 0.00113 & $3.46 \mathrm{E}-07$ & total DALYs \\
\hline $\mathrm{HH}$ - Criteria & Fuel & PM10 & Air & 0.00829 & 1.53E-06 & total DALYs \\
\hline $\mathrm{HH}$ - Criteria & Fuel & PM2.5 & Air & 0.00498 & 1.53E-06 & total DALYs \\
\hline $\mathrm{HH}$ - Criteria & Fuel & NITROGEN OXIDES & Air & 0.0759 & 3.7E-07 & total DALYs \\
\hline $\mathrm{HH}$ - Criteria & Vehicle & NITROGEN OXIDES & Air & 0.0288 & $1.4 \mathrm{E}-07$ & total DALYs \\
\hline $\mathrm{HH}$ - Criteria & Vehicle & PM10 & Air & 0.031 & $5.7 \mathrm{E}-06$ & total DALYs \\
\hline $\mathrm{HH}$ - Criteria & Vehicle & PM2.5 & Air & 0.0186 & 5.7E-06 & total DALYs \\
\hline $\mathrm{HH}$ - Non-can & Feedstock & BENZENE & Air & $1.29 \mathrm{E}-05$ & 4.71E-07 & Ibs $\mathrm{C} 6 \mathrm{H} 6$ equiv \\
\hline $\mathrm{HH}$ - Non-can & Feedstock & ETHYLBENZENE & Air & 1.07E-06 & 7.86E-10 & Ibs $\mathrm{C} 6 \mathrm{H} 6$ equiv \\
\hline $\mathrm{HH}$ - Non-can & Feedstock & TOLUENE & Air & 8.05E-06 & 1.77E-08 & Ibs $\mathrm{C} 6 \mathrm{H} 6$ equiv \\
\hline $\mathrm{HH}$ - Non-can & Feedstock & XYLENE & Air & 4.56E-06 & 2.35E-09 & Ibs $\mathrm{C} 6 \mathrm{H} 6$ equiv \\
\hline $\mathrm{HH}$ - Non-can & Fuel & HYDRAZINE & Air & 0 & 0 & Ibs $\mathrm{C} 6 \mathrm{H} 6$ equiv \\
\hline $\mathrm{HH}$ - Non-can & Fuel & HYDROQUINONE & Air & 0 & 0 & Ibs $\mathrm{C} 6 \mathrm{H} 6$ equiv \\
\hline $\mathrm{HH}$ - Non-can & Fuel & LEAD COMPOUNDS & Air & $1.65 \mathrm{E}-07$ & 0.000546 & Ibs $\mathrm{C} 6 \mathrm{H} 6$ equiv \\
\hline $\mathrm{HH}$ - Non-can & Fuel & M-CRESOL & Air & 0 & 0 & Ibs $\mathrm{C} 6 \mathrm{H} 6$ equiv \\
\hline $\mathrm{HH}$ - Non-can & Fuel & M-XYLENE & Air & 6.4E-06 & 2.34E-09 & Ibs $\mathrm{C} 6 \mathrm{H} 6$ equiv \\
\hline $\mathrm{HH}$ - Non-can & Fuel & MALEIC ANHYDRIDE & Air & 1.77E-09 & $6.73 \mathrm{E}-10$ & Ibs $\mathrm{C} 6 \mathrm{H} 6$ equiv \\
\hline $\mathrm{HH}$ - Non-can & Fuel & MANGANESE COMPOUNDS & Air & $4.32 \mathrm{E}-08$ & 7.56E-07 & Ibs $\mathrm{C} 6 \mathrm{H} 6$ equiv \\
\hline $\mathrm{HH}$ - Non-can & Fuel & MERCURY COMPOUNDS & Air & 2.52E-07 & 0.010697 & Ibs $\mathrm{C} 6 \mathrm{H} 6$ equiv \\
\hline $\mathrm{HH}$ - Non-can & Fuel & METHANOL & Air & 0.000234 & 5.64E-08 & Ibs $\mathrm{C} 6 \mathrm{H} 6$ equiv \\
\hline $\mathrm{HH}$ - Non-can & Fuel & METHYL ETHYL KETONE & Air & 0.000167 & $4.2 \mathrm{E}-08$ & Ibs $\mathrm{C} 6 \mathrm{H} 6$ equiv \\
\hline $\mathrm{HH}$ - Non-can & Fuel & METHYL ISOBUTYL KETONE & Air & 1.23E-05 & 1.99E-08 & Ibs $\mathrm{C} 6 \mathrm{H} 6$ equiv \\
\hline HH - Non-can & Fuel & METHYL TERT-BUTYL ETHER & Air & $9.16 \mathrm{E}-05$ & 1.82E-08 & Ibs $\mathrm{C} 6 \mathrm{H} 6$ equiv \\
\hline
\end{tabular}




\begin{tabular}{|c|c|c|c|c|c|c|}
\hline $\begin{array}{l}\text { Impact } \\
\text { Category }\end{array}$ & Stage & Emission & Media & \begin{tabular}{|l|} 
Mass Flow \\
(grams/mile)
\end{tabular} & $\begin{array}{l}\text { Characterization } \\
\text { Result/mile }\end{array}$ & Factor Measure \\
\hline HH - Non-can & Fuel & N-HEXANE & Air & 0.00017 & $2.27 \mathrm{E}-07$ & Ibs $\mathrm{C} 6 \mathrm{H} 6$ equiv \\
\hline $\mathrm{HH}$ - Non-can & Fuel & NAPHTHALENE & Air & 9.92E-06 & 2.78E-07 & Ibs $\mathrm{C} 6 \mathrm{H} 6$ equiv \\
\hline $\mathrm{HH}$ - Non-can & Fuel & NICKEL COMPOUNDS & Air & 1.04E-06 & 1.89E-05 & Ibs $\mathrm{C} 6 \mathrm{H} 6$ equiv \\
\hline $\mathrm{HH}$ - Non-can & Fuel & O-CRESOL & Air & 0 & 0 & Ibs $\mathrm{C} 6 \mathrm{H} 6$ equiv \\
\hline $\mathrm{HH}$ - Non-can & Fuel & O-XYLENE & Air & 5.43E-06 & 3.36E-09 & Ibs $\mathrm{C} 6 \mathrm{H} 6$ equiv \\
\hline HH - Non-can & Fuel & P-CRESOL & Air & 0 & 0 & Ibs $\mathrm{C} 6 \mathrm{H} 6$ equiv \\
\hline $\mathrm{HH}$ - Non-can & Fuel & P-XYLENE & Air & 6.81E-06 & 4.02E-09 & Ibs $\mathrm{C} 6 \mathrm{H} 6$ equiv \\
\hline $\mathrm{HH}$ - Non-can & Fuel & PHENOL & Air & $6.4 \mathrm{E}-06$ & 8.06E-10 & Ibs $\mathrm{C} 6 \mathrm{H} 6$ equiv \\
\hline $\mathrm{HH}$ - Non-can & Fuel & PROPYLENE OXIDE & Air & 0 & 0 & Ibs $\mathrm{C} 6 \mathrm{H} 6$ equiv \\
\hline HH - Non-can & Fuel & SELENIUM COMPOUNDS & Air & 1.29E-08 & 6.02E-07 & Ibs $\mathrm{C} 6 \mathrm{H} 6$ equiv \\
\hline $\mathrm{HH}$ - Non-can & Fuel & STYRENE & Air & $6.31 \mathrm{E}-07$ & $4.01 \mathrm{E}-11$ & Ibs $\mathrm{C} 6 \mathrm{H} 6$ equiv \\
\hline HH - Non-can & Fuel & TETRACHLOROETHYLENE & Air & 3.03E-06 & 1.44E-06 & Ibs C6H6 equiv \\
\hline $\mathrm{HH}$ - Non-can & Fuel & TOLUENE & Air & 0.000234 & 5.16E-07 & Ibs $\mathrm{C} 6 \mathrm{H} 6$ equiv \\
\hline $\mathrm{HH}$ - Non-can & Fuel & TRICHLOROETHYLENE & Air & 3.24E-06 & 7.01E-09 & Ibs $\mathrm{C} 6 \mathrm{H} 6$ equiv \\
\hline $\mathrm{HH}$ - Non-can & Fuel & TRIETHYLAMINE & Air & 0 & 0 & Ibs $\mathrm{C} 6 \mathrm{H} 6$ equiv \\
\hline HH - Non-can & Fuel & VINYL ACETATE & Air & $1.8 \mathrm{E}-08$ & 7.65E-11 & Ibs $\mathrm{C} 6 \mathrm{H} 6$ equiv \\
\hline HH - Non-can & Fuel & CHLOROMETHANE & Air & 7.02E-08 & 8.34E-08 & Ibs $\mathrm{C} 6 \mathrm{H} 6$ equiv \\
\hline $\mathrm{HH}$ - Non-can & Fuel & XYLENE & Air & 0.000143 & 7.36E-08 & Ibs $\mathrm{C} 6 \mathrm{H} 6$ equiv \\
\hline $\mathrm{HH}$ - Non-can & Fuel & Certain glycol ethers & Air & 1.82E-06 & 1.52E-09 & Ibs $\mathrm{C} 6 \mathrm{H} 6$ equiv \\
\hline $\mathrm{HH}$ - Non-can & Fuel & Polychlorinated biphenyls & Air & $5.07 \mathrm{E}-13$ & $5.37 \mathrm{E}-12$ & Ibs $\mathrm{C} 6 \mathrm{H} 6$ equiv \\
\hline $\mathrm{HH}$ - Non-can & Fuel & HYDROCHLORIC ACID & Air & 4.75E-05 & 4.06E-08 & Ibs $\mathrm{C} 6 \mathrm{H} 6$ equiv \\
\hline $\mathrm{HH}$ - Non-can & Fuel & CHLOROFORM & Air & 8.63E-07 & $1.52 \mathrm{E}-07$ & Ibs $\mathrm{C} 6 \mathrm{H} 6$ equiv \\
\hline HH - Non-can & Fuel & ACETALDEHYDE & Air & 2.94E-08 & $2.54 \mathrm{E}-10$ & Ibs $\mathrm{C} 6 \mathrm{H} 6$ equiv \\
\hline $\mathrm{HH}$ - Non-can & Fuel & ACETONITRILE & Air & $4.92 \mathrm{E}-08$ & 1.71E-08 & Ibs $\mathrm{C} 6 \mathrm{H} 6$ equiv \\
\hline $\mathrm{HH}$ - Non-can & Fuel & ANILINE & Air & $5.07 E-10$ & 4.43E-11 & Ibs $\mathrm{C} 6 \mathrm{H} 6$ equiv \\
\hline $\mathrm{HH}$ - Non-can & Fuel & 1,1,1-TRICHLOROETHANE & Air & $5.8 \mathrm{E}-08$ & 2.56E-08 & Ibs $\mathrm{C} 6 \mathrm{H} 6$ equiv \\
\hline $\mathrm{HH}$ - Non-can & Fuel & 1,2,4-TRICHLOROBENZENE & Air & 7.4E-08 & 4.91E-09 & Ibs $\mathrm{C} 6 \mathrm{H} 6$ equiv \\
\hline $\mathrm{HH}$ - Non-can & Fuel & 1,2-DIBROMOETHANE & Air & 4.97E-07 & 4.48E-06 & Ibs $\mathrm{C} 6 \mathrm{H} 6$ equiv \\
\hline $\mathrm{HH}$ - Non-can & Fuel & 1,2-DICHLOROETHANE & Air & 7.59E-07 & 3.17E-08 & Ibs $\mathrm{C} 6 \mathrm{H} 6$ equiv \\
\hline $\mathrm{HH}$ - Non-can & Fuel & 1,3-BUTADIENE & Air & $3.91 \mathrm{E}-06$ & $1.05 \mathrm{E}-08$ & Ibs $\mathrm{C} 6 \mathrm{H} 6$ equiv \\
\hline $\mathrm{HH}$ - Non-can & Fuel & ANTIMONY COMPOUNDS & Air & $1.58 \mathrm{E}-07$ & $6.73 \mathrm{E}-06$ & Ibs $\mathrm{C} 6 \mathrm{H} 6$ equiv \\
\hline $\mathrm{HH}$ - Non-can & Fuel & BENZENE & Air & 0.000106 & $3.87 \mathrm{E}-06$ & Ibs $\mathrm{C} 6 \mathrm{H} 6$ equiv \\
\hline $\mathrm{HH}$ - Non-can & Fuel & BIPHENYL & Air & 6.33E-07 & $9.37 \mathrm{E}-10$ & Ibs $\mathrm{C} 6 \mathrm{H} 6$ equiv \\
\hline $\mathrm{HH}$ - Non-can & Fuel & CADMIUM COMPOUNDS & Air & 0 & 0 & Ibs $\mathrm{C} 6 \mathrm{H} 6$ equiv \\
\hline $\mathrm{HH}$ - Non-can & Fuel & CARBON DISULFIDE & Air & 1.64E-06 & 1.7E-08 & Ibs $\mathrm{C} 6 \mathrm{H} 6$ equiv \\
\hline HH - Non-can & Fuel & CARBON TETRACHLORIDE & Air & 3.29E-07 & $1 \mathrm{E}-05$ & Ibs $\mathrm{C} 6 \mathrm{H} 6$ equiv \\
\hline HH - Non-can & Fuel & CHLOROBENZENE & Air & 0 & 0 & Ibs $\mathrm{C} 6 \mathrm{H} 6$ equiv \\
\hline $\mathrm{HH}$ - Non-can & Fuel & CHROMIUM COMPOUNDS & Air & 2.72E-08 & 3.82E-07 & Ibs $\mathrm{C} 6 \mathrm{H} 6$ equiv \\
\hline $\mathrm{HH}$ - Non-can & Fuel & COBALT COMPOUNDS & Air & 3.5E-08 & 6.09E-06 & Ibs $\mathrm{C} 6 \mathrm{H} 6$ equiv \\
\hline $\mathrm{HH}$ - Non-can & Fuel & CUMENE & Air & 1.07E-05 & 7.37E-09 & Ibs $\mathrm{C} 6 \mathrm{H} 6$ equiv \\
\hline $\mathrm{HH}$ - Non-can & Fuel & DIBUTYL PHTHALATE & Air & 1.5E-07 & 6.68E-09 & Ibs $\mathrm{C} 6 \mathrm{H} 6$ equiv \\
\hline HH - Non-can & Fuel & DIETHANOLAMINE & Air & 7.37E-06 & 2.35E-07 & Ibs $\mathrm{C} 6 \mathrm{H} 6$ equiv \\
\hline
\end{tabular}




\begin{tabular}{|c|c|c|c|c|c|c|}
\hline $\begin{array}{l}\text { Impact } \\
\text { Category }\end{array}$ & Stage & Emission & Media & $\begin{array}{l}\text { Mass Flow } \\
\text { (grams/mile) }\end{array}$ & $\begin{array}{l}\text { Characterization } \\
\text { Result/mile }\end{array}$ & Factor Measure \\
\hline HH - Non-can & Fuel & ETHYLBENZENE & Air & 3.24E-05 & 2.37E-08 & Ibs $\mathrm{C} 6 \mathrm{H} 6$ equiv \\
\hline HH - Non-can & Fuel & ETHYLENE GLYCOL & Air & 3.87E-06 & 2.09E-09 & Ibs C6H6 equiv \\
\hline $\mathrm{HH}$ - Non-can & Fuel & ETHYLENE OXIDE & Air & 8.8E-07 & 3.84E-06 & Ibs $\mathrm{C} 6 \mathrm{H} 6$ equiv \\
\hline $\mathrm{HH}$ - Non-can & Fuel & FORMALDEHYDE & Air & 6.53E-06 & 6.87E-08 & Ibs $\mathrm{C} 6 \mathrm{H} 6$ equiv \\
\hline Smog & Feedstock & NITROGEN OXIDES & Air & 0.0606 & 0.000166 & g NOX equiv \\
\hline Smog & Feedstock & BENZENE & Air & 1.29E-05 & 6.99E-09 & g NOX equiv \\
\hline Smog & Feedstock & ETHYLBENZENE & Air & 1.07E-06 & 1.73E-09 & g NOX equiv \\
\hline Smog & Feedstock & TOLUENE & Air & 8.05E-06 & 1.83E-08 & g NOX equiv \\
\hline Smog & Feedstock & VOC & Air & 0.00915 & 1.95E-05 & g NOX equiv \\
\hline Smog & Feedstock & CARBON MONOXIDE & Air & 0.022 & 8.05E-07 & g NOX equiv \\
\hline Smog & Fuel & M-XYLENE & Air & $6.4 \mathrm{E}-06$ & 3.84E-08 & g NOX equiv \\
\hline Smog & Fuel & METHANOL & Air & 0.000234 & 1.26E-07 & g NOX equiv \\
\hline Smog & Fuel & METHYL ISOBUTYL KETONE & Air & 1.23E-05 & 3.13E-08 & g NOX equiv \\
\hline Smog & Fuel & METHYL TERT-BUTYL ETHER & Air & 9.16E-05 & 6.67E-08 & g NOX equiv \\
\hline Smog & Fuel & N-HEXANE & Air & 0.00017 & 1.56E-07 & g NOX equiv \\
\hline Smog & Fuel & NAPHTHALENE & Air & 9.92E-06 & 1.64E-08 & g NOX equiv \\
\hline Smog & Fuel & O-XYLENE & Air & 5.43E-06 & $2.31 \mathrm{E}-08$ & g NOX equiv \\
\hline Smog & Fuel & P-XYLENE & Air & 6.81E-06 & $1.64 \mathrm{E}-08$ & g NOX equiv \\
\hline Smog & Fuel & PHENOL & Air & $6.4 \mathrm{E}-06$ & 1.29E-08 & g NOX equiv \\
\hline Smog & Fuel & PROPYLENE OXIDE & Air & 0 & 0 & g NOX equiv \\
\hline Smog & Fuel & STYRENE & Air & 6.31E-07 & 8.62E-10 & g NOX equiv \\
\hline Smog & Fuel & TETRACHLOROETHYLENE & Air & 3.03E-06 & $1.91 \mathrm{E}-10$ & g NOX equiv \\
\hline Smog & Fuel & TOLUENE & Air & 0.000234 & 5.32E-07 & g NOX equiv \\
\hline Smog & Fuel & TRICHLOROETHYLENE & Air & 3.24E-06 & $1.81 \mathrm{E}-12$ & g NOX equiv \\
\hline Smog & Fuel & VOC & Air & 0.0399 & 8.51E-05 & g NOX equiv \\
\hline Smog & Fuel & CARBON MONOXIDE & Air & 0.0274 & $1 \mathrm{E}-06$ & g NOX equiv \\
\hline Smog & Fuel & Certain glycol ethers & Air & 1.82E-06 & 4.08E-09 & g NOX equiv \\
\hline Smog & Fuel & NITROGEN OXIDES & Air & 0.0759 & 0.000207 & g NOX equiv \\
\hline Smog & Fuel & ACETALDEHYDE & Air & 2.94E-08 & 1.16E-10 & g NOX equiv \\
\hline Smog & Fuel & 1,1,1-TRICHLOROETHANE & Air & $5.8 \mathrm{E}-08$ & 2.83E-12 & g NOX equiv \\
\hline Smog & Fuel & 1,3-BUTADIENE & Air & 3.91E-06 & 2.78E-08 & g NOX equiv \\
\hline Smog & Fuel & BENZENE & Air & 0.000106 & 5.76E-08 & g NOX equiv \\
\hline Smog & Fuel & CHLOROBENZENE & Air & 0 & 0 & g NOX equiv \\
\hline Smog & Fuel & ETHYLBENZENE & Air & 3.24E-05 & 5.23E-08 & g NOX equiv \\
\hline Smog & Fuel & ETHYLENE GLYCOL & Air & 3.87E-06 & 1.19E-08 & g NOX equiv \\
\hline Smog & Fuel & ETHYLENE OXIDE & Air & $8.8 \mathrm{E}-07$ & 4.16E-11 & g NOX equiv \\
\hline Smog & Fuel & FORMALDEHYDE & Air & 6.53E-06 & 3.23E-08 & g NOX equiv \\
\hline Smog & Vehicle & NITROGEN OXIDES & Air & 0.0288 & 7.87E-05 & g NOX equiv \\
\hline Smog & Vehicle & VOC & Air & 0.106 & 0.000226 & g NOX equiv \\
\hline Smog & Vehicle & CARBON MONOXIDE & Air & 2.759 & 0.000101 & g NOX equiv \\
\hline
\end{tabular}


Table D-21 TRACI Data for FT Naphtha FCV 2015

\begin{tabular}{|c|c|c|c|c|c|c|}
\hline $\begin{array}{l}\text { Impact } \\
\text { Category }\end{array}$ & Stage & Emission & Media & \begin{tabular}{|l} 
Mass Flow \\
(grams/mile)
\end{tabular} & $\begin{array}{l}\text { Characterization } \\
\text { Result / mile }\end{array}$ & Factor Measure \\
\hline Acidification & Feedstock & NITROGEN OXIDES & Air & 0.0237 & 0.002092 & moles $\mathrm{H}+$ equiv \\
\hline Acidification & Feedstock & SULFUR OXIDES & Air & 0.00806 & 0.000902 & moles $\mathrm{H}+$ equiv \\
\hline Acidification & Fuel & NITROGEN OXIDES & Air & 0.0739 & 0.006523 & moles $\mathrm{H}+$ equiv \\
\hline Acidification & Fuel & SULFUR OXIDES & Air & 0.00991 & 0.00111 & moles $\mathrm{H}+$ equiv \\
\hline Acidification & Vehicle & NITROGEN OXIDES & Air & 0.0072 & 0.000636 & moles $\mathrm{H}+$ equiv \\
\hline Acidification & Vehicle & SULFUR OXIDES & Air & 0 & 0 & moles $\mathrm{H}+$ equiv \\
\hline Ecotoxicity & Feedstock & BENZENE & Air & 0.00007 & 4.63E-13 & Ibs 2,4-D equiv \\
\hline Ecotoxicity & Feedstock & ETHYLBENZENE & Air & 5.65E-06 & $5.48 \mathrm{E}-14$ & Ibs 2,4-D equiv \\
\hline Ecotoxicity & Feedstock & TOLUENE & Air & 4.24E-05 & $4.21 \mathrm{E}-13$ & Ibs 2,4-D equiv \\
\hline Ecotoxicity & Fuel & BENZENE & Air & 0.00003 & $1.98 \mathrm{E}-13$ & Ibs 2,4-D equiv \\
\hline Eutrophication & Feedstock & NITROGEN OXIDES & Air & 0.0237 & 2.31E-06 & $\mathrm{kg} \mathrm{N}$ \\
\hline Eutrophication & Fuel & NITROGEN OXIDES & Air & 0.0739 & 7.22E-06 & $\mathrm{kg} \mathrm{N}$ \\
\hline Eutrophication & Vehicle & NITROGEN OXIDES & Air & 0.0072 & 7.03E-07 & $\mathrm{kg} \mathrm{N}$ \\
\hline $\mathrm{HH}$ - Cancer & Feedstock & BENZENE & Air & 0.00007 & 1.54E-07 & Ibs $\mathrm{C} 6 \mathrm{H} 6$ equiv \\
\hline $\mathrm{HH}$ - Cancer & Fuel & BENZENE & Air & 0.00003 & 6.61E-08 & Ibs $\mathrm{C} 6 \mathrm{H} 6$ equiv \\
\hline $\mathrm{HH}$ - Cancer & Fuel & NICKEL COMPOUNDS & Water & 0.0003 & 0 & Ibs $\mathrm{C} 6 \mathrm{H} 6$ equiv \\
\hline $\mathrm{HH}$ - Criteria & Feedstock & NITROGEN OXIDES & Air & 0.0237 & 1.16E-07 & total DALYs \\
\hline $\mathrm{HH}$ - Criteria & Feedstock & PM10 & Air & 0.000813 & $1.5 \mathrm{E}-07$ & total DALYs \\
\hline $\mathrm{HH}$ - Criteria & Feedstock & PM2.5 & Air & 0.000488 & $1.5 \mathrm{E}-07$ & total DALYs \\
\hline $\mathrm{HH}$ - Criteria & Fuel & NITROGEN OXIDES & Air & 0.0739 & 3.6E-07 & total DALYs \\
\hline $\mathrm{HH}$ - Criteria & Fuel & PM10 & Air & 0.00183 & 3.37E-07 & total DALYs \\
\hline $\mathrm{HH}$ - Criteria & Fuel & PM2.5 & Air & 0.0011 & 3.37E-07 & total DALYs \\
\hline $\mathrm{HH}$ - Criteria & Vehicle & NITROGEN OXIDES & Air & 0.0072 & 3.51E-08 & total DALYs \\
\hline $\mathrm{HH}$ - Criteria & Vehicle & PM10 & Air & 0.021 & 3.86E-06 & total DALYs \\
\hline $\mathrm{HH}$ - Criteria & Vehicle & PM2.5 & Air & 0.0126 & 3.86E-06 & total DALYs \\
\hline $\mathrm{HH}$ - Non-can & Feedstock & BENZENE & Air & 0.00007 & 2.56E-06 & Ibs $\mathrm{C} 6 \mathrm{H} 6$ equiv \\
\hline $\mathrm{HH}$ - Non-can & Feedstock & ETHYLBENZENE & Air & 5.65E-06 & 4.14E-09 & Ibs $\mathrm{C} 6 \mathrm{H} 6$ equiv \\
\hline $\mathrm{HH}$ - Non-can & Feedstock & TOLUENE & Air & 4.24E-05 & 9.35E-08 & Ibs $\mathrm{C} 6 \mathrm{H} 6$ equiv \\
\hline $\mathrm{HH}$ - Non-can & Feedstock & XYLENE & Air & 0.000024 & $1.24 \mathrm{E}-08$ & Ibs $\mathrm{C} 6 \mathrm{H} 6$ equiv \\
\hline $\mathrm{HH}$ - Non-can & Fuel & BENZENE & Air & 0.00003 & $1.1 \mathrm{E}-06$ & Ibs $\mathrm{C} 6 \mathrm{H} 6$ equiv \\
\hline $\mathrm{HH}$ - Non-can & Fuel & NICKEL COMPOUNDS & Water & 0.0003 & 4.42E-05 & Ibs $\mathrm{C} 6 \mathrm{H} 6$ equiv \\
\hline Smog & Feedstock & NITROGEN OXIDES & Air & 0.0237 & 6.48E-05 & g NOX equiv \\
\hline Smog & Feedstock & BENZENE & Air & 0.00007 & $3.8 \mathrm{E}-08$ & g NOX equiv \\
\hline Smog & Feedstock & ETHYLBENZENE & Air & 5.65E-06 & 9.12E-09 & g NOX equiv \\
\hline Smog & Feedstock & TOLUENE & Air & 4.24E-05 & 9.65E-08 & g NOX equiv \\
\hline Smog & Feedstock & VOC & Air & 0.00105 & 2.24E-06 & g NOX equiv \\
\hline Smog & Feedstock & CARBON MONOXIDE & Air & 0.0149 & 5.45E-07 & g NOX equiv \\
\hline Smog & Fuel & NITROGEN OXIDES & Air & 0.0739 & 0.000202 & g NOX equiv \\
\hline Smog & Fuel & BENZENE & Air & 0.00003 & 1.63E-08 & g NOX equiv \\
\hline Smog & Fuel & VOC & Air & 0.017 & 3.63E-05 & g NOX equiv \\
\hline
\end{tabular}




\begin{tabular}{|l|l|l|l|l|l|l|l|}
\multicolumn{1}{c|}{$\begin{array}{c}\text { Impact } \\
\text { Category }\end{array}$} & \multicolumn{2}{c|}{ Stage } & \multicolumn{1}{c|}{$\begin{array}{c}\text { Mass Flow } \\
\text { (grams/mile) }\end{array}$} & $\begin{array}{l}\text { Characterization } \\
\text { Result } / \text { mile }\end{array}$ & Factor Measure \\
\hline Smog & Fuel & CARBON MONOXIDE & Air & 0.0939 & $3.44 \mathrm{E}-06$ & $\mathrm{~g}$ NOX equiv \\
\hline Smog & Vehicle & NITROGEN OXIDES & Air & 0.0072 & $1.97 \mathrm{E}-05$ & $\mathrm{~g}$ NOX equiv \\
\hline Smog & Vehicle & VOC & Air & 0.0156 & $3.33 \mathrm{E}-05$ & $\mathrm{~g}$ NOX equiv \\
\hline Smog & Vehicle & CARBON MONOXIDE & Air & 0.552 & $2.02 \mathrm{E}-05$ & $\mathrm{~g}$ NOX equiv \\
\hline
\end{tabular}

Table D-22 TRACI Data for FRFG FCV 2015

\begin{tabular}{|c|c|c|c|c|c|c|}
\hline $\begin{array}{l}\text { Impact } \\
\text { Category }\end{array}$ & Stage & Emission & Media & $\begin{array}{c}\text { Mass Flow } \\
\text { (grams/mile) }\end{array}$ & $\begin{array}{l}\text { Characterization } \\
\text { Result / mile }\end{array}$ & Factor Measure \\
\hline Acidification & Feedstock & NITROGEN OXIDES & Air & 0.0578 & 0.005102 & moles $\mathrm{H}+$ equiv \\
\hline Acidification & Feedstock & SULFUR OXIDES & Air & 0.00976 & 0.001093 & moles $\mathrm{H}+$ equiv \\
\hline Acidification & Fuel & NITROGEN OXIDES & Air & 0.0724 & 0.006391 & moles $\mathrm{H}+$ equiv \\
\hline Acidification & Fuel & HYDROCHLORIC ACID & Air & 4.52E-05 & 4.45E-06 & moles $\mathrm{H}+$ equiv \\
\hline Acidification & Fuel & HYDROGEN FLUORIDE & Air & 1.13E-05 & 2.02E-06 & moles $\mathrm{H}+$ equiv \\
\hline Acidification & Fuel & SULFUR OXIDES & Air & 0.115 & 0.012877 & moles $\mathrm{H}+$ equiv \\
\hline Acidification & Vehicle & NITROGEN OXIDES & Air & 0.0072 & 0.000636 & moles $\mathrm{H}+$ equiv \\
\hline Acidification & Vehicle & SULFUR OXIDES & Air & 0 & 0 & moles $\mathrm{H}+$ equiv \\
\hline Ecotoxicity & Feedstock & BENZENE & Air & 1.23E-05 & 8.12E-14 & Ibs 2,4-D equiv \\
\hline Ecotoxicity & Feedstock & ETHYLBENZENE & Air & 1.02E-06 & 9.93E-15 & Ibs 2,4-D equiv \\
\hline Ecotoxicity & Feedstock & TOLUENE & Air & 7.67E-06 & 7.61E-14 & Ibs 2,4-D equiv \\
\hline Ecotoxicity & Fuel & CHLOROFORM & Air & 8.22E-07 & $2.17 \mathrm{E}-13$ & Ibs 2,4-D equiv \\
\hline Ecotoxicity & Fuel & 1,1,1-TRICHLOROETHANE & Air & 5.53E-08 & 1.09E-13 & Ibs 2,4-D equiv \\
\hline Ecotoxicity & Fuel & 1,2-DICHLOROETHANE & Air & 7.23E-07 & 8.77E-14 & Ibs 2,4-D equiv \\
\hline Ecotoxicity & Fuel & 1,3-BUTADIENE & Air & 3.73E-06 & 4.36E-16 & Ibs 2,4-D equiv \\
\hline Ecotoxicity & Fuel & BENZENE & Air & 0.000101 & $6.68 \mathrm{E}-13$ & Ibs 2,4-D equiv \\
\hline Ecotoxicity & Fuel & CARBON DISULFIDE & Air & 1.57E-06 & 3.81E-11 & Ibs 2,4-D equiv \\
\hline Ecotoxicity & Fuel & CARBON TETRACHLORIDE & Air & 3.14E-07 & $2.28 \mathrm{E}-12$ & Ibs 2,4-D equiv \\
\hline Ecotoxicity & Fuel & DIBUTYL PHTHALATE & Air & 1.43E-07 & 2.14E-09 & Ibs 2,4-D equiv \\
\hline Ecotoxicity & Fuel & ETHYLBENZENE & Air & 3.09E-05 & $3 E-13$ & Ibs 2,4-D equiv \\
\hline Ecotoxicity & Fuel & FORMALDEHYDE & Air & $6.22 \mathrm{E}-06$ & $3.98 \mathrm{E}-10$ & Ibs 2,4-D equiv \\
\hline Ecotoxicity & Fuel & M-XYLENE & Air & 6.11E-06 & 9.7E-15 & Ibs 2,4-D equiv \\
\hline Ecotoxicity & Fuel & NAPHTHALENE & Air & 9.46E-06 & 7.93E-10 & Ibs 2,4-D equiv \\
\hline Ecotoxicity & Fuel & O-XYLENE & Air & $5.18 \mathrm{E}-06$ & 1.83E-14 & Ibs 2,4-D equiv \\
\hline Ecotoxicity & Fuel & P-XYLENE & Air & 6.49E-06 & $1.36 \mathrm{E}-14$ & Ibs 2,4-D equiv \\
\hline Ecotoxicity & Fuel & PHENOL & Air & 6.1E-06 & 5.11E-10 & Ibs 2,4-D equiv \\
\hline Ecotoxicity & Fuel & PROPYLENE OXIDE & Air & 0 & 0 & Ibs 2,4-D equiv \\
\hline Ecotoxicity & Fuel & STYRENE & Air & 6.02E-07 & 1.59E-15 & Ibs 2,4-D equiv \\
\hline Ecotoxicity & Fuel & TETRACHLOROETHYLENE & Air & $2.88 \mathrm{E}-06$ & $4.25 \mathrm{E}-12$ & Ibs 2,4-D equiv \\
\hline Ecotoxicity & Fuel & TOLUENE & Air & 0.000223 & $2.21 \mathrm{E}-12$ & Ibs 2,4-D equiv \\
\hline Ecotoxicity & Fuel & TRICHLOROETHYLENE & Air & 3.09E-06 & $2.72 \mathrm{E}-14$ & Ibs 2,4-D equiv \\
\hline Eutrophication & Feedstock & NITROGEN OXIDES & Air & 0.0578 & 5.64E-06 & $\mathrm{kg} \mathrm{N}$ \\
\hline Eutrophication & Fuel & NITROGEN OXIDES & Air & 0.0724 & 7.07E-06 & $\mathrm{kg} \mathrm{N}$ \\
\hline
\end{tabular}




\begin{tabular}{|c|c|c|c|c|c|c|}
\hline $\begin{array}{l}\text { Impact } \\
\text { Category }\end{array}$ & Stage & Emission & Media & \begin{tabular}{|l|} 
Mass Flow \\
(grams/mile)
\end{tabular} & $\begin{array}{l}\text { Characterization } \\
\text { Result / mile }\end{array}$ & Factor Measure \\
\hline Eutrophication & Vehicle & NITROGEN OXIDES & Air & 0.0072 & 7.03E-07 & $\mathrm{kg} \mathrm{N}$ \\
\hline $\mathrm{HH}$ - Cancer & Feedstock & BENZENE & Air & 1.23E-05 & 2.71E-08 & Ibs $\mathrm{C} 6 \mathrm{H} 6$ equiv \\
\hline $\mathrm{HH}$ - Cancer & Fuel & CHLOROFORM & Air & $8.22 \mathrm{E}-07$ & 8.28E-09 & Ibs $\mathrm{C} 6 \mathrm{H} 6$ equiv \\
\hline $\mathrm{HH}$ - Cancer & Fuel & ACETALDEHYDE & Air & $2.8 \mathrm{E}-08$ & 2.18E-13 & Ibs $\mathrm{C} 6 \mathrm{H} 6$ equiv \\
\hline $\mathrm{HH}$ - Cancer & Fuel & ANILINE & Air & 4.83E-10 & 2.42E-15 & Ibs $\mathrm{C} 6 \mathrm{H} 6$ equiv \\
\hline $\mathrm{HH}$ - Cancer & Fuel & 1,2-DIBROMOETHANE & Air & 4.74E-07 & $8.8 \mathrm{E}-09$ & Ibs $\mathrm{C} 6 \mathrm{H} 6$ equiv \\
\hline $\mathrm{HH}$ - Cancer & Fuel & 1,2-DICHLOROETHANE & Air & 7.23E-07 & 8.49E-09 & Ibs $\mathrm{C} 6 \mathrm{H} 6$ equiv \\
\hline $\mathrm{HH}$ - Cancer & Fuel & 1,3-BUTADIENE & Air & 3.73E-06 & 2.73E-09 & Ibs $\mathrm{C} 6 \mathrm{H} 6$ equiv \\
\hline $\mathrm{HH}$ - Cancer & Fuel & BENZENE & Air & 0.000101 & 2.23E-07 & Ibs $\mathrm{C} 6 \mathrm{H} 6$ equiv \\
\hline $\mathrm{HH}$ - Cancer & Fuel & CADMIUM COMPOUNDS & Air & 0 & 0 & Ibs $\mathrm{C} 6 \mathrm{H} 6$ equiv \\
\hline $\mathrm{HH}$ - Cancer & Fuel & CARBON TETRACHLORIDE & Air & 3.14E-07 & 5.69E-07 & Ibs $\mathrm{C} 6 \mathrm{H} 6$ equiv \\
\hline $\mathrm{HH}$ - Cancer & Fuel & CHROMIUM COMPOUNDS & Air & 2.59E-08 & 9.56E-09 & Ibs C6H6 equiv \\
\hline $\mathrm{HH}$ - Cancer & Fuel & DIMETHYL SULFATE & Air & 0 & 0 & Ibs $\mathrm{C} 6 \mathrm{H} 6$ equiv \\
\hline $\mathrm{HH}$ - Cancer & Fuel & ETHYLENE OXIDE & Air & 8.39E-07 & 5.7E-08 & Ibs $\mathrm{C} 6 \mathrm{H} 6$ equiv \\
\hline $\mathrm{HH}$ - Cancer & Fuel & FORMALDEHYDE & Air & $6.22 \mathrm{E}-06$ & $4.14 \mathrm{E}-11$ & Ibs $\mathrm{C} 6 \mathrm{H} 6$ equiv \\
\hline $\mathrm{HH}$ - Cancer & Fuel & HYDRAZINE & Air & 0 & 0 & Ibs $\mathrm{C} 6 \mathrm{H} 6$ equiv \\
\hline $\mathrm{HH}$ - Cancer & Fuel & HYDROQUINONE & Air & 0 & 0 & Ibs $\mathrm{C} 6 \mathrm{H} 6$ equiv \\
\hline $\mathrm{HH}$ - Cancer & Fuel & LEAD COMPOUNDS & Air & $1.57 \mathrm{E}-07$ & 1.23E-08 & Ibs $\mathrm{C} 6 \mathrm{H} 6$ equiv \\
\hline $\mathrm{HH}$ - Cancer & Fuel & NICKEL COMPOUNDS & Air & 9.89E-07 & 7.87E-09 & Ibs $\mathrm{C} 6 \mathrm{H} 6$ equiv \\
\hline $\mathrm{HH}$ - Cancer & Fuel & O-TOLUIDINE & Air & 4.83E-10 & $9.68 \mathrm{E}-15$ & Ibs $\mathrm{C} 6 \mathrm{H} 6$ equiv \\
\hline $\mathrm{HH}$ - Cancer & Fuel & PROPYLENE OXIDE & Air & 0 & 0 & Ibs $\mathrm{C} 6 \mathrm{H} 6$ equiv \\
\hline $\mathrm{HH}$ - Cancer & Fuel & TETRACHLOROETHYLENE & Air & 2.88E-06 & 1.16E-08 & Ibs $\mathrm{C} 6 \mathrm{H} 6$ equiv \\
\hline HH - Cancer & Fuel & TRICHLOROETHYLENE & Air & 3.09E-06 & $3.99 \mathrm{E}-10$ & Ibs $\mathrm{C} 6 \mathrm{H} 6$ equiv \\
\hline $\mathrm{HH}$ - Cancer & Fuel & CHLOROMETHANE & Air & $6.69 \mathrm{E}-08$ & $5.2 \mathrm{E}-10$ & Ibs $\mathrm{C} 6 \mathrm{H} 6$ equiv \\
\hline $\mathrm{HH}$ - Criteria & Feedstock & NITROGEN OXIDES & Air & 0.0578 & 2.82E-07 & total DALYs \\
\hline $\mathrm{HH}$ - Criteria & Feedstock & PM10 & Air & 0.00179 & 3.29E-07 & total DALYs \\
\hline $\mathrm{HH}$ - Criteria & Feedstock & PM2.5 & Air & 0.00108 & 3.31E-07 & total DALYs \\
\hline $\mathrm{HH}$ - Criteria & Fuel & NITROGEN OXIDES & Air & 0.0724 & 3.53E-07 & total DALYs \\
\hline $\mathrm{HH}$ - Criteria & Fuel & PM10 & Air & 0.00791 & 1.46E-06 & total DALYs \\
\hline $\mathrm{HH}$ - Criteria & Fuel & PM2.5 & Air & 0.00474 & $1.45 \mathrm{E}-06$ & total DALYs \\
\hline $\mathrm{HH}$ - Criteria & Vehicle & NITROGEN OXIDES & Air & 0.0072 & $3.51 \mathrm{E}-08$ & total DALYs \\
\hline $\mathrm{HH}$ - Criteria & Vehicle & PM10 & Air & 0.021 & 3.86E-06 & total DALYs \\
\hline $\mathrm{HH}$ - Criteria & Vehicle & PM2.5 & Air & 0.0126 & 3.86E-06 & total DALYs \\
\hline $\mathrm{HH}$ - Non-can & Feedstock & BENZENE & Air & 1.23E-05 & 4.49E-07 & Ibs $\mathrm{C} 6 \mathrm{H} 6$ equiv \\
\hline $\mathrm{HH}$ - Non-can & Feedstock & ETHYLBENZENE & Air & $1.02 \mathrm{E}-06$ & 7.49E-10 & Ibs $\mathrm{C} 6 \mathrm{H} 6$ equiv \\
\hline $\mathrm{HH}$ - Non-can & Feedstock & TOLUENE & Air & 7.67E-06 & 1.69E-08 & Ibs $\mathrm{C} 6 \mathrm{H} 6$ equiv \\
\hline $\mathrm{HH}$ - Non-can & Feedstock & XYLENE & Air & 4.35E-06 & 2.24E-09 & Ibs $\mathrm{C} 6 \mathrm{H} 6$ equiv \\
\hline $\mathrm{HH}$ - Non-can & Fuel & HYDROCHLORIC ACID & Air & 4.52E-05 & 3.87E-08 & Ibs $\mathrm{C} 6 \mathrm{H} 6$ equiv \\
\hline $\mathrm{HH}$ - Non-can & Fuel & CHLOROFORM & Air & 8.22E-07 & 1.45E-07 & Ibs $\mathrm{C} 6 \mathrm{H} 6$ equiv \\
\hline $\mathrm{HH}$ - Non-can & Fuel & ACETALDEHYDE & Air & $2.8 \mathrm{E}-08$ & $2.42 \mathrm{E}-10$ & Ibs $\mathrm{C} 6 \mathrm{H} 6$ equiv \\
\hline HH - Non-can & Fuel & ACETONITRILE & Air & 4.69E-08 & 1.63E-08 & Ibs $\mathrm{C} 6 \mathrm{H} 6$ equiv \\
\hline HH - Non-can & Fuel & ANILINE & Air & 4.83E-10 & 4.22E-11 & Ibs $\mathrm{C} 6 \mathrm{H} 6$ equiv \\
\hline
\end{tabular}




\begin{tabular}{|c|c|c|c|c|c|c|}
\hline $\begin{array}{l}\text { Impact } \\
\text { Category }\end{array}$ & Stage & Emission & Media & \begin{tabular}{|l|} 
Mass Flow \\
(grams/mile)
\end{tabular} & $\begin{array}{l}\text { Characterization } \\
\text { Result / mile }\end{array}$ & Factor Measure \\
\hline HH - Non-can & Fuel & 1,1,1-TRICHLOROETHANE & Air & 5.53E-08 & $2.44 \mathrm{E}-08$ & Ibs C6H6 equiv \\
\hline $\mathrm{HH}$ - Non-can & Fuel & 1,2,4-TRICHLOROBENZENE & Air & 7.05E-08 & 4.67E-09 & Ibs $\mathrm{C} 6 \mathrm{H} 6$ equiv \\
\hline $\mathrm{HH}$ - Non-can & Fuel & 1,2-DIBROMOETHANE & Air & 4.74E-07 & 4.27E-06 & Ibs $\mathrm{C} 6 \mathrm{H} 6$ equiv \\
\hline $\mathrm{HH}$ - Non-can & Fuel & 1,2-DICHLOROETHANE & Air & 7.23E-07 & 3.02E-08 & Ibs $\mathrm{C} 6 \mathrm{H} 6$ equiv \\
\hline HH - Non-can & Fuel & 1,3-BUTADIENE & Air & 3.73E-06 & 9.99E-09 & Ibs $\mathrm{C} 6 \mathrm{H} 6$ equiv \\
\hline HH - Non-can & Fuel & ANTIMONY COMPOUNDS & Air & $1.5 \mathrm{E}-07$ & 6.39E-06 & Ibs $\mathrm{C} 6 \mathrm{H} 6$ equiv \\
\hline $\mathrm{HH}$ - Non-can & Fuel & BENZENE & Air & 0.000101 & 3.69E-06 & Ibs $\mathrm{C} 6 \mathrm{H} 6$ equiv \\
\hline $\mathrm{HH}$ - Non-can & Fuel & BIPHENYL & Air & 6.03E-07 & 8.92E-10 & Ibs $\mathrm{C} 6 \mathrm{H} 6$ equiv \\
\hline $\mathrm{HH}$ - Non-can & Fuel & CADMIUM COMPOUNDS & Air & 0 & 0 & Ibs $\mathrm{C} 6 \mathrm{H} 6$ equiv \\
\hline HH - Non-can & Fuel & CARBON DISULFIDE & Air & 1.57E-06 & 1.62E-08 & Ibs $\mathrm{C} 6 \mathrm{H} 6$ equiv \\
\hline $\mathrm{HH}$ - Non-can & Fuel & CARBON TETRACHLORIDE & Air & 3.14E-07 & 9.55E-06 & Ibs $\mathrm{C} 6 \mathrm{H} 6$ equiv \\
\hline HH - Non-can & Fuel & CHLOROBENZENE & Air & 0 & 0 & Ibs C6H6 equiv \\
\hline $\mathrm{HH}$ - Non-can & Fuel & CHROMIUM COMPOUNDS & Air & $2.59 \mathrm{E}-08$ & 3.63E-07 & Ibs $\mathrm{C} 6 \mathrm{H} 6$ equiv \\
\hline $\mathrm{HH}$ - Non-can & Fuel & COBALT COMPOUNDS & Air & 3.33E-08 & $5.8 \mathrm{E}-06$ & Ibs $\mathrm{C} 6 \mathrm{H} 6$ equiv \\
\hline $\mathrm{HH}$ - Non-can & Fuel & CUMENE & Air & $1.02 \mathrm{E}-05$ & 7.02E-09 & Ibs $\mathrm{C} 6 \mathrm{H} 6$ equiv \\
\hline HH - Non-can & Fuel & DIBUTYL PHTHALATE & Air & $1.43 \mathrm{E}-07$ & 6.36E-09 & Ibs $\mathrm{C} 6 \mathrm{H} 6$ equiv \\
\hline HH - Non-can & Fuel & DIETHANOLAMINE & Air & $7.02 E-06$ & 2.24E-07 & Ibs $\mathrm{C} 6 \mathrm{H} 6$ equiv \\
\hline $\mathrm{HH}$ - Non-can & Fuel & ETHYLBENZENE & Air & 3.09E-05 & 2.26E-08 & Ibs $\mathrm{C} 6 \mathrm{H} 6$ equiv \\
\hline $\mathrm{HH}$ - Non-can & Fuel & ETHYLENE GLYCOL & Air & 3.69E-06 & 1.99E-09 & Ibs $\mathrm{C} 6 \mathrm{H} 6$ equiv \\
\hline $\mathrm{HH}$ - Non-can & Fuel & ETHYLENE OXIDE & Air & $8.39 \mathrm{E}-07$ & $3.66 \mathrm{E}-06$ & Ibs $\mathrm{C} 6 \mathrm{H} 6$ equiv \\
\hline $\mathrm{HH}$ - Non-can & Fuel & FORMALDEHYDE & Air & $6.22 \mathrm{E}-06$ & $6.55 \mathrm{E}-08$ & Ibs $\mathrm{C} 6 \mathrm{H} 6$ equiv \\
\hline $\mathrm{HH}$ - Non-can & Fuel & HYDRAZINE & Air & 0 & 0 & Ibs $\mathrm{C} 6 \mathrm{H} 6$ equiv \\
\hline HH - Non-can & Fuel & HYDROQUINONE & Air & 0 & 0 & Ibs $\mathrm{C} 6 \mathrm{H} 6$ equiv \\
\hline $\mathrm{HH}$ - Non-can & Fuel & LEAD COMPOUNDS & Air & $1.57 \mathrm{E}-07$ & 0.00052 & Ibs $\mathrm{C} 6 \mathrm{H} 6$ equiv \\
\hline $\mathrm{HH}$ - Non-can & Fuel & M-CRESOL & Air & 0 & 0 & Ibs $\mathrm{C} 6 \mathrm{H} 6$ equiv \\
\hline $\mathrm{HH}$ - Non-can & Fuel & M-XYLENE & Air & $6.11 \mathrm{E}-06$ & 2.23E-09 & Ibs $\mathrm{C} 6 \mathrm{H} 6$ equiv \\
\hline HH - Non-can & Fuel & MALEIC ANHYDRIDE & Air & $1.69 \mathrm{E}-09$ & $6.43 \mathrm{E}-10$ & Ibs $\mathrm{C} 6 \mathrm{H} 6$ equiv \\
\hline $\mathrm{HH}$ - Non-can & Fuel & MANGANESE COMPOUNDS & Air & 4.12E-08 & 7.21E-07 & Ibs $\mathrm{C} 6 \mathrm{H} 6$ equiv \\
\hline $\mathrm{HH}$ - Non-can & Fuel & MERCURY COMPOUNDS & Air & 2.4E-07 & 0.010188 & Ibs $\mathrm{C} 6 \mathrm{H} 6$ equiv \\
\hline $\mathrm{HH}$ - Non-can & Fuel & METHANOL & Air & 0.000223 & 5.37E-08 & Ibs $\mathrm{C} 6 \mathrm{H} 6$ equiv \\
\hline $\mathrm{HH}$ - Non-can & Fuel & METHYL ETHYL KETONE & Air & 0.000159 & 4E-08 & Ibs $\mathrm{C} 6 \mathrm{H} 6$ equiv \\
\hline $\mathrm{HH}$ - Non-can & Fuel & METHYL ISOBUTYL KETONE & Air & 1.17E-05 & 1.89E-08 & Ibs $\mathrm{C} 6 \mathrm{H} 6$ equiv \\
\hline $\mathrm{HH}$ - Non-can & Fuel & METHYL TERT-BUTYL ETHER & Air & 8.73E-05 & 1.74E-08 & Ibs $\mathrm{C} 6 \mathrm{H} 6$ equiv \\
\hline $\mathrm{HH}$ - Non-can & Fuel & N-HEXANE & Air & 0.000162 & 2.17E-07 & Ibs $\mathrm{C} 6 \mathrm{H} 6$ equiv \\
\hline $\mathrm{HH}$ - Non-can & Fuel & NAPHTHALENE & Air & 9.46E-06 & 2.65E-07 & Ibs $\mathrm{C} 6 \mathrm{H} 6$ equiv \\
\hline $\mathrm{HH}$ - Non-can & Fuel & NICKEL COMPOUNDS & Air & 9.89E-07 & $1.8 \mathrm{E}-05$ & Ibs $\mathrm{C} 6 \mathrm{H} 6$ equiv \\
\hline $\mathrm{HH}$ - Non-can & Fuel & O-CRESOL & Air & 0 & 0 & Ibs $\mathrm{C} 6 \mathrm{H} 6$ equiv \\
\hline $\mathrm{HH}$ - Non-can & Fuel & O-XYLENE & Air & 5.18E-06 & 3.2E-09 & Ibs $\mathrm{C} 6 \mathrm{H} 6$ equiv \\
\hline $\mathrm{HH}$ - Non-can & Fuel & P-CRESOL & Air & 0 & 0 & Ibs $\mathrm{C} 6 \mathrm{H} 6$ equiv \\
\hline $\mathrm{HH}$ - Non-can & Fuel & P-XYLENE & Air & 6.49E-06 & 3.83E-09 & Ibs $\mathrm{C} 6 \mathrm{H} 6$ equiv \\
\hline $\mathrm{HH}$ - Non-can & Fuel & PHENOL & Air & $6.1 \mathrm{E}-06$ & $7.68 \mathrm{E}-10$ & Ibs $\mathrm{C} 6 \mathrm{H} 6$ equiv \\
\hline HH - Non-can & Fuel & PROPYLENE OXIDE & Air & 0 & 0 & Ibs $\mathrm{C} 6 \mathrm{H} 6$ equiv \\
\hline
\end{tabular}




\begin{tabular}{|c|c|c|c|c|c|c|}
\hline $\begin{array}{l}\text { Impact } \\
\text { Category }\end{array}$ & Stage & Emission & Media & \begin{tabular}{|c|} 
Mass Flow \\
(grams/mile)
\end{tabular} & $\begin{array}{c}\text { Characterization } \\
\text { Result / mile }\end{array}$ & Factor Measure \\
\hline HH - Non-can & Fuel & SELENIUM COMPOUNDS & Air & $1.23 \mathrm{E}-08$ & $5.74 \mathrm{E}-07$ & Ibs $\mathrm{C} 6 \mathrm{H} 6$ equiv \\
\hline $\mathrm{HH}$ - Non-can & Fuel & STYRENE & Air & $6.02 \mathrm{E}-07$ & 3.83E-11 & Ibs $\mathrm{C} 6 \mathrm{H} 6$ equiv \\
\hline $\mathrm{HH}$ - Non-can & Fuel & TETRACHLOROETHYLENE & Air & 2.88E-06 & 1.37E-06 & Ibs C6H6 equiv \\
\hline $\mathrm{HH}$ - Non-can & Fuel & TOLUENE & Air & 0.000223 & 4.92E-07 & Ibs $\mathrm{C} 6 \mathrm{H} 6$ equiv \\
\hline HH - Non-can & Fuel & TRICHLOROETHYLENE & Air & 3.09E-06 & 6.69E-09 & Ibs $\mathrm{C} 6 \mathrm{H} 6$ equiv \\
\hline $\mathrm{HH}$ - Non-can & Fuel & TRIETHYLAMINE & Air & 0 & 0 & Ibs $\mathrm{C} 6 \mathrm{H} 6$ equiv \\
\hline $\mathrm{HH}$ - Non-can & Fuel & VINYL ACETATE & Air & 1.72E-08 & 7.31E-11 & Ibs $\mathrm{C} 6 \mathrm{H} 6$ equiv \\
\hline $\mathrm{HH}$ - Non-can & Fuel & CHLOROMETHANE & Air & 6.69E-08 & 7.95E-08 & Ibs $\mathrm{C} 6 \mathrm{H} 6$ equiv \\
\hline $\mathrm{HH}$ - Non-can & Fuel & XYLENE & Air & 0.000136 & 7E-08 & Ibs $\mathrm{C} 6 \mathrm{H} 6$ equiv \\
\hline $\mathrm{HH}$ - Non-can & Fuel & Certain glycol ethers & Air & 1.73E-06 & 1.45E-09 & Ibs $\mathrm{C} 6 \mathrm{H} 6$ equiv \\
\hline $\mathrm{HH}$ - Non-can & Fuel & Polychlorinated biphenyls & Air & 4.83E-13 & $5.12 \mathrm{E}-12$ & Ibs $\mathrm{C} 6 \mathrm{H} 6$ equiv \\
\hline Smog & Feedstock & NITROGEN OXIDES & Air & 0.0578 & 0.000158 & g NOX equiv \\
\hline Smog & Feedstock & BENZENE & Air & 1.23E-05 & 6.67E-09 & g NOX equiv \\
\hline Smog & Feedstock & ETHYLBENZENE & Air & 1.02E-06 & 1.65E-09 & g NOX equiv \\
\hline Smog & Feedstock & TOLUENE & Air & 7.67E-06 & 1.75E-08 & g NOX equiv \\
\hline Smog & Feedstock & VOC & Air & 0.00873 & 1.86E-05 & g NOX equiv \\
\hline Smog & Feedstock & CARBON MONOXIDE & Air & 0.021 & 7.69E-07 & g NOX equiv \\
\hline Smog & Fuel & NITROGEN OXIDES & Air & 0.0724 & 0.000198 & g NOX equiv \\
\hline Smog & Fuel & ACETALDEHYDE & Air & $2.8 \mathrm{E}-08$ & $1.11 \mathrm{E}-10$ & g NOX equiv \\
\hline Smog & Fuel & 1,1,1-TRICHLOROETHANE & Air & 5.53E-08 & $2.7 \mathrm{E}-12$ & g NOX equiv \\
\hline Smog & Fuel & 1,3-BUTADIENE & Air & 3.73E-06 & 2.65E-08 & g NOX equiv \\
\hline Smog & Fuel & BENZENE & Air & 0.000101 & 5.48E-08 & g NOX equiv \\
\hline Smog & Fuel & CHLOROBENZENE & Air & 0 & 0 & g NOX equiv \\
\hline Smog & Fuel & ETHYLBENZENE & Air & 3.09E-05 & 4.99E-08 & g NOX equiv \\
\hline Smog & Fuel & ETHYLENE GLYCOL & Air & 3.69E-06 & 1.13E-08 & g NOX equiv \\
\hline Smog & Fuel & ETHYLENE OXIDE & Air & 8.39E-07 & 3.96E-11 & g NOX equiv \\
\hline Smog & Fuel & FORMALDEHYDE & Air & $6.22 \mathrm{E}-06$ & 3.08E-08 & g NOX equiv \\
\hline Smog & Fuel & M-XYLENE & Air & 6.11E-06 & 3.67E-08 & g NOX equiv \\
\hline Smog & Fuel & METHANOL & Air & 0.000223 & 1.2E-07 & g NOX equiv \\
\hline Smog & Fuel & METHYL ISOBUTYL KETONE & Air & 1.17E-05 & 2.98E-08 & g NOX equiv \\
\hline Smog & Fuel & METHYL TERT-BUTYL ETHER & Air & 8.73E-05 & 6.36E-08 & g NOX equiv \\
\hline Smog & Fuel & N-HEXANE & Air & 0.000162 & 1.49E-07 & g NOX equiv \\
\hline Smog & Fuel & NAPHTHALENE & Air & 9.46E-06 & 1.57E-08 & g NOX equiv \\
\hline Smog & Fuel & O-XYLENE & Air & 5.18E-06 & 2.2E-08 & g NOX equiv \\
\hline Smog & Fuel & P-XYLENE & Air & 6.49E-06 & 1.57E-08 & g NOX equiv \\
\hline Smog & Fuel & PHENOL & Air & $6.1 \mathrm{E}-06$ & 1.23E-08 & g NOX equiv \\
\hline Smog & Fuel & PROPYLENE OXIDE & Air & 0 & 0 & g NOX equiv \\
\hline Smog & Fuel & STYRENE & Air & 6.02E-07 & 8.23E-10 & g NOX equiv \\
\hline Smog & Fuel & TETRACHLOROETHYLENE & Air & 2.88E-06 & $1.82 \mathrm{E}-10$ & g NOX equiv \\
\hline Smog & Fuel & TOLUENE & Air & 0.000223 & 5.07E-07 & g NOX equiv \\
\hline Smog & Fuel & TRICHLOROETHYLENE & Air & 3.09E-06 & 1.73E-12 & g NOX equiv \\
\hline Smog & Fuel & VOC & Air & 0.0381 & 8.13E-05 & g NOX equiv \\
\hline
\end{tabular}




\begin{tabular}{|c|c|c|c|c|c|c|}
\hline $\begin{array}{l}\text { Impact } \\
\text { Category }\end{array}$ & Stage & Emission & Media & $\begin{array}{l}\text { Mass Flow } \\
\text { (grams/mile) }\end{array}$ & $\begin{array}{l}\text { Characterization } \\
\text { Result / mile }\end{array}$ & Factor Measure \\
\hline Smog & Fuel & CARBON MONOXIDE & Air & 0.0261 & $9.55 \mathrm{E}-07$ & g NOX equiv \\
\hline Smog & Fuel & Certain glycol ethers & Air & 1.73E-06 & 3.88E-09 & g NOX equiv \\
\hline Smog & Vehicle & NITROGEN OXIDES & Air & 0.0072 & 1.97E-05 & g NOX equiv \\
\hline Smog & Vehicle & VOC & Air & 0.0565 & 0.000121 & g NOX equiv \\
\hline Smog & Vehicle & CARBON MONOXIDE & Air & 0.552 & 2.02E-05 & g NOX equiv \\
\hline
\end{tabular}

Table D-23 TRACI Data for Methanol FCV 2015

\begin{tabular}{|c|c|c|c|c|c|c|}
\hline $\begin{array}{l}\text { Impact } \\
\text { Category }\end{array}$ & Stage & Emission & Media & $\begin{array}{c}\text { Mass Flow } \\
\text { (grams/mile) }\end{array}$ & \begin{tabular}{|c} 
Characterizatio \\
n Result/mile
\end{tabular} & Factor Measure \\
\hline Acidification & Feedstock & NITROGEN OXIDES & Air & 0.021 & 0.001854 & moles $\mathrm{H}+$ equiv \\
\hline Acidification & Feedstock & SULFUR OXIDES & Air & 0.00714 & 0.000799 & moles $\mathrm{H}+$ equiv \\
\hline Acidification & Fuel & NITROGEN OXIDES & Air & 0.177 & 0.015624 & moles $\mathrm{H}+$ equiv \\
\hline Acidification & Fuel & SULFUR OXIDES & Air & 0.0211 & 0.002363 & moles $\mathrm{H}+$ equiv \\
\hline Acidification & Vehicle & NITROGEN OXIDES & Air & 0.0072 & 0.000636 & moles $\mathrm{H}+$ equiv \\
\hline Acidification & Vehicle & SULFUR OXIDES & Air & 0 & 0 & moles $\mathrm{H}+$ equiv \\
\hline Eutrophication & Feedstock & NITROGEN OXIDES & Air & 0.021 & 2.05E-06 & $\mathrm{kg} \mathrm{N}$ \\
\hline Eutrophication & Fuel & NITROGEN OXIDES & Air & 0.177 & 1.73E-05 & $\mathrm{kg} \mathrm{N}$ \\
\hline Eutrophication & Vehicle & NITROGEN OXIDES & Air & 0.0072 & 7.03E-07 & $\mathrm{kg} \mathrm{N}$ \\
\hline $\mathrm{HH}$ - Criteria & Feedstock & NITROGEN OXIDES & Air & 0.021 & 1.02E-07 & total DALYs \\
\hline $\mathrm{HH}$ - Criteria & Feedstock & PM10 & Air & 0.00072 & 1.32E-07 & total DALYs \\
\hline $\mathrm{HH}$ - Criteria & Feedstock & PM2.5 & Air & 0.000432 & 1.32E-07 & total DALYs \\
\hline $\mathrm{HH}$ - Criteria & Fuel & NITROGEN OXIDES & Air & 0.177 & 8.63E-07 & total DALYs \\
\hline $\mathrm{HH}$ - Criteria & Fuel & PM10 & Air & 0.00572 & 1.05E-06 & total DALYs \\
\hline $\mathrm{HH}$ - Criteria & Fuel & PM2.5 & Air & 0.00343 & 1.05E-06 & total DALYs \\
\hline $\mathrm{HH}$ - Criteria & Vehicle & NITROGEN OXIDES & Air & 0.0072 & 3.51E-08 & total DALYs \\
\hline $\mathrm{HH}$ - Criteria & Vehicle & PM10 & Air & 0.021 & 3.86E-06 & total DALYs \\
\hline $\mathrm{HH}$ - Criteria & Vehicle & PM2.5 & Air & 0.0126 & 3.86E-06 & total DALYs \\
\hline Smog & Feedstock & NITROGEN OXIDES & Air & 0.021 & 5.74E-05 & g NOX equiv \\
\hline Smog & Feedstock & VOC & Air & 0.000931 & 1.99E-06 & g NOX equiv \\
\hline Smog & Feedstock & CARBON MONOXIDE & Air & 0.0132 & 4.83E-07 & g NOX equiv \\
\hline Smog & Fuel & NITROGEN OXIDES & Air & 0.177 & 0.000484 & g NOX equiv \\
\hline Smog & Fuel & VOC & Air & 0.0268 & 5.72E-05 & g NOX equiv \\
\hline Smog & Fuel & CARBON MONOXIDE & Air & 0.0358 & 1.31E-06 & g NOX equiv \\
\hline Smog & Vehicle & NITROGEN OXIDES & Air & 0.0072 & 1.97E-05 & g NOX equiv \\
\hline Smog & Vehicle & VOC & Air & 0.0376 & 8.02E-05 & g NOX equiv \\
\hline Smog & Vehicle & CARBON MONOXIDE & Air & 0.552 & 2.02E-05 & g NOX equiv \\
\hline
\end{tabular}




\section{E.1 INTRODUCTION}

The production of power in combined-cycle gas turbines is a potential market for GTL fuels and for methanol. This section compares the life cycle inventories for power generation from methanol and GTL in the United States with those for coal, domestic natural gas, and liquefied natural gas from stranded natural gas sources, and regional electricity mixes in California and New England, which are two potential markets for power generation from natural-gas-based liquid fuels. The potential market for power from remotely produced methanol and GTL will be for use in modern power plants using gas turbines.

\section{E.2 ASSUMPTIONS FOR POWER GENERATION FROM GTL FUELS}

It is assumed that GTL fuels and methanol will be fired in gas turbines. While there has been little commercial experience operating gas turbines with these liquid fuels, there are studies and information from turbine manufactures that can be used to develop operating condition data, including efficiencies and emissions rates. Gas turbines are commercially operated using petroleum distillate fuels.

Gas turbines consist of an air compressor, a fuel combustor, and a gas expander. Compressed air and the fuel (natural gas, petroleum distillate, or methanol) are injected into the combustor, where the fuel is burned to produce heat, $\mathrm{CO}_{2}$, and $\mathrm{H}_{2} \mathrm{O}$. The combustion products leave the combustor at about $2,000^{\circ} \mathrm{F}-2,500^{\circ} \mathrm{F}$ (depending on the gas turbine type) and are directed toward the turbine expander. As the combustion products expand, a part of their heat content is converted to power and the remaining heat is discharged with the exhaust gas.

Simple-cycle power plants do not recover exhaust gas heat. A simple-cycle plant can be started up and shut down in a short period of time, and thus is typically operated during peak demand hours. A combined-cycle power plant recovers exhaust gas in a heat recovery and steam generator (HRSG) system. The steam raised in the HRSG of the combined-cycle power plant is expanded in a steam turbine to produce additional power. Because of the HRSG and steam turbine, a combined-cycle plant requires more initial capital investment than a simple-cycle plant for a given gas turbine. The combined-cycle plant is, however, more energy-efficient. Since a combined-cycle plant takes several hours to start up and shut down, it is operated in the base load mode, competing with base load generation from coal. A combined-cycle power plant operates steadily under optimum conditions.

Because combined-cycle power plants are more energy-efficient, the emission rates per million Btu of the fuel fired is lower. In the UCF LCA, it was assumed that the methanol/GTL and natural gas power plants are of the combined-cycle type and operate in the base load mode.

GREET does not model power production from methanol and GTL. Section E.3 describes the data development for GTL to power, and Section E. 4 describes the data development for methanol to power. Only a few studies have tested these fuels in gas turbines, and data from these studies is combined with estimates based on fuel properties to estimate emissions factors. 
The power generation efficiency for methanol and GTL in a combined-cycle power plant is assumed to be $55 \%$, the same generation efficiency as for combined-cycle natural gas.

\section{E.3 GTL TO POWER}

\section{E.3.1 Overview}

Most power plant gas turbines in the United States are fueled by natural gas as a primary fuel and by petroleum distillates (fuel oils) as backup fuels. FT liquids (diesel and naphtha) are currently not used as a fuel for commercial gas turbines, and few tests of FT liquids in turbines have been carried out. Therefore, emissions data from the actual operation of FT-liquid-fired power plants does not exist, and emissions data for FT liquids has been extrapolated from petroleum distillate data.

\section{E.3.2 Data and Assumptions}

The fuel production stage for GTL includes extraction of natural gas, gas processing, fuel production, and ocean transport from remote natural gas sites. The power generation stage includes the combustion of GTL fuels in a combined cycle turbine.

\section{E.3.2.1 Combined-Cycle Efficiency}

Published data of gas turbine manufacturers shows that combined-cycle plants fired by distillates have an LHV efficiency that is 2 percentage points lower than those fired by natural gas. GREET assumes an LHV efficiency of a natural-gas-fired combined cycle at $55 \%$. Thus, the LHV efficiency for FT liquids in a combined-cycle power plant is assumed to be $53 \%$. This lower efficiency is due to the lower firing temperature for distillate fuels.

\section{E.3.2.2 GTL Composition}

It was assumed that the GTL fuel composition was 70\% FTD and 30\% FT naphtha.

\section{E.3.2.3 $\quad \mathrm{CO}_{2}$}

An LHV efficiency of 53\% was assumed in determining heat and material balances for a power plant fired with FTD (with the assumed chemical formula $\mathrm{C}_{16} \mathrm{H}_{34}$ ) and heat and material balances for a plant fired with FT naphtha (with the assumed chemical formula $\mathrm{C}_{7} \mathrm{H}_{16}$ ). From the material balance flue gas containing $15 \% \mathrm{O}_{2}$ (dry basis), $\mathrm{CO}_{2}$ emissions were calculated by performing a carbon balance. The calculation showed that the $\mathrm{CO}_{2}$ emissions were 496 and $487 \mathrm{~g} / \mathrm{kWh}$ for the FTD-fired plant and the FT-naphtha-fired plant, respectively. Assuming a composition of FT liquids as $70 \%$ diesel and 30\% naphtha, the combined $\mathrm{CO}_{2}$ emission is $494 \mathrm{~g} / \mathrm{kWh}$.

\section{E.3.2.4 NOX}

$\mathrm{NO}_{\mathrm{X}}$ is produced in two ways: from fuel-bound nitrogen, and from combustion. Thermal $\mathrm{NO}_{\mathrm{X}}$, produced from combustion, is the major fraction of the total, and is controlled kinetically.

Therefore, it increases with increasing combustion air temperature, combustor temperature, and combustor residence time. All $\mathrm{NO}_{\mathrm{X}}$ control technologies control only thermal $\mathrm{NO}_{\mathrm{X}}$ formation. 
Older $\mathrm{NO}_{\mathrm{X}}$ control systems inject steam or water into the gas turbine combustor. The steam or water injection lowers the combustion temperature and thus reduces the thermal $\mathrm{NO}_{\mathrm{X}}$ formation. This is still the most commonly used technology. However, the steam injection removes steam from the steam turbine, thus reducing power generation. Also, the lower combustor temperature reduces combustion efficiency, which in turn increases $\mathrm{CO}$ formation.

Because of the decrease in power generation and increase in $\mathrm{CO}$ formation caused by steam/water injection, combustors have been developed that do not require steam injection. In these combustors, called staging combustors, one part of the combustor handles the fuel-rich fuel/air mixture and the other part handles the oxygen-rich mixture. These combustors reduce thermal $\mathrm{NO}_{\mathrm{X}}$ formation and are being used in newer power plants.

Since FT liquids do not contain nitrogen, fuel-bound $\mathrm{NO}_{\mathrm{X}}$ is not produced, and since the GTL is assumed to be fired in newer power plants, thermal $\mathrm{NO}_{\mathrm{X}}$ is controlled by staging combustors. With 25 ppm $\mathrm{NO}_{\mathrm{X}}$ taken to be the required limit, $\mathrm{NO}_{\mathrm{X}}$ formation was calculated from the material balance of the FTD- and FT-naphtha-fired power plants. The calculation indicated that the $\mathrm{NO}_{\mathrm{X}}$ emissions were $0.307 \mathrm{~g} / \mathrm{kWh}$ for the GTL-fired plant.

\section{E.3.2.5 SOX}

Since FTD and FT naphtha do not contain sulfur, the $\mathrm{SO}_{\mathrm{X}}$ emission rate for GTL is zero.

\section{E.3.2.6 $\quad \mathrm{N}_{2} \mathrm{O}$}

Data for $\mathrm{N}_{2} \mathrm{O}$ is given in a General Electric study (Pavri and Moore, 2001) for distillate fuel oil, with a value of $0.006 \mathrm{~g} / \mathrm{kWh}$. The GREET default for distillate oil, however, is $0.0035 \mathrm{~g} / \mathrm{kWh}$, and that estimate was chosen instead for consistency.

\section{E.3.2.7 Particulates}

Unlike the petroleum-derived fuel oils that contain 20 to 70 carbon atoms per molecule, FTD contains 12 to 20 carbon atoms per molecule, and FT naphtha 5 to 9 carbon atoms per molecule. Furthermore, unlike the fuel oils, FTD and FT naphtha do not contain aromatics, and, as a result, FT liquids will produce less particulate matter; however, it is difficult to quantify this decrease. Therefore the particulate matter for the FT liquids is assumed to be the same as that for distillate fuel oil. According to the USEA/USAID Mitigation Options Handbook (USEA/USAID), the particulate emissions for distillate vary from 0.01 to $0.03 \mathrm{~g} / \mathrm{kWh}$. Because FT liquids are expected to generate less particulate matter, the lower range value of $0.01 \mathrm{~g} / \mathrm{kWh}$ was chosen.

\section{E.3.2.8 CO}

Data for CO is taken from the paper by General Electric (Paavri and Moore, 2001) for distillate fuel oil. CO emissions are set at $0.037 \mathrm{~g} / \mathrm{kWh}$. 


\section{E.3.2.9 VOC}

According to the USEA/USAID Mitigation Options Handbook (USEA/USAID 1999), VOC emission varies from 0.03 to $0.07 \mathrm{~g} / \mathrm{kWh}$, or an average value of $0.05 \mathrm{~g} / \mathrm{kWh}$ for petroleum distillate.

GREET 1.6 uses an emission rate of $0.024 \mathrm{~g} / \mathrm{kWh}$, and the same value was chosen for FT liquids for consistency.

The above emission rates for power generation from FT liquids are summarized in Table E-1.

Table E-1 GTL-Fired Combined-Cycle Gas Turbine Emissions Factors

\begin{tabular}{|l|c|c|}
\hline \multicolumn{1}{|c|}{ Emission } & g/kWh & Data Source \\
\hline $\mathrm{SO}_{\mathrm{X}}$ & 0 & Calculated \\
\hline $\mathrm{N}_{2} \mathrm{O}$ & 0.0035 & General Electric \\
\hline $\mathrm{CO}_{2}$ & 494 & Calculated \\
\hline $\mathrm{VOC}$ & 0.024 & GREET \\
\hline $\mathrm{CO}$ & 0.037 & Calculated \\
\hline $\mathrm{NO}_{\mathrm{X}}$ & 0.307 & Calculated \\
\hline $\mathrm{PM} 10$ & 0.01 & USEA/USAID \\
\hline
\end{tabular}

\section{E.4 METHANOL TO POWER}

\section{E.4.1 Data and Assumptions}

Methanol is currently not used as a fuel for commercial gas turbines, and emissions data from the actual operation of methanol-fired power plants does not exist. However, several tests have been performed in which the power generation rates and emissions production rates from methanolfired gas turbines have been determined. The emissions given in this section are from such tests and studies.

The fuel production stage for methanol includes extraction of natural gas, gas processing, fuel production, and ocean transport from remote natural gas sites. The power generation stage includes the combustion of methanol in a combined cycle turbine.

\section{E.4.1.1 $\quad \mathrm{CO}_{2}$}

The paper by Hemmings and Todd (Hemmings and Todd, 2001) describes the results of a study, performed by Foster-Wheeler and General Electric, in which a conceptual $400 \mathrm{MW}$ combinedcycle power plant is fired with either liquid methanol or vaporized methanol. Methanol is supplied to a 109FA GE gas turbine. Steam produced in the combined cycle is injected into the turbine combustor to control the $\mathrm{NO}_{\mathrm{X}}$ emissions at $25 \mathrm{ppm}$. From the data given, Nexant developed heat and material balances for the liquid-methanol-fired plant and the vapormethanol-fired plant. From the heat and material balances of the two plants, the $\mathrm{CO}_{2}$ emission rate was calculated to be $448 \mathrm{~g} / \mathrm{kWh}$. 


\section{E.4.1.2 NOx}

From the heat and material balances for the $\mathrm{CO}_{2}$ emission calculation, $\mathrm{NO}_{\mathrm{X}}$ emission rates were calculated to be $0.273 \mathrm{~g} / \mathrm{kWh}$ (based on $25 \mathrm{ppm} \mathrm{NO}$ ). However, because $\mathrm{NO}_{\mathrm{X}}$ emissions should not be significantly different from those for natural gas (even though the firing temperature for methanol is lower), the slightly greater GREET $\mathrm{NO}_{\mathrm{X}}$ emission factor of $0.307 \mathrm{~g} / \mathrm{kWh}$ for natural gas is used for methanol. This emission factor should be a worst case for methanol $\mathrm{NO}_{\mathrm{X}}$ emissions.

\section{E.4.1.3 SOx}

Because methanol does not contain sulfur, the $\mathrm{SO}_{\mathrm{X}}$ emission rate is zero.

\section{E.4.1.4 $\quad \mathrm{N}_{2} \mathrm{O}$}

Data for $\mathrm{N}_{2} \mathrm{O}$ is taken from the paper by Pavri and Moore (Pavri and Moore, 2001).

\section{E.4.1.5 Particulates, CO, and VOC}

The paper by Hemmings and Todd does not include emissions for particulates, CO, or VOC. For these emissions, Nexant contacted gas turbine manufacturers, including Foster Wheeler and General Electric. Foster Wheeler and GE supplied a copy of a GE study (General Electric, 2001). On the basis of this study, Nexant determined these emissions as described below.

\section{Particulates}

The principal components of particulates are smoke, ash, ambient non-combustibles, and erosion and corrosion products. Smoke is the visible portion of filterable particulate material. Because methanol is not as rich in carbon as the petroleum distillates, the particulate emission rate is expected to be lower than the petroleum distillates emission rate. GE (General Electric, 2001) refers to an EPRI report (EPRI, 1981) that states, "there was a significant reduction in particulate emission during methanol operation," but gives no data. The EPRI report referred to by GE describes tests conducted during 1978 and 1979 under the sponsorship of Southern California Edison Company. In these tests, methanol was fired into a $26 \mathrm{MW}$ gas turbine for a total of 523 hours. According to the paper (Pavri and Moore, 2001), particulate emissions from gas turbines fueled by conventional fuels vary between trace levels and $25 \mathrm{ppm}$. Because of the low sulfur levels and firing temperatures, particulate emissions for methanol and natural gas should not differ significantly; hence, the GREET particulate emission value for the natural-gas-fired combined-cycle plant of $0.02 \mathrm{~g} / \mathrm{kWh}$ is used.

CO

Since methanol has a lower flame temperature than natural gas and petroleum distillates, the $\mathrm{CO}$ emission rate should be somewhat higher. However, tests in 1974 demonstrated that the CO emissions were comparable with distillate emissions (General Electric, 2001). According to Pavri (Pavri and Moore, 2001), CO emissions from a conventional GE gas turbine combustion system are less than $10 \mathrm{ppm}$ at steady-state operation. The article also presents typical CO emissions from a MS7001EA turbine fired with natural gas and with distillate. According to the article, for a firing temperature greater than $1,500^{\circ} \mathrm{F}$, the emissions from the two fuels are the 
same at about $5 \mathrm{ppm}(0.033 \mathrm{~g} / \mathrm{kWh})$. To establish a comparable baseline with GREET, the GREET CO emission value for the natural-gas-fired combined-cycle plant of $0.047 \mathrm{~g} / \mathrm{kWh}$ is used for methanol as well.

VOC

Unburned hydrocarbons, like CO, are associated with combustion inefficiency. When plotted against firing temperature, the emissions from heavy-duty gas turbine combustors show the same type of hyperbolic curve as for CO. Unfortunately, no studies have reported VOC emission rates. Pavri (Pavri and Moore, 2001) gives emission rates of unburned hydrocarbons as less than 7 ppmw (parts per million by volume wet), or $0.030 \mathrm{~g} / \mathrm{kWh}$. However, the VOC emissions rate for methanol in a gas turbine should be very similar to that for natural gas; therefore the GREET emission value of $0.0065 \mathrm{~g} / \mathrm{kWh}$ is used.

\section{E.4.1.6 Summary}

The above emission rates for power generation from methanol are summarized in Table E- 2 .

Table E-2 Methanol-Fired Combined-Cycle Gas Turbine Emissions Factors

\begin{tabular}{|l|c|c|}
\hline \multicolumn{1}{|c|}{ Emission } & $\mathrm{g} / \mathrm{kWh}$ & Data Source \\
\hline $\mathrm{SO}$ & 0 & Calculated \\
\hline $\mathrm{N}_{2} \mathrm{O}$ & 0.005 & General Electric \\
\hline $\mathrm{CO}_{2}$ & 448 & Calculated \\
\hline $\mathrm{VOC}$ & 0.0065 & GREET \\
\hline $\mathrm{CO}$ & 0.047 & GREET \\
\hline $\mathrm{NO}_{\mathrm{X}}$ & 0.307 & GREET \\
\hline PM10 & 0.02 & GREET \\
\hline
\end{tabular}

\section{E.5 OTHER POWER GENERATION OPTIONS}

Data and results for other power generation options were taken directly from GREET 1.6 for coal, natural gas, liquefied natural gas, and regional power generation mixes for New England and California. These options were also validated against studies in the literature, including a series of studies from the National Renewable Energy Laboratory (Spath et al., 1997, 1999, 2000, 2001). GREET also includes inventory data from fuel extraction, production, and transportation, along with end-use power generation, so that the results represent the full fuel-life cycle for the power generation options.

\section{E.5.1 Coal}

GREET uses an efficiency of 35\% for power generation from coal, and emission factors based on an average U.S. coal composition of $10,275 \mathrm{Btu} / \mathrm{lb}$ (HHV), 1.1\% sulfur, and $9.36 \%$ ash. The inventory results for coal generation in GREET includes emissions of methane from coal mining for the average coal mined in the United States, along with all other energy inputs into coal mining, cleaning, and transportation. These are included in the fuel production stage for coal. Table E-3 shows the life cycle GREET emissions factors for coal-based power generation. 


\section{Table E-3 Coal-Fired Power Plant Emissions Factors} (Btu/kWh or $\mathrm{g} / \mathrm{kWh}$ )

\begin{tabular}{|l|c|c|c|}
\multicolumn{1}{|c|}{ Parameter } & Fuel & Power Generation & Total \\
\hline Total energy & 197 & 9,812 & 10,010 \\
\hline GWP & 41 & 959 & 1,000 \\
\hline VOC & 0.076 & 0.011 & 0.087 \\
\hline $\mathrm{CO}$ & 0.035 & 0.094 & 0.129 \\
\hline $\mathrm{NO}_{\mathrm{X}}$ & 0.206 & 1.265 & 1.470 \\
\hline $\mathrm{PM} 10$ & 0.044 & 0.124 & 0.169 \\
\hline $\mathrm{SO}_{\mathrm{X}}$ & 0.071 & 3.040 & 3.111 \\
\hline
\end{tabular}

\section{E.5.2 Natural Gas}

For power from natural gas, GREET has categories for both simple-cycle and combined-cycle plants. Combined-cycle efficiencies are assumed for natural gas generation. Emissions factors from GREET are shown in Table E-4.

The fuel production stage for domestic natural gas includes extraction, processing and pipeline transport and distribution to the plant.

\section{Table E-4 Natural-Gas-Fired Combined-Cycle Gas Turbine Emissions Factors} (Btu/kWh or $\mathrm{g} / \mathrm{kWh}$ )

\begin{tabular}{|l|c|c|c|}
\hline \multicolumn{1}{|c|}{ Parameter } & Fuel & Power Generation & Total \\
\hline Total energy & 383 & 6,209 & 6,592 \\
\hline GWP & 50 & 376 & 426 \\
\hline VOC & 0.004 & 0.007 & 0.010 \\
\hline $\mathrm{CO}$ & 0.039 & 0.047 & 0.085 \\
\hline $\mathrm{NO}_{\mathrm{X}}$ & 0.067 & 0.307 & 0.374 \\
\hline $\mathrm{PM}_{10}$ & 0.002 & 0.020 & 0.022 \\
\hline $\mathrm{SO}_{\mathrm{X}}$ & 0.019 & 0.002 & 0.021 \\
\hline
\end{tabular}

\section{E.5.3 Liquefied Natural Gas}

Power generation efficiency and emissions for liquefied natural gas are assumed to be the same as for natural gas. It is assumed that LNG is produced from remote sources of natural gas, and upstream emissions reflect transport via ocean tanker to the United States over a distance of 5,000 miles, the same distance used for remote GTL and methanol. GREET assumes a 90.3\% production efficiency in the liquefaction of natural gas. Table E-5 shows the GREET parameters for LNG-fired power generation. 


\section{Table E-5 LNG-Fired Combined-Cycle Gas Turbine Emissions Factors} (Remote Gas) (Btu/kWh or g/kWh)

\begin{tabular}{|l|c|c|c|}
\multicolumn{1}{|c|}{ Parameter } & Fuel & Power Generation & Total \\
\hline Total energy & 1,270 & 6,209 & 7,479 \\
\hline GWP & 115 & 376 & 491 \\
\hline VOC & 0.014 & 0.007 & 0.020 \\
\hline $\mathrm{CO}$ & 0.067 & 0.047 & 0.113 \\
\hline $\mathrm{NO}$ & 0.334 & 0.307 & 0.641 \\
\hline PM10 & 0.008 & 0.020 & 0.029 \\
\hline $\mathrm{SO}_{\mathrm{X}}$ & 0.042 & 0.002 & 0.044 \\
\hline
\end{tabular}

\section{E.5.4 Regional Electricity Baselines}

GREET uses 1997 data from the Energy Information Agency (EIA, 2001) to model U.S. average, New England, and California power generation mixes. Tables E-6 and E-7 show the relative shares of generation types and emissions for each region. All power options, including the regional electricity mixes, include full fuel-cycle inventories of energy and emissions. For natural gas-powered plants, GREET assumes an equal share of simple-cycle plants, at 35\% efficiency, and combined-cycle plants, at 55\% efficiency.

Table E-6 Regional Electricity Generation Mixes

\begin{tabular}{|l|c|c|c|}
\multicolumn{1}{|c|}{ Type of Plant } & U.S. Mix & New England Mix & California Mix \\
\hline Residual-oil-fired power plants & $1.0 \%$ & $2.5 \%$ & $0.0 \%$ \\
\hline Natural-gas-fired power plants & $14.9 \%$ & $31.6 \%$ & $32.9 \%$ \\
\hline Coal-fired power plants & $53.8 \%$ & $28.2 \%$ & $21.3 \%$ \\
\hline Nuclear power plants & $18.0 \%$ & $26.3 \%$ & $14.7 \%$ \\
\hline Other power plants (hydro, wind, etc.) & $12.3 \%$ & $11.4 \%$ & $31.1 \%$ \\
\hline
\end{tabular}

Table E-7 Regional Electricity Generation Emissions Factors (Btu/kWh or g/kWh)

\begin{tabular}{|l|c|c|c|c|c|c|c|c|c|}
\hline & \multicolumn{3}{|c|}{ U.S. Mix } & \multicolumn{3}{c|}{ New England Mix } & \multicolumn{3}{c|}{ California Mix } \\
\hline Parameter & Fuel & Power Gen & Total & Fuel & Power Gen & Total & Fuel & Power Gen & Total \\
\hline Total energy & 232 & 7,336 & 7,568 & 273 & 6,260 & 6,533 & 203 & 5,697 & 5,899 \\
\hline GWP & 35 & 580 & 615 & 35 & 409 & 444 & 27 & 328 & 355 \\
\hline VOC & 0.042 & 0.007 & 0.050 & 0.025 & 0.006 & 0.030 & 0.018 & 0.005 & 0.022 \\
\hline $\mathrm{CO}$ & 0.026 & 0.059 & 0.086 & 0.026 & 0.045 & 0.071 & 0.021 & 0.035 & 0.056 \\
\hline $\mathrm{NO}_{\mathrm{X}}$ & 0.131 & 0.735 & 0.866 & 0.094 & 0.475 & 0.569 & 0.068 & 0.370 & 0.438 \\
\hline PM10 & 0.025 & 0.070 & 0.096 & 0.014 & 0.043 & 0.057 & 0.010 & 0.033 & 0.044 \\
\hline $\mathrm{SO}_{\mathrm{X}}$ & 0.055 & 1.643 & 1.698 & 0.038 & 0.874 & 0.912 & 0.025 & 0.648 & 0.673 \\
\hline
\end{tabular}




\section{E.6 GTL AND METHANOL COMPARISONS WITH OTHER POWER OPTIONS}

The comparative results for GTL and methanol with the power baselines are presented in Sections E.6.1 and E.6.2. Figures E-1 through E-5 in Section E.6.3 summarize all results.

\section{E.6.1 GTL}

The power generation stage for GTL compares very favorably with all other forms of power generation. Because GTL is sulfur-free, $\mathrm{SO}_{\mathrm{X}}$ emissions are below those of all other power options. GTL is lower in every emission category than the U.S. national average (more than $50 \%$ of which is coal generation) except for VOC emissions. GTL VOC emissions are assumed to be the same as for distillate oil. GTL also compares favorably with the New England and California mixes for criteria emissions. $\mathrm{CO}_{2}$ emissions and GWP for GTL, however, are higher than these options, which are made up of a significant share of renewable and nuclear power.

Table E- 8 shows only the emissions for the power generation stage. Tables E-9 and E-10 show the total fuel cycle inventory for GTL compared with other options. The 2006 and 2015 cases differ from one another only by the process efficiency for the production of GTL.

Figures E-1 through E-5 show the total life cycle energy, GWP, and criteria emissions inventories for all power pathways.

Table E-8 shows that total fuel cycle GWP for GTL is lower than for coal and distillate oil. For 2015 , GTL is $37 \%$ and $31 \%$ lower in GWP than coal and oil, respectively. Compared with the U.S. average generating mix, GTL is $2 \%$ greater in GWP.

Criteria pollutant emissions from the power generation stage for GTL (Table E-8) are significantly lower than for coal, and GTL emissions for $\mathrm{NO}_{\mathrm{X}}, \mathrm{SO}_{\mathrm{X}}$, and PM10 are equivalent to or lower than for the other power options. The exception is for VOC emissions, which are assumed to be the same as distillate fuel oil.

Emissions from upstream fuel production stages for GTL, including natural gas extraction, fuel production, and ocean transport from remote sites are a significant part of the full fuel cycle criteria emissions inventories. However these criteria emissions occur in non-urban areas, such as at the remote production site or during ocean tanker transport. From a life cycle impact standpoint, non-urban emissions of criteria pollutants would be potentially of less significance than urban emissions. 
Table E-8 GTL vs. Power Options, Comparison of Power Generation Emissions, 2006/2015 (Btu/kWh or $\mathrm{g} / \mathrm{kWh}$ )

\begin{tabular}{|l|c|c|c|c|c|c|c|c|}
\hline & & \multicolumn{6}{|c|}{ Compared with Power Generation Only } \\
\cline { 2 - 10 } & Power Generation & U.S. Mix & N.E. Mix & CA Mix & Coal & $\begin{array}{c}\text { Natural } \\
\text { Gas }\end{array}$ & LNG & Oil \\
\hline Total energy & 6,443 & $-12 \%$ & $3 \%$ & $13 \%$ & $-34 \%$ & $4 \%$ & $4 \%$ & $-34 \%$ \\
\hline GWP & 496 & $-15 \%$ & $21 \%$ & $51 \%$ & $-48 \%$ & $32 \%$ & $32 \%$ & $-39 \%$ \\
\hline VOC & 0.024 & $231 \%$ & $312 \%$ & $430 \%$ & $114 \%$ & $268 \%$ & $268 \%$ & $0 \%$ \\
\hline CO & 0.037 & $-38 \%$ & $-18 \%$ & $4 \%$ & $-61 \%$ & $-21 \%$ & $-21 \%$ & $-77 \%$ \\
\hline NO $_{\mathrm{X}}$ & 0.307 & $-58 \%$ & $-35 \%$ & $-17 \%$ & $-76 \%$ & $0 \%$ & $0 \%$ & $-64 \%$ \\
\hline PM10 & 0.010 & $-86 \%$ & $-77 \%$ & $-70 \%$ & $-92 \%$ & $-51 \%$ & $-51 \%$ & $-83 \%$ \\
\hline SO $_{\mathrm{X}}$ & 0.000 & $-100 \%$ & $-100 \%$ & $-100 \%$ & $-100 \%$ & $-100 \%$ & $-100 \%$ & $-100 \%$ \\
\hline
\end{tabular}

Table E-9 GTL vs. Power Options, Comparison of Full Fuel Cycle Emissions, 2006 (Btu/kWh or $\mathrm{g} / \mathrm{kWh})$

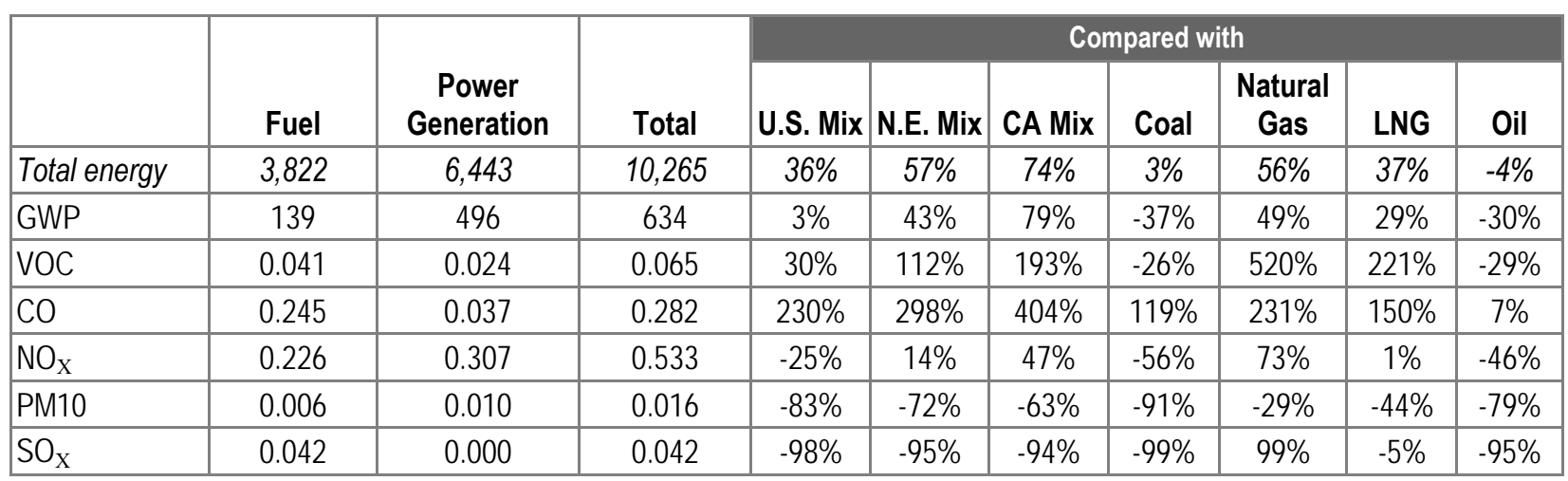

Table E-10 GTL vs. Power Options, Comparison of Full Fuel Cycle Emissions, 2015 (Btu/kWh or $\mathrm{g} / \mathrm{kWh})$

\begin{tabular}{|c|c|c|c|c|c|c|c|c|c|c|}
\hline & \multirow[b]{2}{*}{ Fuel } & \multirow[b]{2}{*}{$\begin{array}{l}\text { Power } \\
\text { Generation }\end{array}$} & \multirow[b]{2}{*}{ Total } & \multicolumn{7}{|c|}{ Compared with } \\
\hline & & & & U.S. Mix & N.E. Mix & CA Mix & Coal & $\begin{array}{l}\text { Natural } \\
\text { Gas }\end{array}$ & LNG & Oil \\
\hline Total energy & 3,387 & 6,443 & 9,830 & $30 \%$ & $50 \%$ & $67 \%$ & $-2 \%$ & $49 \%$ & $31 \%$ & $-9 \%$ \\
\hline GWP & 135 & 496 & 631 & $2 \%$ & $42 \%$ & $78 \%$ & $-37 \%$ & $48 \%$ & $28 \%$ & $-31 \%$ \\
\hline VOC & 0.041 & 0.024 & 0.065 & $30 \%$ & $112 \%$ & $193 \%$ & $-26 \%$ & $520 \%$ & $221 \%$ & $-29 \%$ \\
\hline $\mathrm{CO}$ & 0.242 & 0.037 & 0.279 & $226 \%$ & $294 \%$ & $399 \%$ & $116 \%$ & $227 \%$ & $147 \%$ & $7 \%$ \\
\hline $\mathrm{NO}_{\mathrm{X}}$ & 0.220 & 0.307 & 0.527 & $-26 \%$ & $13 \%$ & $46 \%$ & $-56 \%$ & $72 \%$ & $0 \%$ & $-44 \%$ \\
\hline PM10 & 0.006 & 0.010 & 0.016 & $-83 \%$ & $-72 \%$ & $-63 \%$ & $-91 \%$ & $-29 \%$ & $-44 \%$ & $-79 \%$ \\
\hline $\mathrm{SO}_{\mathrm{X}}$ & 0.040 & 0.000 & 0.040 & $-98 \%$ & $-96 \%$ & $-94 \%$ & $-99 \%$ & $91 \%$ & $-9 \%$ & $-93 \%$ \\
\hline
\end{tabular}




\section{E.6.2 Methanol}

The power generation stage for methanol compares very favorably with all other forms of power generation. Because methanol is sulfur-free, $\mathrm{SO}_{\mathrm{X}}$ emissions are below those of all other power baselines. Methanol is lower in every emission category than the U.S. national average and also compares favorably with the New England and California mixes, even with the significant shares of nuclear and renewable energy in these regions.

For the criteria pollutant emissions inventory for the power generation stage, methanol is effectively equivalent to natural gas. Both methanol (with zero $\mathrm{SO}_{\mathrm{X}}$ emissions) and natural gas (with a very low level of $\mathrm{SO}_{\mathrm{X}}$ emissions) are significantly below regulatory requirements for $\mathrm{SO}_{\mathrm{X}}$. Since natural gas has a higher equivalent heating value than methanol, methanol to power generates about $20 \%$ more $\mathrm{CO}_{2}$ per $\mathrm{kWh}$ than natural gas.

Tables E-11, E-12, and E-13 show percentage differences for methanol relative individually to each of the other power options. (It should be noted that a $100 \%$ reduction of $\mathrm{SO}_{\mathrm{X}}$ relative to coal and a $100 \%$ reduction relative to natural gas are not the same reductions in absolute terms.) Methanol emits zero $\mathrm{SO}_{\mathrm{X}}$, coal emits $3.04 \mathrm{~g} / \mathrm{kWh}$ of $\mathrm{SO}_{\mathrm{X}}$, and natural gas emits $0.002 \mathrm{~g} / \mathrm{kWh}$. (See Table E-11 and Figures E-1, E-2, E-3, and E-5 for absolute differences in emissions between methanol and the other options.)

Table E-11 shows the power generation stage inventories for methanol compared with the other power options. Tables E-12 and E-13 show the 2006 and 2015 total fuel cycle inventory for methanol compared with the other options. The 2006 and 2015 cases for methanol differ by the production efficiency for methanol-2006 uses $68 \%$ and 2015 uses $71 \%$.

Figures E-1 through E-5 show the total life cycle energy, GWP, and criteria emissions inventories for all power pathways.

GWP for methanol is 38\% and 41\% lower than for coal in 2006 and 2015, respectively. In 2006, GWP for methanol is between $26 \%$ higher than LNG and $74 \%$ higher than California electricity generation. In 2015, because of the improved methanol production efficiency, GWP for methanol is between $21 \%$ higher than LNG to $68 \%$ higher than California electricity generation.

The lower methanol conversion efficiency relative to the higher liquefaction efficiency for LNG is the primary upstream contributor to the difference between methanol and LNG, since LNG is also sourced from remote sites. Relative to domestic natural gas, ocean transport and fuel production are primary differentiating factors.

Criteria pollutant emissions from the power generation stage for methanol (Table E-11) are significantly lower than for coal, and methanol emissions for $\mathrm{NO}_{\mathrm{X}}, \mathrm{SO}_{\mathrm{X}}$, and PM10 are equivalent to or lower than for the other power baselines.

Criteria pollutant emissions from upstream fuel production stages for methanol, including natural gas extraction, methanol production, and ocean transport from remote sites are a significant part of the full fuel cycle criteria emissions inventories for methanol to power. For the criteria 
pollutant emissions for methanol of $\mathrm{VOC}, \mathrm{CO}, \mathrm{NO}_{\mathrm{X}}, \mathrm{PM} 10$, and $\mathrm{SO}_{\mathrm{X}}$, the percentage of fuel cycle emissions that come from the upstream fuel production stages are $91 \%, 72 \%, 61 \%, 43 \%$, and $100 \%$, respectively. However, these emissions occur in non-urban areas, such as at a remote production site or during ocean tanker transport. From a life cycle impact standpoint, non-urban emissions of criteria pollutants would be potentially of less significance than urban emissions.

The large percentage differences in life cycle emissions of $\mathrm{VOC}, \mathrm{CO}, \mathrm{NO}_{\mathrm{X}}$, and $\mathrm{SO}_{\mathrm{X}}$ between methanol and natural gas are relative to small values, since the fuel cycle emissions from domestically produced pipeline natural gas are relatively not large.

Table E-11 Methanol vs. Power Options, Comparisons of Power Generation Emissions, 2006/2015 (Btu/kWh or $\mathrm{g} / \mathrm{kWh}$ )

\begin{tabular}{|l|c|c|c|c|c|c|c|}
\hline & & & & \multicolumn{3}{|c|}{ Compared with } \\
\hline Total energy & Power Gen & U.S. Mix & N.E. Mix & CA Mix & Coal & Natural Gas & LNG \\
\hline GWP & 6,209 & $-15 \%$ & $-1 \%$ & $9 \%$ & $-37 \%$ & $0 \%$ & $0 \%$ \\
\hline VOC & 450 & $-22 \%$ & $10 \%$ & $37 \%$ & $-53 \%$ & $20 \%$ & $20 \%$ \\
\hline CO & 0.007 & $-10 \%$ & $12 \%$ & $44 \%$ & $-42 \%$ & $0 \%$ & $0 \%$ \\
\hline NO & 0.047 & $-21 \%$ & $4 \%$ & $33 \%$ & $-50 \%$ & $1 \%$ & $1 \%$ \\
\hline PM10 & 0.307 & $-58 \%$ & $-35 \%$ & $-17 \%$ & $-76 \%$ & $0 \%$ & $0 \%$ \\
\hline SO $_{\mathrm{X}}$ & 0.02 & $-72 \%$ & $-53 \%$ & $-40 \%$ & $-84 \%$ & $-2 \%$ & $-2 \%$ \\
\hline
\end{tabular}

Table E-12 Methanol vs. Power Options, Comparisons of Full Fuel Cycle Emissions, 2006 (Btu/kWh or $\mathrm{g} / \mathrm{kWh}$ )

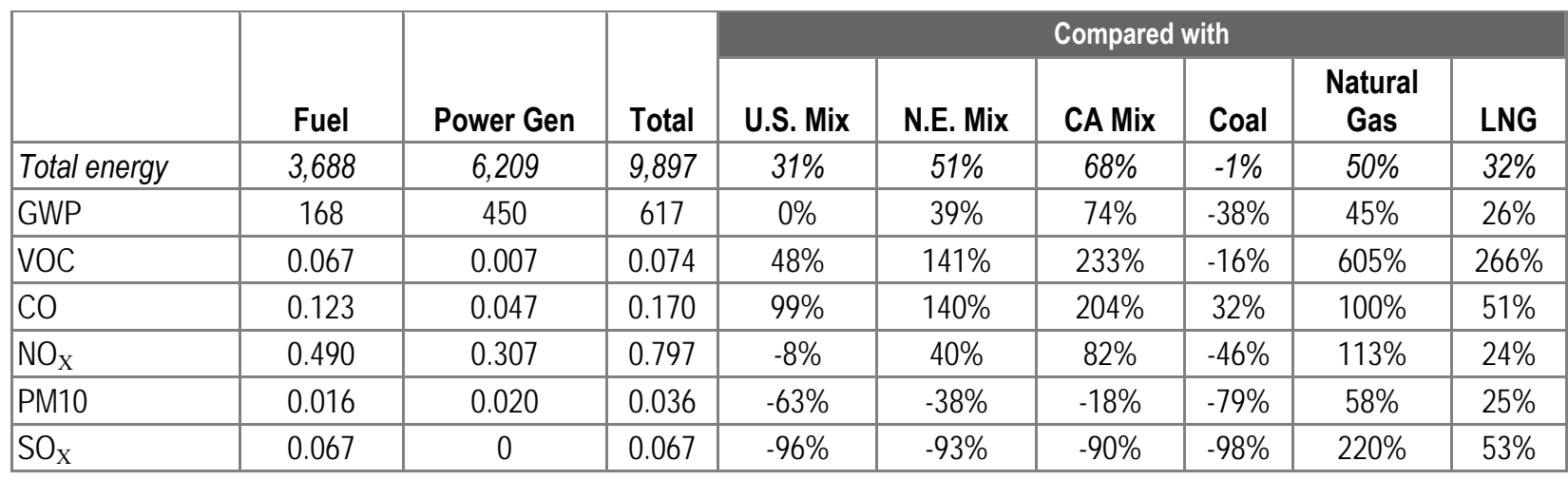


Table E-13 Methanol vs. Power Options, Comparison of Full Fuel Cycle Emissions, 2015 (Btu/kWh or $\mathrm{g} / \mathrm{kWh}$ )

\begin{tabular}{|c|c|c|c|c|c|c|c|c|c|}
\hline & \multirow[b]{2}{*}{ Fuel } & \multirow[b]{2}{*}{$\begin{array}{c}\text { Power } \\
\text { Generation }\end{array}$} & \multirow[b]{2}{*}{ Total } & \multicolumn{6}{|c|}{ Compared with } \\
\hline & & & & U.S. Mix & N.E. Mix & CA Mix & Coal & $\begin{array}{c}\text { Natural } \\
\text { Gas }\end{array}$ & LNG \\
\hline Total energy & 3,286 & 6,209 & 9,494 & $25 \%$ & $45 \%$ & $61 \%$ & $-5 \%$ & $44 \%$ & $27 \%$ \\
\hline GWP & 145 & 450 & 595 & $-3 \%$ & $34 \%$ & $68 \%$ & $-41 \%$ & $40 \%$ & $21 \%$ \\
\hline VOC & 0.067 & 0.007 & 0.073 & $48 \%$ & $141 \%$ & $233 \%$ & $-16 \%$ & $605 \%$ & $265 \%$ \\
\hline $\mathrm{CO}$ & 0.118 & 0.047 & 0.165 & $93 \%$ & $133 \%$ & $195 \%$ & $28 \%$ & $94 \%$ & $46 \%$ \\
\hline $\mathrm{NO}_{\mathrm{X}}$ & 0.478 & 0.307 & 0.785 & $-9 \%$ & $38 \%$ & $79 \%$ & $-47 \%$ & $110 \%$ & $22 \%$ \\
\hline PM10 & 0.016 & 0.020 & 0.036 & $-63 \%$ & $-38 \%$ & $-18 \%$ & $-79 \%$ & $59 \%$ & $25 \%$ \\
\hline $\mathrm{SO}_{\mathrm{X}}$ & 0.067 & 0 & 0.067 & $-96 \%$ & $-93 \%$ & $-90 \%$ & $-98 \%$ & $220 \%$ & $53 \%$ \\
\hline
\end{tabular}

\section{E.6.3 Summary of Power Pathway Results}

Figures E-1 through E-5 present a graphical summary of the results for all power pathways.

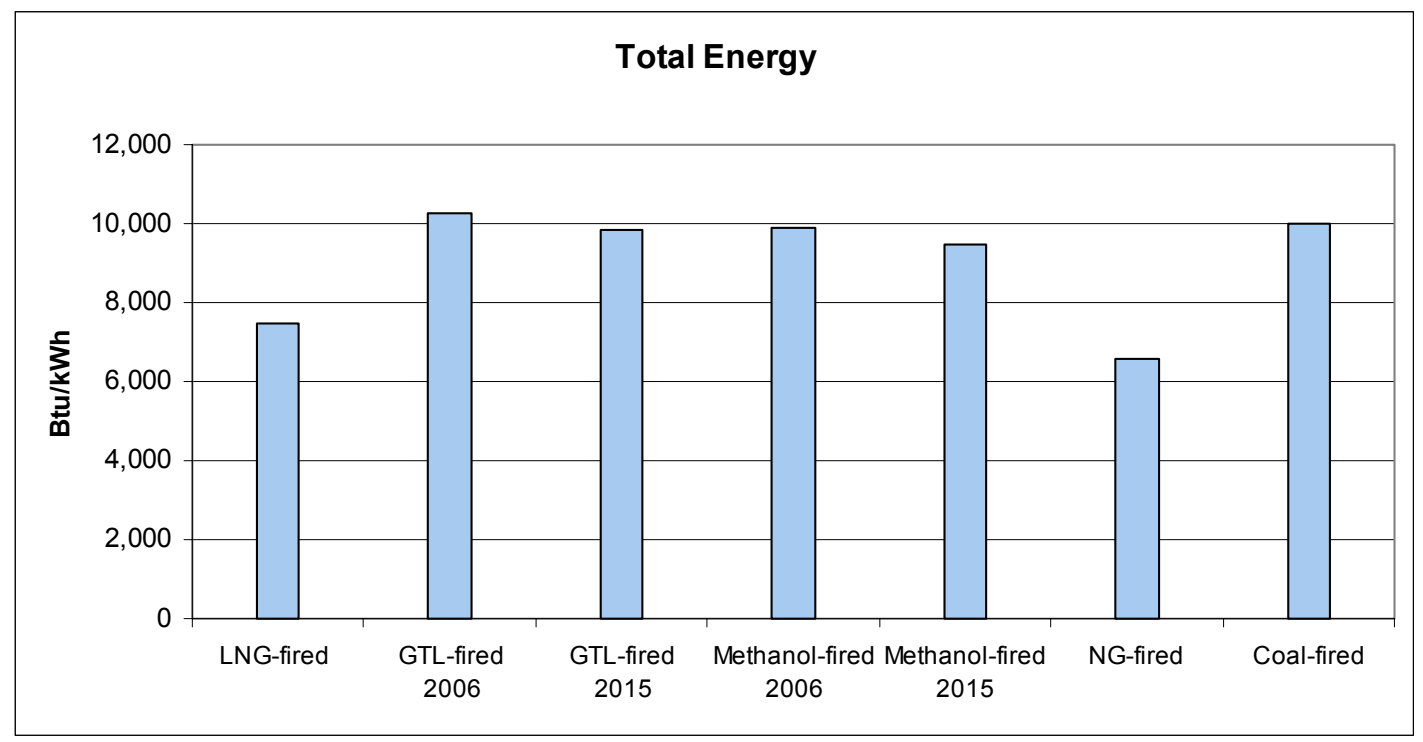

Figure E-1 Total Energy (Btu/kWh) 


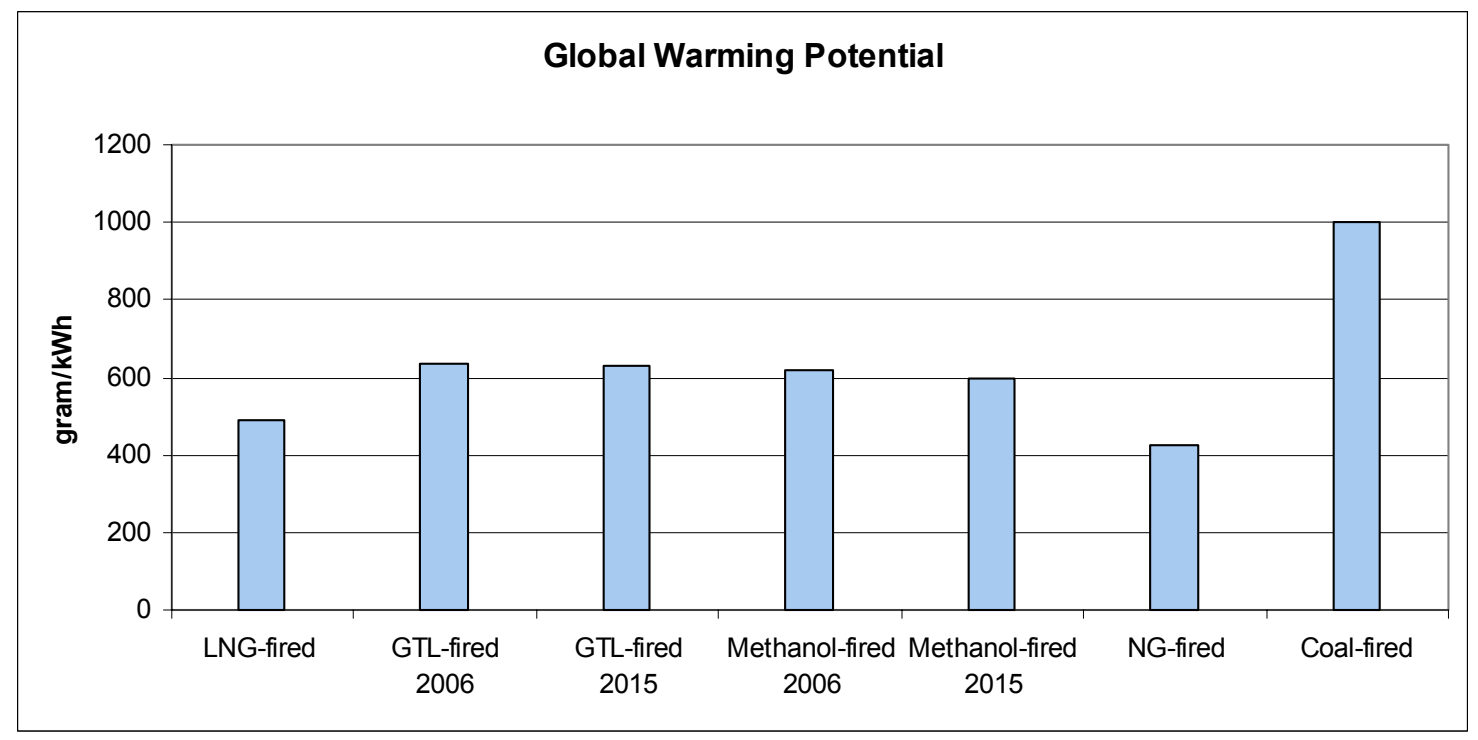

Figure E-2 Global Warming Potential $\left(\mathrm{CO}_{2}\right.$ Equivalents $\left./ \mathrm{kWh}\right)$

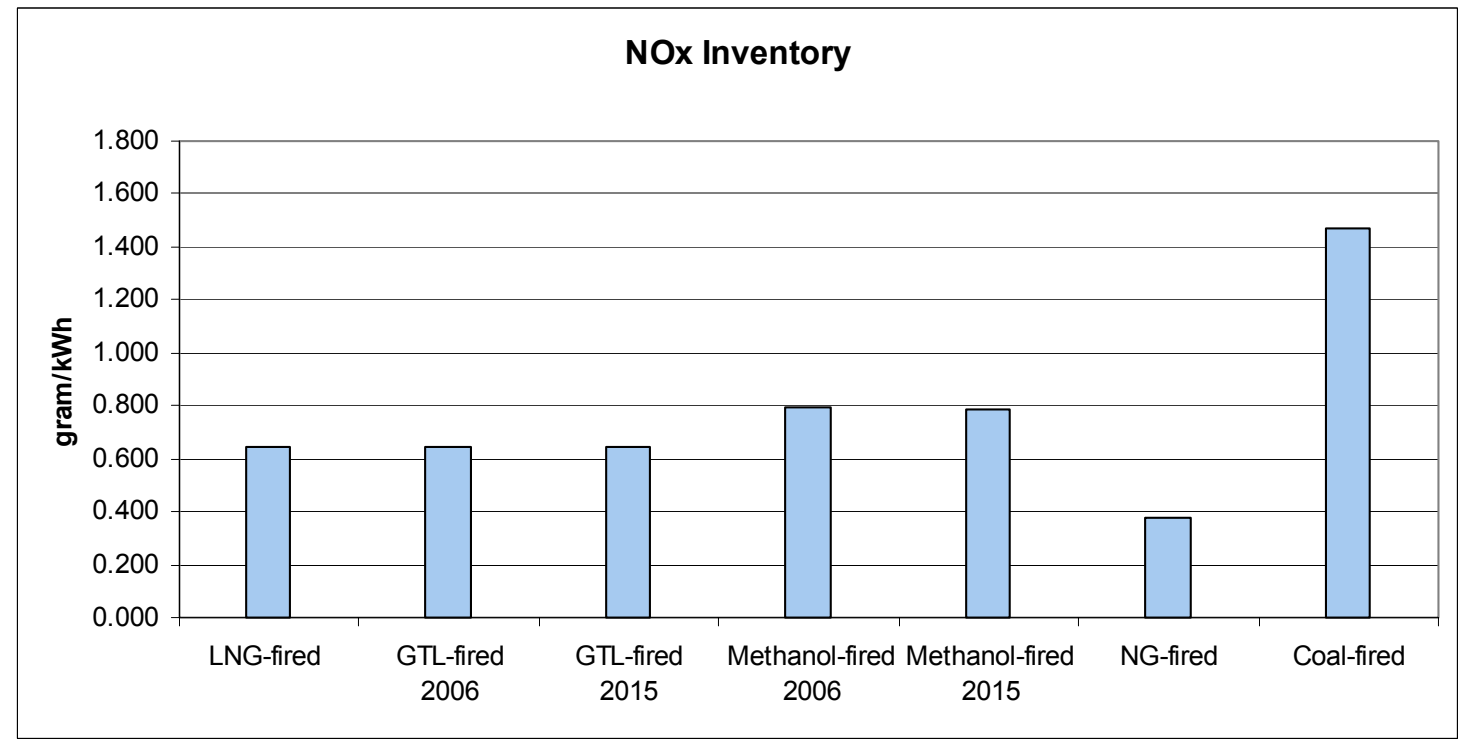

Figure E-3 $\mathrm{NO}$ Inventory ( $\mathrm{g} / \mathrm{kWh}$ ) 


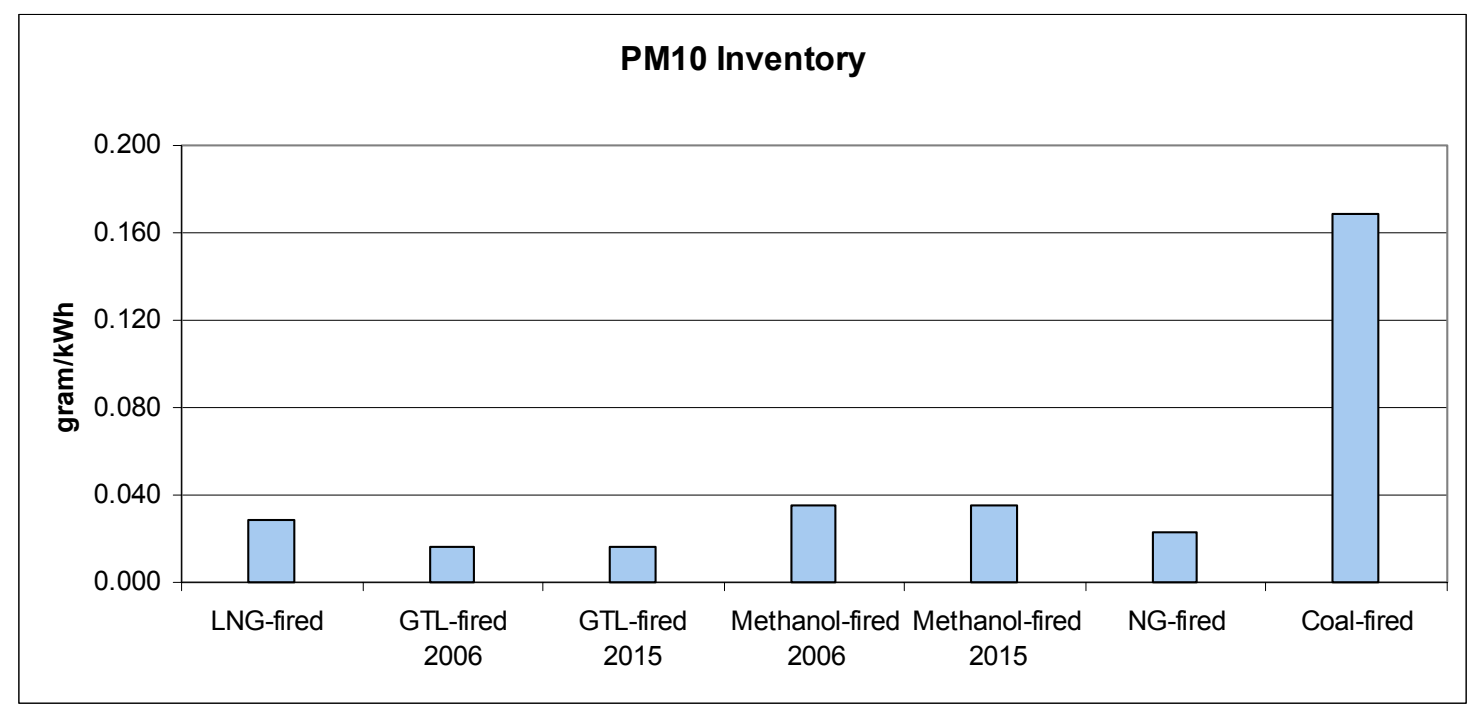

Figure E-4 PM10 Inventory (g/kWh)

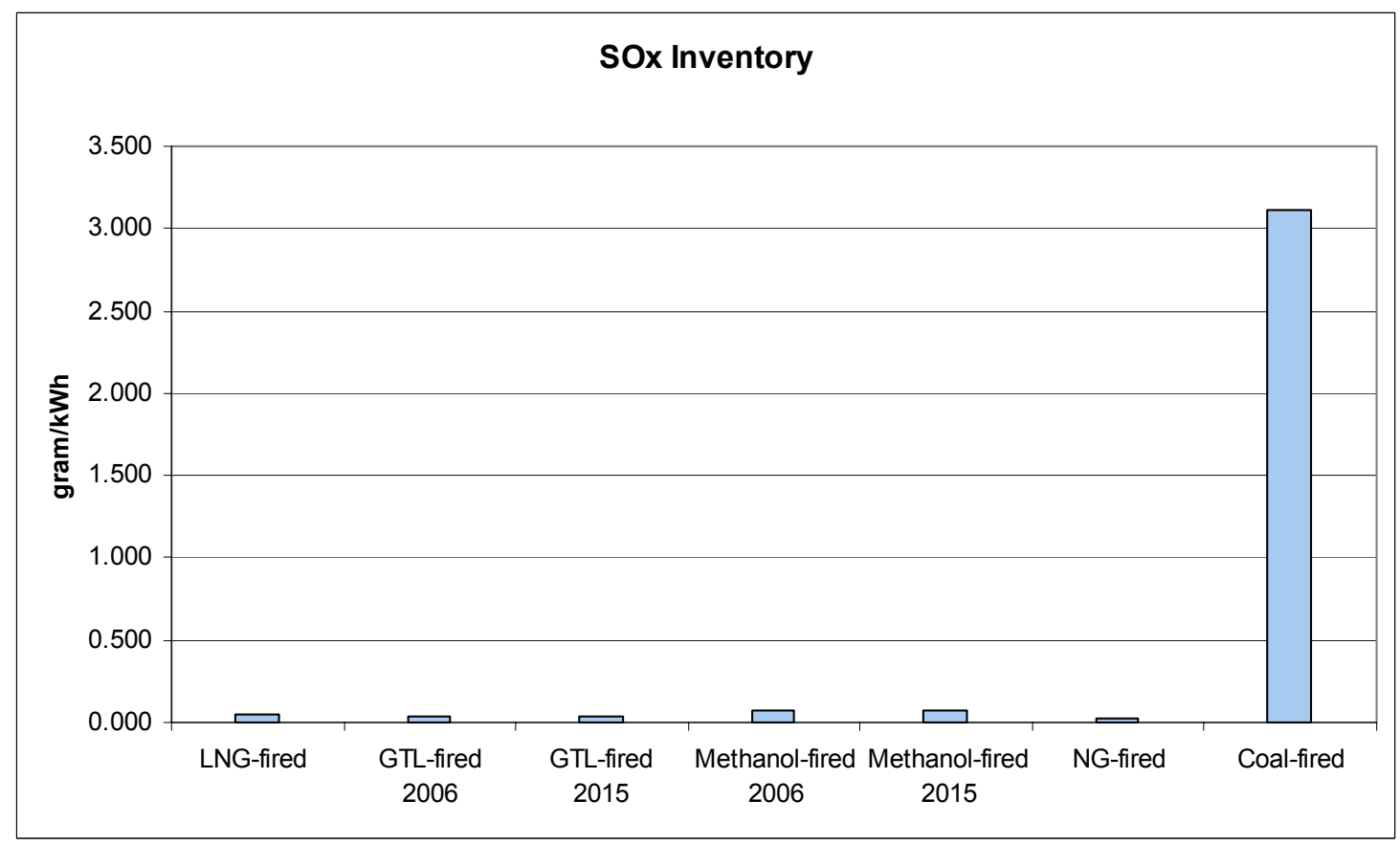

Figure E-5 SOx Inventory (g/kWh) 


\section{E.7 CONCLUSIONS}

- GTL has lower criteria emissions inventories than coal power.

- GTL and methanol have a lower GWP than coal.

- For both methanol and GTL, compared with combined-cycle domestic natural gas to power in North America, there are improvements in $\mathrm{NO}_{\mathrm{X}}, \mathrm{SO}_{\mathrm{X}}$, and PM10 inventories at the power generation stage, but with a penalty on GWP. Comparisons with LNG to power show similar results.

- Compared with all options except coal, there is a life cycle penalty for criteria emission inventories for methanol and GTL. However, most of these criteria emissions occur in non-urban areas during upstream fuel processing and transportation stages. 


\section{E.8 REFERENCES}

Electric Power Research Institute (EPRI), "Test and Evaluation of Methanol in a Gas Turbine System,” Southern California Edison Company, EPRI Report AP-1712, February 1981.

Energy Information Agency, "Voluntary Reporting of Greenhouse Gases 1999," DOE/EIA0608(99), January 2001.

General Electric, “Methanol Position Paper,” May 2001.

Hemmings, J. and D. Todd, "The Starchem Methanol Process, A Low Cost Route to Methanol and Power," Starchem, 2001

Pavri, R. and G. Moore, "Gas Turbine Emissions and Control," GE Power Systems, March 2001.

Spath, P.L. and M.K. Mann, "Life Cycle Assessment of a Biomass Gasification Combined Cycle Power System,” NREL 430-23076, 1997, December 1997.

Spath, P.L., M.K. Mann, and D.R. Kerr, "Life Cycle Assessment of Coal-Fired Power Production,” NREL 570-25119, June 1999.

Spath, P.L., M.K. Mann, "Life Cycle Assessment of a Natural Gas Combined Cycle Power Generation System,” NREL 570-27715, September 2000.

Spath, P.L. and M.K. Mann, "Life Cycle Assessment of Hydrogen Production via Natural Gas Steam Reforming,” NREL, NREL/TP-570-27637, February 2001.

U.S. Energy Association and the U.S. Agency for International Development, "USEA/USAID Handbook of Climate Change Mitigation Options," June 1999. 


\section{F.1 INTRODUCTION}

ConocoPhillips and the Houston/Galveston Council (HGAC), an organization charged by the US EPA under the Clean Air Act with developing long-range plans for addressing air quality issues in the region, have worked collaboratively to model the effects of the introduction of GTL fuels into the Houston-Galveston (H-G) Region on air quality in that region.

ConocoPhillips provided market scenario and emissions data to HGAC, including total vehicle miles traveled (VMT) for light duty and heavy duty vehicles using FTD in the region and the potential $\mathrm{NO}_{\mathrm{X}}$ and VOC emissions reductions achievable through the switch from conventional diesel and ultra-low-sulfur diesel (ULSD) to FTD. HGAC assessed the effects of FTD introduction using the U.S. EPA Mobile6 region air quality model. The modeling is based on actual VMT data (and demographically projected data for future scenarios) for a range of vehicle classes in the H-G Region.

Under the Clean Air Act (CAA) and CAA Amendments, areas that are determined to be in violation of National Ambient Air Quality Standards (NAAQSs) are designated as nonattainment areas (NAAs) for the pollutant(s) of concern. Areas that are marginally in attainment but have the potential to become NAAs are termed marginal attainment areas. Under the CAAA, NAAs must develop a strategy for Reasonable Further Progress (RFP) in complying with the NAAQSs, and this plan must be incorporated in to the State Implementation Plan (SIP), which is submitted to and must be approved by the U.S. EPA. Failure to comply with this requirement may result in the withholding of related federal funding such as from Department of Transportation and other related money normally provided to state pollution control programs.

The HGAC component of the Texas SIP proposes several measures for bringing the H-G Region into compliance with NAAQS for $\mathrm{O}_{3}$, including introduction of clean fuels, transportation measures such as adjustments of speed limits, and more stringent emission standards for new engines.

FTD offers one means of achieving compliance with $\mathrm{O}_{3}$ standards for the $\mathrm{H}-\mathrm{G}$ Region, in additional to the other control measures being considered. HGAC is very interested in assessing the potential for ultra clean GTL fuels in helping the region meet its obligations under the Texas SIP.

\section{F.2 MODELING ASSUMPTIONS AND RESULTS}

HGAC ran the MOBILE6 model with the following assumptions:

- A $25 \%$ rate of FTD use in heavy duty and light duty diesel vehicles, replacing ULSD

- A 5\% rate of use of FTD in light duty vehicles, replacing gasoline

- Two scenarios — 55 mph speed limit and $70 \mathrm{mph}$ speed limit — with all other variables as cited above held constant 
- A $15 \%$ reduction in $\mathrm{NO}_{\mathrm{X}}$ for heavy duty vehicles using FTD vs. heavy duty vehicles using ultra-low sulfur diesel

- A $15 \%$ reduction in $\mathrm{NO}_{\mathrm{X}}$ for light duty vehicles using FTD vs. light duty vehicles using ULSD

- A 4\% reduction in $\mathrm{NO}_{\mathrm{X}}$ for light duty vehicles using FTD vs. light duty vehicles using FRFG (gasoline)

The MOBILE6 model was run for the combined light and heavy duty vehicle scenarios and for $55 \mathrm{mph}$ and $70 \mathrm{mph}$ speed limits. MOBILE6 calculated pounds of $\mathrm{NO}_{\mathrm{X}}$ emitted during the 24hour period of August 30, 2007 for each vehicle class and roadway type for all eight counties of the HGAC Ozone Non-Attainment Area. The 24-hour period is the design period for demonstration of the ability of the SIP to ensure compliance with the NAAQS for $\mathrm{O}_{3}$.

Under the $55 \mathrm{mph}$ speed limit and 25\% share of FTD in the diesel vehicle classes and 5\% in the light duty gasoline vehicle class scenario, Mobile6 predicts a 1.5\% reduction (relative to total $\mathrm{NO}_{\mathrm{X}}$ emissions for all vehicle classes) of 2.1 tons of $\mathrm{NO}_{\mathrm{X}}$ when compared with emissions for use of LSD and gasoline (2007 SIP assumptions). Under the same scenario but with the speed limit raised to $70 \mathrm{mph}$, the model predicts a $1.6 \%$ reduction of 2.3 tons of $\mathrm{NO}_{\mathrm{X}}$ compared with emissions resulting from use of LSD and gasoline. Table F-1 presents a comparison of $\mathrm{NO}_{\mathrm{X}}$ emissions for the two cases.

\section{Table F-1 NOx Emissions Comparisons, FTD vs. HGAC SIP Base Case for August 302007 SIP Scenario (tons of $\mathrm{NO}_{x} /$ day)}

\begin{tabular}{|l|c|c|c|} 
& HGAC SIP Base Case & FTD Scenario & FTD Reduction from SIP \\
\hline 55 mpg scenario & 140.2 & 138.1 & 2.1 \\
\hline 70 mph scenario & 146.1 & 143.8 & 2.3 \\
\hline
\end{tabular}

These reductions represent about $10 \%$ of the required $\mathrm{NO}_{\mathrm{X}}$ reduction targets that $\mathrm{HGAC}$ is required to achieve for the SIP through reductions in mobile emissions sources.

The HGAC target under current SIP is a reduction of 23 tons per day (tpd) of $\mathrm{NO}_{\mathrm{X}}$ via the Voluntary Mobile Source Emission Reduction Programs (VMEP), of which10.4 tpd is to come from on-road sources implementing the Green Vehicles Program. The estimated 2.1 to 2.3 tpd reductions from FTD represent $20 \%$ of on-road emissions reductions in the SIP.

The total target $\mathrm{NO}_{\mathrm{X}}$ emissions for the region in 2005 is $228.11 \mathrm{tpd}$, and for 2007 it is $156.6 \mathrm{tpd}$, a total reduction of 71.51 tpd over the 2005-2007 period.

Reductions due to the introduction of FTD, given the modest market scenarios provided to HGAC, would represent, overall, about $3 \%$ of total reductions, with $10 \%$ of reductions due to all mobile sources and $20 \%$ due to all on-road mobile sources. 


\section{CRITICAL REVIEW OF THE \\ ULTRA CLEAN FUELS LIFE CYCLE ASSESSMENT}

September 15, 2003

This report documents the process and findings of the Critical Review of the Ultra Clean Fuels Life Cycle Assessment study by Nexant Inc. for ConocoPhillips, September 2003.

The UCF LCA study analyzes the environmental life-cycle profile for the production of fuel products from gas-to-liquids (GTL) technology and their use in light-vehicle for transportation purposes. GTL fuels, primarily Fischer-Tropsch diesel, are compared to equivalent systems, particularly petroleum gasoline and diesels.

\section{Review Process}

In accordance with ISO 14040 requirements for "Critical review - Review by interested parties," an external independent expert was selected by ConocoPhillips to act as Chair of the Critical Review Panel for the UCF LCA study. Based on the goal, scope and budget, the Chair selected three additional independent qualified reviewers. The Panel members were:

- Dr. Steven B. Young, University of Waterloo, Ontario, Canada (Chair of the Panel)

- Margaret K. Mann, National Renewable Energy Laboratories, Colorado

- Dr. Rita Schenck, Institute for Environmental Research and Education, Washington State

- Ferry Van Dijk, Shell International Gas Ltd., United Kingdom

From October 2002 to September 2003, the Panel considered multiple drafts of the report and provided comments and recommendations to ConocoPhillips.

\section{Limitations of the Review}

It was outside the purview of the Panel to judge the LCA study goals or to validate data, calculations or results. The Panel does not take any responsibility for study findings, conclusions or ramifications.

The Panel is aware that the UCF LCA report is part of a larger project, which covered other components of work including a UCF market study (published separately), a comparative LCA study of GTL fuels used for electric-power generation (Appendix E of the UCF LCA), and an analysis of air quality ramifications of GTL fuel use in the Houston area (Appendix F of the UCF LCA). None of these other components of work are covered by the LCA Critical Review report. 


\section{Findings}

After detailed review of the UCF LCA study, the Panel is satisfied that:

- the study conforms to the requirements and guidance of the ISO 14040 standards on life cycle assessment,

- the methods and approaches employed in the study are consistent with those presented in the study report, and

- the study followed common and acceptable practices for LCA, which support fair, scientific and clearly presented analysis and results.

The final UCF LCA study report incorporates a full and complete response to all concerns, comments and recommendations made by the Critical Review Panel.

The UCF LCA report provides a prospective analysis of the production and use of novel GTL transportation fuels. The results are applicable to the stated objectives and should be useful to the intended audiences. Given that part of the purpose of the study was to help provide a fair comparison of GTL transportation fuels versus competing petroleum fuels, and is intended for communication of results to the public and other audiences, the study effectively addresses key areas necessary for comparative assertions:

- Analysis of material and energy flows included in the system boundaries, including the treatment of co-products and process allocations.

- Description of data used and data quality, included consideration of gaps and limitations.

- Clear and fair functional unit ensuring equivalence of systems compared.

- Consideration and presentation of life cycle impact assessment indicator results in addition to life cycle inventory results.

- Life cycle impact assessment that employed a comprehensive set of category indicators.

- Sensitivity and uncertainty analyses.

- Evaluation of the significance of the differences found between systems.

Several areas of the study should be noted:

- The study employed a number of different analytical software tools covering fuel-cycle inventories, chemical process simulation, and life-cycle impact assessment.

- The study utilized a mix of data from a variety of sources, ranging from proprietary data from ConocoPhillips to values from the literature.

- The study examined numerous fuel life-cycle scenarios, covering both near-term and long-term future scenarios.

- Sensitivity analysis and uncertainty analysis were applied effectively and in great detail. This included the development of a novel approach to co-products from the petroleum refinery, termed "Co-product Function Expansion," that provides an 
appropriate and meaningful analysis - and represents a valuable contribution to LCA inventory methodology.

\section{Closing}

The Panel commends ConocoPhillips and Nexant for the accomplishment of the UCF LCA study. The study team went to considerable effort to ensure that concerns, comments and recommendations from the Panel were fully addressed. The final result is a significant and solid LCA study.

Signed for the panel,

Steven B. Young

University of Waterloo

sby@sbyoung.com

September 15, 2003

Guelph, Ontario, Canada 


\section{GNexant}

101 Second Street, 11th Floor San Francisco, CA 94105-3672

tel: +1415369 1000 fax: +1 4153699700 email: info@nexant.com

www.nexant.com 


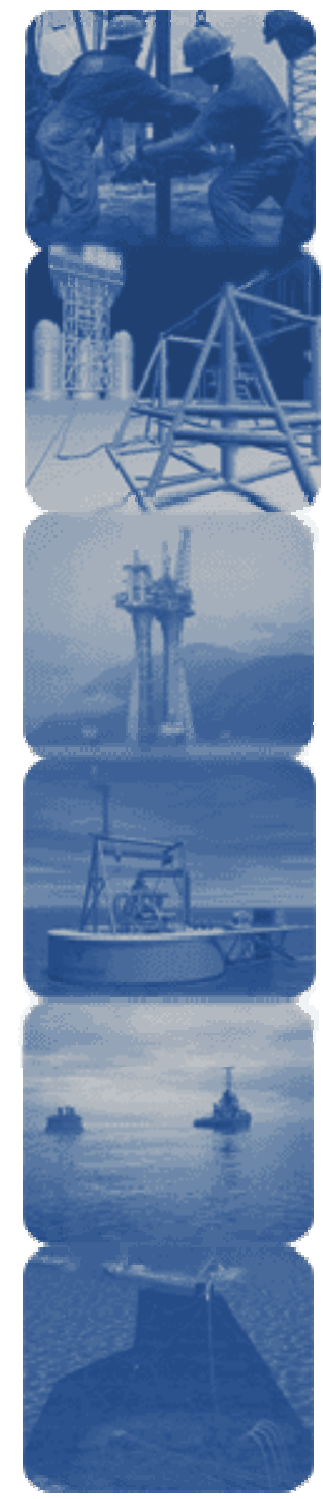

\section{Gas to Liquids Life Cycle Assessment Synthesis Report}

Photo ๑ Infield Systems Ltd.

London, U.K., info@infield.com

August 2004

Prepared for: ConocoPhillips Sasol Chevron Shell International Gas

Prepared by: Five Winds International 


\section{TABLE OF CONTENTS}

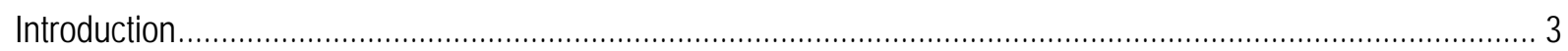

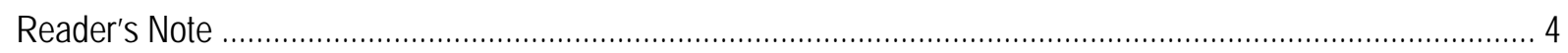

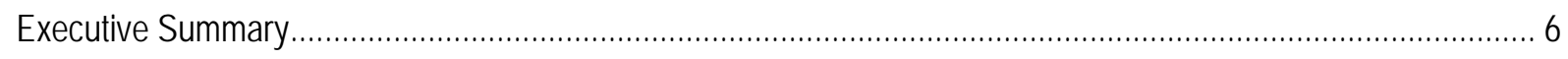

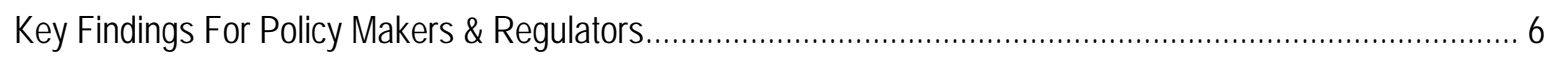

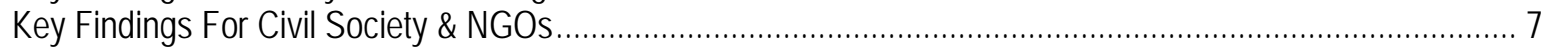

Key Findings For Automotive OEMs \& Fleet Operators ….............................................................. 8

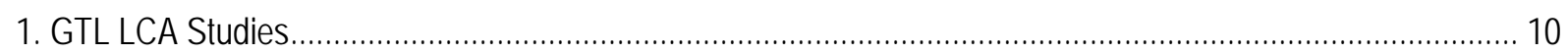

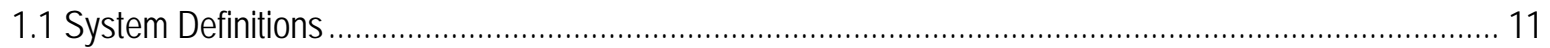

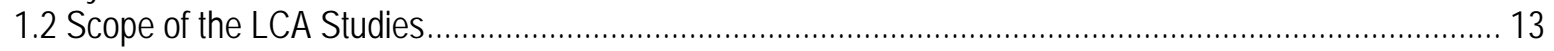

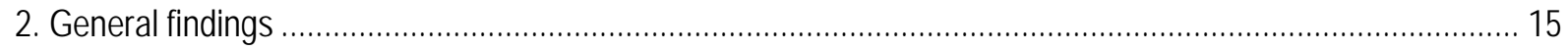

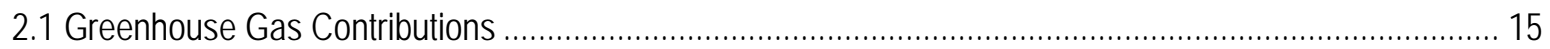

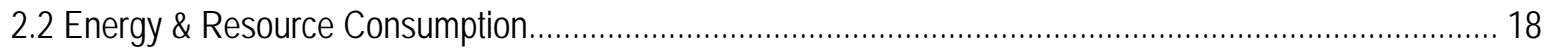

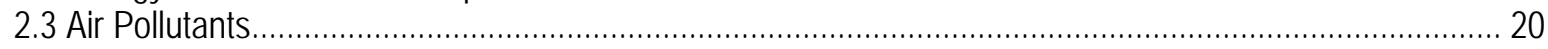

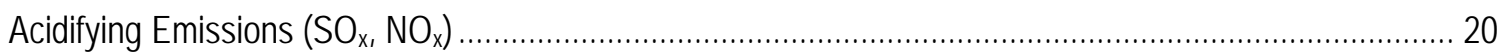

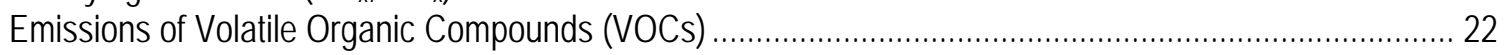

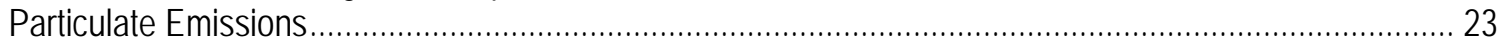

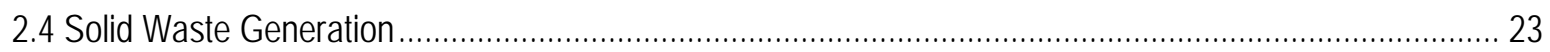

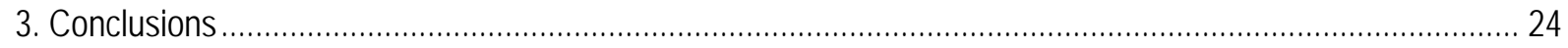

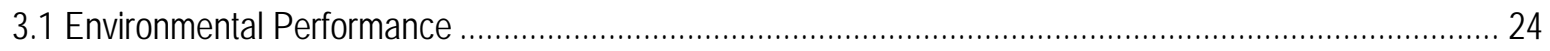

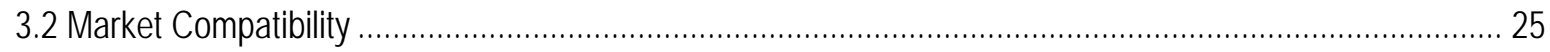

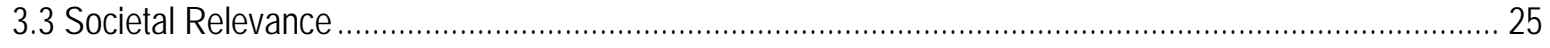

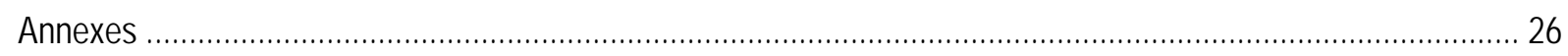

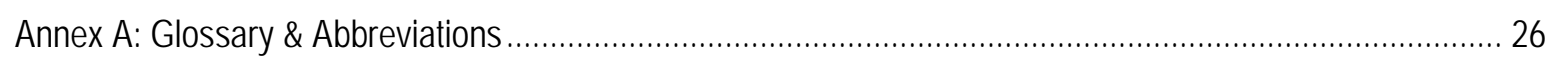

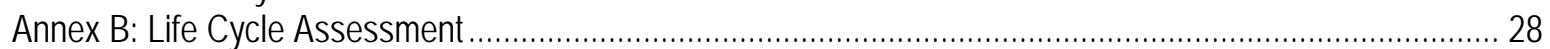

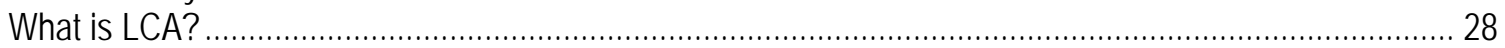

Why LCA?

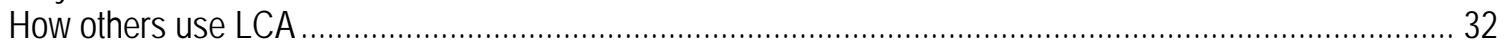

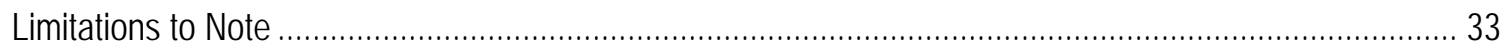

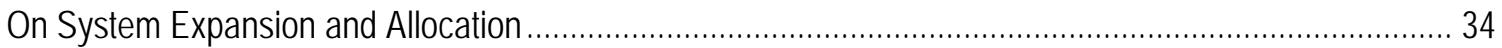

Annex C: Comparative Summary of the Three Gas To Liquids LCA Studies ................................................. 36

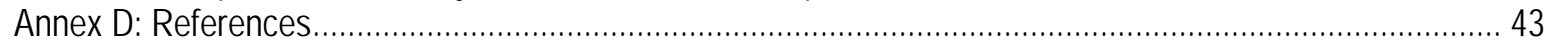




\section{INTRODUCTION}

Conventionally, diesel fuel is a product of crude oil refining. Diesel can also be produced using "Gas to Liquids" (GTL) technology. GTL technology uses natural gas from remote gas reserves (i.e., reserves located a great distance from potential markets) that otherwise could not be used to economically produce transportation fuels. While many attributes of the two technologies differ, they can be compared in terms of the range of functions they provide and the impacts they have on the environment.

This report presents the environmental attributes of GTL fuel or diesel based on the results of three independent studies that compared GTL technologies to conventional refinery based technologies. The three Life Cycle Assessment (LCA) studies are based on ISO standards. The study results provide a holistic view of how the technologies impact the environment by measuring impacts caused by producing, transporting and using the fuels. While each study differs with respect to methodology, scope, sources of data and boundary conditions, the studies' findings do indicate similar overall trends. The goal of this report is to interpret these trends and present them in terms meaningful to different stakeholders, including policy makers, civil society and automotive OEMs and fleet operators. This report provides these audiences with relevant information about the environmental impacts of GTL technology by making complex LCA study findings understandable.

This report is relevant and timely given the market introduction of a diesel fuel from GTL technology and the potential to produce commercial quantities. As it is adopted, the technology can provide high quality fuel and enhance the supply of transportation fuels because it uses otherwise untapped remote natural gas reserves. It should be noted that the conventional refinery system is well established and has gone through decades of continuous improvement. In comparison, the GTL system is relatively new with improvements and innovations to be expected in the future. The comparison therefore is a conservative one, as the results discussed in this report are based on recent design data for GTL systems.

The major emphasis in this report is to provide objective information in a transparent manner. The findings should initiate thought and discussion. The commissioners of the study invite such discussions.

ConocoPhillips, Sasol Chevron and Shell International Gas commissioned Five Winds International, an independent LCA expert, to prepare this report. 


\section{READER'S NOTE}

Structure of this report:

This report is intended for a variety of stakeholders. The Executive Summary summarizes key findings from the LCA studies in three sections. Each section is intended to address the needs and concerns of a specific stakeholder group: policy makers, civil society and automotive OEMs and fleet operators. As these groups share some similar concerns, certain findings are summarized in more than one section. More detailed findings from the studies are presented in the main body of the report. It is organized by environmental themes of concern, including resource and energy consumption, greenhouse gas emissions (GHG), other air pollutants and waste. The conclusion summarizes the GTL technology in terms of environmental performance, market compatibility and societal relevance.

Four annexes support the report. Annex A is a glossary of technical terminology and acronyms used throughout the report. Background reading on LCA methodology is included in Annex B. Annex C summarizes the three LCA studies in detail and bibliographic references to the studies and the ISO LCA Standards are given in Annex D.

\section{Terminology:}

The term "GTL technology" is used to refer to the range of liquid products produced by the Gas to Liquids system. The term "conventional diesel" is used to mean the conventional crude oil refinery based system.

\section{About the LCA Studies:}

LCA is an internationally agreed methodology for system-wide environmental assessments and offers a holistic view of the environmental impacts of products or technologies by considering impacts throughout the value chain under study. The LCA studies underlying this report have been performed in accordance with the internationally accepted standards for LCA. For each study, a third party critical review process ensured compatibility with these standards, including consistency between the studies and their stated goals.

LCA is internationally accepted, recognized and endorsed by the European Commission's work on Integrated Product Policy and the United Nations in proceedings of the World Summit in Johannesburg.

The LCA studies examined for this report compare the underlying broader technology systems, not only the fuels and individual petrochemical products. Producing the fuels generates of a number of co-products. To ensure a fair and realistic comparison, the entire fuel technology systems were compared, not simply the resulting fuels.

While the two systems, GTL and conventional refining, are not directly comparable, the system boundaries were expanded so that both systems produce the same range of functions. The expansion was performed on the basis of existing complementary technologies. Two of the studies look into the full systems, including all products ${ }^{1}$ of the two technologies, from

\footnotetext{
${ }^{1}$ Products include both goods like fuels and services, such as space heating and electricity provided
} 
electricity generation, space heating to refinery products and transportation fuels. The respective products provided by only one of the systems were compensated by a so-called system expansion, where alternative routes to produce such products were added to the other system so that both systems provide identical products and services. One study used a similar co-product system expansion approach focusing on automotive fuels.

\section{Limitations:}

Given that LCA offers a system-wide perspective and includes a variety of potential environmental impacts, it is useful for identifying and comparing attributes of GTL technology with conventional refinery technology. However, using LCA for this comparison does have certain limitations which should be noted when interpreting the findings (Annex B). 


\section{EXECUTIVE SUMMARY}

This Executive Summary summarizes important findings from the three LCA studies and presents them as key findings for each of three audiences: policy makers, civil society and automotive OEMs and fleet operators. As mentioned, these groups share some of the same similar concerns and as result certain key findings are included in more than one section.

\section{KEY Findings FoR POLICY MAKERS \& REgULATORS}

\section{i) GTL Technology in terms of GHG performance goals}

Production and use of GTL fuel can contribute less greenhouse gas to the atmosphere than production and use of conventional diesel fuel. If the GTL fuel is produced from associated gas $^{2}$ that is otherwise flared in amounts of $10 \%$ or greater, the reduction in greenhouse gas emissions is significant. More conservatively, and in cases where the feedstock is from other sources, the greenhouse gas contribution of GTL fuels is comparable to conventional diesel technology. In the expanded GTL technology system, available natural gas is used for space heating and electricity generation, whereas conventional refining technology uses more carbon intensive light fuel oil and residual fuels respectively, to meet these needs. While the GHG emissions from production and upstream processes of the GTL system are higher compared to the refinery-based system, the advantages in the use phase, at a minimum, compensate for the disadvantages in those phases.

ii) GTL Technology to protect \& extend resource availability

Fuelling vehicles with GTL fuel consumes fewer petroleum resources per distance travelled than with conventional diesel. In addition, GTL fuel production will continue after crude oil reserves are depleted based on today's assessment of the life span of crude oil reserves. This is because GTL technology exploits remote gas reserves and not crude oil. Extrapolating from this point, using remote gas to create GTL fuel will extend crude oil reserves accordingly.

However, producing GTL fuel currently requires more energy and resources per unit of mass produced than conventional diesel production.

iii) GTL Technology in relation to air quality in urban centres

GTL fuels are virtually free of sulphur and contain fewer aromatics than conventional petroleum-derived diesel fuel. Per distance travelled, GTL fuels contribute fewer emissions and negative impacts on urban air quality than conventional diesel. According to the studies, GTL technology creates fewer air pollutants $\left(\mathrm{SO}_{2}, \mathrm{NO}_{\mathrm{x}}, \mathrm{VOCs}\right.$ and particulate emissions) and therefore contributes less to acidification of the air and formation of smog. Although the results of each of the studies are somewhat different, it appears that, at a minimum, there are fewer environmental and health impacts from GTL fuel than from conventional diesel.

iv) GTL Technology in terms of air acidification

\footnotetext{
${ }^{2}$ Associated gas is natural gas by-product from crude oil production.
} 
With significantly lower emissions of acidifying gases, GTL technology potentially cause less air acidification than the conventional diesel technology. While the emissions from GTL are lower, there is no direct link between the amount of emissions and actual acidification, because actual acidification depends so heavily on factors specific to the environment where the emissions are received (such as climate, soils, geology, etc.).

v) GTL Technology \& reliability of feedstock supplies for fuel

Natural gas is the cleanest and most abundant fossil fuel. There is potential for remote natural gas to provide energy to the global market for many decades. With respect to environmental impacts, remote natural gas can provide this energy in a manner comparable or better than petroleum reserves.

vi) GTL Technology - Can be used without new capital \& infrastructure

GTL fuel can be used either directly or blended with conventional diesel and burned in conventional diesel-powered vehicles. Tanks, pumps and other fuelling infrastructure can be filled with GTL fuel without significant retrofitting or capital investment. While there is potential to optimize vehicle engines to run even more efficiently on GTL fuel, such re-design is not essential. Technological advances in design of advanced engines can be a longer-term goal consistent with the growth of GTL markets.

vii) GTL technology \& Waste reduction

The GTL system generates less solid waste (up to $40 \%$ less according to one of the LCA studies) and less hazardous waste than conventional diesel technologies.

\section{KEY FINDINGS FOR CIVIL SOCIETY \& NGOS}

\section{i) Balanced environmental profile of GTL}

GTL technology is complementary to the conventional refinery based system. GTL is able to extend the availability of energy sources for a variety of functions. The overall environmental footprint of the GTL system offers advantages for a range of environmental impacts.

The studies suggest, that, based on current estimates, producing GTL fuel requires more energy than the conventional refinery system and is at least GHG neutral.

Being at an earlier stage of its technical development, the GTL technology has room for improvement. GTL fuels have the potential to help alleviate several environmental concerns around fuel and energy systems in such areas as air quality improvements in urban areas and reducing the GHG intensity of fuel systems.

ii) Air quality concerns

Reductions in air acidification, particulate emissions, VOC emissions and the related environmental concerns are important aspects of improving urban air quality. The GTL system offers important advantages. GTL fuels are virtually free of sulphur and aromatic 
compounds resulting in cleaner and more controlled combustion. The result is reduced emissions of particulates, lower (and sometimes eliminated) pollutant emissions and lower emissions of $\mathrm{NO}_{\mathrm{x}}$ in urban areas. Significant reductions in all three categories make the GTL system attractive.

iii) Use of existing infrastructure

Consumers can immediately benefit from the advantages of the GTL system by using existing fuelling infrastructure. GTL fuels can be used in existing vehicle engines directly or in a blended fashion. Expensive modifications to the fuelling infrastructure that could delay adoption of GTL technology are not required.

iv) Greenhouse Gases

From a systems (i.e. holistic) perspective, GTL technology is at least GHG neutral in comparison with the conventional refinery based system. Higher GHG emissions may be associated with the production phase due to the higher process energy requirements, but these are offset by lower emissions in the use phase. Overall GHG emissions are further reduced as less carbon intensive alternatives such as natural gas replace high carbon content fuels such as heavy fuel oils.

\section{Key Findings For Automotive OEMs \& FleEt OPERATORS}

i) GTL technology provide clean fuel

GTL fuels offer significant advantages by providing cleaner fuels to help meet emission limits. With respect to sulphur content and aromatics, the GTL technology has significant advantages meeting recent public and societal health concerns. GTL fuel also enables the development and use of advanced exhaust systems and engines.

ii) Opportunity for efficiency and performance gains

GTL fuels may in some cases offer performance advantages, such as higher distance travelled per unit mass of fuel. There is a further possibility to also reduce other environmental impacts such as the specific GHG or particular matter emissions intensity per unit distance travelled.

iii) Resource base extended

Being based on remote natural gas reserves, the GTL technology extends the resource base of crude oil. These complementary and additional sources for fuels extend the lifetime of known hydrocarbon reserves. This protects existing assets and extends time for research and development for alternative systems and technologies.

iv) Fuels can support fleet owners to document positive contribution in urban areas

The GTL fuel system offers advantages in pollutant emissions, such as $\mathrm{SO}_{2}$, particulates and VOCs (between $26 \%$ to $82 \%$ less VOCs, according to the LCA studies). Fleet operators can 
significantly reduce their impact by utilizing GTL fuels. This may help in maintaining access to certain urban areas, lower cost licenses and other economic incentives.

v) Use existing engine designs, fleet operator infrastructure and general infrastructure

While being able to reduce the environmental footprint of fuel use, no additional investments are necessary to distribute and use GTL fuels. The existing infrastructure is completely compatible with the GTL system and blended GTL fuels, including filling stations, storage, fuelling, etc. Also existing assets can make use of GTL fuel. No engine adjustments or new vehicles are necessary and costly R\&D investments are not required. 


\section{GTL LCA STUDIES}

This report is based on three LCA studies, namely:

- Ultra Clean Fuels Life Cycle Assessment. ConocoPhillips and US Department of Energy. November 2003.

- Use of a Life Cycle Approach to Compare the Environmental Implications of Sasol's Slurry Phase Distillate Technology with Complex Refinery. Sasol Technology Pty and Sasol Chevron. November 2002.

- Shell Middle Distillate Synthesis (SMDS). Update of a Life Cycle Approach to Assess the Environmental Inputs and Outputs, and Associated Environmental Impacts, of Production and Use of Distillates from a complex Refinery and SMDS Route. Shell International Gas. May 2003.

The following chapter discusses the methodology used in each LCA study, the systems studied and the scope of the studies. It is relevant to understand major methodological choices in order to put the findings (presented in the subsequent section) in context. The interested reader is directed to Annex $\mathrm{C}$ for a more comprehensive and systematic overview of the studies. 


\subsection{SYSTEM DEFINITIONS}

The following table describes the system studied in each LCA and specifies which products and services were included. Each study used system expansion, which means the products and functions included in the systems are comparable.

Table 1: System definitions for the three Life Cycle Assessment (LCA) studies.

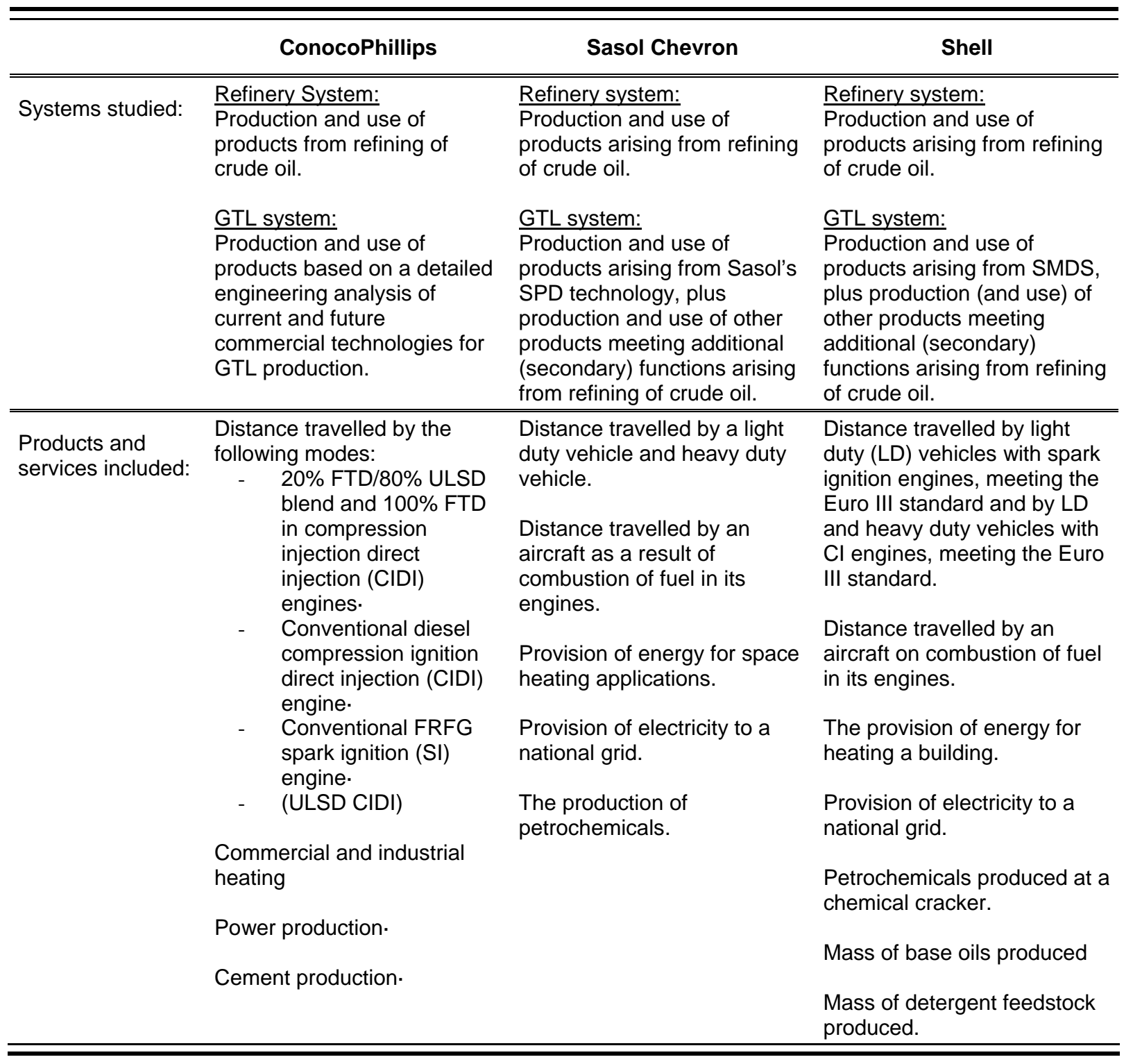

All three LCA studies compare the existing refinery system with an engineering assessment of the GTL technology current at the time the studies were conducted. The GTL data therefore is not measured, but based on engineering analysis and/or pilot plant operations. Engineering approaches are typically conservative in nature. Actual performance data for the GTL system can be expected to at least meet if not exceed the results discussed in this report.

The products and services included in the three studies differ, based on the nature of specific assumptions with respect to location of a plant and markets served. The refinery system has a 
given range of products being produced. All products are part of the system, although not equal in market desire and economic value. In contrast, the GTL system only provides products valued by the market.

The three studies differ in specific products and services included in the system boundaries. The Shell study for example includes the production of base oils for lubricants, n-paraffin and heavy fuel oil production used for electricity generation in the refinery system. For the GTL system, all studies include the production of diesel, LPG and naphtha for the GTL system. The Sasol Chevron study did not include ultra-low sulphur diesel for road transport as part of the refinery system.

Figure 1 illustrates the system boundaries for the expanded system studied. While the figure is taken from the Sasol study, it is illustrative for all studies. To make GTL and conventional diesel technologies comparable, the service provided by the two systems is made identical. To do this, additional products were added to the respective core product each technology provides. This ensured that overall the same functions can be met even though those functions, such as space heating or electricity generation, are not necessarily provided by the same fuels. The overall environmental impacts are measured in reference to the whole system's impact. The results express the total environmental load for all products and services included.

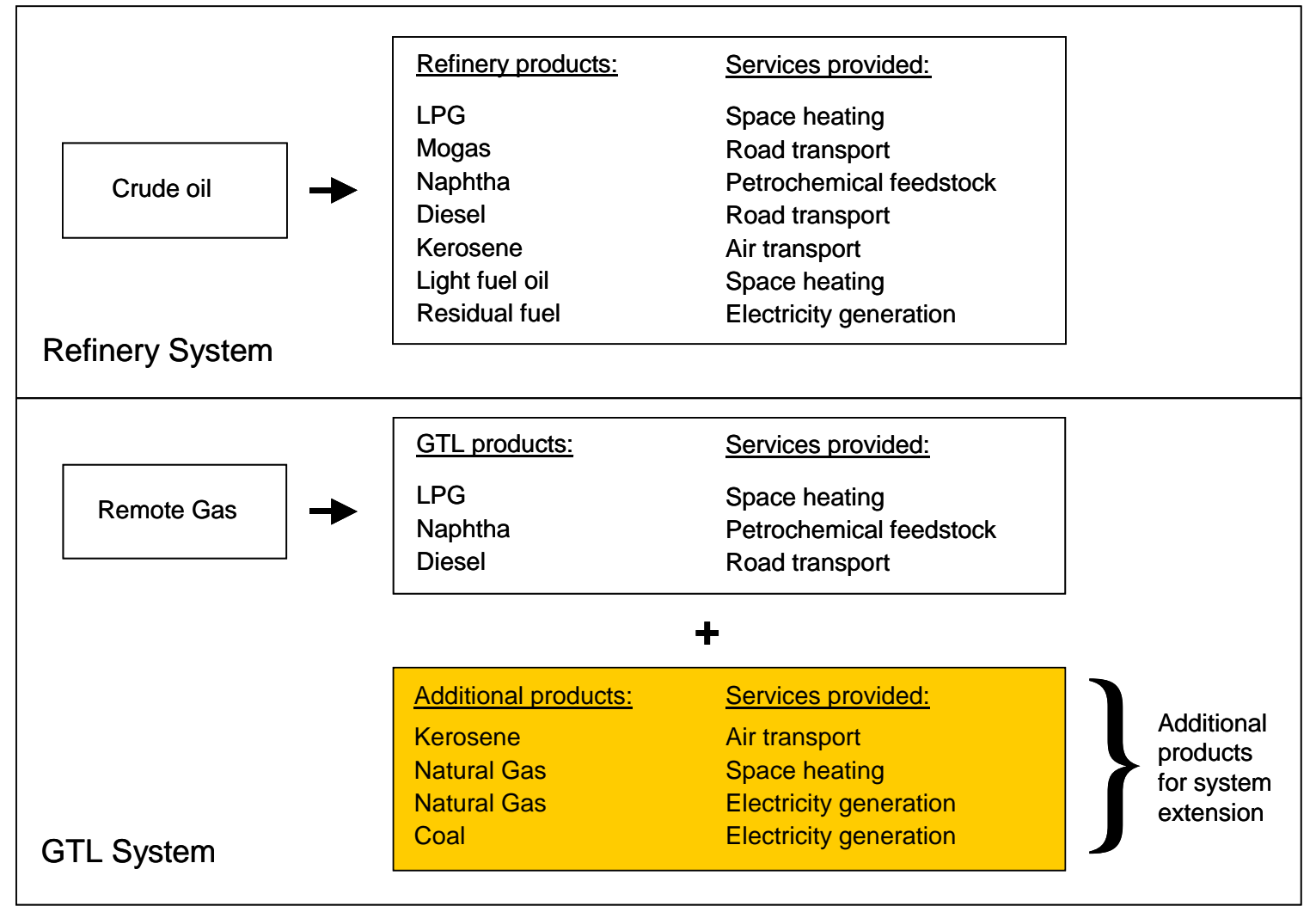

Figure 1: Illustration of the systems studied (Source: Sasol Study).

While the refinery based system is based on crude oil, GTL uses remote natural gas reserves. The refinery system provides LPG (Liquefied Petroleum Gas), Mogas (conventional 
gasoline), diesel, naphtha (a chemical feedstock), light fuel oil and residual oil. The respective uses of the fuels are indicated in Figure 1 and include functions such as transportation fuel, electricity generation and space heating. Additional products needed to meet the same system functions are ethane and naphtha, both serving as chemical feedstock.

The GTL system produces LPG, naphtha and diesel. Here natural gas, coal, kerosene, ethane and naphtha have to be added to the system. While the two systems meet the same functions, they still differ fundamentally in the way the services are being provided. Heavy fuel oil for example is an economically less attractive product from the refinery system. It is mainly used in electricity generation. It has high sulphur content and achieves significantly smaller energy efficiency yields as compared to the natural gas alternative in the GTL system.

The ConocoPhillips LCA used a very similar method where co-product emissions were attributed to the primary product or products in the fuel production stage. Those co-products were then compared with alternative products in downstream applications and the net consumptions or releases are assigned as either credits or debits to the primary products. As a result this study compares different transport fuels. The study expresses the results for the different fuel types in units of consumption or releases per unit of distance travelled.

All studies use sensitivity and uncertainty analysis to better understand the influences from variables and assumptions. Key assumptions have been assessed to the extent they can influence the overall results. The analysis showed that the study results are stable and do not significantly change when altering assumptions and variables.

The studies differ in data sources. This is due to the differences in geographical scope, where the SasolChevron and Shell studies focus on Europe and Asia, as compared to the USA focus of the ConocoPhillips study. Technologies, specifications of fuels and system boundary conditions, such as electricity grid composition, vary. Also data sources and references are different.

\subsection{SCOPE OF THE LCA STUDIES}

Table 2 shown below summarizes the scope of the individual studies. There are small differences in geographical scope and in time horizons. Nevertheless the studies are comparable with respect to system boundaries, scope and comprehensiveness. Two studies reflect actual project engagement and specific design data. As such they are specific assessments and not general technology comparisons. One study assesses the technology from a more generic perspective, but with specific boundary conditions for locations and regional influences, too.

While two of the studies look into broad geographical coverage, one is focusing on the US market only. The choice of geographical coverage is important, since specific regulatory and market circumstances apply, leading to differences in data sources and references, such as emission standards. All three studies are intended to serve internal and external target audiences.

Table 2: Scope of the LCA studies 
Gas to liquids LCA Synthesis Report

\begin{tabular}{|c|c|c|c|}
\hline & ConocoPhillips & Sasol Chevron & Shell \\
\hline Commissioner & $\begin{array}{l}\text { ConocoPhillips and US } \\
\text { Department of Energy }\end{array}$ & Sasol & Shell International Gas \\
\hline Markets covered & U.S. & Europe, U.S., Japan & Europe, Asia. \\
\hline Time Horizon & $2006 \& 2015$ & 2010 & 2010 \\
\hline Inventory & $\begin{array}{l}\text { Greenhouse gases (CO2, } \\
\text { CH4, N2O) } \\
\text { Air pollutants (NOx, SOx, CO, } \\
\text { PM10, VOC) } \\
\text { Total energy. } \\
\text { Solid waste. } \\
\text { Toxics. } \\
\text { Wastewater }\end{array}$ & $\begin{array}{l}\text { Climate change }(\mathrm{CO} 2, \mathrm{CH} 4) \cdot \\
\text { Regional/local air quality } \\
\text { (SOx, NOx, VOCs, CO, } \\
\text { particulates)· } \\
\text { Resource and energy use }\end{array}$ & $\begin{array}{l}\text { Climate change (CO2, } \mathrm{CH} 4) \\
\text { Local/regional air quality } \\
\text { (SOx, NOx, VOCs, } \\
\text { particulates). } \\
\text { Total primary energy } \\
\text { Total waste }\end{array}$ \\
\hline
\end{tabular}




\section{General Findings}

The following chapter provides detailed results from the LCA studies and discusses the most important findings and observations. Key emphasis is put on the following environmental aspects:

1. GHG contributions

2. Energy and resource consumption

3. Air pollutants, including:

- Acidifying emissions (SOx, NOx)

- Emissions of Volatile Organic Compounds (VOCs)

- Particulate emissions

4. Solid Waste Generation

This report only presents environmental aspects covered by at least two of the three LCA studies. These aspects represent a reasonably comprehensive picture of the system comparison and reflect major interests of different stakeholders.

\subsection{GREENHOUSE GAS CONTRIBUTIONS}

The GTL option has at minimum the same GHG impact as the conventional technology. Total GHG emissions of the GTL system are between $12 \%$ less and $11 \%$ more than the refinery system, based on varying assumptions and data. The majority of the scenarios suggest an at least neutral if not positive GHG performance (i.e. reduced emissions) for the GTL system. Disadvantages in the fuel production stages of the technology are offset by the fact that GTL fuels offer slight advantages in the fuel use (combustion) stage, which contribute approximately $75 \%$ or more of the total calculated GHG impact of both options. Readers should note that each study conducted sensitivity analyses and established statistical limitations for the conclusions. While slight GHG advantages for GTL technology over conventional petroleum refining technology were observed, on a conservative basis the differences were not substantial enough to make any claims of superiority. As such, it is safe to conclude that the two technologies are at least equivalent in their GHG contributions.

Carbon dioxide $\left(\mathrm{CO}_{2}\right)$ contributes over $95 \%$ to the total $\mathrm{GHG}$ result. The balance is contributed by methane $\left(\mathrm{CH}_{4}\right)$ and nitrous oxide $\left(\mathrm{N}_{2} \mathrm{O}\right)$.

For the two studies using system boundary expansion, the contributions through the life cycle show the differences between the technologies. The GHG contribution from production and transport is up to $15 \%$ higher in the GTL system. Less energy - and consequently lower GHG emissions - is needed to extract natural gas compared to crude oil. However, the production phase in the GTL system has significantly higher GHG releases due to a lower overall systemwide process efficiency (over $60 \%$ process efficiency for GTL compared with over $90 \%$ for the refinery system). Emissions from the transportation of products are not an important contribution, although significant distances have to be travelled. 
A major advantage for the GTL system is in the use phase of the products, due to replacement of carbon-intense fuels by hydrogen-rich natural gas. This benefit leads to advantages in heating and grid electricity generation. The GHG emissions from the other products, including petrochemicals, show slightly higher contributions for the GTL system.

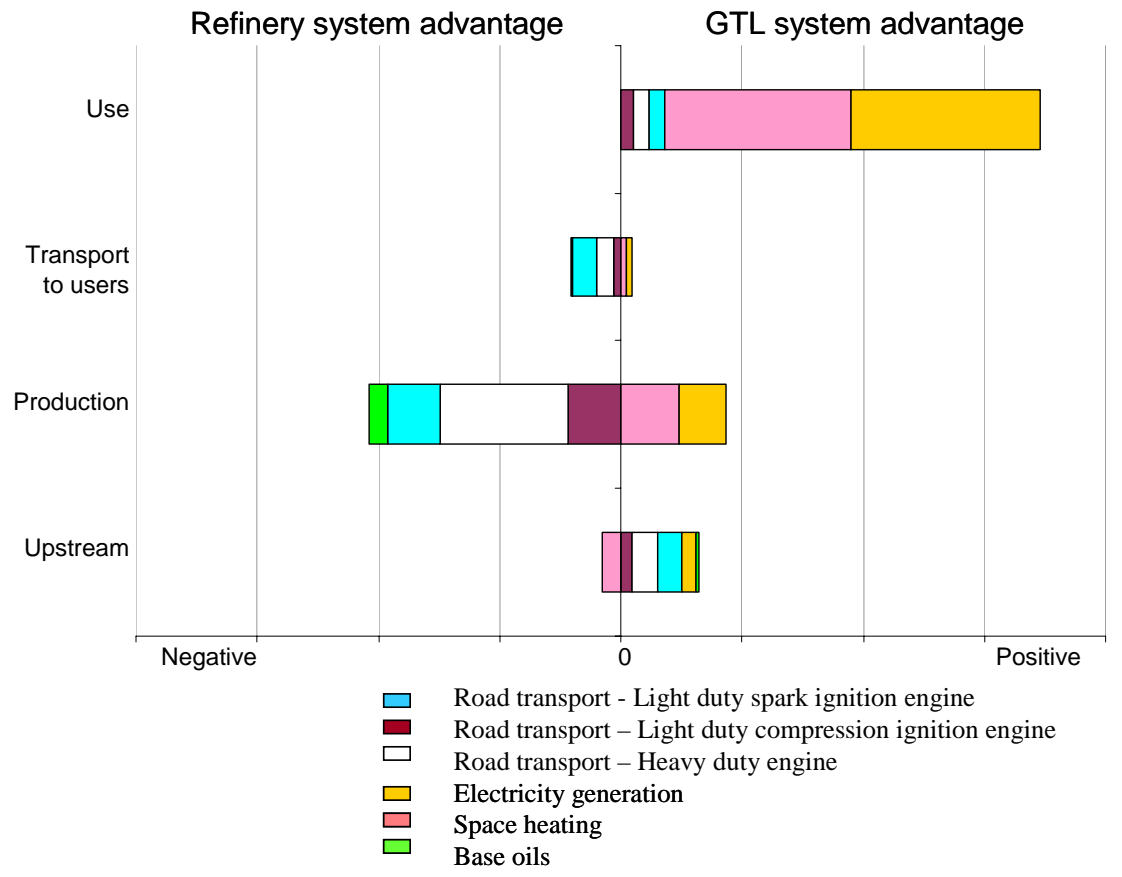

Figure 2a: Relative GHG contributions of the GTL and refinery based system over the life cycle (Source: Shell study)

The production disadvantage of GTL fuels for road transport arises from the higher energy intensity in the production process. In the use phase no specific advantages are considered. While technical studies show a potential for improving the engine efficiency using GTL fuels, this is not accounted for here.

The Sasol Chevron study also documents the potential advantages of the GTL fuels in road transport. Figure $2 \mathrm{~b}$ shows the overall GHG contributions for both systems and the specific contributions from road fuels. Again the production related emissions are greater for the GTL system, with advantages in the use phase of the products. 


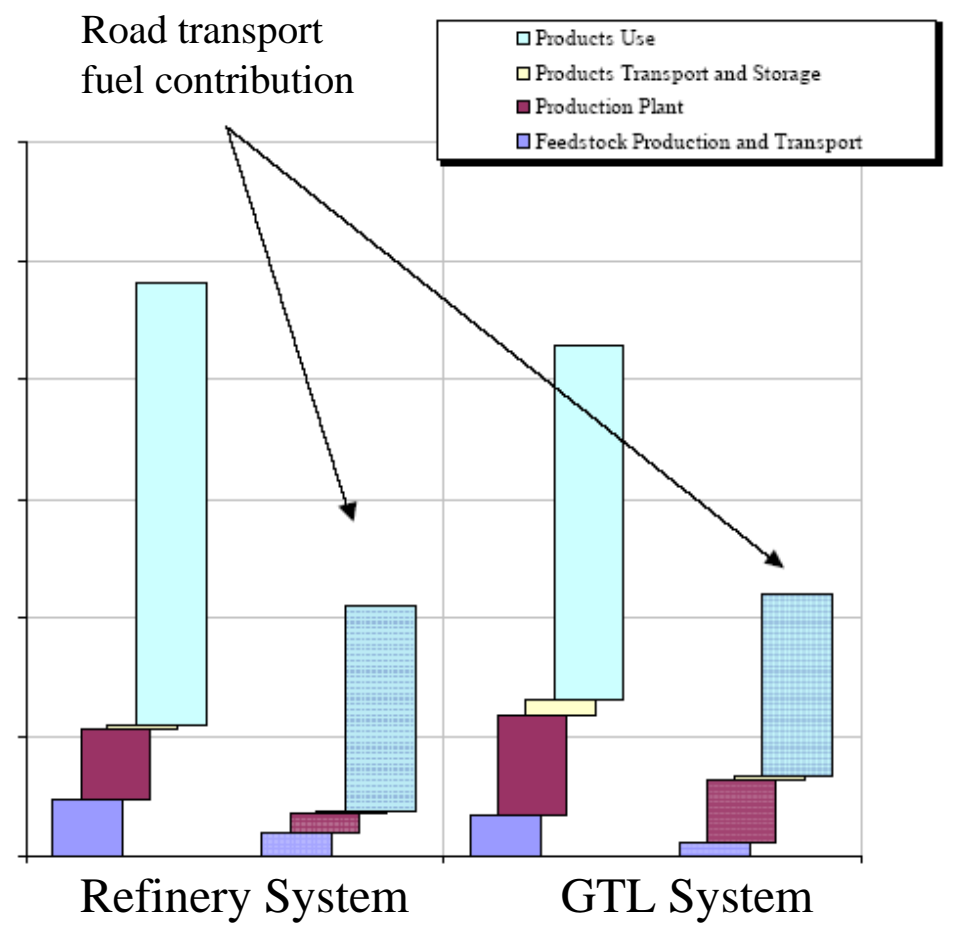

Figure 2b: Relative GHG contributions of the GTL and refinery based system over the life cycle (Source: Sasol Chevron study)

The ConocoPhillips study shows at least a GHG neutral result for GTL fuel as compared to conventional and ultra-low sulphur diesel for the 2006 scenario (see Figure 3a). All three diesel fuels (GTL, conventional and ultra-low sulphur) have advantages over gasoline. This study also suggests that a GHG advantage for GTL fuel can be expected with the technology maturing further, as shown for a 2015 scenario (see Figure 3b).

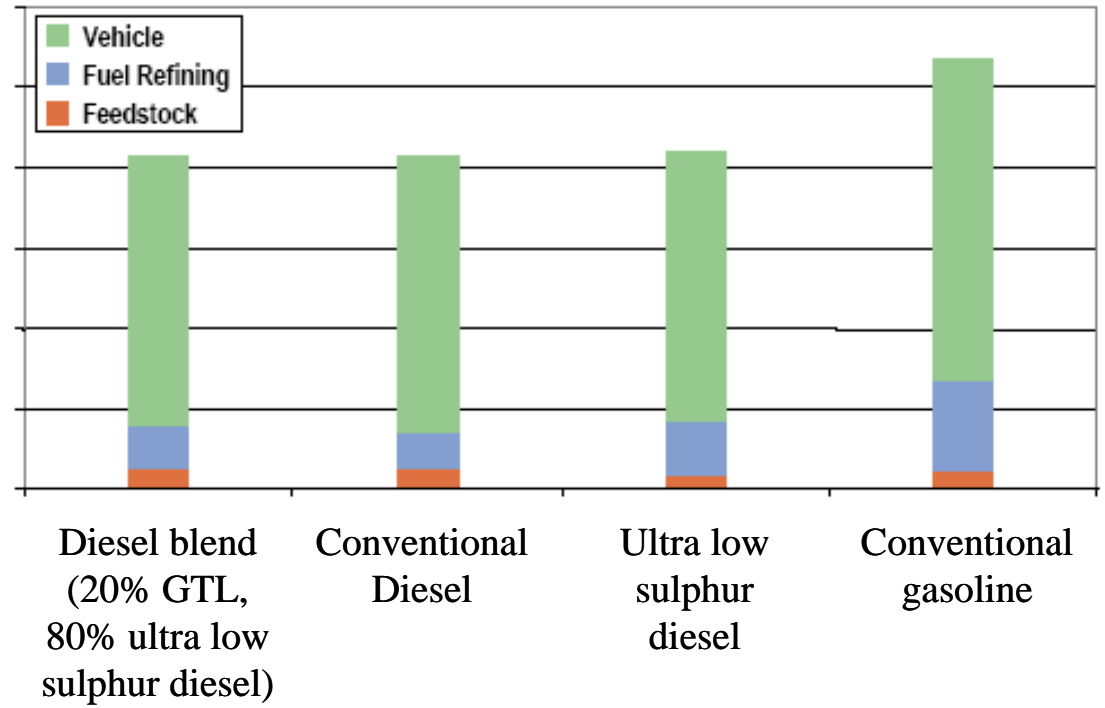

Figure 3a: GHG contributions for GTL fuel, conventional diesel and ultra-low sulphur diesel in comparison with gasoline per distance travelled for a 2006 scenario (Source: ConocoPhillips Study) 


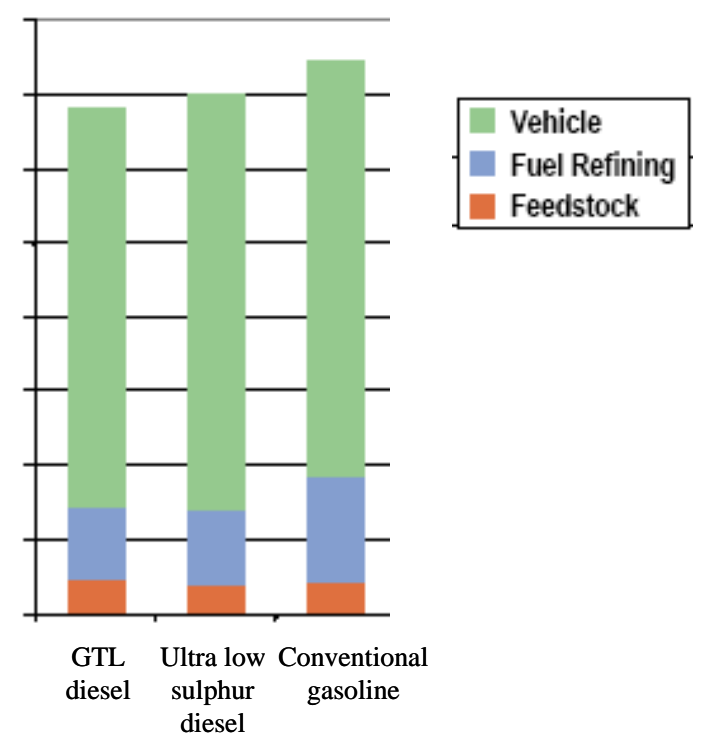

Figure 3b: GHG contributions for GTL fuel, ultra-low sulphur diesel in comparison with gasoline per distance travelled for a 2015 scenario

(Source: ConocoPhillips Study)

\subsection{ENERGY \& RESOURCE CONSUMPTION}

Total energy is used as an indicator for resource depletion. It includes the overall energy consumed in the production process and the energy stored in the products.

The refinery technology has a lower total primary energy requirement, requiring between $17 \%$ to $29 \%$ less energy to meet the same functions as the GTL system. The discrepancy between GHG and total primary energy results arises from the different resources used. While GTL is based on the hydrogen-rich feedstock natural gas, the conventional system is based on the more carbon intensive crude oil, see Figure 4.

Most of the energy difference originates in the fuel processing stage. The larger energy contribution for GTL is due to less efficient processing of feedstock into products (thermal efficiency of over $60 \%$ compared over $90 \%^{3}$ for the refinery). As a consequence, more energy is consumed in order to produce products meeting the same functions as for the conventional system.

Improvements with respect to thermal efficiency in the GTL system can be expected over time since the technology has not gone through the same degree of technological improvement as the conventional system.

\footnotetext{
${ }^{3}$ Source: Shell LCA study
} 


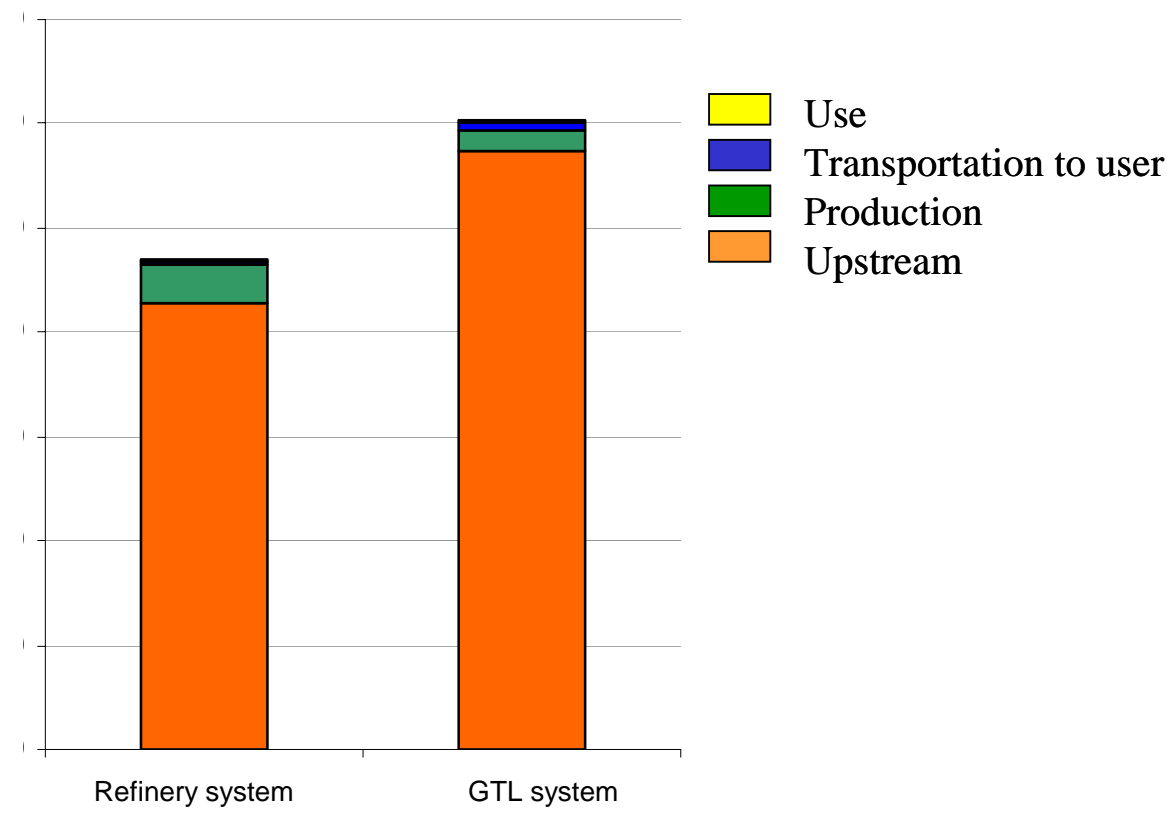

Figure 4: Total system wide energy consumption of the GTL and refinery based system over the life cycle (Source: Shell study)

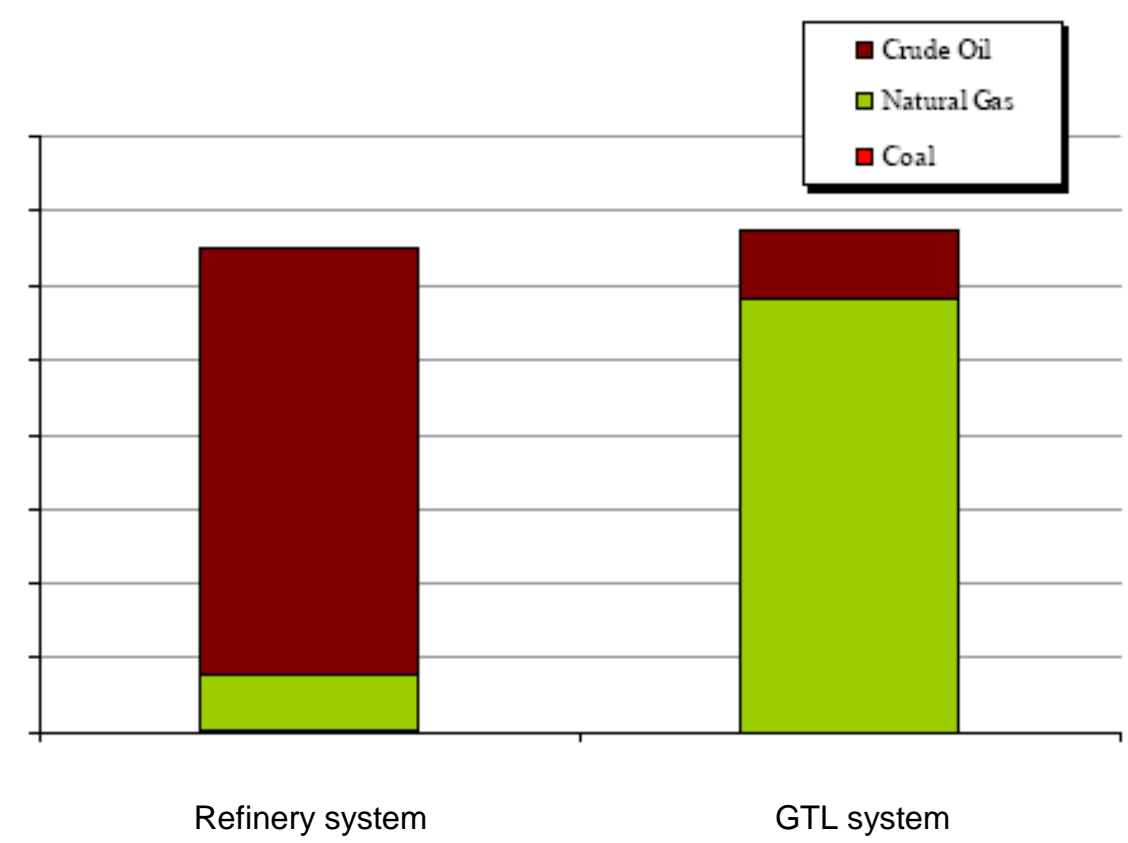

Figure 5: Total system wide energy consumption of the GTL and refinery based system over the life cycle (Source: Sasol Chevron Study) 
The GTL technology provides access to a resource that is not utilized today. As both systems provide the same products, the GTL system extends the availability of crude oil reserves. Figure 5 illustrates that the two technologies are based on two different resources. While the crude oil based system uses already developed and utilized resources, the GTL system will use remote gas reserves.

It can be expected that the general market need for transportation fuels will continue to grow. Known crude oil reserves will continue to serve as a major source to meet this market need. The utilization of remote and otherwise unutilized gas reserves extends the availability of known crude oil reserves by providing an alternative resource for transportation fuels. It also contributes to an enhanced diversity and security in supply.

\subsection{AIR POLLUTANTS}

\section{Acidifying Emissions $\left(\mathrm{SO}_{\mathrm{x}}, \mathrm{NO}_{\mathrm{x}}\right)$}

Acidification impacts arise in particular from sulphur oxides and nitrogen oxides emissions. In this context, other acidifying gases (such as ammonia) are irrelevant.

The Shell and Sasol Chevron studies show the GTL system emits less acidifying emissions, in the range of $19 \%$ to $54 \%$. The ConocoPhillips study suggests a reduction in emissions of up to $20 \%$ comparing GTL fuel with ultra-low sulphur diesel, and up to a $60 \%$ reduction when compared to conventional diesel.

Overall, with the exception of transport, ${ }^{4}$ the GTL system has less air acidification impact potential for all life cycle stages. SOx and NOx emissions account for the majority of the total acidification potential. It is noteworthy that LCA aggregates emissions over different locations and over the lifetime of the products. Therefore contributions to acidification in sensitive and less sensitive environments are counted on an equal basis. The emissions over the sea are an example of acidifying emissions being released into a less sensitive environment. In interpreting the LCA study findings one could consequently consider those contributions as less relevant.

The location of the GTL plants will be in close proximity to the remote gas reserves and therefore in areas less prone to producing air acidification problems. Probably more relevant is the fact that the fuel combustion (use stage) is likely to occur in more sensitive areas, such as for automotive transport and heating. The overall advantage in the use phase comes from the heating and grid electricity generation applications. These differences mainly result from the substitution of gasoil and heavy fuel oil with natural gas. Fuel oils contain significant amounts of sulphur, which is released in the combustion process. Additional advantages arise from the low NOx-intensity from using natural gas, as compared to burning oils. The lower NOx emissions can also be expected in road transport, where the GTL fuels cause lower NOx releases.

\footnotetext{
${ }^{4}$ With the conventional refinery, crude oil is transported to the refinery and finished product is transported to the user. With GTL, transport to the user is farther, but this is offset because there is no transport from extraction to processing. Overall, environmental releases from all transport are essentially equivalent.
} 


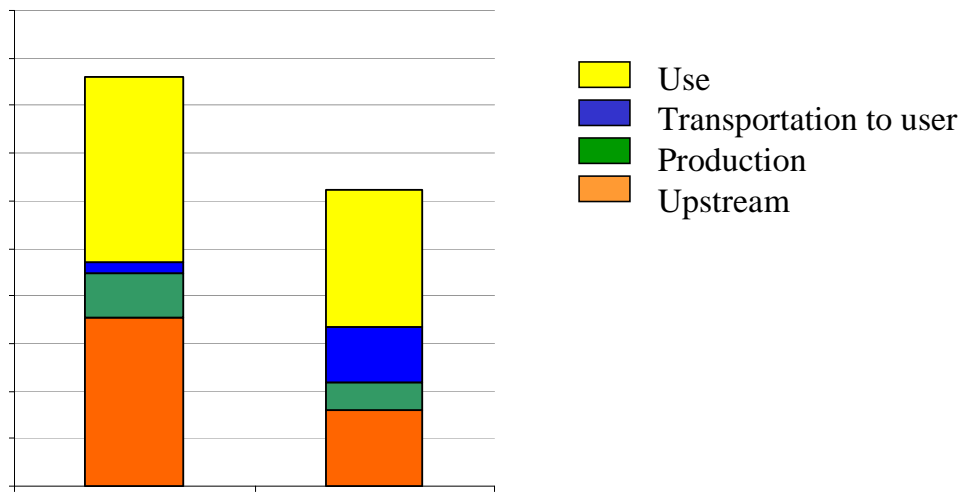

Refinery system GTL system

Figure 6: $\quad$ System wide acidification contributions of the GTL and refinery based system over the life cycle (Source: Shell Study).

The refinery system utilizes crude oil with a sulphur content (assumed in the studies) ranging from $0.15 \%$ to $2.92 \%$ and converts it into products with regulated ${ }^{5}$ sulphur. This processing causes higher sulphur oxides emissions at the refinery during production.

The ConocoPhillips study expresses the results for the comparison of transportation fuels. The advantage of the GTL fuel in the vehicle phase becomes obvious. GTL fuel and ultra-low sulphur diesel produced with the refinery system have significant advantages over conventional diesel and gasoline (mogas).

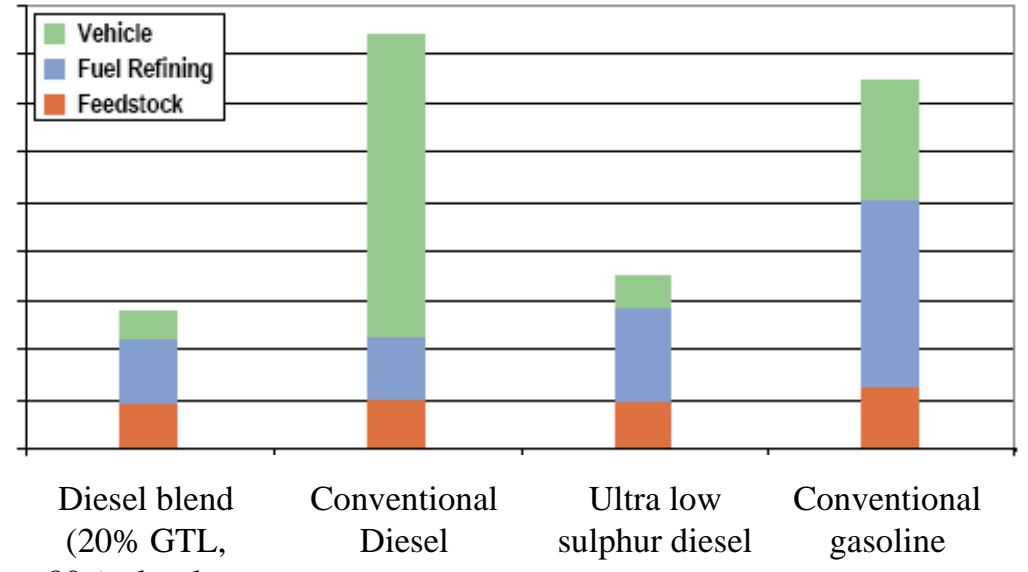

$80 \%$ ultra low

sulphur diesel)

Figure 7: Acidification contributions of GTL fuel, conventional diesel and ultra-low sulphur diesel in comparison with gasoline per distance travelled for a 2006 scenario (Source: ConocoPhillips Study).

\footnotetext{
${ }^{5}$ Recent regulatory developments in different regions have set forth more stringent sulphur content levels in transportation fuels.
} 


\section{Emissions of Volatile Organic Compounds (VOCs)}

Volatile organic emissions include all organic airborne atmospheric emissions. Typically methane, though a contributor to VOCs, is measured separately because it is an important GHG.

Different individual hydrocarbons vary in their contribution to summer smog formation (photochemical oxidant formation). Individual compounds are not distinguished due to lack of data, but an average VOC contribution can be used as a basis for assessment. The GTL system is responsible for up to $36 \%$ lower VOC emissions and resulting reductions in summer smog according to one system expansion study. The other studies show differences up to $82 \%$ in favour of the GTL system. The co-product expansion study concludes as a minimum 5\% and as a maximum up to $64 \%$ reductions in VOC emissions.

It is noteworthy that emission of VOCs does not necessarily lead to a photochemical oxidant formation impact since the actual formation depends on local factors including background NOx concentration, sunlight, temperature, humidity, etc.

Major VOC emissions from the refinery system include upstream processing (here due to extraction and transport of crude oil) and refining. The results suggest a significant VOC advantage from extracting and processing natural gas instead of crude oil.

In addition, GTL fuel used in Light Duty Compression Ignition and Heavy Duty vehicles results in lower VOC emissions. Natural gas in heating and grid electricity applications results in slightly higher VOC emissions for the refinery system (see Figure 8).

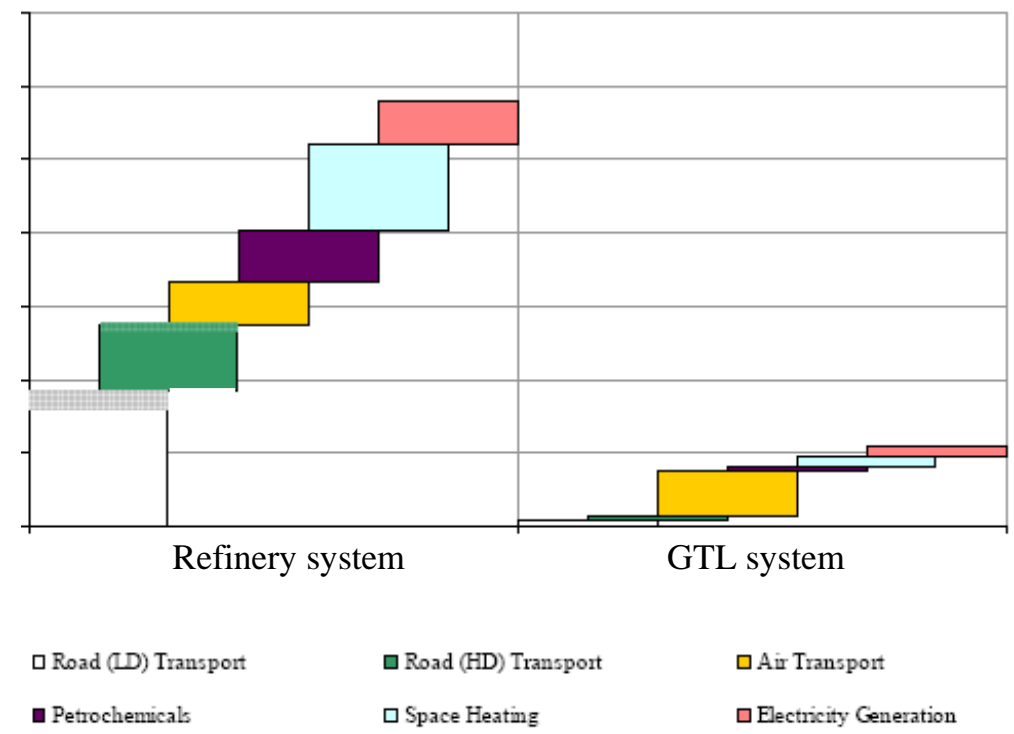

Figure 8: $\quad$ System wide photo-oxidant creation contributions of the GTL and refinery based system over the life cycle (Source: Sasol Chevron Study) 


\section{Particulate Emissions}

The studies did not distinguish between the sizes of particulates (e.g. PM2.5, PM10) due to lack of data. For all particulates, the GTL system has between $40 \%$ to $67 \%$ lower emissions than the conventional refining system. Differences come from all life cycle phases with the exception of transport (see Figure 9).

Like acidifying emissions, particulate emissions also vary in their potential environmental relevance, depending on whether they are released in more or less sensitive environments. Urban areas are very sensitive, while offshore emissions from transport are practically irrelevant as far as possible health impacts are concerned. The advantages of the significant reduction of particulate emissions for the GTL system in road transport, space heating and electricity generation occur in more sensitive urban environments. In particular the lower road transport particulate emissions are very relevant to current discussions about particulate emissions from diesel engines.

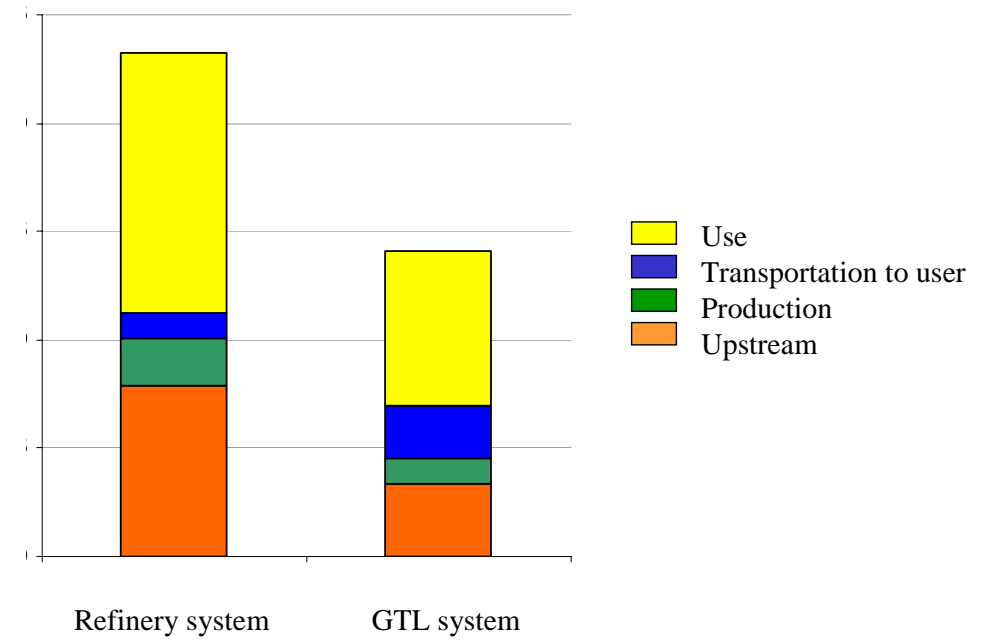

Figure 9: $\quad$ System wide particulate emissions of the GTL and refinery based system over the life cycle (Source: Shell Study)

\subsection{SOLID WASte Generation}

The GTL System generates up to $40 \%$ less solid waste than the conventional refinery system.

For both systems the production stage generates the most waste and accounts for up to $80 \%$ of total waste in the refinery system and $75 \%$ in the GTL system.

The types of wastes generated differ between the systems. While for the GTL system more bio-sludge is produced, the conventional system generates more of all other waste types, including hazardous waste. It should be noted, that only the Shell study examined waste in greater detail. 


\section{Conclusions}

The three LCA studies examine similar technologies and are very similar in scope and objectives. The results of the studies show very similar results. Although different data sources have been used and the boundary conditions of the assessments vary, the overall findings indicate that the conclusions can be generalized.

While conventional refinery systems have undergone decades of continuous improvement, it is prudent to note that the GTL system is relatively new. Improvements and innovations to the GTL system can be expected in the future and thus the comparison between the technologies in this report is conservative.

The overall conclusions from summarizing the three LCA studies can be categorized into environmental performance, market compatibility and societal relevance:

\subsection{EnVIronmental Performance}

\section{Resource consumption:}

- Fuelling vehicles with GTL fuel consumes fewer petroleum resources per mile travelled than with conventional diesel.

- The GTL technology extends the availability of crude oil reserves.

- GTL fuel production is based on a resource that will continue to be available for up to two decades after crude oil reserves are depleted, according to current data. ${ }^{6}$

- Overall energy use of the GTL system is higher.

\section{GHG performance:}

- Production and use of GTL fuel has the potential of contributing less greenhouse gas to the atmosphere than production and use of conventional diesel. As of today, the GTL system is at least neutral in its total GHG impact compared to the refinery system.

- While the GHG emissions from production and upstream processes of the GTL system are higher compared to the refinery based system, the advantages in the fuel consumption or use phase, at a minimum, compensate for those differences.

\section{Air pollutants:}

- One kilogram of GTL fuel takes a vehicle further than one kilogram of petroleumbased diesel. The combustion of less fuel for the same distance travelled can reduce negative impacts on urban air quality.

\footnotetext{
${ }^{6}$ Challenges of Electric Power Industry Restructuring for Fuel Suppliers, Energy Information Agency, Office of Coal, Nuclear, Electric and Alternative Fuels, September 1998.
} 
- With significantly lower emissions of acidifying gases, GTL technology potentially causes less air acidification than the refinery technology.

Waste:

- GTL fuel production generates less solid waste and less hazardous waste.

\subsection{MARKET COMPATIBILITY}

- The GTL technology combines a reliable feedstock with a potential long-term supply.

- GTL fuel can be used neat or blended with conventional diesel in conventional dieselpowered vehicles and existing infrastructure.

- The GTL technology is complementary to the refinery based system.

\subsection{SOCIETAL RELEVANCE}

- Consumers and commercial fleet operators can benefit from the advantages of the GTL system without investment or changes to their existing infrastructure and assets.

- GTL fuels may even offer performance advantages in some cases. Higher distance travelled per unit mass or increased performance may be possible.

The overall environmental profile of the GTL system is well balanced and offers advantages. Being at an earlier stage of its development, the technology has room for improvements. It may contribute to meeting current environmental concerns around fuel and energy systems, including air quality improvements in urban areas and reducing the specific GHG intensity of fuel systems. No single environmental attribute was identified to be a major environmental disadvantage. 


\section{ANNEXES}

\section{AnNex A: Glossary \& ABBReViations}

BAU

Characterization

Critical review

Cut off criteria

Co-product

CFE

$\mathrm{CH}_{4}$

CI

CIDI

CML

$\mathrm{CNG}$

$\mathrm{CO}$

$\mathrm{CO}_{2}$

Functional unit

FCC

FCV

FRFG

FT

FTD

Global warming

GHG

GREET

GTL

GWP
"Business as Usual" (baseline)

Calculation of a life cycle environmental impact by assigning a weighting factor to assigned life cycle inventory results, to achieve a common measure

Procedure whereby the goal and scope, results and interpretations of an LCA are independently reviewed to ensure compliance with ISO standards

Preset significance level defined during the scoping of an LCA (typically on the basis of mass, energy, economic value and/or environmental relevance), below which data values need not be collected

Any two or more products from the same unit process

Co-product Function Expansion

Methane

Compression ignition

Compression ignition direct injection

Centre of Environmental Science at the Leiden University Institute

Compressed natural gas

Carbon monoxide

Carbon dioxide

Quantified performance of a product system for use as a reference unit in an LCA study

Fluid catalytic cracking

Fuel cell vehicle

Federal Reformulated Gasoline

Fischer-Tropsch

Fischer-Tropsch Diesel

LCIA characterization method using indices that quantifies the potential for warming of the atmosphere as a result of specific emissions. It is expressed in terms of the global warming potential of an equivalent mass of carbon dioxide

Greenhouse gas

Greenhouse Gases, Regulated Emissions, and Energy Use in Transportation

Gas to Liquids

Global warming potential - Relative measure to express greenhouse gas 
relevance of an emission expressed in $\mathrm{CO}_{2}$-equivalents

HD

HEV

IPCC

ISO

LCA

LCI

LCIA

LD

LNG

LPG

Mogas

Naphtha

NOx

PM

Sensitivity analysis

SI

SIDI

SMDS

SOx

SPD

TRACI

ULS

ULSD

US DOE

VOC

WMO
Heavy duty

Hybrid electric vehicle

Intergovernmental Panel on Climate Change

International Organization for Standardization

Life cycle assessment - Compilation and evaluation of the inputs, outputs and the potential environmental impacts of a product or technology system throughout its life cycle

Life cycle inventory (analysis) - Phase of LCA involving the compilation and quantification of inputs and outputs for a given product or technology system throughout its life cycle

Life cycle impact assessment - Phase of LCA aimed at understanding and evaluating the magnitude and significance of the potential environmental impacts of a product or technology system

Light duty

Liquefied natural gas

Liquefied petroleum gas (propane, butane)

Gasoline

Chemical feedstock - refinery product

Nitrogen oxides as nitrogen dioxide $\left(\mathrm{NO}_{2}\right)$

Particulate matter

Systematic procedure for estimating the effects on the outcome of a study of the chosen methods and data

Spark Ignition

Spark ignition direct injection

Shell Middle Distillate Synthesis (Gas to Liquids process)

Sulphur oxides as sulphur dioxide $\left(\mathrm{SO}_{2}\right)$

Slurry Phase Distillate (Gas to Liquids process)

Tool for the Reduction and Assessment of Chemical and other Impacts

Ultra low sulphur

Ultra Low Sulphur Diesel

United States Department of Energy

Volatile organic compound

World Meteorological Organization 


\section{ANNEX B: LIFE CyCLE ASSESSMENT}

\section{What is LCA?}

Life Cycle Assessment (LCA) studies involve the collection, assessment and interpretation of data from an environmental perspective over a product's lifecycle (production, use, and endof-life). Studies can evaluate entire product life cycle, often referred to as cradle-to-grave or cradle-to-cradle studies, or parts of a product life cycle, referred to as cradle-to-gate or gateto-gate studies. The ISO 14040 series of standards contain the international standards for Life Cycle Assessment. The series was developed with international experts on LCA from more than fifty countries over a period of more than 10 years. The standards provide detailed guidelines for performing LCA studies, by establishing a consensus approach, while still allowing flexibility; however, individual analysts may still interpret or modify the 14040 approaches into more specific methods or, at the next level, into their specific tools or software. Focus in the standard is on preventing misuse of LCA, particularly for discriminating studies comparing one product versus a competitor's product or other misuse for claims, etc. There are several documents in the ISO 14040 series, covering the methodological steps for LCA and providing illustrations with examples.

According to ISO 14040, the four phases of an LCA are (1) Goal and Scope Definition, (2) Life Cycle Inventory, (3) Impact Assessment, and (4) Interpretation (see Figure B.1).

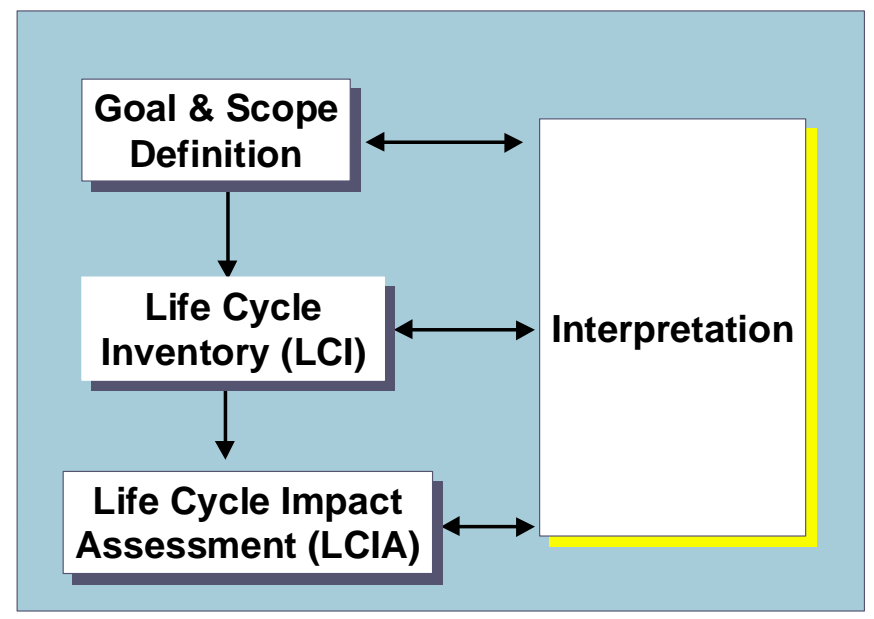

Figure B.1: $\quad$ Life Cycle Assessment methodology: the ISO 14040 framework

The goal of a study includes a definition of the purpose of the study. This includes statements on whether the study will be communicated externally, or used only for internal purposes, whether the study is strategic or tactical and whether a critical review by external parties is to be carried out. Each of these has direct influence on the scope of an LCA study. The scope of a study defines the system boundaries and functional unit for the study. System boundaries are defined according to the goal and determine what will be considered in the study and what will be excluded. Central to this is the functional unit of a study-which explicitly defines the service or function provided by the system (e.g., structural integrity for 50 years). The results of the LCA study should directly relate to the functional unit; for example, if the functional unit were $1 \mathrm{~kg}$ of a product, the results would include the amount of pollutants released for 
every kg of product. This step also defines the data and information that will be collected, and how the data will be assessed for quality, consistency, and environmental impact.

Completing a Life Cycle Inventory involves compiling data about relevant inputs and outputs of a product system that may contribute to multiple environmental issues. The data collection is carried out for each process as defined in the goal and scope definition. Depending on the goal and scope definition, data may be collected first-hand from measurements and estimates of key activities, or may be based on information drawn from existing LCA databases. Different levels of aggregation are possible, including individual processes and sub-systems (such as energy supply or transport, etc.). Typically, the inventory data is collected using questionnaires and modelled using one of many LCA software packages.

The Life Cycle Impact Assessment phase assesses the potential environmental impacts associated with the measured or estimated environmental inputs and outputs compiled in the inventory phase of the LCA. It is important to note here that LCA is not a single-issue tool; rather, the analysis encompasses numerous environmental issues (e.g., energy, water pollution, climate change), thus allowing for broad consideration of the impacts of the system.

Interpretation is the final phase of an LCA. In the interpretation, an investigation of significant environmental aspects (e.g. energy use, greenhouse gases), significant contributions to indicators or scores, and significant unit processes in the system are carried out. For example, if the results of an impact assessment had indicated an unexpected value for the Global Warming Potential indicator, the analyst could refer back to the inventory to determine which outputs are contributing to the value, and which unit processes those outputs are coming from. This is also used as a form of quality control, the results of which are used to refine scope definition. This step helps provide more certain conclusions and recommendations.

LCA can be characterized by the following principles:

- Life Cycle Perspective: LCA is unique in considering the whole physical life cycle of a product (or service) system, from raw material extraction, over energy and material production, manufacturing, use and end of life operations. Through such a perspective burden shifting between life cycle stages or individual processes can be identified and avoided.

- Comprehensiveness: LCA ideally includes all environmental aspects, such as raw material extraction, ecologic systems integrity, and human health considerations. By including all aspects into one common assessment, trade-offs can be identified.

- Transparency: Due to the inherent complexity in LCA system assessments, transparency is an important guiding principle in executing LCA studies, in order to ensure a proper interpretation of the results.

- Flexibility: This standard provides overall principles and guidelines for LCA. The methodology allows specific LCA studies sufficient flexibility in applying this standard while maintaining a common methodological framework.

- Iterative nature: LCA consists of phases: Goal and Scope Definition, LC Inventory, LC Impact Assessment (if performed), and LC Interpretation. This standard defines LCA as iterative in nature, where the individual phases of an LCA use results of the 
preceding phases and requires the standard user to constantly observe the given goal and scope of the study. The iterative approach within and between the phases of LCA is important, because it contributes to the comprehensiveness and consistency of the study and the reported results.

- Environmental Focus: LCA studies the environmental aspects of a product system. Typically economic and social aspects are outside the study. At the same time LCA provides a systems perspective, so that other analytical tools may refer to LCA studies for a more complete environmental assessment than is provided by a site or individual emission perspective.

- Science Based: The LCA methodology and LCA studies should be science based. While the state of scientific knowledge constantly changes, LCA studies are a snapshot of a given state of knowledge at a certain time.

- Relative Nature: LCA' s relate environmental aspects to a product system. All findings are measured and expressed in environmental aspect per reference unit. In addition, LCA relates a product's life cycle impact assessment aspects to reference substances, such as GHG equivalents, which are expressed in equivalent units of carbon dioxide $\left(\mathrm{CO}_{2}\right)$.

- Potential Environmental Impacts: LCA studies only potential environmental impacts. Due to the relative expression of impacts to a reference unit, the integration of environmental releases over space and time, the inherent uncertainty in modelling environmental impacts, and the fact that some possible impacts are clearly future impacts, all impacts are potential in nature.

\section{Why LCA?}

Products and services contribute to different environmental aspects during different stages of their life cycle. Life Cycle Assessment is a tool that aims to identify possibilities to improve the environmental behaviour of the systems under consideration. Therefore it is necessary to systematically collect and interpret material and energy flows for all relevant processes. The whole life cycle of a system has to be considered to prevent overlooking possible important environmental aspects.

LCA enables the necessary dialogue among a product or service's value creation chain participants, authorities and other stakeholders to promote a truly sustainable business strategy. Therefore all the related actors both contribute to and benefit from this approach by saving resources and energy, as well as remediation and abatement cost in an environmentally friendly and socially compatible way.

The possibilities that life cycle studies offer are large. Continuous improvement and further development of methods and data contribute to an increased understanding and usability of study results. LCA methodology has been tested and refined across a wide range of industrial applications. Today it is a very reliable and stable tool, fit for day-to-day industrial work. On the basis of accumulated experience with LCA, the method allows the successful use for various applications such as:

- Material selection for different applications 
- Process comparison

- Product optimization

- Decision support for investment decisions

- Strategic planning / company strategy

- Marketing

- Dialogue with clients and authorities

- Weak point analysis in production and purchasing (economic and environmental)

- Benchmarking for product alternatives

A life cycle approach can help make choices that generate economic value, improve the natural environment and strengthen our social systems. This is because a life cycle approach helps us recognize how our choices - such as buying electricity or a new t-shirt - are one part of a whole system of events. A life cycle starts with raw materials and energy generation, and then includes manufacturing and transport, use (washing the $t$-shirt, for instance) and eventually final disposal or recycling. A life cycle approach helps us recognize how our choices influence each of these stages, so we can choose to make positive impacts on the economy, the environment and society. A life cycle approach means recognizing that our choices and decisions are not isolated, but are connected to a larger system and will surely influence that system.

A life cycle approach is not about making the "right" or "wrong" decisions. It simply helps make decisions in context, knowing all stages of the life cycle. A life cycle approach is about looking for unintentional impacts of our actions and taking responsibility for those impacts.

In all instances, a life cycle approach also enables each of us (product designers, service providers, government agents and individuals) to make choices for the longer term and with consideration of all environmental media. We can try to avoid short-term decisions that lead to environmental degradation - such as over-fishing or polluting our air with mercury. We can also try to avoid decisions that fix one environmental problem, like polluting the air, but cause other unexpected, or costly environmental problems, such as polluting the water. Life cycle approaches avoid shifting problems from one life cycle stage to another, from one geographic area to another and from one environmental medium to another.

At the First Global Ministerial Environmental Forum in May 2000, the European Ministers of Environment stated: "We have at our disposal the human and material resources to achieve sustainable development, not as an abstract concept but as a concrete reality". And further it was stated that our efforts "must be linked to the development of cleaner and more resource efficient technologies for a life cycle economy." By "life cycle economy" the ministers meant a society that views the production, use and disposal of a product as a comprehensive cycle, covering all required processes: extraction and processing; manufacture; transport and distribution; use, reuse and maintenance; recycling; and final disposal.

At the WSSD (World Summit on Sustainable Development) in Johannesburg in 2002, world leaders also recognised the need to change the unsustainable patterns of production and consumption, and stated that: "We must develop production and consumption policies to improve the products and services provided, while reducing environmental and health impacts, using, where appropriate, science based approaches, such as Life Cycle Analysis". According to the WSSD, life cycle approaches will have to play a key role; but these approaches must suit the requirements of all relevant stakeholders, particularly those from 
developing countries. Both capacity building and training have to provide important contributions in order to achieve this. Furthermore the ministers suggested the development of programmes to support sustainable consumption and production patterns, based on sciencebased approaches such as Life Cycle Assessment.

\section{How others use LCA}

LCA is broadly used in many industry sectors. The applications differ significantly and reflect specific requirements and experiences. Figure B.2 highlights typical applications of LCA.

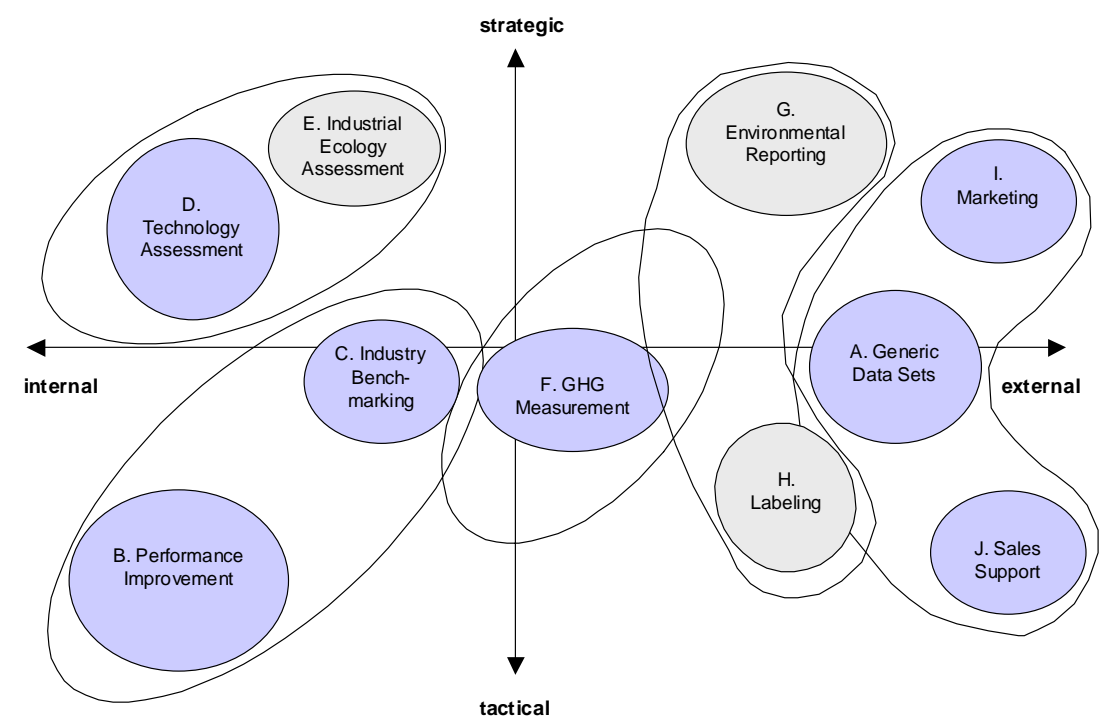

Figure B.2: Applications of LCA

LCA is used mostly internally within an organization or within a value chain. Strategic and tactical decisions are being supported by LCA studies. A major application for LCA is assessing environmental performance improvement opportunities such as energy-efficiency or resource productivity (i.e., in an intra-company benchmarking of operations or comparison of sites). Another major use of LCA is technology assessment and business planning. Here LCA can be used to assess new technologies for their environmental performance. This analysis supports other sources of information concerning business, regulatory, technology, legal, etc. LCA study results are also often used in external communication, such as in environmental reports, for marketing and in customer dialogue processes.

In the auto industry, LCA is an established assessment tool for tactical material and process choices. Material selection for components at an early product design stage requires performance, economic and environmental information. LCA can provide sufficiently comprehensive and accurate information on a component's environmental performance. The life cycle perspective is particularly critical for the auto industry, since material choices for weight reduction significantly influence the fuel consumption of a vehicle in use. Often lighter materials are more energy intensive in manufacture, but compensate these higher environmental burdens over the use phase of the car where fuel consumption is reduced. LCA is the only established tool to assess and analyze such system-wide consequences. 
Consequently, LCA is often used in early design stages to inform designers and product developers about opportunities for improvements.

The packaging industry successfully used LCA to communicate system-wide advantages of packaging alternatives over single environmental attributes of political concern, such as waste generation. LCA studies helped develop an understanding of system-wide impacts, for example beyond the societal debate on the superiority of refillable beverage containers over single-use ones. In Europe, LCA is an established tool to communicate between policy makers and industry, and also between civil society and the private sector. LCA studies have helped by providing a basis for rational thinking in an otherwise emotional debate.

Another well-known application of LCA is the comparison of waste management options. LCA results have challenged the political waste hierarchy from avoiding waste over recycling to disposal. Often recycling is not necessarily superior to novel recovery solutions, where either feedstock products or energy can be recovered from waste streams in a way that the overall environmental impacts are better than mechanical recycling. Emerging practice in this field is that European waste management legislation refers specifically to the application of LCA in cases to demonstrate system-wide environmental advantages for recovery technologies over recycling solutions.

Other industries such as consumer good providers that are closer to the market use LCA for communicating product environmental properties or in labelling schemes. LCA is well established in the criteria development for eco-labels. In a recent effort, the European Commission developed a mandate for the European standards body CEN to develop an LCAbased labelling scheme for building and construction products. The retail industry has begun to evaluate their suppliers with LCA and in part offer preferred shelf space to particularly environmental friendly products.

In summary, LCA is a well-established analytical tool, used by industry and the public sector. LCA is part of the ISO family of environmental management systems tools. As such it is well recognized and established.

\section{Limitations to Note}

Given that LCA offers a system-wide perspective and includes a variety of potential environmental impacts, it is useful for comparing attributes of GTL technology with conventional refinery technology. However, using LCA for this comparison does have certain limitations which should be noted:

- The results of LCAs are subject to interpretation as values and priorities (e.g. relative importance of different environmental impacts such as GHG emissions vs. smog) differ according to the values of the audience using the results;

- The nature of the system-wide analysis in LCA requires the aggregation of inputs (i.e. mass, energy) and outputs (i.e. emissions) over a variety of individual sites, transportation routes, as well as over the whole lifespan of a product or service;

- LCA studies are not absolute environmental assessments. Complementary assessments, in particular on site-specific environmental issues, are required to provide a fuller understanding of actual aspects and impacts; 
- Due to a lack of spatial (i.e. geographic) resolution, LCA results are easier to interpret for global and regional environmental themes. LCA studies can highlight the life cycle properties of the GTL system, but may conceal additional environmental advantages such as reduced tailpipe emissions and possible fuel efficiency gains for diesel engines;

- LCA studies typically do not address economic and social aspects; and

- A careful and balanced view is recommended and additional aspects have to be taken into consideration before making decisions and judgments. In particular, a more comprehensive assessment including economic and social considerations may be necessary to support decision-making.

\section{On System Expansion and Allocation}

In LCA studies, the definition of system boundaries and the selection of the functional unit to be analyzed are most critical to answering the posed question correctly. For both aspects it is critical to understand the influences of the respective choices. In the case of the three GTL LCA studies, a system expansion approach has been utilized, not an allocation approach as is used in well-to-wheel studies. The results of the two approaches are not comparable, since they study two fundamentally different systems.

Allocation is creating a "virtual" product assessment, by eliminating all co- and by-products for the assessment. Allocation uses physical (such as mass or heating value ratios) or in some cases financial properties of co-products to isolate individual product flows out of a more comprehensive system. Well-to-wheel studies for example concentrate solely on transportation fuels. Where a system (such as conventional refining or GTL) produces other products in addition to transportation fuels, these other products are not considered. Those other products are eliminated from the system, by using physical relationships of the coproducts and only accounting for the percentage share of the product of interest. If, for example, a process produces two products $\mathrm{A}$ and $\mathrm{B}$, of which only $\mathrm{A}$ is required, the mass ratio between $\mathrm{A}$ and $\mathrm{B}$ is used to determine how much respective burden the individual products have to carry from the process input and the additional upstream loads. Assessments that use such an approach compare the environmental inputs and outputs, and associated environmental impacts of transportation fuel only. The underlying question may be formulated as: "How does the environmental performance of fuel $\mathrm{X}$ compare with fuel $\mathrm{Y}$ from well-to-wheel?"

The choice of the allocation rule is often independent of the business reality or the rational behind an assessment. For example, the market does not equally value conventional refinery products. Allocating associated environmental burdens according to mass or energy ratios ignores such important considerations.

The system expansion approach takes a more comprehensive view and seeks to ask the question "What are the environmental implications of supplying markets 1, 2, 3 with products from technologies A, B and C?" To answer this question, it is necessary to consider the whole technology system. Specifically for the GTL technology, a system comparison for a complex refinery system would include refining, the main products and markets. 
Refineries produce transportation fuels and a range of other higher value products. Those products supply markets globally and, in turn, produce their own environmental impacts across the supply chain. A decision to build a new refinery is a decision to supply a number of products to a range of markets, not just transportation fuel.

A decision to develop a technology that can supply alternative products is based on financial criteria and knowledge of potential markets, amongst many other factors. The technology and all of its products will have environmental impacts. If the products being produced by such a technology have different characteristics (e.g. improved performance, cleaner properties), then the further development of the technology can serve to shift the markets being supplied.

The three LCA studies intentionally studied the whole technology system and not individual products. The system comparisons are more comprehensive compared to well-to-wheel studies, since they take the whole suite of products into account. They consider the direct market consequences of applying a new technology. 


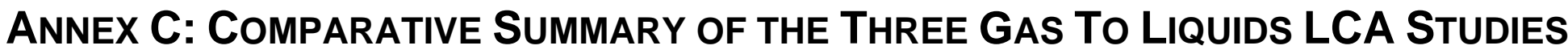

\begin{tabular}{|c|c|c|c|}
\hline Elements of the LCA & Shell & Sasol Chevron & ConocoPhillips \\
\hline \multicolumn{4}{|c|}{ General aspects of the LCA studies } \\
\hline The LCA commissioner & Shell International Gas Limited & $\begin{array}{l}\text { Sasol Technology (Pty) Ltd/Sasol } \\
\text { Chevron }\end{array}$ & ConocoPhillips and US DOE \\
\hline $\begin{array}{l}\text { The practitioner of the } \\
\text { LCA }\end{array}$ & PricewaterhouseCoopers LLP & PricewaterhouseCoopers LLP & Nexant \\
\hline The date of report & May 21, 2003 & November 13, 2002 & November 2003 \\
\hline $\begin{array}{l}\text { Compliant with ISO } \\
\text { standards? }\end{array}$ & Yes & Yes & Yes \\
\hline \multicolumn{4}{|l|}{ Definition of goal and scope } \\
\hline The purpose of the study & $\begin{array}{l}\text { - Update the data and assumptions } \\
\text { used in our earlier work } \\
\text { Report on the life cycle greenhouse } \\
\text { gas (GHG) emissions arising from the } \\
\text { SMDS option and an equivalent BAU } \\
\text { option } \\
\text { - Also analyse potential impacts on air } \\
\text { acidification and photochemical } \\
\text { oxidant formation, as well as resource } \\
\text { depletion (expressed in terms of total } \\
\text { primary energy), and consider } \\
\text { particulates emissions and production } \\
\text { of waste }\end{array}$ & $\begin{array}{l}\text { - Use a life cycle approach to quantify } \\
\text { the environmental inputs and outputs } \\
\text { and associated with potential } \\
\text { environmental impacts from } \\
\text { production and use of diesel and } \\
\text { other products arising from Sasol's } \\
\text { SPD process and from refining crude } \\
\text { oil }\end{array}$ & $\begin{array}{l}\text { - Ensure that investment in and } \\
\text { development of GTL technology } \\
\text { would be sustainable into the future } \\
\text { - Understand life cycle environmental } \\
\text { and human health potential impacts } \\
\text { of GTL products in comparison with } \\
\text { alternatives. } \\
\text { Develop and deploy technologies that } \\
\text { will produce ultra-clean-burning } \\
\text { transportation fuels for the 21st } \\
\text { century from both petroleum and non- } \\
\text { petroleum resources (US DOE) }\end{array}$ \\
\hline The intended audience & Internal and external & $\begin{array}{l}\text { Internal (recommendation from reviewer } \\
\text { to use it externally as well) }\end{array}$ & Internal and external \\
\hline
\end{tabular}




\begin{tabular}{|c|c|c|c|}
\hline Elements of the LCA & Shell & Sasol Chevron & ConocoPhillips \\
\hline $\begin{array}{l}\text { The functions of the } \\
\text { product system(s) }\end{array}$ & $\begin{array}{l}\text { - The provision of energy for heating a } \\
\text { building. } \\
\text { Mass of petrochemicals produced at } \\
\text { a chemical cracker. } \\
\text { Distance travelled by an aircraft on } \\
\text { combustion of fuel in its engines. } \\
\text { Mass of detergent feedstock } \\
\text { produced. } \\
\text { The distance travelled by light duty } \\
\text { (LD) vehicles with spark ignition (SI) } \\
\text { engines, meeting the Euro III } \\
\text { standard. } \\
\text { The distance travelled by LD and } \\
\text { heavy duty (HD) vehicles with Cl } \\
\text { engines (in a ratio of 70:30 by } \\
\text { volume), meeting the Euro III } \\
\text { standard. } \\
\text { The provision of electricity to a } \\
\text { national grid. } \\
\text { Mass of base oils produced. }\end{array}$ & $\begin{array}{l}\text { - The distance travelled by a light duty } \\
\text { (LD) vehicle and heavy duty (HD) } \\
\text { vehicle. } \\
\text { The distance travelled by an aircraft } \\
\text { as a result of combustion of fuel in its } \\
\text { engines. } \\
\text { The provision of energy for space } \\
\text { heating applications. } \\
\text { The provision of electricity to a } \\
\text { national grid. } \\
\text { The production of petrochemicals } \\
\text { (ethylene, propylene, benzene- } \\
\text { toluene-xylene (BTX), butadiene, } \\
\text { hydrogen, alkane, carbon black and } \\
\text { heat exported from the chemical } \\
\text { cracker). }\end{array}$ & 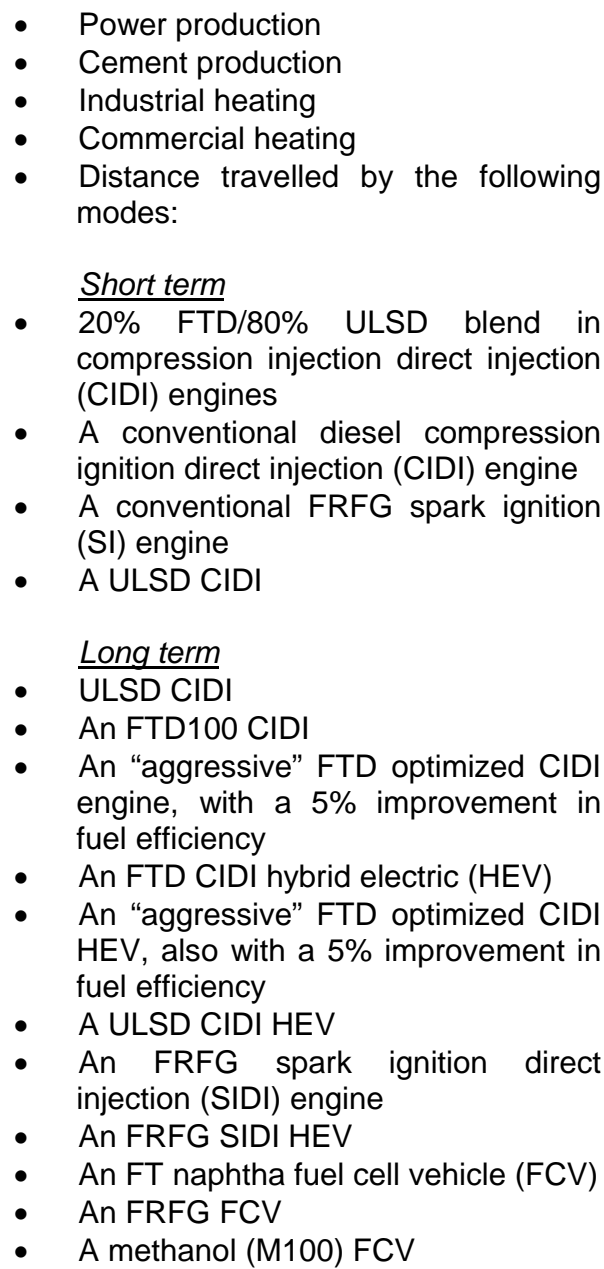 \\
\hline
\end{tabular}




\begin{tabular}{|c|c|c|c|}
\hline Elements of the LCA & Shell & Sasol Chevron & ConocoPhillips \\
\hline The functional unit & $\begin{array}{l}\text { Distance travelled by LD and HD vehicles } \\
\text { (ratio } 70: 30 \text { by volume) with Cl engines, } \\
\text { meeting the Euro III standard: } 7.8 \times 10^{6} \\
\mathrm{~km}(\mathrm{HD}), 63 \times 10^{6} \mathrm{~km} \text { (LD) }\end{array}$ & $\begin{array}{l}\text { Distance travelled by an LD vehicle, with } \\
\text { emissions characteristics associated with } \\
\text { a specific drive cycle: } 10,648,500 \mathrm{~km} \text {. } \\
\text { Distance travelled by an HD vehicle, with } \\
\text { emissions characteristics associated with } \\
\text { a specific drive cycle: } 83,324,200 \mathrm{~km} \text {. }\end{array}$ & $\begin{array}{l}\text { The functional unit for the UCF LCA is } \\
\text { light duty (LD) vehicle miles. LD vehicles } \\
\text { are defined as passenger vehicles with } \\
\text { gross weights of less than } 6,000 \text { pounds }\end{array}$ \\
\hline References flows & $\begin{array}{l}\text { BAU: } 9300 \text { tonnes Ultra low sulphur gasoil } \\
\text { (diesel). } \\
\text { SMDS: } 9130 \text { tonnes SMDS gasoil } \\
\text { (diesel). }\end{array}$ & $\begin{array}{l}\text { "BAU: } 36116 \text { tonnes diesel } \\
\text { SPD: } 35012 \text { tonnes GTL diesel. }\end{array}$ & Not given. \\
\hline Life cycle stages included & $\begin{array}{ll}\text { - } & \text { Upstream } \\
\text { - } & \text { Production } \\
\text { - } & \text { Transport } \\
\text { - } & \text { Use }\end{array}$ & $\begin{array}{ll}\text { - } & \text { Feedstock Production and Transport } \\
\text { - } & \text { Production Plant } \\
\text { - } & \text { Products Transport and Storage } \\
\text { - } & \text { Products Use }\end{array}$ & $\begin{array}{ll}\text { - } & \text { Feedstock Stage } \\
\text { - } & \text { Fuel Stage } \\
\text { - } & \text { Vehicle stage }\end{array}$ \\
\hline Allocation procedures & System boundary expansion & System boundary expansion & Co-product function expansion \\
\hline Data requirements & $\begin{array}{l}\text { Cut-off criteria } 3 \% \text { for mass and energy, } \\
\text { environmental relevance. }\end{array}$ & $\begin{array}{l}\text { Cut-off criteria } 3 \% \text { for mass and energy, } \\
\text { environmental relevance. }\end{array}$ & Not given. \\
\hline
\end{tabular}




\begin{tabular}{|c|c|c|c|}
\hline Elements of the LCA & Shell & Sasol Chevron & ConocoPhillips \\
\hline \multicolumn{4}{|l|}{ Life cycle inventory } \\
\hline $\begin{array}{l}\text { System primary products } \\
\text { and co-products }\end{array}$ & $\begin{array}{ll}\text { BAU } \\
\text { Primary products: } \\
\text { - } \quad \text { Mogas } \\
\text { - } \quad \text { ULS Gasoil } \\
\text { - } \quad \text { Industrial Gasoil } \\
\text { - } \quad \text { LPG } \\
\text { - } \quad \text { Keroshtha } \\
\text { - } \quad \text { Heavy fuel oil } \\
\text { - } \quad \text { Base oils } \\
\text { SMDS } \\
\text { Primary products: } \\
\text { - } \quad \text { LPG } \\
\text { - } \quad \text { Naphtha \& condensate } \\
\text { - } \quad \text { Base oils } \\
\text { - } \quad \text { n-paraffins }\end{array}$ & $\begin{array}{l}\text { BAU } \\
\text { Primary products: } \\
\text { - } \quad \text { Mogas } \\
\text { - } \quad \text { Diesel } \\
\text { Co-products: } \\
\text { - } \quad \text { LPG } \\
\text { - } \quad \text { Naphtha } \\
\text { - } \quad \text { Kerosene } \\
\text { - } \quad \text { Residual Fuel } \\
\text { SPD } \\
\text { Primary products: } \\
\text { - } \quad \text { Diesel } \\
\text { Co-products: } \\
\text { - Naphtha } \\
\text { - } \quad \text { LPG }\end{array}$ & $\begin{array}{l}\text { BAU } \\
\text { Primary products: } \\
\text { - Gasoline } \\
\text { - } \quad \text { Diesel } \\
\text { Co-products: } \\
\text { - Heavy residual oil } \\
\text { - Coke } \\
\text { GTL } \\
\text { Primary products: } \\
\text { - FT Diesel } \\
\text { ("no significant co-products") } \\
\text { Methanol } \\
\text { - Methanol }\end{array}$ \\
\hline Inventory categories & $\begin{array}{l}\text { - } \quad \text { Climate change (CO2, } \mathrm{CH} 4) \\
\text { - Local/regional air quality (SOx, NOx, } \\
\text { VOCs, particulates) } \\
\text { Energy and waste (total primary } \\
\text { energy, total waste (and recovered } \\
\text { sulphur)) }\end{array}$ & $\begin{array}{l}\text { - } \quad \text { Climate change (CO2, } \mathrm{CH} 4) \\
\text { - } \quad \text { Regional/local air quality (SOx, NOx, } \\
\text { - } \quad \begin{array}{l}\text { Resource particulates) } \\
\text { natural gas, total primary energy) }\end{array}\end{array}$ & $\begin{array}{ll}\text { - } & \text { Greenhouse gases (CO2, CH4, N2O) } \\
\text { - } & \text { Air pollutants (NOx, SOx, CO, PM10, } \\
& \text { VOC) } \\
\text { - } \quad \text { Total energy } \\
\text { - } \quad \text { Total petroleum fuel use } \\
\text { - } \quad \text { Total fossil fuel use } \\
\text { - } \quad \text { Waste }\end{array}$ \\
\hline Life cycle inventory & Air emissions outputs & $\begin{array}{l}\text { Main resource inputs and air emissions } \\
\text { outputs }\end{array}$ & Energy and air emission outputs. \\
\hline $\begin{array}{l}\text { Time-related coverage } \\
\text { (when data originated) }\end{array}$ & $\begin{array}{l}\text { SMDS process: } 2002 \\
\text { Various other processes: 1984-2001 }\end{array}$ & $\begin{array}{l}\text { SPD process: } 2001 \\
\text { Various other processes: 1993-2000 }\end{array}$ & $1999-2003$ \\
\hline $\begin{array}{l}\text { Geographical coverage } \\
\text { (where data originates } \\
\text { from) }\end{array}$ & Europe, Asia & Europe, U.S., Japan & U.S. \\
\hline
\end{tabular}




\begin{tabular}{|c|c|c|c|}
\hline Elements of the LCA & Shell & Sasol Chevron & ConocoPhillips \\
\hline $\begin{array}{l}\text { Technology coverage (in } \\
\text { use when this data was } \\
\text { collected) }\end{array}$ & $\begin{array}{l}\text { BAU: "a } 330 \mathrm{kbbl} / \mathrm{d} \text { complex refinery } \\
\text { based in Western Europe, operating with } \\
\text { a thermal efficiency of } 92 \% . " \\
\text { SMDS: "a } 13000 \text { tonne/day SMDS } \\
\text { plant...operates with a thermal efficiency } \\
\text { of } 66 \% \text { " }\end{array}$ & $\begin{array}{l}\text { BAU: "The comparison refinery for Europe } \\
\text { is assumed to be a large and competitive } \\
\text { refinery located in Rotterdam, the heart of } \\
\text { the European refining centre and main } \\
\text { inter-regional exporter. We use a } 390 \\
\text { kbbl/day FCC/ hydrocracking/visbreaking } \\
\text { refinery as a typical configuration } \\
\text { supplying the region." } \\
\text { SPD: "The Sasol SPD plant has a } \\
\text { capacity of } 33 \text { kbbl/day, a carbon } \\
\text { efficiency of } 74 \% \text { and an overall energy } \\
\text { efficiency of } 58 \% . "\end{array}$ & $\begin{array}{l}\text { BAU: Nexent developed Aspen models } \\
\text { based on GREET model } \\
\text { GTL: "ConocoPhillips data based on pilot- } \\
\text { scale plants and efficiency targets } \\
\text { Plus models for validation and theoretical } \\
\text { limits." }\end{array}$ \\
\hline Time Horizon & 2010 & 2010 & 2006 and 2015 \\
\hline Geographical Setting & $\begin{array}{l}\text { BAU fuels produced in the Netherlands. } \\
\text { SMDS fuels are produced in the Middle } \\
\text { East. Fuels are used in Western Europe } \\
\text { (transportation fuels) and Western Europe } \\
\text { and Asia (other fuels). }\end{array}$ & $\begin{array}{l}\text { BAU fuels produced in the Netherlands. } \\
\text { SPD fuels are produced in Western Africa } \\
\text { and the Middle East. Fuels are used in } \\
\text { Western Europe. }\end{array}$ & $\begin{array}{l}\text { BAU fuels produced in the US. GTL fuels } \\
\text { are produced in the Middle East. Fuels } \\
\text { are used in the US. }\end{array}$ \\
\hline \multicolumn{4}{|l|}{ Life cycle impact assessment } \\
\hline $\begin{array}{l}\text { The methodology - } \\
\text { categories (source) }\end{array}$ & $\begin{array}{ll}\text { - } & \text { Global warming potential (IPCC) } \\
\text { - } & \text { Acidification potential (CML) } \\
\text { - Photochemical smog potential } \\
\text { (WMO) }\end{array}$ & $\begin{array}{ll}\text { - } & \text { Global warming potential (IPCC) } \\
\text { - } & \text { Acidification potential (CML) } \\
\text { - } & \text { Photochemical smog potential } \\
\text { - } & \text { Resource Depletion }(\mathrm{CML})\end{array}$ & $\begin{array}{ll}\text { - } & \text { Global warming potential (TRACI) } \\
\text { - } & \text { Acidification potential (TRACI) } \\
& \text { Photochemical smog potential } \\
\text { - } & \text { Eutrophication potential (TRACI) } \\
\text { - } & \text { Human health (criteria, cancer, and } \\
& \text { non-cancer) (TRACl) } \\
\text { - } & \text { Ecotoxicity potential (TRACI) } \\
\text { - } & \text { Resource depletion (TRACI) } \\
\text { - } & \text { Wand use (TRACl) } \\
\text { Tater use (TRACI) }\end{array}$ \\
\hline \multicolumn{4}{|l|}{ Life cycle interpretation } \\
\hline Types of analysis & $\begin{array}{l}\text { Sensitivity analysis } \\
\text { Uncertainty analysis }\end{array}$ & $\begin{array}{l}\text { Sensitivity analysis } \\
\text { Uncertainty analysis }\end{array}$ & $\begin{array}{l}\text { Sensitivity analysis } \\
\text { Uncertainty analysis }\end{array}$ \\
\hline
\end{tabular}




\begin{tabular}{|c|c|c|c|}
\hline Elements of the LCA & Shell & Sasol Chevron & ConocoPhillips \\
\hline $\begin{array}{l}\text { Name and affiliation of } \\
\text { reviewers }\end{array}$ & $\begin{array}{l}\text { Dr Dennis Postlethwaite } \\
\text { LCA Consultant }\end{array}$ & $\begin{array}{l}\text { Michael Wang } \\
\text { Argonne National Laboratory }\end{array}$ & $\begin{array}{l}\text { Dr. Steven B. Young, University of } \\
\text { Waterloo (Panel Chair) } \\
\text { Margaret K. Mann, National Renewable } \\
\text { Energy Laboratories } \\
\text { Dr. Rita Schenck, Institute for } \\
\text { Environmental Research and Education } \\
\text { Ferry Van Dijk, Shell International Gas } \\
\text { Ltd. }\end{array}$ \\
\hline Critical review reports & Yes & Yes & Yes \\
\hline $\begin{array}{l}\text { Responses to } \\
\text { recommendations }\end{array}$ & Yes & Yes & Yes \\
\hline \multicolumn{4}{|l|}{ Comparison } \\
\hline $\begin{array}{l}\text { Are systems compared } \\
\text { using the same functional } \\
\text { unit and methodology? }\end{array}$ & Yes & Yes & Yes \\
\hline $\begin{array}{l}\text { What is the baseline } \\
\text { system that is used in the } \\
\text { comparison? }\end{array}$ & $\begin{array}{l}\text { "Since refineries tend to be close to their } \\
\text { markets, we use a large ( } 330 \mathrm{kbbl} / \mathrm{day} \text { ), } \\
\text { competitive complex refinery based in } \\
\text { Western Europe as the basis for } \\
\text { comparison with SMDS" }\end{array}$ & $\begin{array}{l}\text { "The comparison refinery for Europe is } \\
\text { assumed to be a large and competitive } \\
\text { refinery located in Rotterdam, the heart of } \\
\text { the European refining centre and main } \\
\text { inter-regional exporter. We use a } 390 \\
\text { kbbl/day FCC/ hydrocracking/visbreaking } \\
\text { refinery as a typical configuration } \\
\text { supplying the region." }\end{array}$ & $\begin{array}{l}\text { "Comparison of the energy use and } \\
\text { emissions inventory for the production and } \\
\text { use of GTL products on an equivalent } \\
\text { basis with refined petroleum products } \\
\text { predominantly in use today. For example, } \\
\text { FTD may be compared with petroleum } \\
\text { diesel in application as a transportation } \\
\text { fuel." "Comparison of methanol (as an } \\
\text { alternative natural gas utilization option) } \\
\text { for use in fuel cell vehicles with GTL and } \\
\text { petroleum fuels" }\end{array}$ \\
\hline \multicolumn{4}{|l|}{ Main Findings of the Study } \\
\hline Global Warming Potential & $\begin{array}{l}\text { SMDS slightly lower than BAU, with } \\
\text { consideration of uncertainty they are at } \\
\text { least comparable }\end{array}$ & $\begin{array}{l}\text { SPD } 11 \% \text { lower than BAU, within the } \\
\text { limits of uncertainty as tested }\end{array}$ & FTD and ULSD equivalent \\
\hline Acidification Potential & $\begin{array}{l}\text { SMDS lower SO2e emissions than BAU; } \\
\text { lower AP impact depends on location }\end{array}$ & SPD lower than BAU & $\begin{array}{l}\text { FTD lower than ULSD and FRFG (not } \\
\text { within } 100 \% \text { differential error range) }\end{array}$ \\
\hline
\end{tabular}




\begin{tabular}{|c|c|c|c|}
\hline Elements of the LCA & Shell & Sasol Chevron & ConocoPhillips \\
\hline $\begin{array}{l}\text { Photochemical Oxidation } \\
\text { Potential }\end{array}$ & $\begin{array}{l}\text { SMDS } 33 \% \text { lower emissions of VOCs } \\
\text { than BAU }\end{array}$ & SPD lower than BAU & $\begin{array}{l}\text { FTD lower than ULSD and FRFG (not } \\
\text { within } 100 \% \text { differential error range) }\end{array}$ \\
\hline Primary Energy Demand & SMDS higher than BAU & SPD higher than BAU & FTD higher than ULSD \\
\hline Resource Depletion & SMDS higher than BAU & SPD higher than BAU & \\
\hline Waste & SMDS lower than BAU & & GTL fuel lower than ULSD and FRFG \\
\hline Particulates & SMDS lower than BAU & & \\
\hline Human Health & & & $\begin{array}{l}\text { FTD lower than ULSD (not within } 100 \% \\
\text { differential error range) }\end{array}$ \\
\hline Human Health Cancer & & & FTD and ULSD lower than FRFG \\
\hline Ecotoxicity & & & $\begin{array}{l}\text { FTD and ULSD higher than FRFG (within } \\
\text { error threshold) }\end{array}$ \\
\hline Wastewater & & & GTL fuels lower than ULSD and FRFG \\
\hline
\end{tabular}




\section{ANNEX D: REFERENCES}

Ultra Clean Fuels Life Cycle Assessment. ConocoPhillips and US Department of Energy. November 2003.

Use of a Life Cycle Approach to Compare the Environmental Implications of Sasol's Slurry Phase Distillate Technology with Complex Refinery. Sasol Technology Pty and Sasol Chevron. November 2002.

Shell Middle Distillate Synthesis (SMDS). Update of a Life Cycle Approach to Assess the Environmental Inputs and Outputs, and Associated Environmental Impacts, of Production and Use of Distillates from a complex Refinery and SMDS Route. Shell International Gas. May 2003.

ISO 14040:1997(E) Environmental management - Life cycle assessment - Principles and framework. Geneva: International Organization for Standardization. First edition, 1997.

ISO 14041:1998(E) Environmental management - Life cycle assessment - Goal and scope definition and inventory analysis. Geneva: International Organization for Standardization. First edition, 1998.

ISO 14042:2000(E) Environmental management - Life cycle assessment - Life cycle impact assessment. Geneva: International Organization for Standardization. First edition, 2000.

ISO 14043:2000(E) Environmental management - Life cycle assessment - Life cycle interpretation. Geneva: International Organization for Standardization. First edition, 2000.

Challenges of Electric Power Industry Restructuring for Fuel Suppliers, Energy Information Agency, Office of Coal, Nuclear, Electric and Alternative Fuels, September 1998. 


\section{Conventional Fuels - Market Overview Market Study Report Section I}

Prepared For: ConocoPhillips

Co-operative Agreement DE-FC26-01NT41098

\section{ConocoPhillips GNexant}




\title{
Conventional Fuels - Market Overview Market Study Report Section I
}

\author{
November 2002 \\ Prepared For: \\ ConocoPhillips
}

\section{นNexant}

44 South Broadway, White Plains, New York 10601, USA

Tel: +19146090300 Fax: +19146090399 


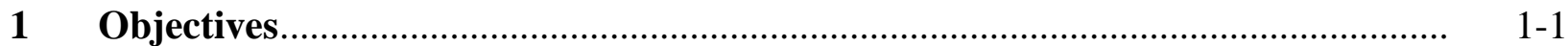

2 Macro Assumptions ..................................................................................... $2-1$

2.1 ECONOMIC GROWTH ................................................................. $2-1$

2.1.1 Historical Review...................................................................... 2-1

2.1.1.1 Global ......................................................................... 2-1

2.2 FORECASTING METHODOLOGY AND ASSUMPTIONS ...................... 2-4

2.3 PROJECTIONS OF ECONOMIC GROWTH............................................ 2-4

2.3.1 North America............................................................................ 2-5

2.3.2 Latin America ............................................................................. 2-6

2.3.3 Western Europe ..................................................................... 2-7

2.3.4 Central Europe ........................................................................... 2-8

2.3.5 Eastern Europe ............................................................................... 2-8

2.3.6 Middle East ........................................................................... 2-9

2.3.7 Africa ................................................................................... 2-9

2.3.8 Asia Excluding Japan ................................................................ 2-10

2.3.9 Japan........................................................................... $2-11$

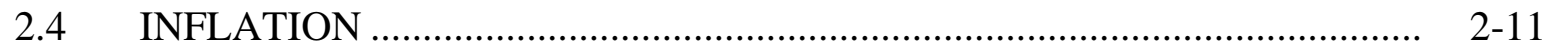

2.5 CRUDE OIL PRICING ................................................................ $2-12$

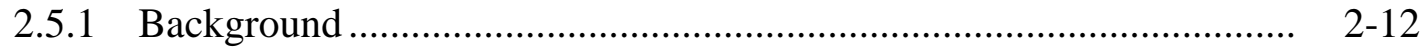

2.5.2 Historical Review.................................................................. 2-13

2.5.3 Projection Methodology and Assumptions ..................................... 2-15

2.5.3.1 Oil Price Cases ............................................................ 2-15

3 Global Refined Product Market Outlook ................................................ $3-1$

3.1 KEY INDUSTRY DRIVING FORCES ..............................................

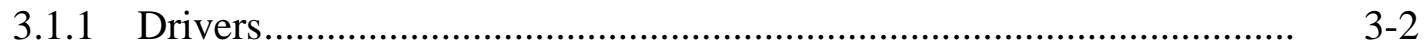

3.1.2 Responses........................................................................... $3-2$

3.2 PETROLEUM PRODUCT DEMAND..................................................... $3-3$

3.3 REFINERY CAPACITY ................................................................ $3-4$

$3.4 \quad$ PETROLEUM PRODUCT TRADE ....................................................... $3-7$ 
$4 \quad$ U.S. Refined Product Market Outlook ……………............................................... 4- 4-1

4.1 KEY INDUSTRY DRIVING FORCES ....................................................... 4-1

4.1.1 Product Quality Trends ...................................................................... 4 4

4.1.1.1 Overview .................................................................. 4-1

4.2 PETROLEUM PRODUCT DEMAND ………………………………….... 4 4-5

4.3 REFINERY PRODUCTION ……..................................................... 4-6

4.4 PETROLEUM PRODUCT TRADE .......................................................... 4-8

5 West European Refined Product Market Outlook ……………………………….... 5-1

$5.1 \quad$ KEY INDUSTRY DRIVING FORCES ...................................................... $5-1$

5.1.1 Product Quality Trends .................................................................... 5-1

5.1.1.1 Overview ................................................................... $5-1$

5.1.1.2 Gasoline....................................................................... $5-2$

5.1.1.3 Diesel..................................................................... 5-3

5.1.1.4 Gas Oil................................................................... 5-5

5.1.1.5 Heavy Fuel Oil (HFO)........................................................ 5-5

$5.2 \quad$ PETROLEUM PRODUCT DEMAND ………………………………..... $5-5$

5.2.1 Overview ................................................................................ $5-5$

5.2.1.1 Gasoline .................................................................... 5-6

5.2.1.2 Jet Fuel ..................................................................

5.2.1.3 Automotive Gas Oil (Diesel)................................................ 5-7

5.2.1.4 Gas Oil/Heating Oil......................................................... $\quad 5-7$

5.2.1.5 Heavy Fuel Oil (HFO)...................................................... 5-8

5.3 REFINERY PRODUCTION …………………................................ $5-8$

$5.4 \quad$ PETROLEUM PRODUCT TRADE........................................................... 5-9

6 East Asian Refined Product Market Overview....................................................... 6- 6-1

6.1 KEY INDUSTRY DRIVING FORCES .................................................. 6-1

6.1.1 Product Quality Trends ................................................................... 6-1

6.1.1.1 Gasoline ........................................................................ 6-1

6.1.1.2 Kerosene/Jet Fuel ........................................................

6.1.1.3 Diesel/Gas Oil ..............................................................

6.1.1.4 Fuel Oil.......................................................................... 
6.2 PETROLEUM PRODUCT DEMAND …................................................ $\quad 6-4$

6.3 REFINERY PRODUCTION ................................................................

6.3.1 Petroleum Product Trade .............................................................. 6 $6-8$

$7 \quad$ Japanese Petroleum Product Market Profile ................................................

7.1 OVERVIEW OF REGULATORY ENVIRONMENT .................................

7.1.1 Energy Use Trends........................................................................... $\quad$ 7-2

7.2 REFINED PRODUCT DEMAND.........................................................

7.3 CURRENT REFINERY PROCESS CONFIGURATIONS .......................... 7-6

7.4 REFINERY PRODUCTION PROJECTIONS ......................................... $\quad$ 7-7

7.4.1 Product Balances..........................................................................

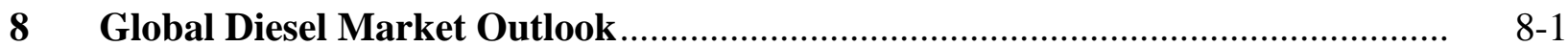

8.1 TOTAL DIESEL DEMAND ..........................................................

8.1.1 Global Overview ..................................................................... 8-1

8.1.1.1 Japan ...................................................................... $8-2$

8.1.1.2 United States ............................................................... 8

8.1.1.3 Western Europe ............................................................. 8-3

8.1.1.4 East Asia and Australia .................................................... 8 8-4

8.1.1.5 Other Countries ................................................................ 8-4

8.1.2 Ultra Low Sulfur Diesel Demand ................................................. 8 8-5

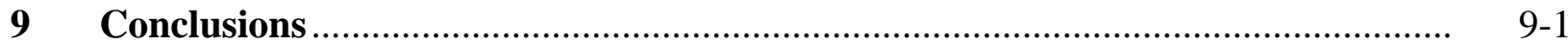


2.1 World Economic Performance, Annual Change in Real GDP ................................ 2-1

2.2 World Economic Performance and Outlook, Real Change in GDP .......................... 2-5

2.3 Historical And Forecast Long Term Economic Trendlines, Real Change in GDP ...... 2-5

2.4 North American Economic Growth, Annual Change in Real GDP.......................... 2-6

2.5 Latin American Economic Performance and Outlook, Annual Change in Real GDP . 2-7

2.6 West European Economic Performance and Outlook, Annual Change in Real GDP .. 2-7

2.7 Central European Economic Performance and Outlook, Annual Change in Real GDP.

2.8 East European Economic Performance and Outlook, Annual Change in Real GDP ... 2-8

2.9 Middle Eastern Economic Performance And Outlook, Annual Change in Real GDP. 2-9

2.10 African Economic Performance and Outlook, Annual Change in Real GDP ............ 2-10

2.11 Asia Ex Japan Economic Performance and Outlook, Annual Change in Real GDP.... 2-10

2.12 Japanese Economic Performance and Outlook ................................................... 2-11

2.13 U.S. GDP Price Deflator ............................................................................ $2-12$

2.14 Historical Brent Crude Oil Prices, FOB North Sea, Monthly Average ..................... 2 2-14

2.15 Nexant Reference Crude Oil Scenarios, Brent, FOB North Sea............................. 2-17

3.1 Global Refining Industry Issues and Challenges ................................................ $3-1$

3.2 Worldwide Petroleum Product Demand, 2000 ......................................................... 3-4

3.3 Global Refining Capacity Utilization Trends .................................................... 3-5

3.4 Global Refining Capacity Trends ................................................................... $3-5$

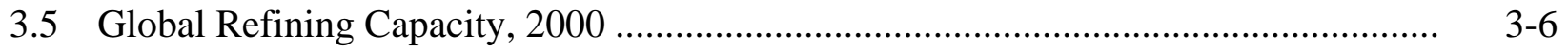

3.6 Global Refinery Complexity …......................................................................... $3-6$

3.7 Global Gasoline Trade Trends ...........................................................................

3.8 Global Middle Distillate Trade Trends ............................................................... 3-8

3.9 Global Residual Fuel Oil Trade Trends ............................................................ 3-8

4.1 Timeline for Major U.S. Product Quality Changes ............................................ $\quad 4-2$

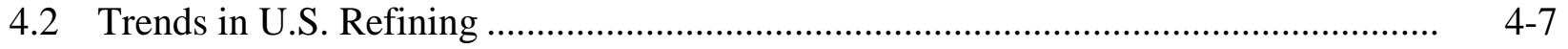

4.3 U.S. Refining Industry Operating Rates ........................................................ $4-8$

4.4 U.S. Refining Industry Import Exposure ......................................................... $4-8$

5.1 Refinery Capacity And Utilization, Western Europe .......................................... $5-9$ 
6.1 East Asian Product Demand Trends .................................................................

6.2 Refinery Capacity Increases - East Asia .......................................................... $6-7$

6.3 Refinery Capacity Increases - East Asia ............................................................ $6-8$

6.4 Refined Product Imports - Major Products - East Asia ...........................................

8.1 Distribution Of Global Diesel Demand, 2001 ..................................................

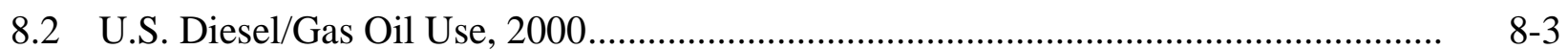

Table

Page

2.1 HISTORICAL AND PROJECTED ECONOMIC GROWTH REGIONAL AND GLOBAL SUMMARY ...................................................................................

2.2 Historical Crude Oil Prices, Current US\$ Per Barrel ............................................. 2-14

2.3 Nexant Crude Oil Scenarios, In Current and Constant 2001 Dollars ........................ 2-16

3.1 Worldwide Major Petroleum Product Demand ${ }^{1}$, Million Barrels Per Day.................. 3-3

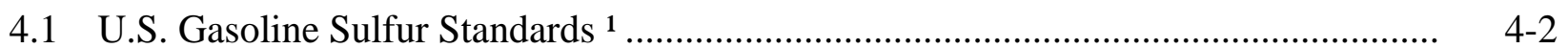

4.2 On-Highway Diesel Fuel Specifications, 2001 .................................................. $4-4$

4.3 U.S. Major Petroleum Product Demand, Thousand Barrels Per Day ......................... $\quad$ 4-6

5.1 EU Unleaded Gasoline Specifications ..........................................................................

5.2 EU Diesel Specifications .................................................................................. $5-4$

5.3 Refined Product Demand - Western Europe, 1990-2010, Million Tons .................... 5-6

6.1 Asian Gasoline Quality Trends ....................................................................... $6-2$

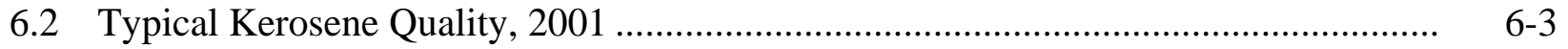

6.3 Asian Diesel/Gas Oil Quality Trends ................................................................

6.4 Petroleum Product Demand - East Asia, Million Barrels Per Day ........................... $\quad 6-5$

7.1 Primary Energy Consumption By Source - Japan, Million tons of Oil Equivalent ..... 7-3

7.2 Petroleum Product Demand - Japan, Thousand Barrels Per Day............................. 7-5

7.3 Japanese Product Demand Trends .....................................................................

7.4 Japanese Refinery Process Unit Capacities, 2001, Thousand Barrels Per Calendar Day

7.5 Refinery Production - Major Products, Japan, Thousand Barrels Per Day................ 7-8

7.6 Refinery Product Balances - Major Products, Japan, Thousand Barrels Per Day ....... 7-9

8.1 Global Diesel Demand All Sulfur Levels, Thousand Barrels Per Day ....................... 8 8-1 
8.2 Global Diesel/Gas Oil Demand All Sulfur Levels..............................................

8.3 Global Diesel Demand Sulfur Content Less Than 15 PPM....................................... 8-5

8.4 Global Diesel Demand Sulfur Content Between 15 and 50 PPM (thousand barrels

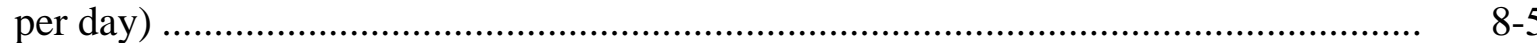


The objective of this section is to provide an overview of major trends that will define the global and regional markets for conventional petroleum-based fuels. Specific elements addressed are:

- Characterize expected developments in the worldwide and regional economy

- Characterize future environmental regulations that will impact the quality of gasoline and diesel fuels

- Trends in global and regional refinery capacity

- Trends in global trade of primary refined products

Results of the analyses presented in this section provide input to other elements of the Market Study, specifically to the regional breakdown and trends in refined products in the United States (Section 4), the assessment of the impact of FT diesel on the U.S. refining industry (Section 8), and the valuation and market potential for FT diesel (Section 9). 


\section{$2.1 \quad$ ECONOMIC GROWTH}

\subsubsection{Historical Review}

\subsubsection{Global}

The global economy experienced a dramatic downturn in 2001 as the major world economic engines: the United States, Japan and Western Europe, all slowed during the year. Global economic growth, measured in terms of real GDP change, declined from a robust level of 3.9 percent in 2000 to an estimated 1.2 percent in 2001. To put this into perspective, over the 19702000 timeframe, the global economy grew at an average annual rate of 3.4 percent, similar to the growth achieved during the last five years (1995-2000). By comparison, the 1990-2000 decade, due to the economic recession of the early 1990's, witnessed sub-average growth of 2.7 percent annually.

The United States and Japan officially entered a recession in 2001. In the United States, high oil prices, declining values of equity assets, and a severe drop in capital spending by business entities and multinationals, particularly in the high-tech sector, had a ripple effect on the West European and Asian economies. Japan's latest recession, which, like the United States started in the $2^{\text {nd }}$ quarter of 2001, has been further aggravated by the weakened state of its banking and financial institutions, which remain overburdened with high risk debt and require major structural reforms. Western Europe, like the U.S., witnessed rising crude oil prices, declining equity markets, and a severe drop in corporate investments, particularly in high-tech industries.

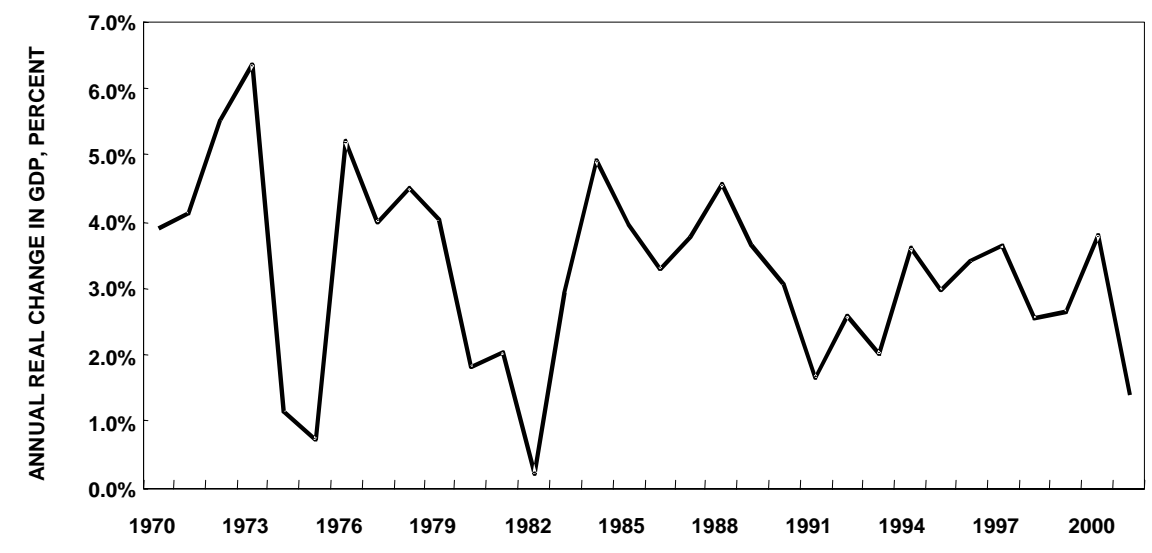

Figure 2.1 World Economic Performance, Annual Change in Real GDP

The North American (U.S., Canada and Mexico) economy, following a sustained period of growth over the past 10 years, experienced a severe downturn in 2001, officially moving into recession at the end of the first quarter. Since mid 2000, a decline in capital spending in key 
industries such as telecommunications, a sluggish equity market, high gasoline prices, and deteriorating manufacturing activity due in part to lower exports contributed to the weakening of the economy. In fact, GDP growth fell from an average of 4.0 percent in 2000 to an estimated 0.3 percent in 2001. The effect of September 11, 2001 further aggravated the economic situation causing the US economy to feel the full impact of the ongoing recession and most likely delaying the timing of the economic recovery. An aggressive monetary policy on the part of the Federal Reserve and planned U.S. tax and investment stimulus programs aimed at improving personal consumption short term are elements designed to revitalize the economy in the near term. Canada and Mexico, both highly integrated economically with the United States, have also felt the impact of the downturn of the US economy and are expected to track U.S. performance.

In 2000, Latin America experienced a strong recovery, fueled by trade growth and investments into the region. In 2001 economic activity deteriorated significantly due to the global economic slowdown, which diminished exports from this region. The Latin economy, which grew at a rate of 3.2 percent in 2000, slowed to an estimated 1.1 percent in 2001. Argentina, the second largest regional economy, entered into a severe financial crisis at the end of 2001 and its economic woes have been felt by neighboring Brazil, Chile and Uruguay. Brazil, by far the largest economy in the region, recently endured an energy crisis due to lengthy drought conditions, and its economy contracted in the later part of 2001.

The economic slowdown in Western Europe, which started in mid 2000, spread even more widely in 2001. GDP growth fell from 3.4 percent in 2000 to 1.7 percent in 2001 . The downturn in economic activity was impacted by several interrelated factors including rising oil prices in 2000, weakening equity markets (parallel to the US situation) and a drop in capital business investment in key industries such as telecommunications, IT and advanced technology. Construction spending in Germany declined substantially in 2001. Germany and Italy experienced weaker demand growth while France instituted tax cuts and employment growth programs to better weather the economic slowdown. Low unemployment rates and healthy corporate earnings in 2001 kept domestic demand strong in the U.K. despite the global economic slowdown.

Continuing a pattern of weak performance over the past decade, in 2000 the Japanese economy experienced marginal growth, and in 2001 the country entered a formal recession. GDP growth declined from 2.2 percent in 2000 to a contraction of $0.4 \%$ in 2001. Production output declined in 2001, particularly after the first quarter, as demand for export goods, especially electronics, fell as a result of weakening global demand. The Japanese economy continues to suffer from an overextended banking system in need of reform, a declining equity market, ongoing corporate restructuring and deterioration of business confidence.

Asian economies excluding Japan performed well in 2000 with an overall GDP growth of 6.8 percent. However the economic picture changed dramatically in 2001 as weaker demand, particularly for technology products, caused emerging economies in Asia to suffer severe declines in industrial production and exports. High prices for crude oil and weakening equity markets contributed to a significant economic downturn in 2001. GDP growth for Asia excluding Japan is estimated at 3.8 percent for 2001. India, a major regional economy, suffered 
a decline in economic activity; higher energy prices, a devastating earthquake, and a drought all hurt the domestic economy. China's economy continued to grow at healthy levels led by domestic demand and public investments, despite a decline in exports.

Oil producing countries in the Middle East benefited from crude oil prices rising for part of 2001, but the region's economy declined abruptly in the second half of the year as crude oil prices dipped below $\$ 20 /$ barrel. In addition, Turkey, a major economy of the region, is suffering through a financial crisis due to weak economic fundamentals and compounded by political uncertainty. Political turmoil in the Middle East, a continuing issue for Israel and surrounding states, but since September 11 having spread to essentially all regional economies that rely heavily on tourism, such as Egypt, has negatively affected trade balances and the general level of economic activity. As a result, economic growth in terms of real GDP dropped from 5.5 percent in 2000 to 0.5 percent in 2001 .

Since many of the economies in Africa rely on exports, particularly to Western Europe, the global economic slowdown has impacted economic growth in a number of regional economies. Non-oil commodities, such as coffee, and minerals like aluminum and copper have also declined in price due to weakening demand and oversupply conditions on a global basis. Despite the above linkages, GDP growth moderately increased from a relatively weak 2.3 percent in 2000 to an estimated 2.8 percent in 2001.

The Central European economy grew at a rate of 4.2 percent in 2001, improving relative to the strong performance of 3.9 percent in 2000. Exports, which had fueled economies in Hungary, the Czech Republic, Poland and Romania, declined considerably in 2001 as economic activity in Western Europe, particularly Germany, slowed. The economies of Hungary and the Czech Republic have remained robust, fueled by healthy domestic demand, while economic growth in Poland declined severely in 2001.

The East European region (composed of countries of the Former Soviet Union), following the devaluation of the Russian rubble in 1998, experienced a strong recovery in 2000 due in part to rising revenues from high oil prices and growth in natural gas exports to Western Europe. The region was only marginally impacted by the global slowdown that occurred in 2001 and saw its GDP growth decline from 8.0 percent in 2000 to 5.8 percent in 2001 . Lower oil prices in the second half of 2001 and depreciation of Russia's currency led to lower revenues and economic growth.

Economic performance and projected outlook by region are summarized in the table below. 
HISTORICAL AND PROJECTED ECONOMIC GROWTH REGIONAL AND GLOBAL SUMMARY Annual Change in Real GDP, Percent

\begin{tabular}{|l|r|r|r|r|r|r|r|r|r|}
\hline \multicolumn{3}{|c|}{} & \multicolumn{3}{|c|}{ Annual Growth, Percent } \\
\hline & & & & Est. & & & & & \\
\hline & 1999 & 2000 & 2001 & 2002 & 2003 & $1992-2002$ & $1997-2002$ & $2002-2015$ \\
\hline North America (1) & $4.1 \%$ & $4.0 \%$ & $0.3 \%$ & $2.2 \%$ & $2.7 \%$ & & $3.2 \%$ & $3.0 \%$ & $2.8 \%$ \\
\hline Latin America (2) & $-0.8 \%$ & $3.1 \%$ & $1.0 \%$ & $-1.1 \%$ & $2.7 \%$ & & $2.4 \%$ & $0.7 \%$ & $3.2 \%$ \\
\hline Western Europe & $2.7 \%$ & $3.5 \%$ & $1.6 \%$ & $1.1 \%$ & $2.3 \%$ & & $2.1 \%$ & $2.4 \%$ & $2.6 \%$ \\
\hline Africa & $2.2 \%$ & $2.4 \%$ & $2.6 \%$ & $1.5 \%$ & $3.7 \%$ & & $2.5 \%$ & $2.4 \%$ & $3.4 \%$ \\
\hline Middle East & $0.0 \%$ & $5.8 \%$ & $-0.1 \%$ & $2.2 \%$ & $3.8 \%$ & & $3.1 \%$ & $2.3 \%$ & $3.7 \%$ \\
\hline Japan & $0.8 \%$ & $2.4 \%$ & $-0.3 \%$ & $-0.5 \%$ & $1.1 \%$ & & $0.9 \%$ & $0.2 \%$ & $2.3 \%$ \\
\hline Other Asia (3) & $6.3 \%$ & $6.7 \%$ & $3.9 \%$ & $5.4 \%$ & $5.6 \%$ & & $6.0 \%$ & $4.8 \%$ & $5.5 \%$ \\
\hline Central Europe (4) & $2.8 \%$ & $3.9 \%$ & $2.6 \%$ & $2.5 \%$ & $3.6 \%$ & & $3.3 \%$ & $2.9 \%$ & $3.6 \%$ \\
\hline Eastern Europe & $4.2 \%$ & $8.1 \%$ & $5.9 \%$ & $4.5 \%$ & $4.9 \%$ & & $-1.3 \%$ & $4.0 \%$ & $3.7 \%$ \\
\hline & & & & & & & & & \\
\hline World & $3.2 \%$ & $4.0 \%$ & $1.1 \%$ & $1.9 \%$ & $2.8 \%$ & & $2.7 \%$ & $2.6 \%$ & $3.1 \%$ \\
\hline
\end{tabular}

(1) United States, Mexico and Canada

(2) South America, Central America and Caribbean. Does not include Mexico

(3) Excludes Japan

(4) Poland, Czech Republic, Slovak Republic, Hungary, Romania, Bulgaria and the Former Yugoslavia

\subsection{FORECASTING METHODOLOGY AND ASSUMPTIONS}

Nexant utilizes a variety of data sources for its historical review and projections of economic performance. The primary historical resources utilized are statistics produced by the International Monetary Fund (IMF). Short-term projections reflect a variety of views published by international funding agencies as well as the financial community. Comparable authoritative long-term forecasts for economic growth are less readily available and thus Nexant develops an independent outlook for long-term regional and global economic performance.

Nexant projects that developing regions will achieve above average growth and that mature economies (the United States, Western Europe and Japan) will grow at slower rates.

\subsection{PROJECTIONS OF ECONOMIC GROWTH}

The world economy is projected to grow only modestly in 2002 with GDP rising by 1.9 percent over 2001. The United States is expected to lead the global economic recovery via aggressive monetary stimulus policies. Resumption of capital spending in both the United States and Western Europe, particularly in the high-tech sector, aided by improved consumer demand and corporate earnings, is likely to restart the high-tech economies in East Asia, but with a one to two quarter lag behind recovery in the United States. Japan's economy, which is suffering from fundamental structural problems, is expected to remain weak for a number of years. Overall economic activity is expected to benefit from low inflationary pressures and relatively low and stable crude oil prices. Overall the global economy is predicted to grow at an average rate of 3.1 percent over the next decade, roughly in line with historical trendline performance. 


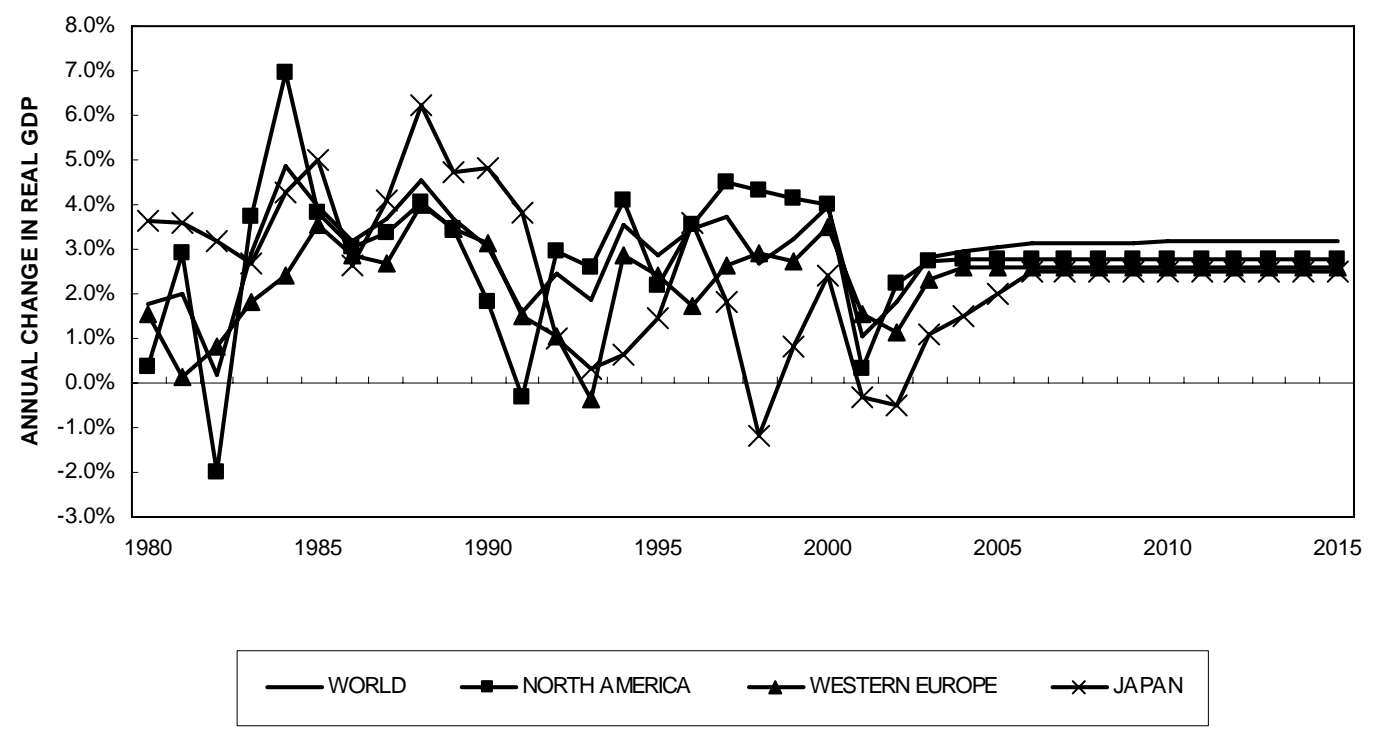

Figure 2.2 World Economic Performance and Outlook, Real Change in GDP

As shown in Figure 2.3, developing economies of Asia (excluding Japan), the Middle East, Central and Eastern Europe and Africa are projected to grow at trendline rates faster than the world's average of 3.1 percent per year. Since GDP rates for Central and Eastern Europe have been available only since 1991, there are no corresponding historical 1970-2000 comparisons for those regions.

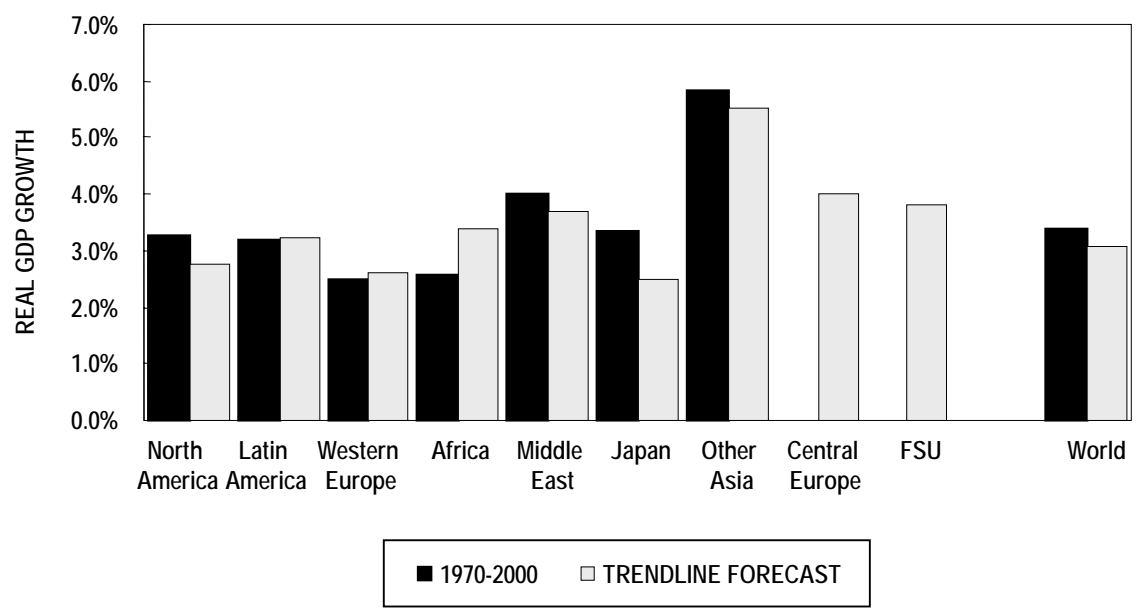

Figure 2.3 Historical And Forecast Long Term Economic Trendlines, Real Change in GDP

\subsubsection{North America}

The North American economy is expected to begin to recover in 2002 with average growth for the year expected to equal 2.5 percent. Initial very high growth in the United States during the 
first quarter of 2002, equal to 5.6 percent, is not expected to be sustainable for the balance of the year. Following projected recovery during 2003/04, the U.S. economy is projected to grow at a trendline growth rate of 2.7 percent, somewhat below the global average of 3.1 percent.

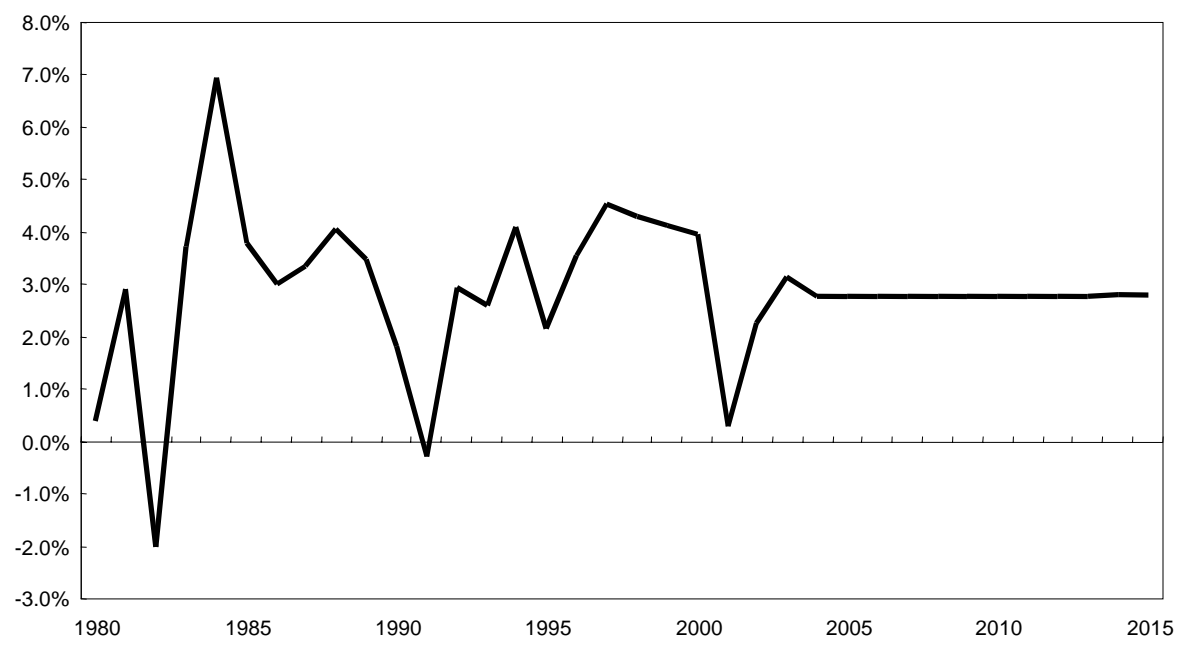

Figure 2.4 North American Economic Growth, Annual Change in Real GDP

\subsubsection{Latin America}

The financial crisis in Argentina, as well as problem areas in other parts of the region, has the potential for significantly delaying regional economic recovery. Brazil, with about 36 percent of the regional economy, will drive Latin recovery. Exports from Latin America are likely to improve in the second half of 2002 once the U.S. economy starts to recover. Argentina's economy is expected to decline by 16.0 percent during 2002, with negative growth also expected in Uruguay ( -3.0 percent) and Venezuela ( -4.2 percent) for the year. Reflecting this, the regional Latin American economy is forecast to contract by -0.7 percent during 2002. Overall, the Latin economy is poised for slightly above average annual trendline growth of 3.2 percent, essentially in line with projected global average growth, reflecting the developing nature of the region. 


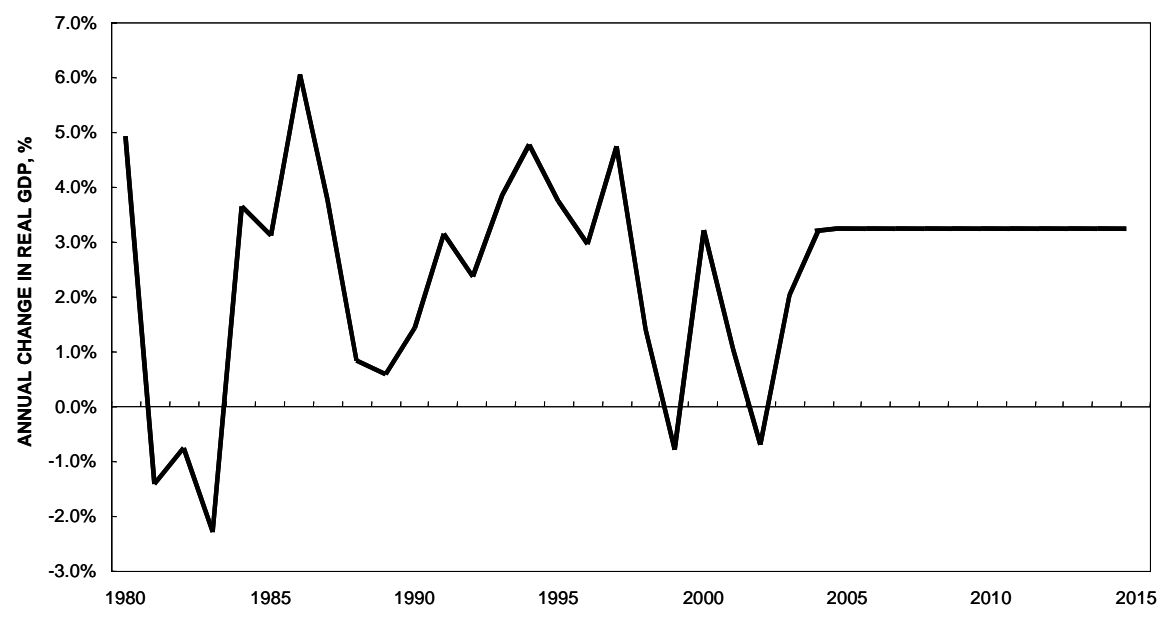

Figure 2.5 Latin American Economic Performance and Outlook, Annual Change in Real GDP

\subsubsection{Western Europe}

The West European economy is expected to lag the recovery in the United States, with average growth of 1.5 percent forecast for 2002, slightly lower than the 1.5 percent achieved in 2001 . Full recovery in 2003 to a growth rate of 2.8 percent is forecast, prior to returning to a long-term average trendline growth rate of 2.6 percent.

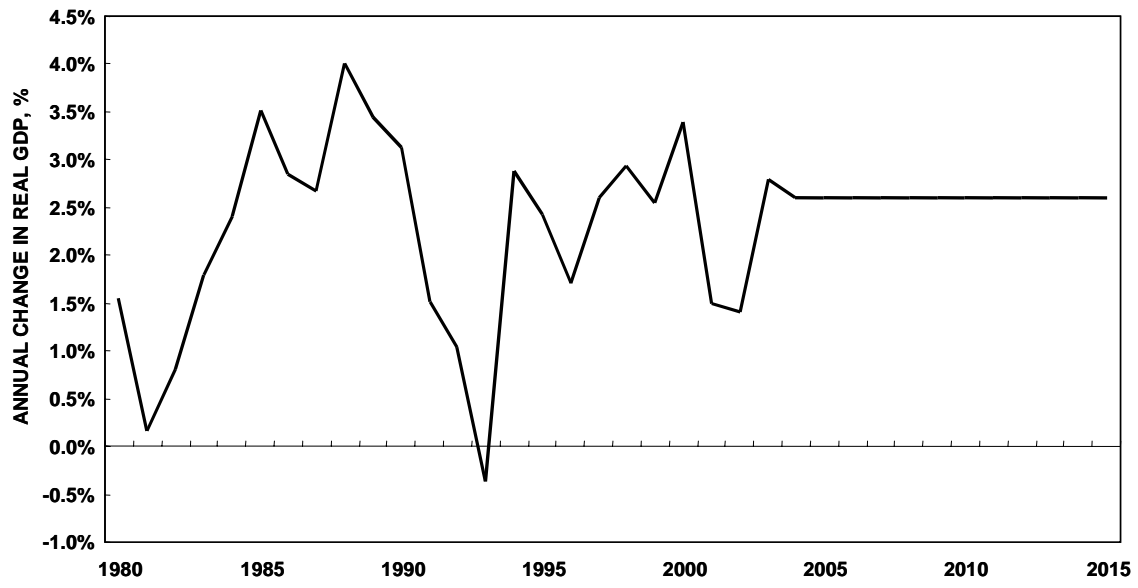

Figure 2.6 West European Economic Performance and Outlook, Annual Change in Real GDP

Inflationary pressures are expected to remain low, given the current weakness in demand. The European Central Bank has also intervened by lowering interest rates to provide monetary stimulus. Western Europe is also projected to benefit through increased export-oriented activities once the U.S. economy starts its recovery. Benefits associated with the implementation of numerous programs aimed at integrating the various European economies, such as the Euro, are expected to support the forecast level of growth for the region. 


\subsubsection{Central Europe}

Economic growth in Central Europe is projected to rise at an average trendline rate of 4.0 percent over the next decade, above the global average of 3.1 percent. Many of the emerging economies of this region are expected to benefit from entry into the EU. The region's exportoriented production will also benefit once Western Europe begins recovery. Continued capital investment in this region is anticipated once financial markets and corporate earnings improve.

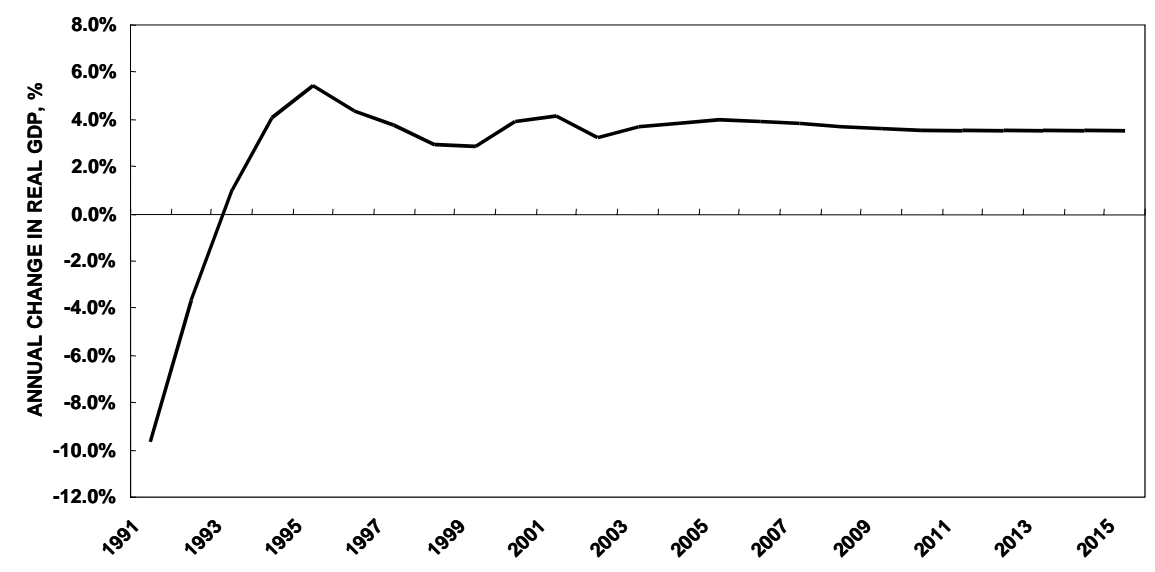

Figure 2.7 Central European Economic Performance and Outlook, Annual Change in Real GDP

\subsubsection{Eastern Europe}

The economy in Eastern Europe, dominated by Russia, is anticipated to grow at a trendline rate of 3.8 percent over the next decade. The rate is roughly in line with growth in the Central European economies, reflecting the historical integration of the two regions. The East European region will continue to rely on oil and natural gas exports to finance a significant part of its economic activities.

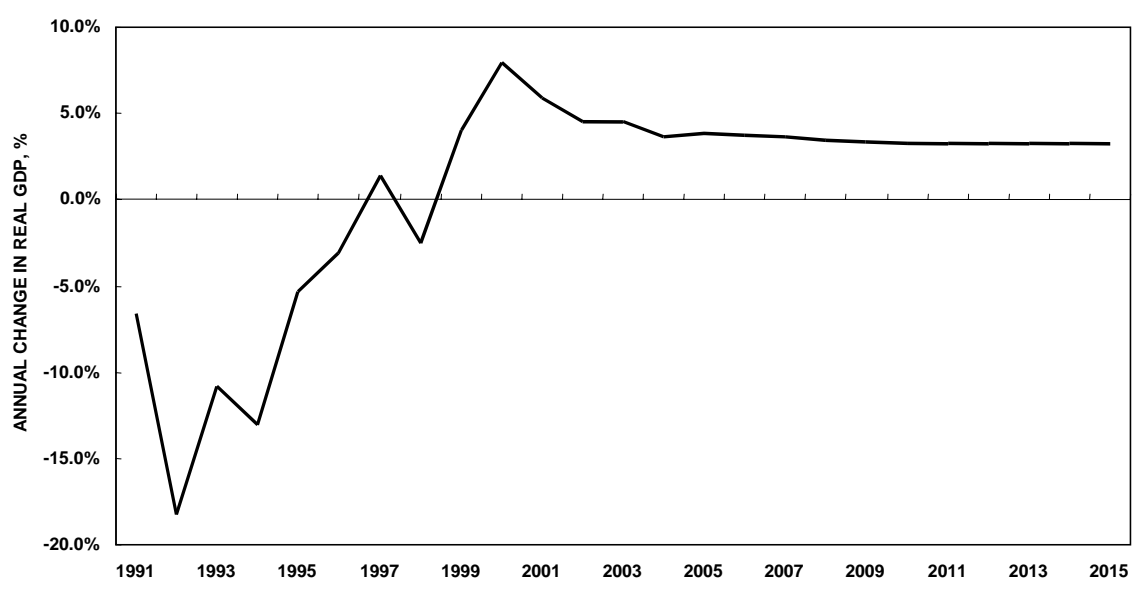

Figure 2.8 East European Economic Performance and Outlook, Annual Change in Real GDP 


\subsubsection{Middle East}

The Middle Eastern region is projected to recover to 2.4 percent growth in 2002 and grow at an above-average trendline rate of 3.7 percent over the coming decade. The economies of this region will be driven by major capital investments, in particular by multinational energy firms eager to access low cost raw materials and centralized location to global markets. Political stability will remain a prerequisite to attract investors, and the region's potential for continued volatility represents its most significant weakness. Stable crude oil prices are expected to benefit OPEC countries in the region.

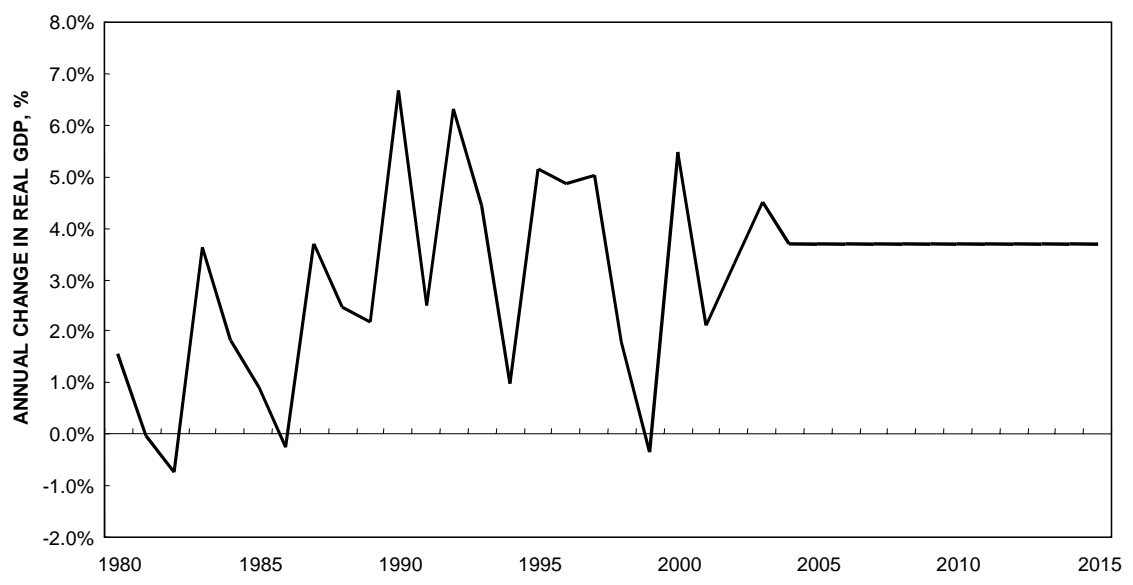

Figure 2.9 Middle Eastern Economic Performance And Outlook, Annual Change in Real GDP Another orphaned figure title

\subsubsection{Africa}

Economic growth in this region is expected to decline slightly in 2002 and then improve in 2003. Energy producing countries such as Algeria and Nigeria will benefit from improving demand for petroleum after 2002. Economic growth in this region, projected to average 3.4 percent annually over the decade on a trendline basis, will continue to rely on export-oriented activities. Do we want to mention Eq. Guinea? 


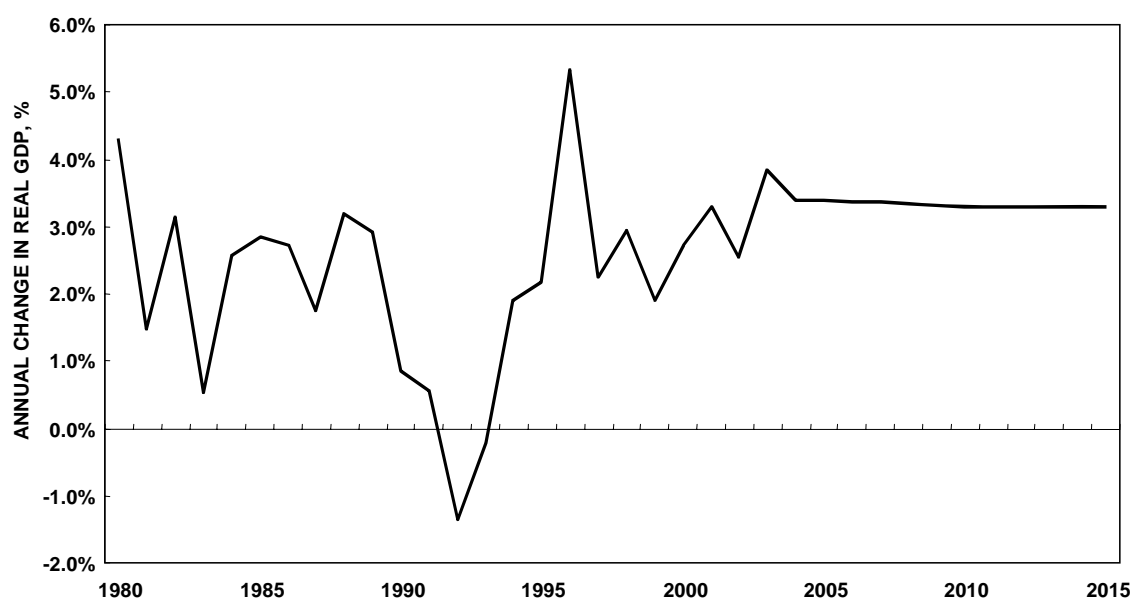

Figure 2.10 African Economic Performance and Outlook, Annual Change in Real GDP

\subsubsection{Asia Excluding Japan}

The Asian economies excluding Japan are projected to show some recovery in 2002 driven by recovery in global trade. Trendline growth levels are expected to lead the global economy, with average trendline growth rates of 5.5 percent. China and India are expected to continue to drive economic performance for the region. Growth prospects appear to be healthier for China as the country is actively implementing economic reform, driven by its recent entry into the World Trade Organization. Economies in East Asia, which serve as important global production platforms for hi-tech multinational firms, are expected to return to healthier levels once capital investment in the technology sector resumes both in North America and Western Europe.

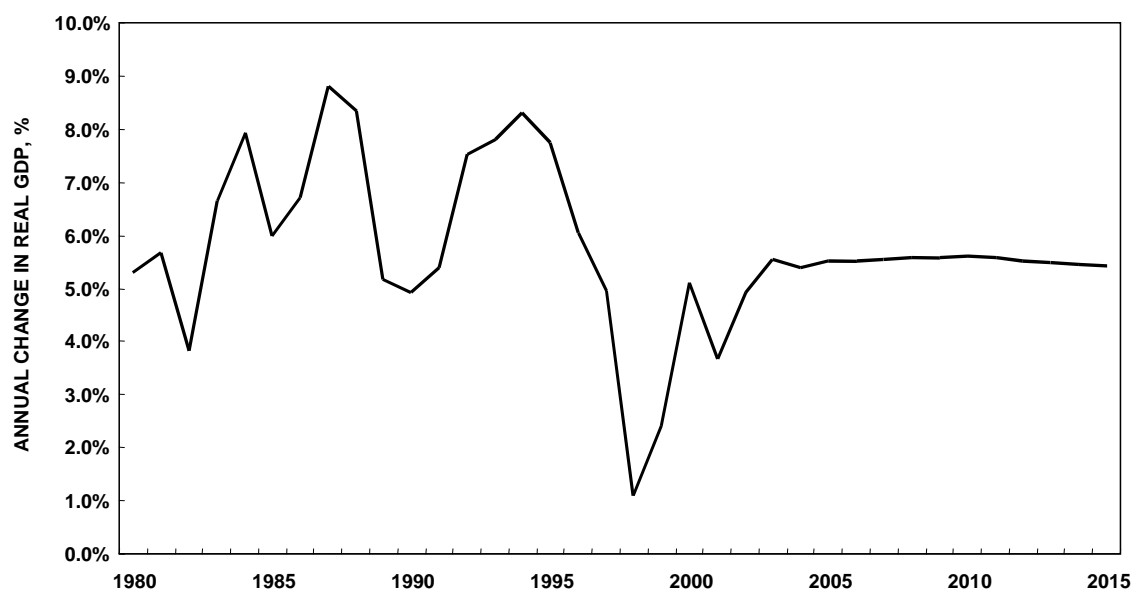

Figure 2.11 Asia Ex Japan Economic Performance and Outlook, Annual Change in Real GDP 


\subsubsection{Japan}

Due to entrenched structural problems with its economy, Japan's economic recovery is anticipated to lag the rest of the world. Although Japan will benefit from recovery in the United States and adjacent emerging Asian economies during 2002, the outlook for the Japanese economy remains uncertain, as the government needs to implement structural reform of its banking system to regain consumer and business confidence and attract needed capital investments. The Japanese economy is forecast to contract by one percent during 2002, with marginal positive growth of 0.8 percent during 2003. Japan's long-term trendline economic growth is forecast to be 2.5 percent annually, somewhat below the other mature world economies of the United States and Western Europe. Japan is not expected to reach this trendline growth level until about 2006.

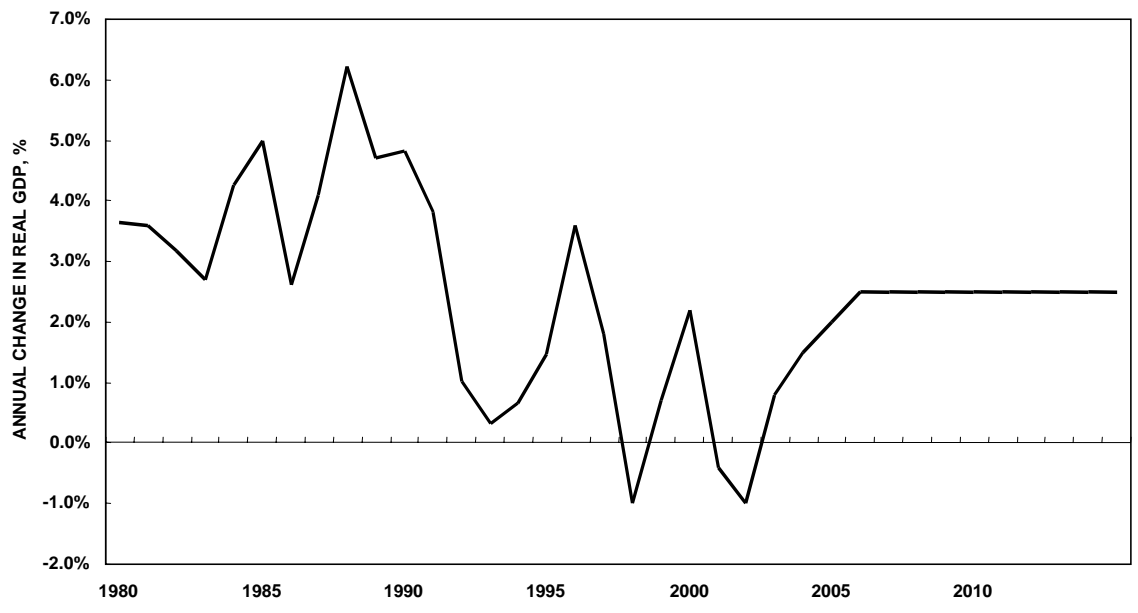

Figure 2.12 Japanese Economic Performance and Outlook

\subsection{INFLATION}

The GDP deflator is the broadest measure of inflation, reflecting the combined experience of government (federal, state and local), businesses, and consumers. Nexant utilizes the U.S. GDP deflator as the basis for converting financials between current U.S. dollar (inflated) and constant U.S. dollar (non-inflated) financial data. The U.S. GDP deflator has declined significantly over the past 30 years, averaging 7 percent annually during the 1970s, 4.3 percent during the 1980s, and 2.2 percent during the 1990s. Nexant forecasts that inflationary pressures will remain at the low end of historical values, with a forecast trendline value of 2.5 percent annually. 


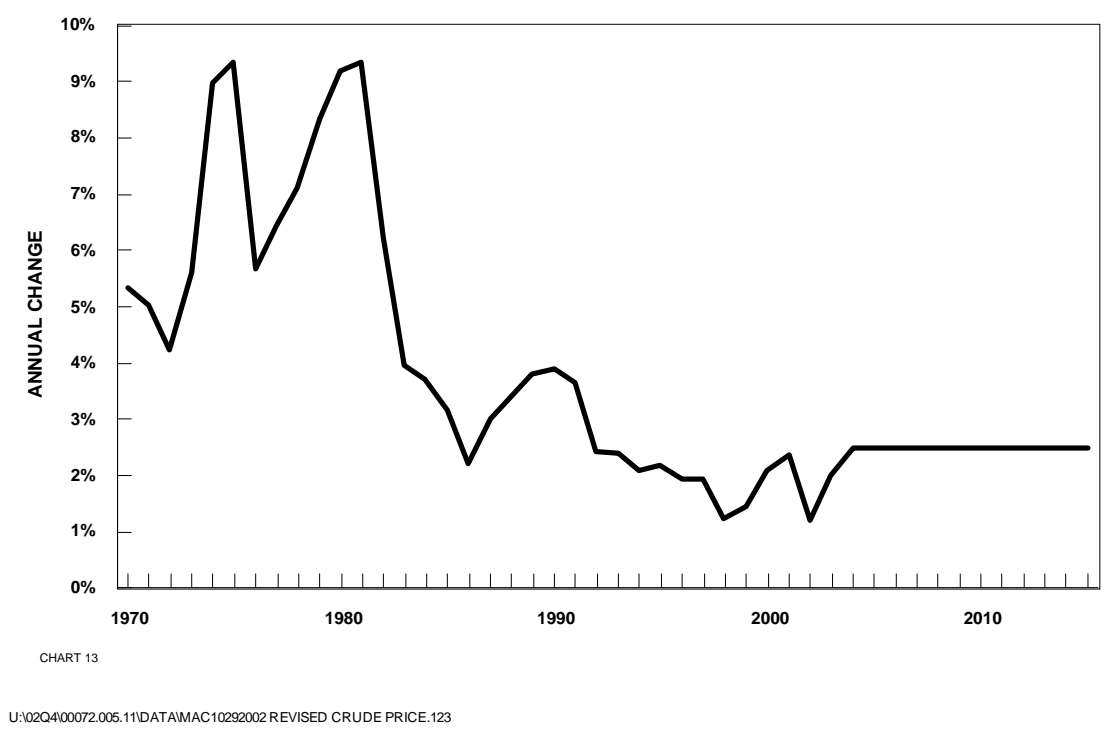

Figure 2.13 U.S. GDP Price Deflator

\subsection{CRUDE OIL PRICING}

\subsubsection{Background}

Currently there are three major "marker" crude oils: West Texas Intermediate (WTI), Dubai and Brent. WTI is commonly used as the marker crude in both North and South America. Dubai, together with Oman crude, is the key crude used to establish prices for Middle Eastern crude oils shipped to Asia while Brent crude is the marker applicable to the pricing of crude oils sold in Europe and produced in West Africa. Dubai's suitability as a global marker crude oil has diminished due to its declining physical availability. Since Brent prices are less susceptible to local pricing distortions and are determined within the most liquid global markets, Nexant utilizes Brent crude oil, on an FOB basis, as its global marker crude oil.

Crude oil prices are subject to considerable price volatility as a result of world events as well as changing perceptions of the balance between future supply and demand. As an indication of the extent of price movements, the average monthly price for a barrel of Brent crude oil was $\$ 10$ per barrel in February 1999, then reached a ten-year high of over $\$ 32$ in September 2000, and subsequently declined to $\$ 19$ in late 2001. Currently (September 2002) Brent is trading in the range of \$25-27 per barrel.

The factors which cause these dramatic price swings are both numerous and complex, and inherently difficult to forecast over the short-to-medium term. As a result, Nexant develops trend projections for crude oils, refined products and petrochemicals, which are based on three different levels of marker crude oil price. 
Unless otherwise stated, all prices quoted in this report are representative of short-term spot, or market-clearing prices. It is recognized that on a day-to-day basis, both refiners and marketers lock in the prices of a certain percentage of their sales or purchases through the use of futures and other derivative markets. However, it is felt that spot pricing is representative of underlying market trends and thus it has been adopted for this analysis.

\subsubsection{Historical Review}

Since 1986, with the exception of recent high price levels, prices of Brent crude oil have generally been within the boundaries of $\$ 14$ and $\$ 22$ per barrel, and Nexant's projected upper and lower bounds for future crude oil prices reflect this range. Nexant believes the upper bound reflects a level above which the demand for petroleum-derived products will be negatively impacted, new production of petroleum will be stimulated and the use of alternative fuels will be promoted. The lower price bound reflects the level at which industry cashflow constraints sharply curtail drilling activities, resulting in lower production from marginal producing fields, while consumption levels increase.

As noted, crude oil prices have been highly volatile over the last few years. Thus, during 1998 and the first quarter of 1999 prices were well below their long-term trendline. Lower prices reflected short-term weakness in demand linked to a slowdown in economic growth outside the United States, a warm 1998 winter in most major markets and increases in crude oil production capacity in OPEC and non-OPEC countries. The FOB price of Brent averaged \$12.8 and \$17.7 per barrel in 1998 and 1999 respectively.

Due to OPEC production cutbacks, combined with the positive effects of a recovery in the global economy, crude oil prices rose sharply from the second quarter of 1999 through the middle of 2000. Pricing for Brent varied between $\$ 23$ and $\$ 33$ per barrel during 2000, and averaged $\$ 28.4$ per barrel for the year.

Cutbacks in OPEC crude oil production supported prices during the first half of 2001, with Brent prices varying between $\$ 24$ and $\$ 28$ per barrel. Following the terrorist attacks in the U.S., prices fell to $\$ 20$ per barrel during October, and below $\$ 20$ in November and December. Brent crude oil price averaged about $\$ 24.6$ per barrel for 2001 . Brent prices recovered to over $\$ 25$ per barrel during March of 2002 and have remained in the \$25-27 range through mid-September, to a large extent reflecting higher tensions in the Middle East, and the potential for supply disruptions. Average Brent prices for the year-to-date through the end of August are \$23.9 per barrel. 


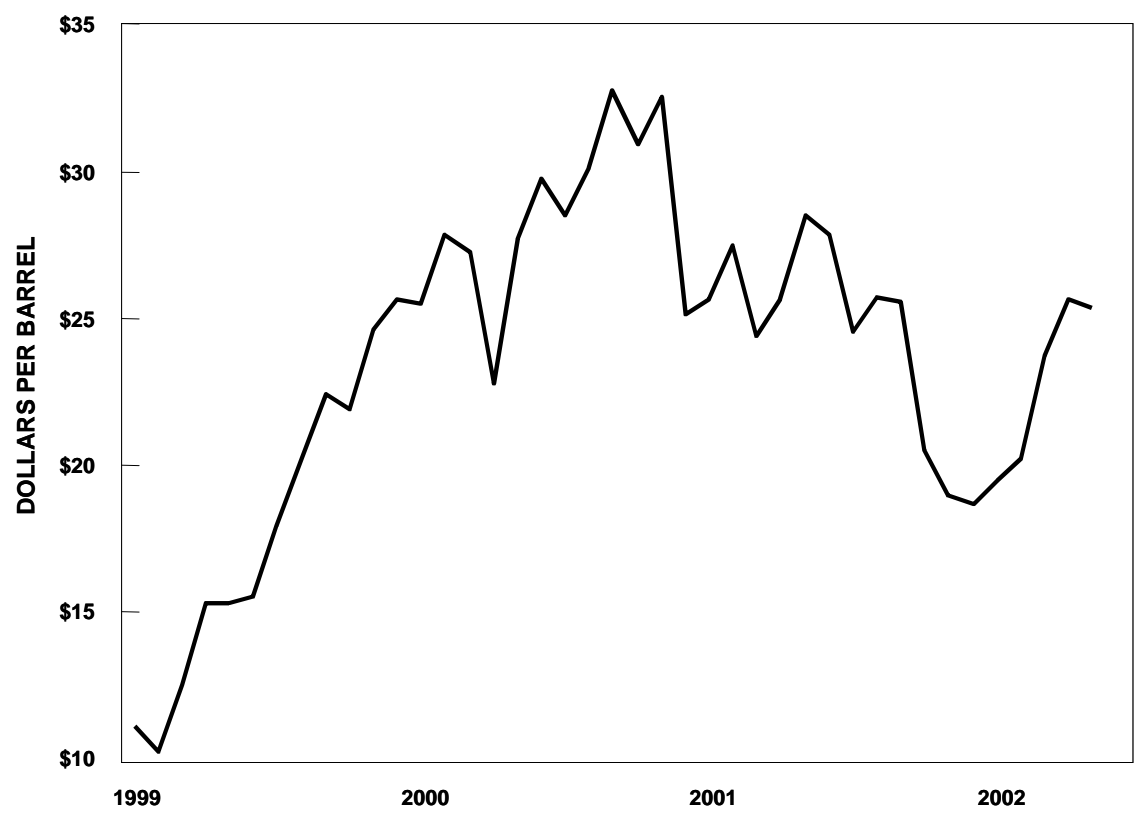

Figure 2.14 Historical Brent Crude Oil Prices, FOB North Sea, Monthly Average

Table 2.2 Historical Crude Oil Prices, Current US\$ Per Barrel

\begin{tabular}{|c|c|c|c|}
\hline & Dubai FOB Fateh & Brent FOB Sullom Voe & WTI FOB Cushing \\
\hline 1986 & 13.0 & 14.1 & 15.1 \\
\hline 1987 & 17.0 & 18.4 & 19.2 \\
\hline 1988 & 13.3 & 15.0 & 16.0 \\
\hline 1989 & 15.8 & 18.5 & 19.8 \\
\hline 1990 & 20.4 & 23.7 & 24.5 \\
\hline 1991 & 16.7 & 20.1 & 21.6 \\
\hline 1992 & 17.2 & 19.3 & 20.5 \\
\hline 1993 & 15.0 & 17.1 & 18.5 \\
\hline 1994 & 14.7 & 15.8 & 17.2 \\
\hline 1995 & 16.1 & 17.0 & 22.4 \\
\hline 1996 & 18.5 & 20.7 & 20.6 \\
\hline 1998 & 18.1 & 19.1 & 14.4 \\
\hline 1999 & 12.2 & 12.8 & 19.3 \\
\hline $\mathbf{2 0 0 0}$ & 17.2 & 17.7 & 30.3 \\
\hline $\mathbf{2 0 0 1}$ & 26.1 & 28.4 & 26.0 \\
\hline
\end{tabular}




\subsubsection{Projection Methodology and Assumptions}

The availability and demand for crude oil is affected by numerous political and economic factors, and as a result accurate medium term (one to two years) forecasting of future crude oil prices is virtually impossible. Nevertheless, it is necessary for the petroleum industry to be able to plan its future, and price projections are an essential input to this process.

Nexant's approach is to develop self-consistent sets of price forecasts for crude oils, refined products and petrochemicals based on a range of crude oil price levels.

\subsubsection{Oil Price Cases}

Nexant's approach to developing outlooks for crude oil pricing is to forecast trendline price levels, recognizing that actual prices will vary considerably on a short-term basis. Nexant addresses future uncertainty in crude oil pricing by projecting an envelope of prices to capture expected future volatility. Three price outlooks have been defined as Low, Medium and High.

Nexant expects that OPEC will maintain some measure of market discipline during 2002, but due to the global economic downturn as well as tensions arising from the on-going war on terrorism, this discipline will be weaker than was achieved during 2000 and the first half of 2001. Therefore, Nexant expects that 2002 will be a transition year where prices, at $\$ 24.5$ per barrel Brent average for the entire year, will be above Nexant's long-term Medium price outlook, returning to the Medium trendline level in 2003.

The Medium trendline outlook is based on an FOB price for Brent crude in 2003 of $\$ 18$ per barrel in constant 2001 dollars. Thereafter, a 1 percent per year decline in real terms is forecast through 2010, reflecting anticipated gains from continued technology improvements in exploration and production activities, resulting in a price of $\$ 16.8$ per barrel by 2010 (on a constant 2001 dollar basis). The current dollar price (inflated based on 2.5 percent per year trend line inflation) for Brent is forecast to equal $\$ 20.8$ per barrel in 2010. After 2010, as the potential for a shortfall in global supplies of petroleum increases, Nexant has assumed that crude oil prices will stabilize in real terms (i.e. no reduction due to technology improvements), such that by 2015 the price of Brent will be $\$ 23.5$ per barrel in current dollars.

Nexant takes the following factors into consideration in developing its forecast envelope of future crude oil price levels:

- Investments to develop new crude oil fields typically requires oil prices in the range $\$ 15$ to 22 per barrel. This includes both fields in deeper offshore regions as well as more remote onshore fields

- Incremental production from existing fields, or new onshore fields close to existing transport infrastructure, can normally be achieved economically at lower price levels

- $\quad$ Long-term crude oil prices, to be sustainable, must support acceptable economic growth in consumer nations as well as stable growth in producer nations 
- Continuing industry investments in oil production and the resulting increase in nonOPEC production capacity means that prices cannot be sustained at levels significantly above $\$ 22$ per barrel on a long term basis

Reflecting these factors, Nexant's envelope of prices (all in constant 2001 dollars) for FOB Brent crude oil is:

- a "High Oil” case at $\$ 22.0$ per barrel in 2003, declining to $\$ 20.5$ in 2015

- a "Medium Oil" case at $\$ 18.0$ per barrel in 2003, declining to \$16.8 in 2015

- a "Low Oil" case at \$ 14.0 per barrel in 2003, declining to $\$ 13.0$ per barrel in 2015

After 2003, crude oil prices are projected to decline at 1.0 percent per year in real terms until 2010, after which prices are forecast to stabilize in real terms. This decline in price reflects trends in other commodities, which continue to show reductions in real prices due to continuing gains in production efficiency. Stabilization of real prices after 2010 reflects the increased potential for a tightening of petroleum availability on a global basis by that time.

Table 2.3 Nexant Crude Oil Scenarios, In Current and Constant 2001 Dollars

\begin{tabular}{|c|c|c|c|c|c|c|c|c|c|}
\hline & \multicolumn{3}{|c|}{ Dubai, FOB Fateh } & \multicolumn{3}{|c|}{ Brent, FOB Sullom Voe } & \multicolumn{3}{|c|}{ WTI, FOB Cushing } \\
\hline \multicolumn{10}{|c|}{ Current US\$ per Barrel } \\
\hline & Low & Medium & High & Low & Medium & High & Low & Medium & High \\
\hline 2003 & 13.1 & 17.3 & 21.4 & 14.6 & 18.8 & 22.9 & 16.4 & 20.6 & 24.8 \\
\hline 2004 & 13.3 & 17.5 & 21.7 & 14.8 & 19.0 & 23.3 & 16.7 & 20.9 & 25.1 \\
\hline 2005 & 13.5 & 17.8 & 22.1 & 15.0 & 19.3 & 23.6 & 16.9 & 21.2 & 25.5 \\
\hline 2010 & 14.5 & 19.1 & 23.7 & 16.2 & 20.8 & 25.4 & 18.2 & 22.8 & 27.4 \\
\hline 2015 & 16.4 & 21.6 & 26.9 & 18.3 & 23.5 & 28.7 & 20.5 & 25.8 & 31.0 \\
\hline \multicolumn{10}{|c|}{ Constant US\$2001 per Barrel } \\
\hline & Low & Medium & High & Low & Medium & High & Low & Medium & High \\
\hline 2003 & 12.6 & 16.6 & 20.6 & 14.0 & 18.0 & 22.0 & 15.8 & 19.8 & 23.8 \\
\hline 2004 & 12.4 & 16.4 & 20.3 & 13.9 & 17.8 & 21.8 & 15.6 & 19.6 & 23.5 \\
\hline 2005 & 12.3 & 16.2 & 20.1 & 13.7 & 17.6 & 21.6 & 15.4 & 19.3 & 23.3 \\
\hline 2010 & 11.7 & 15.4 & 19.2 & 13.0 & 16.8 & 20.5 & 14.6 & 18.4 & 22.1 \\
\hline 2015 & 11.7 & 15.4 & 19.2 & 13.0 & 16.8 & 20.5 & 14.6 & 18.4 & 22.1 \\
\hline
\end{tabular}




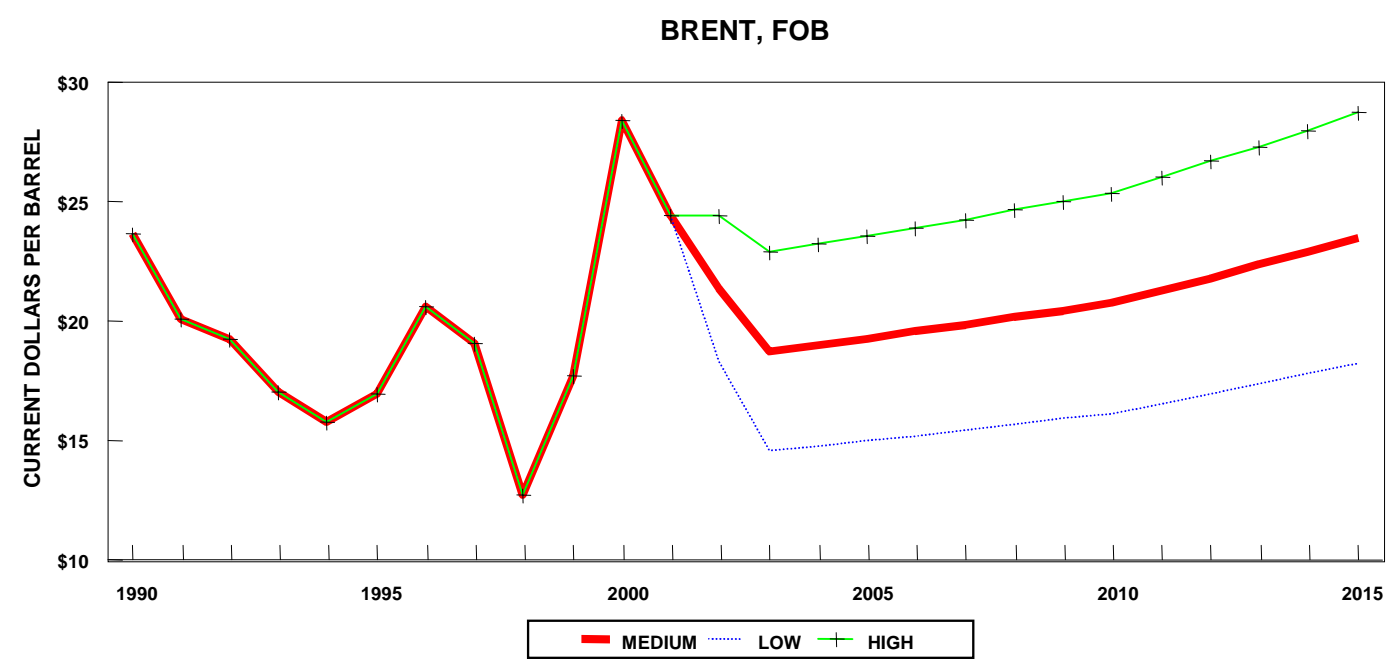

Figure 2.15 Nexant Reference Crude Oil Scenarios, Brent, FOB North Sea

The "Low Oil" case reflects the risk of a return to global oversupply. This scenario may occur if both OPEC and non-OPEC producing countries, driven by the need of revenues, are not disciplined enough to restrict production in relation to demand. The "High Oil" case represents an approximate upper limit but it cannot be sustained for long periods of time as it triggers additional increases in supply and the consequent drop in crude oil prices toward the medium trendline level. The "Medium Oil" case represents the expectation that "real" crude oil prices are projected to moderately decline in real terms until the end of the decade and then stabilize. 


\subsection{KEY INDUSTRY DRIVING FORCES}

The global refining industry has undergone dramatic change over the last three decades, driven by regulatory developments, geopolitics, shifts in market requirements and the rise of alternative energy sources. The rate of change is continuing, and perhaps accelerating, driven by dramatic industry restructuring, slowing product demand growth and more stringent product quality requirements. While the industry is truly global in nature, relative performance differs markedly by region. Thus, rationalization of excess capacity in Europe, combined with demand growth in North and South America, has recently tightened the Atlantic Basin's supply/demand balance for refined products, raising refining margins. However, the Asian market is now over-supplied after a period of strength during the first half of the 1990s, and is suffering below-average profitability.

Mega-mergers and volatile oil prices have recently dominated industry developments. The pace of international restructuring has steadily increased throughout the last 15 years, resulting in the current group of 5 mega-majors. Continuing restructuring is expected, even as the existing majors spend time to focus on internal re-organization of their asset portfolios and to demonstrate the increase in value and efficiency promised by recent mergers.

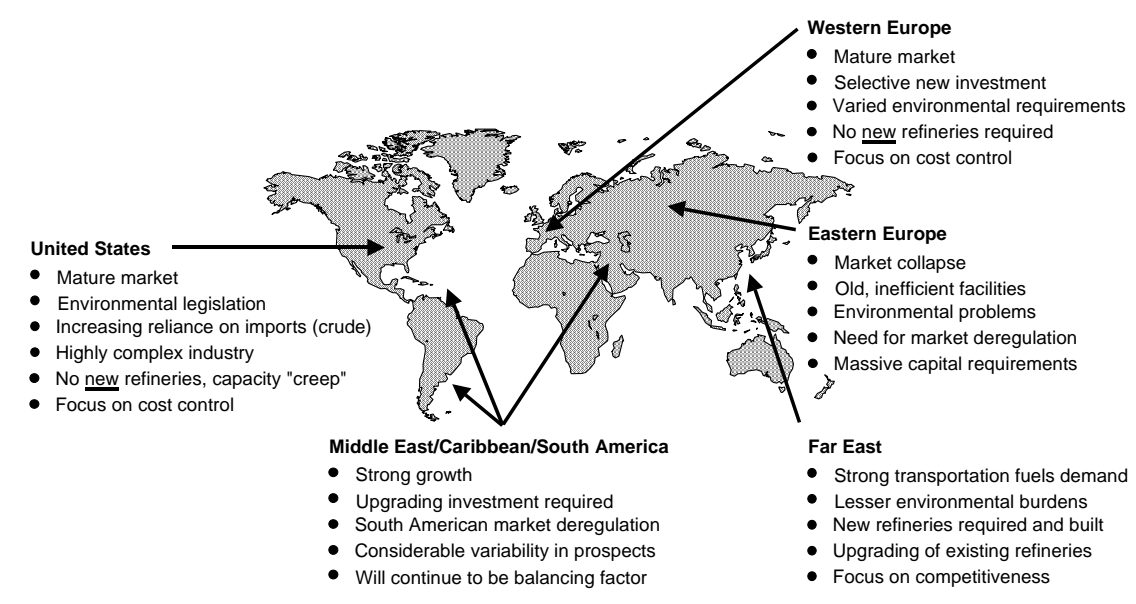

M:ENERGY/DPC/5240/MAP.PRE

Figure 3.1 Global Refining Industry Issues and Challenges

As shown in,Figure 3.1 the refining industry in each region of the world has unique issues and challenges. However, there are seven major issues (organized into drivers and responses) that currently define the refining industry in most regions of the world. 


\subsubsection{Drivers}

- Market characteristics and outlook

- Oil and gas products are commodities

- $\quad$ Demand, prices and margins tend to be volatile

- The industry is highly competitive

- Financial performance

- Global overcapacity has resulted in poor profitability

- $\quad$ Profitability varies based on refinery configurations and location (niche situations)

- $\quad$ As noted, regional performance can vary significantly

- Technological developments

- $\quad$ The industry is capital and technology intensive

- Conventional technologies will continue to dominate, with evolutionary improvements

- $\quad$ A number of emerging technologies may force dramatic change - timing is very

- Environmental difficult to predict (i.e. breakthrough in electric vehicle technology)

- $\quad$ The market continues to shift toward clean, high quality products, thus increasing production costs

- $\quad$ Upcoming environmental regulations will require new investment, against a backdrop of historically poor refining margins and the industry's historical inability to recover/pass through such costs

- Future regulations designed to limit greenhouse gas emissions could have a major impact on petroleum product demand

\subsubsection{Responses}

- Business Restructuring

- $\quad$ Financial and globalization imperatives are leading companies to focus on "core competencies" along the supply chain

- $\quad$ The continuing search for cost savings via operational synergies is forcing consolidation

- Globalization

- $\quad$ The need to achieve economies of scale

- $\quad$ Market and investment opportunities in refining, retail and power generation assets are expanding rapidly in developing regions

- $\quad$ National differences are slowly but inexorably giving way to a regional and global perspective 
- $\quad$ e-Business

- $\quad$ The refining industry has lagged in adoption of e-business capabilities

- $\quad$ Activities are now increasing dramatically

- $\quad$ Key focus is on e-procurement, B2B, and linking of plant information to ERP systems

\subsection{PETROLEUM PRODUCT DEMAND}

As shown in Table 3.1 total global demand for petroleum products grew at an average annual rate of 2.1 percent during the 1995-2000 period. Naphtha and LPG experienced growth well in excess of the average rate and demand for residual fuel oil was stagnant.

Residual fuel oil's share of the world's petroleum product demand mix fell to less than 16 percent in 2000, continuing a long term trend that has prevailed since the early 1970s when its share of the mix exceeded 35 percent. Gasoline's share of the world's petroleum product demand mix declined slightly between 1995 and 2000, and middle distillate's share of the mix increased about 1 percent.

Table 3.1 Worldwide Major Petroleum Product Demand ${ }^{1}$, Million Barrels Per Day

\begin{tabular}{|c|c|c|c|c|c|c|c|c|c|c|}
\hline & \multicolumn{5}{|c|}{ Actual } & \multicolumn{2}{|c|}{ Forecast } & \multicolumn{3}{|c|}{$\begin{array}{c}\text { Growth Rates, } \\
\% \text { per Year }\end{array}$} \\
\hline & 1995 & 1997 & 1998 & 1999 & 2000 & 2005 & 2010 & $\begin{array}{l}1995- \\
2000\end{array}$ & $\begin{array}{l}2000- \\
2005\end{array}$ & $\begin{array}{l}2005- \\
2010\end{array}$ \\
\hline LPG & 5.3 & 5.7 & 5.9 & 6.1 & 6.3 & 7.4 & 8.7 & 3.6 & 3.2 & 3.2 \\
\hline Naphtha & 3.4 & 3.8 & 3.9 & 4.2 & 4.4 & 5.1 & 6.1 & 5.3 & 3.3 & 3.7 \\
\hline Gasoline & 18.2 & 18.9 & 19.3 & 19.6 & 19.7 & 21.7 & 24.2 & 1.6 & 1.9 & 2.2 \\
\hline Kero/Jet Fuel & 5.6 & 6.0 & 6.0 & 6.3 & 6.4 & 7.2 & 8.1 & 2.7 & 2.2 & 2.5 \\
\hline Diesel/Gas Oil & 17.7 & 18.8 & 18.9 & 19.5 & 20.2 & 22.4 & 25.4 & 2.7 & 2.1 & 2.5 \\
\hline Residual Fuel & 10.6 & 10.6 & 10.5 & 10.3 & 10.4 & 10.6 & 11.2 & $(0.3)$ & 0.3 & 1.1 \\
\hline Total & 60.8 & 63.9 & 64.6 & 65.9 & 67.5 & 74.4 & 83.7 & 2.1 & 2.0 & 2.4 \\
\hline & \multicolumn{7}{|c|}{ Percent of Total Demand } & $\begin{array}{l}1995- \\
2000 \\
\end{array}$ & $\begin{array}{l}2000- \\
2005 \\
\end{array}$ & $\begin{array}{l}2005- \\
2010 \\
\end{array}$ \\
\hline LPG & 8.7 & 9.0 & 9.2 & 9.2 & 9.4 & 10.0 & 10.4 & 0.7 & 0.6 & 0.4 \\
\hline Naphtha & 5.5 & 6.0 & 6.1 & 6.3 & 6.5 & 6.9 & 7.3 & 0.9 & 0.4 & 0.4 \\
\hline Gasoline & 30.0 & 29.6 & 29.9 & 29.7 & 29.3 & 29.1 & 28.9 & $(0.7)$ & $(0.1)$ & $(0.2)$ \\
\hline Kero/Jet Fuel & 9.2 & 9.5 & 9.3 & 9.5 & 9.5 & 9.7 & 9.7 & 0.3 & 0.1 & 0.1 \\
\hline Diesel/Gas Oil & 29.2 & 29.5 & 29.3 & 29.5 & 30.0 & 30.2 & 30.4 & 0.8 & 0.2 & 0.2 \\
\hline Residual Fuel & 17.3 & 16.5 & 16.3 & 15.7 & 15.4 & 14.2 & 13.3 & (1.9) & $(1.2)$ & $(0.9)$ \\
\hline
\end{tabular}

The highest future growth is for naphtha, driven by its use as a petrochemical feedstock. Fuel oil will have the lowest growth, as it faces the most competition from other forms of energy. The projected average growth rates for 2000 to 2010 are generally above those achieved between 
1995 and 2000. The Asian financial crisis and economic stagnation in the FSU negatively impacted worldwide growth rates during the second half of the 1990s.

The projected growth rates for clean products (i.e., naphtha, gasoline, jet fuel, kerosene and diesel/gas oil) of 2.2 percent or above annually will outpace fuel oil demand growth of 1.1 percent annually, resulting in a continuing lightening of the barrel. This trend will require the global refining industry to invest in conversion and upgrading capabilities over the forecast period.

Total demand for all products in 2010 is projected to be 24 percent above 2000 levels.

As shown in Figure 3.2, petroleum product demand is concentrated in the U.S., East Asia and Western Europe, with these regions accounting for almost 80 percent of demand. The U.S. alone accounts for over 42 percent of global gasoline demand.

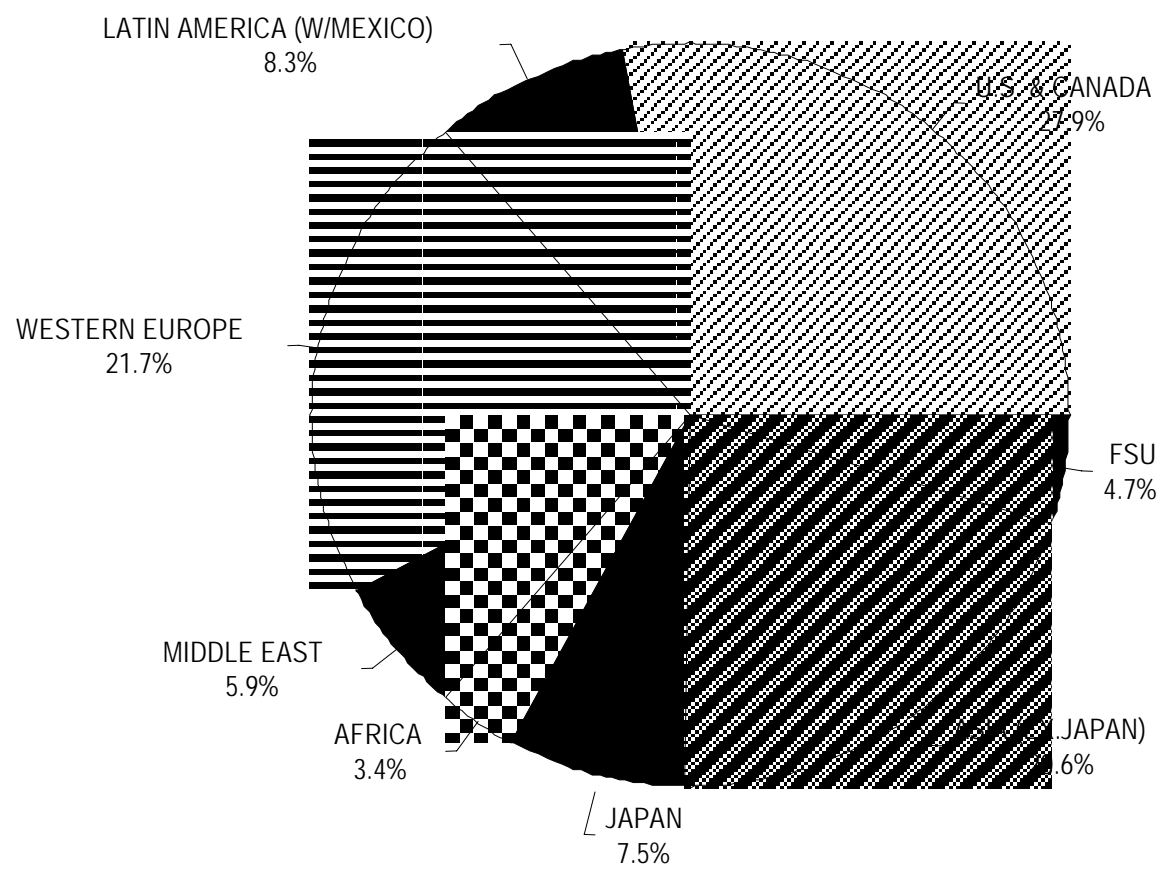

Figure 3.2 Worldwide Petroleum Product Demand, 2000

\subsection{REFINERY CAPACITY}

The global operating rate for refining capacity was very depressed following the crude oil price fly-ups of the 1970 s and subsequent decline in petroleum consumption. Average operating rates bottomed out in 1982 at about 68 percent (excluding operation of FSU facilities), as shown in Figure 3.3. The operating rate recovered during the 1980s and the 1990s, reaching almost 90 percent by 1997. The industry has continued to operate at this high level, despite a temporary decline to about 88 percent in 1999, reflecting the impact of capacity additions in Asia and a 
slowdown in demand growth due to the Asian economic decline. The FSU has about 9-10 million BPD of refinery capacity, but most of it is landlocked and inefficient, and its recent operating rate has been less than 50 percent.

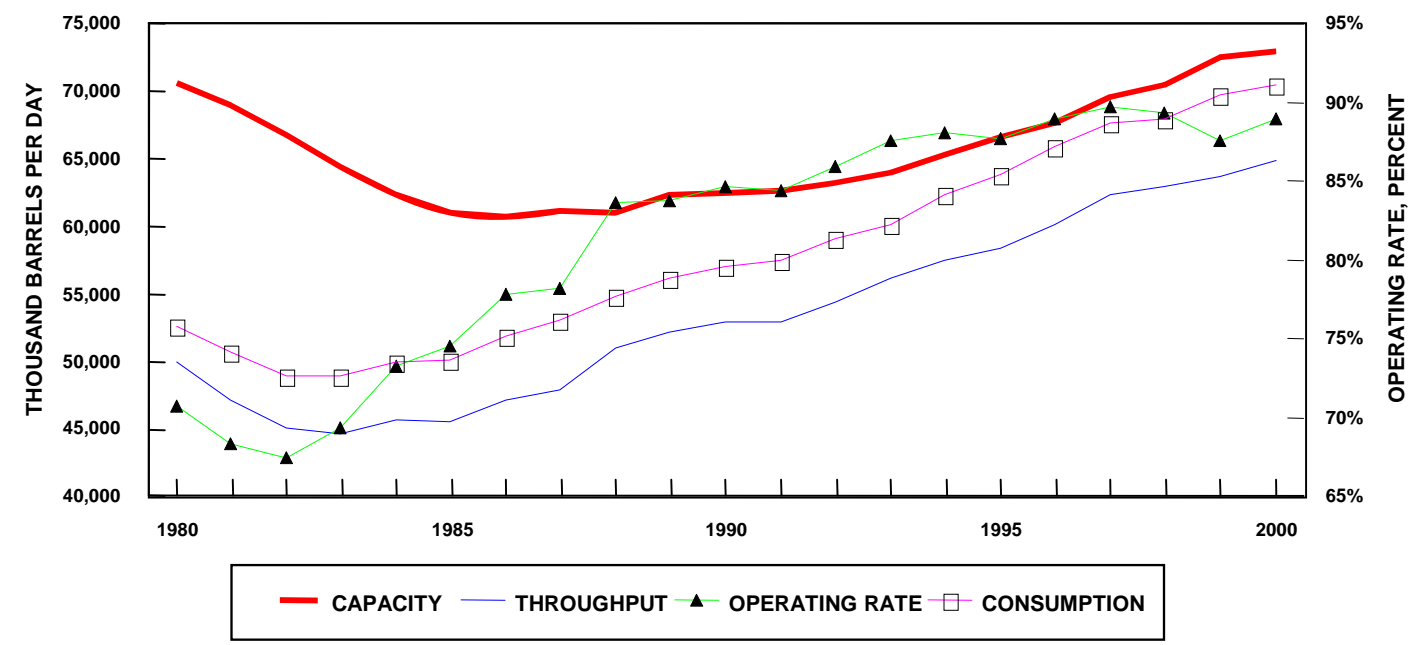

Figure 3.3 Global Refining Capacity Utilization Trends

The global refining industry suffered from excess capacity during the 1980s and extensive capacity, especially that which was not linked to residual fuel oil upgrading facilities, was shut down during the 1980s. Global capacity has been growing again since the early 1990s, as shown in Figure 3.4.

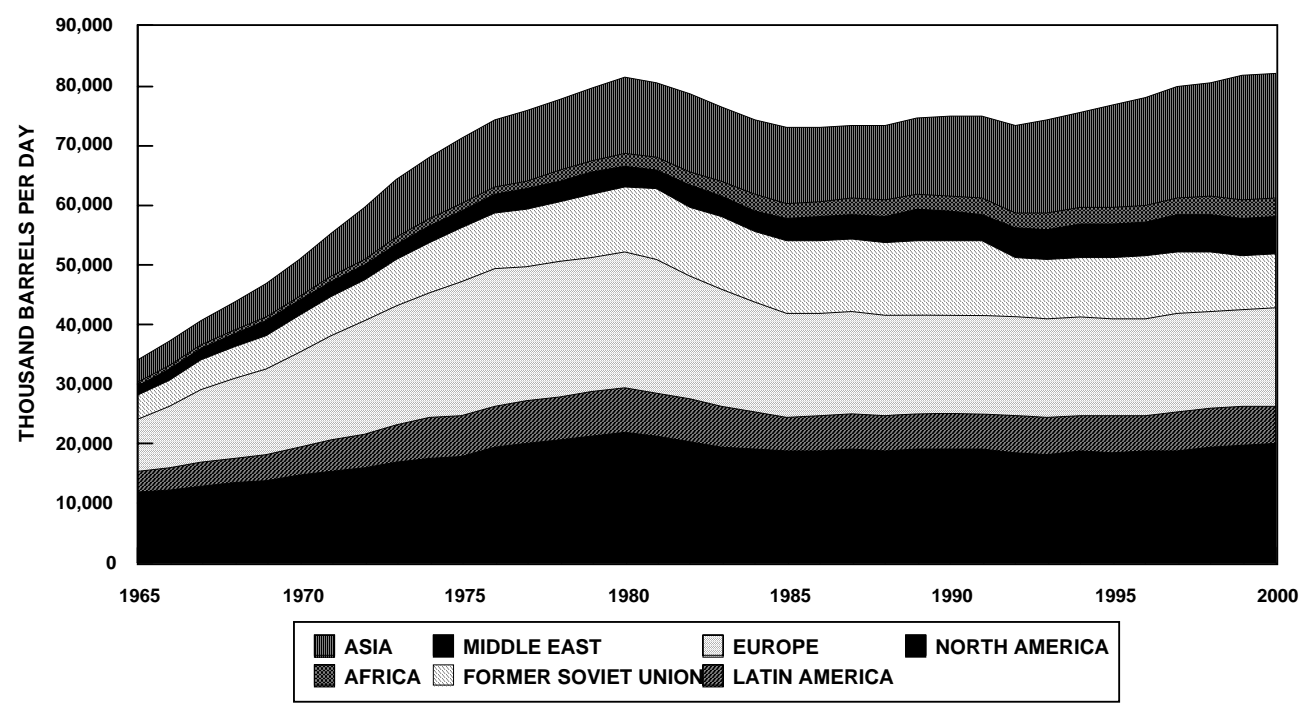

Figure 3.4 Global Refining Capacity Trends 
Refining capacity is evenly spread over the major demand centers, as shown in Figure 3.5. No region dominates from a capacity point of view. Much of the capacity is located where there is a local market. However, there are some notable exceptions, particularly in the Middle East.

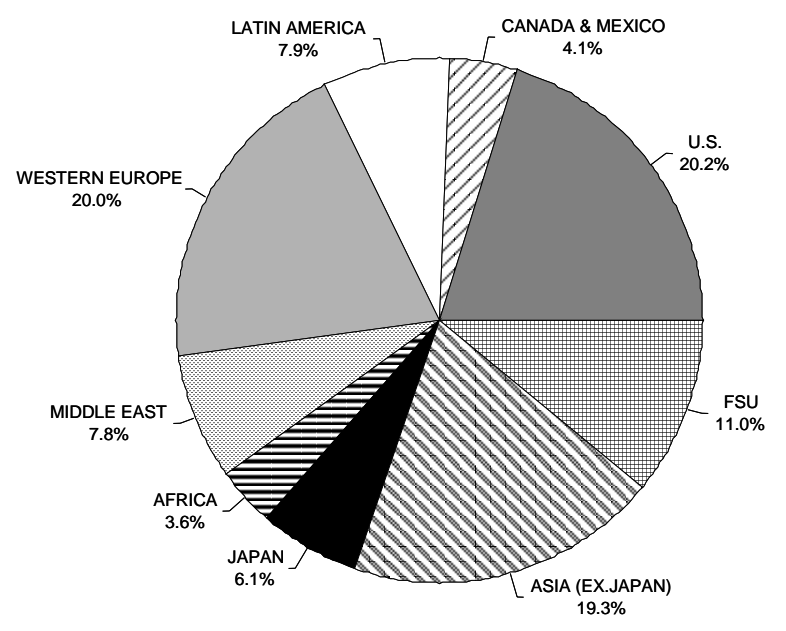

Figure 3.5 Global Refining Capacity, 2000

Refining industry configurations in different regions of the world reflect the local mix of petroleum product demand and the quality of crude oils in closest proximity to the region.

As shown in Figure 3.6, the U.S. industry is a clear leader in terms of the complexity of its refining industry. This situation reflects the high percentage of gasoline and low percentage of residual fuel oil in the U.S. product mix, as well as the industry's reliance on the processing of heavy, high sulfur crude oils from California, Mexico, Canada and Venezuela. Despite its reliance on these heavy crude oils, the U.S. industry produces a lower level of fuel oil - four percent compared with 18 percent in East Asia, and a much higher level of gasoline - 48 percent compared to 21 percent.

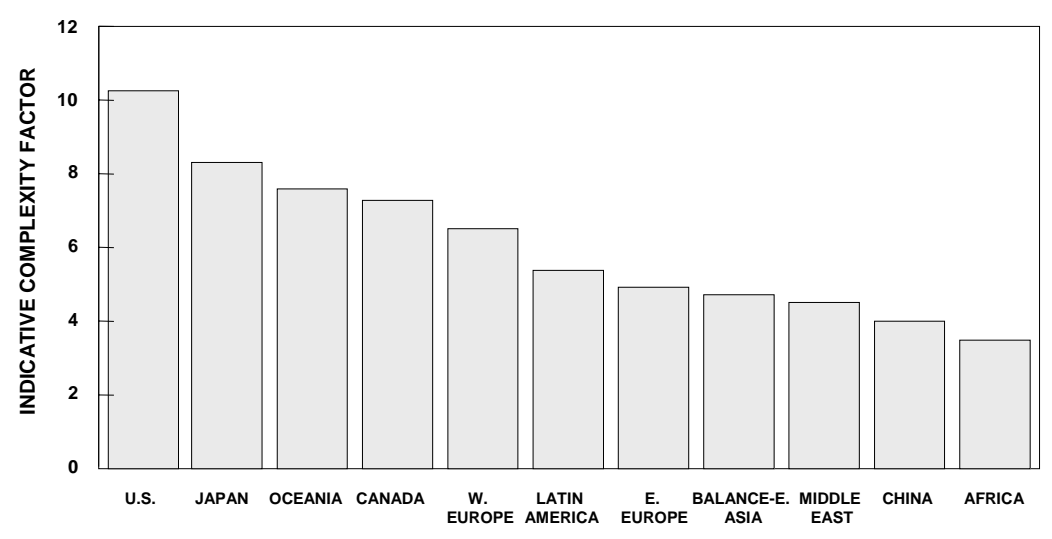

Figure 3.6 Global Refinery Complexity 


\subsection{PETROLEUM PRODUCT TRADE}

An analysis of regional trade balances indicates the following key product trade trends:

- The gasoline deficit in the United States will continue to be met by exports from Canada, Latin America and Western Europe, and reduced U.S. exports to Mexico following the completion of major refinery investments in Mexico (see Figure 3.7)

- Demand growth for middle distillates in East Asia and Europe is expected to exceed increases in local production. The increased deficits will be met by increasing exports from the Middle East and the FSU (see Figure 3.8)

- Growing residual fuel oil deficits in East Asia will primarily be met by increased exports from the Middle East and a shift in Western Europe's trade position from a deficit to roughly a balanced position (see Figure 3.9)

- Naphtha deficits in Western Europe and East Asia are projected to increase, met by growing supply from Africa and the Middle East

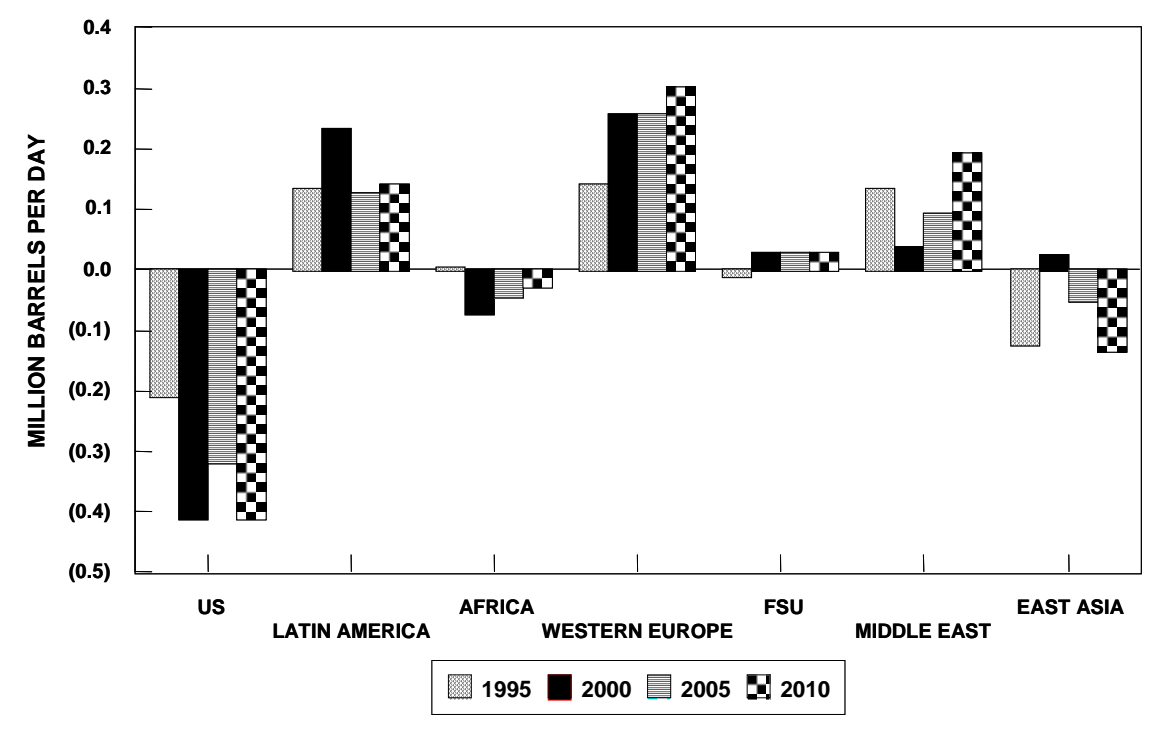

Figure 3.7 Global Gasoline Trade Trends 


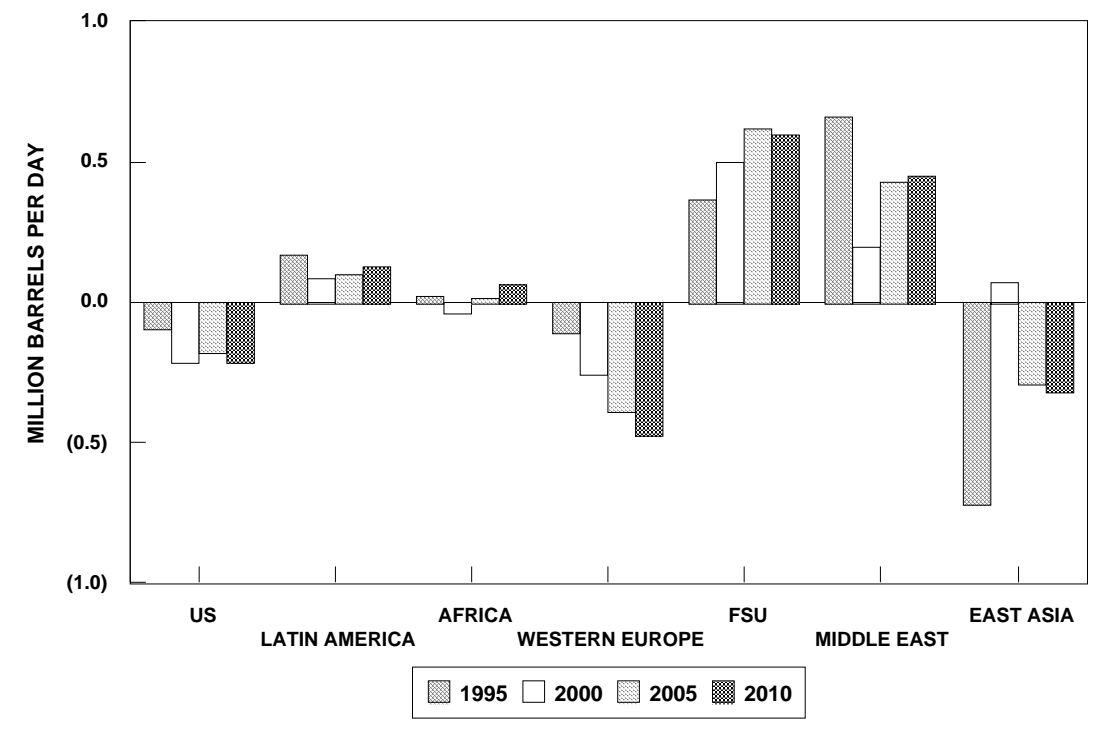

Figure 3.8 Global Middle Distillate Trade Trends

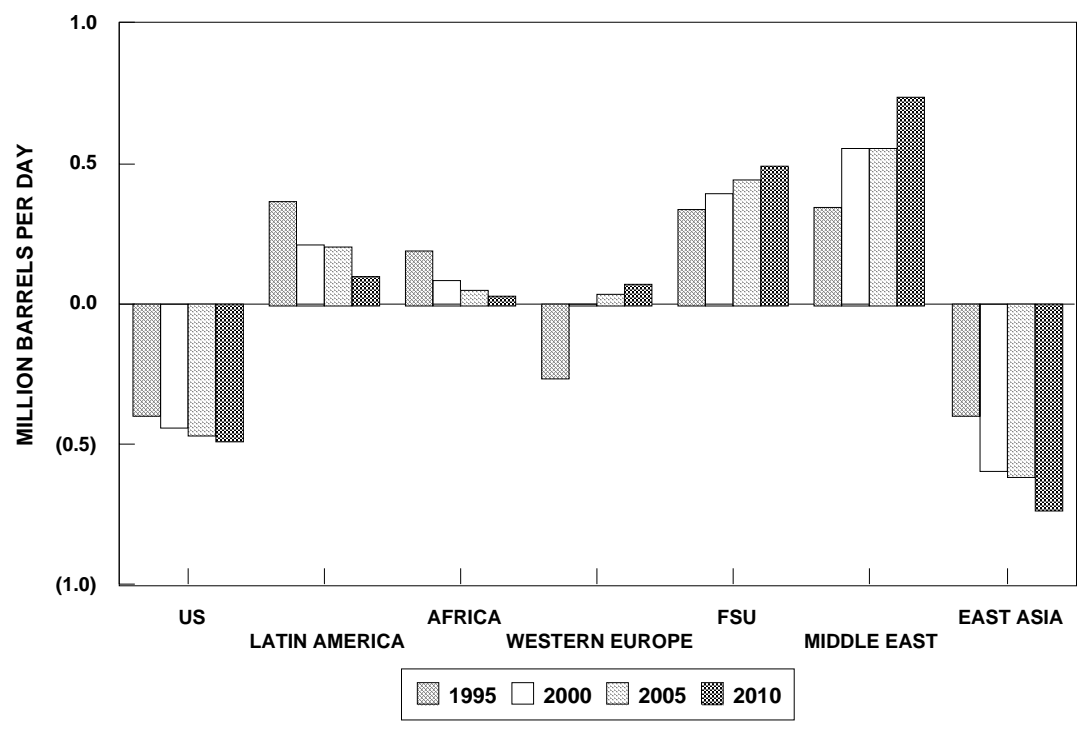

Figure 3.9 Global Residual Fuel Oil Trade Trends 


\subsection{KEY INDUSTRY DRIVING FORCES}

The key factors impacting the U.S. refining industry during the next decade will be:

- The maturity of the U.S. market, which limits refined product demand growth

- Long term gasoline demand uncertainties related to the potential development of more efficient or alternatively powered vehicles

- $\quad$ Significant oil price and refining margin volatility

- Unrelenting competitive pressures, compounded by increasingly transparent and efficient markets due to the use of e-business applications and other factors

- Mandated reductions in gasoline and diesel sulfur levels

- Likely regulatory restrictions on the use of MTBE as a gasoline blendstock

- The need for substantial capital investments to meet these mandated product quality changes, in the face of a history of unsatisfactory industry profitability

- Investment will also be needed in octane production to meet future U.S. gasoline demand growth. Phase out or ban on MTBE use would increase need for octane investments.

- Continued industry restructuring (e.g., Chevron/Texaco merger, Phillips' acquisition of Tosco, Conoco/Philips? (might be topical)divestitures by BP, etc.), slowed somewhat by the industry consolidation to date and the concerns of the Federal Trade Commission

\subsubsection{Product Quality Trends}

\subsubsection{Overview}

During the past year, the U.S. EPA has issued significant new gasoline and diesel sulfur standards for refiners. The main changes are:

- Maximum average sulfur level for gasoline will be reduced to $30 \mathrm{ppm}$ by 2006 from current average of about $300 \mathrm{ppm}$

- Maximum sulfur level for most on-highway diesel will fall to $15 \mathrm{ppm}$ by the middle of 2006 from current maximum level of 500 ppm

In addition, the State of California has passed regulations requiring that MTBE be removed from gasoline in California by December 31, 2002. The U.S. EPA has also proposed a substantial reduction in MTBE use in the balance of the U.S. Although the timing of this reduction is uncertain, a phase down or phase out of MTBE use eventually seems inevitable.

A programmed tightening of reformulated gasoline (RFG) quality specifications also occurred in 2000 and contributed to a dramatic runup in gasoline prices during the early summer in the Midwest region of the U.S. 
The timing for the programmed changes is summarized in Figure 4.1.

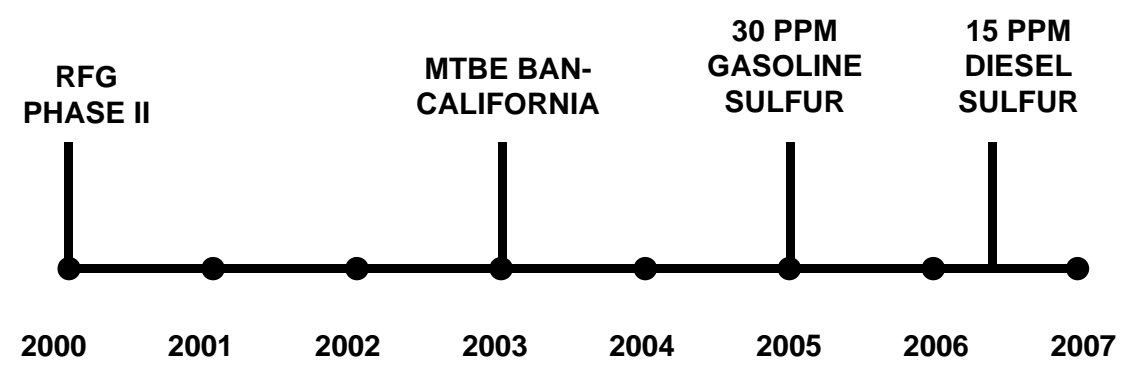

Figure 4.1 Timeline for Major U.S. Product Quality Changes

\section{Gasoline}

Since 1998, RFG composition has been defined by the EPA's complex model. Compliance with RFG regulations requires toxic, VOC and NOx emission reductions relative to 1990 levels. Starting in 2000, RFG quality specifications were tightened, resulting in additional reductions in NOx and summertime VOC emissions. Reducing the RFG sulfur level was one of the strategies adopted by U.S. refiners to comply with the reduction in NOx emissions.

In February 2000, the EPA issued its final rule regulating future gasoline sulfur levels throughout the U.S. (i.e., in areas where RFG must now be sold and also in the balance of the U.S.). The regulation requires most refiners and importers to meet a corporate average gasoline sulfur standard of $120 \mathrm{ppm}$ and a cap of $300 \mathrm{ppm}$ in 2004 . The cap will be reduced to $80 \mathrm{ppm}$ by 2006, when most refiners must produce gasoline averaging no more than 30 ppm sulfur. California already requires a $30 \mathrm{ppm}$ sulfur level in gasolines sold in areas of serious emission non-compliance. The compliance schedule is summarized in Table 4.1.

Table 4.1 U.S. Gasoline Sulfur Standards ${ }^{1}$

\begin{tabular}{|l|c|c|c|}
\hline Compliance & 2004 & 2005 & 2006 \\
\hline & & & \\
\hline Refinery Average, ppm & - & 30 & 30 \\
\hline Corporate Pool Average, ppm & 120 & 90 & - \\
\hline Per Gallon Cap, ppm & 300 & 300 & 80 \\
\hline 1 Excluding Small Refiners and gasoline sold in Geographic Phase-In Areas \\
\hline
\end{tabular}

The regulations provide temporary, less stringent standards for small refiners and for gasoline sold in selective areas in the Western region of the U.S. They also include an averaging, banking and trading program to encourage early sulfur reductions during the 2000-2003 period.

Proposed legislative and regulatory initiatives are also expected to greatly affect the future use of MTBE and other oxygenates in U.S. gasoline. The outcome of these initiatives remains unclear. 
Nexant's conclusions regarding the most likely regulatory changes and their impact on MTBE use in the U.S. are:

- The recommendations of the EPA's Blue Ribbon Panel only offer a framework on how to reduce the occurrence of MTBE in drinking water, rather than a precise ruling or new legislation. The actions needed to implement the Panel's key recommendations, assuming they are accepted in part or full, are a highly complex process. Before any regulatory changes are implemented, Congress, the EPA and others must agree on a course of action. The precise outcome of the process remains unclear.

- The State of California has passed regulations requiring that MTBE be removed from gasoline in California by December 31, 2002. However, the State is not empowered to waive the federal minimum 2 percent oxygen requirement for gasoline sold in California's ozone non-attainment areas; a change needed to minimize the cost of banning MTBE.

- It is clear that there are strong political objections to MTBE use and that the broader population now has a negative perception of MTBE. The EPA's legislative framework proposed in March 2000 reinforces this perception. Since MTBE's political support is very limited, regulatory changes severely restricting or banning its future use in the U.S. seem inevitable.

- $\quad$ Since no regulatory changes affecting MTBE use have yet been legislated, how quickly these changes are implemented remains subject to much uncertainty. In Nexant's view, December 31, 2002 is the earliest date that substantial reductions in California's MTBE use are likely to occur, and this date may slip.

- In the balance of the U.S., it is likely that it will take longer for substantial reductions in MTBE use to occur since amending the Clean Air Act is expected to be a protracted process. It is generally recognized that the refining industry will need several years to engineer and construct facility modifications needed to comply with new gasoline quality regulations. This work can only begin once the new gasoline quality regulations have been finalized.

Diesel

A provision of the 1990 Clean Air Act Amendments required that sulfur levels in on-highway diesel be significantly reduced. This regulation, which went into effect October 1, 1993, reduced the sulfur concentration levels for on-highway diesel from an average 0.25 weight percent to 0.05 weight percent. In addition, specifications were developed for diesel aromatic levels and cetane number/index. Simultaneously, California issued tighter diesel fuel specifications, which feature a very broad definition of use that effectively covers any vehicle that can be driven on the highways. Current U.S. diesel specifications are summarized in Table 4.2.

The maximum sulfur content regulations were implemented to achieve a reduction in particulate sulfate emissions. The other product quality restrictions were introduced to reduce vehicle exhaust emissions such as smoke, particulates and NOx. 


\section{Table 4.2 On-Highway Diesel Fuel Specifications, 2001}

\begin{tabular}{|l|c|c|}
\hline & BALANCE OF U. S. & CALIFORNIA \\
\hline Sulfur, ppm & $500 \mathrm{max}$ & $500 \mathrm{max}$ \\
\hline Aromatics ${ }^{1}$, vol. $\%$ & $36 \mathrm{max}^{1}$ & $10 \mathrm{max}$ \\
\hline Polycyclic aromatic & n.a. & $1.4 \mathrm{max}$ \\
\hline Nitrogen & n.a. & $10 \mathrm{max}$ \\
\hline Cetane number & n.a. & $48 \mathrm{~min}$ \\
\hline Cetane index $^{1}$ & $40 \mathrm{~min}^{1}$ & n.a. \\
\hline API gravity, & ${ }^{\circ}$ & $33-39$ \\
\hline Flash point, ${ }^{\circ} \mathrm{F}$ & $30 \mathrm{~min}$ & $130 \mathrm{~min}$ \\
\hline T90, $^{\circ} \mathrm{F}$ & n.a. & $550-610$ \\
\hline T95, $^{\circ} \mathrm{F}$ & $640 \mathrm{max}$ & $580-660$ \\
\hline${ }^{1}$ Must meet aromatics or cetane specifications & \\
\hline
\end{tabular}

In December 2000, the U.S. EPA issued a Final Rule related to future diesel sulfur levels. The rule, which is being challenged in the courts by the U.S. refining industry, stipulates that U.S. refiners will have to make at least 80 percent of their mid-2006 on-highway diesel as ultra-lowsulfur diesel (ULSD) with a maximum sulfur content of $15 \mathrm{ppm}$. In addition, if all the "small" refiners given temporary exemptions in EPA's new rule delay making ULSD, then about 75 percent of diesel fuel starting in mid-2006 will be ULSD -- until 2010, when all highway diesel fuel will become ULSD. Diesel specifications other than sulfur (e.g., cetane, aromatics, distillation, etc.) are not affected by the new rule.

Diesel engine makers also will be held to strict emissions limits starting in September, 2006. Lowering diesel vehicle emissions is expected to rely more heavily on after treatment. Lower diesel sulfur levels will improve the performance of particulate matter traps and NOx catalysts.

The new regulations include the following compliance deadline schedule:

June 1. 2006:

July 15, 2006:

September 1, 2006:

June 1, 2010:

\section{Refiners and importers must begin producing 15 ppm ULSD}

Terminals must have switched-over ULSD storage tanks

Retail stations and bulk end-users must complete switchover of tanks for storing ULSD

All refineries participating in the on-highway diesel market must produce 100 percent ULSD, with no more sulfur credits allowed

Refiners/importers must produce at least 80 percent ULSD (called a "temporary compliance option" or TCO) in order to participate in the on-highway diesel market, starting June 1, 2006, until the end of 2009. If they produce more than 80 percent ULSD, then they can sell sulfur credits to refiners who want to continue selling today's conventional $500 \mathrm{ppm}$ sulfur diesel to old trucks (pre-2007 model year) that lack sulfur-sensitive catalysts and traps. 
Under the new regulations, sulfur credits can be generated from June 2006 until Dec. 31, 2009, but can only be sold to another refinery (or transferred to an affiliated refinery) in the same region. A refinery can produce less than 80 percent ULSD only if it gets offsetting sulfur credits from another refinery in the same region.

Foreign refiners can also use the TCO option. Such a refiner must demonstrate that at least 80 percent of the highway diesel fuel it imported into each region meets a 15 ppm sulfur level or show that it has enough credits from other refiners in that region to cover the volume of fuel below the 80 percent requirement. Foreign refiners, as well as importers, can also generate sulfur credits by exceeding 80 percent compliance.

The regulations also include carryover provisions and provide extended deadlines for complying with the new gasoline sulfur standards to those small refiners and refiners selling gasoline and diesel in selective areas in the Western region of the U.S. that produce 100 percent ULSD by June, 2006.

\section{Residual Fuel Oil}

Residual fuel oil quality levels are selective according to each end use. Typically higher sulfur product is sold as bunkers to the international shipping community. However, selective initiatives to limit SOx emissions from these vessels have emerged. Currently within the continental U.S. only a few selected points on the U.S. West Coast require higher quality bunkers for operations near shore. Nexant does not expect that the U.S. will enact any broad legislation that will impact bunker quality before the year 2010. Over the past decade the growing market share of high sulfur bunkers, at the expense of lower sulfur uses, is estimated to have resulted in an increase in the average sulfur content of residual fuel oil consumed in the U.S.

\subsection{PETROLEUM PRODUCT DEMAND}

Total U.S. refined product demand is forecast to increase by 1.0 percent annually over the 20002015 period. This is somewhat lower than the 10-year average of 1.5 percent, and reflects the somewhat lower outlook for economic growth as well as potentially higher pricing of crude oil and products that is expected for the forecast period. Historical and forecast U.S. petroleum product demand is presented in Table 4.3. By product, this outlook reflects:

- Nexant's opinion that gasoline demand growth during the 1990s was partially been driven by a number of "step-change" factors (e.g. rapid growth in lower mileage Sport Utility Vehicles (SUVs), each of which has now been incorporated into the base demand levels. The projected growth rate in gasoline demand of 1.1 percent annually assumes that there will be a modest increase in average vehicle fleet efficiency, but that alternatively-powered vehicles will not materially impact gasoline demand during the next 10 years

- Jet fuel consumption is expected to grow 0.5 percent per year, reflecting expected continuing gains in engine efficiency in the commercial air fleet as well as a negative step-change in use that has occurred due to the impact of September 11 attacks 
- Limited growth in off-highway uses of middle distillates, in particular due to continued loss of the residential heating market to natural gas, will offset continued growth in onhighway diesel fuel. Combined growth in on-highway and off-highway uses is expected to average 1.4 percent annually

- $\quad$ Residual fuel oil use, after suffering a step-change reduction in demand between 1994 and 1995, has achieved demand in the 850-950 thousand barrels per day (KBPD) range through 2001. Future consumption is forecast to decline about 0.2 percent annually

- "Other products", which consists of a wide range of relatively minor products, includes: gas liquids (ethane, propane, normal and iso-butane, and pentanes plus), asphalt, chemical feedstocks, petroleum coke, lubricants, waxes, kerosene and miscellaneous products. A number of these products, such as lubricants, and waxes, are very mature with limited growth potential. Others, in particular feedstock for chemical production, are expected to have high growth rates. On balance, this category of products is expected in grow about 1.0 percent annually, in line with overall petroleum demand growth

Table 4.3 U.S. Major Petroleum Product Demand, Thousand Barrels Per Day

\begin{tabular}{|c|c|c|c|c|c|c|c|}
\hline & Gasoline & Jet Fuel & Distillate & $\begin{array}{c}\text { Residual } \\
\text { Fuel }\end{array}$ & $\begin{array}{c}\text { Total } \\
\text { Major } \\
\text { Products }\end{array}$ & $\begin{array}{c}\text { Total } \\
\text { "Other" }\end{array}$ & $\begin{array}{c}\text { Grand } \\
\text { Total }\end{array}$ \\
\hline 1990 & 7,235 & 1,522 & 3,021 & 1,229 & 13,007 & 3,981 & 16,988 \\
\hline 1995 & 7,789 & 1,514 & 3,207 & 852 & 13,362 & 4,363 & 17,725 \\
\hline 1999 & 8,431 & 1,673 & 3,572 & 830 & 14,506 & 5,013 & 19,519 \\
\hline 2000 & 8,472 & 1,725 & 3,722 & 909 & 14,828 & 4,873 & 19,701 \\
\hline 2001 & 8,591 & 1,657 & 3,835 & 936 & 15,019 & 4,644 & 19,663 \\
\hline 2006 & 9,020 & 1,721 & 4,063 & 922 & 15,726 & 4,941 & 20,667 \\
\hline 2010 & 9,424 & 1,784 & 4,281 & 904 & 16,392 & 5,245 & 21,636 \\
\hline 2015 & 9,953 & 1,865 & 4,567 & 881 & 17,267 & 5,650 & 22,917 \\
\hline \multicolumn{7}{|c|}{ Annual Growth Sales, \% } \\
\hline $1990-2000$ & 1.6 & 1.3 & 2.1 & $(3.0)$ & 1.3 & 2.0 & 1.5 \\
\hline $1995-2000$ & 1.7 & 2.6 & 3.0 & 1.3 & 2.1 & 2.2 & 2.1 \\
\hline $2000-2015$ & 1.1 & 0.5 & 1.4 & $(0.2)$ & 1.0 & 1.0 & 1.0 \\
\hline
\end{tabular}

\subsection{REFINERY PRODUCTION}

Processing capacity of the United States refining industry has expanded sharply since 1994, rising a total of about 1.7 million BPD through 2001, or over 10 percent. This recovery is a sharp reversal of the rationalization of almost 0.7 million BPD of capacity that occurred between 1992 and 1994.

While no new grassroots refining capacity is expected to be built in the near future, the projected high average operating rates, and Nexant's expectation of a recovery in underlying refining profitability, will support incremental expansions. Reflecting this, refining nameplate capacity is 
forecast to increase by 1.0 percent per year through 2015. Total nameplate capacity is projected to rise from 16.7 million bpd in 2001 to 19.2 million bpd in 2015, as shown in Figure 4.2.

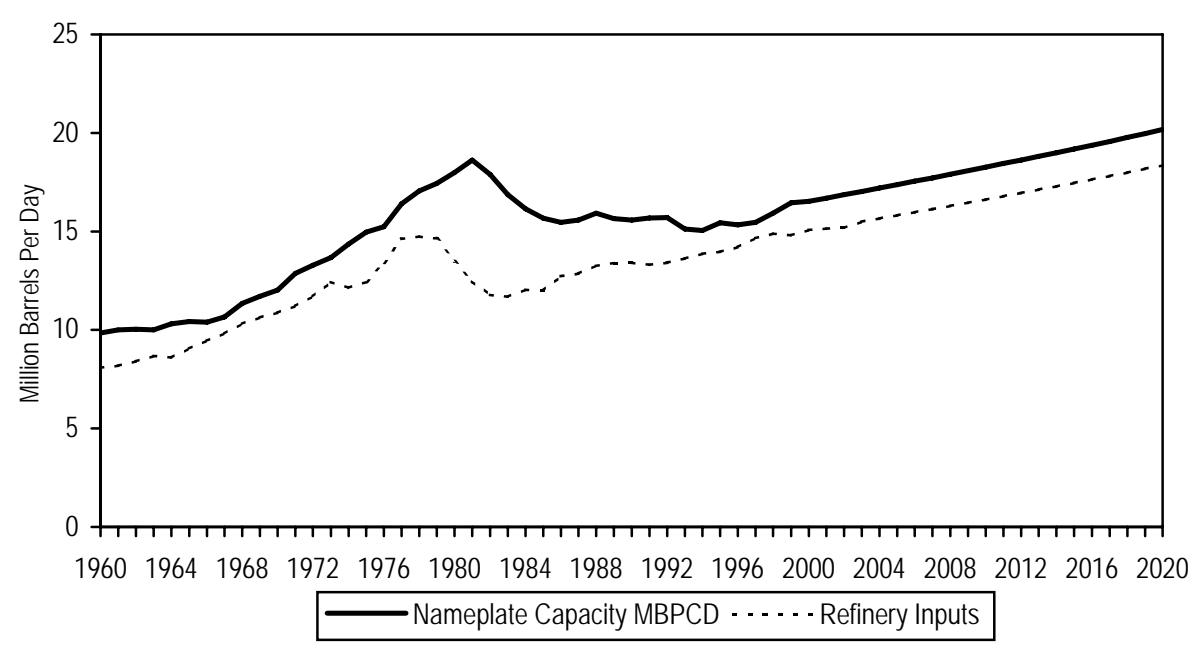

Report 1 Figures.xls

Figure $4.2 \quad$ Trends in U.S. Refining

Industry operating rates have been increasing steadily for the past 15 years, and the industry has been operating at over 90 percent since 1993.

Average industry operating rates approached 97 percent (annual average, based on operating capacity) in 1997, and, despite declines from this level due to oil price volatility and refining capacity expansions, the operating rate remains at historically high levels in the range of 92-93 percent through 2001.

Based on an outlook for sustained growth in domestic product demand, it is expected that the industry will continue to operate close to 93 percent utilization, as shown in Figure 4.3.

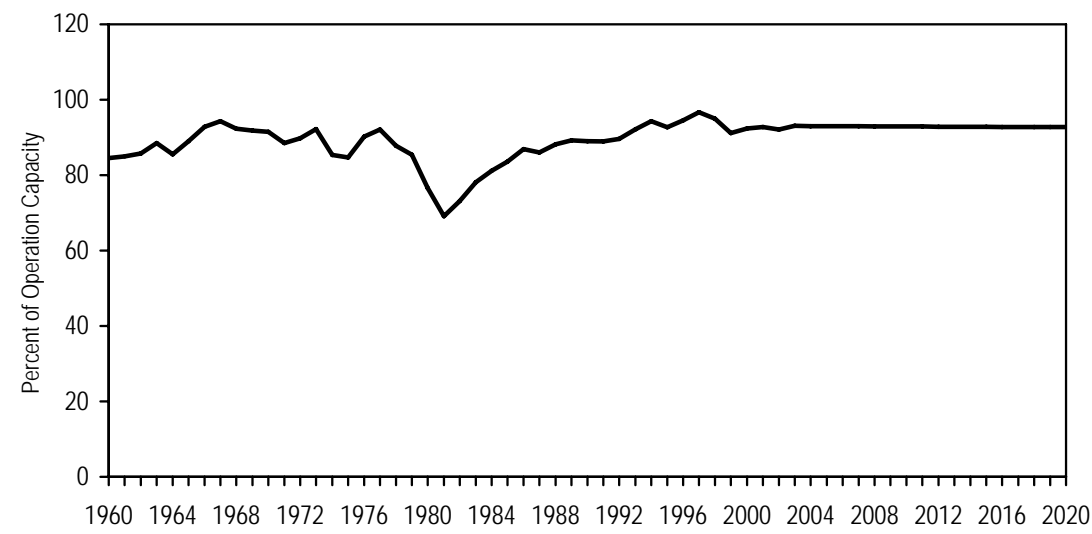




\section{Figure $4.3 \quad$ U.S. Refining Industry Operating Rates}

\subsection{PETROLEUM PRODUCT TRADE}

Based on projected growth of refinery output and product demand of about 1.0 percent per year each, it is expected that net imports of refined products will not change significantly during the next decade. Net imports, measured in absolute terms, are expected to remain close to the same historical range as was experienced during the past decade, as shown in Figure 4.4. It should be noted that future projections for finished product balances are highly dependent on the underlying assumption that U.S. refining capacity, via capacity creep, will expand at about 1.0 percent per year. If this capacity growth does not occur, the potential requirement for product imports would be significantly higher.

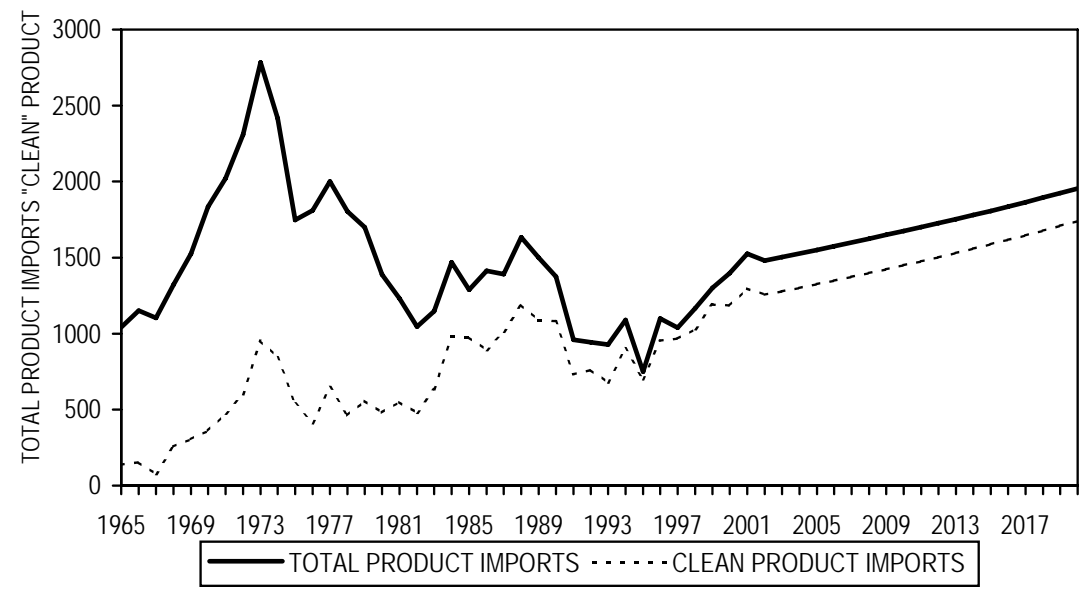

U:IReport 1 charts.xls|Sheet3

Figure 4.4 U.S. Refining Industry Import Exposure 


\subsection{KEY INDUSTRY DRIVING FORCES}

The mandated changes to product specifications through the Auto-Oil program continue to put pressure on the European refining industry. Refineries are now planning for further reductions in gasoline and diesel sulfur from 2005. Although a $50 \mathrm{ppm}$ sulfur limit for these fuels had previously been agreed, individual European governments are now proposing tax incentives to encourage levels down to $10 \mathrm{ppm}$. Even the $50 \mathrm{ppm}$ limit will require investment in many refineries, and in view of the low margins which have generally prevailed over the last five years, shareholders of weaker refineries are reviewing closure as a potential alternative to investment.

Some relief to the continuing tightening of specifications may be provided by recognition that increased processing to improve fuel quality leads to greater carbon dioxide emissions at the refinery level. It is possible that this may slow the rate of required improvement to fuel quality as the total emission picture begins to be considered.

Overall refined product demand in Western Europe is projected to show little growth over the next ten-fifteen years even though limited progress in meeting European Kyoto obligations is anticipated. The European refining industry will need to adapt to the likelihood of further decline in high sulfur fuel oil demand, combined with growth in demand for jet, diesel and petrochemical naphtha.

\subsubsection{Product Quality Trends}

\subsubsection{Overview}

Future product quality requirements in Europe continue to be debated within the European Union (EU), although a number of key decisions on principles for transport fuel specifications from 2005 have been taken. The main legislation falls under two separate frameworks:

- The quality of gasoline and diesel fuels has been modified following completion of the Auto-Oil program

- The new Acidification Strategy was adopted by the European Commission in March 1997. This proposes a number of actions to combat deposition in natural habitats of the main acidifying pollutants of sulfur dioxide and nitrogen oxides.

The main agreed limits are as follows:

- Maximum sulfur levels for gasoline and automotive diesel will fall to 50 ppm starting January 1, 2005. It is possible that individual EU countries may be allowed to offer tax incentives to support sulfur levels down to $10 \mathrm{ppm}$.

- Gasoline aromatics content will fall to 35 ppm starting January 1, 2005 
- Sulfur levels for heavy fuel oil and gas oil will be limited to 1.0 percent and 0.2 percent respectively starting January 1, 2003.

In addition, there is likely to be some reduction in gasoline volatility specifications and an increase in diesel cetane number.

Overall the proposed sulfur reductions and the gasoline composition changes will have the greatest implications for the refining industry.

\subsubsection{Gasoline}

A European Standard (CEN 228) for unleaded "Eurograde" gasoline was established in 1993 with an octane requirement of $95 \mathrm{RON} / 85 \mathrm{MON}$. A maximum sulfur content of 0.05 percent (500 ppm) was introduced in January 1995.

Changes to CEN 228 were developed from the Auto-Oil program and have now been legislated by the European Union in Directive 98/70/EC. This program concluded that:

- Vehicle technology changes already occurring or legislated will lead to substantial improvements in air quality over the next decade with fleet turnover

- Benefits from vehicle technology changes already occurring will be more cost effective than radical fuel reformulation

- A significant amount of emissions emanate from a relatively small proportion of the older vehicles in the overall car population

- Selective changes in fuel quality were therefore necessary, although these were less severe than those adopted in, for example, California.

The legislative proposals developed by the European Commission were debated extensively by the European Parliament and significant amendments were tabled at each of the two parliamentary readings. The focus of the amendments was to achieve tighter fuel product quality specifications on the basis of a cost benefit approach. Auto Oil I legislation came into force starting January 1, 2000. EU gasoline specifications are presented in Table 5.1. 


\section{Table 5.1 EU Unleaded Gasoline Specifications}

\begin{tabular}{|c|c|c|c|c|c|c|c|}
\hline & \multicolumn{2}{|c|}{ Auto Oil Legislation } & \multirow{2}{*}{$\frac{\text { CS Estimate }}{2005}$} & \multirow[b]{2}{*}{ CARB, 1996} \\
\hline & & & 1998 & 2000 & 2005 & & \\
\hline RVP2 $^{2}$ & $\mathrm{kPa}$ & $\max$ & $70-100$ & $60-70$ & TBA & $60-70$ & 48.3 \\
\hline E100 & vol \% & $\min$ & $65-70$ & 46 & TBA & 46 & $N / A$ \\
\hline Olefins $^{3}$ & vol \% & $\max$ & - & 18 & TBA & 18 & $4.0 / 6.0^{4}$ \\
\hline Aromatics & vol \% & $\max$ & - & 42 & 35 & 35 & $22 / 25^{4}$ \\
\hline Benzene & vol \% & $\max$ & 5.0 & 1.0 & TBA & $0.8-1.0$ & $0.8 / 1.0^{4}$ \\
\hline Oxygen & wt \% & $\max$ & 2.7 & 2.7 & TBA & 2.7 & $1.8-2.2$ \\
\hline Sulphur ${ }^{5}$ & ppm & $\max$ & 500 & 150 & 50 & 50 & $30 / 40^{4}$ \\
\hline Lead & $g / l$ & $\max$ & 0.013 & 0.005 & 0.005 & 0.005 & 0.005 \\
\hline \multicolumn{8}{|c|}{$\begin{array}{l}\text { TBA - To be agreed } \\
{ }^{1} \text { California Air Resources Board } 1996 \text { standards for reformulated gasoline; for comparative purposes only. } \\
{ }^{2} \text { Summer period; current limit depends on the volatility class specified. Post 2000, RVP is limited to } 70 \\
\text { kPa for member states with arctic conditions (summer periods starts no later than } 1 \text { May and ends not } \\
\text { before } 31 \text { August.) }\end{array}$} \\
\hline
\end{tabular}

The Auto-Oil legislation also specifies certain lower limits for 2005, reducing:

- Gasoline sulfur content to $50 \mathrm{ppm} \max$

- Gasoline aromatics content to 35 volume percent

The other specifications for 2005, such as olefin and benzene content, are still under discussion in the EU.

Nexant's estimates of gasoline product specifications for Auto-Oil II are based on the following assumptions:

- RVP and volatility limits to remain unchanged due to winter driveabilty concerns in northern areas if lower values were to be applied.

- $\quad$ Olefins set at a range consistent with prior EU Parliament amendments to AutoOil I specifications.

- $\quad$ Oxygen limit retained as research identified increased NOx emissions at higher oxygen levels.

\subsubsection{Diesel}

A European Standard for diesel (CEN 590) was originally adopted in all West European states in 1993. The reductions in diesel and gas oil sulfur specifications to 0.2 percent took effect in 
1994, with a further reduction for diesel to 0.05 percent in October 1996, and 0.035 percent in January 2000.

Some countries improved their fuel quality ahead of the EU Directive. As with gasoline, this has been due to a combination of legislative and marketing reasons. The use of substantial tax incentives for the "green" diesels introduced in Scandinavian countries resulted in these grades making up most of the domestic diesel market.

There will be further changes to CEN 590 from the second stage of the Auto-Oil program. Extensive amendments to diesel specifications were proposed by the European Parliament during the legislative process in the same way as those for gasoline. EU gasoline specifications are presented in Table 5.2.

Table 5.2 EU Diesel Specifications

\begin{tabular}{|c|c|c|c|c|c|}
\hline & & & \multicolumn{2}{|c|}{ Auto-Oil Legislation } & CS Estimate \\
\hline & & 1998 & 2000 & 2005 & 2005 \\
\hline Cetane Number & $\min$ & 49 & 51 & TBA & $51-58$ \\
\hline Density & $\mathrm{kg} / \mathrm{m}^{3} \max$ & 860 & 845 & TBA & $820-845$ \\
\hline Distillation, $95 \%{ }^{1}$ & ${ }^{\circ} \mathrm{C} \max$ & 370 & 360 & TBA & $340-360$ \\
\hline $\mathrm{PAH}^{2}$ & wt $\% \max$ & - & 11 & TBA & $3-11$ \\
\hline Sulfur ${ }^{3}$ & ppm max & 500 & 350 & 50 & 50 \\
\hline \multicolumn{6}{|c|}{$\begin{array}{l}{ }^{1} \text { To be agreed } \\
2 \text { Limit for temperate climates. A lower limit currently applies for Arctic grades } \\
\text { Polycyclic Aromatic Hydrocarbons } \\
{ }^{3} \text { Portugal has derogation until } 31 \text { August } 2003 \text { on diesel sulfur content }\end{array}$} \\
\hline
\end{tabular}

The current legislation further reduces the maximum sulfur level for diesel to $50 \mathrm{ppm}$ in 2005 . Nexant's estimates of diesel product qualities for Auto-Oil II are based on the following assumptions:

- $\quad$ Cetane numbers proposed by the European Parliament as indicative values for 2005. The proposed cetane number of 58 exceeds the auto industry worldwide fuel harmonization standard (cetane number of 55).

- Density and distillation range are set by the auto industry harmonization standards and European Parliament amendments proposed to the Auto-Oil I legislation.

- Sulfur level set at auto industry worldwide fuel harmonization standards as the lower limit of the range.

Polycyclic aromatics limits advocated by the European Parliament amendments as indicative values for 2005 and supported by the auto industry worldwide fuel harmonization standards. 


\subsubsection{Gas Oil}

The sulfur level of gas oil is under review as part of the EU's Acidification Strategy. Current proposals indicate a reduction in gas oil sulfur content to 0.1 percent from 2008 .

\subsubsection{Heavy Fuel Oil (HFO)}

All EU member states set their own quality specifications for inland use of heavy fuel oils (HFO), normally in order to meet their own commitments under the EU's Large Combustion Plant (LCP) Directive. Due to the complex linkage between SO2 emission targets and HFO sulfur specifications, each country has approached their task of reducing emissions differently.

Bunker fuel quality for international shipping is set by the International Maritime Organization (IMO). In 1997, the IMO adopted a Protocol, which provided a new Annex: "Regulations for the Prevention of on Air Pollution from Ships" to the MARPOL Convention. The protocol has adopted a global ceiling on bunker fuel sulfur content of 4.5 percent. The Baltic Sea was also designated a special "SOx Emission Control Area", where the sulfur content of the bunker fuel oil used is limited to 1.5 percent maximum (alternatively, an exhaust gas cleaning system must be utilized).

The 1997 Protocol will enter into force 12 months after the date on which not less than 15 States, with a combined tonnage of at least 50 percent of the gross world merchant fleet, have become parties to the Protocol. At present, only a few countries have ratified the Protocol. Nexant anticipates that it could take several more years before the Protocol is ratified and comes into force. Thus, Nexant projects that average European bunker fuel sulfur levels will remain in the range 3.0 to 3.5 percent. The consumption of low sulfur bunkers (less than one percent sulfur) is not expected to be significant before 2005 .

\subsection{PETROLEUM PRODUCT DEMAND}

\subsubsection{Overview}

The main features of the forecast trends for future European refined product demand are:

- $\quad$ Strong growth in automotive diesel (approaching two percent per year) although this will be partly offset by declining heating gas oil demand.

- Virtually static gasoline demand (declining by 0.2 percent per year) as diesel continues to take most of the transport fuel growth.

- $\quad$ Growth of 2.6 percent per year in jet demand (1999 to 2010) reflecting increasing civil aviation demand.

- Inland heavy fuel oil (HFO) demand is projected to decline to 2005 as sulfur limits tighten. This decline is partially offset by slow growth in bunker fuel demand.

Overall demand is projected to be virtually static over the next ten years. Historical and forecast West European refined product demand is presented in Table 5.3. 
Nexant forecasts show the impact of greenhouse gas (GHG) emission reduction measures by 2010, with reductions in fuel oil and heating gas oil demand, although these are offset by increases in petrochemical naphtha, jet fuel and diesel demand. Gasoline demand is forecast to decline slowly during the period.

Table 5.3 Refined Product Demand - Western Europe, 1990-2010, Million Tons

\begin{tabular}{|c|c|c|c|c|c|c|c|c|}
\hline & \multicolumn{3}{|c|}{ Actual } & \multicolumn{3}{|c|}{ Projection } & \multicolumn{2}{|c|}{$\begin{array}{c}\text { Average Annual Growth } \\
\text { Rate, } \%\end{array}$} \\
\hline & 1990 & 1995 & 1999 & 2001 & 2005 & 2010 & 1999/1998 & $2010 / 1999$ \\
\hline LPG & 19 & 21 & 23 & 24 & 25 & 25 & $(3.9)$ & 0.2 \\
\hline Naphtha & 30 & 38 & 39 & 41 & 45 & 49 & 0.4 & 1.9 \\
\hline Gasoline & 127 & 120 & 124 & 122 & 121 & 121 & $(0.5)$ & $(0.2)$ \\
\hline Jero/Kero & 32 & 38 & 47 & 50 & 55 & 61 & 6.6 & 2.6 \\
\hline \multicolumn{9}{|l|}{ Gas Oil/Diesel } \\
\hline Diesel & 101 & 115 & 131 & 139 & 151 & 161 & 1.3 & 1.8 \\
\hline Other inland & 104 & 105 & 106 & 106 & 100 & 92 & (1.0) & $(1.2)$ \\
\hline Bunkers & 8 & 9 & 8.7 & 9 & 9 & 10 & $(8.3)$ & 0.1 \\
\hline Subtotal & 213 & 229 & 246 & 254 & 261 & 263 & $(0.1)$ & 0.5 \\
\hline \multicolumn{9}{|l|}{ Heavy Fuel Oil } \\
\hline Inland & 83 & 76 & 61 & 60 & 55 & 52 & $(7.2)$ & $(1.9)$ \\
\hline Bunkers & 28 & 27 & 32 & 33 & 35 & 37 & $(4.9)$ & 0.7 \\
\hline Subtotal & 110 & 103 & 93 & 93 & 90 & 89 & (6.4) & $(0.9)$ \\
\hline Other products & 39 & 44 & 49 & 49 & 50 & 50 & $(4.4)$ & $(0.2)$ \\
\hline Total Oil Products & 570 & 592 & 621 & 632 & 646 & 657 & $(1.2)$ & 0.4 \\
\hline
\end{tabular}

\subsubsection{Gasoline}

Improved general economic performance in the last five years has not been accompanied by a recovery in gasoline demand. The main causes for this lack of growth are:

- Increased registration of diesel cars, driven by three inter-dependent factors:

- $\quad$ Generally favorable excise treatment of diesel fuel

- Diesel's favorable consumption per kilometer

- $\quad$ Diesel's perceived environmental benefits

- Improved average economy of gasoline-fuelled vehicles, despite increasing registrations of high performance and sports vehicles.

In recent years the outlook for gasoline demand has grown progressively more pessimistic for the refining industry. Nexant's projection is for flat demand to 2005 followed by a small decline 
to 2010 as cars with a much higher fuel efficiency constitute a larger proportion of the car population.

\subsubsection{Jet Fuel}

Jet fuel is the refined product for which demand is growing most strongly in Western Europe. This has occurred against a background of reduced military consumption with the end of the Cold War, and improved engine efficiency.

Nexant projects continuing strong growth in jet fuel demand, although at a somewhat lower trend than in recent years. Nexant expects jet fuel demand growth will slow slightly due to a combination of a gradual reduction in growth of the business sector as speed of response requires more business to be conducted electronically, through environmental measures to reduce carbon dioxide emissions, and possibly through air traffic infra-structural limits. As passenger jets become larger and more fuel efficient, the growth in jet fuel demand will continue to lag the growth in number of passengers.

\subsubsection{Automotive Gas Oil (Diesel)}

Diesel demand growth is continuing to be driven by:

- Increased consumption by commercial vehicles due to relatively high economic activity.

- Increased numbers of diesel cars.

The heightening awareness, over recent years, of health concerns associated with particulates from diesel combustion might have reduced the potential demand for diesel. However, new diesel car registrations, and the size of the diesel car population continued to increase.

The outlook for demand growth in diesel remains strong: the underlying economics of moving goods by road are likely to remain favorable in comparison with other modes of transport. With the assistance of governments providing fiscal advantages for diesel over gasoline, vehicle manufacturers have been successful in producing diesel engine passenger cars that have gained popularity with consumers.

\subsubsection{Gas Oil/Heating Oil}

West European heating oil demand has remained remarkably stable over recent years, maintaining its volume in the industrial and domestic/commercial sectors, despite the increasing competition from natural gas in most markets.

The outlook is for a decline in heating oil demand, primarily in the domestic and commercial sector. Natural gas will continue to be an aggressive competitor across Europe, and it is likely that tightening environmental legislation will drive efficiency improvements and reduce losses. However, gas oil will continue to be a substitute for both solid fuel and heavy fuel oils. 


\subsubsection{Heavy Fuel Oil (HFO)}

The main influences on HFO demand in Western Europe are:

- The price competitiveness of HFO against other fuels used for power generation

- The availability of competing fuels for power generation

- Restrictions imposed by environmental legislation.

It is therefore Nexant's view that HFO use in Western Europe will decline steadily over the next 15 years, as existing and new legislation starts to take effect. However, the public consensus against new nuclear power projects and the high average sulfur levels of Europe's coal production means that HFO demand will be supported by electric power demand growing more rapidly than net increases in gas power generation capacity.

\subsection{REFINERY PRODUCTION}

Total refinery capacity in Western Europe is currently around 13 million BPD and a total of 131 refineries are in Western and Central Europe. The main refinery center is in the AmsterdamRotterdam-Antwerp (ARA) region and the largest country capacities are in Italy, Germany, France and the UK.

The crude oil price increases of the 1970s and early 1980s led to a downturn in demand for refined products and consequently to a surplus of distillation capacity in Western Europe. This was followed by a reduction of capacity during the 1980s with widespread refinery closures and rationalization. During this period capacity in Western Europe was reduced by around 30 percent.

Several closures have also taken place since 1990. Capacity has also been reduced by rationalization deals between neighboring refineries. Although selective refinery closures have occurred, the industry response to these external pressures has generally been to invest to maintain or enhance the performance of existing refineries. As a result, overall refining industry capacity has remained broadly constant, with expansion roughly compensating for closures. At the same time, production capacity for transport fuels has generally increased as upgrading plant capacity has slowly been expanded.

West European utilization rates have increased in all regions since the mid-1980s. Figure 5.1 shows the decline in overall capacity and growth in utilization rates since 1980.

West European aggregate utilization reached 95 percent in 1998 before falling back as a result of the depressed refining margins in 1999. Demand growth is projected to lead to a progressive increase with a return to levels over 95 percent by 2007.

The projected utilization levels assume some closure of refining capacity in Europe, partially offset by capacity expansion at existing sites, as already described. 


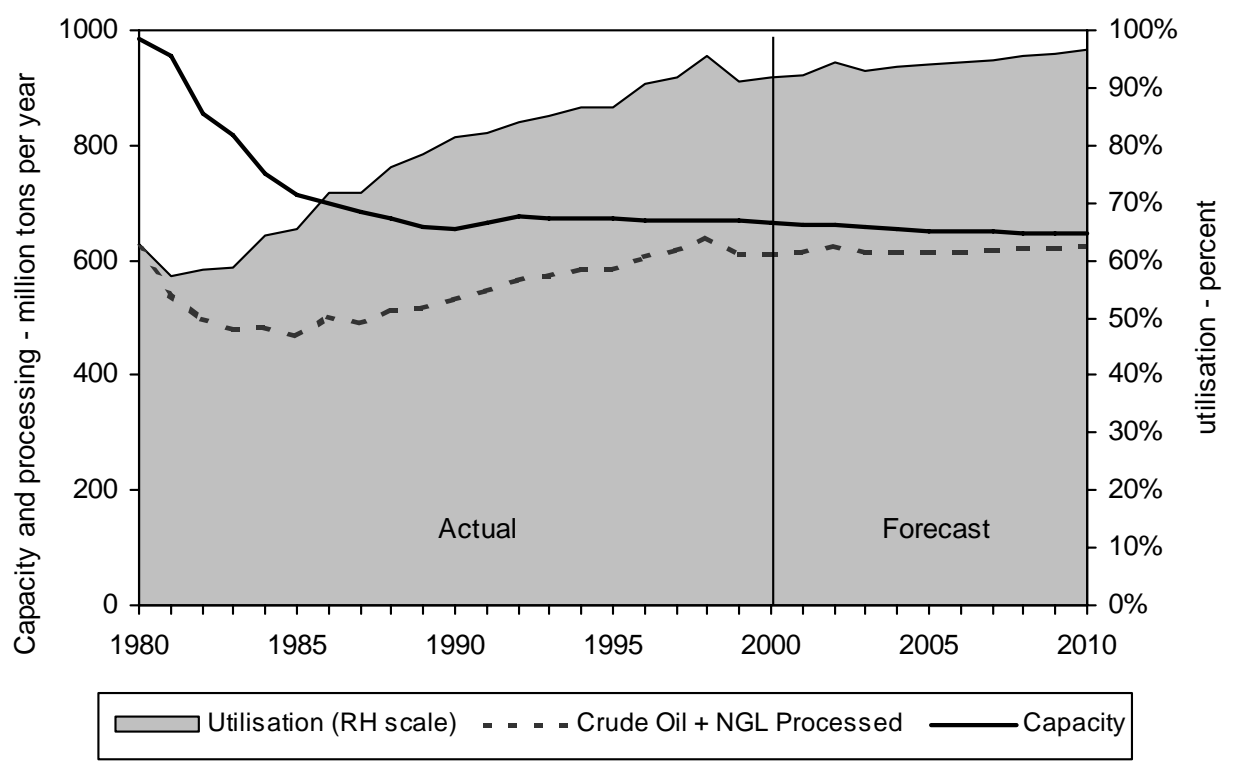

U:102Q4100072.005IDATAISTRUCTURE.XLS F2

Figure 5.1 Refinery Capacity And Utilization, Western Europe

\subsection{PETROLEUM PRODUCT TRADE}

Historically Western Europe has been a net importer of naphtha and gas oil, and a net exporter of gasoline. Fuel oil has also been imported both as a feedstock from Russia and the Middle East, and as a finished product from the Caribbean.

Nexant's projections for future trade can be summarized as follows:

- Net fuel oil trade moves into surplus, made up of continuing imports of low sulfur finished product and high sulfur feedstocks, with increasing exports of high sulfur finished fuel oil as European inland demand declines.

- As a result of growing petrochemical feedstock demand, combined with static refinery production, imports of naphtha are projected to increase, although remaining below the actual levels achieved in the early 1990s.

- Gas oil imports increase significantly from 1995 levels, but remain below historic levels of the early 1990s.

Gasoline exports continue, although declining slowly. 


\subsection{KEY INDUSTRY DRIVING FORCES}

The key factors now impacting the Asian refining industry are:

- The Asian financial crisis of 1997/1998, together with the completion of new refining capacity in the region during the 1996-99 period, has resulted in excess capacity and has severely depressed Asian refining margins

- Many refining companies are struggling to service the debt burden associated with investments made during the 1993-1997 period and the industry's focus is now on cost competitiveness and improving the operation of existing assets

- East Asia's underlying fundamentals remain strong and it is expected that regional refined product demand growth during the 2000-2010 period will be very substantial, reflecting its current low energy use per capita

- Longer term, new investments are expected to be needed and to be concentrated where there are growing domestic markets

- The future of the refining industry in East Asia will be primarily influenced by developments in the six countries, China, India, South Korea, Japan, Indonesia, and Thailand, that are expected to account for three quarters of the region's growth in product demand during the next decade

- $\quad$ The pace of deregulation of refining activities in several major countries (e.g., Indonesia and China) remains a major uncertainty

- Privatization of government-owned companies will continue to progress. However, its slow progress is impeding desirable rationalization, which may be strongly opposed by vested interests, in several countries.

\subsubsection{Product Quality Trends}

\subsubsection{Gasoline}

The introduction of lead phasedown programs in East Asia has generally been in line with the global trend toward improved environmental performance in countries with the highest levels of economic development. Unleaded gasoline is now available in all the region's major countries.

Nexant's projected gasoline qualities for 2005, presented in Table 6.1, are largely based on announced current plans, although these are subject to modification until finally enacted. 


\section{Table 6.1 Asian Gasoline Quality Trends}

\begin{tabular}{|c|c|c|c|c|c|c|c|c|c|c|c|c|c|c|c|c|}
\hline & \multicolumn{8}{|c|}{ Current (2001) } & \multicolumn{8}{|c|}{2005} \\
\hline & \multirow{2}{*}{\multicolumn{3}{|c|}{$\begin{array}{c}\text { RON } \\
\min \end{array}$}} & \multirow{2}{*}{$\begin{array}{c}\text { Lead } \\
\max \\
\end{array}$} & \multirow{2}{*}{\begin{tabular}{|c|} 
Benzene \\
$\max$ \\
\end{tabular}} & \multirow{2}{*}{\begin{tabular}{|c|} 
Aromatics \\
$\max$ \\
\end{tabular}} & \multicolumn{2}{|c|}{ Oxygen } & \multicolumn{3}{|c|}{ RON } & \multirow{3}{*}{\begin{tabular}{|c|} 
Lead \\
$\max$ \\
$(g / l)$ \\
\end{tabular}} & \multirow{3}{*}{\begin{tabular}{|c|} 
Benzene \\
$\max$ \\
$(\% \mathrm{v} / \mathrm{v})$ \\
\end{tabular}} & \multirow{3}{*}{$\begin{array}{c}\text { Aromatics } \\
\max \\
(\% \mathrm{v} / \mathrm{v})\end{array}$} & \multicolumn{2}{|c|}{ Oxygen } \\
\hline & & & & & & & \multirow{2}{*}{$\begin{array}{c}\min \\
(\% w t)\end{array}$} & \multirow{2}{*}{$\begin{array}{l}\max \\
(\% w t)\end{array}$} & \multirow{2}{*}{\begin{tabular}{|c|} 
min \\
lowest \\
\end{tabular}} & \multirow{2}{*}{\begin{tabular}{c|}
$\min$ \\
typical
\end{tabular}} & \multirow{2}{*}{\begin{tabular}{|c|} 
min \\
highest \\
\end{tabular}} & & & & $\min$ & $\max$ \\
\hline & lowest & typical & highest & $(g / l)$ & $(\% \mathrm{v} / \mathrm{v})$ & $(\% \mathrm{v} / \mathrm{v})$ & & & & & & & & & (\%wt) & (\%wt) \\
\hline Country & & & & & & & & & & & & & & & & \\
\hline India & 87 & 87 & 93 & 0.0 & $5.0^{1}$ & - & - & - & 87 & 87 & 93 & 0.0 & $5.0^{1}$ & - & - & - \\
\hline Pakistan & 87 & 87 & 97 & 0.35 & - & - & - & - & 87 & 87 & 97 & 0.0 & - & - & - & - \\
\hline China & 82 & 90 & 95 & 0.0 & 2.2 & 40 & - & - & 82 & 90 & 95 & 0.0 & - & - & - & - \\
\hline Malaysia & 92 & 97 & 97 & $0.15^{2}$ & - & - & - & - & 92 & 97 & 97 & 0.0 & - & - & - & - \\
\hline Philippines & 95 & 95 & 95 & 0.0 & 4.0 & 45 & - & - & 95 & 95 & 95 & 0.0 & 2.0 & 35 & - & - \\
\hline Thailand & 87 & 91 & 95 & 0.0 & 2.0 & 35 & 1.0 & 2.0 & 87 & 91 & 95 & 0.0 & 2.0 & 35 & 1.0 & 2.0 \\
\hline Singapore & 92 & 97 & 98 & 0.0 & 5.0 & - & - & - & 92 & 97 & 98 & 0.0 & 3.0 & - & - & - \\
\hline Australia & 91 & 96 & 96 & $0.2^{2}$ & 5.0 & - & - & - & 91 & 95 & 96 & 0.0 & 5.0 & - & - & - \\
\hline Indonesia & 88 & 88 & 95 & 0.30 & - & - & - & - & 88 & 92 & 95 & 0.0 & - & - & - & - \\
\hline S Korea & 95 & 95 & 95 & 0.0 & 2.0 & 35 & 1.0 & - & 95 & 95 & 95 & 0.0 & 1.0 & 35 & 1.0 & 2.3 \\
\hline Taiwan & 93 & 95 & 97 & 0.0 & 1.0 & - & - & - & 93 & 95 & 97 & 0.0 & 1.0 & - & - & - \\
\hline \begin{tabular}{|l} 
Japan \\
\end{tabular} & 90 & 90 & 100 & 0.0 & 1.0 & - & - & 1.3 & 90 & 90 & 100 & 0.0 & 1.0 & - & - & 1.3 \\
\hline Hong Kong & 95 & 95 & 97 & 0.0 & & & & & 95 & 95 & 95 & 0.0 & 5.0 & - & - & - \\
\hline Vietnam & 83 & 83 & 97 & 0.40 & & & & & 83 & 92 & 97 & 0.0 & - & - & - & - \\
\hline & & & & & & & & & & & & & & & & \\
\hline
\end{tabular}

Increased penetration of unleaded gasoline sales and/or further reductions in gasoline lead levels during the next five years are planned in all major countries that are not now 100 percent unleaded. By 2005 it is anticipated that leaded gasoline will only be sold in Vietnam, if its first refinery is not operational by then. Lead phaseout is expected to be slow enough to avoid straining the regional refining industry's octane production capabilities.

No major new gasoline quality measures are foreseen and the main emphasis is anticipated to be a progressive reduction of benzene and sulfur levels, together with the continued phasing out of lead usage.

\subsubsection{Kerosene/Jet Fuel}

The main end uses of kerosene are for jet fuel and as a domestic fuel for cooking or heating. Although these alternative markets use essentially the identical product, there are some specification differences. 


\section{Table 6.2 Typical Kerosene Quality, 2001}

\begin{tabular}{|l|c|c|c|}
\hline \multicolumn{2}{|l|}{} & Jet & Domestic Kerosene \\
\hline Sulfur & $\% \mathrm{wt}, \max$ & 0.3 & $0.1-0.2$ \\
\hline Smoke point & $\mathrm{mm}, \min$. & 20 & 25 \\
\hline
\end{tabular}

There is some possibility of a future reduction in the sulfur content of jet fuel from the current level of 0.3 percent. However, a number of factors may mean that there is no rapid change:

- Specifications for jet fuel need to be agreed internationally

- Actual current sulfur levels are significantly below 0.3 percent

- Some sulfur is thought to be desirable to maintain lubricity of the fuel

- Much of the SO2 emitted from aircraft engines goes into the upper atmosphere, and does not contribute to acid rain formation

The current jet fuel sulfur specification is however significantly above diesel sulfur limits in many countries, and therefore some action is possible over a 10 to 15 year timeframe.

\subsubsection{Diesel/Gas Oil}

Nexant's projections for diesel/gas oil quality in 2005, presented in Table 6.3, are based on announced plans where available.

Table 6.3 Asian Diesel/Gas Oil Quality Trends

\begin{tabular}{|c|c|c|c|c|c|c|c|c|}
\hline & \multicolumn{8}{|c|}{ Current (2001) } \\
\hline \multirow{2}{*}{ Quality } & Sulfur & $\mathrm{Cl}$ & $\mathrm{CN}$ & $90 \%$ pt max & Sulfur & $\mathrm{Cl}$ & $\mathrm{CN}$ & $90 \%$ pt max \\
\hline & (\%wt max) & \multicolumn{6}{|c|}{$\min$} & $(\operatorname{deg} C)$ \\
\hline \multicolumn{9}{|l|}{ Country } \\
\hline India & 0.25 & 46 & 42 & 366 & 0.25 & & 48 & 366 \\
\hline Pakistan & 1.0 & 47 & 45 & - & 0.25 & 47 & 45 & - \\
\hline China & $0.2^{1}$ & - & 45 & - & 0.2 & - & 45 & - \\
\hline Malaysia & 0.25 & 47 & - & 370 & 0.05 & 47 & - & 370 \\
\hline Philippines & 0.2 & 45 & - & 377 & 0.05 & 45 & - & 377 \\
\hline Thailand & 0.05 & 47 & - & 357 & 0.05 & 47 & - & 357 \\
\hline Singapore & 0.05 & 47 & - & 370 & 0.05 & 47 & - & 370 \\
\hline Australia & 0.4 & 45 & - & 357 & 0.05 & 46 & - & 357 \\
\hline Indonesia & 0.5 & 48 & - & - & 0.25 & 48 & - & - \\
\hline S Korea & 0.05 & 45 & - & 360 & 0.03 & 50 & - & 360 \\
\hline Taiwan & 0.05 & 46 & - & 338 & 0.05 & 46 & - & 338 \\
\hline Japan & 0.05 & 45 & - & 350 & 0.005 & 45 & - & 350 \\
\hline Hong Kong & 0.005 & & 50 & 370 & 0.005 & - & 50 & 370 \\
\hline Vietnam & 1.0 & 45 & - & 370 & 0.25 & 45 & - & 370 \\
\hline
\end{tabular}

A maximum sulfur specification of 0.05 percent now applies in many major Asian countries. By 2005 a sulfur specification of 0.25 percent or less is expected to apply in all countries and a 
maximum sulfur specification of 0.005 percent is expected to apply in Japan and Hong Kong. Longer term, further reductions in sulfur level and modest increases in cetane index/number are possible.

\subsubsection{Fuel Oil}

Regulations governing the maximum allowable sulfur content of heavy fuel oil consumed in inland markets vary widely within the region and broadly fall into three groups, reflecting the level of economic development and availability of domestic energy resources. The trend in East Asia, especially for its major metropolitan areas, has generally been in line with the global trend toward lower maximum allowable sulfur levels. However, the required use of fuel oils having less than 1 percent sulfur is not widespread and several East Asian countries are expected to continue to permit the use of fuel oils with sulfur contents above 2 percent during the 2001-2005 period.

The most developed countries in East Asia have generally introduced regulations requiring the use of low sulfur grades in urban areas, with Japan, South Korea and Taiwan now requiring the use of residual fuel oils having sulfur contents less than 0.5 weight percent.

Fuel oil sulfur specifications are not an issue in a second group of countries where low sulfur domestic crude oils yield fuel oils with low to medium sulfur levels and/or abundant alternative energy reserves (i.e. gas and coal) result in limited residual fuel oil burning. Australia, Indonesia, Malaysia and China are included in this group. However, power plants in China's Guangdong province must now use fuel oils with sulfur contents less than 1.5 percent.

A third group of countries limits the fuel oil sulfur content to about 2 weight percent in most locations. Singapore and Thailand now fall into this group and the Philippines is expected to join them during the next five years.

Sulfur content of residual fuel oil used in bunker markets is not regulated, and is not expected to be restricted during the next ten years.

\subsection{PETROLEUM PRODUCT DEMAND}

The financial crisis of 1997/1998 had a major impact on the economies of East Asia and served as a correction to the overheated growth during the previous several years. For the purpose of this report, East Asia is defined to encompass Pakistan through Japan, and China through Australia and New Zealand. Most observers agree that the region's underlying fundamentals remain strong, including a large population base and economies, which are at early stages of development with enormous long-term prospects for growth.

Growth in East Asian refined product demand resumed in 1999 after contracting about 300 thousand BPD in 1998, its first decline since 1982. Regional product demand is projected to grow at 3.8 percent annually during the $2000-2010$ period, reflecting the current low energy use per capita and trends toward increased industrialization and urbanization. The strongest growth is expected in transport fuels (i.e., gasoline, diesel and jet fuel) and naphtha. 
Increased product demand over the $2000-2010$ period will be very substantial, amounting to about 8 million BPD, or an average annual increase of about 800 thousand BPD. Six countries, China, Indonesia, India, South Korea, Japan and Thailand, are expected to account for 74 percent of the growth in product demand during the period, with China being responsible for over 23 percent of the increase.

Historical demand for petroleum products in East Asia and projected future demand through 2010 are presented in Table 6.4.

Table 6.4 Petroleum Product Demand - East Asia, Million Barrels Per Day

\begin{tabular}{|c|c|c|c|c|c|c|c|c|c|c|c|c|}
\hline & \multicolumn{4}{|c|}{ Actual } & \multirow{2}{*}{ Est. } & \multicolumn{4}{|c|}{ Forecast } & \multicolumn{3}{|c|}{$\begin{array}{l}\text { Average Annual } \\
\text { Growth Rate, \% }\end{array}$} \\
\hline & 1995 & 1998 & 1999 & 2000 & & 2002 & 2003 & 2005 & 2010 & $\begin{array}{r}1995- \\
2000\end{array}$ & $\begin{array}{r}2000- \\
2005\end{array}$ & $\begin{array}{r}2005- \\
2010\end{array}$ \\
\hline LPG & 1.5 & 1.6 & 1.8 & 1.9 & 2.0 & 2.1 & 2.1 & 2.3 & 2.8 & 5.4 & 4.0 & 3.9 \\
\hline Naphtha & 1.6 & 2.1 & 2.3 & 2.4 & 2.5 & 2.6 & 2.7 & 2.8 & 3.5 & 8.4 & 3.7 & 3.9 \\
\hline Gasoline & 2.8 & 3.2 & 3.3 & 3.4 & 3.5 & 3.6 & 3.7 & 4.0 & 4.9 & 3.6 & 3.3 & 4.0 \\
\hline Kero/Jet Fuel & 1.9 & 2.0 & 2.1 & 2.2 & 2.2 & 2.2 & 2.4 & 2.5 & 3.1 & 2.6 & 3.0 & 4.1 \\
\hline Gas oil \& Diesel & 5.0 & 5.3 & 5.6 & 5.8 & 5.9 & 6.1 & 6.3 & 6.8 & 8.4 & 2.9 & 3.2 & 4.2 \\
\hline Residual Fuel & 3.4 & 3.3 & 3.4 & 3.4 & 3.3 & 3.4 & 3.4 & 3.4 & 3.8 & $(0.2)$ & 0.2 & 1.9 \\
\hline Other & 0.7 & 1.0 & 1.1 & 1.1 & 1.1 & 1.2 & 1.2 & 1.3 & 1.7 & 8.3 & 3.7 & 4.5 \\
\hline Total & 17.1 & 18.6 & 19.5 & 20.2 & 20.5 & 21.1 & 21.8 & 23.3 & 28.1 & 3.5 & 2.9 & 3.8 \\
\hline \multicolumn{13}{|c|}{ Percent of Total Demand } \\
\hline & & & & & & & & & & \begin{tabular}{|r|}
$2000 \mathrm{vs}$ \\
1995
\end{tabular} & $\begin{array}{r}2005 \text { vs } \\
2000\end{array}$ & $\begin{array}{r}2010 \mathrm{vs} \\
2005\end{array}$ \\
\hline LPG & 8.6 & 8.9 & 9.1 & 9.4 & 9.5 & 9.7 & 9.8 & 9.9 & 10.0 & 0.8 & 0.5 & 0.0 \\
\hline Naphtha & 9.3 & 11.1 & 11.6 & 11.8 & 12.2 & 12.3 & 12.3 & 12.2 & 12.3 & 2.5 & 0.5 & 0.1 \\
\hline Gasoline & 16.7 & 17.1 & 16.7 & 16.8 & 16.9 & 17.0 & 17.0 & 17.2 & 17.4 & 0.2 & 0.3 & 0.2 \\
\hline Jet Fuel/Kerosene & 11.3 & 10.9 & 11.0 & 10.8 & 10.7 & 10.5 & 10.8 & 10.9 & 11.1 & $(0.5)$ & 0.1 & 0.2 \\
\hline Gas oil \& Diesel & 29.6 & 28.6 & 28.9 & 28.9 & 28.8 & 29.0 & 29.0 & 29.3 & 30.0 & $(0.7)$ & 0.5 & 0.6 \\
\hline Residual Fuel & 20.1 & 17.9 & 17.2 & 16.8 & 16.3 & 15.9 & 15.5 & 14.7 & 13.4 & (3.3) & (2.1) & (1.3) \\
\hline Mid distillate ratio ${ }^{1}$ & 1.6 & 1.4 & 1.4 & 1.4 & 1.4 & 1.3 & 1.4 & 1.4 & 1.4 & & & \\
\hline
\end{tabular}

Major refined product demand trends within East Asia are expected to be:

- Gasoline will have solid growth (averaging 3.7 percent annually) as the region's fleet of gasoline-fueled cars expands, driven by strong increases in personal incomes and relatively low levels of vehicle ownership in most countries

- Naphtha demand is expected to have strong growth (averaging 3.9 percent annually) in step with the development of the region's petrochemical industry

- Demand for middle distillates is projected to grow 3.8 percent annually 
- $\quad$ Kerosene/jet fuel demand is expected to have below average growth (3.3 percent annually), with the strong growth in jet fuel demand (5.2 percent) offset by relatively low growth (1.6 percent) in demand for kerosene

- Combined demand for diesel fuel and gas oil is expected to have strong growth (averaging 4.2 percent annually), driven by its use as a transport fuel. The projected increase in regional demand over the forecast period amounts to 2.6 million BPD, with demand growth in China, India, Japan, Indonesia, Thailand and South Korea accounting for 83 percent of regional growth

- Demand for residual fuel oil is projected to increase 1.1 percent annually. Industrial and bunker markets are expected to provide the most significant growth, but use for power generation will continue to be a substantial, but stable, enduse

Gasoline's share of the mix is projected to increase by about 0.5 percent by 2010 . Middle distillate's share of the mix is projected to increase by about 1.3 percent by 2010 , with diesel/gas oil's share of the mix expected to increase more than 1 percent. However, the proportion of total demand associated with kerosene and jet fuel is forecast to decline almost 1 percent due to kerosene's below-average growth prospects. Strong growth in transport fuels and the use of other energy sources for nearly all of East Asia's power sector growth will result in a 3.4 percent drop in residual fuel oil's share of the product mix.

As shown in Figure 6.1, the 8 million barrels per day of new demand forecast for the next decade will have a significantly different profile compared to the existing demand base. Specifically, incremental demand will consist of proportionately more naphtha, gasoline and diesel/gas oil, largely at the expense of residual fuel.

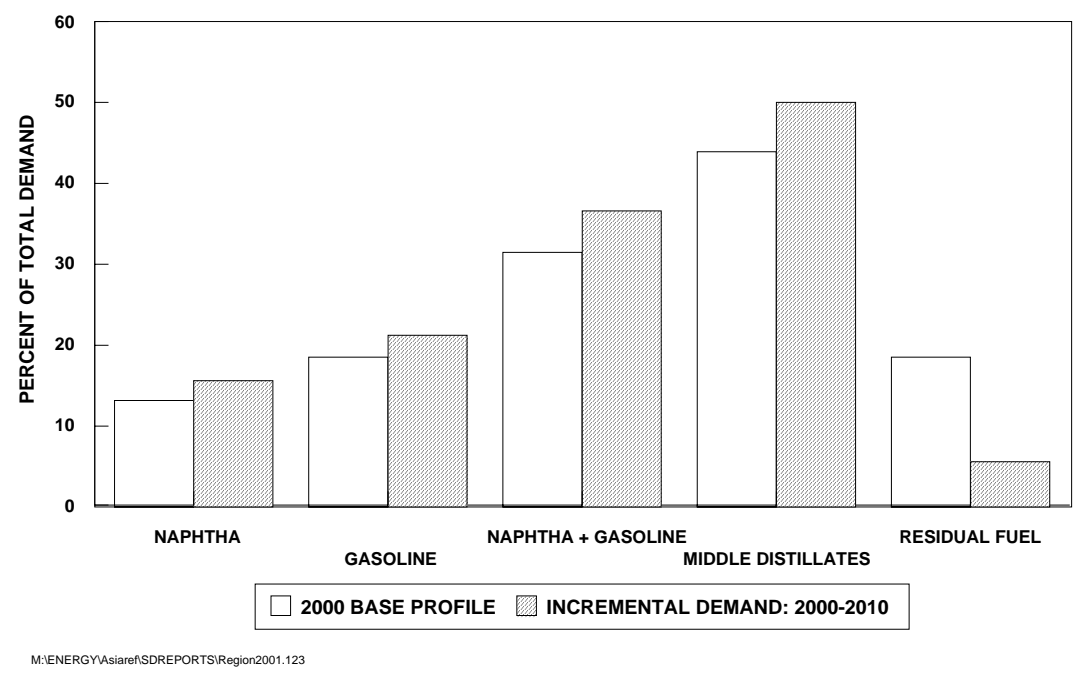

Figure 6.1 East Asian Product Demand Trends 


\subsection{REFINERY PRODUCTION}

Firm capacity additions are expected to increase the crude distillation capacity of the region's refineries to nearly 21 million barrels per calendar day (BPCD) by 2001, up from 19.3 million BPCD at the beginning of 1999. Nearly all the capacity additions during the 1999-2001 period are expected to occur in India, China and Taiwan, with India accounting for 59 percent of them.

The rate of capacity additions peaked in 1996 at 1.3 million BPD, as shown in Figure 6.2. Capacity additions in 2000 equaled 0.7 million BPD after capacity increased about 0.6 million BPD in 1999. It is noteworthy that net capacity additions during 2001, at under 0.5 million BPD, and forecast for 2002, at about 0.3 million BPD per year, are well below forecast increases in regional product demand.

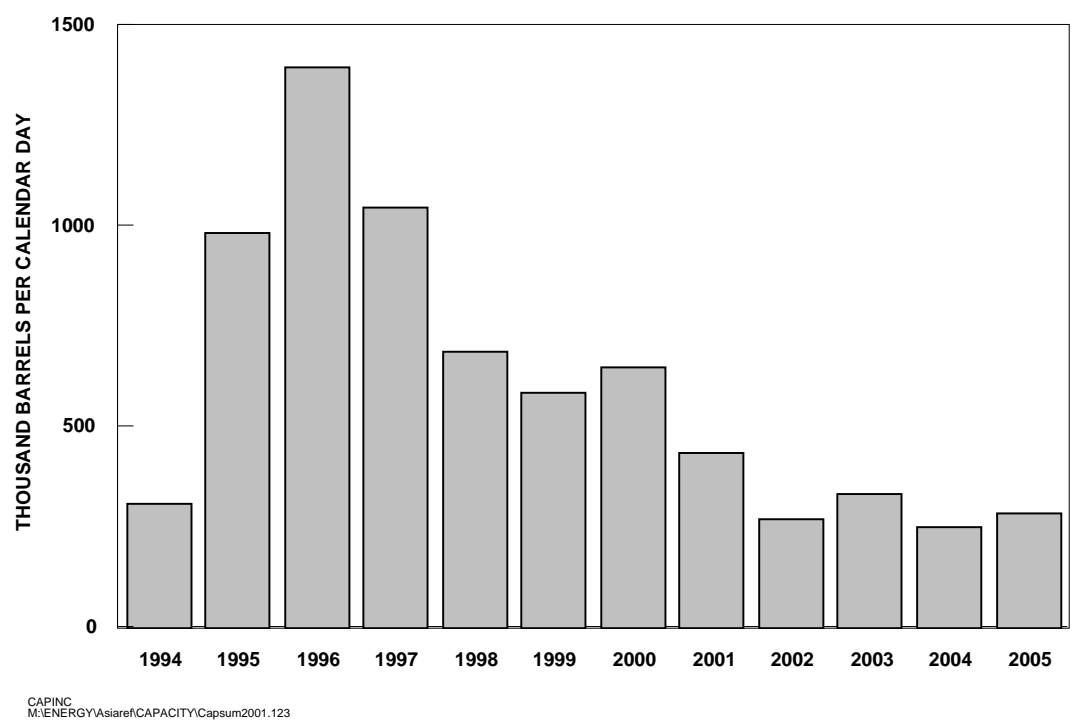

Figure 6.2 Refinery Capacity Increases - East Asia

Beyond 2002, Nexant has assumed that a total of 1.4 million BPCD of additional refinery capacity will be added in the region during the 2003-2005 period. These increases should be viewed as speculative since such projects typically have not yet received firm commitments to proceed.

As shown in Figure6.3, firm capacity additions during the 1999-2002 period are concentrated in China, India, and Taiwan. Speculative additions projected for the 2002-2005 period are also concentrated in China and India, the countries expected to account for most of the region's increase in refined product demand. Commissioning of Vietnam's first major refinery during the period has also been assumed. Capacity reductions are expected in Japan and Australia. 


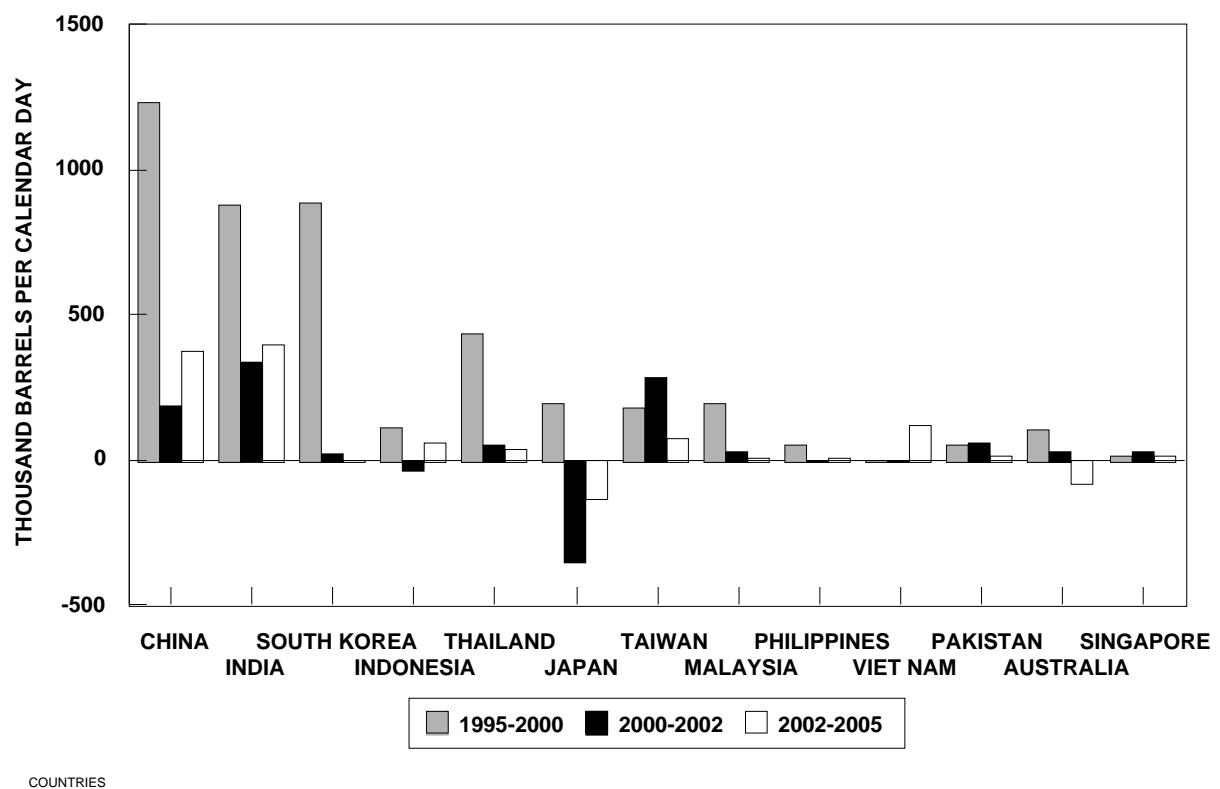

Figure 6.3 Refinery Capacity Increases - East Asia

\subsubsection{Petroleum Product Trade}

The East Asian region has recently had sizeable deficits in all major products, with total imports averaging 1.6 million BPD during 1996 and 1997. However, imports declined to 1.3 million BPD in 1998. Deficits of naphtha and fuel oil increased over the 1995-1999 period, but gasoline and middle distillate imports declined. Overall import levels remained weak during 2000 and 2001, in part reflecting weak economic performance in the region, and also the impact of the high level of new refining capacity that was added over the last five years.

As shown in Figure 6.4, Nexant expects that the East Asian product import requirement will remain weak through 2003/04. Thereafter, the regional deficit is expected to increase, reflecting recovery in growth rates for East Asian demand and the expectation that few new projects will be completed during the next few years. 


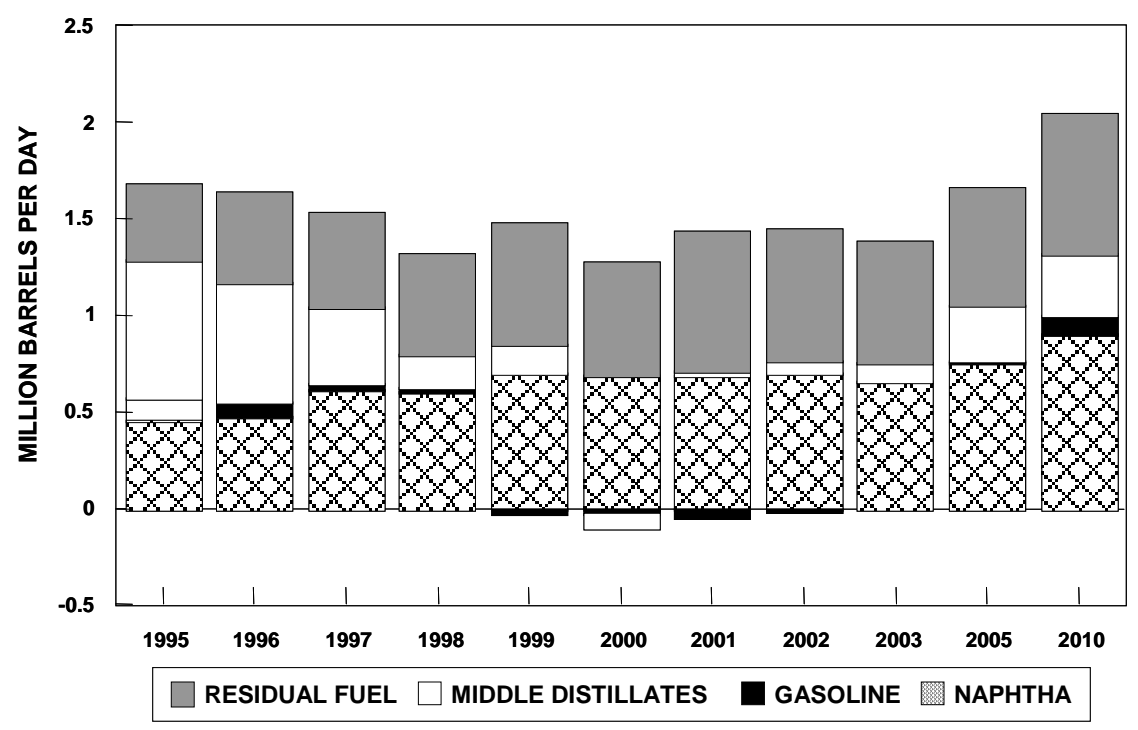

Figure 6.4 Refined Product Imports - Major Products - East Asia 


\subsection{OVERVIEW OF REGULATORY ENVIRONMENT}

The oil industry in Japan had been protected for decades, with the Japanese Government taking the view that security of supply for petroleum products was of paramount national importance and dependent upon ample domestic refining capacity. Thus until April 1996, only refiners were allowed to import products, and all imports and exports had to be licensed.

While protection of the oil industry for strategic reasons may be justified, it has made Japanese refiners much less competitive and market-oriented than their Western counterparts, and the industry was unprepared to compete in a rapidly changing world. Deregulation of the oil industry has therefore been gradually taking place, led by the Ministry of International Trade and Industry (MITI), but progress until recently has been very slow.

Petroleum products are marketed in Japan under a free-market pricing system, and the industry has been characterized by strong inter-company competition for market share. Although the Government does not establish pricing, it has created a complex pricing structure and still plays a significant role in setting prices through indirect means. In addition, distributors and other middlemen have a strong position and use their leverage to obtain retroactive discounts months after product is sold. Several oil companies have taken steps to introduce a more transparent, market-oriented pricing system, but the new pricing structures have not yet been widely accepted.

Deregulation of Japan's oil and other industries received a new impetus with the sharp and sustained downturn in the economy that began in 1992, which was greatly exacerbated by the Asian financial crisis in 1997. Nevertheless it was March 1996 before the oil industry's most fundamental change occurred: the liberalization of gasoline, kerosene and gas oil imports. Previous restrictions, whereby only designated refiner-marketers could import these products, helped to sustain a domestic pricing structure with relatively high gasoline prices and margins. Exports were liberalized in July 1997.

Although gasoline import volumes have not been substantial, the relaxation of product import restrictions resulted in a sharp decline in gasoline market prices. Much of the decline occurred prior to April 1996, in part due to the strength of the yen. However, gasoline prices did not recover during the subsequent period and the resultant lower gasoline margins have substantially reduced industry profitability to the point where the continued viability of some companies is in question.

A number of new companies, such as trading firms and hypermarkets, have entered the market, and competition was further stimulated by the lifting of a ban on self-service retail sites in March 1998. However, the requirements that all importers keep a minimum 70 days of stocks and maintain strict quality standards limit the number of traders that can participate. Also there are few independent storage facilities in Japan and refiners are not anxious to allow third-party use of their facilities. Nevertheless, increased competition in the marketplace has resulted in further 
margin erosion and intense pressure on Japanese oil companies to increase their efficiency. Some closures of small refineries, reductions in staff and rationalization of product distribution have been implemented.

The most far-reaching change was the merger of Nippon Oil and Mitsubishi Oil in April 1999 to create the country's largest oil company. This quickly led to a decision to close Mitsubishi's 75 KBPSD Kawasaki refinery later in the year. The new Nippon Mitsubishi Oil also established a refining and product distribution alliance with Cosmo Oil to operate more than 35 percent of Japan's refining capacity after November 1, 1999. The merger of Exxon and Mobil worldwide also impacted the Japanese market as the combined Exxon/Mobil affiliates in Japan restructured.

More rationalization is expected in the industry. Under these circumstances, the automatic approval of proposals to enter the refining industry or build capacity granted by MITI in June 1998 has proved to be superfluous.

Further steps to liberalize import and export of oil products have also been taken. In January 1997 Japan allowed all products from third party processing (which mainly takes place in Okinawa) to be sold domestically; previously at least half had to be exported. Export restrictions for domestic refiners were also relaxed in July 1997. More flexibility to export products resulted in some of Japan's spare refinery capacity being utilized for export, but the positive effect of this was quickly swamped by the Asian financial crisis that caused regional product demand to collapse. Like refiners elsewhere in developed countries, Japanese refiners are losing their share of the profitable, but mature domestic market to new entrants, increasing their need to become more exposed to international trading activity.

There is a complex system of taxes and duties on petroleum products in Japan relating to their end-uses. Tariffs, the Petroleum Tax (2,040 yen per kiloliter), product-specific excise taxes and a 5 percent Consumption Tax are intended to limit the use of certain products such as gasoline, while providing cost-competitive energy and feedstocks to industrial consumers and some special interests. Some of these taxes also provide protection to the Japanese refining industry. A reduction in the general import tariff on crude oil in April 1997 benefited the industry. The import tariff for refined products was also marginally reduced in April 1997, but there are no plans to phase out these duties.

The import tariff for crude oil, condensates and LPG used for petrochemical production is zero, and is very low for naphtha and other feedstocks. In addition, all these materials are not subject to the Petroleum Tax if they are used for petrochemical production.

\subsubsection{Energy Use Trends}

Table 7.1 presents the development of primary energy consumption since 1995 and projections for 2001, 2005 and 2010. The trends in the distribution of primary energy by source are also shown. 


\section{Table 7.1 Primary Energy Consumption By Source - Japan, Million tons of Oil Equivalent}

\begin{tabular}{|c|c|c|c|c|c|c|c|c|}
\hline & & & & & & \multicolumn{3}{|c|}{$\begin{array}{l}\text { Average Annual } \\
\text { Growth Rate, \% }\end{array}$} \\
\hline & & & \multicolumn{3}{|c|}{ Forecast } & 1995 & 2000 & 2005 \\
\hline & 1995 & 2000 & 2001 & 2005 & 2010 & 2000 & 2005 & 2010 \\
\hline & & & & & & & & \\
\hline Coal & & & & & & & & \\
\hline \begin{tabular}{|l|} 
Petroleum \\
Petrol
\end{tabular} & 82.6 & 95.2 & 96.7 & 100.1 & 111.4 & 2.9 & 1.0 & 2.2 \\
\hline Petroleum & 269.6 & 272.0 & 266.3 & 268.8 & 283.4 & 0.2 & $(0.2)$ & 1.1 \\
\hline Natural gas & 52.0 & 64.3 & 67.0 & 74.3 & 90.3 & 4.3 & 2.9 & 4.0 \\
\hline Nuclear & 75.9 & 82.2 & 81.9 & 84.9 & 96.7 & 1.6 & 0.6 & 2.6 \\
\hline Hydroelectric/other & 10.0 & 11.0 & 11.0 & 11.4 & 11.8 & 1.9 & 0.7 & 0.7 \\
\hline Total & 490.1 & 524.7 & 522.9 & 539.5 & 593.6 & 1.4 & 0.6 & 1.9 \\
\hline & & & & & & & & \\
\hline \multirow{2}{*}{\multicolumn{9}{|c|}{ (percent of total consumption) }} \\
\hline & & & & & & & & \\
\hline & & & & & & $2000 \mathrm{vs}$ & 2005 vs & $2010 \mathrm{vs}$ \\
\hline & & & & & & 1995 & 2000 & 2005 \\
\hline & & & & & & & & \\
\hline Coal & 16.9 & 18.1 & 18.5 & 18.6 & 18.8 & 1.3 & 0.4 & 0.2 \\
\hline Petroleum & 55.0 & 51.8 & 50.9 & 49.8 & 47.7 & (3.2) & (2.0) & (2.1) \\
\hline Natural gas & 10.6 & 12.3 & 12.8 & 13.8 & 15.2 & 1.6 & 1.5 & 1.4 \\
\hline Nuclear & 15.5 & 15.7 & 15.7 & 15.7 & 16.3 & 0.2 & 0.1 & 0.6 \\
\hline Hydroelectric/other & 2.0 & 2.1 & 2.1 & 2.1 & 2.0 & 0.1 & 0.0 & $(0.1)$ \\
\hline
\end{tabular}

U:102Q4100072.005IDATAJAPANTAB.123

Primary energy consumption grew 1.4 percent annually during the 1995-2000 period. It is projected to grow 1.3 percent annually between 2000 and 2010 reflecting the anticipated recovery of Japan's economy.

In 2000, power generation accounted for about 17 percent of total primary energy consumption. Between 1995 and 2000, electricity consumption grew at 1.5 percent annually, compared to an average annual GDP growth rate of 1.3 percent. During the 2000-2010 period, it is projected that electricity consumption will grow 2.0 percent annually.

Petroleum's share of the fuel mix for power generation has decreased 10 percent over the last 10 years to approximately 10 percent in 2000, primarily as a result of new nuclear power generating and coal-fired capacity that came on-line. The share of nuclear power in the fuel mix grew from 35 percent in 1990 to 41 percent by 2000. Petroleum's share of the mix is projected to drop to 6 percent by 2010 as new natural gas, coal, and nuclear power plants are constructed and no new major, oil-fired power plants are built.

Nuclear power and natural gas will continue to account for most of the power sector's increased energy supplies. Natural gas use is expected to account for a large part of the power sector's increased energy supplies, increasing its share of the fuel mix. This will be achieved through LNG imports and the anticipated construction of new gas-fired, combined cycle turbines. Coal's 
share of the sector's fuel mix is also expected to increase. Coal-fired generation remains attractive because of stable fuel supply and cost advantages, but global environmental issues may limit its long-term growth.

Petroleum consumption is projected to grow from 272 million tons of oil equivalent (TOE) in 2000 to 283 million TOE in 2010, an annual growth rate of less than 1 percent. This reflects moderate demand growth increases in transport fuels and within the residential sector. The focus on increasing imports of LNG and coal for electricity generation, along with Japan's growing nuclear capacity, will dampen petroleum's growth. Petroleum's share of primary energy consumption is therefore expected to decline from 52 percent in 2000 to 48 percent in 2010 .

\subsection{REFINED PRODUCT DEMAND}

Historical demand for petroleum products in Japan and projected future demand through 2010 are presented in Table 7.2. Total demand for petroleum products declined 0.1 percent annually during the 1995-2000 period and is projected to grow at 0.1 and 1.2 percent annually during the 2000-2005 and 2005-2010 periods, respectively. Increased product demand over the period will amount to about 0.3 million BPD.

Transportation fuels are expected to be the fastest growing products. Demand for gasoline and jet fuel is projected to grow at an annual rate of 1.7 and 3.2 percent during the 2000-2010 period, respectively. Demand for all middle distillates is forecast to grow 0.9 percent per year over this period.

Naphtha and residual fuel oil both have negative growth rates over the forecast period. Naphtha's growth is limited by weakening demand for exports from Japan's petrochemical industry. Residual fuel oil growth will be significantly constrained by the shift to other fuels in the power generation sector.

Gasoline's share of the product demand mix is projected to increase by about 2 percent between 2000 and 2010 after having increased by more than 2 percent between 1995 and 2000. Middle distillates' share of the mix is also projected to increase by approximately 1 percent over the forecast period, to 38 percent. Strong growth in transport fuels and the use of other energy sources for all of the growth of Japan's power sector will result in a further 1 percent drop in residual fuel oil's share of the product mix.

The projected growth rates and key factors driving demand for each major petroleum product in Japan are summarized in Table 7.3 


\section{Table 7.2 Petroleum Product Demand - Japan, Thousand Barrels Per Day}

\begin{tabular}{|c|c|c|c|c|c|c|c|c|c|c|c|c|c|}
\hline & & & & & & & & & & & \multicolumn{3}{|c|}{$\begin{array}{l}\text { Average Annual } \\
\text { Growth Rate, \% }\end{array}$} \\
\hline & \multicolumn{5}{|c|}{ Actual } & Est. & \multicolumn{4}{|c|}{ Forecast } & 1995- & $2000-$ & $2005-$ \\
\hline & 1995 & 1997 & 1998 & 1999 & 2000 & 2001 & 2002 & 2003 & 2005 & 2010 & 2000 & 2005 & 2010 \\
\hline & & & & & & & & & & & & & \\
\hline LPG & 627 & 633 & 598 & 599 & 600 & 581 & 577 & 576 & 581 & 620 & (0.9) & $(0.6)$ & 1.3 \\
\hline Naphtha & 765 & 810 & 753 & 817 & 813 & 794 & 799 & 803 & 796 & 783 & 1.2 & $(0.4)$ & $(0.3)$ \\
\hline Gasoline & 878 & 932 & 954 & 980 & 1,003 & 1,013 & 1,018 & 1,027 & 1,066 & 1,190 & 2.7 & 1.2 & 2.2 \\
\hline Jet Fuel & 200 & 215 & 214 & 206 & 195 & 197 & 193 & 219 & 234 & 270 & $(0.5)$ & 3.6 & 2.9 \\
\hline Kerosene & 518 & 511 & 488 & 507 & 515 & 511 & 516 & 522 & 534 & 564 & $(0.1)$ & 0.7 & 1.1 \\
\hline Gas oil \& Diesel & 1,268 & 1,278 & 1,238 & 1,250 & 1,243 & 1,230 & 1,219 & 1,213 & 1,226 & 1,299 & $(0.4)$ & (0.3) & 1.2 \\
\hline Residual Fuel & 771 & 687 & 672 & 654 & 609 & 590 & 578 & 568 & 560 & 561 & (4.6) & (1.7) & 0.0 \\
\hline Other & 262 & 285 & 279 & 279 & 281 & 277 & 274 & 272 & 276 & 303 & 1.4 & $(0.3)$ & 1.9 \\
\hline \multirow[t]{2}{*}{ Total } & 5,289 & 5,350 & 5,195 & 5,291 & 5,259 & 5,192 & 5,174 & 5,200 & 5,273 & 5,589 & (0.1) & 0.1 & 1.2 \\
\hline & & & & & & & & & & & & & \\
\hline \multirow[t]{2}{*}{ GDP, \% } & 1.6 & 1.9 & (1.1) & 0.8 & 1.7 & $(0.5)$ & - & 0.5 & 2.0 & 3.0 & 1.3 & 0.7 & 2.9 \\
\hline & & & & & & & & & & & & & \\
\hline \multicolumn{14}{|c|}{ (percent of total demand) } \\
\hline & & & & & & & & & & & 2000 vs & 2005 vs & $2010 \mathrm{vs}$ \\
\hline & & & & & & & & & & & 1995 & \begin{tabular}{|l|}
2000 \\
\end{tabular} & 2005 \\
\hline & & & & & & & & & & & & & \\
\hline LPG & 11.9 & 11.8 & 11.5 & 11.3 & 11.4 & 11.2 & 11.2 & 11.1 & 11.0 & 11.1 & $(0.4)$ & $(0.4)$ & 0.1 \\
\hline Naphtha & 14.5 & 15.1 & 14.5 & 15.4 & 15.5 & 15.3 & 15.4 & 15.4 & 15.1 & 14.0 & 1.0 & $(0.4)$ & (1.1) \\
\hline Gasoline & 16.6 & 17.4 & 18.4 & 18.5 & 19.1 & 19.5 & 19.7 & 19.7 & 20.2 & 21.3 & 2.5 & 1.1 & 1.1 \\
\hline Jet Fuel/Kerosene & 13.6 & 13.6 & 13.5 & 13.5 & 13.5 & 13.6 & 13.7 & 14.3 & 14.5 & 14.9 & $(0.1)$ & 1.0 & 0.4 \\
\hline Gas oil \& Diesel & 24.0 & 23.9 & 23.8 & 23.6 & 23.6 & 23.7 & 23.6 & 23.3 & 23.3 & 23.2 & $(0.3)$ & $(0.4)$ & $(0.0)$ \\
\hline \multirow[t]{2}{*}{ Residual Fuel } & 14.6 & 12.8 & 12.9 & 12.4 & 11.6 & 11.4 & 11.2 & 10.9 & 10.6 & 10.0 & (3.0) & (1.0) & (0.6) \\
\hline & & & & & & & & & & & & & \\
\hline Mid distillate ratio ${ }^{1}$ & 1.2 & 1.2 & 1.1 & 1.1 & 1.1 & 1.1 & 1.1 & 1.1 & 1.1 & 1.1 & & & \\
\hline
\end{tabular}

U:102Q4100072.0051DATAJAPANTAB.123

Table 7.3 Japanese Product Demand Trends

\begin{tabular}{|c|c|c|}
\hline Product & $\begin{array}{l}\text { Annual Growth, } \% \\
2000-2010\end{array}$ & Driving Forces \\
\hline Gasoline & 1.7 & $\begin{array}{l}\text { - Fleet growth linked to high per capita income and low current vehicle ownership } \\
\text { level }\end{array}$ \\
\hline Middle distillates & 0.9 & $\begin{array}{l}\text { - } \quad \text { Growing gas oil and jet fuel use for transportation } \\
\text { - } \\
\text { - }\end{array}$ \\
\hline Residual fuel oil & $(0.8)$ & $\begin{array}{l}\text { - } \quad \text { Policy to diversity energy sources; no new oil-fired power generation facilities } \\
\text { - } \quad \text { Slow growth in bunker fuel oil demand } \\
\text { - } \quad \text { Flat industrial demand }\end{array}$ \\
\hline Naphtha & $(0.4)$ & - Reduced exports for Japanese petrochemical industry \\
\hline
\end{tabular}




\subsection{CURRENT REFINERY PROCESS CONFIGURATIONS}

Total Japanese crude distillation capacity declined from a peak of 5.94 million barrels per stream day (BPSD) in 1982 to 4.55 million BPSD between 1988 and 1990 as capacity was rationalized and mothballed following the sharp drop in the country's demand for refined products. The 1990 Arabian Gulf crisis' cut-off of major sources of Japanese product imports, product demand growth, and deregulation of the industry, resulted in a 500 KBPSD increase in refinery capacity between 1990 and 1993. These capacity additions consisted of unit debottleneckings and the reactivation of some mothballed units. However, there has been minimal growth in refinery capacity since 1993, reflecting the limited economic growth experienced by Japan during this period.

Several resid cat crackers were built at Japanese refineries during the early 1990s, with the most recent addition being one built at Showa Shell Sekiyu's Yokkaichi refinery in central Japan. That unit started up in late 1996 and was part of a major upgrading project at the refinery that added a 55 KBPSD resid cat cracker, a 45 KBPSD resid desulfurizer, 35 KBPSD CCR catalytic reformer and 17 KBPSD alkylation unit.

Tohoku Oil, part of the Mitsubishi Oil group, also added a 45 KBPSD resid desulfurizer at its Sendai refinery and a new 25 KBPSD H-Oil resid hydrocracking unit at Tonen's Kawasaki refinery was completed in mid-1997.

In addition, several refineries added deep desulfurization units for gas oil feedstocks to produce a gas oil product with a sulfur content less than 0.05 percent to comply with the new specification that took effect in 1997. The combined capacity of these projects was greater than 200 KBPSD.

At the end of 2001, there will be 36 refineries operating in Japan with a total crude distillation capacity of 5.0 million BPCD (i.e. 5.3 million BPSD). A consolidation of the process unit capacities for all Japanese refineries is presented in Table 7.4. 


\section{Table 7.4 Japanese Refinery Process Unit Capacities, 2001,} Thousand Barrels Per Calendar Day

\begin{tabular}{|l|r|}
\hline Crude distillation & 5,010 \\
\hline Vacuum Distillation & 1,693 \\
\hline Coking & 86 \\
\hline Visbreaking & 18 \\
\hline Catalytic cracking & 928 \\
\hline Catalytic reforming & 721 \\
\hline Hydrocracking & 120 \\
\hline Naphtha hydrotreating & 923 \\
\hline Middle distillate hydrotreating & 2,090 \\
\hline VGO desulfurization & 800 \\
\hline Resid desulfurization & 569 \\
\hline Alkylation & 85 \\
\hline Lubes & 41 \\
\hline Asphalt & 99 \\
\hline \multicolumn{2}{|r|}{} \\
\hline Gasoline Index & 23 \\
\hline Upgrading Index & 29 \\
\hline
\end{tabular}

12-Nov-02

U:I2002Q4100072.005.11IDatalJapcap2000.123

Although 27 of the remaining Japanese refineries have capacities in excess of $100 \mathrm{KBPCD}$, only seven facilities have capacities greater than $200 \mathrm{KBPCD}$. Japanese refineries have a relatively high concentration of resid desulfurization capacity, as most of these units were built during the 1970s to produce low-sulfur fuel oil from high-sulfur crude oils.

\subsection{REFINERY PRODUCTION PROJECTIONS}

Japan's refinery capacity exceeds its current product demand. However, crude runs have been well below product demand since the industry's utilization rate has averaged only 81 percent since 1990. As discussed below, Japan remains a major importer of refined products, with a net deficit of 639 KBPD in 2000. However, this deficit is much lower than the 1989 level of 980 KBPD. Product export constraints and insufficient facilities to convert crude oil and residues into the deficit products have contributed to these relatively low utilization rates, and to date the pressure to shut down capacity has been tempered by the Government-supported industry environment.

Nexant's refinery throughput projections assume higher Japanese refinery crude runs after 2004. Product demand growth in Japan and the region are expected to contribute to increased utilization rates. The projections assume that the utilization rate will increase from 78 percent in 1999 to 86 percent in 2005, primarily due to capacity rationalization.

Refinery production projections, presented in Table 7.5 were developed based on the refinery throughput increases described above. For the forecast period, it was further assumed that there 
would be additions of fuel oil upgrading capacity. As a result, residual fuel's share of major product output is projected to decline from 16 percent to 14 percent between 2000 and 2010 .

\section{Table 7.5 Refinery Production - Major Products, Japan, Thousand Barrels Per Day}

\begin{tabular}{|c|c|c|c|c|c|c|c|c|c|c|c|c|}
\hline & & & & & & & & & & \multicolumn{3}{|c|}{$\begin{array}{l}\text { Average Annual } \\
\text { Growth Rate, \% }\end{array}$} \\
\hline & \multicolumn{5}{|c|}{ Actual } & Est. & \multicolumn{3}{|c|}{ Forecast } & $1995-$ & 2000 & 2005 \\
\hline & 1995 & 1997 & 1998 & 1999 & 2000 & 2001 & 2002 & 2005 & 2010 & 2000 & 2005 & 2010 \\
\hline & & & & & & & & & & & & \\
\hline Naphtha & 306 & 330 & 310 & 310 & 309 & 318 & 310 & 322 & 285 & 0.2 & 0.8 & (2.4) \\
\hline Gasoline & 874 & 921 & 953 & 970 & 978 & 988 & 992 & 1,031 & 1,155 & 2.3 & 1.1 & 2.3 \\
\hline Middle distillates & 1,886 & 1,943 & 1,913 & 1,885 & 1,891 & 1,812 & 1,782 & 1,787 & 1,923 & 0.1 & (1.1) & 1.5 \\
\hline Residual Fuel & 767 & 721 & $\begin{aligned} 695 \\
\end{aligned}$ & 637 & 604 & 614 & 590 & 543 & 543 & $(4.7)$ & (2.1) & \\
\hline Total & 3,833 & 3,915 & 3,871 & 3,802 & 3,782 & 3,732 & 3,674 & 3,683 & 3,906 & $(0.3)$ & $(0.5)$ & 1.2 \\
\hline & & & & & & & & & & & & \\
\hline \multicolumn{13}{|c|}{ (percent of production) } \\
\hline & & & & & & & & & & $2000 \mathrm{vs}$ & $2005 \mathrm{vs}$ & $2010 \mathrm{vs}$ \\
\hline & & & & & & & & & & 1995 & 2000 & 2005 \\
\hline & & & & & & & & & & & & \\
\hline Naphtha & 8.0 & 8.4 & 8.0 & 8.2 & 8.2 & 8.5 & 8.4 & 8.7 & 7.3 & 0.2 & 0.6 & (1.4) \\
\hline Gasoline & 22.8 & 23.5 & 24.6 & 25.5 & 25.9 & 26.5 & 27.0 & 28.0 & 29.6 & 3.1 & 2.1 & 1.6 \\
\hline Middle distillates & 49.2 & 49.6 & 49.4 & 49.6 & 50.0 & 48.6 & 48.5 & 48.5 & 49.2 & 0.8 & (1.5) & 0.7 \\
\hline \multirow[t]{2}{*}{ Residual Fuel } & 20.0 & 18.4 & 18.0 & 16.8 & 16.0 & 16.5 & 16.1 & 14.7 & 13.9 & (4.0) & $(1.2)$ & $(0.8)$ \\
\hline & & & & & & & & & & & & \\
\hline Middle distillate ratio ${ }^{1}$ & 1.6 & 1.6 & 1.5 & 1.5 & 1.5 & 1.4 & 1.4 & 1.3 & 1.3 & & & \\
\hline
\end{tabular}

\subsubsection{Product Balances}

The above refinery production projections, combined with the product demand projections presented above, resulted in the product balances and net trade presented in Table 7.6.

As shown, Japan is expected to continue to have a net deficit in naphtha and middle distillates. It is noteworthy, however, that net imports are expected to increase during the next few years due to the surplus of refining capacity in the region. MITI relaxed refined product export controls in July 1997. This has not helped increase the industry's operating rate since its surplus capacity is not efficient enough to make exports economically attractive in currently very competitive export markets. Thus the expectation is that the Japanese industry will remain focused on servicing the domestic market and exports will not grow to significant levels. The generally high cost position of the industry will tend to limit its export competitiveness. 


\section{Table 7.6 Refinery Product Balances - Major Products, Japan, Thousand Barrels Per Day}

\begin{tabular}{|c|c|c|c|c|c|c|c|c|c|c|c|}
\hline & \multicolumn{6}{|c|}{ Actual } & Est. & \multicolumn{4}{|c|}{ Forecast } \\
\hline & 1995 & 1996 & 1997 & 1998 & 1999 & 2000 & 2001 & 2002 & 2003 & 2005 & 2010 \\
\hline & & & & & & & & & & & \\
\hline LPG & (470) & (488) & (471) & $(446)$ & $(444)$ & (443) & $(414)$ & $(412)$ & (410) & (414) & (438) \\
\hline Naphtha & (464) & $(485)$ & (478) & (446) & $(512)$ & (533) & $(476)$ & (489) & (490) & $(474)$ & (498) \\
\hline Gasoline & (5) & (5) & (12) & (1) & (10) & (23) & (26) & (26) & (30) & (35) & (35) \\
\hline Middle distillates & (57) & $(158)$ & (57) & (30) & (89) & (74) & $(126)$ & $(146)$ & $(166)$ & $(206)$ & (209) \\
\hline Residual Fuel & 1 & (19) & 29 & 24 & (9) & (9) & (4) & 12 & 5 & $(17)$ & (18) \\
\hline Total ${ }^{1}$ & $(525)$ & $(667)$ & (518) & (453) & (620) & (639) & $(632)$ & (649) & (681) & (732) & (760) \\
\hline & & & & & & & & & & & \\
\hline Net Trade, \% demand & (12) & (15) & (12) & (10) & (14) & (15) & (15) & (15) & (16) & (17) & (16) \\
\hline
\end{tabular}

U:102Q4100072.005IDATAJAPANTAB.123

Most recent middle distillate imports have been jet fuel for international carriers, seeking supplies priced below jet fuel in the domestic market. In the future, regional market conditions and competitive pressures will result in increased middle distillate imports.

Imports of gasoline and gasoline blendstocks are expected to slightly increase during the 20012005 period. The recent increase in imports reflects the growth in Japanese gasoline demand and the use of Korean imports to reduce the cost of supplying product to the west coast of Japan.

Japan's residual fuel oil trade position is expected to remain roughly balanced. However, Taiwan and South Korea will remain destinations for low sulfur residual fuel oil exports. 


\subsection{TOTAL DIESEL DEMAND}

\subsubsection{Global Overview}

Table 8.1 presents historical and forecast global demand for diesel used as a transportation fuel. Nexant estimates that global diesel consumption in 2001 will increase to 12.61 million barrels per day (BPD). As shown in Figure 8.1, Japan and East Asia together now account for about 27 percent of global diesel demand and Western Europe's share is 24 percent.

Global diesel demand is forecast to exceed 18 million BPD by 2015, growing at an average annual rate of 2.9 percent during the 2000-2015 period with East Asia having the strongest growth.

\section{Table 8.1 Global Diesel Demand All Sulfur Levels, Thousand Barrels Per Day}

\begin{tabular}{|c|c|c|c|c|c|c|c|c|c|c|}
\hline & Actual| & Est. & & & recast & & & $\frac{\text { Ave }}{\mathrm{Grc}}$ & $\begin{array}{l}\text { age Anr } \\
\text { wth Rat }\end{array}$ & \\
\hline & 2001 & 2002 & 2005 & 2006 & 2010 & 2011 & 2015 & $\begin{array}{r}2000- \\
2005\end{array}$ & $\begin{array}{r}2005- \\
2010\end{array}$ & $\begin{array}{r}2010- \\
2015\end{array}$ \\
\hline Japan & 639 & 636 & 650 & 660 & 703 & 711 & 736 & 0.2 & 1.6 & 0.9 \\
\hline U.S. & 2,204 & 2,247 & 2,383 & 2,429 & \begin{tabular}{|l|}
2,627 \\
\end{tabular} & 2,678 & 2,896 & 2.0 & 2.0 & 2.0 \\
\hline Western Europe & 2,900 & 2,938 & 3,053 & 3,082 & 3,199 & 3,221 & 3,311 & 1.3 & 0.9 & 0.7 \\
\hline East Asia ${ }^{1}$ & 2,605 & 2,744 & 3,223 & 3,402 & 4,214 & 4,433 & 5,398 & 4.7 & 5.5 & 5.1 \\
\hline Rest of World & 3,808 & 3,933 & 4,331 & 4,482 & 5,146 & 5,312 & 6,036 & 3.2 & 3.5 & 3.2 \\
\hline Total & 12,156 & 12,497 & 13,640 & 14,056 & 15,888 & 16,354 & 18,377 & 2.7 & 3.1 & 3.0 \\
\hline
\end{tabular}

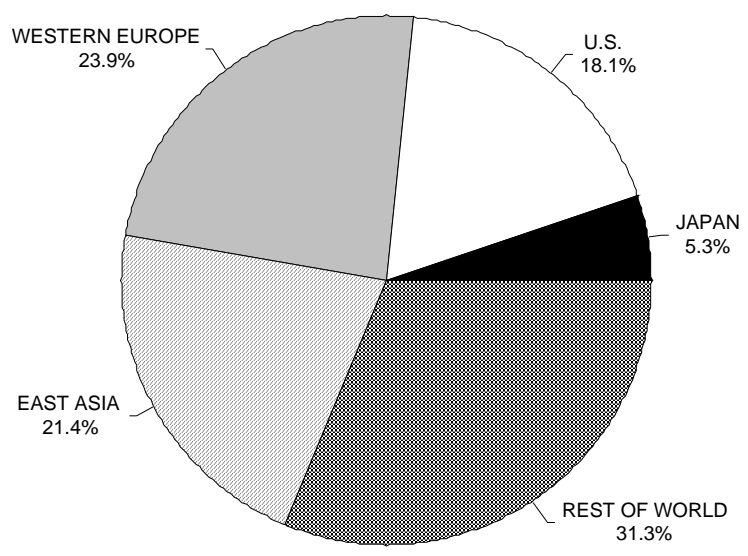

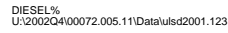

Figure 8.1 Distribution Of Global Diesel Demand, 2001 
Diesel use for transportation now accounts for about 59 percent of total global diesel/gasoil demand, which is about 20 million BPD as shown in Table 8.2. Diesel use for transportation is expected to continue to drive total global diesel/gasoil demand, which is forecast to grow 2.4 percent annually between 2000 and 2015 to nearly 29 million BPD.

Table 8.2 Global Diesel/Gas Oil Demand All Sulfur Levels

(thousand barrels per day)

\begin{tabular}{|c|c|c|c|c|c|c|c|c|c|c|c|}
\hline & & & & & & & & & \multicolumn{3}{|c|}{$\begin{array}{l}\text { Average Annual } \\
\text { Growth Rate, \% }\end{array}$} \\
\hline & Actual & Est. & \multicolumn{6}{|c|}{ Forecast } & $2000-$ & 2005- & 2010 \\
\hline & 2000 & 2001 & 2002 & 2005 & 2006 & 2010 & 2011 & 2015 & 2005 & 2010 & 2015 \\
\hline Japan & 1,243 & 1,230 & 1,219 & 1,226 & 1,238 & 1,299 & 1,312 & 1,358 & $(0.3)$ & 1.2 & 0.9 \\
\hline U.S. & 3,732 & 3,777 & 3,824 & 3,972 & 4,023 & 4,239 & 4,293 & 4,522 & 1.3 & 1.3 & 1.3 \\
\hline Western Europe & 5,108 & 5,125 & 5,142 & 5,200 & 5,202 & 5,220 & 5,222 & 5,232 & 0.4 & 0.1 & 0.0 \\
\hline East Asia ${ }^{1}$ & 4,592 & 4,683 & 4,897 & 5,612 & 5,882 & 7,109 & 7,430 & 8,817 & 4.1 & 4.8 & 4.4 \\
\hline Rest of World & 5,544 & 5,706 & 5,880 & 6,436 & 6,647 & 7,571 & 7,795 & 8,769 & 3.0 & 3.3 & 3.0 \\
\hline Total & 20,219 & 20,521 & 20,963 & 22,446 & 22,994 & 25,438 & 26,052 & 28,698 & 2.1 & 2.5 & 2.4 \\
\hline
\end{tabular}

U:|2002Q4100072.005.11|Datalulsd2001.123

\subsubsection{Japan}

Japanese use of diesel as a transportation fuel, which in Japan is commonly referred to as gas oil, is expected to decline to about 640 thousand BPD in 2001, reflecting Japan's weak economy. Demand is forecast to reach about 740 thousand BPD by 2015, growing at an average annual rate of about 1 percent during the 2000-2015 period.

Most of the balance of Japan's current total diesel/gas oil demand of 1.24 million BPD is Fuel Oil A used for industrial, marine and other applications. Its demand is expected to be flat during the 2000-2015 period, resulting in an annual average growth rate of 0.6 percent for Japan's current total diesel/gas oil demand over the next 15 years.

\subsubsection{United States}

Distillate fuels are marketed into two major end-market sectors: transportation (diesel fuels) and non-transport (heating oils). Total distillate demand is driven by economic growth, severity of winter weather, price competition from alternate fuels, and conservation trends. A very basic aspect of the distillate fuels market in the United States has been the pronounced loss of nontransport markets, primarily for home heating uses, which has been more than offset by growth in uses for transportation. Transportation uses include on-highway diesel, marine diesel and railroad diesel. The breakdown of U.S. diesel/gas oil use during 2000 is shown in Figure 8.2. 


\section{Figure $8.2 \quad$ U.S. Diesel/Gas Oil Use, 2000}

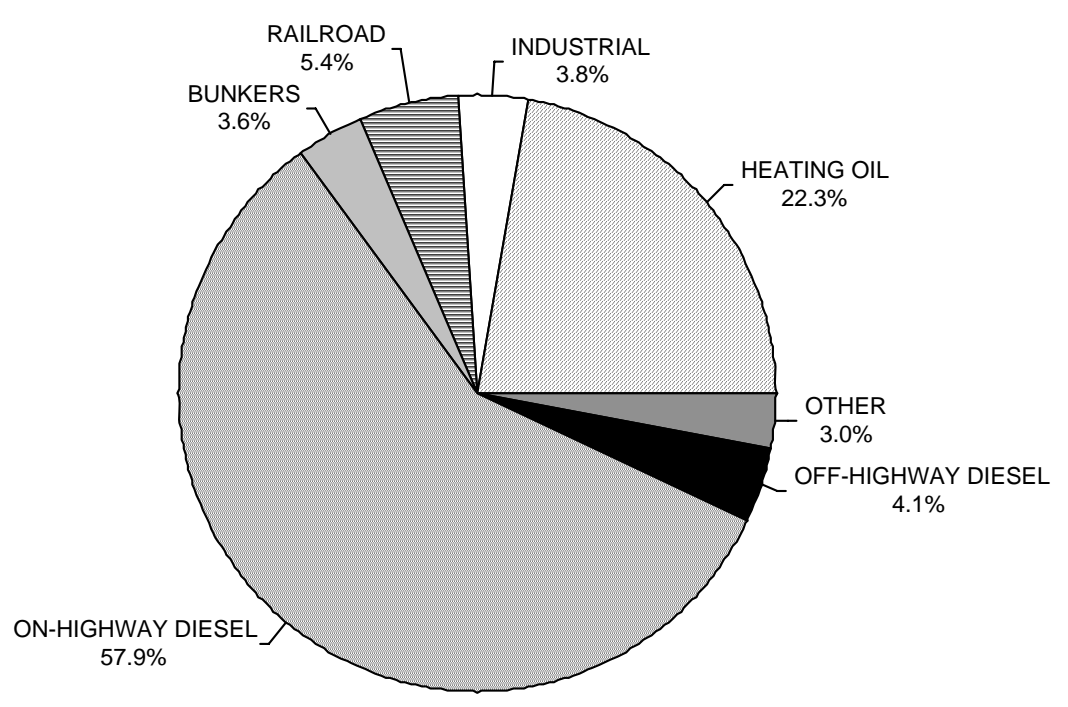

USDISTILLATE
M:IENERGYI2001ProjGTL MARKET STUDYIMARKETSIUISd2001.123

Demand for distillates has increased in line with average growth for total petroleum products, with distillates increasing about 1.3 percent annually between 1990 and 2000 compared to 1.1 percent for all petroleum products. Nexant expects that continued growth in the transportation sector will drive total distillate demand, but will continue to be offset by declines in nontransport uses. Future demand growth is expected to average about 1.3 percent per year between 2000 and 2010, with demand reaching 4.21 million BPD by 2010.

On-highway demand for diesel fuels represents the largest and most rapidly growing segment of the distillates market. From a base of about 35 percent of demand in 1980, on-highway diesel's share of the total distillate demand increased to about 58 percent in 2000. Diesel is expected to grow to about 62 percent by 2010 .

Demand for heating has declined dramatically since the late 1970s because of both conservation and displacement by natural gas and electricity in residential/commercial applications. Although cold winter weather will periodically provide seasonal short-term boosts to heating demand, the long-term trend is for continued displacement by alternative fuel sources and conservation.

\subsubsection{Western Europe}

Automotive Diesel

Diesel demand growth in Western Europe is continuing to be driven by:

- Increased consumption by commercial vehicles due to relatively high economic activity

- Increased numbers of diesel cars 
- Strong fiscal support (lower taxes) for diesel relative to gasoline

The heightening awareness, over recent years, of health concerns associated with particulates from diesel combustion might have reduced the potential demand for diesel. However, new diesel car registrations, and the size of the diesel car population, have continued to increase.

The outlook for demand growth in diesel remains strong: the underlying economics of moving goods by road are likely to remain favorable in comparison with other modes of transport. With the assistance of governments providing fiscal advantages for diesel over gasoline, vehicle manufacturers have been successful in producing diesel-engined passenger cars that have gained popularity with consumers.

\section{Gas Oil/Heating Oil}

West European heating oil demand has remained remarkably stable over recent years, maintaining its volume in the industrial and domestic/commercial sectors, despite the increasing competition from natural gas in most markets.

The outlook is for a decline in heating oil demand, primarily in the domestic and commercial sector. Natural gas will continue to be an aggressive competitor across Europe, and it is likely that tightening environmental legislation will drive efficiency improvements and reduce losses. However, gas oil will continue to be a substitute for both coal and heavy fuel oils.

\subsubsection{East Asia and Australia}

Diesel use for transportation accounted for about 56 percent of East Asia's total 2001 diesel/gasoil demand of 4.6 million BPD.

East Asian diesel demand is forecast to grow at an average annual rate of 5.1 percent during the 2000-2015 period after having grown at an average annual rate of 4.1 percent during the 19952000 period. The region's diesel demand is expected to more than double over the next 15 years, growing from 2.56 million BPD in 2000 to 5.4 million BPD in 2015. Demand growth in China, India, Indonesia, and Thailand is expected to account for 73 percent of the regional growth with more than half of the growth occurring in China and India.

\subsubsection{Other Countries}

Diesel demand in the rest of the world accounts for about 31 percent of global demand and is concentrated in South America and the Middle East, with these regions having over 60 percent of the current diesel demand in this group of countries. Canada and Mexico account for 11 and 6 percent of diesel demand, respectively, in this group of countries. Central Europe, the Former Soviet Union and Africa together account for about 23 percent of this group's diesel demand.

Diesel demand in these regions is forecast to grow at an average annual rate of 2.6 percent during the 2000-2015 period. 


\subsubsection{Ultra Low Sulfur Diesel Demand}

Table 8.3 shows historical and forecast global demand for diesel containing less than $15 \mathrm{ppm}$ of sulfur. Sweden is the only country now using significant quantities of diesel with this very low sulfur content. However, demand for this quality of diesel is forecast to increase from less than 50 thousand BPD in 2000 to over 9 million barrels per day (BPD) by 2015, with most of the increase expected to occur by 2011.

Table 8.3 Global Diesel Demand Sulfur Content Less Than 15 PPM (thousand barrels per day)

\begin{tabular}{|c|c|c|c|c|c|c|c|c|c|c|c|}
\hline & & & & & & & & & \multicolumn{3}{|c|}{$\begin{array}{l}\text { Average Annual } \\
\text { Growth Rate, \% }\end{array}$} \\
\hline & Actual & Est. & \multicolumn{6}{|c|}{ Forecast } & $2000-$ & $2005-$ & $2010-$ \\
\hline & 2000 & 2001 & 2002 & 2005 & 2006 & 2010 & 2011 & 2015 & 2005 & 2010 & 2015 \\
\hline & & & & & & & & & & & \\
\hline Japan & - & - & - & - & - & 703 & 711 & 736 & - & - & 0.9 \\
\hline U.S. & - & - & 5 & 238 & 972 & 2,627 & 2,678 & 2,896 & - & 61.6 & 2.0 \\
\hline Western Europe & 43 & 43 & 43 & 529 & 524 & 847 & 3,221 & 3,311 & 65.0 & 9.9 & 31.3 \\
\hline East Asia ${ }^{1}$ & - & - & - & - & - & - & 508 & 812 & - & - & - \\
\hline Rest of World & - & - & - & - & 221 & 475 & 484 & 1,358 & - & - & 23.4 \\
\hline Total & 43 & 43 & 48 & 767 & 1,717 & 4,652 & 7,602 & 9,113 & 77.8 & 43.4 & 14.4 \\
\hline & & & & & & & & & & & \\
\hline Percent of Total & 0.4 & 0.4 & 0.4 & 5.6 & 12.2 & 29.3 & 46.5 & 49.6 & & & \\
\hline
\end{tabular}

U:12002Q4100072.005.111Datalulsd2001.123

Table 8.4 shows historical and forecast global demand for diesel containing between 15 and 50 ppm of sulfur. Demand for this quality of diesel is forecast to increase from about 350 thousand BPD in 2001 to about 3.8 million barrels per day (BPD) in 2006 and then decline to about 1 million BPD during the 2011-2015 period since all West European countries are expected to have reduced the sulfur content of their diesel to less than 15 ppm by 2011.

Table 8.4 Global Diesel Demand Sulfur Content Between 15 and 50 PPM (thousand barrels per day)

\begin{tabular}{|c|c|c|c|c|c|c|c|c|c|c|c|}
\hline & & & & & & & & & \multicolumn{3}{|c|}{$\begin{array}{l}\text { Average Annual } \\
\text { Growth Rate, \% }\end{array}$} \\
\hline & Actual & \multirow{2}{*}{ Est. } & \multicolumn{6}{|c|}{ Forecast } & $2000-$ & $2005-$ & $2010-$ \\
\hline & 2000 & & 2002 & 2005 & 2006 & 2010 & 2011 & 2015 & 2005 & 2010 & 2015 \\
\hline & & & & & & & & & & & \\
\hline Japan & -1 & 3 & 6 & 650 & 660 & & - & - & -1 & (100.0) & \\
\hline U.S. & & & & & & & - & - & & -1 & \\
\hline Western Europe & 347 & 845 & 1,270 & 2,524 & 2,558 & 2,351 & - & - & 48.7 & (1.4) & $(100.0)$ \\
\hline East Asia ${ }^{1}$ & 16 & 16 & 17 & 17 & 580 & 1,082 & 615 & 450 & 1.2 & \begin{tabular}{l|l|}
128.3 \\
\end{tabular} & (16.1) \\
\hline Rest of World & - & - & -1 & - & - & 263 & 275 & 686 & - & - & 21.1 \\
\hline Total & 363 & 864 & 1,292 & 3,192 & 3,799 & 3,696 & 890 & 1,135 & 54.4 & 3.0 & (21.0) \\
\hline Percent of Total & 3.0 & 7.1 & 10.3 & 23.4 & 27.0 & 23.3 & 5.4 & 6.2 & & & \\
\hline
\end{tabular}


The objective of this section is to provide an overview of major trends that will define the global and regional markets for conventional petroleum-based fuels. Key assumptions and findings include:

\section{- Macroeconomic Assumptions}

The world economy is projected to grow only modestly in 2002 with GDP rising by 1.9 percent over 2001. The United States is expected to lead the global economic recovery via aggressive monetary stimulus policies. Resumption of capital spending in both the United States and Western Europe, particularly in the high-tech sector, aided by improved consumer demand and corporate earnings, is likely to restart the high-tech economies in East Asia, but with a one to two quarter lag behind recovery in the United States. Japan's economy, which is suffering from fundamental structural problems, is expected to remain weak for a number of years. Overall economic activity is expected to benefit from low inflationary pressures and relatively low and stable crude oil prices. As indicated in Figure 9.1, the global economy is predicted to grow at an average rate of 3.1 percent over the next decade, roughly in line with historical trendline performance.

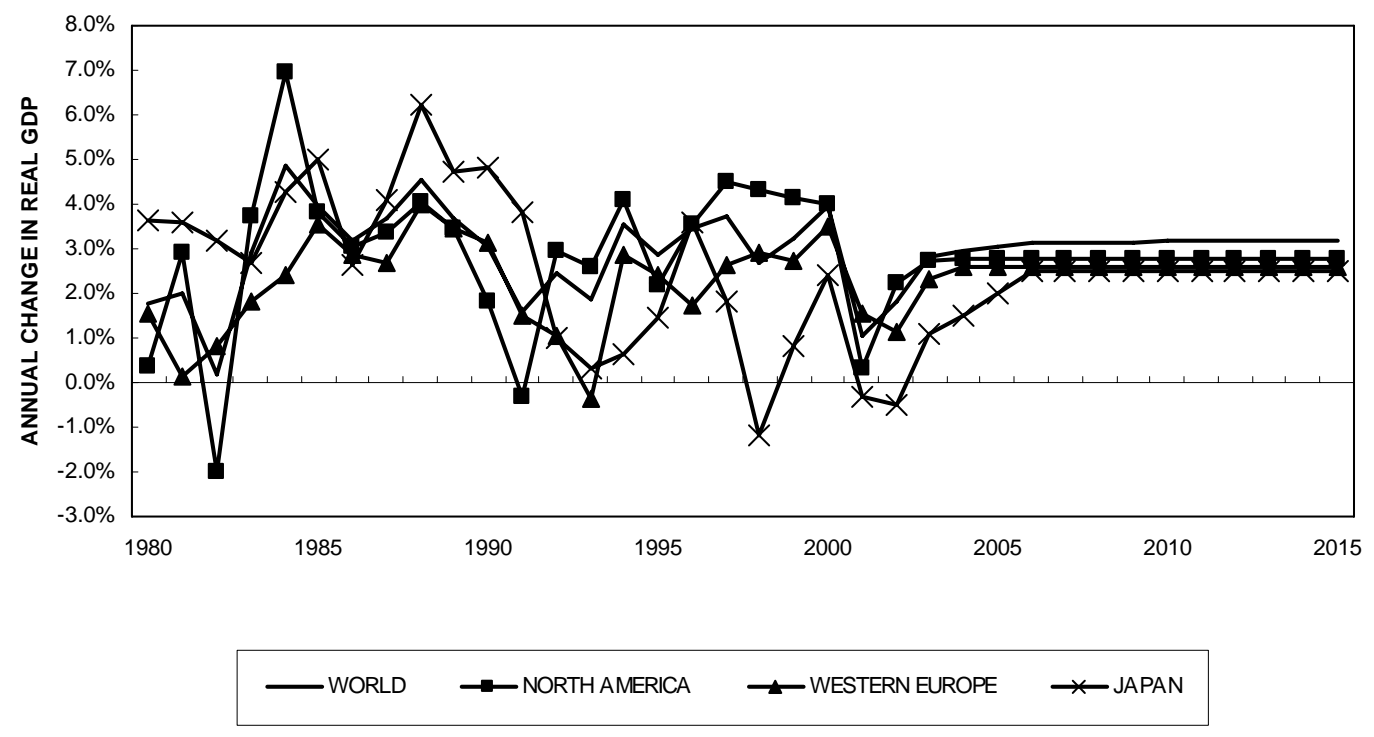

Figure 9.1 World Economic Performance and Outlook, Real Change in GDP

The North American economy is expected to begin to recover 2002 with average growth for the year expected to equal 2.5 percent. Initial very high growth in the United States during the first quarter of 2002, equal to 5.6 percent, is not expected to be sustainable for the balance of the year. As indicated in Figure 9.2, following projected recovery during 2003/04, the U.S. economy is 
projected to grow at a trendline growth rate of 2.7 percent, somewhat below the global average of 3.1 percent.

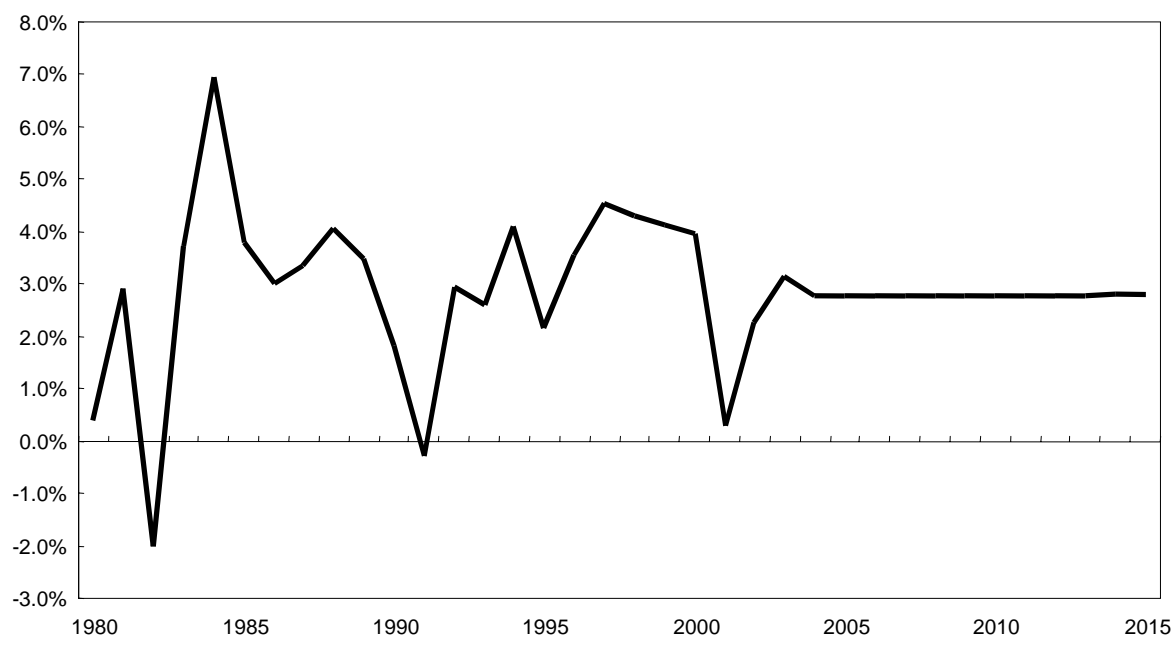

Figure 9.2 North American Economic Growth, Annual Change in Real GDP

The GDP deflator is the broadest measure of inflation, reflecting the combined experience of government (federal, state and local), businesses, and consumers. Nexant utilizes the U.S. GDP deflator as the basis for converting financials between current U.S. dollar (inflated) and constant U.S. dollar (non-inflated) financial data. The U.S. GDP deflator has declined significantly over the past 30 years, averaging 7 percent annually during the 1970s, 4.3 percent during the 1980s, and 2.2 percent during the 1990s. Nexant forecasts that inflationary pressures will remain at the low end of historical values, with a forecast trendline value of 2.5 percent annually.

\section{- Crude Oil Price Outlook}

Recognizing the uncertainty associated with forecasting crude oil prices, Nexant forecasts a future range of crude oil prices that are designed to capture the likely range of actual prices. It should be noted that forecast prices are trendline in nature, and no attempt has been made to try to capture short-term volatility of crude oil pricing. Reflecting these factors, Nexant's envelope of prices (all in constant 2001 dollars) for FOB Brent crude oil is:

- a "High Oil" case at \$22.0 per barrel in 2003, declining to \$20.5 in 2015

- $\quad$ a "Medium Oil" case at $\$ 18.0$ per barrel in 2003, declining to $\$ 16.8$ in 2015

- a "Low Oil" case at \$ 14.0 per barrel in 2003, declining to $\$ 13.0$ per barrel in 2015

After 2003, crude oil prices are projected to decline at 1.0 percent per year in real terms until 2010, after which prices are forecast to stabilize in real terms. This decline in price reflects trends in other commodities, which continue to show reductions in real prices due to continuing 
gains in production efficiency. Stabilization of real prices after 2010 reflects the increased potential for a tightening of petroleum availability on a global basis by that time. Forecast prices are presented in Table 9.1 and Figure 9.3.

Table 9.1 Nexant Crude Oil Scenarios, In Current and Constant 2001 Dollars

\begin{tabular}{|c|c|c|c|c|c|c|c|c|c|}
\hline & \multicolumn{3}{|c|}{ Dubai, FOB Fateh } & \multicolumn{3}{|c|}{ Brent, FOB Sullom Voe } & \multicolumn{3}{|c|}{ WTI, FOB Cushing } \\
\hline \multicolumn{10}{|c|}{ Current US\$ per Barrel } \\
\hline & Low & Medium & High & Low & Medium & High & Low & Medium & High \\
\hline 2003 & 13.1 & 17.3 & 21.4 & 14.6 & 18.8 & 22.9 & 16.4 & 20.6 & 24.8 \\
\hline 2004 & 13.3 & 17.5 & 21.7 & 14.8 & 19.0 & 23.3 & 16.7 & 20.9 & 25.1 \\
\hline 2005 & 13.5 & 17.8 & 22.1 & 15.0 & 19.3 & 23.6 & 16.9 & 21.2 & 25.5 \\
\hline 2010 & 14.5 & 19.1 & 23.7 & 16.2 & 20.8 & 25.4 & 18.2 & 22.8 & 27.4 \\
\hline 2015 & 16.4 & 21.6 & 26.9 & 18.3 & 23.5 & 28.7 & 20.5 & 25.8 & 31.0 \\
\hline \multicolumn{10}{|c|}{ Constant US\$2001 per Barrel } \\
\hline & Low & Medium & High & Low & Medium & High & Low & Medium & High \\
\hline 2003 & 12.6 & 16.6 & 20.6 & 14.0 & 18.0 & 22.0 & 15.8 & 19.8 & 23.8 \\
\hline 2004 & 12.4 & 16.4 & 20.3 & 13.9 & 17.8 & 21.8 & 15.6 & 19.6 & 23.5 \\
\hline 2005 & 12.3 & 16.2 & 20.1 & 13.7 & 17.6 & 21.6 & 15.4 & 19.3 & 23.3 \\
\hline 2010 & 11.7 & 15.4 & 19.2 & 13.0 & 16.8 & 20.5 & 14.6 & 18.4 & 22.1 \\
\hline 2015 & 11.7 & 15.4 & 19.2 & 13.0 & 16.8 & 20.5 & 14.6 & 18.4 & 22.1 \\
\hline
\end{tabular}

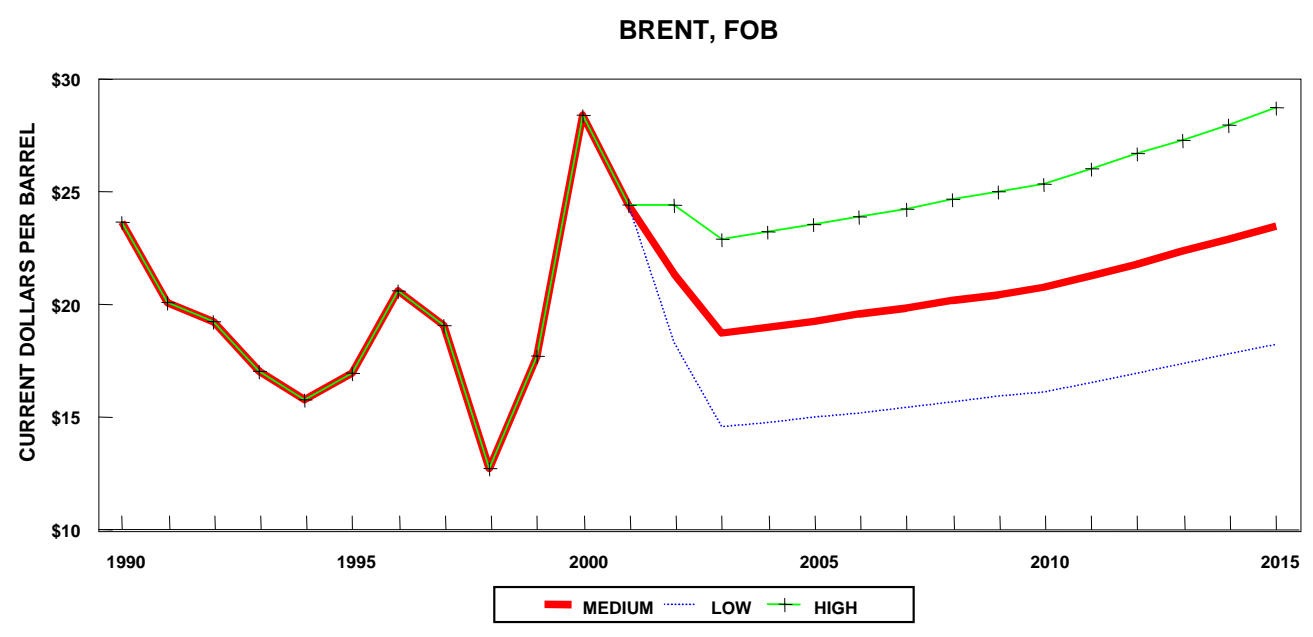

Figure 9.3 Nexant Reference Crude Oil Scenarios, Brent, FOB North Sea

\section{- Environmental regulations}

Current and future environmental regulations that will impact the quality of gasoline and diesel fuels have been reviewed and forecast in the body of the report. The primary trend that will impact gasoline and diesel quality is continued reductions in sulfur content of gasoline and diesel that will continue in all regions of the world. By 2015 about 50 percent of global diesel is forecast to have a sulfur content of 15 ppm or less. 
- Trends in global and regional refinery capacity

The global and regional refining industry has been profiled within the main report. As indicated in Figure 9.4, a key finding is that each region's refining industry is unique, with different characteristics and capabilities to meet local product requirements (mix of products as well as quality). Indicative of this range of capabilities is a profile of global refining complexity, higher values indicating straonger capabilities for refiners to producer higher yields of high value products, and to produce higher quality (e.g. lower sulfur content) products.

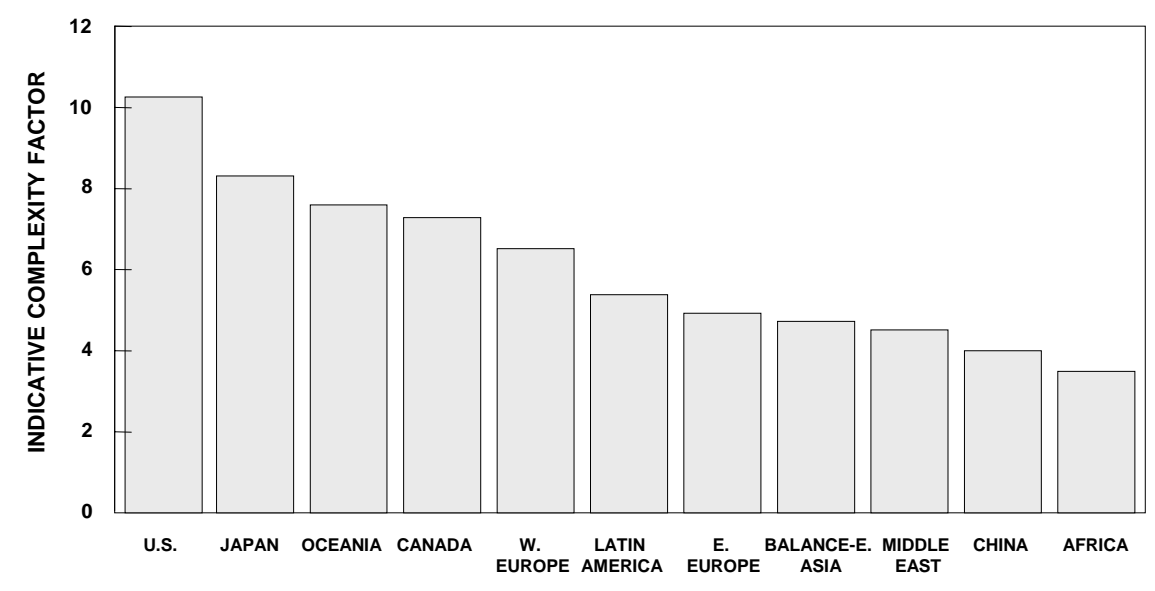

Figure 9.4 Global Refinery Complexity

\section{- Global trade of primary refined products}

Production and consumption of each major refined product has been evaluated for the major regions of the world. An analysis of the resulting regional trade balances indicates the following key product trade trends:

- $\quad$ The gasoline deficit in the United States will continue to be met by exports from Canada, Latin America and Western Europe, and reduced U.S. exports to Mexico following the completion of major refinery investments in Mexico (see Figure 9.5)

- Demand growth for middle distillates in East Asia and Europe is expected to exceed increases in local production. The increased deficits will be met by increasing exports from the Middle East and the FSU (see Figure 9.6)

- Growing residual fuel oil deficits in East Asia will primarily be met by increased exports from the Middle East and a shift in Western Europe's trade position from a deficit to roughly a balanced position (see Figure9.7)

- Naphtha deficits in Western Europe and East Asia are projected to increase, met by growing supply from Africa and the Middle East 


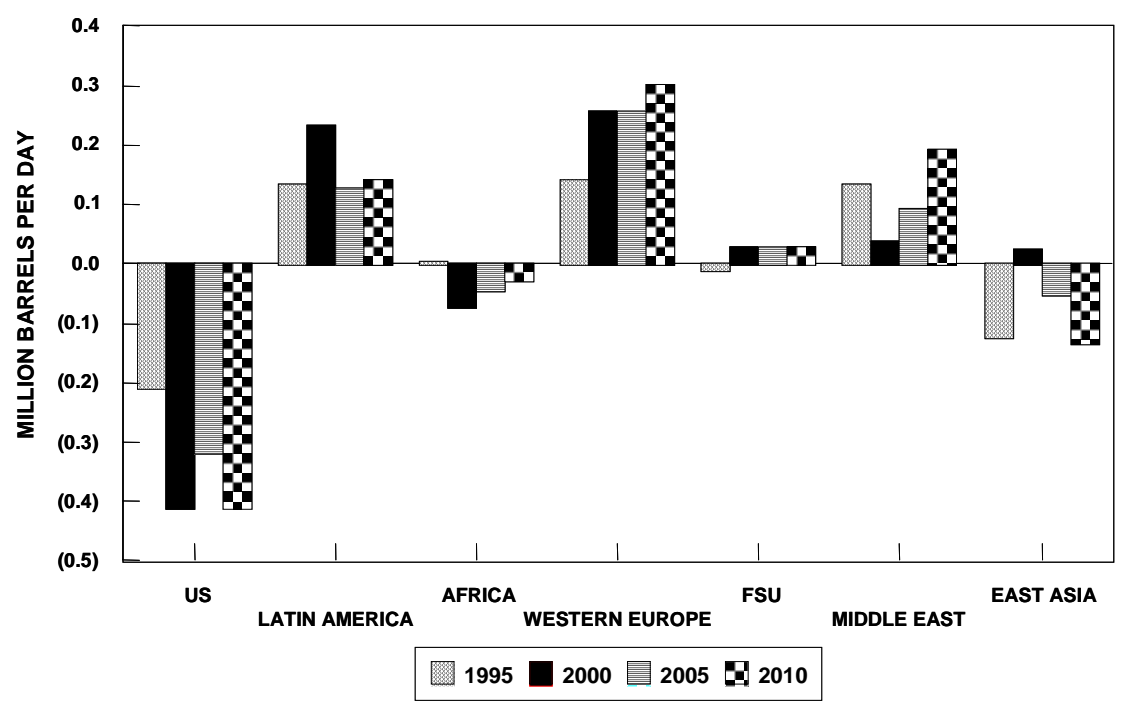

Figure 9.5 Global Gasoline Trade Trends

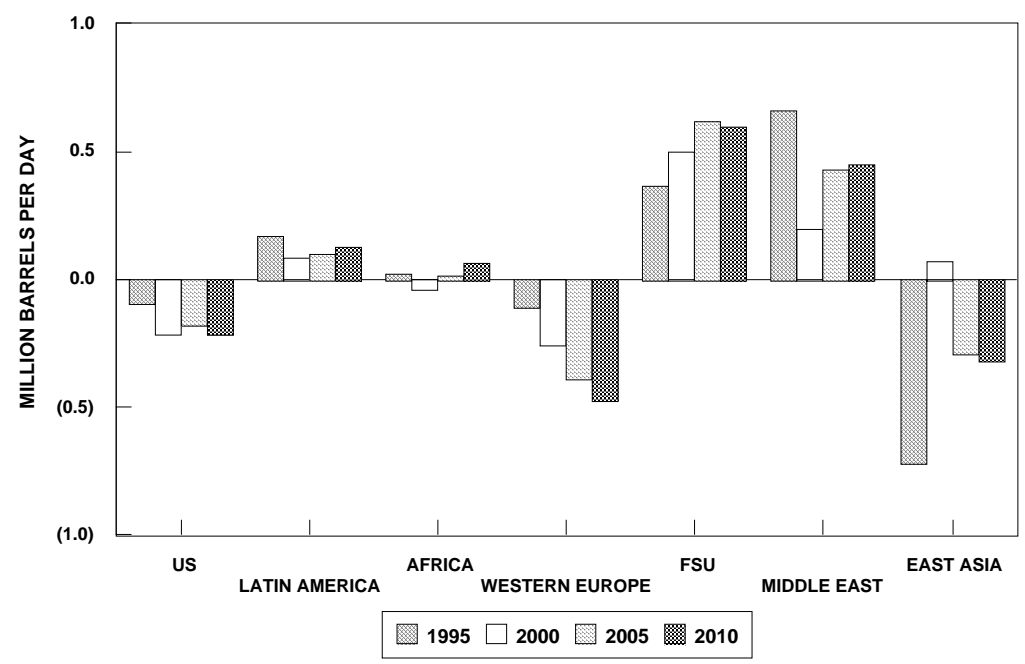

Figure 9.6 Global Middle Distillate Trade Trends 


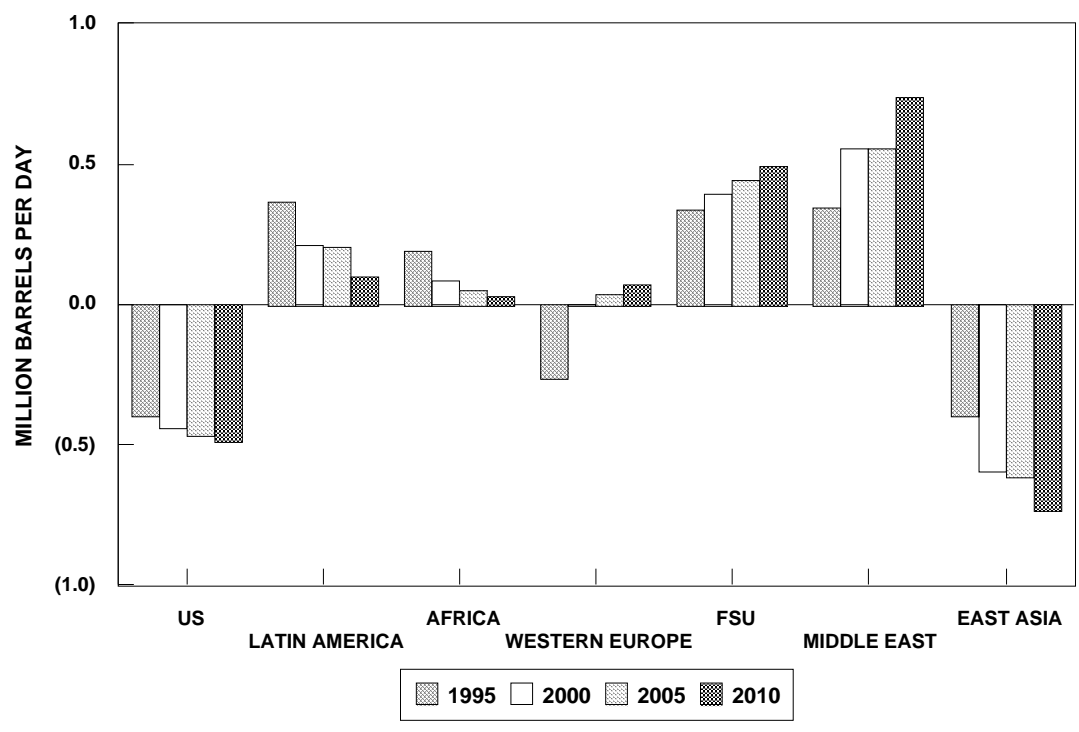

Figure 9.7 Global Residual Fuel Oil Trade Trends 


\section{Ethylene Industry \\ Overview \\ Market Study Report Section II \\ Prepared For: \\ ConocoPhillips}

Co-operative Agreement DE-FC26-01NT41098

ConocoPhillips $\backsim$ Nexant 


\title{
Ethylene Industry Overview Market Study Report Section II
}

November 2002

\author{
Prepared For: \\ ConocoPhillips
}

\section{cNexant}

44 South Broadway, White Plains, New York 10601, USA

Tel: +1 $9146090300 \quad$ Fax: +19146090399 


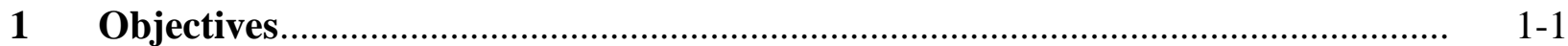

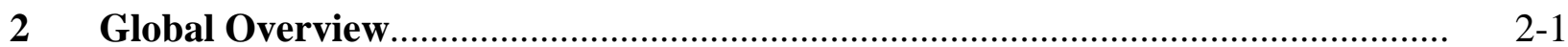

2.1 SUPPLY AND DEMAND................................................................. $2-1$

$2.2 \quad$ FEEDSTOCK PROFILE .................................................................. $2-2$

$2.3 \quad$ NAPHTHA REQUIREMENTS ................................................................

3 United States Market .................................................................................. $3-1$

3.1 SUPPLY AND DEMAND ...............................................................

FEEDSTOCK PROFILE ....................................................................

$3.3 \quad$ NAPHTHA REQUIREMENTS ..........................................................

$4 \quad$ Alternative Uses of FT Naphtha ................................................................

4.1 REFINERY FEEDSTOCK .............................................................. $4-1$

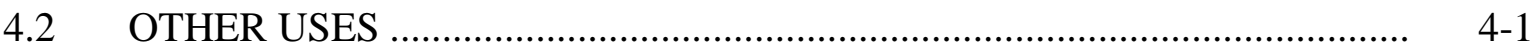

5 Ethylene From FT Liquids................................................................

5.1 TECHNOLOGY OF ETHYLENE PRODUCTION .................................. $5-1$

5.1.1 Chemistry ......................................................................... $5-1$

5.1.2 Process Description....................................................................... $5-4$

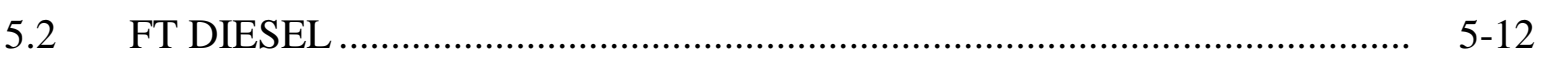

5.2.1 Relevant Qualities.................................................................. $5-12$

5.2.2 Use as Ethylene Feedstock ….................................................. $5-13$

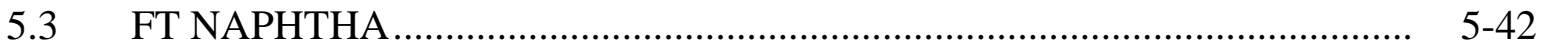

5.3.1 FT Naphtha Qualities ............................................................ $5-42$

5.3.2 Use as Ethylene Feedstock .................................................... $5-43$

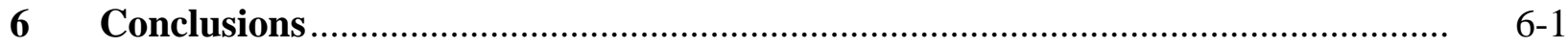

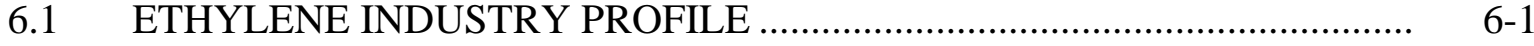

6.2 ALTERNATIVE MARKETS FOR FT NAPHTHA .....................................

6.3 FT DIESEL - TECHNICAL SUITABILITY AS AN ETHYLENE

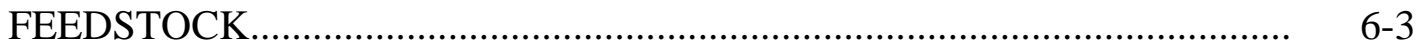

6.4 FT NAPHTHA - TECHNICAL SUITABILITY AS AN ETHYLENE FEEDSTOCK 
6.5 FT DIESEL - ECONOMICS AS AN ETHYLENE CRACKER FEEDSTOCK

6.6 NAPHTHA - ECONOMICS AS AN ETHYLENE CRACKER FEEDSTOCK 6-12

A Cost Of Production Basis

A-1

B Elements of Nexant's Capital Cost Estimates .

B-1 
2.1 Global Ethylene Demand .......................................................................... $2-1$

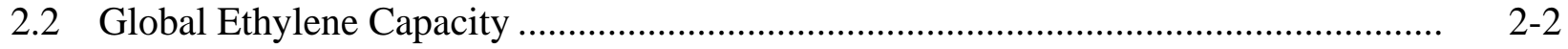

2.3 Global Ethylene Net Trade ${ }^{2}$......................................................................

2.4 Regional Ethylene Feedstock Analysis, 2000 .................................................. 2-3

2.5 Regional Ethylene Production By Feedstock, 2000 ............................................ 2-4

2.6 Firm Ethylene Capacity Expansions - United States, Western Europe, And Japan.... $\quad$ 2-5

2.7 Firm Ethylene Capacity Expansions Asia (Ex. Japan) ......................................... 2-6

2.8 Firm Ethylene Capacity Expansions - Rest Of World ........................................... 2-6

2.9 Global Speculative Ethylene Capacity Additions ............................................... 2-7

2.10 Global Ethylene Capacity and Production ........................................................ 2-7

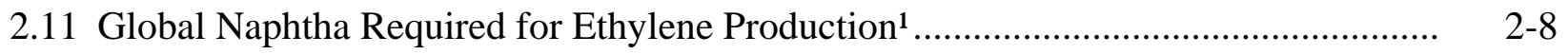

3.1 U.S. Ethylene Supply/Demand Balance ...............................................................

3.2 U.S. Ethylene Capacity Expansions.............................................................. $3-2$

3.3 U.S. Ethylene Production Capacity .................................................................... $3-4$

3.4 U.S. Ethylene Capacity and Production............................................................. $3-5$

3.5 U.S. Naphtha Required for Ethylene Production 1 .............................................. $3-5$

5.1 Typical Product Qualities - GTL Diesel ....................................................... $5-14$

5.2 Once-Through Cracking Yields For Ft Diesel ................................................. $5-16$

5.3 Feedstock and Utilities Pricing and Labor Costs ............................................. $5-21$

5.4 Cash Cost of Production for Cracking Diesel Fuel ${ }^{2}$............................................ 5-22

5.5 Gas Oil Cracking Margins …..................................................................... $5-23$

5.6 Cost of Production Estimate for: Ethylene (Gas Oil Feed) Process: Steam Cracking (Nexant Low Severity)....

5.7 Cost of Production Estimate for: Ethylene (Gas Oil Feed) Process: Steam Cracking (Nexant High Severity)

5.8 Cost of Production Estimate for: Ethylene (Gas Oil Feed) Process: Steam Cracking (Nexant Very High Severity)

5.9 Cost of Production Estimate for: Ethylene (FT Gas Oil/Diesel) Process: Steam Cracking (S\&W, High Severity).

5.10 Cost of Production Estimate for: Ethylene (FT Gas Oil/Diesel) Process: Steam Cracking (Lummus, Low Severity) 
5.11 Cost of Production Estimate for: Ethylene (FT Gas Oil/Diesel) Process: Steam

Cracking (Lummus, High Severity)

5.12 Cost of Production Estimate for: Ethylene (Ft Gas Oil/Diesel) Process: Steam

Cracking (KBR, Very High Severity)....

5.13 Cost of Production Estimate for: Ethylene (FT Gas Oil/Diesel) Process: Steam Cracking (Linde, High Severity).....

5.14 Cost of Production Estimate for: Ethylene (Gas Oil Feed) Process: Steam Cracking (Nexant Low Severity).

5.15 Cost of Production Estimate for: Ethylene (Gas Oil Feed) Process: Steam Cracking (Nexant High Severity)

5.16 Cost of Production Estimate for: Ethylene (Gas Oil Feed) Process: Steam Cracking (Nexant Very High Severity)

5.17 Cost of Production Estimate for: Ethylene (FT Gas Oil/Diesel) Process: Steam Cracking (S\&W, High Severity)

5.18 Cost of Production Estimate for: Ethylene (Ft Gas Oil/Diesel) Process: Steam Cracking (Lummus, Low Severity)

5.19 Cost of Production Estimate for: Ethylene (Ft Gas Oil/Diesel) Process: Steam Cracking (Lummus, High Severity)

5.20 Cost of Production Estimate for: Ethylene (Ft Gas Oil/Diesel) Process: Steam Cracking (KBR, Very High Severity)

5.21 Cost of Production Estimate for: Ethylene (FT Gas Oil/Diesel) Process: Steam Cracking (Linde, High Severity)

5.22 Typical Product Qualities - GTL Naphtha

5.23 Once-Through Cracking Yields for Ft Naphtha

5.24 Feedstock And Utilities Pricing and Labor Costs.

5.25 Cash Cost of Production for Cracking Naphtha

5.26 Naphtha Cracking Margins

5.27 Cost of Production Estimate for: Ethylene (Naphtha Feed) Process: Steam Cracking (Nexant Low Severity)

5.28 Cost of Production Estimate for: Ethylene (Naphtha Feed) Process: Steam Cracking (Nexant Moderate Severity)

5.29 Cost of Production Estimate for: Ethylene (Naphtha Feed) Process: Steam Cracking (Nexant High Severity)

5.30 Cost of Production Estimate for: Ethylene (Naphtha Feed) Process: Steam Cracking (Nexant Very High Severity) 
5.31 Cost of Production Estimate for: Ethylene (Ft Naphtha Feed) Process: Steam Cracking (S\&W, High Severity)

5.32 Cost of Production Estimate for: Ethylene (FT Naphtha Feed) Process: Steam Cracking (Lummus, Low Severity) ....

5.33 Cost of Production Estimate for: Ethylene (FT Naphtha Feed) Process: Steam Cracking (Lummus, High Severity)......

5.34 Cost of Production Estimate for: Ethylene (Ft Naphtha Feed) Process: Steam Cracking (KBR, Very High Severity)....

5.35 Cost of Production Estimate for: Ethylene (FT Naphtha Feed) Process: Steam Cracking (Linde, High Severity)

5.36 Cost of Production Estimate for: Ethylene (Naphtha Feed) Process: Steam Cracking (Nexant Low Severity)

5.37 Cost of Production Estimate for: Ethylene (Naphtha Feed) Process: Steam Cracking (Nexant Moderate Severity)

5.38 Cost of Production Estimate for: Ethylene (Naphtha Feed) Process: Steam Cracking (Nexant High Severity)

5.39 Cost of Production Estimate For: Ethylene (Naphtha Feed) Process: Steam Cracking (Nexant Very High Severity)

5.40 Cost of Production Estimate for: Ethylene (FT Naphtha Feed) Process: Steam Cracking (S\&W, High Severity)

5.41 Cost of Production Estimate for: Ethylene (FT Naphtha Feed) Process: Steam Cracking (Lummus, Low Severity)

5.42 Cost of Production Estimate for: Ethylene (FT Naphtha Feed) Process: Steam Cracking (Lummus, High Severity)

5.43 Cost of Production Estimate for: Ethylene (FT Naphtha Feed) Process: Steam Cracking (KBR, Very High Severity)....

5.44 Cost of Production Estimate for: Ethylene (FT Naphtha Feed) Process: Steam Cracking (Linde, High Severity)

6.1 Global Ethylene Demand.

6.2 Regional Ethylene Feedstock Analysis, 2000. 
2.1 Global Ethylene Demand ................................................................................. 2-1

2.2 Global Ethylene Capacity .................................................................................. 2-2

2.3 Global Ethylene Net Trade ${ }^{2}$................................................................................ 2-2

2.4 Regional Ethylene Feedstock Analysis, 2000 ............................................................ 2-3

2.5 Regional Ethylene Production By Feedstock, 2000 ................................................... 2 2-4

2.6 Firm Ethylene Capacity Expansions - United States, Western Europe, And Japan..... 2-5

2.7 Firm Ethylene Capacity Expansions Asia (Ex. Japan) ………………………......... 2-6

2.8 Firm Ethylene Capacity Expansions - Rest Of World ………………………............... 2- 2-6

2.9 Global Speculative Ethylene Capacity Additions .............................................................. 2- 2-7

2.10 Global Ethylene Capacity and Production ...................................................................... 2 2-7

2.11 Global Naphtha Required for Ethylene Production ${ }^{1}$................................................ 2- 2-8

3.1 U.S. Ethylene Supply/Demand Balance ................................................................... 3-1

3.2 U.S. Ethylene Capacity Expansions............................................................................... 3-2

3.3 U.S. Ethylene Production Capacity ……………........................................................ 3-4

3.4 U.S. Ethylene Capacity and Production .................................................................. 3-5

3.5 U.S. Naphtha Required for Ethylene Production 1 ……............................................ 3-5

5.1 Typical Product Qualities - GTL Diesel …………................................................... 5-14

5.2 Once-Through Cracking Yields For Ft Diesel ........................................................... 5-16

5.3 Feedstock and Utilities Pricing and Labor Costs ..................................................... 5-21

5.4 Cash Cost of Production for Cracking Diesel Fuel ${ }^{2}$................................................. 5-22

5.5 Gas Oil Cracking Margins …………………................................................... 5-23

5.6 Cost of Production Estimate for: Ethylene (Gas Oil Feed) Process: Steam Cracking (Nexant Low Severity) ..................................................................................... 5-26

5.7 Cost of Production Estimate for: Ethylene (Gas Oil Feed) Process: Steam Cracking (Nexant High Severity)

5.8 Cost of Production Estimate for: Ethylene (Gas Oil Feed) Process: Steam Cracking (Nexant Very High Severity)

5.9 Cost of Production Estimate for: Ethylene (FT Gas Oil/Diesel) Process: Steam Cracking (S\&W, High Severity)

5.10 Cost of Production Estimate for: Ethylene (FT Gas Oil/Diesel) Process: Steam Cracking (Lummus, Low Severity) 
5.11 Cost of Production Estimate for: Ethylene (FT Gas Oil/Diesel) Process: Steam

Cracking (Lummus, High Severity)

5.12 Cost of Production Estimate for: Ethylene (Ft Gas Oil/Diesel) Process: Steam

Cracking (KBR, Very High Severity)....

5.13 Cost of Production Estimate for: Ethylene (FT Gas Oil/Diesel) Process: Steam Cracking (Linde, High Severity).....

5.14 Cost of Production Estimate for: Ethylene (Gas Oil Feed) Process: Steam Cracking (Nexant Low Severity).

5.15 Cost of Production Estimate for: Ethylene (Gas Oil Feed) Process: Steam Cracking (Nexant High Severity)

5.16 Cost of Production Estimate for: Ethylene (Gas Oil Feed) Process: Steam Cracking (Nexant Very High Severity)

5.17 Cost of Production Estimate for: Ethylene (FT Gas Oil/Diesel) Process: Steam Cracking (S\&W, High Severity)

5.18 Cost of Production Estimate for: Ethylene (Ft Gas Oil/Diesel) Process: Steam Cracking (Lummus, Low Severity)

5.19 Cost of Production Estimate for: Ethylene (Ft Gas Oil/Diesel) Process: Steam Cracking (Lummus, High Severity)

5.20 Cost of Production Estimate for: Ethylene (Ft Gas Oil/Diesel) Process: Steam Cracking (KBR, Very High Severity)....

5.21 Cost of Production Estimate for: Ethylene (FT Gas Oil/Diesel) Process: Steam Cracking (Linde, High Severity)

5.22 Typical Product Qualities - GTL Naphtha

5.23 Once-Through Cracking Yields for Ft Naphtha

5.24 Feedstock And Utilities Pricing and Labor Costs.

5.25 Cash Cost of Production for Cracking Naphtha

5.26 Naphtha Cracking Margins

5.27 Cost of Production Estimate for: Ethylene (Naphtha Feed) Process: Steam Cracking (Nexant Low Severity)

5.28 Cost of Production Estimate for: Ethylene (Naphtha Feed) Process: Steam Cracking (Nexant Moderate Severity)

5.29 Cost of Production Estimate for: Ethylene (Naphtha Feed) Process: Steam Cracking (Nexant High Severity)

5.30 Cost of Production Estimate for: Ethylene (Naphtha Feed) Process: Steam Cracking (Nexant Very High Severity) 
5.31 Cost of Production Estimate for: Ethylene (Ft Naphtha Feed) Process: Steam Cracking (S\&W, High Severity)

5.32 Cost of Production Estimate for: Ethylene (FT Naphtha Feed) Process: Steam Cracking (Lummus, Low Severity) ....

5.33 Cost of Production Estimate for: Ethylene (FT Naphtha Feed) Process: Steam Cracking (Lummus, High Severity)......

5.34 Cost of Production Estimate for: Ethylene (Ft Naphtha Feed) Process: Steam Cracking (KBR, Very High Severity)....

5.35 Cost of Production Estimate for: Ethylene (FT Naphtha Feed) Process: Steam Cracking (Linde, High Severity)

5.36 Cost of Production Estimate for: Ethylene (Naphtha Feed) Process: Steam Cracking (Nexant Low Severity)

5.37 Cost of Production Estimate for: Ethylene (Naphtha Feed) Process: Steam Cracking (Nexant Moderate Severity)

5.38 Cost of Production Estimate for: Ethylene (Naphtha Feed) Process: Steam Cracking (Nexant High Severity)

5.39 Cost of Production Estimate For: Ethylene (Naphtha Feed) Process: Steam Cracking (Nexant Very High Severity)

5.40 Cost of Production Estimate for: Ethylene (FT Naphtha Feed) Process: Steam Cracking (S\&W, High Severity)

5.41 Cost of Production Estimate for: Ethylene (FT Naphtha Feed) Process: Steam Cracking (Lummus, Low Severity)

5.42 Cost of Production Estimate for: Ethylene (FT Naphtha Feed) Process: Steam Cracking (Lummus, High Severity)

5.43 Cost of Production Estimate for: Ethylene (FT Naphtha Feed) Process: Steam Cracking (KBR, Very High Severity)....

5.44 Cost of Production Estimate for: Ethylene (FT Naphtha Feed) Process: Steam Cracking (Linde, High Severity)

6.1 Global Ethylene Demand.

6.2 Regional Ethylene Feedstock Analysis, 2000.

6.3 Global Naphtha Required for Ethylene Production ${ }^{1}$ 
The objective of this section was to evaluate the potential market for using FT diesel and FT naphtha as a feedstock for ethylene production. The following activities were undertaken to address this objective:

- $\quad$ Provide an overview of the global and United States ethylene industry with an emphasis on identifying the size of future demand for naphtha and diesel/gasoils as feedstocks

- $\quad$ Evaluate alternative markets for FT naphtha

- Evaluate the technical suitability of FT naphtha and FT diesel as ethylene feedstocks

- Develop comparative economics for FT diesel and FT naphtha versus conventional cracking feedstocks 


\subsection{SUPPLY AND DEMAND}

Ethylene is used to produce a wide variety of petrochemicals, but demand is driven by polyethylene. Greater than 50 percent of the ethylene consumed on a global basis is used to produce polyethylene. This is expected to increase to over 60 percent by 2015 . Global ethylene demand and production are forecast to grow at an average annual rate of 4.3 percent through 2015. In developed regions such as the United States, Western Europe, and Japan, the industry is mature and demand growth is expected to be moderate, with growth over the forecast period ranging from 0.1 percent in Japan to 2.2 percent in the United States. In developing regions such as most of Asia, Latin America, and the Middle East, demand growth will continue to be strong, with growth ranging from 6.1 percent in Asia to 9.8 percent in the Middle East. Demand for ethylene is shown in Table 2.1.

Table 2.1 Global Ethylene Demand (thousand metric tons per year)

\begin{tabular}{|c|c|c|c|c|c|c|c|c|c|c|c|}
\hline & \multirow[t]{2}{*}{ Actual } & \multirow[t]{2}{*}{ Est. } & \multicolumn{6}{|c|}{ Forecast } & \multicolumn{3}{|c|}{$\begin{array}{l}\text { Average Annual } \\
\text { Growth Rate, \% }\end{array}$} \\
\hline & & & & & & & & & 2000- & 2005- & 2010- \\
\hline & 2000 & 2001 & 2002 & 2005 & 2006 & 2010 & 2011 & 2015 & 2005 & 2010 & 2015 \\
\hline & & & & & & & & & & & \\
\hline United States & 24,675 & 23,528 & 24,579 & 27,392 & 28,145 & 30,872 & 31,575 & 34,010 & 2.1 & 2.4 & 2.0 \\
\hline Western Europe & 20,016 & 19,853 & 21,081 & 22,802 & 22,400 & 24,362 & 24,600 & 25,700 & 2.6 & 1.3 & 1.1 \\
\hline Japan & 7,372 & 7,199 & 7,201 & 7,146 & 7,033 & 7,202 & 7,280 & 7,450 & $(0.6)$ & 0.2 & 0.7 \\
\hline Asia $^{1}$ & 17,879 & 18,960 & 20,669 & 23,272 & 25,204 & 33,306 & 35,060 & 43,035 & 5.4 & 7.4 & 5.3 \\
\hline Rest of World & 19,029 & 21,364 & 23,262 & 28,586 & 32,550 & 43,034 & 45,261 & 56,900 & 8.5 & 8.5 & 5.7 \\
\hline Total & 88,971 & 90,904 & 96,792 & 109,198 & 115,332 & 138,776 & 143,776 & 167,095 & 4.2 & 4.9 & 3.8 \\
\hline
\end{tabular}

${ }^{1}$ Excluding Japan and including Australia and New Zealand

U:12002Q2INexant100072|rplExcel files|[Ethylene Market Outlook.xls]Global SupplyDemand Summary

In 2000, the United States (28 percent), Western Europe (22 percent), Asia (20 percent), and Japan (9 percent) were the four largest producers of ethylene. This pattern is expected to shift significantly in the future. By 2015, the leading producers will be Asia (25 percent), the United States (20 percent), the Middle East (16 percent), and Western Europe (15 percent).

The forecast production shift can be illustrated by examining announced, planned, and speculative capacity additions. Speculative capacity additions are estimated based on forecast demand and production economics. Global ethylene capacity was 103 million metric tons per year at the end of 2000. An additional 78 million metric tons per year is expected to be added by 2015 in order to meet the required demand. Almost 60 percent of this capacity will be added in Asia and the Middle East, with these regions adding 26 and 21 million metric tons per year, respectively. The regions adding the next largest amounts of capacity are Latin America and the United States, with 9 and 8 million metric tons per year, respectively. Ethylene capacity is shown in Table 2.2. 
Table 2.2 Global Ethylene Capacity

(thousand metric tons per year of ethylene, at year end)

\begin{tabular}{|c|c|c|c|c|c|c|c|c|c|c|c|c|}
\hline \multicolumn{3}{|r|}{ Actual } & Est. & \multicolumn{6}{|c|}{ Forecast } & \multicolumn{3}{|c|}{$\begin{array}{l}\text { Average Annual } \\
\text { Growth Rate, \% }\end{array}$} \\
\hline & & 2000 & 2001 & 2002 & 2005 & 2006 & 2010 & 2011 & 2015 & $\begin{array}{l}2000- \\
2005\end{array}$ & $\begin{array}{l}2005- \\
2010\end{array}$ & $\begin{array}{l}2010- \\
2015\end{array}$ \\
\hline \multicolumn{2}{|c|}{\begin{tabular}{|l|} 
United States \\
\end{tabular}} & 26,761 & 27,290 & 27,410 & 29,447 & 29,901 & 32,396 & 32,396 & 35,106 & 1.9 & 1.9 & 1.6 \\
\hline \multicolumn{2}{|c|}{ Western Europe } & 21,653 & 22,343 & 23,458 & 23,758 & 23,758 & 24,958 & 25,758 & 27,358 & 1.9 & 1.0 & 1.9 \\
\hline Japan & & 7,991 & 7,717 & 7,917 & 8,016 & 8,016 & 7,616 & 7,616 & 8,216 & 0.1 & (1.0) & 1.5 \\
\hline Asia $^{1}$ & & 19,798 & 21,488 & 23,323 & 25,081 & 29,201 & 36,801 & 38,001 & 45,301 & 4.8 & 8.0 & 4.2 \\
\hline \multicolumn{2}{|c|}{\begin{tabular}{|l|} 
Rest of World \\
\end{tabular}} & 26,921 & 27,586 & 28,966 & 36,119 & 42,189 & 51,239 & 51,239 & 64,939 & 6.1 & 7.2 & 4.9 \\
\hline Total & & 103,124 & 106,424 & 111,074 & 122,421 & 133,065 & 153,010 & 155,010 & 180,920 & 3.5 & 4.6 & 3.4 \\
\hline & & & 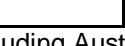 & 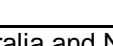 & & & & & & & & \\
\hline
\end{tabular}

U:12002Q2INexant100072lrplExcel filesI[Ethylene Market Outlook.xls]Global SupplyDemand Summary

Compared to other petrochemicals, interregional trade of ethylene is fairly limited due to the high costs associated with shipping and storage. Existing trade patterns are expected to remain approximately the same throughout the forecast period. The major net exporters are the Middle East, Japan, and Africa. The major net importers are Asia and Western Europe. Net trade is shown in Table 2.3.

Table 2.3 Global Ethylene Net Trade ${ }^{2}$

(thousand metric tons of ethylene)

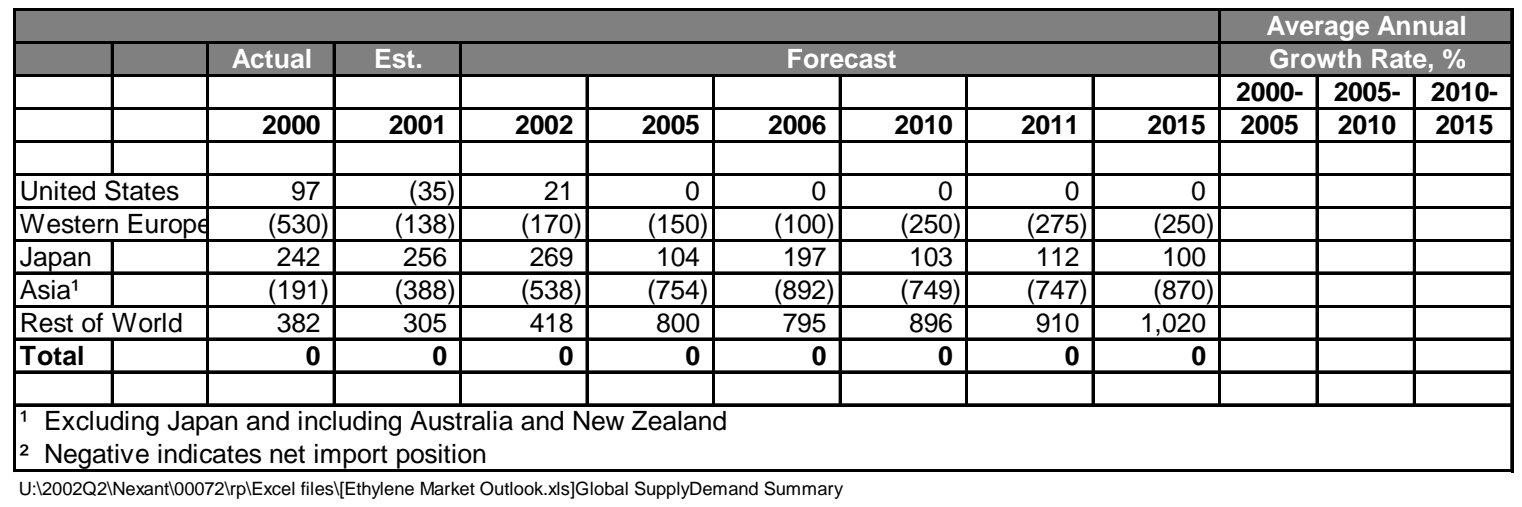

The main export destinations for Middle East exporters are Indonesia, Taiwan, and Western Europe. Japan exports almost exclusively within Asia, with Taiwan, South Korea, China, and the Philippines being the major destinations. Within Asia, Korea is traditionally a net exporter of ethylene, as are Thailand and Malaysia, and more recently, Singapore. All tend to export to other Asian countries. The traditional importers are Taiwan, the Philippines, Indonesia, and to a lesser extent, China. The United States exports ethylene to Western Europe and Latin America, and imports ethylene from Canada.

\subsection{FEEDSTOCK PROFILE}

About fifty percent of global ethylene production is naphtha-based. The portion of naphthabased production varies significantly by region, as shown in Table 2.4 and Figure 2.1. In terms 
of percent of feedstock, the leading naphtha-based regions are Japan, Eastern Europe, Western Europe, and Asia. Ethane is the next largest feedstock, with more than 25 percent of global production. The leading ethane-based regions are the Middle East/Africa, Canada, Latin America, and the United States.

Table 2.4 Regional Ethylene Feedstock Analysis, 2000 (weight percent)

\begin{tabular}{|l|c|c|c|c|c|c|}
\hline Region & Naphtha & Ethane & Propane & Butane & Gas Oil & Other \\
\hline United States & 20 & 45 & 17 & 3 & 12 & 4 \\
\hline Western Europe & 76 & 6 & 4 & 5 & 9 & 1 \\
\hline Japan & 96 & - & 1 & 3 & - & - \\
\hline Asia1 & 61 & 10 & 7 & 3 & 18 & 1 \\
\hline Canada & 17 & 60 & 18 & - & 5 & - \\
\hline Latin America & 44 & 49 & 4 & - & - & 3 \\
\hline Middle East/Africa & 20 & 70 & 4 & 1 & - & 5 \\
\hline Eastern Europe & 71 & 9 & 5 & 8 & 6 & 0 \\
\hline Global Average & $\mathbf{5 0}$ & $\mathbf{2 7}$ & $\mathbf{8}$ & $\mathbf{3}$ & $\mathbf{9}$ & $\mathbf{2}$ \\
\hline
\end{tabular}

1 Excluding Japan and including Australia and New Zealand

U:12002Q2INexant100072lrplExcel files|[Ethylene Market Outlook.xls]RegionalFeedstocks

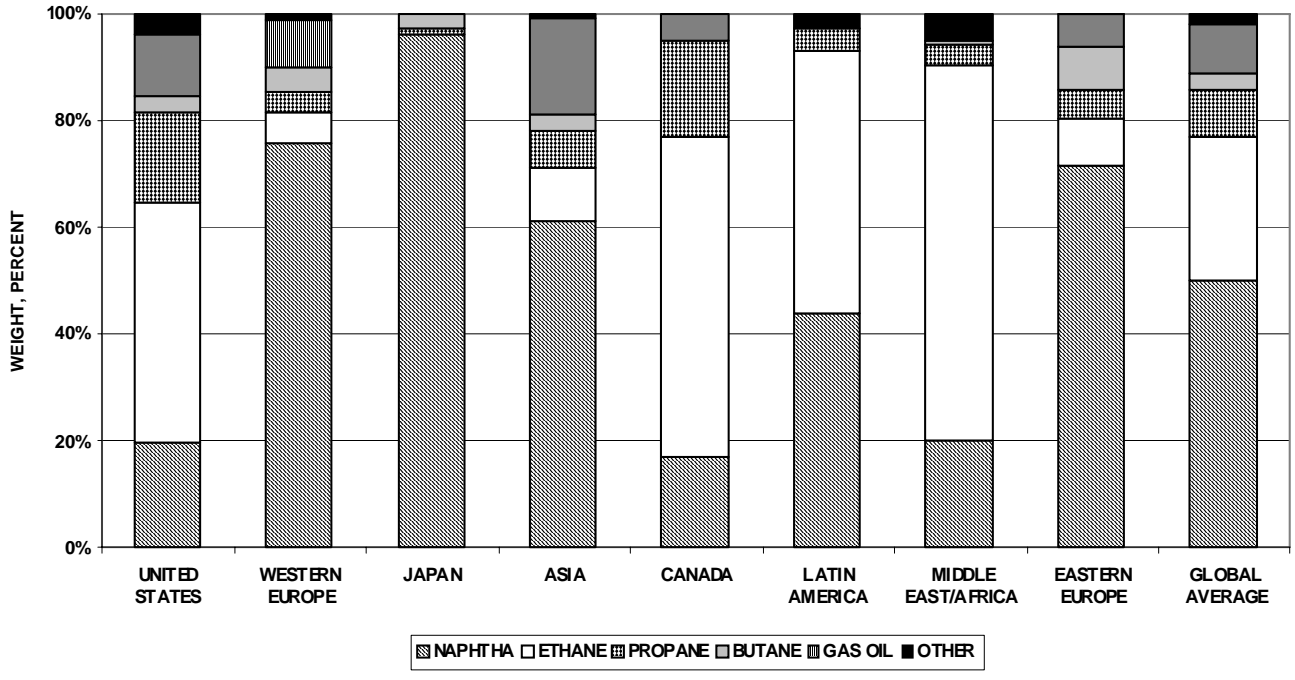

Figure 2.1 Regional Ethylene Feedstock Analysis, 2000 (weight percent)

In terms of overall production, the United States is the fourth leading producer of naphtha-based ethylene due to its large overall production capability. Global ethylene production by feedstock is shown in Table 2.5. 
Table 2.5 Regional Ethylene Production By Feedstock, 2000

(thousand metric tons of ethylene)

\begin{tabular}{|l|r|r|r|r|r|r|r|}
\hline & Naphtha & Ethane & Propane & Butane & Gas Oil & Other & Total \\
\hline United States & 4,911 & 11,113 & 4,142 & 769 & 2,853 & 1,017 & 24,805 \\
\hline Western Europe & 14,770 & 1,091 & 760 & 916 & 1,754 & 195 & 19,486 \\
\hline Japan & 7,309 & - & 76 & 228 & - & - & 7,614 \\
\hline Asia ${ }^{1}$ & 10,790 & 1,769 & 1,238 & 531 & 3,184 & 177 & 17,688 \\
\hline Canada & 604 & 2,131 & 639 & - & 178 & - & 3,551 \\
\hline Latin America & 2,071 & 2,306 & 188 & - & - & 141 & 4,706 \\
\hline Middle East/Africa & 1,518 & 5,313 & 304 & 76 & - & 380 & 7,590 \\
\hline Eastern Europe & 2,548 & 308 & 196 & 288 & 209 & 16 & 3,564 \\
\hline Global & 44,521 & 24,030 & 7,543 & 2,807 & 8,177 & 1,925 & 89,004 \\
\hline \multicolumn{1}{|l|}{} \\
\hline Excluding Japan and including Australia and New Zealand & & & & \\
\hline
\end{tabular}

U:|2002Q2INexant100072IrplExcel files|[Ethylene Market Outlook.xls]Production by Feedstock

When cracking naphtha, numerous co-products are produced, the most significant of which is propylene. Depending on cracking severity, propylene is produced at a rate of approximately 0.5 ton per ton of ethylene. Demand for propylene is growing at a rate faster than for ethylene, so some producers try to maximize propylene production by adjusting the severity of the cracking operation. In addition to propylene, the other co-products result in a naphtha requirement of approximately 3.35 tons per ton of ethylene produced. Cracking FT naphtha will give the same flexibility in adjusting severity to control the amount of ethylene and propylene produced, but will produce less of the other co-products, resulting in a feedstock requirement of approximately 2.9 tons per ton of ethylene produced. In contrast, an ethane cracker produces a much smaller quantity of co-products.

With a few exceptions, ethylene crackers in the Middle East are based on ethane, propane, or ethane/propane mixes. Conversely, in Europe and Japan, with a few exceptions, most crackers are naphtha-based. Crackers in the United States tend to be the most versatile, with very few being able to crack only one feedstock. None of these trends are expected to change significantly in the future.

Most of the new announced ethylene capacity will be located in Asia (mainly China) and the Middle East. Current plans, including likely feedstock, for 2002 through 2008 are shown in the following tables for firm and speculative additions. As shown, the data for the United States, Western Europe, and Japan is presented in Table 2.6. There are very few firm additions planned at this time. In Western Europe, DSM is considering a 500 thousand metric ton per year expansion in the Netherlands, which would be naphtha-based. Future speculative capacity additions in Europe will continue to use naphtha as feedstock, as low regional indigenous production of ethane, propane, and butane will limit significant ethylene capacity development from these sources. Capacity rationalization (shut down of old, small, non-efficient plants) is also expected to occur. The same is true for Japan, where plants were closed in 2000 and 2001 and more closures are expected as a result of planned mergers and acquisitions. Any new capacity built will be naphtha-based. 
Table 2.6 Firm Ethylene Capacity Expansions - United States, Western Europe, And Japan (thousand metric tons per year of ethylene, at year end)

\begin{tabular}{|c|c|c|c|c|c|c|c|c|c|c|}
\hline Country & Company & Location & 2002 & 2003 & 2004 & 2005 & 2006 & 2007 & 2008 & Feedstock \\
\hline United States & BASF FINA & Port Arthur, TX & 0 & $(90)$ & 0 & 0 & 0 & 0 & 0 & Naphtha \\
\hline United States & ExxonMobil & Baytown, TX & 120 & 0 & 0 & 0 & 0 & 0 & 0 & Ethane \\
\hline United States & Shell & Deer Park, TX & 0 & (91) & 0 & 0 & 0 & 0 & 0 & FCC Offgas \\
\hline United States & Shell & Deer Park, TX & 0 & 635 & 0 & 0 & 0 & 0 & 0 & Gas Oil \\
\hline \multicolumn{2}{|c|}{ Total United States } & & 120 & 454 & 0 & 0 & 0 & 0 & 0 & \\
\hline & & & & & & & & & & \\
\hline Belgium & BASF & Antwerp & 0 & 0 & 300 & 0 & 0 & 0 & 0 & Naphtha \\
\hline Belgium & Fina Antwerp Olefins & Antwerp & 100 & 0 & 0 & 0 & 0 & 0 & 0 & Naphtha \\
\hline Belgium & Fina Antwerp Olefins & Antwerp & 65 & 0 & 0 & 0 & 0 & 0 & 0 & Naphtha \\
\hline Finland & Borealis & Porvoo & 30 & 0 & 0 & 0 & 0 & 0 & 0 & Mixed Feed \\
\hline Germany & BP Koln & Dormagen & 200 & 0 & 0 & 0 & 0 & 0 & 0 & Ethane \\
\hline Germany & BP Koln & Dormagen & 20 & 0 & 0 & 0 & 0 & 0 & 0 & Naphtha \\
\hline Netherlands & Dow & Terneuzen & 300 & 0 & 0 & 0 & 0 & 0 & 0 & Mixed Feed \\
\hline Netherlands & Dow & Terneuzen & 300 & 0 & 0 & 0 & 0 & 0 & 0 & Mixed Feed \\
\hline Spain & Dow & Tarragona & 100 & 0 & 0 & 0 & 0 & 0 & 0 & Mixed Feed \\
\hline \multicolumn{2}{|c|}{ Total Western Europe } & & 1,115 & 0 & 300 & 0 & 0 & 0 & 0 & \\
\hline & & & & & & & & & & \\
\hline Japan & Idemitsu Petrochemical & Tokuyama, Yamaguchi & 200 & 0 & 0 & 0 & 0 & 0 & 0 & Naphtha \\
\hline Japan & Mitsubishi Chemical & Kashima, Ibaraki & 0 & 0 & 0 & 99 & 0 & 0 & 0 & Naphtha \\
\hline Total Japan & & & 200 & 0 & 0 & 99 & 0 & 0 & 0 & \\
\hline
\end{tabular}

U:|2002Q2INexant100072IrplExcel files|[Ethylene Market Outlook.xls]Expansions

The outlook for firm capacity additions in Asia (ex. Japan) is presented in Table 2.7. The expansion plans for Asia are extensive and include a number of plants that will not start up until 2006/2007. The largest capacity buildup is occurring in China. These expansions can be classified into three categories: new plants through joint ventures with multinational companies, expansions of existing large-scale crackers, and expansions of existing small-scale crackers. The expansions of existing crackers are proceeding and will be completed in the near-term. The joint venture projects are taking longer to progress, but many are expected to proceed. The BASF project is the first cracker of this type expected to startup, by 2005. The others are expected to follow quickly in 2006 and 2007. Dow also has a joint venture plan, which has recently been postponed from 2008 to 2010. Following a major capacity increase over the past five years, no crackers in India are in construction or in the late approval phase. However, many projects have been proposed for post-2005. Post-2005 crackers are also being planned in Malaysia and Singapore. Most of the new plants will use either naphtha or heavy liquid feedstocks. 
Table 2.7 Firm Ethylene Capacity Expansions Asia (Ex. Japan) (thousand metric tons per year of ethylene, at year end)

\begin{tabular}{|c|c|c|c|c|c|c|c|c|c|c|}
\hline Country & Company & Location & 2002 & 2003 & 2004 & 2005 & 2006 & 2007 & 2008 & Feedstock \\
\hline China & BASF Yangzi Company & Nanjing & 0 & 0 & 0 & 600 & 0 & 0 & 0 & Heavy Liquid \\
\hline China & Beijing Chemical (Dongfang) & Beijing & 0 & 40 & 0 & 0 & 0 & 0 & 0 & Heavy Liquid \\
\hline China & CNOOC / Shell & Huizhou, Guangdong & 0 & 0 & 0 & 0 & 800 & 0 & 0 & Heavy Liquid \\
\hline China & Daqing General & Daqing, Heilongjiang & 0 & 120 & 0 & 0 & 0 & 0 & 0 & Heavy Liquid \\
\hline China & Fujian/ExxonMobil/Aramco & Fuzhou, Fujian & 0 & 0 & 0 & 0 & 0 & 600 & 0 & Naphtha \\
\hline China & Fushun Ethylene & Fushun, Liaoning & 0 & 40 & 0 & 0 & 0 & 0 & 0 & Heavy Liquid \\
\hline China & Jilin Chemical & Jilin, Jilin & 0 & 150 & 0 & 0 & 0 & 0 & 0 & Heavy Liquid \\
\hline China & Lanzhou Petrochemical & Lanzhou, Gansu & 0 & 0 & 80 & 0 & 0 & 0 & 0 & Heavy Liquid \\
\hline China & Liaoyang Petrochemical & Liaoyang, Liaoning & 0 & 0 & 43 & 0 & 0 & 0 & 0 & Heavy Liquid \\
\hline China & Maoming Petrochemical & Maoming, Guangdong & 0 & 0 & 0 & 0 & 450 & 0 & 0 & Heavy Liquid \\
\hline China & Panjin Ethylene & Panjin, Liaoning & 0 & 0 & 0 & 0 & 220 & 0 & 0 & Naphtha \\
\hline China & Secco & Shanghai & 0 & 0 & 0 & 0 & 900 & 0 & 0 & Heavy Liquid \\
\hline China & Shanghai Petrochemical & Shanghai & 400 & 0 & 0 & 0 & 0 & 0 & 0 & Heavy Liquid \\
\hline China & Yangzi Petrochemical & Nanjing & 250 & 0 & 0 & 0 & 0 & 0 & 0 & Heavy Liquid \\
\hline South Korea & LG Petrochem & Yeochon & 0 & 0 & 0 & 120 & 0 & 0 & 0 & Naphtha \\
\hline South Korea & Samsung General & Daesan & 0 & 0 & 0 & 180 & 0 & 0 & 0 & Naphtha \\
\hline Taiwan & CPC & Linyuan & 0 & 0 & 115 & 0 & 0 & 0 & 0 & Naphtha \\
\hline Taiwan & Formosa Petrochemical & Mai Liao & 300 & 0 & 0 & 0 & 0 & 0 & 0 & Naphtha \\
\hline Taiwan & Formosa Petrochemical & Mai Liao & 250 & 0 & 0 & 0 & 0 & 0 & 0 & Naphtha \\
\hline Malaysia & Optimal Olefins & Kertih & 600 & 15 & 0 & 15 & 0 & 0 & 0 & Ethane \\
\hline Thailand & NPC (Thailand) & Map Ta Phut & 35 & 0 & 0 & 25 & 0 & 0 & 0 & Ethane/Propane \\
\hline Thailand & Thai Olefins & Map Ta Phut & 0 & 0 & 0 & 315 & 0 & 0 & 0 & Naphtha \\
\hline India & GAIL & Auraiya & 0 & 0 & 0 & 0 & 200 & 0 & 0 & Ethane/Propane \\
\hline Australia & Qenos & Botany Bay & 0 & 0 & 0 & 100 & 0 & 0 & 0 & Ethane \\
\hline \multicolumn{2}{|c|}{ Total Asia (ex. Japan) } & & 1,835 & 365 & 238 & 1,355 & 2,570 & 600 & 0 & \\
\hline
\end{tabular}

U:L2002Q2INexantl00072lrplExcel files|[Ethylene Market Outlook.xls]Expansions

The outlook for the rest of the world is presented in Table 2.8. As with Asia, there are extensive expansion plans in the Middle East. Another thing to note is the scale of these plants, which are considerably larger than existing plants. Most of the expansions will be in Iran and Saudi Arabia. The only large-scale expansion that will use naphtha is the Equate plant in Kuwait, with the majority of new capacity to be based on ethane and, to a lesser extent, LPG.

Table $2.8 \quad$ Firm Ethylene Capacity Expansions - Rest Of World (thousand metric tons per year of ethylene, at year end)

\begin{tabular}{|c|c|c|c|c|c|c|c|c|c|c|}
\hline Country & Company & Location & 2002 & 2003 & 2004 & 2005 & 2006 & 2007 & 2008 & Feedstock \\
\hline Brazil & Copene & Camacari & 0 & 0 & 0 & 120 & 0 & 0 & 0 & Naphtha \\
\hline Brazil & Copene & Camacari & 80 & 0 & 0 & 0 & 0 & 0 & 0 & Naphtha \\
\hline Brazil & $\mathrm{PQU}$ & Sao Paulo & 0 & 150 & 0 & 0 & 0 & 0 & 0 & Naphtha \\
\hline Brazil & Rio Eteno & Rio de Janeiro & 0 & 0 & 540 & 0 & 0 & 0 & 0 & Ethane/Propane \\
\hline \begin{tabular}{|l|} 
Venezuela \\
\end{tabular} & ExxonMobil/Pequiven & Jose & 0 & 0 & 0 & 930 & 0 & 0 & 0 & Ethane/Propane \\
\hline \multicolumn{2}{|c|}{ Total Latin America } & & 80 & 150 & 540 & 1,050 & 0 & 0 & 0 & \\
\hline Iran & Amir Kabir Petrochem & Bandar Imam & 0 & 520 & 0 & 0 & 0 & 0 & 0 & Mixed Feed \\
\hline Iran & \begin{tabular}{|l|} 
Arak Petrochemical \\
\end{tabular} & Arak & 0 & 0 & 63 & 0 & 0 & 0 & 0 & Naphtha \\
\hline Iran & Arvand Petrochemical & Bandar Imam & 0 & 0 & 0 & 0 & 0 & 0 & 1,100 & Ethane \\
\hline Iran & \begin{tabular}{|l|} 
JAM Petrochemical \\
\end{tabular} & Bandar Asaluyeh & 0 & 0 & 0 & 0 & 1,320 & 0 & 0 & Mixed Feed \\
\hline $\operatorname{Iran}$ & Marun Petrochemical & Bandar Imam & 0 & 0 & 0 & 1,100 & 0 & 0 & 0 & Ethane/Propane \\
\hline Iran & Pars Petrochemical & Bandar Asaluyeh & 0 & 0 & 0 & 0 & 1,000 & 0 & 0 & Ethane \\
\hline Kuwait & Equate Petrochemical & Shuaiba & 0 & 0 & 0 & 0 & 850 & 0 & 0 & Naphtha \\
\hline Qatar & Q-Chem & Mesaieed & 500 & 0 & 0 & 0 & 0 & 0 & 0 & Ethane \\
\hline Qatar & Q-Chem II & Ras Laffan & 0 & 0 & 0 & 0 & 0 & 1,000 & 0 & Ethane \\
\hline Qatar & QAPCO & Mesaieed & 0 & 0 & 195 & 0 & 0 & 0 & 0 & Ethane \\
\hline Saudi Arabia & Jubail United Petrochemicals & Al Jubail & 0 & 0 & 1,000 & 0 & 0 & 0 & 0 & Ethane \\
\hline Saudi Arabia & Saudi Yanbu Petrochemical & Yanbu & 0 & 0 & 0 & 0 & 1,000 & 0 & 0 & Ethane/Propane \\
\hline Saudi Arabia & Yanpet & Yanbu & 0 & 0 & 0 & 500 & 0 & 0 & 0 & Ethane/Propane \\
\hline Turkey & Petkim & Aliaga & 0 & 100 & 0 & 0 & 0 & 0 & 0 & Naphtha \\
\hline UAE & Borouge & Ruwais, Abu Dhabi & 600 & 0 & 0 & 0 & 0 & 0 & 0 & Ethane \\
\hline \multicolumn{2}{|c|}{ Total Middle East } & & 1,100 & 620 & 1,258 & 1,600 & 4,170 & 1,000 & 1,100 & \\
\hline Czech Republic & Chemopetrol & Litvinoy & 0 & 75 & 0 & 0 & 0 & 0 & 0 & Naphtha \\
\hline Russia & Gazprom & Novi Urengoy & 0 & 300 & 0 & 0 & 0 & 0 & 0 & Ethane \\
\hline Turkmenistan & Turkmenneftegas & Gazachak & 0 & 0 & 0 & 200 & 0 & 0 & 0 & Ethane \\
\hline \multicolumn{2}{|c|}{ Total Eastern Europe } & & 0 & 375 & 0 & 200 & 0 & 0 & 0 & \\
\hline
\end{tabular}


Speculative capacity expansions for 2003 through 2015 are shown in Table 2.9. Some regions are expected to shut down older, less economical plants in the future. It is likely that the feedstock slate for these plants will be similar to the existing feedstock slate in each region.

\section{Table 2.9 Global Speculative Ethylene Capacity Additions} (thousand metric tons per year of ethylene, at year end)

\begin{tabular}{|l|r|r|r|r|r|r|r|r|r|r|r|r|r|r|}
\hline & 2003 & $\mathbf{2 0 0 4}$ & $\mathbf{2 0 0 5}$ & $\mathbf{2 0 0 6}$ & $\mathbf{2 0 0 7}$ & $\mathbf{2 0 0 8}$ & $\mathbf{2 0 0 9}$ & $\mathbf{2 0 1 0}$ & $\mathbf{2 0 1 1}$ & $\mathbf{2 0 1 2}$ & $\mathbf{2 0 1 3}$ & $\mathbf{2 0 1 4}$ & $\mathbf{2 0 1 5}$ \\
\hline United States & 454 & 675 & 454 & 454 & 454 & 907 & 680 & 454 & 0 & 900 & 900 & 455 & 455 \\
\hline Western Europe & 0 & 0 & 0 & 0 & 100 & 800 & 0 & 300 & 800 & 0 & 800 & 0 & 800 \\
\hline Japan & 0 & 0 & 0 & 0 & $(400)$ & 0 & 0 & 0 & 0 & 300 & 0 & 300 & 0 \\
\hline Asia & 0 & 0 & $(200)$ & 1,550 & 2,150 & 1,200 & 550 & 3,100 & 1,200 & 2,500 & 2,400 & 1,200 & 1,200 \\
\hline Canada & 0 & 0 & 0 & 0 & 900 & 0 & 0 & 0 & 0 & 900 & 0 & 0 & 0 \\
\hline Latin America & 0 & 0 & 450 & 650 & 850 & 300 & 650 & 1,000 & 0 & 1,000 & 0 & 1,000 & 600 \\
\hline Middle East & 160 & 0 & 500 & 1,000 & 0 & 0 & 0 & 1,000 & 0 & 2,400 & 2,400 & 1,200 & 1,200 \\
\hline Africa & 0 & 0 & 0 & 100 & 1,000 & 1,000 & 0 & 0 & 0 & 1,000 & 1,000 & 0 & 1,000 \\
\hline Eastern Europe & 0 & 250 & 0 & 150 & 0 & 250 & 0 & 0 & 0 & 0 & 0 & 0 & 0 \\
\hline Total & $\mathbf{6 1 4}$ & $\mathbf{9 2 5}$ & $\mathbf{1 , 2 0 4}$ & $\mathbf{3 , 9 0 4}$ & $\mathbf{5 , 0 5 4}$ & $\mathbf{4 , 4 5 7}$ & $\mathbf{1 , 8 8 0}$ & $\mathbf{5 , 8 5 4}$ & $\mathbf{2 , 0 0 0}$ & $\mathbf{9 , 0 0 0}$ & $\mathbf{7 , 5 0 0}$ & $\mathbf{4 , 1 5 5}$ & $\mathbf{5 , 2 5 5}$ \\
\hline
\end{tabular}

U:|2002Q4100072.005.11|DatalExcel files|[Ethylene Market Outlook.xls]Capacity Additions

Since slightly less than half of the new capacity will be added in regions that are predominantly naphtha-based, production of naphtha-based ethylene will grow at a slightly lower rate than ethylene in general. Through 2015, growth is forecast to average 3.7 percent per year, as shown in Table 2.10.

Table 2.10 Global Ethylene Capacity and Production

(thousand metric tons per year of ethylene)

\begin{tabular}{|c|c|c|c|c|c|c|c|c|c|c|c|}
\hline & Actual & Est. & \multicolumn{6}{|c|}{ Forecast } & \multicolumn{3}{|c|}{$\begin{array}{l}\text { Average Annual } \\
\text { Growth Rate, \% }\end{array}$} \\
\hline & 2000 & 2001 & 2002 & 2005 & 2006 & 2010 & 2011 & 2015 & $\begin{array}{l}2000- \\
2005\end{array}$ & \begin{tabular}{|c|}
$2005-$ \\
2010 \\
\end{tabular} & \begin{tabular}{|l}
$2010-$ \\
2015 \\
\end{tabular} \\
\hline Total Expected Capacity & 103,124 & 106,424 & 111,074 & 122,421 & 133,065 & 153,010 & 155,010 & 180,920 & & & \\
\hline Naphtha-Based Capacity & 50,982 & 52,684 & 55,148 & 59,242 & 63,245 & 71,527 & 72,859 & 82,974 & & & \\
\hline Total Ethylene Production & 89,004 & 90,904 & 96,792 & 109,198 & 115,332 & 138,776 & 143,776 & 167,095 & 4.2 & 4.9 & 3.8 \\
\hline Naphtha-Based Production & 44,192 & 45,014 & 47,621 & 52,386 & 54,402 & 64,307 & 66,417 & 75,926 & 3.5 & 4.2 & 3.4 \\
\hline
\end{tabular}

U:|2002Q4|00072.005.11|DatalExcel files|[Ethylene Market Outlook.xIs]Naphtha SupplyDemand Tables

\subsection{NAPHTHA REQUIREMENTS}

Driven by demand for polyethylene, ethylene production is expected to show good growth on a global basis. Naphtha will continue to be a major feedstock for ethylene production, accounting for approximately 45 percent by 2015. Based on the ethylene production forecast, the amount of naphtha required in 2015 will be approximately 70 percent greater than what was required in 2000, an increase of 106 million metric tons, as shown in Table 2.11. 
Table 2.11 Global Naphtha Required for Ethylene Production ${ }^{1}$

(thousand metric tons of naphtha)

\begin{tabular}{|c|c|c|c|c|c|c|c|c|c|c|c|}
\hline & Actual & Est. & \multicolumn{6}{|c|}{ Forecast } & \multicolumn{3}{|c|}{$\begin{array}{l}\text { Average Annual } \\
\text { Growth Rate, \% } \\
\end{array}$} \\
\hline & & & & & & & & & $2000-$ & 2005- & $2010-$ \\
\hline & 2000 & 2001 & 2002 & 2005 & 2006 & 2010 & 2011 & 2015 & 2005 & 2010 & 2015 \\
\hline United States & 16,619 & 15,740 & 16,482 & 18,353 & 18,857 & 20,684 & 21,155 & 22,787 & 2.0 & 2.4 & 2.0 \\
\hline \begin{tabular}{|l|} 
Western Europe \\
\end{tabular} & 48,959 & 49,534 & 52,539 & 56,913 & 56,029 & 60,581 & 61,117 & 63,943 & 3.1 & 1.3 & 1.1 \\
\hline Japan & 24,487 & 23,975 & 24,024 & 23,316 & 23,252 & 23,493 & 23,773 & 24,281 & $(1.0)$ & 0.2 & 0.7 \\
\hline Asia $^{2}$ & 35,560 & 37,431 & 40,580 & 45,384 & 49,010 & 65,745 & 69,308 & 85,251 & 5.0 & 7.7 & 5.3 \\
\hline Rest of World & 22,419 & 24,116 & 25,907 & 31,528 & 35,098 & 44,926 & 47,145 & 58,090 & 7.1 & 7.3 & 5.3 \\
\hline Total & 148,044 & 150,796 & 159,531 & 175,494 & 182,246 & 215,430 & 222,497 & 254,351 & 3.5 & 4.2 & 3.4 \\
\hline $\begin{array}{l}\text { 3ased on } 3.35 \text { tor } \\
\text { xcluding Japan }\end{array}$ & $\begin{array}{l}\text { required } \\
\mathrm{a} \text { and } \mathrm{Ne}\end{array}$ & $\begin{array}{l}\text { ton ethyl } \\
\text { Zealand }\end{array}$ & & & & & & & & & \\
\hline
\end{tabular}

U:|2002Q4100072.005.11|DatalExcel filesI[Ethylene Market Outlook.xIs]Naphtha SupplyDemand Tables

This represents a large market requiring a significant increase in feedstock supply, thus presenting an opportunity for FT naphtha. FT naphtha can be used in any cracker that uses conventional naphtha. The best opportunities would exist in countries where naphtha is already used as an ethylene feedstock since these countries generally already have established markets for the co-products. Given the high quality of FT naphtha, Nexant believes that it can readily be placed in any market. 


\subsection{SUPPLY AND DEMAND}

As in the rest of the world, polyethylene is the major consumer of ethylene in the United States. Polyethylene production is expected to be moderate in the U.S., resulting in an ethylene demand growth rate of 2.2 percent through 2015 .

Currently, the United States has the largest ethylene capacity in the world. By 2007, Asia, as a region, will surpass the U.S. in terms of ethylene capacity. Through 2015, the U.S. is forecast to remain the second largest producer, with the Middle East and Western Europe ranking a relatively distant third.

The United States has historically exported ethylene to Western Europe and Latin America, while importing ethylene from Canada. In the future, the U.S. is expected to remain selfsufficient with a net trade balance of about zero, as shown in Table 3.1.

Table $3.1 \quad$ U.S. Ethylene Supply/Demand Balance (thousand metric tons of ethylene)

\begin{tabular}{|c|c|c|c|c|c|c|c|c|c|c|c|}
\hline & Actual & Est. & \multicolumn{6}{|c|}{ Forecast } & \multicolumn{3}{|c|}{$\begin{array}{l}\text { Average Annual } \\
\text { Growth Rate, \% }\end{array}$} \\
\hline & & & & & & & & & 2000- & 2005- & 2010- \\
\hline & 2000 & 2001 & 2002 & 2005 & 2006 & 2010 & 2011 & 2015 & 2005 & 2010 & 2015 \\
\hline Firm Capacity - Initial & 26,285 & 26,761 & 28,107 & 28,681 & 28,681 & 28,681 & 28,681 & 28,681 & & & \\
\hline - Net Additions & 476 & 1,346 & 120 & 0 & 0 & 0 & 0 & 0 & & & \\
\hline - Total & 26,761 & 28,107 & 28,227 & 28,681 & 28,681 & 28,681 & 28,681 & 28,681 & & & \\
\hline Net Speculative Additions & 0 & $(817)$ & 0 & 454 & 454 & 454 & 0 & 455 & & & \\
\hline Expected Capacity Total ${ }^{1}$ & 26,761 & 27,290 & 27,410 & 29,447 & 29,901 & 32,396 & 32,396 & 35,106 & & & \\
\hline Production & 24,805 & 23,493 & 24,600 & 27,392 & 28,145 & 30,872 & 31,575 & 34,010 & 2.0 & 2.4 & 2.0 \\
\hline Net Trade & 97 & (35) & 21 & 0 & 0 & 0 & 0 & 0 & & & \\
\hline Inventory & 33 & 0 & 0 & 0 & 0 & 0 & 0 & 0 & & & \\
\hline Consumption & 24,675 & 23,528 & 24,579 & 27,392 & 28,145 & 30,872 & 31,575 & 34,010 & 2.1 & 2.4 & 2.0 \\
\hline
\end{tabular}

U:|2002Q4100072.005.11|DatalExcel filesI[Ethylene Market Outlook.xIs]U.S. Supply Demand

Presently, there are not many planned capacity expansions in the United States, as shown in Table 3.2. The shutdown of capacity by BASF FINA in 2003 will occur when their metathesis unit is brought on stream. This unit will increase propylene production at the expense of ethylene. ExxonMobil's expansion in 2002 represents debottlenecking of an existing plant. Shell is refurbishing and expanding an existing facility, which currently only processes FCC offgas. The unit will be converted to a traditional steam cracker, which will process heavy feeds (gas oil and condensate) as well as the existing stream. In addition, Dow has announced a scrap and build program, but the details have not been finalized. A new plant will be built somewhere along the Texas Gulf Coast by 2005, replacing over 1 million tons per year of capacity to be shut down at Seadrift and Texas City, TX (former Union Carbide plants acquired by Dow in 2001). The plants are ethane-based and Dow plans a more flexible feedstock slate for the new cracker. The speculative capacity required for the United States to meet its ethylene requirements through 
2015 is also shown. Speculative capacity additions may be full-scale crackers or debottlenecks of existing facilities.

Table $3.2 \quad$ U.S. Ethylene Capacity Expansions

(thousand metric tons per year of ethylene, at year end)

\begin{tabular}{|l|l|r|r|r|r|r|r|r|r|r|r|r|r|r|r|}
\hline Company & Location & 2002 & 2003 & 2004 & 2005 & 2006 & 2007 & 2008 & 2009 & 2010 & 2011 & 2012 & 2013 & 2014 & 2015 \\
\hline BASF FINA & Port Arthur, TX & 0 & $(90)$ & 0 & 0 & 0 & 0 & 0 & 0 & 0 & 0 & 0 & 0 & 0 & 0 \\
\hline ExxonMobil & Baytown, TX & 120 & 0 & 0 & 0 & 0 & 0 & 0 & 0 & 0 & 0 & 0 & 0 & 0 & 0 \\
\hline Shell & Deer Park, TX & 0 & $(91)$ & 0 & 0 & 0 & 0 & 0 & 0 & 0 & 0 & 0 & 0 & 0 & 0 \\
\hline Shell & Deer Park, TX & 0 & 635 & 0 & 0 & 0 & 0 & 0 & 0 & 0 & 0 & 0 & 0 & 0 & 0 \\
\hline & & & & & & & & & & & & & & & \\
\hline Speculative & & 0 & 454 & 675 & 454 & 454 & 454 & 907 & 680 & 454 & 0 & 900 & 900 & 455 & 455 \\
\hline Total & & $\mathbf{1 2 0}$ & $\mathbf{9 0 8}$ & $\mathbf{6 7 5}$ & $\mathbf{4 5 4}$ & $\mathbf{4 5 4}$ & $\mathbf{4 5 4}$ & $\mathbf{9 0 7}$ & $\mathbf{6 8 0}$ & $\mathbf{4 5 4}$ & $\mathbf{0}$ & $\mathbf{9 0 0}$ & $\mathbf{9 0 0}$ & $\mathbf{4 5 5}$ & $\mathbf{4 5 5}$ \\
\hline
\end{tabular}

U:|2002Q4I00072.005.11IDatalExcel files|[Ethylene Market Outlook.xIs]U.S.CapacityAdditions

\subsection{FEEDSTOCK PROFILE}

The U.S. olefins industry has a wide range of feedstock cracking flexibility. Although Asian and European production facilities are largely naphtha-based and those in the Middle East and Western Canada are largely ethane-based, the U.S. industry has a broad capability to crack significant quantities of naphtha, ethane, propane, butane, and gas oil.

Prior to 1975, the U.S. industry was largely based on cracking ethane/propane mixtures. Ethane/propane mixtures were the feedstock of choice because they were readily and inexpensively available from the large natural gas processing industry. By 1975, however, the growing demand for propylene and aromatics resulted in higher co-product values and encouraged a switch to heavier feedstocks. Thus, much of the new capacity built in the second half of the 1970's was based on liquid feeds (i.e., naphtha and gas oil). Later, light feedstock flexibility was added to these plants.

Currently, there is no clear industry-wide preference for the United States, as evidenced by the last three new crackers - Exxon (now ExxonMobil) started an ethane-based cracker in 1997, BASF FINA started a naphtha-based cracker in 2001, and Formosa started an ethane/propanebased cracker in late 2001.

Crackers designed to use light gas feedstocks are simpler, produce fewer co-products, and have lower capital cost (for an equivalent ethylene capacity) than those designed for liquid feedstocks. There is flexibility to switch feeds in many crackers and the operators of those units will choose the feedstock slate to maximize cash generation. Feedstock selection is largely made when considering the initial cracker investment. Refinery integration can play an important part in the decision. Integration between the refinery and steam cracker can give added value to both units. Flexibility and proximity to a refinery allows integrated operations to rapidly react to changing market conditions and relative valuation of feedstocks.

Currently, approximately 20 percent of ethylene production in the United States is naphthabased, while about 45 percent is ethane-based. Since many crackers are flexible, these numbers 
fluctuate on a monthly basis, depending on feedstock cost and other factors. Over the long-term, however, the ratios are expected to remain fairly consistent, as shown in Figure 3.1.

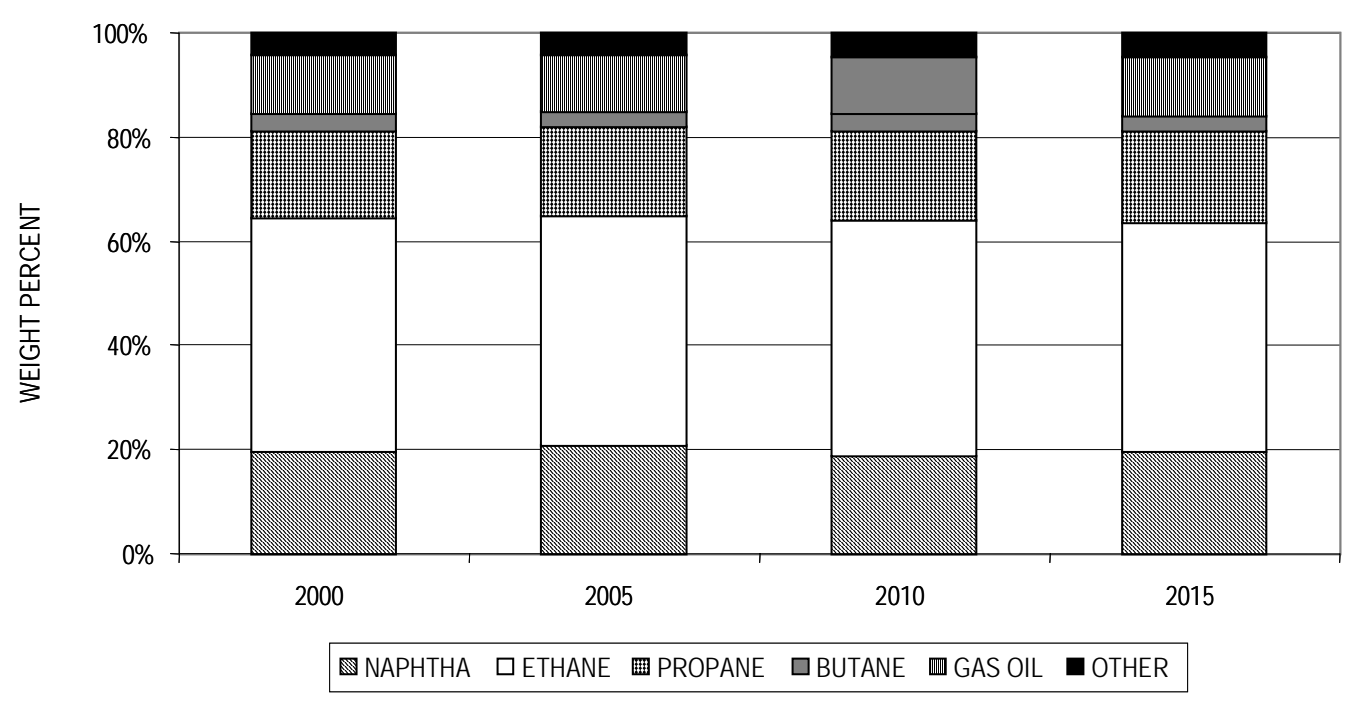

Figure $3.1 \quad$ U.S. Ethylene Feedstock Analysis (weight percent)

Ethylene capacity in the United States is presented in Table 3.3, showing each producer and the feedstock used over a 6-month period.

Production of naphtha-based ethylene in the United States is expected to grow at the same rate as ethylene in general. Through 2015, growth is forecast to average 2.1 percent per year, as shown in Table 3.4. 


\section{Table 3.3 U.S. Ethylene Production Capacity} (thousand metric tons per year of ethylene, at year end)

\begin{tabular}{|c|c|c|c|c|c|c|c|c|}
\hline Company & Location & 2000 & 2001 & 2002 & 2003 & Feedstock & $\begin{array}{c}\text { Mixed Feed } \\
\text { Components }^{1}\end{array}$ & \begin{tabular}{|c|}
$\begin{array}{c}\text { Naphtha } \\
\text { Portion }\end{array}$ \\
\end{tabular} \\
\hline BASF FINA & Port Arthur, TX & 0 & 950 & 950 & 860 & Naphtha & - & 100 \\
\hline $\mathrm{BP}$ & Chocolate Bayou, TX & 794 & 794 & 794 & 794 & Mixed feed & $\mathrm{N}, \mathrm{E}, \mathrm{P}$ & $8-18$ \\
\hline $\mathrm{BP}$ & Chocolate Bayou, TX & 612 & 612 & 612 & 612 & Mixed feed & $\mathrm{N}, \mathrm{E}, \mathrm{P}$ & $8-18$ \\
\hline Chevron Phillips & Port Arthur, TX & 784 & 784 & 784 & 784 & E/P & - & - \\
\hline Chevron Phillips & Sweeny, TX & 181 & 0 & 0 & 0 & $E / P$ & - & - \\
\hline Chevron Phillips & Sweeny, TX & 310 & 310 & 310 & 310 & Ethane & - & - \\
\hline Chevron Phillips & Sweeny, TX & 699 & 699 & 699 & 699 & $E / P$ & - & - \\
\hline Chevron Phillips & Sweeny, TX & 905 & 905 & 905 & 905 & Mixed feed & $E, P, B$ & - \\
\hline Chevron Phillips & Cedar Bayou, TX & 739 & 739 & 739 & 739 & Mixed feed & $\mathrm{N}, \mathrm{E}, \mathrm{P}, \mathrm{B}$ & $10-42$ \\
\hline Dow & Freeport, TX & 590 & 590 & 590 & 590 & Mixed feed & $E, P$ & - \\
\hline Dow & Freeport, TX & 918 & 918 & 918 & 918 & Mixed feed & $N, E / P, P$ & $18-51$ \\
\hline Dow & Plaquemine, LA & 680 & 680 & 680 & 680 & Mixed feed & $\mathrm{N}, \mathrm{E}, \mathrm{P}, \mathrm{B}$ & $7-23$ \\
\hline Dow & Plaquemine, LA & 500 & 500 & 500 & 500 & Mixed feed & $E, P$ & - \\
\hline Dow/UCC & Seadrift, TX & 413 & 413 & 413 & 413 & Ethane & - & - \\
\hline Dow/UCC & Texas City, TX & 680 & 680 & 680 & 680 & $E / P$ & - & - \\
\hline Dow/UCC & Taft, LA & 454 & 454 & 454 & 454 & Mixed feed & $\mathrm{N}, \mathrm{E}, \mathrm{P}$ & $17-58$ \\
\hline Dow/UCC & Taft, LA & 544 & 544 & 544 & 544 & Mixed feed & $\mathrm{N}, \mathrm{E}, \mathrm{P}$ & $17-58$ \\
\hline DuPont & Orange, TX & 590 & 590 & 590 & 590 & Ethane & - & - \\
\hline Eastman & Longview, TX & 635 & 635 & 635 & 635 & Mixed feed & $N, E, P, B$ & $0-10$ \\
\hline Equistar & Clinton, IA & 435 & 435 & 435 & 435 & E/P & - & - \\
\hline Equistar & Deer Park, TX & 816 & 816 & 816 & 816 & Mixed feed & $\mathrm{N}, \mathrm{E} / \mathrm{P}$ & $0-5$ \\
\hline Equistar & Lake Charles, LA & 363 & 0 & 0 & 0 & $\mathrm{E} / \mathrm{P}$ & - & - \\
\hline Equistar & Morris, IL & 512 & 512 & 512 & 512 & $E / P$ & - & - \\
\hline Equistar & Channelview, TX & 873 & 873 & 873 & 873 & Mixed feed & $\mathrm{N}+\mathrm{C}, \mathrm{E} / \mathrm{P}$ & $80-95^{2}$ \\
\hline Equistar & Channelview, TX & 873 & 873 & 873 & 873 & Mixed feed & $\mathrm{N}+\mathrm{C}, \mathrm{E} / \mathrm{P}$ & $80-95^{2}$ \\
\hline Equistar & Chocolate Bayou, TX & 535 & 535 & 535 & 535 & Mixed feed & $\mathrm{N}+\mathrm{C}$ & $100^{2}$ \\
\hline Equistar & Corpus Christi, TX & 771 & 771 & 771 & 771 & Mixed feed & $\mathrm{N}+\mathrm{C}, \mathrm{E} / \mathrm{P}$ & $60-70^{2}$ \\
\hline ExxonMobil & Houston, TX & 342 & 342 & 342 & 342 & Mixed feed & $E, P$ & - \\
\hline ExxonMobil & Baytown, TX & 698 & 698 & 818 & 818 & Ethane & - & - \\
\hline ExxonMobil & Baytown, TX & 1,179 & 1,179 & 1,179 & 1,179 & Mixed feed & $\mathrm{N}, \mathrm{E}, \mathrm{B}$ & $15-70$ \\
\hline ExxonMobil & Baton Rouge, LA & 862 & 862 & 862 & 862 & Mixed feed & $\mathrm{N}, \mathrm{E}, \mathrm{B}, \mathrm{GO}$ & $15-35$ \\
\hline ExxonMobil & Beaumont, TX & 816 & 816 & 816 & 816 & Mixed feed & $E, E / P, B$ & - \\
\hline Formosa & Point Comfort, TX & 0 & 850 & 850 & 850 & Mixed feed & $\mathrm{N}, \mathrm{E} / \mathrm{P}, \mathrm{P}$ & 30 \\
\hline Formosa & Point Comfort, TX & 714 & 714 & 714 & 714 & Mixed feed & $N, E / P, P$ & $30-80$ \\
\hline Gulf Liquids & Geismar, LA & 0 & 90 & 90 & 90 & FCC offgas & - & - \\
\hline Huntsman & Port Neches, TX & 181 & 181 & 181 & 181 & $E / P$ & - & - \\
\hline Huntsman & Odessa, TX & 363 & 363 & 363 & 363 & Mixed feed & $E, P$ & - \\
\hline Huntsman & Port Arthur, TX & 635 & 635 & 635 & 635 & Mixed feed & $\mathrm{N}, \mathrm{E}, \mathrm{P}, \mathrm{E} / \mathrm{P}, \mathrm{B}$ & $42-74$ \\
\hline Javelina & Corpus Christi, TX & 91 & 91 & 91 & 91 & FCC offgas & - & - \\
\hline Sasol/Condea Vista & Lake Charles, LA & 417 & 417 & 417 & 417 & Ethane & - & - \\
\hline Shell & Deer Park, TX & 862 & 862 & 862 & 862 & Mixed feed & $\mathrm{N}, \mathrm{C}, \mathrm{E}, \mathrm{B}, \mathrm{GO}$ & $35-60$ \\
\hline Shell & Deer Park, TX & 91 & 91 & 91 & 0 & FCC offgas & - & - \\
\hline Shell & Deer Park, TX & 0 & 0 & 0 & 635 & Mixed feed ${ }^{3}$ & $\mathrm{~N}, \mathrm{C}, \mathrm{E}, \mathrm{B}, \mathrm{GO}$ & $35-60$ \\
\hline Shell & Norco, LA & 626 & 626 & 626 & 626 & Mixed feed & $\mathrm{N}, \mathrm{E}, \mathrm{P}, \mathrm{B}$ & $25-50$ \\
\hline Shell & Norco, LA & 930 & 930 & 930 & 930 & Mixed feed & $\mathrm{N}, \mathrm{C}, \mathrm{GO}$ & $25-35$ \\
\hline Sunoco & Claymont, DE & 102 & 102 & 102 & 102 & Ethane & - & - \\
\hline Westlake & Calvert City, KY & 159 & 159 & 159 & 159 & Propane & - & - \\
\hline Westlake & Lake Charles, LA & 454 & 454 & 454 & 454 & Ethane & - & - \\
\hline Westlake & Lake Charles, LA & 455 & 455 & 455 & 455 & Mixed feed & $E, P, B$ & - \\
\hline Williams Energy & Geismar, LA & 578 & 578 & 578 & 578 & Mixed feed & $E, P$ & - \\
\hline Total & & 26,761 & 28,107 & 28,227 & 28,681 & & & \\
\hline & & & & & & & & \\
\hline \multicolumn{9}{|c|}{$\begin{array}{l}1 \mathrm{~N}=\text { naphtha, } \mathrm{E}=\text { ethane, } \mathrm{P}=\text { propane, } \mathrm{B}=\text { butane } \\
\mathrm{C}=\text { condensate, } \mathrm{G} \mathrm{O}=\text { gas oil, } \mathrm{RG}=\text { refinery gases } \\
\mathrm{E} / \mathrm{P}=\text { =thane/propane mix } \\
2 \mathrm{~N}+\mathrm{C} \text { portion } \\
3 \text { estimate }\end{array}$} \\
\hline
\end{tabular}


Table $3.4 \quad$ U.S. Ethylene Capacity and Production

(thousand metric tons per year of ethylene)

\begin{tabular}{|c|c|c|c|c|c|c|c|c|c|c|c|}
\hline & Actual & Est. & \multicolumn{6}{|c|}{ Forecast } & \multicolumn{3}{|c|}{$\begin{array}{l}\text { Average Annual } \\
\text { Growth Rate, \% }\end{array}$} \\
\hline & 2000 & 2001 & 2002 & 2005 & 2006 & 2010 & 2011 & 2015 & \begin{tabular}{|c|}
$2000-$ \\
2005 \\
\end{tabular} & \begin{tabular}{|l|}
$2005-$ \\
2010 \\
\end{tabular} & $\begin{array}{c}2010- \\
2015 \\
\end{array}$ \\
\hline Total Expected Capacity & 26,761 & 27,290 & 27.410 & 29,447 & 29.901 & 32,396 & 32,396 & 35,106 & & & \\
\hline Naphtha-Based Capacity & 5,352 & 5,458 & 5,482 & 5,889 & 5,980 & 6,479 & 6,479 & 7,021 & & & \\
\hline Total Production & 24,805 & 23,493 & 24,600 & 27,392 & 28,145 & 30,872 & 31,575 & 34,010 & 2.0 & 2.4 & 2.0 \\
\hline Naphtha-Based Production & 4,961 & 4,699 & 4,920 & 5,478 & 5,629 & 6,174 & 6,315 & 6,802 & & & \\
\hline
\end{tabular}

U:|2002Q4I00072.005.11IDatalExcel files|[Ethylene Market Outlook.xIs]Naphtha SupplyDemand Tables

\subsection{NAPHTHA REQUIREMENTS}

Driven by demand for polyethylene, ethylene production is expected to show steady growth in the United States. Although the growth rate in the United States (2.1 percent per year) will be lower than the global growth rate (3.7 percent per year), the U.S. still represents a significant market. At the current share of 20 percent of the ethylene feedstock market, an additional 6.2 million metric tons of naphtha will be required by 2015 over the 2000 level of 16.6 million metric tons, as shown in Table 3.5.

Table 3.5 U.S. Naphtha Required for Ethylene Production ${ }^{1}$

(thousand metric tons of naphtha)

\begin{tabular}{|c|c|c|c|c|c|c|c|c|c|c|c|}
\hline & \multirow{2}{*}{$\begin{array}{r}\text { Actual } \\
2000 \\
\end{array}$} & \multirow{2}{*}{$\begin{array}{l}\text { Est. } \\
2001\end{array}$} & \multicolumn{6}{|c|}{ Forecast } & \multicolumn{3}{|c|}{$\begin{array}{l}\text { Average Annual } \\
\text { Growth Rate, \% }\end{array}$} \\
\hline & & & 2002 & 2005 & 2006 & 2010 & 2011 & 2015 & \begin{tabular}{|l|}
$2000-$ \\
2005 \\
\end{tabular} & \begin{tabular}{|l|}
$2005-$ \\
2010 \\
\end{tabular} & \begin{tabular}{|l|}
$2010-$ \\
2015 \\
\end{tabular} \\
\hline Total Ethylene Production & 24,805 & 23,493 & 24,600 & 27,392 & 28,145 & 30.872 & 31,575 & 34.010 & & & \\
\hline Naphtha-Based Production & 4,961 & 4,699 & 4,920 & 5,478 & 5,629 & 6,174 & 6,315 & 6,802 & & & \\
\hline Naphtha Required & 16,619 & 15,740 & 16,482 & 18,353 & 18,857 & 20,684 & 21,155 & 22,787 & 2.0 & 2.4 & 2.0 \\
\hline
\end{tabular}

U:I2002Q4100072.005.11|DatalExcel files|[Ethylene Market Outlook.xls]Naphtha SupplyDemand Tables

Given the high quality of the FT naphtha and the increased demand required, from a technical perspective it can be readily placed in the market. FT naphtha can be used in any cracker that uses conventional naphtha. 


\subsection{REFINERY FEEDSTOCK}

FT naphtha, due to its relatively light boiling range, could potentially serve as a blendstock for gasoline production in refineries. However, due to its very low octane levels, FT naphtha would need to be upgraded by one or more refining processes before it could become part of the gasoline pool. To be used effectively within a refinery, FT naphtha initially would have to be fractionated at the refinery into light (C5/C6) and heavy (C7+) fractions, and the following options would likely be required:

- Light Fraction processing options

- Direct blending into the gasoline pool: The light fraction $(\sim 30 \%)$ would have a low value as a gasoline blendstock due to its very high normal paraffins content and resultant low octane

- Isomerization: The octane of the light fraction could be increased to acceptable levels by processing the stream in a naphtha isomerization unit

- Heavy Fraction processing options

- $\quad$ Direct blending into the gasoline pool: The octane of the heavy fraction would be too low for the stream to be used as a gasoline blendstock

- Sell as an ethylene plant feedstock

- Processed in a catalytic reforming unit. However, the yield structure for this highly paraffinic feedstock would be very unattractive and would be uneconomic under all conceivable circumstances

The value of FT naphtha resulting from these refinery processing options is expected to be less that its value as an ethylene plant feedstock

\subsection{OTHER USES}

Other than as an ethylene feedstock, or as a feedstock into refineries, the potential markets for FT naphtha are limited in size and attractiveness. For example, due to its very high purity, demand for FT naphtha might develop to serve the markets for high-purity solvents (i.e. foodgrade). However, these markets are small in size, and highly fragmented. Further, the existing solvents industry is dominated by a relatively small number of entrenched participants, and thus the barriers to entry would be high for a new entrant.

FT naphtha's potential use as a feedstock for fuel cells is addressed in more detail in Market Report Section VI. The conclusion is that fuel cells will not achieve significant market share penetration within the next 10-20 years, and further that liquid hydrocarbon fuels, such as FT naphtha, will not be commercialized as quickly as methanol as fuel cell feedstocks. 


\subsection{TECHNOLOGY OF ETHYLENE PRODUCTION}

As noted in the prior sections of this report, a wide range of hydrocarbons is used as feedstocks for production of ethylene and other high-value chemical products. These feedstocks include ethane, propane, butane, naphthas and diesel-range and heavier streams. Since this report evaluates the potential for FT naphthas and FT Diesels to serve as ethylene feedstocks, the balance of this discussion focuses on naphtha and diesel cracking.

\subsubsection{Chemistry}

Globally, hydrocarbons in the naphtha (gasoline) boiling range are the single largest feedstock. Heavier diesel-range feedstocks, while not as widely used as a feedstock as naphtha, are cracked to ethylene and by-products in a number of important global markets. Since both naphtha and diesel streams are complex hydrocarbon mixtures composed of many individual components, it is technically very difficult to estimate overall yields by examining the cracking behavior of each component. This difficulty is compounded since each component reacts differently at different cracking severities (conditions of temperature and reaction time). Consequently, the general industry practice is to estimate each feedstocks' cracking performance through the use of empirical correlations based on factors that best characterize each feed. The correlating factors most often used are:

- Feed gravity (API or specific gravity)

- ASTM distillation curve

- Molecular structure - percent paraffins (normal to isoparaffin ratio is important), naphthalene, and aromatics

- Chemical characterization - carbon/hydrogen ratio, molecular weight

Since naphthas are much more important than diesel-range streams as feedstocks to product ethylene, the following discussion focuses on naphtha cracking. However, all of the concepts also apply to diesel-range feedstocks.

For naphthas having unusual compositions, for example, highly isoparaffinic (i.e. the usual ratio of normal butane to isobutane is 1.0) or high naphthene content, pilot plant tests are normally required.

In general, naphthas are classified as either paraffinic or naphthenic. Although overly simplified, this approach provides an easy way to establish how a particular feedstock might best be used. Naphthenic feeds are best suited for catalytic reforming, which builds rings and dehydrogenates naphthenic components to aromatics and other high-octane molecules. Thus, naphthenic naphthas typically are reformed in refineries to produce gasoline or aromatic chemicals (primarily benzene, toluene and xylenes). Paraffinic feeds, consisting of a high percentage of straight chain normal paraffins, are generally preferred as steam cracker feeds because of their ease of cracking and their relatively high selectivity to ethylene. 
To appreciate the economics of naphtha steam cracking, it is essential to understand how the yields of ethylene and the various by-products vary with conversion. Conversion is defined as the high-value primary products (ethylene and other chemicals) produced expressed as a percentage of total products from the cracking process. Thus, 65 percent conversion indicates that primary products represent 65 percent of total product yields, and the balance of 35 percent consists of C3 and lighter compounds, and fuel oil. Ethylene yield increases steadily as conversion increases up to a certain level for each feedstock. For naphtha, this maximum level is about 70 percent, after which "overcracking" occurs, resulting in increased degradation of primary products to hydrogen, methane, fuel oil and coke.

Reflecting this, maximum yields of 30 weight percent ethylene for full range naphtha are possible today using highly selective, high-conversion cracking furnaces. These maximum yields are about 10 percent higher than previously thought attainable, taking into account the onstream time of the cracking furnaces.

Production of higher molecular weight olefins (propylene and butanes) and diolefins (butadiene) peaks at lower conversion levels, since these products tend to be more reactive than ethylene, and thus recrack to lighter products at lower temperatures and conversion levels than ethylene. Thus, when butadiene and/or propylene have high market values, the optimum conversion level will be lower than when ethylene is the most valuable product. The same argument may be applied to pyrolysis gasoline production. Reducing feed conversion increases gasoline yield, but at a sacrifice in octane number. The gasoline pool octane/pyrolysis gasoline pricing relationship therefore has an impact on determining optimum conversion levels. However, gasoline yield and/or octane number by themselves rarely determine the overall cracking severity that is employed, since the economics of ethylene/propylene production drive the overall process.

As noted, most cracking-furnace designers use empirical methods, supported by pilot plant tests, to develop yield correlations used to predict product yields for various feeds in their particular furnace configuration. Computer models have also been developed to simulate ultimate yields for multiple feeds. Such models are based on describing the chemicals reactions that take place in cracking with a series of equations representing the kinetics and thermodynamics of the many complex steps involved. A so-called "mechanistic" approach is used to describe these reactions, which are first divided into the following classes:

- Chain initiation and termination reactions

- Hydrogen-abstraction reactions

- Radical decomposition reactions, etc.

For each class of reaction involving a particular feed many specific equations are written including kinetic parameters. To describe ethane and propane cracking in this way (separately or in mixtures) requires the development of more than 150 equations, which are then solved as a matrix on a computer. At least one olefin heater design firm employs computer modeling with reportedly very realistic results, to predict yields from multiple feedstocks. 
The key factors that influence the general yields of products from cracking hydrocarbons may be summarized as follows:

- Maximum ethylene yields are obtained from cracking straight-chain normal paraffins. Normal paraffins containing an even number of carbon atoms give slightly better ethylene yields than odd-numbered ones. Normal paraffins also produce propylene, whose yield decreases with increasing chain length.

- Isoparaffins give lower ethylene and higher methane and propylene yields compared to normal paraffins.

- Aromatics are essentially inert and do not crack into lighter products

- Below approximately a $215^{\circ} \mathrm{F}$ end-point naphtha (i.e. light naphtha), the crude oil that the naphtha is derived from is not a key variable. Above this end point, isoparaffins, naphthenes, and aromatics content can vary significantly depending on the crude oil source, and the yield of ethylene and other key by-products can be impacted.

- Heavier petroleum fractions are subject to more side reactions and consequently produce more tarry products and contain more coke precursors

- Basically, two major crude types give naphthas with different chemical composition beyond a $215^{\circ} \mathrm{F}$ end point: Middle East (Kuwait, Persian Gulf, Iraq, etc.) and Saharan and Venezuelan (Libya, Algeria, Venezuela, etc.). In general, the former increases in aromaticity and decreases in paraffinicity with an increase in feedstock end-point. The latter increases in naphthenicity and decreases in paraffinicity with an increase in feedstock end-point.

- $\quad$ Based on the above, a light virgin naphtha (independent of crude source) is expected to give a high yield of ethylene at high cracking severity.

- $\quad$ Middle East full-range and heavy naphthas are expected to give higher aromatics yields and lower butadiene and ethylene yields than the light naphtha

- Severity, the most significant operating variable controlling the cracking process, is a function of residence time and temperature. In general, increasing severity by minimizing residence time and maximizing temperature leads to a maximum yield of primary olefins and a decrease in secondary reactions that promote coking. The maximum severity level attainable is generally restricted by the physical limitations of the furnace.

- $\quad$ As the furnace outlet temperature increases the yields of ethylene as well as of C5 and heavier materials increase.

- $\quad$ The higher the normal paraffin content of the feed, the more ethylene is produced and less of $\mathrm{C} 5$ and heavier materials for the same outlet temperature.

- Adding steam to the feed reduces the hydrocarbon partial pressure, enabling the cracking reaction to take place at workable temperatures. Increasing the steam-to-hydrocarbon ratio improves the yield of primary olefins and decreases fuel gas production. The 
optimum ratio is the point at which there is an economic balance between increased ethylene yield and the increased operating and capital costs required to handle the larger quantities of steam. The typical steam-to- hydrocarbon ratio for naphtha is 0.5 .

Other factors that influence yields are radiant coil residence time and the rapidity of quenching of the cracked gases. The impact of these factors varies depending on the furnace design and physical layout.

\subsubsection{Process Description}

\subsubsection{Naphtha}

Full range naphtha (FRN) is thought of as any hydrocarbon that boils in the gasoline boiling range, which generally means the $\mathrm{C} 5-430^{\circ} \mathrm{F}$ boiling range, however many olefin units operate on lower end-point (e.g., $\left.350^{\circ} \mathrm{F}\right)$, light naphthas $(\mathrm{LVN})$. Figure 6.9 provides a simplified flow diagram of a steam cracker employing a naphtha feedstock.

Naphtha cracking requires a steam to hydrocarbon weight ratio of about 0.5 to achieve the proper hydrocarbon partial pressure in the cracking furnace. At high severity, the cracking reaction is carried out at a coil outlet temperature of $1,560-1,580^{\circ} \mathrm{F}$. It is standard practice in ethylene plants to add sulfur to feedstocks that contain very little sulfur. This addition is in the form of an additive to prevent catalytic coke formation. Reflecting this practice, it is expected that sulfur addition would be required for FT naphtha due to its very low sulfur content. In the past dimethylsulfide (DMS) or dimethyldisulfide (DMDS) have been used. New alternative products have been developed in recent years that are based on polysufides or phosphorus (NALCO/Exxon (are they still Nalco/Exxon or just Ondeo/Nalco??) and Phillips both supply products) and other products to "coat" or pretreat the surface (Nova Chemicals provides such products). An alternative additive or any type of "coating" may preclude using additional sulfur dosing.

The furnace effluent is quickly cooled in the Transfer Line Exchangers (TLE) to stop the reaction and generate steam. For high severity naphtha cracking, steam is usually generated in the TLEs at 1,600-1,700 psig, which is needed to minimize fouling inside the TLE tubes. Where's the chart??

Since naphtha (and heavier feeds) produce large quantities of pygas and pyrolysis fuel oil, the cooling of the cracked gas requires a tower to remove the fuel oil constituents before the cracked gas enters the water quench tower. By fractionating out the fuel oil, separation of gasoline from the condensed dilution steam is made possible and reuse of the dilution steam made practical. This tower, the primary fractionator, when combined with the water quench tower (which acts as the fractionator overhead condenser), produces an overhead vapor stream containing most of the gasoline and lighter components, a heavy gasoline liquid stream and a fuel oil bottoms stream. For heavier naphthas, a light fuel oil product can also be recovered as a side stream. Low 


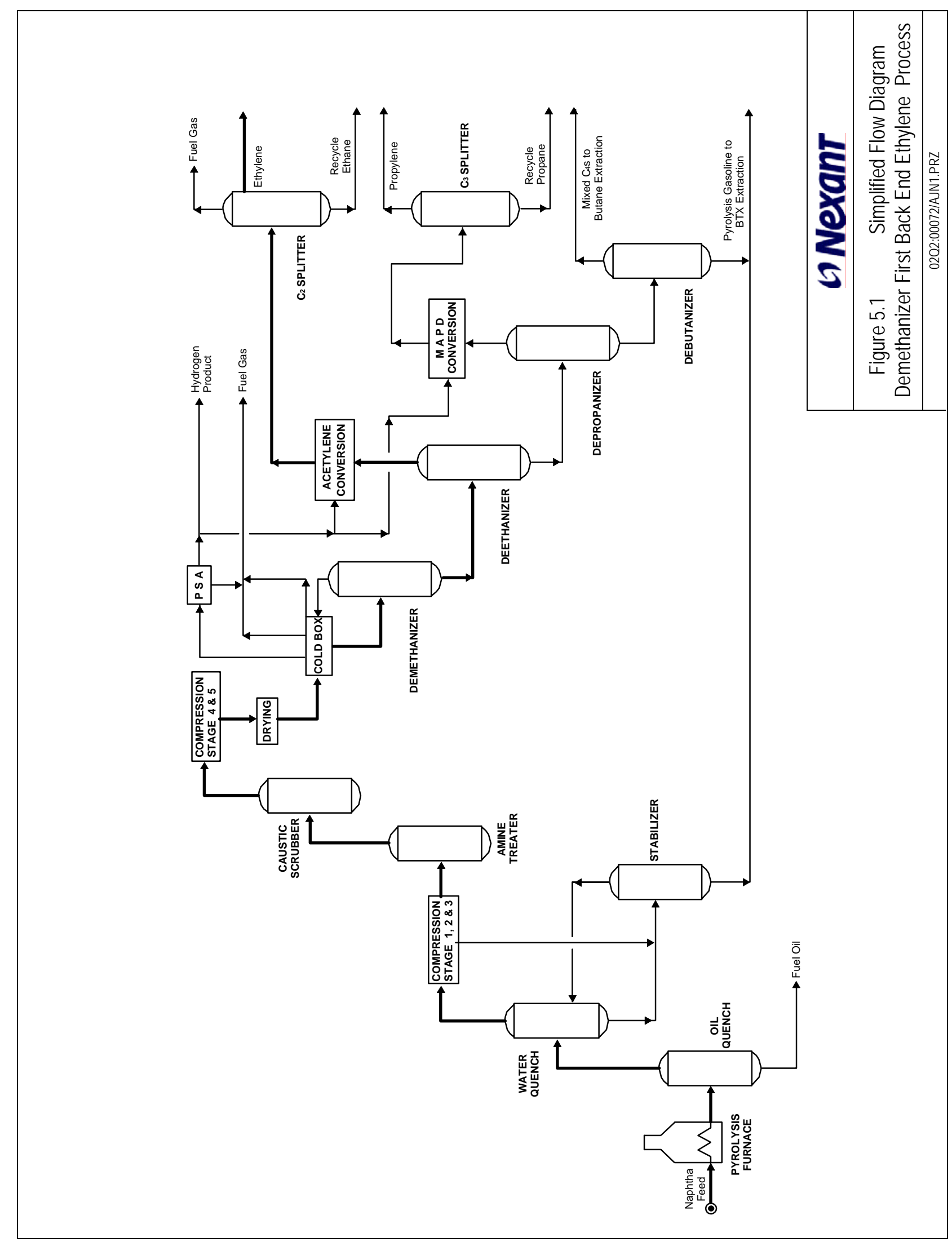


pressure or medium pressure steam is generated in the quench oil system, which is used to cool the TLE effluent from about $800-850^{\circ} \mathrm{F}$ to the tower bottoms temperature of $350-400^{\circ} \mathrm{F}$. The circulating water stream from the water quench tower can provide low level heat for feed preheating and tower reboiling. The net fuel oil products are steam stripped. The heavy gasoline is debutanized and combined with the main gasoline stream from the debutanizer bottoms.

The furnace effluent is cooled further in a quench tower by circulating a water stream. Tar and coke are removed from the water settler as a waste product while most of the dilution steam is condensed, treated and vaporized, to be reused as dilution steam. The cracked gas leaves the tower at $105^{\circ} \mathrm{F}$ ready for compression and separation. Essentially all the gasoline components flow forward into the compression system and exit with the high-pressure cracked gas.

Compression is carried out in five stages. The cracked gas is treated after the third compression stage in a regenerative amine system followed by caustic soda and water washes to remove carbon dioxide and sulfur, as needed. These contaminants would render the ethylene product unsuitable for sale, foul the refrigeration system, and also poison the acetylene and MAPD catalysts.

The hydrocarbon and water, condensed following each compression stage, is flashed back to the previous compressor discharge drum. For propane or n-butane feeds, the hydrocarbon condensates from the fourth and fifth stages are withdrawn, deethanized, and fed to the depropanizer along with the main deethanizer bottoms.

The cracked gas from the last compression stage, at about $500 \mathrm{psig}$, is cooled, chilled to $60^{\circ} \mathrm{F}$ to remove most of the water, and then dried over molecular sieves to remove the last traces of water before being sent to the chilling train.

In the chilling train, the dried cracker gas is successively chilled against propylene and ethylene refrigerants, and against hydrogen and methane off-gases to well below $-200^{\circ} \mathrm{F}$ in order to reduce the ethylene lost to fuel to less than 1 percent of that contained in the cracked gas.

The fractionation sequence is the same as for natural gas liquids (NGL) cracking, except that a C3 splitter is needed only if polymer-grade propylene is required. Typically, the $\mathrm{C}_{3} \mathrm{~s}$ contained in the depropanizer overhead stream are usually higher than 92 weight percent propylene (i.e., chemical grade propylene).

In addition, the debutanizer overhead product is high in butadiene, typically 40-45 weight percent, and thus is an excellent feed to an extraction unit. Usually, sufficient C4 concentrate is produced to justify a down stream recovery unit.

The quantity of cracked gasoline produced can also justify a hydrotreater to produce material suitable for blending into a gasoline pool. Further hydrotreating to saturate di-olefins will make the "heart cut" suitable for aromatics extraction plant feed. 


\subsubsection{Gas Oil}

Gas oils are classified as either atmospheric or vacuum according to their origin, either from an atmospheric crude tower or a crude bottoms vacuum column. Atmospheric gas oil material boils in the range $400-800^{\circ} \mathrm{F}$; vacuum gas oil boils at $800-1000^{\circ} \mathrm{F}$ and higher. Since vacuum gas oils are not cracked commercially to any significant degree, only the processing scheme for an atmospheric gas oil facility is discussed below in relation to naphtha stream cracking. It should be noted, however, that processes for hydrotreating vacuum gas oils have been developed, which greatly enhance their properties as cracking feedstocks and permit their economical use for olefins and aromatics production.

The only significant variation from the naphtha cracking flow scheme occurs in the furnace area and in the primary fractionator. As in naphtha cracking, the cracked gases are cooled by a combination of indirect (TLEs) and direct (oil quench) methods. Since overall ethylene yields are considerably lower from gas oil than from naphtha, more feedstock is required for gas oil feeds. In combination with much higher dilution steam ratios (see below), this imposes a significantly higher loading on the primary fractionator, which is much larger and more complex than in naphtha cracking, employing more heat recovery and producing a greater number of sidestream products.

A dilution steam to hydrocarbon weight ratio of $0.8-1.0$, depending on the feed gravity, is required to achieve the proper hydrocarbon partial pressure at the furnace-cracking conditions. Furnace design is extremely critical when a heavy feedstock such as gas oil is cracked; since the maximum conversion of feed to valuable olefinic products (usually emphasizing ethylene rather than propylene) is required while preventing excessive coking in the furnace tubes and fouling in the transfer line exchangers.

The shortened furnace run lengths and frequent decoking cycles resulting from excessive conversion can materially reduce plant on-stream time and increase maintenance costs. Thus, operating costs will rise while production rates suffer if overcracking occurs. A typical atmospheric gas oil furnace operates at a coil outlet of about $1,510^{\circ} \mathrm{F}$; the furnace is designed for a residence time of less than 0.3 seconds.

Gas oil cracking produces a much larger quantity of fuel oil than naphtha cracking, 15-20 weight percent versus 3-4 weight percent. It is extremely important to recognize this when designing the indirect (TLE) quench operation in order to assure efficient operation and long run lengths. One approach is to allow for buildup of material in the TLE tubes. This results in reducing heat transfer and increasing pressure drop over the course of a run, and the TLE outlet temperature will rise continually. Another approach is to design for a high start-of-run TLE outlet temperature, e.g., $1000^{\circ} \mathrm{F}$, in order to reduce the rate at which the tubes foul. However, the second approach will result in reducing high-pressure steam production an average of 15 percent over the course of a run when compared to the first approach.

The average outlet temperature from the TLEs is considerably higher than when cracking naphtha, and the cracked effluent is more reactive. Therefore, a direct-contact oil quench in a 
specially designed TLE is used to cool the furnace effluent to the primary fractionator feed temperature $\left(450-500^{\circ} \mathrm{F}\right)$ immediately downstream of the indirect quench operation. As in naphtha cracking, the indirect quench operation produces very high pressure steam. However, due to the large amount of heavy fuel resulting from gas oil cracking, the primary fractionator bottoms stream can be run hotter and a portion of the steam from the circulating oil quench is recovered at $200 \mathrm{psig}$, as well as at $50 \mathrm{psig}$. Since indirect quench operation outlet temperatures are higher than with naphtha cracking, less very high pressure steam is produced in proportion to lower pressure steam at 200 psig.

The function of the primary fractionator in gas oil cracking is identical to naphtha cracking, except that the fuel oil is produced in two streams; a side stream of light fuel oil and a bottoms stream of heavy fuel oil. The cracked gas leaving the water quench tower contains all the gasoline and lighter components, except for a small amount of heavy gasoline that is stripped and combined with the main gasoline stream from the debutanizer bottoms.

The remaining recovery section flow scheme for gas oil cracking, beginning with the cracked gas compressor, is essentially identical to that for naphtha cracking. In gas oil cracking, the C4 product is slightly richer in butadiene content and the gasoline stream slightly leaner in BTX components than in naphtha cracking. The weight percent yields of propylene, total $\mathrm{C} 4 \mathrm{~s}$ and pygas tend to be slightly less for gas oil than for naphtha cracking.

\subsubsection{Various Separation Flow Schemes}

A significant amount of licensor time is spent optimizing the recovery section (i.e., back end) of the ethylene plant. The trend is toward improved energy efficiency and increased feedstock flexibility. In order to accomplish this optimization a number of concepts and features are now included in modern ethylene plant designs including high flux exchanger tubes, high efficiency trays, heat integration employing pinch technology, turbine/expanders and computerized distillation control.

Rearranging and optimizing the tower configuration is another approach taken by the major licensors of ethylene technology. The different arrangements fall into three categories depending on the first fractionation tower in the recovery scheme (i.e., demethanizer-first, deethanizer-first, or depropanizer-first). In this section a qualitative analysis of these three tower configurations is discussed.

The refrigerant levels selected are particular to a specific plant. Thus, the number of levels of refrigerant can be used to optimize the heat integration and tower arrangement still further.

The three schemes are described below for a naphtha feed case.

\section{Demethanizer-First Sequence}

A flow diagram of an ethylene production facility employing the more conventional demethanizer-first sequence for the recovery of products and by-products is shown in Figure 6.9 is this the proper figure reference? for a full range naphtha feed case. Kellogg (KBR) and TPL 
usually employ this flow scheme in their plant designs. Lummus uses a similar plan except that it employs a low pressure (100 psig) demethanizer.

The furnace effluent is cooled and the heavier components condensed in a quench column before the gases are compressed. The charge gas is usually compressed in three stages. The gas is caustic washed, followed by another two stages of compression, and drying, before the cryogenic step.

Following, compression, treatment, scrubbing, and drying, the product stream is typically separated from the hydrogen via a cryogenic cold box scheme, where the vapors are cooled against refrigerant (propylene and ethylene) and the condensed liquid separated in stages. The final stage usually employs some type of autorefrigerant plant (plan or plant?) with the byproduct fuel gas stream (hydrogen and methane). The hydrogen can be purified in a pressure swing adsorption unit for use in the downstream acetylene and MAPD units and the pygas hydrotreater.

The condensed liquid from the cold box is sent to the demethanizer, where the final traces of methane are removed by cryogenic distillation. The overhead product is sent to the fuel gas system and the bottoms product is sent to the deethanizer. A turbine/expander system may be employed on the overhead stream to obtain a very low level of refrigeration.

The demethanizer is usually operated at high pressure. The cold box that precedes the demethanizer can be considered a prefractionation section, typically four separate drums operated at consecutively lower temperatures. The cold box is considered more economical and flexible (from an operability standpoint) than the alternative of multiple intercondensers and interreboilers. The optimum number of separation stages is a function of plant size and feedstock. As the number of feed flashes increases, utility consumption decreases, but capital costs increase. A double column demethanizer or prestripping the heavier condensed liquids from the cold box are two energy-efficient steps sometimes employed in this configuration.

The bottoms product from the demethanizer is fed to the deethanizer where the acetylene, ethane and ethylene are separated from the heavier by-products. Acetylene specifications for polymer grade ethylene are generally $1.5 \mathrm{ppm}$ maximum or less; therefore, an efficient means of separating it from the ethylene product is essential. Removal by fractionation is not economical, since ethane, the other major component present in the final purification stages of an ethylene plant, and acetylene form an azeotrope that persists at low pressures. The most frequent method of overcoming this difficulty is to provide a selective catalytic hydrogenation step at a convenient point in the purification train to convert the acetylene to ethane and ethylene. The acetylene can be alternatively separated by absorption in a selective solvent and sold as a byproduct.

When cracking ethane and propane, the hydrogenation facilities can be located either in the compression section immediately following the acid gas treatment systems or in the fractionation section. In cracking heavier feeds, hydrogenation before fractionation is unsuitable, since the cracked gas contains high concentrations of butadiene that would also hydrogenate together with 
the acetylene at about 60 percent conversion. This simultaneous conversion not only reduces the production rate of valuable butadiene but also places an additional reaction heat load on the reactor, causing more fouling of the catalyst and consequently more frequent regeneration. Hence, when naphtha is cracked, the hydrogenation system is located within the fractionation section. This location can also be used in propane cracking units when the production of byproduct butandiene, although less than with naphtha cracking units, is considered valuable and must not be hydrogenated. The two basic choices for locating the acetylene hydrogenation system are either toward the beginning or toward the end of the recovery section, depending on the tower arrangement provided by the licensor. In the demethanizer-first sequence, the acetylene conversion is usually located between the deethanizer and C2 splitter.

In the past, the concentration of acetylene from the pyrolysis furnace was quite low. However, with modern low residence times and high severity cracking, the amount of acetylene has increased significantly. Thus, the need for acetylene conversion becomes important.

A problem that arises from the use of palladium or nickel sulfide catalysts for hydrogenation is the production of green oil. Green oil is a mixture of short-chain C4 based oligomers (i.e. C12, C20 compounds) and oxygenated hydrocarbons. If generated in large quantities, these can foul the downstream ethylene fractionator trays. Although the latest catalysts tend to minimize green oil production, it is still a concern.

Typically in a demethanizer-first design, the acetylene removal is located downstream of the deethanizer. The removal from the ethylene product of methane introduced with the hydrogen fed to the hydrogenation reactor is also important. The quantity of methane contaminant is small and normally can be removed via fractionation along with excess hydrogen. This is accomplished in a pasteurizing section (normally 2 to 4 trays) at the top of the ethylene fractionator, such that the product ethylene is drawn from the column as a side stream.

The C2 splitter separates the ethylene and ethane. In a demethanizer-first design the splitter is operated at a high pressure (230 psig) as opposed to a low pressure design (150 psig). The ethane is recycled to extinction in the cracking furnaces at the front end of the plant in order to maximize conversion.

The by-product bottoms stream from the deethanizer is sent to a depropanizer, where the C3 components are distilled overhead. This stream is also hydrogenated to remove any methylacetylene and propadiene (MAPD).

The resulting C3 stream is usually of chemical grade and needs only to be stripped of light ends formed in the MAPD conversion process. Alternatively, the C3 stream can be sent to a C3 splitter for production of polymer grade propylene. The propane is either recycled to extinction (similar to ethane recycle described above) or used as fuel.

The depropanizer bottoms temperature must be maintained below $100^{\circ} \mathrm{C}\left(212^{\circ} \mathrm{F}\right)$ to prevent excessive fouling of the reboiler. Thus, the column pressure is usually about 120 psig. This 
usually results in a refrigerated overhead condenser. An alternative is a split pressure tower. Although this can lead to higher investment costs, it may also show significant energy savings.

The bottoms product of the depropanizer is debutanized. The mixed C4 stream is usually sent to a butadiene extraction unit. An alternative is to hydrogenate the $\mathrm{C} 4$ stream and recycle the resulting paraffinic $\mathrm{C} 4 \mathrm{~s}$ to extinction. The pygas from the debutanizer bottoms can be used to extract benzene, toluene, and mixed xylenes (BTX) or to blend with motor gasoline (mogas). The former requires two stages of hydrotreating and the latter requires one stage.

\section{Deethanizer-First Sequence}

The compression section of the deethanizer-first configuration is similar to the demethanizerfirst configuration.

After compression, drying, scrubbing, etc., the process gases are deethanized. The overhead product, containing hydrogen, methane, acetylene, ethylene, and ethane is sent to an acetylene converter. Since the hydrogen has not yet been removed from the stream, the hydrogenation of acetylene takes place without the addition of hydrogen from an outside source, as required in the demethanizer-first process discussed previously.

Technology for the recovery of acetylene from the cracked gas is available from Linde AG, and Stone \& Webster, among others.

Acetylene hydrogenation can be located at the front end of the recovery section before the demethanizer, eliminating dependence on hydrogen purification performance and facilitating a large ethylene gain from the converted acetylene. This, in turn, reduces the quantity of recycle ethane, thus saving energy and feedstock. Hydrogen and methane products are totally free of acetylene. Minimum green oil is produced. As noted below, there is no need to remove hydrogen, methane and carbon monoxide from the ethylene product in a pasteurization section of the ethylene/ethane fractionator. However, it requires larger vessels (conversion reactors) than a back-end system (i.e., downstream of the demethanizer) and a pure hydrogen stream is still needed for the selective hydrogenation of the MAPD downstream of the depropanizer.

Another location sometimes used for the acetylene reactor is in the reflux loop of the deethanizer. This allows effective removal of any green oil formed. The green oil is returned to the column with the deethanizer reflux and leaves with the heavier components contained in the deethanizer bottoms.

The cold box operation that follows the acetylene conversion step separates a small hydrogen stream needed for the MAPD hydrogenation and pygas hydrotreatment. The rest of the hydrogen can either be sold as a by-product or combined with the fuel gas stream.

A demethanizer separates any remaining hydrogen and the lighter methane from the condensed liquids of the cold box. In this configuration the location of the acetylene reactor positively eliminates hydrogen, methane and carbon monoxide from the feed to the $\mathrm{C} 2$ splitter and thus, the need for a pasteurization section in the $\mathrm{C} 2$ splitter. 
The demethanizer bottoms product is sent to a $\mathrm{C} 2$ splitter where the ethylene product is distilled from the heavier ethane. The ethane is recycled back to the front end, as is done in the demethanizer-first sequence. The ethylene product is recovered from the overhead stream of the C2 splitter.

The bottoms product from the deethanizer is sent to a depropanizer where the $\mathrm{C} 3 \mathrm{~s}$ are distilled overhead. This stream needs to be hydrogenated to remove the MAPD. A C3 stripper or splitter follows, depending on whether chemical grade or polymer grade propylene is desired.

As in the demethanizer-first design, the depropanizer bottoms product is debutanized to separate the pygas from the mixed $\mathrm{C} 4$ stream.

\section{Depropanizer-First Sequence}

The front end of the depropanizer-first recovery section is similar to the demethanizer-first configuration except that in the former scheme the depropanizer is located upstream between the third and fourth compression stages along with the caustic washing and drying.

After caustic washing and drying, the discharge from the third stage of the compressor is fed to the depropanizer. A split depropanizer design (i.e., two towers operating at different pressures ) can be applied as suggested previously in the demethanizer-first sequence. In either case the overheads stream from the depropanizer containing the $\mathrm{C} 3$ and lighter material is compressed in the fourth stage of the charge gas compressor before being sent to the acetylene conversion unit. Most of the MAPD, as well as the acetylene are converted at this point. This stream is then dried before being sent to a cold box followed by the fractionation sequence of demethanizer, deethanzier and appropriate splitters for recovery of the ethylene and propylene components. As was done in the other configurations, the ethane and propane are recycled to extinction. The bottoms product from the depropanizer, $\mathrm{C} 4+$ material, is sent to the debutanizer for recovery of the butylenes and butadiene.

The advantage and disadvantage of locating the acetylene and MAPD hydrogenation at this point are similar to those described previously for the deethanizer-first design.

\section{$5.2 \quad$ FT DIESEL}

\subsubsection{Relevant Qualities}

Properties for Fischer-Tropsch diesels have been reviewed for a range of GTL processes. This data is presented in Table 5.1 for Conoco, Sasol, Rentech, and ExxonMobil, and is based on published information. For all processes, FT diesel is highly paraffinic with very low sulfur content. The distillation curves of the diesel samples are shown in Figure 5.2. The differences between the various processes are relatively small and should not materially impact the relative performance of FT diesel as an ethylene feedstock.

Heavy liquid (gas oil) crackers in the United States (e.g. as owned and operated by ExxonMobil and Shell) do not crack finished diesel streams, but rather process lower-quality, unfinished refinery streams in the diesel/gas oil boiling range or heavier. Typical qualities of conventional 
gasoil streams that are cracked to ethylene are also shown in Table 5.2. As indicated, relative to FT diesel streams, conventional gasoil feedstocks tend to be heavier (gravity and distillation curve are both higher), higher in sulfur content, and less paraffinic.

\subsubsection{Use as Ethylene Feedstock}

\subsubsection{Cracking Yields for FT Diesel}

Typical Fischer-Tropsch (FT) diesel properties were supplied to four of the top ethylene technology licensors (Kellogg Brown \& Root, Linde AG, ABB Lummus and Stone \& Webster) to obtain yield data for steam cracking of FT diesel. Once-through yield data (i.e., without recycling ethane and propane to extinction) provided by the licensors is summarized in Table 5.3. The data obtained from the licensors is also compared to typical yields that are obtained from cracking conventional gas oils. Data is shown for a range of operating severities. In this case, the severity of the operation is measured by the overall propylene to ethylene ratio (of ethane and propane to extinction). A low severity operation has a high propylene to ethylene ratio and conversely a high severity operation has a low propylene to ethylene ratio.

The yield data obtained from the licensors ranges from low severity ( 0.623 , Lummus) to a very high severity $(0.325, \mathrm{KBR})$. The feed diesel to ethylene ratio is as low as $2.45 \mathrm{mt} / \mathrm{mt}(\mathrm{KBR})$ and averages about 85 percent of the conventional naphtha to ethylene ratio. This indicates that the FT diesel is a very good cracker feed, with a superior yield of ethylene per unit of feedstock. Propylene to ethylene are shown graphically in Figure 5.3 and indicate that FT diesel feedstocks have similar yields to conventional feeds at equivalent operating severities. Combined ethylene and propylene yields are shown in Figure 5.4 and indicate that FT diesel yields will, on average, have measurably superior combined yields of ethylene and propylene at the equivalent operating severity compared to conventional feedstocks. Figure 5.5 shows the ethylene product to gasoil feed ratio. This indicates that less feed is required to produce the equivalent amount of ethylene product when employing an FT feedstock. 
Table 5.1 Typical Product Qualities - GTL Diesel

\begin{tabular}{|c|c|c|c|c|c|}
\hline Product Property & Conoco & Sasol & ExxonMobil & Rentech & $\begin{array}{r}\text { Conventional } \\
\text { Gas Oil }\end{array}$ \\
\hline Density at $15^{\circ} \mathrm{C}, \mathrm{g} / \mathrm{ml}$ & $0.77 \min$ & 0.777 & 0.78 & 0.778 & 0.852 \\
\hline Density, ${ }^{\circ} \mathrm{API}$ & 52.3 & 50.6 & 49.9 & 50.4 & 34.3 \\
\hline \multicolumn{6}{|l|}{ Distillation, ${ }^{\circ} \mathrm{C}$} \\
\hline IBP & 181 & 189 & & 187 & 183 \\
\hline $10 \%$ & 228 & 209 & & 200 & 216 \\
\hline $50 \%$ & 274 & 256 & & 239 & 214 \\
\hline $90 \%$ & 328 & 331 & & 306 & 318 \\
\hline FBP & 361 & 356 & & 324 & 345 \\
\hline Flash Point, ${ }^{\circ} \mathrm{C}$ & 60 & 71 & 81 & & 162 \\
\hline Pour Point, ${ }^{\circ} \mathrm{C}$ & -10 & & & 0 & -45 to 10 \\
\hline Viscosity at $40^{\circ} \mathrm{C}, \mathrm{mm}^{2} / \mathrm{s}$ & 2.9 & 2.43 & & 1.99 & 2.70 \\
\hline Cetane Number & $60 \mathrm{~min}$ & $>73$ & 74 & 74.8 & 45.5 \\
\hline Sulfur, $\% \mathrm{~m} / \mathrm{m}$ & 0 & 0.001 & $<10$ & & 0.035 \\
\hline SFC Aromatics, \% v/v & & 2.68 & & & \\
\hline HPLC Aromatics, $\% \mathrm{~m} / \mathrm{m}$ & & 0.47 & & & \\
\hline Monocyclic & & 0.44 & & & \\
\hline Bicyclic & & 0.03 & & & \\
\hline Polycyclic & & $<0.01$ & & & \\
\hline \multicolumn{6}{|l|}{ Heat of Combustion, MJ/kg } \\
\hline Gross & & 47.1 & & 47.2 & \\
\hline Net & 44.4 & & & & \\
\hline Hydrogen content, $\% \mathrm{~m} / \mathrm{m}$ & & 15.2 & & & \\
\hline Carbon content, $\% \mathrm{~m} / \mathrm{m}$ & & 84.8 & & & \\
\hline Carbon/hydrogen weight ratio & & 5.58 & & & 6.35 \\
\hline CFPP, ${ }^{\circ} \mathrm{C}$ & & -37 & & & \\
\hline Cloud Point, ${ }^{\circ} \mathrm{C}$ & -10 & -29 & -12 & 3 & -22 to 18 \\
\hline LTFT, ${ }^{\circ} \mathrm{C}$ & & -32 & & & \\
\hline Thermal Stability, \% reflectance & & 99.1 & & & \\
\hline \multicolumn{6}{|l|}{ Lubricity } \\
\hline HFRR WSD @ $60^{\circ} \mathrm{C}$, um & & 567 & & & \\
\hline SL BOCLE, g & & 2700 & & & \\
\hline
\end{tabular}




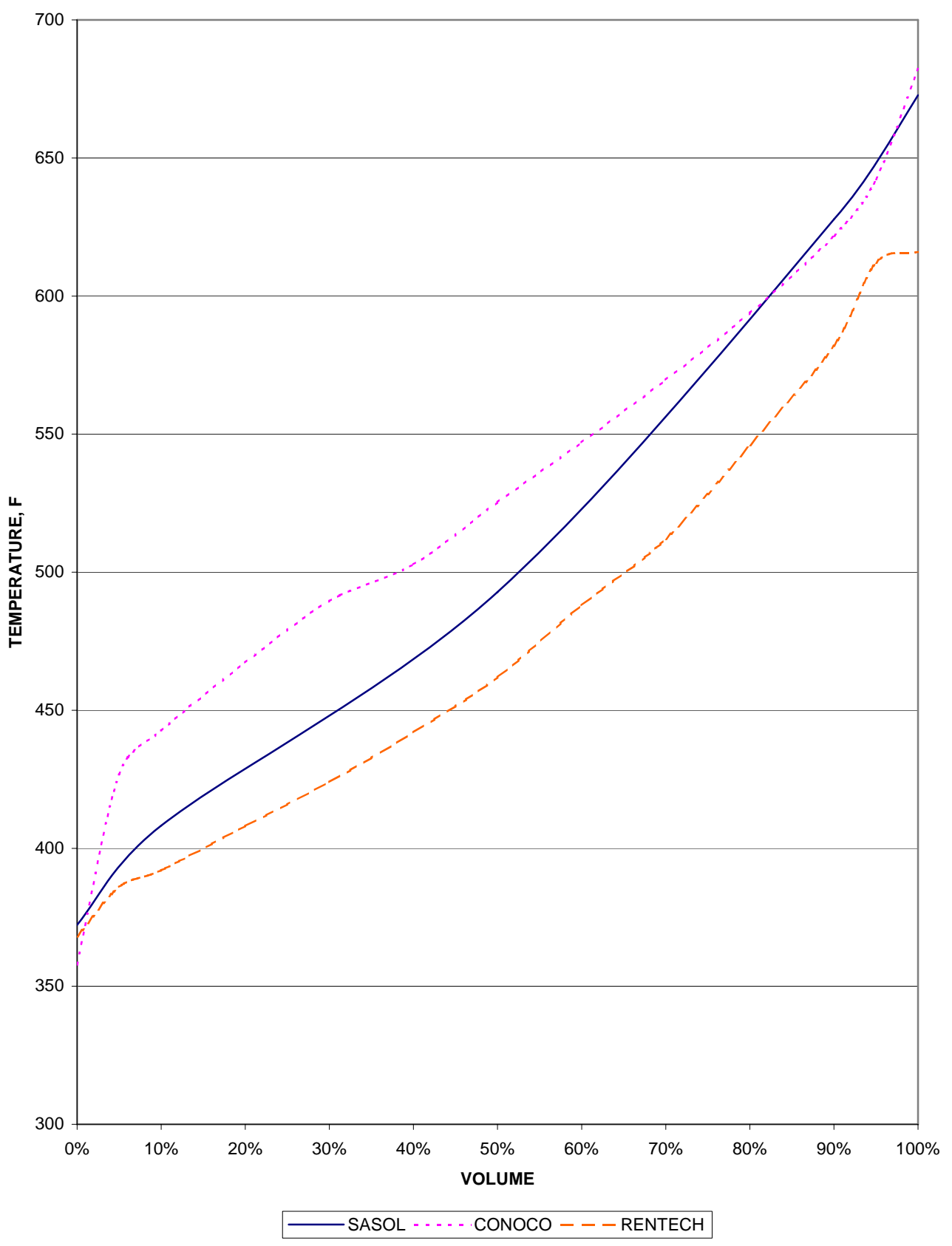

Figure 5.2 FT Diesel Samples 


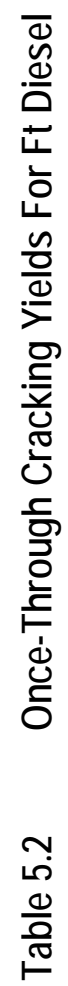
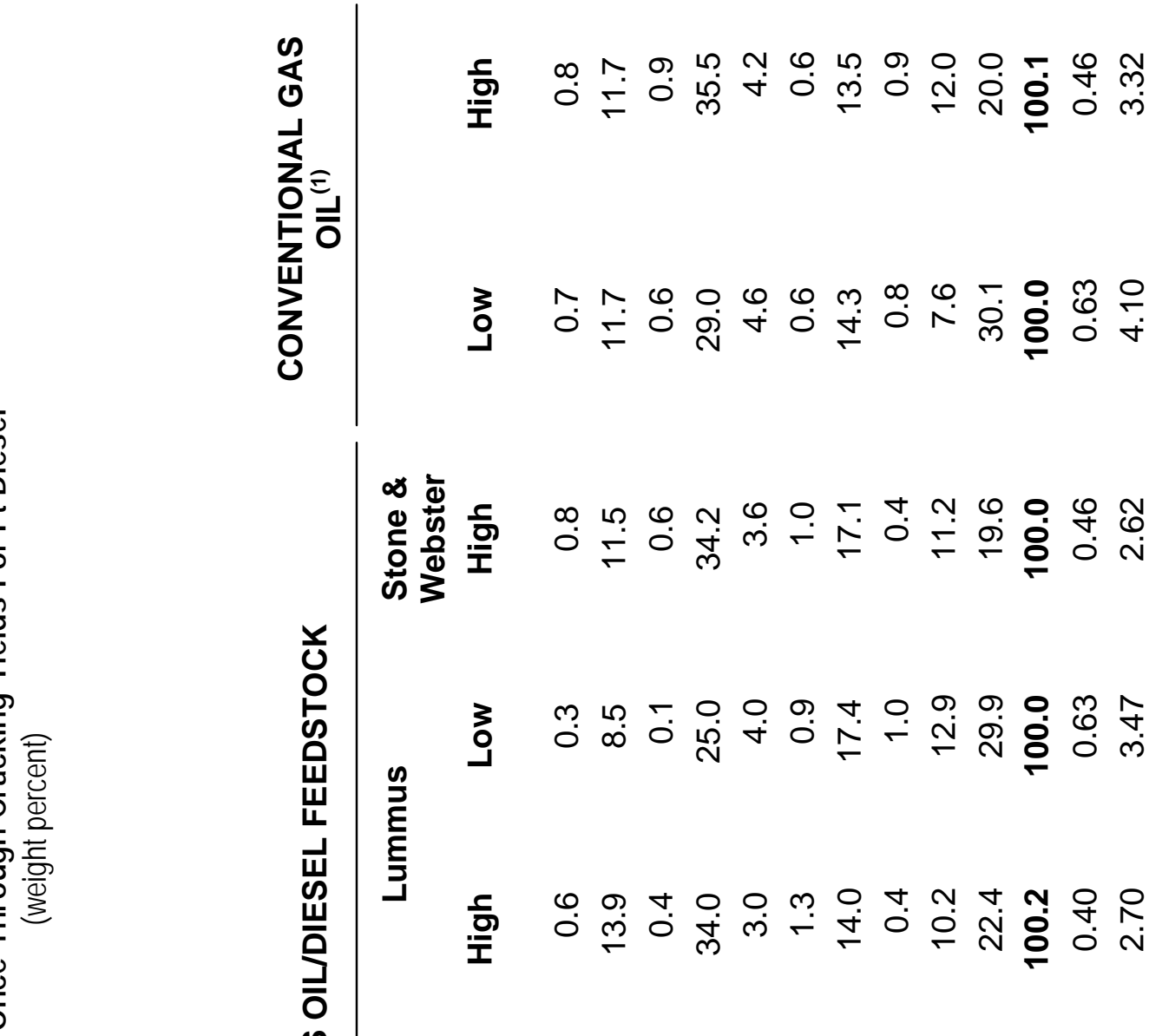

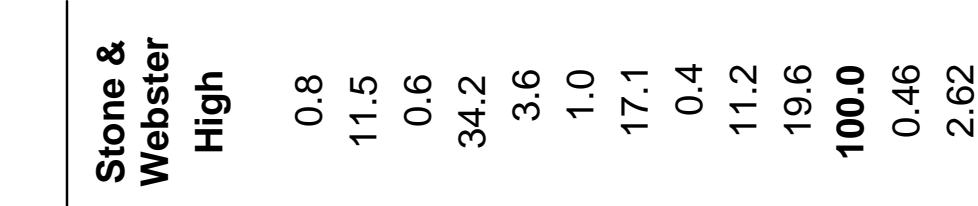

$$
\begin{aligned}
& \text { ํㅡㅁ }
\end{aligned}
$$

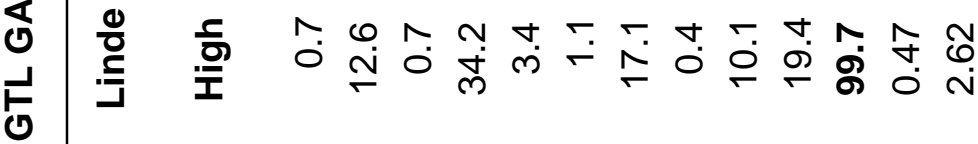

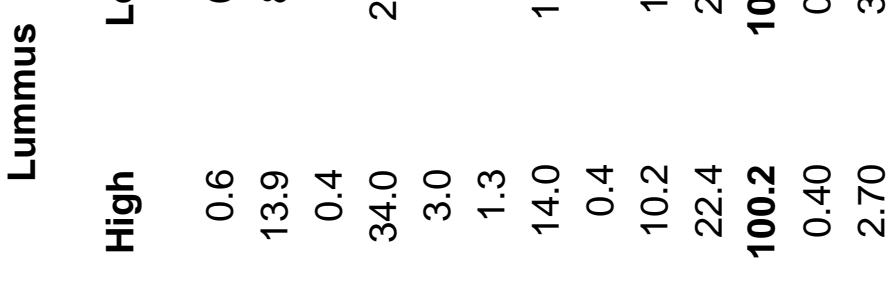

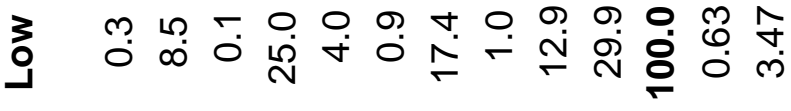

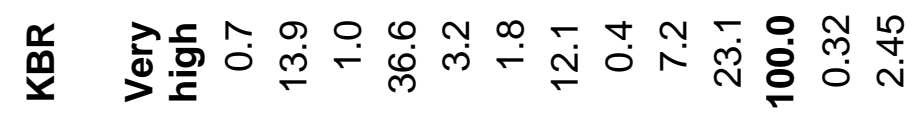

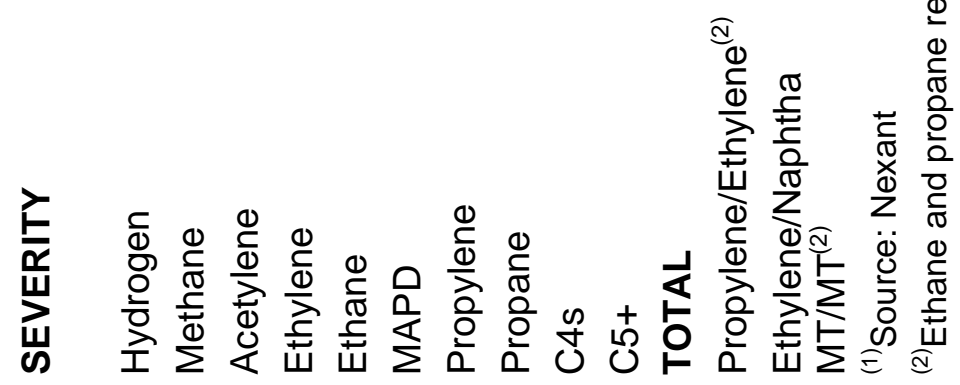




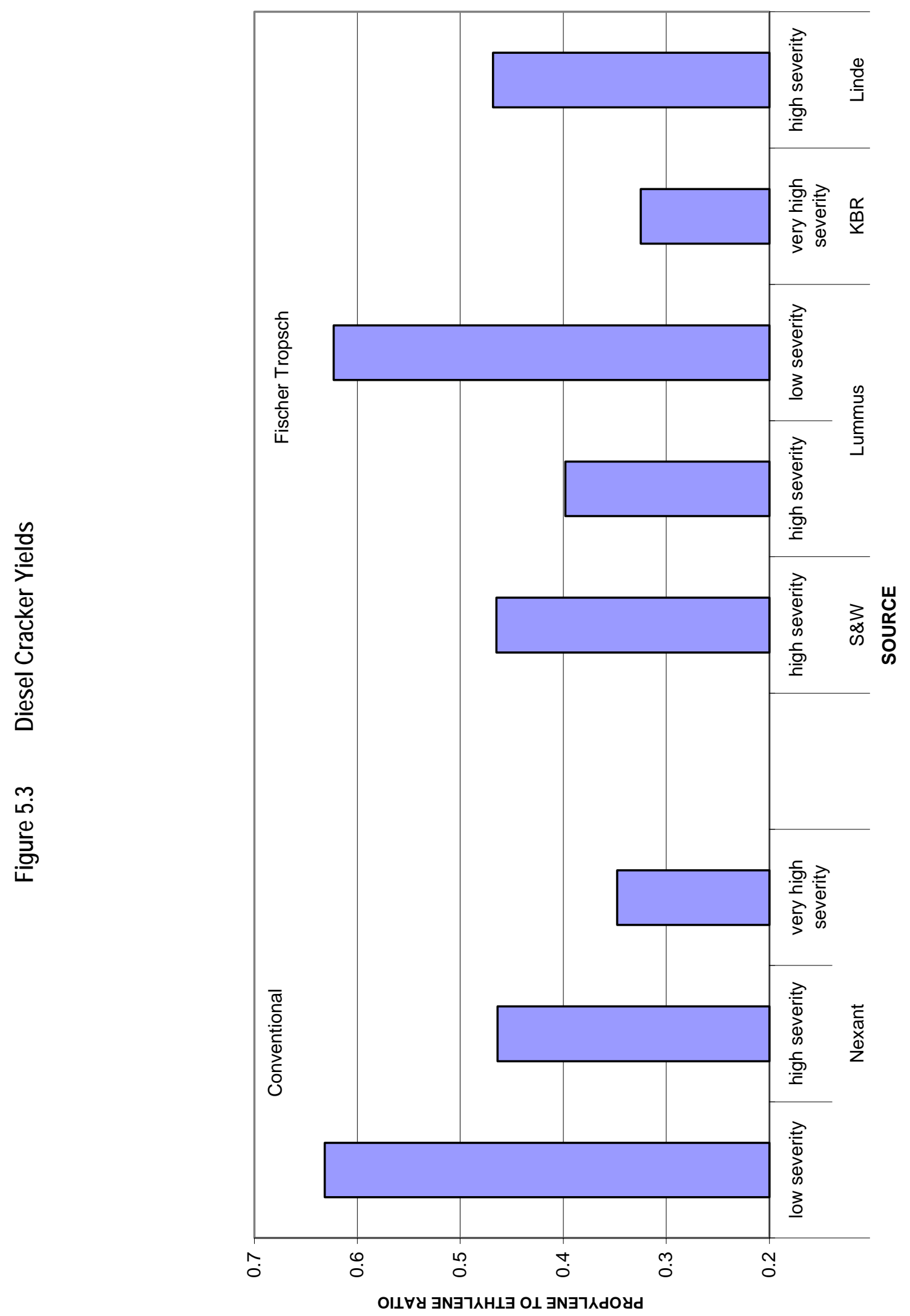




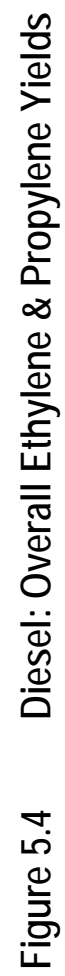

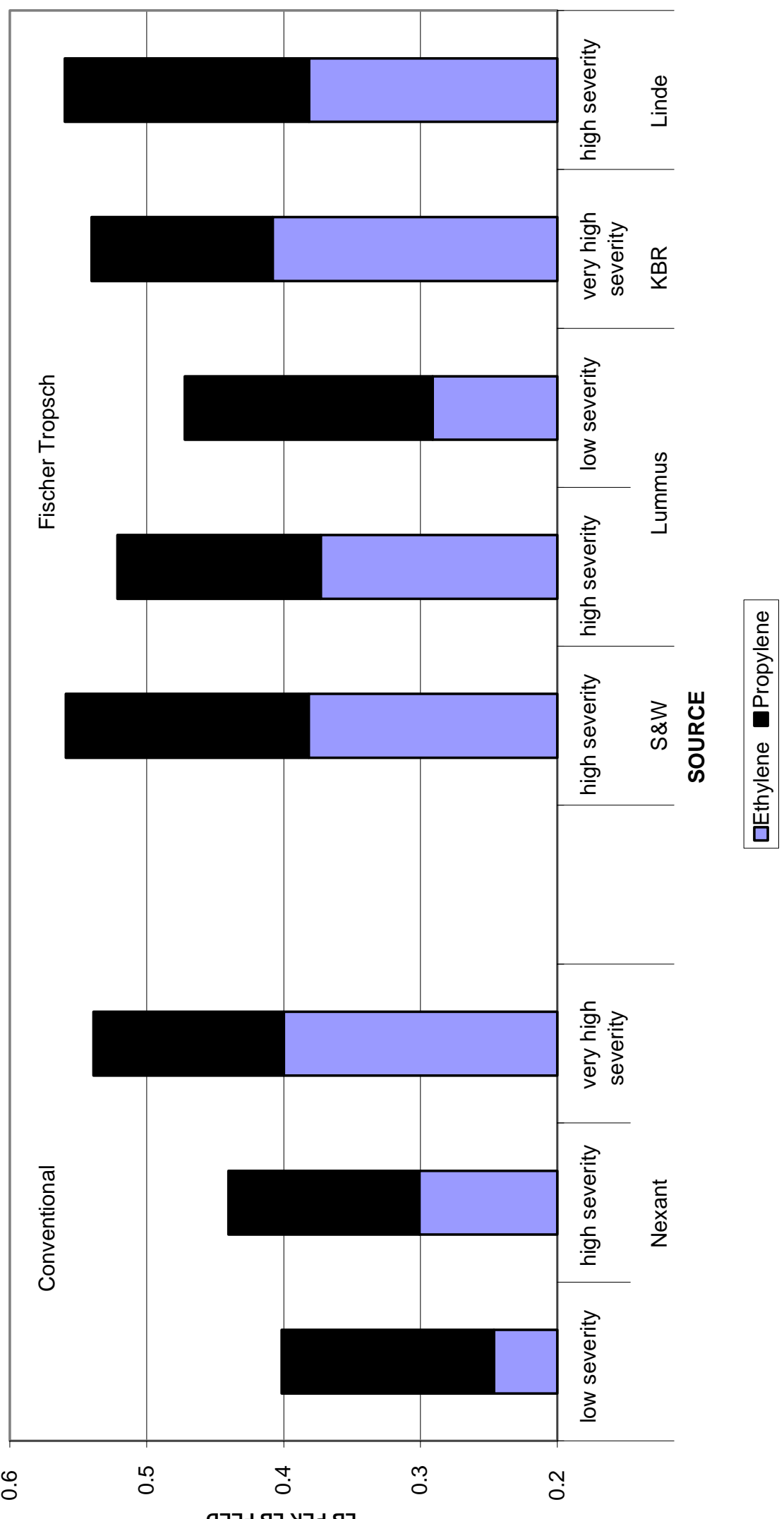




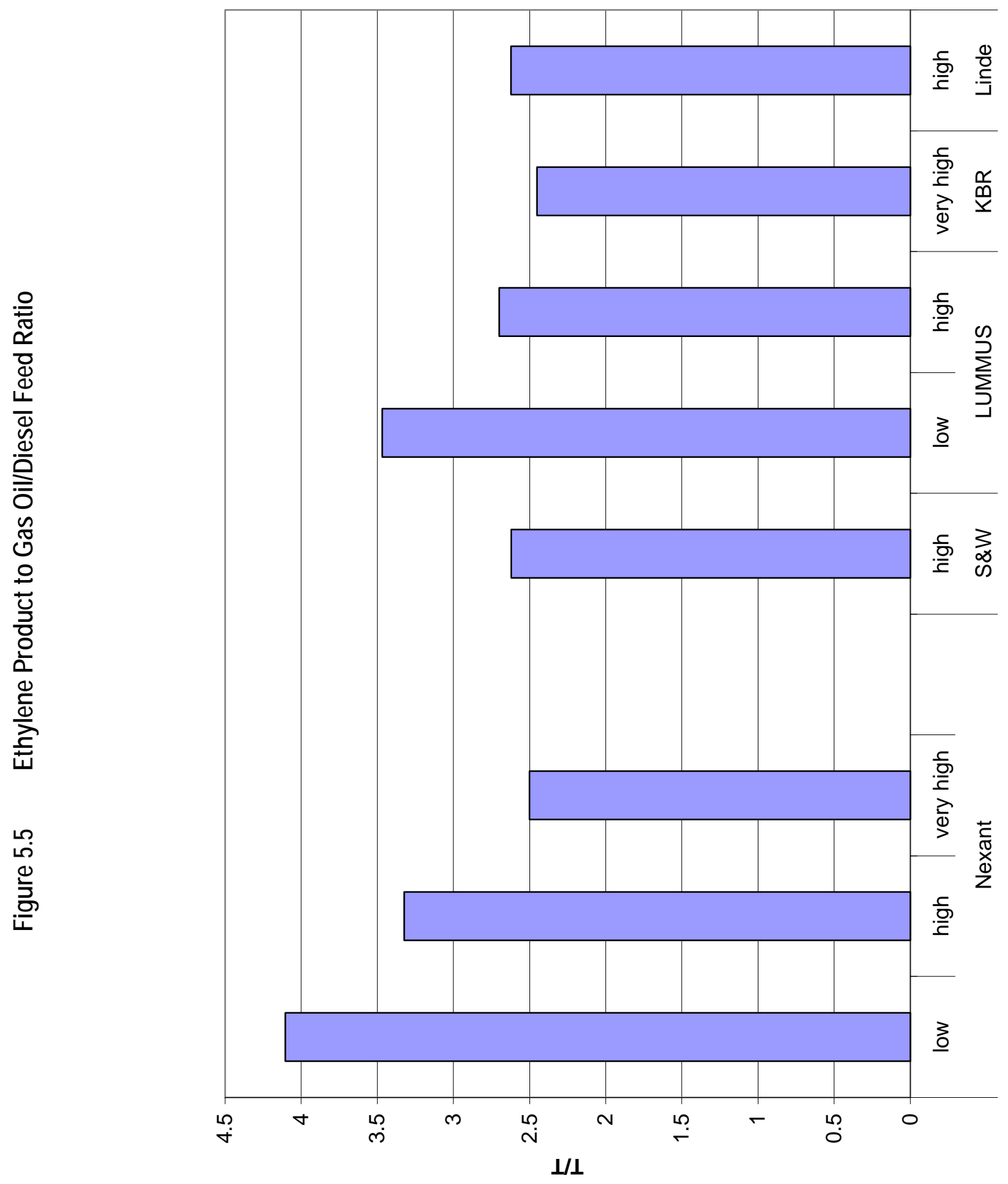




\subsubsection{Basis for Economics}

Nexant has evaluated the relative economic attractiveness of FT diesel feedstocks relative to conventional gasoil feedstocks by examining economics of converting each to ethylene and other chemicals via steam cracking technology. The basis for the steam cracking economics, which follow, is a world scale plant (2,180 million pounds per year, or 989 thousand tons per year of ethylene production) on the USGC with flexibility to process either a full range naphtha or gas oil feedstock. Most steam crackers in the United States are designed to operate for extended periods of time (i.e. one scheduled maintenance turnaround every 4 to 5 years).

The capital investment for a steam cracker designed to process FT liquids will have a slightly lower investment compared to one designed to process conventional feedstocks, reflecting the higher yield of ethylene and propylene per unit of feed for the FT feedstocks. A 6 percent reduction in Inside Battery Limits capital (ISBL) has been used to reflect one less furnace, no amine scrubbing system and less heavy by-product $(\mathrm{C} 4+)$ production. The Outside Battery Limits capital (OSBL) has been reduced by 3 percent primarily due to lower tankage requirements for feedstock and $\mathrm{C} 4+$ by-products.

Utilities for the FT liquid cases have also been reduced as follows:

- Power by 15 percent

- Fuel by 9.5 percent

- Cooling water by 15 percent

These savings reflect the lower production levels of $\mathrm{C} 4+$ by-products within the unit.

\subsubsection{Feedstock and Utilities Pricing and Labor Costs}

Feedstock, by-product, utility and labor rates used in this study are shown in Table 5.3 for historical years 1997 through 2001 and for forecast years 2006 and 2015. These prices are based on Nexant's historical databases and most current price forecast, based on its Medium Crude Oil price outlook. 


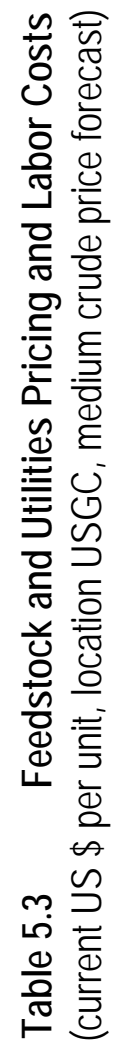

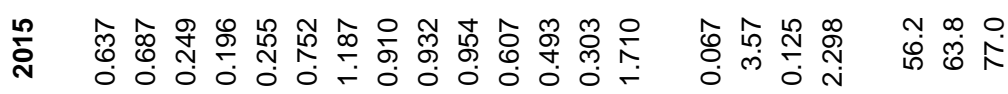

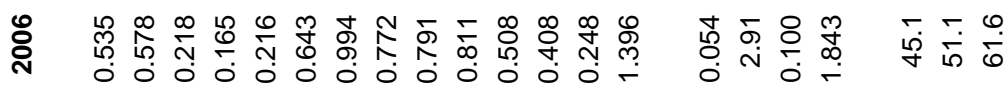

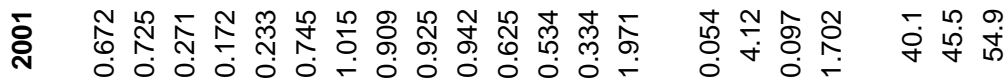

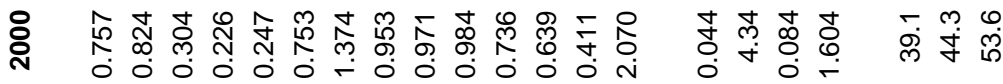

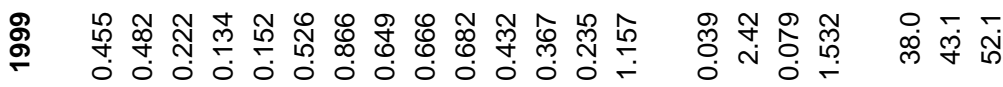

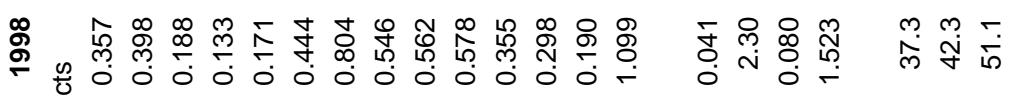

总

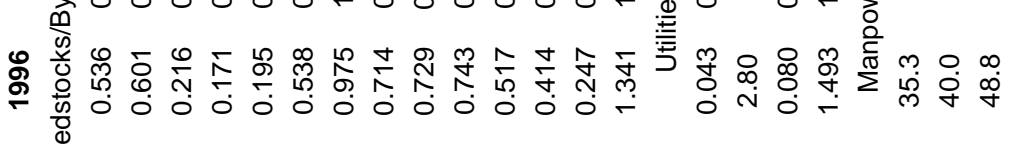

怘

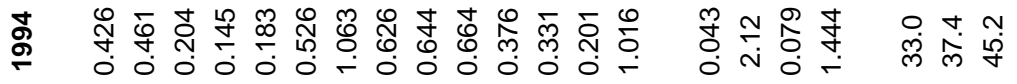

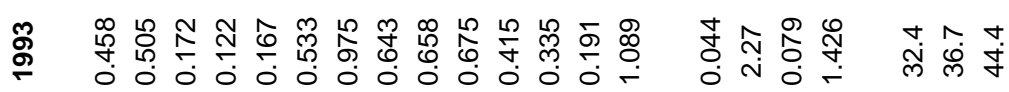

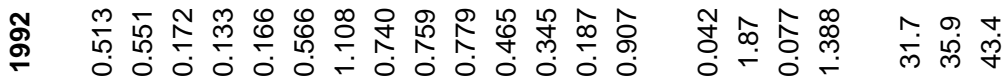

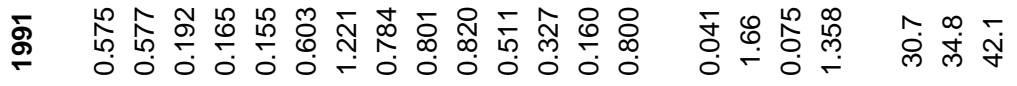

虽 兽

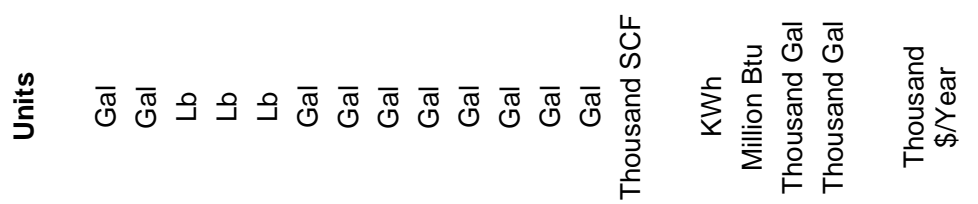

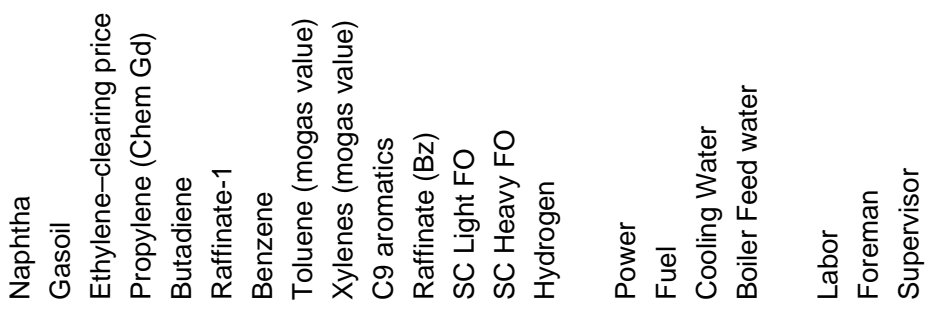




\subsubsection{Economics of Cracking FT Diesel}

The cash cost of production from conventional diesel is compared to that from a typical FT diesel in Table 5.4 for historical years 1997 through 2001 as well as forecast years 2006 and 2015. Figure 5.6 shows the cash cost of production for years 2001, 2006 and 2015.

The cash margins are shown in Table 5.5 by feedstock, severity and year. The Fischer-Tropsch feeds have higher average cash margins than the conventional feedstock in every year examined in this study. This margin premium ranges from a low of $\$ 21$ per metric ton in 1999 to a high of $\$ 39$ per metric ton for the forecast year 2015 . The average premium is $\$ 31$ per metric ton.

Table 5.4 Cash Cost of Production for Cracking Diesel Fuel ${ }^{2}$ (current US dollars per metric ton, medium crude price forecast, USGC)

\begin{tabular}{|c|c|c|c|c|c|c|c|c|}
\hline \multirow{3}{*}{$\begin{array}{l}\text { Yield Source } \\
\text { Severity }\end{array}$} & \multirow{2}{*}{\multicolumn{3}{|c|}{$\begin{array}{c}\text { Conventional Gasoil } \\
\text { Nexant( }{ }^{(1)}\end{array}$}} & \multicolumn{5}{|c|}{ FT Diesel } \\
\hline & & & & \multirow{2}{*}{$\begin{array}{l}\text { S\&W } \\
\text { High }\end{array}$} & \multicolumn{2}{|c|}{ Lummus } & \multirow{2}{*}{$\begin{array}{l}\text { KBR } \\
\text { Very } \\
\text { High }\end{array}$} & \multirow{2}{*}{$\begin{array}{l}\text { Linde } \\
\text { High }\end{array}$} \\
\hline & Low & High & $\begin{array}{l}\text { Very } \\
\text { High }\end{array}$ & & Low & High & & \\
\hline Propylene/Ethylene & 0.63 & 0.46 & 0.35 & 0.46 & 0.63 & 0.40 & 0.32 & 0.47 \\
\hline \multicolumn{9}{|l|}{ Year } \\
\hline 1997 & 124 & 157 & 181 & 125 & 77 & 137 & 169 & 106 \\
\hline 1998 & 95 & 120 & 143 & 98 & 66 & 107 & 131 & 83 \\
\hline 1999 & 134 & 160 & 182 & 142 & 101 & 147 & 170 & 128 \\
\hline 2000 & 239 & 261 & 294 & 234 & 182 & 244 & 275 & 209 \\
\hline 2001 & 244 & 261 & 280 & 230 & 186 & 233 & 260 & 212 \\
\hline 2006 & 169 & 196 & 214 & 164 & 120 & 171 & 200 & 146 \\
\hline 2015 & 206 & 236 & 259 & 199 & 148 & 208 & 241 & 178 \\
\hline
\end{tabular}


Table 5.5 Gas Oil Cracking Margins

(current US dollars per metric ton, medium crude price forecast, USGC)

\begin{tabular}{|c|c|c|c|c|c|c|c|c|c|c|c|c|}
\hline \multirow{3}{*}{$\begin{array}{l}\text { Yield } \\
\text { Source }\end{array}$} & \multicolumn{5}{|c|}{ Conventional Gas Oil } & \multicolumn{6}{|c|}{ FT Diesel } & \multirow[b]{3}{*}{$\begin{array}{l}\text { FT CM Premium } \\
\text { Over Conventional }\end{array}$} \\
\hline & \multirow[b]{2}{*}{$\begin{array}{l}\text { Ethylene } \\
\text { Price }\end{array}$} & \multicolumn{4}{|c|}{ Nexant } & \multirow{2}{*}{$\begin{array}{l}\text { S\&W } \\
\text { high }\end{array}$} & \multicolumn{2}{|c|}{ Lummus } & \multirow{2}{*}{\begin{tabular}{|l} 
KBR \\
$\begin{array}{l}\text { very } \\
\text { high }\end{array}$
\end{tabular}} & \multirow{2}{*}{$\begin{array}{l}\text { Linde } \\
\text { high }\end{array}$} & \multirow[b]{2}{*}{$\begin{array}{c}\text { Average Cash } \\
\text { Margin }\end{array}$} & \\
\hline & & low & high & $\begin{array}{l}\text { very } \\
\text { high }\end{array}$ & $\begin{array}{l}\text { average cash } \\
\text { margin }\end{array}$ & & low & high & & & & \\
\hline 1997 & 548 & 424 & 391 & 367 & 394 & 423 & 471 & 411 & 379 & 442 & 425 & 32 \\
\hline 1998 & 413 & 319 & 293 & 270 & 294 & 315 & 347 & 306 & 283 & 330 & 316 & 22 \\
\hline 1999 & 489 & 355 & 329 & 307 & 331 & 347 & 388 & 342 & 319 & 361 & 351 & 21 \\
\hline 2000 & 670 & 430 & 408 & 376 & 405 & 435 & 488 & 426 & 395 & 460 & 441 & 36 \\
\hline 2001 & 597 & 353 & 336 & 317 & 335 & 368 & 411 & 365 & 337 & 386 & 373 & 38 \\
\hline 2006 & 480 & 311 & 284 & 266 & 287 & 316 & 360 & 309 & 280 & 334 & 320 & 33 \\
\hline 2015 & 549 & 344 & 313 & 290 & 316 & 351 & 401 & 342 & 308 & 372 & 355 & 39 \\
\hline \multicolumn{2}{|c|}{ Average 1997-2015 } & 362 & 336 & 313 & 337 & 365 & 410 & 357 & 329 & 383 & 369 & 31 \\
\hline
\end{tabular}

02Q4:00072/data/00072.ppt 


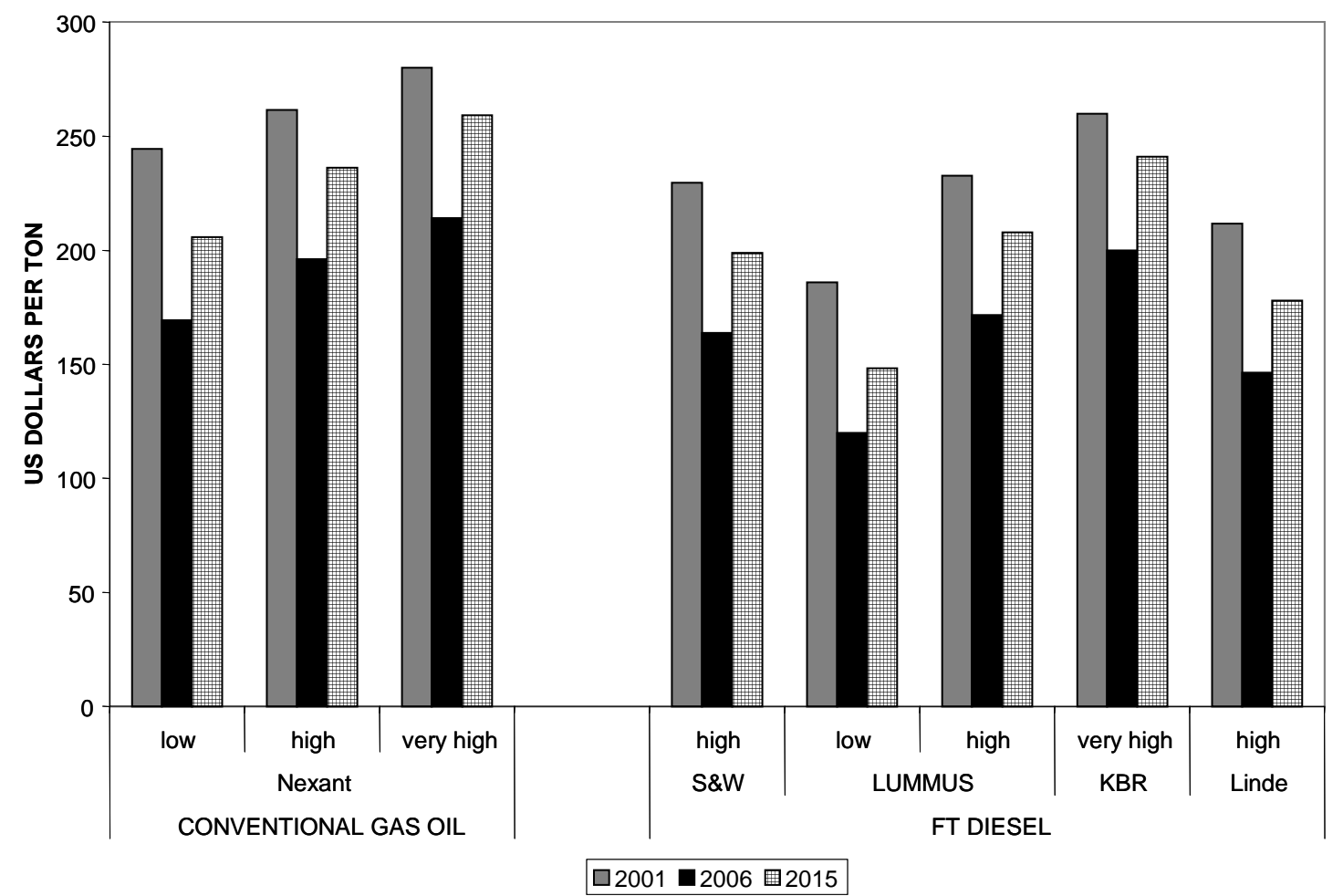

Figure 5.6 Cash Cost of Production for Cracking Diesel Fuel (USGC)

Table 5.6 shows that FT diesel has a measurably lower cost of production at equivalent operating severities, based on setting an equal value for both feedstocks. The results of this analysis indicate that the average ethylene cash margin for the years studied would be about $\$ 31$ per ton higher for the FT liquids, which is about a 9.4 percent increase in the cash margin over ethylene produced from conventional diesel. Another way to examine the value of the FT liquid is to calculate the premium that the FT diesel would be worth based on maintaining a constant ethylene margin. On this basis FT diesel is estimated to be worth $\$ 11$ per ton more than conventional diesel range feedstocks on average over the time period studied. Operating severity has a significant influence on the savings or premium. For the cases studied the delta ethylene cash cost as an average for the years studied ranged from $\$ 15$ per ton to $\$ 47$ per ton and the average premium for the FT diesel ranged from $\$ 6$ per ton to $\$ 18$ per ton. Table 5.7 through Table 5.14 show the detailed production costs for year 2006 and Table 5.14 through Table 5.21 for year 2015. Nexant has utilized its proprietary Cost of Production (COP) system to generate these analyses. Basic information and assumptions employed by this system are presented in the Appendix to this report.

A low severity operation for cracking diesel or gas oil is most common along the USGC. At this severity the delta ethylene cash cost ranges from \$29 per ton (1998) to \$59 per ton (2001). In 
2006 the delta ranges from $\$ 14$ to $\$ 50$ per ton and in 2015 the delta ranges from $\$ 18$ to $\$ 58$ per ton. The overall average for the years studied was $\$ 32$ per ton. The premium for the diesel would be between $\$ 8$ per ton (1998) to $\$ 17$ per ton (2001). The premium ranges between $\$ 6$ and $\$ 19$ per ton in 2006 and $\$ 7$ and $\$ 22$ per ton in 2015 . The overall average for the years studied was $\$ 11$ per ton. The general conclusion is that the diesel cut from the GTL liquids will make a good cracker feed and should be worth a measurable premium to ethylene producers relative to conventional gasoils. 


\section{Table 5.6 Cost of Production Estimate for: Ethylene (Gas Oil Feed) Process: Steam Cracking (Nexant Low Severity)}

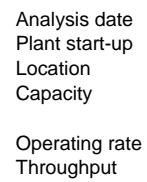

UTILITIES

\begin{tabular}{ll} 
Power (Export) & kWh \\
Fuel & MM Btu \\
Cooling Water & Mgal \\
Boiler Feedwater & MGal \\
\multicolumn{2}{c}{ TOTAL UTILITIES }
\end{tabular}

NET RAW MATERIALS \& UTILITIES

VARIABLE COST

\begin{tabular}{llrl} 
DIRECT FIXED COSTS & Labor, & 62 & Men \\
& Foremen, & 13 & Men \\
& Super., & 1 & Men \\
& Maint., Material \& Labor \\
& Direct Overhead & \multicolumn{1}{c}{ TOTAL DIRECT FIXED COSTS } \\
ALLOCATED FIXED COSTS & $\begin{array}{l}\text { General Plant Overhead } \\
\text { Insurance, Property Tax } \\
\text { Environmental }\end{array}$
\end{tabular}

TOTAL CASH COST

$10 \%$ for ISBL

cost OF PRODUctION

RETURN ON TOTAL CAPITAL INVESTMENT (Ex. WC) @

COST OF PRODUCTION + ROI
$10 \%$ for OSBL \& OPC

$\begin{array}{lr}\text { CAPITAL COST MILLION U.S. \$ } & \\ \text { ISBL } & 763.7 \\ \text { OSBL } & 381.9 \\ \text { Total Plant Capital } & \mathbf{1 1 4 5 . 6} \\ \text { Other Project Costs } & 286.4 \\ \text { Total Capital Investment } & \mathbf{1 , 4 3 2 . 0} \\ \text { Working capital } & 64.4\end{array}$

UNITS PRICE

Per Lb U.S.\$

Product IUnit

$0.5699 \quad 0.5784$

$1.0000 \quad 0.0017$

(0.6317) 0.1653

$(0.1591) \quad 0.2161$

$(0.0438) \quad 0.6432$

$(0.0321) \quad 0.9940$

(0.0175) $\quad 0.7718$

$(0.0113) \quad 0.7914$

$(0.0226) \quad 0.8108$

$(0.0069) \quad 2.9141$

$(0.0862) \quad 0.4081$

$(0.0245) \quad 0.2483$

$(0.0436) \quad 0.5080$

$(0.0043) \quad 1.3961$

$0.0362 \quad 0.0539$

$0.0142 \quad 2.9141$

$0.0516 \quad 0.1003$

$0.0001 \quad 1.8430$

45.02 Thousand U.S. \$

51.08 Thousand U.S. \$

61.63 Thousand U.S. \$

$2.66 \%$ of ISBL

$45 \%$ Labor \& Supervision

$65 \%$ Labor \& Maintenance

$1 \%$ Total Plant Capital

0.5

10 Percent $\underline{0.209}$

\begin{tabular}{|c|c|c|}
\hline $\begin{array}{l}\text { U.S. \$ } \\
\text { Per Lb }\end{array}$ & $\begin{array}{l}\text { COST MM } \\
\text { U.S. \$ }\end{array}$ & $\begin{array}{l}\text { U.S. \$ } \\
\text { Per MT }\end{array}$ \\
\hline 0.330 & 718.53 & \\
\hline 0.002 & 3.76 & \\
\hline 0.331 & 722.29 & 730 \\
\hline (0.104) & (227.66) & \\
\hline$(0.034)$ & (74.98) & \\
\hline$(0.028)$ & (61.46) & \\
\hline$(0.032)$ & (69.59) & \\
\hline (0.014) & (29.46) & \\
\hline (0.009) & (19.44) & \\
\hline (0.018) & (39.91) & \\
\hline$(0.020)$ & (44.13) & \\
\hline$(0.035)$ & (76.67) & \\
\hline$(0.006)$ & (13.28) & \\
\hline$(0.022)$ & (48.33) & \\
\hline$(0.006)$ & (13.17) & \\
\hline (0.329) & (718.08) & (726) \\
\hline 0.002 & 4.21 & 4 \\
\hline 0.002 & 4.25 & \\
\hline 0.041 & 90.08 & \\
\hline 0.005 & 11.28 & \\
\hline 0.000 & 0.32 & \\
\hline 0.049 & 105.93 & 107 \\
\hline 0.051 & 110.14 & 111 \\
\hline$\underline{0.051}$ & $\underline{110.14}$ & 111 \\
\hline 0.001 & 2.79 & \\
\hline 0.000 & 0.66 & \\
\hline 0.000 & 0.06 & \\
\hline 0.009 & 20.31 & \\
\hline 0.001 & 1.58 & \\
\hline 0.012 & 25.41 & 26 \\
\hline 0.007 & 15.49 & \\
\hline 0.005 & 11.46 & \\
\hline 0.003 & 5.73 & \\
\hline 0.015 & 32.67 & 33 \\
\hline$\underline{0.077}$ & $\underline{168.22}$ & 170 \\
\hline 0.066 & 143.20 & 145 \\
\hline$\underline{0.143}$ & $\underline{311.42}$ & 315 \\
\hline 0.066 & 143.20 & 145 \\
\hline$\underline{0.209}$ & $\underline{454.63}$ & 460 \\
\hline
\end{tabular}




\section{Table 5.7 Cost of Production Estimate for: Ethylene (Gas Oil Feed) Process: Steam Cracking (Nexant High Severity)}

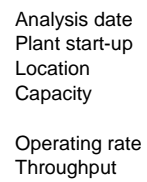

$\begin{array}{llll}\text { Power (Export) } & \text { kWh } & 0.0318 & 0.0539 \\ \text { Fuel } & \text { MM Btu } & 0.0125 & 2.9141 \\ \text { Cooling Water } & \text { Mgal } & 0.0452 & 0.1003 \\ \text { Boiler Feedwater } & \text { MGal } & 0.0001 & 1.8430\end{array}$

NET RAW MATERIALS \& UTILITIES

\begin{tabular}{lcl} 
& NET RAW MATERIALS & kWh \\
UTILITIES & Power (Export) & MM Btu \\
& Fuel & Mgal \\
& Cooling Water & MGal \\
& Boiler Feedwater & \multicolumn{2}{c}{ TOTAL UTILITIES } \\
& &
\end{tabular}

VARIABLE COST

\begin{tabular}{llrl} 
DIRECT FIXED COSTS & Labor, & 62 & Men \\
& Foremen, & 13 & Men \\
& Super., & 1 & Men \\
& Maint., Material \& Labor \\
& Direct Overhead & \multicolumn{1}{c}{ TOTAL DIRECT FIXED COSTS } \\
ALLOCATED FIXED COSTS & $\begin{array}{l}\text { General Plant Overhead } \\
\text { Insurance, Property Tax } \\
\text { Environmental }\end{array}$
\end{tabular}

TOTAL CASH COST

$10 \%$ for ISBL

Depreciation @

COST OF PRODUCTION

RETURN ON TOTAL CAPITAL INVESTMENT (Ex. WC) @

COST OF PRODUCTION + ROI

UNITS PRICE

Per Lb U.S. \$

Product IUnit

$0.4617 \quad 0.5784$

$1.0000 \quad 0.0017$

(0.4637) $\quad 0.1653$

$(0.1333) \quad 0.2161$

$(0.0326) \quad 0.6432$

$(0.0260) \quad 0.9940$

$(0.0099) \quad 0.7718$

$(0.0020) \quad 0.7914$

(0.0013) $\quad 0.8108$

$(0.0065) \quad 2.9141$

$(0.0563) \quad 0.4081$

$(0.0125) \quad 0.2483$

$(0.0626) \quad 0.5080$

$(0.0068) \quad 1.3961$

0.0001

45.02 Thousand U.S. \$

51.08 Thousand U.S. \$

61.63 Thousand U.S. \$

$2.66 \%$ of ISBL

$1 \%$ Total Plant Capital

$0.5 \%$ Total Plant Capital

TOTAL ALLOCATED FIXED COSTS

$\begin{array}{lr}\text { CAPITAL COST MILLION U.S. \$ } & \\ \text { ISBL } & 763.7 \\ \text { OSBL } & 381.9 \\ \text { Total Plant Capital } & \mathbf{1 1 4 5 . 6} \\ \text { Other Project Costs } & 286.4 \\ \text { Total Capital Investment } & \mathbf{1 , 4 3 2 . 0} \\ \text { Working capital } & 64.4\end{array}$

$45 \%$ Labor \& Supervision

$65 \%$ Labor \& Maintenance

$10 \%$ for OSBL \& OPC

\begin{tabular}{|c|c|c|}
\hline $\begin{array}{l}\text { U.S. \$ } \\
\text { Per Lb }\end{array}$ & $\begin{array}{l}\text { COST MM } \\
\text { U.S. \$ }\end{array}$ & $\begin{array}{l}\text { U.S. \$ } \\
\text { Per MT }\end{array}$ \\
\hline 0.267 & 582.16 & \\
\hline 0.002 & 3.76 & \\
\hline 0.269 & 585.91 & 593 \\
\hline$(0.077)$ & (167.13) & \\
\hline$(0.029)$ & $(62.79)$ & \\
\hline$(0.021)$ & (45.68) & \\
\hline$(0.026)$ & (56.29) & \\
\hline (0.008) & (16.61) & \\
\hline$(0.002)$ & (3.49) & \\
\hline$(0.001)$ & $(2.24)$ & \\
\hline$(0.019)$ & (41.60) & \\
\hline$(0.023)$ & (50.08) & \\
\hline$(0.003)$ & $(6.78)$ & \\
\hline (0.032) & (69.31) & \\
\hline$(0.009)$ & (20.62) & \\
\hline$(0.249)$ & (542.62) & (549) \\
\hline 0.020 & 43.29 & 44 \\
\hline 0.002 & 3.73 & \\
\hline 0.036 & 79.25 & \\
\hline 0.005 & 9.89 & \\
\hline 0.000 & 0.32 & \\
\hline 0.043 & 93.19 & 94 \\
\hline 0.063 & 136.48 & 138 \\
\hline$\underline{0.063}$ & $\underline{136.48}$ & 138 \\
\hline 0.001 & 2.79 & \\
\hline 0.000 & 0.66 & \\
\hline 0.000 & 0.06 & \\
\hline 0.009 & 20.31 & \\
\hline 0.001 & 1.58 & \\
\hline 0.012 & 25.41 & 26 \\
\hline 0.007 & 15.49 & \\
\hline 0.005 & 11.46 & \\
\hline 0.003 & 5.73 & \\
\hline 0.015 & 32.67 & 33 \\
\hline$\underline{0.089}$ & $\underline{194.57}$ & 197 \\
\hline 0.066 & 143.20 & 145 \\
\hline$\underline{0.155}$ & $\underline{337.77}$ & 342 \\
\hline 0.066 & 143.20 & 145 \\
\hline 0.221 & 480.97 & 486 \\
\hline
\end{tabular}




\section{Table 5.8 Cost of Production Estimate for: Ethylene (Gas Oil Feed) Process: Steam Cracking (Nexant Very High Severity)}

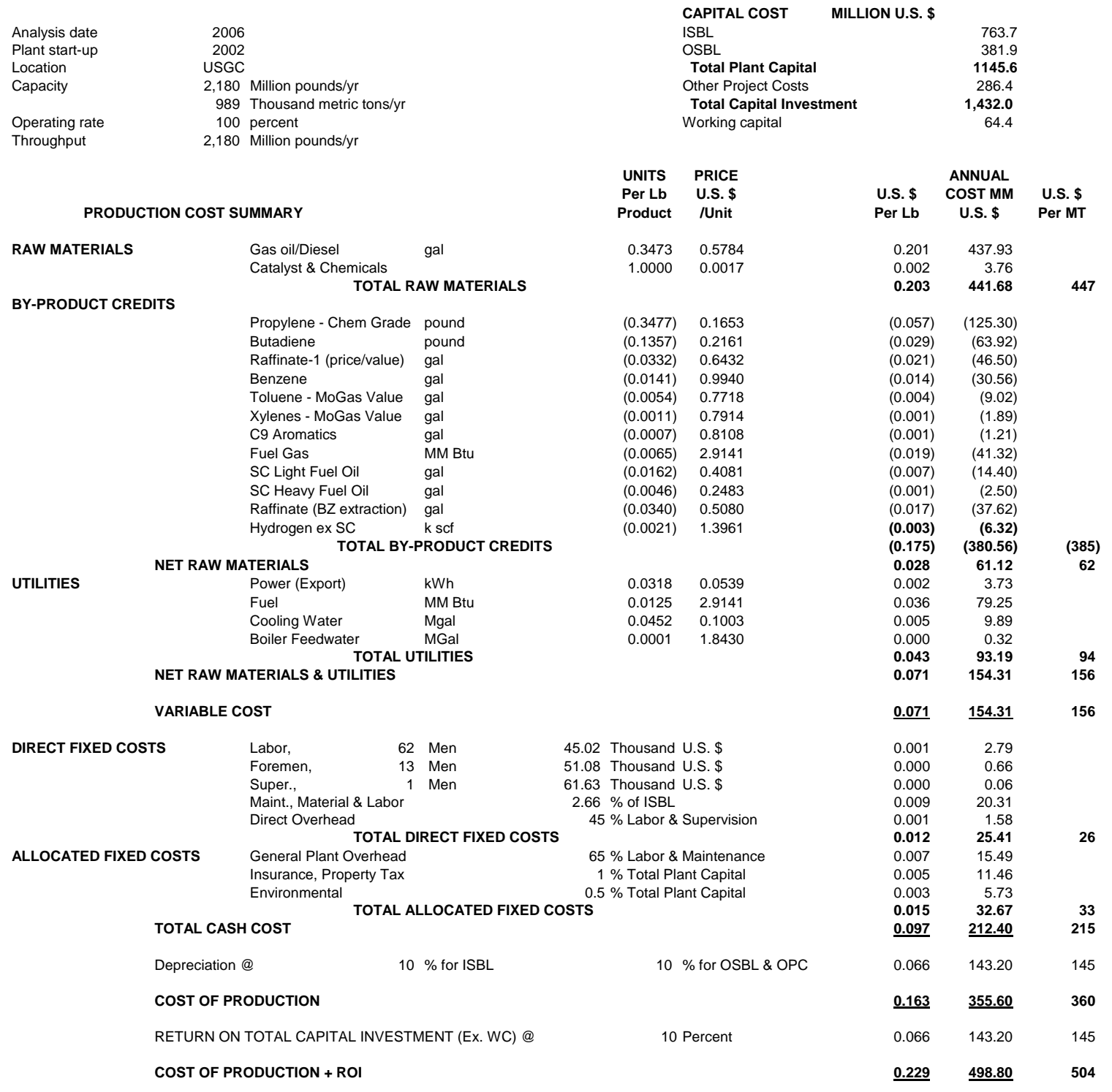




\section{Table 5.9 Cost of Production Estimate for: Ethylene (FT Gas Oil/Diesel) Process: Steam Cracking (S\&W, High Severity)}

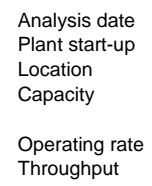

UTILITIES

$\begin{array}{ll}\text { Power (Export) } & \text { kWh } \\ \text { Fuel } & \text { MM Btu } \\ \text { Cooling Water } & \text { Mgal } \\ \text { Boiler Feedwater } & \text { MGal }\end{array}$

NET RAW MATERIALS \& UTILITIES

VARIABLE COST

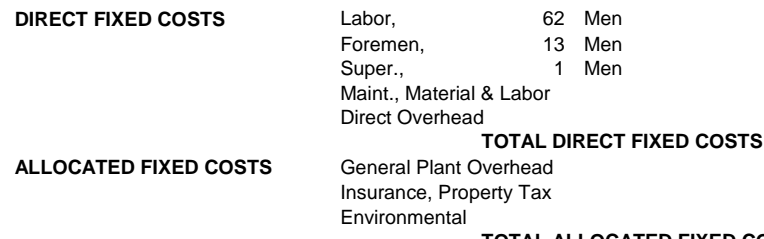

TOTAL CASH COST

Depreciation @

COST OF PRODUCTION

RETURN ON TOTAL CAPITAL INVESTMENT (EX. WC) @

COST OF PRODUCTION + RO

$\begin{array}{lr}\text { CAPITAL COST MILLION U.S. \$ } & \\ \text { ISBL } & 717.9 \\ \text { OSBL } & 370.5 \\ \text { Total Plant Capital } & \mathbf{1 0 8 8 . 3} \\ \text { Other Project Costs } & 272.1 \\ \text { Total Capital Investment } & \mathbf{1 , 3 6 0 . 4} \\ \text { Working capital } & 61.2\end{array}$

UNITS PRICE

Per Lb U.S. \$

Product IUnit

$0.3639 \quad 0.5784$

$1.0000 \quad 0.0017$

$(0.4648) \quad 0.1653$

$(0.1706) \quad 0.2161$

$(0.0255) \quad 0.6432$

$(0.0218) \quad 0.9940$

$(0.0083) \quad 0.7718$

$(0.0027) \quad 0.7914$

$(0.0089) \quad 0.8108$

$(0.0055) \quad 2.9141$

$(0.0072) \quad 0.4081$

$(0.0137) \quad 0.2483$

$(0.0039) \quad 0.5080$

$(0.0066) \quad 1.3961$

$\begin{array}{ll}0.0270 & 0.0539 \\ 0.0113 & 2.9141 \\ 0.0384 & 0.1003 \\ 0.0001 & 1.8430\end{array}$

$10 \%$ for ISBL

45.02 Thousand U.S. \$

51.08 Thousand U.S. \$

61.63 Thousand U.S. \$

$2.66 \%$ of ISBL

$45 \%$ Labor \& Supervision

$65 \%$ Labor \& Maintenance

$1 \%$ Total Plant Capital

$0.5 \%$ Total Plant Capital

TOTAL ALLOCATED FIXED COSTS

$10 \%$ for OSBL \& OPC

10 Percent

0.062

$\underline{0.199}$
60.4

ANNUAL

U.S. \$ COST MM U.S.\$

$\begin{array}{lll}\text { Per Lb } & \text { U.S. } \$ \text { Per MT }\end{array}$

$0.210 \quad 458.8$

$\begin{array}{lrr}0.002 & 3.76 & \\ \mathbf{0 . 2 1 2} & \mathbf{4 6 2 . 5 7} & \mathbf{4 6 8}\end{array}$

$(0.077) \quad(167.52)$

$(0.037) \quad(80.36)$

$(0.016) \quad(35.81)$

$(0.022) \quad(47.21)$

$(0.006) \quad(14.03)$

$(0.002) \quad(4.61)$

$(0.007) \quad(15.80)$

$(0.016) \quad(35.22)$

$(0.003) \quad(6.36)$

$(0.003) \quad(7.41)$

$(0.002) \quad(4.32)$

(0.009) (20.14)

$(0.201) \quad(438.80)$

$0.011 \quad 23.77$

$\begin{array}{lr}0.001 & 3.17\end{array}$

$0.033 \quad 71.72$

$0.004 \quad 8.41$

$0.049 \quad 107.39$

$\underline{0.049} \quad \underline{107.39}$ 


\section{Table 5.10 Cost of Production Estimate for: Ethylene (FT Gas Oil/Diesel) Process: Steam Cracking (Lummus, Low Severity)}

$\begin{array}{lr}\text { Analysis date } & 2006 \\ \text { Plant start-up } & 2002 \\ \text { Location } & \text { USGC } \\ \text { Capacity } & 2,180 \text { Million pounds/yr } \\ & 989 \text { Thousand metric tons/yr } \\ \text { Operating rate } & 100 \text { percent } \\ \text { Throughput } & 2,180 \text { Million pounds/yr }\end{array}$

PRODUCTION COST SUMMARY

\begin{tabular}{|c|c|c|}
\hline \multirow[t]{2}{*}{ RAW MATERIALS } & $\begin{array}{l}\text { Gas oil/Diesel } \\
\text { Catalyst \& Chemicals }\end{array}$ & gal \\
\hline & \multicolumn{2}{|c|}{ TOTAL RAW MATERIALS } \\
\hline \multicolumn{3}{|c|}{ BY-PRODUCT CREDITS } \\
\hline & Propylene - Chem Grade & pound \\
\hline & Butadiene & pound \\
\hline & Raffinate-1 (price/value) & gal \\
\hline & Benzene & gal \\
\hline & Toluene - MoGas Value & gal \\
\hline & Xylenes - MoGas Value & gal \\
\hline & C9 Aromatics & gal \\
\hline & Fuel Gas & MM Btu \\
\hline & SC Light Fuel Oil & gal \\
\hline & SC Heavy Fuel Oil & gal \\
\hline & Raffinate (BZ extraction) & gal \\
\hline & Hydrogen ex SC & k scf \\
\hline
\end{tabular}

NET RAW MATERIALS

UTILITIES

\begin{tabular}{ll} 
Power (Export) & kWh \\
Fuel & MM Btu \\
Cooling Water & Mgal \\
Boiler Feedwater & MGal \\
\multicolumn{2}{c}{ TOTAL UTILITIES }
\end{tabular}

NET RAW MATERIALS \& UTILITIES

VARIABLE COST

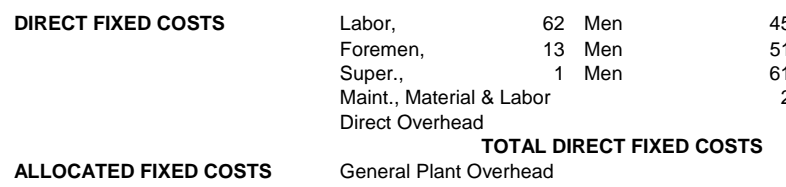

General Plant Overhead

Insurance, Property Tax

Environmental

TOTAL ALLOCATED FIXED COSTS

45.02 Thousand U.S. \$

51.08 Thousand U.S. \$

$2.66 \%$ of ISBL

$45 \%$ Labor \& Supervision

$65 \%$ Labor \& Maintenance

$1 \%$ Total Plant Capital

$0.5 \%$ Total Plant Capita

TOTAL CASH COST

$10 \%$ for ISBL

Depreciation @

COST OF PRODUCTION

RETURN ON TOTAL CAPITAL INVESTMENT (Ex. WC) @

COST OF PRODUCTION + ROI

Product IUnit

$(0.0045) \quad 0.7914$

$0.0438 \quad 0.1003$
CAPITAL COST MILLION U.S. \$

$S B L$

Ther Project Costs $\quad 272.1$

Working capital $\quad 61.2$

UNITS PRICE

$0.4816 \quad 0.5784$

(0.6306) $\quad 0.1653$

$(0.1564) \quad 0.2161$

0.6432

$(0.0159) \quad 0.7718$

$(0.0219) \quad 0.8108$

$\begin{array}{ll}(0.0024) & 0.9141 \\ (0.0069) & 0.2483\end{array}$

$(0.0069) \quad 0.2483$

$(0.0787) \quad 0.5080$

(0.0046) $\quad 1.3961$

$0.0308 \quad 0.0539$

$0.0128 \quad 2.9141$

$0.0001 \quad 1.8430$

$\begin{array}{ccc} & \text { ANNUAL } & \\ \text { U.S. \$ } & \text { COST MM } & \text { U.S. \$ } \\ \text { Per Lb } & \text { U.S. \$ } & \text { Per MT }\end{array}$

$0.279 \quad 607.16$

$\begin{array}{lrr}0.002 & 3.76 & \\ 0.280 & 610.92 & 618\end{array}$

$(0.104) \quad(227.27)$

$(0.034) \quad(73.69)$

$(0.038) \quad(82.95)$

$(0.010) \quad(20.74)$

$(0.012) \quad(26.68)$

$(0.004) \quad(7.77)$

$(0.018) \quad(38.69)$

$(0.017) \quad(37.33)$

$(0.002) \quad(3.76)$

$(0.040) \quad(87.16)$

$(0.006) \quad(14.14)$

$(0.294) \quad(641.86)$

(0.014) (30.94)

$0.002 \quad 3.61$

$0.037 \quad 81.53$

$0.004 \quad 9.59$

$0.000 \quad 0.32$

$0.044 \quad 95.05$

$0.029 \quad 64.11$

$\underline{0.029} \quad \underline{64.11}$

65

$0.001 \quad 2.79$

$0.000 \quad 0.66$

$0.000 \quad 0.06$

$0.009 \quad 19.10$

$0.001 \quad 1.58$

$\mathbf{0 . 0 1 1} \quad 24.19$

$0.007 \quad 14.70$

$0.005 \quad 10.88$

$0.002 \quad 5.44$

$0.014 \quad 31.02$

$\underline{0.055} \quad \mathbf{1 1 9 . 3 2}$

$\begin{array}{lll}0.062 & 136.04 & 138\end{array}$

$\underline{0.117} \quad \underline{255.36} \quad 258$

$\begin{array}{lll}0.062 & 136.04 & 138\end{array}$

$\underline{0.180} \quad \underline{391.41} \quad 396$ 


\section{Table 5.11 Cost of Production Estimate for: Ethylene (FT Gas Oil/Diesel) Process: Steam Cracking (Lummus, High Severity)}

$\begin{array}{lr}\text { Analysis date } & 2006 \\ \text { Plant start-up } & 2002 \\ \text { Location } & \text { USGC } \\ \text { Capacity } & 2,180 \text { Million pounds/yr } \\ & 989 \text { Thousand metric tons/yr } \\ \text { Operating rate } & 100 \text { percent } \\ \text { Throughput } & 2,180 \text { Million pounds/yr }\end{array}$

PRODUCTION COST SUMMARY

RAW MATERIALS

BY-PRODUCT CREDITS
TOTAL RAW MATERIALS

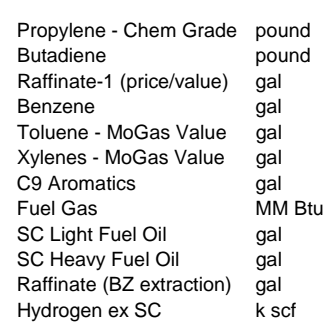

TOTAL BY-PRODUCT CREDITS
CAPITAL COST MILLION U.S. \$

ISBL

OSBL

Total Plant Capital

Other Project Costs

Total Capital Investment

Working capital

UNITS PRICE

Per Lb U.S. \$
Product

$0.3750 \quad 0.5784$

$0.0000 \quad 0.0017$

(0.4043) $\quad 0.1653$

$(0.1488) \quad 0.2161$

$(0.0256) \quad 0.6432$

$(0.0180) \quad 0.9940$

$(0.0150) \quad 0.7718$

$(0.0031) \quad 0.7914$

$(0.0127) \quad 0.8108$

$(0.0073) \quad 2.9141$

$(0.0137) \quad 0.4081$

$(0.0039) \quad 0.2483$

$(0.0223) \quad 0.5080$

$(0.0051) \quad 1.3961$

NET RAW MATERIALS

$\begin{array}{llll}\text { Power (Export) } & \text { kWh } & 0.0270 & 0.0539 \\ \text { Fuel } & \text { MM Btu } & 0.0113 & 2.9141 \\ \text { Cooling Water } & \text { Mgal } & 0.0384 & 0.1003 \\ \text { Boiler Feedwater } & \text { MGal } & 0.0001 & 1.8430\end{array}$

NET RAW MATERIALS \& UTILITIES

UTILITIES

VARIABLE COST

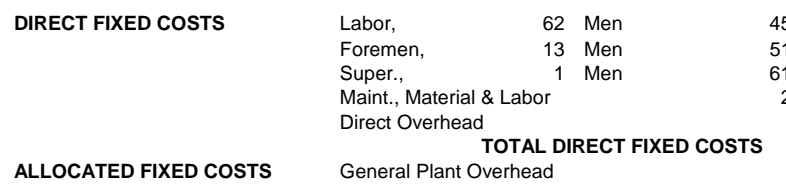

General Plant Overhead

Insurance, Property Tax

Environmental

TOTAL ALLOCATED FIXED COSTS

45.02 Thousand U.S. \$

51.08 Thousand U.S. \$

61.63 Thousand U.S. \$

$2.66 \%$ of ISBL

$45 \%$ Labor \& Supervision

$65 \%$ Labor \& Maintenance

$1 \%$ Total Plant Capital

$0.5 \%$ Total Plant Capital

TOTAL CASH COST

$10 \%$ for ISBL

$10 \%$ for OSBL \& OPC

COST OF PRODUCTION

RETURN ON TOTAL CAPITAL INVESTMENT (Ex. WC) @

10 Percent
717.9

370.5

1088.3

272.1

$1,360.4$

61.2

ANNUAL

$\begin{array}{ccc}\text { U.S. \$ } & \text { COST MM } & \text { U.S. \$ } \\ \text { Per Lb } & \text { U.S. \$ } & \text { Per MT }\end{array}$

$0.217 \quad 472.76$

$\begin{array}{lrr}0.002 & 3.76 & \\ 0.219 & 476.52\end{array}$

$(0.067) \quad(145.69)$

$(0.032) \quad(70.11)$

$(0.016) \quad(35.91)$

$(0.018) \quad(39.07)$

$\begin{array}{ll}(0.018) & (39.07) \\ (0.012) & (25.17)\end{array}$

$(0.012) \quad(25.17)$

$(0.002) \quad(5.43)$

(0.010) (22.40)

$(0.021) \quad(46.58)$

$(0.006) \quad(12.21)$

$\begin{array}{ll}(0.006) & (12.21) \\ (0.001) & (2.12)\end{array}$

$\begin{array}{lr}(0.001) & (2.12) \\ (0.011) & (24.70)\end{array}$

$(0.007) \quad(15.61)$

$(0.204) \quad(444.97)$

$0.014 \quad 31.54$

$0.001 \quad 3.17$

$0.033 \quad 71.72$

$0.004 \quad 8.41$

$0.000 \quad 0.32$

$\begin{array}{lll}0.038 & 83.62 & 85\end{array}$

$0.053 \quad 115.16 \quad 116$

$\underline{0.053}$

$\underline{115.16}$

$0.001 \quad 2.79$

$0.000 \quad 0.66$

$0.000 \quad 0.06$

$0.009 \quad 19.10$

$0.001 \quad 1.58$

$\mathbf{0 . 0 1 1} \quad 24.19$

$0.007 \quad 14.70$

$0.005 \quad 10.88$

$0.002 \quad 5.44$

$0.014 \quad 31.02$

$\underline{0.078 \quad \underline{170.38}}$

$0.062 \quad 136.04$

172

$\underline{0.141} \quad \underline{306.42} \quad 310$

$\begin{array}{lll}0.062 & 136.04 & 138\end{array}$

$\underline{0.203} \quad \underline{442.46} \quad 447$ 


\section{Table 5.12 Cost of Production Estimate for: Ethylene (Ft Gas Oil/Diesel) Process: Steam Cracking (KBR, Very High Severity)}

$\begin{array}{lr} & \\ \text { Analysis date } & 2006 \\ \text { Plant start-up } & 2002 \\ \text { Location } & \text { USGC } \\ \text { Capacity } & 2,180 \text { Million pounds/yr } \\ & 989 \text { Thousand metric tons/yr } \\ \text { Operating rate } & 100 \text { percent } \\ \text { Throughput } & 2,180 \text { Million pounds/yr }\end{array}$

PRODUCTION COST SUMMARY

RAW MATERIALS

BY-PRODUCT CREDITS

Propylene - Chem Grade pound Butadiene pound Raffinate-1 (price/value) gal Benzen Toluene - MoGas Value Xylenes - MoGas Value gal C9 Aromatics Fuel Gas SC Light Fuel Oil SC Heavy Fuel Oil Raffinate (BZ extraction) Hydrogen ex SC TOTAL BY-PRODUCT CREDITS NET RAW MATERIALS

UTILITIES

\begin{tabular}{ll} 
Power (Export) & kWh \\
Fuel & MM Btu \\
Cooling Water & Mgal \\
Boiler Feedwater & MGal \\
\multicolumn{2}{c}{ TOTAL UTILITIES }
\end{tabular}

NET RAW MATERIALS \& UTILITIES

VARIABLE COST

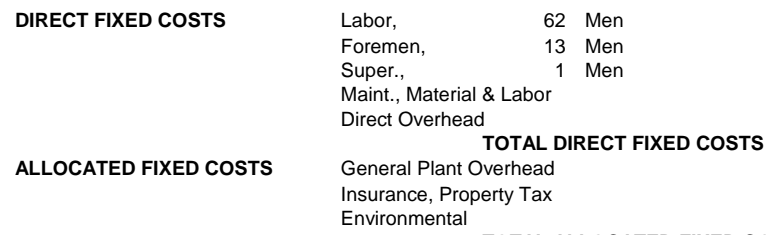

TOTAL CASH COST

TOTAL ALLOCATED FIXED COSTS

45.02 Thousand U.S. \$

51.08 Thousand U.S. $\$$

61.63 Thousand U.S. \$

$2.66 \%$ of ISBL

$10 \%$ for ISBL

COST OF PRODUCTION

RETURN ON TOTAL CAPITAL INVESTMENT (Ex. WC) @

COST OF PRODUCTION + ROI

$45 \%$ Labor \& Supervision

$65 \%$ Labor \& Maintenance $1 \%$ Total Plant Capital $0.5 \%$ Total Plant Capital

$10 \%$ for OSBL \& OPC

10 Percent

CAPITAL COST MILLION U.S. \$

Other Project Costs

Total Capital Investment

orking capital

370.5

1088.3

272.1

$1,360.4$
61.2

UNITS PRICE

Product /Unit

0.5784

0.0017

$\begin{array}{lr}0.199 & 3.76 \\ 033.06\end{array}$

ANNUAL

U.S. \$ COST MM U.S.\$

$\begin{array}{lll}\text { Per Lb } & \text { U.S. } \$ \text { Per MT }\end{array}$

$0.197 \quad 429.31$

$(0.054) \quad(117.07)$

$(0.029) \quad(64.11)$

$(0.006) \quad(13.00)$

$(0.015) \quad(32.12)$

$(0.007) \quad(14.49)$

$(0.004) \quad(9.63)$

$(0.007) \quad(15.26)$

(0.019) (42.03)

$\begin{array}{ll}(0.019) & (42.03) \\ (0.005) & (11.25)\end{array}$

$(0.001) \quad(1.95)$

$(0.016) \quad(35.84)$

$(0.008) \quad(16.69)$

$(0.171) \quad(373.42)$

$0.027 \quad 59.65$

$\begin{array}{lr}0.027 & 5.65 \\ 0.001 & 3.17\end{array}$

$0.033 \quad 71.72$

$0.004 \quad 8.41$

$0.000 \quad 0.32$

$\mathbf{0 . 0 3 8} \quad \mathbf{8 3 . 6 2}$

$0.066 \quad 143.27$

$\underline{0.066 \quad \underline{143.27}}$

$0.001 \quad 2.79$

$0.000 \quad 0.66$

$0.000 \quad 0.06$

$0.009 \quad 19.10$

$0.001 \quad 1.58$

$\begin{array}{ll}0.011 & 24.19\end{array}$

$0.007 \quad 14.70$

$0.005 \quad 10.88$

5.44

$\begin{array}{rr}0.014 & 31.02 \\ \mathbf{0 . 0 9 1} & \mathbf{1 9 8 . 4 8}\end{array}$

$0.062 \quad 136.04$

$136.04 \quad 138$

$\underline{0.153} \quad \underline{334.53} \quad 338$

0.062

136.04

138

$\underline{0.216}$ 


\section{Table 5.13 Cost of Production Estimate for: Ethylene (FT Gas Oil/Diesel) Process: Steam Cracking (Linde, High Severity)}

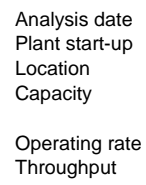

UTILITIES

\begin{tabular}{ll} 
Power (Export) & kWh \\
Fuel & MM Btu \\
Cooling Water & Mgal \\
Boiler Feedwater & MGal \\
\multicolumn{2}{c}{ TOTAL UTILITIES }
\end{tabular}

NET RAW MATERIALS \& UTILITIES

VARIABLE COST

\begin{tabular}{llrl} 
DIRECT FIXED COSTS & Labor, & 62 & Men \\
& Foremen, & 13 & Men \\
& Super., & 1 & Men \\
& Maint., Material \& Labor \\
& Direct Overhead & \multicolumn{1}{c}{ TOTAL DIRECT FIXED COSTS } \\
ALLOCATED FIXED COSTS & $\begin{array}{l}\text { General Plant Overhead } \\
\text { Insurance, Property Tax } \\
\text { Environmental }\end{array}$
\end{tabular}

TOTAL CASH COST

TOTAL ALLOCATED FIXED COSTS

5.02 Thousand U.S. \$

51.08 Thousand U.S. \$

61.63 Thousand U.S.\$

$2.66 \%$ of ISBL

$45 \%$ Labor \& Supervision

$65 \%$ Labor \& Maintenance

$1 \%$ Total Plant Capital

$0.5 \%$ Total Plant Capital

$10 \%$ for ISBL

$10 \%$ for OSBL \& OPC

COST OF PRODUCTION

RETURN ON TOTAL CAPITAL INVESTMENT (Ex. WC) @

10 Percent
CAPITAL COST MILLION U.S. \$

Total Plant Capital

Other Project Costs

Total Capital Investment

orking capital

370.5

1088.3

272.1

$1,360.4$
61.2

UNITS PRICE

Product IUnit

0.5784

0.0017

0.1653

$0.0177) \quad 0.6432$

$\begin{array}{ll}(0.0262) & 0.9940\end{array}$

0.7718

$(0.0078) \quad 0.8108$

2.9141

(0.0025) 0.408

$(0.0195) \quad 0.5080$

$(0.0059) \quad 1.3961$

2.9141

1.8430 


\section{Table 5.14 Cost of Production Estimate for: Ethylene (Gas Oil Feed) Process: Steam Cracking (Nexant Low Severity)}

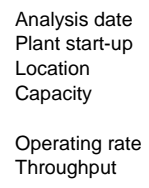

UTILITIES

\begin{tabular}{ll} 
Power (Export) & kWh \\
Fuel & MM Btu \\
Cooling Water & Mgal \\
Boiler Feedwater & MGal \\
\multicolumn{2}{c}{ TOTAL UTILITIES }
\end{tabular}

NET RAW MATERIALS \& UTILITIES

VARIABLE COST

\begin{tabular}{|c|c|c|}
\hline DIRECT FIXED COSTS & $\begin{array}{lr}\text { Labor, } & 62 \\
\text { Foremen, } & 13 \\
\text { Super., } & 1 \\
\text { Maint., Material \& Labor } & \text { Direct Overhead }\end{array}$ & $\begin{array}{l}\text { Men } \\
\text { Men } \\
\text { Men }\end{array}$ \\
\hline ALLOCATED FIXED COSTS & $\begin{array}{l}\text { TOTAL D } \\
\text { General Plant Overhead } \\
\text { Insurance, Property Tax } \\
\text { Environmental }\end{array}$ & IRECT FIXED COSTS \\
\hline
\end{tabular}

TOTAL CASH COST

$10 \%$ for ISBL

26.22 Thousand U.S.\$

63.79 Thousand U.S. \$

76.97 Thousand U.S. \$

$2.66 \%$ of ISBL

$45 \%$ Labor \& Supervision

$65 \%$ Labor \& Maintenance

$1 \%$ Total Plant Capital

Depreciation @

$10 \%$ for OSBL \& OPC

COST OF PRODUCTION

RETURN ON TOTAL CAPITAL INVESTMENT (Ex. WC) @

10 Percent

Other Project Costs

Working capital

UNITS PRICE

Product IUnit

$0.5699 \quad 0.6866$

(0.6317) $\quad 0.1956$

$(0.1591) \quad 0.2554$

$\begin{array}{ll}(0.0438) & 0.7516 \\ (0.0321) & 1.1874\end{array}$

$\begin{array}{ll}(0.0321) & 1.1874 \\ (0.0175) & 0.9099\end{array}$

$(0.0113) \quad 0.9322$

$(0.0226) \quad 0.9544$

$(0.0862) \quad 0.4932$

$(0.0245) \quad 0.3028$

(0.0043) $\quad 1.7100$

$0.0362 \quad 0.0667$

$0.0001-2.2$

\section{5}

CAPITAL COST MILLION U.S. \$

Total Plant Capital

Total Capital Investment

980.7

490.5

$1,839.0$

82.8

3.5693

COST OF PRODUCTION + ROI
0.084

$\underline{0.264}$

\begin{tabular}{|c|c|c|}
\hline $\begin{array}{l}\text { U.S. \$ } \\
\text { Per Lb }\end{array}$ & $\begin{array}{l}\text { COST MM } \\
\text { U.S. \$ }\end{array}$ & $\begin{array}{l}\text { U.S. \$ } \\
\text { Per MT }\end{array}$ \\
\hline 0.391 & 852.99 & \\
\hline 0.002 & 3.76 & \\
\hline 0.393 & 856.74 & 866 \\
\hline (0.124) & (269.42) & \\
\hline$(0.041)$ & $(88.60)$ & \\
\hline (0.033) & (71.83) & \\
\hline (0.038) & (83.13) & \\
\hline$(0.016)$ & (34.73) & \\
\hline$(0.011)$ & (22.90) & \\
\hline$(0.022)$ & $(46.98)$ & \\
\hline$(0.025)$ & (54.05) & \\
\hline$(0.043)$ & (92.65) & \\
\hline$(0.007)$ & (16.20) & \\
\hline$(0.026)$ & (57.76) & \\
\hline$(0.007)$ & (16.13) & \\
\hline$(0.392)$ & (854.38) & (864 \\
\hline 0.001 & 2.36 & 2 \\
\hline 0.002 & 5.26 & \\
\hline 0.051 & 110.34 & \\
\hline 0.006 & 14.01 & \\
\hline 0.000 & 0.40 & \\
\hline 0.060 & 130.01 & 131 \\
\hline 0.061 & 132.38 & 134 \\
\hline$\underline{0.061}$ & $\underline{132.38}$ & 134 \\
\hline 0.002 & 3.49 & \\
\hline 0.000 & 0.83 & \\
\hline 0.000 & 0.08 & \\
\hline 0.012 & 26.09 & \\
\hline 0.001 & 1.98 & \\
\hline 0.015 & 32.46 & 33 \\
\hline 0.009 & 19.81 & \\
\hline 0.007 & 14.71 & \\
\hline 0.003 & 7.36 & \\
\hline 0.019 & 41.88 & 42 \\
\hline$\underline{0.095}$ & $\underline{206.71}$ & 209 \\
\hline 0.084 & 183.90 & 186 \\
\hline$\underline{0.179}$ & $\underline{390.61}$ & 395 \\
\hline 0.084 & 183.90 & 186 \\
\hline$\underline{0.264}$ & $\underline{574.50}$ & 58 \\
\hline
\end{tabular}




\section{Table 5.15 Cost of Production Estimate for: Ethylene (Gas Oil Feed) Process: Steam Cracking (Nexant High Severity)}

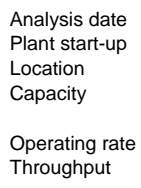

UTILITIES

\begin{tabular}{ll} 
Power (Export) & kWh \\
Fuel & MM Btu \\
Cooling Water & Mgal \\
Boiler Feedwater & MGal \\
\multicolumn{2}{c}{ TOTAL UTILITIES }
\end{tabular}

NET RAW MATERIALS \& UTILITIES

VARIABLE COST

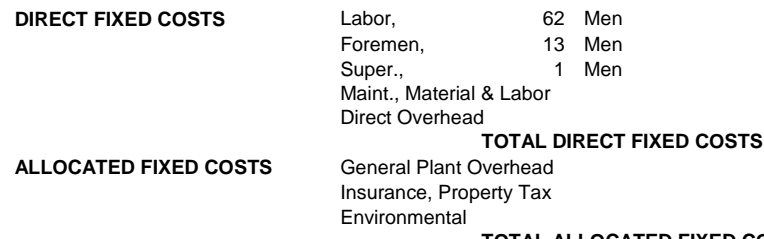

TOTAL CASH COST

$10 \%$ for ISBL

22 Thousand U.S. \$

63.79 Thousand U.S. \$

6.97 Thousand U.S. \$

$2.66 \%$ of ISBL

$45 \%$ Labor \& Supervision

$65 \%$ Labor \& Maintenance

$1 \%$ Total Plant Capital

0.5

Depreciation@

COST OF PRODUCTION

RETURN ON TOTAL CAPITAL INVESTMENT (Ex. WC) @

COST OF PRODUCTION + ROI

$\begin{array}{ll}1.0000 & 0.0017\end{array}$
CAPITAL COST MILLION U.S.\$

Total Plant Capital

Other Project Costs

Working capital

367.8

$1,839.0$
82.8

UNITS PRICE

Product IUnit

$0.4617 \quad 0.6866$

$(0.4637) \quad 0.1956$

$(0.1333) \quad 0.2554$

$(0.0326) \quad 0.7516$

$(0.0260) \quad 1.1874$

$(0.0020) \quad 0.9322$

$(0.0013) \quad 0.9544$

$(0.0065) \quad 3.5693$

$(0.0563) \quad 0.4932$

$(0.0125) \quad 0.3028$

$(0.0068) \quad 1.7100$

$0.0318 \quad 0.0667$

$0.0125 \quad 3.5693$

2.0081

ANNUAL

$0.317 \quad 691.09$

$(0.091) \quad(197.78)$

$(0.034) \quad(74.19)$

$(0.024) \quad(53.38)$

$(0.031) \quad(67.24)$

$(0.009) \quad(19.59)$

$(0.002) \quad(4.11)$

$(0.001) \quad(2.64)$

$(0.023) \quad(50.95)$

$(0.028) \quad(60.52)$

$(0.004) \quad(8.27)$

$(0.038) \quad(82.84)$

$(0.012) \quad(25.26)$

$(0.297) \quad(646.77)$

$0.022 \quad 48.08$

$0.002 \quad 4.62$

$0.045 \quad 97.07$

$0.006 \quad 12.29$

0.40

U.S.\$ COST MM U.S.\$

$\begin{array}{lll}\text { Per Lb } & \text { U.S. } \$ \text { Per MT }\end{array}$

$\begin{array}{lrr}0.002 & 3.76 & \\ \mathbf{0 . 3 1 9} & \mathbf{6 9 4 . 8 5} & \mathbf{7 0 3}\end{array}$

$0.052 \quad 114.38$

$0.075 \quad 162.45$

$\underline{0.075}$

$\underline{162.45}$

$0.019 \quad 41.88$

$\underline{0.109} \quad 236.79$

$0.084 \quad 183.90$

0.084 


\section{Table 5.16 Cost of Production Estimate for: Ethylene (Gas Oil Feed) Process: Steam Cracking (Nexant Very High Severity)}

$\begin{array}{lr}\text { Analysis date } & 2015 \\ \text { Plant start-up } & 2002 \\ \text { Location } & \text { USGC } \\ \text { Capacity } & 2,180 \text { Million pounds/yr } \\ & 989 \text { Thousand metric tons/yr } \\ \text { Operating rate } & 100 \text { percent } \\ \text { Throughput } & 2,180 \text { Million pounds/yr }\end{array}$

PRODUCTION COST SUMMARY

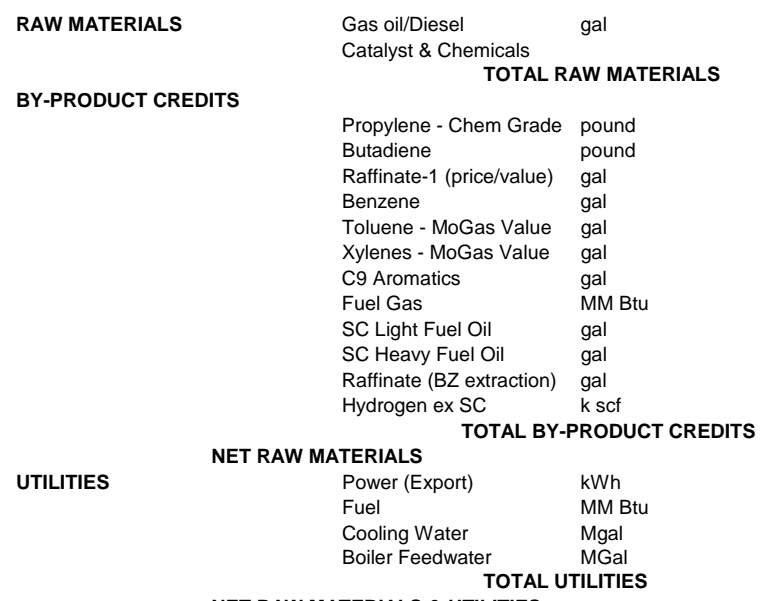

NET RAW MATERIALS \& UTILITIES

VARIABLE COST

\begin{tabular}{llrl} 
DIRECT FIXED COSTS & Labor, & 62 & Men \\
& Foremen, & 13 & Men \\
& Super., & 1 & Men \\
& Maint., Material \& Labor \\
& Direct Overhead & \multicolumn{1}{c}{ TOTAL DIRECT FIXED COSTS } \\
ALLOCATED FIXED COSTS & \multicolumn{2}{c}{ General Plant Overhead } \\
& Insurance, Property Tax \\
& Environmental
\end{tabular}

TOTAL CASH COST

TOTAL ALLOCATED FIXED COSTS

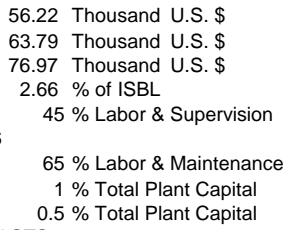

$\begin{array}{cl}\begin{array}{c}\text { UNITS } \\ \text { Per Lb } \\ \text { Product }\end{array} & \begin{array}{l}\text { PRICE } \\ \text { U.S. \$ } \\ \text { IUnit }\end{array} \\ & \\ 0.3473 & 0.6866 \\ 1.0000 & 0.0017 \\ & \\ & \\ (0.3477) & 0.1956 \\ (0.1357) & 0.2554 \\ (0.0332) & 0.7516 \\ (0.0141) & 1.1874 \\ (0.0054) & 0.9099 \\ (0.0011) & 0.9322 \\ (0.0007) & 0.9544 \\ (0.0065) & 3.5693 \\ (0.0162) & 0.4932 \\ (0.0046) & 0.3028 \\ (0.0340) & 0.6071 \\ (0.0021) & 1.7100 \\ & \\ & \\ 0.0318 & 0.0667 \\ 0.0125 & 3.5693 \\ 0.0452 & 0.1247 \\ 0.0001 & 2.2981 \\ & \end{array}$

Depreciation @

$10 \%$ for ISBL

$10 \%$ for OSBL \& OPC

COST OF PRODUCTION

RETURN ON TOTAL CAPITAL INVESTMENT (Ex. WC) @

10 Percent
MILLION U.S. \$

Total Plant Capital $\quad \mathbf{1 4 7 1 . 2}$

Other Project Costs $\quad 367.8$

$\begin{array}{cr}\text { Total Capital Investment } & \mathbf{1 , 8 3 9 . 0} \\ \text { Working capital } & 82.8\end{array}$

ANNUAL

COST MM U.S.\$

$\begin{array}{ccc}\text { U.S. \$ } & \text { COST MM } & \text { U.S. \$ } \\ \text { Per Lb } & \text { U.S. \$ } & \text { Per MT }\end{array}$

$0.238 \quad 519.87$

$0.002 \quad 3.76$

$\mathbf{0 . 2 4 0} \quad 523.63 \quad 530$

(0.068) (148.28)

$(0.035) \quad(75.52)$

$(0.025)$

$(0.017) \quad(36.50)$

(10.63)

$(0.001) \quad(2.23)$

$(0.001) \quad(1.43)$

$(0.023) \quad(50.61)$

(0.008) (17.41)

(0.001) (3.04)

$(0.021) \quad(44.97)$

$\begin{array}{ll}(0.021) & (44.97) \\ (0.004) & (7.74)\end{array}$

$\begin{array}{lr}(0.004) & (7.74) \\ (0.208) & (452.71)\end{array}$

$0.033 \quad 70.92$

$0.002 \quad 4.62$

$0.045 \quad 97.07$

$0.006 \quad 12.29$

$0.000 \quad 0.40$

$0.052 \quad 114.38$

$\begin{array}{lll}0.085 & 185.30 & 116\end{array}$

$\underline{0.085} \quad \underline{185.30} \quad 187$

$0.002 \quad 3.49$

$0.000 \quad 0.83$

$0.000 \quad 0.08$

$0.012 \quad 26.09$

$\begin{array}{lr}0.001 & 1.98 \\ 0.015 & 32.46\end{array}$

$0.009 \quad 19.81$

$0.007 \quad 14.71$

$0.003 \quad 7.36$

$0.019 \quad 41.88$

$\underline{0.119} \underline{259.63}$

$0.084 \quad 183.90$

$\underline{0.203} \quad \underline{443.53}$

0.084

183.90

$\underline{0.288} \quad 627.42$ 


\section{Table 5.17 Cost of Production Estimate for: Ethylene (FT Gas Oil/Diesel) Process: Steam Cracking (S\&W, High Severity)}

$\begin{array}{lr}\text { Analysis date } & 2015 \\ \text { Plant start-up } & 2002 \\ \text { Location } & \text { USGC } \\ \text { Capacity } & 2,180 \text { Million pounds/yr } \\ & 989 \text { Thousand metric tons/yr } \\ \text { Operating rate } & 100 \text { percent } \\ \text { Throughput } & 2,180 \text { Million pounds/yr }\end{array}$

PRODUCTION COST SUMMARY

BY-PRODUCT CREDITS

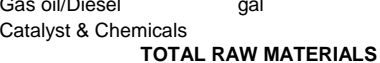

$10 \%$ for ISBL

$10 \%$ for OSBL \& OPC

Cost OF PRODUCTION

RETURN ON TOTAL CAPITAL INVESTMENT (EX. WC) @

10 Percent

CAPITAL COST MILLION U.S. \$

SBL

SBL

Other Project Costs

Total Capital Investmen

Working capital

$\begin{array}{cc}\begin{array}{c}\text { UNITS } \\ \text { Per Lb } \\ \text { Product }\end{array} & \begin{array}{l}\text { PRICE } \\ \text { U.S. \$ } \\ \text { IUnit }\end{array} \\ 0.3639 & 0.6866 \\ 1.0000 & 0.0017 \\ & \\ & \\ (0.4648) & 0.1956 \\ (0.1706) & 0.2554 \\ (0.0255) & 0.7516 \\ (0.0218) & 1.1874 \\ (0.0083) & 0.9099 \\ (0.0027) & 0.9322 \\ (0.0089) & 0.9544 \\ (0.0055) & 3.5693 \\ (0.0072) & 0.4932 \\ (0.0137) & 0.3028 \\ (0.0039) & 0.6071 \\ (0.0066) & 1.7100\end{array}$

$0.0270 \quad 0.0667$

$0.0113 \quad 3.5693$

$\begin{array}{ll}0.0384 & 0.1247 \\ 0.0001 & 2.2981\end{array}$

COST OF PRODUCTION + ROI

921.9
475.7
1397.6
349.4
$1,747.0$
78.6

ANNUAL

$\begin{array}{lll}\text { U.S. } \$ \text { COST MM } & \text { U.S. } \$\end{array}$

$\begin{array}{lcc}\text { Per Lb } & \text { U.S. \$ } & \text { Per MT }\end{array}$

$0.250 \quad 544.67$

$\begin{array}{lr}0.002 & 3.76 \\ \mathbf{0 . 2 5 2} & \mathbf{5 4 8 . 4 3}\end{array}$

555

(0.091) (198.25)

$(0.044) \quad(94.96)$

$(0.019) \quad(41.85)$

$(0.026) \quad(56.40)$

$(0.008) \quad(16.54)$

$\begin{array}{ll}(0.008) & (16.54) \\ (0.002) & (5.43)\end{array}$

$\begin{array}{lr}(0.002) & (5.43) \\ (0.009) & (18.60)\end{array}$

$(0.020) \quad(43.14)$

$(0.004) \quad(7.69)$

$(0.004) \quad(9.04)$

$(0.002) \quad(5.16)$

(0.011) (24.67)

$\begin{array}{lr}(0.011) & (24.67) \\ (0.239) & (521.73)\end{array}$

(0.239) (521.73)

$0.012 \quad 26.71$

$0.002 \quad 3.92$

$0.040 \quad 87.85$

$0.005 \quad 10.45$

$0.000 \quad 0.40$

$0.047 \quad 102.62 \quad 104$

$0.059 \quad 129.32 \quad 131$

$\underline{0.059} \quad \underline{129.32} \quad 131$

$0.002 \quad 3.49$

$0.000 \quad 0.83$

$0.000 \quad 0.08$

$0.011 \quad 24.52$

$0.001 \quad 1.98$

$0.014 \quad 30.89$

$0.009 \quad 18.79$

$0.006 \quad 13.98$

$0.003 \quad 6.99$

$0.018 \quad 39.76 \quad 40$

$\underline{0.092} \underline{199.97} \quad 202$

$\begin{array}{lll}0.080 & 174.70 \quad 177\end{array}$

$\underline{0.172} \quad \underline{374.67} \quad 379$

$0.080 \quad 174.70 \quad 177$

$\underline{0.252} \quad \underline{549.38}$ 


\section{Table 5.18 Cost of Production Estimate for: Ethylene (Ft Gas Oil/Diesel) Process: Steam Cracking (Lummus, Low Severity)}

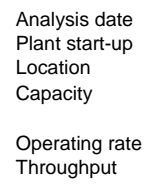

UTILITIES

\begin{tabular}{ll} 
Power (Export) & kWh \\
Fuel & MM Btu \\
Cooling Water & Mgal \\
Boiler Feedwater & MGal \\
\multicolumn{2}{c}{ TOTAL UTILITIES }
\end{tabular}

NET RAW MATERIALS \& UTILITIES

VARIABLE COST

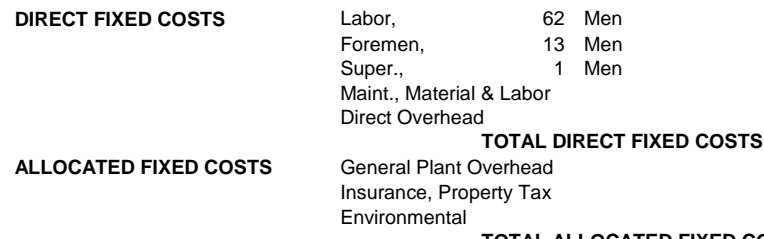

TOTAL CASH COST

$10 \%$ for ISBL

$10 \%$ for OSBL \& OPC and U.S. \$

63.79 Thousand U.S. \$

6.97 Thousand U.S.\$

$2.66 \%$ of ISBL

$65 \%$ Labor \& Maintenance

$1 \%$ Total Plant Capita $0.5 \%$ Total Plant Capital
$45 \%$ Labor \& Supervision

COST OF PRODUCTION

RETURN ON TOTAL CAPITAL INVESTMENT (Ex. WC) @

COST OF PRODUCTION + ROI

10 Percent

CAPITAL COST MILLION U.S. \$

Total Plant Capital

Other Project Costs

Total Capital Investment

orking capital

475.7

1397.6

349.4

$1,747.0$

78.6

UNITS PRICE

Product /Unit

0.6866

0.0017

U.S.\$ COST MM U.S.\$

$\begin{array}{lll}\text { Per Lb } & \text { U.S. } \$ \text { Per MT }\end{array}$

$0.331 \quad 720.77$

$\begin{array}{lrr}0.002 & 3.76 & \\ \mathbf{0 . 3 3 2} & \mathbf{7 2 4 . 5 3} & \mathbf{7 3 3}\end{array}$

$(0.123) \quad(268.96)$

$(0.040) \quad(87.07)$

$(0.044) \quad(96.94)$

$(0.011) \quad(24.78)$

$(0.014) \quad(31.45)$

$(0.004) \quad(9.15)$

$(0.021) \quad(45.54)$

$(0.021) \quad(45.72)$

$\begin{array}{ll}(0.021) & (45.72) \\ (0.012) & (26.19)\end{array}$

$\begin{array}{ll}(0.012) & (26.19) \\ (0.002) & (4.58)\end{array}$

$(0.048) \quad(104.18)$

(0.008) (17.32)

(0.349) (761.89)

$\begin{array}{ll}(0.349) & (761.89) \\ (0.017) & (37.35)\end{array}$

$\begin{array}{cc}\mathbf{( 0 . 0 1 7 )} & \mathbf{( 3 7 . 3 5 )} \\ 0.002 & 4.47\end{array}$

$\begin{array}{lr}0.002 & 4.47 \\ 0.046 & 99.86\end{array}$

$0.005 \quad 11.91$

$0.000 \quad 0.40$

$0.054 \quad 116.64$

$0.036 \quad 79.28$

$\underline{0.036} \quad \underline{79.28}$

(770)

$0.000 \quad 0.83$

$0.000 \quad 0.08$

$0.011 \quad 24.52$

$0.001 \quad 1.98$

$\begin{array}{ll}\mathbf{0 . 0 1 4} & \mathbf{3 0 . 8 9}\end{array}$

$0.009 \quad 18.79$

$0.006 \quad 13.98$

6.99

\begin{tabular}{rr}
0.018 & 39.76 \\
$\mathbf{0 . 0 6 9}$ & $\mathbf{1 4 9 . 9 3}$ \\
\hline
\end{tabular}

$0.080 \quad 174.70$

152

177

$\underline{0.149} \quad \underline{324.63} \quad 328$

$\begin{array}{lll}0.080 & 174.70 \quad 177\end{array}$

$\underline{0.229} \quad \underline{499.34} \quad \mathbf{5 0 5}$ 


\section{Table 5.19 Cost of Production Estimate for: Ethylene (Ft Gas Oil/Diesel) Process: Steam Cracking (Lummus, High Severity)}

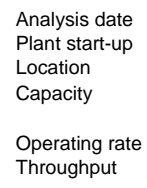

UTILITIES

$\begin{array}{ll}\text { Power (Export) } & \text { kWh } \\ \text { Fuel } & \text { MM Btu } \\ \text { Cooling Water } & \text { Mgal } \\ \text { Boiler Feedwater } & \text { MGal }\end{array}$

NET RAW MATERIALS \& UTILITIES

VARIABLE COST

\begin{tabular}{llrl} 
DIRECT FIXED COSTS & Labor, & 62 & Men \\
& Foremen, & 13 & Men \\
& Super., & 1 & Men \\
& Maint., Material \& Labor \\
& Direct Overhead & \multicolumn{2}{c}{ TOTAL DIRECT FIXED COSTS } \\
ALLOCATED FIXED COSTS & \multicolumn{1}{c}{ General Plant Overhead } \\
& Insurance, Property Tax \\
& Environmental
\end{tabular}

TOTAL CASH COST

$10 \%$ for ISBL

22 Thousand U.S. \$

63.79 Thousand U.S. \$

6.97 Thousand U.S. \$

$2.66 \%$ of ISBL

$45 \%$ Labor \& Supervision

$65 \%$ Labor \& Maintenance

$1 \%$ Total Plant Capital

$0.5 \%$ Total Plant Capital

COST OF PRODUCTION

10 Percent

RETURN ON TOTAL CAPITAL INVESTMENT (Ex. WC) @

COST OF PRODUCTION + ROI

$10 \%$ for OSBL \& OPC

CAPITAL COST MILLION U.S. \$

Total Plant Capital

Ther Project Costs

PRICE

S. \$

6866

0.0017

$\begin{array}{lrr}0.002 & 3.76 & \\ \mathbf{0 . 2 5 9} & \mathbf{5 6 4 . 9 8} & \mathbf{5 7 1}\end{array}$

(0.079) (172.41)

$(0.038) \quad(82.84)$

$(0.019) \quad(41.96)$

$(0.021) \quad(46.67)$

$(0.014) \quad(29.67)$

$(0.003) \quad(6.39)$

$(0.012) \quad(26.36)$

$\begin{array}{ll}(0.012) & (26.36) \\ (0.026) & (57.06)\end{array}$

$\begin{array}{ll}(0.026) & (57.06) \\ (0.007) & (14.76)\end{array}$

$(0.001) \quad(2.58)$

$(0.014) \quad(29.52)$

$(0.009) \quad(19.12)$

(0.243) (529.33)

$0.016 \quad 35.65$

$\begin{array}{ll}0.002 & 3.92 \\ 0.040 & 87.85\end{array}$

$0.040 \quad 87.85$

$0.005 \quad 10.45$

$0.047 \quad 102.62$

$0.063 \quad 138.27$

$\underline{0.063}$

$\underline{138.27}$

$0.018 \quad 39.76$

$\underline{0.096} \quad \underline{208.92}$

$0.080 \quad 174.70$

0.080

174.70 


\section{Table 5.20 Cost of Production Estimate for: Ethylene (Ft Gas Oil/Diesel) Process: Steam Cracking (KBR, Very High Severity)}

$\begin{array}{lr}\text { Analysis date } & 2015 \\ \text { Plant start-up } & 2002 \\ \text { Location } & \text { USGC } \\ \text { Capacity } & 2,180 \text { Million pounds/yr } \\ & 989 \text { Thousand metric tons/yr } \\ \text { Operating rate } & 100 \text { percent } \\ \text { Throughput } & 2,180 \text { Million pounds/yr }\end{array}$

PRODUCTION COST SUMMARY

RAW MATERIAL

BY-PRODUCT CREDITS

Gas oil/Diesel Catalyst \& Chemicals

gal TOTAL RAW MATERIALS

Propylene - Chem Grade pound $\begin{array}{ll}\text { Propylene - Chem Grade pound } \\ \text { Butadiene } & \text { pound }\end{array}$ Raffinate-1 (price/value) Benzene Toluene - MoGas Value Xylenes - MoGas Value C9 Aromatics Fuel Gas SC Light Fuel Oil SC Heavy Fuel Oi Raffinate (BZ extraction) Hydrogen ex SC

gal

k scf

UTILITIES

$\begin{array}{ll}\text { Power (Export) } & \text { kWh } \\ \text { Fuel } & \text { MM Btu } \\ \text { Cooling Water } & \text { Mgal } \\ \text { Boiler Feedwater } & \text { MGal }\end{array}$

NET RAW MATERIALS \& UTILITIES

VARIABLE COST

\begin{tabular}{llrl} 
DIRECT FIXED COSTS & Labor, & 62 & Men \\
& Foremen, & 13 & Men \\
& Super., & 1 & Men \\
& Maint., Material \& Labor \\
& Direct Overhead & \multicolumn{2}{c}{ TOTAL DIRECT FIXED COSTS } \\
ALLOCATED FIXED COSTS & $\begin{array}{l}\text { General Plant Overhead } \\
\text { Insurance, Property Tax } \\
\text { Environmental }\end{array}$
\end{tabular}

TOTAL CASH COST

TOTAL ALLOCATED FIXED COSTS

56.22 Thousand U.S. \$

63.79 Thousand U.S. \$

76.97 Thousand U.S. \$

$2.66 \%$ of ISBL

$10 \%$ for ISBL

COST OF PRODUCTION

RETURN ON TOTAL CAPITAL INVESTMENT (Ex. WC) @

COST OF PRODUCTION + ROI

$45 \%$ Labor \& Supervision

$65 \%$ Labor \& Maintenance

$1 \%$ Total Plant Capital

$0.5 \%$ Total Plant Capital

$10 \%$ for OSBL \& OPC

10 Percent

CAPITAL COST MILLION U.S. \$

Total Plant Capital

Other Project Costs

921.9
475.7
1397.6
349.4

$1,747.0$
78.6

747.0
78.6

UNITS PRICE

Product IUnit

6866

0.0017

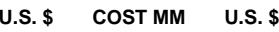

Per Lb U.S. \$ Per MT

$0.234 \quad 509.6$

$\begin{array}{lr}0.002 & 3.76 \\ 0.236 & \mathbf{5 1 3 . 4 0}\end{array}$

519

$(0.064) \quad(138.55)$

$(0.035) \quad(75.75)$

$(0.007) \quad(15.19)$

$(0.018) \quad(38.37)$

$(0.008) \quad(17.08)$

$(0.005) \quad(11.34)$

(17.96)

$(0.024) \quad(51.47)$

$(0.006) \quad(13.60)$

$(0.001) \quad(2.38)$

$(0.020) \quad(42.83)$

$(0.009) \quad(20.44)$

$(0.204) \quad(444.95)$

$0.031 \quad 68.45$

$\begin{array}{ll}0.002 & 3.92\end{array}$

$0.040 \quad 87.85$

$0.005 \quad 10.45$

$0.000 \quad 0.40$

$0.047 \quad 102.62$

$\underline{0.078} \quad \underline{171.07} \quad 173$

$0.002 \quad 3.49$

$0.000 \quad 0.83$

$0.000 \quad 0.08$

$0.011 \quad 24.52$

$0.001 \quad 1.98$

$\begin{array}{ll}\mathbf{0 . 0 1 4} & \mathbf{3 0 . 8 9} \\ 0.009 & 18.79\end{array}$

$0.009 \quad 18.79$

$0.006 \quad 13.98$

\begin{tabular}{rr}
0.018 & 39.76 \\
$\mathbf{0 . 1 1 1}$ & $\mathbf{2 4 1 . 7 2}$ \\
\hline
\end{tabular}

$0.080 \quad 174.70$

244

177

$\underline{0.191} \quad \underline{416.42} \quad 421$

$\begin{array}{lll}0.080 & 174.70 \quad 177\end{array}$

$\underline{0.271} \underline{591.12}$ 


\section{Table 5.21 Cost of Production Estimate for: Ethylene (FT Gas Oil/Diesel) Process: Steam Cracking (Linde, High Severity)}

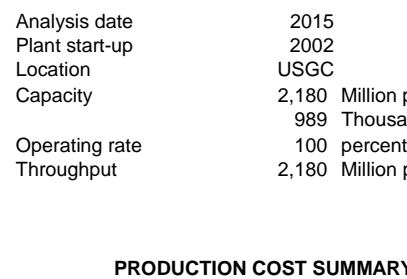

UTILITIES

$\begin{array}{ll}\text { Power (Export) } & \text { kWh } \\ \text { Fuel } & \text { MM Btu } \\ \text { Cooling Water } & \text { Mgal } \\ \text { Boiler Feedwater } & \text { MGal }\end{array}$

NET RAW MATERIALS \& UTILITIES

VARIABLE COST

\begin{tabular}{llrl} 
DIRECT FIXED COSTS & Labor, & 62 & Men \\
& Foremen, & 13 & Men \\
& Super., & 1 & Men \\
& Maint., Material \& Labor \\
& Direct Overhead & \multicolumn{2}{c}{ TOTAL DIRECT FIXED COSTS } \\
ALLOCATED FIXED COSTS & \multicolumn{2}{c}{ General Plant Overhead } \\
& Insurance, Property Tax \\
& Environmental
\end{tabular}

TOTAL CASH COST

$10 \%$ for ISBL

22 Thousand U.S. \$

63.79 Thousand U.S. \$

76.97 Thousand U.S.\$

$2.66 \%$ of ISBL

$45 \%$ Labor \& Supervision

$65 \%$ Labor \& Maintenance

$1 \%$ Total Plant Capital

0.5

Working capital

$\begin{array}{cc}\begin{array}{c}\text { UNITS } \\ \text { Per Lb } \\ \text { Product }\end{array} & \begin{array}{l}\text { PRICE } \\ \text { U.S. \$ } \\ \text { IUnit }\end{array} \\ & \\ 0.3641 & 0.6866 \\ 1.0000 & 0.0017 \\ & \\ & \\ (0.4681) & 0.1956 \\ (0.1827) & 0.2554 \\ (0.0177) & 0.7516 \\ (0.0262) & 1.1874 \\ (0.0084) & 0.9099 \\ (0.0018) & 0.9322 \\ (0.0078) & 0.9544 \\ (0.0063) & 3.5693 \\ (0.0087) & 0.4932 \\ (0.0025) & 0.3028 \\ (0.0195) & 0.6071 \\ (0.0059) & 1.7100\end{array}$

Depreciation @

CAPITAL COST MILLION U.S. \$

Other Project Costs

Total Capital Investmen

349.4

$1,747.0$

78.6

ANNUAL

U.S.\$ COST MM U.S.\$

$\begin{array}{lll}\text { Per Lb } & \text { U.S. } \$ \text { Per MT }\end{array}$

$0.250 \quad 544.94$

0.002

$\mathbf{0 . 2 5 2} \quad \mathbf{5 4 8 . 6 9} \quad \mathbf{5 5 5}$

$\underline{0.242}$

$10 \%$ for OSBL \& OPC

(0.092) (199.65)

$(0.047) \quad(101.71)$

$(0.013) \quad(29.00)$

$(0.031) \quad(67.95)$

$(0.008)$

$(0.002) \quad(3.75)$

$(0.007) \quad(16.29)$

$\begin{array}{ll}(0.007) & (16.29) \\ (0.022) & (48.92)\end{array}$

$\begin{array}{ll}(0.022) & (48.92) \\ (0.004) & (9.40)\end{array}$

$\begin{array}{ll}(0.004) & (9.40) \\ (0.001) & (1.64)\end{array}$

$(0.012) \quad(25.81)$

$(0.010) \quad(21.83)$

$(0.249) \quad(542.72)$

$0.003 \quad 5.98$

$0.002 \quad 3.92$

$0.040 \quad 87.85$

$0.005 \quad 10.45$

$0.000 \quad 0.40$

$0.047 \quad 102.62$

$0.050 \quad 108.60$

$\underline{0.050} \quad \underline{108.60}$

(549)

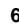

104

110

110

$0.002 \quad 3.49$

$0.000 \quad 0.83$

$0.000 \quad 0.08$

$0.011 \quad 24.52$

$0.001 \quad 1.98$

$\begin{array}{ll}\mathbf{0 . 0 1 4} & \mathbf{3 0 . 8 9}\end{array}$

$0.009 \quad 18.79$

$0.006 \quad 13.98$

$0.003 \quad 6.99$

$0.018 \quad 39.76$

$0.082 \quad \underline{179.24}$

$0.080 \quad 174.70$

COST OF PRODUCTION

$\underline{0.162 \quad 353.95}$

$0.080 \quad 174.70$

10 Percent

55

RETURN ON TOTAL CAPITAL INVESTMENT (Ex. WC) @

Percent 


\subsection{FT NAPHTHA}

\subsubsection{FT Naphtha Qualities}

Properties for Fischer-Tropsch naphthas have been reviewed as reported for a range of GTL processes. This data is presented in Table 5.22 for Conoco, Syntroleum, and Rentech. The Syntroleum and Rentech data are based on published information. For all processes, FT naphtha is highly paraffinic with very low sulfur content. The iso to normal paraffin ratio varied from 14:86 to 40:60. The distillation curves of the naphtha samples are shown in Figure 5.7. The differences between the various processes are relatively small and should not materially impact the relative performance of FT naphtha as an ethylene feedstock. Also shown are properties of a conventional crude oil-based naphtha that would be used as an ethylene feedstock. The distillation curves of the naphtha samples are shown in Figure 5.7.

Table 5.22 Typical Product Qualities - GTL Naphtha

\begin{tabular}{|l|c|c|c|c|c|}
\hline \multicolumn{2}{|c|}{ Product Property } & Conoco & Syntroleum & Rentech & $\begin{array}{c}\text { Conventional } \\
\text { Naphtha }\end{array}$ \\
\hline Specific Gravity & & 0.691 & 0.71 & 0.700 & 0.7063 \\
\hline API Gravity & & 73.3 & 68 & 69.1 & 68.8 \\
\hline Distillation, ${ }^{\circ} \mathrm{C}$ & & & & & 37 \\
\hline & IBP & 54 & 21 & 49 & 62 \\
\hline & $10 \%$ & 62 & 74 & 83 & 114 \\
\hline & $30 \%$ & 82 & 112 & 127 & 103 \\
\hline & $50 \%$ & 106 & 127 & 136 & 122 \\
\hline & $70 \%$ & 138 & 152 & 143 \\
\hline & $90 \%$ & & & & 167 \\
\hline Hydrocarbon Types, vol\% & $95 \%$ & 173 & 174 & & \\
\hline & FBP & & & & \\
\hline & & & & & \\
\hline & Olefins & $<3$ & $<1$ & & 14.9 \\
\hline & Paraffins & & $>99$ & & 7.7 \\
\hline Isoparaffins (vol\% of total paraffins) & Naphthenes & 0 & $<1$ & & \\
\hline Total Sulfur, wt. ppm & Aromatics & $<1$ & $<0.1$ & & \\
\hline Reid Vapor Pressure, psi & & $40+/-10$ & 16 & & \\
\hline
\end{tabular}




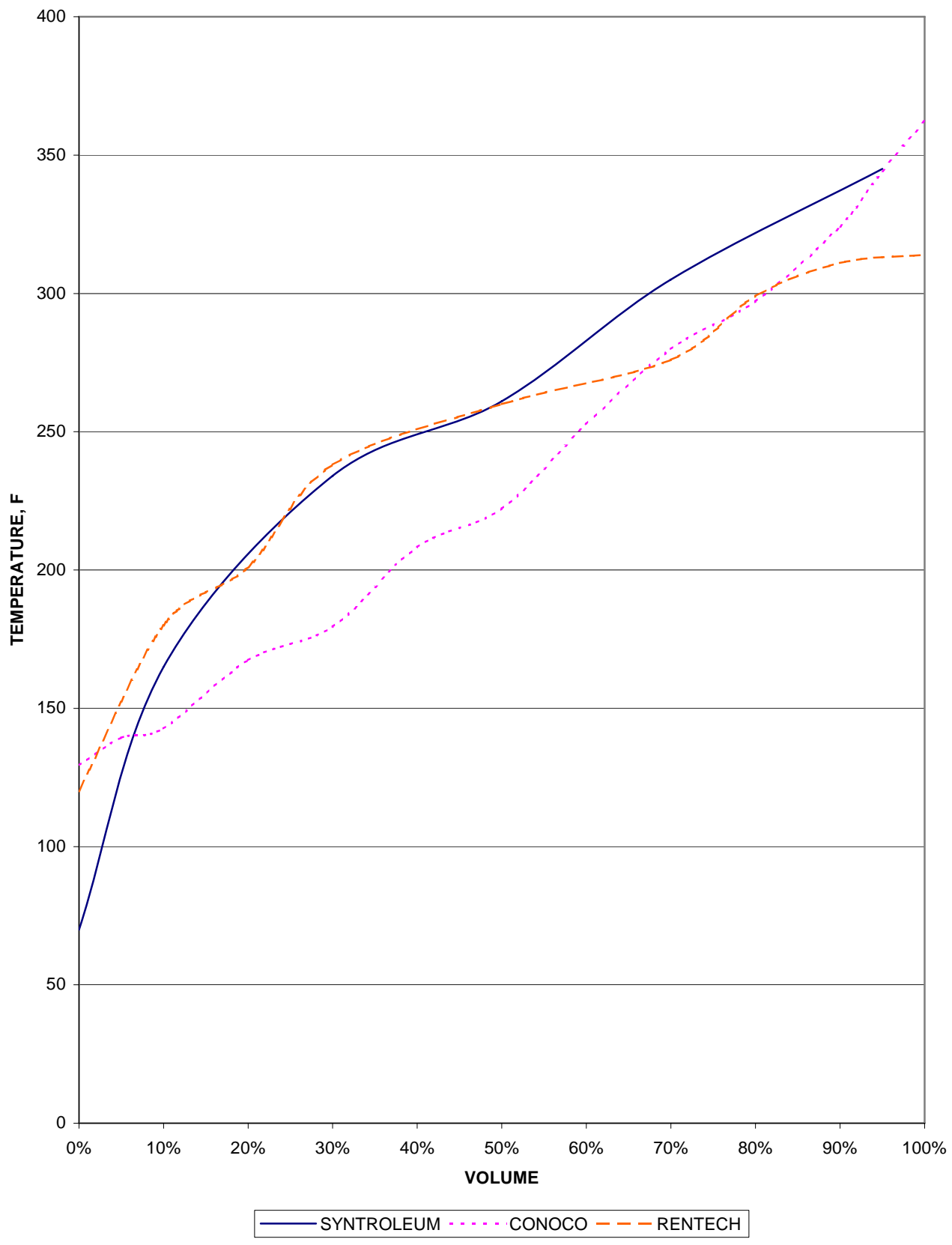

Figure $5.7 \quad$ FT Naphtha Samples

\subsubsection{Use as Ethylene Feedstock}

\subsubsection{Cracking Yields for FT Naphtha}

Typical FT naphtha properties were supplied to four ethylene plant licensors (Kellogg Brown \& Root, Linde AG, ABB Lummus and Stone \& Webster) to obtain yield data for steam cracking to 
ethylene and other chemicals. The licensors indicated that the paraffinic nature of the FT naphtha allows for a higher severity operation than might be normally considered when compared to conventional naphtha cracking.

Once-through yield data (i.e., without recycling ethane and propane to extinction) provided by the licensors is summarized in Table 5.23. The severities (as measured by the overall propylene-to-ethylene ratio including the recycle of ethane and propane to extinction) range from low severity $(\mathrm{P} / \mathrm{E}=0.572$, Lummus) to very high severity $(\mathrm{P} / \mathrm{E}=0.347$, Lummus).

The ratio of feedstock naphtha to ethylene is as low as $2.15 \mathrm{mt} / \mathrm{mt}(\mathrm{KBR})$ and averages about 85 percent of the ratio for conventional naphtha feedstocks. This indicates that FT naphtha is a very good cracker feed in that it requires less feed than conventional naphtha to produce the same amount of ethylene.

The propylene-to-ethylene ratios for conventional and FT naphtha feedstocks are shown in Figure 5.8 and indicate similar yield structure for both feedstocks at equivalent operating severity. Combined ethylene and propylene yields are shown in Figure 5.9 and in general show better combined yields for FT naphtha at equivalent operating severity. This analysis indicates that FT naphthas can be expected to be excellent steam cracker feedstocks for the production of ethylene. Figure 5.10 shows the ethylene product to naphtha feed ratio. In all cases less of the FT feed is needed to produce the same amount of ethylene. 


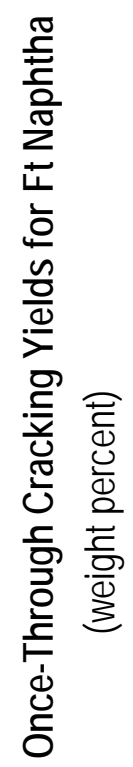

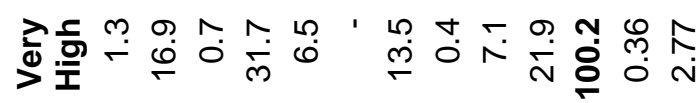

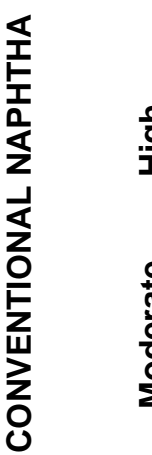

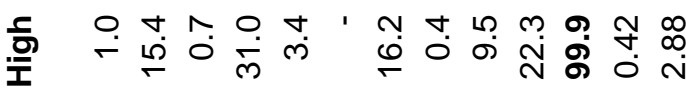

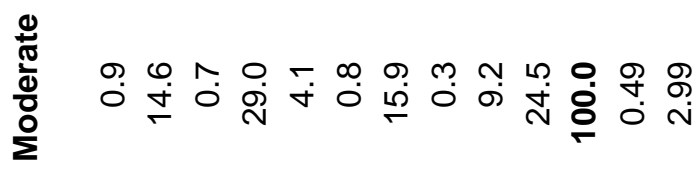

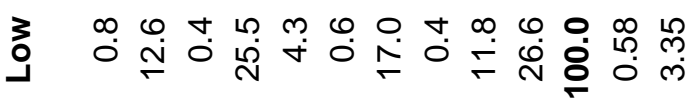

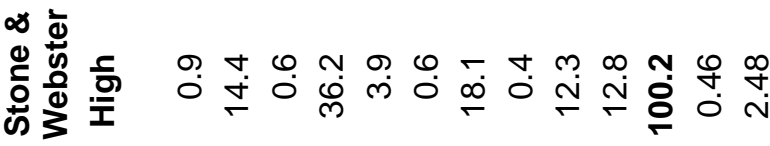

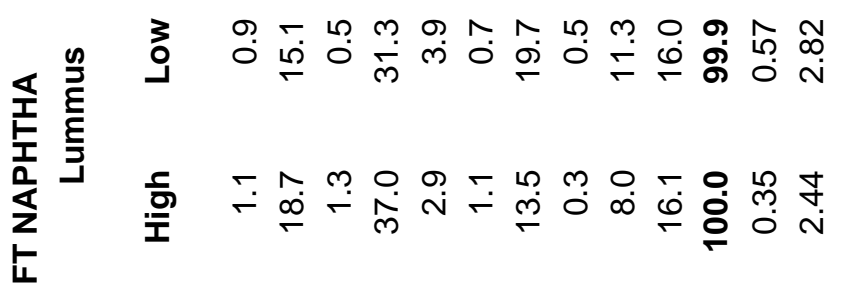

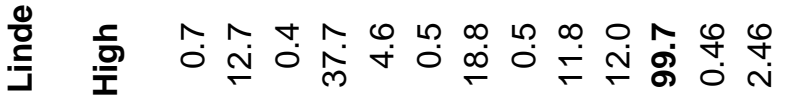

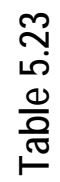

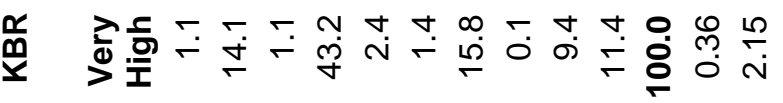

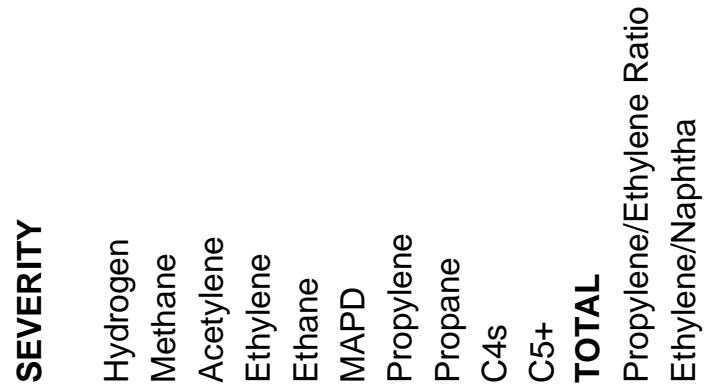




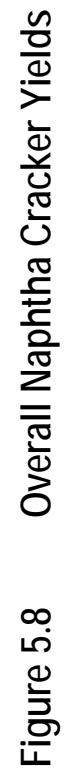

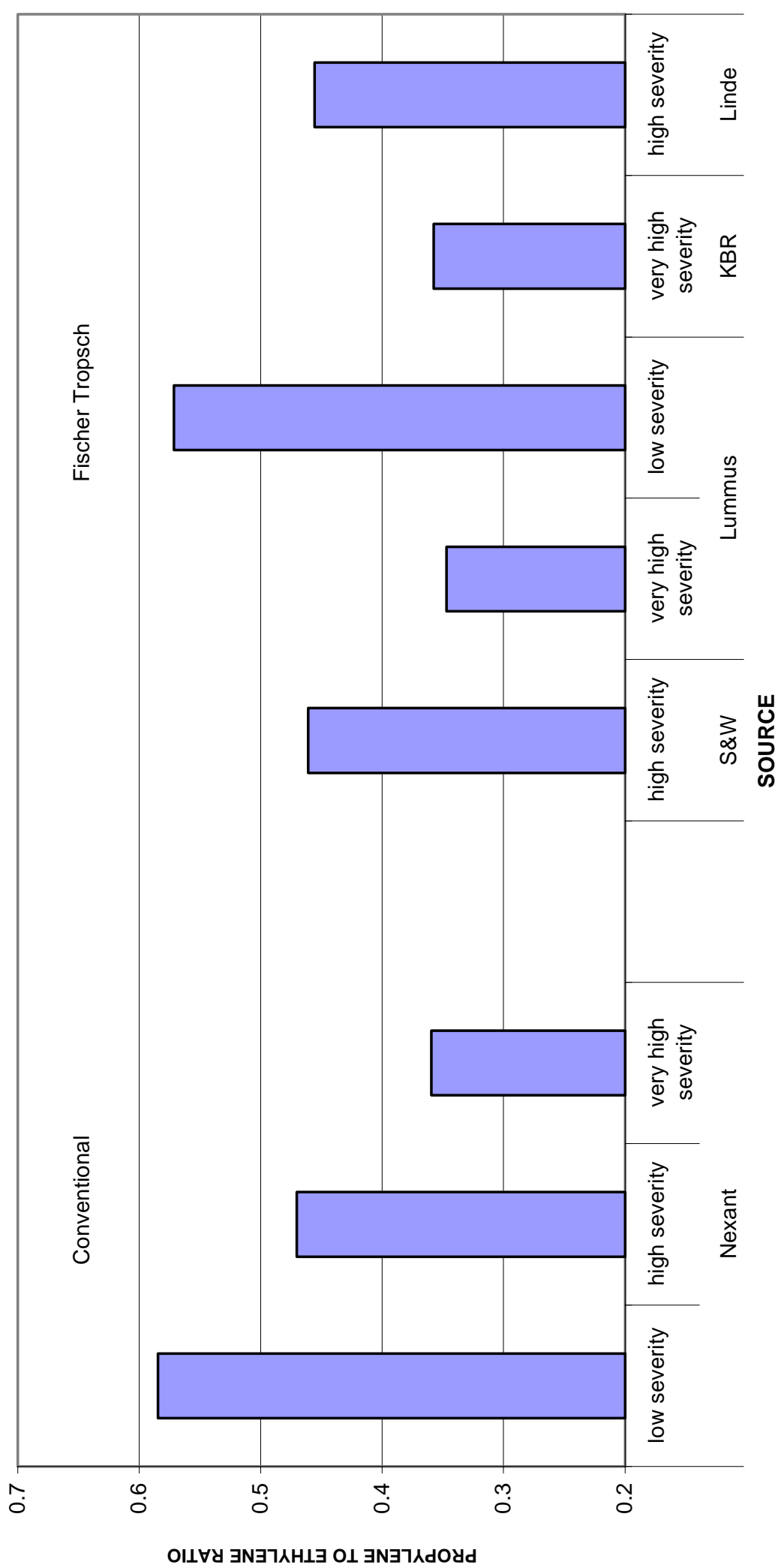




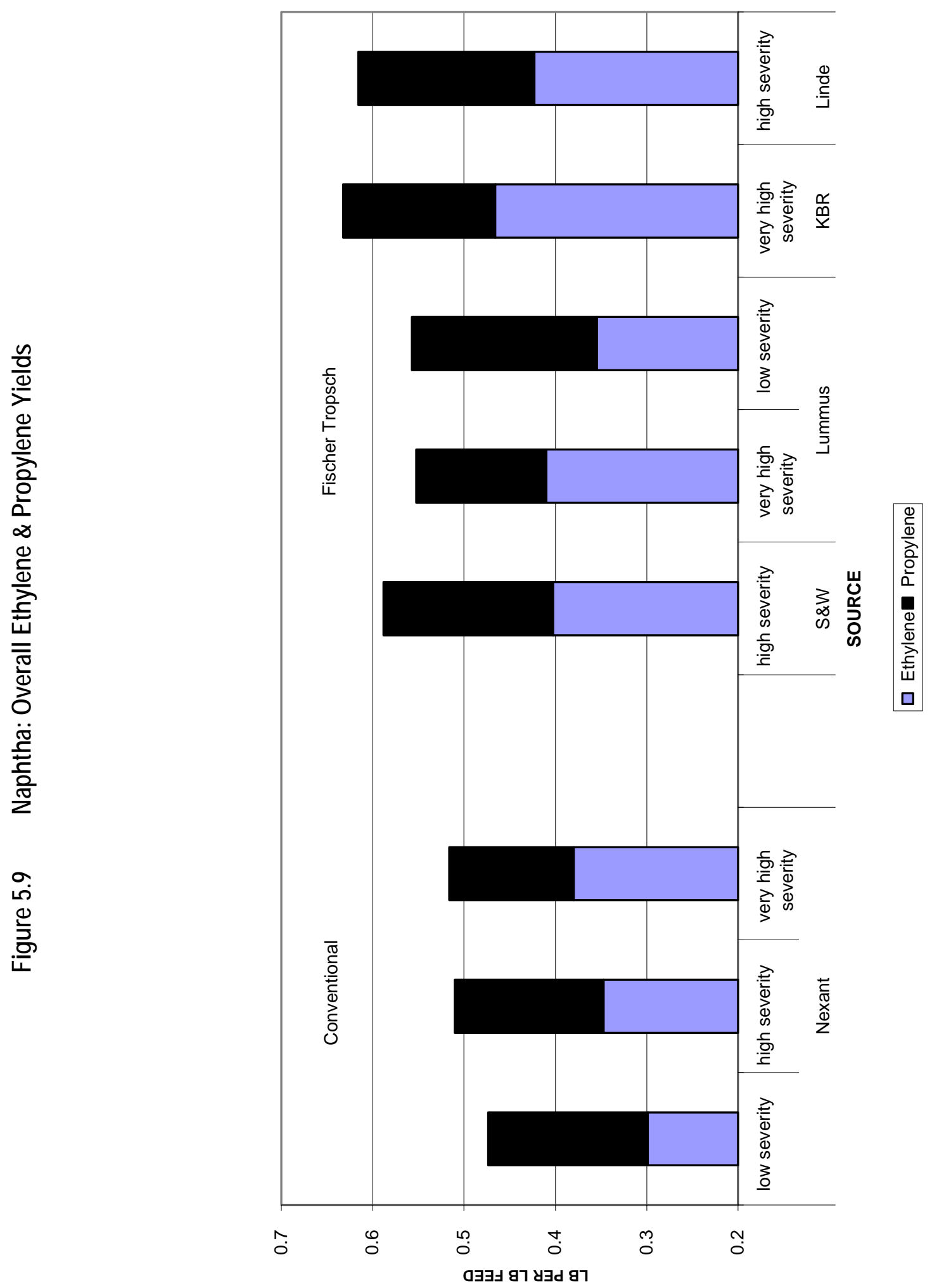




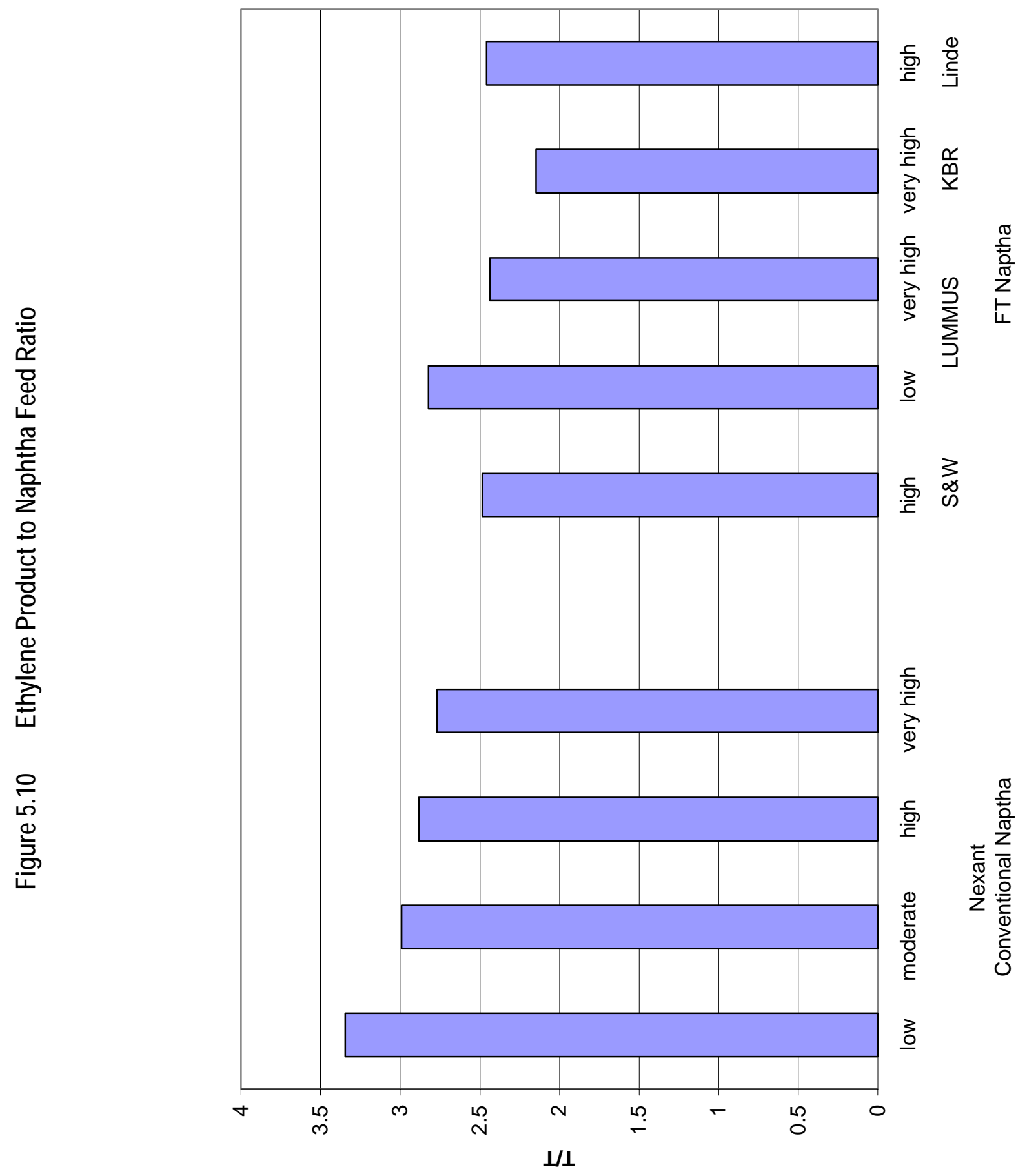




\subsubsection{Basis for Economics}

Nexant has evaluated the relative economic attractiveness of FT naphtha feedstocks relative to conventional naphtha feedstocks by examining economics of converting each to ethylene and other chemicals via steam cracking technology. The basis for the steam cracking economics, which follow, is a world scale plant (2,180 million pounds per year, or 989 thousand tons per year of ethylene production) on the USGC with flexibility to process either a full range naphtha or gas oil feedstock. Most steam crackers in the United States are designed to operate for extended periods of time (i.e. one scheduled maintenance turnaround every 4 to 5 years).

The capital investment for a steam cracker designed to process FT liquids will have a slightly lower investment compared to one designed to process conventional feedstocks, reflecting the higher yield of ethylene and propylene per unit of feed for the FT feedstocks. A 6 percent reduction in Inside Battery Limits capital (ISBL) has been used to reflect one less furnace, no amine scrubbing system and less heavy by-product $(\mathrm{C} 4+)$ production. The Outside Battery Limits capital (OSBL) has been reduced by 3 percent primarily due to lower tankage requirements for feedstock and $\mathrm{C} 4+$ by-products.

Utilities for the FT liquid cases have also been reduced as follows:

- Power by 15 percent

- Fuel by 9.5 percent

- Cooling water by 15 percent

These savings reflect the lower production levels of $\mathrm{C} 4+$ by-products within the unit.

\subsubsection{Feedstock and Utilities Pricing and Labor Costs}

Feedstock, by-product, utility and labor rates used in this study are shown in Table 5.24 for historical years 1997 through 2001 and for forecast years 2006 and 2015. These prices are based on Nexant's historical databases and most current price forecast, based on its Medium Crude Oil price outlook.

\subsubsection{Economics of Cracking FT Naphtha}

The cash cost of production for producing ethylene from conventional naphtha is compared to that from a typical FT naphtha in Table 5.25 for historical years 1997 through 2001 as well as forecast years 2006 and 2015. Figure 5.11 shows the costs for years 2001, 2006 and 2015.

The cash margins are shown in Table 5.26 by feedstock, severity and year. The Fischer-Tropsch feeds have higher average cash margins than the conventional feedstock in every year examined in this study. This margin premiums range from a low of $\$ 12$ per metric ton in 1998 to a high of $\$ 34$ per metric ton for the forecast year 2001. The average premium is $\$ 24$ per metric ton.

Table 5.27 shows that FT naphtha has a measurably lower cost of production at equivalent operating severities, based on setting an equal value for both feedstocks. The results of this analysis indicate that the average ethylene cash margin for the years studied would be about $\$ 24$ 
per ton higher for the FT naphthas, which is about a 10 percent increase in the cash margin over ethylene produced from conventional naphtha. Another way to examine the value of the FT naphtha is to calculate the premium that the FT naphtha would be worth based on maintaining a constant ethylene margin. On this basis FT naphtha is estimated to be worth $\$ 19$ per ton more than conventional naphtha feedstocks on average over the time period studied. In 2006, the average is $\$ 19$ per ton and in 2015 it is $\$ 23$ per ton. Operating severity has a significant influence on the savings or premium. For the cases studied the delta ethylene cash cost as an average for the years studied ranged from $\$ 16$ per ton to $\$ 86$ per ton and the average premium for the FT naphtha ranged from $\$ 6$ per ton to $\$ 40$ per ton. The general conclusion of this analysis is that FT naphthas will make attractive ethylene cracker feedstocks and should be worth a measurable premium to ethylene producers relative to conventionally cracked naphthas. 


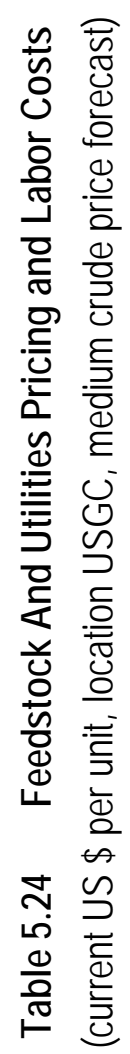

虽

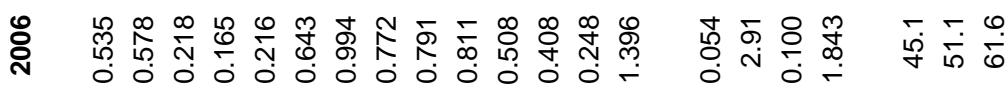

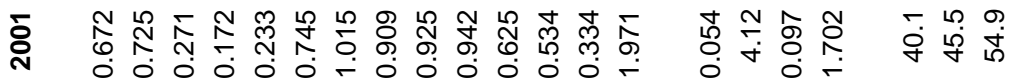

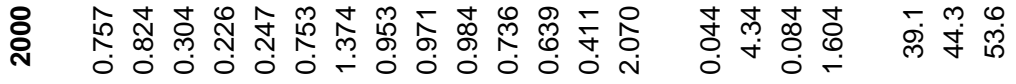

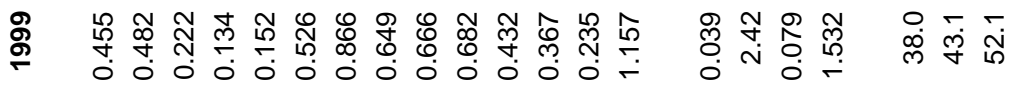

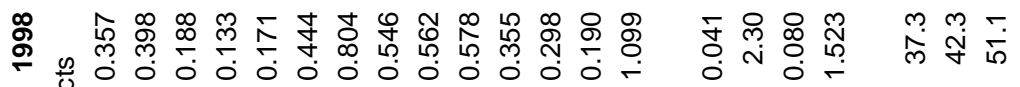

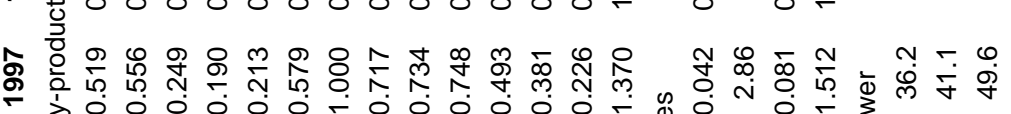

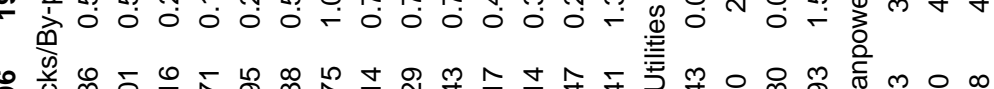

荈总

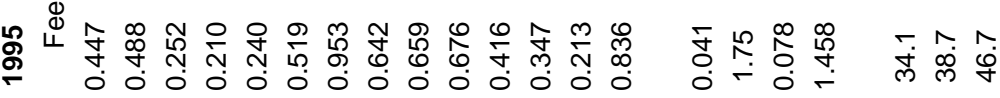

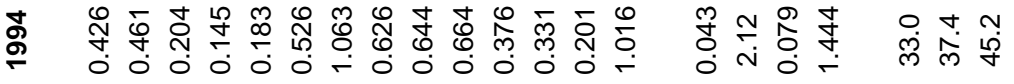

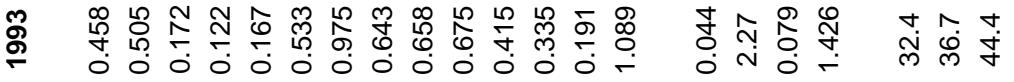

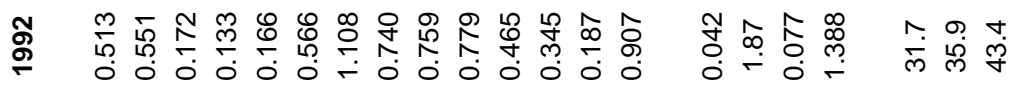

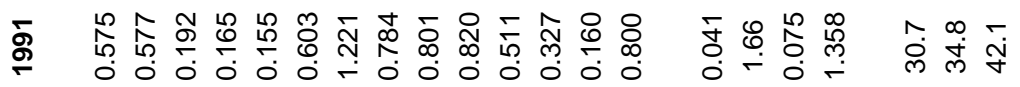

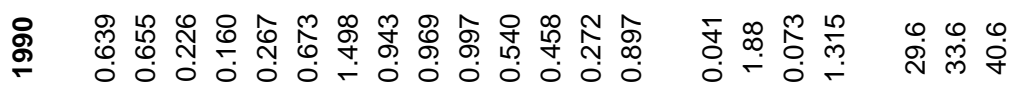

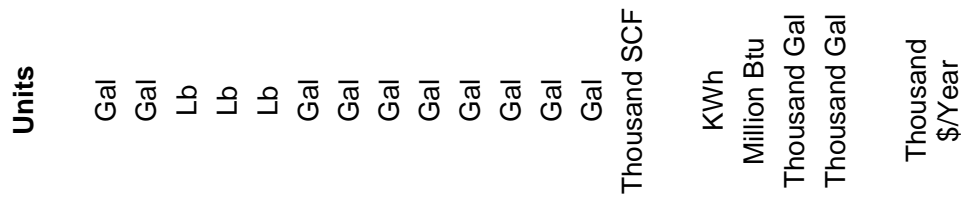

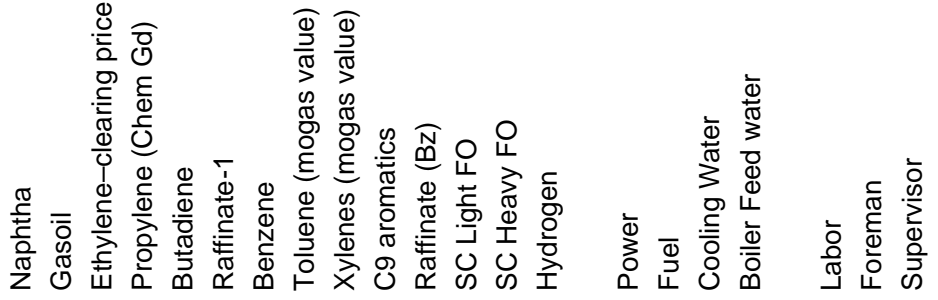


Table 5.25 Cash Cost of Production for Cracking Naphtha (current US dollars per metric ton, USGC)

\begin{tabular}{|c|c|c|c|c|c|c|c|c|c|}
\hline & \multicolumn{3}{|c|}{ Conventional Naphtha } & \multicolumn{6}{|c|}{ FT Naphtha } \\
\hline Yield Source & \multicolumn{4}{|c|}{ Nexant } & \multirow{2}{*}{$\begin{array}{l}\text { S\&W } \\
\text { High }\end{array}$} & \multicolumn{2}{|c|}{ Lummus } & \multirow{2}{*}{$\begin{array}{l}\text { KBR } \\
\text { Very } \\
\text { High }\end{array}$} & \multirow{2}{*}{$\begin{array}{l}\text { Linde } \\
\text { High }\end{array}$} \\
\hline Severity & Low & Moderate & High & $\begin{array}{l}\text { Very } \\
\text { High }\end{array}$ & & Low & $\begin{array}{l}\text { Very } \\
\text { High }\end{array}$ & & \\
\hline $\begin{array}{c}\text { Propylene/Ethylene } \\
\text { Ratio }\end{array}$ & 0.58 & 0.5 & 0.47 & 0.36 & 0.46 & 0.57 & 0.35 & 0.36 & 0.46 \\
\hline \multicolumn{10}{|l|}{ Year } \\
\hline 1997 & 161 & 187 & 199 & 288 & 178 & 169 & 218 & 207 & 176 \\
\hline 1998 & 121 & 139 & 149 & 215 & 136 & 129 & 162 & 158 & 135 \\
\hline 1999 & 200 & 216 & 225 & 292 & 205 & 205 & 232 & 224 & 206 \\
\hline 2000 & 309 & 333 & 341 & 451 & 313 & 311 & 353 & 342 & 311 \\
\hline 2001 & 302 & 321 & 331 & 424 & 299 & 302 & 332 & 321 & 299 \\
\hline 2006 & 214 & 237 & 249 & 332 & 223 & 221 & 259 & 247 & 222 \\
\hline 2015 & 264 & 289 & 303 & 401 & 272 & 270 & 313 & 300 & 271 \\
\hline
\end{tabular}

Table 5.26 Naphtha Cracking Margins

(current US dollars per metric ton, USGC)

\begin{tabular}{|c|c|c|c|c|c|c|c|c|c|}
\hline \multirow{3}{*}{$\begin{array}{l}\text { Yield Source } \\
\text { Severity }\end{array}$} & \multicolumn{4}{|c|}{ Conventional Naphtha } & \multicolumn{5}{|c|}{ FT Naphtha } \\
\hline & \multicolumn{4}{|c|}{ Nexant } & S\&W & \multicolumn{2}{|c|}{ Lummus } & \multirow{2}{*}{$\begin{array}{l}\text { KBR } \\
\begin{array}{l}\text { very } \\
\text { high }\end{array}\end{array}$} & \multirow{2}{*}{$\begin{array}{l}\text { Linde } \\
\text { high }\end{array}$} \\
\hline & low & moderate & high & very high & high & low & $\begin{array}{l}\text { very } \\
\text { high }\end{array}$ & & \\
\hline Propylene/Ethylene Ratio & 0.58 & 0.5 & 0.47 & 0.36 & 0.46 & 0.57 & 0.35 & 0.36 & 0.46 \\
\hline \multicolumn{10}{|l|}{ Year } \\
\hline 1997 & 161 & 187 & 199 & 288 & 178 & 169 & 218 & 207 & 176 \\
\hline 1998 & 121 & 139 & 149 & 215 & 136 & 129 & 162 & 158 & 135 \\
\hline 1999 & 200 & 216 & 225 & 292 & 205 & 205 & 232 & 224 & 206 \\
\hline 2000 & 309 & 333 & 341 & 451 & 313 & 311 & 353 & 342 & 311 \\
\hline 2001 & 302 & 321 & 331 & 424 & 299 & 302 & 332 & 321 & 299 \\
\hline 2006 & 214 & 237 & 249 & 332 & 223 & 221 & 259 & 247 & 222 \\
\hline 2015 & 264 & 289 & 303 & 401 & 272 & 270 & 313 & 300 & 271 \\
\hline
\end{tabular}




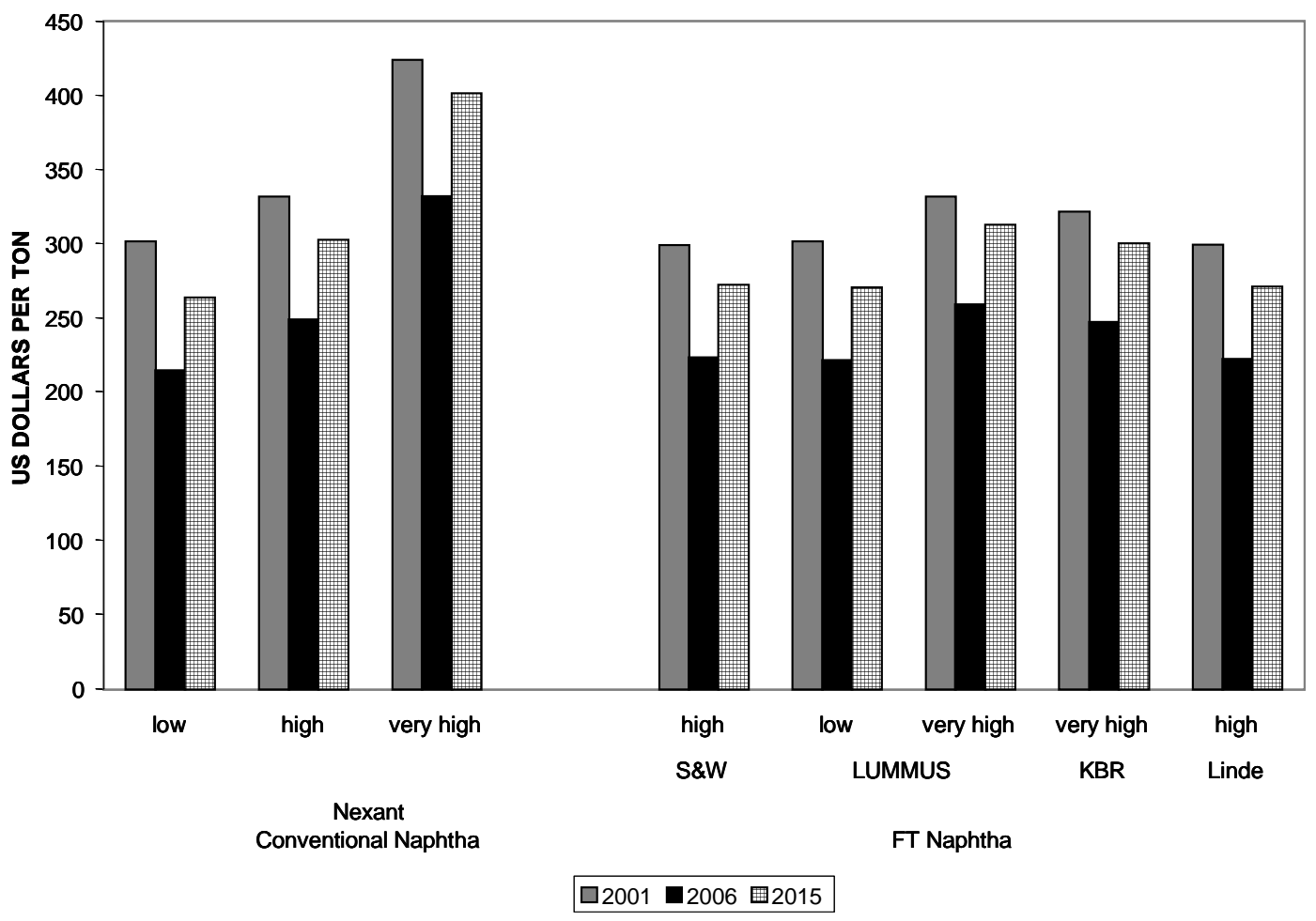

Figure 5.11 Cash Cost of Production for Cracking Naphtha (USGC)

Table 5.26 through Table 5.34 show the detailed production costs for year 2006 and Table 5.35 through Table 5.44 for year 2015. Nexant has utilized its proprietary Cost of Production (COP) system to generate these analyses. Basic information and assumptions employed by this system is presented in Appendices A and B to this report.

As noted previously in this report the iso to normal paraffin ratio could range from 14:86 to 40:60. It is known that while normal butane is a very good cracker feed, cracking iso-butane gives very poor ethylene yields. In order to evaluate this with respect to the iso paraffin contract of the FT naphthas, the licensors were asked to provide additional yield data for a high iso paraffin content case. The results showed that the ethylene yields dropped by between 2.5 and 4 percent as the iso paraffin content increased from 14 to 40 percent. However, the corresponding cost of production changed by less than 1 percent and was, thus, not considered to be a problem. 


\section{Table 5.27 Cost of Production Estimate for: Ethylene (Naphtha Feed) Process: Steam Cracking (Nexant Low Severity)}

$\begin{array}{lr}\text { Analysis date } & 2006 \\ \text { Plant start-up } & 2002 \\ \text { Location } & \text { USGC } \\ \text { Capacity } & 2,180 \text { Million pounds/yr } \\ & 989 \text { Thousand metric tons/yr } \\ \text { Operating rate } & 100 \text { percent } \\ \text { Throughput } & 2,180 \text { Million pounds/yr }\end{array}$

PRODUCTION COST SUMMARY

BY-PRODUCT CREDITS

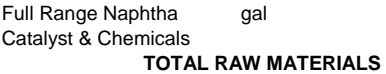

\begin{tabular}{ccc} 
& \multicolumn{2}{c}{ TOTAL BY-PRODUCT CREDITS } \\
\multirow{2}{*}{ UTILITIES } & NET RAW MATERIALS & $\mathrm{kWh}$ \\
& Power (Export) & $\mathrm{MM} \mathrm{Btu}$ \\
& Fuel & Mgal \\
& Cooling Water & MGal \\
& Boiler Feedwater & \multicolumn{2}{c}{ TOTAL UTILITIES }
\end{tabular}

NET RAW MATERIALS \& UTILITIES

VARIABLE COST

\begin{tabular}{llrl} 
DIRECT FIXED COSTS & Labor, & 62 & Men \\
& Foremen, & 13 & Men \\
& Super., & 1 & Men \\
& Maint., Material \& Labor \\
& Direct Overhead & \multicolumn{2}{c}{ TOTAL DIRECT FIXED cosTS } \\
ALLOCATED FIXED COSTS & \multicolumn{2}{c}{ General Plant Overhead } \\
& Insurance, Property Tax
\end{tabular}

TOTAL CASH COS

TOTAL ALLOCATED FIXED COSTS

45.02 Thousand U.S.\$

51.08 Thousand U.S.\$

61.63 Thousand U.S. \$

$2.66 \%$ of ISBL

$45 \%$ Labor \& Supervision

$65 \%$ Labor \& Maintenance

$1 \%$ Total Plant Capital $0.5 \%$ Total Plant Capital

Depreciation @

$10 \%$ for ISBL

$10 \%$ for OSBL \& OPC

COST OF PRODUCTION

RETURN ON TOTAL CAPITAL INVESTMENT (EX. WC) @

10 Percent

ISBL

SBL

Total Plant Capital

Other Project Costs

Total Capital Investment

Wotal Capital In capital

MILLION U.S. \$

721.4
360.8
1082.1
270.5
$\mathbf{1 , 3 5 2 . 7}$
60.9

21.4

360.8

270.5

60.9

ANNUAL

COST MM U.S.\$

$\begin{array}{ccc}\text { U.S. \$ } & \text { COST MM } & \text { U.S. \$ } \\ \text { Per Lb } & \text { U.S. \$ } & \text { Per MT }\end{array}$

$0.302 \quad 658.43$

$0.002 \quad 3.76$

662.18

670

$(0.097) \quad(210.65)$

$(0.033) \quad(71.74)$

$(0.032) \quad(69.27)$

(0.018) (39.56)

$(0.014) \quad(29.58)$

$\begin{array}{ll}(0.008) & (17.59)\end{array}$

$\begin{array}{ll}(0.008) & (17.59) \\ (0.010) & (22.86)\end{array}$

$(0.023) \quad(50.25)$

$(0.005) \quad(10.03)$

$(0.035) \quad(75.39)$

$(0.011) \quad(25.03)$

(0.285) (621.95)

$\mathbf{0 . 0 1 8} \quad 40.24$

$0.003 \quad 6.24$

$0.045 \quad 98.37$

$0.006 \quad 12.46$

$0.000 \quad 0.12$

$\begin{array}{ll}0.054 & 117.18 \\ 0.072 & 157.42\end{array}$

$\begin{array}{lll}0.072 & 157.42 & 159\end{array}$

$\underline{0.072} \quad \underline{157.42} \quad 159$

$0.001 \quad 2.79$

$0.000 \quad 0.66$

$0.000 \quad 0.06$

$0.009 \quad 19.19$

$0.001 \quad 1.58$

$0.011 \quad 24.29$

$0.007 \quad 14.76$

$0.005 \quad 10.82$

$0.002 \quad 5.41$

$0.014 \quad 30.99$

$\underline{0.098} \quad \underline{212.70} \quad 215$

$\begin{array}{lll}0.062 & 135.27 & 137\end{array}$

$\underline{0.160} \quad \underline{347.97} \quad 352$

$0.062 \quad 135.27 \quad 137$

$\underline{0.222} \quad \underline{483.23} \quad 489$ 


\section{Table 5.28 Cost of Production Estimate for: Ethylene (Naphtha Feed) Process: Steam Cracking (Nexant Moderate Severity)}

$\begin{array}{lr}\text { Analysis date } & 2006 \\ \text { Plant start-up } & 2002 \\ \text { Location } & \text { USGC } \\ \text { Capacity } & 2,180 \text { Million pounds/yr } \\ & 989 \text { Thousand metric tons/yr } \\ \text { Operating rate } & 100 \text { percent } \\ \text { Throughput } & 2,180 \text { Million pounds/yr }\end{array}$

PRODUCTION COST SUMMARY

BY-PRODUCT CREDITS

Catalyst \& Chemicals

TOTAL RAW MATERIALS

Propylene - Chem Grade pound

Butadiene

-1 (price/value) gal

Toluene - MoGas Value

Xylenes - MoGas Value

C9 Aromatics

Fuel Gas

(BZ extraction)

Hydrogen ex SC

TOTAL BY-PRODUCT CREDITS

\begin{tabular}{ll} 
NET RAW MATERIALS & \\
Power (Export) & $\mathrm{kWh}$ \\
Fuel & $\mathrm{MM} \mathrm{Btu}$ \\
Cooling Water & Mgal \\
Boiler Feedwater & MGal \\
& \multicolumn{2}{c}{ TOTAL UTILITIES }
\end{tabular}

NET RAW MATERIALS \& UTILITIES

VARIABLE COST

\begin{tabular}{llrl} 
DIRECT FIXED COSTS & Labor, & 62 & Men \\
& Foremen, & 13 & Men \\
& Super., & 1 & Men \\
& Maint., Material \& Labor & \\
& Direct Overhead & \multicolumn{1}{c}{ TOTAL DIRECT FIXED cosTS } \\
ALLOCATED FIXED COSTS & $\begin{array}{l}\text { General Plant Overhead } \\
\text { Insurance, Property Tax } \\
\text { Environmental }\end{array}$
\end{tabular}

TOTAL CASH COST

TOTAL ALLOCATED FIXED COSTS

45.02 Thousand U.S. \$

51.08 Thousand U.S. \$

1.63 Thousand U.S. \$

$2.66 \%$ of ISBL

$45 \%$ Labor \& Supervision

$65 \%$ Labor \& Maintenance

$1 \%$ Total Plant Capital

$0.5 \%$ Total Plant Capital

Depreciation @

$10 \%$ for ISBL

$10 \%$ for OSBL \& OPC

COST OF PRODUCTION

RETURN ON TOTAL CAPITAL INVESTMENT (Ex. WC) @

10 Percent
MILLION U.S. \$

ISBL

721.4

360.8

1082.1

270.5

$1,352.7$

60.9

ANNUAL

$\begin{array}{ccc}\text { U.S. \$ } & \text { COST MM } & \text { U.S. \$ } \\ \text { Per Lb } & \text { U.S. \$ } & \text { Per MT }\end{array}$

$0.270 \quad 588.66$

$\begin{array}{rr}0.002 & 3.76\end{array}$

(0.082) (177.74)

$(0.031) \quad(67.92)$

$(0.017) \quad(37.87)$

(0.024) (53.09)

$(0.013) \quad(27.37)$

$(0.005) \quad(11.23)$

$(0.009) \quad(19.50)$

$(0.024) \quad(52.44)$

$(0.008) \quad(16.48)$

$(0.016) \quad(34.47)$

$(0.011) \quad(24.62)$

(0.240) (522.73)

$0.032 \quad 69.69$

$0.003 \quad 5.85$

$0.042 \quad 92.18$

$0.005 \quad 11.69$

$0.000 \quad 0.12$

$0.050 \quad 109.84$

$0.082 \quad 179.53$

$\underline{0.082 \quad \underline{179.53}}$

$0.001 \quad 2.79$

$0.000 \quad 0.66$

$0.000 \quad 0.06$

$0.009 \quad 19.19$

$0.001 \quad 1.58$

$0.011 \quad 24.29$

$0.007 \quad 14.76$

$0.005 \quad 10.82$

$0.002 \quad 5.41$

$0.014 \quad 30.99$

$\underline{0.108} \underline{234.81}$

$0.062 \quad 135.27$

$\underline{0.170 \quad 370.07}$

$0.062 \quad 135.27$

$\underline{0.232} \quad 505.34$
182

182

$(529)$
70

31

137

374

137

511 


\section{Table 5.29 Cost of Production Estimate for: Ethylene (Naphtha Feed) Process: Steam Cracking (Nexant High Severity)}

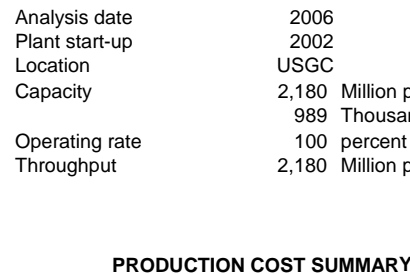

TOTAL BY-PRODUCT CREDITS

\begin{tabular}{lll} 
UTILITIES & NET RAW MATERIALS & $\mathrm{kWh}$ \\
& Power (Export) & MM Btu \\
& Fuel & Mgal \\
& Cooling Water & MGal \\
& Boiler Feedwater & \multicolumn{2}{c}{ TOTAL UTILITIES } \\
& \multicolumn{2}{c}{ NET RAW MATERIALS \& UTILITIES }
\end{tabular}

VARIABLE COST

\begin{tabular}{llrl} 
DIRECT FIXED COSTS & Labor, & 62 & Men \\
& Foremen, & 13 & Men \\
& Super., & 1 & Men \\
& Maint., Material \& Labor \\
& Direct Overhead & \multicolumn{1}{c}{ TOTAL DIRECT FIXED cosTS } \\
ALLOCATED FIXED COSTS & $\begin{array}{l}\text { General Plant Overhead } \\
\text { Insurance, Property Tax } \\
\text { Environmental }\end{array}$
\end{tabular}

TOTAL CASH COST

TOTAL ALLOCATED FIXED COSTS

55.02 Thousand U.S. \$

51.08 Thousand U.S. \$

1.63 Thousand U.S. \$

$2.66 \%$ of ISBL

$45 \%$ Labor \& Supervision

65 \% Labor \& Maintenance

$1 \%$ Total Plant Capital

$0.5 \%$ Total Plant Capital

Depreciation @

$10 \%$ for ISBL

$10 \%$ for OSBL \& OPC

COST OF PRODUCTION

RETURN ON TOTAL CAPITAL INVESTMENT (EX. WC) @

COST OF PRODUCTION + ROI

Other Project Costs

Working capital
UNITS PRICE
Per Lb U.S.\$

Product IUnit

$0.4803 \quad 0.5417$

$(0.4703) \quad 0.1653$

$(0.1250) \quad 0.2161$

$(0.0306) \quad 0.6432$

$(0.0087) \quad 0.7718$

$(0.0018) \quad 0.7914$

0.8108

$(0.0549) \quad 0.5080$

$(0.0029) \quad 1.3961$

$0.0465 \quad 0.0539$

$\begin{array}{ll}0.0135 & 2.9141 \\ 0.0500 & 0.1003\end{array}$

10 Percent
0.4081

CAPITAL COST MILLION U.S. \$

-352.7
60.9

ANNUAL

U.S. \$ COST MM U.S. \$

$\begin{array}{lll}\text { Per Lb U.S. \$ Per MT } & \end{array}$

$0.260 \quad 567.24$

$\begin{array}{lr}0.260 & 567.24 \\ 0.002 & 3.76 \\ \mathbf{0 . 2 6 2} & \mathbf{5 7 1 . 0 0}\end{array}$

$(0.078) \quad(169.49)$

$(0.027) \quad(58.89)$

$(0.020) \quad(42.84)$

$(49.37)$

$(0.007) \quad(14.57)$

$(0.001) \quad(3.06)$

$(0.001) \quad(1.96)$

$\begin{array}{lr}(0.001) & (1.96) \\ (0.028) & (61.60)\end{array}$

$\begin{array}{ll}(0.028) & (61.60) \\ (0.005) & (10.59)\end{array}$

$(0.028) \quad(60.79)$

$(0.004) \quad(8.78)$

(0.221) (481.95)

$0.041 \quad 89.05$

$0.003 \quad 5.46$

$0.039 \quad 85.99$

$0.005 \quad 10.93$

$0.000 \quad 0.12$

$0.047 \quad 102.50$

$0.088 \quad 191.55$

$\underline{0.088 \quad \underline{191.55}}$

104

$0.001 \quad 2.79$

$0.000 \quad 0.66$

$0.000 \quad 0.06$

$0.009 \quad 19.19$

$\begin{array}{rr}0.001 & 1.58 \\ 0.011 & 24.29\end{array}$

$\mathbf{0 . 0 1 1} \quad 24.29$

$0.007-14.76$

$\begin{array}{rr}0.005 & 10.82 \\ 0.002 & 5.41\end{array}$

$\begin{array}{lr}0.002 & 5.41 \\ \mathbf{0 . 0 1 4} & \mathbf{3 0 . 9 9}\end{array}$

$\underline{0.113} \quad \underline{246.83}$

$0.062 \quad 135.27$

$\underline{0.175 \quad 382.10}$

$\begin{array}{lll}0.062 & 135.27 & 137\end{array}$

$\underline{0.237} \quad \underline{517.36}$ 


\section{Table 5.30 Cost of Production Estimate for: Ethylene (Naphtha Feed) Process: Steam Cracking (Nexant Very High Severity)}

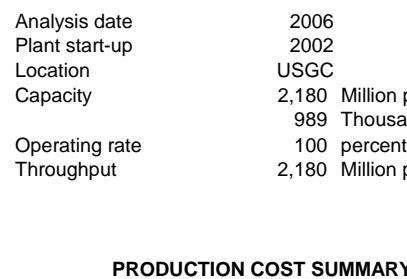

$\begin{array}{llll}\text { Power (Export) } & \mathrm{kWh} & 0.0465 & 0.0539 \\ \text { Fuel } & \mathrm{MM} \mathrm{Btu} & 0.0135 & 2.9141 \\ \text { Cooling Water } & \mathrm{Mgal} & 0.0500 & 0.1003 \\ \text { Boiler Feedwater } & \mathrm{MGal} & 0.0000 & 1.8430\end{array}$

NET RAW MATERIALS \& UTILITIES

UTILITIES

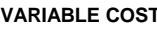

\begin{tabular}{llrl} 
DIRECT FIXED COSTS & Labor, & 62 & Men \\
& Foremen, & 13 & Men \\
& Super., & 1 & Men \\
& Maint., Material \& Labor \\
& Direct Overhead & \multicolumn{2}{c}{ TOTAL DIRECT FIXED coSTS } \\
ALLOCATED FIXED COSTS & $\begin{array}{l}\text { General Plant Overhead } \\
\text { Insurance, Property Tax } \\
\text { Environmental }\end{array}$
\end{tabular}

TOTAL CASH COST

$10 \%$ for ISBL

45.02 Thousand U.S. \$

51.08 Thousand U.S. $\$$

61.63 Thousand U.S. \$

$2.66 \%$ of ISBL

$45 \%$ Labor \& Supervision

$65 \%$ Labor \& Maintenance

$1 \%$ Total Plant Capita (1)

Depreciation @

COST OF PRODUCTION

RETURN ON TOTAL CAPITAL INVESTMENT (Ex. WC) @

COST OF PRODUCTION + ROI

UNITS PRICE
CAPITAL COST MILLION U.S. \$

Total Plant Capital

Other Project Costs

Per Lb U.S. \$

$\begin{array}{ll}0.4613 & 0.5417 \\ 1.0000 & 0.0017\end{array}$

$\begin{array}{ll}(0.3594) & 0.1653\end{array}$

$(0.0861) \quad 0.2161$

$(0.0210) \quad 0.6432$

$\begin{array}{ll}(0.0199) & 0.9940 \\ (0.0075) & 0.7718\end{array}$

$(0.0015) \quad 0.7914$

$(0.0010) \quad 0.8108$

2.9141

$(0.0126) \quad 0.4081$

$\begin{array}{ll}(0.0478) & 0.5080 \\ (0.0011) & 1.3961\end{array}$
(382)

173

104

277

277

$\underline{0.126} \quad \underline{273.72}$

$0.001 \quad 2.79$

$0.000 \quad 0.66$

$0.000 \quad 0.06$

$0.009 \quad 19.19$

$0.001 \quad 1.58$

$\begin{array}{ll}\mathbf{0 . 0 1 1} & \mathbf{2 4 . 2 9}\end{array}$

$0.007 \quad 14.76$

$0.005 \quad 10.82$

$0.002 \quad 5.41$

$0.014 \quad 30.99$

$\underline{0.151 \quad 329.00}$

$0.062 \quad 135.27$

$\underline{0.213} \quad \underline{464.27}$

0.062

135.27

10 Percent

$\underline{0.275}$ 


\section{Table 5.31 Cost of Production Estimate for: Ethylene (Ft Naphtha Feed) Process: Steam Cracking (S\&W, High Severity)}

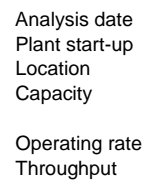

$\begin{array}{llll}\text { Power (Export) } & \text { kWh } & 0.0395 & 0.0539 \\ \text { Fuel } & \text { MM Btu } & 0.0123 & 2.9141 \\ \text { Cooling Water } & \text { Mgal } & 0.0425 & 0.1003 \\ \text { Boiler Feedwater } & \text { MGal } & 0.0000 & 1.8430\end{array}$

NET RAW MATERIALS \& UTILITIES

UTILITIES

VARIABLE COST

\begin{tabular}{llrl} 
DIRECT FIXED COSTS & Labor, & 62 & Men \\
& Foremen, & 13 & Men \\
& Super., & 1 & Men \\
& Maint., Material \& Labor \\
& Direct Overhead \\
ALLOCATED FIXED CoSTS & \multicolumn{2}{c}{ TOTAL DIRECT FIXED CoSTS } \\
& $\begin{array}{l}\text { General Plant Overhead } \\
\text { Insurance, Property Tax }\end{array}$
\end{tabular}

Insurance, Property Tax Environmental TOTAL ALLOCATED FIXED COSTS

45.02 Thousand U.S. \$

51.08 Thousand U.S.\$

61.63 Thousand U.S. \$

$2.66 \%$ of ISBL

$45 \%$ Labor \& Supervision

65 \% Labor \& Maintenance

TOTAL CASH COST

Depreciation @

$10 \%$ for ISBL

COST OF PRODUCTION

RETURN ON TOTAL CAPITAL INVESTMENT (EX. WC) @

COST OF PRODUCTION + ROI
$1 \%$ Total Plant Capital $0.5 \%$ Total Plant Capital

CAPITAL COST MILLION U.S. \$

SBL

Total Plant Capital

Other Project Costs

$\begin{array}{ll}\text { UNITS } & \text { PRICE } \\ \text { Per Lb } & \text { U.S. \$ }\end{array}$

Product IUnit

$0.4195 \quad 0.5346$

(0.4609) 0.1653

$\begin{array}{ll}(0.1279) & 0.2161 \\ (0.0366) & 0.6432\end{array}$

$\begin{array}{ll}(0.0366) & 0.6432 \\ (0.0138) & 0.9940\end{array}$

$(0.0050) \quad 0.7718$

$(0.0014) \quad 0.7914$

0.8108

$(0.0047) \quad 0.4081$

$(0.0189) \quad 0.5080$

(0.0066) 1.3961
$10 \%$ for OSBL \& OPC

10 Percent
678.1

349.9

257.0

$1,285.0$
57.8

ANNUAL

U.S. \$ COST MM U.S.\$

$\begin{array}{lll}\text { Per Lb U.S. } \$ \text { Per MT } & \end{array}$

$0.224 \quad 488.87$

$\begin{array}{lrr}0.002 & 3.76 & \\ 0.226 & 492.63 & 498\end{array}$

(0.076) (166.11)

$(0.028) \quad(60.27)$

$(0.024) \quad(51.28)$

$(0.014) \quad(29.91)$

$(0.004) \quad(8.35)$

$(0.001) \quad(2.42)$

$(0.004) \quad(9.26)$

$(0.020) \quad(42.56)$

$(0.002) \quad(4.15)$

$(0.010) \quad(20.97)$

(0.009) (20.21)

$\begin{array}{lll}(0.191) & \text { (415.48) }\end{array}$

$\begin{array}{lll}0.035 & 77.15 & 78\end{array}$

$0.002 \quad 4.64$

$0.036 \quad 77.82$

$0.004 \quad 9.29$

$0.000 \quad 0.12$

$0.042 \quad 91.87$

$0.078 \quad 169.02$

$\underline{0.078} \quad \underline{169.02}$

$0.001 \quad 2.79$

$0.000 \quad 0.66$

$0.000 \quad 0.06$

$\begin{array}{lr}0.008 & 18.04 \\ 0.001 & 1.58\end{array}$

$\begin{array}{lr}0.001 & 1.58 \\ 0.011 & 23.14\end{array}$

$0.011 \quad 14.01$

$0.005 \quad 10.28$

$0.002 \quad 5.14$

$0.014 \quad 29.43$

$\underline{0.102} \underline{221.59}$

$0.059 \quad 128.50$

$\underline{0.161} \quad \underline{350.09} \quad 354$

$0.059 \quad 128.50 \quad 130$

$\underline{0.220} \quad \underline{478.60} \quad 484$ 


\section{Table 5.32 Cost of Production Estimate for: Ethylene (FT Naphtha Feed) Process: Steam Cracking (Lummus, Low Severity)}

$\begin{array}{lr}\text { Analysis date } & 2006 \\ \text { Plant start-up } & 2002 \\ \text { Location } & \text { USGC } \\ \text { Capacity } & 2,180 \text { Million pounds/yr } \\ & 989 \text { Thousand metric tons/yr } \\ \text { Operating rate } & 100 \text { percent } \\ \text { Throughput } & 2,180 \text { Million pounds/yr }\end{array}$

PRODUCTION COST SUMMARY

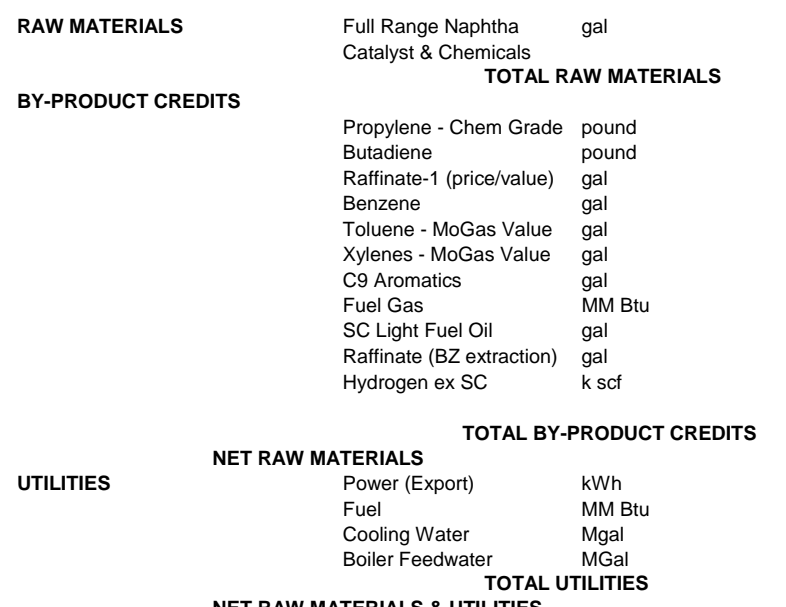

NET RAW MATERIALS \& UTILITIES

VARIABLE COST

\begin{tabular}{llrl} 
DIRECT FIXED COSTS & Labor, & 62 & Men \\
& Foremen, & 13 & Men \\
& Super., & 1 & Men \\
& Maint., Material \& Labor \\
& Direct Overhead & \multicolumn{1}{c}{ TOTAL DIRECT FIXED COSTS } \\
ALLOCATED FIXED COSTS & $\begin{array}{l}\text { General Plant Overhead } \\
\text { Insurance, Property Tax } \\
\text { Environmental }\end{array}$
\end{tabular}

TOTAL CASH COST

TOTAL ALLOCATED FIXED COSTS

$\begin{array}{lr}\text { CAPITAL COST MILLION U.S. \$ } & \\ \text { ISBL } & 678.1 \\ \text { OSBL } & 349.9 \\ \text { Total Plant Capital } & \mathbf{1 0 2 8 . 0} \\ \text { Other Project Costs } & 257.0 \\ \quad \text { Total Capital Investment } & \mathbf{1 , 2 8 5 . 0} \\ \text { Working capital } & 57.8\end{array}$

UNITS

Product IUnit

$0.4765 \quad 0.5346$

$1.0000 \quad 0.0017$

(0.5715) 0.1653

$(0.1284) \quad 0.2161$

$(0.0394) \quad 0.6432$

$(0.0117) \quad 0.9940$

$(0.0033) \quad 0.7718$

$(0.0019) \quad 0.7914$

$(0.0122) \quad 0.8108$

$(0.0080) \quad 2.9141$

$(0.0083) \quad 0.408$

$(0.0338) \quad 0.5080$

$(0.0078) \quad 1.3961$

ANNUAL

$0.255 \quad 555.34$

$0.002 \quad 3.76$

559.09

(0.094) (205.95)

$(0.028) \quad(60.48)$

$(0.025) \quad(55.31)$

$(0.012) \quad(25.34)$

$(0.003) \quad(5.56)$

$(0.002) \quad(3.36)$

$\begin{array}{ll}(0.002) & (3.36) \\ (0.010) & (21.52)\end{array}$

$\begin{array}{ll}(0.010) & (21.52) \\ (0.023) & (50.89)\end{array}$

$(0.003) \quad(7.36)$

$(0.017) \quad(37.38)$

$(0.011) \quad(23.84)$

U.S. \$ COST MM U.S. \$

$\begin{array}{lll}\text { Per Lb } & \text { U.S. } \$ \quad \text { Per MT }\end{array}$

565

(0.228) (496.99)

$\mathbf{0 . 0 2 8} \quad 62.10$

$0.002 \quad 5.30$

$0.041 \quad 89.02$

$0.005 \quad 10.59$

$\begin{array}{lr}0.005 & 10.59 \\ 0.000 & 0.12\end{array}$

$\begin{array}{lr}0.000 & 0.12 \\ 0.048 & 105.03\end{array}$

$\begin{array}{lll}0.048 & 105.03 & 106\end{array}$

$\begin{array}{ll}0.0484 & 0.1003\end{array}$

$0.0000 \quad 1.8430$

$\underline{0.077} \quad \underline{167.13} \quad 169$

$0.001 \quad 2.79$

$0.000 \quad 0.66$

$0.000 \quad 0.06$

$\begin{array}{rr}0.008 & 18.04 \\ 0.001 & 1.58\end{array}$

$0.001 \quad 1.58$

$0.011 \quad 23.14$

$0.006 \quad 14.01$

$0.005 \quad 10.28$

$0.002 \quad 5.14$

$0.014 \quad 29.43$

$\underline{0.101} \quad \underline{219.70}$

$0.059 \quad 128.50$

$10 \%$ for OSBL \& OPC

$\underline{0.160}$

348.21

COST OF PRODUCTION

10 Percent

0.059

128.50

$\underline{0.219} \quad 476.71$

(503)

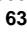

23

30

222

130

352

130

482 


\section{Table 5.33 Cost of Production Estimate for: Ethylene (FT Naphtha Feed) Process: Steam Cracking (Lummus, High Severity)}

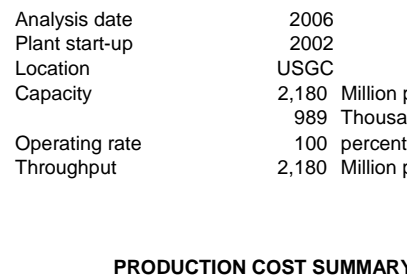

TOTAL BY-PRODUCT CREDITS

UTILITIES

NET RAW MATERIALS

$\begin{array}{llll}\text { Power (Export) } & \text { kWh } & 0.0395 & 0.0539 \\ \text { Fuel } & \text { MM Btu } & 0.0123 & 2.9141 \\ \text { Cooling Water } & \text { Mgal } & 0.0425 & 0.1003 \\ \text { Boiler Feedwater } & \text { MGal } & 0.0000 & 1.8430\end{array}$

NET RAW MATERIALS \& UTILITIES

VARIABLE COST

\begin{tabular}{llrl} 
DIRECT FIXED COSTS & Labor, & 62 & Men \\
& Foremen, & 13 & Men \\
& Super., & 1 & Men \\
& Maint., Material \& Labor \\
& Direct Overhead & \multicolumn{2}{c}{ TOTAL DIRECT FIXED COSTS } \\
ALLOCATED FIXED COSTS & $\begin{array}{l}\text { General Plant Overhead } \\
\text { Insurance, Property Tax } \\
\text { Environmental }\end{array}$
\end{tabular}

TOTAL CASH COST

$10 \%$ for ISBL

cost OF PRODUCTION

RETURN ON TOTAL CAPITAL INVESTMENT (Ex. WC) @

COST OF PRODUCTION + ROI

$1.0000 \quad 0.0017$

$(0.0171) \quad 0.6432$

$\begin{array}{lr}\text { CAPITAL COST MILLION U.S. \$ } & \\ \text { ISBL } & 678.1 \\ \text { OSBL } & 349.9 \\ \text { Total Plant Capital } & \mathbf{1 0 2 8 . 0} \\ \text { Other Project Costs } & 257.0 \\ \quad \text { Total Capital Investment } & \mathbf{1 , 2 8 5 . 0} \\ \text { Working capital } & 57.8\end{array}$

UNITS PRICE

Per Lb U.S.\$

Product IUnit

$0.4118 \quad 0.5346$

$(0.3469) \quad 0.1653$

$(0.1146) \quad 0.2161$

$(0.0210) \quad 0.9940$

$(0.0032) \quad 0.7718$

$(0.0005) \quad 0.7914$

$\begin{array}{ll}(0.0080) & 0.8108\end{array}$

$(0.0086) \quad 2.9141$

$(0.0140) \quad 0.4081$

$(0.0104) \quad 0.5080$

$(0.0078) \quad 1.3961$
$10 \%$ for OSBL \& OPC

76)

114

$0.052 \quad 112.28$

$0.002 \quad 4.64$

$0.036 \quad 77.82$

$0.004 \quad 9.29$

$0.000-0.12$

$\mathbf{0 . 0 4 2} \quad \mathbf{9 1 . 8 7}$

$0.094 \quad 204.16$

$\underline{0.094} \quad \underline{204.16}$

93

206

206

.02 Thousand U.S. \$

51.08 Thousand U.S. \$

1.63 Thousand U.S.\$

$2.66 \%$ of ISBL

$45 \%$ Labor \& Supervision

$65 \%$ Labor \& Maintenance

$1 \%$ Total Plant Capital

0.5

$0.001 \quad 2.79$

$0.000 \quad 0.66$

$0.000 \quad 0.06$

$0.008 \quad 18.04$

$0.001 \quad 1.58$

$\mathbf{0 . 0 1 1} \quad \mathbf{2 3 . 1 4}$

$\begin{array}{ll}0.006 & 14.01 \\ 0.005 & 10.28\end{array}$

$0.002 \quad 5.14$

$0.014 \quad 29.43$

$\underline{0.118} \quad \underline{256.72}$

$0.059 \quad 128.50$

$\underline{0.177 \quad \underline{385.23}}$

10 Percent

0.059

$\underline{0.236}$ 


\section{Table 5.34 Cost of Production Estimate for: Ethylene (Ft Naphtha Feed) Process: Steam Cracking (KBR, Very High Severity)}

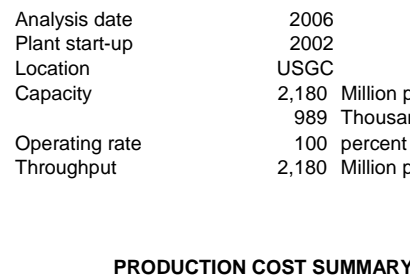

TOTAL BY-PRODUCT CREDITS

\section{NET RAW MATERIALS}

UTILITIES

NET RAW MATERIALS \& UTILITIES

VARIABLE COST

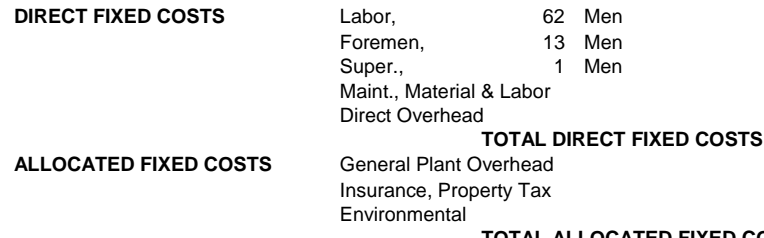

TOTAL CASH COST

$10 \%$ for ISBL

02 Thousand U.S.\$

51.08 Thousand U.S. \$

61.63 Thousand U.S.\$

$2.66 \%$ of ISBL

$45 \%$ Labor \& Supervision

$65 \%$ Labor \& Maintenance

$1 \%$ Total Plant Capital

0

Depreciation @

$10 \%$ for OSBL \& OPC

COST OF PRODUCTION

RETURN ON TOTAL CAPITAL INVESTMENT (Ex. WC) @

10 Percent

Other Project Costs

Working capital

UNITS PRICE

Product /Unit

$0.3625 \quad 0.5346$

$(0.3577) \quad 0.1653$

$(0.1342) \quad 0.2161$

$\begin{array}{ll}(0.0144) & 0.6432 \\ (0.0109) & 0.9940\end{array}$

$\begin{array}{ll}(0.0109) & 0.9940 \\ (0.0049) & 0.7718\end{array}$

$(0.0043) \quad 0.7914$

0.8108

$(0.0046) \quad 0.4081$

$(0.0095) \quad 0.5080$

$0.0395 \quad 0.0539$

$0.0123 \quad 2.9141$

$\begin{array}{ll}0.0425 & 0.1003 \\ 0.0000 & 1.8430\end{array}$

\begin{tabular}{ll} 
Power (Export) & kWh \\
Fuel & MM Btu \\
Cooling Water & Mgal \\
Boiler Feedwater & MGal \\
\multicolumn{2}{c}{ TOTAL UTILITIES }
\end{tabular}

CAPITAL COST MILLION U.S. \$

Total Plant Capital

Total Capital Investment

349.9

1028.0

257.0

$1,285.0$
57.8

COST OF PRODUCTION + ROI

$0.006 \quad 14.01$
NUAL

COST MM U.S. \$

$\begin{array}{lll}\text { Per Lb } & \text { U.S. \$ Per MT }\end{array}$

$0.194 \quad 422.49$

$\begin{array}{lrr}0.002 & 3.76 & \\ \mathbf{0 . 1 9 6} & \mathbf{4 2 6 . 2 5} & \mathbf{4 3 1}\end{array}$

$(0.059) \quad(128.91)$

$(0.029) \quad(63.21)$

$(0.009) \quad(20.17)$

0.011) (23.70)

$(0.004) \quad(8.21)$

$(0.003) \quad(7.41)$

$(0.002) \quad(4.57)$

$(0.016) \quad(34.88)$

$(0.002) \quad(4.05)$

$(0.005) \quad(10.49)$

$(0.009) \quad(19.91)$

(0.149) (325.50) (329)

$\begin{array}{lll}0.046 & 100.74 & 102\end{array}$

$0.002 \quad 4.64$

$0.036 \quad 77.82$

$0.004 \quad 9.29$

$0.000 \quad 0.12$

$0.042 \quad 91.87$

$0.088 \quad 192.62$

$\underline{0.088} \quad \underline{192.62} \quad 195$

$0.001 \quad 2.79$

$0.000 \quad 0.66$

$0.000 \quad 0.06$

$0.008 \quad 18.04$

$0.001 \quad 1.58$

$\mathbf{0 . 0 1 1} \quad \mathbf{2 3 . 1 4}$

$0.002 \quad 5.14$

$0.014 \quad 29.43$

$\underline{0.112 \quad \underline{245.18}}$

$0.059 \quad 128.50$

$\underline{0.171 \quad \underline{373.69}}$

0.059

128.50

$\underline{0.230}$ 


\section{Table 5.35 Cost of Production Estimate for: Ethylene (FT Naphtha Feed) Process: Steam Cracking (Linde, High Severity)}

$\begin{array}{lr}\text { Analysis date } & 2006 \\ \text { Plant start-up } & 2002 \\ \text { Location } & \text { USGC } \\ \text { Capacity } & 2,180 \text { Million pounds/yr } \\ & 989 \text { Thousand metric tons/yr } \\ \text { Operating rate } & 100 \text { percent } \\ \text { Throughput } & 2,180 \text { Million pounds/yr }\end{array}$

PRODUCTION COST SUMMARY

BY-PRODUCT CREDITS

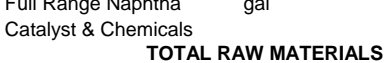

TOTAL BY-PRODUCT CREDITS

UTILITIES
CAPITAL COST MILLION U.S. \$

ISBL

349.9

Total Plant Capital $\quad 1028.0$

Other Project Costs 257.0

Total Capital Investment $\quad \mathbf{1 , 2 8 5 . 0}$

$\begin{array}{cc}\begin{array}{c}\text { UNITS } \\ \text { Per Lb } \\ \text { Product }\end{array} & \begin{array}{l}\text { PRICE } \\ \text { U.S. \$ } \\ \text { IUnit }\end{array} \\ & \\ 0.3992 & 0.5346 \\ 1.0000 & 0.0017 \\ & \\ & \\ (0.4556) & 0.1653 \\ (0.1503) & 0.2161 \\ (0.0269) & 0.6432 \\ (0.0107) & 0.9940 \\ (0.0022) & 0.7718 \\ (0.0007) & 0.7914 \\ (0.0031) & 0.8108 \\ (0.0056) & 2.9141 \\ (0.0009) & 0.4081 \\ (0.0292) & 0.5080 \\ (0.0058) & 1.3961\end{array}$

(0.0058) $\quad 1.3961$

$0.0395 \quad 0.0539$

$0.0123 \quad 2.9141$

$0.0425 \quad 0.1003$

$0.0000 \quad 1.8430$

$\begin{array}{llll}\text { Power (Export) } & \text { kWh } & 0.0395 & 0.0539 \\ \text { Fuel } & \text { MM Btu } & 0.0123 & 2.9141 \\ \text { Cooling Water } & \text { Mgal } & 0.0425 & 0.1003 \\ \text { Boiler Feedwater } & \text { MGal } & 0.0000 & 1.8430\end{array}$

NET RAW MATERIALS \& UTILITIES

VARIABLE COST

\begin{tabular}{llrl} 
DIRECT FIXED COSTS & Labor, & 62 & Men \\
& Foremen, & 13 & Men \\
& Super., & 1 & Men \\
& Maint., Material \& Labor \\
& Direct Overhead & \multicolumn{1}{c}{ TOTAL DIRECT FIXED COSTS } \\
ALLOCATED FIXED COSTS & \multicolumn{2}{c}{ General Plant Overhead } \\
& Insurance, Property Tax \\
& Environmental
\end{tabular}

TOTAL CASH COST

TOTAL ALLOCATED FIXED COST

45.02 Thousand U.S. \$

51.08 Thousand U.S. \$

61.63 Thousand U.S. \$

$2.66 \%$ of ISBL

$45 \%$ Labor \& Supervision

$65 \%$ Labor \& Maintenance

$1 \%$ Total Plant Capital

$0.5 \%$ Total Plant Capital

Depreciation @

$10 \%$ for ISBL

$10 \%$ for OSBL \& OPC

COST OF PRODUCTION

RETURN ON TOTAL CAPITAL INVESTMENT (Ex. WC) @

COST OF PRODUCTION + ROI

\begin{tabular}{|c|c|c|}
\hline U.S. \$ & $\begin{array}{l}\text { ANNUAL } \\
\text { COST MM }\end{array}$ & U.S. \$ \\
\hline Per Lb & U.S. \$ & Per MT \\
\hline 0.213 & 465.21 & \\
\hline 0.002 & 3.76 & \\
\hline 0.215 & 468.96 & 474 \\
\hline$(0.075)$ & (164.20) & \\
\hline$(0.032)$ & $(70.82)$ & \\
\hline (0.017) & (37.65) & \\
\hline$(0.011)$ & (23.10) & \\
\hline$(0.002)$ & (3.78) & \\
\hline$(0.001)$ & (1.12) & \\
\hline (0.003) & (5.55) & \\
\hline$(0.016)$ & (35.70) & \\
\hline$(0.000)$ & $(0.81)$ & \\
\hline (0.015) & (32.34) & \\
\hline (0.008) & (17.78) & \\
\hline (0.180) & (392.87) & (397) \\
\hline 0.035 & 76.10 & 77 \\
\hline 0.002 & 4.64 & \\
\hline 0.036 & 77.82 & \\
\hline 0.004 & 9.29 & \\
\hline 0.000 & 0.12 & \\
\hline 0.042 & 91.87 & 93 \\
\hline 0.077 & 167.97 & 170 \\
\hline$\underline{0.077}$ & $\underline{167.97}$ & 170 \\
\hline 0.001 & 2.79 & \\
\hline 0.000 & 0.66 & \\
\hline 0.000 & 0.06 & \\
\hline 0.008 & 18.04 & \\
\hline 0.001 & 1.58 & \\
\hline 0.011 & 23.14 & 23 \\
\hline 0.006 & 14.01 & \\
\hline 0.005 & 10.28 & \\
\hline 0.002 & 5.14 & \\
\hline 0.014 & 29.43 & 30 \\
\hline$\underline{0.101}$ & $\underline{220.54}$ & 223 \\
\hline 0.059 & 128.50 & 130 \\
\hline$\underline{0.160}$ & $\underline{349.04}$ & 353 \\
\hline 0.059 & 128.50 & 130 \\
\hline$\underline{0.219}$ & $\underline{477.55}$ & 483 \\
\hline
\end{tabular}




\section{Table 5.36 Cost of Production Estimate for: Ethylene (Naphtha Feed) Process: Steam Cracking (Nexant Low Severity)}

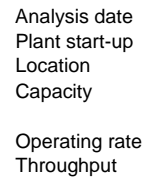

TOTAL BY-PRODUCT CREDITS

UTILITIES

NET RAW MATERIALS

\begin{tabular}{ll} 
Power (Export) & kWh \\
Fuel & MM Btu \\
Cooling Water & Mgal \\
Boiler Feedwater & MGal \\
\multicolumn{2}{c}{ TOTAL UTILITIES }
\end{tabular}

VARIABLE COST

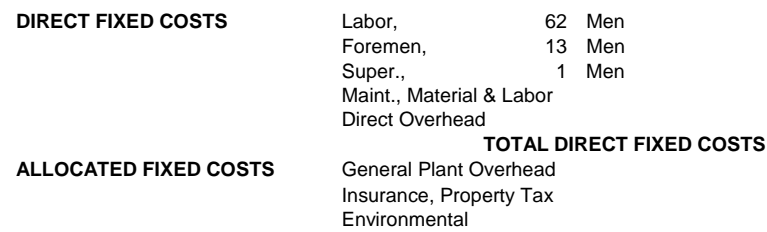

TOTAL CASH COST

TOTAL ALLOCATED FIXED COSTS

56.22 Thousand U.S. \$

63.79 Thousand U.S. \$

76.97 Thousand U.S. \$

$2.66 \%$ of ISBL

$45 \%$ Labor \& Supervision

$65 \%$ Labor \& Maintenance

$1 \%$ Total Plant Capital

$0.5 \%$ Total Plant Capital

Depreciation @

$10 \%$ for ISBL

$10 \%$ for OSBL \& OPC

COST OF PRODUCTION

RETURN ON TOTAL CAPITAL INVESTMENT (EX. WC) @

10 Percent

Other Project Costs

Working capital
Per Lb U.S.\$

Product IUnit

$0.5576 \quad 0.6457$

(0.5845) $\quad 0.1956$

$\begin{array}{ll}(0.1523) & 0.2554 \\ (0.0494) & 0.7516\end{array}$

$\begin{array}{ll}(0.0183) & 1.1874\end{array}$

0.9099

.079) 3.5693

$(0.0113) \quad 0.4932$

$0.0531 \quad 0.0667$

$0.0570 \quad 0.1247$
$(0.0681) \quad 0.6071$

$0.0000 \quad 2.2981$
NET RAW MATERIALS \& UTILITIES

CAPITAL COST MILLION U.S. \$

COST OF PRODUCTION + ROI
737.1
78.2

4389.7

ANNUAL

U.S. \$ COST MM U.S. \$

$\begin{array}{lll}\text { Per Lb } & \text { U.S. \$ Per MT }\end{array}$

$0.360 \quad 784.86$

$\begin{array}{lrr}0.002 & 3.76 & \\ \mathbf{0 . 3 6 2} & \mathbf{7 8 8 . 6 2} & \mathbf{7 9 8}\end{array}$

(0.114) (249.28)

$(0.039) \quad(84.77)$

$(0.037) \quad(80.95)$

$(0.022) \quad(47.26)$

$(0.016)$

$(0.012) \quad(26.90)$

$(0.028) \quad(61.55)$

$(0.006) \quad(12.12)$

$(0.041) \quad(90.11)$

(0.014) (30.65)

$(0.339) \quad(739.19)$

$\begin{array}{rr}0.023 & 49.43 \\ 0.004 & 7.72\end{array}$

$0.055 \quad 120.48$

$0.007 \quad 15.48$

$0.000 \quad 0.15$

$0.066 \quad 143.84$

$0.089 \quad 193.26$

$\underline{0.089} \quad \underline{193.26}$

0.002

0.000

0.000

0.011

31.01

$0.009 \quad 18.87$

$0.006 \quad 13.90$

$0.003 \quad 6.95$

$0.018 \quad 39.72$

$\underline{0.121} \quad 263.99$

$0.080 \quad 173.71$

$\underline{0.201} \quad \underline{437.70}$

0.080

173.71

$\underline{0.280} \quad \underline{611.40}$
31 


\section{Table 5.37 Cost of Production Estimate for: Ethylene (Naphtha Feed) Process: Steam Cracking (Nexant Moderate Severity)}

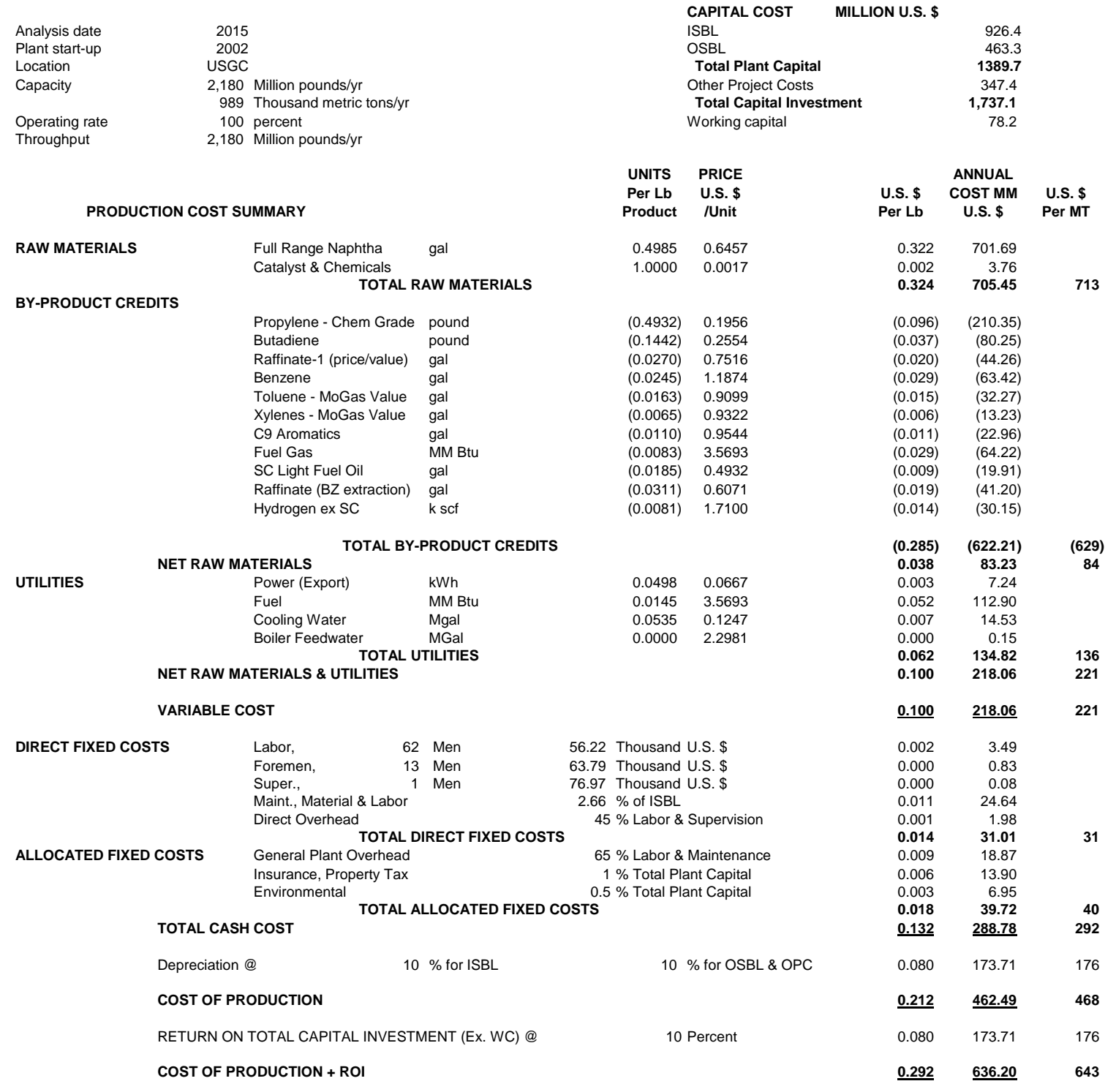




\section{Table 5.38 Cost of Production Estimate for: Ethylene (Naphtha Feed) Process: Steam Cracking (Nexant High Severity)}

$\begin{array}{lr}\text { Analysis date } & 2015 \\ \text { Plant start-up } & 2002 \\ \text { Location } & \text { USGC } \\ \text { Capacity } & 2,180 \text { Million pounds/yr } \\ & 989 \text { Thousand metric tons/yr } \\ \text { Operating rate } & 100 \text { percent } \\ \text { Throughput } & 2,180 \text { Million pounds/yr }\end{array}$

PRODUCTION COST SUMMARY

RAW MATERIALS

Full Range Naphtha gal Catalyst \& Chemicals

TOTAL RAW MATERIALS

BY-PRODUCT CREDITS

$\begin{array}{ll}\text { Propylene - Chem Grade } & \text { pound } \\ \text { Butadiene } & \text { pound } \\ \text { Raffinate-1 (price/value) } & \text { gal } \\ \text { Benzene } & \text { gal } \\ \text { Toluene-MoGas Value } & \text { gal } \\ \text { Xylenes- MoGas Value } & \text { gal } \\ \text { C9 Aromatics } & \text { gal } \\ \text { Fuel Gas } & \text { MM Btu } \\ \text { SC Light Fuel Oil } & \text { gal } \\ \text { Raffinate (BZ extraction) } & \text { gal } \\ \text { Hydrogen ex SC } & \text { k scf }\end{array}$

TOTAL BY-PRODUCT CREDITS

UTILITIES NET RAW MATERIALS

\begin{tabular}{ll} 
Power (Export) & $\mathrm{kWh}$ \\
Fuel & $\mathrm{MM} \mathrm{Btu}$ \\
Cooling Water & Mgal \\
Boiler Feedwater & MGal \\
\multicolumn{2}{c}{ TOTAL UTILITIES }
\end{tabular}

NET RAW MATERIALS \& UTILITIES

VARIABLE COST

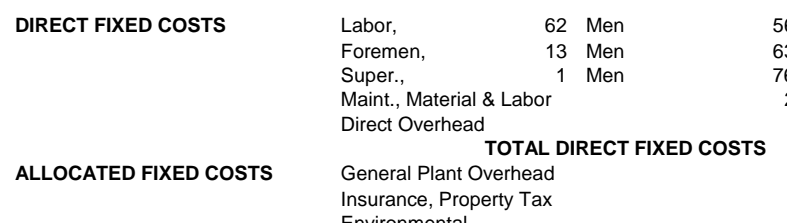

Environmental TOTAL ALLOCATED FIXED COSTS

TOTAL CASH COST

$10 \%$ for ISBL

Depreciation @

6.22 Thousand U.S. \$

3.79 Thousand U.S. \$

6.97 Thousand U.S. \$

$2.66 \%$ of ISBL

$45 \%$ Labor \& Supervision

$65 \%$ Labor \& Maintenance

$1 \%$ Total Plant Capital $0.5 \%$ Total Plant Capital

COST OF PRODUCTION

RETURN ON TOTAL CAPITAL INVESTMENT (Ex. WC) @

COST OF PRODUCTION + ROI

$\begin{array}{lr}\text { CAPITAL COST MILLION U.S. \$ } & \\ \text { ISBL } & 926.4 \\ \text { OSBL } & 463.3 \\ \text { Total Plant Capital } & 1389.7 \\ \text { Other Project Costs } & 347.4 \\ \quad \text { Total Capital Investment } & \mathbf{1 , 7 3 7 . 1} \\ \text { Working capital } & 78.2\end{array}$

$\begin{array}{lll}\text { ANNUAL } & \\ \text { U.S. } \$ & \text { COST MM } & \text { U.S. } \$\end{array}$

Per Lb U.S.\$ Per MT

$0.310 \quad 676.16$

$\begin{array}{lr}0.310 & 67.16 \\ 0.002 & 3.76\end{array}$

$\begin{array}{rrr}0.002 & 3.76 & \\ \mathbf{0 . 3 1 2} & \mathbf{6 7 9 . 9 2} & \mathbf{6 8 8}\end{array}$

(0.092) (200.58)

$(0.032) \quad(69.59)$

$(0.023) \quad(50.07)$

$(0.027) \quad(58.97)$

$\begin{array}{ll}(0.027) & (58.97) \\ (0.008) & (17.18)\end{array}$

$\begin{array}{rr}(0.008) & (17.18) \\ (0.002) & (3.60)\end{array}$

$(0.001) \quad(2.31)$

$(0.035) \quad(75.45)$

$(0.006) \quad(12.79)$

$(0.033) \quad(72.65)$

$(0.005) \quad(10.76)$

$\begin{array}{lll}(\mathbf{0 . 2 6 3 )} & \mathbf{( 5 7 3 . 9 5 )} \quad \mathbf{( 5 8 0 )}\end{array}$

$\mathbf{0 . 0 4 9} \quad \mathbf{1 0 5 . 9 7}$

$0.003 \quad 6.76$

$0.048 \quad 105.33$

$0.006 \quad 13.58$

$0.000 \quad 0.15$

$\begin{array}{lrl}0.058 & 125.81 & 127\end{array}$

$\begin{array}{lll}0.106 & 231.78 & 234\end{array}$

$\underline{0.106} \quad \underline{231.78} \quad 234$

$0.002 \quad 3.49$

$\begin{array}{ll}0.002 & 3.49 \\ 0.000 & 0.83\end{array}$

$\begin{array}{rr}0.000 & 0.08 \\ 0.011 & 24.64\end{array}$

0.001

$\mathbf{0 . 0 1 4} \quad \mathbf{3 1 . 0 1}$

$0.009 \quad 18.87$

$0.006 \quad 13.90$

$0.003 \quad 6.95$

$\mathbf{0 . 0 1 8} \quad 39.72 \quad 40$

$\underline{0.139} \quad \underline{302.51} \quad 306$

$0.080 \quad 173.71 \quad 176$

$\underline{0.218} \quad \underline{476.22} \quad 482$

$0.080 \quad 173.71 \quad 176$

$\underline{0.298} \quad \underline{649.92} \quad 657$ 


\section{Table 5.39 Cost of Production Estimate For: Ethylene (Naphtha Feed) Process: Steam Cracking (Nexant Very High Severity)}

$\begin{array}{lr}\text { Analysis date } & 2015 \\ \text { Plant start-up } & 2002 \\ \text { Location } & \text { USGC } \\ \text { Capacity } & 2,180 \text { Million pounds/yr } \\ & 989 \text { Thousand metric tons/yr } \\ \text { Operating rate } & 100 \text { percent } \\ \text { Throughput } & 2,180 \text { Million pounds/yr }\end{array}$

PRODUCTION COST SUMMARY

RAW MATERIALS

BY-PRODUCT CREDITS

Full Range Naphtha ga Catalyst \& Chemicals TOTAL RAW MATERIALS

$\begin{array}{ll}\text { Propylene-Chem Grade } & \text { pound } \\ \text { Butadiene } & \text { pound } \\ \text { Raffinate-1 (price/value) } & \text { gal } \\ \text { Benzene } & \text { gal } \\ \text { Toluene-MoGas Value } & \text { gal } \\ \text { Xylenes- MoGas Value } & \text { gal } \\ \text { C9 Aromatics } & \text { gal } \\ \text { Fuel Gas } & \text { MM Btu } \\ \text { SC Light Fuel Oil } & \text { gal } \\ \text { Raffinate (BZ extraction) } & \text { gal } \\ \text { Hydrogen ex SC } & \text { k scf }\end{array}$

TOTAL BY-PRODUCT CREDITS

UTILITIES

NET RAW MATERIALS

$\begin{array}{llll}\text { Power (Export) } & \text { kWh } & 0.0465 & 0.0667 \\ \text { Fuel } & \text { MM Btu } & 0.0135 & 3.5693 \\ \text { Cooling Water } & \text { Mgal } & 0.0500 & 0.1247 \\ \text { Boiler Feedwater } & \text { MGal } & 0.0000 & 2.2981\end{array}$

NET RAW MATERIALS \& UTILITIES

VARIABLE COST

\begin{tabular}{llrl} 
DIRECT FIXED COSTS & Labor, & 62 & Men \\
& Foremen, & 13 & Men \\
& Super., & 1 & Men \\
& Maint., Material \& Labor \\
& Direct Overhead & \multicolumn{2}{c}{ TOTAL DIRECT FIXED COSTS } \\
ALLOCATED FIXED COSTS & $\begin{array}{l}\text { General Plant Overhead } \\
\text { Insurance, Property Tax } \\
\text { Environmental }\end{array}$
\end{tabular}

TOTAL CASH COST

TOTAL ALLOCATED FIXED COSTS

56.22 Thousand U.S. \$

63.79 Thousand U.S. \$

76.97 Thousand U.S. $\$$

$2.66 \%$ of ISBL

$45 \%$ Labor \& Supervision

$65 \%$ Labor \& Maintenance

$1 \%$ Total Plant Capital

$0.5 \%$ Total Plant Capital

Depreciation @

$10 \%$ for ISBL

$10 \%$ for OSBL \& OPC

COST OF PRODUCTION

RETURN ON TOTAL CAPITAL INVESTMENT (Ex. WC) @

10 Percent
MILLION U.S. \$

SBL

PBolect Costs

Total Capital Investment

Working capital

$\begin{array}{lr} & \\ & 926.4 \\ & 463.3 \\ \text { MILLION U.S. \$ } & 1389.7 \\ \text { sestment } & 347.4 \\ & \mathbf{1 , 7 3 7 . 1} \\ & 78.2\end{array}$

$\begin{array}{lll}\text { ANNUAL } & \\ \text { U.S. } \$ & \text { COST MM } & \text { U.S. \$ }\end{array}$

$\begin{array}{lll}\text { Per Lb } & \text { U.S. } \$ \text { Per MT }\end{array}$

$0.298 \quad 649.36$

$0.002 \quad 3.76$

0.300
653.12

$(0.070) \quad(153.30)$

$(0.022) \quad(47.92)$

$(0.016) \quad(34.47)$

$(0.024) \quad(51.38)$

$(0.007) \quad(14.97)$

$(0.001) \quad(3.14)$

$(0.001)$

$(0.028) \quad(61.42)$

$(0.006) \quad(13.59)$

$(0.029)$

$(63.30)$

(0.002) (3.99)

(0.206) (449.50) (455)

$0.093 \quad 203.62 \quad 206$

$0.003 \quad 6.76$

$0.048 \quad 105.33$

$0.006 \quad 13.58$

$0.000 \quad 0.15$

$\begin{array}{lll}0.058 & 125.81 & 127\end{array}$

$\begin{array}{lll}0.151 & 329.44 & 333\end{array}$

$\underline{0.151} \quad \underline{329.44} \quad 333$

$0.002 \quad 3.49$

$\begin{array}{ll}0.002 & 3.49 \\ 0.000 & 0.83\end{array}$

$0.000 \quad 0.08$

$0.011 \quad 24.64$

$0.001 \quad 1.98$

$0.014 \quad 31.01$

$0.009 \quad 18.87$

$0.006 \quad 13.90$

$0.003 \quad 6.95$

$0.018 \quad 39.72 \quad 40$

$\underline{0.184} \quad \underline{400.17} \quad 405$

$\begin{array}{lll}0.080 & 173.71 \quad 176\end{array}$

$\underline{0.263} \quad \underline{573.87} \quad 580$

$0.080 \quad 173.71 \quad 176$

$\underline{0.343} \quad \underline{747.58} \quad 756$ 


\section{Table 5.40 Cost of Production Estimate for: Ethylene (FT Naphtha Feed) Process: Steam Cracking (S\&W, High Severity)}

$\begin{array}{lr}\text { Analysis date } & 2015 \\ \text { Plant start-up } & 2002 \\ \text { Location } & \text { USGC } \\ \text { Capacity } & 2,180 \text { Million pounds/yr } \\ & 989 \text { Thousand metric tons/yr } \\ \text { Operating rate } & 100 \text { percent } \\ \text { Throughput } & 2,180 \text { Million pounds/yr }\end{array}$

PRODUCTION COST SUMMARY

RAW MATERIALS

BY-PRODUCT CREDITS

Full Range Naphtha gal Catalyst \& Chemicals

TOTAL RAW MATERIALS

$\begin{array}{ll}\text { Propylene - Chem Grade } & \text { pound } \\ \text { Butadiene } & \text { pound } \\ \text { Raffinate-1 (price/value) } & \text { gal } \\ \text { Benzene } & \text { gal } \\ \text { Toluene-MoGas Value } & \text { gal } \\ \text { Xylenes - MoGas Value } & \text { gal } \\ \text { C9 Aromatics } & \text { gal } \\ \text { Fuel Gas } & \text { MM Btu } \\ \text { SC Light Fuel Oil } & \text { gal } \\ \text { Raffinate (BZ extraction) } & \text { gal } \\ \text { Hydrogen ex SC } & \text { k scf }\end{array}$

TOTAL BY-PRODUCT CREDITS

UTILITIES

NET RAW MATERIALS

$\begin{array}{llll}\text { Power (Export) } & \text { kWh } & 0.0395 & 0.0667 \\ \text { Fuel } & \text { MM Btu } & 0.0123 & 3.5693 \\ \text { Cooling Water } & \text { Mgal } & 0.0425 & 0.1247 \\ \text { Boiler Feedwater } & \text { MGal } & 0.0000 & 2.2981\end{array}$

NET RAW MATERIALS \& UTILITIES

VARIABLE COST

\begin{tabular}{llrl} 
DIRECT FIXED COSTS & Labor, & 62 & Men \\
& Foremen, & 13 & Men \\
& Super., & 1 & Men \\
& Maint., Material \& Labor \\
& Direct Overhead & \multicolumn{1}{c}{ TOTAL DIRECT FIXED COSTS } \\
ALLOCATED FIXED COSTS & $\begin{array}{l}\text { General Plant Overhead } \\
\text { Insurance, Property Tax } \\
\end{array}$
\end{tabular}

TOTAL CASH COST

TOTAL ALLOCATED FIXED COSTS

56.22 Thousand U.S. \$

63.79 Thousand U.S. \$

76.97 Thousand U.S. \$

$2.66 \%$ of ISBL

$45 \%$ Labor \& Supervision

$65 \%$ Labor \& Maintenance

$1 \%$ Total Plant Capital

$0.5 \%$ Total Plant Capital

$10 \%$ for ISBL

$10 \%$ for OSBL \& OPC

COST OF PRODUCTION

RETURN ON TOTAL CAPITAL INVESTMENT (Ex. WC) @
MILLION U.S. \$

\begin{tabular}{ll} 
SBL & 870.8 \\
\hline
\end{tabular}

870.8
449.4

1320.2

330.0

$1,650.2$

74.3

ANNUAL

$\begin{array}{ll}\text { U.S. } \$ \text { COST MM } & \text { U.S. } \$\end{array}$

$\begin{array}{lll}\text { Per Lb } & \text { U.S. } \$ \text { Per MT }\end{array}$

$0.267 \quad 582.75$

$0.002 \quad 3.76$

$0.269 \quad 586.50$

593

(0.090) (196.58)

$(0.033) \quad(71.21)$

$(0.027) \quad(59.93)$

$(0.016) \quad(35.73)$

$(0.005) \quad(9.84)$

$(0.001) \quad(2.85)$

$(0.005) \quad(10.90)$

$(0.024) \quad(52.12)$

$(0.002) \quad(5.01)$

$\begin{array}{ll}(0.011) & (25.07)\end{array}$

$\begin{array}{ll}(0.011) & (25.07) \\ (0.011) & (24.75)\end{array}$

(0.227) (494.00) (500)

$0.042 \quad 92.51 \quad 94$

$0.003 \quad 5.75$

$0.044 \quad 95.32$

$0.005 \quad 11.54$

$0.000 \quad 0.15$

$0.052 \quad 112.76 \quad 114$

$0.094 \quad 205.27 \quad 208$

$\underline{0.094} \quad \underline{205.27} \quad 208$

$0.002 \quad 3.49$

$0.000 \quad 0.83$

$0.000 \quad 0.08$

$0.011 \quad 23.16$

$0.001 \quad 1.98$

$0.014 \quad 29.53$

$0.008 \quad 17.91$

$0.006 \quad 13.20$

$0.003 \quad 6.60$

$\begin{array}{lll}0.017 & 37.71 & 38\end{array}$

$\underline{0.125} \quad \underline{272.51} \quad 276$

$0.076 \quad 165.02 \quad 167$

$\underline{0.201} \quad \underline{437.53} \quad 442$

$\begin{array}{lll}0.076 & 165.02 & 167\end{array}$

$\underline{0.276} \quad \underline{602.56} \quad 609$ 


\section{Table 5.41 Cost of Production Estimate for: Ethylene (FT Naphtha Feed) Process: Steam Cracking (Lummus, Low Severity)}

$\begin{array}{lr}\text { Analysis date } & 2015 \\ \text { Plant start-up } & 2002 \\ \text { Location } & \text { USGC } \\ \text { Capacity } & 2,180 \text { Million pounds/yr } \\ & 989 \text { Thousand metric tons/yr } \\ \text { Operating rate } & 100 \text { percent } \\ \text { Throughput } & 2,180 \text { Million pounds/yr }\end{array}$

PRODUCTION COST SUMMARY

RAW MATERIALS

BY-PRODUCT CREDITS Catalyst \& Chemicals
Full Range Naphtha gal

TOTAL RAW MATERIALS

$\begin{array}{ll}\text { Propylene - Chem Grade } & \text { pound } \\ \text { Butadiene } & \text { pound } \\ \text { Raffinate-1 (price/value) } & \text { gal } \\ \text { Benzene } & \text { gal } \\ \text { Toluene - MoGas Value } & \text { gal } \\ \text { Xylenes - MoGas Value } & \text { gal } \\ \text { C9 Aromatics } & \text { gal } \\ \text { Fuel Gas } & \text { MM Btu } \\ \text { SC Light Fuel Oil } & \text { gal } \\ \text { Raffinate (BZ extraction) } & \text { gal } \\ \text { Hydrogen ex SC } & \text { k scf }\end{array}$

TOTAL BY-PRODUCT CREDITS

NET RAW MATERIALS

\begin{tabular}{ll} 
Power (Export) & kWh \\
Fuel & MM Btu \\
Cooling Water & Mgal \\
Boiler Feedwater & MGal \\
\multicolumn{2}{c}{ TOTAL UTILITIES }
\end{tabular}

NET RAW MATERIALS \& UTILITIES

UTILITIES

VARIABLE COST

\begin{tabular}{llrl} 
DIRECT FIXED COSTS & Labor, & 62 & Men \\
& Foremen, & 13 & Men \\
& Super., & 1 & Men \\
& Maint., Material \& Labor \\
& Direct Overhead & \multicolumn{2}{c}{ TOTAL DIRECT FIXED COSTS } \\
ALLOCATED FIXED COSTS & \multicolumn{2}{c}{ General Plant Overhead } \\
& Insurance, Property Tax \\
& Environmental
\end{tabular}

$\begin{array}{lr}\text { CAPITAL COST } & \\ \text { ISBL } & \\ \text { OSBLLION U.S. \$ } & 870.8 \\ \text { Total Plant Capital } & 449.4 \\ \text { Other Project Costs } & 1320.2 \\ \text { Total Capital Investment } & 330.0 \\ \text { Working capital } & \mathbf{1 , 6 5 0 . 2} \\ & 74.3\end{array}$

UNITS PRICE

Per Lb U.S.\$

Product /Unit

$0.4765 \quad 0.6373$

$\begin{array}{ll}1.0000 & 0.0017\end{array}$

(0.5715) 0.1956

$(0.1284) \quad 0.2554$

(0.0394) $\quad 0.7516$

$(0.0117) \quad 1.1874$

$(0.0033) \quad 0.9099$

$(0.0019) \quad 0.9322$

$(0.0122) \quad 0.9544$

$(0.0080) \quad 3.5693$

$(0.0083) \quad 0.4932$

$(0.0338) \quad 0.6071$

$\begin{array}{ll}(0.0078) & 1.7100\end{array}$

$0.003 \quad 6.56$

$0.050 \quad 109.04$

$0.006 \quad 13.16$

$\begin{array}{lr}0.000 & 0.15\end{array}$

$\begin{array}{lll}0.059 & 128.91 & 130\end{array}$

$0.093 \quad 203.59 \quad 206$

$\underline{0.093} \underline{203.59} \quad 206$

$0.002 \quad 3.49$

$0.000 \quad 0.83$

$0.000 \quad 0.08$

$0.011 \quad 23.16$

$0.001 \quad 1.98$

$0.014 \quad 29.53$

$0.008 \quad 17.91$

$\begin{array}{rr}0.006 & 13.20 \\ 0.003 & 6.60\end{array}$

$\begin{array}{rr}0.003 & 6.60 \\ \mathbf{0 . 0 1 7} & \mathbf{3 7 . 7 1}\end{array}$

$\underline{0.124} \quad 270.84$

TOTAL CASH COST

$1 \%$ Total Plant Capital

$0.5 \%$ Total Plant Capital

Depreciation @

$10 \%$ for ISBL

$10 \%$ for OSBL \& OPC

COST OF PRODUCTION

0.076

165.02

$\underline{0.200} \quad \underline{435.86} \quad 441$

RETURN ON TOTAL CAPITAL INVESTMENT (Ex. WC) @

10 Percent

0.076

165.02

$\underline{0.276} \quad \underline{600.88}$

673

30 


\section{Table 5.42 Cost of Production Estimate for: Ethylene (FT Naphtha Feed) Process: Steam Cracking (Lummus, High Severity)}

$\begin{array}{lr}\text { Analysis date } & 2015 \\ \text { Plant start-up } & 2002 \\ \text { Location } & \text { USGC } \\ \text { Capacity } & 2,180 \text { Million pounds/yr } \\ & 989 \text { Thousand metric tons/yr } \\ \text { Operating rate } & 100 \text { percent } \\ \text { Throughput } & 2,180 \text { Million pounds/yr }\end{array}$

PRODUCTION COST SUMMARY

RAW MATERIALS

BY-PRODUCT CREDITS Catalyst \& Chemicals
Full Range Naphtha gal

\section{TOTAL RAW MATERIALS}

$\begin{array}{ll}\text { Propylene - Chem Grade } & \text { pound } \\ \text { Butadiene } & \text { pound } \\ \text { Raffinate-1 (price/value) } & \text { gal } \\ \text { Benzene } & \text { gal } \\ \text { Toluene - MoGas Value } & \text { gal } \\ \text { Xylenes - MoGas Value } & \text { gal } \\ \text { C9 Aromatics } & \text { gal } \\ \text { Fuel Gas } & \text { MM Btu } \\ \text { SC Light Fuel Oil } & \text { gal } \\ \text { Raffinate (BZ extraction) } & \text { gal } \\ \text { Hydrogen ex SC } & \text { k scf }\end{array}$

TOTAL BY-PRODUCT CREDITS

UTILITIES

\begin{tabular}{ll} 
NET RAW MATERIALS & kWh \\
Power (Export) & MM Btu \\
Fuel & Mgal \\
Cooling Water & MGal \\
Boiler Feedwater & \multicolumn{2}{c}{ TOTAL UTILITIES }
\end{tabular}

NET RAW MATERIALS \& UTILITIES

VARIABLE COST

\begin{tabular}{llrl} 
DIRECT FIXED COSTS & Labor, & 62 & Men \\
& Foremen, & 13 & Men \\
& Super., & 1 & Men \\
& Maint., Material \& Labor \\
& Direct Overhead & \multicolumn{2}{c}{ TOTAL DIRECT FIXED COSTS } \\
ALLOCATED FIXED COSTS & $\begin{array}{l}\text { General Plant Overhead } \\
\text { Insurance, Property Tax } \\
\text { Environmental }\end{array}$
\end{tabular}

$\begin{array}{lr}\text { CAPITAL COST } & \\ \text { ISBL } & \\ \text { OSBLLION U.S. \$ } & 870.8 \\ \text { OSB } & 449.4 \\ \text { Total Plant Capital } & \mathbf{1 3 2 0 . 2} \\ \text { Other Project Costs } & 330.0 \\ \text { Total Capital Investment } & \mathbf{1 , 6 5 0 . 2} \\ \text { Working capital } & 74.3\end{array}$

UNITS PRICE

Per Lb U.S.\$

Product IUnit

$0.4118 \quad 0.6373$

$1.0000 \quad 0.0017$

$(0.3469) \quad 0.1956$

$(0.1146) \quad 0.2554$

$(0.0171) \quad 0.7516$

$(0.0210) \quad 1.1874$

$(0.0032) \quad 0.9099$

$(0.0005) \quad 0.9322$

$(0.0080) \quad 0.9544$

$(0.0086) \quad 3.5693$

$(0.0140) \quad 0.4932$

(0.0104) $\quad 0.6071$

$\begin{array}{ll}(0.0078) & 1.7100\end{array}$

ANNUAL

$0.262 \quad 572.06$

$\begin{array}{lr}0.002 & 3.76 \\ \mathbf{0 . 2 6 4} & \mathbf{5 7 5 . 8 2}\end{array}$

$\mathbf{5 7 5 . 8 2}$

(0.068) (147.97)

$(0.029) \quad(63.80)$

$(0.013) \quad(28.10)$

$(0.025) \quad(54.46)$

$(0.003) \quad(6.33)$

$(0.000) \quad(1.03)$

$(0.008) \quad(16.68)$

$(67.01)$

(15.01)

$(0.006) \quad(13.83)$

$(0.013) \quad(28.93)$ $\begin{array}{lll}\text { U.S. } \$ \text { COST MM U.S.\$ } & \text { U.S.\$ } & \text { Per MT }\end{array}$

(0.203) (443.12) (448)

$\begin{array}{lll}0.061 & 132.69 & 134\end{array}$

$0.003 \quad 5.75$

$0.044 \quad 95.32$

$0.005 \quad 11.54$

$0.000 \quad 0.15$

$\begin{array}{lll}0.052 & 112.76 & 114\end{array}$

$0.113 \quad 245.45 \quad 248$

$\underline{0.113} \quad \underline{245.45} \quad 248$

$0.002 \quad 3.49$

$0.000 \quad 0.83$

$0.000 \quad 0.08$

$0.011 \quad 23.16$

$\begin{array}{lr}0.001 & 1.98 \\ 0.014 & \mathbf{2 9 . 5 3}\end{array}$

$\begin{array}{ll}\mathbf{0 . 0 1 4} & \mathbf{2 9 . 5 3} \\ 0.008 & 17.91\end{array}$

$0.006 \quad 13.20$

$0.003 \quad 6.60$

$0.017 \quad 37.71$

$\mathbf{0 . 1 4 3} \quad 312.69$

$0.076 \quad 165.02$

$\underline{0.219} \quad \underline{477.72}$

$0.076 \quad 165.02$

$\underline{0.295} \quad \underline{642.74}$
582 


\section{Table 5.43 Cost of Production Estimate for: Ethylene (FT Naphtha Feed) Process: Steam Cracking (KBR, Very High Severity)}

$\begin{array}{lr}\text { Analysis date } & 2015 \\ \text { Plant start-up } & 2002 \\ \text { Location } & \text { USGC } \\ \text { Capacity } & 2,180 \text { Million pounds/yr } \\ & 989 \text { Thousand metric tons/yr } \\ \text { Operating rate } & 100 \text { percent } \\ \text { Throughput } & 2,180 \text { Million pounds/yr }\end{array}$

PRODUCTION COST SUMMARY

RAW MATERIALS

BY-PRODUCT CREDITS
Full Range Naphtha gal

TOTAL RAW MATERIALS

$\begin{array}{ll}\text { Propylene - Chem Grade } & \text { pound } \\ \text { Butadiene } & \text { pound } \\ \text { Raffinate-1 (price/value) } & \text { gal } \\ \text { Benzene } & \text { gal } \\ \text { Toluene - MoGas Value } & \text { gal } \\ \text { Xylenes - MoGas Value } & \text { gal } \\ \text { C9 Aromatics } & \text { gal } \\ \text { Fuel Gas } & \text { MM Btu } \\ \text { SC Light Fuel Oil } & \text { gal } \\ \text { Raffinate (BZ extraction) } & \text { gal } \\ \text { Hydrogen ex SC } & \text { k scf }\end{array}$

TOTAL BY-PRODUCT CREDITS

NET RAW MATERIALS

\begin{tabular}{ll} 
Power (Export) & kWh \\
Fuel & MM Btu \\
Cooling Water & Mgal \\
Boiler Feedwater & MGal \\
\multicolumn{2}{c}{ TOTAL UTILITIES }
\end{tabular}

NET RAW MATERIALS \& UTILITIES

UTILITIES

VARIABLE COST

\begin{tabular}{llrl} 
DIRECT FIXED COSTS & Labor, & 62 & Men \\
& Foremen, & 13 & Men \\
& Super., & 1 & Men \\
& Maint., Material \& Labor \\
& Direct Overhead & \multicolumn{2}{c}{ TOTAL DIRECT FIXED COSTS } \\
ALLOCATED FIXED COSTS & \multicolumn{2}{c}{ General Plant Overhead } \\
& Insurance, Property Tax \\
& Environmental
\end{tabular}

$\begin{array}{lr}\text { CAPITAL COST MILLION U.S. \$ } & \\ \text { ISBL } & 870.8 \\ \text { OSBL } & 449.4 \\ \text { Total Plant Capital } & \mathbf{1 3 2 0 . 2} \\ \text { Other Project Costs } & 330.0 \\ \text { Total Capital Investment } & \mathbf{1 , 6 5 0 . 2} \\ \text { Working capital } & 74.3\end{array}$

Working capital

UNITS PRICE

$\begin{array}{cc}\text { Per Lb } & \text { U.S. \$ } \\ \text { Product } & \text { IUnit }\end{array}$

$0.3625 \quad 0.6373$

$\begin{array}{ll}1.0000 & 0.0017\end{array}$

(0.3577) 0.1956

$(0.1342) \quad 0.2554$

$(0.0144) \quad 0.7516$

$(0.0109) \quad 1.1874$

$(0.0049) \quad 0.9099$

$(0.0043) \quad 0.9322$

$(0.0026) \quad 0.9544$

(0.0055) 3.5693

$(0.0046) \quad 0.4932$

$(0.0095) \quad 0.6071$

ANNUAL

$0.231 \quad 503.62$

0.231503 .6

$\begin{array}{lr}0.002 & 3.76 \\ \mathbf{0 . 2 3 3} & \mathbf{5 0 7 . 3 8}\end{array}$

(0.070) (152.55)

$(0.034) \quad(74.69)$

(0.011) (23.57)

$(0.013) \quad(28.31)$

$\begin{array}{ll}(0.013) & (28.31) \\ (0.004) & (9.68)\end{array}$

$(0.004) \quad(8.72)$

$(0.002) \quad(5.39)$

$(0.020)$

$(0.002) \quad(4.89)$

$\begin{array}{ll}(0.002) & (4.89) \\ (0.006) & (12.54)\end{array}$

$(0.011) \quad(24.38)$ Catalyst \& Chemicals

$\begin{array}{ll}(0.0065) & 1.7100\end{array}$

$\begin{array}{ccc}\text { U.S. \$ } & \text { COST MM } & \text { U.S. \$ } \\ \text { Per Lb } & \text { U.S. \$ } & \text { Per MT }\end{array}$

513

(0.178) (387.45)

$0.055 \quad 119.93$

$0.003 \quad 5.75$

$0.044 \quad 95.32$

$0.005 \quad 11.54$

$0.000 \quad 0.15$

$0.052 \quad 112.76 \quad 114$

$0.107 \quad 232.69 \quad 235$

$\underline{0.107} \quad \underline{232.69} \quad 235$

$0.002 \quad 3.49$

$0.000 \quad 0.83$

$0.000 \quad 0.08$

$0.011 \quad 23.16$

$0.001 \quad 1.98$

$0.014 \quad 29.53$

$0.008 \quad 17.91$

$0.006 \quad 13.20$

$\begin{array}{rr}0.003 & 6.60 \\ 0.017 & 37.71\end{array}$

\begin{tabular}{rr}
0.017 & 37.71 \\
0.138 & 299.93 \\
\hline
\end{tabular}

TOTAL CASH COST

TOTAL ALLOCATED FIXED COSTS $1 \%$ Total Plant Capital
$0.5 \%$ Total Plant Capita

Depreciation @

$10 \%$ for ISBL

$10 \%$ for OSBL \& OPC

COST OF PRODUCTION

0.076

165.02

$\underline{0.213} \quad \underline{464.96}$

$0.076 \quad 165.02$

$\underline{0.289} \quad \underline{629.98}$ 


\section{Table 5.44 Cost of Production Estimate for: Ethylene (FT Naphtha Feed) Process: Steam Cracking (Linde, High Severity)}

$\begin{array}{lr}\text { Analysis date } & 2015 \\ \text { Plant start-up } & 2002 \\ \text { Location } & \text { USGC } \\ \text { Capacity } & 2,180 \text { Million pounds/yr } \\ & 989 \text { Thousand metric tons/yr } \\ \text { Operating rate } & 100 \text { percent } \\ \text { Throughput } & 2,180 \text { Million pounds/yr }\end{array}$

PRODUCTION COST SUMMARY

RAW MATERIALS

BY-PRODUCT CREDITS

Full Range Naphtha gal Catalyst \& Chemicals

TOTAL RAW MATERIALS

$\begin{array}{ll}\text { Propylene - Chem Grade } & \text { pound } \\ \text { Butadiene } & \text { pound } \\ \text { Raffinate-1 (price/value) } & \text { gal } \\ \text { Benzene } & \text { gal } \\ \text { Toluene - MoGas Value } & \text { gal } \\ \text { Xylenes - MoGas Value } & \text { gal } \\ \text { C9 Aromatics } & \text { gal } \\ \text { Fuel Gas } & \text { MM Btu } \\ \text { SC Light Fuel Oil } & \text { gal } \\ \text { Raffinate (BZ extraction) } & \text { gal } \\ \text { Hydrogen ex SC } & \text { k scf }\end{array}$

TOTAL BY-PRODUCT CREDITS

NET RAW MATERIALS

$\begin{array}{llll}\text { Power (Export) } & \text { kWh } & 0.0395 & 0.0667 \\ \text { Fuel } & \text { MM Btu } & 0.0123 & 3.5693 \\ \text { Cooling Water } & \text { Mgal } & 0.0425 & 0.1247 \\ \text { Boiler Feedwater } & \text { MGal } & 0.0000 & 2.2981\end{array}$

NET RAW MATERIALS \& UTILITIES

UTILITIES

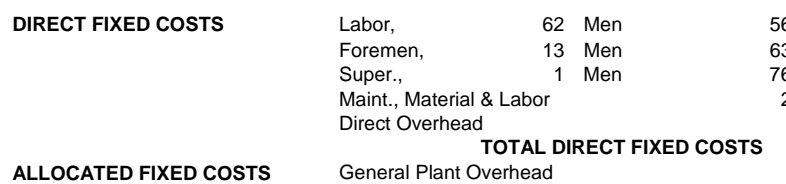

General Plant Overhead

Insurance, Property Tax Environmental

TOTAL ALLOCATED FIXED COSTS

56.22 Thousand U.S. \$

63.79 Thousand U.S. \$

76.97 Thousand U.S. $\$$

$2.66 \%$ of ISBL

$45 \%$ Labor \& Supervision

$65 \%$ Labor \& Maintenance

$1 \%$ Total Plant Capital

$0.5 \%$ Total Plant Capital

TOTAL CASH COST

$10 \%$ for ISBL

$10 \%$ for OSBL \& OPC

COST OF PRODUCTION

RETURN ON TOTAL CAPITAL INVESTMENT (Ex. WC) @

10 Percent

$\begin{array}{lr}\text { CAPITAL COST MILLION U.S. \$ } & \\ \text { ISBL } & 870.8 \\ \text { OSBL } & 449.4 \\ \text { Total Plant Capital } & \mathbf{1 3 2 0 . 2} \\ \text { Other Project Costs } & 330.0 \\ \text { Total Capital Investment } & \mathbf{1 , 6 5 0 . 2} \\ \text { Working capital } & 74.3\end{array}$

74.3

ANNUAL

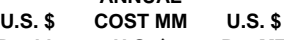

Per Lb U.S. $\$$ Per MT

$0.254 \quad 554.54$

$0.002 \quad 3.76$

$\mathbf{0 . 2 5 6} \quad \mathbf{5 5 8 . 3 0} \quad 565$

$(0.089) \quad(194.32)$

$(0.038) \quad(83.68)$

$(0.020) \quad(44.00)$

$(0.013) \quad(27.60)$

$(0.002) \quad(4.46)$

$(0.001) \quad(1.33)$

$(0.003)$

$(0.020)$

$(0.000) \quad(0.97)$

$(0.018) \quad(38.65)$

$(0.010) \quad(21.77)$

$\begin{array}{lll}(0.214) & (467.05) & (472)\end{array}$

$0.003 \quad 5.75$

$0.044 \quad 95.32$

$0.005 \quad 11.54$

$0.000 \quad 0.15$

$0.052 \quad 112.76 \quad 11$

$0.094204 .00 \quad 206$

$\underline{0.094} \quad \underline{204.00} \quad 206$

$0.002 \quad 3.49$

$0.000 \quad 0.83$

$0.000 \quad 0.08$

$0.011 \quad 23.16$

$0.001-1.98$

$0.014 \quad 29.53$

$0.008 \quad 17.91$

$0.006 \quad 13.20$

$0.003 \quad 6.60$

$0.017 \quad 37.71 \quad 38$

$0.124 \quad 271.24$

$\begin{array}{lll}0.076 & 165.02 & 167\end{array}$

$\underline{0.200} \quad \underline{436.27} \quad 441$

$\begin{array}{lll}0.076 & 165.02 & 167\end{array}$

$\underline{0.276} \quad \underline{601.29} \quad 608$ 
The objective of this section was to evaluate the potential market for using FT diesel and FT naphtha as a feedstock for ethylene production. Key findings are as follows:

- Provide an overview of the global and United States ethylene industry with an emphasis on identifying the size of future demand for naphtha and diesel/gasoils as feedstocks

- Evaluate alternative markets for FT naphtha

- Evaluate the technical suitability of FT naphtha and FT diesel as ethylene feedstocks

- Develop comparative economics for FT diesel and FT naphtha versus conventional cracking feedstocks

\subsection{ETHYLENE INDUSTRY PROFILE}

Ethylene is used to produce a wide variety of petrochemicals, but demand is driven by polyethylene. Greater than 50 percent of the ethylene consumed on a global basis is used to produce polyethylene. This is expected to increase to over 60 percent by 2015 . Global ethylene demand and production are forecast to grow at an average annual rate of 4.3 percent through 2015. In developed regions such as the United States, Western Europe, and Japan, the industry is mature and demand growth is expected to be moderate, with growth over the forecast period ranging from 0.1 percent in Japan to 2.2 percent in the United States. In developing regions such as most of Asia, Latin America, and the Middle East, demand growth will continue to be strong, with growth ranging from 6.1 percent in Asia to 9.8 percent in the Middle East. Demand for ethylene is shown in Table 6.1.

Table 6.1 Global Ethylene Demand (thousand metric tons per year)

\begin{tabular}{|c|c|c|c|c|c|c|c|c|c|c|c|}
\hline & Actual & Est. & \multicolumn{6}{|c|}{ Forecast } & \multicolumn{3}{|c|}{$\begin{array}{l}\text { Average Annual } \\
\text { Growth Rate, \% }\end{array}$} \\
\hline & & & & & & & & & $2000-$ & $2005-$ & $2010-$ \\
\hline & 2000 & 2001 & 2002 & 2005 & 2006 & 2010 & 2011 & 2015 & 2005 & 2010 & 2015 \\
\hline United States & 24675 & 23528 & 24579 & 27392 & 28145 & 30872 & 31575 & 34010 & 21 & 24 & 20 \\
\hline Western Europe & 20,016 & 19,853 & 21,081 & 22,802 & 22,400 & 24,362 & 24,600 & 25,700 & 2.6 & 1.3 & 1.1 \\
\hline \begin{tabular}{|l|} 
Japan \\
\end{tabular} & 7,372 & 7,199 & 7,201 & 7,146 & 7,033 & 7,202 & 7,280 & 7,450 & $(0.6)$ & 0.2 & 0.7 \\
\hline \begin{tabular}{|l|l} 
Asia $^{1}$ \\
\end{tabular} & 17,879 & 18,960 & 20,669 & 23,272 & 25,204 & 33,306 & 35,060 & 43,035 & 5.4 & 7.4 & 5.3 \\
\hline Rest of World & 19,029 & 21,364 & 23,262 & 28,586 & 32,550 & 43,034 & 45,261 & 56,900 & 8.5 & 8.5 & 5.7 \\
\hline Total & 88,971 & 90,904 & 96,792 & 109,198 & 115,332 & 138,776 & 143,776 & 167,095 & 4.2 & 4.9 & 3.8 \\
\hline
\end{tabular}

${ }^{1}$ Excluding Japan and including Australia and New Zealand

U:I2002Q2INexant1000721rplExcel filesI[Ethylene Market Outlook.xls]Global SupplyDemand Summary

In 2000, the United States (28 percent), Western Europe (22 percent), Asia (20 percent), and Japan (9 percent) were the four largest producers of ethylene. This pattern is expected to shift significantly in the future. By 2015, the leading producers will be Asia (25 percent), the United States (20 percent), the Middle East (16 percent), and Western Europe (15 percent). 
About fifty percent of global ethylene production is naphtha-based. The portion of naphthabased production varies significantly by region, as shown in Table 6.2 and Figure 6.1. In terms of percent of feedstock, the leading naphtha-based regions are Japan, Eastern Europe, Western Europe, and Asia. Ethane is the next largest feedstock, with more than 25 percent of global production. The leading ethane-based regions are the Middle East/Africa, Canada, Latin America, and the United States.

Table 6.2 Regional Ethylene Feedstock Analysis, 2000

\begin{tabular}{lcccccc} 
& \multicolumn{3}{c}{ (weight percent) } \\
Region & Naphtha & Ethane & Propane & Butane & Gas Oil & Other \\
United States & 20 & 45 & 17 & 3 & 12 & 4 \\
Western Europe & 76 & 6 & 4 & 5 & 9 & 1 \\
Japan & 96 & - & 1 & 3 & - & - \\
Asia $^{1}$ & 61 & 10 & 7 & 3 & 18 & 1 \\
Canada & 17 & 60 & 18 & - & 5 & - \\
Latin America & 44 & 49 & 4 & - & - & 3 \\
Middle East/Africa & 20 & 70 & 4 & 1 & - & 5 \\
Eastern Europe & 71 & 9 & 5 & 8 & 6 & 0 \\
Global Average & $\mathbf{5 0}$ & $\mathbf{2 7}$ & $\mathbf{8}$ & $\mathbf{3}$ & $\mathbf{9}$ & $\mathbf{2}$
\end{tabular}

1 Excluding Japan and including Australia and New Zealand

IICSI_NET1ISYS1IDPCDATAI2002Q2INexant100072|rp|[Ethylene Market Outlook.xIs]RegionalFeedstocks

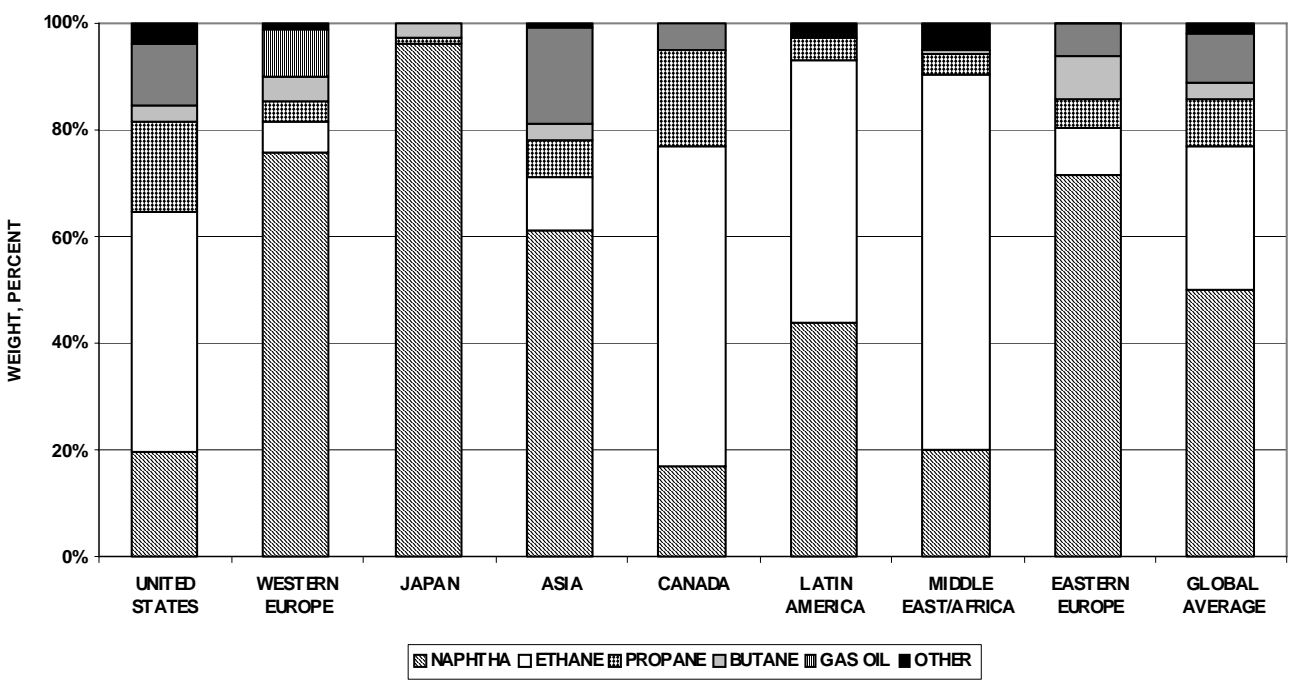

Figure 6.1 Regional Ethylene Feedstock Analysis, 2000 (weight percent)

Driven by demand for polyethylene, ethylene production is expected to show good growth on a global basis. Naphtha will continue to be a major feedstock for ethylene production, accounting for approximately 45 percent by 2015 . Based on the ethylene production forecast, the amount of 
naphtha required in 2015 will be approximately 70 percent greater than what was required in 2000, an increase of 106 million metric tons, as shown in Table 6.3.

Table 6.3 Global Naphtha Required for Ethylene Production ${ }^{1}$

(thousand metric tons of naphtha)

\begin{tabular}{|c|c|c|c|c|c|c|c|c|c|c|c|}
\hline & & & & & & & & & \multirow{2}{*}{\multicolumn{3}{|c|}{$\frac{\text { Average Annual }}{\text { Growth Rate, } \%}$}} \\
\hline & Actual & Est. & \multicolumn{6}{|c|}{ Forecast } & & & \\
\hline & 2000 & 2001 & 2002 & 2005 & 2006 & 2010 & 2011 & 2015 & $\begin{array}{l}2000- \\
2005\end{array}$ & $\begin{array}{l}2005- \\
2010\end{array}$ & $\begin{array}{l}2010- \\
2015\end{array}$ \\
\hline United States & 16,619 & 15,740 & 16,482 & 18,353 & 18,857 & 20,684 & 21,155 & 22,787 & 2.0 & $\begin{array}{ll}2.4 \\
\end{array}$ & 2.0 \\
\hline Western Europe & 48,959 & 49,534 & 52,539 & 56,913 & 56,029 & 60,581 & 61,117 & 63,943 & 3.1 & 1.3 & 1.1 \\
\hline Japan & 24,487 & 23,975 & 24,024 & 23,316 & 23,252 & 23,493 & 23,773 & 24,281 & (1.0) & 0.2 & 0.7 \\
\hline Asia ${ }^{2}$ & 35,560 & 37,431 & 40,580 & 45,384 & 49,010 & 65,745 & 69,308 & 85,251 & 5.0 & 7.7 & 5.3 \\
\hline Rest of World & 22,419 & 24,116 & 25,907 & 31,528 & 35,098 & 44,926 & 47,145 & 58,090 & 7.1 & 7.3 & 5.3 \\
\hline Total & 148,044 & 150,796 & 159,531 & 175,494 & 182,246 & 215,430 & 222,497 & 254,351 & 3.5 & 4.2 & 3.4 \\
\hline
\end{tabular}

${ }^{1}$ Based on 3.35 ton light virgin naphtha required per ton ethylene

2 Excluding Japan and including Australia and New Zealand

U:|2002Q2INexant100072Irp|Excel files|[Ethylene Market Outlook.xls]Naphtha SupplyDemand Tables

This represents a large market requiring a significant increase in feedstock supply, thus presenting an opportunity for FT naphtha. FT naphtha can be used in any cracker that uses conventional naphtha. The best opportunities would exist in countries where naphtha is already used as an ethylene feedstock since these countries generally already have established markets for the co-products. Given the high quality of FT naphtha, Nexant believes that it can readily be placed in any market. The projected market for naphtha is expected to increase about 2.7 million BPD by 2015 - well in excess of potential supply from GTL facilities.

\subsection{ALTERNATIVE MARKETS FOR FT NAPHTHA}

Alternatives to producing ethylene are not considered viable for FT naphtha. These alternatives include:

- Uses as a refinery feedstock which would require too much high cost processing

- Specialty markets are too small with high barriers to entry

- $\quad$ Use as a fuel cell fuel is considered unlikely by 2015.

The most likely target market for FT naphtha produced in a Mideast GTL plant is the Asian ethylene industry due to the high growth in this region and the region being a major naphtha importer.

\subsection{FT DIESEL - TECHNICAL SUITABILITY AS AN ETHYLENE FEEDSTOCK}

Typical FT diesel properties were supplied to four of the top ethylene technology licensors (Kellogg Brown \& Root, Linde AG, ABB Lummus and Stone \& Webster) to obtain yield data for steam cracking of FT diesel. The data obtained from the licensors was compared to typical yields that are obtained from cracking conventional gas oils. This data comparison covered a range of operating severities. In this case, the severity of the operation is measured by the overall propylene to ethylene ratio (of ethane and propane to extinction). A low severity 
operation has a high propylene to ethylene ratio and conversely a high severity operation has a low propylene to ethylene ratio.

The results of this analysis indicates that FT diesel potentially is a very good cracker feed, with the following characteristics:

- Propylene to ethylene yield ratios are shown graphically in Figure 6.2 and indicate that FT diesel feedstocks have similar yields to conventional feeds at equivalent operating severities.

- Combined ethylene and propylene yields are shown in Figure 6.3 and indicate that FT diesel yields will, on average, have measurably superior combined yields of ethylene and propylene at the equivalent operating severity compared to conventional feedstocks.

- Figure 6.4 shows the ethylene product to gasoil feed ratio and indicates that less feed is required to produce the equivalent amount of ethylene product when employing an FT feedstock. 


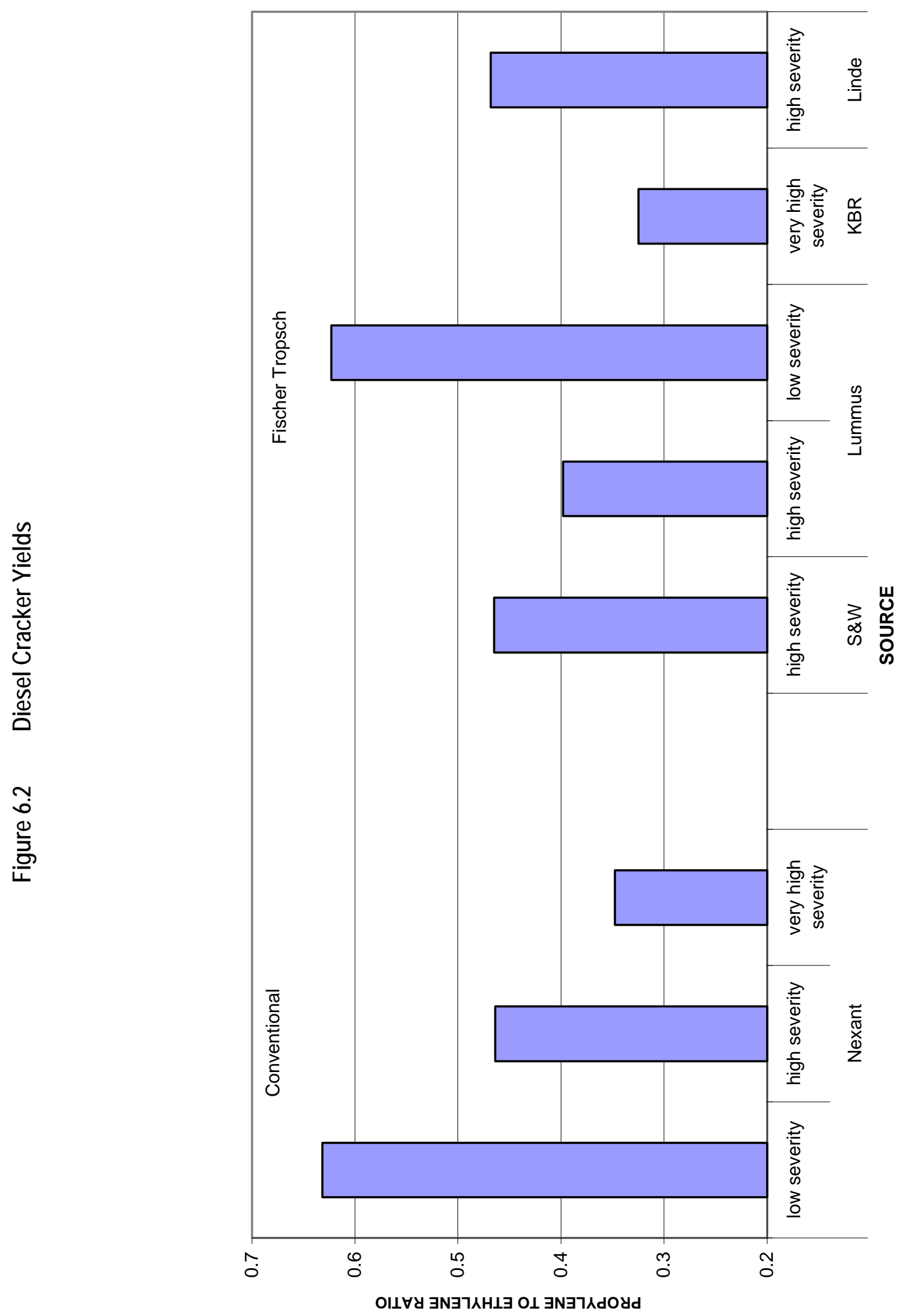




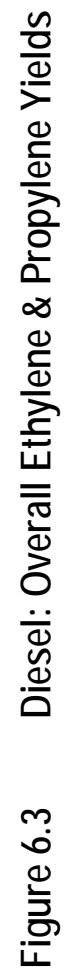

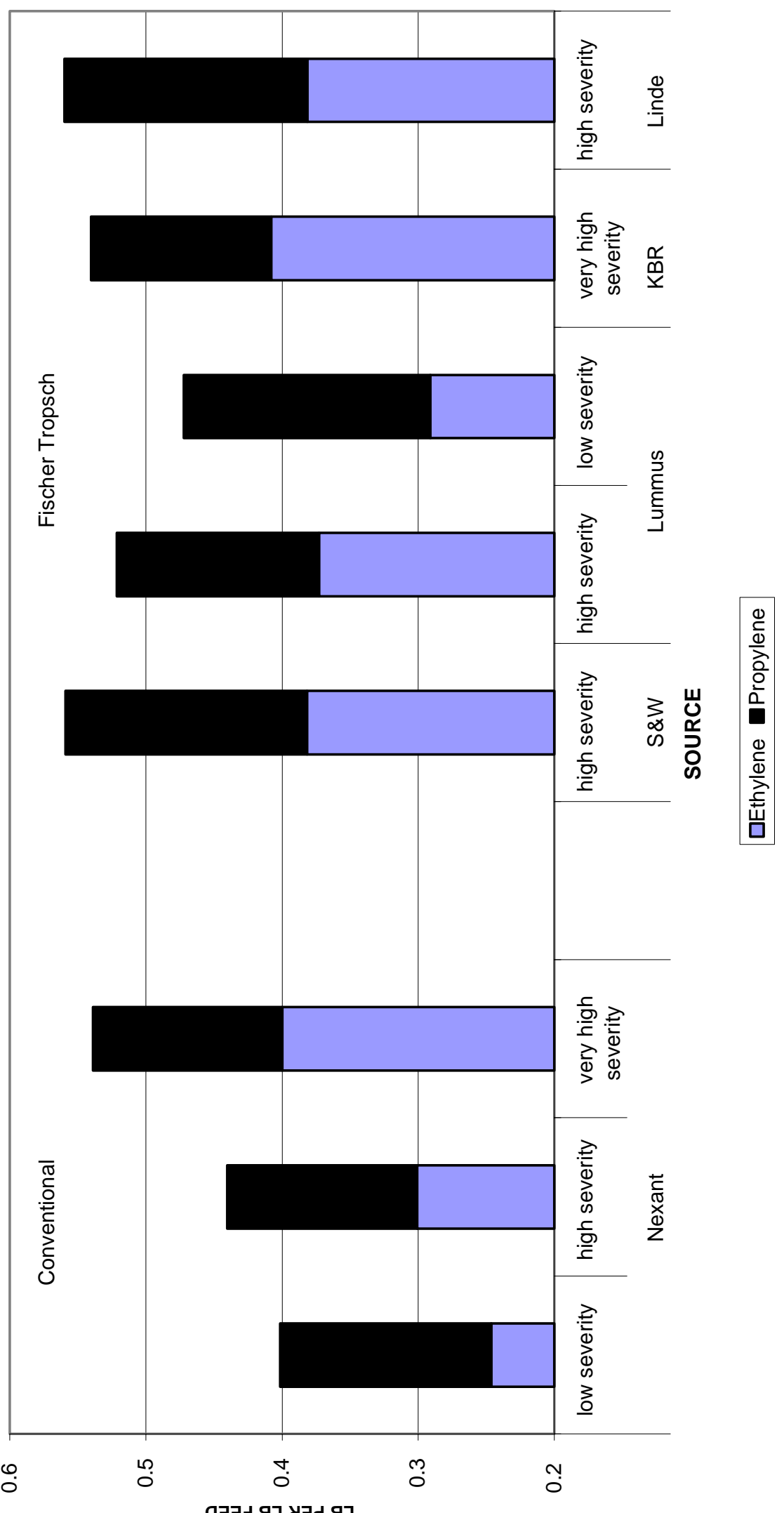




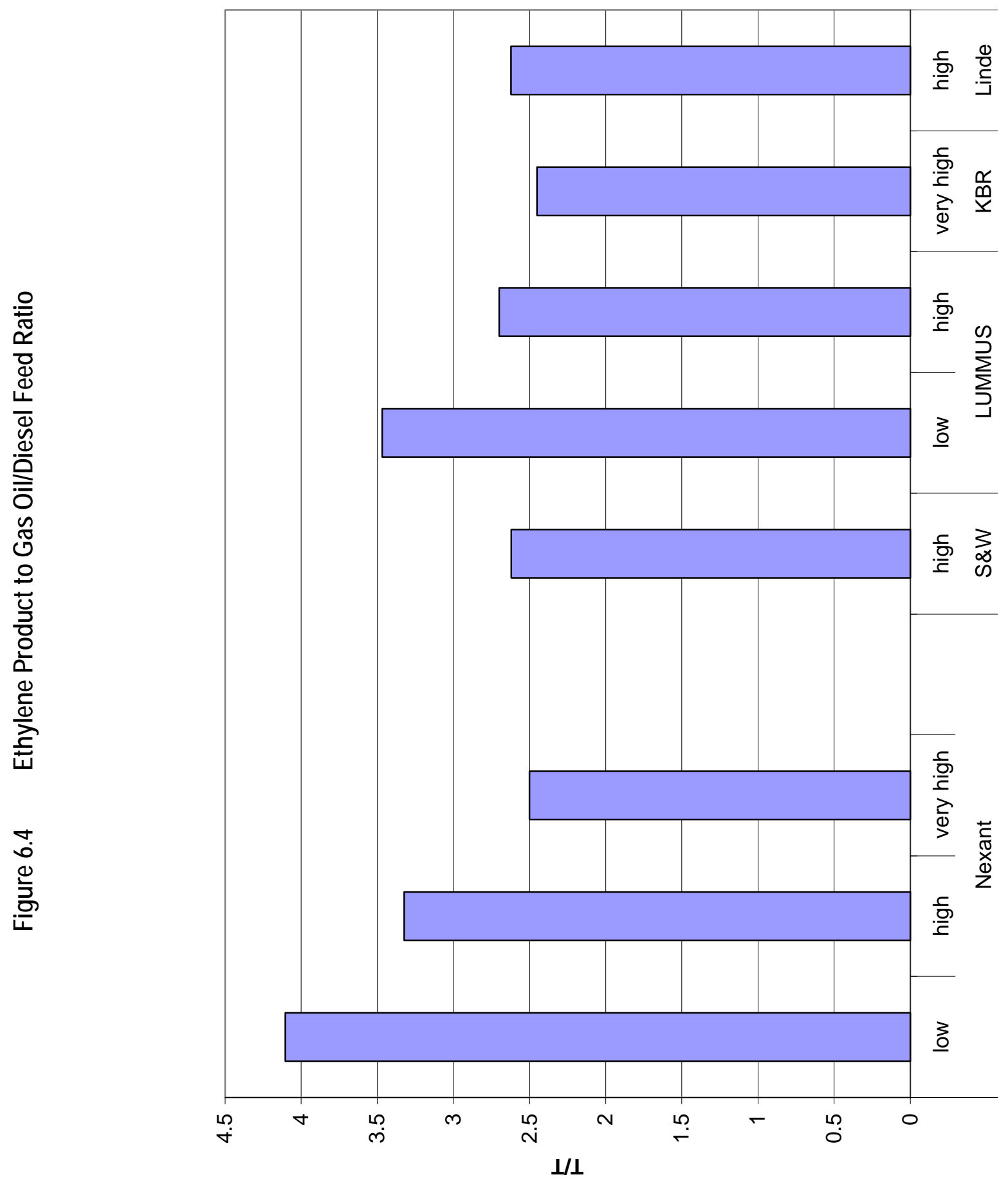




\subsection{FT NAPHTHA - TECHNICAL SUITABILITY AS AN ETHYLENE FEEDSTOCK}

Typical FT naphtha properties were supplied to four ethylene plant licensors (Kellogg Brown \& Root, Linde AG, ABB Lummus and Stone \& Webster) to obtain yield data for steam cracking to ethylene and other chemicals. The licensors indicated that the paraffinic nature of the FT naphtha allows for a higher severity operation than might be normally considered when compared to conventional naphtha cracking.

Similar to FT diesel, the analysis of this data indicates that FT naphtha has the potential to be a very good cracker feed, with the following characteristics:

- The propylene-to-ethylene ratios for conventional and FT naphtha feedstocks are shown in Figure 6.5 and indicate similar yield structure for both feedstocks at equivalent operating severity

- Combined ethylene and propylene yields are shown in Figure 6.6 and in general show better combined yields for FT naphtha at equivalent operating severity

- Figure 6.7 shows the ethylene product to naphtha feed ratio. In all cases less of the FT feed is needed to produce the same amount of ethylene.

The overall conclusion of this analysis is that FT naphthas can be expected to be excellent steam cracker feedstocks for the production of ethylene. 


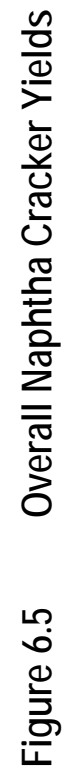

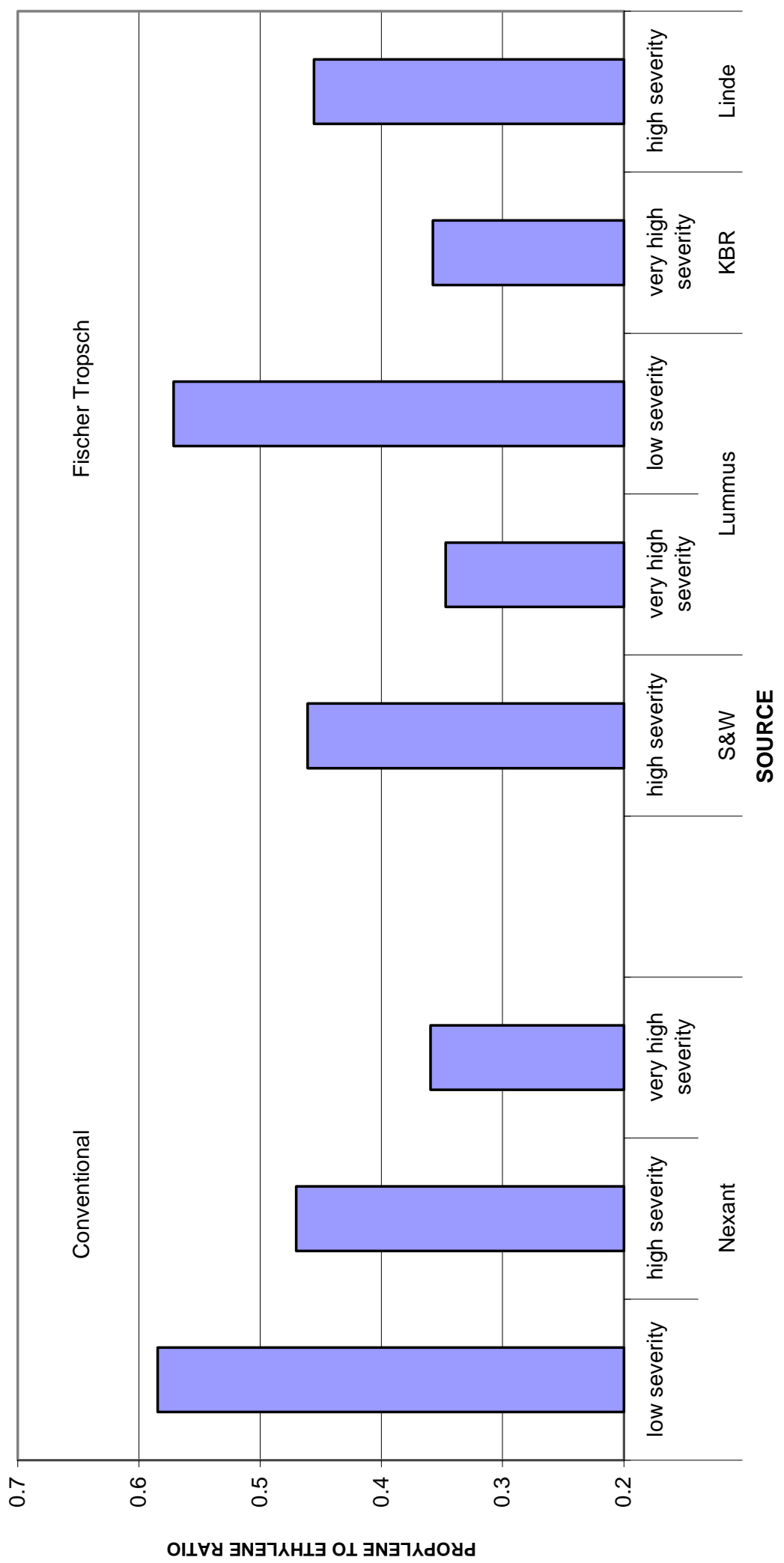




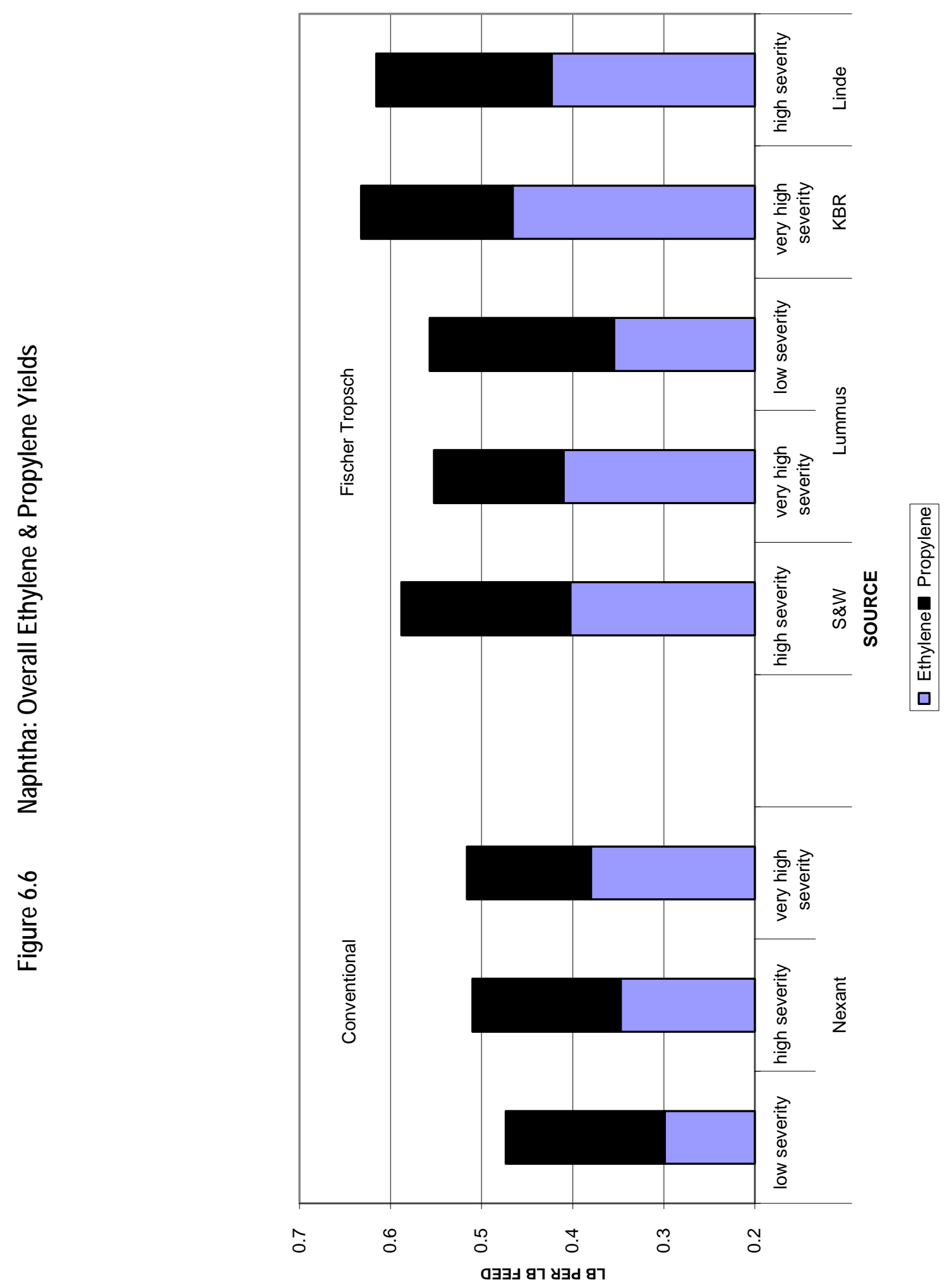




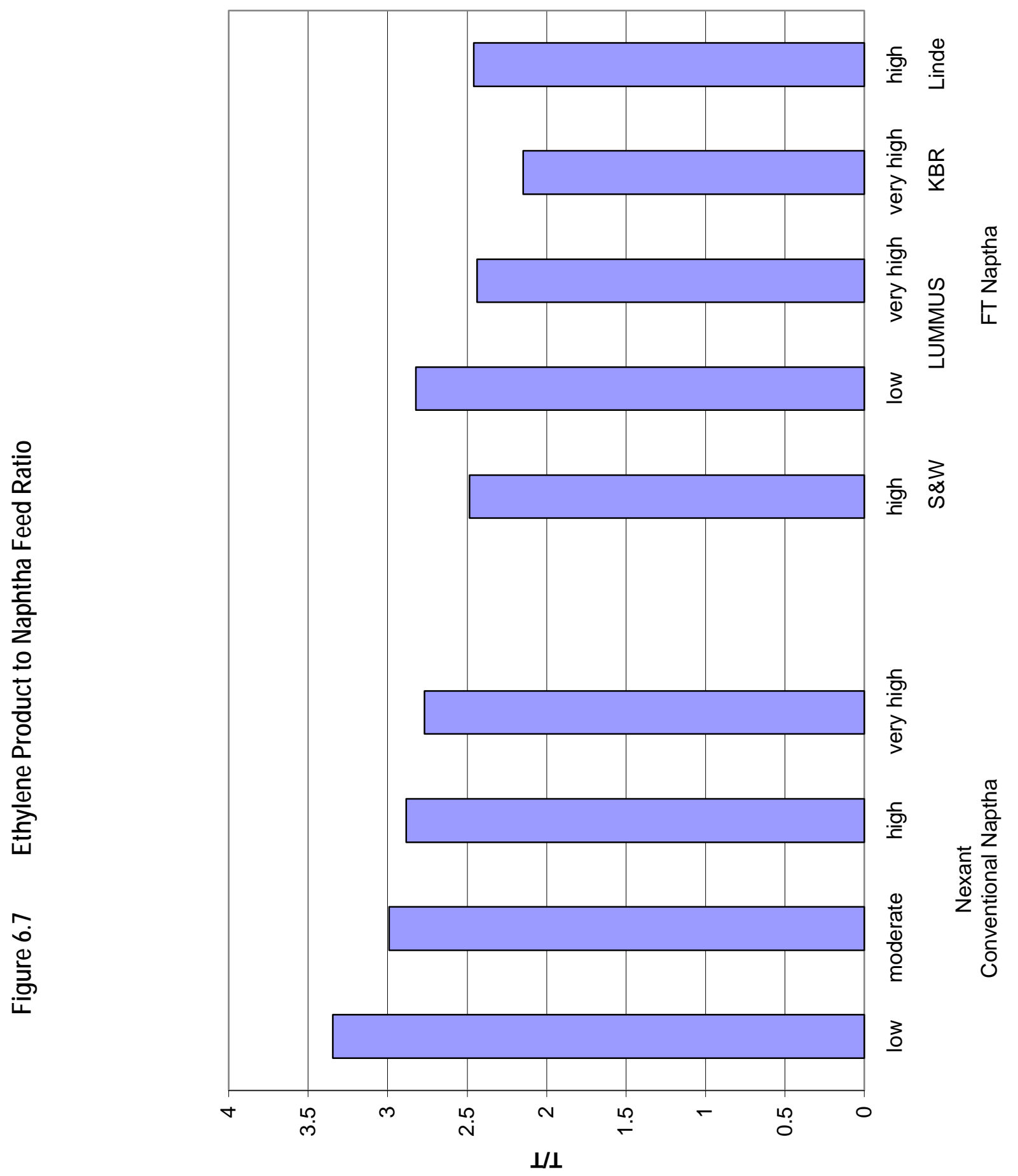




\subsection{FT DIESEL - ECONOMICS AS AN ETHYLENE CRACKER FEEDSTOCK}

The economics for cracking FT diesel are superior to conventional gas oils as an ethylene feedstock (Figure 6.8) with a projected premium of between $\$ 11$ and 31 per ton. However, a gas oil cracker requires higher capital investment ( $+25 \%$ compared to naphtha or NGLs), making this option less likely. In addition no gas oil crackers are being built at this time.

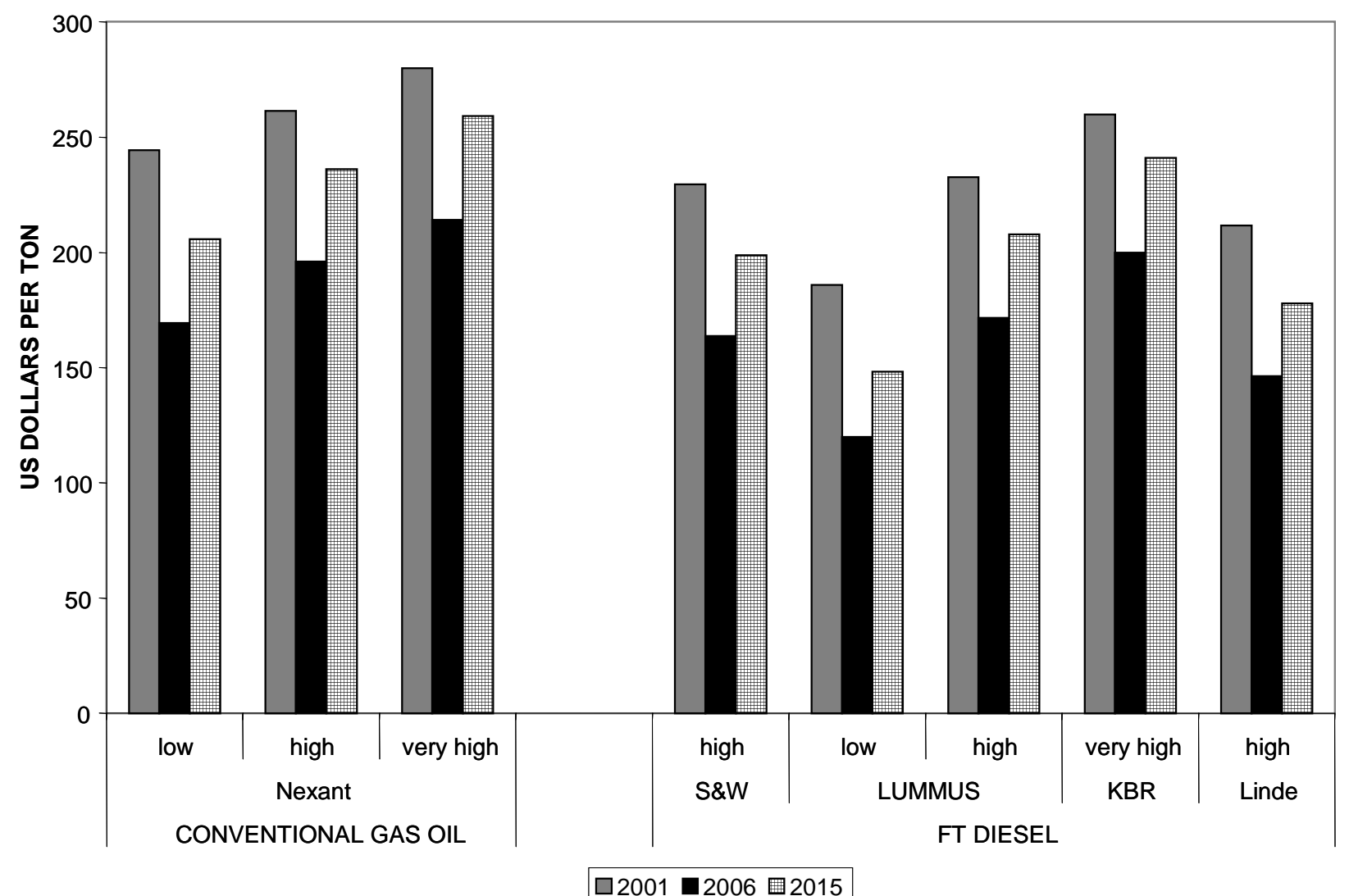

Figure 6.8 Cash Cost of Production for Cracking Diesel Fuel (USGC)

\subsection{NAPHTHA - ECONOMICS AS AN ETHYLENE CRACKER FEEDSTOCK}

The higher quality for FT naphtha is expected to result in a price premium of \$19-24 per ton versus conventional naphtha based on superior yields and cracking economics (Figure 6.9). 


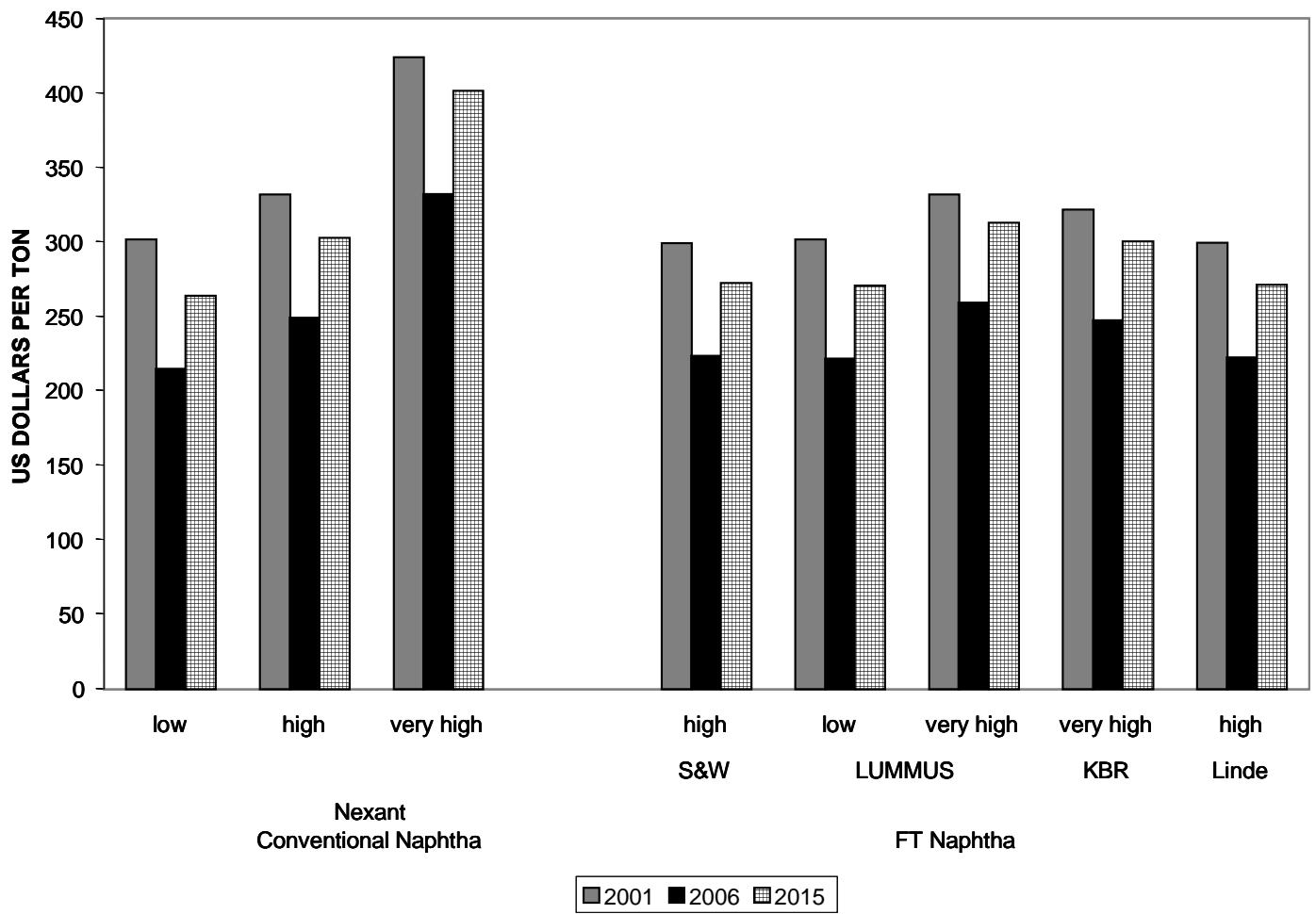

Figure 6.9 Cash Cost Of Production For Cracking Naphtha (USGC) 
Labor costs are based on typical manpower rates for the USGC, while direct overhead and maintenance costs are at normal industry levels (e.g. 45 percent of labor costs and 3-6 percent of ISBL, respectively, for the USGC). Other costs included in the analysis - general overhead, insurance and property taxes and environmental costs - are also based on typical industry levels (e.g. 60 percent of fixed cost, 1 percent of total plant capital and 0.5 percent of total plant capital, respectively, for the USGC).

The detailed investment analysis follows and can be separated into two discrete categories:

- Variable costs - raw material (ethane, propane, naphtha, gas oil), including catalysts and chemicals; utilities, such as purchased electricity, cooling water, natural gas and boiler feedwater; and by-products.

- $\quad$ Fixed costs - direct operating costs, such as labor, maintenance, and direct overheads; allocated costs, such as general plant overhead, insurance, environmental and taxes.

Utilities and by-product credits are considered variable costs since they are, to a large extent, dependent on the plant's operating rate or rate of fuel consumption. Fixed operating and allocated costs, as their title indicates, are largely independent of the operating rate. The sum of variable and fixed costs is termed the "total cash cost of production." This is the out-of-pocket expense an owner incurs before including working capital, capital investment, depreciation and any return on capital employed (ROCE).

Depreciation is assumed to be straight line over 20 years for OSBL and 10 years for ISBL including the capitalized Other Project Costs (OPC). The return on capital employed (ROCE) is assumed to be 10 percent unless otherwise noted.

The on-stream factor assumed for this evaluation is based on operating for 8,000 hours per year. 
Costs typically included in Nexant's estimates are defined as follows:

\section{A.1 BATTERY LIMITS INVESTMENT}

The battery limits (BL) portion of a plant can be thought of as a boundary over which are imported raw materials, catalysts and chemicals, and utility supply streams. In a like manner, main products, byproducts, and spent utility return streams are exported over this boundary.

Battery limits investment includes the cost of the main processing blocks of the chemical plant necessary to manufacture products. It represents an "instantaneous" investment (i.e. no escalation) for a plant ordered from a contractor and built on a prepared site with normal loadbearing and drainage characteristics of a developed country.

Battery limits investment includes the installed ${ }^{(1)}$ cost of the following items:

- Process equipment: vessels and internals, heat exchangers, pumps and compressors, drivers, solids handling

- Major spare equipment/parts (e.g. spare rotor for turbine or compressor)

- Building housing process units

- Process and utility pipes and supports within the major process areas

- Instruments, including computer control systems

- Electrical wires and hardware

- Foundations and pads

- Structures and platforms

- Insulation

- Paint/corrosion protection

- Process sewers

- Fire water pipes and monitors

- Utility stations

\section{A.2 OFFSITES INVESTMENT}

Offsites (OS) include the plant investment items that are required in addition to the main processing units within the battery limits. These auxiliary items are necessary to the functioning

(1) Includes construction overhead: fringe benefits, payroll burdens, field supervision, equipment rentals, small tools (expendables), field office expenses, site support services, temporary facilities. 
of the production unit, but perform in a supporting role rather than being directly involved in production. A distinguishing characteristic is the potential for sharing offsite facilities among several production units in a large plant, in which case investment cost would be allocated or prorated.

Offsites investment includes the installed cost of the following items:

- Storage for feeds, products, byproducts, including tanks/silos, dikes, inerting, process warehouse, and bagging/palletizing equipment

- Steam generation units

- Cooling water systems, including cooling towers and circulation pumps

- Process water treatment systems and supply pumps

- Boiler feed water treatment systems and supply pumps

- Refrigeration systems, including chilled water/brine circulating pumps

- Heat transfer medium systems, including organic vapor, hot oil, molten salts

- Electrical supply, transformers, and switchgear

- Loading and unloading arms, pumps, conveyors, lift trucks, including those to handle barge, tank/hopper car, and tank/hopper/other truck traffic; weigh scales

- Auxiliary buildings, including all services, furnishings, and equipment:

- $\quad$ Central control room

- Maintenance

- $\quad$ Stores warehouse

- $\quad$ Laboratory

- Garages/fire station

- $\quad$ Change house/cafeteria

- Medical/safety

- $\quad$ Administration

- General utilities, including plant air, instrument air, inert gas, stand-by electrical generator, fire water pumps

- $\quad$ Site development, including roads and walkways, parking, railroad sidings, electrical main substation, lighting, water supply, fuel supply, clearing and grading, drainage, fencing, sanitary and storm sewers, and communications

- Yard pipes, including lines for cooling water, process water, boiler feed water, fire water; fuel; plant air, instrument air, inert gas; collection of organic wastes, aqueous wastes, and flare/incinerator feeds; and process tie-ins to storage

- Pollution control, organic waste disposal, aqueous waste treatment, incinerator, flare 
Contractor charges, ${ }^{(1)}$ typically 15 to 25 percent of installed BL and OS costs.

- Detailed design and engineering, including process and offsites design and general engineering, equipment specifications, plant layout, drafting, cost engineering, scale models

- Administrative charges, including project management, engineering supervision, procurement, expediting, inspection, travel and living, home office construction expenses, general home office overhead

- Contractor profit

\section{A.3 PROJECT CONTINGENCY ALLOWANCE(2)}

A project contingency allowance is applied to the total of the above costs to take into account unknown elements of the process being estimated. For well-defined processes where primary input has come from engineering contractors, a contingency of 10 to 20 percent would be typical. At the other end of the spectrum, a capital estimate for a speculative process developed from patent and literature data alone might warrant a contingency of 20 to as much as 50 percent in extreme cases.

\section{A.3.1 Working Capital}

- $\quad$ Accounts receivable (products and byproducts shipped but not paid by customer); typically one month's gross cost of production (COP)

- $\quad$ Cash on hand (short-term operating funds); typically one week's gross COP minus depreciation

- Minor spare equipment and parts inventory; percentage of replacement BL capital

- Credit for accounts payable (feedstocks, catalysts, chemicals, and packaging materials received but not paid to supplier); typically one month's delivered cost

- Value of product and byproduct inventories; typically two weeks' gross COP

- Value of raw material inventory, typically two weeks' delivered cost

(1) These items are included proportionately in the BL and the OS investments. 


\section{A.4 OTHER PROJECT $\operatorname{COSTS}(1)$}

\section{A.4.1 Startup/Commissioning Costs}

- Extra operating manpower

- Owner's technical manpower

- $\quad$ Startup services

- $\quad$ Licensor representatives

- $\quad$ Contractor personnel

- $\quad$ Equipment supplier/other vendor representatives

- Operating manuals and training programs

- Modifications and maintenance during startup

- Operating expenses to the extent that they do not result in saleable product

\section{A.4.2 Miscellaneous Owner's Costs}

- Licensing/royalty/expertise fees: basic process and engineering design package

- Jetties, marine terminals, docks, etc.

- Long distance pipelines for raw material/products

- Land, rights of way, permits, surveys, and fees

- Piling, soil compaction/dewatering, unusual foundation requirements

- Sales, use, and other taxes

- Freight, insurance in transit, and import duties (equipment, pipe, steel, instruments, etc.)

- Escalation/inflation of costs over time $e^{(2)}$

- Interest on construction loan ${ }^{(4)}$

- Overtime pay during construction

- Construction workers' housing, canteen, other infrastructure for remote site

- Field insurance

- Project team, including preliminary planning studies, HAZOP studies, environmental reviews, design, engineering, estimating, inspection, accounting, auditing, legal, construction management, travel, and living

(1) These costs are very site/project specific; however, they typically range from 20 to 40 percent of installed $(\mathrm{BL}+\mathrm{OS})$ costs. A norm value of 25 percent will be used in the absence of more specific information.

(2) Instantaneous construction assumed 
- Initial charges of raw materials, catalysts, chemicals, and packaging materials

- Initial stock of maintenance, laboratory, operating, and office supplies

- Transport equipment, including barges, railcars, tank trucks, bulk shipping containers, plant vehicles

- Provisions for temporary shutdown expenses

- Owner's scope contingency allowance 


\section{Methanol Conventional Markets \\ Market Study Report Section III}

Prepared For:

ConocoPhillips 


\title{
Methanol Conventional Markets Market Study Report Section III
}

November 2002

\author{
Prepared For: \\ ConocoPhillips
}

\section{cNexant}

44 South Broadway, White Plains, New York 10601, USA

Tel: +1 9146090300 Fax: +1 9146090399 


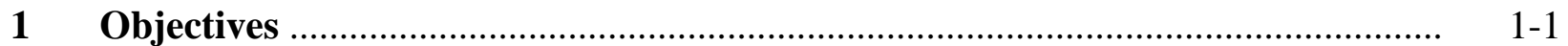

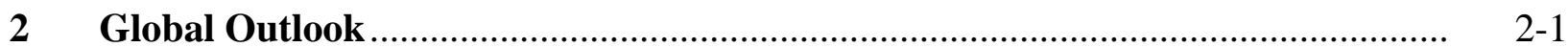

$2.1 \quad$ GLOBAL OUTLOOK ..................................................................

2.1.1 Introduction.......................................................................... 2-1

2.1.2 Chemical Uses ...................................................................... 2-2

2.1.3 MTBE and Fuel Use ................................................................. 2-3

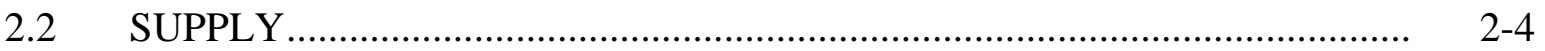

2.2.1 Overview ............................................................................... $2-4$

2.2.2 Historical Capacity Development ................................................. 2-6

2.2.3 New Projects ........................................................................ 2-10

2.2.4 Plant Closures ..................................................................... 2-11

2.2.5 Dynamics of Methanol Capacity Development................................ 2-12

2.3 SUPPLY/DEMAND BALANCE ......................................................... $2-14$

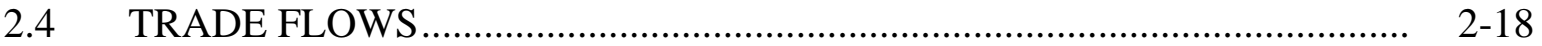

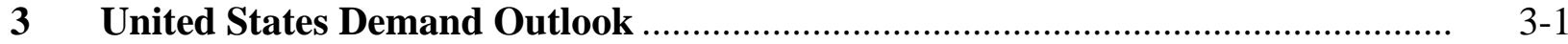

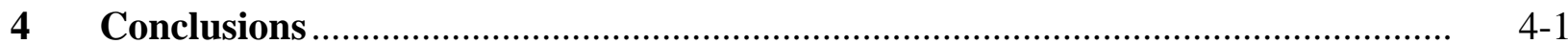


Figure $\quad$ Page

2.1 Regional Breakdown of Methanol Consumption, 2001....................................... 2-1

2.2 Global Methanol Consumption, 1990 To 2015 ................................................... 2-2

2.3 Methanol Consumption by Application, 2001 .................................................. 2-2

2.4 Global MTBE Consumption .......................................................................... 2-4

2.5 Global Methanol Capacity Breakdown, 1990 to 2015, Million Metric Tons Per Year 2-12

2.6 Dynamics in Methanol Capacity Changes ............................................................... 2-13

2.7 Evolution of Global Methanol Production Resource Base ..................................... 2-13

2.8 Global Methanol Supply/Demand Balance ...................................................... 2-14

2.9 Global Methanol Trade Pattern in 2001 - Thousand Tons....................................... 2-19

4.1 Global Methanol Supply/Demand Balance ........................................................... 4-2

Table $\quad$ Page

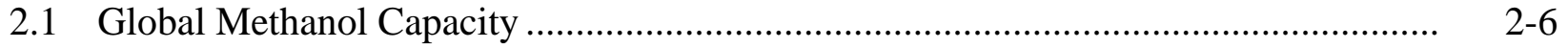

2.2 The Development of Global Methanol Capacity, 1990 to 2000 ................................ 2-7

2.3 Methanol Capacity Additions, 2002 Onwards ................................................... 2-10

2.4 Methanol Plant Closures, 2001 Onwards........................................................... 2-11

2.5 Methanol Supply/Demand Balance ............................................................... 2-15

3.1 U.S. Methanol Demand, Thousand Tons Per Year.............................................. 3-1 
The primary objective of this Section is to describe the current and projected future global demand for methanol in established conventional markets. These markets are primarily in chemical applications and as a feedstock in the production of methyl tertiary-butyl ether (MTBE), a gasoline blending component. The Section also projects methanol supply in the context of conventional uses. This Section provides background for the assessment of the potential for methanol as a neat transportation fuel or as a blending component for producing transportation fuels.

Traditional uses and sources of methanol are analyzed and supply and demand projections are developed through the year 2015. The existing methanol markets and producers are also profiled. 


\subsection{GLOBAL OUTLOOK}

\subsubsection{Introduction}

Consumption for methanol has continued to grow steadily over recent years. Part of the growth has come from traditional end-uses such as formaldehyde, while newer end-uses such as acetic acid and MTBE have been the prime drivers of growth. Overall methanol consumption, split by region, is shown below in Figure 2.1.

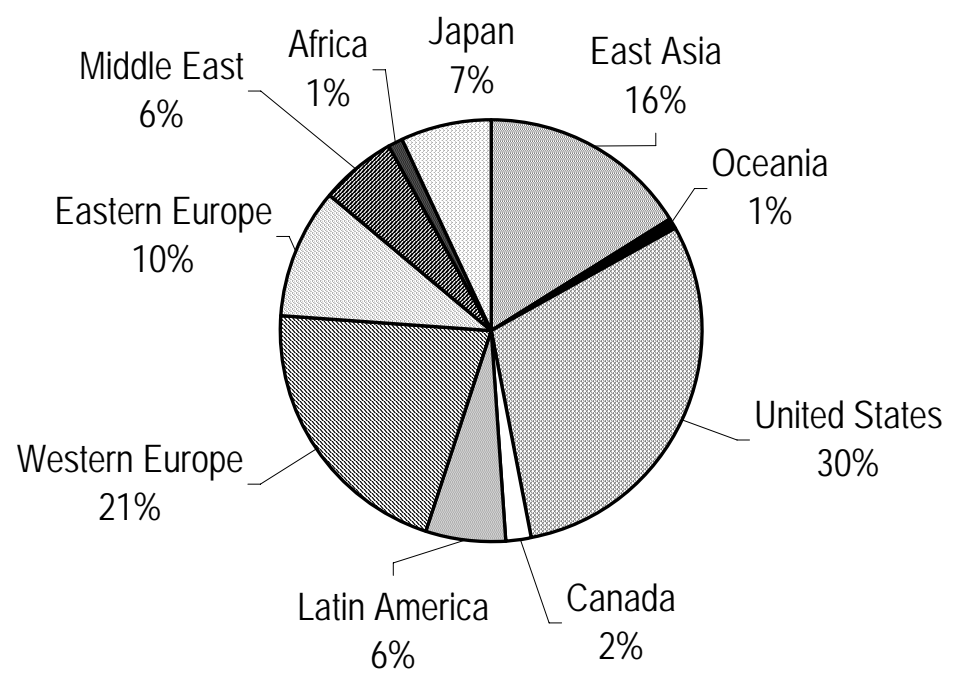

TOTAL CONSUMPTION 29.9 MILLION TONS

Figure 2.1 Regional Breakdown of Methanol Consumption, 2001

The United States is the largest single methanol consumer followed by Western Europe and East Asia. Figure 2.2 shows how methanol demand has evolved since 1990 when it stood at some 18 million tons per year. In 2001 it reached 29.9 million tons and it is forecast to grow to 32.6 million tons in 2006. Global demand will decline to 31.2 million tons in 2007 due to the assumption of a phase out of MTBE in the United States. Thereafter, methanol demand will resume growth, reaching 40.1 million tons by 2015 . 


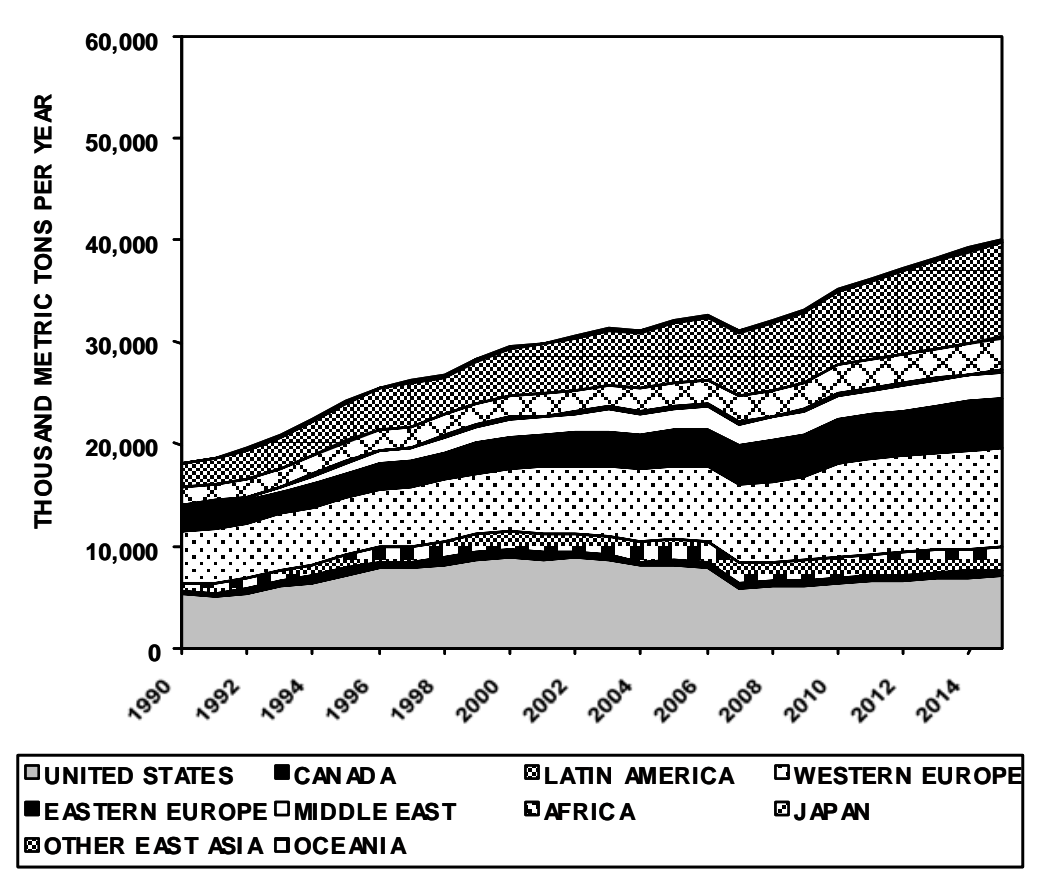

Figure 2.2 Global Methanol Consumption, 1990 To 2015

The other most striking change in regional patterns of consumption is the continuing strong growth in East Asia, based on its high GDP growth, such that this region is forecast to be the largest consuming region by 2005 and will continue to increase market share thereafter.

\subsubsection{Chemical Uses}

Figure 2.3 shows the breakdown of methanol demand by application in 2001 .

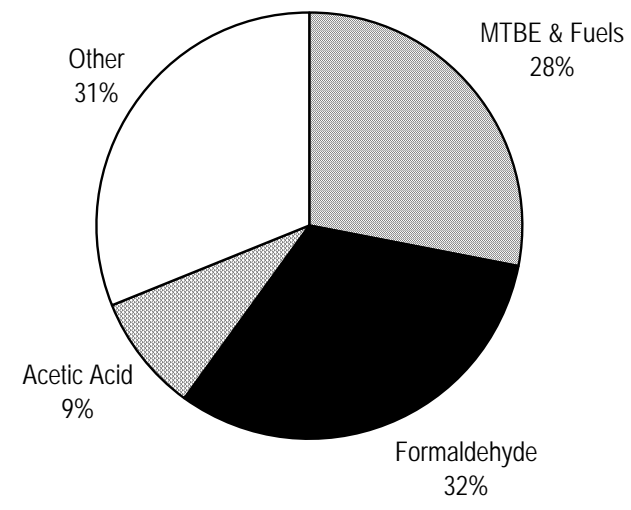

Figure 2.3 Methanol Consumption by Application, 2001 
The major chemical use for methanol is to make formaldehyde. Formaldehyde is predominantly used in producing glues for use in plywood and chipboard/particle board production. These products are primarily used in furniture and construction and as such their growth is linked to general rates of economic expansion. Other formaldehyde uses are in 1.4 butanediol, polyacetal resins and specialty chemicals. Higher growth in these uses will not significantly affect the overall demand for formaldehyde that is forecast as being linked to general GDP growth.

Acetic acid accounts for about nine percent of global methanol demand. Acetic acid is used in the manufacture of vinyl acetate, cellulose acetate and acetate esters, demand for which is linked to the demand for paint, adhesives and textiles. Methanol based acetic acid production technology is now the favored route, with about 80 percent of acetic acid produced by the methanol carbonylation method, and Nexant sees the need for a new plant every two to four years, resulting in a steady demand for methanol, albeit in steps.

Methyl methacrylate accounts for two to three percent of methanol demand and is predominantly used in acrylic sheets, surface coatings and molding resins. Growth is expected to be moderate in developed regions and more rapid in Asia.

Dimethyl terephthalate (DMT) production consumes about three to four percent of global methanol demand. DMT is used to produce polyester fiber, film and bottle resins. Although certain sectors of the polyester market will experience good growth, particularly bottle resins, this will not benefit DMT since the alternative route to polyester using purified terephthalic acid is preferred because of its more favorable economics. Consequently demand for methanol for DMT production will not grow and will decline as DMT plants are retired.

Methanol is also used in the production of methyl halides such as methylene chloride, methyl chloroform, methyl bromide and methyl chloride. Demand for methyl chloride is expected to increase due to increasing demand for silicones (cyclomethicone, etc.) for which it is an intermediate. However, demands for the others will decrease due to environmental concerns about the ozone depleting properties of the compounds and the other products that can be made from them.

Overall, Nexant forecasts steady, GDP level growth for chemical uses of methanol, the few areas of above GDP-level-growth being balanced by those which are static or are in decline.

\subsubsection{MTBE and Fuel Use}

As shown in Figure 2.3 MTBE represents the second largest outlet for methanol. However, a large proportion of this demand is under threat because of concerns about groundwater contamination in the United States.

Overall global demand for MTBE is estimated to be at its peak during the current period (2001/2002/2003). Thereafter, demand is expected to decrease substantially through 2007, after which it will start to grow at GDP-linked rates reflecting ongoing MTBE use as an oxygenate in gasoline elsewhere in the world.

Figure 2.4 presents Nexant's regional outlook for MTBE demand. 


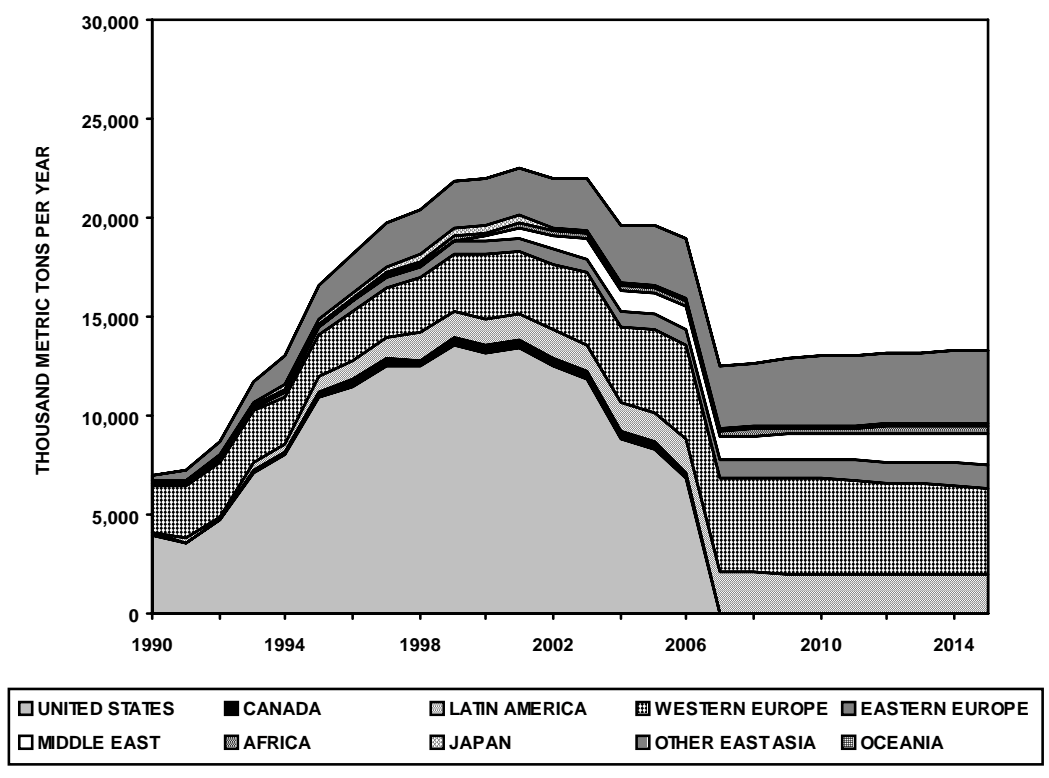

Figure 2.4 Global MTBE Consumption

The groundwater pollution problem that has been experienced in the United States appears to be unique to the United States, since elsewhere gasoline tanks do not appear to have been leaking to the same extent (or monitoring is not as rigorous). In addition, no other region has powerful ethanol lobbies to promote the substitution of MTBE with ethanol as a gasoline oxygenate component. Reflecting these two unique aspects of the United States market, Nexant believes that the rest of the world, driven by the need to produce either cleaner gasoline or increased quantities of octane, will continue to utilize MTBE as a gasoline blendstock.

Nevertheless, global methanol consumption for MTBE will be reduced by some 3.7 million tons per year in 2007 from peak consumption (for MTBE) of 8.3 million tons.

\subsection{SUPPLY}

\subsubsection{Overview}


Table 2.1 profiles the major global methanol producers. Current methanol capacity is in the hands of chemical companies and national energy companies. Methanex is the world's largest methanol producer. Saudi Basic Industries Corporation (SABIC) is the second largest producer. Another large producer is Pequiven, the chemical subsidiary of the Venezuelan national energy company, PDVSA. Trinidad Methanol is the largest of three methanol producers in Trinidad and Tobago, and Terra is the largest U.S. methanol producer. Celanese produces methanol both in the United States and has a 50 percent interest in a plant in Saudi Arabia. 


\section{Table 2.1 Global Methanol Capacity}

\begin{tabular}{|l|c|l|}
\hline Company & $\begin{array}{c}\text { Capacity, 2002 } \\
\text { Thousand MT }\end{array}$ & Comments \\
\hline Methanex & 6,970 & Has 24\% market share through marketing agreements \\
\hline SABIC & 3,920 & Adding 1.5 million tons per yerar \\
\hline Russia (various) & 3,340 & Possibly adding 1 million tons per year \\
\hline Pequiven & 1,465 & Possibly adding 1 million tons per year \\
\hline Trinidad Methanol & 1,010 & BP and others planning 850 thousand tons per year \\
\hline Terra & 990 & \\
\hline Methanor & 840 & \\
\hline Statoil & 830 & \\
\hline QATAR PC & 830 & \\
\hline Iran NPC & 780 & Adding 3 million tons per year \\
\hline Others & 18,791 & \\
\hline & 39,766 & \\
\hline
\end{tabular}

\subsubsection{Historical Capacity Development}

The evolution of global methanol production capacity from 1990, when it stood at a nameplate 20.4 million tons per year, through 2000, when it stood at 38.9 million tons per year, is shown inTable 2.2.

An interesting feature of capacity development during this period is that world scale plant size has increased in line with overall nameplate capacity. Thus in 1990 a new world scale plant with a capacity of 660,000 tons per year represented about a three percent addition to capacity. Currently a world scale plant of around one million tons per year also represents about a three percent increase in capacity. 


\section{Table 2.2 The Development of Global Methanol Capacity, 1990 to 2000 Year-End Capacities in Thousand Tons Per Year}

\begin{tabular}{|c|c|c|c|c|c|c|c|c|c|}
\hline Country & Company & Location & 1990 & 1995 & 1996 & 1997 & 1998 & 1999 & 2000 \\
\hline \multicolumn{10}{|l|}{ Africa } \\
\hline Algeria & Almer & Arzew & 110 & 110 & 110 & 110 & 110 & 110 & 110 \\
\hline Libya & National Petro Chemicals & Marsa El Brega & 330 & 330 & 330 & 330 & 330 & 330 & 330 \\
\hline Libya & National Petro Chemicals & Marsa El Brega & 300 & 300 & 300 & 300 & 300 & 300 & 300 \\
\hline South Africa & $\mathrm{AECl}$ & Modderfontein & 40 & 40 & 40 & 40 & 40 & 40 & 40 \\
\hline South Africa & Sasol & Sasolburg & 0 & 0 & 0 & 0 & 0 & 140 & 140 \\
\hline \multicolumn{3}{|l|}{ Total } & 780 & 780 & 780 & 780 & 780 & 920 & 920 \\
\hline \multicolumn{10}{|l|}{ Canada } \\
\hline & Celanese Canada & Edmonton, $\mathrm{AB}$ & 740 & 740 & 740 & 740 & 740 & 740 & 740 \\
\hline & Methanex & Kitimat, BC & 530 & 530 & 530 & 530 & 530 & 530 & 0 \\
\hline & Methanex & Medicine Hat, $A B$ & 0 & 270 & 270 & 0 & 0 & 0 & 0 \\
\hline & Methanex & Medicine Hat, AB & 440 & 260 & 260 & 260 & 260 & 0 & 0 \\
\hline & Methanex & Medicine Hat, AB & 480 & 570 & 570 & 570 & 570 & 570 & 570 \\
\hline Total & & & 2,190 & 2,370 & 2,370 & 2,100 & 2,100 & 1,840 & 1,310 \\
\hline \multicolumn{10}{|l|}{ East Asia } \\
\hline China & AH Huaihua Group Co. Ltd & Huainan, Anhui & 0 & 50 & 75 & 75 & 75 & 75 & 75 \\
\hline China & Beijin Chemical Experimental Plant & Beying & 0 & 0 & 60 & 60 & 60 & 60 & 60 \\
\hline China & Chemical Fertilizer Works, Jilin Chemical Industry & Jilin, Jilin & 0 & 0 & 60 & 60 & 60 & 60 & 60 \\
\hline China & Dezhou Hengsheng Chemical (Group) Co. Ltd. & Dezhou, Shandong & 0 & 0 & 50 & 50 & 50 & 50 & 50 \\
\hline China & GS Lanzhou Chemical Industry Corp. & Lanzhou, Gansu & 55 & 55 & 55 & 55 & 55 & 55 & 55 \\
\hline China & Guangzhou Guangdan Enterprises Group & Guangzhou, Guangdong & 0 & 0 & 0 & 60 & 60 & 60 & 0 \\
\hline China & Henan Zongyuan Chemical Group Corp. Ltd. & Puyang, Henan & 0 & 0 & 60 & 60 & 60 & 60 & 60 \\
\hline China & Hunan Dacheng Zhidan Group Co. Ltd. & Zhijiang, Hunan & 0 & 0 & 60 & 60 & 60 & 60 & 60 \\
\hline China & Ih Ju Leage Chemical & Dingsheng, Inner Mongolia & 0 & 0 & 0 & 0 & 0 & 210 & 210 \\
\hline China & Jiangyou Northwest of Sichuan Mine Area & Jiangyou, Sichuan & 0 & 0 & 0 & 0 & 0 & 100 & 100 \\
\hline China & Jingbian Methanol Works & Jingbian & 0 & 0 & 0 & 0 & 100 & 100 & 100 \\
\hline China & JS Nanjing Chemical Industrial (Group) Co. Ltd. & Nanjing, Jiangsu & 0 & 55 & 55 & 55 & 55 & 55 & 55 \\
\hline China & Methanol Works, Daqing Oil Field & Daqing, Heilongjiang & 0 & 0 & 60 & 60 & 160 & 160 & 160 \\
\hline China & SD Qilu Petrochemical & Zibo, Shandong & 100 & 100 & 100 & 100 & 100 & 100 & 100 \\
\hline China & Shaanxi Yulin N.G. Chemical Co. Ltd. & Yulin, Shaanxi & 0 & 0 & 30 & 90 & 90 & 90 & 90 \\
\hline China & Shandong Lunan Chemical Fertilizer & Tengzhou, Shandong & 0 & 0 & 0 & 0 & 0 & 0 & 100 \\
\hline China & Shanghai Pacific Chemical Group & Shanghai & 0 & 0 & 310 & 310 & 310 & 310 & 310 \\
\hline China & Sinopec Sichuan Vinylon Works & Changshou, Chongqing & 0 & 0 & 100 & 220 & 220 & 220 & 220 \\
\hline China & Taiyuan Chemical Industrial Group Co. & Taiyuan, Shanxi & 0 & 0 & 60 & 60 & 60 & 60 & 60 \\
\hline China & Turpan-Hami Oil Field & Tu-Ha, Xinjiang & 0 & 0 & 0 & 0 & 0 & 0 & 88 \\
\hline China & Various & Various & 725 & 1,140 & 1,439 & 1,635 & 1,552 & 1,529 & 1,629 \\
\hline China & Xianjiang Nitrogenous, Hunan Jinyang Chemical & Zhuzhou, Hunan & 0 & 0 & 50 & 50 & 80 & 80 & 80 \\
\hline India & Assam Ind Dev & Assam & 0 & 25 & 25 & 25 & 25 & 25 & 25 \\
\hline India & Assam Methanol Company & Duliajan & 0 & 0 & 0 & 0 & 0 & 0 & 0 \\
\hline India & Assam Petrochemical & Assam & 7 & 7 & 7 & 7 & 7 & 7 & 7 \\
\hline India & Assam Petrochemical & Assam & 0 & 0 & 0 & 0 & 0 & 0 & 0 \\
\hline India & Bongaigaon Refinery \& Pet. & Bongaigaon & 0 & 0 & 0 & 0 & 0 & 0 & 0 \\
\hline India & Dalmia Aromatics & Bongaigaon & 0 & 0 & 0 & 0 & 0 & 0 & 0 \\
\hline India & Deepak & Taloja & 0 & 100 & 100 & 100 & 100 & 100 & 100 \\
\hline India & FACT & Alwaye & 0 & 0 & 0 & 0 & 0 & 0 & 0 \\
\hline India & $\mathrm{FCl}$ & Trombay & 32 & 32 & 32 & 32 & 32 & 32 & 32 \\
\hline India & Gujarat Narmada Valley Fert. & Bharuch & 20 & 20 & 20 & 20 & 20 & 20 & 20 \\
\hline India & Gujarat Narmada Valley Fert. & Bharuch & 0 & 100 & 100 & 100 & 100 & 100 & 100 \\
\hline India & National Fertilizer & Nangal & 15 & 15 & 15 & 15 & 15 & 15 & 15 \\
\hline India & Rama & Patalganga & 0 & 0 & 0 & 0 & 0 & 0 & 0 \\
\hline India & Rastriya Chemical & Mumbai & 38 & 38 & 38 & 38 & 38 & 38 & 38 \\
\hline India & Rinki Petrochemicals & Padra & 0 & 100 & 100 & 100 & 100 & 100 & 100 \\
\hline India & WBIDC & Haldia & 41 & 41 & 41 & 41 & 41 & 41 & 41 \\
\hline Indonesia & Kaltim Methanol & Bontang & 0 & 0 & 0 & 0 & 660 & 660 & 660 \\
\hline Indonesia & Pertamina & Bunyu & 330 & 330 & 330 & 330 & 330 & 330 & 330 \\
\hline Malaysia & Petronas & Labuan & 660 & 660 & 660 & 660 & 660 & 660 & 660 \\
\hline Malaysia & Petronas Fertilizer & Gurun & 0 & 0 & 0 & 0 & 0 & 67 & 67 \\
\hline \begin{tabular}{|l|} 
Myanmar \\
\end{tabular} & State & Seiktha & 150 & 150 & 150 & 150 & 150 & 150 & 150 \\
\hline Taiwan & CPDC & Ta-Sheh & 0 & 66 & 66 & 66 & 66 & 66 & 66 \\
\hline \multicolumn{3}{|l|}{ Total } & 2,173 & 3,084 & 4,308 & 4,744 & 5,551 & 5,905 & 6,133 \\
\hline
\end{tabular}


Table 2.2 The Development of Global Methanol Capacity, 1990 to 2000 (Continued)

Year-End Capacities in Thousand Tons Per Year

\begin{tabular}{|c|c|c|c|c|c|c|c|c|c|}
\hline & Company & Location & 1990 & 1995 & 1996 & 1997 & 1998 & 1999 & 2000 \\
\hline \multicolumn{10}{|l|}{ Eastern Europe } \\
\hline FSU - Lithuania & Azot Factory lonava & Ionava & 105 & 105 & 105 & 105 & 105 & 105 & 105 \\
\hline FSU - Russia & Angarsk Petrochemical Company & Angarsk & 200 & 200 & 200 & 200 & 200 & 200 & 200 \\
\hline FSU - Russia & Azot Factory Nevinomyssk & Nevinnomyssk & 100 & 100 & 100 & 100 & 100 & 100 & 100 \\
\hline FSU - Russia & Azot Factory Schenkino & Schenkino & 350 & 350 & 350 & 350 & 350 & 350 & 360 \\
\hline FSU - Russia & JSC Azot & Novomoskovsk & 250 & 250 & 250 & 250 & 250 & 250 & 250 \\
\hline FSU - Russia & Metafrax & Gubakha & 780 & 780 & 780 & 840 & 840 & 840 & 750 \\
\hline FSU - Russia & NCK & Tomsk & 780 & 780 & 780 & 780 & 780 & 780 & 750 \\
\hline FSU - Russia & State & Novocherkassk & 220 & 220 & 220 & 220 & 220 & 220 & 220 \\
\hline FSU - Russia & State & Novogorod & 150 & 150 & 150 & 150 & 150 & 150 & 140 \\
\hline FSU - Russia & Togliattiazot & Togliatti & 0 & 0 & 0 & 0 & 0 & 430 & 430 \\
\hline FSU - Russia & Various & Various FSU - Russia & 150 & 150 & 150 & 150 & 150 & 150 & 150 \\
\hline FSU - Ukraine & Severodonetsk Azot & Severodonetsk & 650 & 650 & 650 & 650 & 650 & 650 & 650 \\
\hline FYU - Serbia & State & Kikinda & 200 & 200 & 200 & 200 & 200 & 200 & 200 \\
\hline FYU - Slovenia & State & Lendava & 185 & 185 & 185 & 185 & 185 & 185 & 185 \\
\hline Poland & Firma Chemiczna Dwory & Oswiecim & 85 & 85 & 85 & 0 & 0 & 0 & 0 \\
\hline Poland & Methanol & Chorzow & 100 & 100 & 100 & 100 & 100 & 0 & 0 \\
\hline Romania & Doljchim & Craiova & 100 & 210 & 210 & 210 & 210 & 210 & 210 \\
\hline Romania & Viromet & Victoria & 50 & 50 & 50 & 50 & 50 & 70 & 70 \\
\hline Romania & Viromet & Victoria & 225 & 225 & 225 & 295 & 295 & 295 & 295 \\
\hline Total & & & 4,680 & 4,790 & 4,790 & 4,835 & 4,835 & 5,185 & 5,065 \\
\hline \multicolumn{10}{|l|}{ Latin America } \\
\hline Argentina & Atanor & Rio Tercero & 15 & 12 & 12 & 12 & 12 & 12 & 12 \\
\hline Argentina & Casco & Pilar & 20 & 21 & 21 & 21 & 0 & 0 & 0 \\
\hline Argentina & Resinfor & San Lorenzo & 50 & 50 & 50 & 50 & 50 & 50 & 50 \\
\hline Argentina & YPF & Ensenada & 25 & 24 & 24 & 24 & 25 & 25 & 25 \\
\hline Brazil & Alba & Sao Paulo & 34 & 34 & 0 & 0 & 0 & 0 & 0 \\
\hline Brazil & Fibra Nordelte & Sao Paulo & 0 & 6 & 6 & 6 & 8 & 8 & 8 \\
\hline Brazil & Metanor & Camacari & 70 & 86 & 86 & 86 & 83 & 83 & 83 \\
\hline Brazil & Polyenka & Sao Paulo & 0 & 6 & 6 & 6 & 6 & 6 & 6 \\
\hline Brazil & Prosint & Rio De Janeiro & 119 & 119 & 138 & 138 & 138 & 138 & 150 \\
\hline Brazil & Ultrafertil & Araucarla & 0 & 6 & 6 & 6 & 8 & 8 & 8 \\
\hline Chile & Methanex & Punta Arenas & 750 & 850 & 850 & 850 & 850 & 850 & 850 \\
\hline Chile & Methanex & Punta Arenas & 0 & 0 & 0 & 925 & 925 & 925 & 925 \\
\hline Chile & Methanex & Punta Arenas & 0 & 0 & 0 & 0 & 0 & 975 & 975 \\
\hline Mexico & Pemex & Texmelucan & 150 & 150 & 150 & 150 & 150 & 150 & 150 \\
\hline Mexico & Pemex & Texmelucan & 22 & 22 & 22 & 22 & 22 & 22 & 22 \\
\hline Trinidad & Caribbean Methanol & Point Lisas & 0 & 500 & 500 & 500 & 500 & 500 & 500 \\
\hline Trinidad & Methanol IV & Point Lisas & 0 & 0 & 0 & 0 & 550 & 550 & 550 \\
\hline Trinidad & Titan Methanol & Point Lisas & 0 & 0 & 0 & 0 & 0 & 0 & 850 \\
\hline Trinidad & Trinidad \& Tobago Methanol Co. & Point Lisas & 460 & 460 & 460 & 460 & 460 & 460 & 460 \\
\hline Trinidad & Trinidad \& Tobago Methanol Co. & Point Lisas & 0 & 0 & 550 & 550 & 550 & 550 & 550 \\
\hline Venezuela & Metor & Jose & 0 & 735 & 735 & 735 & 735 & 735 & 735 \\
\hline Venezuela & Supermetanol & Jose & 0 & 670 & 670 & 670 & 670 & 670 & 730 \\
\hline Total & & & 1,715 & 3,751 & 4,286 & 5,211 & 5,742 & 6,717 & 7,639 \\
\hline \multicolumn{10}{|l|}{ Middle East } \\
\hline Bahrain & Gulf Petrochemical Industry & Sitra & 396 & 425 & 425 & 462 & 462 & 462 & 462 \\
\hline Iran & Kharg Methanol & Kharg Island & 0 & 0 & 0 & 0 & 0 & 0 & 660 \\
\hline Iran & Shiraz Petrochemical & Shiraz & 90 & 120 & 120 & 120 & 120 & 120 & 120 \\
\hline Israel & Dor Chemicals & Haifa & 50 & 50 & 50 & 50 & 50 & 50 & 50 \\
\hline Qatar & QAFAC & Mesaieed & 0 & 0 & 0 & 0 & 0 & 830 & 830 \\
\hline Saudi Arabia & Ar-Razi & Al Jubail & 600 & 660 & 660 & 660 & 660 & 660 & 660 \\
\hline Saudi Arabia & Ar-Razi & Al Jubail & 0 & 660 & 660 & 660 & 660 & 660 & 660 \\
\hline Saudi Arabia & Ar-Razi & Al Jubail & 0 & 0 & 0 & 850 & 850 & 850 & 850 \\
\hline Saudi Arabia & Ar-Razi & Al Jubail & 0 & 0 & 0 & 0 & 0 & 850 & 850 \\
\hline Saudi Arabia & Ibn Sina & Al Jubail & 770 & 770 & 770 & 770 & 900 & 900 & 900 \\
\hline Total & & & 1,906 & 2,685 & 2,685 & 3,572 & 3,702 & 5,382 & 6,042 \\
\hline
\end{tabular}


Table 2.2 The Development of Global Methanol Capacity, 1990 to 2000 (Continued) Year-End Capacities in Thousand Tons Per Year

\begin{tabular}{|c|c|c|c|c|c|c|c|c|c|}
\hline Country & Company & Location & 1990 & 1995 & 1996 & 1997 & 1998 & 1999 & 2000 \\
\hline \multicolumn{10}{|l|}{ Oceania } \\
\hline Australia & BHP & Melbourne & 0 & 54 & 54 & 54 & 54 & 54 & 54 \\
\hline New Zealand & Methanex & Motunui & 0 & 1,400 & 1,400 & 1,400 & 1,400 & 1,400 & 1,400 \\
\hline New Zealand & Methanex & Swing Cap. D11/D111 & 0 & 500 & 500 & 500 & 500 & 500 & 500 \\
\hline New Zealand & Methanex & Waitara & 400 & 530 & 530 & 530 & 530 & 530 & 530 \\
\hline \multicolumn{3}{|l|}{ Total } & 400 & 2,484 & 2,484 & 2,484 & 2,484 & 2,484 & 2,484 \\
\hline \multicolumn{10}{|l|}{ United States } \\
\hline & Air Products And Chemicals & Pensacola, FL & 180 & 180 & 180 & 180 & 180 & 180 & 180 \\
\hline & Ashland & Plaquemine, LA & 390 & 465 & 465 & 465 & 465 & 0 & 0 \\
\hline & Terra Industries & Beaumont, TX & 840 & 840 & 840 & 840 & 840 & 840 & 840 \\
\hline & Borden & Geismar, LA & 330 & 390 & 390 & 390 & 390 & 390 & 390 \\
\hline & Borden & Geismar, LA & 300 & 390 & 390 & 390 & 390 & 390 & 390 \\
\hline & BP Amoco/Sterling & Texas City, TX & 0 & 0 & 450 & 450 & 450 & 450 & 0 \\
\hline & Celanese & Bishop, TX & 480 & 500 & 500 & 500 & 500 & 500 & 500 \\
\hline & Clear Lake Methanol & Clear Lake, TX & 0 & 0 & 600 & 600 & 600 & 600 & 600 \\
\hline & Coastal & Cheyenne, WY & 0 & 75 & 75 & 75 & 75 & 75 & 75 \\
\hline & Eastman Chemical & Kingsport, TN & 180 & 195 & 195 & 195 & 195 & 195 & 195 \\
\hline & Enron & Pasadena, TX & 375 & 375 & 375 & 375 & 375 & 375 & 375 \\
\hline & Fortier Methanol & Westwego, LA & 0 & 570 & 570 & 570 & 570 & 0 & 0 \\
\hline & Georgia Gulf & Plaquemine, LA & 420 & 495 & 495 & 495 & 495 & 0 & 0 \\
\hline & Lyondell & Houston, TX & 660 & 720 & 720 & 720 & 720 & 720 & 720 \\
\hline & Millennium & Deer Park, TX & 180 & 660 & 660 & 660 & 660 & 660 & 660 \\
\hline & Sand Creek & Commerce City, CO & 0 & 90 & 90 & 90 & 90 & 0 & 0 \\
\hline & Star Enterprise & Delaware City, DE & 0 & 270 & 0 & 0 & 0 & 270 & 270 \\
\hline & Terra Industries & Woodward, OK & 0 & 150 & 150 & 150 & 150 & 150 & 150 \\
\hline \multicolumn{3}{|l|}{ Total } & 4,335 & 6,365 & 7,145 & 7,145 & 7,145 & 5,795 & 5,345 \\
\hline \multicolumn{10}{|c|}{ Western Europe } \\
\hline \begin{tabular}{|l|} 
Germany \\
\end{tabular} & BASF & Ludwigshafen & 240 & 240 & 240 & 320 & 320 & 320 & 320 \\
\hline Germany & BASF & Ludwigshafen & 0 & 0 & 0 & 130 & 130 & 130 & 130 \\
\hline Germany & DEA & Wesseling & 400 & 440 & 440 & 440 & 440 & 440 & 440 \\
\hline Germany & Lausitzer Bergbau & Schwarze Pumpe & 0 & 0 & 0 & 100 & 100 & 100 & 100 \\
\hline Germany & Mitteldeutsche Erdoel-Raffinerie & Leuna & 0 & 660 & 660 & 600 & 600 & 600 & 600 \\
\hline Germany & Ruhr Oel & Gelsenkirchen & 240 & 240 & 240 & 240 & 240 & 240 & 240 \\
\hline Italy & Chemie Linz & Castellanza & 120 & 0 & 0 & 0 & 0 & 0 & 0 \\
\hline Netherlands & Methanor & Delfzijl & 360 & 390 & 390 & 420 & 420 & 420 & 420 \\
\hline Netherlands & Methanor & Delfzijl & 350 & 390 & 390 & 420 & 420 & 420 & 420 \\
\hline Norway & Statoil & Tjeldbergodden & 0 & 0 & 0 & 830 & 830 & 830 & 830 \\
\hline United Kingdom & $\mathrm{ICl}$ & Billingham & 480 & 500 & 500 & 500 & 500 & 500 & 500 \\
\hline \multicolumn{3}{|c|}{ Total } & 2,190 & 2,860 & 2,860 & 4,000 & 4,000 & 4,000 & 4,000 \\
\hline \multicolumn{3}{|l|}{ Grand Total } & 20,369 & 29,169 & 31,708 & 34,871 & 36,339 & 38,228 & 38,938 \\
\hline
\end{tabular}




\subsubsection{New Projects}

New projects are listed in Table 2.3. Plants are included in cases where projects have been seriously discussed, in areas of increasing demand (such as the Far East) or where methanol can be produced competitively (such as the Middle East or Latin America). Nexant has categorized projects, which have been strongly promoted, but where we think there is little real likelihood of proceeding, as tentative.

As shown, capacity additions in the near-term will be limited to projects with access to low cost feedstock. With varying degrees of certainty, Nexant has identified a total of 4.95 million tons of new capacity that may be built between 2002 and 2007. This represents about 12 percent of 2002 capacity.

\section{Table 2.3 Methanol Capacity Additions, 2002 Onwards}

\begin{tabular}{|c|c|c|c|c|c|}
\hline Year & Operator & Location & Region & Capacity & Status \\
\hline 2002 & Repsol YPF & Plaza Huincul, Neuquen, Argentina & Latin America & 400 & Starting up \\
\hline 2002 & Fanavaran Chemical Co. & Bandhar Imam, Iran & Middle East & 1,000 & Under construction \\
\hline 2003 & Nitrofert (Gazprom) & Kothla-Jarve, Estonia & Eastern Europe & 486 & Tentative \\
\hline 2003 & Ferrostaal/Gazprom & Arkangelsk & Eastern Europe & 900 & Tentative \\
\hline 2003 & Sonatrach & Arzew, Algeria & Africa & 850 & Tentative \\
\hline 2003 & Ar-Razi & Al Jubail, Saudi Arabia & Middle East & 500 & Probable \\
\hline 2004 & GTL Resources & Western Australia & Australia & 1,000 & Possible \\
\hline 2004 & Methanex/BP & Point Lisas, Trinidad & Latin America & 1,650 & Probable \\
\hline 2004 & Togliattiazot & Togliatti, Russia & Eastern Europe & 500 & Possible \\
\hline 2004 & Saudi Int. Petrochemical Co. (SIPC) & Al Jubail, Saudi Arabia & Middle East & 950 & Probable \\
\hline 2004 & Zagross Petrochemicals & Asaluyeh, Iran & Middle East & 1,650 & Tentative \\
\hline 2004 & Metor & Jose, Venezuela & Latin America & 850 & Possible \\
\hline 2005 & Ferrostaal/Oman Oil/Omzest & Sohar, Oman & Middle East & 1,000 & Possible \\
\hline 2005 & Methanex & Western Australia & Australia & 2,150 & Possible \\
\hline 2006 & Atlantic Methanol Production Co. & Bioko Island, Equatorial Guinea & Africa & 775 & Speculative \\
\hline 2006 & China National Petrochemical Corp. & Western Australia & East Asia & 800 & Possible \\
\hline 2007 & Methanex & Evans Shoal, Timor Sea & Australia & 1,730 & Speculative \\
\hline
\end{tabular}

Notes:

Probable Very likely to proceed, but construction not yet commenced.

Possible Judged to be 50:50 possibility of project proceeding.

Tentative Unlikely to proceed on time.

Speculative Likely location for a plant, capacity needed to maintain supply/demand balance. 


\subsubsection{Plant Closures}

As may be seen in the overall methanol supply/demand balance in Section 2.3, there currently is a significant excess of global methanol supply. In previous oversupply situations many producers have chosen to stay in business and meet contractual obligations, but at the same time they have minimized production either through reducing throughput or bringing maintenance turnarounds forward, etc. In 1999, however, a significant amount of additional capacity came on stream, exacerbating an already weakening methanol market.

In 2001 and 2002, there were several plant closures mainly driven by:

- Recent additions of new capacities in low cost feedstock areas

- A slowing global economy

- Fly-up in the price of North American natural gas, which put local producers at a severe cost disadvantage to offshore producers with access to low cost gas supplies

- Many of the high costs, first generation ICI type low pressure plants are now in their twilight years being around 25 years old, and thus were candidates for closure

Nexant expects to see further permanent plant closures as operators of older plants in North America and Western Europe realize that there is little likelihood of their plants generating an acceptable return. We have recently seen a substantial amount of Canadian and American capacity closed and anticipate more will follow, especially as MTBE phase out in the United States begins to impact methanol consumption.

In Europe, the remaining first generation low-pressure plant, owned by Methanor, is known to be considering a number of options, including possible divestment from the business.

Table 2.4 presents closures in 2001 and 2002 and Nexant's view of likely methanol closures in the next four years.

Table 2.4 Methanol Plant Closures, 2001 Onwards

\begin{tabular}{|l|l|l|l|c|l|}
\hline Year & Operator & Location & Region & Capacity (kt) & Status \\
\hline 2001 & ICl & Billingham, UK & Western Europe & 500 & Closed \\
\hline 2001 & Celanese & Clear Lake, TX & United States & 600 & Closed \\
\hline 2001 & Various & Various small plants & United States & 262 & Speculative \\
\hline 2001 & Borden & Geismar, LA & United States & 780 & Closed \\
\hline 2001 & Methanex & Medecine Hat, AL & Canada & 470 & Closed \\
\hline 2001 & Enron & Pasadena, TX & United States & 375 & Closed \\
\hline 2002 & Motiva & Delaware City, DE & United States & 270 & Indefinitely idled \\
\hline 2004 & Celanese & Bishop, TX & United States & 500 & Speculative \\
\hline 2005 & Methanor & Delfzjil, Netherlands & Western Europe & 840 & Speculative \\
\hline
\end{tabular}


Nexant's overall view on methanol capacity development over the forecast period is summarized in Figure 2.5.

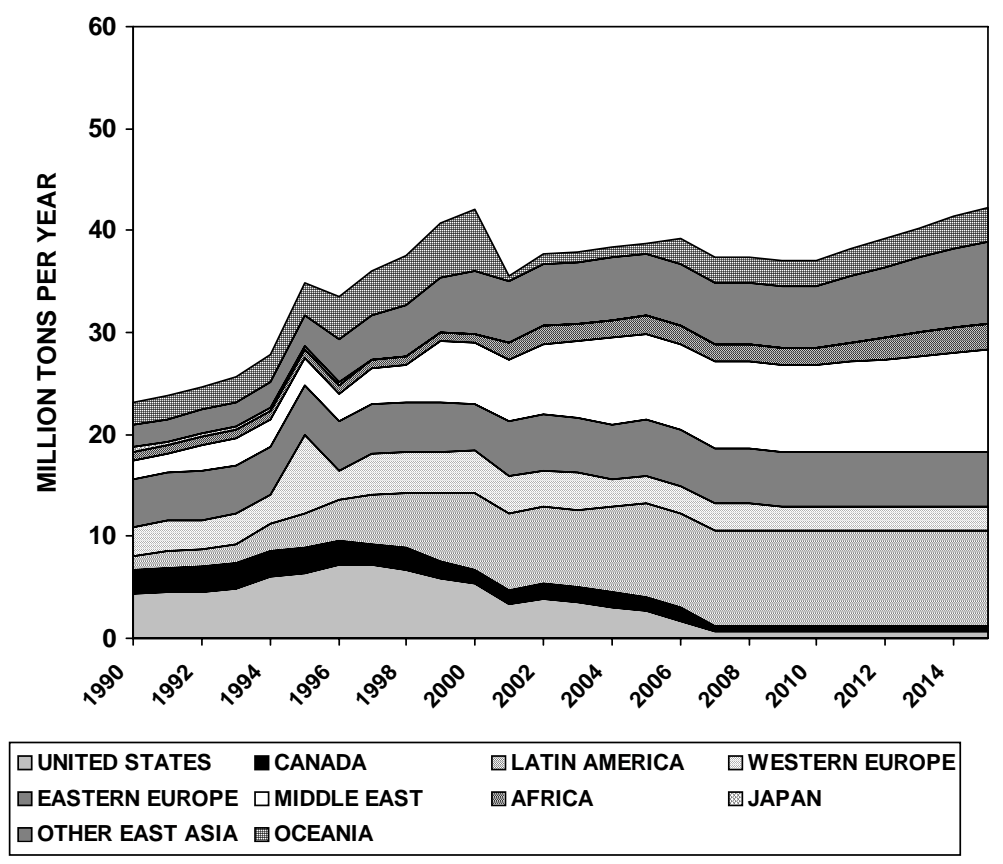

Figure 2.5 Global Methanol Capacity Breakdown, 1990 to 2015, Million Metric Tons Per Year

\subsubsection{Dynamics of Methanol Capacity Development}

The dynamics of the development of methanol capacities reflects the continuous growth in the global consumption of methanol, location of favorable natural gas prices and the location of the primary markets with growing demand.

Major developments in methanol capacities are expected in the regions with access to low cost natural gas resources where there is low local market demand for natural gas. Access to low cost gas and technology allow the construction of plants with very large capacities (up to 1.5 million tons per year) compared with existing capacities (under one million tons per year). Such large plants can take advantage of economies of scale and produce low cost methanol while achieving an acceptable return on their investment.

Such new investments, coupled with a slowdown in demand growth, will lead to a capacity overhang and low average operating rates during the middle of this decade. The lower margins, which are projected, to result from this trough may cause some high cost producers to close, thus further continuing the trend for global methanol production to migrate away from the major markets towards "stranded gas" locations. 
Figure 2.6 summarizes regional capacity development. As the demand for methanol is expected to grow, new capacities will be needed in the long-term future around 2015 in the regions with "stranded gas" resources.

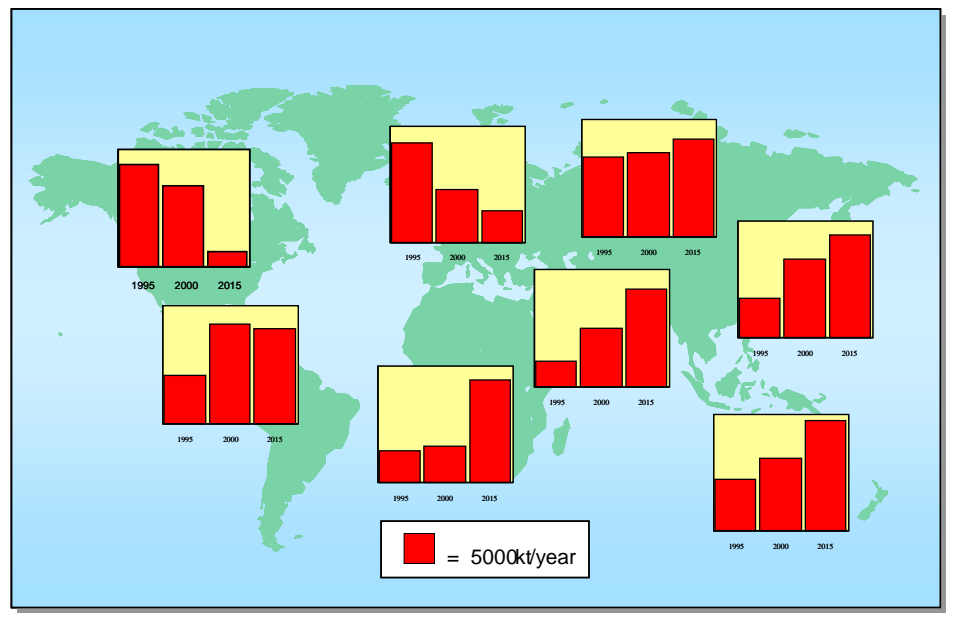

Figure 2.6 Dynamics in Methanol Capacity Changes

As noted, a distinct feature of the global methanol industry is that most development of new plants will occur in regions that have access to low cost "stranded gas" where there is no attractive alternative end uses or value. In such regions, the use of gas to produce methanol is an economical way to exploit the gas resource. Figure 2.7 shows Nexant's forecast evolution of methanol production away from the major consuming markets to "stranded gas" regions of the world. In 1995 around two-thirds of global methanol production was in the major consuming regions. By 2005 this situation is expected to reverse with just one-third of methanol produced in these regions. By 2015, the figure is expected to have reduced to about 25 percent of the total.

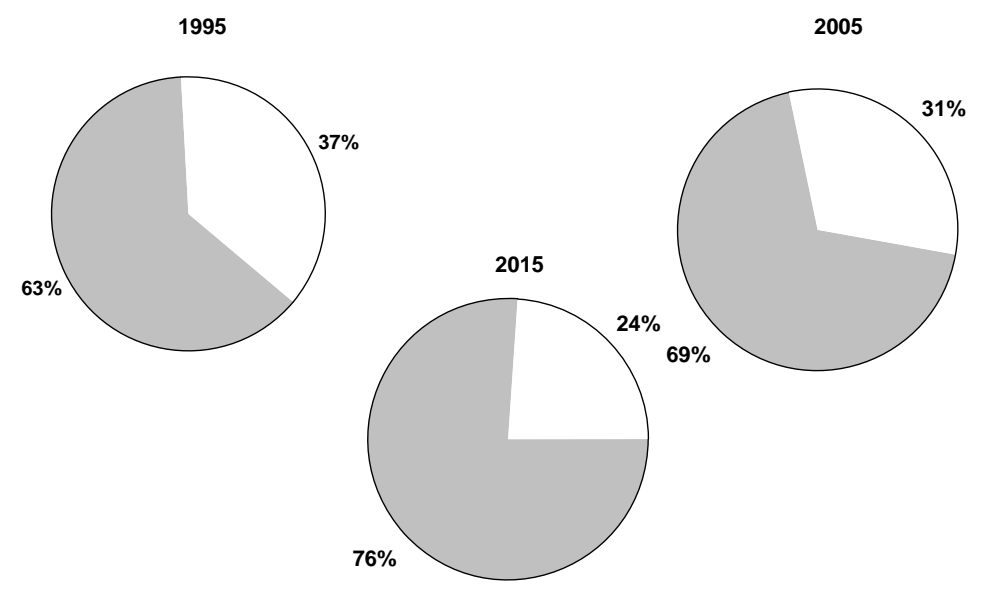

$\square$ STRANDED GAS REGIONS $\square$ REGIONS WITH ALTERNATIVE FUEL VALUE FOR GAS

Figure 2.7 Evolution of Global Methanol Production Resource Base 


\subsection{SUPPLYIDEMAND BALANCE}

Global methanol supply/demand balances are driven by the trends in demand for methanol in various end-uses, discussed earlier, together with an estimate of current capacity and a view of how this will change, both as a result of new projects but also due to plant closures.

Nexant's global forecast of capacity and demand, based on the input described in Sections A and B above, is attached in Table 2.5 and summarized in Figure 2.8.

Overall, Nexant believes nameplate capacity will increase from about 38 million tons in 2001, to reach about 40 million tons in 2006 and then rise to 44 million by 2015 . The global average industry operating rate is predicted to recover from the trough of about 75 percent in 2005, rising to about 90 percent by 2015. It is anticipated that over 3 million metric tons per year of older high cost capacity will be forced to close over the 2005 to 2007 period as a result of the phase out of MTBE in the United States. Most of these shutdowns will take place in the United States, and to a lesser extent Western Europe.

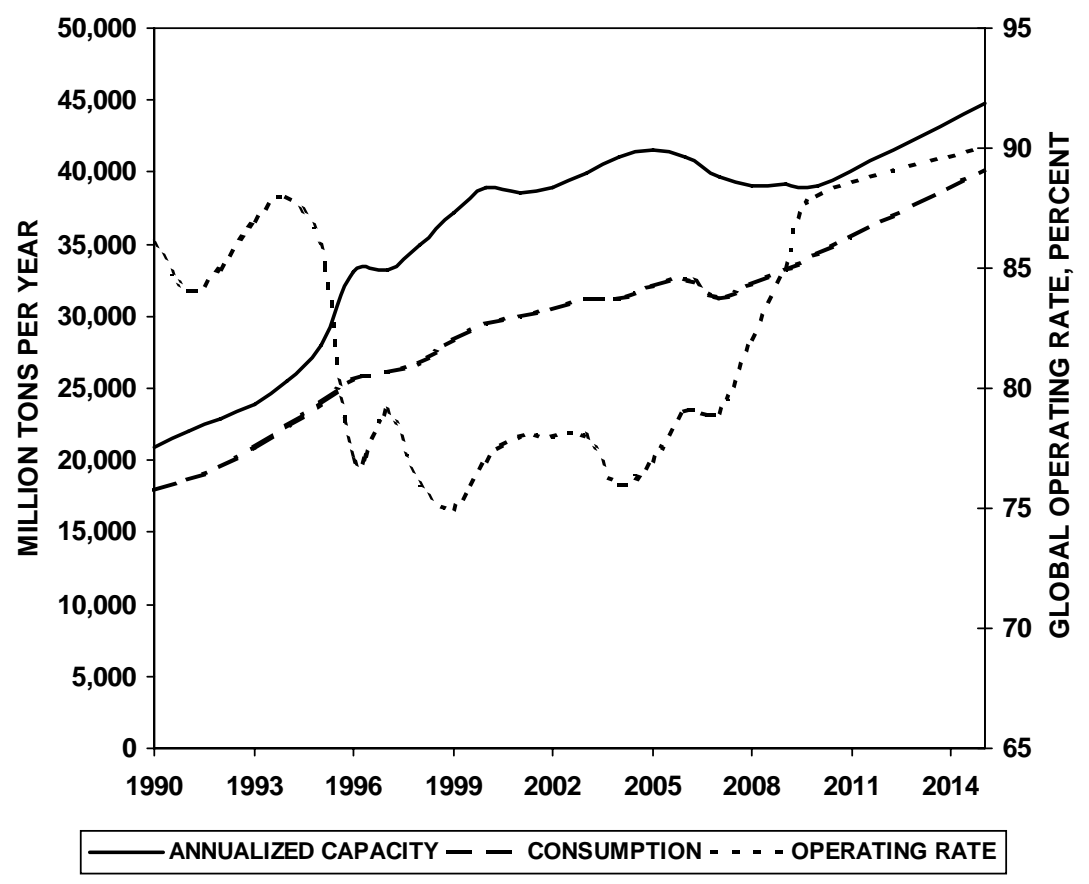

O:/2002Q2/NEXANT/00072/RP/WLT1.PPT

Figure 2.8 Global Methanol Supply/Demand Balance 


\section{Table 2.5 Methanol Supply/Demand Balance}

\begin{tabular}{|c|c|c|c|c|c|c|c|c|c|c|c|c|c|}
\hline \multicolumn{2}{|c|}{ Units: Thousand Ton/Year } & 2000 & 2001 & 2002 & 2003 & 2004 & 2005 & 2006 & 2007 & 2008 & 2009 & 2010 & 2015 \\
\hline \multirow[t]{13}{*}{ United States } & Firm Capacity - Initial & 5,812 & 5,362 & 3,345 & 3,945 & 3,945 & 3,945 & 3,945 & 3,945 & 3,945 & 3,945 & 3,945 & 3,945 \\
\hline & -Net Addition & $(450)$ & $(2,017)$ & 600 & 0 & 0 & 0 & 0 & 0 & 0 & 0 & 0 & 0 \\
\hline & -Total & 5,362 & 3,345 & 3,945 & 3,945 & 3,945 & 3,945 & 3,945 & 3,945 & 3,945 & 3,945 & 3,945 & 3,945 \\
\hline & Net Speculative Additions & 0 & 0 & 0 & $(300)$ & $(500)$ & $(500)$ & $(1,000)$ & $(1,000)$ & 0 & 0 & 0 & 0 \\
\hline & Expected Capacity Total & 5,362 & 3,345 & 3,945 & 3,645 & 3,145 & 2,645 & 1,645 & 645 & 645 & 645 & 645 & 645 \\
\hline & Annualized Capacity & 5,587 & 4,354 & 3,645 & 3,795 & 3,395 & 2,895 & 2,768 & 1,145 & 645 & 645 & 645 & 645 \\
\hline & Production & 4,795 & 3,435 & 2,565 & 2,654 & 2,199 & 2,078 & 1,565 & 500 & 500 & 500 & 500 & 500 \\
\hline & Net Trade & $(4,182)$ & $(5,295)$ & $(6,243)$ & $(6,020)$ & $(5,821)$ & $(6,072)$ & $(6,332)$ & $(5,386)$ & $(5,524)$ & $(5,666)$ & $(5,811)$ & $(6,591)$ \\
\hline & Inventory & & & & & & & & & & & & \\
\hline & Consumption & 8,977 & 8,730 & 8,808 & 8,674 & 8,020 & 8,150 & 7,897 & 5,886 & 6,024 & 6,166 & 6,311 & 7,091 \\
\hline & Operating Rate (Average) & 86 & 79 & 70 & 70 & 65 & 72 & 57 & 44 & 78 & 78 & 78 & 78 \\
\hline & MTBE & 3,743 & 3,782 & 3,740 & 3,482 & 2,701 & 2,701 & 2,368 & 222 & 222 & 222 & 222 & 222 \\
\hline & Other & 5,234 & 4,948 & 5,069 & 5,192 & 5,319 & 5,449 & 5,529 & 5,664 & 5,802 & 5,944 & 6,089 & 6,869 \\
\hline \multirow[t]{13}{*}{ Canada } & Firm Capacity - Initial & 1,840 & 1,310 & 1,370 & 1,370 & 1,370 & 1,370 & 1,370 & 1,370 & 1,370 & 1,370 & 1,370 & 1,370 \\
\hline & -Net Addition & (530) & 60 & 0 & 0 & 0 & 0 & 0 & 0 & 0 & 0 & 0 & 0 \\
\hline & -Total & 1,310 & 1,370 & 1,370 & 1,370 & 1,370 & 1,370 & 1,370 & 1,370 & 1,370 & 1,370 & 1,370 & 1,370 \\
\hline & Net Speculative Additions & 0 & 0 & 0 & 0 & 0 & 0 & 0 & (740) & 0 & 0 & 0 & 0 \\
\hline & Expected Capacity Total & 1,310 & 1,370 & 1,370 & 1,370 & 1,370 & 1,370 & 1,370 & 630 & 630 & 630 & 630 & 630 \\
\hline & Annualized Capacity & 1,575 & 1,340 & 1,370 & 1,370 & 1,370 & 1,370 & 1,370 & 1,000 & 630 & 630 & 630 & 630 \\
\hline & Production & 1,430 & 791 & 1,165 & 1,165 & 1,165 & 1,165 & 1,165 & 850 & 536 & 536 & 536 & 536 \\
\hline & Net Trade & 745 & 95 & 592 & 715 & 702 & 689 & 676 & 348 & 19 & 5 & (10) & (91) \\
\hline & Inventory & 0 & 0 & 0 & 0 & 0 & 0 & 0 & 0 & 0 & 0 & 0 & 0 \\
\hline & Consumption & 685 & 696 & 573 & 450 & 462 & 475 & 489 & 502 & 516 & 531 & 546 & 626 \\
\hline & Operating Rate (Average) & 91 & 59 & 85 & 85 & 85 & 85 & 85 & 85 & 85 & 85 & 85 & 85 \\
\hline & MTBE & 271 & 271 & 135 & 0 & 0 & 0 & 0 & 0 & 0 & 0 & 0 & 0 \\
\hline & Other & 414 & 426 & 437 & 450 & 462 & 475 & 489 & 502 & 516 & 531 & 546 & 626 \\
\hline \multirow[t]{13}{*}{ Latin America } & Firm Capacity - Initial & 7,623 & 7,623 & 7,623 & 7,623 & 7,623 & 7,623 & 7,623 & 7,623 & 7,623 & 7,623 & 7,623 & 7,623 \\
\hline & -Net Addition & 0 & 0 & 0 & 0 & 0 & 0 & 0 & 0 & 0 & 0 & 0 & 0 \\
\hline & -Total & 7,623 & 7,623 & 7,623 & 7,623 & 7,623 & 7,623 & 7,623 & 7,623 & 7,623 & 7,623 & 7,623 & 7,623 \\
\hline & Net Speculative Additions & 0 & 0 & 0 & 0 & 1,650 & 0 & 0 & 0 & 0 & 0 & 0 & 0 \\
\hline & Expected Capacity Total & 7,623 & 7,623 & 7,623 & 7,623 & 9,273 & 9,273 & 9,273 & 9,273 & 9,273 & 9,273 & 9,273 & 9,273 \\
\hline & Annualized Capacity & 7,623 & 7,623 & 7,623 & 7,623 & 8,448 & 9,273 & 9,273 & 9,273 & 9,273 & 9,273 & 9,273 & 9,273 \\
\hline & Production & 6,128 & 6,569 & 6,698 & 6,744 & 6,368 & 7,418 & 7,418 & 7,418 & 7,418 & 7,072 & 7,798 & 9,226 \\
\hline & Net Trade & 4,407 & 4,795 & 4,883 & 4,835 & 4,399 & 5,436 & 5,398 & 5,437 & 5,462 & 5,074 & 5,758 & 6,949 \\
\hline & Inventory & 0 & 0 & 0 & 0 & 0 & 0 & 0 & 0 & 0 & 0 & 0 & 0 \\
\hline & Consumption & 1,721 & 1,774 & 1,815 & 1,909 & 1,969 & 1,983 & 2,020 & 1,982 & 1,956 & 1,998 & 2,040 & 2,277 \\
\hline & Operating Rate (Average) & 80 & 86 & 88 & 88 & 75 & 80 & 80 & 80 & 80 & 76 & 84 & 99 \\
\hline & MTBE & 711 & 731 & 739 & 799 & 823 & 800 & 800 & 723 & 657 & 657 & 657 & 657 \\
\hline & Other & 1,010 & 1,042 & 1,076 & 1,110 & 1,146 & 1,182 & 1,220 & 1,259 & 1,299 & 1,341 & 1,384 & 1,620 \\
\hline
\end{tabular}




\section{Table 2.5 Methanol Supply/Demand Balance (Continued)}

\begin{tabular}{|c|c|c|c|c|c|c|c|c|c|c|c|c|c|}
\hline \multicolumn{2}{|c|}{ Units: Thousand Ton/Year } & \multirow[t]{2}{*}{2000} & \multirow[t]{2}{*}{2001} & \multirow[t]{2}{*}{2002} & \multirow[t]{2}{*}{2003} & \multirow[t]{2}{*}{2004} & \multirow[t]{2}{*}{2005} & \multirow[t]{2}{*}{2006} & \multirow[t]{2}{*}{2007} & \multirow[t]{2}{*}{2008} & \multirow[t]{2}{*}{2009} & \multirow[t]{2}{*}{2010} & \multirow[t]{2}{*}{2015} \\
\hline Western Europe & & & & & & & & & & & & & \\
\hline & Firm Capacity - Initial & 4,000 & 4,060 & 3,560 & 3,560 & 3,560 & 3,560 & 3,560 & 3,560 & 3,560 & 3,560 & 3,560 & 3,560 \\
\hline & -Net Addition & 60 & $(500)$ & 0 & 0 & 0 & 0 & 0 & 0 & 0 & 0 & 0 & 0 \\
\hline & -Total & 4,060 & 3,560 & 3,560 & 3,560 & 3,560 & 3,560 & 3,560 & 3,560 & 3,560 & 3,560 & 3,560 & 3,560 \\
\hline & Net Speculative Additions & 0 & 0 & 0 & 0 & (840) & 0 & 0 & 0 & 0 & $(300)$ & 0 & c \\
\hline & Expected Capacity Total & 4,060 & 3,560 & 3,560 & 3,560 & 2,720 & 2,720 & 2,720 & 2,720 & 2,720 & 2,420 & 2,420 & 2,420 \\
\hline & Annualized Capacity & 4,030 & 3,810 & 3,560 & 3,560 & 3,140 & 2,720 & 2,720 & 2,720 & 2,720 & 2,570 & 2,420 & 2,420 \\
\hline & Production & 3,000 & 3,100 & 3,100 & 3,100 & 2,656 & 2,300 & 2,312 & 2,312 & 2,312 & 2,185 & 2,057 & 2,057 \\
\hline & Net Trade & $(3,295)$ & $(3,404)$ & $(3,580)$ & $(3,762)$ & $(4,394)$ & $(4,944)$ & $(5,132)$ & $(5,339)$ & $(5,553)$ & $(5,901)$ & $(6,257)$ & $(6,492)$ \\
\hline & Inventory & 0 & 0 & 0 & 0 & 0 & 0 & 0 & 0 & 0 & 0 & 0 & 0 \\
\hline & Consumption & 6,295 & 6,504 & 6,680 & 6,862 & 7,050 & 7,244 & 7,444 & 7,651 & 7,865 & 8,085 & 8,314 & 8,549 \\
\hline & Operating Rate (Average) & 74 & 81 & 87 & 87 & 85 & 85 & 85 & 85 & 85 & 85 & 85 & 85 \\
\hline & MTBE & 1,134 & 1,173 & 1,173 & 1,173 & 1,173 & 1,173 & 1,173 & 1,173 & 1,173 & 1,173 & 1,173 & 1,173 \\
\hline & Other & 5,161 & 5,331 & 5,507 & 5,689 & 5,877 & 6,071 & 6,271 & 6,478 & 6,692 & 6,913 & 7,141 & 7,376 \\
\hline \multicolumn{14}{|l|}{ Eastern Europe } \\
\hline & Firm Capacity - Initial & 4,755 & 4,635 & 5,135 & 5,135 & 5,135 & 5,135 & 5,135 & 5,135 & 5,135 & 5,135 & 5,135 & 5,135 \\
\hline & -Net Addition & (120) & 500 & 0 & 0 & 0 & 0 & 0 & 0 & 0 & 0 & 0 & 0 \\
\hline & -Total & 4,635 & 5,135 & 5,135 & 5,135 & 5,135 & 5,135 & 5,135 & 5,135 & 5,135 & 5,135 & 5,135 & 5,135 \\
\hline & Net Speculative Additions & 0 & 300 & 0 & 0 & 0 & 0 & 0 & 0 & 0 & 0 & 0 & 0 \\
\hline & Expected Capacity Total & 4,635 & 5,435 & 5,435 & 5,435 & 5,435 & 5,435 & 5,435 & 5,435 & 5,435 & 5,435 & 5,435 & 5,435 \\
\hline & Annualized Capacity & 4,695 & 5,035 & 5,435 & 5,435 & 5,435 & 5,435 & 5,435 & 5,435 & 5,435 & 5,435 & 5,435 & 5,435 \\
\hline & Production & 3,136 & 3,479 & 3,780 & 3,800 & 3,900 & 3,672 & 3,883 & 3,900 & 3,900 & 4,400 & 4,582 & 4,800 \\
\hline & Net Trade & 138 & 359 & 546 & 460 & 450 & 108 & 201 & 96 & $(30)$ & 340 & 377 & 450 \\
\hline & Inventory & 0 & 0 & 0 & 0 & 0 & 0 & 0 & 0 & 0 & 0 & 0 & 0 \\
\hline & Consumption & 2,998 & 3,120 & 3,234 & 3,340 & 3,450 & 3,564 & 3,682 & 3,804 & 3,930 & 4,060 & 4,205 & 4,350 \\
\hline & Operating Rate (Average) & 67 & 69 & 70 & 70 & 72 & 68 & 71 & 72 & 72 & 81 & 84 & 90 \\
\hline & MTBE & 211 & 235 & 248 & 250 & 252 & 254 & 256 & 258 & 259 & 261 & 274 & 311 \\
\hline & Other & 2,787 & 2,885 & 2,986 & 3,090 & 3,198 & 3,310 & 3,426 & 3,546 & 3,670 & 3,799 & 3,932 & 4,069 \\
\hline \multirow[t]{13}{*}{ Middle East } & Firm Capacity - Initial & 6,042 & 6,042 & 6,042 & 6,042 & 6,042 & 6,042 & 6,042 & 6,042 & 6,042 & 6,042 & 6,042 & 6,042 \\
\hline & -Net Addition & 0 & 0 & 1,000 & 500 & 1,000 & 0 & 0 & 0 & 0 & 0 & 0 & 0 \\
\hline & -Total & 6,042 & 6,042 & 6,042 & 6,042 & 6,042 & 6,042 & 6,042 & 6,042 & 6,042 & 6,042 & 6,042 & 6,042 \\
\hline & Net Speculative Additions & 0 & 0 & 1,000 & 500 & 1,000 & 0 & 0 & 0 & 0 & 0 & 0 & 1,500 \\
\hline & Expected Capacity Total & 6,042 & 6,042 & 7,042 & 7,542 & 8,542 & 8,542 & 8,542 & 8,542 & 8,542 & 8,542 & 8,542 & 10,042 \\
\hline & Annualized Capacity & 6,042 & 6,042 & 6,542 & 7,292 & 8,042 & 8,542 & 8,542 & 8,542 & 8,542 & 8,542 & 8,542 & 10,042 \\
\hline & Production & 4,655 & 5,213 & 5,523 & 5,761 & 6,011 & 6,342 & 6,547 & 6,420 & 6,351 & 7,002 & 6,898 & 7,957 \\
\hline & Net Trade & 2,850 & 3,399 & 3,611 & 3,582 & 3,951 & 4,239 & 4,350 & 4,271 & 4,094 & 4,666 & 4,509 & 3,676 \\
\hline & Inventory & 0 & 0 & 0 & 0 & 0 & 0 & 0 & 0 & 0 & 0 & 0 & 0 \\
\hline & Consumption & 1,806 & 1,815 & 1,912 & 2,179 & 2,060 & 2,103 & 2,197 & 2,149 & 2,257 & 2,336 & 2,389 & 2,398 \\
\hline & Operating Rate (Average) & 77 & 86 & 84 & 79 & 75 & 74 & 77 & 75 & 74 & 82 & 81 & 71 \\
\hline & MTBE & 1,155 & 1,141 & 1,214 & 1,458 & 1,313 & 1,329 & 1,397 & 1,320 & 1,400 & 1,449 & 1,470 & 1,447 \\
\hline & Other & 651 & 674 & 697 & 722 & 747 & 773 & 800 & 828 & 857 & 887 & 918 & 95 \\
\hline
\end{tabular}


Table 2.5 Methanol Supply/Demand Balance (Continued)

\begin{tabular}{|c|c|c|c|c|c|c|c|c|c|c|c|c|c|}
\hline \multicolumn{2}{|c|}{ Units: Thousand Ton/Year } & 2,000 & 2001 & 2002 & 2003 & 2004 & 2005 & 2006 & 2007 & 2008 & 2009 & 2010 & 2015 \\
\hline \multirow[t]{13}{*}{ Africa } & Firm Capacity - Initial & 920 & 920 & 1,745 & 1,745 & 1,745 & 1,745 & 1,745 & 1,745 & 1,745 & 1,745 & 1,745 & 1,745 \\
\hline & -Net Addition & 0 & 825 & 0 & 0 & 0 & 0 & 0 & 0 & 0 & 0 & 0 & 0 \\
\hline & -Total & 920 & 1,745 & 1,745 & 1,745 & 1,745 & 1,745 & 1,745 & 1,745 & 1,745 & 1,745 & 1,745 & 1,745 \\
\hline & Net Speculative Additions & 0 & 0 & 0 & 0 & 0 & 0 & 0 & 0 & 0 & 0 & 0 & 0 \\
\hline & Expected Capacity Total & 920 & 1,745 & 1,745 & 1,745 & 1,745 & 1,745 & 1,745 & 1,745 & 1,745 & 1,745 & 1,745 & 2,645 \\
\hline & Annualized Capacity & 920 & 1,333 & 1,745 & 1,745 & 1,745 & 1,745 & 1,745 & 1,745 & 1,745 & 1,745 & 1,745 & 2,645 \\
\hline & Production & 750 & 1,000 & 1,500 & 1,500 & 1,500 & 1,555 & 1,800 & 2,100 & 1,583 & 1,656 & 2,003 & 2,550 \\
\hline & Net Trade & 594 & 840 & 1,335 & 1,329 & 1,324 & 1,375 & 1,617 & 1,913 & 1,392 & 1,461 & 1,805 & 2,329 \\
\hline & Inventory & 0 & 0 & 0 & 0 & 0 & 0 & 0 & 0 & 0 & 0 & 0 & 0 \\
\hline & Consumption & 156 & 160 & 165 & 171 & 176 & 180 & 183 & 187 & 191 & 195 & 198 & 221 \\
\hline & Operating Rate (Average) & 82 & 75 & 86 & 86 & 86 & 89 & 103 & 120 & 91 & 95 & 115 & 96 \\
\hline & MTBE & 32 & 33 & 34 & 38 & 39 & 39 & 39 & 39 & 40 & 40 & 39 & 41 \\
\hline & Other & 124 & 127 & 130 & 133 & 137 & 140 & 144 & 147 & 151 & 155 & 159 & 179 \\
\hline \multirow[t]{13}{*}{ Japan } & Firm Capacity - Initial & 0 & 0 & 0 & 0 & 0 & 0 & 0 & 0 & 0 & 0 & 0 & 0 \\
\hline & -Net Addition & 0 & 0 & 0 & 0 & 0 & 0 & 0 & 0 & 0 & 0 & 0 & 0 \\
\hline & -Total & 0 & 0 & 0 & 0 & 0 & 0 & 0 & 0 & 0 & 0 & 0 & 0 \\
\hline & Net Speculative Additions & 0 & 0 & 0 & 0 & 0 & 0 & 0 & 0 & 0 & 0 & 0 & 0 \\
\hline & Expected Capacity Total & 0 & 0 & 0 & 0 & 0 & 0 & 0 & 0 & 0 & 0 & 0 & 0 \\
\hline & Annualized Capacity & 0 & 0 & 0 & 0 & 0 & 0 & 0 & 0 & 0 & 0 & 0 & 0 \\
\hline & Production & 0 & 0 & 0 & 0 & 0 & 0 & 0 & 0 & 0 & 0 & 0 & 0 \\
\hline & Net Trade & $(2,094)$ & $(2,155)$ & $(2,137)$ & $(2,199)$ & $(2,264)$ & $(2,331)$ & $(2,399)$ & $(2,470)$ & $(2,542)$ & $(2,617)$ & $(2,694)$ & $(3,116)$ \\
\hline & Inventory & 0 & 0 & 0 & 0 & 0 & 0 & 0 & 0 & 0 & 0 & 0 & 0 \\
\hline & Consumption & 2,094 & 2,155 & 2,137 & 2,199 & 2,264 & 2,331 & 2,399 & 2,470 & 2,542 & 2,617 & 2,694 & 3,116 \\
\hline & Operating Rate (Average) & 0 & 0 & 0 & 0 & 0 & 0 & 0 & 0 & 0 & 0 & 0 & 0 \\
\hline & MTBE & 124 & 127 & 47 & 47 & 47 & 47 & 47 & 47 & 47 & 47 & 47 & 47 \\
\hline & Other & 1,970 & 2,029 & 2,090 & 2,152 & 2,217 & 2,283 & 2,352 & 2,423 & 2,495 & 2,570 & 2,647 & 3,069 \\
\hline \multirow[t]{13}{*}{ East Asia } & Firm Capacity - Initial & 5,904 & 6,132 & 6,132 & 6,132 & 6,132 & 6,132 & 6,132 & 6,132 & 6,132 & 6,132 & 6,132 & 6,132 \\
\hline & -Net Addition & 228 & 0 & 0 & 0 & 0 & 0 & 0 & 0 & 0 & 0 & 0 & 0 \\
\hline & -Total & 6,132 & 6,132 & 6,132 & 6,132 & 6,132 & 6,132 & 6,132 & 6,132 & 6,132 & 6,132 & 6,132 & 6,132 \\
\hline & Net Speculative Additions & 0 & 0 & 0 & 0 & 0 & 0 & 0 & 0 & 0 & 0 & 0 & 0 \\
\hline & Expected Capacity Total & 6,132 & 6,132 & 6,132 & 6,132 & 6,132 & 6,132 & 6,132 & 6,132 & 6,132 & 6,132 & 6,132 & 7,982 \\
\hline & Annualized Capacity & 5,765 & 6,132 & 6,132 & 6,132 & 6,132 & 6,132 & 6,132 & 6,132 & 6,132 & 6,132 & 6,132 & 7,982 \\
\hline & Production & 4,164 & 4,320 & 4,167 & 4,684 & 4,791 & 4,900 & 5,300 & 5,100 & 5,159 & 5,250 & 5,300 & 6,293 \\
\hline & Net Trade & (366) & (486) & (856) & (591) & (749) & $(897)$ & (768) & $(1,253)$ & $(1,495)$ & $(1,737)$ & $(2,039)$ & $(3,081)$ \\
\hline & Inventory & 0 & 0 & 0 & 0 & 0 & 0 & 0 & 0 & 0 & 0 & 0 & 0 \\
\hline & Consumption & 4,530 & 4,806 & 5,023 & 5,275 & 5,540 & 5,797 & 6,068 & 6,353 & 6,654 & 6,987 & 7,339 & 9,374 \\
\hline & Operating Rate (Average) & 72 & 70 & 68 & 76 & 78 & 80 & 86 & 83 & 84 & 86 & 86 & 79 \\
\hline & MTBE & 773 & 843 & 841 & 863 & 886 & 887 & 887 & 888 & 888 & 905 & 922 & 987 \\
\hline & Other & 3,757 & 3,963 & 4,181 & 4,411 & 4,654 & 4,910 & 5,180 & 5,465 & 5,766 & 6,083 & 6,417 & 8,387 \\
\hline
\end{tabular}


Table 2.5 Methanol Supply/Demand Balance (Continued)

\begin{tabular}{|c|c|c|c|c|c|c|c|c|c|c|c|c|c|}
\hline \multicolumn{2}{|c|}{ Units: Thousand Ton/Year } & \multirow{2}{*}{$\begin{array}{l}2000 \\
2,484 \\
\end{array}$} & \multirow{2}{*}{$\begin{array}{l}2001 \\
2,484 \\
\end{array}$} & \multirow{2}{*}{$\begin{array}{l}2002 \\
2,484 \\
\end{array}$} & \multirow{2}{*}{$\begin{array}{l}2003 \\
2,484 \\
\end{array}$} & \multirow{2}{*}{$\begin{array}{l}2004 \\
2,484 \\
\end{array}$} & \multirow{2}{*}{$\begin{array}{l}2005 \\
2,484 \\
\end{array}$} & \multirow{2}{*}{$\begin{array}{l}2006 \\
2,484 \\
\end{array}$} & \multirow{2}{*}{$\begin{array}{l}2007 \\
2,484 \\
\end{array}$} & \multirow{2}{*}{$\begin{array}{l}2008 \\
2,484 \\
\end{array}$} & \multirow{2}{*}{$\begin{array}{l}2009 \\
2,484 \\
\end{array}$} & \multirow{2}{*}{$\begin{array}{l}2010 \\
2,484 \\
\end{array}$} & \multirow{2}{*}{$\begin{array}{l}2015 \\
2,484 \\
\end{array}$} \\
\hline Oceania & Firm Capacity - Initial & & & & & & & & & & & & \\
\hline & -Net Addition & 0 & 0 & 0 & 0 & 0 & 0 & 0 & 0 & 0 & 0 & 0 & 0 \\
\hline & -Total & 2,484 & 2,484 & 2,484 & 2,484 & 2,484 & 2,484 & 2,484 & 2,484 & 2,484 & 2,484 & 2,484 & 2,484 \\
\hline & Net Speculative Additions & 0 & 0 & 0 & 0 & 800 & 0 & 0 & 0 & 500 & 0 & 0 & 0 \\
\hline & Expected Capacity Total & 2,484 & 2,484 & 2,484 & 2,484 & 3,284 & 3,284 & 3,284 & 3,284 & 3,784 & 3,784 & 3,784 & 5,284 \\
\hline & Annualized Capacity & 2,484 & 2,484 & 2,484 & 2,484 & 2,884 & 3,284 & 3,284 & 3,284 & 3,534 & 3,784 & 3,784 & 5,284 \\
\hline & Production & 1,802 & 2,035 & 2,037 & 1,846 & 2,600 & 2,600 & 2,600 & 2,600 & 4,400 & 4,606 & 4,600 & 6,100 \\
\hline & Net Trade & 1,624 & 1,853 & 1,849 & 1,652 & 2,401 & 2,395 & 2,388 & 2,382 & 4,176 & 4,375 & 4,362 & 5,824 \\
\hline & Inventory & 0 & 0 & 0 & 0 & 0 & 0 & 0 & 0 & 0 & 0 & 0 & 0 \\
\hline & Consumption & 177 & 182 & 188 & 194 & 199 & 205 & 212 & 218 & 224 & 231 & 238 & 276 \\
\hline & Operating Rate (Average) & 73 & 82 & 82 & 74 & 90 & 79 & 79 & 79 & 125 & 122 & 122 & 115 \\
\hline & MTBE & 0 & 0 & 0 & 0 & 0 & 0 & 0 & 0 & 0 & 0 & 0 & 0 \\
\hline & Other & 177 & 182 & 188 & 194 & 199 & 205 & 212 & 218 & 224 & 231 & 238 & 276 \\
\hline \multicolumn{14}{|l|}{ Summary } \\
\hline & & 2000 & 2001 & 2002 & 2003 & 2004 & 2005 & 2006 & 2007 & 2008 & 2009 & 2010 & 2015 \\
\hline & Firm Capacity - Initial & 39,810 & 38,998 & 37,866 & 38,466 & 38,466 & 38,466 & 38,466 & 38,466 & 38,466 & 38,466 & 38,466 & 38,466 \\
\hline & -Net Addition & (812) & $(1,132)$ & 600 & 0 & 0 & 0 & 0 & 0 & 0 & 0 & 0 & 0 \\
\hline & -Total & 38,998 & 37,866 & 38,466 & 38,466 & 38,466 & 38,466 & 38,466 & 38,466 & 38,466 & 38,466 & 38,466 & 38,466 \\
\hline & Net Speculative Additions & 0 & 300 & 1,000 & 200 & 2,110 & $(500)$ & $(1,000)$ & $(1,740)$ & 500 & $(300)$ & 0 & 1,500 \\
\hline & Expected Capacity Total & 38,998 & 38,166 & 39,766 & 39,966 & 42,076 & 41,576 & 40,576 & 38,836 & 39,336 & 39,036 & 39,036 & 44,786 \\
\hline & Annualized Capacity & 38,936 & 38,582 & 38,966 & 39,866 & 41,021 & 41,576 & 41,076 & 39,706 & 39,086 & 39,186 & 39,036 & 44,786 \\
\hline & Production & 29,859 & 29,943 & 30,534 & 31,254 & 31,190 & 32,030 & 32,590 & 31,200 & 32,159 & 33,206 & 34,274 & 40,119 \\
\hline & Net Trade & 421 & $(0)$ & 0 & 0 & 0 & $(0)$ & $(0)$ & 0 & $(0)$ & 0 & $(0)$ & 0 \\
\hline & Inventory & 0 & 0 & 0 & 0 & 0 & 0 & 0 & 0 & 0 & 0 & 0 & 0 \\
\hline & Consumption & 29,438 & 29,943 & 30,534 & 31,253 & 31,189 & 32,030 & 32,590 & 31,200 & 32,159 & 33,206 & 34,274 & 40,118 \\
\hline & Operating Rate (Average) & 77 & 78 & 78 & 78 & 76 & 77 & 79 & 79 & 82 & 85 & 88 & 90 \\
\hline & MTBE & 8,153 & 8,335 & 8,172 & 8,109 & 7,233 & 7,230 & 6,968 & 4,670 & 4,686 & 4,753 & 4,804 & 4,932 \\
\hline & Other & 21,285 & 21,608 & 22,362 & 23,144 & 23,956 & 24,800 & 25,622 & 26,530 & 27,473 & 28,453 & 29,470 & 35,186 \\
\hline
\end{tabular}

\subsection{TRADE FLOWS}

Three major regions of the world need to import significant volumes of methanol. These are Western Europe, the United States, and the Japan/Greater Far East region.

Given that the cost of shipping methanol can represent a significant fraction of its delivered cost, target markets for methanol from export-orientated plants are largely determined by the economics of supply logistics.

In general, trade patterns are fairly stable and logical. However there are always exceptions and cargoes from Russia have been observed entering the United States, while material from the Far East has occasionally been seen in Europe. Excluding these exceptions the major trade flows are shown in Figure 4.1. 


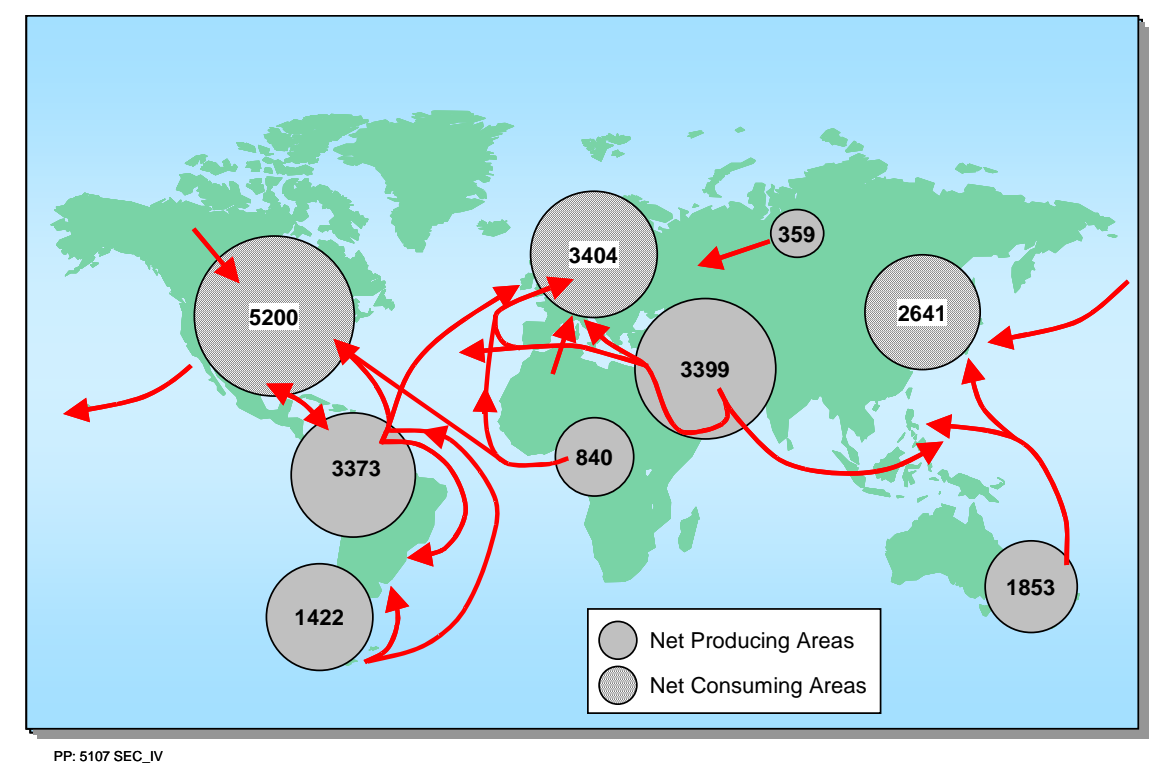

Figure 2.9 Global Methanol Trade Pattern in 2001 - Thousand Tons

Existing trade patterns are expected to continue well into the future reflecting the fact that low cost feedstock producers are generally located in areas with low consumption, whereas in the major consuming regions there is a higher alternative value for natural gas that makes local production less economically attractive.

Typical global flows are as follows:

- Eastern Europe. Expansions and construction of methanol plants in the former Soviet Union are likely to meet the local market demand but net exports from the region are unlikely to grow significantly. The export-orientated plants at Gubakha and Tomsk send methanol primarily to Western Europe. This material tends to move by rail to Kotka in Finland or Ventspills. New plants are planned in Arkhangelsk, Kothla-Jarve and Togliatti that can increase exports. Russia exports about 350,000 tons of methanol per year. Nexant assumes that this trade will not change considerably in the medium term.

- Africa. The new Bioko Island plant in Equatorial Guinea almost doubled the previous capacity in Africa, and there are plans for long-term expansion of this low cost methanol production facility. This plant will focus on the Western Europe and the United States markets. Other export production in Africa is located in Libya and Algeria, and these facilities typically ship across the Mediterranean into Southern Europe.

- Middle East. Material from this region, predominantly from Saudi Arabia (but Iran and Qatar are set to become major producers) moves to all three major consuming regions, the United States, Western Europe and the Far East. With the introduction of more export producers in Latin America, with better logistics to serve the United States market, Middle Eastern material can be expected to focus primarily on the Far East and Western Europe in the future. 
- Far East. Although the Far East and Japan are net importing markets, due to the lack of competitively price feedstock, it is unlikely that there will be new additions of methanol capacity in the region until the end of the decade. However, certain countries such as Malaysia and Indonesia have substantial surplus methanol capacity. Material from these sources is expected to go primarily to meet regional needs. Some high cost plants will probably close in China as tariff protection falls due to China's entry to the WTO.

- Oceania. This region has a very low level of local demand. Methanex in New Zealand, which typically targets the Far East and Japan, produces export material. Additional planned capacities in Australia will be targeting the same regions.

- Canada. Inland material (i.e. the Celanese plant in Edmonton Alberta) travels mainly into the United States northwest and mid-west, although some is exported via Vancouver. Material from Methanex's plant in British Colombia is exported by sea primarily to the Far East. Methanex closed its plant in Alberta and the future of the remaining plants is uncertain as international competition increases, and the cost of Alberta gas is bid up due to a forecast tight North American gas market.

- Latin America including the Caribbean. Venezuela and Trinidad are exporters, but the main markets for this material are within the region, e.g. Brazil, and then Western Europe and the United States. New plants in the region (Argentina and Trinidad) are likely to emerge in the future, focusing on Western Europe and the United States

- United States. The United States is a major importer from Canada, Latin America and the Middle East. The poor competitive position of United States methanol plants, combined with the anticipated major loss of domestic demand due to MTBE phase out, is expected to shift the United States to a much higher reliance on imports to meet domestic demand.

- North America. High natural gas prices and threats of MTBE phasing out has led producers in United States and Canada to close or mothball a significant portion of methanol capacities. Long-term demand is expected to be met by increased imports.

- Western Europe. Similar to the United States, high natural gas prices and older, high cost facilities will result in more closures in the medium-term. Long-term demand is expected to be met by increased imports from low-cost offshore facilities in the Middle East and North Africa. 
The outlook for U.S. methanol demand by major end use is summarized in Table 3.1. U.S. methanol demand in chemical applications is projected to increase 2.4 percent per year from 4.95 million metric tons in 2001 to 6.9 million metric tons in 2015. However, methanol demand for MTBE is projected to fall dramatically from 3.8 million metric tons in 2001 to 222 thousand metric tons beyond 2007. As a result, overall conventional methanol demand in the U.S. will decline from 8.7 million metric tons in 2001 to 7.1 million metric tons in 2015.

Table $3.1 \quad$ U.S. Methanol Demand, Thousand Tons Per Year

\begin{tabular}{|l|r|r|r|r|}
\hline Chemical Markets & 2001 & 2006 & 2015 & $\begin{array}{r}\text { Average Annual } \\
\text { Growth Rate, \% } \\
\text { 2001-2015 }\end{array}$ \\
\hline Formaldehyde & 2,129 & 2,409 & 3,084 & 2.5 \\
\hline HAC & 1,210 & 1,402 & 1,885 & 3.0 \\
\hline Methyl Halides & 317 & 333 & 368 & 1.0 \\
\hline MMA & 251 & 278 & 338 & 2.0 \\
\hline Methylamines & 240 & 272 & 348 & 2.5 \\
\hline DMT & 120 & 120 & 120 & 0.0 \\
\hline Solvents & 380 & 399 & 441 & 1.0 \\
\hline Miscellaneous & 300 & 315 & 348 & 1.0 \\
\hline Subtotal chemical & 4,948 & 5,529 & 6,932 & 2.4 \\
\hline & & & & $(18.3)$ \\
\hline Fuel related: & & & & \\
\hline MTBE & 3,782 & 2,368 & 222 & $(1.4)$ \\
\hline
\end{tabular}


Conventional global methanol demand will grow from 29.9 million metric tons in 2001 to 32.6 million metric tons in 2006. Global demand is projected to decline to 31.2 million metric tons in 2007 due to the phase out of MTBE in the United States. Thereafter, conventional methanol demand will resume growth, reaching 40.1 million metric tons by 2015 .

United States conventional methanol demand is forecast to decline from 8.7 million metric tons in 2001 to 7.15 million metric tons in 2015, primarily due to a drop in MTBE production to minimal levels.

Methanol capacity worldwide was 37.7 million metric tons per year at the end of 2001. The uncertainty about the future demand for MTBE has made the development of new methanol capacity difficult at present. There has been a trend towards larger methanol plants. In 1990, a world scale plant had a capacity of 660 thousand metric tons per year. Currently, a world scale plant is about 1 million metric tons per year, and new projects are being developed with capacities of over 2 million metric tons per year.

In 2001 and 2002 several methanol methanol plants closed down due to:

- Recent additions of new capacity in low cost feedstock regions

- A slowing global economy

- Fly-up in the price of North American natural gas feedstock

Nexant expects further permanent plant closures as operators of older plant in North America and Western Europe conclude they are not competitive with larger plants in gas-rich countries. Global methanol supply and demand will continue to be in oversupply until the latter part of this decade as shown in Figure 4.1. This surplus supply will provide a potential driving force for development of new fuel methanol markets over the next five to ten years. 


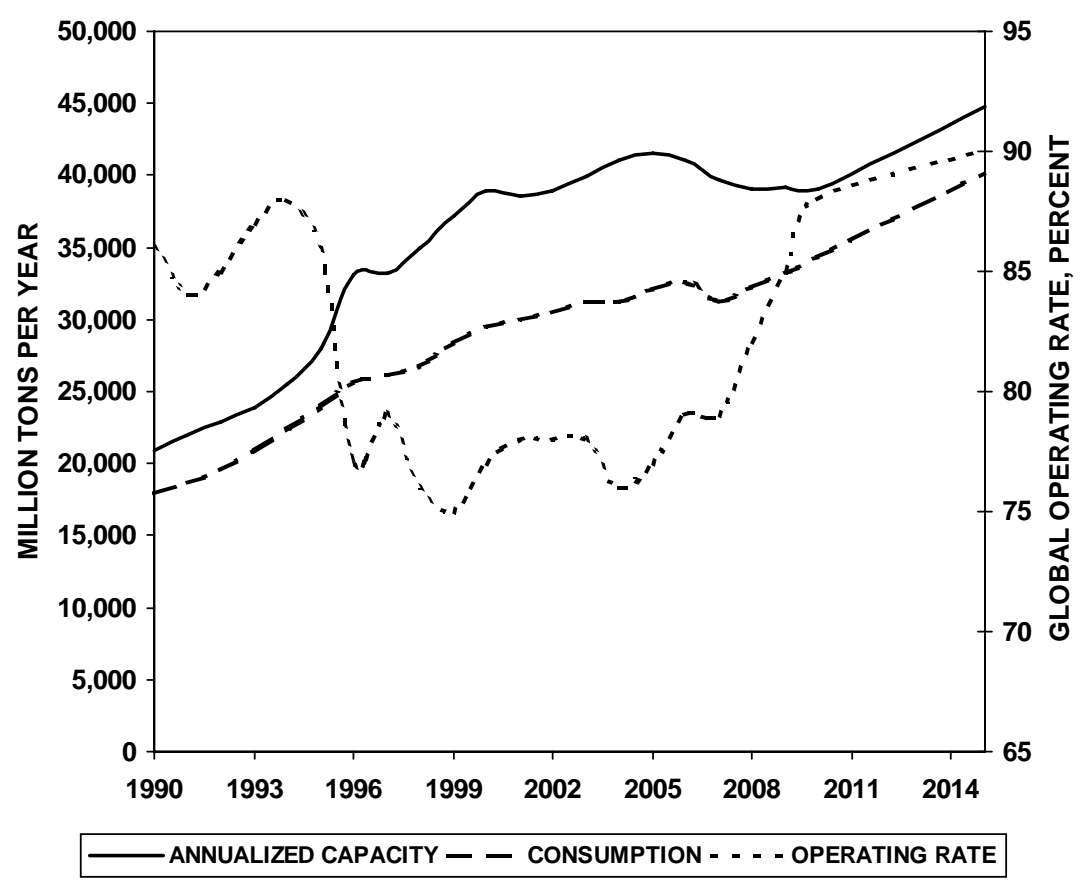

O:/2002Q2/NEXANT/00072/RP/WLT1.PPT

Figure 4.1 Global Methanol Supply/Demand Balance 


\section{United States Regional Fuel Markets \\ Market Study Report Section IV \\ Prepared For: \\ ConocoPhillips}

Co-operative Agreement DE-FC26-01NT41098

\section{ConocoPhillips $\mathfrak{A N e x a n t}$}




\title{
United States Regional Fuel Markets Market Study Report Section IV
}

November 2002

\author{
Prepared For: \\ CononcoPhillips
}

\section{Nexant}

44 South Broadway, White Plains, New York 10601, USA

Tel: +1 $9146090300 \quad$ Fax: +19146090399 


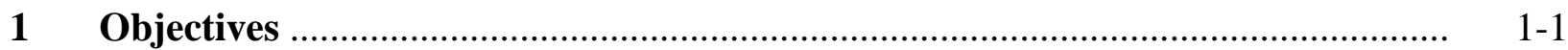

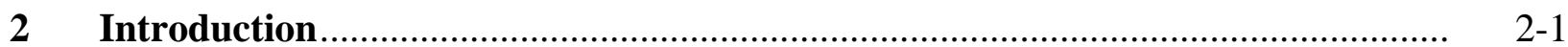

$2.1 \quad$ REGIONAL DEFINITION ..................................................................

2.2 BASIC ASSUMPTIONS …………….............................................. 2-2

$3 \quad$ Fuel Demand............................................................................................

3.1 NATIONAL OUTLOOK.................................................................

3.2 DEMAND OUTLOOK BY PADD REGION …………………………….... 3-2

$4 \quad$ Refining Production And Operations …………………………………………..... 4-.

$4.1 \quad$ NATIONAL OUTLOOK........................................................................ 4-1

4.2 OUTLOOK FOR REFINED PRODUCT PRODUCTION BY PADD REGION ……................................................................................ $4-2$

$5 \quad$ Crude Oil Quality ................................................................................

$5.1 \quad$ NATIONAL PROFILE .......................................................................... $5-1$

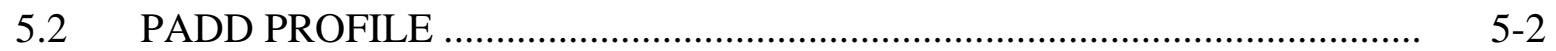

$6 \quad$ Refining Industry Profile ..................................................................................

6.1 NATIONAL PROFILE ............................................................................

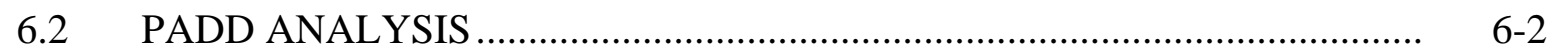

$7 \quad$ Petroleum Trade ........................................................................................

7.1 FOREIGN BASED TRADE ..............................................................

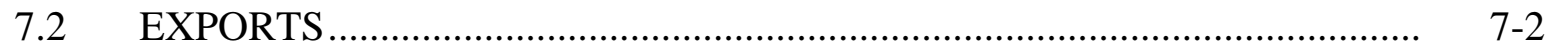

7.3 U.S. PADD TRADE WITH FOREIGN SOURCES......................................... 7-3

$7.4 \quad$ U.S. INTER-PADD TRADE ................................................................

8 Conclusions ................................................................................................

$8.1 \quad 8.1$ PETROLEUM DEMAND ………………………………………….... 8- 8-1

8.2 REFINED PRODUCT PRODUCTION …………………………………..... 8 8-3

8.3 CRUDE OIL QUALITY TRENDS …………………………………….......

8.4 REFINING INDUSTRY PROFILE .............................................................

8.5 PETROLEUM TRADE ………......................................................... 8-9 
2.1 Petroleum Administration for Defense Districts............................................. 2-1

3.1 Geographic Profile Of United States Refined Product Demand.............................. 3-2

3.2 Geographic Profile Of United States Refined Product Demand - 2001 ................... 3-3

3.3 Population Profile Of United States - 2001 ...................................................... 3-3

4.1 Geographic Profile Of United States Refined Product Production............................. 4-3

4.2 Geographic Profile Of United States Refined Product Production - 2001 ................ 4-4

5.1 United States Crude Oil Quality Trends - Gravity............................................. $5-1$

5.2 United States Crude Oil Quality Historical Trends In Sulfur Content ..................... 5 5-2

5.3 Trends in United States Crude Oil Quality - Gravity ............................................ $\quad 5-3$

5.4 Trends in United States Crude Oil Quality - Sulfur.............................................. $5-3$

6.1 Trends In United States Refining ..................................................................

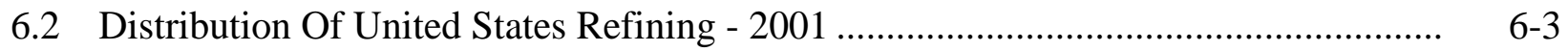

7.1 Import Exposure of The United States Refining Industry - Percent Of Demand........ 7-1

7.2 Import Exposure Of The United States Refining Industry ..................................... $\quad 7-2$

7.3 Product Exports Of The United States Refining Industry ….................................. $\quad 7-3$

7.4 Distribution Of Foreign Sourced Product Imports To The U.S. (Major Products

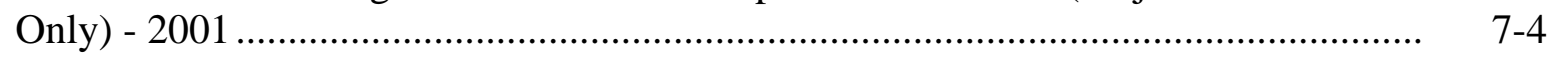

7.5 Distribution of Major Products Received From Other Padds - 2001......................... 7-11

8.1 Geographic Profile Of United States Refined Product Demand - 2001 .................... 8-2

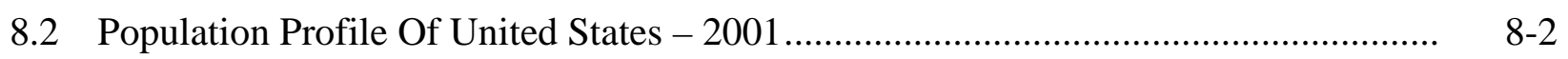

8.3 Geographic Profile Of United States Refined Product Production - 2001 ................. 8-3

8.4 United States Crude Oil Quality Historical Gravity Trends ................................... 8 8-4

8.5 United States Crude Oil Quality Historical Trends In Sulfur Content ....................... 8-5

8.6 Trends In United States Crude Oil Quality - Gravity ............................................ 8-6

8.7 Trends In United States Crude Oil Quality - Sulfur ........................................... 8-6

8.8 Trends In United States Refining ............................................................. $8-7$

8.9 Distribution Of United States Refining - 2001 ................................................... 8-9

8.10 Import Exposure of The United States Refining Industry - Percent Of Demand........ 8-9

8.11 Distribution Of Foreign Sourced Product Imports To The U.S. (Major Products Only) - 2001 
Table

Page

2.1 Nexant Crude Oil Scenarios............................................................................. 2-3

3.1 U.S. Petroleum Product Demand .........................................................................

3.2 PADD 1 Petroleum Product Demand Profile ......................................................... 3-6

3.3 PADD 2 Petroleum Product Demand Profile ...................................................... $3-7$

3.4 PADD 3 Petroleum Product Demand Profile ....................................................... 3-8

3.5 PADD 4 Petroleum Product Demand Profile ........................................................ 3-9

3.6 PADD 5 Petroleum Product Demand Profile ...................................................... 3-10

4.1 U.S. Petroleum Product Production ..........................................................................

4.2 PADD 1 Petroleum Product Production Profile ........................................................ 4-6

4.3 PADD 2 Petroleum Product Production Profile .................................................... 4-7

4.4 PADD 3 Petroleum Product Production Profile ........................................................ 4-8

4.5 PADD 4 Petroleum Product Production Profile ....................................................... 4-9

4.6 PADD 5 Petroleum Product Production Profile .................................................. 4-10

5.1 Trends in United States Crude Oil Quality - Gravity ........................................... 5-4

5.2 Trends In United States Crude Oil Sulfur.........................................................

6.1 Profile of United States Refining Facilities ....................................................... $6-2$

6.2 PADD 1 PROCESS UNIT CAPACITIES, 2001 ................................................. $6-4$

6.3 PADD 2 Process Unit Capacities, 2001 ............................................................... $\quad 6-5$

6.4 PADD 3 Process Unit Capacities, 2001 .............................................................. 6-6

6.5 PADD 4 Process Unit Capacities, 2001 ................................................................. $6-7$

6.6 PADD 5 Refinery Process Unit Capacities, 2001 ..................................................

6.7 California Refinery Process Unit Capacities, 2001 .............................................. 6-8

7.1 Profile of United States Refined Product Import Sources (All Products) - 2001 ....... 7-5

7.2 PADD 1 Petroleum Product Trade - Foreign ..................................................... $7-6$

7.3 PADD 2 Petroleum Product Trade - Foreign ..................................................... $7-7$

7.4 PADD 3 Petroleum Product Trade - Foreign ....................................................... $7-8$

7.5 PADD 4 Petroleum Product Trade - Foreign ...................................................... 
7.6 PADD 5 Petroleum Product Trade - Foreign .............................................................. 7-10

7.7 PADD 1 Petroleum Product Trade : Inter-PADD ..................................................... 7-12

7.8 PADD 2 Petroleum Product Trade : Inter-PADD ........................................................ 7-13

7.9 PADD 3 Petroleum Product Trade : Inter-PADD ......................................................... 7-14

7.10 PADD 4 Petroleum Product Trade : Inter-PADD .................................................... 7-15

7.11 PADD 5 Petroleum Product Trade : INTER-PADD ………………………………..... 7-16

8.1 Profile of United States Refining Facilities ………………………............................ 8-8 
The primary objectives of this report section were to:

- Define historical and forecast profiles of supply, demand and trade for refined petroleum products by major region within the United States. Five (5) regions, based on the Department of Defense Petroleum Administration for Defense Districts (PADD) have been evaluated for this analysis. This regional breakdown is based on, and is consistent with, the national outlook for petroleum fuels markets as presented in Market Report Section I (Conventional Fuels - Market Overview).

- $\quad$ Evaluate historical and forecast trends of crude oil quality by region.

Results of this regional analysis provided key inputs to the technical analysis documented in Market Report Section IIIX (Impact of FT-Diesel on United States Refineries). 


\subsection{REGIONAL DEFINITION}

The five (5) Department of Defense Petroleum Administration for Defense Districts (PADDs) have been evaluated for this analysis, as defined in Figure 2.1.

\section{Petroleum Administration for Defense Districts}

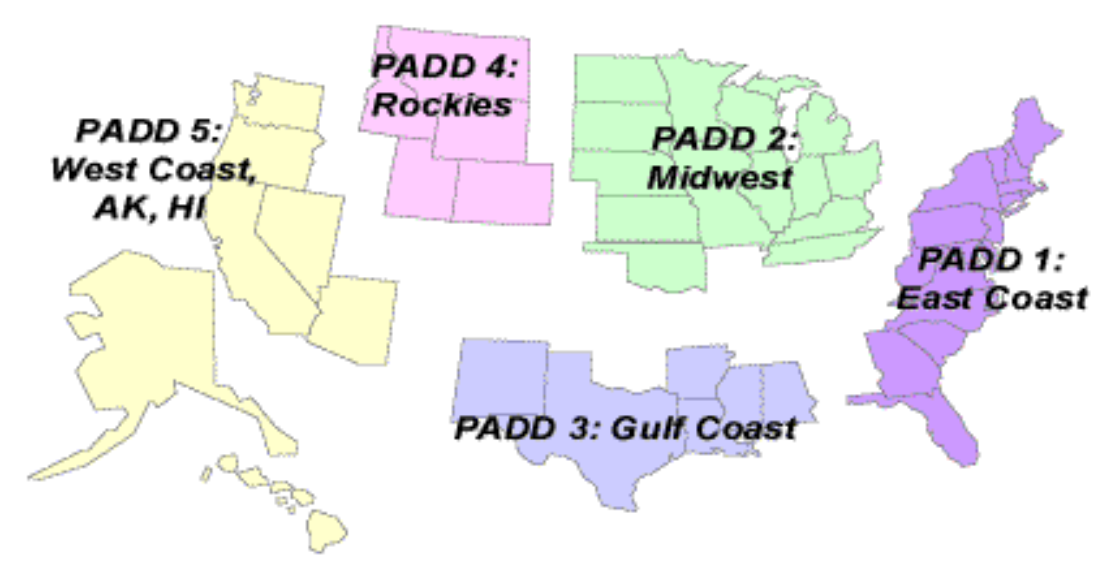

Figure 2.1 Petroleum Administration for Defense Districts

States within each PADD are defined as follows:

- PAD District 1 (East Coast):

- $\quad$ New England: Connecticut, Maine, Massachusetts, New Hampshire, Rhode Island, Vermont

- Central Atlantic: Delaware, District of Columbia, Maryland, New Jersey, New York, Pennsylvania

- Lower Atlantic: Florida, Georgia, North Carolina, South Carolina, Virginia, West Virginia

- PAD District 2 (Midwest): Illinois, Indiana, Iowa, Kansas, Kentucky, Michigan, Minnesota, Missouri, Nebraska, North Dakota, South Dakota, Ohio, Oklahoma, Tennessee, Wisconsin

- $\quad$ PAD District 3 (Gulf Coast): Alabama, Arkansas, Louisiana, Mississippi, New Mexico, Texas

- $\quad$ PAD District 4 (Rocky Mountain): Colorado Idaho, Montana, Utah, Wyoming 
- PAD District 5 (West Coast): Alaska, Arizona, California, Hawaii, Nevada, Oregon, Washington

\subsection{BASIC ASSUMPTIONS}

Basic assumptions employed in this regional analysis have been defined in Market Report Section I, "Conventional Fuels - Market Overview". These include the following:

- Economic growth prospects, which for the United States include trendline real growth in GDP of $2.9 \%$ per year, and trendline inflation (as measured by the GDP deflator) of 2.5 percent per year

- Crude oil price projections. Nexant's envelope of prices (all in constant 2001 dollars) for FOB Brent crude oil is:

- $\quad$ a "High Oil" case at \$22.0 per barrel in 2003, declining to \$20.5 in 2015

- $\quad$ a "Medium Oil" case at $\$ 18.0$ per barrel in 2003, declining to $\$ 16.8$ in 2015

- $\quad$ a "Low Oil" case at $\$ 14.0$ per barrel in 2003, declining to $\$ 13.0$ per barrel in 2015

After 2003, crude oil prices are projected to decline at 1.0 percent per year in real terms until 2010, after which prices are forecast to stabilize in real terms. This decline in price reflects trends in other commodities, which continue to show reductions in real prices due to continuing gains in production efficiency. Stabilization of real prices after 2010 reflects the increased potential for a tightening of petroleum availability on a global basis by that time. Absolute prices are presented in Table 2.1. 


\section{Table 2.1 Nexant Crude Oil Scenarios In Current and Constant 2001 Dollars}

\begin{tabular}{|c|c|c|c|c|c|c|c|c|c|}
\hline & Dub & ai, FOB Fa & teh & \multicolumn{3}{|c|}{ Brent, FOB Sullom Voe } & \multicolumn{3}{|c|}{ WTI, FOB Cushing } \\
\hline & \multicolumn{9}{|c|}{ Current US\$ per barrel } \\
\hline & Low & Medium & High & Low & Medium & High & Low & Medium & High \\
\hline 2003 & 13.1 & 17.3 & 21.4 & 14.6 & 18.8 & 22.9 & 16.4 & 20.6 & 24.8 \\
\hline 2004 & 13.3 & 17.5 & 21.7 & 14.8 & 19.0 & 23.3 & 16.7 & 20.9 & 25.1 \\
\hline 2005 & 13.5 & 17.8 & 22.1 & 15.0 & 19.3 & 23.6 & 16.9 & 21.2 & 25.5 \\
\hline 2010 & 14.5 & 19.1 & 23.7 & 16.2 & 20.8 & 25.4 & 18.2 & 22.8 & 27.4 \\
\hline \multirow[t]{3}{*}{2015} & 16.4 & 21.6 & 26.9 & 18.3 & 23.5 & 28.7 & 20.5 & 25.8 & 31.0 \\
\hline & \multicolumn{9}{|c|}{ Constant US\$2001 per barrel } \\
\hline & Low & Medium & High & Low & Medium & High & Low & Medium & High \\
\hline 2003 & 12.6 & 16.6 & 20.6 & 14.0 & 18.0 & 22.0 & 15.8 & 19.8 & 23.8 \\
\hline 2004 & 12.4 & 16.4 & 20.3 & 13.9 & 17.8 & 21.8 & 15.6 & 19.6 & 23.5 \\
\hline 2005 & 12.3 & 16.2 & 20.1 & 13.7 & 17.6 & 21.6 & 15.4 & 19.3 & 23.3 \\
\hline 2010 & 11.7 & 15.4 & 19.2 & 13.0 & 16.8 & 20.5 & 14.6 & 18.4 & 22.1 \\
\hline 2015 & 11.7 & 15.4 & 19.2 & 13.0 & 16.8 & 20.5 & 14.6 & 18.4 & 22.1 \\
\hline
\end{tabular}




\section{NATIONAL OUTLOOK}

Included in Market Report Section I are projections for total demand for major refined products in the United States over the next 15 years. The resulting forecast by major product group is presented in Table 3.1.

Table $3.1 \quad$ U.S. Petroleum Product Demand Thousand Barrels Per Day

\begin{tabular}{|c|c|c|c|c|c|c|c|}
\hline & Gasoline & $\begin{array}{l}\text { Jet } \\
\text { Fuel }\end{array}$ & Distillate & $\begin{array}{l}\text { Residual } \\
\text { Fuel }\end{array}$ & $\begin{array}{l}\text { Total } \\
\text { Major } \\
\text { Products }\end{array}$ & $\begin{array}{l}\text { Total } \\
\text { "Other" }\end{array}$ & $\begin{array}{c}\text { Grand } \\
\text { Total }\end{array}$ \\
\hline 1990 & 7,235 & 1,522 & 3,021 & 1,229 & 13,007 & 3,981 & 16,988 \\
\hline 1995 & 7,789 & 1,514 & 3,207 & 852 & 13,362 & 4,363 & 17,725 \\
\hline 1999 & 8,431 & 1,673 & 3,572 & 830 & 14,506 & 5,013 & 19,519 \\
\hline 2000 & 8,472 & 1,725 & 3,722 & 909 & 14,828 & 4,873 & 19,701 \\
\hline 2001 & 8,591 & 1,657 & 3,835 & 936 & 15,019 & 4,644 & 19,663 \\
\hline 2006 & 9,020 & 1,721 & 4,063 & 922 & 15,726 & 4,941 & 20,667 \\
\hline 2010 & 9,424 & 1,784 & 4,281 & 904 & 16,392 & 5,245 & 21,636 \\
\hline 2015 & 9,953 & 1,865 & 4,567 & 881 & 17,267 & 5,650 & 22,917 \\
\hline \multicolumn{8}{|c|}{ Annual Growth Rates } \\
\hline 1990-2001 & $1.6 \%$ & $0.8 \%$ & $2.2 \%$ & $-2.4 \%$ & $1.3 \%$ & $1.4 \%$ & $1.3 \%$ \\
\hline 1996-2001 & $1.7 \%$ & $1.0 \%$ & $2.6 \%$ & $2.0 \%$ & $1.9 \%$ & $0.1 \%$ & $1.4 \%$ \\
\hline 2001-2015 & $1.1 \%$ & $0.8 \%$ & $1.3 \%$ & $-0.4 \%$ & $1.0 \%$ & $1.4 \%$ & $1.1 \%$ \\
\hline
\end{tabular}

M:IENERGY1999PROJ12325anni1999|Bal99i.123

Key drivers and assumptions behind these demand projections include:

- Total U.S. refined product demand is forecast to increase by 1.1 percent annually over the 2001-2015 period. This is somewhat lower than the 10 year historical average of 1.3 percent, and reflects the somewhat lower outlook for economic growth as well as potentially higher pricing of crude oil and products that is expected for the forecast period

- High gasoline demand growth during the 1990s was driven by a number of "step-change" factors, including the rapid growth in lower mileage Sport Utility Vehicles (SUVs) and the very strong economic expansion experienced in the United States during this period. The projected growth rate in gasoline demand of 1.1 percent annually assumes that there will be a modest increase in average vehicle fleet efficiency, but that alternativelypowered vehicles will not materially impact gasoline demand during the next 10 years 
- Jet fuel consumption is expected to grow 0.8 percent per year, reflecting expected continuing gains in engine efficiency in the commercial air fleet as well as a negative step-change in use that has occurred due to the impact of September 11 attacks

- Limited growth in off-highway uses of middle distillates, in particular due to continued loss of the residential heating market to natural gas, will offset continued growth in onhighway diesel fuel. Combined growth in on-highway and off-highway uses is expected to average 1.3 percent annually

- $\quad$ Residual fuel oil use, after suffering a step-change reduction in demand between 1994 and 1995, has achieved demand in the 850-950 thousand barrels per day (KBPD) range through 2001. Future consumption is forecast to decline about 0.4 percent annually

- "Other products" consists of a wide range of relatively minor products, including gas liquids (ethane, propane, normal and iso-butane, and pentanes plus), asphalt, chemical feedstocks, petroleum coke, lubricants, waxes, kerosene and miscellaneous products. A number of these products, such as lubricants, and waxes, are very mature with limited growth potential. Others, in particular feedstock for chemical production, are expected to have high growth rates. On balance, this category of products is expected in grow about 1.4 percent annually, somewhat higher than overall petroleum demand growth

\subsection{DEMAND OUTLOOK BY PADD REGION}

Nexant evaluated the historical patterns of regional petroleum use for the period 1990-2001. As shown in Figure 3.1, the geographic distribution of demand has been relatively stable between the PADD regions over this period.

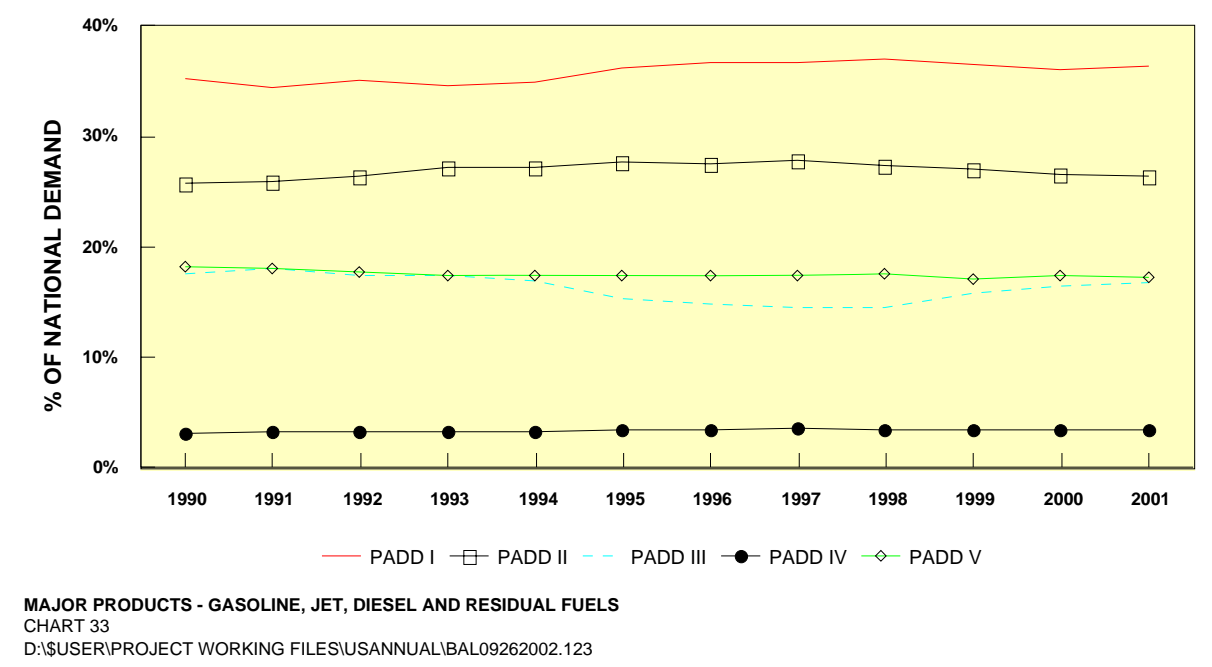

Figure 3.1 Geographic Profile Of United States Refined Product Demand 
The current profile of geographic consumption by PADD for 2001 is shown in Figure 3.2. As shown, PADD 1 has the highest level of petroleum consumption, with about 36 percent of the national total. This is followed by PADD 2 with about 27 percent, and PADDs 3 and 5, each with about 16-17 percent. PADD 4, reflecting its very sparse population, accounts for about 3.5 percent of national demand. As indicated in Figure 3.3, this distribution of demand is very similar to the distribution of population within the United States, indicating a similar level of per capita consumption across the nation.

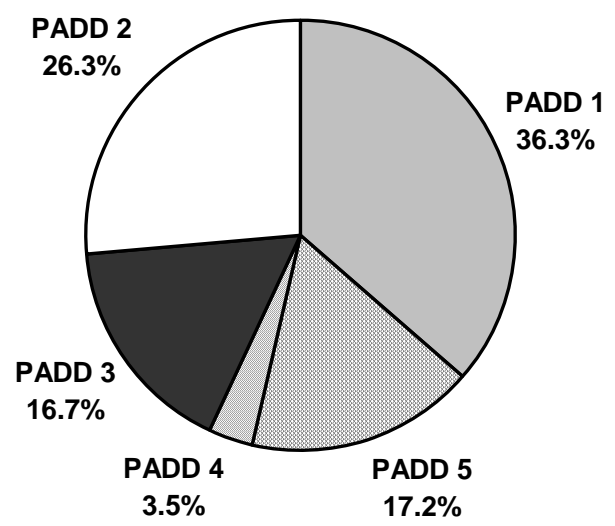

U:|2002Q4100072.005.11|DatalExcel files|[figures for report 4.xIs]GRAPHS

Figure 3.2 Geographic Profile Of United States Refined Product Demand - 2001

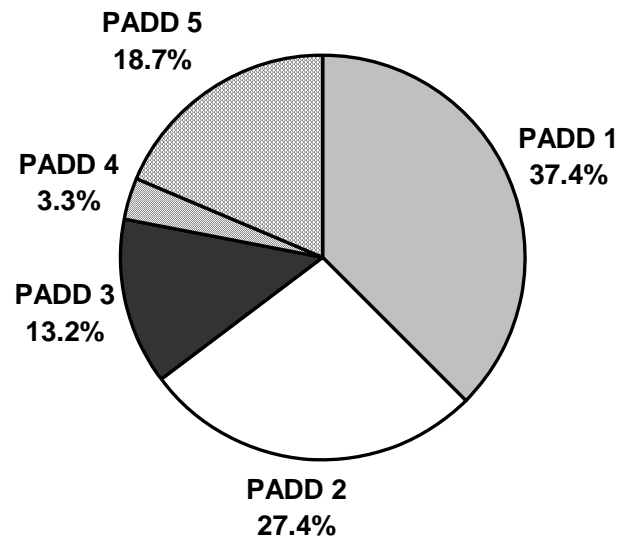

U:I2002Q4100072.005.11IDatalExcel files|[figures for report 4.xIs]GRAPHS

Figure 3.3 Population Profile Of United States - 2001 
Future distribution of demand for refined petroleum products in the United States is expected to remain relatively stable, similar to historical performance. Detailed historical and forecast consumption by key refined product is presented in Table 3.2 to Table 3.6 for PADDs 1-5 respectively. Defining characteristics for each PADD include:

\section{- $\quad$ PADD 1}

- Consumption of major petroleum products is expected to increase somewhat faster than national averages, in line with trends over the last decade. By 2015 consumption will equal about 36.5 percent of national totals, up from 35.8 percent in 2001.

- The mix of products consumed is similar to the national averages. Gasoline demand is a somewhat smaller portion of the mix, and residual fuel consumption is somewhat larger

\section{- $\quad$ PADD 2}

- $\quad$ Consumption of major petroleum products is expected to grow approximately 1.2 percent per year over the study period, somewhat faster than the national average. Consumption in 2015 will equal about 28.3 percent of national totals, up from 27.7 percent in 2001

- $\quad$ The mix of products consumed has a number of significant differences from the national averages. Gasoline and distillate (diesel and home heating oils) demand are higher than the national mix, and jet fuel and residual fuel consumption is significantly lower

- $\quad$ PADD 3

- $\quad$ Consumption of major petroleum products is expected to grow approximately 0.6 percent per year over the study period, somewhat slower than the national average. Consumption in 2015 will equal about 15.0 percent of national totals, down slightly from 15.7 percent in 2001

- $\quad$ The mix of products consumed has a number of significant differences from the national averages. Gasoline and jet fuel demand are both lower than the national mix, and distillates and residual fuel consumption are both higher

- $\quad$ PADD 4

Consumption of major petroleum products is expected to grow approximately 1.3 percent per year over the study period, somewhat higher than the national average. Consumption in 2015 will equal about 3.7 percent of national totals, about the same as in 2001 
- $\quad$ The mix of products consumed has a number of significant differences from the national averages. Distillate demand is significantly higher than the national mix, and gasoline, jet fuel and residual fuel consumption are all lower

\section{- $\quad$ PADD 5}

- $\quad$ Consumption of major petroleum products is expected to grow approximately 0.8 percent per year over the study period, somewhat lower than the national average. Consumption in 2015 will equal about 16.6 percent of national totals, down slightly from 17.2 percent in 2001

- $\quad$ The mix of products consumed has a number of significant differences from the national averages. In particular, consumption of jet fuel is significantly higher than the national mix, and distillates are significantly lower 


\begin{tabular}{|c|c|c|c|c|c|c|}
\hline \multicolumn{2}{|c|}{ Table 3.2} & \multicolumn{5}{|c|}{$\begin{array}{l}\text { PADD } 1 \text { Petroleum Product Demand Profile } \\
\text { (THOUSAND BARRELS PER DAY) }\end{array}$} \\
\hline & Gasoline & Jet & Distillates & Resid & $\begin{array}{r}\text { Total } \\
\text { Major } \\
\text { Products }\end{array}$ & $\begin{array}{r}\text { Total } \\
\text { Clean } \\
\text { Products }\end{array}$ \\
\hline 1990 & 2,399 & 515 & 1,093 & 582 & 4,589 & 4,007 \\
\hline 1995 & 2,684 & 564 & 1,211 & 374 & 4,833 & 4,459 \\
\hline 1999 & 3,030 & 607 & 1,319 & 345 & 5,301 & 4,956 \\
\hline 2000 & 2,987 & 592 & 1,360 & 405 & 5,344 & 4,939 \\
\hline 2001 & 3,043 & 592 & 1,409 & 412 & 5,456 & 5,044 \\
\hline 2006 & 3,218 & 617 & 1,503 & 406 & 5,743 & 5,337 \\
\hline 2015 & 3,595 & 673 & 1,710 & 388 & 6,366 & 5,978 \\
\hline \multicolumn{7}{|c|}{ Annual Change } \\
\hline 1990-2001 & $2.2 \%$ & $1.3 \%$ & $2.3 \%$ & $-3.1 \%$ & $1.6 \%$ & $2.1 \%$ \\
\hline 2001-2015 & $1.2 \%$ & $0.9 \%$ & $1.4 \%$ & $-0.4 \%$ & $1.1 \%$ & $1.2 \%$ \\
\hline \multicolumn{7}{|c|}{ Percent of PADD Totals } \\
\hline & Gasoline & Jet & Distillates & Resid & $\begin{array}{r}\text { Total } \\
\text { Major } \\
\text { Products }\end{array}$ & $\begin{array}{r}\text { Total } \\
\text { Clean } \\
\text { Products }\end{array}$ \\
\hline 1990 & $52.3 \%$ & $11.2 \%$ & $23.8 \%$ & $12.7 \%$ & $100.0 \%$ & $87.3 \%$ \\
\hline 1995 & $55.5 \%$ & $11.7 \%$ & $25.1 \%$ & $7.7 \%$ & $100.0 \%$ & $92.3 \%$ \\
\hline 1999 & $57.2 \%$ & $11.5 \%$ & $24.9 \%$ & $6.5 \%$ & $100.0 \%$ & $93.5 \%$ \\
\hline 2000 & $55.9 \%$ & $11.1 \%$ & $25.4 \%$ & $7.6 \%$ & $100.0 \%$ & $92.4 \%$ \\
\hline 2001 & $55.8 \%$ & $10.9 \%$ & $25.8 \%$ & $7.6 \%$ & $100.0 \%$ & $92.4 \%$ \\
\hline 2006 & $56.0 \%$ & $10.7 \%$ & $26.2 \%$ & $7.1 \%$ & $100.0 \%$ & $92.9 \%$ \\
\hline 2015 & $56.5 \%$ & $10.6 \%$ & $26.9 \%$ & $6.1 \%$ & $100.0 \%$ & $93.9 \%$ \\
\hline \multicolumn{7}{|c|}{ Averages for period } \\
\hline 1990-2001 & $55.1 \%$ & $11.3 \%$ & $24.8 \%$ & $8.8 \%$ & $100.0 \%$ & $91.2 \%$ \\
\hline 2001-2015 & $56.1 \%$ & $10.7 \%$ & $26.3 \%$ & $6.9 \%$ & $100.0 \%$ & $93.1 \%$ \\
\hline \multicolumn{7}{|c|}{ Percent of National Totals } \\
\hline & Gasoline & Jet & Distillates & Resid & $\begin{array}{r}\text { Total } \\
\text { Major } \\
\text { Products }\end{array}$ & $\begin{array}{r}\text { Total } \\
\text { Clean } \\
\text { Products }\end{array}$ \\
\hline 1990 & $33.2 \%$ & $33.8 \%$ & $36.2 \%$ & $47.4 \%$ & $35.3 \%$ & $34.0 \%$ \\
\hline 1995 & $34.5 \%$ & $37.2 \%$ & $37.8 \%$ & $43.9 \%$ & $36.2 \%$ & $35.6 \%$ \\
\hline 1999 & $35.9 \%$ & $36.3 \%$ & $36.9 \%$ & $41.4 \%$ & $36.5 \%$ & $36.2 \%$ \\
\hline 2000 & $35.3 \%$ & $34.3 \%$ & $36.5 \%$ & $44.6 \%$ & $36.0 \%$ & $35.5 \%$ \\
\hline 2001 & $35.4 \%$ & $35.5 \%$ & $36.7 \%$ & $43.3 \%$ & $36.3 \%$ & $35.8 \%$ \\
\hline 2006 & $35.7 \%$ & $35.6 \%$ & $36.9 \%$ & $43.3 \%$ & $36.5 \%$ & $36.0 \%$ \\
\hline 2015 & $36.2 \%$ & $35.9 \%$ & $37.4 \%$ & $43.3 \%$ & $36.8 \%$ & $36.5 \%$ \\
\hline \multicolumn{7}{|c|}{ Averages for period } \\
\hline 1990-2001 & $34.4 \%$ & $35.3 \%$ & $36.9 \%$ & $43.9 \%$ & $35.8 \%$ & $35.2 \%$ \\
\hline $2001-2015$ & $35.8 \%$ & $35.7 \%$ & $37.0 \%$ & $43.3 \%$ & $36.5 \%$ & $36.1 \%$ \\
\hline
\end{tabular}


Table 3.3 PADD 2 Petroleum Product Demand Profile (THOUSAND BARRELS PER DAY)

\begin{tabular}{|c|c|c|c|c|c|c|}
\hline & & (1) & - & - & & \\
\hline & Gasoline & Jet & Distillates & Resid & $\begin{array}{r}\text { Total } \\
\text { Major } \\
\text { Products }\end{array}$ & $\begin{array}{r}\text { Total } \\
\text { Clean } \\
\text { Products }\end{array}$ \\
\hline 1990 & 2,159 & 278 & 868 & 57 & 3,362 & 3,305 \\
\hline 1995 & 2,352 & 301 & 994 & 50 & 3,697 & 3,647 \\
\hline 1999 & 2,434 & 356 & 1,080 & 48 & 3,918 & 3,870 \\
\hline 2000 & 2,437 & 360 & 1,100 & 49 & 3,946 & 3,897 \\
\hline 2001 & 2,442 & 339 & 1,117 & 60 & 3,958 & 3,898 \\
\hline 2006 & 2,587 & 354 & 1,188 & 60 & 4,189 & 4,129 \\
\hline 2015 & 2,899 & 388 & 1,346 & 60 & 4,693 & 4,633 \\
\hline \multicolumn{7}{|c|}{ Annual Change } \\
\hline 2001 & $1.1 \%$ & $1.8 \%$ & $2.3 \%$ & $0.5 \%$ & $1.5 \%$ & $1.5 \%$ \\
\hline 2015 & $1.2 \%$ & $1.0 \%$ & $1.3 \%$ & $-0.1 \%$ & $1.2 \%$ & $1.2 \%$ \\
\hline
\end{tabular}

$1990-2001$
$2001-2015$

\section{1-2015}

1990
1995
1999
2000
2001
2006
2015

1990-2001

2001-2015

\section{Percent of PADD Totals}

$63.1 \%$
$61.7 \%$
Gasoline

$\begin{array}{lll}64.2 \% & 8.3 \% & 25.8 \% \\ 63.6 \% & 8.1 \% & 26.9 \% \\ 62.1 \% & 9.1 \% & 27.6 \% \\ 61.8 \% & 9.1 \% & 27.9 \% \\ 61.7 \% & 8.6 \% & 28.2 \% \\ 61.7 \% & 8.5 \% & 28.4 \% \\ 61.8 \% & 8.3 \% & 28.7 \%\end{array}$

\section{Averages for period}

$\begin{array}{lllll}8.5 \% & 26.9 \% & 1.5 \% & 100.0 \% & 98.5 \% \\ 8.4 \% & 28.4 \% & 1.4 \% & 100.0 \% & 98.6 \%\end{array}$

$\begin{array}{rr}\text { Total } & \text { Total } \\ \text { Major } & \text { Clean } \\ \text { Products } & \text { Products }\end{array}$

$\begin{array}{lll}1.7 \% & 100.0 \% & 98.3 \% \\ 1.4 \% & 100.0 \% & 98.6 \% \\ 1.2 \% & 100.0 \% & 98.8 \% \\ 1.2 \% & 100.0 \% & 98.8 \% \\ 1.5 \% & 100.0 \% & 98.5 \% \\ 1.4 \% & 100.0 \% & 98.6 \% \\ 1.3 \% & 100.0 \% & 98.7 \%\end{array}$

$1.4 \%$

\section{Percent of National Totals}

\begin{tabular}{|c|c|c|c|c|c|c|}
\hline & Gasoline & Jet & Distillates & Resid & $\begin{array}{r}\text { Total } \\
\text { Major } \\
\text { Products }\end{array}$ & $\begin{array}{r}\text { Total } \\
\text { Clean } \\
\text { Products }\end{array}$ \\
\hline 1990 & $29.8 \%$ & $18.3 \%$ & $28.7 \%$ & $4.6 \%$ & $25.8 \%$ & $28.1 \%$ \\
\hline 1995 & $30.2 \%$ & $19.9 \%$ & $31.0 \%$ & $5.9 \%$ & $27.7 \%$ & $29.1 \%$ \\
\hline 1999 & $28.9 \%$ & $21.3 \%$ & $30.2 \%$ & $5.8 \%$ & $27.0 \%$ & $28.3 \%$ \\
\hline 2000 & $28.8 \%$ & $20.9 \%$ & $29.6 \%$ & $5.4 \%$ & $26.6 \%$ & $28.0 \%$ \\
\hline 2001 & $28.4 \%$ & $20.3 \%$ & $29.1 \%$ & $6.3 \%$ & $26.3 \%$ & $27.7 \%$ \\
\hline 2006 & $28.7 \%$ & $20.5 \%$ & $29.2 \%$ & $6.4 \%$ & $26.6 \%$ & $27.9 \%$ \\
\hline 2015 & $29.1 \%$ & $20.7 \%$ & $29.4 \%$ & $6.7 \%$ & $27.1 \%$ & $28.3 \%$ \\
\hline \multicolumn{7}{|c|}{ Averages for period } \\
\hline 1990-2001 & $29.7 \%$ & $19.9 \%$ & $30.0 \%$ & $5.7 \%$ & $26.9 \%$ & $28.6 \%$ \\
\hline 2001-2015 & $28.8 \%$ & $20.5 \%$ & $29.2 \%$ & $6.5 \%$ & $26.7 \%$ & $27.9 \%$ \\
\hline
\end{tabular}


Table 3.4 PADD 3 Petroleum Product Demand Profile (THOUSAND BARRELS PER DAY)

\begin{tabular}{|c|c|c|c|c|c|c|}
\hline & & & & & & \\
\hline & Gasoline & Jet & Distillates & Resid & $\begin{array}{r}\text { Total } \\
\text { Major } \\
\text { Products }\end{array}$ & $\begin{array}{r}\text { Total } \\
\text { Clean } \\
\text { Products }\end{array}$ \\
\hline 1990 & 1,187 & 258 & 511 & 330 & 2,286 & 1,956 \\
\hline 1995 & 1,164 & 175 & 476 & 239 & 2,054 & 1,815 \\
\hline 1999 & 1,256 & 187 & 593 & 251 & 2,287 & 2,036 \\
\hline 2000 & 1,291 & 203 & 648 & 290 & 2,432 & 2,142 \\
\hline 2001 & 1,338 & 179 & 699 & 302 & 2,518 & 2,216 \\
\hline 2006 & 1,382 & 182 & 725 & 295 & 2,584 & 2,289 \\
\hline 2015 & 1,481 & 188 & 784 & 278 & 2,732 & 2,453 \\
\hline \multicolumn{7}{|c|}{ Annual Change } \\
\hline 1990-2001 & $1.1 \%$ & $-3.3 \%$ & $2.9 \%$ & $-0.8 \%$ & $0.9 \%$ & $1.1 \%$ \\
\hline 2001-2015 & $0.7 \%$ & $0.4 \%$ & $0.8 \%$ & $-0.6 \%$ & $0.6 \%$ & $0.7 \%$ \\
\hline \multicolumn{7}{|c|}{ Percent of PADD Totals } \\
\hline & Gasoline & Jet & Distillates & Resid & $\begin{array}{r}\text { Total } \\
\text { Major } \\
\text { Products }\end{array}$ & $\begin{array}{r}\text { Total } \\
\text { Clean } \\
\text { Products }\end{array}$ \\
\hline 1990 & $51.9 \%$ & $11.3 \%$ & $22.4 \%$ & $14.4 \%$ & $100.0 \%$ & $85.6 \%$ \\
\hline 1995 & $56.7 \%$ & $8.5 \%$ & $23.2 \%$ & $11.6 \%$ & $100.0 \%$ & $88.4 \%$ \\
\hline 1999 & $54.9 \%$ & $8.2 \%$ & $25.9 \%$ & $11.0 \%$ & $100.0 \%$ & $89.0 \%$ \\
\hline 2000 & $53.1 \%$ & $8.3 \%$ & $26.6 \%$ & $11.9 \%$ & $100.0 \%$ & $88.1 \%$ \\
\hline 2001 & $53.1 \%$ & $7.1 \%$ & $27.8 \%$ & $12.0 \%$ & $100.0 \%$ & $88.0 \%$ \\
\hline 2006 & $53.5 \%$ & $7.0 \%$ & $28.1 \%$ & $11.4 \%$ & $100.0 \%$ & $88.6 \%$ \\
\hline 2015 & $54.2 \%$ & $6.9 \%$ & $28.7 \%$ & $10.2 \%$ & $100.0 \%$ & $89.8 \%$ \\
\hline \multicolumn{7}{|c|}{ Averages for period } \\
\hline 1990-2001 & $53.6 \%$ & $9.2 \%$ & $24.5 \%$ & $12.7 \%$ & $100.0 \%$ & $87.3 \%$ \\
\hline 2001-2015 & $53.6 \%$ & $7.0 \%$ & $28.2 \%$ & $11.2 \%$ & $100.0 \%$ & $88.8 \%$ \\
\hline \multicolumn{7}{|c|}{ Percent of National Totals } \\
\hline & Gasoline & Jet & Distillates & Resid & $\begin{array}{r}\text { Total } \\
\text { Major } \\
\text { Products }\end{array}$ & $\begin{array}{r}\text { Total } \\
\text { Clean } \\
\text { Products }\end{array}$ \\
\hline 1990 & $16.4 \%$ & $16.9 \%$ & $16.9 \%$ & $26.9 \%$ & $17.6 \%$ & $16.6 \%$ \\
\hline 1995 & $14.9 \%$ & $11.5 \%$ & $14.8 \%$ & $28.0 \%$ & $15.4 \%$ & $14.5 \%$ \\
\hline 1999 & $14.9 \%$ & $11.2 \%$ & $16.6 \%$ & $30.1 \%$ & $15.8 \%$ & $14.9 \%$ \\
\hline 2000 & $15.2 \%$ & $11.8 \%$ & $17.4 \%$ & $31.9 \%$ & $16.4 \%$ & $15.4 \%$ \\
\hline 2001 & $15.6 \%$ & $10.7 \%$ & $18.2 \%$ & $31.8 \%$ & $16.7 \%$ & $15.7 \%$ \\
\hline 2006 & $15.3 \%$ & $10.5 \%$ & $17.8 \%$ & $31.5 \%$ & $16.4 \%$ & $15.5 \%$ \\
\hline 2015 & $14.9 \%$ & $10.0 \%$ & $17.2 \%$ & $31.1 \%$ & $15.8 \%$ & $15.0 \%$ \\
\hline \multicolumn{7}{|c|}{ Averages for period } \\
\hline 1990-2001 & $15.2 \%$ & $13.3 \%$ & $16.5 \%$ & $29.3 \%$ & $16.3 \%$ & $15.3 \%$ \\
\hline 2001-2015 & $15.3 \%$ & $10.4 \%$ & $17.7 \%$ & $31.4 \%$ & $16.3 \%$ & $15.4 \%$ \\
\hline
\end{tabular}


Table 3.5 PADD 4 Petroleum Product Demand Profile (THOUSAND BARRELS PER DAY)

\begin{tabular}{|c|c|c|c|c|c|c|}
\hline & & 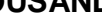 & & & & \\
\hline & Gasoline & Jet & Distillates & Resid & $\begin{array}{r}\text { Total } \\
\text { Major } \\
\text { Products }\end{array}$ & $\begin{array}{r}\text { Total } \\
\text { Clean } \\
\text { Products }\end{array}$ \\
\hline 1990 & 225 & 49 & 115 & 10 & 399 & 389 \\
\hline 1995 & 250 & 59 & 140 & 10 & 459 & 449 \\
\hline 1999 & 272 & 62 & 165 & 12 & 511 & 499 \\
\hline 2000 & 275 & 67 & 172 & 10 & 524 & 514 \\
\hline 2001 & 273 & 68 & 167 & 11 & 519 & 508 \\
\hline 2006 & 287 & 71 & 182 & 11 & 550 & 539 \\
\hline 2015 & 316 & 77 & 215 & 10 & 618 & 608 \\
\hline \multicolumn{7}{|c|}{ Annual Change } \\
\hline 001 & $1.8 \%$ & $3.0 \%$ & $3.4 \%$ & $0.9 \%$ & $2.4 \%$ & $2.5 \%$ \\
\hline 015 & $1.1 \%$ & $0.8 \%$ & $1.8 \%$ & $-0.4 \%$ & $1.3 \%$ & $1.3 \%$ \\
\hline
\end{tabular}

$1990-2001$
$2001-2015$

$1.1 \%$

Percent of PADD Totals

\begin{tabular}{|c|c|c|c|c|c|c|}
\hline & Gasoline & Jet & Distillates & Resid & $\begin{array}{r}\text { Total } \\
\text { Major } \\
\text { Products }\end{array}$ & $\begin{array}{r}\text { Total } \\
\text { Clean } \\
\text { Products }\end{array}$ \\
\hline 1990 & $56.4 \%$ & $12.3 \%$ & $28.8 \%$ & $2.5 \%$ & $100.0 \%$ & $97.5 \%$ \\
\hline 1995 & $54.5 \%$ & $12.9 \%$ & $30.5 \%$ & $2.2 \%$ & $100.0 \%$ & $97.8 \%$ \\
\hline 1999 & $53.2 \%$ & $12.1 \%$ & $32.3 \%$ & $2.3 \%$ & $100.0 \%$ & $97.7 \%$ \\
\hline 2000 & $52.5 \%$ & $12.8 \%$ & $32.8 \%$ & $1.9 \%$ & $100.0 \%$ & $98.1 \%$ \\
\hline 2001 & $52.6 \%$ & $13.1 \%$ & $32.2 \%$ & $2.1 \%$ & $100.0 \%$ & $97.9 \%$ \\
\hline 2006 & $52.1 \%$ & $12.8 \%$ & $33.1 \%$ & $2.0 \%$ & $100.0 \%$ & $98.0 \%$ \\
\hline 2015 & $51.2 \%$ & $12.4 \%$ & $34.8 \%$ & $1.7 \%$ & $100.0 \%$ & $98.3 \%$ \\
\hline \multicolumn{7}{|c|}{ Averages for period } \\
\hline 1990-2001 & $54.7 \%$ & $12.0 \%$ & $30.9 \%$ & $2.4 \%$ & $100.0 \%$ & $97.6 \%$ \\
\hline 2001-2015 & $52.0 \%$ & $12.8 \%$ & $33.3 \%$ & $1.9 \%$ & $100.0 \%$ & $98.1 \%$ \\
\hline \multicolumn{7}{|c|}{ Percent of National Totals } \\
\hline & Gasoline & Jet & Distillates & Resid & $\begin{array}{r}\text { Total } \\
\text { Major } \\
\text { Products }\end{array}$ & $\begin{array}{r}\text { Total } \\
\text { Clean } \\
\text { Products }\end{array}$ \\
\hline 1990 & $3.1 \%$ & $3.2 \%$ & $3.8 \%$ & $0.8 \%$ & $3.1 \%$ & $3.3 \%$ \\
\hline 1995 & $3.2 \%$ & $3.9 \%$ & $4.4 \%$ & $1.2 \%$ & $3.4 \%$ & $3.6 \%$ \\
\hline 1999 & $3.2 \%$ & $3.7 \%$ & $4.6 \%$ & $1.4 \%$ & $3.5 \%$ & $3.6 \%$ \\
\hline 2000 & $3.2 \%$ & $3.9 \%$ & $4.6 \%$ & $1.1 \%$ & $3.5 \%$ & $3.7 \%$ \\
\hline 2001 & $3.2 \%$ & $4.1 \%$ & $4.3 \%$ & $1.2 \%$ & $3.5 \%$ & $3.6 \%$ \\
\hline 2006 & $3.2 \%$ & $4.1 \%$ & $4.5 \%$ & $1.2 \%$ & $3.5 \%$ & $3.6 \%$ \\
\hline 2015 & $3.2 \%$ & $4.1 \%$ & $4.7 \%$ & $1.2 \%$ & $3.6 \%$ & $3.7 \%$ \\
\hline \multicolumn{7}{|c|}{ Averages for period } \\
\hline 1990-2001 & $3.2 \%$ & $3.6 \%$ & $4.3 \%$ & $1.2 \%$ & $3.4 \%$ & $3.6 \%$ \\
\hline 2001-2015 & $3.2 \%$ & $4.1 \%$ & $4.5 \%$ & $1.2 \%$ & $3.5 \%$ & $3.7 \%$ \\
\hline
\end{tabular}




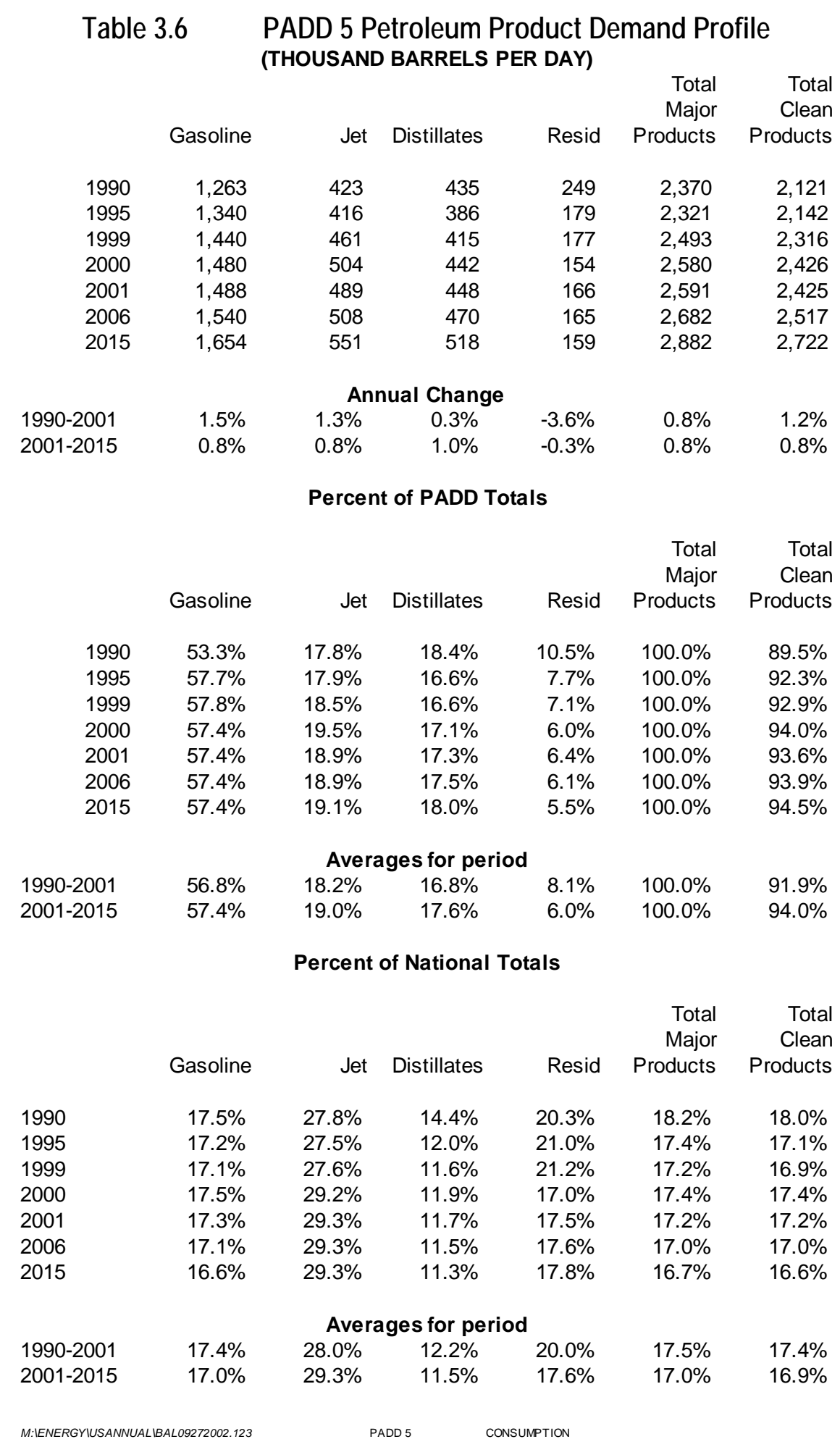




\subsection{NATIONAL OUTLOOK}

Projections for total production for major refined products in the United States over the next 15 years are presented in Table 4.1 .

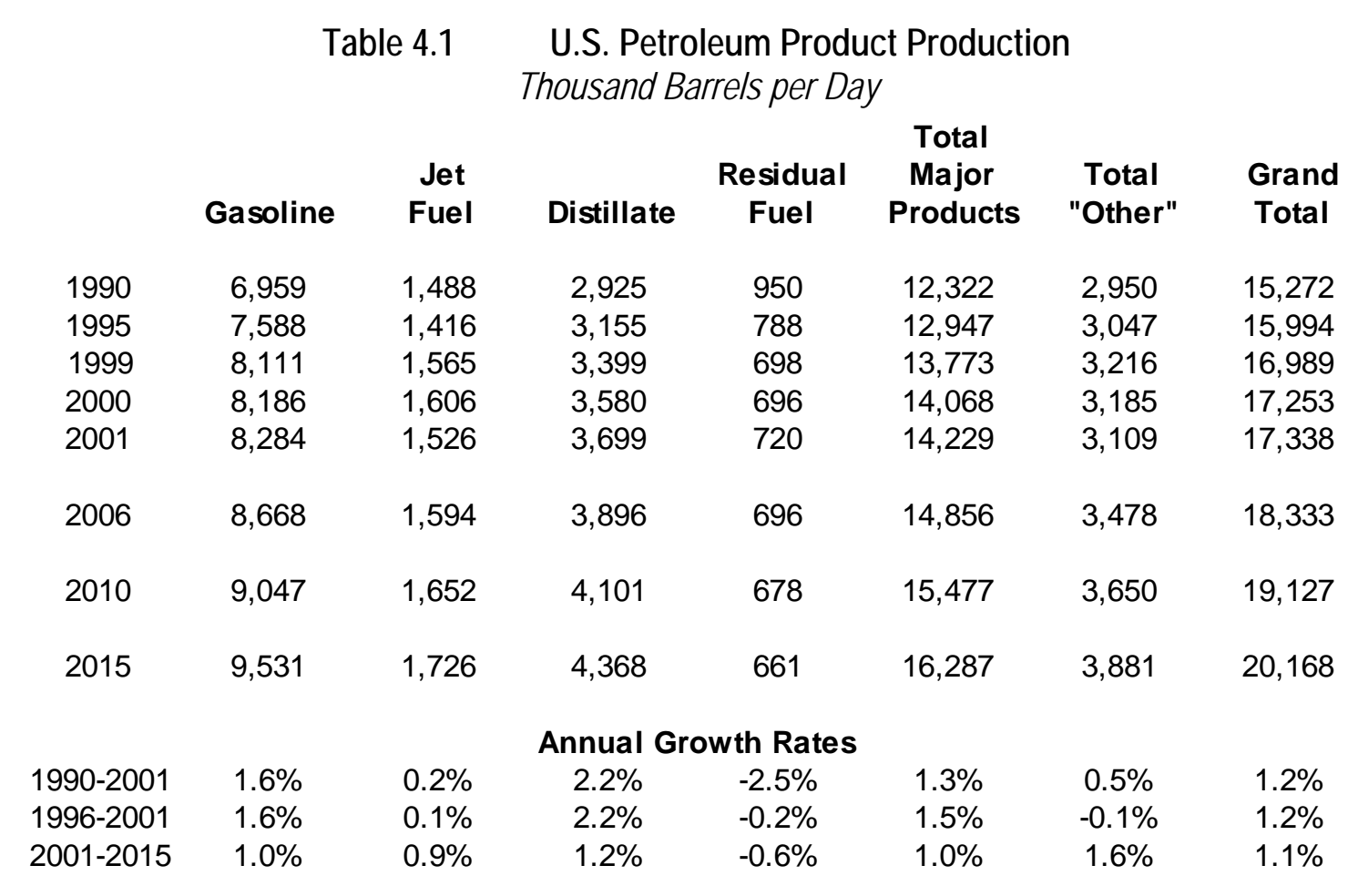

M:IENERGY1999PROJI2325anni1999|Bal99i.123

Nexant has forecast future domestic refinery capacity (primary crude distillation and secondary processing units), product yield profiles and operating rates by considering the following elements:

- $\quad$ Projected trends in domestic demand for total petroleum and for selected major refined products, considering long-term forecast usage of non-traditional transportation fuels

- $\quad$ Product import availability

- Product export trends, which have become more significant over the past 10 years are a balancing mechanism for the domestic industry

- $\quad$ Reasonable operating rates given historical performance and practical limitations on plant hardware

- Expected impact of environmental legislation 
Total domestic production of refined products in the United States will increase throughout the forecast period, with an annual growth rate of 1.1. This is a similar to the 1.1 percent annual growth rate over the previous 10 years. By 2015, refined product output is expected to reach 20.2 million bpd, up 16 percent from 17.3 million bpd in 2001. Consistent with the outlook for consumption, distillates and other products are expected to have the highest annual rate of production growth through 2015 .

Domestic production by major product, both historical and forecast, is expected to continue to shift to reflect trends in consumption. Yields of higher value products from domestic refineries are forecast to continue to increase throughout the forecast period.

Production shifts over the period 1990-2010 can be characterized as follows:

- Gasoline - Gasoline is by far the largest single product produced by U.S. refineries. The average yield of gasoline has been surprisingly stable over the past few decades, averaging about 58 percent of major product production between 1990 and 2001. Recent gasoline yields in 2001 averaged 58.2 percent. U.S. refiners are expected to marginally increase gasoline yields over the forecast period, achieving 58.5 percent average yields through 2015, in part reflecting the impact of continued reduction in residual fuel yields by the domestic industry.

- Jet Fuel - Below average growth in jet fuel demand over the last decade has resulted in a decline in the yield of jet fuel from domestic refiners. Thus, in 1990 jet fuel comprised 12.1 percent of major product output, but had declined to 10.7 by 2001 . Expected modest future demand growth is expected to limit future growth in jet yields to about 10.6 percent.

- Distillate - Distillates, exclusive of jet fuel, represent the second largest product yield in the U.S., averaging 26 percent of major product production in 2001. Reflecting aboveaverage growth over the last decade, this yield represents a significant increase over the 23.7 percent yield achieved in 1990. U.S. refiners are expected to increase distillate yields over the forecast period, reaching 26.8 percent average yields by 2015 .

- Residual Fuel - Production of residual fuel had steadily declined over the past 10 years, falling from 7.7 percent of major product production in 1990 to 5.1 percent in 2001 . Expected continued weakness in residual fuel demand will result in refiners investing in conversion capacity, so that by 2015 the yield of residual fuel is forecast to decline to 4.1 percent.

\subsection{OUTLOOK FOR REFINED PRODUCT PRODUCTION BY PADD REGION}

Nexant evaluated the historical patterns of regional production of refined products in the United States for the period 1990-2001. As shown in Figure 4.1, the geographic distribution of demand has been relatively stable between the PADD regions over this period. 


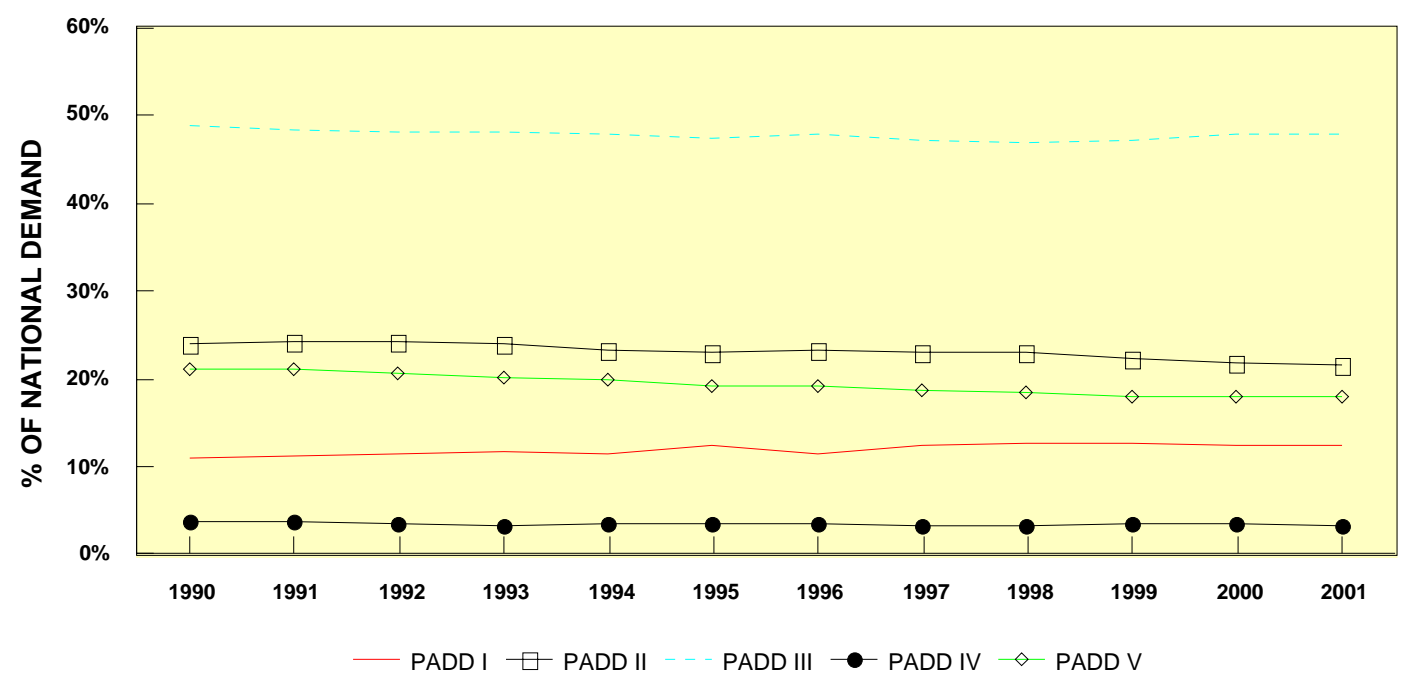

MAJOR PRODUCTS - GASOLINE, JET, DIESEL AND RESIDUAL FUELS

CHART 33

D:I\$USERIPROJECT WORKING FILESIUSANNUALIBAL09262002.123

Figure 4.1 Geographic Profile Of United States Refined Product Production

The current profile of geographic production of major refined products by PADD for 2001 is in Figure 4.2. As shown, PADD 3 has the highest level of petroleum production, with about 46 percent of the national total. This is followed by PADD 2 with about 21 percent, PADD 5 with 17.5 percent, and PADD 1 with 12 percent. PADD 4, reflecting its very sparse population, accounts for about 3.3 percent of national production. 


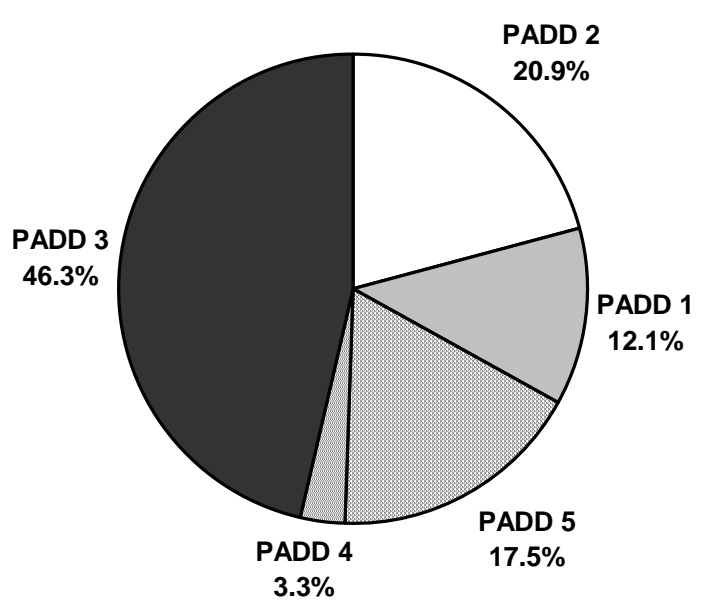

U:|2002Q4100072.005.11|DatalExcel files|[figures for report 4.xls]GRAPHS

\section{Figure 4.2 Geographic Profile Of United States Refined Product Production - 2001}

Future distribution of demand for refined petroleum products in the United States is expected to remain relatively stable, similar to historical performance. Detailed historical and forecast consumption by key refined product is presented in Table 4.2 to Table 4.6 for PADDs 1-5 respectively. Defining characteristics of refined product production for each PADD include:

- $\quad$ PADD 1

- $\quad$ Production of major refined products is expected to increase somewhat slower than consumption in PADD 1, reflecting the expectation that new refining investment in the United States will be more concentrated in PADD 3 over the forecast period. By 2015 production will equal about 12.0 percent of national totals, about the same as in 2001.

- $\quad$ The mix of products produced in PADD 1 is similar to the national averages. Gasoline, distillates and residual fuel production are all somewhat higher than the national yield mix, while jet fuel production is significantly lower

- $\quad$ PADD 2

- $\quad$ Production of major refined products is expected to increase roughly in line with consumption in PADD 2. By 2015 production will equal about 22.6 percent of national totals, up from 21.5 percent in 2001.

- $\quad$ The mix of products produced in PADD 2 varies considerably form the national averages. Yields of gasoline and distillates are both above the national averages, while jet fuel and residual fuel production are significantly lower 
- PADD 3

- Production of major refined products is expected to increase faster than consumption in PADD 3, reflecting the expectation that new refining investment in the United States will be more concentrated in PADD 3 over the forecast period. By 2015 production will equal about 46.0 percent of national totals, similar to the value in 2001 .

- $\quad$ The mix of products produced in PADD 3 is similar to the national averages. Yields of gasoline and residual fuels are both somewhat below the national averages, while jet fuel and distillate fuel production are somewhat higher

\section{- $\quad$ PADD 4}

- Production of major refined products is expected to increase slower than consumption in PADD 4, reflecting the expectation that new refining investment in the United States will be more concentrated in PADD 3 over the forecast period. By 2015 production will equal about 3.2 percent of national totals, down slightly from 3.4 percent in 2001.

- $\quad$ The mix of products produced in PADD 4 is significantly different from the national averages. Yields of distillate are much higher than the national averages, while jet fuel and residual fuel production are significantly lower

\section{- PADD 5}

- Production of major refined products is expected to increase in line with consumption growth in PADD 5. By 2015 production will equal about 16.2 percent of national totals, down from 17.1 in 2001.

- $\quad$ The mix of products produced in PADD 5 is significantly different from the national averages. Yields of gasoline and distillate are both below the national averages, while jet fuel and residual fuel production are higher 


\begin{tabular}{|c|c|c|c|c|c|c|}
\hline \multicolumn{2}{|c|}{ Table 4.2} & \multicolumn{5}{|c|}{ PADD 1 Petroleum Product Production Profile } \\
\hline & Gasoline & Jet & Distillates & Resid & $\begin{array}{r}\text { Total } \\
\text { Major } \\
\text { Products }\end{array}$ & $\begin{array}{r}\text { Total } \\
\text { Clean } \\
\text { Products }\end{array}$ \\
\hline 1990 & 668 & 96 & 352 & 137 & 1,253 & 1,116 \\
\hline 1995 & 851 & 86 & 414 & 154 & 1,505 & 1,351 \\
\hline 1999 & 1,017 & 114 & 431 & 107 & 1,669 & 1,562 \\
\hline 2000 & 995 & 104 & 459 & 111 & 1,669 & 1,558 \\
\hline 2001 & 1,022 & 85 & 470 & 107 & 1,684 & 1,577 \\
\hline 2006 & 1,082 & 88 & 498 & 108 & 1,776 & 1,668 \\
\hline 2015 & 1,206 & 96 & 560 & 109 & 1,971 & 1,862 \\
\hline \multicolumn{7}{|c|}{ Annual Change } \\
\hline 1990-2001 & $3.9 \%$ & $-1.1 \%$ & $2.7 \%$ & $-2.2 \%$ & $2.7 \%$ & $3.2 \%$ \\
\hline 2001-2015 & $1.2 \%$ & $0.8 \%$ & $1.3 \%$ & $0.2 \%$ & $1.1 \%$ & $1.2 \%$ \\
\hline \multicolumn{7}{|c|}{ Percent of PADD Totals } \\
\hline & Gasoline & Jet & Distillates & Resid & $\begin{array}{r}\text { Total } \\
\text { Major } \\
\text { Products }\end{array}$ & $\begin{array}{r}\text { Total } \\
\text { Clean } \\
\text { Products }\end{array}$ \\
\hline 1990 & $53.3 \%$ & $7.7 \%$ & $28.1 \%$ & $10.9 \%$ & $100.0 \%$ & $89.1 \%$ \\
\hline 1995 & $56.5 \%$ & $5.7 \%$ & $27.5 \%$ & $10.2 \%$ & $100.0 \%$ & $89.8 \%$ \\
\hline 1999 & $60.9 \%$ & $6.8 \%$ & $25.8 \%$ & $6.4 \%$ & $100.0 \%$ & $93.6 \%$ \\
\hline 2000 & $59.6 \%$ & $6.2 \%$ & $27.5 \%$ & $6.7 \%$ & $100.0 \%$ & $93.3 \%$ \\
\hline 2001 & $60.7 \%$ & $5.0 \%$ & $27.9 \%$ & $6.4 \%$ & $100.0 \%$ & $93.6 \%$ \\
\hline 2006 & $60.9 \%$ & $5.0 \%$ & $28.1 \%$ & $6.1 \%$ & $100.0 \%$ & $93.9 \%$ \\
\hline 2015 & $61.2 \%$ & $4.9 \%$ & $28.4 \%$ & $5.5 \%$ & $100.0 \%$ & $94.5 \%$ \\
\hline \multicolumn{7}{|c|}{ Averages for period } \\
\hline 1990-2001 & $57.5 \%$ & $6.1 \%$ & $27.6 \%$ & $8.8 \%$ & $100.0 \%$ & $91.2 \%$ \\
\hline 2001-2015 & $60.9 \%$ & $5.0 \%$ & $28.1 \%$ & $6.0 \%$ & $100.0 \%$ & $94.0 \%$ \\
\hline
\end{tabular}

\section{Percent of National Totals}

\begin{tabular}{|c|c|c|c|c|c|c|}
\hline & Gasoline & Jet & Distillates & Resid & $\begin{array}{r}\text { Total } \\
\text { Major } \\
\text { Products }\end{array}$ & $\begin{array}{r}\text { Total } \\
\text { Clean } \\
\text { Products }\end{array}$ \\
\hline 1990 & $9.6 \%$ & $6.4 \%$ & $12.0 \%$ & $14.4 \%$ & $10.2 \%$ & $9.8 \%$ \\
\hline 1995 & $11.4 \%$ & $6.1 \%$ & $13.1 \%$ & $19.5 \%$ & $11.7 \%$ & $11.2 \%$ \\
\hline 1999 & $12.8 \%$ & $7.5 \%$ & $12.7 \%$ & $15.3 \%$ & $12.3 \%$ & $12.2 \%$ \\
\hline 2000 & $12.5 \%$ & $6.5 \%$ & $12.8 \%$ & $15.9 \%$ & $12.1 \%$ & $11.9 \%$ \\
\hline 2001 & $12.8 \%$ & $5.6 \%$ & $12.7 \%$ & $14.7 \%$ & $12.1 \%$ & $11.9 \%$ \\
\hline 2006 & $12.8 \%$ & $5.5 \%$ & $12.7 \%$ & $15.2 \%$ & $12.1 \%$ & $12.0 \%$ \\
\hline 2015 & $12.8 \%$ & $5.5 \%$ & $12.7 \%$ & $16.0 \%$ & $12.1 \%$ & $12.0 \%$ \\
\hline \multicolumn{7}{|c|}{ Averages for period } \\
\hline 1990-2001 & $11.3 \%$ & $6.0 \%$ & $12.5 \%$ & $16.1 \%$ & $11.3 \%$ & $11.0 \%$ \\
\hline 2001-2015 & $12.8 \%$ & $5.5 \%$ & $12.7 \%$ & $15.3 \%$ & $12.1 \%$ & $12.0 \%$ \\
\hline
\end{tabular}




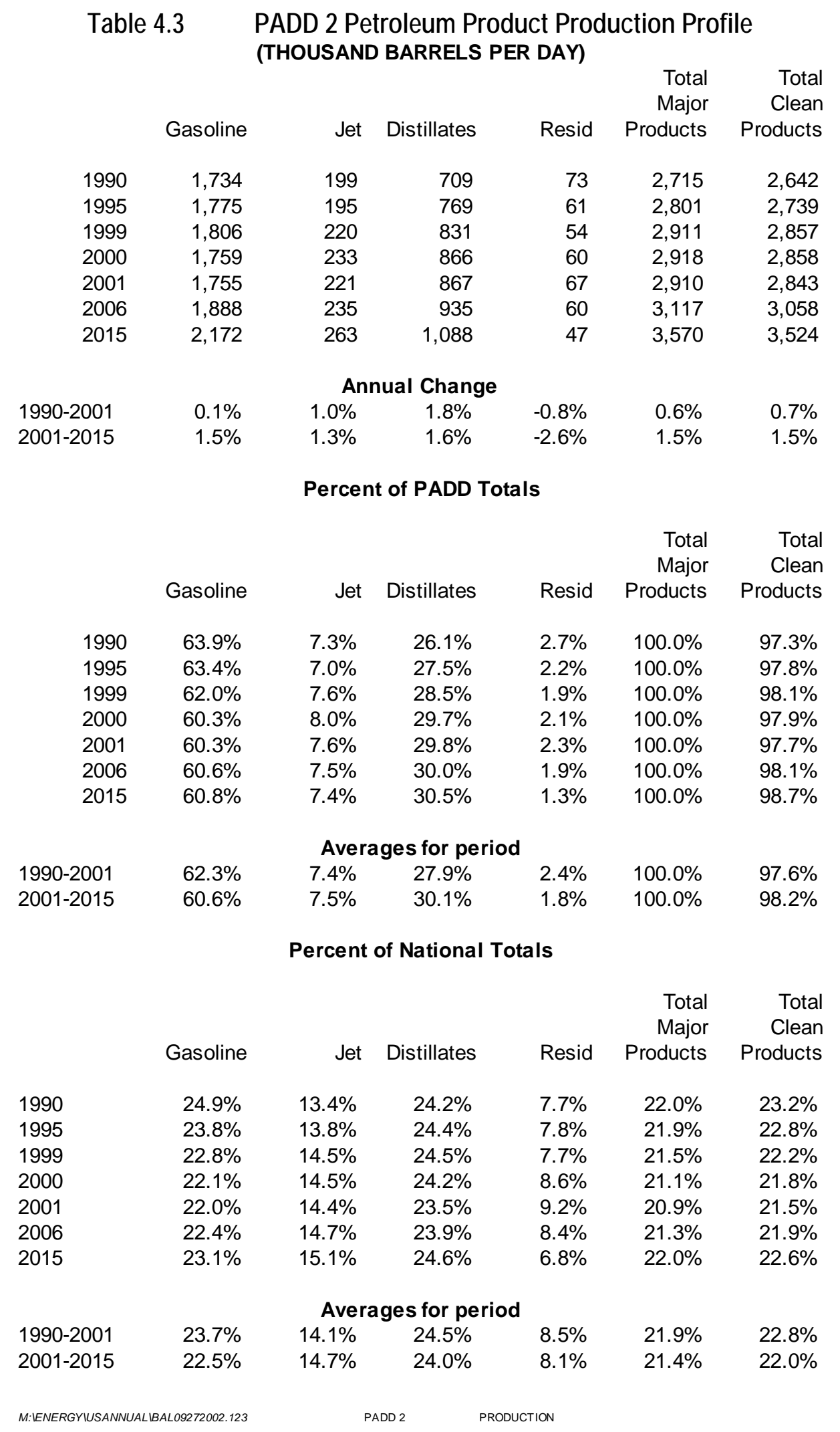




\begin{tabular}{|c|c|c|c|c|c|c|}
\hline \multicolumn{2}{|c|}{ Table 4.4} & \multicolumn{5}{|c|}{$\begin{array}{l}\text { PADD } 3 \text { Petroleum Product Production Profile } \\
\text { (THOUSAND BARRELS PER DAY) }\end{array}$} \\
\hline & Gasoline & Jet & Distillates & Resid & $\begin{array}{r}\text { Total } \\
\text { Major } \\
\text { Products }\end{array}$ & $\begin{array}{r}\text { Total } \\
\text { Clean } \\
\text { Products }\end{array}$ \\
\hline 1990 & 3,125 & 746 & 1,304 & 365 & 5,540 & 5,175 \\
\hline 1995 & 3,326 & 706 & 1,397 & 339 & 5,769 & 5,429 \\
\hline 1999 & 3,537 & 771 & 1,547 & 318 & 6,173 & 5,855 \\
\hline 2000 & 3,569 & 833 & 1,639 & 343 & 6,384 & 6,041 \\
\hline 2001 & 3,578 & 791 & 1,714 & 365 & 6,448 & 6,083 \\
\hline 2006 & 3,774 & 829 & 1,814 & 359 & 6,776 & 6,417 \\
\hline 2015 & 4,202 & 908 & 2,046 & 351 & 7,507 & 7,156 \\
\hline \multicolumn{7}{|c|}{ Annual Change } \\
\hline 1990-2001 & $1.2 \%$ & $0.5 \%$ & $2.5 \%$ & $0.0 \%$ & $1.4 \%$ & $1.5 \%$ \\
\hline $2001-2015$ & $1.2 \%$ & $1.0 \%$ & $1.3 \%$ & $-0.3 \%$ & $1.1 \%$ & $1.2 \%$ \\
\hline \multicolumn{7}{|c|}{ Percent of PADD Totals } \\
\hline & Gasoline & Jet & Distillates & Resid & $\begin{array}{r}\text { Total } \\
\text { Major } \\
\text { Products }\end{array}$ & $\begin{array}{r}\text { Total } \\
\text { Clean } \\
\text { Products }\end{array}$ \\
\hline 1990 & $56.4 \%$ & $13.5 \%$ & $23.5 \%$ & $6.6 \%$ & $100.0 \%$ & $93.4 \%$ \\
\hline 1995 & $57.7 \%$ & $12.2 \%$ & $24.2 \%$ & $5.9 \%$ & $100.0 \%$ & $94.1 \%$ \\
\hline 1999 & $57.3 \%$ & $12.5 \%$ & $25.1 \%$ & $5.1 \%$ & $100.0 \%$ & $94.9 \%$ \\
\hline 2000 & $55.9 \%$ & $13.0 \%$ & $25.7 \%$ & $5.4 \%$ & $100.0 \%$ & $94.6 \%$ \\
\hline 2001 & $55.5 \%$ & $12.3 \%$ & $26.6 \%$ & $5.7 \%$ & $100.0 \%$ & $94.3 \%$ \\
\hline 2006 & $55.7 \%$ & $12.2 \%$ & $26.8 \%$ & $5.3 \%$ & $100.0 \%$ & $94.7 \%$ \\
\hline 2015 & $56.0 \%$ & $12.1 \%$ & $27.3 \%$ & $4.7 \%$ & $100.0 \%$ & $95.3 \%$ \\
\hline \multicolumn{7}{|c|}{ Averages for period } \\
\hline 1990-2001 & $56.6 \%$ & $12.7 \%$ & $24.9 \%$ & $5.9 \%$ & $100.0 \%$ & $94.1 \%$ \\
\hline 2001-2015 & $55.7 \%$ & $12.2 \%$ & $26.9 \%$ & $5.2 \%$ & $100.0 \%$ & $94.8 \%$ \\
\hline \multicolumn{7}{|c|}{ Percent of National Totals } \\
\hline & Gasoline & Jet & Distillates & Resid & $\begin{array}{r}\text { Total } \\
\text { Major } \\
\text { Products }\end{array}$ & $\begin{array}{r}\text { Total } \\
\text { Clean } \\
\text { Products }\end{array}$ \\
\hline 1990 & $44.9 \%$ & $50.1 \%$ & $44.6 \%$ & $38.4 \%$ & $45.0 \%$ & $45.5 \%$ \\
\hline 1995 & $44.6 \%$ & $49.9 \%$ & $44.3 \%$ & $43.0 \%$ & $45.0 \%$ & $45.1 \%$ \\
\hline 1999 & $44.6 \%$ & $50.8 \%$ & $45.5 \%$ & $45.5 \%$ & $45.6 \%$ & $45.6 \%$ \\
\hline 2000 & $44.9 \%$ & $51.9 \%$ & $45.8 \%$ & $49.3 \%$ & $46.2 \%$ & $46.0 \%$ \\
\hline 2001 & $44.8 \%$ & $51.7 \%$ & $46.4 \%$ & $50.3 \%$ & $46.3 \%$ & $46.1 \%$ \\
\hline 2006 & $44.8 \%$ & $51.8 \%$ & $46.4 \%$ & $50.6 \%$ & $46.2 \%$ & $46.0 \%$ \\
\hline 2015 & $44.7 \%$ & $52.1 \%$ & $46.3 \%$ & $51.3 \%$ & $46.2 \%$ & $46.0 \%$ \\
\hline \multicolumn{7}{|c|}{ Averages for period } \\
\hline 1990-2001 & $44.5 \%$ & $50.3 \%$ & $45.1 \%$ & $43.6 \%$ & $45.2 \%$ & $45.4 \%$ \\
\hline $2001-2015$ & $44.8 \%$ & $51.9 \%$ & $46.4 \%$ & $50.7 \%$ & $46.3 \%$ & $46.0 \%$ \\
\hline
\end{tabular}




\begin{tabular}{|c|c|c|c|c|c|c|}
\hline \multicolumn{2}{|c|}{ Table 4.5} & \multicolumn{5}{|c|}{$\begin{array}{l}\text { PADD } 4 \text { Petroleum Product Production Profile } \\
\text { (THOUSAND BARRELS PER DAY) }\end{array}$} \\
\hline & Gasoline & Jet & Distillates & Resid & $\begin{array}{r}\text { Total } \\
\text { Major } \\
\text { Products }\end{array}$ & $\begin{array}{r}\text { Total } \\
\text { Clean } \\
\text { Products }\end{array}$ \\
\hline 1990 & 237 & 40 & 127 & 11 & 415 & 404 \\
\hline 1995 & 242 & 29 & 129 & 10 & 411 & 401 \\
\hline 1999 & 262 & 27 & 143 & 12 & 444 & 432 \\
\hline 2000 & 270 & 29 & 149 & 10 & 458 & 448 \\
\hline 2001 & 266 & 27 & 150 & 11 & 454 & 443 \\
\hline 2006 & 275 & 28 & 156 & 10 & 468 & 459 \\
\hline 2015 & 296 & 29 & 169 & 7 & 501 & 494 \\
\hline \multicolumn{7}{|c|}{ Annual Change } \\
\hline 1990-2001 & $1.1 \%$ & $-3.5 \%$ & $1.5 \%$ & $0.0 \%$ & $0.8 \%$ & $0.8 \%$ \\
\hline $2001-2015$ & $0.8 \%$ & $0.4 \%$ & $0.9 \%$ & $-2.9 \%$ & $0.7 \%$ & $0.8 \%$ \\
\hline \multicolumn{7}{|c|}{ Percent of PADD Totals } \\
\hline & Gasoline & Jet & Distillates & Resid & $\begin{array}{r}\text { Total } \\
\text { Major } \\
\text { Products }\end{array}$ & $\begin{array}{r}\text { Total } \\
\text { Clean } \\
\text { Products }\end{array}$ \\
\hline 1990 & $57.1 \%$ & $9.6 \%$ & $30.6 \%$ & $2.7 \%$ & $100.0 \%$ & $97.3 \%$ \\
\hline 1995 & $59.0 \%$ & $7.0 \%$ & $31.5 \%$ & $2.5 \%$ & $100.0 \%$ & $97.5 \%$ \\
\hline 1999 & $59.0 \%$ & $6.1 \%$ & $32.2 \%$ & $2.6 \%$ & $100.0 \%$ & $97.4 \%$ \\
\hline 2000 & $59.0 \%$ & $6.3 \%$ & $32.5 \%$ & $2.2 \%$ & $100.0 \%$ & $97.8 \%$ \\
\hline 2001 & $58.6 \%$ & $5.9 \%$ & $33.0 \%$ & $2.4 \%$ & $100.0 \%$ & $97.6 \%$ \\
\hline 2006 & $58.8 \%$ & $5.9 \%$ & $33.3 \%$ & $2.0 \%$ & $100.0 \%$ & $98.0 \%$ \\
\hline 2015 & $59.1 \%$ & $5.7 \%$ & $33.7 \%$ & $1.5 \%$ & $100.0 \%$ & $98.5 \%$ \\
\hline \multicolumn{7}{|c|}{ Averages for period } \\
\hline 1990-2001 & $58.4 \%$ & $7.3 \%$ & $31.7 \%$ & $2.6 \%$ & $100.0 \%$ & $97.4 \%$ \\
\hline 2001-2015 & $58.8 \%$ & $5.8 \%$ & $33.3 \%$ & $2.0 \%$ & $100.0 \%$ & $98.0 \%$ \\
\hline \multicolumn{7}{|c|}{ Percent of National Totals } \\
\hline & Gasoline & Jet & Distillates & Resid & $\begin{array}{r}\text { Total } \\
\text { Major } \\
\text { Products }\end{array}$ & $\begin{array}{r}\text { Total } \\
\text { Clean } \\
\text { Products }\end{array}$ \\
\hline 1990 & $3.4 \%$ & $2.7 \%$ & $4.3 \%$ & $1.2 \%$ & $3.4 \%$ & $3.6 \%$ \\
\hline 1995 & $3.3 \%$ & $2.0 \%$ & $4.1 \%$ & $1.3 \%$ & $3.2 \%$ & $3.3 \%$ \\
\hline 1999 & $3.3 \%$ & $1.8 \%$ & $4.2 \%$ & $1.7 \%$ & $3.3 \%$ & $3.4 \%$ \\
\hline 2000 & $3.4 \%$ & $1.8 \%$ & $4.2 \%$ & $1.4 \%$ & $3.3 \%$ & $3.4 \%$ \\
\hline 2001 & $3.3 \%$ & $1.8 \%$ & $4.1 \%$ & $1.5 \%$ & $3.3 \%$ & $3.4 \%$ \\
\hline 2006 & $3.3 \%$ & $1.7 \%$ & $4.0 \%$ & $1.4 \%$ & $3.2 \%$ & $3.3 \%$ \\
\hline 2015 & $3.2 \%$ & $1.6 \%$ & $3.8 \%$ & $1.1 \%$ & $3.1 \%$ & $3.2 \%$ \\
\hline \multicolumn{7}{|c|}{ Averages for period } \\
\hline 1990-2001 & $3.3 \%$ & $2.1 \%$ & $4.1 \%$ & $1.4 \%$ & $3.2 \%$ & $3.4 \%$ \\
\hline 2001-2015 & $3.3 \%$ & $1.7 \%$ & $4.0 \%$ & $1.3 \%$ & $3.2 \%$ & $3.3 \%$ \\
\hline
\end{tabular}




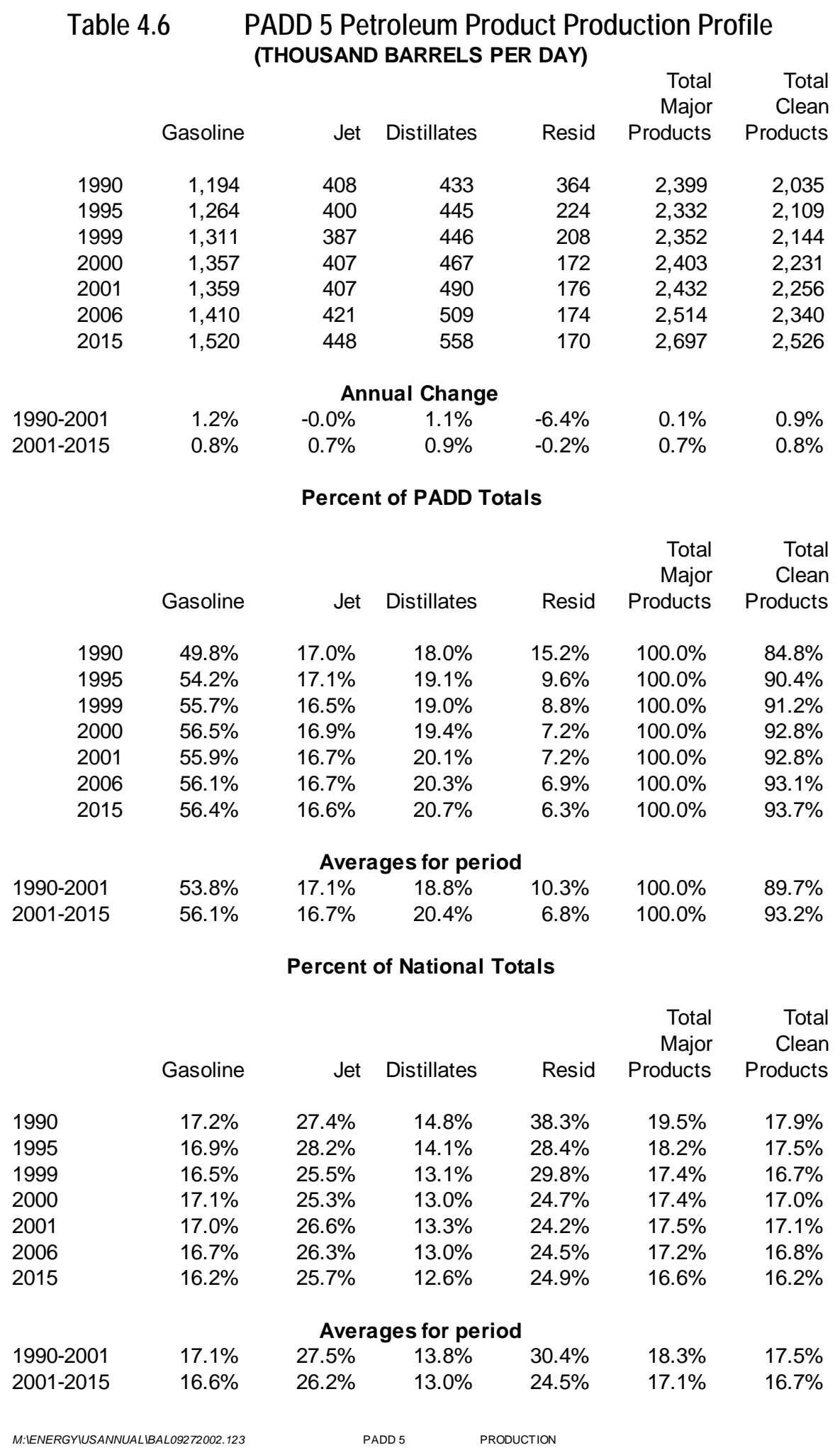




\subsection{NATIONAL PROFILE}

Historical trends as well as expected developments in U.S. and global crude oil supply were reviewed to develop a forecast of the future quality trends of crude oil that will be processed by U.S. refineries. The gravity of domestic and imported crude oils along with the composite average is shown in Figure 5.1 over the 1980 to 2001 period, and indicates a steady deterioration of quality over this 20 year time period.

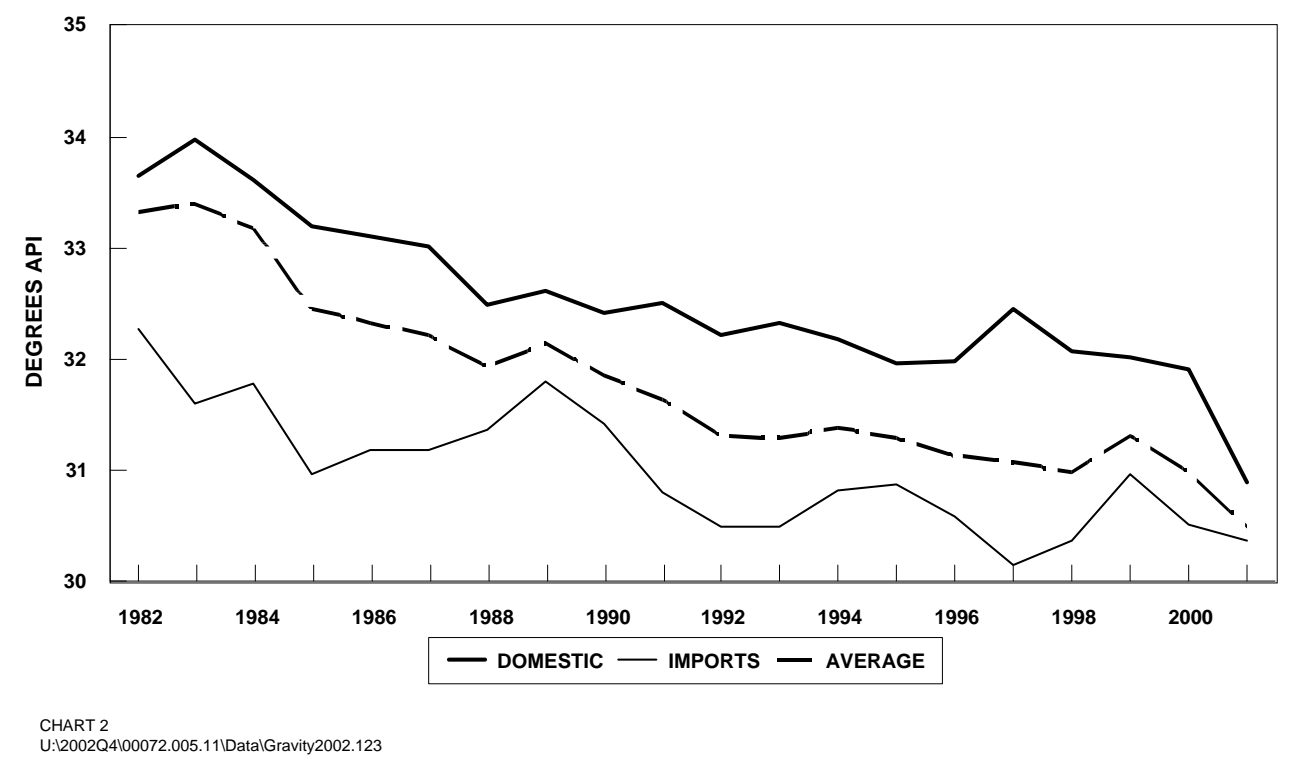

Figure $5.1 \quad$ United States Crude Oil Quality Trends - Gravity

The gravity of domestic crude oil steadily declined before increasing in 1997, with the 1997 increase primarily due to lower heavy Alaskan production. Average crude oil gravity resumed its decline in 1998 due to lower light onshore production from the Lower 48 states and increased heavy offshore Gulf of Mexico production.

The quality of imported crude oil has also generally declined, although, as the mix of import sources has evolved, there has been considerable variability on a year-to-year basis. The major cause of the decline in imported crude quality has been increased imports of heavy Canadian, Mexican and Venezuelan crudes. On average, imported crude oils are significantly heavier than domestic production.

Average trends in crude oil sulfur levels are shown in Figure 5.2. As indicated, average composite crude oil sulfur levels rose from about 0.8 weight percent in 1980 to over 1.3 weight percent in 2001. Increased imports of heavy Canadian, Mexican and Venezuelan crudes have been the major underlying factors driving the long-term increase in crude oil sulfur levels. 


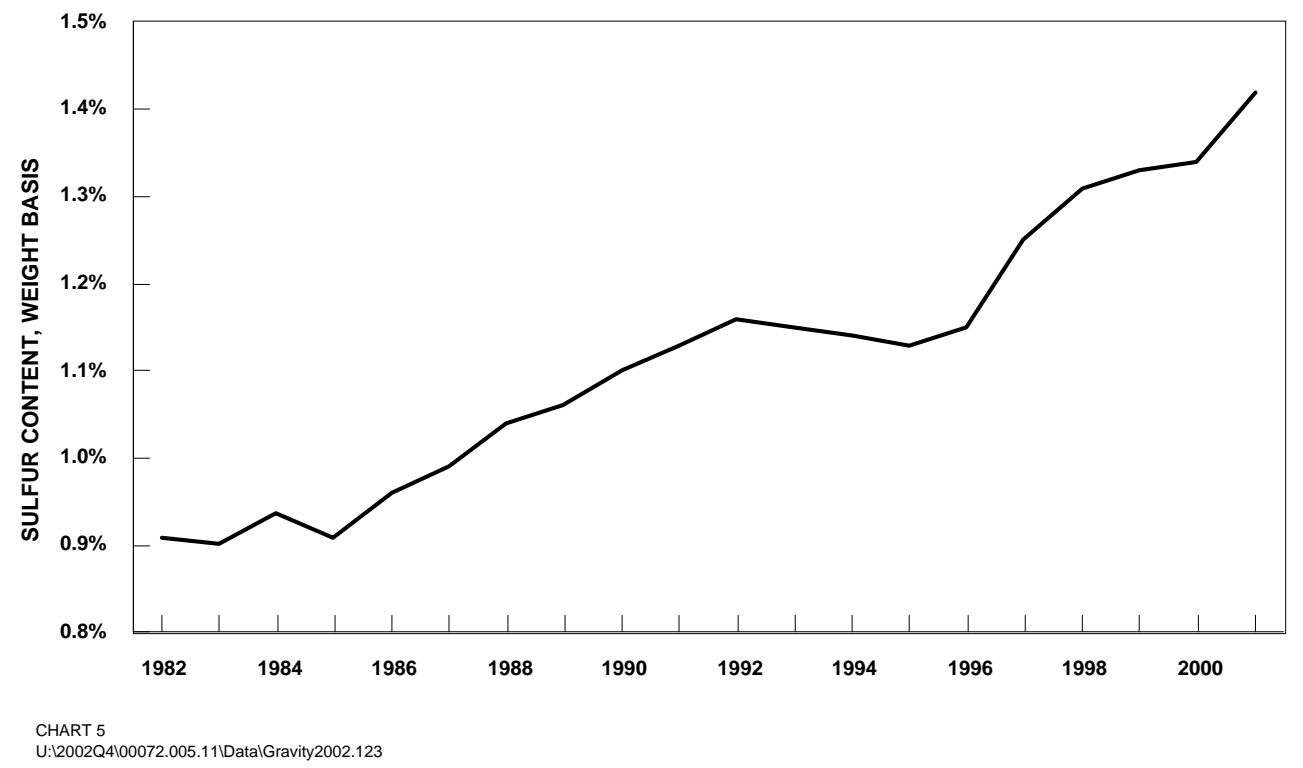

Figure 5.2 United States Crude Oil Quality Historical Trends In Sulfur Content

Table 5.1 is this really supposed to be Table 5.1 ? shows historical and forecast gravity and sulfur levels for the composite mix of crude oils charged to U. S. refineries. Additionally, there is no figure for this in this report! forecasts crude oil imports by gravity (heavy \& light) and sulfur (sweet \& sour). The key points are:

- Average crude quality is forecast to continue to decline, becoming heavier and higher in sulfur content

- Increased heavy offshore Gulf of Mexico crude production will contribute to a gradual decline in domestic crude oil quality, somewhat offset by a slowing in the rate of decline in Alaskan crude production

- Increased heavy, sour crude oil imports from Venezuela and Canada will be primarily responsible for the forecast heavying up of the crude oil import barrel and the resultant decline in composite crude oil slate quality

\subsection{PADD PROFILE}

Crude oil quality by PADD varies considerably relative to the national averages. These differences are shown for crude oil gravity (Figure 5.3 and Table 5.1) and sulfur (Figure 5.4 and Table 5.2). 


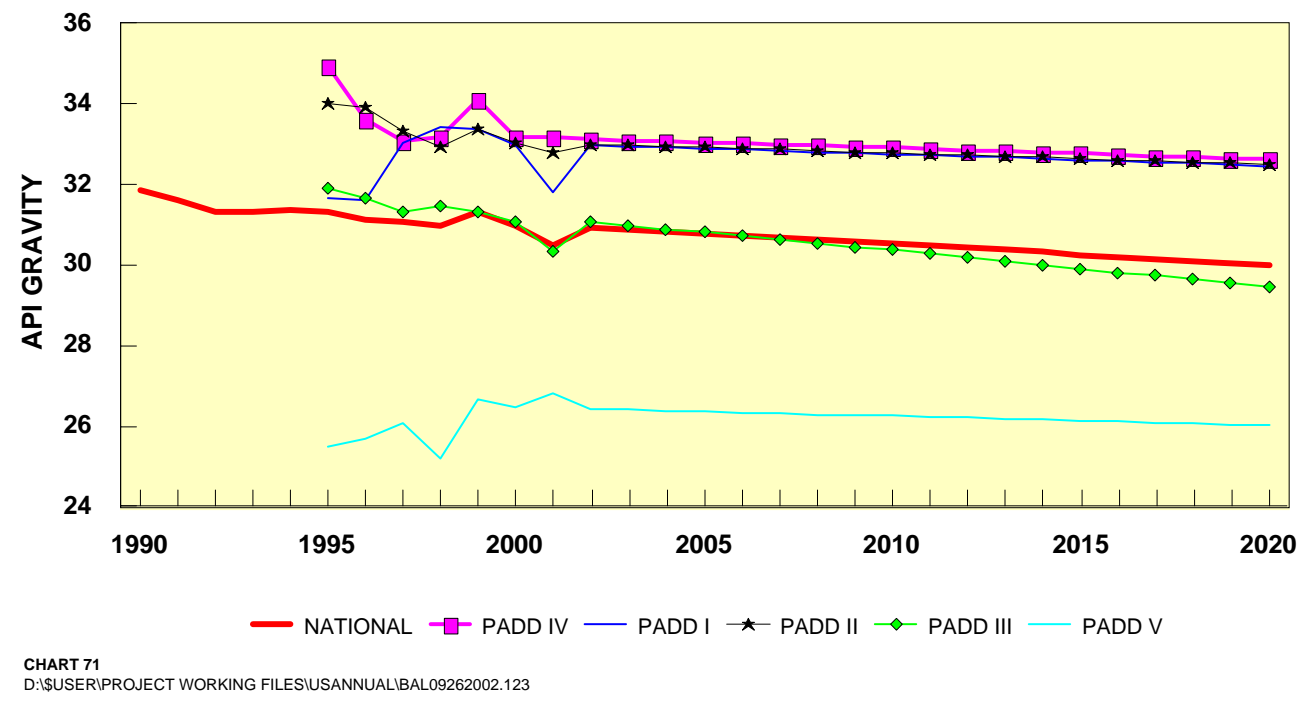

Figure 5.3 Trends in United States Crude Oil Quality - Gravity

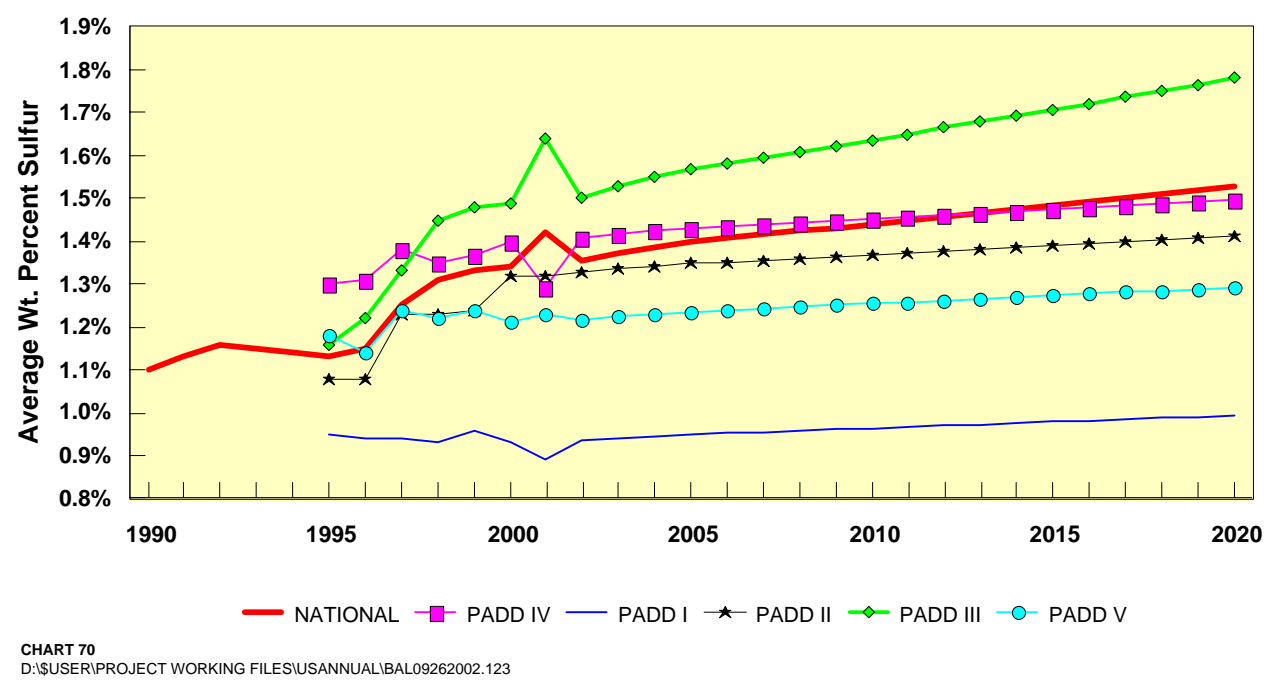

Figure 5.4 Trends in United States Crude Oil Quality - Sulfur 


\section{Table 5.1 Trends in United States Crude Oil Quality - Gravity}

$\begin{array}{rrrrrrr} & \text { National } & \text { PADD I } & \text { PADD II } & \text { PADD III } & \text { PADD IV } & \text { PADD V } \\ \mathbf{1 9 9 5} & 31.3 & 31.7 & 34.0 & 31.9 & 35.0 & 25.5 \\ \mathbf{1 9 9 9} & 31.3 & 33.4 & 33.4 & 31.3 & 34.1 & 26.7 \\ \mathbf{2 0 0 0} & 31.0 & 33.0 & 33.0 & 31.1 & 33.2 & 26.5 \\ \mathbf{2 0 0 1} & 30.5 & 31.8 & 32.8 & 30.3 & 33.2 & 26.8 \\ \mathbf{2 0 0 6} & 30.7 & 32.9 & 32.9 & 30.7 & 33.0 & 26.3 \\ \mathbf{2 0 1 0} & 30.5 & 32.8 & 32.8 & 30.4 & 32.9 & 26.3 \\ \mathbf{2 0 1 5} & 30.3 & 32.6 & 32.6 & 29.9 & 32.8 & 26.1\end{array}$

D:I\$USERIPROJECT WORKING FILESIUSANNUALIBAL09262002.123

Table 5.2 Trends In United States Crude Oil Sulfur

$\begin{array}{lrrrrrr} & \text { National } & \text { PADD I } & \text { PADD II } & \text { PADD III } & \text { PADD IV } & \text { PADD V } \\ \mathbf{1 9 9 5} & 1.13 \% & 0.95 \% & 1.08 \% & 1.16 \% & 1.30 \% & 1.18 \% \\ \mathbf{1 9 9 9} & 1.33 \% & 0.96 \% & 1.24 \% & 1.48 \% & 1.37 \% & 1.24 \% \\ \mathbf{2 0 0 0} & 1.34 \% & 0.93 \% & 1.32 \% & 1.49 \% & 1.40 \% & 1.21 \% \\ \mathbf{2 0 0 1} & 1.42 \% & 0.89 \% & 1.32 \% & 1.64 \% & 1.29 \% & 1.23 \% \\ \mathbf{2 0 0 6} & 1.41 \% & 0.95 \% & 1.35 \% & 1.58 \% & 1.43 \% & 1.24 \% \\ \mathbf{2 0 1 0} & 1.44 \% & 0.96 \% & 1.37 \% & 1.64 \% & 1.45 \% & 1.25 \% \\ \mathbf{2 0 1 5} & 1.48 \% & 0.98 \% & 1.39 \% & 1.71 \% & 1.47 \% & 1.27 \%\end{array}$

D:I\$USERIPROJECT WORKING FILESIUSANNUALIBAL09262002.123

As indicated, crude oil quality in all PADDs is expected to follow national trends, i.e. average crude oil will become heavier and higher in sulfur content in all regions. It is expected that crude oil quality in PADD 3 will decline somewhat faster than in the other regions, reflecting the assumption that a disproportionate percentage of new investment in the United States refining industry will take place in expanding and enhancing the already dominant refining industry at the USGC. Such new investment will tend to allow processing of poorer quality crude oils, and the resulting crude oil slate that the USGC will thus decline somewhat faster than elsewhere in the country. 


\subsection{NATIONAL PROFILE}

The U.S. refining industry comprises about 150 operable refineries. Average processing capabilities, as measured by complexity indices, ${ }^{(1)}$ have been on the rise since the 1980 s. This trend reflects the rationalization of over 100 simple refineries during the period as well as steady investment in residual upgrading and octane enhancement. Further refinery investments have recently been made to produce reformulated/oxygenated gasoline as dictated by the 1990 Amendments to the Clean Air Act. Trends in United States refining are presented graphically inFigure 6.1. As shown, the number of operating refineries in the United States has steadily decreased during the 1990s, reflecting the combined impacts of generally low refining margins as well as industry consolidation. The average refinery size has increased steadily over the last 40 years, as the need to achieve economies of scale has reduced the competitiveness of smaller facilities.

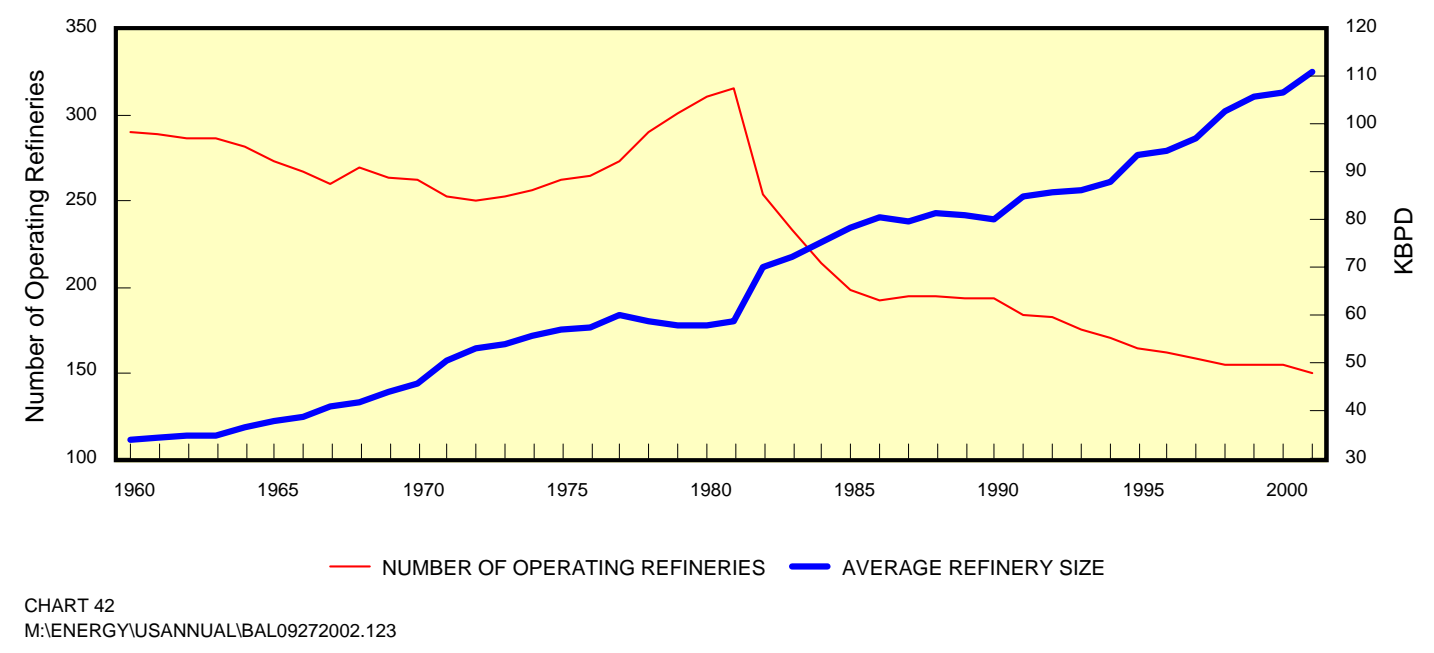

Figure 6.1 Trends In United States Refining

A profile of the United States refining industry is presented in Table 6.1. As shown, crude oil distillation capacity is forecast to increase by about 2.5 million barrels per day between 2001 and 2015. This reflects a 1 percent annual growth rate, which is considered a sustainable range of capacity creep for the domestic industry. As shown, investment in downstream refining facilities, in particular hydrotreating, hydrocraking and coking, is expected to result in an

(1) Complexity indices are developed by assigning index numbers to each processing unit in a given refinery. All index numbers are aligned relative to the crude oil distillation, which by definition has an index number of 1.0. Higher numbers reflect higher capital costs/complexity relative to crude oil distillation. Individual unit indices are weight averaged based on capacities to determine the entire refinery index. As a basic measure, higher refinery indices with greater processing ability. 
increase in the percent of each of these units expressed as a percentage of crude oil distillation capacity. As shown, MTBE capacity in the United States is expected to be completely shut down by 2015 .

Table 6.1 Profile of United States Refining Facilities thousand barrels per day

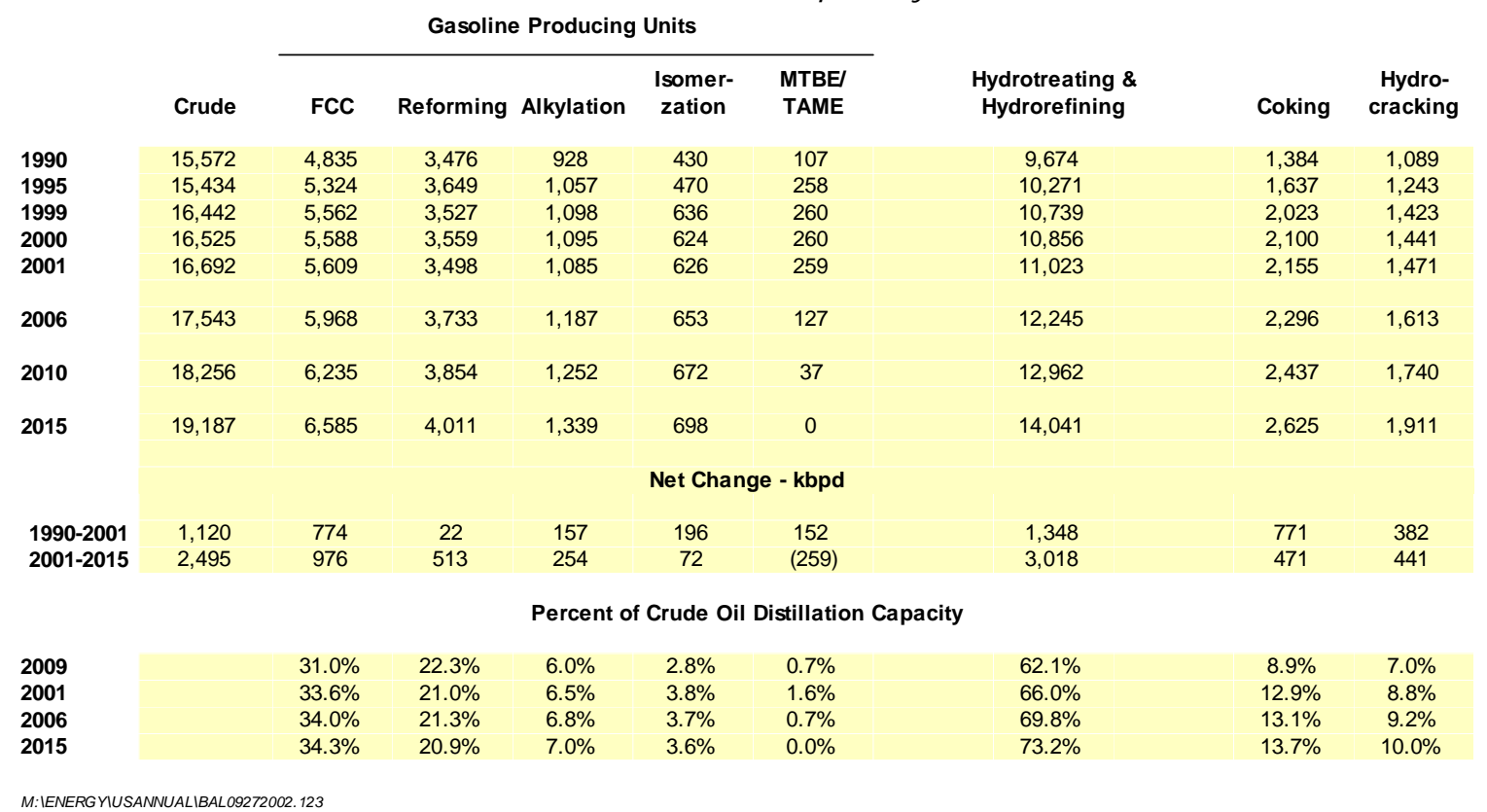

\subsection{PADD ANALYSIS}

A breakdown of crude oil distillation capacity is provided in Figure 6.2. Refining capacity is highly concentrated in PADD 3, with about 46 percent of the national total. PADD 2 (21 percent) and PADD 5 (19 percent) have substantial refining industries. PADD 1 has relatively limited refining capacity relative to its level of consumption, and as a result is the country's primary importer of refined products. PADD 4, reflecting its sparse population and isolation, has limited refining capacity of about 3.5 percent of the national total, roughly in line with its consumption share. 


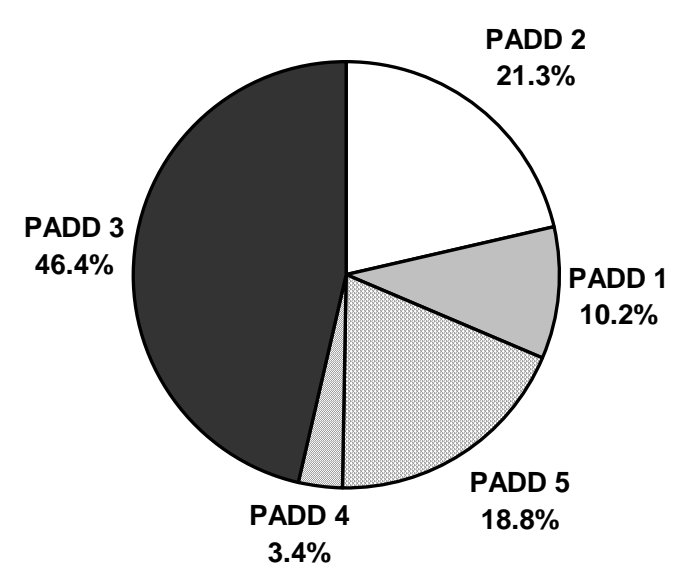

U:12002Q4100072.005.11IDatalExcel files|[figures for report 4.xIs]GRAPHS

Figure 6.2 Distribution Of United States Refining - 2001

A discussion of some of the defining characteristics of the refining industry in each PADD follows.

PADD 1 (the East Coast) contains 15 refineries at the present time and accounts for 9 percent of the refinery capacity in the U.S. Its refineries are concentrated on the coast in New Jersey and in the Philadelphia area.

The region's 10 largest refineries, each having a capacity greater than 50 thousand BPD, account for 98 percent of the region's refining capacity and are considered to be most representative of its refineries. The region's 5 smaller refineries are devoted to the production of specialty products, such as asphalt and lubricants.

Table 6.2 presents the combined capacities in 2001 of major process units at these refineries, which have an average refinery capacity of 152 thousand BPCD. 


\title{
Table 6.2 PADD 1 PROCESS UNIT CAPACITIES, 2001
}

Thousand Barrels per Calendar Day

\author{
Industry Total ${ }^{1}$ Percent $^{2}$
}

Crude Distillation

Vacuum Distillation

Coking

Cat Cracking (FCC)

Cat Reforming

Diesel Hydrotreating

VGO Desulfurization

VGO Hydrocracking

Alkylation

C5/C6 Isomerization

$\begin{array}{rr}1,519 & \\ 603 & 39.7 \\ 91 & 6.0 \\ 679 & 44.7 \\ 275 & 18.1 \\ 441 & 29.0 \\ 107 & 7.1 \\ 17 & 1.1 \\ 85 & 5.6 \\ 17 & 1.1 \\ & \end{array}$

1 Total for PADD 1 refineries $w$ ith capacity greater than 50 KBPCD

All of PADD 1's 10 largest refineries have fluid catalytic cracking (FCC) units and catalytic reforming, and 3 have delayed coking and VGO hydrotreating units. In addition, only 1 of these refineries includes a VGO hydrocracking unit. Relative to national averages, PADD 1 refineries are above average in FCC capacity, but below average in conversion and treating capacity.

PADD 2 (the Midwest) contains 26 refineries at the present time and accounts for 21 percent of the refinery capacity in the U.S. Its refineries are distributed throughout the region with the Chicago area having the largest concentration.

Table 6.3 presents the combined capacities in 2001 of major process units at the region's refineries. Only one of the region's refineries has a capacity less than 20 thousand BPD. The refineries having a capacity greater than 20 thousand BPD have an average refinery capacity of 138 thousand BPCD.

All of the region's 25 largest refineries have catalytic reforming units and only two of them do not have fluid catalytic cracking (FCC) units in their process unit configurations. The configurations of 14 of these refineries include delayed coking units. In addition, 8 of these refineries have VGO hydrotreating units and the configuration for 7 of them includes a VGO hydrocracking unit. On average, PADD 2 refineries have configurations that are similar to national averages, with the exception that hydrocracking capacity is somewhat low. 


\section{Table 6.3 PADD 2 Process Unit Capacities, 2001 Thousand Barrels Per Calendar Day}

Industry Total Percent ${ }^{1}$

$\begin{array}{lrr}\text { Crude Distillation } & 3,441 & \\ \text { Vacuum Distillation } & 1,449 & 42.1 \\ \text { Coking } & 376 & 10.9 \\ \text { Cat Cracking (FCC) } & 1,111 & 32.3 \\ \text { Cat Reforming } & 825 & 24.0 \\ \text { Diesel Hydrotreating } & 945 & 27.5 \\ \text { VGO Desulfurization } & 396 & 11.5 \\ \text { VGO Hydrocracking } & 115 & 3.3 \\ \text { Alkylation } & 239 & 6.9 \\ \text { C5/C6 Isomerization } & 153 & 4.4 \\ & & \\ & \end{array}$

PADD 3 (the U.S. Gulf Coast) contains 57 refineries at the present time and accounts for about 46 percent of the refinery capacity in the U.S., making it the country's major refining district. Its large, complex refineries produce products to supply PADD 1 (East Coast) and 2 (Midwest) markets, as well as PADD 3 markets. Its smaller facilities are generally located at inland locations and focus on supplying local markets that are remote from the region's major pipelines. In addition, 10 of the region's smaller refineries are devoted to the production of specialty products, such as solvents, asphalt and lubricants.

The region's 26 largest refineries, each having a capacity greater than 100 thousand BPD, account for 83 percent of the region's refining capacity and are considered to be most representative of its refineries. Table 6.4 presents the combined capacities in 2001 of major process units at these 26 refineries, which have an average refinery capacity of 246 thousand BPCD.

All of the region's 26 largest refineries have catalytic reforming and fluid catalytic cracking (FCC) units, and 19 have delayed coking and VGO hydrotreating units. In addition, 12 of these refineries include VGO hydrocracking units and 8 of them have resid hydroprocessing units. On average, these 26 large PADD 3 refineries have configurations that are more complex than the national averages, with above average concentrations of FCC, coking, alkylation and hydrocraking capacity. 
Table 6.4 PADD 3 Process Unit Capacities, 2001

Thousand Barrels Per Calendar Day

\begin{tabular}{|c|c|c|}
\hline & Industry Total ${ }^{1}$ & Percent $^{2}$ \\
\hline Crude Distillation & 6,409 & \\
\hline Vacuum Distillation & 3,190 & 49.8 \\
\hline Coking & 941 & 14.7 \\
\hline Cat Cracking (FCC) & 2,389 & 37.3 \\
\hline Cat Reforming & 1,459 & 22.8 \\
\hline Diesel Hydrotreating & 1,308 & 20.4 \\
\hline VGO Desulfurization & 983 & 15.3 \\
\hline VGO Hydrocracking & 434 & 6.8 \\
\hline Resid Hydrocracking/Desulfurization & 498 & 7.8 \\
\hline Alkylation & 468 & 7.3 \\
\hline C5/C6 Isomerization & 188 & 2.9 \\
\hline
\end{tabular}

PADD 4 (the Rocky Mountain region) contains 14 refineries at the present time and accounts for only 3 percent of the refinery capacity in the U.S. Its refineries are concentrated in the East Range (Denver/southern Wyoming), Salt Lake City and Billings, Montana. The region is defined by its low population density, which results in smaller refineries and relatively high product distribution costs.

Table 6.5 presents the combined capacities in 2001 of major process units at the region's refineries. The region's refineries have an average refinery capacity of 38 thousand BPCD and its largest refineries have a capacity of 62 thousand BPD. Relative to the national average refinery configuration, PADD 4 refineries have similar FCC and reforming capacities, but below average coking and hydrocracking. 


\section{Table 6.5 PADD 4 Process Unit Capacities, 2001 Thousand Barrels Per Calendar Day}

Industry Total Percent ${ }^{1}$

$\begin{array}{lrr}\text { Crude Distillation } & 529 & \\ \text { Vacuum Distillation } & 214 & 40.5 \\ \text { Coking } & 42 & 7.9 \\ \text { Cat Cracking (FCC) } & 172 & 32.6 \\ \text { Cat Reforming } & 118 & 22.2 \\ \text { Diesel Hydrotreating } & 162 & 30.6 \\ \text { VGO Desulfurization } & 57 & 10.7 \\ \text { VGO Hydrocracking } & 5 & 0.9 \\ \text { Alkylation } & 37 & 7.0 \\ \text { C5/C6 Isomerization } & 5 & 0.9 \\ \text { Asphalt } & 44 & 8.4 \\ & & \\ & \end{array}$

The region's remoteness and its limited product pipeline connections to major refining centers provide physical and economic barriers that afford protection to PADD 4's smaller refineries from competition in surrounding regions.

PADD 5 (the West Coast) contains 35 refineries at the present time and accounts for about 19 percent of the refinery capacity in the United States. Its refineries are concentrated in the Los Angeles, San Francisco and Seattle areas.

The region's 23 largest refineries, each having a capacity greater than 40 thousand BPD, account for 95 percent of the region's refining capacity and are considered to be most representative of its refineries. Thirteen of these larger refineries are in California, with Washington, Alaska and Hawaii having 5, 3 and 2 of these refineries, respectively. Most of the region's smaller refineries are devoted to the production of asphalt. Table 6.6 presents the combined capacities in 2001 of major process units at all refineries in PADD 5. Relative to the national average refinery configuration, PADD 5 refineries on average have significantly lower FCC and reforming capacity, but significantly higher coking and hydrocracking capacity. 


\section{Table 6.6 PADD 5 Refinery Process Unit Capacities, 2001} Thousand Barrels Per Calendar Day

$\begin{array}{lrr} & \begin{array}{r}\text { Industry Total } \\ \text { Percent }\end{array} \\ \text { Crude Distillation } & 3,157 & \\ \text { Vacuum Distillation } & 1,451 & 46.0 \\ \text { Coking } & 605 & 19.2 \\ \text { Cat Cracking (FCC) } & 783 & 24.8 \\ \text { Cat Reforming } & 555 & 17.6 \\ \text { Diesel Hydrotreating } & 647 & 20.5 \\ \text { VGO Desulfurization } & 463 & 14.7 \\ \text { VGO Hydrocracking } & 579 & 18.3 \\ \text { Alkylation } & 179 & 5.7 \\ \text { C5/C6 Isomerization } & 106 & 3.4\end{array}$

${ }^{1}$ Percent of Crude Distillation Capacity

The process unit configurations of PADD 5 refineries outside of California generally include less fuel oil upgrading capabilities and do not include the additional processing facilities needed to produce CARB diesel and gasoline with their more stringent specifications. The high cetane number of FT diesel is expected to make it an attractive blendstock for a California refinery and result in higher values for FT diesel in California than in other parts of PADD 5.

California's 13 largest refineries have catalytic reforming and fluid catalytic cracking (FCC) units and only two of them do not have coking and VGO hydrocracking units. These refineries have an average refinery capacity of 146 thousand BPCD. Table 6.7 presents the combined capacities in 2001 of major process units at all California refineries.

Table 6.7 California Refinery Process Unit Capacities, 2001 Thousand Barrels Per Calendar Day

$\begin{array}{lrr} & \begin{array}{l}\text { Industry Total } \\ \text { Crude Distillation }\end{array} & \text { Percent }{ }^{1} \\ \text { Vacuum Distillation } & 2,012 & \\ \text { Coking } & 1,098 & 54.6 \\ \text { Cat Cracking (FCC) } & 478 & 23.8 \\ \text { Cat Reforming } & 634 & 31.5 \\ \text { Diesel Hydrotreating } & 393 & 19.5 \\ \text { VGO Desulfurization } & 529 & 26.3 \\ \text { VGO Hydrocracking } & 463 & 23.0 \\ \text { Alkylation } & 493 & 24.5 \\ \text { C5/C6 Isomerization } & 147 & 7.3 \\ & 100 & 5.0 \\ { }^{1} \text { Percent of Crude Distillation Capacity } & & \\ & & \end{array}$




\subsection{FOREIGN BASED TRADE}

The United States has historically been a significant importer of petroleum products. As shown in Figure 7.1 andFigure 7.2, total product imports have averaged about 2 million barrels per day between 1970 and 1998, or about 12 percent of consumption of total refined products. Reflecting shifts in the domestic demand mix as well as changes in the ability of the domestic refining industry to meet domestic needs, the level and mix of product imports has varied considerably over the last 20 years. Thus, while in the 1970s the import mix was dominated by imports of residual fuels, by the early 1990s, imports of "clean" products (gasoline, jet fuel and diesel/heating oils) had become a higher percentage of total product imports. Product imports are expected to increase marginally over the next 20 years, reflecting the combined impact of the following factors:

- U.S. refining capacity is expected to increase about 1 percent per year, via capacity creep of existing refineries

- Projected demand for U.S. refined products is expected to grow about 1.1 percent per year, only slightly higher than the rate of growth in domestic refining capacity

- Availability of suitable quality refined products from outside the United States may become constrained as U.S. quality standards become increasingly severe

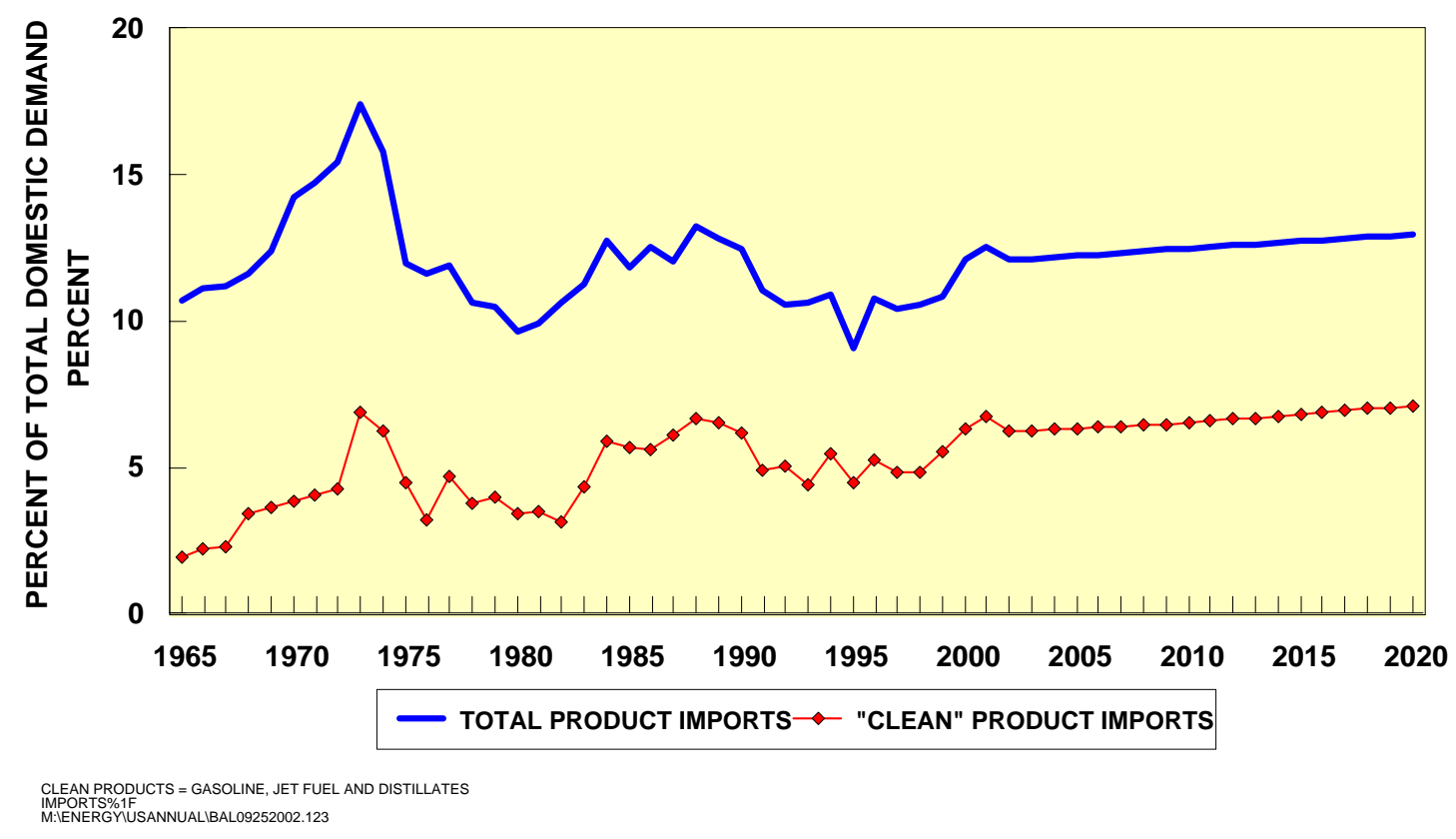

Figure 7.1 Import Exposure of The United States Refining Industry - Percent Of Demand 


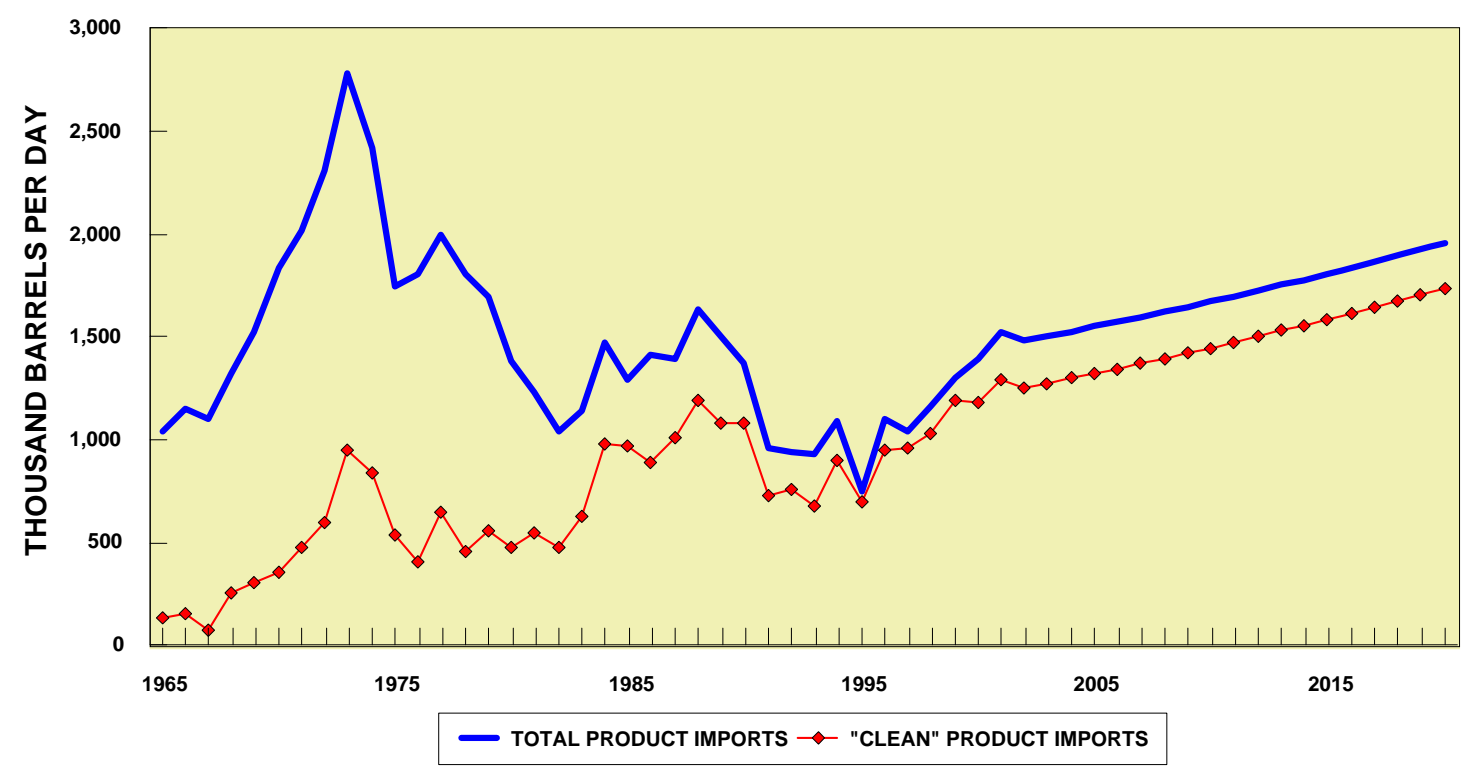

CHART 24

M:IENERGYIUSANNUALIBAL09252002.123

Figure 7.2 Import Exposure Of The United States Refining Industry

\subsection{EXPORTS}

Historically, United States trade in petroleum products has been dominated by imports, with a much lower level of exports. While the flow of products into the country continues to be far higher than the volumes that are exported, a clear trend has been established in which the volume of exports has grown relative to imports. Thus, as shown in Figure 7.3, while in the 1970s exports averaged about 1-2 percent of product consumption, during the 1990s exports increased to the 5-6 percent range. 


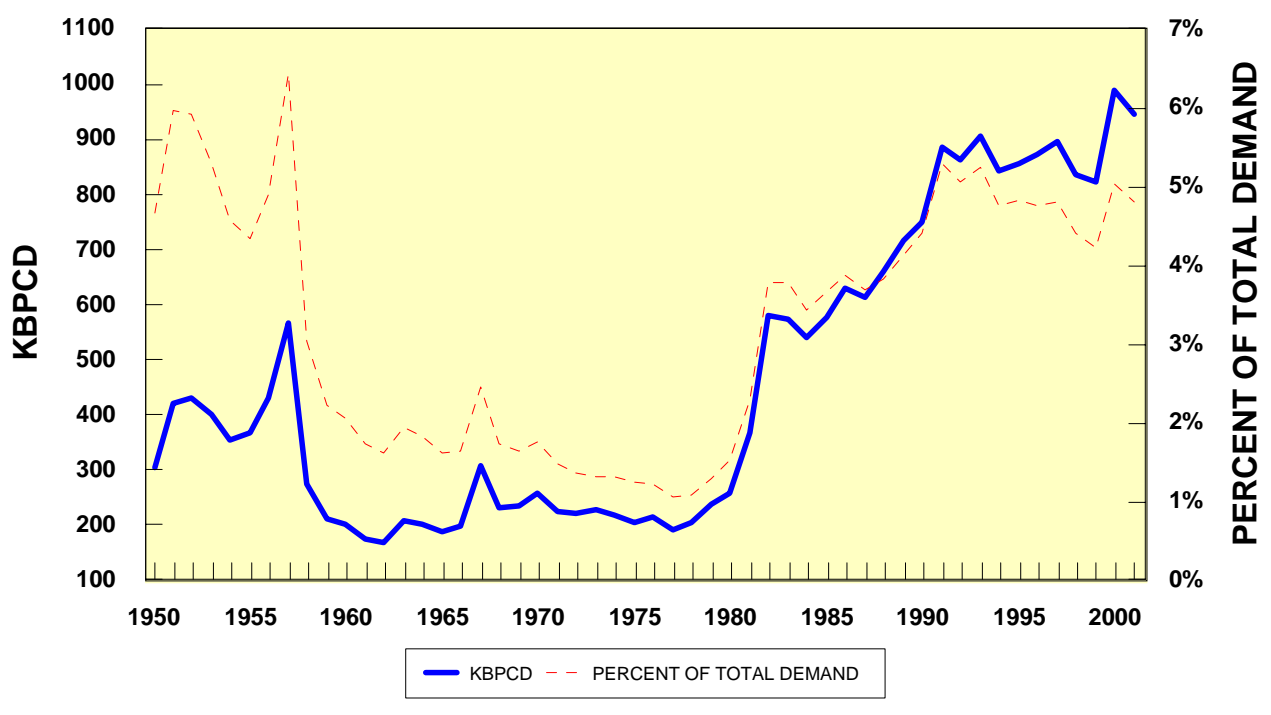

CHART M:ENERGUSANNUALBALL09252002.123

Figure 7.3 Product Exports Of The United States Refining Industry

There are a number of reasons for the rapid growth in export volumes. These include:

- Growth in domestic environmental regulations, which directionally have increased the number of product grades of gasoline and middle distillates. As this has occurred, the accompanying increase in complexity of product transport and distribution systems has at times made it simpler or more economically attractive for refiners to export products

- A growing linkage between regional markets, which has resulted in United States refiners becoming more comfortable with the opportunities presented by foreign export markets.

The major export destinations for United States product exports are Mexico, Japan, and Canada, which as a group account for over 45 percent of total exports of petroleum products.

An important trend over this period has been the significant change in the mix of exported products. Thus exports of major finished products (gasoline, jet fuel, distillate and residual fuel) have risen from about 10 percent of total exports in the 1970s to over 50 percent in the 1990s.

\subsection{U.S. PADD TRADE WITH FOREIGN SOURCES}

Figure 7.4 provides a breakdown by PADD of the distribution of foreign sourced imports of major refined products (gasoline, jet fuel, distillates and residual fuel). As indicated, PADD 1 receives over 80 percent of total foreign-sourced product imports, with about 9 percent each coming into PADDs 3 and 5. The interior of the country, PADDs 2 and 4, receives very little foreign-sourced product imports. 


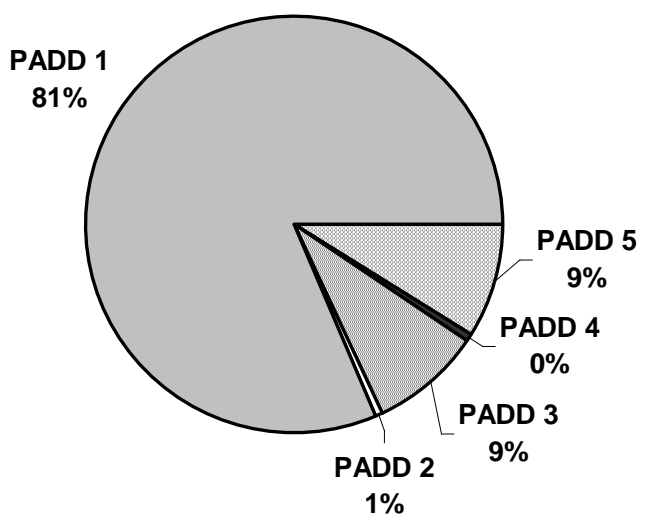

U:|2002Q4100072.005.11|DatalExcel filesI[figures for report 4.xls]Figure 7.4

Figure 7.4 Distribution Of Foreign Sourced Product Imports To The U.S. (Major Products Only) - 2001

Sources of imported petroleum products are profiled in Table 7.1. As indicated, on a national basis the following countries are the primary source of product supply: Canada, U.S. Virgin Islands, Algeria and Venezuela. A breakdown of historical and forecast trade by PADD region is presented in Table 7.2 to Table 7.6 for PADDs 1-5 respectively. 


\section{Table 7.1 Profile of United States Refined Product Import Sources (All Products) - 2001} Thousand Barrels Per Day

\begin{tabular}{|c|c|c|c|c|c|c|c|c|}
\hline \multicolumn{3}{|c|}{ NATIONAL } & \multicolumn{3}{|c|}{ PADD 1} & \multicolumn{3}{|c|}{ PADD 2} \\
\hline \multirow[b]{2}{*}{ Canada } & \multicolumn{2}{|c|}{$\begin{array}{l}\text { Percent } \\
\text { of Total }\end{array}$} & & \multicolumn{2}{|r|}{$\begin{array}{l}\text { Percent } \\
\text { of Total }\end{array}$} & & \multicolumn{2}{|r|}{$\begin{array}{l}\text { Percent } \\
\text { of Total }\end{array}$} \\
\hline & 473 & $19 \%$ & Canada & 286 & $19 \%$ & Canada & 115 & $99 \%$ \\
\hline Virgin Islands, U.S. & 268 & $11 \%$ & Virgin Islands, U.S. & 254 & $17 \%$ & Italy & 1 & $1 \%$ \\
\hline Algeria & 267 & $11 \%$ & Venezuela & 212 & $14 \%$ & & & \\
\hline Venezuela & 262 & $10 \%$ & Algeria & 69 & $5 \%$ & & & \\
\hline Russia & 90 & $4 \%$ & Brazil & 64 & $4 \%$ & & & \\
\hline Netherlands Antilles & 81 & $3 \%$ & United Kingdom & 59 & $4 \%$ & & & \\
\hline United Kingdom & 80 & $3 \%$ & Russia & 53 & $4 \%$ & & & \\
\hline Other & 75 & $3 \%$ & Other & 46 & $3 \%$ & & & \\
\hline Brazil & 69 & $3 \%$ & Netherlands Antilles & 38 & $3 \%$ & & & \\
\hline Others & 877 & $35 \%$ & Others & 409 & $27 \%$ & & & \\
\hline \multirow[t]{2}{*}{ Total } & 2,542 & & Total & 1,490 & & Total & 116 & \\
\hline & & & Percent National & $59 \%$ & & Percent National & $5 \%$ & \\
\hline \multicolumn{2}{|c|}{ PADD 3} & & \multicolumn{3}{|c|}{ PADD 4} & \multicolumn{3}{|c|}{ PADD 5} \\
\hline & & $\begin{array}{l}\text { ercent } \\
\text { Total }\end{array}$ & & & $\begin{array}{l}\text { Percent } \\
\text { of Total }\end{array}$ & & & $\begin{array}{l}\text { Percent } \\
\text { of Total }\end{array}$ \\
\hline Algeria & 188 & $29 \%$ & Canada & 21 & $100 \%$ & Korea, Republic of & 50 & $19 \%$ \\
\hline Netherlands Antilles & 42 & $6 \%$ & & & & Canada & 39 & $15 \%$ \\
\hline Mexico & 40 & $6 \%$ & & & & Saudi Arabia & 23 & $9 \%$ \\
\hline Venezuela & 35 & $5 \%$ & & & & Malaysia & 20 & $8 \%$ \\
\hline Norway & 35 & $5 \%$ & & & & Singapore & 18 & $7 \%$ \\
\hline Russia & 35 & $5 \%$ & & & & Venezuela & 16 & $6 \%$ \\
\hline Belgium & 29 & $4 \%$ & & & & Japan & 11 & $4 \%$ \\
\hline Nigeria & 21 & $3 \%$ & & & & Other & 10 & $4 \%$ \\
\hline Germany, FR & 20 & $3 \%$ & & & & Algeria & 9 & $3 \%$ \\
\hline Others & 209 & $32 \%$ & & & & Others & 62 & $24 \%$ \\
\hline Total & 654 & & Total & 21 & & Total & 258 & \\
\hline Percent National & $26 \%$ & & Percent National & $1 \%$ & & Percent National & $10 \%$ & \\
\hline
\end{tabular}

M:IENERGYIUSANNUALITrade 2001|[US Trade 2001.xIs]TABLES 


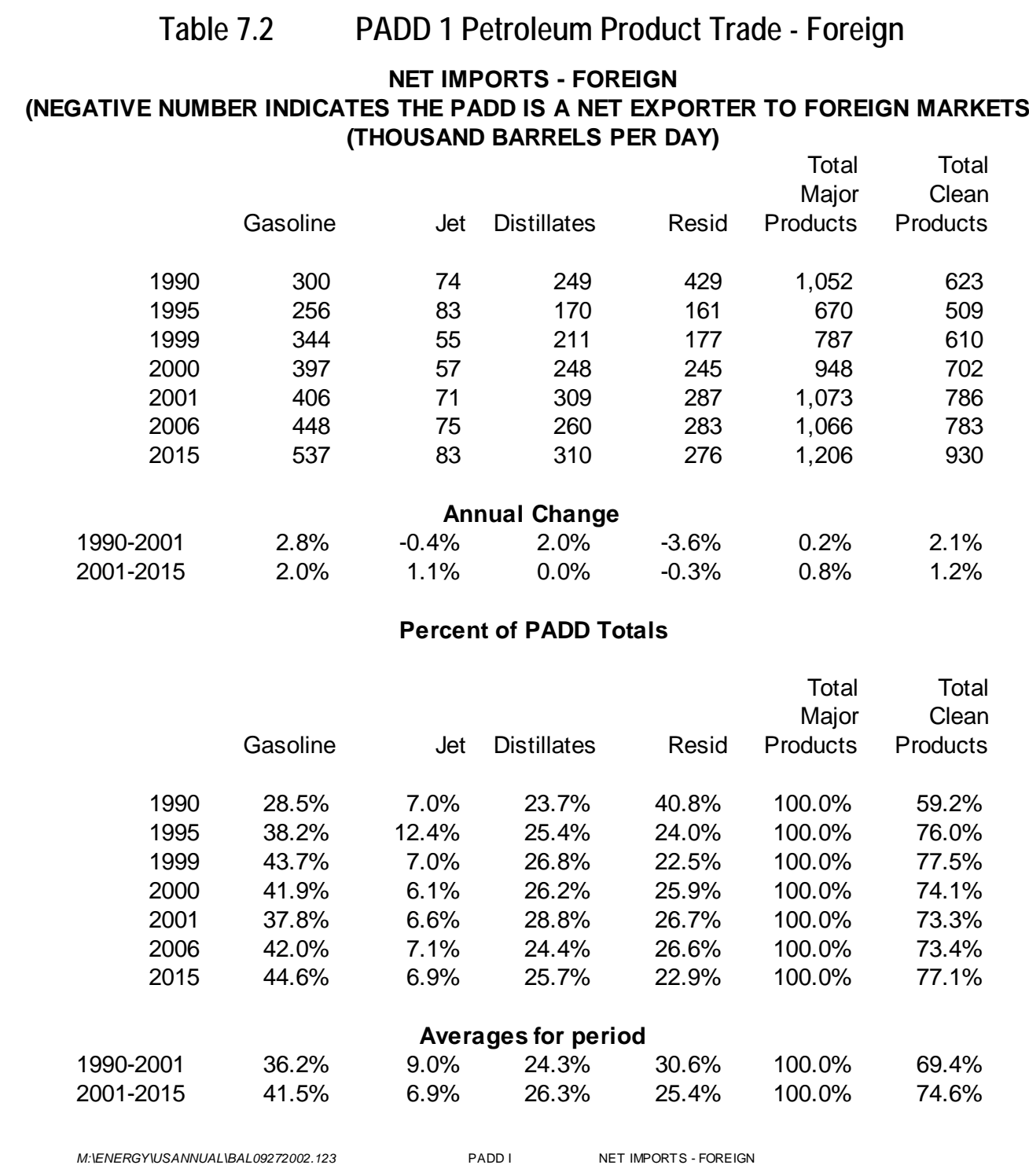




\begin{tabular}{|c|c|c|c|c|c|c|}
\hline \multicolumn{2}{|c|}{ Table 7.3} & \multicolumn{5}{|c|}{$\begin{array}{l}\text { PADD } 2 \text { Petroleum Product Trade - Foreign } \\
\text { NET IMPORTS - FOREIGN }\end{array}$} \\
\hline & Gasoline & Jet & Distillates & Resid & $\begin{array}{r}\text { Total } \\
\text { Major } \\
\text { Products }\end{array}$ & $\begin{array}{r}\text { Total } \\
\text { Clean } \\
\text { Products }\end{array}$ \\
\hline 1990 & 4 & 0 & 5 & 0 & 9 & 9 \\
\hline 1995 & 2 & 0 & 3 & (2) & 3 & 5 \\
\hline 1999 & 1 & (1) & 4 & 1 & 5 & 4 \\
\hline 2000 & 2 & 0 & 6 & 1 & 9 & 8 \\
\hline 2001 & 2 & (1) & 2 & 2 & 5 & 3 \\
\hline 2006 & 2 & (1) & 2 & 2 & 5 & 3 \\
\hline 2015 & 3 & (1) & 2 & 2 & 5 & 3 \\
\hline \multicolumn{7}{|c|}{ Annual Change } \\
\hline 1990-2001 & $-6.1 \%$ & $0.0 \%$ & $-8.0 \%$ & $0.0 \%$ & $-5.2 \%$ & $-9.5 \%$ \\
\hline 2001-2015 & $2.0 \%$ & $1.1 \%$ & $0.0 \%$ & $-0.3 \%$ & $0.6 \%$ & $1.1 \%$ \\
\hline \multicolumn{7}{|c|}{ Percent of PADD Totals } \\
\hline & Gasoline & Jet & Distillates & Resid & $\begin{array}{r}\text { Total } \\
\text { Major } \\
\text { Products }\end{array}$ & $\begin{array}{r}\text { Total } \\
\text { Clean } \\
\text { Products }\end{array}$ \\
\hline 1990 & $44.4 \%$ & $0.0 \%$ & $55.6 \%$ & $0.0 \%$ & $100.0 \%$ & $100.0 \%$ \\
\hline 1995 & $67.3 \%$ & $0.0 \%$ & $101.0 \%$ & $-68.4 \%$ & $100.0 \%$ & $168.4 \%$ \\
\hline 1999 & $22.2 \%$ & $-22.2 \%$ & $88.8 \%$ & $11.2 \%$ & $100.0 \%$ & $88.8 \%$ \\
\hline 2000 & $22.5 \%$ & $0.0 \%$ & $67.4 \%$ & $10.2 \%$ & $100.0 \%$ & $89.8 \%$ \\
\hline 2001 & $40.0 \%$ & $-20.0 \%$ & $40.0 \%$ & $40.0 \%$ & $100.0 \%$ & $60.0 \%$ \\
\hline 2006 & $46.0 \%$ & $-22.2 \%$ & $35.1 \%$ & $41.1 \%$ & $100.0 \%$ & $58.9 \%$ \\
\hline 2015 & $48.9 \%$ & $-21.6 \%$ & $37.1 \%$ & $35.6 \%$ & $100.0 \%$ & $64.4 \%$ \\
\hline \multicolumn{7}{|c|}{ Averages for period } \\
\hline 1990-2001 & $38.0 \%$ & $0.0 \%$ & $75.8 \%$ & $-13.9 \%$ & $100.0 \%$ & $113.9 \%$ \\
\hline $2001-2015$ & $45.0 \%$ & $-21.2 \%$ & $37.4 \%$ & $38.9 \%$ & $100.0 \%$ & $61.1 \%$ \\
\hline
\end{tabular}




\begin{tabular}{|c|c|c|c|c|c|c|}
\hline \\
\hline \multicolumn{2}{|c|}{ Table 7.4} & DD $3 \mathrm{P}$ & etroleum & duct Tr & de - Fore & \\
\hline \multirow{2}{*}{\multicolumn{7}{|c|}{$\begin{array}{l}\text { NET IMPORTS - FOREIGN } \\
\text { (NEGATIVE NUMBER INDICATES THE PADD IS A NET EXPORTER TO FOREIGN MARKE } \\
\text { (THOUSAND BARRELS PER DAY) }\end{array}$}} \\
\hline & & & & & & \\
\hline & & & & & Total & Total \\
\hline & Gasoline & Jet & Distillates & Resid & Products & Products \\
\hline 1990 & (29) & (6) & $(70)$ & (25) & $(130)$ & (105) \\
\hline 1995 & (94) & (7) & (97) & (62) & (260) & (198) \\
\hline 1999 & $(100)$ & (18) & (85) & (37) & (240) & (203) \\
\hline 2000 & (123) & (18) & (98) & (20) & (259) & (239) \\
\hline 2001 & (98) & (14) & (48) & (45) & (205) & (160) \\
\hline 2006 & $(108)$ & (15) & (40) & (44) & (208) & (163) \\
\hline 2015 & (130) & (16) & (48) & (43) & (238) & (194) \\
\hline \multicolumn{7}{|c|}{ Annual Change } \\
\hline $1990-2001$ & $11.7 \%$ & $8.0 \%$ & $-3.4 \%$ & $5.5 \%$ & $4.2 \%$ & $3.9 \%$ \\
\hline $2001-2015$ & $2.0 \%$ & $1.1 \%$ & $0.0 \%$ & $-0.3 \%$ & $1.1 \%$ & $1.4 \%$ \\
\hline \multicolumn{7}{|c|}{ Percent of PADD Totals } \\
\hline & Gasoline & Jet & Distillates & Resid & $\begin{array}{r}\text { Total } \\
\text { Major } \\
\text { Products }\end{array}$ & $\begin{array}{r}\text { Total } \\
\text { Clean } \\
\text { Products }\end{array}$ \\
\hline 1990 & $22.3 \%$ & $4.6 \%$ & $53.8 \%$ & $19.2 \%$ & $100.0 \%$ & $80.8 \%$ \\
\hline 1995 & $36.1 \%$ & $2.7 \%$ & $37.3 \%$ & $24.0 \%$ & $100.0 \%$ & $76.0 \%$ \\
\hline 1999 & $41.7 \%$ & $7.5 \%$ & $35.4 \%$ & $15.4 \%$ & $100.0 \%$ & $84.6 \%$ \\
\hline 2000 & $47.4 \%$ & $6.9 \%$ & $37.8 \%$ & $7.9 \%$ & $100.0 \%$ & $92.1 \%$ \\
\hline 2001 & $47.8 \%$ & $6.8 \%$ & $23.4 \%$ & $22.0 \%$ & $100.0 \%$ & $78.0 \%$ \\
\hline 2006 & $52.0 \%$ & $7.2 \%$ & $19.4 \%$ & $21.4 \%$ & $100.0 \%$ & $78.6 \%$ \\
\hline 2015 & $54.6 \%$ & $6.9 \%$ & $20.3 \%$ & $18.2 \%$ & $100.0 \%$ & $81.8 \%$ \\
\hline \multicolumn{7}{|c|}{ Averages for period } \\
\hline $1990-2001$ & $34.3 \%$ & $6.2 \%$ & $43.8 \%$ & $15.7 \%$ & $100.0 \%$ & $84.3 \%$ \\
\hline 2001-2015 & $51.5 \%$ & $7.0 \%$ & $21.0 \%$ & $20.5 \%$ & $100.0 \%$ & $79.5 \%$ \\
\hline M:IENERGYIUSANNU & AL09272002.123 & & ADD 3 & TT - FOF & & \\
\hline
\end{tabular}




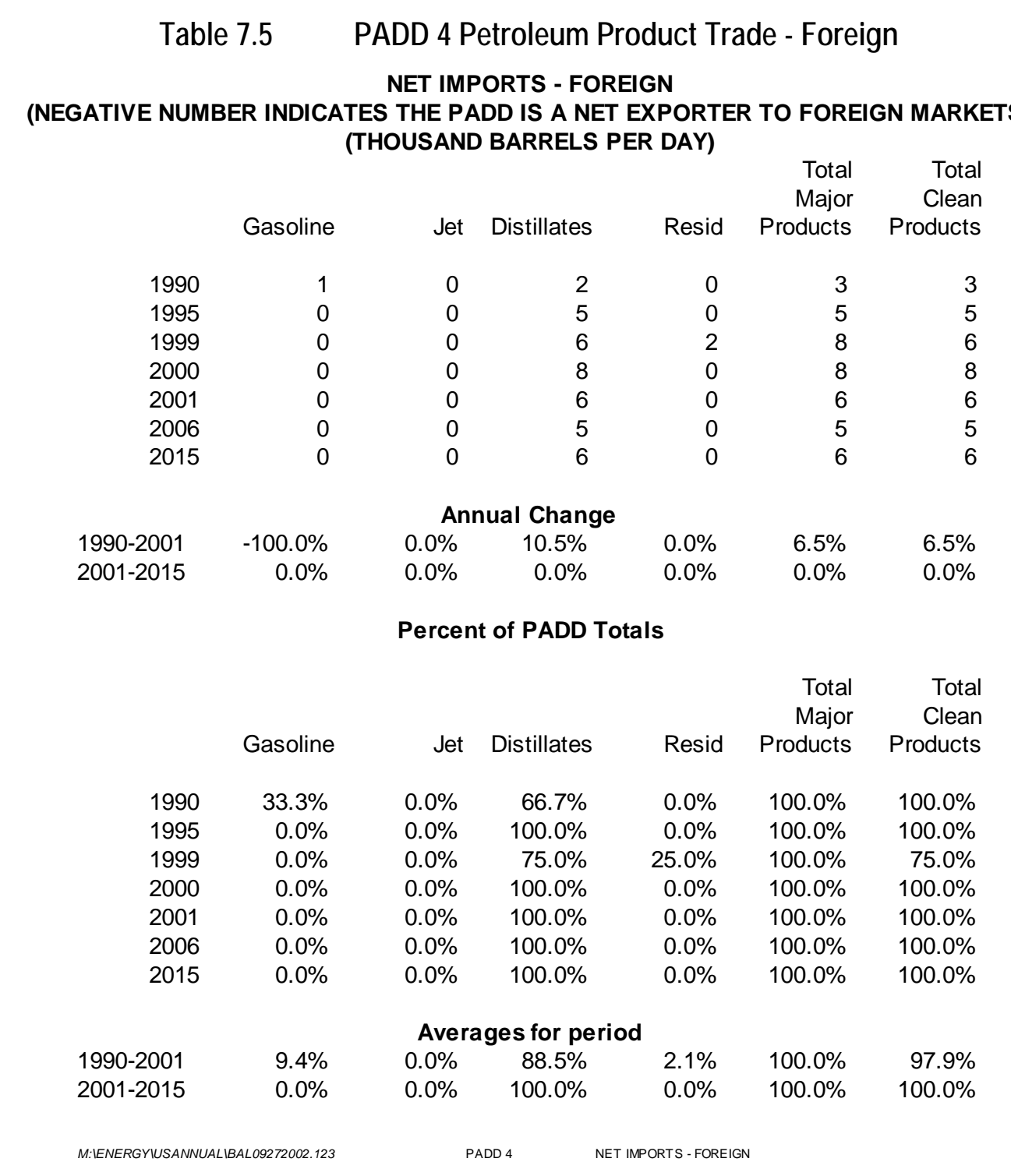




\begin{tabular}{|c|c|c|c|c|c|c|}
\hline Tabl & 7.6 & $\begin{array}{r}\text { PADD } 5 \text { P } \\
\text { NET IMP }\end{array}$ & $\begin{array}{l}\text { etroleum } \\
\text { ORTS - FO }\end{array}$ & $\begin{array}{l}\text { oduct Tr } \\
\text { EIGN }\end{array}$ & de - Fore & \\
\hline NEGATIVE NUM & R INDICA & $\begin{array}{l}\text { ES THE PA } \\
\text { THOUSAND }\end{array}$ & $\begin{array}{l}\text { DD IS A NE } \\
\text { BARRELS }\end{array}$ & $\begin{array}{l}\text { EXPORT } \\
\text { ER DAY) }\end{array}$ & TO FOF & N MARKET \\
\hline & Gasoline & Jet & Distillates & Resid & $\begin{array}{r}\text { Total } \\
\text { Major } \\
\text { Products }\end{array}$ & $\begin{array}{r}\text { Total } \\
\text { Clean } \\
\text { Products }\end{array}$ \\
\hline 1990 & 9 & (3) & (17) & (115) & (126) & (11) \\
\hline 1995 & (3) & 4 & (72) & $(45)$ & (116) & (71) \\
\hline 1999 & 26 & 60 & (47) & (34) & 5 & 39 \\
\hline 2000 & 8 & 91 & (42) & (16) & 41 & 57 \\
\hline 2001 & 7 & 69 & (60) & (10) & 6 & 16 \\
\hline 2006 & 8 & 73 & (50) & (10) & 21 & 31 \\
\hline 2015 & 9 & 81 & (60) & (10) & 20 & 30 \\
\hline & & Anr & ual Chang & & & \\
\hline $1990-2001$ & $-2.3 \%$ & $0.0 \%$ & $12.1 \%$ & $-19.9 \%$ & $0.0 \%$ & $0.0 \%$ \\
\hline 2001-2015 & $2.0 \%$ & $1.1 \%$ & $0.0 \%$ & $-0.3 \%$ & $9.0 \%$ & $4.5 \%$ \\
\hline & & Percen & of PADD & tals & & \\
\hline & Gasoline & Jet & Distillates & Resid & $\begin{array}{r}\text { Total } \\
\text { Major } \\
\text { Products }\end{array}$ & $\begin{array}{r}\text { Total } \\
\text { Clean } \\
\text { Products }\end{array}$ \\
\hline 1990 & $-7.1 \%$ & $2.4 \%$ & $13.5 \%$ & $91.3 \%$ & $100.0 \%$ & $8.7 \%$ \\
\hline 1995 & $2.6 \%$ & $-3.4 \%$ & $62.0 \%$ & $38.8 \%$ & $100.0 \%$ & $61.2 \%$ \\
\hline 1999 & $536.2 \%$ & $1237.3 \%$ & $-969.2 \%$ & $-704.2 \%$ & $100.0 \%$ & $804.2 \%$ \\
\hline 2000 & $19.5 \%$ & $221.8 \%$ & $-102.4 \%$ & $-38.9 \%$ & $100.0 \%$ & $138.9 \%$ \\
\hline 2001 & $116.7 \%$ & $1150.0 \%$ & $-1000.0 \%$ & $-166.7 \%$ & $100.0 \%$ & $266.7 \%$ \\
\hline 2006 & $37.2 \%$ & $353.8 \%$ & $-243.4 \%$ & $-47.6 \%$ & $100.0 \%$ & $147.6 \%$ \\
\hline 2015 & $46.2 \%$ & $401.7 \%$ & $-299.9 \%$ & $-48.0 \%$ & $100.0 \%$ & $148.0 \%$ \\
\hline & & Avera & ges for pe & & & \\
\hline 1990-2001 & $62.1 \%$ & $212.2 \%$ & $-138.2 \%$ & $-36.1 \%$ & $100.0 \%$ & $136.1 \%$ \\
\hline 2001-2015 & $66.7 \%$ & $635.2 \%$ & $-514.4 \%$ & $-87.4 \%$ & $100.0 \%$ & $187.4 \%$ \\
\hline
\end{tabular}




\subsection{U.S. INTER-PADD TRADE}

Figure 7.5 provides a breakdown by PADD of the distribution of domestically sourced imports of major refined products (gasoline, jet fuel, distillates and residual fuel) supplied from other PADD regions. As indicated, PADD 1 receives about 70 percent of product imports, most of which is supplied from PADD 3. PADD 2 receives about 25 percent of domestically sourced supplies, also supplied largely from PADD 3. PADDs 4 and 5, reflecting their geographic isolation, have limited supply links to the rest of the country. PADD 3, reflecting its major production surplus position, receives very little supply from other parts of the country.

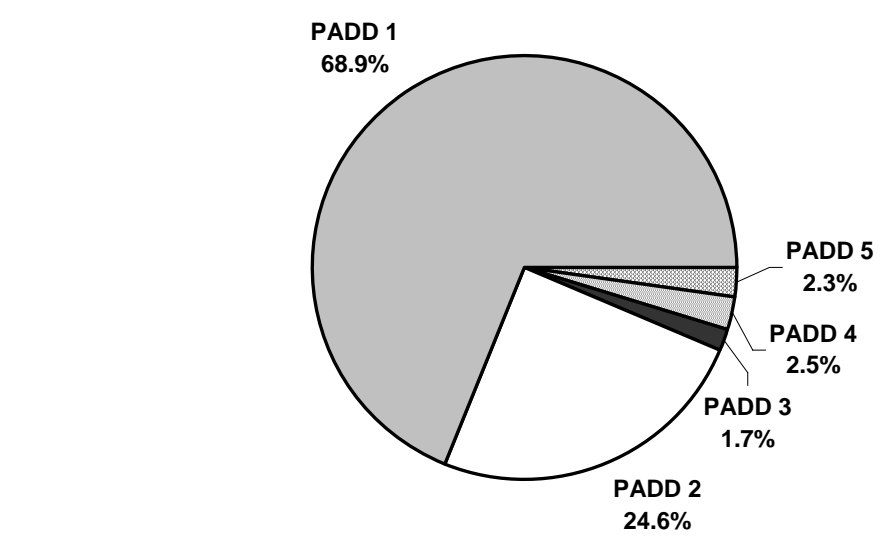

U:|2002Q4100072.005.11|DatalExcel files|[figures for report 4.xIs]GRAPHS

Figure 7.5 Distribution of Major Products Received From Other Padds - 2001

A breakdown of historical and forecast trade by PADD region is presented in Table 7.7 to Table 7.11 for PADDs 1-5 respectively. 


\begin{tabular}{|c|c|c|c|c|c|c|}
\hline \\
\hline Table & \multicolumn{6}{|c|}{ PADD 1 Petroleum Product Trade : Inter-PADD } \\
\hline \multicolumn{7}{|c|}{$\begin{array}{l}\text { NET IMPORTS - DOMESTIC } \\
\text { TES THE PADD IS A NET EXPOF }\end{array}$} \\
\hline \multicolumn{7}{|c|}{ (THOUSAND BARRELS PER DAY) } \\
\hline & & & & & $\begin{array}{r}\text { Total } \\
\text { Major }\end{array}$ & $\begin{array}{l}\text { Total } \\
\text { Clean }\end{array}$ \\
\hline & Gasoline & Jet & Distillates & Resid & Products & Products \\
\hline 1990 & 1,438 & 353 & 549 & 26 & 2,366 & 2,340 \\
\hline 1995 & 1,556 & 388 & 587 & 51 & 2,582 & 2,531 \\
\hline 1999 & 1,600 & 427 & 601 & 44 & 2,672 & 2,628 \\
\hline 2000 & 1,582 & 433 & 634 & 46 & 2,695 & 2,649 \\
\hline 2001 & 1,615 & 436 & 630 & 18 & 2,699 & 2,681 \\
\hline 2006 & 1,688 & 453 & 745 & 15 & 2,901 & 2,886 \\
\hline 2015 & 1,852 & 494 & 840 & 2 & 3,188 & 3,186 \\
\hline \multicolumn{7}{|c|}{ Annual Change } \\
\hline 1990-2001 & $1.1 \%$ & $1.9 \%$ & $1.3 \%$ & $-3.1 \%$ & $1.2 \%$ & $1.2 \%$ \\
\hline $2001-2015$ & $1.0 \%$ & $0.9 \%$ & $2.1 \%$ & $-13.3 \%$ & $1.2 \%$ & $1.2 \%$ \\
\hline \multicolumn{7}{|c|}{ Percent of PADD Totals } \\
\hline & Gasoline & Jet & Distillates & Resid & $\begin{array}{r}\text { Total } \\
\text { Major } \\
\text { Products }\end{array}$ & $\begin{array}{r}\text { Total } \\
\text { Clean } \\
\text { Products }\end{array}$ \\
\hline 1990 & $60.8 \%$ & $14.9 \%$ & $23.2 \%$ & $1.1 \%$ & $100.0 \%$ & $98.9 \%$ \\
\hline 1995 & $60.3 \%$ & $15.0 \%$ & $22.7 \%$ & $2.0 \%$ & $100.0 \%$ & $98.0 \%$ \\
\hline 1999 & $59.9 \%$ & $16.0 \%$ & $22.5 \%$ & $1.7 \%$ & $100.0 \%$ & $98.3 \%$ \\
\hline 2000 & $58.7 \%$ & $16.1 \%$ & $23.5 \%$ & $1.7 \%$ & $100.0 \%$ & $98.3 \%$ \\
\hline 2001 & $59.8 \%$ & $16.2 \%$ & $23.3 \%$ & $0.7 \%$ & $100.0 \%$ & $99.3 \%$ \\
\hline 2006 & $58.2 \%$ & $15.6 \%$ & $25.7 \%$ & $0.5 \%$ & $100.0 \%$ & $99.5 \%$ \\
\hline 2015 & $58.1 \%$ & $15.5 \%$ & $26.3 \%$ & $0.1 \%$ & $100.0 \%$ & $99.9 \%$ \\
\hline \multicolumn{7}{|c|}{ Averages for period } \\
\hline $1990-2001$ & $59.7 \%$ & $15.2 \%$ & $23.7 \%$ & $1.4 \%$ & $100.0 \%$ & $98.6 \%$ \\
\hline 2001-2015 & $58.7 \%$ & $15.8 \%$ & $25.1 \%$ & $0.4 \%$ & $100.0 \%$ & $99.6 \%$ \\
\hline M:IENERGY & 272002.123 & & IDD I & RTS - DOI & & \\
\hline
\end{tabular}




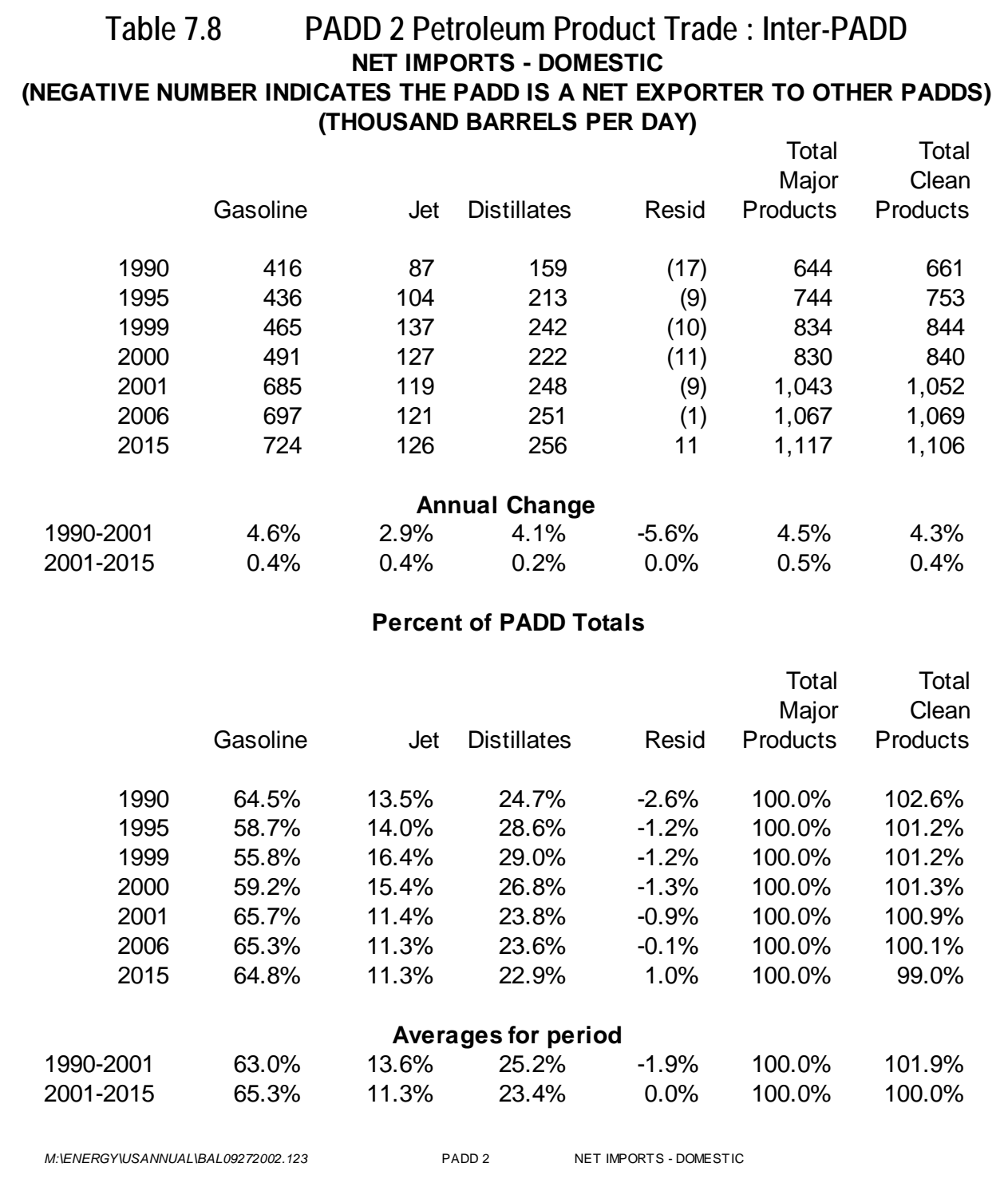




\section{Table 7.9 PADD 3 Petroleum Product Trade : Inter-PADD}

\begin{tabular}{|c|c|c|c|c|c|c|}
\hline \multicolumn{7}{|c|}{$\begin{array}{l}\text { NET IMPORTS - DOMESTIC } \\
\text { (NEGATIVE NUMBER INDICATES THE PADD IS A NET EXPORTER TO OTHER PADDS) } \\
\text { (THOUSAND BARRELS PER DAY) }\end{array}$} \\
\hline & Gasoline & Jet & Distillates & Resid & $\begin{array}{r}\text { Total } \\
\text { Major } \\
\text { Products }\end{array}$ & $\begin{array}{r}\text { Total } \\
\text { Clean } \\
\text { Products }\end{array}$ \\
\hline 1990 & $(1,899)$ & (468) & (714) & (9) & $(3,090)$ & $(3,081)$ \\
\hline 1995 & $(2,056)$ & (533) & (820) & (42) & $(3,450)$ & $(3,409)$ \\
\hline 1999 & $(2,168)$ & (616) & (874) & (34) & $(3,692)$ & $(3,658)$ \\
\hline 2000 & $(2,166)$ & (608) & (891) & (35) & $(3,700)$ & $(3,665)$ \\
\hline 2001 & $(2,142)$ & (598) & (967) & (18) & $(3,725)$ & $(3,707)$ \\
\hline 2006 & $(2,283)$ & (633) & $(1,048)$ & (19) & $(3,984)$ & $(3,965)$ \\
\hline 2015 & $(2,592)$ & (703) & $(1,213)$ & (29) & $(4,538)$ & $(4,509)$ \\
\hline \multicolumn{7}{|c|}{ Annual Change } \\
\hline 1990-2001 & $1.1 \%$ & $2.3 \%$ & $2.8 \%$ & $6.6 \%$ & $1.7 \%$ & $1.7 \%$ \\
\hline 2001-2015 & $1.4 \%$ & $1.2 \%$ & $1.6 \%$ & $3.5 \%$ & $1.4 \%$ & $1.4 \%$ \\
\hline \multicolumn{7}{|c|}{ Percent of PADD Totals } \\
\hline & Gasoline & Jet & Distillates & Resid & $\begin{array}{r}\text { Total } \\
\text { Major } \\
\text { Products }\end{array}$ & $\begin{array}{r}\text { Total } \\
\text { Clean } \\
\text { Products }\end{array}$ \\
\hline 1990 & $61.5 \%$ & $15.1 \%$ & $23.1 \%$ & $0.3 \%$ & $100.0 \%$ & $99.7 \%$ \\
\hline 1995 & $59.6 \%$ & $15.4 \%$ & $23.8 \%$ & $1.2 \%$ & $100.0 \%$ & $98.8 \%$ \\
\hline 1999 & $58.7 \%$ & $16.7 \%$ & $23.7 \%$ & $0.9 \%$ & $100.0 \%$ & $99.1 \%$ \\
\hline 2000 & $58.5 \%$ & $16.4 \%$ & $24.1 \%$ & $0.9 \%$ & $100.0 \%$ & $99.1 \%$ \\
\hline 2001 & $57.5 \%$ & $16.1 \%$ & $26.0 \%$ & $0.5 \%$ & $100.0 \%$ & $99.5 \%$ \\
\hline 2006 & $57.3 \%$ & $15.9 \%$ & $26.3 \%$ & $0.5 \%$ & $100.0 \%$ & $99.5 \%$ \\
\hline 2015 & $57.1 \%$ & $15.5 \%$ & $26.7 \%$ & $0.6 \%$ & $100.0 \%$ & $99.4 \%$ \\
\hline \multicolumn{7}{|c|}{ Averages for period } \\
\hline 1990-2001 & $60.0 \%$ & $15.4 \%$ & $23.9 \%$ & $0.7 \%$ & $100.0 \%$ & $99.3 \%$ \\
\hline 2001-2015 & $57.3 \%$ & $15.8 \%$ & $26.3 \%$ & $0.5 \%$ & $100.0 \%$ & $99.5 \%$ \\
\hline
\end{tabular}




\begin{tabular}{|c|c|c|c|c|c|c|}
\hline \multicolumn{2}{|c|}{ Table 7.10} & \multicolumn{5}{|c|}{ PADD 4 Petroleum Product Trade : Inter-PADD } \\
\hline \multicolumn{7}{|c|}{$\begin{array}{c}\text { NET IMPORTS - DOMESTIC } \\
\text { (NEGATIVE NUMBER INDICATES THE PADD IS A NET EXPORTER TO OTHER PADDS) } \\
\text { (THOUSAND BARRELS PER DAY) }\end{array}$} \\
\hline & Gasoline & Jet & Distillates & Resid & $\begin{array}{r}\text { Total } \\
\text { Major } \\
\text { Products }\end{array}$ & $\begin{array}{r}\text { Total } \\
\text { Clean } \\
\text { Products }\end{array}$ \\
\hline 1990 & (14) & 9 & $(14)$ & 0 & $(20)$ & $(20)$ \\
\hline 1995 & 8 & 30 & 5 & 0 & 43 & 43 \\
\hline 1999 & 12 & 34 & 15 & 0 & 61 & 61 \\
\hline 2000 & 9 & 38 & 17 & 0 & 63 & 63 \\
\hline 2001 & 7 & 41 & 11 & 0 & 59 & 59 \\
\hline 2006 & 11 & 43 & 21 & 1 & 77 & 75 \\
\hline 2015 & 20 & 48 & 40 & 3 & 111 & 108 \\
\hline \multicolumn{7}{|c|}{ Annual Change } \\
\hline 1990-2001 & $0.0 \%$ & $14.7 \%$ & $0.0 \%$ & $0.0 \%$ & $0.0 \%$ & $0.0 \%$ \\
\hline $2001-2015$ & $7.8 \%$ & $1.1 \%$ & $9.6 \%$ & $0.0 \%$ & $4.6 \%$ & $4.4 \%$ \\
\hline \multicolumn{7}{|c|}{ Percent of PADD Totals } \\
\hline & Gasoline & Jet & Distillates & Resid & $\begin{array}{r}\text { Total } \\
\text { Major } \\
\text { Products }\end{array}$ & $\begin{array}{r}\text { Total } \\
\text { Clean } \\
\text { Products }\end{array}$ \\
\hline 1990 & $72.9 \%$ & $-46.5 \%$ & $73.6 \%$ & $-0.0 \%$ & $100.0 \%$ & $100.0 \%$ \\
\hline 1995 & $19.2 \%$ & $68.8 \%$ & $11.9 \%$ & $0.0 \%$ & $100.0 \%$ & $100.0 \%$ \\
\hline 1999 & $19.5 \%$ & $56.3 \%$ & $24.2 \%$ & $0.0 \%$ & $100.0 \%$ & $100.0 \%$ \\
\hline 2000 & $13.6 \%$ & $59.9 \%$ & $26.5 \%$ & $0.0 \%$ & $100.0 \%$ & $100.0 \%$ \\
\hline 2001 & $11.9 \%$ & $69.5 \%$ & $18.6 \%$ & $0.0 \%$ & $100.0 \%$ & $100.0 \%$ \\
\hline 2006 & $14.6 \%$ & $56.3 \%$ & $27.5 \%$ & $1.7 \%$ & $100.0 \%$ & $98.3 \%$ \\
\hline 2015 & $18.2 \%$ & $43.2 \%$ & $35.9 \%$ & $2.8 \%$ & $100.0 \%$ & $97.2 \%$ \\
\hline \multicolumn{7}{|c|}{ Averages for period } \\
\hline $1990-2001$ & $55.7 \%$ & $-208.3 \%$ & $252.7 \%$ & $0.0 \%$ & $100.0 \%$ & $100.0 \%$ \\
\hline $2001-2015$ & $14.9 \%$ & $56.3 \%$ & $27.3 \%$ & $1.5 \%$ & $100.0 \%$ & $98.5 \%$ \\
\hline
\end{tabular}


Table 7.11 PADD 5 Petroleum Product Trade : INTER-PADD NET IMPORTS - DOMESTIC

(NEGATIVE NUMBER INDICATES THE PADD IS A NET EXPORTER TO OTHER PADDS)

(THOUSAND BARRELS PER DAY)

$\begin{array}{rr}\text { Total } & \text { Total } \\ \text { Major } & \text { Clean }\end{array}$

\begin{tabular}{rrrrrrr} 
& Gasoline & Jet & Distillates & Resid & Products & Products \\
1990 & 60 & 19 & 21 & 0 & 100 & 100 \\
1995 & 55 & 12 & 15 & 0 & 82 & 82 \\
1999 & 86 & 13 & 17 & 0 & 116 & 116 \\
2000 & 84 & 10 & 18 & 0 & 112 & 112 \\
2001 & 122 & 13 & 18 & 0 & 153 & 153 \\
2006 & 122 & 14 & 11 & 0 & 147 & 147 \\
2015 & 125 & 22 & 19 & 0 & 166 & 166 \\
\multicolumn{7}{c}{ Annual Change } \\
$1990-2001$ & $6.7 \%$ & $-3.4 \%$ & $-1.3 \%$ & $0.0 \%$ & & \\
$2001-2015$ & $0.2 \%$ & $3.9 \%$ & $0.5 \%$ & $0.0 \%$ & $0.6 \%$ & $0.6 \%$
\end{tabular}

Percent of PADD Totals

\begin{tabular}{|c|c|c|c|c|c|}
\hline Gasoline & Jet & Distillates & Resid & $\begin{array}{r}\text { Total } \\
\text { Major } \\
\text { Products }\end{array}$ & $\begin{array}{r}\text { Total } \\
\text { Clean } \\
\text { Products }\end{array}$ \\
\hline $60.1 \%$ & $19.1 \%$ & $20.8 \%$ & $0.0 \%$ & $100.0 \%$ & $100.0 \%$ \\
\hline $67.7 \%$ & $14.1 \%$ & $18.2 \%$ & $0.0 \%$ & $100.0 \%$ & $100.0 \%$ \\
\hline $74.4 \%$ & $11.1 \%$ & $14.5 \%$ & $0.0 \%$ & $100.0 \%$ & $100.0 \%$ \\
\hline $74.9 \%$ & $8.9 \%$ & $16.2 \%$ & $0.0 \%$ & $100.0 \%$ & $100.0 \%$ \\
\hline $79.7 \%$ & $8.5 \%$ & $11.8 \%$ & $0.0 \%$ & $100.0 \%$ & $100.0 \%$ \\
\hline $83.3 \%$ & $9.4 \%$ & $7.3 \%$ & $0.0 \%$ & $100.0 \%$ & $100.0 \%$ \\
\hline $75.1 \%$ & $13.3 \%$ & $11.7 \%$ & $0.0 \%$ & $100.0 \%$ & $100.0 \%$ \\
\hline \multicolumn{6}{|c|}{ Averages for period } \\
\hline $69.4 \%$ & $13.8 \%$ & $16.8 \%$ & $-0.0 \%$ & $100.0 \%$ & $100.0 \%$ \\
\hline $79.4 \%$ & $10.4 \%$ & $10.2 \%$ & $0.0 \%$ & $100.0 \%$ & $100.0 \%$ \\
\hline
\end{tabular}




\subsection{SECTION 8.1 PETROLEUM DEMAND}

Total U.S. refined product demand is forecast to increase by 1.1 percent annually over the 20012015 period. This is somewhat lower than the 10 year historical average of 1.3 percent, and reflects the somewhat lower outlook for economic growth as well as potentially higher pricing of crude oil and products that is expected for the forecast period. Key drivers and assumptions behind these demand projections include:

- High gasoline demand growth during the 1990s was driven by a number of "step-change" factors, including the rapid growth in lower mileage Sport Utility Vehicles (SUVs) and the very strong economic expansion experienced in the United States during this period. The projected growth rate in gasoline demand of 1.1 percent annually assumes that there will be a modest increase in average vehicle fleet efficiency, but that alternativelypowered vehicles will not materially impact gasoline demand during the next 10 years

- Jet fuel consumption is expected to grow 0.8 percent per year, reflecting expected continuing gains in engine efficiency in the commercial air fleet as well as a negative step-change in use that has occurred due to the impact of September 11 attacks

- Limited growth in off-highway uses of middle distillates, in particular due to continued loss of the residential heating market to natural gas, will offset continued growth in onhighway diesel fuel. Combined growth in on-highway and off-highway uses is expected to average 1.3 percent annually

- $\quad$ Residual fuel oil use, after suffering a step-change reduction in demand between 1994 and 1995, has achieved demand in the 850-950 thousand barrels per day (KBPD) range through 2001. Future consumption is forecast to decline about 0.4 percent annually

- "Other products" consists of a wide range of relatively minor products, including gas liquids (ethane, propane, normal and iso-butane, and pentanes plus), asphalt, chemical feedstocks, petroleum coke, lubricants, waxes, kerosene and miscellaneous products. A number of these products, such as lubricants, and waxes, are very mature with limited growth potential. Others, in particular feedstock for chemical production, are expected to have high growth rates. On balance, this category of products is expected in grow about 1.4 percent annually, somewhat higher than overall petroleum demand growth

The current profile of geographic consumption by PADD for 2001 is shown in Figure 8.1. As shown, PADD 1 has the highest level of petroleum consumption, with about 36 percent of the national total. This is followed by PADD 2 with about 27 percent, and PADDs 3 and 5, each with about 16-17 percent. PADD 4, reflecting its very sparse population, accounts for about 3.5 percent of national demand. As indicated in Figure 8.2, this distribution of demand is very similar to the distribution of population within the United States, indicating a similar level of per capita consumption across the nation. 


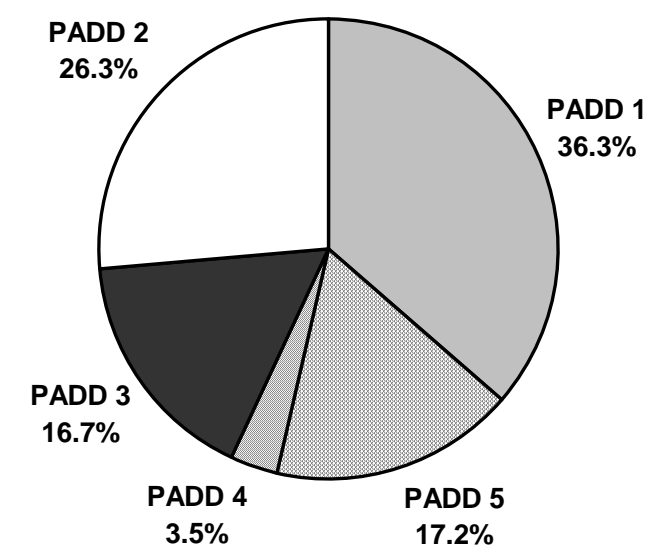

U:|2002Q4|00072.005.11|DatalExcel filesI[figures for report 4.xIs]GRAPHS

Figure 8.1 Geographic Profile Of United States Refined Product Demand - 2001

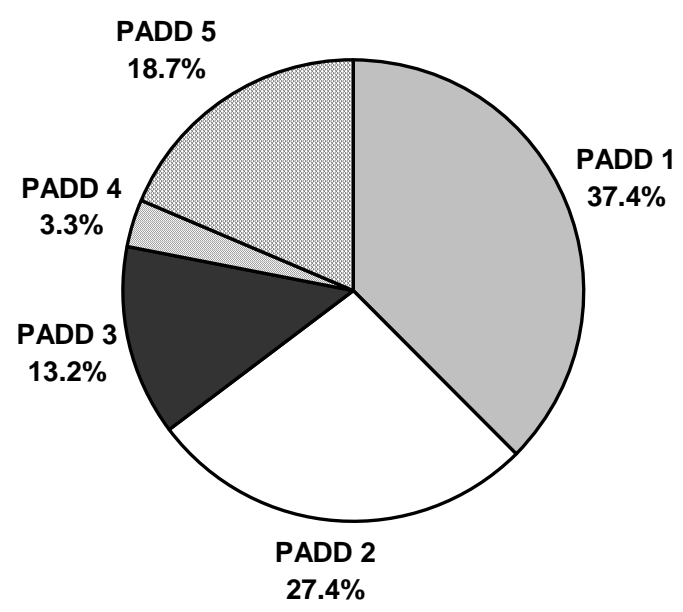

U:I2002Q4|00072.005.11|DatalExcel files|[figures for report 4.xIs]GRAPHS

Figure 8.2 Population Profile Of United States - 2001 
Future distribution of demand for refined petroleum products in the United States is expected to remain relatively stable, similar to historical performance.

\subsection{REFINED PRODUCT PRODUCTION}

Total domestic production of refined products in the United States will increase throughout the forecast period, with an average growth rate of about 1.1 percent per year, in line with average growth achieved over the previous 10 years. By 2015, refined product output is expected to reach 20.2 million bpd, up 16 percent from 17.3 million bpd in 2001. Consistent with the outlook for consumption, distillates and other products are expected to have the highest annual rate of production growth through 2015.

The current profile of geographic production of major refined products by PADD for 2001 is shown in Figure 8.3. As shown, PADD 3 has the highest level of petroleum production, with about 46 percent of the national total. This is followed by PADD 2 with about 21 percent, PADD 5 with 17.5 percent, and PADD 1 with 12 percent. PADD 4, reflecting its very sparse population, accounts for about 3.3 percent of national production.

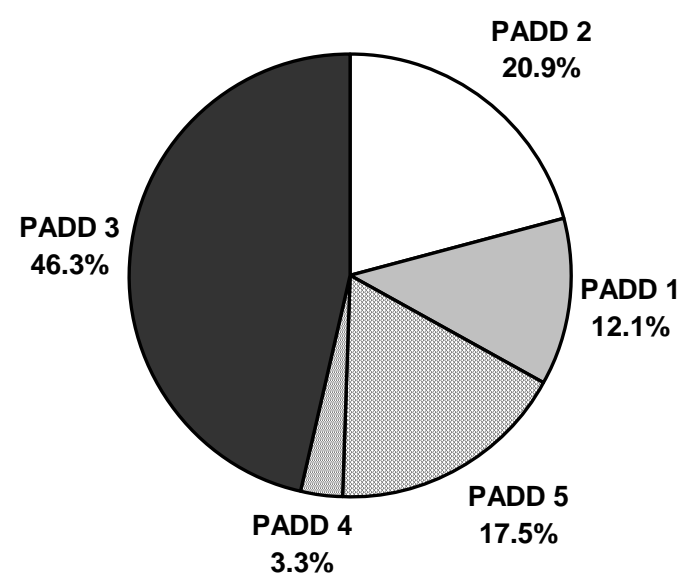

U:|2002Q4100072.005.11|DatalExcel filesl[figures for report 4.xls]GRAPHS

Figure 8.3 Geographic Profile Of United States Refined Product Production - 2001

Future distribution of demand for refined petroleum products in the United States is expected to remain relatively stable, similar to historical performance.

\subsection{CRUDE OIL QUALITY TRENDS}

The gravity of domestic and imported crude oils along with the composite average is shown in Figure 8.4 over the 1980 to 2001 period, and indicates a steady deterioration of quality over this 20 year time period. 


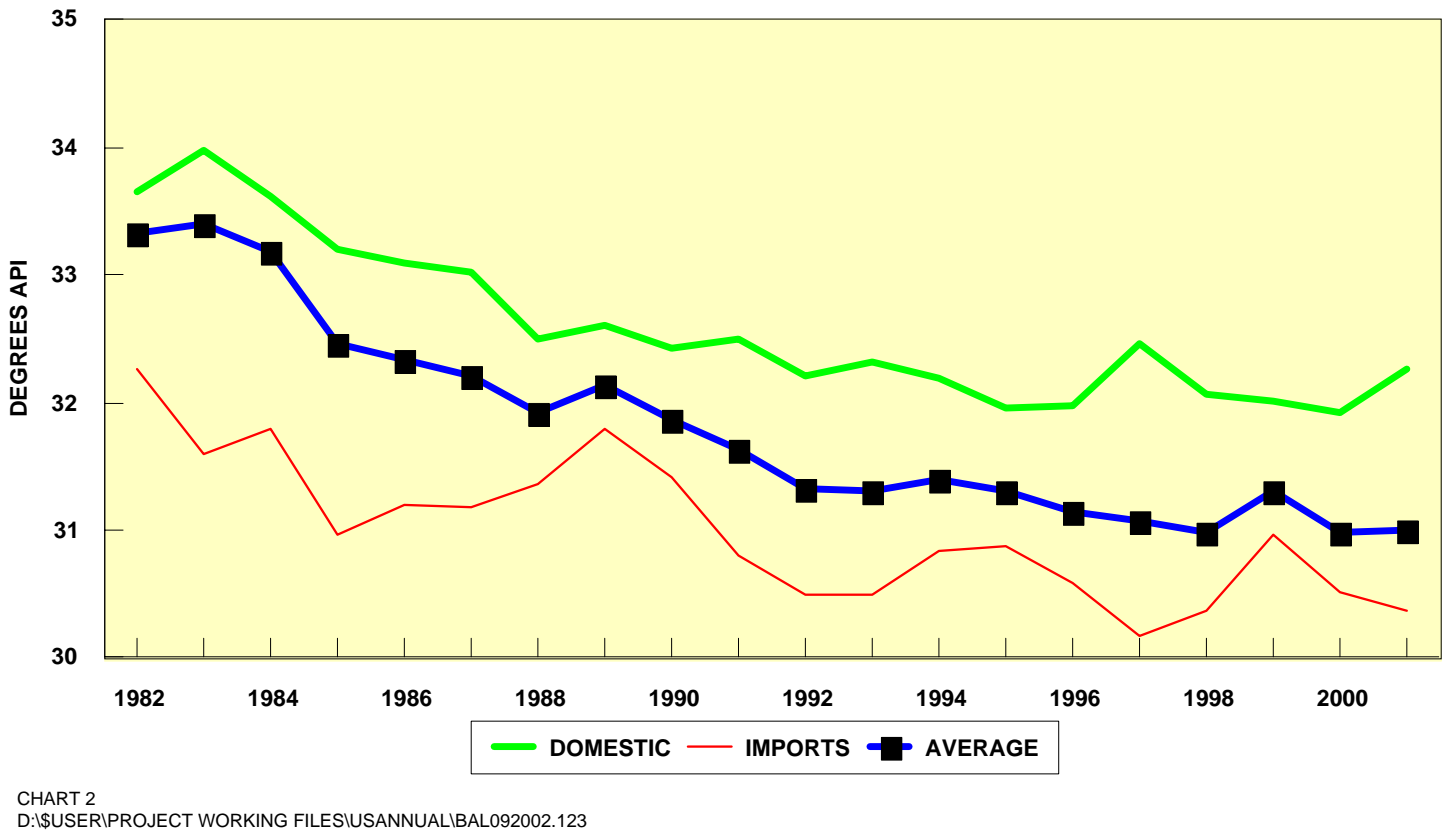

Figure 8.4 United States Crude Oil Quality Historical Gravity Trends

Average trends in crude sulfur levels are shown in Figure 8.5. As indicated, average composite crude oil sulfur levels rose from about 0.8 weight percent in 1980 to over 1.3 weight percent in 2001. Increased imports of heavy Canadian, Mexican and Venezuelan crudes have been the major underlying factors driving the long-term increase in crude oil sulfur levels. 


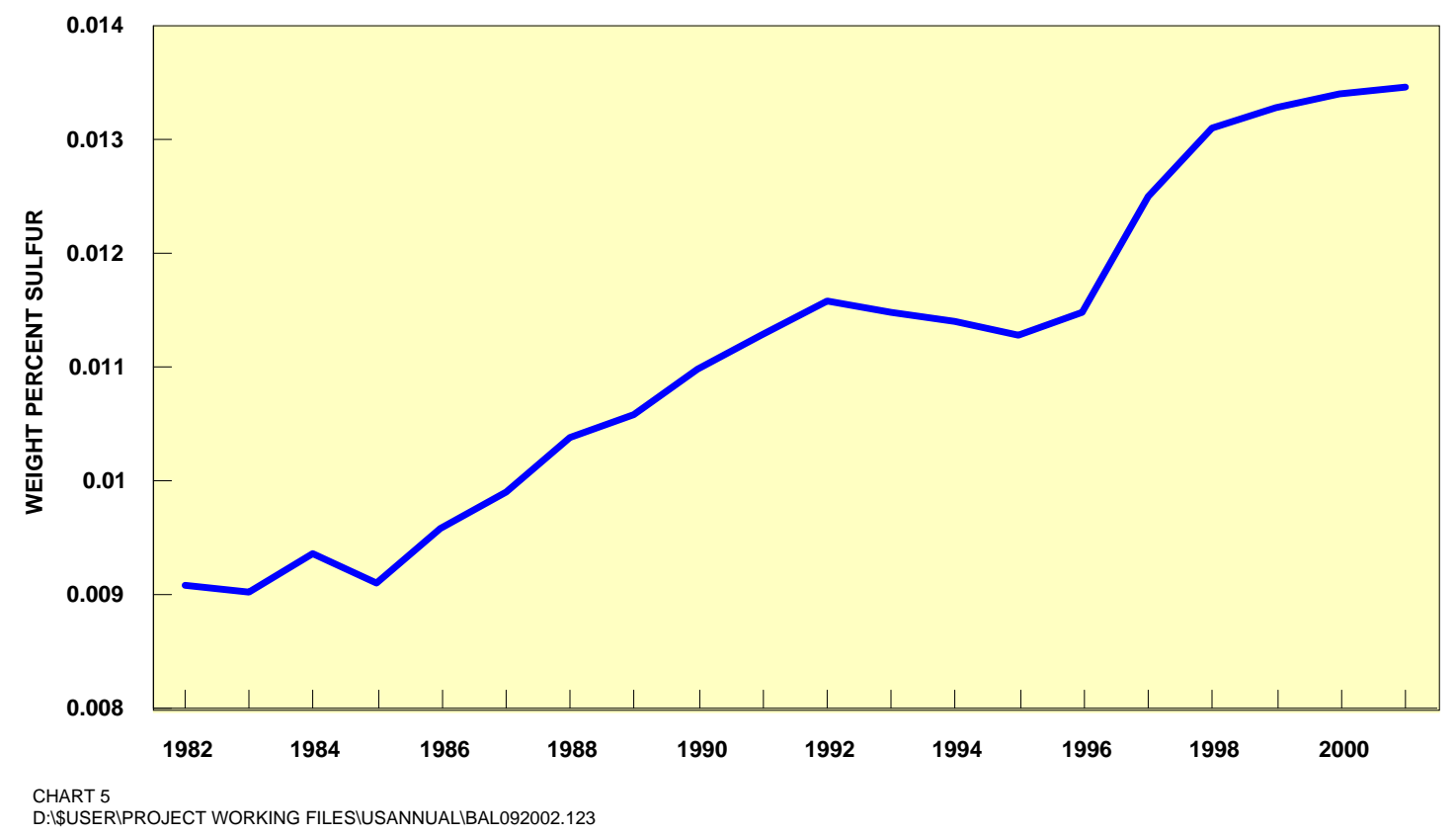

Figure 8.5 United States Crude Oil Quality Historical Trends In Sulfur Content

Average crude oil quality in the United States is forecast to continue to decline, becoming heavier and higher in sulfur content. Key assumptions behind this outlook include:

- Increased heavy offshore Gulf of Mexico crude production will contribute to a gradual decline in domestic crude oil quality, somewhat offset by a slowing in the rate of decline in Alaskan crude production

- Increased heavy, sour crude oil imports from Venezuela and Canada will be primarily responsible for the forecast heavying up of the crude oil import barrel and the resultant decline in composite crude oil slate quality

Crude oil quality by PADD varies considerably relative to the national averages. These differences are shown for crude oil gravity in Figure 8.6) and sulfur in Figure 8.7). 


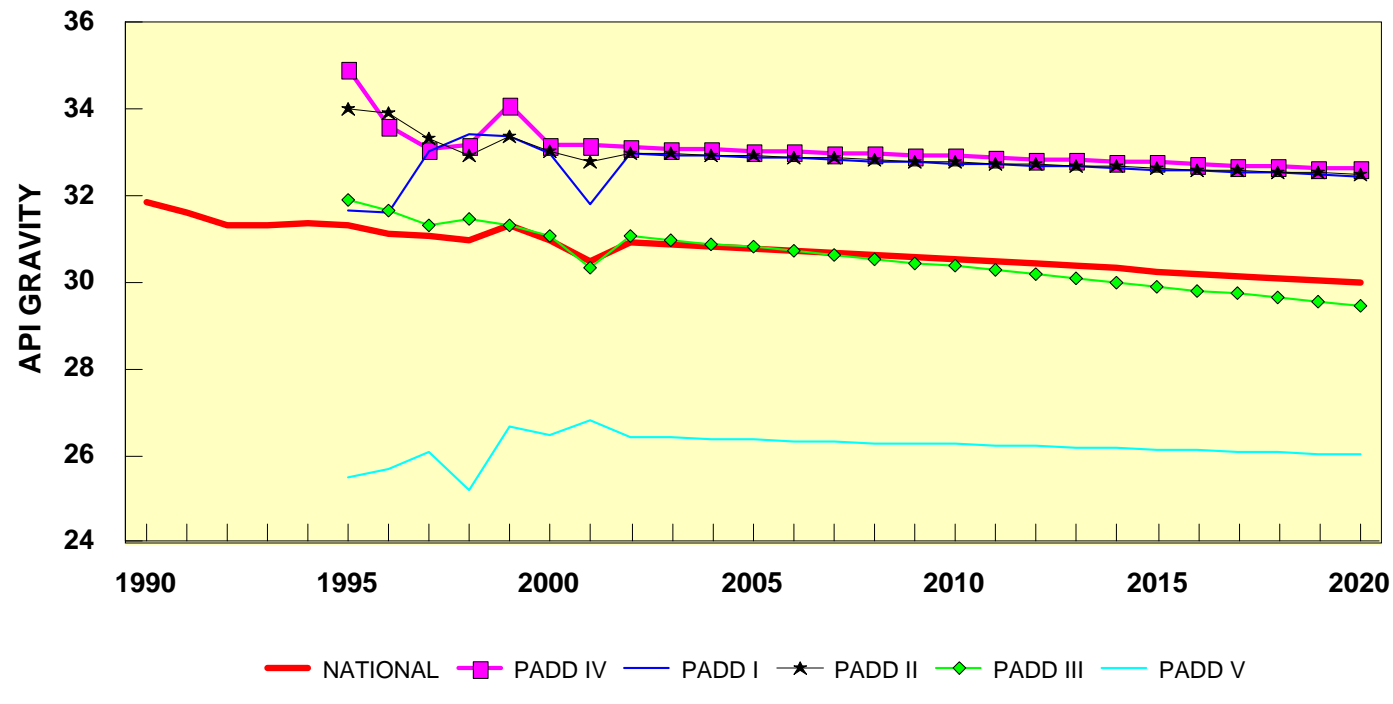

CHART 71
D:I\$USERIPROJECT WORKING FILESIUSANNUALIBAL09262002.123

Figure 8.6 Trends In United States Crude Oil Quality - Gravity

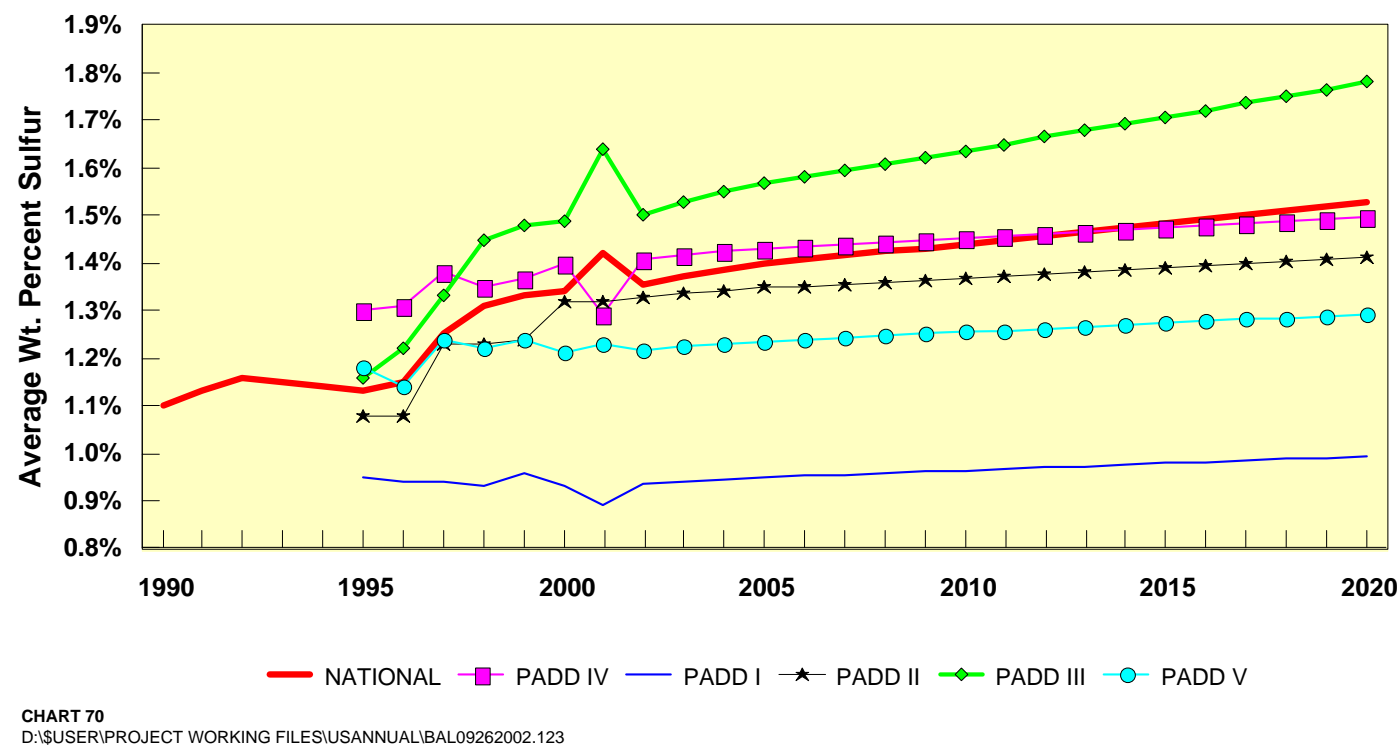

Figure 8.7 Trends In United States Crude Oil Quality - Sulfur

As indicated, crude oil quality in all PADDs is expected to follow national trends, i.e. average crude oil will become heavier and higher in sulfur content in all regions. It is expected that crude oil quality in PADD 3 will decline somewhat faster than in the other regions, reflecting the 
assumption that a disproportionate percentage of new investment in the United States refining industry will take place in expanding and enhancing the already dominant refining industry at the USGC. Such new investment will tend to allow processing of poorer quality crude oils, and the resulting crude oil slate that the USGC will thus decline somewhat faster than elsewhere in the country.

\subsection{REFINING INDUSTRY PROFILE}

The U.S. refining industry consists of about 150 operable refineries. Average processing capabilities have been on the rise since the 1980s. As shown in Figure 8.8, the number of operating refineries in the United States has steadily decreased during the 1990s, reflecting the combined impacts of generally low refining margins as well as industry consolidation. The average refinery size has increased steadily over the last 40 years, as the need to achieve economies of scale has reduced the competitiveness of smaller facilities.

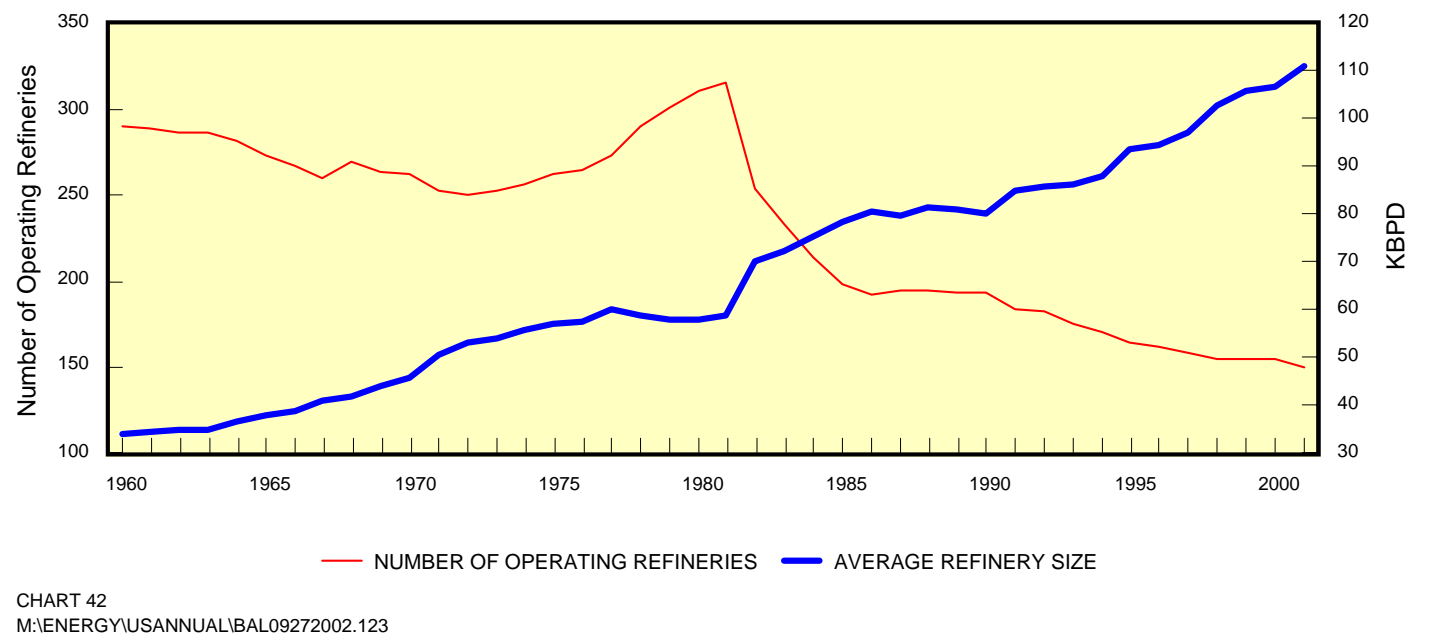

Figure 8.8 Trends In United States Refining

A profile of the historical and forecast refining configuration for the United States refining industry is presented in Table 8.1. Crude oil distillation capacity is forecast to increase by about 2.5 million barrels per day between 2001 and 2015, reflecting a 1 percent annual growth rate, which is considered a sustainable range of capacity creep for the domestic industry. Investment in downstream refining facilities, in particular hydrotreating, hydrocraking and coking, is expected to result in an increase in the percent of each of these units expressed as a percentage of crude oil distillation capacity. MTBE capacity in the United States is expected to be completely shut down by 2015. 


\section{Table 8.1 Profile of United States Refining Facilities}

(thousand barrels per day)

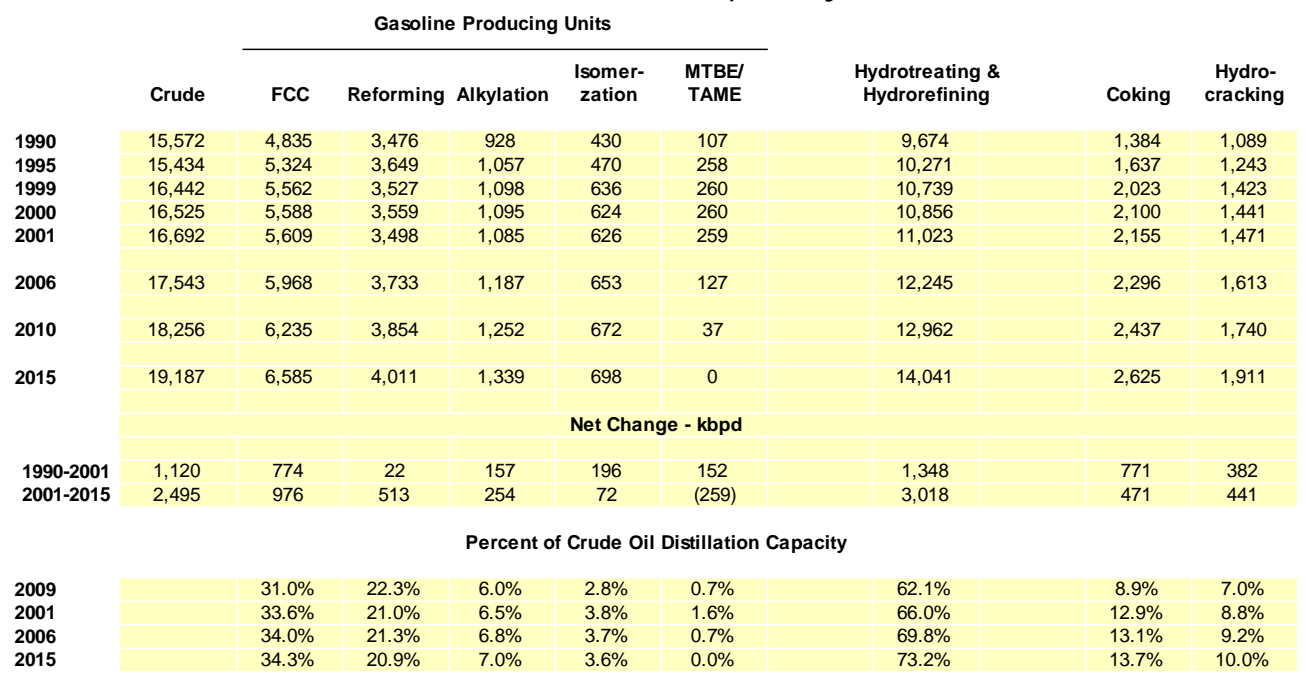

A breakdown of crude oil distillation capacity by PADD is provided in Figure 8.9. Refining capacity is highly concentrated in PADD 3, with about 46 percent of the national total. PADD 2 (21 percent) and PADD 5 (19 percent) have substantial refining industries. PADD 1 has relatively limited refining capacity relative to its level of consumption, and as a result is the country's primary importer of refined products. PADD 4, reflecting its sparse population and isolation, has limited refining capacity of about 3.5 percent of the national total, roughly in line with its consumption share.

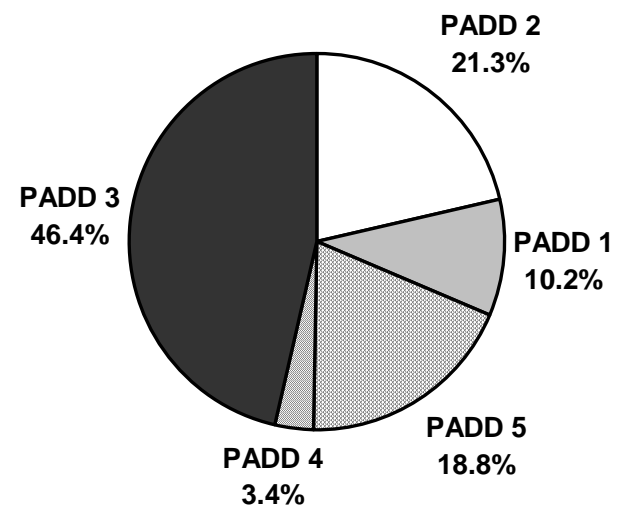

U:I2002Q4I00072.005.11|DatalExcel files|[figures for report 4.xIs]GRAPHS 


\section{Figure 8.9 Distribution Of United States Refining - 2001}

\subsection{PETROLEUM TRADE}

The United States has historically been a significant importer of petroleum products. As shown in Figure 8.10, total product imports have averaged about 2 million barrels per day between 1970 and 1998, or about 12 percent of consumption of total refined products. Product imports are expected to increase only marginally over the next 20 years, reflecting the combined impact of the following factors:

- U.S. refining capacity is expected to increase about 1 percent per year, via capacity creep of existing refineries

- $\quad$ Projected demand for U.S. refined products is expected to grow about 1.1 percent per year, only slightly higher than the rate of growth in domestic refining capacity

- Availability of suitable quality refined products from outside the United States may become constrained as U.S. quality standards become increasingly more stringent

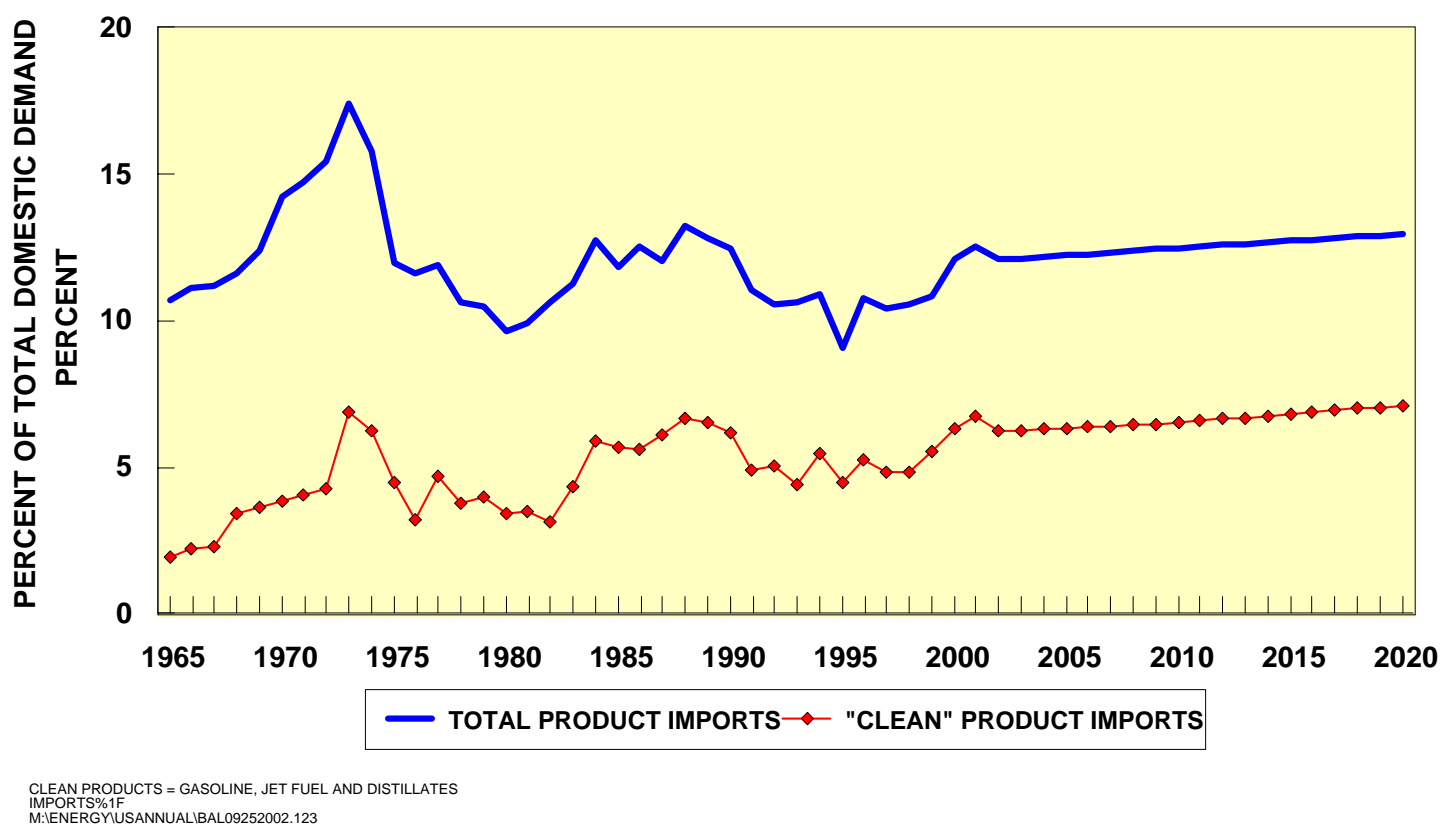

Figure 8.10 Import Exposure of The United States Refining Industry - Percent Of Demand

Figure 8.11 provides a breakdown by PADD of the distribution of foreign sourced imports of major refined products (gasoline, jet fuel, distillates and residual fuel). As indicated, PADD 1 receives over 80 percent of total foreign-sourced product imports, with about 9 percent each 
coming into PADDs 3 and 5. The interior of the country, PADDs 2 and 4, receives very little foreign-sourced product imports.

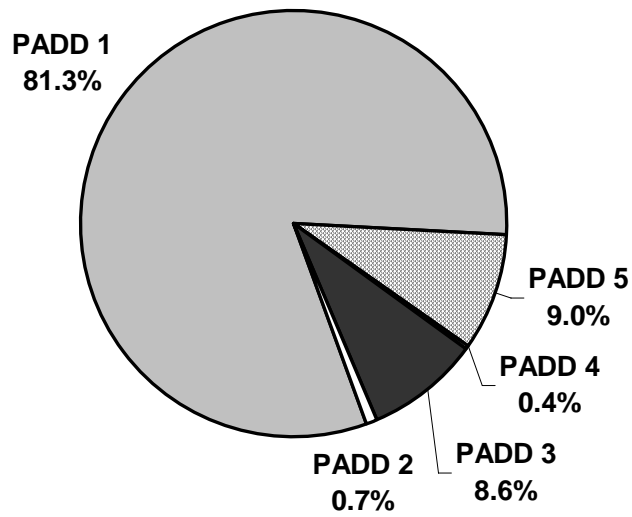

U:I2002Q4100072.005.11|DatalExcel files|[figures for report 4.xIs]GRAPHS

Figure 8.11 Distribution Of Foreign Sourced Product Imports To The U.S. (Major Products Only) - 2001

Figure 8.12 provides a breakdown by PADD of the distribution of domestically sourced imports of major refined products (gasoline, jet fuel, distillates and residual fuel) supplied from other PADD regions. As indicated, PADD 1 receives about 70 percent of product imports, most of which is supplied from PADD 3. PADD 2 receives about 25 percent of domestically sourced supplies, also supplied largely from PADD 3. PADDs 4 and 5, reflecting their geographic isolation, have limited supply links to the rest of the country. PADD 3, reflecting its major production surplus position, receives very little supply from other parts of the country. 


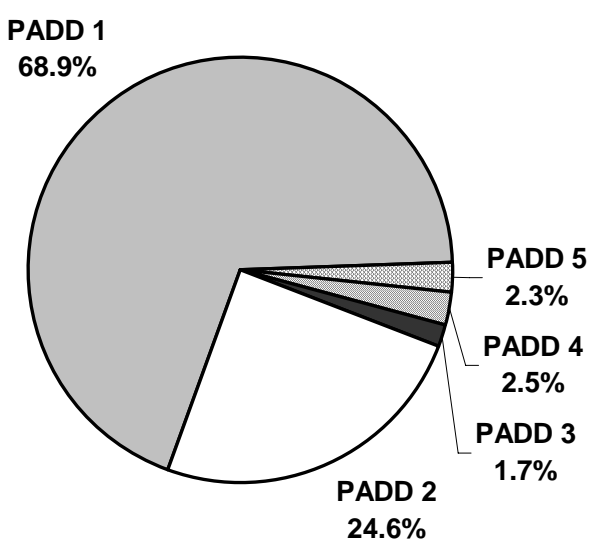

U:I2002Q4I00072.005.11|DatalExcel files|[figures for report 4.xIs]GRAPHS

Figure 8.12 Distribution Of Major Products Received From Other PADDS - 2001 


\section{Technology Evaluation of Selected Alternative Fuels \\ Market Study Report Section V}

Prepared For:

ConocoPhillips

Co-operative Agreement DE-FC26-01NT41098

\section{ConocoPhillips GNexant}




\title{
Technology Evaluation of Selected Alternative Fuels Market Study Report Section V
}

November 2002

\author{
Prepared For: \\ ConocoPhillips
}

\section{hNexant}

44 South Broadway, White Plains, New York 10601, USA

Tel: +1 9146090300 Fax: +1 9146090399 
Section

Page

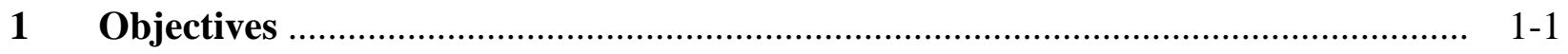

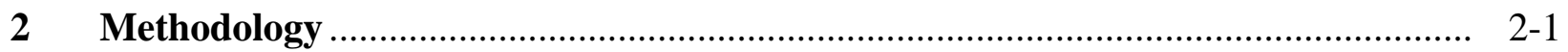

$2.1 \quad$ BASIC TECHNOLOGY ASSUMPTION …………........................................ 2-1

2.2 CAPITAL COST ASSUMPTIONS …………………………………........... 2-3

2.2.1 Inside Battery Limits Investment........................................................... 2-3

2.2.2 Outside Battery Limits Investment ...................................................... 2-4

2.2.3 Contractor Charges ............................................................................. 2-5

2.2.4 Project Contingency Allowance ………………................................... 2-5

2.2.5 Other Project Costs ......................................................................... 2-6

2.2.5.1 Startup/Commissioning Costs ............................................... 2- 2-6

2.2.5.2 Miscellaneous Owner's Costs ................................................ 2- 2-6

2.2.6 Working Capital............................................................................. 2-7

2.3 FIXED COST FACTORS, DEPRECIATION AND RETURN ON

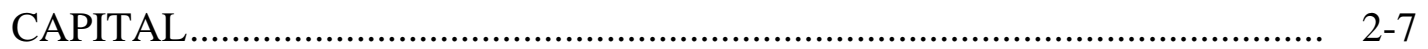
3

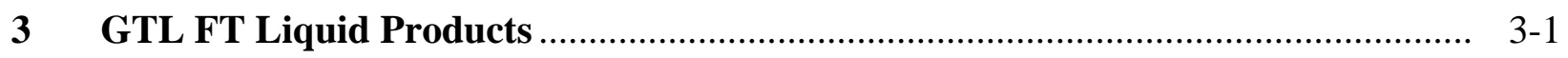

$3.1 \quad$ INTRODUCTION …………......................................................... $3-1$

3.1.1 2006 Commercially Demonstrated Process ............................................. 3-1

3.1.2 2015 Emerging Technology ................................................................. 3-1

$3.2 \quad$ FISCHER-TROPSCH CHEMISTRY ……………................................... $3-1$

3.3 PROCESS DESCRIPTION ………………......................................... 3-2

3.4 ECONOMIC ASSESSMENT …………………….................................. 3-4

3.4.1 Economic Assumptions ................................................................. 3-4

3.4.2 Feedstock and Utilities Pricing and Labor Costs ..................................... 3-7

3.4.3 Economics of Conservative Scenario .................................................... 3-8

3.4.3.1 Process Economics ........................................................... 3-8

3.4.3.2 Sensitivity Analysis............................................................. 3-12

3.4.3.3 Regional Economics............................................................. 3-18

3.4.3.4 Comparison between GTL and Conventional Refining .......... 3-27 
3.4.4 Economics of Aggressive Scenario ................................................. 3-32

3.4.4.1 Process Economics ........................................................ 3-32

3.4.4.2 Sensitivity Analysis....................................................... 3-36

3.4.4.3 Regional Economics...................................................... 3-41

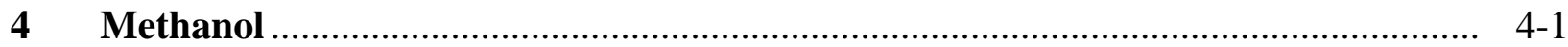

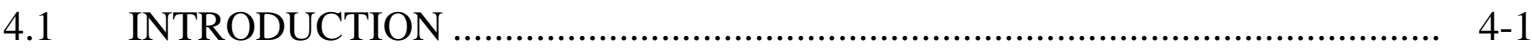

4.1.1 2006 Commercially Demonstrated Process ........................................ 4-1

4.1.2 2015 Emerging Technology ........................................................... 4-2

4.2 METHANOL CHEMISTRY …............................................................. $4-4$

4.3 PROCESS DESCRIPTION (LURGI MEGA METHANOL PROCESS) .......... 4-7

4.3.1 Process Technology ...................................................................... 4-7

4.3.2 Supply of Power and Oxygen ........................................................... 4-14

4.3.3 Feedstock Consumption............................................................. 4-14

$4.4 \quad$ ECONOMIC ASSESSMENT ............................................................... 4-14

4.4.1 Economic Assumptions ................................................................... 4-14

4.4.2 Feedstock and Utilities Pricing and Labor Costs ............................... 4-16

4.4.3 Economics of Conservative Scenario .............................................. 4-17

4.4.3.1 Process Economics ........................................................... 4-17

4.4.3.2 Sensitivity Analysis........................................................ 4-24

4.4.3.3 Regional Economics.......................................................... 4-27

4.4.3.4 Comparison Between Methanol and GTL ........................... 4-38

4.4.4 ECONOMICS OF AGGRESSIVE SCENARIO................... 4-41

4.4.4.1 Process Economics ...................................................... 4-41

4.4.4.2 Sensitivity Analysis........................................................... 4-45

4.4.4.3 Regional Economics.................................................... 4-52

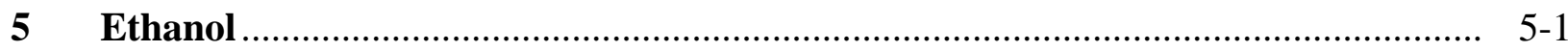

$5.1 \quad$ ETHANOL FROM BIOMASS ........................................................... $5-1$

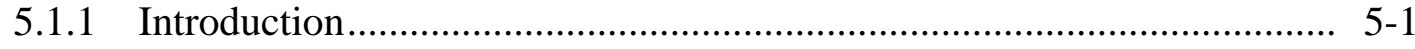

5.1.1.1 2006 Commercially Demonstrated Process .......................... 5-2

5.1.1.2 2015 Emerging Technology …......................................... 5-2

5.1.2 Design Parameters and Feedstock Characteristics............................... 5-2 
5.1.3 Process Description.................................................................. 5-4

5.1.3.1 Overview of Lignocellulosic Biomass to Ethanol Process .... 5-4

5.1.3.2 Pretreatment and Hydrolyzate Conditioning........................ 5-7

5.1.3.3 Simultaneous Saccharification and Co-Fermentation

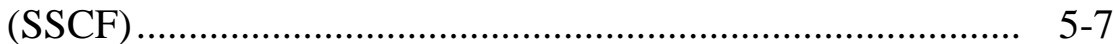

5.1.3.4 Enzyme Production ........................................................ $5-8$

5.1.3.5 Product Recovery (Distillation, Dehydration, and Evaporation) ............................................................... 5-8

5.1.4 Economic Assessment ................................................................. 5-9

5.1.4.1 Economic Assumptions .................................................... 5-9

5.1.4.2 Feedstock and Utilities Pricing and Labor Costs .................. 5-9

5.1.4.3 Process Economics ................................................................ 5-11

5.1.4.4 Sensitivity Analysis...................................................... 5-15

5.1.4.5 Comparative Economics .................................................... 5-19

5.2 ETHANOL FROM CORN …................................................................. 5-19

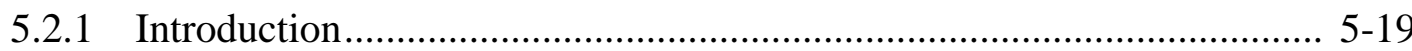

5.2.1.1 2006 Commercially Demonstrated Process .......................... 5-19

5.2.1.2 2015 Emerging Technology .............................................. 5-19

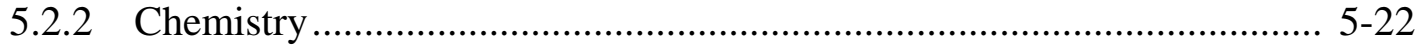

5.2 .3 Process Description................................................................... 5-22

5.2.3.1 Dry Milling....................................................................... 5-22

5.2.3.2 Wet Milling …............................................................ 5-42

5.2.4 Economic Assessment ................................................................. 5-44

5.2.4.1 Economic Assumptions .................................................. 5-44

5.2.4.2 Feedstock and Utilities Pricing and Labor Costs .................. 5-45

5.2.4.3 Process Economics .............................................................. 5-45

5.2.4.4 Sensitivity Analysis.................................................... 5-50

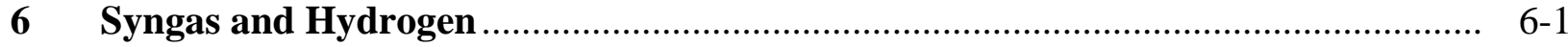

6.1 STEAM METHANE REFORMING (SMR) ............................................... 6-1

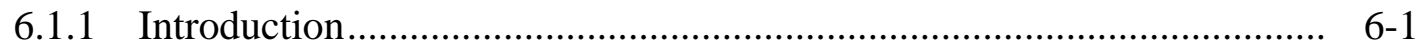

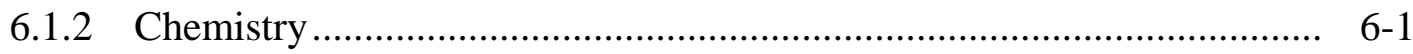

6.1.3 Process Description.................................................................... 6-2 


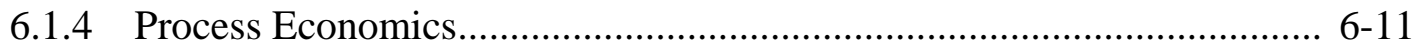

6.1.4.1 Economic Assumptions ..................................................... 6-11

6.1.4.2 Feedstock and Utilities Pricing and Labor Costs .................. 6-11

6.1.4.3 Process Economics ............................................................ 6-11

6.1.4.4 Sensitivity Analysis........................................................... 6-17

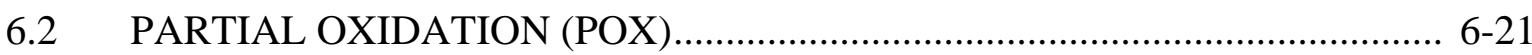

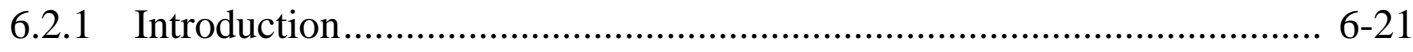

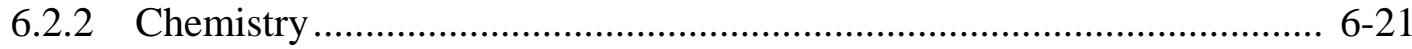

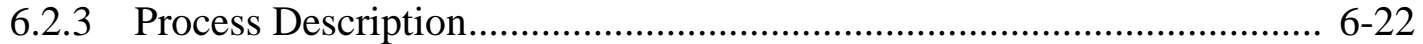

6.2.4 Process Economics................................................................................. 6-25

6.2.4.1 Methodology and Economic Assumptions ........................ 6-25

6.2.4.2 Feedstock and Utilities Pricing and Labor Costs ................. 6-25

6.2.4.3 Process Economics ........................................................ 66-26

6.2.4.4 Sensitivity Analysis...................................................... 6-28

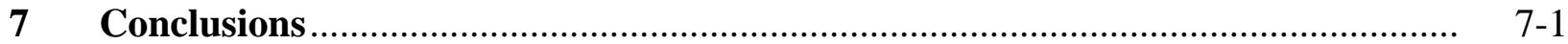

7.1 GTL FT LIQUID PRODUCTS......................................................

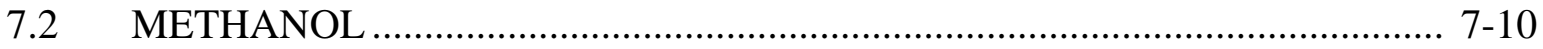

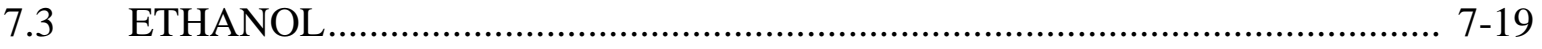

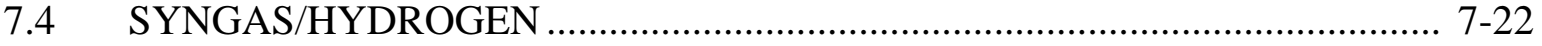

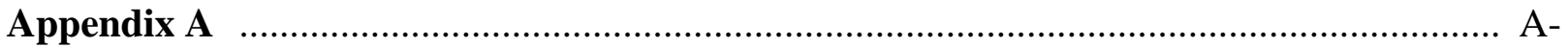


3.1 Slurry Bed Reactor.......................................................................................

3.2 Cost Of Production Of FT Products In Middle East................................................... 3-12

3.3 Sensitivity Of GTL Cost Of Production To Key Variables ......................................... 3-14

3.4 Impact Of GTL Thermal Efficiency On Cost Of Production Of FT Liquids ............... 3-15

3.5 Sensitivity Of GTL Cost Of Production To Key Variables ............................................ 3-17

3.6 FT Products Shipped To USGC From Middle East.................................................... 3-20

3.7 FT Products Shipped To Western Europe From Middle East …….............................. 3-21

3.8 FT Products Shipped To Japan From Middle East …………………………............. 3-22

3.9 Global Freight For FT Diesel/Naphtha ……….................................................... 3-24

3.10 GTL Rate Of Return On Capital Investment (2006) ……………………….............. 3-25

3.11 GTL RATE OF RETURN ON CAPITAL INVESTMENT (2015) ............................. 3-26

3.12 GTL Versus Conventional Refining Production Costs................................................. 3-28

3.13 GTL Versus Conventional Refining Profitability ...................................................... 3-31

3.14 Cost Of Production Of FT Products In Middle East................................................... 3-36

3.15 Sensitivity Of GTL Cost Of Production To Key Variables ........................................... 3-38

3.16 Sensitivity Of GTL Cost Of Production To Key Variables ............................................ 3-40

3.17 FT Products Shipped To USGC From Middle East...................................................... 3-43

5.18 FT Products Shipped To Western Europe From Middle East ..................................... 3-44

3.19 FT Products Shipped To Japan From Middle East ..................................................... 3-45

3.20 GTL Rate Of Return On Capital Investment (2006) ……............................................. 3-46

3.21 GTL Rate of Return on Capital Investment (2015) …………………….................. 3-47

4.1 Lurgi Mega Methanol Process With Autothermal Reforming ....................................... 4. 4

4.2 Lurgi Mega Methanol Process With Combined Reforming ………………….............. 4-8

4.3 Process Flow Diagram For Lurgi Mega Methanol Process - Reforming Section ......... 4-9

4.4 Process Flow Diagram for Lurgi Mega Methanol/ Process - Methanol Synthesis and Distillation Section........................................................................................... 4. $4-10$

4.5 Lurgi Water-and-Gas Cooled Methanol Synthesis Reactor .......................................... 4-13

4.6 Cost Of Production Of Fuel Methanol In Middle East ................................................. 4-22

4.7 Cost Of Production Of Fuel And Chemical Grade Methanol In Middle East ............... 4-23 
4.8 Sensitivity Of Fuel Grade Methanol Cost Of Production To Key Variables ................ 4-25

4.9 Impact Of Thermal Efficiency On Methanol Cost Of Production............................... 4-26

4.10 Sensitivity Of Fuel Grade Methanol Cost Of Production To Key Variables ................. 4-28

4.11 Fuel Methanol Shipped To USGC From Middle East............................................... 4-30

4.12 Fuel Methanol Shipped To Western Europe From Middle East ................................. 4-31

4.13 Fuel Methanol Shipped To Japan From Middle East .............................................. 4-32

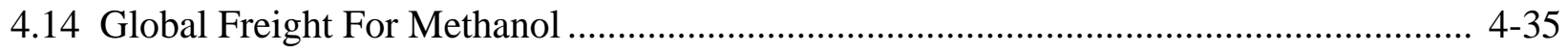

4.15 Methanol Rate Of Return On Capital Investment (2006) ........................................ 4-36

4.16 Methanol Rate Of Return On Capital Investment (2015) ......................................... 4-37

4.17 GTL And Methanol Rate Of Return On Capital Investment (2006) ............................ 4-39

4.18 GTL And Methanol Rate Of Return On Capital Investment (2015) ........................... 4-40

4.19 Cost Of Production Of Fuel Grade Methanol In Middle East ..................................... 4-46

4.20 Cost Of Production Of Fuel And Chemical Grade Methanol In Middle East ............... 4-47

4.21 Sensitivity Of Fuel Grade Methanol Cost Of Production To Key Variables ................ 4-49

4.22 Sensitivity Of Fuel Grade Methanol Cost Of Production To Key Variables ................. 4-51

4.23 Fuel Methanol Shipped To USGC From Middle East.............................................. 4-54

4.24 Fuel Methanol Shipped To Western Europe From Middle East ................................ 4-55

4.25 Fuel Methanol Shipped To Japan From Middle East ............................................... 4-56

4.26 Methanol Rate Of Return On Capital Investment (2006) ......................................... 4-57

4.27 Methanol Rate Of Return On Capital Investment (2015) .......................................... 4-58

5.1 NREL Lignocellulosic Biomass To Ethanol Process ............................................... 5-5

5.2 Sensitivity Of Fuel Ethanol From Biomass Cost Of Production To Key Variables....... 5-16

5.3 Sensitivity Of Fuel Ethanol From Biomass Cost Of Production To Key Variables....... 5-18

5.4 Cost of Production of Fuel Ethanol in U.S. Midwest ............................................... 5-21

5.5 Corn Receiving, Storage and Milling- Whole Kernel Milling .................................... 5-24

5.6 Milling and Hydrolysis Whole Kernel Milling....................................................... 5-25

5.7 Saccarification - Whole Kernel Milling ............................................................. 5-26

5.8 Fermentation - Whole Kernel Milling.............................................................. 5-27

5.9 Beer Still - Corn Dry Milling ......................................................................... $5-28$

5.10 Rectifier \& Dehydration - Corn Dry Milling ….................................................. $5-29$

5.11 DDGS Drying Whole Kernel Milling ............................................................... $5-30$ 
5.12 Ethanol Pasteurization and Vent Recovery - Whole Kernel Milling ........................ 5-31

5.13 Takatherm-II ${ }^{\circledR}$ Temperature-Activity Curves ..................................................... 5-34

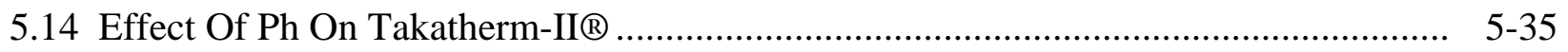

5.15 Baffle Tray Design................................................................................... $5-38$

5.16 Nutter V-Grid $\AA$ Tray Configuration..................................................................... 5-39

5.17 Wet Milling Versus Dry Milling ........................................................................... 5-43

5.18 Sensitivity Of Fuel Grade Ethanol From Corn Cost Of Production To Key Variables... 5-51

5.19 Sensitivity Of Fuel Grade Ethanol From Corn Cost Of Production To Key Variables... 5-53

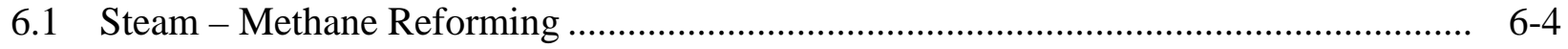

6.2 Combination Reforming ............................................................................... $6-10$

6.3 Hydrogen Cost Of Production Via SMR ............................................................. 6-13

6.4 Steam Methane Reforming/PSA Technology Gas Price Sensitivity ........................... 6-18

6.5 SMR Hydrogen Cost Sensitivity ...................................................................... 6-18

6.6 Steam Methane Reforming/PSA Technology Investment Sensitivity ........................ 6-19

6.7 Steam Methane Reforming/PSA Technology Yield Sensitivity............................... 6-19

6.8 Steam Methane Reforming/PSA Technology ................................................... 6-20

6.9 Texaco Synthesis Gas Generation Process (TSGGP) ............................................ 6-23

6.10 Hydrogen Cost Of Production Via Pox ............................................................ $6-27$

6.11 Partial Oxidation/PSA Technology Gas Price Sensitivity …..................................... 6-33

6.12 Pox Hydrogen Cost Sensitivity ..................................................................... $6-33$

6.13 Partial Oxidation/PSA Technology Investment Sensitivity.................................... 6-34

6.14 Partial Oxidation/PSA Technology Yield Sensitivity ........................................... 6-34

6.15 Partial Oxidation/PSA Technology Economy Of Scale ........................................ 6-35

6.16 Partial Oxidation/PSA Technology Oxygen Price Sensitivity ….............................. 6-35

7.1 FT Products Shipped To USGC From Middle East...............................................

7.2 FT Products Shipped To Western Europe From Middle East ................................. 7-4

7.3 FT Products Shipped To Japan From Middle East ................................................ $\quad 7-5$

7.4 GTL Rate Of Return On Capital Investment (2006) ............................................. 7-6

7.5 GTL Rate Of Return On Capital Investment (2015) ..........................................

7.6 GTL Versus Conventional Refining Production Costs........................................... 7-8

7.7 GTL Versus Conventional Refining Profitability ................................................ $7-9$ 
7.8 Fuel Methanol Shipped To USGC From Middle East............................................ 7-12

7.9 Fuel Methanol Shipped To Western Europe From Middle East ............................. 7-13

7.10 Fuel Methanol Shipped To Japan From Middle East ........................................... 7-14

7.11 Methanol Rate Of Return On Capital Investment 2006 ........................................ 7-15

7.12 Methanol Rate Of Return On Capital Investment 2015 ......................................... 7-16

7.13 GTL And Methanol Rate Of Return On Capital Investment 2006 ........................... 7-17

7.14 GTL And Methanol Rate Of Return On Capital Investment 2015 _.......................... 7-18

9.15 Cost Of Production Of Fuel Ethanol In U.S. Midwest ........................................... 7-21

Table

Page

2.1 Technology Bases And Capital Cost Improvement .............................................. 2-2

2.2 Alternate Fuels Technology and Capacity Evaluation ............................................ 2-3

3.1 Key Parameters For GTL Technology Evaluation .................................................. 3-5

3.2 Technology And Capital Improvements For GTL Technology ............................... 3-5

3.3 Summary Of Efficiencies Of GTL Processes .................................................... 3-6

3.4 Summary Of Efficiencies of GTL Processes ..................................................... $3-7$

3.5 Summary Of Raw Materiall Utility And Labor Costs For GTL PRODUCTION ........ 3-7

3.6 Cost Of Production Estimated For: GTL Synfuels Process: Slurry Reactor ............... 3-9

3.7 Cost Of Production Estimate For: GTL Synfuels Process: Slurry Reactor ................ 3-11

3.8 Economics Of GTL FT Liquid Products ............................................................ 3-19

3.9 Cost Of Production Estimate For: Pro Forma Coking Refinery ................................ 3-29

3.10 Cost Of Production For: Pro Forma Coking Refinery ........................................ 3-30

3.11 Cost of Production Estimate for: GTL Synfuels Process: Slurry Reactor ................... 3-33

3.12 Cost Of Production Estimate For: GTL Synfuels Process: Slurry Reactor ................. 3-35

3.13 Economics Of GTL FT Liquid Products .......................................................... 3-42

4.1 U.S. Methanol Specification ...................................................................... $4-3$

4.2 International Methanol Producers \& Consumers Association Methanol Preference

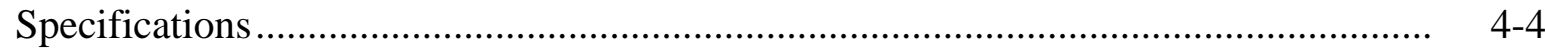

4.3 Operating And Design Parameters For Pre-Reforming And Autothermal Reforming Of Lurgi Mega Methanol Process. 
4.4 Operating And Design Parameters For Methanol Converter Of Lurgi Mega

Methanol Process ....................................................................................... 4. 4

4.5 Key Parameters For Methanol Technology Evaluation......................................... 4-15

4.6 Technology And Capital Improvements For Methanol Technology .......................... 4-15

4.7 Summary Of Efficiencies Of Methanol Processes.................................................. 4-16

4.8 Summary Of Efficiencies Of Methanol Processes................................................ 4-16

4.9 Summary Of Raw Material Utility And Labor Costs For Methanol Production.......... 4 4-17

4.10 Cost Of Production Estimate For : Fuel Grade Methanol Process: Large-Scale

Methanol Process ............................................................................................ 4-18

4.11 Cost Of Production Estimate For: Fuel Grade Methanol Process: Large Scale Methanol Process ......................................................................................... 4-20

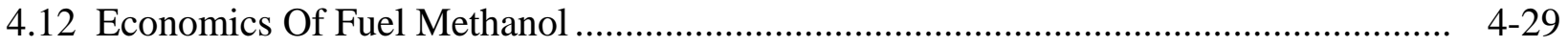

4.13 Cost Of Production Estimate For : Fuel Grade Methanol Process: Large-Scale Methanol Process.

4.14 Cost Of Production Estimate For: Fuel Grade Methanol Process: Large Scale Methanol Process

4.15 Economics Of Fuel Methanol …....................................................................... $4-53$

5.1 General Design Parameters Of NREL Bioethanol Process …................................... 5-3

5.2 Corn And Stover Compositions .......................................................................... $5-3$

5.3 Major Unit Operations Of NREL Bioethanol Process........................................... $5-4$

5.4 Key Parameters For Biomass Ethanol Technology Evaluation............................... 5-10

5.5 Technology And Capital Improvements For Biomass Ethanol Technology ................ 5-10

5.6 Summary Of Raw Materiall Utility And Labor Costs For Biomass Ethanol Production ............................................................................................. $5-11$

5.7 Cost Of Production Estimate For: Fuel Grade Ethanol ........................................ 5-12

5.8 Cost Of Production Estimate For: Fuel Grade Ethanol Process: Dilute Acid And Enzymatic Hydrolysis 2015.

5.9 Economics of Fuel Grade Ethanol ..................................................................... 5-20

5.10 Typical Corn Analysis .................................................................................. $5-22$

5.11 Safe Corn Storage Life ............................................................................ $5-32$

5.12 Key Parameters For Corn Ethanol Technology Evaluation.................................... 5-44

5.13 Technology And Capital Improvements For Corn Ethanol Technology ....................... 5-45

5.14 Summary Of Raw Materiall Utility And Labor Costs For Corn Ethanol Production ..... 5-46 
5.15 Cost Of Production Estimate For: Fuel Grade Ethanol

5.16 Cost Of Production Estimate For: Fuel Grade Ethanol Process: Corn Dry Milling 2015

6.1 Typical Steam/Methane Reforming Operating Conditions .......................................

6.2 CAR Operating Conditions......

6.3 Feedstock And Utilities Pricing And Labor Costs.

6.4 Syngas Cost of Production - Steam Methane Reforming

6.5 Hydrogen Cost Of Production - Steam Methane Reforming/PSA

6.6 Cost Of Production Estimate For: Syngas $(\mathrm{H} 2 / \mathrm{CO}=4.5)$ Process: Steam Methane Reforming 2006

6.7 Cost Of Production Estimate For: Syngas $(\mathrm{H} 2 / \mathrm{CO}=4.5)$ Process: Steam Methane Reforming 2015

6.8 Cost Of Production Estimate For: Hydrogen Process: Steam Methane Reforming/PSA 2006.

6.9 Cost Of Production Estimate For: Hydrogen Process: Steam Methane Reforming/PSA 2015

6.10 Typical Partial Oxidation Operating Conditions

6.11 Feedstock And Utilities Pricing And Labor Costs

6.12 Syngas Cost Of Production - Partial Oxidation

6.13 Hydrogen Cost Of Production - Partial Oxidation/PSA

6.14 Cost Of Production Estimate For: Syngas $(\mathrm{H} 2 / \mathrm{CO}=1.8)$ Process: Partial Oxidation 2006

6.15 Cost Of Production Estimate For: Syngas $(\mathrm{H} 2 / \mathrm{CO}=1.8)$ Process: Partial Oxidation 2015.

6.16 Cost Of Production Estimate For: Hydrogen Process: Partial Oxidation/PSA 2006 ....

6.17 Cost Of Production Estimate For: Hydrogen Process: Partial Oxidation/PSA 2015 ...

7.1 Economics Of GTL FT Liquid Products

7.2 Economics Of Fuel Methanol

7.3 Economics Of Fuel Grade Ethanol

7.4 Syngas Cost Of Production.

7.5 Hydrogen Cost Of Production 
The overall objective of this section was to compare competing technologies' production costs and performance with that of FT liquids and methanol over the period from 2006 to 2015. The 2006 analysis was based on the current state-of-the-art technologies (i.e., recently or currently announced projects) that are expected to be on-stream in the 2006 timeframe. The 2015 economics included learning curve effects, economies of scale and selection of future technologies.

- The economics for GTL FT liquid products from a slurry reactor based GTL process was examined for a 75,000 barrels per day (2006) and a 150,000 barrels per day (2015) facility.

- The economics for methanol based on the Lurgi Mega Methanol Process was examined for a single-train 5,000 metric tons per day (2006) and a single-train 15,000 metric tons per day (2015) facility.

- The economics for ethanol from biomass using a dilute acid hydrolysis and enzymatic saccharification and fermentation of corn stover was examined for a 50 million gallons per year (2006) and a 150 million gallons per year (2015) facility.

- The economics for ethanol from corn via a dry milling process was examined for a 50 million gallons per year (2006) and a 150 million gallons per year (2015) facility.

In support of a hydrogen economy the cost of production of syngas/hydrogen via steam methane reforming (SMR) and via partial oxidation (POX) was also evaluated. 
This report provides the methodology, assumptions and results of the technical and economic evaluation of existing or emerging technologies to produce a number of high quality conventional fuels as well as alternative fuels. Production of the following fuels has been analyzed:

1. Gas-to-Liquid (GTL) Fischer Tropsch (FT) liquid products

2. Methanol

3. Ethanol from biomass

4. Ethanol from corn

5. Syngas and hydrogen

This report is organized according to the above list with the analysis for each alternative fuel presented in its own chapter.

Production costs for these products have been developed for the years 2006 and 2015 based on the following technical and economic assumptions:

\subsection{BASIC TECHNOLOGY ASSUMPTIONS}

For 2006, technologies to produce each of the fuels (both conventional and alternative fuels) are based on the current state-of-the-art processes (i.e. recently or currently announced projects) that are expected to be on-stream in the 2006 timeframe. The production capacities of the products have been set equal to Nexant's estimate of world-scale size for each technology.

For 2015, a more speculative approach has been taken to reflect the expected cutting edge technologies that will be in place at that time. Thus, for a number of the products emerging (i.e. not currently commercially proven) technologies have been considered. The following factors have influenced the 2015 analyses:

- Learning curve effects have been applied to a range of variables, including capacity, capital investment per unit of capacity, raw Material usage, utility consumption rates, number of workers employed, etc.

- Economies of scale factors have been applied to capture the benefits of larger capacity facilities

- Selection of future technologies modeled was based on a qualitative screening of factors such as sustainability, commercialization potential, etc.

Table 2.1 summarizes the technology bases for 2006 and 2015 and assumptions for capital cost improvement. Table 2.2 presents a brief description of the technology and capacity of GTL, methanol, and ethanol employed for this study. Additional economic assumptions specific to 
each individual product and its associated technology are presented in detail in the economic assessment section of each product in the following sections.

Table 2.1 Technology Bases And Capital Cost Improvement

\begin{tabular}{|c|l|}
\hline Technology & \\
\hline $2006:$ & $\begin{array}{l}\text { state-of-the-art technology of announced projects that are expected to be } \\
\text { on-stream in 2006 }\end{array}$ \\
\hline $2015:$ & learning curve improvements or emerging technology \\
\hline $\begin{array}{l}\text { Capital } \\
\text { Improvement }\end{array}$ & Cost \\
\hline $2006:$ & estimated maximum capacity for state-of-the-art technology \\
\hline $2015:$ & learning curve effect increase in capacity \\
\hline Others & $\begin{array}{l}\text { Capital investment per unit capacity, raw Material and utility consumption rate, number of workers, } \\
\text { etc., were adjusted to capture expected future improvements. }\end{array}$ \\
\hline
\end{tabular}


Table 2.2 Alternate Fuels Technology and Capacity Evaluation

\begin{tabular}{|c|c|c|c|c|}
\hline PRODUCT TYPE & FT Fuels & Methanol & \multicolumn{2}{|c|}{ Ethanol } \\
\hline Descriptor & Generic & Fuel Grade & From Corn & From Biomass \\
\hline Location & Middle East & Middle East & U.S. Midwest & U.S. Midwest \\
\hline Technology & $\begin{array}{l}\text { Syngas, Fischer- } \\
\text { Tropsch, \& } \\
\text { Hydrocracking }\end{array}$ & $\begin{array}{c}\text { Syngas \& } \\
\text { Mega-Methanol }\end{array}$ & Dry Milling & $\begin{array}{c}\text { Dilute Acid \& Enzymatic } \\
\text { Hydrolysis }\end{array}$ \\
\hline Technology Basis & $\begin{array}{l}\text { Slurry FT } \\
\text { Reactor }\end{array}$ & $\begin{array}{l}\text { Lurgi Mega } \\
\text { Methanol }\end{array}$ & Conventional & DOE \\
\hline \multicolumn{5}{|l|}{ Capacity } \\
\hline 2006 & $75 \mathrm{kbpd}$ & $5 \mathrm{ktpd}$ & 50 MMgpy & 50 MMgpy \\
\hline 2015 & $150 \mathrm{kbpd}$ & $15 \mathrm{ktpd}$ & 150 MMgpy & 150 MMgpy \\
\hline \multicolumn{5}{|c|}{ Total Natural Gas Consumption, TBtu per Year } \\
\hline 2006 & $\begin{array}{l}228 \mathrm{TBtu} \\
0.226 \mathrm{TCF}\end{array}$ & $\begin{array}{l}56 \text { TBtu } \\
0.056 \text { TCF }\end{array}$ & & \\
\hline 2015 & $\begin{array}{l}437 \mathrm{TBtu} \\
0.433 \mathrm{TCF}\end{array}$ & $\begin{array}{c}162 \mathrm{TBtu} \\
0.162 \mathrm{TCF}\end{array}$ & & \\
\hline
\end{tabular}

02Q4:00072.005.11/dat/00072.ppt

\subsection{CAPITAL COST ASSUMPTIONS}

Cost typically included in Nexant's capital cost estimates are defined as follows:

\subsubsection{Inside Battery Limits Investment}

The inside battery limits (ISBL) portion of a plant can be thought of as a boundary through which raw Materials, catalysts and chemicals, and utility supply streams are imported into the process. In a like manner, main products, by-products, and spent utility return streams are exported through this boundary.

ISBL investment includes the cost of the main processing blocks of the chemical plant necessary to manufacture products. It represents an "instantaneous" investment (i.e. no escalation) for a plant ordered from a contractor and built on a prepared site with normal load-bearing and drainage characteristics of a developed country.

ISBL includes the installed cost of the following major items:

- Process equipment: vessels and internals, heat exchangers, pumps and compressors, drivers, solids handling. etc. 
- Major spare equipment/parts (e.g., spare rotor for turbine or compressor)

- Building housing process units

- $\quad$ Process and utility pipes and supports within the major process areas

- Instruments, including computer control systems

- Electrical wires and hardware

- Foundations and pads

- Structures and platforms

- Insulation

- Paint/corrosion protection

- $\quad$ Process sewers

- $\quad$ Fire water pipes and monitors

- Utility stations

The installed cost also includes construction overhead: fringe benefits, payroll burdens, field supervision, equipment rentals, small tools (expendables), field office expenses, site support services, temporary facilities, etc.

\subsubsection{Outside Battery Limits Investment}

Outside battery limits (OSBL) investment includes the plant investment items that are required in addition to the main processing units defined by the ISBL. These auxiliary items are necessary to the functioning of the production unit, but perform in a supporting role rather than being directly involved in production. A distinguishing characteristic is the potential for sharing offsite facilities among several production units in a large plant, in which case investment costs would be allocated or prorated among the various production units.

OSBL investment includes the installed cost of the following major items.

- Storage for feeds, products, by-products, including tanks/silos, dikes, inerting, process warehouse, and bagging/palletizing equipment

- Steam generation units

- Cooling water systems, including cooling towers and circulation pumps

- $\quad$ Process water treatment systems and supply pumps

- $\quad$ Boiler feed water treatment systems and supply pumps

- Refrigeration systems, including chilled water/brine circulating pumps

- Heat transfer medium systems, including organic vapor, hot oil, molten salts

- Electrical supply, transformers, and switchgear 
- Loading and unloading arms, pumps, conveyors, lift trucks, including those to handle barge, tank/hopper car, and tank/hopper/other truck traffic; weigh scales

- Auxiliary buildings, including all services, furnishings, and equipment:

$\begin{array}{ll}- & \text { Central control room } \\ - & \text { Maintenance } \\ - & \text { Stores warehouse } \\ - & \text { Laboratory } \\ - & \text { Garages/fire station } \\ - & \text { Change house/cafeteria } \\ - & \text { Medical/safety } \\ - & \text { Administration } \\ - & \text { General utilities, including plant air, instrument air, inert gas, stand-by electrical } \\ & \text { generator, fire water pumps } \\ \text { - } & \text { Site development, including roads and walkways, parking, railroad sidings, } \\ & \text { electrical main substation, lighting, water supply, fuel supply, clearing and } \\ & \text { grading, drainage, fencing, sanitary and storm sewers, and communications } \\ \text { - } & \text { Yard pipes, including lines for cooling water, process water, boiler feed water, } \\ & \text { fire water; fuel; plant air, instrument air, inert gas; collection of organic wastes, } \\ \text { aqueous wastes, and flare/incinerator feeds; and process tie-ins to storage }\end{array}$

\subsubsection{Contractor Charges}

These charges are typically 15 to 25 percent of installed ISBL and OSBL costs and are included proportionately in the ISBL and the OSBL investments. Contractor charges include the following major items:

- Detailed design and engineering, including process and offsites design and general engineering, equipment specifications, plant layout, drafting, cost engineering, scale models

- Administrative charges, including project management, engineering supervision, procurement, expediting, inspection, travel and living, home office construction expenses, general home office overhead

- Contractor profit

\subsubsection{Project Contingency Allowance}

A project contingency allowance is typically 15 to 25 percent of installed ISBL and OSBL costs and is included proportionately in the ISBL and the OSBL investments.

A project contingency allowance is applied to the total of the above costs to take into account not-well-defined elements of the process being estimated. For well-defined processes where primary input has come from engineering contractors, a contingency of 10 to 20 percent would 
be typical. At the other end of the spectrum, a capital estimate for a speculative process developed from patent and literature data alone might warrant a contingency of 20 to as much as 50 percent in extreme cases.

\subsubsection{Other Project Costs}

Other project costs include startup/commissioning costs, miscellaneous owner's costs, etc. These costs are very site/project specific; however, they typically range from 20 to 40 percent of installed ISBL + OSBL costs. A normal value of 25 percent will be used in the absence of more specific information.

Typical costs included in this category are described below.

\subsubsection{Startup/Commissioning Costs}

- $\quad$ Extra operating manpower

- Owner's technical manpower

- Startup services

- $\quad$ Licensor representatives

- Contractor personnel

- $\quad$ Equipment supplier/other vendor representatives

- $\quad$ Operating manuals and training programs

- $\quad$ Modifications and maintenance during startup

- $\quad$ Operating expenses to the extent that they do not result in saleable product

\subsubsection{Miscellaneous Owner's Costs}

- Licensing/royalty/expertise fees: basic process and engineering design package

- Jetties, marine terminals, docks, etc.

- Long distance pipelines for raw Products/products

- Land, rights of way, permits, surveys, and fees

- Piling, soil compaction/dewatering, unusual foundation requirements

- Sales, use, and other taxes

- $\quad$ Freight, insurance in transit, and import duties (equipment, pipe, steel, instruments, etc.)

- Escalation/inflation of costs over time, assuming instantaneous construction

- Interest on construction loan, assuming instantaneous construction

- Overtime pay during construction

- Construction workers' housing, canteen, other infrastructure for remote site

- $\quad$ Field insurance 
- $\quad$ Project team, including preliminary planning studies, HAZOP studies, environmental reviews, design, engineering, estimating, inspection, accounting, auditing, legal, construction management, travel, and living

- Initial charges of raw Materials, catalysts, chemicals, and packaging Materials

- Initial stock of maintenance, laboratory, operating, and office supplies

- Transport equipment, including barges, railcars, tank trucks, bulk shipping containers, plant vehicles

- Provisions for temporary shutdown expenses

- Owner's scope contingency allowance

\subsubsection{Working Capital}

Working capital typically includes the following items:

- Accounts receivable (products and by-products shipped but not paid by customer), typically one month's gross cost of production (COP)

- Cash on hand (short-term operating funds), typically one week's gross COP minus depreciation

- Minor spare equipment and parts inventory, percentage of replacement BL capital

- Credit for accounts payable (feedstocks, catalysts, chemicals, and packaging Materials received but not paid to supplier), typically one month's delivered cost

- Value of product and by-product inventories, typically two weeks' gross COP

- Value of raw Material inventory, typically two weeks' delivered cost

\subsection{FIXED COST FACTORS, DEPRECIATION AND RETURN ON CAPITAL}

For consistency and simplicity, the following uniform percentages have been employed to develop the cost of production estimates for all processes in this study regardless of the individual nature of the processes:

Maintenance (Materials and Labor)

Direct Overhead

General Plant Overhead

Insurance, Property Tax, etc.

Environmental Levy

Depreciation

Return on Total Capital Investment
4.0

65.0

1.0

0.5

10.0

10.0 percent of ISBL

percent of Labor and Supervision percent of Labor and Maintenance percent of Total Plant Capital percent of Total Plant Capital percent of Total Plant Capital percent of Total Capital Investment 


\subsection{INTRODUCTION}

The fuels produced from GTL processes are superior from an environmental viewpoint because they are free of aromatics and sulfur, with the diesel having a high cetane number, and the kerosene a high smoke number.

In this study, a slurry reactor based GTL process is employed as the basis for the 2006 and 2015 technical and economic evaluation described below.

It is to be noted that the slurry reactor based GTL process analyzed in this study is not necessarily meant to depict any GTL licensor's technology. Examples of GTL technology developers using similar processes with slurry reactors include Sasol, ExxonMobil, ConocoPhillips, etc.

\subsubsection{Commercially Demonstrated Process}

Economics: $\quad$ Based on a Middle East remote location

Product Mix: $\quad$ FT products consisting of 25 volume percent naphtha and 75 volume percent diesel

Capacity: $\quad 75,000$ barrels per day (bpd)

Capital Investment: $\quad 20,000$ - 30,000 \$/bpd

\subsubsection{Emerging Technology}

Economics:

Product Mix:

Capacity:

Capital Investment:
Based on a Middle East remote location

FT products consisting of 25 volume percent naphtha and 75 volume percent diesel

150,000 barrels per day (bpd)

15,000 - 20,000 \$/bpd

\subsection{FISCHER-TROPSCH CHEMISTRY}

The hydrogenation of carbon monoxide by the Fischer-Tropsch (FT) process primarily produces saturated compounds of the homologous hydrocarbon series. Depending on the catalyst, temperature, and type of process employed, hydrocarbons ranging from methane to higher molecular weight paraffins and olefins can be obtained.

The FT synthesis can be described by two fundamental reactions: 


$$
\begin{aligned}
& \mathrm{CO}+2 \mathrm{H}_{2} \longrightarrow\left(-\mathrm{CH}_{2^{-}}\right)+\mathrm{H}_{2} \mathrm{O} \\
& \mathrm{CO}+\mathrm{H}_{2} \mathrm{O} \rightleftharpoons \mathrm{H}_{2}+\mathrm{CO}_{2}
\end{aligned}
$$

O:/2002Q2/NEXANT/00072/RP/00072-2.CDX

Reaction 1, the hydrogenation of carbon monoxide, takes place preferentially over cobalt and nickel catalysts. Reaction 2, the water/gas shift reaction, takes place most easily over iron catalysts as an equilibrium reaction. This reaction can be shifted to either side depending upon temperature, pressure, and concentration of reactants.

The hydrocarbons produced by FT synthesis have predominantly a straight-chain structure. Impurities normally present in products derived from petroleum, such as sulfur, metals, and nitrogen compounds, are entirely absent from FT products.

Fischer-Tropsch processes have been traditionally employed in indirect coal liquefaction. Coal is gasified in a first step into syngas, and the syngas is then catalytically converted to liquid fuels in the synthesis step. However, the application of FT technology in a coal gasification complex implies very large capital expenditures. Today, the economics of hydrocarbon synthesis using FT technology are improved if less expensive sources of syngas are employed, such as natural gas.

\subsection{PROCESS DESCRIPTION}

A slurry reactor based GTL process typically consists of three main process steps:

1. Natural gas reforming

2. Fischer-Tropsch synthesis

3. Product work-up

The first step is the reforming of natural gas to form a synthesis gas that consists of hydrogen and carbon monoxide. The synthesis gas is then fed to the slurry phase Fischer-Tropsch reactor.

The catalyst in the slurry reactor converts the synthesis gas to a waxy synthetic crude utilizing the Fischer-Tropsch reaction.

The product work-up converts the waxy synthetic crude into diesel and naphtha. While similar to conventional refining technology, the synthetic waxy crude is converted into superior, marketable products in a single hydroisomerization step.

The slurry bed reactor consists of a shell with cooling coils in which steam is generated (Figure 3.1). Syngas is distributed in the bottom and rises through the slurry consisting of liquid reaction products, predominately wax; the iron based catalyst particles are suspended in it. The reagent gases diffuse from the gas bubbles through the liquid phase to the suspended catalyst where they react to produce hydrocarbons and water. The heavy hydrocarbons form part of the slurry phase 
whereas the lighter gaseous products and water diffuse through the liquid. The gaseous products and unreacted syngas pass through the freeboard above the bed and to the gas outlet.

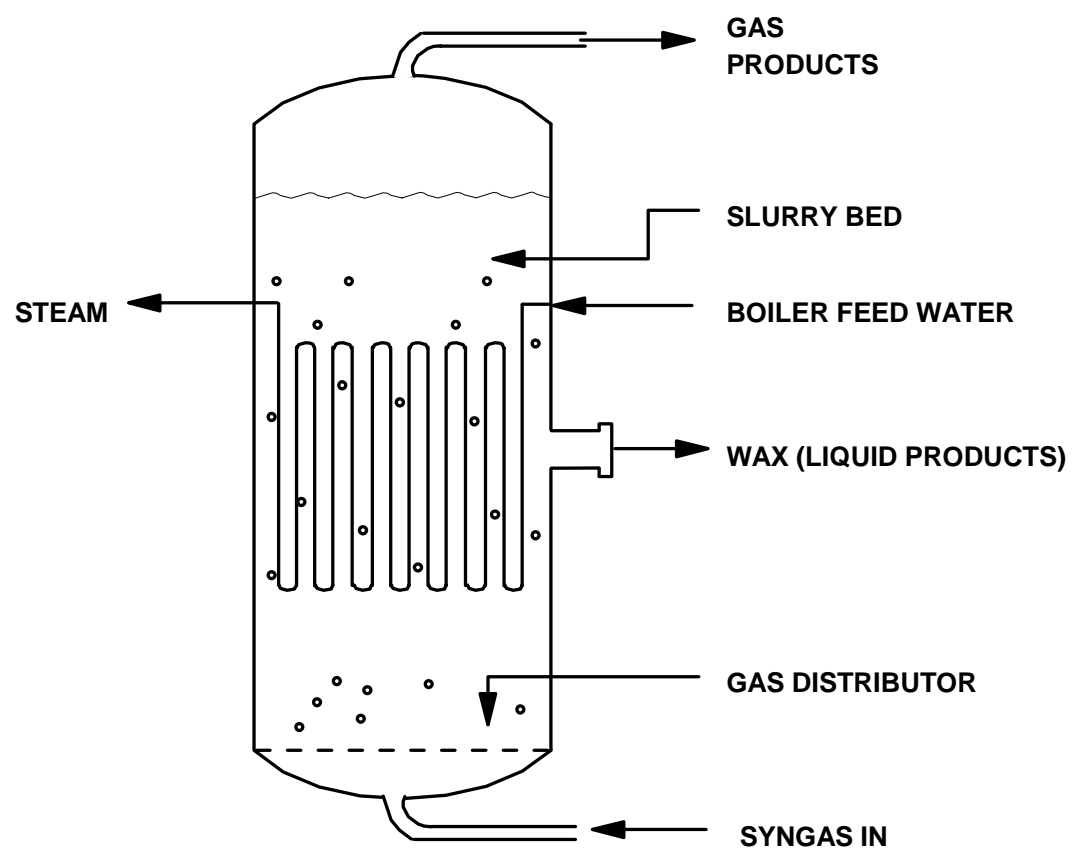

Figure 3.1 Slurry Bed Reactor

Because of the churning nature of the slurry/gas bubble interaction, the slurry phase is well mixed and tends to be isothermal. This gives much better and more flexible temperature control. Temperatures on the average can be much higher than in tubular fixed bed reactors without risking the danger of carbon formation and breakup of catalyst.

The pressure drop across the bed is practically that of the static hydraulic head and is much lower than the pressure drop for a fixed bed reactor. This translates to considerable savings in compression costs. The reactor typically operates at about 20 atmospheres and at temperatures of about $240^{\circ} \mathrm{C}$.

The two main limitations of slurry bed reactors are catalyst attrition and the difficulty in separating the heterogeneous catalyst phase from the waxy product. Catalyst separation from liquid products is a critical point for the successful implementation of the slurry bed reactors system. A filtration method within the slurry bed can be employed. Consequently, losses due to downtime and labor intensive turnarounds can therefore be eliminated.

Better control of product selectivity becomes possible at higher average conversions and makes it ideal for use with high activity catalysts where the problems with excessive radial and axial temperature gradients are much more pronounced. In the case of iron catalysts, the product slate is considerably affected by the age of the catalyst, with wax selectivity decreasing with time. 
Through more or less frequent catalyst renewal it is possible to maintain a steady selectivity profile for a single reactor.

Although scaleup of tubular fixed bed reactors is possible, it is limited from a mechanical point of view. Scale-up is achieved by increasing the shell diameter and increasing the number of tubes. A typical tubular fixed bed reactor can be designed for about 1,500 barrels per day. In the case of the slurry bed reactor capacity can be increased by increasing both the diameter and the height of the reactor. The current maximum single train slurry reactor capacity is about 15,000 to 20,000 barrels per day where full advantage can be taken of the potential for economy of scale.

The capital required for a large scale slurry technology plant was less than 40 percent of that needed for an equivalent tubular fixed bed plant.

Because of the isothermal nature of the slurry reactor, it is ideal for high activity catalyst, which in the case of the fixed bed technology would cause excessive temperature gradients and peaks, leading to the need for smaller diameter tubes. Per pass conversions with iron based catalysts are negatively affected by the water produced, which inhibits the reaction. Cobalt based catalysts do not have the same constraint and near complete conversions are theoretically possible. However, cobalt based catalysts have the disadvantage of operating at lower temperatures in order to get suitable selectivities. With cobalt based catalysts the olefinicity of the product is also much lower. Finally, the cobalt based catalyst product selectivity is also much more sensitive to the $\mathrm{H}_{2}: \mathrm{CO}$ ratio than the iron based catalysts.

\subsection{ECONOMIC ASSESSMENT}

\subsubsection{Economic Assumptions}

The key parameters used for GTL technology evaluation are summarized in Table 3.1 and Table 3.2 . 
Table 3.1 Key Parameters For GTL Technology Evaluation

\begin{tabular}{|l|l|r|r|}
\hline Year & & 2006 & 2015 \\
\hline Natural Gas per BBL of FT Products & & & \\
\hline \multicolumn{1}{|c|}{ Conservative Scenario } & MMBtu (HHV) & 8.341 & 7.984 \\
\hline \multicolumn{1}{|c|}{ Aggressive Scenario } & MMBtu (HHV) & 8.196 & 7.494 \\
\hline Natural Gas Price & US\$/MMBtu & 1.00 & 1.25 \\
\hline FT Products per 100 MMSCF Natural Gas & & & \\
\hline \multicolumn{1}{|c|}{ Conservative Scenario } & BBL & 12,110 & 12,650 \\
\hline \multicolumn{1}{|c|}{ Aggressive Scenario } & BBL & 12,400 & 13,500 \\
\hline Capacity & Mbpd & 75 & 150 \\
\hline Total Capital Investment (Current \$) & BillionUS\$ & 1.912 & 2.727 \\
\hline Capital Investment per bpd & \$/bpd & 25,491 & 18,181 \\
\hline Naphtha/Diesel Volume Ratio in FT Products & & $25 / 75$ & $25 / 75$ \\
\hline
\end{tabular}

Table 3.2 Technology And Capital Improvements For GTL Technology

\begin{tabular}{|l|c|c|c|}
\hline & \multicolumn{3}{|c|}{ Improvement (Reduction), \%/Year } \\
\hline & $\mathbf{2 0 0 1 - 2 0 0 6}$ & $\mathbf{2 0 0 6 - 2 0 1 5}$ & $\begin{array}{c}\mathbf{2 0 0 1 - 2 0 1 5} \\
\text { (Effective) }\end{array}$ \\
\hline Capital & $5 \%$ & $3.3 \%$ & $4 \%$ \\
\hline Technology (Raw Materials) & \multicolumn{3}{|l}{} \\
\hline Conservative Scenario & $0.64 \%$ & $0.49 \%$ & $0.55 \%$ \\
\hline Aggressive Scenario & $1.00 \%$ & $1.00 \%$ & $1.00 \%$ \\
\hline
\end{tabular}

Based on a conservative scenario, the natural gas consumptions are 8.3413 MMBtu (HHV) and 7.9838 MMBtu (HHV) per barrel of GTL FT products for 2006 and 2015, respectively. These gas consumption rates are equivalent to yields of 12,110 barrels and 12,650 barrels per 100 million standard cubic feet (MMSCF) natural gas for 2006 and 2015, respectively. The gas consumption rates correspond to energy efficiencies, on a LHV basis, of 67.0 percent and 70.0 percent for 2006 and 2015, respectively.

For an aggressive scenario, the natural gas consumptions are 8.1958 MMBtu (HHV) and 7.4937 MMBtu (HHV) per barrel of GTL FT products for 2006 and 2015, respectively, assuming the gas consumption rate is reduced by 1 percent per year from 2001 to 2015 due to technology improvement. These gas consumption rates are equivalent to yields of 12,400 barrels and 13,500 
barrels per 100 million standard cubic feet (MMSCF) natural gas for 2006 and 2015, respectively. The gas consumption rates correspond to energy efficiencies, on a LHV basis, of 68.5 percent and 74.9 percent for 2006 and 2015, respectively.

For 2006, the total capital investment for a 75,000 barrels per day (bpd) plant is $\$ 1.912$ billion, assuming the capital is reduced by 5 percent per year from 2001 due to technology improvement (independent of inflation). This corresponds to an investment of $\$ 25,490 / \mathrm{bpd}$. For 2015 , the total capital investment for a 150,000 bpd plant is $\$ 2.727$ billion, assuming the capital is reduced by 3.3 percent per year from 2006 due to technology improvement. This corresponds to an investment of $\$ 18,180 / \mathrm{bpd}$.

Table 3.3 and Table 3.4 summarize the relationship between the efficiency and gas consumption rate for the conservative scenario and the aggressive scenario, respectively. The impact of efficiency assumptions on the cost of production of FT liquids is not significant within the range analyzed in this study and will be discussed in the "Sensitivity Analysis" section later in this report.

Table 3.3 Summary Of Efficiencies Of GTL Processes (conservative scenario)

\begin{tabular}{|c|c|c|c|c|}
\hline & \multicolumn{2}{|c|}{} & \multicolumn{2}{|c|}{$\begin{array}{c}\text { Average \%/Year } \\
\text { Improvement } \\
\text { from } 2000 \text { to } 2015\end{array}$} \\
\hline Gas Consumption & $2000-2001$ & 2006 & 2015 & \\
\hline GTL MMBtu (HHV)/Bbl & \multicolumn{3}{|l|}{} & \\
\hline MMBtu (LHV)/Bbl & 8.700 & 8.341 & 7.984 & 0.55 \\
\hline Bbl/100MMScf & 7.800 & 7.507 & 7.185 & 0.55 \\
\hline Thermal Efficiency & 11700 & 12110 & 12650 & 0.55 \\
\hline GTL, \% & 64.5 & 67.0 & & 0.55 \\
\hline Carbon Efficiency & & & & \\
\hline GTL, \% & 85.0 & 85.0 & 85.0 & \\
\hline
\end{tabular}

02Q3:00072/efficiency meoh(conservative scenario).xls/efficiency gtl 


\section{Table 3.4 Summary Of Efficiencies of GTL Processes} (aggressive scenario)

\begin{tabular}{|c|c|c|c|c|}
\hline & $2000-2001$ & 2006 & 2015 & $\begin{array}{c}\text { Average \%/Year } \\
\text { Improvement } \\
\text { from 2000 to 2015 }\end{array}$ \\
\hline Gas Consumption & \multicolumn{4}{l|}{} \\
\hline GTL MMBtu (HHV)/Bbl & 8.700 & 8.196 & 7.494 & 1.00 \\
\hline MMBtu (LHV)/Bbl & 7.800 & 7.348 & 6.719 & 1.00 \\
\hline Bbl/100MMScf & 11,700 & 12,400 & 13,500 & 1.00 \\
\hline \multicolumn{7}{|l|}{ Thermal Efficiency } & 68.5 & 74.9 & 1.00 \\
\hline GTL, \%
\end{tabular}

02Q3:00072/efficiency meoh(aggressive scenario).xls/efficiency gtl

Appropriate improvement rates for utilities and labor are also assumed. Other economic assumptions can be found in the cost of production table below.

\subsubsection{Feedstock and Utilities Pricing and Labor Costs}

The main feedstock associated with the manufacture of GTL FT products is natural gas. Natural gas prices of \$1.00/MMBtu and \$1.25/MMBtu are assumed for 2006 and 2015, respectively, at a Middle East remote location. For utilities, 2006 and 2015 average Middle East utility prices are used. For labor, 2006 and 2015 average Middle East labor rates are used. Table 3.5 summarizes the raw Material, utility prices, and labor rates used for this study.

Table 3.5 Summary Of Raw Material Utility And Labor Costs For GTL PRODUCTION (current U.S. dollars)

\begin{tabular}{|c|c|c|c|}
\hline & & \multicolumn{2}{|c|}{ Middle East } \\
\hline & & 2006 & 2015 \\
\hline \multicolumn{4}{|l|}{ Raw Materials } \\
\hline Natural Gas & $\$ / \mathrm{MMBtu}$ & 1.0 & 1.25 \\
\hline \multicolumn{4}{|l|}{ Utilities } \\
\hline Fuel Gas & $\$ / \mathrm{MMBtu}$ & 1.00 & 1.25 \\
\hline Power & $\$ / k W h$ & 0.04 & 0.05 \\
\hline Process Water & \$/MGal & 1.35 & 1.69 \\
\hline \multicolumn{4}{|l|}{ Labors } \\
\hline Labor & \$/Man/Year & 27,010 & 33,731 \\
\hline Foremen & \$/Man/Year & 30,647 & 38,273 \\
\hline Supervision & \$/Man/Year & 36,978 & 46,181 \\
\hline
\end{tabular}




\subsubsection{Economics of Conservative Scenario}

\subsubsection{Process Economics}

2006

The economics for the production of 3.380 million metric tons per year ( 75 thousand barrels per day) of GTL FT products at a Middle East remote location are presented in Table 3.6.

The total plant capital cost is estimated to be $\$ 1.529 .4$ billion. This capital cost includes $\$ 1.188$ billion for ISBL and $\$ 340.7$ million for OSBL. Other project costs are estimated to be $\$ 382.4$ million, resulting a total capital investment of $\$ 1.911$ billion. An additional $\$ 137.9$ million is also estimated for the working capital requirement.

With natural gas price at $\$ 1.00$ per MMBtu, the raw Material cost is $\$ 10.00$ per barrel of GTL FT products. With utility cost of $\$ 0.03$ per barrel of GTL FT products, it results in a variable cost of $\$ 10.03$ per barrel of GTL FT products.

The total direct fixed cost, including all labors, maintenance, and direct overhead, is approximately $\$ 1.62$ per barrel of GTL FT products. The total allocated fixed cost of the plant, including general plant overhead, insurance, property taxes, and environmental levy, is about $\$ 1.97$ per barrel of GTL FT products. The total fixed costs bring the total cash cost to $\$ 13.62$ per barrel (\$110 per metric ton) of GTL FT products.

Depreciation, at 10 percent of investment, contributes an additional \$6.98 per barrel of GTL FT products. Return on total capital investment, also at 10 percent of investment, contributes another $\$ 6.98$ per barrel of GTL FT products.

The above cash cost, depreciation, and return on total capital investment yield a full cost of production of $\$ 27.58$ per barrel ( $\$ 223$ per metric ton) of GTL FT products. 


\section{Table 3.6 Cost Of Production Estimated For: GTL Synfuels \\ Process: Slurry Reactor \\ (conservative scenario-2006)}

$\begin{array}{lr} & \\ \text { Plant start-up } & 2006 \\ \text { Analysis date } & 2002 \\ \text { Location } & \text { Middle East } \\ \text { Capacity } & 75.0 \text { Thousand BBL/day } \\ & 3,378.9 \text { Thousand metric tons/yr } \\ \text { Operating rate } & 100 \text { percent } \\ \text { Throughput } & 75.0 \text { Thousand BBL/day }\end{array}$

$\begin{array}{lr}\text { CAPITAL COST } & \text { MILLION U.S. \$ } \\ \text { ISBL } & 1,188.7 \\ \text { OSBL } & 340.7 \\ \text { Total Plant Capital } & \mathbf{1 , 5 2 9 . 4} \\ \text { Other Project Costs } & 382.4 \\ \text { Total Capital Investment } & \mathbf{1 , 9 1 1 . 8} \\ \text { Working capital } & 137.9\end{array}$

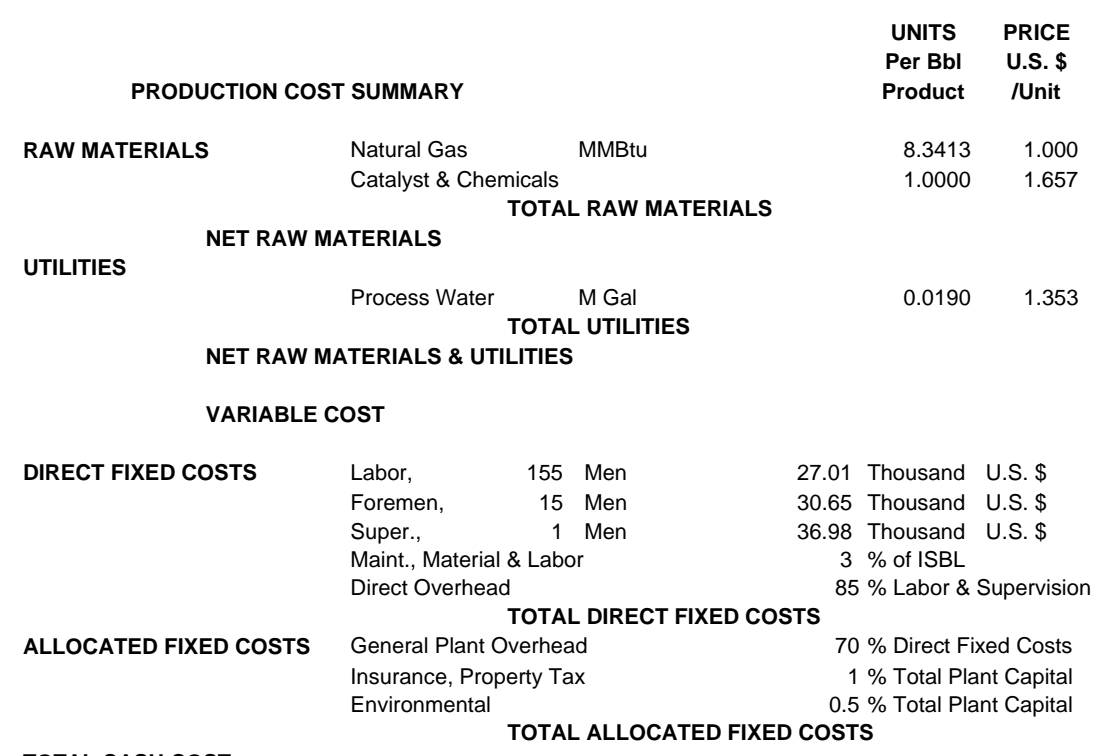

TOTAL CASH COST
Depreciation @
$10 \%$ for ISBL \& OPC
$10 \%$ for OSBL

$\begin{array}{rrr}\begin{array}{c}\text { U.S. \$ } \\ \text { Per Bbl }\end{array} & \begin{array}{c}\text { ANNUAL } \\ \text { COST MM } \\ \text { U.S. \$ }\end{array} & \begin{array}{c}\text { U.S. \$ } \\ \text { Per MT }\end{array} \\ & & \\ 8.34 & 228.34 & \\ 1.66 & 45.37 & \\ 10.00 & 273.72 & \mathbf{8 1} \\ 10.00 & 273.72 & \mathbf{8 1} \\ & & \\ 0.03 & 0.70 & \\ 0.03 & \mathbf{0 . 7 0} & \mathbf{0} \\ 10.02 & \mathbf{2 7 4 . 4 2} & \mathbf{8 1} \\ & & \mathbf{8 1} \\ \mathbf{1 0 . 0 2} & \mathbf{2 7 4 . 4 2} & \end{array}$

COST OF PRODUCTION

10 Percent

$\begin{array}{rrr}0.15 & 4.19 & \\ 0.02 & 0.46 & \\ 0.00 & 0.04 & \\ 1.30 & 35.66 & \\ 0.15 & 3.98 & \\ \mathbf{1 . 6 2} & \mathbf{4 4 . 3 3} & \mathbf{1 3} \\ 1.13 & 31.03 & \\ 0.56 & 15.29 & \\ 0.28 & 7.65 & \\ \mathbf{1 . 9 7} & \mathbf{5 3 . 9 7} & \mathbf{1 6} \\ \mathbf{1 3 . 6 2} & \mathbf{3 7 2 . 7 2} & \mathbf{1 1 0} \\ & & \\ 6.98 & 191.18 & 57 \\ & & \\ \mathbf{2 0 . 6 0} & \mathbf{5 6 3 . 8 9} & \mathbf{1 6 7} \\ & & \\ 6.98 & 191.18 & 57 \\ & & \\ \mathbf{2 7 . 5 8} & \mathbf{7 5 5 . 0 7} & \mathbf{2 2 3}\end{array}$

COST OF PRODUCTION + RO

$27.58 \quad 755.07$

223 
2015

The economics for the production of 6.760 million metric tons per year (150 thousand barrels per day) of GTL FT products at a Middle East remote location via Sasol SPD Process are presented in Table 3.7.

The total plant capital cost is estimated to be $\$ 2.181$ billion. This capital cost includes $\$ 1.695$ billion for ISBL and $\$ 486.0$ million for OSBL. Other project costs are estimated to be $\$ 545.4$ million, resulting in a total capital investment of $\$ 2.727$ billion. An additional $\$ 220.8$ million is also estimated for the working capital requirement.

With natural gas price at $\$ 1.25$ per MMBtu, the raw Material cost is $\$ 11.86$ per barrel of GTL FT products. With utility cost of $\$ 0.03$ per barrel of GTL FT products, it results in a variable cost of $\$ 11.89$ per barrel of GTL FT products.

The total direct fixed cost, including all labors, maintenance, and direct overhead, is approximately $\$ 1.21$ per barrel of GTL FT products. The total allocated fixed cost of the plant, including general plant overhead, insurance, property taxes, and environmental levy, is about $\$ 1.45$ per barrel of GTL FT products. The total fixed costs bring the total cash cost to $\$ 14.55$ per barrel (\$118 per metric ton) of GTL FT products. 


\section{Table 3.7 Cost Of Production Estimate For: GTL Synfuels \\ Process: Slurry Reactor \\ (conservative scenario-2015)}

$\begin{array}{lr} & \\ \text { Plant start-up } & 2015 \\ \text { Analysis date } & 2002 \\ \text { Location } & \text { Middle East } \\ \text { Capacity } & 150.0 \text { Thousand BBL/day } \\ & 6,757.8 \text { Thousand metric tons/yr } \\ \text { Operating rate } & 100 \text { percent } \\ \text { Throughput } & 150.0 \text { Thousand BBL/day }\end{array}$

$\begin{array}{lr}\text { CAPITAL COST } & \text { MILLION U.S. \$ } \\ \text { ISBL } & 1,695.7 \\ \text { OSBL } & 486.0 \\ \text { Total Plant Capital } & \mathbf{2 , 1 8 1 . 7} \\ \text { Other Project Costs } & 545.4 \\ \text { Total Capital Investment } & \mathbf{2 , 7 2 7 . 2} \\ \text { Working capital } & 224.3\end{array}$

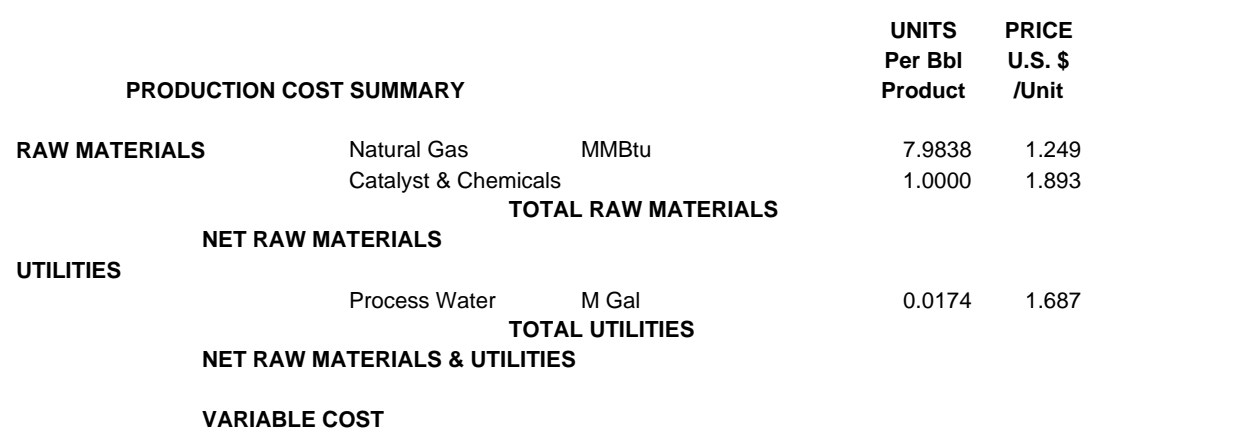

$\begin{array}{ccr}\begin{array}{c}\text { U.S. \$ } \\ \text { Per BbI }\end{array} & \begin{array}{c}\text { ANNUAL } \\ \text { COST MM } \\ \text { U.S. \$ }\end{array} & \begin{array}{c}\text { U.S. \$ } \\ \text { Per MT }\end{array} \\ 9.97 & 545.89 & \\ 1.89 & 103.62 & \\ 11.86 & 649.52 & 96 \\ 11.86 & \mathbf{6 4 9 . 5 2} & \mathbf{9 6} \\ & & \\ 0.03 & 1.61 & \\ \mathbf{0 . 0 3} & \mathbf{1 . 6 1} & \mathbf{0} \\ \mathbf{1 1 . 8 9} & \mathbf{6 5 1 . 1 2} & \mathbf{9 6} \\ & & \end{array}$

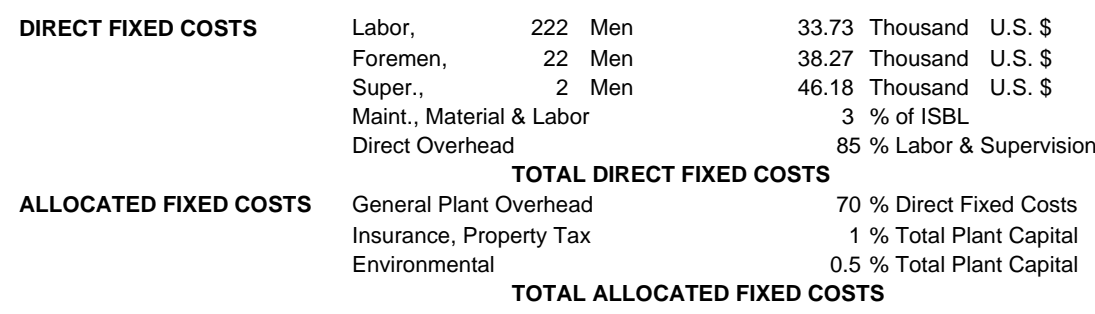

TOTAL CASH COST

$$
\text { Depreciation @ } 10 \% \text { for ISBL \& OPC } \quad 10 \% \text { for OSBL }
$$

COST OF PRODUCTION 
Depreciation, at 10 percent of investment, contributes an additional $\$ 4.98$ per barrel of GTL FT products. Return on total capital investment, also at 10 percent of investment, contributes another $\$ 4.98$ per barrel of GTL FT products.

The above cash cost, depreciation, and return on total capital investment yield a full cost of production of $\$ 24.52$ per barrel ( $\$ 199$ per metric ton) of GTL FT products.

The costs of production of GTL FT products at a Middle East remote location for 2006 and 2015 are summarized graphically in Figure 3.2. As indicated in the figure, due to technology advances and increased scale, GTL FT product costs are forecast to decline despite higher gas pricing.

Figure 3.2 Cost Of Production Of FT Products In Middle East (conservative scenario)

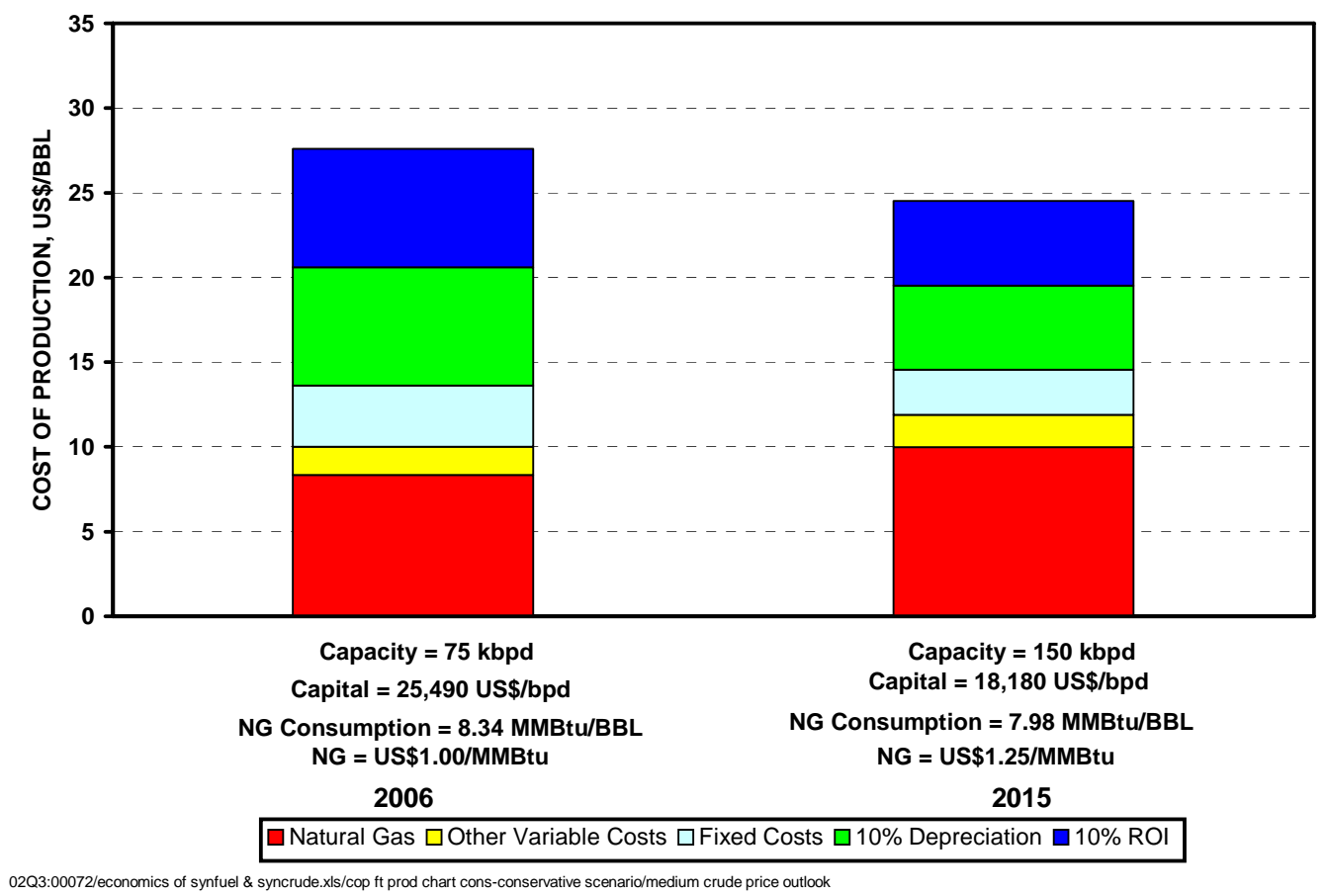

\subsubsection{Sensitivity Analysis}

2006

The effects of natural gas price, capital investment, and GTL FT production capacity on the full cost of production of GTL FT products plus 10 percent ROI are shown in Figure 3.3.

With total capital investment maintained at $\$ 1.912$ billion and GTL FT production capacity maintained at 3.380 million metric tons per year (75 thousand barrels per day), GTL FT products full cost of production plus 10 percent ROI increases from $\$ 27.58 /$ barrel to $\$ 31.75 /$ barrel when 
natural gas price increases from $\$ 1.00 / \mathrm{MMBtu}$ to $\$ 1.50 / \mathrm{MMBtu}$, i.e. 50 percent increase. GTL FT products full cost of production plus 10 percent ROI decreases to $\$ 23.41 /$ barrel when natural gas price decreases to $\$ 0.50 / \mathrm{MMBtu}$, i.e. 50 percent decrease. Thus, every dollar/MMBtu change in natural gas price results in an average change of $\$ 8.34 /$ barrel in GTL FT products full cost of production plus 10 percent ROI. 


\section{Figure 3.3 Sensitivity Of GTL Cost Of Production To Key Variables} (2006 conservative scenario)
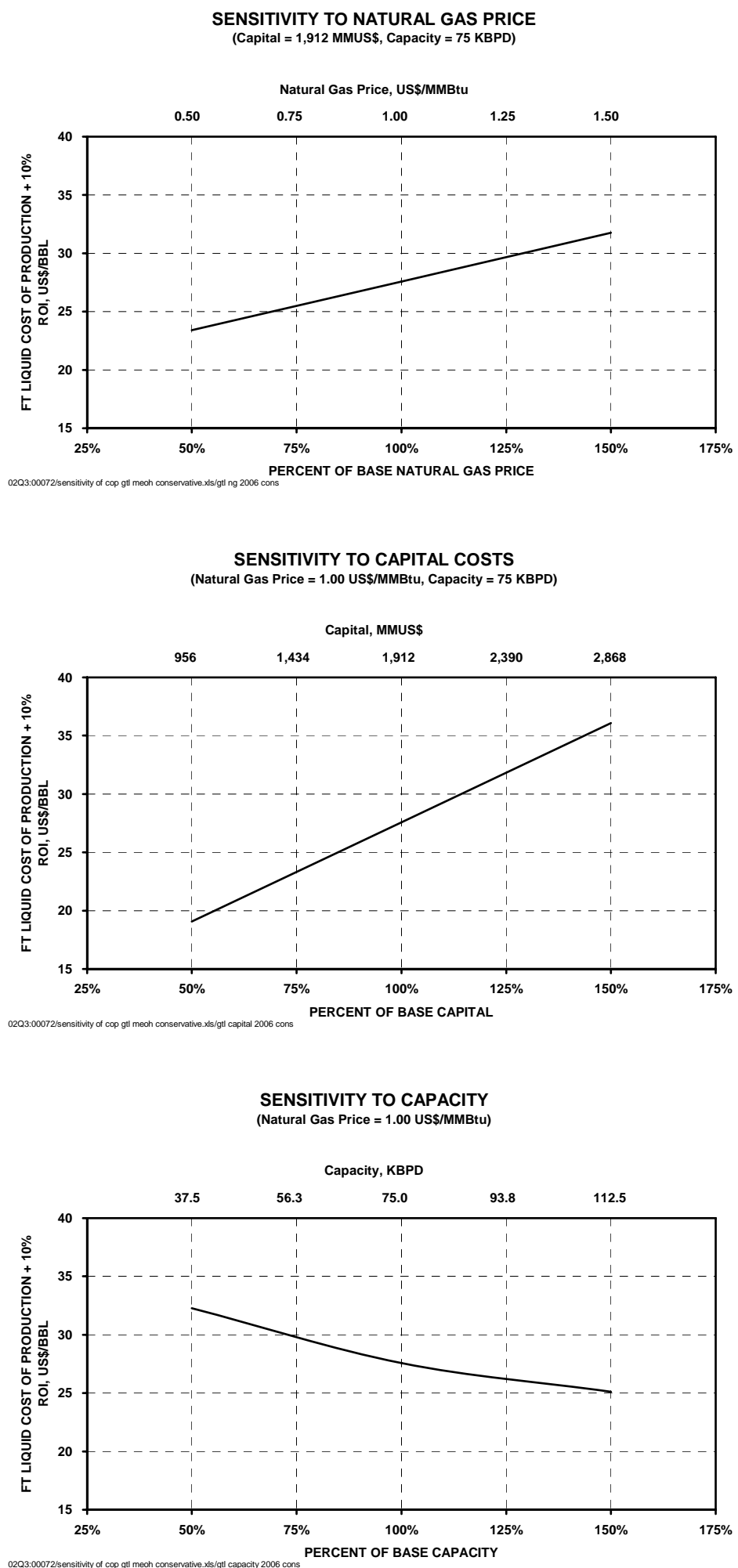
With natural gas price maintained at $\$ 1.00 / \mathrm{MMBtu}$ and GTL FT products production capacity maintained at 3.380 million metric tons per year (75 thousand barrels per day), GTL FT products full cost of production plus 10 percent ROI increases from $\$ 27.58 /$ barrel to $\$ 36.09 /$ barrel when the total capital investment increases from $\$ 1.912$ billion to $\$ 2.868$ billion, i.e. 50 percent increase. GTL FT products full cost of production plus 10 percent ROI decreases to $\$ 19.07 /$ barrel when the total capital investment decreases to $\$ 956$ million, i.e. 50 percent decrease. This represents an average of \$0.89/barrel change in GTL FT products full cost of production plus 10 percent ROI for every $\$ 100$ million change in total capital investment.

With natural gas price maintained at $\$ 1.00 /$ MMBtu, GTL FT products full cost of production plus 10 percent ROI decreases from $\$ 27.58 /$ barrel to $\$ 25.12 /$ barrel when GTL FT production capacity increases from 3.380 million metric tons per year ( 75 thousand barrels per day) to 5.070 million metric tons per year (112.5 thousand barrels per day), i.e. 50 percent increase. GTL FT products full cost of production plus 10 percent ROI increases to $\$ 32.27 /$ barrel when GTL FT products production capacity decreases to 1.690 million metric tons per year (37.5 thousand barrels per day), i.e. 50 percent decrease.

The impact of the GTL thermal efficiency assumptions on the cost of production of FT liquids is not significant within the range analyzed in this study. As shown in Figure 3.4, GTL products' full cost of production plus 10 percent ROI increases from $\$ 27.58 /$ barrel to $\$ 27.82 /$ barrel if the GTL efficiency were 64.5 percent instead of 67.0 percent employed.

Figure 3.4 Impact Of GTL Thermal Efficiency On Cost Of Production Of FT Liquids (2006 Middle East)

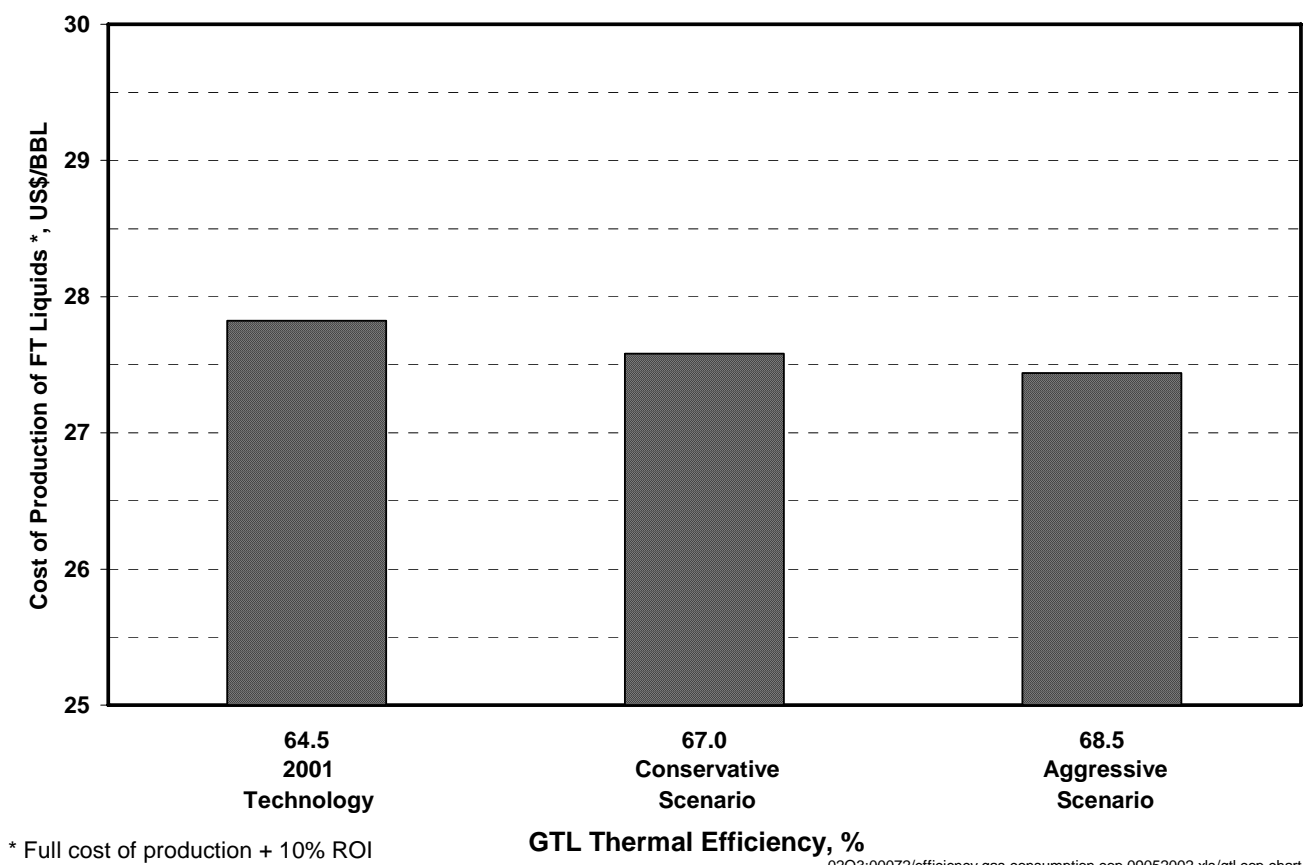


The effects of natural gas price, capital investment, and GTL FT production capacity on the full cost of production of GTL FT products plus 10 percent ROI are shown in Figure 3.5.

With total capital investment maintained at $\$ 2.727$ billion and GTL FT production capacity maintained at 6.760 million metric tons per year (150 thousand barrels per day), GTL FT products full cost of production plus 10 percent ROI increases from $\$ 24.52 / \mathrm{barrel}$ to $\$ 29.50 /$ barrel when natural gas price increases from $\$ 1.25 / \mathrm{MMBtu}$ to $\$ 1.87 / \mathrm{MMBtu}$, i.e. 50 percent increase. GTL FT products full cost of production plus 10 percent ROI decreases to $\$ 19.53 /$ barrel when natural gas price decreases to $\$ 0.62 / \mathrm{MMBtu}$, i.e. 50 percent decrease. Thus, every dollar/MMBtu change in natural gas price results in an average change of $\$ 7.98 /$ barrel in GTL FT products full cost of production plus 10 percent ROI. 


\section{Figure 3.5 Sensitivity Of GTL Cost Of Production To Key Variables} (2015 conservative scenario)
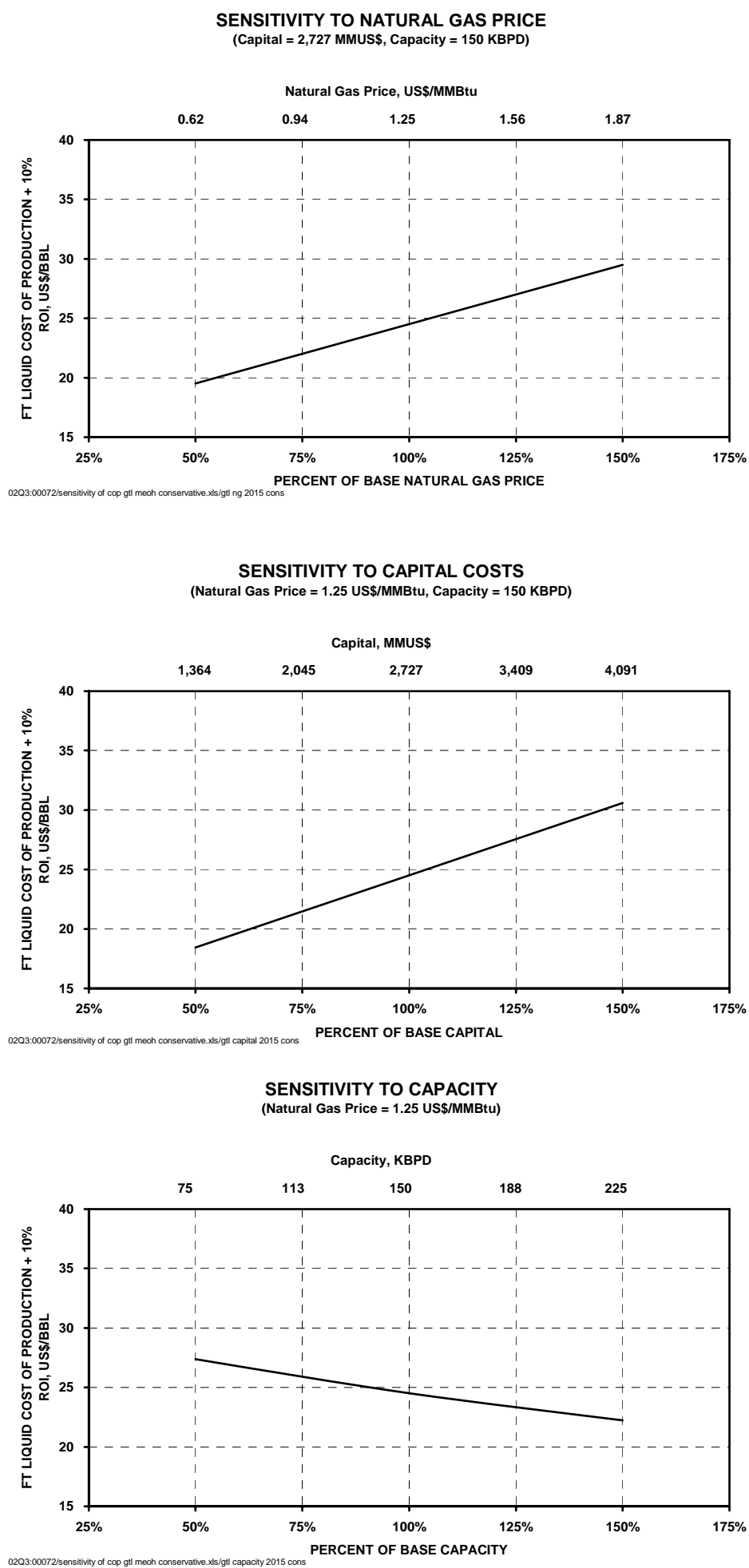
With natural gas price maintained at $\$ 1.25 / \mathrm{MMBtu}$ and GTL FT products production capacity maintained at 6.760 million metric tons per year (150 thousand barrels per day), GTL FT products full cost of production plus 10 percent ROI increases from $\$ 24.52 / \mathrm{barrel}$ to $\$ 30.59 /$ barrel when the total capital investment increases from $\$ 2.727$ billion to $\$ 4.091$ billion, i.e. 50 percent increase. GTL FT products full cost of production plus 10 percent ROI decreases to $\$ 18.45 /$ barrel when the total capital investment decreases to $\$ 1.364$ billion, i.e. 50 percent decrease. This represents an average of $\$ 0.45 /$ barrel change in GTL FT products full cost of production plus 10 percent ROI for every $\$ 100$ million change in total capital investment.

With natural gas price maintained at $\$ 1.25 / \mathrm{MMBtu}$, GTL FT products full cost of production plus 10 percent ROI decreases from $\$ 24.52 /$ barrel to $\$ 22.23 /$ barrel when GTL FT production capacity increases from 6.760 million metric tons per year (150 thousand barrels per day) to 10.140 million metric tons per year (225 thousand barrels per day), i.e. 50 percent increase. GTL FT products full cost of production plus 10 percent ROI increases to $\$ 27.37 /$ barrel when GTL FT products production capacity decreases to 3.380 million metric tons per year (75 thousand barrels per day), i.e. a 50 percent decrease.

\subsubsection{Regional Economics}

The economic viability of remotely produced GTL FT products at the Middle East can be determined by their delivered costs to the USGC, Western Europe, and Japan. The delivered costs have been developed from the estimated production costs for the GTL plant located in the Middle East as described previously. Transportation costs for shipping the FT products from the Middle East to the various regions and tariff, if any, imposed by the various regions are added to the production costs to yield the delivered costs.

Table 3.8 and Figure 3.6 to 3.11 summarize the results of the of the delivered costs of GTL FT products to the various regions and the comparison to regional FT products (25 volume percent naphtha and 75 volume percent diesel) prices forecast for 2006 and 2015 based on low, medium, and high crude price outlooks, respectively.

For 2006, the full cost of production plus 10 percent ROI for FT liquids produced at a 75,000 barrels per day facility in a Middle East remote location will be about $\$ 27.58$ per barrel if natural gas cost is $\$ 1.00$ per million BTU. Taking into account transportation costs and tariff, the total delivered cost of FT liquids will be $\$ 30.72, \$ 29.88$, and $\$ 29.67$ per barrel at the USGC, Western European, and Japanese markets, respectively.

If natural gas price is $\$ 0.50$ per million BTU, i.e., 50 percent of the assumption above, the full cost of production plus 10 percent ROI for FT liquids will be reduced to about $\$ 23.41$ per barrel and the corresponding delivered cost of FT liquids will be $\$ 26.55, \$ 25.71$, and $\$ 25.50$ per barrel at the USGC, Western European, and Japanese markets, respectively. 


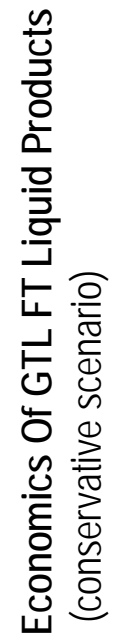

\begin{tabular}{|c|c|c|c|c|c|c|c|c|}
\hline \multirow[b]{3}{*}{$\frac{\overline{0}}{\overline{0}}$} & $\stackrel{\text { คి }}{\rightarrow}$ & 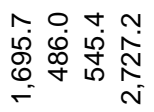 & $\stackrel{\stackrel{n}{\sim}}{\rightarrow}$ & 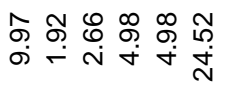 & \multirow{4}{*}{$\frac{5}{\frac{\pi}{\pi}}$} & ભ̊ & $\begin{array}{l}-1 \\
\text { d. } \\
\text { N }\end{array}$ & 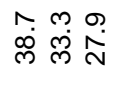 \\
\hline & & 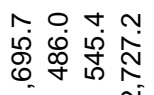 & ֶै. & 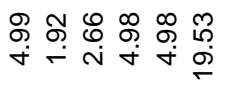 & & लి & $\begin{array}{l}\text { N } \\
\text { - }\end{array}$ & 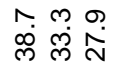 \\
\hline & $\stackrel{2}{\sim}$ & 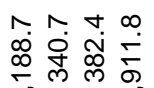 & 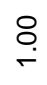 & 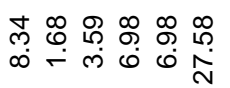 & & $\begin{array}{l}80 \\
\text { ¿ } \\
\text { i }\end{array}$ & $\begin{array}{l}\hat{0} \\
\dot{N}\end{array}$ & 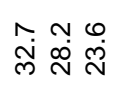 \\
\hline & $\stackrel{\mathfrak{R}}{\sim}$ & 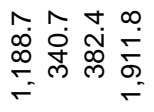 & 号 & 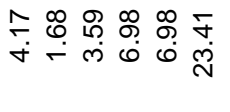 & & $\stackrel{\circ}{\circ} \stackrel{\circ}{\circ}$ & 号 & 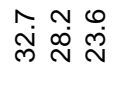 \\
\hline
\end{tabular}

\begin{tabular}{|c|c|c|c|c|c|c|c|c|}
\hline & $\stackrel{\text { ڤొ }}{\rightarrow}$ & 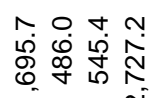 & $\stackrel{\mathscr{L}}{\sim}$ & 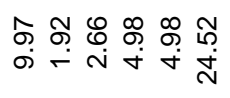 & & @̊ & $\stackrel{\stackrel{L}{\sim}}{\sim}$ & 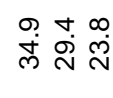 \\
\hline $\begin{array}{l}\breve{n} \\
\text { w్ }\end{array}$ & 号 & 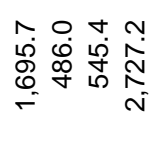 & ֻु & 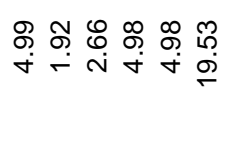 & 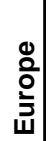 & ڤ̊ & $\begin{array}{l}\stackrel{\sim}{N} \\
\stackrel{N}{N}\end{array}$ & $\begin{array}{l}+\dot{\infty} \\
\dot{m} \\
\dot{m}\end{array}$ \\
\hline$\frac{0}{\frac{0}{0}}$ & $\stackrel{\llcorner}{\sim}$ & 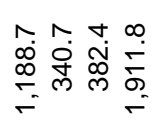 & $\begin{array}{l}\circ \\
\stackrel{-}{-}\end{array}$ & 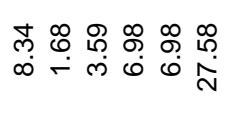 & 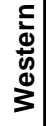 & @্ & $\begin{array}{l}\infty \\
\infty \\
\stackrel{N}{N}\end{array}$ & تี \\
\hline & $\stackrel{\llcorner}{\sim}$ & 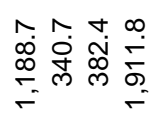 & مُ & 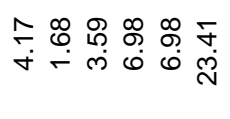 & & 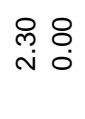 & 홍 & تี \\
\hline
\end{tabular}

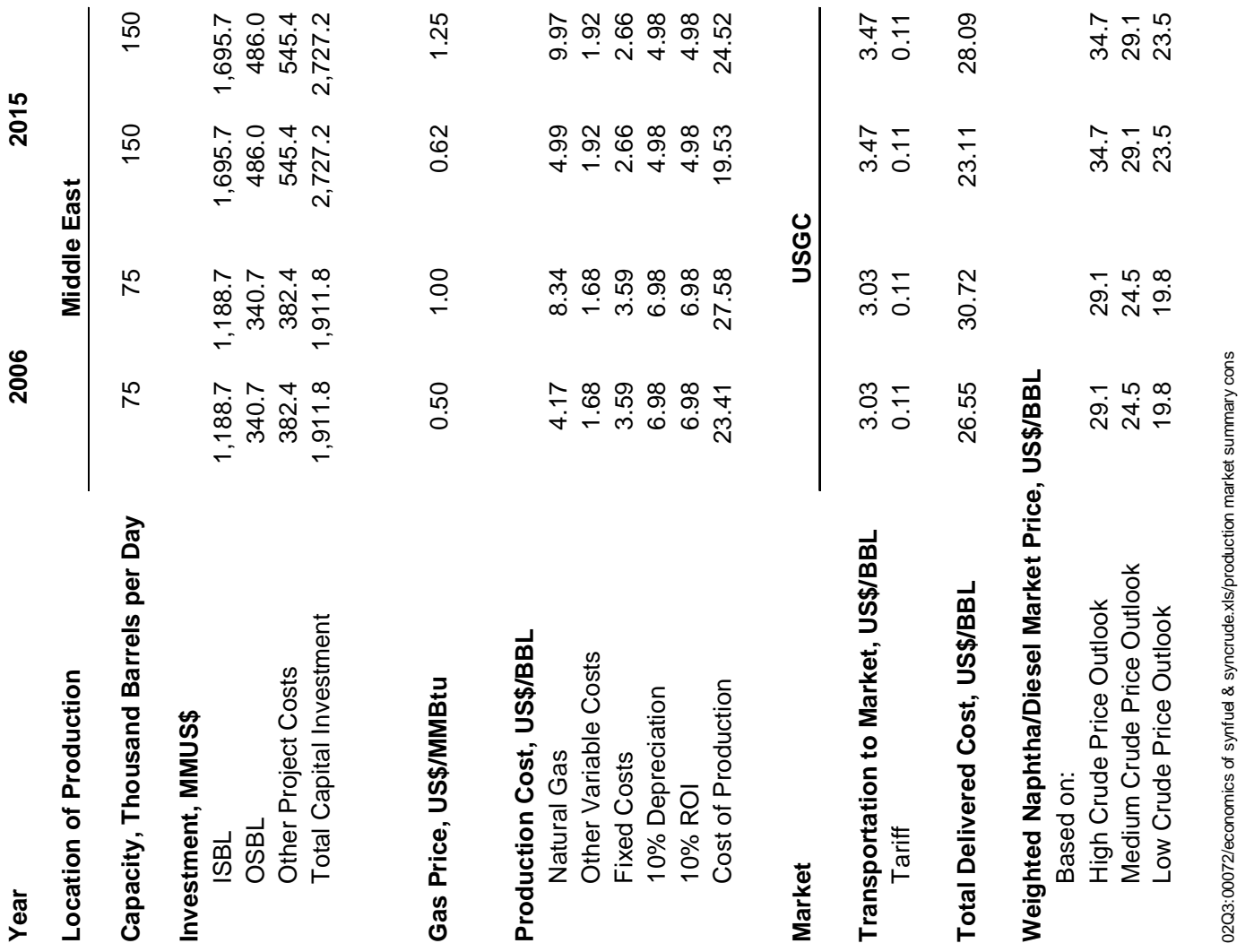




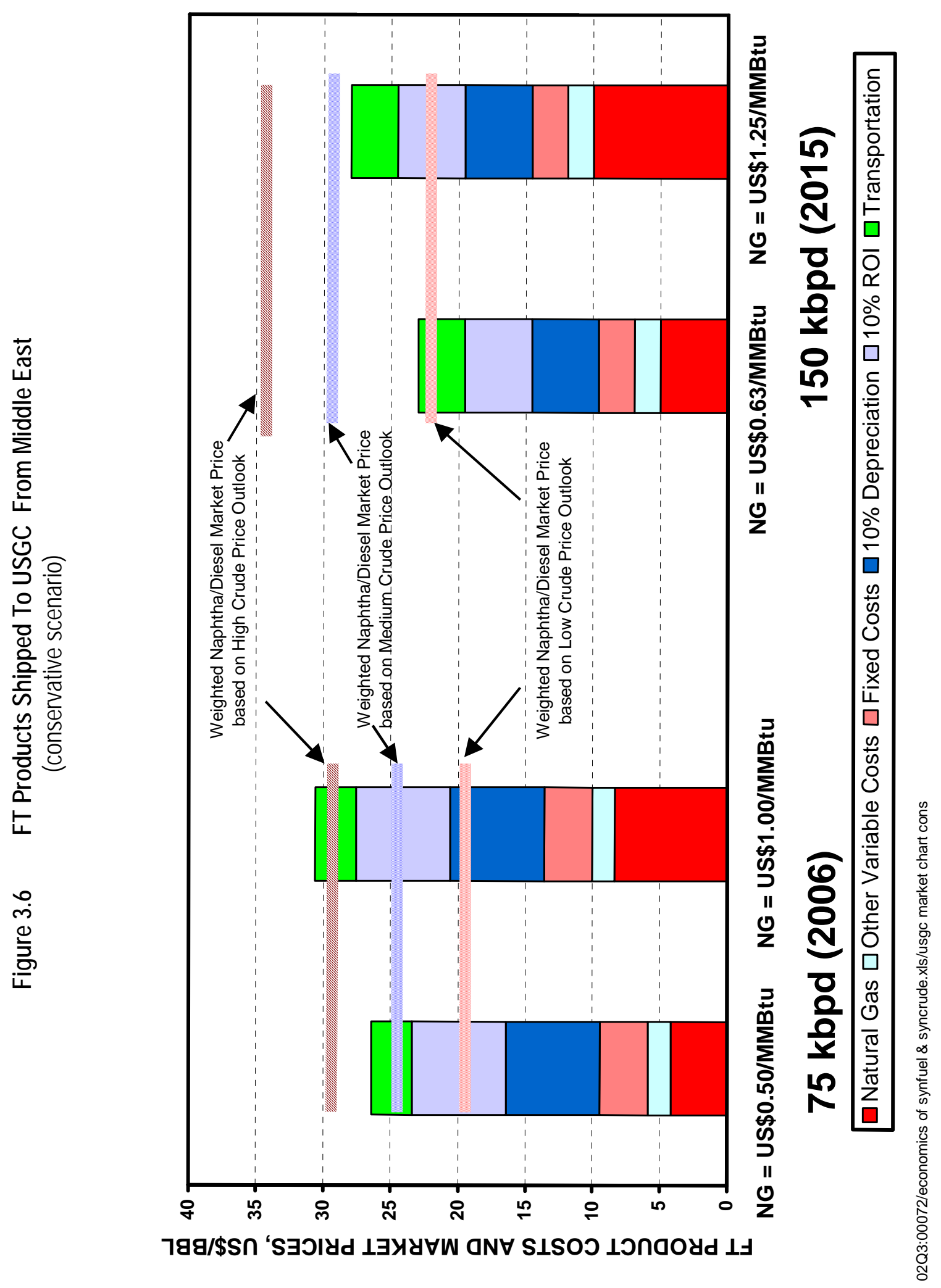




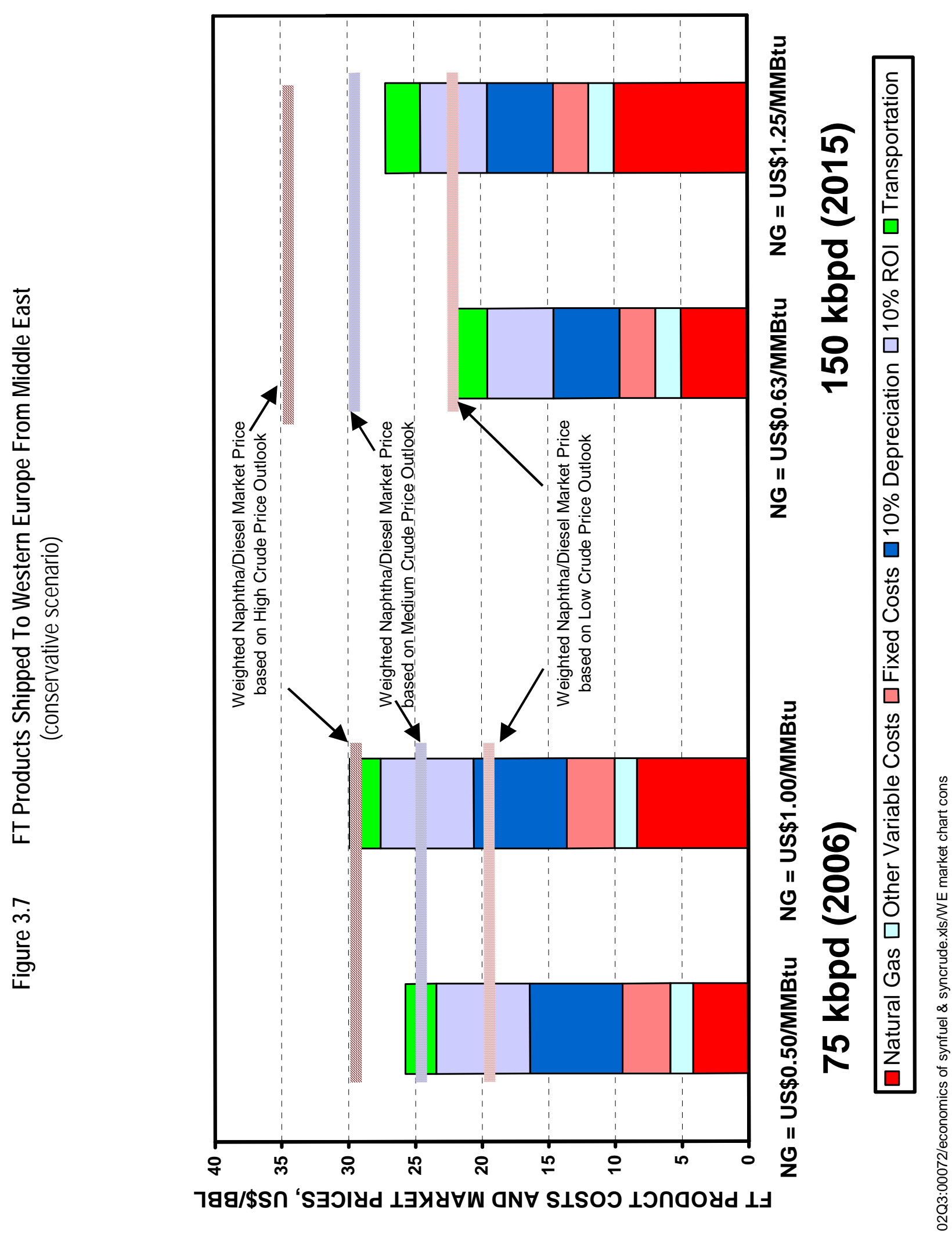




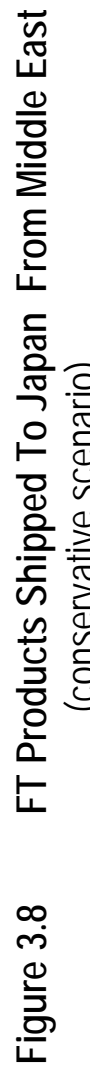

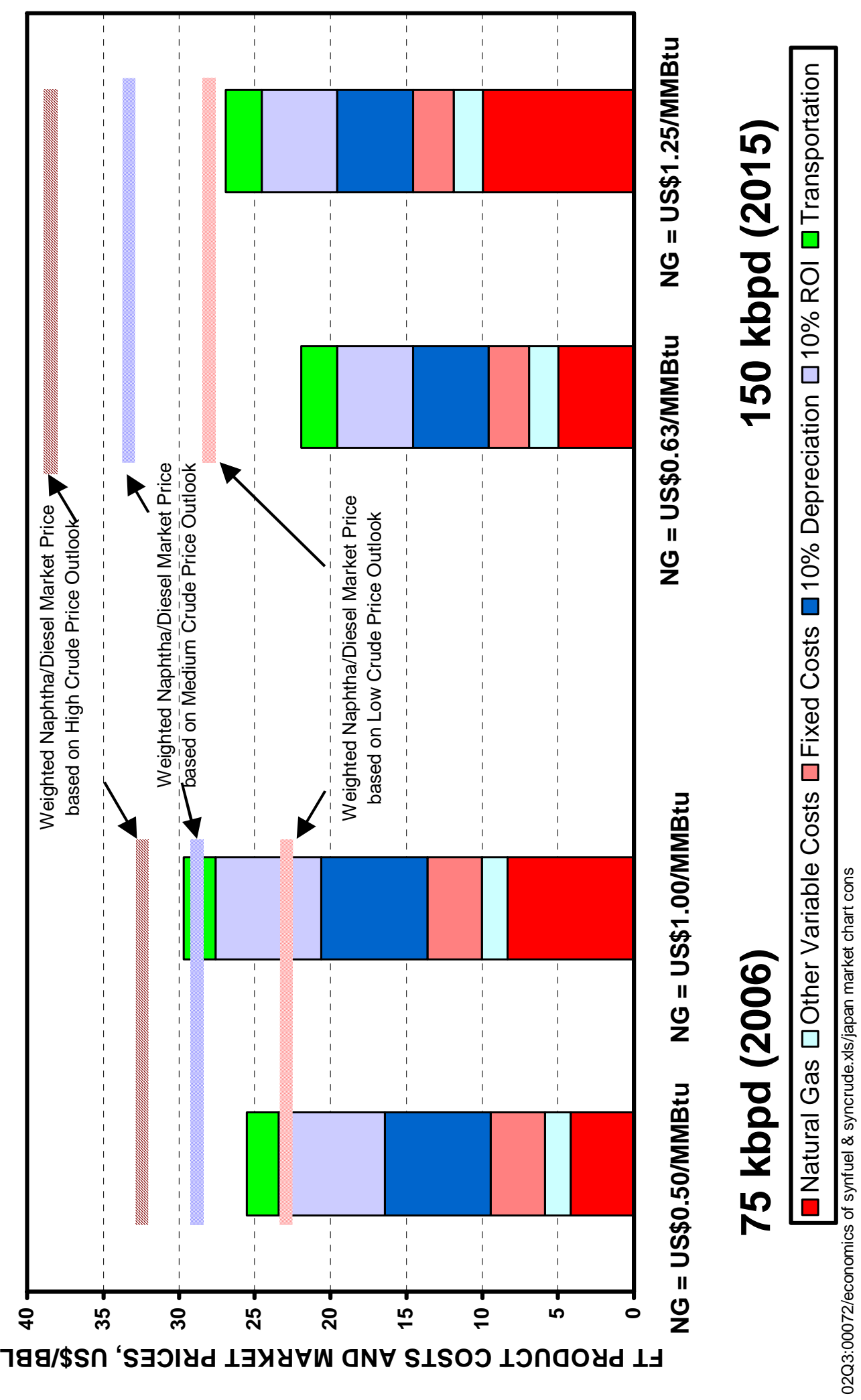


For 2015, the full cost of production plus 10 percent ROI for FT liquids produced at a 150,000 barrels per day facility in a Middle East remote location will be about $\$ 24.52$ per barrel if natural gas cost is $\$ 1.25$ per million BTU. Taking into account transportation costs and tariff, the total delivered cost of FT liquids will be $\$ 28.09, \$ 27.15$, and $\$ 26.91$ per barrel at the USGC, Western European, and Japanese markets, respectively.

If natural gas price is $\$ 0.625$ per million BTU, i.e., 50 percent of the assumption above, the full cost of production plus 10 percent ROI for FT liquids will be reduced to about $\$ 19.53$ per barrel and the corresponding delivered cost of FT liquids will be $\$ 23.11, \$ 22.16$, and $\$ 21.92$ per barrel at the USGC, Western European, and Japanese markets, respectively.

As indicated, GTL profitability is expected to increase for the USGC, Western Europe, and particularly, Japan by 2015. The higher diesel pricing in Japan indicates that this will be an attractive market for GTL FT products.

The transportation costs discussed above are depicted in Figure 3.9.

The economic viability of the Middle East GTL FT products can also be determined by examining the rate of return on investment. The rates of return on capital investment based on the regional market prices netback to the Middle East are presented in Figure 3.10 for 2006 and Figure 3.11 for 2015 .

Based on Nexant's 2006 medium crude price outlook and the weighted average naphtha/diesel market prices of $\$ 24.5, \$ 24.5$ and $\$ 28.2$ per barrel at the USGC, Western European, and Japanese markets, respectively, the GTL process with natural gas cost at $\$ 1.00$ per barrel can deliver FT products at a return on investment of 1.2, 2.3, and 7.9 percent to the USGC, Western European, and Japanese markets, respectively. Based on the weighted average market price of 25 percent USGC naphtha and 75 percent CARB diesel, the GTL process can provide an ROI of 4.8 percent, as also shown in Figure 3.10.

Based on Nexant's 2015 medium crude price outlook and the weighted average naphtha/diesel market prices of \$29.1, \$29.4 and \$33.3 per barrel at the USGC, Western European, and Japanese markets, respectively, the GTL process with natural gas cost at $\$ 1.25$ per barrel can deliver FT products at a return on investment of 12.2, 14.5, and 22.8 percent to the USGC, Western European, and Japanese markets, respectively. Based on the weighted average market price of 25 percent USGC naphtha and 75 percent CARB diesel, the GTL process can provide an ROI of 17.8 percent, as also shown in Figure 7.. 


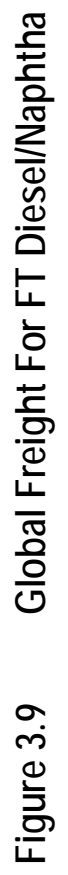

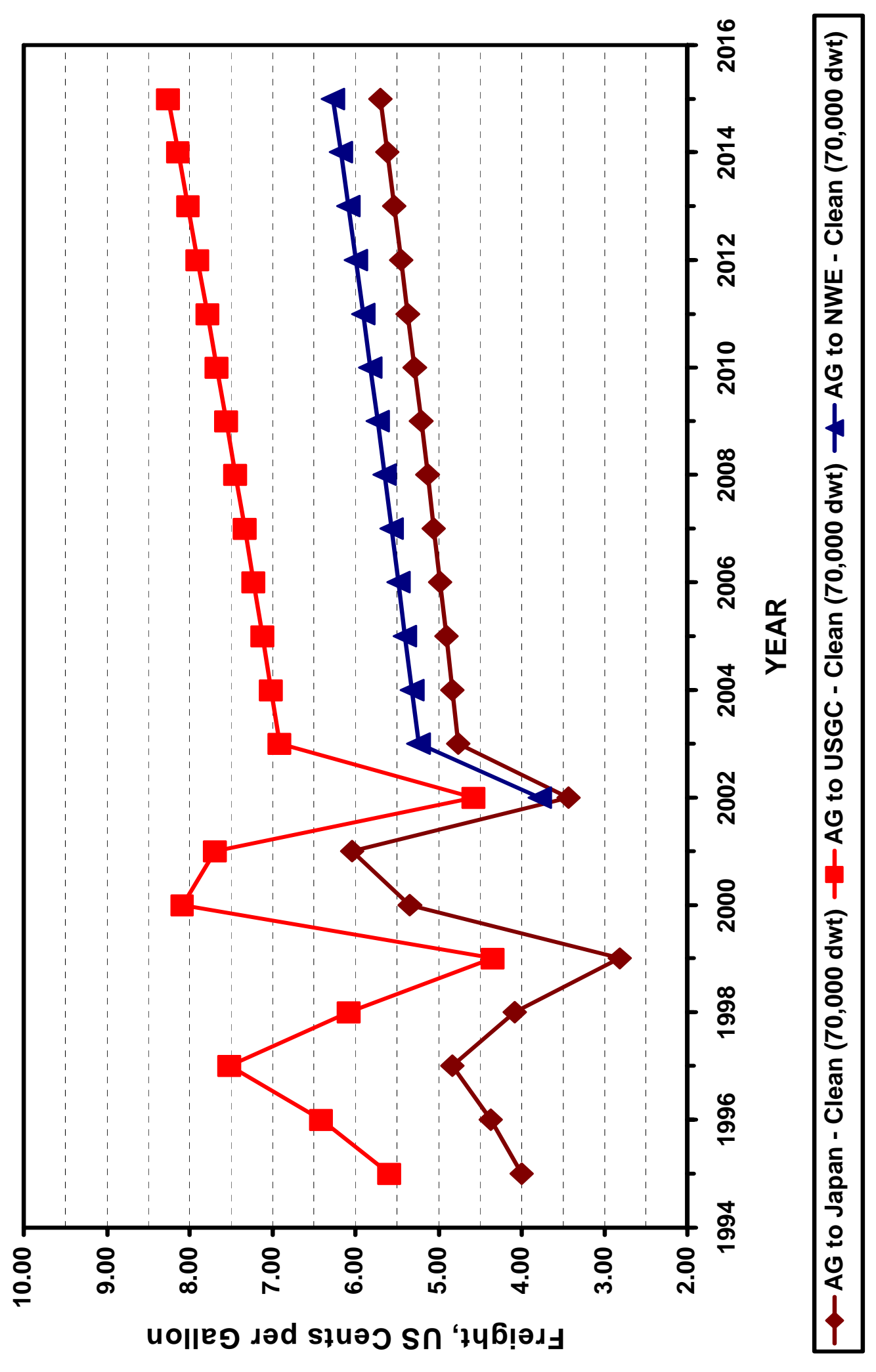




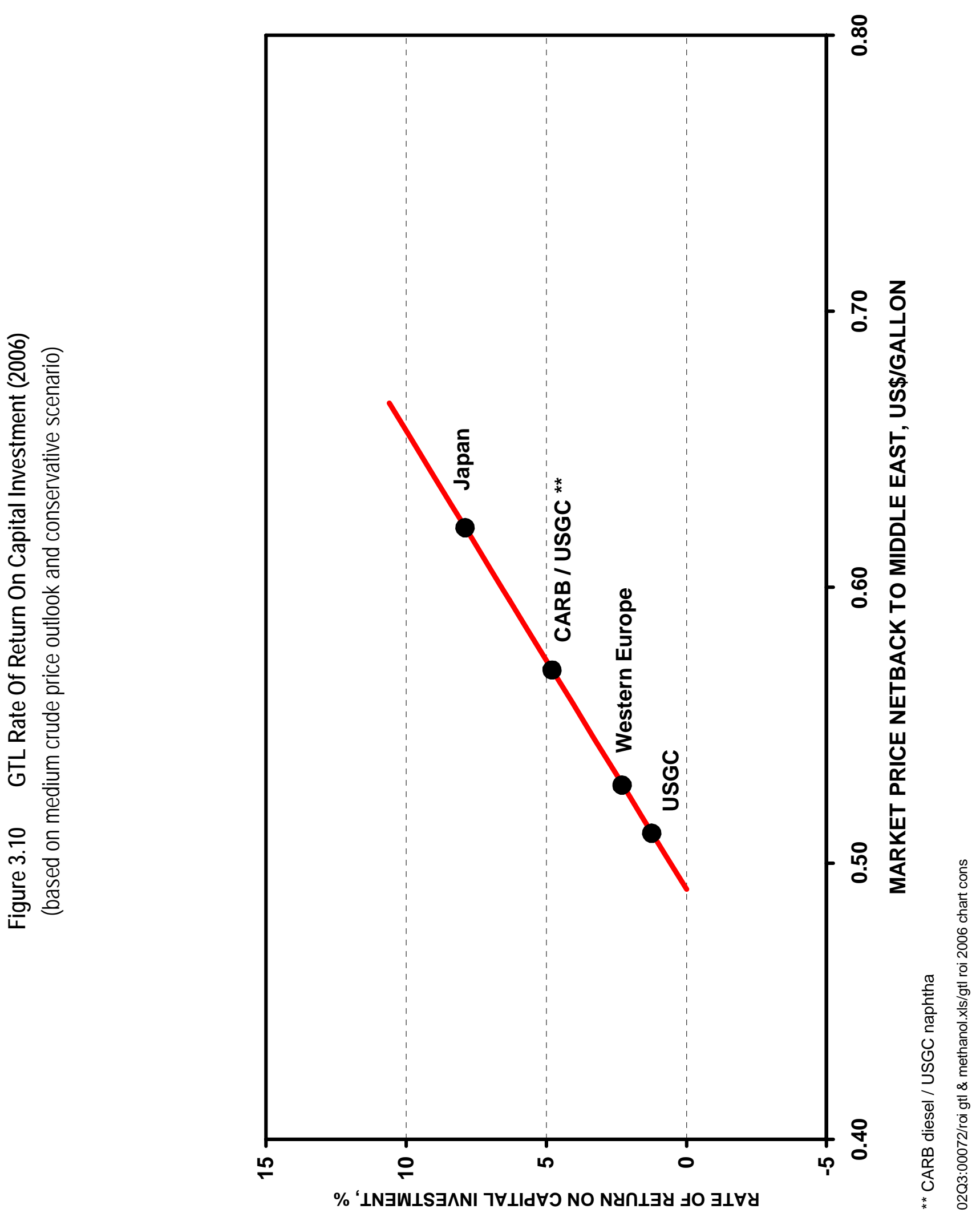




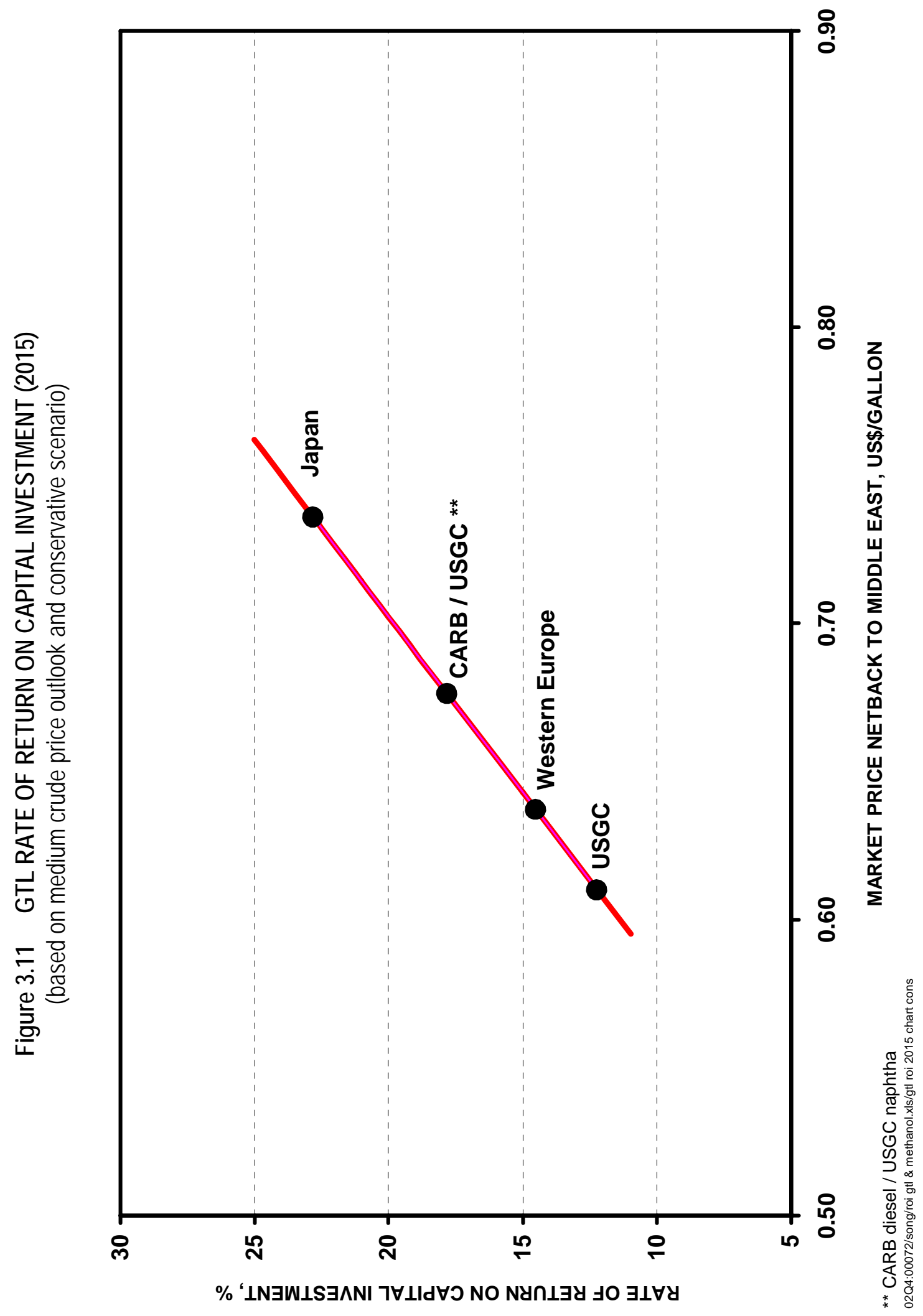




\subsubsection{Comparison between GTL and Conventional Refining}

It is of interest to compare the economics of the GTL technology with that of a conventional refining of crude oil. Figure 7. shows the comparison of production costs of GTL at the Middle East and a coking refinery at the USGC.

For 2006, the cost of production plus 10 percent ROI for a $75 \mathrm{kbpd}$ GTL plant at the Middle East with a capital of $25,490 \mathrm{US} \$ / \mathrm{bpd}$ product and a natural gas price of $1.00 \mathrm{US} \$ / \mathrm{MMBtu}$ is 27.58 US $\$ / b b l$ product. This is compared to $29.11 \mathrm{US} \$ / \mathrm{bbl}$ product for a USGC coking refinery with a capacity of $188 \mathrm{kbpd}$ product (or $200 \mathrm{kbpd}$ crude), a capital of 11,510 US\$/bpd product, and an average crude price of $18.25 \mathrm{US} \$ / \mathrm{bbl}$.

For 2015, the cost of production plus 10 percent ROI for a $150 \mathrm{kbpd}$ GTL plant at the Middle East with a capital of $18,180 \mathrm{US} \$ / \mathrm{bbl}$ product and a natural gas price of $1.25 \mathrm{US} \$ / \mathrm{MMBtu}$ is 24.52 US\$/bbl product. This is compared to $35.06 \mathrm{US} \$ / \mathrm{bbl}$ product for a USGC coking refinery with a capacity of $188 \mathrm{kbpd}$ (or $200 \mathrm{kbpd}$ crude), a capital of 14,060 US\$/bpd product, and an average crude price of $22.08 \mathrm{US} \$ / \mathrm{bbl}$.

The cost of production of a pro forma coking refinery is shown in Table 3.9 and Table 3.10 for 2006 and 2015, respectively. The detailed cost of production of conventional refineries is presented in Market Report Section 9. Taking into account the tariff and the transportation costs from the Middle East to the USGC, the delivered costs of FT liquid products become 30.72 and 28.09 US $\$ / \mathrm{bbl}$ of product for 2006 and 2015, respectively, compared to the weighted average naphtha/diesel market price of 24.5 and $29.1 \mathrm{US} \$ / \mathrm{bbl}$ product discussed previously. The corresponding average revenues for the coking refinery are 25.92 and $30.75 \mathrm{US} \$ / \mathrm{bbl}$ product for 2006 and 2015, respectively. The above profitability comparison is depicted in Figure 3.13. 

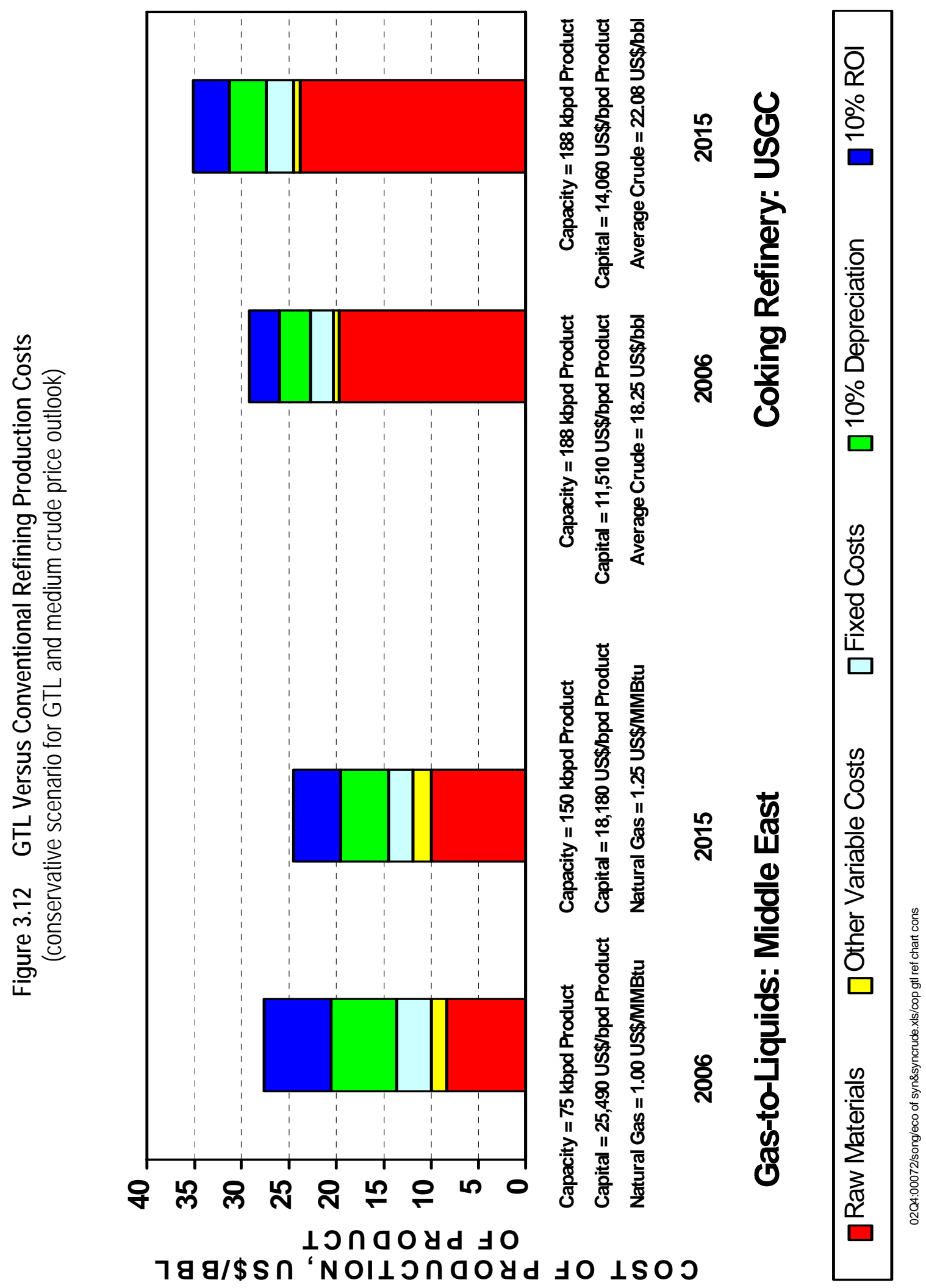


\section{Table 3.9 Cost Of Production Estimate For: Pro Forma Coking Refinery Process: Coking Refinery 2006}

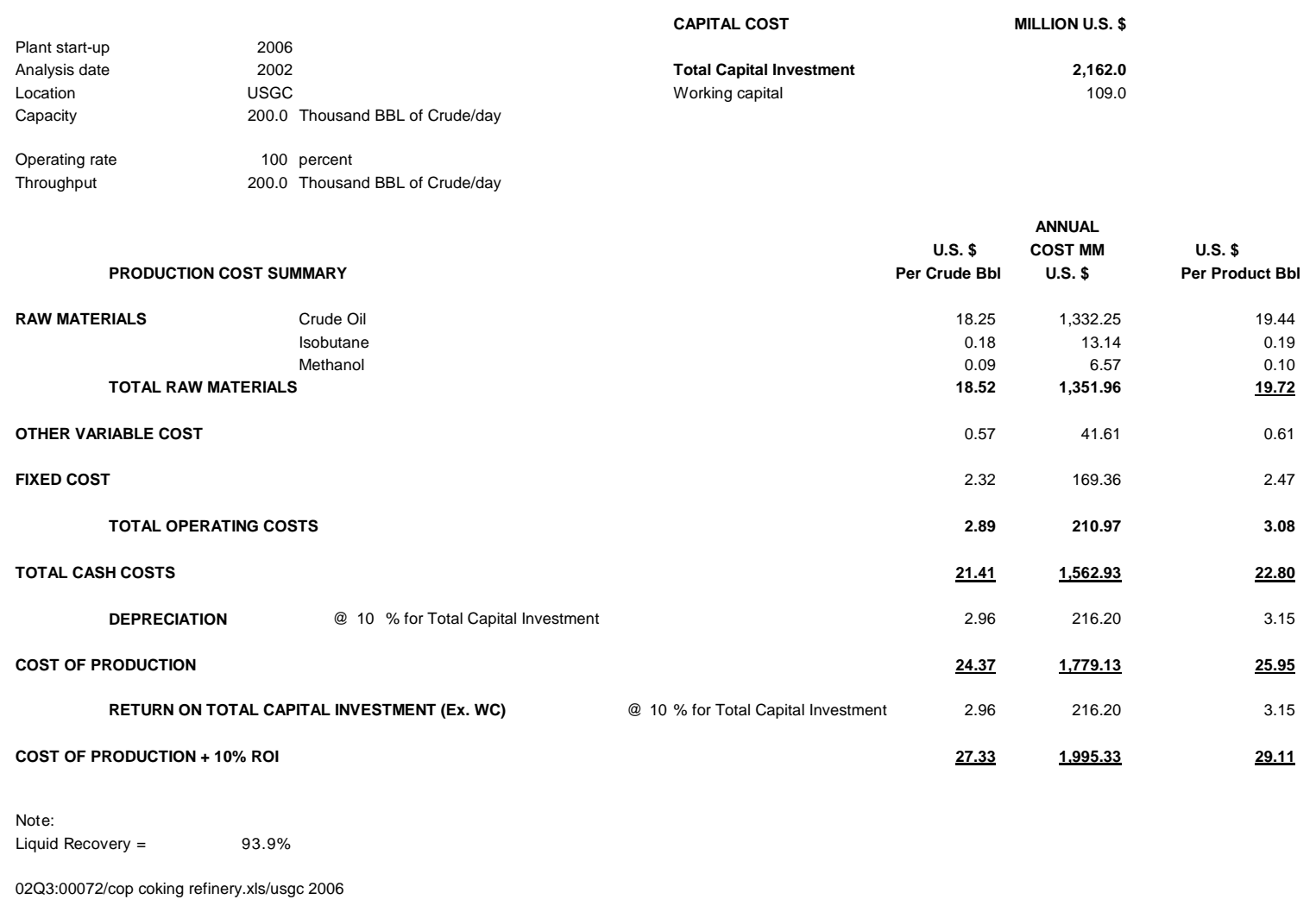




\section{Table 3.10 Cost Of Production For: Pro Forma Coking Refinery Process: Coking Refinery 2015}

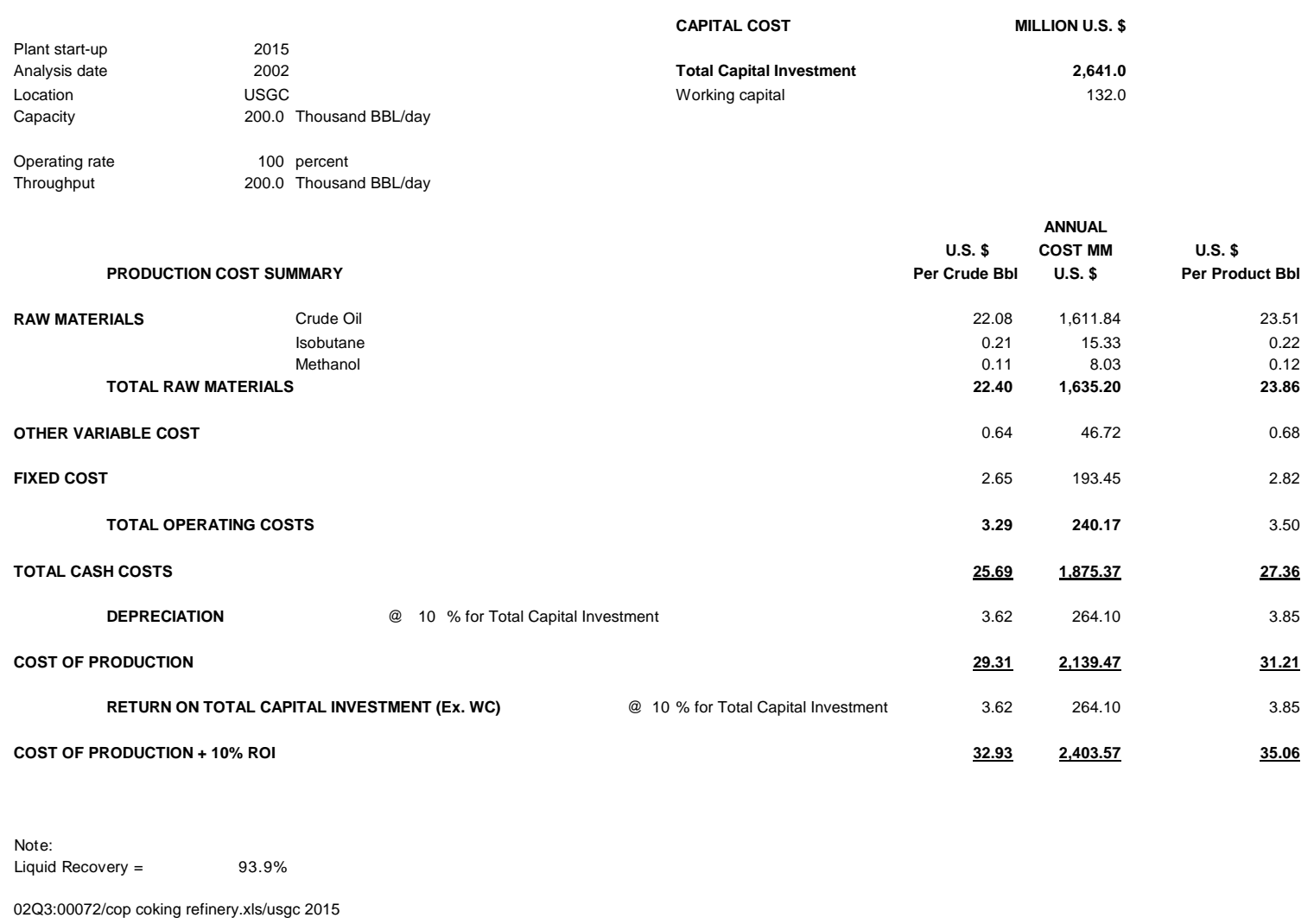




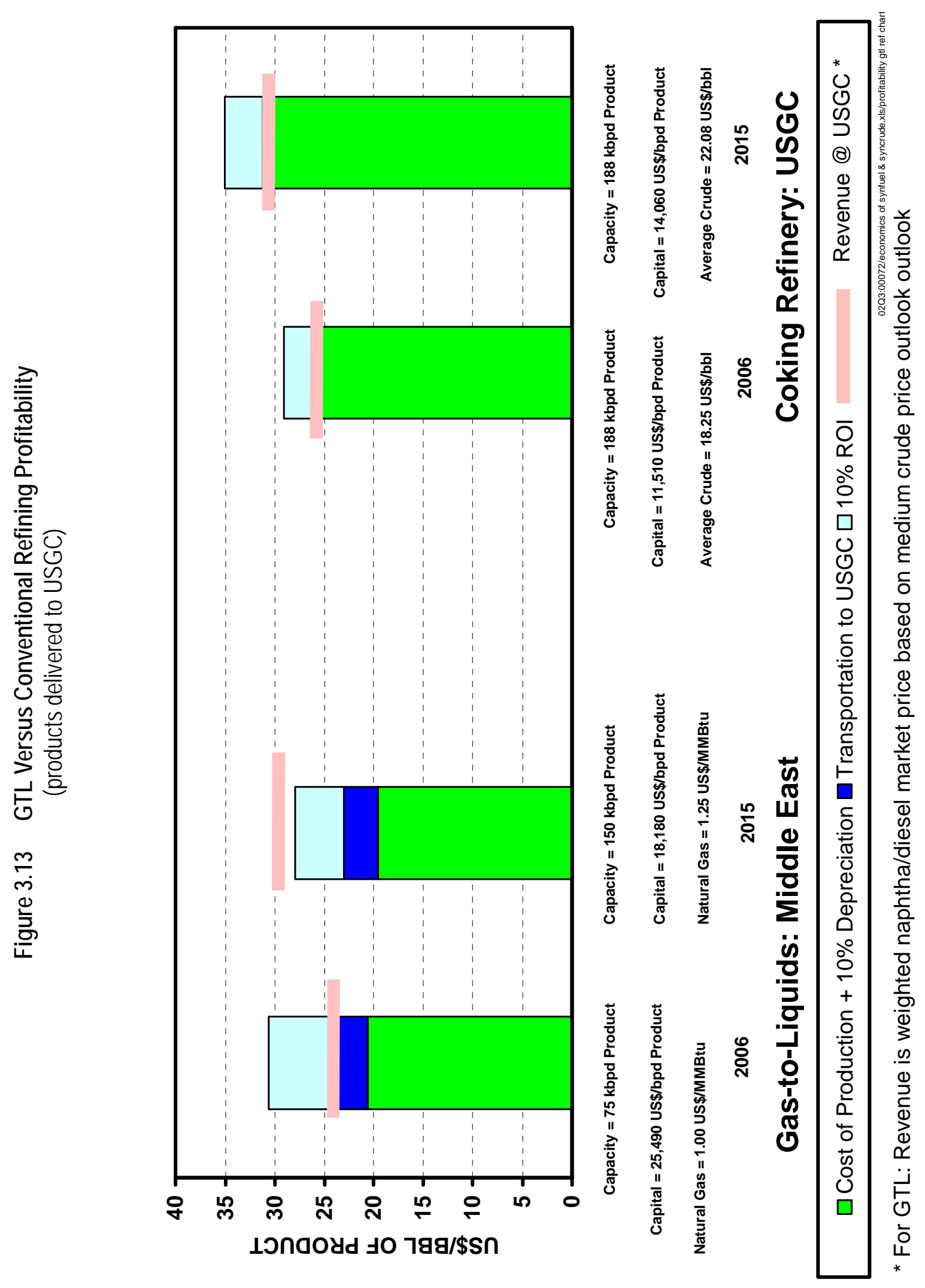




\subsubsection{Economics of Aggressive Scenario}

\subsubsection{Process Economics}

2006

The economics for the production of 3.380 million metric tons per year ( 75 thousand barrels per day) of GTL FT products at a Middle East remote location are presented in Table 3.11. 


\section{Table 3.11 Cost of Production Estimate for: GTL Synfuels \\ Process: Slurry Reactor}

(aggressive scenario-2006)

$\begin{array}{lr}\text { Plant start-up } & 2006 \\ \text { Analysis date } & 2002 \\ \text { Location } & \text { Middle East } \\ \text { Capacity } & 75.0 \text { Thousand BBL/day } \\ & 3,378.9 \text { Thousand metric tons/yr } \\ \text { Operating rate } & 100 \text { percent } \\ \text { Throughput } & 75.0 \text { Thousand BBL/day }\end{array}$

PRODUCTION COST SUMMARY

RAW MATERIALS

$$
\begin{aligned}
& \text { Natural Gas MMBtu } \\
& \text { Catalyst \& Chemicals }
\end{aligned}
$$

TOTAL RAW MATERIALS

NET RAW MATERIALS

UTILITIES

$$
\begin{gathered}
\text { Process Water } \\
\text { TOTAL UTILITIES }
\end{gathered}
$$

NET RAW MATERIALS \& UTILITIES

\author{
CAPITAL COST \\ ISBL \\ OSBL \\ Total Plant Capital \\ Other Project Costs \\ Total Capital Investment \\ Working capital
}

$\begin{array}{cc}\begin{array}{c}\text { UNITS } \\ \text { Per Bbl }\end{array} & \begin{array}{c}\text { PRICE } \\ \text { Uroduct }\end{array} \\ \begin{array}{c}\text { IUnit } \\ \text { IUn }\end{array} \\ 8.1958 & 1.000 \\ 1.0000 & 1.657\end{array}$

VARIABLE COST

\section{DIRECT FIXED COSTS}

ALLOCATED FIXED COSTS

TOTAL CASH COST

$$
\text { Depreciation @ }
$$
Environmental

$$
\begin{array}{lrl}
\text { Labor, } & 155 & \text { Men } \\
\text { Foremen, } & 15 & \text { Men } \\
\text { Super., } & 1 & \text { Men } \\
\text { Maint., Material \& Labor } \\
\text { Direct Overhead }
\end{array}
$$

TOTA

General Plant Overhead Insurance, Property Tax

TOTAL

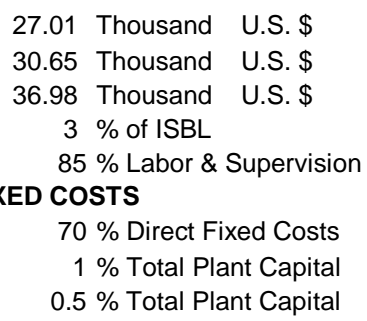

$10 \%$ for ISBL \& OPC

$10 \%$ for OSBL

COST OF PRODUCTION

RETURN ON TOTAL CAPITAL INVESTMENT (Ex. WC) @
10 Percent
MILLION U.S. \$

$1,188.7$

340.7

$1,529.4$

382.4

$1,911.8$

137.4
ANNUAL

U.S. \$ COST MM U.S. \$ $\begin{array}{lll}\text { Per Bbl } & \text { U.S. \$ Per MT }\end{array}$

$\begin{array}{rrr}8.20 & 224.36 & \\ 1.66 & 45.37 & \\ \mathbf{9 . 8 5} & \mathbf{2 6 9 . 7 3} & \mathbf{8 0} \\ \mathbf{9 . 8 5} & \mathbf{2 6 9 . 7 3} & \mathbf{8 0} \\ & & \\ 0.03 & 0.70 & \\ \mathbf{0 . 0 3} & \mathbf{0 . 7 0} & \mathbf{0} \\ \mathbf{9 . 8 8} & \mathbf{2 7 0 . 4 4} & \mathbf{8 0} \\ & & \\ \underline{\mathbf{9 . 8 8}} & \underline{\mathbf{2 7 0 . 4 4}} & \underline{\mathbf{8 0}}\end{array}$

$0.15 \quad 4.19$

$0.02 \quad 0.46$

$0.00 \quad 0.04$

$1.30 \quad 35.66$

$0.15 \quad 3.98$

$1.62 \quad 44.33$

$1.13 \quad 31.03$

$0.56 \quad 15.29$

$0.28 \quad 7.65$

$1.97 \quad 53.97$

$\underline{13.47} \quad \underline{368.73}$ 
The total plant capital cost is estimated to be $\$ 1.529$ billion. This capital cost includes $\$ 1.188$ billion for ISBL and $\$ 340.7$ million for OSBL. Other project costs are estimated to be $\$ 382.4$ million, resulting a total capital investment of $\$ 1.911$ billion. An additional $\$ 137.4$ million is also estimated for the working capital requirement.

With natural gas price at $\$ 1.00$ per MMBtu, the raw Material cost is $\$ 9.85$ per barrel of GTL FT products. With utility cost of $\$ 0.03$ per barrel of GTL FT products, it results in a variable cost of $\$ 9.88$ per barrel of GTL FT products.

The total direct fixed cost, including all labors, maintenance, and direct overhead, is approximately $\$ 1.62$ per barrel of GTL FT products. The total allocated fixed cost of the plant, including general plant overhead, insurance, property taxes, and environmental levy, is about $\$ 1.97$ per barrel of GTL FT products. The total fixed costs bring the total cash cost to $\$ 13.47$ per barrel (\$109 per metric ton) of GTL FT products.

Depreciation, at 10 percent of investment, contributes an additional \$6.98 per barrel of GTL FT products. Return on total capital investment, also at 10 percent of investment, contributes another $\$ 6.98$ per barrel of GTL FT products.

The above cash cost, depreciation, and return on total capital investment yield a full cost of production of $\$ 27.44$ per barrel (\$222 per metric ton) of GTL FT products.

2015

The economics for the production of 6.760 million metric tons per year (150 thousand barrels per day) of GTL FT products at a Middle East remote location are presented in Table 3.12.

The total plant capital cost is estimated to be $\$ 2.181$ billion. This capital cost includes $\$ 1.695$ billion for ISBL and $\$ 486.0$ million for OSBL. Other project costs are estimated to be $\$ 545.4$ million, resulting a total capital investment of $\$ 2.727$ billion. An additional $\$ 220.8$ million is also estimated for the working capital requirement.

With natural gas price at $\$ 1.25$ per MMBtu, the raw Material cost is $\$ 11.25$ per barrel of GTL FT products. With utility cost of $\$ 0.03$ per barrel of GTL FT products, it results in a variable cost of $\$ 11.28$ per barrel of GTL FT products.

The total direct fixed cost, including all labors, maintenance, and direct overhead, is approximately $\$ 1.21$ per barrel of GTL FT products. The total allocated fixed cost of the plant, including general plant overhead, insurance, property taxes, and environmental levy, is about $\$ 1.45$ per barrel of GTL FT products. The total fixed costs bring the total cash cost to $\$ 13.94$ per barrel (\$113 per metric ton) of GTL FT products. 


\section{Table 3.12 Cost Of Production Estimate For: GTL Synfuels \\ Process: Slurry Reactor \\ (aggressive scenario-2015)}

$\begin{array}{lr} & \\ \text { Plant start-up } & 2015 \\ \text { Analysis date } & 2002 \\ \text { Location } & \text { Middle East } \\ \text { Capacity } & 150.0 \text { Thousand BBL/day } \\ & 6,757.8 \text { Thousand metric tons/yr } \\ \text { Operating rate } & 100 \text { percent } \\ \text { Throughput } & 150.0 \text { Thousand BBL/day }\end{array}$

PRODUCTION COST SUMMARY

CAPITAL COST
ISBL
OSBL
Total Plant Capital
Other Project Costs
Total Capital Investment
Working capital

UNITS PRICE

Per Bbl U.S.\$

Product IUnit

$\begin{array}{ll}\text { RAW MATERIALS } & \begin{array}{l}\text { Natural Gas } \\ \text { Catalyst \& Chemicals }\end{array} \\ & \text { TOTAL RAW MATERIALS } \\ \text { UTILITIES } & \text { NET RAW MATERIALS }\end{array}$

$1.0000 \quad 1.893$

$0.0174 \quad 1.687$
$7.4937 \quad 1.249$
1.0000
MILLION U.S. \$

$1,695.7$

486.0

$2,181.7$

545.4

$2,727.2$

220.8

ANNUAL

$\begin{array}{ccc}\text { U.S. \$ } & \text { COST MM } & \text { U.S. \$ } \\ \text { Per Bbl } & \text { U.S. \$ } & \text { Per MT }\end{array}$

$\begin{array}{rrr}9.36 & 512.39 & \\ 1.89 & 103.62 & \\ \mathbf{1 1 . 2 5} & \mathbf{6 1 6 . 0 1} & \mathbf{9 1} \\ \mathbf{1 1 . 2 5} & \mathbf{6 1 6 . 0 1} & \mathbf{9 1} \\ & & \\ 0.03 & 1.61 & \\ \mathbf{0 . 0 3} & \mathbf{1 . 6 1} & \mathbf{0} \\ \mathbf{1 1 . 2 8} & \mathbf{6 1 7 . 6 1} & \mathbf{9 1} \\ & & \\ \mathbf{1 1 . 2 8} & \underline{\mathbf{6 1 7 . 6 1}} & \underline{\mathbf{9 1}}\end{array}$

$0.14 \quad 7.49$

$0.00 \quad 0.09$

$0.93 \quad 50.87$

$0.13 \quad 7.16$

$1.21 \quad 66.45$

$0.85 \quad 46.52$

$0.40 \quad 21.82$

$0.20 \quad 10.91$

$1.45 \quad 79.24$

$\underline{13.94} \underline{763.31}$

$4.98 \quad 272.72$

113

$\underline{18.92} \quad \underline{1,036.03} \quad \underline{153}$

$\begin{array}{lll}4.98 & 272.72 & 40\end{array}$

$\underline{23.90} \quad \underline{1,308.74} \quad \underline{194}$
NET RAW MATERIALS \& UTILITIES UTILITIES

VARIABLE COST
TOTAL CASH COST

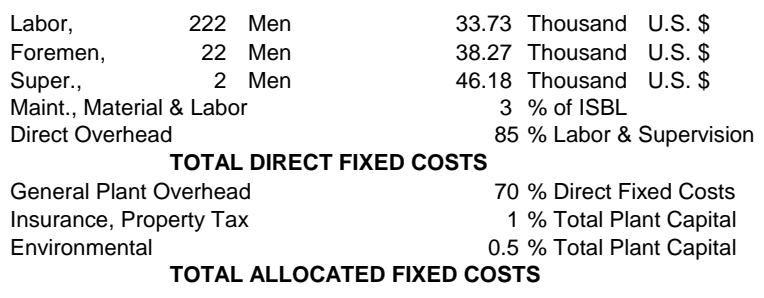

TOTAL ALLOCATED FIXED COSTS

$10 \%$ for ISBL \& OPC

COST OF PRODUCTION

RETURN ON TOTAL CAPITAL INVESTMENT (Ex. WC) @

10 Percent
$0.02 \quad 0.84$

COST OF PRODUCTION + ROI

94


Depreciation, at 10 percent of investment, contributes an additional $\$ 4.98$ per barrel of GTL FT products. Return on total capital investment, also at 10 percent of investment, contributes another $\$ 4.98$ per barrel of GTL FT products.

The above cash cost, depreciation, and return on total capital investment yield a full cost of production of $\$ 23.90$ per barrel ( $\$ 194$ per metric ton) of GTL FT products.

The costs of production of GTL FT products at a Middle East remote location for 2006 and 2015 are summarized graphically in Figure 7.ure 3.14. As indicated in the figure, due to technology advances and increased scale, GTL FT product costs are forecast to decline despite higher gas pricing.

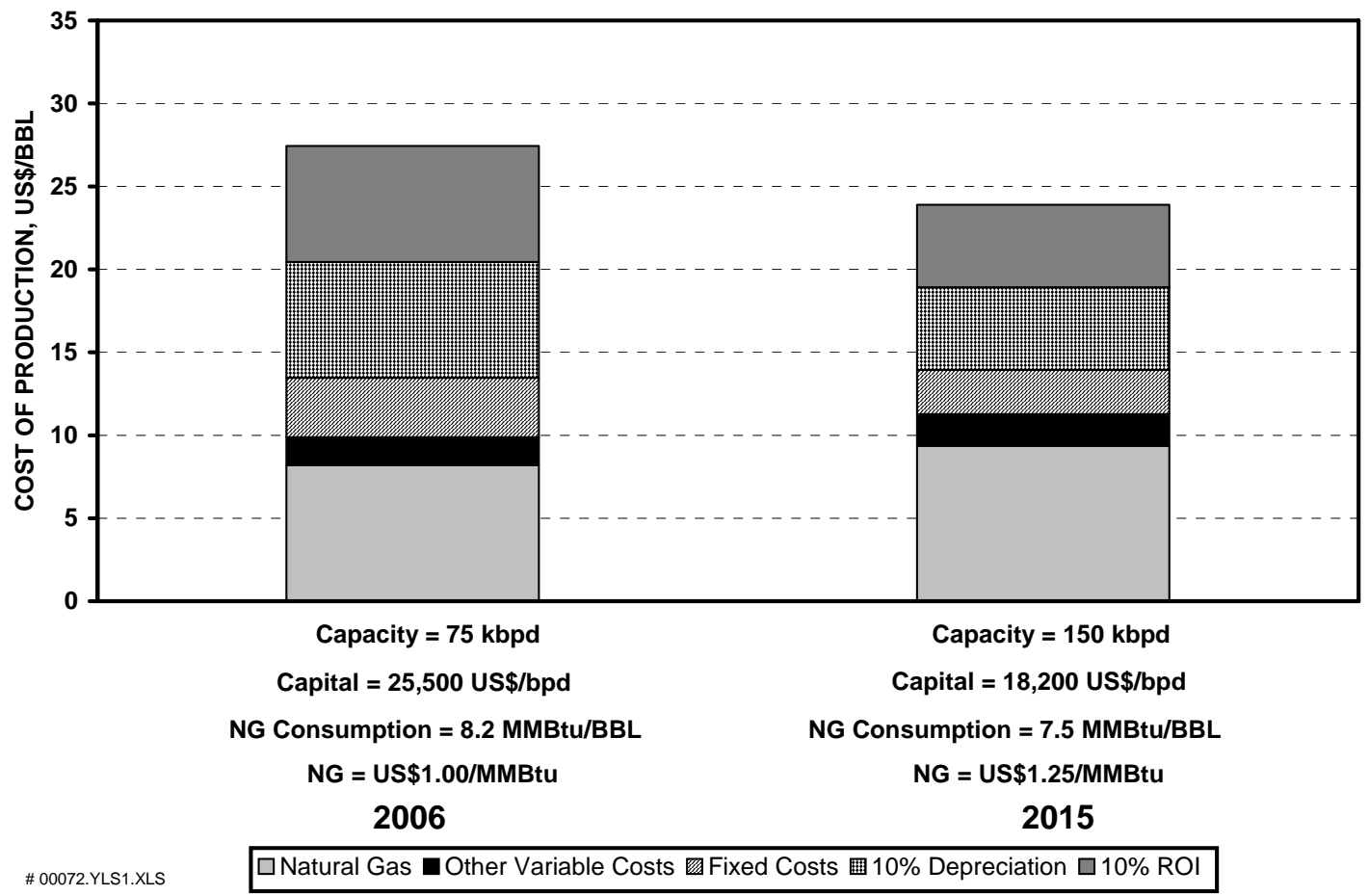

Figure 3.14 Cost Of Production Of FT Products In Middle East (aggressive scenario)

\subsubsection{Sensitivity Analysis}

2006

The effects of natural gas price, capital investment, and GTL FT production capacity on the full cost of production of GTL FT products plus 10 percent ROI are shown in Figure 3.15. 
With total capital investment maintained at $\$ 1.912$ billion and GTL FT production capacity maintained at 3.380 million metric tons per year (75 thousand barrels per day), GTL FT products full cost of production plus 10 percent ROI increases from $\$ 27.44 /$ barrel to $\$ 31.53 /$ barrel when natural gas price increases from $\$ 1.00 / \mathrm{MMBtu}$ to $\$ 1.50 / \mathrm{MMBtu}$, i.e. 50 percent increase. GTL FT products full cost of production plus 10 percent ROI decreases to $\$ 23.34 /$ barrel when natural gas price decreases to $\$ 0.50 / \mathrm{MMBtu}$, i.e. 50 percent decrease. Thus, every dollar/MMBtu change in natural gas price results in an average change of $\$ 8.20 /$ barrel in GTL FT products full cost of production plus 10 percent ROI. 


\section{Figure 3.15 Sensitivity Of GTL Cost Of Production To Key Variables} (2006 aggressive scenario)
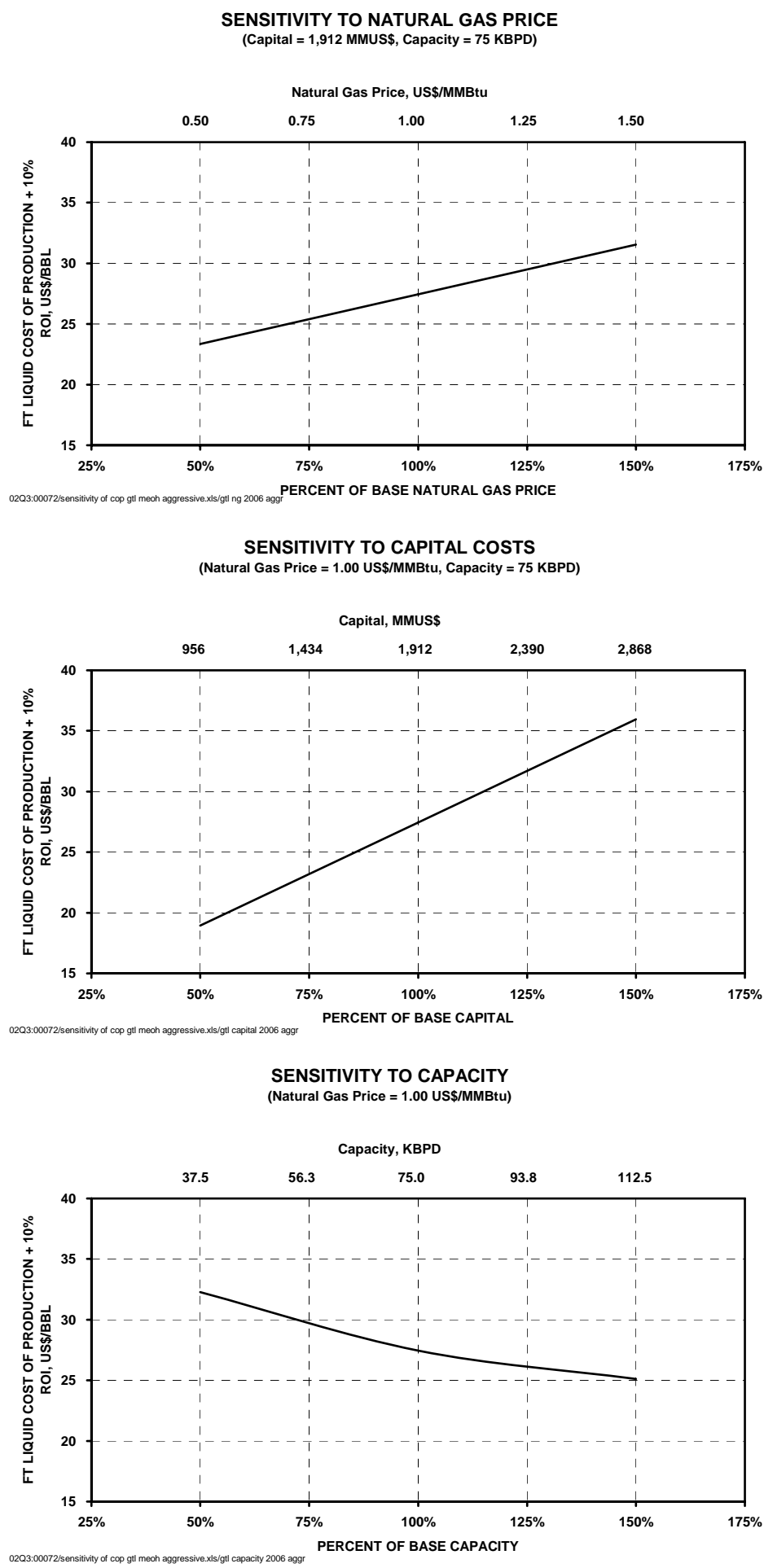
With natural gas price maintained at $\$ 1.00 / \mathrm{MMBtu}$ and GTL FT products production capacity maintained at 3.380 million metric tons per year (75 thousand barrels per day), GTL FT products full cost of production plus 10 percent ROI increases from $\$ 27.44 /$ barrel to $\$ 35.95 /$ barrel when the total capital investment increases from $\$ 1.912$ billion to $\$ 2.868$ billion, i.e. 50 percent increase. GTL FT products full cost of production plus 10 percent ROI decreases to $\$ 18.93 /$ barrel when the total capital investment decreases to $\$ 956$ million, i.e. 50 percent decrease. This represents an average of \$0.89/barrel change in GTL FT products full cost of production plus 10 percent ROI for every $\$ 100$ million change in total capital investment.

With natural gas price maintained at $\$ 1.00 /$ MMBtu, GTL FT products full cost of production plus 10 percent ROI decreases from $\$ 27.44$ /barrel to $\$ 25.12 /$ barrel when GTL FT production capacity increases from 3.380 million metric tons per year ( 75 thousand barrels per day) to 5.070 million metric tons per year (112.5 thousand barrels per day), i.e. 50 percent increase. GTL FT products full cost of production plus 10 percent ROI increases to $\$ 32.27 /$ barrel when GTL FT products production capacity decreases to 1.690 million metric tons per year (37.5 thousand barrels per day), i.e. 50 percent decrease.

\section{5}

The effects of natural gas price, capital investment, and GTL FT production capacity on the full cost of production of GTL FT products plus 10 percent ROI are shown in Figure 3.16.

With total capital investment maintained at $\$ 2.727$ billion and GTL FT production capacity maintained at 6.760 million metric tons per year (150 thousand barrels per day), GTL FT products full cost of production plus 10 percent ROI increases from $\$ 23.90 / \mathrm{barrel}$ to $\$ 28.58 /$ barrel when natural gas price increases from $\$ 1.25 / \mathrm{MMBtu}$ to $\$ 1.87 / \mathrm{MMBtu}$, i.e. 50 percent increase. GTL FT products full cost of production plus 10 percent ROI decreases to $\$ 19.23 /$ barrel when natural gas price decreases to $\$ 0.62 / \mathrm{MMBtu}$, i.e. 50 percent decrease. Thus, every dollar/MMBtu change in natural gas price results in an average change of $\$ 7.50 / \mathrm{barrel}$ in GTL FT products full cost of production plus 10 percent ROI.

With natural gas price maintained at $\$ 1.25 / \mathrm{MMBtu}$ and GTL FT products production capacity maintained at 6.760 million metric tons per year (150 thousand barrels per day), GTL FT products full cost of production plus 10 percent ROI increases from $\$ 23.90 /$ barrel to $\$ 29.97 /$ barrel when the total capital investment increases from $\$ 2.727$ billion to $\$ 4.091$ billion, i.e. 50 percent increase. GTL FT products full cost of production plus 10 percent ROI decreases to $\$ 17.83 /$ barrel when the total capital investment decreases to $\$ 1.364$ billion, i.e. 50 percent decrease. This represents an average of $\$ 0.45 /$ barrel change in GTL FT products full cost of production plus 10 percent ROI for every $\$ 100$ million change in total capital investment. 


\section{Figure 3.16 Sensitivity Of GTL Cost Of Production To Key Variables} (2015 aggressive scenario)
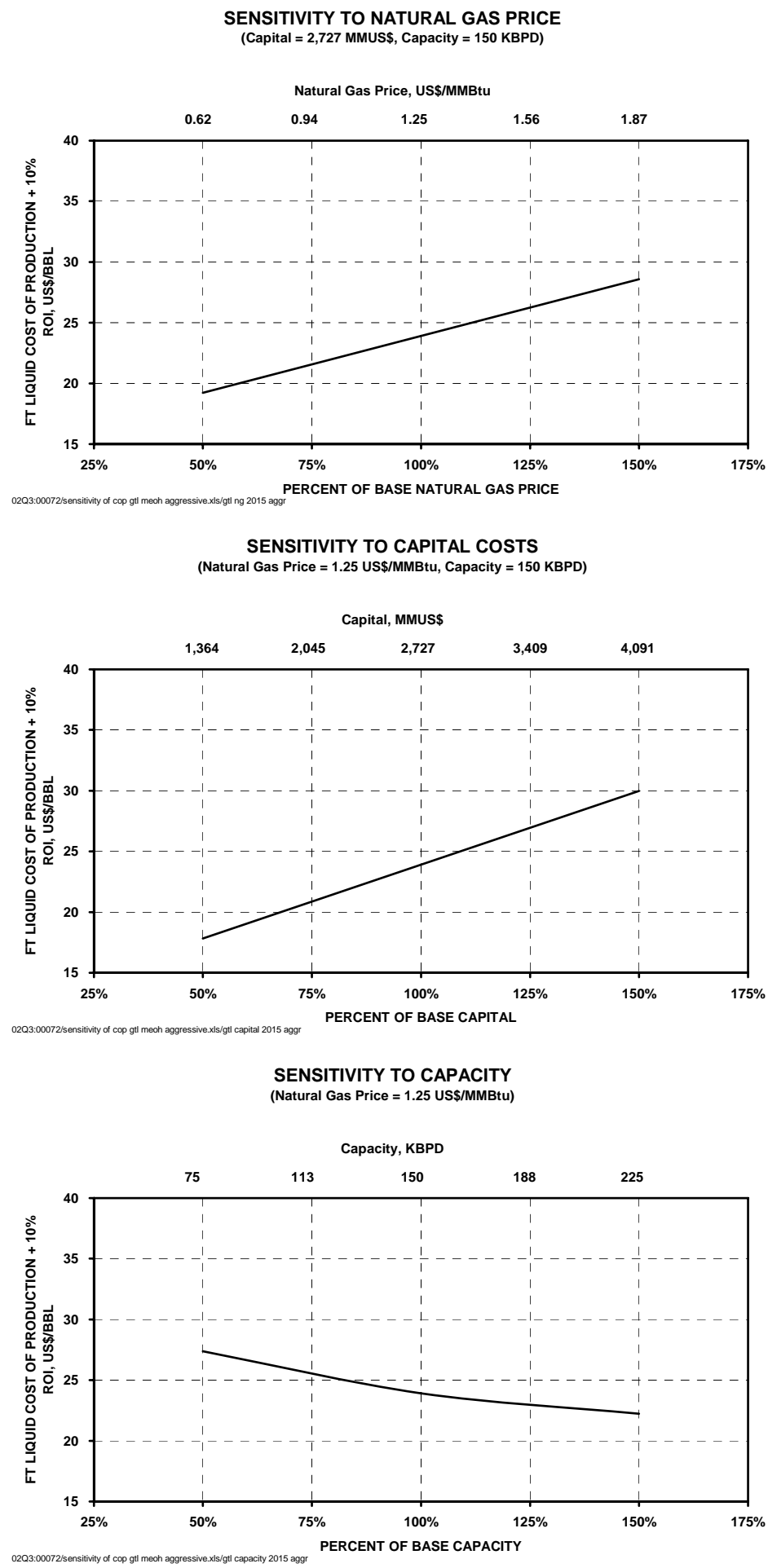
With natural gas price maintained at $\$ 1.25 / \mathrm{MMBtu}$, GTL FT products full cost of production plus 10 percent ROI decreases from $\$ 23.90 /$ barrel to $\$ 22.23 /$ barrel when GTL FT production capacity increases from 6.760 million metric tons per year (150 thousand barrels per day) to 10.140 million metric tons per year (225 thousand barrels per day), i.e. 50 percent increase. GTL FT products full cost of production plus 10 percent ROI increases to $\$ 27.37 /$ barrel when GTL FT products production capacity decreases to 3.380 million metric tons per year ( 75 thousand barrels per day), i.e. 50 percent decrease.

\subsubsection{Regional Economics}

The economic viability of remotely produced GTL FT products at the Middle East can be determined by their delivered costs to the USGC, Western Europe, and Japan. The delivered costs have been developed from the estimated production costs for the GTL plant located in the Middle East as described previously. Transportation costs for shipping the FT products from the Middle East to the various regions and tariff, if any, imposed by the various regions are added to the production costs to yield the delivered costs.

Table 3.13 and Figure 3.17 to Figure 3.19 summarize the results of the of the delivered costs of GTL FT products to the various regions and the comparison to regional FT products ( 25 volume percent naphtha and 75 volume percent diesel) prices forecast for 2006 and 2015 based on low, medium, and high crude price outlooks, respectively.

As indicated, GTL profitability is expected to increase for the USGC, Western Europe, and particularly, Japan by 2015. The higher diesel pricing in Japan indicates that this will be an attractive market for GTL FT products.

The economic viability of the Middle East GTL FT products can also be determined by examining the rate of return on investment. The rates of return on capital investment based on the regional market prices netback to the Middle East are presented in Figure 3.20 for 2006 and Figure 3.21 for 2015. For 2006, the GTL process can deliver FT products at a return on investment of 1.5, 2.5, and 8.1 percent to USGC, Western Europe, and Japan, respectively. For 2015, the GTL process can deliver FT products at a return on investment of 13.5, 15.8, and 24.1 percent to USGC, Western Europe, and Japan, respectively. For 25 percent USGC naphtha and 75 percent CARB diesel, the ROIs are 5.0 and 19.0 percent for 2006 and 2015, respectively. 


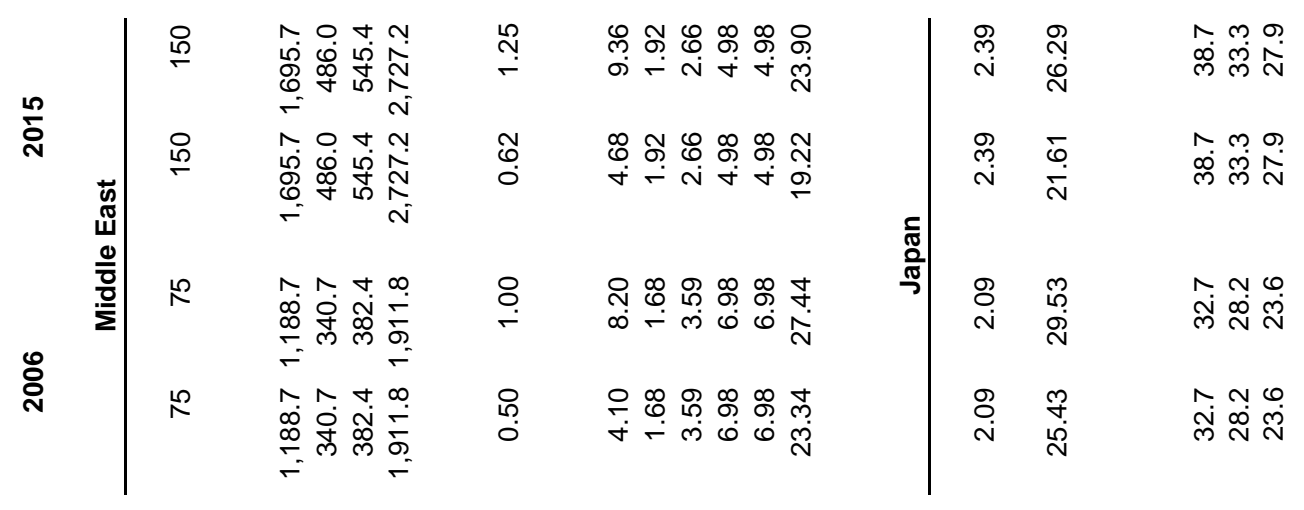

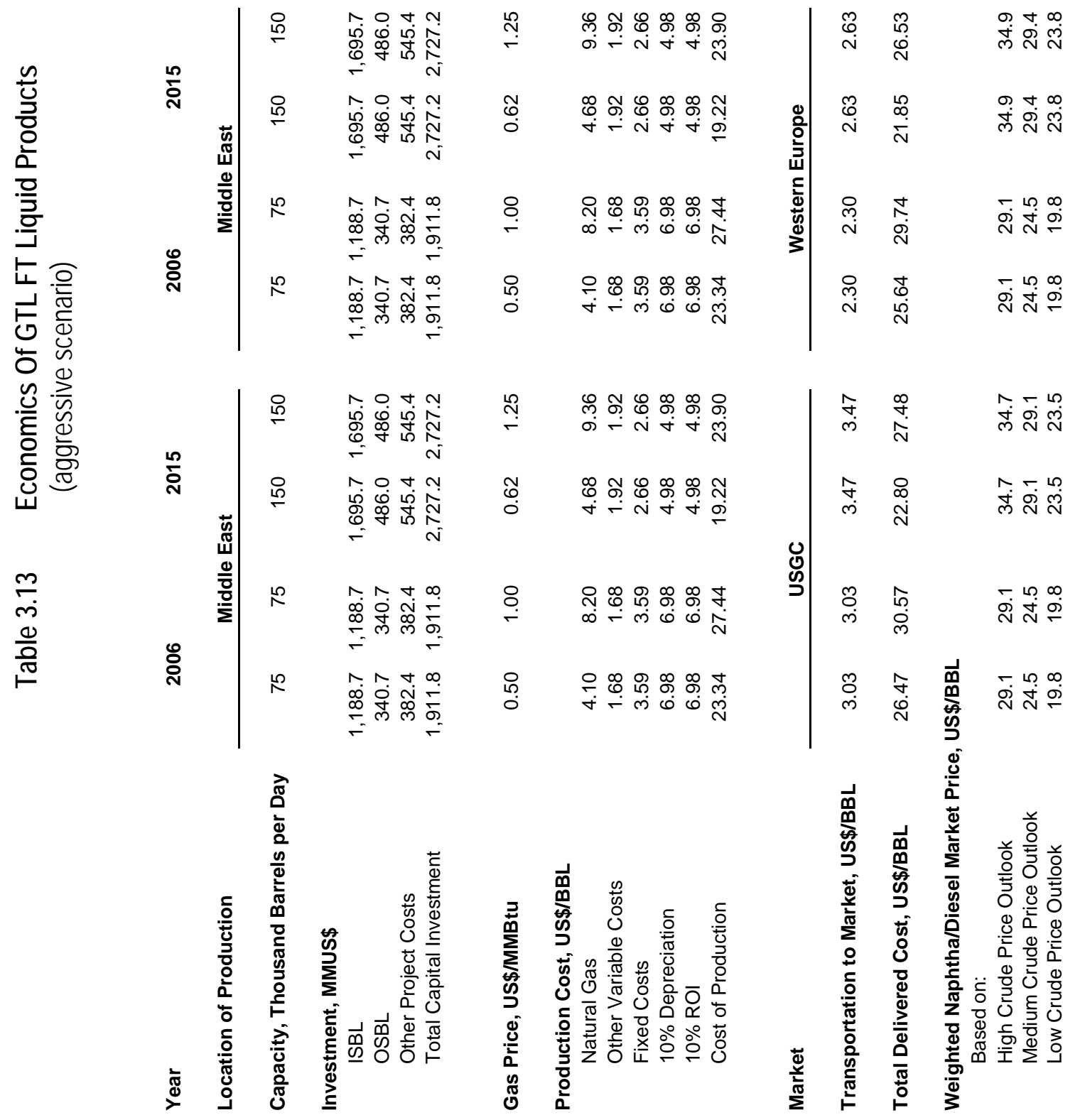




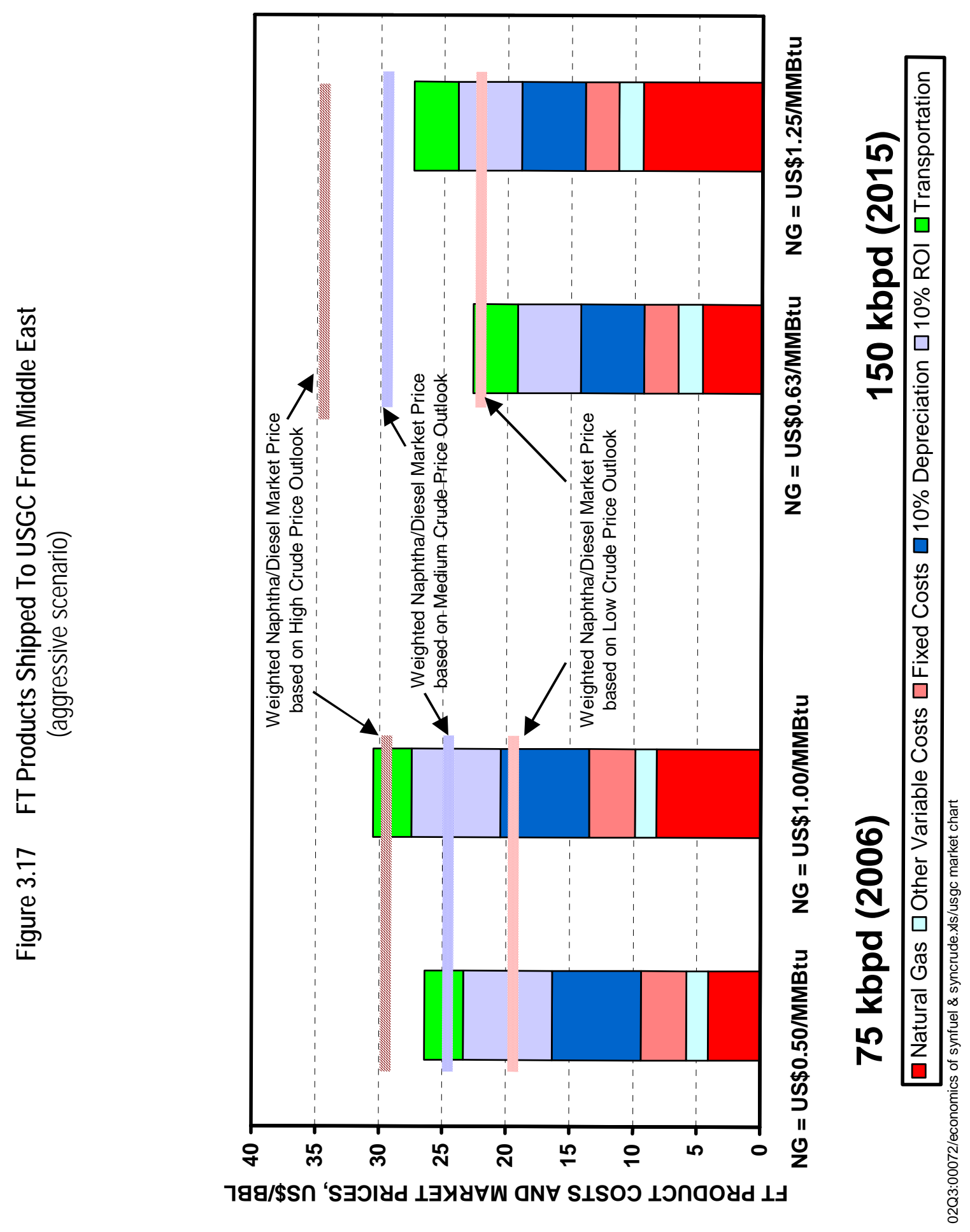



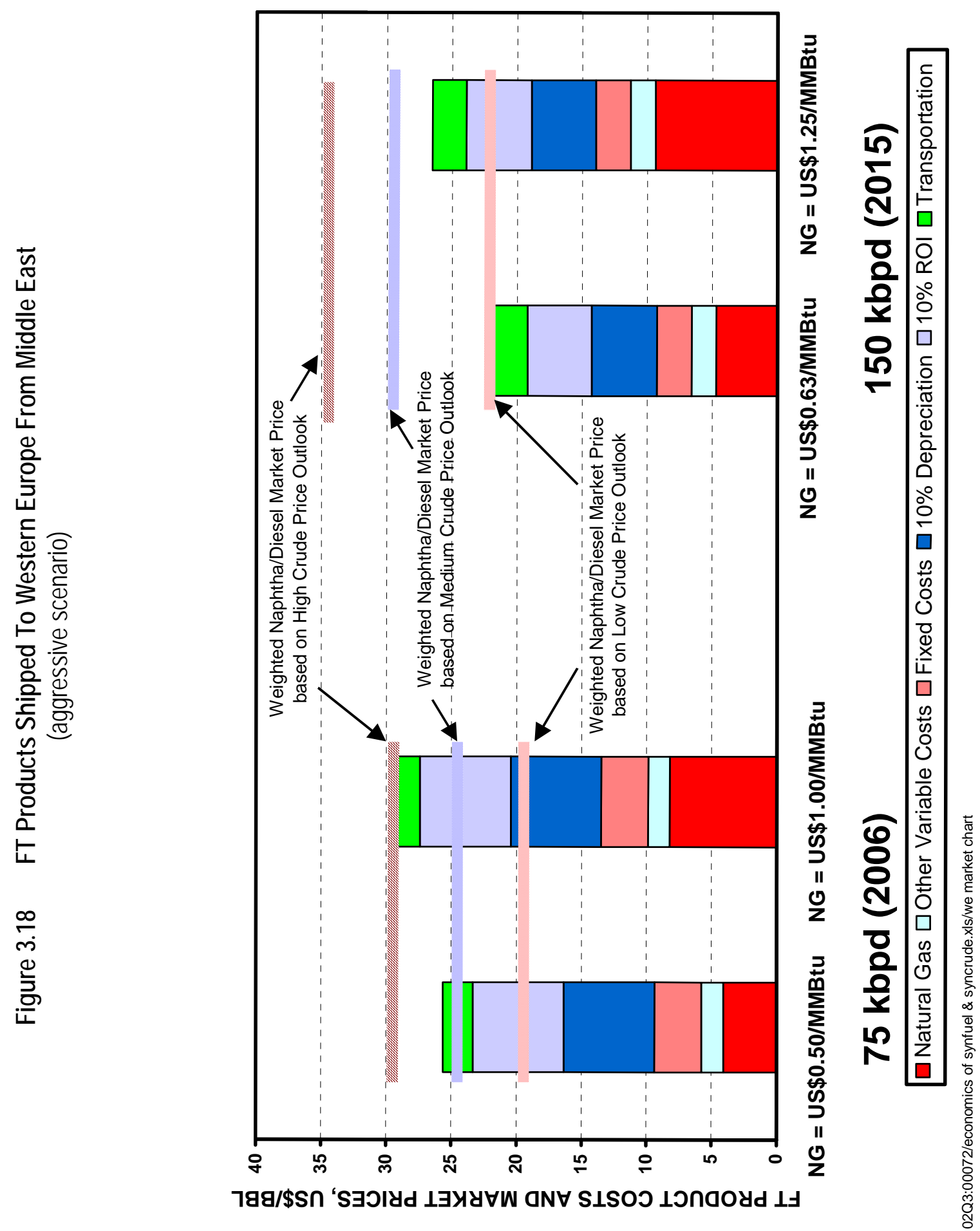

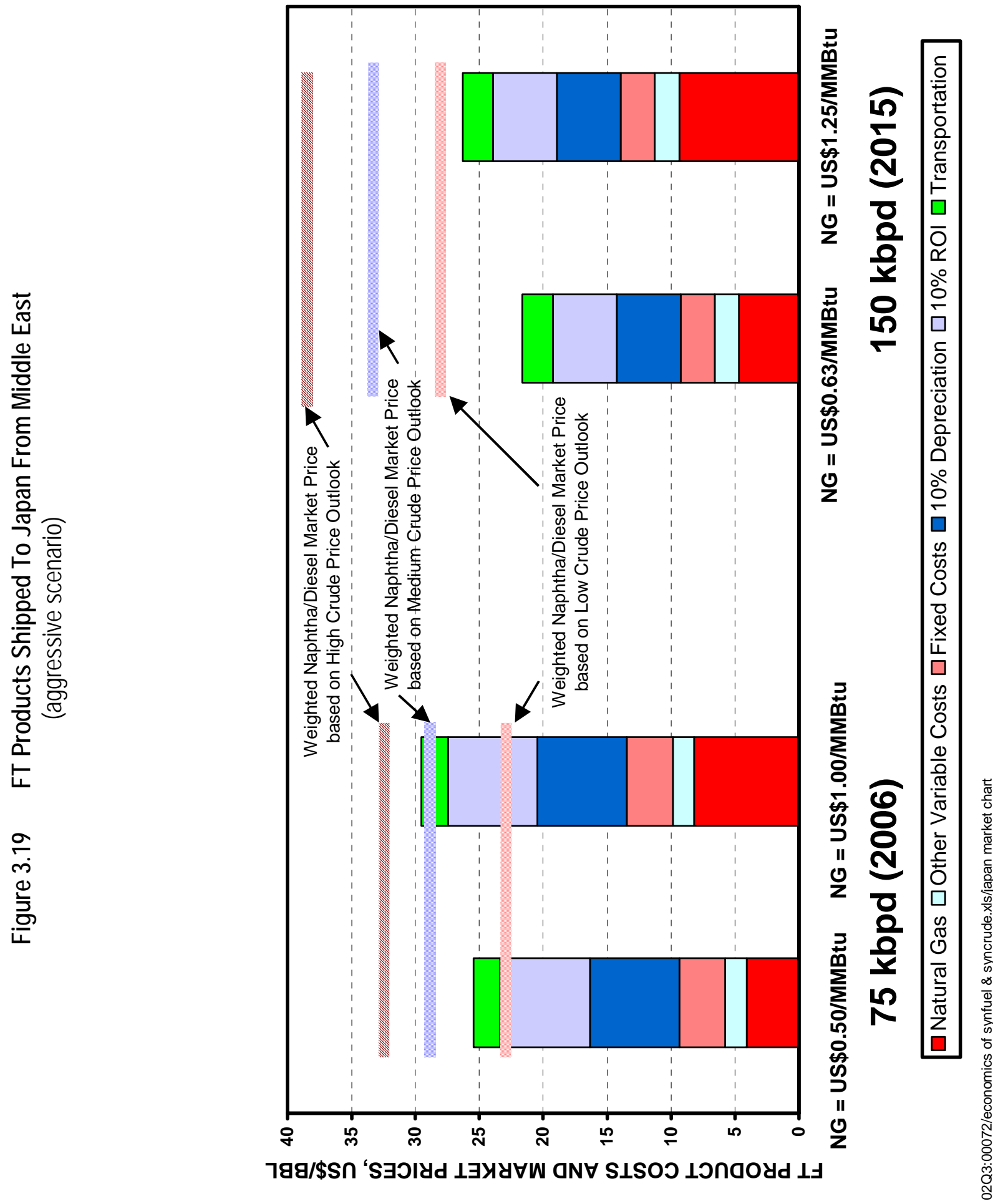


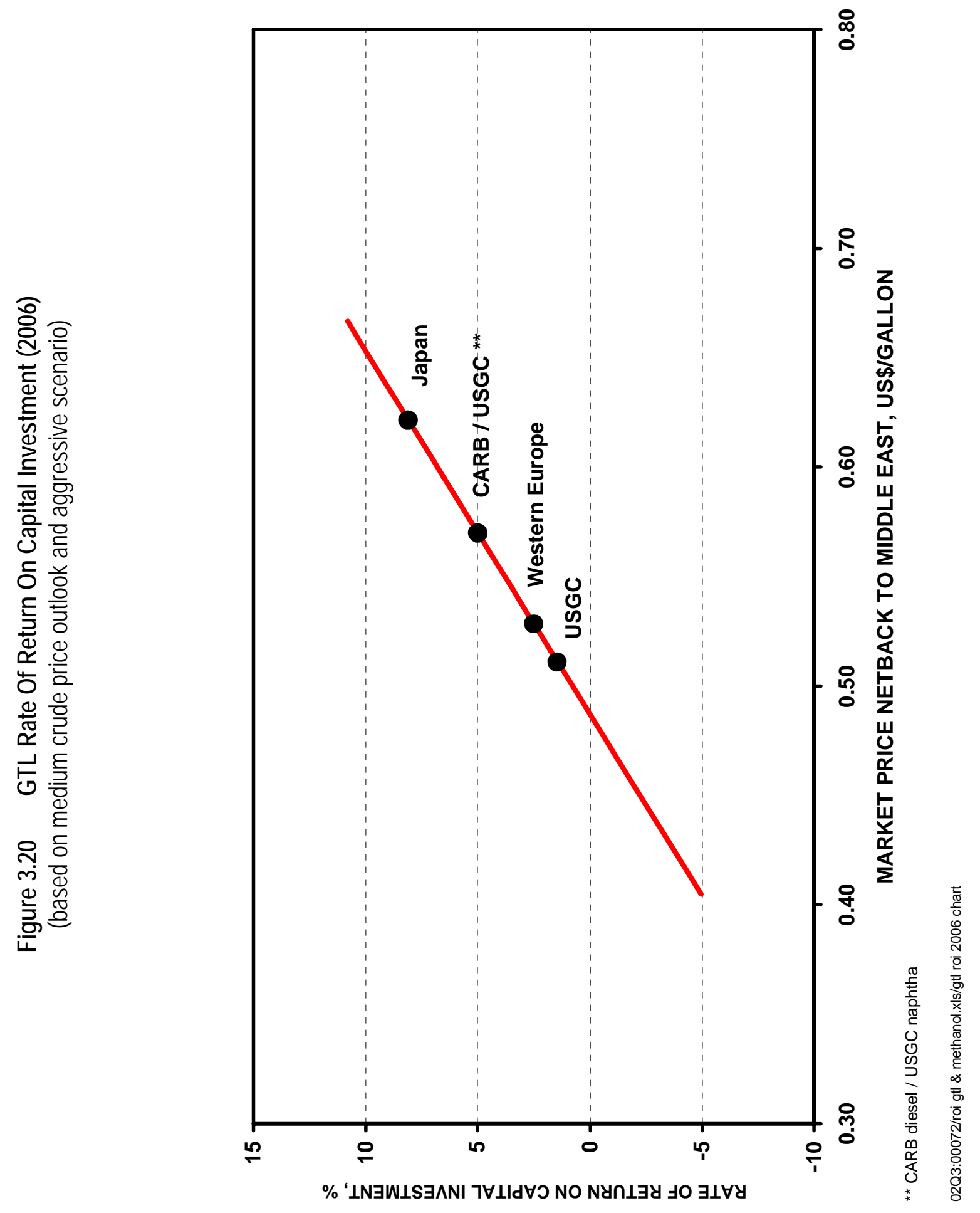




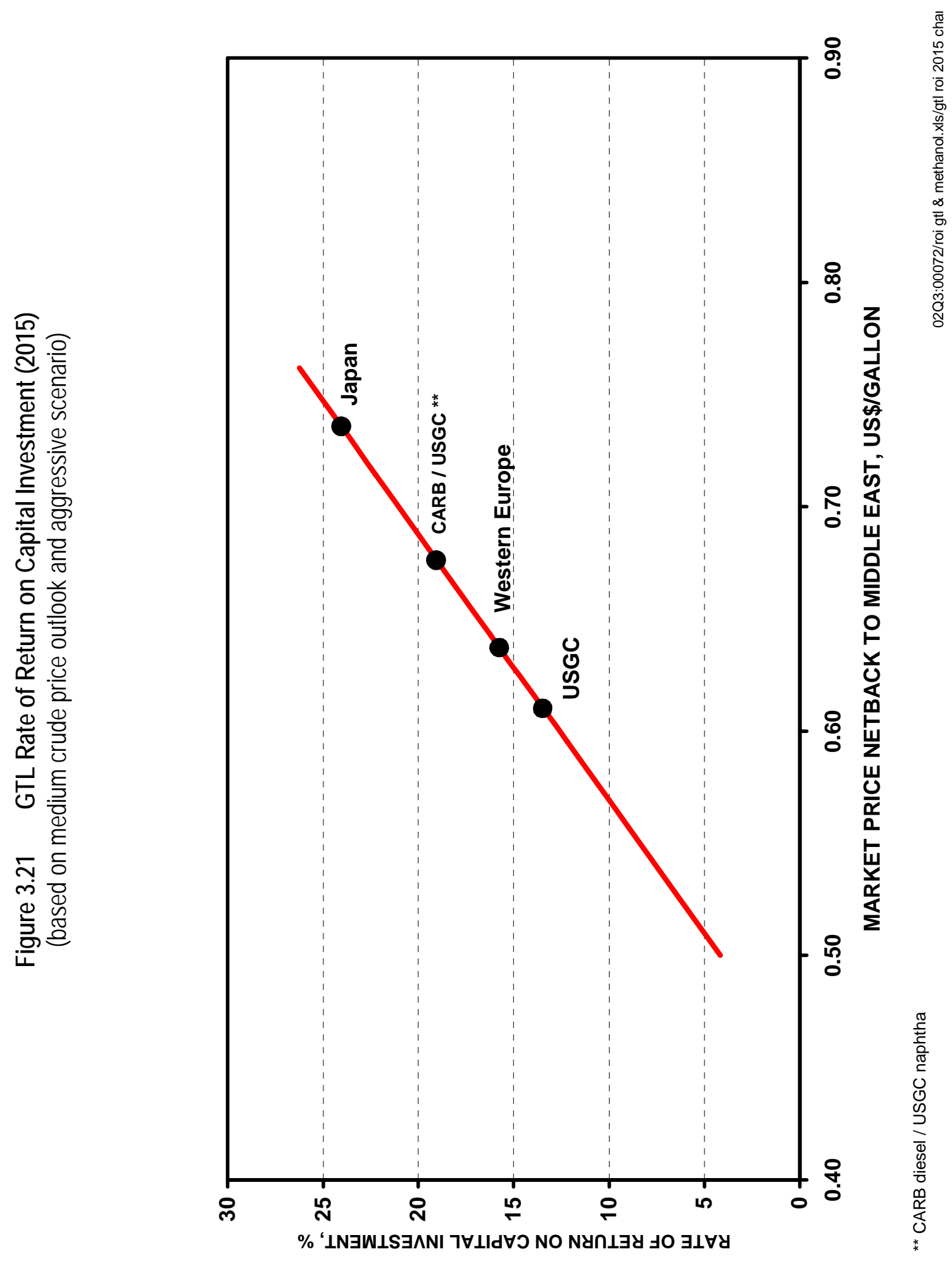




\subsection{INTRODUCTION}

In spite of the current uncertainty and overcapacity in the methanol industry, several recent developments have potentially created massive new demand for methanol. Areas of great promise are:

- Development of methanol fuel cell driven automobiles

- Monetization of stranded remote natural gas

- Power generation

- Direct use as a transportation fuel

These developments are contributing to the drive for the development of large-scale methanol production technologies and plants, which will benefit from large economies of scale. Currently, world-scale methanol plant capacity is on the order of 2,000 to 2,500 metric tons per day (tpd). Several major methanol technology licensors/developers -- Lurgi Öl Gas Chemie GmbH, Kvaerner, Synetix, Toyo Engineering Corporation (TEC), etc. -- have now offered new 5,000 tpd single train methanol process technologies. These new single train large-scale methanol technologies aim at meeting the following criteria:

- Low investment cost

- Advanced but proven and reliable technology

- Cost optimized energy efficiency

- Low environmental impact

In this study, the Lurgi Mega Methanol Process is employed as the basis for the 2006 and 2015 technical and economic evaluation with the following bases:

\subsubsection{Commercially Demonstrated Process}

Economics: Based on a Middle East remote location

Product: $\quad$ Fuel grade methanol

Capacity: $\quad$ Single-train 5,000 metric tons per day (tpd) 


\subsubsection{Emerging Technology}

Economics: Based on a Middle East remote location

Product: $\quad$ Fuel grade methanol

Capacity: $\quad$ Single-train 15,000 metric tons per day (tpd)

There are two U.S. Federal Grades, Grade AA and Grade A, for methanol. The characteristics of the U.S. Federal Grades are shown in Table 4.1. Typically, Grade A methanol requires a two column distillation system, whereas Grade AA requires three columns. However, two column distillation systems producing the Grade AA product are also feasible.

While there is no universal specification for a fuel grade methanol product, it is generally accepted that meeting a water specification is all that is required. Other impurities such as higher alcohols and ethers need not be removed. Therefore, the distillation system can be simplified to a single column for fuel grade methanol or when certain requirements of the Federal Grade A specification can be waived. For some captive uses, only flashing of dissolved gases may be required.

In April 1999, the International Methanol Producers and Consumers Association (IMPCA) in Brussels, Belgium, published the IMPCA Methanol Reference Specifications based on ten ASTM methods and three IMPCA methods. Table 4.2 presents the IMPCA Methanol Reference Specifications, including both the limits and the applicable methods for the specifications.

In this report, fuel grade methanol and chemical grade methanol refer to the "fuel methanol" and "U.S. Federal Grade AA" in Table 4.1, respectively. 


\section{Table 4.1 U.S. Methanol Specification}

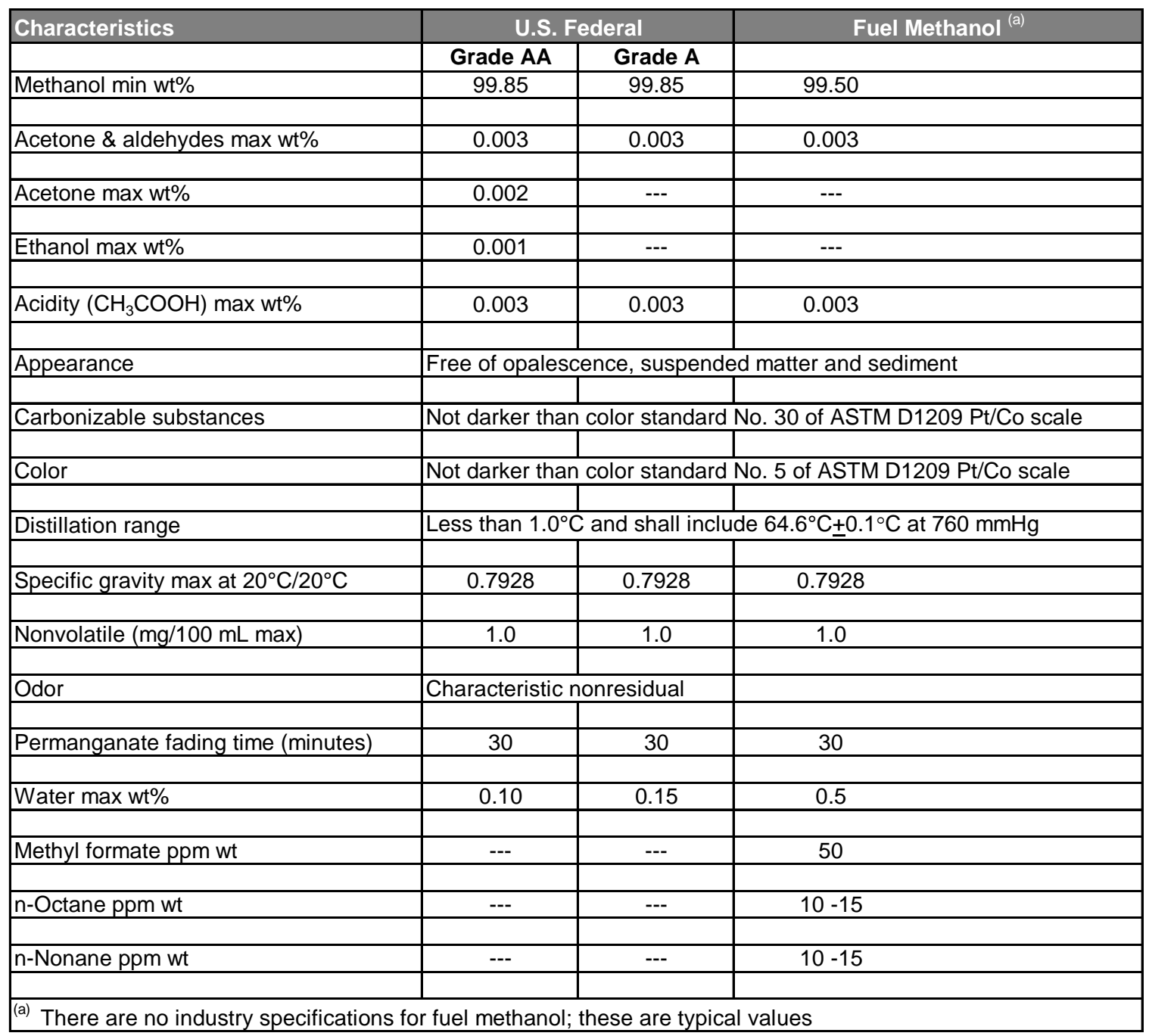




\section{Table 4.2 International Methanol Producers \& Consumers Association Methanol Preference} Specifications

\begin{tabular}{|c|c|c|}
\hline Items & Limit & Method \\
\hline \multirow[t]{2}{*}{ Appearance } & clear and free of & IMPCA 003-98 \\
\hline & suspended matter & \\
\hline Purity wt\% on dry basis & $\min 99.85$ & IMPCA 001-98 \\
\hline Color Pt/Co scale & $\max 5$ & ASTM D 1209-93 \\
\hline Water \% w/w & $\max 0.1$ & ASTM E 1064-92 \\
\hline \multirow[t]{2}{*}{ Distillation range at $760 \mathrm{~mm} \mathrm{Hg}$} & $\max 1.0^{\circ} \mathrm{C}$ to include & ASTM D 1078-97 \\
\hline & $64.6^{\circ}+0.1^{\circ}$ & \\
\hline Specific gravity $20^{\circ} \mathrm{C} / 20^{\circ} \mathrm{C}$ & $0.791-0.793$ & ASTM D 891-95 \\
\hline Potassium permangate time test at $15^{\circ} \mathrm{C}$ & $\min 60^{\prime}$ & ASTM 1363-94 \\
\hline Carbonizable substances Pt/Co scale & $\max 30$ & ASTM E 346-94 \\
\hline \multicolumn{3}{|l|}{ (sulfuric acid wash test) } \\
\hline Ethanol $\mathrm{mg} / \mathrm{kg}$ & $\max 50$ & IMPCA 001-98 \\
\hline Chloride as $\mathrm{Cl}^{-1} \mathrm{mg} / \mathrm{kg}$ & $\max 0.5$ & IMPCA 002-98 \\
\hline Sulfur $\mathrm{mg} / \mathrm{kg}$ & $\max 0.5$ & ASTM D 3961-89 \\
\hline Hydrocarbons & pass test & ASTM D 1722-90 \\
\hline Carbonilic Compound as acetone $\mathrm{mg} / \mathrm{kg}$ & $\max 30$ & ASTM E 346-94 \\
\hline Acidity as acetic acid mg/kg & $\max 30$ & ASTM D 1613-96 \\
\hline Total iron $\mathrm{mg} / \mathrm{kg}$ & $\max 0.1$ & ASTM E 394-94 \\
\hline Nonvolatile matter $\mathrm{mg} / 100 \mathrm{ml}$ & $\max 10$ & ASTM D 1353-96 \\
\hline
\end{tabular}

02Q4:/00072.005.11/SPECIFICATIONS.XLS/IMPCA

\subsection{METHANOL CHEMISTRY}

The ideal methanol production route would be the direct oxidation of methane to methanol via a one step reaction as follows:

$$
\begin{aligned}
& \mathrm{CH}_{4}+1 / 2 \mathrm{O}_{2} \longrightarrow \mathrm{CH}_{3} \mathrm{OH} \quad \Delta \mathrm{H}=-126.4 \mathrm{MJ} / \mathrm{kmol} \\
& \text { G:12000Q1IIBMIPERPIITRWEIRPIITRWE-1.CDX }
\end{aligned}
$$

The theoretical consumption rate, based on the LHV of methane per ton of methanol produced, can be calculated as $25.05 \mathrm{GJ} / \mathrm{t} \mathrm{MeOH}$. Since the LHV of methanol is $19.90 \mathrm{GJ} / \mathrm{t} \mathrm{MeOH}$, the theoretical thermal efficiency of direct methane conversion to methanol is thus about 80 percent.

However, commercially-viable catalysts that can selectively activate methane to methanol, with an acceptable methane conversion and a reasonably high methanol selectivity, have yet to be established. Today's practical methanol production technology still employs the less efficient two-step process by first generating synthesis gas (carbon monoxide and hydrogen) from natural gas (methane) or other hydrocarbon feedstocks, such as naphtha, heavy oils, and coal. The synthesis gas generated in the first step is then converted to methanol in the second step.

Natural gas based synthesis gas can be produced via partial oxidation (Reaction 2 below) and/or steam reforming (Reaction 3 below) of methane as follows: 


$$
\begin{aligned}
& \mathrm{CH}_{4}+1 / 2 \mathrm{O}_{2} \longrightarrow \mathrm{CO}+2 \mathrm{H}_{2} \\
& \mathrm{CH}_{4}+\mathrm{H}_{2} \mathrm{O} \longrightarrow \mathrm{CO}+3 \mathrm{H}_{2} \\
& \text { G:I2000Q1IIBMPERPIITRWEIRPITRWE-1.CDX }
\end{aligned}
$$

Currently, the synthesis gas generation technologies are basically grouped in accordance with Reactions (2) and (3) above as follows:

- Non-catalytic partial oxidation

- Catalytic partial oxidation

- Steam reforming

- Combined reforming

The steam reforming reaction is a highly endothermic reaction. It takes place inside the catalyst filled tubes of a reformer furnace. The endothermic heat is supplied externally by firing additional amounts of natural gas. Simultaneous to the steam reforming reaction, the water/gas shift reaction also takes place:

$$
\mathrm{CO}+\mathrm{H}_{2} \mathrm{O} \longrightarrow \mathrm{CO}_{2}+\mathrm{H}_{2}
$$

G:12000Q1IIBMIPERPIITRWEIRPITRWE-1.CDX

The steam reformer requires a high steam to carbon ratio to prevent carbon from being deposited on the catalyst, thereby reducing its activity:

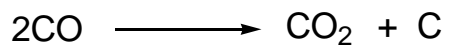

G:I2000Q1IIBMIPERPIITRWEIRPIITRWE-1.CDX

High steam-to-carbon ratios imply high consumption of energy in the process of vaporizing the required steam, and also increased hydrogen production due to the water/gas shift reaction, i.e. Reaction (4).

Alternatively, synthesis gas can be produced via catalytic or non-catalytic partial oxidation of methane (Reaction 2). Reaction (2) is an exothermic reaction, thus it does not require additional heat. However, there is an implicit energy input in the form of power in the generation of pure oxygen from atmospheric air in an air separation unit (ASU).

The conversion of synthesis gas to methanol is a strongly exothermic process. The methanol synthesis reactions can be represented as follows: 


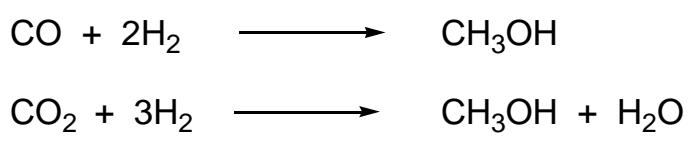

G:I2000Q1IIBMIPERPIITRWEIRPITRWE-1.CDX

The goal is to achieve a relatively high carbon efficiency and thereby minimize the amount of synthesis gas to be processed and, thus, the natural gas or other feedstock consumption.

The carbon efficiency of the synthesis process increases as:

- The synthesis pressure increases (typically 80-100 bar for a world-scale plant)

- The inerts decrease (resulting in a smaller purge)

- The molar ratio of carbon monoxide to carbon dioxide increases

- The conversion rate per pass decreases

However, certain of these process chemistry considerations need to be compromised with process engineering considerations. For example, while it is desirable to employ high synthesis pressure in order to achieve high carbon efficiency, the requirements for increased compression duty and increased wall thickness of the equipment and piping due to the increased pressure need to be taken into account. Equally, while low conversion rate per pass will favor high carbon efficiency, it will result in an increased recycle rate and, thus, in a higher compression duty and investment.

The overall reactions to synthesize methanol from natural gas can be expressed as follows:

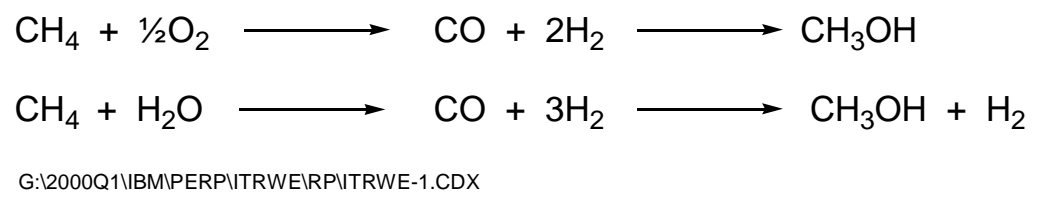

The water gas shift reaction and the subsequent synthesis of methanol from carbon dioxide can be ignored for summary purposes. This is because the water gas shift reaction produces a mole of hydrogen for each mole of carbon dioxide produced, while the methanol synthesis reaction consumes an extra mole of hydrogen for each mole of carbon dioxide converted to methanol.

Reaction (9) demonstrates that the basic steam reforming process is a net producer of hydrogen. Typically this gas is purged from the reactor loop and then burned in the reformer, along with additional natural gas, to provide the energy required to drive the steam reforming process. Or if $\mathrm{CO}_{2}$ is available from other sources, it can be fed into the system to react with the excess hydrogen. 


\subsection{PROCESS DESCRIPTION (LURGI MEGA METHANOL PROCESS)}

\subsubsection{Process Technology}

The Lurgi Mega Methanol Process is based on catalytic pre-reforming and autothermal reforming with oxygen to produce synthesis gas sufficient for 5,000 metric tons per day of pure methanol in a single train two-stage methanol reactor system. Alternatively, Combined Reforming consisting of steam reforming and autothermal reforming can also be designed. The concept for the process units is illustrated in Figure 4.1 and Figure 4.2 and the process flow diagram in Figure 4.3 and Figure 4.4.

The pressure in the reformer (about 40 bar) is significantly higher than that in a conventional reformer and allows synthesis gas compression in a single casing compressor without intercooling. Synthesis gas from an autothermal reforming process is characterized by a stoichiometric number, $\mathrm{SN}=\left(\mathrm{H}_{2}-\mathrm{CO}_{2}\right) /\left(\mathrm{CO}+\mathrm{CO}_{2}\right)$, below 2.0. Adjustment of the stoichiometric number to the optimum value of about 2.05 is achieved by the addition of hydrogen, which is separated from the purge gas of the synthesis loop operating under special process parameters in order to obtain sufficient hydrogen.

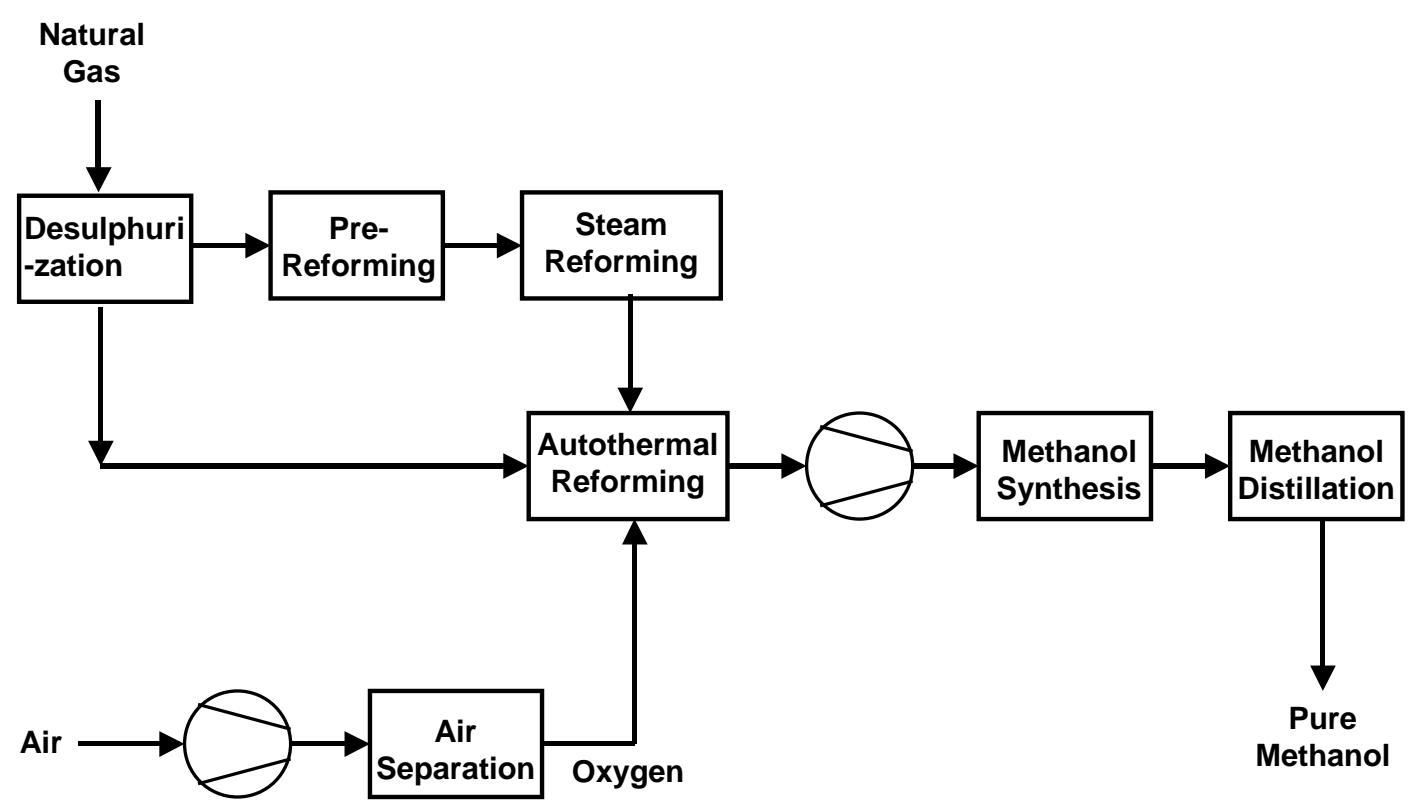

00072.Lurgi Mega MeOH Process.ppt

Figure 4.1 Lurgi Mega Methanol Process With Autothermal Reforming 


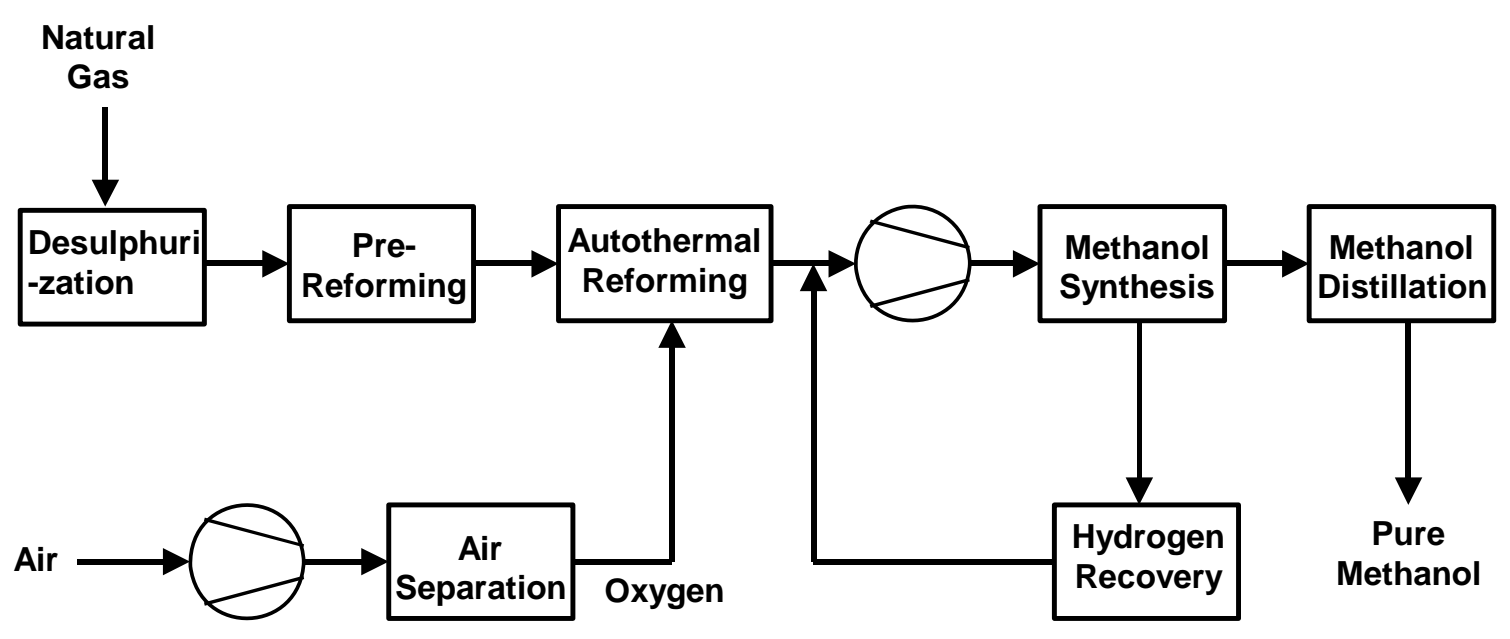

00072.Lurgi Mega MeOH Process.ppt

Figure 4.2 Lurgi Mega Methanol Process With Combined Reforming 


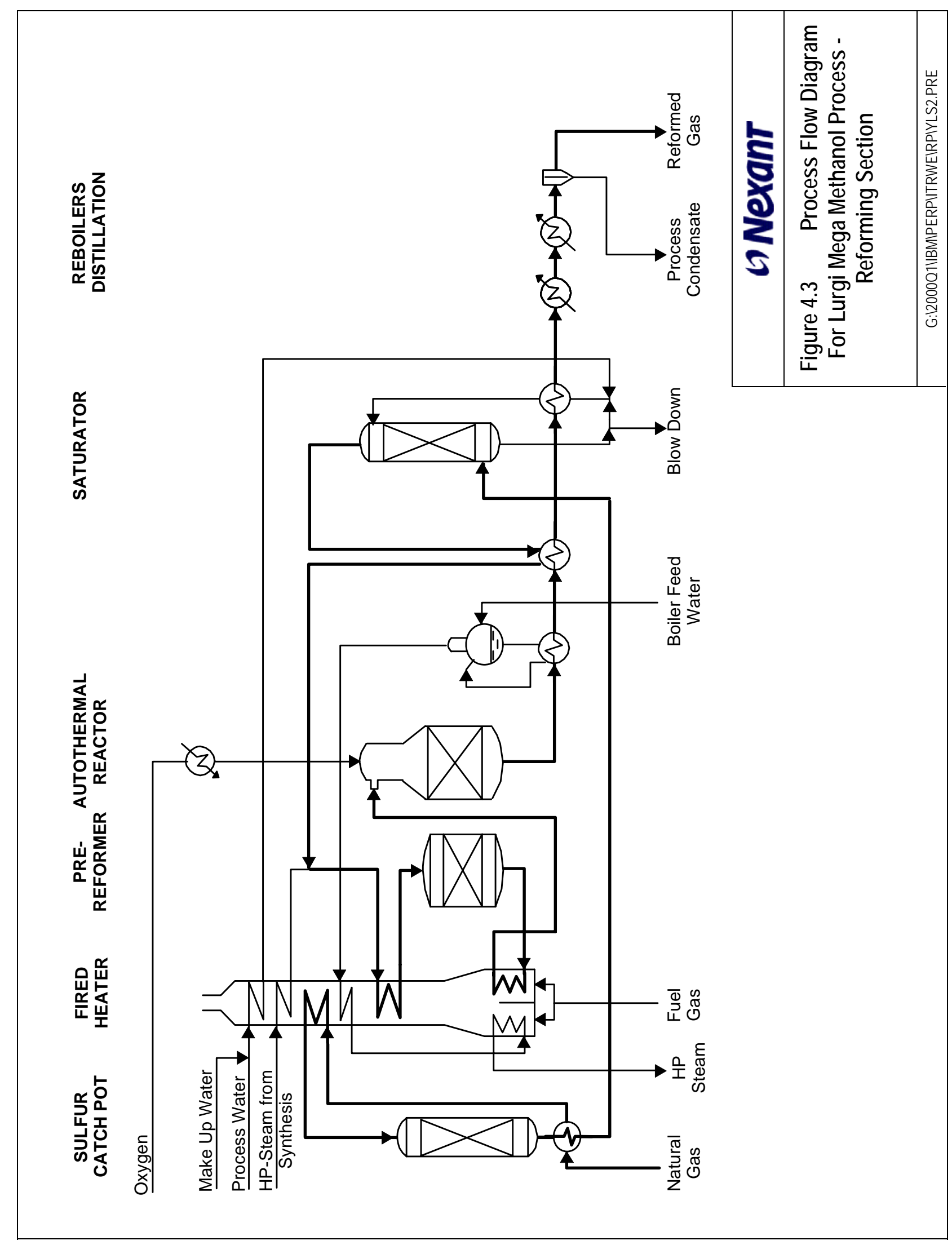




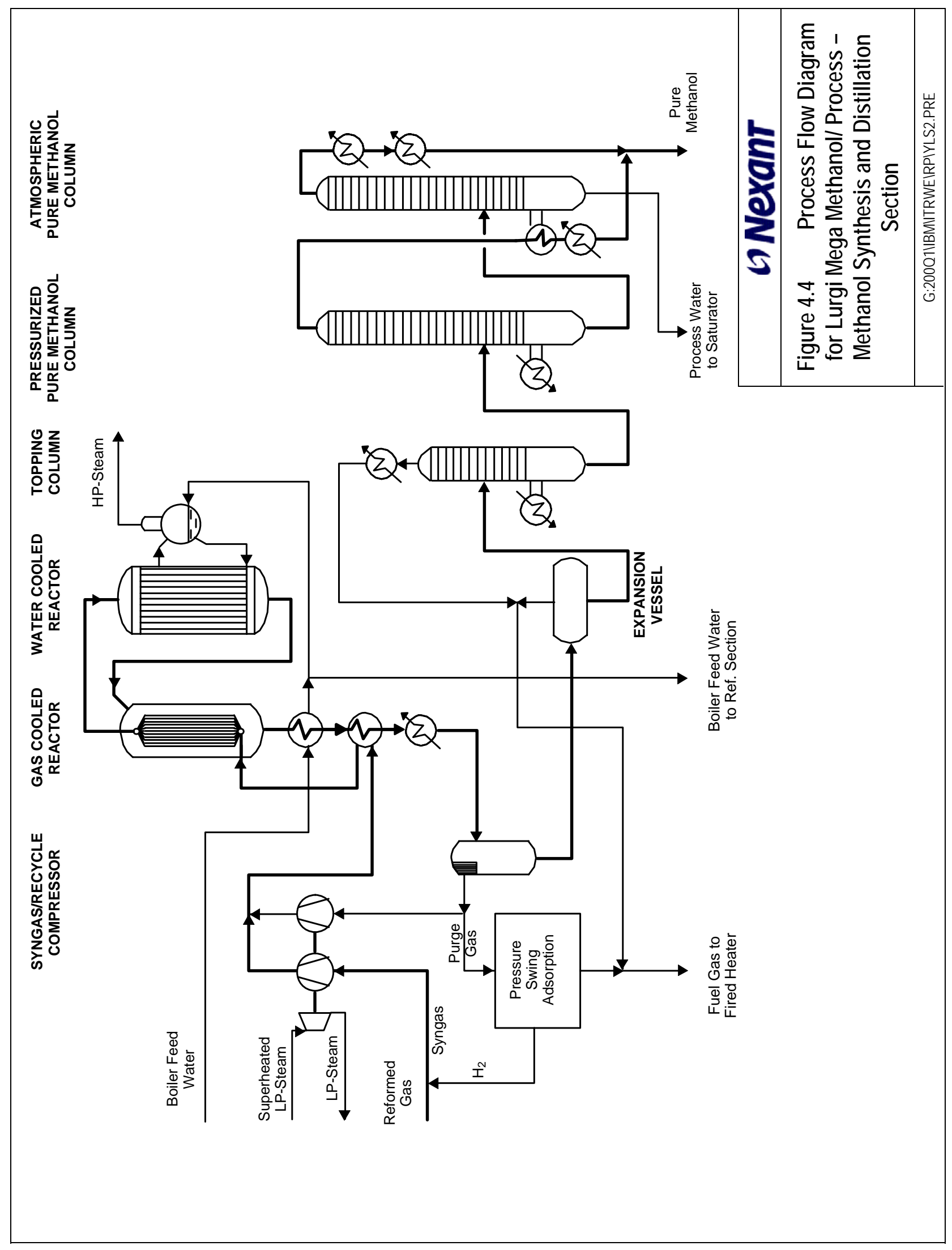


In principle, the autothermal catalytic reforming process can be operated at pressures which obviate the need for compression of the synthesis gas. However, commercial experience with pressures above 40 bar is not yet available. The process characteristics of the autothermal catalytic reforming include:

- Wide range of feedstock and operating flexibility

- Low steam/carbon ratio

- Low methanol slip at high pressure

- Rapid start-up and capacity changes possible

- $\quad$ Fired primary reformer eliminated

The operating and design parameters for the pre-reforming and the autothermal reforming are presented in Table 4.3.

Table 4.3 Operating And Design Parameters For Pre-Reforming And Autothermal Reforming Of Lurgi Mega Methanol Process

\begin{tabular}{|lr|l|}
\hline Pre-reformer outlet temperature & 440 & ${ }^{\circ} \mathrm{C}$ \\
\hline Autothermal reactor outlet temperature & 1,000 & ${ }^{\circ} \mathrm{C}$ \\
\hline Autothermal reactor outlet pressure & 35 & $\mathrm{bar}$ \\
\hline Molar steam to carbon ratio, pre-reformer & 1.4 & \\
\hline Molar steam to carbon ratio, overall & 1.7 & \\
\hline Natural gas flow & 7,188 & $\mathrm{kmol} / \mathrm{hr}$ \\
\hline Oxygen flow & 131 & $\mathrm{metric}$ tons $/ \mathrm{hr}$ \\
\hline Reformer gas ${ }^{1}$ & 105,000 & $\mathrm{~m}^{3} / \mathrm{hr}$ \\
& & \\
\hline${ }^{1}$ At reactor outlet pressure and temperature & & \\
& & \\
\hline
\end{tabular}

The advantages of the production of synthesis gas in the combination of pre-reforming and autothermal reforming include:

- Stoichiometric synthesis gas composition

- Small gas volumes at high pressure

- Compact plant plot 
- High energy efficiency

- Low $\mathrm{CO}_{2}$ and $\mathrm{NOx}$ emission

As illustrated in Figure 4.5, the methanol synthesis is based on Lurgi's Combined Converter Synthesis, which has been developed and patented to improve the overall economics of large methanol plants. In the first stage, the synthesis gas is partly converted to methanol in a conventional water-cooled steam generating Lurgi reactor. This reactor operates at very high yield and at higher than normal reaction temperature allowing higher pressure steam to be produced which improves the energy efficiency of the plant.

In the second converter, the reaction rate is much lower and, consequently, so are the space time yield and the amount and grade of the reaction heat. The remaining reaction heat is used to preheat the feed gas to the first converter. The continuously reduced temperature in this reactor provides increasing thermodynamic equilibrium potential. Since the temperature difference between the reaction and the cooling gases is higher than in a conventional inlet/outlet heat exchange, the required heat exchange surface is relatively small which allows a large catalyst volume at a moderate vessel size.

The operating and design parameters for the methanol converter are presented in Table 4.4.

\section{Table 4.4 Operating And Design Parameters For Methanol Converter Of Lurgi Mega Methanol Process}

\begin{tabular}{|l|c|c|}
\hline Stoichiometric number of reformed gas, $\mathrm{SN}=\left(\mathrm{H}_{2}-\mathrm{CO}_{2}\right) /\left(\mathrm{CO}+\mathrm{CO}_{2}\right)$ & 1.81 & \\
\hline Hydrogen recycle & 1,750 & $\mathrm{kmol} / \mathrm{hr}$ \\
\hline Syngas flow & 19,000 & $\mathrm{~m}^{3} / \mathrm{hr}$ \\
\hline Stoichiometric number of syngas, $\mathrm{SN}=\left(\mathrm{H}_{2}-\mathrm{CO}_{2}\right) /\left(\mathrm{CO}+\mathrm{CO}_{2}\right)$ & 2.06 & \\
\hline Syngas compressor suction pressure & 32 & $\mathrm{bar}$ \\
\hline Syngas compressor discharge pressure & 71 & $\mathrm{bar}$ \\
\hline Recycle ratio & 1.9 & \\
\hline Methanol content in reactor exit gas & 11.5 & $\mathrm{~mol} \%$ \\
\hline & & \\
\hline At suction syngas compressor & & \\
\hline
\end{tabular}

High pressure steam is generated from process heat in the reforming section and is used for the major steam turbine drives. Medium pressure steam is generated in the steam drum of the first methanol reaction stage and mainly used as process steam. 


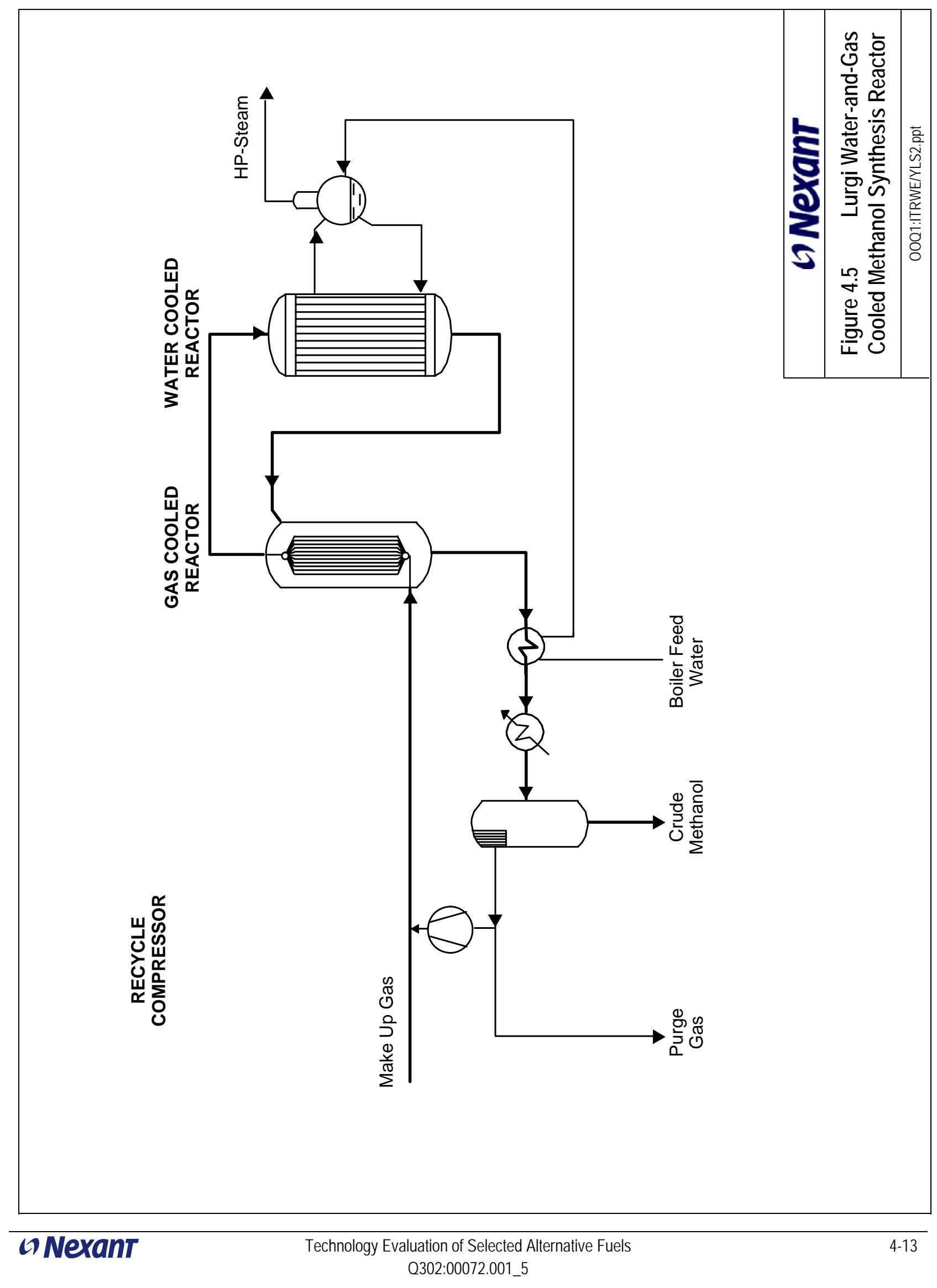


The advantages offered by Lurgi's Combined Converter Synthesis include

- High synthesis gas conversion efficiency

- $\quad$ Extended catalyst life

- High energy efficiency

- Drastically reduced loop size

- Large single train capacity

- Low investment cost

Finally, the crude methanol produced in the converters is routed to the distillation system to produce Federal Grade AA methanol. A three-column design is employed. This design allows a single train distillation for the desired capacity.

\subsubsection{Supply of Power and Oxygen}

Power is generated in three identical steam driven turbogenerator sets. Each of them is operated at about 60 percent of its capacity during operation to assure uninterrupted power supply, even in case of a turbine trip. An additional gas turbine driven generator set serves as a back-up unit and for start-up of the plant.

The air separation unit (ASU) is based on a design with internal compression of the oxygen in liquid phase (no oxygen compressor required). The capacity of the ASU does not exceed the limits of already existing units with a similar design in a single train.

\subsubsection{Feedstock Consumption}

The overall feedstock consumption of the plant is 29.9 GJ (LHV) or 33.1 GJ (HHV) per metric ton of methanol produced. Electric power of $2,800 \mathrm{~kW}$ is simultaneously generated and exported. The specific feedstock consumption is comparable to Lurgi's Integrated Low Pressure Methanol Process with synthesis gas production by combined reforming.

\subsection{ECONOMIC ASSESSMENT}

\subsubsection{Economic Assumptions}

The key parameters used for methanol technology evaluation are summarized in Table 4.5 and Table 4.6.

Based on a conservative scenario, the natural gas consumptions are $0.0928 \mathrm{MMBtu}(\mathrm{HHV})$ and 0.0889 MMBtu (HHV) per gallon of fuel methanol for 2006 and 2015, respectively. These gas consumption rates correspond to energy efficiencies, on a LHV basis, of 68.0 percent and 71.0 percent for 2006 and 2015, respectively. 
For an aggressive scenario, the natural gas consumptions are 0.0890 (HHV) MMBtu and 0.0814 MMBtu (HHV) per gallon of fuel methanol for 2006 and 2015, respectively, assuming the gas consumption rate is reduced by 1 percent per year from 2001 to 2015 due to technology improvement. These gas consumption rates correspond to energy efficiencies, on a LHV basis, of 70.7 percent and 77.3 percent for 2006 and 2015, respectively.

For 2006, the total capital investment for a 5,000 metric tons per day (tpd) plant is $\$ 478$ million. For 2015 , the total capital investment for a 15,000 tpd plant is $\$ 1.243$ billion. The capital investment is based on the assumption that the capital is reduced by 2 percent per year from 2001 to 2015 due to technology improvement (independent of inflation).

Table 4.5 Key Parameters For Methanol Technology Evaluation

\begin{tabular}{|l|l|c|c|}
\hline Year & & 2006 & 2015 \\
\hline Natural gas per gallon of fuel grade methanol & & & \\
\hline \multicolumn{1}{|c|}{ Conservative Scenario } & MMBtu (HHV) & 0.0928 & 0.0889 \\
\hline Aggressive Scenario & MMBtu (HHV) & 0.0891 & 0.0814 \\
\hline Natural gas per metric ton of fuel grade methanol & & & \\
\hline Conservative Scenario & GJ (HHV)/t & 32.5 & 31.2 \\
\hline Aggressive Scenario & GJ (HHV)/t & 31.2 & 28.5 \\
\hline Natural gas price & US\$/MMBtu & 1.00 & 1.25 \\
\hline Capacity & tpd & 5,000 & 15,000 \\
\hline Total capital investment (current \$) & MMUS\$ & 478 & 1,243 \\
\hline
\end{tabular}

Table 4.6 Technology And Capital Improvements For Methanol Technology

\begin{tabular}{|c|c|c|c|}
\hline & \multicolumn{3}{|c|}{ Improvement (Reduction), \%Year } \\
\hline & $2001-2006$ & $\mathbf{2 0 0 6 - 2 0 1 5}$ & $\begin{array}{l}\mathbf{2 0 0 1 - 2 0 1 5} \\
\text { (effective) }\end{array}$ \\
\hline Capital & $2 \%$ & $2 \%$ & $2 \%$ \\
\hline Technology (raw Materials) & & & \\
\hline Conservative Scenario & $0.34 \%$ & $0.49 \%$ & $0.43 \%$ \\
\hline Aggressive Scenario & $1.00 \%$ & $1.00 \%$ & $1.00 \%$ \\
\hline
\end{tabular}

Table 4.5 and Table 4.8 summarize the relationship between the efficiency and gas consumption rate for the conservative scenario and the aggressive scenario, respectively. The impact of efficiency assumptions on the cost of production of methanol is not significant within the range analyzed in this study and will be discussed in the "Sensitivity Analysis" section later in this report. 


\section{Table 4.7 Summary Of Efficiencies Of Methanol Processes} (conservative scenario)

\begin{tabular}{|c|c|c|c|c|}
\hline & $2000-2001$ & 2006 & 2015 & $\begin{array}{l}\text { Average \%/Year } \\
\text { Improvement } \\
\text { from } 2000 \text { to } 2015\end{array}$ \\
\hline \multicolumn{5}{|l|}{ Gas Consumption } \\
\hline \multicolumn{5}{|l|}{$\mathrm{MeOH}$} \\
\hline MMBtu $(\mathrm{HHV}) / \mathrm{Gal}$ & 0.0945 & 0.0928 & 0.0889 & 0.43 \\
\hline MMBtu (LHV)/Gal & 0.0853 & 0.0836 & 0.0800 & 0.43 \\
\hline $\mathrm{GJ}(\mathrm{HHV}) / \mathrm{t}$ & 33.1 & 32.5 & 31.2 & 0.43 \\
\hline GJ (LHV)/t & 29.9 & 29.3 & 28.0 & 0.43 \\
\hline \multicolumn{5}{|l|}{ Thermal Efficiency (LHV basis) } \\
\hline МеOH, \% & 66.6 & 68.0 & 71.0 & 0.43 \\
\hline \multicolumn{5}{|l|}{ Carbon Efficiency } \\
\hline МeOH, \% & 84.0 & 86.0 & 89.0 & \\
\hline
\end{tabular}

Table 4.8 Summary Of Efficiencies Of Methanol Processes (aggressive scenario)

\begin{tabular}{|c|c|c|c|c|}
\hline & \multicolumn{4}{|c|}{ (aggressive scenario) } \\
\hline & $2000-2001$ & 2006 & 2015 & $\begin{array}{l}\text { Average } \% / \text { Year } \\
\text { Improvement } \\
\text { from } 2000 \text { to } 2015\end{array}$ \\
\hline \multicolumn{5}{|l|}{ Gas Consumption } \\
\hline \multicolumn{5}{|l|}{$\mathrm{MeOH}$} \\
\hline MMBtu (HHV)/Gal & 0.0945 & 0.0890 & 0.0814 & 1.00 \\
\hline MMBtu (LHV)/Gal & 0.0853 & 0.0804 & 0.0735 & 1.00 \\
\hline $\mathrm{GJ}(H H V) / \mathrm{t}$ & 33.1 & 31.2 & 28.5 & 1.00 \\
\hline GJ $(\mathrm{LHV}) / \mathrm{t}$ & 29.9 & 28.2 & 25.8 & 1.00 \\
\hline \multicolumn{5}{|l|}{ Thermal Efficiency (LHV basis) } \\
\hline МeOH, \% & 66.6 & 70.7 & 77.3 & 1.00 \\
\hline
\end{tabular}

Appropriate improvement rates for utilities and labor are also assumed. Other economic assumptions can be found in the cost of production table below.

\subsubsection{Feedstock and Utilities Pricing and Labor Costs}

The main feedstock associated with the manufacture of fuel methanol via Lurgi Mega Methanol Process is natural gas. Natural gas prices of $\$ 1.00 / \mathrm{MMBtu}$ and $\$ 1.25 / \mathrm{MMBtu}$ are assumed for 2006 and 2015, respectively, at a Middle East remote location. For utilities, 2006 and 2015 average Middle East utility prices are used. For labor, 2006 and 2015 average Middle East labor rates are used. Table 4.9 summarizes the raw Material, utility prices, and labor rates used for this study. 
Table 4.9 Summary Of Raw Material Utility And Labor Costs For Methanol Production (current U.S. dollars)

\begin{tabular}{|c|c|c|c|}
\hline & & \multicolumn{2}{|c|}{ Middle East } \\
\hline & & 2006 & 2015 \\
\hline \multicolumn{4}{|l|}{ Raw Materials } \\
\hline $\begin{array}{r}\text { Natural Gas } \\
\end{array}$ & \$/MMBtu & 1.00 & 1.25 \\
\hline \multicolumn{4}{|l|}{ Utilities } \\
\hline $\begin{array}{l}\text { Fuel Gas } \\
\end{array}$ & \$/MMBtu & 1.00 & 1.25 \\
\hline Power & $\$ / \mathrm{kWh}$ & 0.04 & 0.05 \\
\hline Process Water & $\$ / M G a l$ & 1.35 & 1.69 \\
\hline \multicolumn{4}{|l|}{ Labors } \\
\hline Labor & $\$ /$ Year & 27,010 & 33,731 \\
\hline Foremen & $\$ /$ Year & 30,647 & 38,273 \\
\hline Supervision & $\$ / Y e a r$ & 36,978 & 46,181 \\
\hline
\end{tabular}

02q4:00072/RAW MATERIALS UTILITIES LABOR.XLS(METHANOL)

\subsubsection{Economics of Conservative Scenario}

\subsubsection{Process Economics}

2006

The economics for the production of 1.825 million metric tons (606 million gallons) per year (or 5 thousand metric tons per day) of fuel grade methanol at a Middle East remote location via the Mega Methanol Process are presented in Table 4.10.

The total plant capital cost is estimated to be $\$ 382.2$ million. This capital cost includes $\$ 223.3$ million for ISBL and $\$ 159.0$ million for OSBL. Other project costs are estimated to be $\$ 96.6$ million, resulting a total capital investment of $\$ 477.8$ million. An additional $\$ 21.5$ million is also estimated for the working capital requirement. 


\section{Table 4.10 Cost Of Production Estimate For : Fuel Grade Methanol Process: Large-Scale Methanol Process \\ (conservative scenario-2006)}

$\begin{array}{lr} & \\ \text { Plant start-up } & 2006 \\ \text { Analysis date } & 2002 \\ \text { Location } & \text { Middle East } \\ \text { Capacity } & 606 \text { Million gallons/yr } \\ & 1,825 \text { Thousand metric tons/yr } \\ \text { Operating rate } & 100 \text { percent } \\ \text { Throughput } & 606 \text { Million gallons/yr }\end{array}$

PRODUCTION COST SUMMARY

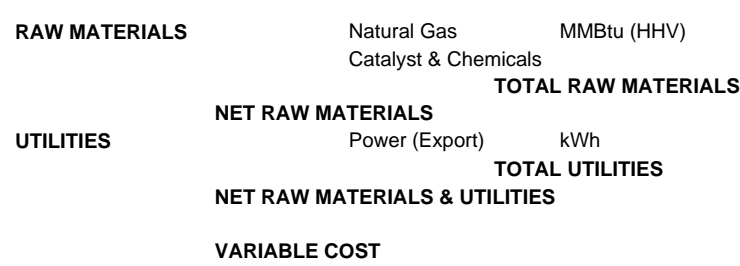

$\begin{array}{lc}\text { CAPITAL COST MILLION U.S. \$ } & \\ \text { ISBL } & 223.3 \\ \text { OSBL } & 159.0 \\ \text { Total Plant Capital } & \mathbf{3 8 2 . 2} \\ \text { Other Project Costs } & 95.6 \\ \quad \text { Total Capital Investment } & \mathbf{4 7 7 . 8} \\ \text { Working capital } & 21.5\end{array}$

$\begin{array}{cc}\text { UNITS } & \text { PRICE } \\ \text { Per Gal } & \text { U.S. \$ }\end{array}$

$\begin{array}{ll}\text { Per Gal U.S. \$ } \\ \text { Product } & \text { IUnit }\end{array}$

$0.0928 \quad 1.0000$

$1.0000 \quad 0.0022$

$(0.0430) \quad 0.0377$
32

32

(1)

31

31

$0.093 \quad 56.59$

$0.002 \quad 1.08$

$0.000 \quad 0.28$

$0.000 \quad 0.04$

$0.011 \quad 6.70$

$0.002 \quad 1.18$

$\mathbf{0 . 0 1 5} \quad \mathbf{9 . 2 8}$

$0.009 \quad 5.66$

$0.006 \quad 3.82$

$0.003 \quad 1.91$

$\mathbf{0 . 0 1 9} \quad \mathbf{1 1 . 4 0}$

$0.127 \quad 77.26$

TOTAL CASH COST

TOTAL ALLOCATED FIXED COSTS

$1 \%$ Total Plant Capital
$0.5 \%$ Total Plant Capital

Depreciation @

$10 \%$ for ISBL

$10 \%$ for OSBL \& OPC

COST OF PRODUCTION

10 Percent

RETURN ON TOTAL CAPITAL INVESTMENT (Ex. WC) @

COST OF PRODUCTION + ROI
$0.079 \quad 47.78 \quad 26$

$0.206 \quad 125.04 \quad 69$

$0.079 \quad 47.78 \quad 26$

$\mathbf{0 . 2 8 5} \quad \mathbf{1 7 2 . 8 2} \quad 95$ 
With natural gas price at $\$ 1.00$ per MMBtu, the raw Material cost is $\$ 0.095$ per gallon of methanol. With a utilities credit (power export) of $\$ 0.002$ per gallon of methanol, it results in a variable cost of $\$ 0.093$ per gallon of methanol.

The total direct fixed cost, including all labors, maintenance, and direct overhead, is approximately $\$ 0.015$ per gallon of methanol. The total allocated fixed cost of the plant, including general plant overhead, insurance, property taxes, and environmental levy, is about $\$ 0.019$ per gallon of methanol. The total fixed costs bring the total cash cost to $\$ 0.127$ per gallon ( $\$ 42$ per metric ton) of methanol.

Depreciation, at 10 percent of investment, contributes an additional \$0.079 per gallon of methanol. Return on total capital investment, also at 10 percent of investment, contributes another \$0.079 per gallon of methanol.

The above cash cost, depreciation, and return on total capital investment yield a full cost of production of $\$ 0.285$ per gallon ( $\$ 95$ per metric ton) of methanol.

2015

The economics for the production of 5.475 million metric tons (1.818 billion gallons) per year (or 15 thousand metric tons per day) of fuel grade methanol at a Middle East remote location via the Mega Methanol Process are presented in Table 4.11.

The total plant capital cost is estimated to be $\$ 994.1$ million. This capital cost includes $\$ 580.7$ million for ISBL and $\$ 413.5$ million for OSBL. Other project costs are estimated to be $\$ 248.5$ million, resulting a total capital investment of $\$ 1.242$ billion. An additional $\$ 55.9$ million is also estimated for the working capital requirement.

With natural gas price at $\$ 1.25$ per MMBtu, the raw Material cost is $\$ 0.114$ per gallon of methanol. With a utilities credit (power export) of $\$ 0.002$ per gallon of methanol, it results in a variable cost of $\$ 0.111$ per gallon of methanol.

The total direct fixed cost, including all labors, maintenance, and direct overhead, is approximately $\$ 0.013$ per gallon of methanol. The total allocated fixed cost of the plant, including general plant overhead, insurance, property taxes, and environmental levy, is about $\$ 0.016$ per gallon of methanol. The total fixed costs bring the total cash cost to $\$ 0.131$ per gallon ( $\$ 47$ per metric ton) of methanol.

Depreciation, at 10 percent of investment, contributes an additional $\$ 0.068$ per gallon of methanol. Return on total capital investment, also at 10 percent of investment, contributes another $\$ 0.068$ per gallon of methanol.

The above cash cost, depreciation, and return on total capital investment yield a full cost of production of $\$ 0.277$ per gallon (\$92 per metric ton) of methanol. 


\section{Table 4.11 Cost Of Production Estimate For: Fuel Grade Methanol Process: Large Scale Methanol Process}

(conservative scenario-2015)

$\begin{array}{lr} & \\ \text { Plant start-up } & 2015 \\ \text { Analysis date } & 2002 \\ \text { Location } & \text { Middle East } \\ \text { Capacity } & 1,818 \text { Million gallons/yr } \\ & 5,475 \text { Thousand metric tons/yr } \\ \text { Operating rate } & 100 \text { percent } \\ \text { Throughput } & 1,818 \text { Million gallons/yr }\end{array}$

$\begin{array}{lr}\text { CAPITAL COST MILLION U.S. \$ } & \\ \text { ISBL } & 580.7 \\ \text { OSBL } & 413.5 \\ \text { Total Plant Capital } & \mathbf{9 9 4 . 1} \\ \text { Other Project Costs } & 248.5 \\ \quad \text { Total Capital Investment } & \mathbf{1 , 2 4 2 . 7} \\ \text { Working capital } & 55.9\end{array}$

PRODUCTION COST SUMMARY

$\begin{array}{cc}\text { UNITS } & \text { PRICE } \\ \text { Per Gal } & \text { U.S. \$ }\end{array}$

Product IUnit

$0.0889 \quad 1.2489$

RAW MATERIALS

Natural Gas MMBtu (HHV)

$\begin{array}{ll}1.0000 & 0.0025\end{array}$

TOTAL RAW MATERIALS

$(0.0470) \quad 0.0467$

UTILITIES

Power (Export)

kWh TOTAL UTILITIES

NET RAW MATERIALS \& UTILITIES

VARIABLE COST

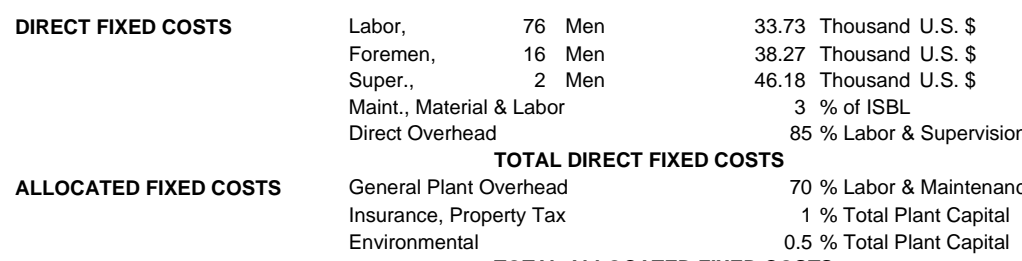

TOTAL CASH COST

TOTAL ALLOCATED FIXED COSTS

$\begin{array}{crc}\begin{array}{cr}\text { U.S. \$ } \\ \text { Per Gal }\end{array} & \begin{array}{c}\text { ANNUAL } \\ \text { COST MM } \\ \text { U.S. \$ }\end{array} & \begin{array}{c}\text { U.S. \$ } \\ \text { Per MT }\end{array} \\ 0.111 & 201.87 & \\ 0.003 & 4.55 & \\ \mathbf{0 . 1 1 4} & \mathbf{2 0 6 . 4 2} & \mathbf{3 8} \\ \mathbf{0 . 1 1 4} & \mathbf{2 0 6 . 4 2} & \mathbf{3 8} \\ (0.002) & (3.99) & \\ (\mathbf{0 . 0 0 2 )} & (3.99) & \mathbf{( 1 )} \\ \mathbf{0 . 1 1 1} & \mathbf{2 0 2 . 4 4} & \mathbf{3 7} \\ & & \\ \mathbf{0 . 1 1 1} & \mathbf{2 0 2 . 4 4} & \mathbf{3 7}\end{array}$

Depreciation @

$10 \%$ for ISBL

$10 \%$ for OSBL \& OPC

0.001

0.000

0.000

0.010

0.002

0.013

0.008

0.005

0.003

0.016

2.56

0.61

0.09

17.42

2.78

23.47

14.48

9.94
4.97

$0.140 \quad 255.30$

COST OF PRODUCTION

0.209

379.56

RETURN ON TOTAL CAPITAL INVESTMENT (Ex. WC) @

10 Percent

$0.068 \quad 124.27$ 
The costs of production of fuel grade methanol at a Middle East remote location for 5,000 and 15,000 tpd for 2015 are summarized graphically in Figure 4.6. As indicated in the figure, methanol cost of production can be reduced with a larger capacity. It is also to be noted that the difference in cost of production between fuel and chemical grade methanol is relatively insignificant as shown in Figure 4.7 for a 5,000 tpd plant for both 2006 and 2015. 


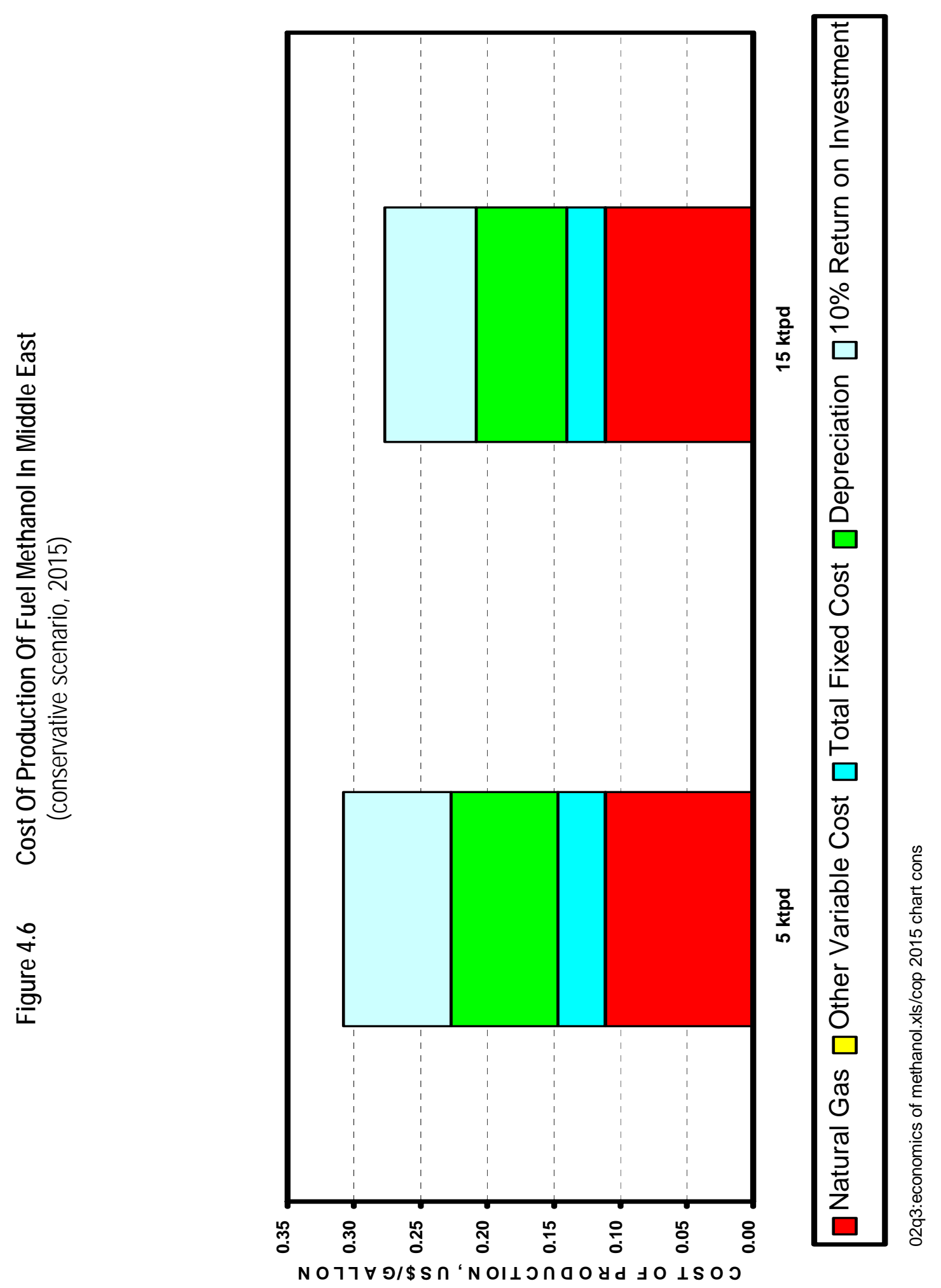



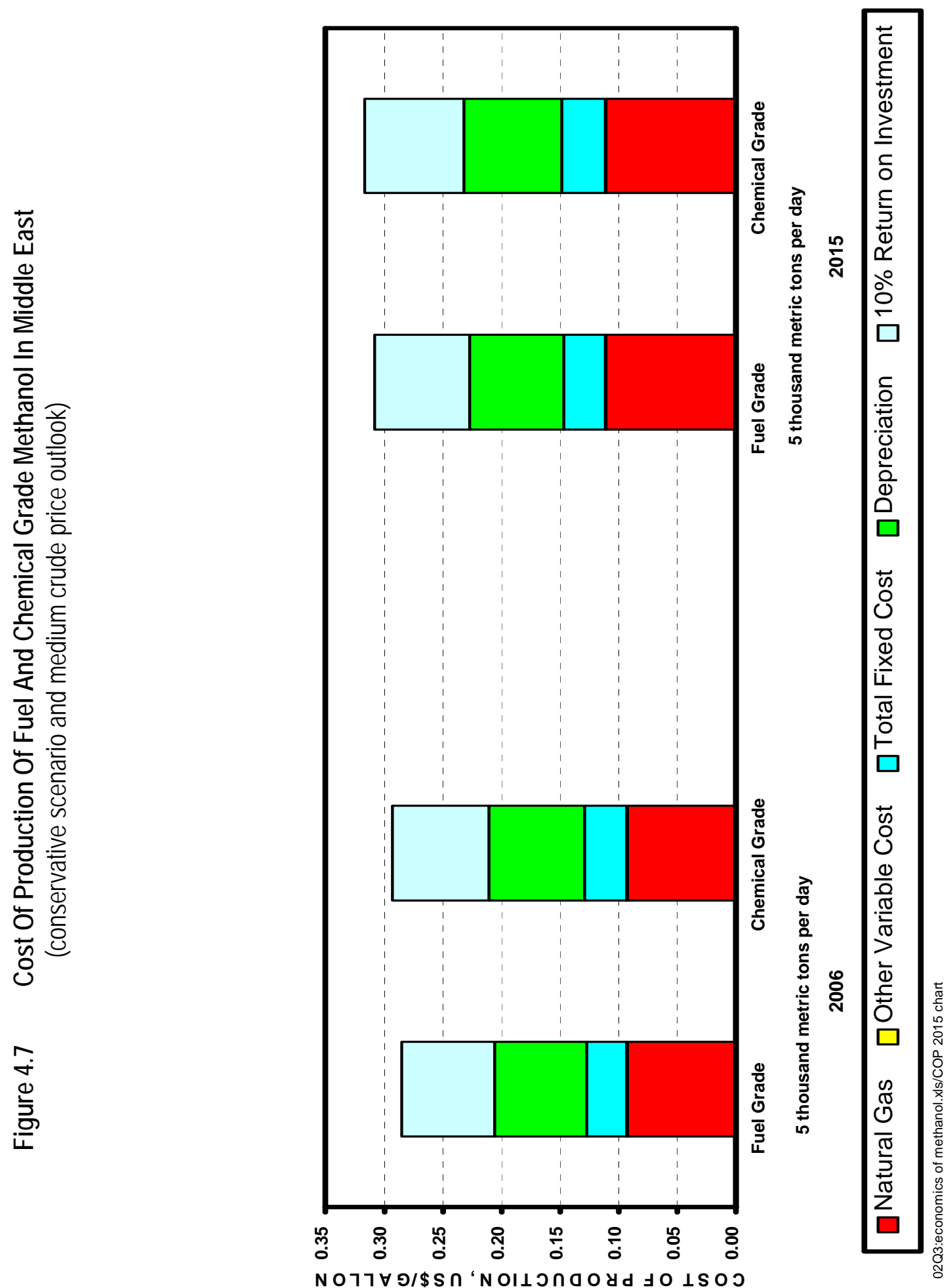


\subsubsection{Sensitivity Analysis}

2006

The effects of natural gas price, capital investment, and methanol production capacity on the full cost of production of methanol plus 10 percent ROI via Lurgi Mega Methanol Process are shown in Figure 4.8.

With total capital investment maintained at $\$ 478$ million and methanol production capacity maintained at 1.825 million metric tons (606 million gallons) per year (or 5 thousand metric tons per day), methanol full cost of production plus 10 percent ROI increases from $\$ 0.285 /$ gallon to $\$ 0.332 /$ gallon when natural gas price increases from $\$ 1.00 / \mathrm{MMBtu}$ to $\$ 1.50 / \mathrm{MMBtu}$, i.e. 50 percent increase. Methanol full cost of production plus 10 percent ROI decreases to $\$ 0.239 /$ gallon when natural gas price decreases to $\$ 0.50 / \mathrm{MMBtu}$, i.e. 50 percent decrease. Thus, every dollar/MMBtu change in natural gas price results in an average change of $\$ 0.093 /$ gallon in methanol full cost of production plus 10 percent ROI.

With natural gas price maintained at $\$ 1.00 / \mathrm{MMBtu}$ and methanol production capacity maintained at 1.825 million metric tons (606 million gallons) per year, methanol full cost of production plus 10 percent ROI increases from $\$ 0.285 /$ gallon to $\$ 0.378 /$ gallon when the total capital investment increases from $\$ 478$ million to $\$ 717$ million, i.e. 50 percent increase. Methanol full cost of production plus 10 percent ROI decreases to $\$ 0.192 /$ gallon when the total capital investment decreases to $\$ 239$ million, i.e. 50 percent decrease. This represents an average of $\$ 0.04 /$ gallon change in methanol full cost of production plus 10 percent ROI for every $\$ 100$ million change in total capital investment.

With natural gas price maintained at $\$ 1.00 / \mathrm{MMBtu}$, methanol full cost of production plus 10 percent ROI decreases from $\$ 0.285 /$ gallon to $\$ 0.256 /$ gallon when methanol production capacity increases from 1.825 million metric tons (606 million gallons) per year to 2.738 million metric tons (909 million gallons) per year, i.e. 50 percent increase. Methanol full cost of production plus 10 percent ROI increases to $\$ 0.334 /$ gallon when methanol production capacity decreases to 913 thousand metric tons (303 million gallons) per year, i.e. 50 percent decrease.

The impact of the thermal efficiency assumptions on the cost of production of methanol is not significant within the range analyzed in this study. As shown in Figure 4.9, methanol full cost of production plus 10 percent ROI increases from $\$ 0.285 /$ gallon to $\$ 0.287 /$ gallon if the efficiency were 67.0 percent instead of 68.0 percent employed. 
Figure 4.8 Sensitivity Of Fuel Grade Methanol Cost Of Production To Key Variables (2006 conservative scenario)
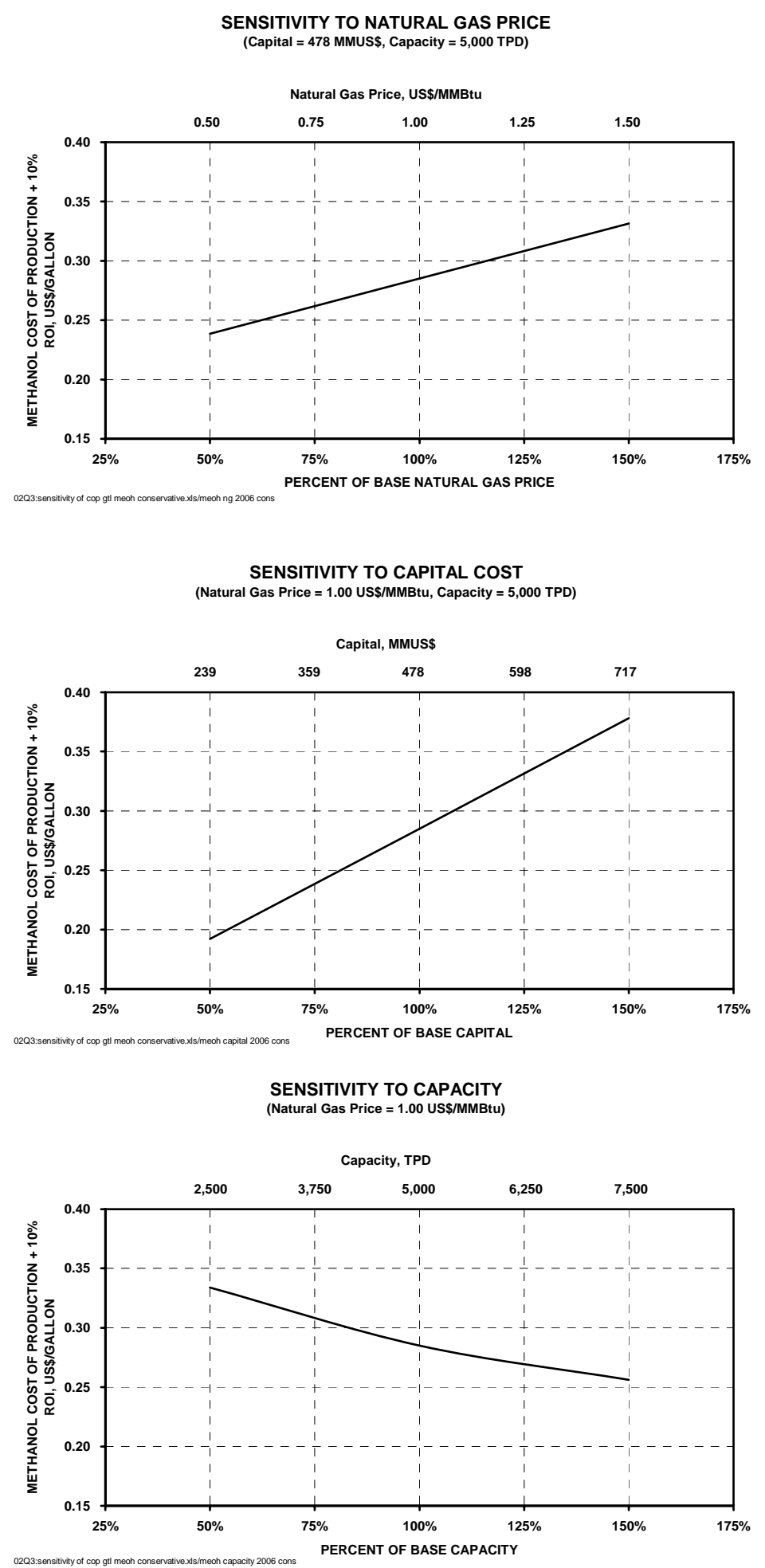


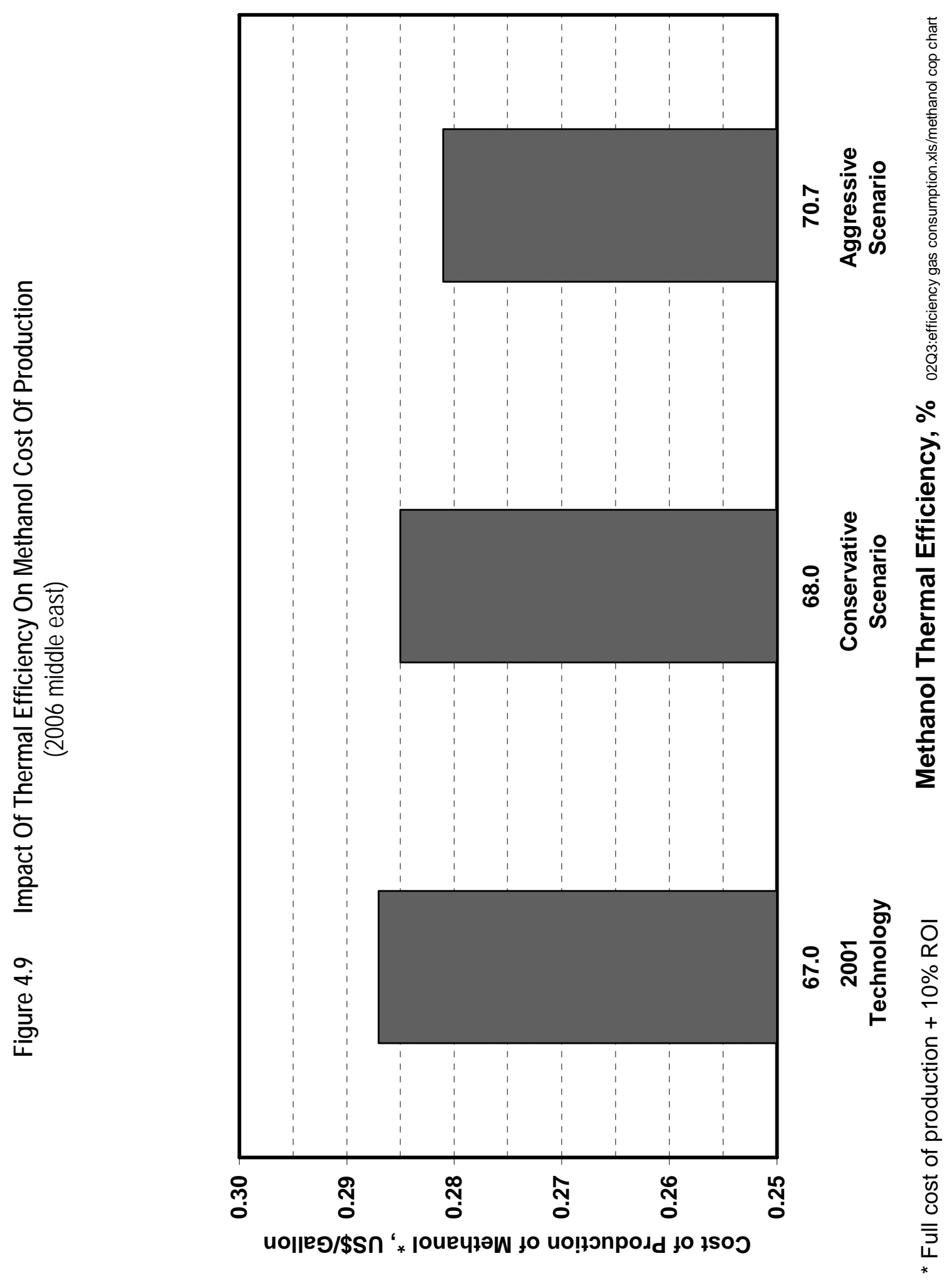


The effects of natural gas price, capital investment, and methanol production capacity on the full cost of production of methanol plus 10 percent ROI via corn dry milling process are shown in Figure 4.10.

With total capital investment maintained at $\$ 1.243$ billion and methanol production capacity maintained at 5.475 million metric tons (1.818 billion gallons) per year (or 15 thousand metric tons per day), methanol full cost of production plus 10 percent ROI increases from $\$ 0.277$ /gallon to $\$ 0.333 /$ gallon when natural gas price increases from $\$ 1.25 / \mathrm{MMBtu}$ to $\$ 1.87 / \mathrm{MMBtu}$, i.e. 50 percent increase. Methanol full cost of production plus 10 percent ROI decreases to $\$ 0.222 /$ gallon when natural gas price decreases to $\$ 0.62 / \mathrm{MMBtu}$, i.e. 50 percent decrease. Thus, every dollar/MMBtu change in natural gas price results in an average change of $\$ 0.089 /$ gallon in methanol full cost of production plus 10 percent ROI.

With natural gas price maintained at $\$ 1.25 / \mathrm{MMBtu}$ and methanol production capacity maintained at 5.475 million metric tons (1.818 billion gallons) per year, methanol full cost of production plus 10 percent ROI increases from $\$ 0.277$ /gallon to $\$ 0.358 /$ gallon when the total capital investment increases from $\$ 1.243$ billion to $\$ 1.864$ billion, i.e. 50 percent increase. Methanol full cost of production plus 10 percent ROI decreases to $\$ 0.197 /$ gallon when the total capital investment decreases to $\$ 621.4$ million, i.e. 50 percent decrease. This represents an average of $\$ 0.01 /$ gallon change in methanol full cost of production plus 10 percent ROI for every $\$ 100$ million change in total capital investment.

With natural gas price maintained at $\$ 1.25 / \mathrm{MMBtu}$, methanol full cost of production plus 10 percent ROI decreases from $\$ 0.277 /$ gallon to $\$ 0.267 /$ gallon when methanol production capacity increases from 5.475 million metric tons (1.818 billion gallons) per year to 8.213 million metric tons (2.727 billion gallons) per year, i.e. 50 percent increase. Methanol full cost of production plus 10 percent ROI increases to $\$ 0.296 /$ gallon when methanol production capacity decreases to 2.738 million metric tons (909 million gallons) per year, i.e. 50 percent decrease.

\subsubsection{Regional Economics}

The economic viability of remotely produced fuel methanol at the Middle East can be determined by their delivered costs to the USGC, Western Europe, and Japan. The delivered costs have been developed from the estimated production costs for the methanol plant located in the Middle East as described previously. Transportation costs for shipping methanol from the Middle East to the various regions and tariff, if any, imposed by the various region are added to the production costs to yield the delivered costs.

Table 4.12 and Figure 4.11 to Figure 4.13 summarize the results of the delivered costs of methanol to the various regions and the comparison to methanol prices forecast for 2006 and 2015. For the United States, USGC and CARB gasoline prices are also compared. 
Figure 4.10 Sensitivity Of Fuel Grade Methanol Cost Of Production To Key Variables (2015 conservative scenario)
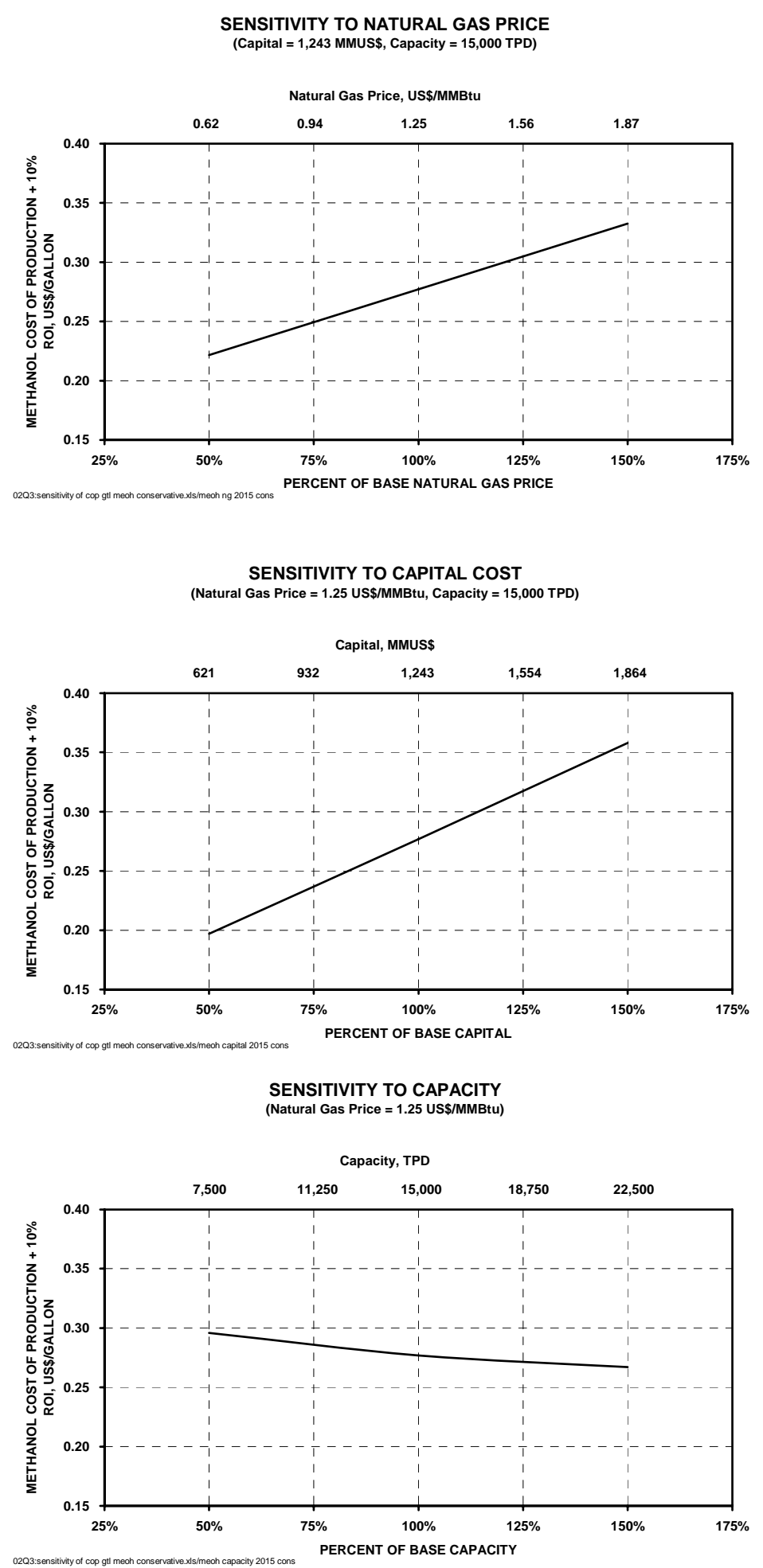


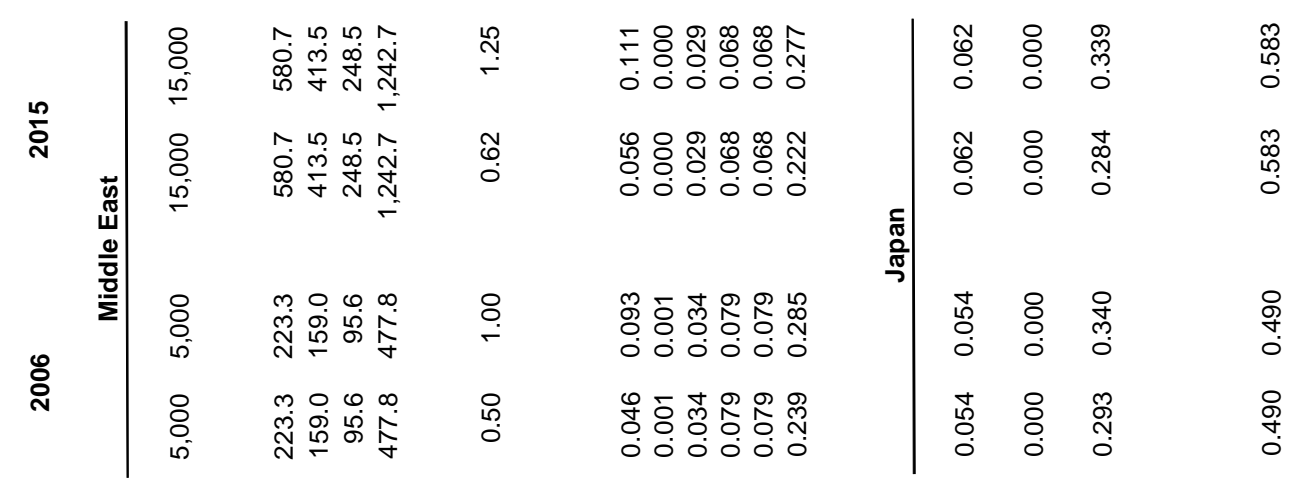

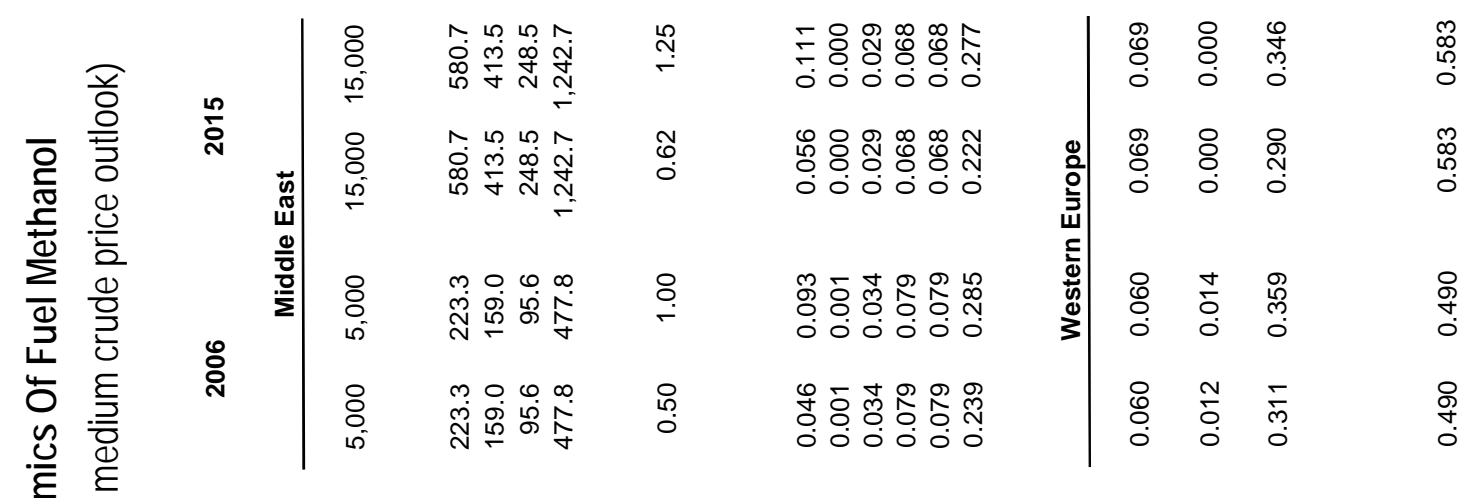

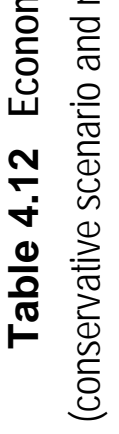

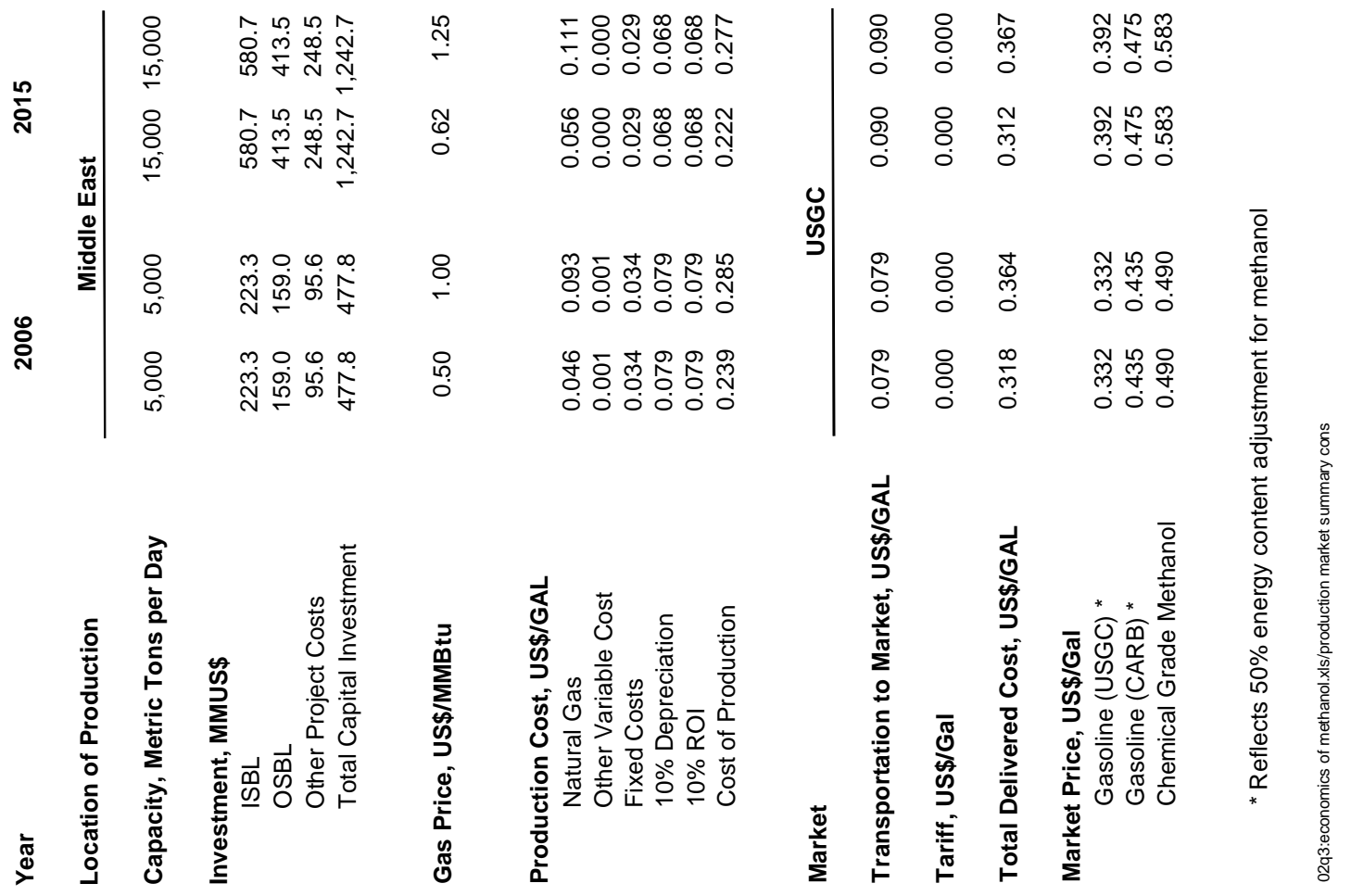




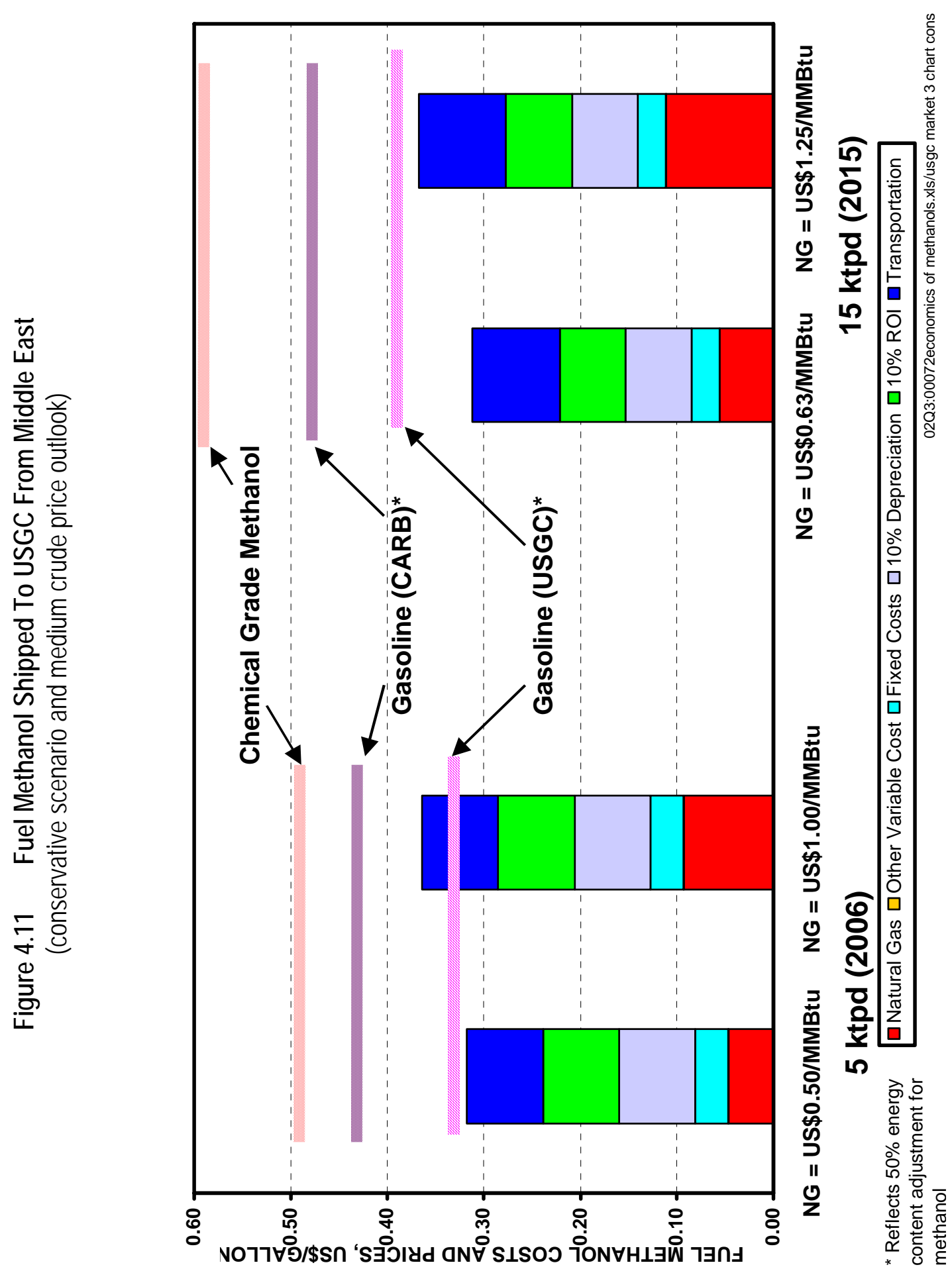




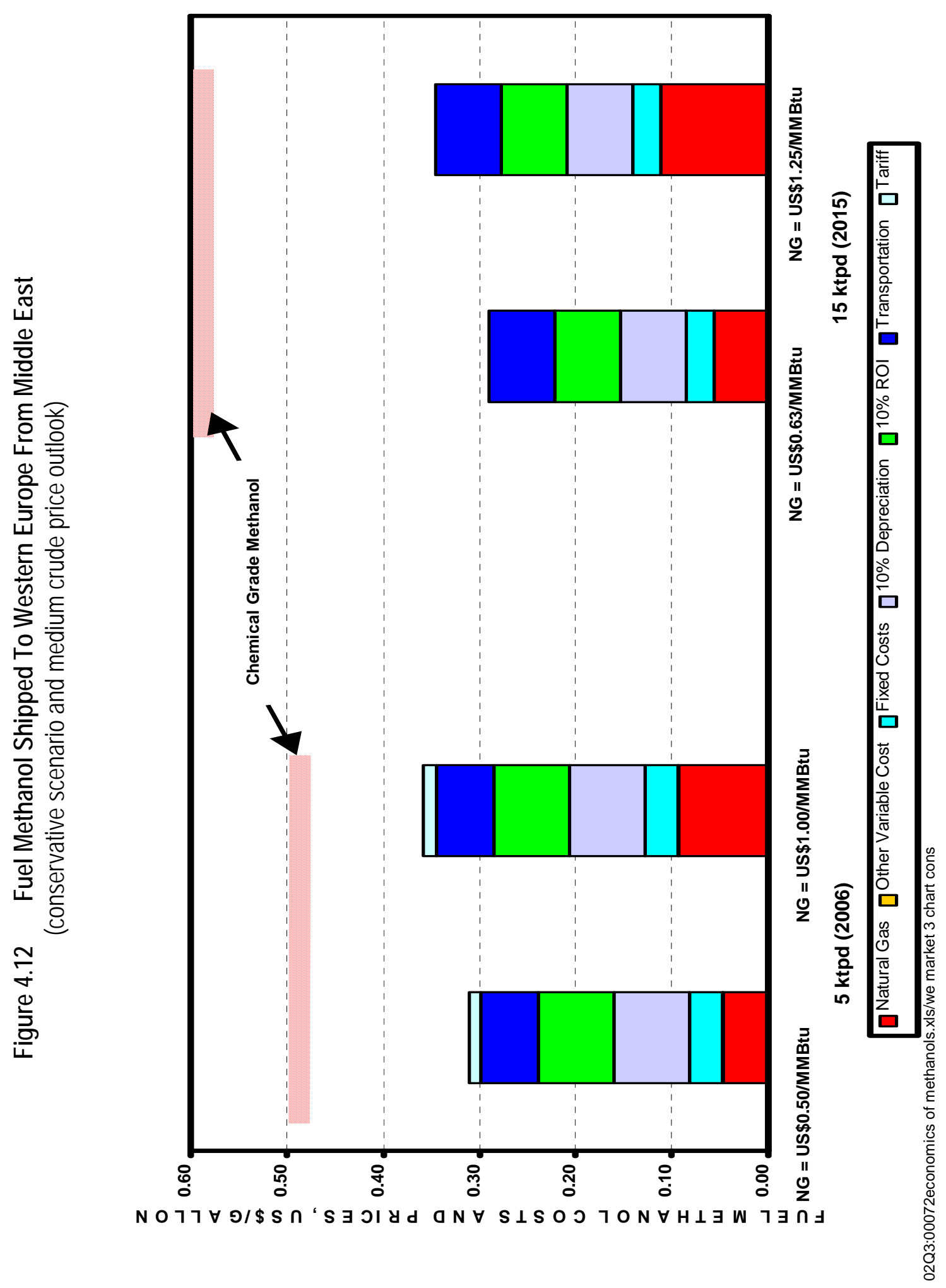




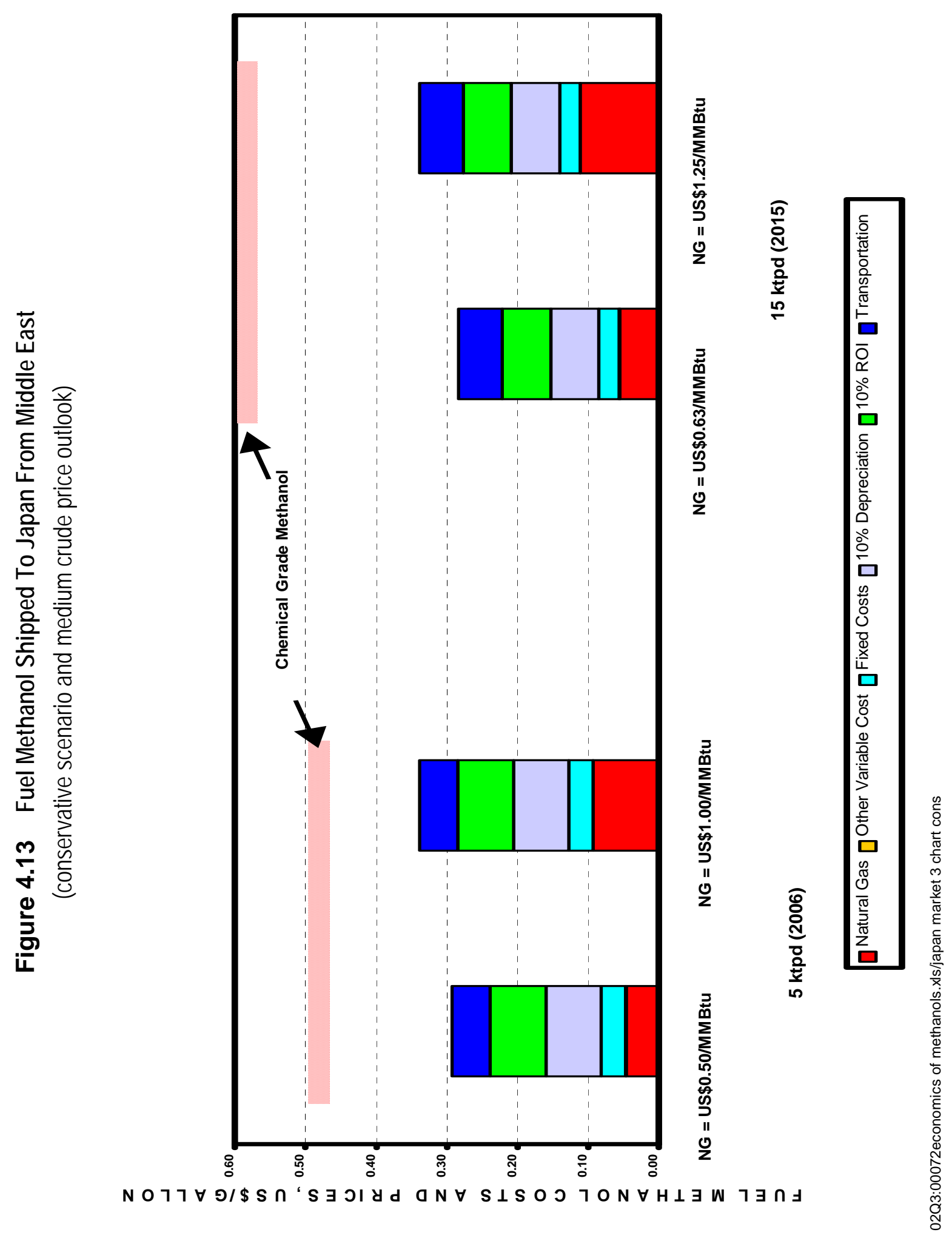


For 2006, the full cost of production plus 10 percent ROI for methanol produced at a 5,000 metric tons per day facility in a Middle East remote location will be about $\$ 0.285$ per gallon if natural gas cost is $\$ 1.00$ per million BTU. Taking into account transportation costs and tariff, the total delivered cost of methanol will be $\$ 0.364, \$ 0.359$, and $\$ 0.340$ per gallon at the USGC, Western European, and Japanese markets, respectively.

If natural gas price is $\$ 0.50$ per million BTU, i.e., 50 percent of the assumption above, the full cost of production plus 10 percent ROI for methanol will be reduced to about $\$ 0.239$ per gallon and the corresponding delivered cost of methanol will be $\$ 0.318, \$ 0.311$, and $\$ 0.293$ per gallon at the USGC, Western European, and Japanese markets, respectively.

For 2015, the full cost of production plus 10 percent ROI for methanol produced at a 15,000 metric tons per day facility in a Middle East remote location will be about $\$ 0.277$ per gallon if natural gas cost is $\$ 1.25$ per million BTU. Taking into account transportation costs and tariff, the total delivered cost of methanol will be \$0.367, \$0.346, and \$0.339 per gallon at the USGC, Western European, and Japanese markets, respectively.

If natural gas price is $\$ 0.625$ per million BTU, i.e., 50 percent of the assumption above, the full cost of production plus 10 percent ROI for methanol will be reduced to about $\$ 0.222$ per gallon and the corresponding delivered cost of methanol will be $\$ 0.312, \$ 0.290$, and $\$ 0.284$ per gallon at the USGC, Western European, and Japanese markets, respectively.

As indicated, methanol produced in the Middle East and shipped to the US has marginal economics for fuel. In the US chemical market, the economics is more attractive than that for the fuel market. Both Western European and Japanese chemical markets are also significantly attractive.

The transportation costs discussed above are based on a 100,000 dwt vessel for methanol and are depicted in Figure 4.14.

The economic viability of the Middle East methanol can also be determined by examining the rate of return on investment. The rates of return on capital investment based on the regional market prices of USGC gasoline, CARB gasoline, and USGC chemical grade methanol netback to the Middle East are presented in Figure 4.15 for 2006 and Figure 4.16 for 2015.

Based on Nexant's 2006 medium crude price outlook, the Mega Methanol Process with a natural gas price at $\$ 1.00$ per million BTU can deliver methanol at a return on investment of 5.9, 19.0, and 26.0 percent based on USGC gasoline, CARB gasoline, and USGC chemical grade methanol, respectively.

Based on Nexant's 2015 medium crude price outlook, the Mega Methanol Process with a natural gas price at $\$ 1.25$ per million BTU can deliver methanol at a return on investment of 13.6, 25.8, and 41.6 percent based on USGC gasoline, CARB gasoline, and USGC chemical grade methanol, respectively. 
For comparison, a conventional methanol process with a capacity of 2,300 metric tons per day, a natural gas price at $\$ 1.25$ per million BTU, and a conventional vessel (e.g. 30,000 dwt) can only deliver to the USGC chemical grade methanol market at about 0 percent ROI. If a bigger methanol vessel (e.g. 100,000 dwt) is used, the ROI will be improved slightly to 5.9 percent as shown in Figure $7 .$. 


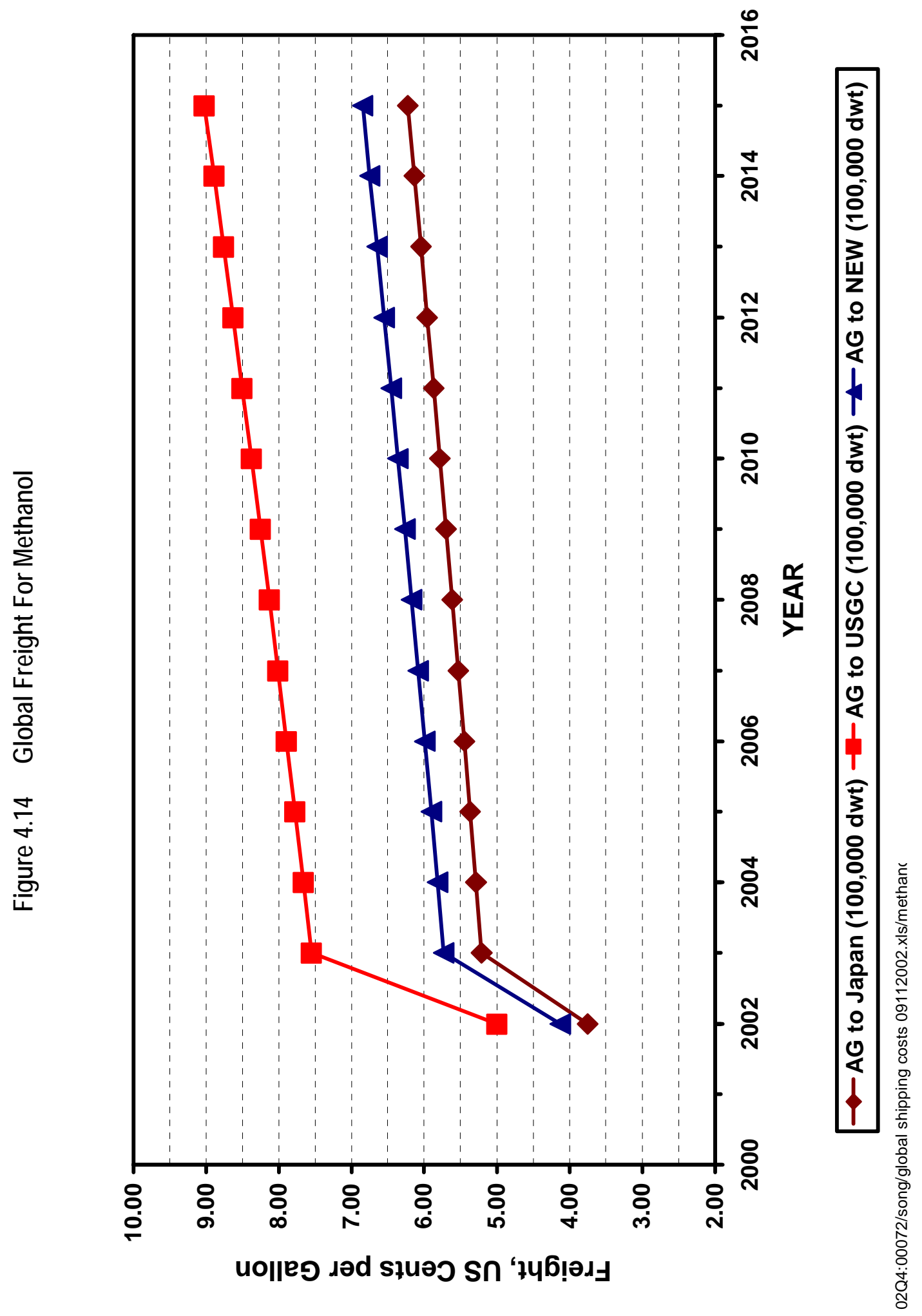




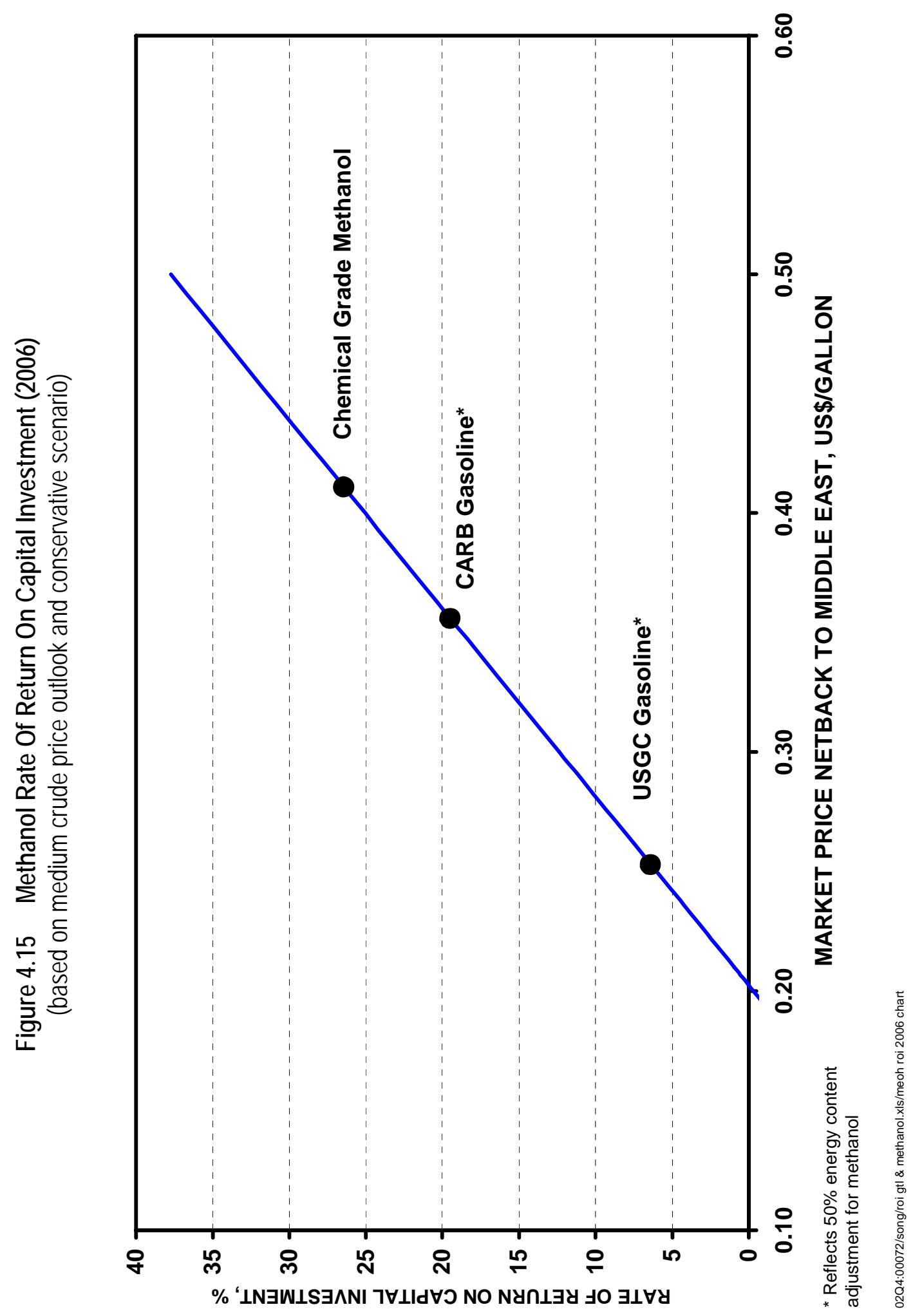




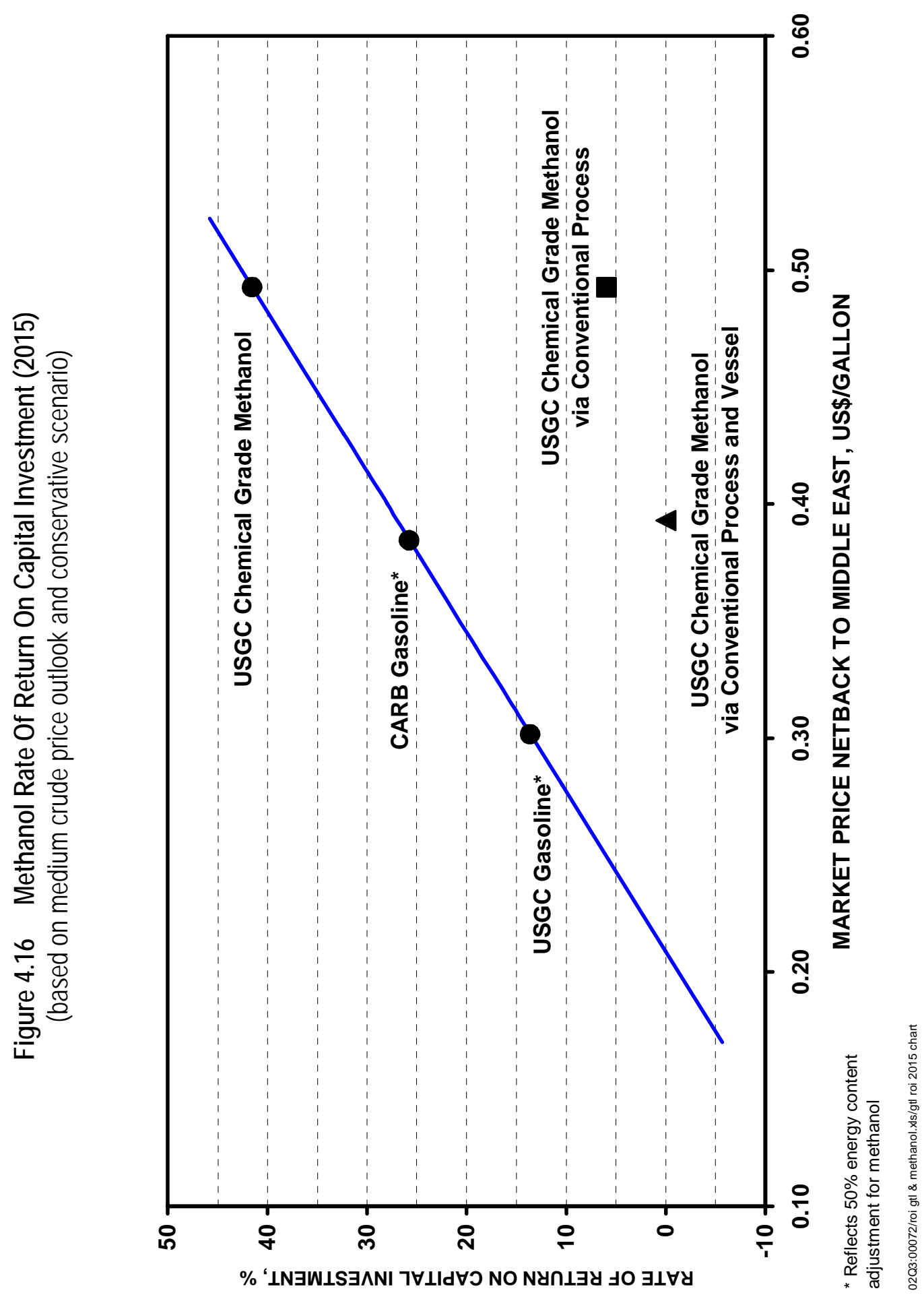




\subsubsection{Comparison Between Methanol and GTL}

It is of interest to compare the economics of methanol with that of the GTL discussed in the previous section.

Figure 4.17 and Figure 4.18 summarize GTL and methanol rates of return for 2006 and 2015, respectively.

Based on a medium crude price outlook, a natural gas price at $1.00 \mathrm{US} \$ \mathrm{MMBtu}$, and a conservative scenario, the ROI for methanol is generally higher than that of GTL for 2006, as shown in Figure 4.17. For example, for 2006, for methanol sold to the USGC gasoline market price, it has an ROI of 5.9 percent compared to an ROI of only 1.2 percent for the FT liquid products sold to the USGC market. Methanol sold to the chemical grade market has an ROI of 26.0 percent while the highest ROI for FT products is only 8.0 percent when the FT products are sold to the Japanese Market.

While both methanol and GTL ROIs improve significantly form 2006 to 2015, the improvement for methanol is more pronounced than that of GTL as shown in Figure 4.19.

For 2015, at the USGC Market, methanol has an ROI of 13.6 percent while FT liquid products has an ROI of 5.9 percent. The highest ROI for FT liquid products is 26.0 percent when the products are sold to the Japanese Market while the ROI for chemical grade methanol is 41.6 percent, i.e., 1.6 times higher than that of FT liquid products. 


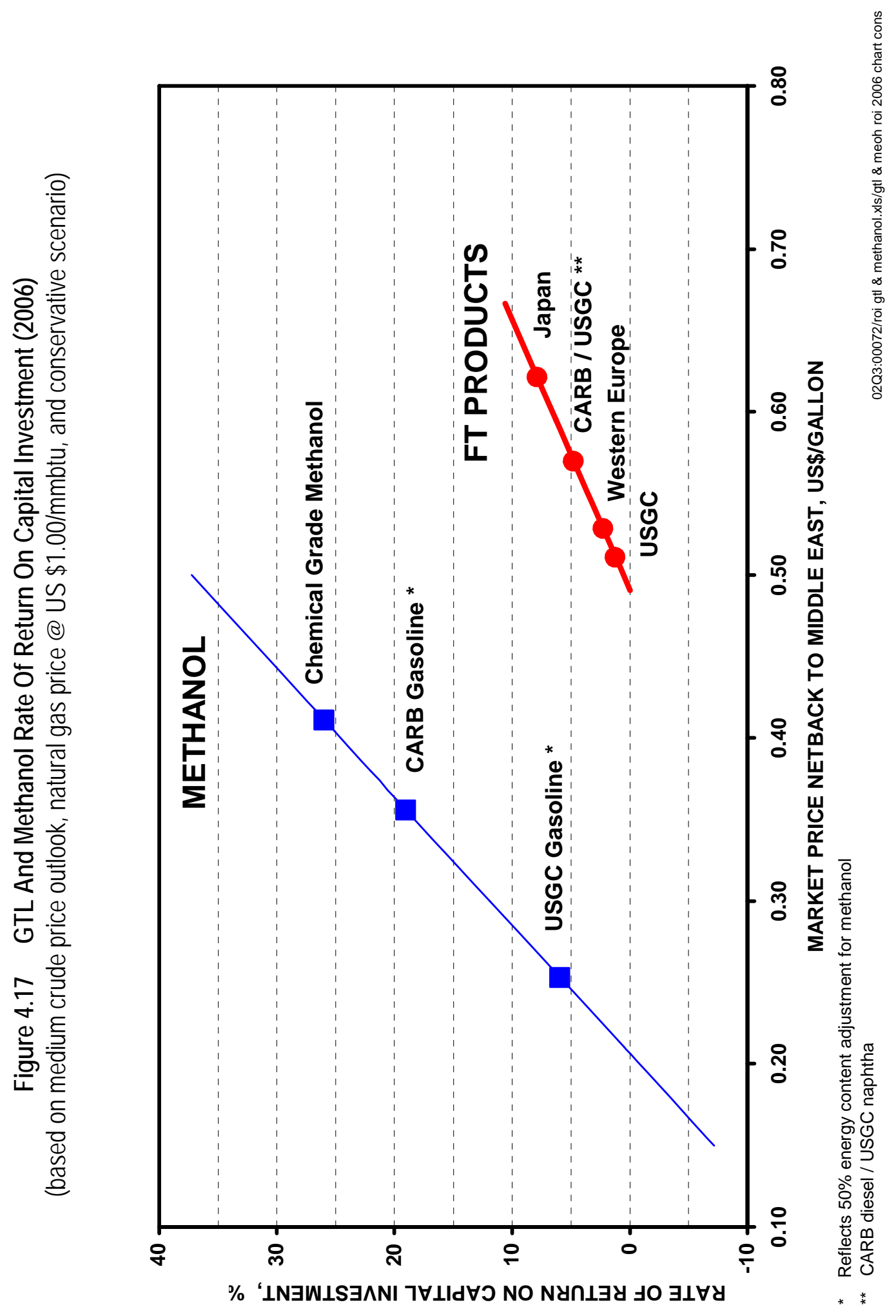




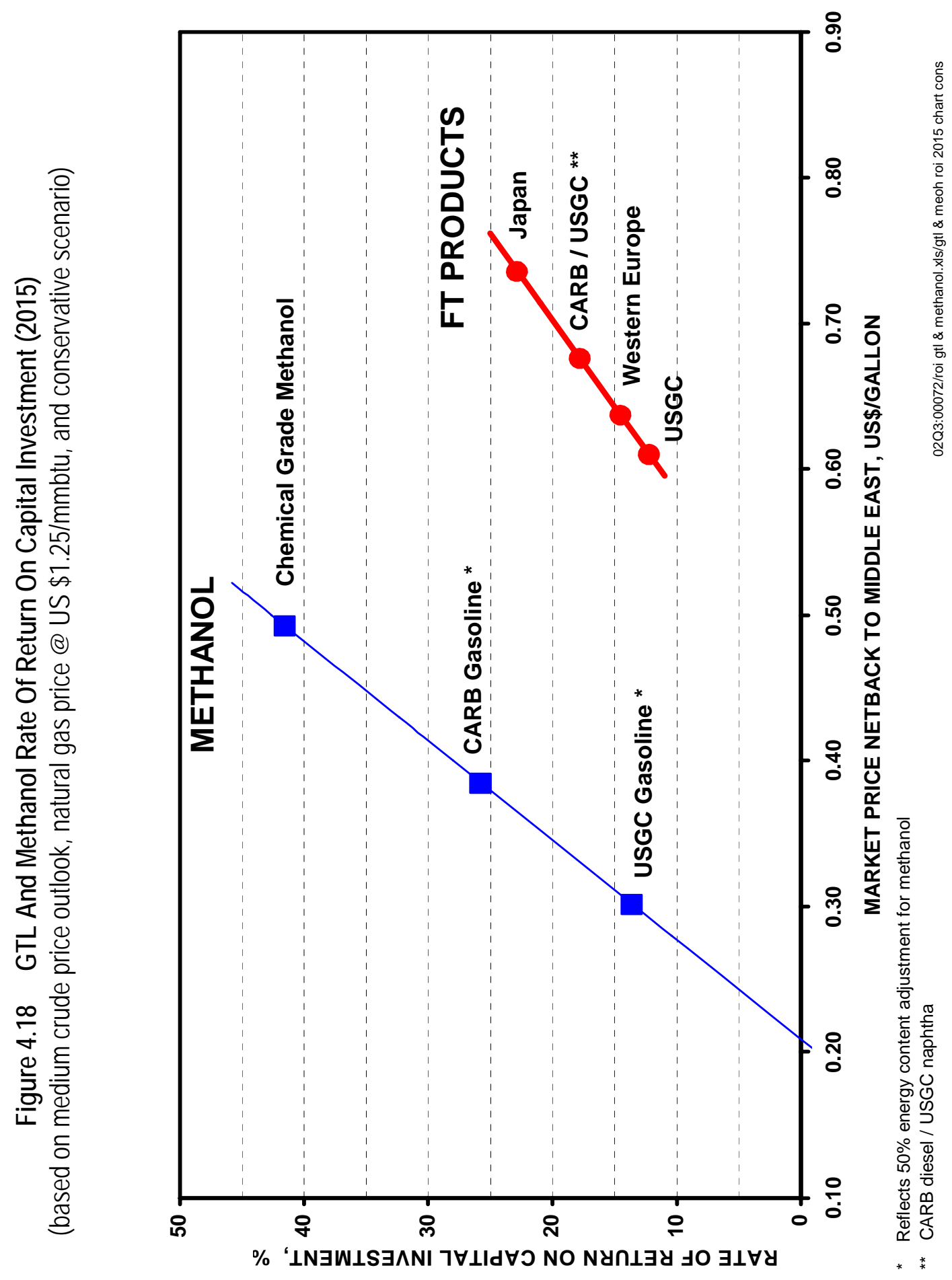




\subsubsection{ECONOMICS OF AGGRESSIVE SCENARIO}

\subsubsection{Process Economics}

2006

The economics for the production of 1.825 million metric tons (606 million gallons) per year (or 5 thousand metric tons per day) of fuel grade methanol at a Middle East remote location via the Mega Methanol Process are presented in Table 4.13.

The total plant capital cost is estimated to be $\$ 382.2$ million. This capital cost includes $\$ 223.3$ million for ISBL and $\$ 159.0$ million for OSBL. Other project costs are estimated to be $\$ 96.6$ million, resulting a total capital investment of $\$ 477.8$ million. An additional $\$ 21.5$ million is also estimated for the working capital requirement.

With natural gas price at $\$ 1.00$ per MMBtu, the raw Material cost is $\$ 0.091$ per gallon of methanol. With a utilities credit (power export) of $\$ 0.002$ per gallon of methanol, it results in a variable cost of $\$ 0.090$ per gallon of methanol.

The total direct fixed cost, including all labors, maintenance, and direct overhead, is approximately $\$ 0.015$ per gallon of methanol. The total allocated fixed cost of the plant, including general plant overhead, insurance, property taxes, and environmental levy, is about $\$ 0.019$ per gallon of methanol. The total fixed costs bring the total cash cost to $\$ 0.124$ per gallon ( $\$ 41$ per metric ton) of methanol.

Depreciation, at 10 percent of investment, contributes an additional $\$ 0.079$ per gallon of methanol. Return on total capital investment, also at 10 percent of investment, contributes another $\$ 0.079$ per gallon of methanol.

The above cash cost, depreciation, and return on total capital investment yield a full cost of production of $\$ 0.281$ per gallon ( $\$ 93$ per metric ton) of methanol.

2015

The economics for the production of 5.475 million metric tons (1.818 billion gallons) per year (or 15 thousand metric tons per day) of fuel grade methanol at a Middle East remote location via the Mega Methanol Process are presented in Table 4.14.

The total plant capital cost is estimated to be $\$ 994.1$ million. This capital cost includes $\$ 580.7$ million for ISBL and $\$ 413.5$ million for OSBL. Other project costs are estimated to be $\$ 248.5$ million, resulting a total capital investment of $\$ 1.242$ billion. An additional $\$ 55.9$ million is also estimated for the working capital requirement. 


\section{Table 4.13 Cost Of Production Estimate For : Fuel Grade Methanol Process: Large-Scale Methanol Process}

(aggressive scenario - 2006)

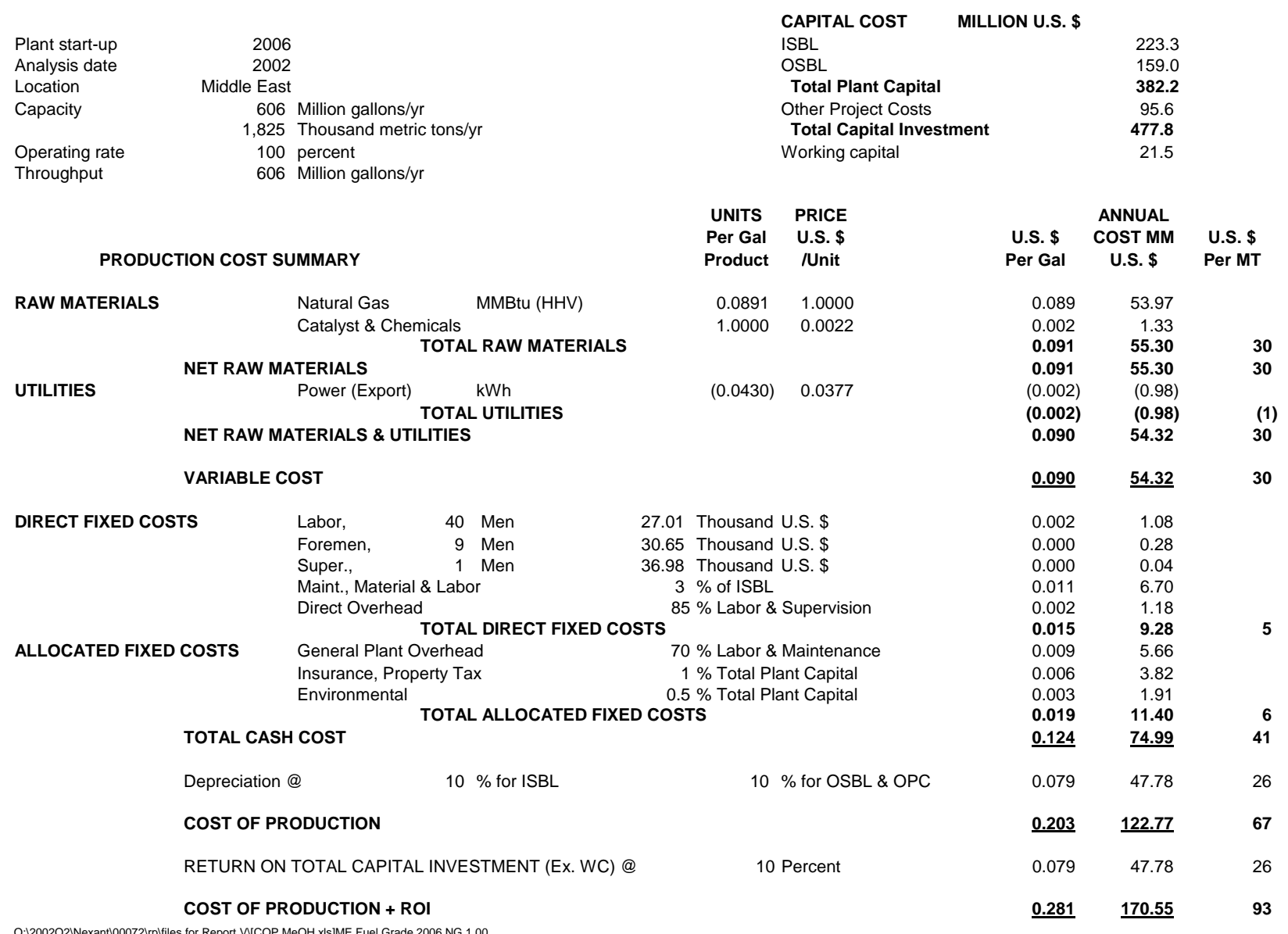


With natural gas price at $\$ 1.25$ per MMBtu, the raw Material cost is $\$ 0.104$ per gallon of methanol. With a utilities credit (power export) of $\$ 0.002$ per gallon of methanol, it results in a variable cost of $\$ 0.102$ per gallon of methanol.

The total direct fixed cost, including all labors, maintenance, and direct overhead, is approximately $\$ 0.013$ per gallon of methanol. The total allocated fixed cost of the plant, including general plant overhead, insurance, property taxes, and environmental levy, is about $\$ 0.016$ per gallon of methanol. The total fixed costs bring the total cash cost to $\$ 0.131$ per gallon ( $\$ 44$ per metric ton) of methanol.

Depreciation, at 10 percent of investment, contributes an additional $\$ 0.068$ per gallon of methanol. Return on total capital investment, also at 10 percent of investment, contributes another $\$ 0.068$ per gallon of methanol.

The above cash cost, depreciation, and return on total capital investment yield a full cost of production of $\$ 0.268$ per gallon ( $\$ 89$ per metric ton) of methanol. 


\section{Table 4.14 Cost Of Production Estimate For: Fuel Grade Methanol Process: Large Scale Methanol Process \\ (aggressive scenario -2015)}

$\begin{array}{lr} & \\ \text { Plant start-up } & 2015 \\ \text { Analysis date } & 2002 \\ \text { Location } & \text { Middle East } \\ \text { Capacity } & 1,818 \text { Million gallons/yr } \\ & 5,475 \text { Thousand metric tons/yr } \\ \text { Operating rate } & 100 \text { percent } \\ \text { Throughput } & 1,818 \text { Million gallons/yr }\end{array}$

CAPITAL COST MILLION U.S. \$

580.7

OSBL 413.5

Total Plant Capital $\quad 994.1$

Other Project Costs 248.5

Total Capital Investment

Working capital $\quad 55.9$

$\begin{array}{cc}\text { UNITS } & \text { PRICE } \\ \text { Per Gal } & \text { U.S. \$ }\end{array}$

PRODUCTION COST SUMMARY

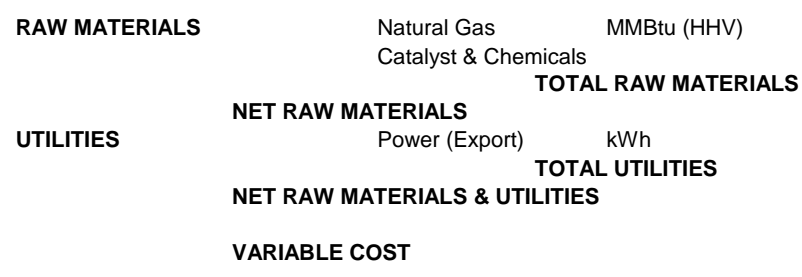

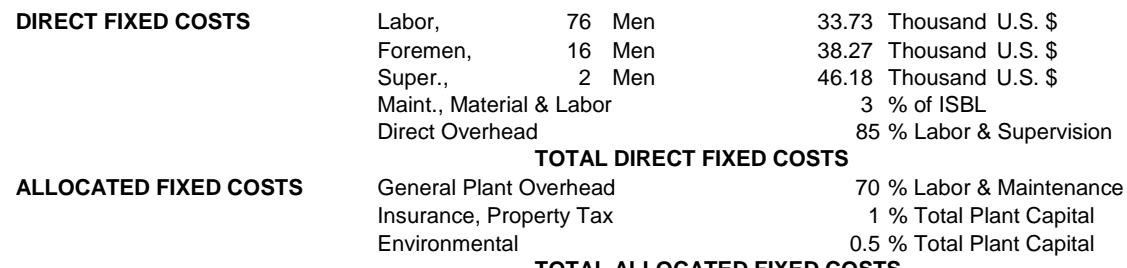

TOTAL CASH COST

TOTAL ALLOCATED FIXED COSTS

Product IUnit

$0.0814 \quad 1.2489$

$\begin{array}{ll}1.0000 & 0.0025\end{array}$

$(0.0470) \quad 0.0467$

$\begin{array}{lll}\text { Depreciation @ } & 10 \% \text { for ISBL } & 10 \% \text { for OSBL \& OPC } \\ \text { COST OF PRODUCTION } & \end{array}$

RETURN ON TOTAL CAPITAL INVESTMENT (Ex. WC) @

COST OF PRODUCTION + ROI

10 Percent

\begin{tabular}{|c|c|c|}
\hline \multicolumn{3}{|c|}{ ANNUAL } \\
\hline U.S. \$ & COST MM & U.S. \$ \\
\hline Per Gal & U.S. \$ & Per MT \\
\hline 0.102 & 184.90 & \\
\hline 0.003 & 4.55 & \\
\hline 0.104 & 189.45 & 35 \\
\hline 0.104 & 189.45 & 35 \\
\hline$(0.002)$ & (3.99) & \\
\hline (0.002) & (3.99) & (1) \\
\hline 0.102 & 185.46 & 34 \\
\hline 0.102 & 185.46 & 34 \\
\hline 0.001 & 2.56 & \\
\hline 0.000 & 0.61 & \\
\hline 0.000 & 0.09 & \\
\hline 0.010 & 17.42 & \\
\hline 0.002 & 2.78 & \\
\hline 0.013 & 23.47 & 4 \\
\hline 0.008 & 14.48 & \\
\hline 0.005 & 9.94 & \\
\hline 0.003 & 4.97 & \\
\hline 0.016 & 29.39 & 5 \\
\hline$\underline{0.131}$ & $\underline{238.32}$ & 44 \\
\hline 0.068 & 124.27 & 23 \\
\hline$\underline{0.199}$ & 362.59 & 66 \\
\hline 0.068 & 124.27 & 23 \\
\hline 0.268 & 486.85 & 89 \\
\hline
\end{tabular}

O:|2002Q21Nexant|00072Irplfiles for Report V[COP MeOH.xls]ME Fuel Grade 2015 15kt NG 1.25 
The costs of production of methanol at a Middle East remote location for 5,000 tpd and 15,000 tpd for 2015 are summarized graphically in Figure 4.19. As indicated in the figure, methanol cost of production can be reduced with a larger capacity. It is also to be noted that the difference in cost of production between fuel and chemical grade methanol is relatively insignificant as shown in Figure 7.9 for a 5,000 tpd plant for both 2006 and 2015.

\subsubsection{Sensitivity Analysis}

2006

The effects of natural gas price, capital investment, and methanol production capacity on the full cost of production of methanol plus 10 percent ROI via Lurgi Mega Methanol Process are shown in Figure 4.19. 


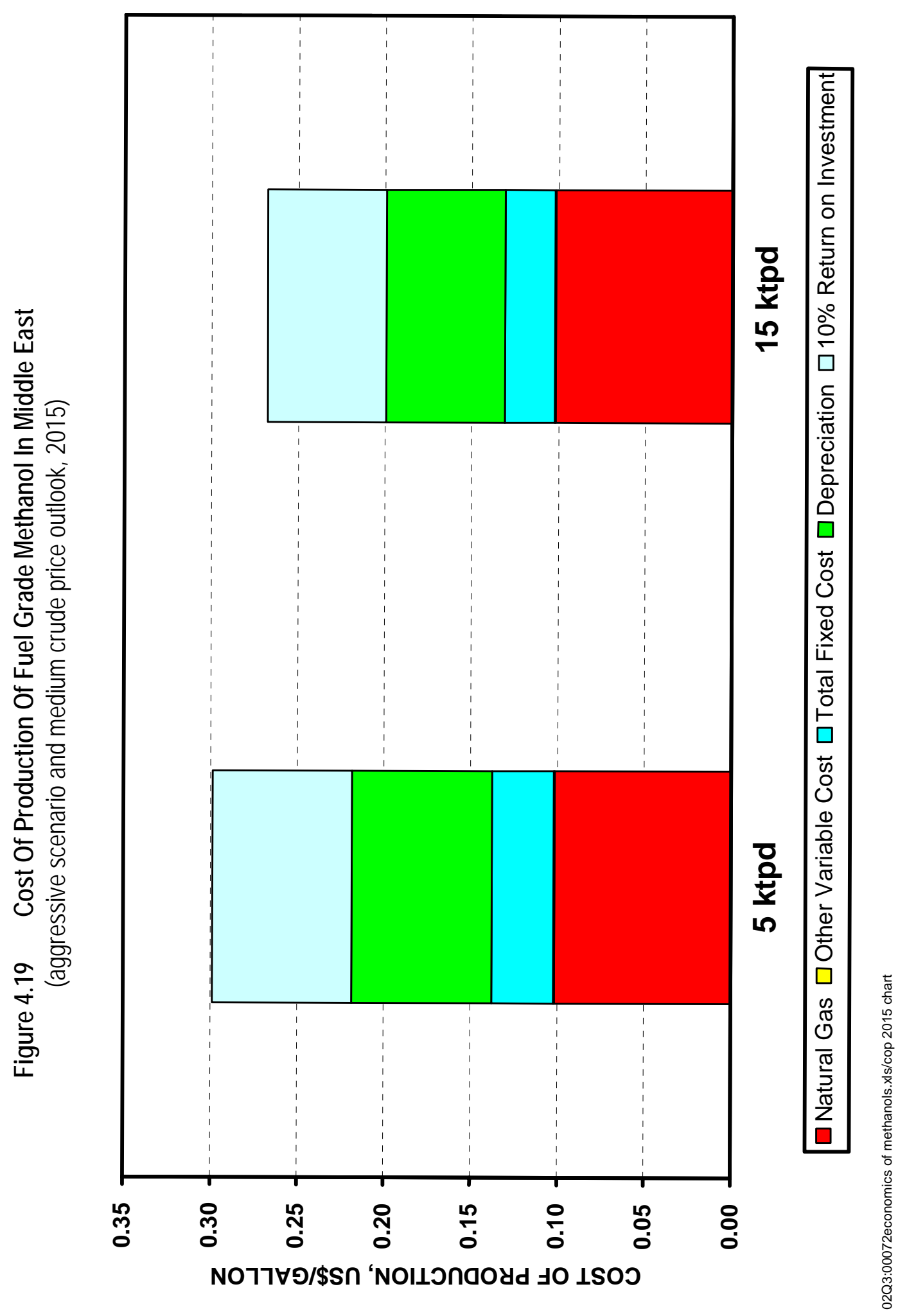




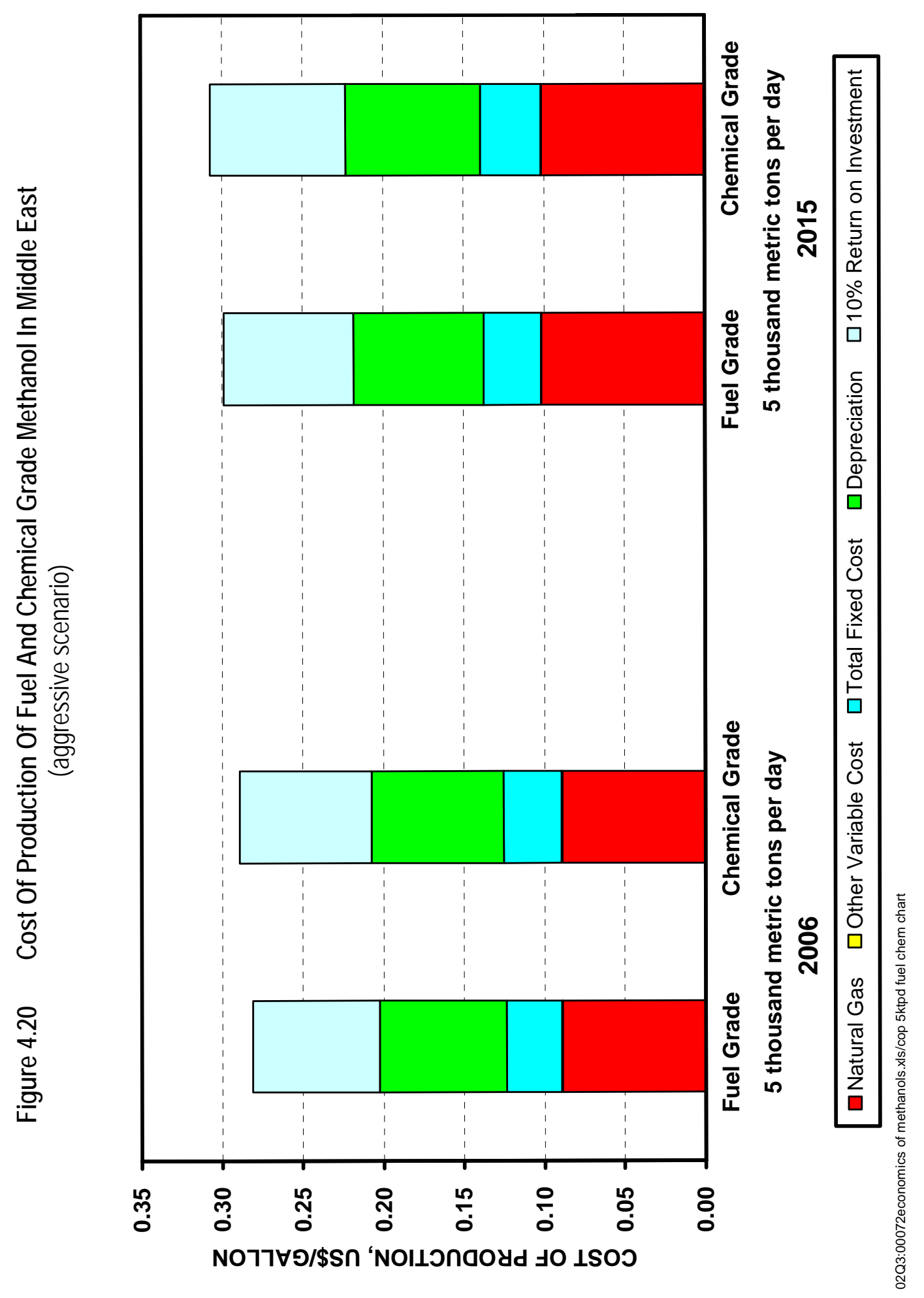


With total capital investment maintained at $\$ 478$ million and methanol production capacity maintained at 1.825 million metric tons (606 million gallons) per year (or 5 thousand metric tons per day), methanol full cost of production plus 10 percent ROI increases from $\$ 0.281 /$ gallon to $\$ 0.326 /$ gallon when natural gas price increases from $\$ 1.00 / \mathrm{MMBtu}$ to $\$ 1.50 / \mathrm{MMBtu}$, i.e. 50 percent increase. Methanol full cost of production plus 10 percent ROI decreases to $\$ 0.237 /$ gallon when natural gas price decreases to $\$ 0.50 / \mathrm{MMBtu}$, i.e. 50 percent decrease. Thus, every dollar/MMBtu change in natural gas price results in an average change of \$0.089/gallon in methanol full cost of production plus 10 percent ROI.

With natural gas price maintained at $\$ 1.00 / \mathrm{MMBtu}$ and methanol production capacity maintained at 1.825 million metric tons (606 million gallons) per year, methanol full cost of production plus 10 percent ROI increases from $\$ 0.281 /$ gallon to $\$ 0.374 /$ gallon when the total capital investment increases from $\$ 478$ million to $\$ 717$ million, i.e. 50 percent increase. Methanol full cost of production plus 10 percent ROI decreases to $\$ 0.188 /$ gallon when the total capital investment decreases to $\$ 239$ million, i.e. 50 percent decrease. This represents an average of $\$ 0.04 /$ gallon change in methanol full cost of production plus 10 percent ROI for every \$100 million change in total capital investment.

With natural gas price maintained at $\$ 1.00 / \mathrm{MMBtu}$, methanol full cost of production plus 10 percent ROI decreases from $\$ 0.281 /$ gallon to $\$ 0.256 /$ gallon when methanol production capacity increases from 1.825 million metric tons (606 million gallons) per year to 2.738 million metric tons (909 million gallons) per year, i.e. 50 percent increase. Methanol full cost of production plus 10 percent ROI increases to $\$ 0.334 /$ gallon when methanol production capacity decreases to 913 thousand metric tons (303 million gallons) per year, i.e. 50 percent decrease. 
Figure 4.21 Sensitivity Of Fuel Grade Methanol Cost Of Production To Key Variables (2006 aggressive scenario)
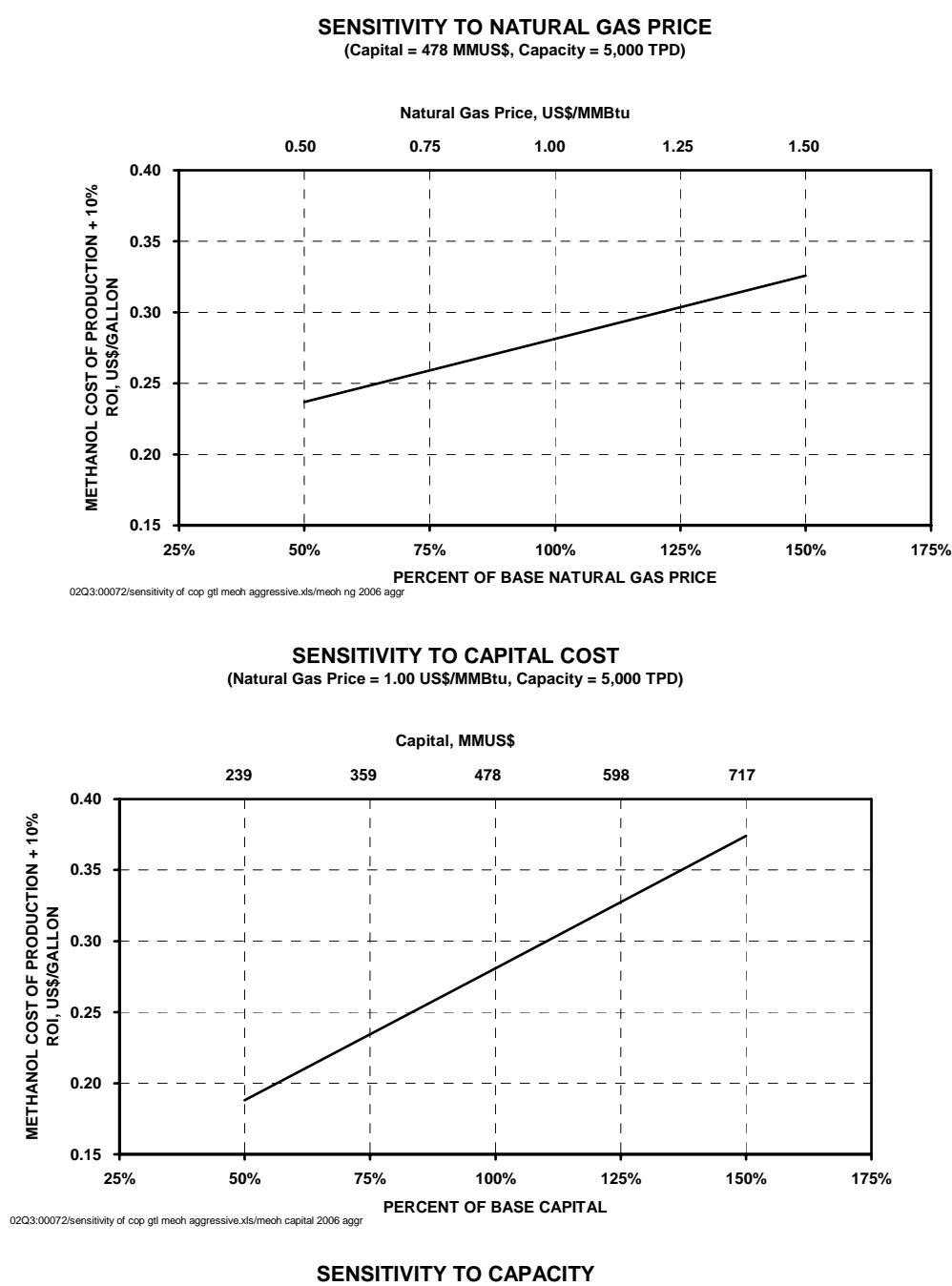

(Natural Gas Price $=1.00$ US $\$$ /MMBtu)

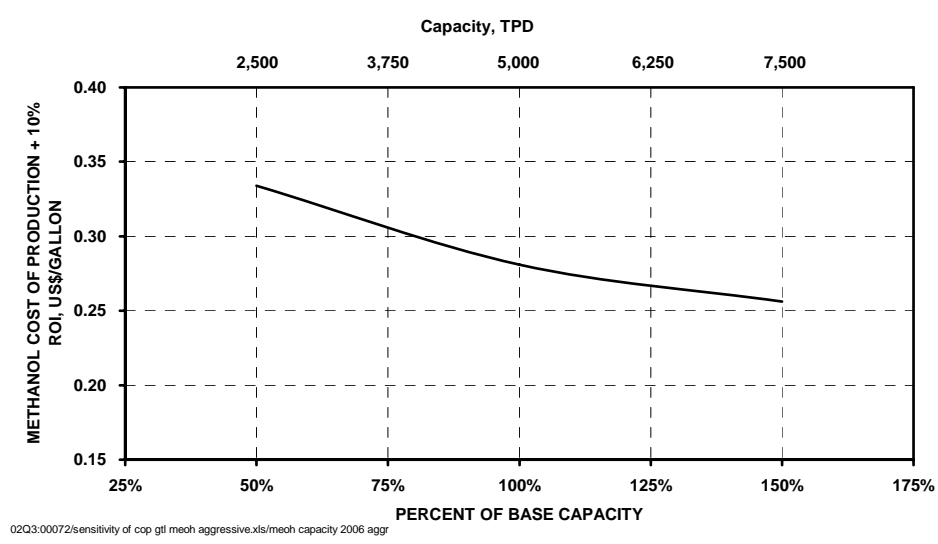


2015

The effects of natural gas price, capital investment, and methanol production capacity on the full cost of production of methanol plus 10 percent ROI are shown in Figure 4.22.

With total capital investment maintained at $\$ 1.243$ billion and methanol production capacity maintained at 5.475 million metric tons (1.818 billion gallons) per year (or 15 thousand metric tons per day), methanol full cost of production plus 10 percent ROI increases from $\$ 0.268 /$ gallon to $\$ 0.319 /$ gallon when natural gas price increases from $\$ 1.25 / \mathrm{MMB}$ tu to $\$ 1.87 / \mathrm{MMBtu}$, i.e. 50 percent increase. Methanol full cost of production plus 10 percent ROI decreases to $\$ 0.217 /$ gallon when natural gas price decreases to $\$ 0.62 / \mathrm{MMBtu}$, i.e. 50 percent decrease. Thus, every dollar/MMBtu change in natural gas price results in an average change of \$0.081/gallon in methanol full cost of production plus 10 percent ROI.

With natural gas price maintained at $\$ 1.25 / \mathrm{MMBtu}$ and methanol production capacity maintained at 5.475 million metric tons (1.818 billion gallons) per year, methanol full cost of production plus 10 percent ROI increases from $\$ 0.268$ /gallon to $\$ 0.348 /$ gallon when the total capital investment increases from $\$ 1.243$ billion to $\$ 1.864$ billion, i.e. 50 percent increase. Methanol full cost of production plus 10 percent ROI decreases to $\$ 0.187 /$ gallon when the total capital investment decreases to $\$ 621.4$ million, i.e. 50 percent decrease. This represents an average of $\$ 0.01 /$ gallon change in methanol full cost of production plus 10 percent ROI for every $\$ 100$ million change in total capital investment.

With natural gas price maintained at $\$ 1.25 / \mathrm{MMBtu}$, methanol full cost of production plus 10 percent ROI decreases from $\$ 0.268 /$ gallon to $\$ 0.258 /$ gallon when methanol production capacity increases from 5.475 million metric tons (1,818 million gallons) per year to 8.213 million metric tons (2,727 million gallons) per year, i.e. 50 percent increase. Methanol full cost of production plus 10 percent ROI increases to $\$ 0.287 /$ gallon when methanol production capacity decreases to 2.738 million metric tons (909 million gallons) per year, i.e. 50 percent decrease. 
Figure 4.22 Sensitivity Of Fuel Grade Methanol Cost Of Production To Key Variables (2015 aggressive scenario)
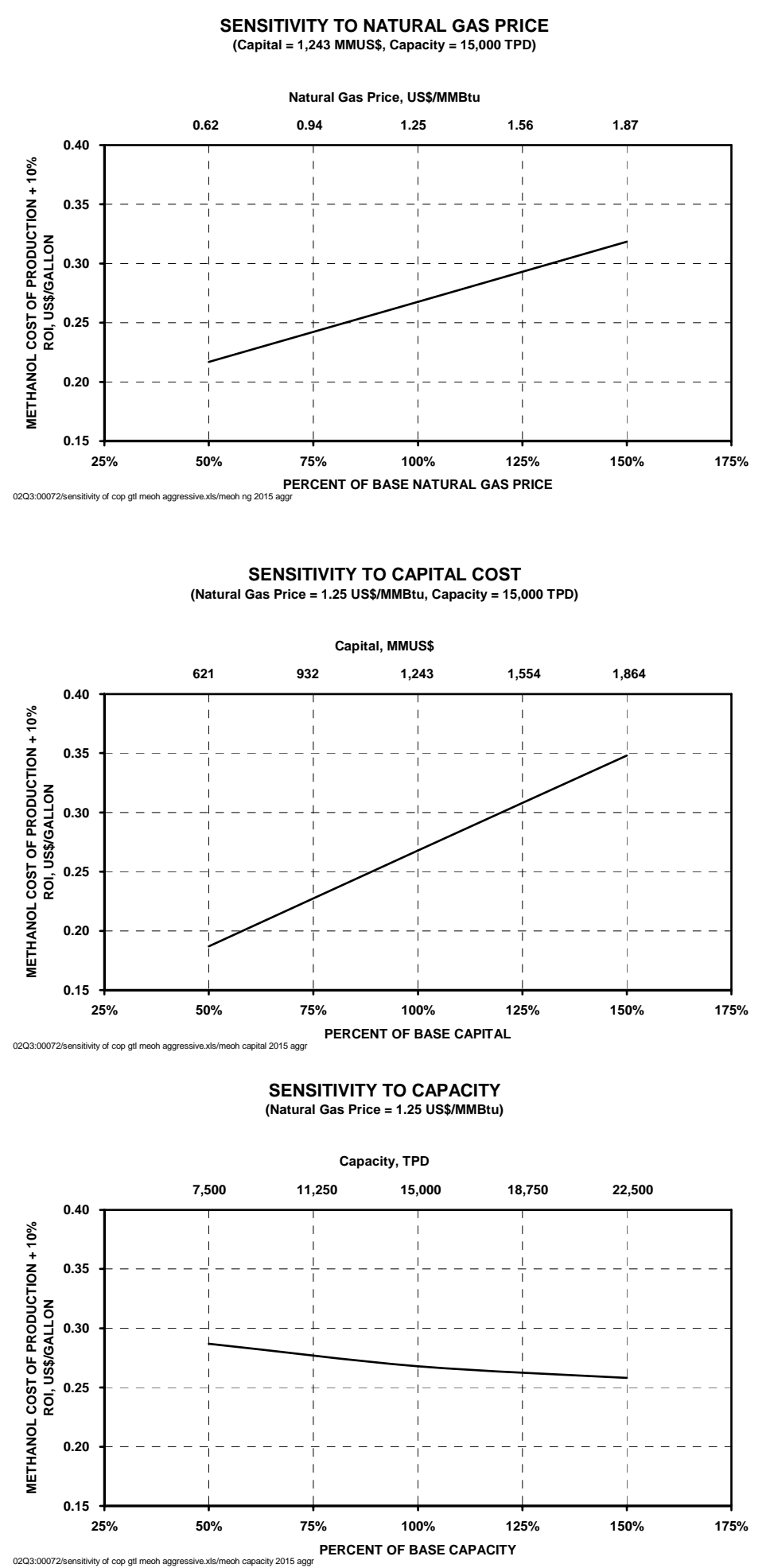


\subsubsection{Regional Economics}

The economic viability of remotely produced fuel methanol at the Middle East can be determined by their delivered costs to the USGC, Western Europe, and Japan. The delivered costs have been developed from the estimated production costs for the methanol plant located in the Middle East as described previously. Transportation costs for shipping methanol from the Middle East to the various regions and tariff, if any, imposed by the various regions are added to the production costs to yield the delivered costs.

Table 4.15 and Figure 4.23 to Figure 4.25 summarize the results of the delivered costs of methanol to the various regions and the comparison to methanol prices forecast for 2006 and 2015. For the United States, USGC and CARB gasoline prices are also compared.

As indicated, methanol produced in the Middle East and shipped to the US has marginal economics for fuel. In the US chemical market, the economics is more attractive than that for the fuel market. Both Western European and Japanese chemical markets are also significantly attractive.

The economic viability of the Middle East methanol can also be determined by examining the rate of return on investment. The rates of return on capital investment based on the regional market prices of USGC gasoline, CARB gasoline, and USGC chemical grade methanol netback to the Middle East are presented in Figure 4.26 for 2006 and Figure 4.27 for 2015. For 2006, the Mega Methanol Process can deliver methanol at a return on investment of 6.4, 19.5, and 26.5 percent based on USGC gasoline, CARB gasoline, and USGC chemical grade methanol, respectively. For 2015, the Mega Methanol Process can deliver methanol at a return on investment of 15.0, 27.1, and 42.9 percent based on USGC gasoline, CARB gasoline, and USGC chemical grade methanol, respectively. 


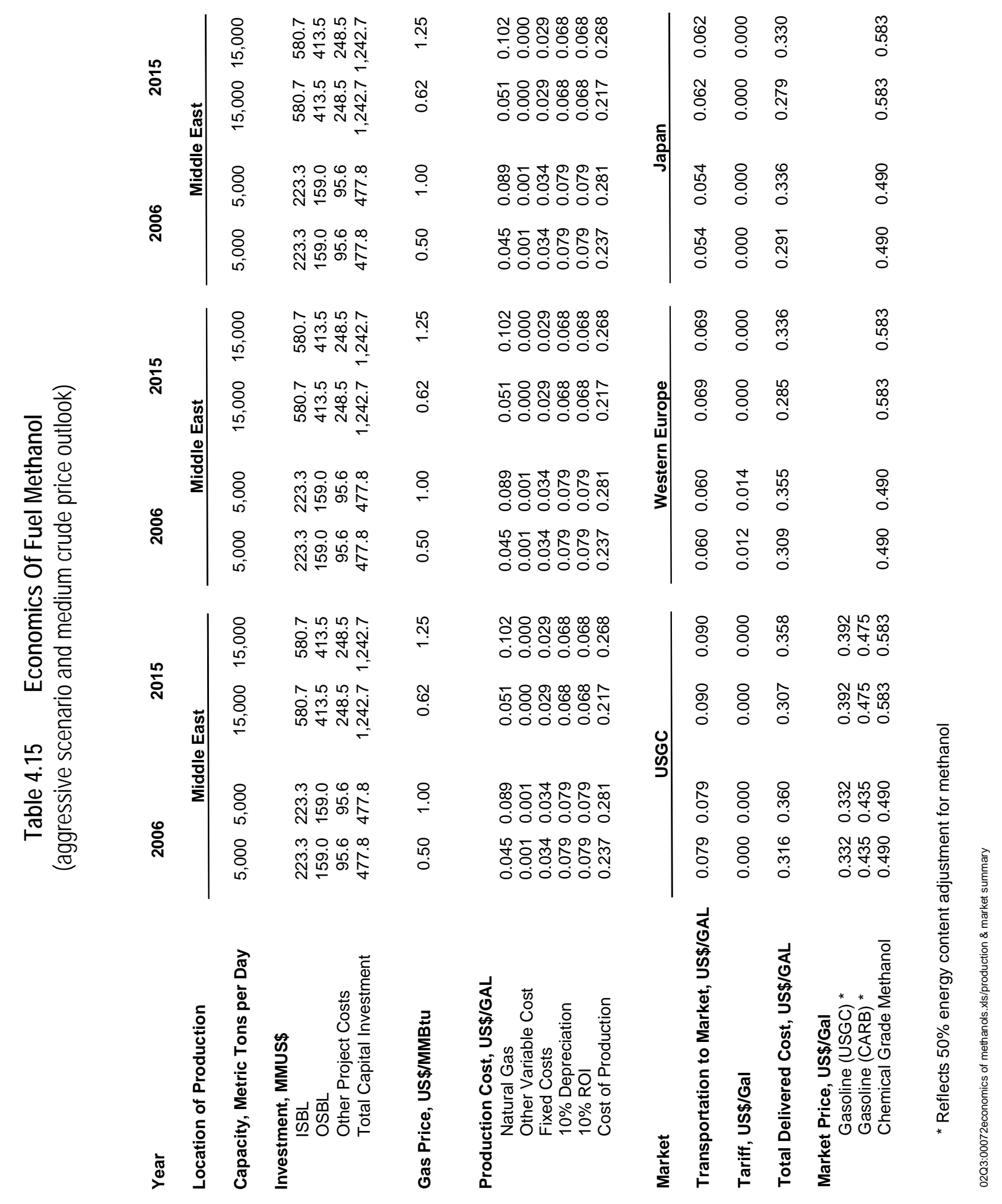




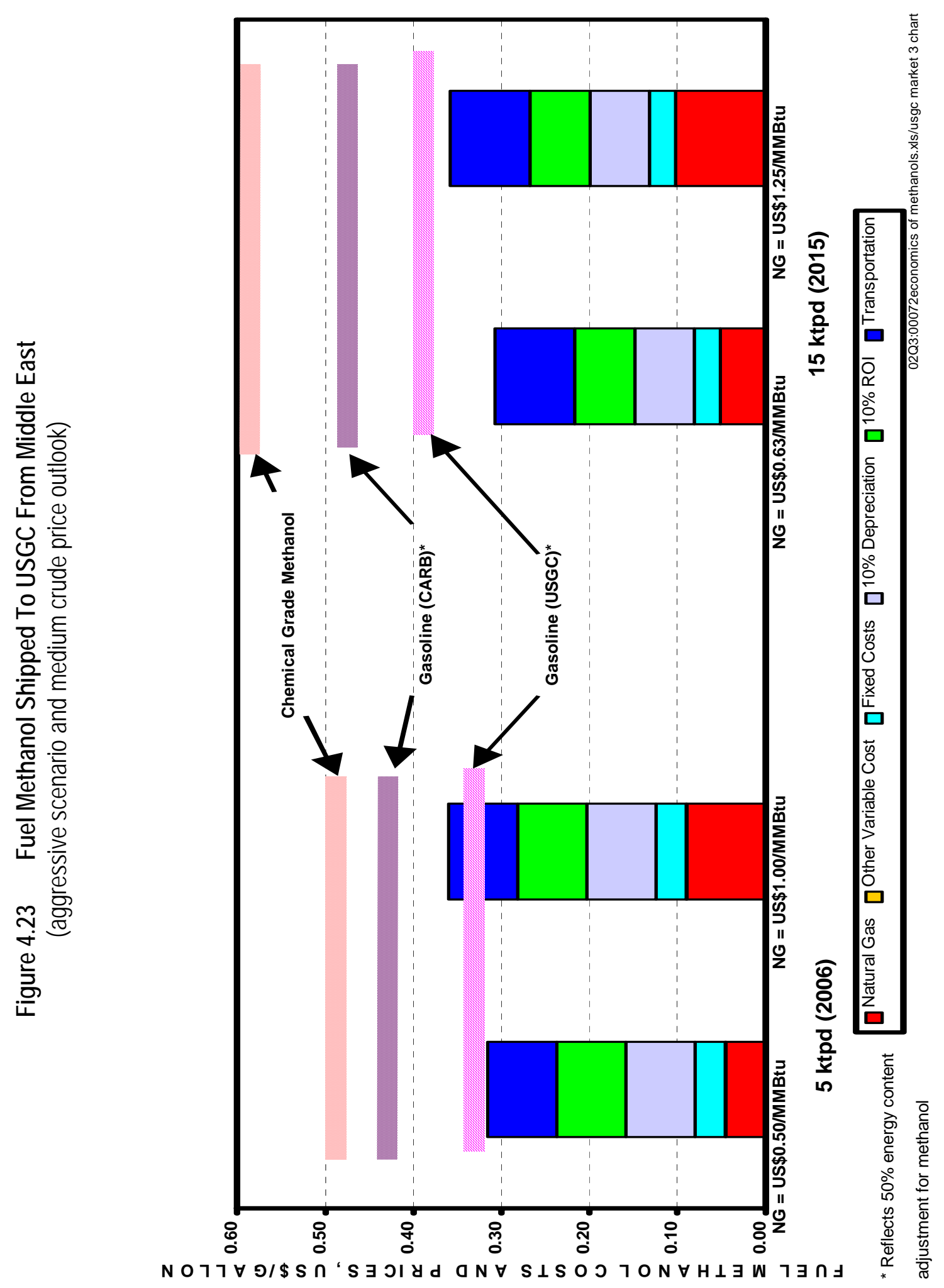




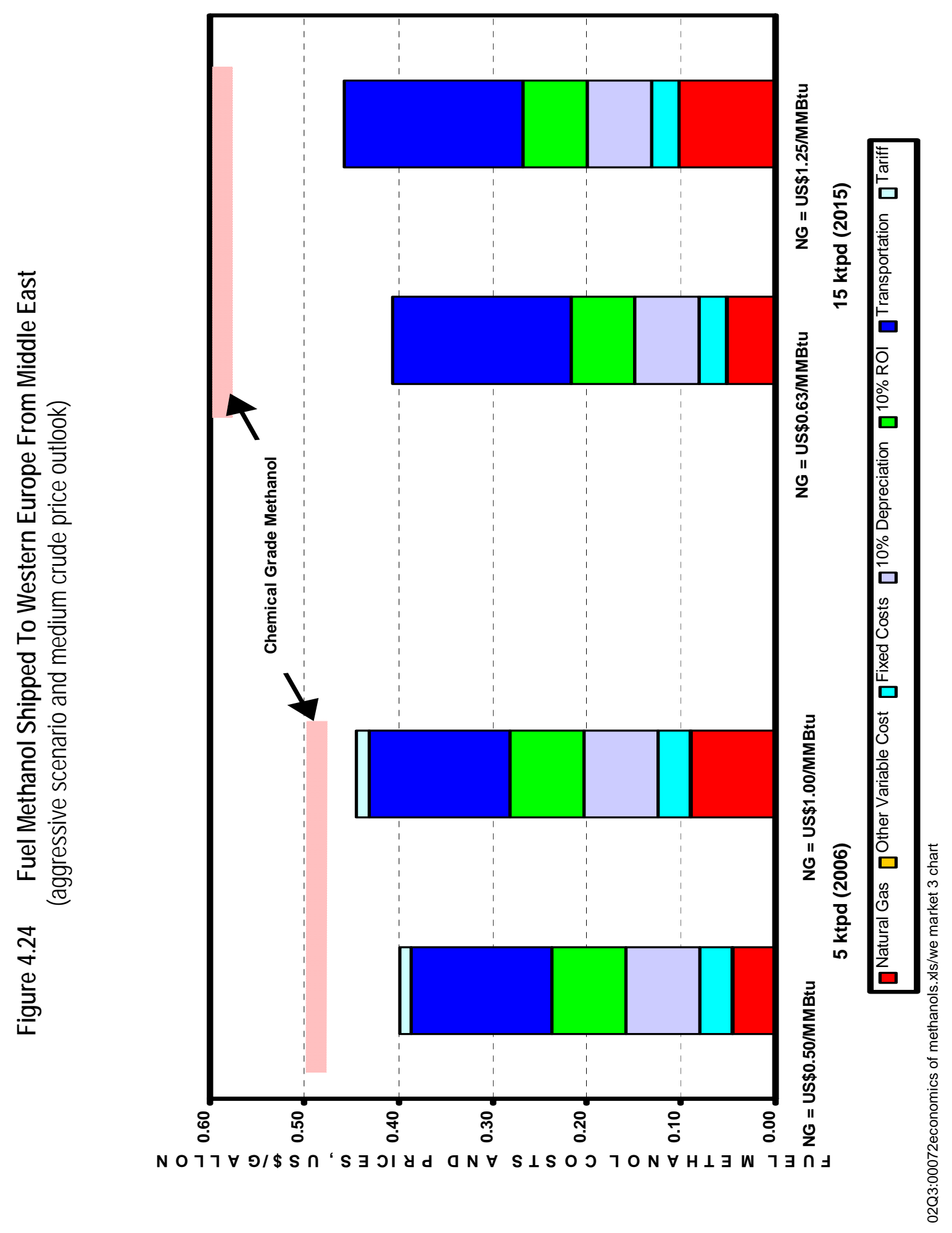




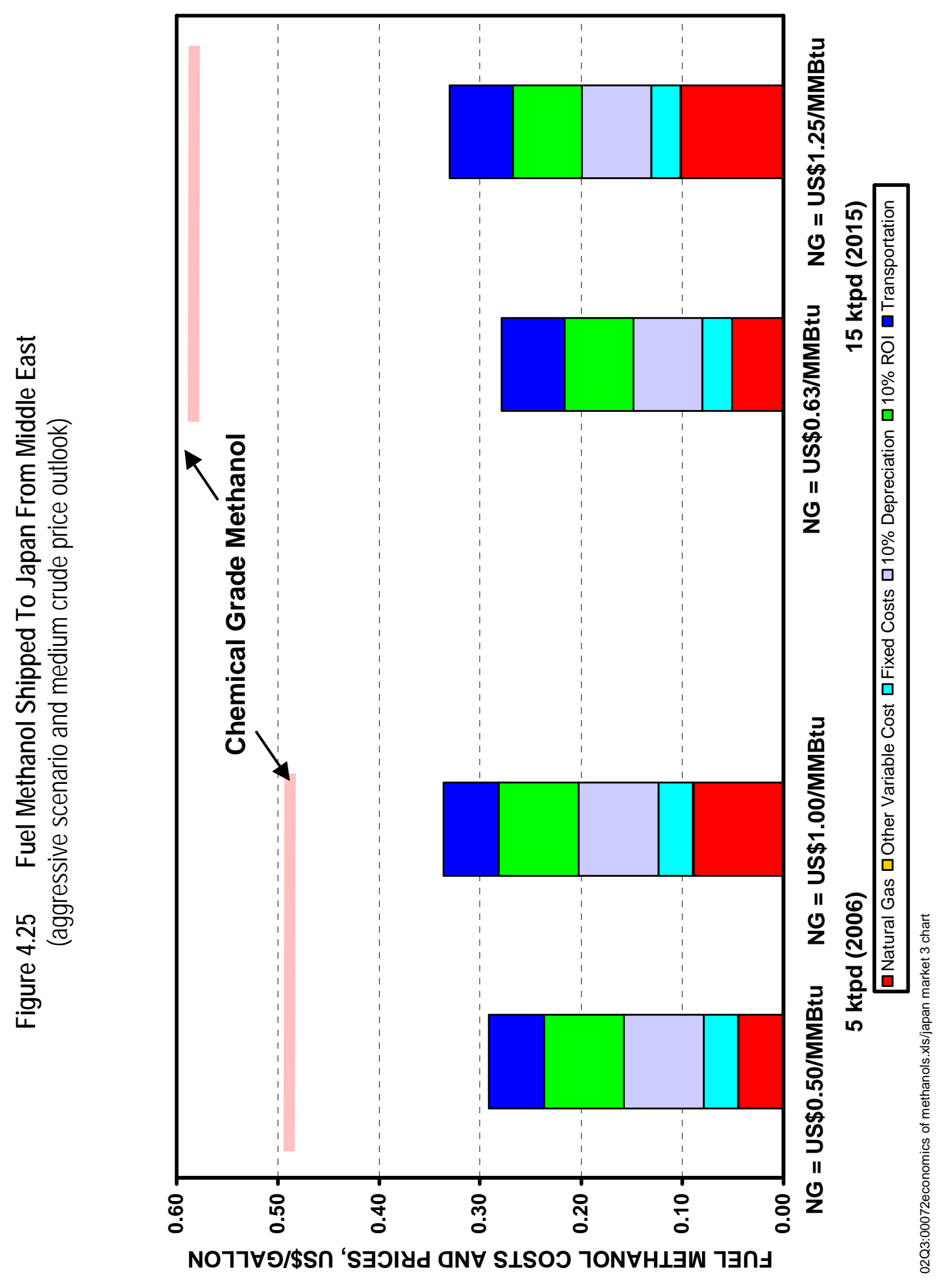




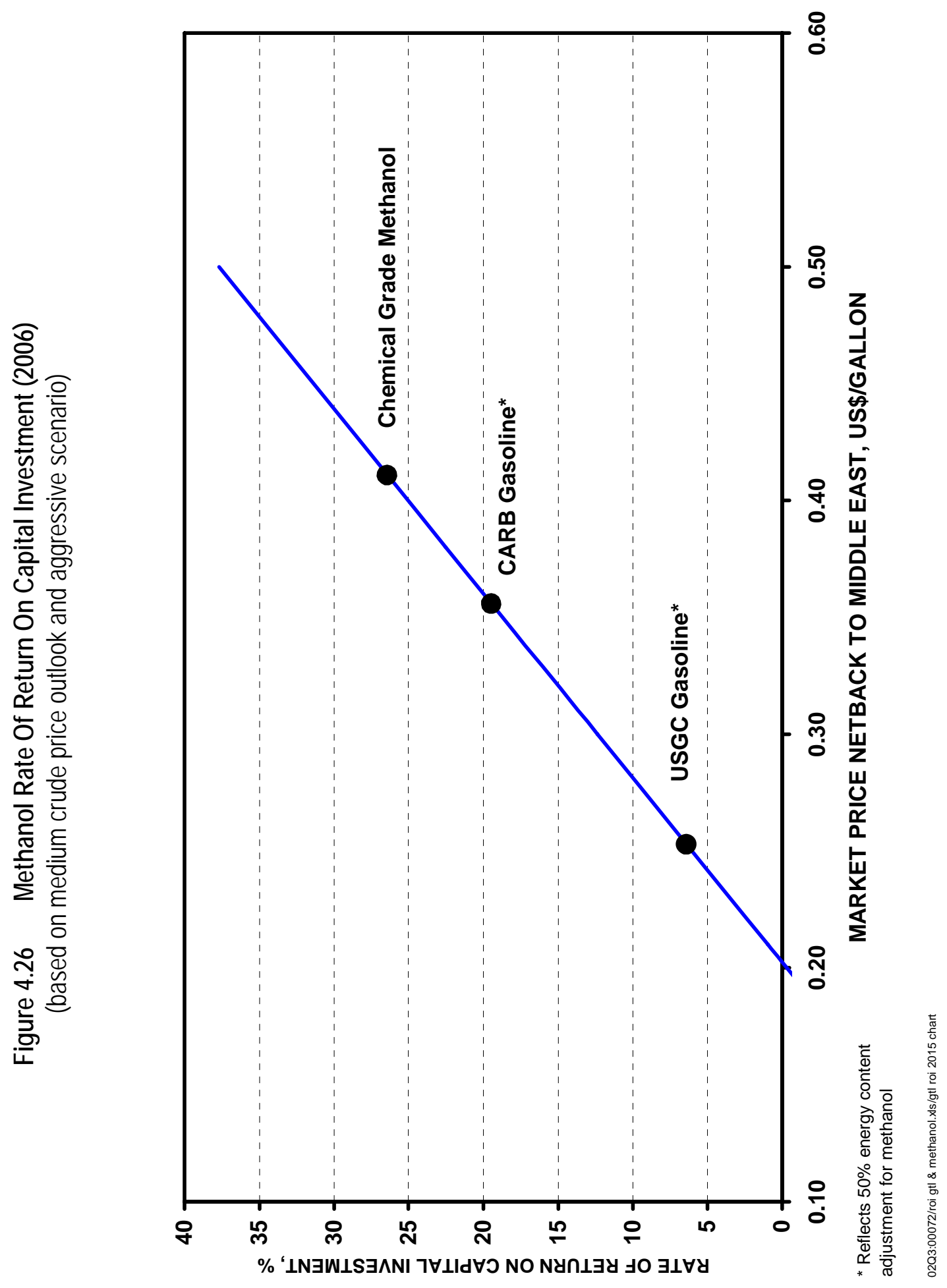




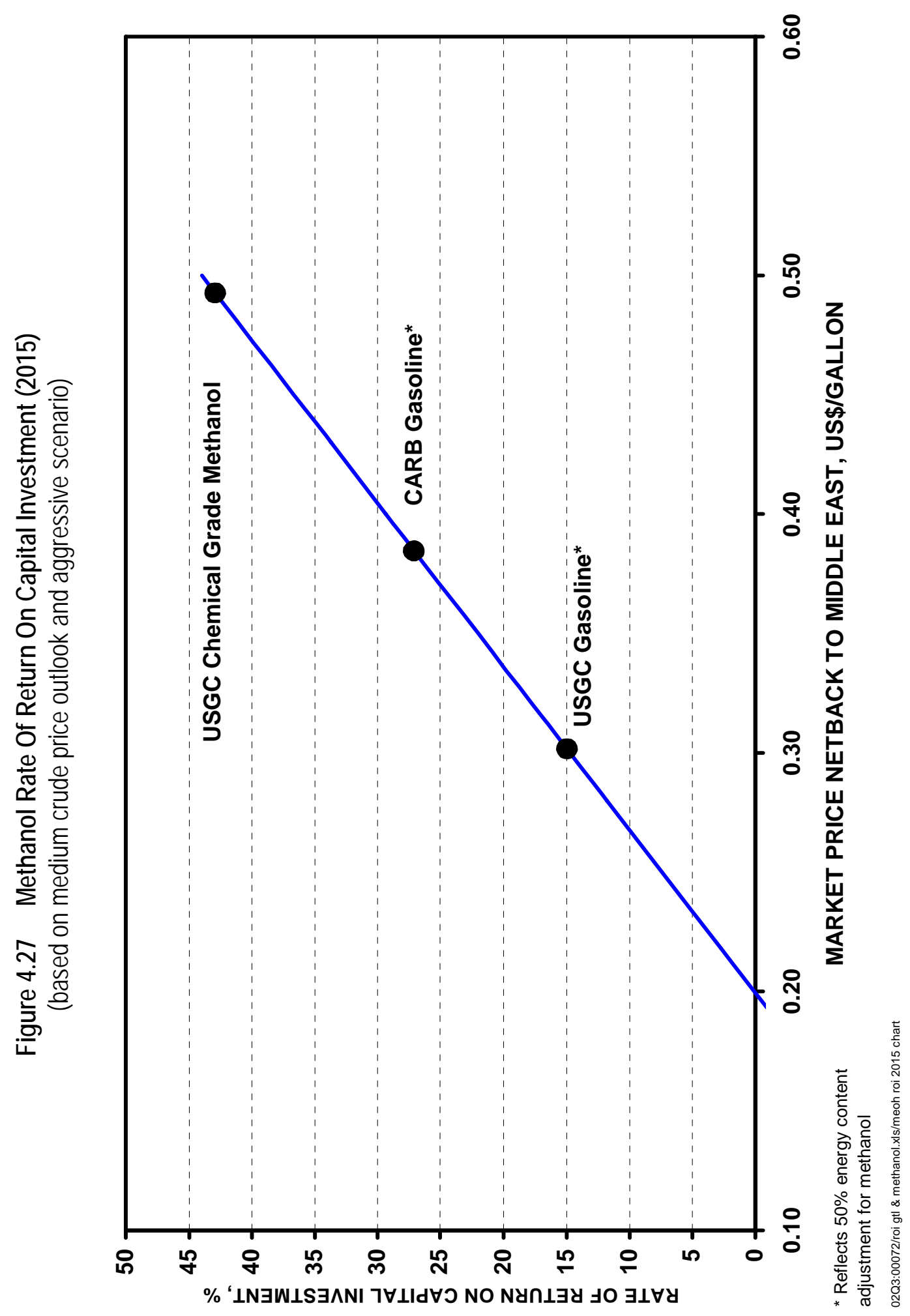


This section deals with ethanol technologies. The techno-economic analyses for ethanol from biomass and from corn are presented in sections 5.1 and 5.2, respectively.

\subsection{ETHANOL FROM BIOMASS}

\subsubsection{Introduction}

Commercial alcohol production from natural sugar sources, namely the fermentation by common yeast of the sugars contained in fruits such as grapes, berries and apples, has been practiced for thousands of years. Fermentation of sugars derived from the starches of grains such as corn, barley and wheat, was developed later in history since another step, the conversion of the starches into $\mathrm{C}_{6}$ sugars, was required. The conversion of the starches is done by hydrolysis, which is simply the dissolution of starch compounds with water.

The structural parts of plants are largely made up of polymers of sugar molecules. The most common polymer is cellulose, formed from $\mathrm{C}_{6}$ sugars, and a polymer called hemicellulose, primarily formed from $\mathrm{C}_{5}$ sugars. Since the mass of the structural parts of plants is much greater than the fruits or seeds, cellulose and hemicellulose are potentially significant sources of sugar for alcohol production. The conversion of cellulose and hemicellulose of plant stalks into their constituent sugars, however, is much more difficult than the same process for starches. Much research and development has focused on developing enzymes and acid treatment methods to free these sugars.

Many companies, universities, and government organizations have made progress in the conversion of biomass to ethanol. Arkenol Inc. of Mission, CA, is developing a biomass to ethanol plant in California, based on a new strains of Zymonomas mobilis bacteria that can ferment five- and six-carbon sugars in biomass such as rice straw. Cayman Islands-based Agrol has developed a new technology using patented micro-organisms to convert Materials such as household waste, paper pulp, forest waste, sawdust and straw into ethanol. Masada OxyNol LLC of Birmingham, AL, is building a plant in New York that will convert 230,000 metric tons/year of municipal solid waste (MSW) and 73,000 metric tons/year of sewage sludge into 9.5 million gallons/year of fuel grade ethanol. Ottawa-based Iogen Corp. is building a demonstration facility in Ottawa using enzyme technology to convert straw and other agricultural biomass to ethanol. Ethxx International, Toronto, Canada, has developed a process for converting biowaste into ethanol and other alcohols via syngas and Fischer-Tropsch routes.

Another company that has been engaged in the development of biowaste-to-ethanol technology since 1992 is BC International (BCI), Dedham, MA. In 1995, the company announced that it would manufacture 20 plus million gallons of ethanol annually in the company's facility in Jennings, LA, using a technology that blends age-old sciences and leading-edge genetic engineering. The key to the technology is a proprietary microorganism that produces a high yield of ethanol from sugars derived from hydrolyzed organic waste (biomass), such as sugar cane residue (bagasse) and rice hulls. The microorganism works by breaking down the sugar compounds that are prevalent in biomass - sugars that current methods, which rely on fermentation, cannot utilize. 
The BCI process uses yeast and a genetically engineered organism to ferment all of the hydrolyzed sugars to alcohol.

The organism was developed by Dr. Lonnie Ingram of the University of Florida's Institute of Food and Agricultural Science. The significance of Ingram's work was recognized in 1991, when the U.S. Department of Commerce awarded him U.S. Patent 5,000,000 in a special Congressional ceremony. This was a landmark patent number, for which thousands of other patents competed.

While the details of the new biomass to ethanol process are considered to be proprietary, there have been a number of publications, which generally describe the dilute acid route to biomass ethanol. A major contributor in this area has been the National Renewable Energy Laboratory (NREL), which has been working in this area for two decades and has built significant expertise. In the following sections, the fundamental operations of each major portion of a "typical" dilute acid bioethanol process will be discussed. The information that follows is based on much of the work done by NREL and presented in a number of forums over the years.

The following are the basis for the 2006 and 2015 technical and economic evaluation:

\subsubsection{2006 Commercially Demonstrated Process}

Economics: Based on a U.S. Midwest location

Feedstock: $\quad$ Corn stover

Capacity: 50 million gallons per year (MMgal/yr) (150 thousand metric tons per year)

Technology: Dilute acid hydrolysis and enzymatic saccharification and fermentation

\subsubsection{2015 Emerging Technology}

Economics: Based on a U.S. Midwest location

Feedstock: Corn stover

Capacity: 150 million gallons per year (MMgal/yr) (450 thousand metric tons per year)

Technology: Dilute acid hydrolysis and enzymatic saccharification and fermentation

\subsubsection{Design Parameters and Feedstock Characteristics}

NREL's process and economic model of the conceptual lignocellulose-to-ethanol process was initially developed in 1995. The model has been refined each year and was published in NREL's Technical Reports in 1999 and 2000. Table 5.1 outlines the overall design parameters that were used in the model. 


\section{Table 5.1 General Design Parameters Of NREL Bioethanol Process}

\begin{tabular}{|l|l|}
\hline Process: & Dilute Acid / Enzymatic Hydrolysis \\
\hline Feedstock: & Corn Stover \\
\hline Plant Type: & Stand Alone \\
\hline Location: & U.S. Midwest \\
\hline Fuel Ethanol Production: & 25 and 56 Million Gallons per Year \\
\hline
\end{tabular}

The feedstock used in the process is corn stover. Corn stover is the residue left in the fields after harvesting corn. It has been identified as a near- to mid-term agriculture residue feedstock for the lignocellulose-to-ethanol process. Corn stover has a high carbohydrate content and can be collected in a sustainable fashion.

Corn stover contains considerable quantities of cellulose, a beta-linked glucose polymer, which is more difficult to break down to glucose monomers than the alpha-linked polymer in starch. In addition, it contains hemicellulose, which is a more complex polymer of several sugars. The predominant sugars in hemicellulose are xylose and arabinose. These five-carbon sugars can also be fermented to ethanol with the proper microorganism. The maximum theoretical yield from corn stover with the composition listed in Table 5.2 is 107 gallons per dry ton (or 91 gallons per ton at 15 percent moisture). For this analysis, a yield of 69 gallons of pure ethanol per dry ton was used, which equates to an average yield of 65 percent of the cellulose and hemicelluosic polymers.

Table $5.2 \quad$ Corn And Stover Compositions

\begin{tabular}{|l|c|l|c|}
\hline CORN & \% Dry Basis & CORN STOVER & \% Dry Basis \\
\hline Starch & 72.0 & Cellulose & 37.3 \\
\hline Hemicellulose/Cellulose & 10.5 & Galactan/Mannan & 1.4 \\
\hline Protein & 9.5 & Xylan & 20.6 \\
\hline Oil & 4.5 & Arabinan & 2.1 \\
\hline Sugars & 2.0 & Lignin & 17.5 \\
\hline Ash & 1.5 & Ash & 6.1 \\
\hline & & Acetate & 2.0 \\
\hline & & Extractives & 13.0 \\
\hline Total & 100.0 & Total & 100.0 \\
\hline \% Moisture & 15.0 & \% Moisture & 15.0 \\
\hline
\end{tabular}

Entwined around the two sugar polymers is lignin, a polymer that does not contain sugars. Lignin, like the fiber in corn, has a by-product value. The fiber by-product is sold as Distillers' Dried Grains with solubles, or DDGS. Lignin, currently recognized for its fuel value, may have a better co-product value, as yet unrealized. 
Stover is typically 15 percent moisture, although it can vary depending on age, growing conditions, and variety.

Because the collection of stover is a new industry, there is little data on the collection costs. The results of a small stover collection program in 1997-1998 by Iron Horse Custom Farming of Harlan, Iowa, reported stover collection costs between $\$ 31-\$ 36$ per dry ton. Studies by contractors for DOE have reported a range of $\$ 33-\$ 46$ per dry ton. Because the stover is considered a residue, it is expected that its price might not fluctuate as much as a commodity crop like corn. However, demand for stover from an established lignocellulosic ethanol industry could escalate the price. For this analysis, \$35 per dry ton, at 2001 was assumed.

\subsubsection{Process Description}

\subsubsection{Overview of Lignocellulosic Biomass to Ethanol Process}

The process used in this analysis can be briefly described as using co-current dilute acid prehydrolysis of the lignocellulosic biomass with simultaneous enzymatic saccharification of the remaining cellulose and co-fermentation of the resulting glucose and xylose to ethanol. In addition to these unit operations, the process involves feedstock handling and storage, product purification, wastewater treatment, enzyme production, lignin combustion, product storage, and other utilities. Table 5.3 summarizes the major process areas of NREL's bioethanol process. The overall process flow diagram of NREL's conceptual design is elucidated in Figure 5.1.

Table 5.3 Major Unit Operations Of NREL Bioethanol Process

1. Feedstock Storage and Handling

2. Pretreatment and Hydrolyzate Conditioning

3. Simultaneous Saccharification and Co-Fermentation

4. Enzyme Production

5. Product Recovery

6. Wastewater Treatment

7. Product and Feed Chemical Storage

8. Burner Boiler and Turbogenerator

9. Utilities 


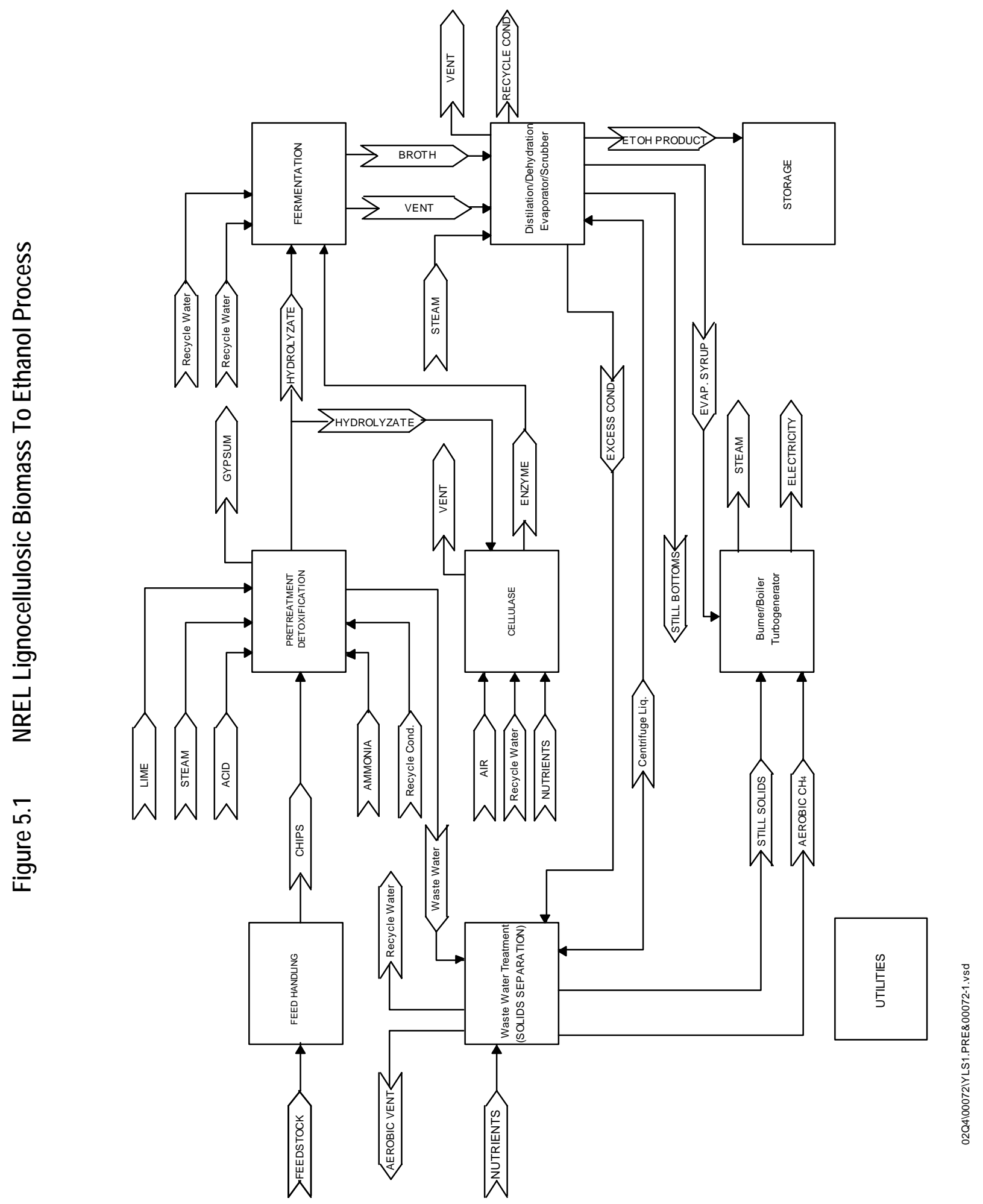


Corn stover is delivered to the feed handling area for storage and size reduction. From there, the biomass is conveyed to pretreatment and conditioning. In this area, the biomass is treated with dilute sulfuric acid at a high temperature for a very short time, liberating the hemicellulose sugars and other compounds. Ion exchange and overliming is required to remove compounds liberated in the pretreatment that will be toxic to the fermenting organism. Only the liquid portion of the hydrolysis stream is conditioned.

After pretreatment, a portion of the hydrolyzate slurry is split off to enzyme production. In enzyme production, seed inoculum is grown in a series of progressively larger aerobic batch fermentors. The inoculum is then combined with additional hydrolyzate slurry and nutrients in aerobic fermentors to produce the enzyme needed for saccharification.

Simultaneous saccharification and co-fermentation, or SSCF, of the hydrolyzate slurry is carried out in a series of continuous anaerobic fermentation trains. The recombinant fermenting organism Zymomonas mobilis is grown in progressively larger batch anaerobic fermentations. This inoculum, along with cellulase enzyme from enzyme production and other nutrients, is added to the first fermentor. After several days of saccharification and fermentation, most of the cellulose and xylose will have been converted to ethanol. The resulting beer with 4-5 percent by weight ethanol is sent to product recovery.

Product recovery consists of a beer column to distill the ethanol from the majority of the water and residual solids. The vapor exiting the beer column is 35 percent by weight ethanol and feeds the rectification column. A mixture of nearly azeotropic ( 92.5 percent) ethanol and water from the rectification column is purified to pure (99.5 percent) ethanol using vapor-phase molecular sieves. The beer column bottoms are sent to the first effect of a three-effect evaporator. The rectification column reflux condenser provides heat for this first effect. After the first effect, solids are separated using a centrifuge and dried in a rotary dryer. A portion (25 percent) of the centrifuge effluent is recycled to fermentation and the rest is sent to the second and third evaporator effects. Most of the evaporator condensate is returned to the process as fairly clean condensate (a small portion, 10 percent, is split off to waste water treatment to prevent build-up of low-boiling compounds) and the concentrated syrup contains 15 - 20 percent by weight total solids.

Biogas (containing 50 percent methane with a heating value of approximately 12,000 Btu/pound) is produced by anaerobic digestion of organic compounds in wastewater treatment. The treated water is considered suitable for recycling and is returned to the process, so there is no water discharge from the process.

The solids from distillation, the concentrated syrup from the evaporator, and biogas from anaerobic digestion are combusted in a fluidized bed combustor, or FBC, to produce steam for process heat. Soluble components in the wet boiler feed are combusted and some water vapor exits through the stack. The majority of the steam demand is for the pretreatment and distillation areas. Generally, the process produces excess steam that is converted to electricity for use in the plant; any excess electricity is sold to the local power grid. 
Since pretreatment and hydrolyzate conditioning, simultaneous saccharification and cofermentation, enzyme production, and product recovery are the heart of the NREL's lignocellulosic biomass to ethanol process, they are described in more detail below.

\subsubsection{Pretreatment and Hydrolyzate Conditioning}

This process area converts, by hydrolysis reactions, most of the hemicellulose portion of the feedstock to soluble sugars, primarily xylose, mannose, arabinose, and galactose. A small portion of the cellulose is converted to glucose. This conversion is accomplished using dilute sulfuric acid and high temperature. These conditions also solubilize some of the lignin in the feedstock and "exposes" the cellulose for subsequent enzymatic hydrolysis. In addition, acetic acid is liberated from the hemicellulose hydrolysis.

Degradation products of pentose sugars, primarily furfural, and hexose sugars, primarily hydroxymethyl furfural (HMF), are also formed.

Following the pretreatment reactor, the hydrolyzate liquid and solids are flash cooled, which vaporizes a large amount of water, much of the furfural and HMF, and a portion of the acetic acid. Removal of these heterocyclic aldehydes is beneficial, as they can be detrimental to downstream fermentation.

In addition to flash removal of aldehydes, the acetic acid must be removed and other conditioning must be performed before fermentation. The acetic acid is removed from the liquid portion of the hydrolyzate using continuous ion exchange. After ion exchange, the liquid is "overlimed." This process, as envisioned, requires that the liquid hydrolyzate's $\mathrm{pH}$ be lowered (by adding sulfuric acid) after ion exchange, then raised to $\mathrm{pH} 10$ (by adding lime) and held for a period of time. Neutralization and precipitation of gypsum follow the overliming step. The gypsum is filtered out and the hydrolyzate is mixed with the solids (cellulose) and dilution water before being sent to fermentation. What happens in the overliming process is not completely understood.

\subsubsection{Simultaneous Saccharification and Co-Fermentation (SSCF)}

Two different operations are performed in this process area - saccharification of the remaining cellulose to glucose using cellulase enzymes, and fermentation of the resulting glucose and other sugars (from the dilute acid pretreatment of hemicellulose) to ethanol. For fermentation, the recombinant $\mathrm{Z}$. mobilis bacterium is used as the ethanologen. This form of Z. mobilis will ferment glucose and xylose to ethanol. It is assumed that no other sugars are fermented.

Hydrolysis or saccharification occurs in the main fermentation vessels. Cellulase enzymes used in the saccharification are produced in the enzyme production area of the process and mixed with the hydrolysis raw Material and nutrients directly in the fermenter.

The ethanologen must be "grown" in a seed fermentation train of vessels in this area. Detoxified hydrolyzate and nutrients are combined with an initial seed inoculum (grown in the laboratory) in a very small vessel. The result of each seed batch is used as the inoculum for the next size 
seed increment. This series of scale-ups is continued until the last step is large enough to support the production fermentation.

Finally the seed inoculum, cellulase enzyme, nutrients, and diluted, cooled, detoxified hydrolyzate are continuously added to the several continuous SSCF production lines. The number of fermenter tanks in a train or line will probably be about five or six, one million gallon fermenters, in three or four lines. The resulting ethanol broth is collected in a beer well (storage tank) to level out any surges or upsets before it is pumped to distillation.

\subsubsection{Enzyme Production}

Cellulase, a collection of enzymes that hydrolyze cellulose to form glucose, is produced in this process area. The enzyme is used in the SSCF area where glucose is produced and then fermented into ethanol.

The enzymes that make up cellulase are: (1) endoglucanases, which attack randomly within the cellulose fiber reducing polymer size rapidly; (2) exoglucanases, which attack the ends of cellulose fibers, allowing it to hydrolyze highly crystalline cellulose; and (3) b-glucosidase, which hydrolyzes cellobiose to glucose. Several bacteria and fungi naturally produce these enzymes, including bacteria in ruminant and termite guts and white rot fungus. The most common organism used to produce cellulase industrially is Trichoderma reesei.

T. reesei is a fibrous fungus that can grow and produce cellulase in aerobic bioreactors. The carbon source for the bioreactors is detoxified, pretreated biomass slurry that has been diluted. Whole corn steep liquor (CSL) and other trace nutrients are also added to the bioreactors. Ammonia is used to control $\mathrm{pH}$ and provides additional fixed nitrogen to the organisms. The bioreactors are sparged with compressed and cooled air and corn oil is used as an antifoam agent to prevent excessive foaming within the reactors. The reactors are cooled by chilled water flowing through internal coils. Inoculum is produced in three trains with three vessel sizes in each train. Each vessel in the seed trains is run batchwise and detoxified, pretreated biomass slurry, CSL, nutrients, dilution water, and ammonia are pumped to it. Air is also sparged through each of the seed vessels, which are cooled with chilled water.

\subsubsection{Product Recovery (Distillation, Dehydration, and Evaporation)}

Distillation and molecular sieve adsorption are used to recover ethanol from the raw fermentation beer and produce very near 100 percent ethanol. Distillation is accomplished in two columns - the first removes the dissolved $\mathrm{CO}_{2}$ and most of the water, and the second concentrates the ethanol to a near azeotropic composition. All the water from the nearly azeotropic mixture is removed by vapor phase molecular sieve adsorption. Regeneration of the adsorption columns requires that an ethanol water mixture be recycled to distillation for recovery.

Fermentation vents (containing mostly $\mathrm{CO}_{2}$, but also some ethanol) as well as the beer column vent are scrubbed in a water scrubber, recovering nearly all of the ethanol. The scrubber effluent is fed to the first distillation column along with the fermentation beer. 
The bottoms from the first distillation contain all the unconverted insoluble and dissolved solids. The insoluble solids are separated by centrifugation and sent to the burner. The liquid from the centrifuge is concentrated using waste heat from the distillation. The concentrated syrup from the evaporator is sent to the burner and the evaporated condensate is used as clean recycle water to the process.

Because the amount of stillage water that can be recycled is limited, an evaporator is included in the process. The total amount of the water from the centrifuge that can be directly recycled is 25 percent. Recycling too large a quantity of this Material can result in levels of ionic strength and osmotic pressures that can be detrimental to the fermenting organism's efficiency. In a typical grain-to-ethanol facility, this recycle can be limited to as low as 10 percent of the centrifuge filtrate stream to minimize this effect. For the water that is not recycled, the evaporator concentrates the solids in the syrup that can be sent to the burner, minimizing the load to wastewater treatment.

\subsubsection{Economic Assessment}

\subsubsection{Economic Assumptions}

The key parameters used for biomass ethanol technology evaluation are summarized in Table 5.4 and Table 5.5.

For 2006, the total capital investment for a 50 million gallons per year (MMgpy) plant is \$296 million. For 2015, the total capital investment for a $150 \mathrm{MMgpy}$ plant is $\$ 639$ million. The capital investment is based on the assumption that the capital is reduced by 1 percent per year from 2001 to 2006 and 4 percent per year from 2006 to 2015 due to technology improvement.

Other economic assumptions can be found in the cost of production table below.

\subsubsection{Feedstock and Utilities Pricing and Labor Costs}

The main feedstocks associated with the manufacture of fuel ethanol via dilute acid and enzymatic hydrolysis process are corn stover, sulfuric acid, ammonia, etc. U.S. Midwest market forecast prices for these feedstocks for 2006 and 2015 have been used for this analysis. For corn stover, the cost is mainly the associated collection and transportation cost. For utilities, 2006 and 2015 average U.S. Midwest utility prices are used. For labors, 2006 and 2015 average U.S. Midwest labor rates are used. Table 5.6 summarizes the raw Material, utility prices, and labor rates used for this study. 
Table 5.4 Key Parameters For Biomass Ethanol Technology Evaluation

\begin{tabular}{|l|c|c|c|}
\hline Year & & 2006 & 2015 \\
\hline Corn Stover & US\$/Metric Ton & 29.28 & 21.64 \\
\hline Capacity & MMgpy & 50 & 150 \\
\hline Total Capital Investment (Current \$) & MMUS\$ & 296 & 639 \\
\hline
\end{tabular}

02q4:00072.005.11/00072.PPT

Table 5.5 Technology And Capital Improvements For Biomass Ethanol Technology

\begin{tabular}{|l|c|c|c|}
\hline & \multicolumn{2}{|c|}{ Improvement (Reduction), \%/Year } \\
\hline & $2001-2006$ & $2006-2015$ & $\begin{array}{c}2001-2015 \\
\text { (Effective) }\end{array}$ \\
\hline Capital & $1 \%$ & $4 \%$ & $3 \%$ \\
\hline Technology (Raw Materials, Utilities, Labor, etc.) & $1 \%$ & $1 \%$ & $1 \%$ \\
\hline
\end{tabular}

02q4:00072.005.11/00072.PPT 
Table 5.6 Summary Of Raw Material Utility And Labor Costs For Biomass Ethanol Production

(current U.S. dollars)

\begin{tabular}{|c|c|c|c|}
\hline & & \multicolumn{2}{|c|}{ U.S. Midwest } \\
\hline & & 2006 & 2015 \\
\hline \multicolumn{4}{|l|}{ Raw Materials } \\
\hline Natural Gas & \$/MMBtu & 2.91 & 3.57 \\
\hline Corn & \$/Bushel & 2.14 & 2.45 \\
\hline Sulfuric Acid & \$/Metric Ton & 56.00 & 69.89 \\
\hline Lime & \$/Metric Ton & 63.99 & 79.91 \\
\hline Sodium Hydroxide & \$/Metric Ton & 214.29 & 257.28 \\
\hline Alpha Amylase & \$/Metric Ton & $3,182.53$ & $3,974.60$ \\
\hline Glucoamylase & \$/Metric Ton & $2,548.27$ & $3,182.48$ \\
\hline Urea & \$/Metric Ton & 199.52 & 275.14 \\
\hline Yeast & \$/Metric Ton & $6,185.44$ & $7,724.88$ \\
\hline DDGS & \$/Metric Ton & 86.12 & 98.34 \\
\hline Ammonia & \$/Metric Ton & 189.38 & 221.34 \\
\hline Ammonium Sulfate & \$/Metric Ton & 56.43 & 70.48 \\
\hline Corn Steep Liquor & $\$ /$ Metric Ton & 188.34 & 235.21 \\
\hline Antifoam & \$/Metric Ton & 628.65 & 785.11 \\
\hline Solid Disposal & \$/Metric Ton & -20.00 & -32.59 \\
\hline \multicolumn{4}{|l|}{ Utilities } \\
\hline \multirow[t]{2}{*}{ Fuel Gas } & $\$ /$ MMBtu & 2.91 & 3.57 \\
\hline & $\$ / G J$ & 2.76 & 3.38 \\
\hline \multirow[t]{2}{*}{ Power } & $\$ / \mathrm{kWh}$ & 0.05 & 0.07 \\
\hline & $\$ /$ MegaWh & 53.87 & 66.67 \\
\hline \multirow[t]{2}{*}{ Process Water } & $\$ / \mathrm{MGal}$ & 1.08 & 1.35 \\
\hline & \$/kMetric Ton & 285.93 & 356.60 \\
\hline \multicolumn{4}{|l|}{ Labors } \\
\hline Labor & \$/Man/Year & 45,016 & 56,219 \\
\hline Foremen & $\$ /$ Man/Year & 51,078 & 63,789 \\
\hline Supervision & \$/Man/Year & 61,630 & 76,968 \\
\hline
\end{tabular}

U:I2002Q4100072.005.11।Datalfiles for Report V[Raw Material Utilities Labors.xIs]Methanol

\subsubsection{Process Economics}

2006

The economics for the production of 150 thousand metric tons (50 million gallons) per year of fuel grade ethanol at a U.S. Midwest location via dilute acid and enzymatic hydrolysis of corn stover are presented in Table 5.7. 


\section{Table 5.7 Cost Of Production Estimate For: Fuel Grade Ethanol Process: Dilute Acid And Enzymatic Hydrolysis 2006}

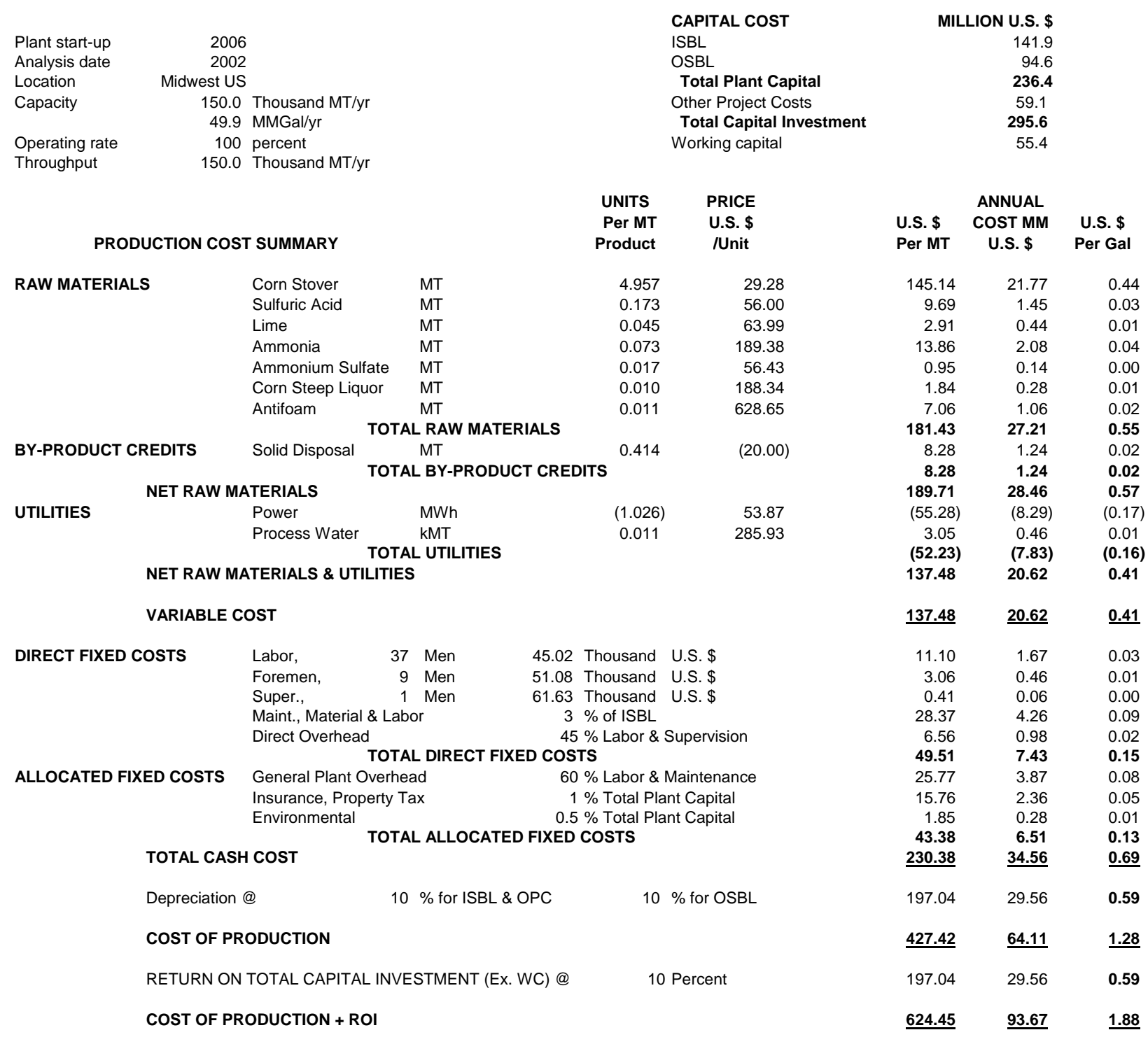


The total plant capital cost is estimated to be $\$ 236.4$ million. This capital cost includes $\$ 141.9$ million for ISBL and $\$ 94.6$ million for OSBL. Other project costs are estimated to be $\$ 59.1$ million, resulting a total capital investment of \$295.6 million. An additional \$55.4 million is also estimated for the working capital requirement.

With corn stover and its collection/transportation cost at $\$ 29.28$ per metric ton, the raw Material cost is $\$ 181.43$ per metric ton of ethanol. By-product debit mainly from solid disposal increases the net raw Material cost to $\$ 189.71$ per metric ton of ethanol. Utilities contribute a credit of $\$ 52.23$ per metric ton, resulting in a variable cost of $\$ 137.48$ per metric ton of ethanol.

The total direct fixed cost, including all labors, maintenance, and direct overhead, is approximately $\$ 49.51$ per metric ton of ethanol. The total allocated fixed cost of the plant, including general plant overhead, insurance, property taxes, and environmental levy, is about $\$ 43.38$ per metric ton of ethanol. The total fixed costs bring the total cash cost to $\$ 230.38$ per metric ton ( $\$ 0.69$ per gallon) of ethanol.

Depreciation, at 10 percent of investment, contributes an additional \$197.04 per metric ton. Return on total capital investment, also at 10 percent of investment, contributes another $\$ 197.04$ per metric ton of ethanol.

The above cash cost, depreciation, and return on total capital investment yield a full cost of production of $\$ 624.45$ per metric ton ( $\$ 1.88$ per gallon) of ethanol.

2015

The economics for the production of 450 thousand metric tons (150 million gallons) per year of fuel grade ethanol at a U.S. Midwest location via dilute acid and enzymatic hydrolysis of corn stover are presented in Table 5.8.

The total plant capital cost is estimated to be $\$ 510.9$ million. This capital cost includes $\$ 306.6$ million for ISBL and $\$ 204.4$ million for OSBL. Other project costs are estimated to be $\$ 127.7$ million, resulting a total capital investment of $\$ 638.7$ million. An additional $\$ 119.8$ million is also estimated for the working capital requirement.

With corn stover and its collection/transportation cost at $\$ 21.64$ per metric ton, the raw Material cost is $\$ 138.52$ per metric ton of ethanol. By-product debit mainly from solid disposal increases the net raw Material cost to $\$ 150.86$ per metric ton of ethanol. Utilities contribute a credit of $\$ 71.34$ per metric ton, resulting in a variable cost of $\$ 79.51$ per metric ton of ethanol. 


\section{Table 5.8 Cost Of Production Estimate For: Fuel Grade Ethanol Process: Dilute Acid And Enzymatic Hydrolysis 2015}

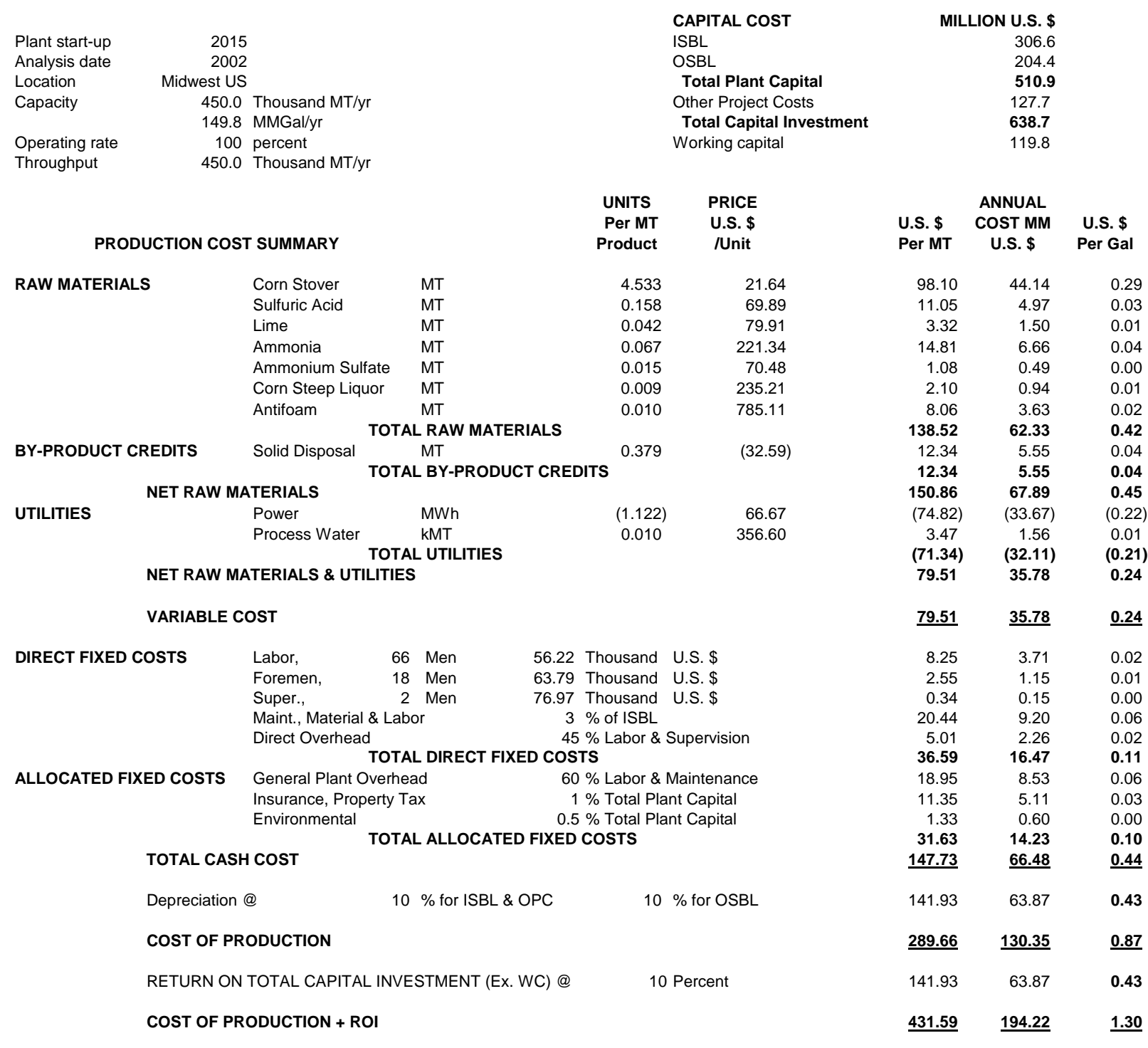


The total direct fixed cost, including all labors, maintenance, and direct overhead, is approximately $\$ 36.59$ per metric ton of ethanol. The total allocated fixed cost of the plant, including general plant overhead, insurance, property taxes, and environmental levy, is about $\$ 31.63$ per metric ton of ethanol. The total fixed costs bring the total cash cost to $\$ 147.73$ per metric ton ( $\$ 0.44$ per gallon) of ethanol.

Depreciation, at 10 percent of investment, contributes an additional \$141.93 per metric ton. Return on total capital investment, also at 10 percent of investment, contributes another $\$ 141.93$ per metric ton of ethanol.

The above cash cost, depreciation, and return on total capital investment yield a full cost of production of $\$ 431.59$ per metric ton $(\$ 1.30$ per gallon) of ethanol.

\subsubsection{Sensitivity Analysis}

2006

The effects of corn stover price, capital investment, and ethanol production capacity on the full cost of production of ethanol plus 10 percent ROI via dilute acid and enzymatic hydrolysis process are shown in Figure 5.2.

With total capital investment maintained at \$295.6 million and ethanol production capacity maintained at 150 thousand metric tons (50 million gallons) per year, ethanol full cost of production plus 10 percent ROI increases from $\$ 624.45 /$ metric ton $(\$ 1.88 /$ gallon) to $\$ 697.02 /$ metric ton $(\$ 2.09 /$ gallon) when corn stover and its collection/transportation cost increases from $\$ 29.28$ /metric ton to $\$ 43.92 /$ metric ton (i.e. 50 percent higher than the current estimate). Ethanol full cost of production plus 10 percent ROI decreases to $\$ 651.88 /$ metric ton (\$1.66/gallon) when corn stover and its collection/transportation cost decreases to $\$ 14.64 /$ metric ton (i.e. 50 percent lower than the current estimate). Thus, every dollar/metric ton change in corn stover and its collection/transportation cost results in an average change of $\$ 4.96 /$ metric ton (\$0.015/gallon) in ethanol full cost of production plus 10 percent ROI.

With corn stover and its collection/transportation cost maintained at \$29.28/metric ton and ethanol production capacity maintained at 150 thousand metric tons (50 million gallons) per year, ethanol full cost of production plus 10 percent ROI increases from $\$ 624.45 /$ metric ton (\$1.88/gallon) to $\$ 852.99 /$ metric ton $(\$ 2.56 /$ gallon) when the total capital investment increases from $\$ 295.6$ million to $\$ 443.4$ million, i.e. 50 percent increase. Ethanol full cost of production plus 10 percent ROI decreases to $\$ 395.91 /$ metric ton $(\$ 1.19 /$ gallon) when the total capital investment decreases to $\$ 147.8$ million, i.e. 50 percent decrease. This represents an average of $\$ 154.6 /$ metric ton change in ethanol full cost of production plus 10 percent ROI for every $\$ 100$ million change in total capital investment. 


\section{Figure 5.2 Sensitivity Of Fuel Ethanol From Biomass Cost Of Production To Key Variables} (2006)
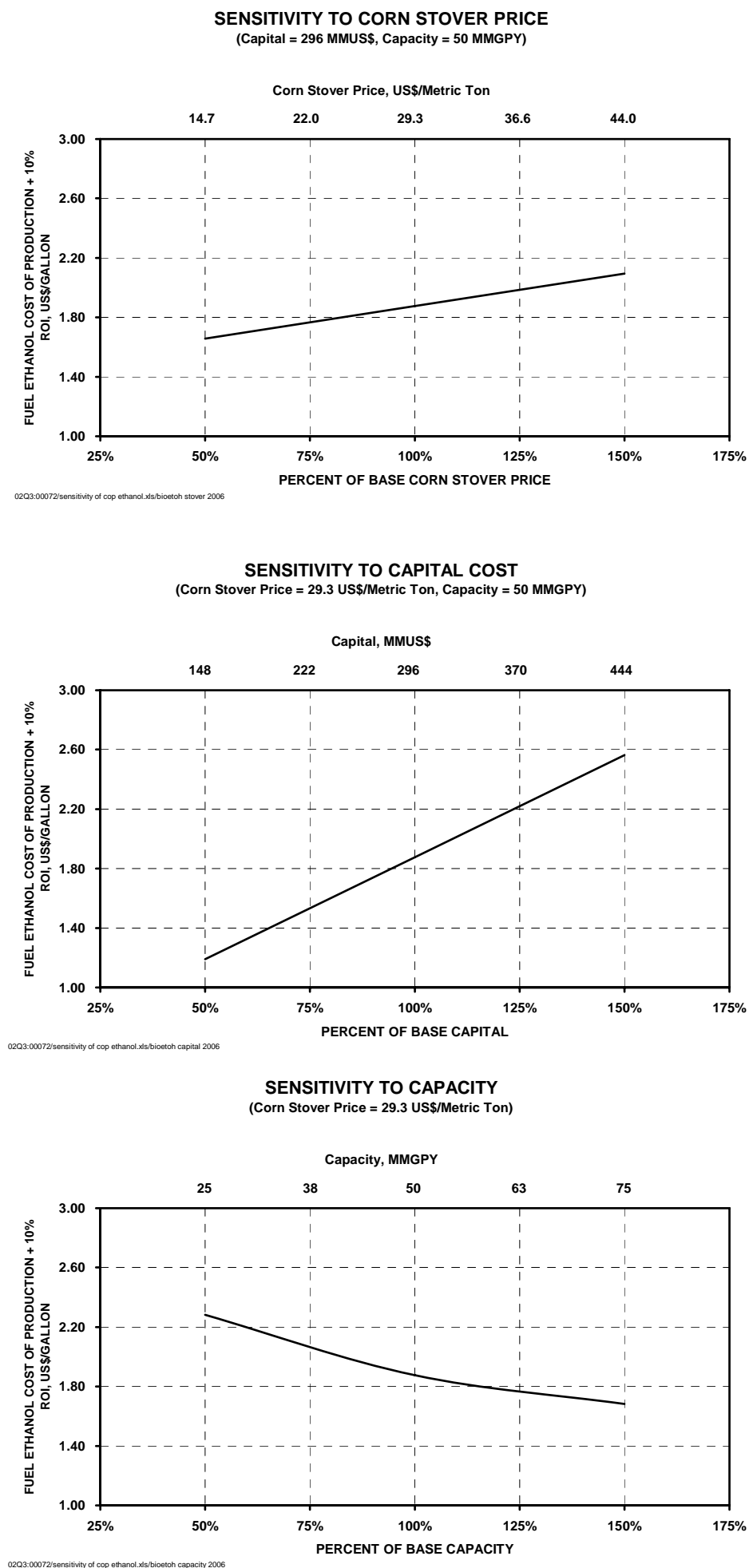
With corn stover and its collection/transportation cost maintained at $\$ 29.28 /$ metric ton, ethanol full cost of production plus 10 percent ROI decreases from $\$ 624.45 /$ metric ton $(\$ 1.88 / \mathrm{gallon})$ to $\$ 559.92 /$ metric ton (\$1.68/gallon) when ethanol production capacity increases from 150 thousand metric tons (50 million gallons) per year to 225 thousand metric tons ( 75 million gallons) per year, i.e. 50 percent increase. Ethanol full cost of production plus 10 percent ROI increases to $\$ 759.65 /$ metric ton $(\$ 2.28 /$ gallon) when ethanol production capacity decreases to 75 thousand metric tons ( 25 million gallons) per year, i.e. 50 percent decrease.

2015

The effects of corn stover price, capital investment, and ethanol production capacity on the full cost of production of ethanol plus 10 percent ROI via dilute acid and enzymatic hydrolysis process are shown in Figure 5.3.

With total capital investment maintained at $\$ 638.7$ million and ethanol production capacity maintained at 450 thousand metric tons (150 million gallons) per year, ethanol full cost of production plus 10 percent ROI increases from $\$ 431.59 /$ metric ton $(\$ 1.30 /$ gallon $)$ to $\$ 480.64 /$ metric ton (\$1.44/gallon) when corn stover and its collection/transportation cost increases from $\$ 21.64 /$ metric ton to $\$ 32.46 /$ metric ton (i.e. 50 percent higher than the current estimate). Ethanol full cost of production plus 10 percent ROI decreases to $\$ 382.54 /$ metric ton ( $\$ 1.15 /$ gallon) when corn stover and its collection/transportation cost decreases to $\$ 10.82 /$ metric ton (i.e. 50 percent lower than the current estimate). Thus, every dollar/metric ton change in corn stover and its collection/transportation cost results in an average change of $\$ 4.53 /$ metric ton (\$0.014/gallon) in ethanol full cost of production plus 10 percent ROI.

With corn stover and its collection/transportation cost maintained at $\$ 21.64 /$ metric ton and ethanol production capacity maintained at 450 thousand metric tons (150 million gallons) per year, ethanol full cost of production plus 10 percent ROI increases from $\$ 431.59 /$ metric ton (\$1.30/gallon) to $\$ 596.22 /$ metric ton $(\$ 1.79 /$ gallon) when the total capital investment increases from $\$ 638.7$ million to $\$ 958.1$ million, i.e. 50 percent increase. Ethanol full cost of production plus 10 percent ROI decreases to $\$ 266.97 /$ metric ton $(\$ 0.80 /$ gallon) when the total capital investment decreases to $\$ 319.4$ million, i.e. 50 percent decrease. This represents an average of $\$ 51.6 /$ metric ton change in ethanol full cost of production plus 10 percent ROI for every $\$ 100$ million change in total capital investment.

With corn stover and its collection/transportation cost maintained at $\$ 21.64 /$ metric ton, ethanol full cost of production plus 10 percent ROI decreases from $\$ 431.59 /$ metric ton $(\$ 1.30 /$ gallon) to $\$ 385.00 /$ metric ton (\$1.16/gallon) when ethanol production capacity increases from 450 thousand metric tons (150 million gallons) per year to 675 thousand metric tons (225 million gallons) per year, i.e. 50 percent increase. Ethanol full cost of production plus 10 percent ROI increases to $\$ 528.34 /$ metric ton $(\$ 1.59 /$ gallon) when ethanol production capacity decreases to 225 thousand metric tons ( 75 million gallons) per year, i.e. 50 percent decrease. 


\section{Figure 5.3 Sensitivity Of Fuel Ethanol From Biomass Cost Of Production To Key Variables} (2015)

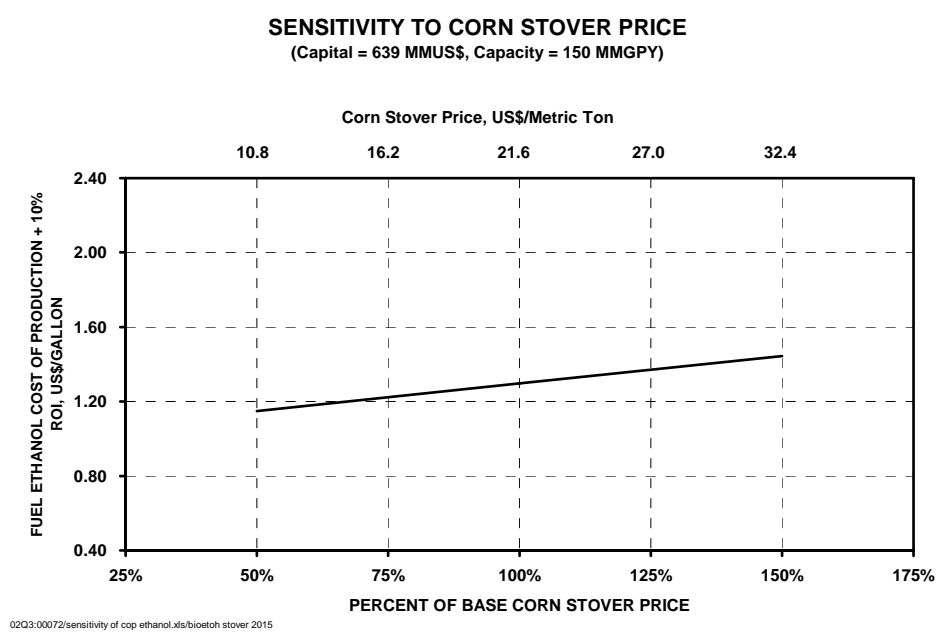

SENSITIVITY TO CAPITAL COST

(Corn Stover Price $=21.6$ USs/Metric Ton, Capacity $=150 \mathrm{MMGPY}$ )

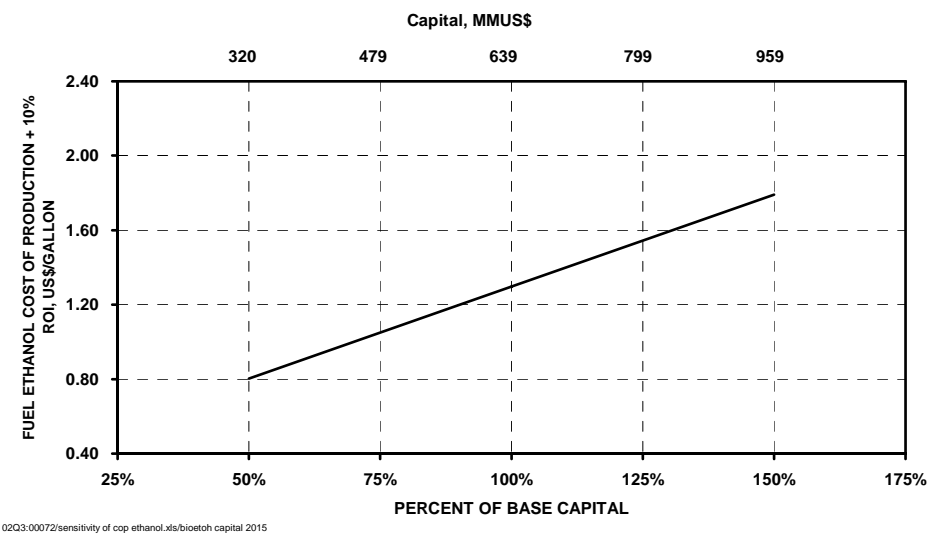

SENSITIVITY TO CAPACITY

(Corn Stover Price $=21.6$ US\$/Metric Ton)

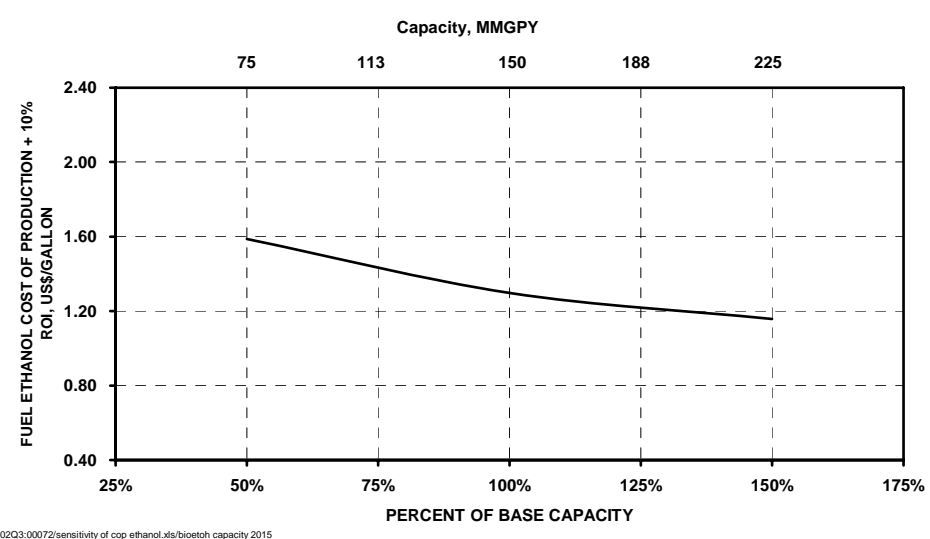




\subsubsection{Comparative Economics}

Table 5.9 and Figure 5.4 summarize the costs of production of biomass-based and corn-based (see next Section) fuel ethanol at a U.S. Midwest location and the comparison with the U.S. Midwest unleaded regular gasoline price, ethanol blending value, and fuel ethanol price with Federal tax credit forecast for 2006 and 2015.

For 2006, the full cost of production plus 10 percent ROI for ethanol produced at a 50 million gallons per year facility in a U.S. Midwest location will be about $\$ 1.12$ and $\$ 1.88$ per gallon from corn and biomass, respectively. These costs compare unfavorably to ethanol blending value of $\$ 0.80$ per gallon and unleaded regular gasoline of $\$ 0.61$ per gallon.

For 2015, the full cost of production plus 10 percent ROI for ethanol produced at a 150 million gallons per year facility in a U.S. Midwest location will be about $\$ 1.06$ and $\$ 1.30$ per gallon from corn and biomass, respectively. These costs compare unfavorably to ethanol blending value of $\$ 0.93$ per gallon and unleaded regular gasoline of $\$ 0.73$ per gallon.

While biomass-based fuel ethanol is more expensive than corn-based fuel ethanol due to the significantly higher capital requirement, both routes require subsidies to be competitive.

\subsection{ETHANOL FROM CORN}

\subsubsection{Introduction}

Fuel ethanol can be produced from corn via either dry milling or wet milling. Dry milling is a simpler process and has lower capital and operating costs. It is generally the one recommended for new entrants into the fuel ethanol market.

The following are the basis for the 2006 and 2015 technical and economic evaluation:

\subsubsection{2006 Commercially Demonstrated Process}

Economics: Based on a U.S. Midwest location

Feedstock: Corn

Capacity: $\quad 50$ million gallons per year (MMgal/yr) (150 thousand metric tons per year)

Technology: Dry milling

\subsubsection{2015 Emerging Technology}

Economics: Based on a U.S. Midwest location

Feedstock: Corn

Capacity: 150 million gallons per year (MMgal/yr) (450 thousand metric tons per year)

Technology: Dry milling 


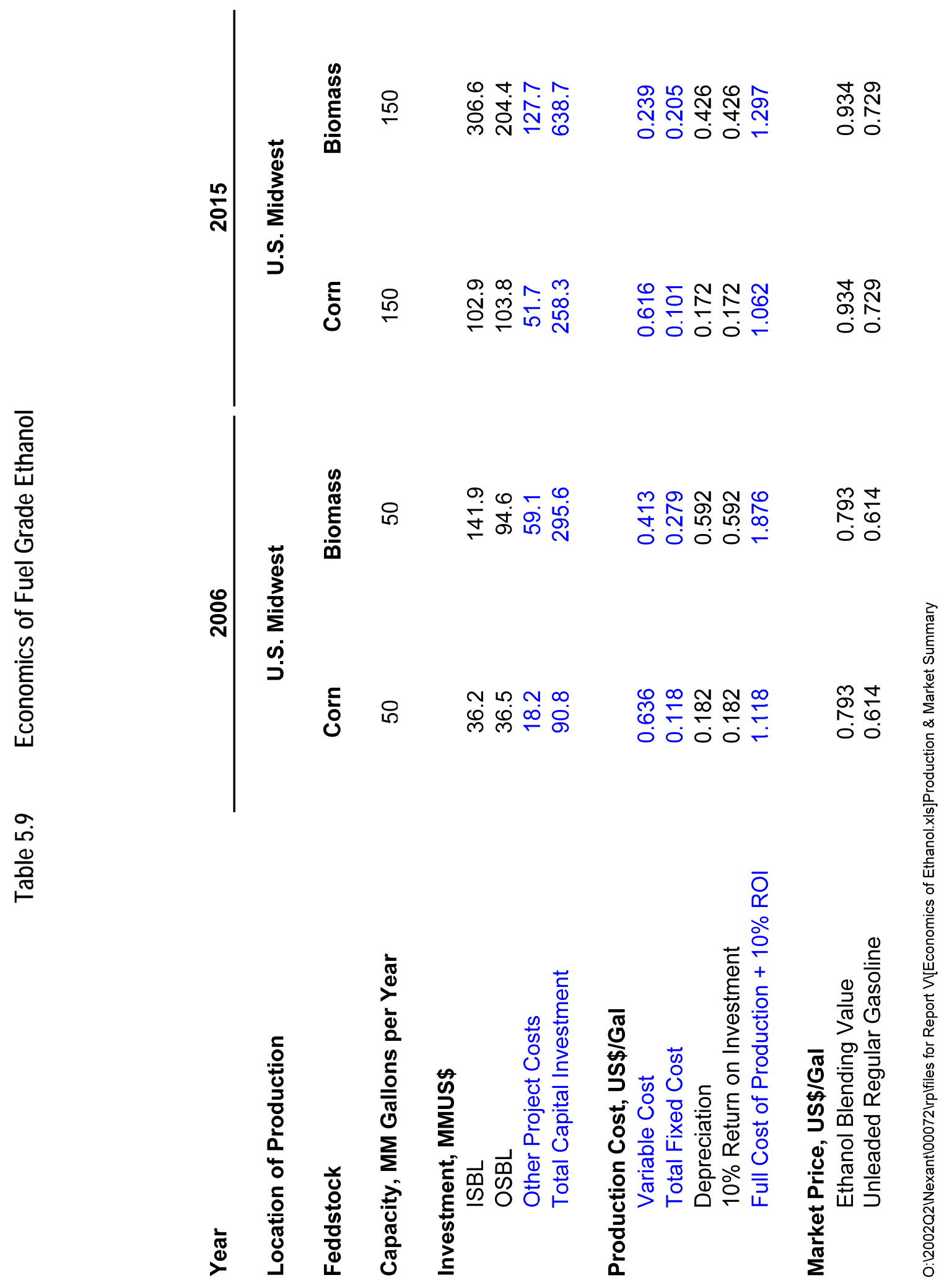




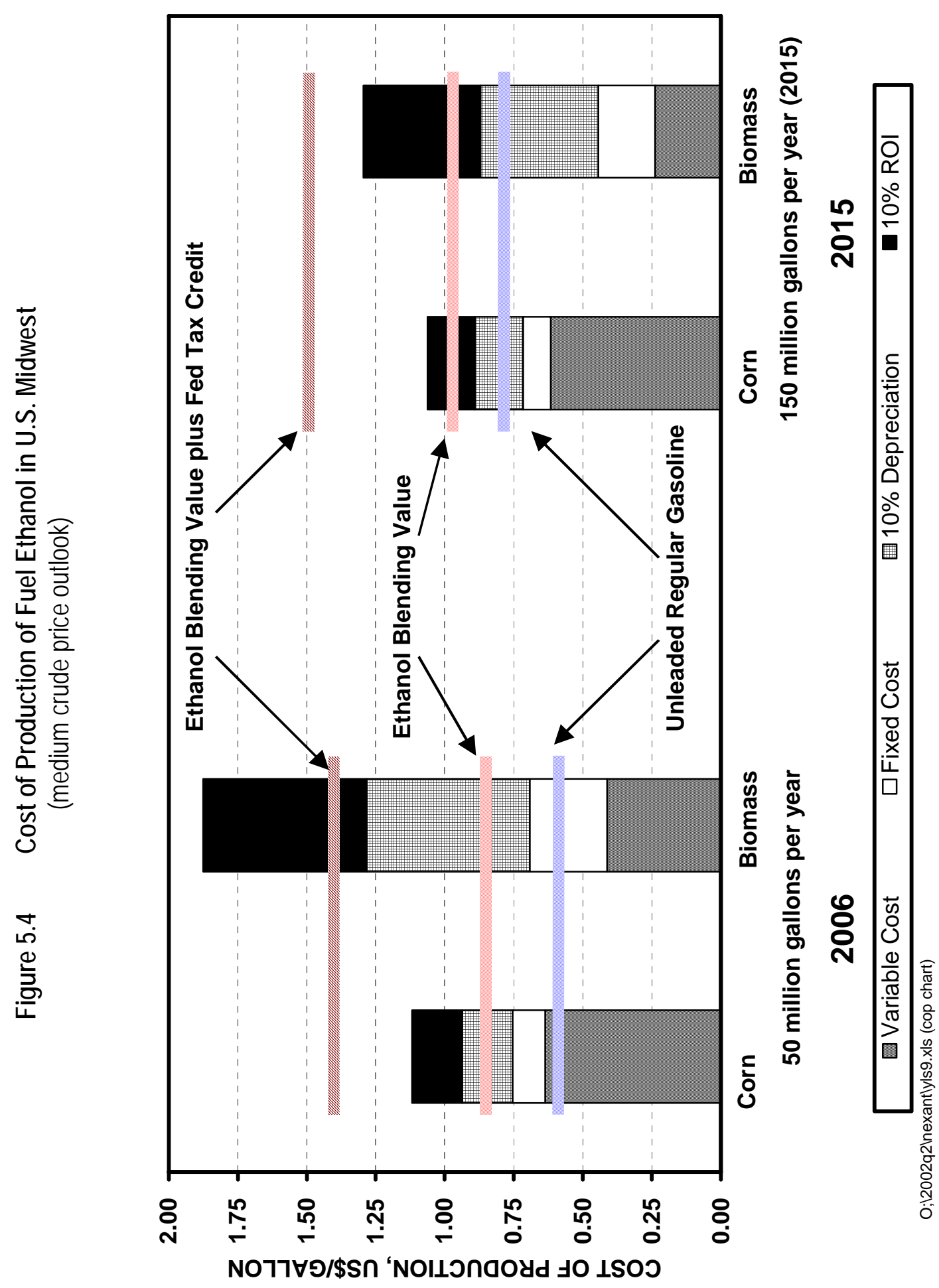




\subsubsection{Chemistry}

Ethanol production from starches begins with the hydrolysis of starches present in the feedstock to simple sugar unites. This involves three primary stages: hydration, gelatinization, and hydrolysis. Once the starches are hydrolyzed, the sugar solution is contacted with yeasts, which convert the sugars to ethanol and carbon dioxide. The basic technology is well established. The major problem is the maintenance of lean processing conditions to prevent bacterial or crosscontamination, which results in carbon competition, decreased yields and selectivities, and in some cases culture death.

Yeasts are the organisms of choice for the final conversion of hexoses (6-carbon sugars) to ethanol. There are 12 possible different hexoses; however, most are either not present naturally or are only available in very small quantities. Of the 12 hexoses, the most important are glucose, fructose, mannose, and galactore. Glucose is the most common, and is the primarily components of starch.

Yeasts convert glucose (and to a lesser extent fructose, mannose, and galactose) to ethanol via aneaerobic bioconversion according to the Gay-Lussac equation:

$$
\mathrm{C}_{6} \mathrm{H}_{12} \mathrm{O}_{6} \longrightarrow 2 \mathrm{C}_{2} \mathrm{H}_{5} \mathrm{OH}+2 \mathrm{CO}_{2}
$$

The theoretical yield from this reaction is 0.51 grams of ethanol produced per gram of glucose consumed. The actual ethanol yield is about 90-95 percent of this value, since some of the carbon consumed is used for cell growth, and because some side reactions compete with the ethanol route to produced byproducts such as acetaldehyde, glycerol, succinate, and fusel oils.

\subsubsection{Process Description}

\subsubsection{Dry Milling}

The whole-kernel dry milling process is the simplest of the processes considered, and is generally the one recommended for new entrants into the market. Dry milling has certain advantages over wet milling:

- The process is simpler to operate than wet milling

- Dry milling has lower capital and operating costs than wet milling

While dry milling produces a slate of by-products that are overall less valuable than the wet milling process, it avoids the need for swing production and syrup integration, hence avoiding the need of the entrant to compete in the corn syrup and sweetener market.

Table 5.10 provides a typical analysis of the corn used in milling operations.

Table 5.10 Typical Corn Analysis

(weight, percent) 


\begin{tabular}{|l|l|}
\hline Component & Composition \\
\hline Ash & 1.0 \\
\hline Fat & 3.7 \\
\hline Fiber & 1.9 \\
\hline Nonfermentable elements (NFE) & 8.6 \\
\hline Protein & 8.4 \\
\hline Starch & 60.8 \\
\hline Water & 15.5 \\
\hline & \\
\hline Total & 100.0 \\
\hline
\end{tabular}

The following figures graphically illustrate the operation of the whole-kernel dry milling process:

Figure 5.5 Corn Receiving, Storage, and Cleaning

Figure 5.6 Corn Milling and Hydrolysis

Figure $5.7 \quad$ Saccharification

Figure $5.8 \quad$ Fermentation

Figure 5.9 Ethanol Beer Still

Figure 5.10 Ethanol Rectifier and Dehydration

Figure 5.11 Distiller's Dried Grains and Solubles (DDGS) Production

Figure 5.12 Ethanol Pasteurization and Vent Recovery 


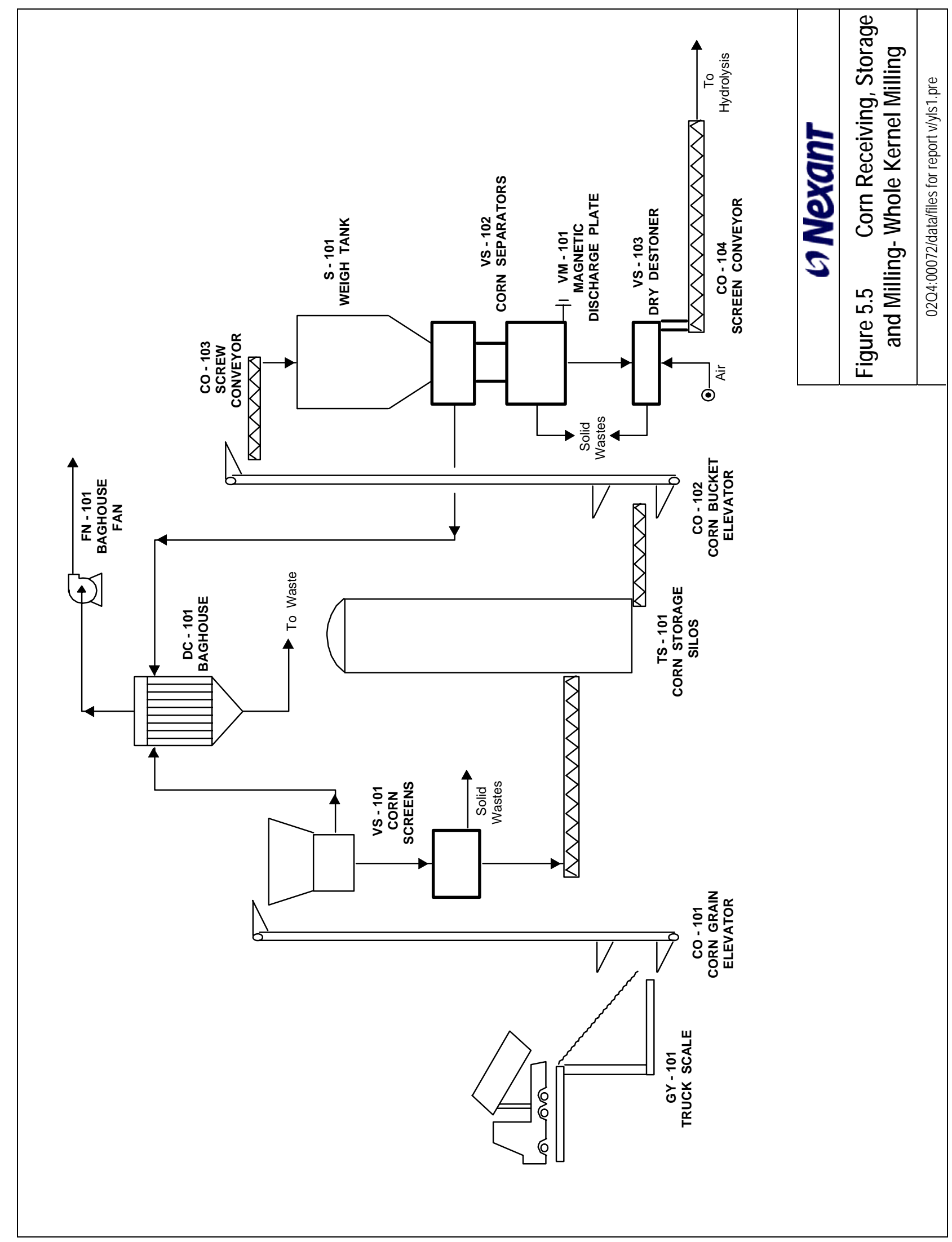




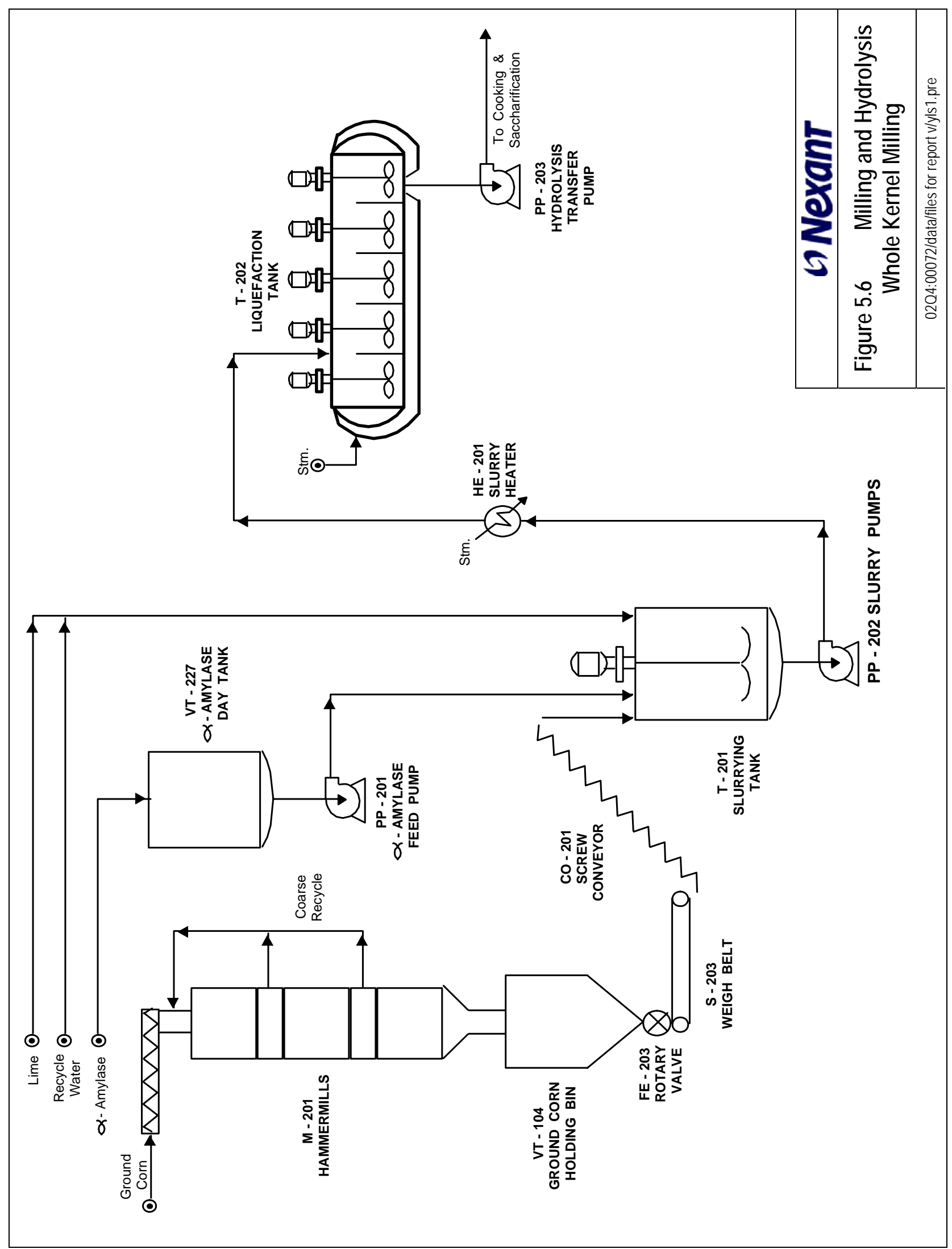




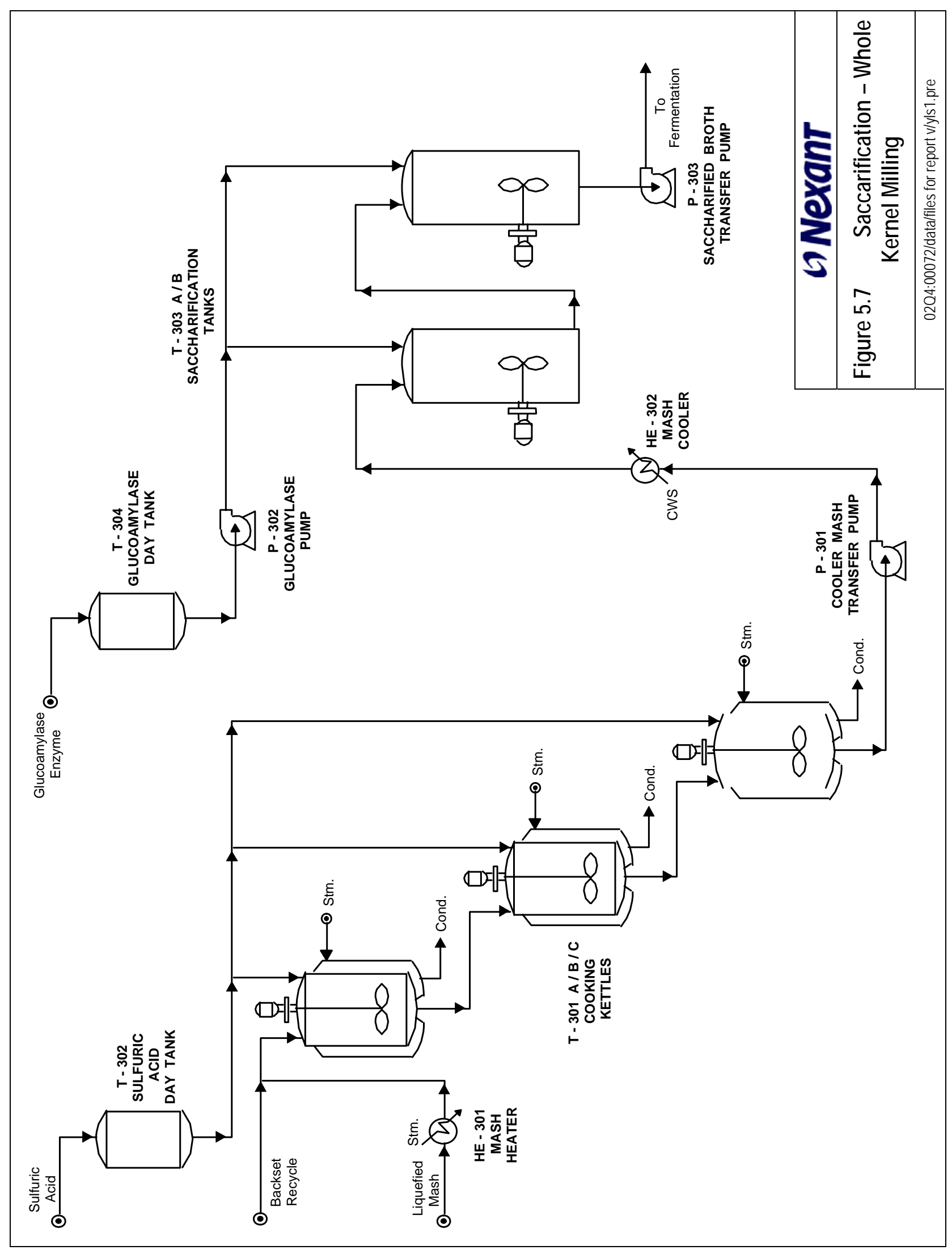




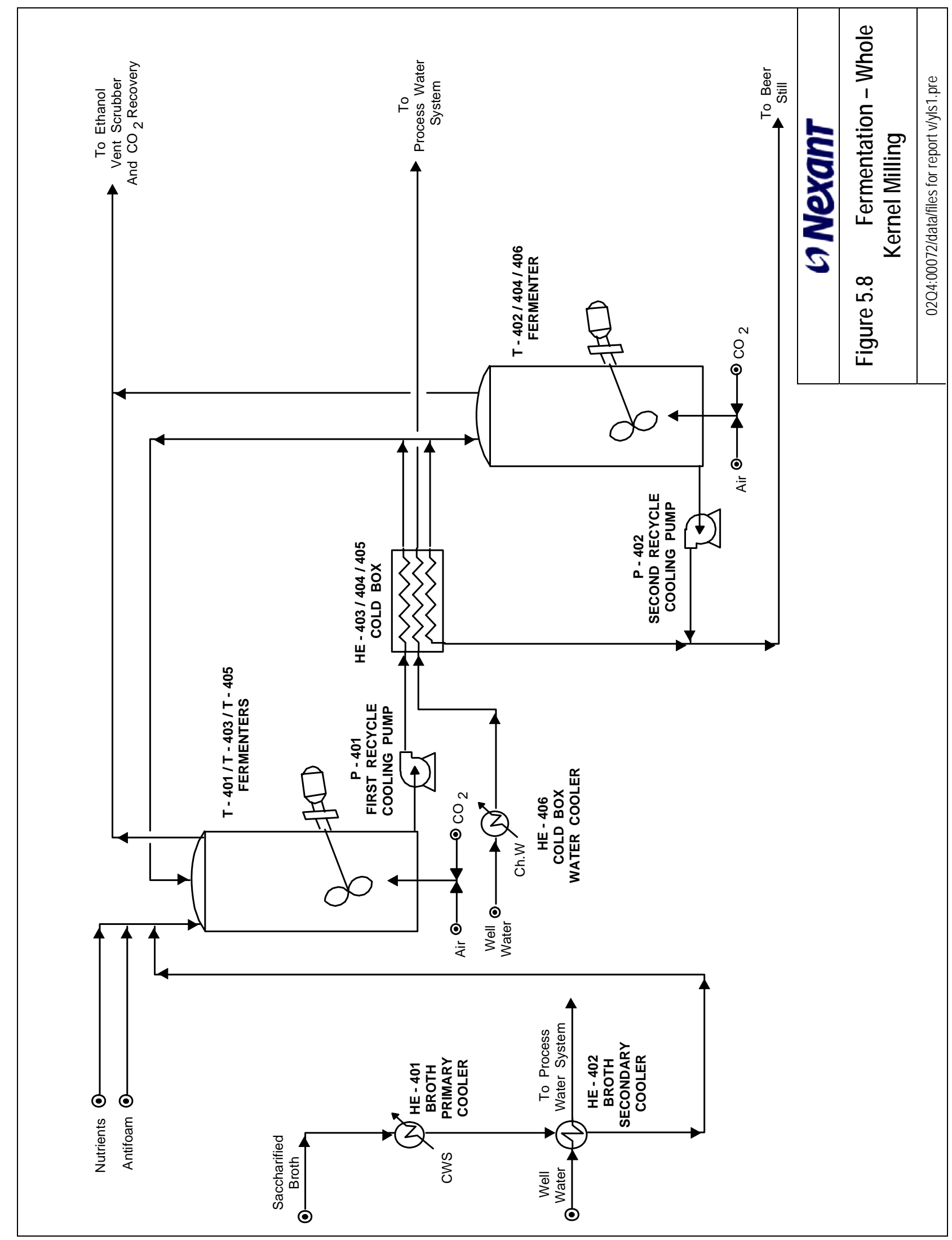




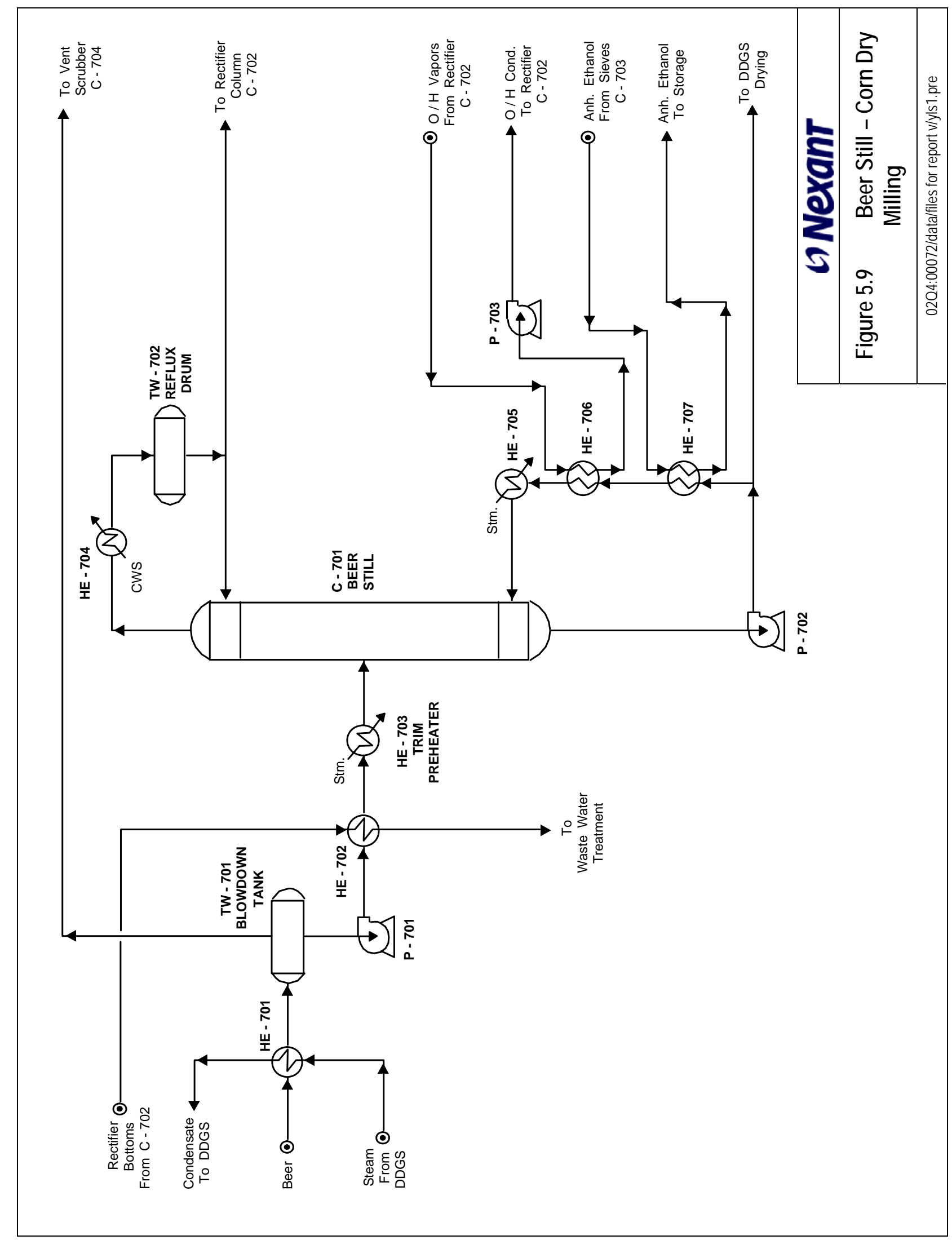




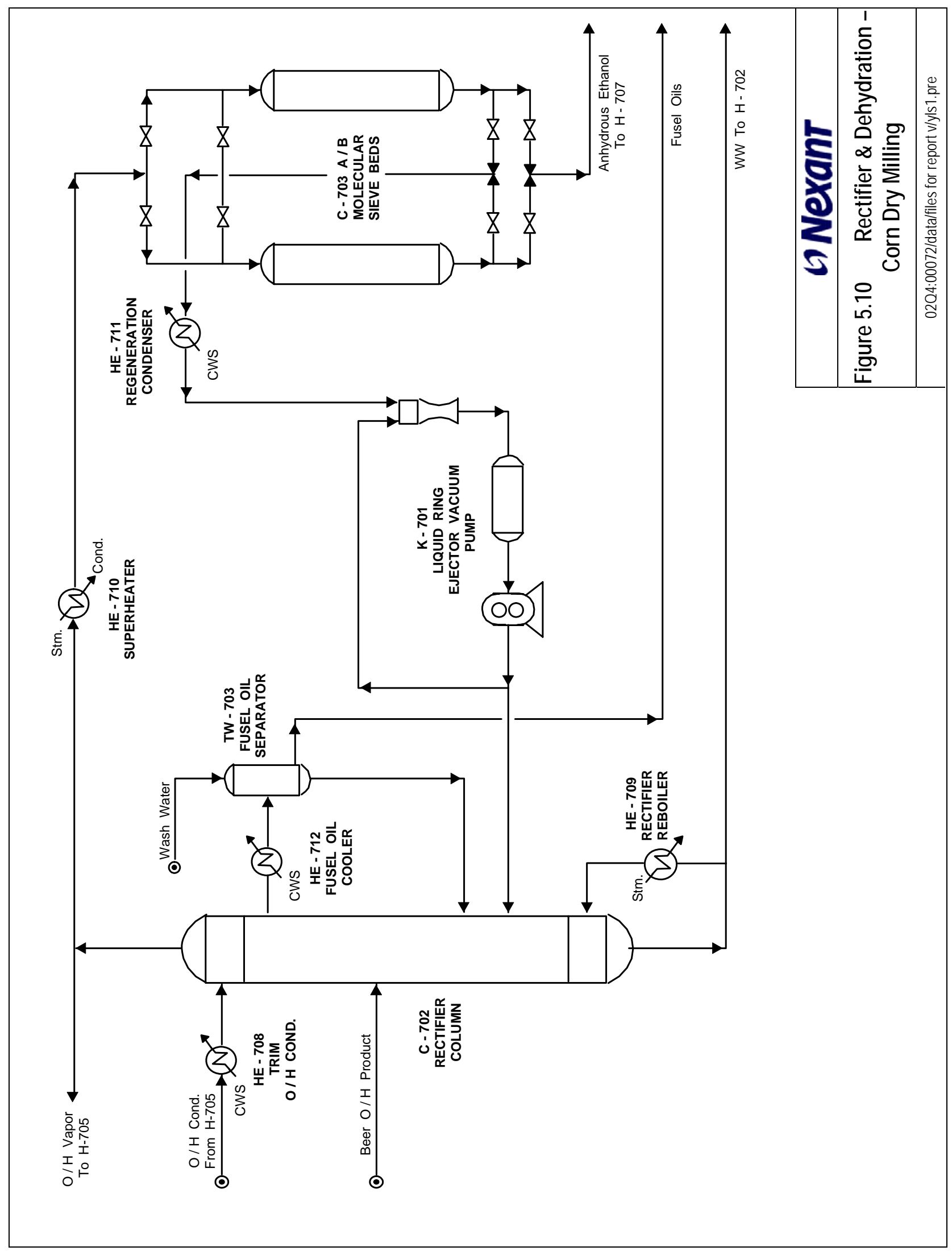




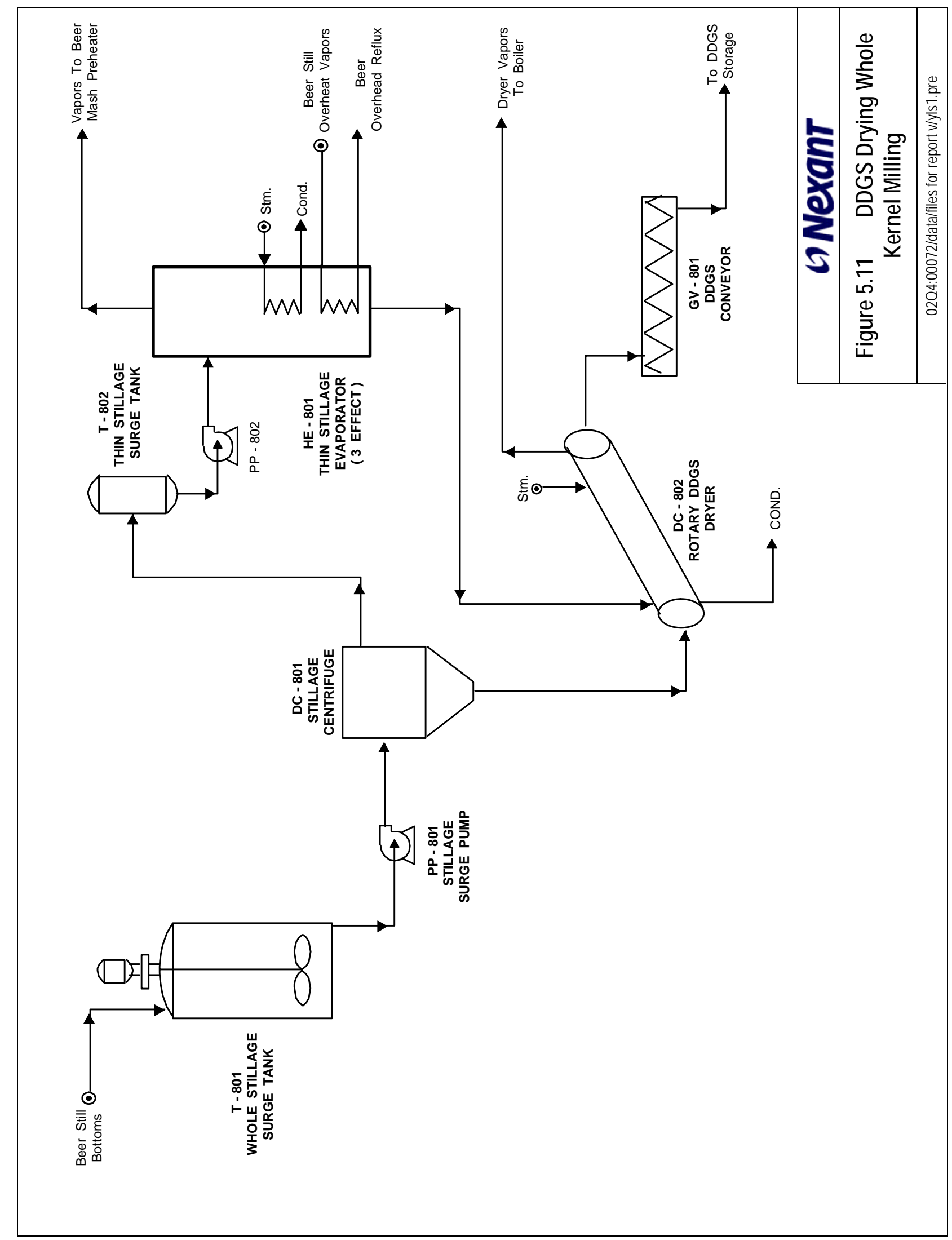




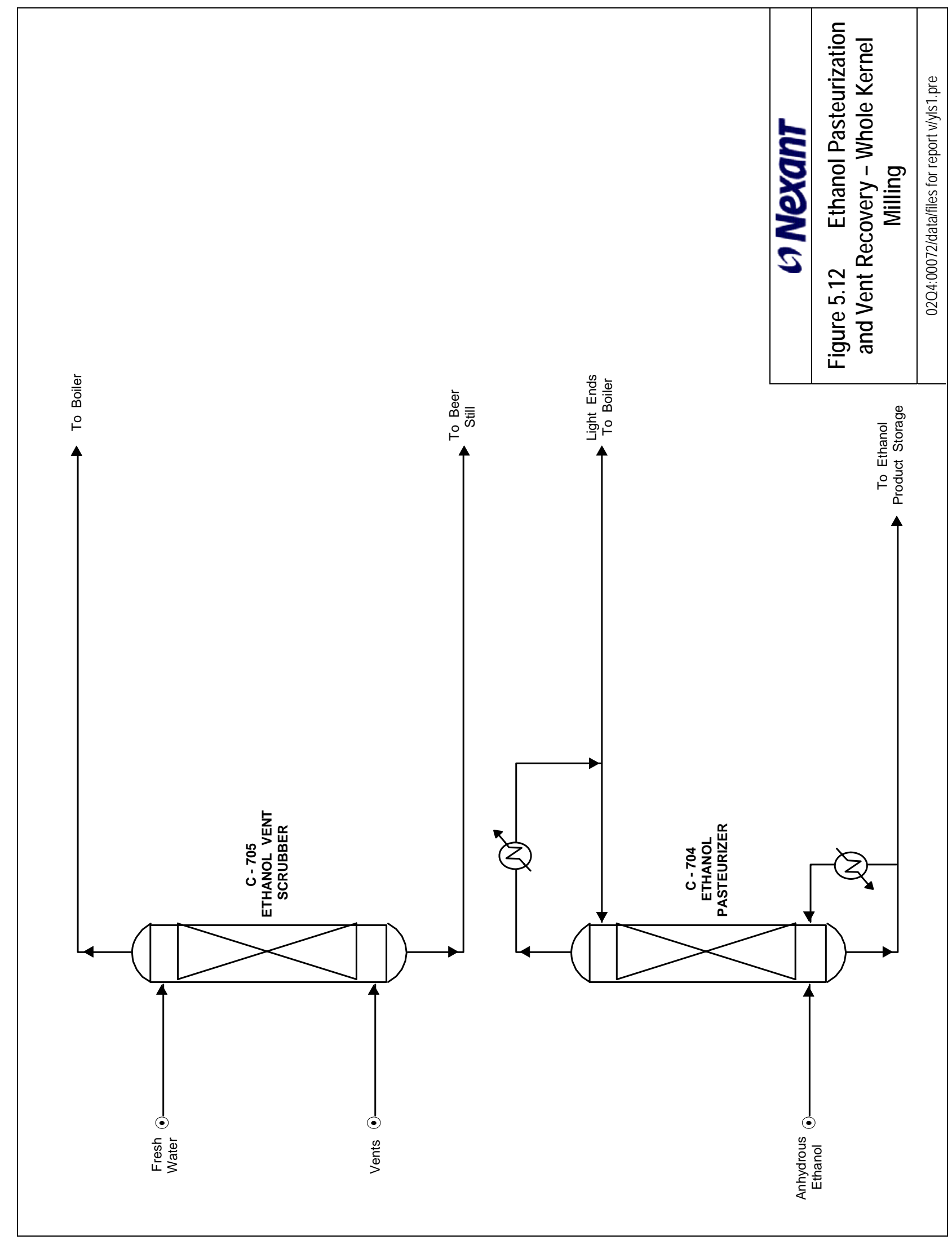


The process description is based on information supplied by the Delta- $T$ Corporation, of Williamsburg, Virginia. The Delta-T Corporation has been involved in all aspects of ethanol from grain fermentation since the 1970s. The plant throughput is rated for 7,150 gallons of ethanol per hour (57 million gallons per year).

\section{Corn Receiving}

Shelled corn is received, usually by truck but occasionally by rail. The trucks and/or railcars are weighed on scale GY-101 on entering and leaving the compound. The corn is offloaded into a temporary storage pit, where it is tested for quality and moisture content. The corn is then screened to remove debris, remaining pieces of cob, chaff, dirt, and other foreign objects (via VS-101 and VM-101). Corn will be received five days per week, eight hours per day, 320 days per year. Ten days corn storage is provided in silos TS-101, assuming the supplier maintains seasonal storage space for the corn to maintain off-season supplies. Table 5.11 illustrates the safe storage life of No. 2 yellow corn, 15.5 percent moisture, stored at various temperatures.

\section{Table 5.11 Safe Corn Storage Life}

(days)

\begin{tabular}{|c|c|c|c|c|}
\hline Storage & \multicolumn{4}{|c|}{ Corn Moisture Content (Wet Basis), \% } \\
\hline Temp, $^{\circ} \mathrm{F}$ & 15 & 20 & 25 & 30 \\
\hline 35 & 1,140 & 118 & 42 & 25 \\
\hline 45 & 725 & 75 & 27 & 16 \\
\hline 55 & 337 & 35 & 12.5 & 7.5 \\
\hline 65 & 207 & 21.5 & 7.8 & 4.6 \\
\hline 75 & 116 & 12.1 & 4.3 & 2.6 \\
\hline
\end{tabular}

Grain is delivered to the plant from the storage silos via bucket elevator CO-102 and overhead screw conveyor CO-103, which convey the corn from the elevator to weigh tank S-101. Once weighed, the corn is gravity-fed to grain separators VS-101A/B for removal of fine and coarse impurities from the corn feed. These separators have a swinging body suspended from a metal frame, which undergo a swinging circular motion over a pair of metal sieve decks. The discharge plate is magnetic to capture any metallic objects that are carried through. From the discharge aspirator, which is between the pair of metal sieve decks, the separated corn gravity flows to the dry destoners VS-102 A/B/C/D for stone and pebble removal. The stones are separated by gravity by floating the corn on a bed of air, and allowing the stones and other Materials of similar or higher density to fall below. The cleaned corn is then conveyed by screw conveyor CO-104 and bucket elevator CO-105 to the mill feed bin VT-101. The weigh belt S102 acts as the primary accounting mechanism for the quantity of corn fed to the dry mill portion of the plant. The cleaning operation loses approximately 1 percent of the corn fed from the delivery units. 


\section{Milling and Hydrolysis}

Hammermills M-201 A and B provide the milling action, grinding the corn into fine flour. Any coarse Material is recycled back to the mill. A hammermill is a vertical mill consisting of flat metal hammers mounted on a rotating shaft, with the hammers free to swing on a pin. The grains fed from the top of the mill fall downward through the enclosed vertical space, and are smashed by the hammers against a flat, stationary breaker plate. The crushed Material falls to a bottom grate, where any particles larger than the grating are recycled to the top of the mill. The mill comprises three such hammer units, placed vertically in series.

The milled Material falls into the ground corn holding bin VT-104. The ground corn is then fed by a rotary valve (FE-201) to weigh belt S-203. The weighed Material is conveyed by screw conveyor CO-201 to the slurrying tanks T-201. Here, the ground corn is mixed with $\alpha$-amylase enzyme and recycled water. The slurry is then mixed in the tank for a total retention time of 5 minutes. The mixed slurry is heated by indirect steam contact in the slurry heaters HE-201, using 150 pound steam from the boiler units. The steam heats the slurry to $180^{\circ} \mathrm{F}$ and sends it to the liquefaction tank T-202. Lime is added to the liquefaction tank to maintain $\mathrm{pH}$.

The liquefaction tank is a multi-baffled system, with each compartment agitated by a dedicated overhead-mounted agitator. The tank retains the slurry for a total of 1 hour, while the $\alpha$-amylase enzyme breaks down the starch into soluble simpler starches, glucose, and dextrose units. During liquefaction, additional steam is fed to the liquefaction tank blanket to maintain temperatures at $180^{\circ} \mathrm{F}$. Residence time is optimized to reduce the formation of dextrin units (glucose dimers) that are not fermentable by downstream yeasts.

The enzymes still used in the majority of industrial starch hydrolysis applications remain $\alpha$ amylase (International Union of Biochemistry nomenclature is $\alpha$-1,4-glucose: orthophosphate glycosyltransferase), available in a cell-free extract from a wide variety of organisms, and a smaller quantity of glucoamylase (which preferentially attacks to 1,6-glucosidic bond). These enzymes are generally derived from Bacillus licheniformis (Solvay Enzymes' TakaTherm-II® or Novo's Termamyl®); TakaTherm-II® is used in this application. The temperature-activity curve and $\mathrm{pH}$ activity curves for Takatherm-II® are provided in Figure 5.13 and Figure 5.14, respectively. It can be seen that the optimum enzyme activity is approximately $90^{\circ} \mathrm{C}$.

The liquefied Material is then transferred by the liquefied mash pump PP-203 to the cooking tank, T-301.

Glucoamylase enzyme (AMG) catalyzes the hydrolysis of the 1,4-glucosidic and 1,6-glucosidic terminal bonds from the nonreducing ends of the starch to free individual glucose units. AMG is usually added as a cell-free extract from Aspergillus niger.

As with all catalysts, AMG also catalyzes the condensation of glucose units into maltose and isomaltose. The latter is not fermentable by yeasts used for ethanol production, but is formed at a much slower rate than maltose, which is fermentable. This reverse catalysis sets a limit on the concentration of glucose available in the broth; at dextrose equivalent conversions of greater 
than 97 percent, the reverse reaction becomes dominant and further conversion of the starch is usually not attainable.

Enzyme concentrations are measured not on a stoichiometric basis but by an activity basis, or activity units. The activity units for each enzyme must be experimentally derived by a rate assay (usually spectrophotometry). Activity units can be converted by determining how many active sites per enzyme are present per weight or volumetric basis (either contained or diluted enzyme).

A wide variety of enzymes with different activity-temperature profiles, activity concentrations, and saccharification potentials exist on the market today, allowing a wide variety of conditions for saccharification. This particular design is set for rapid saccharification at moderately low saccharification temperatures in order to minimize the probability of biological activity from contamination.

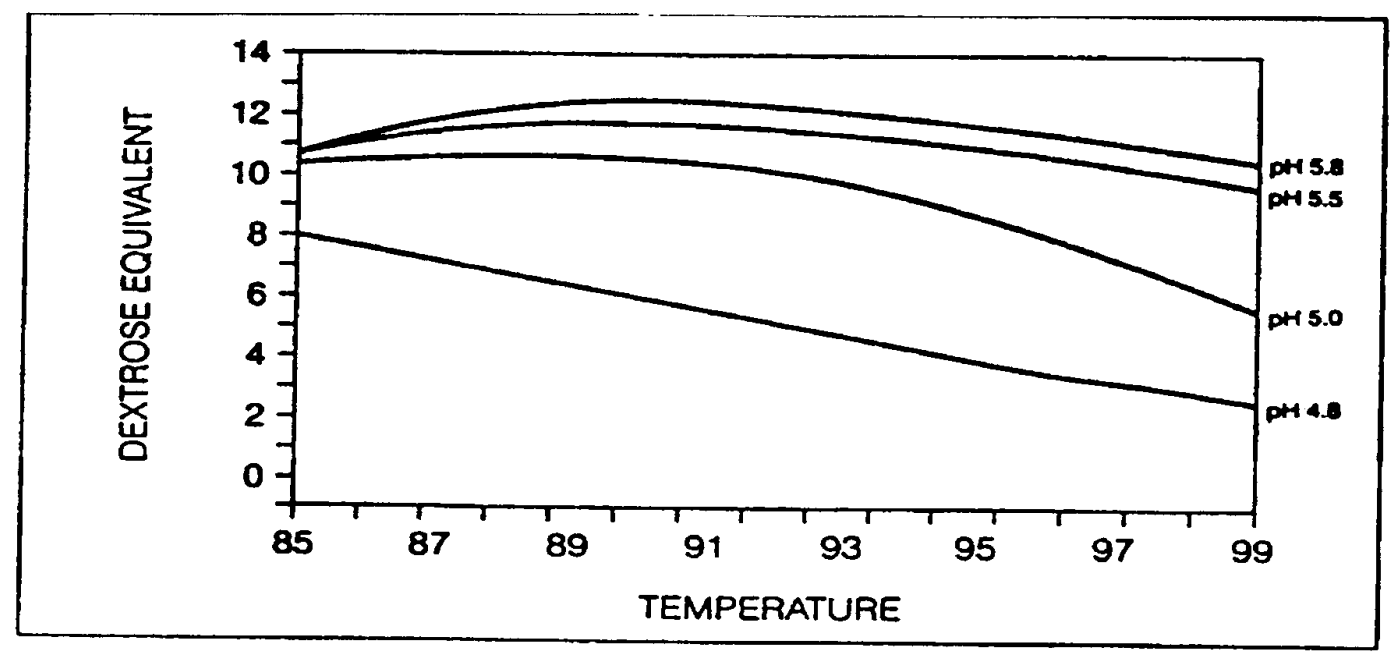

EFFECT OF TEMPERATURE ON TAKATHERM-II. 25 PPM CA $^{++}, 0.12 \%$ ENZYME DSB, $32 \%$ D.S., JET TEMPERATURE: 107 C, RETENTION TIME: 5 MINUTES

Figure 5.13 Takatherm-II ${ }^{\circledR}$ Temperature-Activity Curves 


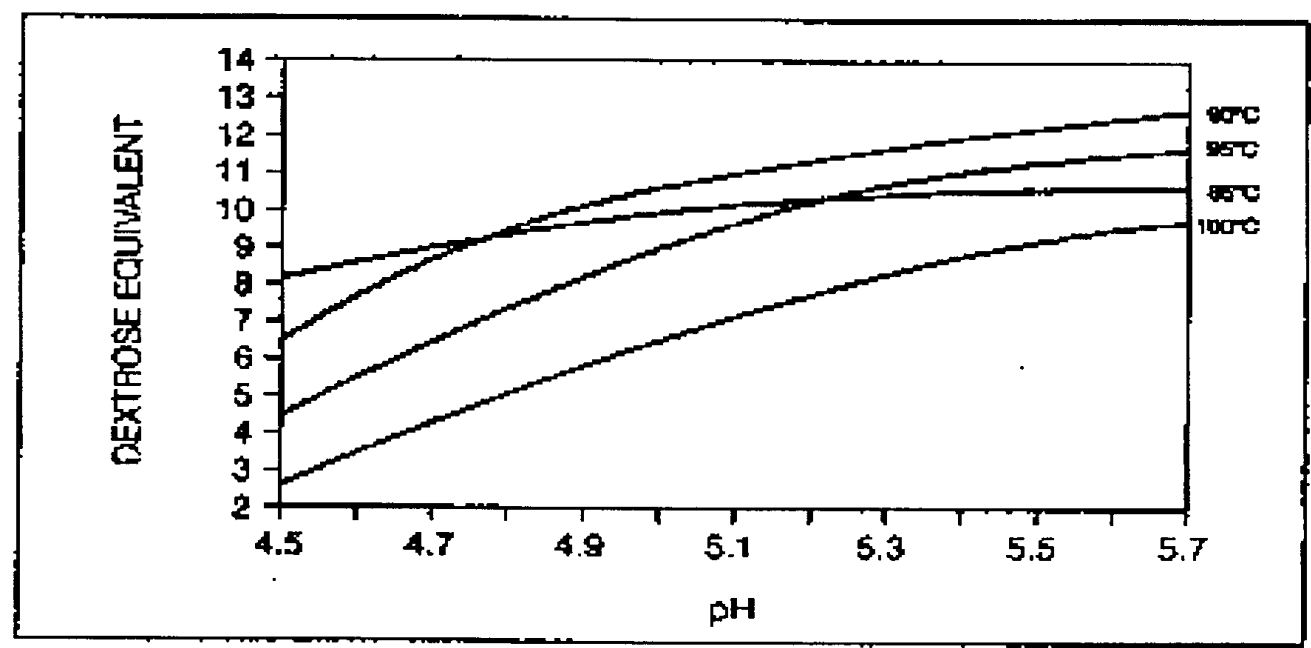

EFFECT OF PH ON TAKATHERM-II. 25 PPM CA , 0.12\% ENZYME DSB, 32\% D.S., JET TEMPERATURE: 107 C, RETENTION TIME: 5 MINUTES

Figure 5.14 Effect Of Ph On Takatherm-II ${ }^{\circledR}$

\section{Cooking and Saccharification}

The liquefied product is transferred from the liquefaction tank and heated using the mash heater HE-301. The mash heater uses 150 pound steam to raise the mash temperature to $230^{\circ} \mathrm{F}$. The hot mash is then sent to the cooking kettles, T-301 A, B, C. Sulfuric acid is added to the mash in the first cooker. The sulfuric acid provides the acid hydrolysis needed to break up and loosen any polymeric Materials (lignin, cellulose, etc.). This acid action also results in some starch to glucose conversion. The acid-hydrolyzed Material has more surface area and higher porosity, which maximizes the conversion efficiency of the glucoamylase enzyme.

The mash flows by gravity to the second and third cookers in series. Total cooking residence time is maintained at 15 minutes to minimize by-product formation. Acid hydrolysis can lead to the formation of undesirable products such as methanol and various fusel oils. Each cooker is maintained at $230^{\circ} \mathrm{F}$ by a steam blanket.

Following the completion of the processes in the last cooker, the mash is transferred via the cooked mash pump PP-301, which passes the mash through the mash cooler HE-302. The mash cooler uses cooling tower water to cool the mash from $230^{\circ} \mathrm{F}$ to $140^{\circ} \mathrm{F}$, the optimal operating temperature for glucoamylase enzymolysis.

The cooled mash is then sent to the saccharification tanks T-303 A/B. The saccharification tanks are also fed with a continuous solution of glucoamylase enzyme. The saccharification tanks are set up as a cascade series, the first feeding the second by gravity flow. The two tanks provide a 
total saccharification residence time of 2 hours. Agitation to the tanks is provided by three sidemounted agitators. The tanks are made of $316 \mathrm{SS}$.

The saccharified broth, typically converted to a dextrin equivalent of 95, is pumped via the saccharified broth pumps P-303 to the fermentation area.

\section{Fermentation}

The saccharified starch is pumped from storage tank T-303 in a two-step cooler: the primary cooler HE-401 uses cooling tower water to cool to $43^{\circ} \mathrm{C}$, and the secondary cooler HE-402 uses well water at $15^{\circ} \mathrm{C}$ to cool the diluted slurry to $35^{\circ} \mathrm{C}$. The well water is then sent to the process water storage tank. Well water use reduces the need for a chilled water system, which introduces significant additional capital and operating costs. In winter months, well water use would be minimal, since the cooling tower would be able to cool the diluted stream sufficiently. A higher capital cost for the larger exchanger surface area of HE-401 is justified by the reduction of the chilled water system.

The saccharified broth is pumped to the cascade set of fermenters. The fermentation occurs in three parallel trains of two tanks each. Each train is designed to ferment 50 percent of the total flow through the fermentation area. The total residence time provided by the equal sized tanks is 20 hours. The tanks are made of 316L stainless steel.

Each tank operates at a steady state condition, with sugar concentration decreasing stepwise and ethanol concentration increasing stepwise from the first to the last tank.

The heat of fermentation, 1.2 MJ per $\mathrm{kg}$ ethanol, is removed by the sidestream coolers HE$403 / 404 / 405$. Well water available at $15^{\circ} \mathrm{C}$ is used as the primary cooling medium. In summer months, the well water is supplanted and/or cooled by a chilled water system.

Oxygen is added to the fermentation broth. While total anaerobic conditions favor yeast growth, not ethanol production, some oxygen is necessary to promote ethanol production. Air is first filtered then pumped into the draft tube along with the feed broth. Carbon dioxide is recycled from the $\mathrm{CO}_{2}$ recovery area to provide additional agitation, and to minimize the contamination of carbon dioxide in those plants where the gas is collected and purified for sale.

Carbon dioxide by-product is separated from the beer in the disengaging section of the reactor. The gas is then pumped through a common header by suction on the scrubber provided by fan FN-105 to the gas scrubbing section.

An alternative design for the fermenters is discussed in the next section, which describes the use of either a flocculating yeast tower or simultaneous saccharification and fermentation (SSF), instead of cascade CSTRs (continuous stirred tank reactors). 


\section{Distillation}

The dilute beer from the fermentation area undergoes a series of preheating steps. First, the beer is preheated against the flash vapors from the distiller's dried grains and solubles (DDGS) drying area in HE-701, heating the beer to $65^{\circ} \mathrm{C}$. The beer is then flashed in flash tank TW-701 to remove any remaining gases and stabilize the column operation. Any vent gases are sent to the fermentation vent scrubber to recover entrained ethanol. The beer is then further preheated to $100^{\circ} \mathrm{C}$ against the rectifier column bottoms in HE-702. The beer still feed trim heater HE-703 preheats the beer to a final $110^{\circ} \mathrm{C}$ prior to the beer still.

The hot, dilute beer enters beer still C-701, which operates at a slightly positive pressure of 130 $\mathrm{kPa}$. The column has 60 actual trays. The solids and nonvolatile liquids work their way downward into the beer still bottoms and are removed as a dilute aqueous stream. The bottoms temperature is approximately $105^{\circ} \mathrm{C}$. The bottoms are sent to the DDGS dryer for stillage recycle and DDGS production. The beer still overheads leave the column as weight 60 percent ethanol. The overheads product, condensed against cooling water in HE-705 and collected in reflux drum TW-702, is split into reflux and product, which is sent to the rectifier still C-702.

The trays in the beer still are highly susceptible to fouling, due to the many dissolved solids, suspended solids, lignin, and proteins present in the mash. The most common tray design used to be sieve trays. More recent designs have replaced sieve trays with baffle trays (disk-anddonut configuration) or Nutter V-Grid® type trays.

Figure 5.15 and Figure 5.16 graphically illustrate these tray designs. Baffle trays are resistant to fouling, since no small holes are used for liquid/gas contact. Each tray is far less efficient than a conventional sieve tray, since surface area contact is limited. However, this negative effect on column height is offset by the closer placement of the baffle trays needed for proper operation. This results in a column with roughly the same height as a sieve tray column, but packed with more expensive internals. Nutter V-Grid ${ }^{\circledR}$ trays typically cost less than baffle trays, and offer a good tradeoff due to lower cost and maintenance, despite lower operating efficiency. 

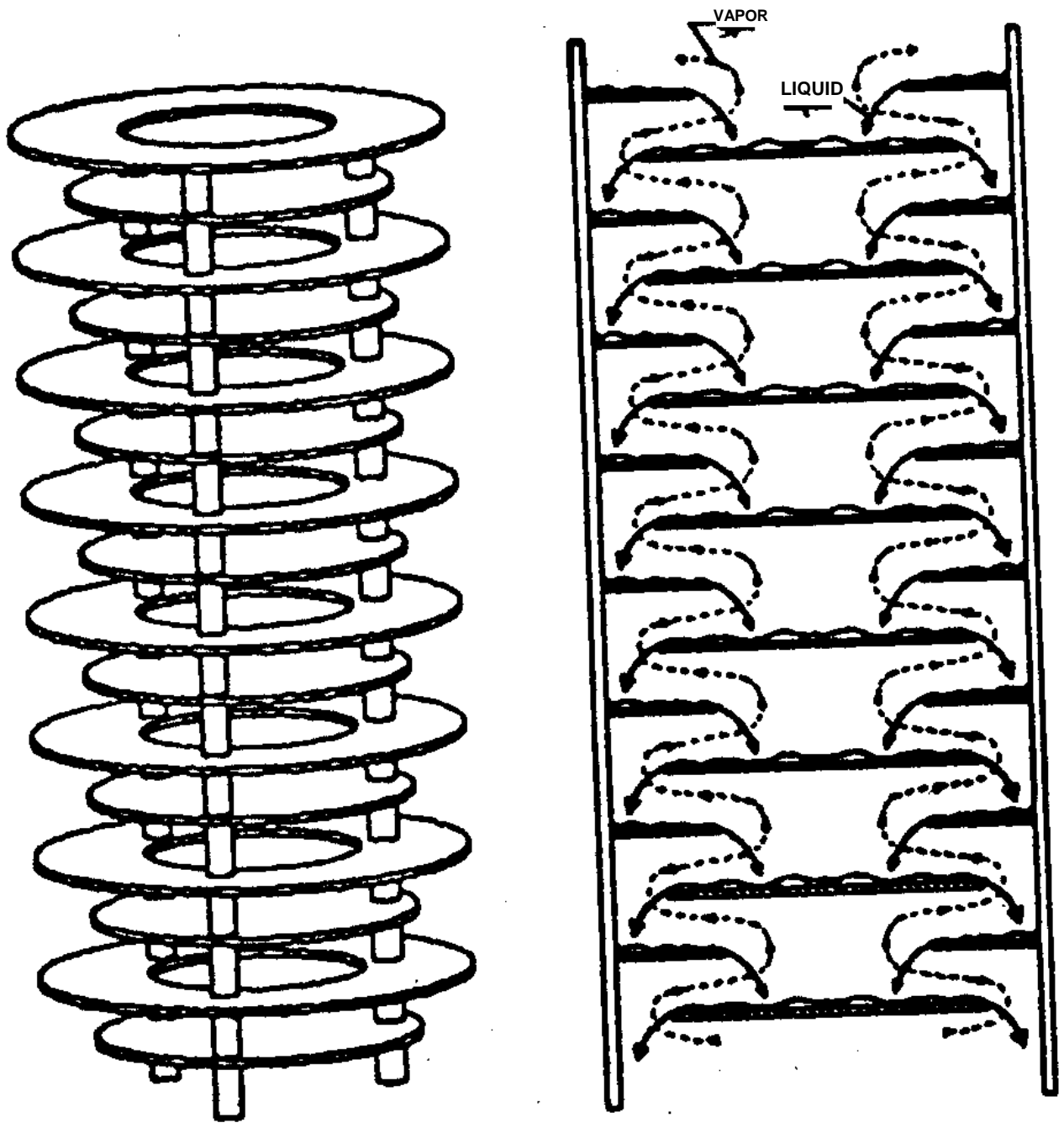

O:101Q214006IRPIYLS2.PRE

Figure 5.15 Baffle Tray Design

(disk-and-donut configuration ) 


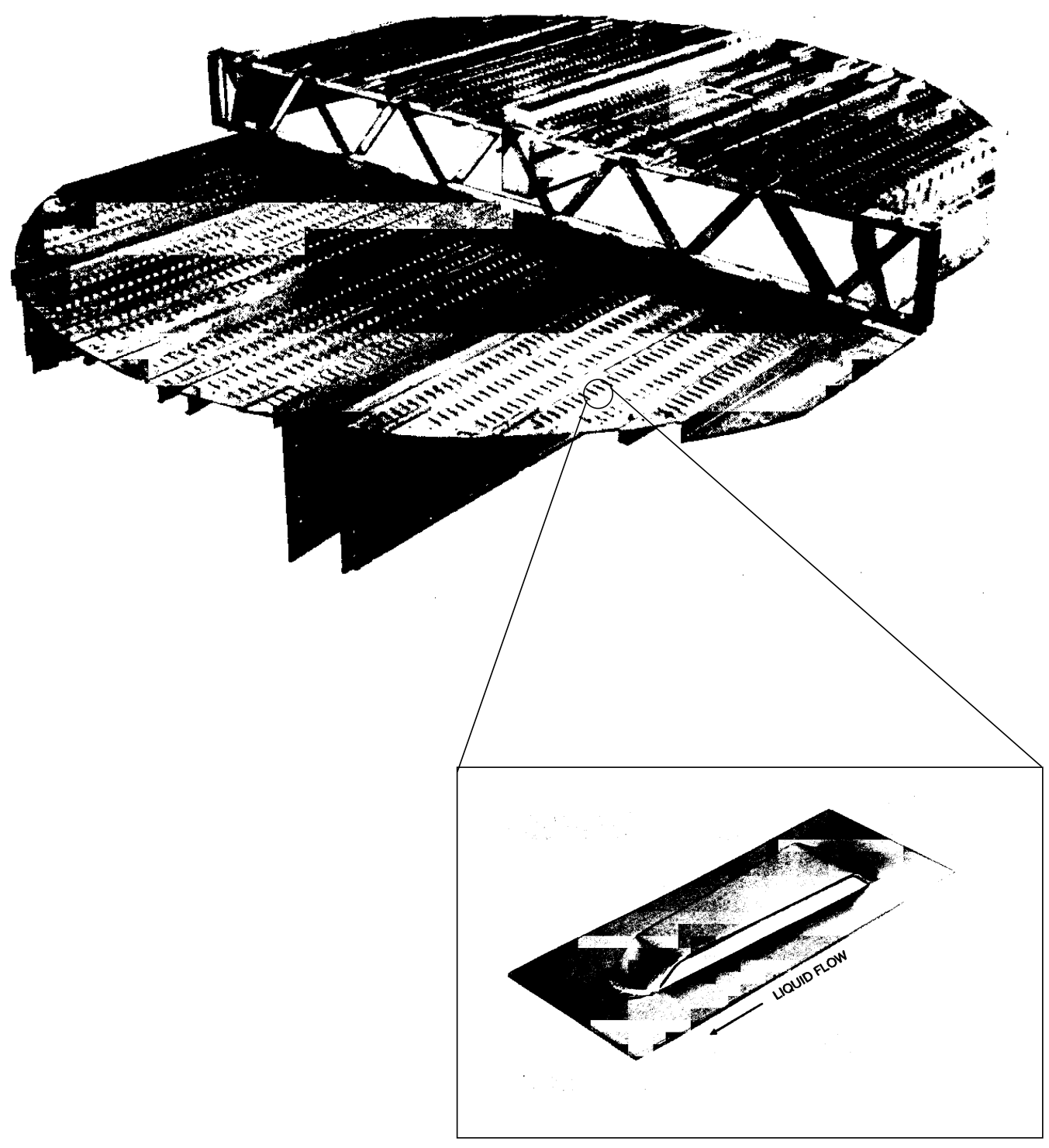

O:I01Q214006IRPIYLS2.PRE

Figure 5.16 Nutter V-Grid ${ }^{\circledR}$ Tray Configuration

The beer still reboiler duty is provided by three sources: HE-707 heats the bottoms against the condensing anhydrous ethanol from the dehydration unit; HE-706 provides the remaining steady-state reboiler duty by condensing the rectifier column overheads. A trim steam reboiler, HE-705, is provided for fluctuations and startup.

The rectifier column is fed from the overheads of the beer still. The column operates at an elevated pressure of $400 \mathrm{kPa}$. This elevated pressure raises the column temperature sufficiently to allow heat integration with the dehydration unit. The rectifier column contains 50 trays, 
which are conventional valve trays. The overhead product, coming off as 190-proof ethanol, is split into two streams: 75 percent is condensed against beer still bottoms in the beer still reboiler, and returned as rectifier column reflux; the remaining vapor is superheated in $\mathrm{HE}-710$ by $15^{\circ} \mathrm{C}$ to prevent condensation in the molecular sieve beds.

The bottoms from the rectifier column, containing $500 \mathrm{ppm}$ ethanol, are used to preheat the beer still feed in HE-702. The cooled bottoms are then sent to OSBL for waste water treatment.

The rectifier column has a side stream leaving from trays 10 to 15 , depending on operation. This side stream contains fusel oils that have formed a separate phase on this tray. Fusel oils are predominantly branched monoalcohols: 40-60 percent isoamyl alcohol, 10-30 percent amyl alcohol, 3-15 percent isopropanol, 3-10 percent n-propanol, and the remainder other 3-5 carbon secondary and tertiary alcohols. Fusel oil composition is a function of the initial feed to the prehydrolysis unit, and the quantity formed is a function of prehydrolysis condition severity. The solubility profiles of fusel oils in water and ethanol result in a tight area where they form a separate phase in one of the column trays. They therefore need to be removed to prevent buildup in the column and eventual process upset. The side draw removes the fusel oils, which are then cooled in fusel oils cooler HE-712. The cooled fusel oils are subsequently washed in the fusel oils decanter/washer, TW-703. The fusel oils are washed counter currently with fresh process water to remove any entrained ethanol. The heavy water phase is recycled back to the rectifier still, while the fusel oil phase is decanted and collected in storage facilities. The fusel oils can be blended with fuel-grade ethanol.

However, due to their strong odor, they are more often burned in the plant boiler as an auxiliary fuel.

The rectifier column overhead vapors leaving the superheater are then sent to the dehydration unit. The description of this unit is based on data supplied by Delta-T Corporation, for its TSX molecular sieve unit. The dehydration unit comprises two fixed beds of artificial aluminosilicate zeolite clay. These zeolites are highly regular crystalline structures, containing millions of molecular-sized pores. For ethanol, these zeolites are made with pores of about $3 \times 10-10$ meters $(3 \AA)$, which trap water molecules but are too small for ethanol and other impurities. The water is adsorbed into these pores, and the ethanol and other impurities pass through the bed and out the bottom. The molecular sieve can usually contain up to 16 percent of its weight in water. The beds in this process are operated to allow the sieve to accept no more than 50 percent of its capacity. This reduces equilibrium effects in the beds.

The two beds operate on an adsorption/regeneration cycle of about 11 minutes total. The two beds operate at opposite cycles, one regenerating, one adsorbing. The adsorbing bed is fed with high-pressure, superheated 190-proof ethanol. The water is selectively adsorbed, and the anhydrous ethanol (with other impurities) leaves the bottom of the bed and is condensed in the beer still reboiler HE-707. The bed under regeneration is placed under vacuum pump K-701. The ejector/liquid ring vacuum pump reduces the pressure in the bed to a slight vacuum (about $90 \mathrm{kPa}$ ). The water desorbs from the bed and is condensed in HE-711. The water is recycled 
back to the rectifier column, since some ethanol is absorbed in the macropore structure of the zeolite bed. This recycle water is approximately 65 percent water, 35 percent ethanol.

The cooled anhydrous ethanol is sent to a small pasteurization column C-704, where any light impurities such as methanol and acetaldehyde are removed prior to product storage. The pasteurization column comprises 20 valve trays, and operates at atmospheric pressure. The overhead product, comprises impurities, is sent directly to the plant boiler as auxiliary fuel. The bottoms are anhydrous ethanol specified to below $500 \mathrm{ppm}$ impurities. This ethanol is sent to product storage.

Any ethanol vented from the fermenters and other process equipment is directed to a vent scrubber. The vent scrubber is a simple packed tower with 20 theoretical trays of random 1-inch Raschig rings for packing. The vent vapors are countercurrently contacted in the column with fresh, cold water. The water absorbs 95 percent of the ethanol entering the vent vapors. The scrubbed gases are sent to the boiler for incineration. The recovered water is sent to the beer still where the captured ethanol is recycled. The returned water stream is preheated by beer still bottoms prior to entering the beer still.

\section{DDGS Separation and Drying}

After exchanging heat with the incoming streams to the beer still, the beer still bottoms are collected in an eight-hour surge tank, T-801. The surge tank supplies constant flow to the stillage centrifuge DC-801, in case of operational interruptions or upsets upstream. The stillage centrifuge separates the solids from the broth, leaving a thick stillage of about 60 percent moisture, and a thin stillage containing the remaining water and minimal solids. The thick stillage is sent to a steam tube rotary dryer DC-802 where the Material is dried to 10 percent moisture. The dryer is heated with steam supplied from the boiler. The dryer contains a variety of anti-explosion and dust collection devices and auxiliary equipment not shown on the diagram. The dried Material is then conveyed to DDGS storage.

The thin stillage is collected in a surge tank, T-802. The thin stillage is continuously fed to a three-effect evaporator system. The overhead vapors from the beer still are the primary heat source for the evaporators. During startup, the evaporators are heated by boiler steam; during normal operation, steam supplies trim heat to the evaporators. A portion of the thin stillage is concentrated to about 35 percent syrup and 65 percent water. The syrup is sent to the dryer to be dried and combined with the DDGS. The unevaporated stillage is recycled back into the process, upstream of the fermentation area.

This particular evaporator system comprises three falling film evaporators arranged in a threeeffect layout. Falling film evaporators have a practical syrup concentration of 30-35 percent solids. Some plants have used forced circulation flash evaporators, which can increase solids concentration in the syrup up to 45 percent. The use of mechanical vapor recompression (MVR) has been successfully used in cases where steam is not readily available for the evaporators. Because of the use of waste energy in the process as the main evaporator heat source, MVR is not used here. 


\subsubsection{Wet Milling}

As discussed previously, corn can be processed into ethanol using two main routes: wet milling and dry milling. Each process has inherent advantages and disadvantages.

Wet milling of corn is the conversion technology used when high-fructose corn syrup (HFCS) is desired as the main by-product of ethanol formation. HFCS is often used in conjunction with or as a substitute for sugar and other sweeteners in many food products, specifically soft drinks and baked goods. The system is highly integrated to disassemble the corn into as many valuable products as possible.

Figure 5.17 compares the block flow diagram of wet milling versus whole-kernel dry milling.

The corn is not milled. Rather, it is first steeped in a solution of water and sulfur dioxide for 24 to 48 hours. This loosens the germ and hull fibers. The germ is then removed from the kernel, and corn oil is extracted from the removed germ. The crude corn oil can be further processed as an edible oil plant.

The remaining germ meal from the corn oil extraction is combined with the hulls and fiber to produce corn gluten feed. The corn gluten feed is combined with the heavy stillage from the beer still and dried forming the corn gluten feed. The high protein fraction of the corn kernel is later separated out to produce corn gluten meal, a high-value animal feed made up of about 60 percent protein.

The remaining starch fraction is liquefied and fermented in a process similar to dry milling. In wet milling, often the clear, liquefied starch is split into two fractions: one fraction diverted to ethanol production, and the other fraction used for the production of HFCS or other sweeteners. The amount of liquefied starch diverted to the production of HFCS versus ethanol depends of the relative price and production economics of each product. Therefore, wet mill plants are usually built to produce both swing products to take maximum advantage of economic conditions. Typically, HFCS enjoys a higher margin, and more starch is diverted to HFCS production than to ethanol.

HFCS is a product of the isomerization of dextrose hydrolyzate. Dextrose (D-glucose) is the saccharification product of hydrolyzed corn starch. Glucoamylase converts the hydrolyzed starch. Since in most cases the purified dextrose is more expensive than HFCS (due largely to crystallizer capital and operating costs), the dextrose solution is more economically converted into HFCS. Essentially, glycose isomerase partially isomerizes the dextrose solution into fructose, producing a mixture of dextrose and fructose. This mixture is further refined and concentrated for sale as HFCS. 


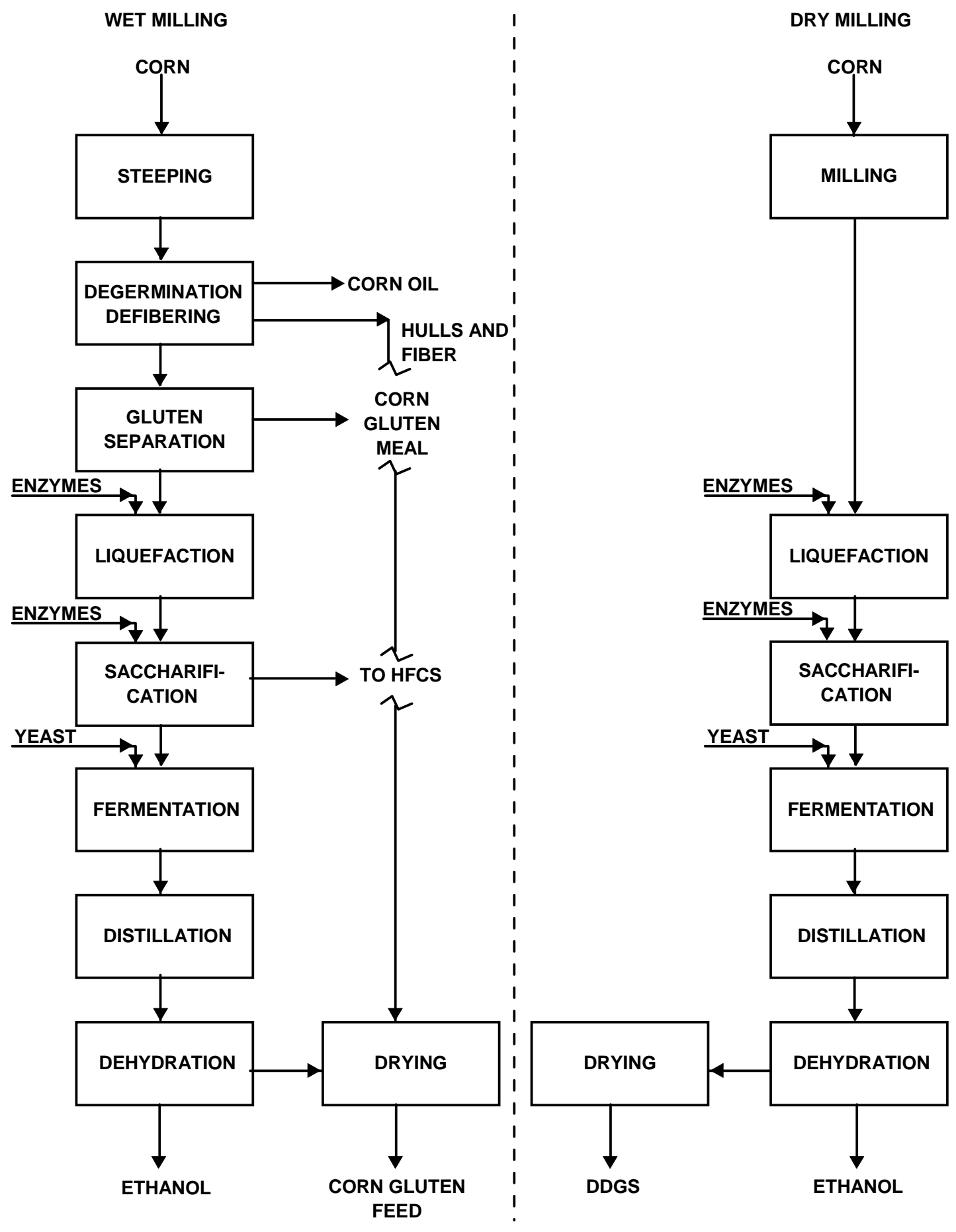

G:|2001Q214006IRPIYLS3.PRE

Figure 5.17 Wet Milling Versus Dry Milling 
The primary capital cost associated with the wet milling plant is the front end, where the corn oil, gluten feed, and gluten meal are separated out. This section normally increases capital costs to more than 75 percent, higher than a simple whole-kernel dry milling plant. This capital cost does not include the HFCS processing facilities, which are usually integrated into the ethanol plant.

Process improvements have mainly focused on the steeping area. The state of the art is the continuous sparging of gaseous SO2 into the steeper tanks. This improves separation between corn components while reducing overall steeping times.

Wet milling is the conversion process most widely used at present in the United States. Archer Daniels Midland, the primary producer of ethanol in the United States, and CPC, a major corn syrup producer, both extensively use this process. It is probable that any future ethanol plants built by these leading companies will be built using the wet milling process, since they would continue to build on their extensive experience in both the ethanol and syrup/sweetener markets. However, since these plants are highly integrated, new entrants would need significant experience before operational proficiency would be developed.

Since these plants would be built predominantly by those companies also interested in sweetener production, with ethanol more a valuable swing by-product than the main product, this process is not covered in further detail in this report.

\subsubsection{Economic Assessment}

\subsubsection{Economic Assumptions}

The key parameters used for corn ethanol technology evaluation are summarized in Table 5.12 and Table 5.13.

For 2006, the total capital investment for a 50 million gallons per year (MMgpy) plant is $\$ 91$ million. For 2015, the total capital investment for a $150 \mathrm{MMgpy}$ plant is $\$ 258$ million. The capital investment is based on the assumption that the capital is reduced by 1 percent per year from 2001 to 2015 due to technology improvement.

\section{Table 5.12 Key Parameters For Corn Ethanol Technology Evaluation}

Year

Corn

Capacity

Total Capital Investment (Current \$)
US\$/Bushel

MMgpy

MMUS\$
2006

2.14

50

91
2015

2.45

150

258

02Q4:00072/files for report v/ethanol summ.xls(corn) 


\section{Table 5.13 Technology And Capital Improvements For Corn Ethanol Technology}

\begin{tabular}{|c|c|c|c|}
\hline & \multicolumn{3}{|c|}{ Improvement (Reduction), \%/Year } \\
\hline & 2001-2006 & 2006-2015 & $\begin{array}{r}\text { 2001-2015 } \\
\text { (Effective) }\end{array}$ \\
\hline Capital & $1 \%$ & $1 \%$ & $1 \%$ \\
\hline Technology (Raw Materials, Utilities, Labor, etc.) & $1 \%$ & $1 \%$ & $1 \%$ \\
\hline
\end{tabular}

The corn consumption rates are 122 bushels and 111 bushels per metric ton of fuel ethanol for 2006 and 2015, respectively. This is based on the assumption that the corn consumption rate is reduced by 1 percent per year from 2001 to 2015 due to technology improvement.

Other economic assumptions can be found in the cost of production table below.

\subsubsection{Feedstock and Utilities Pricing and Labor Costs}

The main feedstocks associated with the manufacture of fuel ethanol via dry milling of corn are corn, sulfuric acid, sodium hydroxide, alpha-amylase, etc. U.S. Midwest market forecast prices for these feedstocks for 2006 and 2015 have been used for this analysis. For corn stover, the cost is mainly the associated collection and transportation cost. For utilities, 2006 and 2015 average U.S. Midwest utility prices are used. For labors, 2006 and 2015 average U.S. Midwest labor rates are used. Table 5.14 summarizes the raw Material, utility prices, and labor rates used for this study.

\subsubsection{Process Economics}

2006

The economics for the production of 150 thousand metric tons (50 million gallons) per year of fuel grade ethanol at a U.S. Midwest location via corn dry milling are presented in Table 5.15.

The total plant capital cost is estimated to be $\$ 72.7$ million. This capital cost includes $\$ 36.2$ million for ISBL and $\$ 36.5$ million for OSBL. Other project costs are estimated to be $\$ 18.2$ million, resulting a total capital investment of $\$ 90.8$ million. An additional $\$ 17.0$ million is also estimated for the working capital requirement.

With corn price at $\$ 2.14$ per bushel, the raw Material cost is $\$ 285.19$ per metric ton of ethanol. By-product credit mainly from distiller's dried grains and solubles (DDGS) reduces the net raw 
Material cost to $\$ 181.49$ per metric ton of ethanol. Utilities contribute a credit of $\$ 30.28$ per metric ton, resulting in a variable cost of $\$ 211.77$ per metric ton of ethanol.

The total direct fixed cost, including all labors, maintenance, and direct overhead, is approximately $\$ 23.04$ per metric ton of ethanol. The total allocated fixed cost of the plant, including general plant overhead, insurance, property taxes, and environmental levy, is about $\$ 16.29$ per metric ton of ethanol. The total fixed costs bring the total cash cost to $\$ 251.10$ per metric ton (\$0.75 per gallon) of ethanol.

Table 5.14 Summary Of Raw Material Utility And Labor Costs For Corn Ethanol Production (current U.S. dollars)

U.S. Midwest

\begin{tabular}{|c|c|}
\hline 2006 & 2015 \\
\hline 2.91 & 3.57 \\
\hline 2.14 & 2.45 \\
\hline 56.00 & 69.89 \\
\hline 63.99 & 79.91 \\
\hline 214.29 & 257.28 \\
\hline $3,182.53$ & $3,974.60$ \\
\hline $2,548.27$ & $3,182.48$ \\
\hline 199.52 & 275.14 \\
\hline $6,185.44$ & $7,724.88$ \\
\hline 86.12 & 98.34 \\
\hline 29.28 & 21.64 \\
\hline 189.38 & 221.34 \\
\hline 56.43 & 70.48 \\
\hline 188.34 & 235.21 \\
\hline 628.65 & 785.11 \\
\hline 2.91 & 3.57 \\
\hline 2.76 & 3.38 \\
\hline 0.05 & 0.07 \\
\hline 53.87 & 66.67 \\
\hline 1.08 & 1.35 \\
\hline 285.93 & 356.60 \\
\hline 45,016 & 56,219 \\
\hline 51,078 & 63,789 \\
\hline 61,630 & 76,968 \\
\hline
\end{tabular}




\section{Table 5.15 Cost Of Production Estimate For: Fuel Grade Ethanol Process: Corn Dry Milling 2006}

$\begin{array}{lr} & \\ \text { Plant start-up } & 2006 \\ \text { Analysis date } & 2002 \\ \text { Location } & \text { Midwest US } \\ \text { Capacity } & 150.0 \text { Thousand MT/yr } \\ & 49.9 \text { MMGal/yr } \\ \text { Operating rate } & 100 \text { percent } \\ \text { Throughput } & 150.0 \text { Thousand MT/yr }\end{array}$

PRODUCTION COST SUMMARY

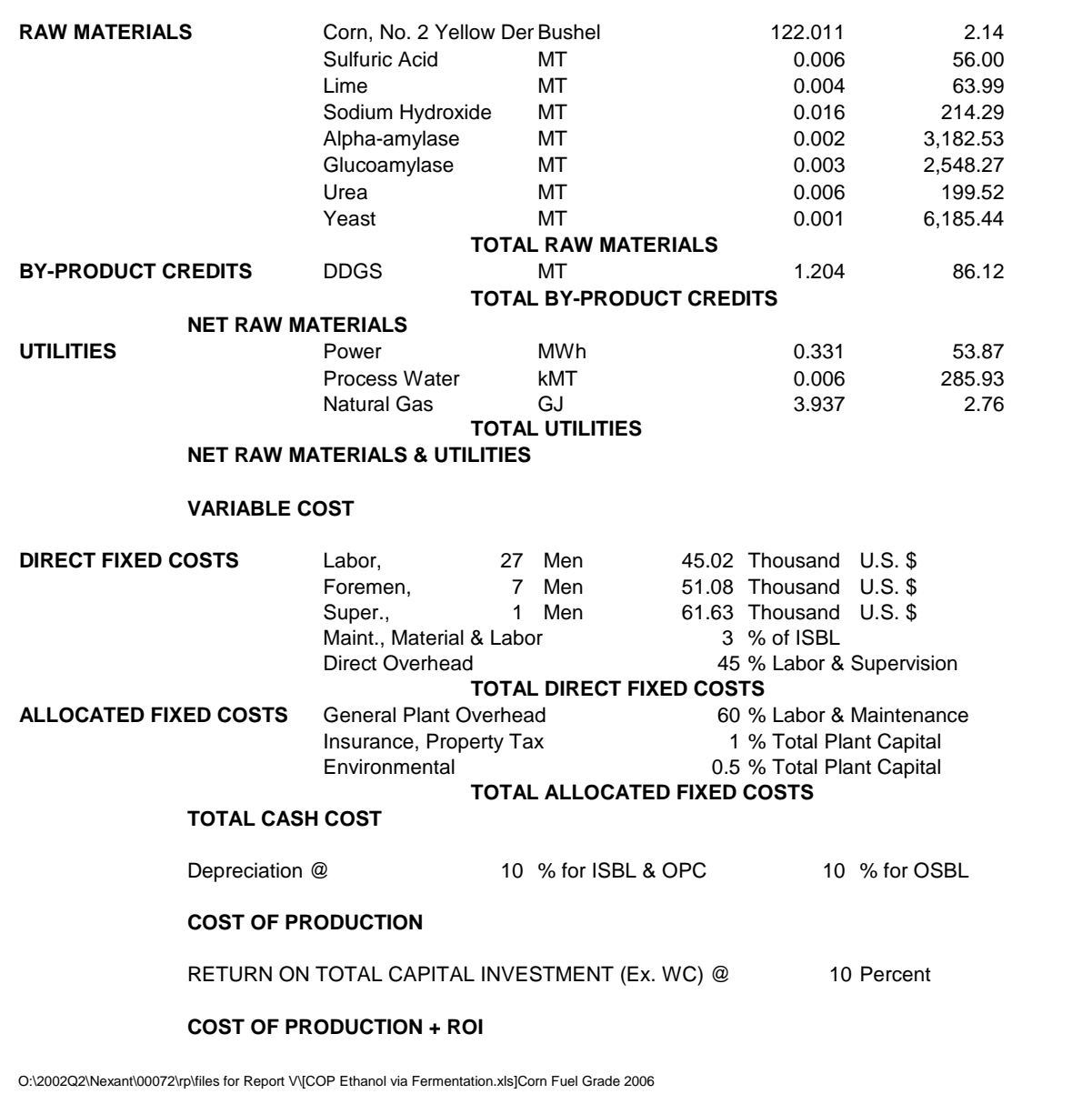

$\begin{array}{lr}\text { CAPITAL COST } & \text { MILLION U.S. \$ } \\ \text { ISBL } & 36.2 \\ \text { OSBL } & 36.5 \\ \text { Total Plant Capital } & 72.7 \\ \text { Other Project Costs } & 18.2 \\ \text { Total Capital Investment } & 90.8 \\ \text { Working capital } & 17.0\end{array}$

$\begin{array}{cc}\text { UNITS } & \text { PRICE } \\ \text { Per MT } & \text { U.S. \$ } \\ \text { Product } & \text { IUnit }\end{array}$

$\begin{array}{lcc} & \text { ANNUAL } & \\ \text { U.S. \$ } & \text { COST MM } & \text { U.S. \$ } \\ \text { Per MT } & \text { U.S. \$ } & \text { Per Gal }\end{array}$

$\begin{array}{lll}261.38 & 39.21 & 0.79\end{array}$

$\begin{array}{lll}0.35 & 0.05 & 0.00\end{array}$

$\begin{array}{lll}0.24 & 0.04 & 0.00\end{array}$

0.01

$\begin{array}{lll}6.96 & 1.04 & 0.02\end{array}$

$\begin{array}{lll}8.00 & 1.20 & 0.02\end{array}$

$\begin{array}{lll}1.23 & 0.19 & 0.00\end{array}$

$\begin{array}{lll}3.71 & 0.56 & 0.01\end{array}$

$\begin{array}{lll}285.19 & 42.78 & 0.86\end{array}$

$\begin{array}{lll}(103.70) \quad(15.56) \quad(0.31) \\ (103.70) & (15.56) & (0.31)\end{array}$

(103.70) (15.56) (0.31)

$\begin{array}{lll}181.49 & 27.22 & 0.55\end{array}$

$\begin{array}{lll}17.84 & 2.68 & 0.05\end{array}$

$\begin{array}{lll}1.58 & 0.24 & 0.00\end{array}$

$\begin{array}{lll}10.86 & 1.63 & 0.03\end{array}$

$30.28 \quad 4.54 \quad 0.09$

$\begin{array}{lll}211.77 & 31.77 & 0.64\end{array}$

$\underline{211.77} \quad \underline{31.77} \quad \underline{0.64}$

$\begin{array}{lll}8.10 & 1.22 & 0.02\end{array}$

$\begin{array}{lll}2.38 & 0.36 & 0.01\end{array}$

$\begin{array}{lll}0.41 & 0.06 & 0.00\end{array}$

$\begin{array}{lll}7.24 & 1.09 & 0.02\end{array}$

$\begin{array}{lll}4.90 & 0.74 & 0.01\end{array}$

$\begin{array}{lll}23.04 & 3.46 & 0.07\end{array}$

$\begin{array}{lll}10.88 & 1.63 & 0.03\end{array}$

0.01

$\begin{array}{lll}0.57 & 0.09 & 0.00\end{array}$

$\begin{array}{lll}16.29 & 2.44 & 0.05\end{array}$

$\underline{251.10} \quad \underline{37.67} \quad \underline{0.75}$

$\begin{array}{lll}60.56 & 9.08 & \mathbf{0 . 1 8}\end{array}$

$\underline{311.67} \underline{46.75} \quad \underline{0.94}$

$\begin{array}{lll}60.56 & 9.08 & \mathbf{0 . 1 8}\end{array}$

$\underline{372.23} \quad \underline{55.83} \quad \underline{1.12}$ 
Depreciation, at 10 percent of investment, contributes an additional $\$ 60.56$ per metric ton. Return on total capital investment, also at 10 percent of investment, contributes another $\$ 60.56$ per metric ton of ethanol.

The above cash cost, depreciation, and return on total capital investment yield a full cost of production of $\$ 372.23$ per metric ton ( $\$ 1.12$ per gallon) of ethanol.

2015

The economics for the production of 450 thousand metric tons (150 million gallons) per year of fuel grade ethanol at a U.S. Midwest location via corn dry milling are presented in Table 5.16.

The total plant capital cost is estimated to be $\$ 206.7$ million. This capital cost includes $\$ 102.9$ million for ISBL and $\$ 103.8$ million for OSBL. Other project costs are estimated to be $\$ 51.7$ million, resulting a total capital investment of $\$ 258.3$ million. An additional $\$ 48.4$ million is also estimated for the working capital requirement.

With corn price at $\$ 2.45$ per bushel, the raw Material cost is $\$ 300.49$ per metric ton of ethanol. By-product credit mainly from distiller's dried grains and solubles (DDGS) reduces the net raw Material cost to $\$ 170.98$ per metric ton of ethanol. Utilities contribute a credit of $\$ 34.17$ per metric ton, resulting in a variable cost of $\$ 205.15$ per metric ton of ethanol.

The total direct fixed cost, including all labors, maintenance, and direct overhead, is approximately $\$ 19.22$ per metric ton of ethanol. The total allocated fixed cost of the plant, including general plant overhead, insurance, property taxes, and environmental levy, is about $\$ 14.36$ per metric ton of ethanol. The total fixed costs bring the total cash cost to $\$ 238.74$ per metric ton (\$0.72 per gallon) of ethanol.

Depreciation, at 10 percent of investment, contributes an additional $\$ 57.41$ per metric ton. Return on total capital investment, also at 10 percent of investment, contributes another $\$ 57.41$ per metric ton of ethanol.

The above cash cost, depreciation, and return on total capital investment yield a full cost of production of $\$ 353.55$ per metric ton (\$1.06 per gallon) of ethanol. 


\section{Table 5.16 Cost Of Production Estimate For: Fuel Grade Ethanol Process: Corn Dry Milling 2015}

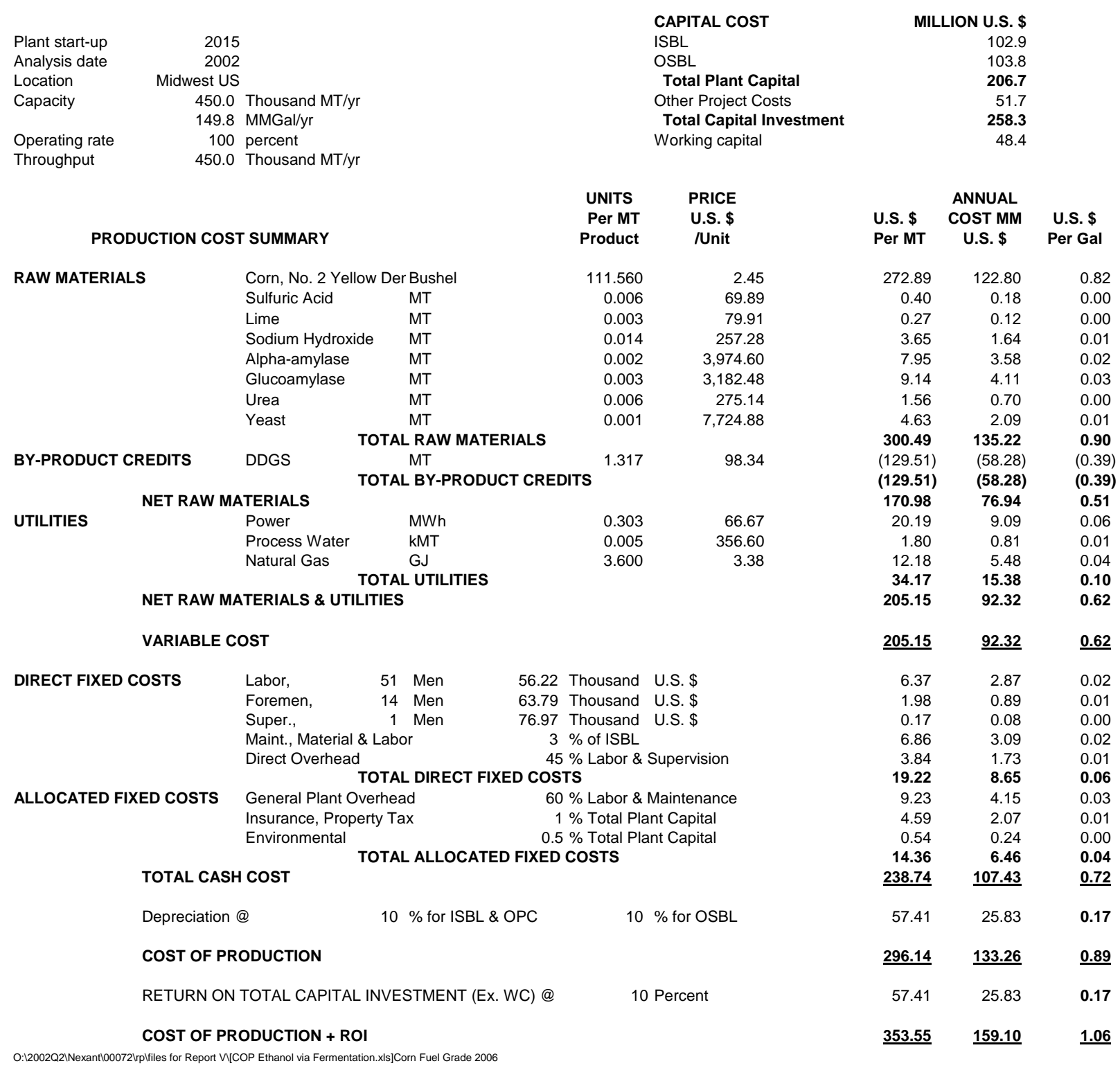




\subsubsection{Sensitivity Analysis}

2006

The effects of corn price, capital investment, and ethanol production capacity on the full cost of production of ethanol plus 10 percent ROI via corn dry milling process are shown in Figure 5.18.

With total capital investment maintained at $\$ 90.8$ million and ethanol production capacity maintained at 150 thousand metric tons (50 million gallons) per year, ethanol full cost of production plus 10 percent ROI increases from $\$ 372.23 /$ metric ton $(\$ 1.12 /$ gallon $)$ to $\$ 502.92 /$ metric ton $(\$ 1.51 /$ gallon) when corn price increases from $\$ 2.14 /$ bushel to $\$ 3.21 /$ bushel (i.e. 50 percent higher than the current estimate). Ethanol full cost of production plus 10 percent ROI decreases to $\$ 241.54 /$ metric ton $(\$ 0.73 /$ gallon) when corn price decreases to $\$ 1.07 /$ bushel (i.e. 50 percent lower than the current estimate). Thus, every dollar/bushel change in corn price results in an average change of $\$ 122.01 /$ metric ton $(\$ 0.37 /$ gallon) in ethanol full cost of production plus 10 percent ROI.

With corn price maintained at $\$ 2.14 /$ bushel and ethanol production capacity maintained at 150 thousand metric tons (50 million gallons) per year, ethanol full cost of production plus 10 percent ROI increases from \$372.23/metric ton (\$1.12/gallon) to $\$ 441.29 /$ metric ton ( $\$ 1.33 /$ gallon) when the total capital investment increases from $\$ 90.8$ million to $\$ 136.2$ million, i.e. 50 percent increase. Ethanol full cost of production plus 10 percent ROI decreases to $\$ 303.17 /$ metric ton $(\$ 0.91 /$ gallon) when the total capital investment decreases to $\$ 45.4$ million, i.e. 50 percent decrease. This represents an average of $\$ 152.1 /$ metric ton change in ethanol full cost of production plus 10 percent ROI for every $\$ 100$ million change in total capital investment.

With corn price maintained at $\$ 2.14 /$ bushel, ethanol full cost of production plus 10 percent ROI decreases from $\$ 372.23 /$ metric ton $(\$ 1.12 /$ gallon) to $\$ 360.85 /$ metric ton $(\$ 1.08 /$ gallon) when ethanol production capacity increases from 150 thousand metric tons (50 million gallons) per year to 225 thousand metric tons (75 million gallons) per year, i.e. 50 percent increase. Ethanol full cost of production plus 10 percent ROI increases to $\$ 393.21 /$ metric ton $(\$ 1.18 /$ gallon) when ethanol production capacity decreases to 75 thousand metric tons ( 25 million gallons) per year, i.e. 50 percent decrease. 


\section{Figure 5.18 Sensitivity Of Fuel Grade Ethanol From Corn Cost Of Production To Key Variables} (2006)
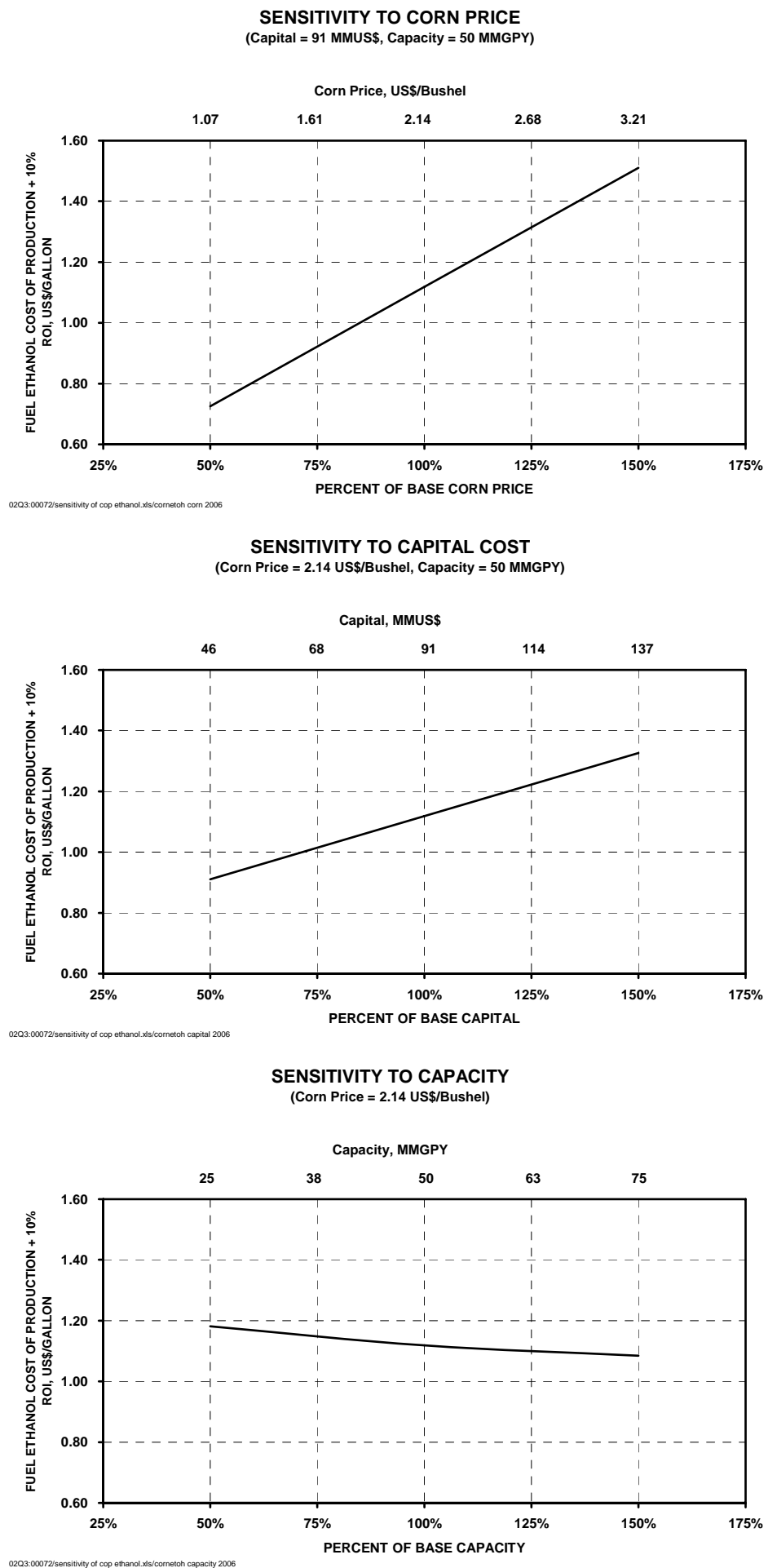


\section{5}

The effects of corn price, capital investment, and ethanol production capacity on the full cost of production of ethanol plus 10 percent ROI via corn dry milling process are shown in Figure 5.19.

With total capital investment maintained at $\$ 258.3$ million and ethanol production capacity maintained at 450 thousand metric tons (150 million gallons) per year, ethanol full cost of production plus 10 percent ROI increases from $\$ 353.55 /$ metric ton $(\$ 1.06 /$ gallon) to $\$ 490.00 /$ metric ton $(\$ 1.47 /$ gallon) when corn price increases from $\$ 2.45 /$ bushel to $\$ 3.68 /$ bushel (i.e. 50 percent higher than the current estimate). Ethanol full cost of production plus 10 percent ROI decreases to $\$ 217.10 /$ metric ton $(\$ 0.65 /$ gallon) when corn price decreases to $\$ 1.23 /$ bushel (i.e. 50 percent lower than the current estimate). Thus, every dollar/bushel change in corn price results in an average change of $\$ 111.56 /$ metric ton $(\$ 0.34 /$ gallon) in ethanol full cost of production plus 10 percent ROI.

With corn price maintained at $\$ 2.45 /$ bushel and ethanol production capacity maintained at 450 thousand metric tons (150 million gallons) per year, ethanol full cost of production plus 10 percent ROI increases from $\$ 353.55 /$ metric ton $(\$ 1.06 /$ gallon) to $\$ 419.01 /$ metric ton ( $\$ 1.26 /$ gallon) when the total capital investment increases from $\$ 258.3$ million to $\$ 387.5$ million, i.e. 50 percent increase. Ethanol full cost of production plus 10 percent ROI decreases to $\$ 288.09 /$ metric ton (\$0.87/gallon) when the total capital investment decreases to $\$ 129.2$ million, i.e. 50 percent decrease. This represents an average of $\$ 50.7 /$ metric ton change in ethanol full cost of production plus 10 percent ROI for every $\$ 100$ million change in total capital investment.

With corn price maintained at $\$ 2.45 /$ bushel, ethanol full cost of production plus 10 percent ROI decreases from $\$ 353.55 /$ metric ton $(\$ 1.06 /$ gallon) to $\$ 343.57 /$ metric ton $(\$ 1.03 /$ gallon) when ethanol production capacity increases from 450 thousand metric tons (150 million gallons) per year to 675 thousand metric tons ( 225 million gallons) per year, i.e. 50 percent increase. Ethanol full cost of production plus 10 percent ROI increases to $\$ 373.25 /$ metric ton $(\$ 1.12 /$ gallon) when ethanol production capacity decreases to 225 thousand metric tons ( 75 million gallons) per year, i.e. 50 percent decrease. 


\section{Figure 5.19 Sensitivity Of Fuel Grade Ethanol From Corn Cost Of Production To Key Variables} (2015)
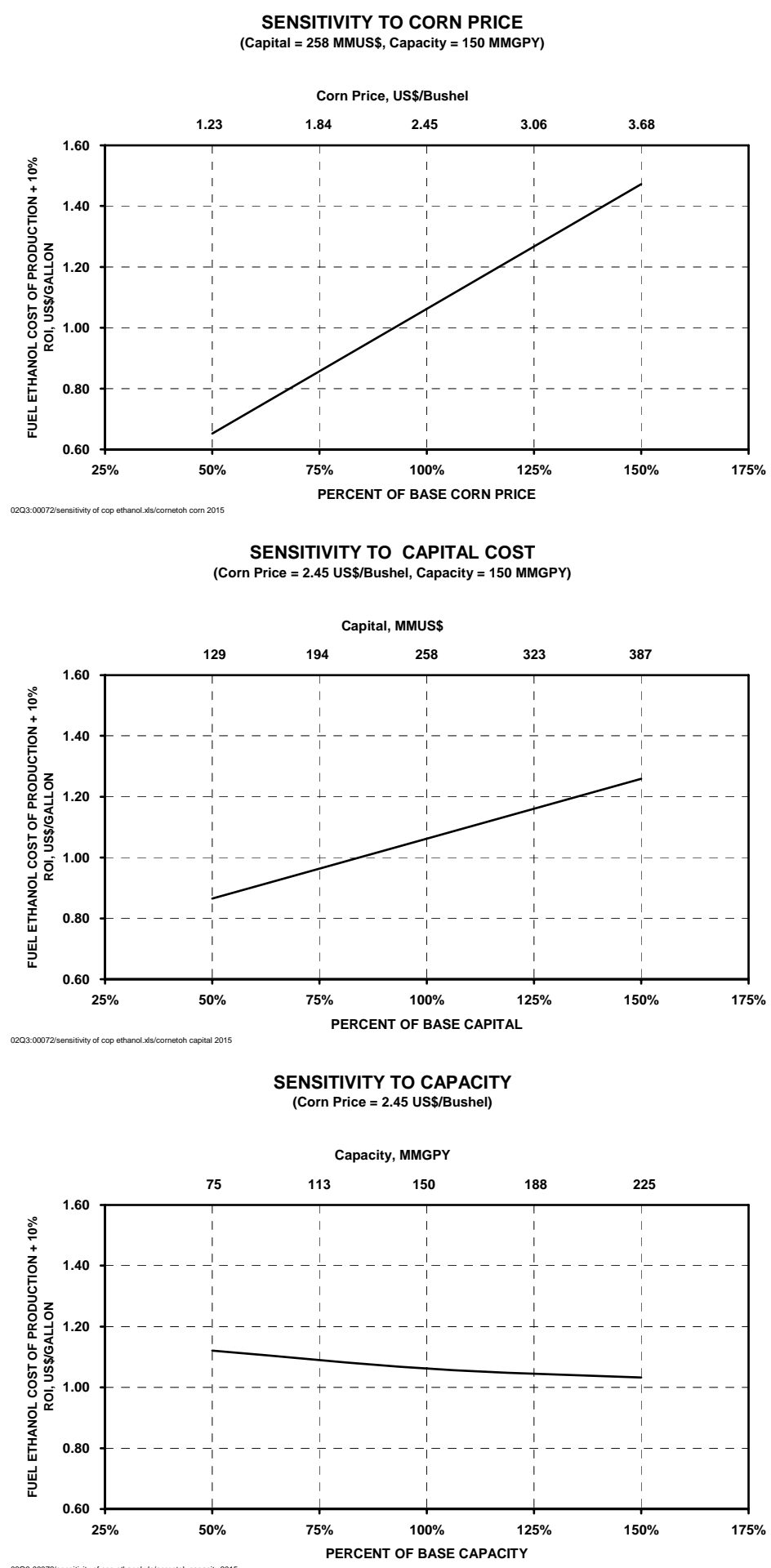


\subsection{STEAM METHANE REFORMING (SMR)}

\subsubsection{Introduction}

Steam reforming is probably the best-studied methane reaction. The catalyst of preference is a first-row transition metal such as nickel, generally supported on alumina. In the presence of this nickel catalyst, steam reacts with natural gas feedstock at elevated temperatures and pressures to give a reformed gas consisting of carbon dioxide, carbon monoxide, hydrogen and methane. The concentration of these constituents in the reformed gas depend on the ratio of steam to hydrocarbon passing over the catalyst, and on the temperature and pressure at which the gases leave the catalyst.

Prior to 1953, steam reforming of methane was conducted at atmospheric pressure. Since 1953, as the economic advantage of minimizing downstream compression costs tended to outweigh the desirability of minimizing the methane content of the reformer effluent, the process has been operated at ever-higher pressures. Pressures as high as 20 atmospheres are currently employed.

\subsubsection{Chemistry}

The nickel-catalyzed steam reforming reaction is typically conducted at $600-800^{\circ} \mathrm{C}(1,112$ $\left.1,472^{\circ} \mathrm{F}\right)$, using alumina-supported nickel, at a few atmospheres pressure and with excess steam to prevent char formation. Several studies have shown that higher temperatures are advantageous. Other catalysts include nickel-cobalt, nickel-uranium, nickel-platinum, on thorium dioxide-aluminum oxide, and nickel on magnesium oxide-silicon nitride. Cobalt has been used, as has cobalt-manganese on alumina, platinum wire, and surfaces of palladium, platinum, and ruthenium. However, the preferred catalyst is a first-row transition metal, usually nickel, and is generally supported, most often by alumina. Conversion to hydrogen and carbon monoxide is favored by relatively low temperature (e.g. below $1,000^{\circ} \mathrm{C}$ or $1,832^{\circ} \mathrm{F}$ ).

The reactions are complex, but the end product is determined by the simultaneous satisfaction of the steam/methane reactions and the water/gas-shift reaction.

$$
\begin{aligned}
& \mathrm{CH}_{4}+\mathrm{H}_{2} \mathrm{O} \longrightarrow \mathrm{CO}+3 \mathrm{H}_{2} \\
& \mathrm{CO}+\mathrm{H}_{2} \mathrm{O} \longrightarrow \mathrm{CO}_{2}+\mathrm{H}_{2}
\end{aligned}
$$

The overall reaction is endothermic. The essential reaction, the methane-steam reaction, is equilibrium-limited, with maximum conversion increasing with increasing temperature and with increasing steam/methane ratio in the feed, but decreasing with increasing pressure. The catalyst quantities and reaction conditions are arranged so that the reformed gases leaving the catalyst beds quite closely approach equilibrium with respect to the methane-steam reaction. This is expressed as "an approach to equilibrium," and usually 10 to $20^{\circ} \mathrm{C}$ is the difference between the actual outlet temperature and the equilibrium temperature for this reaction corresponding to the outlet composition. 
The steam reforming catalyst is also effective with respect to the water-gas shift reaction. The carbon monoxide formed by the methane-steam reaction is therefore partially converted to carbon dioxide by steam, to give an equilibrium temperature for the water-gas shift reaction (corresponding to the outlet composition) that is close to the actual outlet temperature.

When natural gas is the feedstock, the resulting synthesis gas is carbon deficient from the point of view of methanol synthesis reaction stoichiometry. If available, carbon dioxide can be added as supplemental feed to the reformer to compensate up for the carbon deficiency. For example:

$$
1 / 3 \mathrm{CO}_{2}+\mathrm{CH}_{4}+\mathrm{H}_{2} \mathrm{O} \longrightarrow 11 / 3 \mathrm{CO}+22 / 3 \mathrm{H}_{2}+1 / 3 \mathrm{H}_{2} \mathrm{O}
$$

It can also be added directly into the synthesis loop.

The stoichiometric ratio (" $R$ ") determines if the syngas feed is "balanced":

$$
\mathrm{R}=\left(\mathrm{H}_{2}-\mathrm{CO}_{2}\right) /\left(\mathrm{CO}+\mathrm{CO}_{2}\right)
$$

For example, in methanol production, a ratio close to 2 is desirable in order to minimize the excess hydrogen fed to the synthesis loop. Synthesis gas obtained by steam reforming natural gas (alone) produces synthesis gas with a ratio ranging from 2.6 to 3.0. A two-step reforming process combines conventional steam reforming with autothermal reforming. Operating with a synthesis gas close to stoichiometric reduces the recirculation rate and consequently the size of equipment and dipping of the synthesis loop, allowing for construction of larger single units.

\subsubsection{Process Description}

A simplified flow diagram for a steam/methane reformer is shown in Figure 6.1. Sulfur compounds are undesirable in the natural gas feedstock because of their harmful effect on the reforming catalyst. These compounds are poisonous and cause loss of catalyst activity. Hydrogen sulfide is removed by adsorption over zinc oxide granules in two-step reactors. The actual configuration is dependent on the sulfur concentration in the feedstock gas. In order to reduce the elemental sulfur, cyclic sulfur compound, mercaptans and other sulfur compounds to hydrogen sulfide, hydrogen is reacted with heated natural gas over cobalt-or nickel-molybdenum catalysts. The sour gas is then passed over beds of zinc oxide granules. The reaction may be represented as follows:

$$
\mathrm{ZnO}+\mathrm{H}_{2} \mathrm{~S} \longrightarrow \mathrm{ZnS}+\mathrm{H}_{2} \mathrm{O}
$$

The hydrotreaters are typically run at $350-400^{\circ} \mathrm{C}\left(662-752^{\circ} \mathrm{F}\right)$, requiring a feed preheat. The heat is usually supplied from the reformer stack heat recovery unit. In special conditions such as operating temperatures below $300^{\circ} \mathrm{C}\left(572^{\circ} \mathrm{F}\right)$, unusual sulfur compositions or processes using insitu catalyst regeneration, iron-based adsorbents can be used. Since zinc oxide bed desulfurizers can pick up an excess of 25 percent sulfur in the feed, almost complete desulfurization occurs, usually to below 0.5 ppm sulfur. 
In the presence of a nickel catalyst and elevated temperature and pressure, steam reacts with the natural gas feedstock to give a reformed gas consisting of carbon dioxide, carbon monoxide, hydrogen, water, and methane. The concentration of these constituents depends on the ratio of steam to hydrocarbon passing over the catalyst, and on the temperature and pressure at which the gases leave the catalyst.

Typical steam/methane reforming operating conditions (without $\mathrm{CO}_{2}$ addition) are given in Table 6.1. (Approach to equilibrium: water-gas shift $=0^{\circ} \mathrm{F}$ and methane-steam reforming $=$ $40^{\circ} \mathrm{F}$.)

Steam and natural gas are mixed in a ratio of 2.8 mols of steam per mol of carbon contained in the natural gas feedstock. The endothermic reforming reaction takes place inside externally heated vertical tubes located inside a refractory-lined reforming furnace. These tubes are packed with a nickel catalyst. 


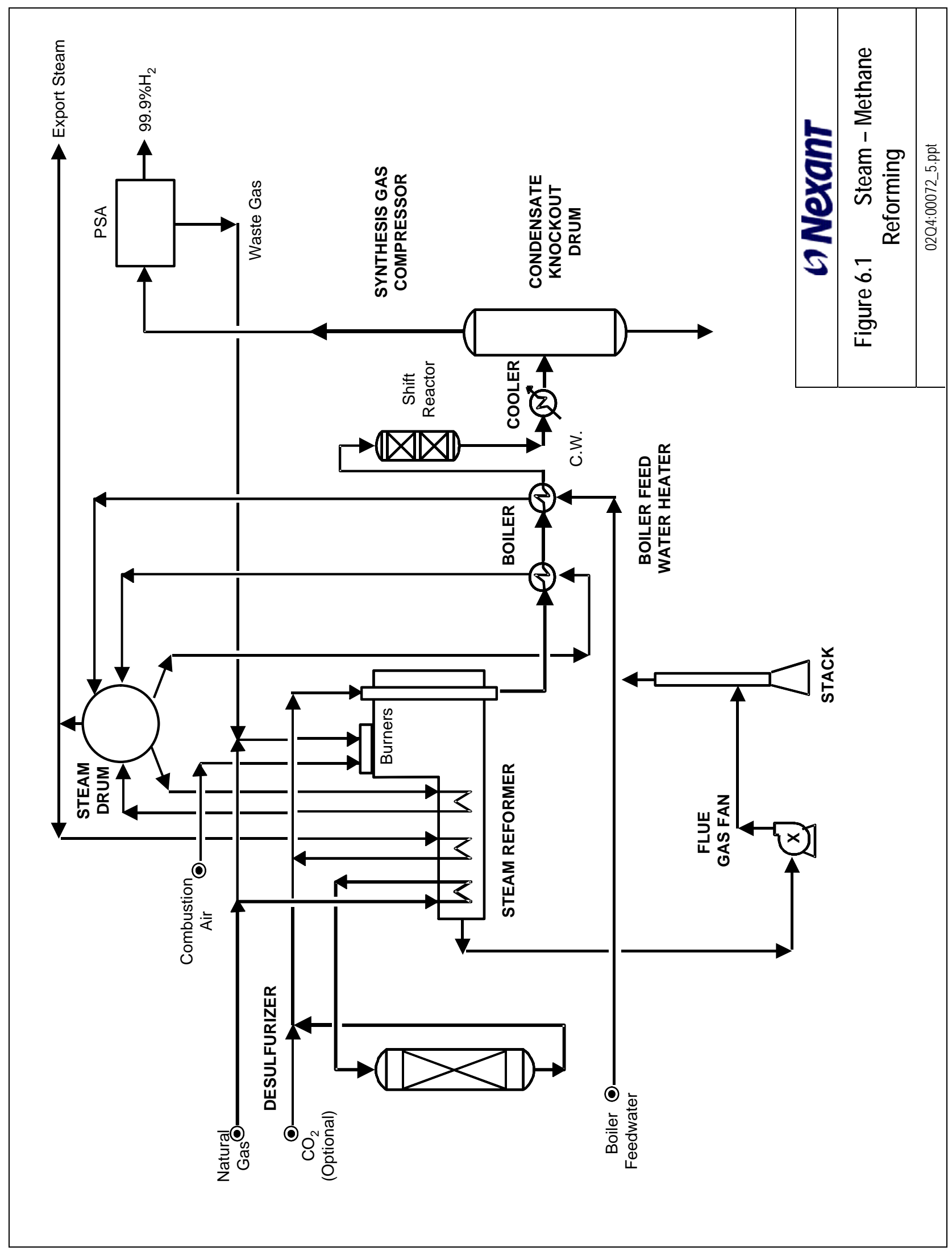




\section{Table 6.1 Typical Steam/Methane Reforming Operating Conditions}

\begin{tabular}{|l|c|}
\hline Methane conversion, pct. & 85.4 \\
\hline Steam to reformer, mols/mol $\mathrm{CH}_{4}$ & 2.8 \\
\hline Preheat temperature, ${ }^{\circ} \mathrm{C}\left({ }^{\circ} \mathrm{F}\right)$ & $371(700)$ \\
\hline Reformer exit temperature, ${ }^{\circ} \mathrm{C}\left({ }^{\circ} \mathrm{F}\right)$ & $886(1,627)$ \\
\hline Operating pressure, bara (psia) & $24(348)$ \\
\hline Effluent composition (dry basis), vol. pct. & 16.44 \\
\hline Carbon monoxide & 73.96 \\
\hline Hydrogen & 6.16 \\
\hline Carbon dioxide & 3.44 \\
\hline Methane & 100.0 \\
\hline $\mathrm{H}_{2} / \mathrm{CO}$ & Total \\
\hline$\left(\mathrm{H}_{2}-\mathrm{CO}_{2}\right) /\left(\mathrm{CO}+\mathrm{CO}_{2}\right)$ & 4.5 \\
\hline
\end{tabular}

Burners located in the furnace supply reaction heat. These burners are designed to handle natural gas or a mixture of natural gas, loop purge gases, and waste streams from the distillation section. The burners are also supplied with air preheated by heat exchange with the reformer flue gases.

Flue gases produced by the fuel combustion leave the furnace and pass into a refractory-lined duct before leaving through the stack. This is the convection section of the reformer; waste heat from the flue gas is recovered in this section to preheat reformer feed gas, preheat desulfurizer feed, pass through a steam-raising economizer, and finally a burner air supply preheater. To meet the process heat duty requirements in the convection bank, it is necessary to fire special burners located in this flue gas duct. These are fired with natural gas fuel and preheated combustion air.

Since only about 50 percent of the generated heat is transferred in the radiant section, heat recovery in the convection section is necessary to recover the remaining waste heat. Design of the waste heat recovery system varies from contractor to contractor, but usually includes the heat recovery systems, in the previously discussed order. The reformer effluent gases are also passed through heat recovery systems similar to flue gas waste heat recovery. The reformed gas is then cooled (usually with cooling water or air cooled exchangers) to condense any remaining water vapor prior to compression.

Reformer design is critical to process efficiency. Many different designs are available from a wide variety of suppliers (e.g. Krupp Uhde, Haldor Topsoe). The primary design characteristics of the reformer are burner location, flue gas heat recovery, and tube layout and design.

Burners located in the furnace supply heat to the reaction. These burners can be designed to handle a multitude of fuels, depending on the location of the reformer and available feedstocks. 
Air supplied to the burners is usually preheated with reformer flue gases. Side- and top-fired reformers are the most common types.

Top-fired reformers (e.g. Krupp Uhde) use turbulent, open-jet burners to provide a stable 2meter flame, providing heat transfer to the tubes mainly via flue gas radiation. The flue gases flow via forced convection down through the reformer to the convection section. The gases heat multiple rows of tubes that extend from top to bottom. These units are appropriate for larger processes, using fewer burners than the side-fired units and a more compact construction. Topfiring allows radiant heat transfer from one burner to two sides of the tubes as opposed to one side, and provides more efficient heat transfer by matching maximum heat flux requirements with the high flame temperature.

Side-fired reformers (e.g. Haldor Topsoe) have burners on the walls at even locations from top to bottom to provide even tube heating of a single row of tubes, located centrally in the radiant box. Heat transfer is primarily via radiation from the refractory wall. This unit is more attractive for smaller processes, since the firebox is small and the flue gases flow out from the top, possibly eliminating the need for a flue gas blower. The main drawbacks are the large number of burners needed and the possibility of flame impingement on the tubes if the burners are poorly controlled or maintained.

Bottom- and terraced-fired reformers are no longer used. Bottom-fired reformers have easy access to the burners and allow natural convection to carry away combustion products. However, they tend to overheat the tube exits, requiring a substantial margin in tube design and forcing lower operating temperatures. Since reformer tube exit temperature determines reaction equilibrium in the reforming section, it is critical that exit temperature is will controlled.

Terrace-fired furnaces are a modification of bottom-fired reformers. They have slightly lower tube temperature, require many burners, and are limited in size due to the need for one terraced bank of burners per single row of tubes. The tubes are also susceptible to a temperature pinch point where the middle of the tubes are subject to both convective heat flux from combustion products and radiative heat flux from the burners and refractory.

Tubes constitute approximately 30 percent of the total reformer cost. Tube placement and thickness are determined by the burner layout and the temperature profile expected in the reformer tubes. Other parameters affecting tube design are thermal expansion and operating conditions. Simulations of these parameters are now commonly done simultaneously with reaction kinetics and thermodynamics on computers to insure an efficient tube design. Once the temperature profile is determined, based on the stress-to-rupture strength for a 100,000-hour lifetime, the tube thickness is calculated.

Spacing between the tubes, or tube pitch, is also critical in terms of heat transfer. If tubes are warped to not evenly spaced, heat transfer will be uneven to each tube and product quality will suffer. In newer designs this spacing is taken into account during computer modeling. 
Reformer tubes are generally 73-125 mm in diameter; have wall thicknesses of 10-20 mm; and exposed ("fired") lengths of 9-15 m. The main constraint on tube design is the Material of construction, which must be able to be operated for long periods at temperature exceeding $800^{\circ} \mathrm{C}$ $\left(1,472^{\circ} \mathrm{F}\right)$. Economics combined with the metallurgical strength (based on temperature/pressure relationships) of acceptable alloys limit operating pressure differential between the tube inside and the firebox to about 25 bar (363 psi). The reformer conditions make the tubes susceptible to creep-to-rupture corrosion: the high temperature approach to softening point of the metals, which eventually thin out enough to rupture. The tubes also undergo significant longitudinal expansion during start-up, which requires the use of expansion joints at the tube connection of the feed or product manifolds.

The most commonly used alloy is $\mathrm{HK} 40$ (G-X $40 \mathrm{CrNiSi} 2520)$, a high carbon, 20 percent nickel/25 percent chromium alloy steel. Tubes are formed in $3 \mathrm{~m}$ lengths via centrifugal casting. Due to the $2-3 \mathrm{~mm}$ porous casting layer caused by centrifugal casting, extra thickness must be added to the tubes; the porous layer is susceptible to corrosion cracking and does not contribute to tube strength. The tube sections are then welded into total desired lengths, 3-6 $\mathrm{m}$ in excess of required fired length.

Uniform heat transfer through the reformer tube walls is the main concern in proper reformer and tube design. High-heat fluxes exceeding $63,000 \mathrm{~W} / \mathrm{m}^{2} \mathrm{hr}\left(20,000 \mathrm{Btu} / \mathrm{ft}^{2}-\mathrm{hr}\right)$ are common, and local hot spots can be a problem. Krupp Uhde now claims to design for a average heat flux of $80,000 \mathrm{~W} / \mathrm{m}^{2} \mathrm{hr}\left(25,400 \mathrm{Btu} / \mathrm{ft}^{2}-\mathrm{hr}\right)$ using a micro-alloy tube Material. This results in a reformer tube number reduction of about 25 percent. The tubes bear the brunt of stresses and corrosion in the reformer and in spite of all improvement of alloys, testing and manufacturing the tubes remain a component of limited lifetime (approx. ten years). The thermal stresses are due to temperature gradients between tube ends and between the tube and reformer box. If the flow to each tube does not balance the heat transferred to that tube, production quality decreases, and thermal stresses increase on the overused tubes. Upsets and flame impingements further attack tube integrity. External tube corrosion is mainly from burner combustion products; unfortunately, metallurgies normally used to protect against corrosion due to sulfur or ash content of burner fuels are not generally strong enough for use as reformer tubes.

Creep is the principal source of tube rupture. At prolonged high temperature, Materials tend to creep (permanent deformation due to elastic flow) independently of stress levels. Eventually creep effects will deform a tube section enough to cause a failure, known as creep rupture. In the elastic temperature range of the tube Material, designs are based on yield strength, while in the creep temperature range, design allowable stress is based on the rupture strength.

Since higher temperature result in faster creep rupture, tube design must incorporate designs that minimize hot spots due to poor internal flow, catalyst problems, furnace impingement, or plugging. The American Petroleum Institute has a set of guidelines, API RP 530, "Recommended Practice for Calculation of Heater Tube Thickness in Petroleum Refineries," which delineate temperature-pressure curves for creep-rupture stress allowances. 
One recent solution to corrosion problems was the introduction of compound tubes. Compound centrifugals casting is used to produce tubes with walls built up of two different Materials, providing customized tubes of heat-resistant Material coupled with a corrosion-resistant outer layer.

Attaching the tubes to one fixed manifold, and allowing the free expansion on the other end via pigtails relieve expansion stresses. The pigtails take up the expansion of the inlet header and branches, with the unfixed manifold pigtail taking up the tube expansion. The pigtails and manifolds are usually made of Incoloy $800 \mathrm{H}$ drawn. For top-fired reformers, tubes are generally suspended from the top via springs, with the stationary header located at the bottom. Location of expansion springs is, of course, dependent on burner configuration.

With natural gas as the feedstock, the resulting synthesis gas is carbon-deficient. Hydrogen purification is completed after converting the carbon monoxide to carbon dioxide via the water gas shift reaction and passing the effluent through a pressure swing adsorption unit (PSA). The resulting hydrogen stream is 99.9 percent pure. The waste gas from the PSA unit is burned in the reformer furnace.

Although conventional reformer technology has been in use for over 60 years, there remain major drawbacks inherent to the basic technology.

- Reformer tubes work under extreme temperature ranges and pressure differentials that lead to thick-walled, expensive tubes. These tubes require exotic metallurgies or construction to provide reasonable lifetimes while dealing with temperatures and pressure extremes, hydrogen stress, and flue gas corrosion.

- The reformer itself is a large piece of equipment; the furnace box is often over five stories high. This necessitates significant on-site fabrication. Given the thermal inertia such a large system has, this also means prolonged start-up and shut-down times.

- The reformers lose large amounts of heat up the stack. To counter these losses, complex heat recovery systems, including air heating, feed preheat and steam raising and superheating, are added to the stack. This greatly increases capital costs and the complexity of the system.

- To improve combustion and heating within the reformer fire box, complex burner and combustion air systems require a high level of manual intervention and start-up, shutdown and normal operation.

The hydrogen production efficiency could be increased due to Material and hardware developments, as well as developments in catalysts. In the recent past improvements to the production of syngas have come from two sources: through the incremental improvement of existing technology and the introduction of newer technologies. The former has been the source of almost all improvements in the process since its commercialization in the 1940s. Only 
recently have new technologies been introduced or studied that have the possibility of offering major improvements in the cost intensive process of syngas production.

Krupp Uhde has taken steam methane reforming and autothermal reforming (or catalytic partial oxidation) an combined both steps into one system, incorporating heat recovery systems comparable to ICI's Heated Reformer technology and KTI's Potformer technology.

Referring to Figure 6.2 desulfurized methane is split between a primary reformer and the Combined Autothermal Reformer (CAR) reactor. The CAR methane feed is mixed with steam and fed into the CAR reactor via a sandwich-type design tubesheet. The feed passes through catalyst-filled tubes that reform the gas. The heat for the reforming reactions is supplied by the autothermal reforming of the bypassed methane. The tubes empty into a lower chamber, where the gas is mixed with oxygen; temperature rise to $1,300^{\circ} \mathrm{C}\left(2,372^{\circ} \mathrm{F}\right)$. The hot gas is then passed over the tubes, supplying the heat duty for the reforming section of the reactor. The cooled gas then exits the CAR unit for downstream compression as necessary. The operating conditions are shown in Table 6.2.

Table 6.2 CAR Operating Conditions

\begin{tabular}{|c|c|}
\hline Steam-to-carbon ratio, mol/mol & \\
\hline Catalytic reforming & 2.5 \\
\hline Overall & 1.5 \\
\hline Syngas composition, vol\% (dry basis) & \\
\hline Hydrogen & 67.0 \\
\hline Carbon monoxide & 24.2 \\
\hline Carbon dioxide & 7.2 \\
\hline Methane & 0.5 \\
\hline Inert Materials & 1.1 \\
\hline
\end{tabular}

The unit runs at pressures of up to 40 barg (580 psig), which reduces compression duties when compared to steam methane reforming. CAR benefits also include the production of stoichiometric syngas (as opposed to hydrogen-rich syngas from steam methane reforming) in terms of methanol production, faster process start-up and a smaller footprint than steam methane reforming.

Drawbacks include requiring imported steam and/or electricity for drivers usually powered by steam turbines and an air separation plant to supply oxygen $(0.5 \mathrm{~mol}$ of oxygen per mol of carbon) for the autothermal portion of the reforming reactions. 


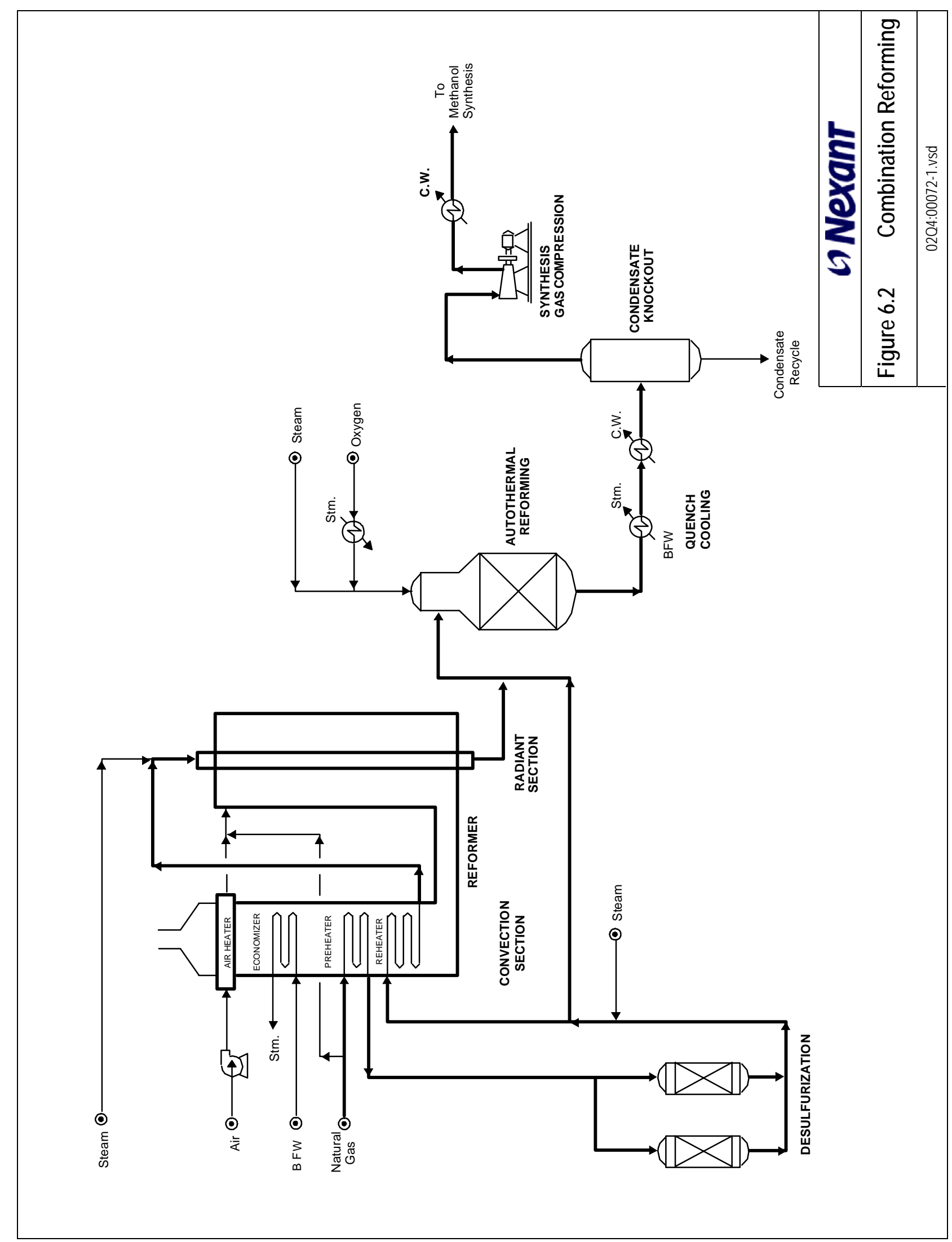




\subsubsection{Process Economics}

\subsubsection{Economic Assumptions}

The cost of production of syngas $\left(\mathrm{H}_{2} / \mathrm{CO}\right)$ via steam methane reforming has been evaluated for commercially demonstrated technology in 2006 and for emerging technology in 2015 for an operating rate of 90 percent. Capacity is based on the same capacity as syngas produced for a 5,000 ton per day methanol facility. The economics for 2015 reflect lower utility consumption, higher yields and lower investment expected through technology improvements.

\subsubsection{Feedstock and Utilities Pricing and Labor Costs}

The pricing basis for the study years (2006 and 2015) are presented in Table 6.3.

Table 6.3 Feedstock And Utilities Pricing And Labor Costs (USGC)

\begin{tabular}{|c|c|c|c|}
\hline & Units & 2006 & 2015 \\
\hline \multicolumn{4}{|l|}{ Feedstocks/By-products } \\
\hline Natural Gas & \$/Million Btu & 2.914 & 3.569 \\
\hline \multicolumn{4}{|l|}{ Utilities } \\
\hline Power & $\$ / K W h$ & 0.054 & 0.067 \\
\hline Fuel & \$/Million Btu & 2.914 & 3.569 \\
\hline Cooling Water & \$/Thousand Gal & 0.100 & 0.125 \\
\hline Boiler Feed water & \$/Thousand Gal & 1.843 & 2.298 \\
\hline MP Steam & \$/Thousand Lb & 5.420 & 6.671 \\
\hline Inert Gas & \$/Thousand SCF & 1.690 & 2.105 \\
\hline \multicolumn{4}{|l|}{ Manpower } \\
\hline Labor & $\$ /$ Man/Year & 45,061 & 56,219 \\
\hline Foreman & $\$ /$ Man/Year & 51,078 & 63,789 \\
\hline Supervisor & \$/Man/Year & 61,630 & 76,968 \\
\hline
\end{tabular}

\subsubsection{Process Economics}

The cost of production of syngas $\left(\mathrm{H}_{2} / \mathrm{CO}\right)$ via steam methane reforming is summarized in Table 6.4. In 2006 the cash cost of production is $\$ 122$ per ton ( $\$ 1.36$ per thousand SCF). Adding in the depreciation and a return on investment results in the full cost of production equal to $\$ 190$ per ton ( $\$ 2.12$ per thousand SCF). The full cost excluding the feed is $\$ 97$ per ton ( $\$ 1.09$ per thousand SCF). In 2015 the cash cost of production increases to $\$ 144$ per ton ( $\$ 1.61$ per thousand SCF) and the full cost of production increases to $\$ 213$ per ton $(\$ 2.38$ per thousand $\mathrm{SCF})$. The full cost excluding the feed is $\$ 100$ per ton ( $\$ 1.12$ per thousand SCF). 
Table 6.4 Syngas Cost of Production - Steam Methane Reforming (USGC, dollars per metric ton)

\begin{tabular}{|l|l|l|}
\hline & 2006 & 2015 \\
\hline Variable costs & 106 & 128 \\
\hline Fixed costs & 16 & 16 \\
\hline Depreciation + Return & 68 & 70 \\
\hline Full Cost of Production & 190 & 213 \\
\hline Full Cost of Production ex. Feed & 97 & 100 \\
\hline
\end{tabular}

Table 6.5 shows the costs for producing pure (99.9 percent) hydrogen via a PSA unit. In 2006 the full cost of production including depreciation and return on investment is $\$ 1,386$ per ton ( $\$ 3.34$ per thousand SCF). In 2015 the cost is $\$ 1,516$ per ton ( $\$ 3.65$ per thousand SCF). The costs are summarized in Figure 6.3.

Table 6.5 Hydrogen Cost Of Production - Steam Methane Reforming/PSA (USGC, dollars per metric ton)

\begin{tabular}{|l|c|c|}
\hline & 2006 & 2015 \\
\hline Variable costs(1) & 722 & 835 \\
\hline Fixed costs & 11 & 11 \\
\hline Depreciation + Return(2) & 652 & 670 \\
\hline Full Cost of Production & 1,386 & 1,516 \\
\hline & & \\
\hline $\begin{array}{l}\text { (1) Syngas at cash cost } \\
\text { (2) Depreciation and return include syngas portion of plant }\end{array}$ \\
\hline
\end{tabular}




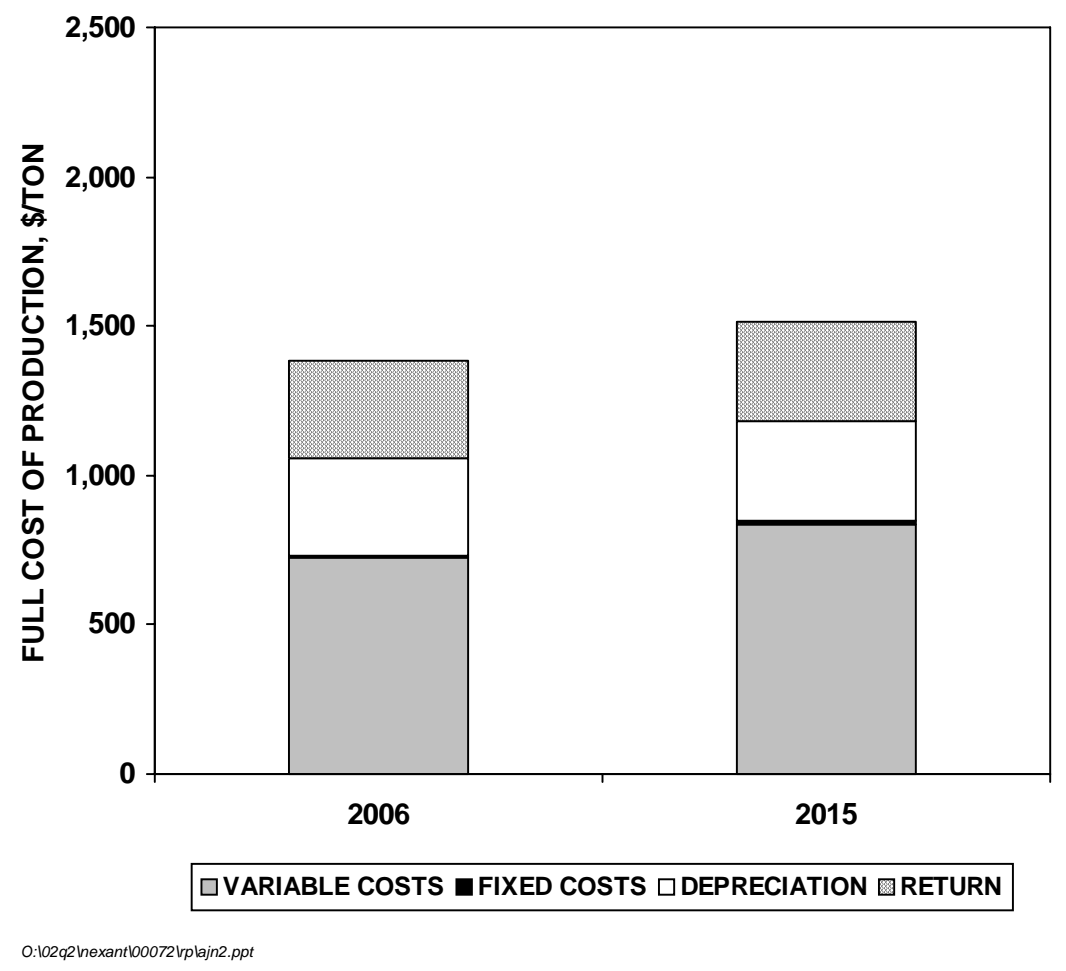

Figure 6.3 Hydrogen Cost Of Production Via SMR

$(>99.9 \%$, USGC)

The detailed estimates of the costs of production are shown on Table 6.6 and Table 6.7 for syngas in 2006 and 2015 and Table 6.8 and Table 6.9 for hydrogen in 2006 and 2015. 


\section{Table 6.6 Cost Of Production Estimate For: Syngas $\left(\mathrm{H}_{2} / \mathrm{CO}=4.5\right)$ Process: Steam Methane Reforming 2006}

$\begin{array}{lc}\text { Plant start-up } & 2006 \\ \text { Analysis date } & 2002 \\ \text { Location } & \text { USGC } \\ \text { Capacity } & 162 \text { Million kSCF/yr } \\ & 1,807 \text { Thousand metric tons/yr } \\ \text { Operating rate } & 90 \text { percent } \\ \text { Throughput } & 146 \text { Million kSCF/yr }\end{array}$

PRODUCTION COST SUMMARY

$\begin{array}{ll}\text { RAW MATERIALS } & \text { Natural Gas (as raw materia) } \\ & \text { Natural Gas (as net fuel) } \\ \text { Catalyst \& Chemicals }\end{array}$

BY-PRODUCT CREDITS Catalyst \& Chemicals

$\begin{array}{cc} & \text { NET RAW MATERIALS } \\ \text { UTILITIES } & \text { Power } \\ & \text { Cooling Water } \\ \text { Steam, MP } \\ \text { Boiler Feedwater }\end{array}$

TOTAL BY-PRODUCT CREDITS

NET RAW MATERIALS \& UTILITIES

VARIABLE COST

\begin{tabular}{ll} 
& \multicolumn{2}{c}{ NET RAW MATERIALS \& UTILITIES } \\
\multicolumn{1}{c}{ VARIABLE COST } \\
DIRECT FIXED COSTS & Labor, \\
& Foremen, \\
& Super., \\
& Maint., Material \& Labor \\
& Direct Overhead \\
ALLOCATED FIXED COSTS & $\begin{array}{l}\text { General Plant Overhead } \\
\text { Insurance, Property Tax } \\
\end{array}$ \\
& Environmental
\end{tabular}

TOTAL CASH COST

$\begin{array}{lcc}\text { kWh } & 1.1700 & 0.0539 \\ \text { M Gal } & 0.4800 & 0.1003 \\ \text { M Lb } & (0.0290) & 5.4196 \\ \text { M Gal } & 0.0220 & 1.8430\end{array}$

CAPITAL COSTMILLION U.S. \$

ISBL

Project Costs

Total Capital Investm

Working capital 24.8

TOTAL UTILITIES

\begin{tabular}{|c|c|}
\hline UNITS & PRICE \\
\hline $\begin{array}{l}\text { Per Gal } \\
\text { Product }\end{array}$ & $\begin{array}{l}\text { U.S. \$ } \\
\text { IUnit }\end{array}$ \\
\hline 0.3540 & 2.9141 \\
\hline 0.046 & 2.9141 \\
\hline 1.0000 & 0.0238 \\
\hline
\end{tabular}

ANNUAL
4 Men
1 Men
45.50 Thousand U.S. \$
54.90 Thousand U.S. \$
$3 \%$ of ISBL
TOTAL DIRECT FIXED COSTS
Labor \& Supervision
$65 \%$ Labor \& Maintenance
$1 \%$ Total Plant Capital
0.5 \% Total Plant Capital

18 Men

40.10 Thousand U.S. \$

Depreciation @

TOTAL ALLOCATED FIXED COSTS

U.S. \$ COST MM U.S. \$

Per Gal U.S. \$ Per MT

$1.032 \quad 150.20$

$0.136 \quad 19.73$

$0.024 \quad 3.46$

$\begin{array}{rrr}1.191 & 173.38 & 107\end{array}$

$0.000 \quad 0.00$

$0.000 \quad 0.00$

$\begin{array}{lll}0.000 & 0.00 & 0\end{array}$

$\begin{array}{rrr}0.000 & 0.00 & 0 \\ 1.191 & 173.38 & 107\end{array}$

$\begin{array}{rr}\mathbf{1 . 1 9 1} & \mathbf{1 7 3 . 3 8} \\ 0.063 & 9.18\end{array}$

$0.048 \quad 7.01$

$(22.88)$

$0.041 \quad 5.90$

$\begin{array}{lll}(0.005) & (0.79) \quad(0)\end{array}$

$\begin{array}{lll}1.185 & 172.59 & 106\end{array}$

$1.185 \quad 172.59$

COST OF PRODUCTION

$10 \%$ for ISBL

$10 \%$ for OSBL \& OPC

$1.742 \quad 253.67$

RETURN ON TOTAL CAPITAL INVESTMENT (Ex. WC) @

10 Percent

$0.378 \quad 55.03$

$\begin{array}{lll}2.120 & 308.71 & 190\end{array}$

COST OF PRODUCTION + ROI 


\section{Table 6.7 Cost Of Production Estimate For: Syngas $\left(\mathrm{H}_{2} / \mathrm{CO}=4.5\right)$ Process: Steam Methane Reforming 2015}

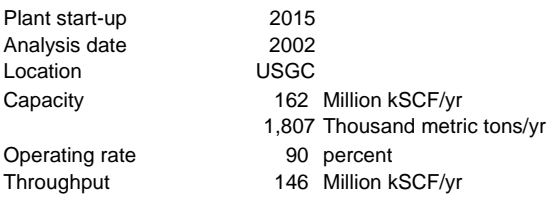

RAW MATERIALS

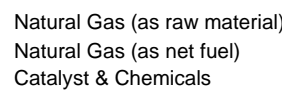

BY-PRODUCT CREDITS

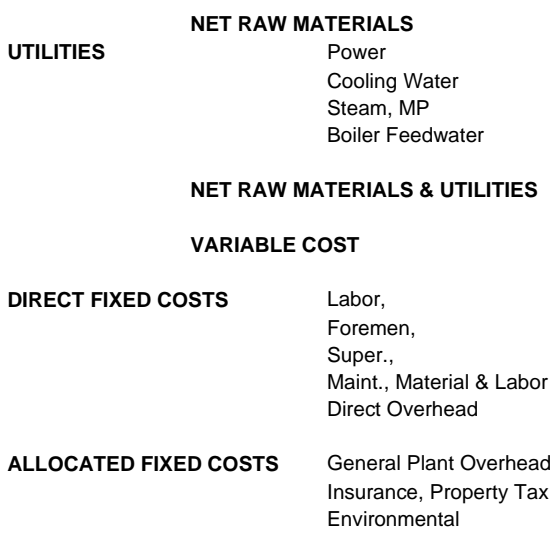

TOTAL CASH COST

Depreciation@

COST OF PRODUCTION

RETURN ON TOTAL CAPITAL INVESTMENT (Ex. WC) @

18 Men

4 Men

1 Men

35.72 Thousand U.S. \$

40.50 Thousand U.S. \$

48.94 Thousand U.S. \$

$3 \%$ of ISBL

TOTAL DIRECT FIXED COSTS

$45 \%$ Labor \& Supervision

$65 \%$ Labor \& Maintenance

$1 \%$ Total Plant Capital

TOTAL ALLOCATED FIXED COSTS

COST OF PRODUCTION + ROI

$\begin{array}{lr}\text { CAPITAL COST MILLION U.S. \$ } & \\ \text { ISBL } & 361.2 \\ \text { OSBL } & 90.3 \\ \text { Total Plant Capital } & \mathbf{5 1 . 5} \\ \text { Other Project Costs } & 112.9 \\ \quad \text { Total Capital Investment } & \mathbf{5 6 4 . 4} \\ \text { Working capital } & 25.4\end{array}$

ANNUAL

U.S. \$ COST MM U.S. \$

Per Gal U.S. \$ Per MT

\begin{tabular}{|c|c|c|}
\hline 1.264 & 183.96 & \\
\hline 0.152 & 22.07 & \\
\hline 0.022 & 3.16 & \\
\hline 1.437 & 209.20 & 129 \\
\hline 0.000 & 0.00 & \\
\hline 0.000 & 0.00 & \\
\hline 0.000 & 0.00 & 0 \\
\hline 1.437 & 209.20 & 129 \\
\hline 0.071 & 10.38 & \\
\hline 0.060 & 8.71 & \\
\hline (0.193) & (28.17) & \\
\hline 0.051 & 7.36 & \\
\hline$(0.012)$ & (1.72) & (1) \\
\hline 1.425 & 207.48 & 128 \\
\hline 1.425 & 207.48 & 128 \\
\hline 0.004 & 0.64 & \\
\hline 0.001 & 0.16 & \\
\hline 0.000 & 0.05 & \\
\hline 0.074 & 10.84 & \\
\hline 0.003 & 0.38 & \\
\hline 0.083 & 12.07 & 7 \\
\hline 0.052 & 7.60 & \\
\hline 0.031 & 4.52 & \\
\hline 0.016 & 2.26 & \\
\hline 0.099 & 14.37 & 9 \\
\hline 1.607 & 233.93 & 144 \\
\hline 0.388 & 56.44 & 35 \\
\hline 1.994 & 290.37 & 179 \\
\hline 0.388 & 56.44 & 35 \\
\hline & 346.80 & 213 \\
\hline
\end{tabular}

$10 \%$ for OSBL \& OPC

10 Percent
2.382

213 


\section{Table 6.8 Cost Of Production Estimate For: Hydrogen Process: Steam Methane Reforming/PSA 2006}

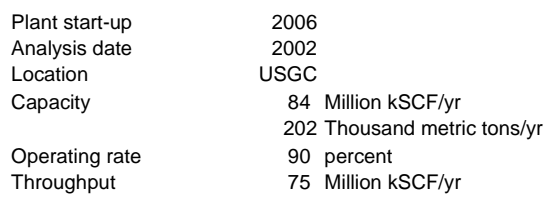

$\begin{array}{lr}\text { CAPITAL COST MILLION U.S. \$ } & \\ \text { ISBL } & 27.1 \\ \text { OSBL } & 6.8 \\ \text { Total Plant Capital } & \mathbf{3 3 . 9} \\ \text { Other Project Costs } & 8.5 \\ \text { Total Capital Investment } & \mathbf{4 2 . 4} \\ \text { Working capital } & 1.9\end{array}$

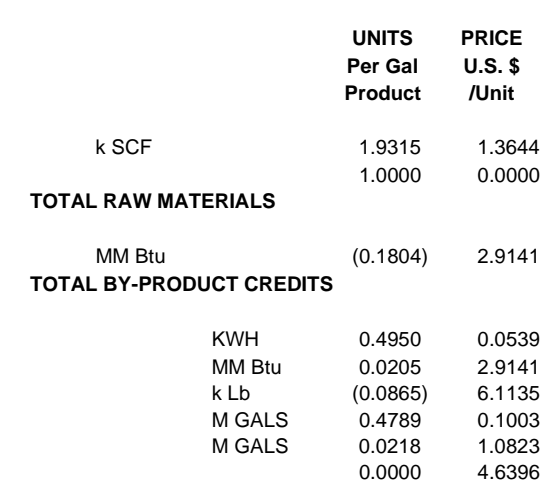

TOTAL UTILITIES

\begin{tabular}{|c|c|c|}
\hline & ANNUAL & \\
\hline U.S. \$ & COST MM & U.S. \$ \\
\hline Per Gal & U.S. \$ & Per MT \\
\hline 2.635 & 198.64 & \\
\hline 0.000 & 0.00 & \\
\hline 2.635 & 198.64 & 1,094 \\
\hline 0.000 & 0.00 & \\
\hline$(0.526)$ & (39.64) & \\
\hline$(0.526)$ & (39.64) & (218) \\
\hline 2.109 & 159.01 & 875 \\
\hline 0.027 & 2.01 & \\
\hline 0.060 & 4.50 & \\
\hline (0.529) & (39.84) & \\
\hline 0.048 & 3.62 & \\
\hline 0.024 & 1.78 & \\
\hline 0.000 & 0.00 & \\
\hline$(0.370)$ & (27.93) & (154) \\
\hline 1.739 & 131.08 & 722 \\
\hline 1.739 & 131.08 & 722 \\
\hline 0.002 & 0.12 & \\
\hline 0.000 & 0.00 & \\
\hline 0.000 & 0.00 & \\
\hline 0.011 & 0.81 & \\
\hline 0.001 & 0.05 & \\
\hline 0.013 & 0.99 & 5 \\
\hline 0.008 & 0.61 & \\
\hline 0.005 & 0.34 & \\
\hline 0.002 & 0.17 & \\
\hline 0.015 & 1.12 & 6 \\
\hline 1.767 & 133.19 & 733 \\
\hline 0.786 & 59.27 & 326 \\
\hline 2.553 & 192.46 & 1,060 \\
\hline 0.786 & 59.27 & 326 \\
\hline 3.340 & 251.74 & 1,386 \\
\hline
\end{tabular}

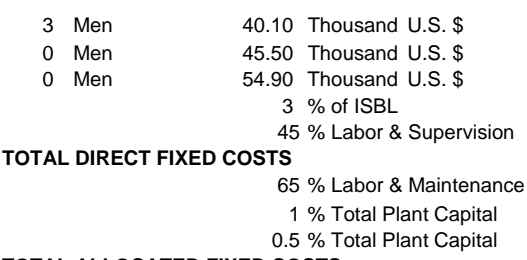

$10 \%$ for ISBL

$10 \%$ for OSBL \& OPC

10 Percent
7.1 


\section{Table 6.9 Cost Of Production Estimate For: Hydrogen Process: Steam Methane Reforming/PSA 2015}

$\begin{array}{lc}\text { Plant start-up } & 2015 \\ \text { Analysis date } & 2002 \\ \text { Location } & \text { USGC } \\ \text { Capacity } & 84 \text { Million kSCF/yr } \\ & 202 \text { Thousand metric tons/yr } \\ \text { Operating rate } & 90 \text { percent } \\ \text { Throughput } & 75 \text { Million kSCF/yr }\end{array}$

PRODUCTION COST SUMMARY

$\begin{array}{ll}\text { RAW MATERIALS } & \begin{array}{l}\text { Syngas (cash cost) } \\ \text { Catalyst \& Chemicals }\end{array} \\ \text { BY-PRODUCT CREDITS } & \\ & \text { Fuel Gas } \\ & \\ \text { UTILITIES } & \text { NET RAW MATERIALS } \\ & \text { Power - Purchased } \\ & \text { Fuel } \\ & \text { HP Steam } \\ & \text { Cooling Water } \\ & \text { Process Water }\end{array}$

NET RAW MATERIALS \& UTILITIES

VARIABLE COST

$\begin{array}{ll}\text { DIRECT FIXED COSTS } & \text { Labor, } \\ & \begin{array}{l}\text { Foremen, } \\ \text { Super., } \\ \text { Maint., Material \& Labor } \\ \text { Direct Overhead }\end{array} \\ \text { ALLOCATED FIXED COSTS } & \begin{array}{l}\text { General Plant Overhead } \\ \text { Insurance, Property Tax } \\ \text { Environmental }\end{array}\end{array}$

\section{TOTAL CASH COST}

Depreciation @

COST OF PRODUCTION

RETURN ON TOTAL CAPITAL INVESTMENT (Ex. WC) @

COST OF PRODUCTION + ROI

$\begin{array}{lc}\text { CAPITAL COST } \quad \text { MILLION U.S. \$ } & \\ \text { ISBL } & 27.8 \\ \text { OSBL } & 7.0 \\ \text { Total Plant Capital } & 34.8 \\ \text { Other Project Costs } & 8.7 \\ \text { Total Capital Investment } & 43.5 \\ \text { Working capital } & 2.0\end{array}$

\begin{tabular}{|c|c|c|c|}
\hline & & $\begin{array}{c}\text { UNITS } \\
\text { Per Gal } \\
\text { Product }\end{array}$ & $\begin{array}{l}\text { PRICE } \\
\text { U.S. \$ } \\
\text { IUnit }\end{array}$ \\
\hline \multicolumn{2}{|l|}{ k SCF } & $\begin{array}{l}1.9315 \\
1.0000\end{array}$ & $\begin{array}{l}1.6067 \\
0.0000\end{array}$ \\
\hline \multicolumn{4}{|c|}{ TOTAL RAW MATERIALS } \\
\hline $\begin{array}{r}\text { MM Btu } \\
\text { TOTAL BY-PR }\end{array}$ & \multicolumn{3}{|c|}{ TOTAL BY-PRODUCT CREDITS } \\
\hline & KWH & 0.3938 & 0.0667 \\
\hline & $\begin{array}{l}\text { MM Btu } \\
\text { k Lb }\end{array}$ & $\begin{array}{c}0.0245 \\
(0.0865)\end{array}$ & $\begin{array}{l}3.5693 \\
7.5256\end{array}$ \\
\hline & M GALS & 0.4789 & 0.1247 \\
\hline & M GALS & 0.0218 & 1.3498 \\
\hline
\end{tabular}

TOTAL UTILITIES

\begin{tabular}{|c|c|c|c|}
\hline 3 & Men & 35.72 & Thousand U.S. \$ \\
\hline 0 & Men & 40.50 & Thousand U.S. \$ \\
\hline 0 & Men & 48.94 & Thousand U.S. \$ \\
\hline & & & $\%$ of ISBL \\
\hline & & & 5 \% Labor \& Supervision \\
\hline \multicolumn{4}{|c|}{ OTAL DIRECT FIXED COSTS } \\
\hline & & & 5 \% Labor \& Maintenance \\
\hline & & & $\begin{array}{l}1 \text { \% Total Plant Capital } \\
5 \text { \% Total Plant Capital }\end{array}$ \\
\hline
\end{tabular}

TOTAL ALLOCATED FIXED COSTS

$10 \%$ for ISBL $\quad 10 \%$ for OSBL \& OPC

\begin{tabular}{|c|c|c|}
\hline & ANNUAL & \\
\hline U.S. \$ & COST MM & U.S. \$ \\
\hline Per Gal & U.S. \$ & Per MT \\
\hline 3.103 & 233.93 & \\
\hline 0.000 & 0.00 & \\
\hline 3.103 & 233.93 & 1,288 \\
\hline 0.000 & 0.00 & \\
\hline (0.644) & (48.55) & \\
\hline (0.644) & (48.55) & (267) \\
\hline 2.459 & 185.38 & 1,021 \\
\hline 0.026 & 1.98 & \\
\hline 0.088 & 6.60 & \\
\hline (0.651) & (49.04) & \\
\hline 0.060 & 4.50 & \\
\hline 0.029 & 2.22 & \\
\hline 0.000 & 0.00 & \\
\hline (0.448) & (33.74) & (186) \\
\hline 2.012 & 151.64 & 835 \\
\hline 2.012 & 151.64 & 835 \\
\hline 0.001 & 0.11 & \\
\hline 0.000 & 0.00 & \\
\hline 0.000 & 0.00 & \\
\hline 0.011 & 0.84 & \\
\hline 0.001 & 0.05 & \\
\hline 0.013 & 0.99 & 5 \\
\hline 0.008 & 0.61 & \\
\hline 0.005 & 0.35 & \\
\hline 0.002 & 0.17 & \\
\hline 0.015 & 1.13 & 6 \\
\hline 2.040 & 153.76 & 847 \\
\hline 0.806 & 60.79 & 335 \\
\hline 2.846 & 214.55 & 1,181 \\
\hline 0.806 & 60.79 & 335 \\
\hline 3.653 & 275.34 & 1,516 \\
\hline
\end{tabular}

\subsubsection{Sensitivity Analysis}

The economics of producing hydrogen via SMR have been examined for sensitivities to natural gas price, investment, yield and capacity. The results are shown for 2006 in Figure 6.4 through Figure 6.8, respectively, and discussed below. 


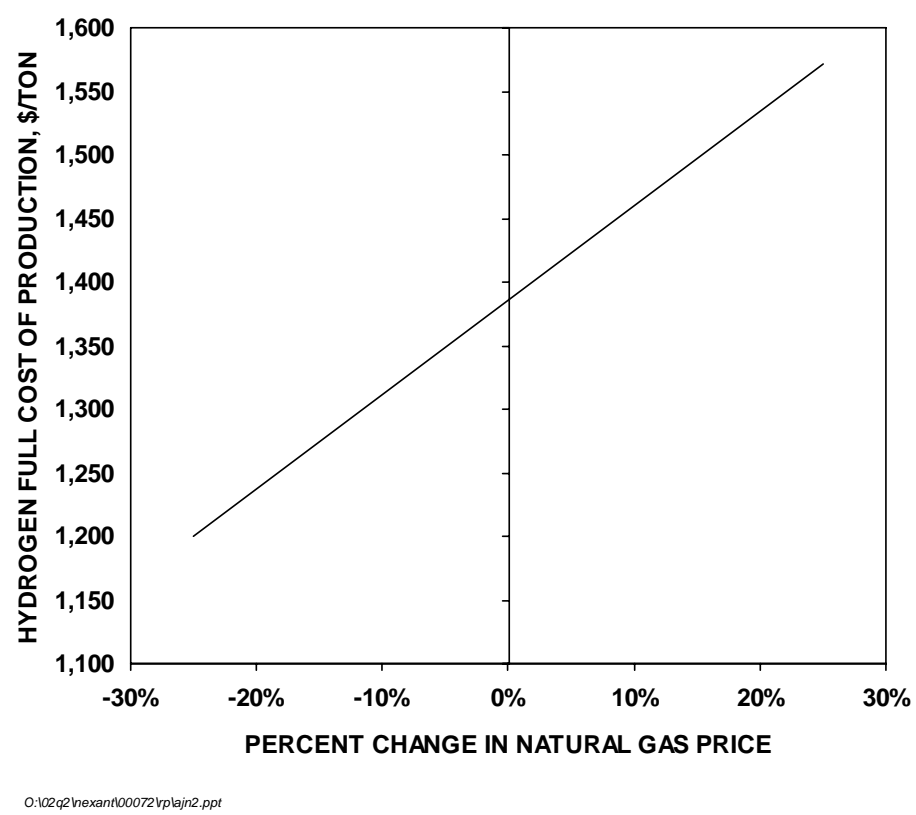

Figure 6.4 Steam Methane Reforming/PSA Technology Gas Price Sensitivity (USGC, 2006)

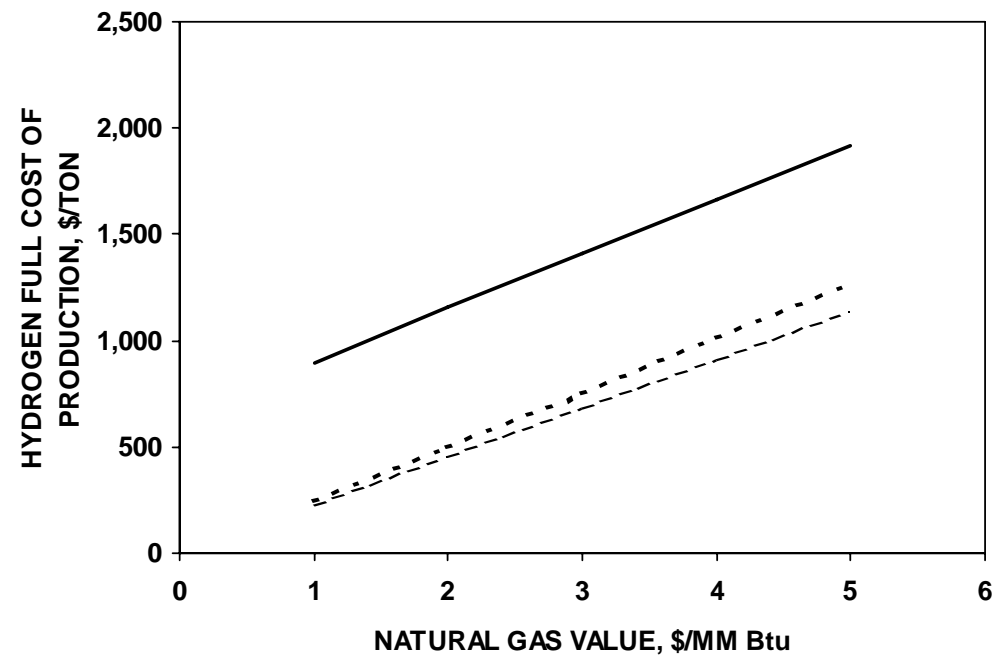

SMR (COST+RETURN) - - - H2@ 2X FUEL - - - - SMR (CASH COST)

Figure 6.5 SMR Hydrogen Cost Sensitivity

(99.9\% pure, USGC, 2006) 


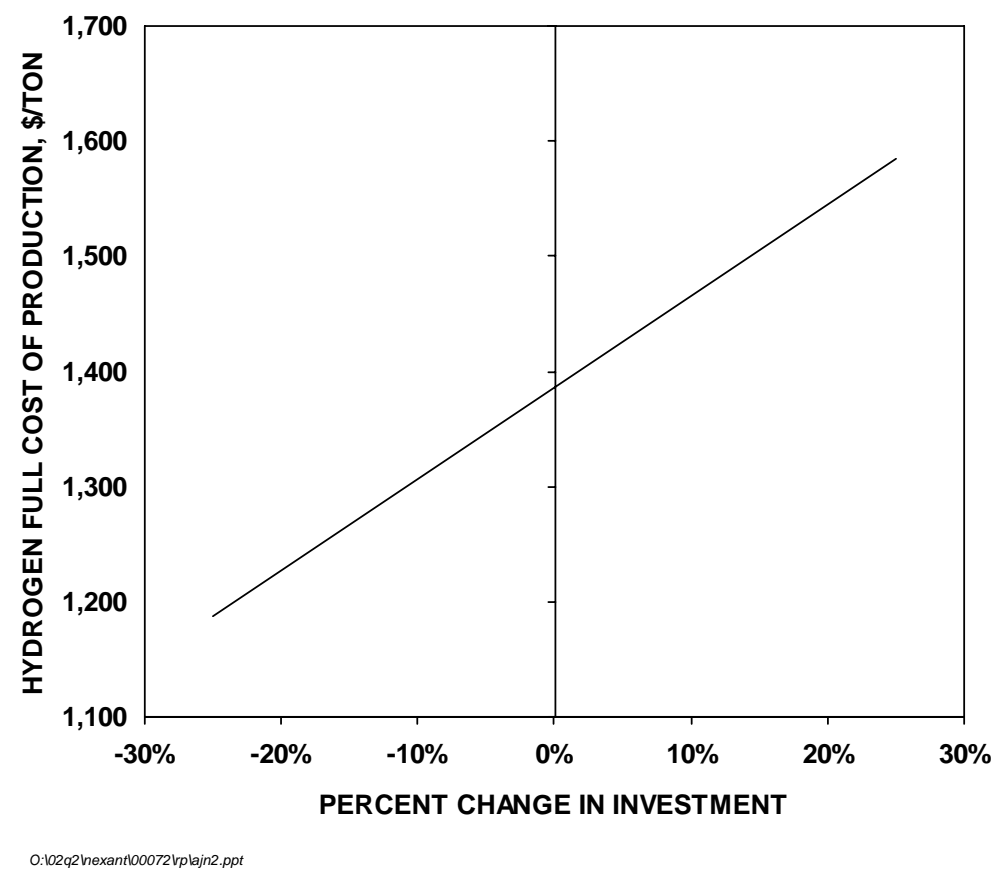

Figure 6.6 Steam Methane Reforming/PSA Technology Investment Sensitivity (USGC, 2006)

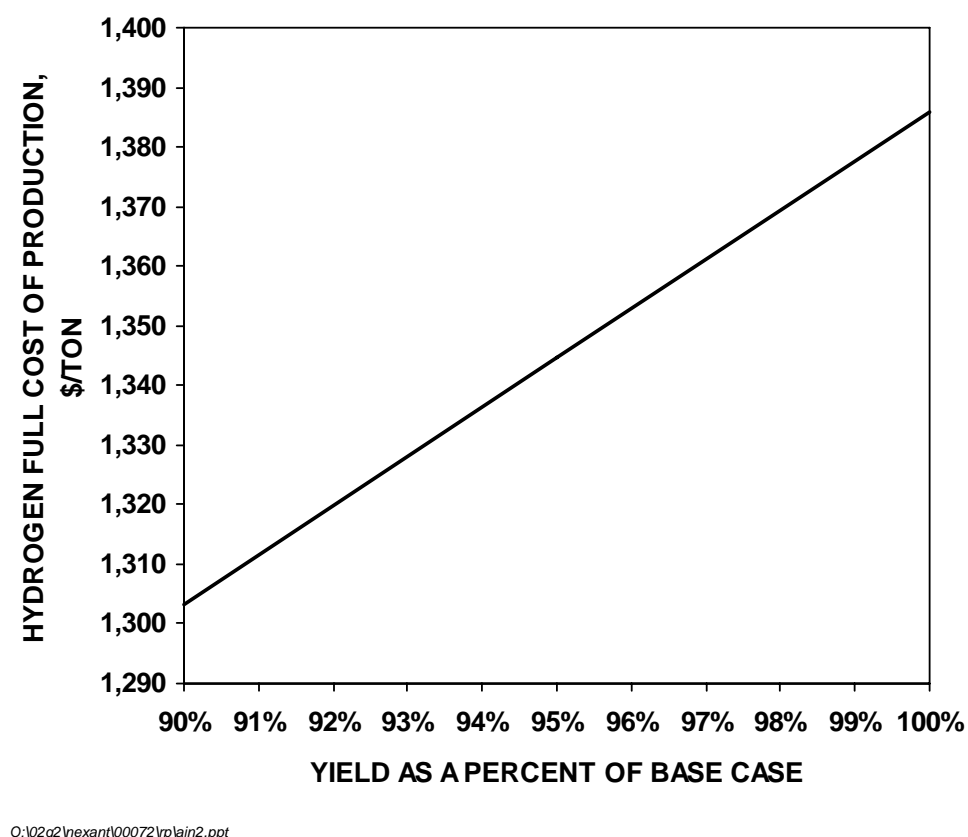

Figure 6.7 Steam Methane Reforming/PSA Technology Yield Sensitivity (USGC, 2006) 


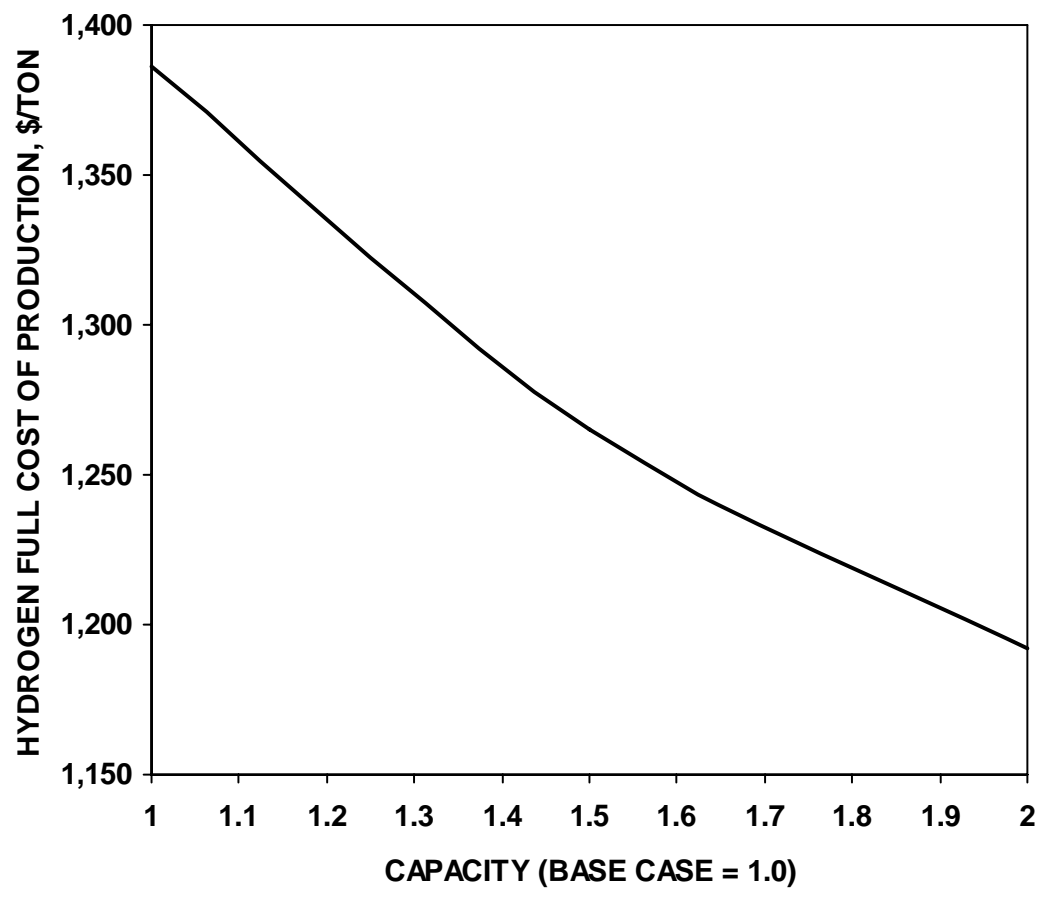

0:102q21nexantl000721rplajn2.ppt

\section{Figure 6.8 Steam Methane Reforming/PSA Technology}

(USGC, 2006)

Until gas price spiked at the end of 2000 at $\$ 7$ per million BTU, the price of natural gas varied between $\$ 1.5$ and $\$ 3$ per million BTU during the 1990's. The sensitivity of the SMR economics has been examined for a fluctuation in price of $+/-25$ percent. The full cash cost of production on the USGC varies from $\$ 1,200$ per ton to $\$ 1,572$ per ton in 2006. This can be seen in Figure 6.4. Figure 6.5 shows that the cash cost of production of hydrogen via SMR is about equal to twice the fuel value of hydrogen.

Nexant's investment estimates are considered to be accurate to about $+/-25$ percent. The sensitivity of the SMR (including the purification section) full cost of production to the capital investment (year 2006) was examined and is presented in Figure 6.6. It can be seen from this chart that the cost of production excluding the feed varies from $\$ 1,187$ per ton to $\$ 1,585$ per ton as the capital investment varies from -25 percent to +25 percent.

The influence that the feed consumption has on the economics is shown in Figure 6.6. SMR technology is relatively mature and significant improvements in the yields are not expected. However, small incremental improvements are made from time to time. Figure 6.7 shows the affect of a 10 percent improvement in the yield. The economics are improved by over 5 percent to $\$ 1,303$ per ton.

Economy of scale is shown in Figure 6.8. As the maximum plant capacity is doubled, the full cost of production is reduced to $\$ 1,192$ per ton from $\$ 1,385$ per ton. 


\subsection{PARTIAL OXIDATION (POX)}

\subsubsection{Introduction}

Synthesis gas can be manufactured by continuous non-catalytic partial combustion of hydrocarbon feedstocks. Both Texaco (now ChevronTexaco) and Shell have developed and widely licensed partial oxidation (POX) processes (Texaco Gasification Process, TGP, and Shell Gasification Process, SGP). The commercial processes can be operated at an elevated pressure using 98 to $99.5 \mathrm{~mol}$ percent oxygen as oxidant; are capable of employing natural gas, refinery off-gas, LPG, naphtha, gas oil, vacuum residual, shale oil, asphalts, or whole crudes as feedstock; and are capable of producing a 2:1 hydrogen to carbon monoxide synthesis gas (although the $\mathrm{R}$ value is less than 2).

\subsubsection{Chemistry}

Partial oxidation involves the combustion of a hydrocarbon feedstock in a flame in the presence of less than a stoichiometric amount of oxygen to form carbon dioxide and steam, which in turn, react with unconverted hydrocarbon feed to produce carbon monoxide and hydrogen. The net reaction can be represented as:

$$
\mathrm{CH}_{4}+1 / 2 \mathrm{O}_{2} \longrightarrow \mathrm{CO}+2 \mathrm{H}_{2}
$$

The highly exothermic oxidation reaction consumes essentially all of the available oxygen. The oxygen concentration employed is equivalent to about 35 percent of the stoichiometric oxygen requirement for complete combustion. The overall partial oxidation reaction is exothermic. Therefore, it is essential that the reactants and intermediate products be well mixed in the reaction phase so that heat evolved from the combustion of part of the feedstock is utilized in the subsequent endothermic reactions. Design of the feedstock inlet spray nozzle is, therefore, critical and each licensor has its own patented/proprietary nozzle design.

A short residence time of between two and five seconds is used. Essentially all of the hydrocarbon feedstock is converted (i.e., methane slip is very small). The product gas can contain some finely divided carbon (i.e., soot) from the cracking reactions if a heavy oil or coal is used as the feedstock. This is removed in a two-stage wash downstream of the reactor. The amount of carbon produced varies but is almost negligible for a methane feedstock. Only natural gas feed is considered herein.

Most of the sulfur present in the hydrocarbon feedstock is converted to hydrogen sulfide. Some carbonyl sulfide is also formed. Nitrogen compounds in the feedstock are converted to elemental nitrogen and/or ammonia.

The composition of the produce synthesis gas is largely determined by the equilibrium of the water/gas shift reaction at the outlet temperature of the reactor, but will consist mostly of hydrogen and carbon monoxide. Pressure has little effect on the equimolar water/gas shift reaction. 


\subsubsection{Process Description}

Figure 6.9 shows a simplified flow sheet for a typical partial oxidation process. High-pressure natural gas (95 volume percent methane) and oxygen are preheated to $470^{\circ} \mathrm{F}$ and then fed into the reactor via a proprietary burner nozzle. A gaseous moderator such as steam or carbon dioxide may be added at this point depending on the desired product. Typical operating conditions are shown in Table 6.10. (Approach to equilibrium: water-gas shift $=600^{\circ} \mathrm{F}$, methane-steam reforming $=350^{\circ} \mathrm{F}$.)

Table 6.10 Typical Partial Oxidation Operating Conditions

\begin{tabular}{|c|c|}
\hline Methane conversion, pct. & 99.3 \\
\hline Steam to reformer, mols/mol $\mathrm{CH}_{4}$ & 0.5 \\
\hline Oxygen to reformer, mols/mol $\mathrm{CH}_{4}$ & 0.7 \\
\hline Preheat temperature, ${ }^{\circ} \mathrm{C}\left({ }^{\circ} \mathrm{F}\right)$ & $371(700)$ \\
\hline Reformer exit temperature, ${ }^{\circ} \mathrm{C}\left({ }^{\circ} \mathrm{F}\right)$ & $1,427(2,600)$ \\
\hline Operating pressure, bara (psia) & $31(455)$ \\
\hline \multicolumn{2}{|c|}{ Effluent composition (dry basis), vol. pct. } \\
\hline Carbon monoxide & 34.51 \\
\hline Hydrogen & 62.42 \\
\hline Carbon dioxide & 2.80 \\
\hline Methane & 0.26 \\
\hline Total & 100.0 \\
\hline $\mathrm{H}_{2} / \mathrm{CO}$ & 1.81 \\
\hline$\left(\mathrm{H}_{2}-\mathrm{CO}_{2}\right) /\left(\mathrm{CO}+\mathrm{CO}_{2}\right)$ & 1.60 \\
\hline
\end{tabular}




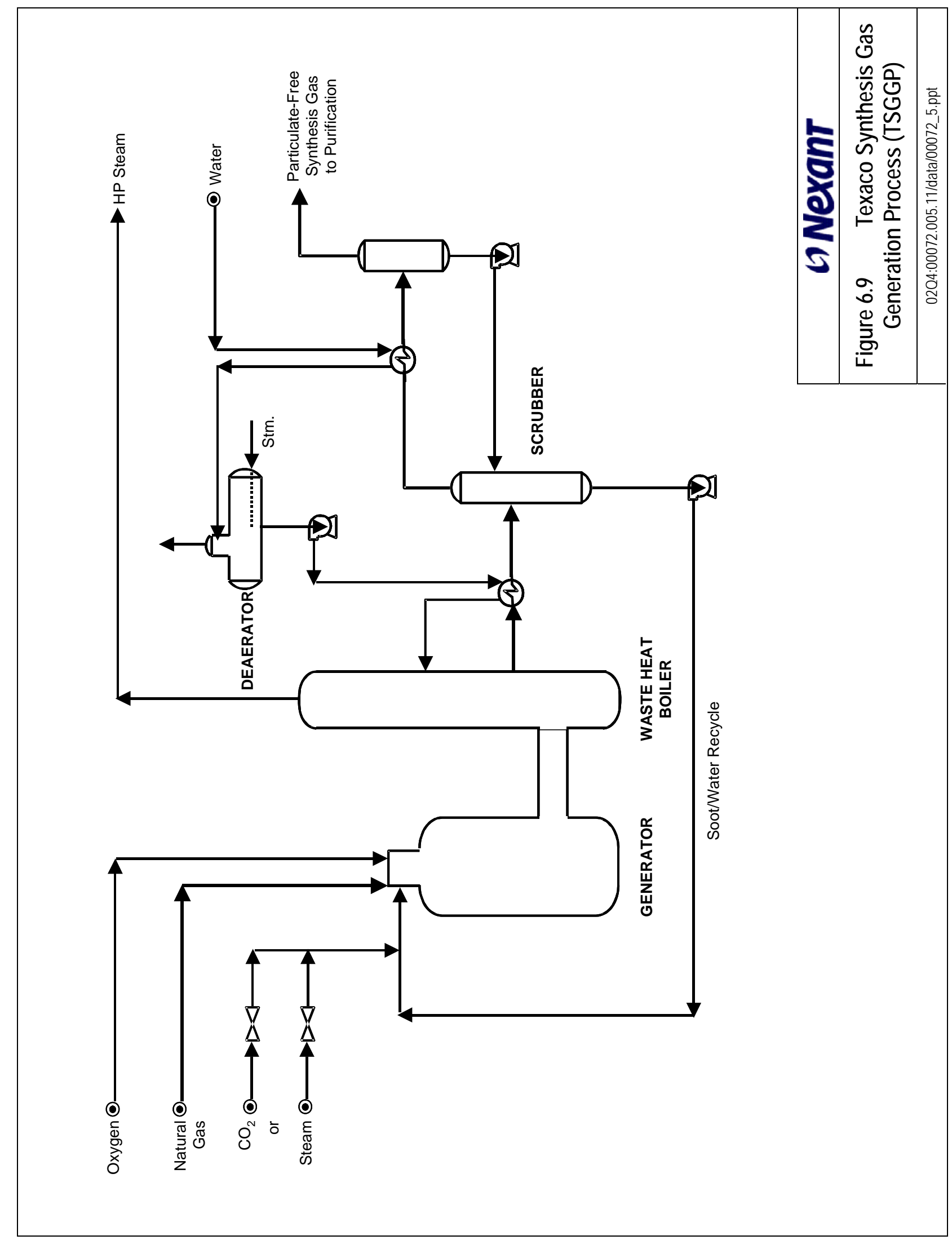


Oxygen and natural gas are mixed and injected into a proprietary burner, where the methane and oxygen undergo non-catalytic partial oxidation. The burner is located at the top of the reformer vessel, a refractory-lined pressure vessel. The reactions are mainly the POX reactions, and to a lesser extent, steam reforming and water/gas shift reactions. The primary reaction is the total oxidation of the hydrocarbon feed to carbon dioxide and water. This reaction, once completed, provides the heat and some of the steam used for the steam methane reforming of the remaining methane to syngas; most of the carbon dioxide is also reformed to carbon monoxide and hydrogen. The reactions take place at higher temperatures than conventional reforming, at about $1,200-1,400^{\circ} \mathrm{C}\left(2,192-2,552^{\circ} \mathrm{F}\right)$. Operating pressures are typically $13-85$ barg $(217-1,233 \mathrm{psig})$; pressures up to 170 barg $(2,465 \mathrm{psig})$ have been used in demonstration plant runs.

Under the reducing conditions present in the gasifier, sulfur compounds are converted to hydrogen sulfide and traces of carbonyl sulfide. Nitrogen is reduced to elemental gas; due to the high temperatures and low oxygen content in the reactor, NOx compounds are formed in negligible quantities.

Methane conversion is greater than 98 percent. Any remaining hydrocarbons can be recycled to extinction. This is accomplished by sending the hot syngas to a quench cooler and heat recovery system, which includes a soot recovery system. This can either be via absorption in a naphtha cascade, where the naphtha is recycled back to the gasifier, or using water as the quenching media, where soot-laden water is returned to the gasifier. The water acts as reactant, coolant and moderator; the soot is oxidized to extinction. The soot can also be removed by physical separation, usually involving filtration and cyclones.

The injection of steam of liquid water into the gasifier, either directly with the methane or in a side stream, can be used to moderate the reaction temperature and increase the overall hydrogen concentration of the products via the water/gas shift reaction.

There are two methods used in POX processes to cool the syngas prior to introduction to the downstream synthesis loops (e.g. methanol): cooler and quench modes.

In the cooler mode, syngas from the gasifier is indirectly cooled to produce high-pressure steam. An optional economizer can provide additional cooling. The cooler mode is usually used when the shift reaction is not needed for downstream operations such as for fuel gas, reducing gas or petrochemical production.

In the quench mode, syngas from the gasifier vessel is directly contacted with water at the bottom of the vessel. The gas is simultaneously cooled and saturated with water. The water stream is sent to recovery, and the saturated syngas goes to the scrubber. The quench mode is generally used in syngas application requiring a downstream shift reaction (such as high-purity hydrogen or fuel as saturation) or for feedstocks with high-impurity content, such as wastes and refinery gases. 
Splitting the syngas between a quencher and a cooler can combine both modes; this can be used for synthesis applications requiring syngas with differing compositions of for cogeneration from a hydrogen plant.

The syngas cooler mode is recommended for methane feedstocks and methanol production. The hot synthesis gas is used to raise high-pressure steam; the steam is for general plant purposes and for recycle back to the gasifier as moderator to adjust the reaction conditions to control syngas composition. This steam injection is used instead of carbon dioxide injection for composition control.

The Texaco process does not include an initial desulfurizing step, since the partial oxidation reactions are not affected by residual sulfur concentrations in the feedstock. The POX reactor itself acts as a desulfurizing unit by reducing to hydrogen sulfide or carbonyl sulfide any sulfur and mercaptans present. As a result, the process can use a variety of feedstocks from sweet gases to heavy crude oils without requiring feed desulfurizing units.

Since there is not feed desulfurization, the cooled syngas is then sent to an acid gas scrubbing system. This process removes any $\mathrm{H}_{2} \mathrm{~S}, \mathrm{CO}_{2}, \mathrm{SOx}$ and $\mathrm{NOx}$ from the process gas, since these gases tend to accelerate corrosion in the following unit operations. The targeted level is $2 \mathrm{ppm}$ or less especially if the downstream catalyst is very sensitive to sulfur poisoning (e.g. methanol). This may require replacing the acid gas scrubbing systems with a desulfurizing unit upstream of the gasifier.

The POX unit does not include a syngas compressor; feed gases to the gasifier are pressurized to the desired level, since the gasifier can operate up to 170 barg $(2,465 \mathrm{psig})$. The syngas product leaves the process at whatever pressure is necessary for the downstream processing (e.g. methanol is 80 barg or 1,160 psig). This reduces energy requirements and initial capital investment. A shift reactor and PSA unit are employed to provide hydrogen at 99.9 percent purity.

\subsubsection{Process Economics}

\subsubsection{Methodology and Economic Assumptions}

The cost of production of hydrogen via partial oxidation of natural gas has been evaluated for commercially demonstrated technology in 2006 and for emerging technology in 2015 for an operating rate of 90 percent. Capacity is based on the same capacity as syngas for a 5,000 ton per day methanol facility. The economics for 2015 reflect lower utility consumption, higher yields and lower investment expected through technology improvements.

\subsubsection{Feedstock and Utilities Pricing and Labor Costs}

The pricing basis for the study years (2006 and 2015) are presented in Table 6.11. 
Table 6.11 Feedstock And Utilities Pricing And Labor Costs (USGC)

\begin{tabular}{|c|l|l|l|}
\hline & Units & 2006 & 2015 \\
\hline Feedstocks/By-products & & & \\
\hline Natural Gas & $\$ /$ Million Btu & 2.914 & 3.569 \\
\hline Oxygen & & 0.019 & 0.023 \\
\hline Utilities & & & \\
\hline Power & $\$ /$ KWh & 0.054 & 0.067 \\
\hline Fuel & \$Million Btu & 2.914 & 3.569 \\
\hline Cooling Water & $\$ /$ Thousand Gal & 0.100 & 0.125 \\
\hline Boiler Feed water & \$Thousand Gal & 1.843 & 2.298 \\
\hline MP Steam & $\$ /$ Thousand Lb & 5.420 & 6.671 \\
\hline Inert Gas & \$/Thousand SCF & 1.690 & 2.105 \\
\hline Manpower & & & \\
\hline Labor & \$/Man/Year & 45,061 & 56,219 \\
\hline Foreman & $\$ /$ Man/Year & 51,078 & 63,789 \\
\hline Supervisor & \$Man/Year & 61,630 & 76,968 \\
\hline
\end{tabular}

\subsubsection{Process Economics}

The cost of production of syngas $\left(\mathrm{H}_{2} / \mathrm{CO}\right)$ via partial oxidation of natural gas is summarized in Table 6.12. In 2006 the cash cost of production is $\$ 117$ per ton $(\$ 1.71$ per thousand SCF). Adding in the depreciation and return on investment, the full cost of production is $\$ 168$ per ton (\$2.28 per thousand SCF). The full cost excluding the feed is $\$ 86$ per ton $(\$ 1.26$ per thousand SCF). In 2015 the cash cost of production increases to $\$ 141$ per ton (\$2.07 per thousand SCF) and the full cost of production increases to $\$ 185$ per ton ( $\$ 2.69$ per thousand SCF). The full cost excluding the feed is $\$ 99$ per ton ( $\$ 1.44$ per thousand SCF).

Table 6.12 Syngas Cost Of Production - Partial Oxidation (USGC, dollars per metric ton)

\begin{tabular}{|l|l|l|}
\hline & 2006 & 2015 \\
\hline Variable cost & 102 & 124 \\
\hline Fixed costs & 15 & 17 \\
\hline Depreciation + Return & 38 & 44 \\
\hline Full Cost of Production & 156 & 185 \\
\hline Full Cost of Production ex. Feed & 86 & 99 \\
\hline
\end{tabular}


Table 6.13 shows the costs for producing pure (99.9 percent) hydrogen via a PSA unit. In 2006 the full cost of production including depreciation and return on investment is $\$ 1,959$ per ton ( $\$ 4.72$ per thousand SCF). In 2015 the cost is $\$ 2,302$ per ton $(\$ 5.55$ per thousand $\mathrm{SCF})$. The costs are summarized in Figure 6.10.

Table 6.13 Hydrogen Cost Of Production - Partial Oxidation/PSA

(USGC, dollars per metric ton)

\begin{tabular}{|l|l|l|}
\hline & 2006 & 2015 \\
\hline Variable costs(1) & 1,346 & 1,618 \\
\hline Fixed costs & 15 & 16 \\
\hline Depreciation + Return(2) & 598 & 668 \\
\hline Full Cost of Production & 1,959 & 2,302 \\
\hline $\begin{array}{l}\text { (1) Syngas at cash cost } \\
\text { (2) Depreciation and return include syngas portion of plant }\end{array}$ \\
\hline
\end{tabular}

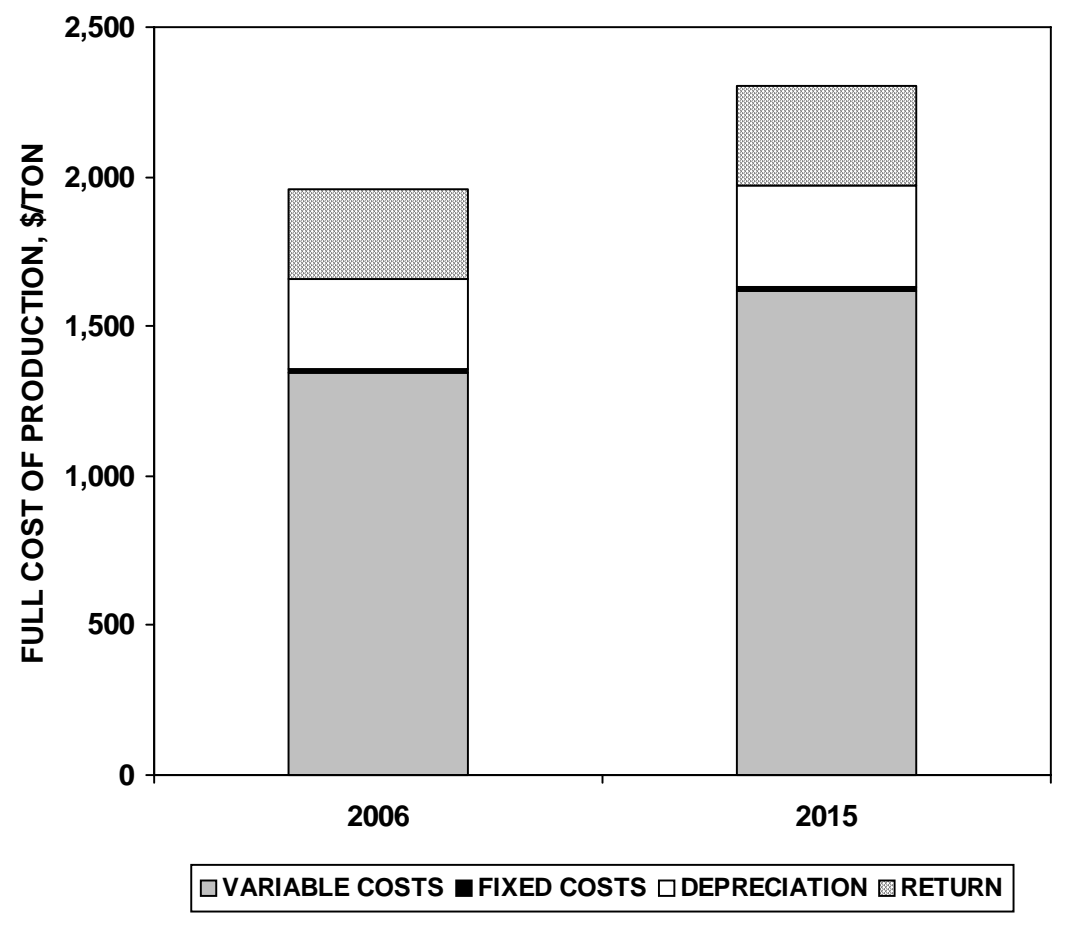

O:102q21nexant1000721rplajn2.ppt

Figure 6.10 Hydrogen Cost Of Production Via Pox

(>99.9\%, USGC) 
The detailed estimates of the costs of production are shown on Table 6.14 and Table 6.15 for syngas in 2006 and 2015 and Table 6.16 and Table 6.17 for hydrogen in 2006 and 2015.

\subsubsection{Sensitivity Analysis}

The economics of producing hydrogen via POX have been examined for sensitivity to natural gas price, investment, yield and capacity. The results are shown for 2006 in Figure 6.11 through Figure 6.16, respectively, and discussed below.

Until gas price spiked at the end of 2000 at $\$ 7$ per million BTU, the price of natural gas varied between \$1.5 and \$3 per million BTU during the 1990's. The sensitivity of the SMR economics has been examined for a fluctuation in price of $+/-25$ percent. The full cash cost of production on the USGC varies from $\$ 1,718$ per ton to just over $\$ 2,200$ per ton in 2006 . This can be seen in Figure 6.11. Figure 6.12 shows that the cash cost of production of hydrogen via POX is significantly higher than twice the fuel value of hydrogen.

Nexant's investment estimates are considered to be accurate to about +/-25 percent. The sensitivity of the SMR full cost of production to the capital investment (year 2006) was examined and is presented in Figure 6.13. It can be seen from this chart that the cost of production excluding the feed varies from $\$ 1,755$ per ton to just over $\$ 2,162$ per ton as the capital investment varies from -25 percent to +25 percent.

The influence that the feed consumption has on the economics is shown in Figure 6.14. SMR technology is relatively mature and significant improvements in the yields are note expected. However, small incremental improvements are made from time to time. Figure 6.12 shows the affect of a 10 percent improvement in the yield. The economics are improved by about 5 percent to $\$ 1,862$ per ton.

Economy of scale is shown in Figure 6.15. As the maximum plant capacity is doubled, the full cost of production is reduced to $\$ 1,756$ per ton from $\$ 1,959$ per ton.

Figure 6.16 shows the sensitivity of POX economics as a function of oxygen cost. Adjusting the base cost by plus or minus 50 percent results in a change of plus or minus over $\$ 175$ per ton in the cost of production. 


\section{Table 6.14 Cost Of Production Estimate For: Syngas $\left(\mathrm{H}_{2} / \mathrm{CO}=1.8\right)$ Process: Partial Oxidation 2006}

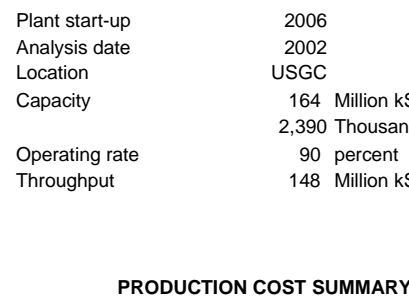

BY-PRODUCT CREDITS

NET RAW MATERIALS
Power
Cooling Water
Steam, HP
Steam, MP
Boiler Feedwater
Inert gas

NET RAW MATERIALS \& UTILITIES

VARIABLE COST

$\begin{array}{ll}\text { DIRECT FIXED COSTS } & \text { Labor, } \\ & \text { Foremen, } \\ & \begin{array}{l}\text { Super., } \\ \text { Maint., Material \& Labor } \\ \text { Direct Overhead }\end{array} \\ \text { ALLOCATED FIXED COSTS } & \begin{array}{l}\text { General Plant Overhead } \\ \text { Insurance, Property Tax } \\ \text { Environmental }\end{array}\end{array}$

TOTAL CASH COST

Depreciation @

COST OF PRODUCTION

RETURN ON TOTAL CAPITAL INVESTMENT (Ex. WC) @

COST OF PRODUCTION + ROI

$\begin{array}{lr}\text { CAPITAL COST MILLION U.S. \$ } & \\ \text { ISBL } & 267.8 \\ \text { OSBL } & 67.0 \\ \text { Total Plant Capital } & \mathbf{3 3 4 . 8} \\ \text { Other Project Costs } & 83.7 \\ \text { Total Capital Investment } & \mathbf{4 1 8 . 5} \\ \text { Working capital } & 18.8\end{array}$

$\begin{array}{cc}\text { UNITS } & \text { PRICE } \\ \text { Per Gal } & \text { U.S. \$ }\end{array}$

Per Gal U.S. \$
Product IUnit

$0.3490 \quad 2.9141$

MMBtu (HHV)

MMBtu (HHV)

pound

$0.0290 \quad 2.9141$

$19.7000 \quad 0.0188$

$\begin{array}{ll}1.0000 & 0.0119\end{array}$

TOTAL RAW MATERIALS

TOTAL BY-PRODUCT CREDITS

$\begin{array}{lcc}\text { kWh } & 0.0850 & 0.0539 \\ \text { M Gal } & 0.3000 & 0.1003 \\ \text { M Lb } & 0.0000 & 5.2355 \\ \text { M Lb } & (0.0210) & 5.4196 \\ \text { M Gal } & 0.0070 & 1.8430 \\ \text { kSCF } & 0.0380 & 1.6902\end{array}$

TOTAL UTILITIES

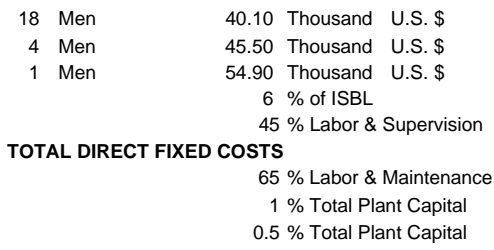

TOTAL ALLOCATED FIXED COSTS

\begin{tabular}{|c|c|c|}
\hline & ANNUAL & \\
\hline U.S. \$ & COST MM & U.S. \$ \\
\hline Per Gal & U.S. \$ & Per MT \\
\hline 1.017 & 150.20 & \\
\hline 0.085 & 12.48 & \\
\hline 0.371 & 54.77 & \\
\hline 0.012 & 1.75 & \\
\hline 1.484 & 219.20 & 102 \\
\hline 0.000 & 0.00 & \\
\hline 0.000 & 0.00 & \\
\hline 0.000 & 0.00 & 0 \\
\hline 1.484 & 219.20 & 102 \\
\hline 0.005 & 0.68 & \\
\hline 0.030 & 4.44 & \\
\hline 0.000 & 0.00 & \\
\hline (0.114) & (16.81) & \\
\hline 0.013 & 1.91 & \\
\hline 0.064 & 9.49 & \\
\hline$(0.002)$ & $(0.30)$ & (0) \\
\hline 1.482 & 218.90 & 102 \\
\hline 1.482 & 218.90 & 102 \\
\hline 0.005 & 0.72 & \\
\hline 0.001 & 0.18 & \\
\hline 0.000 & 0.05 & \\
\hline 0.109 & 16.07 & \\
\hline 0.003 & 0.43 & \\
\hline 0.118 & 17.46 & 8 \\
\hline 0.075 & 11.07 & \\
\hline 0.023 & 3.35 & \\
\hline 0.011 & 1.67 & \\
\hline 0.109 & 16.09 & 7 \\
\hline 1.709 & 252.46 & 117 \\
\hline 0.283 & 41.85 & 19 \\
\hline 1.993 & 294.31 & 137 \\
\hline 0.283 & 41.85 & 19 \\
\hline & & 156 \\
\hline
\end{tabular}

O:I02Q2INEXANTI00072ICOPS SECRION VIII 2006 REV01 


\section{Table 6.15 Cost Of Production Estimate For: Syngas $\left(\mathrm{H}_{2} / \mathrm{CO}=1.8\right)$ Process: Partial Oxidation 2015}

$\begin{array}{lc}\text { Plant start-up } & 2015 \\ \text { Analysis date } & 2002 \\ \text { Location } & \text { USGC } \\ \text { Capacity } & 164 \text { Million kSCF/yr } \\ & 2,390 \text { Thousand metric tons/yr } \\ \text { Operating rate } & 90 \text { percent } \\ \text { Throughput } & 148 \text { Million kSCF/yr } \\ & \\ & \end{array}$

RAW MATERIAL

Natural Gas (as raw material) Natural Gas (as net fuel) Oxygen

Catalyst \& Chemicals

BY-PRODUCT CREDITS

$\begin{array}{ll}\text { UTILITIES } & \text { NET RAW MATERIALS } \\ & \text { Power } \\ & \text { Cooling Water } \\ & \text { Steam, HP } \\ \text { Steam, MP } \\ \text { Boiler Feedwater } \\ \text { Inert gas }\end{array}$

NET RAW MATERIALS \& UTILITIES

VARIABLE COST

\begin{tabular}{|c|c|}
\hline DIRECT FIXED COSTS & $\begin{array}{l}\text { Labor, } \\
\text { Foremen, } \\
\text { Super., } \\
\text { Maint., Material \& Labor } \\
\text { Direct Overhead }\end{array}$ \\
\hline ALLOCATED FIXED COSTS & $\begin{array}{l}\text { General Plant Overhead } \\
\text { Insurance, Property Tax } \\
\text { Environmental }\end{array}$ \\
\hline
\end{tabular}

TOTAL CASH COST

Depreciation @

COST OF PRODUCTION

RETURN ON TOTAL CAPITAL INVESTMENT (Ex. WC) @

COST OF PRODUCTION + ROI

$\begin{array}{lr}\text { CAPITAL COST MILLION U.S. \$ } & \\ \text { ISBL } & 298.9 \\ \text { OSBL } & 74.7 \\ \text { Total Plant Capital } & \mathbf{3 7 3 . 7} \\ \text { Other Project Costs } & 93.4 \\ \text { Total Capital Investment } & 467.1 \\ \text { Working capital } & 21.0\end{array}$

UNITS PRICE

Per Gal U.S. \$

Product IUnit

$0.3490 \quad 3.5693$

$0.0265 \quad 3.5693$

$19.7000 \quad 0.0232$

$\begin{array}{lll}1.0000 & 0.0109\end{array}$

TOTAL RAW MATERIALS

TOTAL BY-PRODUCT CREDITS

$\begin{array}{lcc}\text { kWh } & 0.0776 & 0.0667 \\ \text { M Gal } & 0.3000 & 0.1247 \\ \text { M Lb } & 0.0000 & 5.2355 \\ \text { M Lb } & (0.0210) & 6.6714 \\ \text { M Gal } & 0.0070 & 2.2981 \\ \text { KSCF } & 0.0380 & 2.1049\end{array}$

TOTAL UTILITIES

2.298

\begin{tabular}{|c|c|c|}
\hline \multicolumn{3}{|c|}{ ANNUAL } \\
\hline U.S. \$ & COST MM & U.S. \$ \\
\hline Per Gal & U.S. \$ & Per MT \\
\hline 1.246 & 183.96 & \\
\hline 0.095 & 13.96 & \\
\hline 0.457 & 67.48 & \\
\hline 0.011 & 1.60 & \\
\hline 1.808 & 267.02 & 124 \\
\hline 0.000 & 0.00 & \\
\hline 0.000 & 0.00 & \\
\hline 0.000 & 0.00 & 0 \\
\hline 1.808 & 267.02 & 124 \\
\hline 0.005 & 0.76 & \\
\hline 0.037 & 5.52 & \\
\hline 0.000 & 0.00 & \\
\hline (0.140) & (20.69) & \\
\hline 0.016 & 2.38 & \\
\hline 0.080 & 11.81 & \\
\hline$(0.001)$ & $(0.21)$ & (0) \\
\hline 1.807 & 266.80 & 124 \\
\hline 1.807 & 266.80 & 124 \\
\hline 0.004 & 0.64 & \\
\hline 0.001 & 0.16 & \\
\hline 0.000 & 0.05 & \\
\hline 0.121 & 17.94 & \\
\hline 0.003 & 0.38 & \\
\hline 0.130 & 19.17 & 9 \\
\hline 0.083 & 12.21 & \\
\hline 0.025 & 3.74 & \\
\hline 0.013 & 1.87 & \\
\hline 0.121 & 17.82 & 8 \\
\hline 2.057 & 303.79 & 141 \\
\hline 0.316 & 46.71 & 22 \\
\hline 2.373 & 350.50 & 163 \\
\hline 0.316 & 46.71 & 22 \\
\hline 2.690 & 397.21 & 185 \\
\hline
\end{tabular}

O:I02Q2INEXANTI00072ICOPS SECRION VIII 2015 REV01 


\section{Table 6.16 Cost Of Production Estimate For: Hydrogen Process: Partial Oxidation/PSA 2006}

\begin{tabular}{|c|c|c|}
\hline Plant start-up & 2006 & \\
\hline Analysis date & 2002 & \\
\hline Location & USGC & \\
\hline Capacity & $\begin{array}{c}72 \\
173\end{array}$ & $\begin{array}{l}\text { Million kSCF/yr } \\
\text { Thousand metric tons/yr }\end{array}$ \\
\hline Operating rate & 90 & percent \\
\hline Throughput & 65 & Million kSCF/yr \\
\hline \multicolumn{3}{|c|}{ PRODUCTION COST SUMMARY } \\
\hline RAW MATERIALS & & $\begin{array}{l}\text { Syngas (cash cost) } \\
\text { Catalyst \& Chemicals }\end{array}$ \\
\hline \multicolumn{3}{|c|}{ BY-PRODUCT CREDITS } \\
\hline & & Fuel Gas \\
\hline \multicolumn{3}{|c|}{ NET RAW MATERIALS } \\
\hline UTILITIES & & $\begin{array}{l}\text { Power - Purchased } \\
\text { Fuel } \\
\text { HP Steam } \\
\text { Cooling Water } \\
\text { Process Water }\end{array}$ \\
\hline
\end{tabular}

NET RAW MATERIALS \& UTILITIES

VARIABLE COST

$\begin{array}{ll}\text { DIRECT FIXED COSTS } & \text { Labor, } \\ & \text { Foremen, } \\ & \text { Super., } \\ & \text { Maint., Material \& Labor } \\ & \text { Direct Overhead }\end{array}$

ALLOCATED FIXED costs General Plant Overhead Insurance, Property Tax Environmental

TOTAL CASH COST

Depreciation @

COST OF PRODUCTION

RETURN ON TOTAL CAPITAL INVESTMENT (Ex. WC) @

COST OF PRODUCTION + ROI

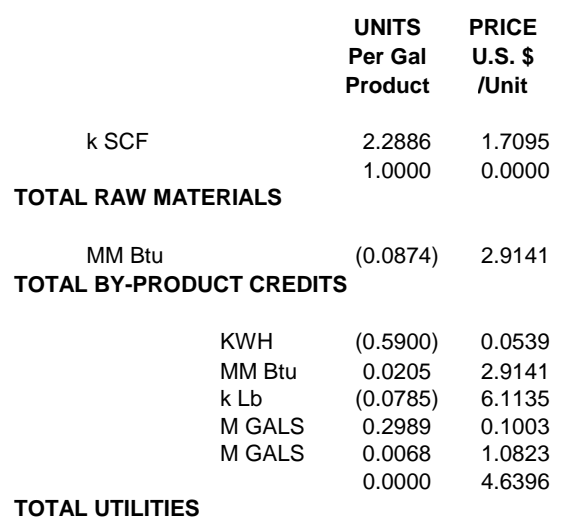

TOTAL UTILITIES

$$
\begin{aligned}
& 40.10 \text { Thousand U.S. } \$ \\
& 45.50 \text { Thousand U.S. } \$ \\
& 54.90 \text { Thousand U.S. } \$ \\
& 3 \% \text { of ISBL } \\
& 45 \% \text { Labor \& Supervision } \\
& \text { cosTS } \\
& 65 \% \text { Labor \& Maintenance } \\
& 1 \% \text { Total Plant Capital } \\
& 0.5 \% \text { Total Plant Capital }
\end{aligned}
$$

$10 \%$ for ISBL

$10 \%$ for OSBL \& OPC
CAPITAL COSTMILLION U.S. \$

ISBL

Total Plant Capital

Other Project Costs

Total Capital Investment

\begin{tabular}{|c|c|c|}
\hline \multicolumn{3}{|c|}{ ANNUAL } \\
\hline U.S. \$ & COST MM & U.S. \$ \\
\hline Per Gal & U.S. \$ & Per MT \\
\hline 3.912 & 252.46 & \\
\hline 0.000 & 0.00 & \\
\hline 3.912 & 252.46 & 1,624 \\
\hline 0.000 & 0.00 & \\
\hline$(0.255)$ & (16.43) & \\
\hline (0.255) & (16.43) & (106) \\
\hline 3.658 & 236.03 & 1,518 \\
\hline (0.032) & (2.05) & \\
\hline 0.060 & 3.85 & \\
\hline$(0.480)$ & (30.95) & \\
\hline 0.030 & 1.93 & \\
\hline 0.007 & 0.48 & \\
\hline 0.000 & 0.00 & \\
\hline$(0.414)$ & (26.73) & (172) \\
\hline 3.243 & 209.29 & 1,346 \\
\hline 3.243 & $\underline{209.29}$ & 1,346 \\
\hline 0.002 & 0.12 & \\
\hline 0.000 & 0.00 & \\
\hline 0.000 & 0.00 & \\
\hline 0.014 & 0.89 & \\
\hline 0.001 & 0.05 & \\
\hline 0.017 & 1.07 & 7 \\
\hline 0.010 & 0.66 & \\
\hline 0.006 & 0.37 & \\
\hline 0.003 & 0.19 & \\
\hline 0.019 & 1.22 & 8 \\
\hline 3.279 & $\underline{211.58}$ & 1,361 \\
\hline 0.721 & 46.50 & 299 \\
\hline$\underline{4.000}$ & $\underline{258.08}$ & 1,660 \\
\hline 0.721 & 46.50 & 299 \\
\hline$\underline{4.720}$ & 304.58 & 1,959 \\
\hline
\end{tabular}

Working capital
29.8

7.4

37.2

9.3

2.1

O:I02Q2INEXANTI00072ICOPS SECRION VIII 2006 REV01 


\section{Table 6.17 Cost Of Production Estimate For: Hydrogen Process: Partial Oxidation/PSA 2015}

$\begin{array}{lc} & \\ \text { Plant start-up } & 2015 \\ \text { Analysis date } & 2002 \\ \text { Location } & \text { USGC } \\ \text { Capacity } & 72 \text { Million kSCF/yr } \\ & 173 \text { Thousand metric tons/yr } \\ \text { Operating rate } & 90 \text { percent } \\ \text { Throughput } & 65 \text { Million kSCF/yr }\end{array}$

PRODUCTION COST SUMMARY

$\begin{array}{ll}\text { RAW MATERIALS } & \begin{array}{l}\text { Syngas (cash cost) } \\ \text { Catalyst \& Chemicals }\end{array} \\ \text { BY-PRODUCT CREDITS } & \\ & \text { Fuel Gas } \\ & \\ \text { UTILITIES } & \text { NET RAW MATERIALS } \\ & \text { Power - Purchased } \\ & \text { Fuel } \\ & \text { HP Steam } \\ & \text { Cooling Water } \\ & \text { Process Water }\end{array}$

NET RAW MATERIALS \& UTILITIES

TOTAL UTILITIES

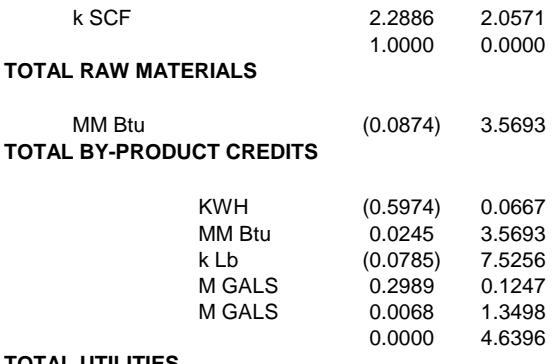

VARIABLE COST

$\begin{array}{ll}\text { DIRECT FIXED COSTS } & \text { Labor, } \\ & \text { Foremen, } \\ \text { Super., } \\ \text { Maint., Material \& Labor } \\ \text { Direct Overhead }\end{array}$

TOTAL CASH COST

3 Men

0 Men

0 Men TOT TOTAL DIRECT FIXED COSTS

TOTAL ALLOCATED FIXED COSTS
35.72 Thousand U.S. \$
40.50 Thousand U.S. $\$$
48.94 Thousand U.S. \$
$3 \%$ of ISBL
$45 \%$ Labor \& Supervision
$65 \%$ Labor \& Maintenance
$1 \%$ Total Plant Capital
$0.5 \%$ Total Plant Capital

Depreciation @

$10 \%$ for ISBL

COST OF PRODUCTION

RETURN ON TOTAL CAPITAL INVESTMENT (Ex. WC) @

COST OF PRODUCTION + ROI
CAPITAL COST MILLION U.S. \$

OSBL

Total Plant Capital

Other Project Costs

Total Capital Investment

Working capital

$\begin{array}{lr} & 33.2 \\ & 8.3 \\ \text { selment } & 41.5 \\ & 10.4 \\ & 51.9 \\ 2.3\end{array}$

ANNUAL

U.S. \$ COST MM U.S. \$

$\begin{array}{lll}\text { Per Gal } & \text { U.S. } \$ \text { Per MT }\end{array}$

$4.708 \quad 303.79$

$\begin{array}{rr}0.000 & 0.00 \\ 4.708 & 303.79\end{array}$

$4.708 \quad 303.79$

$0.000 \quad 0.00$

(0.312) (20.12)

(0.312) (20.12)

(129)

$(0.040) \quad(2.57)$

$0.088 \quad 5.65$

(0.590) (38.10)

$0.037 \quad 2.40$

$0.009 \quad 0.60$

$0.000 \quad 0.00$

(0.496) (32.02) (206)

$\begin{array}{lll}3.900 & 251.65 & 1,618\end{array}$

$\underline{3.900} \quad \underline{251.65} \quad 1,618$

$0.002 \quad 0.11$

$0.000 \quad 0.00$

$0.000 \quad 0.00$

$0.015 \quad 1.00$

$0.001 \quad 0.05$

$\mathbf{0 . 0 1 8} \quad \mathbf{1 . 1 5}$

$0.011 \quad 0.72$

$0.006 \quad 0.42$

$0.003 \quad 0.21$

$0.021 \quad 1.34$

$\underline{3.939} \quad \underline{254.14}$

0.804

51.90

1,635

$\underline{4.743} \quad \underline{306.04} \quad 1,968$

$0.804 \quad 51.90 \quad 334$

$\underline{5.547} \quad \underline{357.94} \quad 2,302$

O:I02Q2INEXANT100072ICOPS SECRION VIII 2015 REV01 


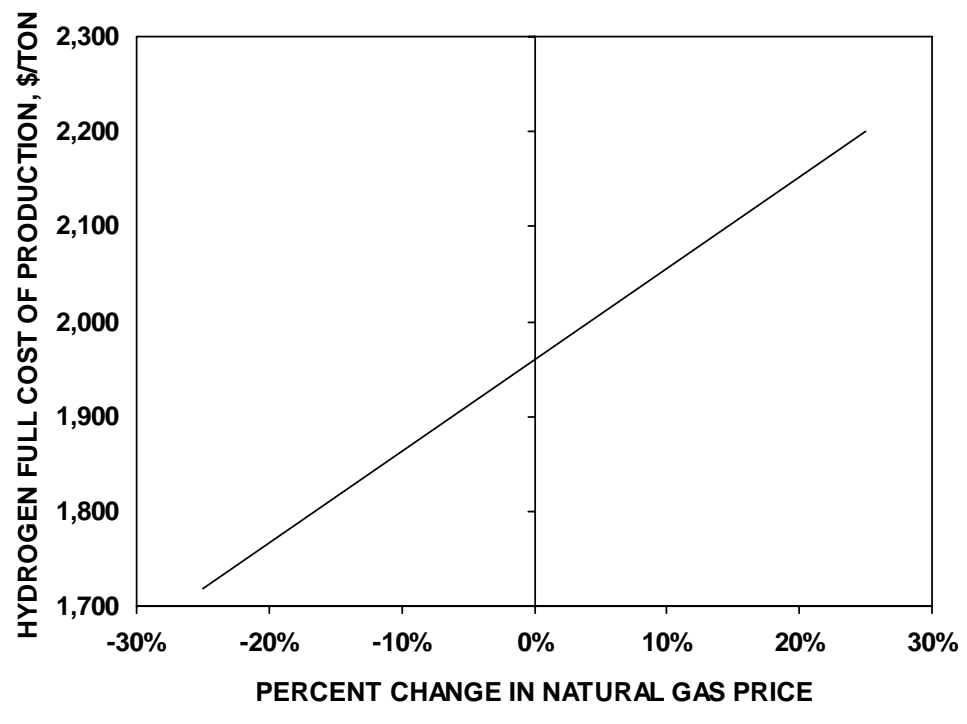

0:102q21nexant100072rplain2.ppt

Figure 6.11 Partial Oxidation/PSA Technology Gas Price Sensitivity (USGC, 2006)

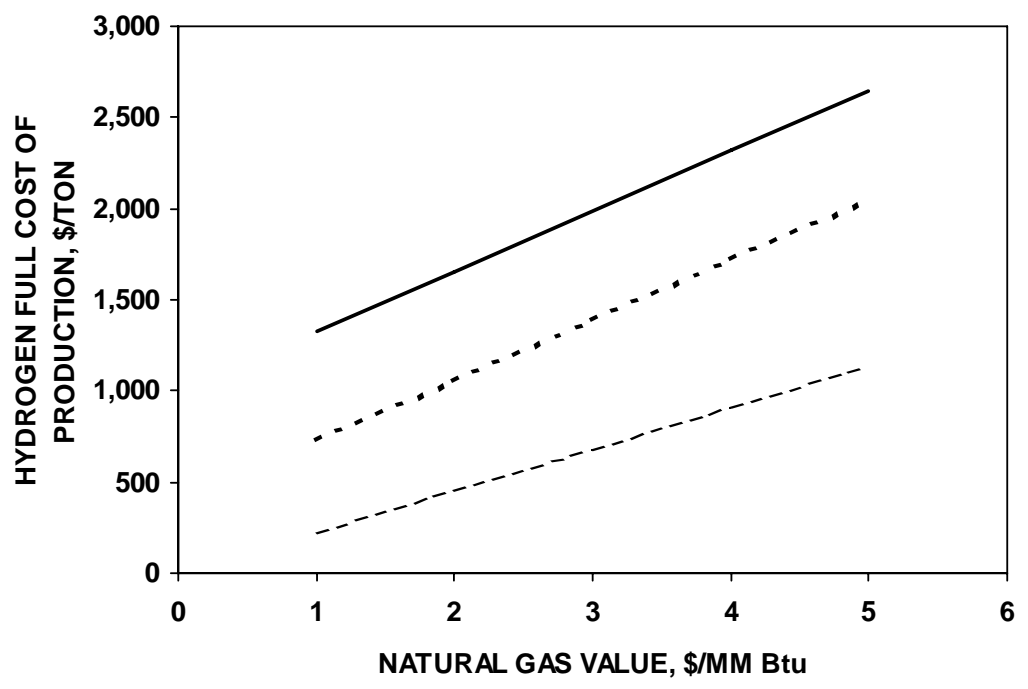

POX (COST+RETURN) - - - - H2@ 2X FUEL - - - - POX (CASH COST)

O:102q2Inexant1000721rplajn2.ppt

Figure 6.12 Pox Hydrogen Cost Sensitivity

(99.9\% pure, USGC, 2006) 


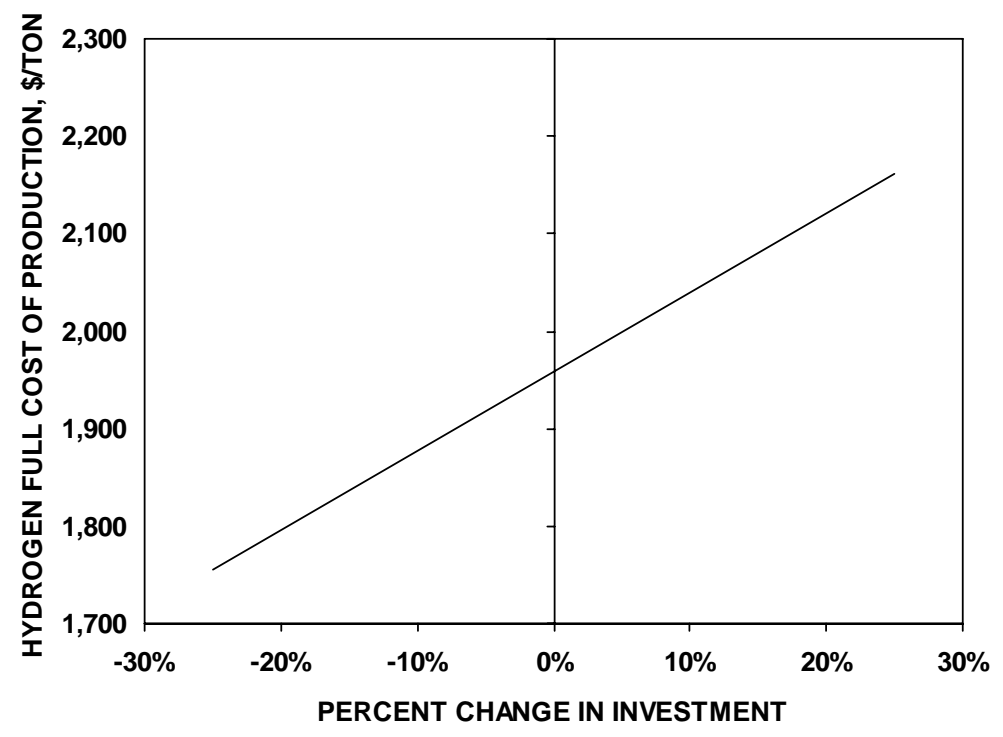

O:102q2Inexant100072Irplajn2.ppt

Figure 6.13 Partial Oxidation/PSA Technology Investment Sensitivity (USGC, 2006)

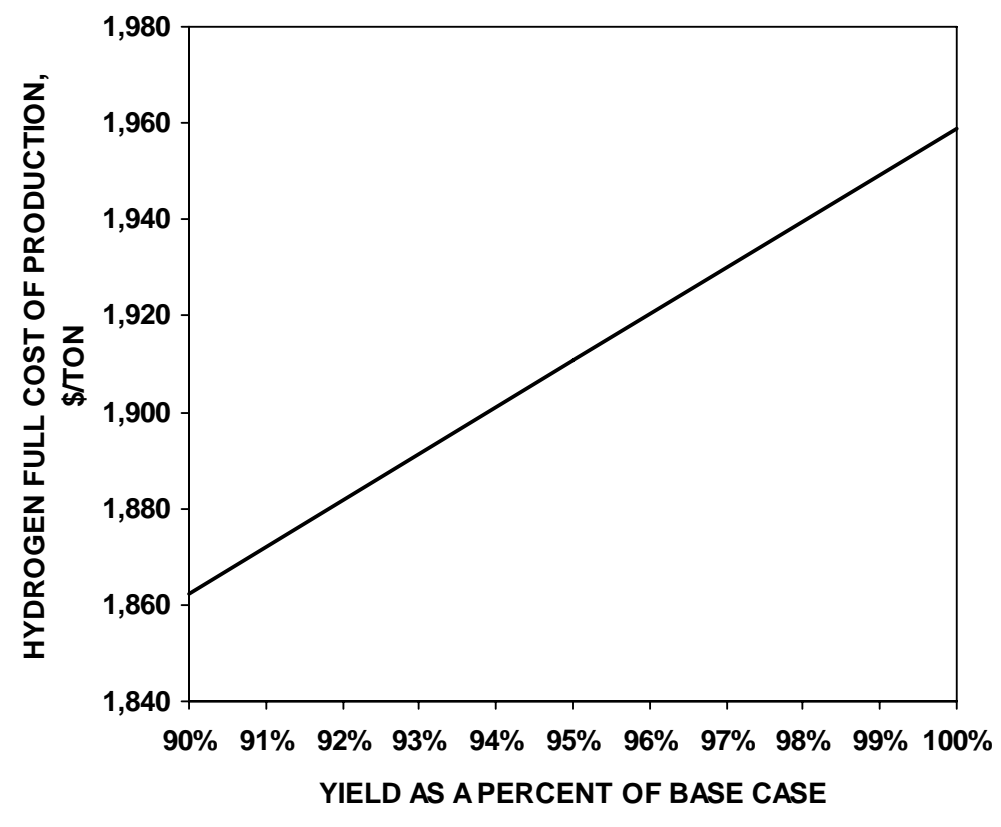

0:102q21nexant1000721rplajn2.ppt

Figure 6.14 Partial Oxidation/PSA Technology Yield Sensitivity (USGC, 2006) 


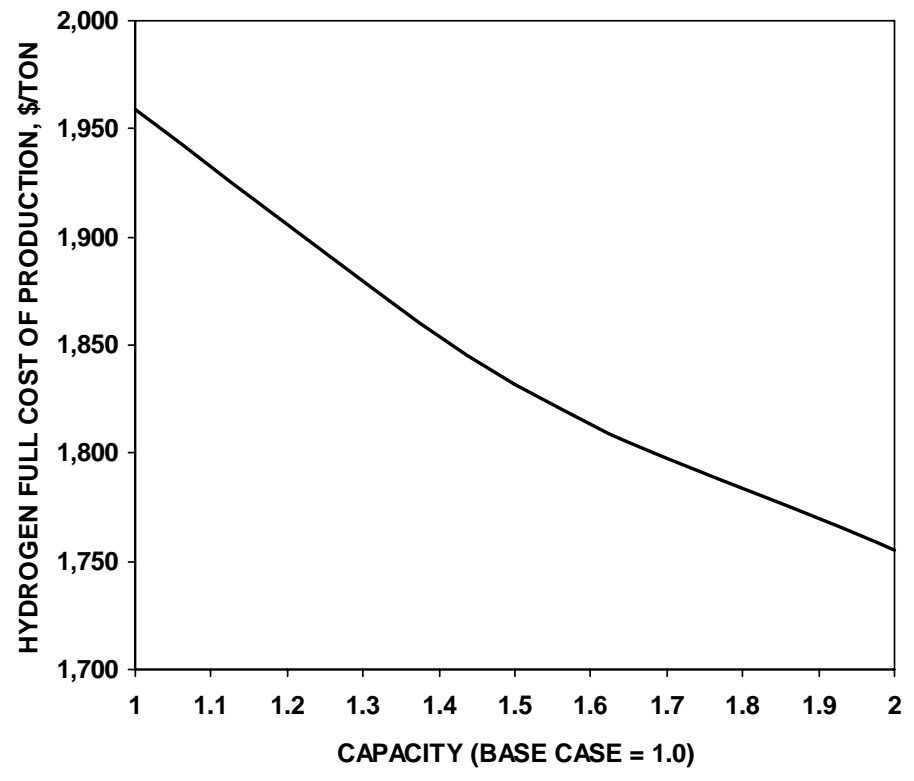

0:102q21nexantlo0o721rplajn2.ppt

Figure 6.15 Partial Oxidation/PSA Technology Economy Of Scale (USGC, 2006)

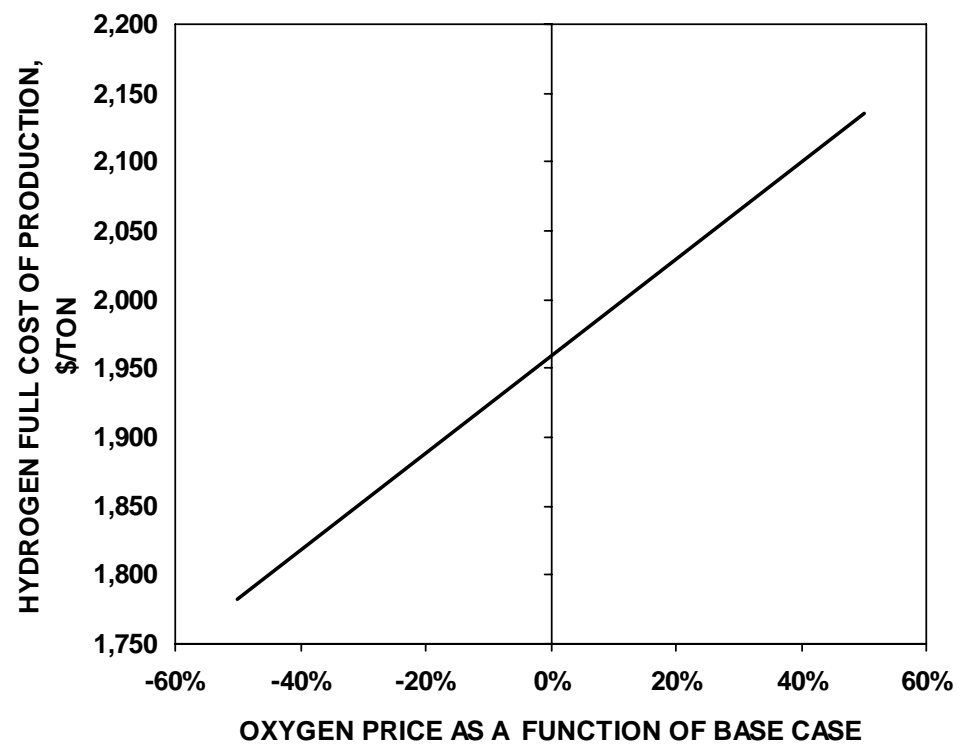

O:102q21nexant|00072Irplajn2.ppt

Figure 6.16 Partial Oxidation/PSA Technology Oxygen Price Sensitivity (USGC, 2006) 


\subsection{GTL FT LIQUID PRODUCTS}

For 2006, the full cost of production plus 10 percent ROI for FT liquids produced at a 75,000 barrels per day facility in a Middle East remote location will be about $\$ 27.58$ per barrel if natural gas cost is $\$ 1.00$ per million BTU. Taking into account transportation costs and tariff, the total delivered cost of FT liquids will be $\$ 30.72, \$ 29.88$, and $\$ 29.67$ per barrel at the USGC, Western European, and Japanese markets, respectively.

Based on Nexant's 2006 medium crude price outlook and the weighted average naphtha/diesel market prices of \$24.5, \$24.5 and \$28.2 per barrel at the USGC, Western Europe, and Japanese markets, respectively, the GTL process with natural gas price at $\$ 1.00$ per million BTU can deliver FT products at a return on investment of 1.2, 2.3, and 7.9 percent to the above markets respectively.

For 2015, the full cost of production plus 10 percent ROI for FT Liquids produced at a 150,000 barrels per day facility in a remote Middle East location will be about $\$ 24.54$ per barrel if natural gas cost is $\$ 1.25$ per million BTU. Taking into account transportation costs and tariff, the total delivered cost of FT liquids will be $\$ 28.09, \$ 27.15$, and $\$ 26.91$ per barrel at the USGC, Western European, and Japanese markets, respectively.

Based on Nexant's 2015 medium crude price outlook and the weighted average naphtha/diesel market prices of $\$ 29.1, \$ 29.4$ and $\$ 33.3$ per barrel at the USGC, Western European, and Japanese markets, respectively, the GTL process with natural gas price at $\$ 1.25$ per million BTU can deliver FT products at a return on investment of $12.2,14.5$, and 22.8 percent to the above markets respectively.

The above GTL full costs of production plus 10 percent ROI are compared favorably with the costs of production of a USGC conventional coking refinery at $\$ 29.11$ and $\$ 35.06$ per barrel of refined products for 2006 and 2015, respectively. The USGC delivered cost of FT liquid product also shows a better profit margin than the conventional refinery products.

The results are summarized in Table 7.1 and Figure 7. to Figure 7.15. 


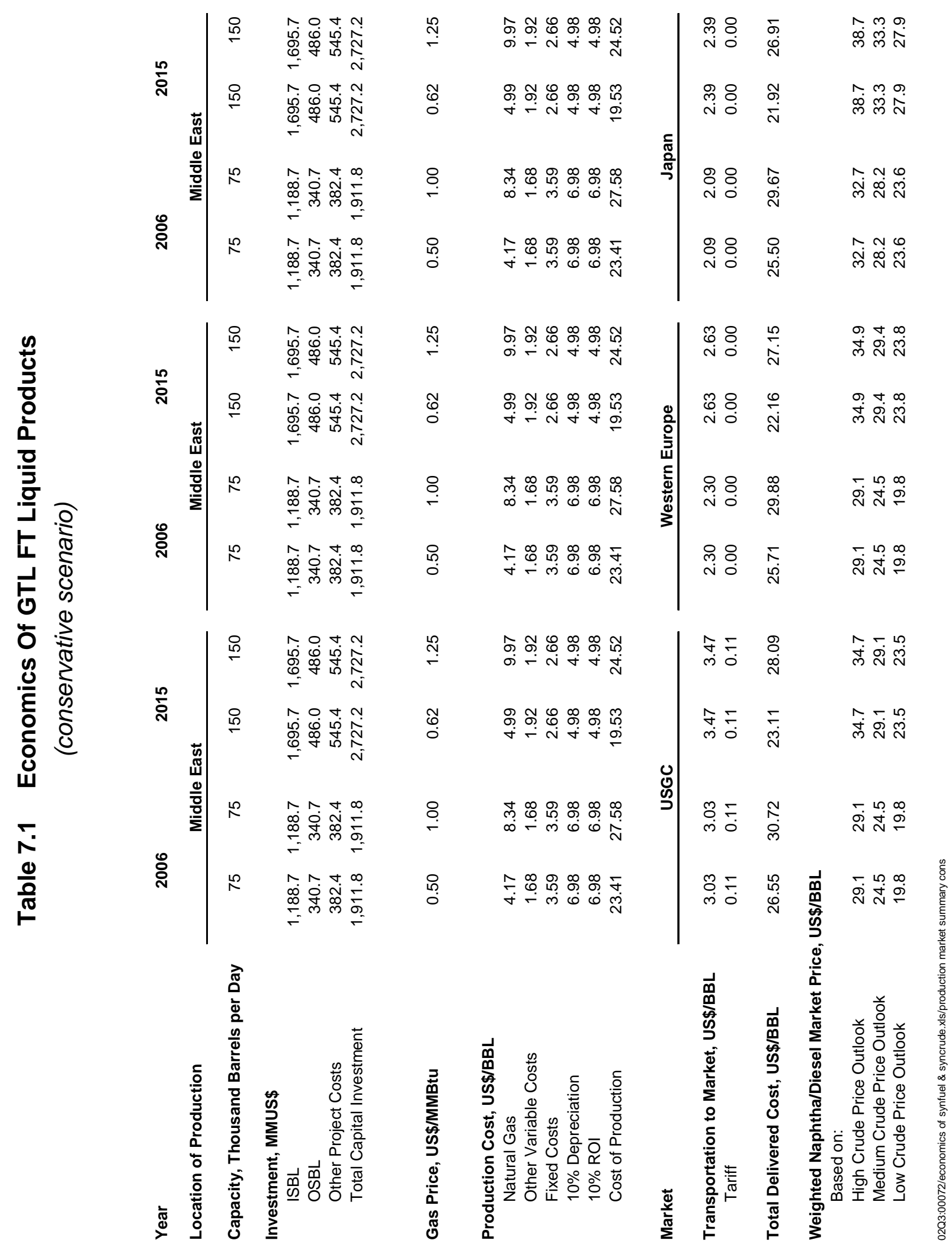




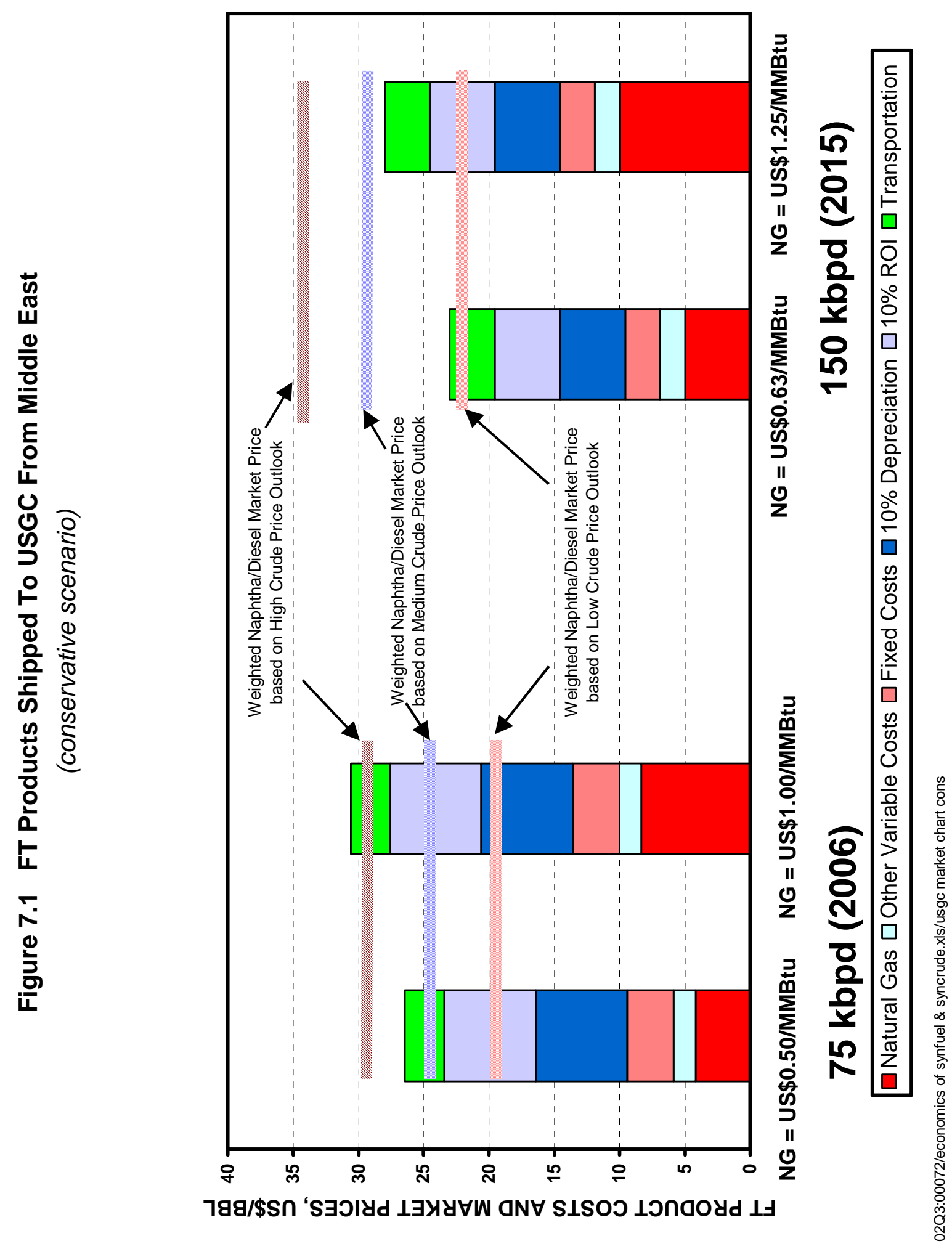




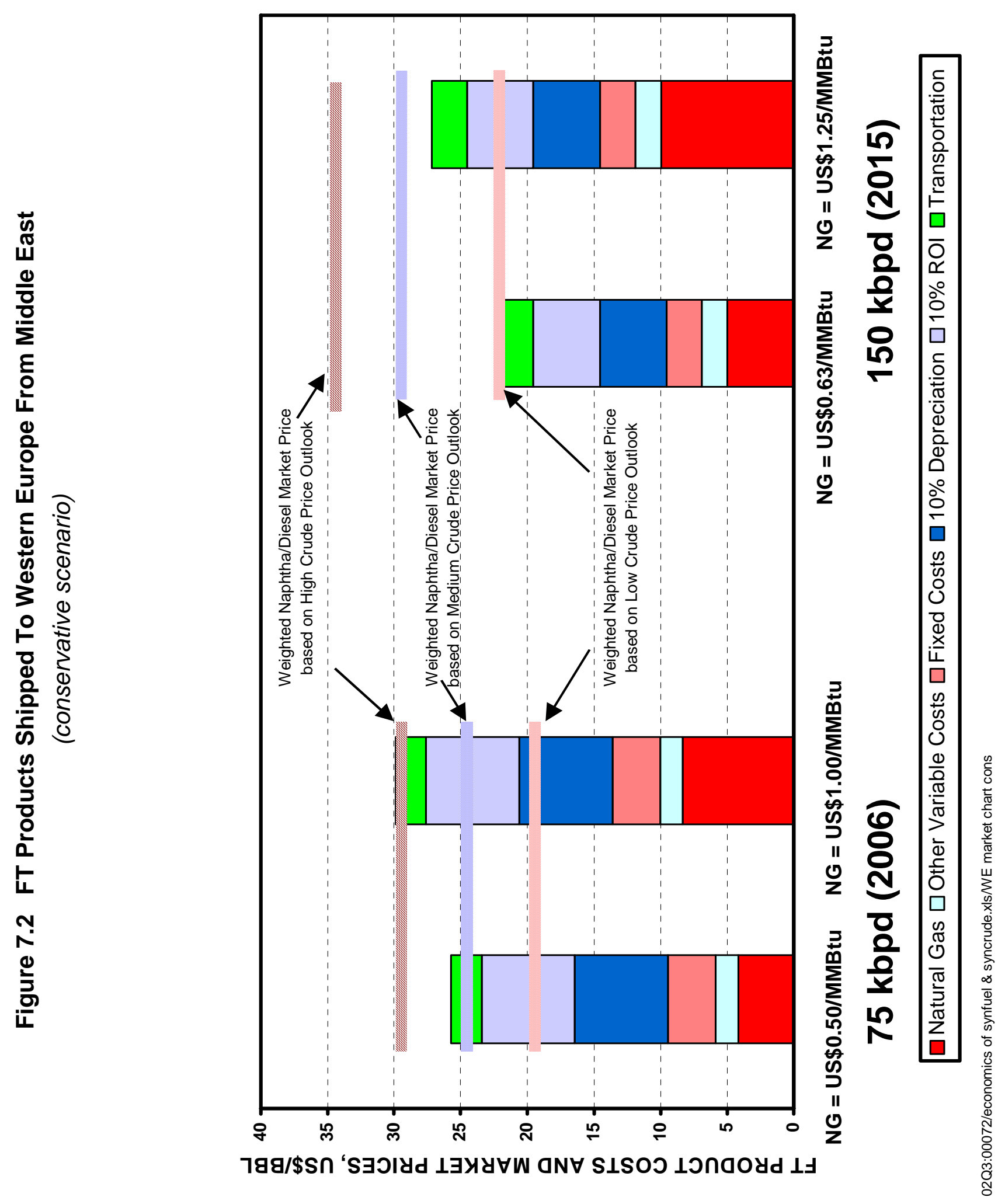




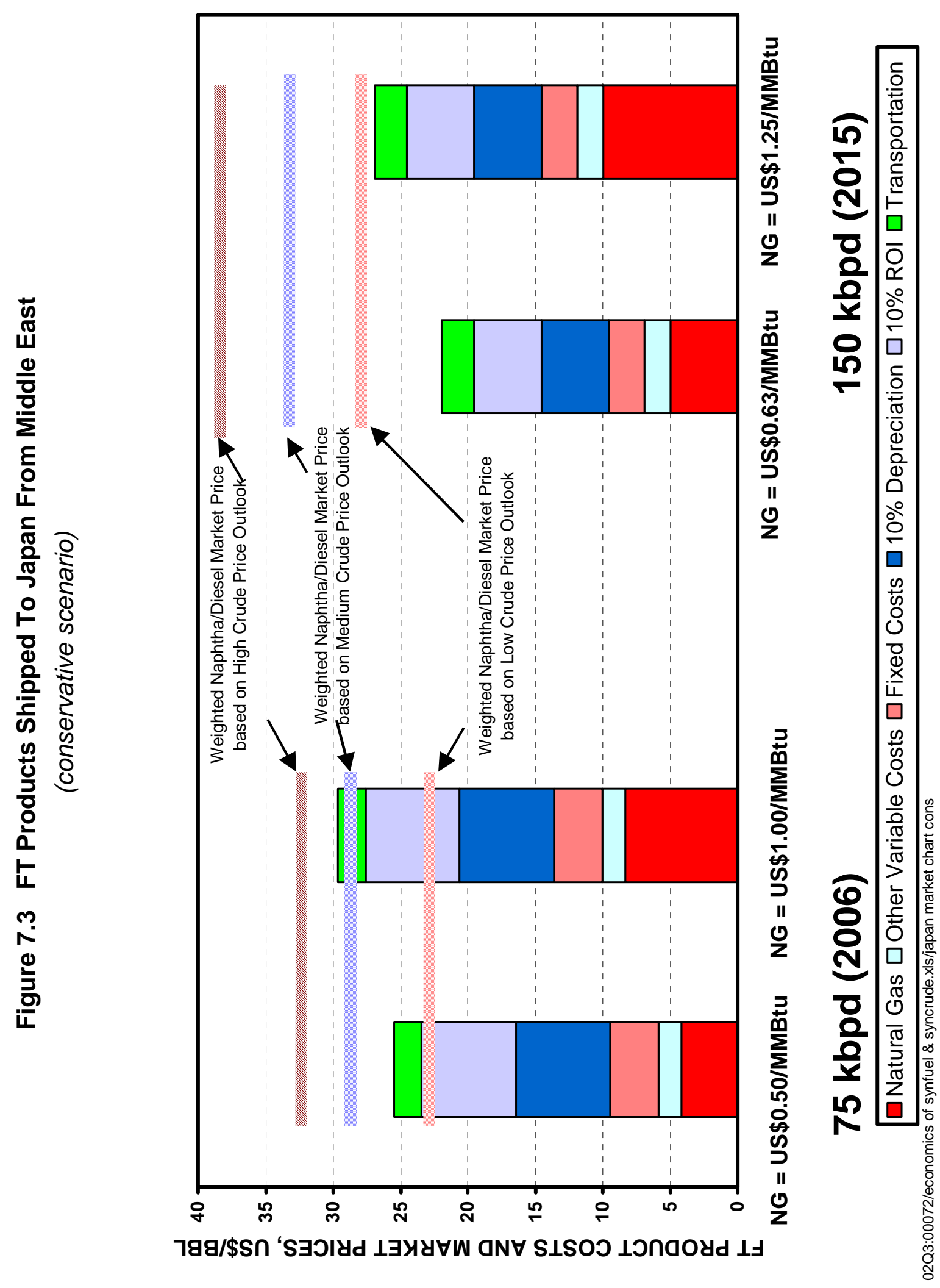




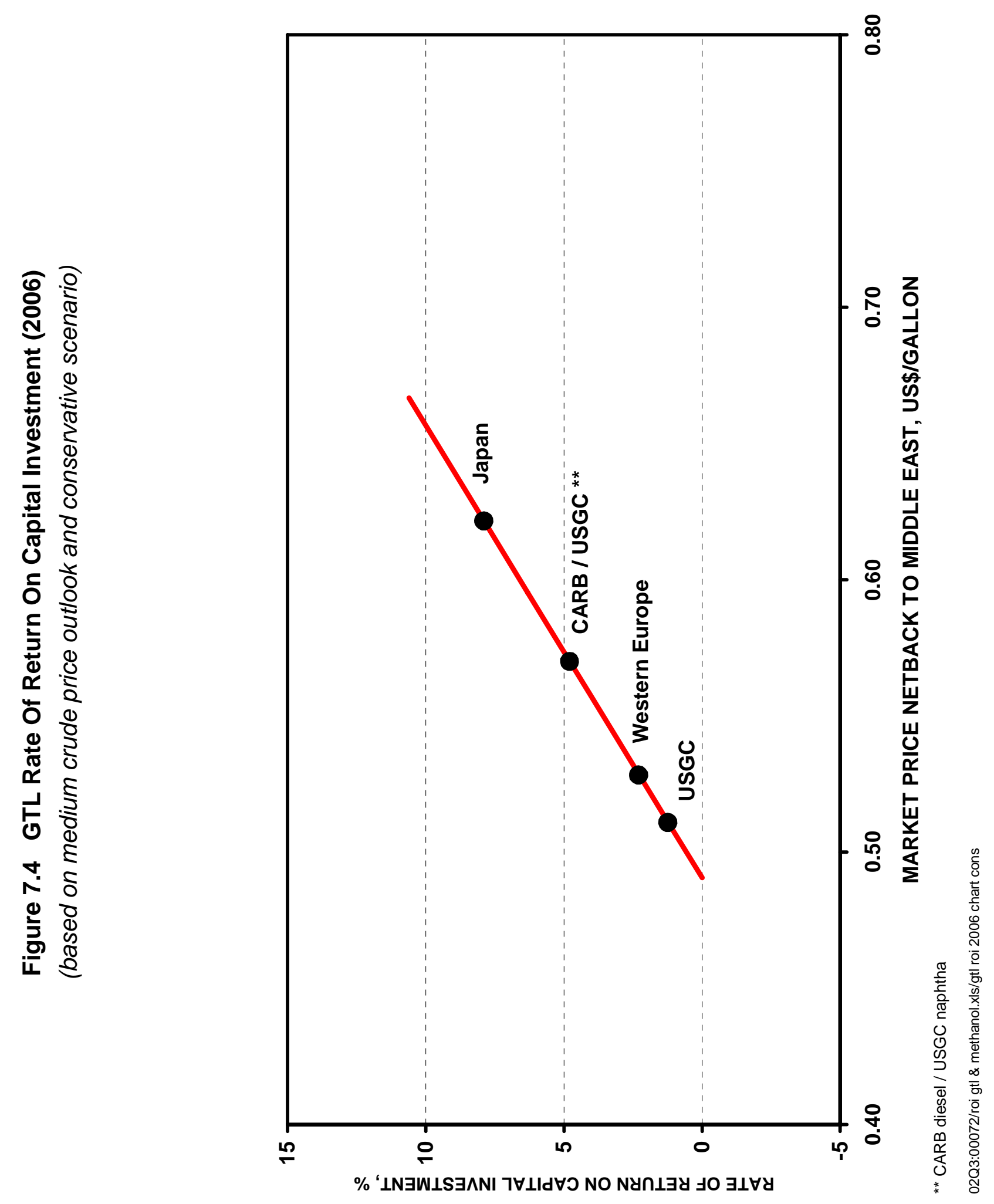




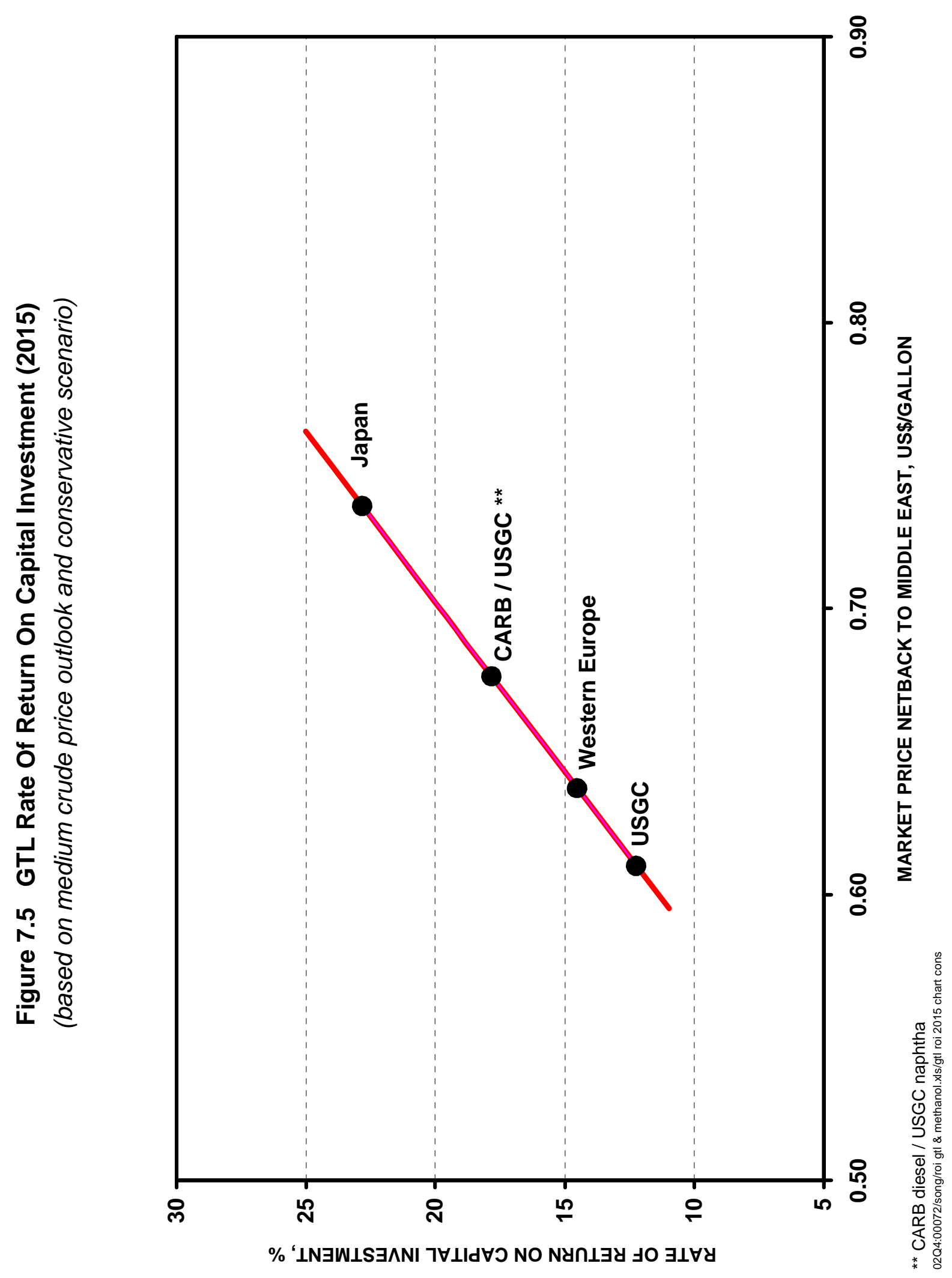



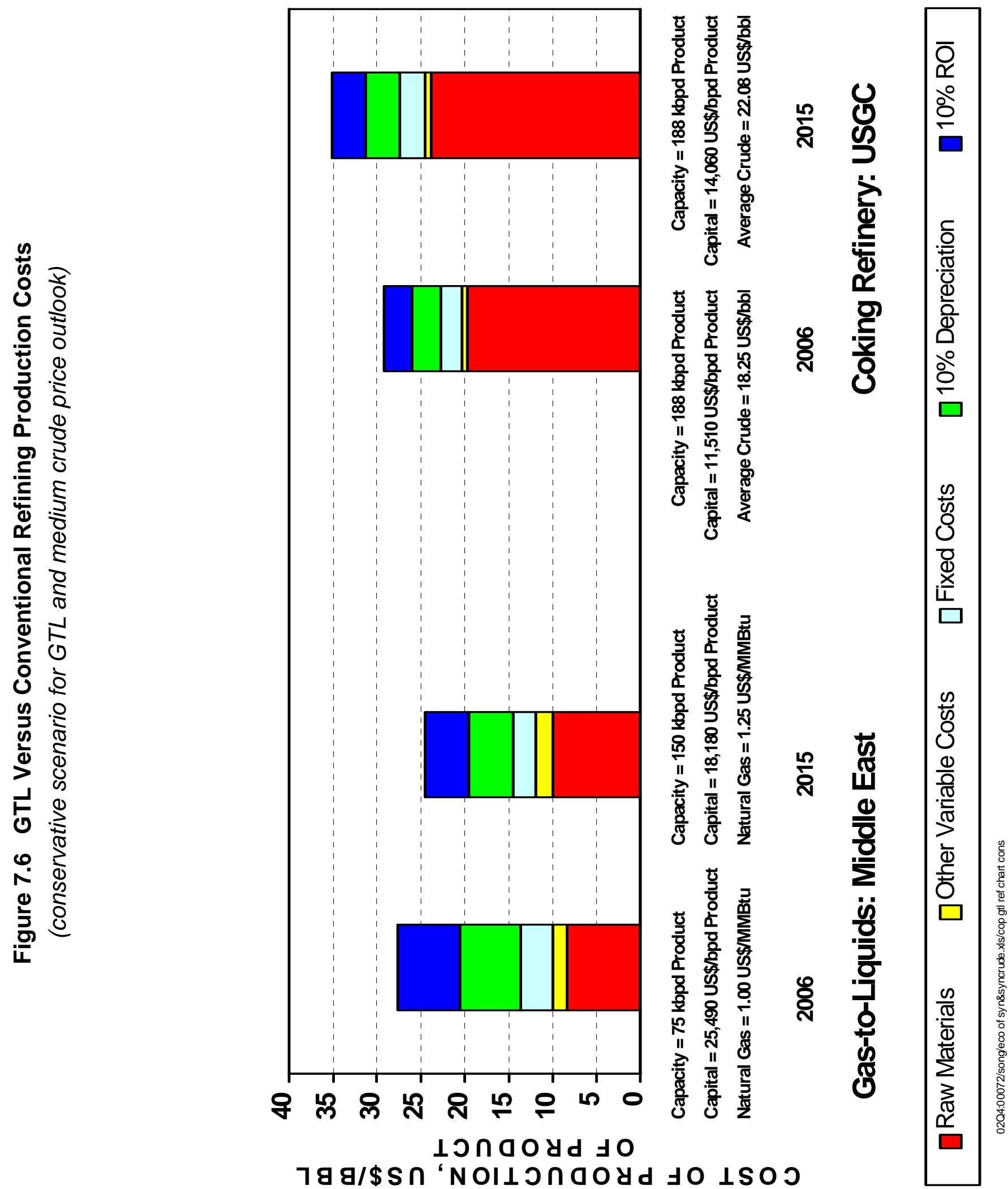


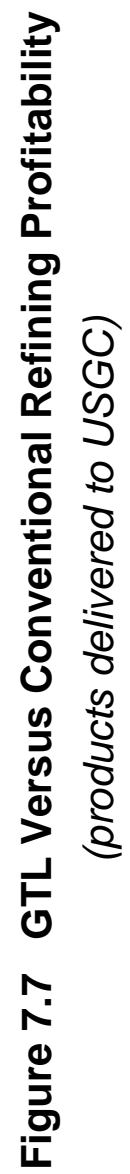




\subsection{METHANOL}

For 2006, the full cost of production plus 10 percent ROI for methanol produced at a 5,000 metric tons per day facility in a Middle East remote location will be about $\$ 0.285$ per gallon if natural gas cost is $\$ 1$ per million BTU. Taking into account transportation costs and tariff, the total delivered cost of methanol will be $\$ 0.364, \$ 0.359$, and $\$ 0.340$ per gallon at the USGC, Western European, and Japanese markets, respectively.

Based on Nexant's 2006 medium crude price outlook, the Mega Methanol Process with natural gas price at $\$ 1.00$ per million BTU can deliver methanol at a return on investment of 5.9, 19.0, and 26.0 percent based on USGC gasoline, CARB gasoline, and USGC chemical grade methanol, respectively.

For 2015, the full cost of production plus 10 percent ROI for methanol produced at a 15,000 metric tons per day facility in a Middle East remote location will be about $\$ 0.277$ per gallon if natural gas cost is $\$ 1.25$ per million BTU. Taking into account transportation costs and tariff, the total delivered cost of methanol will be $\$ 0.367, \$ 0.346$, and $\$ 0.339$ per gallon at the USGC, Western European, and Japanese markets, respectively.

Based on Nexant's 2006 medium crude price outlook, the Mega Methanol Process with natural gas at $\$ 1.25$ per million BTU can deliver methanol at a return on investment of $13.6,25.8$, and 41.6 percent based on USGC gasoline, CARB gasoline, and USGC chemical grade methanol, respectively.

These results are summarized in Table 7.2 and Figure 7.7 to Figure 7.12.

In general, the ROI for methanol is higher than that of FT liquid products. While both methanol and GTL ROIs improve significantly from 2006 to 2015, the improvement for methanol is more pronounced than that of GTL. The ROI comparison for methanol and FT liquid products is shown in Figure 7.3 and Figure 7.5. 


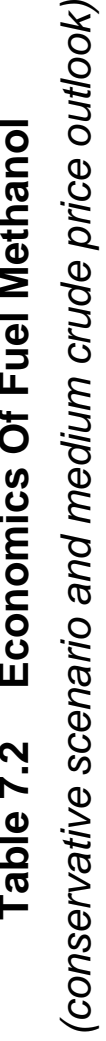

\begin{tabular}{|c|c|c|c|c|c|c|c|c|}
\hline & 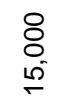 & 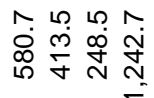 & $\stackrel{\stackrel{L}{\sim}}{i}$ & 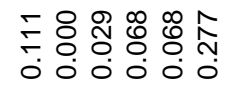 & & Ø̊ & \& & 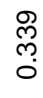 \\
\hline & $\begin{array}{l}8 \\
\text { \& } \\
\text { ș }\end{array}$ & 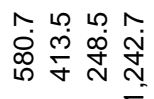 & đั & 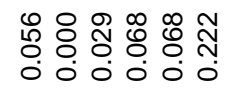 & & $\begin{array}{l}\text { Uै } \\
\text { ठ }\end{array}$ & : & $\begin{array}{l}\text { Dे } \\
\text { N } \\
0\end{array}$ \\
\hline 를 & \& & 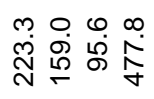 & ( ) & 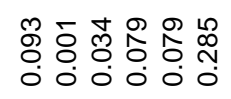 & & 雚 & \& & 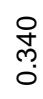 \\
\hline & 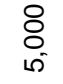 & 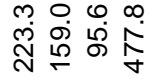 & 菖 & 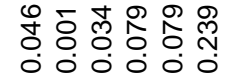 & & $\begin{array}{l}\mathscr{H}_{0}^{\circ} \\
0\end{array}$ & O & 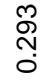 \\
\hline
\end{tabular}

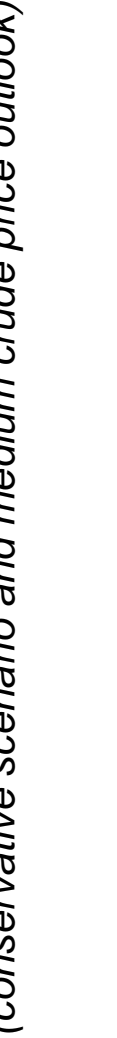

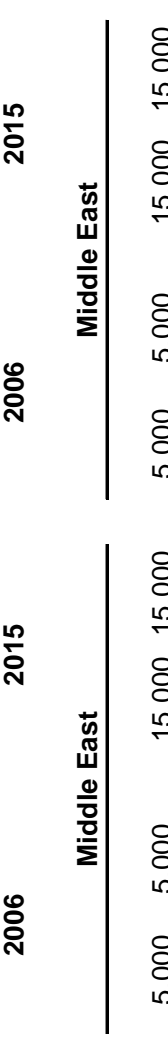

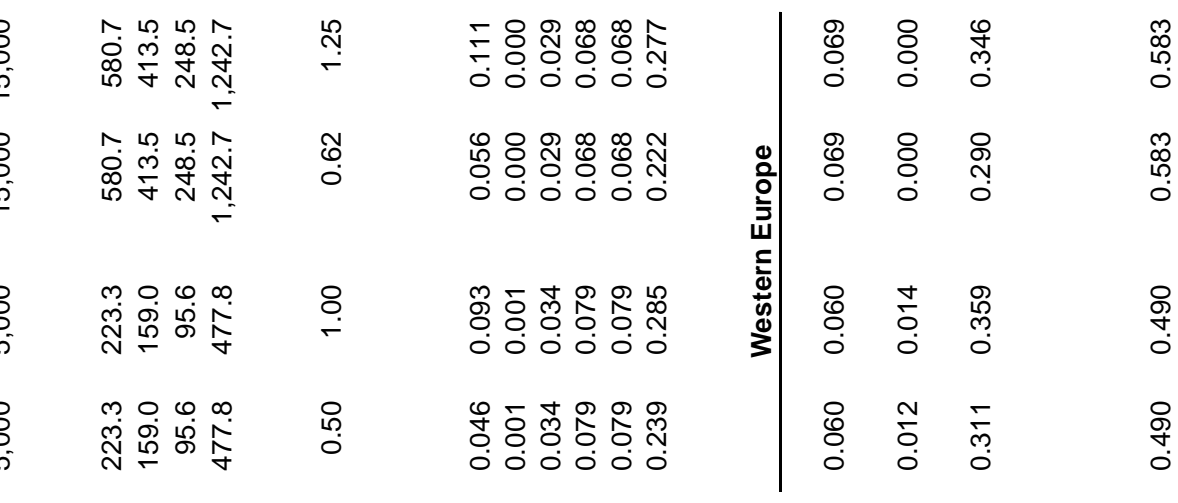

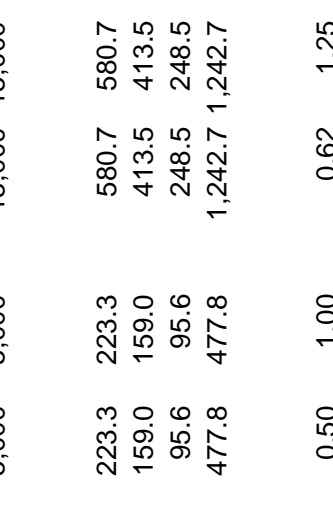

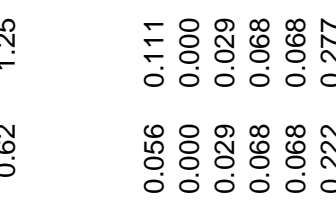

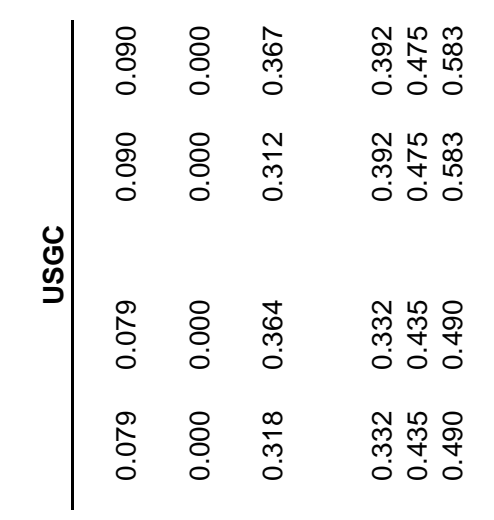
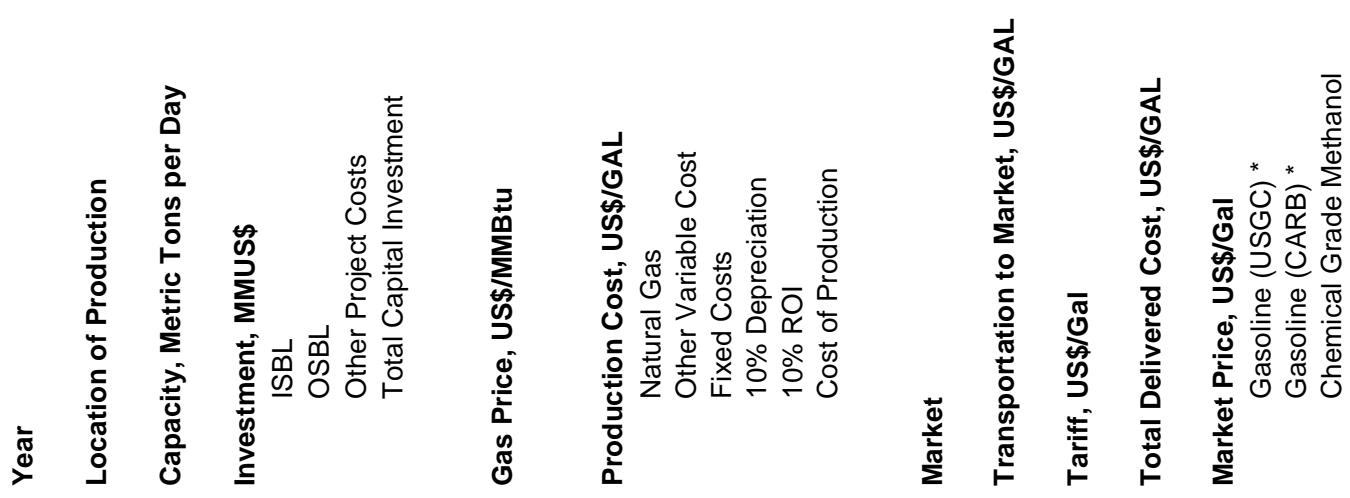


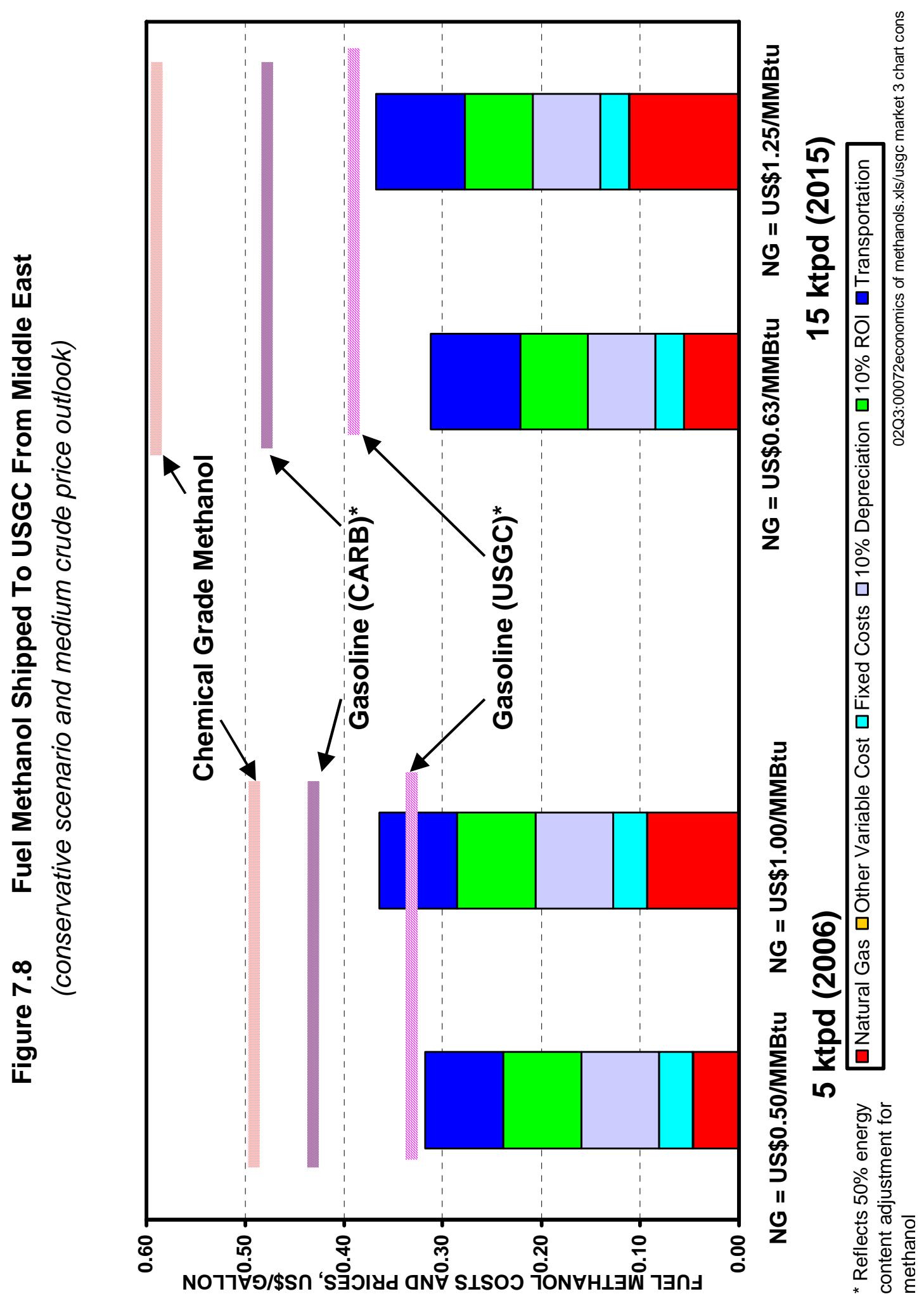



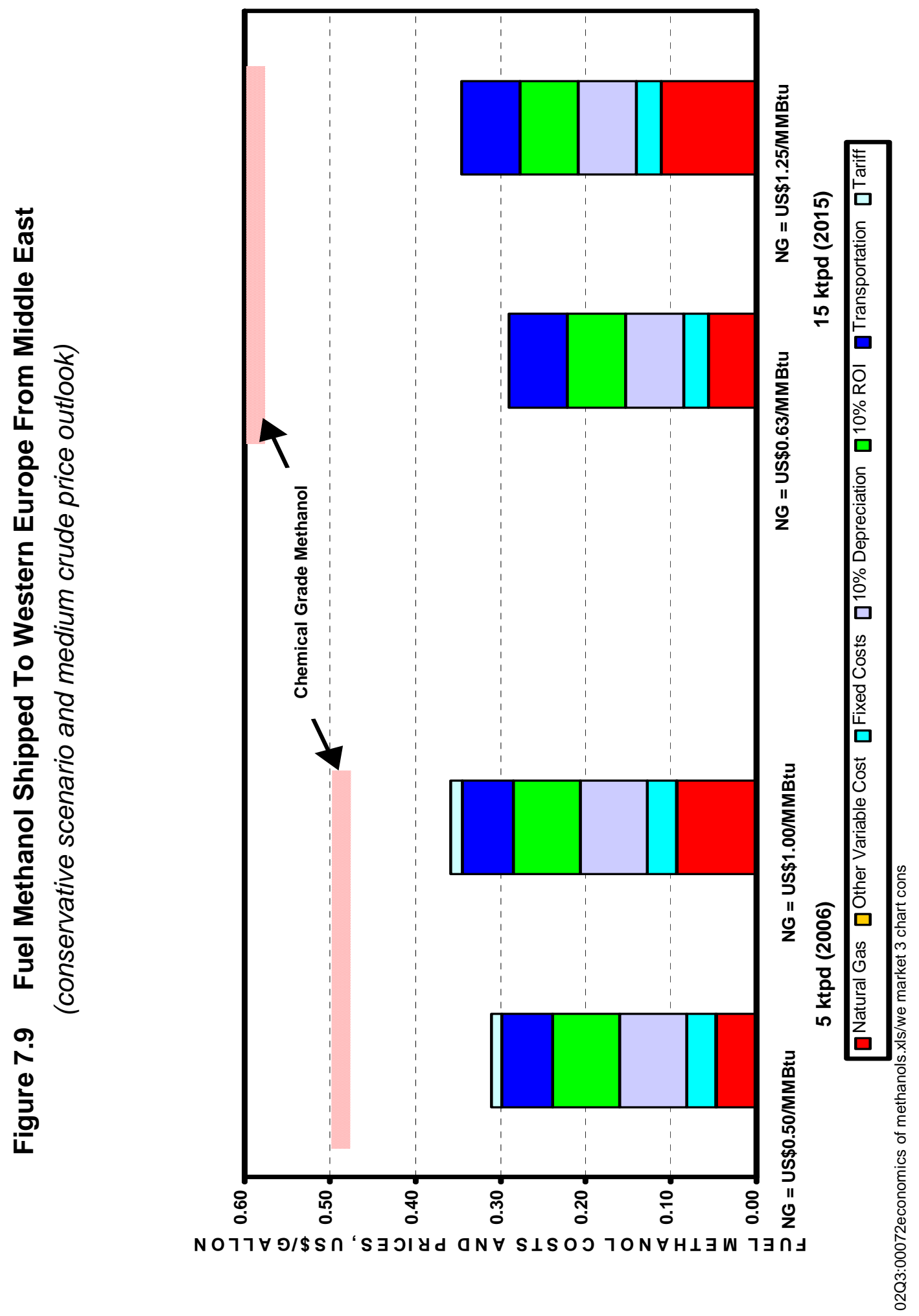

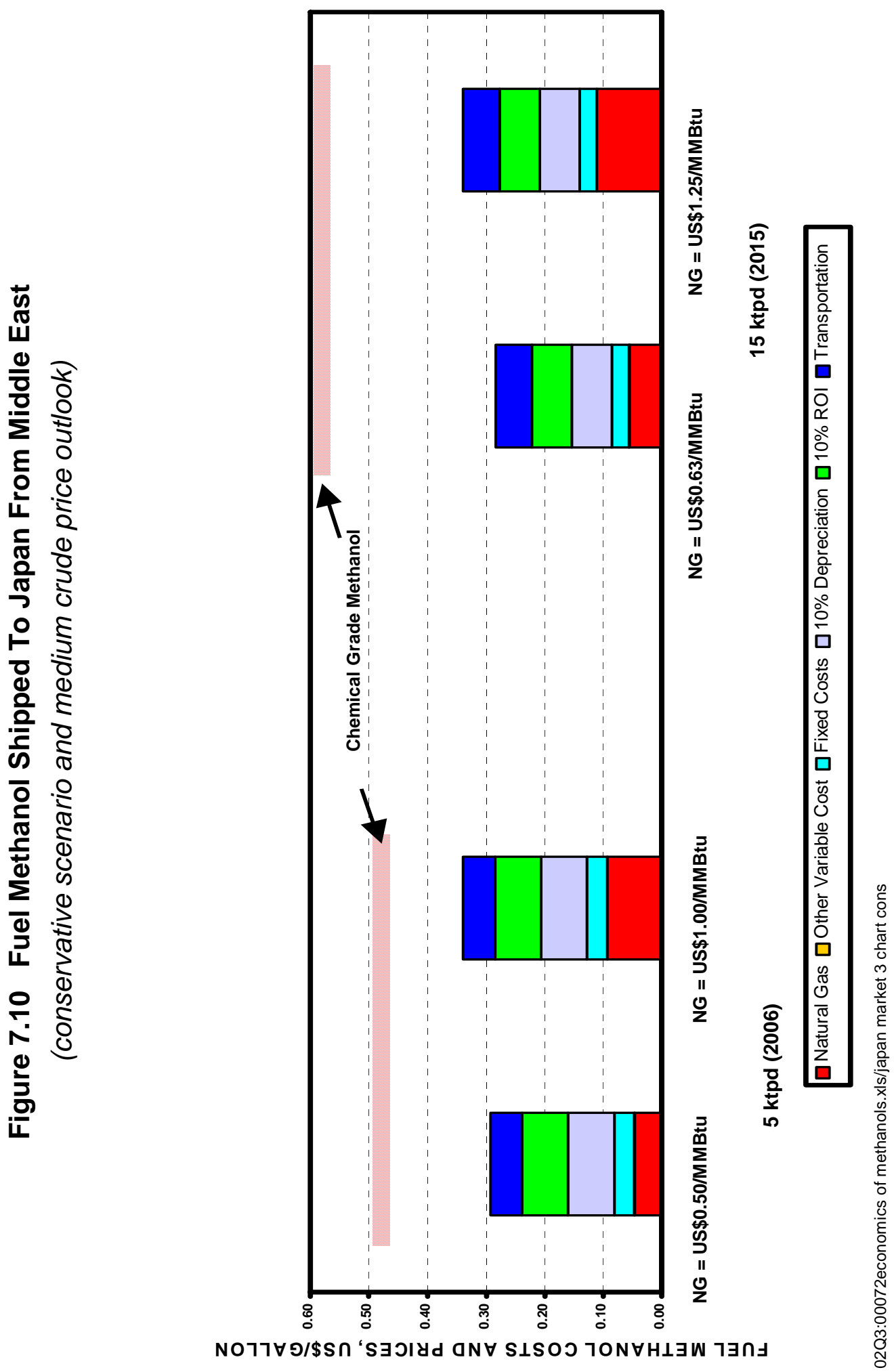


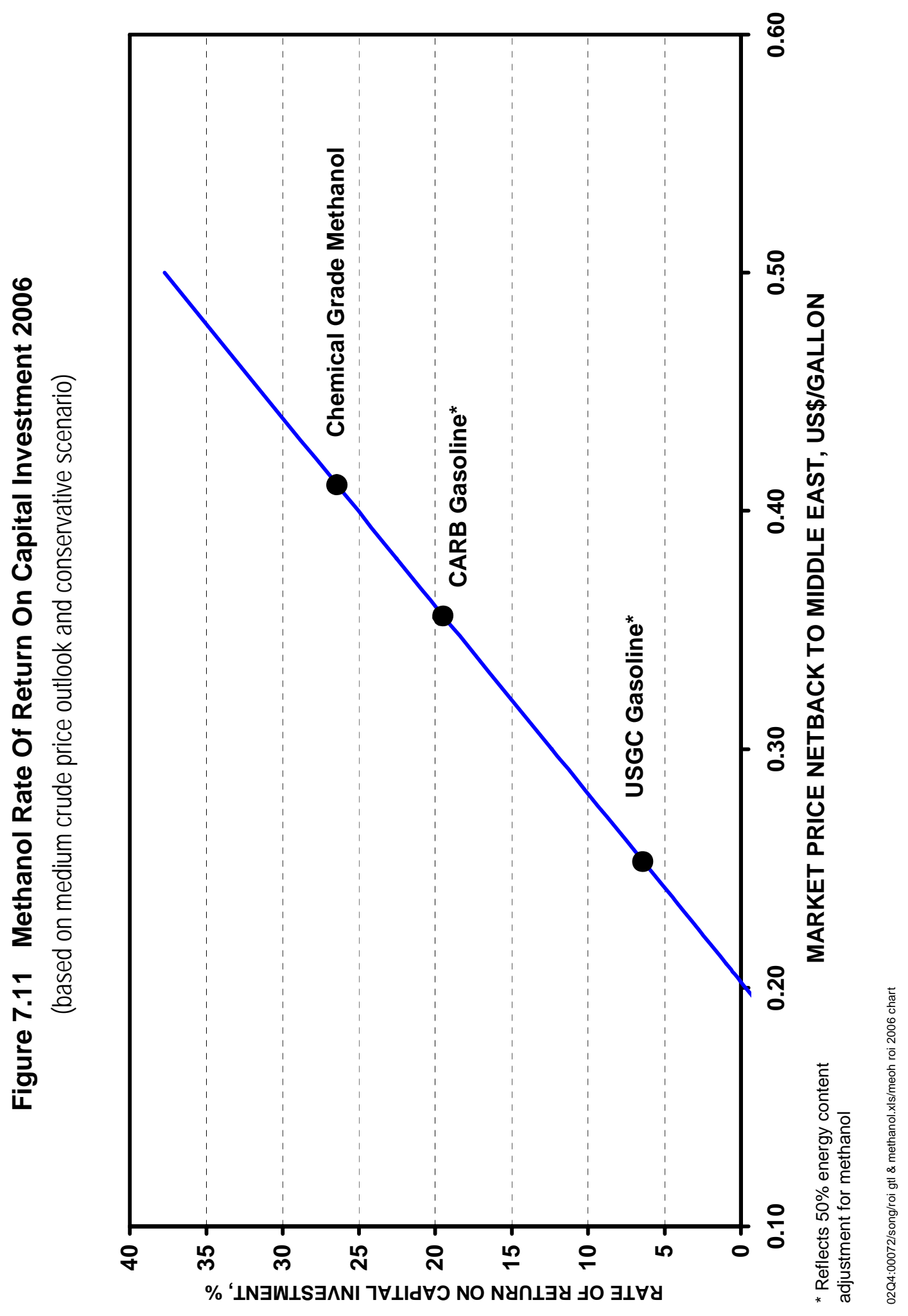




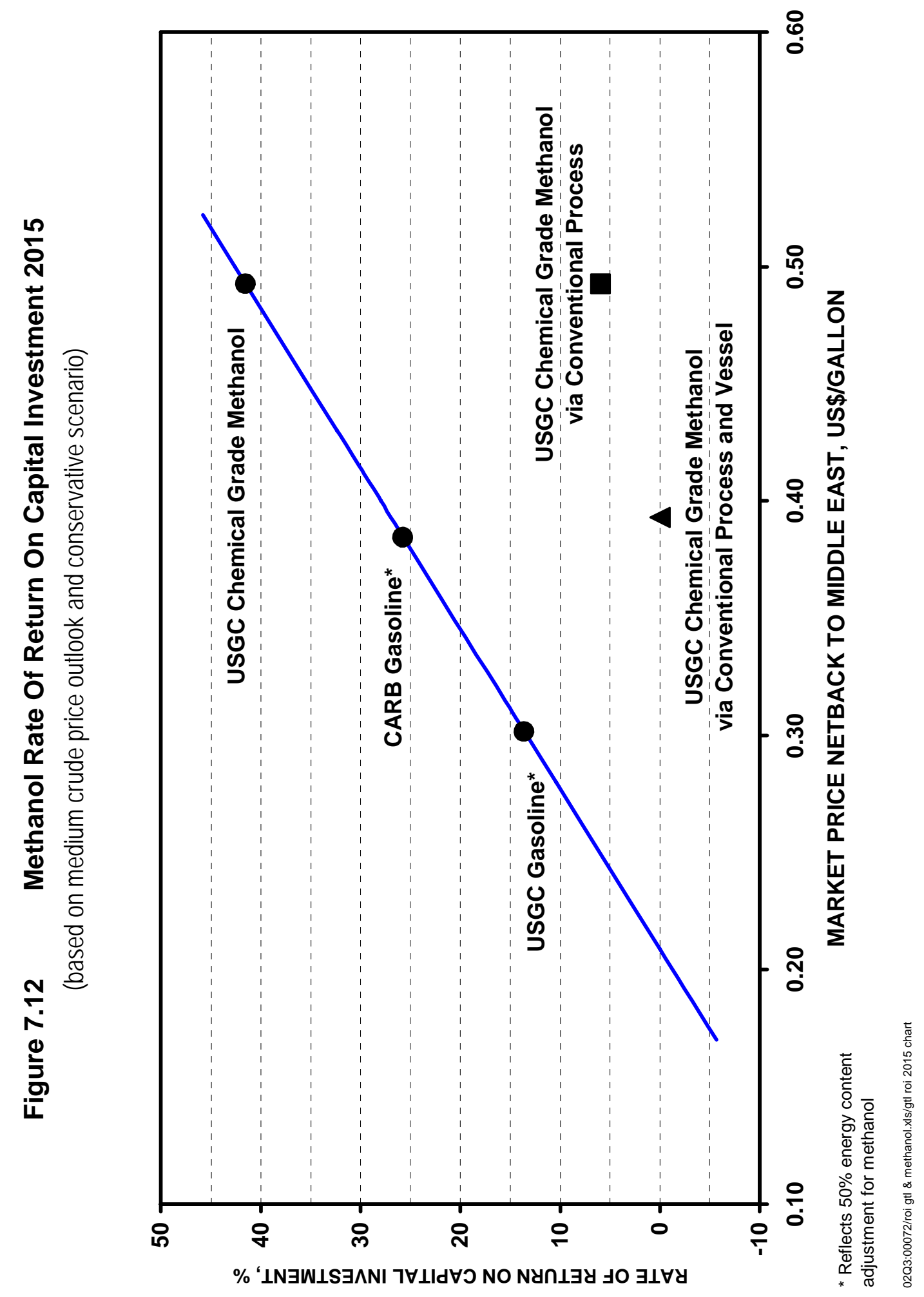




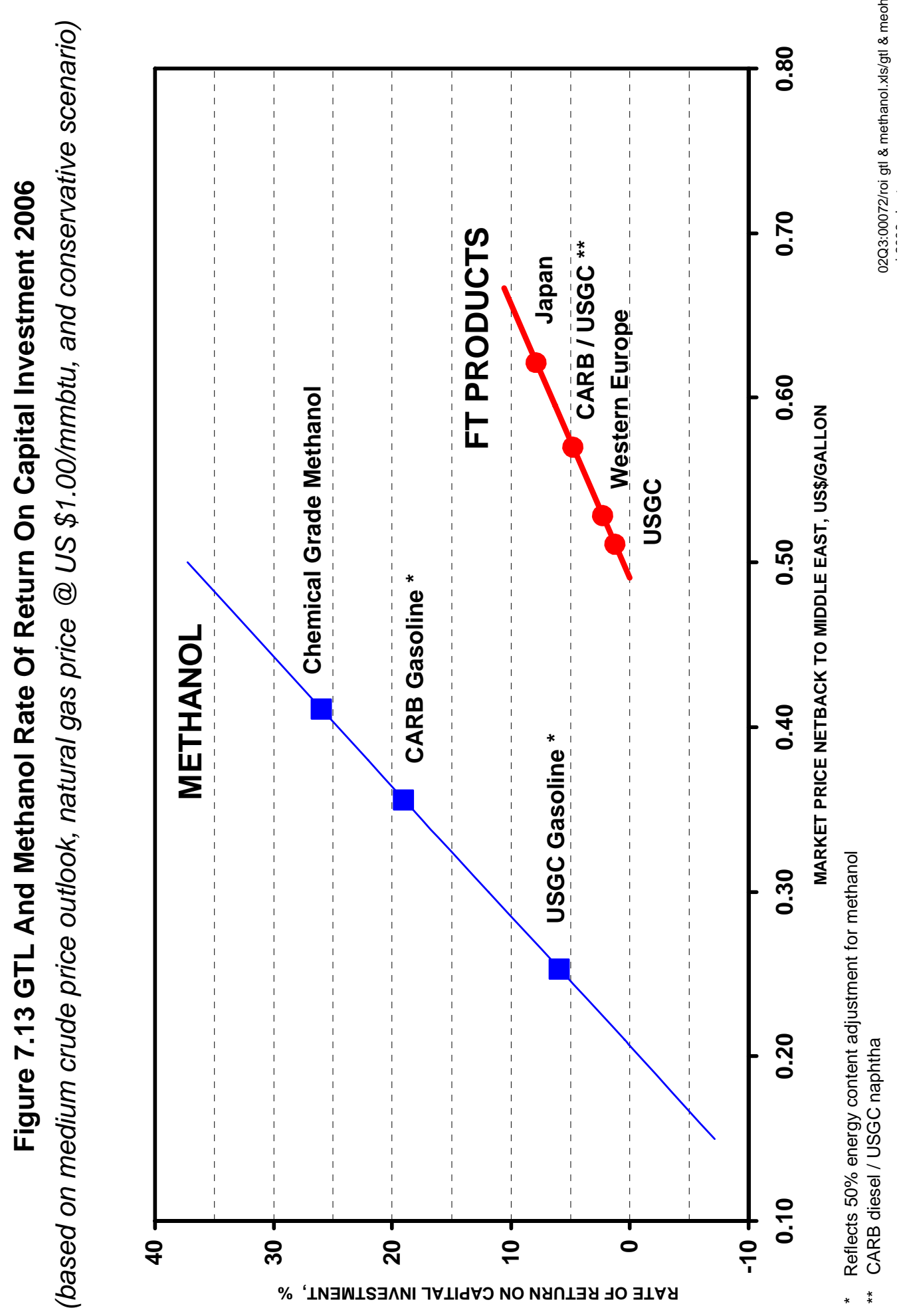




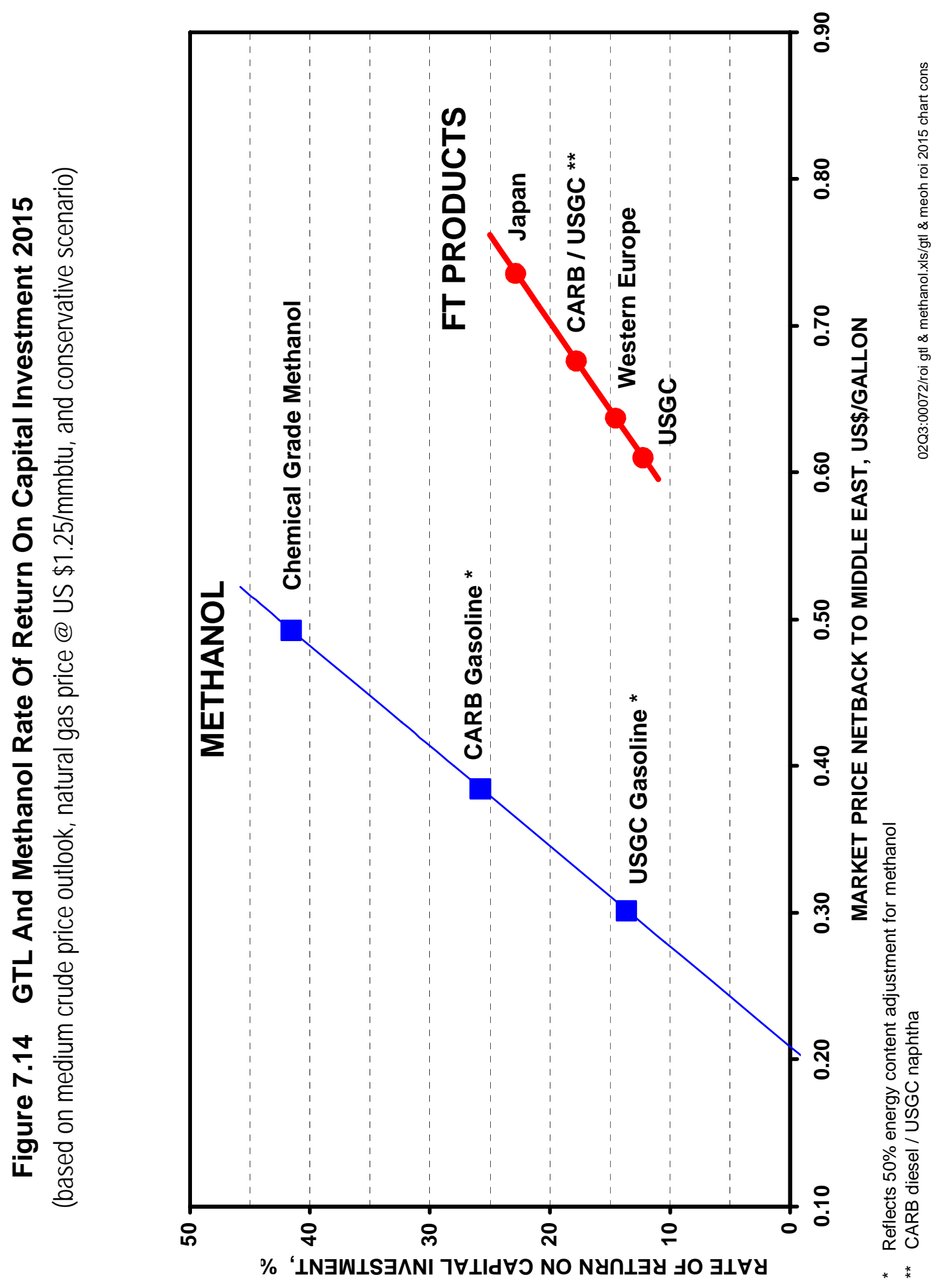




\subsection{ETHANOL}

For 2006, the full cost of production plus 10 percent ROI for ethanol produced at a 50 million gallon per year facility in a U.S. Midwest location will be about $\$ 1.12$ and $\$ 1.88$ per gallon from corn and biomass, respectively. These costs compare unfavorably to ethanol blending value of $\$ 0.80$ per gallon and unleaded regular gasoline of $\$ 0.61$ per gallon.

For 2015, the full cost of production plus 10 percent ROI for ethanol produced at a 150 million gallons per year facility in a U.S. Midwest location will be about $\$ 1.06$ and $\$ 1.30$ per gallon from corn and biomass, respectively. These costs compare unfavorably to ethanol blending value of $\$ 0.93$ per gallon and unleaded regular gasoline of $\$ 0.73$ per gallon.

These results are summarized in Table 7.3 and Figure 7.5. 

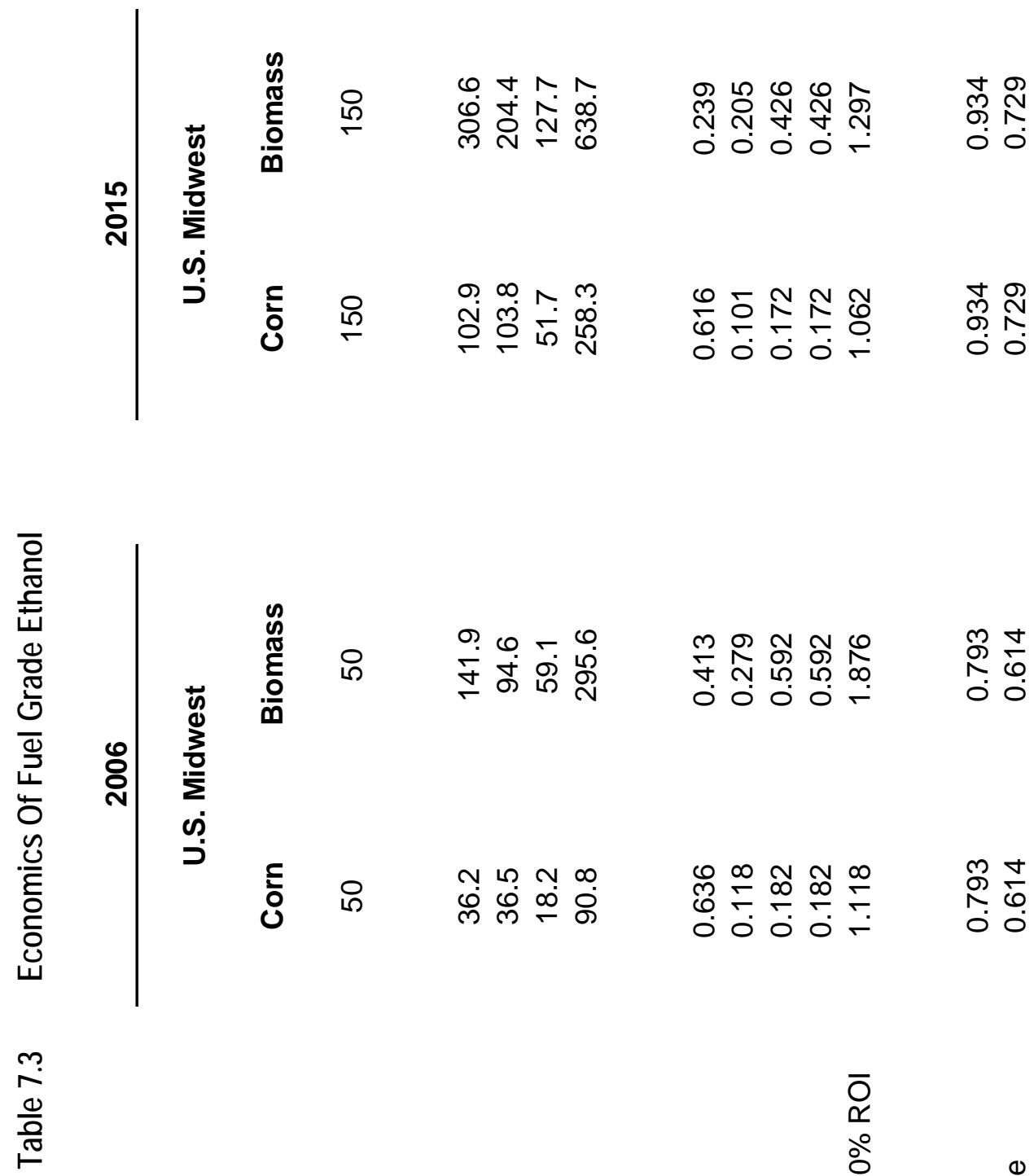

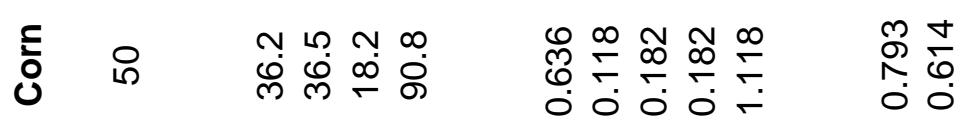

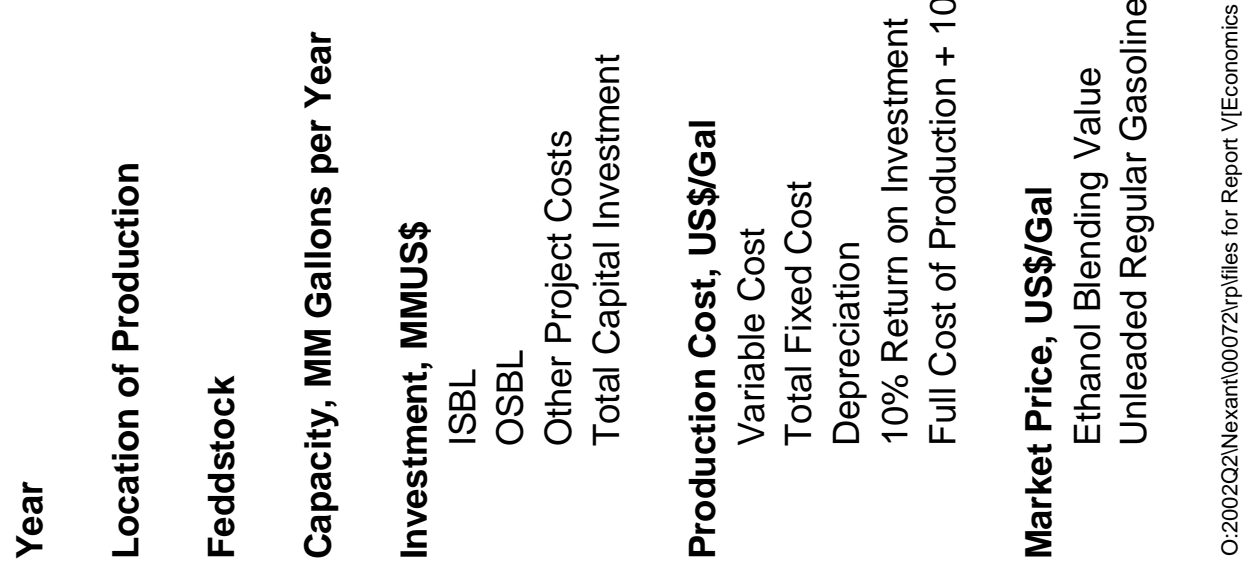




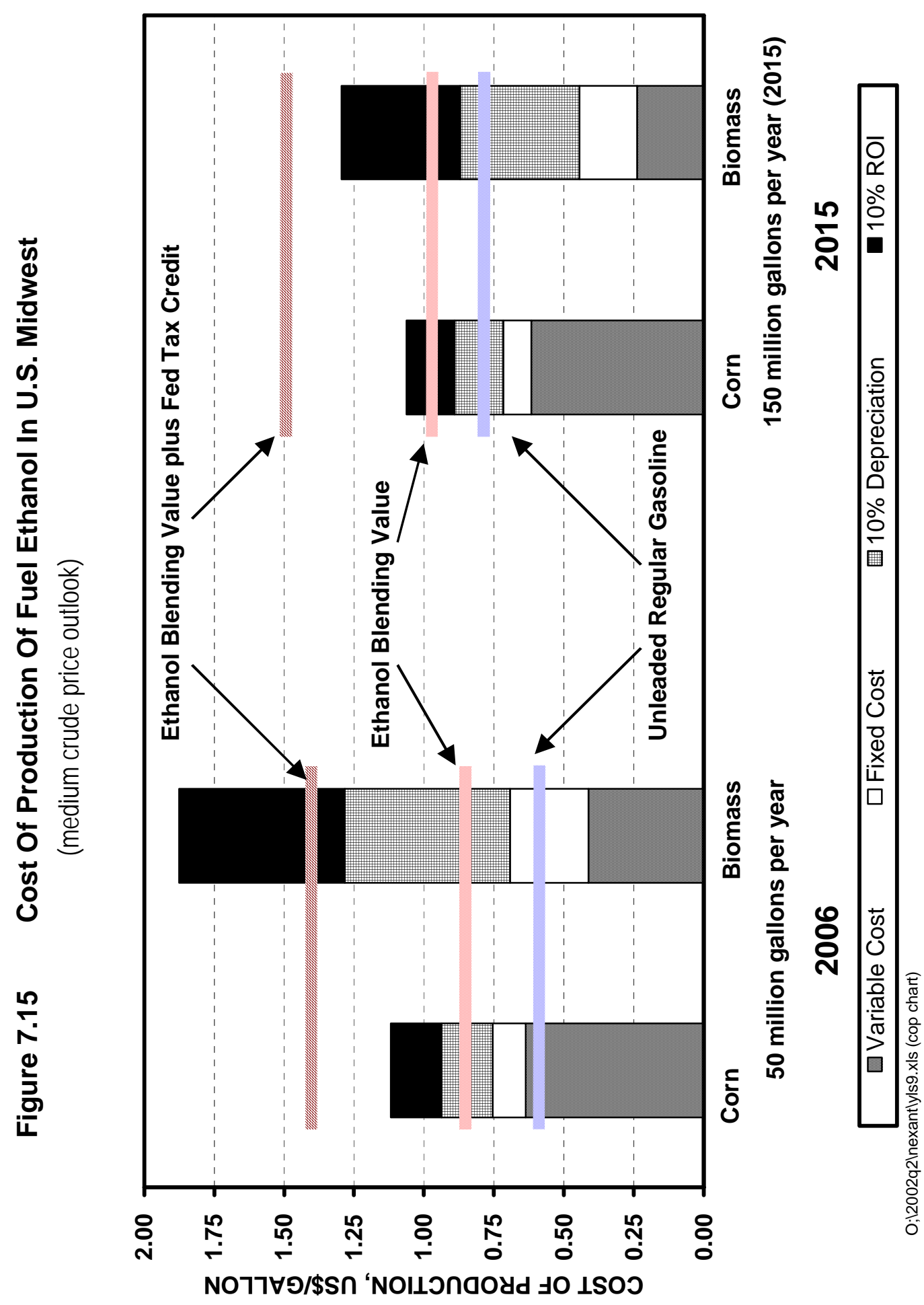




\subsection{SYNGAS/HYDROGEN}

The economics for syngas production are driven by the underlying cost of natural gas. Natural gas feedstock makes up about $50 \%$ of the cost of production as seen in Table 4.

Table 7.4 Syngas Cost Of Production

(USGC, dollars per metric ton caption)

\begin{tabular}{|l|c|c|c|c|}
\hline & $\mathbf{2 0 0 6}$ & $\mathbf{2 0 1 5}$ & $\mathbf{2 0 0 6}$ & $\mathbf{2 0 1 5}$ \\
\hline & 722 & 835 & 1,346 & 1,618 \\
\hline Variable costs(1) & 11 & 11 & 15 & 16 \\
\hline Fixed costs & 652 & 670 & 598 & 668 \\
\hline Depreciation + Return(2) & 1,386 & 1,516 & 1,959 & 2,302 \\
\hline Full Cost of Production & $\begin{array}{l}\text { (1) Syngas at cash cost } \\
\text { (2) Depreciation and return include syngas portion of plant }\end{array}$ \\
\hline
\end{tabular}

Comparing steam methane reforming (SMR) with partial oxidation (POX) economics, SMR has lower costs for producing hydrogen since it produces less carbon monoxide. Thus, SMR is the logical choice for hydrogen production based on the optimal syngas composition. The cost of production for a purified hydrogen product (via PSA) is shown in Table 5.

\section{Table 7.5 Hydrogen Cost Of Production}

(USGC, dollars per metric ton)

\begin{tabular}{|l|c|c|c|c|}
\hline & \multicolumn{2}{|c|}{ SMR } & \multicolumn{2}{c|}{ POX } \\
\hline & $\mathbf{2 0 0 6}$ & $\mathbf{2 0 1 5}$ & $\mathbf{2 0 0 6}$ & $\mathbf{2 0 1 5}$ \\
\hline Variable costs & 106 & 128 & 102 & 124 \\
\hline Fixed costs & 16 & 16 & 15 & 17 \\
\hline Depreciation + Return & 68 & 70 & 38 & 44 \\
\hline Full Cost of Production & 190 & 213 & 156 & 185 \\
\hline Full Cost of Production ex. Feed & 97 & 100 & 86 & 99 \\
\hline
\end{tabular}




\section{Appendix A}

\section{Shultz-Flory Theory: Selectivity of Fischer-Tropsch Catalysts}

The selectivity of Fischer-Tropsch catalysts can be described with only one constant, $\alpha$, the probability of chain growth. The concept of $\alpha$ is very useful and it is the basis of the following derivation.

The principle of equal reactivity of all functional groups during condensation polymerization has also been applied to the linear chain molecules of the FT product. According to this principle, at every stage of the polymerization process an equal opportunity for reaction is available to each functional group of a given type, irrespective of the size of the molecule to which it is attached. In the case of FT synthesis this principle can be stated that, if a given end methylene unit $\left(-\mathrm{CH}_{2}-\right)$ is known to be attached to a sequence of $n$ consecutive methylene units combined in a linear polymer chain, the probability that the other functional group at the other end of the unit has also reacted is equal to and independent of chain length.

Consider the following chain of methylene groups:

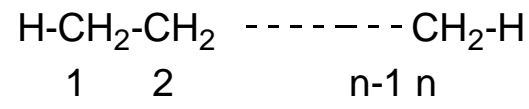

O:/2002Q2/NEXANT/00072/RP/00072-2.CDX

The probability that any methylene group is attached to another is defined as $\alpha$. The probability that the methylene of the second unit is attached to another group is independent of whether or not linkage 1 (the $\mathrm{C}-\mathrm{C}$ bond between the first and second methylene group) has been formed and is likewise equal to $\alpha$. The probability that this sequence continues for $n-1$ linkages is the product of the separate probabilities, or $\alpha^{\mathrm{n}-1}$. The probability that the $\mathrm{n}^{\text {th }}$ methylene group is reacted is also $\alpha$, or stated differently, the probability that the $\mathrm{n}^{\text {th }}$ methylene group is unreacted, thus limiting the chain to exactly $\mathrm{n}$ units, is $1-\alpha$. Hence, the probability that the molecule in question is composed of exactly $n$ units is given by $\alpha^{n-1}(1-\alpha)$.

If only linear open chain polymer molecules are present, then the probability that any molecule selected at random is composed of $\mathrm{n}$ units must equal the mole fraction of molecules with $\mathrm{n}$ units (n-mers).

The total number of n-mers is given by

$$
\mathrm{N}_{\mathrm{n}}=\mathrm{N}(1-\alpha) \alpha^{\mathrm{n}-1}
$$

where $\mathrm{N}$ is the total number of molecules of all sizes. If No represents the total number of units (i.e. $-\mathrm{CH}_{2}$-groups) then: 


$$
N=N_{0}(1-\alpha)
$$

which gives

$$
N_{n}=N_{o}(1-\alpha)^{2} \alpha^{n-1}
$$

If the added weight of the end groups is neglected ( $\mathrm{H}$ atoms), the molecular weight of each species is directly proportional to $\mathrm{n}$, and the weight fraction can be written:

$$
\mathrm{W}_{\mathrm{n}}=\mathrm{n} \mathrm{N}_{\mathrm{n}} / \mathrm{N}_{\mathrm{o}}
$$

The error introduced by this approximation will be significant only at low molecular weights. Substituting 3 in 2 :

From Equation 1

$$
\mathrm{W}_{\mathrm{n}}=\mathrm{n}(1-\alpha)^{2} \alpha^{\mathrm{n}-1}
$$

$$
\mathrm{N}_{\mathrm{n}}=\mathrm{Nx} \alpha^{\mathrm{n}-\mathrm{x}}
$$

The weight distribution (Equation 4) has a maximum at $\mathrm{n}=-1 / \ln (\alpha)$, but the mole distribution (Equation 5) decreases monotonically. A plot of $\log N_{n}$ versus $n$ should be linear.

The correlation between product distribution and carbon number using the Schulz-Flory theory in Fischer-Tropsch syntheses was employed by Robert B. Anderson to characterize various catalysts. For example, Figure A.1 presents the molar distribution of cobalt catalysts used in normal and medium pressure synthesis. The higher value for $\alpha$ shown in the figure corresponds to a pelleted catalyst with frequent hydrogen treatments for which a value of $\alpha$ of 0.85 was found. The typical carbon number distribution using iron, ruthenium, and cobalt catalyst systems are shown in Figure A.2.

Carbon number distribution is rarely measured because of the time and effort involved in separating the product into its components. A more useful equation has been derived that can be applied to the relatively crude fractions of gasoline, diesel oil, and wax that are usually made by FT synthesis. From Equation 5, the weight of product with carbon number greater than $\mathrm{r}-1, \mathrm{Wr}+$ is given by: 


$$
\begin{aligned}
\mathrm{W}_{\mathrm{r}+} & \cong 14 \mathrm{Nx} \sum_{\mathrm{n}=\mathrm{r}}^{\infty} \mathrm{n} \alpha^{\mathrm{n}-\mathrm{x}}\left(\text { molecular weight }-\mathrm{CH}_{2}=14\right) \\
& =14 \mathrm{Nx} \alpha^{(\mathrm{r}-\mathrm{x})}[\mathrm{r}-\alpha(\mathrm{r}-1)] /(1-\alpha)^{2}
\end{aligned}
$$

and

$$
\frac{\mathrm{W}_{\mathrm{r}+}}{\mathrm{W}_{\mathrm{x}+}}=\frac{\alpha^{(\mathrm{r}-\mathrm{x})}[\mathrm{r}-\alpha(\mathrm{r}-1)]}{\mathrm{x}-\alpha(\mathrm{x}-1)}
$$

(G:196Q417409IRPI4249-3)

From Equation 6, with $\mathrm{r}=12$ and 18 and $\mathrm{x}=5$, cumulative distribution curves can be plotted for gasoline $\left(\mathrm{C}_{3}-\mathrm{C}_{11}\right)$, diesel oil $\left(\mathrm{C}_{12}-\mathrm{C}_{18}\right)$, and wax $\left(\mathrm{C}_{19}+\right)$ as a function of $\alpha$. Figure A.3 shows how experimental data for cobalt catalysts follow the predicted curves.

Figure A.4 illustrates the results of the previous mathematical treatment of the hydrocarbon chain growth. Values of $\alpha$ in excess of 0.90 are required to reduce the $C_{1}-C_{4}$ fraction selectivity under 5 percent. 
Figure A.1 Hydrocarbon Carbon Number Distribution Of Cobalt-Based Fischer-Tropsch Catalysts

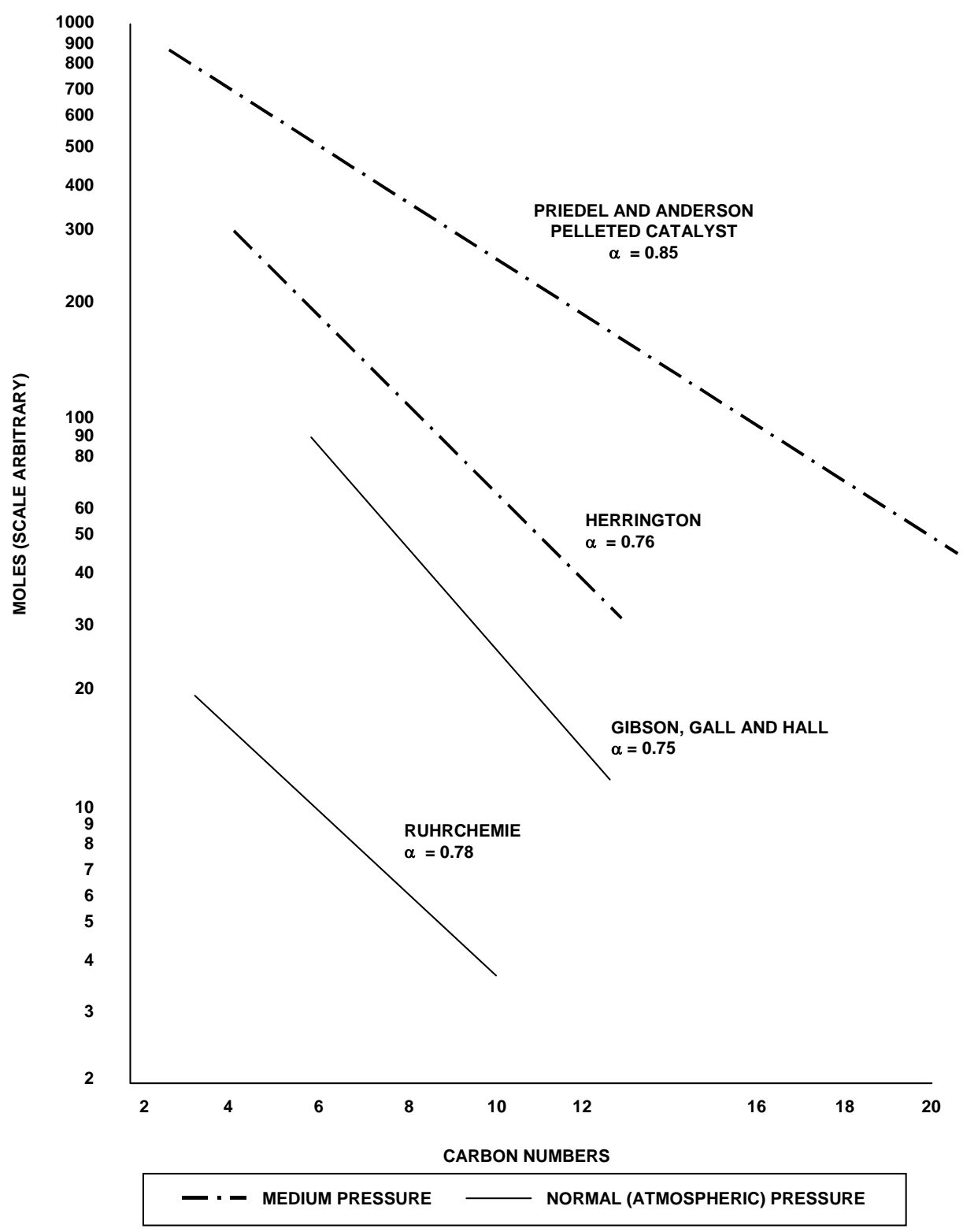

O:/2002Q2/NEXANT/00072/RP/YLS1.PPT 
Figure A.2 Hydrocarbon Carbon Number Distribution For Iron, Ruthenium, And Cobalt Catalysts

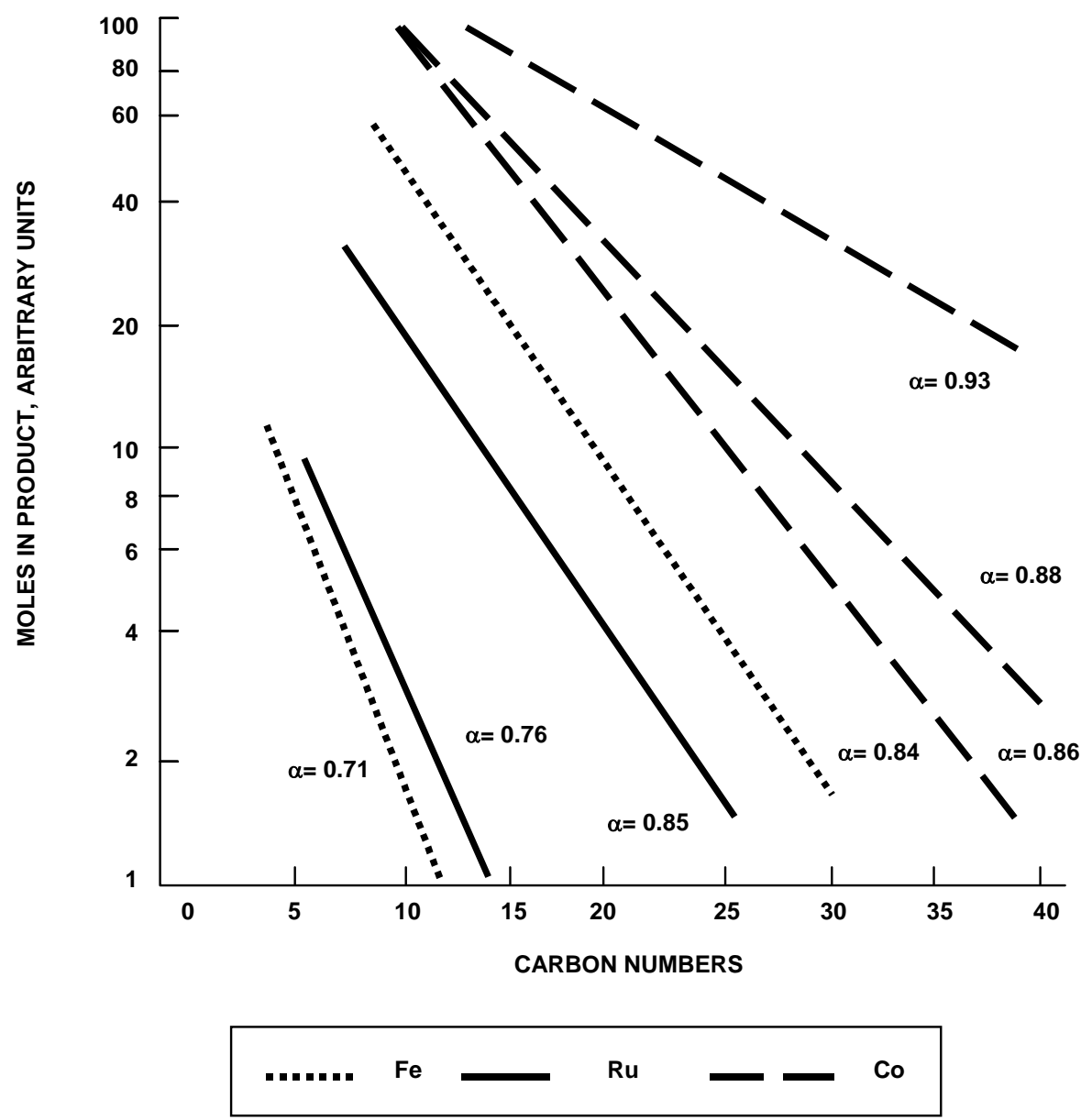

O:/2002Q2/NEXANT/00072/RP/YLS1.PPT 
Figure A.3 Observed Product Distribution Of Liquid And Solid Fischer-Tropsch Hydrocarbons (Cobalt-Catalyzed), Fit To Equation 6

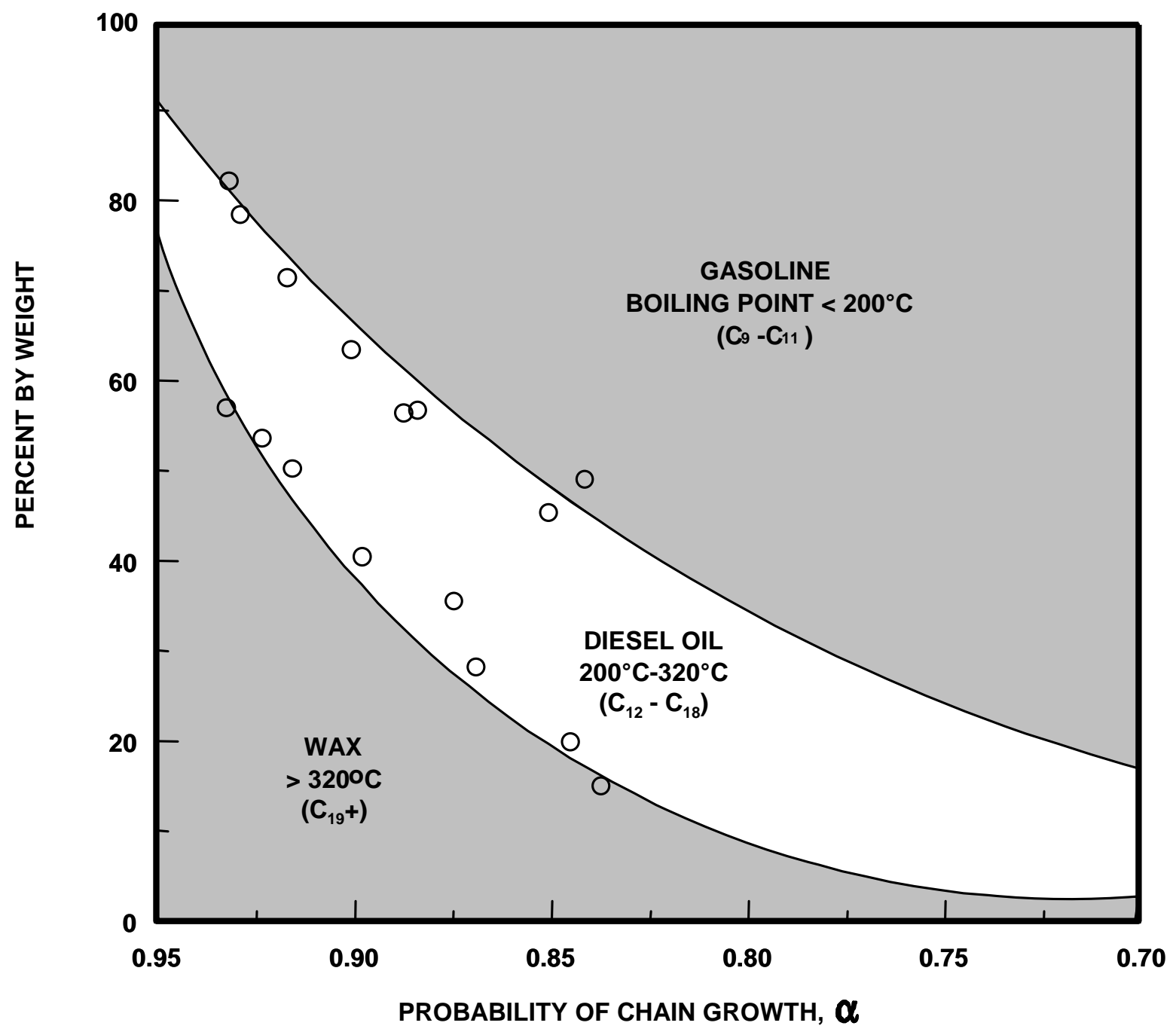

O:/2002Q2/NEXANT/00072/RP/YLS1.PPT 
Figure A.4 Calculated Selectivity Of The Various Product Cuts As A Function Of The Probability Of Chain Growth

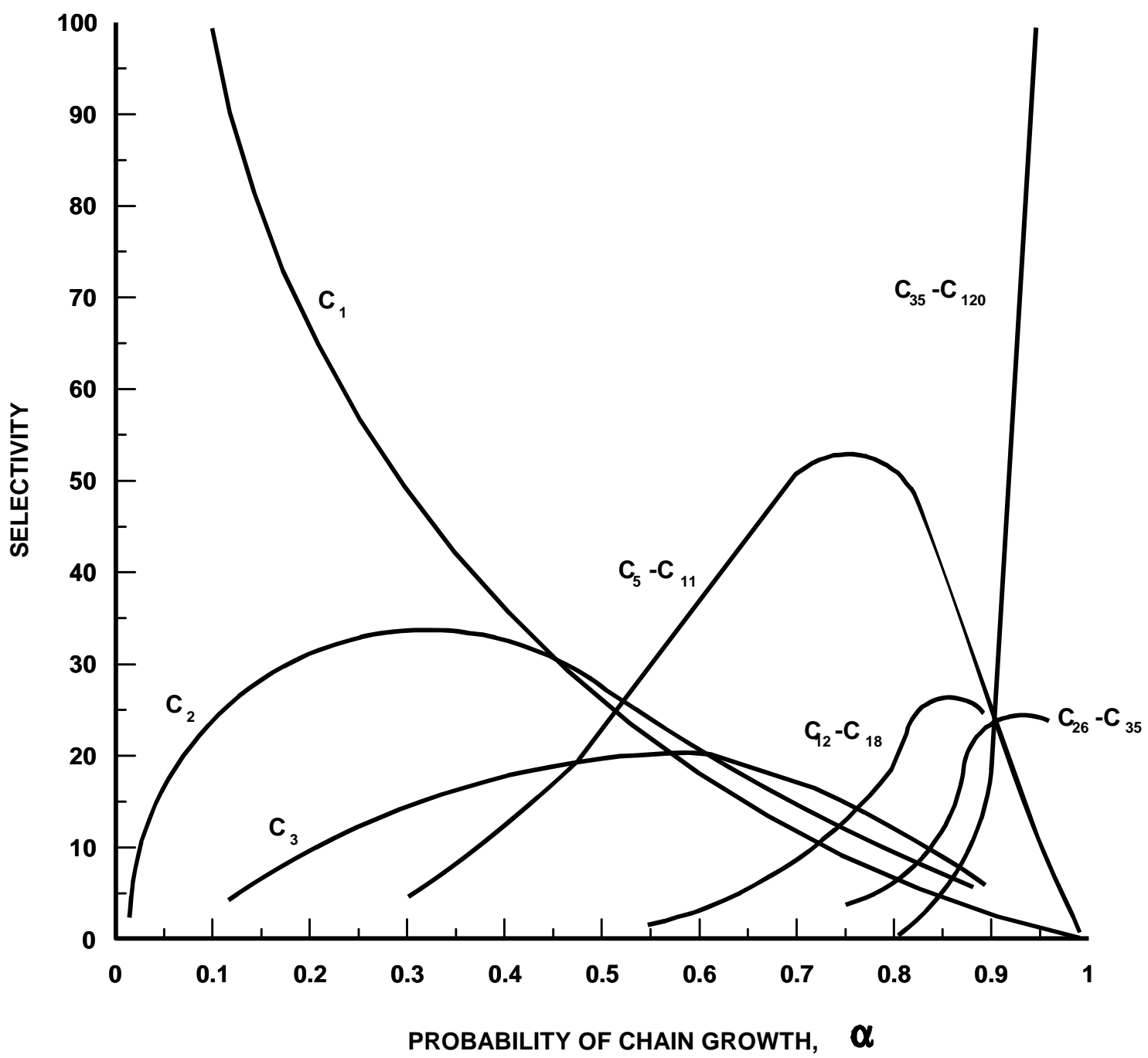

O:/2002Q2/NEXANT/00072/RP/YLS1.PPT

The olefin content of hydrocarbons from cobalt catalysts is essentially zero for $\mathrm{C}_{2}$ and increases to a maximum for $\mathrm{C}_{3}$ or $\mathrm{C}_{4}$ and then decreases monotonically with increasing carbon number. Molecules with straight carbon chains are the principal components of Fischer-Tropsch products. Oxygenated organic molecules are produced in only trivial amounts (about 1 percent) in the atmospheric pressure synthesis with cobalt catalysts and in only slightly greater amounts in the medium pressure synthesis. 
With cobalt and nickel catalysts, water is the principal oxygenated product at the usual operating temperatures (i.e. $220-230^{\circ} \mathrm{C}$ ) with the amount of carbon monoxide converted to carbon dioxide being less than 1 percent at preferred conditions. However, at very high conversions, sizable yields of carbon dioxide are obtained. For example, U.S. Bureau of Mines data for a 2:1 hydrogen/carbon monoxide gas at $206^{\circ} \mathrm{C}$ shows that the carbon dioxide production at 80 percent carbon monoxide conversion exceeds 10 percent of the carbon monoxide consumed.

Another study investigated the effects of the water-gas shift reaction on the overall reaction mechanism. The study was carried out in a fixed bed reactor using a catalyst comprising cobalt and magnesium precipitated on a Kieselguhr framework. A number of kinetic expressions exist implying an inhibiting effect of carbon monoxide, presumably caused by strong adsorption on the catalytically active sites. The water-gas shift reaction is assumed to occur on the same site as the synthesis step. The rate determining step of the water gas shift is taken to be the reaction of carbon monoxide with water.

The study examined the accuracy of the Schulz-Flory equation at lower carbon numbers. Although the Schulz-Flory equation provides good approximation of carbon distribution for carbon numbers greater than $\mathrm{C}_{5}$ or $\mathrm{C}_{6}$, it under predicts $\mathrm{C}_{1}$ products and over predicts $\mathrm{C}_{2}$ products.

A more representative modified Schulz-Flory model can be used to predict carbon number distributions over cobalt. The modification allows for adsorbed multiple carbon intermediates (such as $\mathrm{C}_{2}$ and $\mathrm{C}_{3}$ ) to reincorporate prior to desorption and initiate new hydrocarbon chains. This kinetic model, based on Langmuir-Hinshelwood kinetics, implies strong inhibition by carbon monoxide. The model shows that at high carbon numbers the $\alpha_{0}$ value from the SchulzFlory relationship is related to the modified model by:

$$
\alpha=\frac{\alpha^{5}+4 \alpha^{3} \beta+3 \alpha^{2} \gamma+3 \alpha \beta^{2}+2 \alpha \beta}{\alpha^{4}+3 \alpha^{2} \beta+2 \alpha \gamma+\beta^{2}}
$$

where $\alpha$ is defined as the probability of $\mathrm{C}_{1}$ incorporation, $\beta$ as the probability of $\mathrm{C}_{2}$ incorporation, and $\gamma$ as the probability of $\mathrm{C}_{3}$ incorporation. 


\section{Technical Issues for UCF Use in Transport Market Study Report Section VI \\ Prepared For: \\ ConocoPhillips}

Co-operative Agreement DE-FC26-01NT41098

\section{ConocoPhillips $\mathfrak{A N e x a n t}$}




\title{
Technical Issues for UCF Use in Transport Market Study Report Section VI
}

November 2002

\author{
Prepared For: \\ ConocoPhillips
}

\section{cNexant}

44 South Broadway, White Plains, New York 10601, USA

Tel: +1 $9146090300 \quad$ Fax: +1 9146090399 
1 Objectives .................................................................................... $1-1$

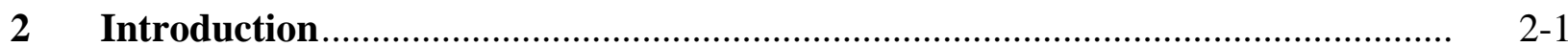

2.1 DRIVERS FOR UCF USE IN VEHICLES ............................................. $2-1$

2.2 DIESEL REGULATORY ISSUES AFFECTING VEHICLE DESIGN......... . 2-3

2.3 OTHER ALTERNATIVE FUELS POTENTIALLY COMPETING WITH

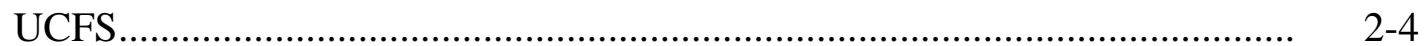

3 Conventional Vehicle Technology ......................................................... $3-1$

FT DIESEL ................................................................................

3.1.1 Relevant Diesel Fuel Characteristics ............................................ 3-1

3.1.1.1 Issues Related to Using Low Sulfur Diesel Fuels .............. . 3-1

3.1.1.2 Viscosity ................................................................ $3-2$

3.1.1.3 Cetane Number........................................................... 3-2

3.1.1.4 Cetane Index........................................................... 3-3

3.1.1.5 FT Diesel Energy Density .............................................. 3-3

3.1.2 Technical Requirements (OEM and Conversion)............................ 3-3

3.1.2.1 Baseline Engine Designs for Emissions Reduction ............ $\quad 3-4$

3.1.2.2 Exhaust Emission Control Using After-Treatment Technologies ........................................................... $3-4$

3.1.3 Performance Characteristics of FT Diesel ........................................ 3-6

3.1.4 Lubricity Concerns ........................................................................... 3-8

3.1.5 Practical Concerns for Long-Term Engine Operations with FT

Diesel

3.1.6 Technology Costs................................................................... 3-11

3.1.8 FT Diesel SWOT Analysis ........................................................... 3-14

3.1.8.1 Strengths............................................................. $\quad 3-14$

3.1.8.2 Weaknesses .............................................................. 3-14

3.1.8.3 Opportunities ......................................................... 3-14

3.1.8.4 Threats .................................................................. $3-15$

3.1.9 Conclusions ......................................................................... $3-15$

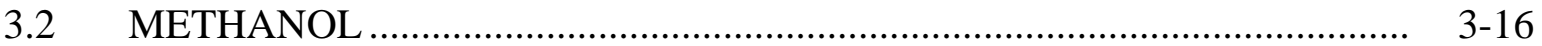


3.2.1 Methanol Use in Passenger Cars (Spark-Ignited Gasoline Engines).... 3-16

3.2.1.1 M100 (Neat Methanol) ................................................ 3-16

3.2.1.2 Methanol As A Fuel Extender........................................ 3-16

3.2.1.3 M85 (Methanol-Gasoline Blend) ................................... 3-17

3.2.1.4 Flexible Fuel Vehicles.................................................... 3-17

3.2.1.5 Materials Problems with Methanol Fuel ............................ 3-18

\subsubsection{Methanol Use in Diesel (Compression-Ignited) Heavy-Duty}

Vehicles.................................................................................. 3-19

3.2.3 Conclusions............................................................................ 3-20

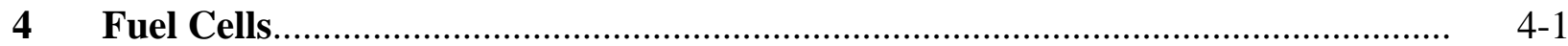

4.1 TECHNICAL OVERVIEW ..................................................................

4.2 COMPETITIVE ASSESSMENT OF FUEL CELL TYPES ........................ 4-6

$4.3 \quad$ FUEL CELLS FOR VEHICLES …...........................................................

4.3.1 Electric Vehicles ...................................................................... 4-8

4.3.2 Competition from Hybrid Vehicles .................................................. 4-9

4.4 FUEL CELL TECHNOLOGY ..............................................................

4.4.1 Basic Principles.......................................................................... 4- 40

4.4.2 Individual Fuel Cell Technologies.................................................. 4-13

4.4.2.1 PAFC Technology ....................................................... 4-13

4.4.2.2 MCFC Technology ...................................................... 4-14

4.4.2.3 SOFC Technology .................................................... 4-15

4.4.2.4 PEMC Technology ....................................................... 4-16

4.4.2.5 DMFC Technology .................................................... 4-19

4.4.2.6 Further Development Work on DMFC ............................ 4 4-20

4.4.2.7 Comparison of Fuel Cell Attributes ................................. 4-22

4.4.3 Reformer Systems ..................................................................... 4-23

4.4.4 Applications Issues and Progress............................................... 4-25

4.4.5 Applications Status ..................................................................... 4-27

4.5 FUEL CELL VEHICLES - DETAILED ANALYSIS ............................... 4-28

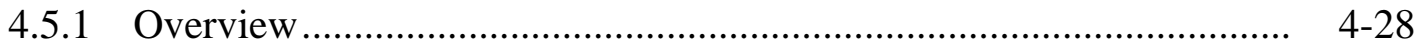

4.5.2 Fuel Selection Issues ........................................................................ $\quad 4-30$ 
4.5.2.1 Hydrogen ................................................................. 4-30

4.5.2.2 Methanol..................................................................... 4-31

4.5.2.3 Gasoline ...................................................................... 4- 4-31

4.5.2.4 Ranking the Leading Fuels................................................. 4-31

4.5.3 Fuel Development Strategies .......................................................... 4-32

4.5.4 The Hydrogen Economy Concept.......................................................... 4. 4-33

4.5.5 Sourcing Hydrogen .................................................................. 4... 4-34

4.5.6 FC Vehicles - Current Situation Analysis ............................................. 4-35

4.5.6.1 Leading Developers of Passenger Automobiles................... 4- 4-35

4.5.6.2 The California Fuel Cell Partnership (CaFCP) ................... . 4-35

4.5.7 Heavy Duty Vehicles (Trucks, Buses and Other) ................................. 4 4-37

4.5.8 Costs (Materials and Operating) ........................................................ 4-37

4.5.9 Emissions Impacts ………………………….................................. $\quad 4-39$

4.5.10 Focus of R\&D ....................................................................... 4... 4

4.5.10.1 Overview of Current Fuel Cell Research and Development 4-40

4.5.10.2 Key Development Issues for Fuel Cell Vehicle System ...... 4-41

4.5.10.3 Achievements to Date ........................................................... 4-41

4.6 REVIEW OF FUEL DEVELOPERS …………....................................... 4-42

4.6.1 AlliedSignal ............................................................................. $\quad 4-42$

4.6.2 Analytic Power Corporation .............................................................. 4-43

4.6.3 Avista Laboratories.............................................................................. 4.. 4-43

4.6.4 Ballard Power Systems .................................................................. 4. 4-43

4.6.5 DCH - Technology Hydrogen Sensors and Fuel Cells ......................... 4 4-43

4.6.6 Energy Partners .................................................................................. 4... 4-43

4.6.7 FuelCell Energy ……………………………............................... 4-4

4.6.8 Ford Motor Company TH!NK Technology ........................................... 4 4-44

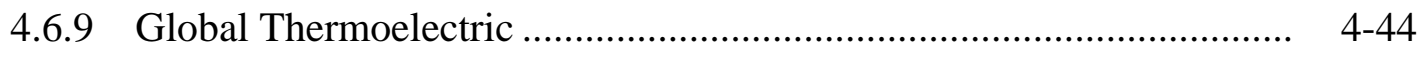

4.6.10 H Power Corporation .......................................................................... 4-44

4.6.11 IdaTech Corp., Bend, OR.................................................................. 4. 4-45

4.6.12 UTC Fuel Cells ........................................................................

4.6.13 Manhattan Scientifics, Inc ……………………............................. 4-45 
4.6.14 M-C Power...................................................................... 4-45

4.6.15 National Renewable Energy Lab (NREL), Colorado (PEM) ............. 4 4-45

4.6.16 Netherlands Energy Research Foundation - ECN - (MCFC, SOFC, and SPFC)

4.6.17 Oak Ridge National Laboratory (ORNL), Tennessee

4.6.18 Pacific Northwest National Laboratory (PNNL), Washington (PAFC, MCFC, and SOFC)

4.6.19 Plug Power, L.L.C.

4.6.20 Proton Energy Systems

4.6.21 Rocky Mountain Institute, Colorado.

4.6.22 Sandia National Labs, New Mexico

4.6.23 Siemens AG, Germany

4.6.24 Small-Scale Fuel Cell Commercialization Group, Oklahoma

4.6.25 Toyota Motor Corporation, Japan.

4.6.26 University of California, Riverside.....

4.6.27 University of California, Davis, Institute for Transportation Studies...

4.6.28 The U.S. Department Of Energy, Office of Fossil Energy

4.6.29 Warsitz Enterprises, California.....

4.6.30 Siemens Westinghouse Power Corporation.....

4.6.31 AQMD's Technology Advancement Office.

4.6.32 The Electric Power Research Institute (EPRI).

4.6.33 California Energy Commission (CEC)

4.6.34 California Fuel Cell Partnership

4.6.35 National Energy Technology Laboratory

4.6.36 Gas Research Institute (now the Gas Technology Institute or GTI).....

4.6.37 Office of Fossil Energy, Department of Energy

4.6.38 The Office of Transportation Technologies.

4.6.39 Solid State Energy Conversion Alliance (SECA).

4.6.40 Fuel Cell Auto Standards

4.7 FUEL CELL FUEL USE OUTLOOK

4.7.1 FT Diesel

4.7.2 FT Naphtha 


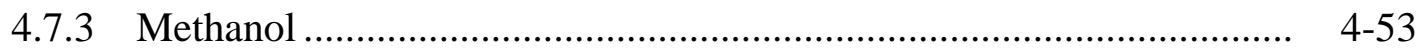

4.8 STATIONARY FUEL CELL APPLICATIONS ........................................

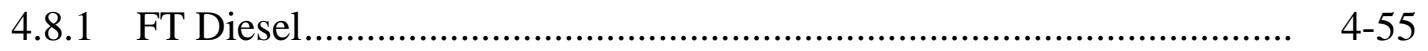

4.8.2 FT Diesel............................................................................... $4-59$

4.8.3 FT Naphtha .......................................................................... 4-60

4.8.4 Methanol .............................................................................. 4-60

4.8.5 Conclusions ........................................................................ 4-61

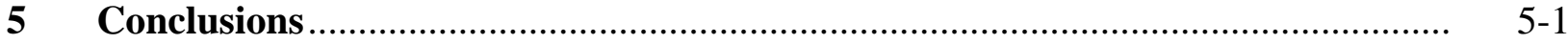

$5.1 \quad$ KEY DEVELOPMENTS IN CONVENTIONAL VEHICLE

TECHNOLOGY …........................................................................... $5-1$

5.1.1 Fuel Cell Technology for Vehicle Propulsion .................................. 5-2

5.1.2 Fuel Cells for Non-vehicle Uses .................................................. 5- 5

5.1.3 FT Diesel as a Vehicle Fuel - Conventional Engines......................... 5-3

$5.1 .4 \quad$ FT Diesel for Fuel Cells ............................................................. $5-4$

5.1.5 FT Naphtha as a Vehicle Fuel..................................................... $5-4$

5.1.6 FT Naphtha Fuel Cells ..................................................................

5.1.7 Methanol as a Vehicle Fuel - Conventional .................................... 5-4

5.1.8 Methanol Fuel Cells .................................................................... 5-5

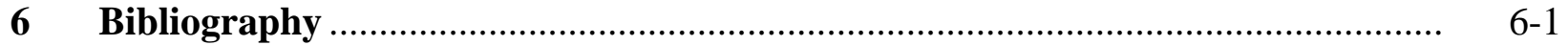


3.1 Fischer-Tropsch Diesel Exhaust Emissions Relative to Typical California Diesel Exhaust Emissions

4.1 Fuel Cell Energy Carrier Quality/Convenience Spectrum.

4.2 Fuel Cell Operation

4.3 Efficiency Operating Curves for FCs and ICEs versus Peak Power

4.4 Fuel Cell Efficiencies Versus Heat Engines as a Function of Temperature.

4.5 Phosphoric Acid Fuel Cell (PAFC)

4.6 Molten Carbonate Fuel Cell (MCFC) ...

4.7 Solid Oxide Fuel Cell (SOFC)

4.8 Proton Exchange Membrane Fuel Cell (PEMC)

4.9 Schematic Diagram Of Polymer Electrolyte Fuel Cell System Incorporating Fuel Processor.

4.10 Direct Methanol Fuel Cell (DMFC)

4.11 Bell Aerospace DMFC Developments

4.12 Efficiency Losses In Overall Fuel Cell Systems.

4.13 Comparative Efficiencies of Electric Power Generators

Table

$2.1 \quad 1998$ U.S. Vehicles and Fuel Use Statistics ..................................................... 2-2

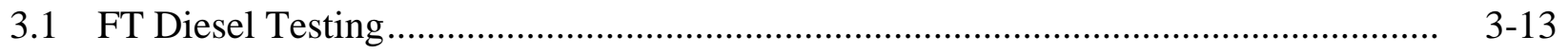

4.1 Characteristics Of Fuel Cell Types ..................................................................... 4

4.2 Energy Technologies Competing With Fuel Cells ............................................... 4-8

4.3 Fuel Cell Technologies and Attributes ............................................................... 4-22

4.4 Applications Related To Fuel Cell Issues ........................................................... 4-26

4.5 Ranking Of Key Characteristics Of Fuels For Vehicle Fuel Cells ........................... 4 4-32

4.6 Leading Fuel Cell Vehicle Developments ........................................................ $4-36$ 
The primary objective of this section is to define the technical issues, status and potential for Ultra Clean Fuels (UCFs), defined as methanol, FT naphtha and FT diesel, to be used in the vehicle transportation sector. The timeframe considered is from the current period to about 2015. However, where appropriate, longer-term issues were addressed where they were believed to impact short-term developments.

To achieve this objective, the following tasks were undertaken:

- Definition of key elements and status of conventional vehicle technology with a focus on developments that will impact the use of UCFs

- Review of regulatory trends that will impact future use of UCFs

- Evaluation of the current status and expected development of fuel cell technology. Fuel cell technologies and auxiliaries were considered in detail, along with their developers and champions

- Definition of technical requirements and impediments for use of UCFs in current and potential future vehicle systems

- Review of other potential key markets for fuel cells, such as stationary power systems and small electronics. Since hydrogen is the primary basic fuel for fuel cells, the potentially competitive long-term development of a "hydrogen economy" was considered

- Technology costs were estimated and projected to the extent practical in various cases.

In addition to developing important conclusions on the technical issues related to UCF use in transport vehicles, results of the analyses presented in this section provide input to other elements of the Market Study. Specifically, this section provides input to the analyses and conclusions developed for Market Report Section IX - "UCF Values and Market Potential". 
The focus of this section is to examine the vehicle technology issues that will contribute to determining the potential to use ultra clean fuels (UCFs) in transportation applications. Two types of UCFs are considered, namely FT distillate (the diesel fraction of hydrocarbons produced by Fischer-Tropsch catalytic technology) and methanol, both derived from natural gas. This section will focus on fueling of on-road vehicles, including passenger cars and small trucks, which mostly have gasoline engines today, and heavy duty trucks and buses, which are mostly petroleum diesel-fueled today. Fueling for other types of transportation, such as marine, aircraft, railroad, off-road or motorcycle applications is not considered. Stationary power, heat generation and smaller scale mobile and portable applications of these fuels are considered, however, because their technical and/or market requirements may be synergistic with some of the transportation applications.

\subsection{DRIVERS FOR UCF USE IN VEHICLES}

Short-term drivers for increased UCF use are mainly increasingly stringent regulations aimed at improving air quality by reducing vehicle emissions. Long-term drivers include these regulations plus concerns over potentially dwindling supplies of liquid petroleum. Consistent with this longer-term view, many governments and private agencies are researching and testing technologies and planning strategies for an ultimately sustainable vehicle fuel scenario in which "renewable" fuels derived from solar and biological sources dominate supply. These latter types include hydrogen, ethanol and biodiesel (typically, ethers of vegetable oils).

Heavy-duty diesel emissions have been increasingly identified as a major source of smog and acid rain precursors in the northeastern United States and in California. Estimates of the contribution of on-highway diesel engines to total oxides of nitrogen (NOx) emissions nationally range from 12 to 18 percent. The US EPA indicates that this fraction is increasing as commercial traffic activity rises and emissions attributable to other sources, such as passenger cars, decline. Particulate matter (PM) is another key air pollutant that is prioritized for reduction nationally and in some more stringent air quality State Implementation Plans (SIPs). Highway diesels are estimated to contribute between 20 and 30 percent of the national loading of emitted PM.

Diesel trucks and buses make up less than 2 percent of all vehicles on the road, but they are estimated to account for up to 5 percent of all vehicle miles traveled. They operate at comparatively high power levels, proportional to the heavy loads they transport, and long distance diesel trucks (as well as other diesel heavy vehicles) are also notable for the amount of idling that occurs in their operations, so they consume about 15 percent of the total road vehicle fuel, gasoline and diesel ${ }^{(1),(2)}$. Table 2.1 gives an inventory and breakdown of types of vehicles in use and the use of gasoline and diesel fuels in the U.S., derived from "Ward's 1999 Motor Vehicle Facts and Figures." 
Table 2.1 1998 U.S. Vehicles and Fuel Use Statistics

\begin{tabular}{|l|r|r|r|}
\hline & $\begin{array}{r}\text { Gallons Fuel } \\
\text { used, Millions }\end{array}$ & $\begin{array}{r}\text { Miles Driven, } \\
\text { Millions }\end{array}$ & $\begin{array}{r}\text { Vehicles, } \\
\text { Millions }\end{array}$ \\
\hline Passenger cars & 72,209 & $1,545,830$ & 131.0 \\
\hline Light Trucks & 50,579 & 866,228 & 70.1 \\
\hline Buses & 1,049 & 6,996 & 0.7 \\
\hline Single Unit Trucks & 9,740 & 67,874 & 1.9 \\
\hline Combination Trucks & 21,100 & 128,159 & 1.5 \\
\hline Total & $\mathbf{1 5 4 , 6 7 7}$ & $\mathbf{2 , 6 1 5 , 0 8 7}$ & $\mathbf{2 0 6}$ \\
\hline & & & \\
\hline Gasoline & 121,011 & & 1.50 \\
\hline Diesel & 33,665 & & 1.93 \\
\hline Total & 154,677 & & 36.20 \\
\hline & & & 17.20 \\
\hline Trucks & & & 16.00 \\
\hline Tractors & & & 0.85 \\
\hline Farm Trucks & & & $\mathbf{7 3 . 6 8}$ \\
\hline Pickups & & & 0.13 \\
\hline Vans & & & 13.32 \\
\hline SUVs & & & 3.5 \\
\hline Other light trucks & & & 3.5 \\
\hline Total Trucks & & & 1.7 \\
\hline & & & \\
\hline Fleets & & & \\
\hline Autos & & & \\
\hline Trucks, class 1-2 & & & \\
\hline Trucks, class 3-5 & & & \\
\hline Trucks, class 6-8 & & & \\
\hline Buses & & & \\
\hline School & & & \\
\hline Other & & & \\
\hline Total Fleet Vehicles & & & \\
\hline
\end{tabular}

Light trucks are largely actually substitutes for conventional passenger vehicles, and are generally gasoline fueled. Because fleet vehicles only comprise a total of about 6.5 percent of the entire vehicle fleet, if an alternative to conventional gasoline or diesel fuel is introduced through fleets (a leading strategy for alternative fuels), its introduction will not make a very large impact on total fuel use.

In diesel engines such as those used in trucks and buses, only NOx and PM emissions (among the criteria air pollutants) are considered problematic. The levels of carbon monoxide (CO) and non-methane hydrocarbons (NMHC) these engines produce are not considered to be major contributors to national air pollution levels. The inclusion of hydrocarbon (HC) emissions in the combined NMHC + NOx standards for the industry only serves to place a cap on such emissions, to ensure that $\mathrm{HC}$ levels will not markedly increase as a result of any new technologies that 
might be implemented. Normalized emissions of the greenhouse gas carbon dioxide (CO2) are somewhat lower from diesels than from most spark-ignited engines because of the greater efficiency of diesels.

\subsection{DIESEL REGULATORY ISSUES AFFECTING VEHICLE DESIGN}

The U.S. EPA's new ultra low sulfur rule requires drastic reductions by refiners in the sulfur content of transportation diesel fuel they produce. It also requires that manufacturers of heavyduty road diesel engines implement emission controls, coordinated with engine modifications, to reduce NOx, particulate matter and hydrocarbon pollutant emissions.

Sulfur in fuel is associated with complex molecular structures in the fuel that burn less easily than the basic hydrocarbons. Low-sulfur fuels burn cleaner and reduce engine particulate emissions. Particulate emissions depend largely on engine design and are only partly derived from fuel. Combustion of crankcase oil entering the combustion chamber can contribute between $20 \%$ and $80 \%$ of engine particulate emissions.

Low-sulfur diesel is being introduced primarily to reduce engine particulate formation, but also to enable post-combustion controls to reduce tailpipe emissions of $\mathrm{CO}, \mathrm{NOx}$, and hydrocarbons, as well as particulates. The need to reduce sulfur content in diesel fuel to enable use of tailpipe particulate traps and gaseous pollutant emissions catalytic converters will drive interest in Fischer-Tropsch (FT) fractions as blend stocks for this market.

Making the reductions in diesel emissions that will be required by tightening regulations will require changes in fuel compositions, engine designs and tailpipe controls.

Diesel on-road engines are used in localized fleets, such as sanitation trucks, urban and school buses and utility service vehicles, but largely in inter-urban bus and long-haul trucking. For the latter, refueling will require access to a consistent fuel quality, or, alternatively, the capability to use diesel fuels with somewhat varying thermal and physical qualities.

Throughout the developed world, regulations are being tightened on tailpipe emissions from onroad diesel engines. Until now, engine manufacturers have met evolving emissions standards through modifying engine designs.

New U.S. emission standards for model year 2007 heavy-duty diesel engines were finalized on December 20, 2000. The adopted emission standards are $0.01 \mathrm{~g} / \mathrm{bhp}$-hr for particulate matter (PM), $0.20 \mathrm{~g} / \mathrm{bhp}-\mathrm{hr}$ for nitrogen oxides (NOx), and $0.14 \mathrm{~g} / \mathrm{bhp}-\mathrm{hr}$ for non-methane hydrocarbons (NMHC). The PM standard will take full effect in 2007, while the NOx and NMHC standards will be phased in for diesel engines between 2007 and 2010. Compared with current standards, the new rule represents a 95 percent reduction in the NOx level (currently at 4 $\mathrm{g} / \mathrm{bhp}-\mathrm{hr}$; an intermediate standard of $2.4 \mathrm{~g} / \mathrm{bhp}-\mathrm{hr}$ of combined NOx + NMHC takes affect in 2004) and an 80-90 percent reduction in PM emission (currently at 0.1 for truck engines and 0.05 $\mathrm{g} / \mathrm{bhp}-\mathrm{hr}$ for urban buses). 
The NOx and NMHC standards are to be phased in at 50 percent of new vehicle sales in model years 2007 through 2009. In 2010, all new on-road vehicles will be required to meet the NOx and HC standards. Recognizing the anticipated technical challenges associated with meeting the new NOx standards, the EPA regulation allows diesel engine manufacturers flexibility in meeting the NOx and HC standards for years 2007 through 2009. Engine manufacturers are provided the option of producing all diesel engines to meet an average of 2004 and 2007 NOx and $\mathrm{HC}$ emission standards (1.1 g/bhp-hr).

To meet the U.S. 2007 emissions standard, manufacturers will need to rely on tailpipe emissions controls developed by others, particularly exhaust after-treatment ("tailpipe") NOx adsorption catalyst technology, and particulate filters. There is still uncertainty over the feasibility of NOx absorbers, which are to be applied with lean-burn (fuel-rich) engine operation and exhaust gas recirculation (EGR). NOx control catalysts are poisoned by sulfur, so diesel sulfur content must be lowered to below 15 ppm to enable their use. It must be emphasized here that the long-term operability and effectiveness of the controls has not yet been definitively demonstrated.

Since the after treatment technologies that will be required to meet the new standards are not tolerant to sulfur, as a "technology enabler", the regulation established new product quality standards for highway diesel fuel that will require diesel fuel to have a maximum sulfur content of 15 ppm by 2006. The U.S. has followed the lead of the European Union in adopting emission standards that are designed to force emission after treatment devices on heavy-duty diesel engines. However, the U.S. EPA's 2007 rule sets emission limits that are much tighter than those adopted in the EU, becoming the most stringent diesel emission standard worldwide.

The Japan's Ministry of the Environment recommended stricter regulations on emissions from diesel-powered vehicles to be sold starting in the fall 2005. The new regulation would tighten the relatively relaxed Japanese emission standards to levels comparable with standards currently implemented in the United States and Europe. The planned standards would be more stringent than the short-term emission limits that will become effective in 2003/2004 in the U.S. and Europe.

In February 2002 the Central Environment Council (advisory panel to the Japanese Ministry of the Environment) first announced a plan for the new 2005 standard. The plan called for tightening diesel NOx and PM emission standards for new heavy- and light-duty highway vehicles. Under the plan, NOx would be reduced by $41-50 \%$, and PM by $75-85 \%$.

Development of the new emission regulation is likely to take approximately one year. The Japanese government is expected to publicly announce it in the spring of 2003.

\subsection{OTHER ALTERNATIVE FUELS POTENTIALLY COMPETING WITH UCFS}

The key drivers for UCF use are environmental regulations in the short term plus petroleum substitution in the longer term, and the key impediments are vehicle technology (manufacturing and maintenance) and fuel infrastructure substitution and/or conversion. For the short term, UCFs will compete primarily with other means of exploiting natural gas reserves of various types, such as by using compressed or liquefied natural gas (CNG or LNG) carried on board 
vehicles. In the longer term, many strategists and researchers are looking to biologically based, solar and other renewable energy sources, carried to the user in many cases in the fungible form of hydrogen.

Natural gas has long been considered as a fuel for heavy-duty engines to provide an alternative to diesel fuel changes, engine re-designs and tailpipe controls to reduce the air pollutant emissions, and as a hedge against the waning of petroleum supplies. It is feasible to use natural gas as a fuel in heavy diesel-like engines, in versions with and without spark ignition. Heavyduty diesel engines can be converted to natural gas use either by modifying them for spark ignition, or by using a dual fuel system that injects a small amount of diesel fuel to ignite the natural gas in the compression stroke of the diesel engine cycle. Such dual fuel systems somewhat compromise the markedly lower emissions obtainable with natural gas fueling.

Natural gas is a cleaner fuel than diesel, but not necessarily cleaner than low sulfur diesel with the new mandated tailpipe controls. Natural gas vehicles generally have negligible particulate and hydrocarbon tailpipe emissions, and lower, but still significant, NOx and CO emissions that can be more easily controlled with catalytic systems than in liquid-fueled diesels. Stationary (power generation and primary driver) natural gas-fueled and vehicle heavy-duty CNG engine systems have been widely demonstrated and some are commercialized.

Because of the limited capacity of compressed natural gas (CNG) stored on board vehicles, applications are generally limited to on-site vehicles, fleets with urban routes and other shortrange vehicle fleets. Long-range hauling is less feasible than short-hauling and fixed routes, since it presents challenges to both fuel carrying and refueling logistics. However, liquefied natural gas (LNG) has refueling patterns and fuel carrying capacities similar to conventional fuels that are liquids at or nearer ambient conditions - diesel, gasoline, alcohols, butane, and liquefied petroleum gas (LPG). In fact, while there are more than 1,200 CNG refueling sites in the U.S., LNG is the alternative engine fuel with the highest growth rate in the nation, primarily in trucks and buses. (About 0.1 percent of heavy-duty buses and trucks use LNG, contrasted with only 0.02 percent of the total vehicle fleet using any alternative fuel).

The concept of directly supplying hydrogen, relative to methanol and other potential alternative fueling strategies for fuel cells, will be discussed in the body of this report. Ethanol is an important potential competitor UCF for use in conventional spark-ignited internal combustion engines (ICE), fuel cells or hybrid ICE vehicles. Its manufacture from grains and from biomass sources by conventional and genetically modified biological routes is being advanced, and costs are being continually reduced. Biodiesel fuels (esters of various types of vegetable oils, made more feasible by genetically-modified agriculture) are being developed and commercialized in the U.S., and more so in Europe (for example, it is reported that about 5 percent of the diesel fuel pool in France is biodiesel). Biodiesel is an ultra-low sulfur fuel and also offers a number of technical advantages, such as excellent lubricity, biodegradability and nontoxicity. However, this report provides no further analysis of these biologically based competitive options. 


\subsection{FT DIESEL}

\subsubsection{Relevant Diesel Fuel Characteristics}

To provide the ultra low sulfur specification products that will become required over the next decade in the U.S., Europe, Japan and elsewhere, FT diesel range distillate can be used in diesel engines, either neat or in blends with conventional petroleum derived diesel fuel processed to a low sulfur level. FT diesel has a highly paraffinic composition in contrast to the wide mixture of paraffins, aromatics and other unsaturated hydrocarbons found in conventional petroleum stocks. Because of this, FT diesel fractions have high cetane numbers, and therefore could perform more efficiently and with lesser emissions of certain criteria air pollutants in diesel engines designed for their use.

The following discussion of fundamental diesel fuel and engine issues is to serve as a basis for understanding the advantages and challenges of utilizing FT diesel in conventional diesel engines and in new improved versions. These advanced engines are being developed and commercialized by manufacturers as part of a coordinated, three-pronged strategy to reduce air pollutant emissions from diesel engines:

- Diesel fuel sulfur reductions

- Internal engine modifications

- Tailpipe NOx and particulate controls

\subsubsection{Issues Related to Using Low Sulfur Diesel Fuels}

The performance of emission after-treatment devices is not materially affected by the aromatics content of conventional diesel fuel. However, NOx adsorbers do not tolerate sulfur and it is expected that these devices will be used to achieve the new stringent NOx emissions standards. As a result, the U.S. and Europe have adopted regulations that will require a maximum sulfur content of 10-15 ppm for diesel by 2010. They have also deferred any further reductions in the aromatics content of diesel fuel due to the expected widespread use of emission after-treatment devices on new diesel vehicles.

In contrast to its environmental liabilities, sulfur also has some benefits. Some of the sulfurcontaining compounds in hydrocarbon liquid fuels enhance the lubrication properties (lubricity) of the fuel and help protect the fuel from oxidation degradation. Fuels with moderate concentrations of sulfur reduce wear and deposit forming products of thermal degradation and oxidation in fuel pumps and injectors.

Electronic fuel injectors on modern heavy-duty diesel engines operate at very high pressure, typically around 20,000 psi, so as to achieve maximum atomization and minimize particulate emissions. These are highly precise systems with some clearances typically of 1 micron. Controlled combustion also requires precise control of the size, shape and surface finish of the fuel injector components. The operating pressures are likely to increase to as high as 35,000 psi 
to help meet the emerging emissions regulations. The increased pressures will increase the wear and scuffing of fuel injector plungers and erosion, and wear and fatigue problems in fuel injector nozzles. These problems are becoming more severe in modern high-pressure fuel systems that are also cooled by fuel. FT Diesel contains essentially no sulfur, but small amounts of lubricity additives can be used to compensate. The additives can also reduce adverse affects on fuel filter life due to the increased clogging with deposit-forming sludge that can occur with low-sulfur diesel.

\subsubsection{Viscosity}

The viscosity of a fuel is a measure of resistance to flow. Viscosity also affects the performance of diesel engine fuel injection equipment. Correct fuel atomization depends on the fuel viscosity, as well as injection pressure and injector hole size. To burn most cleanly, fuel must be injected in a manner that the momentum of the atomized fuel disperses it evenly throughout a combustion chamber. The rate and timing of the injection event is also important. To minimize NOx formation, pilot injection has been used to prolong the combustion time, thereby reducing maximum combustion temperature. Further reductions might be achieved by combusting in several steps, still over a very brief time. Obviously, such precise control would demand even more of fuel properties and maintaining the dimensional integrity of the system.

Higher viscosity fuels will atomize into larger droplets with a higher momentum, which are more likely to impinge on the relatively cooler liner wall, thus quenching the flame and increasing soot deposits and emissions. Eventually, the fuel striking the cylinder walls will flush away the film of lubricating oil and dilute the oil in the crankcase, which leads to excessive engine wear. Conversely, a fuel with viscosity that is too low produces a soft spray that does not penetrate far enough into the combustion chamber, affecting combustion to reduce both power output and fuel economy. In addition, a soft spray produces a fuel rich zone around the injector, which leads to excessive soot formation.

FT diesel fuels have viscosities similar to conventional diesel, but small variations may become more significant over time. Also, the density of the fuel, which is generally significantly lower for FT diesel, has some bearing on the control of fuel injection for a fixed set of design parameters.

\subsubsection{Cetane Number}

Diesel cycle engines are described as "compression ignited", or self ignited, engines, as contrasted with gasoline engines (Otto Cycle), which are spark ignited. The cetane number of a diesel fuel is measured through an empirical test in a standard test engine. Cetane number indicates how readily the fuel is able to self ignite in a diesel engine. Cetane number is related to the time delay between injection and ignition. A number around 100 has a negligible time delay while a cetane number of 0 (zero) has an excessively long delay. After injection begins, it takes time for the atomized fuel particles to evaporate and mix with the compressed air in the combustion chamber to form a flammable mixture. Injection continues after ignition is initiated. The combustion chamber then contains eddies of burning fuel together with areas of evaporating raw fuel. 
Because combustion is inefficient during the time that the flame is propagating, the ignition delay period that causes flame propagation should be as brief as possible. The engine design can be manipulated to achieve this, but the nature of the fuel is the most important factor in reducing ignition delay. Local temperatures and air-fuel ratios vary greatly. If the cetane number is too high, fuel will ignite too close to the injector, forming a fuel rich zone around the injector, while the remainder of the combustion chamber has a weak air-fuel ratio. Incomplete combustion and soot particle formations occur in fuel rich zones.

For typical conventional on and off highway engines, a cetane number of 45-50 is considered ideal. Higher cetane numbers may be required for future high-speed engines, but this will depend on combustion chamber design and particularly, the air swirl within the chamber. Under cold start conditions, higher cetane number fuels ignite more readily and generate less white smoke on startup. Balancing emissions between start up and a hot engine is a major challenge for modern engine designers. A cetane number greater than 40 is considered adequate for modern diesel engines.

To the driver, the most noticeable effect of low cetane fuels is the familiar diesel knock (increased noise). Starting may also be difficult, especially at low temperatures. Other effects include rougher running and increased exhaust emissions. When using fuels with higher cetane numbers, the engine starts more easily with a shorter warm up period and a better fuel consumption is achieved. However if the cetane number is too high, the engine is more likely to produce a sooty exhaust. This is because the short ignition delay means that some raw fuel is sprayed into an established flame, producing soot.

\subsubsection{Cetane Index}

Cetane index is a parameter calculated from the physical properties of diesel fuel to predict the cetane number. This is not an exact relationship, but only a correlation and only works well within the bounds of experience. A cetane index may be two digits above the cetane number for diesel fuel derived from crude oil. With FT distillates having cetane numbers above 60, cetane index may not be reliably correlated.

\subsubsection{FT Diesel Energy Density}

FT distillate has approximately 3 percent greater combustion heat content, on a weight basis, than petroleum diesel, but a 6 percent lower density, so that on a volume basis, it provides about 3 percent less heat. FT distillate also offers higher cetane values than petroleum diesel fractions, which property also contributes to reducing emissions, but not nearly enough to avoid tailpipe controls even if FT diesel were used neat.

\subsubsection{Technical Requirements (OEM and Conversion)}

Engine, tailpipe controls and fuel issues relevant to FT diesel are discussed in the following. 


\subsubsection{Baseline Engine Designs for Emissions Reduction}

Regardless of fuel quality, the technology and design of diesel engines will change dramatically over the next five years to meet the new lower emissions limits. Thus, typical design features of diesel engines in the near future, primarily to reduce NOx and particulates emissions, will include:

- Large exhaust gas recirculation (EGR) systems, including coolers

- Redesigned combustion space ("bowl") to tolerate high rate EGR systems

- Dual NOx reduction ("deNOx") catalyst systems using secondary fuel injected upstream

- Exhaust cooler to achieve optimum temperature into the deNOx catalyst

- Particulate traps

EGR systems will be part of standard diesel engine designs starting in 2003.

\subsubsection{Exhaust Emission Control Using After-Treatment Technologies}

Historically, engine manufactures have met new emissions standards through modifications to engine design. The continuation of this trend is seen in the projection of technologies used to meet the EPA's 2004 emission standards for heavy-duty diesel engines. Engine manufacturers are expected to meet those standards with engine control strategies-primarily, EGR and highpressure fuel injection systems with retarded fuel injection strategies.

However, it is also anticipated that various catalyst technologies may be used to meet the NOx and PM standards. Although the US EPA expects that commercially-proven particulate traps or oxidation catalysts will be used to control PM, they expect that engine manufacturers will opt for engine control strategies to meet the NOx standard for 2004, due to both economic and technological concerns regarding the catalyst technologies for NOx reduction.

The adopted U.S. emission regulation for 2007 poses a significantly greater technological challenge. The emission standards are tailored to force the use of diesel particulate filters on new heavy-duty engines. Some form of NOx catalysts will be also required for nitrogen oxides control. While engine manufacturers have been able in the past (and perhaps in 2004) to meet new emission standards by using advanced engine controls and modified engine technologies, they will have to rely heavily on component and system development by emission control equipment manufacturers to meet the 2007 standard and will have no choice but to implement exhaust after-treatment catalyst technology to control NOx emissions.

Several NOx control after-treatment devices are currently being investigated, including:

- Lean-NOx catalysts,

- NOx adsorber catalysts

- Urea-based selective catalytic reduction (SCR) devices 
Lean-NOx catalysts have not seen significant improvement in NOx reduction efficiency during the past few years and are not considered a viable option, but NOx adsorber and SCR systems have shown potential for significant reduction of NOx emissions.

The NOx adsorber catalyst works by temporarily storing NOx on the adsorbent during normal engine operation. When the adsorbent becomes saturated, engine operating conditions and fuel delivery rates are adjusted to produce a fuel-rich exhaust, which is used to convert and release the $\mathrm{NOx}$ as $\mathrm{N}_{2}$.

Most stationary SCR units, such as on power plant stacks, use ammonia injection. However, ammonia is a hazardous and noxious compound that is difficult to manage, while urea, a less volatile and non-noxious compound of ammonia and $\mathrm{CO} 2$, is easier to manage, especially in solution. The SCR process involves injecting a liquid urea solution into the stack exhaust stream before it reaches a catalyst. The urea breaks down there into ammonia and $\mathrm{CO} 2$ and the ammonia reacts with NOx to produce nitrogen and water. By using an SCR system, it might be possible to meet the NOx emission standard without ultra-low-sulfur diesel fuel. Industry experts have indicated that the SCR system shows more promise than the NOx adsorber system for reduction of NOx emissions in truck applications. Although urea is a widely distributed, common farm and household fertilizer component, there is currently no infrastructure in place for the distribution of urea solution for the proposed NOx control use. The SCR technology will not be viable until infrastructure plans are established and engine manufacturers can demonstrate to the EPA that compliance cssured through reasonable engine control strategies.

Currently therefore, the EPA expects NOx adsorbers to be the most likely emission control technology applied by the diesel engine manufacturing industry. The EPA believes that the NOx adsorber-catalyst technology will mature enough to allow for the 2007-2010 implementation, as required by the standard. However, this technology is still under development and has not yet been demonstrated on heavy-duty engines. Although NOx adsorbers have demonstrated compliance using diesel with a sulfur content of $7 \mathrm{ppm}$, the systems show losses in conversion efficiency after 2,000 miles of operation. Concerns have also been raised about the ability of the technology to perform over a range of operating temperatures and loads. Industry and government researchers are seeking ways to overcome the impediments facing the NOx adsorber technology. Since these $\mathrm{NO}_{\mathrm{x}}$ adsorbers do not tolerate sulfur well, the EPA has mandated a maximum fuel sulfur content of $15 \mathrm{ppm}$ to reduce the fuel economy penalty associated with periodic desulfurization and to increase NOx absorber efficiency.

To help reduce engine and vehicle-maker apprehensions over the development of emission aftertreatment devices, EPA promised a biannual technology update, with the first report due by the end of 2002. The EPA has indicated that, should these reviews reveal unexpected limitations in vehicle technologies, it will address these issues through appropriate modifications of the standards or test procedures. However, the EPA has no intention of dropping requirements for emission after-treatment technologies or the 15 ppm sulfur cap on diesel. 


\subsubsection{Performance Characteristics of FT Diesel}

Based on contacts with a number of leading engine manufacturers, the consensus emerged that FT Diesel can be burned in existing heavy duty diesel engines, although with several minor penalties. Opinions varied somewhat as to the ultimate risk to engines of having both conventional and FT diesel fuels in the market simultaneously. Nexant has examined whether there are significant increased costs, or possibly, cost savings associated with adapting new engine and/or emissions control system designs to optimally use FT diesel fuels, if aftermarket adaptations are required to use FT diesel and what these might cost.

There are important differences between conventional diesel and FT diesel fuels, which can impact engine operation and performance. These include:

- Although it is of minor technical significance, lower energy density in FT diesel may be perceived by the market as "less miles per gallon" - a potential problem for market acceptance

- Lower lubricity affects the fuel supply and injection systems - this can be handled with additives and/or engine design modifications at some expense to either the fuel marketer, engine OEM or both, but it is probably not a show stopper

- No sulfur - a big advantage in technology and perception - tends to reduce particulate make and reduces the challenge for particulate traps

- Higher cetane content, in a complex relationship to engine timing, etc., can result in lower NOx production, making tailpipe emission control system performance less critical

FT diesel range distillates, blended with conventional diesel, are in commercial use in South Africa and Asia and also in California.

FT diesel has a number of superior characteristics, compared also to other competitive alternatives to heavy duty engine fuel being considered, including:

- It is a liquid at ambient conditions (as contrasted with CNG, LNG, propane, and DME)

- It has a low vapor pressure (as contrasted with methanol)

- It is completely miscible in conventional petroleum-based diesel

- It has good auto-ignition characteristics (typical cetane number of 50 to 75)

- It has low sulfur (typically below 10 ppm)

- It has low aromatics content (can have less than 3 volume percent)

- Energy density of FT diesel is only slightly lower than conventional diesel (typically about 3 percent lower by volume)

- Fuel tank flammability is similar to conventional diesel (as contrasted with methanol)

- It can be used in unmodified diesel engines 
- It can be handled as a liquid in existing petroleum infrastructure (as contrasted with CNG, LNG, DME and methanol)

- It can contribute to tailpipe emissions reductions

A number of tests of various types of heavy-duty diesel engines (trucks and buses) were carried out in the 1990s under controlled conditions, using conventional and advanced engines, and with FT diesel fuels from various sources. Typical reductions in exhaust emissions for FT diesel are indicated in Figure 3.1.

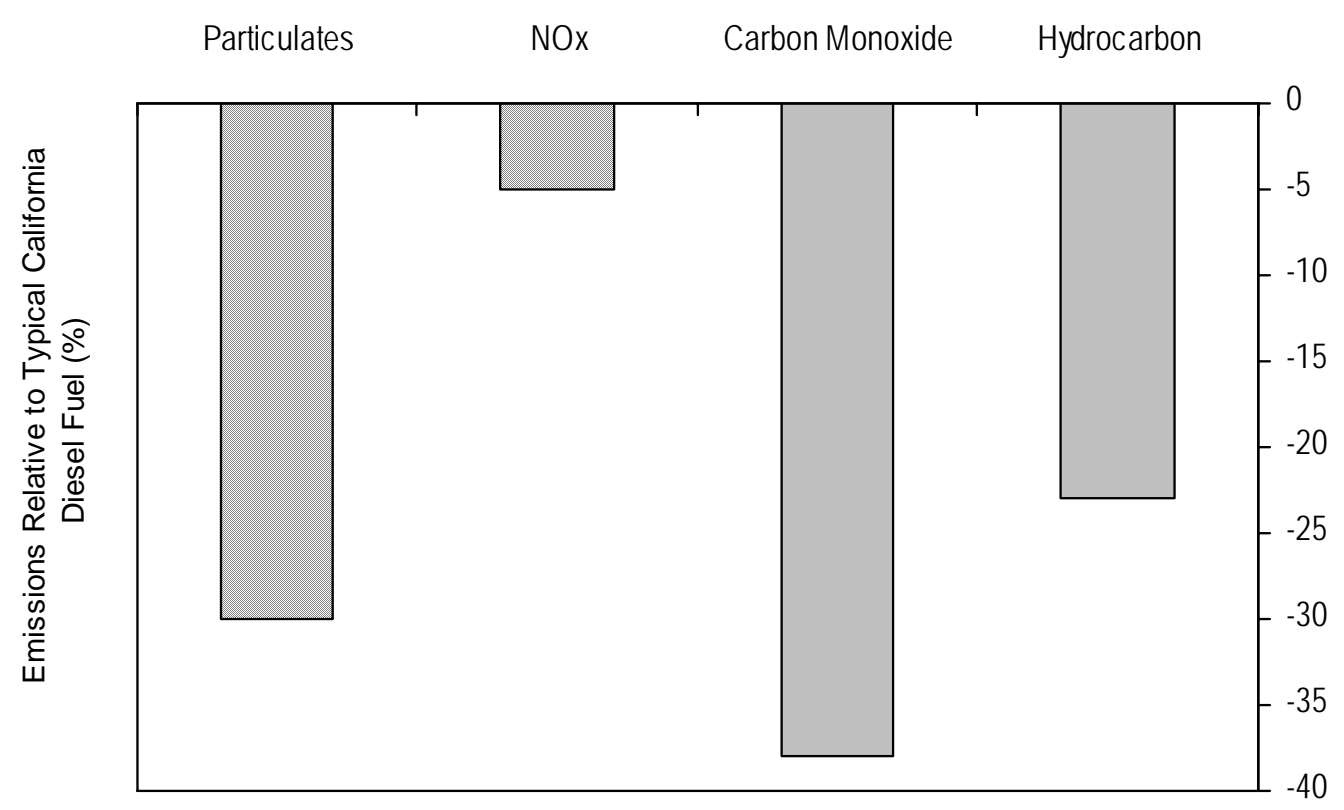

Q402:00072_Report 6graphs.Xs

\section{Figure 3.1 - Fischer-Tropsch Diesel Exhaust Emissions Relative to Typical California Diesel Exhaust Emissions}

Although it is expected that using FT diesel will provide these many benefits (even over ultra low sulfur diesel from conventional sources) in engine operation and performance, there are three levels of technical concerns in substituting FT diesel for conventional diesel, as follows:

- Because of lower lubricity and different solvent properties, seals, gaskets, certain metals and other materials in engine system components may degrade faster with FT diesel

- FT diesel's physical chemical properties could create problems, including lower energy density affecting fuel injection volumetric control, and possible problems in cold weather with fuel flow and atomization 
- Switching back and forth between conventional and FT diesel could possibly damage engines that are optimized for one or the other

Thus, a likely solution is designed-in flexibility to allow engines to handle a range of fuel properties, which is probably feasible by providing electronic automatic controls on fuel injection and engine timing.

The National Renewable Energy Laboratory (NREL), International Truck and Engine, Sasol and others are working on developing truck engine technologies for use with FT fuels. A number of major truck manufacturers supply engines in the U.S. and internationally, including:

- Cummins

- Detroit Diesel

- Caterpillar

- International Truck and Engine

- Mack Trucks

- Volvo Trucks

- $\mathrm{GM}$

- John Deere

- Isuzu

- Navistar

Some of these systems are limited in the quality of fuel that can be handled, even with adjustments. Engine wear is an issue with diesel fuel quality changes, since lower sulfur generally reduces the lubricity of the fuel. Nonetheless, one could implement some degree of phase-in of FT diesel by using lubricity additives and by simply using the fuel without adjustments and accepting lower performance.

At issue is the realization that it will take many years for turnover of the heavy duty on-road vehicle fleet. In the mid-90s, CARB reduced the sulfur levels in diesel and then allowed higher levels to be used again. This wrecked havoc with elastomeric components - seals, gaskets, etc. in the diesel systems and caused engine failures and severe maintenance problems. This is the problem of "backward compatibility" in systems where different diesel fuel blends with FT and different engine designs may exist within the market at the same time. If engines are developed to take advantage of FT diesel's better properties, their use could have a penalty if conventional diesel fuels remain in the distribution system and are used later in these engines.

\subsubsection{Lubricity Concerns}

Lubricity additives will likely be required (but only in low concentrations) to enable long-term use of FT diesel. Lubricity additives are used to compensate for the poor lubricity of severely hydrotreated diesel fuels. In light and medium duty diesel fuel systems, the fuel itself provides lubrication for the fuel pump and injectors. Actually, in heavy duty diesel engines, inherent fuel 
lubricity is less of a problem than with lighter duty systems, because some of the key lubrication of fuel pumping systems is by crankcase oil.

However, in general, a poor lubricity fuel can result in excessive wear and premature failure of critical components. With reductions in fuel sulfur level, lubricity is becoming a larger concern. Many refiners are using lubricity improver additives to restore the lubricating properties of the fuel. Many pump tests and bench tests have been developed to measure the lubricity of diesel fuels. The most widely used method is called the High Frequency Reciprocating Rig (HFRR).

Lubricity additives are now used in most countries where regulations require sulfur levels of 500 ppm or less in automotive diesel fuel. These levels were required since 1992 in Sweden, and extended in 1998 to the U.S., Canada, nearly all of Western Europe, Japan and Taiwan. Low sulfur $(500 \mathrm{ppm})$ diesel fuels have been marketed in California since 1988, and the current average is about $140 \mathrm{ppm}$ or less. Because of the refining approach to achieve these levels, however, lubricity problems were not generally encountered. In Canada, UK, and Sweden, in contrast, low sulfur diesel use did require lubricity additives, which gave good performance results

A number of different chemistries have been used for lubricity additives, all of which can restore lubricity levels to those of higher sulfur diesel fuel. High molecular weight compounds, naphthalenes, polyaromatics, nitrogen compounds, nitrogen and sulfur free polar compounds, and oxygenated compounds have been identified as potential lubricity agents. The fundamental principle is that the additive should contain a polar group that is attracted to metal surfaces, causing the additive to form a thin surface film. The film acts as a boundary lubricant when two metal surfaces come in contact. Two additive chemistries, fatty acids and esters, are most commonly used. The fatty acid type is typically used in the concentration range of $10 \mathrm{ppm}$ to 50 ppm. Since esters are less polar, they require a higher concentration range of $50 \mathrm{ppm}$ to $250 \mathrm{ppm}$. There has been long experience with (soy oil) methyl ester - based lubricity additives, typically used at levels of 50 to $200 \mathrm{ppm}$. Another common type is based on high levels of Stoddard Solvent, with possible contents of naphthalene, methyl benzenes at up to 4.0 percent, and other minor aromatics all at less than 1.0 percent each. Many products are offered as a package of lubricity additive with other diesel additives such as cetane enhancers, corrosion inhibitors, detergents, stabilizers, etc.

Any new chemicals proposed for use need to be monitored to ensure that secondary problems do not arise. The SAE has tested four types of additives based on different chemistries - an aliphatic ester derivative and three types of carboxylic acids. Studies were conducted with these of effects on in-line diesel pumps, fuel filter plugging, high-temperature cylinder bore polishing, foam inhibition, and water in the fuel. The aliphatic ester type was found to perform much better in comparisons with the carboxylic acid types and gave rise to far fewer secondary problems in the categories tested.

Even though all gasoline and diesel motor vehicle fuel additives are required to be registered in accordance with the regulations at 40 CFR 79, currently in the U.S., lubricity additives are a voluntary matter, not regulated by EPA as part of the low sulfur diesel regulations. Leading 
sources of lubricity additives include Stanadyne (Stanadyne Automotive Corp., Windsor, CT, Stanadyne Lubricity Formula) and West Central Soy. These and other stakeholders are working with ASTM to develop an ASTM D-975 lubricity additive specification. Other sources and their lubricity additive products listed by the EPA include:

- Cartel Products, Inc, Woodstock, IL

- Lubricity Improver

- CENEX Harvest States, Inc., Laurel, MT

- Diesel Fuel Lubricity Enhancer Concentrate

- Ford Motor Company

- Diesel Fuel Lubricity Additive

- Hydrotex, Inc., Carrollton, TX

- Lubricity Plus

- Petronomics Manufacturing Group, Hutchinson, KS

- $\quad$ Petron Plus Formula 7- All Season Diesel Fuel Conditioner with Lubricity

- Unifide Industries, LLC West Long Branch, NJ

- $\quad$ TMP-TFM 220 64oz. Diesel Lubricant

- $\quad$ TMP-TFM 310 32oz. Anti-Gel w/Lubricity

- $\quad$ TMP-TFM 910 32oz. Diesel Fuel Condition w/Lubricity

\subsubsection{Practical Concerns for Long-Term Engine Operations with FT Diesel}

Electronic control systems, which may possibly help to accommodate a switch to FT diesel or blends, are currently relatively rudimentary in diesel engines as contrasted with the latest gasoline automotive engines. Diesel fuel injection systems are volumetric control devices with a fixed piston volume and air/fuel ratio, without automatic adjustments. There is some flexibility in the controls, but the manufacturer must discretely adjust these to accommodate fuel changes. Could electronic ("ignition computer") controls, such as in gasoline automobiles, be used to adjust fuel injection based on say, the inferential parameter of density to accommodate different fuel blends with FT? Electronic controls will be increased dramatically over the next several years, but will be mainly aimed at meeting warrantees on emissions controls, not to adjust performance to fuel type.

Trucking/bus fleet operators are "tough customers". Trucking is a low-margin industry, and engine sales are also very competitive. Cost and complexity are both concerns for truck and bus company operators. Government transportation, sanitation, and other authorities that operate fleets deal with the same issues and have similar concerns.

With its new low-emissions engine designs, Cummins will offer a 435,000-mile warrantee on meeting emissions limits, but it will be contingent upon good operating and maintenance practices. Diesel engines are routinely run for 1 million miles before major overhauls. A 3 percent difference in volumetric fuel content, although perhaps not immediately noticeable to a 
driver, might cause significant damage to engine systems over a long operating period. However, these are not insurmountable challenges, and there may be a number of practical solutions available to achieve the modest degree of fuel adaptability required to cope with the variations.

Cummins is party to an FT fuels evaluation program with Penn State/Conoco and other diesel engine OEMs, and was also party to a Southwest Research Institute / EPA four-manufacturer "generic study" of performances of FT diesel in the OEMs' diesel engines in which the results were normalized to reflect typical factors.

California's South Coast Air Quality Management District (SCAQMD) also has a program to make current technology diesel engines compatible with FT fuel. But, "FT is not FT" - that is, there are differences between FT products from different sources that could affect performance. For example, some FT diesel fractions, such as that made by Mossgas, have significant aromatics content, but most other FT diesel products have little or no aromatics.

As to the costs of accommodating FT diesel fuels - no diesel engine manufacturer has been able to provide an estimate of such differential costs in the face of the changes needed in basic engine designs to handle the new low sulfur diesel fuels and to reduce pollutant emissions with these tailpipe controls. Engine systems and components are affected in minor ways that involve mainly tuning adjustments rather than different systems and materials, contrasted with, for example, the materials and systems changes needed to use methanol (M85) in a flexible fuel spark ignited engine vehicle, or to convert a heavy duty diesel-type system to natural gas (CNG / LNG) use.

\subsubsection{Technology Costs}

The U.S. EPA estimated the costs of diesel engine modifications that manufacturers would likely make to meet the new 2004 emissions standards, assuming fuel injection and turbocharger improvements would occur even without the new diesel standards (e.g., excluding 50 percent of technology costs). It was estimated that heavy duty engines would cost incrementally more by $\$ 803$ in 2004 , but that this increment would decrease to $\$ 368$ by 2009 . The corresponding increments for medium duty engines were estimated to be $\$ 657$ and $\$ 275$, respectively.

Increased operating costs were estimated to be $\$ 104$ and $\$ 49$ annually for heavy and medium duty engines, respectively, for EGR system maintenance. For NOx adsorber maintenance, costs for heavy duty engines were estimated to go from \$3,227 in 2007 to \$1,866 in 2012, while corresponding costs for medium duty engines would be $\$ 2,564$ and $\$ 1,412$.

Engine manufacturers are reported to consider these estimates to be optimistic. There is no indication of what differences there may be, if any, with using FT diesel fuels instead of the petroleum-derived low sulfur mandated fuels (which these estimates assume will be phased in according to the regulations).

\subsubsection{Engine/Fuel Testing Experience}


FT diesel use has been extensively tested under controlled "laboratory" conditions, neat and in blends to predict potential problems with its use and assess its benefits in reducing emissions. There has been much less testing and field demonstration under conditions that are more practical (less controlled)

FT diesel fuels from several sources (Shell Bintulu [Malaysia], South Africa - Mossgas and Sasol) were tested in the 1990s by the U.S. DOE, West Virginia University, Southwest Research Institute and others in a variety of heavy duty diesel engines (Detroit Diesel, Daimler-Benz, Navistar, Caterpillar, etc.), both neat and in 50/50 blends, and were compared with conventional \#2 diesel grades meeting 49-state U.S. specifications as well as with higher grade California \#2 diesel. The results were very positive in terms of engine responsive performance, efficiency, and reduced emissions, and indicate the feasibility of overcoming lubricity shortcomings with additives.

In general, the performance and emissions of various brands and types of diesel engines with various types of FT diesel fuels have been tested under controlled and repeatable conditions intended to simulate on-road service patterns of both buses and trucks. These studies have indicated that FT diesel fuel can be used in unmodified diesel engines, either of older, conventional designs, or advanced designs to meet new U.S. regulatory changes, and that in all cases at least some emissions benefits can be obtained. These tests have included a range of FT diesel types, blending fuels, and comparison fuels and engine types.

Some of the FT diesel fuels are essentially paraffinic, whereas the Mossgas fuel contained about $10 \%$ aromatics. These tests highlighted the benefits of using FT diesel, even as compared to the California reformulated fuel, and the further benefits of FT diesel fuels under (simulated) in-use driving conditions. Table 3.1 lists many of the relevant tests conducted on FT diesel in heavy duty systems.

The tests that were run in 1999 in buses were with rebuilt engines and catalytic converters, and Mossgas FT diesel (with relatively high aromatics for an FT diesel), neat and in 50/50 blends, was tested against conventional (Federal No. 2) diesel fuel. These tests, on average, indicated only moderate emission reductions:

- NOx by 8 percent

- PM by $31 \%$

- Carbon monoxide by $35 \%$

- Hydrocarbons by $49 \%$

The similar tests on trucks run in California in 1998 used Shell and Sasol FT diesel fuels in a number of leading diesel engine brands. These tests were run with Federal No. 2 diesel as well as with higher-grade California No. 2 diesel. Similar moderate, but consistent average reductions in emissions were found even against the California diesel grade:

- NOx by $12 \%$ 
- PM by $24 \%$

- Carbon monoxide by $18 \%$

- Hydrocarbons by $40 \%$

It was projected that even greater emissions reductions could be obtained against the Federal grade.

For the buses and trucks tested in the series of tests detailed above for emissions performance, fuel consumption (mpg) was not strongly affected by the fuel type. No more than $3 \%$ deviation from the average occurred for any one of the bus tests. For the trucks, there was much greater variation among trucks and engine types (as much as 19\%) than among fuels (generally only $4 \%)$.

\section{Table $3.1 \quad$ FT Diesel Testing}

\begin{tabular}{|c|l|l|l|}
\hline Year & Fuel Tested & Engine Type & Findings \\
\hline 1997 & $\begin{array}{l}\text { Sasol SSD 60/40 w/ } \\
\text { No.2-D }\end{array}$ & $\begin{array}{l}\text { Detroit Diesel Series } 6012.7 \text { liter truck diesel } \\
\text { engine }\end{array}$ & Reduced NOx and PM \\
\hline 1998 & 3 FT types -N/A & $\begin{array}{l}\text { Detroit Diesel Series } 6011.1 \text { liter truck diesel } \\
\text { engine }\end{array}$ & $\begin{array}{l}\text { Reduced NOx and PM, } \\
\text { minor power loss }\end{array}$ \\
\hline 1998 & $\begin{array}{l}\text { Shell MD, vs. } \\
\text { with No.2-D } \\
\text { Shell Bintulu MD, } \\
\text { and 100\% }\end{array}$ & $\begin{array}{l}\text { Daimler-Benz OM611 2.2 liter turbo diesel } \\
\text { engine }\end{array}$ & $\begin{array}{l}\text { Reduced NOx and PM, } \\
\text { also for light duty }\end{array}$ \\
\hline 1998 & $\begin{array}{l}\text { Shell FT vs. } \\
\text { No.2-D vs. } \\
\text { California No. 2 } \\
(100 \% \text { AND 50\%) }\end{array}$ & $\begin{array}{l}\text { N) Caterpillar 3176B 10.3 liter - } \\
\text { diesel \& dual-fuel types }\end{array}$ & $\begin{array}{l}\text { Tests by SwRI, used } \\
\text { Exxon Paradyne } \\
665 \text { lubricity additive }\end{array}$ \\
\hline 1999 & $\begin{array}{l}\text { Mossgas SD } \\
-100 \% \text { and 50/50 } \\
\text { vs. 49-state \#2-D }\end{array}$ & $\begin{array}{l}\text { Detroit Diesel 6V92 2-stroke bus diesels } \\
\text { (6 - 40-ft buses); w/ and w/o catalytic } \\
\text { converters }\end{array}$ & $\begin{array}{l}\text { Lower emissions, good } \\
\text { performance; lubricity additive } \\
\text { effective }\end{array}$ \\
\hline 1998 & $\begin{array}{l}\text { Shell } \\
\text { Malaysian FT; } \\
\text { with California \#2 } \\
\text { trailer truck tractors }\end{array}$ & $\begin{array}{l}\text { Lower NOx } \\
\text { PM; over simulated } \\
\text { downtown route }\end{array}$ \\
\hline
\end{tabular}

These tests were performed on conventional diesel engine platforms. However, going forward, one FT diesel engine and fuel researcher, Ricardo, Inc., indicates that there are strong tradeoffs of particulate emissions and NOx emissions, as well as well as with fuel economy, as exhaust 
gas recirculation (EGR) in modified engines is increased in the new diesel engine designs. With conventional diesel fuel, an extreme but feasibly high EGR rate would:

- Decrease uncontrolled NOx emissions from around 4.0 grams $/ \mathrm{mile}$ to about 0.15 grams $/ \mathrm{mile}$

- Degrade fuel economy from a normal level of about $13.8 \mathrm{mpg}$ to below $13.0 \mathrm{mpg}$

- Increase uncontrolled particulates (PM) from about 0.14 grams/mile to about 0.36 grams/mile

Ricardo outlined a strategy of using FT diesel in engines optimized for it to get from $4 \mathrm{~g} / \mathrm{mi}$. NOx to the goal of $0.01 \mathrm{~g} / \mathrm{mi}$. NOx. Using FT diesel would reduce uncontrolled PM (e.g., without particulate filters) to a maximum of $0.11 \mathrm{~g} / \mathrm{mi}$. at the point in the transition before 2007 when particulate filters and Lean NOx catalyst systems are not yet required. This result would not be possible with baseline \#2 diesel fuel (i.e., with $10 \%$ aromatics).

\subsubsection{FT Diesel SWOT Analysis}

\subsubsection{Strengths}

FT diesel range distillates as blending components offer an attractive strategy for reducing sulfur in diesel fuel while at the same time enhancing cetane number. There do not appear to be any significant technical impediments to FT diesel use, either in blends in the short run, or neat in the long run. FT diesel has been demonstrated in a wide variety of tests to offer attractive, if not overwhelming environmental advantages under all conditions tested, in both conventional heavy-duty diesel engines as well as advanced engines with both combustion design modifications and exhaust controls.

\subsubsection{Weaknesses}

In a transition from conventional diesel, whether at current sulfur levels or with reduced sulfur, it is possible that degraded engine performance will be experienced over long periods of operation if engines are not modified to accommodate the somewhat lower net energy density of FT diesel. Other kinds of problems in injection system wear may be encountered with the very low sulfur of FT blends or neat fuels, unless a suitable lubricity additive is used. If engines are modified for FT diesel, switching back to conventional diesel may also create similar problems. The specification for diesel fuel would have to be modified to accommodate the lower energy density of FT diesel in the U.S. to make it legally marketable.

\subsubsection{Opportunities}

As refiners struggle to meet the new low sulfur specifications, FT diesel offers an alternative strategy. FT diesel producers have the opportunity and need to work with the diesel fuel suppliers, engine manufacturers, regulators, professional societies and fleet owners to qualify and demonstrate the technical feasibility of these products. The market may be most quickly penetrable in "boutique" fuel areas, such as in California and Texas, where severe environmental problems have created a need for cleaner fuels earlier than in the nation in general. 


\subsubsection{Threats}

Other alternative fuels, including CNG, LNG and biodiesel are being extensively pursued for use in heavy-duty diesels and may compete with FT diesel. The technology for using natural gas in heavy duty diesel engines, with and without spark ignition, is being widely demonstrated in fleets around the world and is completely commercialized for stationary power and combined heat and power applications. Biodiesel has many advantages and good qualities (similar to FT diesel - no sulfur, high cetane, etc. - but also good lubricity) few technical problems, and a high level of environmentalist and farm region political support.

\subsubsection{Conclusions}

The conclusions drawn from Nexant's assessment of FT diesel's suitability to be used as a fuel in vehicle engines are as follow:

- On balance, Nexant believes that there are minimal impediments presented by engine technology issues for FT diesel use as a supplement to or replacement for conventional petroleum derived diesel fuel in conventional diesel engines

- Nexant believes that the impediments are no greater for FT diesel use in the advanced technology engines being developed

- FT distillate appears to have its greatest potential as blend stock to achieve the ultra low sulfur levels needed to meet emerging regulations for NOx and PM and enable emissions controls in future diesel fuel in North America, Europe, Japan and elsewhere (in either hybrid or conventional vehicle configurations). Significant market penetration could be achieved by 2015.

- The recent and anticipated technical development of emission after-treatment devices has prompted the U.S. and the European Union to adopt emission standards that are designed to force the use of these devices on heavy duty diesel engines. The use of these technologies can achieve much greater reductions in PM and NOx emissions than can be achieved by only improving the quality of diesel fuel by lowering its sulfur and aromatics contents.

- Based on their technical qualities, market shares already achieved and their growth rates, CNG/LNG and biodiesel could compete with FT diesel, but methanol is not a serious contender.

- The EPA and other stakeholders need to collaborate to set specs for FT diesel. It cannot be a case of "make it and they will come". The stakeholders that must collaborate are:

$\begin{array}{ll}- & \text { Engine providers } \\ - & \text { Regulators (federal and state) } \\ - & \text { Fuel makers } \\ - & \text { Customers (fleet owners) }\end{array}$




\subsection{METHANOL}

\subsubsection{Methanol Use in Passenger Cars (Spark-Ignited Gasoline Engines)}

The Clean Air Act of 1977 began the U.S. EPA's and the States' regulation of the use and properties of fuels containing alcohols and ethers (oxygenates). The Clean Air Act Amendments of 1990 required oxygenates content in gasoline to achieve lower emissions of NOx and CO. Federal and some state oxygenate requirements were generally achieved by the gasoline producers with blends containing either ethanol (gasohol) or methyl-tert butyl ether (MTBE, which requires methanol for its manufacture).

\subsubsection{M100 (Neat Methanol)}

For over two decades methanol producers, auto manufacturers, and to a lesser extent, some integrated petroleum and natural gas producers have promoted methanol as a fuel for passenger automobiles and heavy duty buses and trucks with conventional IC engines. It is a common fuel for racecars (e.g., in the Indianapolis 500), so the automotive engineering profession and auto industry is familiar with its use. In the 1980s, the U.S. DOE began to consider methanol as a "Fuel of the Future", and mounted diverse programs to support development of technologies for its manufacture by gasifying coal, heavy oil and other resources and by natural gas conversion, and for engine development and vehicle demonstration.

Methanol, however, has some serious challenges for use as a general passenger car fuel. The most basic and critical impediment (for which there are no technical fixes) is its low energy density, which is about half that of gasoline or diesel, because its molecule is roughly half hydrocarbon and half water. Ethanol and MTBE, which also contain hydroxide radicals, have much higher proportions of hydrocarbon groups and thus, higher energy density than methanol. Further, because of cold start problems and other technical and practical challenges, neat methanol (M100) was found to be impractical for use in spark-ignited, light duty (gasoline-type) ICE passenger cars. There continues to be some limited interest in neat methanol as a fleet vehicle and niche market fuel in heavy and medium duty compression vehicles (diesel-type engines), possibly partly as a hedge against a petroleum supply catastrophe. There is far more interest in methanol for heavy duty vehicle fueling in Japan than in the U.S., and somewhat less in Europe. However, for the partisans of methanol AFVs in all regions, most of the emphasis has shifted to fuel cell vehicles.

\subsubsection{Methanol As A Fuel Extender}

Also, unlike ethanol, methanol cannot be blended with gasoline in low concentrations without causing a disproportional, high vapor pressure increase. A concentration of 0.35 methanol will increase gasoline vapor pressure from a level in the range of 7-15 psi to $40 \mathrm{psi}$. This is because methanol is a polar solvent and gasoline components are generally non-polar.

In 1981, the EPA qualified aliphatic alcohols and ethers (except methanol) as "substantially similar" in achieving seasonal and geographical volatility class limits (Reid Vapor Pressure, or RVP limitations). Methanol was excluded from this categorization above 0.3 percent by volume because of questions concerning the chemical effects of methanol on fuel system components, 
water separation and evaporative emissions. Due to these issues, there was only limited commercial interest in blending low levels of methanol as a fuel extender. However, waivers were granted to ARCO, DuPont and Texas Methanol during the 1980s for methanol-gasoline blends with up to 3.7 percent oxygen content, using co-solvents and corrosion inhibitors. Still, little methanol is used in this way. In stark contrast, ethanol blending as an extender and to achieve the mandated fuel oxygen content remains of great interest.

\subsubsection{M85 (Methanol-Gasoline Blend)}

Under the Energy Policy Act of 1982, methanol and ethanol blends must have an alcohol content of 85 percent or more and be blended with conventional gasoline to achieve cold starting, vehicle safety, and other practical vehicle requirements (with certain potential for waivers to lower levels down to 70 percent). M85 blends (85 percent methanol with 15 percent unleaded gasoline added) were developed to solve problems experienced with neat methanol on cold startup for methanol use in spark-ignited as well as compression-ignited engines.

Adding volatile hydrocarbons to neat methanol (or ethanol) is an acceptable, practical solution to the cold start problem. Consumers demand that cars start in 10 to 15 seconds even at $-20^{\circ} \mathrm{F}$ with auxiliary devices or additives. Gasoline can be blended for seasonal temperature changes to adjust volatility and combustion characteristics to give good performance while maintaining acceptable levels of volatiles emissions, whereas neat alcohols cannot. Neat alcohols do not have adequate volatility at low temperatures (ethanol constant $\mathrm{bp}=173^{\circ} \mathrm{F}$, methanol constant $\mathrm{bp}=148^{\circ} \mathrm{F}$ ) to give good engine starting and also require more heat for vaporization than hydrocarbon fractions.

\subsubsection{Flexible Fuel Vehicles}

M85 was market tested mainly in California, in so-called "Flexible Fuel Vehicles", or FFVs. At the height of California's demonstration program in the 1990s, the California Energy Commission established an M85 refueling infrastructure from San Diego to Sacramento in cooperation with major gasoline retailers to serve the FFVs in the state. In addition to about 55 public methanol stations, more than 50 private stations were operated in California. Outside the state, there were 40 methanol fueling stations in 14 states and Canada. This infrastructure has now dwindled to a fraction of that level. According to U.S. Department of Energy statistics (as can be found at url- (www.eia.doe.gov/cneaf/alternate/page/datatables/table1.html), at the peak of interest in 1997, there were over 21,000 M85-capable vehicles nationally in the U.S., and over 400 M100 vehicles at the peak in 1994. Today, there are fewer than 17,000 dual-fuel M85 vehicles left, nearly all operating on gasoline, and less than 190 M100 vehicles.

FFVs have a single fuel tank, fuel system, and engine and are designed to run on regular unleaded gasoline and an alcohol fuel (either ethanol or methanol) in any mixture - for example, $100 \%$ gasoline, M85, E85 (85\% ethanol, 15\% gasoline), or any combination of these fuels. FFVs address the problem of an alternative fuel vehicle leaving the territory where refueling stations exist and needing to refuel on conventional fuels to keep running. In 1997, Ford and Chrysler had committed to building an order of magnitude more FFVs each year. Today, when the U.S. 
and state governments and companies talk about FFVs, they are often referring to E85 FFVs, for which there is long-standing and now growing political support in farm states.

Early testing of alcohols as gasoline fuel extenders (5-15\%) showed reductions in emissions of some criteria pollutants to improve air quality, but high evaporative emissions with older refueling equipment led to reduced air quality. Dedicated fuel vehicles for general use were also rejected because of driver frustration with finding refueling stations.

The test program in California of FFVs lasted about ten years. At its peak, this program had about 105 M85 stations operating in California. Today, only 10 are listed by the SCAQMD (www.cleancarmaps.com) as operating, consisting of 5 in the Bay area and 5 in and around Los Angeles, run by several oil companies and other types of sponsors. This can be contrasted with other alternative fuels, among which there are, nationally, 5,540 fueling stations currently listed by NREL (www.afdc.nrel.gov) as follows:

- 3,417 for LPG (plus many farm operations that refuel LPG autos from their own on-site tanks)

- 1,235 for $\mathrm{CNG}$

- 685 for electric vehicles

- 147 for E85

- 44 for LNG

- 12 for biodiesel

In the late 1990s, there were over 14,000 M85 FFVs on California highways, mostly operated by government, corporate and rental fleets. Although it has lower energy content, methanol burns more cleanly and efficiently than gasoline. It takes about 1.6 gallons of M-85 to provide the same vehicle range as a gallon of gasoline. On an energy equivalent basis, the actual cost of methanol fuel without subsidies was in the range of premium gasoline blends. Methanol has a research octane number of 107, a motor octane number of 92 and an average $((\mathrm{R}+\mathrm{M}) / 2)$ octane of 100 .

It is apparent that California M85 testing was a technical success and a commercial failure.

\subsubsection{Materials Problems with Methanol Fuel}

FFVs for alcohol fuels have been supplied by OEMs, and not created by conversion of existing vehicles with kits, as have many LPG and CNG fueled vehicles. Unlike LPG and CNG dual-fuel vehicles (with separate fuel tanks), conversion kits were not and are not a common item of commerce for alcohol fuels. Utilizing alcohol fuels requires a set of materials in the fuel system and engine, including metals, elastomers, polymers and lubricants that can be compatible with both fuels for the life of the vehicle. It also requires controls and tuning to accommodate both fuels. Methanol is an aggressive solvent. Gasoline blends with methanol were found to cause swelling of some fuel system elastomers and attack some metals. Not only is there concern with materials in the automobile deteriorating, but also for contamination of the fuel with non- 
compatible materials in its handling. These are not high cost issues, but they would require both dedicated vehicle manufacturing and fuel infrastructure systems.

Specifically, both M85 and M100 have been reported to attack lead-tin coated plate steel used to fabricate gasoline fuel tanks in the U.S. Suitable corrosion inhibitors have not been found to solve this problem without a change in fuel tank materials. Coating the interior of fuel tanks with polyolefin may be a viable solution. Type 304 stainless steel and nickel-coated steel are other viable solutions. Other metals that may be attacked more than with gasoline are copper, brass, zinc, bronze, magnesium and die-cast zinc. Chlorides and peroxides are soluble in methanol and can increase degradation and corrosion of engine components, including anodized aluminum parts. Besides engine degradation, corrosion products, even from refueling system components, can cause fuel filter or injector plugging. Chrome plating can help protect some critical components, such as engine rings.

Elastomers are reported to tend to degrade more with mixtures of methanol or ethanol and gasoline than with either pure component. Types of parts attacked include fuel floats, diaphragms, gaskets (including cork), o-rings and seals. Fluorocarbons, which work very well with hydrocarbons, are attacked by methanol.

Methanol also has low viscosity and poor lubricity, and so makes components, especially in fuel pumping and injection systems, more vulnerable to wear. This can be countered by addition of less than 0.1 percent lubricity additive. Special lubricants are needed to protect the cylinders and piston rings when methanol is used. Some of this may be due to formic acid attack in cold engine conditions. Even with additives, more frequent oil changes will likely be required.

\subsubsection{Methanol Use in Diesel (Compression-Ignited) Heavy-Duty Vehicles}

Alcohols have been recognized for many years as a useful supplement in diesel engines to reduce particulate emissions, especially from diesel combustion with rich fuel/air mixtures. Because of its high heat of vaporization, methanol reduces peak combustion temperatures and thus reduces $\mathrm{NOx}$ and $\mathrm{CO}$ formation. A common technique of supplementing diesel with methanol is known as fumigation, which consists of injecting methanol into the engine intake air, at as high a ratio as the engine will tolerate without quenching the compression ignition. Up to 60 percent by volume in air fumigation has been found practical (equivalent to about 26 percent of the total fuel heat input). This has been accomplished in a variety of ways, including heated vaporizers, carburetors, manifold injectors and mist generators. Alternatively, separate fuel injectors can be used to introduce methanol.

Methanol is not miscible with diesel fuel and requires a separate fuel system. Methanol has a cetane rating of 0 (zero), but it can be upgraded by adding paraffinic hydrocarbons or ignition improver additives (typically in the range of 6 to 13 weight percent), such as cyclohexylnitrate, dimethyl ether (DME), 2-ethylhexyl nitrate, tri-ethylene glycol nitrate, or a commercial additive package called Avocet.

Much development work and commercial demonstrations of diesel methanol use took place in the 1980s. Detroit Diesel and German MAN and KHD developed early versions of heavy-duty 
methanol diesel engines. Caterpillar, Navistar, Daimler-Benz, Cummins and Komatsu also developed methanol-burning engine designs for bus and/or truck service. Many of these were tested and some were even used in commercial service. This experience showed higher or equal fuel efficiencies and lower emissions of NOx, particulates and hydrocarbons that with diesel fuel or uncarburated systems. Many of these engines can run on neat methanol, but others ran on M85. Major engine modifications, such as adding glow plugs to cylinder heads and modified pistons with increased compression ratios are required to use methanol in older engines.

Overall, because engine modifications and additives, plus increased fuel volume carrying capacity and fuel distribution infrastructure expansions are required for methanol, the barriers to entry for methanol use in heavy duty diesel engines are very high, and it has not been seen as cost effective to offer economic incentives for adoption of methanol diesel systems.

\subsubsection{Conclusions}

The conclusions drawn from Nexant's assessment of methanol's suitability to be used as a fuel in vehicle engines are as follow:

- Methanol was tested for many years as an ICE fuel in California and in many other locations as a strategy to reduce air pollutant emissions and reduce dependence on petroleum liquids. Despite these efforts, methanol was not a commercial success.

- Despite extensive support from the California and federal governments, methanol interests, auto and diesel engine companies, and the cooperation of the petroleum industry, there are very few ICE vehicles currently running on methanol in the U.S. today (fewer than for any other salient alternative fuel)

- Methanol fuel has not found enthusiastic consumer acceptance because it:

- Has challenges in materials compatibility

- $\quad$ Offers no real advantages in price, convenience or performance

- Has not been subsidized as has ethanol, and lacking comparable political support, is unlikely to receive required subsidies in the future

- Methanol's relatively low energy density (roughly half of that of gasoline) has been a real impediment to acceptance in terms of vehicle range, and there are concerns over its toxicity and other health, safety and environmental issues

- The M100 option is not practical for cars primarily because of cold start problems

- The gasoline-blended M85, flexible fuel vehicle option currently seems to have little potential for use in light duty gasoline-type passenger automobiles in the U.S. because it requires special, more expensive car designs without a significant savings in fuel cost or other advantages to the consumer

- Neither M100 nor M85 has been seen as attractive to date for (heavy duty diesel-type) transit vehicles and trucks because it has a very low cetane rating, incompatible with diesel engines, and no advantages for the owner/operator 
- Methanol is not expected to have any share of the conventional vehicle fuel market in the timeframe of this report

- Despite all the demonstrations and its status as a commercial commodity, there appears to be a low little probability of its widespread commercialization for any methanol ICE fuel in the U.S. or Europe

- Japan seems to have a greater interest in fuel methanol in general

The methanol industry has largely abandoned its support of methanol in ICEs for the reasons listed above, but the industry is now instead championing methanol use in fuel cells, especially for vehicle and portable power applications 


\subsection{TECHNICAL OVERVIEW}

Fuel cells have promised to be the answer to mankind's power generation needs for many years. Given the right fuel and distribution and refueling infrastructure, they are capable of delivering electrical power at far greater efficiencies than is achieved in current power generation devices, including ones that can be used in vehicle systems. Because of the growing concern about air pollution, global warming and the depletion of crude oil reserves, many companies, encouraged by a number of governments, are putting significant effort into commercializing fuel cell and supporting technology (notably in North America, Germany and Japan).

The development of fuel cells, particularly in the automotive sector, will likely have an impact on the long-term demand growth of transportation fuels and greatly influence which types are to be developed or deselected.

The purpose of this section is to review the technology, status of development and future prospects for fuel cells to determine what role they are likely to have specifically in vehicles in the future, and how and when they are likely to be developed and used. This inquiry is aimed at understanding the prospects for using methanol or Fischer-Tropsch distillates (most likely in the naphtha range) as fuels for fuel cell vehicles and in stationary applications. Stationary applications are examined herein both because they may also create a significant demand for FT fractions and/or methanol, which could be synergistic with transportation in developing a manufacturing and distribution infrastructure, and because their technology and manufacturing development could synergistically help advance fuel cell technology and build scale for savings in manufacturing. Portable applications are also considered, with less expectation of significant impact on fuel systems (mainly methanol) or manufacturing scale, but a similar possibility of technology synergy.

William Grove's early work in the 19th century on the underlying electrochemical principles to be exploited in fuel cells led to creating the first alkaline one-kilowatt fuel cell system in the 1950s. In the 1960s, NASA adopted fuel cells in the Gemini, Apollo, and space shuttle programs. Since their initial use in space, fuel cells have been improved and are becoming commercially available in products such as automobiles, computers, cell phones, residential and small business power generators, and large-scale stationary power generators. Fuel cells are also potential independent or distributed power providers for such users as credit card processing centers, jails, cellular phone towers, mining equipment, communication centers, navigation equipment, road signs, defense installations, urban transit buses, and even portable household appliances.

There are four major types of fuel cells currently under development with mass market potential today:

- Two low temperature types -

- $\quad$ Proton exchange membrane (PEMFC) 
- $\quad$ Phosphoric acid (PAFC)

- Two high temperature types -

- $\quad$ Solid oxide (SOFC)

- $\quad$ Molten carbonate (MCFC)

The PEMFC and SOFC types use solid state membranes, while the PAFC and MCFC types are based on liquid exchange media. Two versions of SOFC are being developed, planar and tubular, which each has distinct potential advantages in manufacturing and operating characteristics.

There are other forms of fuel cells and many types of auxiliary systems that are required for fuel cell utilization, but these four are the most important basic technologies. None of these is a "best bet" for all applications, and there is little general consensus among developers, investors, and other stakeholders on many of the key issues of fuel cell and fuel selection among the major potential applications. Some types, such as PEMFC, have many different development champions and sponsors, with either broad interests interest in whole systems (such as the car companies and governments), or specific interests in components, materials, supporting technologies, relevant applications or fuels (such as various chemical companies, electrical equipment OEMs, etc.). Other types have fewer champions and developers involved.

PEMFC has the greatest potential for modularization, small sizing, light weighting and lower cost mass production. SOFC may also be quite amenable to modularization and mass production cost savings. The higher temperature technologies are less sensitive to fuel impurities.

Two major markets for fuel cells that may have an impact on large commodity fuel use may emerge in the near term - electric power generation and motor vehicles.

Although technically relevant and probably synergistic at least with vehicle development, fuel cells for powering portable electronics are also emerging rapidly, but will not likely create a significant fuel volume demand in the near term.

Some patterns are emerging in the multi-faceted, complex, entrepreneurial and politicallycharged field of fuel cell development:

- PAFC is a commercial reality today for stationary power generation, but in the long term, the higher temperature MCFC and SOFC technologies may provide more benefits; for example, hybrid systems have been demonstrated of SOFCs integrated with gas turbines (GTs) to recover SOFC waste heat

- PEMFC appears to be favored for passenger cars, but SOFC may be more beneficial for larger vehicles in the future

- Portable electronics fuel cell applications today are focused on a special type of PEMFC that can directly use methanol without converting first to hydrogen, the direct methanol fuel cell (DMFC) 
- PEMFCs lead in development of fuel cell autos, but SOFC developers have also targeted this market along with stationary power

- Breakthroughs in DMFCs for portable electronics applications could lead to significant technology crossovers to vehicles

- Auto companies have started demonstrating PEMFCs on hydrogen to simplify, to be followed by fuel processing demonstrations, but they are still open to other technologies and fuels

- PAFCs lead in stationary applications, but SOFCs have many of the same advantages, and have greater potential for cost reduction when mass-produced. UTC, developer of the only fully commercial stationary PAFC technology, is also developing PEMFCs for smaller power applications

- Breakthroughs in enabling technology areas - including polymer and ceramic membranes, catalysts, fuel processing system designs, or hydrogen storage media - could rapidly change the landscape

Hydrogen is the fuel needed for fuel cells. If hydrogen is not the fuel provided, but rather a liquid or gaseous hydrocarbon or oxygenated hydrocarbons (e.g., alcohols), fuel processing will be required for both high-temperature and low-temperature fuel cells to convert these fuels to hydrogen. (This is with the exception of types of fuel cells being developed that can convert these other fuels to hydrogen within the cell stack and use fuels such as methanol directly.)

Many organizations champion and sponsor development of direct hydrogen use in fuel cells, but many other types of fuels or "energy carriers" are being widely researched, developed and demonstrated for use in fuel cell vehicles. These range along a spectrum from hydrogen (which is the ideal for direct use in fuel cells, but very inconvenient to store, distribute and carry with the current state of technology) to very low-sulfur gasoline (which is the most convenient since it fits best into the current fuel infrastructure, but is relatively inefficient because of its very high reforming temperature, contaminants and other non-ideality in use). There is at least one sponsoring organization for each major hydrocarbon and oxygenated hydrocarbon fuel (renewable and non-renewable) being considered as an interim or long term strategy - natural gas, LPG, propane, "clean gasoline", ultra low sulfur diesel, Fischer-Tropsch liquid fractions, methanol, ethanol, DME, landfill gas, etc.

Methanol is the in-between energy carrier - moderately convenient and probably the most efficient in use. Methane, in spite of its being well-distributed in the U.S., would be both relatively inconvenient for mobile use and not particularly attractive for on-board reforming because of a high reforming temperature. FT distillate in the naphtha range, further towards gasoline in this spectrum, is also been considered, but does not appear to be as attractive as methanol. Figure 4.1 illustrates the spectrum of the leading fuels (energy carriers) being considered for fuel cells according to their relative technical fit versus convenience of handling and distribution. 
Technical qualities

Convenience

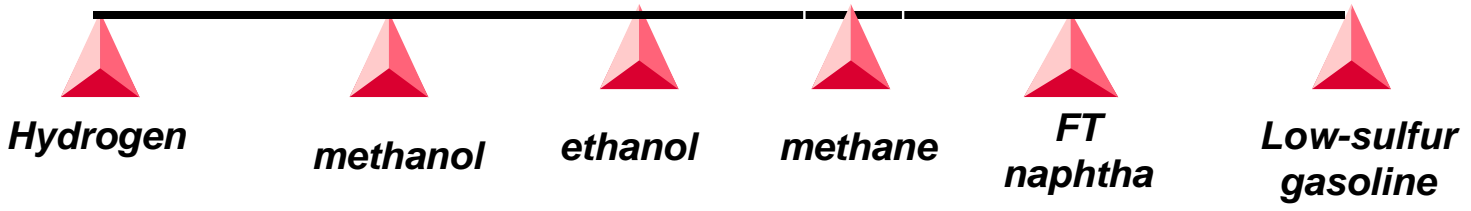

Figure 4.1 Fuel Cell Energy Carrier Quality/Convenience Spectrum

Source: Nexant

Methanol appears to have significant advantages and good technical potential for use in fuel cell vehicles, either with on-board reforming for hydrogen fed to conventional fuel cells or in the direct methanol designs that are being developed.

One key problem is that hydrocarbon reformers need to operate at temperatures $200-400^{\circ} \mathrm{C}$ higher than reformers operating on methanol or other alcohols. In commercialized stationary systems, which commonly use natural gas or other hydrocarbons, the waste heat resulting from such an operation can be recovered and used, but this may not be an attractive option in most vehicles. To ultimately minimize cost, weight and certain system difficulties, vehicle propulsion applications are aimed mostly at low-temperature PEMFC systems that integrate least well among all options with higher temperature reformers. Methanol is therefore most attractive among liquid fuels with respect to onboard systems applications.

However, methanol is perceived to have significant infrastructure challenges to meet if it is to be used as a general fuel for automotive fuel cells. On the other hand, it may be found that, as its proponents contend, methanol is a more convenient approach than the widely hoped-for "hydrogen economy" to distribute various methane resources and other more renewable alternative energy sources to the vehicle fleet. Methanol is receiving much attention for much smaller volume applications, such as reformer/fuel cell or direct methanol fuel cell designs in portable electronics, military, outdoors, and other mobile electrical energy systems.

The needs and potentials of high and low temperature fuel cells differ significantly with respect to their integration with fuel processors. Salient points include:

- That hydrocarbon fuels and alcohol fuels can both be used as fuels for reforming in stationary systems as well as in vehicle applications on-board

- Alcohol fuels can be reformed at lower temperatures, but hydrocarbon fuels have the advantages of existing production and distribution infrastructures and market familiarity

- Much more research and development is needed to improve energy efficiency and reduce the size and complexity of fuel processors

- More effective ways of deep removal of sulfur before or after fuel reforming, and more energy-efficient and stable catalysts and processes for reforming hydrocarbon fuels are needed for both high- and low-temperature types of fuel cells 
- More active and robust catalysts for water-gas-shift, more selective and active catalysts for preferential $\mathrm{CO}$ oxidation at lower temperature, and more $\mathrm{CO}$-tolerant anode catalysts would advance the development and implementation of low-temperature fuel cells, particularly PEMFCs

It is highly likely that fuel cells will have a major role in future energy utilization, but which fuel cells, with which fuels and when?

The characteristics of the different types of fuel cells in use or under development are summarized in Table 4.1.

Table 4.1 Characteristics Of Fuel Cell Types

\begin{tabular}{|c|c|c|c|c|c|c|}
\hline Fuel Cell Type & $\begin{array}{l}\text { Proton } \\
\text { Exchange } \\
\text { Membrane }\end{array}$ & Alkaline & $\begin{array}{l}\text { Phosphoric } \\
\text { Acid }\end{array}$ & $\begin{array}{l}\text { Molten } \\
\text { Carbonate }\end{array}$ & $\begin{array}{l}\text { Tubular } \\
\text { Solid Oxide }\end{array}$ & $\begin{array}{l}\text { Planar } \\
\text { Solid Oxide }\end{array}$ \\
\hline Operating Temperature & $70-80^{\circ} \mathrm{C}$ & $80-100^{\circ} \mathrm{C}$ & $200-220^{\circ} \mathrm{C}$ & $600-650^{\circ} \mathrm{C}$ & $800-1000^{\circ} \mathrm{C}$ & $500-800^{\circ} \mathrm{C}$ \\
\hline Current Density & High & High & Moderate & Moderate & Moderate & High \\
\hline $\begin{array}{l}\text { Stage of } \\
\text { Development }\end{array}$ & $\begin{array}{l}\text { Field } \\
\text { Demos. }\end{array}$ & Use in aerospace & $\begin{array}{l}\text { Early } \\
\text { commercial }\end{array}$ & $\begin{array}{l}\text { Field } \\
\text { Demos. }\end{array}$ & $\begin{array}{l}\text { Field } \\
\text { Demos. }\end{array}$ & $\begin{array}{l}\text { Lab } \\
\text { Demos. }\end{array}$ \\
\hline Likely Applications & $\begin{array}{l}\text { Distributed } \\
\text { Generation, } \\
\text { Portable power, } \\
\text { Vehicles }\end{array}$ & Space & $\begin{array}{l}\text { Industrial, } \\
\text { Commercial }\end{array}$ & $\begin{array}{l}\text { Industrial, } \\
\text { Commercial, } \\
\text { electric utilities }\end{array}$ & $\begin{array}{l}\text { Industrial, } \\
\text { Commercial, } \\
\text { electric utilities }\end{array}$ & $\begin{array}{l}\text { Distributed } \\
\text { Generation }\end{array}$ \\
\hline Advantages & $\begin{array}{l}\text { Low temperature, } \\
\text { quick startup, solid } \\
\text { electrolyte }\end{array}$ & High performance & $\begin{array}{l}\text { High } \\
\text { Efficiency } \\
\text { for Co- } \\
\text { generation }\end{array}$ & $\begin{array}{l}\text { High } \\
\text { Efficiency, } \\
\text { Fuel flexible, } \\
\text { Allows CO }\end{array}$ & $\begin{array}{l}\text { High } \\
\text { Efficiency, } \\
\text { Fuel flexible, } \\
\text { Allows CO, } \\
\text { solid } \\
\text { electrolyte }\end{array}$ & $\begin{array}{l}\text { High } \\
\text { Efficiency, } \\
\text { Fuel flexible, } \\
\text { allows } \\
\text { cO, solid } \\
\text { Electrolyte }\end{array}$ \\
\hline Disadvantages & $\begin{array}{l}\text { Sensitive to fuel } \\
\text { impurities, needs } \\
\text { cO removal from } \\
\text { fuel }\end{array}$ & $\begin{array}{l}\text { NeedsCO2, CO, } \\
\text { sulfur removal } \\
\text { from fuel and air }\end{array}$ & $\begin{array}{l}\text { Low current } \\
\text { and power, } \\
\text { large and } \\
\text { heavy }\end{array}$ & $\begin{array}{l}\text { High } \\
\text { temperature } \\
\text { causes } \\
\text { breakdown of } \\
\text { components }\end{array}$ & $\begin{array}{l}\text { Problems with } \\
\text { ceramic } \\
\text { structure, } \\
\text { seals } \\
\text { during cycling }\end{array}$ & $\begin{array}{l}\text { Problems with } \\
\text { ceramic } \\
\text { structure, } \\
\text { seals } \\
\text { during cycling }\end{array}$ \\
\hline $\begin{array}{l}\text { Prospects for High } \\
\text { Efficiency }\end{array}$ & Acceptable & Poor & Good & Excellent & Excellent & Excellent \\
\hline $\begin{array}{l}\text { Prospects for } \\
\text { Low costs }\end{array}$ & Good & Fair & Fair & Fair & Fair-good & Good \\
\hline
\end{tabular}




\subsection{COMPETITIVE ASSESSMENT OF FUEL CELL TYPES}

\section{Competition among Fuel Cell Technologies - Application Issues}

How, when and where and for which applications fuel cells will achieve commercialization and what fuels they will use depends on many factors and types of issues to be resolved, including:

- Basic thermodynamic limits

- Materials development

- Mechanical systems

- Chemical/electrochemical properties, developments

- Refueling logistics

- Competition with other advancing technology alternatives

- Costs/economies of scale

- Energy geopolitics

- Life Cycle Performance/Societal Benefits

- Business development/technology championing

- Research sponsorship/intellectual property

- Research and development/commercialization synergies

- Consumer preferences/product convenience

All of this must be understood also within the context of the "QWERTY Paradigm" (which refers to the leftmost keys of the top row of the less-than optimum arrangement of letters on a standard typewriter/PC keyboard), or the VHS videotape format's market hegemony over Betamax, etc. That is - the best technology does not always win, but very often, an only adequate technology that is first to dominate a market will win.

\section{Fuel Cell Technology Supporters}

Although the market will eventually determine who or what wins or loses, government support is likely to be an important element in setting priorities in the near term. The U.S. Federal DOE is ending the current Partnership for a New Generation Vehicle (PNGV), a joint venture that was started by the Clinton Administration in 1993 to help the auto industry develop higher mileage vehicles (family sedans getting $80 \mathrm{mpg}$ available by 2004). The $\$ 1.5$ billion spent on this program was failing to get the desired results. Replacing this is a recently announced program to support fuel cell development for autos called the "Freedom Cooperative Automotive Research", or Freedom CAR". This program has gained the support of USCAR, a pre-competitive research coalition between DaimlerChrysler, Ford and GM. Some skeptics see this shift as a way for the automakers to avoid commitments to shorter-term progress in better gas mileage, by diverting to 
goals that will necessarily be aimed at the more distant future. But the reasoning of supporters is that the goals of PNGV were merely evolutionary, while Freedom CAR is revolutionary and could radically change the environmental and energy efficiency of automobiles while addressing the ultimate sustainability of road transport.

NASA was the first government developer and user of fuel cells and it still has an interest in advancing this field. The support of the military agencies will likely count large in accelerating the development of fuel cells for communications, portable and other mobile, remote and vehicle uses relevant to battlefield or expeditionary situations. Some of this support is focused on DMFCs and diesel reforming.

On other government fronts, California is deeply involved in many aspects of developing and demonstrating low-emission and alternative fuel vehicles, including fuel cell cars. New York State, through setting renewable fuel purchasing goals and the programs of the New York State Energy Research and Development Authority (NYSERDA) and the New York Power Authority (NYPA) supports fuel cell development, demonstration and mass market implementation, mainly for stationary combined heat and power (CHP) and distributed generation (DG) applications. The Governors of Michigan, with its auto industry primacy, and Connecticut, already home to some key fuel cell developers, have each declared their states to be "fuel cell incubators".

Life Cycle considerations count large in policy formation for some governments and for (e.g., auto and energy) multinational and other companies that are interested in making the most responsible choices possible in their $\mathrm{R} \& \mathrm{D}$ and business planning, or at least want to promote a positive image of their corporate environmental responsibility. However, it has been demonstrated in focus groups and by past behavior that the majority of consumers are motivated more by pleasure, convenience and price than by environmental concerns in their major purchases. In any case, the infamous and ambiguous diaper and hamburger packaging debates of the 1990s have soured many consumers (and professionals) on the notion of Lifecycle Analysis to drive decision-making. The continually growing popularity of inherently less gas-efficient SUVs in North America and elsewhere, while consumers profess environmental concerns, is clear evidence of this dichotomy. Therefore, functionality, economic cost and market attractiveness and not social cost will be the focuses of this section's analysis.

\section{Fuel Cell Competition with Other Energy Technologies}

Many alternative technologies for envisioned vehicle and stationary power fuel cell applications are being researched, developed and championed; some are being demonstrated and commercialized; others are already commercial and are gaining market share. The key serious competitive challenges for key fuel cell applications are listed in Table 4.2. Significant technical and commercial advances in any of these or a combination of them could slow down the commercial progress of fuel cells. 


\section{Table 4.2 Energy Technologies Competing With Fuel Cells}

\begin{tabular}{|l|l|l|}
\hline Fuel Cell Application & Competitive technology & Issues (GTL substitution) \\
\hline Vehicles & $\begin{array}{l}\text { ULS diesel and gasoline in ICES } \\
\text { W/ tailpipe controls }\end{array}$ & $\begin{array}{l}\text { Available soon, but long-term petroleum } \\
\text { reserves reduction (FT) }\end{array}$ \\
\hline & $\begin{array}{l}\text { Gasoline and Diesel ICES - } \\
\text { Electric Hybrids }\end{array}$ & $\begin{array}{l}\text { Mileage competitive, infrastructure } \\
\text { compatible (FT, methanol) }\end{array}$ \\
\hline Stationary Power Generation & CNG, LNG ICEs & Reduced emissions / fuel cost \\
\hline - large facilities, CHP & GTCC w/ HRSG, advanced \\
combustors, and SCR & $\begin{array}{l}\text { High efficiency, reduced emissions, many } \\
\text { sites for applications }\end{array}$ \\
\hline - distributed generation, CHP & natural gas, diesel ICEs & Completely commercial (FT) \\
\hline & Microturbines & Commercialized \\
\hline - distributed power generation & Photovoltaics & $\begin{array}{l}\text { Improving, very simple, but } \\
\text { daylight only }\end{array}$ \\
\hline & Wind power & Margin economics, only some locations \\
\hline $\begin{array}{l}\text { Note: ICEs = internal combustion engines; CNG = compressed natural gas; , LNG=liquefied natural gas; CHP=combined heat and } \\
\text { power; GTCC = gas turbine combined cycle; SCR=selective catalytic (NOx) reduction }\end{array}$
\end{tabular}

Fuel cells are an electricity generating technology. They have obvious potential for power generation, with their DC power output converted to an AC current for local use in AC devices or for distribution on the grid.

\subsection{FUEL CELLS FOR VEHICLES}

\subsubsection{Electric Vehicles}

Off-road vehicles (railroad engines, golf carts, fork lifts, mobile mining equipment, etc.) and onroad vehicles such as automobiles, pickups, vans, buses, and trucks are all capable of being electric vehicles (EVs). An EV is any vehicle with an electric drive train, some of the major advantages of which are:

- Cold start and good driving response

- High torque at low speeds avoids gear shifting

- Capability to function as generators during braking to recover vehicle kinetic energy as electricity stored in a buffer battery system

- Low-noise operation 
Three types of electric vehicles are in use or being demonstrated:

- Battery-powered (EV)

- Hybrid (HEV)

- Fuel cell (FV, or FCH)

A battery-powered electric vehicle uses the electricity from onboard rechargeable batteries to run an electric motor, which powers the vehicle's wheels. This type of vehicle embodies two of the subsystems of potential hybrid and fuel cell vehicles of the future - reversible motor/generator drives and battery storage/buffer systems. An internal combustion (IC) engine (gasoline or diesel) electric hybrid vehicle contains power conditioning and controls systems and thus also serves to advance the state of the art relevant to FC vehicles.

Electric vehicle and battery technology continues to improve and experience rapid growth, however, today's battery-powered electric vehicle still does not offer the range of a gasolinepowered vehicle. The typical driving range for these electric vehicles is 50 to 130 miles, depending upon the vehicle's weight, number and type of batteries, and engineering and design features. Weather extremes and use of accessories (such as heating and air conditioning) can also affect the range. Air conditioning and heating will become greater issues as power plants for passenger autos become more efficient and smaller. For comfort, these systems must reach full capability rapidly after startup and must maintain comfort conditions during operation. This would lead to problems with power system balance and stability, if power for passenger space $\mathrm{AC}$ and heating begin to overwhelm motive power requirements in future passenger vehicles.

Battery pack replacement costs are high, so, for example, battery replacement has usually been included in the price of leased EVs. Well-designed battery-powered EVs can travel at the same speeds as conventional vehicles and provide the same safety and performance capabilities. But with typical battery recharging times of 6 to 8 hours, most EVs, especially fleet vehicles, must be recharged overnight.

HEVs and FCVs are two of the most promising vehicle technologies for the future to substitute on-board fuel for chemically stored energy in a battery in ultimately providing electric motive power. HEVs may use either a gasoline or diesel engine in combination with an electric motor. FCVs can operate using hydrogen stored on the vehicle or processed from gasoline or methanol using a reformer on board.

\subsubsection{Competition from Hybrid Vehicles}

Electric motor-IC engine hybrids, which are currently being commercialized, can serve as precursors for electric motor-fuel cell vehicle systems in the future. However, if their performance is good enough, because they can use fuels that are the same as or similar to current petroleum-based vehicle fuels and their mechanics are similar to those of conventional vehicles, consumers and regulators may find them so attractive that they may stave off the commercialization of fuel cell vehicles long into the future. 
A hybrid vehicle is a vehicle that uses two power sources: an energy conversion device and an energy storage device. Diesels, lean burn gasoline engines, fuel cells or traditional gasoline engines can be used as the energy conversion device. Batteries, flywheels, or ultracapacitors can be used for energy storage.

Hybrid vehicles have longer ranges than battery-powered vehicles and do not require extensive changes to the fuel supply and refueling infrastructure. Hybrid vehicles have several advantages over traditional internal combustion engine vehicles, including:

- Regenerative braking capability that helps minimize the net energy lost when driving

- Reduced engine weight

- Increased fuel efficiency

- Decreased emissions

Since hybrid vehicles can also be operated using alternative fuels, they need not depend on fossil fuels. However, nearly all the hybrid vehicles currently in the marketplace are gasoline IC engine/battery combinations.

Life cycle analyses have concluded that diesel-electric hybrid vehicles can achieve the highest total energy efficiency and lowest level of greenhouse gas emissions among all other light vehicle technologies. Therefore, development of hybrid vehicles is being driven by their improved fuel economy and resultant reduction in greenhouse gas emissions, primarily carbon dioxide (CO2). Hybrid vehicles will result in some, but not dramatic reductions in particulate matter (PM, or soot) and nitrogen oxides (NOx) emissions, and do not necessarily require the use of fuels with more stringent quality requirements.

Strong growth in the use of hybrid electric vehicles is expected in the short term:

- Toyota has been selling its hybrid Prius in Japan and introduced the vehicle to the U.S. market in 2000

- Honda started selling Insight, its gasoline-fueled hybrid, in the United States at the end of 1999

Ford and General Motors have developed concept vehicles powered by diesel-hybrid systems, but the commercialization of these vehicles has not yet occurred

\subsection{FUEL CELL TECHNOLOGY}

\subsubsection{Basic Principles}

Generically, a fuel cell uses an electrochemical process to generate electrical power through catalytic oxidation of a fuel.

Figure 4.2 illustrates a generic fuel cell operation. 


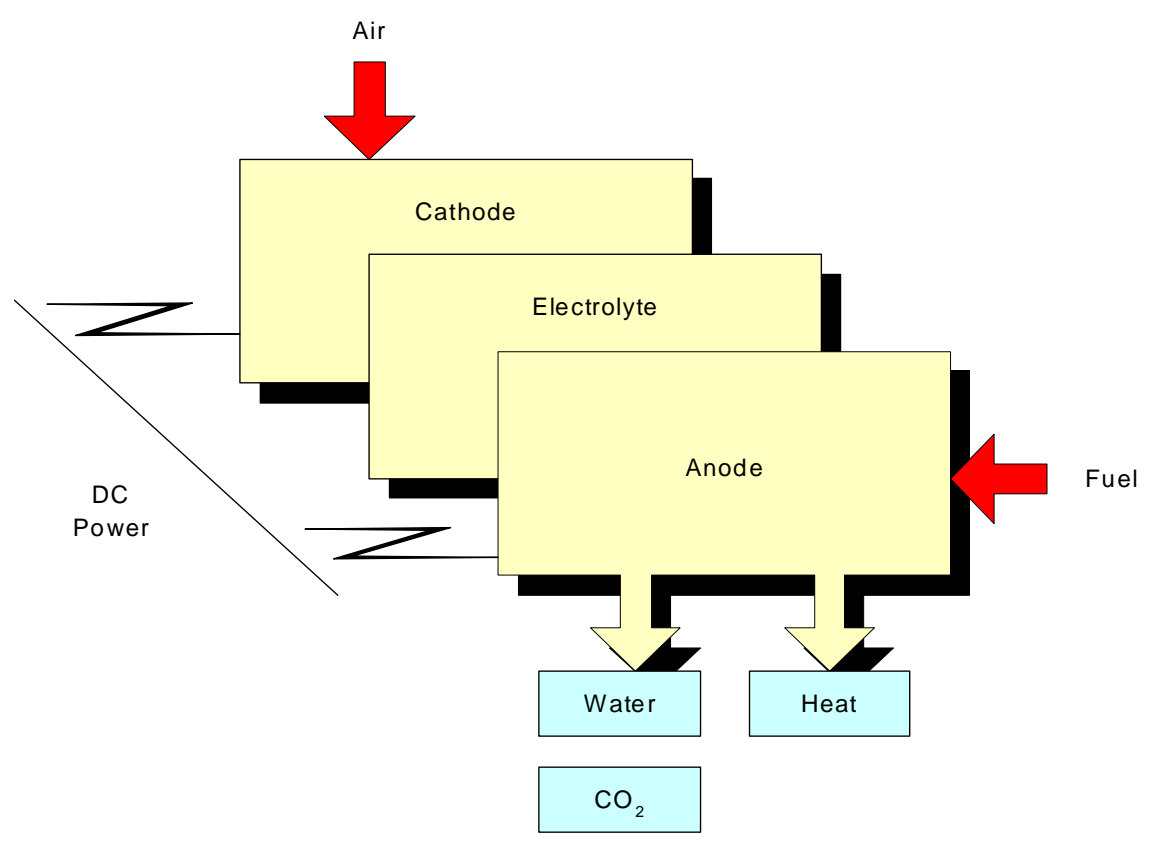

U1AAGTJ:APP_EnergyBalances:F4

Figure 4.2 Fuel Cell Operation

In its simplest chemical form, the fuel cell catalytically oxidizes hydrogen using the following steps:

- Hydrogen molecules adsorb on the surface of the anode catalyst

- The hydrogen molecule is split, with the two resulting atoms being ionized to H+ ions (protons) with the residual electrons being conducted away through an electrical circuit

- Protons desorb from the anode catalyst and diffuse through an electrolyte layer to the cathode, driven by potential and diffusion gradients

- At the cathode, oxygen molecules are adsorbed and split into individual atoms

- The oxygen atoms accept free electrons from the electrical circuit to form $\mathrm{O}^{2-}$ ions

- Finally, two protons combine with the $\mathrm{O}^{2-}$ ions to form water, which desorbs from the cathode - nitrogen in the air is vented from the cathode area and carries off waste heat

A voltage potential develops across the cell, due to the concentrations of hydrogen ions at the anode and oxygen ions at the cathode. This, combined with the free electrons that are available to travel through the external circuit result in the fuel cell providing useful power, derived from the energy available in the oxidation process. Individual cell voltages are generally too low for larger scale practical applications. In a Proton Exchange Membrane (PEM) fuel cell, for example, a cell generates about 0.7 volts. To get higher voltages and more power, many cells are ganged together in a stack. 
Fuel cells are very different kinds of power generators than heat engines. There are distinct differences between the thermodynamic efficiencies achievable with fuel cells and with combustion engines:

- Fuel cell efficiency decreases with increasing temperature (increasing electrical resistance) the exact opposite is the case for a Carnot cycle engine (Otto or diesel cycle)

An ideal fuel cell can achieve 90 percent efficiency with an $\mathrm{H} 2-\mathrm{O} 2$ fuel, at an operating temperature of $600 \mathrm{~K}$, contrasted with a Carnot cycle heat engine that would need to operate at nearly $3000 \mathrm{~K}$ to achieve the same efficiency

Figures 4.43 and 4.4 compare the relationship of device energy utilization to efficiency of operation for generic fuel cells and heat engines.

Figure 4.3 Efficiency Operating Curves for FCs and ICEs versus Peak Power

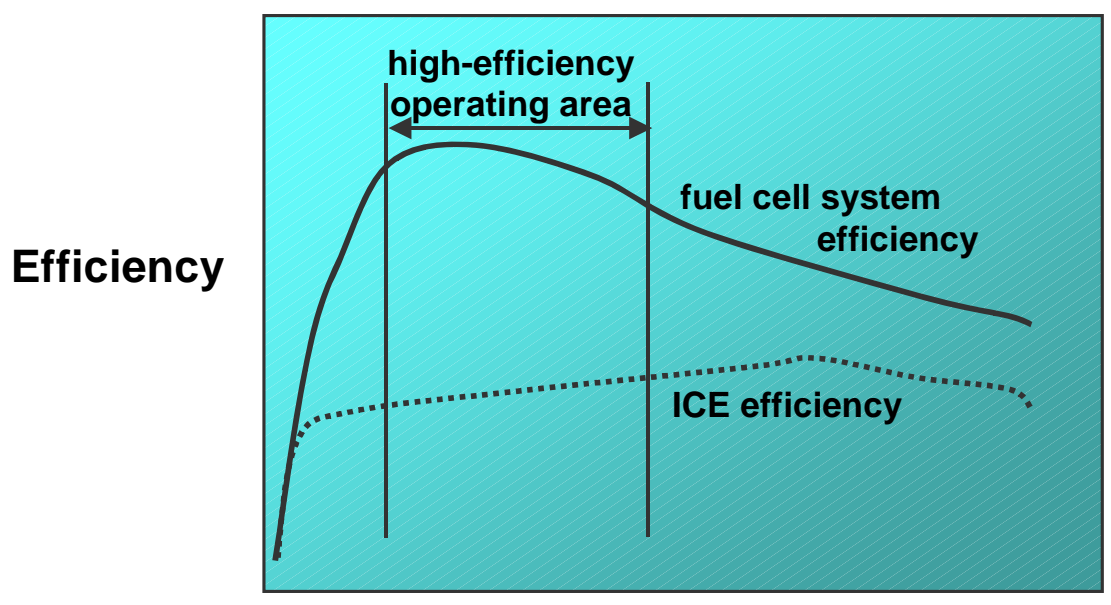

Percent of Peak Power 


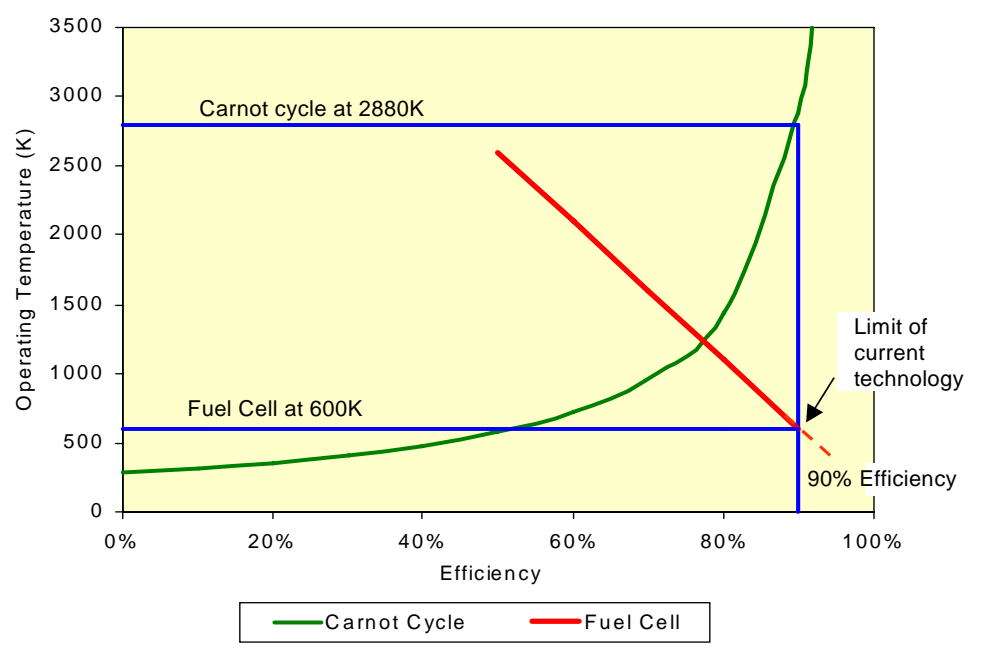

U1AAGTJ:APP_EnergyBalances:F7

Figure 4.4 Fuel Cell Efficiencies Versus Heat Engines as a Function of Temperature

\subsubsection{Individual Fuel Cell Technologies}

Fuel cells have been under development for many years. This long gestation period has resulted in many different competing technologies. Among the reasons for this technical divergence is that the cells themselves operate best using pure hydrogen and air feeds, whereas the obvious globally available fuel is currently gasoline - a varying mix of components including impurities that are harmful to fuel cell operation. There are therefore separate developments that either maximize performance of a cell given a varying feed, or add processing steps to the system to ensure that the fuel cell itself sees a chemically simple feed.

\subsubsection{PAFC Technology}

Phosphoric Acid Fuel Cells (PAFC) have been under development for more than 20 years. The technology was initially selected because among the low temperature fuel cells it showed the greatest tolerance to reformed hydrocarbon fuels. Figure 4.5 is a simple schematic of a PAFC. 


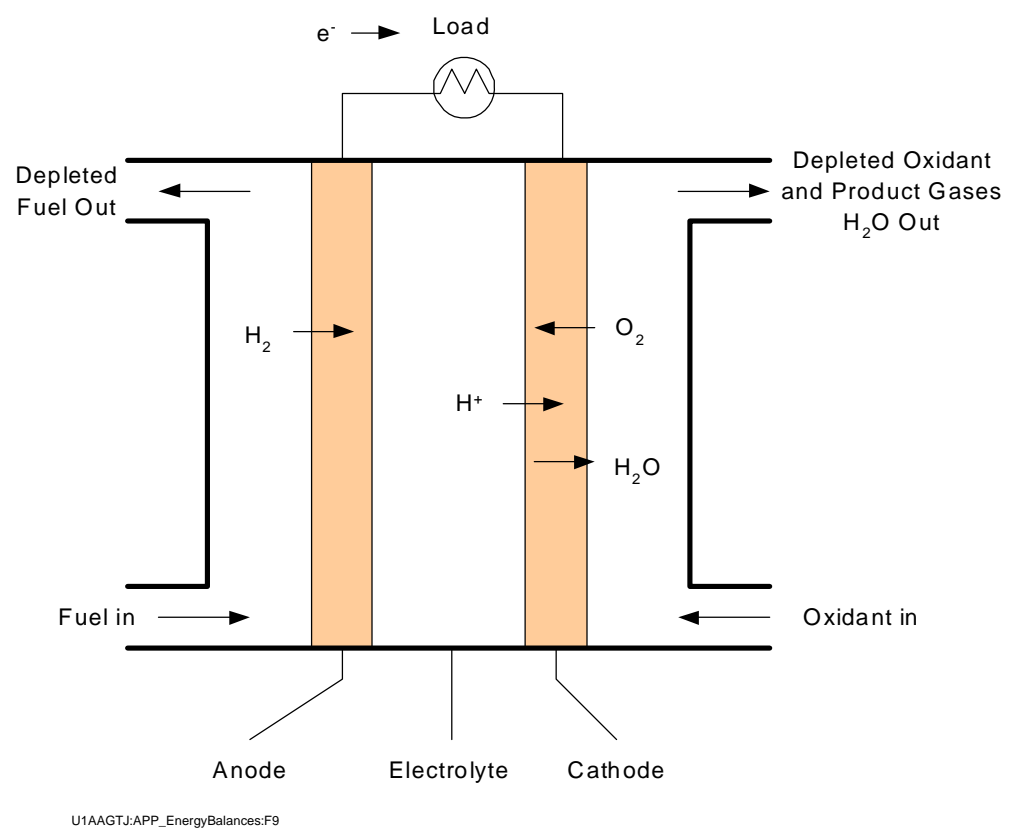

Figure 4.5 Phosphoric Acid Fuel Cell (PAFC)

As its name suggests, the PAFC uses liquid phosphoric acid as an electrolyte, contained in a Teflon bonded silicone matrix. The electrochemical reaction in the cell is as follows:

$$
\begin{array}{ll}
\text { Anode: } & \mathrm{H}_{2} \rightarrow 2 \mathrm{H}^{+}+2 \mathrm{e}^{-} \\
\text {Cathode: } & 1 / 2 \mathrm{O}_{2}+2 \mathrm{H}^{+}+2 \mathrm{e}^{-} \rightarrow \mathrm{H}_{2} \mathrm{O}
\end{array}
$$

The cell operates at around $190^{\circ} \mathrm{C}$ to ensure that the $\mathrm{H}_{2} \mathrm{O}$ product leaves the cathode as steam. Lower temperatures result in the formation of liquid water, which can dissolve into the electrolyte, and higher temperatures cause the decomposition of the phosphoric acid. Power densities of 1880 watts per $\mathrm{m}^{2}$ can be achieved using this technology.

\subsubsection{MCFC Technology}

A Molten Carbonate Fuel Cell (MCFC) uses a carbonate salt as its electrolyte. The electrochemical operation of this type of cell relies on the transport of carbonate ions rather than hydrogen. Typically, the salt consists of lithium and potassium carbonates with operating temperatures at around $650^{\circ} \mathrm{C}$ to ensure that the salt is liquid and hence a good ionic conductor.

$$
\begin{array}{ll}
\text { Anode: } & \mathrm{H}_{2}+\mathrm{CO}_{3}{ }^{2-} \rightarrow \mathrm{H}_{2} \mathrm{O}+\mathrm{CO}_{2}+2 \mathrm{e}^{-} \\
& \mathrm{CO}+\mathrm{CO}_{3}{ }^{2-} \rightarrow 2 \mathrm{CO}_{2}+2 \mathrm{e}^{-} \\
\text {Cathode: } & \mathrm{O}_{2}+2 \mathrm{CO}_{2}+4 \mathrm{e}^{-} \rightarrow 2 \mathrm{CO}_{3}{ }^{2-}
\end{array}
$$

Figure 4.6 is a simple schematic of an MCFC. 


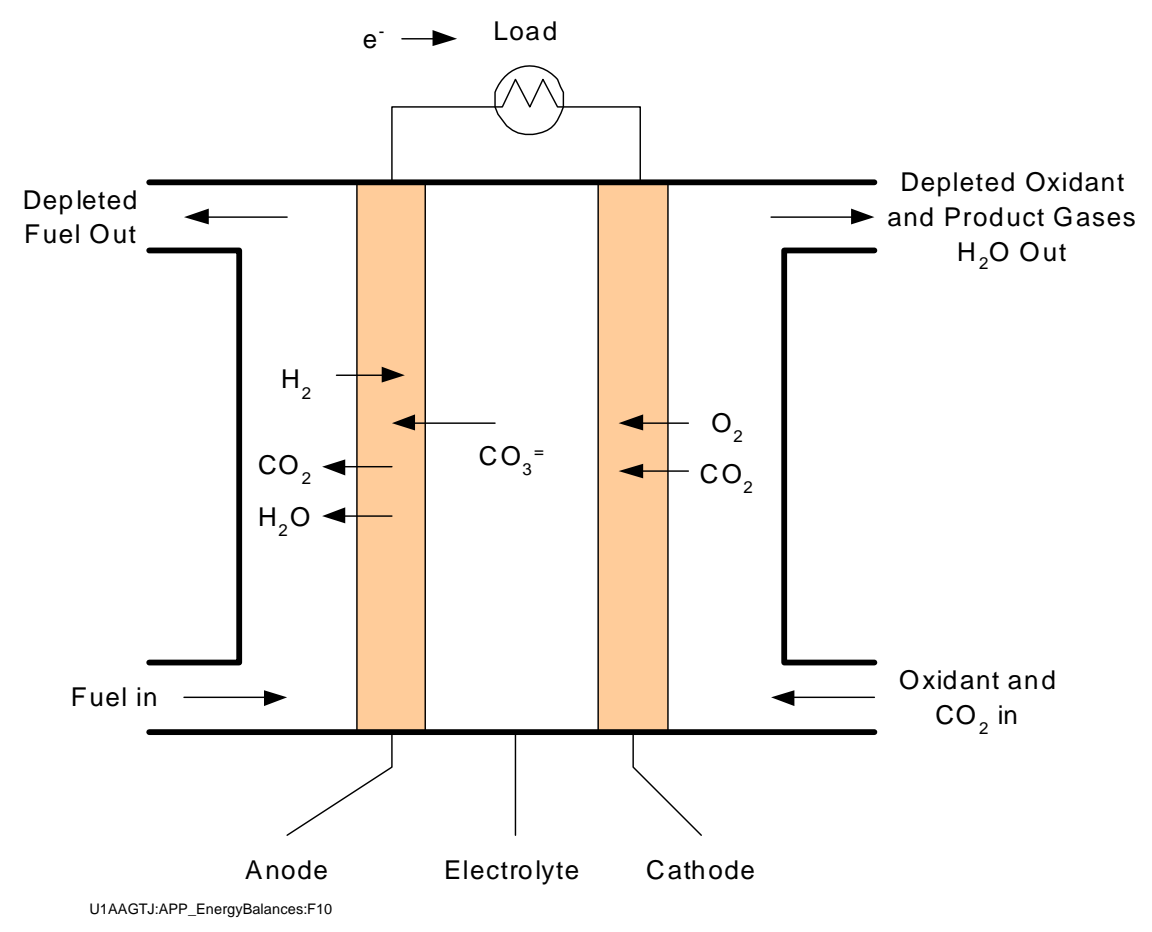

Figure 4.6 Molten Carbonate Fuel Cell (MCFC)

The MCFC offers a number of advantages. The high operating temperature lends itself to fuel reforming to produce hydrogen within the cell itself, and the high temperature exhaust gases are suitable for raising high pressure steam, which can be used for heating or additional power generation. However, it has the drawback that $\mathrm{CO}_{2}$ is needed on the cathode side of the system. MCFC fuel cells typically obtain this $\mathrm{CO}_{2}$ from the exhaust gases after residual hydrogen has been removed.

\subsubsection{SOFC Technology}

Solid Oxide Fuel Cell technology (SOFC) is based on a solid ceramic electrolyte and hence eliminates the issue of electrolyte loss associated with liquid electrolytes.

To obtain adequate ionic conductivity in the ceramic, it is necessary to operate at around $1000^{\circ} \mathrm{C}$. Hence, as with $\mathrm{MCFC}$, it is possible to reform the fuel within the fuel cell itself (if starting with methane, say, to produce a mixture of $\mathrm{H}_{2}, \mathrm{CO}, \mathrm{CO}_{2}$ and unconverted $\mathrm{CH}_{4}$ ), and also use the exhaust gases in steam raising and power generating applications.

Within the SOFC fuel cell the electrochemical reaction proceeds as follows, with the oxide ion $\mathrm{O}^{2-}$ providing the ionic charge transfer.

$$
\begin{array}{ll}
\text { Anode: } & \mathrm{H}_{2}+\mathrm{O}^{2-} \rightarrow \mathrm{H}_{2} \mathrm{O}+2 \mathrm{e}^{-} \\
& \mathrm{CO}+\mathrm{O}^{2-} \rightarrow \mathrm{CO}_{2}+2 \mathrm{e}^{-} \\
& \mathrm{CH}_{4}+4 \mathrm{O}^{2-} \rightarrow 2 \mathrm{H}_{2} \mathrm{O}+\mathrm{CO}_{2}+8 \mathrm{e}^{-}
\end{array}
$$


Cathode: $\quad \mathrm{O}_{2}+4 \mathrm{e}^{-} \rightarrow 2 \mathrm{O}^{2-}$

Figure 4.7 is a schematic of an integrated SOFC system, including electrical controls, fuel processing and other support systems.

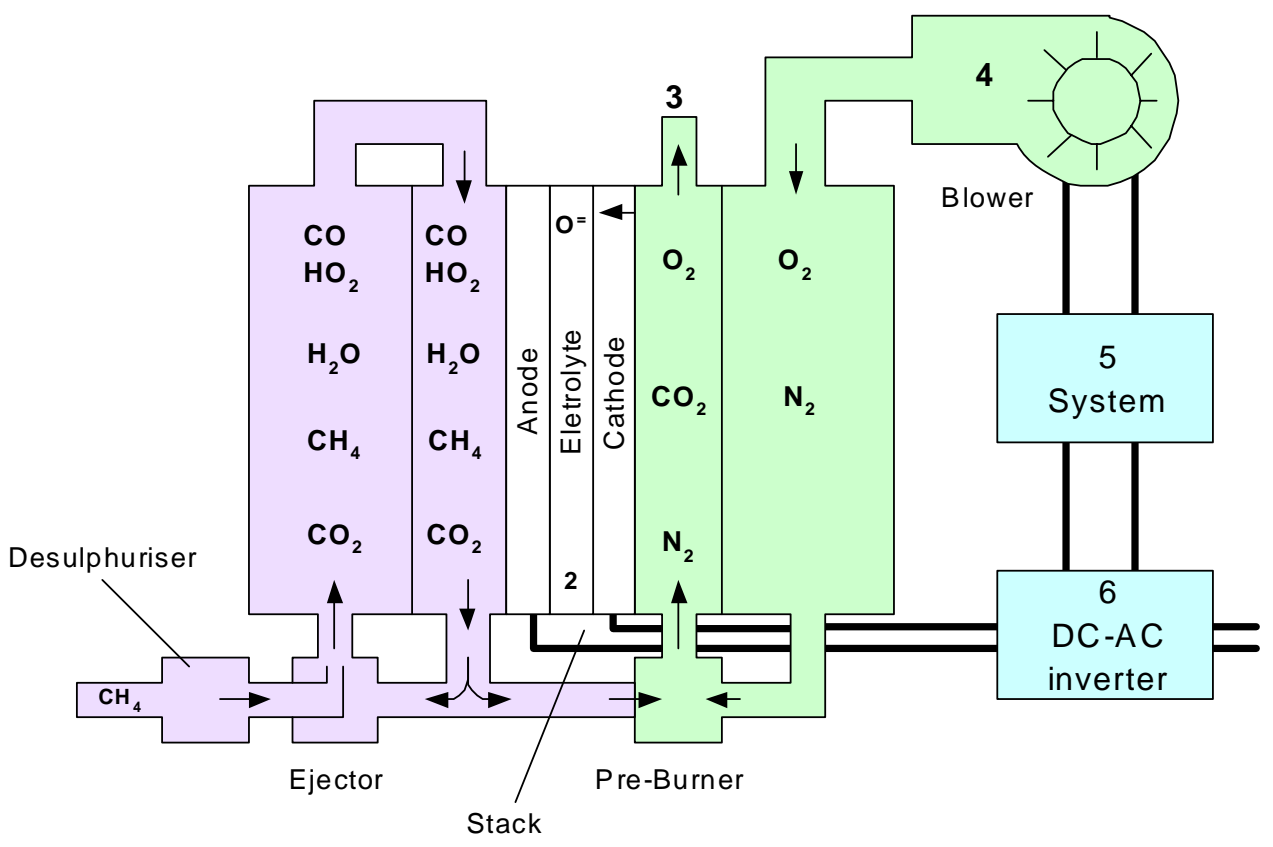

U1AAGTJ:APP_EnergyBalances:F11

Figure 4.7 Solid Oxide Fuel Cell (SOFC)

Power densities of 1500 watts $/ \mathrm{m}^{2}$ have been achieved in SOFC fuel cells.

\subsubsection{PEMC Technology}

Proton Exchange Fuel Cell technology (PEMC) uses a polymer membrane as an electrolyte. This membrane operates as a conductor of hydrogen ions to allow the formation of an electrochemical cell. As with the solid oxide fuel cell this eliminates the problems associated with liquid electrolytes. The electrochemical cell operates under the same principle as the phosphoric acid cell, namely:

$$
\begin{array}{ll}
\text { Anode: } & \mathrm{H}_{2} \rightarrow 2 \mathrm{H}^{+}+2 \mathrm{e}^{-} \\
\text {Cathode: } & \mathrm{O}_{2}+4 \mathrm{H}^{+}+4 \mathrm{e}^{-} \rightarrow 2 \mathrm{H}_{2} \mathrm{O}
\end{array}
$$

Figure 4.8 is a simple schematic of a PEMC. 


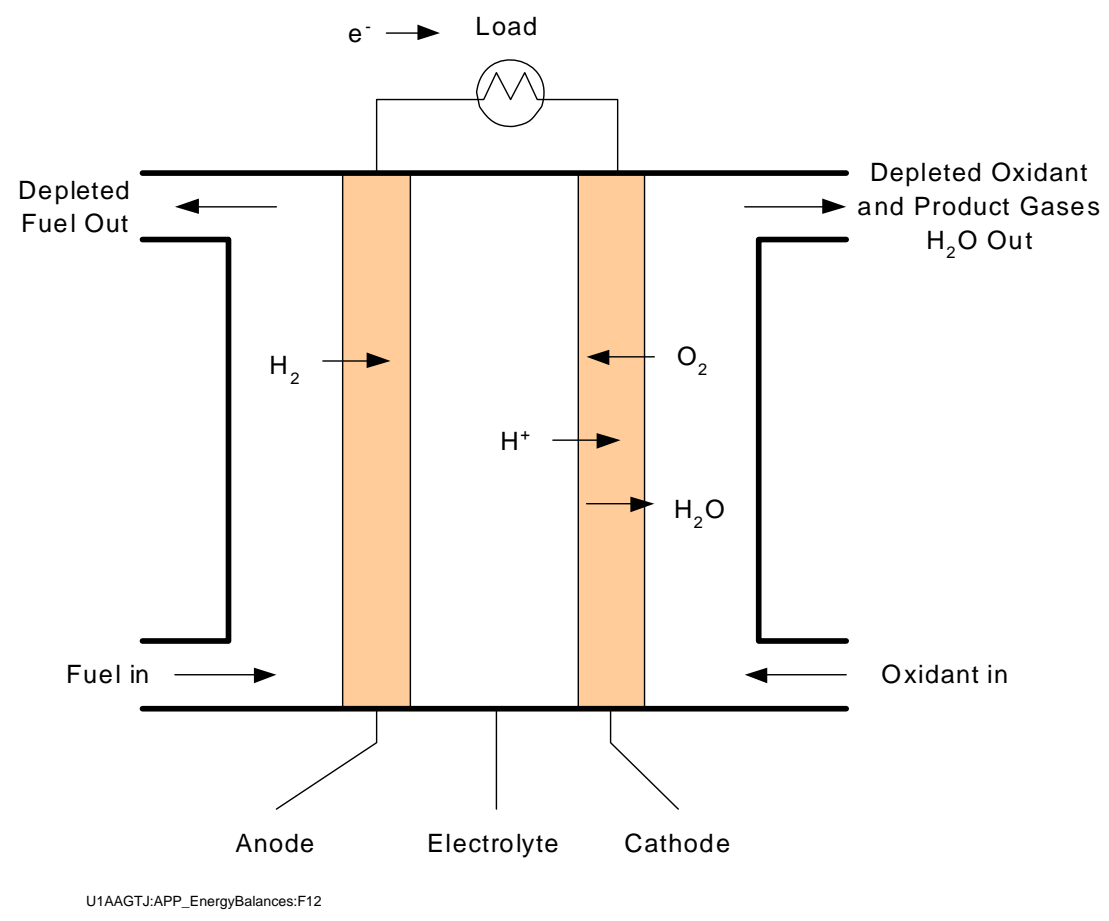

Figure 4.8 Proton Exchange Membrane Fuel Cell (PEMC)

Figure 4.9 is a diagram of a PEMC fuel cell incorporating fuel processing sub systems. 


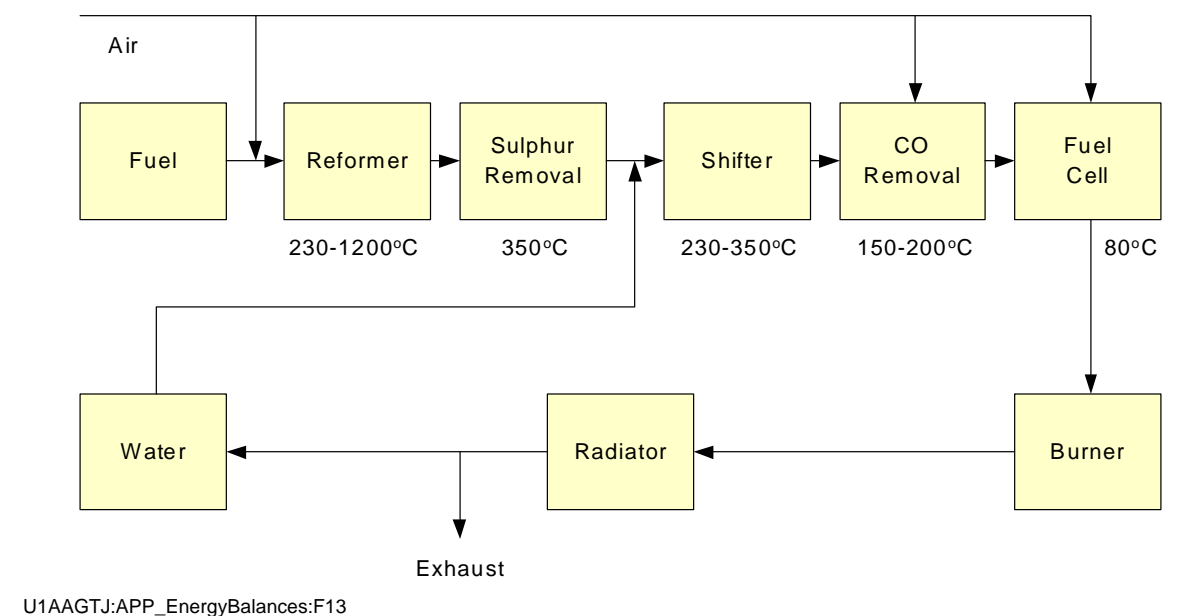

Figure 4.9 Schematic Diagram Of Polymer Electrolyte Fuel Cell System Incorporating Fuel Processor

PEMC operates at a relatively modest $80^{\circ} \mathrm{C}$, which allows relatively quick start up, but the heat dissipated by the system is very low grade. The PEMC fuel cell is currently very sensitive to chemicals impurities on the fuel side, but research is focusing on improving its tolerance for catalyst poisons.

For applications with fuels other than hydrogen it is necessary to include upstream reformers to produce hydrogen that the cell can use. In PEMCs, it is also essential that the upstream fuel processing systems remove carbon monoxide to very low levels since it also acts as a catalyst poison. These additions add to the cost, weight and also reduce the dynamic response times of the fuel cell system.

The advanced PRIMEA Series Membrane Electrode Assemblies (MEAs) exposed to levels of up to $10,000 \mathrm{ppm} \mathrm{CO}$ in hydrogen have been studied in a laboratory PEMFC. As the PEMFC industry approaches commercialization, fuel cell stack and systems suppliers are performing field testing and are consequently being confronted with operating their systems in more demanding environments (real world) than those utilized in well controlled laboratory testing. Thus, these tests were conducted to study the effect of contaminants in the fuel and air streams on the performance and recovery of the system.

The literature contains a number of references reporting the effect of impurities on the performance of perfluorosulfonic acid membranes in chloralkali electrolyzers. In addition, there is substantial data outlining the effect on the performance of PAFCs. Some limited work has been carried out on the effect of impurities such as ammonia and hydrogen sulfide on the performance of PEMFCs. The tests show that the PRIMEA MEAs recover performance quickly upon the reintroduction of contaminant-free gases. 
The PEMC shows great promise for portable applications, in spite of the above drawbacks, as it offers power densities that are a magnitude higher than achieved in the other cells mentioned above, reaching as high as $6000 \mathrm{watts} / \mathrm{m}^{2}$, and its materials lend it to light weight designs.

\subsubsection{DMFC Technology}

Direct Methanol Fuel Cells (DMFCs) are a development primarily of PEMC technology that allows the direct use of methanol in the fuel cell rather than hydrogen from a reformer. As such, it is possibly the most promising fuel cell technology for portable applications. Since the DMFC runs directly on methanol, the system does not need either the reformer or carbon monoxide elimination processes that are necessary in a PEMC application. This considerably simplifies the system design. Figure 4.10 is a schematic of a DMFC system, including ancillaries and support systems.

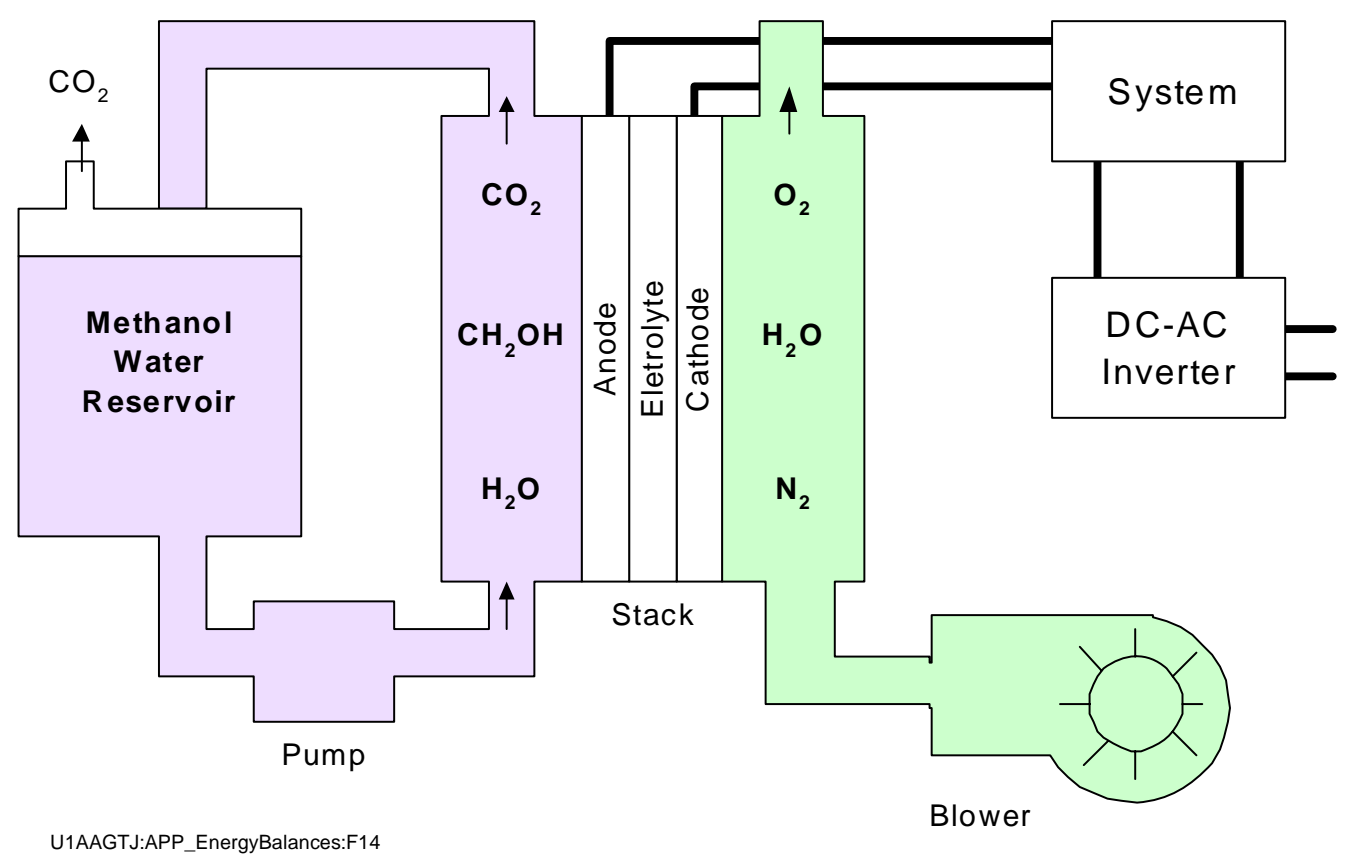

Figure 4.10 Direct Methanol Fuel Cell (DMFC)

Current DMFC technology, however, cannot match the power density of a PEMC cell, due to lower cell voltages and current densities. Development is also needed to prevent fuel crossover from the anode to the cathode, as well as to eliminate certain corrosion issues that arise from the chemical by-products.

A team of researchers at NASA's Jet Propulsion Laboratory, Pasadena, CA, has redesigned the traditionally large, bulky stacks of layered fuel cells into a compact, flat fuel cell, reducing its weight substantially. JPL's goal is to develop materials, components, and operating conditions for direct methanol fuel cells to be used in transportation applications. JPL's parent institution is 
the California Institute of Technology. TechSys, Inc., Florham Park, N.J., a technology affiliate of JPL, sponsors work on the design for portable fuel cells. TechSys intends to commercialize the technology for civil and defense applications.

Unlike batteries, these fuel cells can be recharged almost instantaneously by refueling with liquid methanol (typically in battery-size cartridges). Also unlike batteries, which contain toxic materials and must be disposed of properly, these cartridges are simply inert containers and can be easily reused or recycled. However, issues of U.S.DOT regulation of hazardous substances transport and others of mitigating corporate legal risk have been raised regarding the toxicity of methanol in cartridges full of methanol, which could be a critical impediment to commercialization.

JPL researchers have eliminated the weight and bulk of conventional fuel cell bipolar plates and created a "monopolar pack", which is flat with the cells linked by electrical interconnects.

To demonstrate the feasibility of the portable fuel cell technology, JPL developed a 5-watt portable power unit using the new lightweight monopolar flat pack technology, which is roughly the size of two paperback books standing tall, back-to-back. It operates efficiently at ambient temperature without a fan, unlike conventional designs.

JPL engineers rigged a cell phone to this power unit. They estimate that the 5-watts could simultaneously power five cell phones. The next phase underway is to make the system smaller, more robust and user-friendly.

JPL's fuel cell group has been working on direct methanol fuel cells since the early 1990s and is credited with inventing the technology, largely under funding from the U.S. Defense Advanced Research Projects Agency. The creation of the portable power source builds on that work and experience.

Many researchers think direct methanol fuel cells (DMFCs) will become the first large-scale commercial application of polymer electrolyte membrane (PEM) fuel cells. DMFCs stand some chance of being used in portable electronics to replace batteries and in onboard auxiliary power units (APUs) for civilian and military transportation. Backers hope that, in the longer term, DMFCs could serve for vehicular propulsion power.

\subsubsection{Further Development Work on DMFC}

Researchers are working to advance DMFC technology in three areas:

1. Enhance cell performance by optimizing membrane electrode assemblies (MEAs) and enhancing the long-term stability of MEAs using various membrane materials. MEAs, the key component of all PEM fuel cells, are composed of a proton-conducting polymer sandwiched in between two fuel cell electrodes - the anode, where methanol is oxidized, and the cathode, where oxygen from air is reduced. 
2. Reduce the total precious metal loading in catalysts both single-cell and short-stack operations and better understand the effect of catalyst composition on cell performance at various temperatures.

3. Prove the long-term operational viability and stability of cell components in single cells and short stacks.

Figure 4.11 shows photographs of DMFC systems being developed by Bell Aerospace.

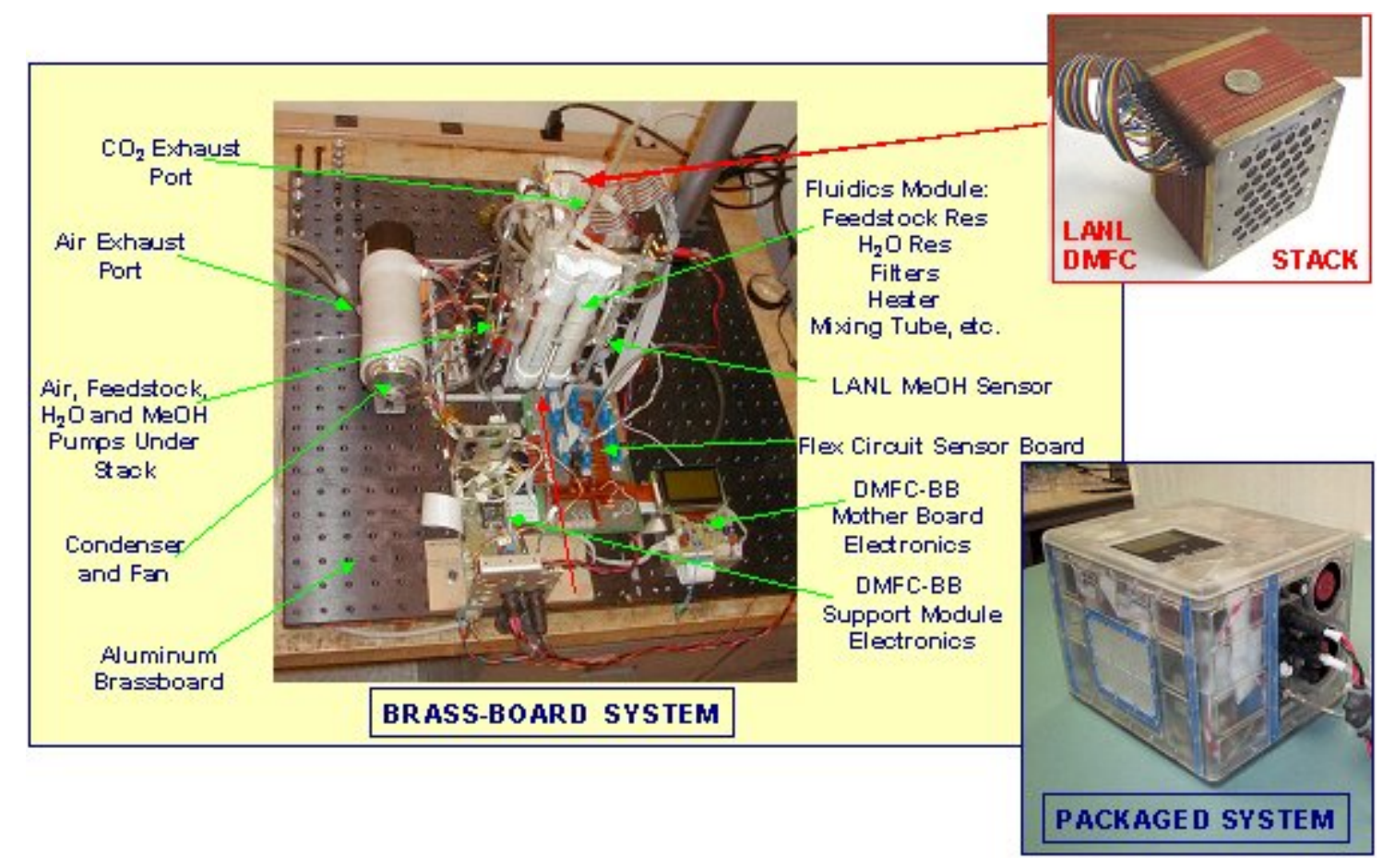

Figure 4.11 Bell Aerospace DMFC Developments

DMFC research is addressing fundamental issues - catalysts, membranes, and electrode structures - as well as cell and stack hardware design and testing. A major problem with the existing device is that the membrane used allows not just protons to cross to the cathode side, but also methanol, degrading performance and shortening the life of the cell.

Researchers achieved a development milestone by demonstrating a five-cell DMFC stack that reduces MEA platinum loading by more than $95 \%$, with a tolerable reduction of performance. (Lower precious metal requirements reduce manufacturing costs.) In addition, researchers have identified promising new high-efficiency membranes that reduce methanol crossover, resulting in much improved energy-conversion efficiency.

Hardware and stack development research is continuing. Collaborative work with Bell Aerospace Technologies Corporation led to the fully integrated 60-W DMFC system shown in 
Figure 4.11 (above). The success of this effort will serve as a basis for scaling up the system to $0.5 \mathrm{~kW}$, a level that would pave the way for even higher-power systems (up to $5 \mathrm{~kW}$, suitable for APU applications).

A cool-process, zero-emission DMFC was patented by JPL and USC and is being developed for a wide range of uses. It produces 50 watts of power, consuming about a pint of methanol fuel per day. Units of up to 5-kilowatt output, powerful enough to run a small vehicle, have been designed. A private corporation, DTI Energy Inc. of West Los Angeles, has licensed the technology and intends to develop vehicular applications. The JPL-USC device is called a "direct methanol, liquid feed fuel cell" (DMLFFC). Prototype cells have been assembled and tested at JPL, which reported models to have run for more than 200 hours continuously and for more than 3,000 hours intermittently without loss of performance. Current design goals envision units that can operate continuously for 1,000 or more hours, and eventually, units that can produce the 40 kilowatts or more, as required to power a full-sized car.

The research team also hopes to drastically cut the cost of the proton-exchange membrane, the major economic roadblock to widespread DMLFFC applications. JPL has developed improved proton membranes that will permit the construction of a new generation of cells with greater efficiency by blocking methanol migration. USC has applied for a patent on these new membranes.

\subsubsection{Comparison of Fuel Cell Attributes}

For the discussions of fuel processors (reformers) and for understanding the challenges of fuel cell applications in vehicles, it is useful to compare some key attributes of the various fuel cell types. Table 4.3 presents such a comparison.

\section{Table 4.3 Fuel Cell Technologies and Attributes}

\begin{tabular}{|ccc|} 
Technology & $\begin{array}{c}\text { Power Density } \\
(\mathrm{kW} / \mathrm{m} 2)\end{array}$ & Comments \\
\hline PAFC & $\sim 1.9$ & Highest tolerance to hydrocarbon fuels at low temperatures. \\
MCFC & $\sim 2.0$ & Capability to internally reform fuel $\mathrm{CO}_{2}$ needed as feed. \\
SOFC & $\sim 1.5$ & Operates at around $1000{ }^{\circ} \mathrm{C}$ using solid ceramic electrolyte. \\
PEMC & $\sim 6.0$ & High power density at low temperature. Good transient response. \\
DMFC & & Direct fuelled PEMC cell, operating without reformer. \\
\hline
\end{tabular}

U1AAGT J:App-EnergyBalances:T3

Source: Nexant 


\subsubsection{Reformer Systems}

With the exception of the high temperature MCFC and SOFC processes that are capable of internal fuel reforming, the majority of fuel cells currently being considered need to have a fuel conditioning system upstream of the cell itself. This system is needed to convert the primary fuel (hydrocarbon or oxygenate, such as ethanol, methanol or DME) into a mixture of hydrogen (H2) and carbon dioxide $(\mathrm{CO} 2)$.

The reforming takes place over a catalyst with the addition of steam to vaporized fuel and results in the formation of syngas, a mixture primarily of $\mathrm{H} 2$, carbon monoxide $(\mathrm{CO})$ and $\mathrm{CO} 2$. A secondary reaction, called the "water gas shift", usually must be employed, usually with the addition of more steam, to convert the $\mathrm{CO}$ into more hydrogen and $\mathrm{CO} 2$. In many cases, such as for PEMs, it is also essential to remove virtually all carbon monoxide since it acts as a poison to the catalysts in the cell. The $\mathrm{CO}_{2}$ may be removed by various means, depending on the needs of the type of fuel cell being supplied. The exact system configuration depends on the type of primary fuel, with complexity increasing from simple hydrogen systems to those that may be able to pre-treat conventional gasoline.

Reformer technologies include:

- Steam reforming (SR)

- Partial Oxidation (POX)

- Autothermal Reforming (ATR)

SR requires external heating and uses a catalyst to react the steam and the hydrocarbon or oxygenate to $\mathrm{H}_{2}, \mathrm{CO}$ and $\mathrm{CO}_{2}$, followed by the water gas shift of $\mathrm{CO}$ to $\mathrm{H} 2$ and $\mathrm{CO}$. A purification step removes $\mathrm{CO}, \mathrm{CO} 2$ and other impurities. Low levels of sulfur can be removed with guard beds of zinc oxide or other sacrificial adsorbents.

The relative impact of reforming on the efficiencies of PEM (PEFC), SOFC and DMFC fuel cells is generically illustrated in Figure 4.12.

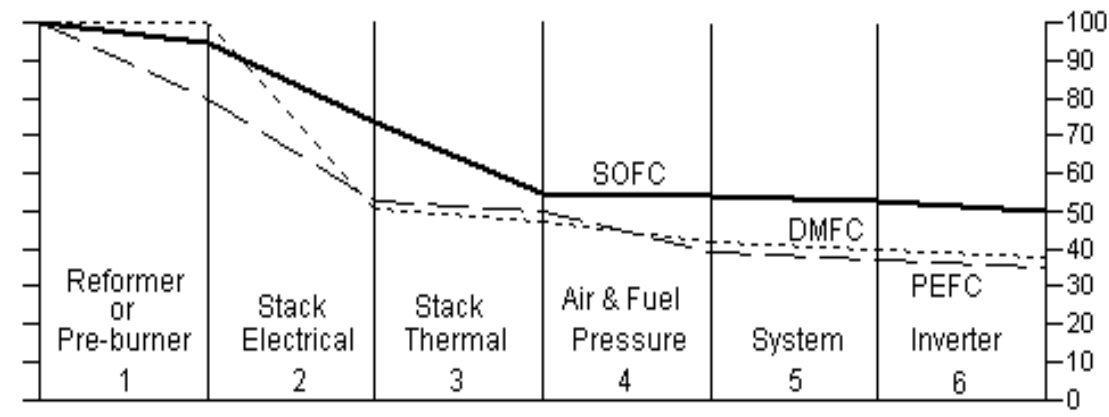

Figure 4.12 Efficiency Losses In Overall Fuel Cell Systems 
This increasing complexity adds to the cost and places limits on the dynamic response capabilities of the system. Considerable effort is being applied to reduce the size and weight of these additional systems.

New POX systems are competing with traditional reforming processes as the most cost effective way of converting a hydrocarbon stream into one containing $\mathrm{H} 2$ and $\mathrm{CO} 2$. POX reforming is similar to SR in that steam and fuel are reacted, but with added oxygen to provide the heating by oxidation of some of the fuel. This process is less efficient than SR, but more responsive to variable load, an important advantage for automotive applications. POX can more easily handle heavier fuels than SR.

ATR combines SR and POX, with the exothermic heat release of POX supplying the endothermic requirements of SR. ATR produces a lower concentration of $\mathrm{H} 2$ than SR, but more than POX. It has a relatively rapid response and a moderate efficiency. It is also a state-of-the-art development in stationary syngas process technology, such as in fertilizers and methanol plants.

Where fuel cell systems use on-board fuel processing of available fuels, the fuel processor will require high-purity water for the reforming and downstream processes. For utility applications, such high-purity water may be available on-site and can also be recovered from the fuel cell exhaust. However, for most applications, and especially for vehicles, the process water requirement can only be met by recovering it from the fuel cell exhaust gas. For such applications, it is critically important that the fuel cell system be a net water-producing device. A variety of environmental conditions (ambient temperature, pressure), fuel cell system design and operating conditions, and the fuel used determine whether the fuel cell system consumes or produces water.

Transportation application of reformers and integrated fuel processing systems have unique technical challenges due to severe constraints on thermal efficiency, weight, volume, and mechanical durability in addition to the requirements for long life (up to thousands of thermal cycles), quick start-up and system integration. The commercialization of these systems is dependent on the ability to reduce the manufacturing and maintenance costs by simplifying fuel processor configuration and using less expensive materials, while maintaining high efficiency of hydrogen conversion to motive power.

The hydrogen-rich gas stream generated by fuel processors for use in PEM fuel cells has to be substantially free of carbon monoxide to minimize poisoning of the fuel cell anode. Processing of fossil fuel by either auto-thermal reforming (ATR) or steam reforming produces gas streams which contain typically between 6 and 10 percent $\mathrm{CO}$ on a dry gas basis. The removal of the $\mathrm{CO}$ is generally achieved by the water gas shift (WGS) reaction, followed by preferential oxidation (PROX) of the remaining CO. WGS can reduce CO levels to below $0.3 \%$ while generating more hydrogen, but is a slow reaction and requires a large volume of catalyst. On the other hand, preferential oxidation (PROX) is a much faster reaction but oxidizes some hydrogen because of its finite selectivity. 
There are trade-offs in size, cost, system complexity and efficiency of CO cleanup solutions that rely, to varying degrees, on WGS and PROX. Efficiency may have to be compromised to reduce the size of the reactor in applications such as transportation. Development of more CO-tolerant fuel cells can reduce the size of WGS systems.

Another concern in a hydrogen generator fed a hydrocarbon, such as natural gas, LPG, diesel distillate or gasoline, is contamination of downstream catalysts by sulfur. Although in the feasible fuel scenarios being considered, most sulfur species are removed prior to reforming (down to $10 \mathrm{ppm}$ or even $1 \mathrm{ppm}$ and below), the reducing environment of the initial reforming stage (such as ATR), converts any residual sulfur to hydrogen sulfide (H2S). Any H2S in the reformer syngas must be removed to protect the catalysts in down-stream processing and in the anode chamber of fuel cell systems. Zinc oxide $(\mathrm{ZnO})$ traps are feasible approaches for this need. Extremely low H2S concentrations (to $20 \mathrm{ppb}$ ) can be obtained over long periods. Sulfur trapping capacity (amount of $\mathrm{H} 2 \mathrm{~S}$ trapped before breakthrough) depends on space velocity, temperature, steam concentration, and particle size. Trap capacity tends to decrease with increasing temperature.

GM claims to have developed a gasoline reforming system, and to have it in road testing on the platform of a Chevrolet S-10 fuel cell powered vehicle with a drive train of about $25 \mathrm{~kW}$ (33 hp). This third generation system, according to GM, starts producing hydrogen after only 3 minutes, in contrast to earlier generation systems that required 15 minutes to start producing hydrogen. GM proposes that a tank of compressed hydrogen can be used to supplement the fuel cell operation until the reformer starts producing hydrogen.

Aspen Systems, Inc. and Argonne National Laboratory have also reported progress with systems to reform gasoline, although sulfur in the fuel remains a problem for all the developers.

\subsubsection{Applications Issues and Progress}

Fuel cells have been proposed as alternative fuel sources for applications ranging from portable devices through to multi-megawatt combined heat and power units. In all these applications the fuel cell offers advantages over existing methods of power generation, be it in efficiency, weight or noise level. Actual market penetration depends on the development of commercially viable systems - in many of the promising applications, this is still "over the horizon" although recent progress has been significant.

However, as was stated earlier, some developmental and technology selection challenges stem from the diverse technology and operating characteristics among the various types of fuel cells PEM (including DMFC), PAFC, MCFC, and SOFC. The applications also carry distinctions that map into the properties of these fuel cell types. Table 4.4 relates some of the differing characteristics of the key applications we are considering to the characteristics and issues of the fuel cells. Note that many of the representations of this table are a matter of degree. 


\section{Table 4.4 Applications Related To Fuel Cell Issues}

\begin{tabular}{|c|c|c|c|c|c|c|c|}
\hline Issue & $\begin{array}{l}\text { Private } \\
\text { Cars, } \\
\text { Vans, } \\
\text { SuVs }\end{array}$ & $\begin{array}{l}\text { Fleet } \\
\text { Cars, } \\
\text { Vans, } \\
\text { SUVs }\end{array}$ & $\begin{array}{l}\text { Long-Haul } \\
\text { Trucks, } \\
\text { Interurban } \\
\text { Buses } \\
\end{array}$ & $\begin{array}{l}\text { Local } \\
\text { Trucks, } \\
\text { Urban } \\
\text { Buses }\end{array}$ & $\begin{array}{l}\text { Large } \\
\text { Power } \\
\text { Generation }\end{array}$ & $\begin{array}{c}\text { Small, } \\
\text { Distributed } \\
\text { Power } \\
\text { Generation }\end{array}$ & $\begin{array}{l}\text { Portable } \\
\text { Electronics }\end{array}$ \\
\hline Use waste heat & & & & & $\checkmark$ & $\checkmark$ & \\
\hline $\begin{array}{l}\text { Methanol - } \\
\text { attractive fuel }\end{array}$ & $\checkmark$ & $\checkmark$ & $\checkmark$ & $\checkmark$ & & & $\checkmark$ \\
\hline $\begin{array}{l}\text { CNG, LNG fuel } \\
\text { feasible }\end{array}$ & & $\checkmark$ & $\checkmark$ & & & & \\
\hline $\begin{array}{l}\text { Fuel infrastructure } \\
\text { critical }\end{array}$ & $\checkmark$ & & $\checkmark$ & & & & \\
\hline $\begin{array}{l}\text { Component } \\
\text { vibration } \\
\text { resistance }\end{array}$ & $\checkmark$ & $\checkmark$ & $\checkmark$ & $\checkmark$ & & & $\checkmark$ \\
\hline $\begin{array}{l}\text { Fuel energy density } \\
\text { critical }\end{array}$ & $\checkmark$ & & $\checkmark$ & & & & $\checkmark$ \\
\hline $\begin{array}{l}\text { System startup, } \\
\text { response time }\end{array}$ & $\checkmark$ & & & & & $\checkmark$ & $\checkmark$ \\
\hline $\begin{array}{l}\text { Component size, weight, } \\
\text { complexity }\end{array}$ & $\checkmark$ & $\checkmark$ & & & & & $\checkmark$ \\
\hline $\begin{array}{l}\text { Lower temperature } \\
\text { better }\end{array}$ & $\checkmark$ & $\checkmark$ & & & & & $\checkmark$ \\
\hline
\end{tabular}

In any development scenario for new technology, especially where modularity is a key feature or possibility, achieving economy of scale in OEM production systems enables lower costs, which in turn encourages market growth.

One such area in PEM fuel cells involves the cost of polysulfonic membrane materials, for which DuPont is the leading manufacturer. These materials today have a limited production volume for such electrochemical applications as in electrolytic production cell membranes in the chlor-alkali industry. DuPont has forged a strategic alliance with Mechanical Technology Inc. (MTI), a developer of micro fuel cells for the portable electronics market. But, through joint ownerships and partnerships, MTI is part of an industrial complex that includes SatCon Technology Corporation, a developer of power electronics and energy management products, and Plug Power Inc., a leading player in fuel cell development and manufacturing.

Shell Hydrogen, which was set up in 1999 to engage in opportunities related to hydrogen, fuel cells and other renewable energy technical areas, has recently forged a joint venture with HydroQuebec and German Gesellschaft fur Elektrometallurgie (GfE) to develop and commercialize metal hydride hydrogen storage products.

The U.S. DOE has set program goals for 2004 to 2008 to have molten carbonate fuel cells (MCFC) and tubular solid oxide fuel cells (TSOFC) up to a megawatt in size at a cost of $\$ 1,500$ per kilowatt operating at up to 60 percent efficiency. In addition to the MCFC and TSOFC technology development, DOE is pursuing more widely applicable fuel cells for 2010 . The DOE has projected that that a $5-\mathrm{kW}$ planar solid oxide fuel cell (PSOFC) system can reach 
$\$ 400 /$ kilowatt $(\mathrm{kW})$ at reasonable manufacturing rates. With this low-cost potential, the PSOFC could have wider and deeper market penetration for many applications than other types fuel cells, if its high temperature operation fits well in other ways in any one application. That planar SOFC can achieve low-cost at small sizes gives it a better chance of reaching more and bigger markets. At the 3-10 kW size SOFC is suitable for stationary, transportation, and military residential, auxiliary power unit, telecommunication, and battery replacement applications and markets. These vast markets include the automotive industry, which is proficient at reducing costs in mass manufacturing. If a common-module can be produced for these vast markets, it will be easier to achieve the high volume needed to reduce costs. SECA (Solid State Energy Conversion Alliance) was formed by NETL and PNNL to accelerate the commercial readiness of planar solid-oxide fuel cell systems in the $3-10 \mathrm{~kW}$ size range by taking advantage of the projected economies of production from such a "mass customization" approach.

For the existing MCFC and tubular SOFC developers, the market is projected to be large -2 gigawatt/year is $\$ 2$ billion/year at $\$ 1000 / \mathrm{kW}$, but for the class of SECA fuel cells it could be much larger, including the residential and auxiliary power (APU) markets. In addition, if the modular 3-10 kW units can be "ganged" or "scaled-up" to larger sizes with no increase in cost, then commercial, microgrid and other DG markets will be attainable. Further scale-up could result in penetration of the bulk power market.

These are just limited examples of a very broad and comprehensive ferment of market entry, joint development and commercialization among leading companies in energy, chemicals, equipment, diversified technology, and focused fuel cell development. This is a multinational phenomenon.

\subsubsection{Applications Status}

Figure 4.13 maps in a "four-square diagram" the key attributes of the four leading types of fuel cells under development, their current applications, and their most appropriate and most likely applications in the future.

The four major fuel cell technologies, in the order of their technical and commercial development status, are: PAFC, MCFC, PEMFC AND SOFC (where PA=phosphoric acid; $\mathrm{MC}=$ molten carbonate; $\mathrm{PEM}=$ polymer electrolyte membrane; $\mathrm{SO}=$ solid oxide). $\mathrm{PEMFC}$ is aimed at vehicle use. Because of its physical attributes, PEMFCs appear to have good ultimate potential for low cost mass production, and because of their light weight, high efficiency and fast response, seem most attractive for vehicle propulsion, except that they need elaborate fuel processing to use hydrocarbons and most oxygenate fuels. To compete with current engines, PEMFC systems need to become 10 times less expensive than at present. Higher manufacturing cost factors at limited initial production volumes is also a challenge in competing for market share.

Nexant believes that fuel cells may have significant market potential in auxiliary power systems for transportation, including also marine and rail systems, but will probably not gain significant 
market share in road vehicle propulsion systems (i.e., in passenger cars, buses and trucks) in the near term (to 2015).

Figure 4.13 FC Development Status for Target Applications

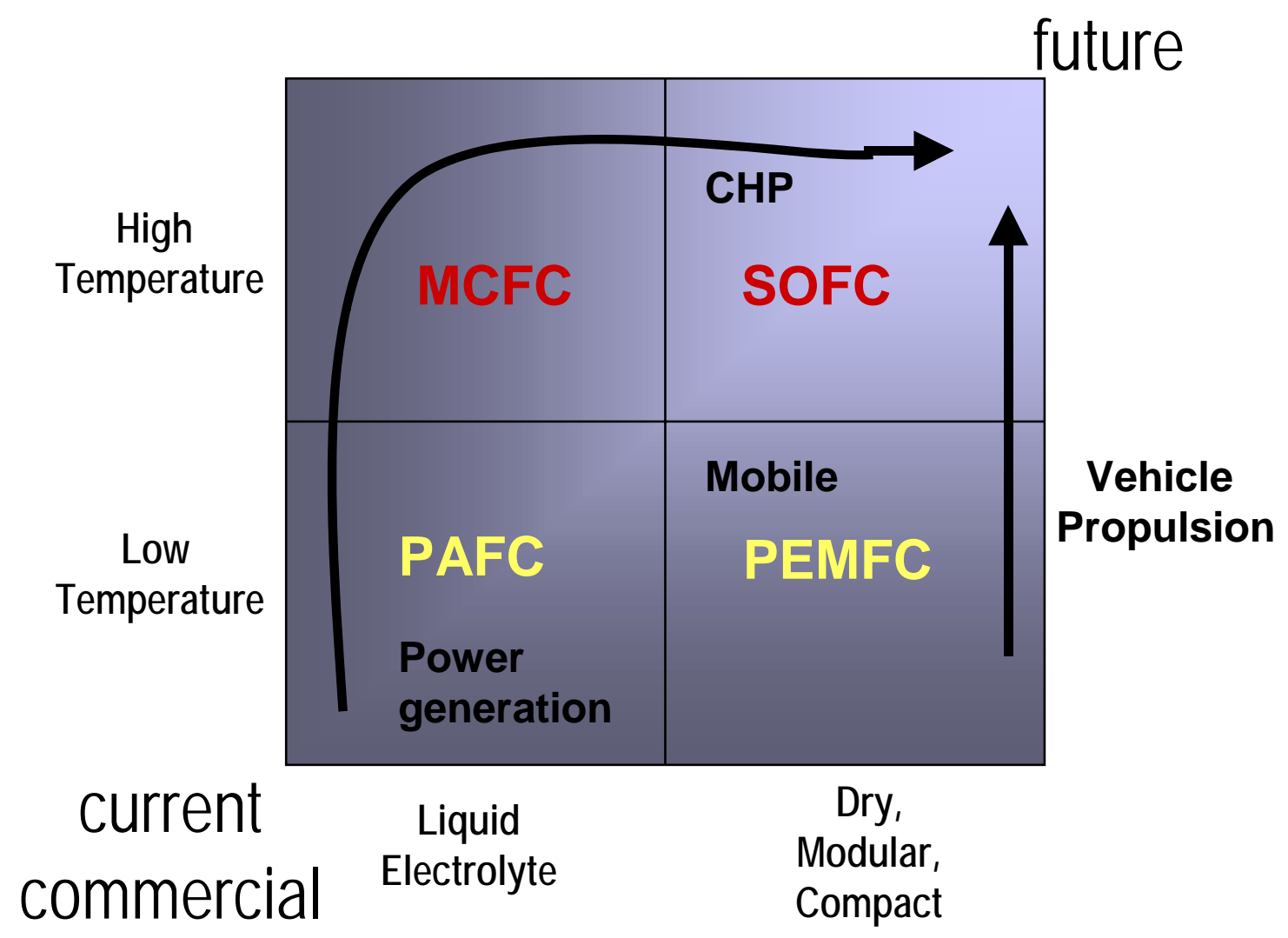

PAFC and MCFC are already well demonstrated for stationary power applications, but are probably too inconvenient for vehicle drives. Achieving mass production economy of scale is less of an issue in the power market than for vehicles. The higher temperature MCFC and SOFC technologies have the potential to use hydrocarbons, especially natural gas, and their waste heat is potentially recoverable and usable in cogeneration (combined heat and power - CHP) applications. SOFC is the least developed and demonstrated, but is well funded and could eventually serve in vehicle auxiliary power systems and even in hybrid propulsion systems using some conventional fuels.

\subsection{FUEL CELL VEHICLES - DETAILED ANALYSIS}

\subsubsection{Overview}

As described above, a fuel cell vehicle uses electricity from fuel cells instead of batteries. A fuel cell operates like a battery in that it converts chemical energy directly into electricity. A fuel cell combines oxygen from the air with hydrogen gas. Unlike a battery, a fuel cell does not run down or need recharging; it produces electricity as long as fuel, in the form of hydrogen, is supplied. 
Hydrocarbon, alcohol, ether, and other organic fuels can be utilized by fuel cells if they are processed or "reformed" to provide a hydrogen-rich mixture. Alternative fuels being considered for use in fuel cells include methanol, GTL naphtha, ultra clean gasoline, ethanol, natural gas, propane, and hydrogen.

Current reformer technology and the types of fuel cells being considered for mobile applications require a fuel that is essentially sulfur-free or whose sulfur content is no more than a few parts per billion. Technologies are also being developed to directly use methanol or other liquid organic fuels directly without separate reforming first. Direct fuel cells (e.g., direct methanol, direct GTL naphtha, etc.) would integrate reforming into the fuel cell stack. DMFCs have been demonstrated for mobile communication applications and are heading for vehicle applications.

As an alternative to IC engines, fuel cells for transport applications offer significantly higher fuel efficiencies. Like a battery-powered electric vehicle, a fuel cell electric vehicle produces very little or no tailpipe emissions and it has the driving range and convenience of a conventional gasoline-powered engine.

With good design these systems will exhaust essentially only a mixture of air, carbon dioxide and water vapor. The fuel cell vehicle will also be far quieter than the equivalent internal combustion based model, an advantage that would benefit many built up urban areas.

Fuel cell vehicle (FCV) technology is currently in the development stage. Although fuel cell applications for buses have been implemented for demonstration purposes, special emphasis is on development for light-duty vehicles since these vehicles offer the greatest potential in energy and environmental benefits.

There are still major challenges ahead in the development of fuel cells and progress has been slower than expected. However, recent advances have increased the confidence that technology development is unlikely to be an ultimate barrier to adoption of fuel cells. A most fundamental challenges remaining are "chicken-egg" in nature:

- Cost Reduction - The general view is that costs need to be reduced by 50 to 70 percent. In any development scenario for a new technology, especially where modularity is a key feature or possibility, achieving economy of scale in OEM production systems enables lower costs, which in turn encourages market growth.

- Infrastructure Development - It will be critical to create enough of an infrastructure quickly, or leverage or integrate with existing systems (as for any alternative fuel vying to be a general fuel in private passenger vehicles) so as to provide consumers with a sufficient level of comfort in being able to readily refuel upon demand. Focus groups have shown that most consumers in an urban setting on the average require 25-30 percent of refueling stations to carry the alternative fuel before they will buy a car that uses it. This hurdle percentage increases to 50 percent in a rural setting.

Other important detailed challenges facing industry in overall fuel cell development, and especially fuel cells for vehicles and other mobile or portable applications, are as follows: 
- Increasing power density, by 30 to 50 percent (key for vehicles)

- Integrating components

- Improving cold start performance for vehicles

- Reducing size of cooling system

- Making components more durable

- Assuring prevention of stack freezing (for outdoor applications)

- Improving transient performance

- Addressing hydrogen safety (for hydrogen fueled systems)

- Deciding on pathways for infrastructure development

- Increasing vehicular driving range

- Reducing the complexity of components

The champions of fuel cell vehicles generally recognize these challenges. The international divisions of automobile OEMs and organizational partnerships are spearheading the research, development, and market testing of fuel cell vehicles. Some OEMs have announced plans to make fuel cell electric vehicles commercially available as early as 2004 and several concept vehicles have been built and demonstrated in trials.

In spring 1999, DaimlerChrysler made public its first fuel cell vehicle, called NECAR 4 (short for New Electric Car), which is based on a Mercedes-Benz compact car. DaimlerChrysler is also developing NECAR 5 and a concept vehicle, based on the Jeep Commander, that utilizes a methanol hybrid fuel cell system. DaimlerChrysler says that for fleet applications, emphasis will be on using pure hydrogen fuel; for vehicles sold to the public, hydrogen reformed from methanol will be emphasized.

Ford Motor Company produced a concept fuel cell vehicle called the P2000 Prodigy, which operates using on-board stored hydrogen and performs with the same efficiency as Ford's Taurus.

Ford and Toyota have each designed concept fuel cell Sport Utility Vehicles (SUVs).

\subsubsection{Fuel Selection Issues}

The choice of fuel for fuel cell vehicles is still very uncertain. Presently, hydrogen, methanol and "simplified" gasoline are the apparent leaders. None of these fuels is a clear winner.

\subsubsection{Hydrogen}

The use of hydrogen seems problematic, as the energy content on a volumetric basis of compressed hydrogen is the lowest of the fuels considered and would need to be stored in heavy cylinders. Liquid hydrogen is both expensive to produce and difficult to store and transport. However, hydrogen stored in metal hydrides and in other adsorption media or chemically bonded 
forms actually can have a significantly higher energy density than liquid hydrogen, and thus may be the key to the long-promised "hydrogen economy" of the future if adsorption media of this type are commercialized.

\subsubsection{Methanol}

Methanol is a technically attractive fuel for fuel cells for many reasons, but it suffers from logistical problems. There is extensive distribution capability available already today for methanol, but mostly only on a business-to-business basis. There is little existing infrastructure for direct retail sales to customers. Methanol has a potential environmental protection risk in that it is both toxic and soluble in water. It is more soluble in water than MTBE and so leakage from underground storage tanks could pose a threat. However, methanol is more biodegradable than MTBE and is less noticeable in water than MTBE to humans. Gasoline is also toxic, but has far less mobility in groundwater. Methanol has some potential for achieving higher energy efficiency in FC systems than gasoline because its reforming temperature can be lower. However, cutting into this advantage is that it will always suffer from an energy density that is much lower than that of any liquid hydrocarbon due to the incombustible oxygen that constitutes half the weight of a methanol molecule.

\subsubsection{Gasoline}

Gasoline offers the best energy density, already has an infrastructure in place and would only need to be modified to remove components such as certain aromatics and catalyst poisons, primarily those containing metal and sulfur heteroatoms. Gasoline does, however, require the most complex fuel treatment (reformer, $\mathrm{CO}$ removal, etc.) in a fuel cell system. The gasoline used in fuel cell vehicles need not be to the same specification as current gasoline, as octane properties are of little relevance to fuel cell operation. Hydrotreated heavy naphthas or FT naphthas would be suitable feedstocks because of their low level of impurities, such as sulfur. An integrated gasoline powered fuel cell is in operation under test laboratory conditions, and vehicles were demonstrated in 2000.

\subsubsection{Ranking the Leading Fuels}

Despite its drawbacks, methanol currently seems to many to be the most promising of these fuels considered for fuel cells, due to greater convenience than hydrogen, and lower emissions and higher efficiency than gasoline. However, methanol's logistics will be challenging in the long term because of its lower energy density. Arguably, breakthrough technologies being intensively researched by many in industry, academia and government agencies could overcome hydrogen's low energy density and the reformer penalties for gasoline. In addition, hydrogen can be derived from almost any renewable source and methanol and FT liquids can also be made from some renewable resources, whereas gasoline is from fossil sources. A ranking of the key characteristics of methanol, hydrogen and gasoline that are expected to influence the selection of fuels for fuel cells are summarized in Table 4.5. 


\section{Table 4.5 Ranking Of Key Characteristics Of Fuels For Vehicle Fuel Cells}

\begin{tabular}{|c|c|c|c|c|}
\hline Ranking & Energy Density & $\begin{array}{c}\text { Convenience of } \\
\text { Phase In }\end{array}$ & $\begin{array}{c}\text { Environmental } \\
\text { Benefits }\end{array}$ & $\begin{array}{c}\text { Demonstrated } \\
\text { Technology }\end{array}$ \\
\hline 1 & GFC & GFC & HFC & MFC \\
\hline 2 & MFC & MFC & MFC & HFC \\
\hline 3 & HFC & HFC & GFC & GFC \\
\hline \multicolumn{2}{|l|}{ MFC-Methanol Fuel Cell, GFC-Gasoline Fuel Cell, HFC-Hydrogen Fuel Cell } \\
\hline
\end{tabular}

\subsubsection{Fuel Development Strategies}

This section examines fuel cells in transportation applications as potential users of commercial quantities of methanol or FT distillates (naphtha range) in the near and longer term.

Fuel cells used in either stationary or mobile/portable applications each have separate and distinct requirements, which tend to favor one or another type of fuel cell technology. Separate reforming of gaseous or liquid fuels is a lesser issue with stationary applications than with mobile or portable ones (vehicles, cell phones, laptop PCs, etc.). Stationary fuel cells that generate waste heat can be used in combined heat and power (CHP) configurations (i.e., as "cogenerators"), and are especially attractive in residential, commercial, industrial and utility "distributed generation" (DG) modes to help decentralize the power grid and provide better power supply security and/or quality. CHP is of no interest in most mobile and portable applications because the waste heat is of no use, or even a liability.

For vehicle and portable applications, liquid fuels currently provide the most convenient and practical options, but their practicality varies among the fuel types and among applications. The more a fuel resembles gasoline, diesel or LPG, the more familiar and convenient it will be to consumers. Gasoline prices are likely to remain stable and competitive with alternative fuels in the near term. It is likely that advances in conventional gasoline and diesel internal combustion engines will continue to increase their fuel efficiency and keep these systems competitive for the next 15 or 20 years. Engine-electric hybrid systems, the integration of electronic controls and engine mechanics, and advanced lubricants and materials of construction are likely also to contribute keeping the engine systems and gasoline and diesel-type fuels viable even longer. Diesel fuel for passenger vehicles has a greater role in Europe than in the U.S., and as particulate and NOx controls are introduced along with very low sulfur diesel, these improvements will extend the life of this somewhat more environmentally problematic fuel.

For stationary applications, natural gas, LPG and fuel oil are the most familiar fuels with the most developed distribution infrastructures throughout the economy. Most of the U.S. population, commerce and industry is served by natural gas, and rural areas that are not generally have an LPG and/or fuel oil infrastructure. 
Coal is used today only for power generation and other heavy industrial fueling, but can be used to produce hydrogen, as can biomass and other carbonaceous primary fuels. Processes are being developed using biotechnology (genetic modification techniques) to generate hydrogen directly from biomass using enzymatic processes that may be more energy conservative and have less environmental impact than conventional pyrolysis or combustion based routes.

Biomass utilization, various versions of solar, hydropower, wind and ocean energy and geothermal energy are considered by most to be "renewable" and sustainable energy strategies and to have much less impact on global warming than any mode of utilizing fossil fuels ("nonrenewable" resources). A few of the utilization strategies for these "renewables" are well developed and practical, but most are still developmental and / or uneconomic. In most cases, they would be used to produce electricity for hydrogen production by electrolytic dissociation of water.

\subsubsection{The Hydrogen Economy Concept}

As discussed below, fuel cells operate by oxidizing hydrogen to directly generate an electric current. Hydrogen used directly in fuel cells gives their highest efficiency and produces no tailpipe emissions of any pollutants. The imagined end game of all fuel cell development, which is hoped and planned for by many, is the "hydrogen economy". In such a scenario, hydrogen is widely distributed for use in vehicles, home, commercial and industrial power and heat systems, portable devices, etc. The hydrogen economy is envisioned as the key to sustainable development towards the end of this century and into the next century and beyond. In this, hydrogen would be the ultimately fungible fuel, capable of being made in the short term by reforming a wide variety of hydrocarbon, oxygenate and carbohydrate sources, and, then in the long term, electrolytically using electricity made with renewable resources such as hydro, wave and wind power, solar thermal, photovoltaic, geothermal, and biomass combustion.

A global total of about 40 million metric tons of hydrogen is currently produced annually. Most of this produced captively in ammonia and methanol production, oil refining, and fats hydrogenation, and as merchant hydrogen in other chemical applications and in metal treating, semiconductor manufacture and other high-tech applications. Only a minor amount is used as a fuel, for aerospace (and now, for fuel cell development). Most hydrogen is produced onsite by methane steam reforming and a small amount is generated as a byproduct in electrolytic processes, such as in chlor-alkali (where it may be burned on-site as a fuel). Currently, only about 5 percent of total hydrogen production is not used on-site.

Hydrogen is colorless and odorless, and has a low ignition temperature and a wide flammability range, and it burns with an invisible flame. As such, it has some unique fire hazards, but in leaks, it self-ignites easily and if it does not, in ventilated areas it will dissipate quickly, so explosion hazards are mitigated. There is long and varied experience with handling hydrogen in many sectors, including the chemical industry, petroleum refining, vegetable oil hydrogenation, government and private aerospace, semiconductors, and the metals industry. Leak detection systems and other precautions will generally be able to minimize the hazards. 
The fuel cells commercially available today need to have hydrogen fed directly from storage or by decomposing ("reforming") gaseous or liquid fuels, such as methane, LPG, methanol, ethanol, naphtha (special gasoline) or diesel fuel. Most of the demonstrations of fuel cell vehicles operating or planned today are using manufactured hydrogen as the on-board fuel. This is not because the developers have necessarily decided that producing and distributing additional hydrogen, refueling with it, and carrying it on board will be the best strategy in the near or long term, but that this is the best way to reduce the variables and simultaneous challenges among multiple on-board system components while demonstrating the basic set of fuel cell/electric motor/control systems. This type of "divide and conquer" strategy avoids any possible additional problems with the step of reforming on-board liquid fuels (which are also developmental for vehicle and portable systems), and reserves until later development of manufacturing, storage, distribution, refueling and on-board fuel carrying technologies and strategies.

\subsubsection{Sourcing Hydrogen}

Hydrogen is not a "fuel source" found in nature, but must be manufactured from primary sources, and so, in the context of supplying fuel cells is only an energy carrier. Strategically, hydrogen can be made near the primary source, or in a centralized process facility closer to the point of use, or made as required adjacent to or integral with the fuel cell stack. Hydrogen production by reforming fuels or by electrolytic dissociation of water can be practiced near the primary energy source.

Remotely located natural gas resources ("stranded gas") can be reformed and the resulting hydrogen-carbon monoxide mixture can be reacted to produce methanol by conventional or advanced routes, or made with synthetic hydrocarbon liquids via established Fischer-Tropsch technology or its emerging competitors. These can be shipped nearer to the point of use for reforming to hydrogen at or adjacent to the point of refueling, or possibly used directly in advanced versions of the technology not yet commercialized.

Manufactured hydrogen can be stored, transported and carried on board a vehicle as:

- Compressed gas (very high pressures required)

- Cryogenic liquid (at the lowest cryogenic liquid temperature, next to helium)

- Metal hydrides or adsorbed on nanoparticles with high surface area and specialized molecular structures (usually requiring pressure swings and/or heating to release stored hydrogen)

The first two forms are well known, but are expensive and can be problematic. Hydride and nanoparticle technologies are being developed as media to enhance hydrogen storage efficiencies. SOFCs and MCFCs are being developed to utilize methanol, ethanol, or even methane, LPG, low-sulfur gasoline (naphtha), diesel fuels or other hydrocarbons directly by reforming them to hydrogen integrally within the fuel cell stack, and DMFC- PEMs for direct methanol use. 
The following is a partial listing of companies and government, non-profit and other organizations active in fuel cell development.

\subsubsection{FC Vehicles - Current Situation Analysis}

\subsubsection{Leading Developers of Passenger Automobiles}

Table 4.6 lists the leading FCV developments by mass-market passenger automobile manufacturers in the recent past, currently and announced for the next few years.

\subsubsection{The California Fuel Cell Partnership (CaFCP)}

This is a unique collaborative of auto manufacturers, oil companies, a fuel cell company, and the State of California. Its mission is to advance and evaluate a new automobile technology with an emphasis on practicality, affordability and environmental improvements. The project will demonstrate fuel cell electric passenger cars and transit buses. Demonstrations are to be under real day-to-day driving conditions.

The Partnership formally began in April, 1999. It includes:

- Auto manufacturers (DaimlerChrysler, Ford, General Motors, Honda, Hyundai, Nissan, Toyota and Volkswagen)

- Energy providers (BP, Shell, Texaco)

- Fuel cell companies (Ballard Power Systems, International Fuel Cells and XCELLSiS)

- Government agencies (the California Air Resources Board, the California Energy Commission, the South Coast Air Quality Management District, the U.S. Department of Energy, and the U.S. Department of Transportation)

The team also includes Associate Partners who assist with specific areas of expertise. They are:

- Hydrogen Gas Suppliers (Air Products and Chemicals, Inc., and Praxair)

- Hydrogen Fueling Station Infrastructure (Hydrogen Burner Technology; Pacific Gas and Electric; Proton Energy Systems, Inc.; and Stuart Energy Systems)

- Methanol Supplier - Methanex

- Bus Transit Agencies (AC Transit [Alameda-Contra Costa County area]; SunLine Transit Agency [Palm Springs area]) 


\section{Table 4.6 Leading Fuel Cell Vehicle Developments}

\begin{tabular}{|l|l|l|l|}
\hline Auto Maker & Vehicle Name & $\begin{array}{c}\text { Year } \\
\text { Introduced }\end{array}$ & Fuel \\
\hline BMW & Series 7 Sedan & 1999 & Hydrogen \\
\hline BMW & SOFC/IC Motor Hybrid & 2001 & Gasoline \\
\hline DaimlerChrysler & NECAR 1 & 1993 & Gaseous Hydrogen \\
\hline DaimlerChrysler & NECAR 2 & 1995 & Gaseous Hydrogen \\
\hline DaimlerChrysler & NECAR 3 & 1997 & Methanol \\
\hline DaimlerChrysler & NECAR 4 & 1999 & Liquid Hydrogen \\
\hline DaimlerChrysler & NECAR 5 & 2000 & Methanol \\
\hline DaimlerChrysler & Jeep Commander & 2000 & Methanol \\
\hline DaimlerChrysler & Direct Methanol Go-cart & 2000 & Methanol \\
\hline Energy Partners & Green car & 1993 & Hydrogen \\
\hline Ford Motor Company & P2000 HFC & 1999 & Hydrogen \\
\hline Ford Motor Company & P2000 SUV & 1999 & Methanol \\
\hline Ford Motor Company & Th!nk FC5 & 2000 & Methanol \\
\hline Ford Motor Company & Focus FCV & 2001 & Hydrogen \\
\hline General Motors/Opel & Zafira & 1998 & Methanol \\
\hline General Motors/Opel & Precept & 2000 & Hydrogen \\
\hline General Motors/Opel & HydroGen 1 & 2000 & Hydrogen \\
\hline General Motors & HydroGen 3 & 2001 & Hydrogen \\
\hline General Motors & Chevrolet S-10, Gen III & 2001 & Gasoline \\
\hline Honda & FCX -1 & 1999 & Hydrogen \\
\hline Honda & FCX -2 & 1999 & Methanol \\
\hline Honda & FCX -3 & 2000 & Hydrogen \\
\hline H Power & New Jersey Venturer & 1999 & Hydrogen \\
\hline H Power & New Jersey Genesis & 2000 & Hydrogen \\
\hline Hyundai & Santa Fe SUV & 2000 & Hydrogen \\
\hline Mazda & Demio & 1997 & Hydrogen \\
\hline Nissan & R'nessa SUV & 1999 & Methanol \\
\hline Nissan & Xterra SUV & 2000 & Methanol \\
\hline Renault & FEVER & 1997 & Liquid Hydrogen \\
\hline Renault & Laguna Estate & 1998 & Liquid Hydrogen \\
\hline Toyota & RAV 4 FCEV & 1996 & Hydrogen \\
\hline Toyota & RAV 4 FCEV & 1997 & Methanol \\
\hline Toyota & FCHV-3 (hybrid) & 2001 & Hydrogen \\
\hline Toyota & FCHV-4 (hybrid SUV) & $2003)$ & Hydrogen \\
\hline Volkswagen/Volvo & Bora HyMotion & 1999 & Hydrogen \\
\hline & & & \\
\hline & & & \\
\hline
\end{tabular}

The Partnership plans to road test more than 50 fuel cell vehicles (cars and buses) between 2000 and 2003. In addition to testing the fuel cell vehicles, the Partnership intends to also identify fuel infrastructure issues and prepare the California market for using fuel cell technology.

The passenger cars include DaimlerChrysler's NECAR, Ford's Focus FC6; and Honda's FCX, as well as vehicles from General Motors, Hyundai, Nissan, Toyota and Volkswagen. The transit buses include the ZEBus P-4, developed by XCELLSiS. 


\subsubsection{Heavy Duty Vehicles (Trucks, Buses and Other)}

Heavy duty vehicles, generally with diesel drives, as contrasted with primarily gasoline drives on autos in North America, are not constructed and provided to the market in the same way as passenger vehicles. The engines for these are often provided separately from the chassis, coach and other platform components. The designs of these systems are more under the control of the fleet owners and government agencies. Therefore, demonstrations and developments tend to be more in the hands of consortia and fleet agencies than for passenger automobiles.

\subsubsection{Costs (Materials and Operating)}

Examined below are projected costs and performance factors of hybrid electric autos for a variety of potential systems:

- PEM Fueled by Hydrogen

- PEM Fueled by Steam Reformed (SR) Methanol

- PEM Fueled by Steam Reformed (SR) Ethanol

- PEM Fueled by Auto Thermal Reforming (ATR) of Gasoline

The potential manufacturing costs for FC autos, primarily PEM systems, have also been studied, projected and analyzed by a number of researchers, companies and agencies. These options have been compared in various studies to gasoline IC engine systems. Purchase costs are not projected to vary markedly among the developmental options - all fuel cell options are estimated to have around $\$ 10,000$ ( $\$ 8,970$ to $\$ 11,100)$ additional cost over gasoline IC engines. Cases examined include both moderate assumptions on the technology of vehicle hybridization and for aggressive hybridization (e.g., more robust role for buffer energy storage in the battery system).

One very useful study that was sponsored by the U.S. DOE and reported by Arthur D. Little in March, 2000, assesses and projects manufactured costs of gasoline ATR PEM vehicle systems under a comprehensive set of technical parameters and qualifications. The basis is a $50-\mathrm{kW}$ net passenger automobile, with a production volume of 500,000 per year (a small car with a high rate of production). To put this in context, there are typically only about 400,000 Ford Taurus automobiles, sold in the U.S. in a year, the most for any single model.

Table 4.7 examines the year 2000 subsystem manufacturing cost breakdown estimated by A.D. Little for gasoline ATR PEMs. The fuel cell stack dominates the fuel cell subsystem costs. The membrane electrode assembly (MEA), which includes the membranes, the electrodes and the gas diffusion layers, with their precious metal content and polymer electrolyte materials currently dominate the cost of the fuel cell stack. With the current technology, there are minimum prospects to overcome the costs of the precious metals, but at higher scales of production, PEM membrane costs could be reduced significantly. 


\section{Table 4.7 Factory Costs for Gasoline PEMFC-ATR Propulsion Systems at Production Scale}

\begin{tabular}{|l|r|r|r|}
\hline Subsystem & $\begin{array}{c}\text { Estimated Yr } \\
\mathbf{2 0 0 0} \mathbf{\$}\end{array}$ & $\mathbf{\$}$ / kW & $\begin{array}{c}\text { Yr 2004 } \\
\text { Goal } \\
\mathbf{\$} / \mathbf{~ k W}\end{array}$ \\
\hline Fuel Cell - total & $(8,850)$ & $(177)$ & 40 \\
\hline -Electrodes & 3,590 & 72 & \\
\hline -Membrane & 1,340 & 27 & \\
\hline - Bipolar plate & 1,058 & 21 & \\
\hline -Gas Diffusion Layers & 430 & 8.6 & \\
\hline -Gaskets & 353 & 7.1 & \\
\hline -Tailgas Burner & 460 & 9.2 & \\
\hline -Air Supply & 860 & 17 & \\
\hline -Cooling System & 480 & 9.6 & \\
\hline - Other FC Costs & 279 & 5.6 & \\
\hline Fuel Processor & 4,310 & 86 & \\
\hline Balance of Plant & 500 & 10 & \\
\hline System Assembly & 1,040 & 21 & \\
\hline Total & 14,700 & $\mathbf{2 9 4}$ & $\mathbf{5 0}$ \\
\hline
\end{tabular}

Unlike manufacturing costs, however, operating factors are projected to vary more widely among the options. Table 4.8 gives estimates of these distinctions, with both moderate and aggressive electrical buffering cases indicated.

Table 4.8 Projected Comparative FCV Fuel Economies

$\begin{array}{lcc}\text { Vehicle Type } & \begin{array}{c}\text { Fuel Economy } \\ \text { (mpg gasoline equivalent) }\end{array} & \text { Fuel Economy } \\ \text { Gasoline Baseline } & 30.6 & 1.0 \\ \text { Hydrogen PEM } & 76.2 / 83.8 & 2.5 / 2.7 \\ \text { Methanol SR PEM } & 49.0 / 55.5 & 1.6 / 1.8 \\ \text { Ethanol PEM } & 45.6 / 53.4 & 1.5 / 1.7 \\ \text { Gasoline ATR PEM } & 45.5 / 52.2 & 1.5 / 1.7\end{array}$

Source: California Energy Commission (CEC) - sponsored study, "Projected Automotive Fuel Use in California", 2001, by Arthur D. Little, Appendix - projections of FC costs by ADL, and EPRI estimated costs of HEVs, the common platform for all of the non-gasoline IC drive options. 
Some conclusions that may be drawn from this analysis are:

- With current gasoline prices of $\$ 1.50$ per gallon, average driving of 15,000 miles per year and a difference of about $49 \mathrm{mpg}$ for gasoline ATR-PEM HFC versus $30.6 \mathrm{mpg}$ for a conventional gasoline IC auto, fuel savings with the gasoline HFC would be only $\$ 275$ per year, which provides no significant fuel cost savings to provide an incentive for the average buyer to pay $\$ 10,000$ more for a car.

- Even if hydrogen (with an average of say, $80 \mathrm{mpg}$ ) could be delivered to the fuel tank at the same price as gasoline, the savings would be only about $\$ 455$ per year, and it would take over twenty years to justify the sticker price difference.

- Assuming price parity with gasoline or nearly so, on an energy basis, these conclusions are not materially different for either the other two fuel / fuel cell combinations considered - ethanol and methanol in PEMs.

- If gasoline became four times as expensive, say, $\$ 6.00$ per gallon, and ethanol and methanol remained the same; it would take 4 years to pay out the additional investment in an HFCV.

Commercial development of the battery-operated lawn mower was retarded in the early 1990s by the need to reduce price by economy of scale balanced by the high costs of developing more compact battery technology. Electric mowers with power cords were already common. It took the South Coast Air Quality Management District's prohibition of IC engine mowers on the California South Coast to create a large enough market to give Black \& Decker and others to advance the technologies and get the products to market. This pathway is not likely to work as well for \$20,000-plus fuel cell automobiles as it did for \$200 lawn mowers.

\subsubsection{Emissions Impacts}

Projecting and comparing criteria air pollutant and toxic air pollutant emissions and other environmental risks for fuel cell vehicles of various types with their alternatives is a very tenuous exercise (even limited just to emissions from refueling, off-vehicle and tailpipe). Some of the regulations, systems and technologies that are likely for controlling such emissions, even for the near future, are unknown today. Clearly, there are more health, safety and environmental risks of various types underlying the use of some fuels versus others (e.g., gasoline and methanol are quite toxic, while hydrogen is non-toxic but very flammable and will likely have to be carried on board vehicles at high pressures, at least in the near term). It is not known whether fuel cell vehicles will prevail over gasoline IC-electric hybrids in the middle term, or which type(s) of fuel cells will become dominant for vehicles. Since fuel cell technologies are in the early development stage, it is still not clear what the practical aspects of their environmental performance will be. This complexity is largely being addressed in the LCA part of this study. However, it is useful to compare fuel economy on an energy basis for the various alternatives as a rough proxy for greenhouse gas emissions. Table 4.9 shows a comparison derived from a survey conducted by the Argonne National Laboratory Transportation Technology R\&D Center. 


\section{Table 4.9 Range Of Fuel Economy, Normalized for Gasoline FCV}

\subsubsection{Focus of R\&D}

\begin{tabular}{|l|c|}
\hline Vehicle type & $\begin{array}{c}\mathrm{mpg} / \\
\text { FCV mpg }\end{array}$ \\
\hline Gasoline FCV & $1.0-2.1$ \\
\hline Gasoline ICE-Electric Hybrid & $1.2-1.7$ \\
\hline Methanol FCV & $1.3-2.0$ \\
\hline CNG ICE- Electric Hybrid & $1.35-2.1$ \\
\hline Ethanol FCV & $1.45-1.55$ \\
\hline Gasoline ICE-Electric Hybrid & $1.5-2.3$ \\
\hline Hydrogen FCV & $2.1-2.7$ \\
\hline
\end{tabular}

\subsubsection{Overview of Current Fuel Cell Research and Development}

The issues and challenges in fuel cell development and in fuel choices are largely dictated by the application, its size, its market volume, the fuel cell technology employed, the potential to use waste heat, etc. The issues and challenges are quite different for the three major fuel cell application areas considered here: vehicle, stationary power and small portable power uses. Issues and challenges can even differ significantly among applications in large vehicle fleets (urban and school buses, sanitation trucks and other local route trucks), highway trucks and interurban buses, passenger vehicle fleets (taxis, corporate, service, etc.) and private passenger cars, vans and SUVs. For example, vehicle range (a challenge with hydrogen or methanol today) and related logistics concerns are less of an issue with urban buses and other short-route fleet vehicles than for all highway and private passenger vehicles.

The research and development for vehicles, stationary power and small portables, however, can converge or cross over to some extent. For example, PEM development is being pushed hard for vehicles, and by some very powerful sponsors (the major auto manufacturers), but with an emphasis on hydrogen fueling. PEM is attractive in vehicles because it is has the lightest weight, coolest operation (leading to the fastest startup and greatest potential responsiveness) and best perceived potential for mass production. These are all good characteristics for portable applications, but are not as relevant to stationary power situations.

Portable power developers (mostly electronics companies, entrepreneurs, and the national labs) are the leaders in MCFC development, primarily because they want to commercialize in the next few years. Methanol cartridges are convenient drop-in replacements for the battery paradigm, methanol energy density and logistics are less at issue than for auto refueling, and hydrogen may never be relevant to small portable applications. If they are successful in overcoming the efficiency loss due to methanol migration across the fuel cell membrane and other challenges, automakers may adapt their DMFC developments to vehicle use.

Stationary power applications can exploit a wider range of fuel cell types because they tolerate or even benefit from higher fuel cell operating temperatures (such as with MCFCs and SOFCs), 
and higher reforming temperatures for natural gas and liquid hydrocarbons than for methanol. Hydrogen as an energy carrier in the short term is not as relevant, but stationary fuel cells may exploit industrial reforming capacity or waste hydrogen sources and thus be operating economically on hydrogen sooner than any other application could.

Fuel cell research has grown substantially since 1992, with double the number of articles published in 1997, and geometrically greater publications today.

The current research is still focused at fundamentals of electrical/electronic and chemical engineering. Over the past ten years, approximately 80 percent of research (as measured by articles published) related to basic/process science, technology and materials, with recent years continuing this trend. The research remains over a diverse base, with the top ten companies (in terms of publication) accounting for only 20 percent of the articles published in 1997.

Universities in the United States and Japan currently dominate fuel cell publications, with corporate research representing less than 20 percent of articles. This is attributed to increasing involvement of academics in projects initiated by corporations.

The research focus on basic/process science indicates that widespread fuel cell commercialization is unlikely in the near term. This is reflected in the status of applications to date.

\subsubsection{Key Development Issues for Fuel Cell Vehicle System}

In each subsystem, improved efficiency, size, cost and durability are key issues and development, but each also has unique issues to be addressed, as follows:

- Fuel Cell Stack

- Reformer $\quad$ Power density

- $\quad$ Start-up time

- $\quad$ Response in operation

- H2 Absorbing Alloy or Other Storage Strategy

$$
\begin{array}{ll}
- & \text { Capacity } \\
- & \text { Weight }
\end{array}
$$

\subsubsection{Achievements to Date}

Dramatic improvements were made in fuel cell technology for vehicles in recent years, most notably:

- Seven fold increases in fuel cell power density over the last decade, allowing fuel cells powering passenger cars to be contained within the vehicle floor space, rather than reducing passenger and luggage space or increasing vehicle size 
- Dramatically reduced costs, though not sufficiently reduced to attract mass consumers. Current commercial fuel cell costs are over US $\$ 1000 / \mathrm{kW}$ and development units are 3 times expensive. Most developers believe that fuel cells costs (at demonstration production volumes) need to be reduced to below about US $\$ 150 / \mathrm{kW}$ to make fuel cell autos costcompetitive with conventional gasoline engines when extrapolated to mass-production conditions. Mass-produced conventional automotive IC gasoline engines cost on the order of US\$3000-4000 (for a power output of about 100 bhp, or $75 \mathrm{~kW}-$ about $\$ 50 / \mathrm{kW}$ )

There are still many significant challenges in vehicle fuel cell development, but recent progress has increased confidence that further development of the technology of the fuel cells and related power systems is unlikely to be a barrier to adoption of fuel cells in vehicles.

The challenges for automotive fuel cell use are much greater than for stationary or even portable uses. Stationary users have little concern for fuel density, can often exploit inefficiencies (such as in fuel reforming) for combined heat and power production, and involve less concern for system weight, compactness, temperature and vibration resistance, responsiveness, and system complexity.

For portable applications, such as in small electronics, there is less concern for efficiency and cost; the key is to reduce the size and complexity of the system, hence the emphasis on DMFCs.

For specific vehicle fuel strategies, there is less confidence that enabling technologies will be developed to allow distribution, fuel carrying or fuel conversion sufficiently attractive for the consumer markets. For example, hydrogen fueling will require some kind of condensed onboard storage such as by surface adsorption or in hydrides or other such compounds. These developments are promising, but not yet sufficient. Methanol has a much higher efficiency in on-board reformers, but, because of its low energy density would always face a logistic penalty if the efficiencies of using other liquid fuels can be raised. More efficient and less problematic reforming of clean gasoline, diesel or FT naphtha might make methanol uncompetitive as the future fuel strategy.

\subsection{REVIEW OF FUEL DEVELOPERS}

The following lists some important players in the fuel cell field. It is not an exhaustive list, but emphasizes the organizations whose activities have high transparency, or who have announced interest and progress in fuel cells and related or enabling technologies.

\subsubsection{AlliedSignal}

AlliedSignal Aerospace Company has been the primary U.S. developer of monolithic SOFCs, as sponsored by the U.S. Department of Energy and the U.S. Department of Defense. The monolithic SOFC structure resembles the corrugated assembly used in cardboard boxes. The small channels are formed from thin $(25$ to $100 \mathrm{~mm}$ ) layers of active cell components, which serve for passage of the fuel and oxidant streams. In this design the anode, cathode and solid electrolyte are tapecast or tape calendared into thin layer structures. AlliedSignal has tested small SOFCs of this type, which have demonstrated relatively high current densities. 


\subsubsection{Analytic Power Corporation}

Boston-based Analytic Power Corporation was founded in 1984 and holds U.S. Patents for Unitized Fuel Cells and Electrochemical Refrigeration. Products offered and products in testing include: an ammonia cracker hydrogen source for small fuel cell power supplies; 150-, 200- and 1,750-watt fuel cell power supplies; a meteorological hydrogen generator; and a residential power generator. Other technology currently under development includes: $2.5 \mathrm{MW}$ fuel cell power plant for Naval surface vessels; an electrochemically driven heat pump for microclimate cooling applications; and a $10 \mathrm{~kW}$ advanced fuel cell power plant with autothermal reforming fuel processor and electrochemical compressor. Analytic Power is investigating advanced fuel processing methods as part of their attempt to develop a low-cost, natural gas reforming power plant for distributed power applications.

\subsubsection{Avista Laboratories}

Avista Laboratories (Spokane, WA) currently is involved in the development, research and testing of a 2-kilowatt PEM fuel cell plant for on-site power generation. Avista is supported by Washington Water Power and the Spokane Intercollegiate Research and Technology Institute (SIRTI). They also are working on development of new low cost membrane technologies, aimed at higher performance and increased reliability.

\subsubsection{Ballard Power Systems}

Ballard Power Systems has developed a PEM fuel cell for both stationary and vehicular applications, in systems that can utilize natural gas, methanol or hydrogen. Ballard has teamed with Ford and Daimler-Benz to develop vehicle engines. Having produced an engine that it considers to have a viable size/power ratio, Ballard is now working to reduce its cost and develop volume production capability. The company's stationary applications subsidiary, Ballard Generation Systems, is developing power plant applications that emphasize high quality electrical output and power security during outages. In addition, remote, recreational, and emergency power applications are planned.

\subsubsection{DCH - Technology Hydrogen Sensors and Fuel Cells}

DCH Technology, Inc. (Valencia, CA) specializes in licensing and converting new ideas and technologies into state-of-the-art products. They have developed a PEM fuel cell, through a wholly owned subsidiary, EnAble ${ }^{\mathrm{TM}}$ Fuel Cell Corporation, as well as sensors for hydrogen and other gases.

\subsubsection{Energy Partners}

Energy Partners was founded in 1990 by John H. Perry, Jr., a pioneer of fuel cell research since 1968, for research and development of PEM fuel cells. The company has delivered prototypes producing up to $10 \mathrm{~kW}$ dc. In a joint venture with Western Golf Car and Telesis Cogeneration they developed the Genesis Zero Emission Transporter, an electric, zero-emission concept vehicle, powered by hydrogen fuel, and designed to address California's emission regulations. Another vehicle, the "Gator," a utility vehicle completed in 1996, and developed with Deere \& Company as a test platform, is powered by a hydrogen-fueled $10 \mathrm{~kW}$ PEM fuel cell. This 
vehicle, normally used for lawn and grounds care, also includes a dc/ac inverter, which allows the fuel cell to power electric tools.

\subsubsection{FuelCell Energy}

FuelCell Energy (founded in 1969, headquartered in Danbury, CT) is engaged in development and commercialization of electrochemical technology for electric power generation and storage, including fuel cells and batteries. The Fuel Cell Group implements the commercialization program for FCE's MCFC power plant. "Direct Fuel Cell" (DFC) can utilize natural gas, methanol, ethanol, biogas and any other fuel that contains methane. During the past five years, FCE has operated its DFC technology in a series of successively larger demonstrations, culminating in the largest fuel cell power plant ever operated in the North America - the Santa Clara Demonstration Project. Knowledge gained from these proof-of-concept demonstrations is being applied to the next generation of DFC power plants. These $2.5 \mathrm{MW}$ power plants will use the DFC Model 9000 stack, each of which can produce 300 kilowatts.

\subsubsection{Ford Motor Company TH!NK Technology}

Ford Motor Company's TH!NK Technologies is dedicated to engineering fuel cell and battery electric vehicles. The Ford Focus FCV and Ford P2000 hydrogen fuel cell vehicles have high fuel economy, performance and comfort, together with other desirable electric vehicle attributes such as improved noise, vibration and harshness (NVH). The P2000 utilizes a stretched aluminum Ford Contour platform and the Focus FCV is based on the Ford Focus - the world's best selling compact car.

\subsubsection{Global Thermoelectric}

Global Thermoelectric (Alberta, Canada) launched its Fuel Cell Division in 1997. The division is developing next generation power products that will provide Global customers additional alternatives. The Solid Oxide Fuel Cell program is based on the development and commercialization of one of the leading SOFC technologies from the Julich Research Institute (Germany).

\subsubsection{H Power Corporation}

H Power Corp. (Belleville, NJ) was founded in 1989 with one primary business focus - PEM fuel cells. H Power has developed a line of fuel cells for use in smaller, portable applications, ranging from 30 watts to 1,000 watts, for consumer and business products and the US military. The company also has patents and is developing a range of multi-kilowatt PEM fuel cells for powering buses, trucks and cars, as well as for stationary applications to power homes and small businesses. In Q1-1998, H Power Corp. signed a \$749,000 contract with the New Jersey Department of Transportation to retrofit 65 "variable message" traffic signs with fuel-cell backup power sources. The deal is noted as the world's first commercial sale of mass-manufactured PEM fuel cell systems. 


\subsubsection{IdaTech Corp., Bend, OR}

IdaTech changed names from Northwest Power Systems in 2000. This entrepreneurial firm is dedicated to developing fuel cell systems and components for generally smaller stationary and portable electric power generation systems. Key technologies are an advanced fuel processor, capable of converting methanol, natural gas, propane, diesel and kerosene to hydrogen with less than $1 \mathrm{ppm} \mathrm{CO}$. Target markets include: portable power units, interruptible power supply (UPS) systems consumer (RV and marine) power products and home energy systems. IdaTech has a number of important alliances, including with power companies and with Syntroleum.

\subsubsection{UTC Fuel Cells}

UTC Fuel Cells, a unit of United Technologies Corp., develops and manufactures fuel cell power plants for commercial, transportation, residential and space applications. The company has been the sole supplier of fuel cells for U.S. space missions since the Apollo missions and continuing today with the Space Shuttle program. The company has manufactured a 200-kilowatt commercial fuel cell power plant, the PC25, since 1991 and delivered more than 235 to customers in 19 countries on five continents. Those power plants have together accumulated some 4.7 million hours of operation. UTC Fuel Cells is partnered with several automakers, including Hyundai and BMW, to develop fuel cells for cars, and with Irisbus and Thor Industries to develop fuel cells for buses. The company is also developing a 5-kilowatt residential fuel cell with its partner, Toshiba, which owns 10 percent of UTC Fuel Cells.

\subsubsection{Manhattan Scientifics, Inc}

Manhattan Scientifics, Inc. (Los Alamos, NM) focuses on identifying, developing, and commercializing emerging technologies on the leading edge advancement of consumer electronics. Currently, Manhattan Scientifics Inc. is developing two technologies for commercialization: a Micro-Fuel Cell ${ }^{\mathrm{TM}}$ for portable electronic devices and a holographic storage medium. Closely associated with Los Alamos National Laboratory, they have created a technology incubator.

\subsubsection{M-C Power}

M-C Power is a leading developer of MCFC technology using a patented design concept invented by the Institute of Gas Technology (IGT). Along with IGT, M-C Power has partnered with the Bechtel Group of San Francisco, CA and Stewart \& Stevenson Services, Inc. of Houston, TX. An aggressive development and demonstration program is currently underway with the goal of making MCFC a commercial reality by the year 2000. Part of the technology development program is a MCFC power plant designed to supply $250 \mathrm{KW}$ of electricity o the Naval Air Station at Miramar, CA. The plant cogenerates steam for the district heating system and includes an innovative plate-type reformer, which processes natural gas fuel.

\subsubsection{National Renewable Energy Lab (NREL), Colorado (PEM)}

NREL's web site collects information on a variety of alternative energy technologies, including electricity technologies, photovoltaics, wind energy, and renewable energy resources. The NREL Thermal Test Facility in Colorado is a research laboratory and the building is used as a research 
medium. The building is designed as an integrated system to link lighting, mechanical, water heating, and daylight design technologies in an energy-efficient combination whose effects can be measured and evaluated. A collection of articles that maps the future of hydrogen technologies, and especially their use in vehicle fuel cells, is available on Hydrogen InfoNet.

\subsubsection{Netherlands Energy Research Foundation - ECN - (MCFC, SOFC, and SPFC)}

ECN is the Netherlands' leading energy research institute, performing basic and applied research on both established and new "environmentally friendly" energy resources. ECN is developing three types of fuel cell technologies, MCFC and SOFC (both of which operate at high temperatures), and the low-temperature solid polymer fuel cell (SPFC, or PEM). The MCFC program concentrates on developing higher-performance and more robust systems. The SOFC program focuses on ceramic parts for micro- and mini-cogeneration systems. The SPFC program is working to develop an affordable methanol-fed fuel-cell system for use in vehicles.

\subsubsection{Oak Ridge National Laboratory (ORNL), Tennessee}

Among the wide-ranging programs at ORNL is its research on SOFC technologies. The goal of the research is to refine design and production of these technologies and to reduce their cost. ORNL is developing containment and insulating materials, fabrication processes for the air delivery tube and air electrode, and an activated carbon to remove sulfur compounds from natural gas. Although these technologies are being designed to work with the Westinghouse fuel cell, they are compatible with other systems.

\subsubsection{Pacific Northwest National Laboratory (PNNL), Washington (PAFC, MCFC, and SOFC)}

The Pacific Northwest National Laboratory is a facility operated by Battelle Memorial Institute primarily to provide research support for the Department of Energy.

\subsubsection{Plug Power, L.L.C.}

Plug Power, L.L.C., is the largest PEM fuel cell development company in the United States. Their goal is to develop and manufacture affordable fuel cell systems for both residential and automotive applications. In 1997, a Plug Power PEM fuel cell module was the first to successfully convert gasoline to electricity. Recently, Plug Power unveiled its proprietary Plug Power 7000, a prototype residential power generation system, with a first-time demonstration of a fuel cell able to provide a home's complete electrical needs. Commercial production of this system is underway.

\subsubsection{Proton Energy Systems}

Proton Energy Systems, Inc., (Rocky Hill, CT), was founded in 1996, dedicated to the manufacture of cost effective hydrogen-fueled PEM systems. Two main focuses include the development of industrial hydrogen generators (electrolyzers) and two-way fuel cells. Proton's HOGEN hydrogen generators make high purity, process pressure hydrogen from water and electricity for diverse uses in industry, homes, and the military. Proton's UNIGEN fuel cell systems are designed to compete with battery systems. 


\subsubsection{Rocky Mountain Institute, Colorado}

The Rocky Mountain Institute is a nonprofit research and educational foundation aimed at efficient, economic and sustainable resource use. RMI's research interests include environmentally friendly energy sources, a fuel cell-powered "hypercar," and "green" construction design. The hypercar represents RMI's hopes for geometrically increasing ("leapfrogging") benefits to accrue to vehicle owners and the environment through use of this technology.

\subsubsection{Sandia National Labs, New Mexico}

Sandia is a national security laboratory that supports the U.S. Department of Energy. In addition to involvement in some aspects of weapons development, Sandia performs energy research and development. DOE has a special agency, the Russian/American Fuel Cell Consortium (RAFCO), which fosters nuclear non-proliferation and cooperative development of fuel cell technology. The consortium currently has eight funded fuel cell projects, which focus on such applications as sealants and the mechanical properties of the electrolyte.

\subsubsection{Siemens AG, Germany}

Siemens is a German electrical engineering and electronics company with branches worldwide; its services include plant design, consulting, and various kinds of electronic products, among many others. Its energy research and development includes fossil fuel power, hydroelectric power, nuclear power, and fuel cells. Siemens' work in fuel cells has been quite secretive.

\subsubsection{Small-Scale Fuel Cell Commercialization Group, Oklahoma}

The Small-Scale Fuel Cell Commercialization Group promotes marketable fuel cells in three small-scale environments: residential, small commercial and small industrial settings. The site concentrates on the economics involved in operating and producing fuel cells powered by different fuels. The SFCCG evaluates natural gas, propane, and methanol according to a number of variables coordinated for cost and output of the service.

\subsubsection{Toyota Motor Corporation, Japan}

Toyota was one of two manufacturers who had developed a prototype of a fuel cell-powered vehicle by the summer of 1997. Toyota has developed a fuel cell that is roughly the size of a conventional gasoline engine and an alloy that holds 250 cc's of hydrogen per gram.

\subsubsection{University of California, Riverside}

The College of Engineering Center for Environmental Research and Technology at UC Riverside coordinates cooperative research on the environment among academia, the regulatory community, and industry, concentrating its research on air pollution. The Renewable Energy and Fuels group is working on three primary fuel areas: the production and evaluation of hydrogen fuel, solar energy, and renewable alcohol fuels. In addition, its Advanced Vehicle Engineering group is conducting research on fuel cells, among various other vehicle power sources. One project is for reforming diesel fuel for fuel cells in U. S. Army vehicles. Another project has 
been developing a hydrogen fuel cell-powered vehicle, which has evolved from an early golfcart model to a full-sized model based on a Ford Ranger. The Advanced Vehicle Engineering group also is working on electric power and other alternative vehicle fuels.

\subsubsection{University of California, Davis, Institute for Transportation Studies}

UC Davis's Institute for Transportation Studies performs multidisciplinary research on a variety of transportation issues, with current focuses on advanced technologies, energy and environmental aspects of transportation, and travel behavior. Included in its work on hybrid and electric-drive vehicles is testing and design of fuel cells, storage batteries, and ultracapacitors, which is conducted at the Electric Vehicle Power Systems Laboratory. A central feature of the program is its solicitation of both engineers and social scientists to collaborate in research. One study, Fuel Cell Cathode Performance Analysis, has discovered that precise control of temperature, humidity, and water management is needed to improve fuel cell design. Another project has devised an enzyme catalyst to resolve the power density problems that result from using dioxygen as a fuel.

\subsubsection{The U.S. Department Of Energy, Office of Fossil Energyl}

DOE, overall, is the largest funder of fuel cell technology in the U.S. (other branches, individual laboratories and funding recipients are listed herein). The DOE Office of Fossil Energy 2002 Budget is some $\$ 58$ million for stationary power fuel cells for distributed generation (DG) alone.

\subsubsection{Warsitz Enterprises, California}

Warsitz Enterprises is a commercial company that markets alternative energy products, primarily small fuel cells and related products. The company's products range from an electric-powered scooter called the Zappy, to an electric bicycle powered by a fuel cell, and a portable hydrogen fuel cell power generator. Other fuel cells have capacities ranging from 10 to 130 watts. Warsitz is manufacturing a small sports car powered by a hydrogen fuel cell.

\subsubsection{Siemens Westinghouse Power Corporation}

Siemens Westinghouse's SOFC internally converts natural gas or other fuels to carbon monoxide and hydrogen, without the need for external heat or steam. Cells are built around a core of ceramic tubes to increase thermal cycles, which perform reliably at their normal range of between $1000^{\circ} \mathrm{C}$ and ambient temperature and at greater than 70 percent efficiency. Siemens Westinghouse expects the SOFC to be commercially viable soon.

\subsubsection{AQMD's Technology Advancement Office}

The AQMD established the Technology Advancement Office in order to help the private sector develop low- and zero-emission technologies designed to reduce Southern California's smog. The office has funded technologies for both mobile and stationary sources of pollution, but now concentrates on vehicle technologies. 


\subsubsection{The Electric Power Research Institute (EPRI)}

EPRI is a nonprofit research consortium created by U.S. electrical utilities to advance electric power delivery and use, managing $R \& D$ and product implementation for organizations worldwide that transmit electricity. The program of EPRI's Environment Group includes an Air Quality Health and Risk Assessment component that develops models to evaluate air pollutants. The Generation Group oversees development and evaluation in the areas of Fossil Power Plants, Gas and New Coal Generation, Renewables and Hydro, and Environmental Control. Among EPRI's products is the largest phosphoric-acid fuel-cell plant for power generation.

\subsubsection{California Energy Commission (CEC)}

The CEC has sponsored testing of methanol fueled IC engine autos and other AFVs. It has also sponsored numerous studies of FCVs and fueling options.

\subsubsection{California Fuel Cell Partnership}

(see discussion preceding)

\subsubsection{National Energy Technology Laboratory}

The NETL is a federally owned and operated agency that partners with industry, universities, national laboratories, nonprofit organizations, and other government agencies to move technical research into the marketplace. NETL manages research development for the Office of Fossil Energy's fuel cell program

\subsubsection{Gas Research Institute (now the Gas Technology Institute or GTI)}

GTI coordinates R\&D and commercialization for the natural gas industry, primarily by contracting these efforts to universities, research laboratories, and industry. GTI provides support for development and testing of natural gas vehicles (NGV) technology, blast furnace gas injection for the steel industry, and natural gas reburning for industrial applications, as well as a gas turbine combustor with Solar Turbines Incorporated.

\subsubsection{Office of Fossil Energy, Department of Energy}

The DOE's Office of Fossil Energy oversees four areas, including the Government's coal, natural gas, and petroleum technology R\&D, the Strategic Petroleum Reserve, and the three commercial oil fields of the Naval Petroleum and Oil Shale Reserves. OFE has partnered with the U.S. firm ONSI Corporation, a subsidiary of the International Fuel Cells Corporation, to produce the phosphoric acid fuel cell. ONSI is producing 200-kilowatt fuel cells for commercial use, 60 of which have been sold in the U.S. One of these is operated at Riverside, CA's, Kaiser Permanente Hospital. OFE's R\&D program is in the process of developing two fuel cell technologies MCFC and SOFC. Southern California has two prototype MCFC plants, both of which have been operating successfully. 


\subsubsection{The Office of Transportation Technologies}

The Office of Transportation Technologies administers four programs: Automotive Technologies, Fuels Development, Heavy Vehicle Technologies, and Technology Utilization. Among automotive technologies, OTT has developed a Fuel Cell Program. OTT has initiated programs with General Motors and with Ford and Pentastar (a Chrysler subsidiary) to produce a light-duty PEM fuel cell vehicle program. These fuel cells have been powered by methanol and by hydrogen, but a later program with Arthur D. Little has been developing technology capable of transforming gasoline and other common transportation fuels. By 2004, the program hopes to develop marketable fuel cell propulsion systems.

\subsubsection{Solid State Energy Conversion Alliance (SECA)}

The Solid State Energy Conversion Alliance (SECA) was initiated in the fall of 1999 to encourage the development of environmentally friendly SOFC modules for use with commonly available fossil fuels at low cost. The Alliance is coordinated by the U.S. Department of Energy's NREL and PNNL. Commercial developers, universities, government agencies, and other national laboratories will all participate in the Alliance to produce commercial costeffective prototypes for generating power from fossil fuels.

\subsubsection{Fuel Cell Auto Standards}

The U.S. DOE is reported to have awarded the Society of Automotive Engineers (SAE) about $\$ 700,000$ over 2002-2003 in a cost-sharing program to develop codes and standards for fuel cell vehicles. As an example of the issues perceived in fuel cells making a transition into the marketplace, the SAE has established a Fuel Cell Standards Committee, including working groups on emissions, interface, performance, reliability, recyclability, safety and terminology. Participants will be auto manufacturers and subsystem suppliers, fuel cell developers and manufacturers, energy suppliers, government agencies and trade and professional associations with interests in fuel cells.

\subsection{FUEL CELL FUEL USE OUTLOOK}

\subsubsection{FT Diesel}

The limited role of FT diesel in FC applications would be to supplement as a blend stock or substitute for low sulfur grades of diesel currently being considered and researched as a strategic option for use in FCVs.

Research is being carried out by a number of organizations on reforming low sulfur diesel for use in FCVs, primarily because, together with ultra clean gasoline, and until petroleum resources begin to dwindle, they are seen to be attractive possible options for more rapidly and economically transitioning the fuel distribution and refueling station infrastructure to support FCVs. Low sulfur diesel ( $<1 \mathrm{ppm}$ sulfur) can be reformed with less coking than gasoline because of lower aromatics content, but its reforming requires a somewhat higher temperature.

Including FT diesel would serve to extend the lifetime and keep the costs down for such a strategy if it were implemented. Unlike gasoline, for which the analogous FT distillate has lower 
than adequate octane, FT diesel range distillates have an enhanced cetane number for blending to achieve ultra low sulfur diesel fuels or as a neat diesel fuel substitute.

FT diesel or blends could be shared among conventional ICE, hybrid and FC vehicles, thus providing a great advantage for fuel suppliers. The only downside of FT diesel is its roughly 6 percent lower density than conventional diesel, which, netted against about 3 percent higher value by weight, gives it about 3 percent net lower heating value by volume. This is an issue, though probably not an insurmountable impediment in conventional diesel engine fueling, but should not be a problem in an FC (non-mechanical) system designed to accommodate this property. Of course the problem is reduced, perhaps to insignificance, when blends are made of FT with conventional diesel.

Diesel fuel is used only to a minor extent in passenger automobiles in the U.S., where gasoline is dominant, but is used about equally with gasoline in Europe, and is used about 2 to 1 versus gasoline in passenger cars in Asia.

An FT diesel product (Blue Star S-2 diesel) is reported being tested in a reformer system with flow sufficient to support a five-kW fuel cell stack.

IdaTech Corp. (which changed names from Northwest Power Systems in 2000) claimed in a release in early 2000 that synthetic FT fuels made by Syntroleum performed as well or better than conventional fuels in tests in their FC fuel processor (which could be used with several different types of FCs, but would primarily serve PEMs). This processor consists of a steam reformer and a hydrogen purifier. IdaTech characterizes this system as fuel-neutral. The hydrogen purification is in two stages: a hydrogen-selective membrane (typically at 600 to $1000^{\circ} \mathrm{F}$ for hydrogen) as the first stage provides bulk separation of hydrogen from the crude reformate. A catalytic polishing step (a catalytic methanation bed) as the second stage removes trace levels of $\mathrm{CO}$ and $\mathrm{CO}_{2}$. The hydrogen-selective membrane is a proprietary palladium alloy, which is not poisoned by sulfur (an advantage if sulfur resistant reformer catalysts are developed in the future). The first and second stages of the hydrogen purifier are thermally integrated with the steam-reformer region of the fuel processor.

In short-term tests, it was claimed Syntroleum FT diesel fuel yielded sufficient hydrogen equivalent of $9.05 \mathrm{kWh}$ per gallon. (Syntroleum gasoline yielded the hydrogen equivalent of $9.68 \mathrm{kWh}$ per gallon.) For reference, under comparable conditions, conventional petroleumderived diesel fuel yields the hydrogen equivalent $8.67 \mathrm{kWh}$ per gallon. At equivalent scale, a commercial diesel generator set $(4.8 \mathrm{~kW}$ maximum continuous, operating at half load) will produce about $6.9 \mathrm{kWh}$ of electricity per gallon of fuel, according to manufacturers' information.

There is no indication in the company's information that further action to demonstrate or commercialize Syntroleum fuel use in fuel cells was made by IdaTech.

\subsubsection{FT Naphtha}

FT Naphtha is a distillate in the volatility range of gasoline, but it is very paraffinic and thus has a low octane rating. Octane rating has no relevance for fuel fed to a reformer to make hydrogen 
for FCs. Similar to FT distillates in the diesel range, its application in FCs would be to supplement as a blend stock or substitute for low sulfur, low octane grades of gasoline currently being considered and researched as a strategic option for use in FCVs.

The research and development being carried out for reforming hydrocarbons for FCV systems often includes diesel and ultra clean gasoline such as future CARB Phase III gasoline with 20 ppm sulfur. However, unlike such an advanced gasoline that will have normal octane ratings, and unlike FT diesel, FT naphtha could not be shared among conventional ICE, hybrid and fuel cell vehicles, thus eliminating a great advantage for fuel suppliers. Refiners would have to process FT naphtha by such means as isomerization to raise its octane rating to sufficient to make the gasoline co-marketable for spark-ignited ICEs that are expected to continue to dominate the auto market in the U.S. for the next 15 to 20 years and throughout any transition period to FVCs.

One of the challenges for reforming current types of petroleum gasoline with high octane ratings is for a reformer to process aromatics contained without coking and to tolerate gasoline's content of sulfur and other potential catalyst poisons. In reforming fuels for FCs, reforming lighter hydrocarbons such as natural gas, methanol and gasoline has received the most attention. PEM FCs do not require pure $\mathrm{H}_{2}$ feed. Dilution of the $\mathrm{H}_{2}$ with inert gases such as nitrogen, water vapor and $\mathrm{CO}_{2}$ is permissible. However sulfur, $\mathrm{CO}$, chlorine and ammonia act as poisons and must be mitigated. A "conventional approach" has evolved using catalytic reactors based on autothermal reforming, water gas shift and preferential $\mathrm{CO}$ oxidation reactions. However, variations or less conventional approaches have also been proposed, based on objectives for system improvement including cost, efficiency, volume, and the potential for system simplification. The alternatives considered include several for sulfur removal, plasma reforming, membrane separations, membrane reactors, methanation and adsorption.

Some refiners have proposed producing "clean gasoline" (with less than 20 ppm sulfur) and less of other contaminants for use in fuel cells. For this, petroleum naphtha cuts would need to be the main component. Since the difficult and expensive processing to make required octane levels would be eliminated, refining resources could be spent on achieving less than 1-ppm sulfur. For these reasons, FT naphtha would fit well. Again, however, without sufficient octane, the attractive goal of shared fuel uses among ICEs, hybrids and FCVs in a transition would have to be abandoned, and additional infrastructure costs would begin to approach those of other FC fuel options such as methanol.

Alternatively, International Fuel Cells (IFC), which has an aggressive program underway to develop PEM fuel cells for transportation markets, claims it has developed an integrated fuel processing systems that desulfurizes commercially available gasoline fuel to less than $50 \mathrm{ppb}$. The efficiency of the fuel processing system is claimed to be about 70 percent. They report that this fuel processor was integrated into a $50 \mathrm{~kW}$ fuel cell power plant that demonstrated an efficiency of 33 percent. IFC expects that additional development of fuel processing catalysts will reduce the size of these power plants, enabling their demonstration in automobiles. 


\subsubsection{Methanol}

Methanol is being strongly promoted for auto fuel cell use by the Methanol Institute, Methanex, Statoil and other producers, and by some partisans in government, the auto industry and among technology developers. Methanol has high technical potential in many ways to dominate the fuel cell auto market, but as has been stated throughout this report, its introduction and use would represent a major paradigm shift and a challenge for suppliers, distributors, regulators, and consumers. Methanol's challenges are not mainly technological, but are more practical in nature. There are still some technical development challenges to be overcome, and methanol's low energy density, though less an impediment in FCs, where it has higher efficiency than in ICEs, still presents practical problems for private automobile range.

Methanol may find solid markets in fleets, where professionals will do the refueling, and in locations where a chemical methanol market infrastructure already exists. However, there is no way to predict, even if the technical challenges are overcome soon, whether methanol's practical, infrastructure, environmental, health and safety challenges can ever be overcome to allow it to realize this potential for the broader market. Some would argue that even if carrying hydrogen on board an auto were to be made more practical by some technical breakthroughs, methanol would still be an attractive fuel. Against this view is that with hydrogen, fuel processing (though comparatively least severe for methanol than for other fuels) would be eliminated, greatly simplifying the on-board system, auto emissions would be absolutely minimized and efficiency would be maximized. Hydrogen as an energy carrier has some safety problems, but few if any environmental and health issues. If effective and practical means to transport and carry hydrogen on-board are found in the next two decades, this will probably doom methanol as a vehicle fuel.

However, Nexant has estimated the potential maximum methanol market volumes for several potentially more promising markets for DMFCs and other methanol fuel cells in the applications of portable electronics and auxiliary power units (APUs) for heavy duty trucks. Considerable research is being carried out to develop fuel cells suitable for a number of small use markets such as for portable electronics and as vehicle APUs. Each of these markets was examined to determine the maximum potential demand for methanol. Estimates are based on $100 \%$ market penetration, and a range of demand was considered based on current and anticipated efficiencies of methanol fuel cells.

To estimate the potential methanol demand for the portable electronics market, two primary mass market technologies were considered, cell phones and laptop computers. Each would be based on utilizing neat methanol fuel, or in water solutions, in cartridges. In addition to these two technologies, there many other small portable electronic products are in common use to consider, including portable CD players, palm computers, and pagers, as well as hand and garden tools, vacuum cleaners, and other potential small power applications. However, none of these other uses have the combination of volume, intensity of use, market turnover and growth, and known demographics that makes cell phones and laptops so relevant.

Based on published estimates by the Information Technology business consultant, Gartner, Inc., and other sources, the current global sales of cell phones are about 400 million per year. If we 
assume a 2-year average turnover for cell phones, this implies a population of 800 million cell phones.

Cell phones are becoming "convergent devices", in which voice communications, paging, Internet access, banking functions, stock quotes, entertainment, and other functions are being combined, leading to greater power use. The greater potential power use requirements of these devices will raise the requirements for fuel cell power packs. As a result, Direct Methanol Fuel Cells (DMFCs) must be able to deliver sufficient power density to meet this increased demand.

If a typical digital cell phone is kept on standby most of each day and actively used about 200 hours per year, then it will require about 60,000 milliamp hours (mAh) of electricity to run per year. Based on current best performance of DMFCs, this would require about 1160 milliliters (ml) of methanol per year. At projected future performance rates, the requirement would drop to about $124 \mathrm{ml}$ per year. At $100 \%$ market penetration of the current population of cell phones operated this way, the global annual demand generated for methanol would be 750,000 tons with the present efficiency, and 80,350 tons at a projected future efficiency. At the present developmental efficiencies, it is unlikely that the technology would achieve any significant market penetration, except perhaps for specialized applications, such as military.

In addition, there are a number of regulatory barriers, due to the toxic classification of methanol, to the widespread use of methanol at the retail level. Also being developed as alternatives to methanol-based micro-power fuel cells are competitive ethanol-based systems (e.g., by Medis Technologies, NYC, NY). U.S. Department of Transportation regulations currently preclude concentrated methanol to be carried by passengers onto commercial air flights. This regulation would need to be changed to make micro-power DMFCs viable in the market. Further, even if the regulation were to be changed, since methanol is otherwise regulated as a hazardous substance, corporate attorneys of companies whose electronic devices may incorporate DMFCs would likely oppose their use. Medis' ethanol-based system would not have these problems, and in fact, Medis chose to avoid methanol for these very reasons.

Our estimate of the current global sales of laptop computers, also based on published estimates by Gartner, Inc. and other sources, is for about 120 million per year. If we assume a 4-year average turnover for laptops, this implies a population of 480 million laptops worldwide.

A typical laptop today has a battery with a working capacity of 2.5 hours at 3.36 Amps. Estimated typical monthly demand is about $8400 \mathrm{mAh}$ per month under typical battery usage patterns (i.e., infrequent for most users), or 100,800 mAh per year. This represents 1,940 ml of methanol consumption per year at present DMFC best developmental efficiency, and $208 \mathrm{ml}$ per year at projected future efficiency. At $100 \%$ penetration of the estimated global laptop population of 480 million, this implies a potential demand of 754,000 tons per year or 80,800 tons, respectively. DMFCs for laptops would face similar regulatory and corporate risk mitigation challenges as for cell phones.

Another type of potential early application of fuel cells in vehicles is serving as APUs. Onboard power requirements (e.g., for power steering, pumping, valve actuation, HVAC, etc.) are 
increasing as a fraction of propulsion power for both cars and trucks. Alternators running parasitically on the engine currently provide this power. It has been estimated by the U.S. Department of Energy that a typical Class 8 heavy-duty truck could require a continuous auxiliary power supply of 2-10 kW (including engine needs and cab amenities), and cars, of up to $5 \mathrm{~kW}$ in the future.

The National Energy Technology Laboratory (NETL) has estimated (1) that, of the 2.1 million Class 8 trucks in the U.S., about 311,000 have overnight routes, and this makes them candidates for APU systems. It is further estimated by NETL that the diesel fuel saved by using fuel cell APUs in all of these would be about 419 million gal/yr. Assuming that at typical estimates of future methanol efficiencies in large-scale fuel cells as appear in current published reports by DOE, California state agencies, and others, it will take 1.42 gallons of methanol to replace a gallon of diesel. This implies a demand of 1.8 million tons/year of methanol for truck APUs, assuming $100 \%$ penetration.

Among issues to consider is that potential competition to methanol use in APUs is growing from Solid Oxide Fuel Cells (SOFCs). Key developers and supporters include Delphi Automotive Systems, the leading aftermarket and automotive components manufacturer in the world, BMW, several U.S. DOE national laboratories, and other private corporations. They make strong and credible arguments for SOFCs (versus PEMs or DMFCs) use in APUs, and are promoting use of SOFCs with naphtha, CNG, propane, or ethanol, all less problematic and already more widely available than methanol. Some of the advantages perceived for SOFCs are their potential for thermal integration in the vehicle to gain higher fuel efficiency, greater system simplicity, wider latitude in exploiting different fuels, and less sensitivity to fuel impurities. These advantages would tend to offset SOFCs' disadvantages relative to PEMs such as longer startup time and greater bulk and weight. However, these disadvantages may be less critical for an APU than for primary vehicle propulsion.

Note (1) Fuel Cells - Presentation - Dr. Mark C. Williams, National Energy Technology Laboratory (NETL), U.S. Department of Energy, Strategic Center for Natural Gas, pg. 25

\subsection{STATIONARY FUEL CELL APPLICATIONS}

\subsubsection{FT Diesel}

Potential stationary applications of fuel cells include utility, industrial, commercial, institutional, military and residential electric power generation and combined heat and power (CHP) systems for any of these sectors of the economy. Locations for these applications can be centralized, distributed within a societal infrastructure (either linked with, or independent from the grid), or in remote locations such as mines, oil platforms, communications sites, along roads or on other transportation infrastructure, battlefields, etc.

The Electric Power Research Institute (EPRI) defines distributed generation (DG) as the "integrated or stand-alone use of small modular resources by utilities, utility customers, and third parties (such as independent power producers) in applications that benefit the electric system, specific customers, or both." DG is essentially synonymous with onsite generation and is often 
linked with cogeneration, or the concept of CHP generation. DG and CHP are receiving much support from the federal DOE and state energy agencies such as NYSERDA in New York, the Energy Center of Wisconsin and the California Energy Commission (CEC). Figure 4.14, adapted from an analysis by the Energy Center of Wisconsin, indicates the targeted and relevant market sectors / applications of the various leading fuel cell technologies being developed.

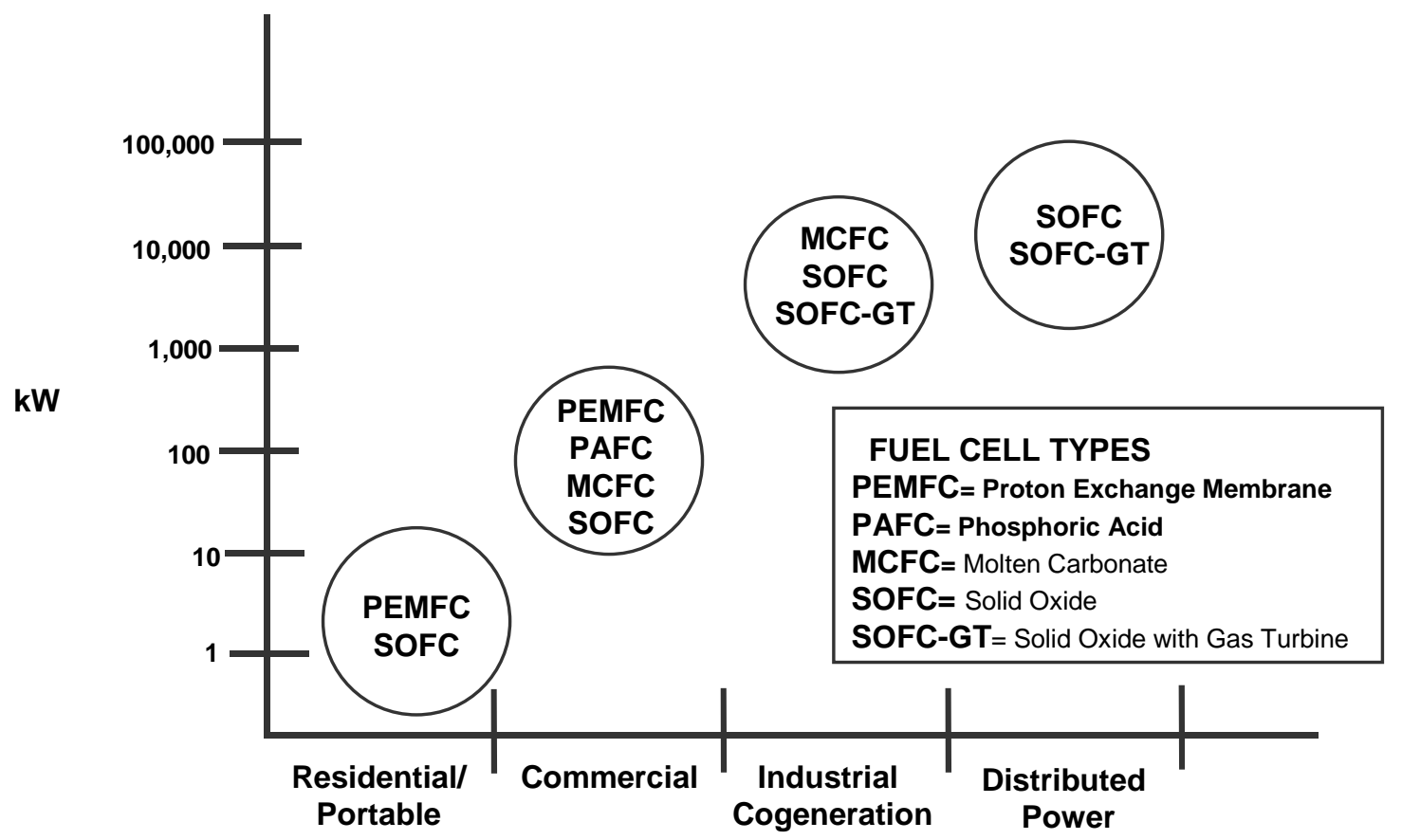

Figure 4.14 Fuel Cell Distributed Generation Market Sectors

All of these can (and would prefer to) run on hydrogen. For all of these FCs, sulfur and chlorine compounds are poisons, so any fuel with these compounds present would be problematic and/or must be treated by guard beds or the like to protect the cells. Methane, or natural gas, is not directly usable in PEMFC or PAFC, but can be used essentially directly as fuel in MCFC and SOFC technologies, without reforming to hydrogen, as can methanol. Methanol can also be used directly without reforming in the emerging DMFC (PEMFC) technology, which is primarily targeted for very small power applications.

Fuel efficiency is important in selecting a stationary power technology for the DG market and for central generation applications. Figure 4.15, adapted from information provided by FuelCell Energy, Inc. (Danbury, CT) shows the relative efficiencies of these various fuel cell and competing conventional technologies for power generation at various scales in the range from residential and small commercial $(0.01 \mathrm{MW}$ or $10 \mathrm{~kW})$ to $1000 \mathrm{MW}$ central stations indicates that MCFC and SOFC combined with power generating turbine expanders used to recover system waste heat can achieve electric generation fuel efficiencies approaching 80 percent, roughly double that of current base-load power plants. 


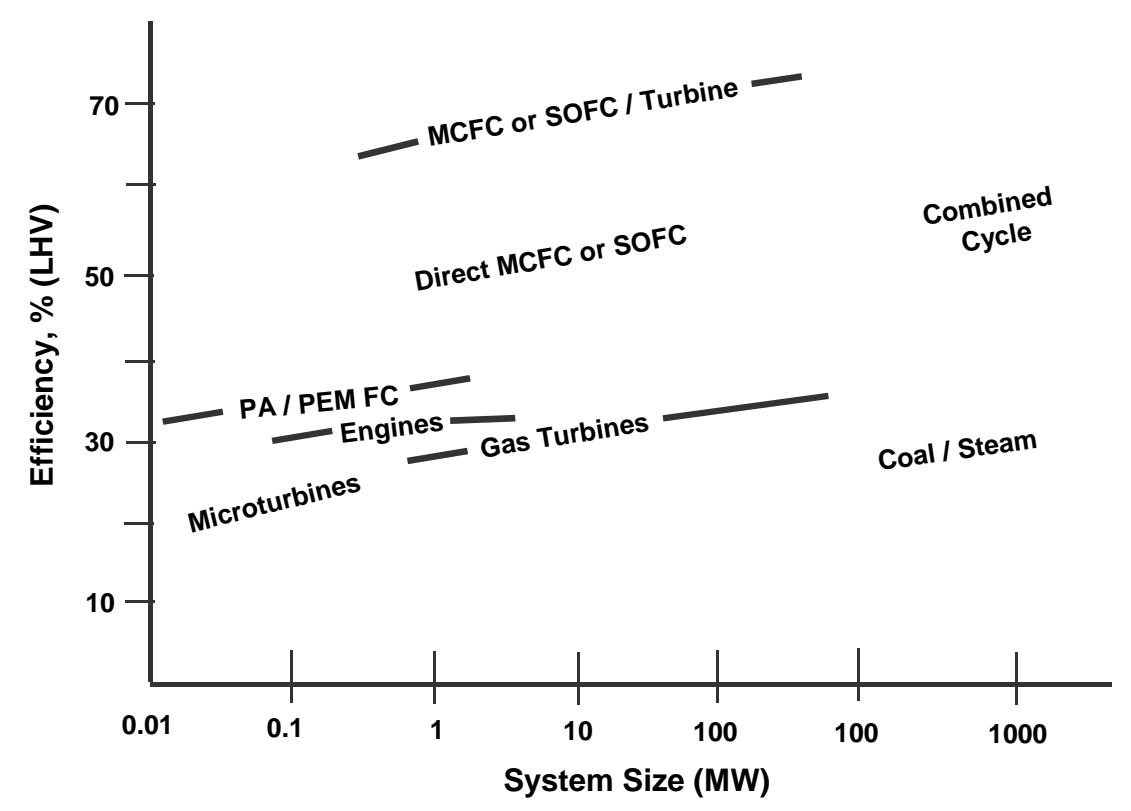

Figure 4.13 Comparative Efficiencies of Electric Power Generators

Currently, PAFC and MCFC appear to have the developmental and commercial lead for larger scale DG applications. Over 250 PAFC units, 5 MCFC units and several SOFC units have been operating around the world, with many hundreds of thousands of hours of operation. PEMFC and PEM-DMFC operating experience for DG is still at only a fraction of this total.

For large-scale power applications (whether centralized utility systems or DG), which will be operated and maintained by professionals, the qualities of quick startup, and low temperature operation, weight and bulk are of minimal concern (in contrast to PEMFC's advantages in vehicle and portable applications). Power generation systems, including most DG systems, can usually be connected directly to a gas pipeline distribution system. For these applications, efficiency of fuel utilization, whether for power production only or CHP is the most important criterion. The direct methane or methanol fueling of MCFC (or SOFC, which is less commercially demonstrated and may have higher capital cost) appears to have efficiency advantages over all other fuel cell and fuel-based DG technologies (i.e., excluding solar, geothermal, hydro, etc.).

The efficiencies of methane versus methanol fuel in the high temperature MCFC and SOFC technologies are roughly the same, although capital costs may be somewhat different for dedicated production of units. Fuel Cell Energy, the leading developer of MCFC, is primarily developing systems to utilize methane, but is also developing and demonstrating methanol and LPG-fueled versions of their technology.

In developed countries, most of the population has access to the electrical grid and many also are served by the natural gas distribution system. However, the number of people without ready access to electricity has been estimated to be about 2 billion, or 33 percent of the total world population, and FCs may be candidates for power generation. Many of these are not served with 
natural gas, so these would be candidates for fuel cells utilizing liquid fuels. It is less likely that population served now neither by electricity nor natural gas would be in any position but the last to participate in a "hydrogen economy". In these countries, methanol may serve well for DG applications.

In most stationary applications, commercialization will be far less dependent than with road vehicles on achieving mass-market hegemony and resolving fuel distribution logistics to fix on one or very few options (e. a "winner takes all" scenario). In stationary power generation today, many different fuels and conversion and generation technologies exist simultaneously. The technological challenges are also less severe than for vehicle fuel cells. There is less concern in stationary systems for size, weight and complexity than with automobiles. Because they are not mobile, and will often be indoors, these systems are less likely to be subject to the extremes and rapid changes in temperature, altitude and humidity to which vehicles can be subject.

Notwithstanding the many benefits of FCs, whether and how they may ultimately achieve widespread commercial status depends primarily on the capital costs of the FC system. To be considered a viable option in a broad field of options, they need to be cost competitive with both conventional electricity generation and CHP technologies, such as ICEs and gas turbines, as well as with emerging distributed generation technologies, such as microturbines, photovoltaic solar cells and wind turbines. Table 4.10 summarizes the capital costs of fuel cells compared to other conventional and emerging electricity generation options, each indicated as to whether or not it potentially can serve in a CHP application.

Table 4.10 Fuel Cells Compared to Other Stationary Energy Technologies

\begin{tabular}{|l|c|c|l|}
\hline \multicolumn{1}{|c|}{ Generation Technology } & $\begin{array}{c}\text { Typical Installed } \\
\text { Capital Cost } \\
\text { (US\$ per kilowatt) }\end{array}$ & $\begin{array}{c}\text { CHP } \\
\text { Capability }\end{array}$ & \multicolumn{1}{|c|}{$\begin{array}{c}\text { Air } \\
\text { Emissions }\end{array}$} \\
\hline Gas Turbine & 700 to 900 & Yes & Small \\
\hline Microturbine & 450 to 1000 & Yes & Small \\
\hline Steam Turbine & 800 to 1000 & Yes & Moderate \\
\hline Wind Turbine & 800 to 1300 & No & None \\
\hline Natural Gas IC Engine & 200 to 350 & Yes & Moderate \\
\hline Fuel Cell & 3700 to 5000 & No & Negligible \\
\hline Solar Photovoltaic (PV) & over 5000 & & \\
\hline \multicolumn{2}{|l|}{ Source: Northeast Regional Biomass Program, Xenergy report, 2002} \\
\hline
\end{tabular}

Another key mode of application is for distributed generation, whether or not CHP is a need or even a possibility, in which a broader set of concerns and performance criteria must be assessed. Table 4.11 compares the attributes of FC and other energy technologies in CHP applications. 


\section{Table 4.11 Energy Technologies in CHP Applications}

\begin{tabular}{|c|c|c|c|c|c|}
\hline & IC engine & Micro-turbine & $\begin{array}{l}\text { Photo- } \\
\text { voltaics }\end{array}$ & Wind Turbine & Fuel Cells \\
\hline Easily Dispatched? & Yes & Yes & No & No & Yes \\
\hline Capacity Range & 50 kW-5 MW & $25 \mathrm{~kW}-25 \mathrm{MW}$ & $1 \mathrm{~kW}-1 \mathrm{MW}$ & $10 \mathrm{~kW}-1 \mathrm{MW}$ & $200 \mathrm{~kW}-2 \mathrm{MW}$ \\
\hline Efficiency -\% & 35 & $29-42$ & $6-19$ & 25 & $40-57$ \\
\hline Capital Cost (\$/kW) & $200-350$ & $450-1000$ & 6,600 & 1,000 & $3,700-5,000$ \\
\hline O\&M Cost $(\$ / k W)$ & 0.01 & $.005-.0065$ & $.001-.004$ & .01 & .0017 \\
\hline $\begin{array}{l}\text { NOx (lb/mm Btu)- nat. } \\
\text { gas }\end{array}$ & 0.3 & 0.10 & $\mathrm{~N} / \mathrm{A}$ & $\mathrm{N} / \mathrm{A}$ & $0.003-0.02$ \\
\hline NOx (lb/mm Btu) -oil & 3.7 & 0.17 & $\mathrm{~N} / \mathrm{A}$ & N/A & $\mathrm{N} / \mathrm{A}$ \\
\hline Technology status & Commercial & Commercial & Commercial & Commercial & Commercial \\
\hline
\end{tabular}

Obviously wind turbines are not universally applicable; their practicality and economic feasibility depends on local meteorological conditions. Gas turbines are often employed with heat recovery steam generators (HRSGs) in combined cycle gas turbine/steam turbine systems, and are fueled most often with natural gas, but also with liquid fuels. Such systems are the most common choice today for large and medium size independent power and steam-host cogeneration projects. Microturbines are becoming popular for exploiting fuels of opportunity such as process waste gases, biodigester gas, landfill gas, etc., as well as for DG systems using purchased conventional fuels, primarily natural gas. The emissions from fuel burning to generate the steam for a steam turbine depend on the fuel, burner technologies and stack controls. Gas turbines are being designed with very low emission combustion cans, but still may require stack controls in some air quality management areas.

\subsubsection{FT Diesel}

There is little evidence of interest in using FT diesel for stationary power applications. One possible opportunity would occur if FT diesel and/or FT diesel blends became commercially developed for the transportation fuel cell market. However, if only FT diesel ultra low sulfur blends become commercialized for IC on-road engine diesel use, the sulfur levels of up $15 \mathrm{ppm}$ that would be allowed for this application would probably be too high (requiring aggressive sulfur removal in fuel processing) to make such blends attractive for fuel cell stationary power generation. Also, competitively there are too many low cost, logistically attractive optional fuels being championed for this market to allow FT diesel to compete, including natural gas (championed by Institute of Gas Technology, the American Gas Association and individual gas companies), LPG (championed by the LPG industry), and landfill and biodigestor gas (NYPA, NYSERDA, DOE, EPA and other government agencies). Further, using a liquid fuel in the diesel range is counter to the trend of conversion of residential, commercial, institutional and industrial heat and energy systems from distillate fuels to natural gas, on the basis of perceived advantages in price, convenience, environmental performance and supply security. 
There is not a significant role projected for FT diesel in the stationary power market in the U.S., except perhaps in some niche areas (such as for uninterruptible power systems [UPS]), and wherever diesel FT may penetrate transportation markets. However, in Europe, Asia and other areas where diesel is more prevalent than gasoline as a transportation fuel, and there is less natural gas local distribution infrastructure, FT diesel may compete well with methanol and other candidate liquids for fueling stationary FCs. This would be further enabled if higher temperature FC technologies, such as MCFCs and SOFCs are more aggressively developed for the stationary market, and especially if SOFCs gain a competitive role in transportation, such as for large vehicles (buses and trucks), which will allow synergy in lower cost manufacturing.

\subsubsection{FT Naphtha}

FT naphtha is less likely to be used as a transportation fuel and therefore is even less likely than FT diesel to a find a place in the stationary power market. In the U.S., there will be a need to share a market with electric/ICE hybrids and other spark-ignited ICE cars for 15 to 20 years into the future at least. In such a scenario, if FT naphtha is to gain a role as a gasoline supplement or replacement, FT liquids producers or refiners will have to isomerize to build octane to serve the shared market. Such processing of FT naphtha will likely make it too expensive to compete at all in the stationary power market. It would have no advantages except leveraging the gasoline distribution system in the U.S., but, because of higher volatility, it would have safety issues for residential and commercial fuel storage and use.

\subsubsection{Methanol}

Methanol is the GTL fuel with the greatest, though still limited, potential to gain some market share in stationary power production because of its technical advantages in ease of reforming over natural gas and other hydrocarbons.

There is little evidence that methanol is a development priority for residential and light commercial stationary heat and power, and its safety and health issues may be untenable in the context of household and commercial storage and handling. For CHP applications, the waste heat involved in reforming hydrocarbons at a higher temperature than for methanol may not be a disadvantage.

Neat and near-neat methanol are excellent fuels for gas turbines and boilers because methanol's low flame luminosity and combustion temperature reduces NOx formation, and it has no sulfur emissions and negligible particulate emissions, comparable with natural gas. Except for natural gas or hydrogen, it is the cleanest burning fuel for industrial purposes. Only increased fuel storage and modified burners with respect to nozzle designs would be required to accommodate methanol's lower energy density, lower viscosity, low flash point and wide flammability range in converting to methanol from other liquid turbine and boiler fuels such as middle distillate. Also, care in infrastructure design and management would be required to prevent contamination with salt water, from which the sodium would cause corrosion of fuel nozzles and turbine blades.

Methanol can also be used in utility boilers with natural gas or distillate fuels in a mode of overfiring or staged combustion to reduce NOx emissions. 


\subsubsection{Conclusions}

- The commercialization and widespread use of fuel cell vehicles is not likely to occur during the next 10-15 years, especially if more stringent fuel economy standards are mandated or encouraged via tax credits, or other incentives and subsidies.

- The most popular hybrid-electric vehicle models are initially likely to follow current preferences and be gasoline-fueled in the U.S. and diesel-fueled in Europe. These hybrid vehicles will not necessarily require the use of fuels with radically more stringent quality requirements

- The preferred fuel for initial fuel cell vehicle models has not been determined, but if technical advantages weigh heavily in the determination, then it is more likely that methanol (because of its lead in DMFCs and its higher efficiency in reforming), rather than ultra clean hydrocarbon fuels such as FT naphtha or naphtha, will be selected for this purpose

- Neither the introduction of hybrid vehicles or fuel cell vehicles is expected to result in major increases in the demand for FT diesel as a fuel during the next 10-15 years

- For stationary applications, including both central and DG and CHP systems, reforming natural gas has few of the issues or drawbacks that mobile and vehicle applications have, and direct use is possible with the high temperature MCFC and SOFC technologies. In the populated areas within the U.S., Europe and Japan, which contain a large part of the global power and heating demand, the natural gas distribution infrastructure is generally well developed. Natural gas is expected be available to these regions from various conventional and some new sources for the near future, transported to market centers by pipeline and LNG infrastructures

- Even if DMFC fuel cells were to be widely commercialized for consumer small electronics such as cell phones and laptops despite the regulatory and corporate risk challenges, their methanol demands would be relatively small.

- SOFCs, which are targeted for a wide range of fuel use in stationary and vehicle auxiliary power applications, appear to have a better long-term chance of success than methanolfueled PEMs or DMFCs

It is not expected that either methanol or FT naphtha will be significantly used in fuel cells for stationary power or CHP generation in the U.S. in the near future 
The primary objective of this section is to define the technical issues, status and potential for Ultra Clean Fuels (UCFs), defined as methanol, FT naphtha and FT diesel, to be used as vehicle fuels in the transportation sector. The timeframe considered is from the current period to about 2015. However, where appropriate, longer-term issues are addressed if they are believed to impact short-term developments.

The primary conclusions from this analysis are summarized below.

\subsection{KEY DEVELOPMENTS IN CONVENTIONAL VEHICLE TECHNOLOGY}

The primary drivers for the potential development of methanol and FT naphtha or diesel as UCFs are:

- Requirements for refiners to drastically reduce the sulfur content of diesel fuel to enable use of particulate traps and catalytic converters to achieve significant reductions in fine particulate (PM or soot) and NOx emissions. The recent and anticipated technical development of these emission after-treatment devices has prompted the U.S. and the European Union to adopt emission standards that are designed to force the use of these devices on heavy-duty diesel engines.

- The desire among vehicle manufacturers to begin early development and demonstration of technical and market approaches to cope with the expected eventual decline of petroleum supplies for fueling vehicles in the longer term, along with:

- Increasing levels of sulfur in crude oil supplies in the near term

○ The greater abundance of natural gas supplies, including "stranded gas"

- These drivers have led the manufacturers of gasoline engine passenger automobiles for the North American market, along with government agencies and other stakeholders, to focus on developing gasoline-electric hybrids for the short term and fuel cell vehicles and auxiliary power units (APUs) for the long term. In addition to the need for cab amenities in long-haul trucks, auxiliary (non-propulsion) power requirements, including many systems that in the past were manual or mechanically linked to the engine, are increasing in proportion to propulsion power in conventional trucks and automobiles.

- Manufacturers of heavy-duty diesel engines have focused on fundamental internal engine design modifications, primarily in fuel injection and combustion configurations, to achieve lower NOx and PM emissions, in addition to add-on particulate traps and catalytic converters. APUs are also of great interest in these vehicles. 


\subsubsection{Fuel Cell Technology for Vehicle Propulsion}

Most developers of fuel cell vehicles (FCVs) and FC propulsion systems have focused on lowtemperature, lightweight, fast response, but chemically sensitive Polymer Electrolyte Membrane (PEM) technology. PEM requires complex fuel processing systems to utilize hydrocarbon and oxygenate fuels, with the exception of the Direct Methanol Fuel Cell (DMFC), which is being pursued by some developers and is supported by the methanol industry.

Solid Oxide Fuel Cells (SOFCs) dominate in the shorter-term development of APUs and, as suggested in Figure 5.1, are potentially applicable also for longer-term use in vehicle propulsion. They are similar to PEMs in their modularity, simplicity and on-board robustness for vehicle use. However, their disadvantage is longer start-up and response time. High-temperature SOFCs have greater potential flexibility to use hydrocarbon and oxygenated fuels without separate fuel processing, and their waste heat can potentially be utilized in the automobile system.

Figure 5.1 FC Development Status for Target Applications

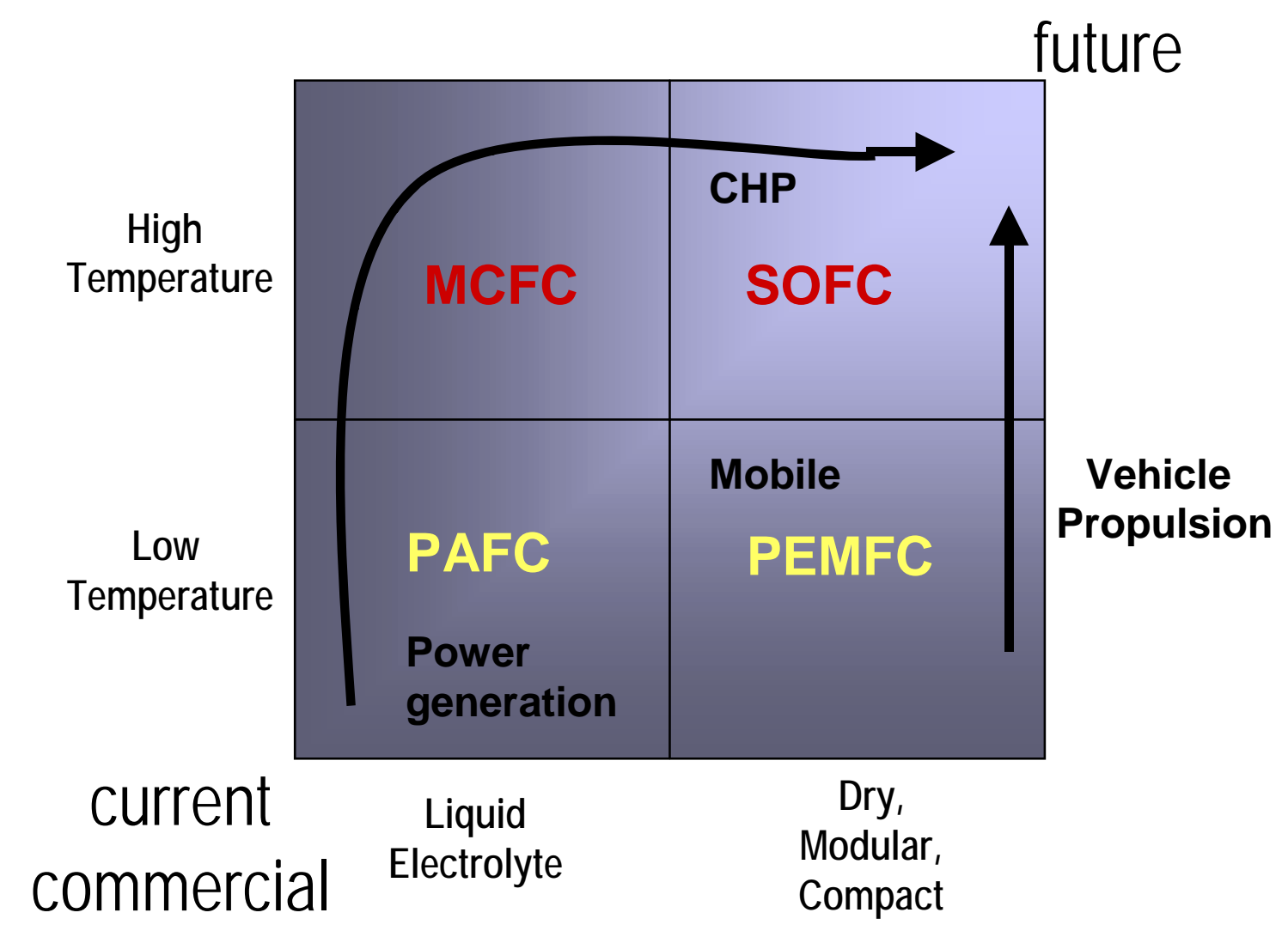

- Despite tremendous on-going development efforts, Nexant does not expect FCVs to achieve significant commercial market share within the next 10-20 years. Hybrid gasoline-electric or diesel-electric automobiles will strongly compete with FCVs, especially if more stringent 
fuel economy standards are mandated or encouraged via tax credits, or other incentives and subsidies.

- The most popular ICE hybrid-electric vehicle models are initially likely to follow current preferences and be gasoline-fueled in the U.S. and diesel-fueled in Europe. These hybrid vehicles will not necessarily require the use of fuels with radically more stringent quality requirements

\subsubsection{Fuel Cells for Non-vehicle Uses}

Non-vehicle fuel cell developments are expected to be synergistic with vehicle fuel cells. There are great incentives to develop stationary fuel cells for residential, commercial, industrial and military distributed generation (DG), remote power, or mobile power applications. For mobile applications like small electronics and in battlefield systems, qualities similar to those for automobiles are sought and infrastructure is less of a concern, PEMs, and especially DMFCs, may be attractive. However, for most DG markets, where natural gas will predominate as a fuel, the higher-temperature, potentially more robust SOFC and Molten Carbonate (MCFC) technologies, as well as the moderate-temperature Phosphoric Acid (PAFC) technology, are more likely to prevail in many applications.

- For stationary applications, including both central and DG and combined heat and power (CHP) systems, reforming natural gas has few of the issues or drawbacks that mobile and vehicle applications have, and direct use is possible with the high temperature MCFC and SOFC technologies. In the populated areas within the U.S., Europe and Japan, which contain a large part of the global power and heating demand, the natural gas distribution infrastructure is generally well developed. Natural gas is expected be available to these regions from various conventional and some new sources for the near future, transported to market centers by pipeline and LNG infrastructures

- SOFCs, which are targeted for a wide range of fuel use in stationary and vehicle auxiliary power applications, appear to have a better long-term chance of success than methanolfueled PEMs or DMFCs

- It is not expected that either methanol or FT naphtha will be significantly used in fuel cells for stationary power or CHP generation in the U.S. in the near future

\subsubsection{FT Diesel as a Vehicle Fuel - Conventional Engines}

- Nexant believes that there are minimal impediments presented by engine technology issues for FT diesel use as a supplement to, or replacement for, conventional petroleum derived diesel fuel in conventional diesel engines

- Nexant believes that the impediments are no greater for FT diesel use in the advanced technology engines being developed

- FT diesel appears to have its greatest potential as a blendstock to achieve the ultra low sulfur levels needed to meet emerging regulations for NOx and PM and enable emissions controls in future diesel fuel in North America, Europe, Japan and elsewhere (in either hybrid or 
conventional vehicle configurations). Significant market penetration could be achieved by 2015.

- Based on their technical qualities, market penetration already achieved and their growth rates, CNG/LNG and biodiesel could compete with FT diesel, but methanol is not a serious contender as a fuel for ICE vehicles. Biodiesel will always be limited in its production volume potential, but can be advantageously blended to enhance FT diesel's lubricity.

- The EPA and other stakeholders need to collaborate to set specifications for FT diesel because lack of standards is a key objection of engine providers. The stakeholders that must collaborate are:

$\begin{array}{ll}- & \text { Engine providers } \\ - & \text { Regulators (federal and state) } \\ - & \text { Fuel makers } \\ - & \text { Customers (fleet owners) }\end{array}$

\subsubsection{FT Diesel for Fuel Cells}

FT diesel offers no technical advantages versus, say, ultra low sulfur gasoline, CNG, or alcohols for reforming to hydrogen for use with lower temperature vehicle fuel cells (e.g., PEMs) or for potential direct in use in SOFCs. Neither the introduction of hybrid vehicles or fuel cell vehicles is expected to result in major increases in the demand for FT diesel as a fuel during the next 1015 years

\subsubsection{FT Naphtha as a Vehicle Fuel}

FT naphtha has insufficient octane to be useful in spark-ignited gasoline internal combustion engines (ICEs). However, because it is paraffinic and essentially sulfur-free, it may be attractive to use it in fuel cells with reformer systems, potentially directly in SOFCs applied in APUs and/or in hybrid propulsion systems. Developers of fuel processing systems (reformers, etc.) are testing FT naphtha for vehicle fuel cells.

\subsubsection{FT Naphtha Fuel Cells}

FT naphtha has some potential for use with reformers in lower temperature vehicle fuel cell propulsion systems or in SOFCs for APUs. In competition with methanol, naphtha has even less infrastructure, but is potentially more compatible chemically with the hydrocarbon fuel infrastructure.

\subsubsection{Methanol as a Vehicle Fuel - Conventional}

As a conventional ICE vehicle fuel, methanol is technically demonstrated but is not market attractive.

- Despite extensive support from the California and federal governments, methanol interests, auto and diesel engine companies, and the cooperation of the petroleum industry, there are very few ICE vehicles currently running on methanol in the U.S. today (fewer than for any other salient alternative fuel) 
- Methanol was tested for many years as an ICE fuel in California as a strategy to reduce air pollutant emissions and reduce dependence on petroleum liquids. Despite these efforts, methanol was not a commercial success.

- Methanol fuel has not found enthusiastic consumer acceptance because it:

- Has challenges in materials compatibility, and because of this, it is impractical to retrofit an auto for its use and new cars designed for dual fuel would cost more than gasoline-only engines, unless subsidized

- $\quad$ Offers no real advantages in price, convenience or performance

- Has not been subsidized as has ethanol, and lacking comparable political support, is unlikely to receive required subsidies in the future

- Methanol's relatively low energy density (roughly half of that of gasoline) has been a real impediment to acceptance in terms of vehicle range, and there are concerns over its toxicity and other health, safety and environmental issues

- The neat methanol (M100) option is not practical for cars primarily because of cold start problems

- The option of using gasoline-blended methanol (M85) in flexible fuel vehicles currently seems to have little potential for light duty gasoline-type passenger automobiles in the U.S. because it requires special, more expensive car designs without a significant savings in fuel cost or other advantages to the consumer

- Neither M100 nor M85 has been seen as attractive to date for heavy duty diesel transit vehicles and trucks because it has a very low cetane rating, incompatible with diesel engines, and has no advantages for the owner/operator

- Despite all the demonstrations and its status as a commercial commodity, there appears to be a low little probability of its widespread commercialization for any methanol ICE fuel in the U.S. or Europe. Methanol is not expected to gain any share of the conventional vehicle fuel market in the timeframe of this report.

- Japan currently seems to have a greater interest in fuel methanol in general.

- The methanol industry has largely abandoned its support of methanol in ICEs for the reasons listed above, but the industry is now instead championing methanol use in fuel cells, especially for vehicle and portable power applications

\subsubsection{Methanol Fuel Cells}

- The preferred fuel for initial fuel cell vehicle models has not been determined, but if technical advantages weigh heavily in the determination, then it is more likely that methanol (because of its lead in DMFCs and its higher efficiency in reforming), rather than ultra clean hydrocarbon fuels such as FT naphtha or naphtha, will be selected for this purpose.

- Even if DMFC fuel cells were to be widely commercialized for consumer small electronics, such as cell phones and laptops despite the regulatory and corporate risk challenges, their methanol demands would be relatively small. 
1. Ward's Motor Vehicle Facts and Figures 2000, Ward's Communications, Southfield, MI, USA

2. National Petroleum News market Facts 2001, Adams Business Media, Chicago, IL, USA

3. Alcohols and Ethers - A technical Assessment of Their Application as Fuels and Fuel Components, API Publication 4261, Third Edition, June 2001 (information as of November 1999)

4. Fuel Cell Update, Daniel Holt, Service Tech Magazine, Sept 2001, pg. 2.

5. Hirschenhofer, J.H. 1994. "Fuel Cell Status, 1994." American Institute of Aeronautics and Astronautics, AIAA-94-3909-CP

6. Northeast Regional Biomass Program. "Toward a Renewable Power Supply: The Use of Bio-based Fuels in Stationary Fuel Cells." April 2002, Xenergy and Energetic Management Associates.

7. "ABCs of AFVs - A Guide to Alternative Fuel Vehicles", Fifth Edition, November 1999. California Energy Commission.

8. Remarks of Larry Burns, "Autonomy: Reinventing the Automobile." May 3, 2002 to the MIT Sustainable Mobility Symposium.

9. Mintz, Marianne; Folga, Stephen; Molburg, John; Gillette, Jerry. "Infrastructure Requirements of Advanced Vehicles Using Natural-Gas Based Fuels." 10th Annual NEMS/AEO Conference, March 12, 2002, Argonne National Laboratory, Transportation Technology R\&D Center.

10. Watts, Philip, Remarks at the Launch of "Energy Needs, Choices and Possibilities - Scenarios to 2050." Royal Dutch/Shell Group. New York October 3, 2001.

11. Amar, Praveen; Heywood, John; Mundt, Diane. "The Future of Diesel: Scientific Issues", MIT Energy Laboratory. Energy Laboratory Publication No. L 00-007, December 2000.

12. Wang, M.; Mintz, J; Singh, M.; Stork, K.; Vyas, A.; Johnson, L. "Assessment of PNGV Fuels Infrastructure - Phase 2 Report: Additional Capital Needs and Fuel-Cycle Energy and Emissions Impacts. The Center for Transportation Research, Energy Systems Division, Argonne National Laboratory.

13. "California Clean Fuels Market Assessment 2001 - Consultant Report." California Energy Commission, September 2001, P600-01-018.

14. "A Multiyear Plan for the Hydrogen R\&D Program - Rationale, Structure and Technology Roadmaps." Office of Power Delivery, Office of Power Technologies, Energy Efficiency and Renewable Energy, August 1999. 
15. "Fuel Cells for Distributed Generation - A Technology and Marketing Summary, March 2000." Energy Center of Wisconsin.

16. "Realizing a Hydrogen Future - Hydrogen Technical Advisory Panel Recommendations." HTAP National Renewable Energy Laboratory.

17. Ohi, J., "Blueprint for Hydrogen Fuel Infrastructure Development." National Renewable Energy Laboratory - a U. S. Department of Energy Laboratory operated by Midwest Research Institute.

18. "A National Vision of America's Transition to a Hydrogen Economy - To 2030 and Beyond", based on the results of the National Hydrogen Vision Meeting, Washington, D.C., November 2001. February 2002.

19. Proceedings - National Hydrogen Vision Meeting, Washington, D.C. - November 15-16, 2001.

20. "Encyclopedia of Energy Science", Complex Energy Topics Simplified - Ben Weins Energy Science.

21. Contadini, J. Fernando, "Social Cost Comparison Among Fuel Cell Vehicle Alternatives." Institute of Transportation Studies - University of California at Davis.

22. Holt, Daniel (Editor), "Fuel Cell Update", Service Tech Magazine, September 2001.

23. Holmes, John W., "Fuel Choices for Fuel Cell Powered Vehicles", Exxon Corporation on behalf of the American Petroleum Institute before the Subcommittee on Energy and Environment of the Committee on Science - U. S. House of Representatives, October 5, 1999.

24. Tullo, Alexander H., "A Fuel Cell in Every Car." Chemical \& Engineering News, March 5, 2001.

25. Ahmed, S.; Kopasz, J. P. Argonne National Laboratory and Russell, B. J.; Tomlinson, H.L., Syntroleum Corporation. "Gas-to-Liquids Synthetic Fuels for Use in Fuel Cells: Reformability, Energy Density and Infrastructure Compatibility". International Fuel Cell Conference, Nov. 30 - Dec. 3, 1999 - Nagoya, Japan.

26. "GM Unveils Gasoline-Fed Fuel Cell Pickup." Motor Trend News - Monday, May 20, 2002.

27. Wang, Michael, "Fuels for Fuel-Cell Vehicles: Energy and Emission Implications." Center for Transportation Research, Argonne National Laboratory. Presentation at the EVAA's Electric Transportation Industry Conference - December 13, 2001.

28. "Can Fuel Cells Make the Jump to the Family Garage?" CEP, February 2001,

29. "Fuel Choices for Fuel Cell Powered Vehicles". American Petroleum Institute.

30. "A Driving Force". Focus, Volume 105, Number 6, June 1997, Environmental Health Perspective. 
31. "Projected Automotive Fuel Cell use in California". California Energy Commission - Consultant Report - October 2001, P600-01-022F.

32. Thomas, Sharon; Zalbowitz, Marcia, Los Alamos National Laboratory, "Fuel Cells - Green Power. U. S. Department of Energy.

33. Hermance, David - Toyota Technical Center, U.S.A., Inc. "ZEV Mandates: Concerns \& Potential Impact." NEMS Conference Presentations.

34. Perkins, S., "Electric Cars - Fueled by Gasoline?" Science News Online, 4/1/2002.

35. Ford, Tim - Shell International Petroleum Co., Ltd., London. "Fuel-Cell Vehicles Offer Clean and Sustainable Mobility for the Future." Oil \& Gas Journal - December 13, 1999.

36. Baxter, Dave - Toyota Technical Center, U.S.A., Inc. "Advanced Technology Vehicles - What, When, How Many?"

37. Freedman, David H., "Fuel Cells vs. the Grid - The Road to True Hydrogen is Proving a Long One, Can Power Generation Pave the Way to a Fuel Cell in Every Home, Car and Appliance?" Technology Review, January/February 2002.

38. Hart, David; Bauen, A.; Fouquet, R.; Leach, M.; Pearson, P.; Anderson, D. - "Hydrogen Supply for SPFC Vehicles", a study conducted for the UK DTI Fuel Cell Program under contract to ETSU, published 2000.

39. Browning, Dr. Darren, "DERA Research on H2 Storage and Generation Methods for Fuel Cells". DERA, Crown Copyright 2000.

40. Hawkes, Freda R., "Biohydrogen Production by Fermentative Processes". Wastewater Treatment Research Unit, School of Technology and School of applied Sciences, University of Glamorgan.

41. Wolff, David. "Producing Hydrogen On-Site". Chemical Processing, March 2001.

42. "Hydrogen - Today and Tomorrow." Produced by the IEA Greenhouse Gas R\&D Program.

43. Singh, Rajindar, "Will Developing Countries Spur Fuel Cell Surge?" Chemical Engineering Progress, March 1999.

44. "Diesel Emission Control - Sulfur Effects (DECSE) Program - Phase I Interim Data Report No. 3: Diesel Fuel Sulfur Effects on Particulate Matter Emissions", November 1999. U. S. Department of Energy. 
45. Norton, Paul; Vertin, Keith; Bailey, Brent - National Renewable Energy Lab; Clark, Nigel N.; Lyons, Donald W. - West Virginia University; Goeguen, Stephen; Eberhardt, James - U. S. Department of Energy, "Emissions from Trucks Using Fisher-Tropsch Diesel Fuel". International Fall Fuels and Lubricants Meeting and Exposition, San Francisco, CA - October 19-22, 1998. The Engineering Society for Advancing Mobility, Land, Sea, Air and Space.

46. Norton, Paul; Vertin, Keith - National Renewable Energy Lab; Clark, Nigel N.; Lyons Donald W. - West Virginia University; Goguen, Stephen; Eberhardt, James - U. S. Department of Energy, "Emissions from Buses with DDC 6V92 Engines Using Synthetic Diesel Fuel". International Spring Fuels and Lubricants Meeting \& Exposition, Dearborn, Michigan - May 3-6, 1999. The Engineering Society for Advancing Mobility, Land, Sea, Air and Space.

47. "Refiners Rip EPA 'FACA' Diesel Rule Review Even Before it Starts" - " 'Great Deference' Prods Court to Trash U. S. EPA Diesel Rule Lawsuits", Diesel Fuel News, Vol. 6, No. 10, May 13, 2002.

48. Johnson, D. Ray - Oak Ridge National Laboratory; Diamond, Sidney - U. S. Department of Energy, "Heavy Vehicle Propulsion Materials: Recent Progress and Future Plans." Government/Industry Meeting - Washington, D.C. - May 14-16, 2001. The Engineering Society for Advancing Mobility, Land, Sea, Air and Space.

49. Clark, Nigel; Gautam, Mridul; Lyons, Donald; Atkinson, Chris; Xie, Wenwei - West Virginia University; Norton, Paul; Vertin, Keith - National Renewable Energy Laboratory; Goguen, Stephen; Eberhardt, James; U.S. Department of Energy, "On-Road Use of Fischer-Tropsch Diesel Blends." Government/Industry Meeting - Washington, D. C., April 26-28, 1999. The Engineering Society for Advancing Mobility, Land, Sea, Air and Space.

50. Norton, Paul; Vertin, Keith; Bailey, Brent - National Renewable Energy Lab; Clark, Nigel N.; Lyons, Donald W. - West Virginia University; Goeuen, Stephen; Eberhardt, James - U. S. Department of Energy, "Emissions from Trucks Using Fischer-Tropsch Diesel Fuel." International Fall Fuels and Lubricants Meeting and Exposition, San Francisco, California - October 19-22, 1998. The Engineering Society for Advancing Mobility, Land, Sea, Air and Space.

51. "Regulatory Impact Analysis: Control of Emissions of Air Pollution from Highway Heavy-Duty Engines." U. S. Environmental Protection Agency. EPA 420-R-00-010 - July 2000.

52. "Petroleum Market Dynamics - Western Europe", PPE. Chem Systems, December 2001.

53. "Bringing Fuel Cell Vehicles to Market: Scenarios and Challenges with Fuel Alternatives" - Consultant Study Report - October 2001. Prepared for California Fuel Cell Partner by Bevilacqua Knight, Inc.

54. Alternative Energy Institute, Inc. -http://www.alternenergy.org/2/renewables/hydrogen_and fuel_cells 2/26/2002 
55. Hydrogen Vehicles 2001 - http://www/hydrogen.org/h2cars/overview/timeline07.html

56. Truly, Richard H. (Admiral), "The Hydrogen Century Begins", Remarks to the National Press Club March 14, 2002. California Hydrogen Business Council. http://ch2bc.org/indexh.htm 3/18/02

57. DOE Hydrogen Research Program - http://www.eren.doe.gov/hydrogen/research.html

58. "Hydrogen - The Fuel for the Future." Document produced for the U.S. Department of Energy by the National Renewable Energy Laboratory - DOE/GO-10095-099 - DE95004024 - March 1995.

59. "Quantum Ships Hydrogen Storage System for Fuel Cell Bus", Quantum Technologies Worldwide, Inc. - http://composite.about.com/library/PR/2001/blquantum6.htm?iam=dpile\&terms=hydrogen

60. "Proton Energy Systems" - Proton Energy Systems, Inc. http://www.protonenergy.com/index.php/html/energysystems/home/index.html

61. Dagani, Ron, "Tempest in a Tiny Tube", Chemical and Engineering News - January 14, 2002.

62. "Update - E-Learning to Grow Rapidly", CEP, January 2002. www.cepmagazine.org

63. "Hydrogen and Fuel Cell Vehicle Developments (status: 98-08-26)." http://www.hydrogen.org/News/fcevs.html - 2/26/2002

64. "Urban Bus Particulate Emissions Compliance Made Simple", Riker Products - Johnson Matthey, Catalytic Converter Division.

65. "Clean Diesel Solutions for Today's Engines", Diesel Technology Forum. http://www/dieselforumj.org/retrofit/tech_casestudy.html - 4/22/2002

66. "Class 8 Trucks Operating on Ultra-low Sulfur Diesel with Particulate Filter Systems: A Fleet Start-up Experience." Society for Automotive Engineers.

http://www.ctts.nrel.gov/heavy_vehicle/what/paper2.html - 4/24/2002

67. "NREL,SCAQMD to Test Clean Diesel Fuels", Transportation Times - September 29, 2000. http://www.ctts.nrel.gov/transtimes/archives/times_092900.html

68. "DECSE Program Releases Final Report on "Lean-NOx Catalysts and Diesel Oxidation Catalysts", Transportation Time - June 29, 2001.

69. "Do You Need to Reduce Toxic Diesel Exhaust Fumes?", Clean Air Systems. http://www.cleanairsys.com/html/dc.html 4/22/2002

70. "Methanol Vehicles: On the Road", Technology: Mitsubishi Automagic. http://www.mitsubishimotors.co.jp/inter/technology/env_06.html 4/22/2002 
71. Fairbanks, John W., "Overview of Emerging Clean Diesel Engine Technology", U. S. Department of Energy.

72. "Vehicle Emissions Testing", Heavy Vehicle Projects at NREL.

http://www/ctts.nrel/gov/heavy_vehicle/emissions.html - 5/9/2002.

73. Scott, Dave, "SA Diesel: Facts \& Fiction", Fleet Watch.

http://www.fleetwatch.co.za/supplements/SADiesel/DieselFactsFictionS.htm- 5/14/02

74. "Environmental Benefits of the Rentech Process". Rentech, Inc. http://www.rentech.com/benefits.htm - 5/14/2002

75. Agee, Mark A., "GTL Projects and Future Demand Implications", Syntroleum Corporation. EFI Gas Conversion: Projects, Technologies \& Strategies, San Francisco, CA, October 20-22, 1999. http://www.syntroleum.com/news/1999pr/10201999.htm

76. National Petrochemical \& Refiners Association, Petitioner v. Environmental Protection Agency, Respondent - United States Court of Appeals for the District of Columbia Circuit, Argued February 26, 2002 - Decided May 3, 2002 - International Truck and Engine Corporation, et al - on petition for review of orders of the Environmental Protection Agency. http://pacer.cadc.uscourts.gov/common/opinions/200205/01-1052a.txt 


\section{Methanol Distribution Infrastructure Issues Market Study Report Section VII \\ Prepared For: \\ ConocoPhillips}

Co-operative Agreement DE-FC26-01NT41098 


\title{
Methanol Distribution Infrastructure Issues Market Study Report Section VII
}

November 2002

\author{
Prepared For: \\ ConocoPhillips
}

\section{↔Nexant}

44 South Broadway, White Plains, New York 10601, USA

Tel: +1 9146090300 Fax: +1 9146090399 
Section

Page

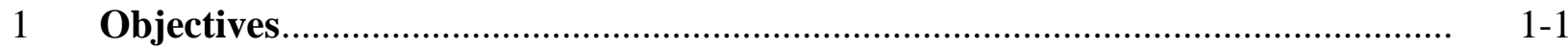

2 Introduction .....................................................................................

3 Methanol Chemical and Physical Properties ....................................................... 3-1

$4 \quad$ U.S. Experience With Methanol Fuels .................................................................. 4-. 4

4.1 HISTORICAL DRIVERS FOR METHANOL USE ......................................... 4- 4-1

4.21977 CLEAN AIR ACT AMENDMENTS ………………………………..... 4-1

4.31990 CLEAN AIR ACT AMENDMENTS ……………………………….... 4-2

4.4 LOW LEVEL METHANOL GASOLINE BLENDS ……………………..... 4. 4-2

4.5 NEAT METHANOL AS A TRANSPORTATION FUEL ............................... 4. 4

4.5.1 CEC Experience .......................................................................... 4-5

4.5.2 California Fuel Cell Partnership .......................................................... 4.. 4

4.5.3 Methanol Fuel Cell Alliance................................................................. 4. 4-9

$5 \quad$ Distribution and Storage .................................................................................

$5.1 \quad$ EXISTING METHANOL SUPPLY CHAIN ……………………………..... 5-1

5.1.1 System Characteristics .................................................................. 5-1

5.1.2 Case Study Examples of Conventional Methanol Supply System ....... 5-2

5.1.2.1 Ocean Shipments ................................................................ 5-2

5.1.2.2 In Land Distribution ....................................................... 5-2

5.2 SHIPPING METHANOL IN PETROLEUM DISTRIBUTION SYSTEM ..... $5-3$

5.2.1 Refinery Operations ....................................................................... 5-3

5.2.2 Pipeline Shipping ...................................................................... 5-3

5.2.3 Terminals ...........................................................................

5.2.4 Service Stations........................................................................ 5-7

5.2.5 Similarities with and Differences form Conventional Gasoline Refueling Stations ........................................................................ $\quad 5-10$

5.2.6 Fuel Quality and Equipment Compatibility for Methanol .................... 5-12

5.2.7 Immunity of Equipment from Attack...................................................... 5-13

5.2.8 Overview of Definitions of Methanol Compatibility and Discussion of Standards and Certifications ....................................................... $\quad 5-14$ 
5.2.9 Importance of Proper Fueling System Components in Maintaining Fuel Quality

5.2.10 Upgrading Existing Installations …............................................ 5-15

5.2.10.1 Hardware Requirements ............................................... 5-15

5.2.11 Tank Venting Requirements ..................................................... 5-20

5.2.12 Recommended Features ................................................................ 5-20

5.2.13 Leak Detection Systems................................................................. 5-20

5.2.14 Remote Monitoring Systems....................................................... 5-21

5.2.15 Fill Cap Identifications to Prevent Bulk Cross-Fueling ...................... 5-21

5.2.16 Manhole Cover Plate Split Box Modifications ................................ 5-21

5.2.17 Secondary Containment of Piping Runs ....................................... 5-27

5.2.18 Vent Piping and Vapor Recovery Piping ........................................ 5-27

5.2.19 Pump Selection ....................................................................... 5-28

5.2.20 Dispensers and Metering Equipment ............................................. 5-28

5.2.21 Product Hoses and Fittings …....................................................... 5-28

5.2.22 Venting and Vapor Recovery Systems ......................................... 5-31

5.2.23 Fuel Filters ......................................................................... $5-37$

5.2.24 Existing Systems - Cardlocks and M85 EPOS System..................... 5-38

5.2.24.2 Standard Installation Practices .......................................... 5-40

5.2.24.3 Methanol Service Station Capital Costs............................. 5 5-40

5.3 COMPARISON OF METHANOL, CNG, LNG, AND HYDROGEN DISTRIBUTION INFRASTRUCTURE REQUIREMENTS ..................... $5-41$

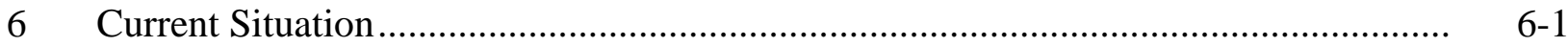

6.1 STAKEHOLDERS AND ACTIVITIES ....................................................

6.1.1 Methanex................................................................................ $6-1$

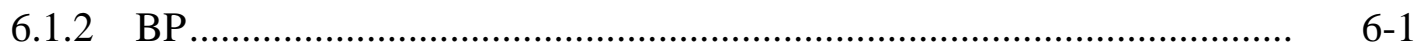

6.1.3 Shell ............................................................................. $6-1$

6.1.4 Daimler Chrysler....................................................................... 6-2

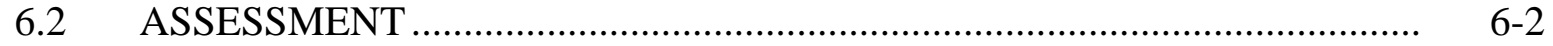

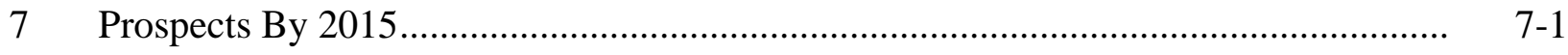

7.1 REQUIREMENTS FOR SUCCESS......................................................

7.2 PROJECTED RANGE OF POTENTIAL USE ........................................ 
7.2.1 Transportation Fuel .................................................................

7.2.1.1 California............................................................... $7-2$

7.2.1.2 New York .................................................................... 7-3

7.2.2 Methanol Supply .....................................................................

7.2.3 Distributed Power .........................................................................

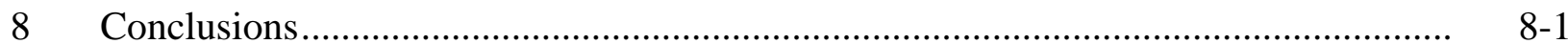

8.1 NEAT FUEL SUPPLIED FOR INTERNAL COMBUSTION ENGINE

VEHICLES …............................................................................ 8. 8

8.2 METHANOL BLENDED WITH CONVENTIONAL GASOLINE............... $\quad 8-1$

8.3 METHANOL USE IN FUEL CELL VEHICLES ........................................

8.4 METHANOL DISTRIBUTION INFRASTRUCTURE ................................ $8-2$

8.4.1 Requirements for Significant Market Penetration ............................ 8-2

8.4.2 Comparison of Methanol Distribution Infrastructure Requirements with Other Alternative Fuels............................................................. 8. 8-3

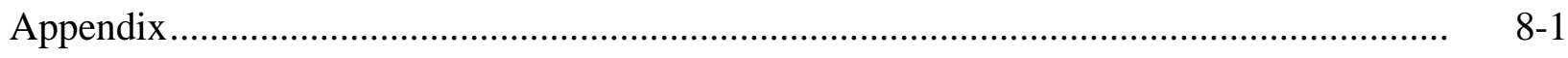

Methanol Bibliography ........................................................................................ B-1 
4.1 Typical Distillation Curves for Volatile Fuels..................................................... 4-3

4.2 METHANOL FFVs in CALIFORNIA, 1987 to 1998, Revised 11-20-98 .................. 4-8

5.1 Methanol Infrastructure in Place .........................................................................

5.2

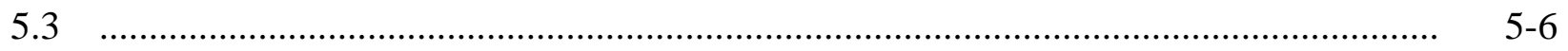

5.4 Schematic of Methanol Fueling Station........................................................... $5-7$

5.5 Fueling Facility Isometric Drawing .......................................................... $5-8$

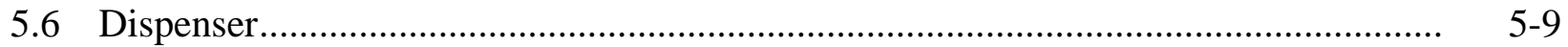

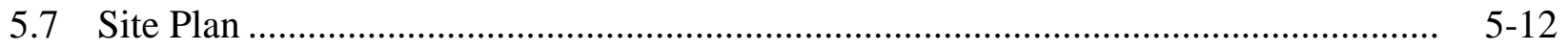

5.8 Above-Ground Tank and Dispenser ........................................................... $5-17$

5.9 Underground Tank ........................................................................................ $\quad 5-19$

5.10 Spill Containment Box Installed …............................................................... $5-22$

5.11 Spill Containment Box................................................................................... $5-23$

5.12 Installation of CNI Fil-Spil Spill Container ...................................................... $5-24$

5.13 Rain Gutter (by One Manufacturer) …......................................................... $5-25$

5.14 Installation of the Above Rain Gutter ............................................................. $5-25$

5.15 Flexible Gasket Installation ..................................................................... $5-26$

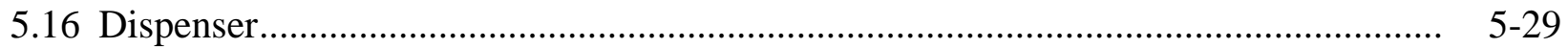

5.17 Dispenser Configuration ........................................................................ $5-30$

5.18 Venting Systems ….................................................................................. $5-32$

5.19 Dual-Point Stage I and II Piping Systems....................................................... $5-33$

5.20 Dual-Point Piping Systems …....................................................................... $5-33$

5.21 Coaxial Stage I And II Piping System ............................................................. $5-34$

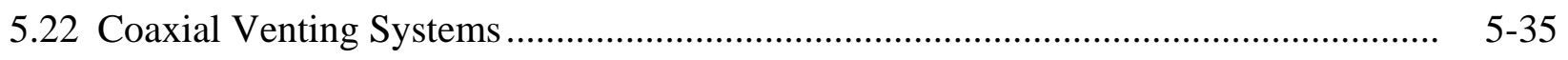

5.23 Pressure/Vacuum Vent.............................................................................. $5-36$

5.24 Flame Arrester....................................................................................... $5-37$

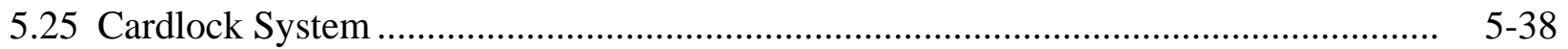


3.1 IMPCA Methanol Reference Specifications................................................... $3-2$

3.2 Properties of Gasoline, MTBE and Alcohols ................................................... $3-3$

3.3 Estimated Half-Lives Of Methanol And Benzene In The Environment...................... 3-4

4.1 Major Fuel Retailers M85 Stations - January 1996.............................................. 4-7

5.1 Methanol Service Station Capital Cost, Thousand Dollars, 2001 ............................. 5-41

5.2 Comparative Retail Station Costs ................................................................... $5-42$

7.1 Methanol Cost Plus Return, Delivered to California Retail Service Station ............... $\quad$ 7-2

7.2 Methanol Cost Plus Return, Delivered to New York Retail Service Station .............. 7-3

7.3 Cost Plus Return, Delivered to Retail Service Station...............................................

8.1 Cost Plus Return, Delivered to Retail Service Station............................................ 8-2

8.2 Comparative Retail Station Costs .................................................................. $8-4$ 
The objective of this section is to evaluate issues related to methanol distribution infrastructure that impact its potential as a transportation or stationary power fuel and to suggest strategies to overcome any hurdles to its use. There is an existing methanol distribution infrastructure for serving current conventional methanol markets (chemical uses and MTBE feedstock). However, a much larger distribution infrastructure will be required if methanol becomes a significant transportation fuel.

The following options for fuel methanol uses have been analyzed from the perspective of required infrastructure to support:

- Neat methanol supplied for use in internal combustion engine vehicles

- Methanol blended with conventional gasoline

- Methanol use in fuel cell vehicles

Each of these options has been screened to determine the feasibility of significant commercialization by 2015. For the one option that passes the screening analysis, fuel cell use, an assessment of the stakeholders and their development activities, the requirements for success, and the projected range methanol demand through 2015 have been developed and presented.

In addition, a limited comparison of the methanol distribution infrastructure and those for competing alternative fuels - hydrogen, compressed natural gas, and liquefied natural gas - have been presented.

Results of these analyses have provided important input to the assessment of the market potential for UCFs as presented in Market Report Section IX. 
Methanol is increasingly produced from stranded natural gas in remote locations. To use methanol as an ultra clean transportation or distributed power fuel in the United States, an infrastructure is required to deliver methanol from the remote production site to the point of ultimate consumption to vehicle fleets or retail consumers. The objective of this section is to identify the distribution infrastructure issues, discuss development work to date, and assess future prospects. Infrastructure issues are particularly important for methanol because:

- The volumetric energy density is only about one-half that of conventional hydrocarbon fuels. Therefore, twice the volume of methanol must be transported compared to gasoline to deliver the equivalent energy to the point of sale of transportation fuel.

- Methanol cannot be delivered in the existing petroleum product infrastructure.

This report considers the methanol supply chain infrastructure to consist of three elements:

- Ocean transportation from production site to coastal terminal in the U.S.

- $\quad$ Barge, pipeline, rail, and truck distribution within the U.S. and

- Retail fuel dispensing stations.

Methanol has been under development as a transportation fuel in a number of different ways:

- As a low level blending component in gasoline

- $\quad$ As an 85 percent blend with 15 percent gasoline (M85)

- As a neat fuel for internal combustion engines or fuel cells

Each of these options has different implications for infrastructure needs and different prospects for commercialization. This report describes the state of development and prospects for each. 
A reference specification for methanol of the International Methanol Producers and Consumers Association (IMPCA) is shown in Table 3.1. Methanex asserts that the current specifications for commercial grade methanol have been used successfully for fuel cell vehicles ${ }^{1}$. The California Energy Commission has expressed some concern about the consistency of methanol quality as it exists in the distribution infrastructure based on a customer survey ${ }^{2}$. The physical properties of methanol are compared with those of gasoline and other alcohols in Table 3.2. Key characteristics of methanol are as follows:

- A much higher hydrogen to carbon ratio compared to gasoline

- 50 percent oxygen by weight

- Slightly more dense than gasoline

- Roughly one-half the volumetric energy content of gasoline

- The boiling point of methanol falls within the boiling range of gasoline

- Harder to ignite than gasoline (higher flash point)

- Burns much slower than gasoline

- Burns with a light blue flame that is not easily seen in bright sunlight

- Is an excellent solvent and readily dissolves many plastics and corrodes some metals

- Is toxic if ingested

- Biodegrades rapidly if a spill occurs

The implications of the oxygen content and the relatively simple structure of the methanol molecule is that it burns more completely when ignited and is easier to reform to hydrogen or use directly in a fuel cell compared to conventional gasoline.

Because of the lower density roughly twice the volume of methanol must be transported compared to gasoline to deliver the equivalent energy. This may be somewhat offset by potentially higher energy efficiency in fuel cells with methanol compared to other fuels.

\footnotetext{
${ }^{1}$ Presentation to EVAA, December 2001

${ }^{2}$ Peter F. Ward, Manager of Infrastructure, Personal Communication, March 2002.
} 


\section{Table 3.1 IMPCA Methanol Reference Specifications}

\begin{tabular}{|l|l|l|l|}
\hline Specification & & Value & Test \\
\hline Appearance & & Clear and free of suspended matter & IMPCA 03-98 \\
\hline Purity \% WT on dry basis & & Min 99,85 & IMPCA 001-98 \\
\hline Color PT-CO & & Max. 5 & ASTM D 1209-93 \\
\hline Water \% W/W & & Max. 0,1 & ASTM E 1064-92 \\
\hline Distillation range at $760 \mathrm{~mm} \mathrm{Hg}$ & Max. 1,0 ${ }^{\circ} \mathrm{C}$ to include 64, $6^{\circ} \pm 0,1^{\circ}$ & ASTM D 1078-97 \\
\hline Specific gravity $20^{\circ} / 20^{\circ}$ & & $0,791-0,793$ & ASTM D 891-95 \\
\hline $\begin{array}{l}\text { Potassium permanganate } \\
\text { Time test at } 15^{\circ} \mathrm{C} \text {, minutes }\end{array}$ & & Minimum 60 & ASTM 1363-94 \\
\hline $\begin{array}{l}\text { Carbonizable substances (Sulphuric } \\
\text { Acid Wash Test) Pt-Co Scale }\end{array}$ & & Max 30 & \\
\hline Ethanol & $\mathrm{Mg} / \mathrm{kg}$ & Max 50 & ASTM E 346-94 \\
\hline Chloride as Cl & $\mathrm{Mg} / \mathrm{kg}$ & Max 0,5 & IMPCA 001-98 \\
\hline Sulphur & $\mathrm{Mg} / \mathrm{kg}$ & Max 0,5 & IMPCA 002-98 \\
\hline Hydrocarbons & & Pass test & ASTM D 3961-89 \\
\hline Carbonilic compounds as acetone & $\mathrm{Mg} / \mathrm{kg}$ & Max 30 & ASTM D 1722-90 \\
\hline Acidity as acetic acid & $\mathrm{Mg} / \mathrm{kg}$ & Max 30 & ASTM E 346-94 \\
\hline Total iron & $\mathrm{Mg} / \mathrm{kg}$ & Max 0,1 & ASTM D 1613-96 \\
\hline Non volatile matter & $\mathrm{Mg} / 1000 \mathrm{ml}$ & Max 8 & ASTM E 394-94 \\
\hline
\end{tabular}


Table $3.2 \quad$ Properties of Gasoline, MTBE and Alcohols

\begin{tabular}{|c|c|c|c|c|c|c|}
\hline & & Gasoline & MTBE & $\overline{\text { Methanol }}$ & Ethanol & Tertiary Butanol \\
\hline Formula & & $\mathrm{C}_{4}-\mathrm{C}_{10}$ & $\mathrm{C}_{5} \mathrm{H}_{12} \mathrm{O}$ & $\mathrm{CH}_{3} \mathrm{OH}$ & $\mathrm{C}_{2} \mathrm{H}_{5} \mathrm{OH}$ & $\mathrm{C}_{4} \mathrm{H}_{9} \mathrm{OH}$ \\
\hline Molecular Weight & & 100-105 (avg) & 88 & 32 & 46 & 74 \\
\hline \multicolumn{7}{|l|}{ Composition, Wt. \% } \\
\hline Carbon & & $85-88$ & 68.7 & 37.5 & 52.2 & 16.2 \\
\hline Hydrogen & & $12-15$ & 13.6 & 12.5 & 13.1 & 13.5 \\
\hline Oxygen & & - & 18.2 & 50 & 34.7 & 21.6 \\
\hline Specific Gravity & & 0.741 & 0.747 & 0.796 & 0.794 & 0.791 \\
\hline Density, Ib/gal & & 6.18 & 6.22 & 6.63 & 6.61 & 6.59 \\
\hline \multirow[t]{2}{*}{ Higher Heating Value, } & Btu/Lb & 20,260 & 18,290 & 9,750 & 12,800 & 16,920 \\
\hline & Btu/Gal & 125,300 & 114,000 & 64,600 & 84,600 & 111,500 \\
\hline Boiling Point, ${ }^{\circ} \mathrm{F}$ & & $80-440$ & 131 & 149 & 172 & 181 \\
\hline $\begin{array}{l}\text { Vapor Pressure }{ }^{(1)}, \text { psi } \\
100^{\circ} \mathrm{F}\end{array}$ & & $7-15$ & 8.0 & 4.6 & 2.5 & 7 \\
\hline $77^{\circ} \mathrm{F}$ (Reid) & & 0.3 & 4.7 & 2.3 & 0.8 & \\
\hline Flammability Limits, Vol.\% & & $1.4-7.6$ & $1.6-8.4$ & $6.7-36$ & $4.3-19$ & $2.4-8.0$ \\
\hline Stoichiometric Air/Fuel & & $14.2-14.8$ & 11.7 & 6.45 & 9.0 & 10.6 \\
\hline \multirow[t]{2}{*}{ Heat of Vaporization, } & Btu/Lb & 150 & & 506 & 396 & \\
\hline & Btu/Gal & 900 & & 3320 & 2380 & \\
\hline Flash Point, ${ }^{\circ} \mathrm{F}$ & & -45 & & 52 & 55 & 52 \\
\hline \multicolumn{7}{|c|}{ Pure Component Octane Numbers } \\
\hline \multicolumn{2}{|l|}{ Research Octane Number } & & 117 & $106-112$ & 111 & 109 \\
\hline \multicolumn{2}{|l|}{ Motor Octane Number } & & 101 & $90-92$ & 92 & 97 \\
\hline$(\mathrm{R}+\mathrm{M}) / 2$ & & $88-92$ & 109 & $98-102$ & 101 & 103 \\
\hline \multicolumn{7}{|l|}{ Blending Octane Number ${ }^{(2)}$} \\
\hline Research Octane Number & & & $115-135$ & $132-139$ & $128-136$ & 105 \\
\hline Motor Octane Number & & & $98-110$ & $93-120$ & $96-112$ & 90 \\
\hline$(\mathrm{R}+\mathrm{M}) / 2$ & & $88-92$ & 106-122 & $112-129$ & $112-124$ & 97.5 \\
\hline \multicolumn{7}{|c|}{$\begin{array}{l}1 \text { In gasoline blends, alcohols cause higher (non-linear) vapor pressures than would be expected based on their pure comp } \\
\text { vapor pressure. } \\
{ }^{2} \text { Blending value octane numbers vary from company to company, depending upon the base gasoline stock into which the } \\
\text { additive is blended, its concentration, the age and type of vehicles used for motor octane testing, and other factors. }\end{array}$} \\
\hline
\end{tabular}

As a result of its lower flash point, methanol is more difficult to cold start in an internal combustion engine. It has been mixed with 15 percent gasoline (M85) to achieve acceptable internal engine starting characteristics. 
However, the lower flash point of methanol reduces the risk of a fire. In the case of a vehicle fire, the fire will spread much more slowly than with gasoline. Methanol fires are also easily extinguished with water.

The toxicity of methanol has led to the development of a spill-free methanol dispensing nozzle by Identic SA., which is being used in the California Fuel Cell Partnership Demonstration begun this year in Sacramento. This nozzle eliminates the possibility of human contact with methanol.

Table 3.3 compares the biodegradability of methanol with benzene, a typical gasoline component. The half-life of methanol in the soil or in water is only a fraction that of benzene. In fact, methanol is sometimes used as an additive in wastewater treatment plants to promote biodegradation.

Table 3.3 Estimated Half-Lives Of Methanol And Benzene In The Environment

\begin{tabular}{|l|c|c|}
\hline Environmental Medium & $\begin{array}{c}\text { Methanol Half-Life } \\
\text { (days) }\end{array}$ & Benzene Half-Life (days) \\
\hline Soil & $1-7$ & $5-16$ \\
\hline Air & $3-30$ & $2-20$ \\
\hline Surface water & $1-7$ & $5-16$ \\
\hline Ground water & $1-7$ & $10-730$ \\
\hline \multicolumn{2}{||}{} \\
\hline \multicolumn{2}{|l|}{ Source: Handbook of Environmental Degradation Rates, 1992 } \\
\hline
\end{tabular}

Although flame luminosity is an issue, during an accident burning materials other than the fuel (such as paint, plastics, upholstery, engine oil, etc.) would likely produce both smoke and a visible flame. Moreover, luminosity agents could be added to methanol, if needed.

A recent study by Xcellsis has explored methanol quality needs for Proton Exchange Membrane Fuel Cells ${ }^{3}$. Most fuel cell engine testing to date has been performed using very pure grades of methanol to minimize the potential for reformer catalyst contamination. Concerns have been raised regarding the requirement for fuel additives such as flame luminosity indicators, odorants, and lubricants. Such compounds could be detrimental to reformer catalyst operation.

The overall objective of the Xcellsis study was to examine the methanol quality characteristics of the existing methanol distribution infrastructure. The project consisted of five main steps:

- A comprehensive evaluation of the most likely contamination mechanisms

\footnotetext{
${ }^{3}$ Methanol Fuel Quality Specification Study for Proton Exchange Membrane Fuel Cells, prepared for AQMD by Xcellsis, Contract \#00029, February 2002
} 
- Analysis of quality at different stages of the methanol distribution infrastructure to determine the most likely sources of contamination and quality control needs

- Evaluation of automotive guidelines to determine the requirement for additives in an automotive methanol fuel

- A physical evaluation of additive and contaminant impact on reformer conversion

Significant research has been carried out to determine which compounds are most damaging to methanol reforming over copper zinc oxide catalysts. Significant literature is available on which contaminants and additives could be present in methanol along the distribution infrastructure. However, little is available on the potential impact of these contaminants and additives on the methanol reforming process.

The supply chain was analyzed in order to determine if the contaminants found in the chemical analysis are avoidable through more strict controls or if they are indicative of a more pervasive problem. It was found that many of the contaminants detected in the distribution infrastructure samples can be categorized by their source as follows:

- Contaminants from the production process, including acetic acid, acetone, 2-butanone, and water

- Petrochemical contaminants from cross contamination (contact with residues of another chemical) including various hydrocarbons

- Leaks in water vessels which transport methanol, introducing water and chlorides

In addition, nickel or zinc that could potentially be a methanol contaminant introduced from piping systems has been identified as potential reformer catalyst poisons.

California requires the use of both a bitterant and an odorant for methanol used as a transportation fuel ${ }^{4}$. The bitterant must have a distinct and noxious taste for purposes of preventing inadvertent human consumption. Currently, Bitrex (denatonium benzoate) is the most economical of foul-tasting additives, due to its relatively low bitterness threshold and corresponding low cost in use.

The odorant requirement maintains that upon vaporization at ambient conditions, the M100 fuel methanol must have a distinctive odor potent enough for its presence to be detected down to a concentration in air of not over one-fifth of the lower limit of flammability.

Although methanol burns with a colorless flame creating a potentially hazardous scenario, the California Code of Regulations does not currently require M100 fuel methanol to contain an additive which would provide a luminous flame if the methanol were to ignite, but the regulation does require an on-board flame arrester. In selecting an additive for flame luminosity, aromatics would be the best candidates to increase the luminosity of methanol flames as they are capable of forming azeotropic mixtures with methanol and increasing the $\mathrm{C}: \mathrm{H}$ ratio with minimum amount

\footnotetext{
${ }^{4}$ California Code of Regulations
} 
of additives. However, all aromatics are potentially poisonous to the methanol reforming catalyst because of their complex hydrocarbon content.

In the Xcellsis study, six samples were taken at various points in the distribution supply chain and evaluated in a small-scale reformer evaluation hardware. The sample locations were as follows:

- Manufacturing facility

- Ocean tanker, U.S.G.C. vessel

- Bulk storage terminal

- Tanker truck, dedicated methanol service

- Tanker truck, non-dedicated methanol service

- $\quad$ End-user, non-dedicated storage tank

The sample from the manufacturing facility had the lowest contaminant levels. Evaluation of fuel conversion in the test reformer showed a rapid initial drop in conversion, followed by relative stabilization at a very slow degradation rate. The other samples followed a similar pattern, although the amplitude of the initial drop and the slope of the subsequent "plateau" region increased in proportion to the level of contaminant in the fuel. Of particular interest were alcohols, chloride, and complex hydrocarbons.

In addition, three additives and ethanol were evaluated in isolation. Bitrex, a bitterant, was evaluated at $15 \mathrm{ppm}$; sodium chloride, a potential flame luminosity additive, was evaluated at 50 ppm; ethanethiol, an odorant, was evaluated at $2.5 \mathrm{ppm}$, and ethanol was evaluated at $100 \mathrm{ppm}$. Ethanol and sodium chloride both caused the catalyst to degrade very rapidly. When the reforming process was switched back to the manufacturing facility sample, the catalyst showed complete reversibility. Bitrex and ethanethiol caused less pronounced degradation in catalyst activity, but the degradation did not appear to be reversible. Only limited additive testing was performed due to the limitations of the Xcellsis program, and further tests need to be performed to confirm the preliminary indications. The details of the supply chain sample qualities are contained in the Appendix. 


\subsection{HISTORICAL DRIVERS FOR METHANOL USE}

There has been interest in alcohol fuels for vehicles for most of the last century in the U.S. and in several other regions of the world, but the most significant commercial activities centered on ethanol blends (Gasohol in the U.S.) and neat ethanol (e.g., in Brazil and elsewhere), not methanol. Neat methanol's special niche was as the fuel for Indy 500 racecars since the 1950s.

Methanol vehicle fuel has been promoted as a market expansion strategy by those companies that have been producing methanol for chemical markets and later, in the 1990s, expanded production to serve the MTBE market, as that oxygenate additive came into use in North America and Europe. Methanol production was also driven by the need to exploit stranded gas resources as more associated gas was found and gas flaring was curtailed in such key regions as Tierra del Fuego, the Middle East and Western Canada. Other interests saw methanol as a clean fuel strategy, and a more fungible replacement for liquid petroleum fuels.

However, ethanol, methanol per se and other alcohols (and ethers) were not regulated as vehicle fuels or components in U.S. Federal or state law before passage of the U.S. Clean Air Act Amendments of 1977. The drivers for use of methanol are being considered herein as both related to direct methanol use in vehicle fuels as well as for the demand for methanol as a raw material to manufacture MTBE, the key oxygenate in the U.S. market during the 1990s, but now being phased out in the U.S. Methanol can also be used as the reactant with vegetable oils, such as soy oil, to make biodiesel (typically methyl esters of fatty acids derived from these). We will not consider the market implications of these potential developments for methanol.

\subsection{CLEAN AIR ACT AMENDMENTS}

A renewed interest in alcohols was driven by dual government agency agendas - by the DOE, seeing alcohols as blend stocks as a strategy for energy independence - and by the EPA, seeing alcohols as octane enhancers in the phase down of lead as an antiknock agent in 1980, and further in 1989 with the need to limit gasoline vapor pressure by reducing higher octane lighter components such as butane. The Act in 1977 required that fuels with lead removed and with oxygenates substituted used in vehicles marketed after 1974 needed to be "substantially similar" to the fuels used in federal emissions certification testing to assure that tailpipe and evaporative emissions would not become problems as a result of the use of oxygenates. In 1981 the EPA ruled that in unleaded gasoline, alcohols (except methanol) and ethers blended in gasoline at less than 2 percent weight oxygen content qualified as substantially similar. This was later extended to 2.7 percent oxygen content. Methanol was limited to 0.3 percent by volume because of concerns over fuel system component degradation, water separation, and evaporative emissions. This is the traditional level of methanol use as a deicer and cosolvent for other additives.

Waivers were granted for use of methanol over 0.3 percent to several oil companies. First, Sun Oil Company was allowed to use methanol in equal parts with TBA (tertiary-butyl alcohol) up to 2 percent by weight oxygen in the blend, having shown that TBA reversed some of the problems with methanol use in gasoline. This waiver was superceded by the 1981 substantially similar 
rule. ARCO got a waiver in 1981 for 1:1 blends of methanol and "gasoline grade TBA “(GTBA) with up to 3.5 percent oxygen (OXINOL). This implied methanol concentrations up to 4.8 percent in typical gasoline. DuPont and Texas Methanol were allowed other cosolvent methanol blends in 1985 and 1988 with 5 percent maximum methanol implied.

\subsection{CLEAN AIR ACT AMENDMENTS}

In 1995, Air Toxics controls of the 1990 Clean Air Act were implemented, which required the reduction of the aromatics and unsaturates contents of gasoline, leading to more interest in oxygenate additives. In addition, the 1990 Amendments required the use of oxygenates to reduce tailpipe emissions. As a result of the conflicting objectives of the Act, most of the regulatory actions by the EPA and state governments and maneuvering by refiners and gasoline marketers involved politically popular ethanol, and MTBE

State implementation plans (SIPs) were mandated to be developed or revised for regions with non-attainment of standards for atmospheric carbon monoxide. Ethanol and ethanol-methanol cosolvent blends were part of a number of state strategies, but many of these are being mitigated or reversed now. In the very complex and tortuous history of developments of fuel modifications (concerning primarily issues of reformulated gasoline or RFG) since 1990 (which will not be detailed here), methanol has been a minor player, except as a raw material for MTBE and the fuel test programs in California and in several other locations (which are not regulatory, but technical issues). In these developments, ethanol and MTBE have been the primary oxygenates at issue.

Fuels and fuel additives also have required registration with the EPA since 1975, subject to reregistration and toxicity testing since 1994. Any of the previously allowed cosolvent blends with methanol could have been reregistered.

\subsection{LOW LEVEL METHANOL GASOLINE BLENDS}

Methanol has been under investigation as an alternative transportation fuel for over 20 years. The initial driving force in the 1970s was the phase down of lead from gasoline in the U.S. Refiners looked for alternative approaches to replace the octane in the gasoline pool that had previously been supplied by lead. In addition to the established refinery processing options to raise octane (primarily reforming), the use of oxygenated, high octane blending components such as methanol, ethanol, tertiary-butyl alcohol (TBA), and MTBE began to be evaluated.

The commercialization of methanol in gasoline blends was hampered by a number of undesirable properties such as:

- Water tolerance - At very low water levels (400 PPM), phase separation occurs in methanol gasoline blends, and methanol dissolves in the water layer, separating out of the gasoline product

- Material compatibility - Methanol can corrode many of the materials used in the vehicle fuel system and gasoline distribution system 
- Volatility - The addition of even small quantities of methanol to gasoline increases the vapor pressure (RVP) disproportionately, requiring that low-valued butane be backed out of the gasoline (see Figure 4.1). Moreover, methanol addition considerably increases low and mid-range volatility and reduces vapor lock temperature

- The optimum air/fuel ratio for combustion of methanol differs considerably from gasoline, which requires adjustments of air/fuel mixture. Emission controlled cars could require modification since their air/fuel mixtures are normally quite lean.

- The energy density of methanol is only one-half that of gasoline on a volumetric basis

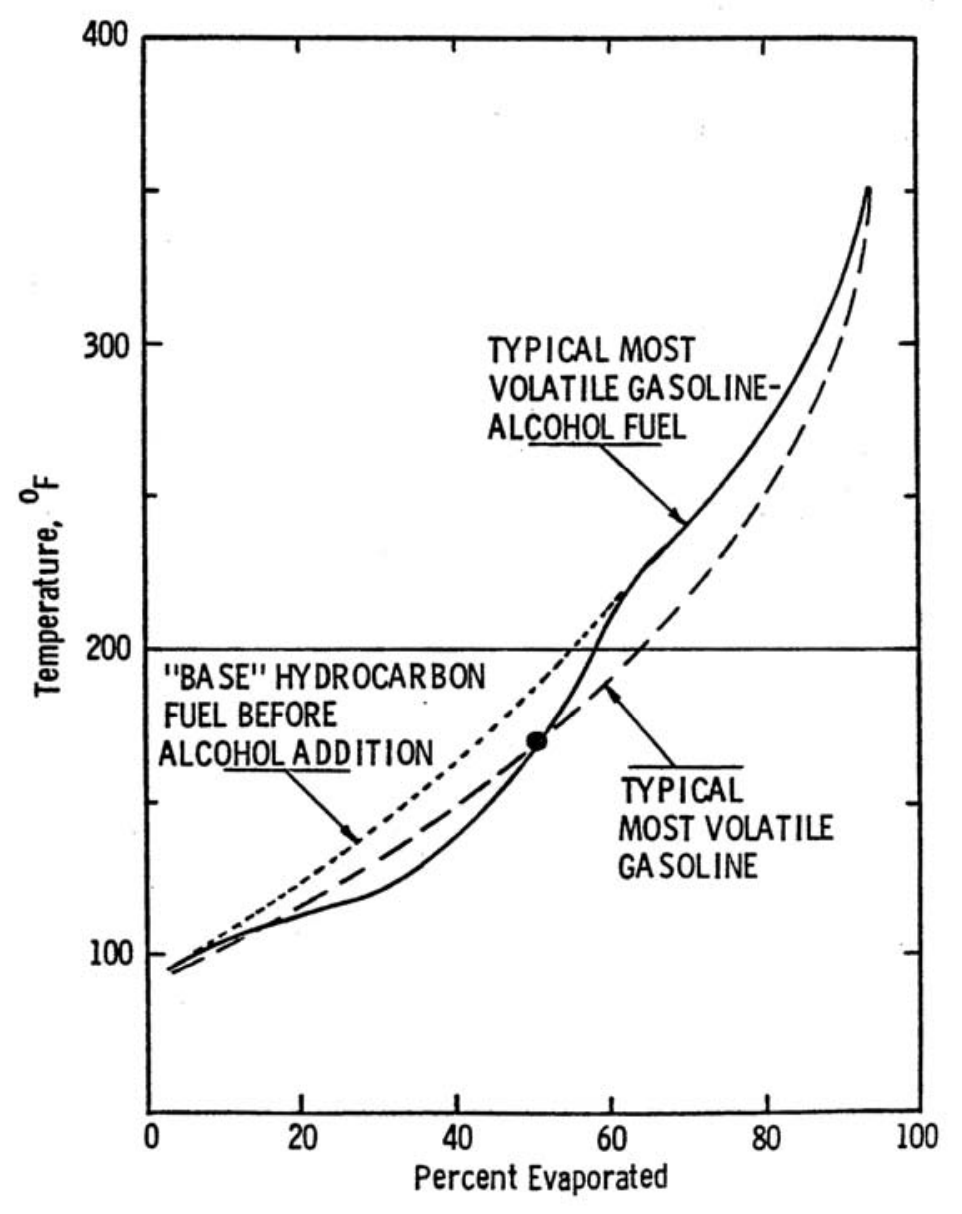

Source: Figure X-4 in DuPont Wairen Application

\section{Figure 4.1 Typical Distillation Curves for Volatile Fuels}

The use of higher $\left(\mathrm{C}_{2}\right.$ to $\left.\mathrm{C}_{4}\right)$ co-solvent alcohols with methanol reduced these problems, and was an important factor in the commercialization of methanol gasoline blends. 
Tertiary-butyl alcohol (TBA) was first blended into gasoline commercially in 1969 . It was available from ARCO Chemical Company as a co-product of its propylene oxide manufacturing process.

Following the energy crisis of 1979, interest in alcohol blends in gasoline containing methanol increased. In November 1981, the Environmental Protection Agency approved a Clean Air Act waiver request by ARCO to allow the blending of methanol and TBA at a maximum ratio of 1:1 and a maximum concentration in gasoline of 9.6 percent by volume. This level represented an oxygen content of 3.5 percent in gasoline, the same level allowed for ethanol/gasoline blends. ARCO called its methanol/TBA blends OXINOL®.

ARCO Petroleum Products Company conducted a test-marketing program in 1982 blending OXINOL into gasoline at its Philadelphia, PA refinery, transporting the blended gasoline through a company pipeline to a terminal near Pittsburgh, and selling it through 100 retail outlets. In preparation for its Pittsburgh market trial, ARCO dewatered this distribution system, including pumping out any water heel in the service station storage tanks. Sun Refining and Marketing Company also participated in the Pittsburgh market trial through twenty Sonoco retail outlets. The Sun Company originated the concept of the methanol: TBA blends. ARCO subsequently expanded the trial to over 1300 service stations in the Northeast with the goal of blending OXINOL into all ARCO gasoline produced at the 120 thousand barrel per day Philadelphia refinery. At its peak it used an estimated 35 million gallons of methanol per year in gasoline blends. Sunoco also offered methanol blends commercially during the same period.

To minimize transportation costs gasoline is exchanged between companies with refineries in different locations. Despite having sufficient market position in the Northeast to try and pressure its exchange partners to accept gasoline containing OXINOL, ARCO was unsuccessful in getting other oil companies to commercially introduce methanol gasoline blends.

The DuPont Company, a methanol producer at the time, was granted a Clean Air Waver on January 14, 1985 allowing the blending of methanol and any $C_{2}$ to $C_{4}$ alcohol to a mixture consisting of a maximum of 5 percent methanol, a minimum of 2.5 percent co-solvent alcohol, and a maximum of 3.7 percent oxygen by weight. To ensure the gasoline blend would not increase evaporative emissions, the EPA required the blend meet a volatility specification as measured by an Evaporative Index, defined by DuPont. One of the factors limiting methanol gasoline blends was an economic source of co-solvent alcohol. While the DuPont waiver increased the options to use co-solvent alcohol for methanol blending, the blends did not turn out to be economic, and methanol blends were abandoned in favor of other oxygenates such as ethanol and MTBE.

\subsection{NEAT METHANOL AS A TRANSPORTATION FUEL}

Methanol has been under development as a neat or near-neat transportation fuel for over twenty years. The only significant demonstration program has been by the California Energy Commission, and their experience is summarized in the following section. 


\subsubsection{CEC Experience}

The California Energy Commission (CEC) has had over fifteen years of experience in distributing methanol to retail service stations for vehicles fueled by methanol. The experience covered the period 1979 to 1996 . It represents the largest demonstration of its kind in the world. Their experience included:

- The cost-shared establishment of a network of methanol retail stations

- Cooperative efforts of methanol dispensing equipment manufacturers and automakers to assure fuel quality, new materials, and the interaction of fuel methanol with gasoline fuel additives

- The analysis of in-use economics of fuel methanol including wholesale and retail pricing for both retail and fleet-operated dispensing

The program began in 1979 in response to the second "energy crisis". The central driving force for the program was to reduce dependence on oil, not improvement of air quality. The alternative fuels evaluated included electricity, natural gas, methanol, ethanol, hydrogen, and propane. Methanol was selected as having the greatest potential for replacing petroleum-based fuels for internal combustion engines on a widespread basis. A blend of 85 percent methanol and 15 percent unleaded gasoline, designated M85, was used to accommodate the needs of internal combustion engines.

Initiatives were taken to overcome institutional barriers and to explore potential incentives, both financial and regulatory, to advance the commercialization of methanol as a fuel. The CEC formed the Three-Agency Methanol Task Force (subsequently renamed the Clean Fuels Working Group) with the California Air Resources Board (CARB), and the South Coast Air Quality Management District (SCAQMD), as well as with other local districts.

The initial Alcohol Fleet Test Program in 1980/81 consisted of three fleets operating on both methanol and ethanol. Fleet One consisted of eight 1980 Ford Pintos operating on methanol and ethanol and used in daily fleet service with the California Department of General Services and the Department of Transportation for approximately eighteen months. Fleet Two consisted of thirty-nine factory-produced methanol and ethanol Volkswagen Rabbits and light-duty pickup trucks, which logged 350 thousand miles in fleet service. Fleet Three consisted of forty Ford Escorts operating on methanol in the Los Angeles County fleet, which accumulated over 500 thousand miles in reliable service. These vehicles were produced as gasoline vehicles, shipped to California, and equipped by aftermarket converters to methanol use. These fleets were fueled from two retail fueling facilities and one Los Angeles County fueling station.

Methanol was delivered to the service stations through the existing chemical methanol infrastructure. It was transported from methanol plants in Western Canada, Houston, and Chile by ship to a coastal terminal in Los Angeles. From there it was transported by truck to the retail stations. 
The success of these fleets led to the planning of a 500-vehicle demonstration fleet along with funding for the establishment of methanol fueling stations in 1982. Over a two-year period eighteen retail methanol fueling facilities were established, and these stations continued to operate over a period of five years from 1982 to 1987. These stations were the first network of methanol service stations established in the U.S.

Nevertheless, the relatively small number of fueling sites provided limited options for drivers of the 500 dedicated methanol vehicles to refuel, despite the stations' proximity to the participating fleets. The program was a technical success, but an "emotional" failure. Drivers expressed anxiety as to whether they would be able to locate a fueling station to complete their trips.

The recognition of this difficulty led to the concept of a fuel-flexible vehicle (FFV). The FFV was capable of using either M85 or gasoline as its fuel. The first FFV, a prototype Ford Escort, was assembled and delivered to California in 1987. A fuel-flexible vehicle demonstration program of 5,000 vehicles was developed. It was essential to work with the existing fuel retailing industry to make methanol available in as may retail outlets as possible. It was also necessary to provide funding to offset the differential cost of FFVs.

A breakthrough was achieved in 1988 when the CEC reached an agreement with ARCO Petroleum Products for the establishment of up to twenty-five methanol retail fueling facilities. Existing gasoline service stations were modified to be able to handle methanol. The equipment purchased included an underground 10 to 12 thousand gallon storage tank, fuel dispensing pump, all product and vapor recovery lines, flame arrestors, dispenser, filter, hose, nozzle and a standalone fuel card reader.

Soon after the ARCO agreement, Chevron also agreed to establish and operate up to twenty-five methanol retail stations. Exxon, Mobil, Shell, Texaco, and Ultramar Refining and Marketing also entered into such cooperative agreements over the ensuing two years. By 1996, there were 53 publicly accessible M85 fueling stations (Table 4.1). However, enthusiasm of the major fuel retailers to site methanol stations waned. Methanol was not price competitive with gasoline in FFVs, which could not make optimal use of methanol as a fuel.

Large fleet operators were approached about locating methanol fueling stations to serve both their FFV fleets and the general public. GTE California established a public fueling site at its Thousand Oaks, California location. The CEC sought assistance from the local air quality management districts and various independent fuel retailers to continue its station siting efforts. This led to the establishment of an additional thirteen sites, seven of which are open to the public. Companies included Olympian Oil, P.C.I, E.R. Vines \& Sons, Ramos Oil, Hertz, City of Yorba Linda, Parallel Products, and Brea Auto Spa. 
Table 4.1 Major Fuel Retailers M85 Stations - January 1996

\begin{tabular}{|l|c|c|c|}
\hline \multicolumn{2}{|c|}{} & \multicolumn{2}{c|}{ California Location } \\
\hline Company & Stations in Operation & North & South \\
\hline ARCO & 14 & 2 & 12 \\
\hline Chevron & 13 & 7 & 6 \\
\hline Exxon & 5 & 5 & -- \\
\hline Mobil & 3 & -- & 4 \\
\hline Shell & 12 & 4 & 8 \\
\hline Texaco & 3 & 1 & 2 \\
\hline Ultramar & 2 & 1 & 1 \\
\hline GET Corp. & 1 & -- & 1 \\
\hline Total & $\mathbf{5 3}$ & $\mathbf{2 0}$ & $\mathbf{3 4}$ \\
\hline
\end{tabular}

The Cooperative Agreements called for the CEC to purchase all necessary equipment for each fuel methanol location. In turn, the fuel retailer was obligated to install, operate, and maintain that equipment for a period of ten years. The sites were mutually selected by the CEC and fuel retailers. Several of the fuel retailers would not allow the placement of methanol dispensers on the regular fueling islands. Despite cooperation received from fuel retailers, none undertook any marketing efforts for M85, and the retailing companies have generally lobbied against methanol as an alternative fuel in various public forums.

At the same time, the CEC was encouraging other fuel methanol demonstration participants to establish methanol storage and dispensing systems. Chief among these was a 150 methanol school bus demonstration. Non-public methanol fuel storage and dispensing facilities were established at a number of school district sites to serve these buses. Several state and local agencies, notably the California Department of Transportation, also established private methanol dispensing facilities to serve their own equipment.

As part of the CEC methanol fuel demonstration, it was important to perform essential functions of a retail fuel distribution system. An Electronic Point of Sale (EPOS) system to handle M85 sales transactions was needed. In addition, it was necessary to devise a fail-safe means of preventing misfueling of conventional gasoline vehicles from the methanol dispensers. The system that evolved was a dedicated magnetic stripe card reader network that was located at all methanol fuel retail sites. A radio frequency identification (RFID) transponder technology was selected as the safety system for the prevention of cross-fueling, but was not implemented.

Another key component of the 5000 FFV demonstration program was the creation of the California Fuel Methanol Reserve (CFMR). The goal of the CFMR was to provide a constant fuel methanol supply from several suppliers to wholesale customers and the M85 retail network 
at stable, consistent prices. Developed in 1988, the CFMR was carefully designed to comply with anti-trust laws regarding pooled supply and fuel pricing. By 1990, methanol consumption reached one million gallons. At its peak in 1994, the CFMR handled 12 million gallons of methanol. The number of methanol flexible fuel vehicles peaked at over 15 thousand as shown in Figure 4.2.

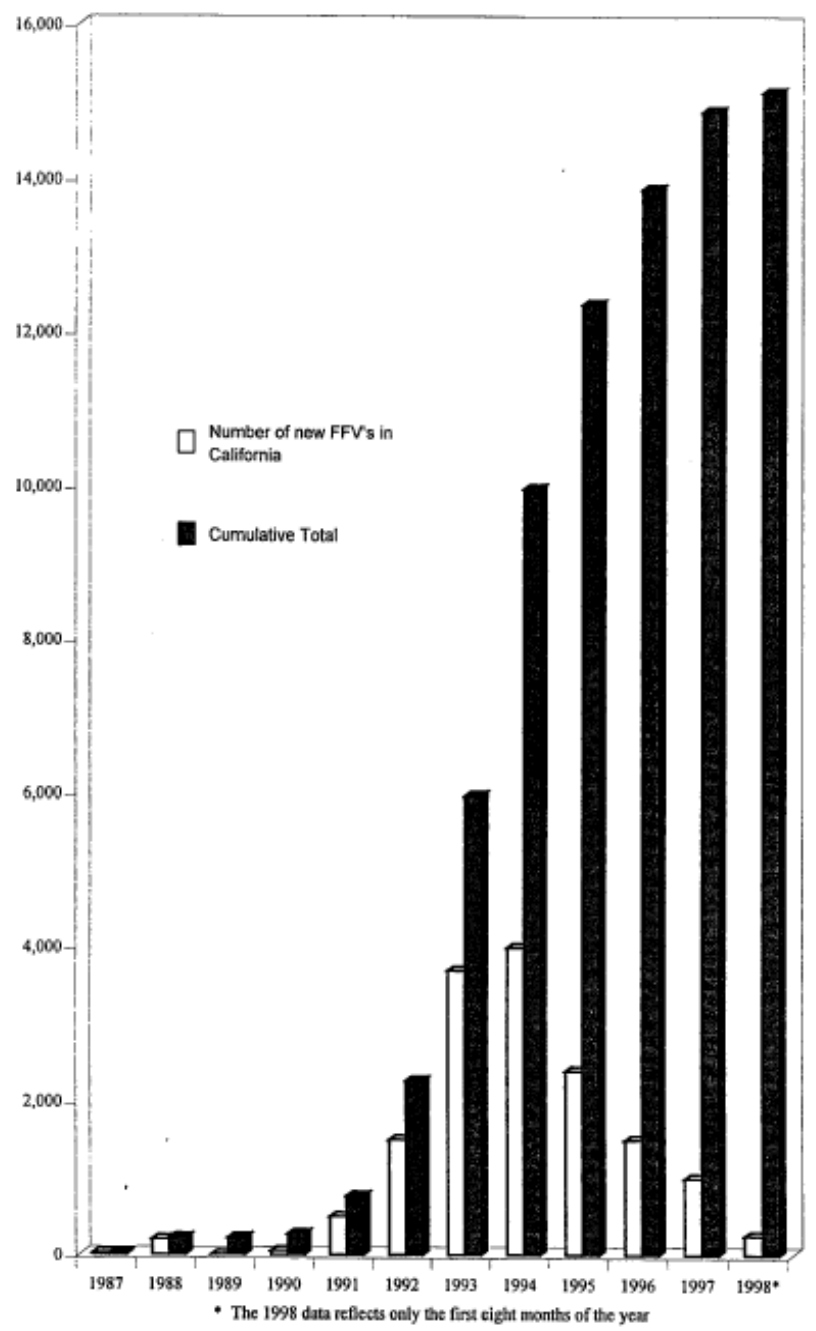

Figure 4.2 METHANOL FFVs in CALIFORNIA, 1987 to 1998, Revised 11-20-98

The methanol retail fuel network and FFV demonstration in California provided a great deal of insights into the issue of fuel quality and materials compatibility. Initially, the concept of methanol compatibility meant that the fueling system hardware components would not deteriorate as a result of coming into contact with the fuel. Methanol fuel system malfunctions, however, led to the realization that the fueling system parts could impair the quality of the fuel itself. As a result, the definition of methanol compatibility has been expanded to include the 
condition that the fuel quality not be deteriorated by coming into contact with components or materials that are methanol incompatible.

Among the lessons learned were the following. Aluminum nozzles, vapor recovery splitter valves, and certain internal parts had to be nickel-plated to prevent fuel contamination. Methanol would leach contaminants from elastomers and/or filter materials used in the manufacture of gasoline and diesel product hoses. Nylon 11 veneer applied to the inner surface of the inner product hose eliminated the problem. Some gasoline detergent additives, namely polybutylamines, were found to be incompatible with methanol, while others, polyetheramines, were compatible with methanol.

While much was learned from the methanol fuel demonstrations, the fuel retailers have generally lost interest in the program because methanol was not cost competitive with gasoline in FFVs. Chevron withdrew its commitment in 1992; ARCO and Shell announced in 1995 that they would not establish any more M85 retail stations. All three continued to operate their existing stations until the end of the agreed ten-year period.

\subsubsection{California Fuel Cell Partnership}

The CFCP has been created with three primary goals:

- Demonstrate vehicle technology for four candidate fuels (on-board hydrogen, methanol, gasoline, and ethanol)

- Demonstrate the viability of alternative fuel infrastructure, including hydrogen and methanol retail stations

- Explore the path to commercialization

The time line envisioned is to conduct pilot tests between 2002 and 2004; market introduction between 2004 and 2006; mass production from 2007 on, at which point there would be 500 stations and vehicle production at 40 thousand per year.

\subsubsection{Methanol Fuel Cell Alliance}

The MFCA was formed in September 2000. Members include Methanex Corporation, DaimlerChrysler AG, BP, BASF, Statoil and XCELLSIS. The MFCA will work together with the goal of producing the following:

- A joint position on the use and introduction of MFCVs after examination of any associated health, safety, environmental and infrastructure issues.

- Documentation and publication of this position for the use and benefit of the entire fuel cell industry.

- The expected implementation of findings in a real world application in the near future.

A report summarizing their study is due to be issued by the end of September 2002. 


\subsection{EXISTING METHANOL SUPPLY CHAIN}

\subsubsection{System Characteristics}

There are nine companies producing methanol in North America. However, the company with the most extensive distribution infrastructure by far is Methanex, as shown in Figure 5.1.

\section{Methanol Infrastructure}

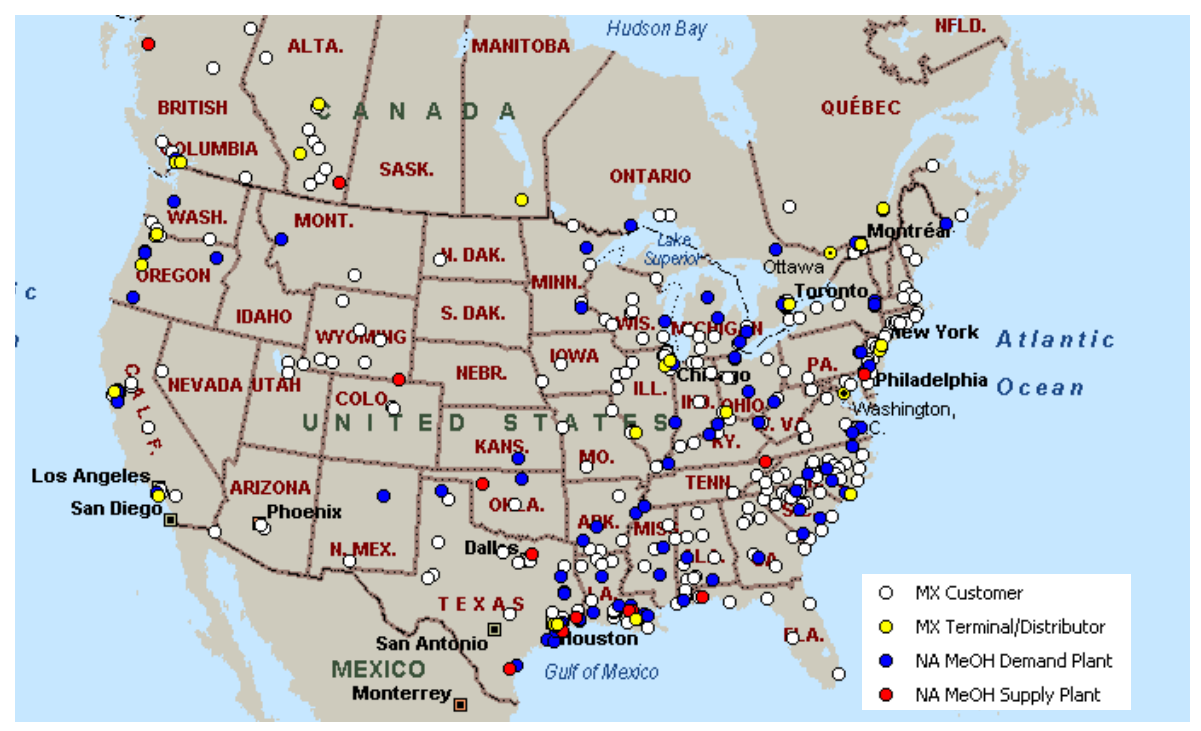

Figure 5.1 Methanol Infrastructure in Place ${ }^{5}$

Methanex has its own coastal terminal at one of its manufacturing plants in Kitamat B.C., and access to eight coastal terminals owned by its distributors. At these coastal terminals, Methanex brings methanol into the United States from low cost production plants in Trinidad, Chile, and other locations. The other major U.S. methanol Distributor is Southern Chemical Corporation. Current conventional methanol demand is quite fragmented, but is geographically concentrated in the USGC. Methanol is shipped by barge up river to terminals in St. Louis and Chicago.

\footnotetext{
${ }^{5}$ Methanex Corporation, September 2002
} 


\subsubsection{Case Study Examples of Conventional Methanol Supply System}

\subsubsection{Ocean Shipments}

Methanol was traditionally shipped in chemical parcel tankers. These tankers had several compartments to hold different clean chemicals, and typically held methanol in lots of 10 thousand tons or less. Parcel tankers allowed shipment of a variety of chemicals to one or multiple destinations. However, as methanol plants were often located remote from other facilities, tankers had to make several stops to load other products. For this reason, dedicated methanol tankers were developed. Given the scale of methanol plants in existence today, these dedicated tankers typically had a capacity in the order of 30 thousand tons of methanol. Another constraint on vessel size has been the size and draft of the dock available at the methanol plant.

Today, the largest scale of methanol ocean transport is 100 thousand metric tons. Vessel loading is often accomplished using deep-ocean type mooring systems such as single-point mooring systems rather than building docks large enough to accommodate such large vessels.

Dedicated vessels are built to serve particular methanol plants either owned by the methanol producer or under a contract of affreightment. There is no surplus shipping capacity. As new methanol plants are built in remote locations, new dedicated methanol ships will need to be built.

\subsubsection{In Land Distribution}

Because current chemical methanol markets in the United States are diverse and geographically dispersed, there is an extensive methanol distribution infrastructure in place in the U.S. Methanol is moved from coastal terminals by barge, rail, and truck throughout the U.S. Methanol is also moved by dedicated pipelines, but only to a limited number of major consuming plants, such as formaldehyde and MTBE plants. For example, there are pipelines from Celanese's methanol plant to its formaldehyde plant at Bishop Texas, and a few pipelines from methanol plants in Houston to MTBE plants in Houston.

Barges and trucks currently used to transport gasoline probably can be used for methanol, but any gaskets in hose couplings would likely need to be changed to ones which are methanolcompatible. Barges typically have carbon steel tanks, which can be used with methanol. Many trucks have aluminum trailers. While methanol is corrosive to aluminum when wet, chemical grade methanol is shipped in aluminum trailers today.

The two largest consumers of methanol are formaldehyde and MTBE producers. Together these two markets account for two-thirds of total conventional methanol demand. There are forty-nine formaldehyde plants spread over the United States, but concentrated in the Southeast and Northwest due to ultimate use in the wood products industry. There are forty-four MTBE plants, with a majority of capacity located in the US Gulf Coast, and most have access to terminals. For these major methanol markets, methanol is shipped primarily by barge and in some cases by rail and truck. 


\subsection{SHIPPING METHANOL IN PETROLEUM DISTRIBUTION SYSTEM}

\subsubsection{Refinery Operations}

In the early 1980s methanol and co-solvent alcohols were blended into gasoline at a number of refineries on a trial basis. However, ARCO was the only company to do it commercially, and the practice has been abandoned due to the commercial failure of methanol: gasoline blends.

\subsubsection{Pipeline Shipping}

In the early 1980s there was consideration of moving methanol and gasoline blends through petroleum product pipelines, and some testing was done by Transmountain Pipeline, Colonial Pipeline and Tepco. Transmountain Pipeline shipped neat methanol which was burned in a pulp mill at the far end of the pipeline. However, none of the common carrier pipelines approved the shipping of methanol gasoline blends because of concern over water pickup, the scouring of scale off of pipeline walls, and potential contamination. Moreover, it is considered impractical to move neat methanol through petroleum product pipelines due to the likelihood of picking up water and other contaminants.

Ethanol is moved through common carrier pipelines. Williams moves ethanol from the Gulf Coast to Midwestern terminals in 25 to 50 thousand barrel batches where it is blended with gasoline. $\mathrm{BP}$ is planning to use existing pipelines for transporting ethanol from port of entry to terminals in California as it prepares for the state's MTBE ban and Phase 3 reformulated gasoline. However, ethanol's water sensitivity and tendency to scour scale off of pipeline walls is much less than for methanol.

\subsubsection{Terminals}

Methanol has been splash blended into gasoline at terminals into trucks. In splash blending, methanol and a co-solvent and gasoline are pumped from separate storage tanks through a common line at specified ratios into a truck. However, only ARCO moved methanol through petroleum terminals.

The reason was concerns about water pickup in the low-level methanol blends in gasoline being tested at that time. In fact, the tanks and piping at methanol storage terminals are identical to those used for petroleum fuel distribution.

Methanol is primarily a chemical commodity and is typically stored in clean-product (nonpetroleum) terminals to maintain its 99.85 percent purity standard. In addition, chemical-grade methanol is transported in specified chemical tank trucks, which are distinct from the tanker trucks used to haul other liquid products, including gasoline. During the California fuel methanol program, fuel methanol was available in Northern California from bulk storage at a petroleum terminal. By contrast, in southern California fuel methanol was distributed from a chemical terminal. The difference in loading procedures between these two types of terminals is discussed below.

- Chemical terminal 
In general it is a violation of California state or local air quality regulations for a fuel transporter to "pop the dome" caps of its tanker carrying gasoline or gasoline vapors. Doing so would release regulated evaporative emissions to the atmosphere. The Southern California chemical terminal is not equipped for bottom loading. However, it is equipped for vapor recovery for toploading the fuel through the dome cap.

Tank trucks are not required to be steam-cleaned and dried for the transportation of fuel methanol. Fuel methanol can be loaded providing that the tank truck contains methanol vapors only. Methanol cannot be loaded if the tank truck contains liquid fuel retained from a nonmethanol previous load. Terminal personnel may ask the hauler or purchaser entity to sign a waiver, thereby transferring liability to the purchaser for potentially off-specification or contaminated fuel. In order to assure an acceptable level of fuel methanol purity and to avoid the need for a waiver of fuel quality, it is recommended that the procedures shown in Figure 5.2 be followed when loading methanol from a conventional chemical terminal. 


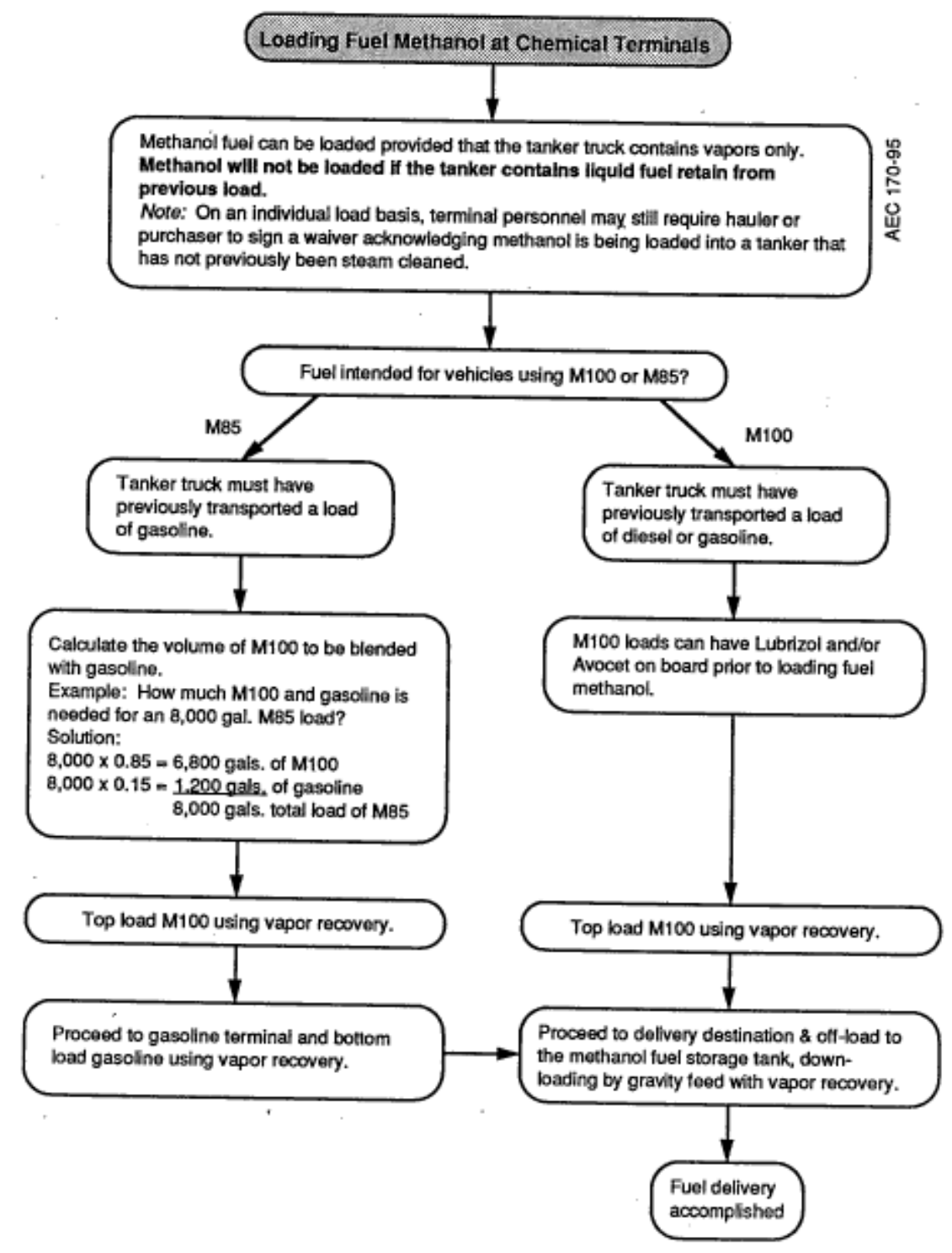

Source: CEC Fueling System Manual, 1998

\section{- Petroleum terminals}

Figure 5.2

Because of its simplicity, loading fuel methanol from a petroleum terminal is preferable, where this is possible. Care must be given to assure fuel quality and safe handling. The flowchart in Figure 5.3 shows the suggested guidelines for loading fuel methanol from petroleum terminals. 


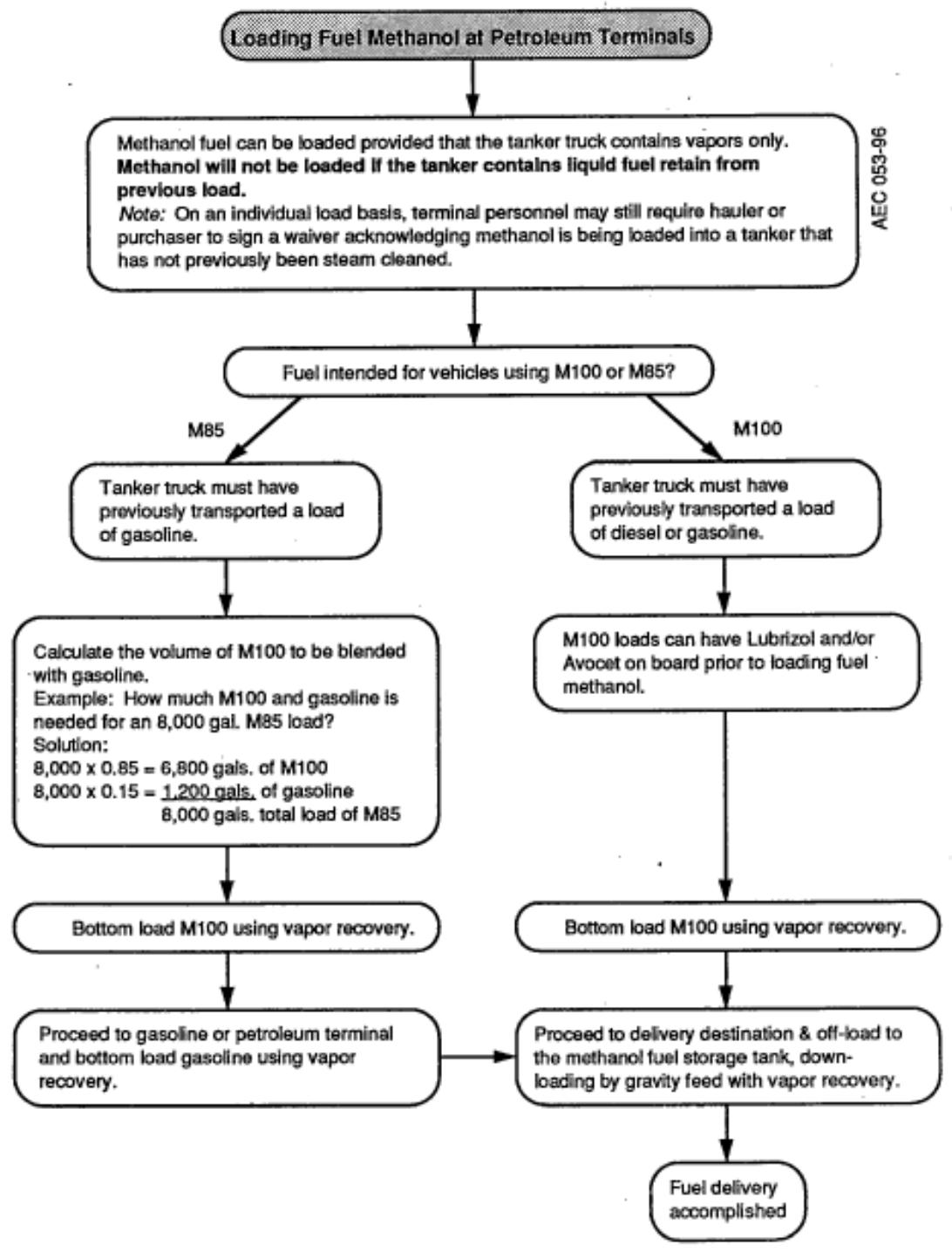

Source: CEC Fueling System Manual, 1998

Figure 5.3 


\subsubsection{Service Stations}

The requirements for adding methanol fueling capabilities to gasoline retail stations are outlined in Figure 5.4 below. The components include a double-walled fuel storage tank, a fuel dispenser, a vapor recovery system, and associated pipes, hoses, and fittings. The storage tank may be buried, as shown in the figure, or if space and local codes permit, may be located above ground. The equipment and arrangement are essentially the same as those found in retail gasoline or diesel stations.

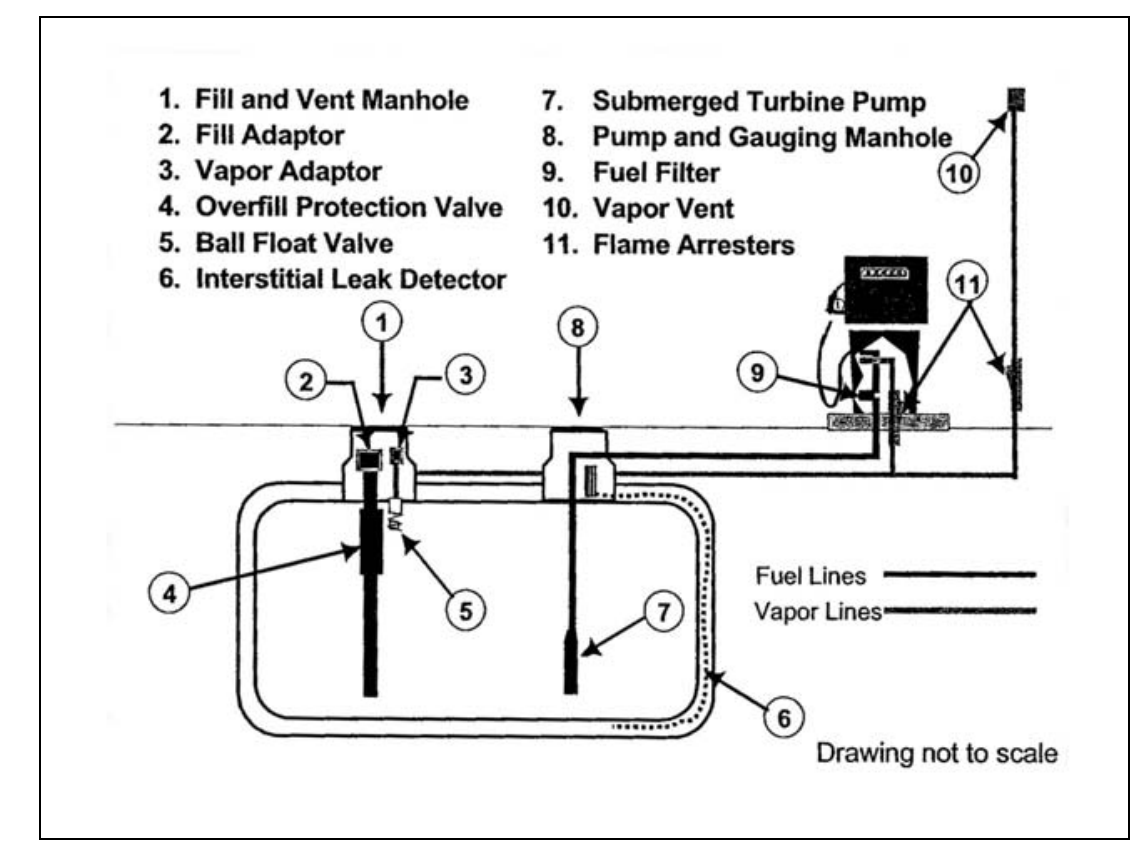

Source: CEC Fueling System Manual, 1998

Figure $5.4 \quad$ Schematic of Methanol Fueling Station

Storage facilities, tanks, hoses, pumps and piping require the use of methanol compatible materials because methanol will attack or corrode rubber, aluminum, galvanized metals, and certain plastics. In general, other than these differences, methanol refueling stations are identical to gasoline stations.

Figure 5.5 is a schematic of the basic components of a fueling facility. Figure 5.6 shows components of particular concern at the dispenser. These components include, but are not limited to the following: 


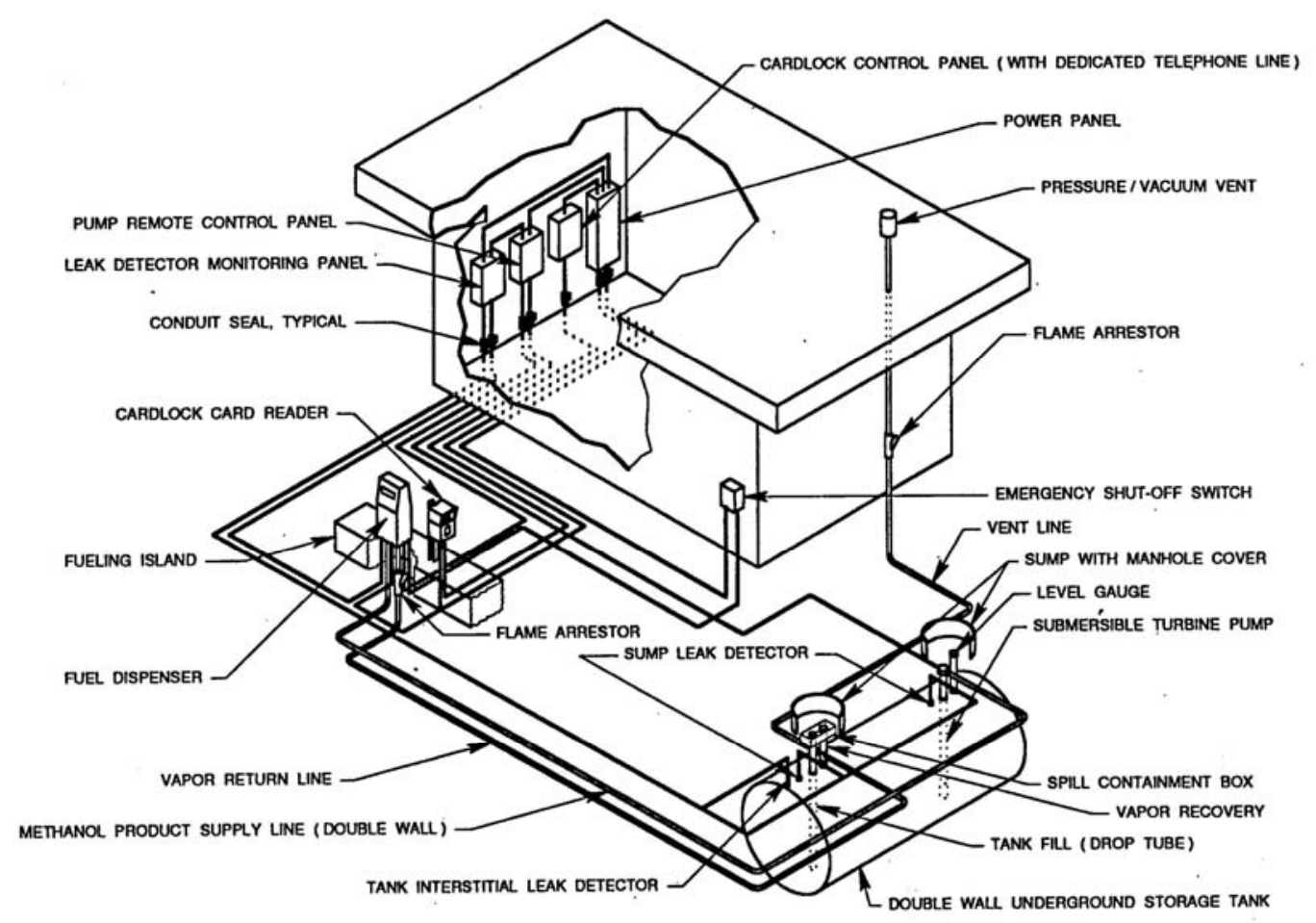

Figure 5.5 Fueling Facility Isometric Drawing 


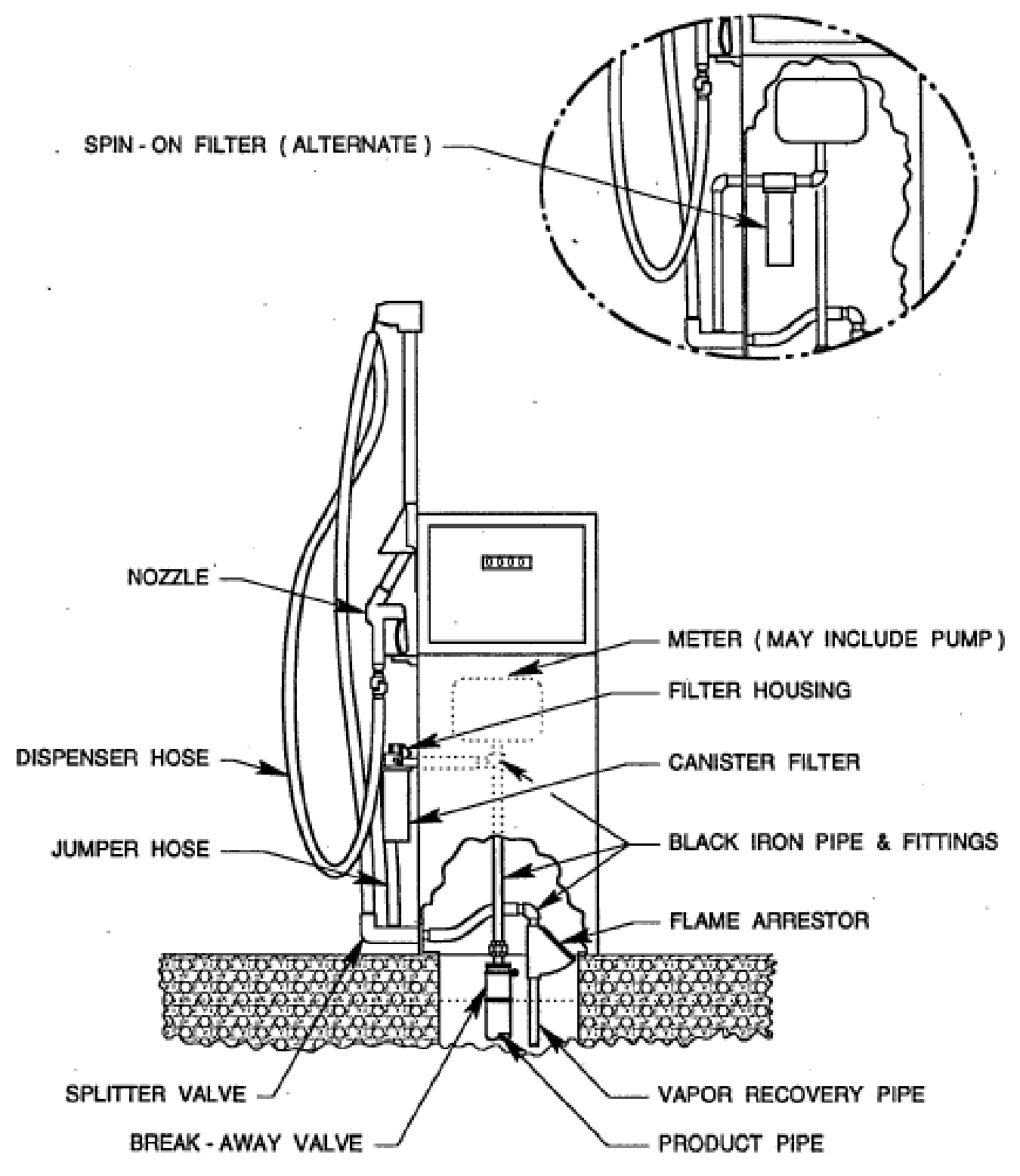

Source: CEC Fueling System Manual, 1998

Figure 5.6 Dispenser

- Underground piping system

- Containment of product piping system (secondary containment per federal and state underground storage tank regulations)

- $\quad$ Submerged turbine pump

- Drop tube in tank 
- $\quad$ Dispenser meter (and pump, if system uses a suction pump)

- Break-away valve

- $\quad$ Filter and housing

- Jumper hose

- Product hose

- Product hose

- Vapor return hose

- Nozzle

- Splitter valve (coaxial adaptor)

- $\quad$ Flame arresters

- Pressure/vacuum vents

- $\quad$ Fittings and piping connections

\subsubsection{Similarities with and Differences form Conventional Gasoline Refueling Stations}

Generally speaking, except for the use of methanol-tolerant materials and certain additionally required fittings, such as flame arresters and pressure/vacuum vents, a methanol fueling station differs little from its gasoline counterpart. The main differences occur in the area of product compatibility (as noted above), and the cardlock system employed as a safety feature to prevent dispensing methanol into a vehicle not designed to operate on the fuel.

The sequence of construction operations are virtually identical for both gasoline and methanol, with the exception of the addition of flame arresters on the vapor recovery pipe at the dispenser and on the vent standpipe, and pressure/vacuum vent caps on the vent standpipe. Materials of construction vary only in their methanol compatibility and are physically very similar. At the pump, the methanol user notices little difference from gasoline purchases utilizing the selfservice ATM/credit card in-dispenser units now found in many service stations. The principal difference is that the cardlock systems also require the customer to enter a PIN number.

Underground storage tanks (USTs) for methanol are classified as chemical USTs, and are regulated by the Environmental Protection Agency. These regulations state that chemical USTs installed after December 1988 must have secondary containment and interstitial monitoring. Secondary containment may be provided in a number of ways, the most common being to place one tank within another, making a double walled tank. Interstitial monitoring devices detect the presence of a leak in the space between the two tanks. 
Test procedures have been developed for materials used in fabricating equipment for dispensing methanol and methanol/gasoline blends for use in internal combustion engines ${ }^{6}$.

Acceptable materials of construction for methanol storage tanks include carbon steel and fiberglass. Underground carbon steel storage tanks must be protected from corrosion, usually by a fiberglass coating.

Existing gasoline storage tanks can be converted for methanol use. Tank cleaning vendors suggest two techniques for cleaning USTs. In the first, personnel wearing self-contained breathing apparatus enter the tank and manually wash its inner surfaces. In the second, the tank is pressure washed from the outside. In both cases, the process leaves the tank in a clean gasoline-free state, indicating the absence of explosive vapors. The tank may, however, contain residual moisture, which can be removed by additional methanol rinses.

Another way to reuse existing tanks is to construct a new fiberglass tank inside the existing tank. Fiberglass panels, prefabricated at the factory to fit the contours of the existing tank, may be installed in the existing tank, while it is still in the ground. All tank fittings are relocated to new manways and upgraded to current standards. The ReTank ${ }^{\mathrm{TM}}$ System, introduced in 1994, is an example of this approach.

In the event that an existing tank is reused, all product and vapor piping leading to and from the tank should be replaced. Secondary containment will also be required for new product and vapor piping.

A site plan for a typical urban/suburban fueling station located on a corner $110 \mathrm{ft}$. $\mathrm{x} 110 \mathrm{ft}$. lot is shown in Figure 5.7. The station has three USTs for storage of three grades of gasoline, two pump islands, and four dispensers capable of refueling eight vehicles simultaneously. At an average fill-up of 13.5 gallons in six minutes, a station such as the one illustrated may service between 200 and 400 vehicles per day and have a gasoline throughput of 85 to 170 thousand gallons per month.

\footnotetext{
${ }^{6}$ Pending SAE Standards J1747, Recommended Methods for Conducting Corrosion Tests in Gasoline/Methanol Fuel Mixtures, and J 1748, Recommended Methods for Determining Physical Properties of Polymeric Materials Exposed to Gasoline/Methanol Fuel Mixtures
} 


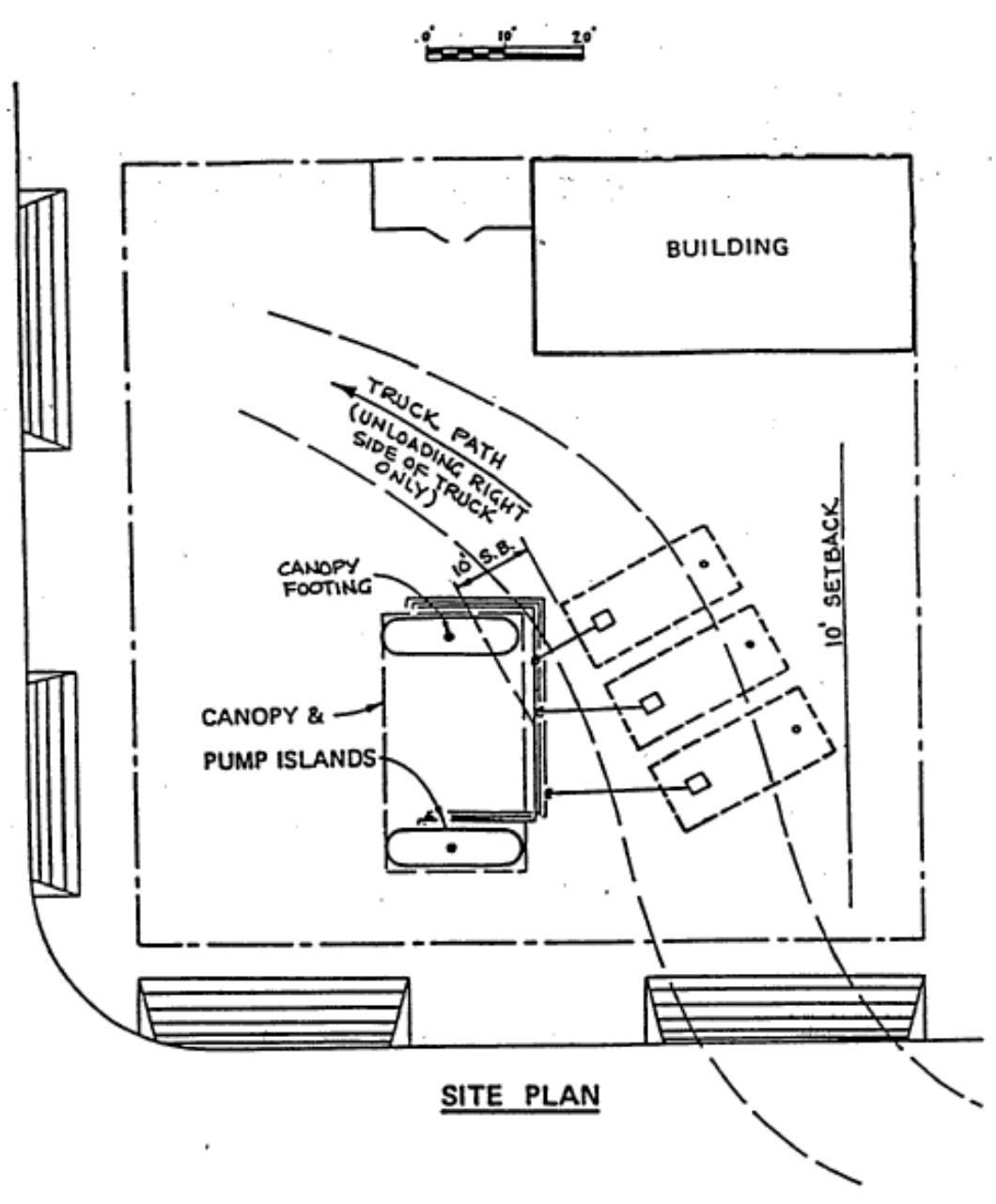

Source: CEC Fueling System Manual, 1998

Figure $5.7 \quad$ Site Plan

\subsubsection{Fuel Quality and Equipment Compatibility for Methanol}

The CEC's experience with M85 has shown that fuel system reliability has sometimes adversely affected both the integrity of the vehicle delivery system and fuel performance as well.

Fuel contamination was a major cause of these reliability problems. The chemical processes that occur between the dispensing equipment and the fuel, and the resulting by-products that contaminate the fuel are discussed below. Several of the factors contributing to customer dissatisfaction are:

- Vehicle fuel filter clogged after only weeks of service

- Vehicle fuel systems have not been standardized by manufacturers, leading to incompatible equipment and/or poor availability of parts 
- Fuel regulatory agencies have varying standards, leading to widely varying performance and also to contamination

- Sampling for fuel quality analysis is often not performed at the point of use, and, therefore, does not account for fuel contamination occurring in the delivery system downstream of the sampling point

- Fuel analysis results varied with the volume of fuel purged from the dispenser, and, therefore, did not account for fuel contamination occurring in the delivery system over an extended time period between one purchase and the next

- Some methanol-wetted parts decomposed and/or corroded into the fuel

- There was not existing compatibility standard for methanol equipment

- No authoritative source existed for approved methanol equipment, which could result in incompatible equipment being installed

- The UL listing for equipment does not address all aspects of methanol compatibility that can result from incompatible equipment being installed

- Poor equipment installation and maintenance practices can result in fuel contamination

\subsubsection{Immunity of Equipment from Attack}

Due to the more corrosive nature of alcohol fuels generally, and of methanol in particular, materials used in the fabrication of methanol dispensing equipment must be more chemically resistant than those used for conventional fuels (gasoline and diesel). There are three distinctive types of corrosion that can occur between methanol and the materials it contacts. The first of these is chemical dissolution, in which the methanol literally dissolves certain materials. The second corrosion problem that can occur is incompatibility of materials. In this case, the methanol chemically reacts with certain materials resulting in weakening of molecular bonds and subsequent material deterioration or fracture. The last type of corrosion that can occur in a methanol system is galvanic corrosion. This occurs when there are dissimilar metals coupled by conductive fluids. Furthermore, the higher the conductivity of the fluid, the more rapid the galvanic corrosion can occur. The interesting fact about these types of corrosion is that they can all occur simultaneously, and can influence or act as catalysts for one another. Extensive fuel testing and equipment analysis has shown that these mechanisms are all active components of the methanol fuel contamination problem.

Early-generation methanol fuel dispenser hoses were found to contaminate the M85 fuel. The M85 would leach plasticizer and filler (zinc oxide) from the hose, thus increasing the fuel conductivity. This may have been the cause of two observed synergistic problems. Enhanced fuel conductivity may lead to increased overall corrosion rates, and specifically, galvanic corrosion where different metals come in contact. Of specific concern was the potential for increased aluminum corrosion. The enhanced corrosion rates from increased conductivity also may explain extensive pitting observed on some standard aluminum parts. Furthermore, high concentration of aluminum (as aluminum hydroxide) has been suggested as the source of filter clogging problems. In at least one filer clogging case, however, aluminum oxide or hydroxide was not present in the filter. Aluminum was present, though, and the combination of aluminum 
ion and plasticizer may have been the culprit. Clogging could occur when the combined solubility of aluminum and plasticizer is decreased by the addition of straight gasoline to he M85 fuel, leading to precipitation in the filter. The problem was successfully addressed by changes in hose liner materials in the CEC demonstration program that led to substantially decreased the leaching of hose components into the fuel.

The nickel-plating of aluminum components or replacement with stainless steel resulted in minimum pitting and little or no aluminum introduction into the fuel itself. Additionally, improvements in material selection for hose material drastically reduced the conductivity measured in methanol dispensing systems indicating that chemical breakdown was lessened. Efforts need to be continued along both avenues to ensure contamination is not a problem and that fuel quality, vehicle drivability and reliability are kept at high levels. Many contamination problems can be avoided by proper maintenance practices. Therefore, it is important to take every step possible to provide the customer with as high quality fuel product as possible.

\subsubsection{Overview of Definitions of Methanol Compatibility and Discussion of Standards and Certifications}

Most of the testing procedures for equipment, which is to interface with methanol and methanol/gasoline blends, relate to the degradation of the equipment itself, and not to the quality of the fuel. It has generally been the quality and durability of the parts that manufacturers have targeted. As long as material degradation of a part did not affect its operation, it has been deemed satisfactory. This has generally been a successful technique when applied to gasoline and diesel products. With methanol and methanol/gasoline blends, however, this is inappropriate. Though less than the quality requirement for chemical grade methanol, the high quality requirements of methanol fuels dictate that wetted parts not only have a satisfactory operating life, but that they also do not in any way degrade the product that comes into contact with them. New methods of testing must be devised to satisfy this requirement.

The term " methanol-compatible" means not only no deterioration in the equipment, but also no deterioration in fuel quality. All components, which come into contact with the fuel, should be verified by soak testing. The conductivity, chemical stability, and filter plugging tendencies (particulates and unwashed gum) of the soak test fuel should be tested before and after soak testing the equipment and its constituent materials. Soak test fuels should be chosen per SAE Standard J1681, Gasoline/Methanol Mixtures for Material Testing (e.g., CM85A). Pending SAE Standards J1747, Recommended Methods for Determining Corrosion Tests in Gasoline/Methanol Fuel Mixtures, and J1748, Recommended Methods for Determining Physical Properties of Polymeric Materials Exposed to Gasoline/Methanol Fuel Mixtures, prescribing test methods for evaluating elastomeric materials and metals in methanol fuel blends. In addition, to be "methanol compatible", a dispensing site should be constructed to avoid the coupling of dissimilar metals in contact with the fuel. Dissimilar metals are those that are separated widely on the galvanic series. Additional information regarding equipment testing is available from the American Automobile Manufacturers Association M85 Fuel Specifications and Dispensing Equipment Compatibility Standards for M85 Vehicles. 


\subsubsection{Importance of Proper Fueling System Components in Maintaining Fuel Quality}

During the initial design of a methanol fueling station, it is essential that the designer chose equipment whose wetted parts will not degrade the product be selected. A list of Approved Components List for Methanol-Compatible Equipment is found in Appendix I of this report ${ }^{7}$. UL-listed components are required by most local agencies. It is equally important that equipment be properly installed. Construction specifications should place emphasis on quality work and cleanliness of the workplace so as not to contaminate the inside of the tank or any of the equipment. Final acceptance must be based on a satisfactory product being dispensed at the point of use. Regular maintenance of methanol fueling facilities is required. One of the most important regular maintenance cycles that should be conducted is a fuel filter preventative maintenance schedule

\subsubsection{Upgrading Existing Installations}

Careful inspection to verify that equipment used is compatible with the methanol fuel must be carried out for every new installation, and whenever upgrading an existing methanol dispensing facility. An existing fuel station is going to have equipment or parts that are non-compatible with methanol be replaced with compatible counterparts when upgrading existing facilities to dispense methanol.

\subsubsection{Hardware Requirements}

The typical systems components used in distributing conventional petroleum fuels are acceptable in most cases or are easily modified to adapt them for use with fuel methanol. For example, the tanks and piping at methanol storage terminals are identical to those used for petroleum fuel distribution. Similarly, tanker trucks for delivery from terminal to fuel station, station underground storage tanks, dispensing pumps, underground piping, dispensers, filters, hoses, and nozzles are equally suited, with minor adaptations. Moreover, the materials and components developed or upgraded fro fuel methanol applications provide an additional practical application in the distribution of reformulated gasoline and diesel fuels, as these use oxygenates such as ethanol, MTBE or ETBE as well as other additives that may require enhanced chemical resistance in fuel storage and handling equipment.

The establishment of methanol distribution and dispensing systems in California has led to an evolution in dispensing equipment, which appears likely to form the basis for the expansion of these facilities in the future. The expense of modifying the typical petroleum dispensing components for methanol does not significantly increase the cost for methanol systems. Accordingly, the cost of fuel methanol systems is directly comparable to conventional petroleum fuel systems cost and remains well below the cost of distribution and dispensing gaseous fuels.

\section{Storage Tanks}

Methanol storage tanks can be installed either above or below ground. Installation practices are generally the same whether the tank contains gasoline or methanol. The decision to install an

\footnotetext{
${ }^{7}$ California Energy Commission Methanol Fueling System Installation and Maintenance Manual, 1998
} 
above or below-ground tank will depend on site location, installation logistics, ground conditions, cost, and local codes and regulations.

Above ground tanks are common for public and private fleet fueling facilities. This is because in many cases utilization of space is not as critical a factor as cost and ease of installation. They are rarely used for retail fueling stations. Most retail fueling stations are underground storage tanks because they allow for greater utilization of the land for commercial purposes such as driveway access, parking, and dispenser islands. Aboveground tanks can be purchased in sizes ranging from about 250 to 12,000 gallons, while underground tanks from 500 to 50,000 gallons are available. The most common size of underground tank is 10,000 gallons.

A storage tank's compatibility with methanol is not directly affected by its being above or below ground.

An aboveground tank is more susceptible to weather because it is exposed to the elements. Therefore, an above-ground tank system must be protected be either an overhang or selection of appropriate materials that are not degraded but exposure to the sun's ultraviolet light. Generally, an aboveground tank will be required to have a spill containment dike around it. This containment space must either be protected from rain, by a roof system, or other arrangements must be made to pump out and dispose of any water that might accumulate within the diked area. Physical damage is also more of a problem for aboveground storage tanks. The chance of a vehicle impact does not really exist for underground storage tanks. Therefore, the aboveground tanks require protective barriers. The possibility of fire is or greater concern for an aboveground tank. Burning material can come in contact with the exterior of tank, which, if conditions are right, can result in detonation of the interior fuel. This is highly unlikely to occur with an underground tank.

Underground tanks are not susceptible to the same problems that aboveground tanks are. However, underground tanks are susceptible to ground corrosion, earth movement, and flotation, and may require tank tie-downs and secondary containment according to local codes and regulations. In addition, underground tanks must be protected from rainwater intrusion and/or accidental spills draining into the tank manholes and tank access areas. Figure 5.8 shows an above-ground tank with components labeled. The storage tank pictured has the dispenser and meter located on top of the fill tube to the storage tank. The methanol fuel pump can be located wither in the storage tank or in the dispenser located remotely. 

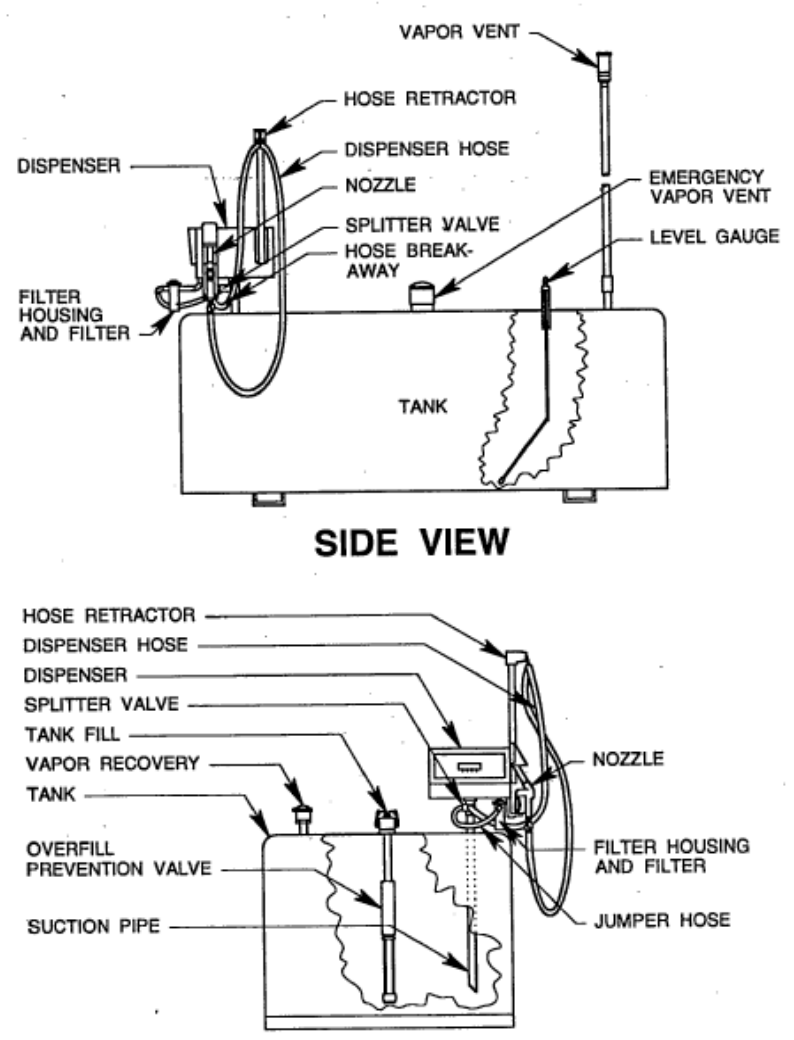

FRONT VIEW

Figure 5.8 Above-Ground Tank and Dispenser

In general, aboveground storage tanks come under closer scrutiny by fire departments than do underground tanks for the reasons discussed above. For this reason, they are usually enclosed in a fire-protective coating such as concrete. Planning department are also often involved because of the visual aspect. Building departments and environmental agencies will be concerned with the chance of vehicle impact, causing rupture and spills. Typical agencies involved in regulating above-ground storage tanks are described in Section 5.2.2 below.

As previously mentioned, the regulations for new underground storage tank installations are the same whether the tanks contain gasoline or methanol. Typical agencies regulating underground storage tanks are listing in Section 5.2.2. Most regulatory agencies require that underground tanks be of double-walled construction, and have active leak-detection systems installed (see below). Regulations require that the crown of a buried tank have a minimum covering of 36 inches of fill material, or 30 inches of fill material with an 8-inch reinforced concrete slab overlaying the tank. Fill material for all-fiberglass or fiberglass-over-steel composite tanks must be pea gravel. Sand or other suitable fill materials may be used for all-steel tanks. These materials are required in order to ensure that the tank is not damaged by vehicles driving over it. The requirement for antiflotation tie-downs depends on the level of the ground water table for the proposed tank location. If the water table is high enough to interfere with the tank, then the 
tie-downs will be required by the local building department. With fiberglass tanks, the maximum crown depth below grade should be less than 7 feet. A typical underground storage tank is shown in Figure 5.9. As discussed above, the fire danger for underground tanks is far less than for aboveground tanks. The greatest concern that regulatory agencies have with underground storage tanks is with leakage.

In cases where a new methanol storage tank is not a feasible option, an existing double-walled unleaded gasoline tank may be reused for M85, although this is generally not a recommended practice. Singe-walled tanks cannot be used for methanol. In addition, tanks that have contained leaded gasoline or diesel must not be reused to hold methanol, as such tanks may contain a methanol-incompatible residue that could impact fuel quality. In the case of M100, no gasoline or diesel tank should ever be reused to hold it. 


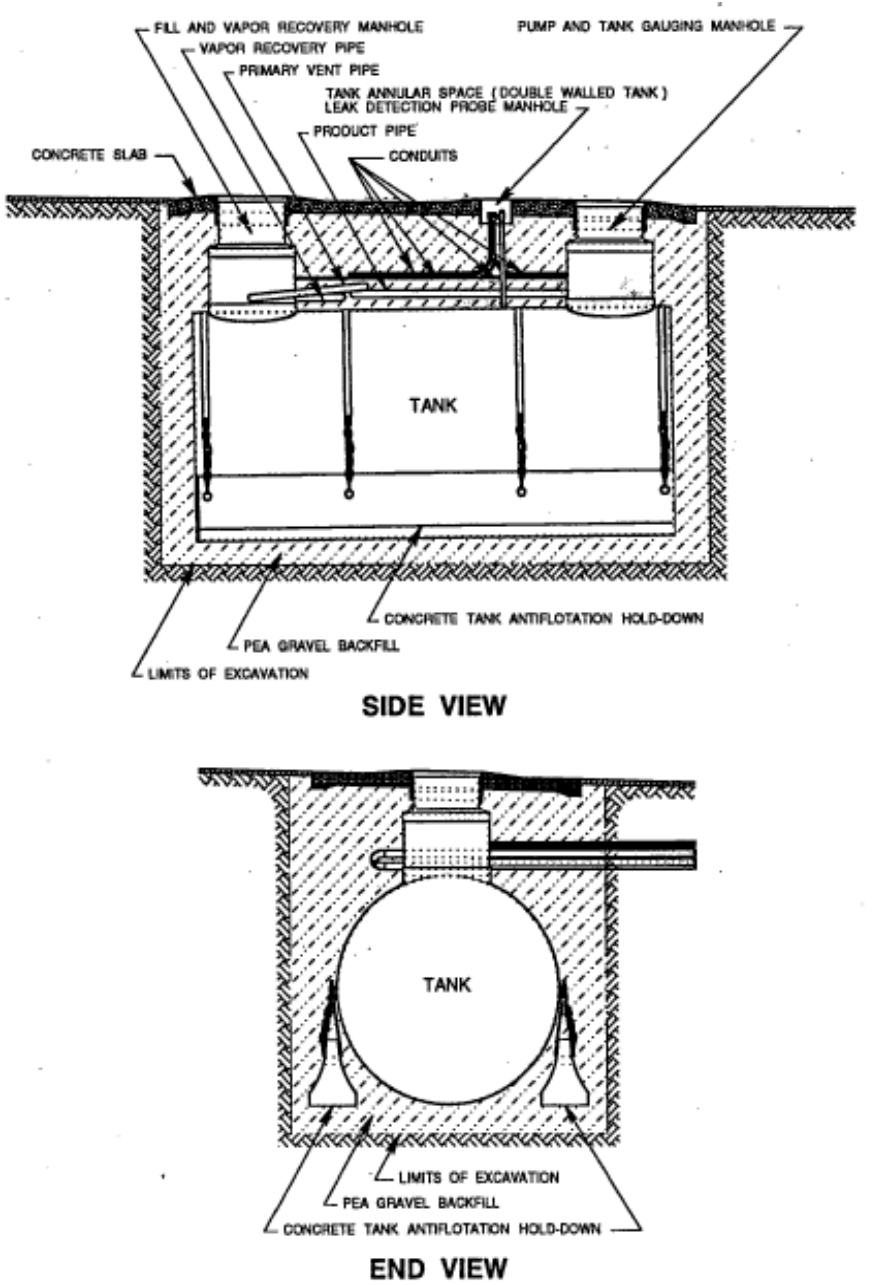

Figure 5.9 Underground Tank

If tanks to be reused are of all fiberglass construction, the tank manufacturer should be consulted, and written documentation obtained stating that the tank resin is incompatible with M85 fuel methanol

Double-walled tanks that have previously been used only for unleaded gasoline, not leaded gasoline, may, if practical, be cleaned and used for M85, but not for M100. M85 contains unleaded gasoline, so any residue from unleaded gasoline will not impact fuel quality. In the cleaning of such tanks, it is vitally important that all sediments, scale, and any water that may have entered the tank be removed. Tank cleaning should be performed only by a contractor who can show proof of being qualified to do such work and of having cleaned other tanks successfully. Tanks should then be pressure tested using the same procedures for a new tank, see Section 5.2.11 below. 
Tank materials in contact with methanol must be "Approved" fuel-compatible. These materials include, but are not limited to, all-steel (carbon steel), all-fiberglass, carbon steel with an external protective fiberglass coating, carbon steel with an external protective concrete coating, and stainless steel. Due to cost constraint, stainless steel tanks will be rare. Because of cost factors, the most common underground tank type installed for methanol service to date is carbon steel with an external fiberglass coating.

In the past, all-fiberglass tanks manufactured for gasoline and diesel service utilized a resin incompatible with methanol. At the beginning of the CEC fuel-methanol program, manufacturers of all-fiberglass tanks wanted a high premium for using an "Approved" methanolcompatible resin. Today many all-fiberglass tanks used for gasoline and diesel service are being manufactured with the "Approved methanol-compatible resins, and all-fiberglass tanks are thus becoming much more cost-competitive.

All steel tanks have been generally avoided because of the need for cathodic protection, which can be very costly.

The most common aboveground tank type installed for methanol service to date is the carbon steel tank with an external protective concrete coating. This is due to its inherent insulation properties and its resistance to external fires.

\subsubsection{Tank Venting Requirements}

The venting system required for methanol fueling facilities is nearly identical to those systems used for gasoline and diesel fueling facilities. It incorporates both a tank vent, which prevents excessive pressure or vacuum conditions in the tank, and a vapor recovery system, which prevents the escape of fuel vapors during dispensing or storage tank refilling operations. The details of these systems are described below in the section on pumping, metering, and miscellaneous equipment.

\subsubsection{Recommended Features}

Optional safety and/or operating features are recommended for use with methanol fueling facilities. These features include remote monitoring for leak detection systems, fill cap identifications, fill cap padlocks, special labeling, color coding to prevent cross fueling, and modification of manhole spill box and cover plate rain gutters.

\subsubsection{Leak Detection Systems}

Federal and some state laws require that all underground hazardous material storage facilities be monitored for leaks to prevent contamination of the soil and seepage into the water table. To comply with these laws and ensure the integrity of leak detection, different approaches are taken.

Liquid/vapor leak detectors, which can be placed in the following locations:

- The interstitial space of a double walled tank

- At low points of secondary containment pipes 
- In sumps, manhole, and caisson compartments

- $\quad$ At the inside high point of tanks to prevent overfill

Where submersible pumps are utilized, pressure measurement monitors placed on the supply pipeline register pressure decay, indicating leakage

Methanol compatibility of interstitial leak detection devices is not considered critical because the detection device should not come in contact with methanol until a leak occurs. However, once the interstitial leak detector is exposed to methanol it may need to be replaced to ensure continued reliability.

Leak detection devices that monitor pressure are in direct contact with methanol and need to be methanol compatible. These leak detectors are usually located on the submerged turbine pump or on the supply pipeline between the pump and dispenser. A list of currently available leak detectors and manufacturers is provided in the Appendix.

\subsubsection{Remote Monitoring Systems}

A wide range of remote monitoring systems are available to carry the signal once a leak have been detected. These systems are removed from any contact with methanol and will operate without concern for methanol compatibility. Systems can generate an alarm and may shut down specific components if the liquid/vapor probe detects methanol or if the preset parameters of the pressure sensor are exceeded.

\subsubsection{Fill Cap Identifications to Prevent Bulk Cross-Fueling}

It is extremely important that the fill caps of the methanol tanks be boldly labeled to prevent other fuel deliveries from accidentally introducing their product (gasoline, diesel, etc.) into the methanol tank. Color-coding can be utilized. Padlocks should be attached to the caps, thereby requiring the presence of the station operator at any filling operation.

\subsubsection{Manhole Cover Plate Split Box Modifications}

The manhole spill box at the product fill/vapor recovery ports is designed to catch any spillage that may occur during bulk filling of the tank. Although these spill boxes vary from manufacturer, most generally consist of the following components:

- A cast iron outer ring

- A steel cover plate with two hatch plate openings

- A rectangular fill port steel cover plate

- A rectangular vapor recovery port steel cover plate

- A rain gutter or other rain exclusion device

- A spill containment box 
The cast iron outer ring is imbedded into the concrete slab over the tank. The cover plate, with cutouts for the fill/vapor covers, bolts onto the outer ring with a gasket to prevent rainwater intrusion. The rectangular fill and vapor recovery port covers fit into the openings in the cover plate. Below these openings, and attached to the cover plate, is a rain gutter to catch any rain water intrusion. Bolted to the underside of the rain gutter is a spill containment box that attaches, via a watertight connection, to the fill pipe riser and the vapor recovery pipe riser as shown in Figure 5.10 and Figure 5.11.
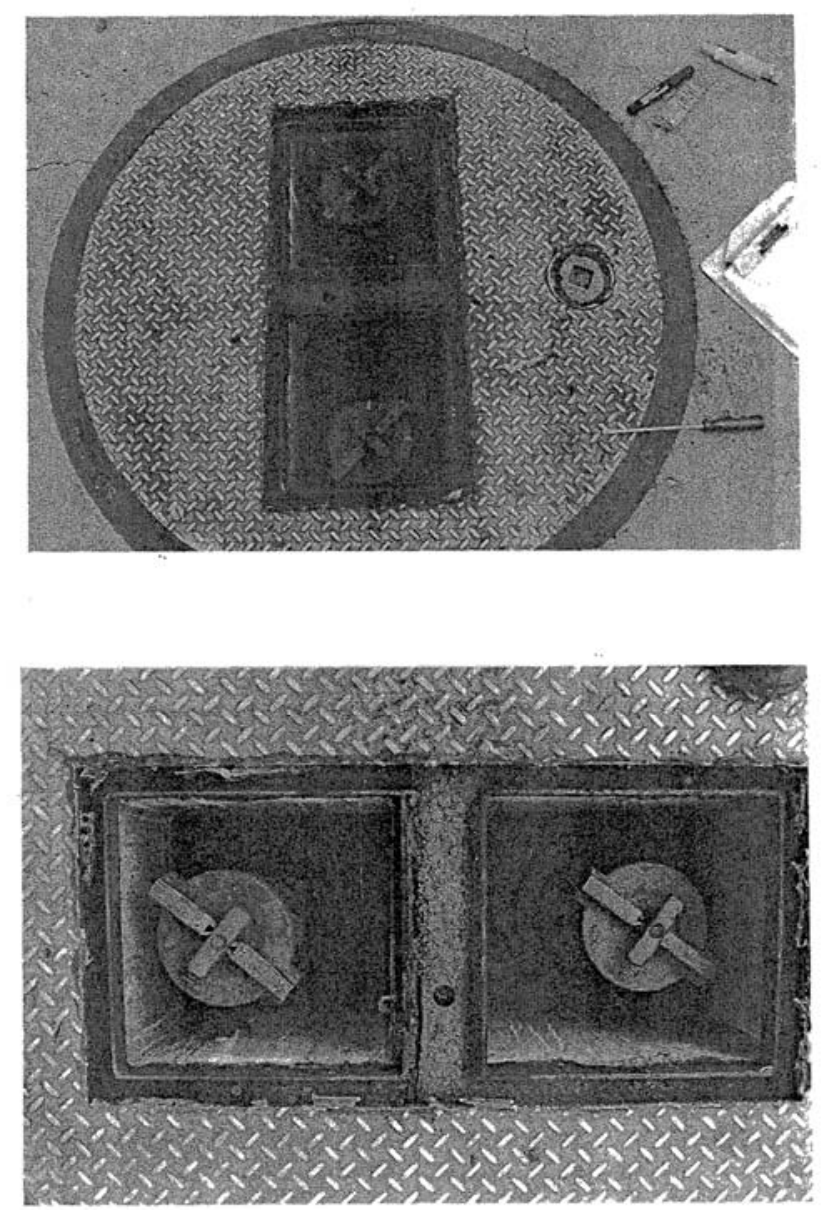

Figure 5.10 Spill Containment Box Installed 


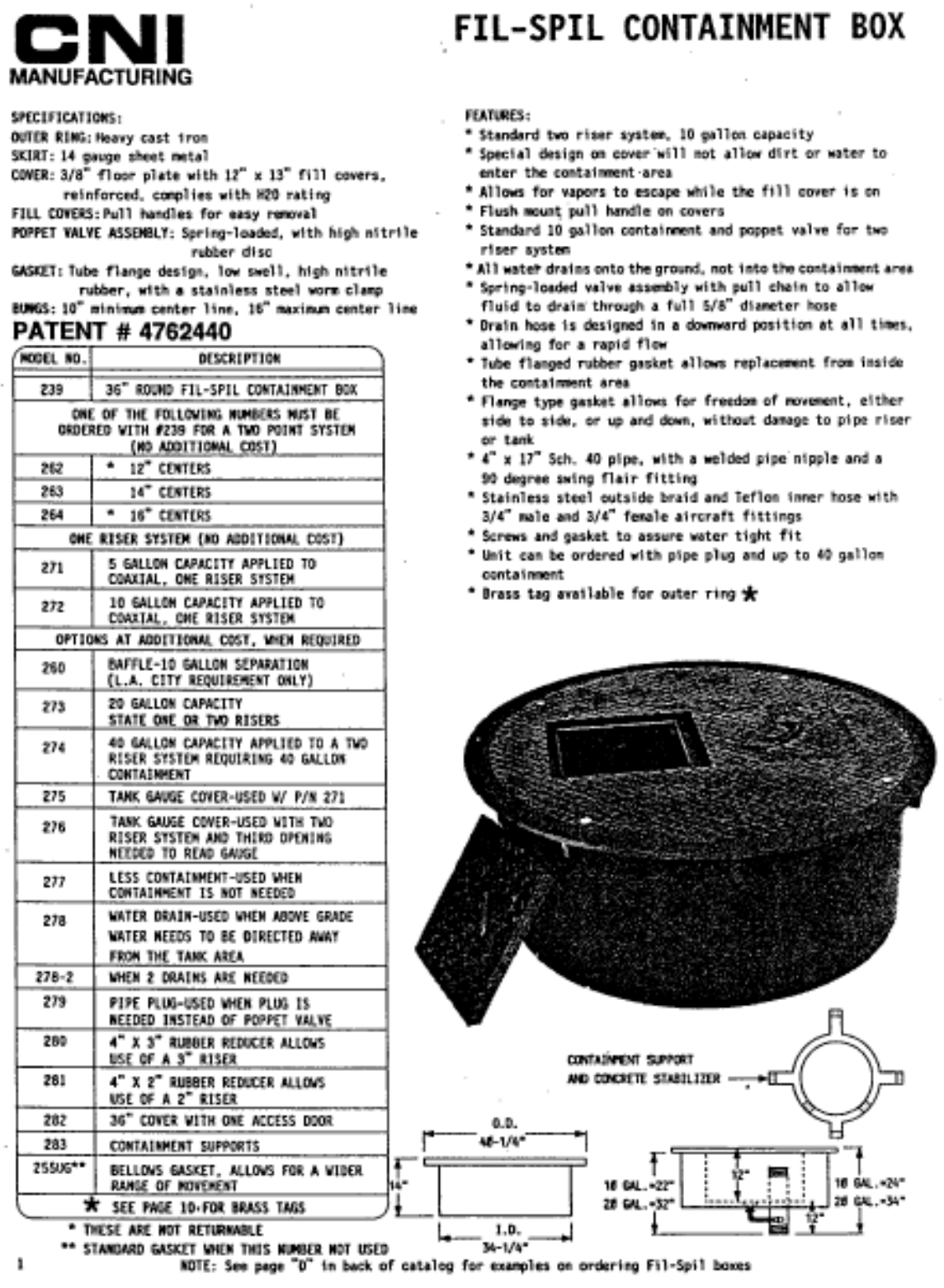

\section{Figure 5.11 Spill Containment Box}

The spill containment box described above is equipped with a puppet drain valve (see item in Figure 5.12) on the bottom that must be removed and replaced with a pipe plug. In gasoline installations, this valve drains any spilled product into the tank fill pipe riser. With methanol's requirement for high quality, however, it is not advisable to drain spilled product into the tank, as this has the potential to also introduce dirt, oils, and/or water, which may have entered the box, into the methanol tank. If a spill occurs during filling, it must be mopped out of the spill box by hand. 


\section{CNI INSTRUCTIONS}

\section{INSTALLATION OF CNI FIL-SPIL SPILL CONTAINER}

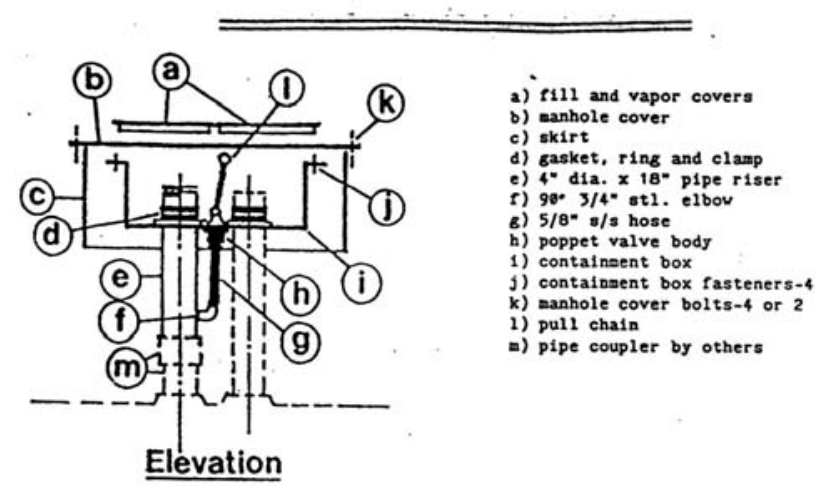

\section{Special Instructions:}

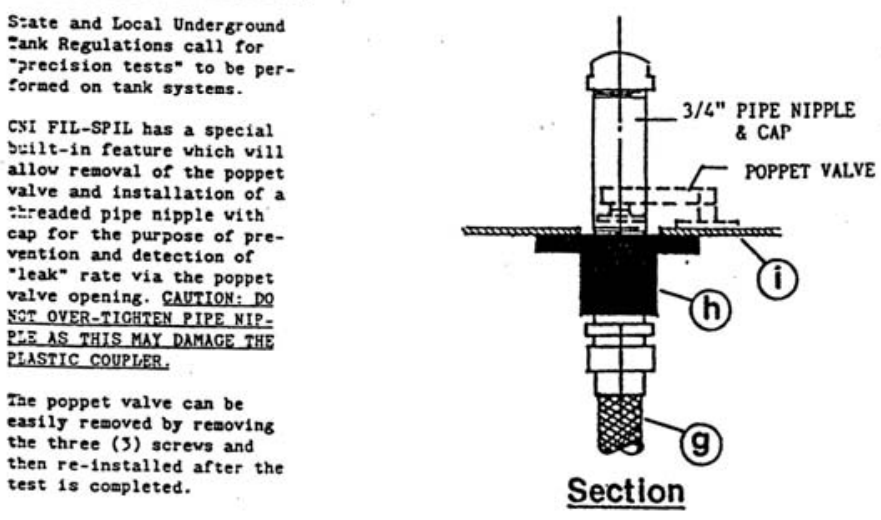

Figure 5.12 Installation of CNI Fil-Spil Spill Container

Another modification that should be made to the above box is shown in Figure 5.13 and Figure 5.14. In brief, there is a rain gutter channel just below the rectangular cover plates with a threaded pipe coupling drain port that, if not modified, would drain any water infiltration into the spill box. Therefore, a watertight bulkhead fitting should be installed through the side of the spill containment box, as shown. Next, a flexible hose is connected between the rain gutter pipe coupling drain port and the bulkhead fitting on the inside of the box; this allows for the removal of the cover plate, if necessary. A plastic drain hose is then run form the bulkhead fitting, on the outside of the box, to a suitable collection or discharge point outside the walls of the sump. 


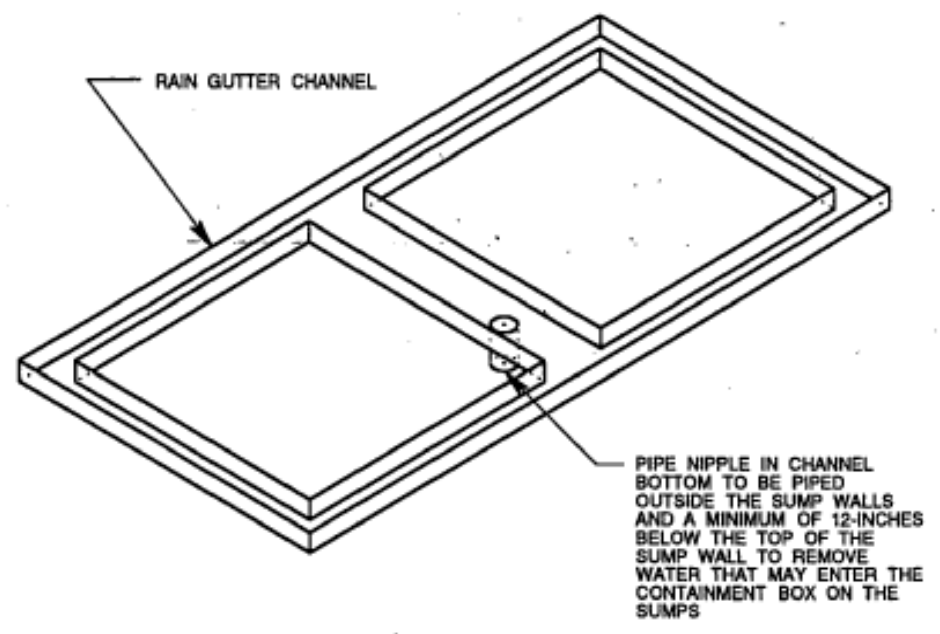

Source: CEC Fueling System Manual, 1998

Figure 5.13 Rain Gutter (by One Manufacturer)

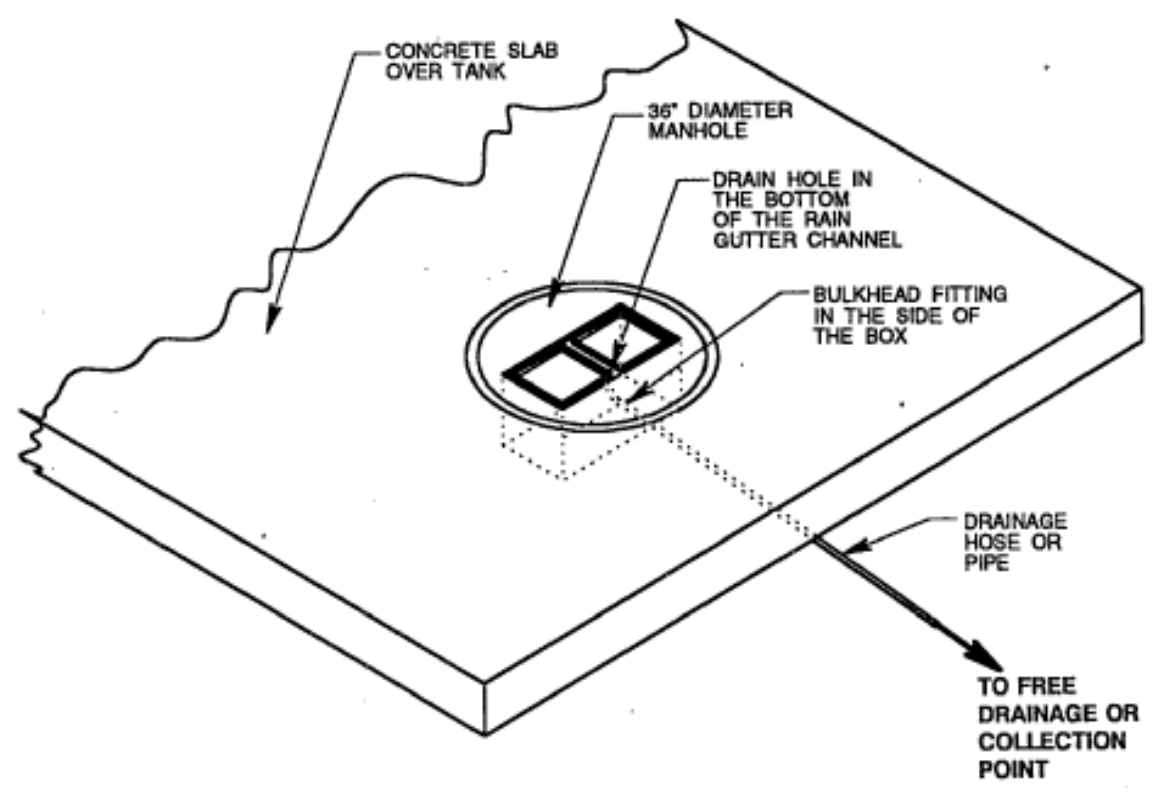

Source: CEC Fueling System Manual, 1998

Figure 5.14 Installation of the Above Rain Gutter 
It is also very important that the spill containment box be connected in a watertight fashion to both the fill pipe riser and the vapor recovery pipe riser. Item $d$ in Figure 5.10 and Item $d$ in Figure 5.15 show the flexible gasket (or boot) that provides this watertight connection.

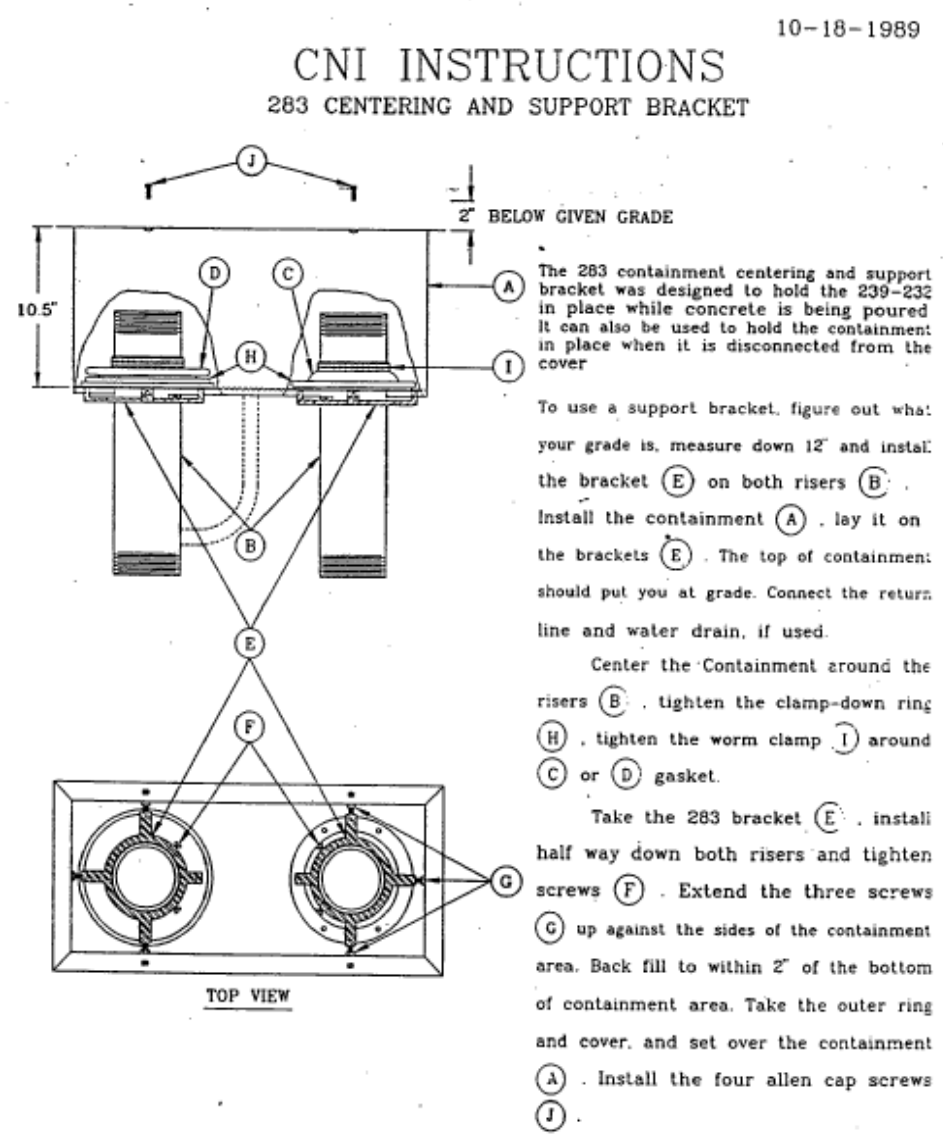

Source: CEC Fueling System Manual, 1998

Figure 5.15 Flexible Gasket Installation

\section{Piping}

Acceptable piping and fitting materials that are compatible with M85 and M100 are black iron , stainless steel, and certain types of fiberglass. Fiberglass piping has become popular in underground installations due to its light weight, long life, and ease of installation. If fiberglass piping is used, documentation should be obtained indicating that the piping is methanol compatible.

There are only two materials for primary piping of service station rehabilitation and new construction for methanol: fiberglass piping and schedule 40 black iron pipe. 
Fiberglass piping has become popular in underground installations due to its light weight, long life, and ease of installation. There are presently tow manufacturers in the U.S., Ameron and A.O. Smith, who produce fiberglass pipe approved for use with either M85 of M100.

Black iron pipe is also acceptable for use with methanol. Due to the corrosive nature of methanol with iron, black pipe will require more extensive filtering to protect components form dislodged rust particles. Black iron pipe must be externally wrapped, or plastic covered, for corrosion protection, if used for buried service.

To allow for ground movement, piping connections to the tank and dispenser must provide for flexibility; Teflon inner core tube with an exterior braid of stainless steel is recommended for this purpose.

Using methanol-compatible pipe dopes when connecting threaded pipe joints is important to prevent leakage.

\subsubsection{Secondary Containment of Piping Runs}

In the event that a secondary containment system is required, polyethylene secondary containment piping is available which offers an easy and effective solution.

\subsubsection{Vent Piping and Vapor Recovery Piping}

Vent and vapor recovery piping should be the same as described above under piping. Fueling facilities for M100 or M85 are required to use both Stage I and Stage II vapor recovery systems. A coaxial dispenser hose, a coaxial vapor recovery nozzle, and a coaxial splitter valve are components specific to a Stage II vapor recovery system and must be methanol-compatible.

The coaxial drop tube and the coaxial adapter are specific to the Stage I coaxial vapor recovery system, and must be methanol-compatible as well.

Drop (Fill) Tubes

Most currently available coaxial drop tubes are made of aluminum. A methanol-compatible polyethylene drop tube is available for a dual-point system. In order to prevent the exposure of aluminum to methanol, aluminum drop tubes must be anodized to 0.0002 inch. Care must be taken to prevent any cuts and scrapes from occurring during aluminum tube installation. If any cut or scrap penetrates the anodized surface, the drop tube must be reanodized to protect the exposed aluminum surfaces from contact with methanol. This must be considered when an anodized drop tube is cut in the field by the installer. When an anodized drop tube is cut to length, the cut edge is unprotected and will be exposed to methanol. In such situations, the tube must be reanodized to protect the aluminum exposed by the cut. 


\section{Pumping, Metering, and Miscellaneous Equipment}

Any equipment that comes into direct contact with methanol must be methanol-compatible. Such equipment includes pumps, meters, hoses, fittings, nozzles, and filters. In addition, color coding and marking will help distinguish the methanol equipment from other fueling equipment.

\subsubsection{Pump Selection}

The methanol fuel pump can be located wither at the storage tank or within a dispenser located remotely. Pumps located at the storage tank can be mounted on top of the tank or submersed within the tank. Pumps must be rated compatible for the fuel being used (i.e., M85 or M100). Pump size, capacity, pressure rating, and horsepower are selected in the same manner as any other pump installation.

\subsubsection{Dispensers and Metering Equipment}

The methanol dispenser can be located either at the storage tank or remotely. Dispensers located at the aboveground storage tank can be mounted on top of the tank and be an integral part of the pump. The dispenser metering equipment and any interior piping must be rated compatible for the fuel being used (M85 or M100). For aboveground storage tank systems, with the dispenser not located on top of the tank, it is required that a fuel-compatible pressure regulating valve be used. Failure to use the proper pressure regulation valve could result in siphoning of fuel out of the tank. Figure 5.16 shows a modified free-standing methanol dispenser. All of the major components have been noted. The dispenser is bolted to a pump island and connected electrically and mechanically to conduits and piping projecting through the cutout on the island. Figure 5.17 shows the dispenser configuration of several manufacturers. They are included to indicate the various possible configurations available, and must not be construed as being "Approved" for methanol-compatible service.

\subsubsection{Product Hoses and Fittings}

Product hoses must be rated methanol-compatible. These include the hose connected to the dispenser nozzle, the jumper hose from the dispenser fuel filter to the coaxial splitter valve, and, in some instances, the product supply hose from an above-ground tank to the dispenser. To avoid potential incompatibility problems, the jumper hose can be hard-plumbed with black iron pipe form the filter to the coaxial splitter valve.

All fittings used for methanol fueling stations must be methanol-compatible, meaning that neither the hose nor the fuel should be adversely affected by contact with one another. The equipment supplier should be requested to warrant that the fuel is not significantly affected by contact with the equipment. Compatible materials include black iron pipe, stainless steel, and naval brass. Aluminum is considered acceptable only if it is electroless-nickel plated. Anodized aluminum fittings are not considered acceptable due to the complexity of achieving a thorough anodization of the wetted surface of the part. However, aluminum fittings, whether plated or anodized, are not as desirable as iron or brass because any surface scratches or cuts will negate the effectiveness of the coating and expose the aluminum to methanol. This can lead to fuel quality problems. 


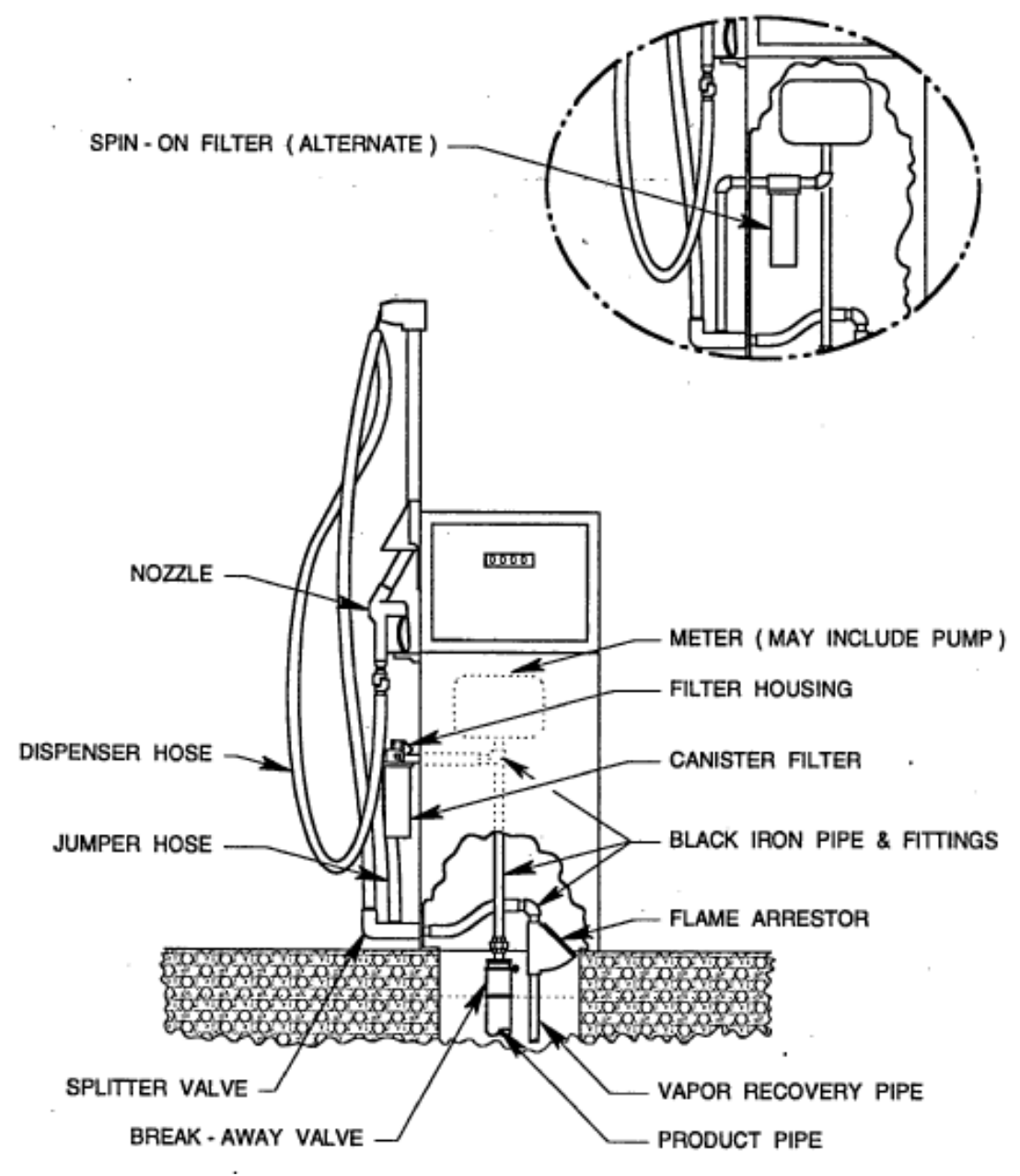

Source: CEC Fueling System Manual, 1998

Figure 5.16 Dispenser 
STAGE 留 VAPOR REGCVERY HOSE CONFIGUIRATIUNS FOR LUHHON UISIPENSERS

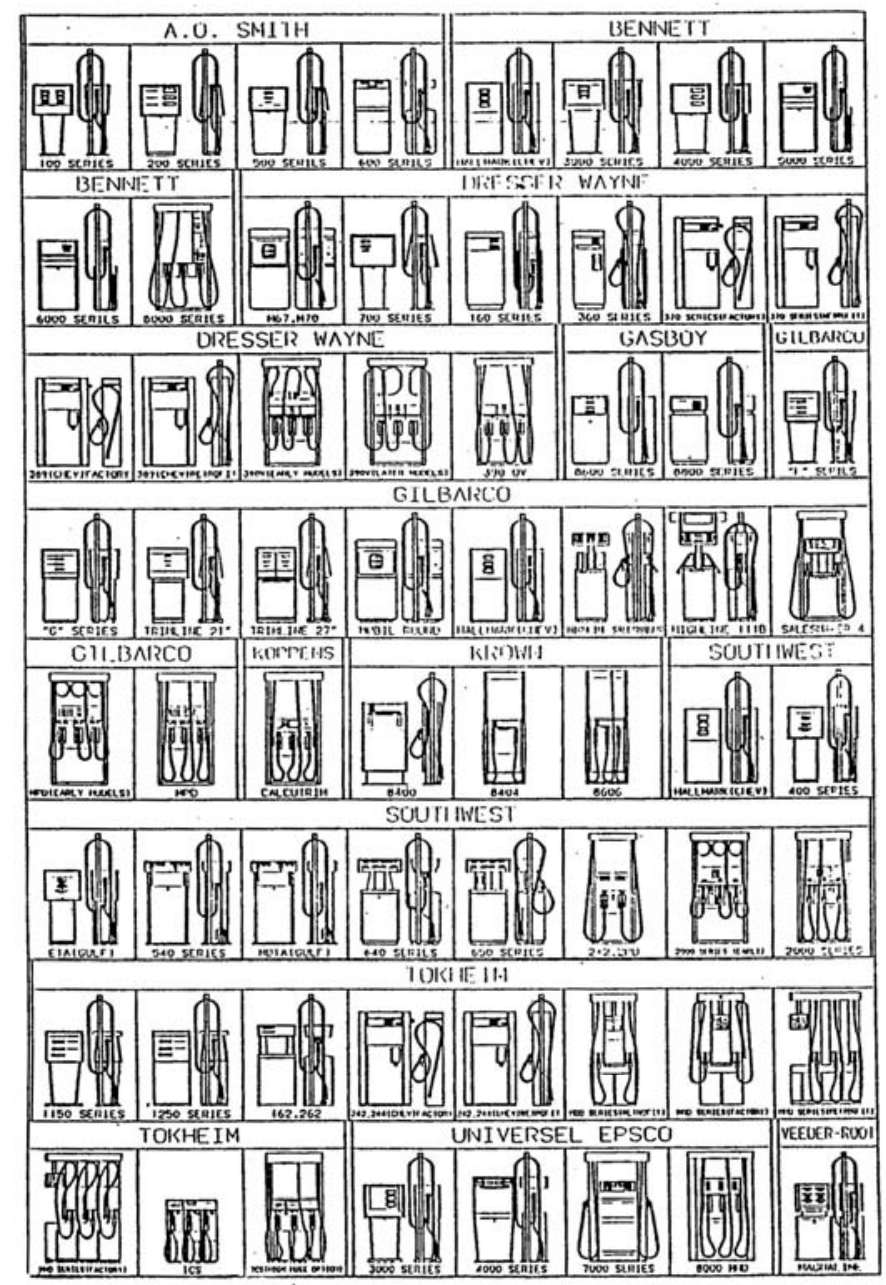

Source: CEC Fueling System Manual, 199

Figure 5.17 Dispenser Configuration 


\section{Nozzles}

Nozzles must be methanol-compatible. Because current commercial nozzles have aluminum bodies, the nozzles must be ordered electroless-nickel plated.

\subsubsection{Venting and Vapor Recovery Systems}

The venting system required for methanol fueling stations, which is nearly identical to those for gasoline fueling facilities, incorporates both Stage I and Stage II vapor recovery systems. Stage I refers to the recovery of vapors emitted during storage tank filling, and Stage II to the recovery of vapors emitted during vehicle refueling at the dispenser.

The unregulated method of filling underground storage tanks does not provide for vapor recovery, and is no longer permitted in most areas (see Figure 5.18, Conventional Systems).

An approved system utilizes tow access pipes to the underground tank: one for product drop and one for returning displaced vapors back to the delivery vehicle. This system is called a dual point vapor recovery system (see Figure 5.18, Dual Point Vapor Recovery System, and Figure 5.19). Dual-point configurations use a ball float valve (see Figure 5.20) in the tank connected to the vapor return line. In the event of an overfill condition, the float valve restricts flow and gives the delivery person time to react.

Another approved tank filling system is the coaxial vapor recovery system. This system accomplishes product drop and vapor return through the existing fuel drop tube from the underground tank. As product is dropped through a coaxial elbow, vapors in the tank are displaced up and through the area between the riser pipe and drop tube and follow a vapor path in the elbow back to the delivery vehicle. The delivery vehicle creates a vacuum as product is dropped to help draw vapors back to the transport. This vacuum function also applies to the dual-point system discussed above. A typical Stage II coaxial piping system is shown in Figure 5.18, Coaxial Vapor Recovery System, and Figure 5.21). Figure 5.22 shows a coaxial dispenser discharging into a customer's vehicle, and indicates how the vapor recovery system of the dispenser works. 


\section{Coaxial}

Vapor Recovery System

Cowxial Vapor Recowery systems accomplish product drop and vepor return through the existing riser pipe from the underground tank; therefore, installation is easy and requires no excavation. As product is dropped through a coavial elbow, vapors in the tank are displaced up and through the area between the riser pipe and drop tube and follow a vapor path in the elbow back to the delinery vehicle. The deliwery vehicle creates a vacuum as product is drocped to help draw vapors back to the transport.

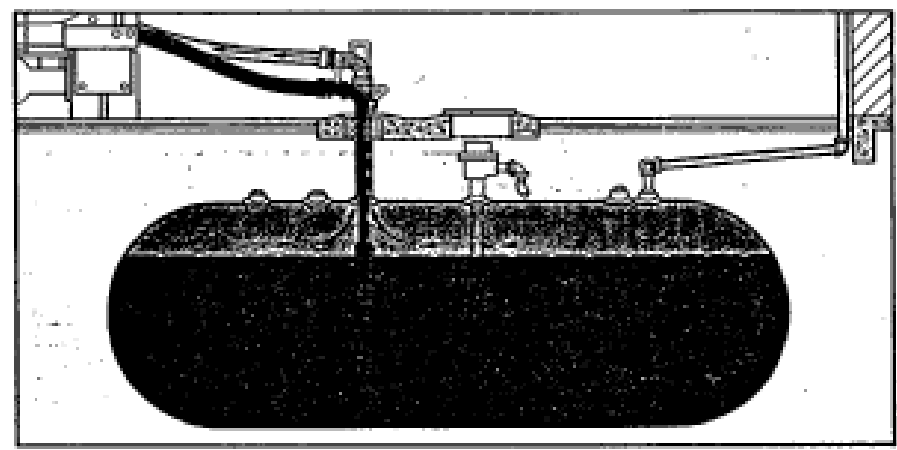

\section{Dual Point}

\section{Vapor Recovery System}

Dual Point Vapor Recovery sys.

terns utlize two access pipes to the underground tank: one for product drop and one for returning displaced vapors back to the delivery vehicle. Dual point conficurations use a bal toat valve in the tank connected to the vapor return ine. in the event of an overfil condition, the float valve restricts flow and alows the driver time to react

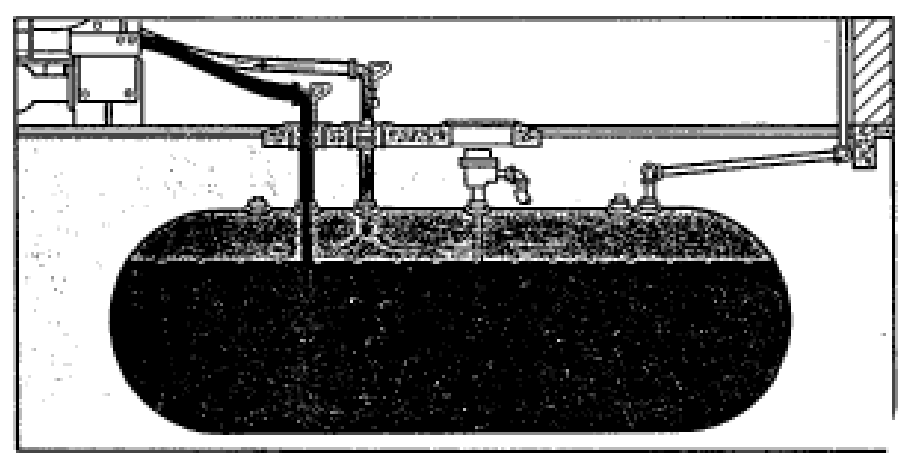

\section{Conventional}

\section{System}

The cormentional method of fliting underground storage tanks provides for no vapor rocovery. As product enters the tank througt, the drop tube, vapors are displaced through tanik vent lines and released to the atmosphere.

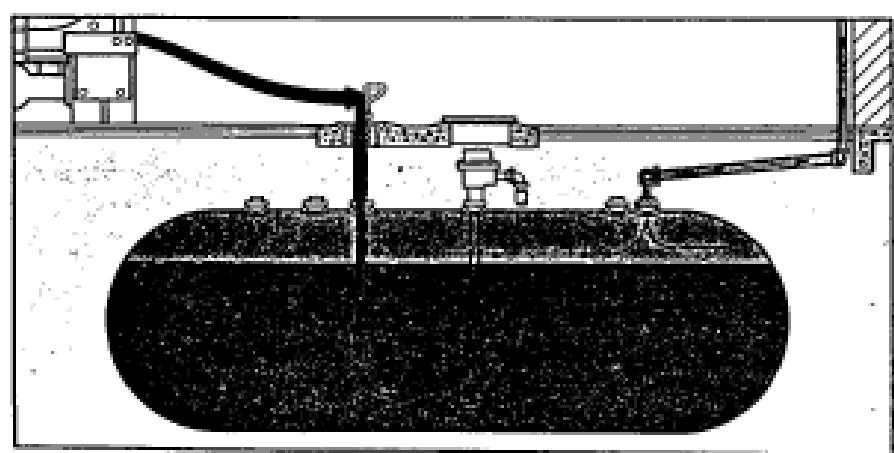

Source: CEC Fueling System Manual, 1998

Figure 5.18 Venting Systems 


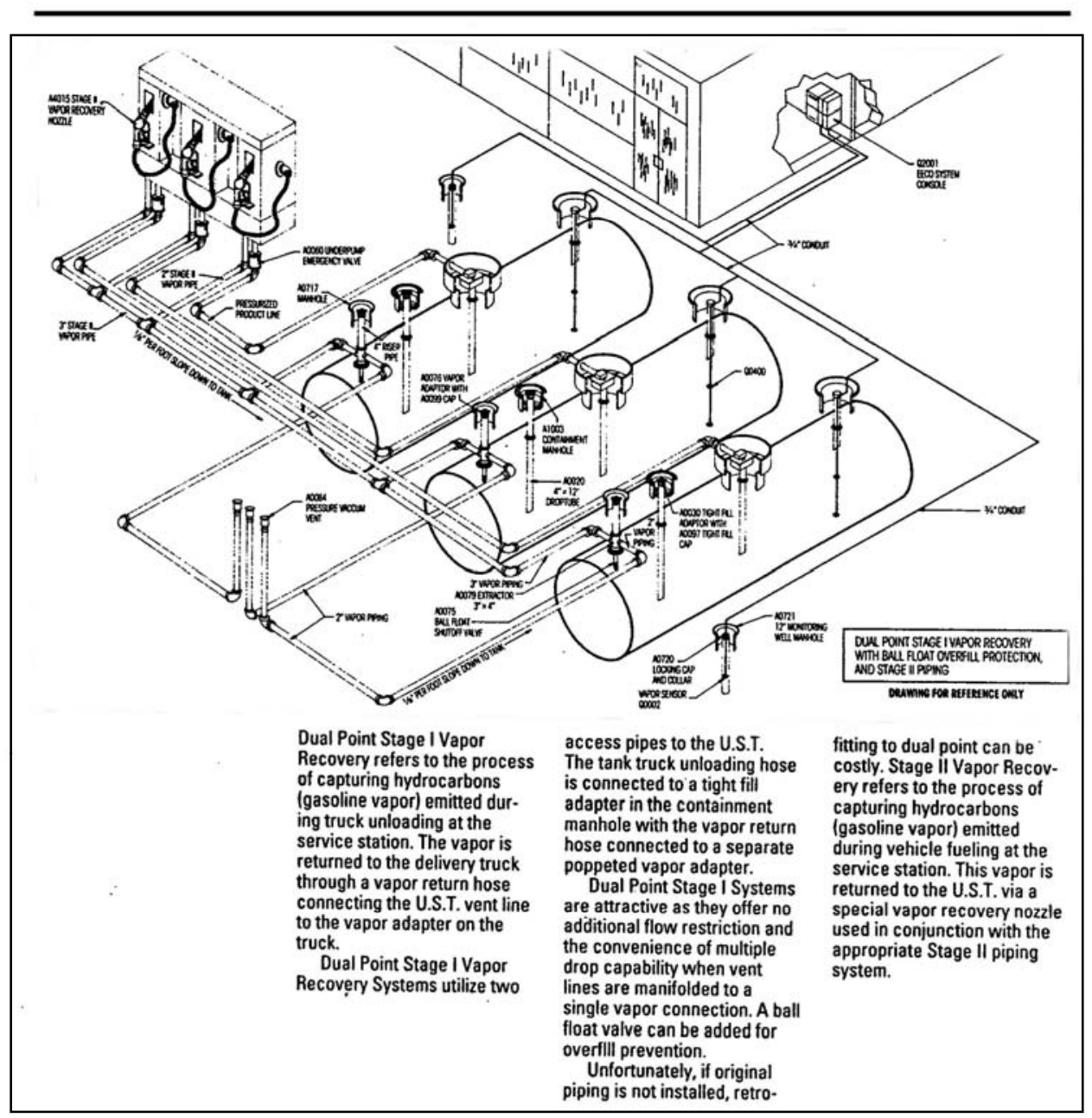

Source: CEC Fueling System Manual, 1998

Figure 5.19 Dual-Point Stage I and II Piping Systems

Source: CEC Fueling System Manual, 1998

Figure 5.20 Dual-Point Piping Systems 


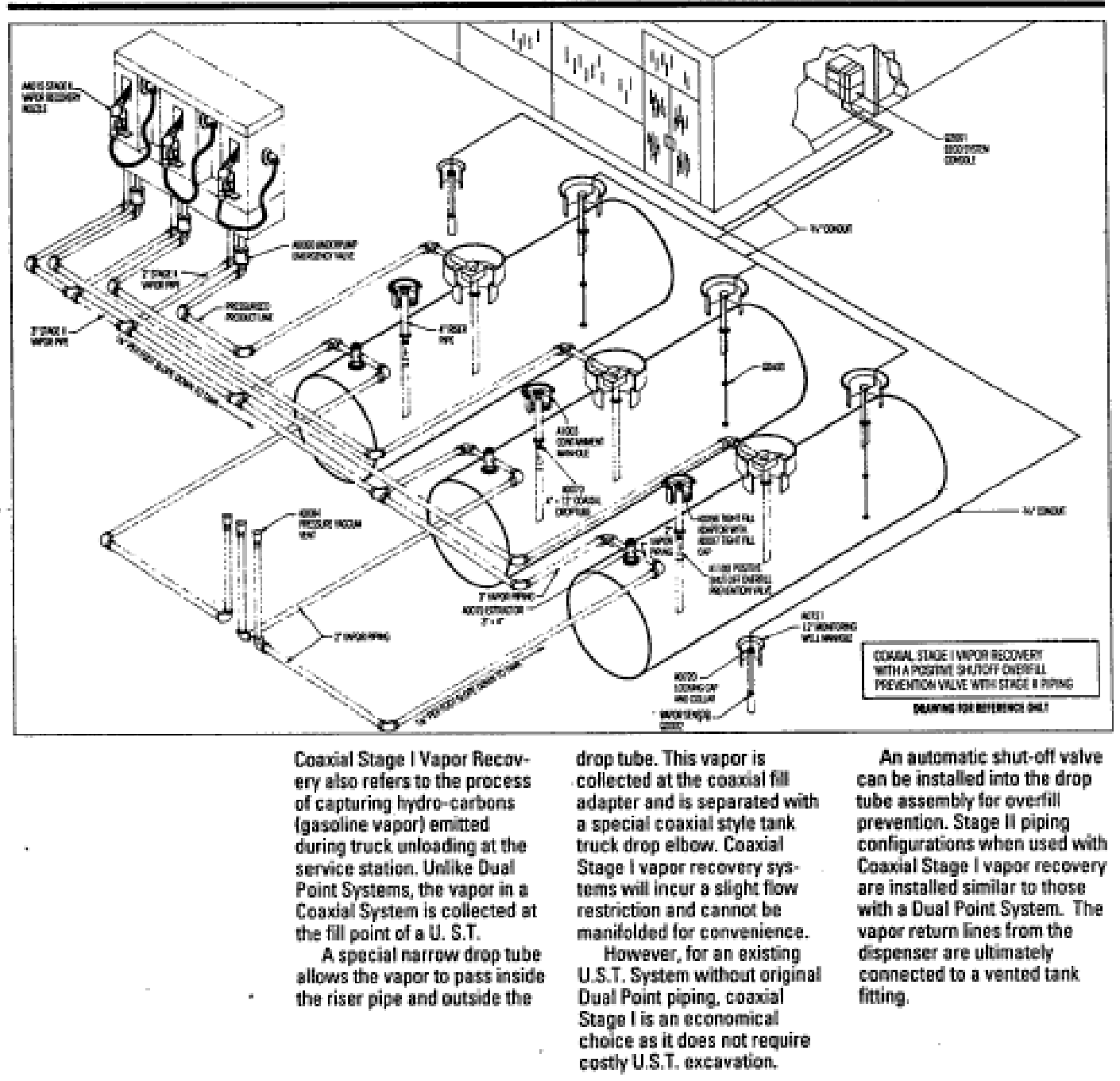

Source: CEC Fueling System Manual, 1998

Figure 5.21 Coaxial Stage I And II Piping System 

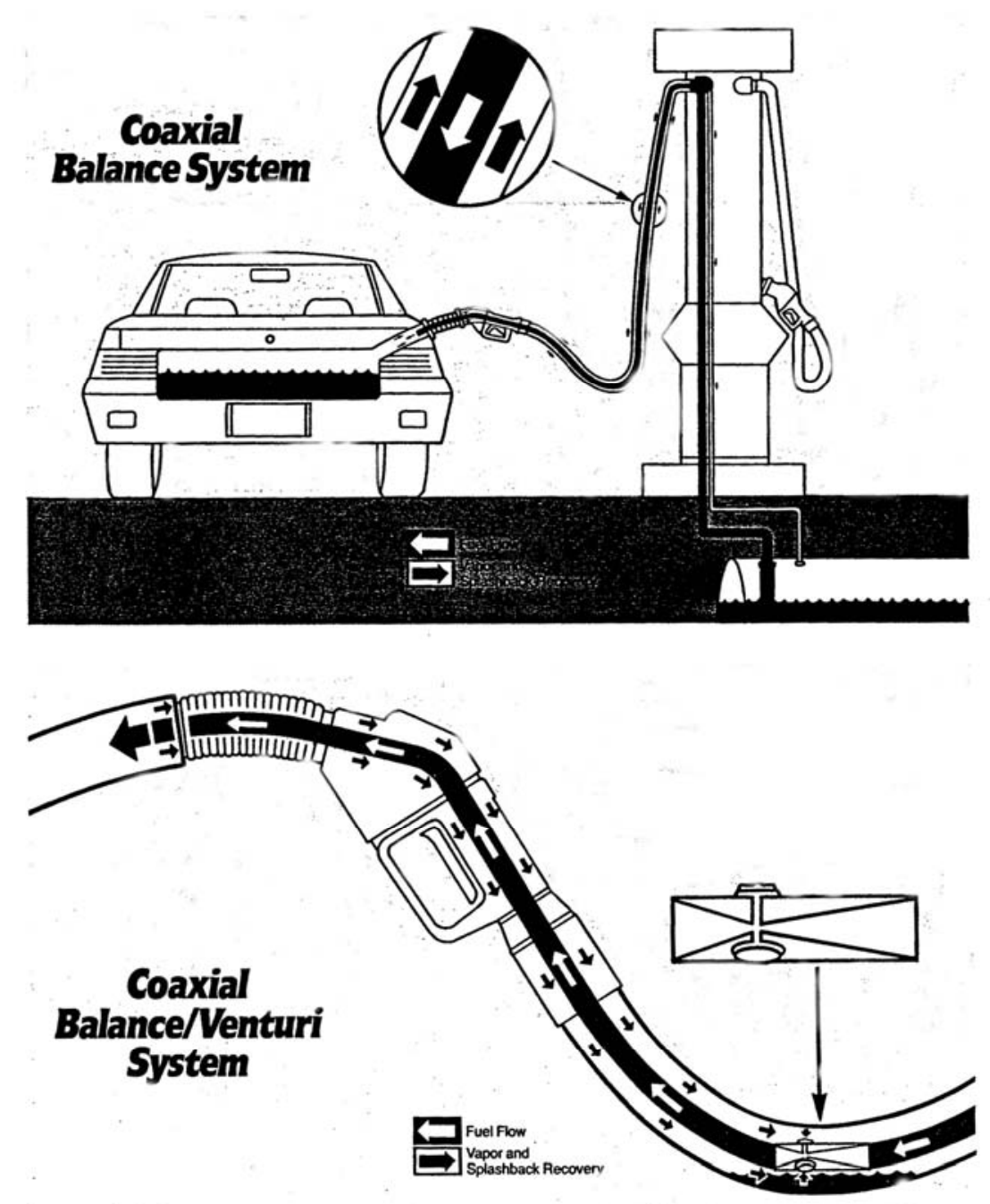

Source: CEC Fueling System Manual, 1998

\section{Figure 5.22 Coaxial Venting Systems}

The atmospheric vent pipe that vents the underground methanol storage tank may need a pressure-vacuum (P-V) vent cap (see Figure 5.23) designed to meet local venting regulations. A specific model shown (produced by Emco Wheaton) has no internal pressure/vacuum valve that restricts vapor escape during product drops. Under normal storage condition the vent cap equalizes underground tank pressure. The unit attaches quickly and easily to standard 2-inch vent lines. 


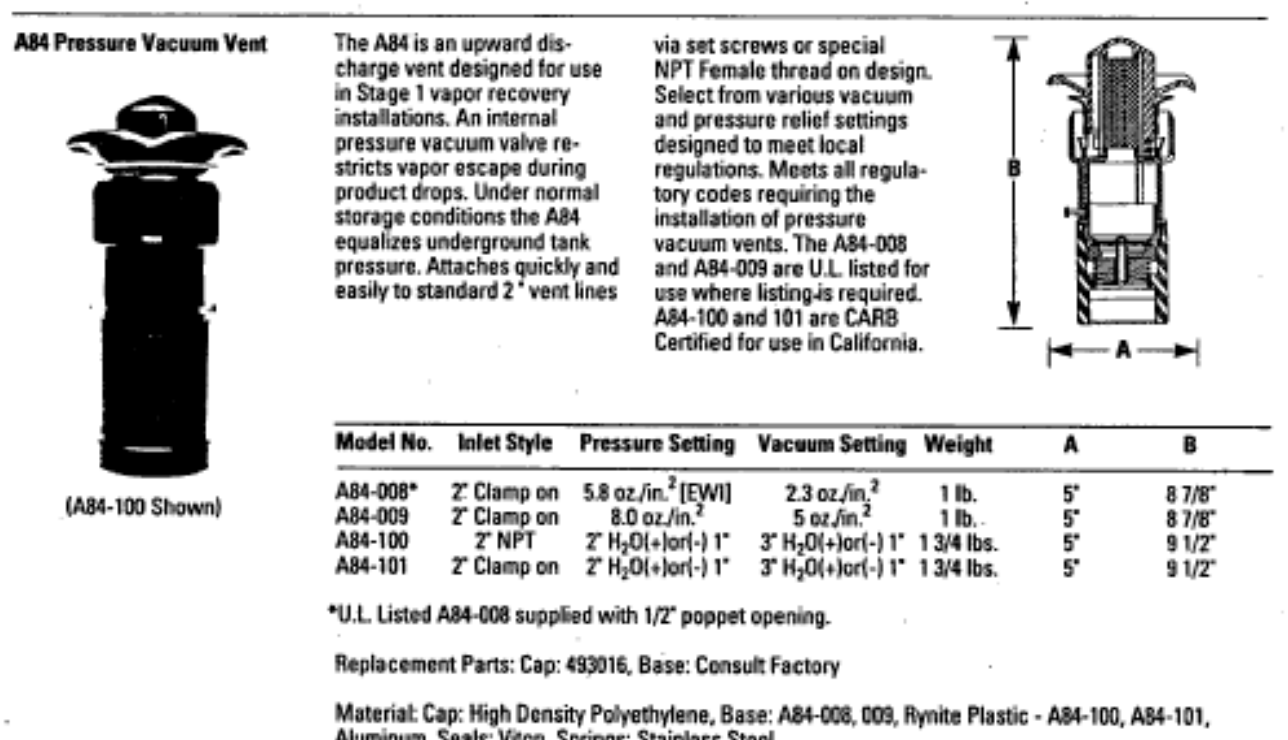

Source: CEC Fueling System Manual, 1998

Figure 5.23 Pressure/Vacuum Vent

In methanol applications, a flame arrester (Figure 5.24) must be installed on the vapor recovery pipe at the dispenser and on the storage tank vent line near its termination. Flame arrester locations vary from 20 to 50 feet from the open end of the vent pipe, depending upon pipe diameters. The larger the pipe diameter, the closer the flame arrester will be located to the open end of the vent line.

The Stage II vapor recovery system can be of the dual point type, as shown in Figure 5.19) or of the coaxial design, as shown in Figure 5.21. There are limited components available to complete a methanol-compatible dual-point systems installation. For this reason, it is best to plan on the installation of a coaxial vapor recovery system. 


\section{int. 4950 Vent-Line Flame Arrester}

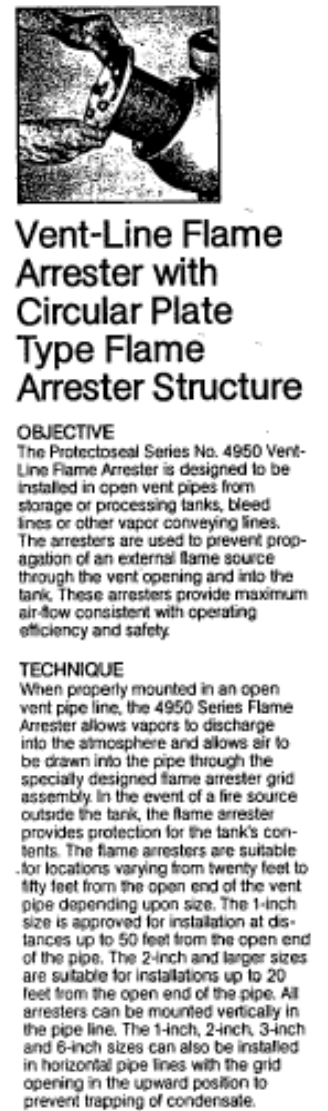

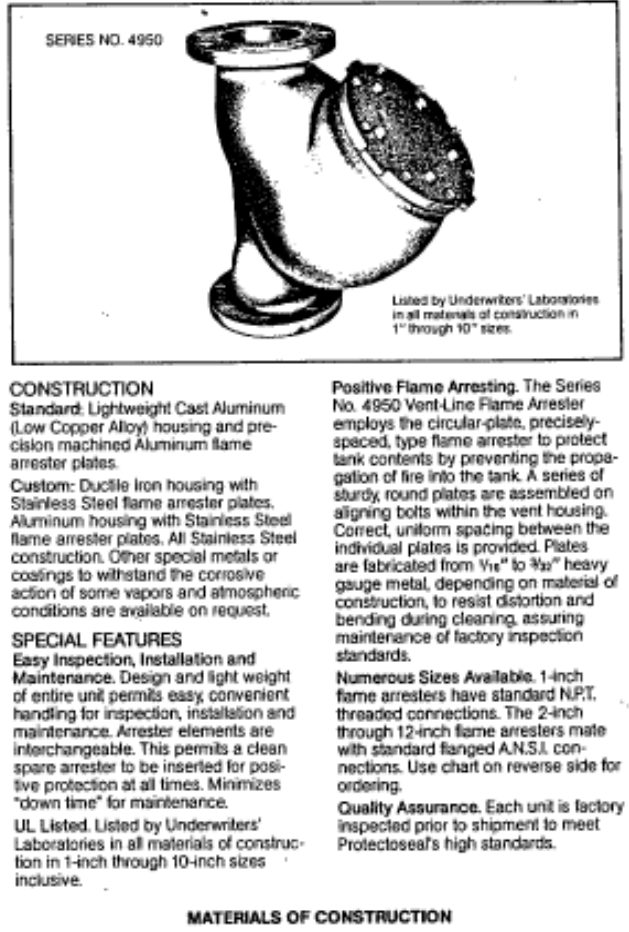

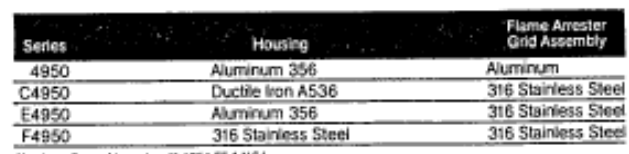

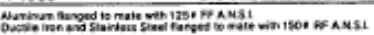

Source: CEC Fueling System Manual, 1998

\section{Figure 5.24 Flame Arrester}

\subsubsection{Fuel Filters}

Fuel filters must be methanol-compatible, and capable of removing at least 95 percent of 1 micron particles.

\section{Misfueling Interlocks}

This section describes misfueling interlocks for methanol fuels as used in California during the methanol fuel demonstration. It includes descriptions of systems such as cardlocks and electronic point of sale (EPOS) systems, and the misfueling interlock under development in California. 


\subsubsection{Existing Systems - Cardlocks and M85 EPOS System}

Misfiring interlock systems as used in California are actually access control, billing, and accounting systems. Some systems, such as the Gascard system, allow only certain types of fuels to be dispensed to a given vehicle.

Most existing systems are cardlock systems, (see Figure 5.25). Cardlock networks include Gascard, Gasboy, Petrovend, CFN, FuelMan, Pacific Pride, and Wright Express. Most card systems use magnetic strip cards, similar to most automatic teller cards and credit cards. Some systems also use optical cards.

To use a cardlock system for fueling, the operator follows a procedure similar to that involved in using an automatic teller machine:

- $\quad$ Swipe card through the reader

- Follow the prompts and/or written instructions to enter information, usually including a personal identification number (PIN) and odometer mileage

- $\quad$ Select a pump and dispense fuel, as done at a self-service fueling station

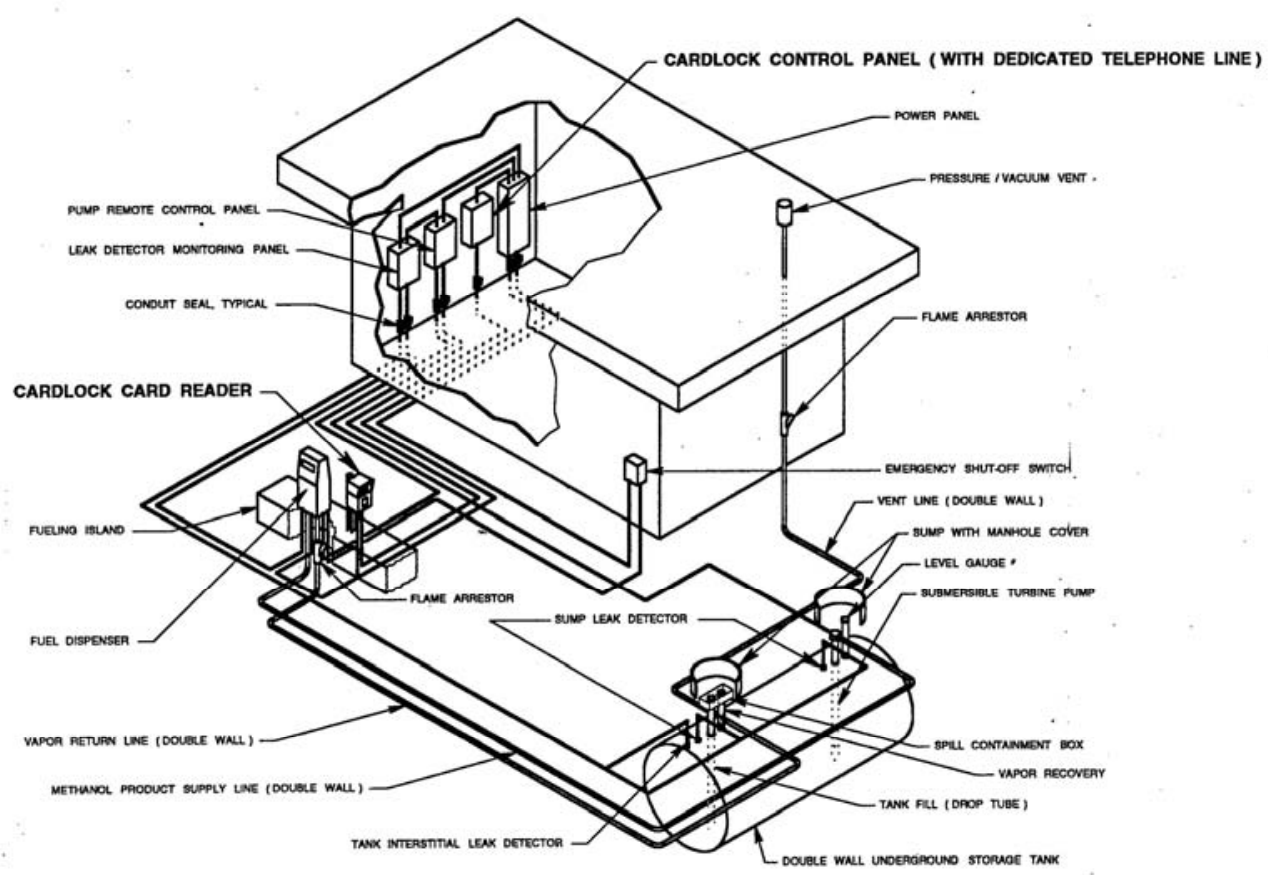

Source: CEC Fueling System Manual, 1998

Figure 5.25 Cardlock System 
The cardlock system performs some or all of the following functions, locally and/or via a computer network/telephone link, depending on model design and configuration options:

- Verifies the validity of the card

- Verifies the compatibility of the card and PIN

- Verifies the authorization of the individual and card to fuel the identified vehicle at the particular station

- Range-checks the odometer entry, compared to the previous odometer data, and prompts the operator to reenter the mileage if the original entry is out of range

- Verifies that the selected fuel is authorized for the identified vehicle

- Verifies that fuel or dollar amount allotments have not been exceeded for the operator and/or vehicle for the day, billing period, or any other given time period.

If all of the criteria have been satisfied, the system permits the dispensing of fuel to the vehicle, possibly limiting the amount to the maximum capacity of the vehicle's fuel tank as recorded in the computer network. This is to prevent the individual from filling multiple vehicles during one transaction (i.e., a company car and a personal car). The system bills the party responsible for the payment, by mail or electronic medium. The billing statement may include fleet management data, such as miles per gallon, cents per mile, needed maintenance, and data variances.

In addition to the magnetic and optical cardlock systems, other possible technologies for fueling interlocks include simple mechanical keys, PINs, smart keys (which include electronic memory), optical bar codes, and active or passive radio frequency identification (RFID). In particular, smart key and RFID systems are presently in use for fleet fueling, as well as for access control at automatic gates. RFID systems, with transponders attached to each vehicle, automatically provide the vehicle identification, and in some cases, the odometer mileage, to the fueling interlock system, instead of prompting the operator to type them in.

For methanol fuel dispensing in the public sector, existing point of sale (EPOS) systems will prevent misfueling vehicles as part of how it controls transactions.

\section{Electrical Requirements}

The National Electrical Code (NED, 1990 Edition) classifies methanol, like gasoline, as a Class I Group D Hazardous Atmosphere. Thus, all electrical equipment, wiring, and installation methods must adhere to applicable sections of the NEC (including Articles 500-504, and 510516) for use in hazardous classified areas, as well as any applicable local codes. The code digest and vendor literature in Crouse-Hinds Codes Digest 1993 provides a good summary of the NEC requirements 


\subsubsection{Standard Installation Practices}

This section gives an overview of appropriate construction practices for a methanol facility.

\section{Transport Truck Access Requirements}

Tractor trailer access requirements for fuel drops are important considerations when planning fuel facility layouts. Figure 5.25 above shows a possible facility layout for a convenient fuel drop. Many variations are possible, and depend on many variables particular to the facility. Some considerations are site location, traffic, street or highway access, and vehicle sizes that will use the facility. Different length tractors trailer combinations will require different turning radii and the vehicles used by the methanol fuel supplier must be ascertained when space limitations may cause potential problems.

\section{Permitting Requirements}

Construction of a methanol fueling facility or expansion of an existing gasoline station to include a methanol dispensing system will undoubtedly require the procurement of one or more permits to construct and/or operate. There may be only one permitting agency, or several may be involved. In general, only the property owner or a licensed contractor can procure a construction permit. It is a locally specific jurisdictional situation, so a single set of procedural steps cannot be set forth. The following section outlines the situation in California as an example.

Most cities and counties in California have a Building Department. They may be the only regulatory agency that must be contacted. Often they will gather all the information needed and will do the interfacing with other agencies. Generally, the types of agencies, which may get involved, are as follows:

- $\quad$ Building Department (city or county)

- $\quad$ Electrical Department (city or county)

- $\quad$ Fire Department (city or county)

- $\quad$ Planning Department (city or county)

- Environmental Agency (city, county, or special district)

- $\quad$ Air Pollution Regulatory Agency (city, county, or special district)

- Water District (city, county, or special district)

- Hazardous Materials/Risk Management

\subsubsection{Methanol Service Station Capital Costs}

Methanol station refueling costs have been estimated by EA Engineering, Science and Technology Inc. in a 1999 study sponsored by the American Methanol Foundation. The retail 
station cost estimates by EA are based on components considered by their manufacturers to be fully methanol compatible. The estimated capital cost for installing methanol fuel dispensing capability at an existing station ranges from \$21 thousand to $\$ 77$ thousand depending on the assumptions. Estimated costs for different cases are listed in Table 5.1 below.

Table 5.1 Methanol Service Station Capital Cost, Thousand Dollars, 2001

\begin{tabular}{|l|c|}
\hline Assumption & Cost \\
\hline Displace existing gasoline storage capacity with Methanol \\
\hline Clean existing 10 thousand gallon underground tank & 21 \\
\hline Replace existing underground 10 thou. gal. tank & 77 \\
\hline Increase storage capacity at existing stations & 69 \\
\hline Add new 10 thousand gallon underground tank & 60 \\
\hline Add new 10 thousand gallon above-ground tank & \\
\hline
\end{tabular}

\subsection{COMPARISON OF METHANOL, CNG, LNG, AND HYDROGEN DISTRIBUTION INFRASTRUCTURE REQUIREMENTS}

Table 5.2 compares the capital investment for retail service stations designed to dispense methanol, CNG, LNG and hydrogen. Methanol retail outlets cost a fraction of those for the other clean fuel alternatives.

There are over $240 \mathrm{CNG}$ stations currently operating in California. Over 100 offer full or partial public access. There are a number of specific codes and standards that must be met in building and operating CNG stations. Of these, the Uniform Building Code and NFPA 52 are the most important. CNG stations cost approximately ten times the cost of a methanol station.

There are over 140 LNG stations operating in California. LNG storage requires double walled, stainless steel, "superinsulated" storage tanks. Because of the higher cost, LNG has primarily been used for buses and other heavy fleet vehicles to ensure maximum throughput. The operating costs are lower than for $\mathrm{CNG}$, since no compressor is required. However, training costs are higher and maintenance costs have been estimated at 3 to 6 cents per gallon ${ }^{8}$. LNG stations must meet similar standards and codes as CNG stations. The main requirements are NFPA 57 (Liquefied Natural Gas Vehicular Fuels Systems Code) and NFPA 59A (Standard for the Production, Storage and Handling of Liquefied Natural Gas). The cost of LNG stations are up to 50 percent higher than that for CNG. Virtually all LNG currently consumed in California is transported into the state by truck, rail, or ship from small liquefaction facilities.

Some LNG stations are designed to also supply CNG. Such systems consist of a conventional LNG station with the addition of high-pressure cryogenic pumps that compress the LNG to 4 to

\footnotetext{
${ }^{8}$ Jim Harger, Vice President of Marketing, Pickens Fuel Corporation, 12/6/00.
} 
5 thousand psi, and then vaporize the compressed liquid. The advantages of these combined stations is that the cryogenic pumps consume much less energy than the compressors used at conventional CNG stations and are require less maintenance. Second, L/CNG is delivered to the vehicle at ambient temperature, facilitating complete filling of the vehicle storage tank and eliminating the need for temperature compensation systems. Furthermore, since LNG is nearly pure methane, $\mathrm{L} / \mathrm{CNG}$ is delivered to the vehicle with virtually no contaminants or undesirable fuel elements such as oil carryover, moisture, and higher hydrocarbons.

There is less commercial experience with hydrogen stations. Only a few hand-built first generation stations have been built, including two different systems in California used by Sunline Transit to fuel its direct-hydrogen fuel cell bus in the Coachella Valley. For this reason, the capital costs for hydrogen stations are not fully known at this time. Station designs are only conceptual at this stage, and few hydrogen-specific codes and standards exist. Capital cost will depend, in part, on whether a liquefied hydrogen or compressed form of hydrogen will be stored and/or produced at the station by reforming natural gas. In either case, costly fire and safety requirements are likely to be the norm, especially in the early years of deployment. Recent estimates for first-generation stations being built in Sacramento and other areas under the California Fuel Cell Partnership indicate that they can cost between 2 and 3 million dollars.

Table 5.2 Comparative Retail Station Costs

\begin{tabular}{|l|r|r|r|r|}
\hline & Methanol & CNG & LNG & Hydrogen \\
\hline $\begin{array}{l}\text { Storage Capacity } \\
\text { (thousand gallons) }\end{array}$ & $10-20$ & - & 15 & 15 \\
\hline $\begin{array}{l}\text { Throughput } \\
\text { Thousand GGE9 per Month }\end{array}$ & 50 & 20 & $15-50$ & $15-50$ \\
\hline Capital Cost, Thousands \$ & 60 & $430-750$ & $650-800$ & $2000-3000$ \\
\hline
\end{tabular}

\footnotetext{
${ }^{9}$ Gasoline gallon equivalent
} 


\subsection{STAKEHOLDERS AND ACTIVITIES}

\subsubsection{Methanex}

Methanex is the world's largest methanol producer and is proactively supporting the development of methanol fuel cell vehicles. Its CEO has stated that "Methanex is adopting a leadership position to ensure that methanol infrastructure is not a barrier to commercialization of methanol fuel cell development". It has the most extensive chemical methanol distribution infrastructure in North America. It is a member of the Methanol Fuel Cell Alliance and an associate member of the California Fuel Cell Partnership.

Methanex, Mitsubishi, Mitsui, and Marubeni are members of the Japanese Methanol Alliance to promote and support the introduction of methanol-based fuel cells in Japan. The Alliance is cooperating with the Japanese government, methanol retailers, and automobile producers to plan for the practical issues related to the cost effective retail introduction of methanol for fuel cell vehicles in Japan. The parties have joined the Fuel Cell Commercialization Conference of Japan to support methanol as the fuel option for fuel cell vehicles ${ }^{10}$.

\subsubsection{BP}

$\mathrm{BP}$ is a methanol producer with a plant on standby in Texas City, Texas, an 850 thousand metric ton per day plant operating in Trinidad (Titan) and new plant under development there (Atlas Methanol with a capacity of 1.5 million metric tons per year). However, its support of methanol is also driven by its major natural gas holdings worldwide and its ownership of ARCO, a longterm advocate of methanol as a fuel. It is a member of the Methanol Fuel Cell Alliance and the California Fuel Cell Partnership.

BP has asserted that hydrogen produced from natural gas or its derivatives such as methanol is the most efficient source of "well to wheels" energy known for transportation ${ }^{11}$. It has also stated the belief that in North America methane reforming at service stations would be more efficient than distributing methanol throughout the country and reforming on-board vehicles ${ }^{12}$.

\subsubsection{Shell}

Shell is a member of the California Fuel Cell Partnership. Shell believes that, for the transition period, hydrogen from natural gas or gasoline is the best solution. Some companies have suggested the use of other transition fuels such as onboard methanol to hydrogen conversion. Such fuels would require significant infrastructure investments, which would be difficult to justify what could be short-lived solutions ${ }^{13}$. Hydrogen is the ultimate fuel of the future, and Shell has created Shell Hydrogen Business to exploit opportunities. Shell Hydrogen has formed Chrysalix Energy Systems, a Vancouver B.C. based joint venture with Ballard Power Systems

\footnotetext{
${ }^{10}$ Methanex press release, September 18, 2001

${ }^{11}$ Richard Flury, Chief Executive, BP Amoco, World Energy Council, May 19, 2000

${ }^{12}$ Dr. Peter Histon, Scientific Advisor, BP, personal communication, February 18, 2002

${ }^{13}$ Sir Mark Moody-Stuart, Chairman, Royal Dutch Shell, Hyforum 2000, 11/9/2000
} 
and Westcoast Energy promoting early stage companies with high growth potential in fuel cells and related systems, hydrogen infrastructure, maintenance and support techniques.

\subsubsection{Daimler Chrysler}

Daimler Chrysler is fuel neutral but has selected methanol as the most practical near-term choice for a fuel cell vehicle ${ }^{14}$. It has developed a prototype methanol fuel cell vehicle, NECAR5, which recently completed a cross-country trip in the U.S. Methanol is reformed to hydrogen in the vehicle, and hydrogen is used to create the electrical energy. It plans to offer a commercial fuel cell vehicle by 2004, and has offered to provide 50 to 100 million dollars to facilitate the development of a fuel methanol distribution infrastructure in the U.S., provided the State of California and the methanol producers put up matching funds. ${ }^{15}$

It is working on a direct methanol fuel cell using a noble metal catalyst, which it believes can be commercial by 2010. Methanol has a higher energy density than hydrogen, and Daimler Chrysler believes the existing petroleum distribution infrastructure can be used for methanol with modification at a much lower cost than to develop a hydrogen distribution infrastructure.

\subsection{ASSESSMENT}

The posture of the methanol suppliers interviewed as part of this study is that the existing methanol infrastructure demonstrates the feasibility of distributing methanol throughout the U.S. The issue is covering the cost of expanding that infrastructure to handle a much larger volume associated with a significant transportation fuel market. If methanol captures 20 percent of the U.S. transportation fuel market, U.S. methanol demand would be on the order of five times the current volume with a much more fragmented distribution pattern to thousands of retail stations. Furthermore, the operation of over 60 retail service stations in California for ten years has demonstrated the feasibility of handling methanol in properly designed service stations. The methanol fuel cell demonstration just beginning in California is to be supplied out of a single above ground methanol dispensing station at the headquarters of the California Fuel Cell Partnership in Sacramento, rather than from a network of methanol stations.

In the next section of the report, scenarios are developed on the potential commercial introduction of methanol fuel cell vehicles in California and the New York metropolitan area as the first two steps in an ultimate nation wide methanol fuel distribution system. The greatest cost is likely to be the retail station conversions to methanol. However, potentially the cost of terminals and truck transportation could be even larger.

A prior survey by the $\mathrm{DOE}^{16}$ identified 166 bulk liquid terminals as reasonable candidates for offloading and storing fuel methanol. These terminals were located at both coastal and inland ports. Product storage capacity ranged from 6500 barrels to over 11 million barrels. Each fulfilled three criteria:

${ }^{14}$ Dr. Ferdinand Panik, Director of DaimlerChrysler's Fuel Cell Project, Automotive Engineering International, Volume 108, No. 3, p173, March 2000.

${ }^{15}$ Octane Week, March 29, 1999

16 Assessment of Costs and Benefits of Flexible and Alternative Fuel Use in the U.S. Transportation Section, U.S. DOE PP\&A, August 1990. The analysis assumed M85 rather than neat methanol fuel 
- The terminals are located at ports that can accommodate barges or tankers

- The terminals provide storage for hire

- They are currently used for storing petroleum products

If methanol fuel becomes a large enough market, it is believed that it would be profitable for terminal operators to convert a portion of its petroleum storage capacity to methanol or add capacity at locations where large-scale truck loading already exists. If existing gasoline storage tanks are used for methanol service, they would need to be switched to cone roofs with internal floaters, at a minimum. Although most terminals have truck loading racks, it is expected that new methanol truck loading racks would be needed. The new methanol truck racks will require a vapor control system for emissions control during truck loading, as do gasoline truck racks. Revisions to the fire protection equipment are needed: the optimal foaming agents for methanol fire control differ from that for gasoline. Laboratory equipment to check methanol quality will be needed.

Terminals operated by petroleum companies may be reluctant to handle methanol. However, there are a large number of independent liquid terminal operators in the United States ${ }^{17}$

It is assumed that methanol will be loaded into trucks at these marine terminals rather than transported through pipelines, at least initially, due to the threat of water contamination, scale removal from pipeline walls, and cross contamination.

Methanol can be transported in tank trucks identical to those used for gasoline and diesel. No modifications to equipment are needed in this phase of methanol distribution. However, trucks would have to be dedicated to methanol service due to the risk of potential cross contamination from other products. Moreover, additional tank trucks will likely be needed.

Many methanol tank trucks are aluminum. Although methanol corrodes aluminum nozzles with moving parts in extended service in retail stations, corrosion is not an issue when contact is of limited duration as it is in tank trucks and the water content is low, as it is with IMPCA specification methanol $^{18}$

\footnotetext{
${ }^{17}$ A list of the terminals within the Independent Liquid Terminals Association is contained in the Appendix

${ }^{18}$ Personal communication, Blair Heffelfinger, Methanex Corporation and Jan Spin, Southern Chemical, July, 2002.
} 


\subsection{REQUIREMENTS FOR SUCCESS}

If a significant fuel methanol market is to develop, the existing conventional supply systems must be dramatically expanded. Current U.S. methanol demand totals 8.7 million metric tons (3 billion gallons) per year. A scenario has been developed to determine distribution infrastructure requirements assuming 20 percent of the projected U.S. transportation fuel demand is met by methanol. The implied fuel methanol demand is 15 billion gallons per year ${ }^{19}$. Based on the current petroleum product distribution infrastructure ${ }^{20}$ Nexant estimates that approximately 120 coastal/Great Lakes terminals with a storage capacity of 15 million barrels of storage and 75 inland terminals with a storage capacity of 75 million barrels would be required. In addition, an estimated 80 ships ocean barges, 500 river barges, 20 thousand tank trucks, and 30 thousand rail cars capable of transporting methanol from terminals to service stations would be needed. This infrastructure would require an investment of up to 4.3 billion dollars. The reason for using the phrase "up to" is that existing terminals, barges, rail cars and trucks that are part of the existing distribution infrastructure can be converted to some extent from other uses, such as in distributing petroleum products or other chemicals, to dedicated methanol use. The American Petroleum Institute has estimated the cost of the methanol distribution infrastructure for each million barrels per day of methanol use at 4 to 8 billion dollars ${ }^{21}$.

A focus group study conducted for Shell, BP, and Exxon in 2000 concluded that 25 percent of urban and 50 percent of rural service stations would ultimately need to offer methanol in order not to restrict driving flexibility with methanol FCVs. There are currently about 175 thousand retail gasoline outlets in the U.S. Assuming an average cost per station of $\$ 50$ thousand to add methanol fuel dispensing capability, the capital investment needed for 25 percent of total stations to offer methanol would be $\$ 2.2$ billion. According to the American Petroleum Institute, this amount is spent annually for the refurbishing of existing stations. The U.S. refining industry spent more than $\$ 12$ billion to retool for the refining of reformulated gasoline. An estimated 2 billion dollars is spent annually in maintenance on U.S. retail service stations. In context, the amount needed in methanol retail station infrastructure is not extraordinary. The total 6.5 billion dollars (current dollars) of maximum new methanol infrastructure amortized over twenty years would correspond to roughly 2 cents per gallon of methanol.

\subsection{PROJECTED RANGE OF POTENTIAL USE}

\subsubsection{Transportation Fuel}

Methanol transportation fuel markets are likely to develop in the U.S. in stages. Nexant speculates that the first two stages could be:

- $\quad$ Stage 1: California

\footnotetext{
${ }^{19}$ Assumes 50 miles per gallon with a methanol fuel cell

${ }^{20}$ Petroleum Liquids Transportation, National Petroleum Council, April 1989

${ }^{21}$ Fuel Choices for Fuel Cell Powered Vehicles, the American Petroleum Institute, 1999
} 
- $\quad$ Stage 2: Another coastal metropolitan area, say New York

Nexant does not expect methanol use to go beyond these two stages through the year 2015. Methanol demand in fuel cells has been projected at 2.8 billion gallons by 2015,2 percent of the projected U.S. transportation fuel market. The basis for the estimated methanol demand and the corresponding infrastructure investments associated with these first two stages follow.

\subsubsection{California}

If methanol were to capture 20 percent of the California gasoline market, the corresponding methanol demand would be in the order of 1.5 billion gallons per year, one-half the size of the current U.S. methanol market. Methanex has estimated that at least 10 percent of the service stations in California would need to be retrofitted for dispensing methanol for a sizable methanol market to develop ${ }^{22}$. Nexant feels this is too low for the penetration assumed in this case. There are 9500 service stations in California, which accounts for one-half of the gasoline demand in PADD V. We assume 2500 service stations would need to be fitted for methanol both in California and in surrounding states to provide sufficient flexibility for consumers to be willing to purchase methanol vehicles. The cost of converting these stations would be 125 million dollars. Based on analogy with the current petroleum distribution infrastructure ${ }^{23}$, we estimate the need for 10 terminals with 6 to $9^{24}$ million barrels of methanol storage capacity and 2500 tank trucks with the additional distribution infrastructure is estimated at up to 200 million dollars. The station conversion and distribution infrastructure investment corresponds to 2.2 cents per gallon of methanol amortized over 10 years (assumes faster amortization for a first of a kind program). Table 7.1 summarized the estimated cost plus return on investment for methanol.

Table 7.1 Methanol Cost Plus Return, Delivered to California Retail Service Station (current cents per gallon)

\begin{tabular}{|l|c|}
\hline Middle East Cost of Production +10\% ROI & $26^{25}$ \\
\hline Shipping, ME to Los Angeles Harbor & $7^{26}$ \\
\hline Distribution Los Angeles Harbor to Retail Service Station in California & $10^{27}$ \\
\hline Retail service station margin & $2^{28}$ \\
\hline Distribution infrastructure and Retail Station Conversion & $2^{29}$ \\
\hline Total Delivered Cost Plus Return & 47 \\
\hline
\end{tabular}

\footnotetext{
${ }^{22}$ California Clean Fuels Market Assessment, 2001, California Energy Commission, September 2001

${ }^{23}$ Petroleum Liquids Transportation, National Petroleum Council, April 1989

${ }^{24}$ The low end assumes 1.5 turns per month in storage and a 70 percent average utilization rate; the high end is by analogy with the current petroleum product storage quantity

${ }^{25}$ Section V, Table 6.10

${ }^{26}$ Derived from shipping cost ME to USGC, see Table 7.3 below

${ }^{27}$ By analogy with increases in quoted gasoline prices from the harbor to wholesale prices

${ }^{28}$ Industry estimate. National Association of Convenience Stores, 2002 State of the Industry report reports total margin per gallon of gasoline is 12 cents per gallon (including margins on other products)

${ }^{29}$ Assumes costs associated with the California estimate above
} 


\subsubsection{New York}

If methanol were to capture 20 percent of the New York metropolitan gasoline market (N.Y., New Jersey, and Connecticut), the corresponding methanol demand would be an estimated 1.3 billion gallons per year. Adding Pennsylvania would add another 50 percent to the potential methanol demand at this market penetration. The required distribution is estimated at 2850 retail station conversions, 13 terminals with 8 billion barrels of storage and 2200 tank trucks. On this basis, the distribution infrastructure investment is estimated to be 316 million dollars, and the cost per gallon of methanol to amortize this investment would be comparable to that for California. Table 7.2 summarizes the cost plus return for methanol.

\section{Table 7.2 Methanol Cost Plus Return, Delivered to New York Retail Service Station} (current cents per gallon)

\begin{tabular}{|l|c|}
\hline Middle East Cost of Production +10\% ROI & 26 \\
\hline Shipping, ME to New York Harbor & 5 \\
\hline Distribution New York Harbor to Retail Station in Tri-state area & 12 \\
\hline Retail station margin & 2 \\
\hline Distribution infrastructure and Retail Station Conversion & $2^{30}$ \\
\hline Total Delivered Cost Plus Return & 47 \\
\hline
\end{tabular}

\subsubsection{Methanol Supply}

With the anticipated phase out of MTBE in the U.S. by 2006, approximately 40 percent of current U.S. methanol demand will be lost and a total of 5 million metric tons or 1.6 billion gallons per year of methanol demand, both domestic and overseas demand for MTBE production exported to the U.S. will be lost between now and then. This material could provide enough methanol to supply a first phase commercialization in California or in general to displace about 1 percent of the U.S. gasoline demand with methanol fuel cell vehicles.

New methanol plants being developed in low cost natural gas regions such as Trinidad, Australia and other areas are in the 2 to 3 million metric ton per year size range. There is sufficient stranded natural gas to meet demand at any level. The rate of progress will be determined by the economics of methanol as a transportation fuel versus other alternatives. Table 7.3 below compares methanol based on remote natural gas used in a fuel cell vehicle with a hybrid vehicle operating on gasoline. Diesel from GTL is assumed to be too difficult to reform for use in fuel cells.

\footnotetext{
${ }^{30}$ Assumes costs associated with the NY estimates above
} 


\section{Table 7.3}

\section{Cost Plus Return, Delivered to Retail Service Station} (current cents per gallon)

\begin{tabular}{|l|c|c|}
\hline & $\begin{array}{c}\text { Methanol } \\
\text { Fuel Cell }\end{array}$ & $\begin{array}{c}\text { Gasoline } \\
\text { Hybrid }\end{array}$ \\
\hline Middle East Cost of Production +10\% ROI & 26 & NA \\
\hline Refinery rack gasoline price, USGC & NA & 60 \\
\hline Shipping, ME to USGC & $5^{31}$ & NA \\
\hline Distribution USGC to Retail Gasoline Station & $10^{32}$ & $6^{33}$ \\
\hline Retail station margin & 2 & 2 \\
\hline Distribution infrastructure and Retail Station Conversion & $2^{34}$ & NA \\
\hline Total Delivered Cost Plus Return & 45 & 68 \\
\hline Cost to Consumer, Cents per 100 miles 35 & 90 & 136 \\
\hline
\end{tabular}

The relative cost to consumer will depend on the relative efficiency of methanol fuel cells compared to that of gasoline hybrids. The methanol fuel cell performance with on-board reforming to hydrogen has been demonstrated, and there is the potential for lower costs with direct methanol fuel cells. This comparison assumes the price of the methanol fuel cell vehicle will be the same as that for the gasoline hybrid. This has not been demonstrated.

It is also important to note that there are no infrastructure impediments to growth of gasoline hybrid vehicles, but there are for methanol fuel cell vehicles. The sizable investment in methanol distribution infrastructure will have to be made in parallel with methanol fuel cell vehicle market development and the costs shown in Table 7.3 are those after the market is in place. This is a "chicken and egg" dilemma, which will likely require government incentives to facilitate getting the methanol distribution infrastructure in place. Moreover, the annual savings to the customer driving 12 thousand miles per year on a methanol fuel cell vehicle is estimated at roughly $\$ 100$ based on the cost comparison in Table 7.3. This may be insufficient to motivate consumers to purchase a methanol fuel cell vehicle.

\subsubsection{Distributed Power}

Nexant has considered the potential as methanol fuel cells for distributed applications compared to methane or LPG fuel cells. Using the information from Table 7.3, the delivered cost of

\footnotetext{
${ }^{31}$ Personal communication, Blair Heffelfinger, Methanex Corporation, March 1, 2002; assumes shipment in 100 thousand metric dead weight ton dedicated ship under a long-term time charter with no backhaul

${ }^{32}$ Personal communication, Blair Heffelfinger, Methanex Corporation, March 1, 2002

${ }^{33}$ Assuming conventional pipeline movement from refinery to terminal and truck to retail outlet

${ }^{34}$ Assumes costs associated with the California, NY, or national estimates above

${ }^{35}$ Assumes 50 miles per gallon with methanol and $50 \mathrm{mpg}$ for a gasoline hybrid (methanol 1.2 to 1.4 times the energy efficiency of naphtha in a fuel cell, but twice the energy efficiency of a gasoline hybrid)
} 
methanol sourced from the Middle East, assuming the distribution infrastructure is available for transportation fuel applications, is 48 cents per gallon, or 7.42 dollars per million BTU. Natural gas is expected to be less than 4 dollars per million BTU, delivered to the Northeast U.S. and LPG about one dollar per gallon, or 10.9 dollars per million BTU, delivered to an industrial consumer in Northeast U.S.

Molten carbonate and solid oxide technologies are the two leading fuel cell technologies for distributed power applications. In both of these technologies there are no advantages in energy efficiency with methanol compared to either natural gas or propane. In fact, there is a thermodynamic advantage for natural gas in that waste heat recovery is more practical than with methanol due to the higher reforming temperatures with natural gas compared to those with methanol. Therefore, Nexant concludes that distributed power applications for methanol will be limited to those in which natural gas distribution infrastructure is not available. This is a very limited opportunity. 
The objective of this section is to evaluate issues related to methanol distribution infrastructure that impact its potential as a transportation or stationary power fuel and to suggest strategies to overcome any hurdles to its use. There is an existing methanol distribution infrastructure for serving current conventional methanol markets (chemical uses and MTBE feedstock). However, a much larger distribution infrastructure will be required if methanol becomes a significant transportation fuel.

The following options for fuel methanol uses have been analyzed from the perspective of required infrastructure to support:

\subsection{NEAT FUEL SUPPLIED FOR INTERNAL COMBUSTION ENGINE VEHICLES}

Neat or near-neat (M85) methanol was demonstrated in California in the 1990s as a fuel for fuelflexible vehicles capable of using either M85 or gasoline. At its peak, there were about fifteen thousand flexible fuel vehicles and over fifty public service stations operating on methanol. However, the program was a commercial failure. Methanol could not economically compete with gasoline because its energy density is only one-half that of gasoline, and thermal efficiency of methanol in an internal combustion engine is similar to that of gasoline.

\subsection{METHANOL BLENDED WITH CONVENTIONAL GASOLINE}

Methanol blends in gasoline and neat methanol in internal combustion engines are not projected to be commercialized in the future. Methanol blends were commercially demonstrated in the early 1980s. ARCO and Sunoco both marketed a blend of about 5 percent methanol and 5 percent tertiary-butyl alcohol with a total oxygen content of 9.6 percent (comparable oxygen content as ethanol blends) in the northeast U.S. out of refineries in Philadelphia. However, the products were abandoned in the mid-1980s due to the sensitivity of methanol to water present in the conventional gasoline distribution system.

\subsection{METHANOL USE IN FUEL CELL VEHICLES}

Methanol fuel cell vehicles are projected to have a lower fuel cost per mile than hybrid vehicles operating on gasoline. Table 8.1 compares delivered cost of methanol to a service station in the U.S. with that of gasoline. The table also compares the cost per mile for a methanol fuel cell vehicle with a gasoline hybrid. However, the economic incentive to the consumer is only about 100 dollars per year per vehicle. Penetration of methanol fuel cell vehicles is projected to be less than 2 percent of the total light vehicle transportation fuel market through 2015 . Initial commercialization is projected to be in the state of California followed by one other major metropolitan area, possibly the New York area. 
Table 8.1 Cost Plus Return, Delivered to Retail Service Station (current cents per gallon)

\begin{tabular}{|l|c|c|}
\hline & $\begin{array}{c}\text { Methanol } \\
\text { Fuel Cell }\end{array}$ & $\begin{array}{c}\text { Gasoline } \\
\text { Hybrid }\end{array}$ \\
\hline Middle East Cost of Production +10\% ROI & 26 & $\mathrm{NA}$ \\
\hline Refinery rack gasoline price, USGC & $\mathrm{NA}$ & 60 \\
\hline Shipping, ME to USGC & $5^{36}$ & $\mathrm{NA}$ \\
\hline Distribution USGC to Retail Gasoline Station & $10^{37}$ & $6^{38}$ \\
\hline Retail station margin & 2 & 2 \\
\hline Distribution infrastructure and Retail Station Conversion & $2^{39}$ & $\mathrm{NA}$ \\
\hline Total Delivered Cost Plus Return & 45 & 68 \\
\hline Cost to Consumer, Cents per 100 miles & 90 & 136 \\
\hline
\end{tabular}

\subsection{METHANOL DISTRIBUTION INFRASTRUCTURE}

\subsubsection{Requirements for Significant Market Penetration}

Methanol distribution infrastructure investment costs in the U.S. could total as much as $\$ 6.5$ billion dollars for methanol to capture 20 percent of the light vehicle transportation market. Table 8.2 outlines the components of the new infrastructure.

\section{Table 8.2 Components of Methanol Distribution Infrastructure}

\begin{tabular}{|l|c|c|}
\hline & Number & Cost \\
\hline Barges & & (Million \$) \\
\hline Terminal Storage (Million Gallons) & 500 & 500 \\
\hline Trucks & 3,800 & 1500 \\
\hline Rail Cars & 20,000 & 800 \\
\hline Retail station conversion to methanol & 30,000 & 1500 \\
\hline Total & 43,750 & 2200 \\
\hline
\end{tabular}

\footnotetext{
${ }^{36}$ Personal communication, Blair Heffelfinger, Methanex Corporation, March 1, 2002; assumes shipment in 100 thousand metric dead weight ton dedicated ship with no backhaul

${ }^{37}$ Personal communication, Blair Heffelfinger, Methanex Corporation, March 1, 2002

${ }^{38}$ Assuming conventional pipeline movement from refinery to terminal and truck to retail outlet

${ }^{39}$ Assumes costs associated with the California, NY, or national estimates above

${ }^{40}$ Assumes 50 miles per gallon with methanol and $50 \mathrm{mpg}$ for a gasoline hybrid (methanol 1.2 to 1.4 times the energy efficiency of naphtha in a fuel cell, but twice the energy efficiency of a gasoline hybrid)
} 
However, this investment could be phased in over time as an extension to the existing methanol distribution infrastructure. It is likely to involve the companies that represent the independent fuel distributors as well as existing methanol suppliers and the major integrated oil companies

\subsubsection{Comparison of Methanol Distribution Infrastructure Requirements with Other Alternative Fuels}

Table 8.2 compares the capital investment for retail service stations designed to dispense methanol, CNG, LNG and hydrogen. Methanol retail outlets cost a fraction of those for the other clean fuel alternatives.

There are over $240 \mathrm{CNG}$ stations currently operating in California. Over 100 offer full or partial public access. CNG stations cost approximately ten times the cost of a methanol station.

There are over 140 LNG stations operating in California. LNG storage requires double walled, stainless steel, "superinsulated" storage tanks. Because of the higher cost, LNG has primarily been used for buses and other heavy fleet vehicles to ensure maximum throughput. The operating costs are lower than for $\mathrm{CNG}$, since no compressor is required. However, training costs are higher and maintenance costs have been estimated at 3 to 6 cents per gallon ${ }^{41}$. LNG stations must meet similar standards and codes as CNG stations.

Some LNG stations are designed to also supply CNG. Such systems consist of a conventional LNG station with the addition of high-pressure cryogenic pumps that compress the LNG to 4 to 5 thousand psi, and then vaporize the compressed liquid. The advantages of these combined stations (L/CNG systems) is that the cryogenic pumps consume much less energy than the compressors used at conventional CNG stations and require less maintenance. Second, L/CNG is delivered to the vehicle at ambient temperature, facilitating complete filling of the vehicle storage tank and eliminating the need for temperature compensation systems. Furthermore, since LNG is nearly pure methane, L/CNG is delivered to the vehicle with virtually no contaminants or undesirable fuel elements such as oil carryover, moisture, and higher hydrocarbons.

There is less commercial experience with hydrogen stations. Only a few hand-built first generation stations have been built, including two different systems in California used by Sunline Transit to fuel its direct-hydrogen fuel cell bus in the Coachella Valley. For this reason, the capital costs for hydrogen stations are not fully known at this time. Station designs are only conceptual at this stage, and few hydrogen-specific codes and standards exist. Capital cost will depend, in part, on whether a liquefied hydrogen or compressed form of hydrogen will be stored and/or produced at the station by reforming natural gas. In either case, costly fire and safety requirements are likely to be the norm, especially in the early years of deployment. Recent estimates for first-generation stations being built in Sacramento and other areas under the California Fuel Cell Partnership indicate that they can cost between 2 and 3 million dollars each.

\footnotetext{
${ }^{41}$ Jim Harger, Vice President of Marketing, Pickens Fuel Corporation, 12/6/00.
} 


\section{Table 8.2 Comparative Retail Station Costs}

\begin{tabular}{|l|r|r|r|r|}
\hline & Methanol & CNG & LNG & Hydrogen \\
\hline $\begin{array}{l}\text { Storage Capacity } \\
\text { (thousand gallons) }\end{array}$ & $10-20$ & - & 15 & 15 \\
\hline $\begin{array}{l}\text { Throughput } \\
\text { Thousand GGE42 per Month }\end{array}$ & 50 & 20 & $15-50$ & $15-50$ \\
\hline Capital Cost, Thousands \$ & 60 & $430-750$ & $650-800$ & $2000-3000$ \\
\hline
\end{tabular}

\footnotetext{
${ }^{42}$ Gasoline gallon equivalent
} 


\section{Appendix}

1. Xcellsis Report on the Evaluation of Fuel Cell Grad Methanol, Section 6 Supply Chain Analysis

2. Excerpts from the Independent Liquid Terminals Association Directory, 2002 


\section{Methanol Bibliography}

1. Methanol Fuels and Fire Safety, www.epa.gov/oms/08-fire.htm

2. Oxy-Fuel News, Vol 13, no. 29, July 23, 2001

3. Automotive Engineering International, Vol 13, no. 2, March 2000

4. Oxy-Fuel News, Vol 11, no. 19, May 17, 1999

5. Octane Week, Vol 14, no. 13, March 29, 1999

6. Automotive News, March 22, 1999, p. 6

7. Fifteen Years of Fuel Methanol Distribution, Peter F. Ward, California Energy Commission, 1996

8. Methanol Refueling Station Lists, EA Engineering, Science and Technology Inc., February 1, 1999

9. Methanol Fueling System Installation and Maintenance Manual, California Energy Commission, November 20, 1998

10. Methanol Presentation to the EVAA, December 2001

11. Oxy-Fuel News, Vol 9, no. 28, August 4, 1997

12. Oxy-Fuel News, Vol 8, no. 41, October 21, 1996

13. PR Newswire, pl, January 3, 1992

14. Automotive News, February 25, 1991, pg 32

15. Methanol Transportation Costs, a Chem Systems Study for U.S.D.O.E Office of Policy, Planning and Analysis, November, 1989

16. Oxy-Fuel News, Vol 11, no.15, April 19, 1999

17. www.sae.org.automag/features/fuelcells/fuelcell3.htmandfuelcell5.htm

18. www.texaco.com/archive/agenda/archive/----/docs/powering2.html

19. The Fuels Report, California Energy Commission, July 1999

20. New and Evolving Uses of Methanol, Chem Systems, Inc. August, 1981

21. Cosolvent Alcohols, Chem Systems, Inc. September 1985

22. Global Methanol Business, Chem Systems, Inc. July 1983

23. Global Methanol Business Update, Chem Systems, Inc. March 1985

24. North American Methanol Business, Chem Systems Inc. 1980 
25. North American Methanol Business, Chem Systems Inc. 1981

26. US Petroleum Refining, Industry, the Adequacy and Affordability of Cleaner Fuels, National Petroleum Council, June 2000

27. Petroleum Liquids Transportation, National Petroleum Council, April 1989

28. Petroleum Inventories and Storage, National Petroleum Council, April 1989

29. A Summary of Federal Regulations for Underground Storage Tank Systems, EPA, July 1995

30. Projected Automotive Fuel Cell Use in California, ADL Report to the CEC, October 2001

31. The Future of Fuel Cells for Transportation, The Northeast Advanced Fuel Consortium, November 2000

32. Fuel Cells for Distributed Generation, A Technology and Marketing Summary, Energy Center of Wisconsin, March 2000

33. Social Cost Comparison Among Fuel Cell Alternatives, J. Fernando Contadini, Fuel Cell Vehicle Modeling Program, Institute of Transportation Studies, University of California at Davis, www.methanol.com

34. Fuel Cell Options for the Fuel Cell Vehicle: Hydrogen, Methanol or Gasoline?, C.E. Thomas Et. Al., International Journal of Hydrogen Energy 25 (2000, pp 551-567)

35. Beyond the Internal Combustion Engine: The Promise of Methanol Fuel Vehicles, Prepared for the American Methanol Institute by Breakthrough Technologies, 2001

36. Evaluation of the Fate and Transport of Methanol in the Environment, Malcolm Pirnie Inc., January 1999

37. Storage and Handling of Gasoline-Methanol/Cosolvent Blends at Distribution Terminals and Service Stations, API Recommended Practice 1627, August 1986

38. Assessment of Partnership for a New Generation of Vehicles Fuels Infrastructure, Phase 2 Report, Additional Capital Needs and Fuel-Cycle Energy and Emission Impacts, Argonne National Laboratory, August, 1998 


\section{Impact of FT Diesel on U.S. Refineries Market Study Report Section VIII \\ Prepared For: ConocoPhillips}

Co-operative Agreement DE-FC26-01NT41098

\section{ConocoPhillips GNexant}




\title{
Impact of FT Diesel on U.S. Refineries Market Study Report Section VIII
}

November 2002

\author{
Prepared For: \\ ConocoPhillips
}

\section{(Nexant}

44 South Broadway, White Plains, New York 10601, USA

Tel: +1 $9146090300 \quad$ Fax: +1 9146090399 
1 Objectives .................................................................................... $1-1$

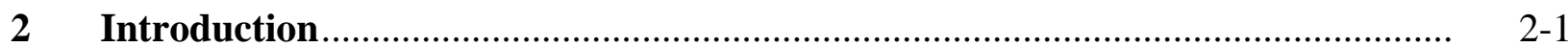

$2.1 \quad$ MODEL DEVELOPMENT .................................................................. $2-1$

$2.2 \quad$ FT DIESEL EVALUATIONS ............................................................. $2-2$

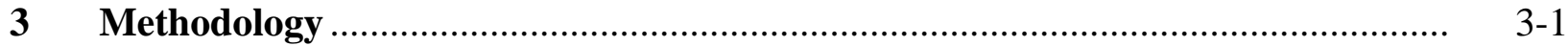

3.1 INTRODUCTION …..................................................................... $3-1$

3.1.1 Background ..................................................................... $3-1$

3.1.2 Linear Programming ................................................................. $3-1$

3.2 MODEL DEVELOPMENT ACTIVITIES ............................................. $3-2$

3.2.1 Preliminary PADD 3 Model Development..................................... 3-2

3.2.2 Development of PADD 3 2001 Model ........................................... 3-7

3.2.3 Key Generic Model Changes ............................................................. 3-8

3.2.4 Key California Refinery Model Changes ....................................... 3-10

3.3 MODEL METHODOLOGY …......................................................... $3-10$

3.3.1 2001 Base Case ............................................................................. 3-10

3.3.1.1 Product Slate Assumptions............................................ 3-10

3.3.1.2 Development of Representative Refinery Configuration..... 3-11

3.3.2 2006 Cases ............................................................................ $3-11$

3.3.3 2015 Cases ............................................................................ 3-13

3.3.4 Other PADDs ............................................................................. $3-14$

3.4 FT DIESEL QUALITY ASSUMPTIONS ................................................ $3-14$

CAPITAL COST ASSUMPTIONS ......................................................... $3-16$

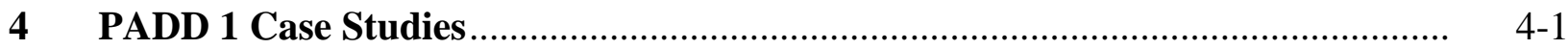

4.1 KEY MARKET ASSUMPTIONS .........................................................

4.1.1 Profile of Existing Refineries......................................................... 4-1

4.1.2 Crude Slate .........................................................................

4.1 .3 Product Slate ........................................................................ $4-2$

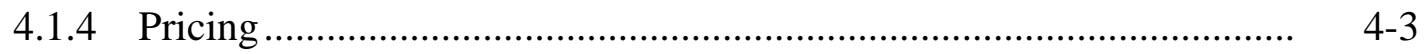

4.2 2001 BASE CASE ................................................................................ 


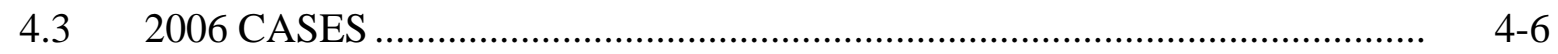

4.3.1 Representative Base Refinery without FT Diesel ............................ . 4-6

4.3.2 Representative Refinery with FT Diesel........................................... . 4-9

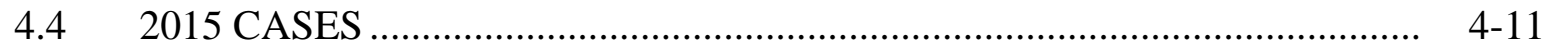

4.4.1 Representative Base Refinery without FT Diesel........................... 4-11

4.4.2 Representative Refinery with FT Diesel....................................... 4-13

$5 \quad$ PADD 2 Case Studies ............................................................................... $5-1$

$5.1 \quad$ KEY MARKET ASSUMPTIONS ....................................................... $5-1$

5.1.1 Profile of Existing Refineries ........................................................ $\quad 5-1$

5.1 .2 Crude Slate ........................................................................... $5-1$

5.1 .3 Product Slate .......................................................................... $5-2$

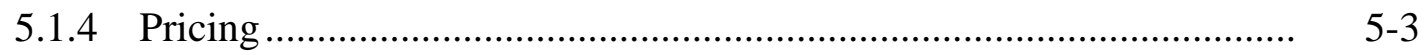

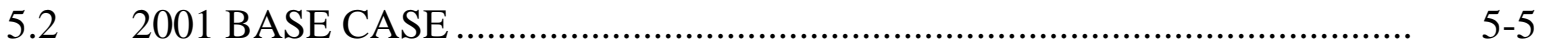

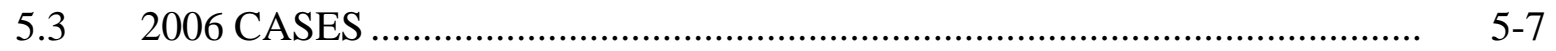

5.3.1 Representative Base Refinery without FT Diesel ........................... 5-7

5.3.2 Representative Refinery with FT Diesel ........................................ $5-9$

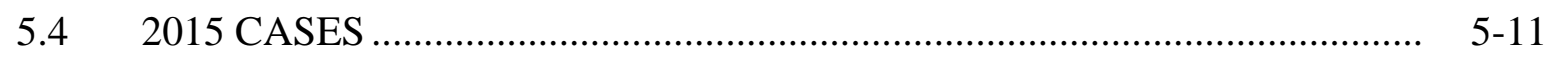

5.4.1 Representative Base Refinery without FT Diesel ............................. 5-11

5.4.2 Representative Refinery with FT Diesel.......................................... 5-13

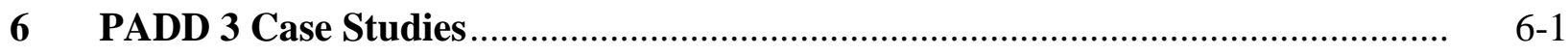

6.1 KEY MARKET ASSUMPTIONS ........................................................ $6-1$

6.1.1 Profile of Existing Refineries .................................................. $6-1$

6.1.2 Crude Slate .................................................................................. 6-2

6.1.3 Product Slate .............................................................................. $\quad$ 6-2

6.1.4 Pricing ................................................................................ $6-3$

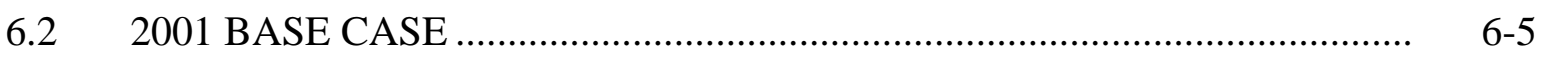

6.3 2006 CASES .................................................................................

6.3.1 Representative Base Refinery without FT Diesel ............................... 6-6

6.3.2 Representative Refinery with FT Diesel............................................ 6-9

6.4 2015 CASES ........................................................................... $6-11$

6.4.1 Representative Base Refinery without FT Diesel .......................... 6-11 
6.4.2 Representative Refinery with FT Diesel...................................... 6-13

6.4.3 Alternative Diesel Sulfur Specifications......................................... 6-15

6.4.4 Alternative Crude Oil and Diesel Price Outlooks............................ 6- 6-16

6.4.5 Fixed Product Slate .................................................................. 6-18

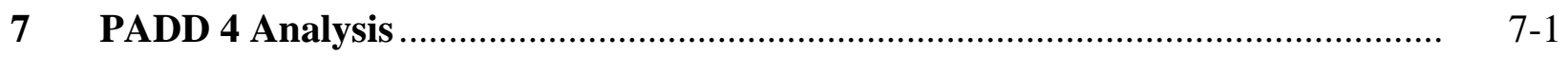

7.1 KEY MARKET ASSUMPTIONS .......................................................... $7-1$

7.1.1 Profile of Existing Refineries .................................................. $7-1$

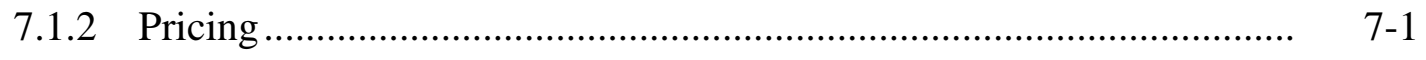

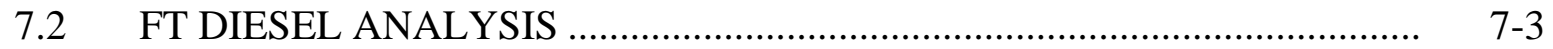

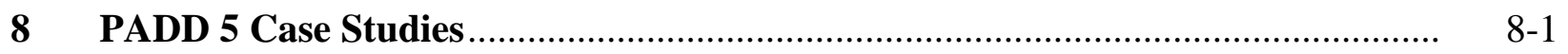

8.1 KEY MARKET ASSUMPTIONS ...................................................... $8-1$

8.1.1 Profile of Existing Refineries ................................................. $8-1$

8.1.2 Crude Slate.................................................................................. 8 $8-2$

8.1.3 Product Slate ....................................................................

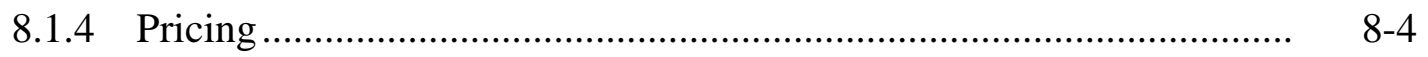

8.2 2001 BASE CASE ................................................................................

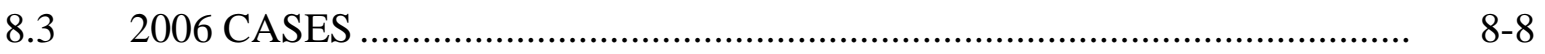

8.3.1 Representative Base Refinery without FT Diesel .............................. 8 8-8

8.3.2 Representative Refinery with FT Diesel........................................ 8- 8-10

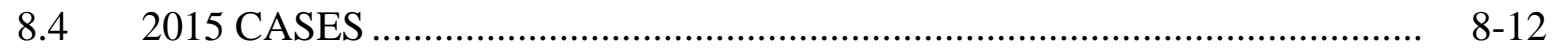

8.4.1 Representative Base Refinery without FT Diesel ........................... 8-12

8.4.2 Representative Refinery with FT Diesel...................................... 8-14

8.4.3 Fixed Product Slate ...................................................................... 8 8-16

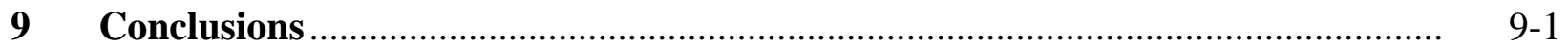


4.1 PADD 1 Refinery FT Diesel Premium, 2006.

4-11

4.2 PADD 1 Refinery FT Diesel Premium, 2015.

5.1 PADD 2 Refinery FT Diesel Premium, 2006

5.2 PADD 2 Refinery FT Diesel Premium, 2015

6.1 PADD 3 Refinery FT Diesel Premium, 2006.

6.2 PADD 3 Refinery FT Diesel Premium, 2015.

6.3 PADD 3 Refinery FT Diesel Values, 2015 Alternative Diesel Sulfur Specifications. 6-16

6.4 PADD 3 Refinery FT Diesel Values, 2015 Alternative Crude Oil Price Outlooks ..... 6-18

6.5 PADD 3 Refinery FT Diesel Premium, 2015 Fixed Product Slate.

8.1 California Refinery FT Diesel Premium, 2006.

8.2 California Refinery FT Diesel Premium, 2015.

8.3 California Refinery FT Diesel Premium, 2015 Fixed Product Slate 8-18

9.1 VALUE OF FT DIESEL TO U.S. REFINERS - 2006

Table

3.1 Representative PADD 3 Refinery With FT Diesel Test Case With Fixed Product Rates - 2001

3.2 Representative PADD 3 Refinery With FT Diesel

3.3 Representative PADD 3 Refinery With FT Diesel

3.4 Representative PADD 3 Refinery With FT Diesel

3.5 Conoco GTL Diesel Qualities

3.6 Capital Cost Criteria

3.7 Process Unit Capital Cost Assumptions

3.8 Process Unit Capital Cost Factors, 2006.

4.1 PADD 1 Process Unit Capacities, 2001

4.2 PADD 1 Crude Quality, 2000-2015.

4.3 Representative PADD 1 Refinery Product Slate, 2001-2015

4.4 PADD 1 Pricing Assumptions, 2001-2015 Medium Crude Oil Price Scenario 
4.5 Representative PADD 1 Refinery Results, 2001 ................................................ $4-5$

4.6 Representative PADD 1 Refinery Process Unit Utilizations, 2001 .......................... 4-6

4.7 Representative PADD 1 Refinery Results, 2006 Base Refinery - No FT Diesel........ 4 4-8

4.8 Representative Base PADD 1 Refinery ..................................................................

4.9 Representative PADD 1 Refinery With FT Diesel, 2006 ..................................... $4-10$

4.10 Representative PADD 1 Refinery Results, 2015 Base Refinery - No FT Diesel....... 4-12

4.11 Representative Base PADD 1 Refinery .................................................................. $4-13$

4.12 Representative PADD 1 Refinery With FT Diesel, 2015 ....................................... 4-14

5.1 PADD 2 Process Unit Capacities, 2001 ............................................................ $5-1$

5.2 PADD 2 Crude Quality, 2000-2015 ..................................................................... $5-2$

5.3 Representative PADD 2 Refinery Product Slate, 2001-2015 ................................. 5-3

5.4 PADD 2 Pricing Assumptions, 2001-2015 ........................................................ $5-4$

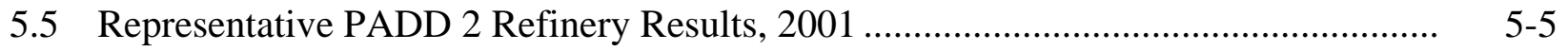

5.6 Representative PADD 2 Refinery Process Unit Utilizations, 2001 ......................... 5-6

5.7 Representative PADD 2 Refinery Results, 2006 Base Refinery - No FT Diesel....... 5-8

5.8 Representative Base PADD 2 Refinery ............................................................ $5-9$

5.9 Representative PADD 2 Refinery With FT Diesel, 2006 .................................... 5-10

5.10 Representative PADD 2 Refinery Results, 2015 ............................................. $5-12$

5.11 Representative Base PADD 2 Refinery ............................................................. $5-13$

5.12 Representative PADD 2 Refinery With FT Diesel, 2015 .................................... 5-14

6.1 PADD 3 Process Unit Capacities, 2001 ............................................................ $6-1$

6.2 PADD 3 Crude Quality, 2000-2015 .................................................................. $6-2$

6.3 Representative PADD 3 Refinery Product Slate, 2001-2015 ................................. 6-3

6.4 PADD 3 Pricing Assumptions, 2001-2015 Medium Crude Oil Price Scenario ........... 6-4

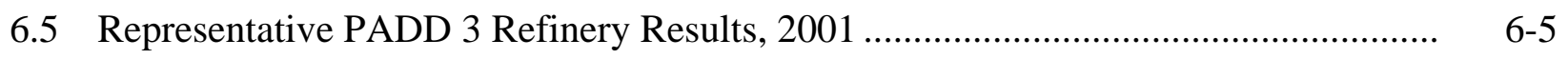

6.6 Representative PADD 3 Refinery Process Unit Utilizations, 2001 .......................... 6-6

6.7 Representative PADD 3 Refinery Results, 2006 Base Refinery - No FT Diesel....... 6-8

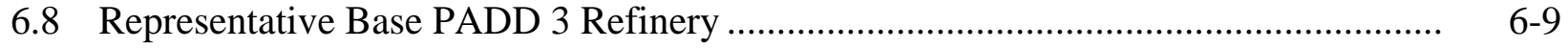

6.9 Representative PADD 3 Refinery With FT Diesel, 2006 ...................................... 6-10

6.10 Representative PADD 3 Refinery Results, 2015 Base Refinery - No FT Diesel....... 6-12

6.11 Representative Base PADD 3 Refinery ........................................................... $6-13$ 
6.12 Representative PADD 3 Refinery With FT Diesel, 2015 ..................................... 6-14

6.13 PADD 3 Refinery FT Diesel Values, 2015 Alternative Diesel Sulfur Specifications. 6-15

6.14 PADD 3 Refinery FT Diesel Values, 2015 Alternative Crude Oil Price Outlooks ...... 6-17

6.15 PADD 3 Refinery FT Diesel Values, 2015 Fixed Product Slate ................................ 6-19

6.16 PADD 3 Refinery Process Unit Utilizations, 2015 Fixed Product Slate .................... 6-20

7.1 PADD 4 PROCESS UNIT CAPACITIES, 2001 .................................................. 7-1

7.2 PADD 4 Pricing Assumptions, 2001-2015 Medium Crude Oil Price Scenario ........... 7-2

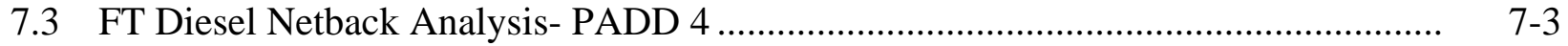

8.1 PADD 5 Refinery Process Unit Capacities, 2001 ................................................. 8-1

8.2 California Refinery Process Unit Capacities, 2001 .................................................. $8-2$

8.3 California Refinery Crude Quality, 2000-2015 ................................................ 8-3

8.4 Representative California Refinery Product Slate, 2001-2015 ............................... 8-4

8.5 PADD 5 Pricing Assumptions, 2001-2015 Medium Crude Oil Price Scenario ........... 8-5

8.6 Representative California Refinery Results, 2001 ….......................................... 8-6

8.7 Representative California Refinery Process Unit Utilizations, 2001 ........................ 8-7

8.8 Representative California Refinery Results, 2006 .............................................. 8-9

8.9 Representative Base California Refinery Process Unit Utilizations, 2006............... 8 8-10

8.10 Representative California Refinery With FT Diesel, 2006................................... 8-11

8.11 Representative California Refinery Results, 2015 Base Refinery - No FT Diesel ..... 8-13

8.12 Representative Base California Refinery Process Unit Utilizations, 2015............... 8 8-14

8.13 Representative California Refinery With FT Diesel, 2015 ................................... 8-15

8.14 California Refinery FT Diesel Values, 2015 Fixed Product Slate............................. 8-17

8.15 California Refinery Process Unit Utilizations, 2015 Fixed Product Slate.................. 8 8-18 
The objectives of this report section were:

- To develop a linear programming model for different Petroleum Administration for Defense District s (PADDs)

- Determine the volumes of FT Diesel that can be economically blended with petroleumderived fuels

- Evaluate the modifications that may be required in existing refineries to process FT Diesel

- Evaluate the value of FT Diesel to refiners 


\subsection{MODEL DEVELOPMENT}

Refinery linear programming (LP) models were developed for different PADDs using the Process Industry Modeling System (PIMS ${ }^{\mathrm{TM}}$ ) software licensed from Aspen Technology to reflect a representative facility and operation for each region. The LP models were developed for four of the five PADDs based on the following approach:

- A validation analysis was developed to establish representative refinery configurations for each PADD based on refinery and process unit capacities reported for 2001. This analysis was used to validate the LP models and provided a basis for comparison for the forecast period

- $\quad$ A Base Case analysis was developed for 2006 to reflect modifications to existing refineries that are likely to occur by 2006 to comply with the currently defined regulations for gasoline and diesel quality

- $\quad$ A second Base Case analysis was performed for 2015 to reflect modifications to existing refineries that are likely to occur between 2006 and 2015 to comply with projected markets and projected regulations for gasoline, diesel and jet fuel quality.

Key assumptions for these analyses were developed as follows:

- $\quad$ Product demand trends for transportation fuels and other refined products were consistent with the market analysis presented in Market Report Section 4.

- The crude oil slate for the 2001 base analysis reflected the existing mix of crude oils processed in each region and was represented by a mixture of three to five major crude oils. The crude oil slate for the 2006 and 2015 analyses was adjusted to reflect the projected crude oil supply outlook and quality trends presented in Market Report Section 4.

- $\quad$ Pricing assumptions were consistent with the price forecasts for 2006 and 2015 developed and presented in Market Report Section 9.

Case analyses to address the impact and value of processing FT Diesel for 2006 and 2015 were developed for four PADDs (PADDs 1, 2, 3, and 5). A program of case studies was developed such that the impact of the various market and regulatory scenarios on FT Diesel values could be evaluated relative to the Base Cases.

The PIMS model development and analyses began with PADD 3, the region that has the most refineries, and did not include PADD 4, the region that has the least refining capacity and is too remote for imported FT Diesel to be economically supplied to refineries in the region. 


\subsection{FT DIESEL EVALUATIONS}

This Market Report Section also presents the results of the analyses of the effects of FT Diesel properties, blending composition, and performance, crude mix and properties, and emission and fuel formulation regulations on the operating conditions of the existing refineries and the required production costs of the ultra clean fuels. This task sought to answer the question "What impact, if any, will the availability FT Diesel fuel have on the U.S. downstream petroleum industry in the time horizon we are considering?"

The Base Case LP models developed for this project were used to perform these analyses, which analyzed the following:

- Different ratios for blending FT Diesel with petroleum-derived fuels

- Modifications that may be required or avoided in the existing refineries as a result of the availability of the FT Diesel

- Market values of FT Diesel to refiners

Various cases, incorporating the availability of FT Diesel, were prepared in which the following parameters was varied:

- Level and type of FT Diesel that is available

- Crude oils pricing

FT Diesel market values for each case considered were developed based on both variable cost breakeven analyses and analyses of the total (i.e., fixed and variable operating costs plus incremental capital costs) avoided costs associated with using FT Diesel to meet transportation fuel demand. 


\subsection{INTRODUCTION}

\subsubsection{Background}

Nexant Inc. (formerly under Bechtel National Inc.) was awarded a 'study' in November 1993 by the U.S. Department of Energy's (DOE) Federal Energy Technology Center (FETC) to determine the most cost effective combination of upgrading processes needed to make high quality, liquid transportation fuels from petroleum crude oil and 'direct and indirect' coal liquefaction products in an existing petroleum refinery.

In 1995, a refinery model was developed using the PIMSTM (Process Industry Modeling System) linear programming (LP) software to simulate a generic Midwest/PADD 2 petroleum refinery of the future.

The "petroleum-only" version of the model established the size and complexity of a representative Midwest refinery for the year 2000. The year 2000 was chosen during the 1995 study because fuel property and emissions standards set by the U.S. Environmental Protection Agency had been established for 2000, but not for later years. The previous study's "petroleumonly" model of a representative Midwest refinery in the year 2000 was used as the starting point for developing the LP models used for the analyses in this project.

\subsubsection{Linear Programming}

Linear programming (LP) models of refineries are widely used in the industry for long term planning purposes to perform conceptual refinery configuration studies, detailed economic analyses and to evaluate refinery investment options. They are often used to analyze projects involving product specification changes requiring refinery process unit additions and/or modifications. In addition to being used to simulate individual refineries, LP models can be used to simulate a combination of refineries or the refining sector within a particular geographical region.

The linear programming software used for the project's analyses was Aspen PIMS ${ }^{\text {TM }}$, a computer software package designed for the development of LP models to represent the process and economic arrangements of an oil refining or petrochemical processing/supply configuration.

PIMS $^{\mathrm{TM}}$ may be applied in a wide variety of situations, including:

- Evaluation of alternative feed stocks

- $\quad$ Sizing of plant in grass-roots studies

- Optimization of product mix for a given feed slate.

- Optimization of product blending and other operating decisions 
- Evaluation of plant configurations

- Planning of feed-stock and product inventory

\subsection{MODEL DEVELOPMENT ACTIVITIES}

\subsubsection{Preliminary PADD 3 Model Development}

The PIMS ${ }^{\mathrm{TM}}$ model developed for this project began with a sequence of trial runs for PADD 3, using the PADD 2 model described above as the starting model basis. Actual 2000 refined product pricing for PADD 3 was used for during these runs. To validate the model, preliminary criteria, as described below, were used to establish the design basis for a PADD 3 refinery. PADD 3 was selected for the project's initial analyses because it is the largest refining region in U.S. with the largest numbers of refineries and largest refined product production.

The actual 2000 product slate for PADD 3 refineries and a representative mix of crude oils processed in the region's refineries were used as the primary basis for the model configuration. Specified product qualities were also revised to be consistent with representative qualities of PADD 3 refinery production during 2000.

The existing PADD 2 refinery model was first expanded from 150 thousand barrels per day (KBPD) to $250 \mathrm{KBPD}$ to simulate a typical and generic refinery in the PADD 3 area. A blend of three to four crude oils using representative crude oil assay data in the available PIMS ${ }^{\mathrm{TM}}$ software domain was selected as the representative feedstock for the trial model. With the PADD 3 refining product slate and product specifications defined, a generic PADD 3 refinery configuration for 2000 was developed with major unit capacities simulating the average size of the corresponding units in that region.

A sequence of trial runs was carried out to test the preliminary PADD 3 model and to develop a specific analytical approach for this project. The trial runs included analyses with varying quantities of FT diesel used as a refinery feedstock and/or blendstock for the following alternative analytical approaches:

Fixed Crude Mix, Crude Feedrate and Product Slate---The objective function (i.e., the refinery operating margin) was calculated when different quantities of FT diesel were processed by the representative PADD 3 refinery while maintaining a fixed crude mix and crude feedrate of $250 \mathrm{KBPD}$. The product slate (i.e. each refined product's percentage of the total production) was fixed, but total refinery production was allowed to increase in proportion to the volume of FT diesel available. The values of the FT diesel evaluated by this trial run were well below the market price of conventional diesel fuel and were only marginally better than the refinery's cost of crude oil. In this approach, the modeled refinery was basically forced to produce more refined products with the FT diesel behaving as feedstock/crude oil and hence the FT diesel was valued by the model almost like crude oil. In practice, refineries have more flexibility to vary their production and product slate and therefore it was concluded that this analytical approach is not the preferred way to evaluate the FT Diesel. 
- Fixed Crude Mix and Fixed Product Rates ---For this analytical approach, both the product slate and rates were fixed, with the initial production rates being consistent with a crude feedrate of $250 \mathrm{KBPD}$. To maintain these product rates, the use of FT Diesel as a refinery feedstock/blendstock necessitates the displacement of approximately an equal volume of crude oil. The values of the FT diesel obtained by this trial run were also well below the price of diesel (similar to the results of the first analytical approach discussed above) because the model was forced to displace crude oil, whose cost is low relative to prices for refined products such as diesel, while maintaining the same product rates/mix and refinery revenue. The results of this test case are presented in Table 3.1 and Table 3.2. As shown, the values of the FT diesel evaluated by alternative were well below the price of diesel and were only about $\$ 2$ per barrel above the refinery's cost of crude oil of $\$ 19.2$ per barrel. Crude oil purchases declined when FT Diesel was available as a blendstock and the Distillate Hydrotreater utilization declined from 52.0 to 40.5 KBPD when $15 \mathrm{KBPD}$ of FT Diesel was available. However, the utilization of all other major process units, except the Crude Distillation Unit, remained unchanged as more straight run diesel was diverted from diesel blending to Cat Cracker feed to maintain Cat Cracker utilization as FT Diesel availability increased and crude oil purchases declined. 


\section{Table 3.1 Representative PADD 3 Refinery With FT Diesel Test Case With Fixed Product Rates - 2001 \\ (refinery feedstocks and production)}

Feedstock Purchases, KBPD
Crude Oil
Methanol
MTBE
Normal Butane
Iso Butane
Natural Gas (as EFO)
FT-Diesel
Total

Refinery Production, KBPD

Propylene

LPG

Unleaded Regular

Unleaded Premium

Reformulated Regular

Reformulated Premium

Jet Fuel

Low Sulfur Diesel

No. 2 Fuel Oil

Low Sulfur Fuel Oil

High Sulfur Fuel Oil

Asphalt

Fuel Coke, Tons

Sulfur, Ltons

Cat Slurry

Other Products

Total
FT Diesel Purchase Cases

\begin{tabular}{rrrrrrr}
\hline 271.5 & 270.4 & 269.3 & 268.2 & 265.9 & 260.5 & 254.5 \\
1.0 & 1.0 & 1.0 & 1.0 & 1.0 & 1.0 & 1.0 \\
0.2 & 0.2 & 0.3 & 0.3 & 0.4 & 0.5 & 0.9 \\
2.4 & 2.4 & 2.3 & 2.3 & 2.3 & 2.2 & 2.1 \\
3.9 & 3.9 & 3.9 & 3.9 & 3.9 & 4.1 & 4.2 \\
4.1 & 4.1 & 4.0 & 4.0 & 4.0 & 3.9 & 3.9 \\
0.0 & 1.0 & 2.0 & 3.0 & 5.0 & 10.0 & 15.0 \\
$\mathbf{2 8 3 . 1}$ & $\mathbf{2 8 3 . 0}$ & $\mathbf{2 8 2 . 9}$ & $\mathbf{2 8 2 . 8}$ & $\mathbf{2 8 2 . 5}$ & $\mathbf{2 8 2 . 2}$ & $\mathbf{2 8 1 . 7}$
\end{tabular}

$\begin{array}{rrrrrrr}6.8 & 6.8 & 6.8 & 6.8 & 6.8 & 6.8 & 6.8 \\ 7.6 & 7.6 & 7.6 & 7.6 & 7.7 & 7.7 & 7.8 \\ 99.4 & 99.4 & 99.4 & 99.4 & 99.4 & 99.4 & 99.4 \\ 21.1 & 21.1 & 21.1 & 21.1 & 21.1 & 21.1 & 21.1 \\ 22.8 & 22.8 & 22.8 & 22.8 & 22.8 & 22.8 & 22.8 \\ 4.9 & 4.9 & 4.9 & 4.9 & 4.9 & 4.9 & 4.9 \\ 36.5 & 36.5 & 36.5 & 36.5 & 36.5 & 36.5 & 36.5 \\ 44.5 & 44.5 & 44.5 & 44.5 & 44.5 & 44.5 & 44.5 \\ 22.6 & 22.6 & 22.6 & 22.6 & 22.6 & 22.6 & 22.6 \\ 0.0 & 0.0 & 0.0 & 0.0 & 0.0 & 0.0 & 0.0 \\ 12.0 & 12.0 & 12.0 & 12.0 & 12.0 & 12.0 & 12.0 \\ 0.0 & 0.0 & 0.0 & 0.0 & 0.0 & 0.0 & 0.0 \\ 2,000 & 1,995 & 1,990 & 1,986 & 1,976 & 1,980 & 1,971 \\ 290 & 290 & 289 & 288 & 286 & 294 & 294 \\ 1.7 & 1.7 & 1.6 & 1.6 & 1.5 & 1.3 & 1.1 \\ 235.3 & 235.3 & 235.3 & 235.3 & 235.2 & 235.0 & 234.9 \\ 279.8 & 279.8 & 279.8 & 279.8 & 279.8 & 279.6 & 279.4\end{array}$

Operating Costs, \$ per barrel crude

Utility Costs

(1.09) (1.09)

(1.09) (1.10)

$(0.23)$

$(0.23)$

(0.23)

(0.23)

$(0.23) \quad(0.22)$

(0.21)

Value of FT Diesel, \$ per barrel

$\begin{array}{cccccc}21.40 & 21.14 & 21.25 & 21.15 & 21.03 & 20.78 \\ (4.00) & (4.26) & (4.15) & (4.25) & (4.37) & (4.62)\end{array}$

FT Diesel Premium, $\$$ per barrel ${ }^{1}$$$
\text { (4.00) }
$$

${ }^{1}$ Relative to price of ultra low sulfur (15 ppm) diesel 


\section{Table 3.2 Representative PADD 3 Refinery With FT Diesel \\ Test Case With Fixed Product Rates \\ Process Unit Utilizations \\ (KBPD)}

\begin{tabular}{lrrrrrrr} 
& \multicolumn{7}{c}{ FT Diesel Purchase Cases } \\
\cline { 2 - 8 } & 0 & 1 & 2 & 3 & 5 & 10 & 15 \\
FT Diesel Purchases & & & & & & & \\
Process Unit Capacity Utilizations & & & & & & & \\
Crude Distillation & 271.5 & 270.4 & 269.3 & 268.2 & 265.9 & 260.5 & 254.5 \\
Vacuum Distillation & 113.6 & 113.6 & 113.6 & 113.6 & 113.6 & 113.6 & 113.6 \\
Cat Reforming & 50.6 & 50.6 & 50.6 & 50.6 & 50.6 & 50.5 & 50.3 \\
Kero/Jet Hydrotreating & 17.2 & 17.2 & 17.2 & 17.2 & 17.2 & 17.2 & 17.2 \\
Distillate Hydrotreating & 52.0 & 51.2 & 50.4 & 49.6 & 48.0 & 45.0 & 40.5 \\
VGO Desulfurization & 21.8 & 21.8 & 21.8 & 21.8 & 21.8 & 21.8 & 21.8 \\
Coking & 34.9 & 34.9 & 34.9 & 34.9 & 34.9 & 34.9 & 34.9 \\
VGO Hydrocracking & 17.0 & 17.0 & 17.0 & 17.0 & 17.0 & 17.0 & 17.0 \\
Cat Cracking (FCC) & 87.4 & 87.4 & 87.4 & 87.4 & 87.2 & 87.4 & 86.9 \\
Alkylation & 18.2 & 18.2 & 18.2 & 18.2 & 18.2 & 18.2 & 18.2 \\
C5/C6 Isomerization & 18.0 & 18.0 & 18.0 & 18.0 & 18.0 & 17.9 & 17.1 \\
Gasoline Desulfurization & 50.7 & 50.7 & 50.7 & 50.7 & 50.7 & 50.7 & 50.7
\end{tabular}

- $\quad$ Fixed Crude with Modified Product Slate---Another analytical approach was tested in an effort to increase the value of FT diesel. In this approach, Low Sulfur Diesel and Jet Fuel production were allowed to increase in a 1:1 ratio above the levels for a representative 250 KBPD PADD 3 refinery, with the total increase in production being equal to the volume of FT diesel fed into the refinery. The PIMS model effectively treated the FT diesel as blendstocks for producing more Low Sulfur Diesel and Jet Fuel, and the resultant FT diesel value calculated was between the Jet Fuel and Low Sulfur Diesel prices. The results of this test case are presented in Table 3.3 and Table 3.4. As shown, the Low Sulfur Diesel and Jet Fuel production increased 5.0 KBPD when 5 KBPD of FT Diesel was available as a blendstock and the combined Kerosene and Distillate Hydrotreater utilization declined from 50.9 to 48.5 KBPD. However, the utilization of all other major process units remained unchanged until more than $15 \mathrm{KBPD}$ of FT Diesel was available as a blendstock. 


\section{Table 3.3 Representative PADD 3 Refinery With FT Diesel \\ Test Case With Modified Product Rates - 2001 \\ (refinery feedstocks and production)}

Feedstock Purchases, KBPD
Crude Oil
Methanol
MTBE
Normal Butane
Iso Butane
Natural Gas (as EFO)
FT-Diesel
Total

Refinery Production, KBPD

Propylene

LPG

Unleaded Regular

Unleaded Premium

Reformulated Regular

Reformulated Premium

Jet Fuel

Low Sulfur Diesel

No. 2 Fuel Oil

Low Sulfur Fuel Oil

High Sulfur Fuel Oil

Asphalt

Fuel Coke, Tons

Sulfur, Ltons

Cat Slurry

Other Products

Total

Operating Costs, \$ per barrel crude

Utility Costs

Cat/Chem Costs

(0.13)

(1.41)

(0.13)

$(1.41)$

(1.41)

(0.13)

(0.13)

(1.41)

(0.13)

(1.42)

31.12

0.52

31.11

0.51

30.98

$30.91 \quad 30.61$

FT Diesel Premium, $\$$ per barrel ${ }^{1}$

FT Diesel Purchase Cases

$\begin{array}{rrrrrr}250.0 & 250.0 & 250.0 & 250.0 & 250.0 & 250.0 \\ 0.9 & 0.9 & 0.9 & 0.9 & 0.9 & 0.9 \\ 0.3 & 0.3 & 0.3 & 0.3 & 0.4 & 0.5 \\ 5.0 & 5.0 & 5.0 & 5.0 & 5.0 & 4.7 \\ 5.8 & 5.8 & 5.8 & 5.8 & 5.9 & 6.5 \\ 5.1 & 5.1 & 5.1 & 5.1 & 5.0 & 4.7 \\ 0.0 & 2.0 & 5.0 & 10.0 & 15.0 & 16.0 \\ \mathbf{2 6 7 . 2} & \mathbf{2 6 9 . 2} & \mathbf{2 7 2 . 2} & \mathbf{2 7 7 . 2} & \mathbf{2 8 2 . 2} & \mathbf{2 8 3 . 2}\end{array}$

${ }^{1}$ Relative to price of low sulfur (400 ppm) diesel 


\section{Table 3.4 Representative PADD 3 Refinery With FT Diesel \\ Test Case With Modified Product Rates \\ Process Unit Utilizations \\ (KBPD)}

FT Diesel Purchases
Process Unit Capacity
Crude Distillation
Vacuum Distillation
Cat Reforming
Kero/Jet Hydrotreating
Distillate Hydrotreating
VGO Desulfurization
Coking
VGO Hydrocracking
Cat Cracking (FCC)
Alkylation
C5/C6 Isomerization

\subsubsection{Development of PADD 32001 Model}

FT Diesel Purchase Cases

\begin{tabular}{rrrrrr}
\multicolumn{7}{c}{ FT Diesel Purchase Cases } \\
\hline & 2 & 5 & 10 & 15 & 16 \\
& & & & & \\
250.0 & 250.0 & 250.0 & 250.0 & 250.0 & 250.0 \\
117.3 & 117.3 & 117.3 & 117.3 & 117.3 & 117.3 \\
43.0 & 43.0 & 43.0 & 43.0 & 43.0 & 42.3 \\
12.6 & 11.0 & 10.0 & 11.0 & 12.7 & 12.6 \\
38.4 & 38.6 & 38.6 & 37.9 & 37.8 & 39.7 \\
90.2 & 90.2 & 90.2 & 90.2 & 90.2 & 84.7 \\
32.1 & 32.1 & 32.1 & 32.1 & 32.1 & 32.0 \\
20.4 & 20.4 & 20.4 & 20.4 & 20.1 & 20.4 \\
87.5 & 87.5 & 87.5 & 87.5 & 87.5 & 88.2 \\
17.1 & 17.1 & 17.1 & 17.1 & 17.1 & 17.8 \\
15.7 & 15.7 & 15.7 & 15.7 & 15.7 & 15.7
\end{tabular}

After the model's testing with the trial runs, the preliminary PADD 3 model was further modified to establish the process unit capacities and refinery configuration for a representative PADD 3 refinery based on actual 2001 pricing. The 2001 PADD 3 refinery configuration was established using the following analytical approach:

- Fixed Crude Mix, Crude Feedrate and Floating Diesel Rate ---This approach provided for flexible low sulfur diesel production, hence paving the way for the evaluation of FT diesel as a low sulfur diesel blending stock. Test cases using this approach resulted in FT Diesel values that were equal to or slightly above the price of diesel fuel. This approach assumes that a particular refinery serves a larger market than it can now supply and has the flexibility, unlike the total industry, to increase diesel production by as much as 50 percent when economic or when additional diesel blendstocks, such as FT Diesel, can be purchased. The approach also recognizes that economic alternative options for disposing of refinery distillate streams are rare, so keeping distillate production constant while blending FT Diesel is not a real option.

The Fixed Crude Mix, Crude Feedrate and Floating Diesel Rate approach was adopted for all the subsequent and final analyses performed for this project after also considering the following alternative analytical approaches:

- $\quad$ Fixed Crude Mix, Crude Feedrate and Floating Diesel and Jet Fuel Rates ---This approach allowed both low sulfur diesel and jet fuel production rates to vary, with the 
production rates being optimized based on pricing for these products. The approach resulted in wide variations in product yields and often product yields that were very different from actual PADD 3 refinery operations. Therefore, this approach was not given further consideration.

- $\quad$ Fixed Crude Mix, Crude Feedrate and Floating Diesel, Gasoline and Jet Fuel Rates ---This approach allowed low sulfur diesel, gasoline and jet fuel production rates to vary, with the production rates being optimized based on pricing for these products. Similar to the above approach that floated diesel and jet fuel production, this approach resulted in wide variations in product yields and often product yields that were very different from actual PADD 3 refinery operations. Therefore, this approach was not given further consideration.

\subsubsection{Key Generic Model Changes}

During the development of the PADD 32001 model used for the project, many changes were made to the PADD 2 refinery model developed in 1995. The primary focus of the changes was to make the model's production yields and qualities of potential diesel blendstocks more representative so that the impact of FT Diesel used as a refinery blendstock on refinery operations could be accurately simulated and a representative value for FT Diesel could be obtained from the analyses. Key assumptions relating to Distillate Hydrotreater and Hydrocracker operations were also carefully reviewed since they are likely to influence FT Diesel values for certain analytical approaches. The yields of other key process units and the assumed qualities of key product streams were also checked, verified and revised, where appropriate.

Some of the key changes made to the model during the development of the PADD 32001 model were:

- $\quad$ Cracked stocks, as a percentage of the hydrocracker feedstock pool, were limited to 50 percent. This limit is in line with typical hydrocracker unit operations and limits the volume of low quality diesel streams, such as light cycle oil, that can be upgraded in the hydrocracker

- $\quad$ The assumed levels of desulfurization for kerosene and diesel streams in the model's Distillate Hydrotreaters were increased to be more in line with performance being achieved with the latest generation of hydrotreating catalysts

- A higher severity mode of operation was created for the Distillate Hydrotreaters to reflect the expected operation of new and revamped units producing Ultra Low Sulfur Diesel (ULSD) with a sulfur content less than 15 ppm beginning in 2006

- A gasoline desulfurization unit was added to the model to permit the desulfurization of the gasoline product from the catalytic cracking unit (cat gasoline) needed to produce Ultra Low Sulfur Gasoline (ULSG) with a sulfur content less than $30 \mathrm{ppm}$ beginning in 2004. Process unit yields, utility consumption and other performance factors for this process unit were established based on data for the Phillips Z Sorb technology. 
- A propane/propylene splitter was added to the refinery's configuration to permit the recovery of propylene for sale as a chemical feedstock. Propylene recovery is very common in PADD 3 refineries, with propylene sales typically reducing alkylate and gasoline production

- The model's depentanizer for cat gasoline was deactivated in the model since this operation is not typically employed in PADD 3 refineries and was not considered to be a feature of a representative PADD 3 refinery

After developing a preliminary version of PADD 32001 model, it became apparent that the refinery model was not accurately simulating Distillate Hydrotreater operations and did not have the flexibility to fully reflect the impact on refinery operations of using FT Diesel as a refinery blendstock. The major shortcoming of the initial model was that it had separate distillate hydrotreating units for cracked and straight run diesel streams, and each unit had different levels of desulfurization severity. Refineries typically have only one unit that desulfurizes a blend of cracked and straight run diesel streams. As a result, the initial model had the potential to "overoptimize" the desulfurization of diesel streams and it was possible that this situation could result in artificially low values for FT Diesel during the project's analyses. Therefore the following additional changes were made to the model:

- The two distillate hydrotreating units were combined into one unit and all potential feedstocks to the unit were pooled together

- Cracked stocks (light cycle gas oil and coker distillate), as a percentage of the Distillate Hydrotreater feedstock pool, were limited to 30 percent. This limit is in line with typical refinery operations

- Four levels of desulfurization severity (producing desulfurized diesel with sulfur contents of 400, 30, 10 and $3 \mathrm{ppm}$ ) were incorporated into the model's new, single distillate hydrotreating units

- Desulfurized diesel streams resulting from the operation of the model's distillate hydrotreating unit at more than one level of severity were pooled into one stream that became the model's only desulfurized diesel blendstock

The 400 ppm severity is representative of the current operation of most distillate hydrotreating units in the U.S., the $10 \mathrm{ppm}$ mode will become representative (via new units and revamps) beginning in 2006 and the 3 ppm severity might be required in the future if the U.S. sulfur spec for ULSD is reduced below $15 \mathrm{ppm}$. The $30 \mathrm{ppm}$ severity was included to provide the model with the flexibility to reduce severity in the analyses including sulfur-free FT Diesel as a potential ULSD blendstock.

Results obtained when testing these modifications to the model were in line with expectations. The availability of FT Diesel resulted in a lower Distillate Hydrotreater desulfurization severity, which resulted in lower hydrogen usage and lower catalyst and utilities costs. 


\subsubsection{Key California Refinery Model Changes}

During the performance of the analyses for PADD 5, which was based on the configuration of a representative California refinery, several additional changes were made to the generic model developed for the PADD 3 analyses. These changes were required primarily to meet the more stringent specifications of the California Air Resources Board (CARB) that now apply to gasoline and diesel sold in California. Some of the key changes made to the model for the PADD 5 analyses were:

- Specifications for reformulated gasoline and low sulfur diesel in the model were revised to reflect the typical qualities of CARB gasoline and CARB diesel now being produced by California refineries

- $\quad$ A C4 Isomerization unit was added to the model

- A Benzene Saturation unit was added to the model since this unit is a feature of many California refineries, and to provide the model with the flexibility needed to meet the low levels of benzene (i.e. 0.6 percent) that are characteristic of CARB gasoline

- The gasoline desulfurization unit for cat gasoline in the generic model for 2006 was activated in the 2001 analyses for the California refinery to provide it with the flexibility to produce gasoline with the very low levels of sulfur (i.e. $22 \mathrm{ppm}$ ) that are now characteristic of $\mathrm{CARB}$ gasoline and to reduce the olefins content of reformulated gasoline

- An additional mode of operation was added to the model's Distillate Hydrotreater to provide it with the flexibility to dearomatize, as well as desulfurize, diesel streams in this unit since low levels of aromatics are required for diesel production to comply with CARB diesel specifications and the configurations of several California refineries now includes process units with such capabilities

- The model's depentanizer for cat gasoline was reactivated in the model to provide it with the flexibility to produce a feedstock for C5 alkylation and TAME production and to produce gasoline with a low RVP, in line with CARB gasoline requirements

- The model used for the 2006 California refinery analyses was given the flexibility to purchase ethanol and isooctane, since California refiners are expected to need to import these products following the ban on MTBE use, now scheduled to take effect in California at the end of 2003

\subsection{MODEL METHODOLOGY}

\subsubsection{Base Case}

\subsubsection{Product Slate Assumptions}

The product slate assumptions developed for the representative 2001 refineries in each refining region were based on actual industry data for 2000 published in the Petroleum Supply Annual 2000 by the Department of Energy's Energy Information Administration (EIA). Similar data for 2001 industry operations was not available when most of this project's analyses were performed. Changes in refinery product slates between 2000 and 2001 are expected to be minor and to have 
limited material impact on study results and conclusions. Therefore, the actual 2000 product slates were considered to be a sound basis for developing representative product slates for each region's refining industry during 2001. Since industry yields historically have not changed significantly from year-to-year, it is believed that use of 2001 (or estimated 2002 data) would not materially impact the results of this analysis.

The EIA data includes several relatively low volume refinery products, such as naphtha used as a petrochemical feedstock, other petrochemical feedstock, special naphthas, lubricants, waxes and miscellaneous products, that were not included in the representative regional refinery product slates used for the analyses in this project. The production of these minor products was allocated to similar major products that were included in this project's representative product slates.

Similarly, the product yields were adjusted to reflect low volume refinery feedstocks, such as pentanes plus, unfinished oils and gasoline blend components, which were reported in the EIA data but were not included in the feedstock mixes used for the analyses in this project.

\subsubsection{Development of Representative Refinery Configuration}

The 2001 Base Refinery configuration was established using the "Fixed Crude Mix, Crude Feedrate and Floating Diesel Rate" analytical approach by using 2001 assumptions for crude oil slate, product slate, product specifications, and crude oil and product pricing.

The process unit capacities for the representative 2001 Base Case refinery were developed by fixing the capacities at average industry levels for those units that are not common to all refineries in the region. For example, this applied to VGO hydrocracking capacity since the configuration of many refineries in some regions does not include a hydrocracker. This approach was necessary to avoid having excessive capacities for these units. If their capacities had been allowed to float in the LP analyses, they would have been too high since capital charges were not applied in these analyses and the results would have reflected the availability of "free" capacity.

Capacities of major process units that are common to all refineries, such as cat crackers and catalytic reformers, were allowed to float and the level of their capacity in the configuration of the representative 2001 Base Case refinery was established based on the LP results. The resulting capacities were compared to actual industry levels to ensure that the results were reasonable and that the resulting refinery configuration was reasonable. This approach was taken since such units are normally fully utilized and operate at their effective capacities.

Only the 400 ppm severity mode for the Distillate Hydrotreating unit was activated in the model used to establish the representative 2001 Base Case refinery.

\subsubsection{Cases}

The 2006 cases were developed using 2006 assumptions for crude oil slate, product slate, product specifications, and crude oil and product pricing. In particular, the diesel sulfur specification was reduced to $10 \mathrm{ppm}$, to provide a safety margin to meet the regulatory 
specification for ULSD of $15 \mathrm{ppm}$, and the sulfur specifications for all grades of gasoline were reduced to $25 \mathrm{ppm}$, in line with the $30 \mathrm{ppm}$ specification for ULSG. The projected regional trends in gasoline production between 2001 and 2006 were adjusted downward to take into account the likely passage of legislation including a renewable fuels mandate that would increase the use of ethanol as a gasoline blendstock and reduce the production of refinery-produced gasoline.

The configuration of the 2001 Base Refinery was used as the basis for establishing the configuration of the 2006 Base Refinery. The configuration of the 2001 Base Refinery was modified to satisfy the revised crude oil slate, product slate and product specifications for 2006. The following methodology was employed to establish the configuration for the 2006 Base Refinery and to determine FT Diesel values:

\section{Base Refinery}

- All the process units in the 2001 Base Refinery were allowed to expand, with a capital charge (as described below in Section III.G of this report) applying to capacity additions. Therefore, "free" capacity additions were not allowed and process unit capacities only increased when economic benefits justified incurring the capital charges

- The model's 10, 30 and 400 ppm severity modes for the Distillate Hydrotreating unit were activated

- The gasoline desulfurization unit for cat gasoline was activated in the model, with a capital charge applying when the unit is utilized

- Initially the model was allowed to vary the level of crude oil processed while maintaining the specified, fixed blend of crude oils. This initial case was used to establish a reasonable crude oil feedrate for the refinery based on the revised product slate and crude oil blend. In this case, the production of all major products, including diesel, was fixed.

- The crude oil volume resulting from the initial case was fixed as the crude oil feedrate for the case used to establish the process unit capacities of the 2006 Base Refinery using the "Fixed Crude Mix, Crude Feedrate and Floating Diesel Rate" analytical approach

\section{FT Diesel Evaluation}

- The revised process unit capacities of the 2006 Base Refinery were fixed for the FT Diesel evaluation and were no longer allowed to increase in exchange for a capital charge. Similarly process unit capacities were not allowed to decrease and avoid capital charges that otherwise might be incurred. This approach reflects the assumption that significant volumes of FT Diesel will not be available to U.S. refiners prior to 2006 and in time for them to alter their capital spending needed to meet product specifications and market conditions in 2006 
- The availability of various volumes of FT diesel was analyzed using the "Fixed Crude Mix, Crude Feedrate and Floating Diesel Rate" analytical approach, which resulted in increased ULSD production

- Changes in the model's calculated level of refinery profitability were attributed to the availability of FT Diesel and were used to calculate the FT Diesel value for each FT Diesel volume

\subsubsection{Cases}

The 2015 cases were developed using the "Fixed Crude Mix, Crude Feedrate and Floating Diesel Rate" analytical approach by using 2015 assumptions for crude oil slate, product slate, product specifications, and crude oil and product pricing. The projected regional trends in gasoline production between 2001 and 2015 were adjusted downward to take into account the likely passage of legislation including a renewable fuels mandate that would increase the use of ethanol as a gasoline blendstock and reduce the production of refinery-produced gasoline.

The configuration for the 2015 Base Refinery was established using a methodology similar to the one employed for the 2006 Cases. However, the methodology for determining FT Diesel values was modified. The following methodologies were employed:

\section{Base Refinery}

- All the process units in the 2006 Base Refinery were allowed to expand, with a capital charge (as described below in Section III.G of this report) applying to capacity additions.

- The diesel sulfur specification was reduced to $7 \mathrm{ppm}$, to provide a safety margin to meet a lower regulatory specification for ULSD of $10 \mathrm{ppm}$. The sulfur specifications for all grades of gasoline were maintained at $25 \mathrm{ppm}$

- The model's 3, 10, 30 and 400 ppm severity modes for the Distillate Hydrotreating unit were activated

- MTBE production was shut down and MTBE was no longer allowed as a gasoline blendstock, reflecting an anticipated country-wide ban on MTBE use

- Reformulated gasoline's minimum oxygen specification of 2.1 percent was removed, reflecting an anticipated change in the RFG regulatory specification when MTBE is banned

- Initially the model was allowed to vary the level of crude oil processed while maintaining the specified, fixed blend of crude oils. This initial case was used to establish a reasonable crude oil feedrate for the refinery based on the revised product slate and crude oil blend. In this case, the production of all major products, including diesel, was fixed.

- The crude oil volume resulting from the initial case was fixed to establish the process unit capacities of the 2015 Base Refinery using the "Fixed Crude Mix, Crude Feedrate and Floating Diesel Rate" analytical approach 


\section{FT Diesel Evaluation}

- The revised process unit capacities of the 2015 Base Refinery were allowed to vary for the FT Diesel evaluation and increase or decrease (down to the 2006 Base Refinery level) in exchange for a higher or lower capital charge. This approach reflects the assumption that after 2006 a number of GTL plants will be built and in operation throughout the world. Availability of FT diesel to U.S. refiners prior to 2015 potentially will allow them sufficient leadtime to alter their capital spending needs to meet product specifications and market conditions in that year

- The availability of various volumes of FT Diesel was analyzed using the "Fixed Crude Mix, Crude Feedrate and Floating Diesel Rate" analytical approach, which resulted in increased ULSD production

- Changes in the model's calculated level of refinery profitability were attributed to the availability of FT Diesel and were used to calculate the FT Diesel value for each FT Diesel volume

\subsubsection{Other PADDs}

The development of the models for the other PADDs generally followed the same methodology used for PADD 3, starting with the development of a 2001 Base Case model and then developing the 2006 and 2015 cases for evaluating FT diesel. The following assumptions were varied for each refining region's representative refinery based on actual and forecast values for each region:

- Crude oil slate

- $\quad$ Product slate

- $\quad$ Product specifications

- Process unit capacities/refinery configuration

- Crude oil and product pricing

Assay data available in the PIMSTM program for additional crude oils was used to develop crude oil blends that were representative of the actual crude slates for each region.

\subsection{FT DIESEL QUALITY ASSUMPTIONS}

The FT Diesel evaluations presented in this report were primarily based on the properties expected for the diesel product to be produced based on Conoco's GTL technologies. Conoco provided Nexant with estimated typical qualities for this diesel product, which are presented in Table 3.5. 


\section{Table 3.5 Conoco GTL Diesel Qualities}

\begin{tabular}{|c|c|c|}
\hline \multicolumn{2}{|l|}{ Property } & Value \\
\hline \multicolumn{2}{|c|}{ Density at $15^{\circ} \mathrm{C}\left(\mathrm{g} / \mathrm{mm}^{2}\right)$} & $>.77$ \\
\hline Distillation $\left({ }^{\circ} \mathrm{C}\right)$ & $\mathrm{IBP}$ & 181 \\
\hline & $10 \%$ & 228 \\
\hline & $50 \%$ & 274 \\
\hline & $90 \%$ & 328 \\
\hline & FBP & 361 \\
\hline Flash Point $\left({ }^{\circ} \mathrm{C}\right)$ & & 60 \\
\hline Viscosity at $40^{\circ} \mathrm{C}$ & $\left(\mathrm{mm}^{2} / \mathrm{s}\right)$ & 2.9 \\
\hline Cetane Number & & $>60$ \\
\hline Sulfur (weight \%) & & 0 \\
\hline Aromatics (volum & e \%) & $<1$ \\
\hline Pour Point $\left({ }^{\circ} \mathrm{C}\right)$ & & -10 \\
\hline Cloud Point $\left({ }^{\circ} \mathrm{C}\right)$ & & -10 \\
\hline
\end{tabular}

Since Conoco provided only a lower limit and not a specific value for the cetane number, the analyses for this project assumed a cetane number of 70 for FT Diesel. This value is consistent with the properties of FT Diesel products reported in the literature by other developers of GTL technologies, such as Sasol.

FT Diesel has a very low aromatics content and is virtually free of sulfur, and one of the most important features of FT Diesel is that it consists almost entirely of paraffins. This has a number of important consequences:

- Due to their higher hydrogen to carbon $(\mathrm{H} / \mathrm{C})$ ratio, paraffins have a lower density than other hydrocarbon types. Consequently the density of the FT Diesel $\left(0.77 \mathrm{~g} / \mathrm{m}^{3}\right)$ is significantly lower than that of conventional crude oil derived diesel fuels, which generally have a significantly higher aromatic content and densities in the range of 0.83 to $0.85 \mathrm{~g} / \mathrm{m}^{3}$.

- The high $\mathrm{H} / \mathrm{C}$ ratio also results in the paraffins having a higher energy content (on a mass basis) than the other hydrocarbon types. The heating value of FT Diesel is 4-5 percent higher than the typical value for a crude oil derived diesel fuel. However, due to their low density the volumetric energy content of paraffinic fuels is usually lower than fuels with a significant aromatic content. In effect, a ton of FT Diesel has more energy content than a ton of crude oil derived diesel, but a barrel of FT Diesel has less energy than a barrel of crude oil derived diesel.

The major use for the FT Diesel product is expected to be as a blendstock for producing diesel fuel, with its very high quality enabling it to upgrade lower quality diesel blendstocks under some circumstances. Reflecting its lack of aromatics and high cetane number, the FT Diesel product will be particularly desirable as a blendstock in California. The California diesel market is equal to about $300 \mathrm{KBPD}$ and the aromatics specification for California Air Resources Board 
(CARB) diesel is more stringent than the specification for diesel sold in the balance of the U.S. and most other global markets.

\subsection{CAPITAL COST ASSUMPTIONS}

Table 3.6 presents the criteria used in this project to determine the capital cost factors associated with process unit capacity additions.

\section{Table 3.6 Capital Cost Criteria}

\section{Assumption}

Offsites factor

Owner's costs

Maintenance \& operations (\% of capital)

Debt financing

Internal rate of return

Onstream Factor

Overall annual capital charge factor

Cost escalation (per year between $2001 \& 2015$ )

\section{Percent}

20

10

5

0

15

90

24

2.3

The base capital costs assumed for each type of process unit are presented in Table 3.7. The resulting capital cost factors that were developed for each type of process unit in each refining region for the 2006 analysis are presented in Table 3.8. Capital cost factors developed for each type of process unit in each refining region for the 2015 analysis were 22 percent above the values presented in Table 3.8, reflecting the assumed cost escalation of 2.3 percent per year over the 2006-2015 period. 


\section{Table 3.7 Process Unit Capital Cost Assumptions}

Unit

Atmospheric column ${ }^{3}$

Vacuum column

Sulfuric acid alkylation

C5/C6 Isomerization

MTBE

Naphtha hydrotreater

Kerosene hydrotreater

Distillate hydrotreater-Medium Severity

Distillate hydrotreater--High Severity

VGO hydrotreater

Catalytic reformer

Catalytic cracker

Hydrocracker

Delayed coker

Depentanizer

Dehexanizer

Hydrogen plant, MMSCFD

Sulfur plant, TPD

Gasoline S Zorb

Diesel S Zorb

C4 Isomerization

Benz Saturation/Reformate Splitter

\section{Base Capital \\ Cost, \$M ${ }^{1}$}

62

31

69

31

12

19

29

31

31
39

50

62

187

137

137

2.1

2.1

62

25

32

48

7.6

15
Base Capacity, KBPSD

Revamp 2

150

40

19

15

2.0

23

27

30

30

35

35

70

30

25

20

20

60

200

35

40

4.4

21

1 U.S. Gulf Coast (PADD 3), 2001

$2 \mathrm{Y}$ indicates units where capacity increases assumed to be achieved through debottlenecking with capital costs equal to $75 \%$ of new units costs. N indicates no capacity increase can be achieved through debottlenecking

3 Includes factor for non-specific offsite costs 
Table 3.8 Process Unit Capital Cost Factors, 2006

(current dollars per barrel of additional capacity)

\author{
Refining Region \\ Location Factor ${ }^{1}$ \\ Unit \\ Atmospheric column \\ Vacuum column \\ Sulfuric acid alkylation \\ C5/C6 Isomerization \\ MTBE \\ Naphtha hydrotreater \\ Kerosene hydrotreater \\ Distillate hydrotreater-Medium Severity \\ Distillate hydrotreater--High Severity \\ VGO hydrotreater \\ Catalytic reformer \\ Catalytic cracker \\ Hydrocracker \\ Delayed coker \\ Depentanizer \\ Dehexanizer \\ Hydrogen plant, MMSCFD \\ Sulfur plant, TPD \\ Gasoline S Zorb \\ Diesel S Zorb \\ C4 Isomerization \\ Benz Saturation/Reformate Splitter \\ ${ }^{1}$ Relative to PADD 3 Capital Costs
}

$\begin{array}{rrrrr}\text { PADD 1 } & \text { PADD 2 } & \text { PADD 3 } & \text { PADD 4 } & \text { California } \\ & & & & \\ 1.2 & 1.2 & 1.0 & 1.2 & 1.4 \\ & & & & \\ 0.59 & 0.59 & 0.41 & 0.94 & 0.54 \\ 0.91 & 0.91 & 0.63 & 1.44 & 0.79 \\ 4.56 & 4.56 & 3.18 & 7.25 & 5.87 \\ 3.02 & 3.02 & 2.10 & 4.79 & 2.70 \\ 7.89 & 7.89 & 5.50 & 12.53 & 8.10 \\ 0.85 & 0.85 & 0.59 & 1.35 & 1.03 \\ 1.74 & 1.74 & 1.21 & 2.76 & 1.56 \\ 1.19 & 1.19 & 0.83 & 1.89 & 1.35 \\ 1.49 & 1.49 & 1.04 & 2.36 & 1.69 \\ 1.48 & 1.48 & 1.03 & 2.35 & 1.63 \\ 2.12 & 2.12 & 1.47 & 3.36 & 2.60 \\ 3.38 & 3.38 & 2.35 & 5.36 & 3.91 \\ 7.59 & 7.59 & 5.29 & 12.05 & 5.94 \\ 6.64 & 6.64 & 4.62 & 10.54 & 6.05 \\ 0.10 & 0.10 & 0.07 & 0.17 & 0.14 \\ 0.10 & 0.10 & 0.07 & 0.17 & 0.14 \\ 1.368 & 1,368 & 953 & 2,172 & 1,401 \\ 139 & 139 & 97 & 221 & 168 \\ 1.79 & 1.66 & 0.99 & 2.63 & 1.62 \\ 2.39 & 2.21 & 1.10 & 3.51 & 2.15 \\ 2.55 & 2.36 & 2.49 & 3.75 & 2.31 \\ 1.02 & 0.94 & 0.95 & 1.50 & 0.92 \\ & & & & \end{array}$




\subsection{KEY MARKET ASSUMPTIONS}

\subsubsection{Profile of Existing Refineries}

PADD 1 (the East Coast) contains 15 refineries at the present time and accounts for 9 percent of the refinery capacity in the U.S. Its refineries are concentrated on the coast in New Jersey and in the Philadelphia area.

The region's 10 largest refineries, each having a capacity greater than 50 thousand BPD, account for 98 percent of the region's refining capacity and are considered to be most representative of its refineries. The region's 5 smaller refineries are devoted to the production of specialty products, such as asphalt and lubricants.

Table 4.1 presents the combined capacities in 2001 of major process units at these refineries, which have an average refinery capacity of 152 thousand BPCD. The representative PADD 1 refinery considered in the study's PIMS ${ }^{\text {TM }}$ LP analyses was therefore assumed to be capable of processing 150 thousand BPCD of crude oil.

All of the region's 10 largest refineries have fluid catalytic cracking (FCC) units and catalytic reforming, and 3 have delayed coking and VGO hydrotreating units. In addition, only 1 of these refineries includes a VGO hydrocracking unit.

Table 4.1 PADD 1 Process Unit Capacities, 2001

(thousand barrels per calendar day)

\begin{tabular}{lrr} 
& \multicolumn{1}{c}{ Industry $^{\text {Total }}{ }^{{ }^{*}}$} & Percent $^{2}$ \\
Crude Distillation & 1,519 & \\
Vacuum Distillation & 603 & 39.7 \\
Coking & 91 & 6.0 \\
Cat Cracking (FCC) & 679 & 44.7 \\
Cat Reforming & 275 & 18.1 \\
Diesel Hydrotreating & 441 & 29.0 \\
VGO Desulfurization & 107 & 7.1 \\
VGO Hydrocracking & 17 & 1.1 \\
Alkylation & 85 & 5.6 \\
C5/C6 Isomerization & 17 & 1.1 \\
& & \\
${ }^{1}$ Total for PADD 1 refineries with capacity greater than 50 KBPCD \\
${ }^{2}$ Percent of Crude Distillation Capacity
\end{tabular}

\subsubsection{Crude Slate}

Most PADD 1 refineries are designed to process low sulfur crude oils, with the region's asphalt refineries being the primary ones that can process heavy, high sulfur crude oils. All of the 
region's crude oil supplies are imported, with Nigeria, Angola, Norway, Canada, Venezuela and Saudi Arabia representing the major sources. The current and forecast quality for the region's crude oil mix, discussed in more detail in Report Section IV covering United States Regional Fuel Markets, is presented in Table 4.2.

The quality of the crude oil processed by the region's representative refinery in this study was assumed to be equal to the average crude oil quality for the region. The PIMS modeling system provides a range of representative crude oils (light through heavy, sour through sweet). The average crude oil quality for the region was simulated in the analyses by blending crude oil streams from the PIMS crude oil assay database to approximately match the region's average API gravity and sulfur content. Due to the limited number of crude oils available in the PIMS systems, exact matching of actual crude oils run in the PADD was not possible. The calculated average quality of the crude oil blends used in the LP models for this study's analyses are also presented in Table 4.2.

Table 4.2 PADD 1 Crude Quality, 2000-2015

$\begin{array}{lrrr} & 2000 & 2006 & 2015 \\ \text { Industry Average } & \text { Actual } & \text { Forecast } & \text { Forecast } \\ \text { API Gravity } & 33.0 & 33.0 & 32.8 \\ \text { Sulfur, wt\% } & 0.93 & 0.95 & 0.98 \\ \text { Model Assumption } & & & \\ \text { API Gravity } & 33.2 & 33.0 & 32.8 \\ \text { Sulfur, wt\% } & 0.93 & 0.95 & 0.98\end{array}$

\subsubsection{Product Slate}

Actual PADD 1 refinery production in 2000, summarized in Table 4.3, was used as the basis for establishing the product slate of this study's representative PADD 1 refinery in 2001 . The forecast trends in the region's refinery production, discussed in more detail in Report Section IV covering United States Regional Fuel Markets, were used to establish the product slate of this study's representative PADD 1 refinery in 2006 and 2015, which are also presented in Table 4.3. 
Table 4.3 Representative PADD 1 Refinery Product Slate, 2001-2015

$\begin{array}{lrrr} & 2001 & 2006 & 2015 \\ \text { Production, KBPCD } & & & \\ \text { Propylene } & & & \\ \text { Unleaded Regular } & 3.3 & 3.8 & 5.0 \\ \text { Unleaded Premium } & 15.8 & 16.7 & 18.1 \\ \text { Reformulated Regular } & 4.1 & 4.3 & 4.7 \\ \text { Reformulated Premium } & 47.4 & 50.2 & 54.6 \\ \text { Jet Fuel } & 12.4 & 13.1 & 14.3 \\ \text { Low Sulfur Diesel } & 11.2 & 11.7 & 12.6 \\ \text { No. 2 Fuel Oil } & 20.8 & 22.8 & 27.1 \\ \text { Low Sulfur Fuel Oil } & 23.0 & 23.6 & 24.9 \\ \text { Asphalt } & 5.0 & 5.1 & 5.1 \\ & 9.6 & 9.8 & 10.3 \\ \text { Volume \% of Crude Oil Processed } & & & \\ \text { Propylene } & & & \\ \text { Unleaded Regular } & 2.2 & 2.4 & 2.9 \\ \text { Unleaded Premium } & 10.5 & 10.5 & 10.4 \\ \text { Reformulated Regular } & 2.7 & 2.7 & 2.7 \\ \text { Reformulated Premium } & 31.6 & 31.6 & 31.3 \\ \text { Jet Fuel } & 8.3 & 8.2 & 8.2 \\ \text { Low Sulfur Diesel } & 7.5 & 7.3 & 7.2 \\ \text { No. 2 Fuel Oil } & 13.9 & 14.3 & 15.5 \\ \text { Low Sulfur Fuel Oil } & 15.4 & 14.8 & 14.3 \\ \text { Asphalt } & 3.4 & 3.2 & 2.9 \\ & 6.4 & 6.2 & 5.9\end{array}$

\subsubsection{Pricing}

The New York area prices used in the PADD 1 analyses, whose bases are discussed in Report Section IX covering Ultra Clean Fuel Valuations, are presented in Table 4.4. It should be noted that since the volume and mix of crude oils processed in the study's PIMSTM LP analyses were fixed, the price of crude oils did not affect the results of the analyses. Similarly, the quantity of all major products produced, except low sulfur diesel, was fixed in the analyses. Therefore, only the low sulfur diesel price influenced the results of the economic analyses. 


\section{Table 4.4 PADD 1 Pricing Assumptions, 2001-2015 Medium Crude Oil Price Scenario}

\begin{tabular}{|c|c|c|c|c|}
\hline & & Actual & Fore & \\
\hline & & 2001 & 2006 & 2015 \\
\hline Feedstock Pricing & & & & \\
\hline Crude Oil Mix (Varying Quality) & $\$ / b b l$ & 23.8 & 20.2 & 24.2 \\
\hline Normal Butane & $\$ / b b l$ & 21.6 & 18.1 & 21.6 \\
\hline Iso Butane & $\$ / b b l$ & 23.7 & 19.1 & 22.8 \\
\hline MTBE & $\$ / b b l$ & 46.5 & 37.5 & 40.3 \\
\hline Methanol & $\$ / b b l$ & 21.7 & 23.7 & 28.1 \\
\hline Natural Gas & $\$ / M M B t u$ & 4.7 & 3.0 & 3.7 \\
\hline Product Pricing & & & & \\
\hline Propane & $\$ / b b l$ & 21.8 & 18.8 & 22.6 \\
\hline Normal Butane & $\$ / b b l$ & 21.2 & 17.6 & 21.0 \\
\hline Propylene-Polymer Grade & $\$ / b b l$ & 34.4 & 33.3 & 38.8 \\
\hline Unleaded Regular-87 & $\$ / b b l$ & 30.8 & 27.2 & 32.2 \\
\hline Unleaded Premium-93 & $\$ / b b l$ & 33.9 & 29.6 & 35.0 \\
\hline Reformulated Regular-87 & $\$ / b b l$ & 33.0 & 28.3 & 33.5 \\
\hline Reformulated Premium-93 & $\$ / b b l$ & 36.0 & 31.3 & 36.9 \\
\hline Kero/Jet & $\$ / b b l$ & 30.9 & 26.0 & 30.9 \\
\hline Low Sulfur Diesel-500 ppm & $\$ / b b l$ & 30.1 & 25.4 & 30.2 \\
\hline Low Sulfur Diesel-15 ppm & $\$ / b b l$ & NA & 26.3 & 31.3 \\
\hline No. 2 Fuel Oil & $\$ / b b l$ & 29.5 & 24.6 & 29.3 \\
\hline Low Sulfur Fuel Oil (1\%S) & $\$ / b b l$ & 20.7 & 17.1 & 20.7 \\
\hline High Sulfur Fuel Oil (3\%S) & $\$ / b b l$ & 17.3 & 13.5 & 16.6 \\
\hline Asphalt & $\$ / b b l$ & 19.3 & 15.8 & 19.4 \\
\hline Fuel Coke & $\$ /$ short ton & 15 & 16 & 19 \\
\hline Sulfur & $\$ /$ ton & 48 & 54 & 68 \\
\hline Cat Slurry & $\$ / b b l$ & 16.3 & 12.4 & 15.2 \\
\hline
\end{tabular}

\subsection{BASE CASE}

Feedstock purchases, refinery production and refinery profitability results for the 2001 PADD 1 Base Case analysis are presented in Table 4.5. 


\section{Table 4.5 Representative PADD 1 Refinery Results, 2001}

\begin{tabular}{|c|c|}
\hline \multicolumn{2}{|l|}{ Feedstock Purchases, KBPD } \\
\hline Crude Oil & 150.0 \\
\hline Methanol & 0.6 \\
\hline MTBE & 5.0 \\
\hline Normal Butane & 0.0 \\
\hline \multicolumn{2}{|l|}{ Iso Butane } \\
\hline Natural Gas (as Equiv.Fuel Oil) & 1.0 \\
\hline \multicolumn{2}{|l|}{ FT Diesel } \\
\hline Total & 156.6 \\
\hline \multicolumn{2}{|l|}{ Refinery Production, KBPD } \\
\hline Propylene & 3.3 \\
\hline LPG & 5.8 \\
\hline Unleaded Regular & 15.8 \\
\hline Unleaded Premium & 4.1 \\
\hline Reformulated Regular & 47.4 \\
\hline Reformulated Premium & 12.4 \\
\hline Jet Fuel & 11.2 \\
\hline Low Sulfur Diesel & 21.8 \\
\hline No. 2 Fuel Oil & 23.0 \\
\hline Low Sulfur Fuel Oil & 5.0 \\
\hline High Sulfur Fuel Oil & 2.2 \\
\hline Asphalt & 9.6 \\
\hline Fuel Coke, Tons & 237 \\
\hline Sulfur, Ltons & 73 \\
\hline \multicolumn{2}{|l|}{ Cat Slurry } \\
\hline Total & 161.7 \\
\hline \multicolumn{2}{|l|}{ Key Product Qualities } \\
\hline Diesel Sulfur Content, ppm & 400 \\
\hline Diesel Cetane Index & 44 \\
\hline \multicolumn{2}{|c|}{ Refinery Profitability, \$ per barrel crude } \\
\hline Product Revenues & 32.63 \\
\hline Feedstock Costs & 25.62 \\
\hline Gross Margin & 7.00 \\
\hline Utility Costs & $(0.95)$ \\
\hline Cat/Chem Costs & $(0.14)$ \\
\hline Variable Margin & 5.92 \\
\hline
\end{tabular}

Consumption of natural gas has been divided into two categories. Thus, feedstock purchases only include the portion of natural gas purchases used as a hydrogen plant feedstock. Purchased utilities include electricity, water and natural gas used as a refinery fuel. The variable margin is the value of product minus cost of feedstocks (i.e. gross margin) less variable costs for purchased utilities, catalysts and chemicals.

To achieve the processing objective, which is to maximize refinery contribution margin, the LP model adjusts the process unit capacities with only coking, VGO hydrocracking and VGO hydrotreating capacities being constrained to approximate actual average levels as a percentage 
of crude distillation capacity since these units are not included in all major PADD 1 refineries. The utilized process unit capacities are presented in Table 4.6.

\section{Table 4.6 Representative PADD 1 Refinery Process Unit Utilizations, 2001}

Thousand Barrels per Calendar Day

Percent ${ }^{1}$

Crude Distillation
Vacuum Distillation
Cat Cracking (FCC)
Coking
VGO Hydrocracking
Cat Reforming
Kero/Jet Hydrotreating
Distillate Hydrotreating
VGO Desulfurization
Alkylation

${ }^{1}$ Percent of Crude Distillation Capacity

$\begin{array}{rr}150.0 & \\ 68.8 & 45.9 \\ 50.6 & 33.7 \\ 8.7 & 5.8 \\ 1.5 & 1.0 \\ 23.8 & 15.9 \\ 12.0 & 8.0 \\ 24.6 & 16.4 \\ 10.6 & 7.1 \\ 8.7 & 5.8\end{array}$

The results for the Base Case are mainly of interest as a basis for comparison for the 2006 and 2015 analyses, and to confirm that the process configuration of the study's representative PADD 1 refinery is generally consistent with the actual configuration of the PADD 1 industry. In this regard, some key comparisons include:

- The levels of catalytic reforming, alkylation and middle distillate hydrotreating (i.e., the combined total of kero/jet and distillate hydrotreating) for the representative PADD 1 refinery as a percent of crude distillation capacity are within four percent of their actual average industry values presented in Table 4.1

- The level of cat cracking for the representative PADD 1 refinery as a percent of crude distillation capacity is somewhat less than the actual average industry value. This is due to the fact that PADD 1 refineries purchase extensive volumes of FCCU feedstocks produced in refineries outside the region, and these purchases were not considered in these analyses. Their exclusion is not considered material to the analysis or to the resulting conclusions

\subsection{CASES}

\subsubsection{Representative Base Refinery without FT Diesel}

Available information on industry plans does not provide any reliable insight into refinery investment and construction that will take place during the period between now and 2006. The LP model was thus allowed to expand process units in the 2001 Base Refinery and to build any new process units required to meet the 2006 specifications in the most economic way. New process unit capacity will also be required to increase refinery production (see Table 4.3) and to 
cope with poorer quality crude oil feedstock (see Table 4.2). It was assumed that the availability of FT diesel would not affect the configuration of the 2006 Base Refinery. As discussed in the Methodology section of this report, this approach reflects the assumption that significant volumes of FT Diesel will not be available to U.S. refiners prior to 2006 and in time for them to alter their capital spending needed to meet product specifications and market conditions in 2006.

The model has the latitude to:

- Add crude distillation capacity and fuel oil conversion capacity, such as FCC, coking and hydrocracking capacity

- $\quad$ Add gasoline desulfurization capacity

- Increase the percentage of sulfur removed in the distillate desulfurization unit, which would necessitate a revamp of the unit involving the addition of more reactor capacity, catalyst volume, etc.

The feedstock purchases, refinery production and refinery profitability results for the 2006 PADD 1 Base Case analysis are presented in Table 4.7. The utilized process unit capacities, and changes relative to the 2001 Base Case, are presented in Table 4.8. 


\section{Table 4.7 Representative PADD 1 Refinery Results, 2006 Base Refinery - No FT Diesel}

Feedstock Purchases, KBPD

Crude Oil

158.0

Methanol

0.7

MTBE

5.4

Normal Butane $\quad 0.3$

Iso Butane $\quad 0.2$

Natural Gas (as Equiv.Fuel Oil) 1.2

FT Diesel $\quad 0.0$

Total $\quad 165.7$

Refinery Production, KBPD

Propylene $\quad 3.8$

LPG $\quad 5.9$

Unleaded Regular $\quad 16.7$

Unleaded Premium $\quad 4.3$

Reformulated Regular $\quad 50.2$

Reformulated Premium 13.1

Jet Fuel $\quad 11.7$

Low Sulfur Diesel 23.3

No. 2 Fuel Oil 23.6

Low Sulfur Fuel Oil $\quad 5.1$

High Sulfur Fuel Oil $\quad 3.0$

Asphalt $\quad 9.8$

Fuel Coke, Tons 299

Sulfur, Ltons 82

Cat Slurry $\quad 0.0$

Total $\quad 170.5$

Key Product Qualities

Diesel Sulfur Content, ppm 10

Diesel Cetane Index $\quad 45$

Refinery Profitability, \$ per barrel crude

Product Revenues

28.10

Feedstock Costs $\quad 21.77$

Gross Margin $\quad 6.33$

Utility Costs

(1.01)

Cat/Chem Costs

(0.22)

Variable Margin

5.10 


\section{Table 4.8 Representative Base PADD 1 Refinery}

Process Unit Utilizations, 2006

(thousand barrels per calendar day)

\begin{tabular}{lrrr} 
& & Change from 2001 \\
\cline { 3 - 4 } & $\mathbf{2 0 0 6}$ & KBPD & Percent \\
Crude Distillation & & & \\
Vacuum Distillation & 158.0 & 8.0 & 5.1 \\
Cat Cracking (FCC) & 69.5 & 0.7 & 1.0 \\
Coking & 53.7 & 3.1 & 5.8 \\
VGO Hydrocracking & 8.7 & 0.0 & 0.0 \\
Cat Reforming & 1.5 & 0.0 & 0.0 \\
Kero/Jet Hydrotreating & 25.6 & 1.8 & 6.9 \\
Distillate Hydrotreating & 12.8 & 0.8 & 6.0 \\
Alkylation & 25.6 & 1.1 & 4.1 \\
Gasoline Desulfurization & 9.2 & 0.5 & 5.3 \\
& 28.8 & 28.8 & 100.0
\end{tabular}

Highlights of the results include:

- The levels of cat cracking, catalytic reforming, distillate hydrotreating and alkylation increased in line with the $8 \mathrm{KBPCD}$ increase in crude distillation capacity needed to satisfy increased refinery production requirements

- Nearly 30 KBPCD of gasoline desulfurization capacity was added to process cat naphtha production in order to meet the lower gasoline sulfur content specification that will be in effect by 2006

\subsubsection{Representative Refinery with FT Diesel}

The impact of introducing FT diesel on the operations of the representative base 2006 PADD 1 refinery was analyzed for increasing levels of FT diesel availability. For this analysis, the quantity of crude oil processed by the representative refinery was held constant at the same level processed in the base 2006 representative refinery analysis and the refinery's low sulfur diesel production was allowed to vary. The "Fixed Crude Mix, Crude Feedrate and Floating Diesel Rate" analytical approach used is described in the Methodology section of this report.

The feedstock purchases, refinery production and refinery operating cost results for the 2006 PADD 1 analyses with FT diesel are presented in Table 4.9. 
Table 4.9 Representative PADD 1 Refinery With FT Diesel, 2006

Feedstock Purchases, KBPD
Crude Oil
Methanol
MTBE
Normal Butane
Iso Butane
Natural Gas (as EFO)
FT Diesel
Total

Refinery Production, KBPD

Low Sulfur Diesel

Other Products

Total

Operating Costs, \$ per barrel crude

Utility Costs

Cat/Chem Costs

Value of FT Diesel, \$ per barrel FT Diesel Premium, $\$$ per barrel ${ }^{1}$
FT Diesel Purchase Cases

\begin{tabular}{rrrr}
\hline 158.0 & 158.0 & 158.0 & 158.0 \\
0.7 & 0.7 & 0.7 & 0.7 \\
5.4 & 5.3 & 5.3 & 5.3 \\
0.3 & 0.3 & 0.3 & 0.3 \\
0.2 & 0.2 & 0.2 & 0.2 \\
1.2 & 1.2 & 1.2 & 1.2 \\
0.0 & 1.0 & 5.0 & 10.0 \\
165.7 & $\mathbf{1 6 6 . 7}$ & $\mathbf{1 7 0 . 7}$ & $\mathbf{1 7 5 . 7}$
\end{tabular}

$\begin{array}{rrrr}23.3 & 24.3 & 28.3 & 33.3 \\ 147.1 & 147.1 & 147.1 & 147.2 \\ \mathbf{1 7 0 . 5} & \mathbf{1 7 1 . 4} & \mathbf{1 7 5 . 4} & \mathbf{1 8 0 . 4}\end{array}$

$(1.01) \quad(1.01) \quad(1.00) \quad(1.00)$

$(0.22) \quad(0.21) \quad(0.21) \quad(0.21)$

$27.35 \quad 26.71 \quad 26.51$

$\begin{array}{lll}1.05 & 0.41 \quad 0.21\end{array}$

${ }^{1}$ Relative to price of ultra low sulfur (15 ppm) diesel

The use of up to $10 \mathrm{KBPD}$ of FT diesel in the PADD 1 refinery model did not affect the throughput of any refinery process units. However, the availability of FT diesel allowed a reduction in the severity of the Distillate Hydrotreating Unit, with a resulting decrease in hydrogen consumption, and lower catalyst usage and cost. The operating cost savings indicate that the value of the first $1 \mathrm{KBPD}$ of FT diesel used as a blendstock is $\$ 27.35$ per barrel. The value of the FT diesel declined with increasing availability, as shown in Figure 4.1. The value of the FT diesel approached the ULSD price of $\$ 25.40$ per barrel when 10 KBPD was used as a blendstock. As FT diesel purchases increased above $1 \mathrm{KBPD}$, the density of the blend of low sulfur diesel reached the minimum allowable level and additional FT diesel was used as a blendstock for No. 2 fuel oil, a lower valued product. When the availability of FT diesel increased above $10 \mathrm{KBPD}$, the minimum allowable density level for No. 2 fuel oil was also reached. 


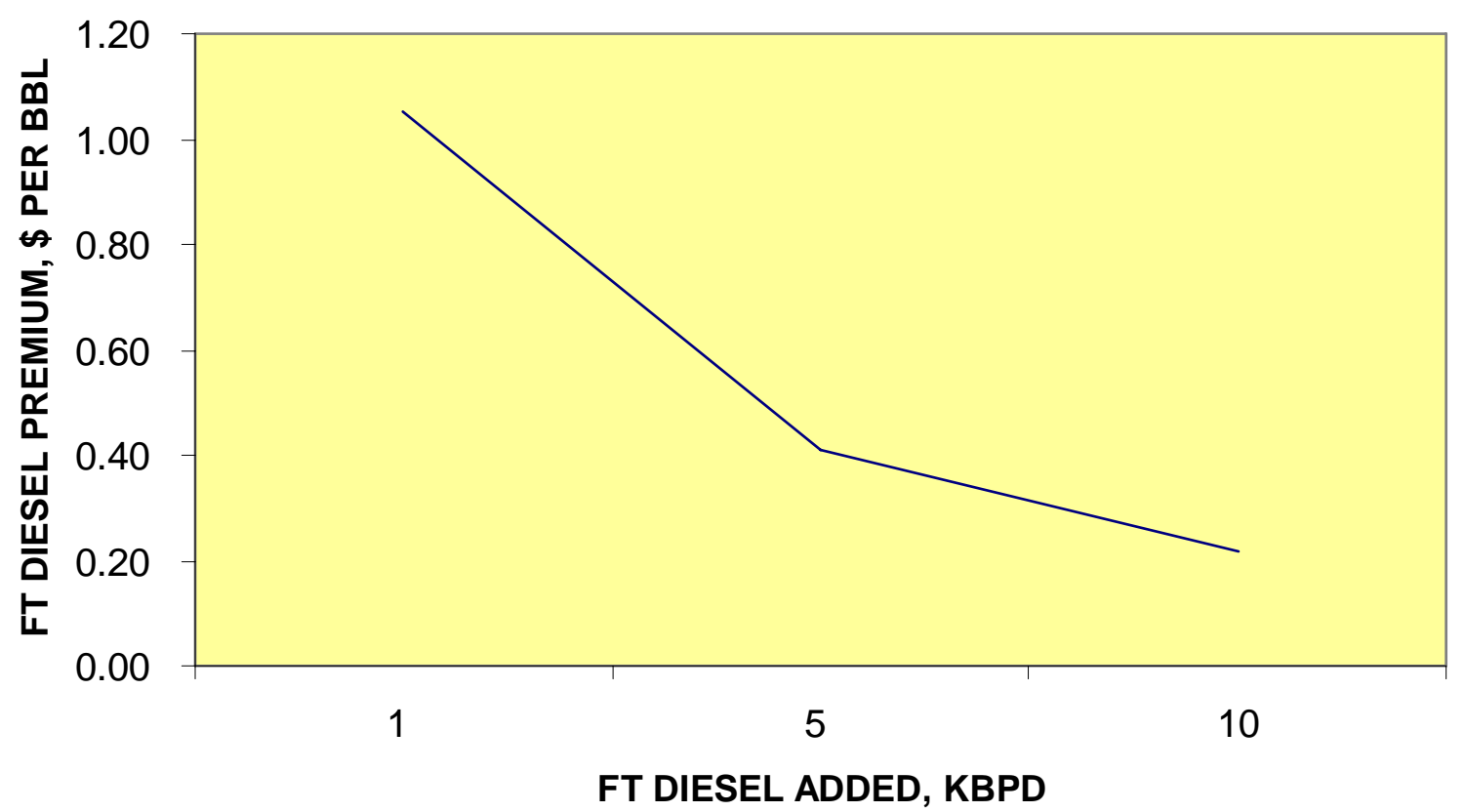

Figure 4.1 PADD 1 Refinery FT Diesel Premium, 2006

\subsection{CASES}

\subsubsection{Representative Base Refinery without FT Diesel}

The LP model was allowed to expand process units in the 2006 Base Refinery and to build any new process units required to meet 2015 specifications in the most economic way. The addition of new process unit capacity was also allowed to meet increased product demand (see Table 4.3) and to cope with a poorer quality crude oil feedstock (see Table 4.2).

The feedstock purchases, refinery production and refinery profitability results for the 2015 PADD 1 Base Case analysis are presented in Table 4.10. The utilized process unit capacities, and changes relative to the 2006 Base Case, are presented in Table 4.11. 


\section{Table 4.10 Representative PADD 1 Refinery Results, 2015 Base Refinery - No FT Diesel}

Feedstock Purchases, KBPD

Crude Oil

181.4

Normal Butane

0.1

Iso Butane

2.5

Natural Gas (as Equiv.Fuel Oil)

0.0

FT Diesel

0.0

Total

184.1

Refinery Production, KBPD

Propylene

LPG

6.6

Unleaded Regular

18.1

Unleaded Premium

4.7

Reformulated Regular

54.6

Reformulated Premium $\quad 14.3$

Jet Fuel

12.6

Low Sulfur Diesel 27.6

No. 2 Fuel Oil 24.9

Low Sulfur Fuel Oil $\quad 5.1$

High Sulfur Fuel Oil $\quad 5.2$

Asphalt $\quad 10.3$

Fuel Coke, Tons $\quad 347$

Sulfur, Ltons $\quad 87$

Cat Slurry $\quad 0.0$

Total $\quad 189.2$

Key Product Qualities

Diesel Sulfur Content, ppm $\quad 7$

Diesel Cetane Index 44

Refinery Profitability, \$ per barrel crude

Product Revenues

32.20

Feedstock Costs

24.53

Gross Margin

7.67

Utility Costs

(1.71)

Cat/Chem Costs

$(0.23)$

Variable Margin

5.72 


\section{Table 4.11 Representative Base PADD 1 Refinery Process Unit Utilizations, 2015 \\ (thousand barrels per calendar day)}

\begin{tabular}{lrrr} 
& & \multicolumn{2}{c}{ Change from 2006 } \\
\cline { 3 - 4 } & $\mathbf{2 0 1 5}$ & KBPD & Percent \\
Crude Distillation & & & \\
Vacuum Distillation & 181.4 & 23.5 & 12.9 \\
Cat Cracking (FCC) & 75.6 & 6.1 & 8.1 \\
Coking & 62.6 & 8.9 & 14.2 \\
VGO Hydrocracking & 8.7 & 0.0 & 0.0 \\
Cat Reforming & 1.5 & 0.0 & 0.0 \\
Kero/Jet Hydrotreating & 31.2 & 5.7 & 18.1 \\
Distillate Hydrotreating & 14.8 & 2.1 & 13.9 \\
Alkylation & 32.0 & 6.3 & 19.8 \\
Gasoline Desulfurization & 13.7 & 4.6 & 33.2 \\
& 34.0 & 5.2 & 15.2
\end{tabular}

As shown, the levels of cat cracking, catalytic reforming, distillate hydrotreating, alkylation and gasoline desulfurization increased by a greater percentage than the increase in crude distillation capacity due to the heavier crude oil slate and lighter product slate forecast for 2015.

\subsubsection{Representative Refinery with FT Diesel}

The impact of introducing FT diesel on the operations of the representative Base 2015 PADD 1 refinery was analyzed for increasing levels of FT diesel availability. For this analysis, the quantity of crude oil processed by the representative refinery was held constant at the same level processed in the base 2015 representative refinery analysis. The refinery's low sulfur diesel production was allowed to vary in accordance with the "Fixed Crude Mix, Crude Feedrate and Floating Diesel Rate" analytical approach described in the Methodology section of this report.

Feedstock purchases, refinery production and refinery operating cost results for the 2015 PADD 1 analyses with FT diesel are presented in Table 4.12. 
Table 4.12 Representative PADD 1 Refinery With FT Diesel, 2015

\author{
Feedstock Purchases, KBPD \\ Crude Oil \\ Normal Butane \\ Iso Butane \\ Natural Gas (as EFO) \\ FT Diesel \\ Total
}

Refinery Production, KBPD
Low Sulfur Diesel
Other Products
Total

Operating Costs, \$ per barrel crude

Utility Costs

Cat/Chem Costs

Additional Capital Costs

Value of FT Diesel, \$ per barrel
FT Diesel Premium, \$ per barrel ${ }^{1}$
FT Diesel Purchase Cases

\begin{tabular}{rrrrrr}
\hline 181.4 & 181.4 & 181.4 & 181.4 & 181.4 & 181.4 \\
0.1 & 0.1 & 0.2 & 0.1 & 0.1 & 0.4 \\
2.5 & 2.5 & 2.6 & 2.5 & 2.5 & 2.6 \\
0.0 & 0.0 & 0.0 & 0.0 & 0.0 & 0.0 \\
0.0 & 1.0 & 5.0 & 10.0 & 15.0 & 20.0 \\
184.1 & 185.1 & 189.1 & 194.0 & 199.1 & 204.4 \\
& & & & & \\
27.6 & 28.5 & 32.4 & 37.4 & 42.0 & 44.7 \\
161.5 & 161.7 & 161.7 & 161.7 & 161.8 & 164.8 \\
189.2 & 190.2 & 194.2 & 199.1 & 203.8 & 209.6 \\
& & & & & \\
$(2.09)$ & $(1.69)$ & $(1.67)$ & $(1.68)$ & $(1.61)$ & $(1.63)$ \\
$(0.23)$ & $(0.23)$ & $(0.23)$ & $(0.22)$ & $(0.22)$ & $(0.23)$ \\
$(0.38)$ & $(0.37)$ & $(0.36)$ & $(0.36)$ & $(0.37)$ & $(0.38)$ \\
& & & & & \\
& 32.64 & 32.49 & 32.08 & 31.62 & 29.60 \\
& 1.24 & 1.09 & 0.68 & 0.22 & $(1.80)$
\end{tabular}

${ }^{1}$ Relative to price of ultra low sulfur (10 ppm) diesel

The use of up to $20 \mathrm{KBPD}$ of FT diesel in the PADD 1 refinery model for 2015 did not materially affect the throughput of any refinery process units. Therefore, the availability of FT diesel would not reduce the capital cost of additional process unit capacities needed for 2015. However, the availability of FT diesel allowed a reduction in the severity of the Distillate Hydrotreating Unit, with a resulting decrease in hydrogen consumption, and lower catalyst usage and cost. The operating cost savings indicate that the value of the first $1 \mathrm{KBPD}$ of FT diesel used as a blendstock is $\$ 32.64$ per barrel.

The value of the FT diesel declined with increasing availability up to $15 \mathrm{KBPD}$, as shown in Figure 4.2. The value of the FT diesel fell below the ULSD price of $\$ 25.40$ per barrel when more than 15 KBPD was used as a blendstock. At this level of availability, the addition of FT diesel reduced the density of both low sulfur diesel and No. 2 fuel oil blends to their minimum allowable levels. 


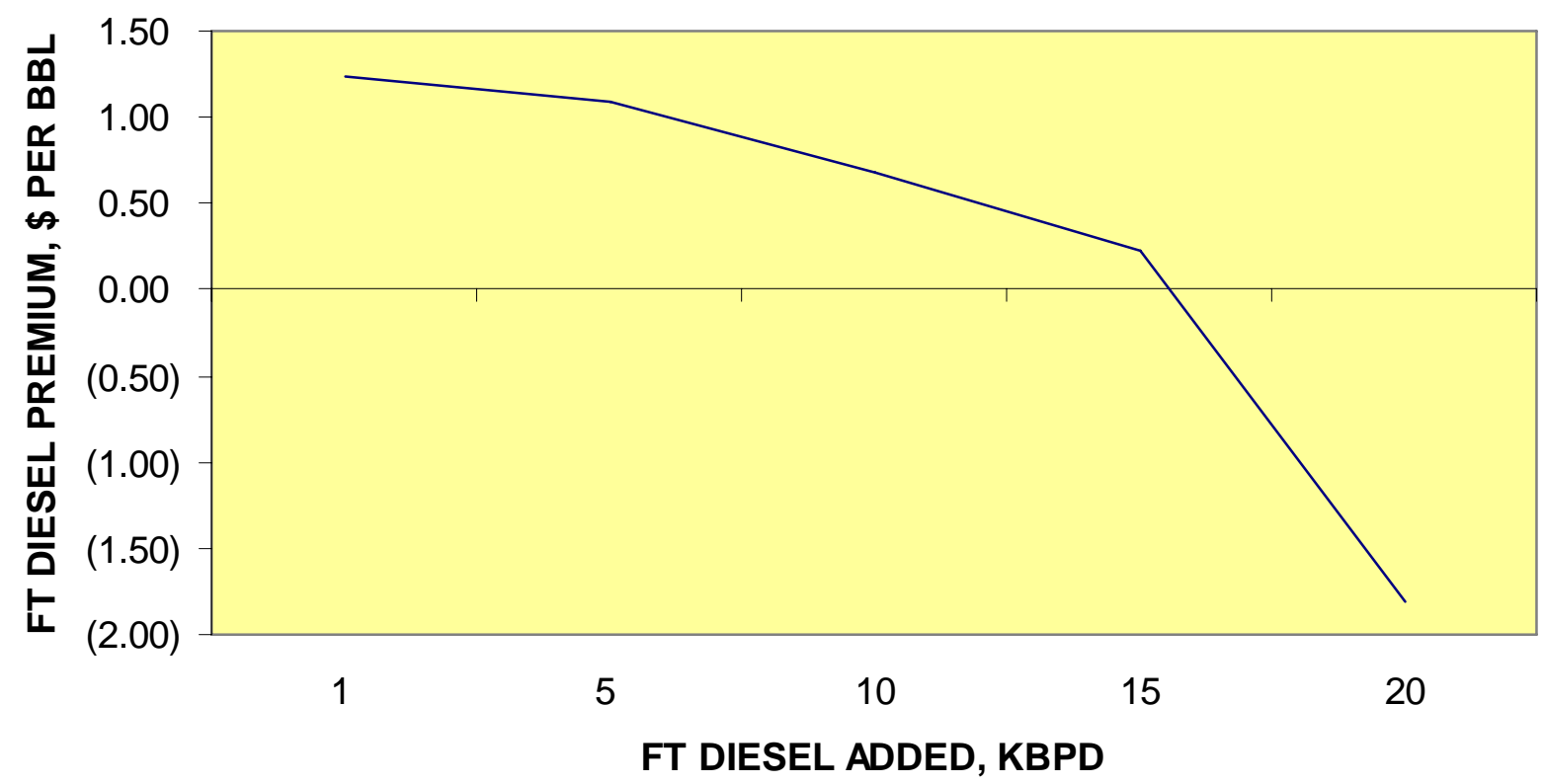

Figure 4.2 PADD 1 Refinery FT Diesel Premium, 2015 


\subsection{KEY MARKET ASSUMPTIONS}

\subsubsection{Profile of Existing Refineries}

PADD 2 (the Midwest) contains 26 refineries at the present time and accounts for 21 percent of the refinery capacity in the U.S. Its refineries are distributed throughout the region with the Chicago area having the largest concentration of the region's refining capacity.

Table 5.1 presents the combined capacities in 2001 of major process units at the region's refineries. Only one of the region's refineries has a capacity less than 20 thousand BPD. The refineries having a capacity greater than 20 thousand BPD have an average refinery capacity of 138 thousand BPCD. The representative PADD 2 refinery considered in the study's PIMS ${ }^{\text {TM }}$ LP analyses was therefore assumed to be capable of processing 150 thousand BPCD of crude oil.

All of the region's 25 largest refineries have catalytic reforming units and only two of them do not have fluid catalytic cracking (FCC) units in their process unit configurations. The configurations of 14 of these refineries include delayed coking units. In addition, 8 of these refineries have VGO hydrotreating units and the configuration for 7 of them includes a VGO hydrocracking unit.

$\begin{array}{lrr}\begin{array}{l}\text { Table 5.1 } \\ \text { PADD 2 Process Unit Capacities, } 2001 \\ \text { (thousand barrels per calendar day) }\end{array} \\ & & \\ & \text { Industry Total } & \text { Percent }{ }^{\mathbf{1}} \\ & & \\ \text { Crude Distillation } & 3,441 & \\ \text { Vacuum Distillation } & 1,449 & 42.1 \\ \text { Coking } & 376 & 10.9 \\ \text { Cat Cracking (FCC) } & 1,111 & 32.3 \\ \text { Cat Reforming } & 825 & 24.0 \\ \text { Diesel Hydrotreating } & 945 & 27.5 \\ \text { VGO Desulfurization } & 396 & 11.5 \\ \text { VGO Hydrocracking } & 115 & 3.3 \\ \text { Alkylation } & 239 & 6.9 \\ \text { C5/C6 Isomerization } & 153 & 4.4\end{array}$

1 Percent of Crude Distillation Capacity

\subsubsection{Crude Slate}

Some PADD 2 refineries are designed to only process low sulfur crude oils and others are designed to process heavy, high sulfur crude oils. Approximately 50 percent of the region's crude oil supplies are imported, with Canada accounting for over 60 percent of the imports. Most of the heavy, high sulfur crude oils processed in the region comes from Canada. Nigeria and Saudi Arabia also represent the major sources, each accounting for approximately 10 percent 
of the region's crude oil imports. The current and forecast quality for the region's crude oil mix, discussed in more detail in Report Section IV covering United States Regional Fuel Markets, is presented in Table 5.2.

The quality of the crude oil processed by the region's representative refinery in this study was assumed to be equal to the average crude oil quality for the region. The average crude oil quality was achieved in the analyses by blending together several major crude oil streams to approximately match the average API gravity and sulfur content. The calculated average quality of the crude oil blends used in the LP models for this study's analyses are also presented in Table 5.2 .

Table 5.2 PADD 2 Crude Quality, 2000-2015

$2000 \quad 2006 \quad 2015$

$\begin{array}{lrrr}\text { Industry Average } & \text { Actual } & \text { Forecast } & \text { Forecast } \\ \text { API Gravity } & 33.0 & 32.9 & 32.6 \\ \text { Sulfur, wt\% } & 1.32 & 1.35 & 1.39\end{array}$

$\begin{array}{llll}\text { Model Assumption } & & & \\ \text { API Gravity } & 33.0 & 32.9 & 32.6 \\ \text { Sulfur, wt\% } & 1.32 & 1.36 & 1.41\end{array}$

\subsubsection{Product Slate}

Actual PADD 2 refinery production in 2000, summarized in Table 5.3, was used as the basis for establishing the product slate of this study's representative PADD 2 refinery in 2001. The forecast trends in the region's refinery production, discussed in more detail in Report Section IV covering United States Regional Fuel Markets, were used to establish the product slate of this study's representative PADD 2 refinery in 2006 and 2015, which are also presented in Table 5.3. 
Table 5.3 Representative PADD 2 Refinery Product Slate, 2001-2015

$\begin{array}{lrrr} & \mathbf{2 0 0 1} & \mathbf{2 0 0 6} & \mathbf{2 0 1 5} \\ \text { Production, KBPCD } & & & \\ \text { Propylene } & & & \\ \text { Unleaded Regular } & 1.9 & 2.2 & 2.9 \\ \text { Unleaded Premium } & 59.2 & 63.7 & 71.5 \\ \text { Reformulated Regular } & 8.2 & 8.8 & 9.9 \\ \text { Reformulated Premium } & 12.5 & 13.5 & 15.1 \\ \text { Jet Fuel } & 1.7 & 1.9 & 2.1 \\ \text { Low Sulfur Diesel } & 11.2 & 11.9 & 13.4 \\ \text { No. 2 Fuel Oil } & 29.1 & 32.4 & 39.8 \\ \text { Low Sulfur Fuel Oil } & 9.7 & 9.4 & 8.6 \\ \text { Asphalt } & 5.3 & 4.7 & 3.7 \\ & 7.2 & 7.3 & 7.7 \\ \text { Volume \% of Crude Oil Processed } & & & \\ \text { Propylene } & & & \\ \text { Unleaded Regular } & 1.3 & 1.4 & 1.6 \\ \text { Unleaded Premium } & 39.5 & 39.3 & 38.8 \\ \text { Reformulated Regular } & 5.5 & 5.5 & 5.4 \\ \text { Reformulated Premium } & 8.3 & 8.3 & 8.2 \\ \text { Jet Fuel } & 1.2 & 1.2 & 1.1 \\ \text { Low Sulfur Diesel } & 7.5 & 7.4 & 7.3 \\ \text { No. 2 Fuel Oil } & 19.4 & 20.0 & 21.6 \\ \text { Low Sulfur Fuel Oil } & 6.5 & 5.8 & 4.7 \\ \text { Asphalt } & 3.5 & 2.9 & 2.0 \\ \text { a } & 4.8 & 4.5 & 4.2\end{array}$

\subsubsection{Pricing}

The Chicago area prices used in the PADD 2 analyses, whose bases are discussed in Report Section IX covering Ultra Clean Fuel Valuations, are presented in Table 5.4. It should be noted that since the volume and mix of crude oils processed in the study's PIMS ${ }^{\mathrm{TM}}$ LP analyses were fixed, the price of crude oils did not affect the results of the analyses. Similarly, the quantity of all major products produced, except low sulfur diesel, was fixed in the analyses. Therefore, only the low sulfur diesel price influenced the results of the economic analyses. 
Table 5.4 PADD 2 Pricing Assumptions, 2001-2015

Medium Crude Oil Price Scenario

stock Pricing

Crude Oil Mix (Varying Quality)

$\$ / b b l$

Normal Butane

Iso Butane

Ethanol

Natural Gas

\section{Product Pricing}

Propane

Normal Butane

Propylene-Polymer Grade

Unleaded Regular-87

Unleaded Premium-93

Reformulated Regular-87

Reformulated Premium-93

Kero/Jet

Low Sulfur Diesel-500 ppm

Low Sulfur Diesel-15 ppm

No. 2 Fuel Oil

Low Sulfur Fuel Oil (1\%S)

High Sulfur Fuel Oil (3\%S)

Asphalt

Fuel Coke

Sulfur

Cat Slurry

NA = Not Applicable

$\$ / b b l$

$\$ / b b l$

\$/MMBtu

$\$ / b b l$

$\$ / b b l$

$\$ / b b l$

$\$ / b b l$

$\$ / b b l$

$\$ / b b l$

$\$ / b b l$

$\$ / b b l$

$\$ / b b l$

$\$ /$ short ton

$\$ /$ ton

$\$ / b b l$

\begin{tabular}{rlr} 
Actual & \multicolumn{2}{c}{ Forecast } \\
2001 & 2006 & 2015
\end{tabular}

24.7

21.3

25.4

22.0

18.5

22.2

23.7

19.1

22.8

33.1

28.1

32.7

4.2

2.7

3.3

20.9

17.9

21.4

21.2

17.6

21.0

34.4

34.4

34.4

34.3

28.1

33.2

36.1

29.9

35.0

36.5

29.2

34.5

38.1

31.6

37.0

33.0

26.6

31.6

33.3

26.0

30.9

NA

26.9

31.9

31.3

23.7

28.1

18.2

14.3

17.4

18.2

14.3

17.4

20.2

16.5

20.3

15

48

17.2

16

19

68

16.0 


\subsection{BASE CASE}

Feedstock purchases, refinery production and refinery profitability results for the 2001 PADD 2 Base Case analysis are presented in Table 5.5.

Table 5.5 Representative PADD 2 Refinery Results, 2001

Feedstock Purchases, KBPD

Crude Oil $\quad 150.0$

Methanol $\quad 0.2$

Ethanol $\quad 0.8$

Normal Butane $\quad 1.4$

Iso Butane $\quad 1.2$

Natural Gas (as Equiv.Fuel Oil) 1.7

FT Diesel

$\begin{array}{ll}\text { Total } & 155.2\end{array}$

Refinery Production, KBPD
Propylene

LPG $\quad 4.5$

Unleaded Regular $\quad 59.2$

Unleaded Premium $\quad 8.2$

Reformulated Regular $\quad 12.5$

Reformulated Premium $\quad 1.7$

Jet Fuel $\quad 11.2$

Low Sulfur Diesel $\quad 33.3$

No. 2 Fuel Oil $\quad 9.7$

High Sulfur Fuel Oil $\quad 5.3$

Asphalt $\quad 7.2$

Fuel Coke, Tons 443

Sulfur, Ltons $\quad 150$

$\begin{array}{ll}\text { Total } & 154.7\end{array}$

Key Product Qualities

Diesel Sulfur Content, ppm 400

Diesel Cetane Index $\quad 47$

Refinery Profitability, \$ per barrel crude

Product Revenues $\quad 33.65$

Feedstock Costs $\quad 25.56$

Gross Margin $\quad 8.08$

Utility Costs (0.99)

Cat/Chem Costs (0.14)

Variable Margin $\quad 6.94$

Consumption of natural gas has been divided into two categories. Thus, feedstock purchases only include the portion of natural gas purchases used as a hydrogen plant feedstock. Purchased utilities include electricity, water and natural gas used as a refinery fuel. The variable margin is the value of product minus cost of feedstocks (i.e. gross margin) less variable costs for purchased utilities, catalysts and chemicals. 
To achieve the processing objective, which is to maximize refinery contribution margin, the LP model adjusted the process unit capacities with only VGO hydrocracking, VGO hydrotreating, MTBE and naphtha isomerization capacities being constrained to approximate actual average levels as a percentage of crude distillation capacity since these units are not included in all major PADD 2 refineries. The utilized process unit capacities are presented in Table 5.6.

\section{Table 5.6 Representative PADD 2 Refinery Process Unit Utilizations, 2001}

Thousand Barrels per Calendar Day

Crude Distillation

Vacuum Distillation

Cat Cracking (FCC)

Coking

VGO Hydrocracking

Cat Reforming

Kero/Jet Hydrotreating

Distillate Hydrotreating

VGO Desulfurization

Alkylation
150.0

$65.4 \quad 43.6$

$48.1 \quad 32.0$

$11.2 \quad 7.4$

$\begin{array}{ll}5.0 & 3.3\end{array}$

$27.8 \quad 18.5$

$27.0 \quad 18.0$

$21.0 \quad 14.0$

$17.2 \quad 11.5$

$11.3 \quad 7.5$

${ }^{1}$ Percent of Crude Distillation Capacity

The results for the Base Case are mainly of interest as a basis for comparison for the 2006 and 2015 analyses, and to confirm that the process configuration of the study's representative PADD 2 refinery is generally consistent with the actual configuration of the PADD 2 industry. In this regard, some key comparisons include:

- The levels of cat cracking and alkylation for the representative PADD 2 refinery as a percent of crude distillation capacity are within one percent of their actual average industry values presented in Table 5.1

- $\quad$ The levels of VGO hydrocracking, VGO hydrotreating for the representative PADD 2 refinery as a percent of crude distillation capacity are equal to the actual average industry values since they were fixed at those values

- The levels of coking and middle distillate hydrotreating (i.e., the combined total of kero/jet and distillate hydrotreating) for the representative PADD 2 refinery as a percent of crude distillation capacity are within four percent of their actual average industry values presented in Table 5.1

- The level of catalytic reforming for the representative PADD 2 refinery was somewhat lower than the actual average industry nameplate reforming capacity (expressed as a percentage of crude oil distillation capacity). This reflects the fact that industry nameplate capacity includes capacity to meet peak gasoline demand levels during the 
summer driving season. This Market Study analysis was performed on a annual average basis, thus requiring less reforming capacity relative to actual capacity levels

\subsection{CASES}

\subsubsection{Representative Base Refinery without FT Diesel}

Available information on industry plans does not provide any reliable insight into refinery investment and construction that will take place during the period between now and 2006. The LP model was thus allowed to expand process units in the 2001 Base Refinery and to build any new process units required to meet the 2006 specifications in the most economic way. New process unit capacity will also be required to increase refinery production (see Table 5.3) and to cope with poorer quality crude oil feedstock (see Table 5.2). It was assumed that the availability of FT diesel would not affect the configuration of the 2006 Base Refinery. As discussed in the Methodology section of this report, this approach reflects the assumption that significant volumes of FT Diesel will not be available to U.S. refiners prior to 2006 and in time for them to alter their capital spending needed to meet product specifications and market conditions in 2006.

The model has the latitude to:

- Add crude distillation capacity and fuel oil conversion capacity, such as FCC, coking and hydrocracking capacity

- $\quad$ Add gasoline desulfurization capacity

- Increase the percentage of sulfur removed in the distillate desulfurization unit, which would necessitate a revamp of the unit involving the addition of more reactor capacity, catalyst volume, etc.

The feedstock purchases, refinery production and refinery profitability results for the 2006 PADD 2 Base Case analysis are presented in Table 5.7. The utilized process unit capacities, and changes relative to the 2001 Base Case, are presented in Table 5.8. 
Table 5.7 Representative PADD 2 Refinery Results, 2006 Base Refinery - No FT Diesel

$\begin{array}{lr}\text { Feedstock Purchases, KBPD } & \\ \text { Crude Oil } & 155.6 \\ \text { Methanol } & 0.2 \\ \text { Ethanol } & 0.9 \\ \text { Normal Butane } & 1.5 \\ \text { Iso Butane } & 1.3 \\ \text { Natural Gas (as Equiv.Fuel Oil) } & 1.9 \\ \text { FT Diesel } & 0.0 \\ \text { Total } & 161.3 \\ & \\ \text { Refinery Production, KBPD } & \\ \text { Propylene } & 2.2 \\ \text { LPG } & 4.8 \\ \text { Unleaded Regular } & 63.7 \\ \text { Unleaded Premium } & 8.8 \\ \text { Reformulated Regular } & 13.5 \\ \text { Reformulated Premium } & 1.9 \\ \text { Jet Fuel } & 11.9 \\ \text { Low Sulfur Diesel } & 32.4 \\ \text { No. 2 Fuel Oil } & 9.4 \\ \text { High Sulfur Fuel Oil } & 4.7 \\ \text { Asphalt } & 7.3 \\ \text { Fuel Coke, Tons } & 513 \\ \text { Sulfur, Ltons } & 164 \\ \text { Total } & 160.5\end{array}$

Key Product Qualities

Diesel Sulfur Content, ppm 10

Diesel Cetane Index 48

Refinery Profitability, \$ per barrel crude

Product Revenues $\quad 27.51$

Feedstock Costs $\quad 22.01$

Gross Margin $\quad 5.50$

Utility Costs

Cat/Chem Costs

Variable Margin $\quad 4.21$ 


\section{Table 5.8 Representative Base PADD 2 Refinery \\ Process Unit Utilizations, 2006 \\ (thousand barrels per calendar day)}

\begin{tabular}{lrcc} 
& & \multicolumn{2}{c}{ Change from 2001 } \\
\cline { 3 - 4 } & $\mathbf{2 0 0 6}$ & KBPD & Percent \\
Crude Distillation & 155.6 & 5.6 & 3.6 \\
Vacuum Distillation & 68.6 & 3.2 & 4.6 \\
Cat Cracking (FCC) & 48.5 & 0.4 & 0.9 \\
Coking & 12.9 & 1.7 & 13.2 \\
VGO Hydrocracking & 5.4 & 0.4 & 7.4 \\
Cat Reforming & 33.6 & 5.8 & 17.2 \\
Kero/Jet Hydrotreating & 21.8 & $(5.2)$ & $(23.7)$ \\
Distillate Hydrotreating & 24.0 & 3.0 & 12.5 \\
Alkylation & 11.0 & $(0.3)$ & $(2.6)$ \\
Gasoline Desulfurization & 28.7 & 28.7 & 100.0
\end{tabular}

Highlights of the results include:

- The levels of coking, catalytic reforming, distillate hydrotreating and alkylation increased by a greater percentage than the increase in crude distillation capacity due to the heavier crude oil slate and lighter product slate forecast for 2006

- Nearly 30 KBPCD of gasoline desulfurization capacity was added to process cat naphtha production in order to meet the lower gasoline sulfur content specification that will be in effect by 2006

- The level of kero/jet hydrotreating declined since in order to continue to use kerosene as a diesel blendstock it was assumed that the sulfur content of hydrotreated kerosene would be reduced to near $10 \mathrm{ppm}$, necessitating some modifications to the kero/jet hydrotreating unit

\subsubsection{Representative Refinery with FT Diesel}

The impact of introducing FT diesel on the operations of the representative base 2006 PADD 2 refinery was analyzed for increasing levels of FT diesel availability. For this analysis, the quantity of crude oil processed by the representative refinery was held constant at the same level processed in the base 2006 representative refinery analysis and the refinery's low sulfur diesel production was allowed to vary. The "Fixed Crude Mix, Crude Feedrate and Floating Diesel Rate" analytical approach used is described in the Methodology section of this report.

The feedstock purchases, refinery production and refinery operating cost results for the 2006 PADD 2 analyses with FT diesel are presented in Table 5.9. 
Table 5.9 Representative PADD 2 Refinery With FT Diesel, 2006

Feedstock Purchases, KBPD
Crude Oil
Methanol
Ethanol
Normal Butane
Iso Butane
Natural Gas (as EFO)
FT Diesel
Total

Refinery Production, KBPD

Low Sulfur Diesel

Other Products

Total

Operating Costs, \$ per barrel crude

Utility Costs

Cat/Chem Costs

\section{Value of FT Diesel, \$ per barrel} FT Diesel Premium, $\$$ per barrel ${ }^{1}$
FT Diesel Purchase Cases

\begin{tabular}{rrrrrr}
\hline 155.6 & 155.6 & 155.6 & 155.6 & 155.6 & 155.6 \\
0.2 & 0.2 & 0.2 & 0.2 & 0.2 & 0.2 \\
0.9 & 0.9 & 0.9 & 0.9 & 0.9 & 0.9 \\
1.5 & 1.5 & 1.5 & 1.5 & 1.5 & 1.5 \\
1.3 & 1.3 & 1.3 & 1.3 & 1.3 & 1.3 \\
1.9 & 1.9 & 1.9 & 1.9 & 1.9 & 1.9 \\
0.0 & 1.0 & 2.0 & 3.0 & 5.0 & 7.0 \\
161.3 & 162.3 & 163.3 & 164.3 & 166.3 & 168.3 \\
& & & & & \\
32.4 & 33.4 & 34.4 & 35.4 & 37.4 & 39.4 \\
128.2 & 128.2 & 128.2 & 128.2 & 128.2 & 128.2 \\
160.5 & 161.6 & 162.6 & 163.6 & 165.6 & 167.6 \\
& & & & & \\
$(1.07)$ & $(1.07)$ & $(1.07)$ & $(1.07)$ & $(1.07)$ & $(1.07)$ \\
$(0.22)$ & $(0.21)$ & $(0.21)$ & $(0.21)$ & $(0.21)$ & $(0.21)$ \\
& & & & & \\
& 27.28 & 27.28 & 27.30 & 27.30 & 27.23 \\
& 0.38 & 0.38 & 0.40 & 0.40 & 0.33
\end{tabular}

${ }^{1}$ Relative to price of ultra low sulfur (15 ppm) diesel

The use of up to $7 \mathrm{KBPD}$ of FT diesel in the PADD 2 refinery model did not affect the throughput of any refinery process units. However, the availability of FT diesel allowed a reduction in the severity of the Distillate Hydrotreating Unit, with a resulting decrease in hydrogen consumption, and lower catalyst usage and cost. The operating cost savings indicate that the value of the first $1 \mathrm{KBPD}$ of FT diesel used as a blendstock is $\$ 27.28$ per barrel. The value of the FT diesel remained stable with increasing availability, as shown in Figure 5.1. The value of the FT diesel remained $\$ 0.33$ per barrel above the ULSD price of $\$ 26.90$ per barrel when 7 KBPD was used as a blendstock. As FT diesel purchases increased above 5 KBPD, the density of the blend of low sulfur diesel reached the minimum allowable level and additional FT diesel was used as a blendstock for No. 2 fuel oil, a lower valued product. However, the density of No. 2 fuel oil did not drop down to its minimum allowable level for any FT diesel levels considered in the analysis. As a result, the cost savings associated with a reduced Distillate Hydrotreating Unit severity determined the value of FT diesel for the entire range of FT diesel availabilities considered. 


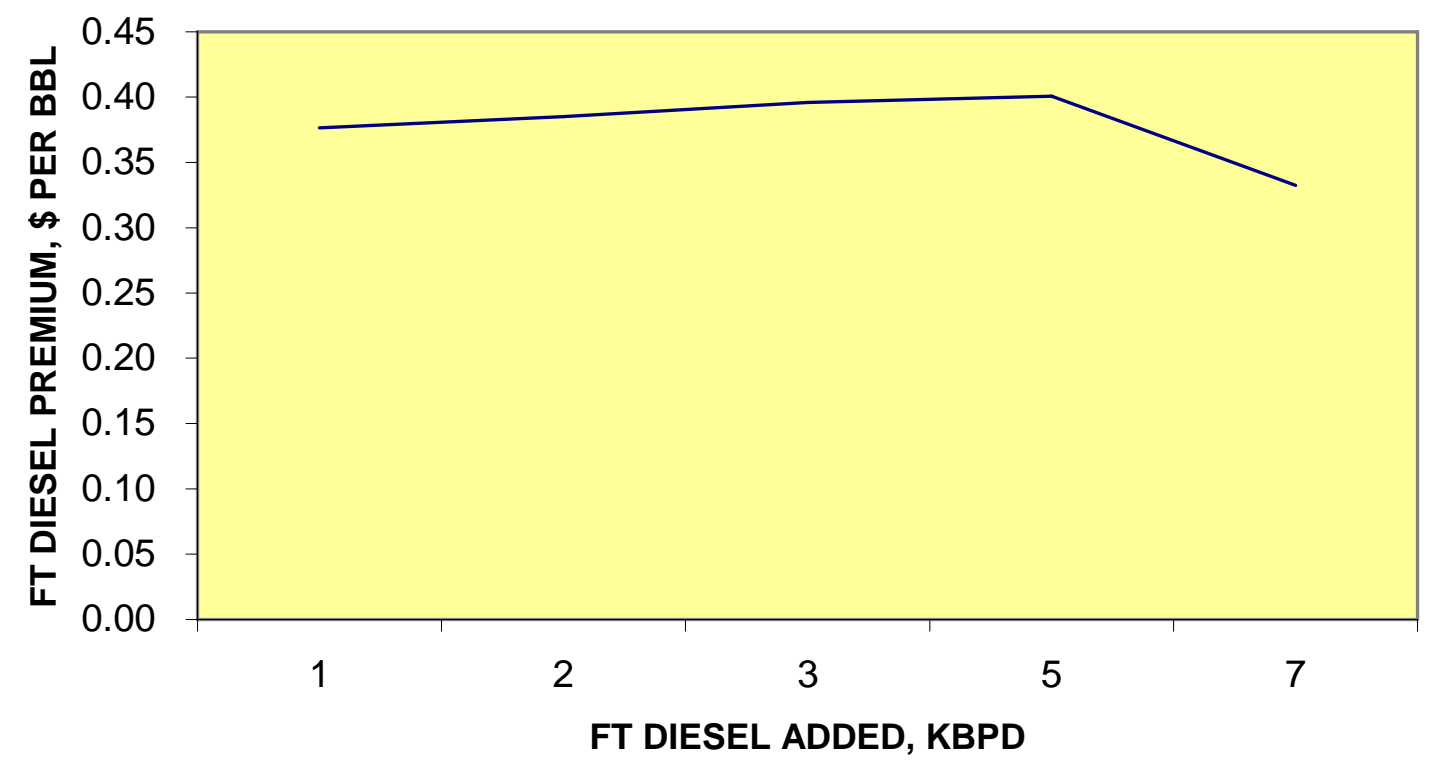

Figure 5.1 PADD 2 Refinery FT Diesel Premium, 2006

\subsection{CASES}

\subsubsection{Representative Base Refinery without FT Diesel}

The LP model was allowed to expand process units in the 2006 Base Refinery and to build any new process units required to meet 2015 specifications in the most economic way. The addition of new process unit capacity was also allowed to meet increased product demand (see Table 5.3) and to cope with a poorer quality crude oil feedstock (see Table 5.2).

The feedstock purchases, refinery production and refinery profitability results for the 2015 PADD 2 Base Case analysis are presented in Table 5.10. The utilized process unit capacities, and changes relative to the 2006 Base Case, are presented in Table 5.11. 


\section{Table 5.10 Representative PADD 2 Refinery Results, 2015 Base Refinery - No FT Diesel}

$\begin{array}{lr}\text { Feedstock Purchases, KBPD } & \\ \text { Crude Oil } & 174.2 \\ \text { Ethanol } & 1.2 \\ \text { Normal Butane } & 1.7 \\ \text { Iso Butane } & 1.5 \\ \text { Natural Gas (as Equiv.Fuel Oil) } & 2.8 \\ \text { FT Diesel } & 0.0 \\ \text { Total } & \mathbf{1 8 1 . 4}\end{array}$

Refinery Production, KBPD

Propylene $\quad 2.9$

LPG $\quad 5.6$

Unleaded Regular $\quad 71.5$

Unleaded Premium $\quad 9.9$

Reformulated Regular $\quad 15.1$

Reformulated Premium $\quad 2.1$

Jet Fuel $\quad 13.4$

Low Sulfur Diesel $\quad 39.8$

No. 2 Fuel Oil $\quad 8.6$

High Sulfur Fuel Oil $\quad 3.7$

$\begin{array}{ll}\text { Asphalt } & 7.7\end{array}$

Fuel Coke, Tons $\quad 680$

Sulfur, Ltons $\quad 226$

$\begin{array}{ll}\text { Total } & 180.3\end{array}$

Key Product Qualities

Diesel Sulfur Content, ppm 7

Diesel Cetane Index 48

Refinery Profitability, \$ per barrel crude

Product Revenues $\quad 32.92$

Feedstock Costs $\quad 26.35$

Gross Margin 6.57

Utility Costs

Cat/Chem Costs $\quad(0.22)$

Variable Margin $\quad 4.38$ 


\section{Table 5.11 Representative Base PADD 2 Refinery Process Unit Utilizations, 2015 \\ (thousand barrels per calendar day)}

Crude Distillation

Vacuum Distillation

Cat Cracking (FCC)

Coking

VGO Hydrocracking

Cat Reforming

Kero/Jet Hydrotreating

Distillate Hydrotreating

Alkylation

Gasoline Desulfurization

$2015 \frac{\text { Change from } 2006}{\text { KBPD Percent }}$

174.2

77.5

52.9

17.8

7.0

38.1

26.0

27.6

12.4

31.0
18.6

$8.9 \quad 11.5$

$4.4 \quad 8.3$

$4.9 \quad 27.7$

$1.6 \quad 23.1$

$4.5 \quad 11.8$

$4.2 \quad 16.3$

$3.7 \quad 13.2$

$1.4 \quad 11.2$

$2.2 \quad 7.1$

As shown, the levels of coking, VGO hydrocracking catalytic reforming, distillate hydrotreating and alkylation increased by a greater percentage than the increase in crude distillation capacity due to the heavier crude oil slate and lighter product slate forecast for 2015.

\subsubsection{Representative Refinery with FT Diesel}

The impact of introducing FT diesel on the operations of the representative Base 2015 PADD 2 refinery was analyzed for increasing levels of FT diesel availability. For this analysis, the quantity of crude oil processed by the representative refinery was held constant at the same level processed in the base 2015 representative refinery analysis. The refinery's low sulfur diesel production was allowed to vary in accordance with the "Fixed Crude Mix, Crude Feedrate and Floating Diesel Rate" analytical approach described in the Methodology section of this report.

Feedstock purchases, refinery production and refinery operating cost results for the 2015 PADD 2 analyses with FT diesel are presented in Table 5.12. 
Table 5.12 Representative PADD 2 Refinery With FT Diesel, 2015

Feedstock Purchases, KBPD
Crude Oil
Ethanol
Normal Butane
Iso Butane
Natural Gas (as EFO)
FT Diesel
Total

Refinery Production, KBPD Low Sulfur Diesel

Other Products

Total

Operating Costs, \$ per barrel crude Utility Costs

Cat/Chem Costs

Additional Capital Costs

Value of FT Diesel, \$ per barrel FT Diesel Premium, $\$$ per barrel ${ }^{1}$
FT Diesel Purchase Cases

\begin{tabular}{rrrrrrr}
\hline & & & & & & \\
174.2 & 174.2 & 174.2 & 174.2 & 174.2 & 174.2 & 174.2 \\
1.2 & 1.2 & 1.2 & 1.2 & 1.2 & 1.2 & 1.2 \\
1.7 & 1.7 & 1.7 & 1.7 & 1.7 & 1.7 & 1.7 \\
1.5 & 1.5 & 1.5 & 1.5 & 1.5 & 1.5 & 1.5 \\
2.8 & 2.8 & 2.8 & 2.8 & 2.8 & 2.8 & 2.8 \\
0.0 & 1.0 & 2.0 & 3.0 & 5.0 & 7.0 & 10.0 \\
181.4 & 182.4 & 183.4 & 184.4 & 186.3 & 188.4 & 191.4 \\
& & & & & & \\
39.8 & 40.8 & 41.8 & 42.8 & 44.8 & 46.8 & 49.6 \\
140.5 & 140.5 & 140.5 & 140.5 & 140.5 & 140.5 & 140.5 \\
180.3 & 181.2 & 182.2 & 183.2 & 185.2 & 187.2 & 190.1 \\
& & & & & & \\
$(2.34)$ & $(1.97)$ & $(1.97)$ & $(1.97)$ & $(1.96)$ & $(1.97)$ & $(1.96)$ \\
$(0.22)$ & $(0.22)$ & $(0.22)$ & $(0.22)$ & $(0.22)$ & $(0.22)$ & $(0.21)$ \\
$(0.37)$ & $(0.37)$ & $(0.37)$ & $(0.37)$ & $(0.37)$ & $(0.37)$ & $(0.37)$ \\
& & & & & & \\
& 32.12 & 32.13 & 32.13 & 32.12 & 31.99 & 31.78 \\
& 0.22 & 0.23 & 0.23 & 0.22 & 0.09 & $(0.12)$
\end{tabular}

${ }^{1}$ Relative to price of ultra low sulfur (10 ppm) diesel

The use of up to $10 \mathrm{KBPD}$ of FT diesel in the PADD 2 refinery model for 2015 did not materially affect the throughput of any refinery process units. Therefore, the availability of FT diesel would not reduce the capital cost of additional process unit capacities needed for 2015. However, the availability of FT diesel allowed a reduction in the severity of the Distillate Hydrotreating Unit, with a resulting decrease in hydrogen consumption, and lower catalyst usage and cost. The operating cost savings indicate that the value of the first 1 KBPD of FT diesel used as a blendstock is $\$ 32.12$ per barrel.

The value of the FT diesel remained stable with increasing availability up to 5 KBPD, as shown in Figure 5.2. The value of the FT diesel remained $\$ 0.22$ per barrel above the ULSD price of $\$ 31.90$ per barrel when $5 \mathrm{KBPD}$ was used as a blendstock. As FT diesel purchases increased above $5 \mathrm{KBPD}$, the density of the blend of low sulfur diesel reached the minimum allowable level. The value of the FT diesel fell below the ULSD price when $10 \mathrm{KBPD}$ was used as a blendstock. At this level of availability, the addition of FT diesel reduced the density of both low sulfur diesel and No. 2 fuel oil blends to their minimum allowable levels. 


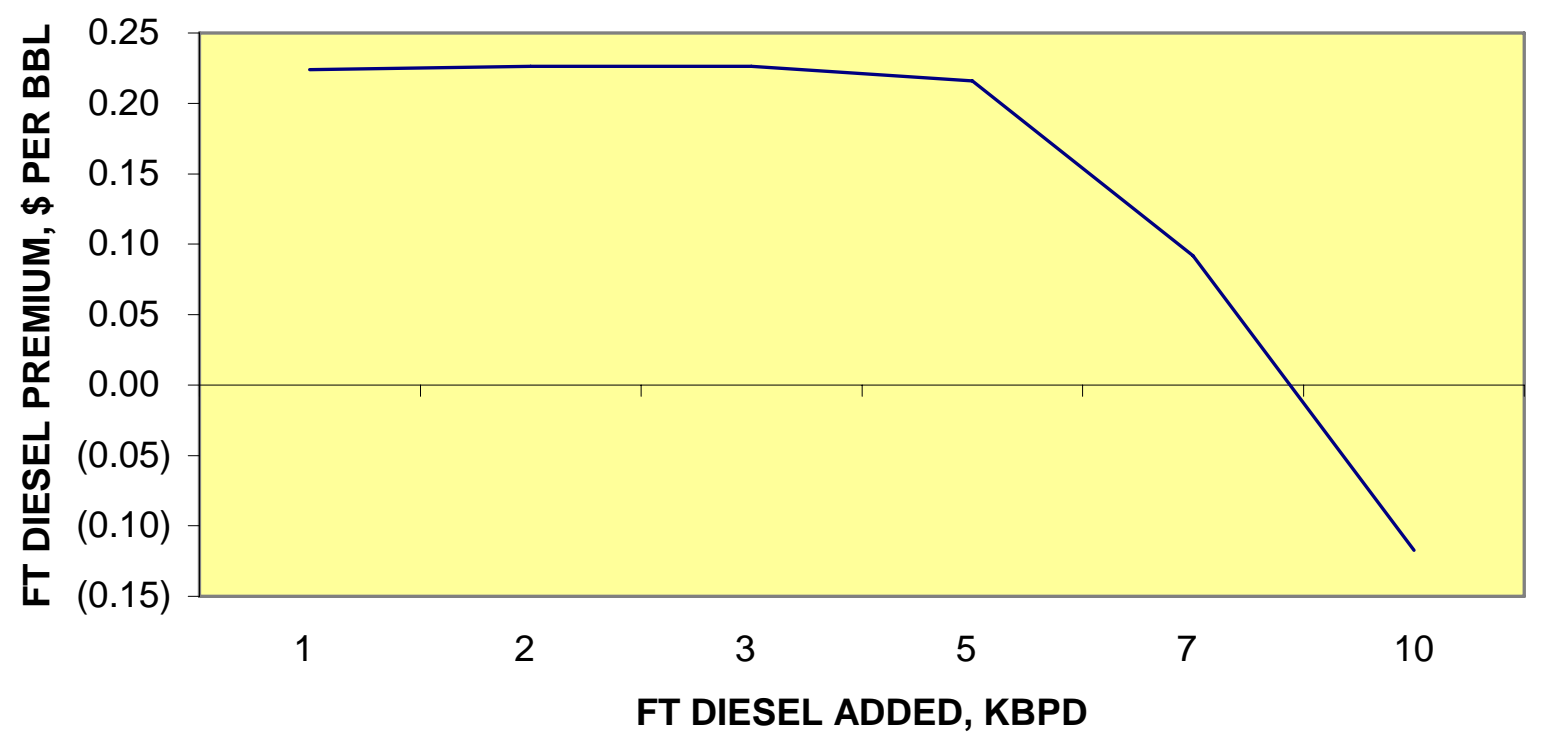

Figure 5.2 PADD 2 Refinery FT Diesel Premium, 2015 


\subsection{KEY MARKET ASSUMPTIONS}

\subsubsection{Profile of Existing Refineries}

PADD 3 (the U.S. Gulf Coast) contains 57 refineries at the present time and accounts for 47 percent of the refinery capacity in the U.S., making it the country's major refining district. Its large, complex refineries produce products to supply PADD 1 (East Coast) and 2 (Midwest) markets, as well as PADD 3 markets. Its smaller facilities are generally located at inland locations and focus on supplying local markets that are remote from the region's major pipelines. In addition, 10 of the region's smaller refineries are devoted to the production of specialty products, such as solvents, asphalt and lubricants.

The region's 26 largest refineries, each having a capacity greater than 100 thousand BPD, account for 83 percent of the region's refining capacity and are considered to be most representative of its refineries. Table 6.1 presents the combined capacities in 2001 of major process units at these refineries, which have an average refinery capacity of 246 thousand BPCD. The representative PADD 3 refinery considered in the study's PIMS ${ }^{\mathrm{TM}}$ LP analyses was therefore assumed to be capable of processing 250 thousand BPCD of crude oil.

All of the region's 26 largest refineries have catalytic reforming and fluid catalytic cracking (FCC) units, and 19 have delayed coking and VGO hydrotreating units. In addition, only 12 of these refineries include VGO hydrocracking units and only 8 of them have resid hydroprocessing units.

Table 6.1 PADD 3 Process Unit Capacities, 2001

(thousand barrels per calendar day)

$\begin{array}{lrr} & \text { Industry Total }{ }^{\mathbf{1}} & \text { Percent }^{\mathbf{2}} \\ \text { Crude Distillation } & 6,409 & \\ \text { Vacuum Distillation } & 3,190 & 49.8 \\ \text { Coking } & 941 & 14.7 \\ \text { Cat Cracking (FCC) } & 2,389 & 37.3 \\ \text { Cat Reforming } & 1,459 & 22.8 \\ \text { Diesel Hydrotreating } & 1,308 & 20.4 \\ \text { VGO Desulfurization } & 983 & 15.3 \\ \text { VGO Hydrocracking } & 434 & 6.8 \\ \text { Resid Hydrocracking/Desulfurization } & 498 & 7.8 \\ \text { Alkylation } & 468 & 7.3 \\ \text { C5/C6 Isomerization } & 188 & 2.9 \\ & & \\ { }^{1} \text { Total for PADD 3 refineries with capacity greater than 100 KBPCD } & \\ { }^{2} \text { Percent of Crude Distillation Capacity } & & \end{array}$




\subsubsection{Crude Slate}

Most PADD 3 refineries are designed to process high sulfur crude oils and many can process heavy, high sulfur crude oils. Approximately 75 percent of the region's crude oil supplies are imported, with Mexico, Venezuela and Saudi Arabia representing the major sources. The current and forecast quality for the region's crude oil mix, discussed in more detail in Report Section IV covering United States Regional Fuel Markets, is presented in Table 6.2.

The quality of the crude oil processed by the region's representative refinery in this study was assumed to be equal to the average crude oil quality for the region. The average crude oil quality was achieved in the analyses by blending together several major crude oil streams to approximately match the average API gravity and sulfur content. The calculated average quality of the crude oil blends used in the LP models for this study's analyses are also presented in Table 6.2 .

Table 6.2 PADD 3 Crude Quality, 2000-2015

2000

Actual

Industry Average

API Gravity

Sulfur, wt\%

\section{Model Assumption}

API Gravity

Sulfur, wt\%
31.1

1.5

31.0

1.5
2006

2015

Forecast

29.8

30.6

1.6

1.7

29.8

30.6

1.6

\subsubsection{Product Slate}

Actual PADD 3 refinery production in 2000, summarized in Table 6.3, was used as the basis for establishing the product slate of this study's representative PADD 3 refinery in 2001. The forecast trends in the region's refinery production, discussed in more detail in Report Section IV covering United States Regional Fuel Markets, were used to establish the product slate of this study's representative PADD 3 refinery in 2006 and 2015, which are also presented in Table 6.3. 


\section{Table 6.3 Representative PADD 3 Refinery Product Slate, 2001-2015 \\ $20012006 \quad 2015$}

Production, KBPCD

Propylene

Unleaded Regular

Unleaded Premium

Reformulated Regular

Reformulated Premium

Jet Fuel

Low Sulfur Diesel

No. 2 Fuel Oil

High Sulfur Fuel Oil

$\begin{array}{rrr}5.9 & 6.8 & 7.7 \\ 94.2 & 99.4 & 102.4 \\ 20.0 & 21.1 & 21.7 \\ 21.6 & 22.8 & 23.5 \\ 4.7 & 4.9 & 5.1 \\ 34.9 & 36.5 & 38.2 \\ 40.4 & 44.2 & 48.2 \\ 22.4 & 22.6 & 21.8 \\ 12.2 & 12.0 & 11.9\end{array}$

Volume $\%$ of Crude Oil Processed

Propylene

Unleaded Regular

Unleaded Premium

Reformulated Regular

Reformulated Premium

Jet Fuel

Low Sulfur Diesel

No. 2 Fuel Oil

High Sulfur Fuel Oil

$\begin{array}{rrr}2.4 & 2.6 & 2.8 \\ 37.7 & 37.7 & 37.2 \\ 8.0 & 8.0 & 7.9 \\ 8.6 & 8.6 & 8.5 \\ 1.9 & 1.9 & 1.8 \\ 13.9 & 13.9 & 13.9 \\ 16.2 & 16.8 & 17.5 \\ 9.0 & 8.6 & 7.9 \\ 4.9 & 4.5 & 4.3\end{array}$

\subsubsection{Pricing}

The prices used in the PADD 3 analyses, whose bases are discussed in Report Section IX covering Ultra Clean Fuel Valuations, are presented in Table 6.4. It should be noted that since the volume and mix of crude oils processed in the study's PIMSTM LP analyses were fixed, the price of crude oils did not affect the results of the analyses. Similarly, the quantity of all major products produced, except low sulfur diesel, was fixed in the analyses. Therefore, only the low sulfur diesel price influenced the results of the economic analyses. 


\section{Table 6.4 PADD 3 Pricing Assumptions, 2001-2015 Medium Crude Oil Price Scenario}

\begin{tabular}{|c|c|c|c|c|}
\hline & & \multirow{2}{*}{$\begin{array}{r}\text { Actual } \\
2001\end{array}$} & \multicolumn{2}{|c|}{ Forecast } \\
\hline & & & 2006 & 2015 \\
\hline \multicolumn{5}{|l|}{ Feedstock Pricing } \\
\hline Crude Oil Mix (Varying Quality) & $\$ / b b l$ & 22.7 & 19.2 & 22.8 \\
\hline Normal Butane & $\$ / b b l$ & 22.8 & 19.5 & 23.3 \\
\hline Iso Butane & $\$ / b b l$ & 24.5 & 20.0 & 23.9 \\
\hline MTBE & $\$ / b b l$ & 45.3 & 36.0 & 38.6 \\
\hline Methanol & $\$ / b b l$ & 21.7 & 23.7 & 28.1 \\
\hline Natural Gas & \$/MMBtu & 4.1 & 2.9 & 3.6 \\
\hline \multicolumn{5}{|l|}{ Product Pricing } \\
\hline Propane & $\$ / b b l$ & 19.7 & 16.4 & 19.7 \\
\hline Normal Butane & $\$ / b b l$ & 22.4 & 19.0 & 22.8 \\
\hline Propylene-Polymer Grade & $\$ / b b l$ & 34.4 & 33.3 & 38.8 \\
\hline Unleaded Regular-87 & $\$ / b b l$ & 31.1 & 25.8 & 30.6 \\
\hline Unleaded Premium-93 & $\$ / b b l$ & 33.0 & 27.8 & 32.9 \\
\hline Reformulated Regular-87 & $\$ / b b l$ & 33.3 & 26.9 & 31.9 \\
\hline Reformulated Premium-93 & $\$ / b b l$ & 35.2 & 28.9 & 34.2 \\
\hline Kero/Jet & $\$ / b b l$ & 30.3 & 24.9 & 29.7 \\
\hline Low Sulfur Diesel-500 ppm & $\$ / b b l$ & 29.7 & 24.5 & 29.2 \\
\hline Low Sulfur Diesel-15 ppm & $\$ / b b l$ & NA & 25.4 & 30.2 \\
\hline No. 2 Fuel Oil & $\$ / b b l$ & 29.0 & 23.7 & 28.2 \\
\hline Low Sulfur Fuel Oil (1\%S) & $\$ / b b l$ & 21.8 & 16.8 & 20.3 \\
\hline High Sulfur Fuel Oil (3\%S) & $\$ / b b l$ & 17.2 & 13.2 & 16.2 \\
\hline Fuel Coke & $\$ /$ short ton & 15 & 16 & 19 \\
\hline Sulfur & $\$ /$ ton & 48 & 54 & 68 \\
\hline Cat Slurry & $\$ / b b l$ & 16.2 & 12.0 & 14.8 \\
\hline
\end{tabular}




\subsection{BASE CASE}

Feedstock purchases, refinery production and refinery profitability results for the 2001 PADD 3 Base Case analysis are presented in Table 6.5.

Table 6.5 Representative PADD 3 Refinery Results, 2001

\begin{tabular}{|c|c|}
\hline \multicolumn{2}{|l|}{ Feedstock Purchases, KBPD } \\
\hline Crude Oil & 250.0 \\
\hline Methanol & 0.9 \\
\hline MTBE & 0.3 \\
\hline Normal Butane & 1.1 \\
\hline Iso Butane & 3.9 \\
\hline Natural Gas (as Equiv.Fuel Oil) & 4.1 \\
\hline \multicolumn{2}{|l|}{ FT Diesel } \\
\hline Total & 260.3 \\
\hline \multicolumn{2}{|l|}{ Refinery Production, KBPD } \\
\hline Propylene & 5.9 \\
\hline LPG & 7.5 \\
\hline Unleaded Regular & 94.2 \\
\hline Unleaded Premium & 20.0 \\
\hline Reformulated Regular & 21.6 \\
\hline Reformulated Premium & 4.7 \\
\hline Jet Fuel & 34.9 \\
\hline Low Sulfur Diesel & 35.2 \\
\hline No. 2 Fuel Oil & 22.4 \\
\hline \multicolumn{2}{|l|}{ Low Sulfur Fuel Oil } \\
\hline High Sulfur Fuel Oil & 12.2 \\
\hline \multicolumn{2}{|l|}{ Asphalt } \\
\hline Fuel Coke, Tons & 1,709 \\
\hline Sulfur, Ltons & 284 \\
\hline Cat Slurry & 0.5 \\
\hline Total & 259.0 \\
\hline \multicolumn{2}{|l|}{ Key Product Qualities } \\
\hline Diesel Sulfur Content, ppm & 400 \\
\hline Diesel Cetane Index & 45 \\
\hline \multicolumn{2}{|c|}{ Refinery Profitability, \$ per barrel crude } \\
\hline Product Revenues & 31.32 \\
\hline Feedstock Costs & 23.72 \\
\hline Gross Margin & 7.60 \\
\hline Utility Costs & $(1.18)$ \\
\hline Cat/Chem Costs & $(0.15)$ \\
\hline Variable Margin & 6.27 \\
\hline
\end{tabular}

Consumption of natural gas has been divided into two categories. Thus, feedstock purchases only include the portion of natural gas purchases used as a hydrogen plant feedstock. Purchased utilities include electricity, water and natural gas used as a refinery fuel. The variable margin is the value of product minus cost of feedstocks (i.e. gross margin) less variable costs for purchased utilities, catalysts and chemicals. 
To achieve the processing objective, which is to maximize refinery contribution margin, the LP model adjusts the process unit capacities with only VGO hydrocracking and hydrotreating capacities being constrained to approximate actual average levels as a percentage of crude distillation capacity since these units are not included in all major PADD 3 refineries. The utilized process unit capacities are presented in Table 6.6.

\section{Table 6.6 Representative PADD 3 Refinery Process Unit Utilizations, 2001}

\begin{tabular}{lrr} 
& \multicolumn{2}{c}{$\begin{array}{c}\text { Thousand Barrels } \\
\text { per Calendar Day }\end{array}$} \\
& & Percent ${ }^{1}$ \\
Crude Distillation & 250.0 & \\
Vacuum Distillation & 113.6 & 45.5 \\
Cat Cracking (FCC) & 77.7 & 31.1 \\
Coking & 32.0 & 12.8 \\
VGO Hydrocracking & 17.0 & 6.8 \\
Cat Reforming & 50.0 & 20.0 \\
Kero/Jet Hydrotreating & 16.5 & 6.6 \\
Distillate Hydrotreating & 46.3 & 18.5 \\
VGO Desulfurization & 38.0 & 15.2 \\
Alkylation & 17.2 & 6.9 \\
& & \\
1 Percent of Crude Distillation Capacity &
\end{tabular}

The results for the Base Case are mainly of interest as a basis for comparison for the 2006 and 2015 analyses, and to confirm that the process configuration of the study's representative PADD 3 refinery is generally consistent with the actual configuration of the PADD 3 industry. In this regard, some key comparisons include:

- The levels of catalytic reforming, delayed coking, alkylation and distillate hydrotreating for the representative PADD 3 refinery as a percent of crude distillation capacity are within three percent of their actual average industry values presented in Table 6.1

- The level of cat cracking for the representative PADD 3 refinery as a percent of crude distillation capacity is about 6 percent less than the actual average industry value since the analysis is based on annual average gasoline yields, not peak summer yields that utilize more FCC capacity

\subsection{CASES}

\subsubsection{Representative Base Refinery without FT Diesel}

Available information on industry plans does not provide any reliable insight into refinery investment and construction that will take place during the period between now and 2006. The LP model was thus allowed to expand process units in the 2001 Base Refinery and to build any new process units required to meet the 2006 specifications in the most economic way. New 
process unit capacity will also be required to increase refinery production (see Table 6.3) and to cope with poorer quality crude oil feedstock (see Table 6.2). It was assumed that the availability of FT diesel would not affect the configuration of the 2006 Base Refinery. As discussed in the Methodology section of this report, this approach reflects the assumption that significant volumes of FT Diesel will not be available to U.S. refiners prior to 2006 and in time for them to alter their capital spending needed to meet product specifications and market conditions in 2006.

The model has the latitude to:

- Add crude distillation capacity and fuel oil conversion capacity, such as FCC, coking and hydrocracking capacity

- $\quad$ Add gasoline desulfurization capacity

- Increase the percentage of sulfur removed in the distillate desulfurization unit, which would necessitate a revamp of the unit involving the addition of more reactor capacity, catalyst volume, etc.

The feedstock purchases, refinery production and refinery profitability results for the 2006 PADD 3 Base Case analysis are presented in Table 6.7. The utilized process unit capacities, and changes relative to the 2001 Base Case, are presented in Table 6.8. 


\section{Table 6.7 Representative PADD 3 Refinery Results, 2006 Base Refinery - No FT Diesel}

Feedstock Purchases, KBPD

Crude Oil

271.5

Methanol

MTBE

0.2

Normal Butane

2.4

Iso Butane

3.9

Natural Gas (as Equiv.Fuel Oil)

4.1

FT Diesel

0.0

Total

283.2

\section{Refinery Production, KBPD}

$\begin{array}{lr}\text { Propylene } & 6.8 \\ \text { LPG } & 7.6 \\ \text { Unleaded Regular } & 99.4 \\ \text { Unleaded Premium } & 21.1 \\ \text { Reformulated Regular } & 22.8 \\ \text { Reformulated Premium } & 4.9 \\ \text { Jet Fuel } & 36.5 \\ \text { Low Sulfur Diesel } & 44.5 \\ \text { No. 2 Fuel Oil } & 22.6 \\ \text { Low Sulfur Fuel Oil } & 0.0 \\ \text { High Sulfur Fuel Oil } & 12.0 \\ \text { Asphalt } & 0.0 \\ \text { Fuel Coke, Tons } & 2,000 \\ \text { Sulfur, Ltons } & 294 \\ \text { Cat Slurry } & 1.7 \\ \text { Total } & 279.9\end{array}$

Key Product Qualities

Diesel Sulfur Content, ppm 10

Diesel Cetane Index

45

Refinery Profitability, \$ per barrel crude

Product Revenues

25.99

Feedstock Costs

20.04

Gross Margin

5.95

Utility Costs

Cat/Chem Costs

$(0.23)$

Variable Margin

4.63 


\section{Table 6.8 Representative Base PADD 3 Refinery}

Process Unit Utilizations, 2006

(thousand barrels per calendar day)

\begin{tabular}{lrr} 
& \multicolumn{2}{c}{ Change } \\
& $\mathbf{2 0 0 6}$ & $\mathbf{2 0 0 1}$ \\
Crude Distillation & & \\
Vacuum Distillation & 271.5 & 21.5 \\
Cat Cracking (FCC) & 113.6 & 0.0 \\
Coking & 87.4 & 9.7 \\
VGO Hydrocracking & 34.9 & 2.9 \\
Cat Reforming & 17.0 & 0.0 \\
Kero/Jet Hydrotreating & 50.6 & 0.6 \\
Distillate Hydrotreating & 17.2 & 0.6 \\
Alkylation & 52.0 & 5.7 \\
Gasoline Desulfurization & 18.2 & 1.0 \\
& 50.7 & 50.7
\end{tabular}

Highlights of the results include:

- The levels of cat cracking, coking, distillate hydrotreating and alkylation increased in line with the 22 KBPCD increase in crude distillation capacity needed to satisfy increased refinery production requirements

- Over 50 KBPCD of gasoline desulfurization capacity was added to process cat naphtha production in order to meet the lower gasoline sulfur content specification that will be in effect by 2006

\subsubsection{Representative Refinery with FT Diesel}

The impact of introducing FT diesel on the operations of the representative base 2006 PADD 3 refinery was analyzed for increasing levels of FT diesel availability. For this analysis, the quantity of crude oil processed by the representative refinery was held constant at the same level processed in the base 2006 representative refinery analysis and the refinery's low sulfur diesel production was allowed to vary. The "Fixed Crude Mix, Crude Feedrate and Floating Diesel Rate" analytical approach used is described in the Methodology section of this report.

The feedstock purchases, refinery production and refinery operating cost results for the 2006 PADD 3 analyses with FT diesel are presented in Table 6.9. 
Table 6.9 Representative PADD 3 Refinery With FT Diesel, 2006

Feedstock Purchases, KBPD
Crude Oil
Methanol
MTBE
Normal Butane
Iso Butane
Natural Gas (as EFO)
FT Diesel
Total

Refinery Production, KBPD Low Sulfur Diesel

Other Products

Total

Operating Costs, \$ per barrel crude

Utility Costs

Cat/Chem Costs

Value of FT Diesel, \$ per barrel FT Diesel Premium, $\$$ per barrel ${ }^{1}$
FT Diesel Purchase Cases

\begin{tabular}{rrrrrr}
\hline 271.5 & 271.5 & 271.5 & 271.5 & 271.5 & 271.5 \\
1.0 & 1.0 & 1.0 & 1.0 & 1.0 & 1.0 \\
0.2 & 0.2 & 0.2 & 0.2 & 0.2 & 0.5 \\
2.4 & 2.4 & 2.4 & 2.4 & 2.4 & 2.5 \\
3.9 & 3.9 & 3.9 & 3.9 & 3.9 & 4.0 \\
4.1 & 4.1 & 4.1 & 4.1 & 4.1 & 3.8 \\
0.0 & 1.0 & 5.0 & 10.0 & 20.0 & 30.0 \\
$\mathbf{2 8 3 . 2}$ & $\mathbf{2 8 4 . 2}$ & $\mathbf{2 8 8 . 2}$ & $\mathbf{2 9 3 . 2}$ & $\mathbf{3 0 3 . 2}$ & $\mathbf{3 1 3 . 3}$ \\
& & & & & \\
44.5 & 45.5 & 49.5 & 54.5 & 64.5 & 74.5 \\
235.3 & 235.3 & 235.3 & 235.3 & 235.3 & 235.3 \\
$\mathbf{2 7 9 . 9}$ & $\mathbf{2 8 0 . 9}$ & $\mathbf{2 8 4 . 9}$ & $\mathbf{2 8 9 . 9}$ & $\mathbf{2 9 9 . 9}$ & $\mathbf{3 0 9 . 8}$ \\
& & & & & \\
$(1.08)$ & $(1.08)$ & $(1.08)$ & $(1.08)$ & $(1.07)$ & $(1.05)$ \\
$(0.23)$ & $(0.23)$ & $(0.23)$ & $(0.23)$ & $(0.22)$ & $(0.22)$ \\
& & & & & \\
& 25.72 & 25.68 & 25.60 & 25.59 & 25.38 \\
& 0.32 & 0.28 & 0.20 & 0.19 & $(0.02)$
\end{tabular}

${ }^{1}$ Relative to price of ultra low sulfur (15 ppm) diesel

The use of up to $30 \mathrm{KBPD}$ of FT diesel in the PADD 3 refinery model did not affect the throughput of any refinery process units. However, the availability of FT diesel allowed a reduction in the severity of the Distillate Hydrotreating Unit, with a resulting decrease in hydrogen consumption, and lower catalyst usage and cost. The operating cost savings indicate that the value of the first $1 \mathrm{KBPD}$ of FT diesel used as a blendstock is $\$ 25.72$ per barrel. The value of the FT diesel slightly declines with increasing availability, as shown in Figure 6.1. The value of the FT diesel falls below the ULSD price of $\$ 25.40$ per barrel when $30 \mathrm{KBPD}$ is used as a blendstock. At this level of availability, the addition of FT diesel reduces the density of the blends of both low sulfur diesel and No. 2 fuel oil to their minimum allowable levels, resulting in less economic process unit operations (e.g. a lower cat cracker conversion rate). 


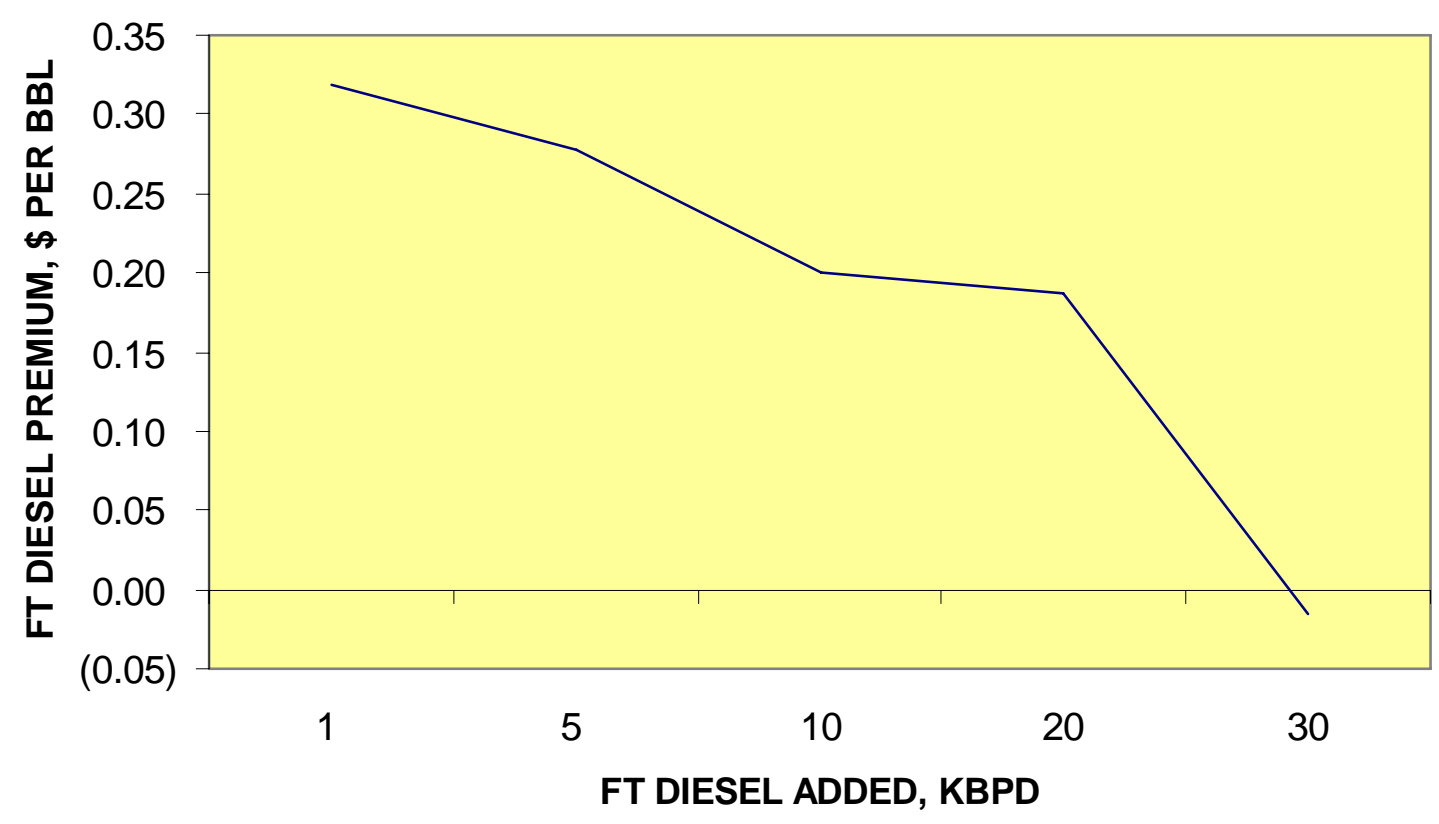

Figure 6.1 PADD 3 Refinery FT Diesel Premium, 2006

\subsection{CASES}

\subsubsection{Representative Base Refinery without FT Diesel}

The LP model was allowed to expand process units in the 2006 Base Refinery and to build any new process units required to meet 2015 specifications in the most economic way. The addition of new process unit capacity was also allowed to meet increased product demand (see Table 6.3) and to cope with a poorer quality crude oil feedstock (see Table 6.2).

The feedstock purchases, refinery production and refinery profitability results for the 2015 PADD 3 Base Case analysis are presented in Table 6.10. The utilized process unit capacities, and changes relative to the 2006 Base Case, are presented in Table 6.11. 
Table 6.10 Representative PADD 3 Refinery Results, 2015 Base Refinery - No FT Diesel

Feedstock Purchases, KBPD

Crude Oil

283.1

Normal Butane

3.0

Iso Butane

7.1

Natural Gas (as Equiv.Fuel Oil)

4.1

FT Diesel

0.0

Total

297.4

Refinery Production, KBPD

Propylene

7.7

LPG

8.1

Unleaded Regular

102.4

Unleaded Premium

21.7

Reformulated Regular

23.5

Reformulated Premium

5.1

Jet Fuel

38.2

Low Sulfur Diesel

49.6

No. 2 Fuel Oil

21.8

Low Sulfur Fuel Oil

0.0

High Sulfur Fuel Oil

11.9

Asphalt

0.0

Fuel Coke, Tons

2,481

Sulfur, Ltons

340

Cat Slurry

1.6

Total

291.5

Key Product Qualities

Diesel Sulfur Content, ppm

7

Diesel Cetane Index

Refinery Profitability, \$ per barrel crude

Product Revenues

30.99

Feedstock Costs

23.96

Gross Margin

7.03

Utility Costs

(1.50)

Cat/Chem Costs

$(0.25)$

Variable Margin

5.28 


\section{Table 6.11 Representative Base PADD 3 Refinery Process Unit Utilizations, 2015 \\ (thousand barrels per calendar day)}

\begin{tabular}{lrrr} 
& & \multicolumn{2}{c}{ Change from 2006 } \\
\cline { 3 - 4 } & $\mathbf{2 0 1 5}$ & KBPD & Percent \\
Crude Distillation & & & \\
Vacuum Distillation & 283.1 & 11.5 & 4.1 \\
Cat Cracking (FCC) & 126.7 & 13.1 & 10.3 \\
Coking & 93.2 & 5.8 & 6.2 \\
VGO Hydrocracking & 42.9 & 8.0 & 18.6 \\
Cat Reforming & 17.0 & 0.0 & 0.0 \\
Kero/Jet Hydrotreating & 50.2 & 0.0 & 0.0 \\
Distillate Hydrotreating & 20.7 & 3.5 & 16.9 \\
Alkylation & 56.1 & 4.1 & 7.3 \\
Gasoline Desulfurization & 23.0 & 4.8 & 21.0 \\
& 54.3 & 3.6 & 6.6
\end{tabular}

As shown, the levels of cat cracking, coking, distillate hydrotreating and alkylation increased by a greater percentage than the increase in crude distillation capacity due to the heavier crude oil slate forecast for 2015 .

\subsubsection{Representative Refinery with FT Diesel}

The impact of introducing FT diesel on the operations of the representative Base 2015 PADD 3 refinery was analyzed for increasing levels of FT diesel availability. For this analysis, the quantity of crude oil processed by the representative refinery was held constant at the same level processed in the base 2015 representative refinery analysis. The refinery's low sulfur diesel production was allowed to vary in accordance with the "Fixed Crude Mix, Crude Feedrate and Floating Diesel Rate" analytical approach described in the Methodology section of this report.

Feedstock purchases, refinery production and refinery operating cost results for the 2015 PADD 3 analyses with FT diesel are presented in Table 6.12. 
Table 6.12 Representative PADD 3 Refinery With FT Diesel, 2015

\begin{tabular}{|c|c|c|c|c|c|c|c|c|}
\hline \multirow{3}{*}{ Feedstock Purchases, KBPD } & \\
\hline & & & & & & & & \\
\hline & 283.1 & 283.1 & 283.1 & 283.1 & 283.1 & 283.1 & 283.1 & 283.1 \\
\hline Normal Butane & 3.0 & 3.0 & 3.0 & 3.0 & 3.0 & 3.0 & 3.1 & 3.8 \\
\hline Iso Butane & 7.1 & 7.1 & 7.1 & 7.1 & 7.0 & 6.9 & 7.0 & 9.1 \\
\hline Natural Gas (as EFO) & 4.1 & 4.1 & 4.1 & 4.1 & 4.1 & 4.1 & 4.1 & 4.1 \\
\hline FT Diesel & 0.0 & 1.0 & 5.0 & 10.0 & 20.0 & 30.0 & 35.0 & 40.0 \\
\hline Total & 297.4 & 298.4 & 302.3 & 307.3 & 317.2 & 327.2 & 332.3 & 340.2 \\
\hline \multicolumn{9}{|l|}{ Refinery Production, KBPD } \\
\hline Low Sulfur Diesel & 49.6 & 50.6 & 54.6 & 59.5 & 69.5 & 79.4 & 84.4 & 89.6 \\
\hline Other Products & 241.9 & 241.9 & 241.9 & 241.9 & 241.9 & 241.9 & 242.0 & 242.7 \\
\hline Total & 291.5 & 292.5 & 296.5 & 301.5 & 311.4 & 321.3 & 326.3 & 332.3 \\
\hline \multicolumn{9}{|l|}{ Operating Costs, \$ per barrel crude } \\
\hline Utility Costs & $(1.70)$ & $(1.50)$ & $(1.50)$ & $(1.49)$ & $(1.48)$ & $(1.49)$ & $(1.48)$ & $(1.38)$ \\
\hline Cat/Chem Costs & $(0.25)$ & $(0.25)$ & $(0.25)$ & $(0.25)$ & $(0.24)$ & $(0.24)$ & $(0.24)$ & $(0.25)$ \\
\hline Additional Capital Costs & $(0.20)$ & $(0.20)$ & $(0.20)$ & $(0.20)$ & $(0.20)$ & $(0.20)$ & $(0.20)$ & $(0.20)$ \\
\hline Value of FT Diesel, \$ per barrel & & 30.69 & 30.69 & 30.68 & 30.68 & 30.56 & 30.47 & 29.74 \\
\hline FT Diesel Premium, \$ per barrel ${ }^{1}$ & & 0.37 & 0.37 & 0.36 & 0.36 & 0.24 & 0.15 & $(0.58)$ \\
\hline
\end{tabular}

The use of up to $30 \mathrm{KBPD}$ of FT diesel in the PADD 3 refinery model for 2015 did not materially affect the throughput of any refinery process units. Therefore, the availability of FT diesel would not reduce the capital cost of additional process unit capacities needed for 2015. However, the availability of FT diesel allowed a reduction in the severity of the Distillate Hydrotreating Unit, with a resulting decrease in hydrogen consumption, and lower catalyst usage and cost. The operating cost savings indicate that the value of the first 1 KBPD of FT diesel used as a blendstock is $\$ 30.69$ per barrel.

The value of the FT diesel slightly declines with increasing availability up to $35 \mathrm{KBPD}$, as shown in Figure 6.2. The value of the FT diesel falls below the ULSD price of $\$ 25.40$ per barrel when more than $35 \mathrm{KBPD}$ is used as a blendstock. At this level of availability, the addition of FT diesel reduces the density of the blends of both low sulfur diesel and No. 2 fuel oil to their minimum allowable levels, resulting in less economic process unit operations (e.g. a lower delayed coker throughput). 


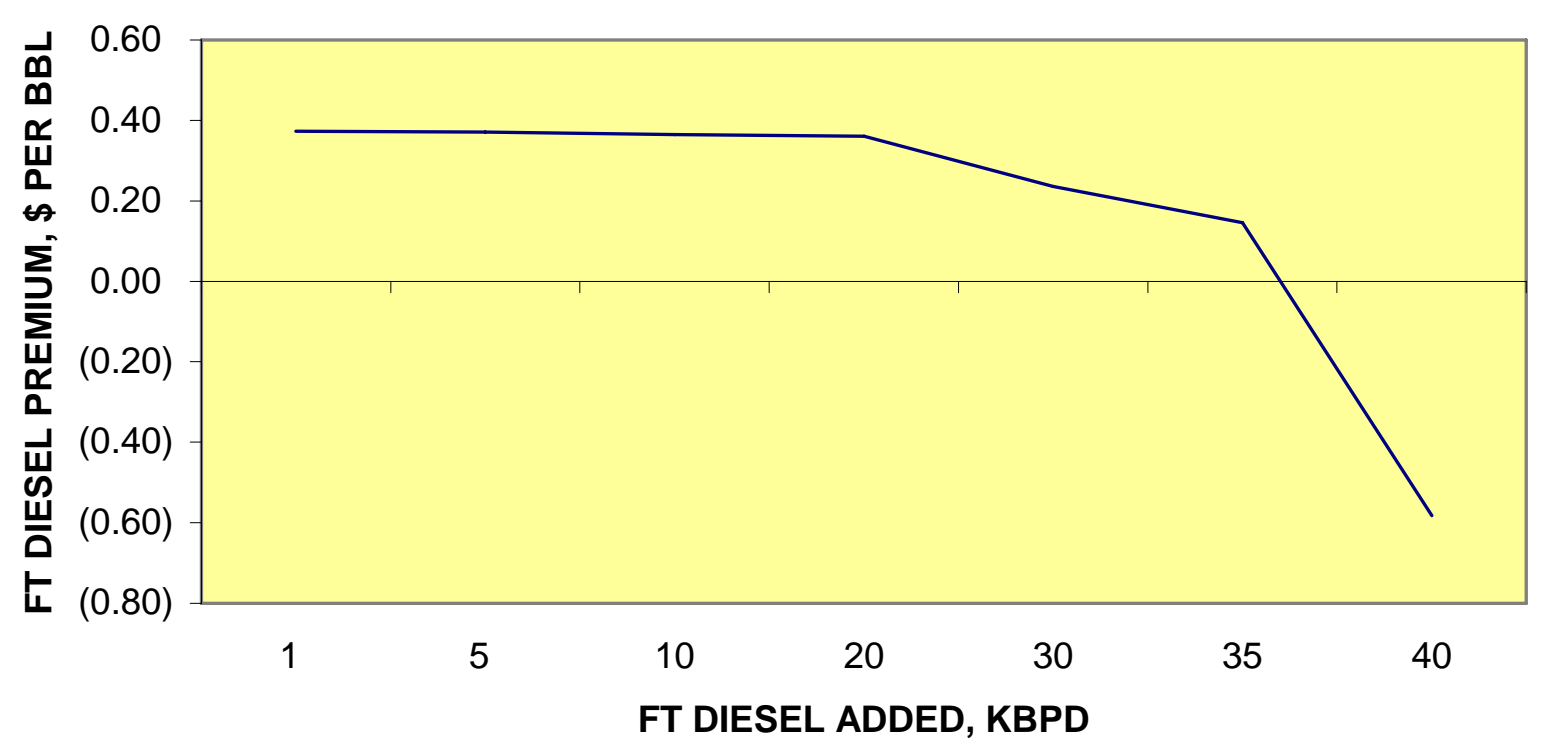

Figure 6.2 PADD 3 Refinery FT Diesel Premium, 2015

\subsubsection{Alternative Diesel Sulfur Specifications}

The value of FT diesel presented in Table 6.12 is based on an assumed maximum sulfur specification of $10 \mathrm{ppm}$ for diesel as sold and a maximum sulfur content of $7 \mathrm{ppm}$ at the refinery gate. The value of FT diesel was also evaluated for two alternative diesel sulfur specifications based on Nexant's Medium Oil Price Outlook and the results are summarized in Table 6.13.

Table 6.13 PADD 3 Refinery FT Diesel Values, 2015 Alternative Diesel Sulfur Specifications

FT Diesel Purchases

ULSD Sulfur Spec=15 ppm ULSD Price

Value of FT Diesel

FT Diesel Premium

ULSD Sulfur Spec=10 ppm

ULSD Price

Value of FT Diesel

FT Diesel Premium

ULSD Sulfur Spec $=\mathbf{5 p m}$

ULSD Price

Value of FT Diesel

FT Diesel Premium
FT Diesel Purchase Cases

\begin{tabular}{cccccccc} 
& \multicolumn{7}{c}{ FT Diesel Purchase Cases } \\
\cline { 2 - 3 } & 1 & 5 & 10 & 20 & 30 & 35 & 40
\end{tabular}

$\begin{array}{lrrrrrrr}\text { \$ per barrel } & 30.19 & 30.19 & 30.19 & 30.19 & 30.19 & 30.19 & 30.19 \\ \text { \$ per barrel } & 30.44 & 30.43 & 30.43 & 30.42 & 30.33 & 30.28 & 29.66 \\ \text { \$ per barrel } & 0.25 & 0.24 & 0.24 & 0.23 & 0.14 & 0.09 & (0.53) \\ & & & & & & & \\ & & & & & & & \\ \text { \$ per barrel } & 30.32 & 30.32 & 30.32 & 30.32 & 30.32 & 30.32 & 30.32 \\ \text { \$ per barrel } & 30.69 & 30.69 & 30.68 & 30.68 & 30.56 & 30.47 & 29.74 \\ \text { \$ per barrel } & 0.37 & 0.37 & 0.36 & 0.36 & 0.24 & 0.15 & (0.58) \\ & & & & & & & \\ & & & & & & & \\ \text { \$ per barrel } & 30.45 & 30.45 & 30.45 & 30.45 & 30.45 & 30.45 & 30.45 \\ \text { \$ per barrel } & 30.69 & 30.69 & 30.68 & 30.68 & 30.60 & 30.53 & 29.81 \\ \text { \$ per barrel } & 0.24 & 0.24 & 0.23 & 0.23 & 0.15 & 0.08 & (0.64)\end{array}$


As shown in Figure 6.11, the value of the first 20 KBPD of FT diesel used in a representative PADD 3 refinery in 2015 is approximately \$30.69 for ULSD sulfur specifications of 5 and 10 ppm, and approximately $\$ 0.25$ per barrel less for an ULSD sulfur specification of $15 \mathrm{ppm}$.

The value of FT diesel is approximately $\$ 0.37$ per barrel above the price of ULSD for an ULSD sulfur specification of $10 \mathrm{ppm}$ reflecting the variable cost of sulfur removal for sulfur contents below $10 \mathrm{ppm}$. Although the value of FT diesel is the same, the FT diesel premium is approximately $\$ 0.13$ per barrel lower for an ULSD sulfur specification of 5 ppm reflecting the higher price assumed for ULSD with this sulfur content. The FT diesel premium is approximately $\$ 0.12$ per barrel lower for an ULSD sulfur specification of $15 \mathrm{ppm}$, reflecting slightly lower variable costs for sulfur removal than were assumed for sulfur contents in the range of $10-20 \mathrm{ppm}$.

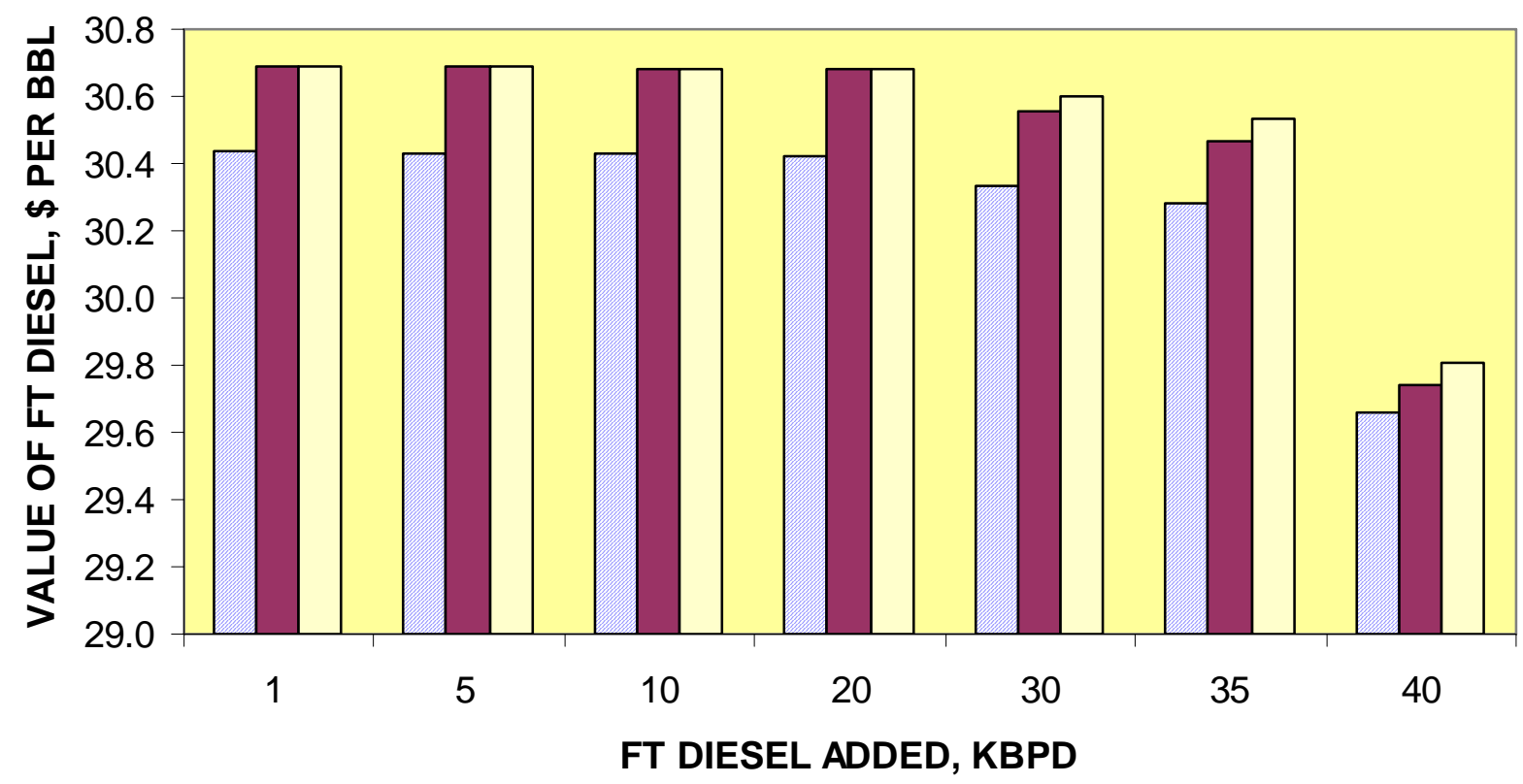

$\square 15$ PPM $\square 10$ PPM $\square 5$ PPM

Figure 6.3 PADD 3 Refinery FT Diesel Values, 2015

Alternative Diesel Sulfur Specifications

\subsubsection{Alternative Crude Oil and Diesel Price Outlooks}

The value of FT diesel presented in Table 6.12 is based on Nexant's Medium Crude Oil Price Outlook. The value of FT diesel for a representative PADD 3 refinery was also evaluated for the High and Low Crude Oil Price Outlooks and the results are summarized in Table 6.14. 


\section{Table 6.14 PADD 3 Refinery FT Diesel Values, 2015 Alternative Crude Oil Price Outlooks}

FT Diesel Purchases

High Crude Oil Pricing

ULSD Price

Value of FT Diesel

FT Diesel Premium

Medium Crude Oil Pricing

ULSD Price

Value of FT Diesel

FT Diesel Premium

Low Crude Oil Pricing

ULSD Price

Value of FT Diesel

FT Diesel Premium

ULSD Sulfur Spec=10 ppm

FT Diesel Purchase Cases

$\begin{array}{lrrrrrrr}\text { Units } & & & & & & & \\ \text { KBPD } & 1 & 5 & 10 & 20 & 30 & 35 & 40 \\ & & & & & & & \\ & & & & & & & \\ \text { \$ per barrel } & 35.93 & 35.93 & 35.93 & 35.93 & 35.93 & 35.93 & 35.93 \\ \text { \$ per barrel } & 36.17 & 36.18 & 36.17 & 36.16 & 36.03 & 35.93 & 35.12 \\ \text { \$ per barrel } & 0.24 & 0.25 & 0.24 & 0.23 & 0.10 & (0.00) & (0.81) \\ & & & & & & & \\ & & & & & & & \\ \text { \$ per barrel } & 30.32 & 30.32 & 30.32 & 30.32 & 30.32 & 30.32 & 30.32 \\ \text { \$ per barrel } & 30.69 & 30.69 & 30.68 & 30.68 & 30.56 & 30.47 & 29.74 \\ \text { \$ per barrel } & 0.37 & 0.37 & 0.36 & 0.36 & 0.24 & 0.15 & (0.58) \\ & & & & & & & \\ \text { \$ per barrel } & 24.63 & 24.63 & 24.63 & 24.63 & 24.63 & 24.63 & 24.63 \\ \text { \$ per barrel } & 24.87 & 24.87 & 24.87 & 24.87 & 24.75 & 24.66 & 24.01 \\ \text { \$ per barrel } & 0.24 & 0.24 & 0.24 & 0.24 & 0.12 & 0.03 & (0.62)\end{array}$

As shown in Figure 6.4, the value of FT diesel for a representative PADD 3 refinery ranges between approximately $\$ 36$ per barrel for the High Crude Oil Price Outlook and approximately $\$ 25$ per barrel for the Low Crude Oil Price Outlook. The value of FT diesel is approximately $\$ 0.3$ per barrel above the price of ULSD with a maximum sulfur content of $10 \mathrm{ppm}$ sulfur for each crude oil price outlook. Therefore, the crude oil price does not have a material effect on the FT diesel premium although the crude oil price heavily influences the absolute value of FT diesel. 


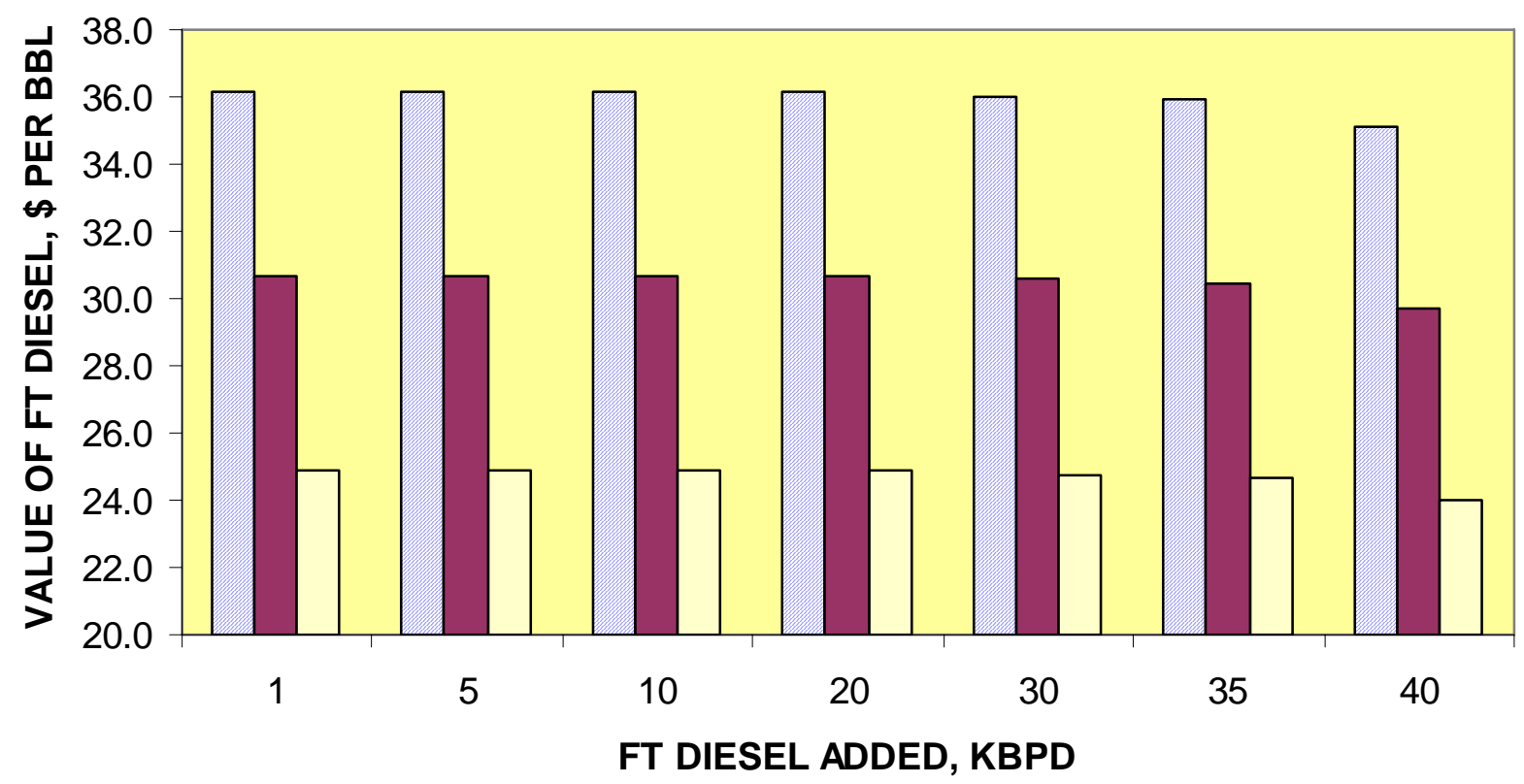

\section{$\square$ HIGH CRUDE $\square$ MEDIUM CRUDE $\square$ LOW CRUDE}

Figure 6.4 PADD 3 Refinery FT Diesel Values, 2015 Alternative Crude Oil Price Outlooks

\subsubsection{Fixed Product Slate}

The value of FT diesel for a representative PADD 3 refinery was also evaluated for a fixed product slate and the results are summarized in Table 6.15. The purpose of this supplemental evaluation was to analyze potential savings in the refinery's capital investments needed to meet the market demand growth between 2006 and 2015 that could be attributed to the availability of FT diesel. In this evaluation, the total volume of crude oil was allowed to float while fixing the production of all major products, including low sulfur diesel, for FT diesel volumes up to 20 KBPD. 
Table 6.15 PADD 3 Refinery FT Diesel Values, 2015

Fixed Product Slate

Feedstock Purchases, KBPD
Crude Oil
Normal Butane
Iso Butane
Natural Gas (as EFO)
FT Diesel
Total

Refinery Production, KBPD

Low Sulfur Diesel

Other Products

Total

Operating Costs, \$ per barrel crude

Utility Costs

Cat/Chem Costs

Additional Capital Costs

Value of FT Diesel, \$ per barrel FT Diesel Premium, $\$$ per barrel ${ }^{1}$
FT Diesel Purchase Cases

\begin{tabular}{rrrrrr}
\hline 281.8 & 281.2 & 277.2 & 273.1 & 271.4 & 264.1 \\
3.0 & 2.8 & 2.8 & 2.8 & 2.3 & 1.7 \\
6.9 & 6.5 & 6.3 & 5.7 & 5.2 & 5.6 \\
4.1 & 4.3 & 4.2 & 4.2 & 4.1 & 5.2 \\
0.0 & 1.0 & 5.0 & 10.0 & 15.0 & 20.0 \\
295.8 & 295.8 & 295.6 & 295.7 & 298.0 & 296.7 \\
& & & & & \\
48.2 & 48.2 & 48.2 & 48.2 & 48.2 & 48.2 \\
241.9 & 241.9 & 241.8 & 241.9 & 244.9 & 242.8 \\
290.1 & 290.1 & 290.0 & 290.1 & 293.1 & 290.9 \\
& & & & & \\
$(1.69)$ & $(1.68)$ & $(1.65)$ & $(1.61)$ & $(1.66)$ & $(2.05)$ \\
$(0.25)$ & $(0.25)$ & $(0.24)$ & $(0.24)$ & $(0.23)$ & $(0.21)$ \\
$(0.19)$ & $(0.18)$ & $(0.15)$ & $(0.14)$ & $(0.17)$ & $(0.20)$ \\
& & & & & \\
& 27.98 & 27.66 & 26.79 & 24.56 & 19.67 \\
& $(2.34)$ & $(2.66)$ & $(3.53)$ & $(5.76)$ & $(10.65)$
\end{tabular}

${ }^{1}$ Relative to price of ultra low sulfur (15 ppm) diesel

The value of the FT diesel based on these assumptions is well above the average cost of the mix of crude oils, which is $\$ 22.8$ per barrel, but is below the ULSD price of $\$ 30.32$ per barrel for all volumes of FT diesel evaluated, as shown in Figure 6.5. In addition, the value of the FT diesel begins to decline sharply when more than 5 KBPD of FT diesel is processed. These results are in line with expectations since reducing crude oil processing reduces the value added potential of a refinery and this reduction must be reflected in the value of any alternative feedstock.

The use of up to $20 \mathrm{KBPD}$ of FT diesel in the PADD 3 refinery model reduces the volume of crude oil processed and the required addition to crude distillation capacity by approximately the volume of FT diesel purchased. As presented in Table 6.16, there are also reductions in the throughput of some refinery process units, such as the cat cracking and gasoline desulfurization units. However, increases in the throughput of other refinery process units, such as the cat reforming unit, are required. 


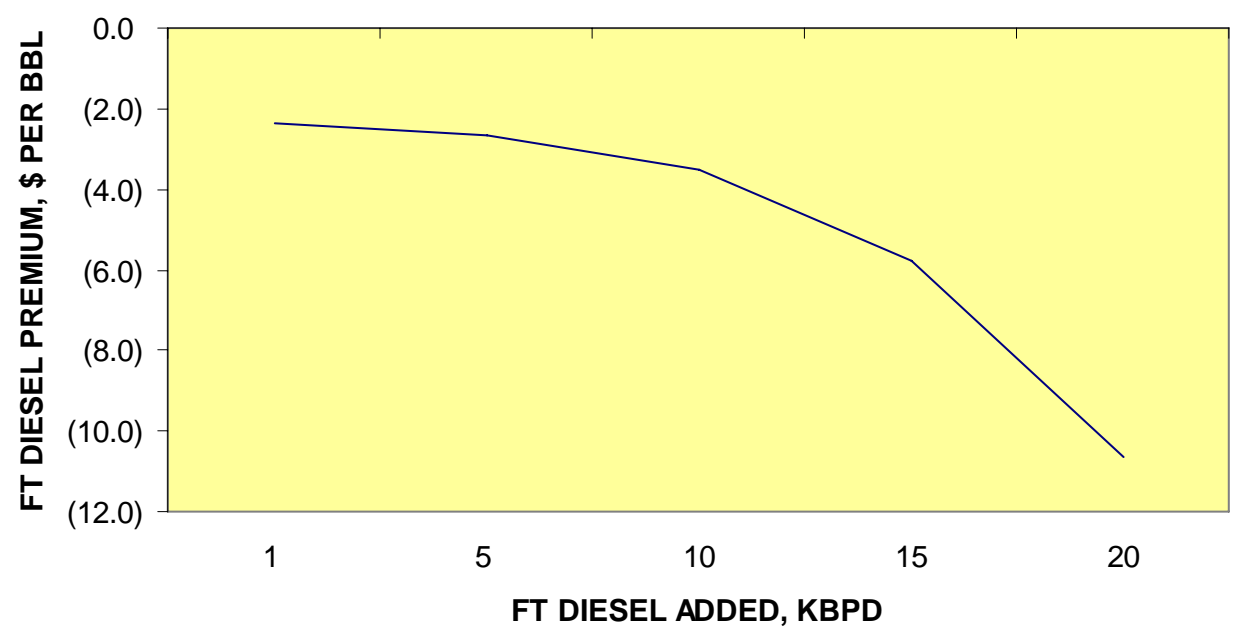

Figure 6.5 PADD 3 Refinery FT Diesel Premium, 2015

Fixed Product Slate

Table 6.16 PADD 3 Refinery Process Unit Utilizations, 2015 Fixed Product Slate

FT Diesel Purchase Cases

FT Diesel Purchases

Process Unit Capacity Utilizations

Crude Distillation

Vacuum Distillation

Cat Reforming

Kero/Jet Hydrotreating

Distillate Hydrotreating

VGO Desulfurization

Coking

VGO Hydrocracking

Cat Cracking (FCC)

Alkylation

C5/C6 Isomerization

Gasoline Desulfurization

$\begin{array}{rrrrrr}281.8 & 281.2 & 277.2 & 273.1 & 271.4 & 264.1 \\ 126.4 & 126.2 & 125.2 & 124.1 & 131.8 & 128.3 \\ 50.6 & 50.6 & 51.7 & 54.8 & 55.4 & 59.8 \\ 20.7 & 20.5 & 20.9 & 22.8 & 23.3 & 19.9 \\ 55.8 & 56.2 & 52.9 & 52.0 & 46.3 & 38.0 \\ 23.0 & 23.0 & 23.0 & 23.0 & 23.0 & 23.0 \\ 42.7 & 42.6 & 42.5 & 41.6 & 43.2 & 44.3 \\ 17.0 & 17.0 & 17.0 & 17.0 & 17.8 & 29.0 \\ 92.5 & 92.0 & 91.0 & 89.2 & 87.4 & 80.0 \\ 22.8 & 22.6 & 22.2 & 21.3 & 20.8 & 20.9 \\ 18.0 & 18.0 & 18.0 & 18.0 & 17.7 & 16.6 \\ 53.9 & 53.6 & 53.1 & 51.0 & 51.0 & 46.4\end{array}$

Results of this analysis indicate that refiners can achieve a significantly higher value for FT diesel by using it to supplement (increase) their diesel production, as opposed to backing out crude oil purchases. 


\subsection{KEY MARKET ASSUMPTIONS}

\subsubsection{Profile of Existing Refineries}

PADD 4 (the Rocky Mountain region) contains 14 refineries at the present time and accounts for only 3 percent of the refinery capacity in the U.S. Its refineries are concentrated in the East Range (Denver/southern Wyoming), Salt Lake City and Billings, Montana. The region is defined by its lower population density, which results in smaller refineries and relatively high product distribution costs.

Table 7.1 presents the combined capacities in 2001 of major process units at the region's refineries. The region's refineries have an average refinery capacity of 38 thousand BPCD and its two largest refineries each have a capacity of 62 thousand BPD.

Table 7.1 PADD 4 PROCESS UNIT CAPACITIES, 2001

(thousand barrels per calendar day)

$\begin{array}{lrr} & \text { Industry Total } & \text { Percent }^{{ }^{1}} \\ \text { Crude Distillation } & 529 & \\ \text { Vacuum Distillation } & 214 & 40.5 \\ \text { Coking } & 42 & 7.9 \\ \text { Cat Cracking (FCC) } & 172 & 32.6 \\ \text { Cat Reforming } & 118 & 22.2 \\ \text { Diesel Hydrotreating } & 162 & 30.6 \\ \text { VGO Desulfurization } & 57 & 10.7 \\ \text { VGO Hydrocracking } & 5 & 0.9 \\ \text { Alkylation } & 37 & 7.0 \\ \text { C5/C6 Isomerization } & 5 & 0.9 \\ \text { Asphalt } & 44 & 8.4 \\ & & \\ { }^{1} \text { Percent of Crude Distillation Capacity } & & \end{array}$

The region's remoteness and its limited product pipeline connections to major refining centers provide physical and economic barriers that afford protection to PADD 4's smaller refineries from competition in surrounding regions.

Diesel production from PADD 4 refineries averaged 145 KBPD during 1999 and 2000, of which $120 \mathrm{KBPD}$ was low sulfur on-highway diesel with a sulfur content less than $500 \mathrm{ppm}$.

\subsubsection{Pricing}

Refinery gate pricing in the PADD 4 region is not reported by the pricing services, such as Platts and OPIS. However, wholesale prices in the region are reported. Under normal market conditions, Denver area wholesale prices average approximately 6 cents per gallon above wholesale prices for product sold on the Gulf Coast. Industry sources have advised that Denver 
area prices for diesel at the refinery gate vary between 5 and 10 cents per gallon above Gulf Coast refinery gate prices. The Denver area premium over Gulf Coast pricing for gasoline is usually a bit higher than the premium for diesel.

Nexant developed the Denver area refinery gate prices used in the PADD 4 analyses based on the above input. These prices are presented in Table 7.2. Their bases are discussed in Report Section IX covering Ultra Clean Fuel Valuations.

\section{Table 7.2 PADD 4 Pricing Assumptions, 2001-2015} Medium Crude Oil Price Scenario

\begin{tabular}{rlr} 
Actual & \multicolumn{2}{c}{ Forecast } \\
2001 & 2006 & 2015
\end{tabular}

\section{Feedstock Pricing}

Crude Oil Mix (Varying Quality)

$\$ / b b l$

$\$ / b b l$

Normal Butane

$\$ / b b l$

Iso Butane

\$/MMBtu

23.2
23.3
24.9
3.5

20.1

20.0

20.5

Natural Gas

3.5

2.2

24.2

\section{Product Pricing}

Propane

$\$ / b b l$

19.7

16.4

19.0

30.1

Unleaded Regular-87

$\$ / b b l$

22.4

36.9

31.7

$\$ / b b l$

39.0

30.7

39.4

28.4

Low Sulfur Diesel-500 ppm

$\$ / b b l$

37.1

29.3

NA

27.5

$\$ / b b l$

35.2

13.2

High Sulfur Fuel Oil (3\%S)

17.2

15.4

19.7

22.8

35.6

36.7

36.5

33.6

34.6

$\$ / b b l$

19.2

32.6

16.2

Asphalt

$\$ / b b l$

NA $=$ Not Applicable 


\subsection{FT DIESEL ANALYSIS}

Shipments of FT diesel to Denver area refineries from the U.S. Gulf Coast using railcars, each holding 700 barrels, would be the only practical way to supply PADD 4 refineries with FT diesel from foreign sources. However, the current transportation cost for such shipments is 17 cents per gallon (\$7.14 per barrel) and terminalling charges in the Gulf Coast could increase the transportation cost by up to 2 cents per gallon.

It was decided not to develop PIMS ${ }^{\mathrm{TM}}$ LP analyses for a representative PADD 4 refinery for this project since logistical considerations and the high transportation costs are likely to prevent the use of foreign-produced FT diesel as a blendstock in PADD 4 refineries. However, a netback analysis was developed and is presented in Table 7.3. This analysis is based on the PADD 4 low sulfur diesel prices presented in Table 7.3 and the results of the LP analyses for other PADDs that indicated the value of FT diesel as a diesel blendstock outside of California is up to $\$ 1$ per barrel above a region's ULSD price.

As shown, despite the high value of FT diesel as a diesel blendstock in PADD 4/Denver area refineries, its value when netted back to the Gulf Coast is approximately $\$ 4$ per barrel less than the forecast Gulf Coast prices for ULSD. Therefore, FT diesel would have a higher value when sold in the much larger (by an order of magnitude) and more liquid Gulf Coast market than it would if transported to a Denver area refinery. The results of the analysis confirm that high transportation costs will prevent the use of foreign-produced FT diesel as a blendstock in PADD 4 refineries.

Table 7.3 FT Diesel Netback Analysis- PADD 4 (current \$ per barrel)

\begin{tabular}{lrr}
\multicolumn{1}{c}{ (current \$ per barrel) } & & \\
& $\mathbf{2 0 0 6}$ & $\mathbf{2 0 1 5}$ \\
& & \\
Low Sulfur Diesel-15 ppm (Denver) & 29.3 & 34.6 \\
Maximum FT Diesel Premium & 1.0 & 1.0 \\
FT Diesel Value (Denver) & $\mathbf{3 0 . 3}$ & $\mathbf{3 5 . 6}$ \\
& $(7.7)$ & $(8.8)$ \\
Transportation to Gulf Coast & $(0.9)$ & $(1.0)$ \\
Terminalling & $\mathbf{2 1 . 7}$ & $\mathbf{2 5 . 8}$ \\
FT Diesel Netback (Gulf Coast) & & \\
& 25.4 & 30.2 \\
Low Sulfur Diesel-15 ppm (Gulf Coast) & & \\
& 3.7 & 4.4
\end{tabular}




\subsection{KEY MARKET ASSUMPTIONS}

\subsubsection{Profile of Existing Refineries}

PADD 5 (the West Coast) contains 35 refineries at the present time and accounts for 19 percent of the refinery capacity in the U.S. Its refineries are concentrated in the Los Angeles, San Francisco and Seattle areas.

The region's 23 largest refineries, each having a capacity greater than 40 thousand BPD, account for 95 percent of the region's refining capacity and are considered to be most representative of its refineries. Thirteen of these larger refineries are in California, with Washington, Alaska and Hawaii having 5, 3 and 2 of these refineries, respectively. Most of the region's smaller refineries are devoted to the production of asphalt. Table 8.1 presents the combined capacities in 2001 of major process units at all refineries in PADD 5.

Table 8.1 PADD 5 Refinery Process Unit Capacities, 2001 (thousand barrels per calendar day)

$\begin{array}{lrr} & \text { Industry Total } & \text { Percent }^{{ }^{1}} \\ \text { Crude Distillation } & 3,157 & \\ \text { Vacuum Distillation } & 1,451 & 46.0 \\ \text { Coking } & 605 & 19.2 \\ \text { Cat Cracking (FCC) } & 783 & 24.8 \\ \text { Cat Reforming } & 555 & 17.6 \\ \text { Diesel Hydrotreating } & 647 & 20.5 \\ \text { VGO Desulfurization } & 463 & 14.7 \\ \text { VGO Hydrocracking } & 579 & 18.3 \\ \text { Alkylation } & 179 & 5.7 \\ \text { C5/C6 Isomerization } & 106 & 3.4 \\ & & \\ { }^{1} \text { Percent of Crude Distillation Capacity } & & \end{array}$

The process unit configurations of PADD 5 refineries outside of California generally include less fuel oil upgrading capabilities and do not include the additional processing facilities needed to produce CARB diesel and gasoline with their more stringent specifications. The high cetane number of FT diesel is expected to make it an attractive blendstock for a California refinery and result in higher values for FT diesel in California than in other parts of PADD 5. The representative PADD 5 refinery considered in the study's PIMS ${ }^{\mathrm{TM}}$ LP analyses was therefore assumed to be a California refinery.

California's largest refineries have catalytic reforming and fluid catalytic cracking (FCC) units and only two of them do not have coking and VGO hydrocracking units. These refineries have an average refinery capacity of 146 thousand BPCD. The representative California refinery considered in the study's PIMS ${ }^{\mathrm{TM}}$ LP analyses was therefore assumed to be capable of 
processing 150 thousand BPCD of crude oil. Table 8.2 presents the combined capacities in 2001 of major process units at all California refineries.

$\begin{array}{lrr}\text { Table 8.2 } & \begin{array}{c}\text { California Refinery Process Unit Capacities, 2001 } \\ \text { (thousand barrels per calendar day) }\end{array} \\ & \\ & \\ & \text { Industry Total } & \text { Percent }{ }^{\text {1 }} \\ \text { Crude Distillation } & 2,012 & \\ \text { Vacuum Distillation } & 1,098 & 54.6 \\ \text { Coking } & 478 & 23.8 \\ \text { Cat Cracking (FCC) } & 634 & 31.5 \\ \text { Cat Reforming } & 393 & 19.5 \\ \text { Diesel Hydrotreating } & 529 & 26.3 \\ \text { VGO Desulfurization } & 463 & 23.0 \\ \text { VGO Hydrocracking } & 493 & 24.5 \\ \text { Alkylation } & 147 & 7.3 \\ \text { C5/C6 Isomerization } & 100 & 5.0 \\ & & \\ { }^{1} \text { Percent of Crude Distillation Capacity } & \end{array}$

\subsubsection{Crude Slate}

California refineries are designed to process heavy, high sulfur crude oils, with Alaskan and Californian crude oils accounting for most of the state's crude oil supplies. Ecuador, Saudi Arabia and Iraq are the major sources of imported crude oils processed in the California refineries. The current and forecast quality for the state's crude oil mix, discussed in more detail in Report Section IV covering United States Regional Fuel Markets, is presented in Table 8.3.

The quality of the crude oil processed by the state's representative refinery in this study was assumed to be equal to the average crude oil quality for the state. The average crude oil quality was achieved in the analyses by blending together several major crude oil streams to approximately match the average API gravity and sulfur content. The calculated average quality of the crude oil blends used in the LP models for this study's analyses are also presented in Table 4.3 . 
Table 8.3 California Refinery Crude Quality, 2000-2015

$\begin{array}{lrrr} & \mathbf{2 0 0 0} & \mathbf{2 0 0 6} & \mathbf{2 0 1 5} \\ \text { Industry Average } & \text { Estimated } & \text { Forecast } & \text { Forecast } \\ \text { API Gravity } & 24.0 & 23.8 & 23.4 \\ \text { Sulfur, wt\% } & 1.32 & 1.35 & 1.41 \\ \text { Model Assumption } & & & \\ \text { API Gravity } & 23.9 & 23.8 & 23.4 \\ \text { Sulfur, wt\% } & 1.32 & 1.35 & 1.40\end{array}$

\subsubsection{Product Slate}

Actual California refinery production in 2000 was used as the basis for establishing the product slate of this study's representative California refinery in 2001 that is presented in Table 8.4. The forecast trends in the region's refinery production, discussed in more detail in Report Section IV covering United States Regional Fuel Markets, were used to establish the product slate of this study's representative California refinery in 2006 and 2015, which are also presented in Table 8.4 . 
Table 8.4 Representative California Refinery Product Slate, 2001-2015

$\begin{array}{lrrr} & \mathbf{2 0 0 1} & \mathbf{2 0 0 6} & \mathbf{2 0 1 5} \\ & & & \\ \text { Production, KBPCD } & & & \\ \text { Propylene } & 1.3 & 1.5 & 1.9 \\ \text { Unleaded Regular } & 5.7 & 5.9 & 6.2 \\ \text { Unleaded Premium } & 1.7 & 1.7 & 1.8 \\ \text { Regular CARB Gasoline } & 70.6 & 73.2 & 77.0 \\ \text { Premium CARB Gasoline } & 20.6 & 21.4 & 22.5 \\ \text { Jet Fuel } & 21.7 & 22.4 & 23.9 \\ \text { Low Sulfur Diesel } & 9.4 & 10.1 & 11.7 \\ \text { CARB Diesel } & 16.1 & 17.2 & 20.0 \\ \text { No. 2 Fuel Oil } & 2.2 & 1.9 & 1.6 \\ \text { High Sulfur Fuel Oil } & 6.6 & 6.5 & 6.4 \\ \text { Asphalt } & 4.0 & 4.1 & 4.3 \\ & & & \\ \text { Volume \% of Crude Oil Processed } & & \\ \text { Propylene } & 0.9 & 1.0 & 1.2 \\ \text { Unleaded Regular } & 3.8 & 3.8 & 3.9 \\ \text { Unleaded Premium } & 1.1 & 1.1 & 1.1 \\ \text { Regular CARB Gasoline } & 47.0 & 46.9 & 48.1 \\ \text { Premium CARB Gasoline } & 13.7 & 13.7 & 14.1 \\ \text { Jet Fuel } & 14.5 & 14.4 & 14.9 \\ \text { Low Sulfur Diesel } & 6.3 & 6.5 & 7.3 \\ \text { CARB Diesel } & 10.7 & 11.0 & 12.5 \\ \text { No. 2 Fuel Oil } & 1.4 & 1.2 & 1.0 \\ \text { High Sulfur Fuel Oil } & 4.4 & 4.2 & 4.0 \\ \text { Asphalt } & 2.7 & 2.6 & 2.7\end{array}$

\subsubsection{Pricing}

The Los Angeles area prices used in the California refinery analyses, whose bases are discussed in Report Section IX covering Ultra Clean Fuel Valuations, are presented in Table 8.5. It should be noted that since the volume and mix of crude oils processed in the study's PIMS ${ }^{\mathrm{TM}}$ LP analyses were fixed, the price of crude oils did not affect the results of the analyses. Similarly, the quantity of all major products produced, except low sulfur diesel, was fixed in the analyses. Therefore, only the CARB diesel price influenced the results of the economic analyses. 


\section{Table 8.5 PADD 5 Pricing Assumptions, 2001-2015 Medium Crude Oil Price Scenario}

\begin{tabular}{|c|c|c|c|c|}
\hline & & \multirow{2}{*}{$\begin{array}{r}\text { Actual } \\
2001\end{array}$} & \multicolumn{2}{|c|}{ Forecast } \\
\hline & & & 2006 & 2015 \\
\hline \multicolumn{5}{|l|}{ Feedstock Pricing } \\
\hline Crude Oil Mix (Varying Quality) & $\$ / b b l$ & 21.5 & 18.2 & 21.8 \\
\hline Normal Butane & $\$ / b b l$ & 23.0 & 15.2 & 18.0 \\
\hline Iso Butane & $\$ / b b l$ & 34.1 & 24.7 & 29.9 \\
\hline MTBE & $\$ / b b l$ & 48.2 & NA & NA \\
\hline Methanol & $\$ / b b l$ & 21.7 & 23.7 & 28.1 \\
\hline Ethanol & $\$ / b b l$ & 38.6 & 34.3 & 40.4 \\
\hline Iso Octane & $\$ / b b l$ & NA & 41.6 & 45.6 \\
\hline Natural Gas & $\$ / M M B t u$ & 4.7 & 3.0 & 3.7 \\
\hline \multicolumn{5}{|l|}{ Product Pricing } \\
\hline Propane & $\$ / b b l$ & 26.2 & 18.8 & 22.6 \\
\hline Normal Butane & $\$ / b b l$ & 22.2 & 14.3 & 16.8 \\
\hline Propylene-Polymer Grade & $\$ / b b l$ & 34.4 & 33.3 & 38.8 \\
\hline Unleaded Regular-87 & $\$ / b b l$ & 36.2 & 31.9 & 36.2 \\
\hline Unleaded Premium-91 & $\$ / b b l$ & 39.5 & 35.1 & 39.3 \\
\hline CARB Regular-87 & $\$ / b b l$ & 39.9 & 34.8 & 38.4 \\
\hline CARB Premium-91 & $\$ / b b l$ & 42.7 & 37.4 & 41.0 \\
\hline Kero/Jet & $\$ / b b l$ & 32.3 & 27.6 & 32.8 \\
\hline Low Sulfur Diesel-500 ppm & $\$ / b b l$ & 32.4 & 26.7 & 31.7 \\
\hline Low Sulfur Diesel-15 ppm & $\$ / b b l$ & NA & 27.6 & 32.7 \\
\hline CARB Diesel-500 ppm & $\$ / b b l$ & 34.2 & 28.8 & 34.1 \\
\hline CARB Diesel-15 ppm & $\$ / b b l$ & NA & 29.3 & 34.6 \\
\hline No. 2 Fuel Oil & $\$ / b b l$ & 30.4 & 24.5 & 28.9 \\
\hline Low Sulfur Fuel Oil (1\%S) & $\$ / b b l$ & 19.3 & 15.7 & 19.0 \\
\hline High Sulfur Fuel Oil (3\%S) & $\$ / b b l$ & 19.6 & 14.6 & 18.0 \\
\hline Asphalt & $\$ / b b l$ & 21.6 & 16.9 & 20.9 \\
\hline Fuel Coke & $\$$ /short ton & 15 & 16 & 19 \\
\hline Sulfur & $\$ /$ ton & 48 & 54 & 68 \\
\hline Cat Slurry & $\$ / b b l$ & 18.6 & 13.5 & 16.6 \\
\hline
\end{tabular}




\subsection{BASE CASE}

Feedstock purchases, refinery production and refinery profitability results for the 2001 California Base Case analysis are presented in Table 8.6.

Table 8.6 Representative California Refinery Results, 2001

$\begin{array}{lr}\text { Feedstock Purchases, KBPD } & \\ \text { Crude Oil } & 150.0 \\ \text { Methanol } & 0.4 \\ \text { MTBE } & 8.9 \\ \text { Normal Butane } & 1.5 \\ \text { Iso Butane } & 0.9 \\ \text { Natural Gas (as Equiv.Fuel Oil) } & 6.0 \\ \text { FT Diesel } & 0.0 \\ \text { Total } & 167.7 \\ & \\ \text { Refinery Production, KBPD } & \\ \text { Propylene } & 1.3 \\ \text { LPG } & 5.3 \\ \text { Unleaded Regular } & 5.7 \\ \text { Unleaded Premium } & 1.7 \\ \text { Reformulated Regular } & 70.6 \\ \text { Reformulated Premium } & 20.6 \\ \text { Jet Fuel } & 21.7 \\ \text { Low Sulfur Diesel } & 9.4 \\ \text { CARB Diesel } & 16.7 \\ \text { No. 2 Fuel Oil } & 2.2 \\ \text { Low Sulfur Fuel Oil } & 0.0 \\ \text { High Sulfur Fuel Oil } & 6.6 \\ \text { Asphalt } & 4.0 \\ \text { Fuel Coke, Tons } & 1,415 \\ \text { Sulfur, Ltons } & 218 \\ \text { Cat Slurry } & 0.0 \\ \text { Total } & 165.7 \\ & \\ \text { Key Product Qualities } & \\ \text { CARB Diesel Sulfur Content, ppm } & 110 \\ \text { CARB Diesel Cetane Index } & 53 \\ & \\ \text { Refinery Profitability, \$ per barrel crude } & \\ \text { Product Revenues } & 40.37 \\ \text { Feedstock Costs } & 25.97 \\ \text { Gross Margin } & 14.39 \\ \text { Utility Costs } & (2.13) \\ \text { Cat/Chem Costs } & (0.22) \\ \text { Variable Margin } & 12.04 \\ & \\ & \end{array}$

Consumption of natural gas has been divided into two categories. Thus, feedstock purchases only include the portion of natural gas purchases used as a hydrogen plant feedstock. Purchased utilities include electricity, water and natural gas used as a refinery fuel. The variable margin is the value of product minus cost of feedstocks (i.e. gross margin) less variable costs for purchased utilities, catalysts and chemicals. 
It is noteworthy that the chemicals cost includes the cost of cetane number improver that must be added to low sulfur diesel production to increase its cetane number enough to comply with the specifications for CARB diesel.

To achieve the processing objective, which is to maximize refinery contribution margin, the LP model adjusts the process unit capacities with only VGO hydrocracking, VGO hydrotreating, Cat Cracking, C5/C6 Isomerization, and MTBE capacities being constrained to approximate actual average levels as a percentage of crude distillation capacity since these units are included in all major California refineries. The utilized process unit capacities are presented in Table 8.7.

\section{Table 8.7 Representative California Refinery Process Unit Utilizations, 2001}

$\begin{array}{lrr} & \begin{array}{c}\text { Thousand Barrels } \\ \text { per Calendar Day }\end{array} & \text { Percent }{ }^{1} \\ \text { Crude Distillation } & 150.0 & \\ \text { Vacuum Distillation } & 88.1 & 58.7 \\ \text { Cat Cracking (FCC) } & 47.0 & 31.3 \\ \text { Coking } & 29.2 & 19.4 \\ \text { VGO Hydrocracking } & 37.0 & 24.7 \\ \text { Cat Reforming } & 37.5 & 25.0 \\ \text { Kero/Jet Hydrotreating } & 16.2 & 10.8 \\ \text { Distillate Hydrotreating } & 17.4 & 11.6 \\ \text { VGO Desulfurization } & 39.3 & 26.2 \\ \text { Alkylation } & 15.9 & 10.6 \\ & & \\ \text { 1 Percent of Crude Distillation Capacity } & & \end{array}$

The results for the Base Case are mainly of interest as a basis for comparison for the 2006 and 2015 analyses, and to confirm that the process configuration of the study's representative California refinery is generally consistent with the actual configuration of the California industry. In this regard, some key comparisons include:

- The levels of cat cracking and VGO hydrocracking for the representative California refinery as a percent of crude distillation capacity are within one percent of their actual average industry values presented in Table 8.2

- The levels of delayed coking, alkylation and middle distillate hydrotreating (i.e., the combined total of kero/jet and distillate hydrotreating) for the representative California refinery as a percent of crude distillation capacity are within four percent of their actual average industry values presented in Table 8.2 


\subsection{CASES}

\subsubsection{Representative Base Refinery without FT Diesel}

Available information on industry plans does not provide any reliable insight into refinery investment and construction that will take place during the period between now and 2006. The LP model was thus allowed to expand process units in the 2001 Base Refinery and to build any new process units required to meet the 2006 specifications in the most economic way. New process unit capacity will also be required to increase refinery production (see Table 8.4 ) and to cope with poorer quality crude oil feedstock (see Table 8.3). It was assumed that the availability of FT diesel would not affect the configuration of the 2006 Base Refinery. As discussed in the Methodology section of this report, this approach reflects the assumption that significant volumes of FT Diesel will not be available to U.S. refiners prior to 2006 and in time for them to alter their capital spending needed to meet product specifications and market conditions in 2006.

The model has the latitude to:

- $\quad$ Add crude distillation capacity and fuel oil conversion capacity, such as FCC and coking capacity

- Increase the percentage of sulfur removed in the distillate desulfurization unit, which would necessitate a revamp of the unit involving the addition of more reactor capacity, catalyst volume, etc.

The feedstock purchases, refinery production and refinery profitability results for the 2006 California Base Case analysis are presented in Table 8.8. The utilized process unit capacities, and changes relative to the 2001 Base Case, are presented in Table 8.9. 
Table 8.8 Representative California Refinery Results, 2006

Base Refinery - No FT Diesel

Feedstock Purchases, KBPD

Crude Oil

155.5

Ethanol

5.6

Normal Butane

1.1

Iso Butane

1.0

Iso Octane

6.3

Natural Gas (as Equiv.Fuel Oil)

6.0

FT Diesel

0.0

Total

175.5

Refinery Production, KBPD

Propylene $\quad 1.5$

LPG $\quad 5.2$

Unleaded Regular $\quad 5.9$

Unleaded Premium $\quad 1.7$

Regular CARB Gasoline $\quad 73.2$

Premium CARB Gasoline $\quad 21.4$

Jet Fuel $\quad 22.4$

Low Sulfur Diesel $\quad 10.7$

CARB Diesel $\quad 18.7$

No. 2 Fuel Oil $\quad 1.9$

Low Sulfur Fuel Oil $\quad 0.0$

High Sulfur Fuel Oil $\quad 6.5$

Asphalt $\quad 4.1$

Fuel Coke, Tons $\quad 1,472$

Sulfur, Ltons $\quad 226$

Cat Slurry $\quad 0.7$

Total $\quad \mathbf{1 7 4 . 0}$

Key Product Qualities

Diesel Sulfur Content, ppm 10

Diesel Cetane Index 53

Refinery Profitability, \$ per barrel crude

Product Revenues $\quad 35.17$

Feedstock Costs $\quad 22.07$

Gross Margin $\quad 13.10$

Utility Costs

Cat/Chem Costs

Variable Margin $\quad 11.03$ 
Table 8.9 Representative Base California Refinery Process Unit Utilizations, 2006

(thousand barrels per calendar day)

\begin{tabular}{lrc} 
& \multicolumn{2}{c}{ Change from } \\
& $\mathbf{2 0 0 6}$ & $\mathbf{2 0 0 1}$ \\
Crude Distillation & 155.5 & \\
Vacuum Distillation & 91.6 & 5.5 \\
Cat Cracking (FCC) & 47.3 & 3.5 \\
Coking & 30.3 & 0.3 \\
VGO Hydrocracking & 37.0 & 1.1 \\
Cat Reforming & 37.8 & 0.0 \\
Kero/Jet Hydrotreating & 15.4 & 0.3 \\
Distillate Hydrotreating & 18.7 & $(0.9)$ \\
Alkylation & 15.9 & 1.3 \\
MTBE & 0.0 & $(0.0)$ \\
Gasoline Desulfurization & 9.8 & $(0.7)$ \\
& & $(0.2)$
\end{tabular}

Highlights of the results include:

- The levels of cat cracking, coking, distillate hydrotreating and VGO Hydrotreating increased in line with the 5.5 KBPCD increase in crude distillation capacity needed to satisfy increased refinery production requirements

- The MTBE unit was shut down to be consistent with the ban on MTBE use in California after 2003. Ethanol was imported as a substitute to satisfy the oxygenates requirement in the CARB gasoline products.

\subsubsection{Representative Refinery with FT Diesel}

The impact of introducing FT diesel on the operations of the representative base 2006 California refinery was analyzed for increasing levels of FT diesel availability. For this analysis, the quantity of crude oil processed by the representative refinery was held constant at the same level processed in the base 2006 representative refinery analysis and the refinery's low sulfur diesel production was allowed to vary. The "Fixed Crude Mix, Crude Feedrate and Floating Diesel Rate" analytical approach used is described in the Methodology section of this report.

The feedstock purchases, refinery production and refinery operating cost results for the 2006 California analyses with FT diesel are presented in Table 8.10. 
Table 8.10 Representative California Refinery With FT Diesel, 2006

\begin{tabular}{|c|c|c|c|c|c|c|c|c|c|}
\hline \multirow{2}{*}{ Feedstock Purchases, KBPD } & \multicolumn{9}{|c|}{ FT Diesel Purchase Cases } \\
\hline & & & & & & & & & \\
\hline Crude Oil & 155.5 & 155.5 & 155.5 & 155.5 & 155.5 & 155.5 & 155.5 & 155.5 & 155.5 \\
\hline Ethanol & 5.6 & 5.6 & 5.6 & 5.6 & 5.6 & 5.6 & 5.6 & 5.6 & 5.6 \\
\hline Normal Butane & 1.1 & 1.1 & 1.1 & 1.2 & 1.1 & 1.1 & 1.2 & 1.1 & 1.1 \\
\hline Iso Butane & 1.0 & 1.0 & 1.0 & 1.0 & 1.0 & 1.0 & 1.0 & 1.0 & 1.0 \\
\hline Iso Octane & 6.3 & 6.3 & 6.2 & 6.4 & 6.2 & 6.2 & 6.4 & 6.2 & 6.2 \\
\hline Natural Gas (as EFO) & 6.0 & 6.0 & 6.0 & 6.0 & 6.0 & 6.0 & 6.0 & 6.0 & 6.0 \\
\hline FT Diesel & 0.0 & 1.0 & 2.0 & 3.0 & 4.0 & 5.0 & 6.0 & 7.0 & 8.0 \\
\hline Total & 175.5 & 176.5 & 177.4 & 178.6 & 179.3 & 180.3 & 181.6 & 182.3 & 183.4 \\
\hline \multicolumn{10}{|l|}{ Refinery Production, KBPD } \\
\hline Low Sulfur Diesel & 10.7 & 10.1 & 10.1 & 10.1 & 10.1 & 10.1 & 10.1 & 10.1 & 10.1 \\
\hline CARB Diesel & 18.7 & 20.3 & 21.2 & 22.4 & 23.1 & 24.1 & 25.5 & 26.1 & 27.2 \\
\hline Other Products & 144.7 & 144.6 & 144.7 & 144.6 & 144.7 & 144.7 & 144.7 & 144.7 & 144.7 \\
\hline Total & 174.0 & 175.0 & 176.0 & 177.2 & 177.9 & 178.9 & 180.2 & 180.9 & 182.0 \\
\hline \multicolumn{10}{|l|}{ Operating Costs, \$ per barrel crude } \\
\hline Utility Costs & $(1.82)$ & $(1.82)$ & $(1.82)$ & $(1.82)$ & $(1.82)$ & $(1.81)$ & $(1.81)$ & $(1.81)$ & (1.81) \\
\hline Cat/Chem Costs & $(0.25)$ & $(0.23)$ & $(0.22)$ & $(0.22)$ & $(0.22)$ & $(0.21)$ & $(0.21)$ & $(0.21)$ & $(0.21)$ \\
\hline Value of FT Diesel, \$ per barrel & & 33.79 & 32.69 & 31.12 & 31.36 & 30.98 & 30.45 & 30.57 & 30.40 \\
\hline FT Diesel Premium, $\$$ per barrel ${ }^{1}$ & & 4.39 & 3.29 & 1.72 & 1.96 & 1.58 & 1.05 & 1.17 & 1.00 \\
\hline
\end{tabular}

The use of up to 8 KBPD of FT diesel in the California refinery model did not affect the throughput of any refinery process units. However, the availability of FT diesel allowed a reduction in the severity of the Distillate Hydrotreating Unit, with a resulting decrease in hydrogen consumption, and lower catalyst usage and cost. In addition, the high cetane number of FT diesel reduced/eliminated cetane number improver usage, resulting in a further reduction in operating costs. The operating cost savings indicate that the value of the first $1 \mathrm{KBPD}$ of FT diesel used as a blendstock is $\$ 33.79$ per barrel, with savings from reduced purchase of the expensive cetane number improver. The value of FT diesel declined rapidly at around the second and third KBPD of FT diesel purchases after no cetane number improver was any longer needed. Subsequent FT diesel purchases still attracted a premium of over $\$ 1$ per barrel (as compared to CARB diesel) due to other operating cost savings, as shown in Figure 8.1. The value of the FT diesel declined to a $\$ 1$ per barrel premium over the CARB price of $\$ 29.40$ per barrel when 8 KBPD was used as a blendstock. At this level of purchases, the addition of FT diesel reduced the density of the blends of both low sulfur diesel and CARB diesel to their minimum allowable levels. Consequently, additional FT diesel decreased the premium over the CARB diesel price since a portion of the FT diesel purchased was used as a blendstock to make the No. 2 Fuel Oil, a lower valued product. 


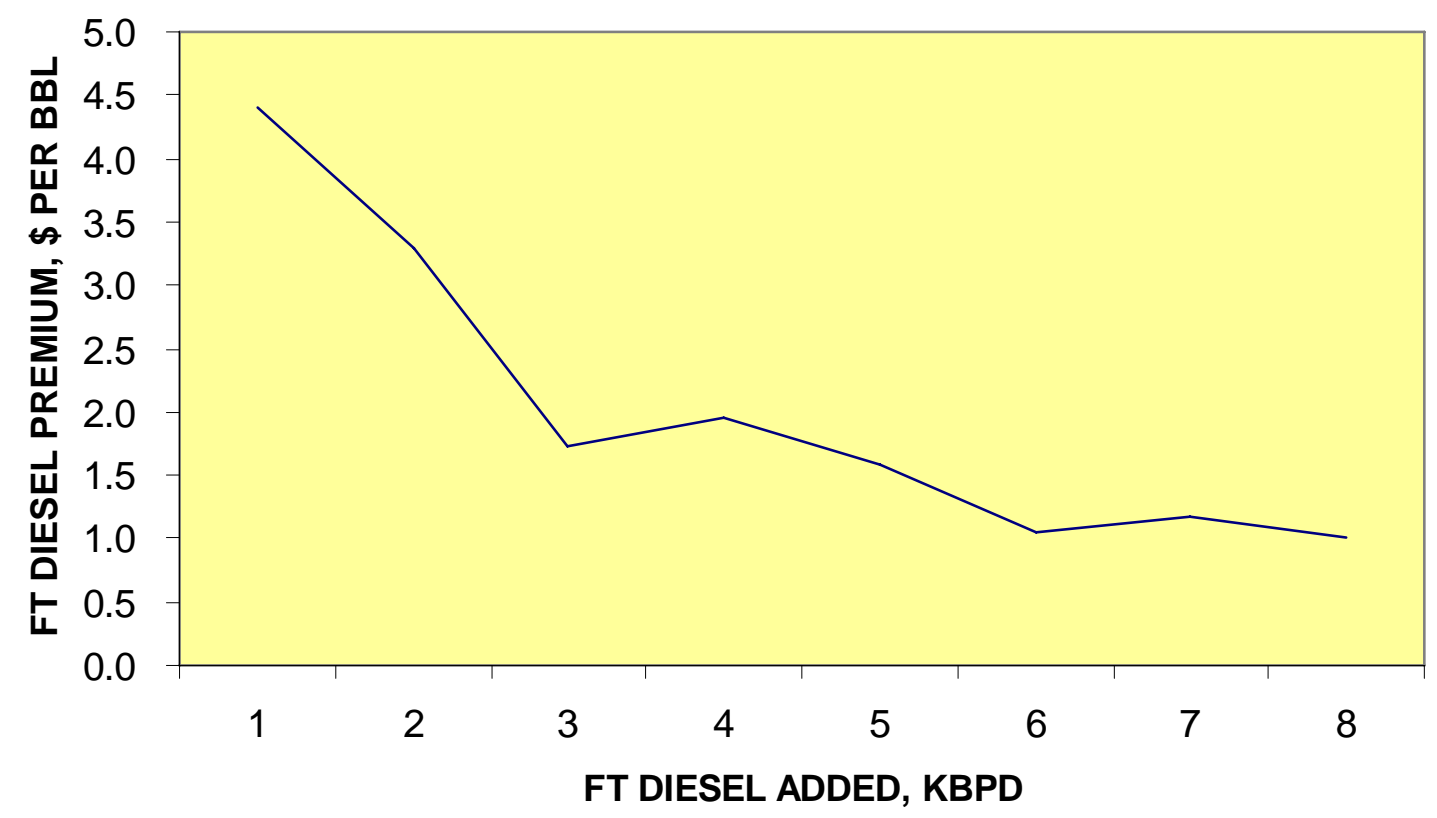

Figure 8.1 California Refinery FT Diesel Premium, 2006

\subsection{CASES}

\subsubsection{Representative Base Refinery without FT Diesel}

The LP model was allowed to expand process units in the 2006 Base Refinery and to build any new process units required to meet 2015 specifications in the most economic way. The addition of new process unit capacity was also allowed to meet increased product demand (see Table 8.4) and to cope with a poorer quality crude oil feedstock (see Table 8.3).

The feedstock purchases, refinery production and refinery profitability results for the 2015 California Base Case analysis are presented in Table 8.11. The utilized process unit capacities, and changes relative to the 2006 Base Case, are presented in Table 8.12. 


\section{Table 8.11 Representative California Refinery Results, 2015} Base Refinery - No FT Diesel

Feedstock Purchases, KBPD

Crude Oil

163.7

Ethanol

5.9

Normal Butane

1.5

Iso Butane

0.0

Iso Octane

7.4

Natural Gas (as Equiv.Fuel Oil)

FT Diesel

6.5

Total

0.0

Refinery Production, KBPD

Propylene

184.9

LPG

1.9

Unleaded Regular

5.6

Unleaded Premium

6.2

Regular CARB Gasoline

1.8

Premium CARB Gasoline

77.0

Jet Fuel

22.5

Low Sulfur Diesel

23.9

CARB Diesel

11.7

20.0

No. 2 Fuel Oil

1.6

Low Sulfur Fuel Oil

0.0

High Sulfur Fuel Oil

6.4

Asphalt

4.3

Fuel Coke, Tons

1,712

Sulfur, Ltons

254

Cat Slurry

0.0

Total

182.9

Key Product Qualities

Diesel Sulfur Content, ppm

Diesel Cetane Index

Refinery Profitability, \$ per barrel crude

Product Revenues

39.97

Feedstock Costs

26.34

Gross Margin

13.63

Utility Costs

(2.54)

Cat/Chem Costs

(0.26)

Variable Margin

10.83 


\section{Table 8.12 Representative Base California Refinery Process Unit Utilizations, 2015 \\ (thousand barrels per calendar day)}

\begin{tabular}{lrrr} 
& & \multicolumn{2}{c}{ Change from 2006 } \\
\cline { 3 - 4 } & $\mathbf{2 0 1 5}$ & KBPD & Percent \\
Crude Distillation & & & \\
Vacuum Distillation & 163.7 & 5.2 & 5.0 \\
Cat Cracking (FCC) & 97.2 & 5.6 & 5.8 \\
Coking & 49.9 & 2.6 & 5.2 \\
VGO Hydrocracking & 34.3 & 4.0 & 11.5 \\
Cat Reforming & 37.0 & 0.0 & 0.0 \\
Kero/Jet Hydrotreating & 39.1 & 1.2 & 3.2 \\
Distillate Hydrotreating & 16.2 & 0.9 & 5.3 \\
Alkylation & 20.2 & 1.5 & 7.2 \\
Gasoline Desulfurization & 16.1 & 0.2 & 1.4 \\
& 9.4 & 0.0 & 0.0
\end{tabular}

As shown, the levels of cat cracking, coking and distillate hydrotreating increased by a greater percentage than the increase in crude distillation capacity due to the heavier crude oil slate forecast for 2015 .

\subsubsection{Representative Refinery with FT Diesel}

The impact of introducing FT diesel on the operations of the representative Base 2015 California refinery was analyzed for increasing levels of FT diesel availability. For this analysis, the quantity of crude oil processed by the representative refinery was held constant at the same level processed in the base 2015 representative refinery analysis. The refinery's low sulfur diesel production was allowed to vary in accordance with the "Fixed Crude Mix, Crude Feedrate and Floating Diesel Rate" analytical approach described in the Methodology section of this report.

Feedstock purchases, refinery production and refinery operating cost results for the 2015 California analyses with FT diesel are presented in Table 8.13. 
Table 8.13 Representative California Refinery With FT Diesel, 2015

\begin{tabular}{|c|c|c|c|c|c|c|c|c|c|}
\hline \multirow{2}{*}{\multicolumn{10}{|c|}{ Feedstock Purchases, KBPD }} \\
\hline & & & & & & & & & \\
\hline Crude Oil & 163.7 & 163.7 & 163.7 & 163.7 & 163.7 & 163.7 & 163.7 & 163.7 & 163.7 \\
\hline Ethanol & 5.9 & 5.8 & 5.9 & 5.9 & 5.8 & 5.8 & 5.8 & 5.9 & 5.9 \\
\hline Normal Butane & 1.5 & 1.5 & 1.5 & 1.5 & 1.5 & 1.5 & 1.5 & 1.5 & 1.5 \\
\hline Iso Butane & 0.0 & 0.0 & 0.0 & 0.0 & 0.0 & 0.0 & 0.0 & 0.0 & 0.5 \\
\hline Iso Octane & 7.4 & 7.2 & 7.1 & 7.2 & 7.2 & 7.2 & 7.6 & 7.7 & 7.7 \\
\hline Natural Gas (as EFO) & 6.5 & 6.5 & 6.5 & 6.5 & 6.5 & 6.5 & 6.5 & 6.5 & 6.4 \\
\hline FT Diesel & 0.0 & 1.0 & 3.0 & 5.0 & 7.0 & 9.0 & 12.0 & 15.0 & 18.0 \\
\hline Total & 184.9 & 185.7 & 187.7 & 189.7 & 191.7 & 193.7 & 197.2 & 200.3 & 203.7 \\
\hline \multicolumn{10}{|l|}{ Refinery Production, KBPD } \\
\hline Low Sulfur Diesel & 11.7 & 11.7 & 11.7 & 11.7 & 11.7 & 11.7 & 11.7 & 11.7 & 11.7 \\
\hline CARB Diesel & 20.0 & 20.7 & 22.6 & 24.7 & 26.7 & 28.7 & 32.3 & 35.5 & 38.0 \\
\hline Other Products & 151.2 & 151.2 & 151.2 & 151.2 & 151.2 & 151.2 & 151.2 & 151.1 & 151.0 \\
\hline Total & 182.9 & 183.7 & 185.6 & 187.6 & 189.6 & 191.6 & 195.2 & 198.3 & 200.7 \\
\hline \multicolumn{10}{|l|}{ Operating Costs, \$ per barrel crude } \\
\hline Utility Costs & $(2.54)$ & $(2.53)$ & (2.54) & (2.53) & $(2.53)$ & $(2.53)$ & $(2.52)$ & $(2.51)$ & (2.53) \\
\hline Cat/Chem Costs & $(0.26)$ & $(0.25)$ & $(0.23)$ & $(0.23)$ & $(0.23)$ & $(0.23)$ & $(0.22)$ & $(0.23)$ & $(0.24)$ \\
\hline Value of FT Diesel, \$ per barrel & & 37.93 & 36.64 & 36.41 & 35.96 & 35.68 & 35.53 & 35.24 & 32.55 \\
\hline FT Diesel Premium, $\$$ per barrel ${ }^{1}$ & & 3.23 & 1.94 & 1.71 & 1.26 & 0.98 & 0.83 & 0.54 & $(2.15)$ \\
\hline
\end{tabular}

The use of up to $18 \mathrm{KBPD}$ of FT diesel in the California refinery model for 2015 did not materially affect the throughput of any refinery process units. Therefore, the availability of FT diesel would not reduce the capital cost of additional process unit capacities needed for 2015. However, the availability of FT diesel allowed a reduction in the severity of the Distillate Hydrotreating Unit, with a resulting decrease in hydrogen consumption, and lower catalyst usage and cost. In addition, the high cetane number of FT diesel reduced/eliminated cetane number improver usage, resulting in a further reduction in operating costs. The operating cost savings indicate that the value of the first $1 \mathrm{KBPD}$ of FT diesel used as a blendstock is $\$ 37.93$ per barrel.

The value of the FT diesel declined with increasing availability up to $18 \mathrm{KBPD}$, as shown in Figure 8.2. The value of the FT diesel fell below the CARB diesel price of $\$ 34.60$ per barrel when more than 15 KBPD was used as a blendstock. At this level of availability, the addition of FT diesel reduced the density of the blends of both CARB diesel and low sulfur diesel to their minimum allowable levels, hence forcing the additional FT diesel into No. 2 fuel oil production/blending. Consequently, the premium for FT diesel declined as it did in the 2006 Cases presented above. 


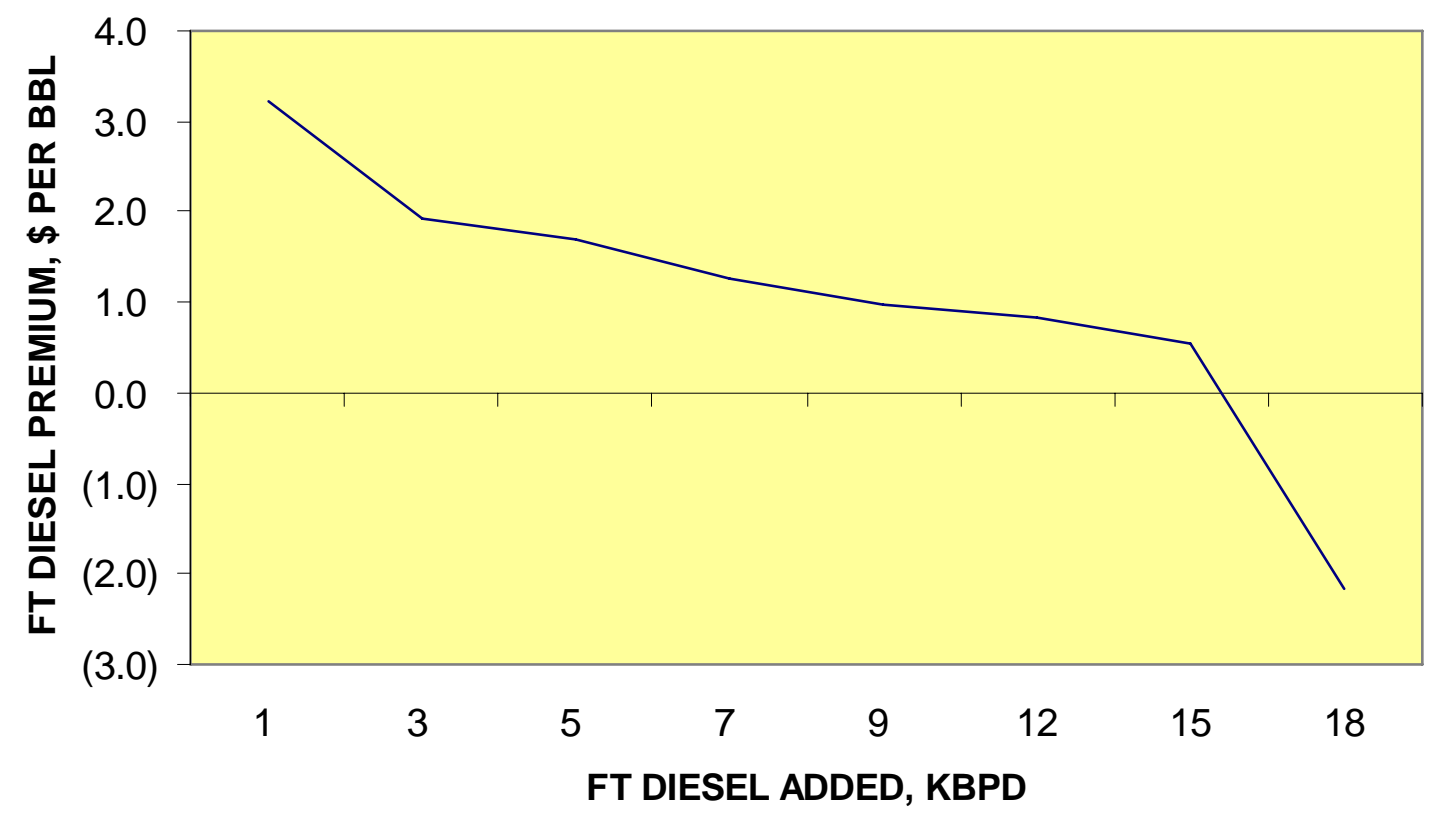

Figure 8.2 California Refinery FT Diesel Premium, 2015

\subsubsection{Fixed Product Slate}

The value of FT diesel for a representative California refinery was also evaluated for a fixed product slate and the results are summarized in Table 8.14. The purpose of this supplemental evaluation was to analyze potential savings in the refinery's capital investments needed to meet the market demand growth between 2006 and 2015 that could be attributed to the availability of FT diesel. In this evaluation, the total volume of crude oil was allowed to float while fixing the production of all major products, including low sulfur diesel, for FT diesel volumes up to 12 KBPD. 


\section{Table 8.14 California Refinery FT Diesel Values, 2015} Fixed Product Slate

\begin{tabular}{|c|c|c|c|c|c|c|c|c|}
\hline \multirow{3}{*}{ Feedstock Purchases, KBPD } & \\
\hline & & & & & & & & \\
\hline & 164.6 & 163.9 & 162.8 & 161.7 & 159.2 & 157.1 & 154.9 & 151.2 \\
\hline Ethanol & 5.9 & 5.9 & 5.9 & 5.9 & 5.9 & 5.9 & 5.8 & 5.9 \\
\hline Normal Butane & 1.5 & 1.5 & 1.5 & 1.5 & 1.4 & 1.5 & 1.5 & 1.5 \\
\hline Iso Butane & 0.0 & 0.0 & 0.0 & 0.0 & 0.0 & 0.0 & 0.0 & 0.0 \\
\hline Iso Octane & 6.7 & 6.3 & 6.3 & 6.3 & 6.8 & 6.6 & 6.8 & 7.7 \\
\hline Natural Gas (as EFO) & 6.5 & 6.5 & 6.5 & 6.5 & 6.4 & 6.4 & 6.3 & 6.2 \\
\hline FT-Diesel & 0.0 & 1.0 & 2.0 & 3.0 & 5.0 & 7.0 & 9.0 & 12.0 \\
\hline Total & 185.2 & 185.0 & 184.9 & 184.8 & 184.7 & 184.5 & 184.3 & 184.5 \\
\hline \multicolumn{9}{|l|}{ Refinery Production, KBPD } \\
\hline Low Sulfur Diesel & 11.7 & 11.7 & 11.7 & 11.7 & 11.7 & 11.7 & 11.7 & 11.7 \\
\hline CARB Diesel & 20.0 & 20.0 & 20.0 & 20.0 & 20.0 & 20.0 & 20.0 & 20.0 \\
\hline Other Products & 151.3 & 151.3 & 151.3 & 151.3 & 151.2 & 151.2 & 151.2 & 150.9 \\
\hline Total & 183.0 & 183.0 & 183.0 & 183.0 & 182.9 & 182.9 & 182.9 & 182.6 \\
\hline \multicolumn{9}{|l|}{ Operating Costs, $\$$ per barrel crude } \\
\hline Utility Costs & $(2.78)$ & $(2.80)$ & $(2.77)$ & $(2.73)$ & $(2.59)$ & $(2.56)$ & $(2.50)$ & $(2.45)$ \\
\hline Cat/Chem Costs & $(0.26)$ & $(0.25)$ & $(0.24)$ & $(0.23)$ & $(0.23)$ & $(0.22)$ & $(0.23)$ & $(0.23)$ \\
\hline Additional Capital Costs & $(0.27)$ & $(0.25)$ & $(0.23)$ & $(0.20)$ & $(0.13)$ & $(0.09)$ & $(0.05)$ & $(0.10)$ \\
\hline Value of FT Diesel, \$ per barrel & & 35.43 & 34.91 & 34.95 & 33.57 & 32.62 & 32.11 & 27.94 \\
\hline FT Diesel Premium, $\$$ per barrel ${ }^{1}$ & & 0.73 & 0.21 & 0.25 & $(1.13)$ & $(2.08)$ & $(2.59)$ & $(6.76)$ \\
\hline
\end{tabular}

${ }^{1}$ Relative to price of ultra low sulfur (10 ppm) CARB diesel

The value of the FT diesel based on these assumptions is well above the average cost of the mix of crude oils, which is $\$ 21.8$ per barrel, and is slightly over the CARB diesel price of $\$ 34.6$ per barrel for up to $3 \mathrm{KBPD}$ of FT diesel purchased, as shown in Figure 8.3. However, the value of the FT diesel begins to decline sharply when more than 5 KBPD of FT diesel is processed. These results are in line with expectations since reducing crude oil processing reduces the value added potential of a refinery and this reduction must be reflected in the value of any alternative feedstock.

The use of up to $12 \mathrm{KBPD}$ of FT diesel in the California refinery model reduced the volume of crude oil processed and the required addition to crude distillation capacity by approximately the volume of FT diesel purchased. As presented in Table 8.15, there are also reductions in the throughput of some refinery process units, such as the cat cracking, distillate hydrotreating, and coking units. However, increases in the throughput of other refinery process units, such as the cat reforming unit, are required. 


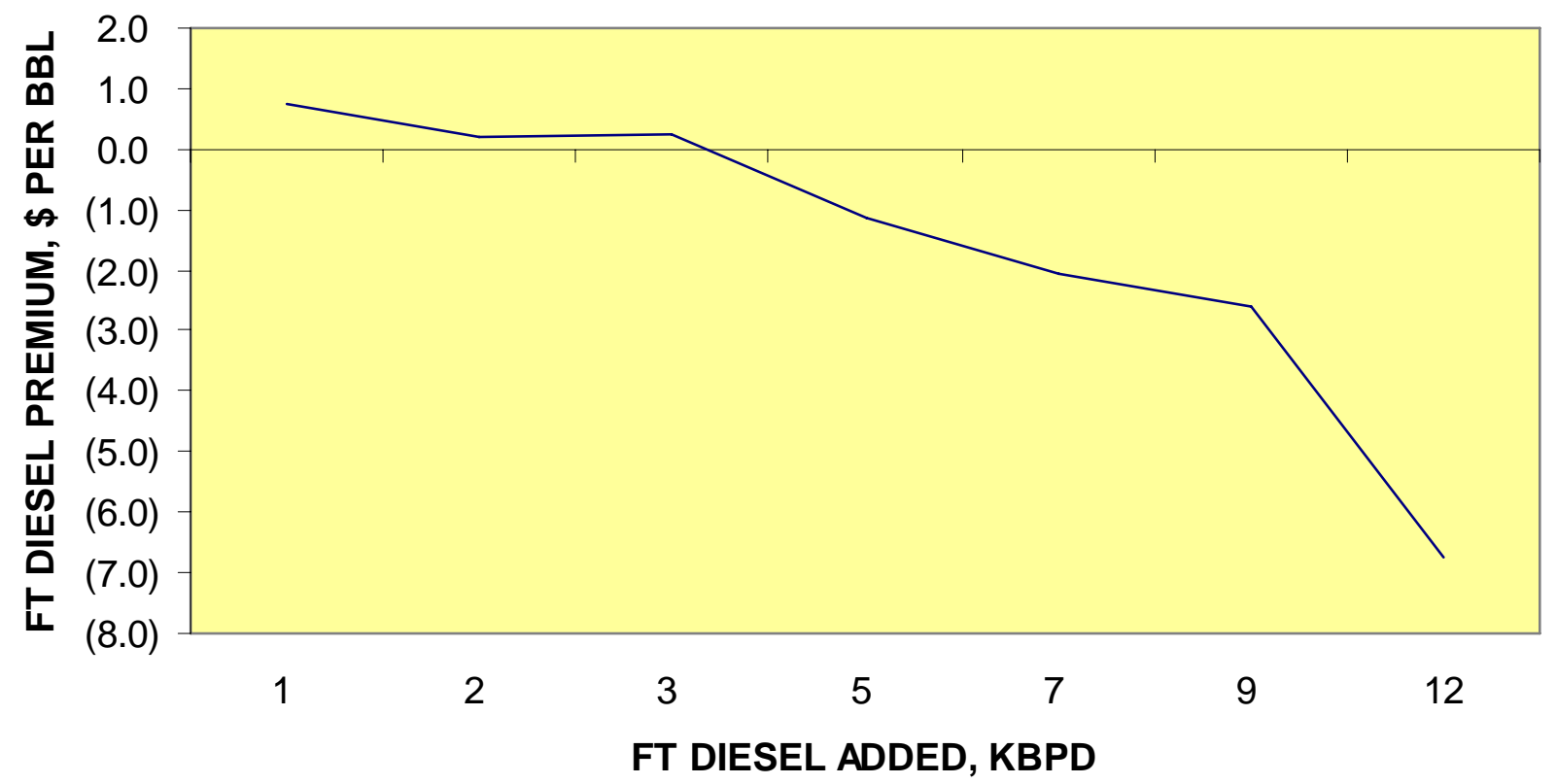

Figure 8.3 California Refinery FT Diesel Premium, 2015

Fixed Product Slate

Table 8.15 California Refinery Process Unit Utilizations, 2015 Fixed Product Slate

\begin{tabular}{rrrrrrrr}
\multicolumn{7}{c}{ FT Diese I Purchase Case } \\
\hline 0 & 1 & 2 & 3 & 5 & 7 & 9 & 12 \\
& & & & & & & \\
164.6 & 163.9 & 162.8 & 161.7 & 159.2 & 157.1 & 154.9 & 151.2 \\
97.8 & 97.4 & 96.7 & 96.0 & 94.6 & 93.3 & 92.0 & 89.8 \\
39.8 & 39.7 & 39.8 & 39.7 & 40.1 & 40.2 & 40.4 & 41.5 \\
16.2 & 16.2 & 16.2 & 16.2 & 16.2 & 16.2 & 16.2 & 9.9 \\
20.4 & 20.1 & 19.8 & 19.7 & 19.2 & 18.6 & 18.2 & 15.5 \\
45.3 & 45.1 & 44.7 & 44.2 & 42.7 & 42.3 & 41.7 & 45.4 \\
34.5 & 34.3 & 34.0 & 33.7 & 33.1 & 32.5 & 31.9 & 30.9 \\
37.0 & 37.0 & 37.0 & 37.0 & 37.0 & 37.0 & 37.0 & 34.9 \\
50.3 & 50.8 & 50.7 & 50.6 & 49.4 & 49.6 & 49.3 & 47.8 \\
16.2 & 16.4 & 16.4 & 16.4 & 16.0 & 16.1 & 16.1 & 15.1 \\
3.0 & 3.3 & 3.2 & 3.2 & 2.9 & 2.9 & 2.9 & 2.4 \\
9.5 & 10.0 & 10.0 & 10.0 & 10.0 & 10.0 & 10.0 & 10.3
\end{tabular}

Results of this analysis indicate that refiners can achieve a significantly higher value for FT diesel by using it to supplement (increase) their diesel production, as opposed to backing out crude oil purchases. 
The analysis performed in this section has examined the potential impact of FT diesel fuel on U.S. refining operations. Key findings include the following:

\section{Upside Potential of FT Diesel Value}

The study analysis was structured to evaluate refinery configurations that were deemed to be representative of average refining industry operation and structure in key regions of the United States. Therefore, the results of this analysis should be considered from this perspective, as average representative values for FT diesel. However, it should be recognized that the value of FT diesel for some specific refineries, especially those producing diesel with a cetane number close to the minimum specified level, may be higher than those estimated in this analysis.

\section{Impact of FT Diesel on Refinery Operations}

- Using FT diesel as a diesel blendstock, in small volumes, is expected to have little impact on refinery process unit operations in 2006 and beyond. The primary reason for this conclusion is that FT diesel quality is very close to finished ULSD product quality specs (i.e., 15 ppm sulfur specification) and, the stream can be used directly as a blendstock without processing by refinery unit

- The primary processing impact on refining operations of blending of FT Diesel was a reduction in required Distillate Hydrotreater desulfurization severity, which resulted in lower hydrogen usage and lower catalyst and utilities costs

- For each refinery operation considered, the initial volumes of FT diesel blended generate the highest value to the refiner. As the volume of FT diesel blended increases, the refinery must begin to make processing adjustments in order to make on-specification diesel product. These adjustments are required to compensate for the low density of FT diesel, and the value of the FT diesel declines at these higher blend rates

- $\quad$ For each region considered, FT diesel value to refineries is attractive only at relatively low blending levels, typically in the range of 4-5 percent of crude oil processed. Thereafter FT diesel values decline rapidly and eventually fall below the value of conventional diesel fuels

\section{Value of FT Diesel Relative to Market Value}

- Even though there is currently little commercially available, FT diesel, primarily due to its very low sulfur content, would command a premium value to conventional $500 \mathrm{ppm}$ diesel fuel. There will continue to be a premium value over the next 15 years, but the size of the premium will decline as the quality differential between FT diesel and conventional diesel declines 


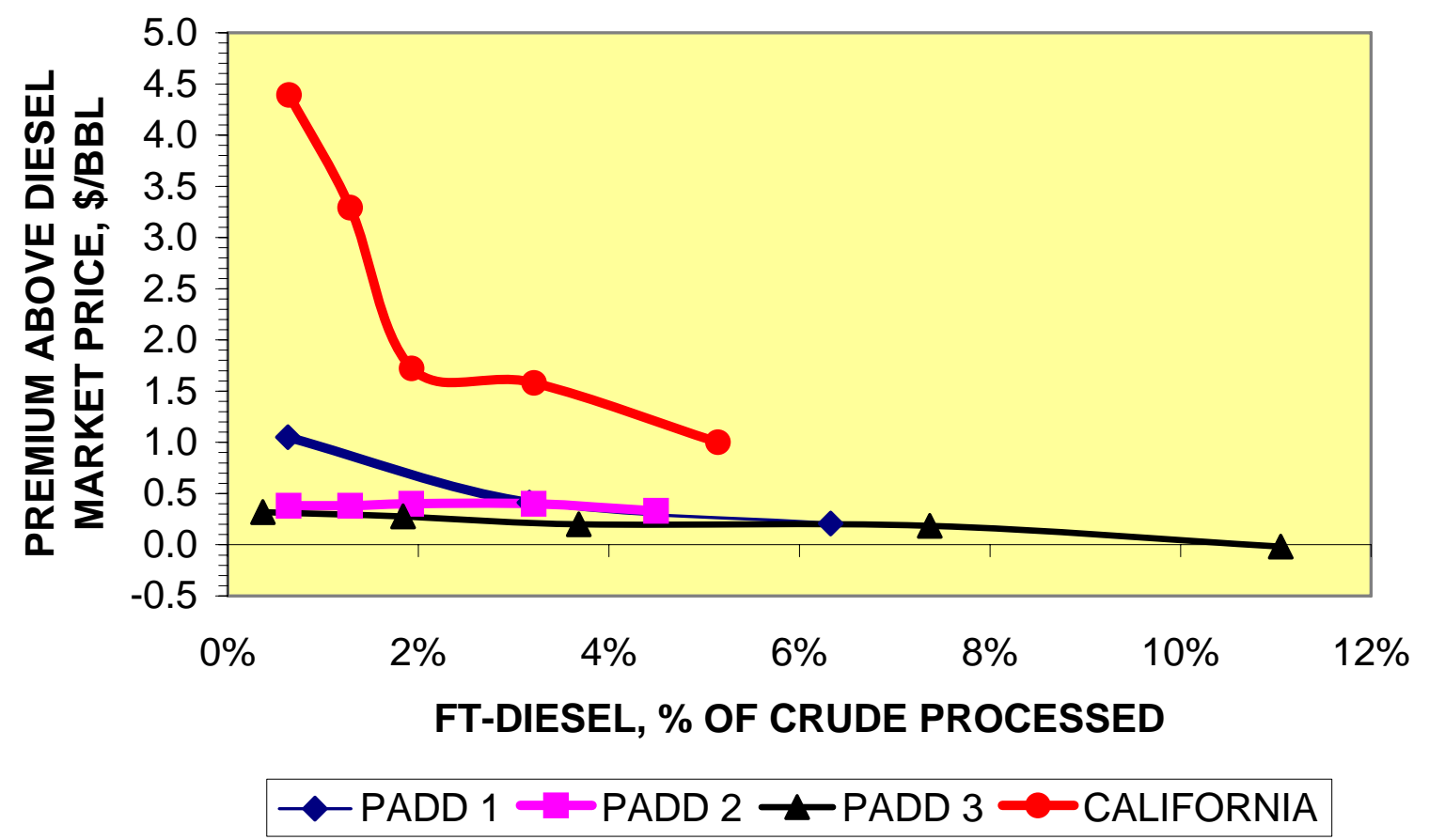

Figure 9.1 VALUE OF FT DIESEL TO U.S. REFINERS - 2006

- $\quad$ Based on the analysis performed for this study, PADD 3 (USGC), due to the highly competitive nature of the region, achieved the lowest values in major markets for FT diesel relative to conventional diesel fuels. For blending up to $4-5$ percent, the value of FT diesel was estimated to be about $\$ .40 / \mathrm{bbl}$ above the market price of diesel

- $\quad$ As shown in Figure 9.1, PADDs 1 (East Coast) and 2 (Midwest) achieved somewhat higher values for FT diesel than PADD 3. For blending up to 4-5 percent, the value of FT diesel was estimated to be about $\$ .40-0.50 / \mathrm{bbl}$ above the market price of diesel

- The California market achieved the highest value for FT diesel, reflecting the value associated with FT diesel's high cetane rating, which is a premium quality in the California market. For blending up to 2 percent, the value of FT diesel was estimated to be over $\$ 3.00 / \mathrm{bbl}$ above the market price of diesel. This premium declined to about $\$ 1.00 / \mathrm{bbl}$ at a blending level of 5 percent of crude processed

\section{FT Diesel Absolute Value}

- The value of FT diesel in absolute terms will reflect the price of conventional diesel plus the premium value of FT diesel to each region's refining industry 
- $\quad$ As shown in Figure 9.2, the lowest absolute value for FT diesel is expected in PADD 3 (USGC), primarily reflecting the low market price for conventional diesel as well as low estimated premium for FT diesel

- Somewhat higher absolute values for FT diesel are expected for PADDs 2 and 3, largely reflecting the higher market price for conventional diesel that these markets command

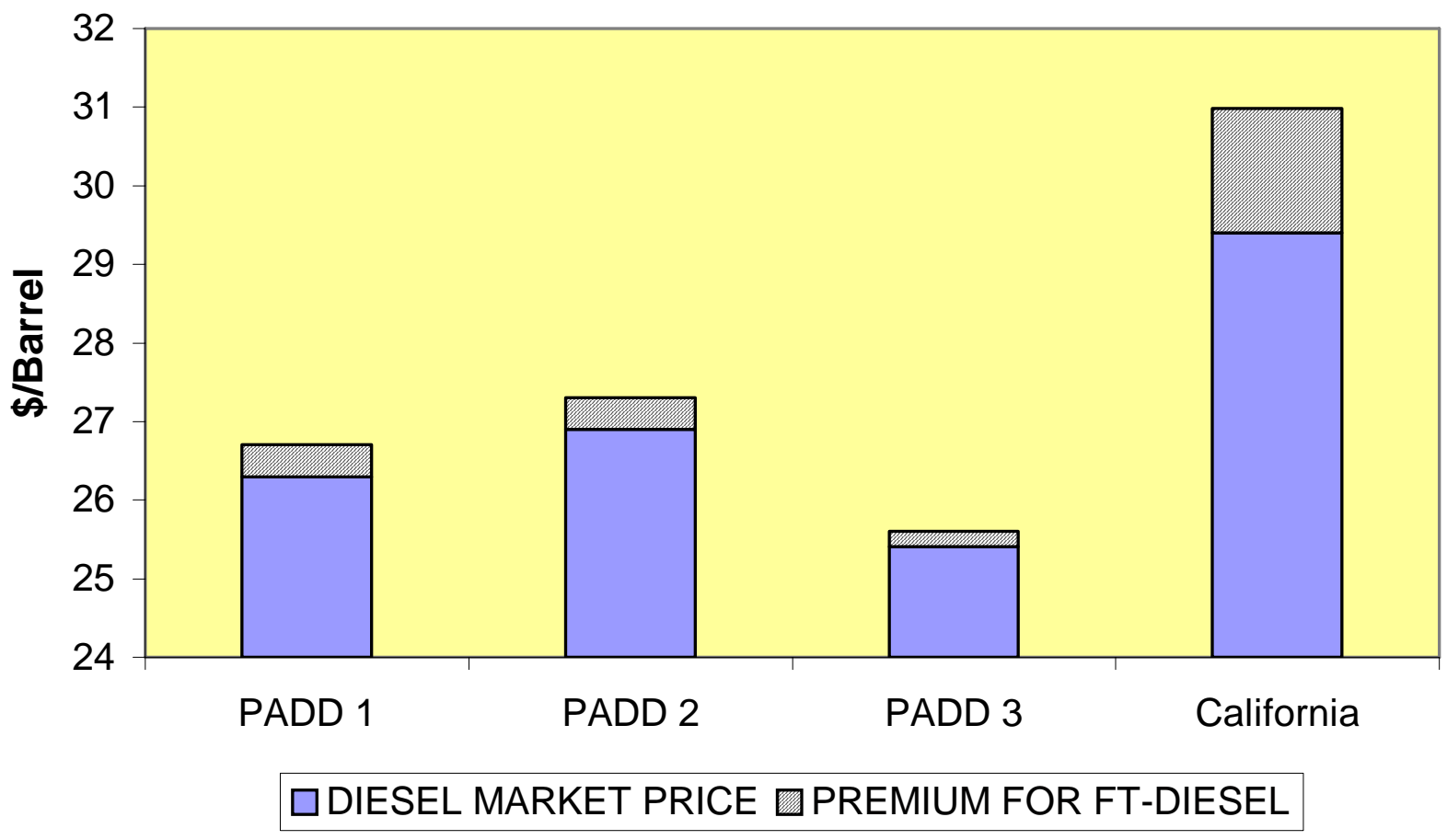

Figure 9.2 ABSOLUTE VALUE OF FT DIESEL TO REFINERS - 2006

- $\quad$ FT diesel is expected to have the highest absolute value in California due to the generally higher level of product prices in California and the more stringent quality requirements of $\mathrm{CARB}$ diesel. In particular, the $\mathrm{CARB}$ requirement for a lower aromatics content/higher cetane number necessitates the use of expensive cetane number improver by many California refineries. The use of high cetane number FT diesel as a California refinery blendstock would help to alleviate this constraint

- Due to the high cost of shipping FT diesel to PADD 4 (Rocky Mountain region), it was estimated that the netback value at the USGC of FT diesel on an absolute $\$ / \mathrm{bbl}$ basis would be less than the market price of conventional diesel 


\section{UCF Values and Market Potential Market Study Report Section IX \\ Prepared For: \\ ConocoPhillips}

Co-operative Agreement DE-FC26-01NT41098

\section{ConocoPhillips GNexant}




\title{
UCF Values and Market Potential Market Study Report Section IX
}

November 2002

\author{
Prepared For: \\ ConocoPhillips
}

\section{cNexant}

44 South Broadway, White Plains, New York 10601, USA

Tel: +1 9146090300 Fax: +1 9146090399 


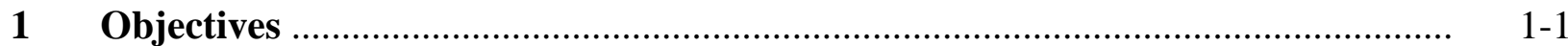

2 Conventional Fuels Price Outlook ............................................................... $2-1$

$2.1 \quad$ CRUDE OIL PRICING …................................................................ $2-1$

2.1.1 Global Marker Crude Oil ............................................................... 2-1

2.1.2 North American Crude Oil Pricing ................................................ 2-3

2.1.2.1 WTI Crude Oil .............................................................. 2-3

2.1.2.2 Maya Crude Oil............................................................ 2-3

2.1.2.3 U.S. Refiners' Acquisition Cost of Crude Oil .................... 2 2-5

2.1.3 Crude Oil Pricing Summary .............................................................. 2-6

$2.2 \quad$ FORECASTING METHODOLOGIES ….............................................. $2-7$

2.2.1 Refinery Margins …....................................................................... 2-7

2.2.2 Refined Product Pricing........................................................... 2-11

2.2.2.1 Introduction ......................................................... 2-11

2.2.2.2 Forecasting Methodology ............................................... 2-12

$2.3 \quad$ REFINERY MARGIN TRENDS N......................................................... $2-13$

2.3.1 Historical Refinery Profitability ................................................... 2-13

2.3.2 Outlook For Refinery Margins ..................................................... 2-16

2.3.2.1 Global Trends ............................................................ 2-16

2.3.2.2 U.S. Gulf Coast Trends ................................................ 2-17

$2.4 \quad$ PRODUCT PRICE FORECASTS ........................................................ 2-21

2.4.1 Introduction.......................................................................... 2-21

2.4.2 Major Refined Product Prices ........................................................ 2-25

2.4.2.1 Gasoline................................................................ 2-27

2.4.2.2 Diesel Fuel................................................................ 2-29

2.4.2.3 No. 2 Fuel Oil............................................................ 2-29

2.4.2.4 Jet Fuel .................................................................... 2-30

2.4.2.5 Residual Fuel Oil......................................................... 2-30

2.4.3 Natural Gas Price Forecast ......................................................... 2-33

2.4.4 Natural Gas Liquids .............................................................. 2-39 
2.4.4.1 Ethane ................................................................... 2-39

2.4.4.2 Natural Gas Liquids Extraction...................................... 2-40

2.4.4.3 Propane .................................................................... 2-45

2.4.4.4 n-Butane ................................................................ 2-47

2.4.4.5 Isobutane .................................................................. $2-50$

2.4.5 Gasoline Blendstocks And Petrochemical Feedstocks ....................... 2-52

2.4.5.1 Octane Valuation ............................................................ 2-53

2.4.5.2 Naphtha ............................................................. $2-55$

2.4.5.3 Gasoline Blendstock Valuation......................................... 2-57

2.4.5.4 Petrochemical Feedstocks ................................................. 2-58

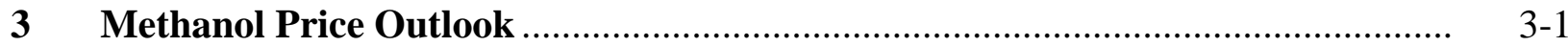

3.1 THE PRICE OUTLOOK FOR METHANOL ........................................

3.1.1 Historical Price Analysis ........................................................... 3-1

3.2 METHANOL PRICE FORECASTING METHODOLOGY ......................... 3-5

3.3 METHANOL PRICE FORECASTS ............................................................

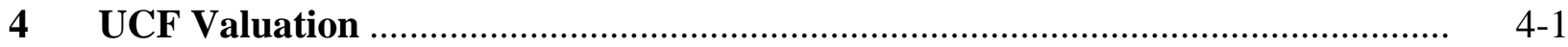

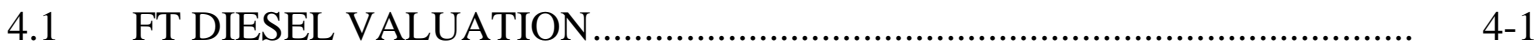

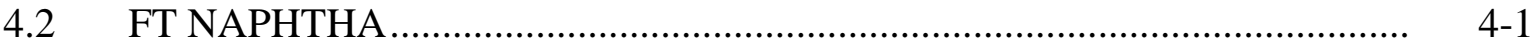

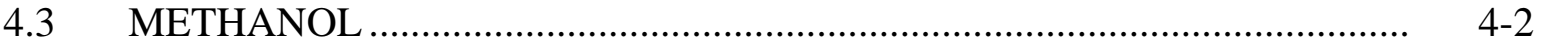

$5 \quad$ UCF Market Potential ...................................................................................

$5.1 \quad$ FT DIESEL ............................................................................. $5-1$

5.2 FT NAPHTHA ............................................................................... $5-1$

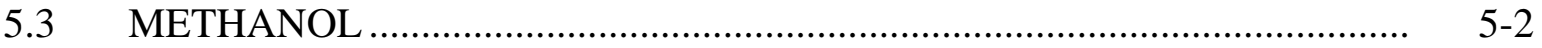

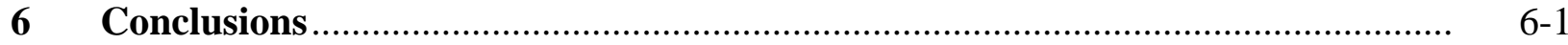

6.1 CONVENTIONAL FUEL PRICE OUTLOOK …..................................... 6-1

6.2 UCF PRICING OUTLOOK...............................................................

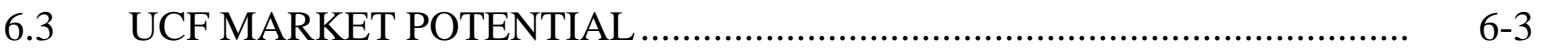

6.3.1 FT Diesel...............................................................................

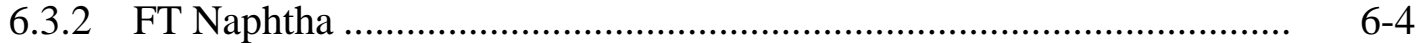

6.3.3 Methanol ..................................................................................... 6... 
2.1 Brent Crude Oil Trend ................................................................................ 2-2

2.2 Light/Heavy Crude Price Differential ${ }^{1}$, U.S. Gulf Coast ............................................... 2 2-4

2.3 U.S. Industry's Average Crude Cost Vs. Brent Crude Price ${ }^{1}$..................................... 2 2-5

2.4 Primary Price Linkages .................................................................................. 2-12

2.5 USGC Cash Cost Refining Margins ......................................................................... 2-14

2.6 Incremental Coking Return-USGC ${ }^{1}$................................................................... 2-16

2.7 Global Refining Margin Comparison Cash Cost Margin - Cracking Refinery............ 2-17

2.8 Variable Cost Hydroskimming Margin - USGC ..................................................... 2-18

2.9 USGC Cash Cost Refining Margins ........................................................................ 2-. 2-19

2.10 USGC Refined Product Pricing Differentials To Crude Oil Pricing .......................... 2 2-26

2.11 USGC Product Price Differentials ............................................................................ 2-27

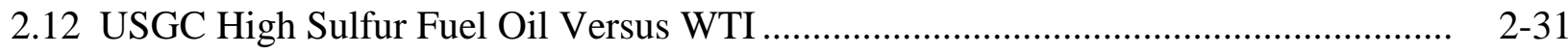

2.13 USGC Upgrading Incentive High Sulfur Fuel Oil Versus "Clean” Products.............. . 2-33

2.14 USGC Natural Gas Pricing Trends .................................................................. 2-35

2.15 U.S. East Coast Natural Gas ${ }^{1}$ Versus Residual Fuel Pricing ……….......................... 2- 2-37

2.16 USGC Natural Gas ${ }^{1}$ Versus Residual Fuel Pricing.................................................... 2-39

2.17 Ethane Recovery Economics Integrated Operations Cash Margin............................... 2 2-43

2.18 Incremental Ethane Recovery Economics Variable Margin......................................... 2-4

2.19 U.S. Gulf Coast Fuel Prices ............................................................................ 2-46

2.20 Propane: Natural Gasoline Price Relationship......................................................... 2-48

2.21 U.S. Gulf Coast Fuel Prices, Medium Crude Pricing ………......................................... 2 2-49

2.22 Normal Butane Pricing Trends .................................................................................. 2-50

2.23 Pro Forma Normal Butane Isomerization Economics ................................................ 2-52

2.24 USGC Cost Of Octane ………………………................................................. 2-5

2.25 Naphtha Pricing Trends ................................................................................ 2-56

2.26 Projected Trends In Petrochemical Feedstock Pricing ……........................................... 2- 2-60

3.1 United States Methanol Price History ............................................................................... 3-3

3.2 West European Methanol Price History …………...................................................... 3-3

3.3 Global Methanol Pricing .......................................................................................... 3-4

3.4 Effect Of US Natural Gas On Methanol Price ………………………………............. 3-5 
3.5 US Methanol Margin History …................................................................... 3-6

3.6 Methanol Price Forecasts ............................................................................

6.1 USGC Cash Cost Refining Margins .................................................................. $6-2$

Table

Page

2.1 North American Crude Oil Pricing Medium Crude Oil Pricing Outlook ................... 2-6

2.2 Typical Refinery Configurations .........................................................................

2.3 Feedstocks And Product Yields For Typical USGC Refineries ............................... 2-11

2.4 Pro Forma USGC Coking Refinery Income Statement Medium Crude Pricing ......... 2 2-20

2.5 Pricing Summary ..................................................................................... $2-21$

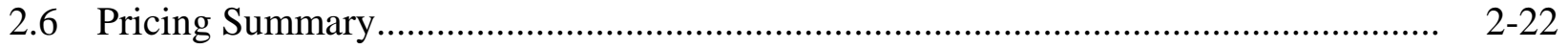

2.7 Price Forecasts Medium Crude Pricing .......................................................... 2-23

2.8 Price Forecasts Medium Crude Pricing ............................................................. 2-24

2.9 Refined Product Price Differential Forecast Medium Crude Pricing ........................ 2-25

2.10 U.S. Northeast Natural Gas Vs. Residual Fuel Oil Spot Pricing Medium Crude

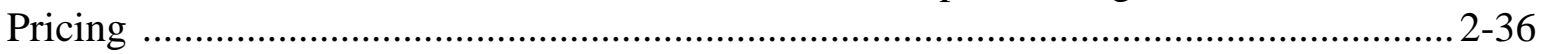

2.11 Ethane Extraction Economics And Pricing - Rich Gas Medium Crude Pricing......... 2-41

2.12 Ethane Extraction Economics And Pricing - Lean Gas Medium Crude Pricing ......... 2-42

2.13 Historical U.S. Gulf Coast Fuels Pricing ........................................................... 2-45

2.14 Average USGC Octane Costs Medium Crude Pricing …...................................... 2-54

2.15 Gasoline Blendstock Values - Market Basis Medium Crude Pricing ....................... 2-58

2.16 Petrochemical Feedstock Prices Medium Crude Pricing ........................................ 2-59

3.1 Methanol Price History ...................................................................................... $3-2$

3.2 Methanol Price Forecasts .............................................................................

3.3 Methanol Price Forecasts .................................................................................. 3-8 


\section{Section 1}

Objectives

The primary objectives of this report section are:

- To develop a basis for valuing UCFs (FT-diesel, FT naphtha and methanol) over the period 2002-2015

- $\quad$ To provide a view on potential markets for UCF over the 2002-2015 period 


\subsection{CRUDE OIL PRICING}

\subsubsection{Global Marker Crude Oil}

Nexant utilizes Brent crude oil, on a free on board (FOB) basis, as its global marker crude oil. The suitability of Dubai crude oil as a global marker crude oil has diminished due to its declining physical availability. Since Brent prices are less susceptible to local pricing distortions and are determined within the most liquid global markets, Nexant utilizes Brent crude oil, on an FOB basis, as its global marker crude oil.

Cutbacks in OPEC crude oil production supported Brent prices during the first half of 2001, with prices varying between $\$ 24$ and $\$ 28$ per barrel. Following the terrorist attacks in the U.S., prices fell to $\$ 20$ per barrel during October, and below $\$ 20$ per barrel in November and December. The Brent crude oil price averaged $\$ 24.6$ per barrel for 2001. Brent prices recovered to over $\$ 25$ per barrel during March of 2002 and have remained in the \$25-27 range through mid-September, to a large extent reflecting higher tensions in the Middle East, and the potential for supply disruptions. Average Brent prices for the year-to-date through the end of August are \$23.9 per barrel.

Nexant addresses future uncertainty in crude oil pricing by projecting an envelope of prices to capture expected future volatility. Three price scenarios have been defined as Low, Medium and High.

These scenarios are intended to define the envelope within which annual average trend prices will generally be contained and do not represent expected price levels on particular dates. While periodic movements outside the range set by the High and Low Oil cases will occur, prolonged periods when prices are outside this range are not anticipated.

The "Low Oil" case reflects the risk of a return to global oversupply. This might result from future inability of OPEC to restrict production in relation to demand, either as a result of a growth in non-OPEC production, or following a downturn in global economic growth. The "High Oil" case represents an approximate upper limit on sustainable pricing. If prices are maintained above this level for long periods the likelihood of growth in non-OPEC production becomes significant leading to increased supply. Sustained periods of high oil prices result in a reduction of global economic growth, increased energy conservation and development of alternative energy sources, all of which reduce oil demand. Consequently prices above the high oil scenario are not sustainable. The "Medium Oil" case represents an arithmetic mean of the two boundary pricing.

The Medium trendline outlook is based on an FOB price for Brent crude in 2003 of $\$ 18$ per barrel in constant 2001 dollars. Thereafter, a 1 percent per year decline in real terms is forecast through 2010, reflecting anticipated gains from continued technology improvements in exploration and production activities, resulting in a price of $\$ 16.8$ per barrel by 2010 (on a 
constant 2001 dollar basis). The current dollar price (inflated based on 2.5 percent per year trendline inflation) for Brent is forecast to equal \$21 per barrel in 2010.

After 2010, as the potential for a shortfall in global supplies of petroleum increases, Nexant has assumed that crude oil prices will stabilize in real terms (i.e. no reduction due to technology improvements), such that by 2015 the price of Brent will be $\$ 23.7$ per barrel in current dollars.

Nexant expects that OPEC discipline will weaken during 2002 resulting in average prices that are slightly below OPEC's target range ( $\$ 22$ to $\$ 28$ per barrel), but above the Medium price outlook. By 2003, it is anticipated that prices will return to their long-term trendline, which is approximated by the Medium price outlook. The price of Brent crude is forecast to average $\$ 21.5$ per barrel in 2002 .

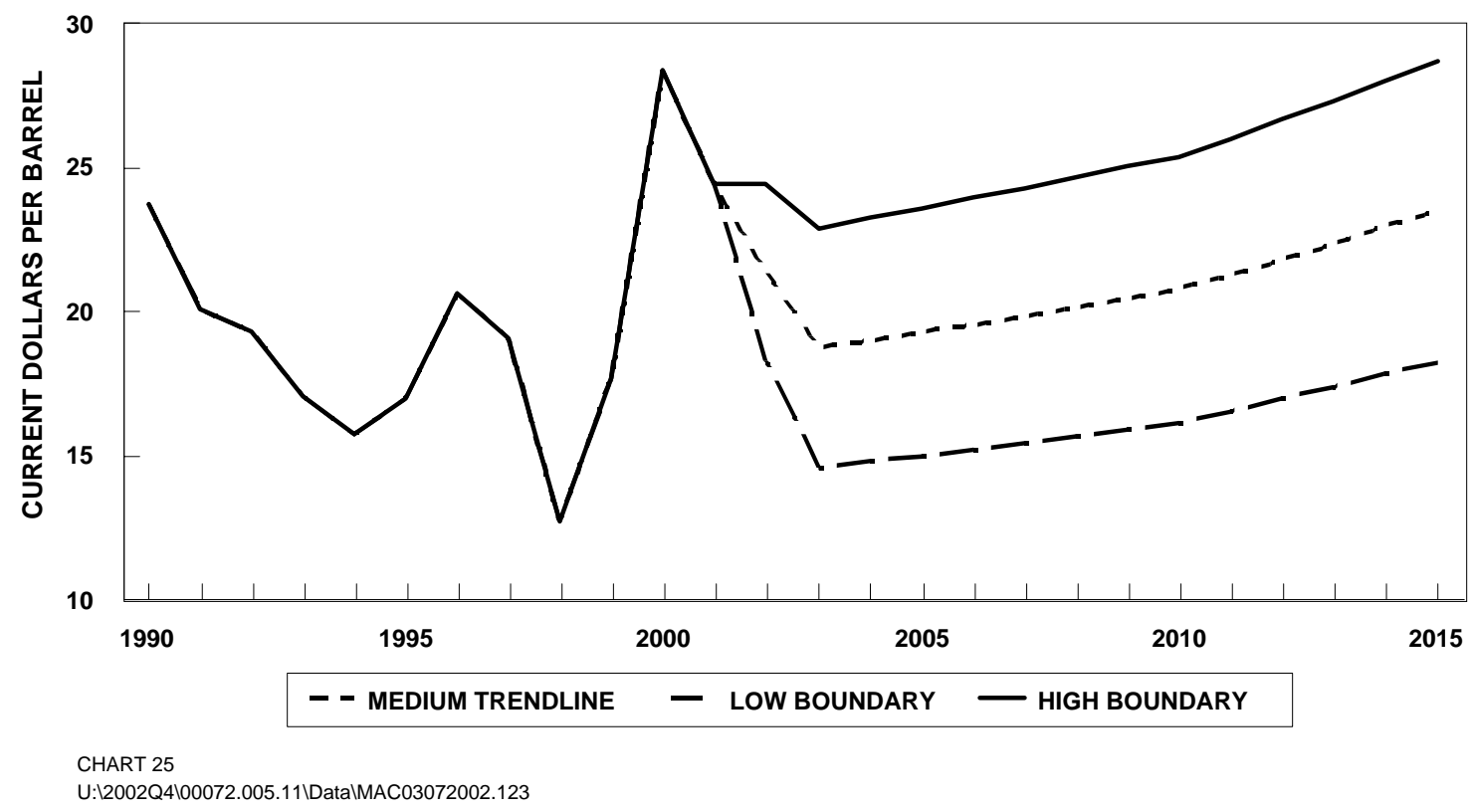

Figure 2.1 Brent Crude Oil Trend (FOB North Sea) 


\subsubsection{North American Crude Oil Pricing}

\subsubsection{WTI Crude Oil}

Nexant forecasts U.S. crude oil prices by considering the impact of each of the following factors:

- $\quad$ Forecast future Brent crude oil price - FOB North Sea (Sullom Voe)

- Transportation costs for delivering crude imports to the U.S.

- $\quad$ Forecast quality-related price differentials for key domestic and imported crudes

The differential between WTI=s price at Cushing and the FOB price of Brent crude has varied within a narrow range over the last ten years, with annual averages ranging between $\$ 1.2$ and $\$ 1.8$ per barrel. On average, during the $1990-2001$ period, WTI=s price was $\$ 1.5$ per barrel above the FOB price of Brent crude. The premium declined from $\$ 1.8$ per barrel during 2000 to $\$ 1.4$ per barrel in 2001, primarily reflecting lower costs for transporting crude oil across the Atlantic.

Relative to Chem System's long-term forecast for Brent crude oil, the average premium for West Texas Intermediate (WTI) crude is forecast to be about $\$ 1.7$ per barrel (2001\$) in the long term on a trendline basis. As a result, Nexant's long-term (i.e. post-2002) Medium crude price outlook for WTI crude oil is for prices to be in the range of \$21-22 per barrel on a current dollar basis.

Forecast WTI prices take into account: quality differences between WTI and Brent crude oils, USGC refined product price trends, locational factors and historical price differentials. Relative to 2001, Nexant's forecast for WTI crude oil prices reflects anticipated costs for transporting crude oil to the U.S. that are generally in line with the average freight cost for 2001.

\subsubsection{Maya Crude Oil}

Maya crude oil is one of the more common heavy, high sulfur (sour) crudes processed in the complex coking refineries located in the U.S. Gulf Coast region. Maya crude has an API gravity of 22.2 and a sulfur content of 3.3 weight percent, while WTI crude, a light, low sulfur (sweet) crude oil, has an API gravity of 40.8 and a sulfur content of 0.3 weight percent.

The FOB price of Maya crude oil for U.S. Gulf Coast destinations is determined by PEMEX using a pricing formula. The formula is based on the weighted average of the spot prices of West Texas Sour crude oil (40 percent), High Sulfur Fuel Oil - USGC waterborne basis (40 percent), Light Louisiana Sweet crude oil (10 percent), and Brent crude oil (10 percent). In addition, the formula includes a constant that is reviewed monthly by officials responsible for marketing Maya crude oil, and is adjusted if necessary based on market conditions. The average value of this constant dropped from $-\$ 2.41$ per barrel in 2000 to $-\$ 3.97$ per barrel in 2001 , peaking at $-\$ 4.95$ per barrel in May 2001 when the supply of heavy crude oils was plentiful and prices for light refined products, such as gasoline, were peaking. 
Average annual FOB prices of Maya crude were between $\$ 4.5$ and $\$ 10.4$ per barrel (2001\$) below the price of WTI crude during the 1990-2001 period. The price differential averaged $\$ 7.0$ per barrel (2001\$) during the period and was $\$ 7.4$ and $\$ 8.7$ per barrel in 2000 and 2001, respectively.

Long term, Nexant expects that the relative pricing of heavy, high sulfur crude oils, such as Maya, will decline from the 2001 level and be between the 1999 and 2000 levels on a trendline basis. This projected trend for the Medium crude price outlook takes into account the forecast decline in crude oil prices, a lower premium for light refined products and a more balanced heavy crude oil market.

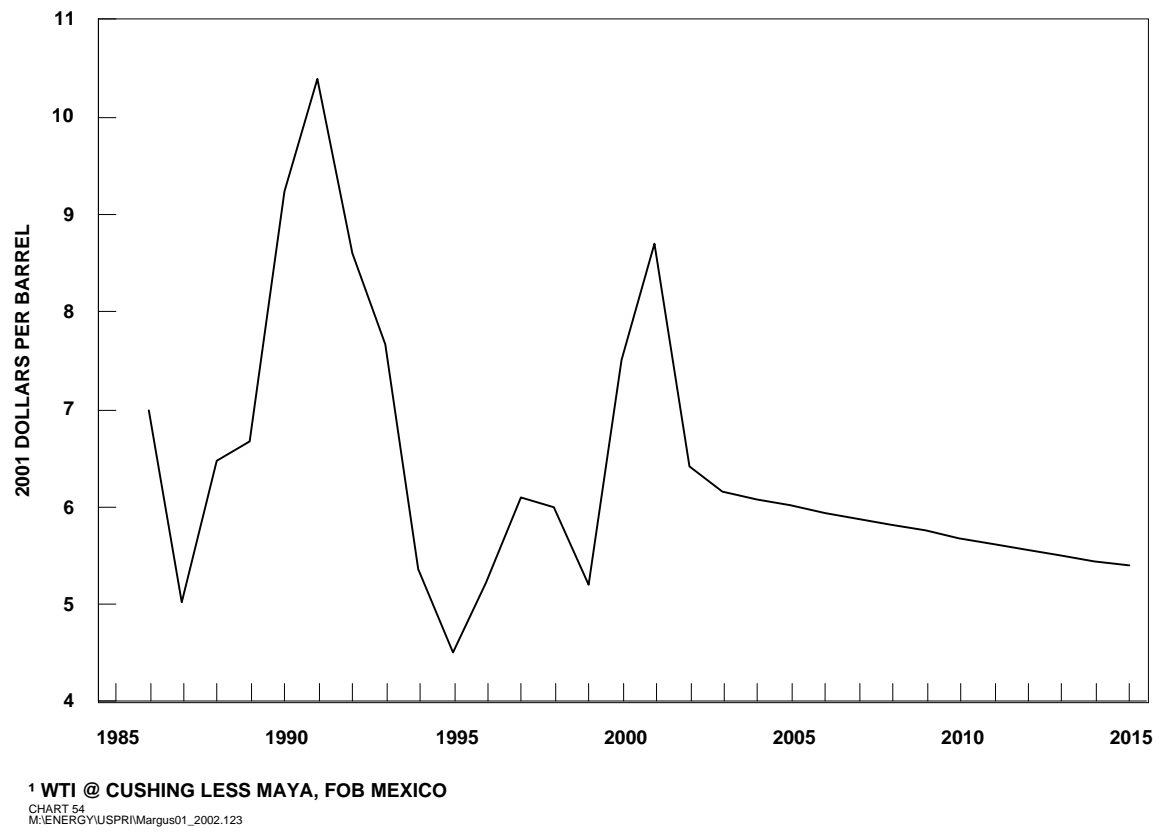

Figure 2.2 Light/Heavy Crude Price Differential ${ }^{1}$, U.S. Gulf Coast

Developments during the second half of 2001 has already resulted in a decrease in the price differential between light and heavy refined products from its 2000/early 2001 peak. The projected trend of heavy, high sulfur crude prices will reflect this narrower price differential between light and heavy products. However, this price differential historically has been volatile since the construction of conversion plant capacity has been cyclical. Nexant expects future price differentials between light and heavy products, and between light and heavy crude oils, will continue to be volatile.

Nexant's Medium crude price outlook for international crude oil pricing includes FOB prices for Maya crude oil in the range of $\$ 14-15$ per barrel during the 2003-2010 period, or prices that will be \$6-7 per barrel below the forecast prices of WTI crude oil. 


\subsubsection{U.S. Refiners' Acquisition Cost of Crude Oil}

In the United States, refiners' average acquisition cost of crude oil is a composite of the cost of domestic and imported crude oil. Nexant forecasts future average costs by considering the impact of each of the following factors:

- $\quad$ Forecast future Brent crude oil price - FOB North Sea

- Transportation costs for delivering crude imports to U.S. refineries

- Estimated trends in quantities and qualities of imported and domestic crudes processed

- $\quad$ Forecast quality-related price differentials for key domestic and imported crudes

The composite mix of crude delivered to U.S. refiners is heavier and has a higher sulfur content than Brent crude oil, making it a lower quality refinery feedstock. The differential between the average cost of crude delivered to U.S. refiners and the FOB price of Brent crude has varied considerably over the last ten years, reflecting variations in the price differential between heavy and light crude oils, changes in average U.S. crude oil quality and changes in the sources of imported crude. On average, during the 1990-2001 period, the average acquisition cost for the industry was $\$ 0.5$ per barrel below the FOB price of Brent crude, but the discount shot up to $\$ 1.50$ per barrel in 2001 reflecting the wider price differential between heavy and light crude oils.

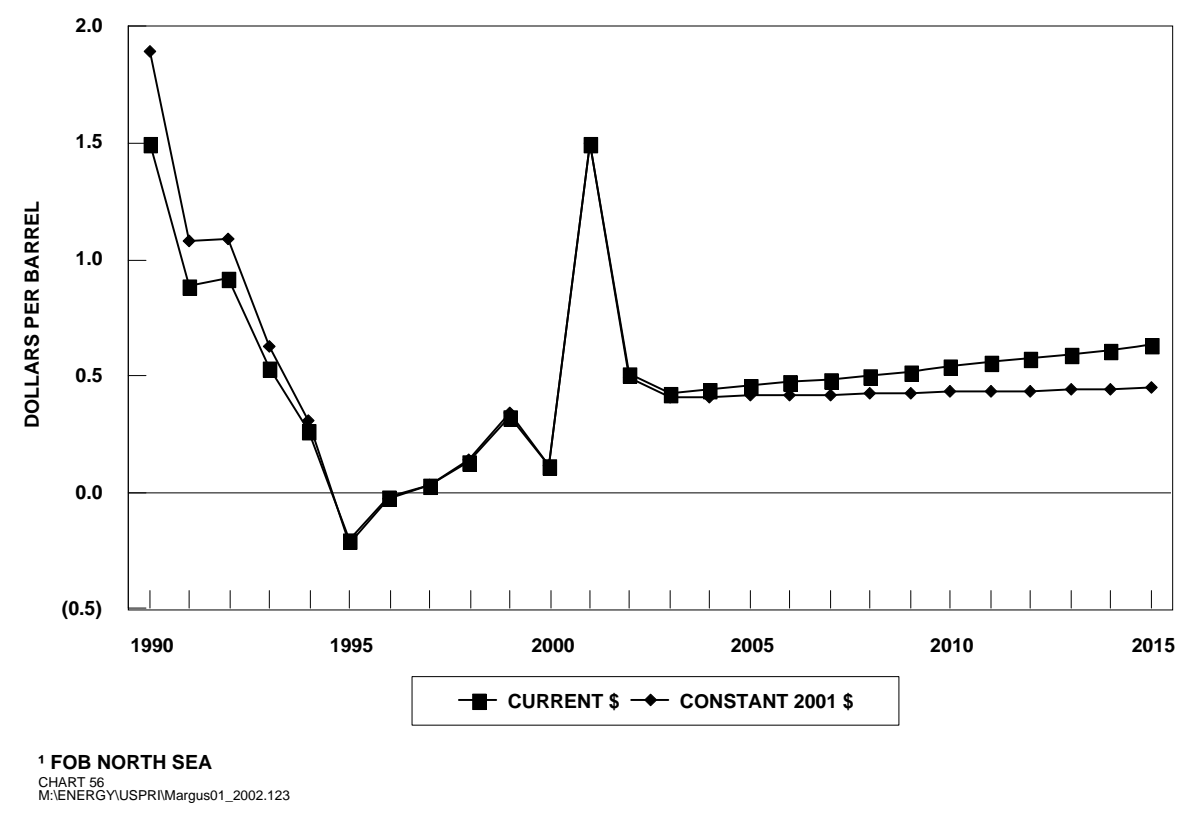

Figure 2.3 U.S. Industry's Average Crude Cost Vs. Brent Crude Price ${ }^{1}$ 
Relative to Chem System's long-term forecast for Brent crude oil, the average discount for crude delivered to U.S. refiners is forecast to be about $\$ 0.5$ per barrel over the 2002-2010 period. This projection reflects the anticipated decline in average U.S. crude oil quality, costs for transporting crude oil to the U.S. near the 2001 average cost, and a narrowing of the price differential between heavy and light crude oils.

\subsubsection{Crude Oil Pricing Summary}

Nexant monitors and forecasts prices for key U.S. and imported crude oils that are representative of the light-sweet, light-sour and heavy-sour crude oils processed in USGC refineries. The forecast prices take into account; quality differences between the crude oils, USGC refined product price trends, locational factors and historical price differentials.

\section{Table 2.1 North American Crude Oil Pricing Medium Crude Oil Pricing Outlook}

\begin{tabular}{|c|c|c|c|c|c|c|c|c|c|c|}
\hline \multicolumn{11}{|c|}{ Actual } \\
\hline CRUDE & CRUDE TYPE & LOCATION & 1990 & 1995 & 1999 & 2000 & 2001 & 2006 & 2010 & 2015 \\
\hline \multicolumn{11}{|c|}{ Current Dollars per Barrel } \\
\hline Brent & Light Sweet & FOB Sullom Voe & 23.7 & 17.0 & 17.7 & 28.4 & 24.5 & 19.8 & 21.0 & 23.7 \\
\hline Dubai & Medium Sour & FOB Mideast & 20.4 & 16.1 & 17.2 & 26.1 & 22.8 & 18.2 & 19.3 & 21.8 \\
\hline Avg. U.S. Acquisition & & & 22.2 & 17.2 & 17.4 & 28.3 & 23.0 & 19.3 & 20.4 & 23.1 \\
\hline WTI & Light Sweet & FOB Cushing & 24.5 & 18.4 & 19.3 & 30.3 & 25.9 & 21.6 & 22.9 & 25.9 \\
\hline LLS & Light Sweet & FOB St. James & 24.8 & 18.6 & 19.1 & 30.3 & 25.9 & 21.5 & 22.8 & 25.7 \\
\hline Maya & Heaw Sour & FOB Mexico & 17.1 & 14.4 & 14.3 & 22.9 & 17.2 & 14.9 & 15.8 & 18.2 \\
\hline Arab Light & Light Sour & CIF US Gulf Coast & 22.0 & 17.0 & 17.4 & 27.5 & 21.5 & 18.9 & 20.1 & 22.8 \\
\hline Arab Heavy & Heaw Sour & CIF US Gulf Coast & 19.8 & 16.0 & 15.9 & 25.4 & 19.2 & 16.8 & 17.8 & 20.4 \\
\hline \multicolumn{11}{|c|}{ Constant 2001 Dollas per Barrell } \\
\hline Brent & & FOB Sullom Voe & 29.9 & 18.9 & 18.5 & 29.0 & 24.5 & 17.5 & 16.8 & 16.8 \\
\hline Dubai & & \multirow[t]{2}{*}{ FOB Mideast } & 25.7 & 17.9 & 17.9 & 26.7 & 22.8 & 16.1 & 15.4 & 15.4 \\
\hline Avg. U.S. Acquisition & & & 28.0 & 19.2 & 18.2 & 28.9 & 23.0 & 17.0 & 16.3 & 16.3 \\
\hline WTI & & & 30.9 & 20.5 & 20.1 & 30.9 & 25.9 & 19.1 & 18.4 & 18.3 \\
\hline LLS & & FOB St. James & 31.3 & 20.7 & 19.9 & 30.9 & 25.9 & 19.0 & 18.2 & 18.2 \\
\hline Maya & & FOB Mexico & 21.6 & 16.0 & 14.9 & 23.4 & 17.2 & 13.2 & 12.7 & 12.9 \\
\hline Arab Light & & CIF US Gulf Coast & 27.8 & 18.9 & 18.1 & 28.1 & 21.5 & 16.7 & 16.1 & 16.2 \\
\hline Arab Heavy & & CIF US Gulf Coast & 24.9 & 17.8 & 16.6 & 26.0 & 19.2 & 14.8 & 14.3 & 14.4 \\
\hline \multicolumn{3}{|c|}{ Factor to Constant $2001 \$$} & 1.262 & 1.113 & 1.043 & 1.022 & 1.000 & 0.884 & 0.801 & 0.708 \\
\hline
\end{tabular}




\subsection{FORECASTING METHODOLOGIES}

\subsubsection{Refinery Margins}

Reflecting its role as the major supply and price-setting region of the United States, Nexant focuses on the United States Gulf Coast (USGC) in evaluating and forecasting refining margins and refined product prices.

Refinery economic analyses were prepared for four basic refinery configurations, covering the range of USGC refining facilities. These are:

- Hydroskimming

- Cracking

- Coking

- H-Oil/Coking

These configurations were chosen because they represent important segments of the USGC refining industry. Analysis of these configurations provides valuable insights into historical and forecast trends in regional margins. The costs associated with operating USGC refineries with these configurations were estimated, and USGC product prices were used to calculate proforma margins for each refinery configuration.

Most USGC refineries have a process configuration that is a weighted average of two or more of these typical refineries. However, the coking refinery configuration, with a complexity of 11.1, is generally representative of the USGC refining industry which has an average complexity of about 11 . Complexity indices are developed by assigning index numbers to each processing unit in a given refinery. Higher numbers reflect higher capital costs/complexity relative to crude oil distillation. As a basic measure, higher refinery indices imply greater processing ability.

The hydroskimming configuration is important as a proxy for the U.S. industry's incremental producer of refined products, and is examined when setting margins and prices. Although the hydroskimming configuration does not exist on a stand-alone basis on the USGC, it generally reflects a USGC refiner's actual capabilities when processing incremental crude above installed upgrading capacity.

No USGC refinery exactly resembles the H-Oil/Coking configuration, but several have processing trains with this configuration.

The refinery and process unit capacities assumed for each of these typical configurations determine the estimated operating cost structures and replacement cost of each type of refinery. The operating costs are calculated in dollars per barrel of crude processed and are broken down into variable costs, fixed cash costs and depreciation. Variable costs include all cash processing costs directly proportional to the amount of feedstock processed such as catalysts, chemicals, natural gas purchases, utilities and power. 
Total energy requirements, i.e. steam plus fuel for direct heating, were estimated by aggregating the energy requirement of the processing units for each of the configurations considered. The amount of purchased natural gas was calculated based on the refinery's total refinery fuel requirement and the estimated availability of refinery-produced gas.

Fixed cash costs include manpower, maintenance, direct overhead, general plant overhead, insurance and property taxes. Interest on working capital is not included.

Typical depreciation charges (based on replacement capital value) are calculated for each refinery configuration. These charges can only be considered as indicative because actual charges vary significantly depending on several factors including accounting procedures and age of plant. It should be noted that the majority of US refineries are now quite old, and therefore depreciation charges based on the full replacement value would not be applied. 
Table 2.2 Typical Refinery Configurations

(thousand barrels per stream day)

\begin{tabular}{|c|c|c|c|c|}
\hline & & Type of & & \\
\hline & $\begin{array}{r}\text { Hydro- } \\
\text { skimming }\end{array}$ & Cracking & Coking & $\begin{array}{l}\text { H-Oil } \\
\text { Coking }\end{array}$ \\
\hline Process Unit Capacities & & & & \\
\hline Amospheric disitlation & 50 & 150 & 200 & 200 \\
\hline \begin{tabular}{|l|} 
Vacuum distillation \\
\end{tabular} & 17 & 61 & 93 & 106 \\
\hline Delayed coking & & & 47 & 19 \\
\hline Solvent deasphalting & & 28 & & \\
\hline FCCU & & 52 & 66 & 83 \\
\hline Semi-regen reforming & 9 & 29 & & \\
\hline Continuous regeneration reforming & & & 40 & 36 \\
\hline Resid hydrocracking & & & & 57 \\
\hline FCCU feed desulfurizing & & & 65 & 60 \\
\hline Heavy naphtha hydrotreating & 9 & 29 & 40 & 36 \\
\hline Kero hydrotreating & & 20 & 24 & 21 \\
\hline Diesel hydrotreating & & 32 & 50 & 44 \\
\hline Alkylation & & 6 & 9 & 11 \\
\hline MTBE & & 2 & 2 & 3 \\
\hline Naphtha isomerization & & 9 & 13 & 12 \\
\hline Sulfur (tons per day) & & 150 & 400 & 800 \\
\hline Hydrogen (MMSCFD) & & & 15 & 98 \\
\hline Refinery complexity & 2.9 & 8.0 & 11.1 & $14.8>>>3$ \\
\hline & & & & \\
\hline Replacement cost, \$ million ${ }^{1}$ & 126 & 964 & 1,940 & 2,478 \\
\hline 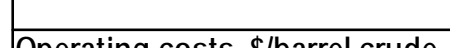 & & & & \\
\hline Operating costs, Slbarrel crude & & & & \\
\hline Variable & 0.46 & 0.61 & 0.70 & 2.10 \\
\hline Fixed at 90\% ublization & 0.70 & 1.60 & 2.17 & 2.72 \\
\hline Total cash oneratina costs ${ }^{2}$ & & 2,1 & 207 & 182 \\
\hline $\begin{array}{l}\text { Iotal cash operating costs } \\
\text { Depreciation }{ }^{3}\end{array}$ & $\begin{array}{l}1.10 \\
0.51 \\
\end{array}$ & $\frac{2.21}{1.31}$ & 1.97 & 2.51 \\
\hline
\end{tabular}

1 USGC location in 2000 dollars

2 Excluding crude oil cost, depreciation and return on investment

3 Straight line over 15 years based on replacement cost

U:12002Q4100072.005.11IDatalPROFORMAS.123

Different crude slates were assumed for each refinery configuration, to reflect the types of crudes normally processed in each type of refinery. The crude slates consist of different combinations of three crude oils - Light Louisiana Sweet (LLS), Arabian Light and Arabian Heavy. These crude oils were selected since market prices are reported for them and they are representative of the light-sweet, light-sour and heavy-sour crude oils processed on the USGC.

For each refinery configuration, product yields based on typical, not state-of-the-art, process unit operations were developed. 
Refinery losses have also been considered in the yield evaluations. These include both processing and effluent losses. An average level of 0.5 percent of refinery throughput has been assumed. The same loss value was used for each of the refinery configurations. Volume gain generated for each configuration is also reflected.

Refinery margins can be calculated on several different bases, all of which are used within the industry for different purposes:

- Variable margins (cost basis reflects only variable operating costs)

- Cash cost margins (includes fixed operating costs)

- Full cost margins (includes depreciation)

The variable margin indicates whether incremental production is profitable for an incremental yield structure. That is, crude cost and incremental utility costs are taken into consideration, but manpower and other fixed costs are not as they should not change with incremental crude processing. The cash cost margin indicates profitability in a more general sense as it applies to the whole production in a refinery. The full cost margin more closely mirrors the profitability reported by refining companies in their financial statements. 


\section{Table 2.3 Feedstocks And Product Yields For Typical USGC Refineries (liquid volume percent crude)}

\begin{tabular}{|c|c|c|c|c|}
\hline & \multicolumn{4}{|c|}{ Type of Refinery } \\
\hline & $\begin{array}{r}\text { Hydro- } \\
\text { skimming }\end{array}$ & Cracking & Coking & $\begin{array}{r}\text { H-Oill } \\
\text { Coking }\end{array}$ \\
\hline \multicolumn{5}{|l|}{ Feedstocks } \\
\hline Light Louisiana Sweet (LLS) & 100 & & & \\
\hline Arabian Light & & 100 & 50 & \\
\hline Arabian Heavy & & & 50 & 100 \\
\hline Methanol & & 0.4 & 0.4 & 0.5 \\
\hline Isobutane & & 1 & 0.9 & 1.4 \\
\hline \multicolumn{5}{|l|}{ Products } \\
\hline Propane & 0.3 & 1.7 & 2.4 & 2.0 \\
\hline Propylene & & 2.2 & 2.5 & 2.8 \\
\hline MTBE & & 1.2 & 1.2 & 1.5 \\
\hline n-Butane & 0.9 & 0.7 & 0.6 & 0.4 \\
\hline Premium unleaded gasoline & 0.3 & 15.4 & 17.2 & 16.5 \\
\hline Regular unleaded gasoline & 18.5 & 28.2 & 27.7 & 32.4 \\
\hline Kero/jet & 15.7 & 13.4 & 12.0 & 10.5 \\
\hline No. 2 fuel oil ( $0.2 \%$ sulfur) & 24.7 & & & \\
\hline Low sulfur diesel (0.05\% sulfur) & & 19.8 & 28.6 & 31.8 \\
\hline Low sulfur HVGO & 26.3 & & & \\
\hline Residual fuel oil ( $0.7 \%$ sulfur) & 11.5 & & & \\
\hline Residual fuel oil (3\% sulfur) & & 17.6 & 3.0 & 3.7 \\
\hline Coke (weight percent) & & & 8.2 & 3.3 \\
\hline Liquid recovery & 98.2 & 98.8 & 93.9 & 99.7 \\
\hline
\end{tabular}

M:IENERGYDPCIPPEITVGTIPROFORMAS.123

\subsubsection{Refined Product Pricing}

\subsubsection{Introduction}

Nexant uses an integrated approach when forecasting energy pricing. Users of energy in the United States often have several options to choose from when deciding on which type of energy to use. For example, some utility companies have the choice of using natural gas, coal or petroleum for generating electricity. Similarly, the petrochemical industry selects, often on a daily basis, the optimal slate of feedstocks to be processed into basic petrochemicals. Price represents one of the primary factors determining which type of energy is consumed.

The resulting price forecasts take into account expected interactions of supply and demand (both globally and regionally), competition between energy sources, refining economics and environmental constraints. 
Product price forecasts are also developed in relation to projected prices for these products in the world's other major price-setting markets. It is assumed that although prices and margins in these regional refining centers will vary depending on their respective supply/demand balances, variations over the medium to long term will not exceed the freight costs between regions.

Prices for major refined products in a region are set by the margin of the region's incremental producer. Therefore, after establishing an outlook for pricing of "marker" crudes, Nexant's first step when forecasting refined product prices is to project this margin based on expected global and regional supply/demand trends. Product prices are projected based on this margin and expected price differentials between major products.

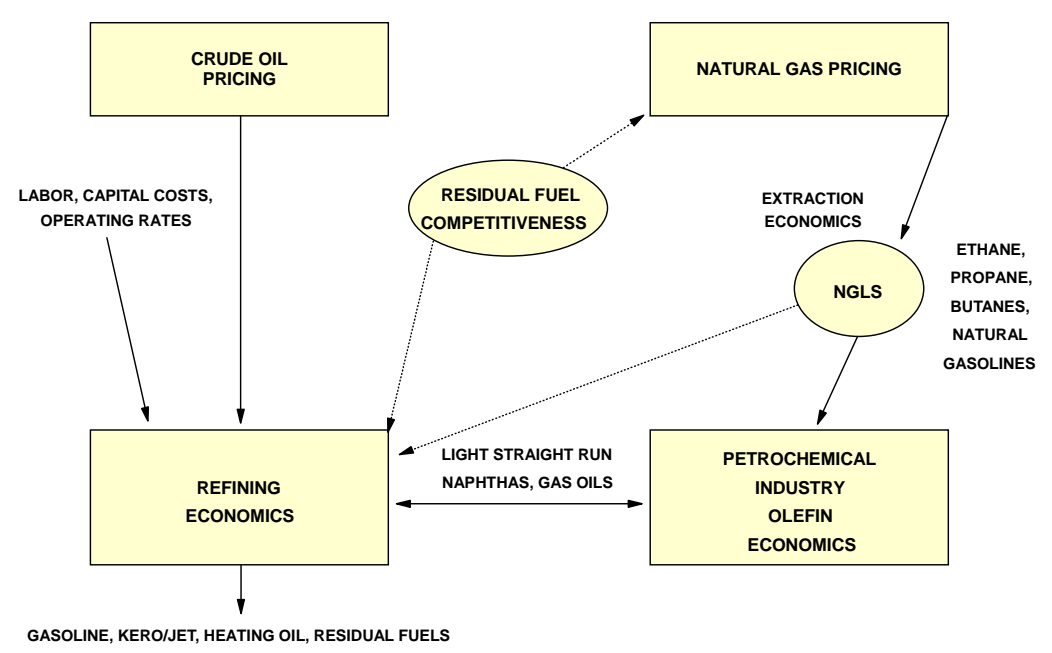

Figure 2.4 Primary Price Linkages

\subsubsection{Forecasting Methodology}

The approach utilized to develop product price forecasts is dependent upon the time horizon involved. Long term forecasts are concerned with projecting "trend" prices. The "actual" movements around the trend line are inherently unpredictable, since they result from constantly fluctuating short term market pressures. A credible basis for long term price forecasts is a cost related approach, requiring that several important factors be evaluated. The most important of these are:

- Projections of crude oil cost

- Product supply/demand trends

- Trade of petroleum products

- Changes in industry structure

- $\quad$ Product quality trends 
- Estimates of refining costs

- $\quad$ Assessment of future refinery margins (i.e. profitability)

Nexant's methodology for forecasting refined product prices can be simplified and broken down into several principal steps:

- Identifying the refinery configuration most representative of a region's incremental producer of refined products

- Forecasting the variable margin for the incremental refinery configuration

- $\quad$ Forecasting price differentials between major refined products

Given the crude oil price outlook and these variable margin and price differential forecasts, the individual refined product prices can be calculated algebraically.

Nexant utilizes a cost-based approach to forecast refined product prices, which is comprised of a projection of the global economic environment (real economic growth and price inflation), the projected underlying international crude oil price (discussed above), and the business environment for each key refined product. The outlook for each product's price on the U.S. Gulf Coast reflects the industry's expected supply/demand balance and refinery operating rates that determine the price relationships between key products, refinery margins and profitability.

\subsection{REFINERY MARGIN TRENDS}

\subsubsection{Historical Refinery Profitability}

The attempt by Saudi Arabia to regain market share in 1985/1986 and the introduction of "netback" pricing rapidly gave a boost to margins. This ended as OPEC reverted to its policy of controlling price through production quotas. The refinery capacity reductions during the early 1980s, combined with constrained octane capacity following lead phase down and increased oil product demand, led to a general tightening of supply and an overall improvement in refinery margins during the late 1980s. 


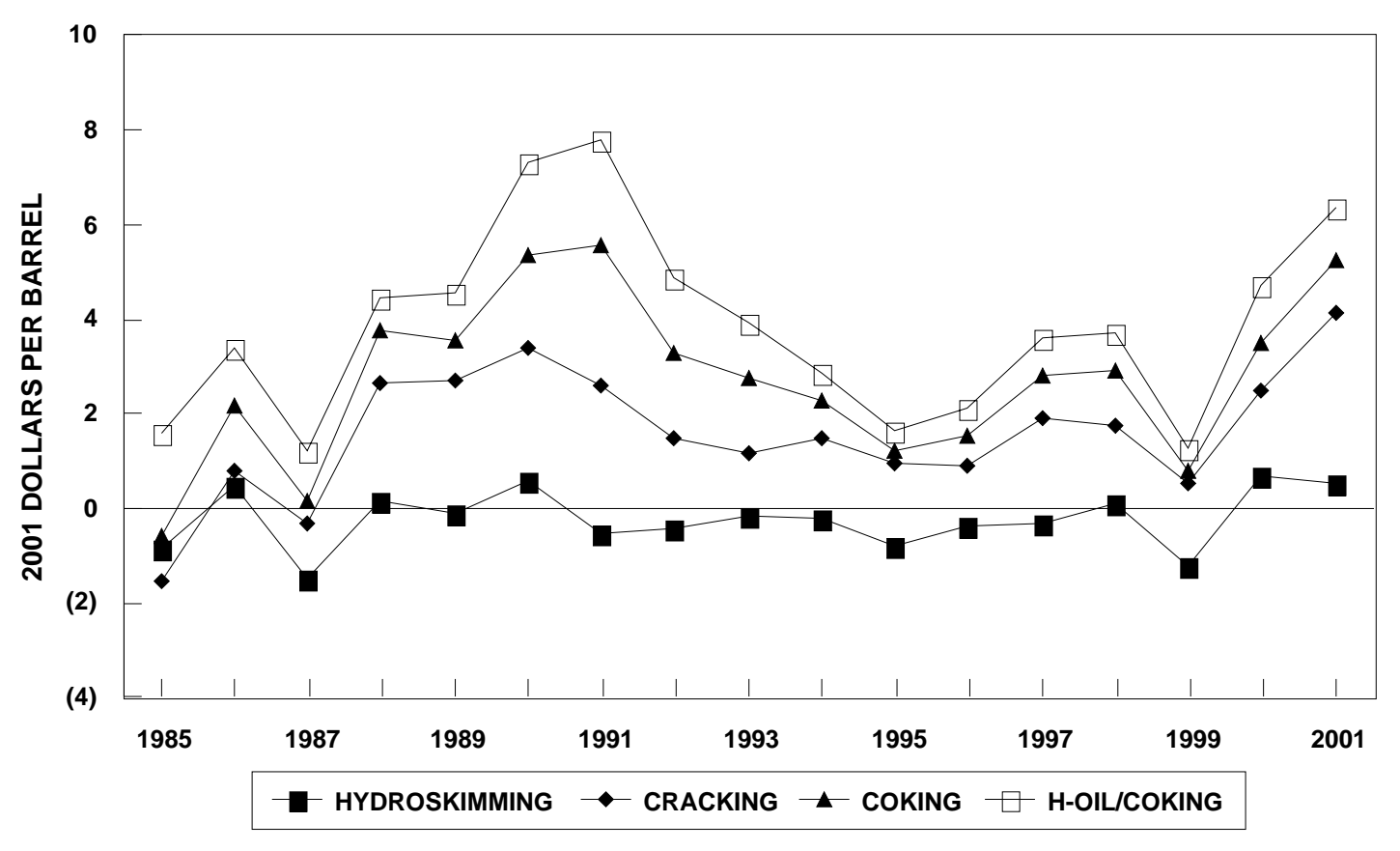

CASHCONSHIST
M:IENERGYUSPRIMMargus01_2002.123

Figure 2.5 USGC Cash Cost Refining Margins

Industry profitability during the first half of 1990 continued to rise. However, the invasion of Kuwait by Iraq resulted in lower margins by the end of 1990 for cracking and hydroskimming refineries due to sharply higher crude prices and lower oil demand. Margins continued to fall during 1992 and 1993 due to increased domestic gasoline production and stagnant demand. During 1994 and 1995, increased production of light North Sea crude oils, the reduced availability of heavier crude oils and the start up of new fuel oil upgrading facilities narrowed the price differential between light and heavy crude oils. This resulted in a further decline in margins for coking and more sophisticated refineries.

Margins began to recover in 1996 due to higher product demand resulting from an unseasonably cold winter and a strong economy. Limited increases in refinery production and low gasoline inventory levels throughout the year contributed to the margin recovery. Margins were substantially higher in 1997, increasing $\$ 1.0$ and $\$ 1.2$ per barrel for cracking and coking refineries, respectively. A sharp increase in gasoline prices during the third quarter drove margins higher. The run up in gasoline prices was attributed to strong demand, low inventory levels and the unscheduled shutdown of gasoline producing units in several major U.S. refineries.

Weak fuel oil prices contributed to a higher margin for coking refineries during the first quarter of 1998. During the second quarter, margins were supported by relatively strong gasoline prices, linked to the seasonal increase in demand and unscheduled refinery shutdowns on all three 
coasts. Margins for coking refineries were much lower during the second half of 1998, averaging $\$ 1.5$ per barrel below the first half average, as high inventory levels depressed gasoline and distillate prices. Low prices also stimulated residual fuel oil demand, narrowing the differential between light and heavy products, and margins for coking and more sophisticated refineries. Product prices did not match the dramatic run up in crude oil prices that occurred during 1999, and as a result refining profitability was severely depressed during the year.

Low gasoline and distillate inventory levels during 2000 and the first half of 2001 were primarily responsible for tight product markets, resulting in a strong recovery in margins during 2000. Margins peaked at their highest level in 11 years during the second quarter of 2001 when unscheduled refinery shutdowns drove reformulated gasoline prices to very high levels. In addition, increased OPEC production of heavy crude oil, that had been preferentially cut back during 1998/99, contributed to a wider fuel oil upgrading margin.

The higher margins achievable with a coking refinery as compared with a cracking refinery can be translated into indicative rates of return on investment for new conversion units. Investment in new conversion units was attractive in the early 1980s, but became unattractive during the mid 1980s. Consequently, no new projects were initiated. One effect of the invasion of Kuwait and the destruction of its refineries with their extensive fuel oil upgrading capability was to make fuel oil upgrading economically very attractive. However, the incentive peaked in 1991 and rates of return fell sharply during the 1992-1995 period before beginning to recover in 1996. After continuing to rise in 1997 and 1998, the incentive fell in 1999 due to cutbacks in OPEC heavy crude oil production. However, the incentive recovered in 2000 and 2001 when these cutbacks were reversed and tight product inventories resulted in strong markets for light products, such as gasoline and heating oil. 


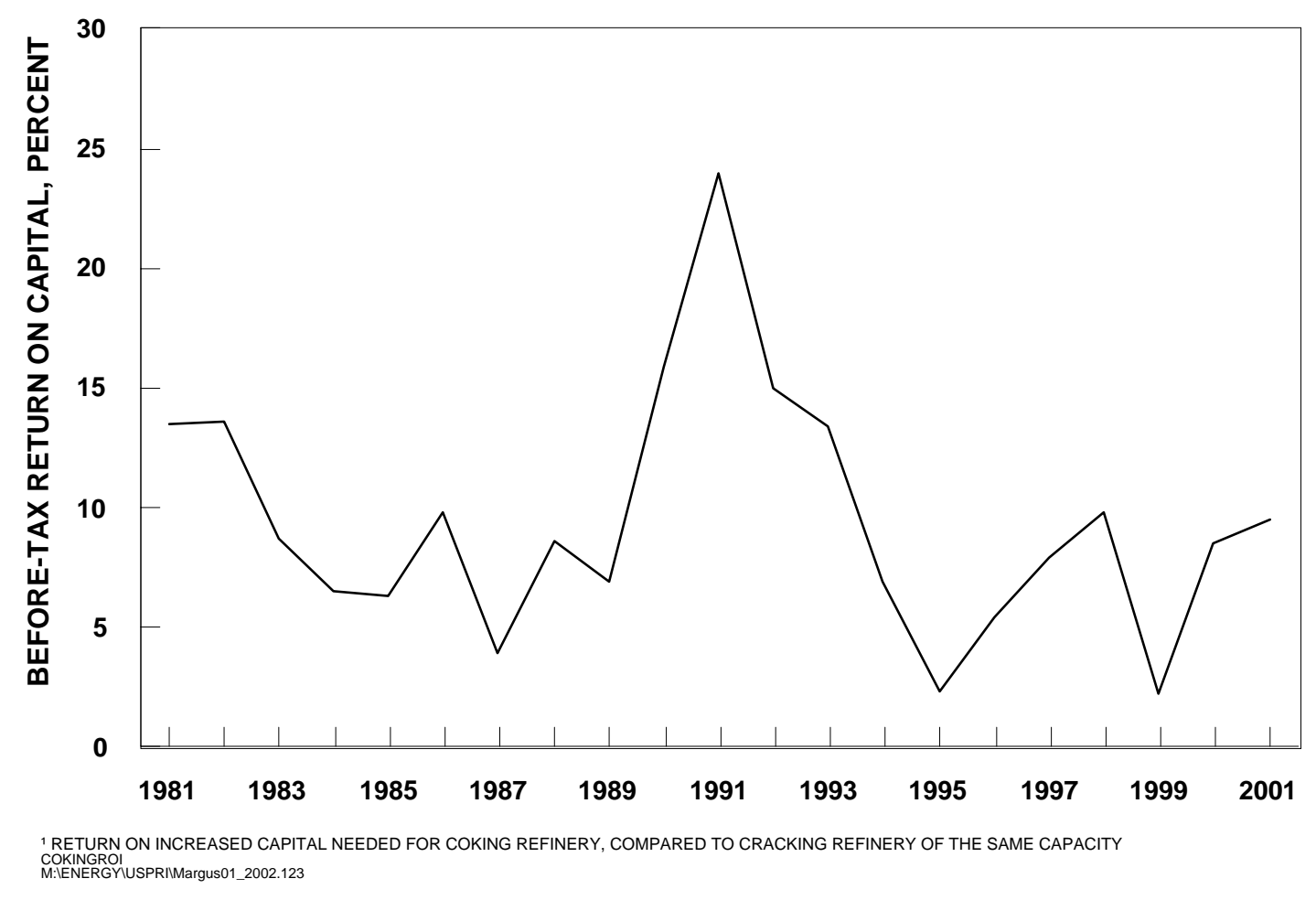

Figure 2.6 Incremental Coking Return-USGC ${ }^{1}$

\subsubsection{Outlook For Refinery Margins}

\subsubsection{Global Trends}

Nexant projects firm refining margins in most regions of the world over the next few years. Primarily, this outlook reflects the following key developments:

- A tight balance between refining capacity and petroleum product demand in the Atlantic Basin has resulted in industry operating rates at relatively high levels. This tightness supports margins for production of incremental supplies of refined products from the global industry's least complex refineries

- The price differentials between light and heavy crude oils, and refined products have widened, improving the economics of fuel oil upgrading

With global light oil product demand forecast to rise faster than residual fuel oil use, Nexant expects trendline upgrading margins in the Atlantic Basin to be above the 1998/1999 level, but below the peak level experienced from the middle of 2000 through the middle of 2001. Increased OPEC production of heavy crude oil, that was preferentially cut back during 1998/99, has also contributed to higher upgrading margins. However, Nexant expects that future price 
differentials between light and heavy products will be volatile since the construction of conversion plants historically has been cyclical.

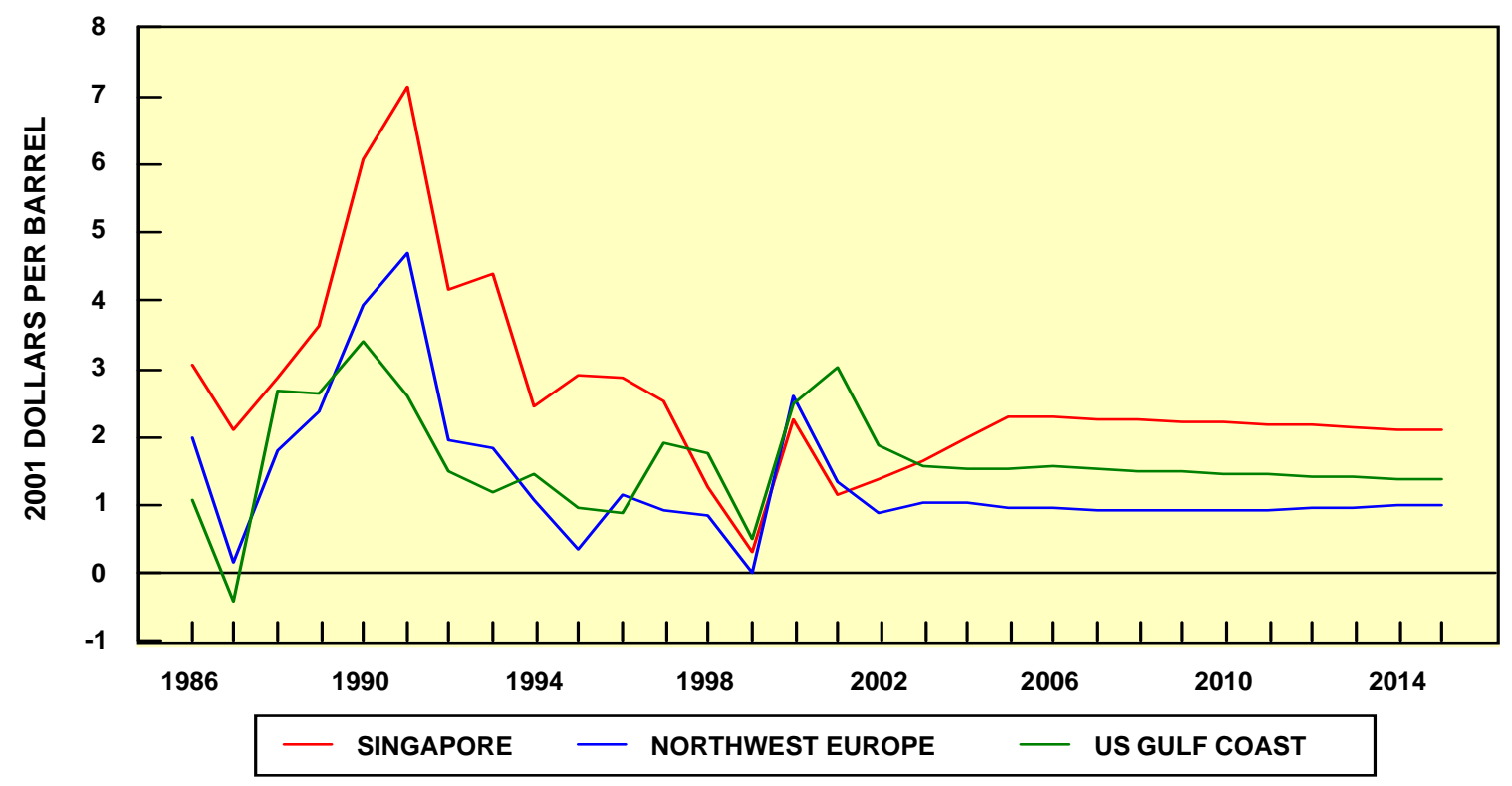

GLOBALCASH
O:12002Q1INEXANTIPPE10010012000.0002.05IMARGSI012002.123

Figure 2.7 Global Refining Margin Comparison Cash Cost Margin - Cracking Refinery

\subsubsection{U.S. Gulf Coast Trends}

USGC refining margins will reflect trends in U.S. and Atlantic Basin product balances and refinery operating rates. In particular, the U.S. is expected to have a continuing gasoline deficit, some of which will need to be met by imports from more distant sources, including Europe and the Middle East.

For the USGC, Nexant expects that the yields and variable costs of the hydroskimming configuration will establish prices for major refined products. Although there no longer are any large hydroskimming refineries still operating on the USGC, cracking and coking refineries typically fully utilize their conversion capacity, but have some primary distillation and catalytic reforming capacity available for use on a discretionary basis, provided it generates a positive variable margin. Nexant forecasts that the variable margin on the USGC for a hydroskimming configuration will be about $\$ 0.50$ per barrel on a trendline basis, providing enough incentive for some refineries to expand. 


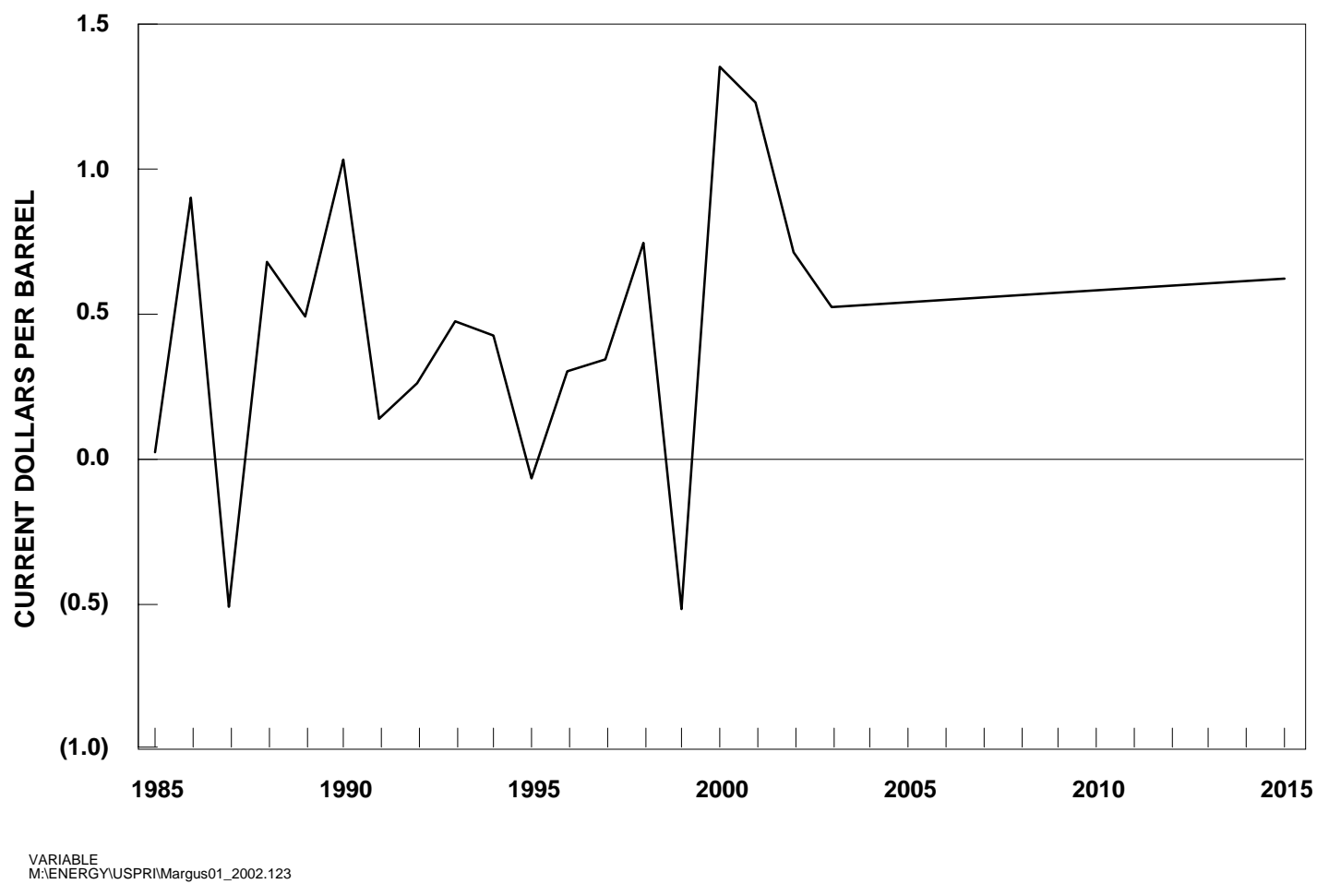

Figure 2.8 Variable Cost Hydroskimming Margin - USGC

Long term, Nexant foresees a generally positive environment for the profitability of U.S. refineries with cokers or other major fuel oil upgrading facilities. In addition to the factors expected to result in firm global refining margins during the next few years, this outlook primarily reflects the following developments:

- $\quad$ Although several major coker projects will be completed during the next few years, very few projects involving major refinery capacity additions in the U.S. have been initiated during the past 3 years

- More stringent U.S. product quality requirements for gasoline and diesel, mandated to take effect beginning in 2004, will be the focus of new refinery investments during the next five years. Furthermore, the capital expenditures needed to comply with these requirements may precipitate the closure of some of the U.S.'s smallest refineries.

Tempering the long-term outlook for improved economics for the industry are the regulatory uncertainties faced by the industry. Each added regulatory requirement will result in higher processing costs to the refiner. Ultimately, future profitability will be impacted by the average refiner's ability to pass on these added costs.

Despite these uncertainties and consistent with the market outlook, Nexant expects that the domestic industry will achieve higher levels of profitability during the 2002-2006 period than applied during the 1995-1999 period. However, the peak 2000/2001 level is not expected to be 
sustainable. Although future margins will yield positive operating cash flows for USGC refineries with extensive fuel oil upgrading capabilities and provide satisfactory returns to support incremental expansions/add-ons, they will not be sufficient to support new grassroots facilities.

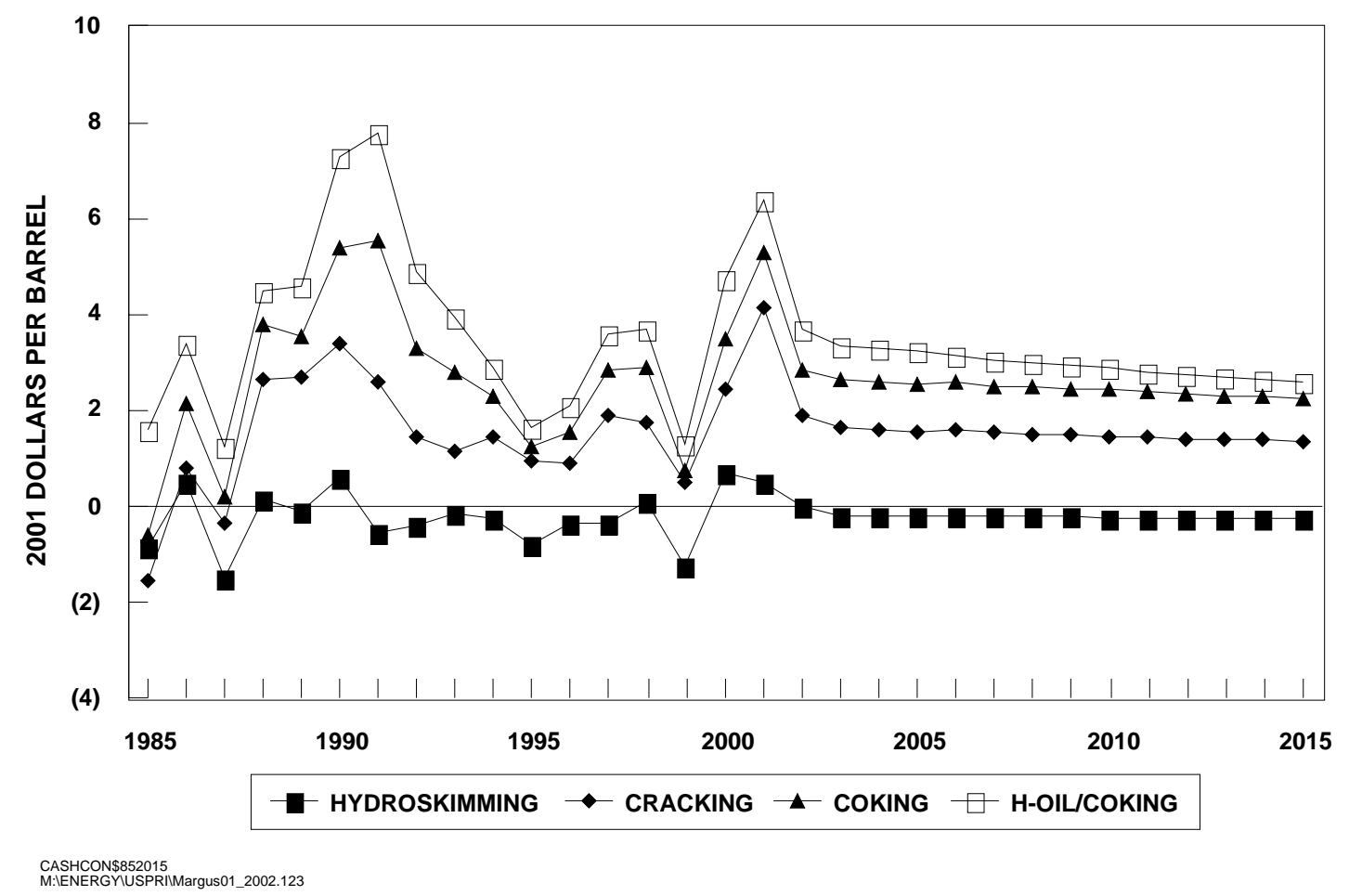

Figure 2.9 USGC Cash Cost Refining Margins

The price and margin forecasts developed by Nexant to calculate these margins are trendline forecasts and do not attempt to forecast future price/margin volatility. Refining margins have historically been volatile and are expected to remain so in the future. Thus, the price and margin forecasts developed by Nexant for long term planning purposes and presented in this report are trend line forecasts and do not attempt to reflect future price/margin volatility. The projected margins are trendlines around which future margins are expected to average. Nexant expects trendline margins to be near the 1997/1998 level, below the peak 2000 level and above the depressed 1999 level.

The proforma income statement for a USGC coking refinery during the 1997-2015 period indicates that the average 1999 cash margin for this type of refinery was about $\$ 2.0$ per barrel below the average 1997/1998 level. The depressed 1999 margin reflected the general lag in product prices that occurred relative to the run up in crude oil prices. However, margins rebounded in 2000 and 2001, with margins averaging \$2.70 and \$4.50 per barrel above the 1999 level during 2000 and 2001, respectively. 
Table 2.4 Pro Forma USGC Coking Refinery Income Statement Medium Crude Pricing (current \$ per barrel of crude)

\begin{tabular}{|c|c|c|c|c|c|c|c|}
\hline & \multicolumn{7}{|c|}{ Actual } \\
\hline & 1998 & 1999 & 2000 & $2001^{-}$ & 2006 & 2010 & 2015 \\
\hline \multicolumn{8}{|l|}{ Revenues } \\
\hline Gross Product Revenues & 16.87 & 20.51 & 33.45 & 29.18 & 24.34 & 25.77 & 28.87 \\
\hline \multicolumn{8}{|l|}{ Raw Materials } \\
\hline Crude Oil & 11.45 & 16.96 & 26.86 & 20.73 & 18.25 & 19.39 & 22.08 \\
\hline Isobutane & 0.12 & 0.15 & 0.25 & 0.22 & 0.18 & 0.19 & 0.21 \\
\hline Methanol & 0.06 & 0.06 & 0.09 & 0.09 & 0.09 & 0.10 & 0.11 \\
\hline Total Raw Materials & 11.63 & 17.17 & 27.20 & 21.04 & 18.52 & 19.68 & 22.40 \\
\hline \multicolumn{8}{|l|}{ Operating Costs } \\
\hline Variable & 0.49 & 0.51 & 0.73 & 0.70 & 0.57 & 0.60 & 0.64 \\
\hline Fixed (ex. Depreciation) & 2.01 & 2.08 & 2.11 & 2.17 & 2.32 & 2.46 & 2.65 \\
\hline Total Operating Costs & 2.51 & 2.59 & 2.84 & 2.87 & 2.89 & 3.05 & 3.29 \\
\hline Total Cash Costs & 14.14 & 19.76 & 30.04 & 23.91 & 21.41 & 22.73 & 25.69 \\
\hline Depreciation (over 15 years) & 1.82 & 1.88 & 1.91 & 1.96 & 2.19 & 2.40 & 2.68 \\
\hline Net Costs & 15.96 & 21.65 & 31.95 & 25.87 & 23.60 & 25.13 & 28.37 \\
\hline \multicolumn{8}{|l|}{ Margin Analysis } \\
\hline Gross Margin & 5.24 & 3.33 & 6.25 & 8.14 & 5.82 & 6.09 & 6.46 \\
\hline Variable Margin & 4.75 & 2.83 & 5.52 & 7.44 & 5.25 & 5.49 & 5.82 \\
\hline Cash Margin & 2.73 & 0.74 & 3.41 & 5.27 & 2.93 & 3.03 & 3.18 \\
\hline Net Margin & 0.91 & $(1.14)$ & 1.50 & 3.31 & 0.73 & 0.64 & 0.50 \\
\hline \multicolumn{8}{|l|}{ Asset Base, \$ million } \\
\hline Fixed Asset Replacement Cost & 1,832 & 1,856 & 1,897 & 1,934 & 2,162 & 2,363 & 2,641 \\
\hline Working Capital & 69 & 102 & 161 & 124 & 109 & 116 & 132 \\
\hline Before-Tax Return on Assets, \% & 9.6 & 2.5 & 11.0 & 16.8 & 8.5 & 8.0 & 7.5 \\
\hline
\end{tabular}

M:IENERGYUSPRIIMARGUS09_2002.123 


\subsection{PRODUCT PRICE FORECASTS}

\subsubsection{Introduction}

Price forecasts for refined products, natural gas and natural gas liquids have been developed for the High, Medium and Low crude oil price outlooks. Forecast prices for the High and Low crude price levels are included in the Appendix. Historical and forecast prices in dollars per metric ton are also included in the Appendix.

Table 2.5 Pricing Summary

(current dollars-FOB U.S. Gulf Coast)

\begin{tabular}{|c|c|c|c|c|c|c|c|c|}
\hline & & 1990 & 1995 & 1996 & 1997 & 1998 & 1999 & 2000 \\
\hline \multicolumn{9}{|l|}{ Crude oils } \\
\hline Brent, FOB Sullom Voe & $\$ / b b l$ & 23.7 & 17.0 & 20.7 & 19.1 & 12.8 & 17.7 & 28.4 \\
\hline Dubai, FOB Arabian Gulf & $\$ / b b l$ & 20.4 & 16.1 & 18.5 & 18.1 & 12.2 & 17.2 & 26.1 \\
\hline West Texas Intermediate & $\$ / b b l$ & 24.5 & 18.4 & 22.1 & 20.6 & 14.4 & 19.3 & 30.3 \\
\hline Avg. U.S. acquisition & $\$ / b b l$ & 22.2 & 17.2 & 20.7 & 19.1 & 12.6 & 17.4 & 28.3 \\
\hline \multicolumn{9}{|c|}{ Refined products-waterborne spot } \\
\hline Unleaded regular gasoline & $\mathrm{ct} / \mathrm{gal}$ & 71.0 & 50.5 & 59.6 & 58.9 & 41.8 & 52.0 & 83.5 \\
\hline Unleaded premium gasoline ${ }^{1}$ & $\mathrm{ct} / \mathrm{gal}$ & 76.6 & 54.1 & 62.6 & 62.1 & 45.2 & 55.4 & 86.4 \\
\hline Reformulated regular gasoline & ct/gal & --- & 54.3 & 61.7 & 61.5 & 44.3 & 54.1 & 88.8 \\
\hline Reforming naphtha & $\mathrm{ct/gal}$ & 66.6 & 46.5 & 55.9 & 54.1 & 37.1 & 47.4 & 78.9 \\
\hline Kerosene/jet & $\mathrm{ct} / \mathrm{gal}$ & 72.4 & 49.5 & 60.5 & 56.1 & 40.6 & 49.5 & 84.7 \\
\hline Diesel fuel & $\mathrm{ct} / \mathrm{gal}$ & 65.5 & 48.5 & 60.0 & 55.1 & 40.0 & 48.7 & 82.5 \\
\hline No. 2 heating oil & $\mathrm{ct} / \mathrm{gal}$ & 65.5 & 47.3 & 58.6 & 54.1 & 38.2 & 46.7 & 80.9 \\
\hline No. 6 fuel oil $(0.7 \%$ S) & $\$ / b b l$ & 19.9 & 15.0 & 17.9 & 16.5 & 12.8 & 15.7 & 27.4 \\
\hline No. 6 fuel oil (3\% S) & $\$ / b b l$ & 14.5 & 13.6 & 15.5 & 14.3 & 9.7 & 14.0 & 20.5 \\
\hline \multicolumn{9}{|l|}{ U.S. Natural gas } \\
\hline Delivered to Gulf Coast user & $\$ / \mathrm{mmbtu}$ & 1.88 & 1.75 & 2.80 & 2.86 & 2.30 & 2.41 & 4.35 \\
\hline Henry Hub spot price & $\$ / m m b t u$ & 1.64 & 1.64 & 2.61 & 2.59 & 2.11 & 2.27 & 3.96 \\
\hline \multicolumn{9}{|l|}{ Natural gas liquids } \\
\hline Ethane & $\mathrm{ct} / \mathrm{gal}$ & 21.8 & 15.8 & 26.2 & 22.7 & 18.9 & 27.8 & 39.7 \\
\hline Propane & $\mathrm{ct} / \mathrm{gal}$ & 34.5 & 31.9 & 42.0 & 37.5 & 26.4 & 33.5 & 57.4 \\
\hline Normal butane & $\mathrm{ct} / \mathrm{gal}$ & 43.0 & 38.3 & 46.8 & 43.9 & 31.5 & 40.4 & 66.2 \\
\hline Isobutane & $\mathrm{ct} / \mathrm{gal}$ & 50.0 & 40.3 & 50.0 & 46.3 & 32.1 & 40.8 & 67.0 \\
\hline Natural gasoline & $\mathrm{ct} / \mathrm{gal}$ & 53.4 & 40.6 & 51.0 & 48.3 & 34.5 & 42.2 & 72.7 \\
\hline Factor to Constant $2001 \$$ & & 1.262 & 1.113 & 1.092 & 1.071 & 1.059 & 1.043 & 1.022 \\
\hline
\end{tabular}

M:IENERG YIUSPRIIMARGUS09_2002.123 


\section{Table 2.6 Pricing Summary}

(constant 2001 dollars-FOB U.S. Gulf Coast)

\begin{tabular}{|c|c|c|c|c|c|c|c|c|}
\hline & & 1990 & 1995 & 1996 & 1997 & 1998 & 1999 & 2000 \\
\hline \multicolumn{9}{|l|}{ Crude oils } \\
\hline Brent, FOB Sullom Voe & $\$ / b b \mid$ & 29.9 & 18.9 & 22.6 & 20.5 & 13.5 & 18.5 & 29.0 \\
\hline Dubai, FOB Arabian Gulf & $\$ / b b l$ & 25.7 & 17.9 & 20.2 & 19.4 & 12.9 & 17.9 & 26.7 \\
\hline West Texas Intermediate & $\$ / b b l$ & 30.9 & 20.5 & 24.1 & 22.1 & 15.3 & 20.1 & 30.9 \\
\hline Avg. U.S. acquisition & $\$ / b b l$ & 28.0 & 19.2 & 22.6 & 20.5 & 13.4 & 18.2 & 28.9 \\
\hline \multicolumn{9}{|l|}{ Refined products-waterborne } \\
\hline Unleaded regular gasoline & $\mathrm{ctgal}$ & 89.6 & 56.2 & 65.0 & 63.1 & 44.3 & 54.2 & 85.4 \\
\hline Unleaded premium gasoline ${ }^{1}$ & ctgal & 96.6 & 60.2 & 68.3 & 66.5 & 47.9 & 57.8 & 88.3 \\
\hline Reformulated regular gasoline & $\mathrm{ctgal}$ & --. & 60.4 & 67.3 & 65.9 & 46.9 & 56.5 & 90.8 \\
\hline Reforming naphtha & ct/gal & 84.0 & 51.8 & 61.0 & 57.9 & 39.3 & 49.4 & 80.6 \\
\hline Kerosene/jet & $\mathrm{ctgal}$ & 91.3 & 55.1 & 66.0 & 60.1 & 42.9 & 51.7 & 86.5 \\
\hline Diesel fuel & $\mathrm{ct} / \mathrm{gal}$ & 82.6 & 54.0 & 65.5 & 59.1 & 42.3 & 50.9 & 84.3 \\
\hline No. 2 heating oil & $\mathrm{ct} / \mathrm{gal}$ & 82.6 & 52.6 & 64.0 & 58.0 & 40.5 & 48.8 & 82.7 \\
\hline No. 6 fuel oil (0.7\% S) & $\$ / b b l$ & 25.1 & 16.7 & 19.6 & 17.7 & 13.5 & 16.4 & 28.0 \\
\hline No. 6 fuel oil (3\% S) & $\$ / b b l$ & 18.3 & 15.1 & 16.9 & 15.3 & 10.2 & 14.6 & 20.9 \\
\hline \multicolumn{9}{|l|}{ U.S. Natural gas } \\
\hline Delivered to Gulf Coast user & $\$ / m m b t u$ & 2.37 & 1.95 & 3.06 & 3.06 & 2.43 & 2.51 & 4.45 \\
\hline Henry Hub spot price & $\$ / m m b t u$ & 2.07 & 1.82 & 2.85 & 2.77 & 2.23 & 2.37 & 4.05 \\
\hline \multicolumn{9}{|l|}{ Natural gas liquids } \\
\hline Ethane & $\mathrm{ctgal}$ & 27.5 & 17.6 & 28.6 & 24.3 & 20.0 & 29.0 & 40.6 \\
\hline Propane & $\mathrm{ctgal}$ & 43.5 & 35.5 & 45.8 & 40.2 & 27.9 & 35.0 & 58.6 \\
\hline Normal butane & $\mathrm{ct} / \mathrm{gal}$ & 54.3 & 42.6 & 51.1 & 47.0 & 33.3 & 42.1 & 67.7 \\
\hline Isobutane & $\mathrm{ct} / \mathrm{gal}$ & 63.1 & 44.8 & 54.6 & 49.6 & 34.0 & 42.6 & 68.5 \\
\hline Natural gasoline & $\mathrm{ct} / \mathrm{gal}$ & 67.4 & 45.2 & 55.7 & 51.7 & 36.5 & 44.0 & 74.2 \\
\hline Factor to current $\$$ & & 0.793 & 0.899 & 0.916 & 0.934 & 0.945 & 0.958 & 0.978 \\
\hline${ }^{1}$ Octane $(R+M / 2)$ of 92 & & & & & & & & \\
\hline
\end{tabular}




\section{Table 2.7 Price Forecasts Medium Crude Pricing} (current dollars-FOB U.S. Gulf Coast)

\begin{tabular}{|c|c|c|c|c|c|}
\hline & & Actual & & & \\
\hline & & 2001 & 2006 & 2010 & 2015 \\
\hline Crude oils & & & & & \\
\hline Brent, FOB Sullom Voe & $\$ / b b l$ & 24.5 & 19.8 & 21.0 & 23.7 \\
\hline Dubai, FOB Arabian Gulf & $\$ / b b l$ & 22.8 & 18.2 & 19.3 & 21.8 \\
\hline West Texas Intermediate & $\$ / b b l$ & 25.9 & 21.6 & 22.9 & 25.9 \\
\hline Avg. U.S. acquisition & $\$ / b b l$ & 23.0 & 19.3 & 20.4 & 23.1 \\
\hline Refined products-waterborne & & & & & \\
\hline Unleaded regular gasoline $^{1}$ & $\mathrm{ct} / \mathrm{gal}$ & 74.0 & 63.6 & 67.4 & 75.4 \\
\hline Unleaded premium gasoline ${ }^{12}$ & $\mathrm{ct} / \mathrm{gal}$ & 77.8 & 67.7 & 71.7 & 80.1 \\
\hline Reformulated regular gasoline ${ }^{1}$ & $\mathrm{ct} / \mathrm{gal}$ & 79.4 & 66.3 & 70.3 & 78.5 \\
\hline Reforming naphtha & $\mathrm{ct} / \mathrm{gal}$ & 67.7 & 56.4 & 59.8 & 67.3 \\
\hline Kerosene/jet & $\mathrm{ct} / \mathrm{gal}$ & 72.2 & 59.4 & 62.9 & 70.6 \\
\hline Diesel fuel ${ }^{3}$ & $\mathrm{ct} / \mathrm{gal}$ & 70.8 & 60.5 & 64.1 & 71.9 \\
\hline No. 2 heating oil & $\mathrm{ct} / \mathrm{gal}$ & 69.0 & 56.3 & 59.7 & 67.2 \\
\hline No. 6 fuel oil $(0.7 \%$ S) & $\$ / b b l$ & 22.9 & 17.6 & 18.7 & 21.3 \\
\hline No. 6 fuel oil (3\% S) & $\$ / b b l$ & 17.2 & 13.2 & 14.0 & 16.2 \\
\hline U.S. Natural gas & & & & & \\
\hline Delivered to Gulf Coast user & $\$ / m m b t u$ & 4.09 & 2.94 & 3.14 & 3.60 \\
\hline Henry Hub spot price & $\$ / m m b t u$ & 3.95 & 2.72 & 2.92 & 3.37 \\
\hline Natural gas liquids & & & & & \\
\hline Ethane & $\mathrm{ct} / \mathrm{gal}$ & 33.5 & 24.6 & 26.1 & 29.6 \\
\hline Propane & $\mathrm{ct} / \mathrm{gal}$ & 46.9 & 39.1 & 41.5 & 46.8 \\
\hline Normal butane & $\mathrm{ct} / \mathrm{gal}$ & 53.4 & 45.3 & 48.0 & 54.2 \\
\hline Isobutane & $\mathrm{ct} / \mathrm{gal}$ & 56.8 & 46.3 & 49.1 & 55.4 \\
\hline Natural gasoline & $\mathrm{ct} / \mathrm{gal}$ & 59.1 & 49.8 & 52.8 & 59.7 \\
\hline Factor to Constant 2001 \$ & & 1.000 & 0.884 & 0.801 & 0.708 \\
\hline${ }^{1}$ Sulfur content less than $30 \mathrm{ppm}$ & & & & & \\
\hline${ }^{2}$ Octane $(R+M / 2)$ of 92 & & & & & \\
\hline${ }^{3}$ Sulfur content less than $15 \mathrm{ppm}$ & & & & & \\
\hline
\end{tabular}




\section{Table 2.8 Price Forecasts Medium Crude Pricing}

(constant 2001 dollars-FOB U.S. Gulf Coast)

$\begin{array}{llll}\text { Actual } & & & \\ 2001 & 2006 \quad 2010 \quad 2015\end{array}$

Crude oils

Brent, FOB Sullom Voe

Dubai, FOB Arabian Gulf

West Texas Intermediate

Avg. U.S. acquisition

$\begin{array}{lllll}\text { \$/bbl } & 24.5 & 17.5 & 16.8 & 16.8 \\ \$ / \text { bbl } & 22.8 & 16.1 & 15.4 & 15.4 \\ \$ / \text { bbl } & 25.9 & 19.1 & 18.4 & 18.3 \\ \$ / b b l & 23.0 & 17.0 & 16.3 & 16.3\end{array}$

Refined products-waterborne

Unleaded regular gasoline ${ }^{1}$

$\begin{array}{lllll}\mathrm{ct} / \mathrm{gal} & 74.0 & 56.2 & 54.0 & 53.4\end{array}$

Unleaded premium gasoline ${ }^{12}$

$\begin{array}{lllll}\mathrm{ct} / \mathrm{gal} & 77.8 \quad 59.8 & 57.4 & 56.7\end{array}$

Reformulated regular gasoline ${ }^{1}$

$\begin{array}{lllll}\text { ct/gal } & 79.4 & 58.6 & 56.3 & 55.6\end{array}$

Reforming naphtha

Kerosene/jet

$\begin{array}{lllll}\text { ct/gal } & 67.7 & 49.9 & 47.9 & 47.6\end{array}$

Diesel fuel ${ }^{3}$

No. 2 heating oil

No. 6 fuel oil $(0.7 \% \mathrm{~S})$

No. 6 fuel oil (3\% S)

$\begin{array}{lllll}\mathrm{ct} / \mathrm{gal} & 72.2 & 52.5 & 50.4 & 50.0\end{array}$

$\begin{array}{lllll}\text { ct/gal } \quad 70.8 & 53.5 & 51.3 & 50.9\end{array}$

$\begin{array}{lllll}c t / g a l & 69.0 & 49.8 & 47.8 & 47.5\end{array}$

$\begin{array}{lllll}\$ / \mathrm{bbl} & 22.9 & 15.6 & 15.0 & 15.1\end{array}$

$\begin{array}{lllll}\$ / b b l & 17.2 & 11.6 & 11.2 & 11.5\end{array}$

U.S. Natural gas

Delivered to Gulf Coast user

Henry Hub spot price

$\begin{array}{lllll}\$ / m m b t u & 4.09 & 2.60 & 2.52 & 2.55\end{array}$

Natural gas liquids

Ethane

Propane

Normal butane

Isobutane

Natural gasoline

$\begin{array}{lllll}\$ / m m b t u & 3.95 & 2.41 & 2.34 & 2.38\end{array}$

Factor to current \$

$\begin{array}{lllll}\text { ct/gal } & 33.5 & 21.8 & 20.9 & 21.0 \\ \text { ct/gal } & 46.9 & 34.6 & 33.2 & 33.1 \\ \text { ct/gal } & 53.4 & 40.0 & 38.4 & 38.3 \\ \mathrm{ct} / g a l & 56.8 & 40.9 & 39.3 & 39.2 \\ \mathrm{ct} / g a l & 59.1 & 44.0 & 42.3 & 42.3 \\ & & & & \\ & 1.000 & 1.131 & 1.249 & 1.413\end{array}$

${ }^{1}$ Sulfur content less than 30 ppm from 2005 onward

2 Octane $(R+M / 2)$ of 92

${ }^{3}$ Sulfur content less than 15 ppm from 2006 onward

M:IENERGYYUSPRIIMARGUS09_2002.123 


\subsubsection{Major Refined Product Prices}

Refined product price forecasts were developed based on the crude oil price outlook, the expected variable margin for the incremental refinery configuration, and the projected price differentials between major refined products presented in this section.

Table 2.9 Refined Product Price Differential Forecast Medium Crude Pricing (constant 2001 dollars)

\begin{tabular}{|c|c|c|c|c|c|c|c|}
\hline \multicolumn{2}{|c|}{2001} & \multicolumn{2}{|c|}{2006} & \multicolumn{2}{|c|}{2010} & \multicolumn{2}{|c|}{2015} \\
\hline Delta off & Delta off & Delta off & Delta off & Delta off & Delta off & Delta off & Delta \\
\hline ULR & WTI & ULR & WTI & ULR & WTI & ULR & \\
\hline (ct/gal) & $(\$ / b b l)$ & (ct/gal) & $(\$ / b b l)$ & (ct/gal) & $(\$ / b b l)$ & (ct/gal) & \\
\hline
\end{tabular}

Unleaded regular mogas

Unleaded Premium Mogas

Naphtha

Kero/Jet

Diesel

No. 2 Heating Oil

Low Sulfur HVGO

No. 6 Fuel Oil ( $0.7 \%$ Sul.)

No. 6 Fuel Oil (3.0\% Sul.)

Hydroskimming Variable

Margin, \$/bbl

M:IENERGYIUSPRIIMARGUS09_2002.123

- $\quad 5$

$\begin{array}{ll}3.7 & 6.8\end{array}$

(6.4) $\quad 2.6$

(1.9) $\quad 4.5$

(3.2) $\quad 3.9$

(5.0) $\quad 3.1$

(7.7) $\quad 2.0$

(19.5) (3.0)

(33.2) (8.7)

1.23

\section{6}

$3.6 \quad 5.1$

(4.3) $\quad 1.8$

(1.7) 2.9

(2.6) 2.5

(4.4) $\quad 1.8$

(6.5) 0.9

(17.1)

(26.5)

(3.5)

(7.5)

0.49

$\begin{array}{rrrr}- & 3.5 & - & 3.4 \\ 3.5 & 4.9 & 3.3 & 4.7 \\ (4.2) & 1.7 & (4.0) & 1.7 \\ (1.7) & 2.8 & (1.6) & 2.7 \\ (2.5) & 2.4 & (2.4) & 2.3 \\ (4.2) & 1.7 & (4.0) & 1.7 \\ (6.2) & 0.9 & (5.8) & 0.9 \\ (16.4) & (3.4) & (15.7) & (3.2) \\ (25.4) & (7.2) & (24.3) & (6.8) \\ & & & \\ & 0.47 & & 0.48\end{array}$




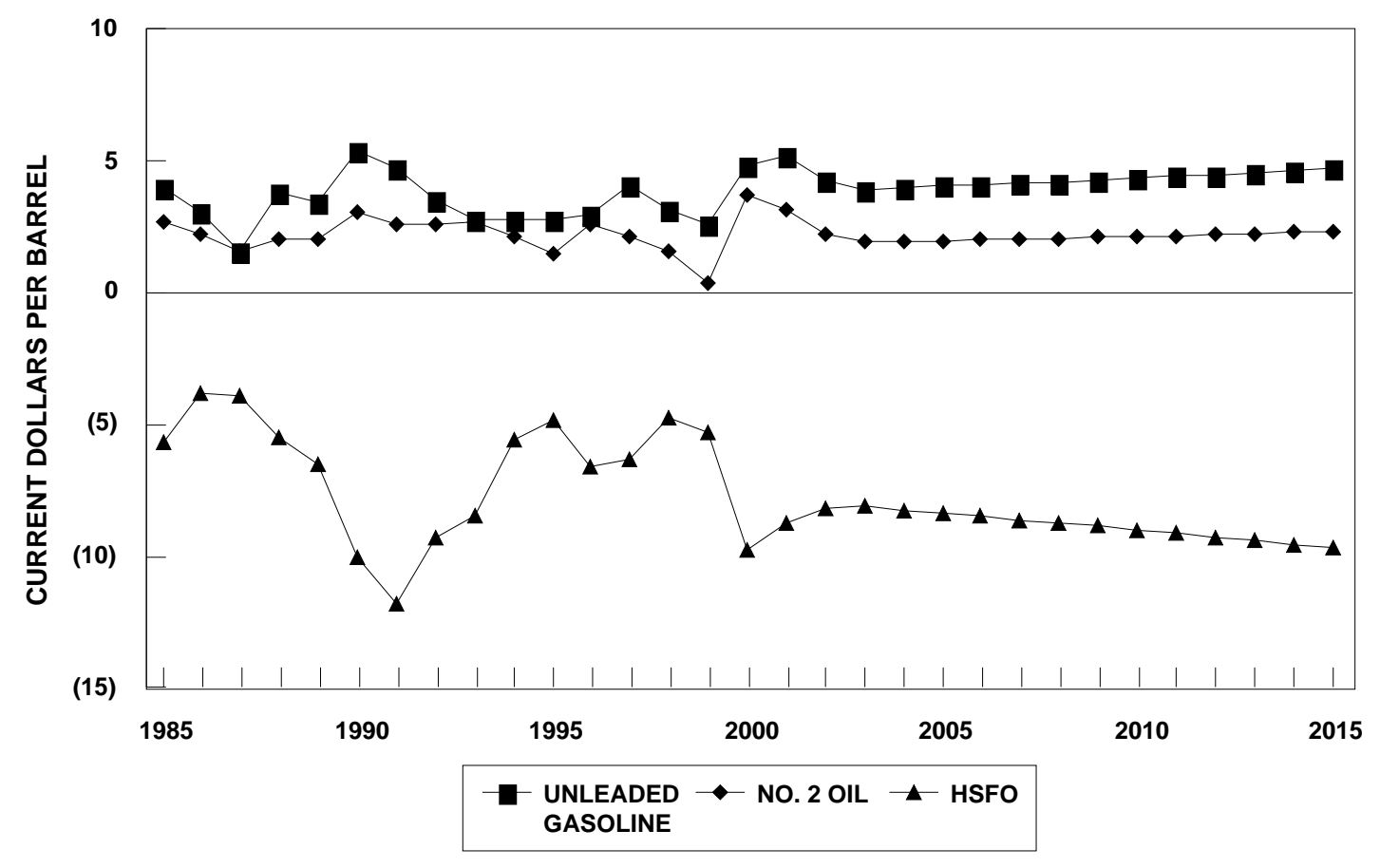

PRODVSWTI

M:IENERGYIUSPRIIMargus01_2002.123

Figure 2.10 USGC Refined Product Pricing Differentials To Crude Oil Pricing (GC Waterborne versus WTI Crude Oil) 


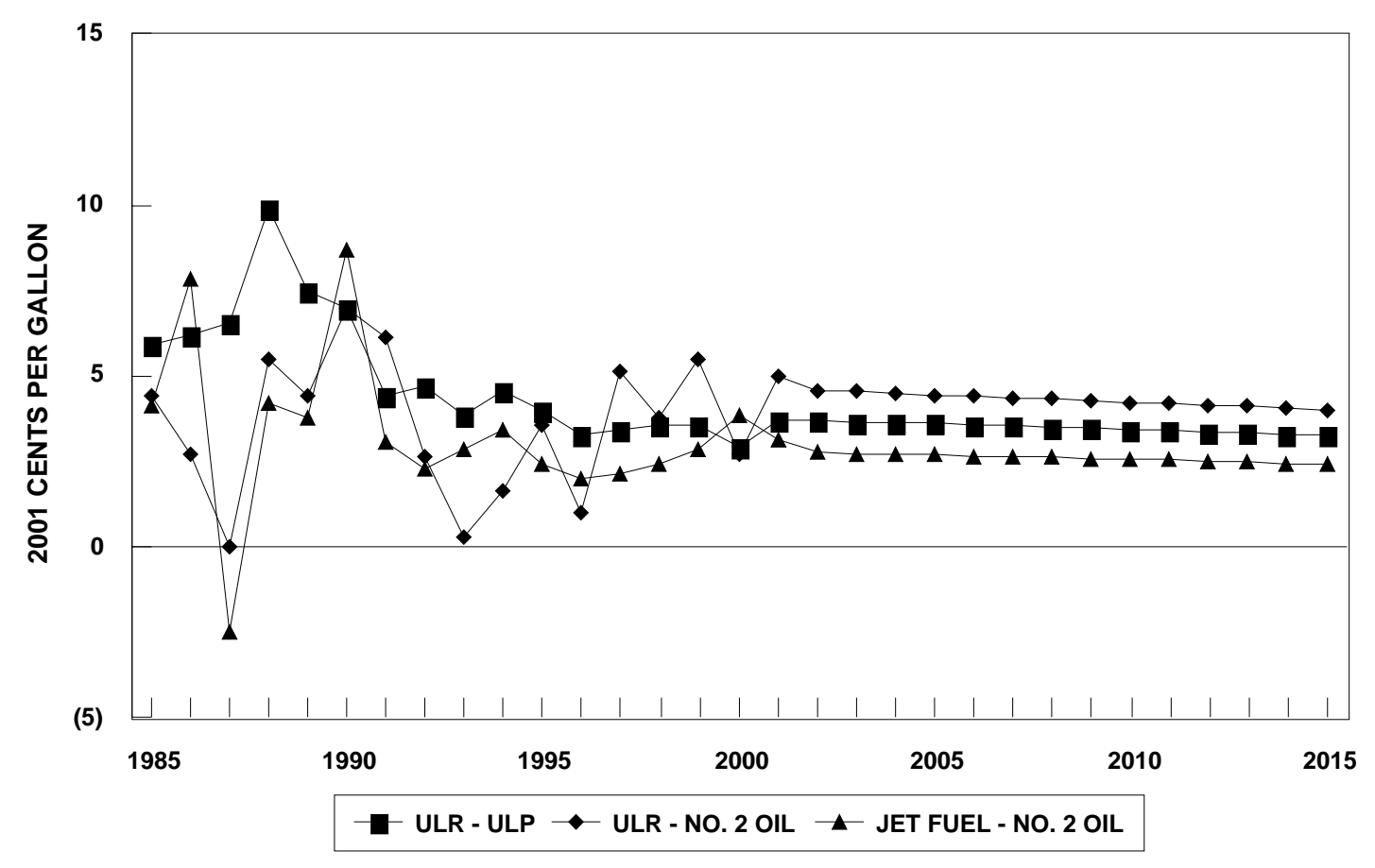

PRODDIFFS
M:IENERGYIUSPRIIMargus01_2002.123

Figure 2.11 USGC Product Price Differentials

\subsubsection{Gasoline}

\section{Regular Unleaded Gasoline}

Reflecting U.S. gasoline demand and refining margin trends, unleaded regular gasoline (ULR) prices relative to the price of WTI crude oil (i.e., the USGC gasoline crackspread) fell to a low of about $\$ 1.5$ per barrel in 1987 due to a surplus of refining capacity. The gasoline crackspread recovered to about $\$ 3.50$ per barrel in 1988/89 due to increased demand and peaked at $\$ 5.4$ per barrel in 1990 due to the crisis in the Middle East. It fell to \$2.8-3.5 per barrel in 1992/1993 and its annual averages remained in this range for most of the 1994-1998.

The gasoline crackspread fell to $\$ 2.6$ per barrel in 1999 due to the sharp rise in crude oil prices. However, it rebounded to average $\$ 4.8$ per barrel in 2000 as gasoline prices in many parts of the U.S. soared during the late spring due to low inventories and the introduction of the summer grade of Phase II reformulated gasoline. A continuation of tight inventories, compounded by several unscheduled shutdowns of major refineries, resulted in a gasoline crackspread of $\$ 7.6$ per barrel during the first half of 2001 and an average value of \$5.2 per barrel for all of 2001 .

Given the expected trends in USGC refining margins, the USGC gasoline crackspread is forecast to be remain near $\$ 4$ per barrel during the 2002-2005 period and then increase to about $\$ 4.5$ per barrel by 2010 . 


\section{Premium Unleaded Gasoline}

The premium for unleaded 92 RON premium gasoline (ULP) relative to unleaded regular (ULR) averaged over 7 cents per gallon in 1988 due to a severe octane shortfall for much of the year. During 1989 and 1990 the price premium paid for ULP remained over 5 cents per gallon, reflective of continued strong demand for premium gasoline.

During the second half of 1990, the fly-up in crude oil and gasoline prices and the economic recession negatively impacted total U.S. gasoline sales and also led to some consumer resistance to premium grades. Reflecting the weaker demand for unleaded premium gasoline, the price differential between premium and regular grades dropped below 4 cents per gallon in 1991. This lower differential persisted during the 1992-1995 period, averaging 3.6 cents per gallon in 1995, even though U.S. gasoline demand increased more than six percent. The addition of significant volumes of high-octane oxygenates, mandated under the 1990 amendments to the Clean Air Act, and cat cracker modifications/capacity expansions increased the gasoline production capability of U.S. refineries.

The differential continued to narrow in 1996 and 1997 due to continued declines in demand for premium gasoline, but firmed to 3.4 cents per gallon in 1998 and 1999. After narrowing to 2.9 cents per gallon in 2000 when higher prices negatively impacted demand, a tight gasoline market drove the premium up to 3.7 cents per gallon in 2001.

The U.S. refining industry is expected to have adequate capacity for octane production over the next few years due to the availability of spare catalytic reforming capacity, and gasoline and MTBE imports. However, gasoline demand growth and regulatory initiatives to phase out MTBE use may result in octane crunches during peak gasoline demand periods. The annual average differential for premium gasoline is forecast to average about 3.5 cents per gallon (2001 dollars) in the future. This forecast assumes that any mandatory reduction in MTBE use will provide the industry with adequate time to invest in alternative octane production facilities. If an MTBE phase out is enacted that does not provide the industry with an adequate lead time for investments in replacement octane production facilities, a higher differential is likely during the middle of the decade.

\section{Ultra Low Sulfur Gasoline}

The EPA's Tier 2 Gasoline Sulfur Rule will require most U.S. refineries to produce gasoline averaging no more than $30 \mathrm{ppm}$ sulfur by 2005 . The future premium for this ultra low sulfur gasoline (ULSG) relative to conventional gasoline grades is forecast to be 2.0 cents per gallon (2001 dollars), reflecting some, but not all, of the additional operating and capital costs associated with producing this higher quality product.

\section{Reformulated Gasoline}

Reformulated gasoline (RFG) sold in ozone non-attainment areas commanded an average premium of 3.8 cents per gallon in 1995, relative to non-reformulated grades at the gate of a USGC refinery. The premium was close to 5 cents during the first quarter of 1995, reflecting the 
extremely high cost of methanol used to produce MTBE. The premium fell to 2.5 cents per gallon during the 1996-1999 period as MTBE fell closer to its octane blending value.

The premium shot up to an average of 5.3 cents per gallon in both 2000 and 2001 and peaked at 8-9 cents per gallon during the second quarters of both years when the introduction of the summer grade of Phase II reformulated gasoline and unscheduled refinery and pipeline shutdowns resulted in low RFG supplies.

The future premium for RFG relative to conventional gasoline grades is expected to be 2.5 cents per gallon (2001 dollars), primarily reflecting the cost of oxygenates over their octane blending value plus the increased cost of segregating, transporting and certifying RFG. After ULSG becomes mandatory in 2005, RFG's premium relative to ULSG grades is expected to be 0.5 cents per gallon (2001 dollars).

\subsubsection{Diesel Fuel}

Gasoline's premium over diesel price was 2 cents per gallon in 1995 due to an unseasonably warm winter, but cold weather early in the year and strong European demand for low-sulfur diesel late in the year drove the average diesel price slightly above gasoline's average price in 1996. Strong gasoline prices and a weaker distillate market resulted in gasoline averaging 3.8 cents per gallon above the price of diesel in 1997.

Strong economic growth and increased diesel demand contributed to relatively higher prices in 1998 and diesel's discount to ULR narrowed to 1.8 cents per gallon. The differential increased to 3.3 cents per gallon in 1999 as an unseasonably warm winter resulted in weaker distillate demand. Low inventories for both gasoline and distillates created firm markets for both products in 2000 and diesel's discount to ULR declined to 1.0 cent per gallon. Very strong gasoline markets increased gasoline's premium over the diesel price to 3.2 cents per gallon in 2001 .

In December 2000, the U.S. EPA issued a Final Rule related to future diesel sulfur levels. The rule stipulates that U.S. refiners will have to make at least 80 percent of their mid-2006 onhighway diesel as ultra low sulfur diesel (ULSD) with a maximum sulfur content of $15 \mathrm{ppm}$. The future premium for ULSD, relative to the price of diesel with a maximum sulfur content of $500 \mathrm{ppm}$ that is now sold, is forecast to be 2.0 cents per gallon (2001 dollars), reflecting some, but not all, of the additional operating and capital costs associated with producing this higher quality product.

Long term, Nexant forecasts that ultra low sulfur unleaded regular gasoline will maintain a premium vis-à-vis ULSD of 3 to 3.5 cents per gallon. Higher growth rates for middle distillate products, compared to gasoline, are expected to support this price differential.

\subsubsection{No. 2 Fuel Oil}

Historically, No. 2 fuel oil and diesel prices tracked each other very closely at the wholesale level, reflecting the interchangeability of the two grades. Due to the mandated sulfur reduction in diesel fuels starting in mid-1993, distillate sold into the heating markets is discounted relative 
to on-highway uses. During the 1994-1997 period, the discount averaged 1.2 cents per gallon before widening to 1.8 cents per gallon in 1998. It widened to 2.0 cents in 1999 and averaged 1.7 cents per gallon during 2000 and 2001. This price premium for diesel has not been sufficient for most refiners to achieve an acceptable return on new investments made to produce the lower sulfur diesel product.

Diesel fuel with a maximum sulfur content of $500 \mathrm{ppm}$ is expected to command a premium over No. 2 fuel oil at the refinery gate of about 2 cents per gallon during the 2002-2005 period. After it becomes established in the market, ULSD is forecast to command a premium over No. 2 fuel oil at the refinery gate of 4 to 4.5 cents per gallon during the 2007-2015 period.

\subsubsection{Jet Fuel}

The price of jet fuel has recently enjoyed a premium of 2-3 cents per gallon over the No. 2 fuel oil price. This premium reflects the higher quality requirements of jet fuel and supports the costs associated with segregated tankage, etc.

Long term, Nexant expects that the projected growth in jet fuel demand will sustain a premium over No. 2 fuel oil of about 2.8 cents per gallon. Based on the projected differential between ULSD and No. 2 fuel oil, jet fuel will be priced about 1 cent per gallon below the ULSD prices after 2006.

\subsubsection{Residual Fuel Oil}

Historically, the price of residual fuel oil has varied considerably relative to crude oil. The relative price of high sulfur residual fuel oil (HSRFO) reached a cyclical high in 1984 after major residual conversion capacity additions came on stream and a United Kingdom coal strike temporarily boosted worldwide residual fuel demand. During 1988 and 1989, the relative price of residual fuel weakened to 67 percent of WTI, reflecting significantly higher production and competitive pressure from depressed natural gas pricing. 


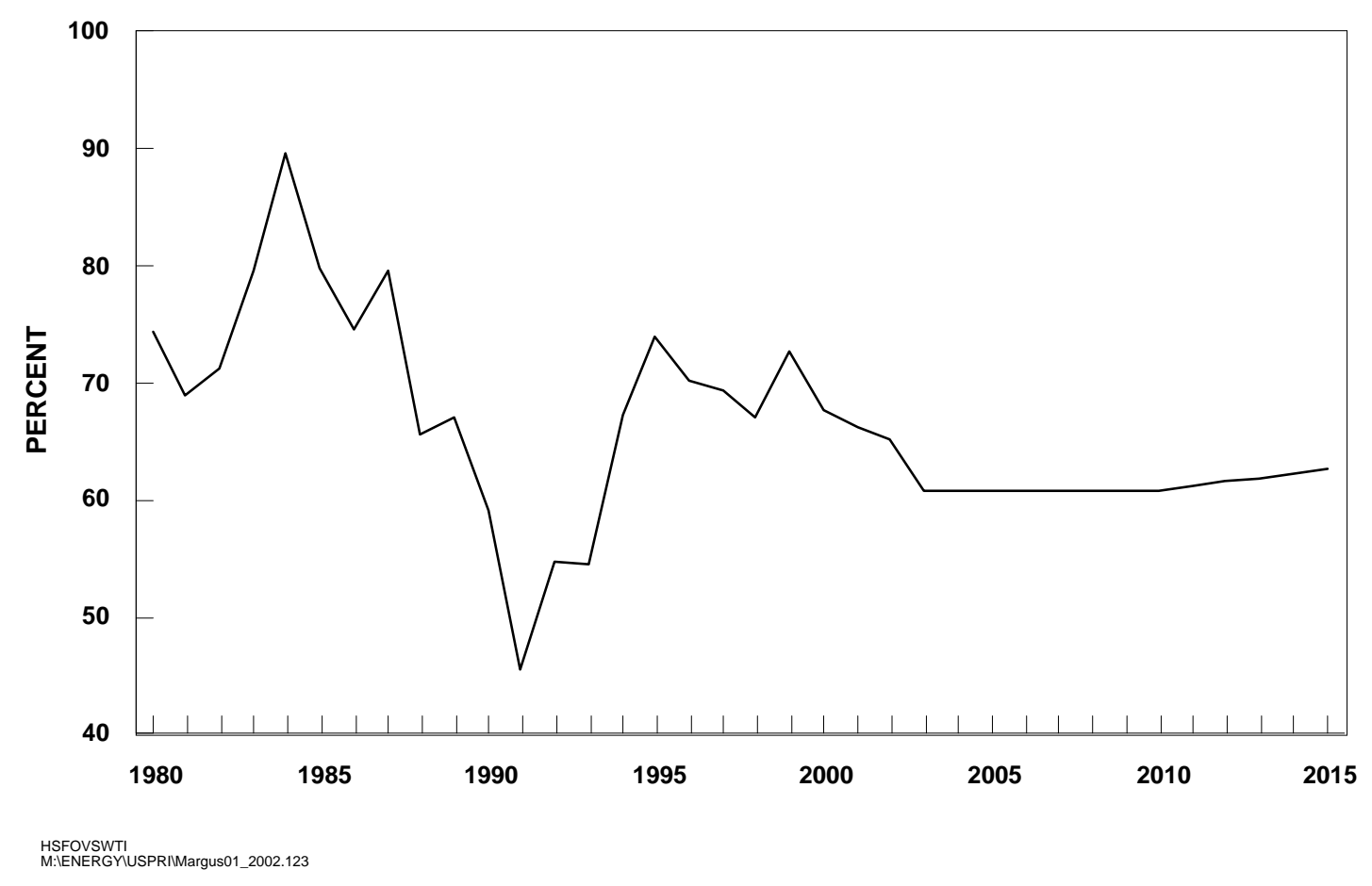

Figure 2.12 USGC High Sulfur Fuel Oil Versus WTI

In 1990 and 1991 the relative price of residual fuel weakened dramatically, as a combination of factors, including continued competition from low cost natural gas and the impact of the Middle East conflict which caused the shut-in of light crude oil production and local residual conversion capability. During 1992 and 1993, the ratio recovered to about 55 percent as light crude oils became more readily available in international markets, reducing WTI's price premium. During 1994 and 1995 residual fuel prices continued to strengthen due to further worldwide increases in light crude oil production, the start up of new residual conversion facilities and the reduced availability of heavy Saudi and Mexican crude oils.

Residual fuel prices weakened during the 1996-1998 period as demand for lighter products in global markets exceeded residual fuel oil's demand growth and oil prices dropped in 1998. Cutbacks in OPEC production of heavy crude oil contributed to stronger residual fuel prices in 1999, but increased production of heavy crude oil, that had been preferentially cut back during 1998/99, contributed to weaker prices in 2000 and 2001.

Long term, Nexant expects that the pricing of high sulfur residual fuel oil will decline relative to WTI crude oil, with variations around a trend line ratio of about 61 percent. This projected weakness takes into account the forecast global growth in HSRFO demand, which is expected to lag the growth in demand for light products, and the expectation that there will be few further major increases in the world's light crude oil production. 
Residual oil conversion, including upgrading residual oil in FCC, coking and hydrocracking units, has its economic incentive in the price spread between the value of residual oil feedstock and light products. The price spreads between HSRFO and No. 2 fuel oil and ULR are often used as a trend indicator. This differential versus No. 2 fuel oil peaked at about \$18 (2001 dollars) per barrel in 1991, rising from a low of about $\$ 8$ per barrel during 1987. This differential dropped to \$13-14 per barrel in 1992-1993, as weaker crude oil prices made residual fuel oil use more competitive while some heavy crude oil production was cutback. The differential fell during 1994 and 1995 to \$7 per barrel in 1995 due to increases in light North Sea crude oil production, the start up of new residual conversion facilities and strong Asian demand for HSRFO.

Strong European and Asian demand for distillates increased the differential to $\$ 10$ and $\$ 9$ per barrel in 1996 and 1997, respectively. Lower oil prices and cutbacks in heavy crude oil production were primarily responsible for the differential dropping to $\$ 7$ and $\$ 6$ per barrel in 1998 and 1999, respectively. During 2000 the differential shot up to about $\$ 14$ per barrel, reflecting the combined impact of low product inventories, increased heavy crude oil production and higher crude oil prices. The differential remained at about $\$ 14$ per barrel during the first half of 2001 , but fell to an average value of $\$ 9.8$ per barrel during the second half of the year. Weak light product markets and reduced heavy crude production were primarily responsible for the narrowing of the differential.

This differential is expected to average \$9-10 (2001 dollars) per barrel in the longer term, but continue to be volatile. This long-term weakness in high sulfur residual fuel pricing reflects anticipated weak demand as higher environmental standards restrict its worldwide use. The forecast long-term trend for the differential provides the required incentive to selectively install additional residual upgrading capacity. In general the incentive to upgrade to gasoline has tracked that for distillates. 


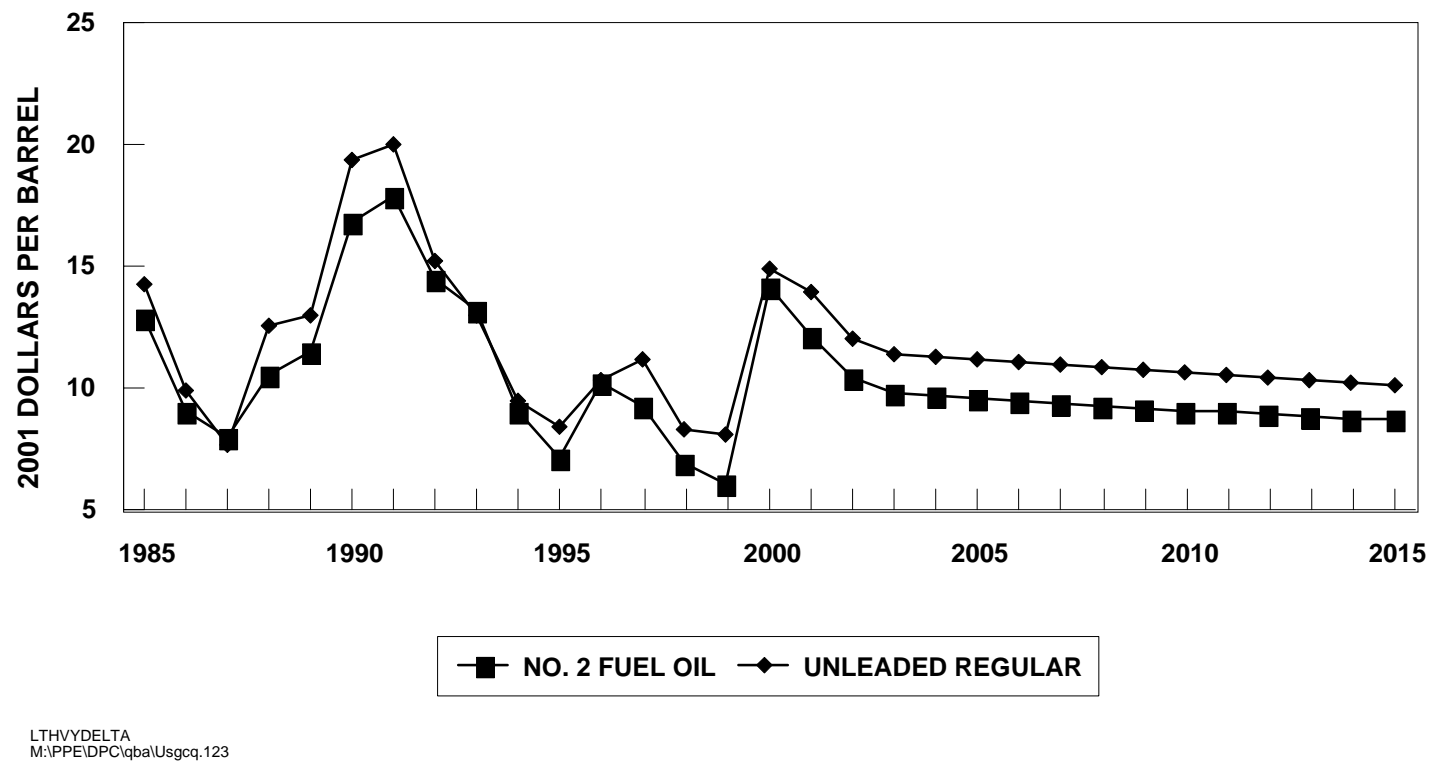

Figure 2.13 USGC Upgrading Incentive High Sulfur Fuel Oil Versus "Clean" Products

\subsubsection{Natural Gas Price Forecast}

Nexant's methodology for forecasting natural gas prices is based on two key elements. First, the price of natural gas generally reflects the price of competitive fuel oil in its incremental market. The market clearing sectors for natural gas are typically the fuel-switching utilities and industries in the U.S. Northeast, which represent the incremental market for gas sellers. In addition, the price of natural gas reflects the degree of gas-to-gas competition associated with gas surpluses. Nexant's methodology, therefore, is as follows:

- Prices of crude oil and refined products (specifically, low-sulfur residual fuel oil) are forecast for the Gulf Coast market. Typical transportation costs are added to adjust prices for delivery to the U.S. Northeast industrial/utility market. Other competitive factors (i.e. imports of residual fuel oil into the U.S. Northeast) are also relevant in assessing the price of gas in the market. The burner tip price on a Btu basis of low-sulfur residual fuel oil in the Northeast market forms a competitive ceiling price for natural gas

- This value, less transportation and distribution costs to the U.S. Gulf Coast, yields a market clearing price for natural gas at the Gulf Coast

- The degree to which natural gas will be priced above or below its competitive ceiling in the U.S. Northeast or other competitive gas markets also reflects the degree of gas-to-gas competition. As a result, Nexant's forecast of the natural gas surplus or deficit also has a 
bearing on the price of natural gas relative to its competing fuel (i.e. low-sulfur residual fuel oil)

Changes in federal rules, which regulate the domestic natural gas transportation system, have had a major impact on how gas transmission companies conduct business. The U.S. natural gas industry can be characterized as follows:

- Short-term spot transactions and contract sales linked to spot prices have become a very high percentage of total sales. This trend reflects the strong correlation between spot gas pricing in the Gulf Coast and the average cost of gas to utility and large industrial consumers

- New pipeline capacity from Canada and within the U.S. has sharply reduced the deliverability problems that occurred in the late 1980s during peak winter demand periods

- The growth of the natural gas futures market and the "unbundling" of the industry's services, which has expanded gas storage capacity and made it more market responsive, have reduced seasonal price variations

- Market hubs with numerous pipeline connections have been developed in key locations around the country. The hubs have intensified competition within the industry and helped to promote new services in the industry. The Henry Hub in Louisiana has become a key market hub since it is the delivery point for the New York Mercantile Exchange (NYMEX) natural gas futures contract.

- Natural gas has become the preferred fuel for new power generation facilities, resulting in strong demand growth 


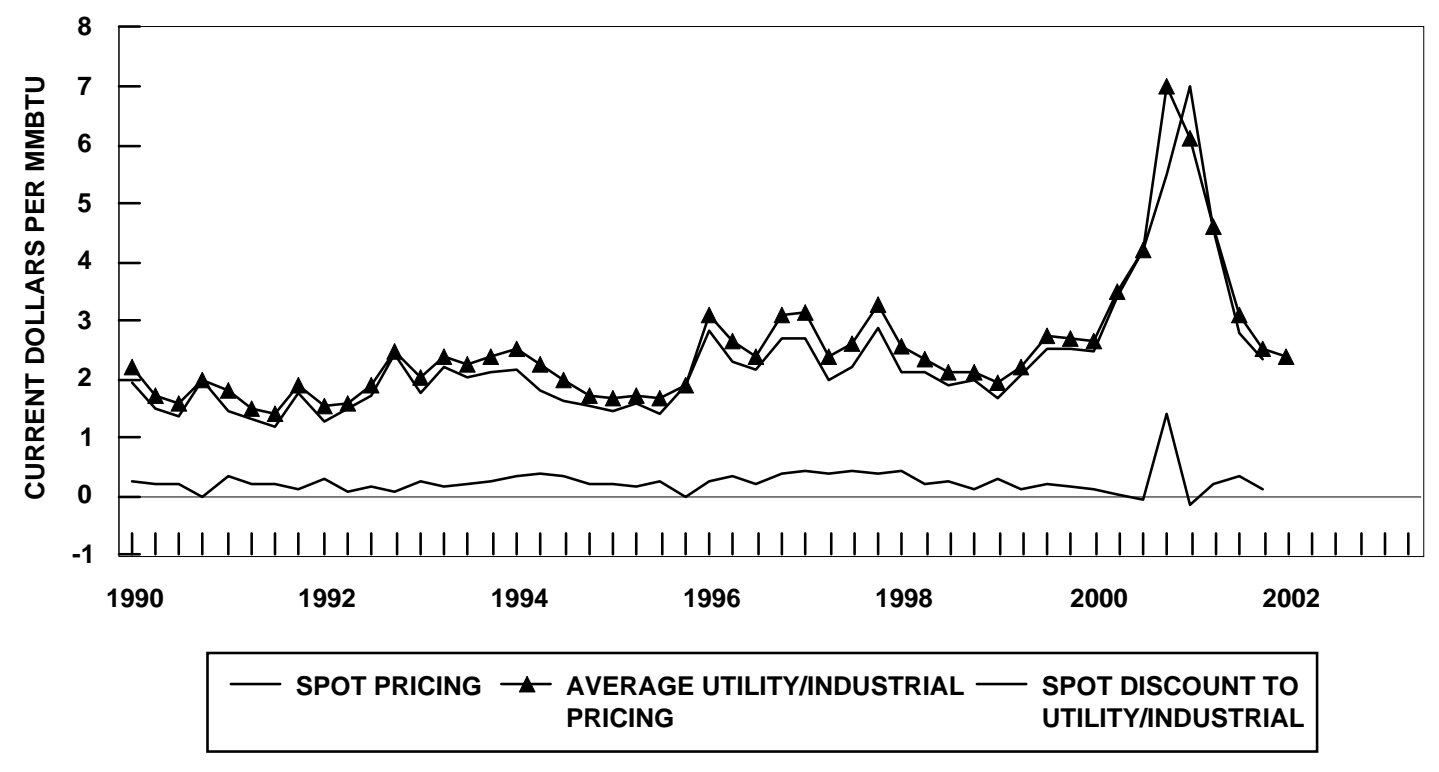

LATRENDSQ
O:IWorkingIPPE US PricinglNatgas.123

Figure 2.14 USGC Natural Gas Pricing Trends

The increasing flexibility of the natural gas industry, as evidenced by the replacement of very long, 20-plus-year fixed contracts, with much shorter agreements, has had the practical result that gas pricing tends to change much more rapidly to reflect market-related and competitive factors. Increases or decreases in the price of crude oil and, therefore, residual fuel, now directly impact each month's fuel purchasing for facilities with dual-fuel capabilities.

The spot price of natural gas in the U.S. Northeast averaged between 65 and 98 percent of the price of 1.0 percent sulfur residual fuel during the 1985 to 1992 period. The trend in this relationship reflected the differing effects of gas-to-gas competition and gas supply surpluses throughout the period. 
Table 2.10 U.S. Northeast Natural Gas Vs. Residual Fuel Oil Spot Pricing Medium Crude Pricing (current dollars per million Btu)

$1 \%$ Sulfur

Residual Fuel -

U.S. Northeast

1985

1990

1995

1996

1997

1998

1999

2000

2001

2006

2010

2015
3.9

3.1

2.5

2.9

2.6

2.0

2.4

3.9

3.3

2.7

2.9

3.3
Natural Gas -

Delivered New York

2.6

2.1

1.8

2.8

2.9

2.4

2.6

4.4

4.7

3.0

3.2

3.7
U.S. Northeast

Gas/Resid Ratio

(Percent)

M:IENERGYUSPRIMMARGUS09_2002.123

65

69

73

97

109

121

106

113

143

111

112

112 


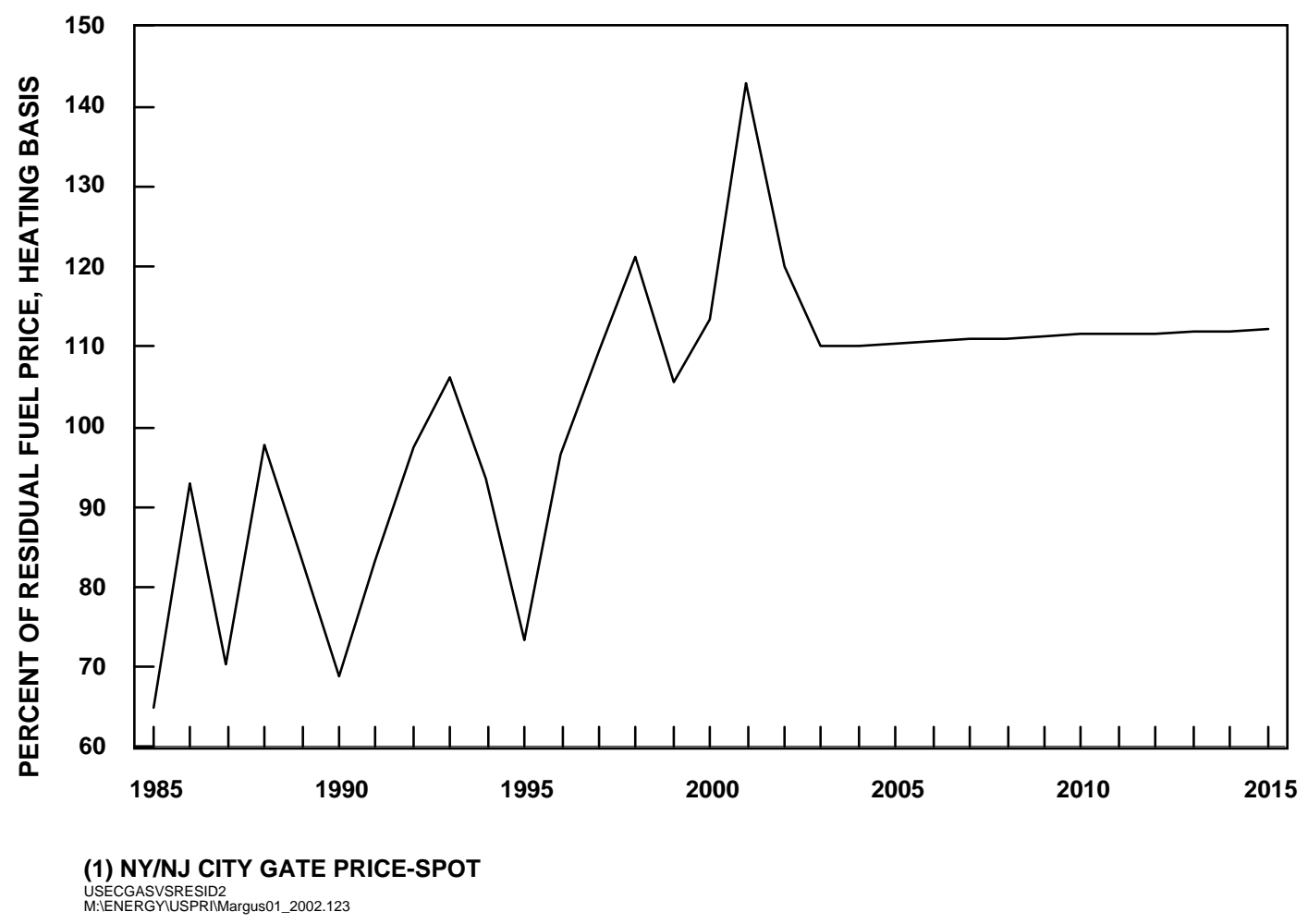

Figure 2.15 U.S. East Coast Natural Gas ${ }^{1}$ Versus Residual Fuel Pricing

In 1993 tighter gas supplies and higher prices pushed spot gas prices above the equivalent price for residual fuel oil. A cold winter sustained relatively high gas prices in 1994, but a mild winter and increased availability of Canadian gas resulted in weak gas prices during 1995, prompting the shut-in of some U.S. production early in the year.

In 1996 gas prices strengthened due to unseasonably cold weather early in the year that resulted in low levels of gas in storage throughout the year. Low inventories also contributed to higher prices in late 1996/early 1997, with spot prices for gas flying up to over $\$ 4.4$ per million Btu. Although gas prices averaged $\$ 2.4$ per million Btu during the second and third quarters of 1997 , prices again flew up late in the year to over $\$ 3.4$ per million Btu due to renewed concerns that inventories would not be adequate throughout the winter.

A mild 1997/98 winter resulted in high inventory levels and prices fell during the first quarter of 1998 to an average of $\$ 2.5$ per million Btu. The average cost of gas to USGC utility and large industrial consumers eroded during the balance of 1998 and averaged $\$ 2.3$ per million Btu for the year. Lower crude oil prices and prices for low-sulfur residual fuel oil put pressure on gas prices, but fully utilized pipelines from Canada and firm demand supported gas prices. As a result the spot price of natural gas strengthened to 121 percent of the cost of 1.0 percent sulfur residual fuel in the U.S. Northeast, versus 109 percent in 1997. 
Natural gas prices rose during 1999 in response to higher oil prices. During 2000, strong natural gas demand for power generation and flat U.S. gas production resulted in below average inventory levels and drove natural gas prices to their highest levels since industry deregulation began in the early 1980's. Prices during the second half of the year hovered around \$5 per million Btu and peaked above $\$ 8$ per million Btu. The average cost of gas to USGC utility and large industrial consumers averaged $\$ 4.35$ per million Btu during 2000 . These high prices still remained close to parity with the cost of 1.0 percent sulfur residual fuel in the U.S. Northeast, whose price was driven higher by high crude oil and cat cracker feedstock prices.

Colder than normal weather and low inventory levels drove natural gas spot prices to a record level of about $\$ 10$ per million Btu during the second half of December 2000 and early January 2001. After peaking in early January, prices fell to $\$ 6.5$ per million Btu by the end of the month as mild weather and fuel switching reduced natural gas demand. Prices continued to weaken during the next three months and reached $\$ 4$ per million Btu during May as inventory levels exceeded prior year levels for the first time in 2001. Prices continued to decline during most of the second half of the year, averaging $\$ 2.8$ per million Btu during this period. The average cost of gas to USGC utility and large industrial consumers averaged $\$ 4.1$ per million Btu during 2001.

As a result of the flyup in prices early in the year, the average spot price of natural gas in 2001 shot up to 143 percent of the cost of 1.0 percent sulfur residual fuel in the U.S. Northeast, but price again dropped to parity with the cost of 1.0 percent sulfur residual fuel during the second half of the year.

The underlying premise of Nexant's natural gas pricing outlook is that gas prices on a long-term basis will be competitive with low sulfur fuel oil at the burner tip. As a result, the forecast price of low sulfur residual fuel represents a long term, sustainable cap for U.S. Northeast natural gas pricing. The price of 1.0 percent sulfur fuel, the swing fuel of many Northeast utilities, has traditionally had the most influence on natural gas pricing.

Nexant forecasts that natural gas prices over the long term will be slightly higher than low sulfur residual fuel prices at the burner tip, reflecting that there will be periods when gas is the higher priced fuel due to weather-related factors and other short term market developments. The expectation is that normal inventory levels will usually exist and that increased gas supplies from higher domestic production, Canada and increased LNG imports will satisfy increased natural gas demand.

Based on an anticipated weakening in oil prices, the Henry Hub gas price is expected to average about \$2.7 per million Btu for the Medium Crude pricing outlook and about \$3.3 per million Btu for the High Crude pricing outlook in subsequent years. The price of natural gas delivered to major USGC users is forecast to be about $\$ 0.20$ per million Btu above these Henry Hub spot prices. 


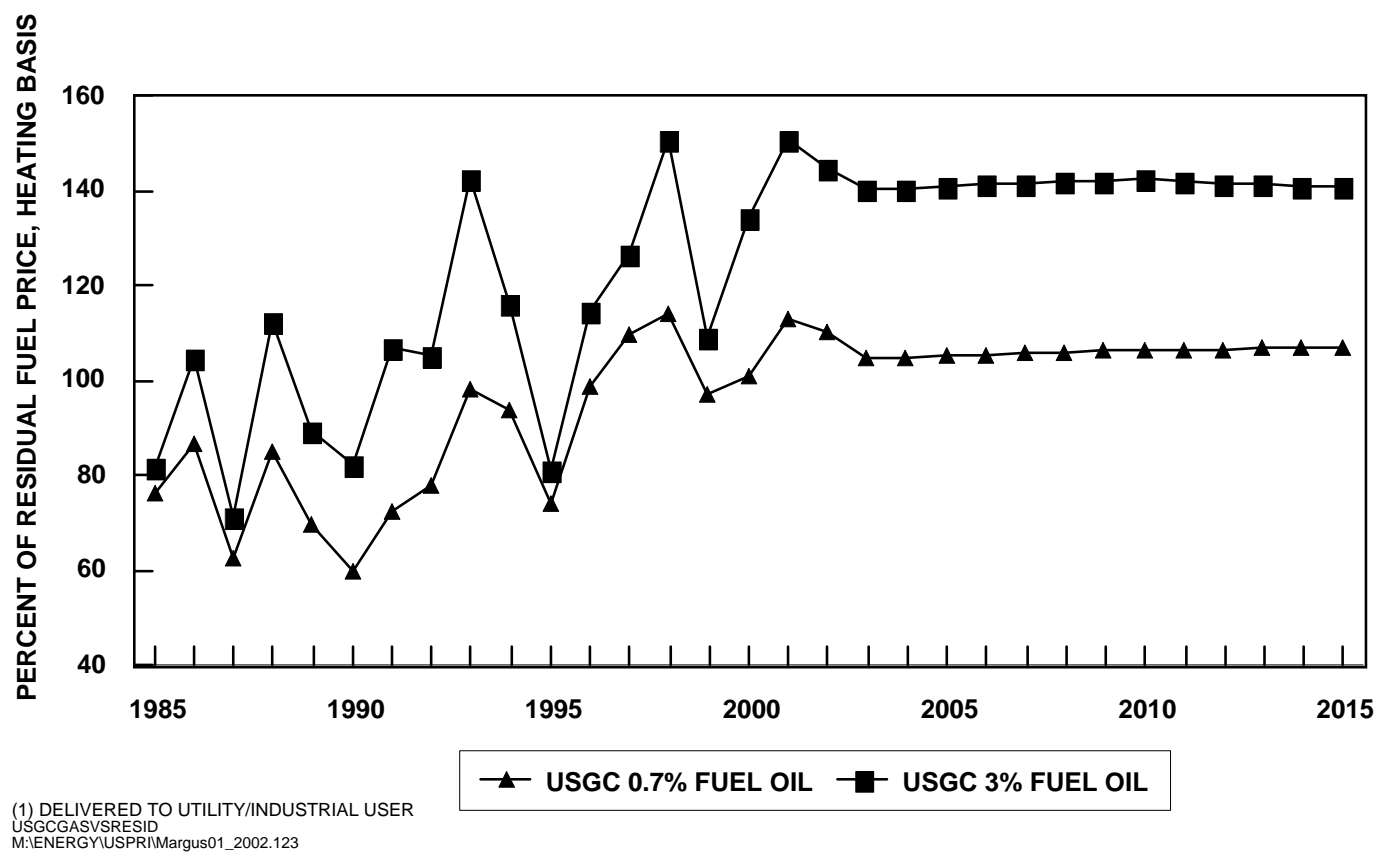

Figure 2.16 USGC Natural Gas ${ }^{1}$ Versus Residual Fuel Pricing

\subsubsection{Natural Gas Liquids}

Ethane pricing, due to its exclusive use as a petrochemical feedstock, is highly dependent on the price of natural gas from which it is extracted. In contrast, market prices for propane, butanes, and natural gasoline generally are relatively insensitive to the value of the natural gas from which they were extracted. Rather, their prices are influenced by competition with crude oilderived products in markets where they compete as alternative fuels or petrochemical feedstocks. Therefore, ethylene price and steam cracker economics have a major impact on NGL pricing.

\subsubsection{Ethane}

The only significant use for ethane is as a steam cracker feedstock for the production of ethylene. Approximately 70 percent of the ethylene produced in the United States is derived from ethane and ethane/propane cracking.

The factors that influence ethane pricing are 1) its value to an ethylene plant operator and 2) the cost of intentionally extracting it from natural gas. Ultimately, the ethane market price is established by the supply/demand balance. The gas plant operator controls the supply based on how much ethane can be extracted economically, and the ethylene plant operator controls the demand based on how much ethane can be cracked at a lower net variable cost than that achievable with alternative cracking feedstocks.

Nexant's methodology for forecasting ethane price is to analyze the following two mechanisms: 
- The maximum market price of ethane is defined. The maximum ethane market price is defined as the highest price an ethylene producer is willing to pay and still achieve a lower net variable cost than that achievable with alternative cracking feedstocks

- The minimum market price of ethane is defined. The minimum price is defined as the cost of incrementally extracting ethane from gas of a given quality and price in a gas processing plant, given the forecast prices of the propane, butanes and natural gasoline by-products

Theoretically, the minimum price of ethane at the gas processing plant is its equivalent value if left in the gas. Determining the minimum market price for ethane has historically been complicated by the wide variability that exists between the cost structures of different gas processors. Among the factors that need to be considered are:

- Gas composition (i.e. lean gas versus rich gas)

- Minimum conditioning requirements to meet pipeline specifications on quality (i.e. dew point, sulfur and inerts) versus the cost of additional liquids removal

- The location and type of gas processing plant

The actual USGC market price for ethane will exist between the two limits. Those limits will be dependent upon: 1) the supply of ethane available versus the incentive for the ethylene industry to use it, 2) the price of natural gas relative to petroleum (from which comes other competing ethylene feedstocks), 3) the demand for ethylene, and 4) the price of alternative ethylene feedstocks (e.g. propane and naphthas).

\subsubsection{Natural Gas Liquids Extraction}

To determine a reasonable range of production economics for ethane extraction plants, Nexant analyzes extraction plant economics for two types of operations. Extraction margins based on "rich" or high-NGL-content gas, and "lean" or low-NGL-content gas respectively have been examined for the 1990 to 2001 period and projected through 2015. These analyses are representative of integrated facilities and the ethane economics reflect the benefits of recovering higher value by-product LPG and natural gasoline. The feedstock price is based on Nexant's estimate of the average cost of gas to a large industrial/utility user at the U.S. Gulf Coast for each year, as developed earlier. 


\section{Table 2.11 Ethane Extraction Economics And Pricing - Rich Gas Medium Crude Pricing} (constant 2001 dollars)

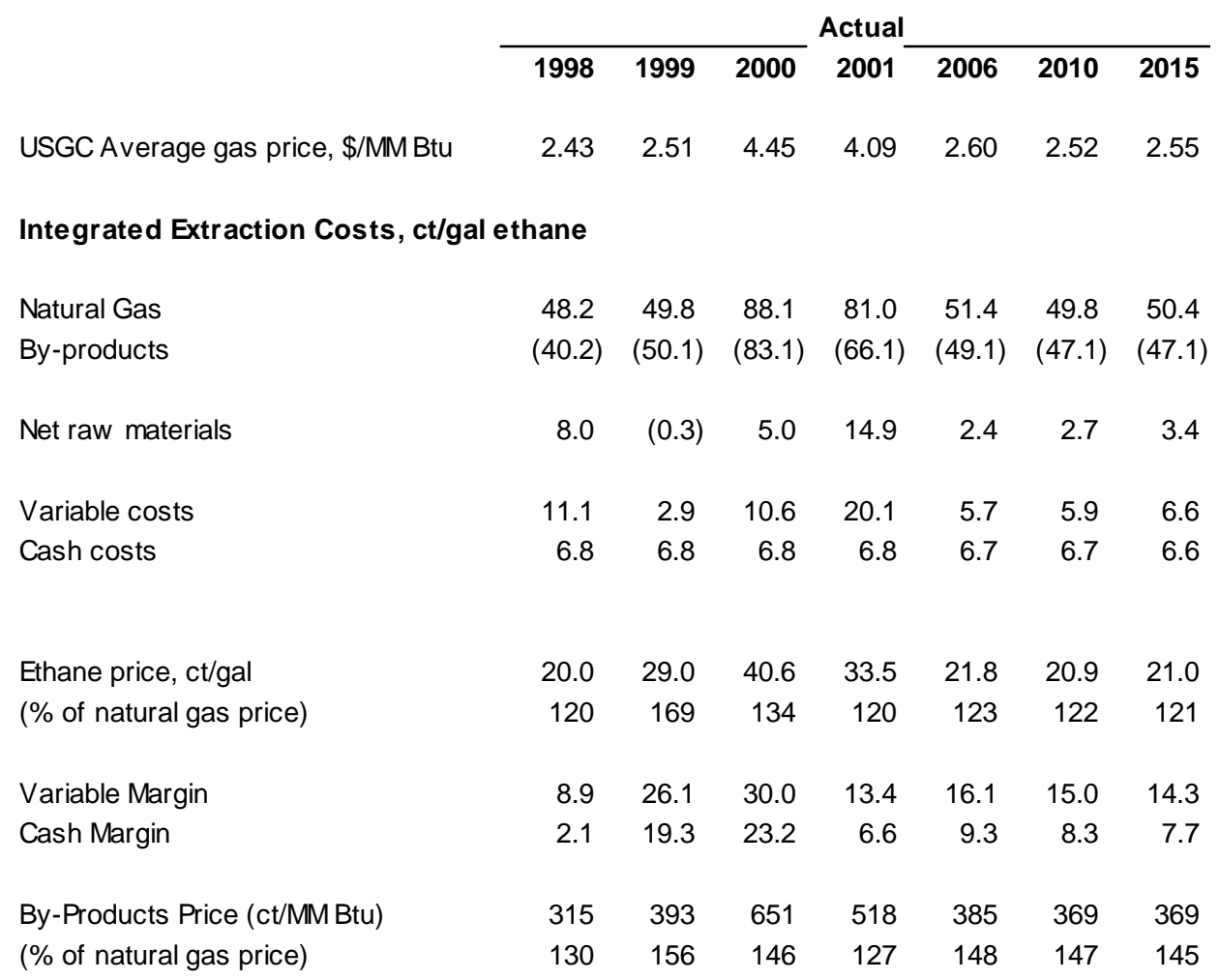

Incremental Extraction Costs, ct/gal ethane

$\begin{array}{lrrrrrrr}\text { Variable costs } & 17.7 & 18.2 & 32.2 & 29.6 & 18.8 & 18.2 & 18.5 \\ \text { Cash costs } & 24.4 & 25.0 & 39.0 & 36.4 & 25.6 & 24.9 & 25.1 \\ & & & & & & & \\ \text { Variable Margin } & 2.3 & 10.8 & 8.4 & 3.8 & 2.9 & 2.6 & 2.5 \\ \text { Cash Margin } & -4.5 & 4.0 & 1.6 & -2.9 & -3.8 & -4.0 & -4.1\end{array}$

M:IENERGYIUSPRIIMARGUS09_2002.123 


\section{Table 2.12 Ethane Extraction Economics And Pricing - Lean Gas Medium Crude Pricing} (constant 2001 dollars)

\begin{tabular}{|c|c|c|c|c|c|c|c|}
\hline & \multicolumn{7}{|c|}{ Actual } \\
\hline & 1998 & 1999 & 2000 & 2001 & 2006 & 2010 & 2015 \\
\hline USGC Average gas price, \$/MM Btu & 2.43 & 2.17 & 4.45 & 4.09 & 2.60 & 2.52 & 2.55 \\
\hline \multicolumn{8}{|c|}{ Integrated Extraction Costs, ct/gal ethane } \\
\hline Natural Gas & 44.1 & 39.3 & 80.6 & 74.2 & 47.1 & 45.6 & 46.2 \\
\hline By-products & $(35.7)$ & $(38.2)$ & $(73.5)$ & $(58.5)$ & $(43.4)$ & $(41.7)$ & $(41.7)$ \\
\hline Net raw materials & 8.5 & 1.1 & 7.1 & 15.7 & 3.6 & 3.9 & 4.5 \\
\hline Variable costs & 11.4 & 3.7 & 12.4 & 20.5 & 6.8 & 6.9 & 7.6 \\
\hline Cash costs & 13.5 & 11.6 & 13.5 & 13.5 & 13.4 & 13.3 & 13.2 \\
\hline Ethane price, ct/gal & 20.0 & 25.0 & 40.6 & 33.5 & 21.8 & 20.9 & 21.0 \\
\hline (\% of natural gas price) & 120 & 169 & 134 & 120 & 123 & 122 & 121 \\
\hline Variable Margin & 8.6 & 21.3 & 28.2 & 12.9 & 15.0 & 14.0 & 13.4 \\
\hline Cash Margin & $(4.9)$ & 9.7 & 14.7 & $(0.5)$ & 1.6 & 0.7 & 0.2 \\
\hline By-Products Price (ct/MM Btu) & 280 & 299 & 576 & 458 & 341 & 327 & 327 \\
\hline (\% of natural gas price) & 115 & 138 & 130 & 112 & 131 & 130 & 128 \\
\hline \multicolumn{8}{|c|}{ Incremental Extraction Costs, ct/gal ethane } \\
\hline Variable costs & 17.7 & 15.8 & 32.4 & 29.8 & 18.9 & 18.3 & 18.6 \\
\hline Cash costs & 31.2 & 27.4 & 45.9 & 43.3 & 32.3 & 31.6 & 31.8 \\
\hline Variable Margin & 2.2 & 9.2 & 8.2 & 3.7 & 2.8 & 2.6 & 2.4 \\
\hline Cash Margin & $(11.2)$ & $(2.4)$ & $(5.3)$ & $(9.8)$ & $(10.6)$ & $(10.8)$ & $(10.8)$ \\
\hline
\end{tabular}

M:IENERG YIUSPRIIMARGUS09_2002.123 


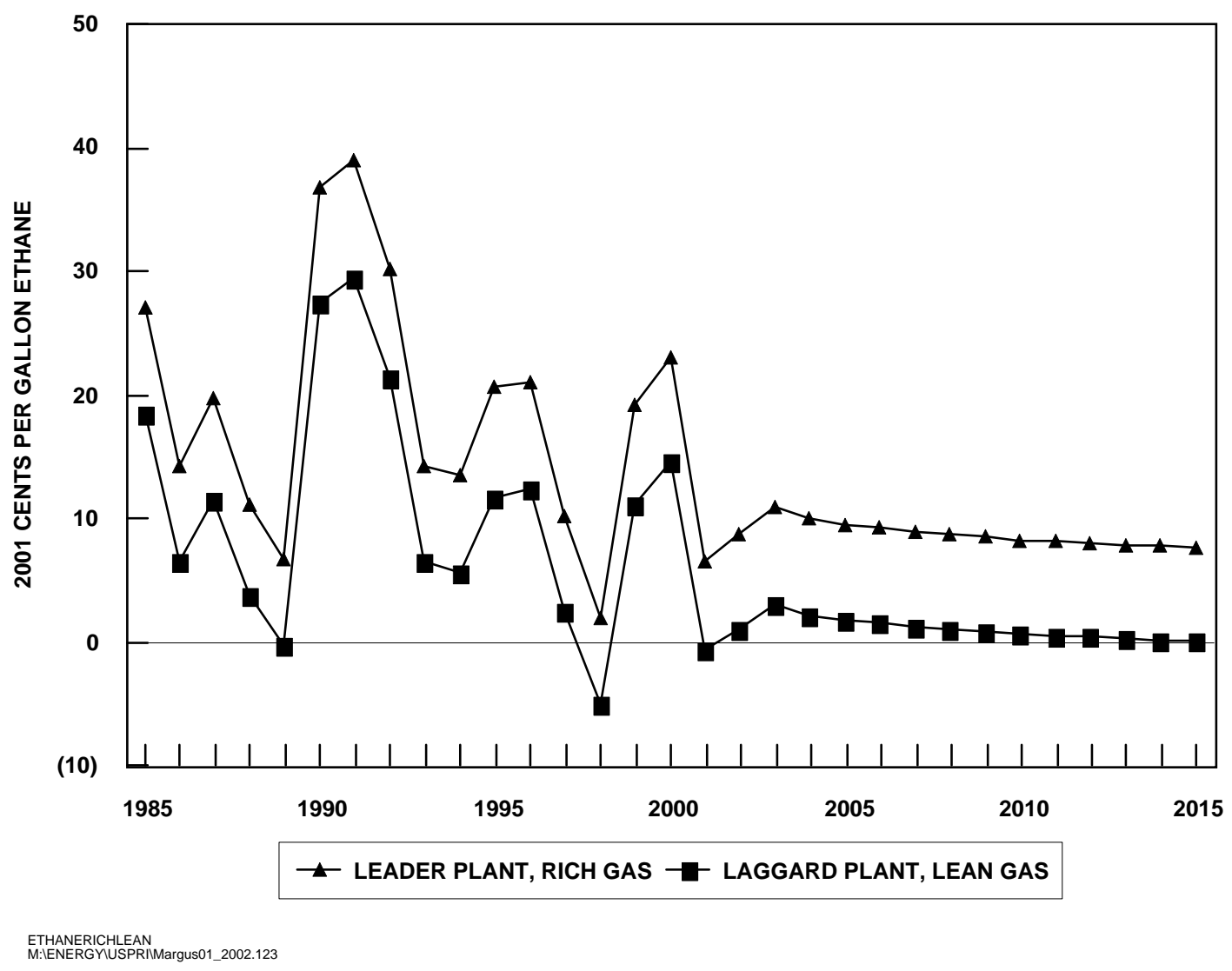

Figure 2.17 Ethane Recovery Economics Integrated Operations Cash Margin

Very weak LPG pricing during 1989, when lower RVP specifications reduced butane use in gasoline, negatively impacted extraction economics. A combination of factors resulted in a rebound of extraction economies during 1990 and 1991. Depressed natural gas pricing, combined with ethane and NGL price fly-ups in the latter half of both years resulted in average cash margins of about 30 cents per gallon of ethane. Margins declined in 1992 and 1993 as natural gas prices strengthened while NGL prices were weaker.

After stabilizing in 1994, extraction margins rebounded in 1995 and 1996 due to lower gas prices and higher prices for NGLs. Extraction margins were sharply lower in 1997 and 1998 due to lower NGL prices and firm natural gas prices. Rising oil and NGL prices resulted in sharply higher extraction margins during 1999 and 2000 in spite of a corresponding rise in natural gas prices. Widening of the price differential between light petroleum products, whose prices influence NGL prices, and residual fuel oils, whose prices impact natural gas prices, also contributed to improved extraction economics during 2000. The flyup in natural gas prices during 2001 resulted in sharply lower extraction margins during the year. 
Nexant expects that over the next several years, extraction economics will be slightly better than the 2001 due to lower gas prices. Longer term, extraction economics are expected to remain attractive due to the anticipated strength in U.S. NGL prices linked to their demand as petrochemical feedstocks. Cash cost margins for extraction are expected to be to about 10 cents (2001 dollars) per gallon of ethane for rich gas and 2 cents per gallon for lean gas on a trend line basis. Thus, future margins are forecast to be sufficient to provide a limited cash margin for lean gas extraction. Ethane will be economical to extract from natural gas for an existing plant. However, replacement economics for new extraction facilities processing lean gas will not be supported in general.

Another way of looking at ethane recovery economics is to consider only the variable costs (shrinkage and utilities) that are directly associated with ethane recovery and not to include the benefits of by-product NGL recovery. In effect, this reflects the way that gas processing operators must look at ethane economics when deciding whether to recover only LPG and heavier or to also recover ethane. On this basis, the incentive to recover ethane from lean gas on an incremental basis is forecast to support a variable margin of about 3 cents per gallon (2001 dollars) for USGC processors.

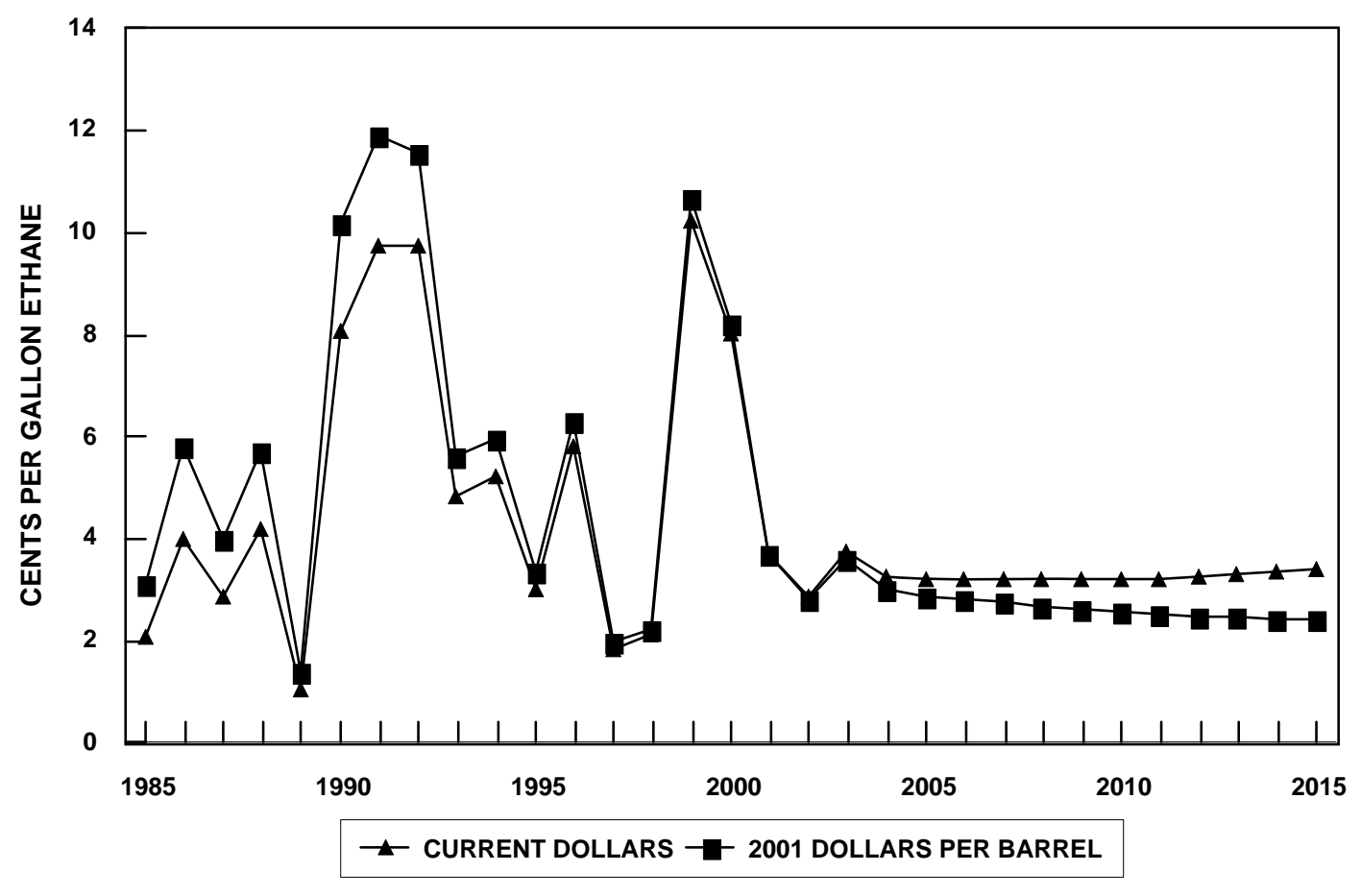

ETHANEINCREMENT
M:IENERGYIUSPRIIMargus01_2002.123

Figure 2.18 Incremental Ethane Recovery Economics Variable Margin 


\subsubsection{Propane}

Propane has many uses as a fuel and as a feedstock for petrochemicals. About 70-80 percent of propane uses are in fuel applications where it competes with natural gas, No. 2 fuel oil, electricity, etc. In rural residential uses, it typically competes with No. 2 fuel oil.

In developing future propane prices at the USGC, Nexant has examined the historical relationships between propane and other competing petrochemical feedstocks and fuels. There has been significant volatility in the relative cost of these fuels.

A factor contributing to the volatility of wholesale propane prices is that propane and its competing fuels are used primarily by the commercial and residential sectors. As a result, although there is some inter-fuel competition in these sectors, it is not as dynamic as that in the utility and industrial sectors. In addition, wholesale prices are heavily impacted by relatively high distribution costs and inventory effects, as well as by end-use economics.

Table 2.13 Historical U.S. Gulf Coast Fuels Pricing (constant 2001 dollars)

\begin{tabular}{|c|c|c|c|c|c|c|c|c|c|c|c|c|c|}
\hline & & & & & & & & & & & & & Actual \\
\hline & & 1990 & 1991 & 1992 & 1993 & 1994 & 1995 & 1996 & 1997 & 1998 & 1999 & 2000 & 2001 \\
\hline No. 2 Fuel Oil & & & & & & & & & & & & & \\
\hline & $\mathrm{ct} / \mathrm{gal}$ & 82.6 & 70.3 & 65.5 & 58.6 & 52.4 & 52.6 & 64.0 & 58.0 & 40.5 & 48.8 & 82.7 & 69.0 \\
\hline & \$/MM Btu & 5.96 & 5.07 & 4.73 & 4.23 & 3.78 & 3.79 & 4.61 & 4.18 & 2.92 & 3.52 & 5.96 & 4.98 \\
\hline Propane & & & & & & & & & & & & & \\
\hline & ct/gal & 43.5 & 41.0 & 38.0 & 36.1 & 33.8 & 35.5 & 45.8 & 40.2 & 27.9 & 35.0 & 58.6 & 46.9 \\
\hline & $\$ / M M B t u$ & 4.75 & 4.48 & 4.15 & 3.94 & 3.69 & 3.88 & 5.01 & 4.39 & 3.05 & 3.82 & 6.40 & 5.12 \\
\hline Btu parity with & & & & & & & & & & & & & \\
\hline No. 2 Fuel Oil & Percent & 80 & 88 & 88 & 93 & 98 & 102 & 108 & 105 & 104 & 109 & 107 & 103 \\
\hline Normal Butane & & & & & & & & & & & & & \\
\hline & ct/gal & 54.3 & 51.1 & 45.4 & 42.1 & 39.2 & 42.6 & 51.1 & 47.0 & 33.3 & 42.1 & 67.7 & 53.4 \\
\hline & $\$ / M M B t u$ & 5.23 & 4.93 & 4.38 & 4.06 & 3.78 & 4.11 & 4.93 & 4.53 & 3.21 & 4.06 & 6.53 & 5.15 \\
\hline Btu parity w ith & & & & & & & & & & & & & \\
\hline Propane & Percent & 110 & 110 & 105 & 103 & 103 & 106 & 98 & 103 & 105 & 106 & 102 & 101 \\
\hline Btu parity w ith & & & & & & & & & & & & & \\
\hline No. 2 Fuel Oil & Percent & 88 & 97 & 93 & 96 & 100 & 108 & 107 & 108 & 110 & 116 & 109 & 103 \\
\hline
\end{tabular}




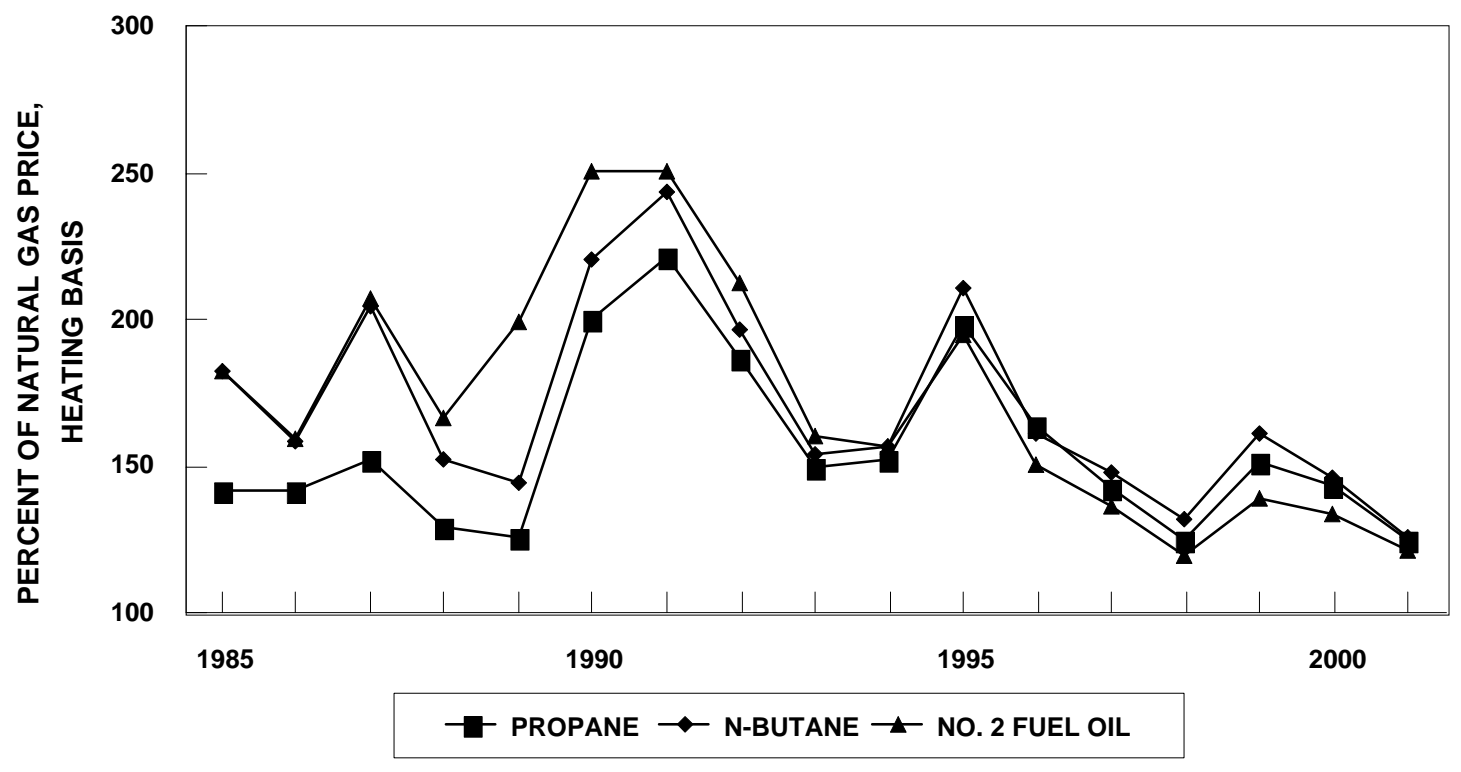

FUELSHIST
M:IENERGYUSPRIMMargus01_2002.123

Figure 2.19 U.S. Gulf Coast Fuel Prices

Propane prices declined relative to heating oil (on an equivalent heating basis) during the 1980s as major new associated and non-associated gas projects were installed, increasing recovery of LPGs on a global basis. The new LPG supplies had to be absorbed in lower-value markets.

The role of lower-value markets is reflected in the seasonal variations in propane price. During the winter season when more propane is used for heating, propane prices reflect the prices of other fuels. For the rest of the year, prices are more closely linked to natural gasoline (i.e. light naphtha) prices since both propane and light naphtha compete as marginal ethylene plant feedstocks.

LPG's use as a residential fuel in Asian countries has significantly increased since 1990. In addition, new petrochemical facilities using LPG as a captive feedstock, principally in the U.S. and the Middle East, have been commissioned. The increased global demand resulted in rising propane prices during the 1993-1996 period, relative to prices for No. 2 heating oil and natural gasoline/naphtha. Propane prices weakened slightly relative to prices for No. 2 heating oil during 1997 and 1998 due to increased supplies and milder winter weather. However, they remained at historically-high relative levels. Strong natural gas prices reduced propane's price relative to natural gas during the 1996-1998 period. Higher light product and NGL prices increased propane's relative pricing during 1999 and 2000. However, strong natural gas prices 
during 2001 again brought propane and natural gas pricing, and natural gas pricing set propane pricing during late 2000/early 2001 when high gas prices prompted some gas users to switch to propane and NGL producers to forego some production.

Nexant expects that new international supplies of LPG will exceed its demand growth in premium markets. As a result, international propane prices are expected to be linked to naphtha prices in key international markets via its relative value as an ethylene feedstock.

The ratio of USGC propane to natural gasoline prices slightly declined in 1997 and 1998 from the historically-high ratios seen during the 1994-1996 period. Propane prices were especially strong during the second half of 1996 due to several short-term developments, including unusually low inventories, colder-than-normal weather early in the winter, heavy crop-drying demand in the Midwest, and an explosion at a Mexican gas processing plant that reduced propane exports to the U.S. Relatively low inventory levels resulted in firmer propane prices during 1999. Strong demand for propane as a petrochemical feedstock supported prices during the first half of 2000 before ethylene producers shifted more to ethane later in the year. Strong natural gas prices supported propane prices during the balance of 2000 and most of 2001. The forecast ratio between USGC propane and natural gasoline prices is near the recent level.

Propane is expected to sell at close to parity on a calorific value with other clean liquid fuels (i.e. n-butane and No. 2 fuel oil), but at a premium to natural gas and low-sulfur residual fuel oil.

\subsubsection{4 n-Butane}

Butanes traditionally have been used as the control component for meeting gasoline vapor pressure specifications. Butanes are also high-octane components and less expensive than gasoline. It has almost always been economically advisable to use as much as possible in a gasoline blend. Thus, butanes have historically followed a different pricing pattern than that indicated for propane. 


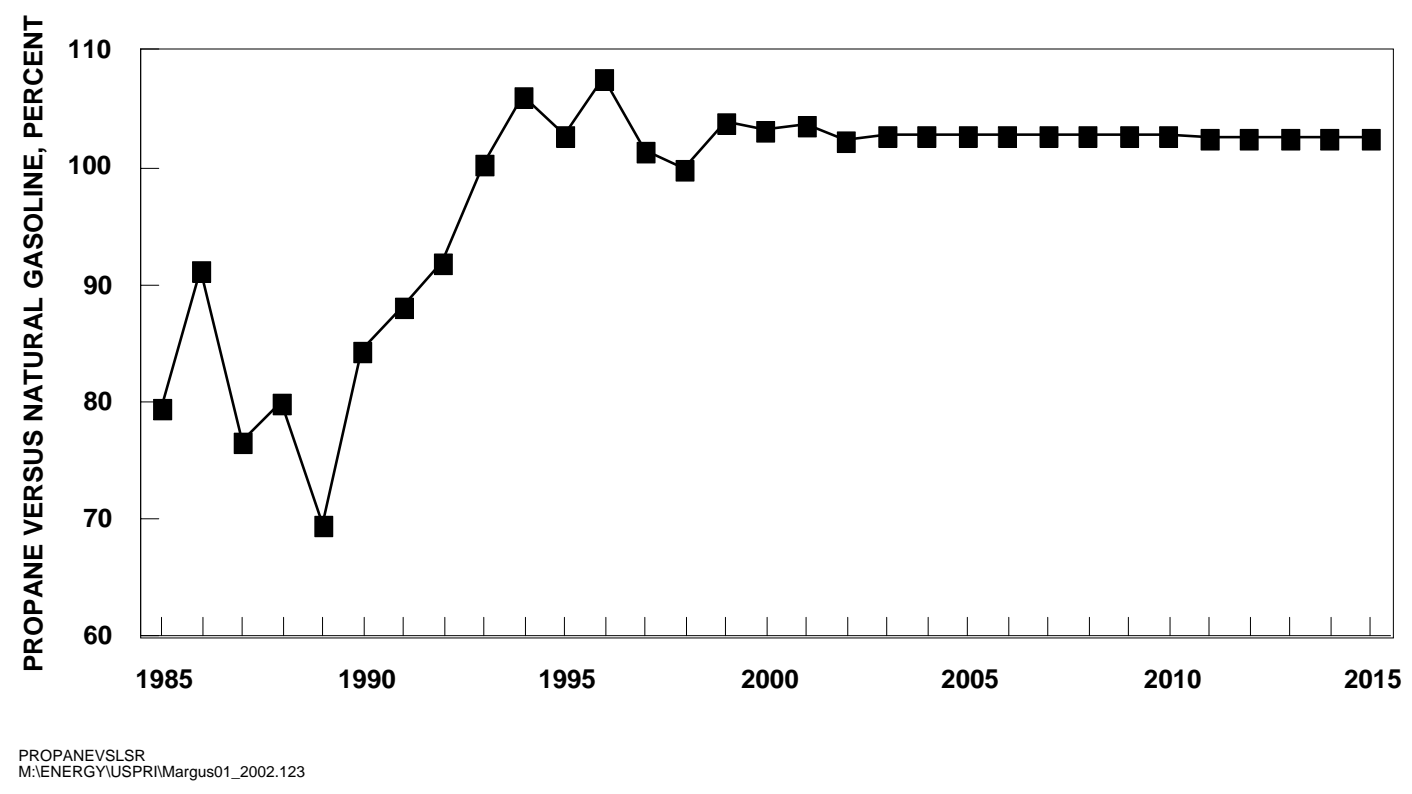

Figure 2.20 Propane: Natural Gasoline Price Relationship 


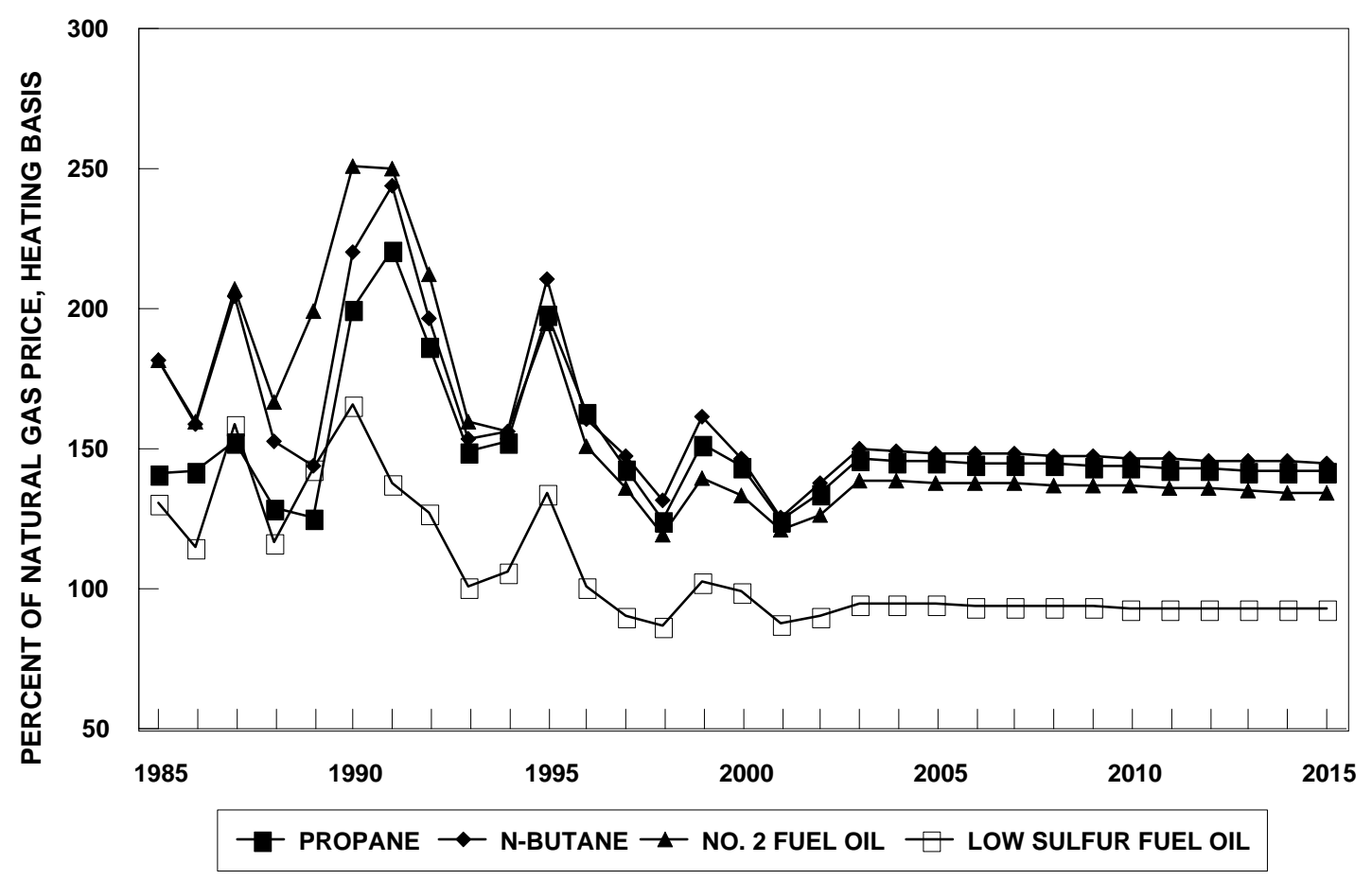

FUELS

M:IENERGYIUSPRIIMargus01_2002.123

Figure 2.21 U.S. Gulf Coast Fuel Prices, Medium Crude Pricing

Since butanes are primarily consumed either directly for blending in gasoline or indirectly through alkylation of isobutane with propylene and butylenes, the price of butane has tended to reflect gasoline price movements and pressures more than fuel and petrochemical feedstock markets (as has historically been true for propane). Due to its higher-value use, butane has normally exhibited a Btu price premium above propane. Thus, butane pricing must be analyzed vis-à-vis price trends for both propane and gasoline.

Butane use as a percent of the gasoline pool is expected to continue its decline, reflecting the need for lower volatility gasolines during summer months to meet air quality standards. As a result, butane summertime supplies will continue to exceed its requirements for gasoline blending resulting in the seasonal swings in butane prices relative to gasoline.

Global supplies of butane, similar to propane, are expected to exceed the demand of premium end use markets throughout the forecast period. As has been the case since the introduction of lower summer RVP limits in 1989 and 1992, the surpluses will be directed to the ethylene plant feedstock market and/or storage for use in gasoline during winter months. Both these outlets are lower-value markets, resulting in a lower butane price relative to gasoline during summer months. 
In summary, Nexant's outlook for normal butane pricing reflects three major trends:

- Anticipated growing global butane supplies, in tandem with a similar outlook for propane, will exceed its demand in higher-value markets

- Limited potential for blending normal butane into gasoline during the summer months due to volatility regulations

- Continuing importance of relative ethylene plant feedstock economics as a summertime price-setting mechanism for normal butane

Nexant's forecast for future butane prices at the USGC reflects these various factors. Average annual butane prices are forecast to be about 74 percent of gasoline price, well above the 1989 trough but slightly below the levels achieved during the 1995-2000 period.

The price forecast for normal butane reflects summertime olefin plant economics throughout the study period that provide an incentive to consume butane as a cracker feedstock, establishing a lower limit for normal butane prices.

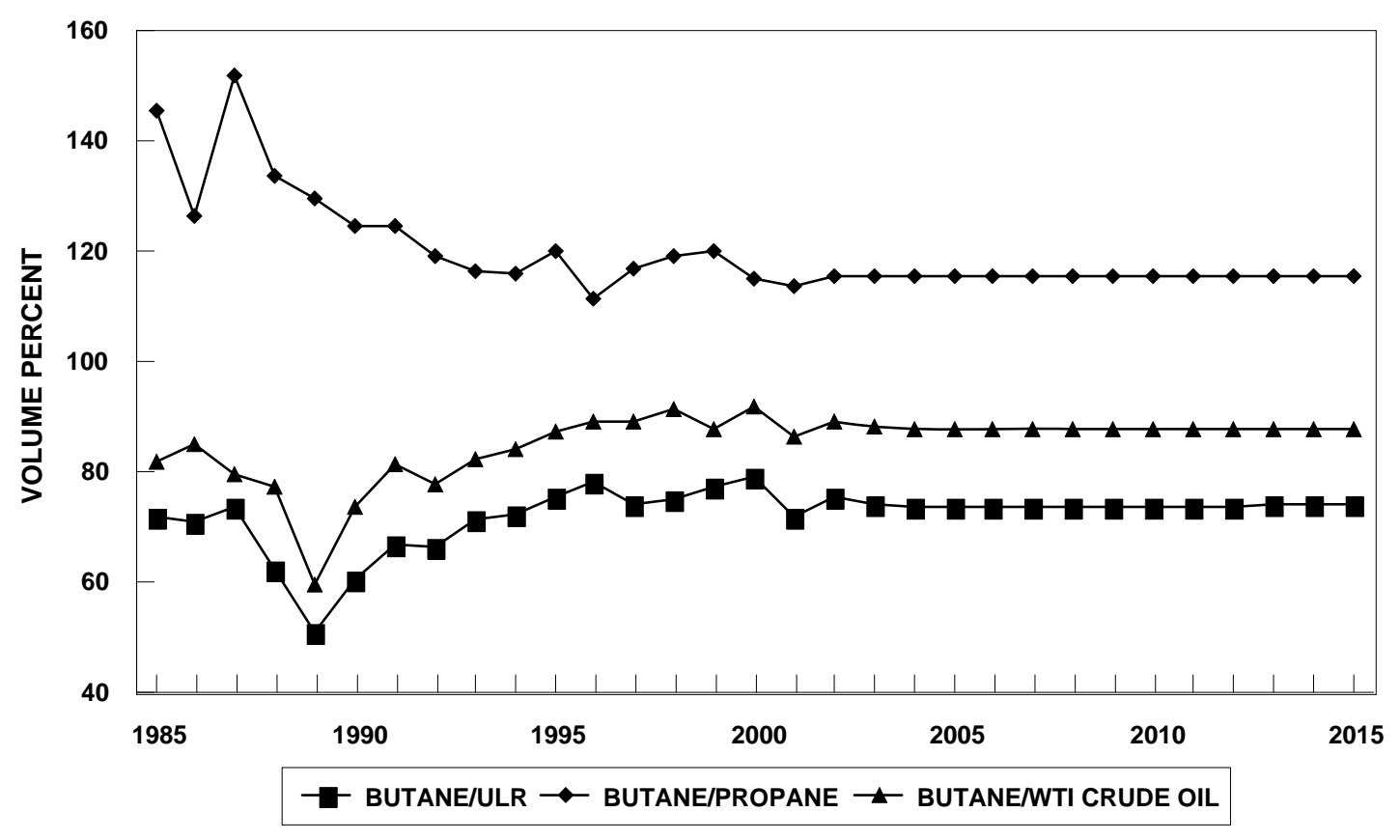

BUTANETRENDS
M:IENERGYIUSPRIIMargus01_2002.123

Figure 2.22 Normal Butane Pricing Trends

\subsubsection{Isobutane}

The relationship between normal butane and isobutane generally is set by the cost of separating the two isomers by distillation, because both are always produced together whether the source is 
natural gas liquids extraction, refinery processing, or isomerization. Typical separation-only costs are in the range of one to three cents per gallon.

Similar to n-butane, historically isobutane pricing has tended to reflect gasoline price movements since isobutane is primarily used in alkylation with either propylene or butylene to make alkylate. During the first half of the 1990s, MTBE production represented a new major end use for isobutane as a dehydrogenation unit feedstock to produce isobutylene and provided the driving force for investments in large merchant butane isomerization facilities at Mt. Belvieu.

The spot price differential between isobutane and normal butane during 1985 resulted in negative returns on investment (ROI) for on-purpose isobutane production. The indicative ROI rose during the late 1980s and averaged 34 percent during the 1989-92 period as its demand increased. However, the indicative ROI was negative again in 1993 as butane isomerization capacity additions exceeded demand increases and has remained negative since then.

Due to limited growth in demand for isobutane and the availability of adequate isomerization capacity, spot prices for isobutane at Mt. Belvieu in the future are forecast to average about 1.3 cents per gallon over n-butane. This price premium will yield slightly positive variable cost margins for isomerization, but will not provide a justification for investments in new isomerization capacity in most locations. Higher differentials will apply to term processing arrangements and in areas where transportation costs add several cents per gallon to the delivered cost of isobutane and reduce the ex-refinery value of normal butane surpluses by a corresponding amount. 


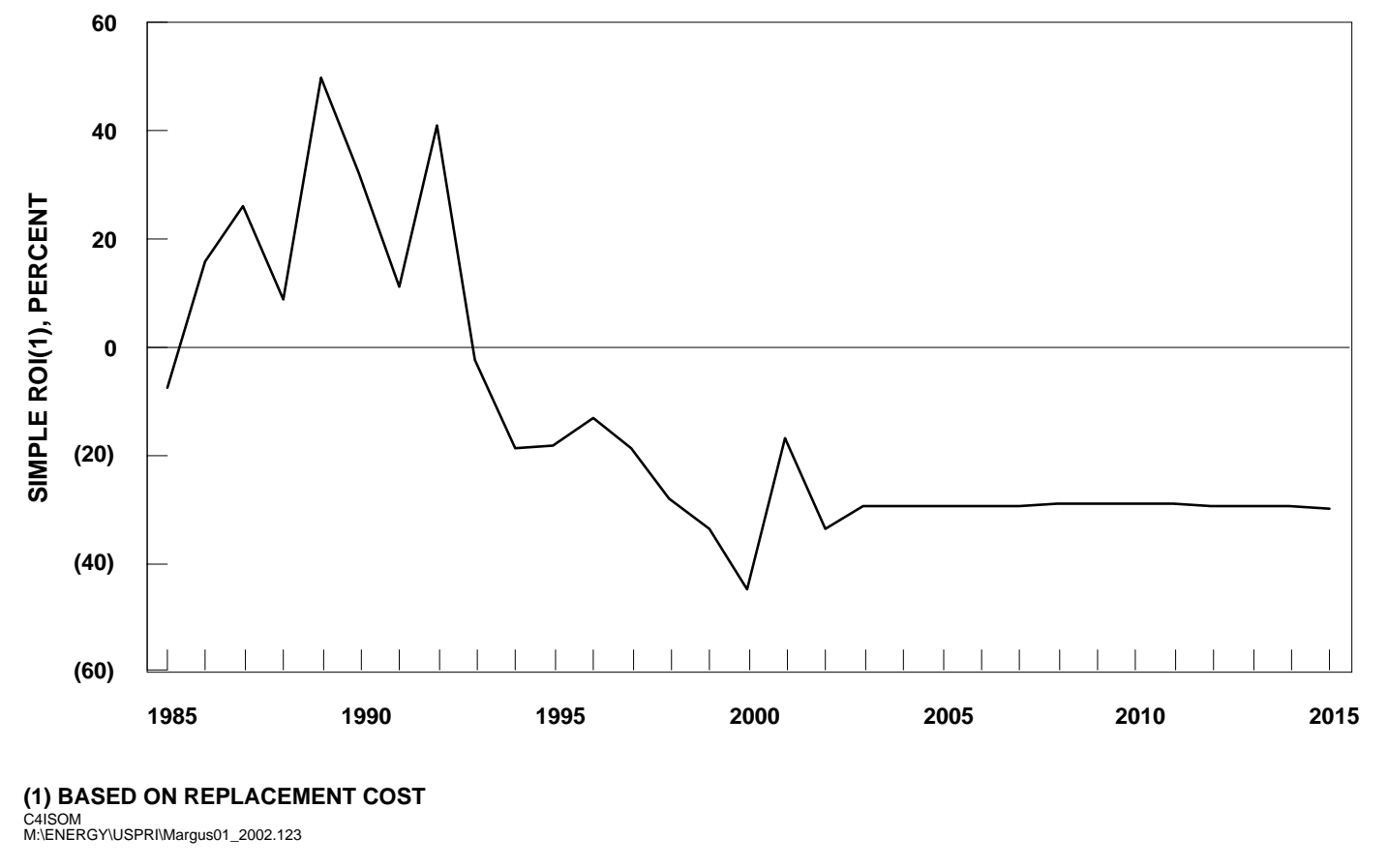

Figure 2.23 Pro Forma Normal Butane Isomerization Economics

\subsubsection{Gasoline Blendstocks And Petrochemical Feedstocks}

After forecasting prices for crude oil, refined products and natural gas liquids, values for gasoline blendstocks are forecast. These streams are blended into gasoline, and accordingly, their values are determined based on their octane and vapor pressure contributions to the gasoline pool. These streams include:

- $\mathrm{C}_{3}$ Alkylate

- $\mathrm{C}_{4}$ Alkylate

- Natural gasoline

- Toluene

- Isomerate

- Dimate

- Reformate

- Light straight-run (LSR) naphtha

- Naphtha 
- $\quad \mathrm{MTBE}$

Some of these gasoline blendstock streams also have major alternative dispositions as petrochemical feedstocks (e.g. natural gasolines, light and full range paraffinic naphthas for olefins production, toluene for benzene production, etc.). Normally, when used as a petrochemical feedstock these streams are sold at a premium to their refinery blendstock value to provide an incentive to move them out of the refinery.

\subsubsection{Octane Valuation}

The gasoline pool consists of a blend of numerous refinery streams, which typically have a wide range of octane and vapor pressure values. In order to meet a given pool octane specification, the final blend must contain enough high-octane blendstocks (i.e. alkylate, reformate, MTBE, etc.) to offset the presence of low-octane naphthas (i.e. straight run naphthas, natural gasoline, raffinates, etc.).

The values of gasoline blendstocks are imputed primarily on the basis of their octane and vapor pressure contributions to a gasoline blend. Inasmuch as the lowest cost alternative for most refiners who want to boost the octane number of their gasoline pool is to increase the severity of catalytic reforming, this cost is typically used as the basis for imputing octane credits. However, this will not be true for all refiners since some may not have incremental catalytic reforming capacity. It should also be noted that even when incremental catalytic reforming capacity is available, the cost of increasing reforming severity can vary significantly from one refiner to another.

An individual refiner generally will attempt to maximize net margins by operating at the highest practical throughput and maximum production of high-value products, such as gasoline and distillate. As long as incremental revenues cover incremental operating costs, there is incentive to process more feedstocks and convert them into saleable products. Reflecting this relationship, in determining the cost of incremental octane, only variable costs need be considered as long as additional capacity is available (as will generally be true for most U.S. refiners). However, if additional investment is required to debottleneck or replace an old unit, incremental octane costs should also reflect costs associated with this additional investment.

If it is not practical to produce incremental volumes of high-octane blendstocks within the refinery, there is still the option of purchasing these components. Toluene has often been purchased on this basis, especially during occasional seasonal octane shortages or during temporary equipment shutdowns. Oxygenates, such as ethanol and MTBE, represent blending options that are also used for meeting pool octane requirements.

The most common method used by a refiner to regulate pool octane is through controlling the operation of the catalytic reformer. A typical cost analysis of increasing severity from 93 Research Octane Number (RON) to 97 RON may be compared to the market-related cost of octane, as measured by the differential between unleaded premium and unleaded regular grade pricing, which has traditionally been at a premium to incremental reforming costs. 


\section{Table 2.14 Average USGC Octane Costs Medium Crude Pricing} (cents per octane number gallon)

\begin{tabular}{lccccc} 
& \multicolumn{2}{c}{ Incremental Reforming } & & \multicolumn{2}{c}{ Market Related } \\
\cline { 2 - 3 } \cline { 5 - 5 } & Constant 2001 \$ & Current \$ & & Constant 2001 \$ & Current \$ \\
1985 & 0.98 & 0.66 & & 1.19 & 0.80 \\
1990 & 0.92 & 0.73 & & 1.40 & 1.11 \\
1995 & 0.45 & 0.40 & & 0.80 & 0.72 \\
1996 & 0.42 & 0.39 & 0.66 & 0.60 \\
1997 & 0.42 & 0.39 & 0.68 & 0.64 \\
1998 & 0.25 & 0.24 & 0.72 & 0.68 \\
1999 & 0.36 & 0.34 & 0.71 & 0.68 \\
2000 & 0.52 & 0.51 & 0.59 & 0.57 \\
2001 & 0.44 & 0.44 & 0.75 & 0.75 \\
2006 & 0.38 & 0.43 & 0.72 & 0.81 \\
2010 & 0.37 & 0.46 & 0.69 & 0.86 \\
2015 & 0.37 & 0.52 & & 0.93
\end{tabular}

M:IENERGYUSPRIMMARGUS09_2002.123

The market related premium for octane increased substantially during the second half of the 1980s, reflecting a tightening of the octane balance as lead was removed from gasoline. During the 1988-1990 period, the industry faced a shortfall in octane production capabilities, reflecting lead phasedown and growth in high octane premium sales.

During the second half of 1990, the fly-up in crude oil and gasoline prices and the economic recession negatively impacted total U.S. gasoline sales. The market related premium for octane declined sharply in 1991, reflecting the weaker demand for gasoline, especially premium grades. The lower premium persisted throughout the 1992-2001 period even though U.S. gasoline demand increased, as refinery debottlenecking projects, declining demand for premium gasoline and the availability of significant volumes of high-octane oxygenates for the mandated oxyfuel and RFG programs increased the effective gasoline production capability of U.S. refineries.

The cost of octane based on incremental reforming costs fell in 1998 due to lower natural gas prices, but more than doubled over the 1999-2000 period in line with higher natural gas prices. However, the market related cost of octane rose only 12 percent over the period.

The U.S. refining industry is expected to have adequate capacity for octane production over the next few years due to the availability of spare catalytic reforming capacity, and gasoline and MTBE imports. However, gasoline demand growth and regulatory initiatives to phase out MTBE use may result in octane crunches during peak gasoline demand periods. The market related cost of octane is expected to remain near recent levels, with a narrow differential relative to incremental reforming octane costs also persisting. This forecast assumes that any mandatory reduction in MTBE use will provide the industry with adequate time to invest in alternative 
octane production facilities. If an MTBE phaseout is enacted that does not provide the industry with an adequate lead time for investments in replacement octane production facilities, a higher differential is likely during the middle of the decade.

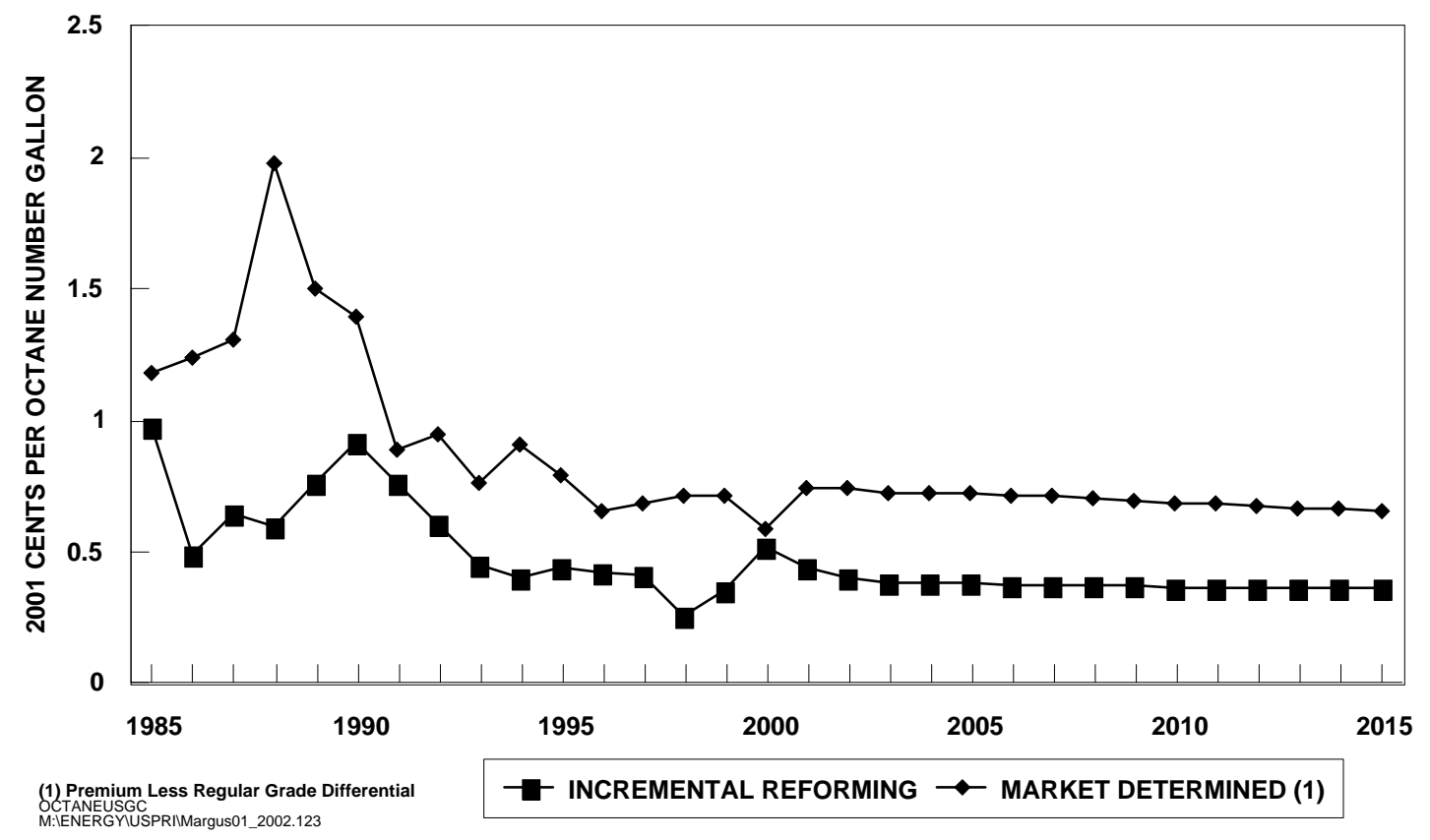

Figure 2.24 USGC Cost Of Octane

\subsubsection{Naphtha}

\section{Reforming Grade Naphtha}

On the U.S. Gulf Coast (USGC), the two "standard" commercial grades of naphtha are reforming-grade naphtha and natural gasoline/light naphtha. Reforming-grade naphtha, also referred to as $\mathrm{N}$ plus $\mathrm{A}$ (naphthenes plus aromatics) naphtha or heavy naphtha, is used, after hydrotreating, as a catalytic reforming feedstock for gasoline or aromatics production. The "standard" USGC reforming-grade naphtha has an N plus A content in the range of 40 to 45 percent and a specific gravity of 0.74 to 0.76 .

The prices of Gulf Coast naphtha streams are usually linked to Gulf Coast gasoline prices since most of the naphtha and natural gasoline is used to produce gasoline. Most commercial transactions set the naphtha price as a negotiated discount below the Platts USGC unleaded gasoline quote. USGC naphtha prices, being linked to gasoline that is sold on a volumetric basis, are established on a volumetric basis. Reforming-grade naphtha prices reflect the supply/demand balance for reformer feed, which in turn is primarily influenced by refinery operating rates and the supply/demand balance for gasoline. 
During the 1989-1990 period, reforming-grade naphtha's price was about 4 cents per gallon less than unleaded regular gasoline. However, between 1991 and 1996 the discount to ULR dropped to an average of 3.5 cents per gallon, reflecting the reduced pressures on gasoline supplies and lower octane values. Due to firmer gasoline prices, the discount was wider during the 19972000 period, averaging about 5 cents per gallon. The discount widened to 6.4 cents per gallon in 2001, reflecting the year's very strong gasoline market. Nexant expects that it will average about 4.5 cents per gallon (2001 dollars) in the future since gasoline supplies are expected to be tight, but not strained.

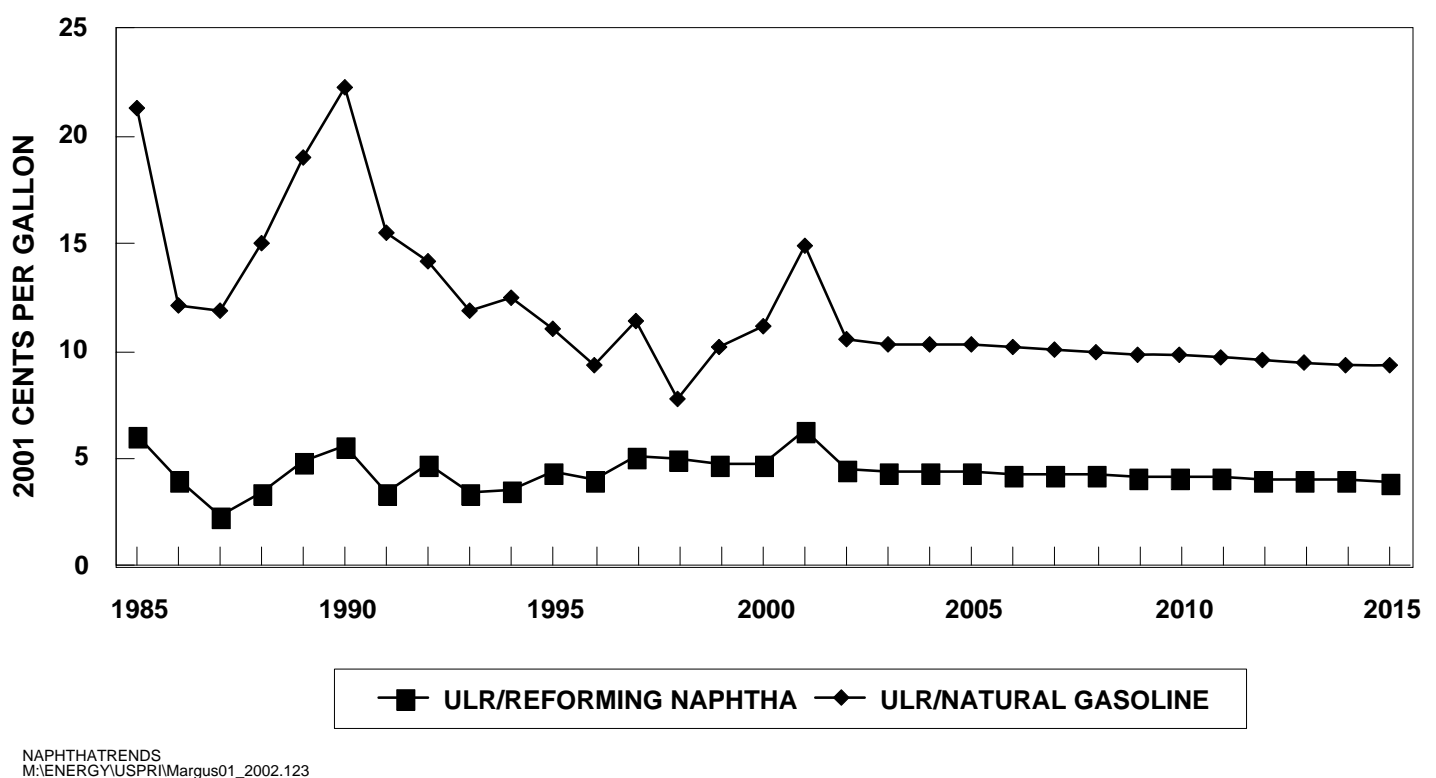

Figure 2.25 Naphtha Pricing Trends

\section{Natural Gasoline/Light Naphtha}

U.S. Gulf Coast natural gasoline, the heaviest product obtained from natural gas processing facilities, is predominantly pentanes and hexanes. It is rich in isoparaffins and typically has a specific gravity in the range of 0.66 to 0.67 . Natural gasoline has from $25-40$ percent of $160^{0}+$ material that is fairly high in aromatic precursors; that is, this fraction is a good reformer feedstock. The highly naphthenic "heavy end" offers a refiner the option of fractionating natural gasoline into a $\mathrm{C} 5-160^{\circ} \mathrm{F}$ cut and $160^{\circ} \mathrm{F}+$ cut. Light naphthas, typically obtained from fractionating full-range naphthas, have a boiling range and gravity similar to natural gasoline. However, a light naphtha has an endpoint in the range of 160 to $180^{\circ} \mathrm{F}$ and no distillation tail.

Light naphtha is usually paraffinic material, from the following sources: 
- $\quad$ Light straight run from virgin crude oil

- Light raffinate from aromatics extraction

- Light ends from natural gasoline fractionation.

Historically, the majority of these streams found ultimate disposition in the leaded gasoline pool because of their good response to lead. Alternatively, their high paraffinicity made them excellent olefins plant feedstocks. Since lead phaseout, light naphtha's contribution to the U.S. gasoline pool has diminished considerably, and much of this material is now isomerized or cracked as ethylene feedstock.

Natural gasoline prices at Mont Belvieu reflect both fixed price natural gasoline sales and transactions that are based on a negotiated discount to unleaded gasoline prices. Natural gasoline's price usually reflects its value as a gasoline blendstock since that is the major USGC use for this stream.

During the 1985-1990 period, natural gasoline's price was 12 to 22 cents (2001 dollars) per gallon less than unleaded regular gasoline. The maximum discount occurred in 1985 and 1990 when high market values for octane increased the penalty associated with blending low-octane natural gasoline into gasoline. In the 1993-1999 period the average discount to ULR dropped below 11 cents per gallon, reflecting lower market octane values. Although this differential widened to 11 cents per gallon in 2000 and averaged nearly 15 cents per gallon in 2001, Nexant expects that it will average about 10 cents (2001 dollars) per gallon in the future, reflecting the projected continuation of low octane values.

\section{Full-Range Naphtha}

There is a very limited USGC market for full-range naphtha. Prices for full-range naphtha streams (i.e. those naphthas having an initial boiling point as low as 82 degrees $\mathrm{F}$ and an endpoint of 300 to 390 degrees F) are established on a stream-specific basis, somewhere between the prices for light naphtha and reforming-grade naphtha. The price often reflects the stream's light naphtha content based on the stream's percent volume distilled at 180 degrees $\mathrm{F}$ shown in its ASTM D-86 distillation. For example, the price of a full-range naphtha whose 30 percent point is 180 degrees $\mathrm{F}$ would approximate 30 percent of the light naphtha price plus 70 percent of the reforming-grade naphtha price less a splitting cost of up to one cent per gallon. Full-range naphtha can be either split into light and heavy naphtha streams or used directly as a steam cracker feedstock. In the latter case, its minimum price on a weight basis would be about the same as the price of natural gasoline/light naphtha on a weight basis.

\subsubsection{Gasoline Blendstock Valuation}

Historical and forecast values for light naphtha, natural gasoline, and other gasoline blendstocks are based on their key blendstock properties. 


\section{Table 2.15 Gasoline Blendstock Values - Market Basis Medium Crude Pricing} (cents per gallon, constant 2001 dollars)

\begin{tabular}{|c|c|c|c|c|c|c|c|c|c|}
\hline & & & \multicolumn{4}{|r|}{ Actual } & \multirow{2}{*}{2006} & \multirow[b]{2}{*}{2010} & \multirow[b]{2}{*}{2015} \\
\hline & & & 1990 & 1995 & 2000 & 2001 & & & \\
\hline Gasoline Components & $\mathrm{R}+\mathrm{M} / 2$ & RVP & & & & & & & \\
\hline C9 Aromatics & 107.5 & 0.0 & 127 & 75 & 101 & 93 & 72 & 69 & 68 \\
\hline MTBE & 110.0 & 7.0 & 126 & 76 & 100 & 93 & 72 & 69 & 68 \\
\hline Xylenes & 105.2 & 0.3 & 123 & 74 & 99 & 92 & 70 & 67 & 66 \\
\hline Toluene & 102.9 & 1.0 & 120 & 72 & 98 & 90 & 68 & 66 & 65 \\
\hline Benzene & 100.0 & 3.0 & 115 & 69 & 96 & 87 & 66 & 63 & 62 \\
\hline Alkylate - C4 & 93.0 & 3.0 & 105 & 63 & 92 & 82 & 61 & 58 & 58 \\
\hline Alkylate - C3 & 90.0 & 4.0 & 100 & 61 & 89 & 79 & 58 & 56 & 55 \\
\hline Reformate -100 RON & 94.1 & 4.2 & 106 & 64 & 92 & 82 & 61 & 59 & 58 \\
\hline Reformate - $98 \mathrm{RON}$ & 92.3 & 4.1 & 103 & 62 & 91 & 81 & 60 & 58 & 57 \\
\hline Reformate - 95 RON & 89.8 & 3.9 & 100 & 60 & 89 & 79 & 58 & 56 & 55 \\
\hline Reformate - $92 \mathrm{RON}$ & 87.3 & 3.8 & 96 & 58 & 88 & 77 & 56 & 54 & 54 \\
\hline Dimate & 89.5 & 7.0 & 97 & 59 & 88 & 77 & 57 & 55 & 54 \\
\hline Polygasoline & 85.0 & 7.0 & 91 & 56 & 86 & 74 & 54 & 52 & 51 \\
\hline Isomerate & 83.1 & 12.5 & 84 & 52 & 82 & 70 & 51 & 49 & 48 \\
\hline Natural Gasoline & 73.3 & 12.0 & 70 & 45 & 77 & 63 & 44 & 42 & 42 \\
\hline Light Naphtha & 68.0 & 11.0 & 64 & 41 & 74 & 60 & 40 & 39 & 39 \\
\hline Raffinate & 65.0 & 4.1 & 65 & 41 & 75 & 60 & 40 & 39 & 39 \\
\hline C5/C6 & 67.2 & 11.0 & 63 & 40 & 74 & 59 & 40 & 38 & 38 \\
\hline
\end{tabular}

M:IENERGYUUSPRIIMARGUS09_2002.123

\subsubsection{Petrochemical Feedstocks}

Various refinery products that find frequent alternative disposition as petrochemical feedstocks include the various naphtha and gas oil streams that are essential components of the U.S. olefins plant feedstock mix. 


\section{Table 2.16 Petrochemical Feedstock Prices Medium Crude Pricing (cents per gallon, constant 2001 dollars)}

\begin{tabular}{|c|c|c|c|c|c|c|c|}
\hline & \multicolumn{4}{|c|}{ Actual } & \\
\hline & 1990 & 1995 & 2000 & 2001 & 2006 & 2010 & 2015 \\
\hline \multicolumn{8}{|l|}{ Natural Gas Liquids } \\
\hline Ethane & 27.5 & 17.6 & 40.6 & 33.5 & 21.8 & 20.9 & 21.0 \\
\hline Propane & 43.5 & 35.5 & 58.6 & 46.9 & 34.6 & 33.2 & 33.1 \\
\hline Normal Butane & 54.3 & 42.6 & 67.7 & 53.4 & 40.0 & 38.4 & 38.3 \\
\hline \multicolumn{8}{|l|}{ Gasoline Based } \\
\hline \multicolumn{8}{|l|}{ Natural Gasoline/Light Naphtha } \\
\hline Market Price & 67.4 & 45.2 & 74.2 & 59.1 & 44.0 & 42.3 & 42.3 \\
\hline Delta off ULR & 22.3 & 11.0 & 11.1 & 14.9 & 10.2 & 9.8 & 9.3 \\
\hline As Unleaded gasoline blendstock & 70.3 & 44.8 & 76.7 & 63.1 & 43.8 & 42.1 & 42.1 \\
\hline Market Price, \% Gasoline Value & 95.9 & 100.9 & 96.8 & 93.7 & 100.4 & 100.4 & 100.4 \\
\hline \multicolumn{8}{|l|}{ Naphtha } \\
\hline Reforming Quality & 84.0 & 51.8 & 80.6 & 67.7 & 49.9 & 47.9 & 47.6 \\
\hline Delta off ULR & 5.6 & 4.4 & 4.8 & 6.4 & 4.3 & 4.2 & 4.0 \\
\hline Premium over Light Naphtha (2001 \$ per ton) & 28 & 3 & $(12)$ & 3 & 0 & 0 & $(1)$ \\
\hline \multicolumn{8}{|l|}{ Distillate Based } \\
\hline Gas Oil & 82.6 & 52.6 & 82.7 & 69.0 & 49.8 & 47.8 & 47.5 \\
\hline Delta off ULR & 7.0 & 3.6 & 2.7 & 5.0 & 4.4 & 4.2 & 4.0 \\
\hline Vacuum Gas Oil & 77.8 & 52.3 & 79.1 & 66.3 & 47.7 & 45.9 & 45.7 \\
\hline
\end{tabular}

M:IENERGYUSPRIIMARGUS09_2002.123

Ethane price changes are expected to outpace the forecast price decreases for other feedstocks, reflecting its recent price strength, underlying trends in ethylene production economics, and natural gas and naphtha pricing trends. Propane, butane and naphtha prices are expected to decline in concert from their 2001 levels as crude oil prices weaken, reflecting the fact that they compete with each other as ethylene production feedstocks. 


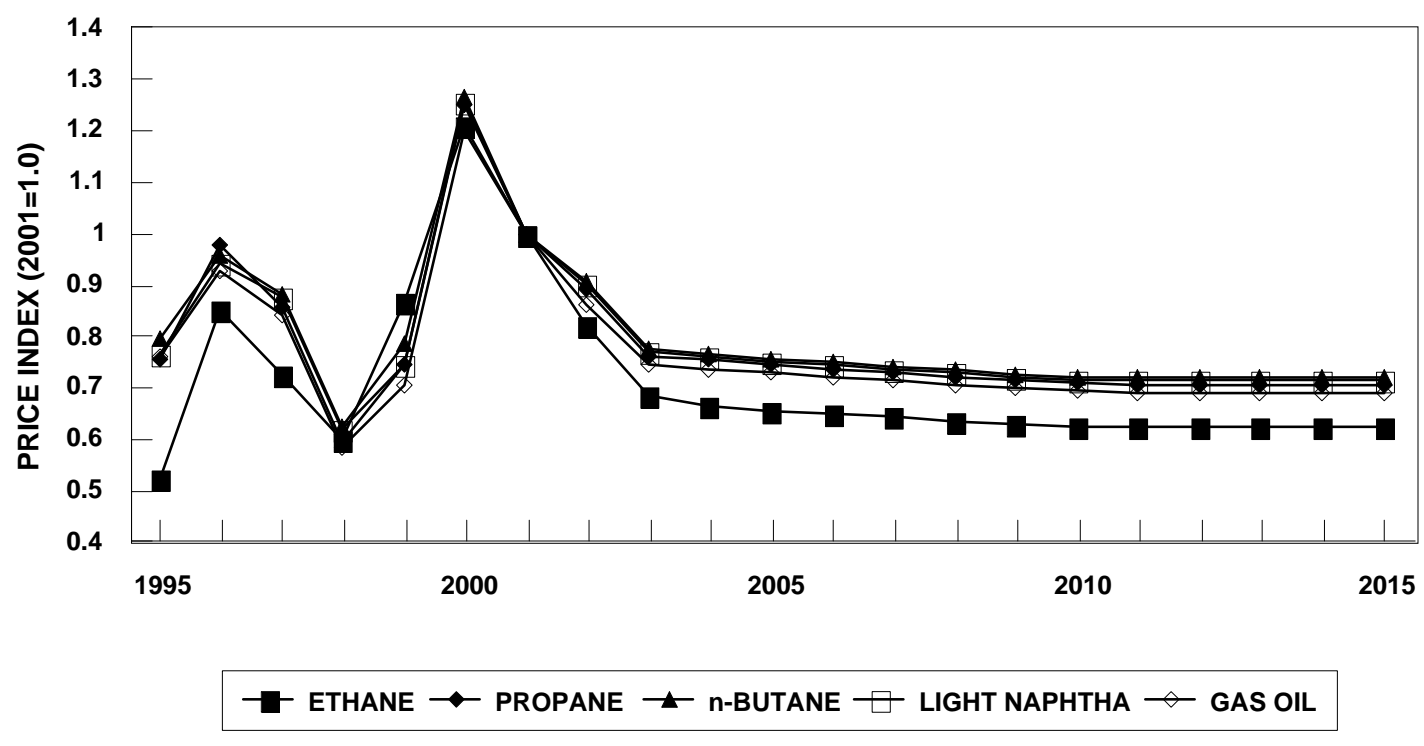

Figure 2.26 Projected Trends In Petrochemical Feedstock Pricing 


\subsection{THE PRICE OUTLOOK FOR METHANOL}

\subsubsection{Historical Price Analysis}

In developing a price forecast for a commodity chemical such as methanol it is important to review historical performance. Table 3.1 present 20 years of methanol price history for the United States Gulf Coast, Western Europe, Singapore and Japan.

The data is also presented graphically in Figures 3.1 and Figure 3.2, for the USGC and Western Europe, respectively. Figure 3.3 shows historic global methanol prices.

Key features of this past data are:

- The average contract price in the USGC between 1983 and 2002 was US\$155/ton, while that in Western Europe was US\$162/ton.

- Over the same period spot and contract prices have been closely related with the USGC spot price averaging US\$3/ton below the USGC contract price and US $\$ 2 /$ ton below the West European contract price.

- During this period the differential between the West European and USGC contract prices averaged around $\$ 10$. The differential has declined on average over this time period, from about $\$ 18$ per ton in 1983 to parity by early 2002. This reduction in inter-regional pricing reflects the increasing percentage of global production capacity in remote locations, such as Chile, Venezuela and the Middle East, which can supply all major markets and thus tends to limit pricing differentials on global markets.

Typically, the prices in the markets have moved in concert, reflecting the global nature of the methanol market. Four price peaks have been evident in recent years:

- 1988 - prompted by plant outages

- 1991 - Gulf War

- $\quad 1994 / 95$ - rapid demand growth in certain areas coupled with plant outages

- 2000/01 - very high US winter natural gas pricing.

In the first three cases the movements reflect real, or perceived, tightness in the market. In the latter case the effect of very high US costs resulted in high prices (and high margins for non-US producers). Figure 3.4 demonstrates that US methanol prices increases that occurred in late 2000/early 2001 very closely matched the increases in US natural gas cost per ton of methanol. This is significant because it illustrates that despite the considerable amount of US capacity closure in recent years, US production costs remain the most influential factor in pricing as opposed to non-US delivered costs. 


\section{Table 3.1 Methanol Price History}

\begin{tabular}{|c|c|c|c|c|c|c|c|}
\hline \multirow[b]{2}{*}{ Year } & \multirow[b]{2}{*}{ Quarter } & \multicolumn{2}{|c|}{ United States } & \multicolumn{2}{|c|}{$\begin{array}{l}\text { US\$ perton } \\
\text { Western Europe }\end{array}$} & \multirow{2}{*}{$\frac{\text { Singapore }}{\text { Spot }}$} & \multirow{2}{*}{$\frac{\text { Japan }}{\text { Spot }}$} \\
\hline & & Spot & Contract & Spot & Contract & & \\
\hline 1983 & 1 & 146 & 140 & 195 & 191 & & \\
\hline & 2 & 149 & 140 & 189 & 177 & & \\
\hline & 3 & 156 & 146 & 170 & 170 & & \\
\hline & 4 & 149 & 138 & 172 & 161 & & \\
\hline 1984 & 1 & 133 & 131 & 172 & 166 & & \\
\hline & 2 & 126 & 129 & 168 & 164 & & \\
\hline & 3 & 133 & 135 & 154 & 158 & & \\
\hline & 4 & 129 & 129 & 146 & 146 & & \\
\hline 1985 & 1 & 126 & 125 & 143 & 135 & & \\
\hline & 2 & 146 & 139 & 160 & 162 & & \\
\hline & 3 & 139 & 138 & 159 & 176 & & \\
\hline & 4 & 123 & 125 & 149 & 157 & & \\
\hline 1986 & 1 & 123 & 121 & 139 & 151 & & \\
\hline & 2 & 110 & 112 & 100 & 102 & & \\
\hline & 3 & 93 & 96 & 91 & 98 & & \\
\hline & 4 & 82 & 85 & 82 & 95 & & \\
\hline 1987 & 1 & 84 & 80 & 100 & 84 & & \\
\hline & 2 & 97 & 94 & 114 & 108 & & \\
\hline & 3 & 108 & 106 & 126 & 128 & & \\
\hline & 4 & 133 & 126 & 144 & 138 & & \\
\hline 1988 & 1 & 209 & 167 & 179 & 176 & & \\
\hline & 2 & 242 & 180 & 191 & 184 & & \\
\hline & 3 & 219 & 195 & 182 & 182 & & \\
\hline & 4 & 183 & 199 & 184 & 186 & & \\
\hline 1989 & 1 & 163 & 183 & 169 & 173 & & \\
\hline & 2 & 143 & 169 & 146 & 166 & & \\
\hline & 3 & 102 & 135 & 89 & 133 & & \\
\hline & 4 & 82 & 102 & 91 & 85 & & 96 \\
\hline 1990 & 1 & 125 & 129 & 125 & 124 & & 125 \\
\hline & 2 & 116 & 133 & 124 & 125 & & 140 \\
\hline & 3 & 103 & 120 & 127 & 132 & & 131 \\
\hline & 4 & 169 & 153 & 156 & 156 & & 151 \\
\hline 1991 & 1 & 201 & 199 & 253 & 189 & & 202 \\
\hline & 2 & 169 & 196 & 182 & 202 & & 207 \\
\hline & 3 & 125 & 153 & 144 & 164 & & 152 \\
\hline & 4 & 129 & 163 & 128 & 148 & & 139 \\
\hline 1992 & 1 & 127 & 132 & 139 & 139 & 147 & 149 \\
\hline & 2 & 113 & 117 & 113 & 133 & 127 & 137 \\
\hline & 3 & 103 & 110 & 110 & 116 & 108 & 120 \\
\hline & 4 & 123 & 124 & 108 & 110 & 114 & 121 \\
\hline 1993 & 1 & 117 & 123 & 113 & 122 & 129 & 135 \\
\hline & 2 & 114 & 123 & 116 & 117 & 132 & 140 \\
\hline & 3 & 125 & 128 & 119 & 113 & 137 & 139 \\
\hline & 4 & 155 & 152 & 150 & 131 & 180 & 175 \\
\hline 1994 & 1 & 168 & 168 & 179 & 165 & 200 & 185 \\
\hline & 2 & 237 & 205 & 235 & 192 & 225 & 194 \\
\hline & 3 & 405 & 319 & 416 & 282 & 408 & 319 \\
\hline & 4 & 521 & 452 & 538 & 437 & 490 & 449 \\
\hline 1995 & 1 & 335 & 402 & 412 & 551 & 390 & 505 \\
\hline & 2 & 136 & 153 & 178 & 193 & 201 & 264 \\
\hline & 3 & 131 & 143 & 160 & 175 & 168 & 176 \\
\hline & 4 & 100 & 110 & 156 & 158 & 144 & 152 \\
\hline 1996 & 1 & 113 & 126 & 149 & 153 & 158 & 143 \\
\hline & 2 & 123 & 126 & 141 & 148 & 172 & 149 \\
\hline & 3 & 163 & 156 & 157 & 150 & 172 & 150 \\
\hline & 4 & 156 & 157 & 198 & 189 & 183 & 162 \\
\hline 1997 & 1 & 191 & 187 & 199 & 174 & 235 & 182 \\
\hline & 2 & 197 & 194 & 199 & 201 & 250 & 208 \\
\hline & 3 & 197 & 193 & 177 & 183 & 205 & 205 \\
\hline & 4 & 195 & 193 & 194 & 188 & 181 & 191 \\
\hline 1998 & 1 & 124 & 148 & 140 & 182 & 149 & 185 \\
\hline & 2 & 90 & 108 & 110 & 139 & 121 & 145 \\
\hline & 3 & 93 & 107 & 100 & 116 & 98 & 122 \\
\hline & 4 & 83 & 102 & 103 & 118 & 91 & 117 \\
\hline 1999 & 1 & 77 & 93 & 89 & 100 & 96 & 108 \\
\hline & 2 & 109 & 107 & 99 & 95 & 108 & 105 \\
\hline & 3 & 130 & 126 & 106 & 115 & 126 & 115 \\
\hline & 4 & 114 & 122 & 121 & 126 & 109 & 127 \\
\hline 2000 & 1 & 108 & 115 & 118 & 126 & 116 & 126 \\
\hline & 2 & 194 & 158 & 175 & 133 & 159 & 132 \\
\hline & 3 & 226 & 214 & 202 & 190 & 203 & 190 \\
\hline & 4 & 221 & 229 & 211 & 222 & 189 & 218 \\
\hline 2001 & 1 & 262 & 262 & 241 & 235 & 197 & 233 \\
\hline & 2 & 214 & 244 & 204 & 223 & 169 & 237 \\
\hline & 3 & 109 & 154 & 142 & 196 & 135 & 199 \\
\hline & 4 & 104 & 122 & 103 & 134 & 102 & 153 \\
\hline 2002 & 1 & 109 & 121 & 97 & 110 & 109 & 114 \\
\hline
\end{tabular}


Figure 3.1 United States Methanol Price History

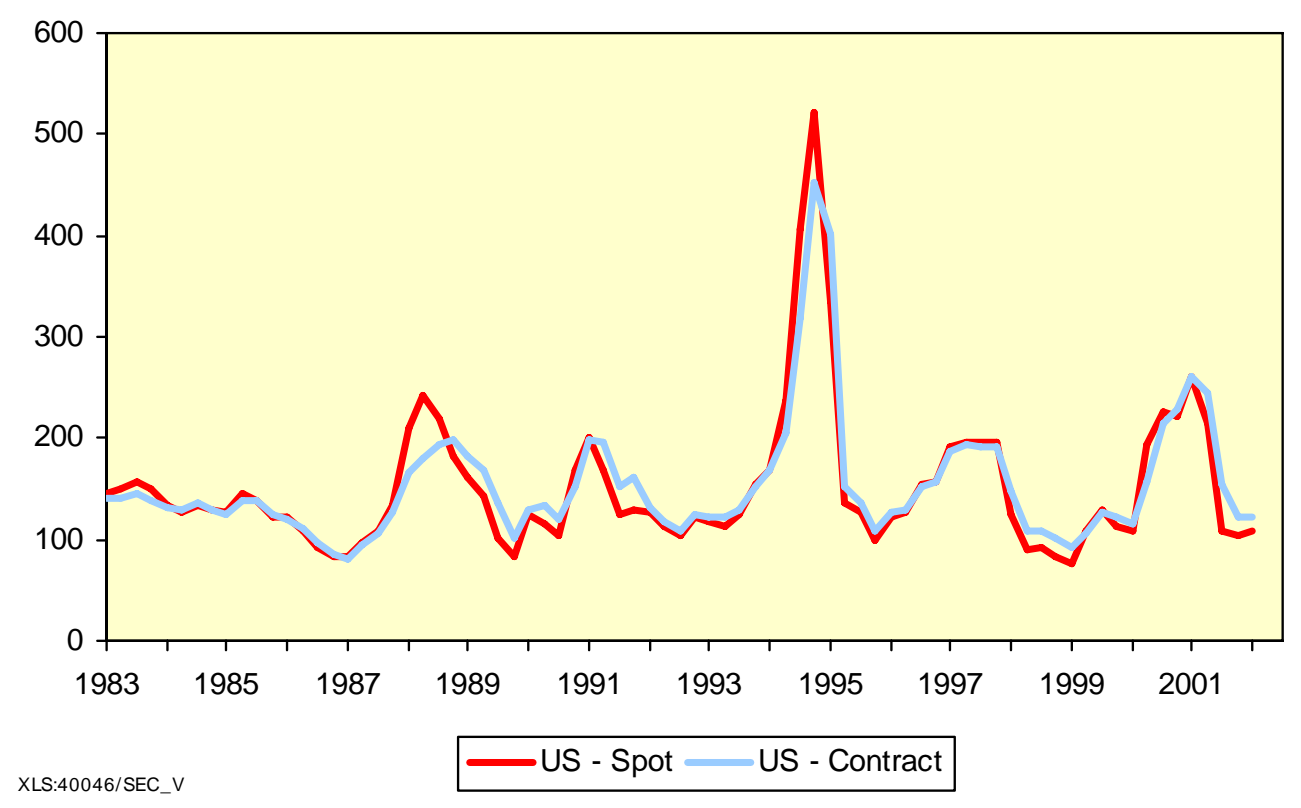

Figure 3.2 West European Methanol Price History

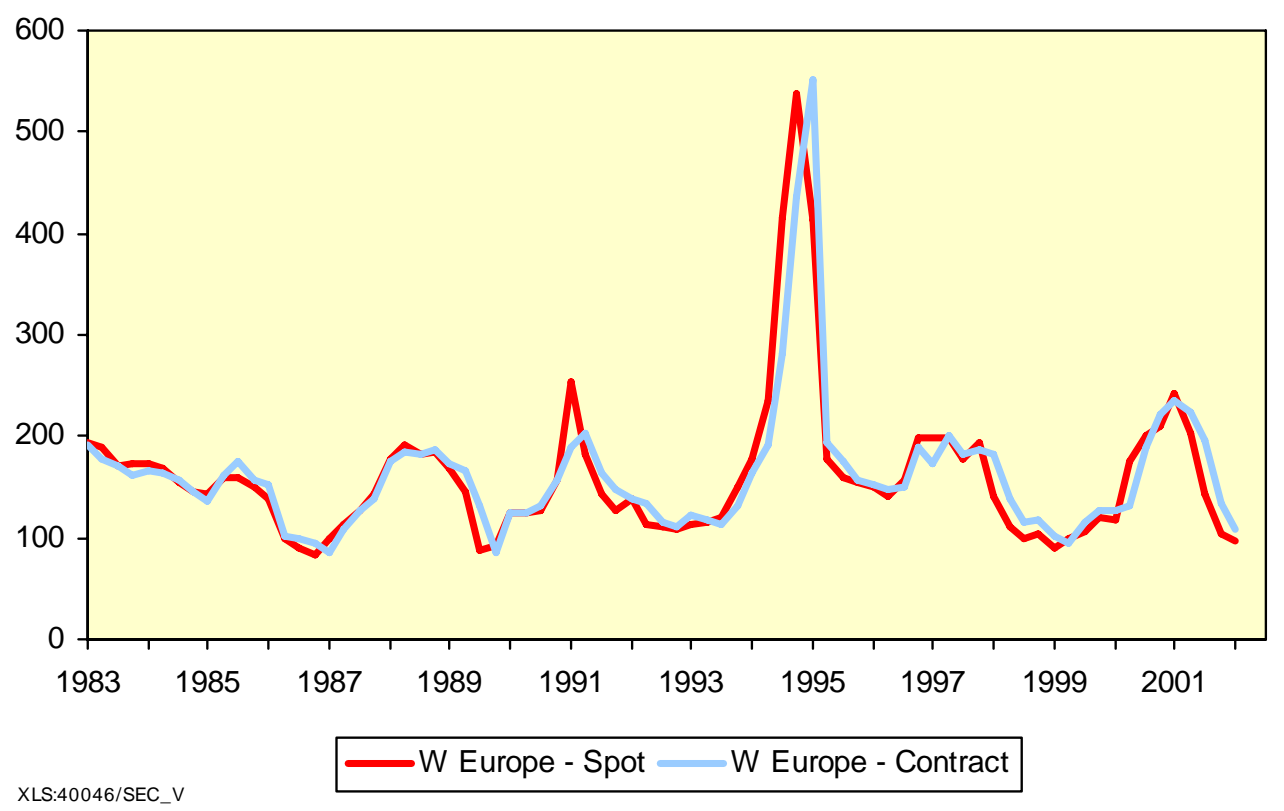


An additional parameter that could affect pricing is the separation of production and marketing/sales in certain new projects. In some cases such as the new Trinidad plant or the new Qatari plant the methanol is sold either through traders or other parties. There is a risk in this approach because traders receive a commission on the tons sold. Unless the offtake agreements are extremely well designed and written, the traders may not realize the maximum possible price and instead will pursue the sale of the maximum possible volume. If this practice were to become widespread it would tend to weaken market prices.

Figure 3.3 Global Methanol Pricing (US\$ per ton)

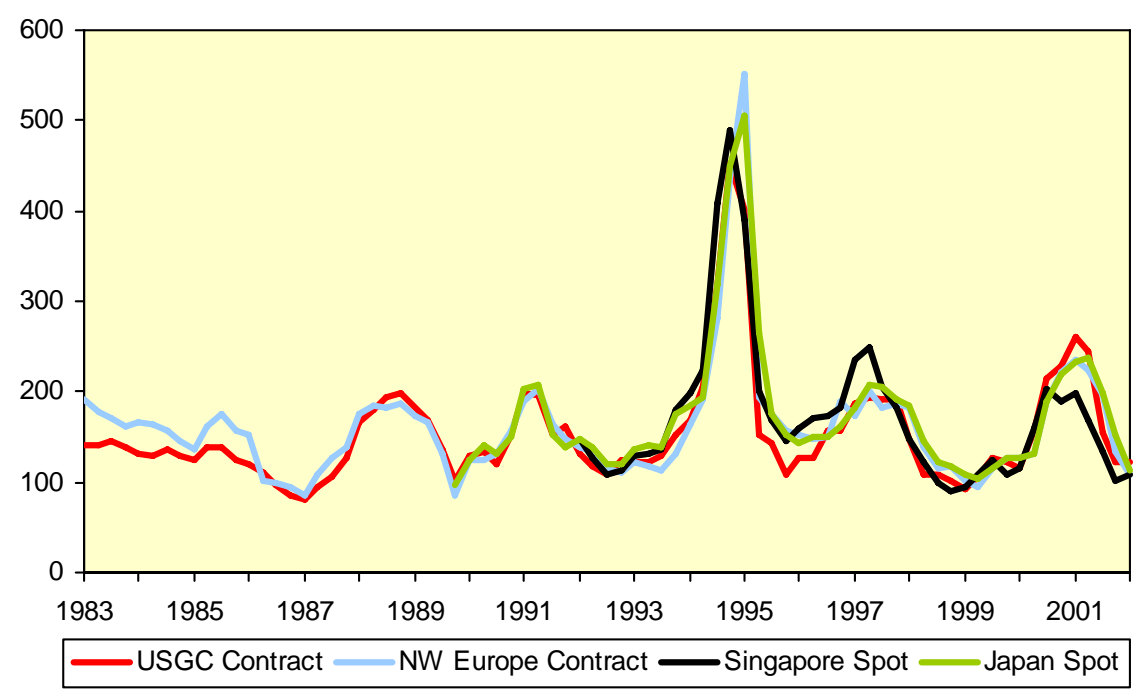

XLS:40046/SEC_V 
Figure 3.4 Effect Of US Natural Gas On Methanol Price

(US dollars)

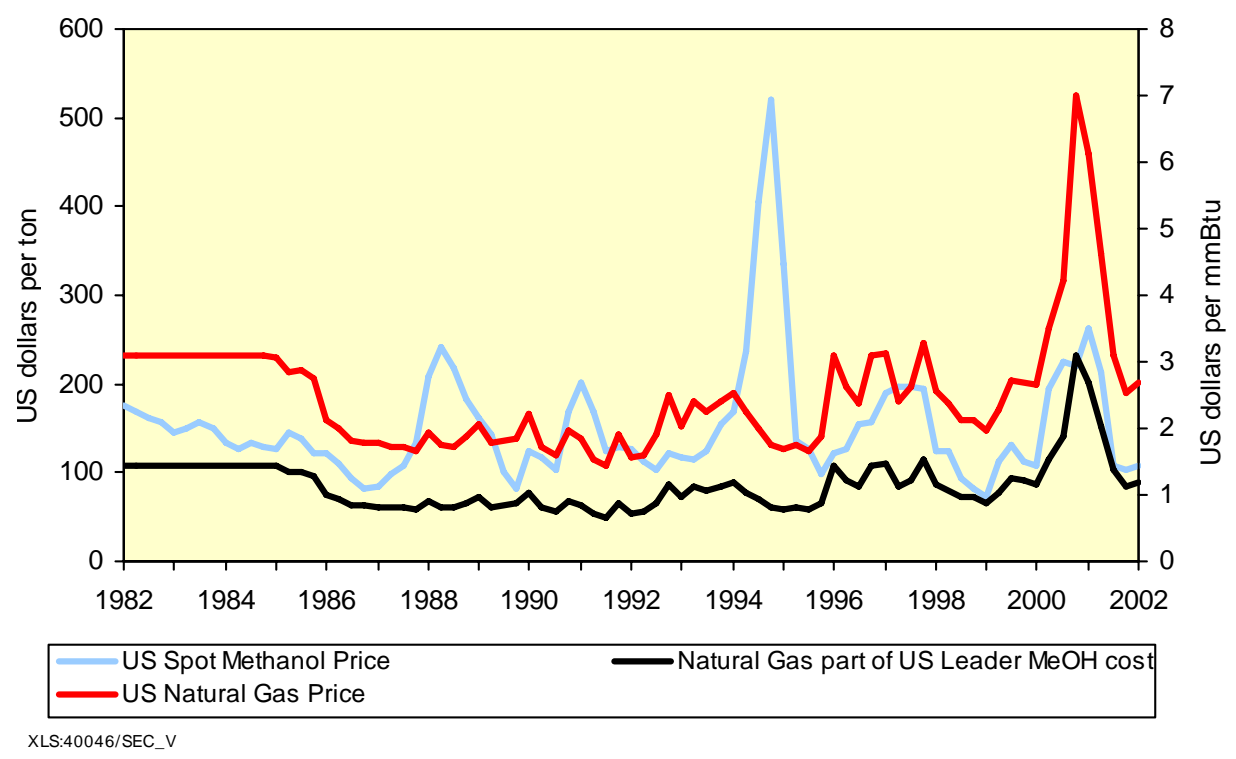

\subsection{METHANOL PRICE FORECASTING METHODOLOGY}

Methanol is a global commodity the price of which responds to complex and widespread market forces. However, the key market is the United States, which accounts for about 30 percent of global consumption and has a leading influence on global pricing. U.S. producers' Leader/Laggard costs consequently have a significant bearing on pricesetting under normal circumstances. (A Leader producer is defined as a producer with production costs in the lowest 20 percent, while a Laggard producer is defined as a producer with production costs in the highest 20 percent of viable producers. US prices are then translated via differential shipping and tariff costs to other markets.

Figure 3.5 presents the historical margin analysis for the USGC, showing the Leader's variable and cash cost margin and the Laggard's variable cost margin. The graph provides good confirmation that the floor price reflects these benchmarks. The exception to this was Q4 2000 when US natural gas prices peaked at levels which Nexant/Nexant considers to be unsustainable. On the basis of Nexant/Nexant's US natural gas prices forecasts, it is expected that the historical norms for floor pricing will hold true. 


\section{Figure 3.5 US Methanol Margin History}

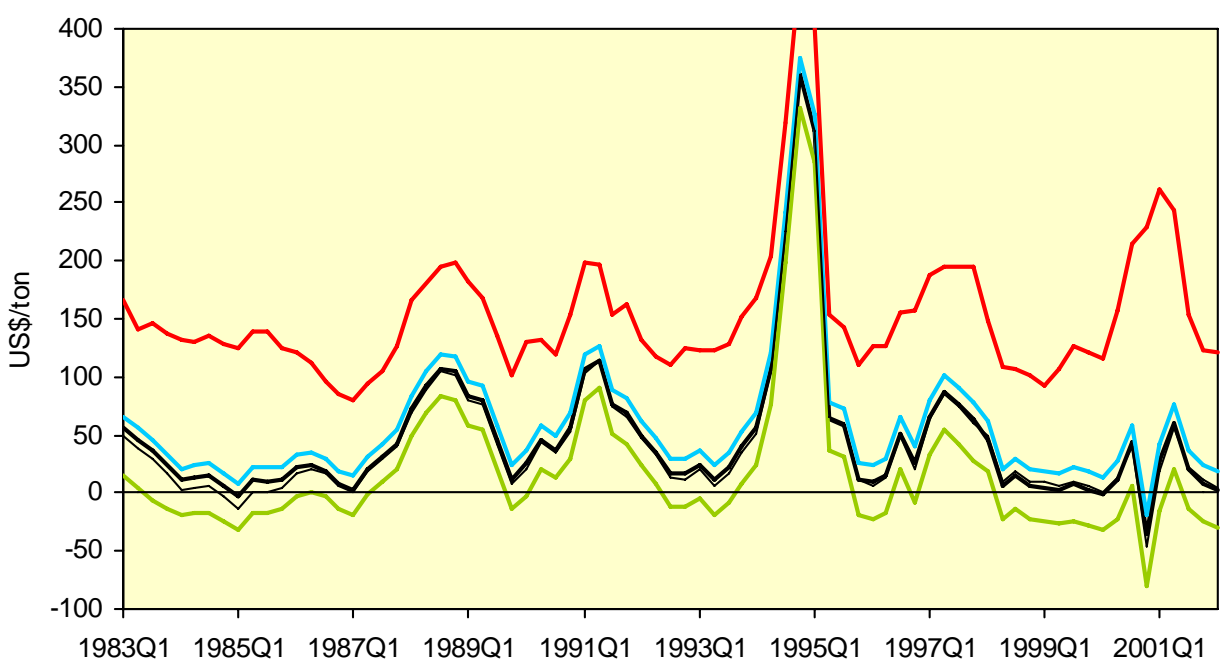

$\begin{array}{ll}\text { _US Contract Price } & \text { Leader Cash Margin } \\ \text { Leader Variable Margin } & \text { Laggard Cash Margin }\end{array}$

XLS:40046/SEC_V

Over the period the Leader cash margin has averaged \$46/ton and the Laggard cash and variable cost margins have averaged \$17/ton and \$44/ton, respectively. However it is Nexant/Nexant's opinion that this is excessively distorted by the uncharacteristically high and long spike of mid1994 to mid-1995. Consequently Nexant/Nexant considers that a better estimate of the real average margin requires that a certain proportion of the 1994/95 spike be omitted from the calculation of average margin. This has been done by capping the spike at a leader cash margin of $\$ 120$ per ton, in line with peak margins seen in previous spikes. On this basis the margins are reduced by about $\$ 5 /$ ton.

As discussed in Market Study Report Section III, Nexant/Nexant anticipates depressed global operating rates resulting from the reduction in demand for methanol for US MTBE consumption and the addition of large-scale methanol plants in "stranded gas" regions of the world. Reflecting these developments, Nexant/Nexant has based its margin forecast on a cash cost breakeven basis to a US laggard producer. Nexant/Nexant thus projects a US Leader cash cost margin of $\$ 29$ per ton, declining by one percent per year in real terms reflecting the impact of increasing unit size on fixed costs and the increasing percentage of production in low cost remote locations.

As previously discussed, global methanol prices are closely linked reflecting the ease with which methanol can be, and is, shipped around the world. The distribution of large-scale, export-orientated production facilities around the world ensures that global prices cannot diverge for any sustained period of time. Nexant/Nexant expects global pricing to continue to converge reflecting the start-up of more large-scale, export-orientated plants. Asian prices are forecast to be the arithmetic average of USGC and North West Europe price forecasts. This formula also reflects Nexant/Nexant's understanding of certain existing contracts for methanol sold in Asia by export-orientated producers. 


\subsection{METHANOL PRICE FORECASTS}

The methanol price forecasts for the medium oil trend case are presented in Table 3.2 (constant 2001 US\$), Table 3.3 (current US\$) and graphically in Figure 6.1.

Figure 3.6 Methanol Price Forecasts

(current US\$/ton, medium oil trend case)

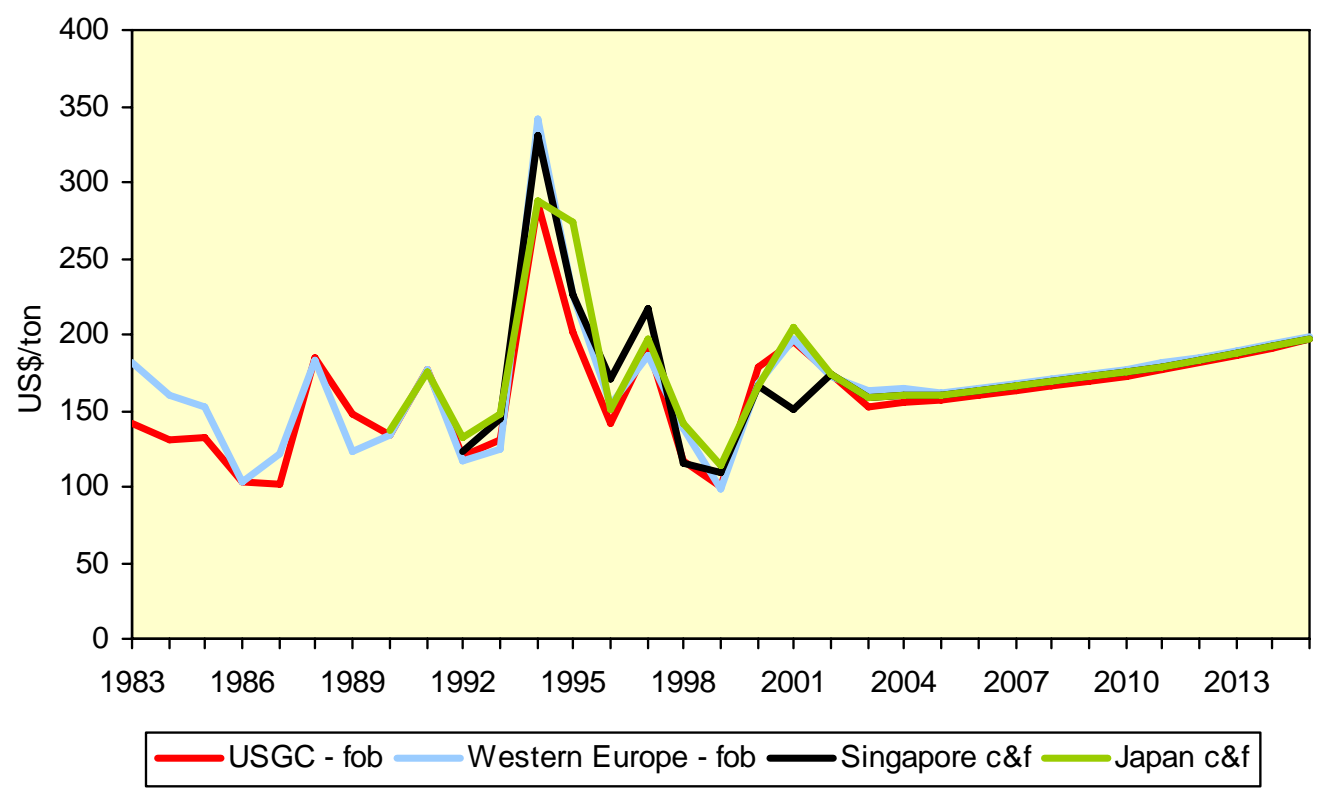

XLS:40046/SEC_V 


\section{Table 3.2 Methanol Price Forecasts \\ (constant 2001 US\$ per ton, medium oil trend case)}

\begin{tabular}{|c|c|c|c|c|c|c|c|c|c|c|c|c|c|c|}
\hline & 2002 & 2003 & 2004 & 2005 & 2006 & 2007 & 2008 & 2009 & 2010 & 2011 & 2012 & 2013 & 2014 & 2015 \\
\hline USGC - fob & 170 & 145 & 144 & 143 & 142 & 141 & 140 & 139 & 138 & 139 & 139 & 139 & 139 & 139 \\
\hline Western Europe & 168 & 156 & 154 & 146 & 145 & 145 & 144 & 143 & 142 & 141 & 141 & 141 & 141 & 141 \\
\hline Singapore $c \& f$ & 169 & 150 & 149 & 145 & 144 & 143 & 142 & 141 & 140 & 140 & 140 & 140 & 140 & 140 \\
\hline Japan c\&f & 169 & 150 & 149 & 145 & 144 & 143 & 142 & 141 & 140 & 140 & 140 & 140 & 140 & 140 \\
\hline
\end{tabular}

Current\$/2001\$

USGC - fob

Western Europe - fob

Singapore c\&f

Japan c\&f

\section{Table 3.3 Methanol Price Forecasts}

(current US\$ per ton, medium oil trend case)

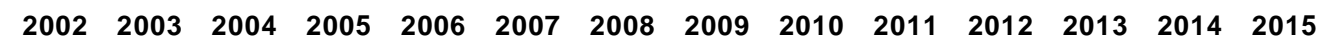

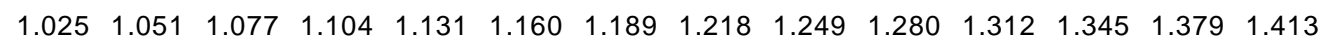

$\begin{array}{llllllllllllll}174 & 153 & 155 & 158 & 160 & 164 & 167 & 170 & 173 & 177 & 182 & 187 & 191 & 196 \\ 172 & 163 & 165 & 162 & 165 & 168 & 171 & 174 & 177 & 181 & 185 & 190 & 194 & 199 \\ 173 & 158 & 160 & 160 & 163 & 166 & 169 & 172 & 175 & 179 & 184 & 188 & 193 & 197 \\ 173 & 158 & 160 & 160 & 163 & 166 & 169 & 172 & 175 & 179 & 184 & 188 & 193 & 197\end{array}$


The outlook for future pricing of UCF's (FT Diesel, FT Naphtha and methanol) is dependent on a number of key factors as follows:

- underlying value of conventional competing fuels

- comparative quality of UCFs relative to conventional fuels, with associated premium or discount to conventional fuel market pricing

The analysis of the future valuation of UCFs reflects the above factors, and draws upon analyses performed in a number of other sections of the overall market study. These are defined in the following sections.

\subsection{FT DIESEL VALUATION}

As indicated in Section 2.4.2 of this section of the Market Report, pricing for conventional diesel fuel in the United States will reflect strong market growth as well as tightening specifications on sulfur content. As a result, diesel pricing will track underlying prices of crude oil, but will be at the high end of historical relationships to crude oil price. Thus, diesel fuel will average about $\$ 3.60$ per barrel premium over WTI crude oil over the next 10 years, as compared to an average of about $\$ 2.70$ per barrel over the previous decade.

The analysis of the value of FT diesel to United States refiners, documented in Market Report Section VIII, indicates that in general, outside of California, FT diesel will have only a modest value premium to conventional diesel if it is used as a blendstock in relatively small quantities. As a result, the conclusion reached in this study is that FT diesel will command, at best, a price premium of \$0.40-0.50 per barrel in the United States excluding California. FT diesel, due to its high cetane number, will command a higher value premium in California, on the order of about $\$ 3.00$ per barrel. In all cases these premiums will apply only if FT diesel is blended with conventional diesel in a ratio up to about 15-20 percent of the final blended product.

\subsection{FT NAPHTHA}

As indicated in Section 2.4.5 of this section of the Market Report, conventional naphtha that is suitable as a feedstock to produce ethylene and other basic chemicals is forecast to track pricing of unleaded regular gasoline. On average, conventional naphtha is expected to sell at about 1012 cents per gallon less than unleaded regular gasoline. This discount reflects naphtha's poor quality as a gasoline blendstock (i.e. low octane and relatively high vapor pressure).

The value of FT naphtha as an ethylene feedstock was analyzed in Market Report Section II. The conclusion of that analysis was that FT naphtha, due to its highly paraffinic nature as well as its uniform composition, should command a value premium above conventional naphthas. The actual premium will be dependent on each ethylene complex's specific situation (i.e. severity of the cracking process, mix of products required in the local market, etc.). On average, Nexant 
forecasts that FT naphtha will command a premium of between 10-20 cents per metric ton (2.55.5 cents per gallon, or about $\$ 1.00-\$ 2.00$ per barrel).

\subsection{METHANOL}

As indicated in Section 3 of this section of the Market Report, pricing for methanol in the U.S. market has historically been closely linked to the underlying cost of natural gas, such that leader methanol plants operating in the United States have achieved a modest, but acceptable, level of profitability. Methanol is a feedstock for MTBE production, so that methanol demand in the U.S. will be severely reduced over the next 5-10 years due to the anticipated elimination of MTBE use in U.S. motor gasoline. As a result of this change, most of the methanol facilities currently operating in the United States are expected to shut down, with only 1-2 relatively large facilities still in operation by 2015. Future methanol pricing will be sufficient to provide a modest return for these remaining plants.

Methanol value as an UCF faces many significant barriers to success over the next 10-15 years. Based on the analysis performed in Market Report Section V, the value of methanol would have to be discounted about 33 percent from the forecast price of methanol for chemical markets in order to have the equivalent price of motor gasoline (adjusted for methanol's lower heat content). Such a reduction would result in pricing for methanol that would not provide acceptable economics for a Middle East mega methanol plant (5,000 metric tons per day capacity) in 2006, and only marginal economics in 2015 for a far larger facility (15,000 metric tons per day capacity). Price discounts of this magnitude would effectively shut down most of the smaller methanol production facilities that currently produce all of the world's supply (currently there are no plants with capacity equal to 5,000 metric tons per day). As a result, in order to make the global methanol industry economically viable, the price of methanol would have to be significantly subsidized, or the price of gasoline or diesel would have to be significantly increased (most likely via high tax levels). Currently there is no indication of a move to dramatically increase motor fuel taxes in the United States, and as a result, it is expected that the forecast price of methanol will be too expensive to compete with conventional fuels over through 2015, the time horizon for this analysis. 


\section{$5.1 \quad$ FT DIESEL}

The potential for FT diesel to serve as a transportation fuel has been assessed from a number of perspectives in this Market Study Report. Specifically the following has been concluded:

- FT diesel is expected to be an acceptable fuel to help meet low sulfur requirements in vehicle engines and systems that will be developed over the coming decade. There may be a need for lubricity additives due to the very low sulfur content of FT diesels. Details of this analysis are provided in Market Report Section VI

- FT diesel is expected to be an acceptable diesel blendstock for United States refineries. Blends containing up to 15-20 percent FT diesel are expected to be economically attractive to produce for domestic refiners. Details of this analysis are provided in Market Report Section VIII

- As presented in Market Study Report Section I, the United States market for diesel/gas oil fuel is expected to increase by about 1.4 percent per year, representing an absolute increase of about 730,000 barrels per day between 2001 and 2015. Globally, the market for diesel/gas oil fuel is expected to increase about 2.3 percent per year, or about 5 million barrels per day by 2015 . Approximately 60 percent of these volumes are consumed as onroad diesel fuel. A typical worldscale GTL facility is expected to produce about 50,000 barrels per day of FT diesel. Thus, to achieve a 10 percent market share of new U.S. demand by 2015, a total of about 9 new GTL plants would need to be built and in operation. To achieve the same level on a global basis, approximately 60 new plants would be needed. Realistic projects for GTL capacity construction call for at most 20-25 plants to be built by 2015. As a result, this study concludes that the global market for diesel fuel is sufficiently large and robust to absorb the industry's ability to build GTL facilities over the next 15 years.

\subsection{FT NAPHTHA}

The potential market for naphtha as an ethylene feedstock was evaluated in Market Study Report II. The United States market for naphtha is expected to increase about 2.2 percent per year, or by about 150,000 barrels per day. Global demand for petrochemical-grade naphtha is forecast to increase by 3.6 percent annually, or about 2.3 million barrels per day by 2015 . A typical worldscale GTL facility is expected to produce about 18,000 barrels per day of FT naphtha. Thus, to achieve a 10 percent market share of new U.S. demand by 2015, a total of about 9 new GTL plants would need to be built and in operation. To achieve the same level on a global basis, approximately 130 new plants would be needed. Realistic projects for GTL capacity construction call for at most 20-25 plants to be built by 2015. Therefore, similar to the result for FT diesel, this study concludes that the global market for naphtha as an ethylene feedstock is sufficiently large and robust to absorb the industry's ability to build GTL facilities over the next 15 years. 


\subsection{METHANOL}

As defined in Market Study Report Section VII, the theoretical market for methanol as a transportation fuel is enormous. To put this into perspective, the current demand for chemical methanol in the United States is about 3 billion gallons per year. Achieving a 20 percent market penetration in the United States gasoline market, the minimum level required to achieve a selfsustaining infrastructure, would result in slightly more than tripling the amount of methanol consumed in the country. Substantially larger consumption numbers would apply on a global basis. Thus, the transport market represents a very large area of potential new demand for methanol. However, based on the analysis performed in Market Study Report Section VI, methanol faces a number of critical barriers to successful commercialization and use as a transportation fuel over the next 15 years. Although many of these problems can be addressed at a technical level, ultimately the key issue comes down to making methanol acceptable to the consuming public. Thus, despite considerable effort and expense, methanol has failed as a transportation fuel due to its low energy density (resulting in limited vehicle range), requirement for subsidies (both for vehicles and fuel) to be economically neutral to consumers, and its potentially significant issues of health/toxicity. As a result of these issues, this study concludes that methanol will not become a significant fuel for conventional motor vehicles over the next 15 years.

In contrast to its limitations for use in conventional motor vehicles, methanol appears to be hypothetically more attractive as a fuel for fuel cells. This potential was also examined in Market Study Report Section VI. The analysis concluded that the technology for fuel cells is still too immature to achieve significant commercialization within the next 15 years. Fundamental issues such as high cost, feedstock limits due to the need to improve fuel reforming technology, limited infrastructure and the long lead-time to commercialize such a fundamentally different transport technology for vehicles has all contributed to this conclusion. Of the fuel cell fuels considered, methanol has some strong advantages. However, they are not sufficient to overcome the more fundamental issues that must first be addressed to commercialize fuel cell technology.

In summary, this study concludes that methanol will not achieve significant demand as a transportation fuel over the next 15 years. 


\subsection{CONVENTIONAL FUEL PRICE OUTLOOK}

The methodology utilized in this analysis for forecasting refined product prices can be simplified and broken down into several principal steps:

- Identifying the refinery configuration most representative of a region's incremental producer of refined products

- Forecasting the variable margin for the incremental refinery configuration

- $\quad$ Forecasting price differentials between major refined products

Given the crude oil price outlook and these variable margin and price differential forecasts, the individual refined product prices can be calculated algebraically.

Nexant utilizes a cost-based approach to forecast refined product prices, which is comprised of a projection of the global economic environment (real economic growth and price inflation), the projected underlying international crude oil price, and the business environment for each key refined product. The outlook for each product's price on the U.S. Gulf Coast reflects the industry's expected supply/demand balance and refinery operating rates that determine the price relationships between key products, refinery margins and profitability. As indicated in Figure 6.1 , the trendline outlook for refinery profitability is expected to be in line with historical performance. Profitability margins are expected to decline in real terms due to the commodity nature of the refining business.

Diesel fuel pricing will track underlying prices of crude oil, but, due to expected strong growth and tightening quality specifications, will be at the high end of historical relationships to crude oil price. Thus, diesel fuel will average about $\$ 3.60$ per barrel premium over WTI crude oil over the next 10 years, as compared to an average of about $\$ 2.70$ per barrel over the previous decade.

Conventional naphtha that is suitable as a feedstock to produce ethylene and other basic chemicals is forecast to track pricing of unleaded regular gasoline. On average, conventional naphtha is expected to sell at about 10-12 cents per gallon less than unleaded regular gasoline. This discount reflects naphtha's poor quality as a gasoline blendstock (i.e. low octane and relatively high vapor pressure).

Pricing for methanol in the U.S. market has historically been closely linked to the underlying cost of natural gas, such that leader methanol plants operating in the United States have achieved a modest, but acceptable, level of profitability. Methanol is a feedstock for MTBE production, so that methanol demand in the U.S. will be severely reduced over the next 5-10 years due to the anticipated elimination of MTBE use in U.S. motor gasoline. As a result of this change, most of the methanol facilities currently operating in the United States are expected to shut down, with only 1-2 relatively large facilities still in operation by 2015 . Future methanol pricing will be sufficient to provide a modest return for these remaining plants. 


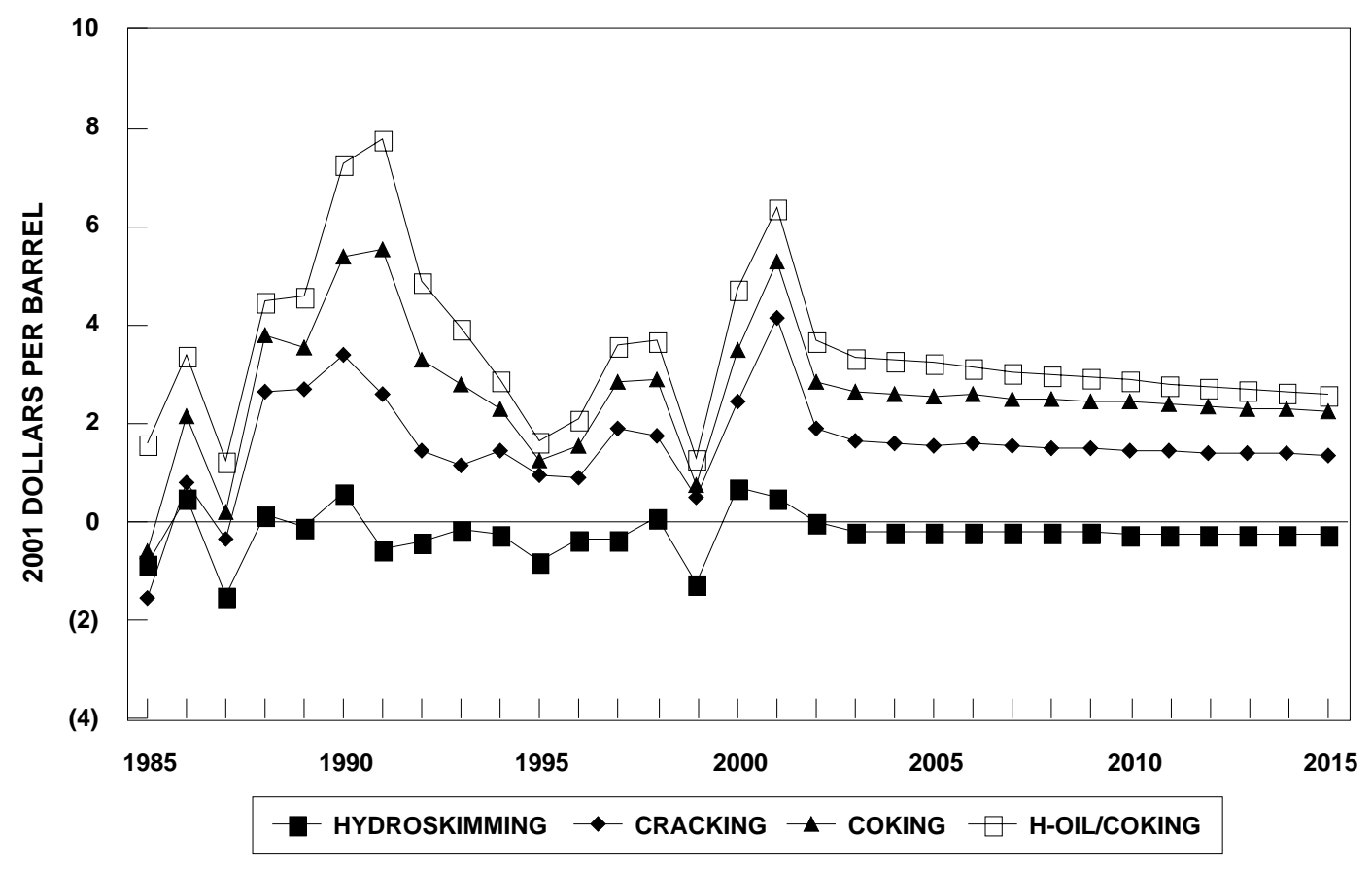

CASHCONS852015 M:IINERGYUSPRIMargus01_2002.123

Figure 6.1 USGC Cash Cost Refining Margins

\subsection{UCF PRICING OUTLOOK}

The analysis of the value of FT diesel to United States refiners, documented in Market Report Section VIII, indicates that in general, outside of California, FT diesel will have only a modest value premium to conventional diesel if it is used as a blendstock in relatively small quantities. As a result, the conclusion reached in this study is that FT diesel will command, at best, a price premium of \$0.40-0.50 per barrel in the United States excluding California. FT diesel, due to its high cetane number, will command a higher value premium in California, on the order of about $\$ 3.00$ per barrel. In all cases these premiums will apply only if FT diesel is blended with conventional diesel in a ratio up to about 15-20 percent of the final blended product.

The value of FT naphtha as an ethylene feedstock was analyzed in Market Report Section II. The conclusion of that analysis was that FT naphtha, due to its highly paraffinic nature as well as its uniform composition, should command a value premium above conventional naphthas. The actual premium will be dependent on each ethylene complex's specific situation (i.e. severity of the cracking process, mix of products required in the local market, etc.). On average, Nexant forecasts that FT naphtha will command a premium of between 10-20 cents per metric ton (2.55.5 cents per gallon, or about $\$ 1.00-\$ 2.00$ per barrel).

Based on the analysis performed in Market Report Section V, the value of methanol would have to be discounted about 33 percent from the forecast price of methanol for chemical markets in 
order to have the equivalent price of motor gasoline in the United States (adjusted for methanol's lower heat content). Such a reduction would result in pricing for methanol that would not provide acceptable economics for a Middle East mega methanol plant (5,000 metric tons per day capacity) in 2006, and only marginal economics in 2015 for a far larger facility (15,000 metric tons per day capacity). Price discounts of this magnitude would effectively shut down most of the smaller methanol production facilities that currently produce all of the world's supply (currently there are no plants with capacity equal to 5,000 metric tons per day). As a result, in order to make the global methanol industry economically viable, the price of methanol would have to be significantly subsidized, or the price of gasoline or diesel would have to be significantly increased (most likely via high tax levels). Currently there is no indication of a move to dramatically increase motor fuel taxes in the United States, and as a result, it is expected that the forecast price of methanol will be too expensive to compete with conventional fuels over through 2015, the time horizon for this analysis.

\subsection{UCF MARKET POTENTIAL}

\subsubsection{FT Diesel}

The potential for FT diesel to serve as a transportation fuel has been assessed from a number of perspectives in this Market Study Report. Specifically the following has been concluded:

- FT diesel is expected to be an acceptable fuel to help meet low sulfur requirements in vehicle engines and systems that will be developed over the coming decade. There may be a need for lubricity additives due to the very low sulfur content of FT diesels. Details of this analysis are provided in Market Study Report Section VI

- FT diesel is expected to be an acceptable diesel blendstock for United States refineries. Blends containing up to 15-20 percent FT diesel are expected to be economically attractive to produce for domestic refiners. Details of this analysis are provided in Market Study Report Section VIII

- As presented in Market Study Report Section I, the United States market for diesel/gas oil fuel is expected to increase by about 1.4 percent per year, representing an absolute increase of about 730,000 barrels per day between 2001 and 2015. Globally, the market for diesel/gas oil fuel is expected to increase about 2.3 percent per year, or about 5 million barrels per day by 2015. Approximately 60 percent of these volumes are consumed as onroad diesel fuel. A typical worldscale GTL facility is expected to produce about 50,000 barrels per day of FT diesel. Thus, to achieve a 10 percent market share of new U.S. demand by 2015, a total of about 9 new GTL plants would need to be built and in operation. To achieve the same level on a global basis, approximately 60 new plants would be needed. Realistic projects for GTL capacity construction call for at most 20-25 plants to be built by 2015. As a result, this study concludes that the global market for diesel fuel is sufficiently large and robust to absorb the industry's ability to build GTL facilities over the next 15 years. 


\subsubsection{FT Naphtha}

The potential market for naphtha as an ethylene feedstock was evaluated in Market Study Report II. The United States market for naphtha is expected to increase about 2.2 percent per year, or by about 150,000 barrels per day. Global demand for petrochemical-grade naphtha is forecast to increase by 3.6 percent annually, or about 2.3 million barrels per day by 2015 . A typical worldscale GTL facility is expected to produce about 18,000 barrels per day of FT naphtha. Thus, to achieve a 10 percent market share of new U.S. demand by 2015, a total of about 9 new GTL plants would need to be built and in operation. To achieve the same level on a global basis, approximately 130 new plants would be needed. Realistic projects for GTL capacity construction call for at most 20-25 plants to be built by 2015 . Therefore, similar to the result for FT diesel, this study concludes that the global market for naphtha as an ethylene feedstock is sufficiently large and robust to absorb the industry's ability to build GTL facilities over the next 15 years.

\subsubsection{Methanol}

As defined in Market Study Report Section VII, the theoretical market for methanol as a transportation fuel is enormous. To put this into perspective, the current demand for chemical methanol in the United States is about 3 billion gallons per year. Achieving a 20 percent market penetration in the United States gasoline market, the minimum level required to achieve a selfsustaining infrastructure, would result in slightly more than tripling the amount of methanol consumed in the country. Substantially larger consumption numbers would apply on a global basis. Thus, the transport market represents a very large area of potential new demand for methanol. However, based on the analysis performed in Market Report Section VI, methanol faces a number of critical barriers to successful commercialization and use as a transportation fuel over the next 15 years. Although many of these problems can be addressed at a technical level, ultimately the key issue comes down to making methanol acceptable to the consuming public. Thus, despite considerable effort and expense, methanol has failed as a transportation fuel due to its low energy density (resulting in limited vehicle range), requirement for subsidies (both for vehicles and fuel) to be economically neutral to consumers, and its potentially significant issues of health/toxicity. As a result of these issues, this study concludes that methanol will not become a significant fuel for conventional motor vehicles over the next 15 years.

In contrast to its limitations for use in conventional motor vehicles, methanol appears to be hypothetically more attractive as a fuel for fuel cells. This potential was also examined in Market Report Section VI. The analysis concluded that the technology for fuel cells is still too immature to achieve significant commercialization within the next 15 years. Fundamental issues such as high cost, feedstock limits due to the need to improve fuel reforming technology, limited infrastructure and the long lead-time to commercialize such a fundamentally different transport technology for vehicles has all contributed to this conclusion. Of the fuel cell fuels considered, methanol has some strong advantages. However, they are not sufficient to overcome the more fundamental issues that must first be addressed to commercialize fuel cell technology. 
In summary, this study concludes that methanol will not achieve significant demand as a transportation fuel over the next 15 years. 


\section{Ultra Clean Fuels Market Assessment-Executive Summary Market Study Report Section X}

Prepared For:

ConocoPhillips

Co-operative Agreement DE-FC26-01NT41098

\section{ConocoPhillips $\backsim$ Nexant}




\title{
Ultra Clean Fuels Market Assessment- Executive Summary Market Study Report Section X
}

November 2002

\author{
Prepared For: \\ ConocoPhillips
}

\section{cNexant}

44 South Broadway, White Plains, New York 10601, USA

Tel: +1 9146090300 Fax: +1 9146090399 
Contents

Section

Page

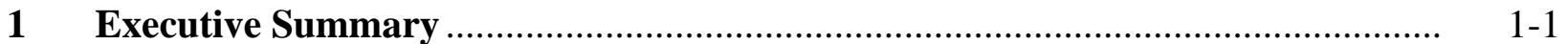

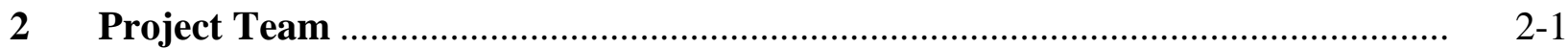

3 Market Study Structure …..................................................................... 
The overall objective of this study was to assess the potential markets through 2015 for selected ultra clean transportation fuels (UCFs, defined as FT diesel, FT naphtha, FT jet and methanol). Coverage was global, with primary focus on the United States market. Comparative economics were developed for key UCF technologies for 2006 and 2015.

FT diesel qualities are in general superior to conventional ultra-low sulfur (ULS) petroleumbased diesel, with virtually zero sulfur content, high cetane and generally lower emission characteristics. With the necessary additives, particularly for lubricity, FT diesel can be blended with other refinery-based diesel streams to make finished products. When used as a blendstock, the primary processing impact on refining operations is a reduction in the required distillate hydrotreater desulfurization severity, resulting in lower hydrogen usage and lower catalyst and utilities costs.

FT diesel used as a diesel blendstock will have only a modest value premium to ULS diesel, on the order of \$0.40-0.50 per barrel in the United States excluding California. Due to the unique requirement for a high cetane number in California, the premium range is higher, on the order of about $\$ 1.50-\$ 1.50$ per barrel. In all cases these premiums will apply only if FT diesel is blended with conventional diesel in a ratio up to about 15-20 percent of the final product, since currently FT diesel cannot be sold as a neat fuel due to its low density. Future growth in global markets for diesel is expected to be sufficient to absorb all likely production of FT diesel over the next 15 years.

FT naphtha's properties make it an ideal feedstock to produce ethylene and other basic chemicals, and ethylene production is expected to be its primary market. Other potential uses are not considered viable for high volume consumption, including as a refinery feedstock, refinery gasoline blendstock, sale into specialty markets (e.g. white oils, hydrocarbon solvents, light lubricant base stocks), and as a fuel for fuel cells.

The most likely target market for FT naphtha produced in a Mideast GTL plant is the Asian ethylene industry due to the region's high growth and its position as a major naphtha importer. Due to its superior properties, FT naphtha should command a value premium relative to conventional naphthas on the order of $\$ 10$ to $\$ 20$ per metric ton (2.5 to 5.5 cents per gallon, or about $\$ 1.00$ to $\$ 2.00$ per barrel). Future growth in global markets for ethylene is expected to be sufficient to absorb all likely production of FT naphtha over the next 15 years.

FT Jet Fuel: Currently up to 49\% FT-derived material can be blended in jet fuel (with lubricity additives required) and these blends are currently being used in some non-US locations. Although FT jet fuel has a number of superior qualities relative to conventional jet fuel, specifically low sulfur and low freeze point, there are no active regulatory initiatives being considered that will require these properties. As a result, FT derived jet fuel does not command a price premium when blended into jet fuel, and this is expected to remain the situation in the foreseeable future. 
Methanol as a transportation fuel. Two transport market options for methanol were examined; as a fuel in conventional internal combustion engines and to power fuel cells. Methanol is not economic for the first option, primarily due to its low energy density. It is estimated that methanol price would have to decline by about one-third in order to match the equivalent price of motor gasoline in the United States. None of the existing methanol plants in the industrialized world would be viable at this price. There are also potential health/toxicity issues with methanol that need to be addressed. Methanol does appear to have technical promise as a fuel for fuel cells. However, fuel cell technology is too immature to achieve performance required for significant commercialization within the next 15 years.

Significant distribution infrastructure investments will be required for methanol to capture an appreciable share of transportation fuel markets. While this study has defined scenarios in which these costs would be manageable, the overall financial incentive for consumers to purchase methanol fuel cell vehicles under the most optimistic assumptions appear to be insufficient to conclude that methanol will achieve a significant transportation fuel market in the United States over the next fifteen years.

Gas-to-Liquid (GTL) production economics were examined for a speculative new state-of-theart facility operating in a Middle Eastern location. Assuming a capacity of 75,000 barrels per day (bpd) and a gas price of $\$ 1.00$ per million BTU, and based on Nexant's medium crude oil price outlook, in 2006 this plant would generate simple returns on investment (ROI) of 1.2, 2.3, and 7.9 percent to supply the USGC, West European, and Japanese markets, respectively.

The same analysis was performed for 2015, but adjusted to reflect speculative improvements in GTL technology and costs. Based on a 150,000 bpd facility and assuming $\$ 1.25$ per million BTU gas cost, this plant in 2015 would generate simple returns on investment of 12.2, 14.5, and 22.8 percent for supplying product to the USGC, West European, and Japanese markets respectively. The conclusion of the economic and market analysis for a Middle East-based project indicates that the most attractive target market will be in Asia.

GTL production economics for the speculative Middle East plant were compared to a USGC conventional coking refinery. For 2006, GTL economics were found to be roughly competitive to conventional refining, with both operations only covering cash costs of production, and neither generating any return on investment. By 2015, forecast improvements in the cost base of GTL technology (improvements in capital costs as well as operating efficiency are anticipated) resulted in superior economics for the GTL operation relative to conventional refining, with the GTL plant achieving about 15 percent ROI, while the conventional refinery remained at breakeven relative to cash costs.

Methanol production economics were examined for a speculative state-of-the-art facility operating in a Middle Eastern location. Assuming a capacity of 5,000 metric tons per day and a gas price of $\$ 1.00$ per million BTU, this plant in 2006 would generate a simple return on investment of about 26.0 percent based on supplying the United States market. This high rate of 
return reflects the very large size of this facility, as well as the assumed high efficiency of this plant.

The same analysis was performed for 2015, but adjusted to reflect speculative improvements in methanol technology and costs. Based on a very large 15,000 metric ton per day facility and assuming \$1.25 per million BTU gas cost, this plant in 2015 would generate a very attractive simple return on investment of about 40 percent for supplying product to the United States market. Similar to 2006, this very attractive level of profitability reflects the very large plant size (currently not commercial) as well as forecast improvements in plant efficiency.

Comparison of GTL versus methanol production economics indicates that in general, the expected ROI for methanol will be higher than that of GTL facilities. However, it should be noted that the very high profitability of methanol developed for this study should be considered to be of a somewhat lesser level of confidence than that for GTL, since the size and associated capital costs for the very large methanol facilities modelled have not been commercially demonstrated. In addition, as noted above, the market potential for methanol as a transportation fuel in the United States is expected to be relatively limited over the next 15 years. Thus, even if the forecast economics for methanol are realized, the required market to support such a large new supply source is not expected to be in place. 
The primary members of Nexant's Market Study project team were:

- Sam Tam, Study Executive

- Bruce Burke - Study Manager

- John Boepple - PIMS analysis, Global Fuels Markets

- Ronald Cascone - UCF in End-use Industries

- Luann Farrell, Ethylene Markets

- King Ng, PIMS analysis

- Binh Nguyen, PIMS analysis

- Alan Nizamoff - Technology analysis, Ethylene, HDS, H2

- Larry Song - Technology analysis, GTL, Methanol, Ethanol

- William Tittle - Methanol Chemical Markets, Methanol Infrastructure 
The objective of this Market Study was to assess the potential markets through 2015 for selected ultra clean fuels (UCFs, defined as FT diesel, FT naphtha and methanol) as transportation fuels. Coverage was global, with primary focus on the United States market.

Key activities were undertaken to meet this objective, and have been organized into the following nine Market Study Report Sections:

1. Conventional Fuels - Market Overview

2. Ethylene Industry Overview

3. Methanol Conventional Markets

4. United States Regional Fuel Markets

5. Technology Evaluation of Selected Alternative Fuels

6. Technical Issues for UCF Use in Transport

7. Methanol Distribution Infrastructure Issues

8. Impact of FT Diesel on U.S. Refineries

9. UCF Values and Market Potential 
Final Technical Report for Project Entitled "Evaluation of Ultra Clean Fuels from Natural Gas"

July 10, 2001 - November 30, 2005

Mahabubul Alam, Juhun Song, James Szybist, Ragini Acharya, Vince Zello, David Morris, Patrick Flynn, Stephen Kirby, Krishan Bhatia, Jeff Gonder, Yun Wang, Wenpeng Liu, Hua Meng, Subramani Velu, Jian-Ping Shen, Weidong Gu, Elise Bickford, Chunshan Song, Chao-Yang Wang, André Boehman

Report Issue Date:

December 2005

DOE Award Number: DE-FC26-01NT41098

The Pennsylvania State University

The Energy Institute University Park, PA 16802 


\section{Disclaimer}

This report was prepared as an account of work sponsored by an agency of the United States Government. Neither the United States Government nor any agency thereof, nor any of their employees, makes any warranty, express or implied, or assumes any legal liability or responsibility for the accuracy, completeness, or usefulness of any information, apparatus, product, or process disclosed, or represents that its use would not infringe privately owned rights. Reference herein to any specific commercial product, process, or service by trade name, trademark, manufacturer, or otherwise does not necessarily constitute or imply its endorsement, recommendation, or favoring by the United States Government or any agency thereof. The views and opinions of authors expressed herein do not necessarily state or reflect those of the United States Government or any agency thereof. 


\begin{abstract}
Through the National Energy Technology Laboratory's "Ultra Clean Fuels" program, ConocoPhillips has partnered with Nexant Inc., Cummins Engine Company and the Pennsylvania State University to study applications for and optimization of ultra clean fuels. Penn State University and Cummins Engine Company were tasked with the duty to perform "engine testing," under Task 3 of the Conoco-Phillips Ultra Clean Fuels project. One major task under this program is to evaluate the application of methanol production from natural gas in fuel cell systems, both those that directly utilize methanol and those that indirectly utilize methanol. This work covers both the performance of direct methanol fuel cells and hydrogen-fueled fuels cells running on reformed methanol, and the reforming of the methanol. This work has included experimental and numerical studies of the transport and electrocatalysis within the DMFC and IDMFC. The work has also included development of a tri-reforming process using commercial catalysts wherein simultaneous oxidative steam reforming and water gas shift reactions take place. Another major task under this program is to evaluate Fischer-Tropsch diesel fuel in a compression ignition engine with aftertreatment devices and in-cylinder instrumentation to optimize formulation, and thereby production, of the F-T diesel fuel. An outcome of these efforts will be demonstration of a fully optimized fuel-engine-exhaust aftertreatment system, with underlying scientific studies of the formulation and combustion. This work has included high-speed digital photography of the in-cylinder combustion process to compare spray flame structure and luminosity for operation on conventional diesel fuel, biodiesel blends, neat F-T diesel and F-T diesel fuel blends. The engine and exhaust system studies have included particulate and NOx controls to demonstrate compliance with the 2007 engine emissions standards.
\end{abstract}




\section{Table of Contents}

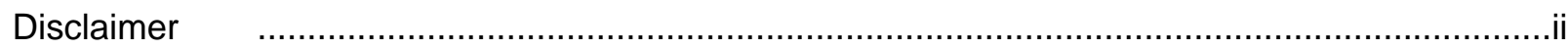

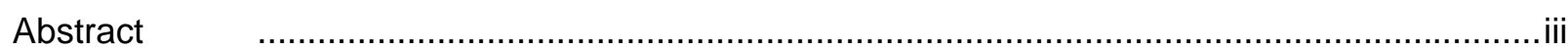

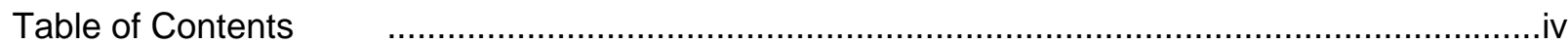

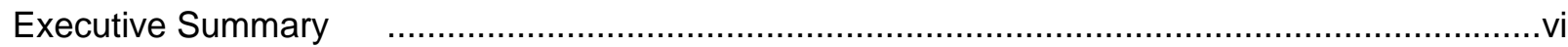

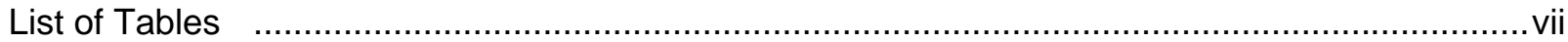

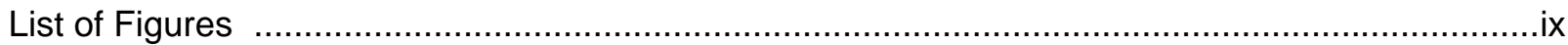

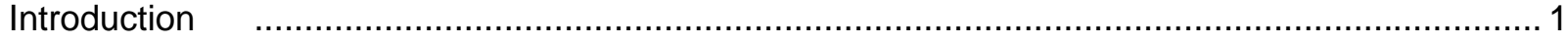

Subtask 3.1 - Database Compilation and Definition of Testing Needs ................................. 2

Subtask 3.1 .3 - Preliminary Fuel Property Analyses ..................................................... 3

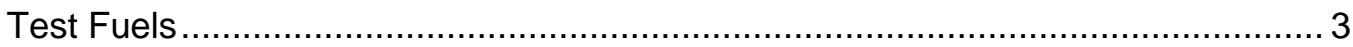

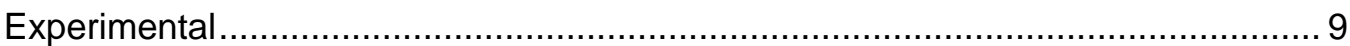

Relationship between Bulk Modulus and Injection Timing ............................... 11

Determination of Controlling Factors in NOx Formation via Combustion Analysis. 19

Premixed Ignition Behavior of Alternative Diesel Fuel-Relevant Compounds........ 27

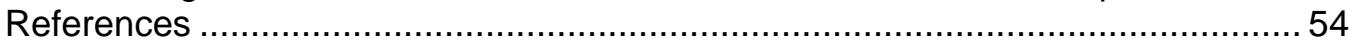

Subtask 3.2 - Indirect and Direct Methanol Fuel Cell testing .............................................. 56

Subtask 3.2.1- Methanol Fuel Cell Testing ................................................................... 56

Design and Construction of 15 W Fuel Cell Stack for Indirect Methanol............... 57

Formulation and Coding of a CFD Model for Interpretation of Experimental

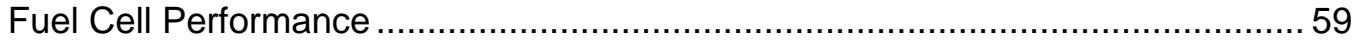

Study of Anode and Cathode Species as a Function of Operating

Conditions and Fuel Consumption................................................................... 105

Integration of Reformer and Fuel Cell Stack, Examination of System

Effects from Fuel Composition..................................................................... 120

Design and Construction of 15 W Fuel Cell Stack for Direct Methanol ................ 132

Formulation and Coding of a CFD Model for Interpretation of Experimental

Direct Methanol Fuel Cell Performance .................................................................. 134

Study of Anode and Cathode Species as a Function of Operating

Conditions and Fuel Composition for Direct Methanol fuel Cell .......................... 156

Comparison of direct and Indirect Methanol Fuel Cell Efficiency and

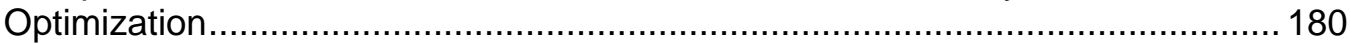

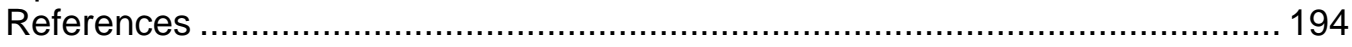

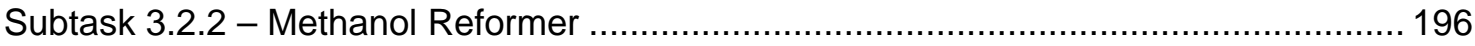

Catalyst Review and Selection for Screening, Configuration of Reactor

for Catalyst Studies.................................................................................... 197

Screening Experiments for Catalysts and Process Conditions ......................... 201

Catalyst selection and Configuration in a Prototype Reformer ...........................220

Comparison of Fixed-bed Catalyst and Monolith Catalyst Core

in a Prototype Reformer........................................................................... 224

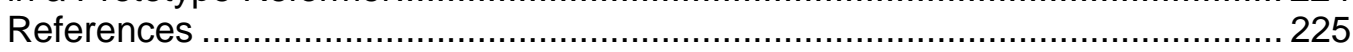

Subtask 3.3 - Compression Ignition Engine Studies.................................................. 226

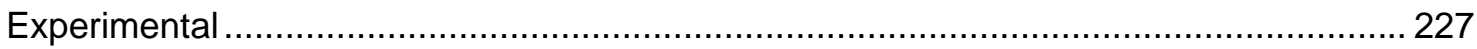

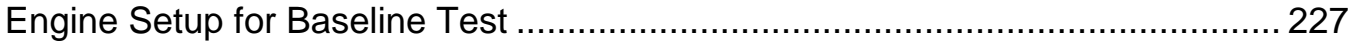




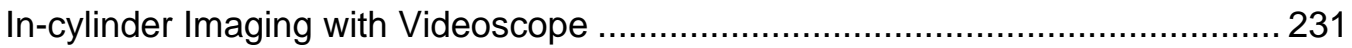

Diesel Particulate Filter ................................................................................. 235

Cold Flow Simulation of Urea Injector...................................................... 242

Experimental Setup for Engine Testing with Urea-SCR ............................... 246

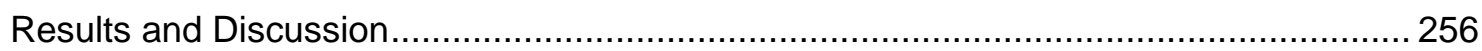

Engine Evaluation of Low Sulfur and Ultra Low Sulfur Diesel Fuel.................... 256

Spray and Combustion Visualization ............................................................. 269

Diesel Particulate Filter ............................................................................. 291

Impact of Alternative Fuels on Soot Properties and DPF Regeneration .............. 301

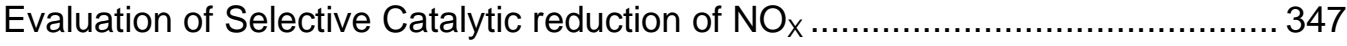

Evaluation of Performance and Emissions of GTL Diesel Fuel ......................... 382

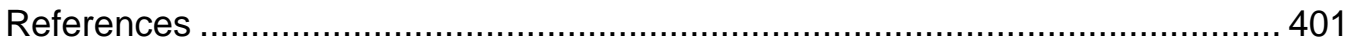

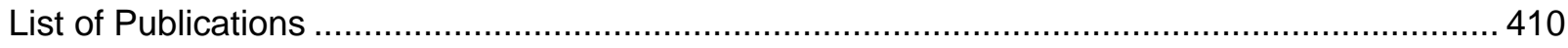

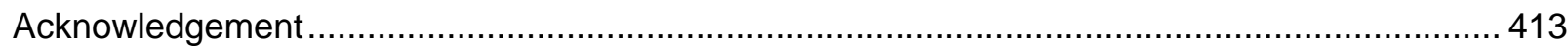




\section{Executive Summary}

Under the Conoco-Phillips - DOE Ultra Clean Fuels Project, Penn State University and Cummins Engine Company were tasked with the duty to perform "Engine Testing" activities under Task 3 of the program. The work performed under Task 3 was organized into three subtasks: Database Compilation and Definition of Testing Needs, which included supporting fuel property analyses and a comprehensive literature survey; Indirect and Direct Methanol Fuel Cell Testing, including IDMFC, DMFC and methanol reformer studies; and Compression Ignition Engine Studies.

The Database Compilation and Definition of Testing Needs task (Task 3.1) included a detailed literature review in several major subject areas including impacts of diesel fuel formulation, alternative diesel fuels (especially Fischer-Tropsch fuels), methanol reforming for fuel cell applications and the development of PEM fuel cell technologies. This literature review helped to guide the development of the research plans for Task 3.

Also under Task 3.1, fuel property characterization provided essential information on the differences in fuel injection behavior for fuels ranging from methyl esters to pure normal paraffins (e.g., spanning the range from biodiesel to Fischer-Tropsch diesel). The measurements helped to show that the chemical structure of a fuel substantially alters the injection timing and therefore the combustion phasing and emissions formation.

Under Task 3.2.1, indirect and direct methanol fuels cell experiments and simulation showed how $\mathrm{CO}$ generated in the reforming of methanol influences the operation and efficiency of an IDMFC and how cycling of the methanol federate can serve to enhance the efficiency of a DMFC. Key observations included the enhancement of the $\mathrm{CO}$ poisoning effect when dilute hydrogen (e.g., from a reformer) is fed to the IDMFC and the remediation of this poisoning effect when air bleed into the anode is used to oxidize $\mathrm{CO}$ from the catalyst.

Under Task 3.2.2, a novel "tri-reforming" approach based on commercially available catalyst formulation demonstrated an ability to produce reformate gas with between $50-60$ vol.\% hydrogen but less than 30 ppmv CO during methanol reforming. This highly effective methanol reformer strategy was incorporated into a reactor system that was connected to the IDMFC fuel cell experiment in Task 3.2.1. The combined reformer and fuel cell experiment for the IDMFC was compared against the DMFC and showed a much higher efficiency for the IDMFC and an efficiency of over $70 \%$ of that obtained with pure hydrogen. Together the outcomes from Task 3.2.1 and Task 3.2.2 demonstrated the practicality of combining a methanol reformer and PEM fuel cell.

Under Task 3.3, observations of injection, combustion, emissions formation and emissions control with fuels of substantially different formulation provided important insights into how to interpret the performance of a turbodiesel engine operated on different fuel formulations and how fuel formulation can impact the characteristics of the emissions. A key observation was that variations in the bulk modulus of compressibility between fuels leads to shifts in injection timing, shifts in combustion phasing and emissions formation. This observation has substantial significance for Fischer-Tropsch fuels, which possess substantially different bulk modulus than low or ultra low sulfur diesel fuels. Another key observation was that the nanostructure of diesel soot and the corresponding oxidative reactivity of diesel soot can shift significantly as fuel formulation changes. Biodiesel derived soots from a Cummins turbodiesel engine showed much less ordered structure in the primary soot particles in the case of B20 soot, a much different oxidation process for B100 soot and a greater rate of oxidation than for diesel and F-T diesel soot, which has significant implications for the regeneration of diesel particulate filters.

Finally, a number of journal articles and conference papers have been produced from the work performed under this Ultra Clean Fuels project. An invention conception record and two provisional patents were filed based on data obtained during the course of the project. 


\section{List of Tables}

\section{Subtask 3.1.3 - Preliminary Fuel Property Analyses}

Table 3.1.3.1 Fuel properties of low sulfur diesel BP-325 fuel 4

Table 3.1.3.2 Fuel properties of ultra low sulfur diesel BP-15 fuel 5

Table 3.1.3.3 Fuel properties of biodiesel blends $\quad 6$

$\begin{array}{ll}\text { Table 3.1.3.4 Properties of paraffinic distillate } & 7\end{array}$

Table 3.1.3.5 Properties of FT diesel fuel $\quad 8$

Table 3.1.3.6 Derived Cetane Number Results 21

Table 3.1.3.7 Fuel property information for FT diesel, BP325_light,

BP325_FBR, and BP325_heavy 30

Table 3.1.3.8 Comparison of methyl decanoate to common biodiesel components, data taken from Graboski and McCormick 30

Table 3.1.3.9 Derived Cetane Number (DCN) results for test fuels 30

Table 3.1.3.10 Reactions associated with LTHR, taken from Curran et al. 34

Table 3.1.3.11 Species identified during GC/MS analysis of n-heptane exhaust condensate $\quad 40$

Table 3.1.3.12 Species identified during GC/MS analysis of methyl decanoate exhaust condensate

\section{Subtask 3.2.1 Methanol Fuel Cell Testing}

Table 3.2.1.1 Geometrical and physical parameters for the $50 \mathrm{~cm}^{2}$ PEFC 73

Table 3.2.1.2 Source terms for the conservation equations in each region $\quad 74$

$\begin{array}{ll}\text { Table 3.2.1.3 Electrochemical properties } & 75\end{array}$

Table 3.2.1.4 Physical and transport properties $\quad 76$

Table 3.2.1.5 Geometrical parameters of the PEFC with single channel 77

Table 3.2.1.6 Constants used for solving kinetics model 111

Table 3.2.1.7 Reformer Specifications and Operating Conditions 122

Table 3.2.1.8 Terms in Governing Equations of DMFC Model 152

Table 3.2.1.9 Geometric Data and Operation Conditions 153

Table 3.2.1.10 Physical Properties $\quad 154$

Table 3.2.1.11 Electrochemical Properties $\quad 155$

Table 3.2.1.12 Current density (i) ranges for transient performance testing, 167 and the resulting steady state voltage levels. Operating conditions: Temperature $=75 \mathrm{C}$; Air stoichiometry $=20$ at $100 \mathrm{~mA} / \mathrm{cm}^{2} ;$ Backpressure $=0$ psig; Indicated methanol concentration with constant flow rate $=14 \mathrm{~mL} / \mathrm{min}$

Table 3.2.1.13 Comparison of performance improvement for interrupted $1 \mathrm{M}$ methanol flow. Operating conditions: Temp $=75 \mathrm{C}$, Air stoich $=20$ at 100 $\mathrm{mA} / \mathrm{cm}^{2}$, Backpressure $=0$ psig. Reported rise values incorporate a diminished contribution of voltage spikes near the mass transport limited condition

Table 3.2.1.14 Cell characteristics at two operating points 168

Table 3.2.1.15 Operating Conditions for the DMFC and IDMFC 184

Table 3.2.1.16 Cost comparison for both systems various power levels 185 
Table 3.2.1.17 System efficiency comparisons: Methanol to DC Electric

Power

Table 3.2.1.18 Vehicle specifications for IDMFC automobile

\section{Subtask 3.2.2 Methanol Reformer}

Table 3.2.2.1 Commercial catalysts used for methanol reforming 197

Table 3.2.2.2 Commercial Cu/Zn/Al catalysts and their chemical and physical 201 properties

Table 3.2.2.3 Catalyst activity at different temperature $\left(180-275^{\circ} \mathrm{C}\right) \quad 206$

Table 3.2.2.4 Oxidative Steam Reforming of Methanol over C18HA Catalyst at 214 $230^{\circ} \mathrm{C}$

Table 3.2.2.5 Methanol conversion and $\mathrm{H}_{2}$, $\mathrm{CO}$ composition over integrated

222

\section{Subtask 3.3 Compression Ignition Engine Studies}

Table 3.3.1 Specifications of the test engine $\quad 228$

Table 3.3.2 AVL 8-Mode test protocol 229

Table 3.3.3 Comparison of urea and liquid n-butane 242

Table 3.3.4 Engine operating points for ramp test cycle $\quad 249$

Table 3.3.5 Properties of urea used in present work 253

Table 3.3.6 List of analyzers on AVL emissions bench 254

Table 3.3.7 List of methods for ammonia analysis $\quad 255$

Table 3.3.8 Calorific value of base and blended fuels 256

Table 3.3.9 Comparison of start of injection timing 258

Table 3.3.10 Sulfate mass contribution to the PM mass emissions 265

Table 3.3.11 Fuel properties of the base diesel and blended fuels 269

Table 3.3.12 Comparison of Emissions of all the Fuels 283

Table 3.3.13 Composition of particulates measured. (a) Soxhlet extraction and 298 gravimetrics (b) Thermal Carbon Analyzer

Table 3.3.14 Comparison of kinetic parameters for all soot samples 310

Table 3.3.15 Prediction of graphene layer size (La) 323

Table 3.3.16 Calculation of surface area based oxidation rate 328

Table 3.3.17 PM composition via Soxhlet extraction 330

Table 3.3.18 Summary of diameter change as a function of wt\% burn off 345

Table 3.3.19 Reduction efficiency of available $\mathrm{NO}_{x}$ reduction technologies 351

Table 3.3.20 Catalyst formulations of lean $\mathrm{NO}_{x}$ catalysts 352

Table 3.3.21 Performance of different catalyst materials 353

Table 3.3.22 Specification of aqueous urea for SCR applications 358

Table 3.3.23 Calorific value and other properties of base, FT100 and blended 382 fuels

Table 3.3.24 Comparison of start of injection timing 


\section{List of Figures}

\section{Subtask 3.1.3 - Preliminary Fuel Property Analyses}

Figure 3.1.3.1 Measured fuel injection timing for biodiesel blends in conventional diesel fuel shown as relative spray intensity as a function of crank angle position relative to TDC. (ম) Baseline diesel fuel, ( $\square$ ) B20, (O) B100, ( ) 16vol.\% Soy oil in diesel fuel

Figure 3.1.3.2 Measured bulk modulus of $(\square)$ Soy oil, (@) Biodiesel, B100, (A) 20\% biodiesel blend in BP15 diesel fuel, B20, ( $\boldsymbol{\nabla}$ ) BP15 diesel fuel and $(\bigcirc)$ Fischer-Tropsch diesel and ( $\boldsymbol{\square})$ Norpar-13 as a function of pressure

Figure 3.1.3.3 Measured fuel injection timing for paraffinic fuels versus conventional diesel fuel shown as relative spray intensity as a function of crank angle position relative to TDC. (A) $15 \mathrm{ppm}$ sulfur diesel fuel (BP15), ( $\square) 325$ ppm sulfur diesel fuel, and (O) Norpar-13

Figure 3.1.3.4 Needle lift and heat release versus crank angle for the "early" static injection timing at 25\% load and $3600 \mathrm{rpm}$, in a Yanmar L70 DI diesel engine. (-) BP15 ultra low sulfur diesel fuel, (--) B20 blend in BP15, (- $)$ Fischer-Tropsch diesel fuel, and (- - ) B20 blend in GTL diesel

Figure 3.1.3.5 Needle lift and heat release versus crank angle for the "late" static injection timing at 25\% load and $3600 \mathrm{rpm}$, in a Yanmar L70 DI diesel engine. (-) BP15 ultra low sulfur diesel fuel, (--) B20 blend in BP15, (Fischer-Tropsch diesel fuel, and (- - ) B20 blend in GTL diesel

Figure 3.1.3.6 NOx emissions versus fuel injection timing for the various test fuels, based on three settings of static injection timing, in a Yanmar L70 DI diesel engine. (O) BP15 ultra low sulfur diesel fuel, ( $\mathbf{\square})$ B20 blend in BP15, $(\times)$ Fischer-Tropsch diesel fuel, and $(\boldsymbol{\nabla})$ B20 blend in GTL diesel

Figure 3.1.3.7 NOx emissions for three injection timing settings at $25 \%$ load and $3600 \mathrm{rpm}$ for BP15 ultra low sulfur diesel fuel, a B20 blend in BP15, Fischer-Tropsch diesel fuel, and B20 blend in GTL diesel

Figure 3.1.3.8 CO emissions for three injection timing settings at $25 \%$ load and $3600 \mathrm{rpm}$ for BP15 ultra low sulfur diesel fuel, a B20 blend in BP15, Fischer-Tropsch diesel fuel, and B20 blend in GTL diesel

Figure 3.1.3.9 Brake specific fuel consumption for three injection timing settings at 25\% load and 3600 rpm for BP15 ultra low sulfur diesel fuel, a B20 blend in BP15, Fischer-Tropsch diesel fuel, and B20 blend in GTL diesel

Figure 3.1.3.10 Needle lift and heat release versus crank angle for the "early" static injection timing at 75\% load and $3600 \mathrm{rpm}$, in a Yanmar L70 DI diesel engine. (-) BP15 ultra low sulfur diesel fuel, (---) B20 blend in BP15, (Fischer-Tropsch diesel fuel, and (- - ) B20 blend in GTL diesel

Figure 3.1.3.11 Needle lift and heat release versus crank angle for the "late" static injection timing at 75\% load and $3600 \mathrm{rpm}$, in a Yanmar L70 DI diesel engine. (-) BP15 ultra low sulfur diesel fuel, (---) B20 blend in BP15, (- - ) Fischer-Tropsch diesel fuel, and (- - ) B20 blend in GTL diesel

Figure 3.1.3.12 NOx emissions for three injection timing settings at $75 \%$ load and $3600 \mathrm{rpm}$ for BP15 ultra low sulfur diesel fuel, a B20 blend in BP15, Fischer-Tropsch diesel fuel, and B20 blend in GTL diesel

Figure 3.1.3.13 $\mathrm{CO}$ emissions for three injection timing settings at $75 \%$ load and 3600 rpm for BP15 ultra low sulfur diesel fuel, a B20 blend in BP15, 
Fischer-Tropsch diesel fuel, and B20 blend in GTL diesel

Figure 3.1.3.14 Brake specific fuel consumption for three injection timing

settings at $75 \%$ load and 3600 rpm for BP15 ultra low sulfur diesel fuel, a B20

blend in BP15, Fischer-Tropsch diesel fuel, and B20 blend in GTL diesel

Figure 3.1.3.15 Bulk modulus as a function of pressure for (ㅁ) BP15, (•) B20,

( $\Delta$ ) B100, and $(\triangle) \mathrm{FT}$, and calculated values for $(\cdots \cdots) \mathrm{B} 40,(\cdots) \mathrm{FT} 20$, and (.....) FT40

Figure 3.1.3.16 Needle lift and fuel line pressure for mid fuel injection timing, high load (3600 RPM and 75\% maximum output)

Figure 3.1.3.17 Needle lift and fuel line pressure for mid fuel injection timing, high load (3600 RPM and 75\% maximum output)

Figure 3.1.3.18 Brake specific NOx emissions for (a) high load (3600 RPM and $75 \%$ maximum output) and (b) low load (3600 RPM and 25\% maximum

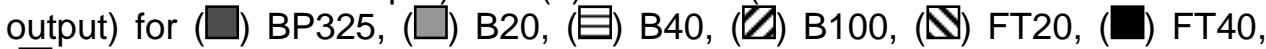
( $\square)$ FT100

Figure 3.1.3.19 NOx emissions as a function of maximum bulk cylinder temperature for (a) high load (3600 RPM and 75\% maximum output) and (b) low load (3600 RPM and 25\% maximum output) for ( ) BP325, (o) B20,

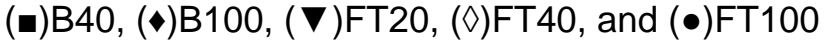

Figure 3.1.3.20 NOx emissions as a function of maximum heat release for (a) high load (3600 RPM and 75\% maximum output) and (b) low load (3600 RPM and 25\% maximum output) for ( ) BP325, (०) B20, (匹)B40, (॰)B100, $(\boldsymbol{\nabla})$ FT20, ( () FT40, and $(\bullet) F T 100$

Figure 3.1.3.21 NOx emissions as a function of the timing of maximum heat release rate at (a) high load (3600 RPM and 75\% maximum output) and (b) low load (3600 RPM and 25\% maximum output) for ( ) BP325, (o) B20,

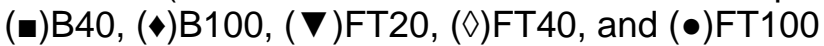

Figure 3.1.3.22 NOx emissions as a function of the timing of the maximum cylinder temperature for (a) high load (3600 RPM and 75\% maximum output) and (b) low load (3600 RPM and 25\% maximum output) for ( ) BP325, (o)

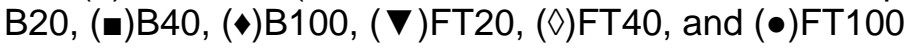

Figure 3.1.3.23 Schematic of modified intake manifold system for the octane rating engine

Figure 3.1.3.24 Gas chromatograms for (a) BP325_light, and (b) FT diesel

Figure 3.1.3.25 Ignition progression of FT fuel at $\Phi=0.75$ and an intake temperature of $260^{\circ} \mathrm{C}$ for compression ratios of (a) 4.47 , (b) 5.70 , (c) 6.52 , and (d) 7.04

Figure 3.1.3.26 LTHR as percent of the total heat release for $(\boldsymbol{\Delta}) \mathrm{n}$-heptane, $(\circ)$ BP325_light, $(\diamond)$ FT diesel, and ( $\bullet$ ) methyl decanoate

Figure 3.1.3.27 Heat release/temperature profiles and FTIR spectra for nheptane at $\Phi=0.25$ at an intake temperature of $110^{\circ} \mathrm{C}$ for compression ratios of (a) 4.47, (b) 6.62, and (c) 11.07

Figure 3.1.3.28 FTIR spectra for n-heptane at an intake temperature of $110^{\circ} \mathrm{C}$ and (a) $\Phi=0.25$ with no dilution, (b) $\Phi=0.5$ with no dilution, (c) $\Phi=0.75$ with $40 \%$ dilution, (d) $\Phi=1.0$ with $40 \%$ dilution, (e) $\Phi=1.25$ with $40 \%$ dilution, (f) $\Phi=1.5$ with $40 \%$ dilution, and $(\mathrm{g}) \Phi=2.0$ with $80 \%$ dilution for $(\boldsymbol{\Delta})$ carbon dioxide, $(\diamond)$ carbon monoxide, $(\circ)$ formaldehyde, and $(\mathbf{\square})$ acetaldehyde

Figure 3.1.3.29 GC for $\mathrm{n}$-heptane exhaust condensate at $\Phi=0.25$ and an intake temperature of $110^{\circ} \mathrm{C}$ for a compression ratio 6.16 
Figure 3.1.3.30 Mass spectra for (a) n-heptane exhaust condensate peak at a

retention time of 18 minutes, and (b) 2,5-hexanedione from NIST library

Figure 3.1.3.31 Low temperature reaction mechanism of $n$-heptane, taken from Curran et al.

Figure 3.1.3.32 Quantified FTIR spectra for iso-octane at an intake temperature of $230^{\circ} \mathrm{C}$ and (a) $\Phi=0.25$ with no dilution, (b) $\Phi=0.5$ with no dilution, (c) $\Phi=0.75$ with $70 \%$ dilution, (d) $\Phi=1.0$ with $70 \%$ dilution, (e) $\Phi=$ 1.25 with $70 \%$ dilution, and $(\mathrm{f}) \Phi=1.5$ with $70 \%$ dilution for $(\boldsymbol{\Delta})$ carbon dioxide, $(\diamond)$ carbon monoxide, $(\circ)$ formaldehyde, and $(\boldsymbol{\square})$ acetaldehyde

Figure 3.1.3.33. FTIR spectra for BP325_light at an intake temperature of $260^{\circ} \mathrm{C}$ and (a) $\Phi=0.25$ with no dilution, (b) $\Phi=0.5$ with no dilution, (c) $\Phi=$ 1.0 with $70 \%$ dilution, (d) $\Phi=1.25$ with $70 \%$ dilution, (e) $\Phi=1.5$ with $70 \%$ dilution, and (f) $\Phi=2.0$ with $70 \%$ dilution for $(\boldsymbol{\Delta})$ carbon dioxide, $(\diamond)$ carbon monoxide, (०) formaldehyde, and ( $\mathbf{\square})$ acetaldehyde

Figure 3.1.3.34. GC/MS analysis of BP325_light exhaust condensate for (a) aldehydes at $\mathrm{m} / \mathrm{z}=44$, (b) 2-ketones at $\mathrm{m} / \mathrm{z}=58$, and (c) organic acids at $\mathrm{m} / \mathrm{z}$ $=60$

Figure 3.1.3.35. FTIR spectra for FT diesel exhaust at an intake temperature of $260^{\circ} \mathrm{C}$ and (a) $\Phi=0.5$ with $45 \%$ dilution, (b) $\Phi=0.75$ with $45 \%$ dilution, (c) $\Phi=1.0$ with $100 \%$ dilution, (d) $\Phi=1.25$ with $100 \%$ dilution, (e) $\Phi=1.5$ with $100 \%$ dilution, and (f) $\Phi=2.0$ with $100 \%$ dilution for $(\boldsymbol{\Delta})$ carbon dioxide, $(\diamond)$ carbon monoxide, ( $(\circ)$ formaldehyde, and (घ) acetaldehyde

Figure 3.1.3.36. GC/MS analysis of FT diesel exhaust condensate for (a) aldehydes at $\mathrm{m} / \mathrm{z}=44$, (b) 2-ketones at $\mathrm{m} / \mathrm{z}=58$, and (c) organic acids at $\mathrm{m} / \mathrm{z}$ $=60$

Figure 3.1.3.37. Quantified FTIR spectra for methyl decanoate exhaust at an intake temperature of $230^{\circ} \mathrm{C}$ and (a) $\Phi=0.25$ with no dilution, (b) $\Phi=0.75$ with $100 \%$ dilution, (c) $\Phi=1.0$ with $100 \%$ dilution, (d) $\Phi=1.25$ with $100 \%$ dilution, (e) $\Phi=1.5$ with $100 \%$ dilution, and (f) $\Phi=2.0$ with $100 \%$ dilution for $(\boldsymbol{\Delta})$ carbon dioxide, $(\diamond)$ carbon monoxide, ( $\odot)$ formaldehyde, and (घ) acetaldehyde

Figure 3.1.3.38. GC/MS analysis of methyl decanoate exhaust condensate for (a) TIC, (b) unknowns at $\mathrm{m} / \mathrm{z}=85$, and (c) unknowns at $\mathrm{m} / \mathrm{z}=139$

\section{Subtask 3.2.1 Methanol Fuel Cell Testing}

Figure 3.2.1.1 Fuel cell flow plate

Figure 3.2.1.2 Experimental set-up

Figure 3.2.1.3 Fuel cell experimental

Figure 3.2.1.4 (a) - (d) Geometry, grids and top view of the computational domain of the double-path PEFC with thirty-six channels

Figure 3.2.1.5 Velocity distribution at the mid-depth of the cathode gas channel without convection in the GDL

Figure 3.2.1.6 Average $\mathrm{O}_{2} / \mathrm{H}_{2} \mathrm{O}$ concentrations in the cathode gas channel for each flow path without convection in the $\mathrm{GDL}$ at $\mathrm{V}_{\text {cell }}=0.65 \mathrm{~V}$ and $\mathrm{I}=0.91 \mathrm{~A} / \mathrm{cm}^{2}$

Figure 3.2.1.7 (a) $\mathrm{H}_{2} \mathrm{O}$, and (b) $\mathrm{O}_{2}$ distributions, respectively, in the cathode at the mid-length cross-section between $\mathrm{Ch} .1$ and $\mathrm{Ch}$. 2 without convection in the $G D L$ at $V_{\text {cell }}=0.65 \mathrm{~V}$ and $\mathrm{I}=0.91 \mathrm{~A} / \mathrm{cm}^{2}$

Figure 3.2.1.8 (a) $\mathrm{H}_{2} \mathrm{O}$, and (b) $\mathrm{O}_{2}$ distributions, respectively, in the cathode at 
the mid-length cross-section between $\mathrm{Ch} .5$ and $\mathrm{Ch} .6$ without convection in the $\mathrm{GDL}$ at $\mathrm{V}_{\text {cell }}=0.65 \mathrm{~V}$ and $\mathrm{I}=0.91 \mathrm{~A} / \mathrm{cm}^{2}$

Figure 3.2.1.9 (a) $\mathrm{H}_{2} \mathrm{O}$, and (b) $\mathrm{O}_{2}$ distributions, respectively, in the cathode at the mid-length cross-section between $\mathrm{Ch} .35$ and $\mathrm{Ch} .36$ without convection in the $\mathrm{GDL}$ at $\mathrm{V}_{\text {cell }}=0.65 \mathrm{~V}$ and $\mathrm{I}=0.91 \mathrm{~A} / \mathrm{cm}^{2}$

Figure 3.2.1.10 Water flux across surfaces of the cathode GDL at the midlength cross-section without convection in the GDL under $\mathrm{V}_{\text {cell }}=0.65 \mathrm{~V}$ and $\mathrm{I}=0.91 \mathrm{~A} / \mathrm{cm}^{2}$

Figure 3.2.1.11 Net water transport coefficient per proton at the mid-length cross-section without convection in the GDL at $\mathrm{V}_{\text {cell }}=0.65 \mathrm{~V}$ and $\mathrm{I}=0.91 \mathrm{~A} / \mathrm{cm}^{2}$

Figure 3.2.1.12 Pressure distribution in the cathode GDL and average velocity scaled by the cathode inlet velocity at the mid-length cross-section with convection in the GDL

Figure 3.2.1.13 (a) $\mathrm{H}_{2} \mathrm{O}$, and (b) $\mathrm{O}_{2}$ distributions and velocity in the cathode side at the mid-length cross-section between $\mathrm{Ch} .1$ and $\mathrm{Ch} .2$ with convection in the $\mathrm{GDL}$ at $\mathrm{V}_{\text {cell }}=0.65 \mathrm{~V}$ and $\mathrm{I}=0.88 \mathrm{~A} / \mathrm{cm}^{2}$

Figure 3.2.1.14 (a) $\mathrm{H}_{2} \mathrm{O}$, and (b) $\mathrm{O}_{2}$ distributions and velocity in the cathode side at the mid-length cross-section between $\mathrm{Ch} .5$ and $\mathrm{Ch} .6$ with convection in the $\mathrm{GDL}$ at $\mathrm{V}_{\text {cell }}=0.65 \mathrm{~V}$ and $\mathrm{I}=0.88 \mathrm{~A} / \mathrm{cm}^{2}$

Figure 3.2.1.15 Average $\mathrm{H}_{2} \mathrm{O} / \mathrm{O}_{2}$ concentrations in the cathode gas channel for each flow path with convection in the $G D L$ at $V_{\text {cell }}=0.65 \mathrm{~V}$ and $\mathrm{I}=0.88 \mathrm{~A} / \mathrm{cm}^{2}$

Figure 3.2.1.16 Water content profile at the interface of the membrane and cathode catalyst layer at the mid-length cross-section

Figure 3.2.1.17 Current density distribution profile at the mid-length crosssection

Figure 3.2.1.18 Current density contours for Case 1 at $V_{\text {cell }}=0.65 \mathrm{~V}$ and $\mathrm{I}=0.91 \mathrm{~A} / \mathrm{cm}^{2}$

Figure 3.2.1.19 Current density contours for Case 2 at $V_{\text {cell }}=0.65 \mathrm{~V}$ and $\mathrm{I}=0.88 \mathrm{~A} / \mathrm{cm}^{2}$

Figure 3.2.1.20 The details of computational domain and mesh of the singlechannel PEFC. Lines 1, 2 and 3 are three typical positions chosen to display detailed results

Figure 3.2.1.21 Dynamic responses of average current density to the step change of the cathode inlet humidification from $\mathrm{RH}=0 \%$ to $100 \%$, under 0.6 , 0.65 and $0.7 \mathrm{~V}$

Figure 3.2.1.22 The effective factor, $\varepsilon^{\text {eff }}$, in Eq. 3.2.1.17 in the middle of the membrane, under $0.65 \mathrm{~V}$ and $\mathrm{RHa} / \mathrm{c}=100 / 0 \%$

Figure 3.2.1.23 Evolution of water concentration profiles along Line $1\left(x, L_{y} / 2\right.$, $\mathrm{L}_{z} / 2$ ), when the cathode inlet humidification changes from $\mathrm{RH}=0 \%$ to $100 \%$ under $0.65 \mathrm{~V}$

Figure 3.2.1.24 Evolution of water content profiles along Line $3\left(L_{x} / 2, y, L_{z} / 2\right)$, when the cathode inlet humidification changes from $\mathrm{RH}=0 \%$ to $100 \%$ under $0.65 \mathrm{~V}$

Figure 3.2.1.25 Dynamic responses of average current density to the step change of the cathode inlet humidification from $\mathrm{RH}=100 \%$ to $0 \%$, under 0.6 , 0.65 and $0.7 \mathrm{~V}$

Figure 3.2.1.26 Evolution of water content profiles along Line $3\left(L_{x} / 2, y, L_{z} / 2\right)$, when the cathode inlet humidification changes from $\mathrm{RH}=100 \%$ to $0 \%$ under $0.65 \mathrm{~V}$ 
Figure 3.2.1.27 Evolution of water and oxygen concentration profiles along

Line $1\left(x, L_{y} / 2, L_{z} / 2\right)$, when the cathode inlet humidification changes from $\mathrm{RH}=100 \%$ to $0 \%$ under $0.65 \mathrm{~V}$

Figure 3.2.1.28 Dynamic responses of average current density to the step change of cell voltages from $0.6 \mathrm{~V}$ to $0.7 \mathrm{~V}$, under $\mathrm{RHa} / \mathrm{c}=100 / 100 \%$ and $100 / 0 \%$

Figure 3.2.1.29 Evolution of oxygen concentration profiles along Line 1 (x, $\left.\mathrm{L}_{y} / 2, \mathrm{~L}_{z} / 2\right)$ and Line $2\left(\mathrm{x}, \mathrm{L}_{\mathrm{y}} / 40, \mathrm{~L}_{\mathrm{z}} / 2\right)$, when cell voltages change from $0.6 \mathrm{~V}$ to $0.7 \mathrm{~V}$, under $\mathrm{RHa} / \mathrm{c}=100 / 100 \%$

Figure 3.2.1.30 Dynamic responses of average current density to the step change of cell voltages from $0.7 \mathrm{~V}$ to $0.6 \mathrm{~V}$, under $\mathrm{RHa} / \mathrm{c}=100 / 100 \%$ and 100/0\%

Figure 3.2.1.31 Cell performance map at $0.6 \mathrm{~V}$ versus cell pressure and cathode relative humidity, isometric view

Figure 3.2.1.32 Cell performance map at $0.6 \mathrm{~V}$ versus cell pressure and cathode relative humidity

Figure 3.2.1.33 Cell performance map at $0.4 \mathrm{~V}$ versus cell pressure and cathode relative humidity, isometric view

Figure 3.2.1.34 Cell performance map at $0.4 \mathrm{~V}$ versus cell pressure and cathode relative humidity

Figure 3.2.1.35 Diagram for analysis of cell exit relative humidity

Figure 3.2.1.36 Bulk cell exit relative humidity versus cathode inlet relative humidity

Figure 3.2.1.37 Steady state cell polarization for $100 \% \mathrm{H}_{2}$ and $40 \% \mathrm{H}_{2}$ anode fed gas

Figure 3.2.1.38 Cell polarization at various time steps (in minutes) throughout the poisoning process, with $100 \% \mathrm{H}_{2}, 10 \mathrm{ppm} \mathrm{CO}$ anode feed

Figure 3.2.1.39 Cell polarization at various time steps (in minutes) throughout the poisoning process, with $40 \% \mathrm{H}_{2}, 10 p p m \mathrm{CO}$ anode feed

Figure 3.2.1.40 Cell polarization at various time steps (in minutes) throughout the poisoning process, with $100 \% \mathrm{H}_{2}, 100 p p m \mathrm{CO}$ anode feed

Figure 3.2.1.41 Cell polarization at various time steps (in minutes) throughout the poisoning process with, $40 \% \mathrm{H}_{2}, 100 p p m \mathrm{CO}$ anode feed

Figure 3.2.1.42 Current at $0.6 \mathrm{~V}$ during the poisoning process vs. time for all four different anode feed gas compositions. The points represent actual experimental results, and the curves represent simulations based on the model developed

Figure 3.2.1.43 Current at $0.6 \mathrm{~V}$ during the recovery process vs. time

Figure 3.2.1.44 Computed normalized steady state current at 0.6V vs. CO various hydrogen dilution levels

Figure 3.2.1.46 Cell polarization curves at atmospheric pressure with different anode feed gases and $10 \%$ anode air injection

Figure 3.2.1.47 Cell polarization curves at 15 psig with different anode feed

Figure 3.2.1.48 Cell polarization curves at 30 psig with different anode feed gases and $10 \%$ anode air injection 
Figure 3.2.1.49 Cell polarization curves at 30 psig with 100ppm CO simulated

reformate gas feed and varying anode air injection levels

Figure 3.2.1.50 Cell power curves at 30 psig with 100ppm CO simulated reformate gas feed and varying anode air injection levels

Figure 3.2.1.51 Cell polarization curves at 30 psig with 600ppm CO simulated reformate gas feed and varying anode air injection levels

Figure 3.2.1.52 Cell power curves at 30 psig with 600ppm $\mathrm{CO}$ simulated reformate gas feed and varying anode air injection levels

Figure 3.2.1.53 Percent available current (as compared to a pure hydrogen feed) verses air injection levels for two different simulated reformate gas feeds Figure 3.2.1.54 Normalized current density at $0.6 \mathrm{~V}$ verses $\mathrm{CO}$ to $\mathrm{H}_{2}$ ratio for different air injection levels

Figure 3.2.1.55 Image of the integrated methanol reformer, fuel cell, and CO remediation system

Figure 3.2.1.56 Cell polarization curves for the reformer feed and reformer feed plus air injection as compared to a pure hydrogen feed at atmospheric pressure

Figure 3.2.1.57 Cell power curves for the reformer feed and reformer feed plus air injection as compared to a pure hydrogen feed at atmospheric pressure

Figure 3.2.1.58 Cell polarization curves for the reformer feed and reformer feed plus air injection as compared to a pure hydrogen feed at 15 psig

Figure 3.2.1.59 Cell power curves for the reformer feed and reformer feed plus air injection as compared to a pure hydrogen feed at 15 psig

Figure 3.2.1.60 Cell polarization curves for the reformer feed and reformer feed plus air injection as compared to a pure hydrogen feed at 30 psig

Figure 3.2.1.61 Cell power curves for the reformer feed and reformer feed plus air injection as compared to a pure hydrogen feed at 30 psig

Figure 3.2.1.62 Cell polarization curves, for the reformer feed plus air injection as compared to a pure hydrogen feed, at atmospheric pressure with varying levels of cathode relative humidity

Figure 3.2.1.63 Peak cell power, as compared to a pure hydrogen feed, verses cathode relative humidity. This was data was taken utilizing a reformer feed plus air injection

Figure 3.2.1.64 Continuous flow system schematic

Figure 3.2.1.65 System schematic for periodically injected anode feed

Figure 3.2.1.66 Schematic of methanol, water and carbon dioxide transports

Figure 3.2.1.67 Schematic of a two-dimensional simulation domain for the liquid-feed DMFC and shaded area stands for porous medium which is also numerical domain

Figure 3.2.1.68 Polarization curve of a liquid-feed DMFC at operating temperature of $25^{\circ} \mathrm{C}$, with different initial methanol feeding concentrations

Figure 3.2.1.69 Methanol concentration distribution in the anode backing and membrane of the DMFC at cell voltage of $0.1 \mathrm{~V}$ and initial methanol feeding concentration of $0.8 \mathrm{M}$

Figure 3.2.1.70 Current density distribution along the cell length for average cell current density of $0.44 \mathrm{~A} / \mathrm{cm}^{2}$, at cell voltage of $0.1 \mathrm{~V}$ and initial methanol 
Figure 3.2.1.71 Liquid water saturation distribution in the anode backing and cathode backing separately at cell voltage of $0.1 \mathrm{~V}$ and initial methanol feeding concentration of $0.8 \mathrm{M}$

Figure 3.2.1.72 Periodic methanol feeding leads to the average cell voltage promoted under the same current loading of $100 \mathrm{~mA} / \mathrm{cm}^{2}$

Figure 3.2.1.73 Cell voltage transient response under pulsing methanol feeding strategy using $\mathrm{M}^{2}$ transient model. Current density is kept constant at $0.1 \mathrm{~A} / \mathrm{cm}^{2}$ during the simulation

Figure 3.2.1.74 Parasitic current density due to the methanol crossover profile under the pulsing methanol feeding strategy. Current density is kept constant at $0.1 \mathrm{~A} / \mathrm{cm}^{2}$ during the simulation

Figure 3.2.1.75 Definition of transient response characteristics using an example where cell load is switched between constant 40 and $60 \mathrm{~mA} / \mathrm{cm}^{2}$ current draws. Operating conditions: Temperature $=75 \mathrm{C}$; Const air stoichiometry $=20$; Backpressure $=0$ psig; $1 \mathrm{M}$ methanol flow $=14 \mathrm{~mL} / \mathrm{min}$ (stoichiometry $=27$ at $100 \mathrm{~mA} / \mathrm{cm}^{2}$ )

Figure 3.2.1.76 Additional definitions of transient characteristics using the same example from Figure 3.2.1.75

Figure 3.2.1.77 Percent voltage under/overshoot for the transient conditions given in Table 3.2.1 12

Figure 3.2.1.78 Rise time comparison for the transient conditions given in Table 3.2.1.12

Figure 3.2.1.79 Peak time comparison for the transient conditions given in Table 3.2.1.12

Figure 3.2.1.80 Settling time comparison for the transient conditions given in Table 3.2.1.12

Figure 3.2.1.81 Magnified comparison of the settling time associated with the transient conditions given in Table 3.2.1.12

Figure 3.2.1.82 Voltage response to methanol flow shut-off

150

151

Figure 3.2.1.83 1-D model and governing methanol flux equations

Figure 3.2.1.84 Diffusion layer concentration profiles for (a) uniform step and (b) non-uniform step methanol pulsing

Figure 3.2.1.85 Problem formulation for determining transmission time of a step concentration disturbance. Figure used to indicate the (a) initial condition and (b)

Figure 3.2.1.86 Simulation objective: determine the time it takes for the catalyst layer concentrating to reach a selected limit. Methanol feed should be shut off after this time period in order to prevent the catalyst layer concentration from significantly exceeding this limit

Figure 3.2.1.87 Theoretical time response of catalyst layer concentration to a 10 M step impulse

Figure 3.2.1.88 Cell voltage under $100 \mathrm{~mA} / \mathrm{cm}^{2}$ loading. Periodic $2 \mathrm{M}$ fuel delivery (performed first): pause $\sim 2.1$ min between each $10 \mathrm{sec}, 1.2 \mathrm{ml}$ fuel injection. Periodic $4 \mathrm{M}$ fuel delivery (later testing days): pause $\sim 1.1 \mathrm{~min}$ between each $6 \mathrm{sec}, 0.7 \mathrm{ml}$ fuel injection. Peak SS performance measured before periodic injection testing. Degraded SS performance measured after several days of testing, and consistent with normal rate of degradation 
Figure 3.2.1.89 Cell voltage under $200 \mathrm{~mA} / \mathrm{cm}^{2}$ loading. Periodic $2 \mathrm{M}$ fuel delivery (performed first): pause $\sim 18 \mathrm{sec}$ between each $10 \mathrm{sec}, 1.2 \mathrm{ml}$ fuel injection. Periodic $4 \mathrm{M}$ fuel delivery (later testing days): pause $\sim 1.1 \mathrm{~min}$ between each $8 \mathrm{sec}, 1.0 \mathrm{ml}$ fuel injection. Peak SS performance measured before periodic injection testing. Degraded SS performance measured after several days of testing, and consistent with normal rate of degradation

Figure 3.2.1.90 Periodic 4 $\mathrm{M}$ fuel injection performance with a fresh membrane under $200 \mathrm{~mA} / \mathrm{cm}^{2}$ loading. Performance matches that of constant $1 \mathrm{M}$ methanol flow, allowing for a quadrupling of the fuel energy density

Figure 3.2.1.91 Fuel-grade methanol performance comparison. Durability test description: draw a constant $100 \mathrm{~mA} / \mathrm{cm}^{2}$ during full day test, interrupting for 15 min every two hours to take a polarization sweep. First and last polarization curve given for each full day. Data at $100 \mathrm{~mA} / \mathrm{cm}^{2}$ also given for first 40 min of the first M100 durability test and last 40 min of the last durability test

Figure 3.2.1.92 Accelerated lifetime test with chemical-grade methanol

Figure 3.2.1.93 Performance degradation rate comparison. Saw tooth lines give performance under $100-\mathrm{mA} / \mathrm{cm} 2$ loading

Figure 3.2.1.94 Durability testing with added contaminants. Added contaminant concentration to pure $\mathrm{M}-100$ for indicated tests: 2-butanone = $450 \mathrm{ppm}$; methylene chloride $=350 \mathrm{ppm}$; chloride $=5 \mathrm{ppm}$. Saw tooth lines give performance under $100-\mathrm{mA} / \mathrm{cm} 2$ loading

Figure 3.2.1.95 Polarization curve comparison from contaminant addition durability testing

Figure 3.2.1.96 Comparison of the cell polarization curves for the direct (DMFC) and indirect (IDMFC) fuel cell systems.

Figure 3.2.1.97 Comparison of the cell power density curves for the direct (DMFC) and indirect (IDMFC) fuel cell systems

Figure 3.2.1.98 Historic cost of platinum

Figure 3.2.1.99 Power Density and Efficiency (not including parasitic losses)

for the indirect methanol fuel cell system (IDMFC) across the entire polarization curve

Figure 3.2.1.100 Power Density and Efficiency (not including parasitic losses) for the direct methanol fuel cell system (DMFC) across the entire polarization curve

Figure 3.2.1.101 FTP-75 Driving Cycle

Figure 3.2.1.102 Vehicle power requirements during the FTP-75 driving cycle

Figure 3.2.1.103 Cell voltage during drive cycle $\quad 191$

Figure 3.2.1.104 Cell current density during drive cycle $\quad 192$

Figure 3.2.1.105 Instantaneous well-to-wheel efficiency during drive cycle 192

Figure 3.2.1.106 Cumulative well-to-wheel efficiency during drive cycle 193

Figure 3.2.1.107 Comparison of well-to-wheel efficiencies from various 193 studies

\section{Subtask 3.2.2 Methanol Reformer}

Figure 3.2.2.1 Effect of CO on PEMFC performance. [Springer et al., 2001]

Figure 3.2.2.2 Diagram of the current set-up necessary to remove CO from the feed gas in a hydrocarbon of alcohol-based fuel cell system 
Figure 3.2.2.3 Schematic of a fixed-bed reaction system

Figure 3.2.2.4 Reactor internal thermocouple, catalyst bed and borosilicate beads

Figure 3.2.2.5 SEM image of $\mathrm{CuO} / \mathrm{ZnO} / \mathrm{Al}_{2} \mathrm{O}_{3}$ (C18-7-01) catalyst particles before reduction or reaction

Figure 3.2.2.6 SEM image of unreduced, unreacted 0.5\% $\mathrm{Pt}_{\mathrm{Al}} \mathrm{O}_{2} \mathrm{O}_{3}$

205

Figure 3.2.2.7 Yield of $\mathrm{H}_{2}$ over Syntix 83-3 at different temperatures

206

Figure 3.2.2.8 Yield of $\mathrm{H}_{2}$ over Sud-Chemie C18-7-01 at different

207 temperatures

Figure 3.2.2.9 Yield of $\mathrm{H}_{2}$ over Sud-Chemie C18HALM at different temperatures

Figure 3.2.2.10 Yield of $\mathrm{H}_{2}$ over Sud-Chemie C18HA at different temperatures

Figure 3.2.2.11 Yield of $\mathrm{CO}_{2}$ over Syntix 83-3 at different temperatures

208

Figure 3.2.2.12 Yield of $\mathrm{CO}_{2}$ over Sud-Chemie C18-7-01 at different

Figure 3.2.2.13 Yield of $\mathrm{CO}_{2}$ over Sud-Chemie C18-HALM at different temperatures

Figure 3.2.2.14 Yield of $\mathrm{CO}_{2}$ over Sud-Chemie $\mathrm{C} 18 \mathrm{HA}$ at different temperatures

Figure 3.2.2.15 Yield of $\mathrm{CO}$ at $230^{\circ} \mathrm{C}$ over different commercial catalysts at $230^{\circ} \mathrm{C}$

Figure 3.2.2.16 Methanol conversion with different He carrier gas flow rate over C18HA at $210^{\circ} \mathrm{C}$

Figure 3.2.2.17 Methanol conversion with different He carrier gas flow rate over C18-7-01 at $210^{\circ} \mathrm{C}$

Figure 3.2.2.18 Methanol conversion with different feed flow rate over $\mathrm{C} 18 \mathrm{HA}$ at $210^{\circ} \mathrm{C}$

Figure 3.2.2.19 Comparison of conversion of methanol steam reforming over different catalysts at $230^{\circ} \mathrm{C}$ (WHSV $5.2 \mathrm{~h}^{-1}$, time on stream $2 \mathrm{~h}$ )

Figure 3.2.2.20 Comparison yield of $\mathrm{CO}$ of methanol reforming over different catalysts at $230^{\circ} \mathrm{C}$ (WHSV $5.2 \mathrm{~h}^{-1}$, time on stream $2 \mathrm{~h}$ )

Figure 3.2.2.21 TPR of $\mathrm{CuO} / \mathrm{ZnO} / \mathrm{Al}_{2} \mathrm{O}_{3}(\mathrm{C} 18-7-01)$ using $5 \% \mathrm{H}_{2}$ in $\mathrm{Ar}$

210

210

211

212

212

213

214

Figure 3.2.2.22 Effect of reaction temperature on CO conversion of 2000ppm over $\mathrm{CuO} / \mathrm{ZnO} / \mathrm{Al}_{2} \mathrm{O}_{3}$ catalyst, $\mathrm{SV}=12,000 \mathrm{~h}^{-1}$ at hour 4

Figure 3.2.2.23 Effects of water to $\mathrm{CO}$ ratio on CO conversion of 2000ppm, $\mathrm{T}=210^{\circ} \mathrm{C}, \mathrm{SV}=12,00 \mathrm{~h}^{-1}$ at $\mathrm{hr} 4$

Figure 3.2.2.24 Effects of dry space velocity on CO conversion of 2000ppm, $\mathrm{T}=210^{\circ} \mathrm{C}$ at hour 4

Figure 3.2.2.25 Ratio testing of (x)0.5\% $\mathrm{Pt} / \mathrm{Al}_{2} \mathrm{O}_{3}$ and $(100-\mathrm{x}) \mathrm{CuO} / \mathrm{ZnO} / \mathrm{Al}_{2} \mathrm{O}_{3}$ (C18-7-01), where $\mathrm{T}=210^{\circ} \mathrm{C}, \mathrm{SV}=12,000 \mathrm{~h}^{-1}$ at hour 4

Figure 3.2.2.26 Effect of $\mathrm{Pt} / \mathrm{Al}_{2} \mathrm{O}_{3}$ catalyst position in the bed of $10 \% \mathrm{Pt} / \mathrm{Al}_{2} \mathrm{O}_{3}$ $90 \% \mathrm{CuO} / \mathrm{ZnO} / \mathrm{Al}_{2} \mathrm{O}_{3}$ when converting 2000ppm of $\mathrm{CO}$ in the $\mathrm{O}_{2}+$ WGS reaction at $210^{\circ} \mathrm{C}$ and $\mathrm{SV}=12,00 \mathrm{~h}^{-1}$ at hour 4

Figure 3.2.2.27 Scheme of integrated methanol reformer

Figure 3.2.2.28 Comparison of the catalytic activity for oxidative steam methanol reforming at $230^{\circ} \mathrm{C}$

Figure 3.2.2.29 Comparison of $\mathrm{H}_{2}$ selectivity of oxidative steam reforming at $230^{\circ} \mathrm{C}$ 
Figure 3.2.2.30 Comparison of $\mathrm{CO}$ formation of oxidative steam reforming at $230^{\circ} \mathrm{C}$

\section{Subtask 3.3 Compression Ignition Engine Studies}

Figure 3.3.1 Schematic diagram of the experimental system for baseline testing

Figure 3.3.2 Piezoelectric cylinder pressure transducer

Figure 3.3.3 Hall-effect proximity sensor for measuring needle lift 228

Figure 3.3.4 Speed and load points for AVL 8-Mode test protocol 229

Figure 3.3.5 Performance of the test engine $\quad 230$

Figure 3.3.6 Schematic diagram of the experimental system 231

Figure 3.3.7 Endoscope and light source installed on the Cummins 5.9L test 232 engine

Figure 3.3.8 (a) 0, 30 and 70 degree glass windows (b) 0, 30 and 70 degree illumination tips (C) 0,30 and 60 degree endoscopes

232

Figure 3.3.9 Combustion chamber image through endoscope 233

Figure 3.3.10 Sketch of endoscope view angle 233

Figure 3.3.11 (a) Fresh window and illumination tip (b) soot deposition during 234 incylinder observation

Figure 3.3.12 External view of the diesel particulate filter used in this experiment

Figure 3.3.13 Close-up inside view of the catalyzed diesel particulate filter used in this study

Figure 3.3.14 Torque control for DPF system showing regeneration test cycles starting from 200 to $480{ }^{\circ} \mathrm{C}$

Figure 3.3.15 Air assisted atomizer performance shown as liquid flow rate (gph) versus air supply pressure (psia) for various liquid supply pressures

Figure 3.3.16 Air assisted atomizer performance at 8.5 psig liquid pressure

Figure 3.3.17 Schematic of cold flow simulation experimental setup

Figure 3.3.18 Air assisted atomizer fitting in the transparent pipe

Figure 3.3.19 Experimental details of cold flow simulation test

Figure 3.3.20 Thermocouple fitting [7]

Figure 3.3.21 Schematic of (a) experimental set up (b) urea-supply system

Figure 3.3.22 Experimental setup of the urea-SCR NO control system

Figure 3.3.23 Cummins ISB performance over ramp test cycle

Figure 3.3.24 (a) $\mathrm{NO}_{x}$ structure in AVL 8-Mode emissions test with BP15 fuel fuel

Figure 3.3.24 (d) $\mathrm{NO}_{\mathrm{x}}$ structure in AVL 8-Mode emissions test with B20-

Figure 3.3.26 Needle lift and rate of heat release at mode $2 \quad 257$

Figure 3.3.27 Needle lift and rate of heat release at mode $3 \quad 258$

Figure 3.3.28 Needle lift and rate of heat release at mode $6 \quad 259$

Figure 3.3.29 Needle lift and rate of heat release at mode $8 \quad 259$ 
Figure 3.3.30 Enlarged view of needle lift at mode 8

Figure 3.3.31 $\mathrm{NO}_{x}$ emissions per unit fuel consumed

Figure 3.3.32 Brake specific $\mathrm{NO}_{x}$ emissions $\quad 261$

Figure 3.3.33 HC emissions per unit fuel consumed 262

Figure 3.3.34 Brake specific HC emissions $\quad 262$

Figure 3.3.35 CO emissions per unit fuel consumed 263

Figure 3.3.36 Brake specific CO emissions 263

Figure 3.3.37 PM emissions per unit fuel consumed $\quad 264$

Figure 3.3.38 Brake-specific PM emissions $\quad 265$

Figure 3.3.39 Brake-specific SOF emissions 266

Figure 3.3.40 Weighted mode average emissions $\quad 267$

Figure 3.3.41 Start of injection with ultra low sulfur diesel and $20 \mathrm{wt} \%$ blends 271

with biodiesel (B-20) and diglyme (O-20)

Figure 3.3.42 End of injection with ultra low sulfur diesel and blends with 20

wt\% biodiesel (B-20) and diglyme (O-20)

Figure 3.3.43 Start of combustion with ultra low sulfur diesel fuel and blends with $20 \mathrm{wt} \%$ biodiesel (B-20) and diglyme (O-20)

Figure 3.3.44 Rate of heat release analysis with BP-15, B-20 and 0-20 test fuels

Figure 3.3.45 Combustion images from TDC to 20 deg ATDC of the combustion process with 2.0 CAD interval

Figure 3.3.46 Start of injection with ultra low sulfur diesel (BP-15), neat biodiesel and B-20 blend

Figure 3.3.47 End of injection with ultra low sulfur diesel (BP-15), neat biodiesel and B-20 blend

Figure 3.3.48 Rate of heat release analysis with BP-15, B-20 and B-100 test fuels

Figure 3.3.49 Start of combustion with ultra low sulfur diesel (BP-15), neat biodiesel and B-20 blend

Figure 3.3.50 Combustion images from TDC to $30 \mathrm{deg}$ ATDC of the combustion process with 3.0 CAD intervals

Figure 3.3.51 Start of injection with low sulfur diesel (BP-325), ultra low sulfur diesel (BP-15) and its blends with biodiesel

Figure 3.3.52 Spray penetration with low sulfur diesel (BP-325), ultra low sulfur diesel (BP-15) and biodiesel blends

Figure 3.3.53 End of injection with low sulfur diesel (BP-325), ultra low sulfur diesel (BP-15) and its blends with biodiesel

Figure 3.3.54 Rate of heat release analysis with BP-325, BP-15, B-20, B-40, B-60 and B-80 test fuels

Figure 3.3.55 Start of injection with low sulfur diesel (BP-325), ultra low sulfur diesel (BP-15), FT and its blends

Figure 3.3.56 Spray penetration with low sulfur diesel (BP-325), ultra low sulfur diesel (BP-15), FT and its blends

Figure 3.3.57 End of injection with low sulfur diesel (BP-325), ultra low sulfur diesel (BP-15), FT and its blends

Figure 3.3.58 Rate of heat release analysis with BP-325, BP-15, B-20, FT-20

273

274

275

276

277

277

278

278

280

281

282

283

285

286

287

BP15-80, FT-80 B-20 and FT-100 test fuels 
Figure 3.3.59 Combustion images from TDC to 30 deg ATDC of the combustion process with 3.0 CAD interval

Figure 3.3.60 Filter temperature versus slope of the pressure drop, indicating

the break even temperature for the various test fuels

Figure 3.3.61 Variation in outlet $\mathrm{NO}_{2}$ generated across the DPF during the filter regeneration process

Figure 3.3.62 Variation in outlet PM generated across the DPF during the filter regeneration process

Figure 3.3.63 Variation in regeneration rate during high temperature regeneration progress

Figure 3.3.64 Variation in $\mathrm{NO}_{2}$ produced during high temperature regeneration progress

Figure 3.3.65 (a) Mass reduction TGA curve of pretreated samples under 21\% oxygen; (b) DSC burning rate of pretreated samples under $21 \%$ oxygen. Treated sample is prepared by 30 minutes heating at $500{ }^{\circ} \mathrm{C}$ under inert argon.

Figure 3.3.66 HRTEM images of Diesel and its B20 soots at two different stages of oxidation

Figure 3.3.67 TEM images of diesel and its B20 soot at 105,000 magnification

Figure 3.3.68 (a) Variation in BET Temperature indicating $30{ }^{\circ} \mathrm{C}$ BET temperature decrease with $\mathrm{B} 100$ fuel relative to ULSD fuel, (b) Variation in DPF outlet $\mathrm{NO}_{2}$ indicating $30{ }^{\circ} \mathrm{C}$ shift of temperature where maximum $\mathrm{NO}_{2}$ is produced over DPF with B100 relative to ULSD fuel

Figure 3.3.69 (a) Variation in pressure drop based oxidation rate, (b) internal $\mathrm{NO}_{2}$ production over DPF during high temperature regeneration period

Figure 3.3.70 (a) DPF inlet temperature, (b) inlet NO concentration during high temperature regeneration period

Figure 3.3.71 Engine responses at particulate loading condition, (a) injection timing (b) heat release, (c) temperature and time history prior to regeneration period indicating a longer residence time at high temperature that B100 soot is exposed to than ULSD and FT

Figure 3.3.72 Mass based oxidation rate at isothermal conditions of (a) 500 , (c) 600 , (d) $700{ }^{\circ} \mathrm{C}$ after mildly pretreated under $500{ }^{\circ} \mathrm{C}$ of inert gas, (b) oxidation at the same $500{ }^{\circ} \mathrm{C}$ as (a) after severe pretreatment at $900{ }^{\circ} \mathrm{C}$; ULSD soot ( $\square)$, B20 soot( $($ ), B100 soot( $\triangle$ ), FT soot( $(\mathbf{\Delta})$

Figure 3.3.73 (a) Exponential curve fit (straight line) to raw curve (dotted line) at $500^{\circ} \mathrm{C}$, (b) Arrhenius plot of apparent rate constant of soot-air reaction, reduced from isothermal oxidation data measured at 3 different temperatures

Figure 3.3.74 Mass reduction TGA curve for soot samples obtained from various test fuels

Figure 3.3.75 HRTEM imaging between various soot samples (a) B100; (b) FT; (c) ULSD; (d) B20 soot, indicating no significant variation in initial nanostructure between B100, FT and ULSD soot while extremely amorphous arrangement of short range and defective layer for B20 soot

Figure 3.3.76 Micro-Raman Spectra for all samples of initial stage

Figure 3.3.77 002 peak of XRD indicating higher stacking order for both B100 and FT soot than ULSD and B20 soot

Figure 3.3.78 Comparison of (a) initial FT soot; (b) oxidized FT after 30 min 
outer periphery

Figure 3.3.79 Comparison of (a) initial B100 soot; (b) oxidized B100 after 30

min oxidation (40 wt\% burn off), indicating a drastic structural change in B100 soot

Figure 3.3.80 Defect band change of Raman Spectra indicating (a) only 5\% change for FT soot (b) a drastic change of $60 \%$ in inner structure for B100 soot

Figure 3.3.81 $\mathrm{I}_{\pi} / \mathrm{I}_{\sigma}$ peak ratio of EELS indicating graphitic peak absence in B100 oxidized soot (a) and its greater structure change than FT soot in (b)

Figure 3.3.82 Comparison of BF (phase contrast) in left and 002 DF image (diffraction contrast) in right (a) oxidized $\mathrm{FT}$ at $30 \mathrm{~min}$ of $500{ }^{\circ} \mathrm{C}$, (b) oxidized $\mathrm{B} 100$ at $30 \mathrm{~min}$ of $500{ }^{\circ} \mathrm{C}$, indicating much lesser bright spot in oxidized B100 soot associated with a greater structure change of B100 soot

Figure 3.3.83(a) Raman spectra after $30 \mathrm{~min}$ oxidized at $500{ }^{\circ} \mathrm{C}$, (b) Calculation of $\mathrm{I}_{\mathrm{d}} / \mathrm{lg}$ ratio, (c) correlation between rate constant and \%change to disorder, indicating soot that becomes easily disordered such as B100 soot is likely to enhance an oxidation

Figure 3.3.84 (a) Example of raw XRD profile for B20 soot at 3 different times of oxidation, multi-Lorentzian fits for (b) B20 soot, (c) B100 soot, (d) ULSD soot, (e) FT soot

Figure 3.3.85 (a) Calculation of crystallite size, indicating an increase of thickness (LC) in the direction normal to graphene layer during an early oxidation (b) correlation between rate constant and \% change of number of stacking order

Figure 3.3.86 Morphology and diameter change after 30min burn off, (a) B100 soot at initial, (b) B100 oxidized at $30 \mathrm{~min}$ of $500{ }^{\circ} \mathrm{C}$, (c) FT soot at initial, (d) FT oxidized at $30 \mathrm{~min}$ of $500{ }^{\circ} \mathrm{C}$

Figure 3.3.87 Size distributions for two extreme soot samples between initial and oxidation state (a) B100 soot at initial, Std: $\pm 0.29 \mathrm{~nm}$, (b) B100 oxidized at $30 \mathrm{~min}$ of $500{ }^{\circ} \mathrm{C}$, Std: $\pm 0.16 \mathrm{~nm}$, (c) FT soot at initial, Std: $\pm 0.24 \mathrm{~nm}$, (d) FT oxidized at $30 \mathrm{~min}$ of $500{ }^{\circ} \mathrm{C}$, Std: $\pm 0.29 \mathrm{~nm}$

Figure 3.3.88 Comparison of surface area based and mass based oxidation rate

Figure 3.3.89 (a) Variation in surface oxygen group of FTIR spectra indicating a higher presence of oxygen group in B100 soot rather than FT soot (b) Correlation between oxidation rate and ratio of two IR spectra peaks suggesting a difference in oxidation rate of soots with similar nanostructure (previously revealed) is from the difference in surface oxygen groups

Figure 3.3.91 TEM image(a) and its size distribution(b), HRTEM images at $500 \mathrm{k}(\mathrm{c})$, and $800 \mathrm{k}(\mathrm{d})$, Fringe length analysis(e,f) and diffraction pattern(g) at three different burn off stage of B100 soot, indicating a transition to internal burning and further coalescence at $75 \%$ burn off

Figure 3.3.92 (a) Raman spectra, (b) EELS spectra, supporting a presence of long and straight layer for B100 soot oxidized at 75\% burn off compared to $40 \%$ burnoff

Figure 3.3.93 Simplified oxidation progression model for B100 soot

Figure 3.3.94 TEM image(a) and its size distribution(b), HRTEM images at $500 \mathrm{k}(\mathrm{c})$, and $800 \mathrm{k}(\mathrm{d})$, Fringe length analysis(e,f) at three different burn off stages for FT soot

Figure 3.3.95 (a) Raman spectra, (b) EELS spectra, supporting a continuous 
tendency toward disordered state during an oxidation for FT soot

Figure 3.3.96 Simplified oxidation progression model for FT soot, indicating progressive shrinking core type oxidation with lesser indication of internal burning and layer rearrangement even up to 75\% burn off than B100 soot

Figure 3.3.97 Comparison of 002 diffraction contrast images taken at 230,000 magnifications indicating a prevalence of more hollow inside particle with B100 soot(a) compared to FT soot(b) at the same $75 \%$ burnoff

Figure 3.3.98 (a) Diameter change for two soot samples as function of burn off indicating a transition from surface burning to internal burning after $40 \mathrm{wt} \%$ burn off, (b) Oxygen content as function of burn off indicating higher oxygen at initial stage and more abrupt oxygen consumption after $40 \%$ burnoff in B100 soot

Figure 3.3.99 Surface area evolution during an oxidation for two soot samples, NIST represents soot sample with high volatile content, while NEUsoot has low volatile content, respectively

Figure 3.3.100 United States and European Union emissions regulations

Figure 3.3.101 Trends in $\mathrm{NO}_{\mathrm{x}}$ reduction technology

Figure 3.3.102 Typical zeolite structure

Figure 3.3.103 Layout of available $\mathrm{NO}_{\mathrm{x}}$ reduction technologies

Figure 3.3.104 $\mathrm{NO}_{\mathrm{x}}$ adsorber catalysts: Sorption period

Figure 3.3.105 $\mathrm{NO}_{\mathrm{x}}$ adsorber catalysts: Regeneration period

Figure 3.3.106 Section of NTP reactor

Figure 3.3.107 Physics of NTP reactor

Figure 3.3.108 Performance of hydrocarbon SCR with various hydrocarbons ( $5 \%$ Ag/Alumina/Sol-gel, catalyst mass $=1.00$ grams, Flow rate $=4,000 \mathrm{cc} / \mathrm{min}$, Ramp rate $=10^{\circ} \mathrm{C} / \mathrm{min}$ )

Figure 3.3.109 Operating temperature windows for different catalyst formulations

Figure 3.3.110 Cross sectional plane of pipe

Figure 3.3.111 Concentration distributions along the $x$-axis

Figure 3.3.112 Concentration distributions along the $y$-axis

Figure 3.3.113 Concentration distribution along $x$-axis at different butane flow rates

Figure 3.3.114 Baseline nitric oxide emissions (g/bhp-hr) over ramp cycle

Figure 3.3.115 Baseline nitrogen oxide emissions $\left(\mathrm{NO}_{\mathrm{x}}\right)$ over ramp cycle

Figure 3.3.116 Baseline nitrogen dioxide emissions (g/bhp-hr) over ramp cycle

Figure 3.3.117 Comparison of peak $\mathrm{NO}_{\mathrm{x}}$ reduction efficiency of catalyst with different fuels

Figure 3.3.118 $\mathrm{NO}_{\mathrm{x}}$ Reduction efficiency of catalyst at varying urea dosage for BP15 fuel

Figure 3.3.119 $\mathrm{NO}_{x}$ Reduction efficiency of catalyst at varying urea dosage for

Figure 3.3.120 $\mathrm{NO}_{x}$ reduction efficiency of catalyst at varying urea dosage for

Figure 3.3.121 $\mathrm{NO}_{\mathrm{x}}$ Reduction efficiency of catalyst at varying urea dosage for B20-BP325 fuel 
Figure 3.3.122 Ammonia slip as a function of catalyst temperature with varying urea dosage for $\mathrm{BP} 15$ fuel $\left(\mathrm{NH}_{3}\right.$ slip and $\mathrm{NO}_{x}$ inlet are in $\left.\mathrm{ppm}\right)$

Figure 3.3.123 Ammonia slip as a function of catalyst temperature with varying urea dosage for BP325 fuel $\left(\mathrm{NH}_{3}\right.$ slip and $\mathrm{NO}_{x}$ inlet are in ppm)

Figure 3.3.124 Ammonia slip as a function of catalyst temperature with

372 varying urea dosage for $\mathrm{B} 20-\mathrm{BP} 15$ fuel $\left(\mathrm{NH}_{3}\right.$ slip and $\mathrm{NO}_{x}$ inlet are in ppm)

Figure 3.3.125 Ammonia slip as a function of catalyst temperature with 373 varying urea dosage for $\mathrm{B} 20-\mathrm{BP} 325$ fuel $\left(\mathrm{NH}_{3}\right.$ slip and $\mathrm{NO}_{x}$ linlet are in $\left.\mathrm{ppm}\right)$

Figure 3.3.126 Ammonia consumption as a function of $\mathrm{NO}_{2}$ inlet for $\mathrm{BP} 15$ fuel

Figure 3.3.127 Ammonia consumption as a function of $\mathrm{NO}_{2}$ inlet for BP325 fuel $\left(\mathrm{NH}_{3}\right.$ consumed and $\mathrm{NO}_{x}$ consumed are in $\mathrm{ppm}$ )

Figure 3.3.128 Ammonia consumption as a function of $\mathrm{NO}_{2}$ inlet for $\mathrm{B} 20$ BP325 fuel

Figure 3.3.129 Ammonia consumption as a function of $\mathrm{NO}_{2}$ inlet for $\mathrm{B} 20$ BP325 fuel

Figure 3.3.130 Ammonia consumption as a function of $\mathrm{NO}_{2}$ inlet for $\mathrm{B} 20-\mathrm{BP} 15$ fuel

Figure 3.3.131 Comparison of $\% \mathrm{NO}_{2}$ conversion and \% $\mathrm{NO}$ conversion over $0.65 \mathrm{NH}_{3} / \mathrm{NO}_{\mathrm{x}}$ and $0.75 \mathrm{NH}_{3} / \mathrm{NO}_{\mathrm{x}}$ urea dosing rates for BP15 fuel

Figure 3.3.132 Comparison of $\% \mathrm{NO}_{2}$ conversion and \% $\mathrm{NO}$ conversion over $0.65 \mathrm{NH}_{3} / \mathrm{NO}_{\mathrm{x}}$ and $0.75 \mathrm{NH}_{3} / \mathrm{NO}_{\mathrm{x}}$ urea dosing rates for BP325 fuel

Figure 3.3.133 Comparison of $\mathrm{NH}_{3}$ consumption as a function of $\mathrm{NO}_{2}$ inlet for different urea dosing rates for BP15 fuel

Figure 3.3.134 Comparison of $\mathrm{NH}_{3}$ consumption as a function of $\mathrm{NO}_{2}$ inlet for different Urea dosing rates for BP325 fuel

Figure 3.3.135 Comparison of $\mathrm{NH}_{3}$ consumption as a function of $\mathrm{NO}_{2}$ inlet for different urea dosing rates for B20-BP15 fuel

Figure 3.3.136 FTIR spectra of SCR-out exhaust at $1400 \mathrm{rpm}$ and $380 \mathrm{lb}-\mathrm{ft}$ load for BP15 fuel at $\mathrm{NH}_{3} / \mathrm{NO}$ ratio 0.75

Figure 3.3.137 FTIR spectra of SCR-out exhaust at $1400 \mathrm{rpm}$ and $380 \mathrm{lb}-\mathrm{ft}$ load for BP15 fuel at $\mathrm{NH}_{3} / \mathrm{NO}$ ratio 0.75

Figure 3.3.138 FTIR spectra of SCR-out exhaust at $1400 \mathrm{rpm}$ and $380 \mathrm{lb}-\mathrm{ft}$ load for B20- BP15 fuel at $\mathrm{NH}_{3} / \mathrm{NO}$ ratio 0.75

Figure 3.3.139 FTIR spectra of SCR-out exhaust at $1400 \mathrm{rpm}$ and $380 \mathrm{lb}-\mathrm{ft}$ load for $\mathrm{B} 20-\mathrm{BP} 325$ fuel at $\mathrm{NH}_{3} / \mathrm{NO}$ ratio 0.75

Figure 3.3.140 Fuel consumption per unit time

Figure 3.3.141 Brake-specific fuel consumption

Figure 3.3.142 Injector needle lift at (a) M2, and (b) M4

Figure 3.3.143 Injector needle lift at (a) M5, and (b) M7

Figure 3.3.144 Enlarged injector needle lift at M4

Figure 3.3.145 Cylinder pressure time histories at M1 
Figure 3.3.147 Rate of heat release at (a) M2 and (b) M4 391

Figure 3.3.148 Rate of heat release at (a) M5 and (b) M7 392

Figure 3.3.149 Enlarge rate of heat release at M4 393

Figure 3.3.150 $\mathrm{NO}_{x}$ emissions per unit fuel consumed 394

Figure 3.3.151 Brake specific $\mathrm{NO}_{\mathrm{X}}$ emissions 394

Figure 3.3.152 HC emissions per unit fuel consumed 395

Figure 3.3.153 Brake specific HC emissions 395

Figure 3.3.154 CO emissions per unit fuel consumed 396

Figure 3.3.155 Brake specific CO emissions 396

Figure 3.3.156 PM emissions per unit fuel consumed 397

$\begin{array}{ll}\text { Figure 3.3.157 Brake-specific PM emissions } & 398\end{array}$

$\begin{array}{ll}\text { Figure 3.3.158 Brake-specific SOF emissions } & 398\end{array}$

Figure 3.3.159 Time history of pressure drop across the diesel particulate filter 399 and engine load during an attempted BET measurement with neat GTL diesel fuel, test failed due to engine stall during the load ramp 


\section{Introduction}

Large reserves of natural gas on the Alaskan North Slope, as well as many proven reserves worldwide, are currently stranded because the cost of development, transportation or conversion to transportable liquid products is too high to be economic. Therefore ConocoPhillips, a global and integrated energy company, plans to unleash the potential of stranded gas by coupling innovations in gas to syngas conversion and Fischer-Tropsch (F-T) synthesis for the production of high quality, environmentally superior F-T products. Converting natural gas into liquids will enable the economic development of stranded gas reserves. 


\section{Subtask 3.1 Database Compilation and Definition of Testing Needs}




\section{Subtask 3.1.3 - Preliminary Fuel Property Analyses}

\subsubsection{Test Fuels}

An ideal diesel fuel should flow at all relevant temperatures without plugging a fuel filter, even under cold conditions. It should be clean and free from foreign contaminants and separated wax. It should have suitable ignition characteristics and burn quietly during combustion within the engine cylinder. Exhaust emissions should be minimum and it should be as inexpensive as possible.

Tables 3.1.3.1 through 3.1.3.5 show properties of the fuels used in this study. Two base fuels including a low sulfur diesel fuel BP325 (Table 3.1.3.1) and US 2006 ultra low sulfur diesel fuel BP15 (Table 3.1.3.2). Table 3.1.3.3 shows properties of two $20 \mathrm{wt} \%$ blends of biodiesel with the base fuels, B20-BP325 and B20-BP15. A paraffinic distillate fuel (Table 3.1.3.4) and a Fisher Tropsch diesel fuel (Table 3.1.3.5) are also considered to compare their performance and emissions reduction potential with the base and blended fuels.

Appropriate fuel viscosity ensures satisfactory operation of the fuel injection equipment. A higher viscosity fuel tends to produce larger droplet diameters during spray atomization, which might have significant influence on the evaporation characteristics, resulting in changes in the combustion process. However, the viscosity of the present test fuels does not vary widely and the range is between $2.48 \mathrm{cSt}$ and $2.73 \mathrm{cSt}$.

Sometimes lubricity is referred to as the film strength of a liquid and viscosity is referred to as the resistance to flow of a liquid. Recent developments have shown that lubricity and viscosity are correlated, but this is dependent on the test procedure used to determine lubricity. If the fuel does not have sufficient lubrication quality, fuel injection pump failure can occur, because current technology pumps are designed to make use of the fuel to lubricate the precision moving parts.

In general, lower density fuel will produce lower power, increase fuel consumption, lengthen the fuel injection period, lower the heat release rate, decrease soot emissions, while higher density fuel will produce higher power but higher smoke emissions. Density is also well correlated with the bulk modulus of the fuel and is responsible for changes in injection timing. The higher the density, the earlier the start of injection event occurs. Therefore, density plays important role during the injection event and has a direct effect on the engine-out $\mathrm{NO}_{x}$ emissions. An early start of injection can cause higher $\mathrm{NO}_{x}$ emissions and the opposite happens when start of injection event is retarded. A higher density is observed with BP325 fuel compared to BP15 fuel. Density increases when biodiesel is blended with the base fuels. The lowest density is observed with the paraffinic distillate fuel, while the density of FT diesel fuel is around 3\% higher than the paraffinic distillate fuel. However, the density of FT is around 6\% lower than the base ultra low sulfur diesel fuel BP15. Similarly, many other fuel properties including cold flow properties, cetane number, flash point, volatility, and sulfur content and aromatic content are also important to satisfy performance and emissions requirements.

The two base fuels were tested several times to check the consistency and repeatability of their properties. Most of the properties of the two base diesel fuels differ, however the basic difference between the two base fuels is their sulfur content. The low sulfur diesel BP325 fuel contains around 325 wt. ppm of sulfur and ultra low sulfur diesel BP15 fuel has sulfur level of 15 wt. ppm. Blending biodiesel with the base fuels further reduces sulfur level. Around 2 wt. ppm of sulfur level is observed with paraffinic distillate fuel and FT diesel fuel. There is not much difference in aromatic content between the base fuels. Total as well as poly-aromatic content of the two base fuels are comparable. It was not possible to detect total aromatic content of the biodiesel blends due to the limitation of the test apparatus. Aromatic content of the paraffinic distillate fuel is below the detection limit.

A higher cetane number is observed with BP15 fuel compared to other base fuel BP325. An addition of biodiesel into the base fuels increases cetane number of the blends. Both the paraffinic distillate fuel and FT diesel fuel have cetane number higher than 74. This higher cetane number of 
Table 3.1.3.1 Fuel properties of low sulfur diesel BP-325 fuel

\begin{tabular}{|c|c|c|c|c|c|c|}
\hline Test & Unit & Method & $\begin{array}{c}\text { Manufacturer's } \\
\text { Data }\end{array}$ & $\begin{array}{l}1^{\text {st }} \text { set } \\
\text { SwRI }\end{array}$ & PennState & $\begin{array}{l}2^{\text {nd }} \text { set } \\
\text { SwRI }\end{array}$ \\
\hline Cetane Index (Calculated) & & ASTM D 976 & 47.3 & & & \\
\hline Cetane Number (Engine) & & ASTM D 613 & 46.8 & 48.4 & & 46.8 \\
\hline Corrosion, Cu Strip & & ASTM D 130 & $1 a$ & $1 a$ & & $1 a$ \\
\hline Distillation & & ASTM D 86 & & & & \\
\hline IBP & $\operatorname{deg} C$ & & 173.5 & 181 & & 180 \\
\hline T10 & $\operatorname{deg} C$ & & & 215.8 & & 205.6 \\
\hline T20 & $\operatorname{deg} C$ & & & 235.2 & & 214.8 \\
\hline T30 & $\operatorname{deg} C$ & & & 241 & & 222.2 \\
\hline T40 & $\operatorname{deg} C$ & & & 251 & & 249.8 \\
\hline T50 & $\operatorname{deg} C$ & & 257.9 & 260 & & 258.9 \\
\hline T60 & $\operatorname{deg} C$ & & & 269.2 & & 267.9 \\
\hline T70 & $\operatorname{deg} C$ & & & 279.1 & & 277.9 \\
\hline T80 & $\operatorname{deg} C$ & & & 291.1 & & 290.1 \\
\hline T90 & $\operatorname{deg} C$ & & & 308 & & 307.3 \\
\hline T95 & $\operatorname{deg} C$ & & & 323.4 & & 323.5 \\
\hline FBP & $\operatorname{deg} C$ & & 330.6 & 332.9 & & 330.5 \\
\hline \% Recovered & & & & 98.2 & & 97.9 \\
\hline \% Residue & & & & 1.2 & & 0.9 \\
\hline Density@60C & $\mathrm{Kg} / \mathrm{m} 3$ & ASTM D 4052 & 0.8324 & 0.8431 & & 0.8432 \\
\hline Carbon Residue & $\%$ & ASTM D 524 & 0.07 & & & \\
\hline Flash Point & $\operatorname{deg} C$ & ASTM D 93 & 63.5 & 63 & 70.975 & 64 \\
\hline Viscosity @ 40C & $\mathrm{cSt}$ & ASTM D 445 & 2.482 & 2.46 & 2.402 & 2.5 \\
\hline Pour Point & $\operatorname{deg} C$ & ASTM D 97 & -27 & -27 & & -27 \\
\hline Cloud Point & $\operatorname{deg} C$ & ASTM D 5773 & -20 & -20.3 & & -19 \\
\hline Sulfur, Total & PPM (wt) & ASTM D 2622 & 325 & 322 & & 322 \\
\hline Lubricity HFRR @ 60C & $\mathrm{mm}$ & ISO $12156-1$ & 0.425 & & & \\
\hline Lubricity (SLBOCLE) & gm & ASTM D6078 & & 4450 & & 4600 \\
\hline Aromatic Content PNA & mass $\%$ & ASTM D 5186-99 & & $23.1 / 5.25$ & & $22.8 / 4.8$ \\
\hline PAH Content, GC-SFC, Wt\% & wt $\%$ & & 8.29 & & & \\
\hline Lower Heating Value & BTU/lb & ASTM D3338 & & 18486 & & 18402 \\
\hline
\end{tabular}


Table 3.1.3.2 Fuel properties of ultra low sulfur diesel BP-15 fuel

\begin{tabular}{|c|c|c|c|c|c|c|c|c|}
\hline Test & Unit & Method & $\begin{array}{c}\text { Manufacturer's } \\
\text { Data }\end{array}$ & $\begin{array}{l}1^{\text {st }} \text { Sample set from } \\
\text { PennState to SwRI }\end{array}$ & $\begin{array}{l}\text { Sample } \\
\text { from BP to } \\
\text { SwRI }\end{array}$ & PennState & Conoco & $\begin{array}{l}2^{\text {nd }} \text { set } \\
\text { SwRI }\end{array}$ \\
\hline Cetane Index (Calculated) & & ASTM D 976 & 48.8 & & & & & \\
\hline Cetane Number (Engine) & & ASTM D 613 & 49.7 & 53.5 & & & & 50.5 \\
\hline Corrosion, Cu Strip & & ASTM D 130 & $1 \mathrm{a}$ & $1 \mathrm{a}$ & & & & $1 a$ \\
\hline Distillation & & ASTM D 86 & & & & & & \\
\hline IBP & $\operatorname{deg} C$ & & 165.7 & 170.5 & & & & 167.4 \\
\hline T10 & $\operatorname{deg} C$ & & & 203.8 & & & & 203.4 \\
\hline T20 & $\operatorname{deg} C$ & & & 220.4 & & & & 219.5 \\
\hline T30 & $\operatorname{deg} C$ & & & 235.6 & & & & 234.1 \\
\hline $\mathrm{T} 40$ & $\operatorname{deg} C$ & & & 248.6 & & & & 247.2 \\
\hline T50 & $\operatorname{deg} C$ & & 260.38 & 261.7 & & & & 2360.4 \\
\hline T60 & $\operatorname{deg} C$ & & & 275.4 & & & & 273.4 \\
\hline T70 & $\operatorname{deg} C$ & & & 289.6 & & & & 287.2 \\
\hline T80 & $\operatorname{deg} C$ & & & 205.3 & & & & 303.1 \\
\hline T90 & $\operatorname{deg} C$ & & & 325.6 & & & & 322.3 \\
\hline T95 & $\operatorname{deg} C$ & & & 342.7 & & & & 337.7 \\
\hline FBP & $\operatorname{deg} C$ & & 345.5 & 347.8 & & & & 347.7 \\
\hline \% Recovered & $\%$ & & & 97.2 & & & & 98.3 \\
\hline \% Residue & $\%$ & & & 1.4 & & & & 1.2 \\
\hline Density @ 60C & $\mathrm{Kg} / \mathrm{m} 3$ & ASTM D 4052 & 0.8374 & 0.837 & & & & 0.837 \\
\hline Carbon Residue & $\%$ & ASTM D 524 & 0.04 & & & & & \\
\hline Flash Point & $\operatorname{deg} C$ & ASTM D 93 & 63.8 & 62 & & 62.8 & & 63 \\
\hline Viscosity @ 40C & $\mathrm{cSt}$ & ASTM D 445 & 2.5 & 2.48 & & 2.492 & & 2.48 \\
\hline Pour Point & $\operatorname{deg} C$ & ASTM D 97 & -18 & -15 & & & & -33 \\
\hline Cloud Point & $\operatorname{deg} C$ & ASTM D 5773 & -12 & -12 & & & & -10 \\
\hline Sulfur, Total & PPM (wt) & ASTM D 2622 & $13^{1}$ & $17^{2}$ & & & & \\
\hline Sulfur, Total & PPM (wt) & ASTM D 5453 & & $16^{3}$ & $14.7^{4}$ & & $16.12 / 16.21^{9}$ & 15 \\
\hline Sulfur, Total & PPM (wt) & Antek & & & & $46.71^{5} / 21^{8}$ & & \\
\hline Lubricity HFRR & $\mathrm{mm}$ & ISO 12156-1 & & & & & & \\
\hline Lubricity, Boccle Pass/Fail & gm & ASTM D 6078 & $4200 / 4500^{7}$ & & & & & \\
\hline Lubricity (SLBOCLE) & gm & ASTM D 6078 & & $3800^{6}$ & & & & 3800 \\
\hline Aromatic Content PNA & mass $\%$ & ASTM D 5186-99 & & $21.2 / 3.54$ & & & & $20.4 / 5.2$ \\
\hline PAH Content, GC-SFC & wt $\%$ & & 6.9 & & & & & \\
\hline Lower Heating Value & $\mathrm{BTU} / \mathrm{lb}$ & ASTM D 3338 & & 18516 & & & & 18358 \\
\hline
\end{tabular}


Table 3.1.3.3 Fuel properties of biodiesel blends

\begin{tabular}{|c|c|c|c|c|}
\hline & Unit & Method & B20-BP15 & B20-BP325 \\
\hline $\begin{array}{l}\text { Cetane Index } \\
\text { (Calculated) }\end{array}$ & & ASTM D 976 & & \\
\hline $\begin{array}{l}\text { Cetane Number } \\
\text { (Engine) }\end{array}$ & & ASTM D 613 & 52.5 & 49.2 \\
\hline Corrosion, Cu Strip & & ASTM D 130 & $1 a$ & $1 a$ \\
\hline Distillation & & ASTM D 86 & & \\
\hline IBP & $\operatorname{deg} C$ & & 171.9 & 183.3 \\
\hline T10 & $\operatorname{deg} C$ & & 198 & 220.7 \\
\hline T20 & & & 209.8 & 236.5 \\
\hline T30 & & & 229.6 & 250.6 \\
\hline T40 & & & 248.4 & 262.7 \\
\hline T50 & $\operatorname{deg} C$ & & 265.6 & 274.8 \\
\hline T60 & & & 282 & 287.8 \\
\hline T70 & & & 279.9 & 301.5 \\
\hline T80 & & & 311.9 & 315.8 \\
\hline T90 & $\operatorname{deg} C$ & & 323.6 & 325.6 \\
\hline T95 & & & 334 & 336.6 \\
\hline FBP & $\operatorname{deg} C$ & & 342.9 & 342.7 \\
\hline \% Recovered & & & 97.8 & 98.7 \\
\hline \% Residue & & & 0.9 & 0.5 \\
\hline Density @ 60C & $\mathrm{Kg} / \mathrm{m} 3$ & ASTM D 4052 & 0.8464 & 0.851 \\
\hline Carbon Residue & $\%$ & ASTM D 524 & & \\
\hline Flash Point & $\operatorname{deg} C$ & ASTM D 93 & 66 & 68 \\
\hline Viscosity @ 40C & $\mathrm{cSt}$ & ASTM D 445 & 2.73 & 2.71 \\
\hline Pour Point & $\operatorname{deg} C$ & ASTM D 97 & -30 & -30 \\
\hline Cloud Point & $\operatorname{deg} C$ & ASTM D 5773 & -9 & -13 \\
\hline Sulfur, Total & PPM (wt) & ASTM D 2622 & 13 & 252 \\
\hline $\begin{array}{c}\text { Lubricity HFRR @ } \\
60 \mathrm{C}\end{array}$ & $\mathrm{mm}$ & ISO 12156-1 & & \\
\hline $\begin{array}{l}\text { Lubricity } \\
\text { (SLBOCLE) }\end{array}$ & $\mathrm{gm}$ & ASTM D6078 & 5850 & 6100 \\
\hline $\begin{array}{c}\text { Aromatic Content } \\
\text { PNA }\end{array}$ & mass $\%$ & ASTM D 5186-99 & $\mathrm{N} / \mathrm{A}$ & $N / A$ \\
\hline $\begin{array}{l}\text { PAH Content, GC- } \\
\text { SFC, Wt } \%\end{array}$ & wt $\%$ & & & \\
\hline $\begin{array}{c}\text { Lower Heating } \\
\text { Value }\end{array}$ & BTU/lb & ASTM D3338 & 18122 & 18101 \\
\hline
\end{tabular}


Table 3.1.3.4 Properties of paraffinic distillate

\begin{tabular}{|c|c|c|c|c|c|}
\hline Test & Unit & Method & $\begin{array}{c}\text { Manufacturer's } \\
\text { Data }\end{array}$ & SwRI & PennState \\
\hline $\begin{array}{l}\text { Cetane Index } \\
\text { (Calculated) }\end{array}$ & & ASTM D 976 & & & \\
\hline $\begin{array}{l}\text { Cetane Number } \\
\text { (Engine) }\end{array}$ & & ASTM D 613 & & $>76 *$ & \\
\hline $\begin{array}{c}\text { Corrosion, } \mathrm{Cu} \\
\text { Strip }\end{array}$ & & ASTM D 130 & & $1 a$ & \\
\hline Distillation & & ASTM D 86 & & & \\
\hline IBP & $\operatorname{deg} C$ & & & 2003 & \\
\hline T10 & $\operatorname{deg} C$ & & & 229.5 & \\
\hline T20 & & & & 241.8 & \\
\hline T30 & & & & 251.2 & \\
\hline $\mathrm{T} 40$ & & & & 258.3 & \\
\hline T50 & $\operatorname{deg} C$ & & & 264.9 & \\
\hline T60 & & & & 271.8 & \\
\hline T70 & & & & 278.9 & \\
\hline $\mathrm{T} 80$ & & & & 287.9 & \\
\hline T90 & $\operatorname{deg} C$ & & & 300.3 & \\
\hline T95 & & & & 311.8 & \\
\hline FBP & $\operatorname{deg} C$ & & & 319.7 & \\
\hline \% Recovered & & & & 97.9 & \\
\hline \% Residue & & & & 1.1 & \\
\hline Density @60C & $\mathrm{Kg} / \mathrm{m} 3$ & ASTM D 4052 & & 0.7734 & \\
\hline $\begin{array}{c}\text { API Gravity @ } \\
60 \mathrm{C}\end{array}$ & & ASTM D 1298 & & 51.4 & \\
\hline Carbon Residue & $\%$ & ASTM D 524 & & & \\
\hline Flash Point & $\operatorname{deg} C$ & ASTM D 93 & & 82 & 83.8 \\
\hline Viscosity @ 40C & $\mathrm{cSt}$ & ASTM D 445 & & 2.37 & 2.54 \\
\hline Pour Point & $\operatorname{deg} C$ & ASTM D 97 & & -2 & \\
\hline Cloud Point & $\operatorname{deg} C$ & ASTM D 5773 & & 3 & \\
\hline Sulfur, Total & wt $\%$ & ASTM D 5453 & & 0.0002 & \\
\hline $\begin{array}{c}\text { Lubricity HFRR } \\
@ \text { @ 60C }\end{array}$ & $\mathrm{mm}$ & ISO $12156-1$ & & & \\
\hline $\begin{array}{l}\text { Lubricity } \\
\text { (SLBOCLE) }\end{array}$ & gm & ASTM D6078 & & 3000 & \\
\hline $\begin{array}{c}\text { Aromatic } \\
\text { Content PNA }\end{array}$ & mass $\%$ & ASTM D 5186-99 & & $\begin{array}{c}\text { no } \\
\text { detection }\end{array}$ & \\
\hline $\begin{array}{l}\text { PAH Content, } \\
\text { GC-SFC, Wt } \%\end{array}$ & wt $\%$ & & & & \\
\hline $\begin{array}{c}\text { Lower Heating } \\
\text { Value }\end{array}$ & BTU/lb & ASTM D3338 & & 18968 & \\
\hline
\end{tabular}


Table 3.1.3.5 Properties of FT diesel fuel

\begin{tabular}{|c|c|c|c|c|}
\hline & Unit & Method & $\begin{array}{c}\text { GTL Diesel } \\
\text { Batch \#1 }\end{array}$ & $\begin{array}{c}\text { GTL Diesel } \\
\text { Batch \#2 }\end{array}$ \\
\hline $\begin{array}{l}\text { Cetane Number } \\
\text { (Engine) }\end{array}$ & & ASTM D 613 & 83.48 & 87 \\
\hline IQT & & & 87.1 & 80.1 \\
\hline Corrosion, Cu Strip & & ASTM D 130 & $1 a$ & $1 a$ \\
\hline Distillation & & ASTM D 86 & & \\
\hline IBP & $\operatorname{deg} F$ & & 398 & 342 \\
\hline T5 & $\operatorname{deg} \mathrm{F}$ & & 413 & 367 \\
\hline T10 & $\operatorname{deg} F$ & & 426 & 381 \\
\hline T50 & $\operatorname{deg} F$ & & 532 & 460 \\
\hline T90 & $\operatorname{deg} F$ & & 630 & 575 \\
\hline T95 & $\operatorname{deg} F$ & & 643 & 602 \\
\hline FBP & $\operatorname{deg} F$ & & 650 & 626 \\
\hline Distillation & & SimDist & & \\
\hline IBP & $\operatorname{deg} F$ & & 302 & 264 \\
\hline T5 & $\operatorname{deg} F$ & & 357 & 310 \\
\hline T10 & $\operatorname{deg} F$ & & 384 & 352 \\
\hline T50 & $\operatorname{deg} F$ & & 548 & 463 \\
\hline T90 & $\operatorname{deg} \mathrm{F}$ & & 676 & 628 \\
\hline T95 & $\operatorname{deg} F$ & & 695 & 654 \\
\hline FBP & $\operatorname{deg} F$ & & 727 & 754 \\
\hline Density & $\mathrm{Kg} / \mathrm{m} 3$ & ASTM D 4052 & 0.79 & 0.77 \\
\hline API Gravity & & ASTM D 287 & 47.2 & 53.8 \\
\hline Flash Point & $\operatorname{deg} F$ & ASTM D 93 & 166 & 138 \\
\hline Viscosity@ 40C & $\mathrm{cSt}$ & ASTM D 445 & 2.5 & 1.95 \\
\hline Pour Point & $\operatorname{deg} F$ & ASTM D 97 & 32 & 35 \\
\hline Cloud Point & $\operatorname{deg} F$ & ASTM D 2500 & 39 & 67 \\
\hline Sulfur & PPB & & $<20$ & $<20$ \\
\hline Lubricity HFRR @ 60C & $\mathrm{mm}$ & ISO 12156-1 & 327 & 650 \\
\hline
\end{tabular}


the synthetic fuels might show early start of combustion and lower premixed burn peak which in turn reduces $\mathrm{NO}_{x}$ emissions and possibly increases particulate matter emissions.

Cold flow properties of diesel fuel vary from region to region and reflect the local climate because of their influence on cloud point. Cetane number of the diesel fuel normally specifies the ignition quality, or the ease of ignition at the beginning of the combustion process. Power output, emissions and combustion noise are related to cetane number. Volatility is less directly related to power output compared to engine operation and emissions. Flash point is primarily related to the handling safety of the fuel. Variation in flash point may not influence engine performance, auto-ignition temperature or other combustion characteristics. Fuel sulfur and aromatic content have significant influence on exhaust emissions.

\subsubsection{Experimental}

Two different experimental systems were used in this subtask. The first is a system designed to measure the bulk modulus or viscosity of fluids at high pressure. The second is a highly instrumented engine test stand and with emissions measurement capabilities. The diesel fuels used in this study contain $15 \mathrm{ppm}$ sulfur and $325 \mathrm{ppm}$ sulfur and were obtained from BP (BP15 and BP 325), and biodiesel (B100) was obtained from World Energy Corporation. For example, BP15B20 is a 20 vol\% blend of B100 in BP15. The GTL diesel fuel in these tests is listed as GTL Fuel Batch\#1 in Table 3.1.3.5.

The fundamental principle of the bulk modulus measurements is that under a sufficiently high pressure, a reduction in liquid volume occurs. The bulk modulus is calculated using (1).

$$
B=\left(P-P_{o}\right) * V_{o} /\left(V_{o}-V\right)
$$

where $B$ is the bulk modulus, $P$ is the applied pressure, $V_{o}$ is the volume of the sample at atmospheric pressure, and $V$ is the volume of the sample at pressure $P$.

The technique used to measure the bulk modulus was developed by O'Brien [OBrien MS Thesis]. The sample is placed in a closed-bottom pycnometer, which is housed inside of a modified 21-R-30 Stainless Jerguson gage capable of handling pressures up to 4000 psi. The gage is equipped with quartz windows to allow for the observation of the sample height in the capillary of the pycnometer, which is etched with lines of a known height. The Jerguson gage is kept in a constant temperature bath $\left(100^{\circ} \mathrm{F}\right)$ to ensure that the measurement is isothermal. A compressed cylinder of helium is capable of directly providing pressures up to 1000 psi. For higher pressures a 4.5L Aminco hydrogenation bomb is filled with helium and oil is pumped into the bomb using a pneumatically driven positive displacement pump. The oil compresses the helium, thereby increasing the pressure applied to the sample.

For the emissions testing, a Yanmar L70 EE air-cooled, 4-stroke, single cylinder, DI diesel engine with a maximum power output of $7 \mathrm{hp}$ was operated at $75 \%$ load and 3600 RPM (operating mode 2 from the ISO 8178 G2 test). Cylinder pressure and fuel-line pressures were measured using Kistler piezoelectric pressure transducer models 6052B and 601B1, respectively. A Hall-effect proximity sensor, installed by Wolff Controls Corporation, was used to measure needle-lift in the injector. An AVL 364 shaft encoder installed on the engine crankshaft, along with a Keithley DAS 1800 data acquisition board enabled 0.1 CA degree resolutions of these signals. NOx emissions were measured using an Eco-Physics NOx analyzer integral in an AVL GEM 110 emissions bench.

To investigate autoignition behavior ignition and low temperature heat release (LTHR) studies of the test fuels in this program, a CFR octane rating engine was used to perform a series of motored engine experiments. The compression ratio of the octane rating engine was adjustable over a wide range, from 4.0 to 13.75. There are two factory speed settings for the octane rating engine: $600 \mathrm{rpm}$ for the research octane method and $900 \mathrm{rpm}$ for the 
motor octane method. All experiments in this study were performed at $900 \mathrm{rpm}$. The carbureted fueling system used for octane rating was replaced with a custom intake manifold designed to deliver a hot, premixed charge of fuel and air. Electric heaters provided intake temperatures of up to $260^{\circ} \mathrm{C}$. A fuel injector designed for a gasoline direct injection (GDI) fueling system was located in the intake system approximately $1 \mathrm{~m}$ upstream from the intake valve to allow for mixing of the fuel and air. The ASTM knock meter used for octane rating was replaced with a Kistler 6052B piezoelectric pressure transducer. Combustion analysis was performed from an average of 40 consecutive cycles using an in-house LabVIEW-based program that assumed a temperature dependency for the polytropic gas coefficient, and did not use a heat-loss correction. A shaft encoder allowed combustion analysis to be performed at $0.1 \mathrm{CA}$ resolution (3600 data points per revolution).

Primary reference fuel grade $n$-heptane and iso-octane, obtained from Chevron-Phillips Chemical Co., were used to benchmark the performance of the system because wellestablished autoignition mechanisms exist for these fuels $[4,18]$. The maximum operating temperature of the intake heaters, $260^{\circ} \mathrm{C}$, largely dictated the remainder of the fuels that could and could not be used. It was desirable to use fuels that were fully vaporized at the operating temperature of the intake system to minimize fuel droplets, because vaporization and mixing effects of droplets could potentially obscure autoignition effects. Since full boiling range (FBR) diesel fuel, FT diesel fuel, or biodiesel could not be used because they have final boiling points that can exceed $350^{\circ} \mathrm{C}$, it was necessary to use modified fuels or surrogates. A modified diesel fuel was prepared by vacuum-distilling a $325 \mathrm{ppm}$ sulfur diesel fuel from BP, referred to here as BP325, and using only the light fraction of the fuel (BP325_light) for the autoignition tests. A cut of FT diesel with a reduced final boiling point was obtained for this study. A methyl decanoate product (CE-1095 produced by Proctor \& Gamble Chemical Co.) which has a boiling point of $224^{\circ} \mathrm{C}$, was used as a biodiesel surrogate.

Using a heated sample line at $190^{\circ} \mathrm{C}$, exhaust gas was delivered from the CFR octane rating engine to a Nicolet FTIR with a $2 \mathrm{~m}$ gas cell at $140^{\circ} \mathrm{C}$ and 680 torr at a flow rate of 3 slpm for analysis. The spectra were quantified for carbon monoxide, carbon dioxide, formaldehyde, and acetaldehyde. In addition to FTIR analysis, an ice bath was used to condense a portion of the exhaust using a dry impinger method. The exhaust condensate formed a two-phase system, and the non-aqueous phase was extracted from the aqueous phase using methylene chloride for analysis. The solvent used for the extraction was subsequently evaporated under ultra-high purity nitrogen so that the sample could be weighed and re-blended in methylene chloride at the desired concentration. A Shimadzu GC/MS with a Restec XTi-5 column was used for analyzing the condensate, enabling many of the condensed species to be identified. This technique was designed for species identification, and not for quantification. Thus, the GC/MS response factors were not calibrated with different standards for each of the identified species, and no quantification was attempted.

Experiments were performed for each fuel at equivalence ratios $(\Phi)$ of $0.25,0.5,0.75$, 1.0, 1.25, 1.5, and 2.0. At each equivalence ratio considered, compression ratio started low and was then gradually increased in a stepwise manner to increase the extent of reaction. At sufficiently low compression ratios, depending on the fuel and intake temperature, no reactions occur. At slightly higher compression ratios conditions were sufficiently severe to initiate LTHR, but not HTHR. As the compression ratio increased further, both the LTHR and HTHR occurred. At $\Phi>0.5$, the temperature rise associated with LTHR accelerated the system into HTHR, even at low compression ratios. Thus, at $\Phi>0.5$, it was necessary to dilute the intake charge of fuel and air with nitrogen in order to isolate LTHR from HTHR. The dilution rate, as a percentage of the intake air and fuel charge, is reported when the FTIR results for each fuel are discussed in the Results and Discussion section. At each compression ratio set point, combustion analysis data and an FTIR spectrum were collected. 
Condensate samples were collected less often, but a minimum of three were collected during the compression ratio sweep for each fuel at each equivalence ratio.

As was stated earlier, it was desirable to fully vaporize the fuel in the intake manifold to minimize the effects of droplets during the combustion process. To do this, the operating temperature of the intake manifold changed depending on fuel composition. The boiling point of $\mathrm{n}$-heptane is $98^{\circ} \mathrm{C}$, so a marginally higher intake temperature of $110^{\circ} \mathrm{C}$ was used. Similarly, the boiling point of methyl decanoate is $224^{\circ} \mathrm{C}$, so a marginally higher boiling point of $230^{\circ} \mathrm{C}$ was used as the intake temperature. Both BP325_light and FT diesel are distillate fuels with T90 values of $245.9^{\circ} \mathrm{C}$ and $279.7^{\circ} \mathrm{C}$, respectively. Thus, both of these fuels were operated at the maximum intake operating temperature of $260^{\circ} \mathrm{C}$. Although iso-octane has a boiling point of only $100^{\circ} \mathrm{C}$, an intake charge temperature of $230^{\circ} \mathrm{C}$ had to be used in order to achieve ignition. Each fuel was operated at only one intake charge temperature which was not changed with equivalence ratio or compression ratio.

\subsubsection{Relationship between Bulk Modulus and Injection Timing}

Figures 3.1.3.1 and 3.1.3.2 show results from the measurements of injection timing and the bulk modulus of compressibility for diesel, Fischer-Tropsch and biofuel blends. If one takes the indication of 0.4 relative spray intensity as an indication of the start of fuel injection, Figure 3.1.3.1 indicates that there is a 0.2 to $0.3 \mathrm{CA}$ advance of fuel injection timing for the diesel-biodiesel (B20) and diesel - soy oil blends, while there is an advance of 1.0 CA with pure biodiesel (B100). Figures 3.1.3.2 and 3.1.3.3 show that the effect of paraffinic fuels is to retard the fuel injection timing. The injection timing is retarded for Norpar by $0.5 \mathrm{CA}$., which also has the lowest bulk modulus.

As shown in Figure 3.1.3.1, fuel injection timing advances of 0.3 crank angle (CA degrees) and 1 CA degree are observed in "pump-line-nozzle" configuration fuel systems, for B20 and B100 respectively. This injection timing advance in a purely mechanical fuel injection system may not be as likely in an electronically controlled fuel injection system.

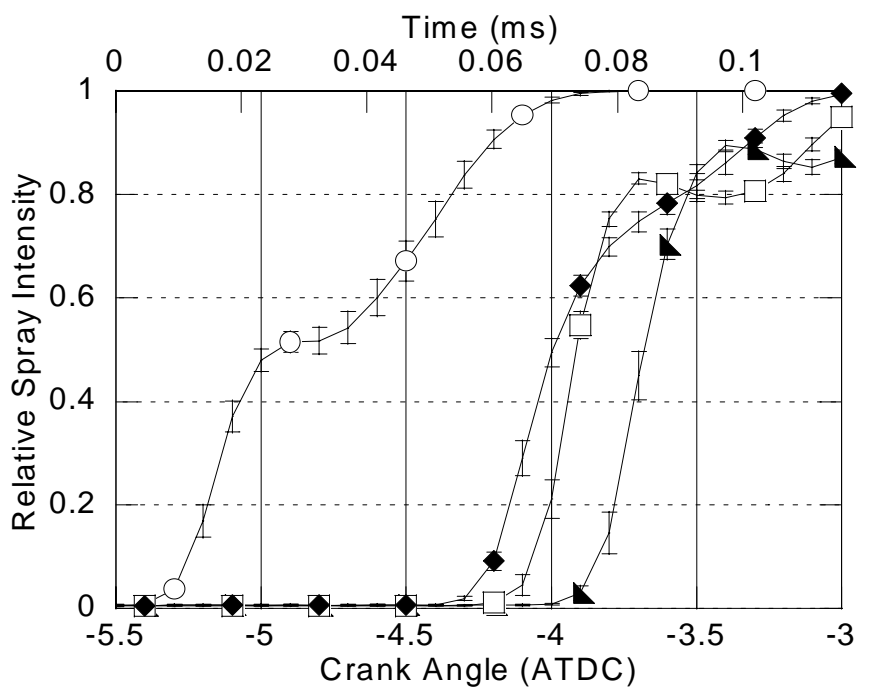

Figure 3.1.3.1 Measured fuel injection timing for biodiesel blends in conventional diesel fuel shown as relative spray intensity as a function of crank angle position relative to TDC. (-) Baseline diesel fuel, ( $\square$ ) B20, (O) B100, ( ) 16vol.\% Soy oil in diesel fuel. 
In Figures 3.1.3.1 and 3.1.3.3, light scattering caused the spray from the fuel injector is used to indicate the start of injection. In subsequent work, a cylinder pressure probe and a fuel injector with a needle lift sensor were installed in the Yanmar L70EE DI diesel engine. In Figures 3.1.3.4 - 3.1.3.5, needle lift and heat release measurements are shown for the three injection timing settings and the four test fuels. For the "early" injection timing shown in Figure 3.1.3.4, the injection of both of the B20 blends is advanced and the injection of both of the F-T fuels is retarded relative to the BP15 fuels. As seen in the heat release profiles, the start of combustion is advanced for the F-T fuels relative to the BP15 fuels, due to the high cetane number of the GTL diesel, despite the retarded injection timing for the F-T fuels. The heat release shows a significantly higher peak pressure for the BP15 fuels due to the longer ignition delay. For the "late" injection timing in Figure 3.1.3.5, the peak pressures for the BP15 fuels are lower and the start of combustion is delayed. The heat release profile shows evidence of degraded combustion for the conventional diesel fuels. However, despite the "late" injection timing and the additional retardation of injection of the F-T fuels, the heat release peak for the F-T fuels is still sharp.

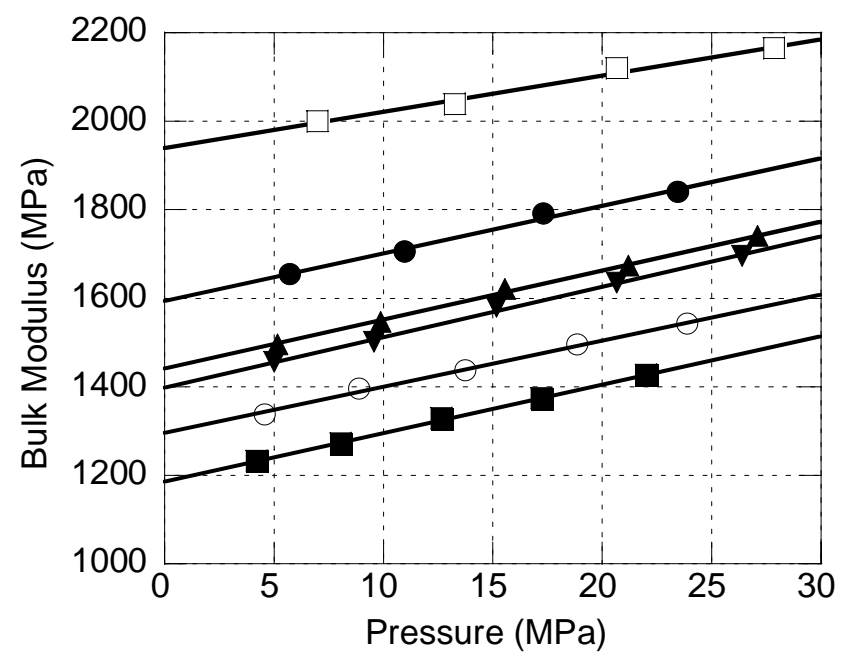

Figure 3.1.3.2 Measured bulk modulus of $(\square)$ Soy oil, (๑) Biodiesel, B100, (A) 20\% biodiesel blend in BP15 diesel fuel, B20, ( $\boldsymbol{\nabla}$ ) BP15 diesel fuel and (O) Fischer-Tropsch diesel and ( $\mathbf{\square})$ Norpar-13 as a function of pressure. 


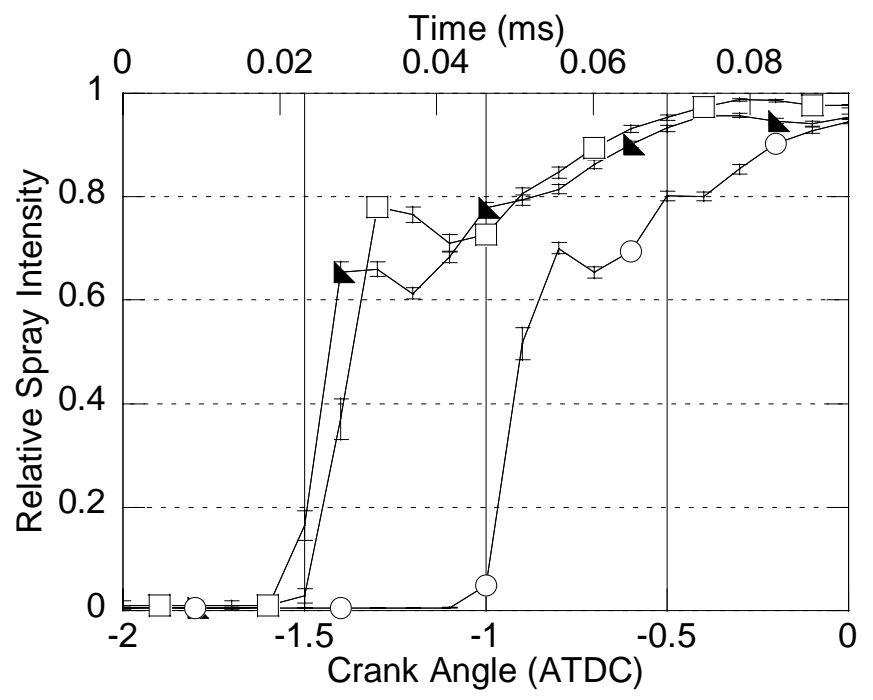

Figure 3.1.3.3 Measured fuel injection timing for paraffinic fuels versus conventional diesel fuel shown as relative spray intensity as a function of crank angle position relative to TDC. (A) 15 ppm sulfur diesel fuel (BP15), ( $\square) 325$ ppm sulfur diesel fuel, and (O) Norpar-13.

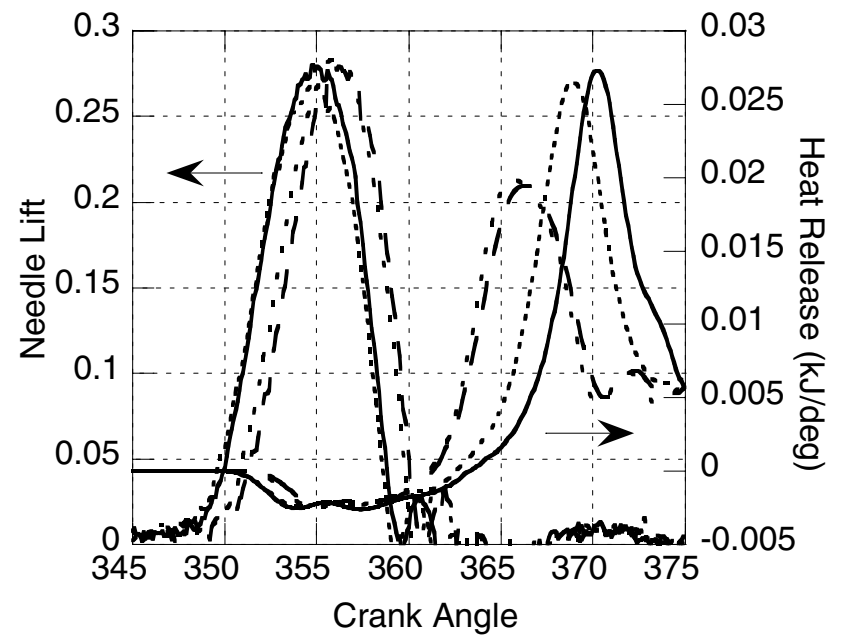

Figure 3.1.3.4 Needle lift and heat release versus crank angle for the "early" static injection timing at 25\% load and $3600 \mathrm{rpm}$, in a Yanmar L70 DI diesel engine. (-) BP15 ultra low sulfur diesel fuel, (--) B20 blend in BP15, (Fischer-Tropsch diesel fuel, and (- - ) B20 blend in GTL diesel. 


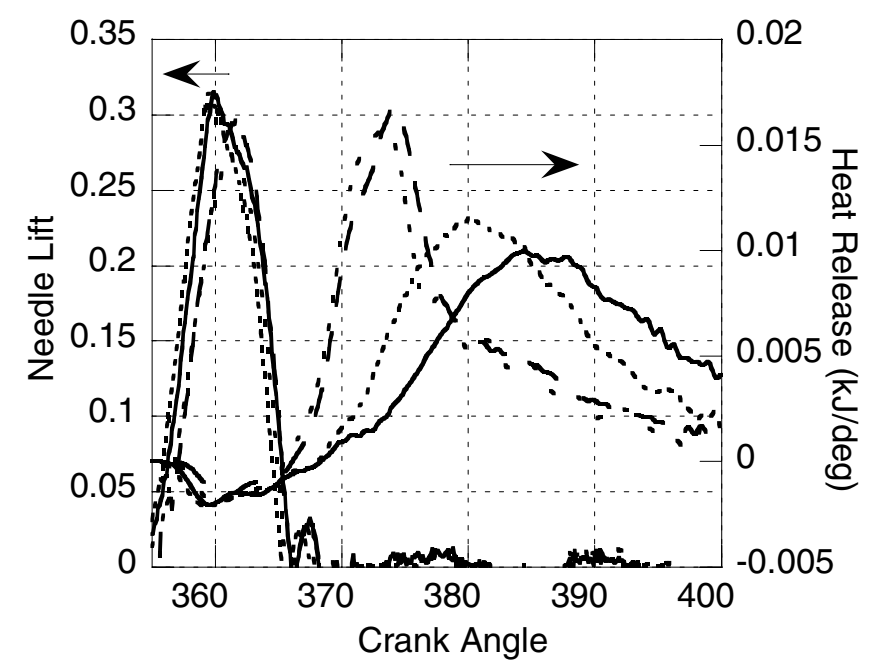

Figure 3.1.3.5 Needle lift and heat release versus crank angle for the "late" static injection timing at 25\% load and $3600 \mathrm{rpm}$, in a Yanmar L70 DI diesel engine. (-) BP15 ultra low sulfur diesel fuel, (--) B20 blend in BP15, (--) Fischer-Tropsch diesel fuel, and (- - -) B20 blend in GTL diesel.

These variations in injection timing, ignition delay and rate of combustion between the test fuel lead to significant variations in engine emissions. In Figure 3.1.3.6, the linear relationship between fuel injection timing and NOx emissions is displayed for the test fuels. One can also see that the "B20" blends of either the BP15 ultra low sulfur diesel fuel or the GTL diesel fuel shift to earlier injection timing and higher NOx emissions.

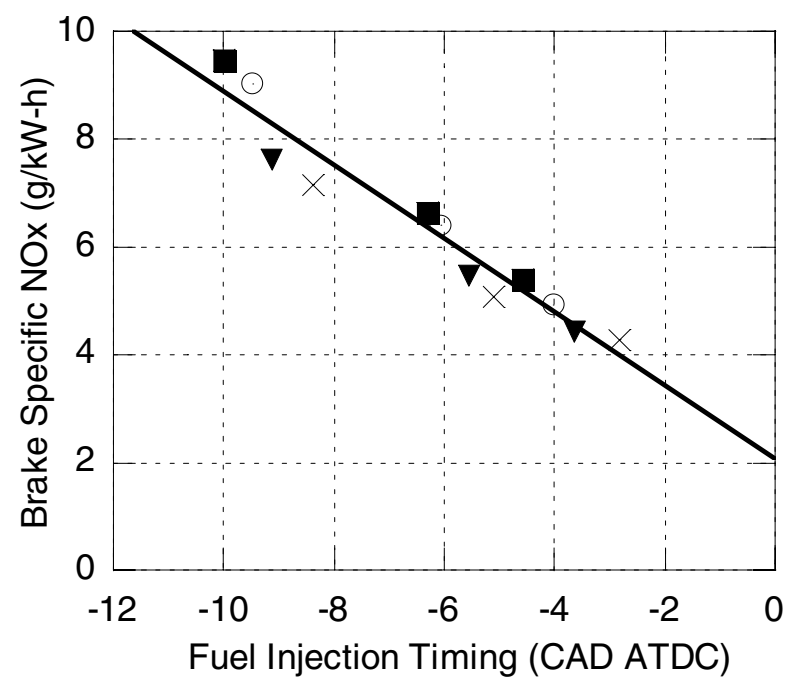

Figure 3.1.3.6 NOx emissions versus fuel injection timing for the various test fuels, based on three settings of static injection timing, in a Yanmar L70 DI diesel engine. (O) BP15 ultra low sulfur diesel fuel, (ם) B20 blend in BP15, $(\times)$ Fischer-Tropsch diesel fuel, and $(\boldsymbol{\nabla})$ B20 blend in GTL diesel.

The NOx and CO emissions clearly show that the effects of these variations in injection timing and cetane number. In Figure 3.1.3..7, at the "early" injection timing setting the NOx levels for BP15 and the GTL diesel are the same and slightly higher for both B20 blends. At 
the "mid" and "late" injection timing settings, the GTL diesel and F-T/B20 blend show higher NOx that the BP15 and BP15/B20 blend. However, as seen in Figures 3.1.3.8 and 3.1.3.9, the $\mathrm{CO}$ emissions and BSFC are higher for BP15 and BP15/B20 than the GTL diesel and FT/B20. So, the GTL diesel permits retarded injection timing without a penalty on CO emissions and fuel consumption, on a mass basis. Since the density of the GTL diesel is lower than for conventional and ultra low sulfur diesel fuels, the volumetric fuel consumption will be higher for the GTL fuel.

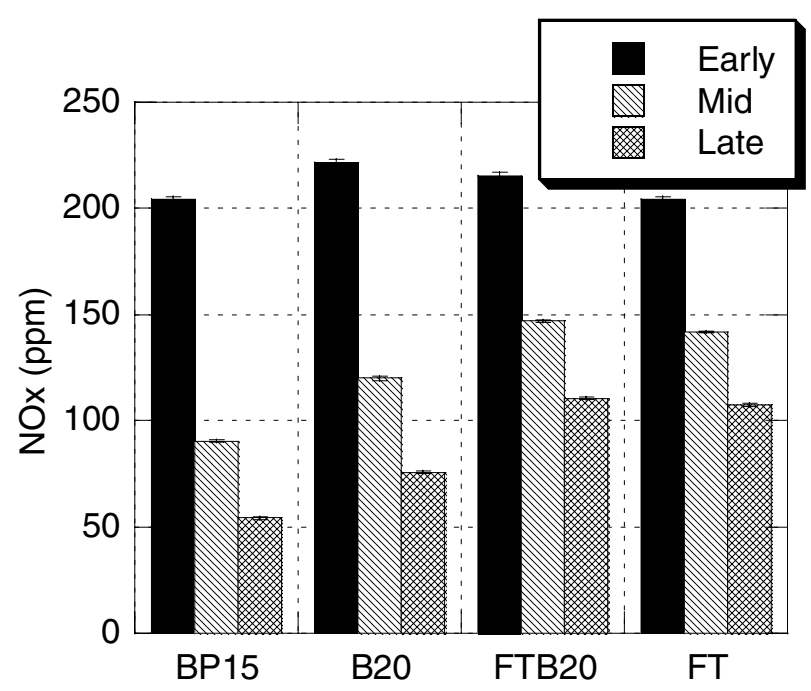

Figure 3.1.3.7 NOx emissions for three injection timing settings at $25 \%$ load and 3600 rpm for BP15 ultra low sulfur diesel fuel, a B20 blend in BP15, Fischer-Tropsch diesel fuel, and B20 blend in GTL diesel.

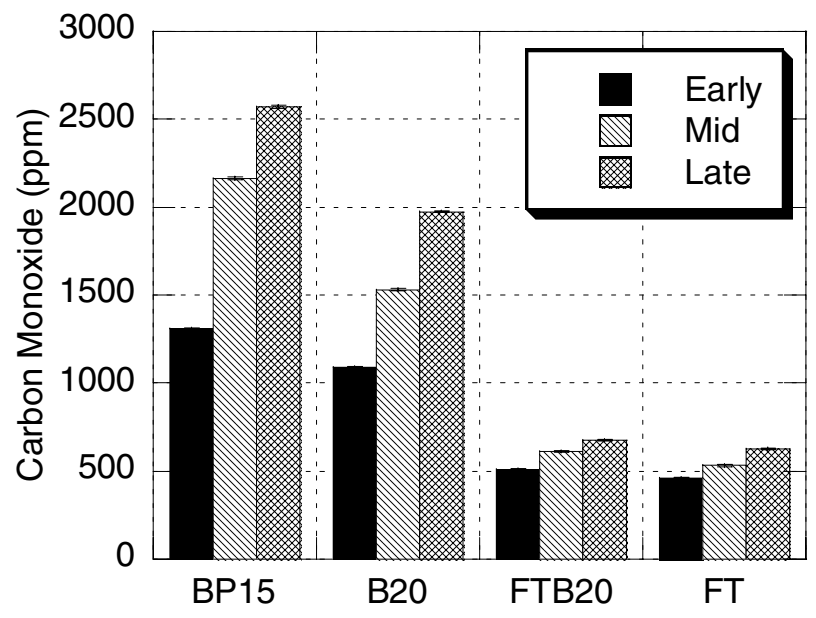

Figure 3.1.3.8 CO emissions for three injection timing settings at $25 \%$ load and $3600 \mathrm{rpm}$ for BP15 ultra low sulfur diesel fuel, a B20 blend in BP15, Fischer-Tropsch diesel fuel, and B20 blend in GTL diesel. 


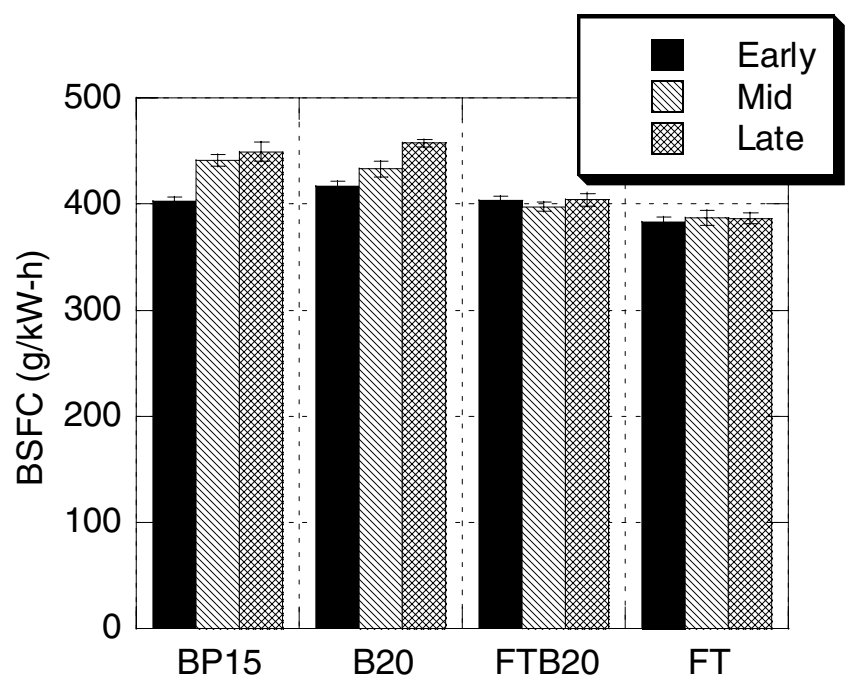

Figure 3.1.3.9 Brake specific fuel consumption for three injection timing settings at 25\% load and 3600 rpm for BP15 ultra low sulfur diesel fuel, a B20 blend in BP15, Fischer-Tropsch diesel fuel, and B20 blend in GTL diesel.

Similar trends are observed in Figures 3.1.3.10 and 3.1.3.11 at 75\% load as were observed in Figures 3.1.3.4 and 3.1.3.5 at 25\% load. For the ultra low sulfur diesel fuel, BP15, combustion is delayed as injection is delayed leading to degraded combustion. The higher cetane number of the GTL diesel causes the F-T diesel and F-T/B20 blend to perform well despite retarded injection timing. As Figures 3.1.3.12, 3.1.3.13 and 3.1.3.14 show, emissions and fuel consumption are adversely affected by retarding injection timing for BP15 and BP15/B20, while the GTL diesel and F-T/B20 blend maintain lower emissions and lower fuel consumption.

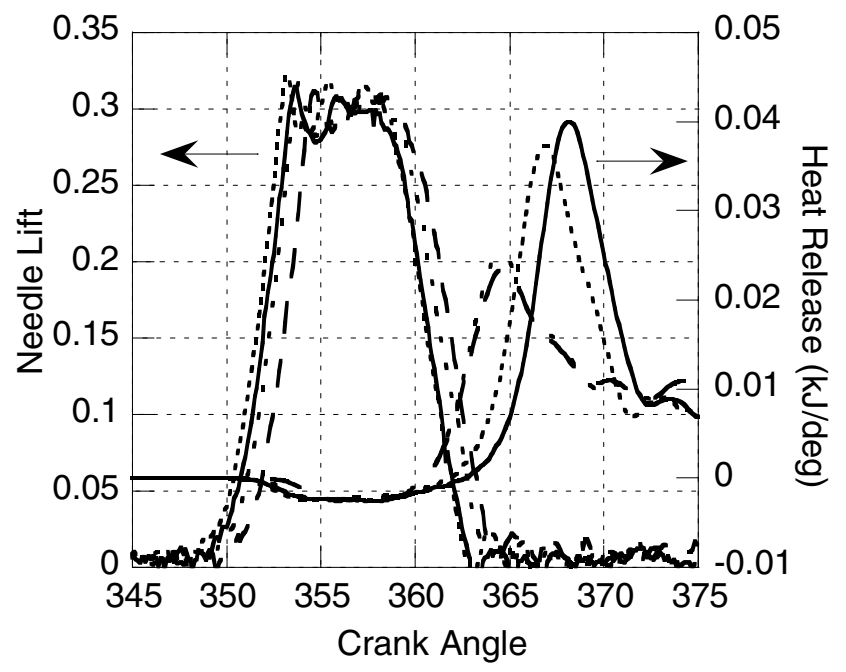

Figure 3.1.3.10 Needle lift and heat release versus crank angle for the "early" static injection timing at 75\% load and $3600 \mathrm{rpm}$, in a Yanmar L70 DI diesel engine. (-) BP15 ultra low sulfur diesel fuel, (--) B20 blend in BP15, (--) Fischer-Tropsch diesel fuel, and (- - ) B20 blend in GTL diesel. 


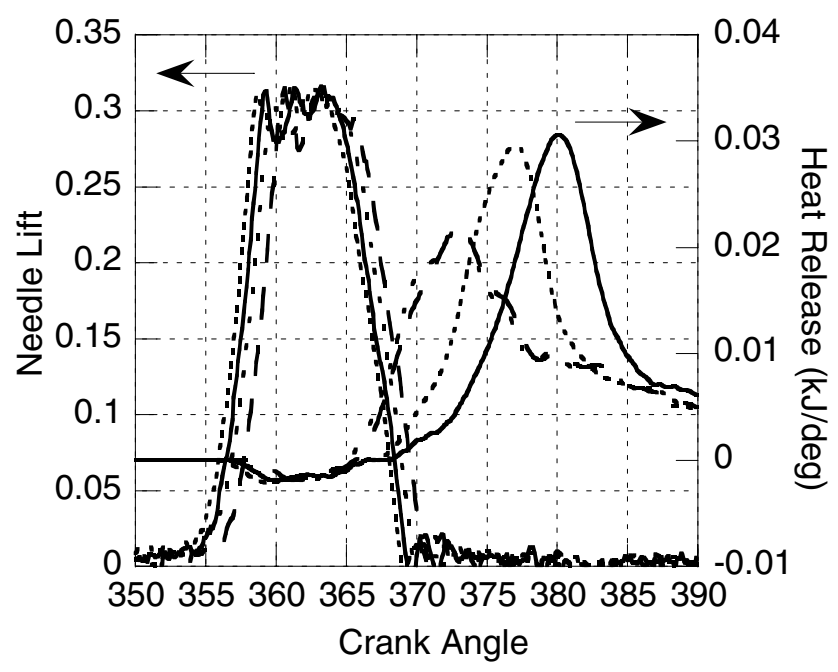

Figure 3.1.3.11 Needle lift and heat release versus crank angle for the "late" static injection timing at 75\% load and $3600 \mathrm{rpm}$, in a Yanmar L70 DI diesel engine. (-) BP15 ultra low sulfur diesel fuel, (---) B20 blend in BP15, (- - ) Fischer-Tropsch diesel fuel, and (- - -) B20 blend in GTL diesel.

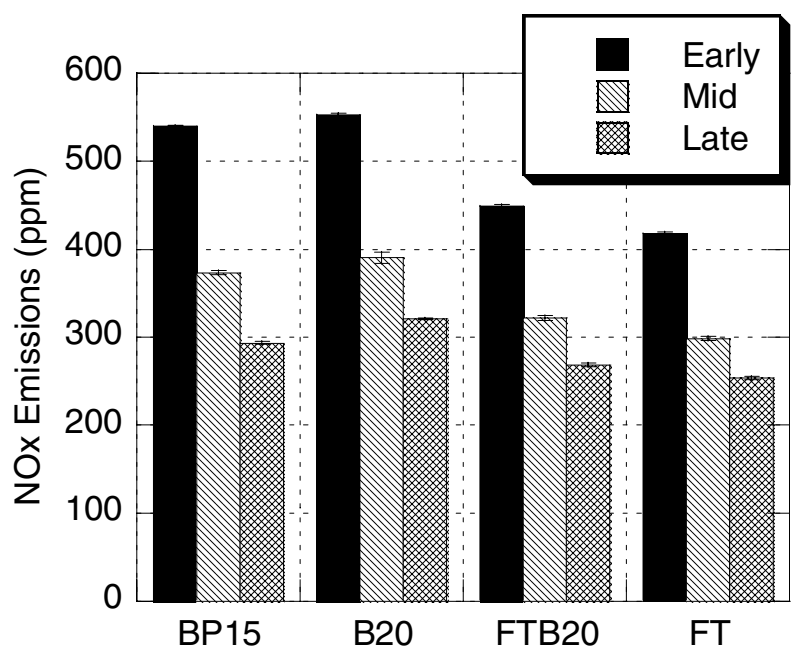

Figure 3.1.3.12 NOx emissions for three injection timing settings at $75 \%$ load and 3600 rpm for BP15 ultra low sulfur diesel fuel, a B20 blend in BP15, Fischer-Tropsch diesel fuel, and B20 blend in GTL diesel. 


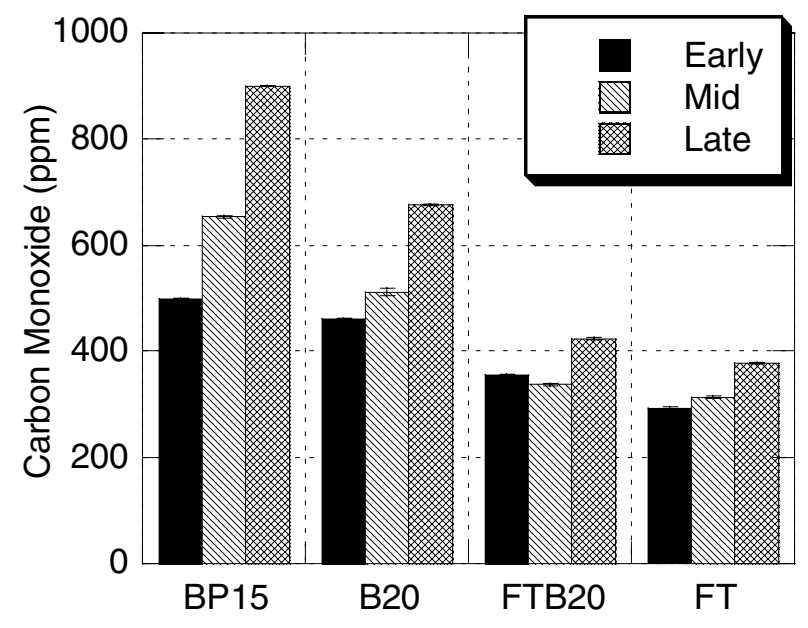

Figure 3.1.3.13 $\mathrm{CO}$ emissions for three injection timing settings at $75 \%$ load and $3600 \mathrm{rpm}$ for BP15 ultra low sulfur diesel fuel, a B20 blend in BP15, Fischer-Tropsch diesel fuel, and B20 blend in GTL diesel.

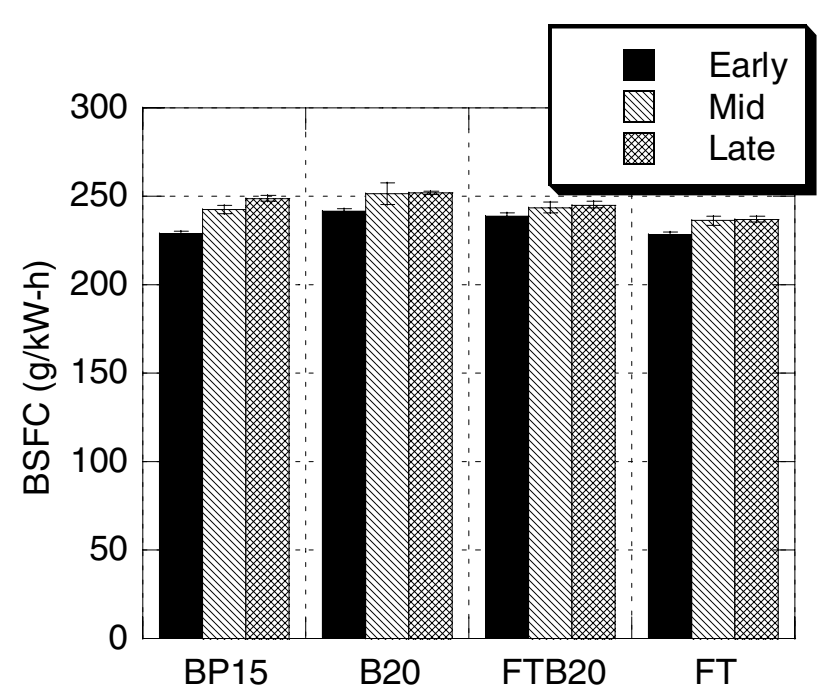

Figure 3.1.3.14 Brake specific fuel consumption for three injection timing settings at $75 \%$ load and 3600 rpm for BP15 ultra low sulfur diesel fuel, a B20 blend in BP15, Fischer-Tropsch diesel fuel, and B20 blend in GTL diesel. 


\subsubsection{Determination of Controlling Factors in NOx Formation via Combustion Analysis}

In order to better understand the relationship between bulk modulus, injection timing and NOx emissions, an expanded study of blending and NOx emissions was undertaken. Both FT diesel fuel and biodiesel were investigated alone, and in blends of 20 and 40 vol\% with petroleum-based diesel. The biodiesel blends of 20,40 , and $100 \mathrm{vol} \%$ are represented by B20, B40, and B100. Similarly, the FT blends of 20,40 , and 100 vol\% are represented by FT20, FT40, and FT100. The Derived Cetane Number (DCN) of each of the fuel blends, measured in accordance with ASTM D6890-03 using the Ignition Quality Tester (IQT), are given in Table 3.1.3.6. The IQT measures the ignition delay of a fuel in a constant volume vessel, and the delay is converted into a DCN which correlates well to $\mathrm{CN}$.

Additional bulk modulus results for the fuel blends in these experiments are shown as functions of pressure in Figure 3.1.3.15. The bulk moduli for BP325, B20, B100, and FT100 were measured, and calculated for B40, FT20, and FT40 as weighted averages of BP325 and either FT100 or B100. The bulk modulus of B100 is the highest of the fuels tested, nearly $11 \%$ higher than BP325, whereas the bulk modulus of FT100 is the lowest of the fuels tested, roughly $8 \%$ lower than BP325.

The needle lift trace and fuel line pressure data from the mid fuel injection timing at high load is shown in Figure 3.1.3.16 and is representative of all engine operation conditions. Both the fuel line pressure and the needle lift show that compared to BP325, the fuel injection timing is advanced with increased biodiesel content, and the fuel injection timing is delayed with increased FT diesel content.

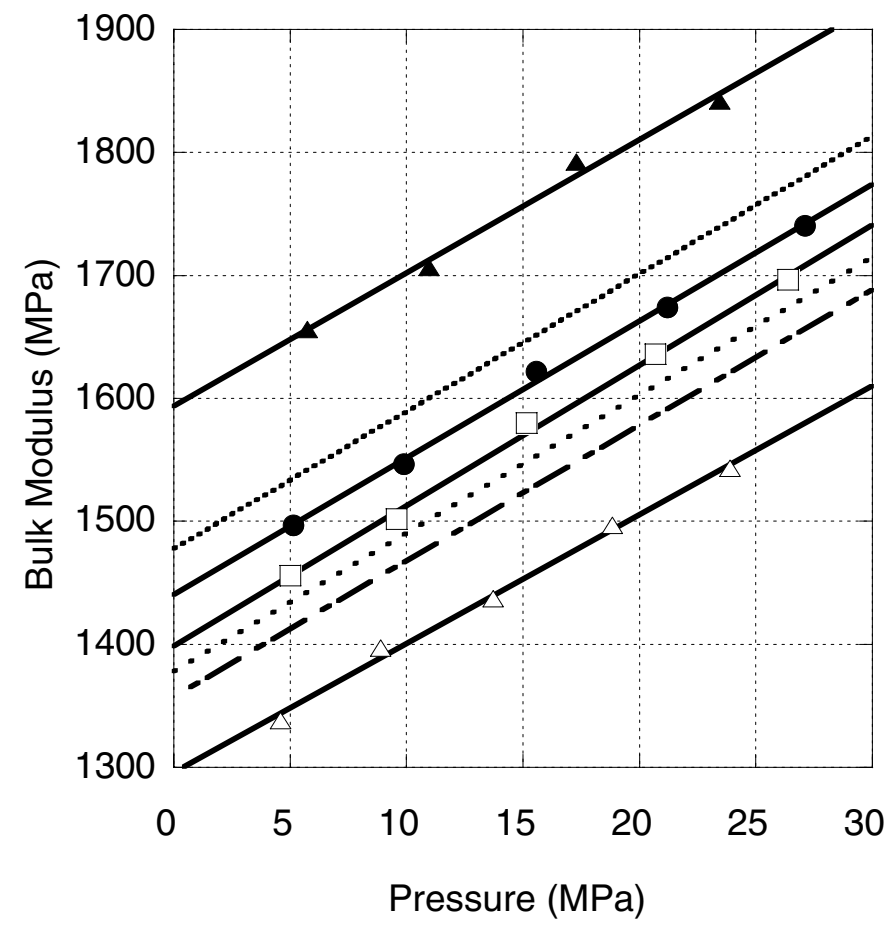

Figure 3.1.3.15 Bulk modulus as a function of pressure for ( $\square) \mathrm{BP} 15,(\bullet) \mathrm{B} 20$, $(\boldsymbol{\Delta}) \mathrm{B} 100$, and $(\triangle) \mathrm{FT}$, and calculated values for $(\cdots \cdots) \mathrm{B} 40,(\cdots)$ FT20, and

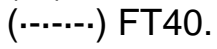



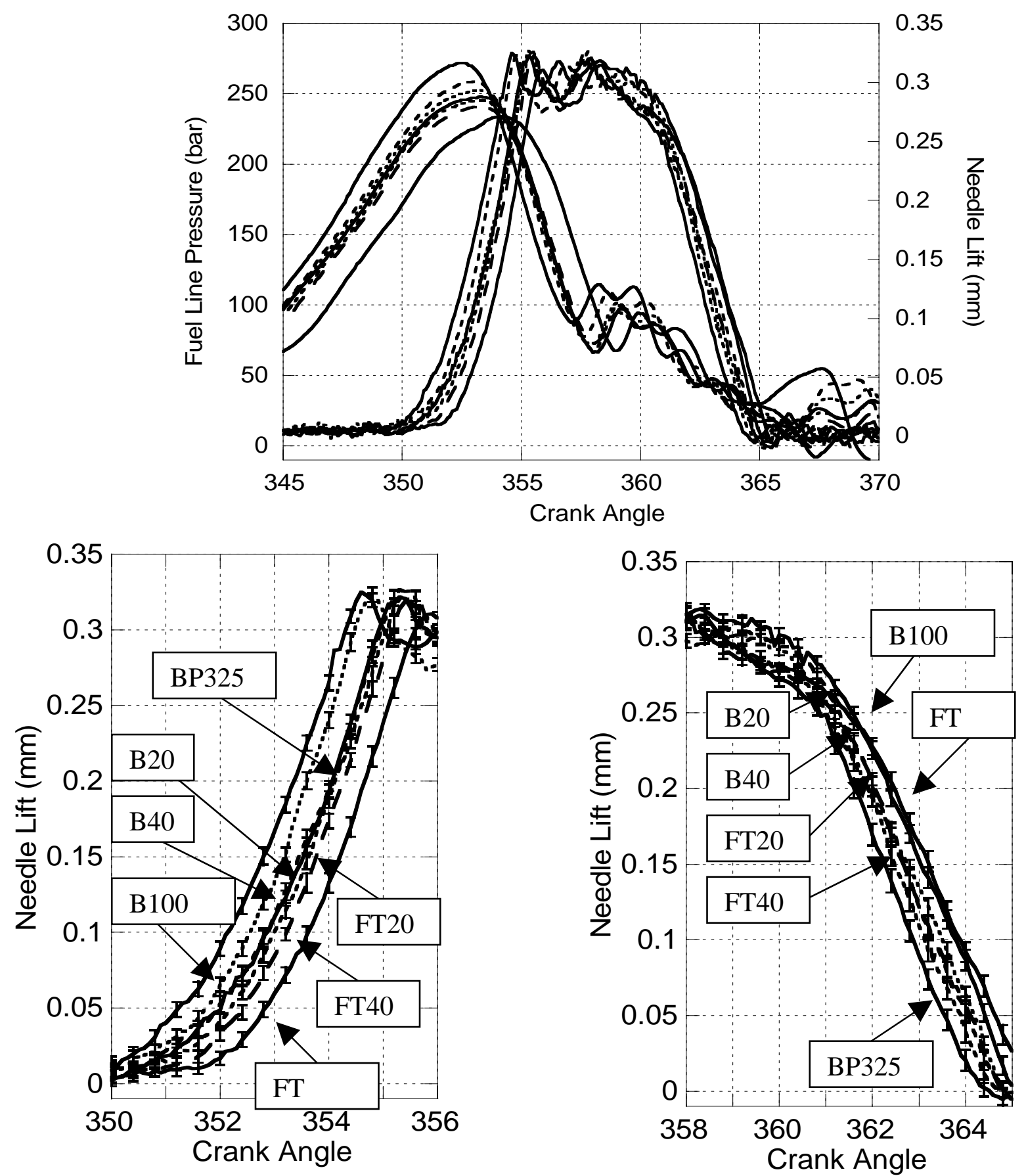

Figure 3.1.3.16 Needle lift and fuel line pressure for mid fuel injection timing, high load (3600 RPM and 75\% maximum output).

The fuel injection timings were quantified by taking the start of injection (SOI) as the crank angle at which the needle-lift exceeded a threshold value of $0.02 \mathrm{~mm}$. The fuel injection timing values are reported as functions of bulk modulus for high load and low load in Figure 3.1.3.17. At all test conditions, the start of injection timing trends linearly with bulk modulus. Relative to BP325, B100 causes an advance in SOI timing of 0.9 to 1.1 CA deg, whereas FT100 diesel causes a delay in SOI timing of 1.2 to $2.4 \mathrm{CA}$ deg. 


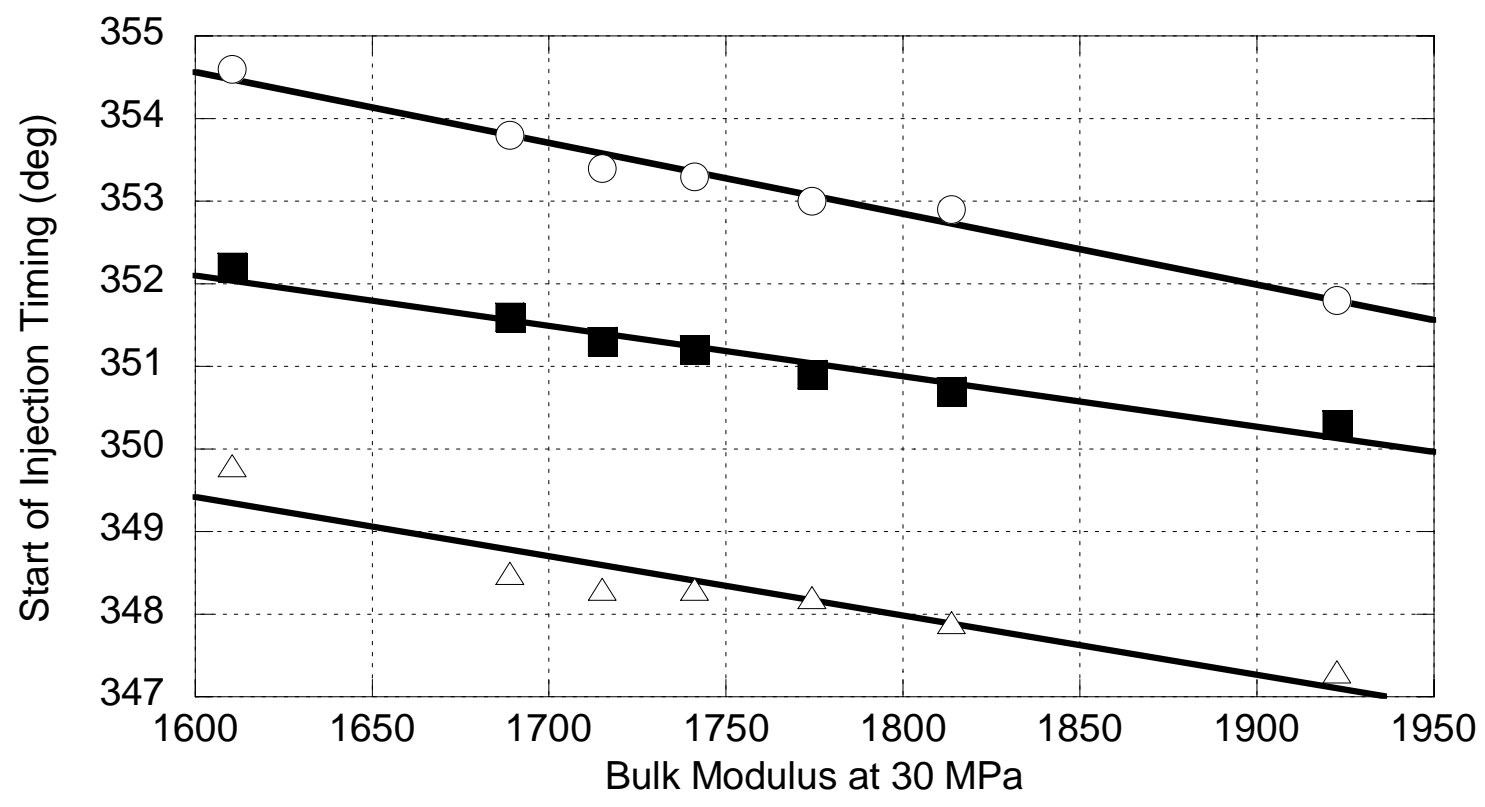

(a)

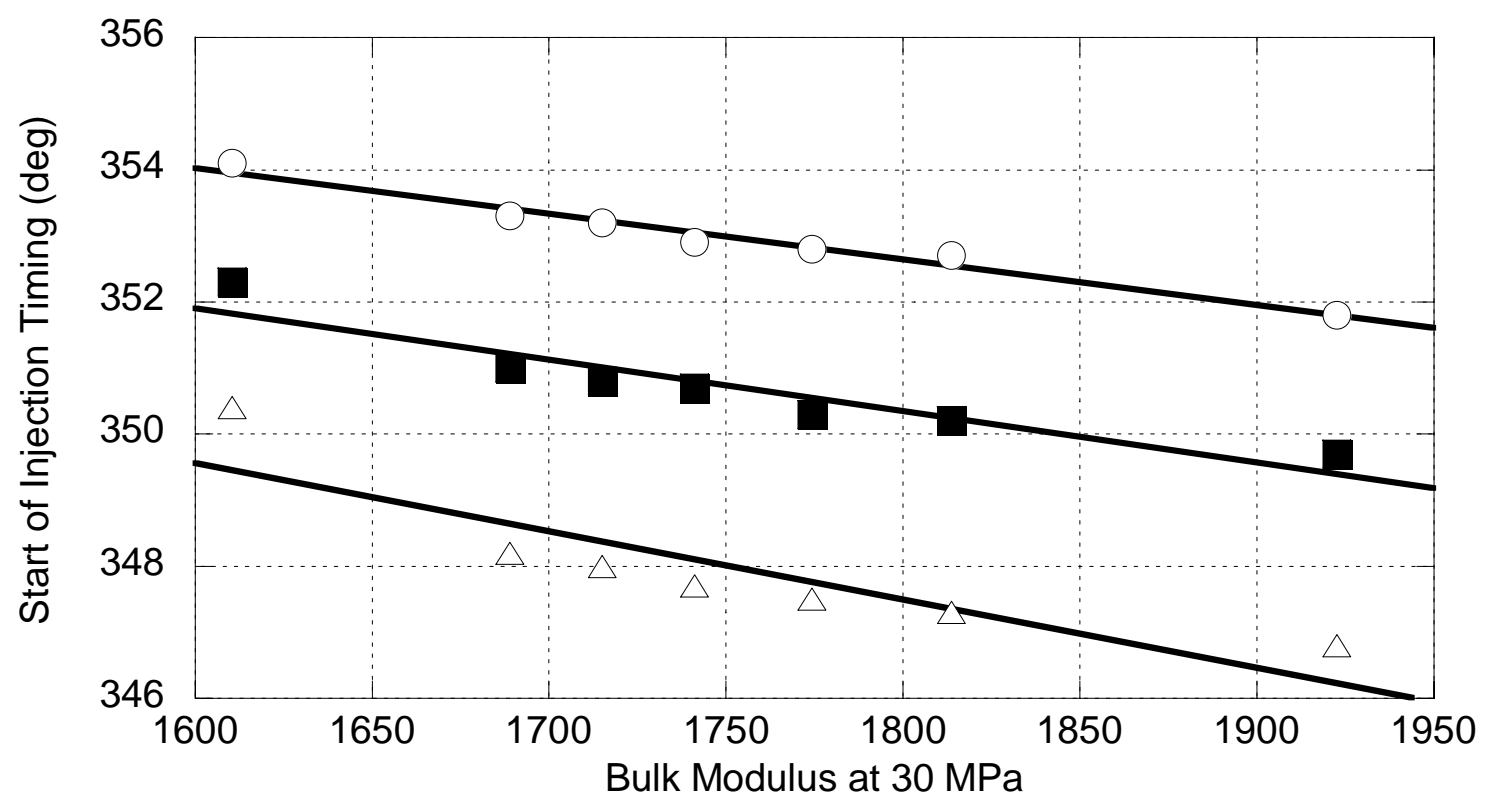

(b)

Figure 3.1.3.17 Needle lift and fuel line pressure for mid fuel injection timing, high load (3600 RPM and 75\% maximum output).

Table 3.1.3.6 Derived Cetane Number Results

\begin{tabular}{|l|l|l|l|l|l|l|l|}
\hline & BP325 & B20 & B40 & B100 & FT & FT20 & FT40 \\
\hline DCN & 42.8 & 47.1 & 48.2 & 55.0 & 87.1 & 50.7 & 58.9 \\
\hline
\end{tabular}

Figure 3.1.3.18 shows the brake specific NOx emissions for both engine load conditions and all fuel injection timing conditions, with error bars representing the standard deviation. For both the 
high and low load conditions the NOx emissions decrease as the fuel injection is retarded from the early to late timing for any individual fuel.

The biodiesel fuels at high load show a trend of increasing NOx emissions as the biodiesel content increases. Compared to BP325, increases in NOx emissions are 3-4\% for B20, 4-6\% for $\mathrm{B} 40$, and $6-9 \%$ for B100. At the mid and late fuel injection timings, these increases are statistically significant at more than 95\% confidence based on two-sample t-test comparison of means and assuming equal variance. A high variance in NOx emissions for BP325 at the early injection timing caused none of the biodiesel fuels to be statistically significant at better than $90 \%$ confidence. However, this result is thought to be the result of an outlying data point, although the reason for the outlier is unknown. Similar results are seen for the biodiesel fuels at low load, although the magnitudes of the NOx differences are greatly increased. Increases in NOx emissions are 10-30\% with B20, 15-53\% for B40, and $25-97 \%$ for B100. The increases in NOx emissions at all three fuel injection timing conditions are statistically significant at greater than 98\% for B20, B40 and B100.

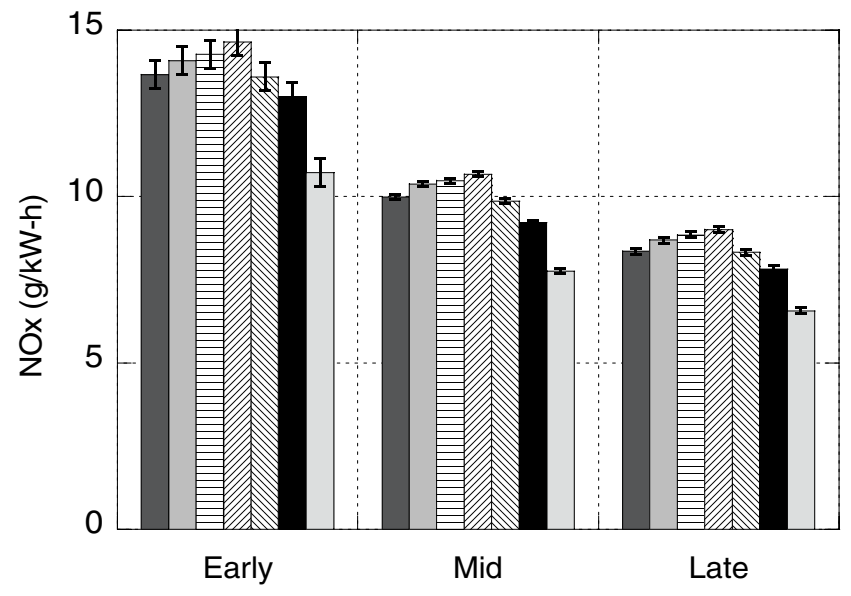

(a)

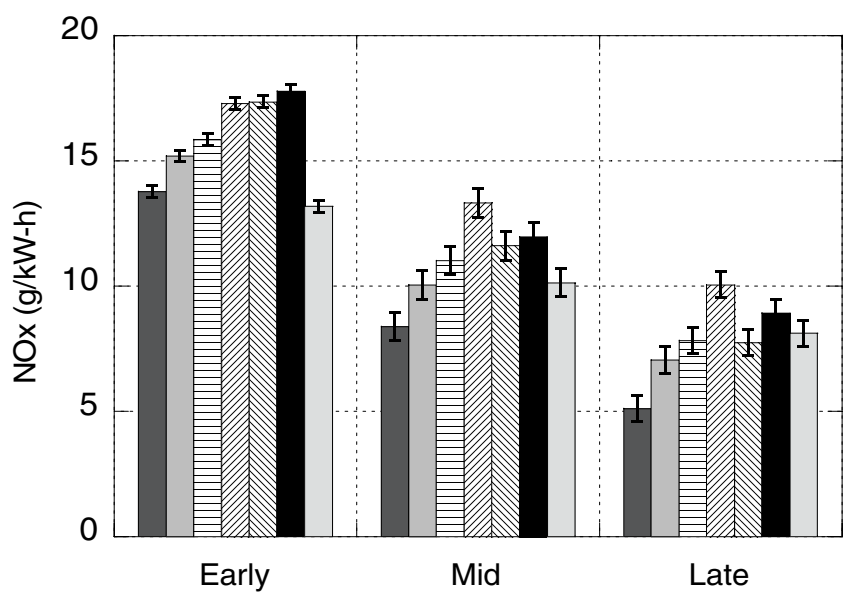

(b)

Figure 3.1.3.18 Brake specific NOx emissions for (a) high load (3600 RPM and 75\% maximum output) and (b) low load (3600 RPM and 25\% maximum output) for ( $\square$ )

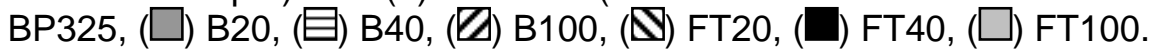


At high load the FT fuels show a similar, but inverse trend in NOx emissions compared to the biodiesel fuels. Decreases in NOx emissions compared to BP325 are $0.5-1.5 \%$ for FT20, 3-6\% for FT40, and $21-22 \%$ for FT100. The decreases in NOx emissions for FT20 are not statistically significant. The decreases are statistically significant for FT40 at greater than $90 \%$ at the mid and late fuel injection timing conditions, but not at the early timing condition because of the high variance for BP325. The decrease for FT100 is statistically significant at greater than 99\% confidence at all three fuel injection timing conditions. At low load there is a substantial difference in the trend of NOx emissions for the FT fuels compared to the high load condition. Instead of NOx emissions decreasing with FT content as they did at the high load condition, NOx emissions increase with FT content from $0 \%$ ( i.e. BP325) up to FT40 where NOx emissions reach a maximum (26-51\% increase for FT20, and $30-74 \%$ increase for FT40). As the FT content is increased further, from FT40 to FT100, NOx emissions decrease to levels of $-4 \%$ to $+60 \%$ of that of BP325. While most researchers report decreases in NOx with FT diesel, Alleman and McCormick noted that at light load conditions it was fairly common for FT fuels to produce higher NOx emissions than the baseline diesel fuel [1].

It is well-established that diesel NOx formation is a thermal phenomenon [2]. Thus, the relationship between NOx and maximum cylinder temperature was investigated, and is shown in Figure 3.1.3.19. At high load, no correlation can be seen between NOx and maximum cylinder temperature, and only a weak trend of increasing NOx with increasing maximum cylinder temperature can be seen at low load, with an $\mathrm{R}^{2}$ value of only 0.48 . Figure 3.1.3.20 shows a relationship where NOx increases with higher maximum heat release rates, where there is an $R^{2}$ value of 0.64 at high load, and an $R^{2}$ value of 0.82 at low load. However, this still does not appear to be a universal relationship that is consistent across all fuels.

The absence of a strong relationship between NOx and maximum cylinder temperature may seem surprising because NOx formation is a thermal process. However, by looking only at the maximum heat release rate and maximum cylinder temperature we do not take into account that the $\mathrm{NO}_{\mathrm{x}}$ formation process begins well after the start of combustion [3], and the concentration is kinetically frozen during the expansion stroke before an equilibrium concentration at the lower temperatures can be achieved [2]. Thus, at later combustion timings, less time is available for $\mathrm{NO}_{\mathrm{x}}$ formation before the reactions are quenched and the concentration is frozen. Figure 3.1.3.21 shows the relationship between NOx and the timing of maximum heat release rate. At high load, three distinct trends can be seen, one for FT100, another for FT40, and a third for the remaining 5 fuels. Similarly, at low load two relationships are observed, one for FT100, and another for all other fuels. This is similar to the relationship between NOx and the SOI timing (e.g. Fig. 3.1.3.6), where the SOI timing affected NOx emissions, but an additional, fuel-specific dependence was also observed, especially for FT100.

This fuel-specific behavior, however, is not seen in the relationship between NOx and the timing of maximum temperature, shown in Figure 3.1.3.22. The timing of maximum temperature lacks the fuel-specificity in the NOx formation process that is seen with the timing of the maximum heat relase rate and SOI timing, with an $R^{2}$ value of 0.89 at high load, and an $R^{2}$ value of 0.82 at low load. These results extend those shown by Szybist et al. [4] where NOx emissions showed nearly identical dependences on $\mathrm{SOI}$, maximum heat release rate timing, and maximum cylinder temperature timing for biodiesel and various B20 blends. This study presents a wider variety of fuel properties by including FT fuel. Thus, it is not surprising that the dependence of NOx on SOI timing and maximum heat release rate timings do not persist. Instead, with the wider variety of fuels, these trends were separated and the timing of the maximum cylinder temperature now appears to be the most universal factor affecting NOx formation during DI diesel combustion. 


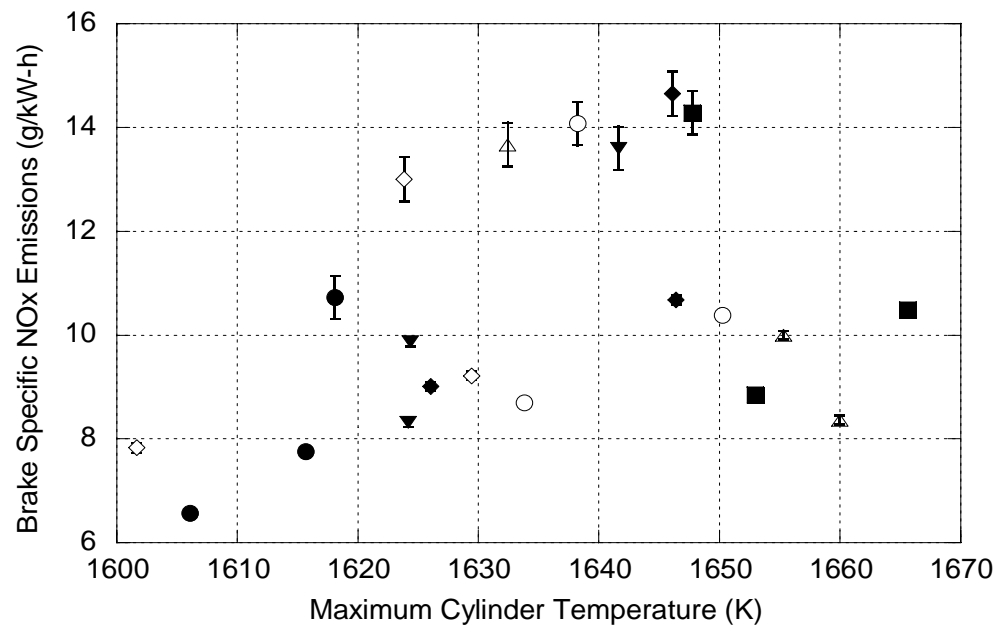

(a)

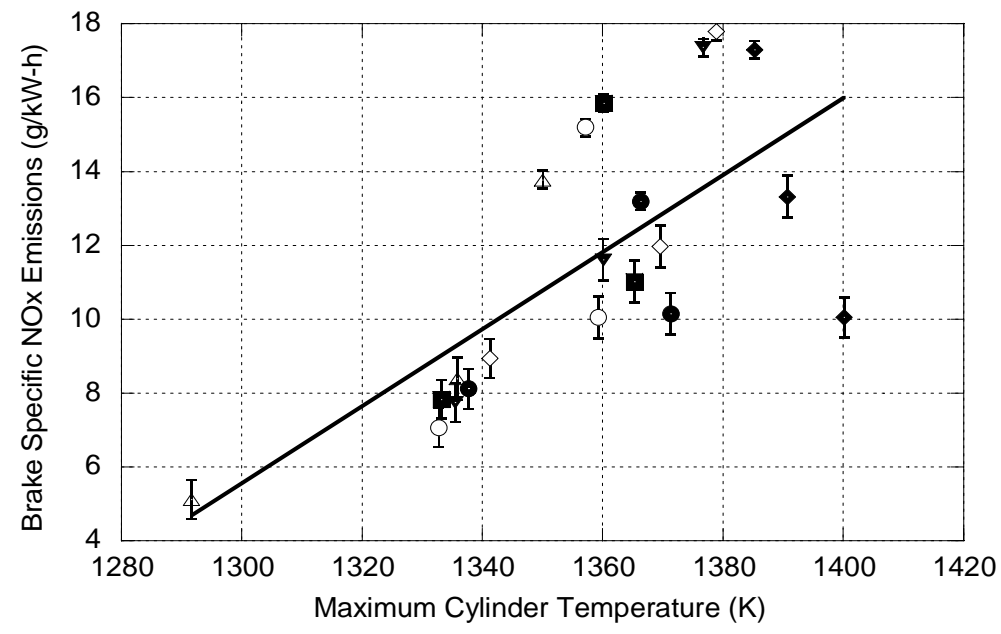

(b)

Figure 3.1.3.19 NOx emissions as a function of maximum bulk cylinder temperature for (a) high load (3600 RPM and 75\% maximum output) and (b) low load (3600 RPM

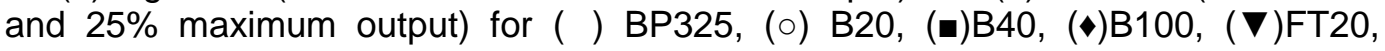
$(\diamond)$ FT40, and $(\bullet)$ FT100. 


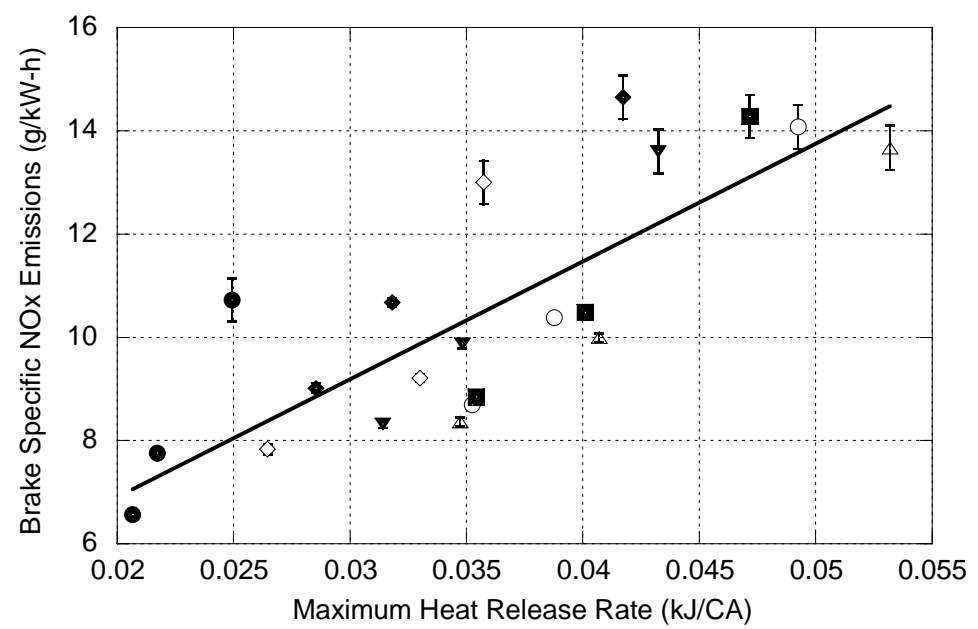

(a)

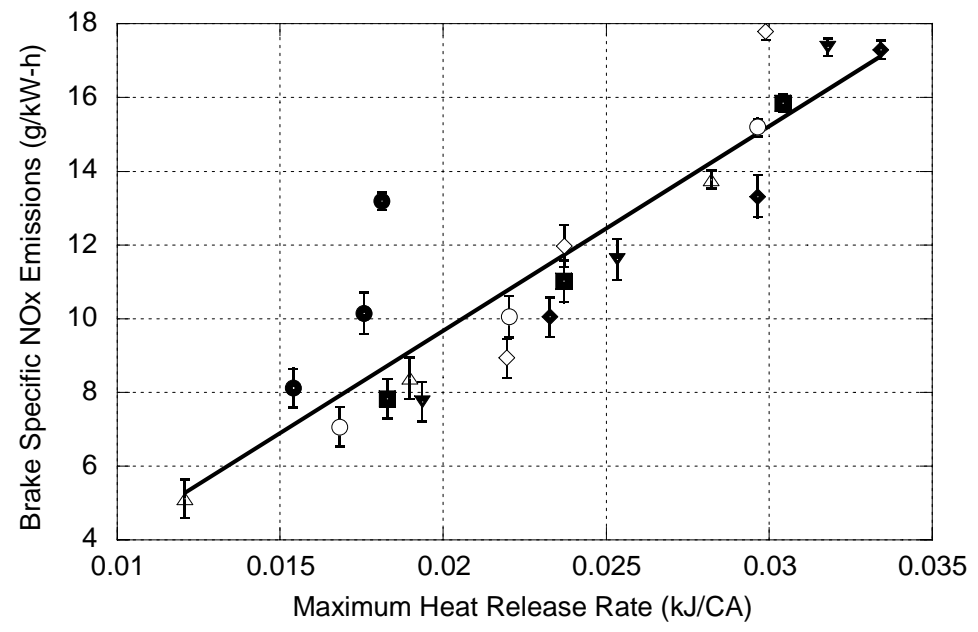

(b)

Figure 3.1.3.20 NOx emissions as a function of maximum heat release for (a) high load (3600 RPM and 75\% maximum output) and (b) low load (3600 RPM and 25\%

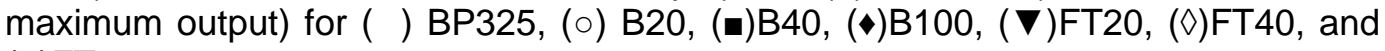
$(\bullet)$ FT100. 


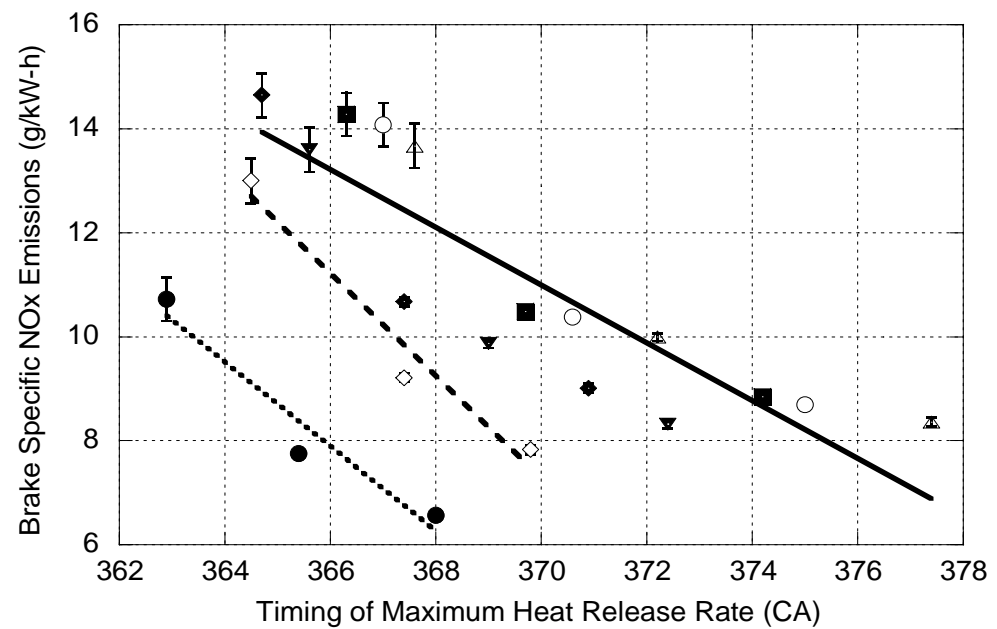

(a)

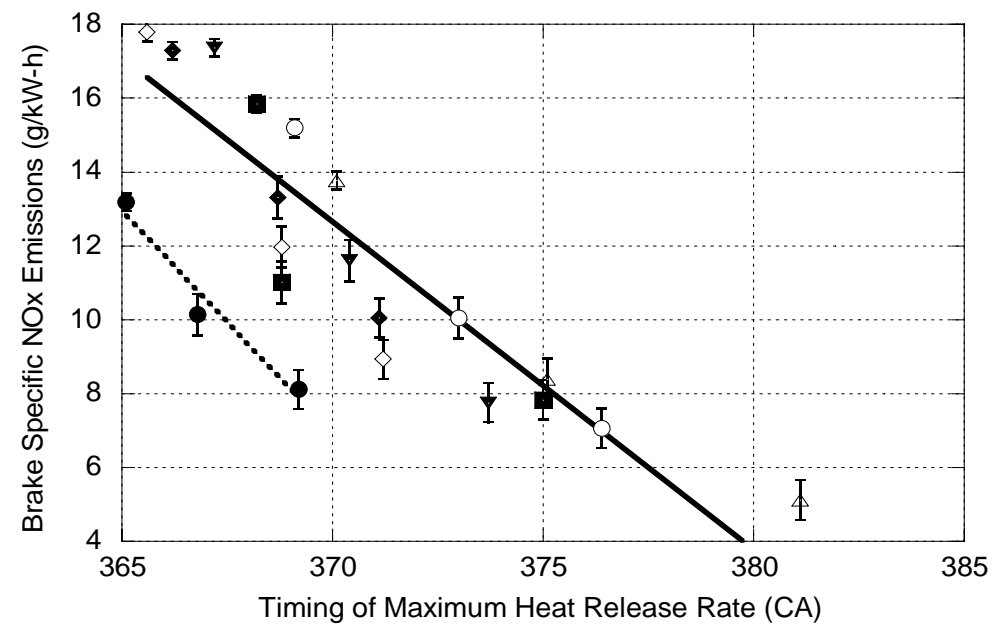

(b)

Figure 3.1.3.21 NOx emissions as a function of the timing of maximum heat release rate at (a) high load (3600 RPM and 75\% maximum output) and (b) low load (3600 RPM and 25\% maximum output) for ( ) BP325, ( ) B20, (匹)B40, (•)B100, ( $\mathbf{\nabla}) F T 20$, $(\diamond)$ FT40, and $(\bullet)$ FT100. 


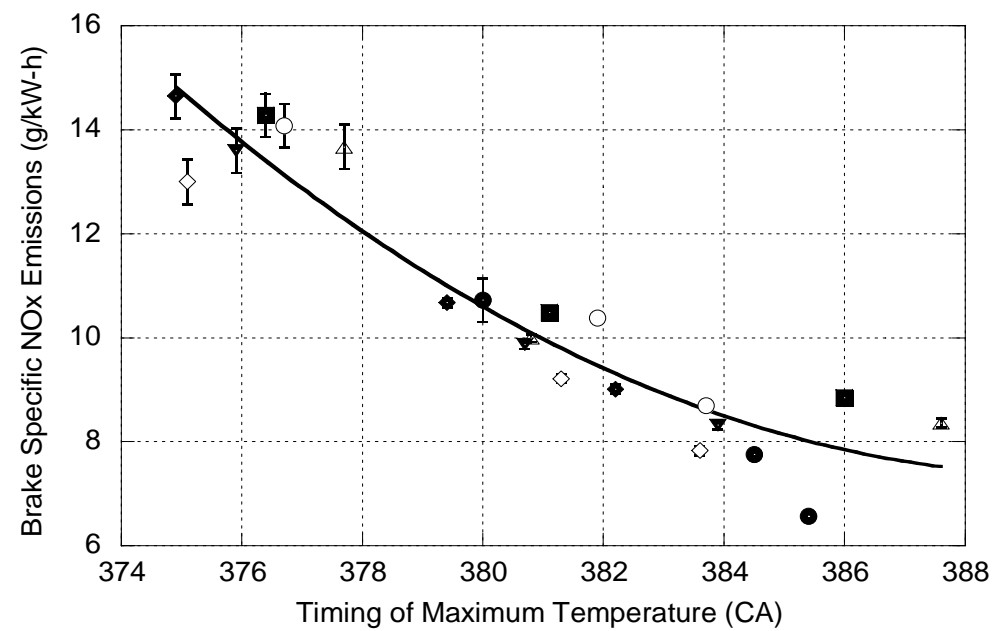

(a)

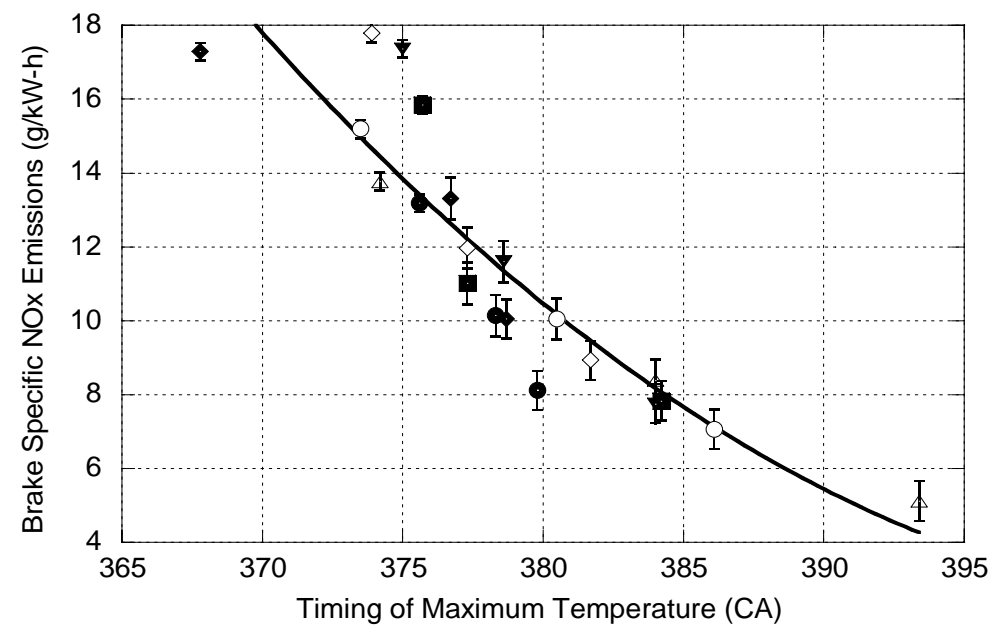

(b)

Figure 3.1.3.22 NOx emissions as a function of the timing of the maximum cylinder temperature for (a) high load (3600 RPM and 75\% maximum output) and (b) low load (3600 RPM and 25\% maximum output) for ( ) BP325, (०) B20, (•)B40, ( )B100, $(\nabla) F T 20,(\diamond) F T 40$, and $(\bullet) F T 100$.

\subsubsection{Premixed Ignition Behavior of Alternative Diesel Fuel-Relevant Compounds}

A schematic of the experiment, with approximate residence times, is shown in Figure 3.1.3.23. Shown in Table 3.1.3.6 is the distillation information for BP325 light and FT diesel, as well as the distillation information for full boiling range BP325 (BP325_FBR) and the byproduct heavy cut of BP325 (BP325_heavy), determined by using SimDis, a GC/FID method (ASTM D2887). While the T90 point for the FT diesel fuel of $245.9^{\circ} \mathrm{C}$ was below the operating temperature of the intake system, the T90 point for the BP325 light cut of $279.9^{\circ} \mathrm{C}$ exceeded the maximum operating temperature of $260^{\circ} \mathrm{C}$, but it did have the desired effect of reducing the boiling range, and thus reducing the potential effects of fuel droplets compared to BP325_FBR. Shown in Figure 3.1.3.24 are the gas chromatograms for BP325 light and for FT diesel, which both show a series of nalkanes from n-octane to n-pentadecane, with n-undecane and n-dodecane being the most abundant peaks. BP325_light has a greater number of minor peaks than the FT diesel, as well as a large unresolved complex mixture along the baseline, indicative of a large number of low-abundance species. 
The aromaticity of the FT diesel, BP325_light, BP325_heavy, and BP325 FBR was measured using $\mathrm{C}^{13} \mathrm{nmr}$ and proton nmr, with the results shown in Table 3.1.3.7. An aromaticity measurement (reported as $\mathrm{f}_{a}$ and $\mathrm{f}_{\mathrm{a}}{ }^{\mathrm{H}}$ for $\mathrm{C}^{13}$ and proton nmr, respectively) indicates the fraction of the carbon or hydrogen atoms that are aromatic, and does not yield a fraction of molecules which are aromatic. For example, ethylbenzene would be reported as an aromatic molecule using a GC technique, but using $C^{13} \mathrm{nmr}$, six carbon atoms appear as aromatic, while two appear as aliphatic. The aromatic content of BP325_FBR, reported by BP using a GC method, is $23.1 \%$, while the aromaticity measurements yield $\mathrm{f}_{\mathrm{a}}=0.114$ and $\mathrm{f}_{\mathrm{a}}{ }^{\mathrm{H}}=0.039$. The respective aromaticities for BP325_light and BP325_heavy are $f_{a}=0.113$ and 0.109 , and $f_{a}{ }^{H}=0.040$ and 0.038 . These measurements show that by distilling BP325_FBR, the fraction of aromatic carbon or hydrogen did not significantly change in the light fraction, and actually decreases in the heavy. This is likely because the T90 cut point for BP325_light of 279.9 is higher than the boiling point for most single ring aromatic species, including toluene and xylene. The aromaticity for FT diesel $\left(f_{a}=0.0002\right.$ and $\left.f_{a}{ }^{H}=0.000\right)$ is negligible, a result that is consistent with previous reports of FT diesel composition [1].

Unlike BP325 and FT diesel, a light cut of soy-based biodiesel could not be produced because its initial boiling point is nearly $300^{\circ} \mathrm{C}$ [5]. A methyl decanoate product (CE-1095 produced by Proctor \& Gamble Chemical Co.) which has a boiling point of $224^{\circ} \mathrm{C}$, was used as a biodiesel surrogate. In addition to methyl decanoate (also known as capyric acid methyl ester), CE-1095 also contained trace amounts of methyl octanoate and methyl dodecanoate, both of which are as relevant to biodiesel as methyl decanoate. Methyl decanoate has a fully saturated aliphatic chain of 10 carbon atoms, whereas the major components of biodiesel have an 18 atom carbon chain, with anywhere from zero to three degrees of unsaturation. The properties of methyl decanoate are compared to the major components of soy-based biodiesel in Table 3.1.3.8. For the remainder of this study the CE-1095 product is referred to as methyl decanoate.

The Derived Cetane Number (DCN) of each of the test fuels, measured in accordance with ASTM D6890-03 using the Ignition Quality Tester (IQT), is given in Table 3.1.3.9. The IQT measures the ignition delay of a fuel in a constant volume vessel, which is also reported for completeness in Table 3.1.3.9, and the delay is converted into a DCN which correlates well to CN. For a more comprehensive description of the DCN test methodology see Allard and coworkers [6]. In the DCN test, n-heptane is used as a calibration standard, and by definition has a DCN of 52.55 , and the DCN of 17.8 for iso-octane reflects its well-documented ability to resist autoignition. The DCN of the BP325_light, 39.4, is lower than that of BP325_FBR, which is lower than that of BP325_heavy, a result that trends with fuel aromaticity. The DCN of methyl decanoate, 49.5, agrees reasonably well with the $\mathrm{CN}$ of 47.9 reported by Graboski and McCormick [5], and the DCN of 65.5 for FT diesel agrees well with previously reported values for similar fuels [1]. 


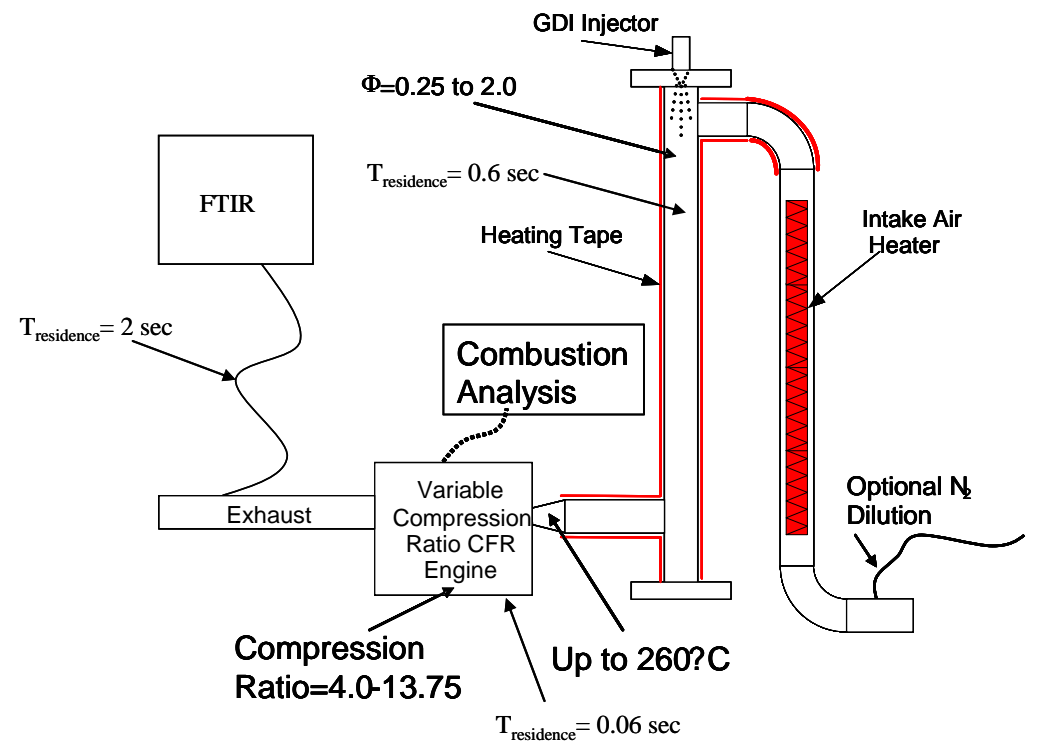

Figure 3.1.3.23 Schematic of modified intake manifold system for the octane rating engine.

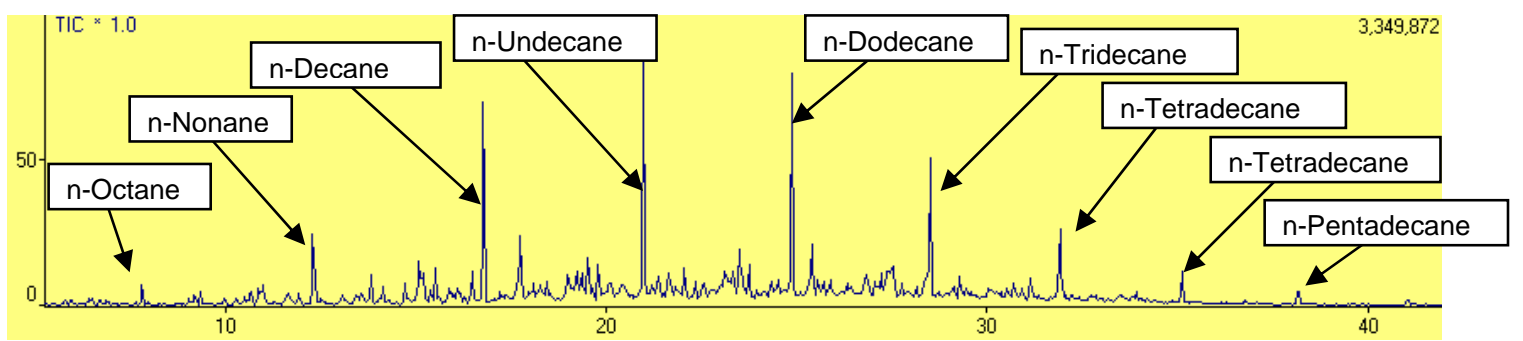

(a)

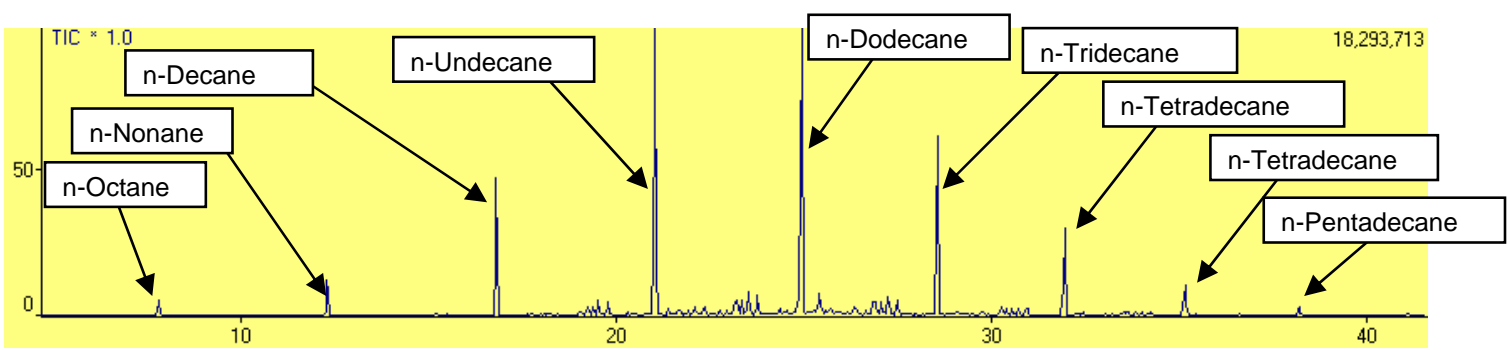

(b)

Figure 3.1.3.24 Gas chromatograms for (a) BP325_light, and (b) FT diesel. 
Table 3.1.3.7 Fuel property information for FT diesel, BP325_light, BP325_FBR, and BP325_heavy.

\begin{tabular}{|c|c|c|c|c|}
\hline & FT diesel & BP325_light & BP325_FBR & BP325 heavy \\
\hline T10 & 170.2 & 167.6 & 183.9 & 246.4 \\
\hline T25 & 183.0 & 192.0 & 221.4 & 264.1 \\
\hline T50 & 206.3 & 219.2 & 257.6 & 287.2 \\
\hline T75 & 226.5 & 244.4 & 292.4 & 314.3 \\
\hline T90 & 245.9 & 279.7 & 321.1 & 340.0 \\
\hline $\begin{array}{c}\text { Aromatic Content } \\
(\%)\end{array}$ & -- & -- & $23.1^{1}$ & -- \\
\hline $\begin{array}{c}\mathrm{C}^{13} \mathrm{nmr} \\
\text { aromaticity }\left(\mathrm{f}_{\mathrm{a}}\right)\end{array}$ & 0.0002 & 0.113 & 0.113 & 0.109 \\
\hline $\begin{array}{l}\text { Proton } \mathrm{nmr} \\
\text { aromaticity }\left(\mathrm{f}_{\mathrm{a}}{ }^{\mathrm{H}}\right)\end{array}$ & 0.000 & 0.040 & 0.039 & 0.038 \\
\hline
\end{tabular}

1. Aromatic content specified by BP.

Table 3.1.3.8 Comparison of methyl decanoate to common biodiesel components, data taken from Graboski and McCormick [5].

\begin{tabular}{|l|l|l|l|l|l|}
\hline & $10: 0$ & $18: 0$ & $18: 1$ & $18: 2$ & $18: 3$ \\
\hline $\begin{array}{l}\text { Boiling Point } \\
\left({ }^{\circ} \mathrm{C}\right)\end{array}$ & 224 & 352 & 349 & 366 & -- \\
\hline $\begin{array}{l}\text { Cetane } \\
\text { Number }\end{array}$ & 47.9 & $75.6-86.9$ & $53.9-55.0$ & $37.1-42.2$ & $22.7-26.7$ \\
\hline $\begin{array}{l}\% \text { of Soy- } \\
\text { Based } \\
\text { Biodiesel }\end{array}$ & 0 & $5-10$ & $\sim 25$ & $\sim 50$ & $5-10$ \\
\hline
\end{tabular}

10:0 - methyl decanoate

18:0 - methyl state

18:1 - methyl oleate

18:2 - methyl linoleate

18:3 - methyl linolenate

Table 3.1.3.9 Derived Cetane Number (DCN) results for test fuels.

\begin{tabular}{|l|l|l|l|l|l|l|l|}
\hline & n-heptane & $\begin{array}{l}\text { iso- } \\
\text { octane }\end{array}$ & $\begin{array}{l}\text { BP325 } \\
\text { light }\end{array}$ & FT diesel & $\begin{array}{l}\text { BP325 } \\
\text { heavy }\end{array}$ & $\begin{array}{l}\text { BP325 } \\
\text { FBR }\end{array}$ & $\begin{array}{l}\text { Methyl } \\
\text { decanoate }\end{array}$ \\
\hline DCN & 52.55 & 17.8 & 39.4 & 65.5 & 47.0 & 44.3 & 49.5 \\
\hline $\begin{array}{l}\text { Ignition } \\
\text { Delay (ms) }\end{array}$ & 3.78 & 16.37 & 5.15 & 3.10 & 4.25 & 4.51 & 4.02 \\
\hline
\end{tabular}

The results and discussion section on these ignition behavior experiments is partitioned into two subsections. The first subsection compares the significance of the LTHR for each fuel using the combustion analysis results. The second subsection discusses the exhaust analysis via FTIR and GC/MS. The exhaust analysis is used to develop an overall understanding of the autoignition process for each fuel.

\subsection{Low Temperature Heat Release}

Figure 3.1.3.25 shows a progression of heat release rate and cylinder temperature traces at four different compression ratios for FT diesel fuel at $\Phi=0.75$. In Figure 3.1.3.25 (a), which is at a compression ratio of 4.47 , the in-cylinder temperature and pressure are sufficiently high to initiate LTHR approximately 20 crank angle degrees (CAD) before top dead center (TDC), but are not sufficiently high to initiate HTHR. The onset of LTHR advances to an earlier crank angle timing with each compression ratio increase, shown in Figure 3.1.3.25 (b), (c), and (d), because the temperature 
and pressure required for LTHR are achieved earlier. In Figure 3.1.3.25 (c), which takes place at a compression ratio of 6.52, the in-cylinder temperature and pressure conditions are sufficiently high to achieve HTHR, where the magnitude of heat release rate can be higher than the LTHR rate by more than an order of magnitude. Just as the timing of LTHR advanced as the compression ratio was increased because higher temperatures and pressures are achieved at earlier crank angles, the timing of the HTHR also advances, as seen by comparing Figure 3.1.3.25 (c) and (d). The trend shown in Figure 3.1.3.25, with only LTHR at low compression ratios, and both LTHR and HTHR at higher compression ratios, is qualitatively representative of all equivalence ratio conditions for $\mathrm{n}$ heptane, BP325_light, FT diesel, and methyl decanoate. LTHR was not detectable for iso-octane by combustion analysis for any of the conditions tested.

The two-stage ignition shown in Figure 3.1.3.25 (c) and (d) is commonly seen by $\mathrm{HCCl}$ researchers, for example see Christensen et al. [7]. Shibata et al. [8] found that the temperature rise during LTHR aids the initiation of HTHR. Fuels with a high magnitude LTHR achieve HTHR more easily than fuels that do not exhibit LTHR. Fuels that do not exhibit LTHR require more severe conditions to achieve HTHR ignition, either in the form of a higher compression ratio engine or higher intake charge temperature. Because iso-octane did not exhibit any LTHR, a compression ratio of greater than 12.0 was required to achieve HTHR ignition, whereas the remainder of the fuels initially achieved HTHR at compression ratios of less than 8.0.

Figure 3.1.3.26 (a) shows the LTHR for n-heptane as a \% of the total heat release (i.e., LTHR / $(\mathrm{LTHR}+\mathrm{HTHR}) * 100)$, which exhibits a strong $\Phi$ dependence. The \% LTHR was taken at the highest compression ratio for each $\Phi$, a condition where the HTHR was the dominant form of heat release. The highest \% LTHR takes place at the lowest $\Phi$, and as $\Phi$ is increased, the $\%$ LTHR initially drops, but is roughly constant at $\Phi>0.75$. The initial drop in $\%$ LTHR can be explained with the help of the oxidation model of $n$-heptane from Curran [9]. As was described in the Introduction, oxygen addition reaction during LTHR, reaction (2) in Table 3.1.3.10, is only favored over a narrow temperature window, above which dissociation is favored. At low $\Phi$, the amount of LTHR required to increase the mixture temperature above where reaction (2) in Table 3.1.3.10 is favored in the forward direction represents a larger percentage of the total heat release when conditions are lean. However, at $\Phi \geq 1$, the total heat release from the mixture is roughly constant, as is the amount of LTHR required to raise the temperature beyond where reaction (2) in Table 3.1.3.10 is favored. Thus, the \% LTHR at these conditions is also roughly constant.

The \% LTHR is also highly dependent on fuel composition, as can be seen in Figure 3.1.3.26 (b), showing the \% LTHR for BP325_light, FT diesel, and methyl decanoate. It should be noted that the \% LTHR for BP325_light and FT diesel were taken from experiments performed at $260^{\circ} \mathrm{C}$, while that of methyl decanoate was taken from an experiment performed at $230^{\circ} \mathrm{C}$, and that of $\mathrm{n}$-heptane was taken from an experiment performed at $110^{\circ} \mathrm{C}$. Caution should be taken when making direct comparisons amongst these fuels because the extent of pre-ignition reaction in a motored engine decreases with increases in charge temperature, as established by Leppard [10]. However, only $30^{\circ} \mathrm{C}$ separates methyl decanoate from FT diesel and BP325_light, and thus a comparison is made for qualitative purposes. Of FT diesel, BP325_light, and methyl decanoate, the highest \% LTHR is exhibited by FT diesel, followed by methyl decanoate and BP325_light last. This equates to a direct correlation between \% LTHR and DCN, which is reported in Table 3.1.3.9. This supports the theory that LTHR occurs during the early stages of diesel combustion and has an acceleratory effect on HTHR initiation.

LTHR is mainly a phenomenon of n-paraffins, so it was expected that FT diesel fuel, which is comprised mainly of n-paraffins, would exhibit the highest \% LTHR. BP325_light exhibited a much lower \% LTHR than FT diesel and methyl decanoate. BP325_light contains a much higher concentration of aromatics than FT diesel, as shown in Table 3.1.3.7, and in an $\mathrm{HCCl}$ study using several different fuel types, Shibata et al. [8] showed that not only do aromatic fuels not contribute to the overall LTHR, but they actually can suppress the LTHR of other fuels. Thus, it is not surprising that the LTHR for BP325_light is significantly lower than that for FT diesel fuel. 
The \% LTHR for methyl decanoate was only marginally lower than for FT diesel. This can be explained by drawing an analogy to aromatic and olefinic species, which themselves do not contribute to LTHR. However, it is well-established that when aromatics and olefins have long aliphatic chains, the saturated portion of the molecule undergoes LTHR while the double bond or aromatic ring does not [11]. Thus, it is likely that the fully saturated-10 carbon on methyl decanoate is responsible for the LTHR while the ester group does not participate. It is also well-established that the presence of olefinic sites in aliphatic chains greatly reduces the magnitude of low-temperature reactions, depending on the location of the double bond, because they hinder the ability of the molecule to undergo internal isomerizations, such as reaction (3) in Table 3.1.3.10 [12]. For example, Tanaka et al. [13] showed that 1-heptene and 2-heptene both exhibit two-stage ignition, although the LTHR magnitude is lower than for n-heptane. However, 3-heptene exhibits only single stage ignition because it does not possess a continuous saturated carbon chain long enough to undergo isomerization. So, while methyl decanoate is fully saturated, over $80 \%$ of soy-based biodiesel has a minimum of one olefinic site, and over $55 \%$ has a minimum of two, as shown in Table 3.1.3.8. Thus, it is likely that the LTHR of methyl decanoate over-predicts the LTHR for biodiesel, although not enough information is known to accurately predict the reduced LTHR magnitude for biodiesel. 

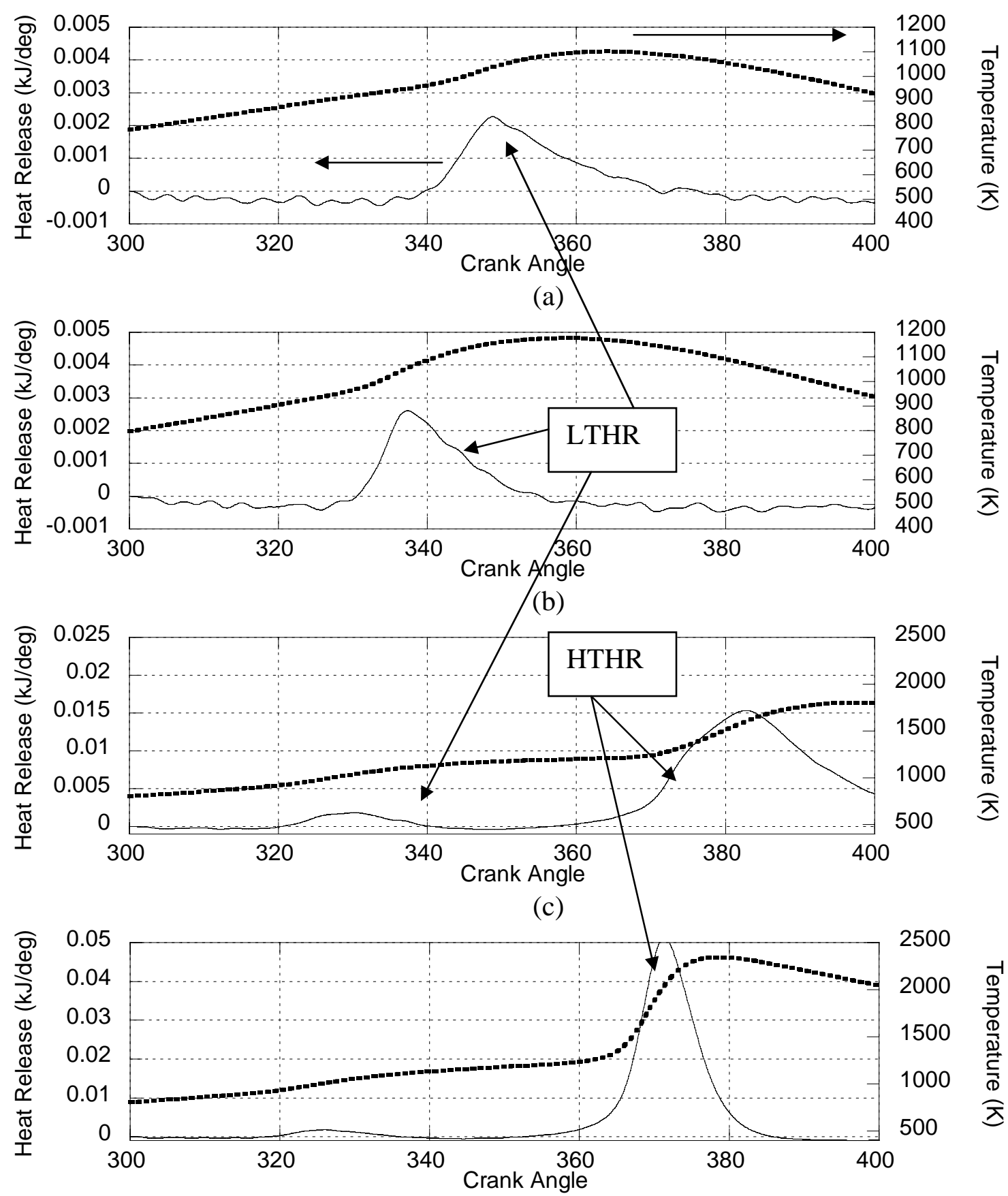

(d)

Figure 3.1.3.25 Ignition progression of FT fuel at $\Phi=0.75$ and an intake temperature of $260^{\circ} \mathrm{C}$ for compression ratios of (a) 4.47 , (b) 5.70 , (c) 6.52 , and (d) 7.04 . 


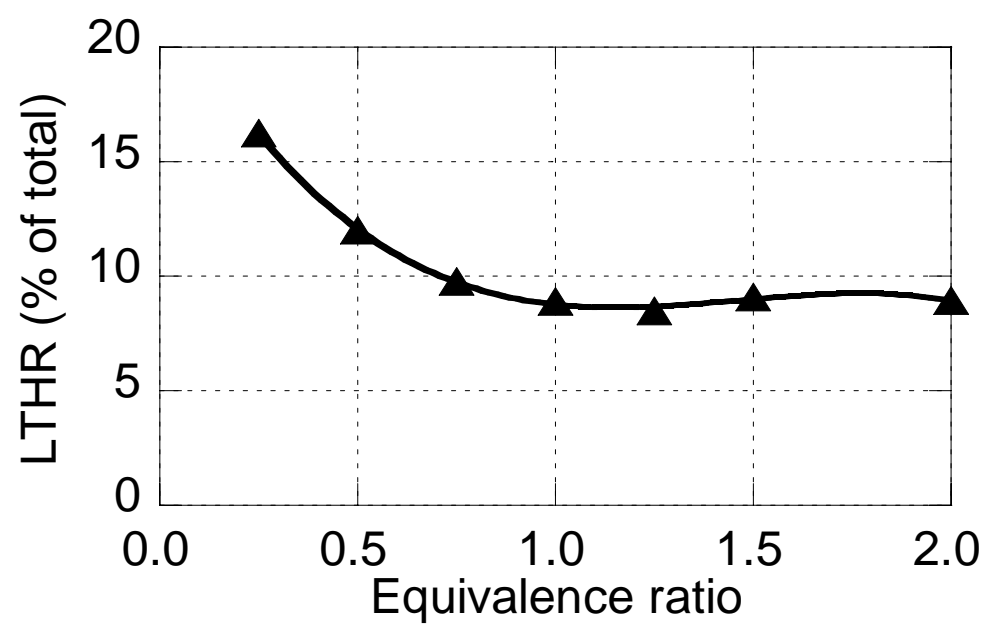

(a)

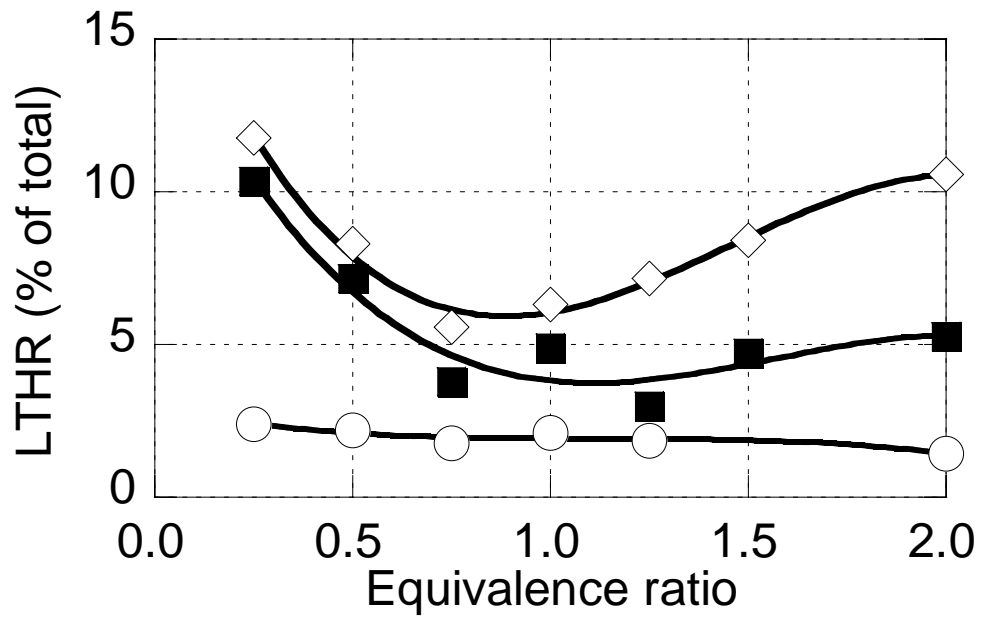

(b)

Figure 3.1.3.26 LTHR as percent of the total heat release for $(\mathbf{\Delta}) \mathrm{n}$-heptane, (०) BP325_light, $(\diamond)$ FT diesel, and ( $\mathbf{\bullet})$ methyl decanoate.

Table 3.1.3.10 Reactions associated with LTHR, taken from Curran et al. [9].

\begin{tabular}{|l|r|}
\hline $\mathrm{RH}+\mathrm{O}_{2} \rightarrow \mathrm{R} \bullet+\mathrm{HO}_{2}$ & $(1)$ \\
\hline $\mathrm{R} \bullet+\mathrm{O}_{2} \rightarrow \mathrm{ROO} \bullet$ & $(2)$ \\
\hline $\mathrm{ROO} \cdot \rightarrow \cdot \mathrm{QOOH}$ & $(3)$ \\
\hline$\cdot \mathrm{QOOH} \rightarrow \mathrm{Carbonyl}+$ Olefin $+\mathrm{OH} \bullet$ & $(4)$ \\
\hline$\cdot \mathrm{QOOH}+\mathrm{O}_{2} \rightarrow \cdot \mathrm{OOQOOH}$ & $(5)$ \\
\hline$\cdot \mathrm{OOQOOH} \rightarrow \mathrm{HOOQ}=\mathrm{O}+\mathrm{OH} \bullet$ & $(6)$ \\
\hline $\mathrm{HOOQ}=\mathrm{O} \rightarrow \cdot \mathrm{OR}=\mathrm{O}+\mathrm{OH} \bullet$ & $(7)$ \\
\hline
\end{tabular}

\subsection{Ignition Behavior}

In this section, the exhaust analysis of each fuel, as well as the significance it has on the ignition chemistry, is discussed in detail. Each of the following subsections discusses the ignition behavior of one particular fuel. 


\section{n-Heptane}

Select FTIR spectra, as well as the corresponding heat release traces for $n$-heptane at $\Phi=0.25$ are shown in Figure 3.1.3.27. For condition (a), the compression ratio of 4.47 did not raise the temperature sufficiently to initiate LTHR. Therefore, the corresponding spectra shows only the absorption pattern of $n$-heptane with two overlapping bands between $2850 \mathrm{~cm}^{-1}$ and $3050 \mathrm{~cm}^{-1}$, and a third smaller absorption band at $1350-1550 \mathrm{~cm}^{-1}$. A higher compression ratio of 6.62 was sufficient to initiate the LTHR, but not HTHR, as shown in condition (b) of 3.1.3.27. The corresponding spectra shows three distinct absorption bands: aldehyde $\mathrm{CH}$ stretching at $2650 \mathrm{~cm}^{-1}$ to $2850 \mathrm{~cm}^{-1}$, carbonyl $\mathrm{C}=\mathrm{O}$ absorption at $1675-1825 \mathrm{~cm}^{-1}$, and carbon monoxide absorption at $2025-2275 \mathrm{~cm}^{-1}$. A distinction between aldehydes and ketones cannot be made based only on the $\mathrm{C}=\mathrm{O}$ absorption band, but the wide band of carbonyl absorption indicates that a number of different species are contributing to the net absorption. When the compression ratio was increased further to initiate HTHR, as shown in condition (c) of 3.1.3.27, the absorption bands that were prominent in conditions (a) and (b) decrease and the dominant absorption bands that appear are for water at $3550-3800 \mathrm{~cm}^{-}$ ${ }^{1}$ and carbon dioxide at $2200-2400 \mathrm{~cm}^{-1}$.

The quantified concentrations for formaldehyde, acetaldehyde, carbon monoxide, and carbon dioxide for n-heptane are shown in Figure 3.1.3.28 as functions of compression ratio at $\Phi=0.25$, $0.5,0.75,1.0,1.25,1.5$, and 2.0. At each equivalence ratio, LTHR, which occurs at low compression ratios, produces high levels of carbon monoxide, formaldehyde, and acetaldehyde, while virtually no carbon dioxide is produced. As the compression ratio is increased, the extent of LTHR also increases, as do the concentrations of formaldehyde, acetaldehyde, and carbon monoxide. The absence of carbon dioxide during the LTHR conditions was expected because during low-temperature oxidation conditions, carbon monoxide is not oxidized to carbon dioxide if hydrocarbons are present [14]. The onset of HTHR at higher compression ratios, characterized by a sharp increase in carbon dioxide, causes a decrease in formaldehyde and acetaldehyde. At lean or stoichiometric conditions (see conditions (a) through (d) of Figure 3.1.3.28), carbon monoxide decreases with the onset of HTHR, but when the conditions are fuel rich, as with conditions (e) through (g) of Figure 3.1.3.28, carbon monoxide increases because there is insufficient oxygen to form carbon dioxide.

Using the FTIR spectra as well as the heat release data, a stepwise understanding of the autoignition process can be developed. During the LTHR process, the fuel is partially oxidized to form a mixture that is rich in carbon monoxide, aldehydes, and other carbonyl species. If the pressure/temperature conditions in the cylinder are sufficient to initiate the HTHR, the in-cylinder mixture, which already contains a high concentration of partially oxidized species produced during LTHR, readily oxidizes to carbon dioxide and water.

Additional information about the autoignition process can be learned from the GC/MS results of the condensed sample, shown for n-heptane at $\Phi=0.25$ at a compression ratio of 6.16 in Figure 3.1.3.29, a condition where LTHR occurred, but not HTHR. The species seen in the condensate did not change with compression ratio or equivalence ratio, although their relative concentrations did vary somewhat, and the overall concentration of condensable exhaust was reduced with the onset of HTHR. The largest peak in all of the condensed exhaust samples for n-heptane occurred at a retention time of 18 minutes, but could not be satisfactorily matched in any common mass spectrometry library (i.e., NIST 12, 21, 62, 107), despite its strong signal strength. Figure 3.1.3.30 (a) shows the mass spectrum and mass table of the peak at a retention time of 18 minutes for the $n$ heptane condensate. This shows that the species has a molecular ion of $\mathrm{m} / \mathrm{z}=128$, which due to the low molecular ion signal strength, was confirmed via chemical ionization mass spectrometry, a soft ionization technique that reduces molecular fragmentation so that the molecular ion can be determined. The closest mass spectrum match was 2,5-hexanedione, which has a molecular ion of $\mathrm{m} / \mathrm{z}=114$ and is shown in Figure 3.1.3.30 (b). This mass spectrum is relatively unique for carbonyl species because there are no prominent mass fragments with an even $\mathrm{m} / \mathrm{z}$ value. Carbonyls often have mass fragments with even $\mathrm{m} / \mathrm{z}$ values because, during fragmentation, they undergo a 
rearrangement process where the $\gamma$ carbon donates a hydrogen atom to the carbonyl prior to a $\beta$ cleavage, resulting in a mass fragment with an even $\mathrm{m} / \mathrm{z}$ value, commonly referred to as the McLafferty rearrangement [15]. The McLafferty rearrangement proceeds through a six-memberedring transition state, but because 2,5-hexanedione has carbonyl groups on both the 2 and 5 carbons, there is a steric hindrance to the rearrangement process. For that same reason, it was concluded that the strong GC peak at a retention time of 18 minutes from the condensed n-heptane exhaust samples was 2,5-heptanedione.

The presence of 2,5-heptanedione has not been previously reported in connection with the autoignition of $n$-heptane, but it is similar to a key compound in the autoignition mechanism reported by Curran et al. [9], from which key steps are reproduced here in Figure 3.1.3.31. After an initial hydrogen abstraction (1) and oxygen addition (2) to form an alkylperoxy radical, an internal isomerization through a six-membered-ring transition state (3) forms an alkylhydroperoxy radical (4). This is followed by a second oxygen addition (5), and a second internal isomerization through a sixmembered-ring transition state (6), resulting in a ketohydroperoxide species and a hydroxyl radical (7). Although the autoignition model by Curran [9] does not proceed further, a dehydration of 2-keto, 5-hydroperoxide would produce the 2,5-heptanedione species identified here. It is possible that the ketohydroperoxide species is present in the exhaust, but is not stable enough to withstand the sample collection and preparation process, and that it forms 2,5-heptanedione before it can be detected by the GC/MS. Thus, the most abundant condensable species in the exhaust for $n$ heptane can be tied closely to the well-established autoignition mechanism for $\mathrm{n}$-heptane.

Additional species in the condensed exhaust are listed in Table 3.1.3.11, although there were several peaks that could not be identified. Among those that were identified were several ketones, including four additional diones, with butanal being the only aldehyde that could be positively identified. The size of the species with single carbonyl groups agree well with the mechanism by Curran et al. [9] where carbonyls and olefins are formed simultaneously by the $\beta$-scission of the alkylhydroperoxy radical, shown in reaction (4) of Table 3.1.3.10. Thus, the largest carbonyl that can be formed through this mechanism from n-heptane has a carbon chain length of 5 , whereas the carbonyl formation pathway suggested by Wagner and Wyszynski [16] does not require the cleavage of any carbon-carbon bonds, and therefore would expect to see aldehydes and ketones with a carbon chain length of the 7 , the same as the starting material.

Many of the peaks that could not be identified in Table 3.1.3.11 had similar fragmentation patterns, with the base peak at $\mathrm{m} / \mathrm{z}=43$, and additional peaks at 57 and 71 . However, there was severe fragmentation for all of these species, preventing the acquisition of a molecular ion, thereby preventing a positive identification. The fragmentation pattern observed for many of these species fits the characteristic pattern for carbonyls, but the pattern is not sufficiently unique to make a definitive conclusion.

Two organic acids, butanoic and pentanoic, are also listed among the species identified in the condensed exhaust for n-heptane. The only well-established mechanism for the formation of organic acids during combustion is through the ring-opening of aromatic species [3]. In the case of n-heptane, no aromatic species are present, and the aliphatic chain of the acid is too long for it to have originated from an aromatic. Further, these species were produced during LTHR, a condition where aromatics remain largely non-reactive. The formation of organic acids from n-paraffins through the LTHR process is discussed in more detail in the FT Diesel section. 


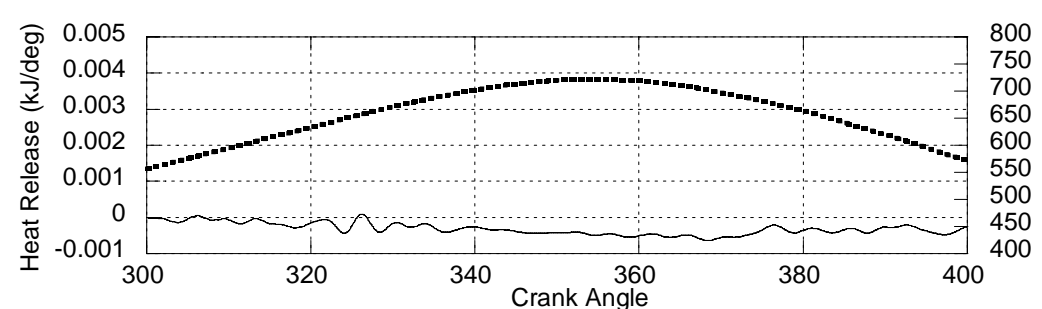

(a)

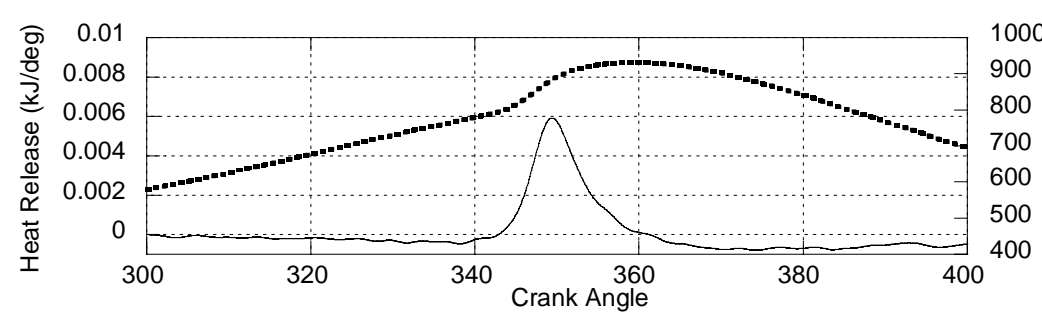

(b)

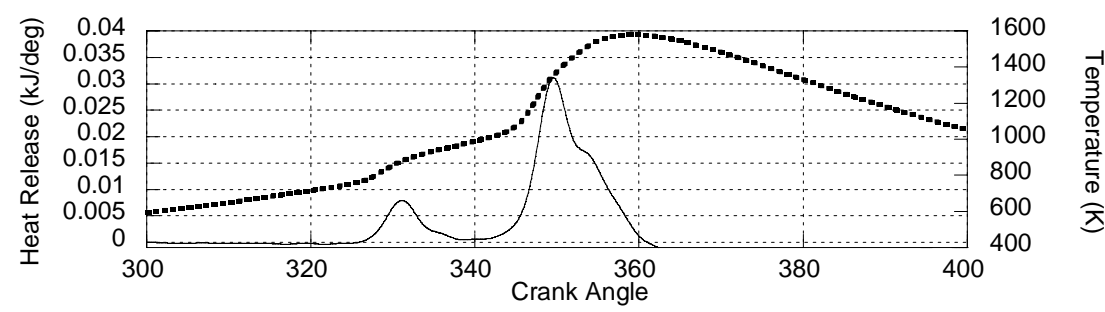

(c)

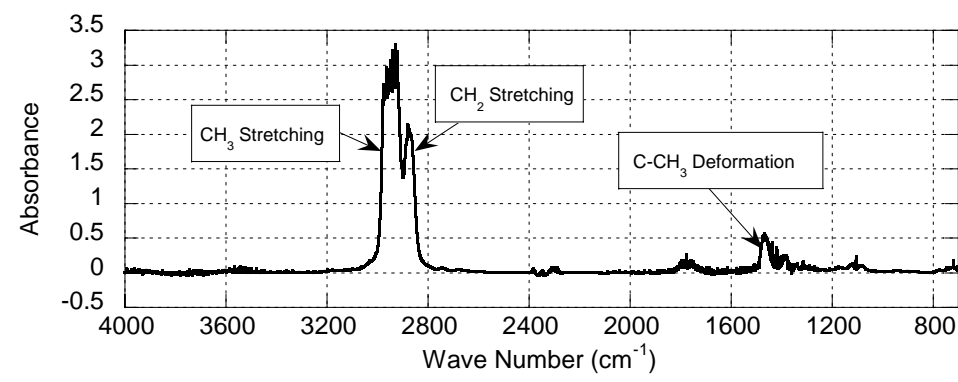

(a)

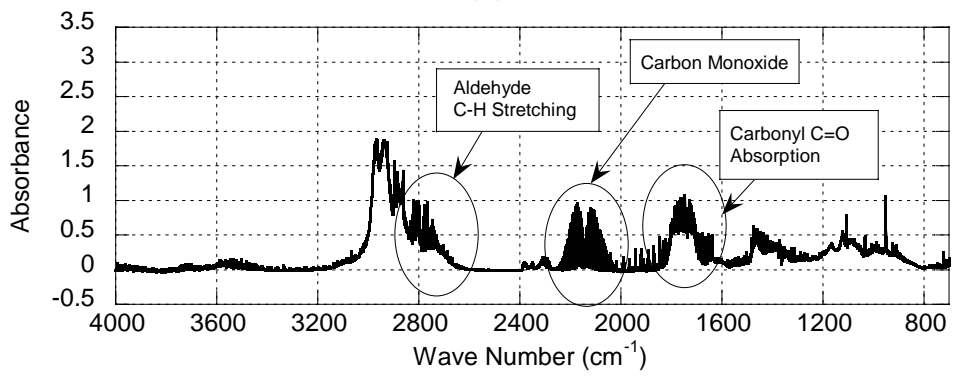

(b)

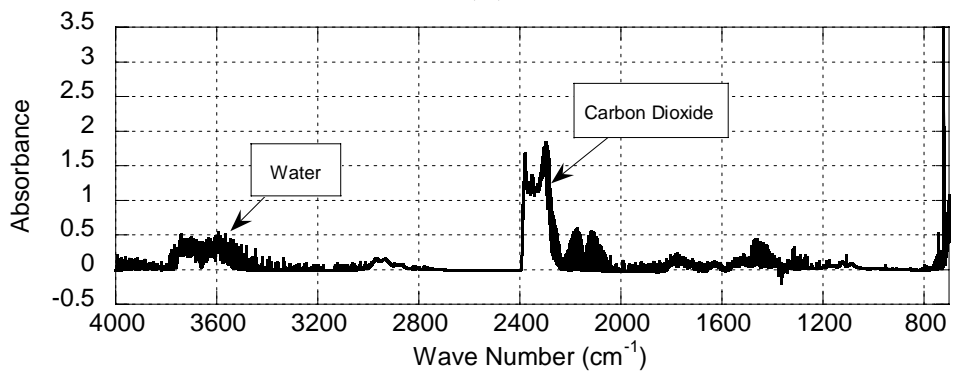

(c)

Figure 3.1.3.27 Heat release/temperature profiles and FTIR spectra for $n$-heptane at $\Phi=0.25$ at an intake temperature of $110^{\circ} \mathrm{C}$ for compression ratios of (a) 4.47 , (b) 6.62 , and (c) 11.07 . 


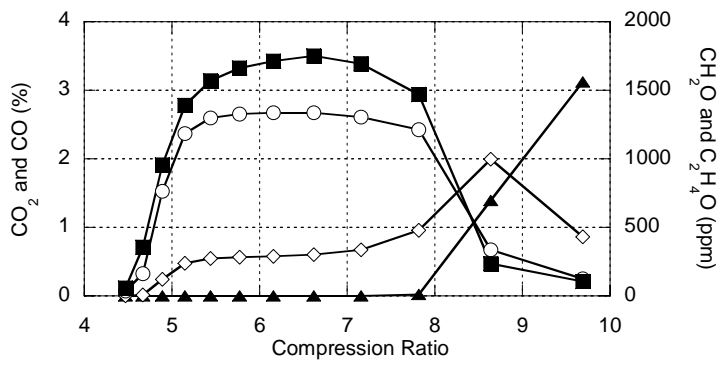

(a)

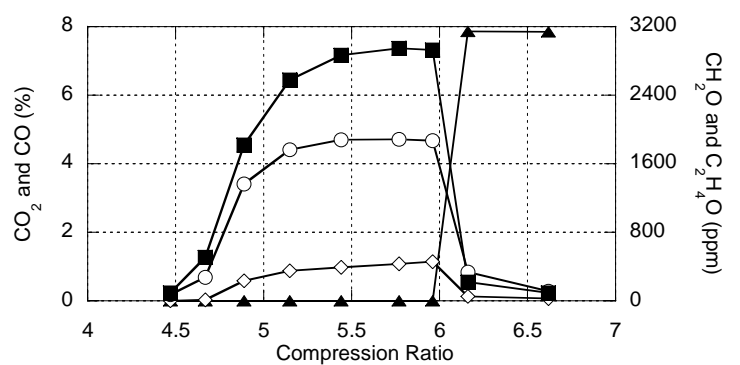

(b)

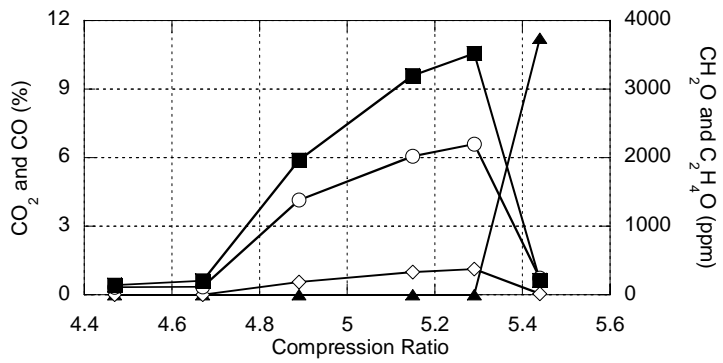

(c)

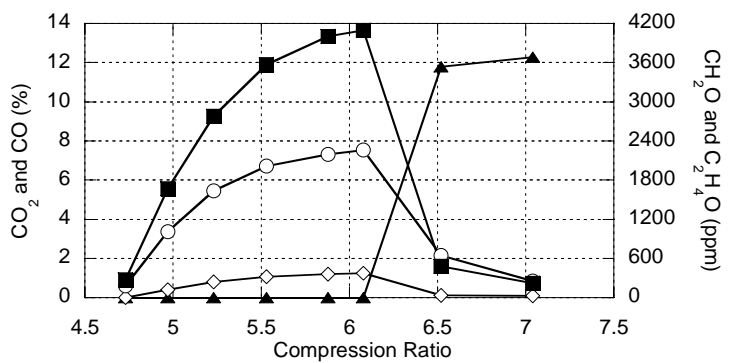

(d)

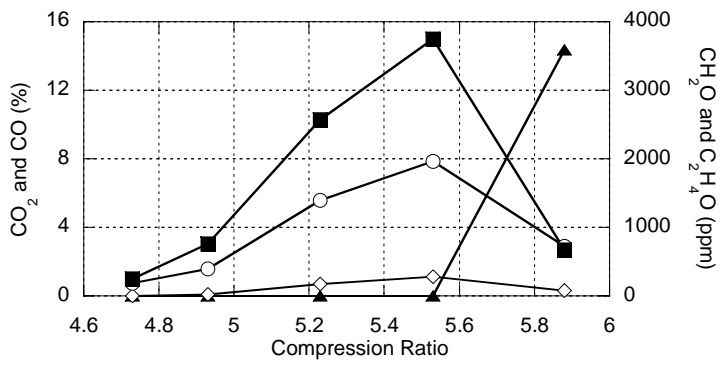

(e)

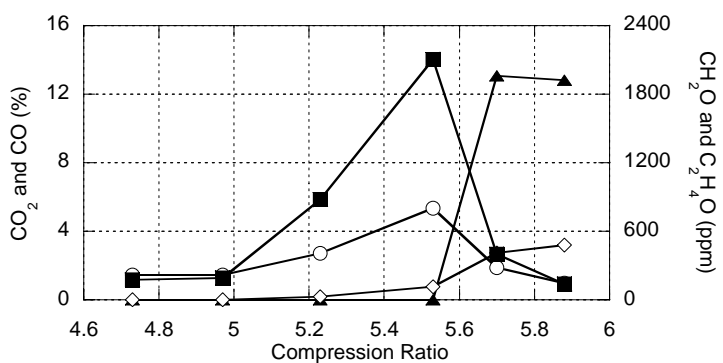

(f)

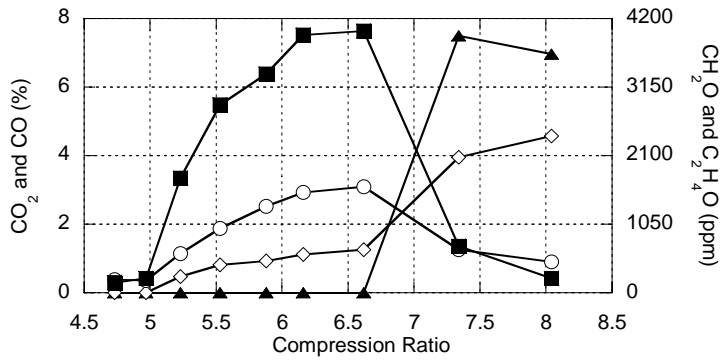

(g)

Figure 3.1.3.28 FTIR spectra for n-heptane at an intake temperature of $110^{\circ} \mathrm{C}$ and (a) $\Phi=0.25$ with no dilution, (b) $\Phi=0.5$ with no dilution, (c) $\Phi=0.75$ with $40 \%$ dilution, (d) $\Phi=1.0$ with $40 \%$ dilution, (e) $\Phi=1.25$ with $40 \%$ dilution, (f) $\Phi=1.5$ with $40 \%$ dilution, and $(\mathrm{g}) \Phi=2.0$ with $80 \%$ dilution for $(\boldsymbol{\Delta})$ carbon dioxide, $(\diamond)$ carbon monoxide, $(\circ)$ formaldehyde, and $(\mathbf{\square})$ acetaldehyde. 


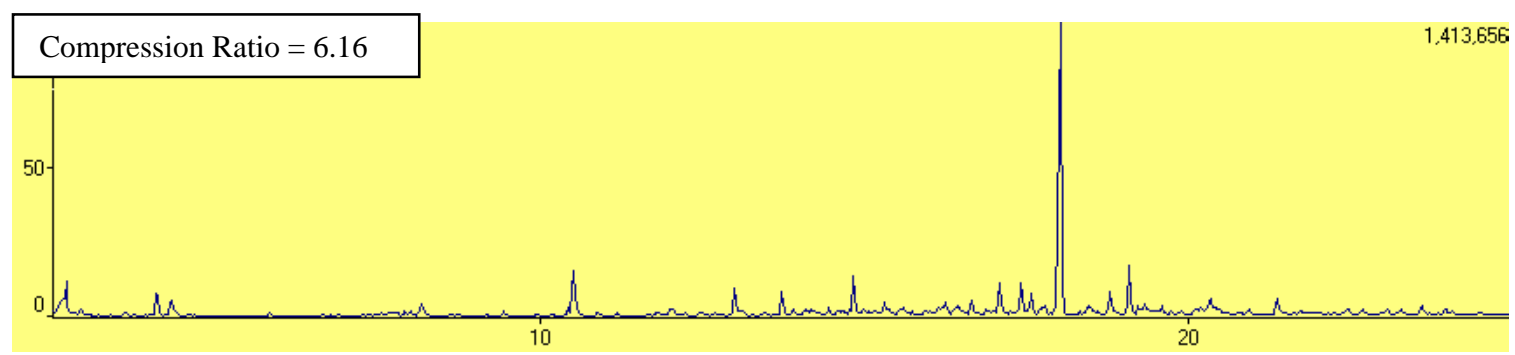

Figure 3.1.3.29 GC for $\mathrm{n}$-heptane exhaust condensate at $\Phi=0.25$ and an intake temperature of $110^{\circ} \mathrm{C}$ for a compression ratio 6.16 .

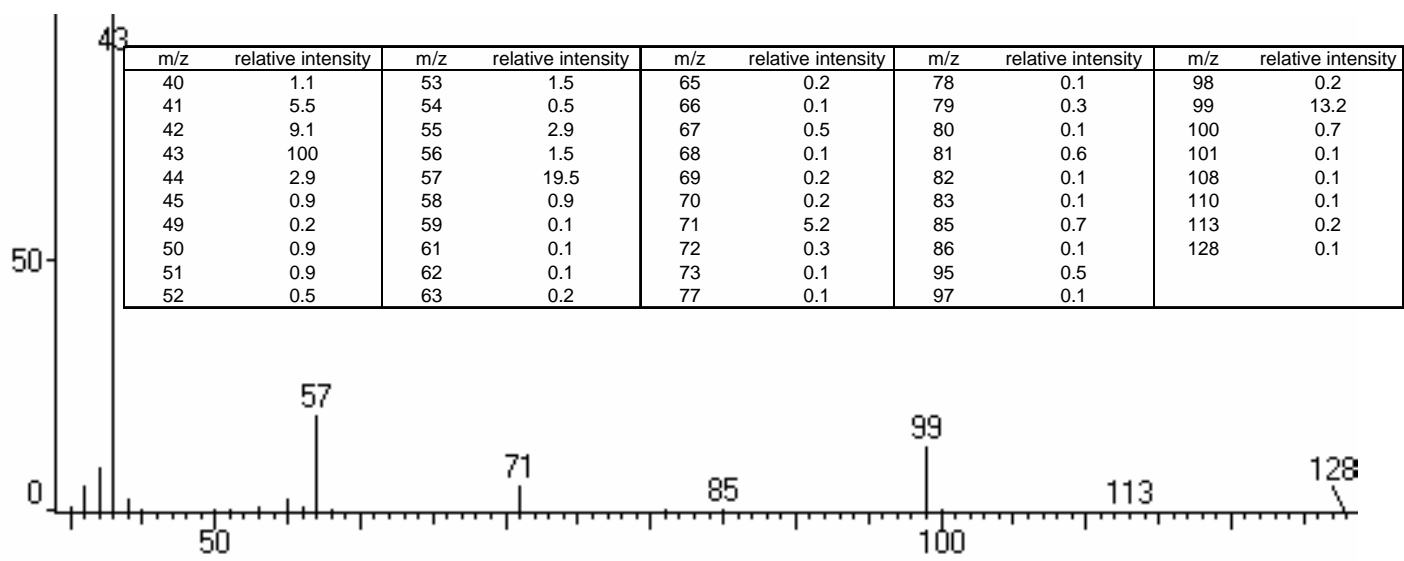

(a)

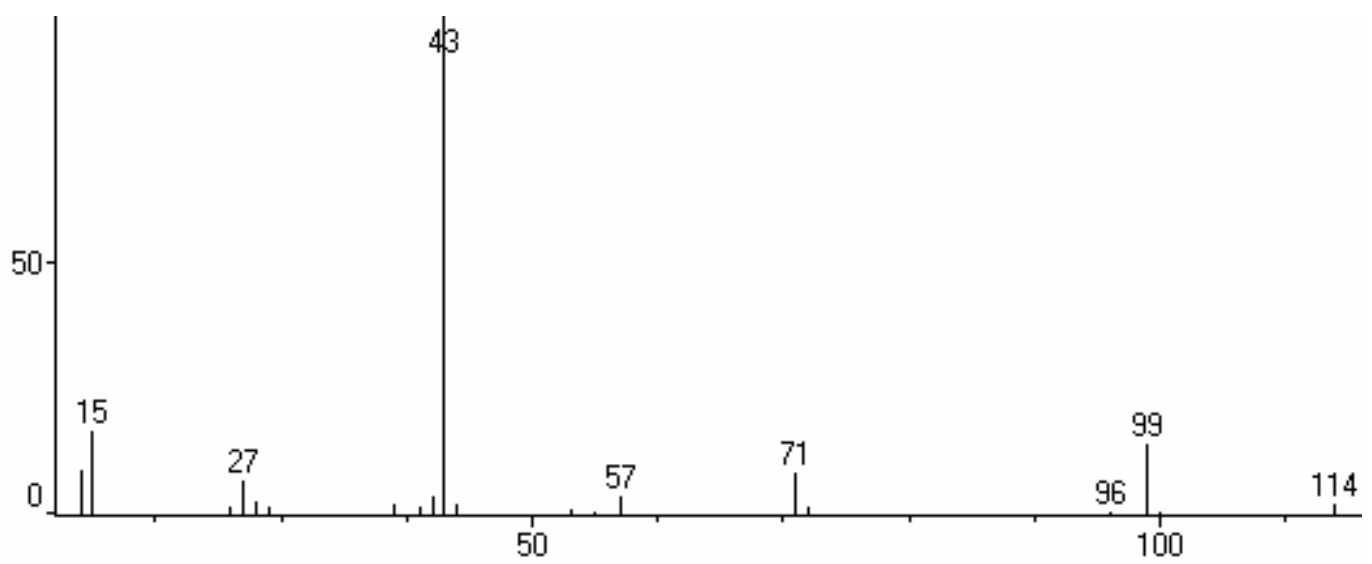

(b)

Figure 3.1.3.30 Mass spectra for (a) n-heptane exhaust condensate peak at a retention time of 18 minutes, and (b) 2,5-hexanedione from NIST library. 


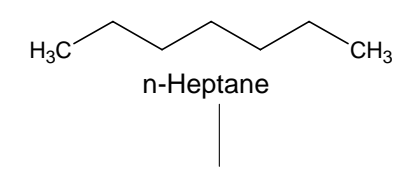

Hydrogen Abstraction
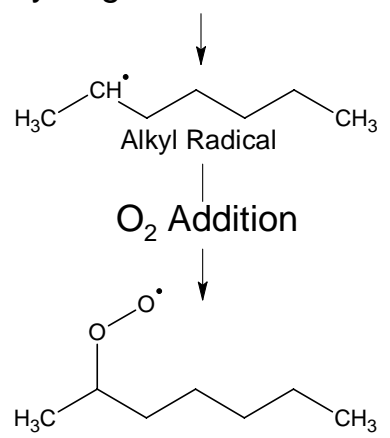

Hydroperoxy Radical

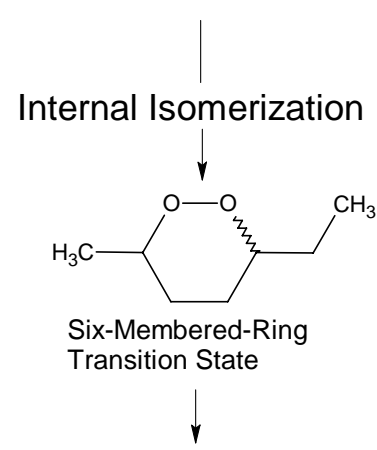<smiles>CC[C]CCC(C)OO</smiles><smiles>CCC(CCC(C)OO)O[O]</smiles>

Internal Isomerization

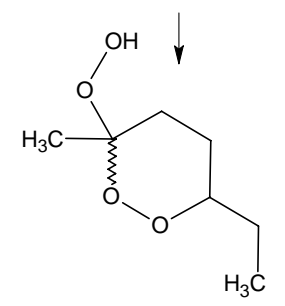

Six-Membered-Ring Transition State<smiles>CCC(CCC(C)=O)OO</smiles>

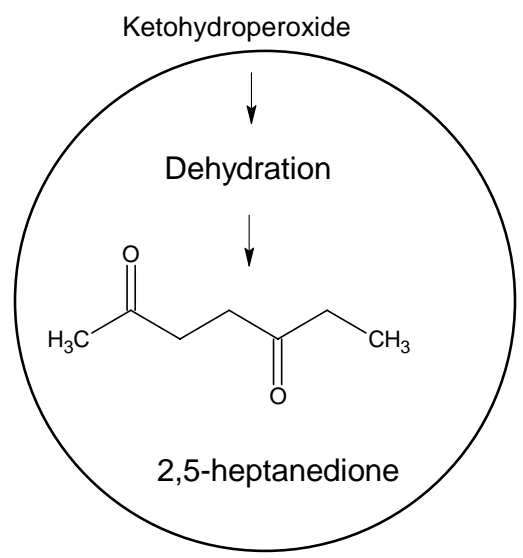

Figure 3.1.3.31 Low temperature reaction mechanism of n-heptane, taken from Curran et al. [9].

Table 3.1.3.11 Species identified during GC/MS analysis of $n$-heptane exhaust condensate.

\begin{tabular}{|l|l|}
\hline Identification & Retention Time \\
\hline Butanal & 2.68 \\
\hline 2,3 Butanedione & 2.72 \\
\hline 4-penten-2-one & 3.63 \\
\hline 2-pentanone & 4.11 \\
\hline Unidentified & 4.33 \\
\hline Butanoic acid & 7.88 \\
\hline Unidentified & 8.20 \\
\hline Unidentified & 10.53 \\
\hline Pentanoic acid & 12.02 \\
\hline Unidentified & 13.00 \\
\hline 2,5 hexanedione & 13.74 \\
\hline Unidentified & 14.84 \\
\hline Unidentified & 16.66 \\
\hline Unidentified & 16.91 \\
\hline Heptanedione isomer & 17.11 \\
\hline 2-pentanone, 5-(1,2-propadienyloxy)- & 17.42 \\
\hline Unidentified & 17.58 \\
\hline 2,5 heptanedione & 18.00 \\
\hline Unidentified & 18.78 \\
\hline Heptanedione isomer & 19.09 \\
\hline
\end{tabular}




\section{Iso-Octane}

In the combustion analysis section, it was shown that LTHR was not detected for iso-octane. However, the quantified FTIR data for $\Phi=0.25,0.5,0.75,1.0,1.25$, and 1.5 in Figure 3.1.3.32 shows that there are pre-ignition reactions that take place. At the lowest compression ratio shown for each equivalence ratio, the concentration of acetaldehyde in the exhaust is close to its maximum value while the concentrations of carbon monoxide and formaldehyde are low. As the compression ratio is increased, the concentrations of formaldehyde and carbon monoxide gradually increase while the concentration of carbon dioxide remains negligible, although these increases are not accompanied by detectable heat release. At a compression ratio sufficiently high to initiate HTHR, the concentration of carbon dioxide increases, while the concentrations of the aldehydes decrease. As with n-heptane, the concentration of carbon monoxide decreases with HTHR if the engine is operated under fuel-lean conditions, but increases if it is operated under fuel-rich conditions. This trend is in good agreement with the motored engine study by Leppard [10] in which carbon monoxide in the exhaust was used to determine the extent of iso-octane pre-ignition chemistry, with concentration of carbon monoxide similar to those observed here.

Only iso-octane and water could be detected in the exhaust condensate collected for isooctane, regardless of whether it was a pre-ignition condition, or whether it was a condition with HTHR. The absence of the high molecular weight, partially oxidized species, similar to those seen for n-heptane, is likely due to a lower extent of low-temperature reactions, illustrated by there being no detectable LTHR in the combustion analysis. As stated above, the increasing concentration of carbon monoxide provides evidence of pre-ignition chemistry, but was much lower than for nheptane. Thus, it is possible that the concentration of the high molecular weight, partially oxidized species were too low to enable collection and identification with the GC/MS using the current methodology.

\section{BP325_Light}

The quantified FTIR results for BP325_light at $\Phi=0.25,0.5,1.0,1.25,1.5$, and 2.0 are shown in Figure 3.1.3.33. The results for BP325_light are similar to those of n-heptane, with LTHR producing high concentrations of formaldehyde, acetaldehyde, and carbon monoxide without producing carbon dioxide. As with $\mathrm{n}$-heptane, when the compression ratio is sufficiently high for HTHR, the aldehydes produced during LTHR are largely consumed. Also, if the conditions are fuellean or stoichiometric, the carbon monoxide is largely consumed during HTHR as well. With fuelrich conditions, the carbon monoxide concentration is comparable to the carbon dioxide concentration with the onset of HTHR. The most significant difference between BP325_light and nheptane revealed during the FTIR analysis was that the concentrations of carbon monoxide, formaldehyde, and acetaldehyde were significantly lower. This result was expected because these species are products of LTHR, and as was shown in 3.1.3.26, of the fuels that exhibited a two-stage ignition process, BP325_light exhibited the lowest magnitude LTHR.

BP325 light is comprised nearly entirely of species that are less volatile than n-heptane. This resulted in a high concentration of unreacted fuel in the exhaust condensate for BP325_light. However, a series of aldehydes, 2-ketones, and organic acids could be identified by their respective characteristic mass fragments of $\mathrm{m} / \mathrm{z}=44,58$, and 60, respectively, as shown in Figure 3.1.3.34 (a), (b), and (c), respectively for $\Phi=0.25$ and a compression ratio of 6.16. The series of aldehydes, shown in Figure 3.1.3.34 (a), range in size from C7 (heptanal) to C11 (undecanal), while the ketones, shown in 3.1.3.34 (b), range in size from C9 (2-nonanone) to C12 (2-dodecanone). The carbon chains for these carbonyl species are significantly smaller than the carbon chains of the most prominent n-alkanes in BP325_light, which ranged in size from C8 (n-octane) to C15 (pentadecane). This finding supports the carbonyl mechanism given by Curran et al. [9] who show that carbonyl 
species and olefins are formed simultaneously through $\beta$-scissions of an alkylhydroperoxy radical, as shown by reaction (4) in Table 3.1.3.10. The identifiable organic acids for BP325_light range in size from C5 (pentanoic acid) to C11 (undecanoic acid), which extends to shorter carbon chains than either aldehydes or ketones. The formation of organic acids from n-alkanes during LTHR is explored in more detail in the FT Diesel section.

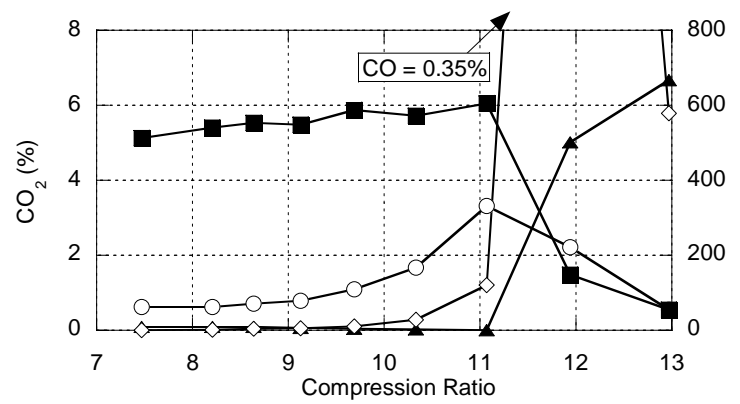

(a)

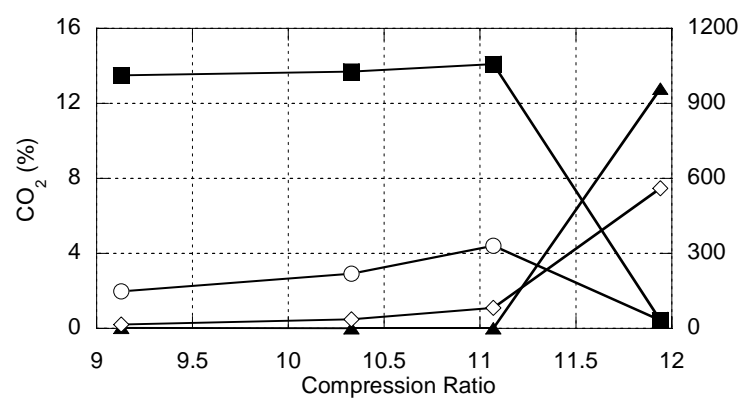

(b)

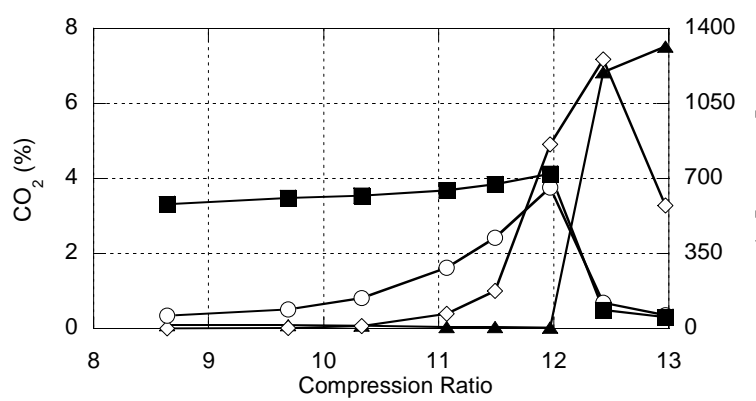

(c)

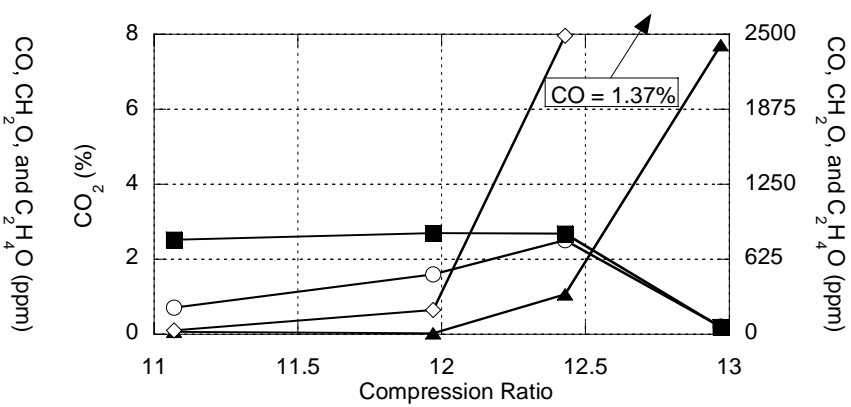

(d)

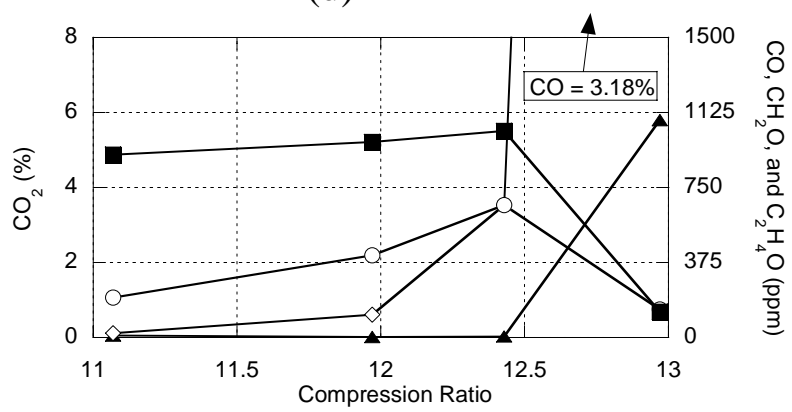

(e)

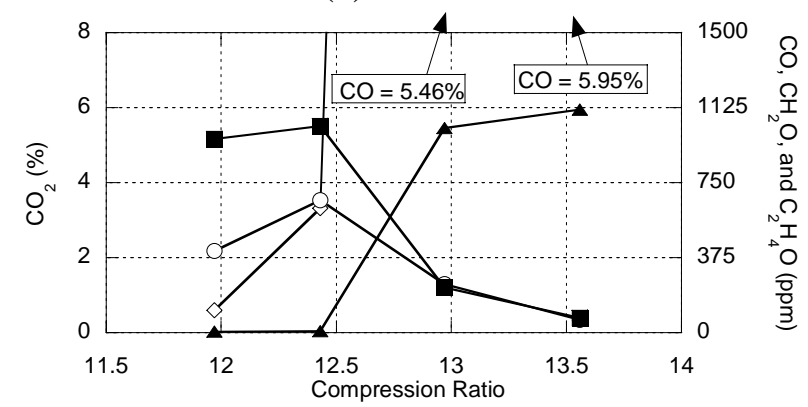

(f)

Figure 3.1.3.32 Quantified FTIR spectra for iso-octane at an intake temperature of $230^{\circ} \mathrm{C}$ and (a) $\Phi=0.25$ with no dilution, (b) $\Phi=0.5$ with no dilution, (c) $\Phi=0.75$ with $70 \%$ dilution, (d) $\Phi=1.0$ with $70 \%$ dilution, (e) $\Phi=1.25$ with $70 \%$ dilution, and (f) $\Phi=1.5$ with $70 \%$ dilution for $(\boldsymbol{\Delta})$ carbon dioxide, $(\diamond)$ carbon monoxide, $(\circ)$ formaldehyde, and $(\mathbf{\square})$ acetaldehyde. 


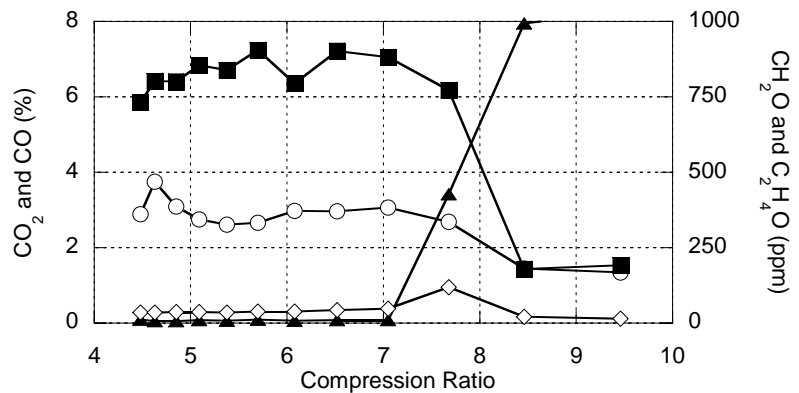

(a)

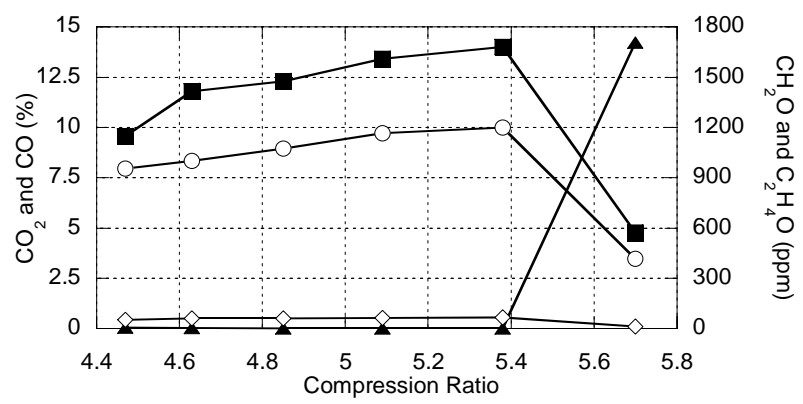

(b)

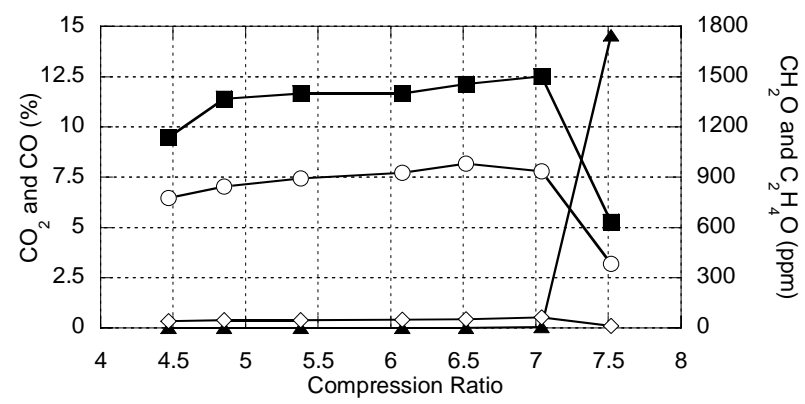

(c)

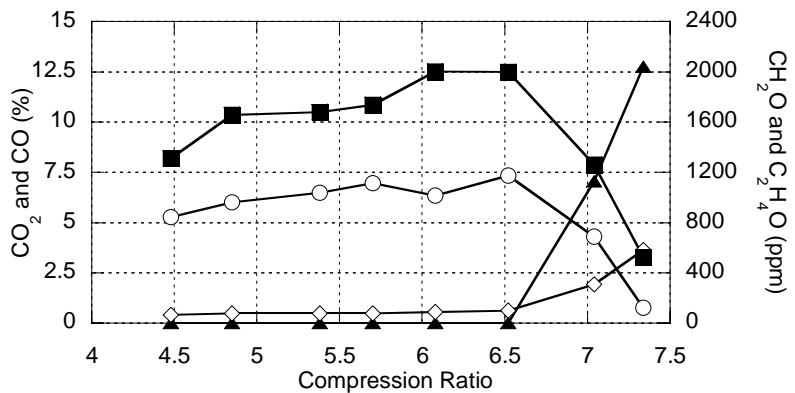

(d)

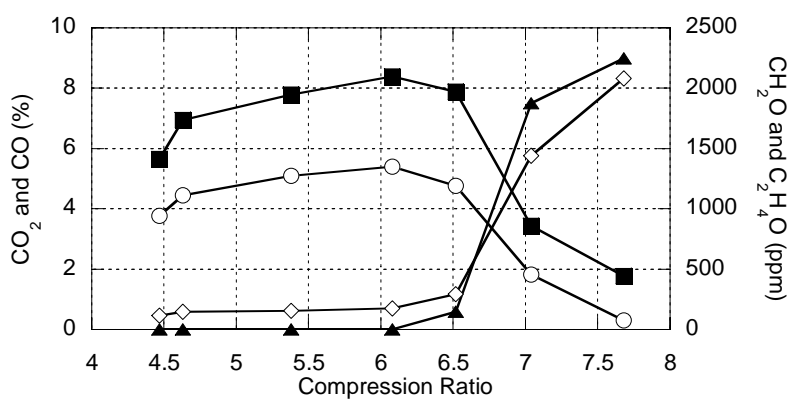

(e)

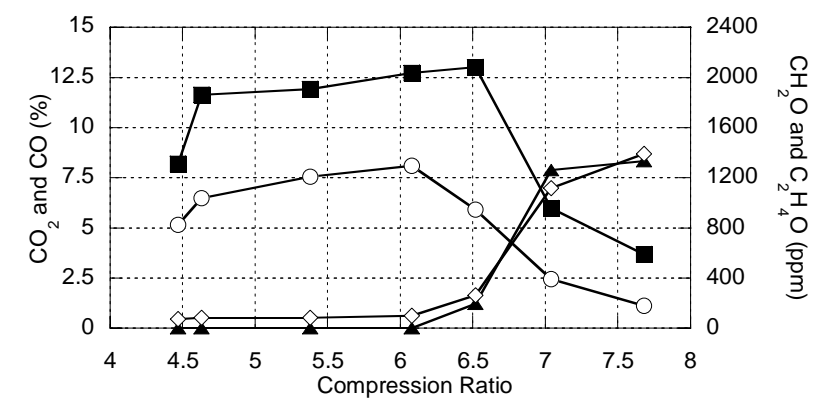

(f)

Figure 3.1.3.33. FTIR spectra for BP325_light at an intake temperature of $260^{\circ} \mathrm{C}$ and (a) $\Phi=$ 0.25 with no dilution, (b) $\Phi=0.5$ with no dilution, (c) $\Phi=1.0$ with $70 \%$ dilution, (d) $\Phi=1.25$ with $70 \%$ dilution, (e) $\Phi=1.5$ with $70 \%$ dilution, and (f) $\Phi=2.0$ with $70 \%$ dilution for $(\mathbf{A})$ carbon dioxide, $(\diamond)$ carbon monoxide, $(\circ)$ formaldehyde, and ( $\mathbf{a})$ acetaldehyde. 


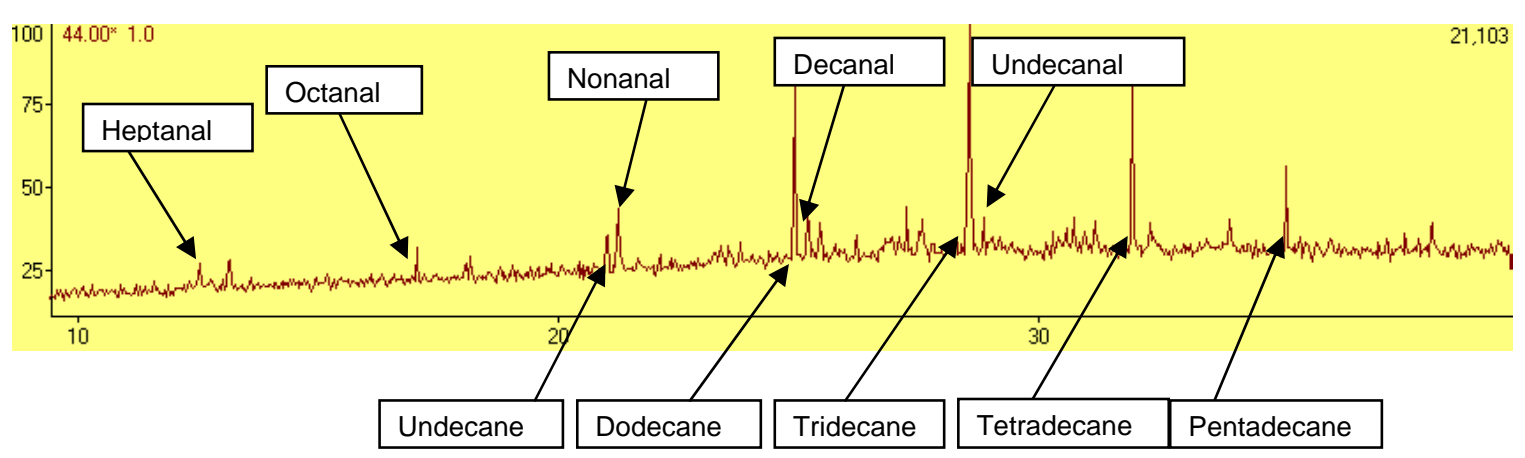

(a)

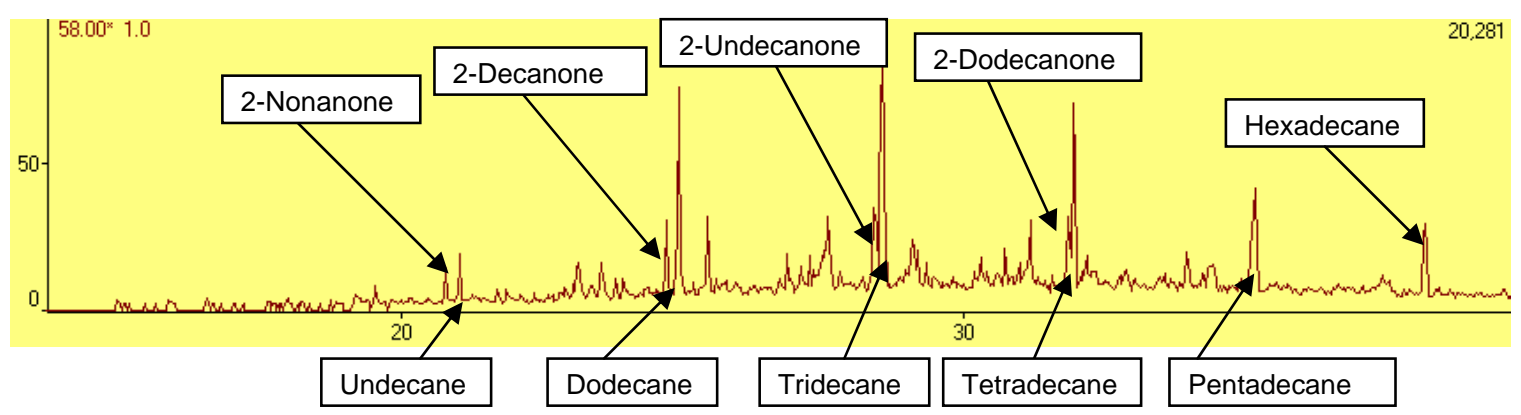

(b)

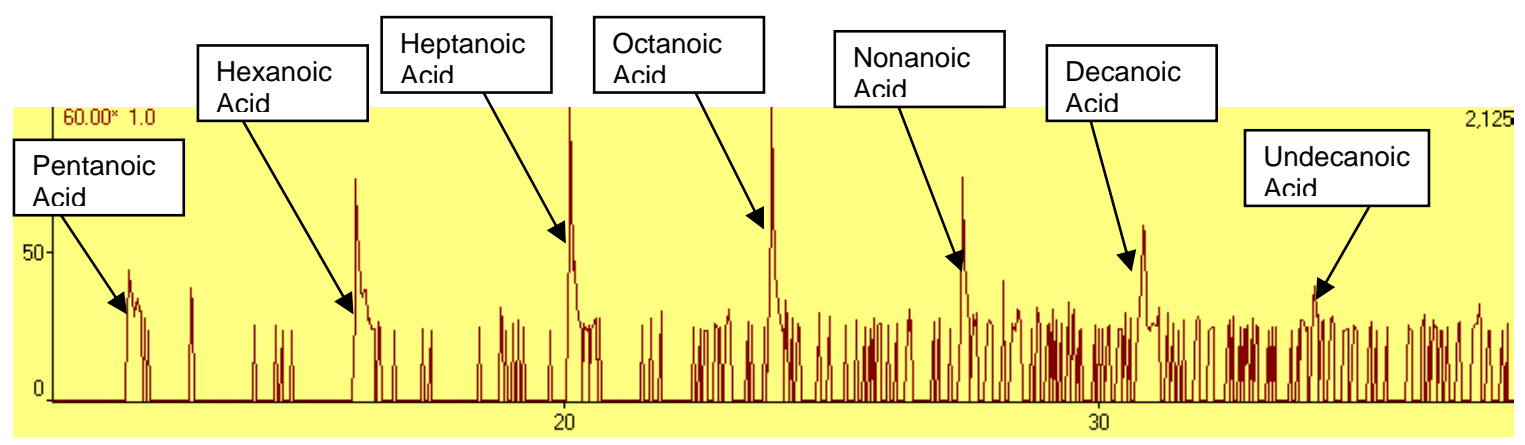

(c)

Figure 3.1.3.34. GC/MS analysis of BP325_light exhaust condensate for (a) aldehydes at $\mathrm{m} / \mathrm{z}=44$, (b) 2-ketones at $\mathrm{m} / \mathrm{z}=58$, and (c) organic acids at $\mathrm{m} / \mathrm{z}=60$. 


\section{FT Diesel}

The quantified FTIR data for FT diesel at $\Phi=0.5,0.75,1.0,1.25,1.5$, and 2.0, shown in Figure 3.1.3.35, is similar to that of n-heptane and BP325_light at lean equivalence ratios, but differs significantly at higher equivalence ratios. As with n-heptane and BP325_light, LTHR produces high concentrations of carbon monoxide, formaldehyde, and acetaldehyde while producing virtually no carbon dioxide, and the formaldehyde and acetaldehyde concentrations decrease with the onset of the HTHR. However, unlike BP325_light and nheptane, carbon monoxide is more strongly favored at all equivalence ratios. Above $\Phi=0.5$, the carbon monoxide concentration does not decrease with the onset of the HTHR. At $\Phi=$ 0.75 , the concentration of carbon monoxide remains relatively unchanged with the onset of HTHR, and by $\Phi=1.0$, the concentration of carbon monoxide is comparable to that of carbon dioxide. The trend of carbon monoxide becoming increasingly favored as $\Phi$ increases continues until, at $\Phi=2.0$, the onset of HTHR was not accompanied by a rise in carbon dioxide, but instead remained at negligible levels. Given that the FT diesel fuel consists almost entirely of paraffins, it was expected that its behavior would be similar to that of $\mathrm{n}$-heptane. It is unclear why it has a much stronger affinity than $\mathrm{n}$-heptane to produce carbon monoxide rather than carbon dioxide.

Similar to BP325_light, the GC/MS analysis of exhaust condensate for FT diesel shown for $\Phi=1.0$ and a compression ratio of 5.09 (a condition that is representative of all conditions where only LTHR occurs) revealed a series of aldehydes, 2-ketones, and organic acids, shown in Figure 3.1.3.36 (a), (b), and (c), respectively. The series of aldehydes, shown in Figure 3.1.3.36 (a), range in size from C6 (hexanal) to C11 (undecanal), while the ketones, shown in Figure 3.1.3.36(b), range in size from C8 (2-octanone) to C12 (2dodecanone). Both of these series extend to chains with one less carbon than was observed for BP325_light, and like BP325_light, the carbon chains for these carbonyl species are significantly smaller than the carbon chains than the most prominent n-alkanes in FT diesel, which ranged in size from C8 (n-octane) to C15 (pentadecane), as is shown in (b). The finding that the carbonyl species that are produced during the LTHR are shorter than their parent molecules is again consistent with the model by Curran et al. [9], which shows that an olefin and carbonyl are produced simultaneously, as shown in reaction (4) of Table 3.1.3.10.

The series of organic acids for FT diesel, shown in Figure 3.1.3.36 (c), ranged in size from C4 (butanoic acid) to C11 (undecanoic acid). Although the experimental technique used here is not quantitative, as was discussed in the Experimental section, the signal strength of the acids from the FT diesel fuel is much stronger than they were from BP325_light. That FT diesel has a much lower aromatic content than BP325_light, as shown in Table 3.1.3.7, and that the acids identified here have long, saturated carbon chains strongly suggests that they are not a product of aromatic ring opening in the mechanism given by Glassman [3]. Further, the acids seen here are products of LTHR, a combustion regime where aromatics are difficult to oxidize because of the stability of the aromatic rings.

It could be suggested that the organic acids identified in this study are not the products of combustion, but instead the product of aldehyde hydrolysis during the collection and preparation of the sample. It is true that, in the presence of water, an aldehyde will react to form a 1,1-diol, or a hydrate, which is the initial step to forming an acid. However, the reaction will not go to completion to form an organic acid unless a catalyst, such as $\mathrm{CrO}_{3}$, is present [17]. Thus, it can be concluded that the organic acids detected in the condensate are not hydrolysis products from aldehydes, but rather are condensed from the exhaust directly.

This study cannot offer any mechanism by which carboxylic acids are formed by $\mathrm{n}$ paraffins, but two mechanism requirements can be offered. First, we have shown that organic acids are produced in significant concentrations during LTHR, a combustion regime 
where there is a very low concentration of hydroxyl radicals. Thus, it is likely that the formation mechanism does not require the addition of a hydroxyl group. This requirement excludes several of the mechanisms suggested by Zervas et al. [18], such as hydroxyl radical addition to a carbonyl radical. Second, the organic acids that were identified in the condensate have carbon chains that are shorter than the parent molecules. Thus, it is likely that their formation involves a carbon-carbon bond cleavage. 


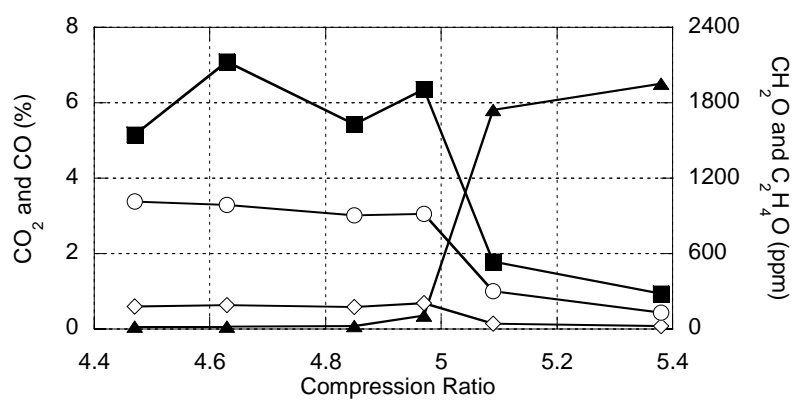

(a)

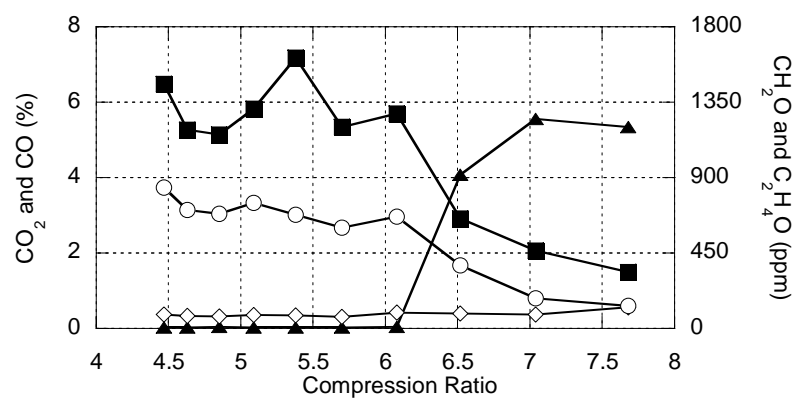

(b)

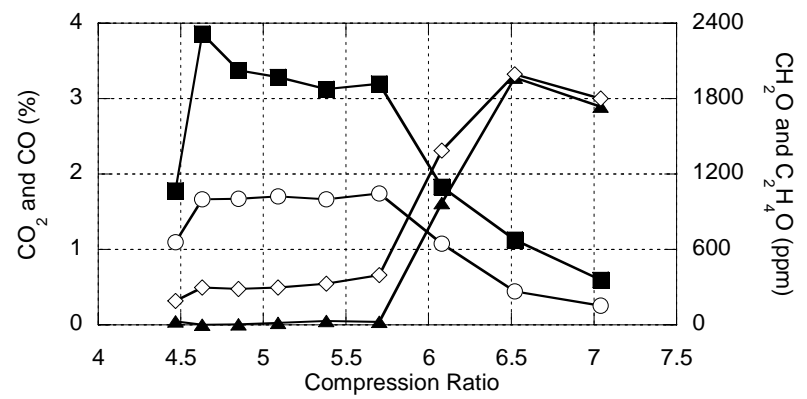

(c)

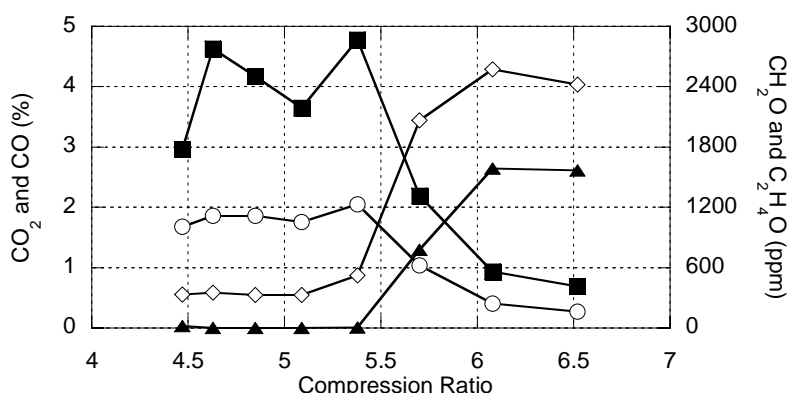

(d)

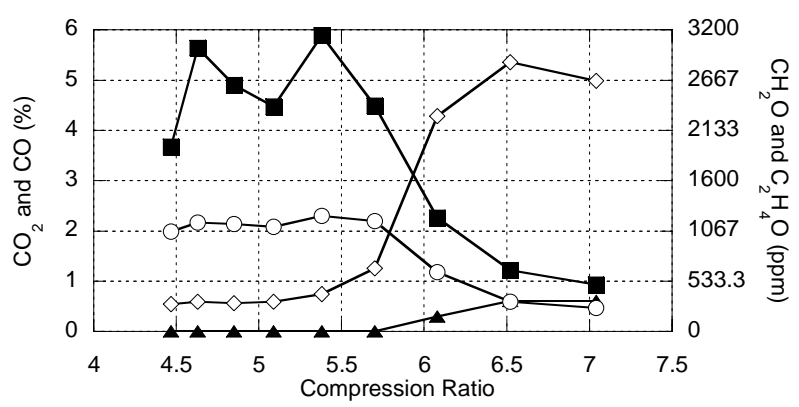

(e)

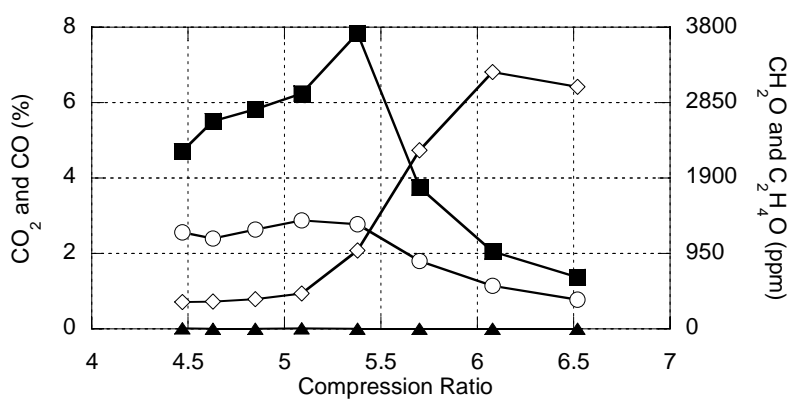

(f)

Figure 3.1.3.35. FTIR spectra for FT diesel exhaust at an intake temperature of $260^{\circ} \mathrm{C}$ and (a) $\Phi=$ 0.5 with $45 \%$ dilution, (b) $\Phi=0.75$ with $45 \%$ dilution, (c) $\Phi=1.0$ with $100 \%$ dilution, (d) $\Phi=1.25$ with 100\% dilution, (e) $\Phi=1.5$ with 100\% dilution, and (f) $\Phi=2.0$ with $100 \%$ dilution for ( $\mathbf{\Delta}$ ) carbon dioxide, $(\diamond)$ carbon monoxide, $(\circ)$ formaldehyde, and $(\mathbf{\square})$ acetaldehyde. 


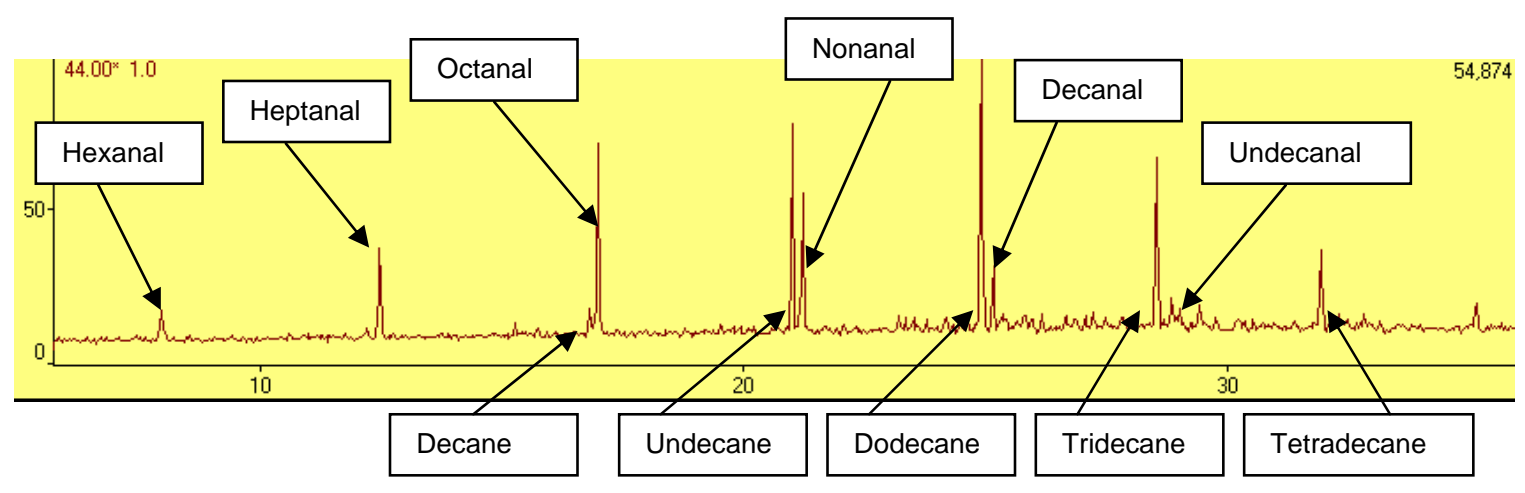

(a)

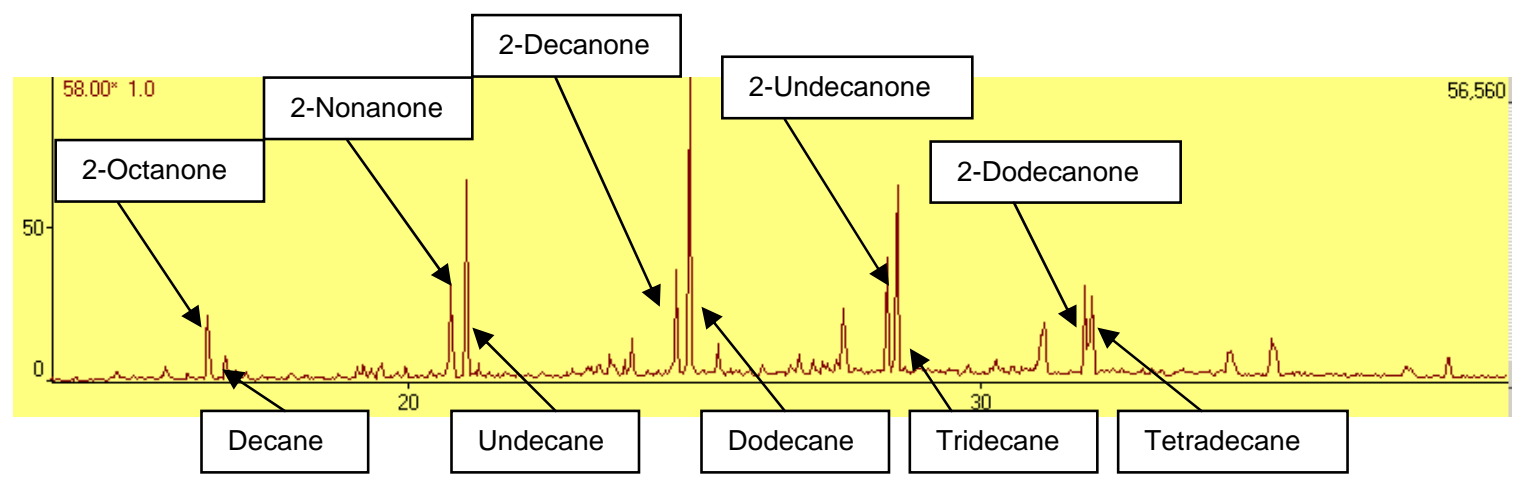

(b)

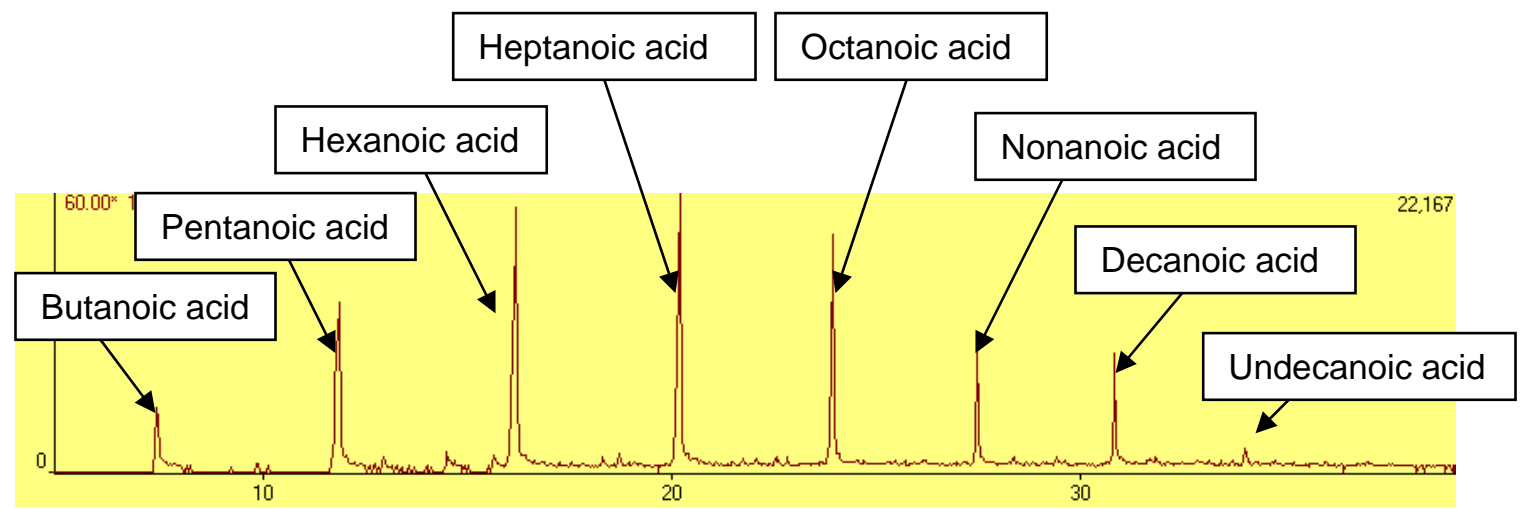

(c)

Figure 3.1.3.36. GC/MS analysis of FT diesel exhaust condensate for (a) aldehydes at $\mathrm{m} / \mathrm{z}=44$, (b) 2-ketones at $\mathrm{m} / \mathrm{z}=58$, and (c) organic acids at $\mathrm{m} / \mathrm{z}=60$. 


\section{Methyl Decanoate}

The quantified FTIR data for methyl decanoate at $\Phi=0.25,0.75,1.0,1.25,1.5$, and 2.0, given in Figure 3.1.3.37, shows similarities to the previous fuels, but also displays some unique behavior. As seen with the other 2-stage ignition fuels, LTHR produces high concentrations of carbon monoxide, formaldehyde, and acetaldehyde. The onset of HTHR causes the concentrations of formaldehyde and acetaldehyde to decrease. The concentration of carbon monoxide decreases at lean equivalence ratios with the onset of HTHR, and rises at fuel-rich conditions to concentrations comparable to carbon dioxide, thus making it more similar to n-heptane and BP325_light than to FT diesel.

Methyl decanoate is unique from all of the other fuels in that it forms significant quantities of carbon dioxide during LTHR, concentrations comparable to those of the carbon monoxide. As stated earlier, the oxidation of carbon monoxide to carbon dioxide does not take place at low temperature conditions when hydrocarbons are present [14]. Thus, the occurrence of carbon dioxide in a regime that has been previously shown to only produce carbon monoxide with nonoxygenated fuels is direct evidence of decarboxylation. This finding is in agreement with previous researchers who have concluded that decarboxylation occurs with other oxygenated fuels with ester groups [19-21].

Figure 3.1.3.38 shows the GC/MS trace for methyl decanoate at $\Phi=0.75$ and a compression ratio of 5.60 , which is representative of all conditions where only LTHR occurs. A high concentration of unreacted methyl decanoate was found in the condensed exhaust, necessitating that the detector sensitivity be dramatically attenuated at the retention time for methyl decanoate, causing an oddshaped peak at 29.5 minutes. As can be seen by the other peaks, species with both lower and higher retention times than the starting material were formed during the LTHR process. The species identified from the exhaust can be classified into methyl esters, oxo-methyl esters, aldehydes, carboxylic acids, and others, all of which are listed with their retention times in Table 3.1.3.12. The group of methyl esters consists of both fully saturated and unsaturated aliphatic chains, and they range in size from 2-methyl butanoate to methyl dodecanoate, the latter of which was present in trace amounts in the CE-1095 starting material, as described in the Fuel Selection section. The oxomethyl esters identified here are fully saturated methyl esters with a carbonyl functionality on the aliphatic carbon chain, most of which are ketone functionalities, with the aliphatic chain length ranging in size from C5 (4-oxopentanoate) to C10 (9-oxodecanoate). The structure of 4oxopentanoate is shown in Figure 3.1.3.38 (a).

The combination of the unsaturated, short chain, and oxo-methyl esters demonstrate that the aliphatic chain of the methyl ester can participate in the reactions associated with LTHR while the ester portion of the molecule remains intact. Further evidence of this is given by the identification of 5-methoxycarbonylpentanon-4-olide, whose structure is shown in Figure 3.1.3.38 (a), which appears to be the result of a cyclic ether being formed from the carbon chain while the methyl ester remains intact. Thus, while the FTIR results show that decarboxylation of the ester group occurs at significant levels, the analysis of exhaust condensate suggests that other reactions consistent with LTHR, forming high molecular weight oxygenated species, similar to those of n-paraffins, also take place. Decarboxylation could be the end result of the LTHR process, but the evidence here strongly indicates that additional oxygen, if available, is incorporated into the aliphatic portion of the molecule through LTHR reactions before decarboxylation occurs.

A series of organic acids was also identified, ranging from C4 (butanoic acid) to C8 (octanoic acid), as well as C10 (decanoic acid). It is not possible to determine whether the carboxylic acids detected here are formed directly from the loss of the methyl radical from the ester group, followed by a hydrogen addition, or if they are formed from the aliphatic chain during LTHR as they were for n-heptane, BP325_light, and FT diesel. However, the formation of the acid directly from the methyl ester is likely because the most abundant organic acid identified here was decanoic acid, which has an aliphatic chain length of $\mathrm{C} 10$, the same as methyl decanoate, whereas the organic acid aliphatic 
chain lengths for FT diesel and BP325 were significantly shorter than the n-paraffins from which they were formed.

Other species identified in the exhaust condensate included 2-nonanone, heptanal, and nonanal, although the concentrations of all three of these species were relatively low compared to the methyl esters and oxo-methyl esters. The low abundance of aldehydes and ketones further suggests that LTHR reactions occur while the ester group remains intact; otherwise we would expect to see higher concentrations of aldehydes and ketones, similar to what was observed for FT diesel. There were also several prominent peaks from the GC analysis that could not be identified, most notably two species with base peaks of $\mathrm{m} / \mathrm{z}=85$ with retention times of 32.65 and 32.97 , and two species with prominent peaks at $\mathrm{m} / \mathrm{z}=139$ with retention times of 32.24 and 32.52 . The two peaks at $\mathrm{m} / \mathrm{z}=85$ appear to be isomers because of the similarities in the mass spectra, shown in Figure 3.1.3.38 (b), and although a base peak at $\mathrm{m} / \mathrm{z}=85$ is characteristic of many cyclic ethers, an acceptable match could not be made to positively identify these peaks as such. The two peaks with prominent mass fragments at $\mathrm{m} / \mathrm{z}=139$ also appear to be isomers of each other because of the similarities in their mass spectra, given in Figure 3.1.3.38 (c). Among the species that show prominent peaks at $\mathrm{m} / \mathrm{z}=139$ are unsaturated ketones, and tetrahydrofuran with an unsaturated alkyl chain. However, as with the species with a base peak at $\mathrm{m} / \mathrm{z}=85$, no satisfactory identifications could be made for these peaks.

With the accumulated data, a sequential autoignition process for methyl decanoate can be postulated. The GC/MS data suggests that the aliphatic chain of the methyl decanoate participates in a series of low-temperature reactions, similar to those of $n$-heptane, producing carbon monoxide, carbonyl sites, and reducing the length of the aliphatic chain. This process occurs while the ester group remains intact, a finding that is in agreement with the kinetic model from Fisher et al. [22]. The FTIR data here also shows that decarboxylation also plays a large role in the methyl decanoate combustion process. However, considering that the ester group was identified on nearly all of the condensable species in the exhaust, it is likely that low-temperature reactions on the alkyl chain shorten the molecule, and decarboxylation does not proceed until the aliphatic chain has been largely consumed by LTHR reactions. This is a different picture of decarboxylation than that given by Mueller et al. [19] and by Glaude et al. [21] who both propose that ester compounds undergo unimolecular decomposition without oxygen addition during low-temperature reactions. 


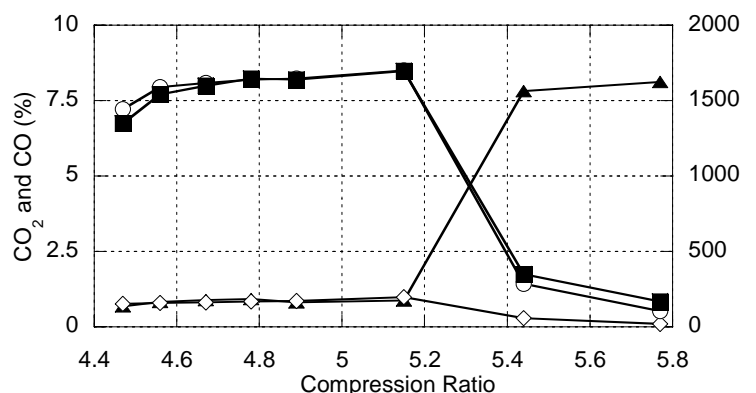

(a)

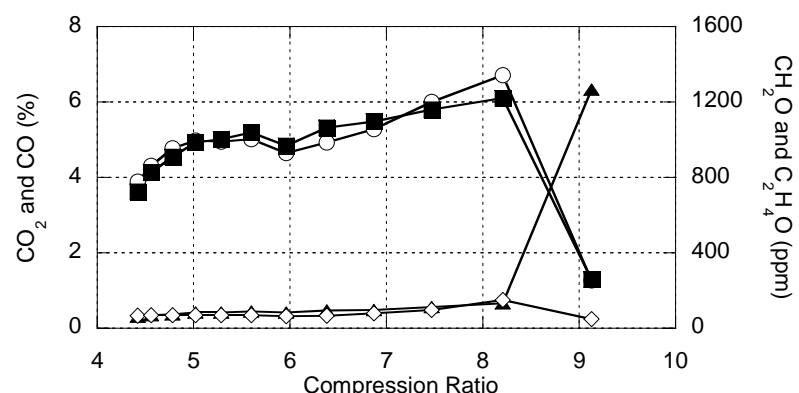

(b)

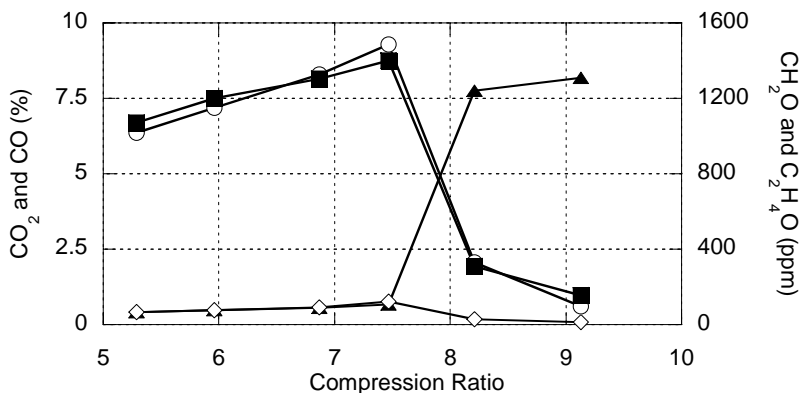

(c)

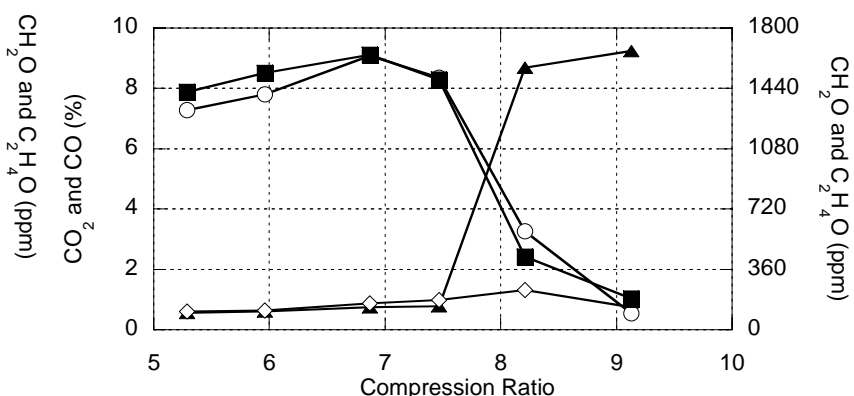

(d)

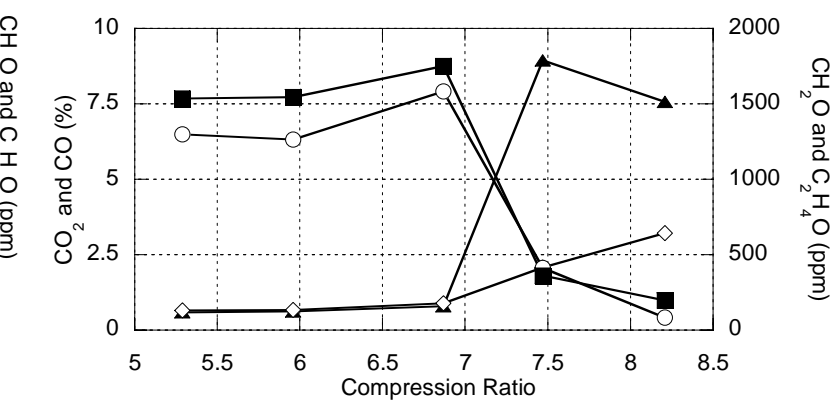

(e)

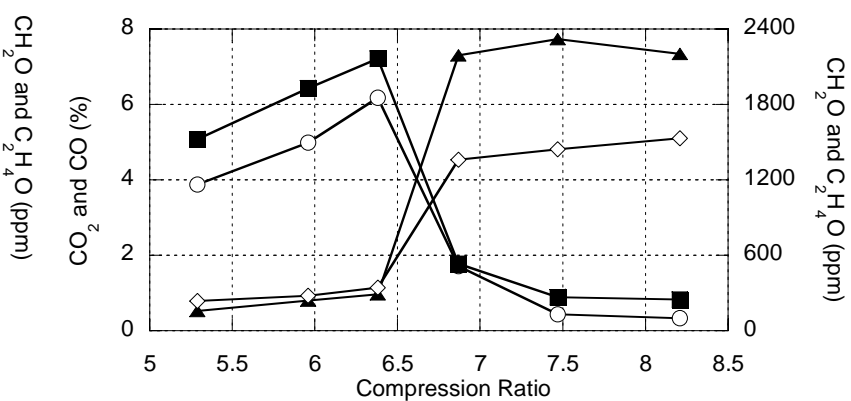

(f)

Figure 3.1.3.37. Quantified FTIR spectra for methyl decanoate exhaust at an intake temperature of $230^{\circ} \mathrm{C}$ and (a) $\Phi=0.25$ with no dilution, (b) $\Phi=0.75$ with $100 \%$ dilution, (c) $\Phi$ $=1.0$ with $100 \%$ dilution, (d) $\Phi=1.25$ with $100 \%$ dilution, (e) $\Phi=1.5$ with $100 \%$ dilution, and (f) $\Phi=2.0$ with $100 \%$ dilution for $(\boldsymbol{\Delta})$ carbon dioxide, $(\diamond)$ carbon monoxide, $(\circ)$ formaldehyde, and ( $\square$ ) acetaldehyde. 


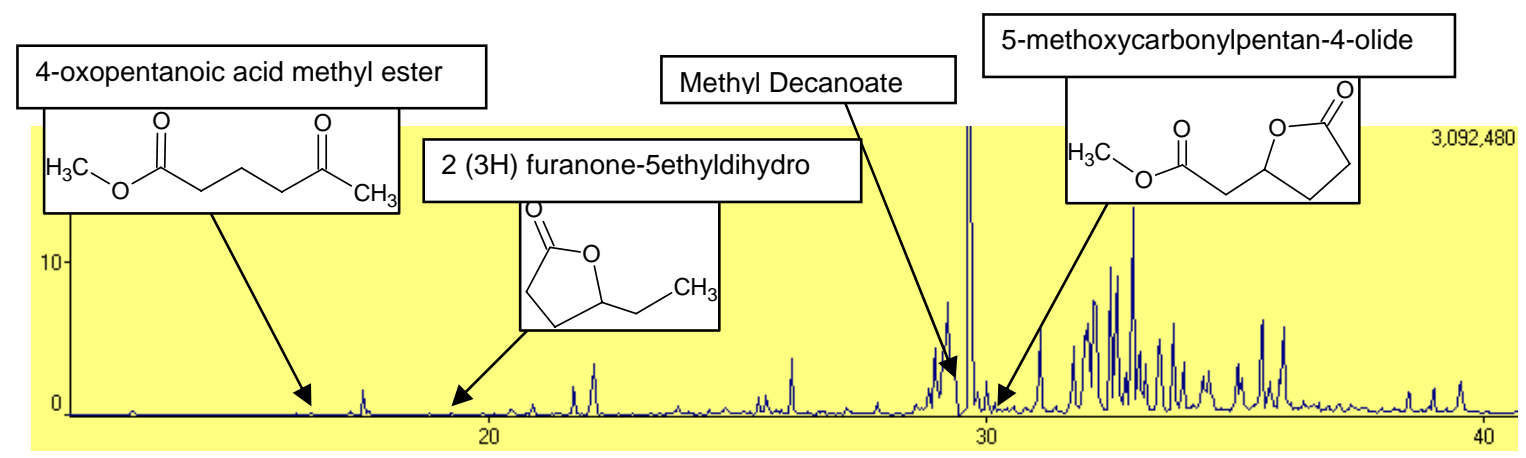

(a)

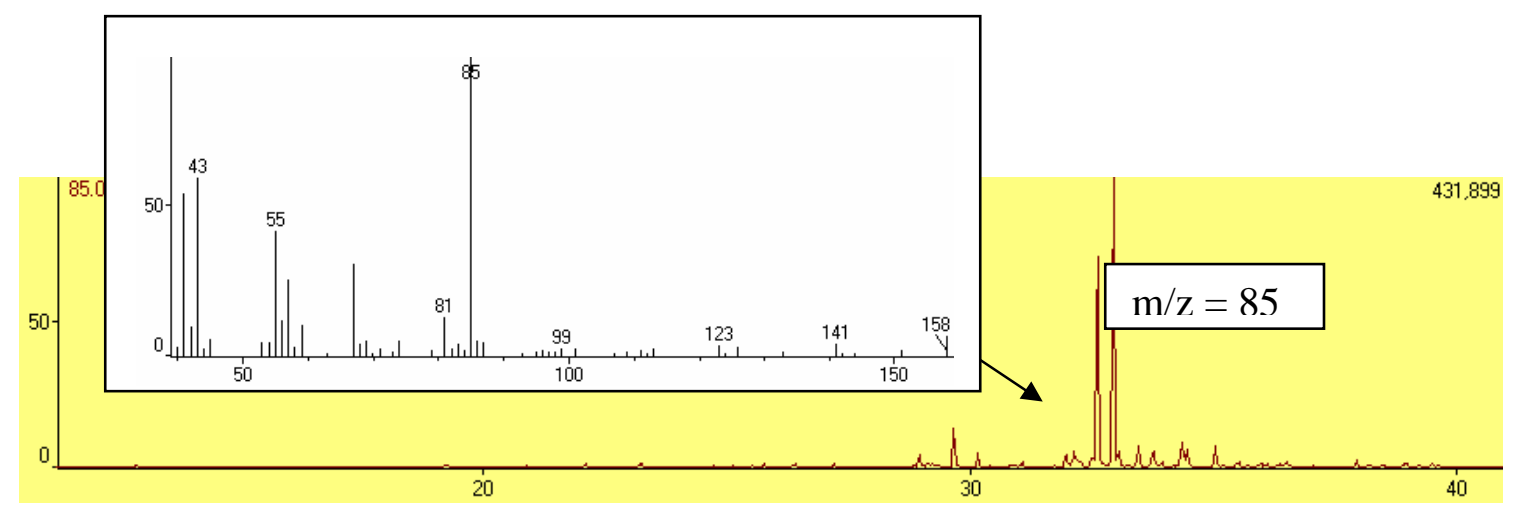

(b)

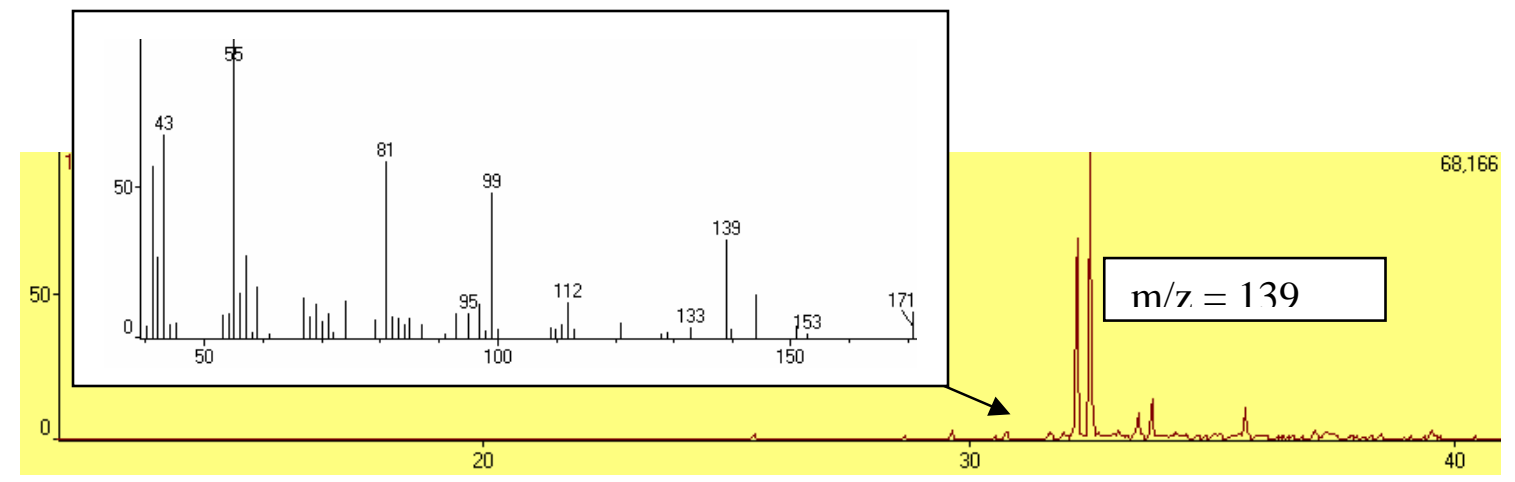

(c)

Figure 3.1.3.38. GC/MS analysis of methyl decanoate exhaust condensate for (a) TIC, (b) unknowns at $\mathrm{m} / \mathrm{z}=85$, and (c) unknowns at $\mathrm{m} / \mathrm{z}=139$. 
Table 3.1.3.12 Species identified during GC/MS analysis of methyl decanoate exhaust condensate.

\begin{tabular}{|l|l|}
\hline Identification & Retention Time \\
\hline Methyl Esters & 12.86 \\
\hline 2-methyl butanoic acid methyl ester & 17.45 \\
\hline Methyl hexanoate & 17.59 \\
\hline Methyl heptenoate & 21.72 \\
\hline Methyl octenoate & 22.06 \\
\hline Methyl octanoate & $22.12,25.85$ \\
\hline Methyl nonenoate (isomers) & 25.90 \\
\hline Methyl nonanoate & $28.83,28.97,29.14,29.24$, \\
\hline Methyl decenoate (isomers) & $29.74,30.03,31.10$ \\
\hline methyl decanoate & 29.50 \\
\hline Methyl dodecenoate & 33.77 \\
\hline Methyl dodecanoate & 35.99 \\
\hline Oxo-methyl esters & \\
\hline 4-oxopentanoic acid methyl ester & 16.45 \\
\hline 5-oxopentanoic acid methyl ester & 17.45 \\
\hline 5-oxohexanoic acid methyl ester & 20.90 \\
\hline 6-oxoheptanoic acid methyl ester & 25.44 \\
\hline 4-oxooctanoic acid methyl ester & 29.86 \\
\hline 2-oxodecanoic acid methyl ester & 30.03 \\
\hline 9-oxodecanoic acid methyl ester & 32.06 \\
\hline Organic Acids & \\
\hline Butanoic acid & 7.39 \\
\hline Pentanoic acid & 11.79 \\
\hline Hexanoic acid & 16.10 \\
\hline Heptanoic acid & 20.13 \\
\hline Octanoic acid & 24.03 \\
\hline Decanoic acid & 30.97 \\
\hline Additional Species & \\
\hline 2-nonanone & 19.12 \\
\hline Heptanal & 12.52 \\
\hline Nonanal & 21.24 \\
\hline 2 (3H) Furanone - 5ethyldihydro & 19.25 \\
\hline 5-methoxycarbonylpentan-4-olide & 30.18 \\
\hline & \\
\hline & \\
\hline & \\
\hline
\end{tabular}




\section{Summary}

A motored engine experiment was successfully used to investigate autoignition differences between n-heptane, iso-octane, conventional diesel fuel (BP325_light), FT diesel fuel, and methyl decanoate, a biodiesel-relevant fuel. Each of these fuels, with the exception of iso-octane, exhibited two-stage ignition, with LTHR followed by HTHR, whereas iso-octane exhibited only HTHR. Of the fuels of interest, the magnitude of LTHR was highest for FT diesel, followed by methyl decanoate, and BP325 last. It was determined that the LTHR for methyl decanoate is due to the fully saturated 10-carbon aliphatic chain and not the ester group. Because biodiesel is highly unsaturated, it is likely that methyl decanoate over-predicts the LTHR of biodiesel because olefinic sites reduce the magnitude of LTHR.

FTIR analysis showed that for n-heptane, FT diesel, and BP325_light, LTHR produces high concentrations of carbonyl species and carbon monoxide while producing virtually no carbon dioxide. Methyl decanoate differed from the other fuels that exhibited LTHR in that it produced significant quantities of carbon dioxide during LTHR. It was concluded that the carbon dioxide produced by methyl decanoate during LTHR was due to decarboxylation and not oxidation. The FTIR data also showed that pre-ignition reactions do take place for iso-octane, producing significant quantities of carbon monoxide and aldehydes, even though no LTHR is detectable.

GC/MS analysis of the LTHR exhaust condensate for $n$-heptane revealed high concentrations of 2,5-heptanedione, a di-ketone that is similar to ketohydroperoxide species in the n-heptane oxidation model by Curran et al. [9]. It could not be determined whether 2,5-heptanedione is formed during the combustion process, or whether it is formed via dehydration during the sample preparation process before it was sent to the GC/MS.

GC/MS analysis of the LTHR exhaust condensates for BP325_light and FT diesel revealed series of aldehydes and 2-ketones. The highest intensity carbonyl peaks were for C9 (nonanal and 2-nonanone) through C10 (decanal and 2-decanone) whereas the highest intensity $\mathrm{n}$-alkanes in BP325-light and FT diesel were C11 (n-undecane) and C12 (n-dodecane). This loss of carbon chain length strongly supports carbonyl species being formed by a $\beta$-scission reaction, which simultaneously forms an olefin as well as a carbonyl. A series of organic acids were also identified for BP325_light and FT diesel. Although no mechanism could be given for their formation, it was shown that they form during the LTHR process.

The GC/MS analysis of the LTHR exhaust condensate for methyl decanoate shows that the aliphatic chain undergoes LTHR reactions, forming carbonyl sites and shortening the carbon chain, while the ester group remains intact. While the FTIR data does indicate that decarboxylation occurs at a significant rate, the GC/MS data suggests that it does not occur until the aliphatic chain has been largely consumed by LTHR reaction.

\subsubsection{References}

1. Alleman, T.L. and R.L. McCormick, "Fischer-Tropsch Diesel Fuels - Properties and Exhaust Emissions: A Literature Review." Society of Automotive Engineers, 2003, Technical Paper 2003-01-0763.

2. Heywood, J.B., Internal Combustion Engine Fundamentals, 1998, McGraw-Hill, Inc., New York, NY.. p.864.

3. Glassman, I. Combustion, 1996, Academic Press, San Diego, p.631.

4. Szybist, J.P., A.L. Boehman, R.L. McCormick, and J.D. Taylor, "Evaluation of Formulation Strategies to Eliminate the Biodiesel NOx Effect." Fuel Processing Technology, Vol. 86, 1109-1126 (2005). 
5. Graboski, M.S. and R.L. McCormick. Combustion of Fat and Vegetable Oil Derived Fuels in Diesel Engines. Progress in Energy and Combustion Science, 1998. 24(2). p. 125-164.

6. Allard, L.N., G.D. Webster, T.W.I. Ryan, A.C. Matheaus, G. Baker, A. Beregszaszy, H. Read, K. Mortimer, and G. Jones. Diesel Fuel Ignition Quality as Determined in the Ignition Quality Tester (IQT $\left.T^{T M}\right)$ - Part IV. Society of Automotive Engineers, 2001, Technical Paper 2001-013527.

7. Christensen, M., A. Hultqvist, and B. Johansson. Demonstrating the Multi Fuel Capability of a Homogeneous Charge Compression Ignition Engine with Variable Compression Ratio. Society of Automotive Engineers, 1999, Technical Paper 1999-01-3679.

8. Shibata, G., K. Oyama, T. Urushihara, and T. Nakano. Correlation of Low Temperature Heat Release with Fuel Composition and $\mathrm{HCCl}$ Engine Combustion. Society of Automotive Engineers, 2005, Technical Paper 2005-01-0138.

9. Curran, H.J., P. Gaffuri, W.J. Pitz, and C.K. Westbrook. A Comprehensive Modeling Study of n-Heptane Oxidation. Combustion and Flame, 1998. 114. p. 149-177.

10. Leppard, W.R. The Chemical Origin of Fuel Octane Sensitivity. Society of Automotive Engineers, 1990, Technical Paper 902137.

11. Zhao, F., T.W. Asmus, D.N. Assanis, J.E. Dec, J.A. Eng, and P.M. Najt. Homogeneous Charge Compression Ignition $(\mathrm{HCCl})$ Engines: Key Research and Development Issues. 2003, Warrendale, PA. Society of Automotive Engineers.

12. Minetti, R., A. Roubaud, E. Therssen, M. Ribaucour, and L.R. Sochet. The Chemistry of PreIgnition of n-Pentane and 1-Pentene. Combustion and Flame, 1999. 118(1-2). p. 213-220.

13. Tanaka, S., F. Ayalan, J.C. Keck, and J.B. Heywood. Two-Stage Ignition in HCCI Combustion and $\mathrm{HCCl}$ Control by Fuels and Additives. Combustion and Flame, 2003. 132. p. 219-239.

14. Yetter, R.A. and F.L. Dryer. Inhibition of Moist Carbon Monoxide Oxidation by Trace Amounts of Hydrocarbons. Proceedings of the Combustion Institute, 1992. 24. p. 757-767.

15. McLafferty, F.W. and F. Turecek. Interpretation of Mass Spectra Fourth Edition. 1993, Mill Valley, CA. University Science Books.

16. Wagner, T. and M.L. Wyszynski. Aldehydes and Ketones in Engine Exhaust Emissions - a Review. Proceedings of the Institute of Mechanical Engineers, Part D: Journal of Automobile Engineering, 1996. 210. p. 109-122.

17. McMurray. Organic Chemistry, Second Edition. 1988, Belmont, CA. Brooks/Cole Publishing Company. pp. 1138.

18. Zervas, E. Formation of Organic Acid from Propane, Isooctane and Toluene/Isooctane Flames. Fuel, 2005. 84. p. 691-700.

19. Mueller, C.J., W.J. Pitz, L.M. Pickett, G.C. Martin, D.L. Siebers, and C.K. Westbrook. Effects of Oxygenates on Soot Processes in DI Diesel Engines: Experiments and Numerical Simulations. Society of Automotive Engineers, 2003, Technical Paper 2003-01-1791.

20. Buchholz, B.A., C.J. Mueller, A. Upatnieks, G.C. Martin, W.J. Pitz, and C.K. Westbrook. Using Carbon-14 Isotope Tracing to Investigate Molecular Structure Effects of the Oxygenate Dibutyl Maleate on Soot Emissions from a DI Diesel Engine. Society of Automotive Engineers, 2004, Technical Paper 2004-01-1849.

21. Glaude, P.A., W.J. Pitz, and M.J. Thomson. Chemical Kinetic Modeling of Dimethyl Carbonate in an Opposed-Flow Diffusion Flame. Proceedings of the Combustion Institute, 2005. 30. p. 1111-1118.

22. Fisher, E.M., W.J. Pitz, H.J. Curran, and C.K. Westbrook. Detailed Chemical Kinetic Mechanisms for Combustion of Oxygenated Fuels. Proceedings of the Combustion Institute, 2000. 28. p. 1579-1586. 
Subtask 3.2 - Indirect and Direct Methanol
Fuel Cell Testing

Subtask 3.2.1 - Methanol Fuel Cell Testing 


\section{Subtask 3.2.1.1 - Design and Construction of 15 W Fuel Cell Stack for Indirect Methanol (0-9 months)}

The experimental tests for the indirect methanol fuel cell were performed in a $50 \mathrm{~cm}^{2}$ titanium fuel cell fixture supplied by Lynntech Industries, Ltd. (College Station, TX). Both anode and cathode flow fields consisted of 6 parallel channels following a serpentine path to cover the $50 \mathrm{~cm}^{2}$ of active area. The cell flow plates used are shown in Figure 3.2.1.1. The cell was arranged to have the anode and cathode run in a counter flow manner. The plates were manufactured from titanium, and coated with a platinum layer to promote durability and surface electrical conductivity. The membrane electrode assembles (MEAs), also supplied by Lynntech Industries, were composed of 40 wt.\% platinum on carbon, Nafion ${ }^{\circledR} 112$, with a platinum catalyst loading of $0.5 \mathrm{mg} / \mathrm{cm}^{2}$ on each side. The MEA also had an ELAT carbon cloth gas diffusion layer pressed on the catalyst surface.

The polarization measurements were taken using an Arbin Instruments (College Station, TX) fuel cell test station and electronic load bank. A diagram of the experimental set-up is shown in Figure 3.2.1.2, with the entire fuel cell testing system and measurement equipment shown in Figure 3.2.1.3. The flow rates of both streams were continually modified with respect to the instantaneous current draw to maintain a molar flow level corresponding to a constant stoichiometry condition of 1.5 and 2.5 on the anode and cathode respectively. The cell itself was kept at $80^{\circ} \mathrm{C}$.

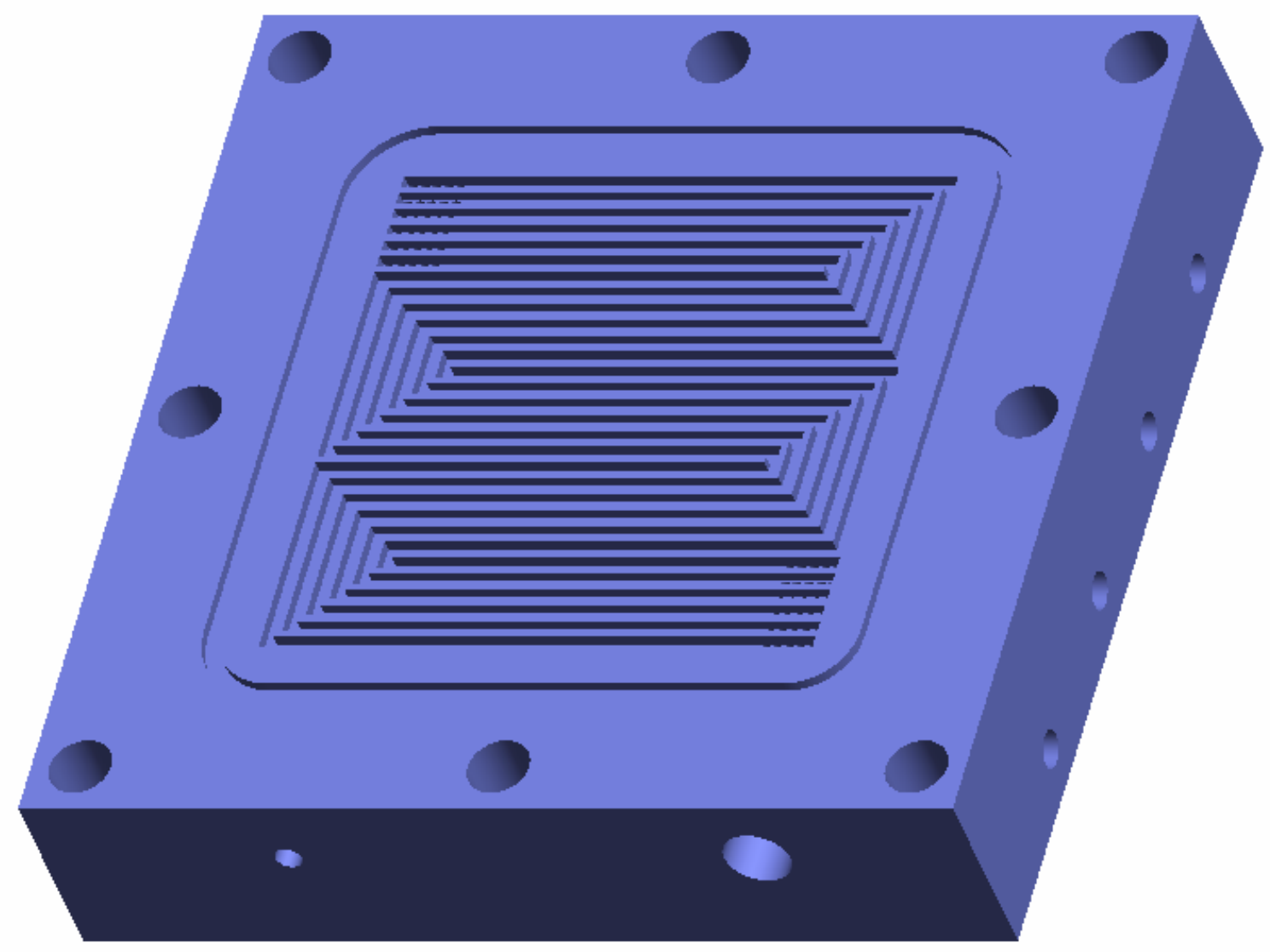

Figure 3.2.1.1 Fuel cell flow plate 


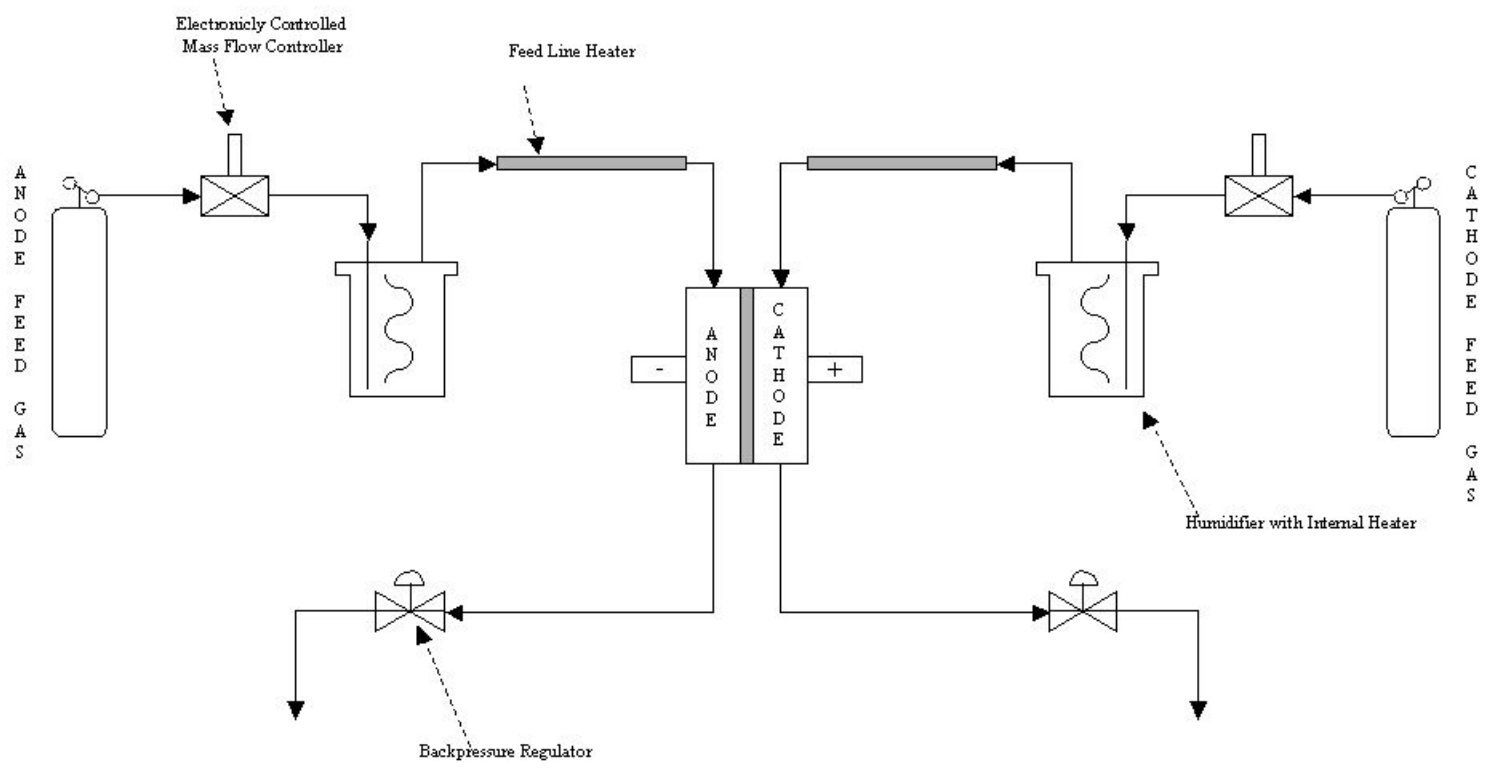

Figure 3.2.1.2 Experimental Set-up.

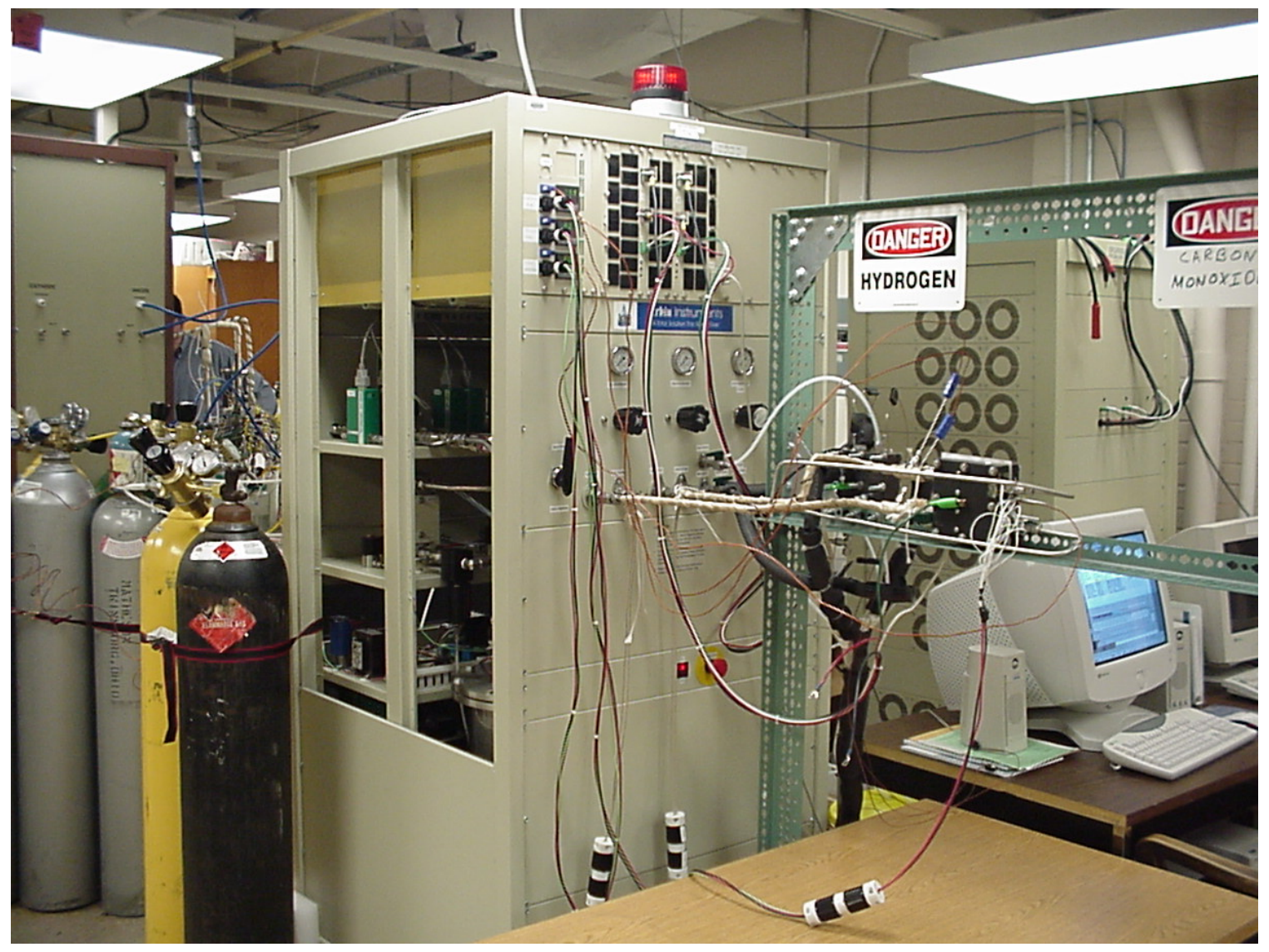

Figure 3.2.1.3 Fuel Cell Experimental Apparatus 


\section{Subtask 3.2.1.2 Formulation and Coding of a CFD Model for Interpretation of Experimental Fuel Cell Performance}

\subsection{Introduction}

Mathematic models, describing detailed physico-chemical processes and coupling transport equations with electrochemical kinetics, are an important tool to aid in fundamental understanding of relevant phenomena in PEFCs. To date, mathematic models have been developed from the simple one-dimensional [1-3], two-dimensional [4,5] to the complex three-dimensional models. Springer et al. $[2,3]$ presented a detailed description of water behavior in the membrane and experimentally measured the water-diffusion coefficient, electro-osmotic drag coefficient, and membrane proton conductivity as functions of membrane water content. Fitted curves were incorporated into their onedimensional model to capture water transport phenomena in the membrane via molecular diffusion and electro-osmotic drag. Fuller and Newman [4] considered two-dimensional MEA in the throughplane and flow directions operating on reformed methanol. Water management, thermal management and utilization of fuel were examined in detail.

A comprehensive non-isothermal, three-dimensional model was developed by Berning et al.[6]. They simulated a half of a single channel to study the temperature distribution. However, their model ignored the membrane-electrode assembly (MEA), thus not capturing the transport and electrochemical mechanisms in these vital components of PEFCs. The same assumption also existed in the model of Dutta et al.[7,8]. An important contribution of Dutta's work is to simulate a fuel cell with twenty-branch serpentine channels. However, only about 200,000 grid points were employed in the simulations, raising the concern of grid dependence and numerical inaccuracy. In addition, the governing equations were employed only in the gas channels and GDLs, with the MEA excluded. Water transport in the MEA was analytically modeled based on the approximations of constant transport properties, and the diffusion flux through the membrane was calculated based on the difference of water concentrations in the two catalyst layers. In contrast, Wang and co-workers [9-13] presented a single-domain model, including detailed mechanisms in the MEA, such as electrolyte potential, current, and water distributions in the membrane as well as catalyst layers. Thus, their model is chosen for this study of internal humidification and membrane hydration.

The goal of this subtask is to develop a comprehensive PEFC model to assist in interpreting experimental results.

\subsection{Numerical Model}

Figure 3.2.1.4 (a) shows the computational domain of the double-path PEFC with thirty-six channels under consideration. There are two parallel branches of eighteen channels in a serpentine fashion on each side. Anode-side and cathode-side flow channels are symmetric and properly aligned on top of each other. Figure 3.2.1.4 (b) shows part of the mesh near inlet and outlet areas. Finer grids are used to capture the transport phenomena in channel $U$ turns and inlet regions. Detailed mesh in the through-plane direction of the MEA is plotted in Figure 3.2.1.4 (c). Threedimensional mesh is necessary to capture the important electrochemical and transport mechanisms occurring in the MEA and GDL. These include species transport in the through-plane direction, flow and reactant consumption in the flow direction, and gas flow and water transport in the in-plane direction in the GDL over the land separating two neighboring channels. Figure 3.2.1.4 (d) schematically shows the top view of the computational domain of double-path PEFC with thirty-six channels and the positions of inlets and outlets. In order to focus on the effects of internal humidification, we consider counter flow only in the cathode flowfield and use a common co-flow pattern in the anode one. In addition, dry air is fed into Ch. 1 and Ch. 35 on the cathode, and fullyhumidified hydrogen is injected into Ch. 1 and Ch. 2 for the anode. The mid-length cross-section of the fuel cell is typically selected to show the detailed profiles of flow and transport parameters. To distinguish the two flow paths in the cathode side, the one with Ch. 1 as the inlet is defined as Path 1 while the other one starting from the other end is Path 2. The PEFC geometry is shown in Table 3.2.1.1. 
Numerical model - The PEFC model consists of nonlinear, coupled partial differential equations describing the conservation of mass, momentum, species, and charge with electrochemical reactions. The equations can be written, in the vector form, as [9]:

$$
\begin{array}{ll}
\text { Continuity conservation } & \nabla \cdot(\rho \vec{u})=0 \\
\text { Momentum conservation } & \frac{1}{\varepsilon^{2}} \nabla \cdot(\rho \vec{u} \vec{u})=-\nabla p+\nabla \cdot \tau+S_{u} \\
\text { Species conservation } & \nabla \cdot\left(\vec{u} C_{k}\right)=\nabla \cdot\left(D_{k}^{e f f} \nabla C_{k}\right)+S_{k} \\
\text { Charge conservation } & \nabla \cdot\left(\kappa^{e f f} \nabla \Phi_{e}\right)+S_{e}=0
\end{array}
$$

where $\rho, \vec{u}, p, C_{k}$, and $\phi_{e}$, respectively, denote the density, superficial fluid velocity vector, pressure, mole fraction of species $\mathrm{k}$ and electrolyte potential. The species considered are hydrogen, oxygen and water. Source terms, electrochemical properties, and physical properties, identified for various regions of a fuel cell, are listed in Tables 3.2.1.2 through 3.2.1.4, respectively.

In the GDL, a small value of permeability $K$ will result in a large source term $S_{u}$ in Eq. 3.2.1.2, turning Eq. 3.2.1.2 into the Darcy's law for porous media:

$$
\nabla p=\frac{\mu}{K} \vec{u}
$$

In addition, notice that the present model is a single-phase approach in which the total water amount is tracked without distinguishing liquid water from water vapor. Such a single-phase model is valid generally under the condition that the liquid volume fraction is low or liquid droplets are small to form a mist flow. This approach is particularly well suited for the present study since only the lowhumidity operation is concerned.

Boundary conditions - Eqs. 3.2.1.1 - 3.2.1.4 form a complete set of governing equations with eight unknowns: $\vec{u}, P, C_{\mathrm{H}_{2}}, C_{\mathrm{O}_{2}}, C_{\mathrm{H}_{2} \mathrm{O}}$ and $\phi_{e}$. Their corresponding boundary conditions are specified as follows:

Flow Inlet Boundaries

The inlet velocity $\vec{u}_{i n}$ in a gas channel is expressed by the respective stoichiometric flow ratio, i.e., $\xi_{a}$ or $\xi_{c}$, defined at a reference current density, Iref, as:

$$
\xi_{a}=\frac{C_{H_{2}} \rho_{a} u_{i n, a} A_{a}}{\frac{I_{r e f} A}{2 F}} \text { and } \quad \xi_{c}=\frac{C_{O_{2}} \rho_{c} u_{i n, c} A_{c}}{\frac{I_{r e f} A}{4 F}}
$$

where $A_{a}$ and $A_{c}$ are the flow cross-sectional areas of the anode and cathode gas channels, respectively. The inlet molar concentrations are determined by the inlet pressure and humidity according to the ideal gas law. 


\section{Outlet Boundaries}

Fully developed or no-flux conditions are applied:

$$
\frac{\partial \vec{u}}{\partial n}=0, \quad \frac{\partial C_{k}}{\partial n}=0, \quad \frac{\partial \phi_{e}}{\partial n}=0
$$

Walls

No-slip and impermeable velocity condition and no-flux condition are applied:

$$
\vec{u}=0, \quad \frac{\partial C_{k}}{\partial n}=0, \quad \frac{\partial P}{\partial n}=0, \quad \frac{\partial \phi_{e}}{\partial n}=0
$$

Numerical procedure-The conservation equations are solved by Star-CD software with SIMPLE algorithm [14], using a parallel computational methodology for a Linux PC cluster. The source terms and physical properties are incorporated in the user codes. After grid-independence study, about 2.7 million computational elements $(44 \times 100 \times 576)$ were determined to be necessary to capture fine details of flow and transport phenomena in this PEFC configuration. A simulation typically requires about 100 iterations and takes nearly 5 hours on 9 nodes of $1.4 \mathrm{GHz}$ AMD Athelon Thunderbird CPU and 512MB DDR SDRAM.

\subsection{RESULTS AND DISCUSSION}

Two cases are compared in our study, in Case 1, we assume there is no velocity in the GDL, thus species transport is dominated by diffusion. The other one, Case 2, is to apply the Darcy's law in the GDL based on its permeability and explore the convection effect on internal humidification additionally.

Figure 3.2.1.5 shows the local velocity distribution at the mid-depth of the cathode gas channels for Case 1. The grid is much finer at the U-turns, inlet and outlet, in order to capture the complex flow in these locations, such as flow recirculation. From the inlet of $\mathrm{Ch}$. 1, the gas velocity profile undergoes a change from the uniform flow to fully-developed flow which can be seen in $\mathrm{Ch} .4$ before the U-turn. A similar parabolic profile velocity is displayed at $\mathrm{Ch}$. 2, which is the outlet channel of Path 2. In the gas channel, the convection dominates the mass transport, and species is distributed down the flow paths.

Figure 3.2.1.6 shows the distributions of average $\mathrm{O}_{2}$ and $\mathrm{H}_{2} \mathrm{O}$ concentrations in the cathode gas channel of each flow path for Case $1 . \mathrm{O}_{2}$ concentration is seen to decrease along the channels from the two inlets, due to the oxygen reduction reaction (ORR). The concentration difference between the two flow paths is maximum in the inlet and outlet areas and diminishes to zero in the middle of the cell. In addition, $\mathrm{O}_{2}$ displays a nearly symmetric profile between the two flow paths, indicating that nearly equal amount of $\mathrm{O}_{2}$ is consumed along each path.

In contrast, $\mathrm{H}_{2} \mathrm{O}$ concentration increases along the channel from the inlet to outlet due to water production of ORR. Furthermore, $\mathrm{H}_{2} \mathrm{O}$ concentration exhibits asymmetric distributions between the two flow paths. This is due to the effect of anode co-flow pattern where humidified $\mathrm{H}_{2}$ is fed into $\mathrm{Ch}$. 1 and Ch. 2 from same end of the cell. In addition, there exists great difference of water concentration between the two flow paths in the inlet or outlet areas, where internal humidification is expected to occur due to lateral diffusion through the porous GDL. 
Details of the lateral transport of $\mathrm{H}_{2} \mathrm{O}$ and $\mathrm{O}_{2}$ between two adjacent channels in the different flow paths are shown in Figure 3.2.1.7 (a) and (b), respectively. The cross-section is taken on the cathode side at the mid-length of the fuel cell between $\mathrm{Ch} .1$ and $\mathrm{Ch}$. 2 under $\mathrm{V}_{\text {cell }}=0.65 \mathrm{~V}$ and $\mathrm{I}=0.91 \mathrm{~A} / \mathrm{cm}^{2}$. A clear gradient in the water concentration towards the dry inlet channel (Ch. 1) is evident. Figure 3.2.1.7 (b) shows $\mathrm{O}_{2}$ concentration is lowest in the GDL under the land. This is due to the ORR under the land and the fact that the thin GDL limits the $\mathrm{O}_{2}$ supply.

Figure 3.2.1.8 (a) and (b) display the corresponding $\mathrm{H}_{2} \mathrm{O}$ and $\mathrm{O}_{2}$ distributions, respectively, between Ch. 5 and Ch. 6 under the same conditions as in Figure 3.2.1.7. Figure 3.2.1.8 (a) shows that there also exist dramatic concentration differences between these two channels both for water and oxygen. Similar to Figure 3.2.1.7 (a), the highest concentration of $\mathrm{H}_{2} \mathrm{O}$ appears under the land. Figure 3.2.1.8 (b) also indicates virtually no $\mathrm{O}_{2}$ exchange between the two channels.

The reason why there is no direct water exchange between the two channels in Figures 3.2.1.7 and 3.2.1.8 is due to local water production under the land. If there were no such water source, water vapor would diffuse from the humid channel to the dry one under the concentration difference. However, water source under the land raises the local water concentration even beyond the wet channel nearby, thus preventing water diffusion between the two channels. Nonetheless, a larger portion of product water is laterally removed into the drier gas channel, so there is a limited extent of internal humidification.

Figure 3.2.1.9 (a) and (b) show $\mathrm{H}_{2} \mathrm{O}$ and $\mathrm{O}_{2}$ distributions, respectively, in the cathode side between Ch. 35 and $\mathrm{Ch}$. 36. In this location, different to Figures 3.2.1.7 and 3.2.1.8, water concentration under the land is lower than the humid $\mathrm{Ch}$. 36, so a lateral water flux induced by diffusion occurs through the GDL between the two channels. Simultaneously, water produced under the land also enters the dry $\mathrm{Ch}$. 35. This more beneficial effect of internal humidification occurs in the very last channel towards the exit. Figure 3.2.1.9 (b) shows that there is still no $\mathrm{O}_{2}$ exchange between the two channels. Rather, $\mathrm{O}_{2}$ needed for the electrochemical reaction under the land is supplied from both channels.

The effect of internal humidification is shown quantitatively in Figure 3.2.1.10, which indicates the water flux across the two surfaces of the cathode GDL along the mid-length cross-section for Case 1. The areas under the curves, i.e. the integrals of the curves, represent the amount of water across each face of the GDL per unit length. Due to no water production in the GDL, the area between the two curves across the two surfaces of the GDL represents the net water flux along the lateral direction. It can be seen that the amount of water into the gas channel is almost twice that across the interface between the catalyst layer and GDL under Ch. 1, while the water fluxes across the two surfaces of the GDL are almost equal under Ch. 2. The different amount of product water captured by the inlet Ch. 1 and outlet Ch. 2 indicates that internal humidification exists and has a significant effect on humidifying the dry inlet flow. The same trend also exists in the channels close to the air inlet such as Chs. 4, 5, 34, and 35, and the channels close to the exhaust outlet such as Chs. 3, 6, 33 and 36. In Ch. 36, there exists a negative flux across the front face of the GDL, which means that water diffuses from Ch. 36 into the GDL and is transported laterally through the GDL to Ch. 35. Similar phenomenon also appears in the outlet channels, such as Ch. 32 and Ch. 33. However, the amount of water transported between the two neighboring channels remains very small. In addition, the highly oscillatory nature of these surface water fluxes is indicative of the complex water transport phenomena occurring in the flow field and thus calls for a fine mesh to resolve sharp gradients in the lateral direction.

Figure 3.2.1.11 shows the distribution of net water transport coefficient per proton at the same cross-section. The $\alpha$-value reflects the combined effect of electro-osmotic drag and back diffusion of water, with positive values being water transported from the anode to cathode. It is highly dependent on the location and varies from -0.5 to 1.5. The peak values appear near the cathode dry inlet channels, Chs. 1, 4, 34 and 35, while near the cathode outlet channels, such as Chs. 2, 3 and $36, \alpha$ is less than unity because of strong back diffusion. In addition, under the land, such as the 
one between Ch. 33 and Ch. 34, a dramatically changes from a positive to a negative value. This can be explained by water accumulation under lands. Furthermore, Figure 3.2.1.11 clearly indicates that $\alpha$ is highly dependent upon the local conditions.

In Case 1, the velocity in the GDL has been ignored and the species transport is only by diffusion. However, velocity will be induced by the pressure gradient following the Darcy's law in porous media. Figure 3.2.1.12 shows the gas pressure distribution in the cathode GDL at the midlength cross-section when lateral gas flow is considered (i.e. for Case 2). It is seen that there exists a large pressure drop in the GDL between the adjacent channels in different flow paths at the two ends of the fuel cell. Between Chs. 1 and 2, c.a. $1.5 \mathrm{kPa}$ pressure difference is present. According to the Darcy's law, Eq. 3.2.1.5, and using the GDL permeability of $10^{-12} \mathrm{~m}^{2}$, one obtains a lateral velocity of about $0.15 \mathrm{~m} / \mathrm{s}$ in the GDL from the dry Ch. 1 to wet $\mathrm{Ch}$. 2. As a result, there is a certain amount of inlet fresh air bypassing through the GDL and directly flowing into the channel in the other flow path towards the exit. This gas bypass, or "short circuit", greatly reduces the reactant utilization in the cell.

To quantify the bypass, average gas velocity in the cathode gas channels is also presented in Figure 3.2.1.12. It can be seen that bypass causes severe leakage of injected flow. For Path 1 , from the inlet Ch. 1 to the middle of the fuel cell, e.g. Ch. 17, the mass of flow in the channel decreases by about $80 \%$. From the middle to the outlet $\mathrm{Ch}$. 36 , the flow acquires four times mass from the other flow path.

Besides severe gas bypass, the lateral convection from the dry inlet channel to the wet outlet channel opposes to water diffusion, thus greatly diminishing the self-humidification benefit. The effect of convection on species transport is indicated in Figure 3.2.1.13, which superposes $\mathrm{H}_{2} \mathrm{O} / \mathrm{O}_{2}$ concentration contours with the velocity vector plot in the cathode side between $\mathrm{Ch} .1$ and $\mathrm{Ch}$. 2 . It is seen that about $0.1 \mathrm{~m} / \mathrm{s}$ velocity in the porous GDL is induced by the pressure difference between the two channels, in consistency with the estimate made earlier. If we define the Peclet number as a parameter to measure the relative strength of convection to molecular diffusion, then:

$$
P e=\mathrm{v} \frac{\delta_{\text {land }}}{D_{G D L}^{e f f}}
$$

For $D_{G D L}^{e f f} \approx 10^{-5} \mathrm{~m}^{2} / \mathrm{s}$ and $\delta_{\text {land }}=0.001 \mathrm{~m}, P e$ is about 10 , demonstrating that convection is dominant in the lateral species transport through the GDL. As a result, the bypass flow significantly offsets the internal humidification induced by diffusion. In addition, bypass loses fresh air of higher concentration in $\mathrm{O}_{2}$ to the outlet channel towards the exit from the fuel cell.

Similarly, strong bypass exists between other inlet and outlet channels, as shown in Figure 3.2.1.14 between $\mathrm{Ch} .5$ and $\mathrm{Ch}$. 6 . The magnitude of the lateral velocity is reduced to about 0.05 $\mathrm{m} / \mathrm{s}$ but convection still dominates the species transport.

An integral effect of gas bypass is shown in Figure 3.2.1.15, which plots $\mathrm{H}_{2} \mathrm{O} / \mathrm{O}_{2}$ concentrations in the cathode gas channel for each flow path. Contrary to Case 1 , along each flow path, $\mathrm{H}_{2} \mathrm{O}$ concentration increases first due to ORR water production but decreases later due to addition of drier gas from the other flow path. Furthermore, water concentration reaches as high as $30 \mathrm{~mol} / \mathrm{m}^{3}$ in the middle of the fuel cell, due partly to the deceleration of channel flow as shown in Figure 3.2.1.12.

The trends of $\mathrm{O}_{2}$ concentrations of the two flow paths are also different from Figure 3.2.1.6. It is shown that $\mathrm{O}_{2}$ concentration decreases first along the flow due to ORR consumption, then increases due to bypass of fresher air. In addition, high $\mathrm{O}_{2}$ concentration at the outlet indicates that bypass causes a very serious leakage of $\mathrm{O}_{2}$ and hence lower cell performance in this case. Furthermore, 
because $\mathrm{O}_{2}$ concentration becomes very low, around $2 \mathrm{~mol} / \mathrm{m}^{3}$, in the middle of the flow field, $\mathrm{O}_{2}$ transport limitation occurs and leads to low current density locally.

The benefit of self-humidification is best reflected by the membrane water content profile. Figure 3.2.1.16 shows such profiles at the interface between the membrane and cathode catalyst layer for both cases. On the two ends of the fuel cell, it can be seen that the membrane hydration in Case 1 is better than Case 2 where internal humidification is suppressed by flow bypass.

Figure 3.2.1.17 shows the current density distributions at the same cross-section. Focusing on the inlet Ch. 1 and Ch. 35, it can be seen internal humidification increases the current density for Case 1, comparing to Case 2 . In addition, bypass forces the dry air across the GDL between the adjacent inlet and outlet channels so that lower current density, resulting from higher ionic resistance, appears under the land in Case 2. As another result of bypass, higher current densities under Ch. 2 and Ch. 36 are seen in Case 2 because $\mathrm{O}_{2}$-rich air is added into these moisture channels by bypass. Meanwhile, there exist very low current densities under lands for Case 2, such as the land between Ch. 14 and Ch. 15. This is because $\mathrm{O}_{2}$ concentration reaches a low level, as shown in Figure 3.2.1.15. Highly non-uniform current distribution is apparent from channel to channel in this flowfield.

Figure 3.2.1.18 shows the current density contours for Case 1. This local performance of the PEFC is mainly determined by two factors, $\mathrm{O}_{2}$ concentration and membrane hydration. The asymmetry of the distributions is remarkable due to the co-flow pattern in the anode side. In addition, the highest current density occurs near Ch. 2 and Ch. 3 because these locations are near the wet cathode outlet and anode inlet. Under the inlet channels in cathode, such as Ch. 2 and Ch. 35 , the current density is low due to dry air injection. Along the flow path, the current density increases because water production and self-humidification raise the membrane hydration level. This trend is clearly shown in Path 2. For Path 1 , more $\mathrm{O}_{2}$ consumption near the inlet results in decreasing current density in the latter part of this flow path. Figure 3.2.1.19 shows the current density contours for Case 2.

Summary - Numerical simulations of a double-path flowfield PEFC with thirty-six channels have been carried out to study the complex flow phenomena and water transport in PEFCs. The simulation results reveal that the effect of internal humidification induced by diffusion promoted by making the two neighboring channels in counter flow is significant, but is in reality offset by the opposed gas bypass flow induced also by the same flow configuration. In addition, the bypass phenomenon leads to significant leakage of gas, substantially reducing the reactant utilization. To decrease the effect of bypass, small permeability of GDLs was recommended for the double-path, counter-flow PEFCs.

While the counter flow between two neighboring flow paths in the same cathode flowfield is found ineffective through this extensive numerical study, this configuration provides a unique opportunity to explore the rich physics behind the complex flow and transport phenomena occurring in a PEFC as well as to test any numerical models of PEFCs.

\subsection{Transient Analysis}

Much has been done in the literature to numerically study water management in PEFCs. However, most of them were concerned only with the steady-state condition, while the dynamic behavior is of paramount importance to automotive PEFCs, given the rapid variation of loads in the application. Transient phenomena in PEFCs have been studied by several researchers. Amphlett et al. [20] presented an analytical model to study the dynamic responses of temperature and current during start-up, load step-up and shut-down for a PEFC stack. Their transient model only considered the time domain and was based on coupling the steady-state electrochemical kinetic equation with an unsteady, lumped-parameter thermal model. Their subsequent work [21] experimentally studied the coupled system of a fuel cell stack and a lead-acid battery. An electric circuit, which included the ohmic resistance in the electrolyte and current collector, overvoltage due 
to diffusion, migration and charge transfer, and double-layer capacitance, was used to describe the response of the battery. The same circuit was adopted for the fuel cell stack. A methodology was presented to predict the response of this fuel cell/battery hybrid system under various loads. Ceraolo et al. [22] studied the static and dynamic behavior of PEFCs numerically. Their onedimensional model only considered the cathode side, and the transient terms were added to the species balance and phase potential equation. Experiments were also performed to provide the model input parameters and to validate the simulation results. In general, these models were too simple to completely understand the intricate dynamics of PEFCs, particularly the governing fundamental processes.

On the other hand, several accurate steady-state models have been proposed in the open literature, which include a detailed description of the physico-chemical processes and couple the transport equations with electrochemical kinetics in PEFCs. Specially, the model of Dutta et al.[7,8] treats the MEA as an interface without thickness and ignores the membrane water storage capability; thus this model cannot be used to simulate transient phenomena. In contrast, the model of Wang and co-workers [9-13] includes the full description of water and proton co-transport in the three-dimensional MEA, thus it could provide detailed information of water behaviors in this vital component, such as water accumulation, which is essential to the transient study. The importance of water accumulation in the membrane on the PEFC transient behavior will be discussed in the following section. In addition, Um et al. [9] also performed a brief transient analysis, where the membrane remained fully hydrated and thus only the transient process of gas transport was captured.

In this section, dynamic responses of a single-channel PEFC with N112 membrane are numerically explored under both humidified and dry cathode conditions using the foregoing CFD model.

Governing Equations - The basic transport equation for water-containing membrane can be stated as:

$$
\varepsilon_{m} \frac{\partial C_{w}^{m}}{\partial t}=\nabla \cdot\left(D_{w}^{m^{e f f}} \nabla C_{w}^{m}\right)-\frac{1}{F} \nabla \cdot\left(n_{d} i_{e}\right)
$$

where $\varepsilon_{m}$ is the volume fraction of ionomer in the membrane and the last term on the right describes the electro-osmotic drag effect. Here, $C_{w}^{m}$ is the equivalent water concentration in the membrane defined as:

$$
C_{w}^{m}=\frac{\rho \lambda}{E W}
$$

where $\rho$ and EW are the density and equivalent molecular weight of the membrane, respectively. The water content, $\lambda$, is the number of water molecules per sulfonic acid group within the membrane. This is an important parameter on which proton conductivity and transport properties of the membrane are based, and can be calculated from [2]:

$$
\lambda=\left\{\begin{array}{lr}
0.043+17.81 a-39.85 a^{2}+36.0 a^{3} & \text { for } 0<a \leq 1 \\
14+1.4(a-1) & \text { for } 1 \leq a \leq 3
\end{array}\right.
$$


where the water activity is defined as:

$$
a=\frac{C_{w} R T}{p^{s a t}}
$$

Physically, Eq. 3.2.1.10 indicates that water accumulation in the membrane is balanced by the net flux of diffusion and electro-osmotic drag, given that the convection effect is ignored. Considering that a dry membrane is hydrated by product water generated at a constant current density of $I$, the time constant for membrane hydration can be estimated by equating the rate of water storage to that of water production. That is:

$$
\tau_{m}=\frac{\frac{\rho \delta_{m} \Delta \lambda}{E W}}{\frac{I}{2 F}}
$$

For Nafion ${ }^{\circledR} 112$ and $\mathrm{I}=1 \mathrm{~A} / \mathrm{cm}^{2}, \tau_{m}$ is equal to about 25 seconds. This immediately points out the importance of the transient term in Eq. 3.2.1.10.

Within the catalyst layer, the conservation equation of water transport in the transient form then can be expressed as:

$$
\varepsilon_{g} \frac{\partial C_{w}}{\partial t}+\varepsilon_{m} \frac{\partial C_{w}^{m}}{\partial t}=\nabla \cdot\left(D_{w}^{g^{e f f}} \nabla C_{w}\right)+\nabla \cdot\left(D_{w}^{m^{e f f}} \nabla C_{w}^{m}\right)-\frac{1}{F} \nabla \cdot\left(n_{d} i_{e}\right)
$$

The two terms on the left hand represent the rates of water storage in the gas and membrane phases, respectively. Assuming thermodynamic equilibrium of water between the gas and membrane phases, the above equation can be rearranged as

$$
\varepsilon^{e f f} \frac{\partial C_{w}}{\partial t}=\nabla \cdot\left(D_{w}^{e f f} \nabla C_{w}\right)-\frac{1}{F} \nabla \cdot\left(n_{d} i_{e}\right)
$$

where the effective factor, $\varepsilon^{\text {eff }}$, is defined as:

$$
\varepsilon^{e f f}=\varepsilon_{g}+\varepsilon_{m} \frac{d C_{w}^{m}}{d C_{w}}=\varepsilon_{g}+\varepsilon_{m} \frac{d C_{w}^{m}}{d C_{w}}=\varepsilon_{g}+\varepsilon_{m} \frac{1}{E W} \frac{R T}{p_{s a t}}\left(\rho+\lambda \frac{d \rho}{d \lambda}\right) \frac{d \lambda}{d a}
$$

For Nafion ${ }^{\circledR} 11$-series membranes having EW of $1.1 \mathrm{~kg} / \mathrm{mol}$, and membrane density, $\rho$, of 1980 $\mathrm{kg} / \mathrm{m}^{3}$ at $80^{\circ} \mathrm{C}$, the effective factor, $\varepsilon^{\text {eff }}$, is on the order of $10^{2} \sim 10^{3}$ for water activity $a<1$.

Another transient phenomenon in PEFCs is charging or discharging of the electrochemical double-layer. The double-layer occurs in a thin layer (of the order of $\mathrm{nm}$ ) adjacent to the reaction interface and acts as a capacitor during transience. Similar to porous electrodes of batteries, the 
double-layer in the catalyst layer of a PEFC can be regarded as being in parallel to a charge transfer reaction resistor. The importance of the double-layer can be evaluated by its time constant [23]

$$
\tau_{d l}=\delta_{C L}{ }^{2} a C\left(\frac{1}{\kappa}+\frac{1}{\sigma}\right)
$$

where the symbols are defined in the nomenclature section. Normally, the capacity, $C$, is around $20 \mu \mathrm{F} / \mathrm{cm}^{2}$ and specific area, $a$, is about $10^{3} / \mathrm{cm}$. Thickness of the catalyst layer, $\delta_{C L}$, is $10^{-3}$ $\mathrm{cm}, \kappa$ is around $0.1 \mathrm{~S} / \mathrm{cm}$ and $\sigma$ is about $50 \mathrm{~S} / \mathrm{cm}$, which lead to a time constant of $0.2 \mu \mathrm{s}$, sufficiently short to be safely ignored for automotive PEFCs.

On the other hand, the time constant for species transport (e.g. diffusion) can be easily estimated by the diffusion time, i.e.

$$
\tau_{k}=\frac{\delta_{G D L}^{2}}{D_{g}^{e f f}}
$$

Using the parameters shown in Table 3.2.1.4 and $D_{g}^{\text {eff }}$ around $10^{-5} \mathrm{~m}^{2} / \mathrm{s}$ in the porous GDL yields $\tau_{k}$ on the order of $0.01 \mathrm{~s}$.

To summarize, the time constants of membrane hydration and gas transport are sufficiently long to be important in transient analyses of automotive PEFCs, whereas the time constant of the electrochemical double-layer is sufficiently short to be neglected. Consequently, the governing equations for a transport and electrochemical coupled PEFC model can be written in a singledomain form as follows:

Continuity: $\nabla \cdot \vec{u}=0$

Momentum: $\frac{1}{\varepsilon}\left[\frac{\partial \vec{u}}{\partial t}+\frac{1}{\varepsilon} \nabla \cdot(\vec{u} \vec{u})\right]=-\nabla\left(\frac{p}{\rho}\right)+\nabla \cdot \tau+S_{u}$

Species: $\varepsilon \frac{\partial C_{k}}{\partial t}+\nabla \cdot\left(\vec{u} C_{k}\right)=\nabla \cdot\left(D_{k}^{e f f} \nabla C_{k}\right)+S_{k}$

Charge: $0=\nabla \cdot\left(\kappa^{e f f} \nabla \Phi_{e}\right)+S_{\Phi}$

where $\varepsilon$ becomes unity in gas channels. Moreover, Eq. 3.2.1.22 encompasses the water transport equations in the MEA, i.e. Eq. 3.2.1.10 and Eq. 3.2.1.16. The various source terms $S$, 
electrochemical and physical properties are listed in Tables 3.2.1.1 through 3.2.1.3, respectively. The present model is a transient extension of the previous model [9-13].

Results and discussion - A single-channel PEFC with Nafion ${ }^{\circledR} 112$ membrane is chosen for a parametric study. While the focus of the present work is on elucidating dynamic behaviors under low-humidity operation, a fully humidified case is also simulated for comparison as this case features the transience of gas transport only with the transient process of membrane hydration (remains always hydrated) becoming irrelevant. All results are intended to explore the transient response to a step change from one steady state operating point to another. The two types of step change studied are in the cell voltage and cathode inlet relative humidity.

Figure 3.2.1.21 shows dynamic responses of average current densities to the step change of cathode inlet humidification from $\mathrm{RH}=0 \%$ to $100 \%$ under various cell voltages. The humidity step change occurs at $t=0$ from the steady state of $\mathrm{RHa} / \mathrm{c}=100 / 0 \%$. It is seen that it takes approximately 20 seconds for the fuel cell to reach the new steady state, in accordance with the time constant of membrane water uptake estimated by Eq. 3.2.1.14. In addition, the transition period under higher cell voltage is slightly longer because lower current density in this condition results in less water production, making it longer to hydrate the membrane. In addition, despite that humidified air stream contains less oxygen, the current density continues to increase in the transition process, which demonstrates that the ohmic resistance, controlled by water content in the membrane, dominates the PEFC performance.

It is of interest to compare water uptake by the membrane to that by the reactant gases within the PEFC. This ratio can be estimated by:

$$
\frac{\varepsilon^{e f f} V_{m}}{V_{a, c h}+V_{c, c h}}
$$

where $V_{m}, V_{a, c h}$ and $V_{c, c h}$ are the volumes of the membrane, anode gas channel and cathode gas channels, respectively. Figure 3.2.1.22 shows the contour of $\varepsilon^{\text {eff }}$ in the membrane under the steady state of $\mathrm{V}_{\text {cell }}=0.65 \mathrm{~V}$ and $\mathrm{RHa} / \mathrm{c}=100 / 0 \%$. It can be seen that $\varepsilon^{\text {eff }}$ varies from $10^{2}$ to $10^{3}$. Noting that the depth of gas channels is usually 10 to 100 times the membrane thickness, Eq. 3.2.1.24 indicates that the membrane holds $10-10^{2}$ times more water than the reactant gases. Thus, membrane water is the most important part in the transient process of water management.

Figure 3.2.1.23 shows the evolution of water concentration profiles in the fuel cell cross-section at the mid-length, i.e. along Line $1\left(x, L_{y} / 2, L_{z} / 2\right)$ (see Figure 3.2.1.20), when the inlet cathode humidity is switched from $0 \%$ to $100 \%$ under $0.65 \mathrm{~V}$. It can be seen that the transition time is of the same order as the one shown in Figure 3.2.1.5. Interestingly, it is shown that in the $0.1 \mathrm{~s}$ after the switch, water concentration changes much in the cathode side while there is nearly no change occurring in the anode side. This can be explained by the time for species to be convected down the channel, namely $\frac{L_{y}}{u_{y}}$. Given $u_{y}=1.0 \mathrm{~m} / \mathrm{s}$ at the cathode side and $L_{y}=0.1 \mathrm{~m}, \tau_{k}$ is on the order of $0.1 \mathrm{~s}$. However, it takes about 15 seconds for the middle plane to reach the inlet value, $15.9 \mathrm{~mol} / \mathrm{m}^{3}$, instead of $0.1 \mathrm{~s}$. This is due to the quick species transport in the through-plane direction across the GDL, as indicated by Eq. 3.2.1.19, making the wet inlet stream lose water to the dry membrane for the initial period. 
Evolution of the water concentration profiles in the cathode GDL shown in Figure 3.2.1.23 is of interest to note. At $t=0$, the gas in the cathode channel is relatively dry and the product water generated in the cathode catalyst layer is removed to the channel, thus a water concentration gradient is directed from the catalyst layer/GDL interface to the GDL/channel one. However, once the inlet instantly switches to the fully humidified state, the high humidification front propagates into the middle of the gas channel, altering the water concentration gradient to go from the GDL/channel interface to the catalyst layer/GDL one. This means that the membrane takes up water not only from ORR production but also from the humidified gas stream in the channel. The consequent rise in the membrane water content then gives rise to a higher current density and hence more water production under the same cell voltage. Further increase in the membrane hydration will finally make the product water removed to the cathode gas stream, changing the water concentration gradient in GDL back to the initial shape.

The increase in anode water concentration with time can be readily explained by Figure 3.2.1.24. Figure 3.2.1.24 shows evolution of water content profiles along Line $3\left(L_{x} / 2, y, L_{z} / 2\right)$, when inlet cathode humidification changes from $0 \%$ to $100 \%$ under $0.65 \mathrm{~V}$. It is seen that the water content reaches the steady state first near to the flow inlet. After the membrane in the inlet area reaches full humidification within 10 seconds, it takes additional 15 seconds for the membrane in the outlet area to be fully hydrated.

Figure 3.2.1.25 shows the dynamic responses of the average current density to the reverse step change in cathode inlet humidification from $100 \%$ to $0 \%$, again under $0.6,0.65$ and $0.7 \mathrm{~V}$ cell voltages. First, it is seen that the transition occurs within about $40 \mathrm{~s}$, while remaining on the same order of magnitude as theoretical time constant estimated by Eq. 3.2.1.14, it is twice longer than the reverse transition shown in Figure 3.2.1.21. This is clearly indicative of a hysteretic effect that it takes longer for a fully hydrated membrane generating high current density to be de-hydrated by dry cathode gas. Second, there are obvious overshoots occur while the membrane is still hydrated and exhibits low ohmic resistance but the catalyst layer is already experienced with enriched oxygen supplied by the dry cathode gas. After the overshoots, current densities steadily decrease to their steady state values as a result of membrane water reduction. In addition, contrary to the reverse case shown in Figure 3.2.1.21, the time required to reach the steady state is shorter for the higher cell voltages. This can be explained by the fact that more water stored in the membrane needs to be removed under lower cell voltages.

Figure 3.2.1.26 presents the evolution of the water content profiles in the middle of the membrane during the first several seconds when overshoots occur. It is seen that water content in the membrane around the inlet area responds quickly to the step change in cathode gas humidification, similar to the result shown in Figure 3.2.1.24. In addition, water content maintains fully hydrated level at most part of the membrane during the first $0.5 \mathrm{~s}$, and even after $5 \mathrm{~s}$, nearly half of the membrane is still fully hydrated.

Figure 3.2.1.27 presents the evolutions of water and oxygen concentration profiles at the midlength of the cell, showing that the water concentration is substantially reduced in the cathode side, while there is little change in the anode during the first $5 \mathrm{~s}$. However, the gas in the cathode side still remains nearly fully humidified (i.e. $C_{\text {sat }}=15.9 \mathrm{Mol} / \mathrm{m}^{3}$ ) during this period. Meanwhile, the oxygen concentration increases significantly in $0.1 \mathrm{~s}$ due to the injection of dry, undiluted gas into the cathode. This result confirms the phenomenon of initial overshoot in the current density explained earlier.

Figure 3.2.1.28 presents the dynamic responses of the average current density to a step change in cell voltages comparing a fully humidified case (i.e. $\mathrm{RHa} / \mathrm{c}=100 / 100 \%$ ) with a dry cathode case (i.e. $\mathrm{RHa} / \mathrm{c}=100 / 0 \%$ ). Times for onset of step changes are chosen arbitrarily to set apart the two response curves. For the fully humidified case, only the transience of reactant transport to the catalyst layer to meet the demand of reaction rate is operational. Thus, only the undershoot discovered previously by Um et al. [9] is seen, which is characteristic of low oxygen concentration at 
catalyst sites under lower cell voltage or high current density. The most part of undershoot occurs in a fraction of a second, consistent with the time constant of species diffusion. In contrast, for the dry condition, current density undergoes an undershoot followed by an overshoot. The overshoot, similarly to the ones in Figure 6, can be explained by the fact that response of membrane hydration lags the one of oxygen transport in the cell. Also, the transition between the two steady states corresponding to the two cell voltages takes about $10 \mathrm{~s}$, indicative of the dominance of membrane uptake phenomenon in the cell dynamic response.

Focusing on the first second after the step change in cell voltages, Figure 3.2.1.29 shows the evolution of oxygen concentration profiles along Line 1 ( $\left.x, L_{y} / 2, L_{z} / 2\right)$ and Line $2\left(x, L_{y} / 40, L_{z} / 2\right)$. In the inlet area, i.e. Line 2, it takes about $0.1 \mathrm{~s}$ for the oxygen concentration in the gas diffusion layer to increase to its steady state. At the mid-length of the cell, i.e. Line 1, longer time is needed due to the influence from the upstream.

Figure 3.2.1.30 presents the dynamic responses of the average current density to the reverse change in cell voltages from $0.7 \mathrm{~V}$ back to $0.6 \mathrm{~V}$ again, considering two cases: $\mathrm{RHa} / \mathrm{c}=100 / 100 \%$ and 100/0\%. Similar to Figure 3.2.1.28, the transition takes around 10 seconds, and the curve jumps immediately after the step change, then gradually gets to its steady state in the fully humidified case. Overshoot occurs only in the full humidification case. Similar to the undershoot revealed in Figure 3.2.1.28, the overshoot is characteristic of high oxygen concentration at catalyst sites under low current density. In contrast, in the dry cathode case, the hydration level of the membrane plays a more dominant role in the cell performance. More water production continues to enhance the cell performance after the pumping effect of high oxygen concentration under low current density, thus there exists no overshoot in this situation.

Summary - A transient model of PEFCs has been presented to study the intricate dynamic response to step changes in operating conditions. Time constants for electrochemical double-layer, gas transport, and water accumulation in the membrane were estimated to identify the dominant effects of membrane water uptake and gas transport processes on the transient performance of PEFCs. Numerical simulations were carried out to study the transience of a singe-channel PEFC with N112 membrane. Results indicate that after the step change, the transition takes place on the order of 10 seconds, and the membrane hydration was the controlling process in the transient analyses. In addition, overshoot or undershoot in the current density was found in certain cases. Detailed species distributions within the cell were provided to explain the physics underlying the transient phenomena and to indicate that under low-humidity operation membrane water accumulation is responsible, while under high-humidity operation oxygen transport dictates the dynamic response of PEFCs. The dynamic behaviors of PEFCs captured herein for the first time, including undershoot and overshoot in the current output, are expected to be useful for the design of power electronics and control algorithms for fuel cell engines. 


\subsection{Notation}

A superficial electrode area, $\mathrm{m}^{2}$

a effective catalyst area per unit volume, $\mathrm{m}^{2} / \mathrm{m}^{3}$

$C_{k} \quad$ molar concentration of species $\mathrm{k}, \mathrm{mol} / \mathrm{m}^{3}$

D mass diffusivity of species, $\mathrm{m}^{2} / \mathrm{s}$

F Faraday's constant, 96,487 C/equivalent

I current density, $\mathrm{A} / \mathrm{cm}^{2}$

$i_{0}$ exchange current density, $\mathrm{A} / \mathrm{m}^{2}$

j transfer current, $\mathrm{A} / \mathrm{cm}^{3}$

$\mathrm{K}$ permeability, $\mathrm{m}^{2}$

$\mathrm{n}$ the direction normal to the surface

$n_{d}$ electro-osmotic drag coefficient, $\mathrm{H}_{2} \mathrm{O} / \mathrm{H}^{+}$

$\mathrm{P}$ pressure, $\mathrm{Pa}$

$\mathrm{R}$ gas constant, $8.134 \mathrm{~J} / \mathrm{mol} \mathrm{K}$

$\mathrm{S}$ source term in transport equations

$t$ time, $\mathrm{s}$

$\mathrm{T}$ temperature, $\mathrm{K}$

$\vec{u}$ velocity vector, $\mathrm{m} / \mathrm{s}$

$\mathrm{U}_{\mathrm{o}}$ open circuit potential, $\mathrm{V}$

$\mathrm{V}_{\text {cell }} \quad$ cell potential, $\mathrm{V}$

$X$ mole fraction

\section{Greek}

$\alpha$ transfer coefficient or net water transport coefficient per proton

$\varepsilon$ porosity

$\phi$ phase potential, $\mathrm{V}$

$\eta$ surface overpotential, $\mathrm{V}$

$\kappa$ ionic conductivity, $\mathrm{S} / \mathrm{m}$

$\lambda$ membrane water content

$\mu$ viscosity, $\mathrm{kg} / \mathrm{m} \mathrm{s}$

$\sigma$ electronic conductivity, $\mathrm{S} / \mathrm{cm}$

$\rho$ density, $\mathrm{kg} / \mathrm{m}^{3}$

$\tau$ shear stress, $\mathrm{N} / \mathrm{m}^{2}$, or tortuosity factor 
$\xi$ stoichiometric flow ratio

\section{Superscripts and Subscripts}
a anode
c cathode
e electrolyte
eff effective value
g gas phase
in inlet
k species
m membrane
o standard condition, $273.15 \mathrm{~K}$ and $101.3 \mathrm{kPa}$ (1 atm)
ref reference
s solid phase of electrode
satsaturate value
w water 
Table 3.2.1.1 Geometrical and physical parameters for the $50 \mathrm{~cm}^{2}$ PEFC.

\begin{tabular}{ll}
\hline Quantity & Value \\
\hline Gas channel depth & $1.0 \mathrm{~mm}$ \\
Gas channel width & $1.0 \mathrm{~mm}$ \\
Shoulder width & $1.0 \mathrm{~mm}$ \\
Diffusion layer thickness, $\delta_{G D L}$ & $0.3 \mathrm{~mm}$ \\
Catalyst layer thickness, $\delta_{C L}$ & $0.01 \mathrm{~mm}$ \\
Membrane (N112) thickness, $\delta_{m}$ & $0.051 \mathrm{~mm}$ \\
Fuel cell height/length & $72.0 / 72.0 \mathrm{~mm}$ \\
Anode/cathode pressure, $\mathrm{P}$ & $2.0 / 2.0 \mathrm{~atm}$ \\
Reference current density, $I_{r e f}$ & $1.0 \mathrm{~A} / \mathrm{cm}^{2}$ \\
Stoichiometric ratio $\xi$ in the anode/cathode & $2.0 / 2.0$ \\
RH of anode/cathode inlet & $100 \% / 0 \%$ \\
Temperature of fuel cell, $\mathrm{T}$ & $353 \mathrm{~K}$ \\
Porosity of the GDL, $\varepsilon$ & 0.6 \\
Porosity of catalyst layers, $\varepsilon_{a}$ & 0.4 \\
Volume fraction of membrane phase in catalyst layers, $\varepsilon_{m}$ & 0.26 \\
$\mathrm{H}_{2}$ diffusivity in anode gas channel at standard condition, $D_{o, \mathrm{H} 2, \mathrm{a}}$ & $1.1028 \times 10^{-4} \mathrm{~m}^{2} / \mathrm{s}$ \\
$\mathrm{H}_{2} \mathrm{O}$ diffusivity in anode gas channel at standard condition, $D_{o, \mathrm{w}, \mathrm{a}}$ & $1.1028 \times 10^{-4} \mathrm{~m}^{2} / \mathrm{s}$ \\
$\mathrm{O}_{2}$ diffusivity in cathode gas channel at standard condition, $D_{o, \mathrm{O}, \mathrm{c}}$ & $3.2348 \times 10^{-5} \mathrm{~m}^{2} / \mathrm{s}$ \\
$\mathrm{H}_{2} \mathrm{O}$ diffusivity in cathode gas channel at standard condition, $D_{o, \mathrm{w}, \mathrm{c}}$ & $7.35 \times 10^{-5} \mathrm{~m}^{2} / \mathrm{s}$ \\
Permeability of the GDL, $K$ & $10 \mathrm{~m}^{-12}$ \\
\hline & \\
\hline
\end{tabular}


Table 3.2.1.2 Source terms for the conservation equations in each region.

\begin{tabular}{|c|c|c|c|}
\hline & $S_{u}$ & $S_{k}$ & $S_{\phi}$ \\
\hline Gas channels & 0 & 0 & - \\
\hline Diffusion layers & $S_{u}=-\frac{\mu}{K} \vec{u}$ & 0 & 0 \\
\hline Catalyst Layers & $S_{u}=-\frac{\mu}{K} \vec{u}$ & $S_{k}=-\nabla \cdot\left(\frac{n_{d}}{F} i_{e}\right)-\frac{s_{k} j}{n F}$ & $S_{\phi}=j$ \\
\hline Membrane & $S_{u}=-\frac{\mu}{K} \vec{u}$ & 0 & 0 \\
\hline
\end{tabular}

Note: $n_{d}$ is the electro-osmotic drag coefficient for water. For $\mathrm{H}_{2}$ and $\mathrm{O}_{2}, n_{d}=0$. 
Table 3.2.1.3 Electrochemical properties.

\begin{tabular}{lcc}
\hline Description & Anode & Cathode \\
\hline $\begin{array}{c}\text { Transfer current } \\
\text { density, } j\left(\mathrm{~A} / \mathrm{m}^{3}\right)\end{array}$ & $a i_{0, a}\left(\frac{C_{\mathrm{H} 2}}{C_{\mathrm{H} 2, \text { ref }}}\right)^{1 / 2}\left(\frac{\alpha_{a}+\alpha_{c}}{R T} \cdot F \cdot \eta\right)$ & $-a i_{0, c}\left(\frac{C_{\mathrm{O} 2}}{C_{\mathrm{O} 2, \text { ref }}}\right) e^{\left(-\frac{\alpha_{c} F}{R T} \cdot \eta\right)}$ \\
$\begin{array}{c}\text { Surface } \\
\text { overpotential, } \eta(\mathrm{V})\end{array}$ & $\Phi_{s}-\Phi_{e}-U_{o}\left(\right.$ with $\left.\Phi_{\mathrm{s}}=0\right)$ & $\Phi_{s}-\Phi_{e}-U_{o}\left(\right.$ with $\left.\Phi_{\mathrm{s}}=\mathrm{V}_{\text {cell }}\right)$ \\
$\begin{array}{c}\text { Equilibrium } \\
\text { potential, } U_{0}(\mathrm{~V})\end{array}$ & 0 & \\
$\begin{array}{c}\text { Exchange current } \\
\text { density } \mathrm{x} \text { reaction } \\
\text { surface area, } \\
\begin{array}{c}\text { a } i_{0}\left(\mathrm{~A} / \mathrm{m}^{3}\right) \\
\text { Transfer coefficient, } \\
\alpha\end{array}\end{array}$ & $1.23-0.9 \times 10^{-3}(T-298)$ \\
\hline
\end{tabular}


Table 3.2.1.4 Physical and transport properties.

\begin{tabular}{|c|c|}
\hline Quantity & Value \\
\hline Water activity, a [2] & $\begin{array}{c}a=\frac{C_{w} R T}{p^{\text {sat }}} \\
\log _{10} p^{\text {sat }}=-2.1794+0.02953(T-273.15)-9.1837 \times 10^{-5}(T- \\
273.15)^{2}+1.4454 \times 10^{-7}(T-273.15)^{3}\end{array}$ \\
\hline $\begin{array}{l}\text { Water content in } \\
\text { membrane, } \lambda[2]\end{array}$ & $\lambda=\left\{\begin{array}{lr}0.043+17.81 a-39.85 a^{2}+36.0 a^{3} & \text { for } 0<a \leq 1 \\
14+1.4(a-1) & \text { for } 1 \leq a \leq 3\end{array}\right.$ \\
\hline $\begin{array}{l}\text { Ionic conductivity of } \\
\text { membrane, } \kappa[2]\end{array}$ & $(0.005139 \lambda-0.00326) \exp \left[1268\left(\frac{1}{303}-\frac{1}{T}\right)\right]$ \\
\hline $\begin{array}{l}\mathrm{H}_{2} \mathrm{O} \text { diffusivity in } \\
\text { membrane, } D_{w}^{m}[15]\end{array}$ & $D_{w}^{m}=\left\{\begin{array}{l}3.1 \times 10^{-3} \lambda\left(e^{0.28 \lambda}-1\right) \cdot e^{[-2346 / T]} \text { for } 0<\lambda \leq 3 \\
4.17 \times 10^{-4} \lambda\left(1+161 e^{-\lambda}\right) \cdot e^{[-2346 / T]} \text { otherwise }\end{array}\right.$ \\
\hline $\begin{array}{l}\text { Electroosmotic drag } \\
\text { coefficient, } n_{d}[16]\end{array}$ & $n_{d}=\left\{\begin{array}{l}1.0 \text { for } \lambda \leq 14 \\
\frac{1.5}{8}(\lambda-14)+1.0 \quad \text { otherwise }\end{array}\right.$ \\
\hline Membrane density, $\rho$ [17] & $\rho=\frac{1.98+0.0324 \lambda}{1+0.0648 \lambda} \times 10^{3}$ \\
\hline $\begin{array}{l}\mathrm{H}_{2} / \mathrm{O}_{2} \text { diffusivity in } \\
\text { membrane, } \\
D_{\mathrm{H} 2}^{\mathrm{m}} / D_{\mathrm{O} 2}^{\mathrm{m}}[1]\end{array}$ & $2.59 \times 10^{-6} / 1.22 \times 10^{-6}$ \\
\hline $\begin{array}{l}\text { Gas Diffusion Coefficient in } \\
\text { porous media, } D^{\text {eff }}\end{array}$ & $D^{e f f}=\varepsilon^{1.5} D$ \\
\hline $\begin{array}{l}\text { Diffusivity in the gas } \\
\text { channels, } D[18]\end{array}$ & $D o\left(\frac{T}{353}\right)^{3 / 2}\left(\frac{1}{p}\right)$ \\
\hline $\begin{array}{l}\text { Viscosity of anode/cathode } \\
\text { gas, } \mu[19]\end{array}$ & $\begin{aligned} \mu= & 9.88 \times 10^{-6} X_{\mathrm{H} 2}+1.12 \times 10^{-5} X_{\mathrm{H} 2 \mathrm{O}} \\
& +2.01 \times 10^{-5} X_{\mathrm{N} 2}+2.3 \times 10^{-5} X_{\mathrm{O} 2}\end{aligned}$ \\
\hline
\end{tabular}


Table 3.2.1.5 Geometrical parameters of the PEFC with single channel.

\begin{tabular}{ll}
\hline Quantity & Value \\
\hline Gas channel depth/ width & $1.0 / 1.0 \mathrm{~mm}$ \\
Shoulder width & $1.00 \mathrm{~mm}$ \\
Diffusion layer thickness, $\delta_{G D L}$ & $0.3 \mathrm{~mm}$ \\
Catalyst layer thickness, $\delta_{C L}$ & $0.01 \mathrm{~mm}$ \\
Membrane (N112) thickness, $\delta_{m}$ & $0.051 \mathrm{~mm}$ \\
Fuel cell height/length & $2.0 / 100.0 \mathrm{~mm}$ \\
\hline
\end{tabular}




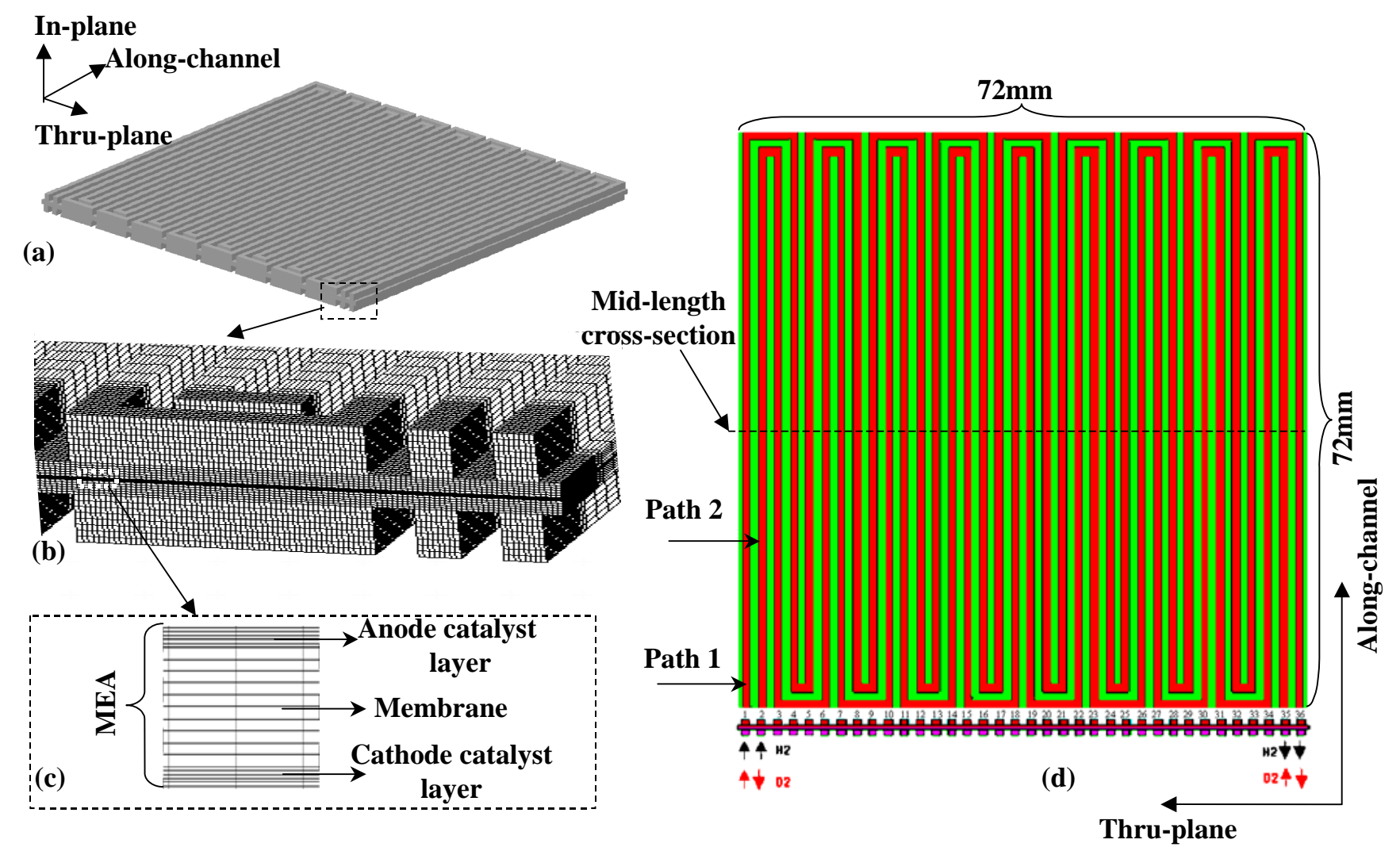

Figure 3.2.1.4 Geometry, grids and top view of the computational domain of the double-path PEFC with thirty-six channels. 


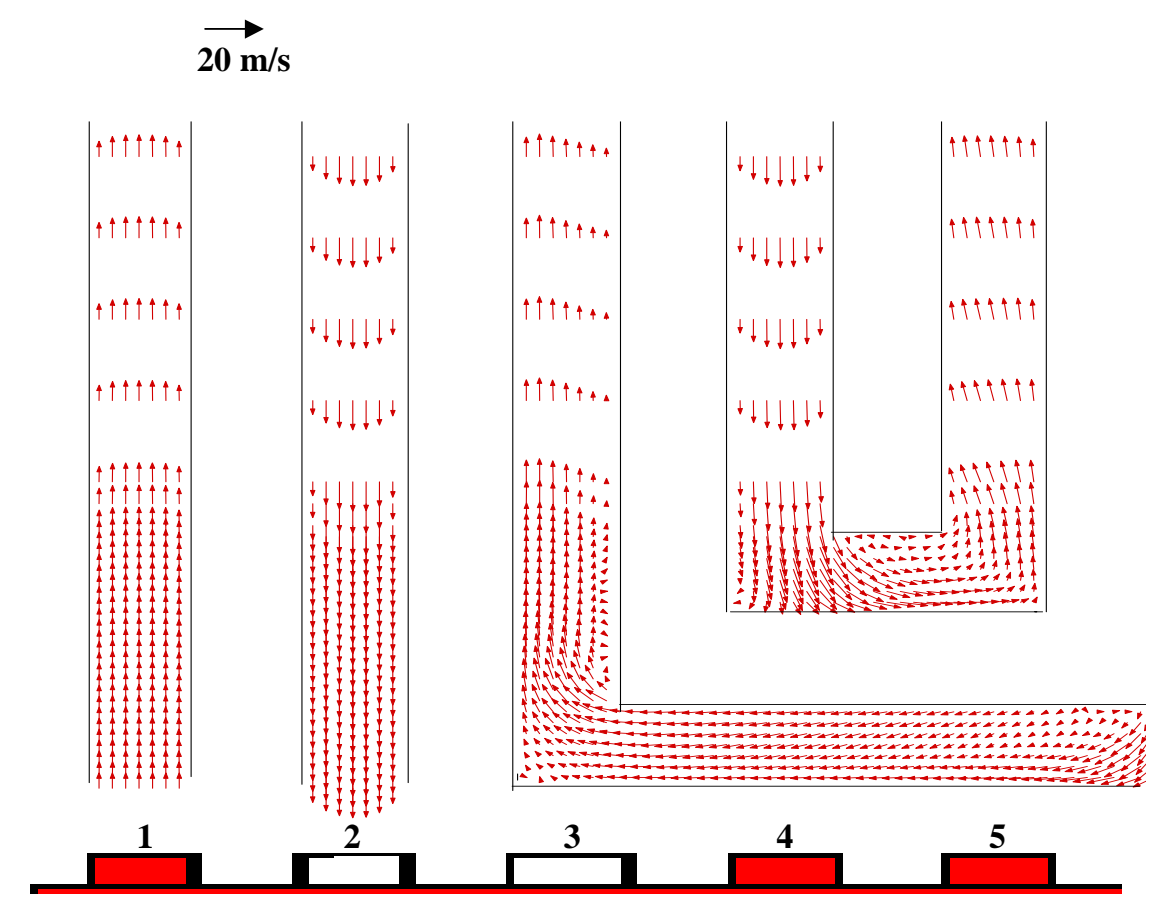

Figure 3.2.1.5 Velocity distribution at the mid-depth of the cathode gas channel without convection in the GDL. 


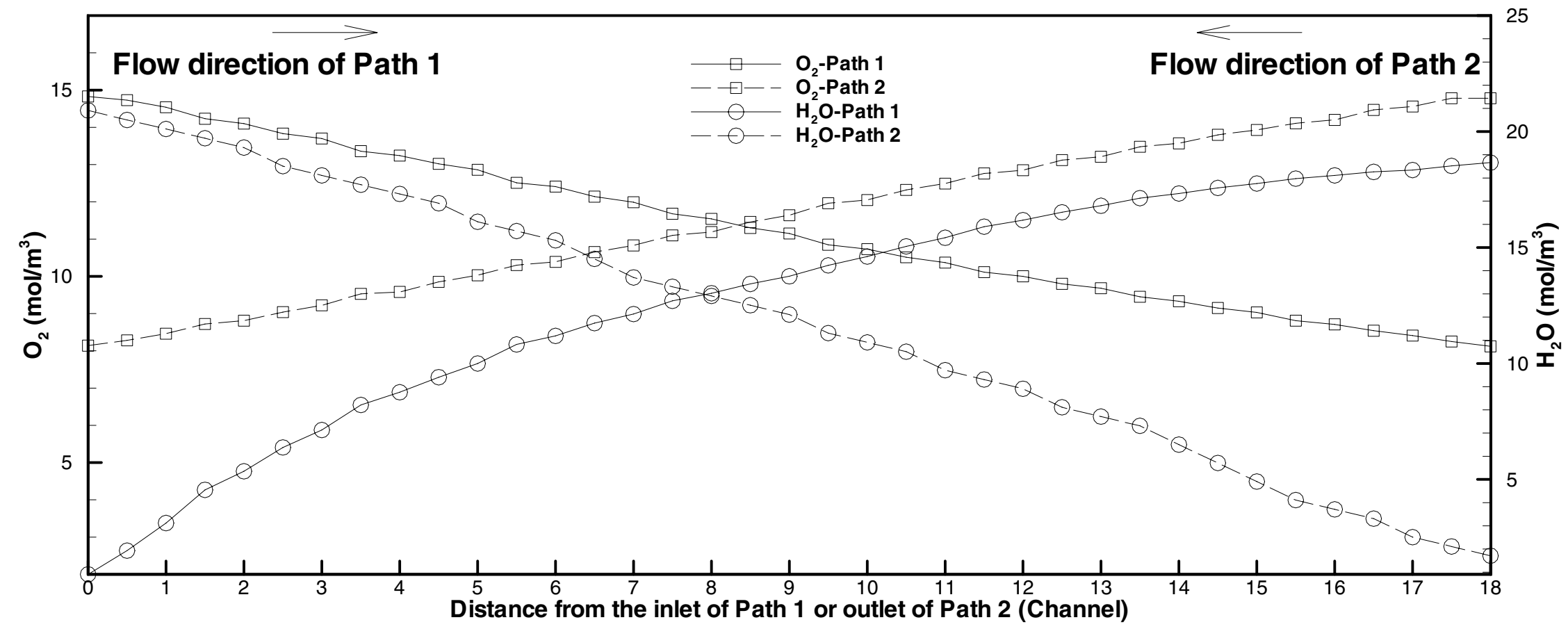

Figure 3.2.1.6 Average $\mathrm{O}_{2} / \mathrm{H}_{2} \mathrm{O}$ concentrations in the cathode gas channel for each flow path without convection in the GDL at $\mathrm{V}_{\text {cell }}=0.65 \mathrm{~V}$ and $\mathrm{I}=0.91 \mathrm{~A} / \mathrm{cm}^{2}$. 

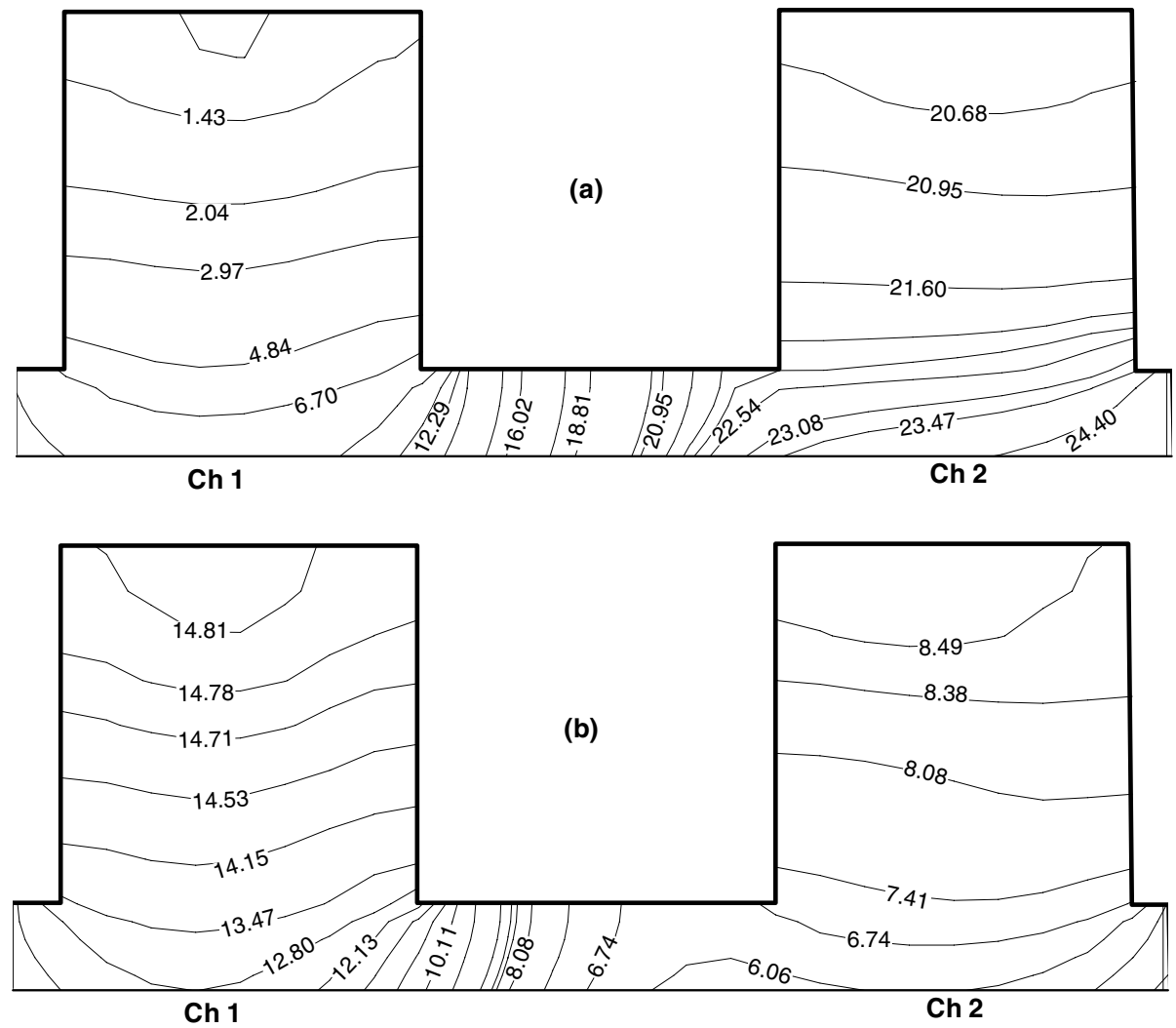

Figure 3.2.1.7 (a) $\mathrm{H}_{2} \mathrm{O}$ and (b) $\mathrm{O}_{2}$ distributions, respectively, in the cathode at the mid-length cross-section between Ch. 1 and Ch. 2 without convection in the GDL at $\mathrm{V}_{\text {cell }}=0.65 \mathrm{~V}$ and $\mathrm{I}=0.91 \mathrm{~A} / \mathrm{cm}^{2}$ 


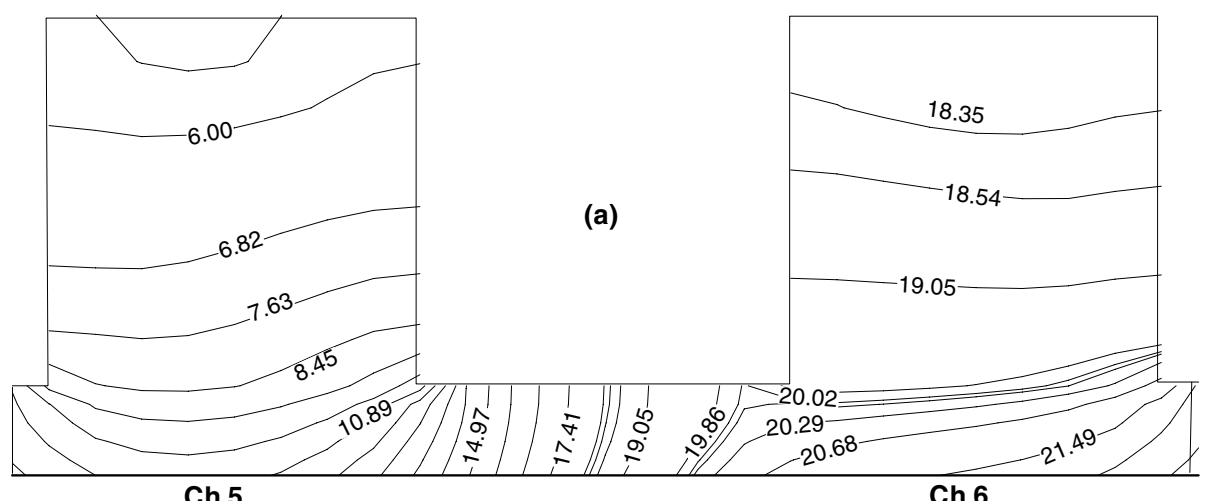

Ch 5

Ch 6

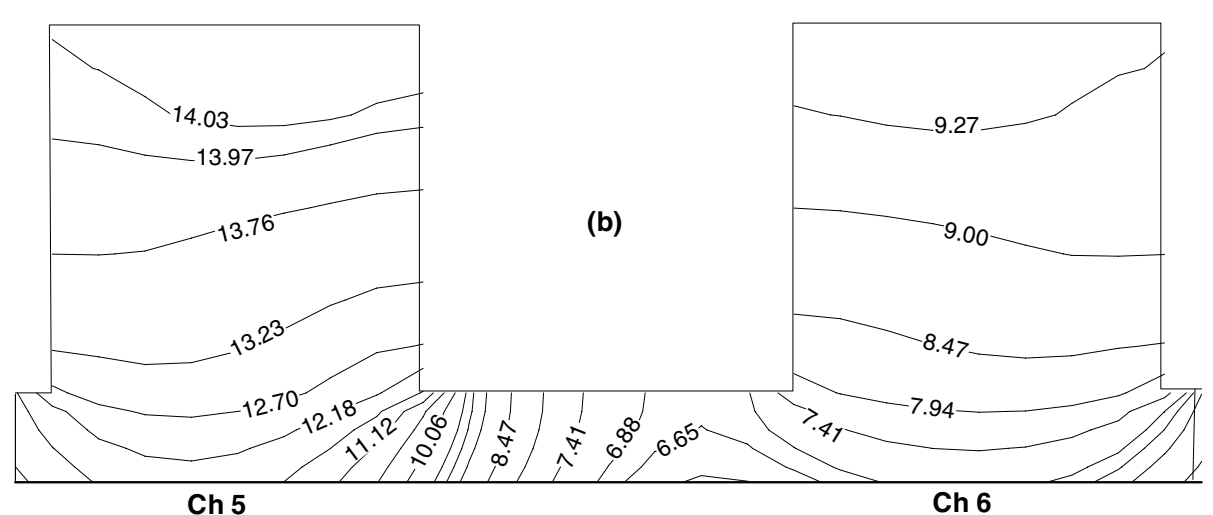

Figure 3.2.1.8 (a) $\mathrm{H}_{2} \mathrm{O}$ and (b) $\mathrm{O}_{2}$ distributions, respectively, in the cathode at the mid-length cross-section between $\mathrm{Ch} .5$ and Ch. 6 without convection in the $\mathrm{GDL}$ at $\mathrm{V}_{\text {cell }}=0.65 \mathrm{~V}$ and $\mathrm{l}=0.91 \mathrm{~A} / \mathrm{cm}^{2}$. 

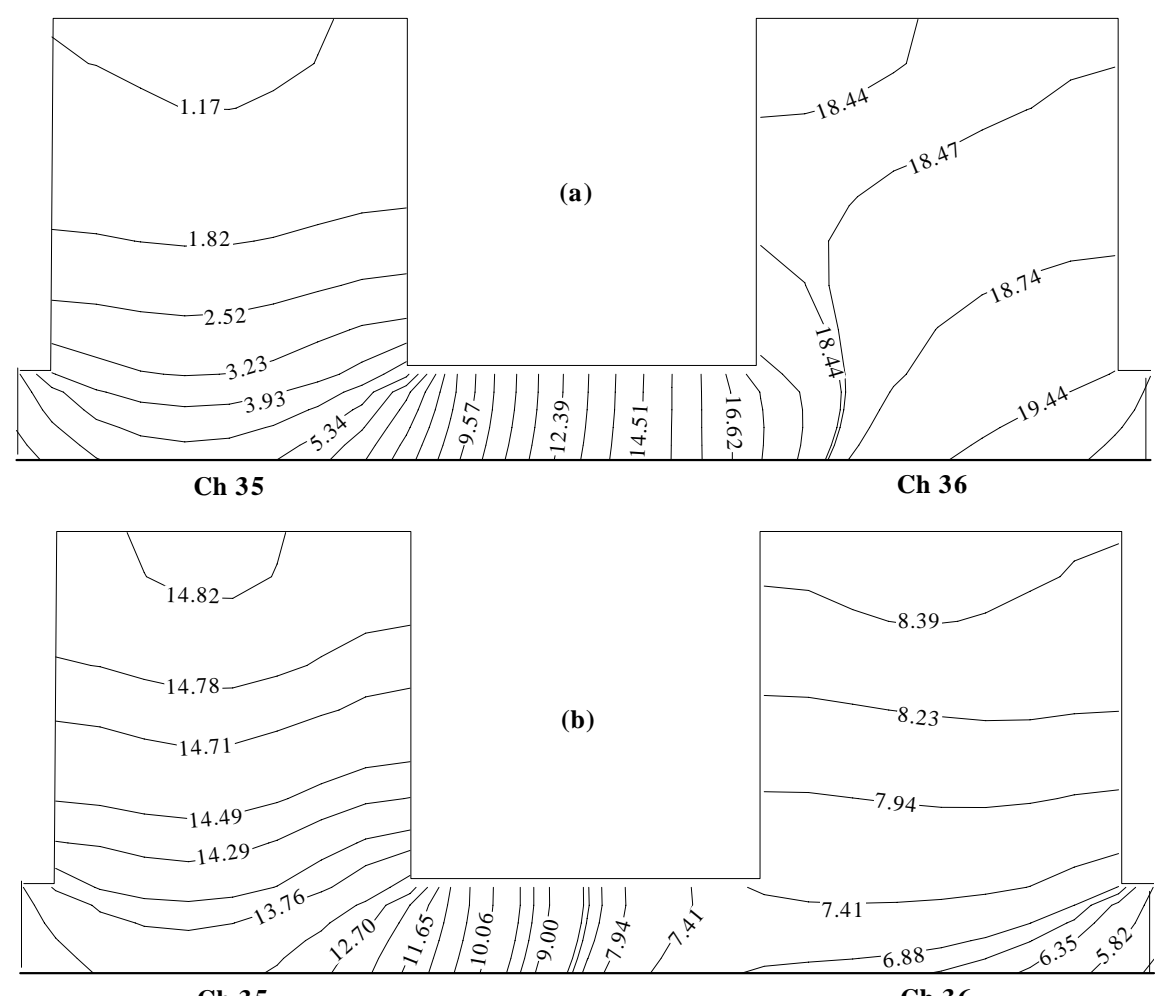

Ch 35

Ch 36

Figure 3.2.1.9 (a) $\mathrm{H}_{2} \mathrm{O}$ and (b) $\mathrm{O}_{2}$ distributions, respectively, in the cathode at the mid-length cross-section between Ch. 35 and $\mathrm{Ch} .36$ without convection in the GDL at $\mathrm{V}_{\text {cell }}=0.65 \mathrm{~V}$ and $\mathrm{I}=0.91 \mathrm{~A} / \mathrm{cm}^{2}$. 


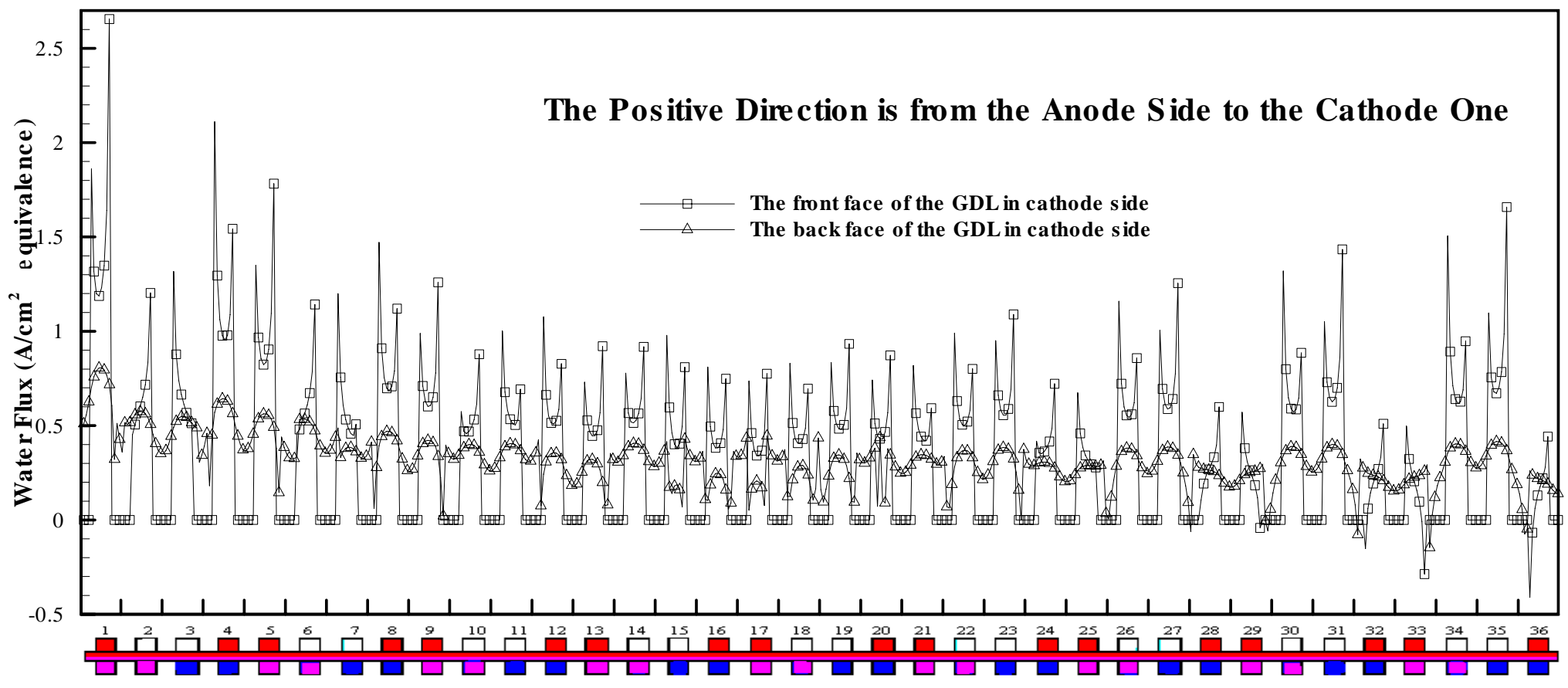

Figure 3.2.1.10 Water flux across surfaces of the cathode GDL at the mid-length cross-section without convection in the GDL under $\mathrm{V}_{\text {cell }}=0.65 \mathrm{~V}$ and $\mathrm{I}=0.91 \mathrm{~A} / \mathrm{cm}^{2}$. 


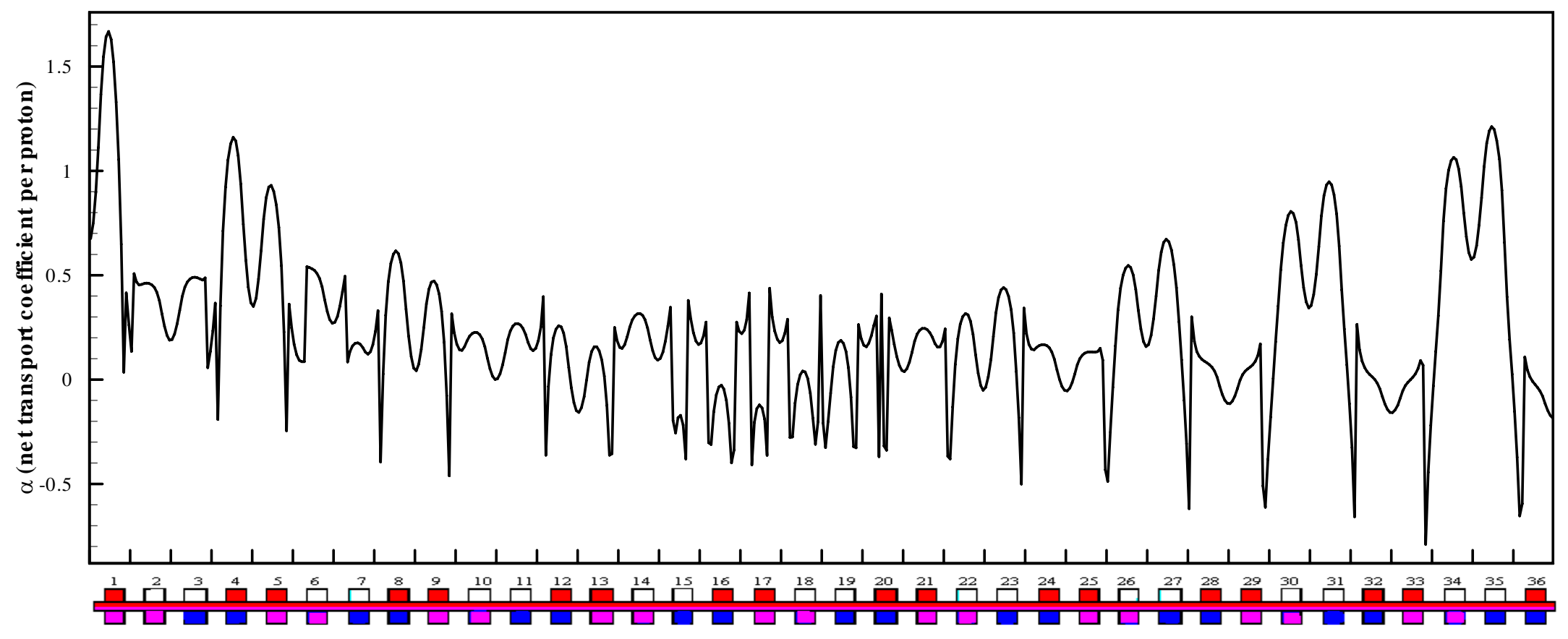

Figure 3.2.1.11 Net water transport coefficient per proton at the mid-length cross-section without convection in the GDL at $\mathrm{V}_{\text {cell }}=0.65 \mathrm{~V}$ and $\mathrm{l}=0.91 \mathrm{~A} / \mathrm{cm}^{2}$. 


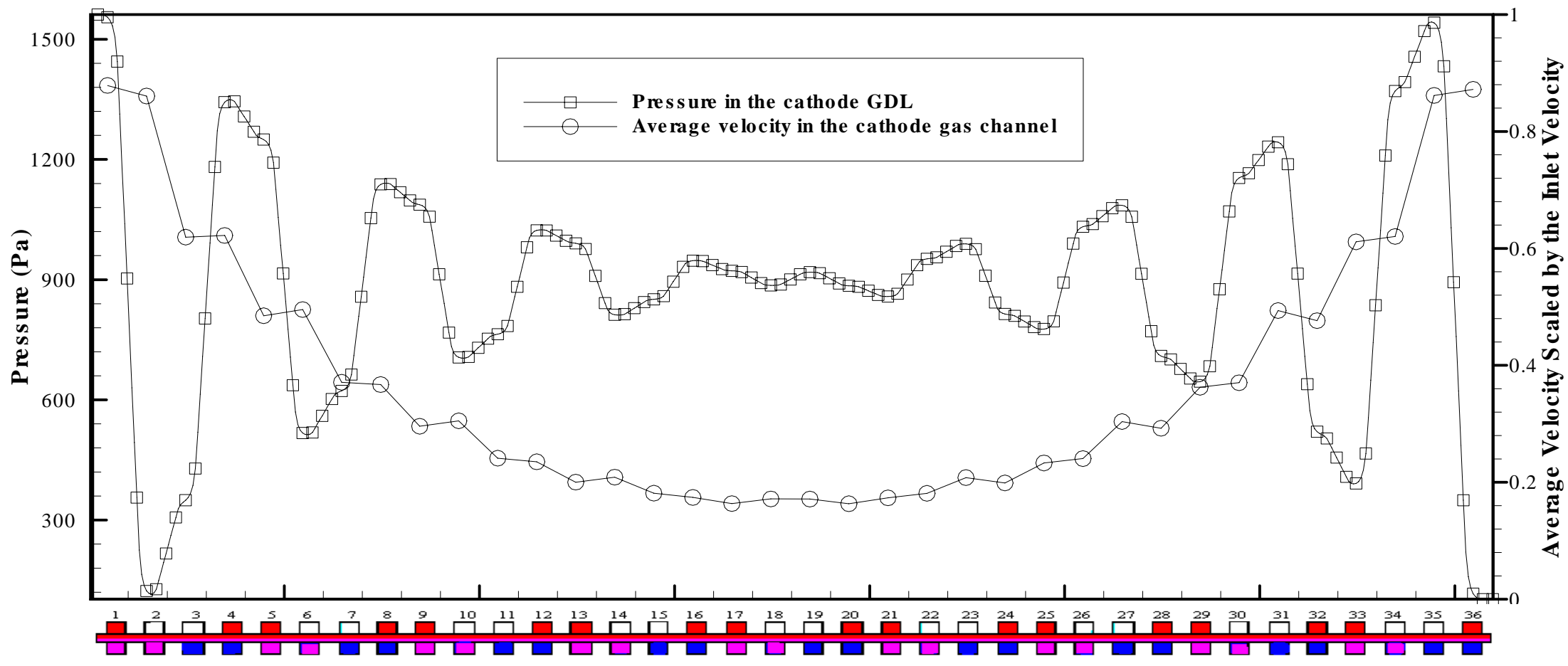

Figure 3.2.1.12 Pressure distribution in the cathode GDL and average velocity scaled by the cathode inlet velocity at the midlength cross-section with convection in the GDL. 

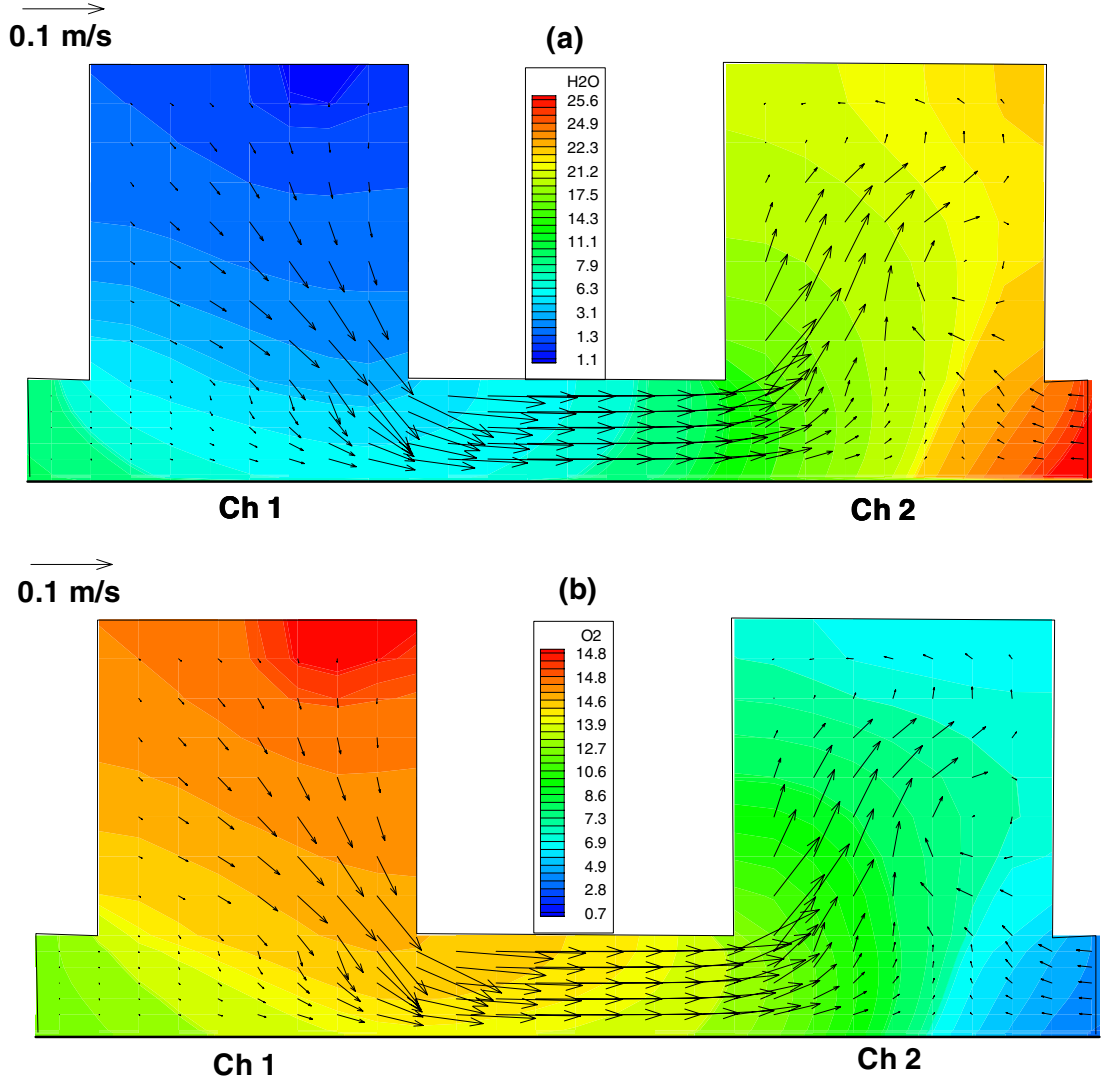

Figure 3.2.1.13 (a) $\mathrm{H}_{2} \mathrm{O}$ and (b) $\mathrm{O}_{2}$ distributions and velocity in the cathode side at the mid-length cross-section between Ch. 1 and Ch. 2 with convection in the GDL at $V_{\text {cell }}=0.65 \mathrm{~V}$ and $\mathrm{I}=0.88 \mathrm{~A} / \mathrm{cm}^{2}$. 

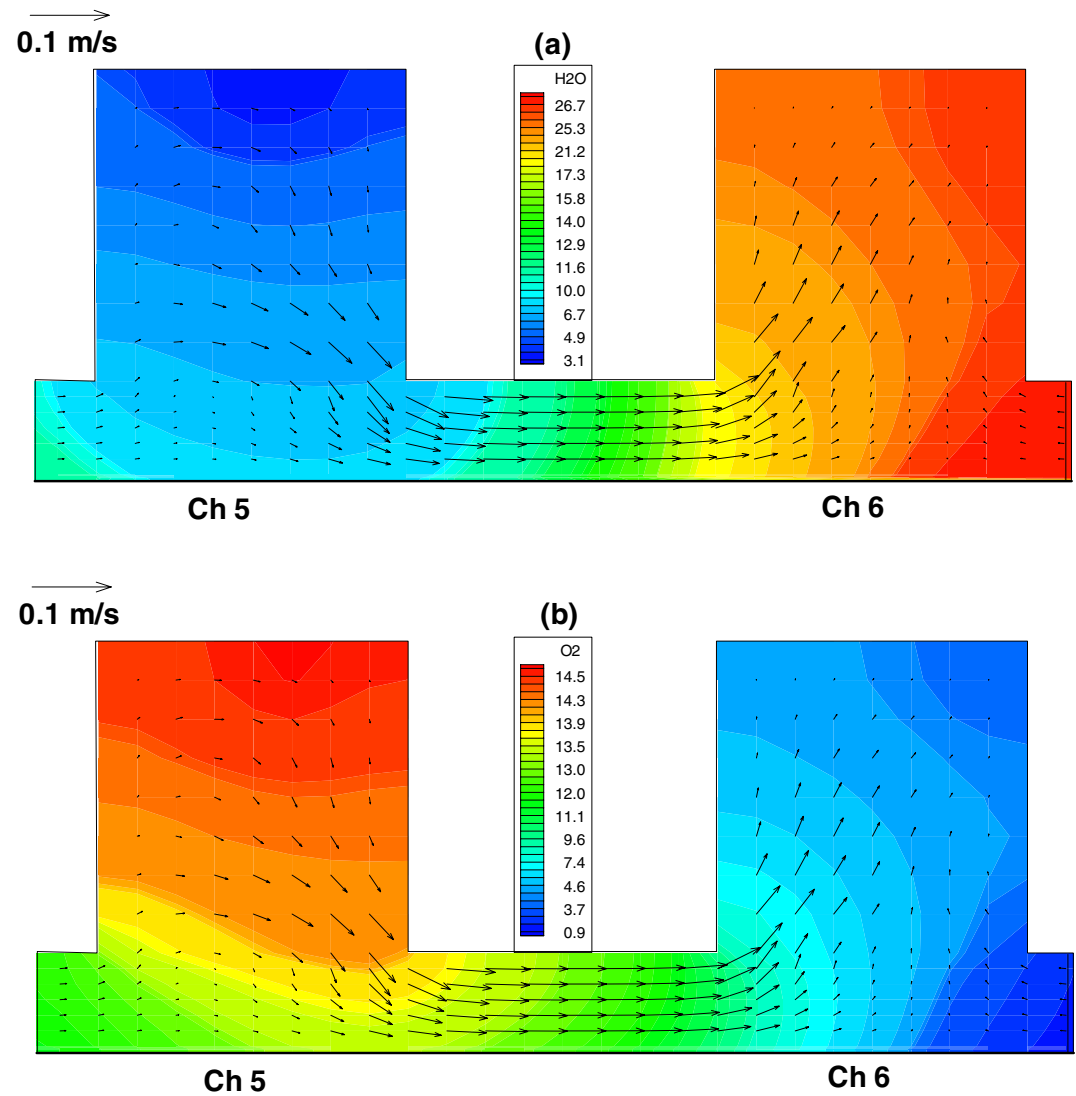

Figure 3.2.1.14 (a) $\mathrm{H}_{2} \mathrm{O}$ and (b) $\mathrm{O}_{2}$ distributions and velocity in the cathode side at the mid-length cross-section between Ch. 5 and $\mathrm{Ch} .6$ with convection in the GDL at $\mathrm{V}_{\text {cell }}=0.65 \mathrm{~V}$ and $\mathrm{I}=0.88 \mathrm{~A} / \mathrm{cm}^{2}$. 


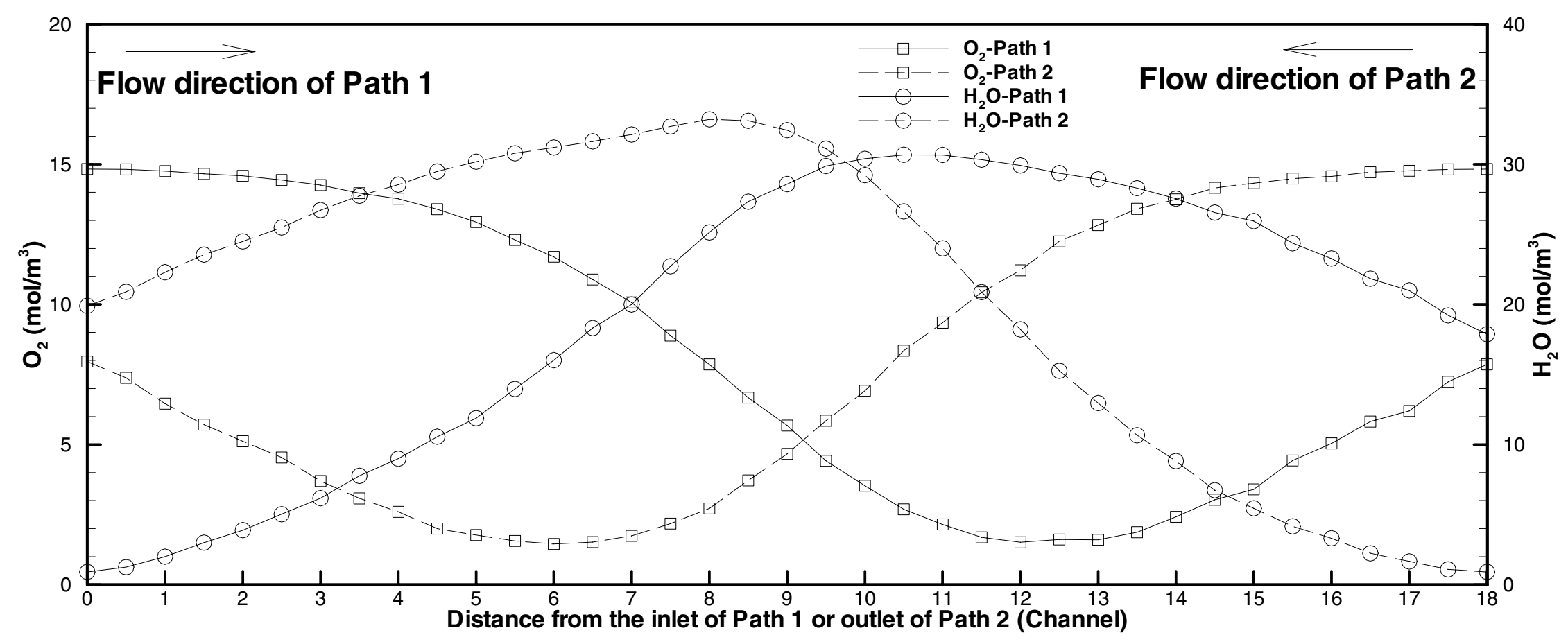

Figure 3.2.1.15 Average $\mathrm{H}_{2} \mathrm{O} / \mathrm{O}_{2}$ concentrations in the cathode gas channel for each flow path with convection in the GDL at $\mathrm{V}_{\text {cell }}=0.65 \mathrm{~V}$ and $\mathrm{I}=0.88 \mathrm{~A} / \mathrm{cm}^{2}$. 


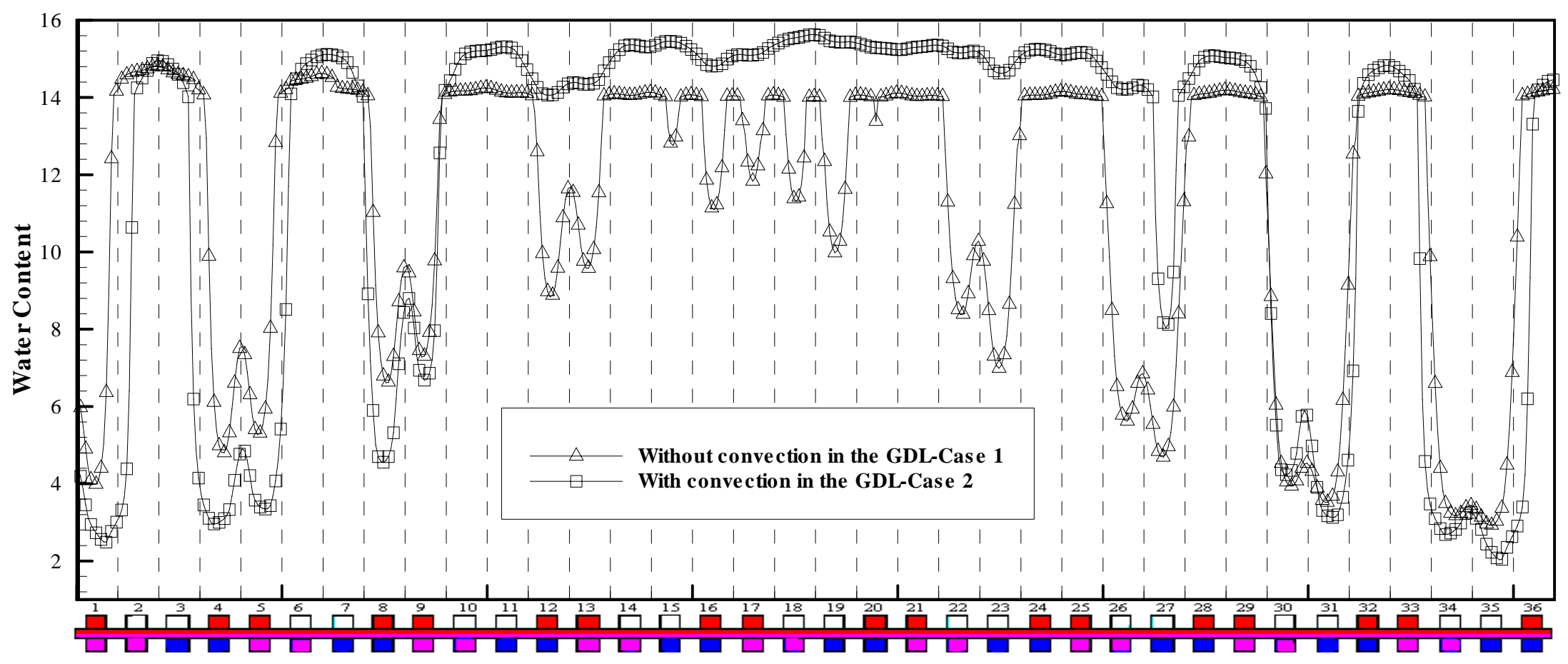

Figure 3.2.1.16 Water content profile at the interface of the membrane and cathode catalyst layer at the mid-length cross-section. 


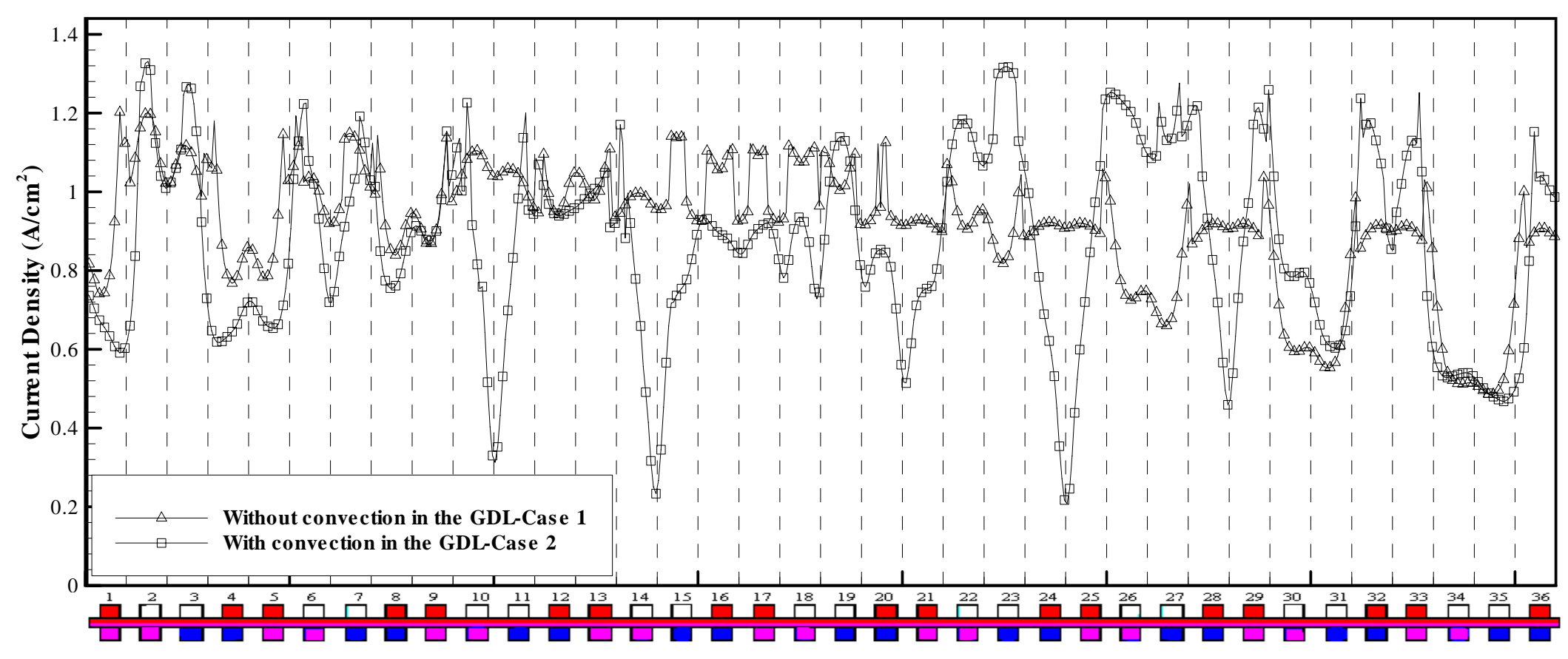

Figure 3.2.1.17 Current density distribution profile at the mid-length cross-section. 


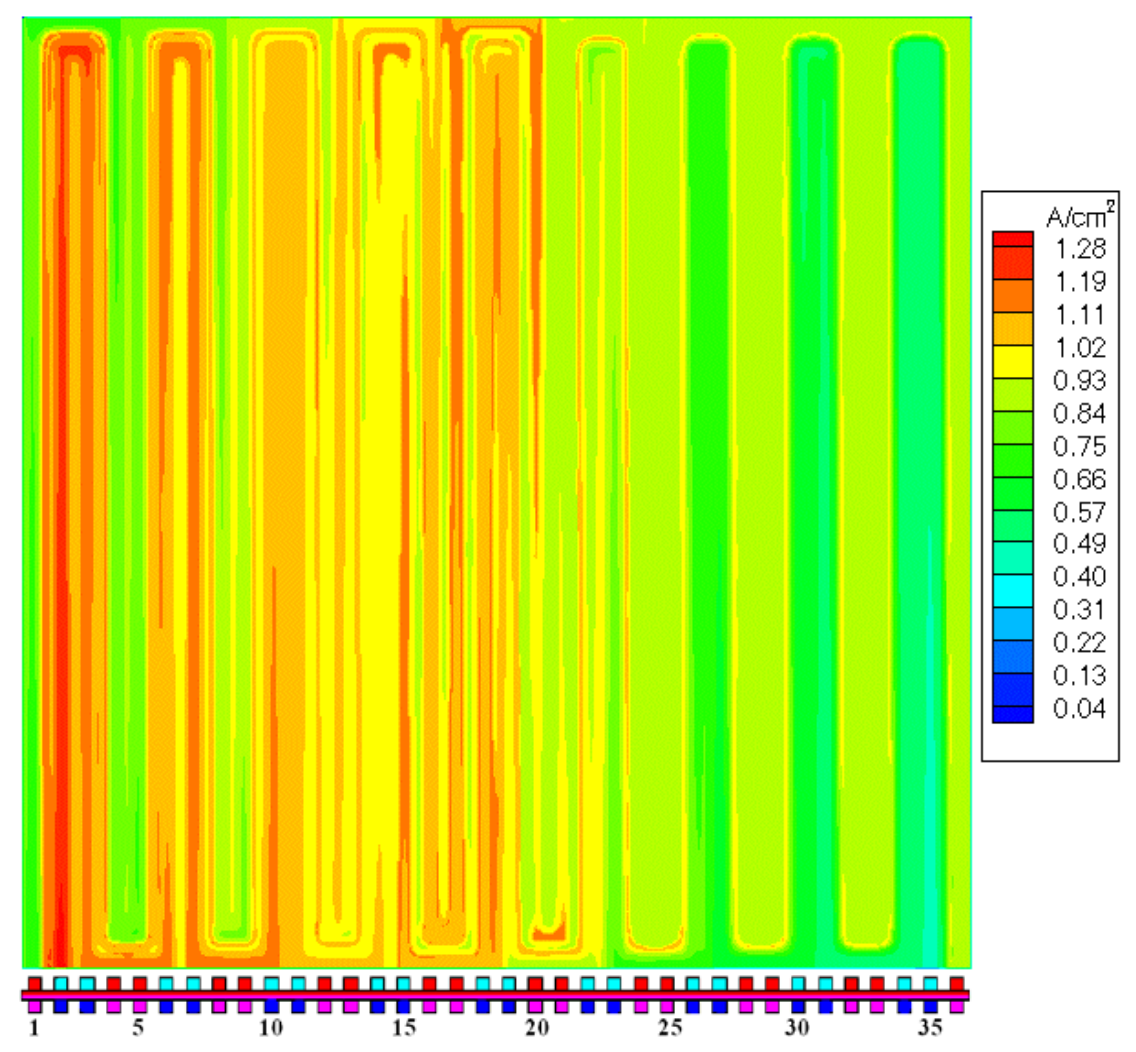

Figure 3.2.1.18 Current density contours for Case 1 at $\mathrm{V}_{\text {cell }}=0.65 \mathrm{~V}$ and $\mathrm{I}=0.91 \mathrm{~A} / \mathrm{cm}^{2}$. 


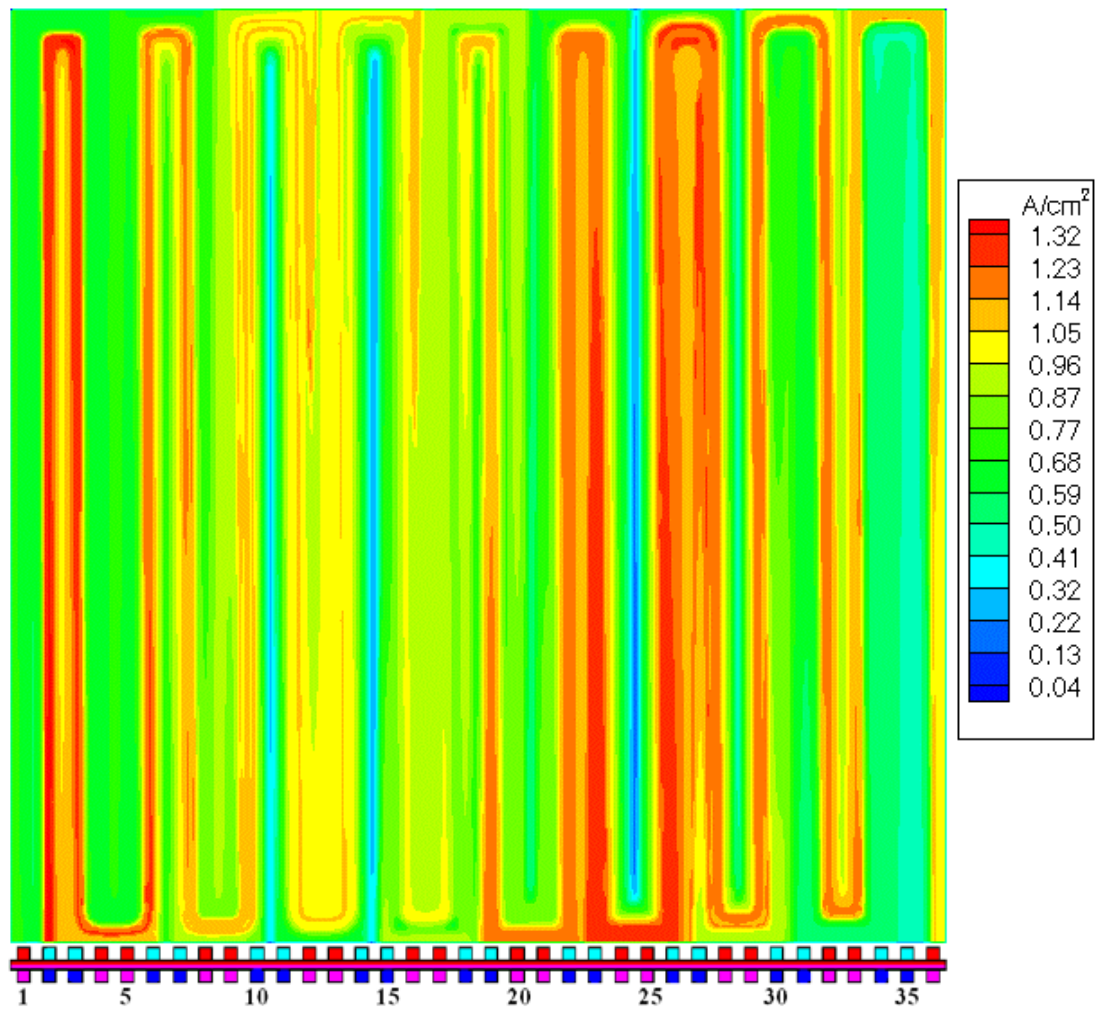

Figure 3.2.1.19 Current density contours for Case 2 at $V_{\text {cell }}=0.65 \mathrm{~V}$ and $\mathrm{I}=0.88 \mathrm{~A} / \mathrm{cm}^{2}$. 


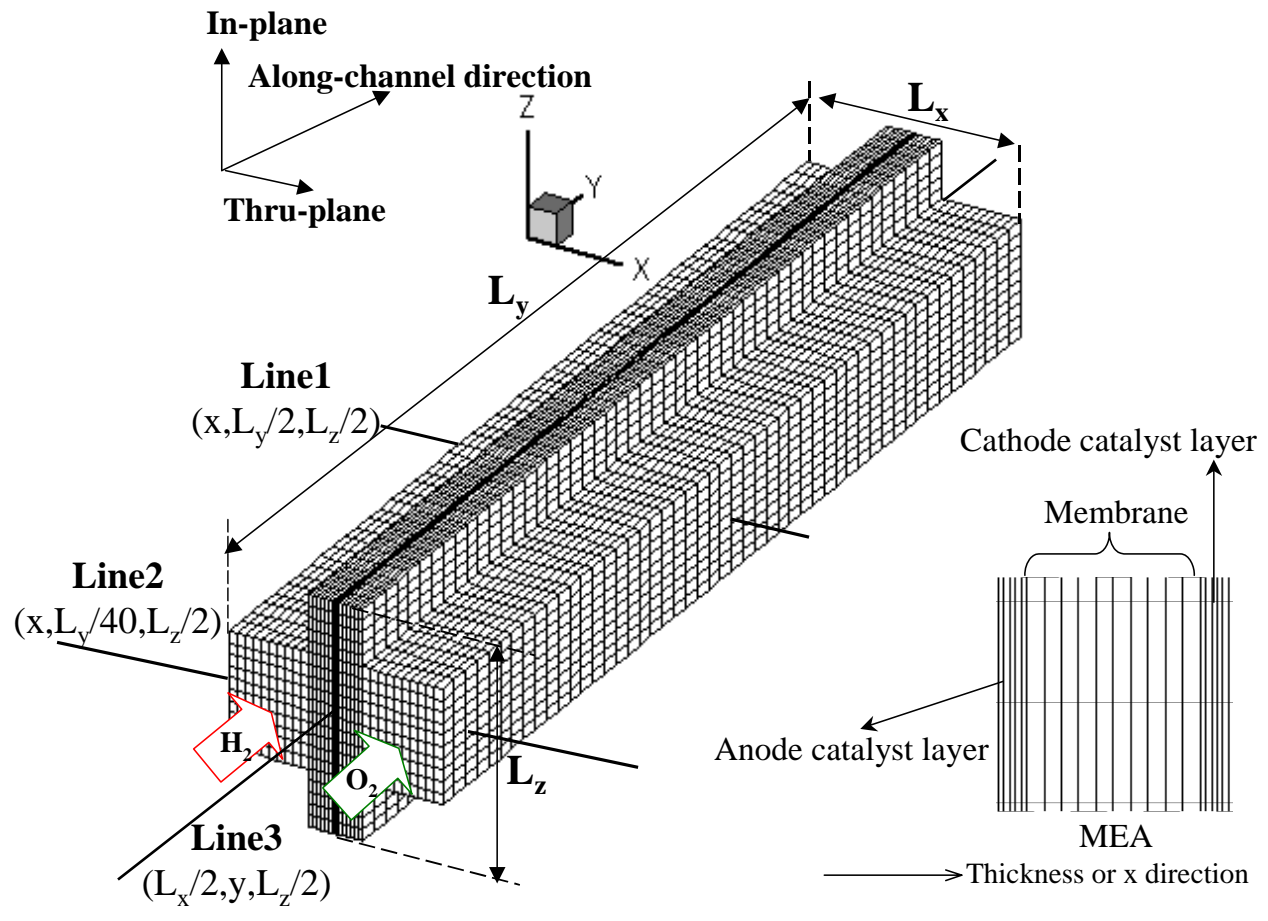

Figure 3.2.1.20 The details of computational domain and mesh of the single-channel PEFC. Lines 1, 2 and 3 are three typical positions chosen to display detailed results. 


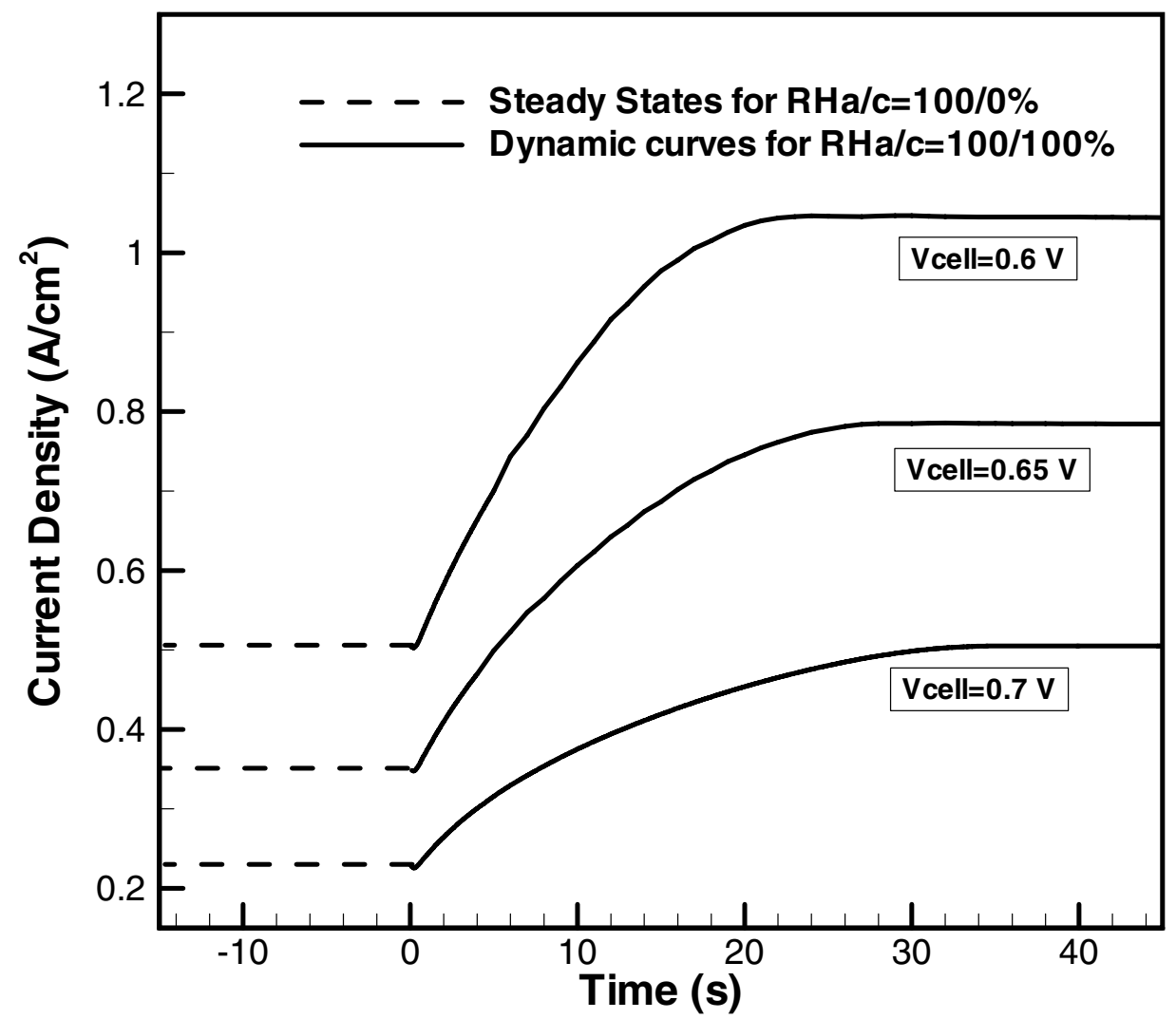

Figure 3.2.1.21 Dynamic responses of average current density to the step change of the cathode inlet humidification from $\mathrm{RH}=0 \%$ to $100 \%$, under 0.6 , 0.65 and $0.7 \mathrm{~V}$. 


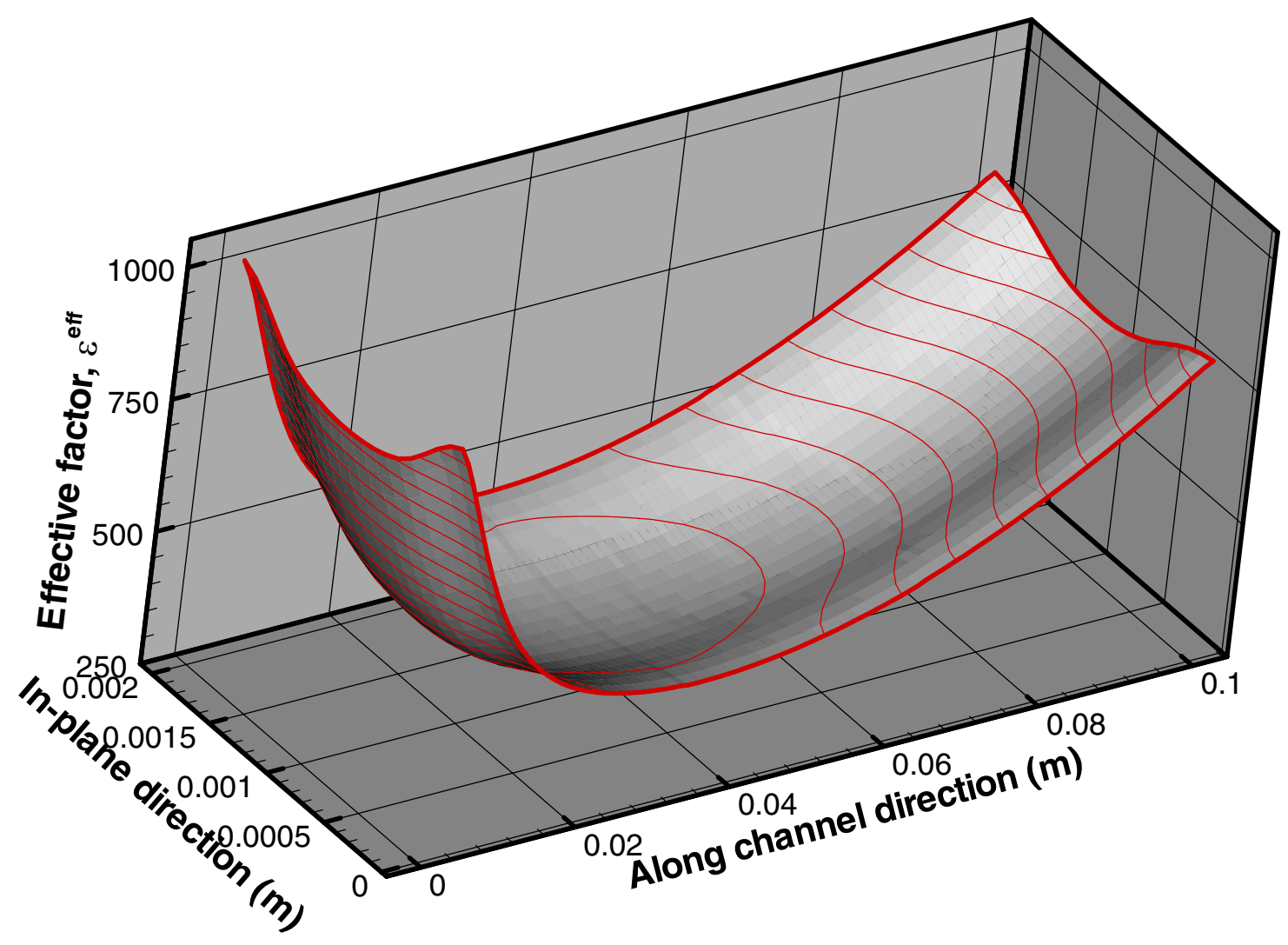

Figure 3.2.1.22 The effective factor, $\varepsilon^{\text {eff }}$, in Eq. 3.2.1.17 in the middle of the membrane, under $0.65 \mathrm{~V}$ and $\mathrm{RHa} / \mathrm{c}=100 / 0 \%$. 


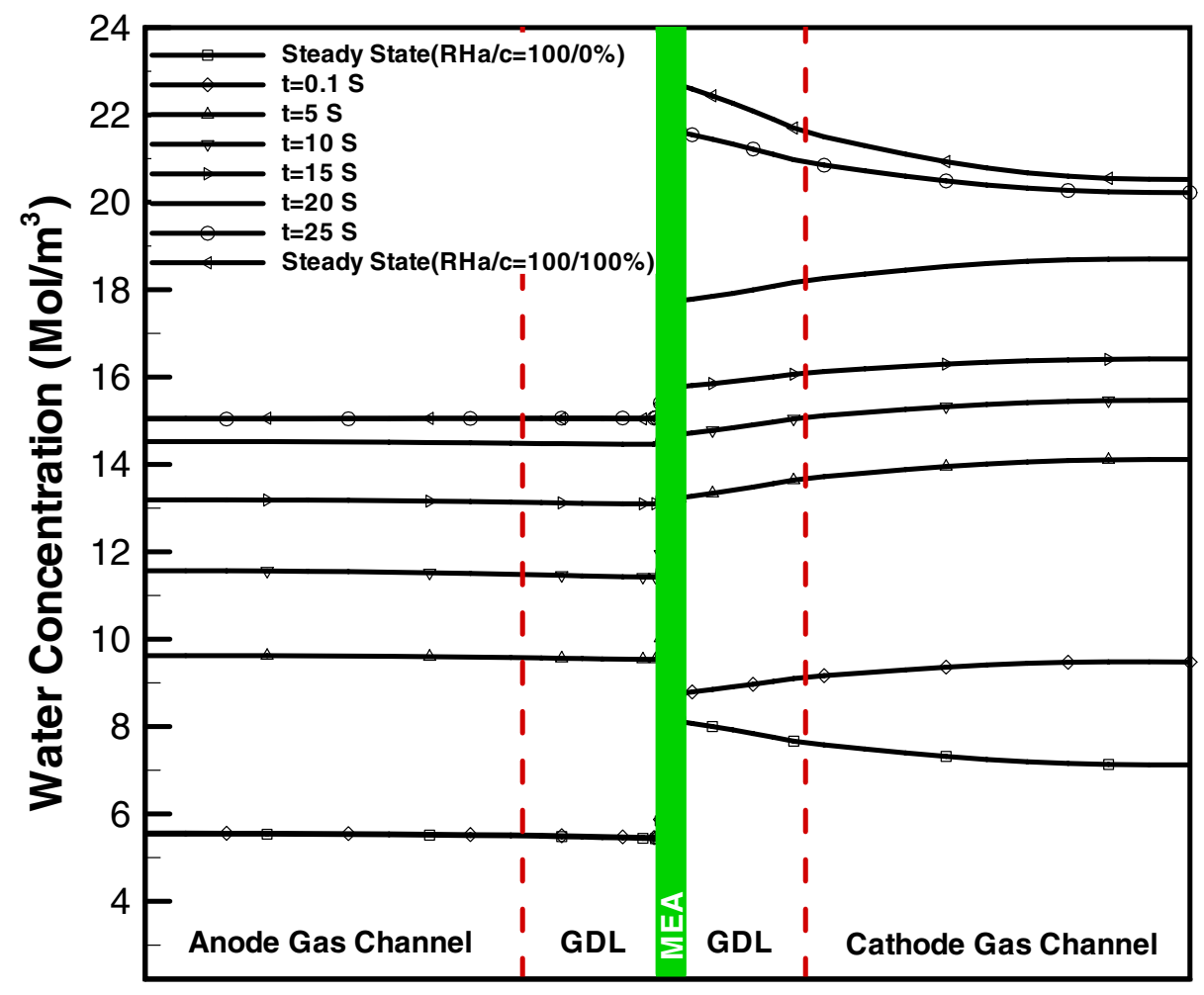

Figure 3.2.1.23 Evolution of water concentration profiles along Line $1\left(x, L_{y} / 2, L_{z} / 2\right)$, when the cathode inlet humidification changes from $\mathrm{RH}=0 \%$ to $100 \%$ under $0.65 \mathrm{~V}$. 


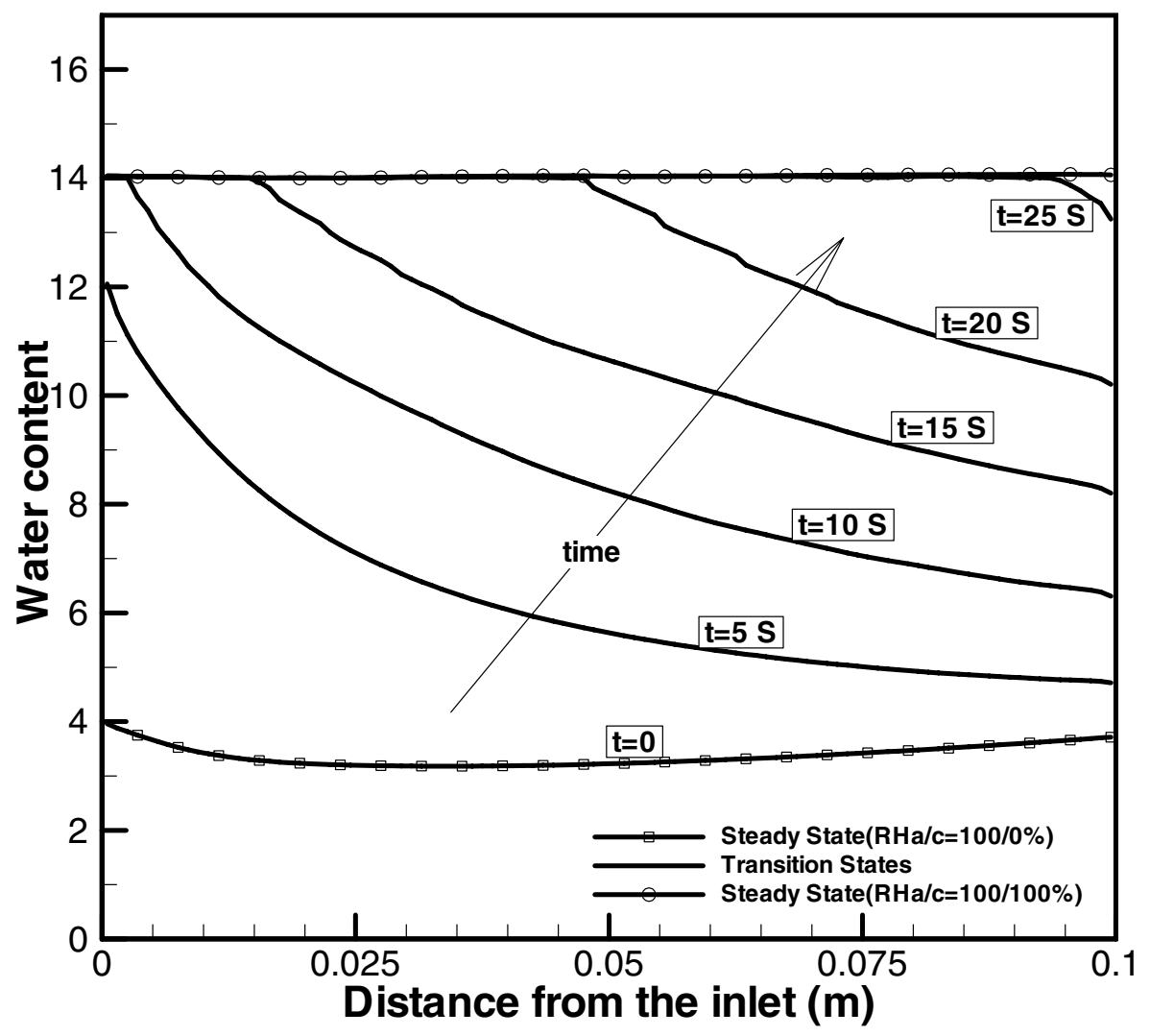

Figure 3.2.1.24 Evolution of water content profiles along Line $3\left(L_{x} / 2, y, L_{z} / 2\right)$, when the cathode inlet humidification changes from $\mathrm{RH}=0 \%$ to $100 \%$ under 0.65 $\mathrm{V}$. 


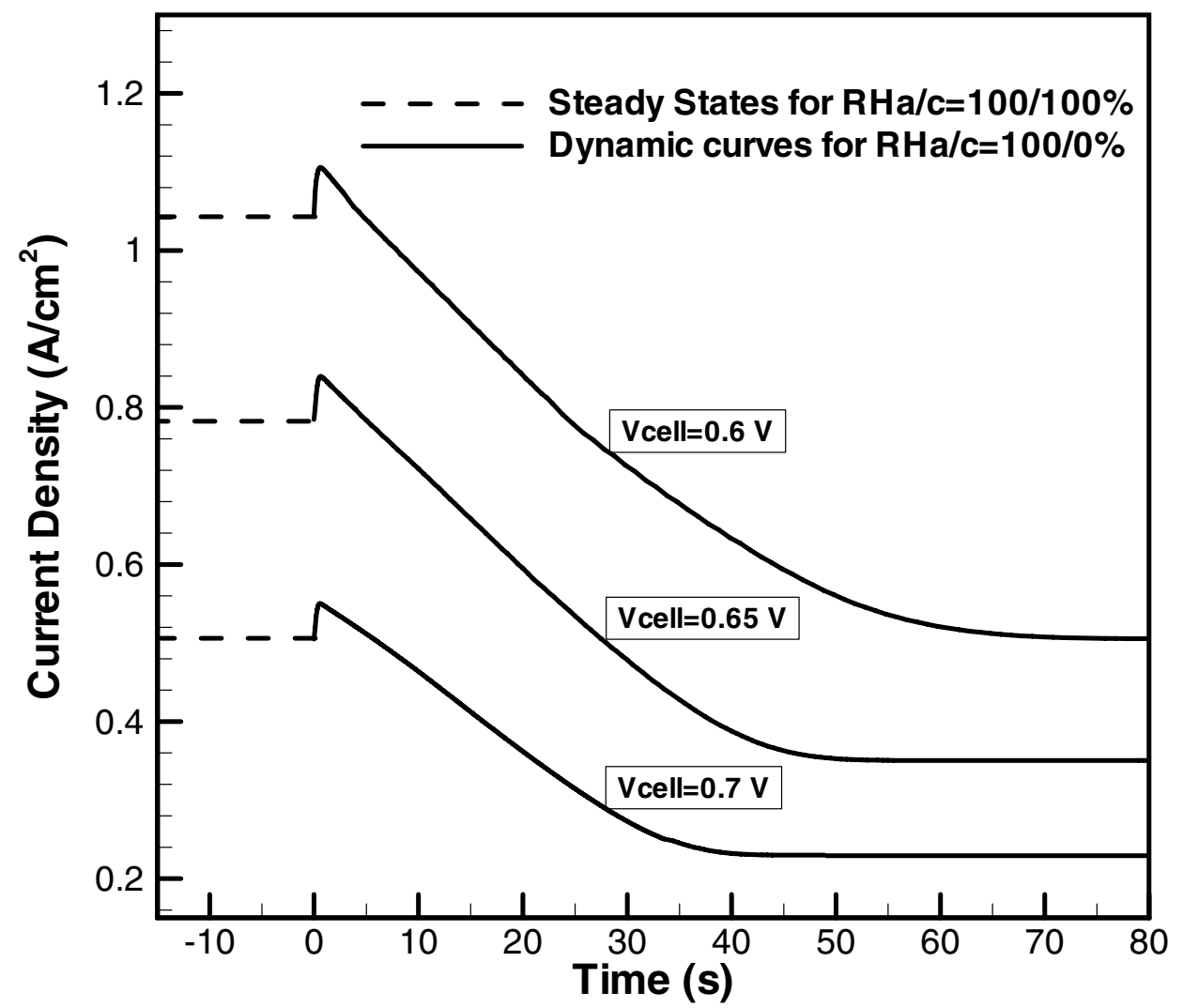

Figure 3.2.1.25 Dynamic responses of average current density to the step change of the cathode inlet humidification from $\mathrm{RH}=100 \%$ to $0 \%$, under 0.6 , 0.65 and $0.7 \mathrm{~V}$. 


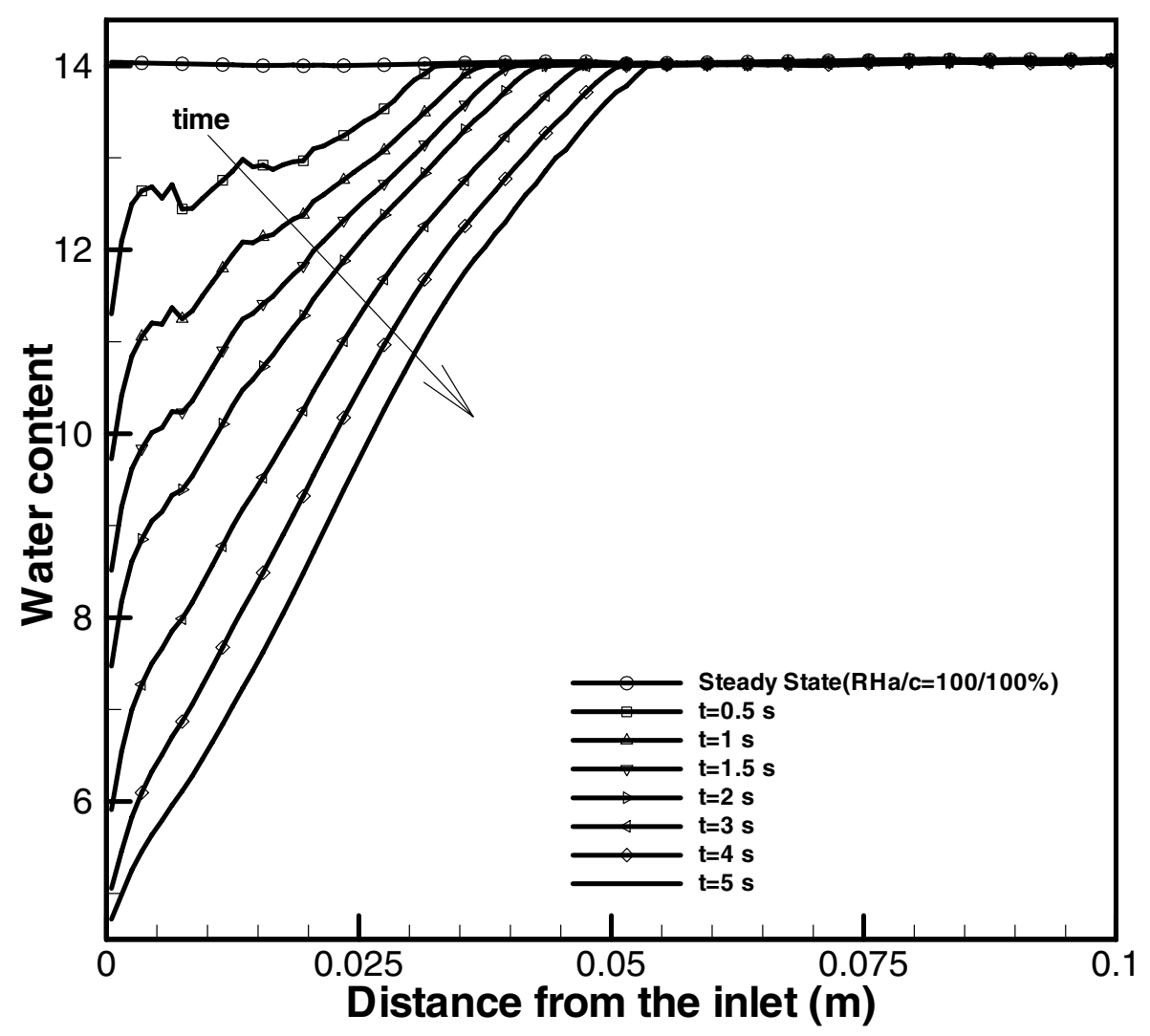

Figure 3.2.1.26 Evolution of water content profiles along Line $3\left(L_{x} / 2, y, L_{z} / 2\right)$, when the cathode inlet humidification changes from $\mathrm{RH}=100 \%$ to $0 \%$ under $0.65 \mathrm{~V}$. 


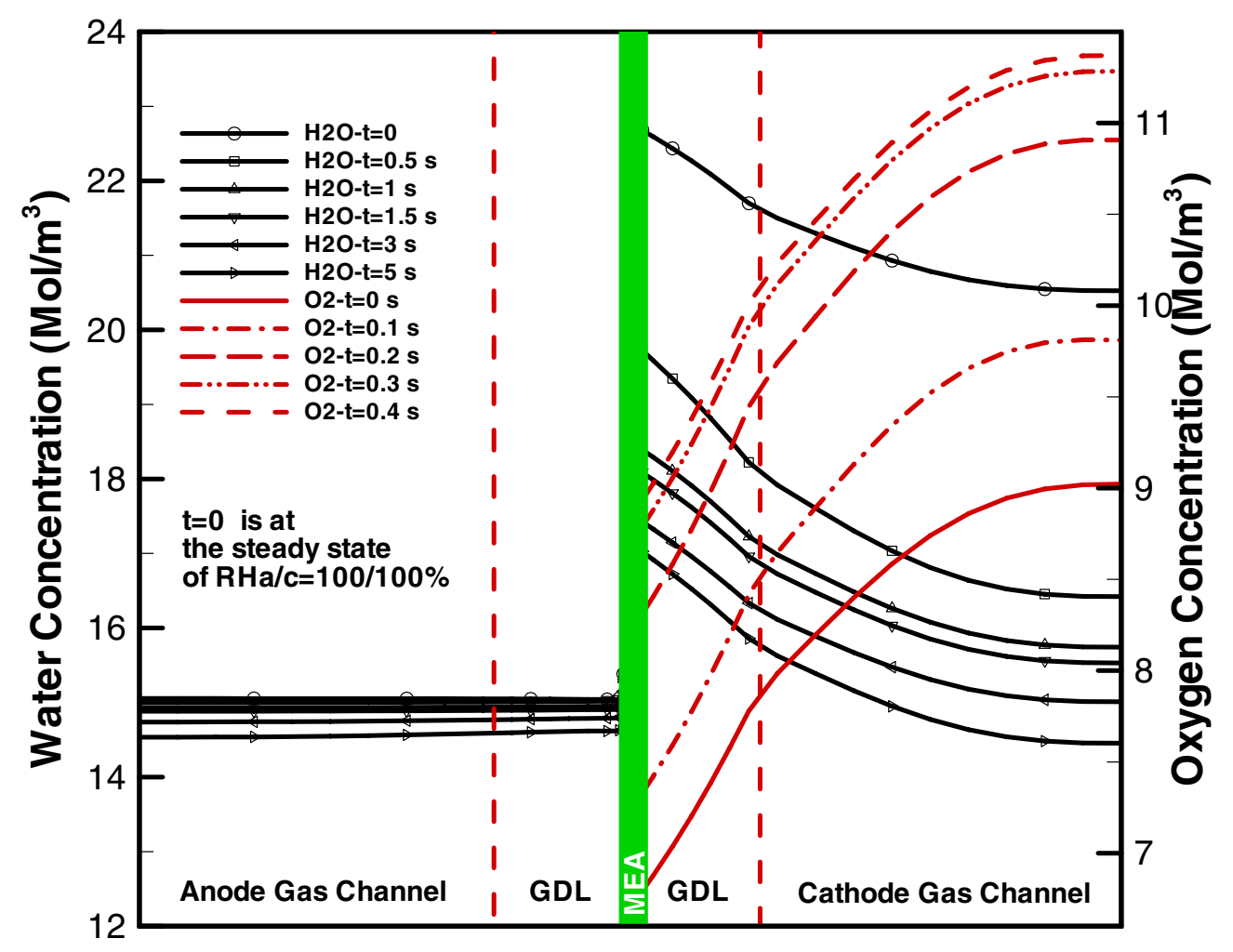

Figure 3.2.1.27 Evolution of water and oxygen concentration profiles along Line 1 ( $\mathrm{x}$, $\left.\mathrm{L}_{\mathrm{y}} / 2, \mathrm{~L}_{\mathrm{z}} / 2\right)$, when the cathode inlet humidification changes from $\mathrm{RH}=100 \%$ to $0 \%$ under $0.65 \mathrm{~V}$. 


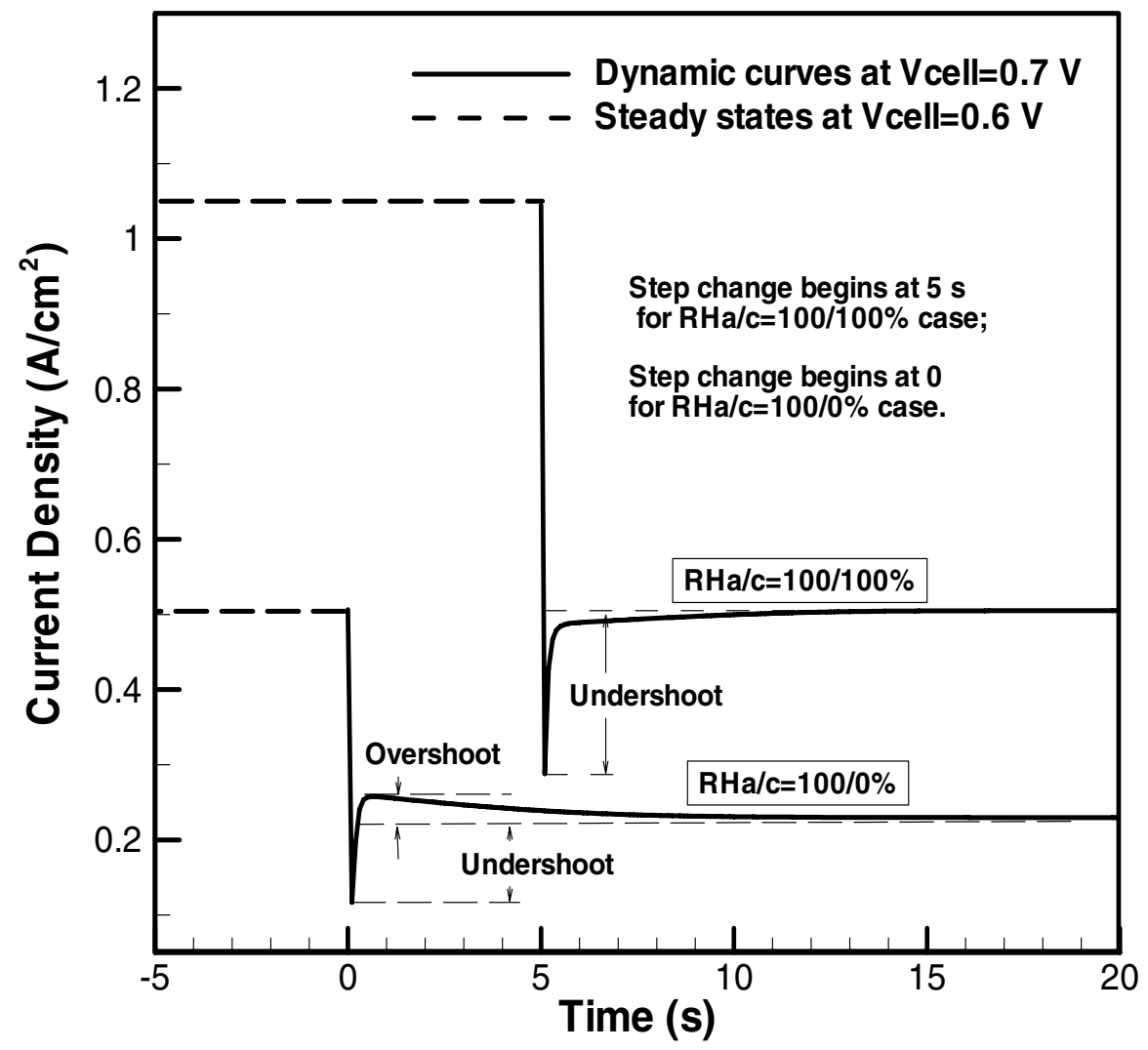

Figure 3.2.1.28 Dynamic responses of average current density to the step change of cell voltages from $0.6 \mathrm{~V}$ to $0.7 \mathrm{~V}$, under $\mathrm{RHa} / \mathrm{c}=100 / 100 \%$ and $100 / 0 \%$. 


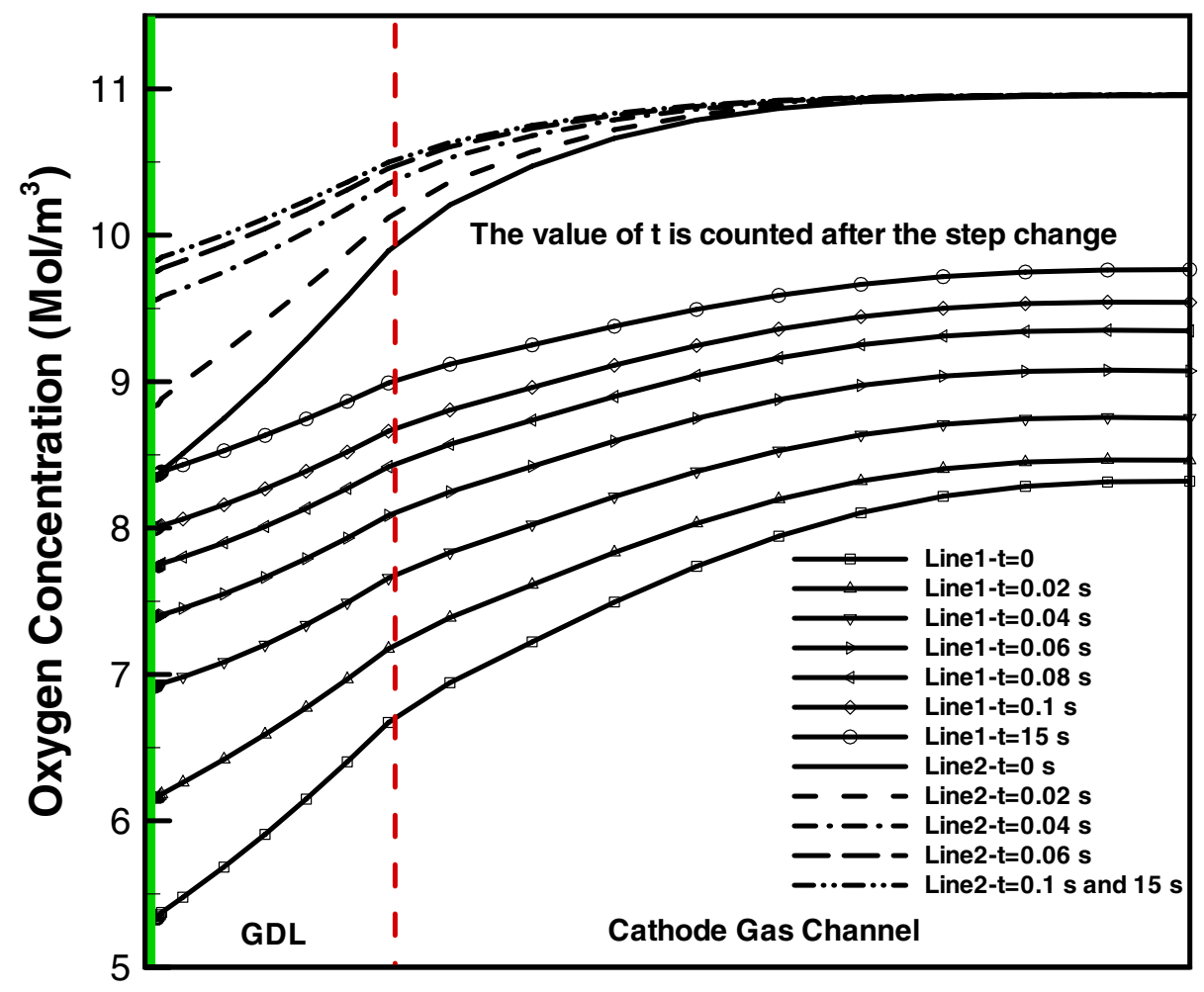

Figure 3.2.1.29 Evolution of oxygen concentration profiles along Line $1\left(x, L_{y} / 2, L_{z} / 2\right)$ and Line $2\left(x, L_{y} / 40, L_{z} / 2\right)$, when cell voltages change from $0.6 \mathrm{~V}$ to 0.7 $\mathrm{V}$, under $\mathrm{RHa} / \mathrm{c}=100 / 100 \%$. 


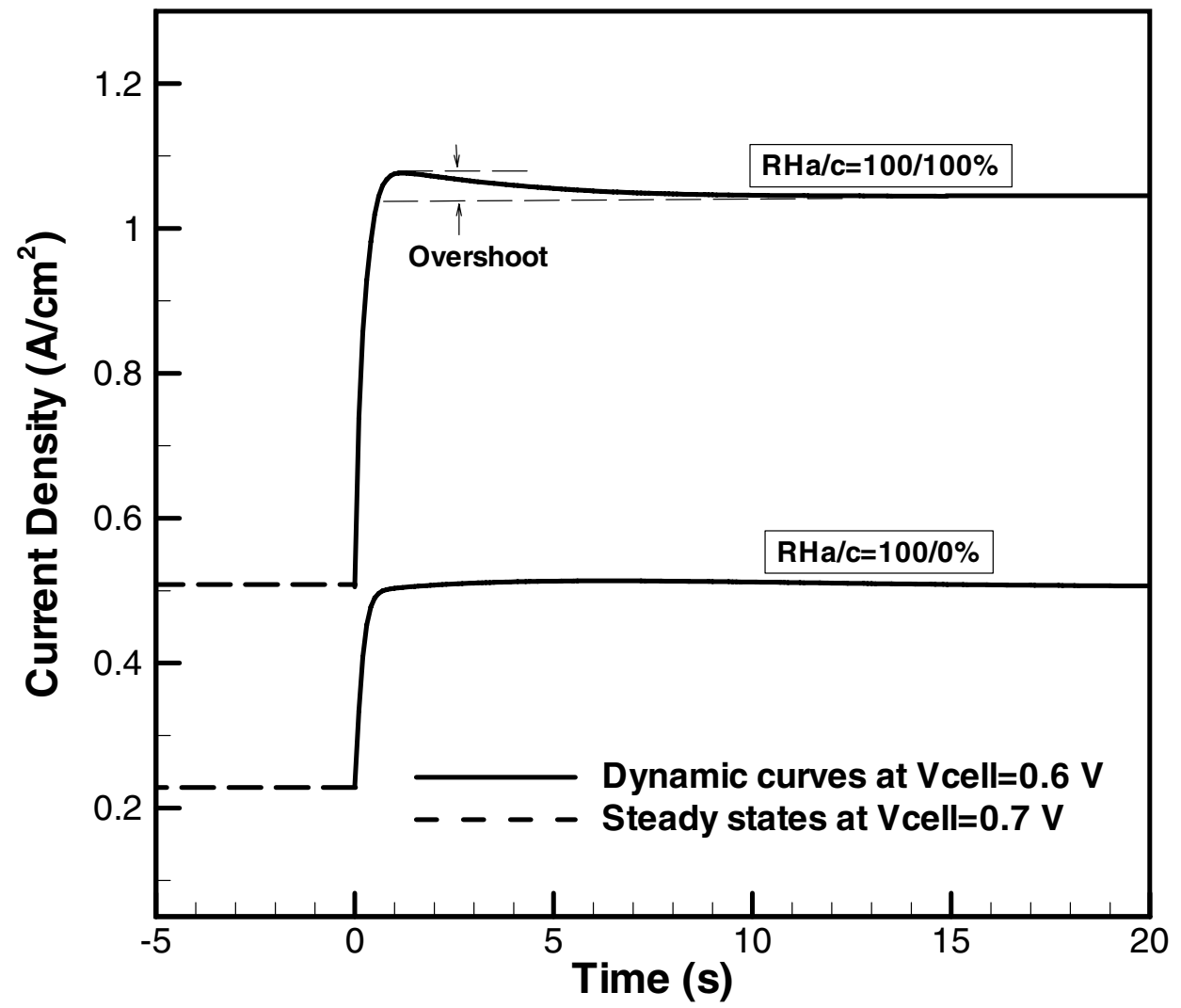

Figure 3.2.1.30 Dynamic responses of average current density to the step change of cell voltages from $0.7 \mathrm{~V}$ to $0.6 \mathrm{~V}$, under $\mathrm{RHa} / \mathrm{c}=100 / 100 \%$ and $100 / 0 \%$. 


\section{Subtask 3.2.1.3 - Study of Anode and Cathode Species as a Function of Operating Conditions and Fuel Composition (10-24 months)}

\subsection{Study of Water generation in the Indirect Methanol Fuel Cell}

Due to the hydrogen and oxygen reactions in a fuel cell, water is generated on the cell's cathode side. Because of this internal water generation, the cathode side has potential for reduction or elimination of external humidification. So, for this study, the anode was kept fully saturated and only the cathode side was investigated for humidification optimization. The cathode relative humidity was varied from 0 to $100 \%$ at 5 distinct levels $(0,25,50,75$, and 100\%). The cell pressure, which was kept equal on both sides, was also varied at 5 distinct levels above atmospheric pressure $(0,10$, 20,30 , and 45 psig). Thus, with 5 humidity levels and 5 pressure levels, a total of 25 tests were required to complete the parametric study. During each test, the cell was allowed to reach a steady state condition, and the cell polarization was measured.

Comparing 25 polarization curves taken under different conditions, and trying to determine overall trends in performance, can be a quite complex task. In order to simplify the data and analysis, it was decided to plot the cell current at specific voltages instead of showing the entire polarization curve. Thus, the effects of pressure and cathode relative humidity can be understood more easily. Figure 3.2.1.31 displays the current available at a cell voltage of $0.6 \mathrm{~V}$ versus cell pressure and cathode relative humidity. The surface was obtained by using a cubic interpolation function between the 25 experimental data points (one data point from each polarization curve). Figure 3.2.1.31 displays the surface in an isometric view, while Figure 3.2.1.32 shows an overhead view of the surface. Figures 3.2.1.33 and 3.2.1.34 are similar to the first two, but they show the current obtainable at a cell potential of $0.4 \mathrm{~V}$.

The isometric views of the current obtainable at $0.6 \mathrm{~V}$ and $0.4 \mathrm{~V}$ (Figures 3.2.1.31 and 3.2.1.33) clearly show the performance trend as a function of cell pressure and cathode relative humidity. As shown, the current is strong function of cell pressure, while displaying only a mild dependence on cathode humidity. This mild dependence on cathode relative humidity indicates that anode gas humidification and water generation on the cathode side is sufficient to maintain the membrane at an adequate ionic conductivity level. As a result of sufficient internal humidification of the cathode feed stream, at 45 psig the cell performance is reduced by only $10 \%$ with completely dry cathode feed gas as compared to the maximum performance obtainable with a wet cathode fed gas. At 45 psig, the maximum performance is obtainable with a cathode inlet relative humidity in the $50-75 \%$ range, indicating that full saturation of the cathode feed gas results in an excess of water in the cell, and leads to some degree cell flooding. Also, as shown, only at atmospheric pressure operation does a dry cathode feed result in a significant drop in cell current.

The trends observable in Figures 3.2.1.31 through 3.2.1.34 also show that while there exists a strong dependence of current on cell pressure, the dependence is not linear. A sharp rise in performance is seen as pressure is increased from atmospheric to roughly 20 psig. After that, increasing cell pressure results in only marginal gains in available current. For example, with a dry cathode feed, the current at $0.4 \mathrm{~V}$ and atmospheric pressure is only $53 \%$ of the current at 45 psig. However, at 20psig, $85 \%$ of the current at 45 psig is available. These findings demonstrate that the potential exists for low cell pressure operation (i.e. 20 psig) and complete elimination of the cathode humidifier, while only suffering a marginal loss in cell performance.

\subsection{Analysis of Bulk Cell Exit Relative Humidity}

As found experimentally in Section 2.2 , cathode feed gas relative humidity has little impact on overall cell performance, except at very low cell pressures. This finding suggests that water generation on the cathode side and electro-osmotic drag of water from the anode to cathode is sufficient in keeping the membrane at a fully saturated state, and thus maintaining its ionic conductivity. This finding can be backed up with a simple bulk model of water balance in a fuel cell based on the inlet gas conditions and water generation rate. The result yields an approximation for the average relative humidity within the cell. 
Figure 3.2.1.35 shows a simple model of water balance in a fuel cell. The molar flow rate of the inlet feed gases on the anode and cathode side, $n_{a}$ and $n_{c}$, along with the inlet relative humidities, is specified. The molar flow rates are calculated knowing the cell current draw and respective stoichiometries on both sides. The production of water within the cell is also known from the current draw. Thus, knowing the inlet amount of water coming into the cell and the water generated within the cell, an overall water balance can be done to determine the exit amount of water. The exit molar flow rate of gaseous hydrogen and air can also be determined knowing the inlet flow rates and the consumption of the gases within the cell due to the electrochemical reaction. Knowing both the exit molar flow rate of water and gases, the exit relative humidity can be determined. The details of this calculation are given in Appendix A.

This analysis assumes the fuel cell to behave as a continuously stirred reactor, and the membrane to be sufficiently thin that water transport across it ensures the relative humidities at the exit on both the anode and cathode sides to be equal. The simulation was conducted under the same operating conditions as the experimental tests (i.e. temperature maintained at $80^{\circ} \mathrm{C}$, fully humidified anode, anode stoichiometry of 1.5, and cathode stoichiometry of 2.5). Figure 3.2.1.36 shows the bulk cell relative humidity as a function of cathode inlet relative humidity. To maintain ionic conductivity of the MEA, the cell must maintain a bulk relative humidity of at least unity. A relative humidity greater than unity means that liquid water is condensing within the cell, and must be entrained with the gas flow to exit the cell. As shown in Figure 3.2.1.36, at 3 and 4 atmospheres absolute, an absolutely dry cathode feed still ensures full bulk humidification of the cell. In fact, it was calculated that a cell pressure of 2.55 atmospheres absolute $(23.25$ psig) and a completely dry cathode inlet will result in a bulk cell humidity of exactly unity. This supports the experimental results (Figure 3.2.1.34), which show very little dependence of performance on cathode inlet relative humidity above cell pressures of $30 \mathrm{psig}$ ( $3 \mathrm{~atm}$ absolute). The water balance model was also used to calculate the minimum pressure required to have complete internal humidification of the cell (i.e. both anode and cathode feed streams are dry, and the cell relies on water generation for humidification). At $80^{\circ} \mathrm{C}$, with an anode and cathode stoichiometry of 1.5 and 2.5 respectively, complete internal humidification is possible with a cell pressure of 3.25 atmospheres absolute (33 psig). This of course assumes that the fuel cell behaves as a well-stirred reactor. Although the wellstirred reactor assumption is not true in practice, novel cell flow field designs and ultra-thin MEAs can make the possibility of completely eliminating external humidification, on both anode and cathode sides, a reality.

\subsection{Transient Carbon Monoxide Poisoning}

Theoretical Background on CO Poisoning - Most hydrocarbon reforming methods, whether it be steam reforming, partial oxidation, or autothermal reforming, generate an effluent which is dilute in hydrogen and contains varying amounts of trace carbon monoxide (CO). Depending on the hydrocarbon feedstock, reformer effluent can contain hydrogen as dilute as 32\% (Brown, 2001). The effect of dilution with a CO-free feed gas has been studied, and is widely understood at a fundamental level (Um, 2000). The decrease in cell polarization at increased current draw is attributed to the reduction in average hydrogen concentration in the anode flow field, thus requiring a larger anode overpotential to maintain the hydrogen oxidation reaction at a specified current density. Fortunately, due to the anode normally exhibiting very fast kinetics, the inlet hydrogen concentration has to be very dilute to have an appreciable effect on cell polarization. Carbon monoxide (CO), however, is a known fuel cell catalyst poison even in trace amounts, and is preferentially adsorbed on the catalyst surface. CO concentrations as low as $10 \mathrm{ppm}$ are extremely detrimental to fuel cell performance.

Gottesfeld et al. (1988) conducted some of the earliest work on CO poisoning of fuel cells. In that work, the poisoning phenomenon was documented with CO levels varying from 10 to $100 \mathrm{ppm}$. A membrane remediation technique using oxygen injection into the anode feed stream, called air bleeding, was also proposed (Gottesfeld, 1988). Springer et al. (2001) have developed a kinetic model for hydrogen and $\mathrm{CO}$ adsorption and subsequent electro-oxidation. This model was then 
solved under steady state conditions for the fractional surface coverage of hydrogen and CO, as well as the cell current. It was calculated that under conditions of CO-free feed gas, the performance loss should not exceed $10 \%$ of full stack power with hydrogen concentrations as low as $40 \%$ (Springer, 2001). However, in the presence of CO levels as low as $10 \mathrm{ppm}$, the losses start to become significant, and were calculated to be exaggerated even further under the combined conditions of anode feed gas having a low hydrogen concentration and trace amounts of $\mathrm{CO}$. This is in agreement with findings by Divisek et al., who showed that with a $75 \%$ hydrogen, $25 \% \mathrm{CO}_{2}$, and $100 \mathrm{ppm}$ CO fuel feed, the steady state cell performance was lower than that with a $100 \%$ hydrogen, 100 ppm CO feed (Divisek, 1998). The model developed by Springer et al. has also been extended and modified several times by other researchers (Chan, 2003 and Zhang, 2002).

The transient process of poisoning in a hydrogen/oxygen fuel cell has also been experimentally studied. Oetjen et al. (1996) found that for Pt catalysts and feed gas containing 100 ppm CO, performance degradation was observable even after 5 minutes of exposure, with the cell reaching the fully steady state poisoned condition after roughly 2 hours (Oetjen, 1996). However, the feed consisted of $100 \%$ hydrogen with trace CO. Moreover, oxygen was used on the anode instead of air. Murthy et al. (2001) found that a small amount of air injection in the anode feed stream can significantly reduce the transient decay rate of fuel cell performance during the poisoning process. Aside from cell polarization measurements, other methods, such as electrochemical impedance spectroscopy, have been used to study the CO poisoning process (Wagner, 2003).

This past work shows that while much is known about steady state poisoning with a $100 \%$ hydrogen feed containing trace amounts of $\mathrm{CO}$, there is a lack of experimental data to quantify the transient $\mathrm{CO}$ poisoning process with diluted hydrogen, which is the actual case for fuel cells being fed a hydrocarbon reformate gas. In addition, even less is known fundamentally about the transient process of fuel cell poisoning with reformate gas. Understanding this process is critical in determining the minimum purity requirements for anode fed gas as well as developing any sort of poisoning remediation method.

Theoretical Analysis - Springer et al. (2001) present the following set of reactions to describe the adsorption, desorption, and electro-oxidation of hydrogen and $\mathrm{CO}$ on the catalyst surface, where $M$ represents a free catalyst site. These assume that any inert species, such as nitrogen or carbon dioxide, which may be diluting the anode feed stream, do not participate in the surface adsorption chemistry.

$$
\begin{aligned}
& H_{2}+2 M \stackrel{{ }^{k} f h}{\longrightarrow} 2(M-H)
\end{aligned}
$$

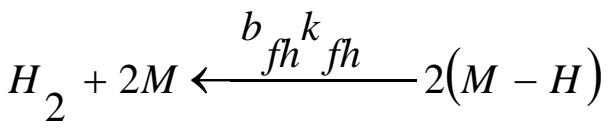

$$
\begin{aligned}
& \mathrm{CO}+\mathrm{M} \stackrel{{ }^{k}}{\stackrel{f C}{\longrightarrow}} \mathrm{M}-\mathrm{CO} \\
& C O+M \longleftarrow{ }_{f_{c}{ }^{k} f_{C}} M-C O \\
& (M-H) \stackrel{{ }_{e h}}{\longrightarrow} H^{+}+e^{-}+M \\
& \mathrm{H}_{2} \mathrm{O}+(\mathrm{M}-\mathrm{CO}) \stackrel{k_{e c}}{\longrightarrow} \mathrm{M}+\mathrm{CO}_{2}+2 \mathrm{H}^{+}+2 e^{-}
\end{aligned}
$$


From this, a set of kinetic equations describing the rate of change of hydrogen and $\mathrm{CO}$ coverage on the catalyst surface in terms of the rates of adsorption, desorption, and electrooxidation can be written. Springer et al. (2001) drop the rate of change of surface coverage with time in order to find the steady state cell polarization. However, here we are interested in the transient cell behavior, and thus include these terms in our calculations. These kinetics equations developed by Springer et al. (2001) have been modified to assume that the adsorption and desorption of species are first order in nature. Also, the charge transfer coefficient, $\alpha$, is assumed to be equal to 0.5 , which reduces the general Butler-Volmer equation for electro-oxidation into a hyperbolic sine relationship.

$$
\begin{gathered}
\rho \frac{d \theta_{h}}{d t}=k_{f h^{X} h} P\left(1-\theta_{h}-\theta_{C}\right)-b_{f h}{ }^{k} f_{h} \theta_{h}-2 k_{e h} \theta_{h} \sinh \left(\frac{\eta_{a}}{R T / \alpha F}\right) \\
\rho \frac{d \theta_{C}}{d t}=k_{f c} x_{C} P\left(1-\theta_{h}-\theta_{C}\right)-b_{f c} k_{f C} \theta_{C}-2 k_{e c} \theta_{C} \sinh \left(\frac{\eta_{a}}{R T / \alpha F}\right)
\end{gathered}
$$

Equations 3.2.1.31 and 3.2.1.32 balance the rate of change of hydrogen and $\mathrm{CO}$ fractional surface coverage, $\theta_{\mathrm{h}}$ and $\theta_{\mathrm{c}}$, with respect to time against the respective rates of adsorption, desorption, and electro-oxidation from the catalyst surface. The terms $\rho, x_{h}, x_{c}$, and $\eta_{a}$ represent the molar area density of catalyst sites times Faraday's Constant, hydrogen mole fraction, CO mole fraction, and anode overpotential respectively.

The hydrogen electro-oxidation term was then re-written in terms of hydrogen current, $i$. The CO electro-oxidation term was dropped due to its relatively small magnitude at the cell voltages considered here as compared to the $\mathrm{CO}$ adsorption and desorption terms. An additional equation for cell voltage in terms of current was also needed to close the system. This zero-dimensional, lumped model for cell voltage assumes Tafel kinetics on the cathode and linear ohmic losses through the membrane electrode. This results in the following set of equations:

$$
\begin{aligned}
& \rho \frac{d \theta_{h}}{d t}=k_{f h}{ }^{{ }_{h}} P\left(1-\theta_{h}-\theta_{C}\right)-b_{f h}{ }^{k} f \theta \theta^{-i} \\
& \rho \frac{d \theta_{c}}{d t}=k_{f c}{ }^{x_{C}} P\left(1-\theta_{h}-\theta_{C}\right)-b_{f c}{ }^{k} f_{C} \theta_{C} \\
& V_{\text {cell }}=V_{o}-\eta_{a}-\eta_{c}-\eta_{\text {ohmic }}
\end{aligned}
$$

Where the terms in Equations 3.2.1.35 are given by:

$$
\eta_{a}=\frac{R T}{\alpha F} \sinh ^{-1}\left(\frac{i}{2 k_{e h} \theta_{h}}\right)
$$




$$
\begin{aligned}
& \eta_{C}=\frac{R T}{\alpha F} \ln \left(\frac{i}{i_{\text {oC }}}\right) \\
& \eta_{\text {ohmic }}=i R_{\text {ohmic }}
\end{aligned}
$$

Equations 3.2.1.33 - 3.2.1.38 can be solved numerically for the time variation of fractional surface coverage of hydrogen, $\mathrm{CO}$, and the cell current at a constant cell voltage. This theoretical model will be used later to compare and explain the experimental results. Values for the constants in Equations 3.2.1.33 - 3.2.1.38 are given in Table 3.2.1.6. Values for pressure, temperature, and cell voltage represent the actual operating conditions that the experiments were conducted under. Values for the ohmic resistance, $\mathrm{R}_{\text {ohmic }}$, and cathode exchange current density, $\mathrm{i}_{\mathrm{oc}}$, were found from curve fits to baseline cell performance data. Values for all of the kinetic parameters were borrowed from those used previously in the literature (Springer, 2001), except for $b_{\mathrm{fc}}$ and $\mathrm{k}_{\mathrm{fh}}$. Springer et al. (2001) note that these two kinetic parameters are functions of the fractional CO coverage; however, for the purposes of this study, they are assumed to be constant. The values for these two parameters were chosen to best match the transient cell performance data. These numeric values for these two parameters fall within the range of variability that has been previously reported.

\subsection{Experimental}

Like the tests described concerning water generation, the $\mathrm{CO}$ poisoning experiments here were performed in a $50 \mathrm{~cm}^{2}$ titanium fuel cell fixture supplied by Lynntech Industries, Ltd. (College Station, TX). Both anode and cathode flow fields consisted of 6 parallel channels following a serpentine path to cover the $50 \mathrm{~cm}^{2}$ of active area. The membrane electrode assembles (MEAs), also supplied by Lynntech Industries, were composed of 40 wt.\% platinum on carbon, Nafion ${ }^{\circledR} 112$, with a platinum catalyst loading of $0.5 \mathrm{mg} / \mathrm{cm}^{2}$ on each side. The MEA also had an ELAT gas diffusion layer pressed on top of the catalyst surface.

The polarization measurements were taken using an Arbin Instruments (College Station, TX) fuel cell test station and electronic load bank. Both anode and cathode feed streams were fully saturated with water at $80^{\circ} \mathrm{C}$ and maintained at that temperature while being fed to the cell. All numbers for the hydrogen dilution in the anode feed streams are based on the dry gas condition before saturation with water at $80^{\circ} \mathrm{C}$. The flow rates of both streams were continually modified with respect to the instantaneous current draw to maintain a molar flow level corresponding to a constant stoichiometry condition of 1.5 and 2.5 on the anode and cathode respectively. The cell itself was kept at $80^{\circ} \mathrm{C}$ and pressurized to $300 \mathrm{kPa}$ (absolute) on both anode and cathode sides. Tests were performed under a variety of hydrogen dilution levels and $\mathrm{CO}$ concentrations. During these tests, the cell polarization was measured at specific times throughout the $\mathrm{CO}$ poisoning process. Between polarization scans, the cell was maintained at a current draw corresponding to a constant cell potential of $600 \mathrm{mV}$.

\subsection{Results and Discussion}

The $50 \mathrm{~cm}^{2}$ fuel cell was tested under a variety of conditions to simulate a wide range of actual reformate gases. First, the cell was tested with CO-free feed gas consisting of $100 \%$ hydrogen and then $40 \%$ hydrogen, balanced with nitrogen (Figure 3.2.1.37). Both CO-free cases do not exhibit any transient performance loss, and thus only the steady state cell polarization is shown. As shown, almost no performance loss is observable even with the low hydrogen concentration feed gas. Then, the cases of anode feed gas having varying levels of $\mathrm{CO}$ and hydrogen dilution were considered. Figures 3.2.1.38 and 3.2.1.39 show the entire cell polarization at various times throughout the poisoning process for an anode feed of $100 \%$ and $40 \%$ hydrogen respectively, with $10 \mathrm{ppm}$ CO. The curves at 120 minutes represent the fully poisoned, steady state cell polarization. Similar curves for 100\% and 40\% hydrogen with 100ppm CO are shown in Figures 3.2.1.40 and 
3.2.1.41 respectively. Figure 3.2.1.42 shows the current obtainable at a cell voltage of $0.6 \mathrm{~V}$ vs. time for all four feed gas cases considered here, as well as the calculated current from the model described by Equations 3.2.1.33 - 3.2.1.38. In all four cases, after the poisoning process was complete, the membrane was recovered by feeding the cell with a CO-free, 100\% hydrogen anode feed for a period of 2 hours. The current obtainable at $0.6 \mathrm{~V}$ during the recovery process for all four cases is shown in Figure 3.2.1.43. For all cases, the cell performance was revived after the poisoning process with the use of a pure hydrogen anode feed stream.

As shown in Figures 3.2.1.38 through 3.2.1.41, the detrimental effects of $\mathrm{CO}$ can be measured even after just 10 minutes of exposure to the cell, with the fully poisoned steady state condition reached in roughly 120 minutes. It is clear from these polarization curves that while the presence of 10 ppm CO in 100\% hydrogen has a noticeable effect (Figure 3.2.1.38), 10ppm CO in 40\% hydrogen has an extremely detrimental effect (Figure 3.2.1.39). The same is true at the 100ppm level (Figures 3.2.1.40 and 3.2.1.41). Figure 3.2.1.42, which plots the current at a cell voltage of 0.6V vs. time, shows the transient performance drop for all four cases very clearly. At 10ppm of CO in a 100\% hydrogen fed stream, the steady state current obtainable is $26 \%$ less than that before the poisoning process began. With $40 \%$ hydrogen and $10 \mathrm{ppm} \mathrm{CO}$, the drop is $60 \%$. At the 100ppm level, the respective drops in current for $100 \%$ vs. $40 \%$ hydrogen are $67 \%$ and $86 \%$ respectively.

It is clear from both experimental and computational results that while hydrogen dilution alone has almost no effect on cell performance, and $\mathrm{CO}$ alone has a detrimental effect on cell performance, the combined effects of trace quantities of $\mathrm{CO}$ and hydrogen dilution have an extremely detrimental effect. This can be explained using the zero-dimensional model developed earlier. Under normal cell operating conditions with pure hydrogen, the anode kinetic losses, $\eta_{a}$, are very low as compared to the kinetic losses at the cathode and the ohmic losses through the membrane. These normally small anode losses are given by Equation 3.2.1.36, and are a function of fractional surface coverage of hydrogen, $\theta_{\mathrm{h}}$. Because $\theta_{\mathrm{h}}$ appears in the denominator of an inverse hyperbolic sine relationship, the hydrogen fractional coverage must be very low for the anode overpotential losses to have a significant detrimental effect on cell performance. Thus, dilution alone, which reduces the hydrogen mole fraction, $x_{h}$ in Equation 3.2.1.33, and subsequently $\theta_{h}$, does not have an appreciable affect on cell performance (Figure 3.2.1.37).

The existence of $\mathrm{CO}$ in the anode feed stream, and its preferential adsorption on the catalyst surface, does have a substantial effect on cell performance. The presence of CO slows the hydrogen adsorption to such a degree that the fractional coverage $\theta_{h}$ falls by an order of magnitude, and thus the anode kinetic losses become significant in effecting overall cell voltage. Since the presence of $\mathrm{CO}$ reduces $\theta_{\mathrm{h}}$ to a degree that the anode losses are now significant, hydrogen dilution, which further reduces $\theta_{h}$, now causes an additional decrease in cell performance.

This finding has enormous implications in terms of minimum purity requirements for anode feed gas. As Figure 3.2.1.42 clearly illustrates, the commonly quoted number of 10ppm CO as the limit for platinum catalyst based PEM fuel cells is highly dependent on the associated hydrogen dilution level of the feed gas. The performance loss from $40 \%$ hydrogen with $10 \mathrm{ppm} \mathrm{CO}$ is almost equal to the loss associated with 100\% hydrogen and 100ppm CO.

Although the simulation does not match the experimental data exactly for all cases, it does predict the general trend of transient poisoning, and demonstrates the combined effects that hydrogen dilution and $\mathrm{CO}$ can have on the cell performance. The differences between the data and the simulation can be attributed to various causes. First, the $\mathrm{CO}$ poisoning model here is coupled with a zero-dimensional fuel cell performance model. Thus, no consideration is given for the spatial variations in fuel cell performance resulting from gradients in hydrogen, $\mathrm{CO}$, water, and oxygen concentration that may exist within the cell flow field and the gas diffusion layer. Secondly, as mentioned earlier, the $\mathrm{CO}$ poisoning model here assumes the $\mathrm{CO}$ electro-oxidation term to be negligible as compared to CO surface adsorption and desorption terms. While true for low anode overpotential values, this assumption becomes decreasingly valid as the anode overpotential rises. This may explain to some degree the steady state error between the data and model. Lastly, the 
model is highly dependent on the hydrogen and CO adsorption, desorption, and electro-oxidation parameters chosen. Exact values for these parameters are unknown, and vary from membrane to membrane. Also, as noted earlier, several of these parameters are believed to vary with the fractional CO coverage rather than being constant, as assumed here. Despite these drawbacks, the model still predicts the profile of the resulting current vs. time curve of the transient poisoning process, as well as simulates the mutually detrimental effects that $\mathrm{CO}$ and dilute hydrogen can have.

Using the model, simulation of cell behavior under a host of different hydrogen dilution levels and $\mathrm{CO}$ concentrations is possible. Two of these such parametric simulations are shown in Figures 3.2.1.44 and 3.2.1.45. The first shows the steady state current obtainable at a cell voltage of 0.6V versus $\mathrm{CO}$ concentration. The current has been normalized with respect to the maximum current obtainable with CO-free feed gas. This is plotted for various hydrogen dilution levels. Figure 3.2.1.45 compares the time constant for the poisoning process, for various hydrogen dilution levels, versus $\mathrm{CO}$ concentration. This time constant was found by calculating the period required for the cell current to suffer $90 \%$ of its steady state losses. The inverse of this time constant is plotted versus $\mathrm{CO}$ concentration in Figure 3.2.1.45. Thus, a condition that poisons the cell faster has a higher inverse of time constant. The CO-free cases never get to a poisoned state, and thus take infinite time. Consequently, the CO-free condition has an inverse time constant equal to zero. Figures 3.2.1.44 and 3.2.1.45 reinforce the finding that hydrogen concentration has an effect on both the extent and the rate of $\mathrm{CO}$ poisoning.

\subsection{Conclusion}

The transient polarization of a PEM fuel cell undergoing the $\mathrm{CO}$ poisoning process has been experimentally measured. This process was observed under variable $\mathrm{CO}$ and hydrogen dilution levels. The transient poisoning model developed by Springer et al. (2001), which was modified and solved here, agrees well with the experimentally observed results of transient CO poisoning for both pure and dilute hydrogen feed streams.

It was found that while hydrogen dilution alone lowers the fractional coverage on the catalyst surface, it is only when $\mathrm{CO}$ is present that the coverage is lowered to a degree that affects cell voltage. Under this condition, the addition of hydrogen dilution will compound the low surface coverage problem even further, and thus cause very poor cell performance. Even with low CO levels normally considered safe for cell operation (i.e. 10ppm), hydrogen dilution can cause an extremely severe loss of cell polarization. These results are easily explainable by the hydrogen and $\mathrm{CO}$ adsorption, desorption, and electro-oxidation model developed.

Table 3.2.1.6 Constants used for solving kinetics model.

$\begin{array}{cccc}\mathrm{b}_{\mathrm{fc}} & 2.75 \times 10^{-7} \mathrm{~atm} & \mathrm{R} & 8.314 \mathrm{~J} \mathrm{~mol}^{-1} \mathrm{~K}^{-1} \\ \mathrm{~b}_{\mathrm{fh}} & 0.5 \mathrm{~atm} & \mathrm{R}_{\text {ohmic }} & 0.3 \mathrm{ohm} \mathrm{cm} \\ \mathrm{F} & 96485 \mathrm{C} \mathrm{mol}^{-1} & \mathrm{~T} & 353 \mathrm{~K} \\ \mathrm{i}_{\mathrm{oc}} & 7.0 \times 10^{-4} \mathrm{~A} \mathrm{~cm}^{-2} & \mathrm{~V}_{\text {cell }} & 0.6 \mathrm{~V} \\ \mathrm{k}_{\mathrm{eh}} & 4 \mathrm{~A} \mathrm{~cm}^{-2} & \mathrm{~V}_{\mathrm{o}} & 1.2 \mathrm{~V} \\ \mathrm{k}_{\mathrm{fc}} & 10 \mathrm{~A} \mathrm{~cm}^{-2} \mathrm{~atm}^{-1} & \alpha & 1 / 2 \\ \mathrm{k}_{\mathrm{fh}} & 100 \mathrm{~A} \mathrm{~cm}^{-2} \mathrm{~atm}^{-1} & \alpha & 0.1 \mathrm{~mol} \mathrm{~cm}^{-2} \\ \mathrm{P} & 3 \mathrm{~atm} \mathrm{absolute} & & \end{array}$




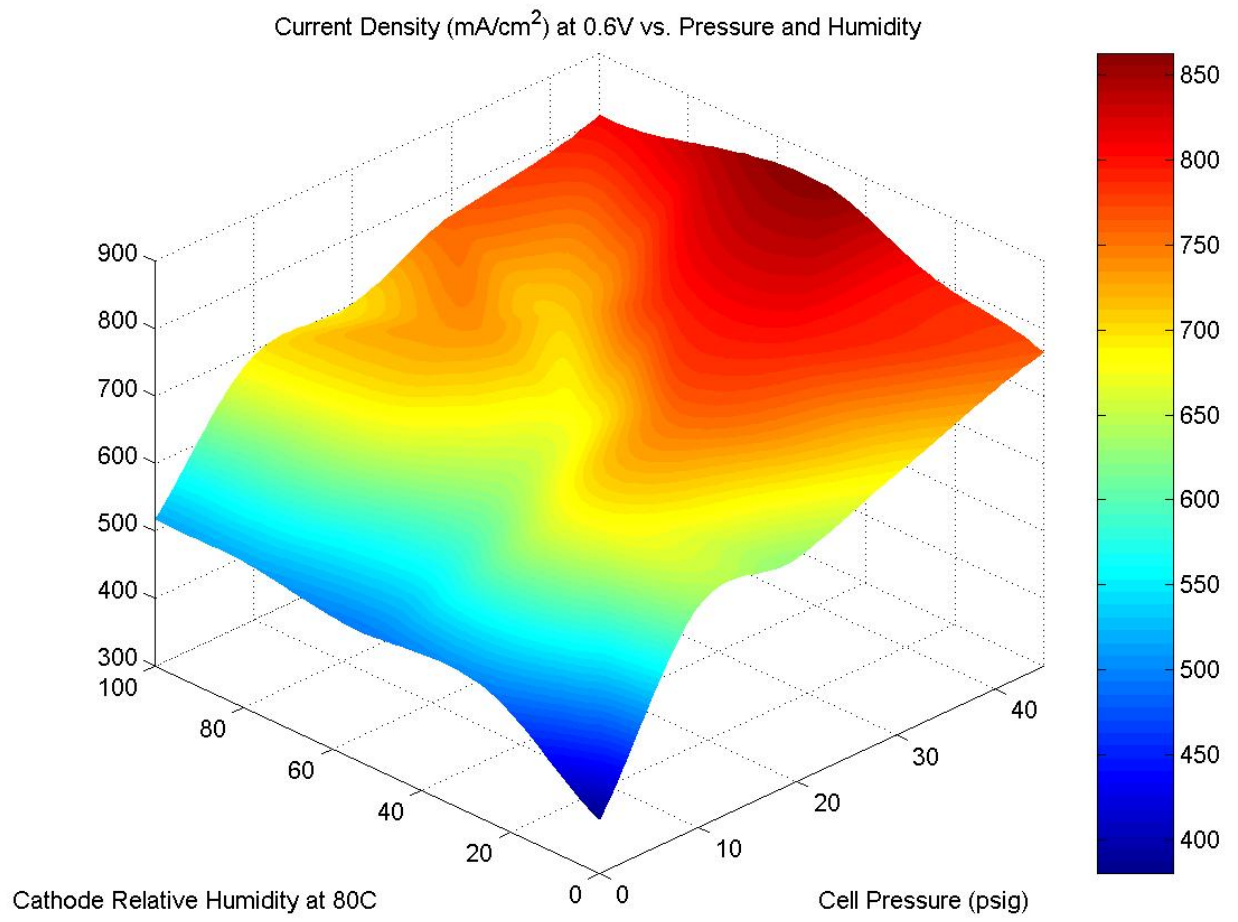

Figure 3.2.1.31 Cell performance map at $0.6 \mathrm{~V}$ versus cell pressure and cathode relative humidity, isometric view.

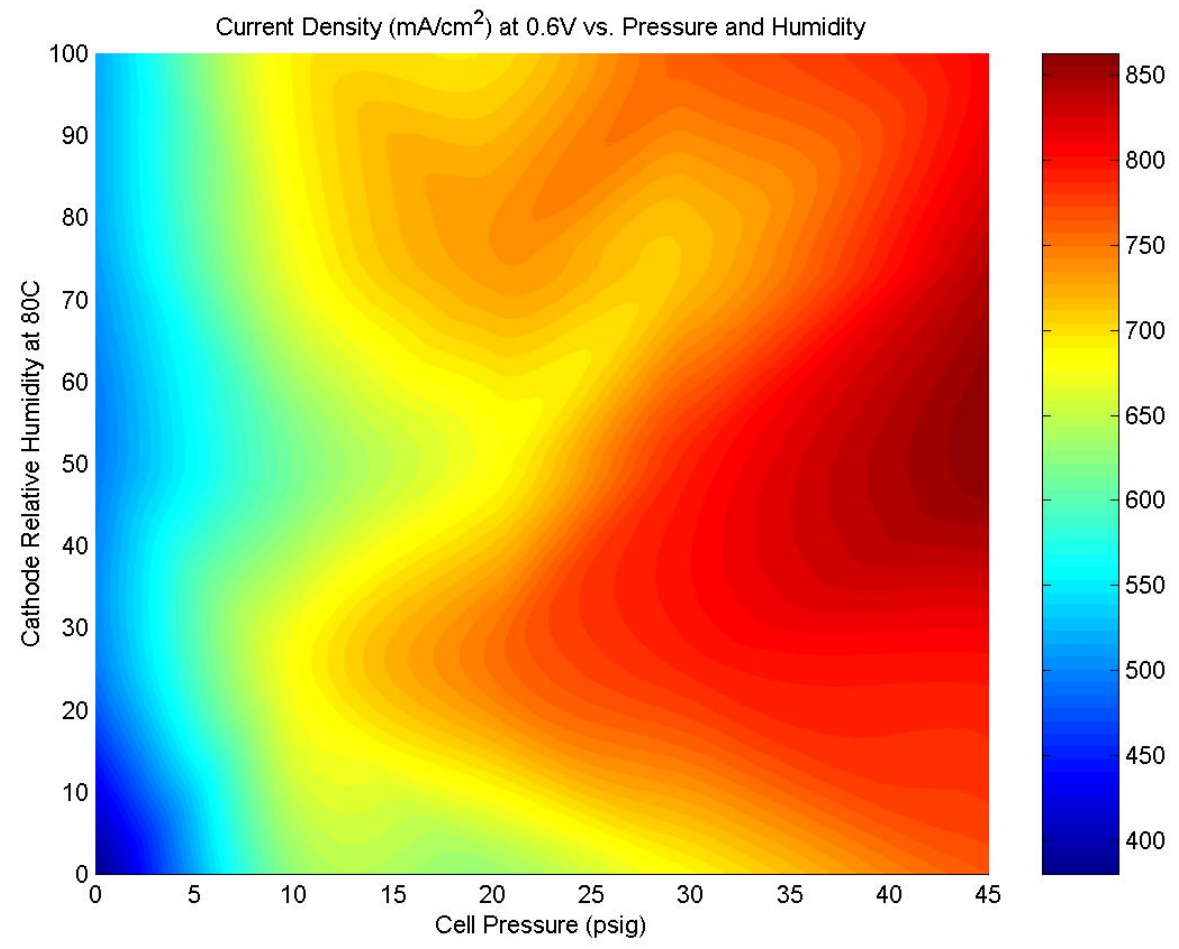

Figure 3.2.1.32 Cell performance map at $0.6 \mathrm{~V}$ versus cell pressure and cathode relative humidity. 


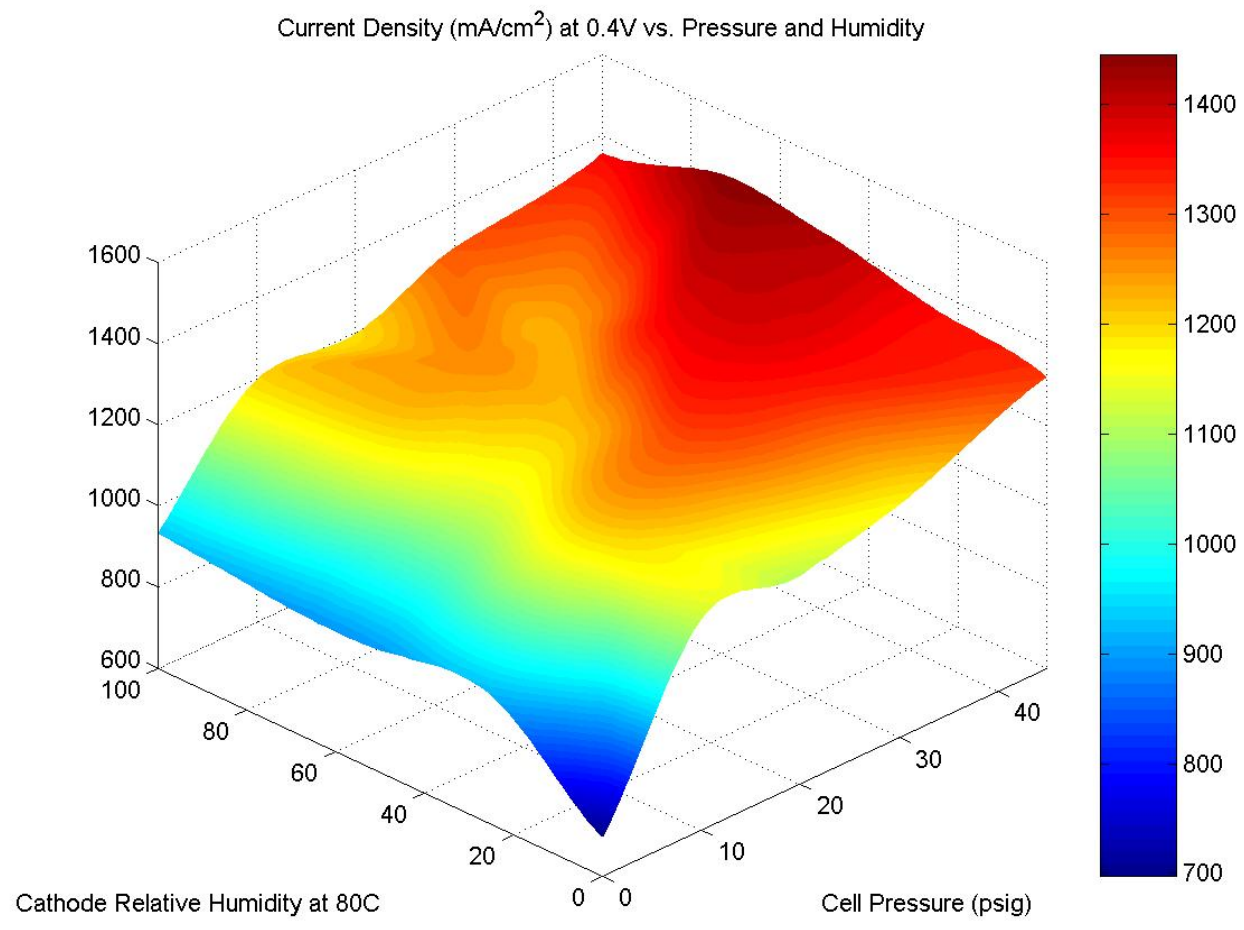

Figure 3.2.1.33 Cell performance map at $0.4 \mathrm{~V}$ versus cell pressure and cathode relative humidity, isometric view.

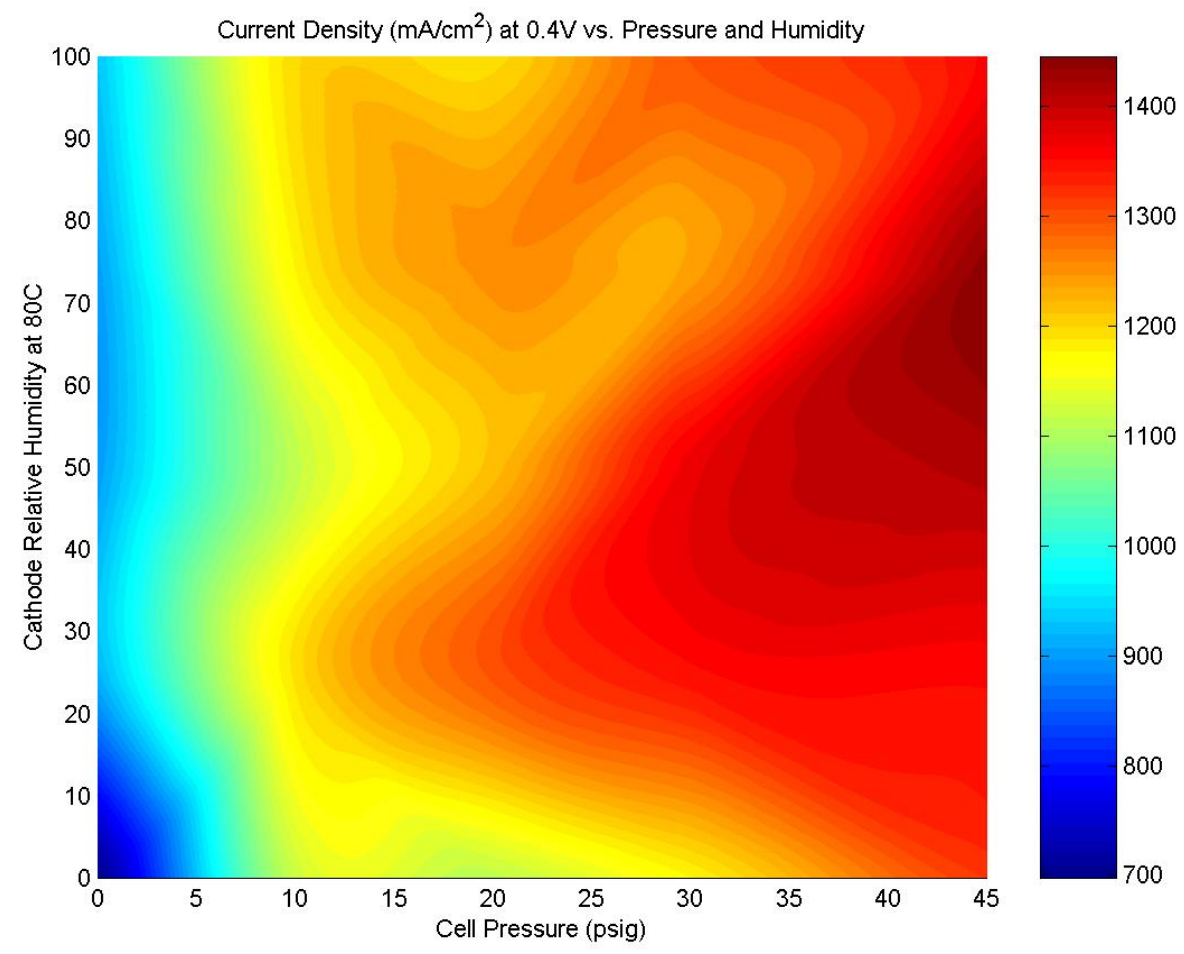

Figure 3.2.1.34 Cell performance map at $0.4 \mathrm{~V}$ versus cell pressure and cathode relative humidity. 


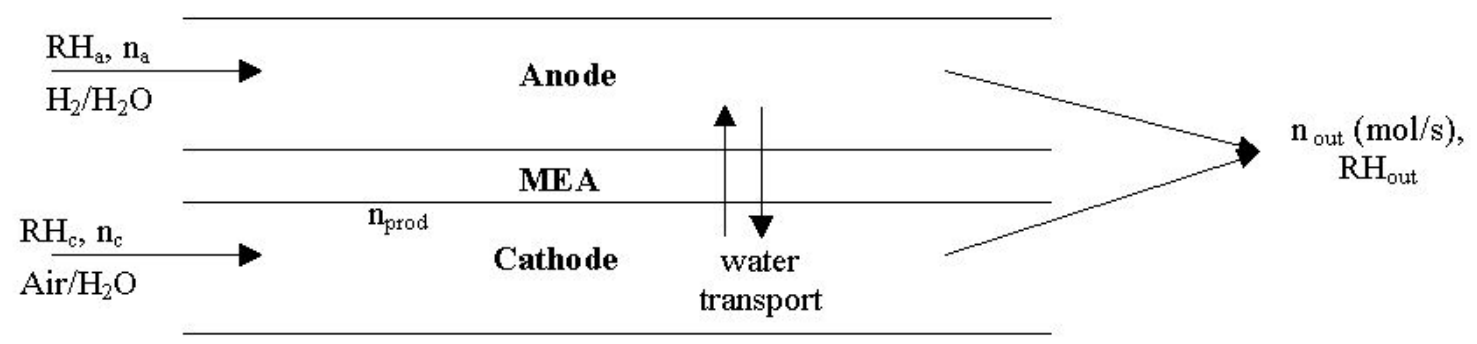

Figure 3.2.1.35 Diagram for analysis of cell exit relative humidity.

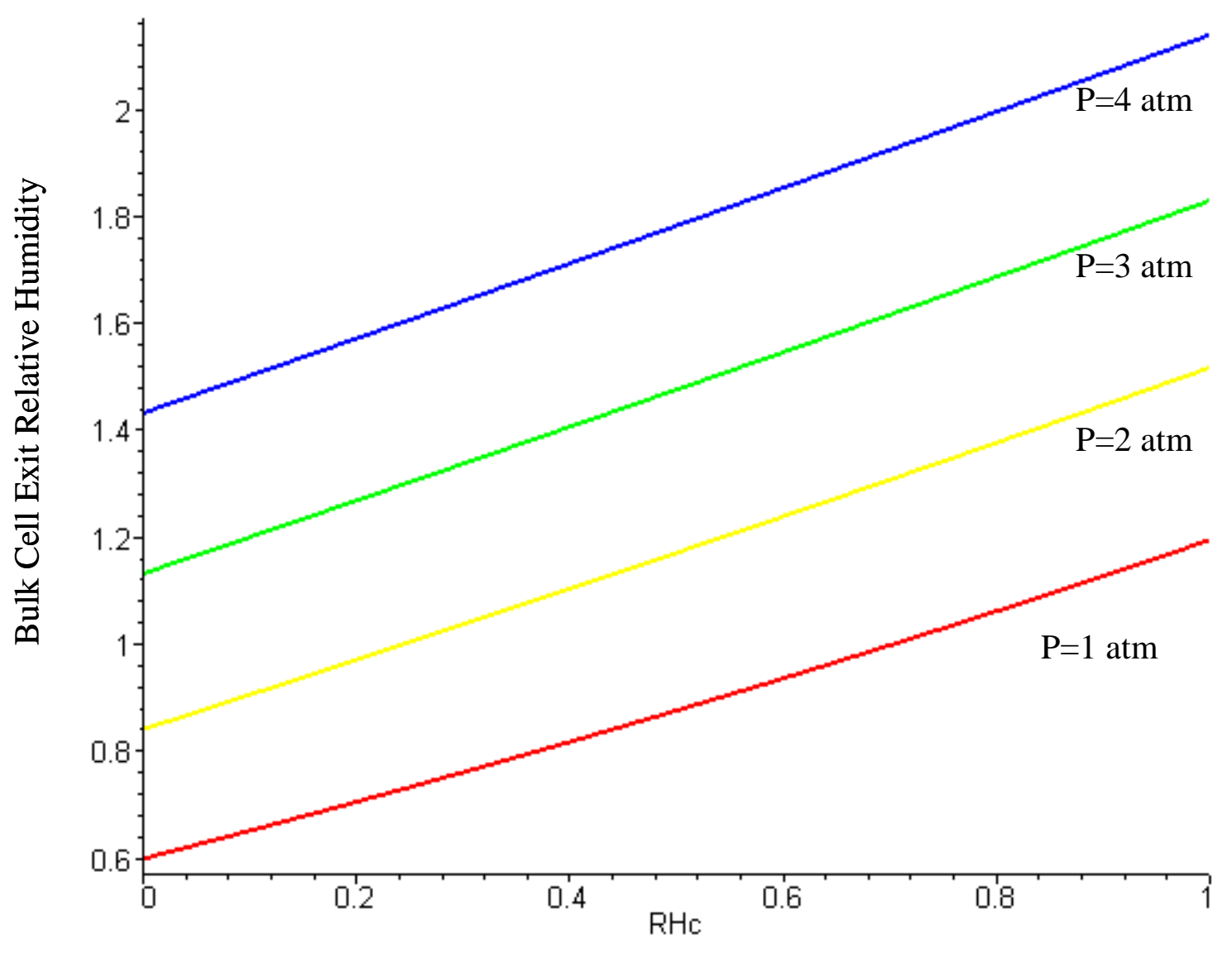

Cathode Inlet Relative Humidity

Figure 3.2.1.36 Bulk cell exit relative humidity versus cathode inlet relative humidity. 


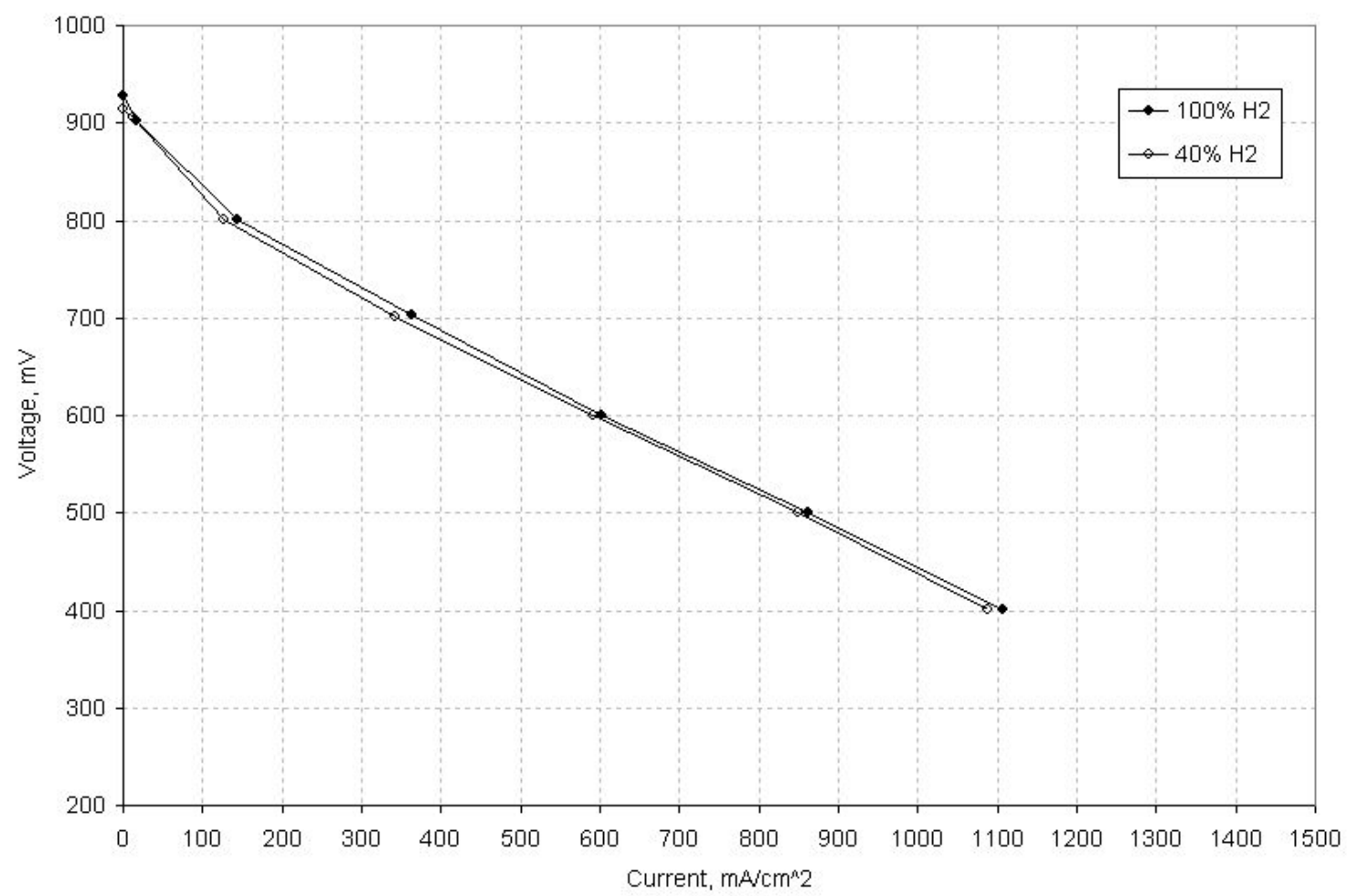

Figure 3.2.1.37 Steady state cell polarization for $100 \% \mathrm{H}_{2}$ and $40 \% \mathrm{H}_{2}$ anode fed gas.

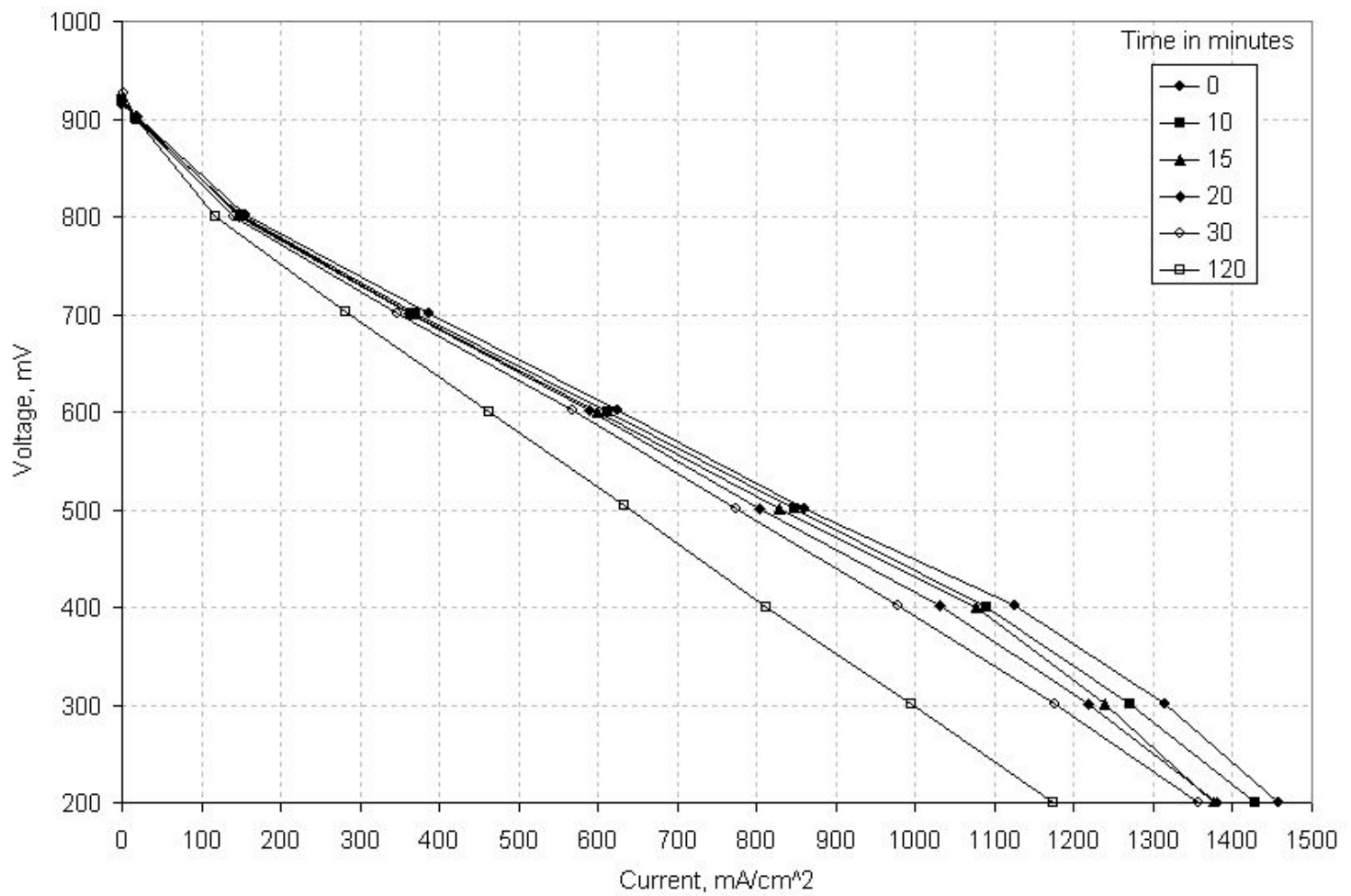

Figure 3.2.1.38 Cell polarization at various time steps (in minutes) throughout the poisoning process, with $100 \% \mathrm{H}_{2}, 10 \mathrm{ppm} \mathrm{CO}$ anode feed. 


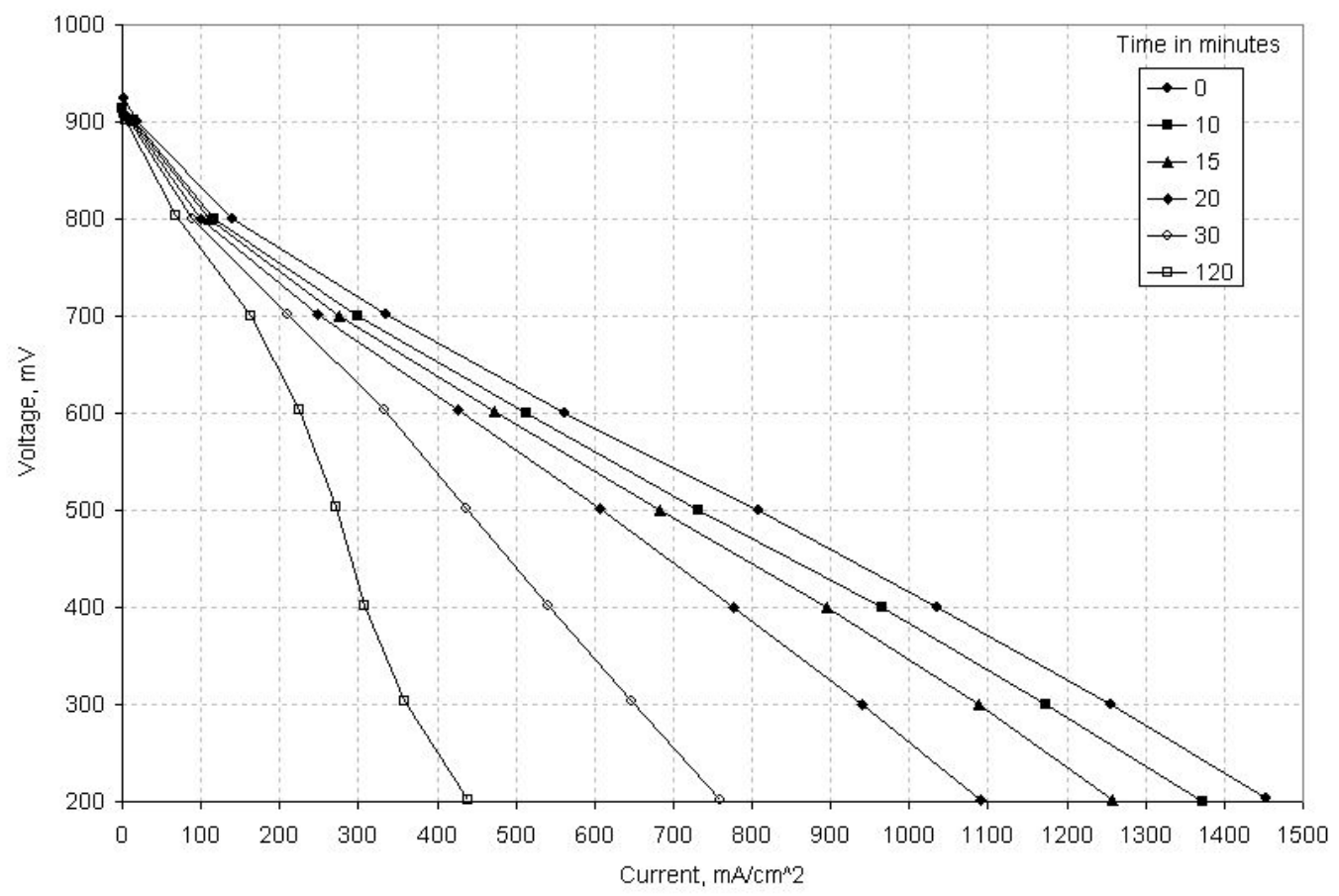

Figure 3.2.1.39 Cell polarization at various time steps (in minutes) throughout the poisoning process, with $40 \% \mathrm{H}_{2}, 10 \mathrm{ppm} \mathrm{CO}$ anode feed.

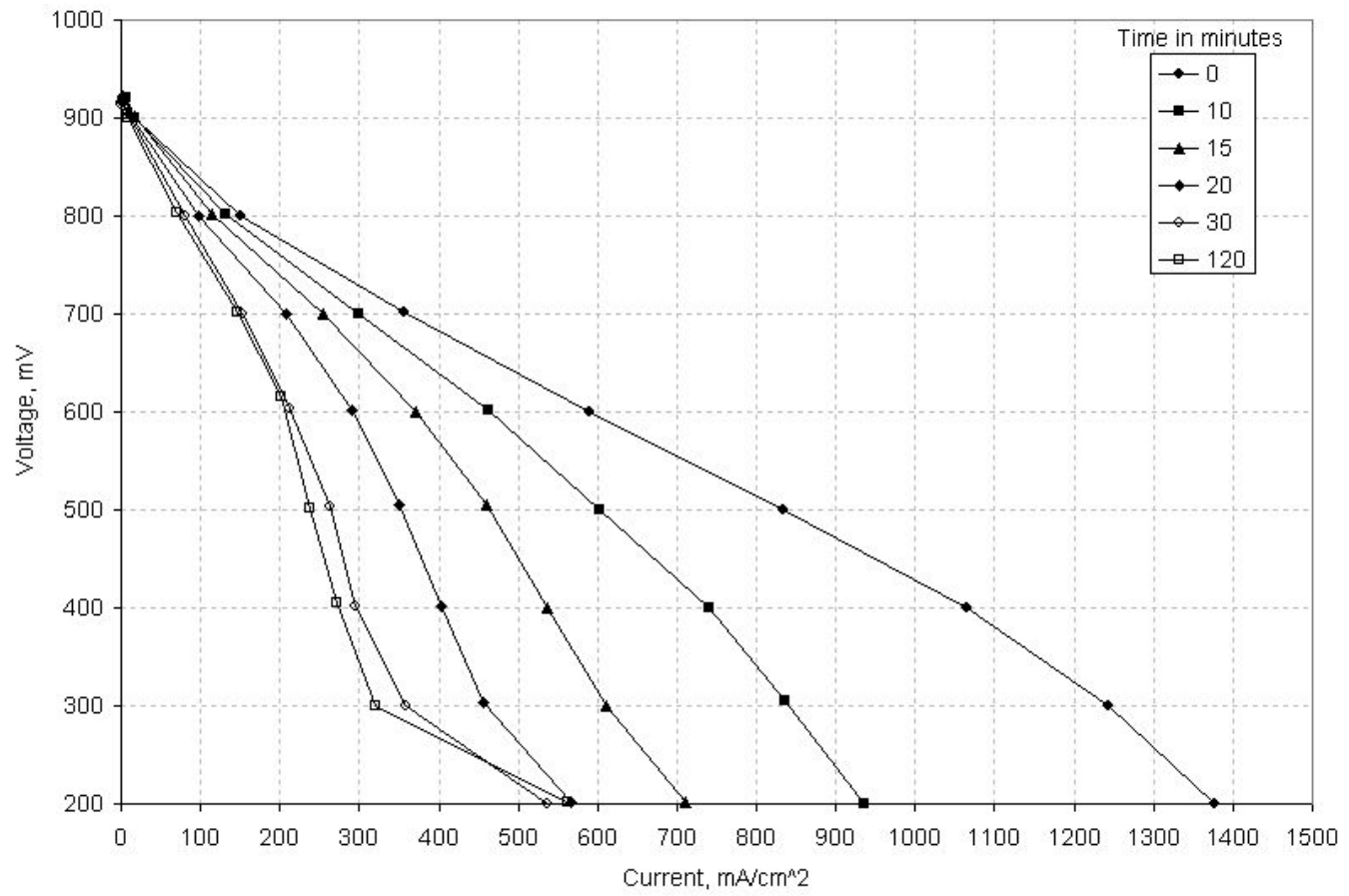

Figure 3.2.1.40 Cell polarization at various time steps (in minutes) throughout the poisoning process, with $100 \% \mathrm{H}_{2}, 100$ ppm CO anode feed. 


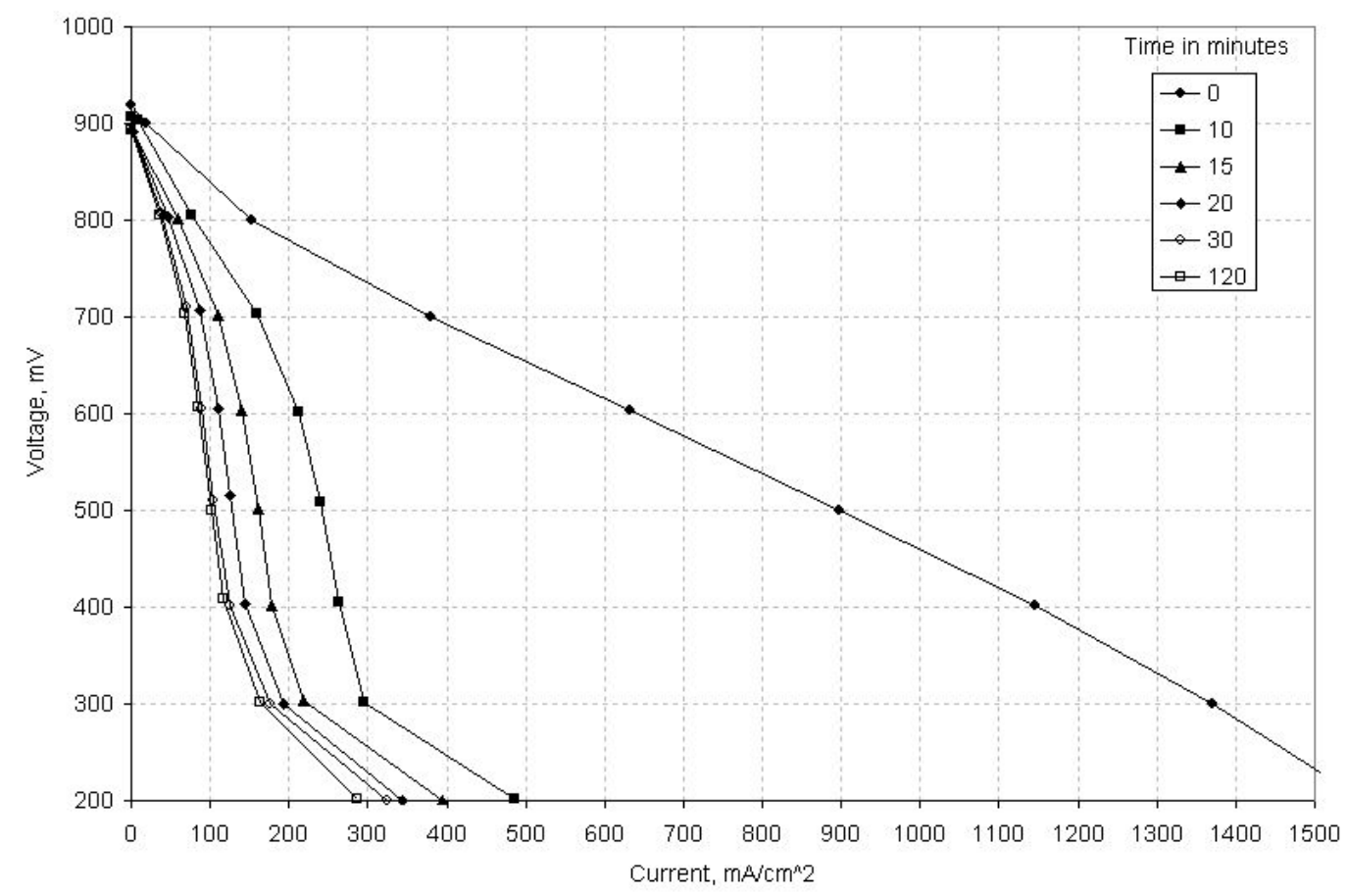

Figure 3.2.1.41 Cell polarization at various time steps (in minutes) throughout the poisoning process with, $40 \% \mathrm{H}_{2}, 100 \mathrm{ppm} \mathrm{CO}$ anode feed.

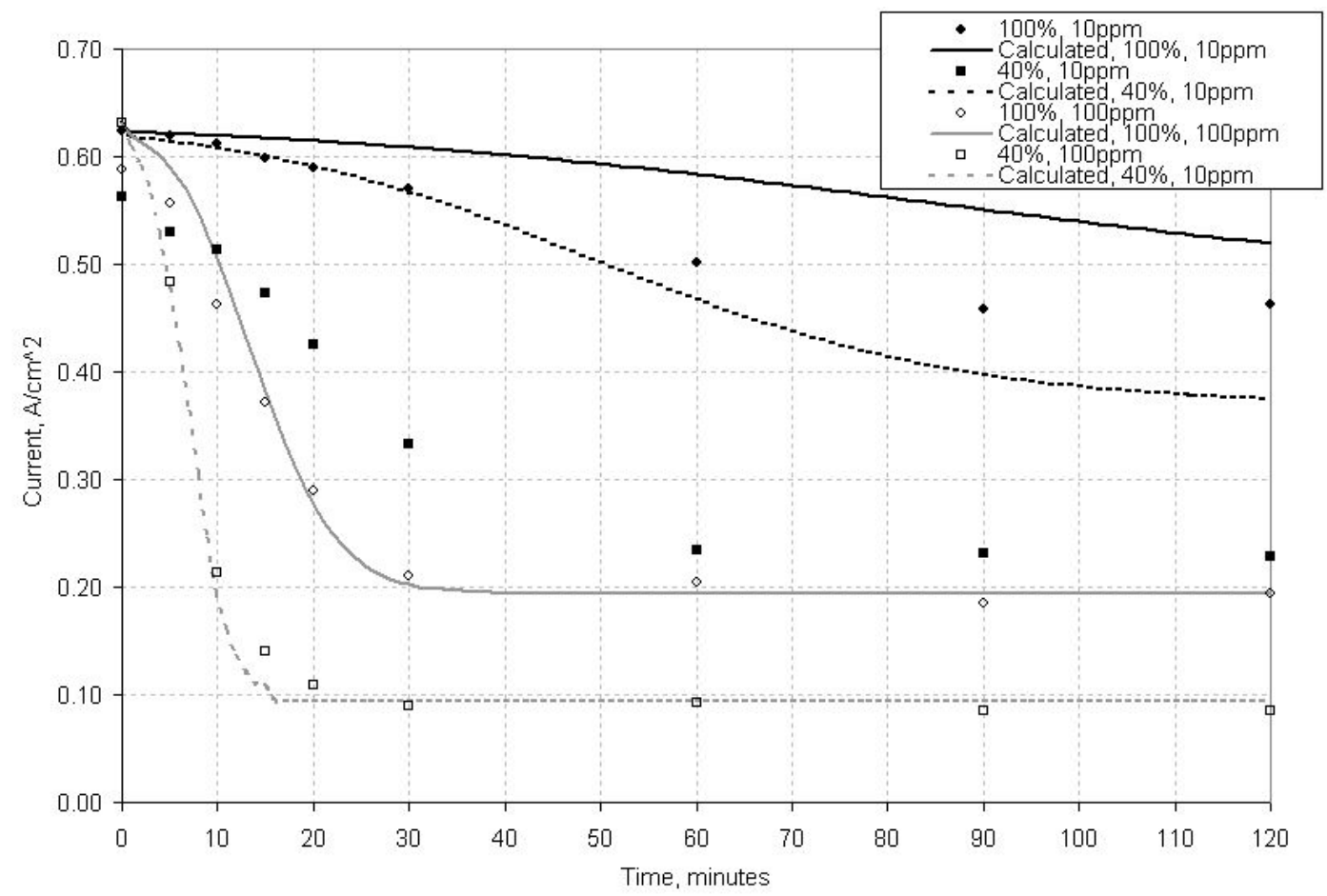

Figure 3.2.1.42 Current at $0.6 \mathrm{~V}$ during the poisoning process vs. time for all four different anode feed gas compositions. The points represent actual experimental results, and the curves represent simulations based on the model developed. 


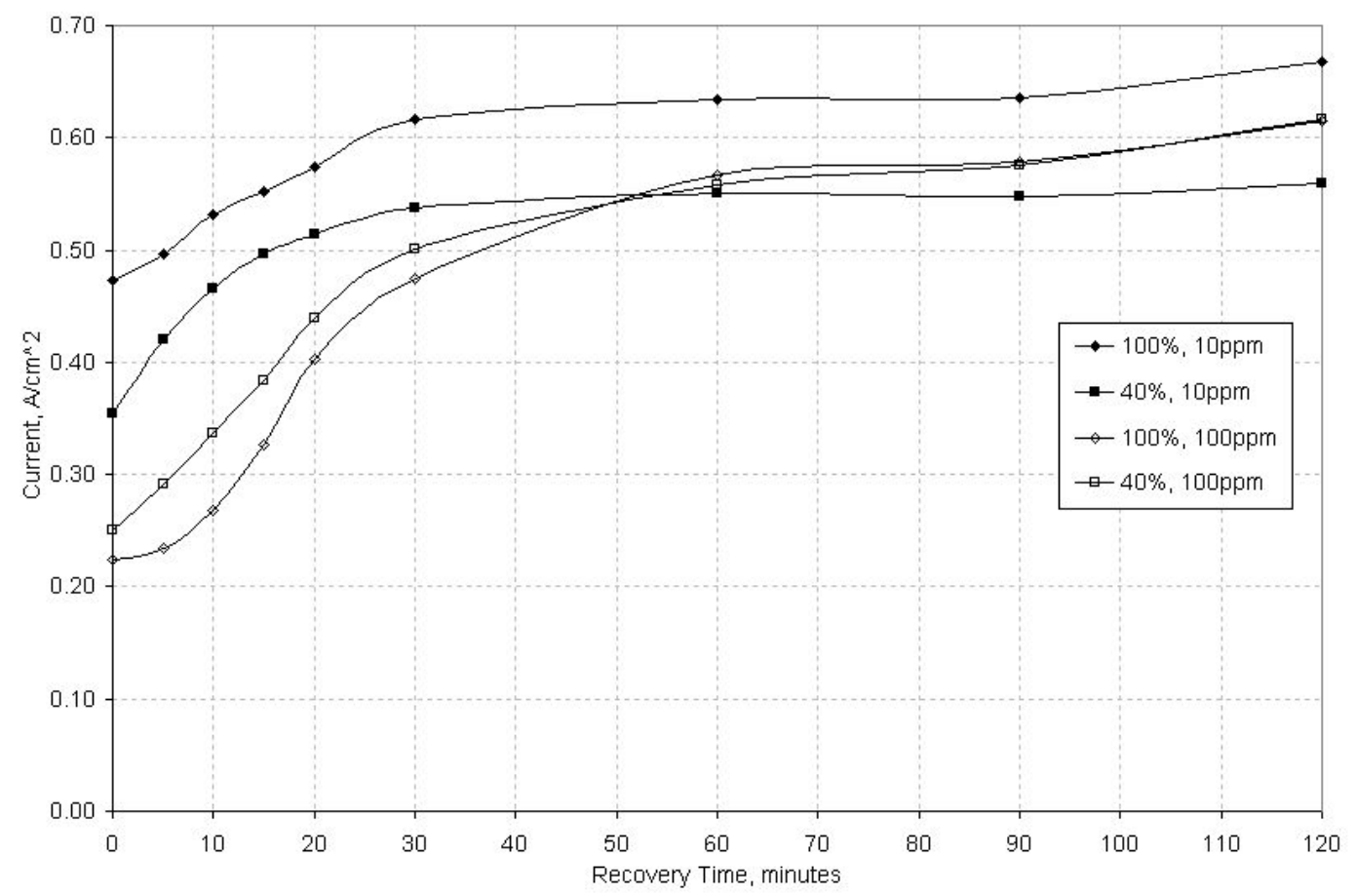

Figure 3.2.1.43 Current at 0.6V during the recovery process vs. time.

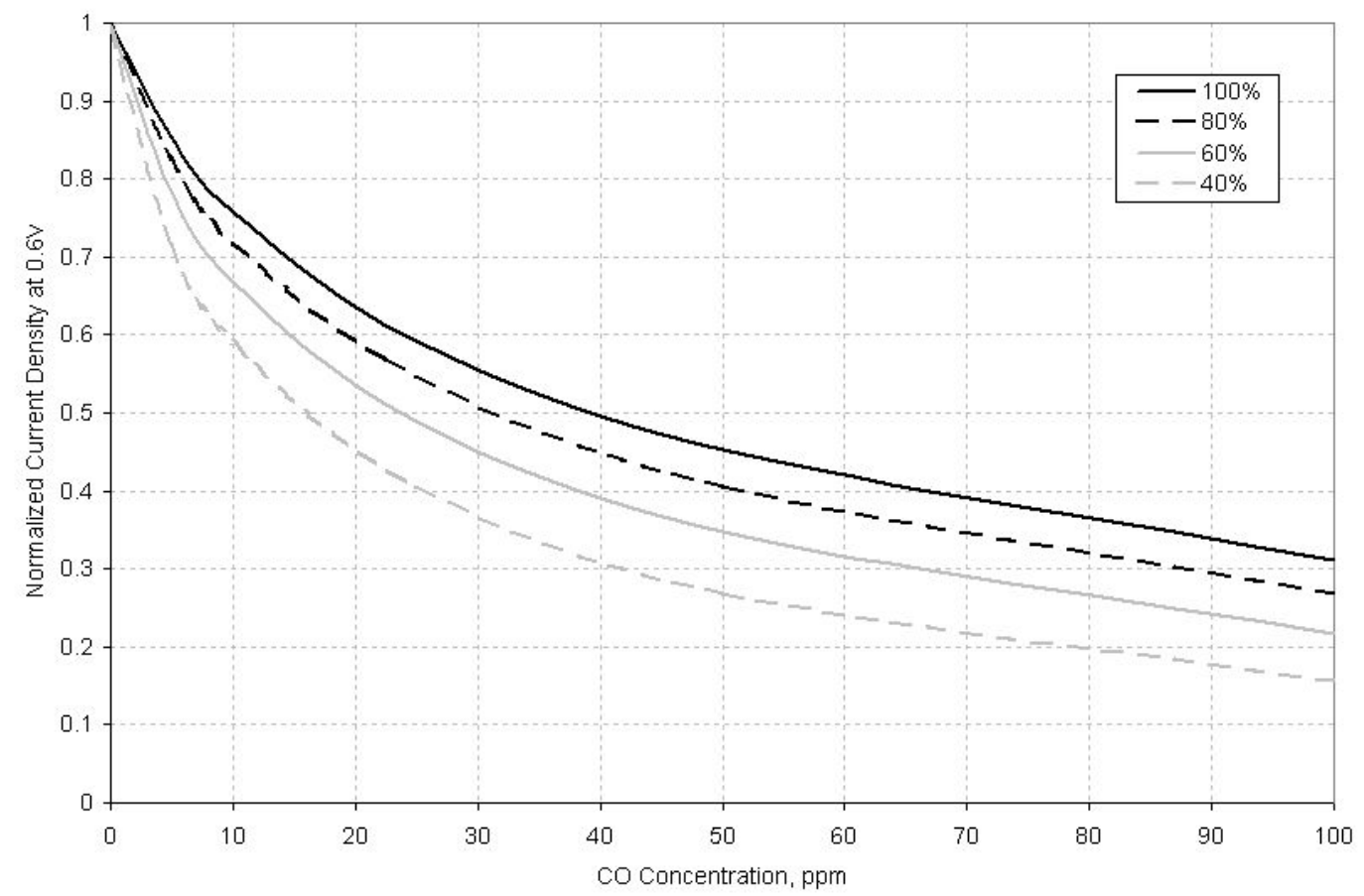

Figure 3.2.1.44 Computed normalized steady state current at 0.6V vs. CO concentration for various hydrogen dilution levels. 


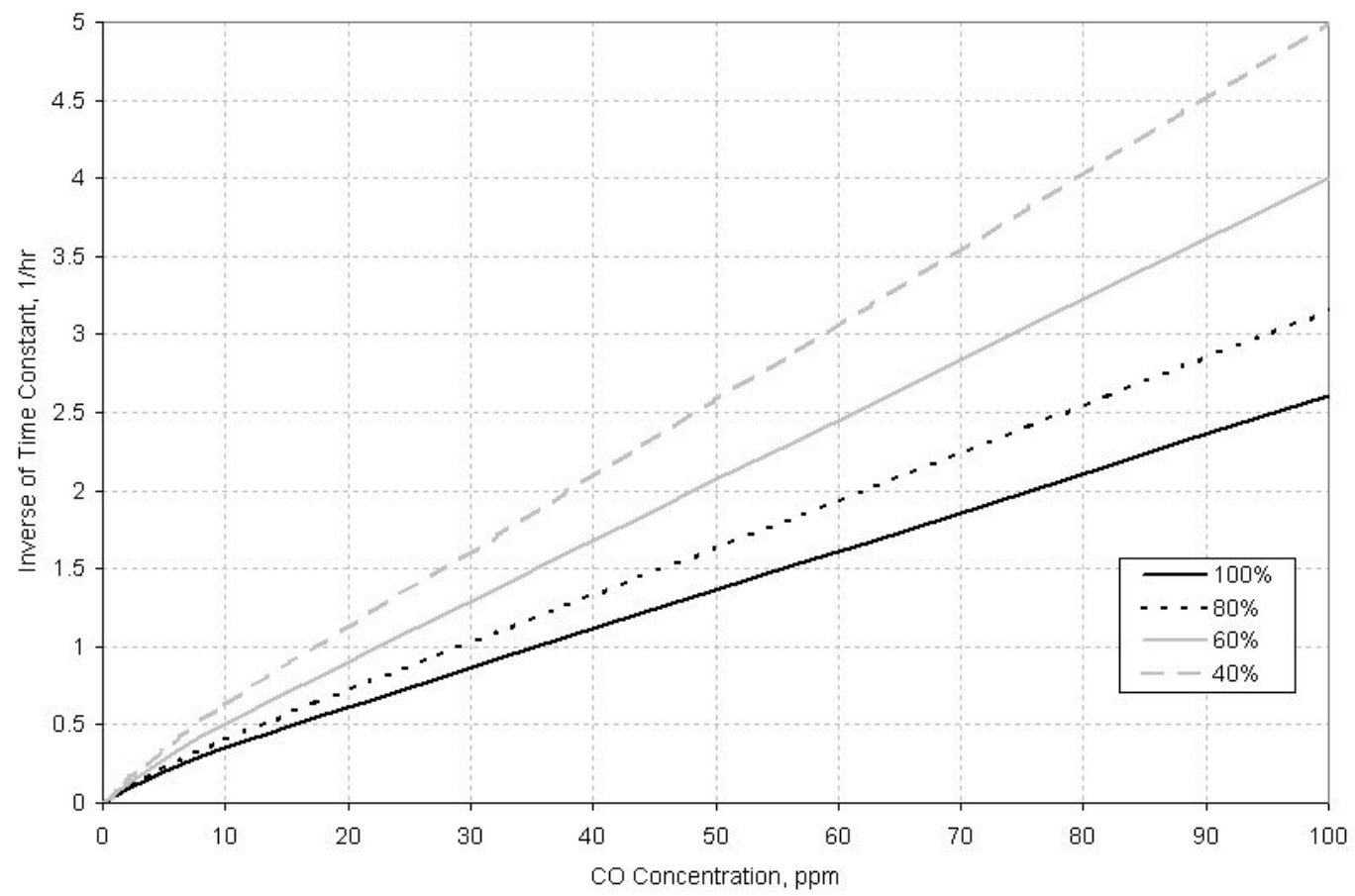

Figure 3.2.1.45 Computed poisoning time constant vs. CO concentration for various hydrogen dilution levels. 


\section{Subtask 3.2.1.4 - Integration of Reformer and Fuel Cell Stack, Examination of System Effects from Fuel Composition (25-27 months)}

\subsection{Anode Air Injection Studies}

Due to the carbon monoxide (CO) present in hydrocarbon reformate gas, a system was developed to deal with this $\mathrm{CO}$ and to prevent poisoning of the fuel cell catalyst layer. This remediation system involves the injection of oxygen, in the form of air, directly into the anode feed stream shortly before entering the fuel cell. This technique is also refered to as "air bleed". This system was developed, integrated with the fuel cell, and optimized using simulated reformate gas. To closely simulate methanol reformate gas, many of these tests were conducted with diluted hydrogen at the $40 \%$ level, and $\mathrm{CO}$ at the $100 \mathrm{ppm}$ level. The performance under various conditions is compared to that of a $\mathrm{CO}$ free, pure hydrogen feed stream.

Figure 3.2.1.46 shows the cell polarization curves, at atmospheric pressure, for various anode feed gases, with and without the air injection system. As shown, with out air injection, the poisoning effect with 100ppm of CO is prominent with both a $100 \%$ and $40 \%$ hydrogen feed stream. However, with a $10 \%$ anode air injection (mole basis relative to hydrogen), cell performance is recoverable. Similar trends were observed at higher cell pressures. Figures 3.2.1.47 and 3.2.1.48 show the results at 2 atmospheres (15 psig) and 3 atmospheres (30 psig) respectively. In both higher pressure cases, the $10 \%$ anode air bleed was sufficient to return to the cell back to, or near, the performance with a pure hydrogen feed stream. However, excessive anode air injection has the side effect of reducing overall efficiency in two ways. First and foremost, in addition to oxidizing carbon monoxide from the catalyst layer, oxygen injection also oxidizes hydrogen fuel to water. This consumption of hydrogen on the anode reduces overall fuel utilization, and thus efficiency. Secondly, in an integrated system, excessive air injection can lead to increased parasitic pumping losses due to additional air feed required. Thus, an optimized methanol reformer/hydrogen fuel cell system would try to not only minimize $\mathrm{CO}$ generation from the reformer, but also minimize the amount of air injection required to deal with the CO. Therefore, the effect of variable air injection was studied. With a simulated reformate feed of $40 \%$ hydrogen and 100ppm CO, the effects of varying air injection levels from 0 to $10 \%$ were studied. The cell polarization curves are shown in Figure 3.2.1.49, while the power density curves are shown in Figure 3.2.1.50. As observed, even a $2 \%$ air injection can help to recover performance, but full recovery is not possible without larger amounts of air bleed. Similar trends were observed at the 600ppm level (Figures 3.2.1.51 and 3.2.1.52), with a $2 \%$ injection contributing to a large recovery, with 5 and $10 \%$ injections providing only marginal additional gains in performance. It is important to note that at the 600ppm level, even a $10 \%$ air injection is insufficient to fully rectify the catalyst layer. This performance data at the 100 and 600ppm CO levels verses amount of air injection is shown in Figure 3.2.1.53. As illustrated, there are diminishing performance gains in increasing air bleed beyond $2 \%$. There is also an observable limit to the extent of performance recovery. With a $40 \%$ hydrogen, $100 \mathrm{ppm} \mathrm{CO}$ feed stream, this limit appears to be roughly $80 \%$. However, at the high CO level of 600ppm, this maximum performance limit is roughly $60 \%$ of that of a pure hydrogen feed.

In order to sort through this multitude of fuel cell data, it was decide to collapse the polarization curves by looking at the performance at a fixed cell voltage (0.6V). Figure 3.2.1.54 shows the normalized current available, relative to pure hydrogen, verses the ratio of $\mathrm{CO}$ to hydrogen in the anode feed stream. Once again, it is shown that without air injection, even low cO to hydrogen ratios have an extremely detrimental effect. However, a small amount of air bleed contributed to a great deal of cell recovery, with increasing bleed rates contributing marginal gains. Like Figure 3.2.1.53, Figure 3.2.1.54 illustrates the inability of large quantities of air injection to rectify cell performance at high $\mathrm{CO}$ to hydrogen ratios. This graph in particular can be very useful for determining the amount of air bleed necessary to maintain a certain cell performance level despite varying reformer $\mathrm{CO}$ to hydrogen ratio output conditions. 


\subsection{Reformer Integration and Experimentation}

A methanol reformer, completely designed, developed, and built by the groups of Dr. Chunshan Song and Dr. André L. Boehman of Pennsylvania State University, was integrated into a hydrogen fuel cell test stand. An image of the entire system in shown in Figure 3.2.1.55. The reformer was fed a methanol/water solution and air for the oxidative steam reforming and CO clean-up reactions. The reformer produced an effluent containing roughly 50-60 \% hydrogen and less than 30ppm of carbon monoxide. This reformer effluent was fed directly into a hydrogen PEM fuel cell. The system also utilized the anode air injection method, outlined in the previous section, to deal with the $\mathrm{CO}$ levels. This was done to prevent catalyst layer poisoning of the PEM fuel cell. All of the critical reformer specifications are given in Table 3.2.1.7.

Figure 3.2.1.56 shows the performance of the fuel cell, at atmospheric pressure, with a pure hydrogen feed, the reformer feed alone, and the reformer feed plus $10 \%$ anode air injection. As shown, the use of air bleed was able to recover a great deal of performance, which would otherwise be lost due to the $\mathrm{CO}$ poisoning effect of reformate gas. The corresponding power curves at atmospheric pressure are given in Figure 3.2.1.57. Similar trends in the data were observed at 2 and 3 atmospheres of cell pressure, and are illustrated in Figures 3.2.1.58 - 3.2.1.61. While the reformer feed alone yields extremely inferior performance, approximately $70-76 \%$ of the peak power obtainable with pure hydrogen is available utilizing the reformer feed in combination with anode air injection. This capability was observed at all three pressure levels.

One point to note in this data is that while the reformer effluent was feed directly into the fuel cell without humidification, the cathode air feed was humidified in certain cases. At 2 and 3 atmospheres of pressure, the cathode gas was fed dry. However, at atmospheric pressure, the air was fully humidified. As discussed in the previous section (3.2.1.3), humidified gas is critical to maintaining membrane conductivity. At higher pressures, water generation on the cathode is sufficient to maintain the cell internally humidified. However, this is not the case at atmospheric pressure. Thus, for the atmospheric pressure test, the cathode feed gas was fully humidified. This need to fully humidify the cathode gases introduces further parasitic losses to the system. The promising performance results with the reformer feed, combined with anode air injection, led to the investigation of reducing cathode humidification as a further method of overall system optimization.

Figure 3.2.1.62 shows the cell polarization, at atmospheric pressure, utilizing a reformer feed plus anode air injection. The different curves represent varying cathode relative humidity levels. This data was then analyzed to determine the peak cell power available in each case. Figure 3.2.1.63 shows the peak power available, relative to a pure hydrogen feed, verses cathode relative humidity. As shown, with a dry cathode feed gas, only $44 \%$ of the power is obtainable. This is as opposed to a fully humidified cathode stream, where $76 \%$ of the pure hydrogen anode feed power is obtainable. Thus, combining low cathode relative humidity levels with a reformer fed anode greatly reduces overall cell power density. However, at certain mid-range humidity levels, this drop in cell power density may be offset by an increase in system efficiency due to the need to no longer fully humidify the cathode air stream. 
Table 3.2.1.7 Reformer Specifications and Operating Conditions

\begin{tabular}{|c|c|c|}
\hline \multirow{4}{*}{ Catalyst Composition } & $\mathrm{CuO}$ & $58+/-2.0 \%$ \\
\hline & $\mathrm{ZnO}$ & $31+/-3.0 \%$ \\
\hline & $\mathrm{Al}_{2} \mathrm{O}_{3}$ & $11+/-1.5 \%$ \\
\hline & C (graphite) & $1.5-2.5 \%$ \\
\hline \multirow{4}{*}{ Catalyst Properties } & Total Loading & 3 grams \\
\hline & Surface Area & $60+/-20 \mathrm{~m}^{2} / \mathrm{gram}$ \\
\hline & Bulk Density & $67+/-5 \mathrm{lbs} / \mathrm{ft}^{3}$ \\
\hline & Catalyst Bed Temperature & $230^{\circ} \mathrm{C}$ \\
\hline \multirow{3}{*}{ Solution Composition } & Molarity & $15.2 \mathrm{M}$ \\
\hline & $\mathrm{MeOH}$ to Water Molar Ratio & $1: 1.4$ \\
\hline & Methanol Concentration (vol. \%) & $61.6 \%$ \\
\hline \multirow{5}{*}{ Reformer Feed Rates } & Solution Flow Rate & $0.6 \mathrm{ml} / \mathrm{min}$ \\
\hline & Air Feed Flow Rate & $319 \mathrm{ml} / \mathrm{min}$ \\
\hline & CO Clean-up Air Flow Rate & $159 \mathrm{ml} / \mathrm{min}$ \\
\hline & Oxygen to Methanol Molar Ratio & $0.3: 1$ \\
\hline & Clean-up Air to Air Feed Molar Ratio & $0.5: 1$ \\
\hline \multirow{5}{*}{$\begin{array}{l}\text { Reformer Output } \\
\text { (approximate) }\end{array}$} & Hydrogen Production & $600 \mathrm{ml} / \mathrm{min}$ \\
\hline & Hydrogen & $50 \%$ \\
\hline & Nitrogen & $20 \%$ \\
\hline & Carbon Dioxide & $30 \%$ \\
\hline & Carbon Monoxide & $<30$ ppm \\
\hline
\end{tabular}




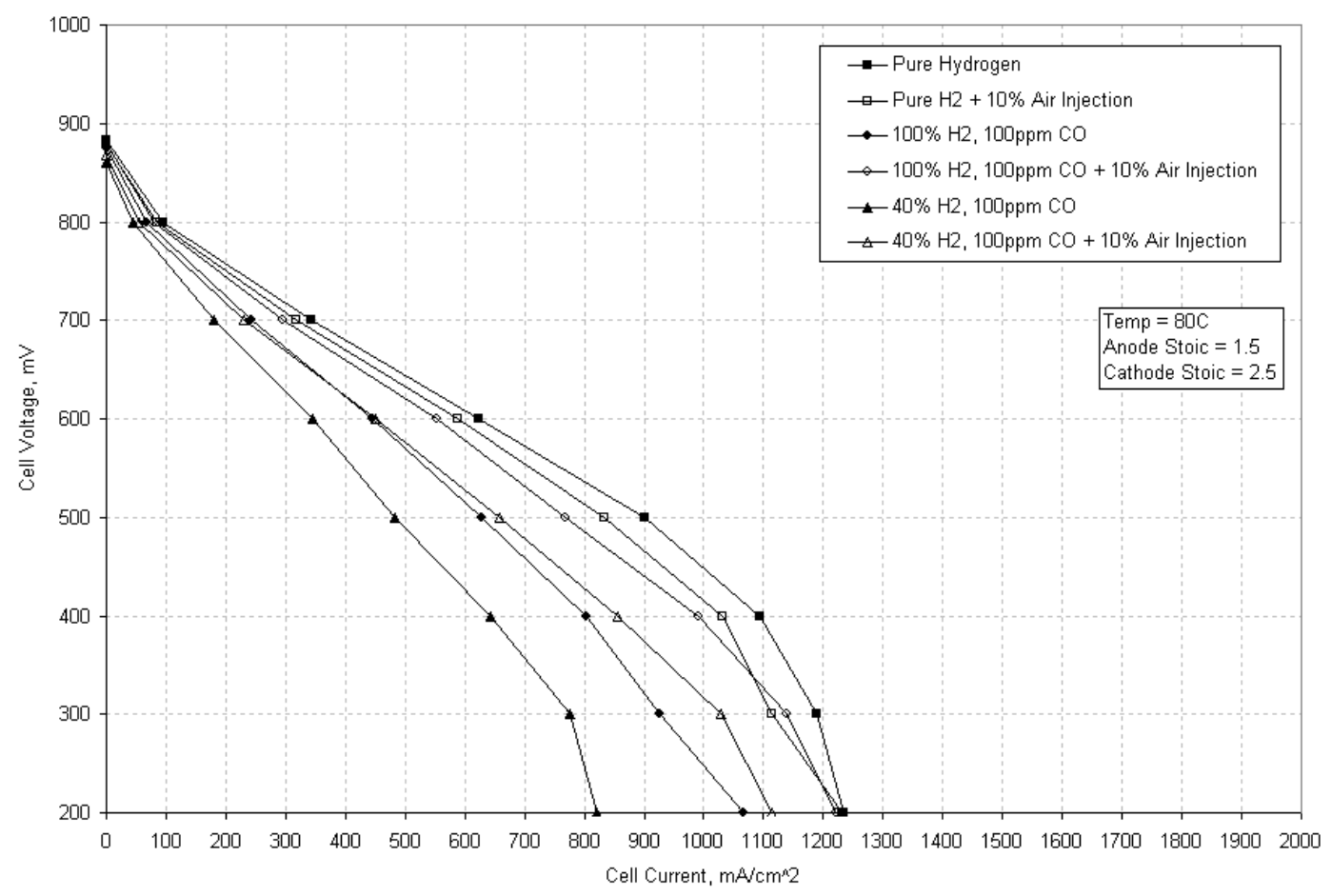

Figure 3.2.1.46 Cell polarization curves at atmospheric pressure with different anode feed gases and $10 \%$ anode air injection.

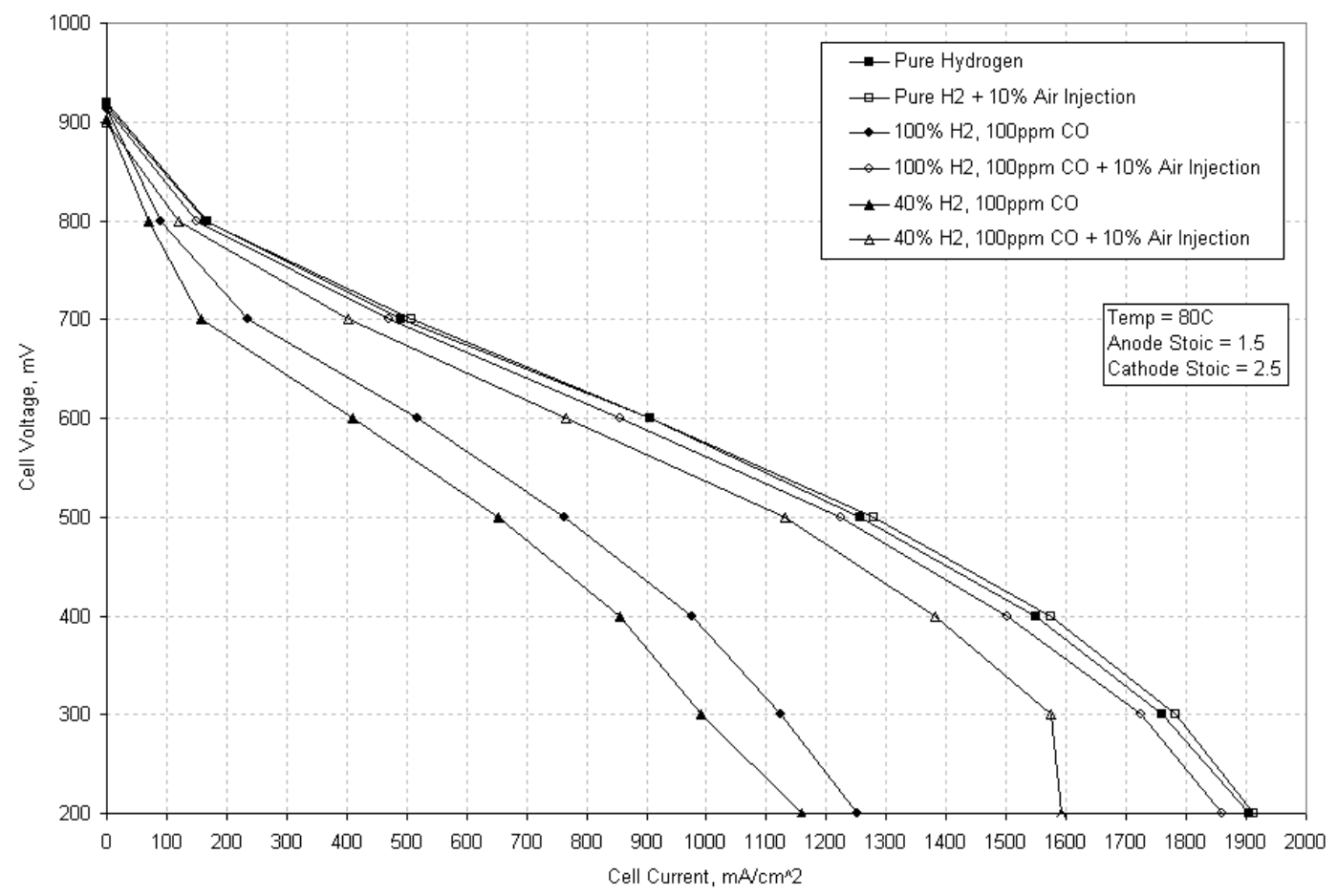

Figure 3.2.1.47 Cell polarization curves at 15 psig with different anode feed gases and 10\% anode air injection. 


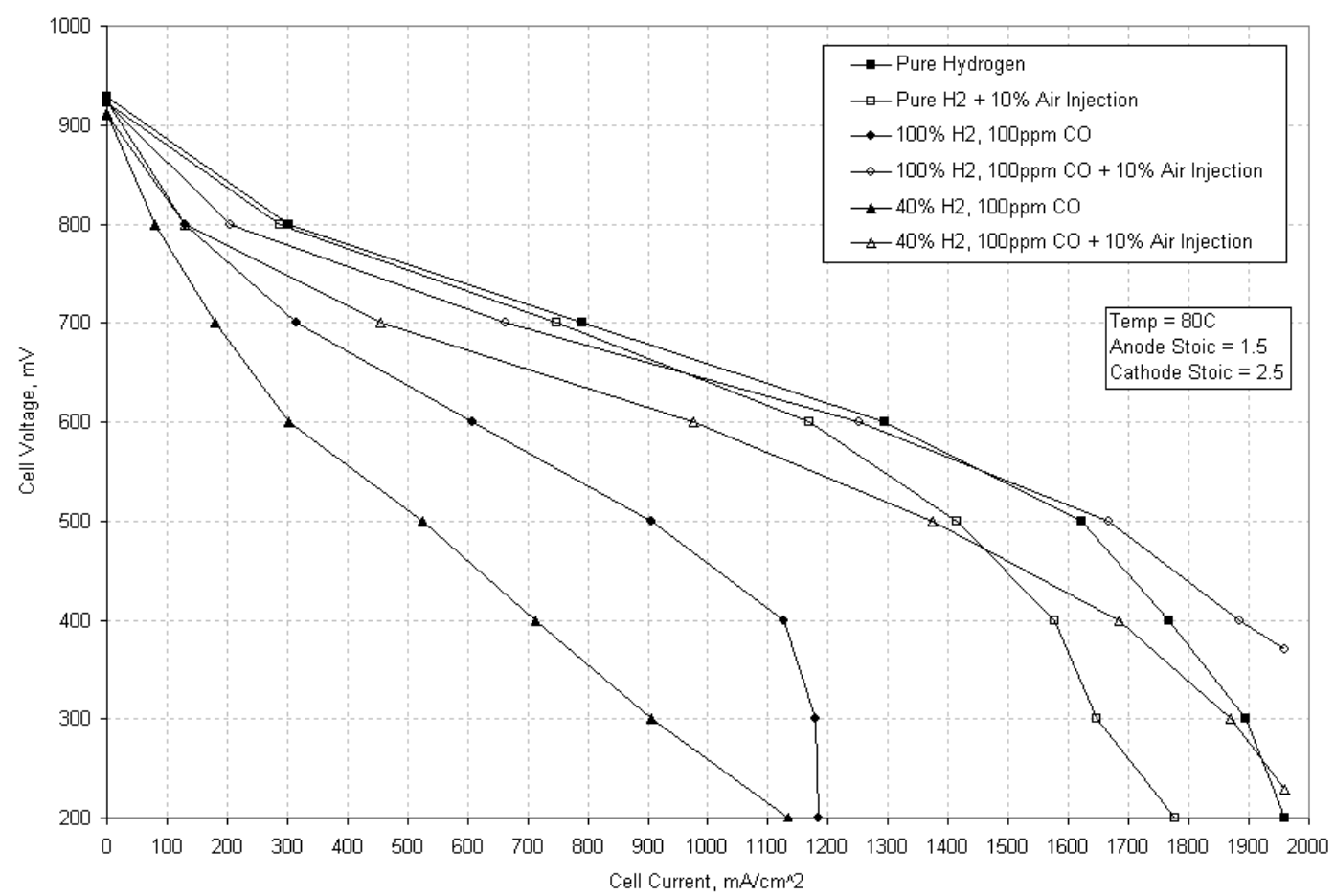

Figure 3.2.1.48 Cell polarization curves at 30 psig with different anode feed gases and $10 \%$ anode air injection.

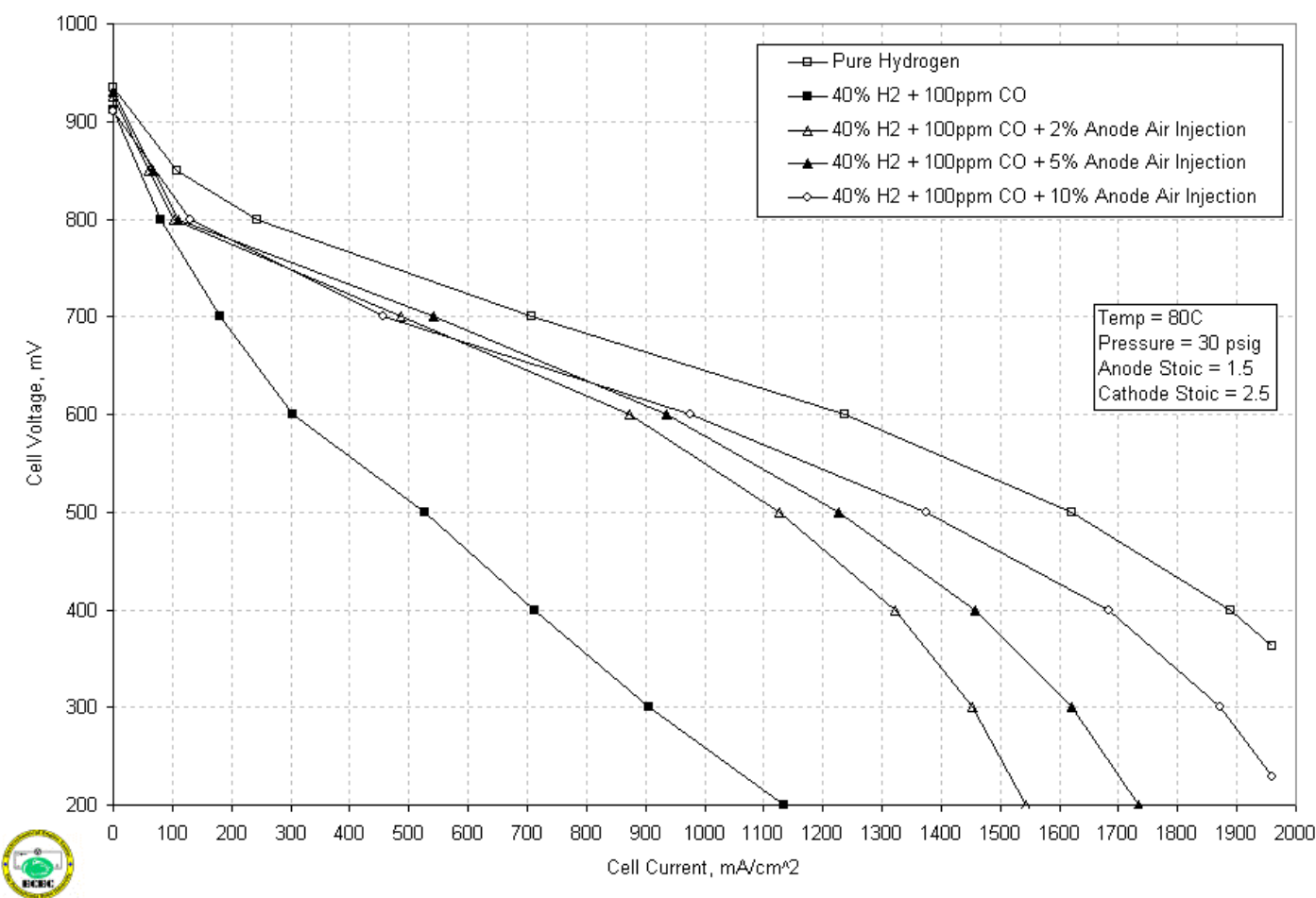

Figure 3.2.1.49 Cell polarization curves at 30 psig with 100ppm CO simulated reformate gas feed and varying anode air injection levels. 


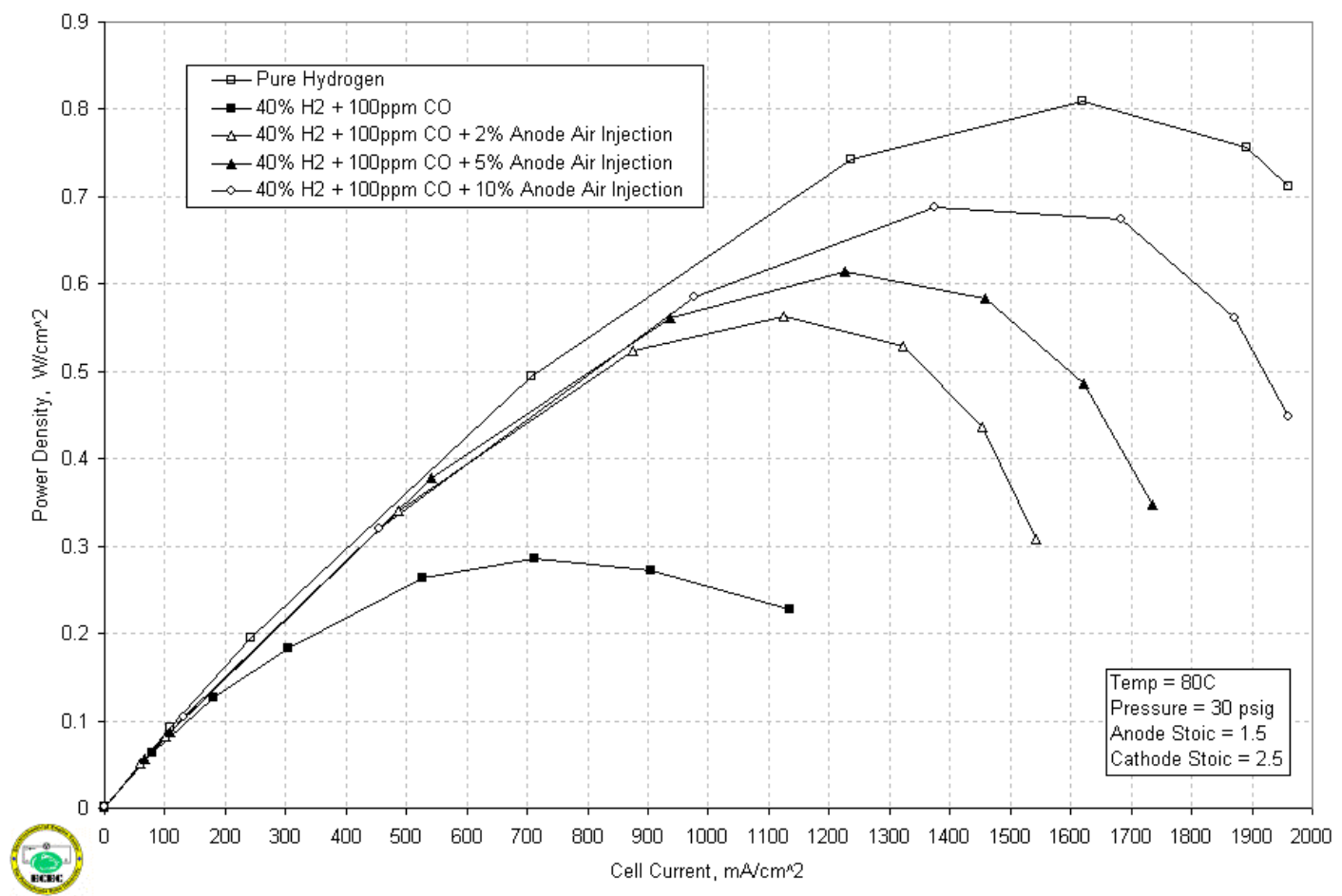

Figure 3.2.1.50 Cell power curves at 30 psig with 100ppm CO simulated reformate gas feed and varying anode air injection levels.

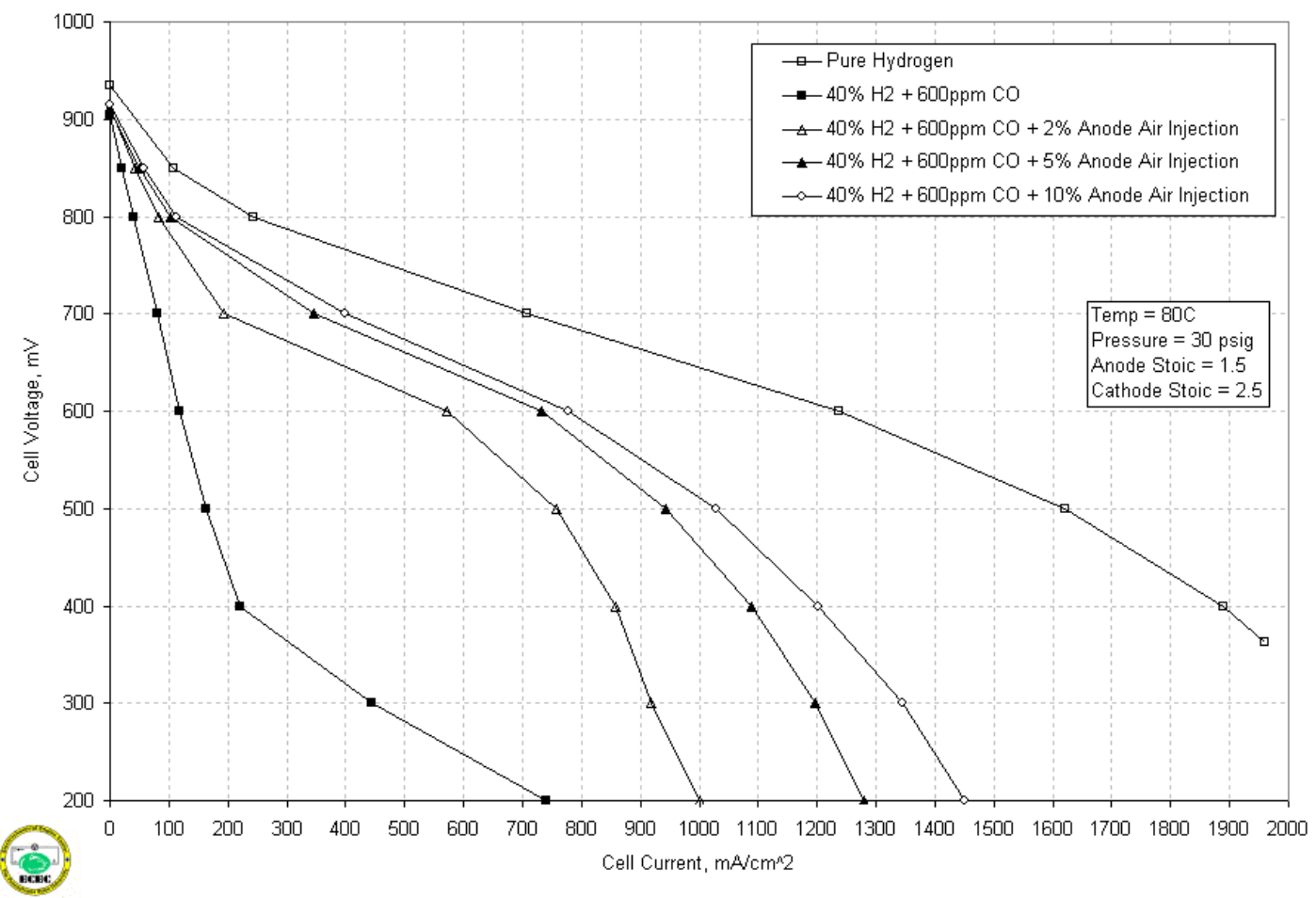

Figure 3.2.1.51 Cell polarization curves at 30 psig with 600ppm CO simulated reformate gas feed and varying anode air injection levels. 


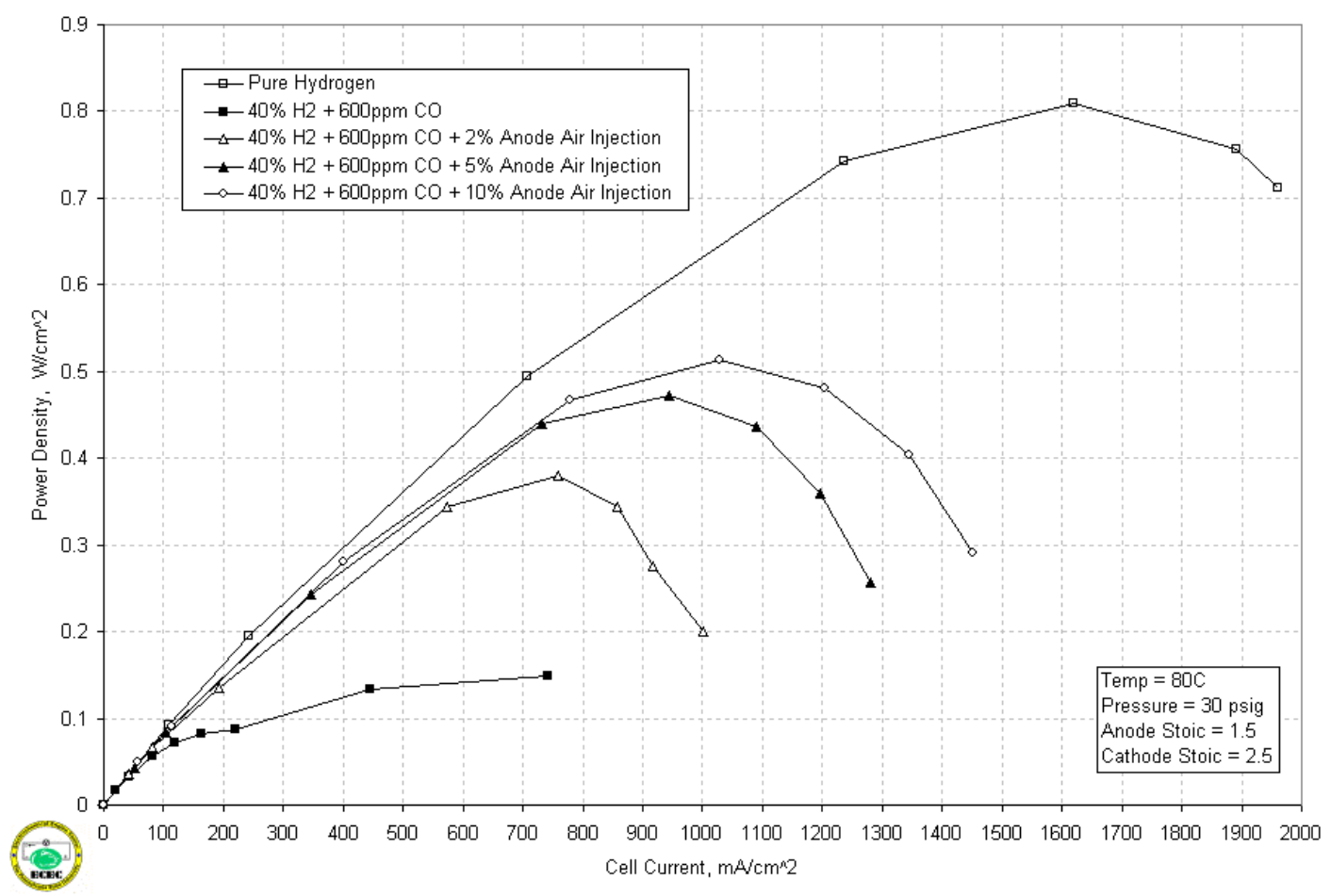

Figure 3.2.1.52 Cell power curves at 30 psig with 600ppm CO simulated reformate gas feed and varying anode air injection levels.

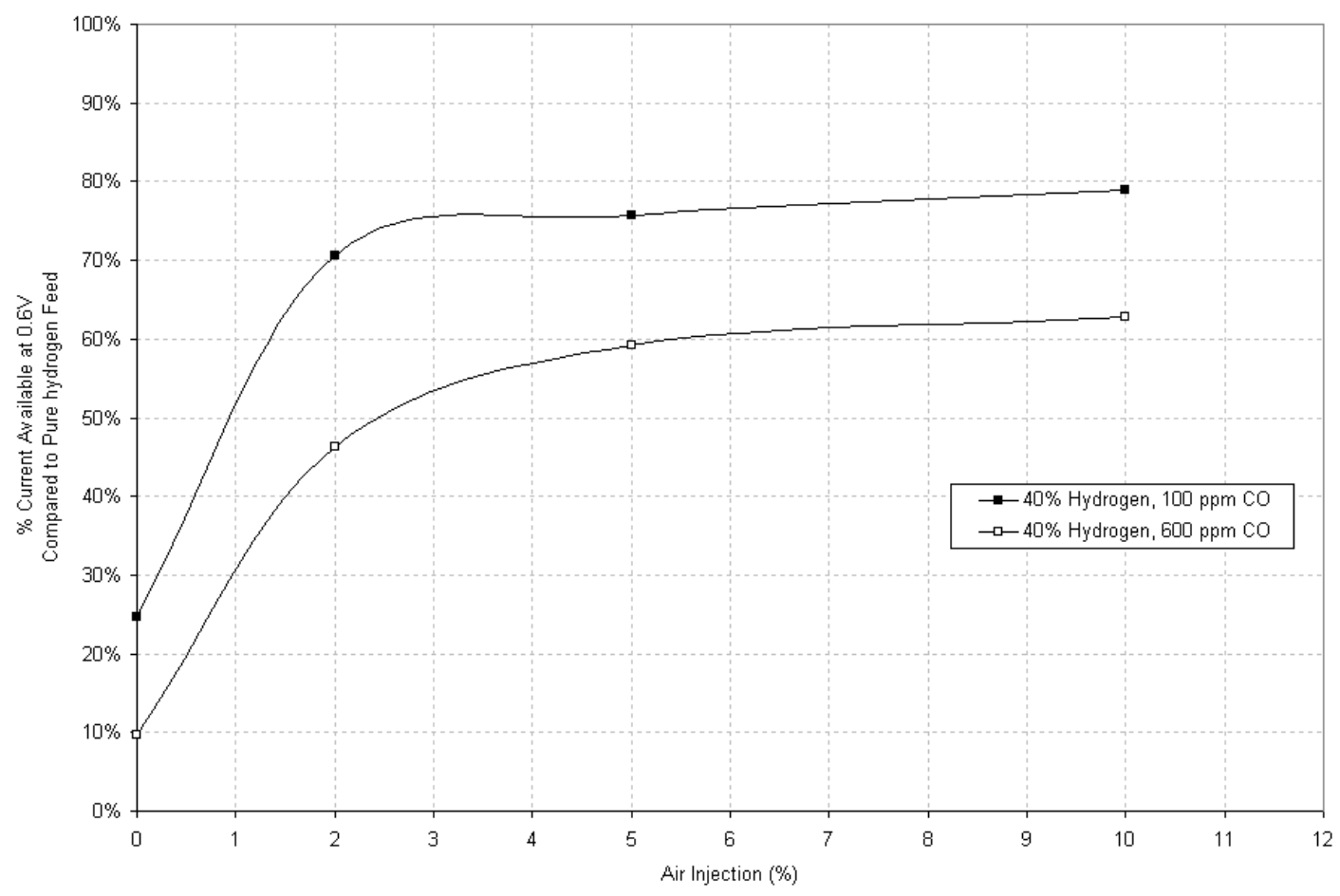

Figure 3.2.1.53 Percent available current (as compared to a pure hydrogen feed) verses air injection levels for two different simulated reformate gas feeds. 


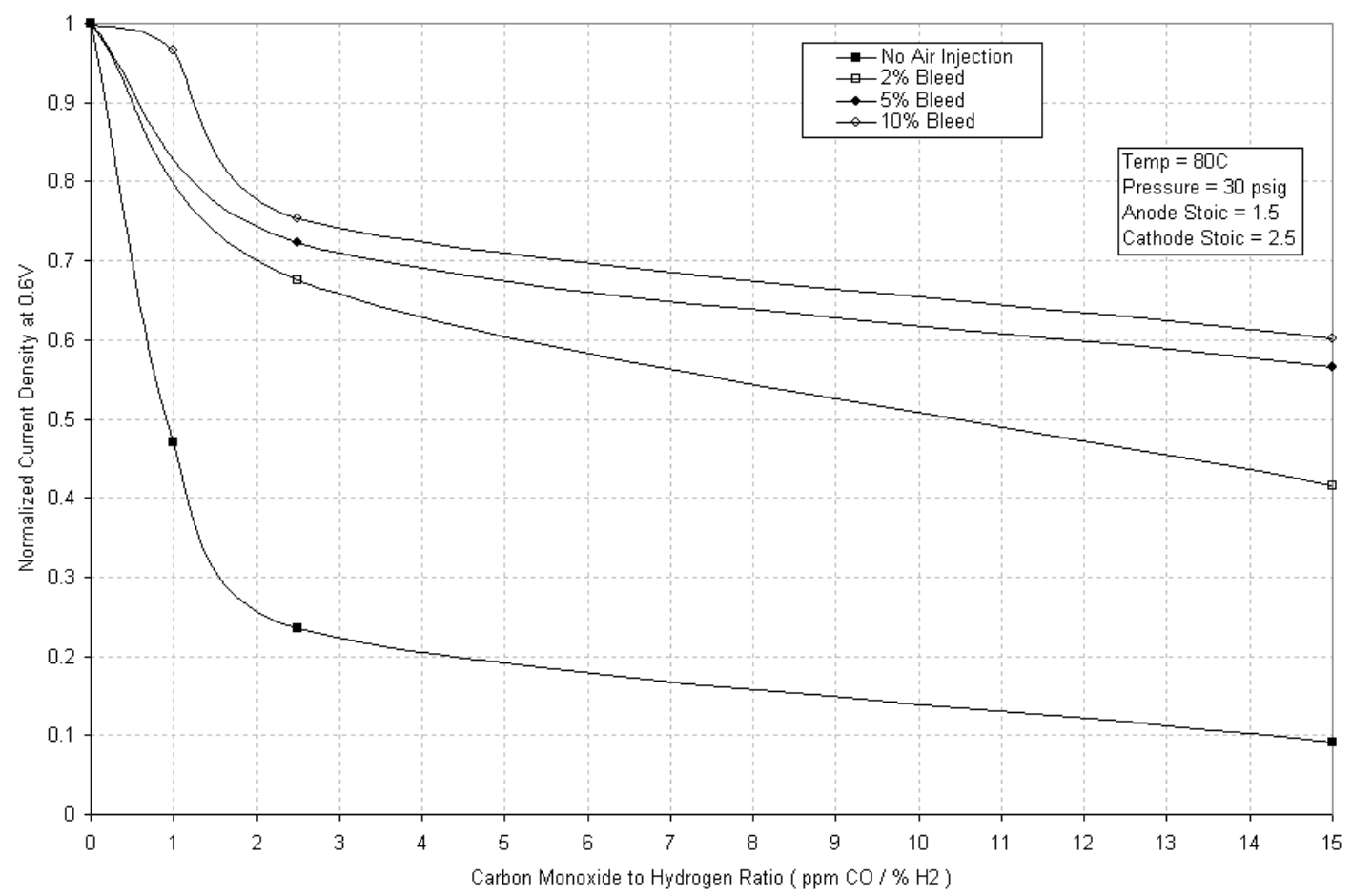

Figure 3.2.1.54 Normalized current density at $0.6 \mathrm{~V}$ verses $\mathrm{CO}$ to $\mathrm{H}_{2}$ ratio for different air injection levels.

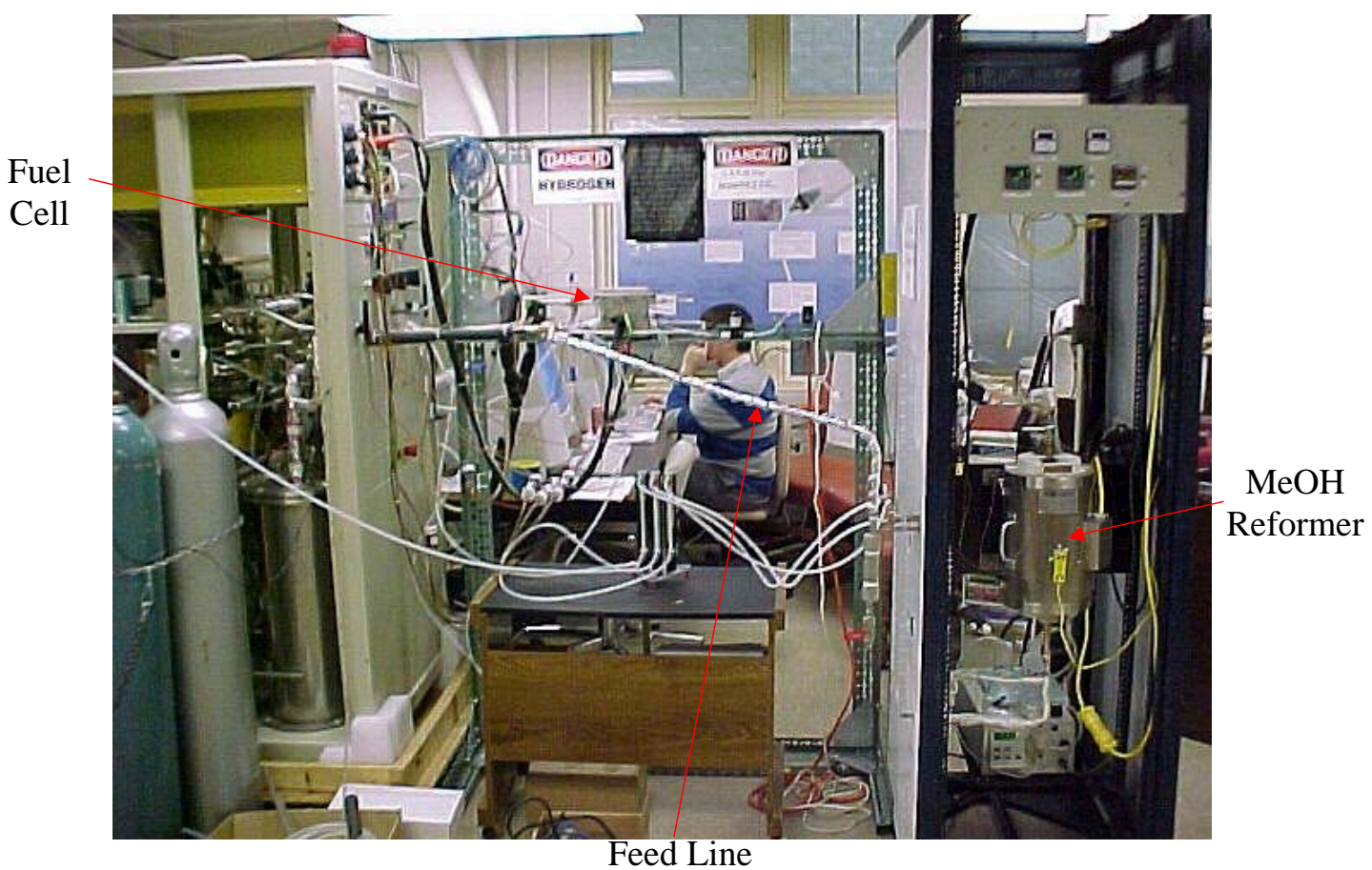

From Reformer

Figure 3.2.1.55 Image of the integrated methanol reformer, fuel cell, and CO remediation system. 


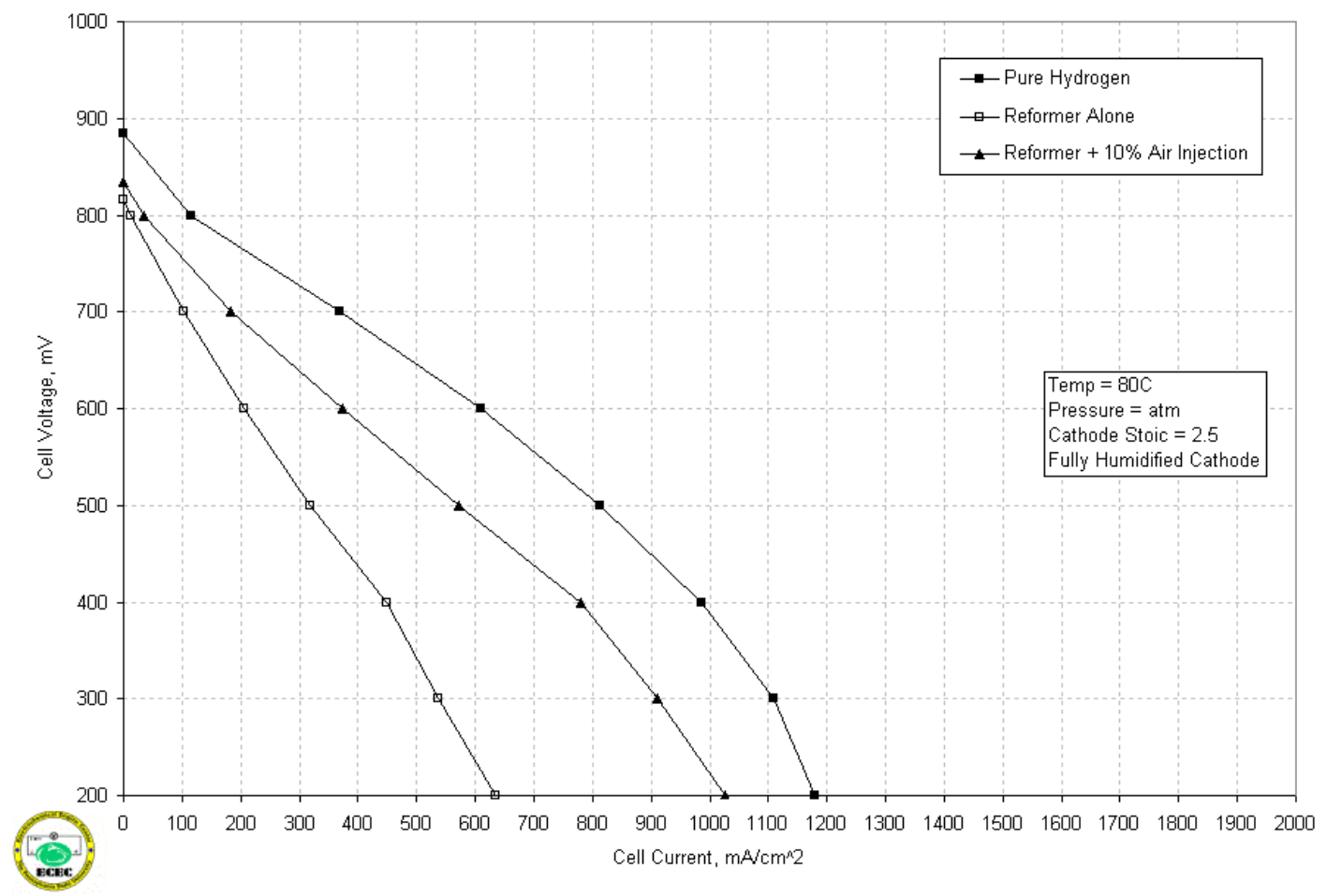

Figure 3.2.1.56 Cell polarization curves for the reformer feed and reformer feed plus air injection as compared to a pure hydrogen feed at atmospheric pressure.

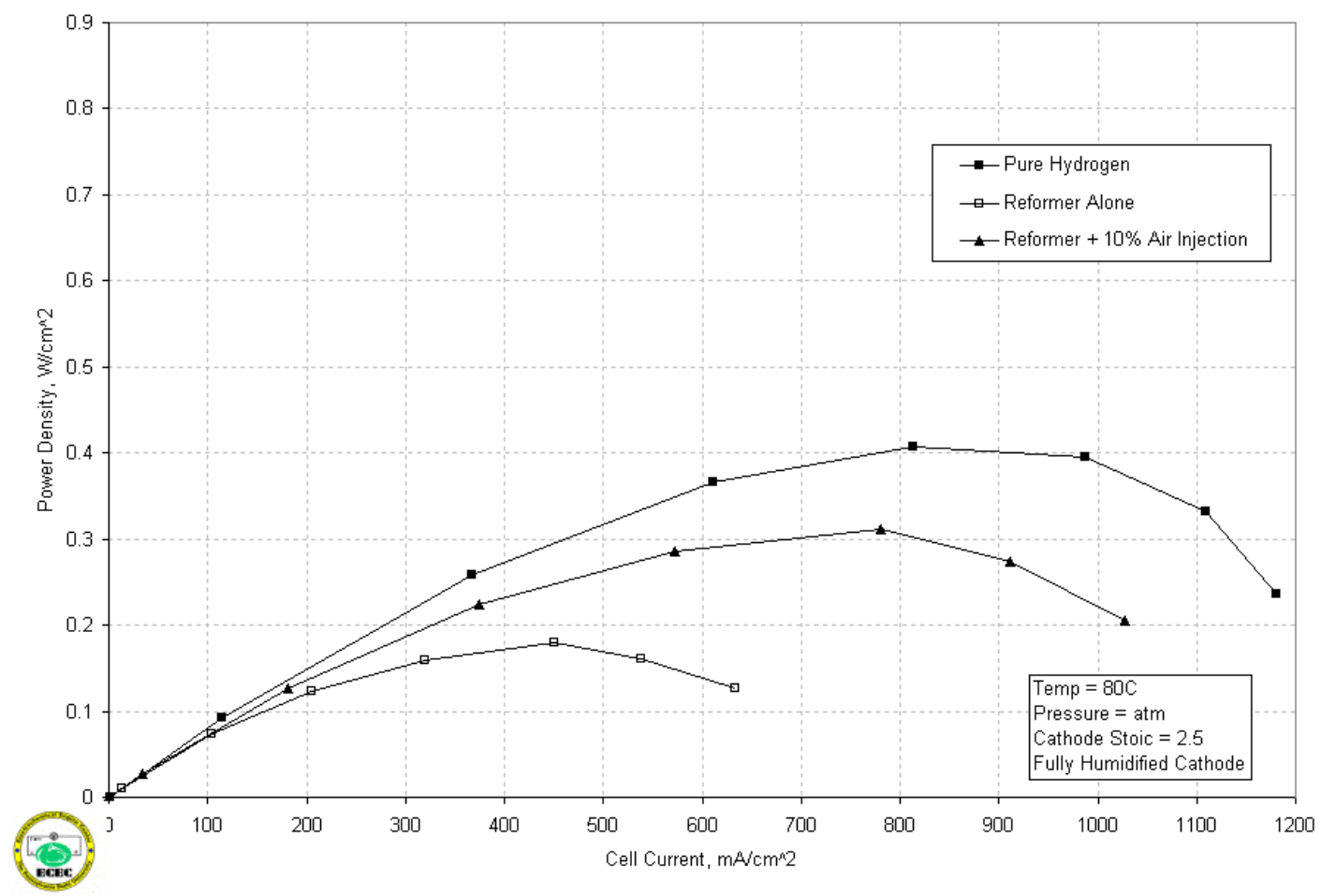

Figure 3.2.1.57 Cell power curves for the reformer feed and reformer feed plus air injection as compared to a pure hydrogen feed at atmospheric pressure. 


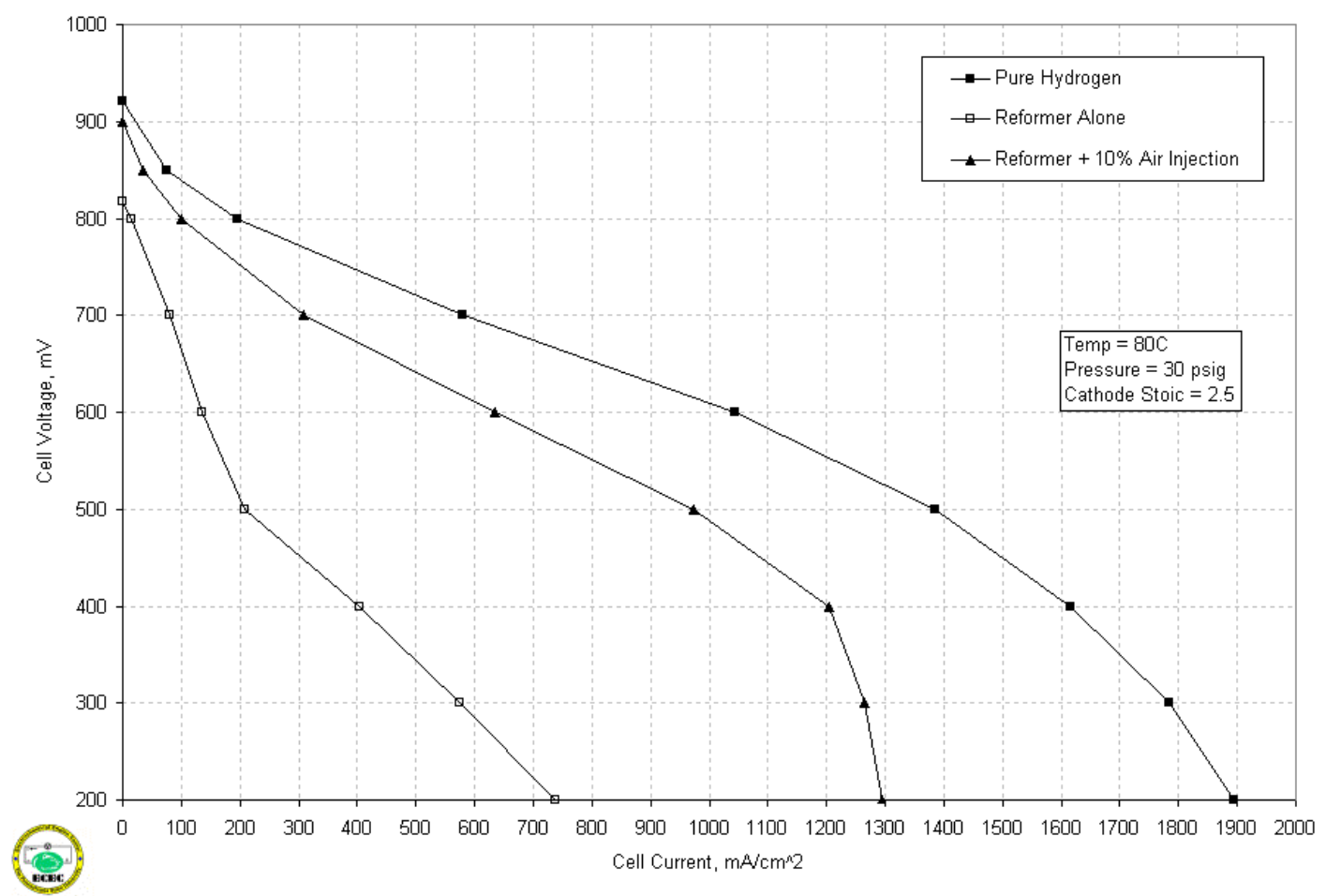

Figure 3.2.1.58 Cell polarization curves for the reformer feed and reformer feed plus air injection as compared to a pure hydrogen feed at 15 psig.

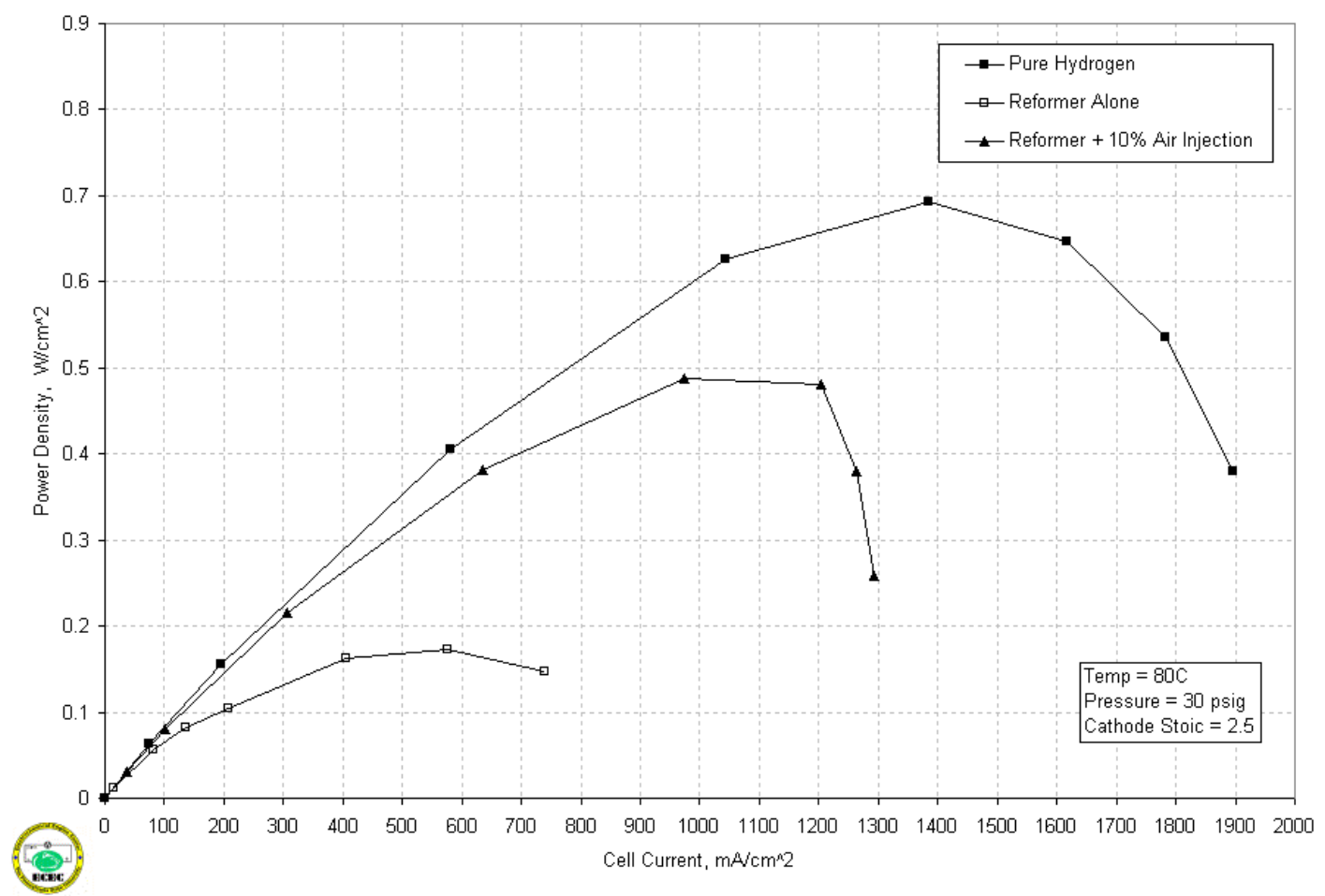

Figure 3.2.1.59 Cell power curves for the reformer feed and reformer feed plus air injection as compared to a pure hydrogen feed at 15 psig. 


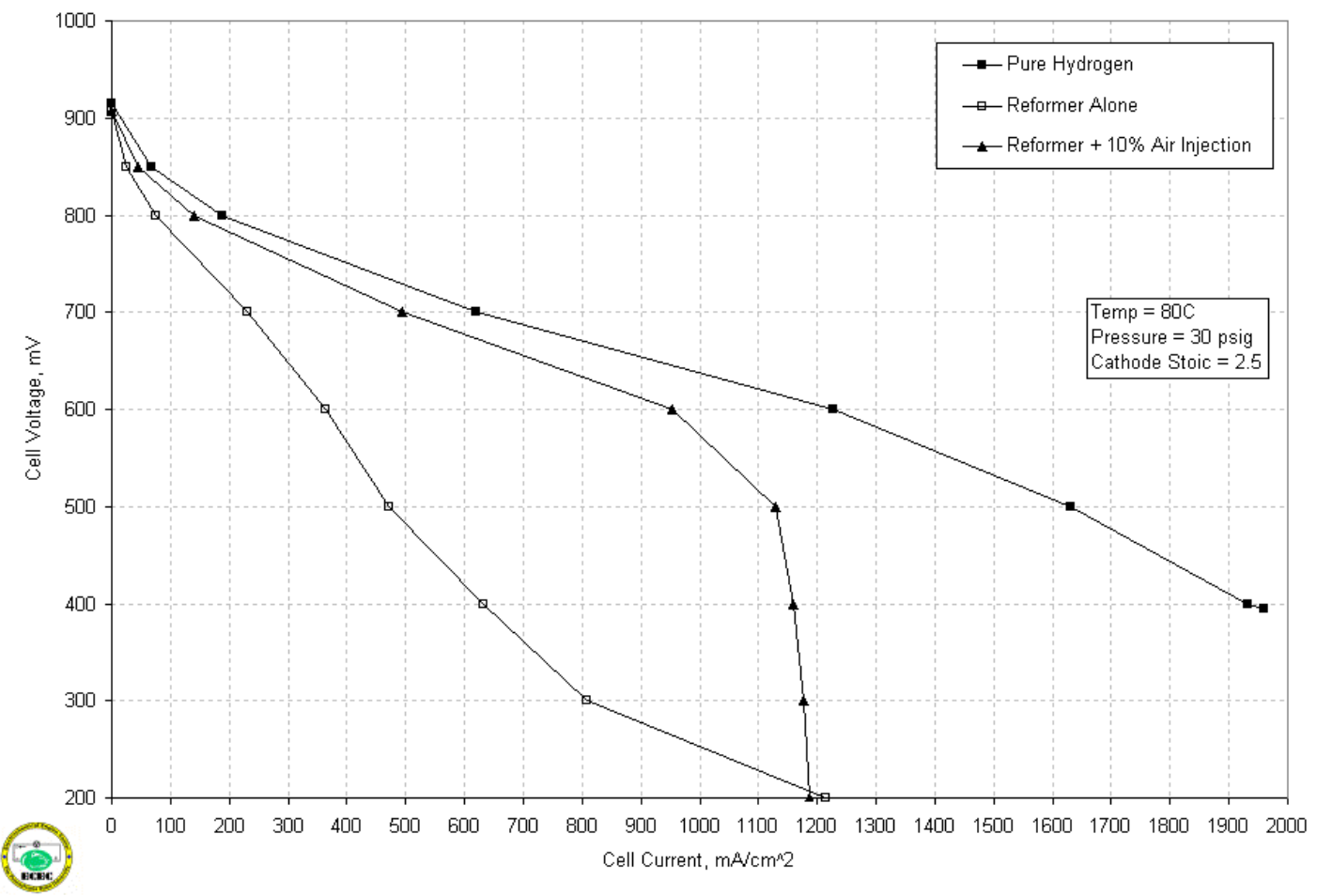

Figure 3.2.1.60 Cell polarization curves for the reformer feed and reformer feed plus air injection as compared to a pure hydrogen feed at 30 psig.

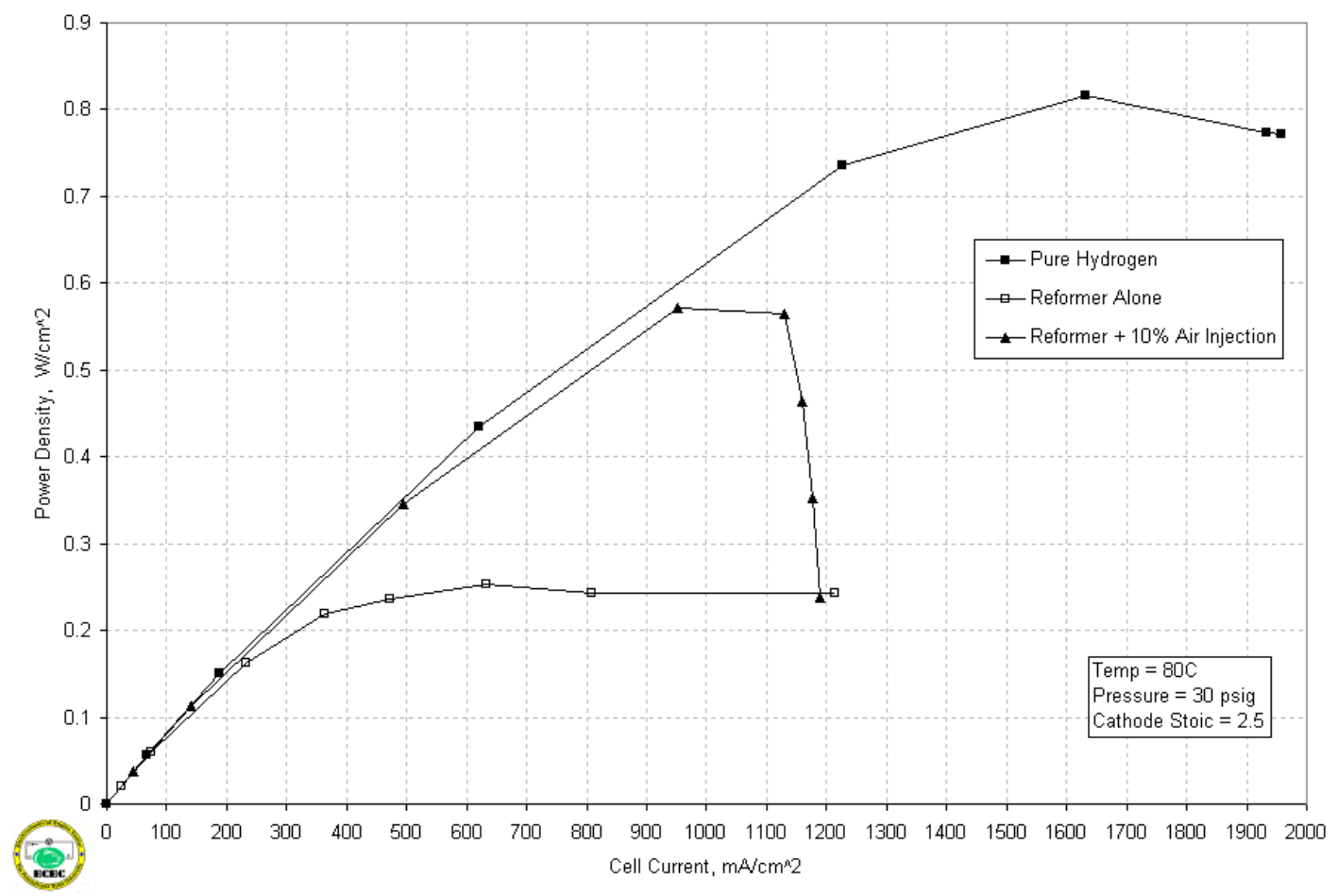

Figure 3.2.1.61 Cell power curves for the reformer feed and reformer feed plus air injection as compared to a pure hydrogen feed at 30 psig. 


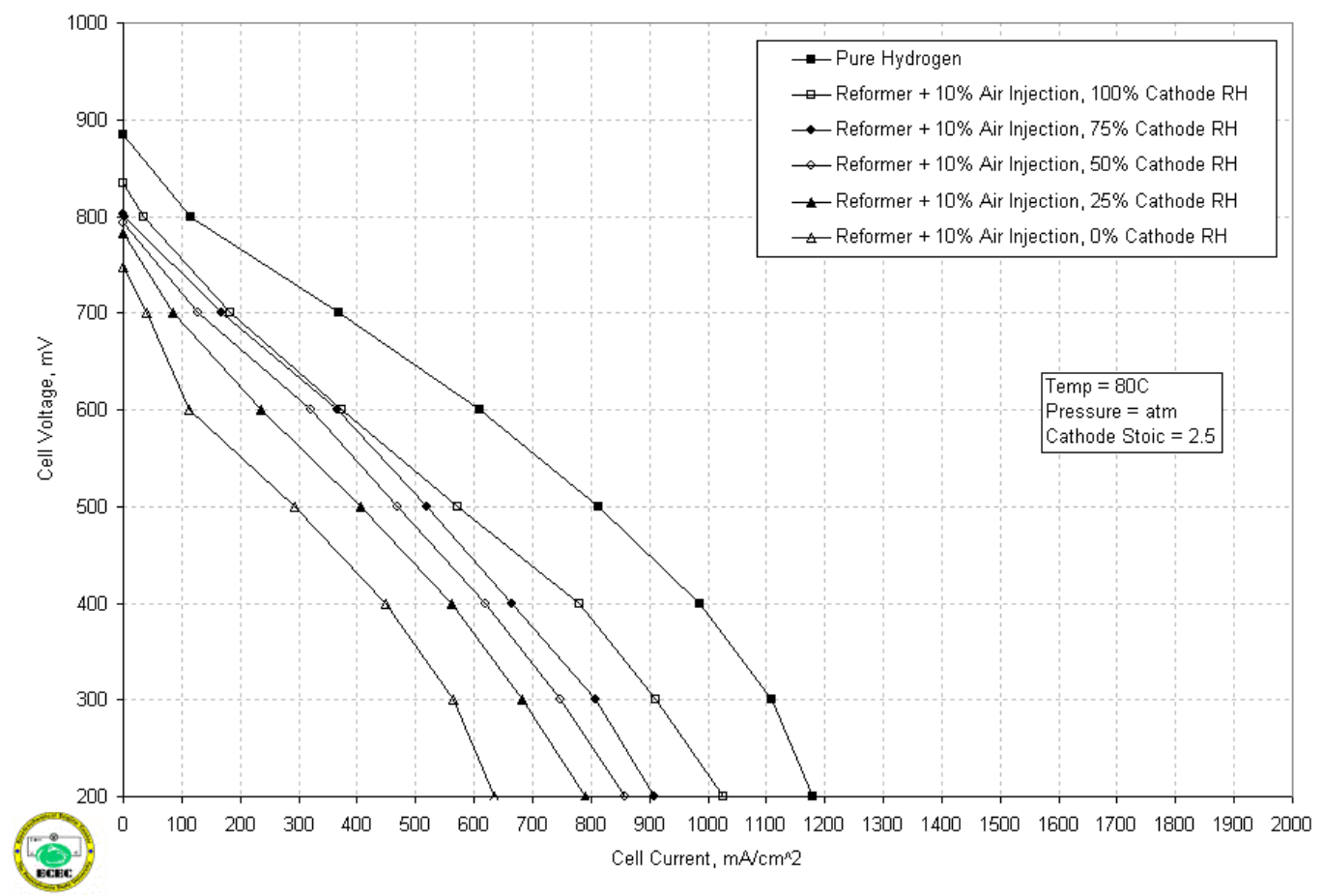

Figure 3.2.1.62 Cell polarization curves, for the reformer feed plus air injection as compared to a pure hydrogen feed, at atmospheric pressure with varying levels of cathode relative humidity.

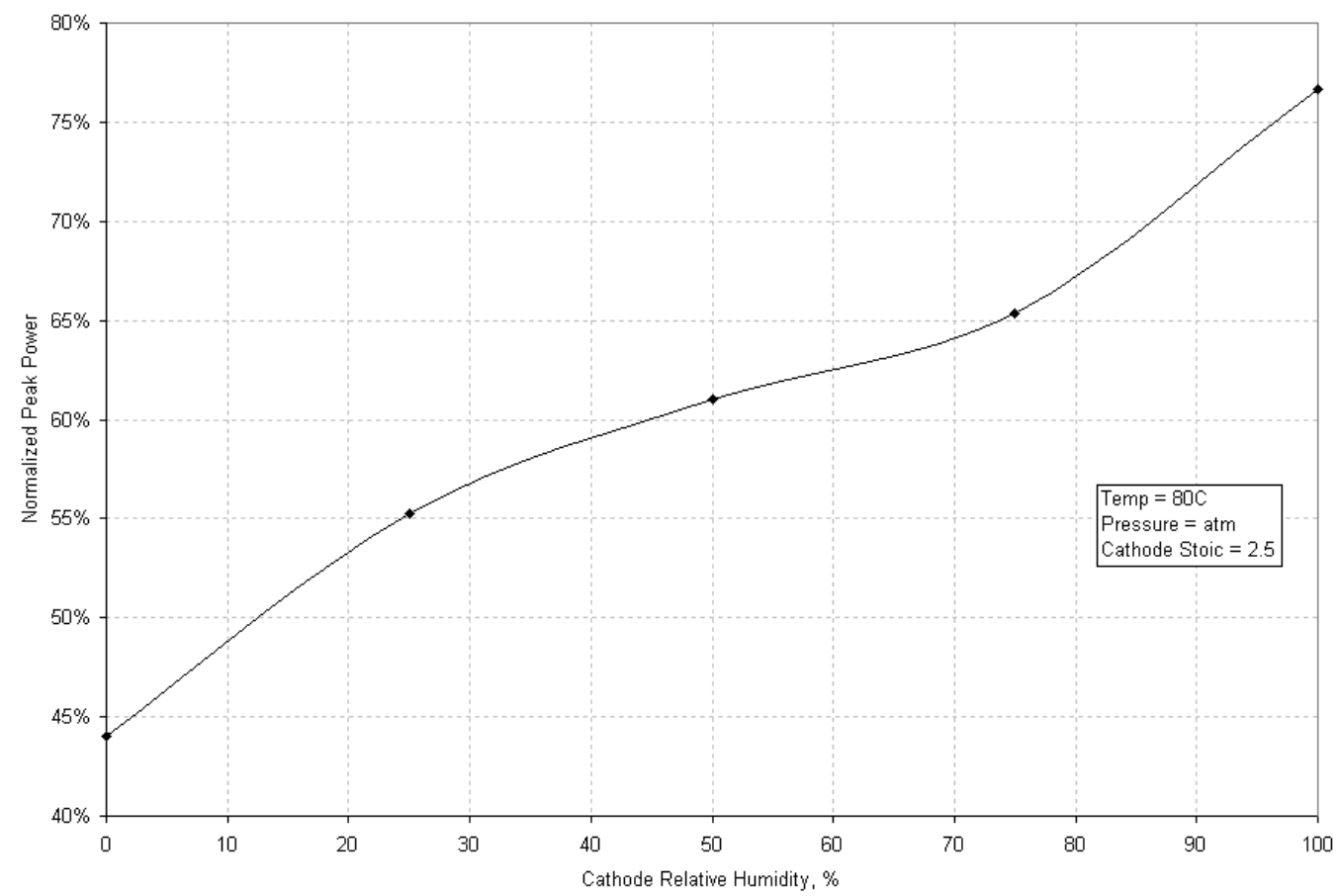

Figure 3.2.1.63 Peak cell power, as compared to a pure hydrogen feed, verses cathode relative humidity. This was data was taken utilizing a reformer feed plus air injection. 


\section{Subtask 3.2.1.5 - Design and Construction of 15 W Fuel Cell Stack for Direct Methanol (0-12 months)}

The DMFC testing was performed with a fuel cell having an active area of $50-\mathrm{cm}^{2}$. The fuel cell used commercial backing plates, manufactured out of titanium and covered with a proprietary conductivity-enhancing oxide coating by Lynntech Inc. of College Station, TX. The flow fields consisted of six parallel flow channels traversing each plate in a five-pass serpentine path. Each flow channel was machined to be $1.5 \mathrm{~mm}$ wide, $2.5 \mathrm{~mm}$ deep and spaced $1 \mathrm{~mm}$ apart. Each plate also contained an O-ring groove, in which $1.6 \mathrm{~mm}$-diameter EPDM gasket material was used to seal the cell.

Lynntech also supplied the membranes used in the fuel cell. Each MEA had $4 \mathrm{mg} / \mathrm{cm}^{2}$ unsupported $\mathrm{Pt} / \mathrm{Ru}$ anode catalyst loading with a 1:1 molar ratio of $\mathrm{Pt}$ to $\mathrm{Ru}$, and an unsupported $4 \mathrm{mg} / \mathrm{cm}^{2}$ platinum loading at the cathode. The catalyst layers were deposited directly onto Nafion $^{\circledR} 115$ separator material. The "free floating" diffusion layers were not physically attached to the membrane, and consisted of carbon cloth on the anode side and single-sided ELAT ${ }^{\circledR}$ carbon cloth on the cathode side.

Eight stainless steel bolts, insulated from the cell by nylon shoulder washers, achieved cell compression of 30 in-lbs per bolt. Water at a regulated temperature flowed through separate flow fields in the backing plates in order to maintain the cell at a constant temperature. The anode and cathode inlet flow temperatures were also regulated, as is described in the following section.

An Arbin Instruments system was used to control the fuel cell and record data during the testing. The system contained a potentiostat for electrical control of the tests, which was capable of maintaining a desired potential by adjusting current flow, or maintaining a set current flow. Figure 3.2.1.64 gives a schematic of the system's control over reactant flow rate and temperature measurements.

On the anode side, a methanol solution tank is pressurized to 20 psig with an inert nitrogen feed. The pressurized methanol feed is then supplied to a liquid flow controller, across which the pressure drops to roughly atmospheric at a flow rate regulated through a computer interface. A heat exchanger then preheats the solution with the anode exhaust. Before entering the cell, the anode feed is next brought up to operating temperature with a line heater regulated by a PID controller. In this experimental set-up, after exiting the cell and passing through the heat exchanger, the anode exhaust is simply collected for disposal.

On the cathode side, compressed air is fed from a reservoir through a pressure regulator at a constant 100 psig. This pressurized feed is then supplied to a mass flow controller, across which the pressure drops to the cathode operating pressure at a flow rate regulated through a computer interface. As with the anode, cathode inlet air is brought up to the operating temperature by a line heater utilizing a PID controller. Before being exhausted, the cathode outlet first passes through a pressure gauge and then through an adjustable flow restriction providing backpressure regulation.

For experimentation with a periodically injected methanol feed, the system schematic is modified as reflected in Figure 3.2.1.65. In this configuration, an unpressurized methanol tank is placed at an elevated position relative to the fuel cell. The methanol solution from this tank is gravity fed to a solenoid valve, which is controlled with an adjustable timer in order to regulate the duration of each injection and the length of time between successive fuel deliveries. An additional flow restriction in the line allows calibration of the delivered volume of solution associated with each injection duration. A PID-controlled preheat chamber then ensures that the solution is fed into the cell at the desired operating temperature. In this configuration, the anode exhaust is not routed through a heat exchanger. 


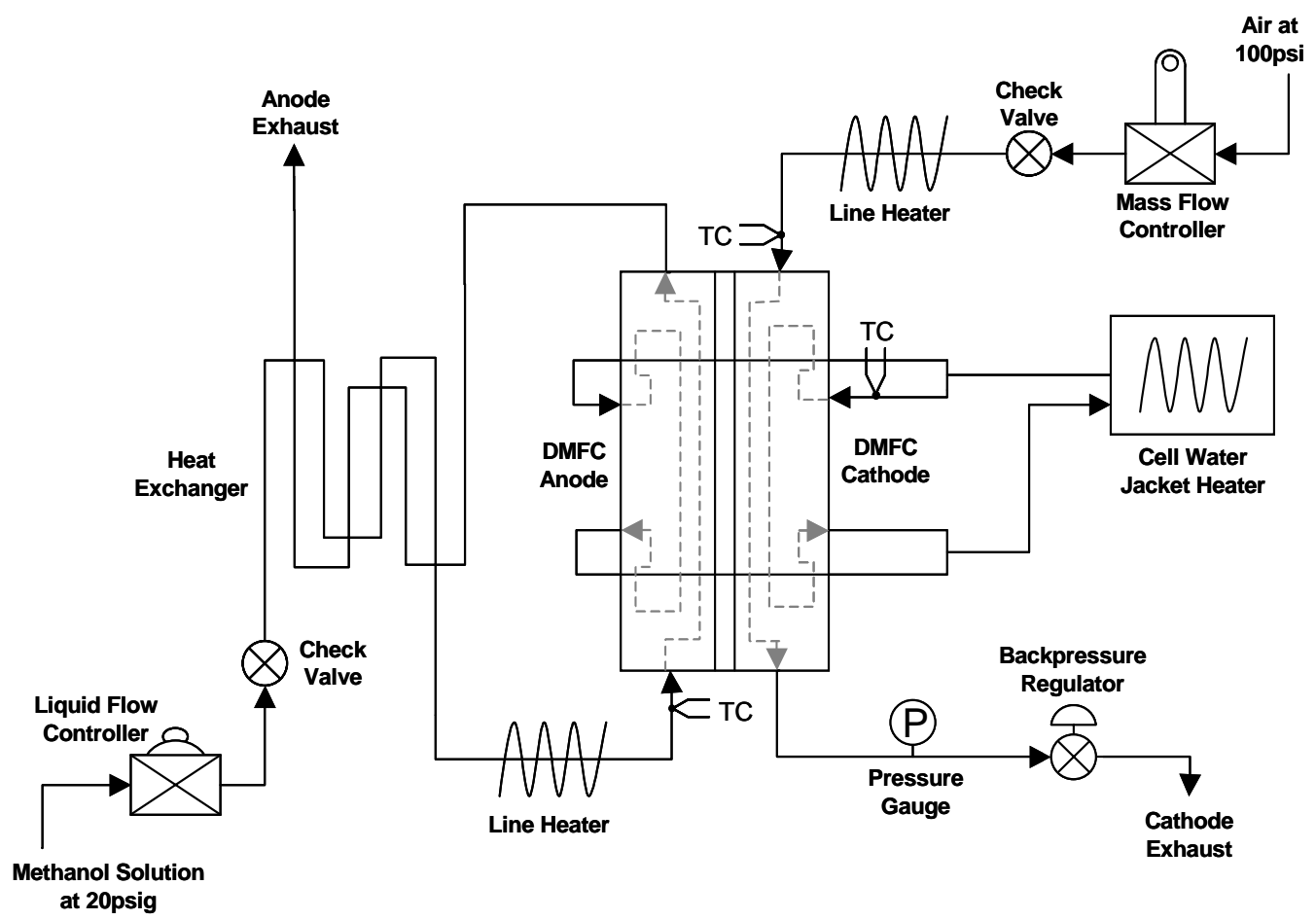

Figure 3.2.1.64 Continuous flow system schematic.

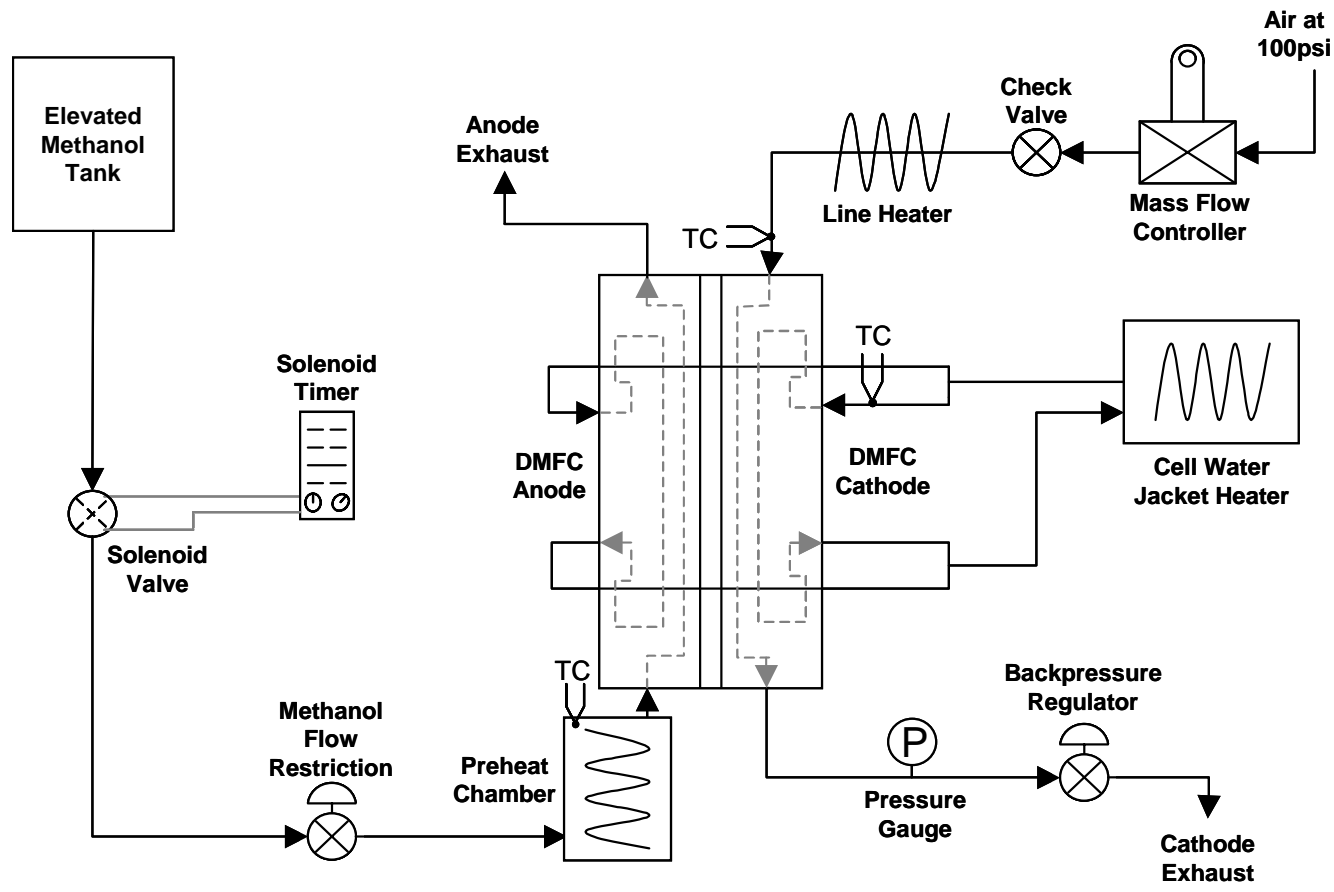

Figure 3.2.1.65 System schematic for periodically injected anode feed. 


\section{Subtask 3.2.1.6 Formulation and Coding of a CFD Model for Interpretation of Experimental Direct Methanol Fuel Cell Performance}

\subsection{Introduction}

Mathematic models, describing detailed physico-chemical processes and coupling transport equations with electrochemical kinetics, are an important tool to aid in fundamental understanding of relevant phenomena in DMFCs. To date, mathematic models have been developed from the onedimensional to the two-dimensional models, from the simple single-phase to the complex two-phase models.

Assuming single-phase processes only in DMFC's anode, Baxter et al. [27] presented a onedimensional isothermal mathematical model for liquid-feed DMFC in the steady state, mainly focused on the anode catalyst layer. Based on a two-dimensional DMFC model, Kulikovsky et al. [28-29] numerically studied both current density distributions by comparing the conventional and a new current collector in a vapor-feed DMFC and methanol transport through the liquid phase in a liquid-feed DMFC. Scott et al. [30-31] also developed several single-phase models to study the transport and electrochemical processes in liquid-feed DMFC and showed cell performance was limited by the slow diffusion of methanol in liquid. Although all these numerical simulations dealt with some kind of physical problems in the transport and electrochemical processes of the DMFC, they could not actually reflect the realistic physical nature of transport schemes since they did not treat the dominating two-phase flow effect in DMFCs.

Based on ongoing two-phase flow phenomenological study and existing numerical models, Wang et al. [32] successfully developed a multi-phase mixture modeling framework, presented originally by Wang and Cheng [33], applying in the air cathode of PEMFC and proved that capillary action was the dominant mechanism for water transport inside the two-phase zone of the hydrophilic structure. Further, such model is also applied for GDLs and membrane of the DMFC by Wang and Wang [34] and simulation results show importance of the gas-phase transport of the methanol in the two-phase GDL.

The transient response of the DMFC is of paramount importance too. Argyropoulos et al. [35] evaluated the effect of the loading pattern and operating conditions on the cell's response time and performance. Simoglou et al. [36-37] developed an empirical dynamic model based on canonical variant analysis (CVA) to validate the experimental data and studied the feasibility of the system scale problems based on this model. Additional numerical modeling work by Sundmacher et al. [38] analyzed the relation between the anode transport and transient performance and the simulation results showed good agreement with experimental data. However, such simulations have no further compatibility with the DMFC research because of the lack of detailed physical transport processes considered.

The goal of this subtask is to develop a comprehensive numerical model for DMFC systems to assist in interpreting experimental results of DMFCs.

\subsubsection{2 Numerical Model}

Figure 3.2.1.66 shows the detailed species transport in a two-dimensional DMFC schematic, where the multi-phase mixture transport of methanol, water, carbon dioxide and oxygen is clearly shown. In this subtask, the channel is not porous medium and thus can not be numerically solved by the multi-phase mixture $\left(\mathrm{M}^{2}\right)$ DMFC model. Therefore, the simulation domain includes only the porous medium regions such as backing layers, catalyst layers and membrane, which are the shaded areas in Figure 3.2.1.67.

Numerical model

Compared with many other two-phase flow models, the $\mathrm{M}^{2}$ DMFC model, first presented by Wang et al. [33], has more advantages to deal with two-phase flow in the DMFC. Advantages include strong resemblance to single-phase transport theory, thus facilitating both theoretical and 
numerical analysis. The resulting differential equations eliminate the need to track interfaces separating single-phase from two-phase regions. More important, it is mathematically equivalent and provides the same predictive capabilities as conventional two-phase models, without loss of intrinsic two-phase flow and transport characteristics.

The $M^{2}$ DMFC model consists of nonlinear, coupled partial differential equations describing the conservation of mass, momentum and species. The governing equations can be written as,

Continuity conservation $\quad \frac{\partial(\varepsilon \rho)}{\partial t}+\nabla \cdot(\rho u)=0$

Momentum conservation $\quad u=-\frac{K}{\mu} \nabla p$

Methanol transport

$\begin{aligned} \frac{\partial\left(\varepsilon \rho C^{\mathrm{MeOH}}\right)}{\partial t}+ & \nabla \cdot\left(\gamma \rho u C^{\mathrm{MeOH}}\right)=\nabla \cdot\left(\rho_{l} D_{l, e f f}^{\mathrm{MeOH}} \nabla C_{l}^{\mathrm{MeOH}}+\right. \\ & \left.\rho_{g} D_{g, \text { eff }}^{\mathrm{MeOH}} \nabla C_{g}^{\mathrm{MeOH}}\right)-\nabla \cdot\left[\left(C_{l}^{\mathrm{MeOH}}-C_{g}^{\mathrm{MeOH}}\right) j_{l}\right]+\dot{m}^{\mathrm{MeOH}}\end{aligned}$

Water transport

$$
\frac{\partial\left(\varepsilon \rho_{l} s\right)}{\partial t}=\nabla \cdot\left(\rho_{l} D_{c} \nabla s\right)+\dot{m}^{H_{2} O}
$$

where $\rho, \vec{u}, p, C^{\mathrm{MeOH}}$, and $s$, respectively, denote the density, superficial fluid velocity vector, pressure, mass fraction of methanol and liquid water saturation. Terms in the governing equations, geometry data, simulation conditions and physical properties, identified for various regions of a DMFC, are listed in Tables 3.2.1.8 through 3.2.1.11, respectively.

In the governing equations of the DMFC model, the mixture variables and properties are defined in terms of liquid water saturation.

$$
\begin{aligned}
& \rho=\rho_{l} s+\rho_{g}(1-s) \\
& \rho C=\rho_{l} C_{l} s+\rho_{g} C_{g}(1-s) \\
& \rho_{\kappa}=\rho_{l} \lambda_{l}(s)+\rho_{g} \lambda_{g}(s) \\
& \lambda_{l}(s)=\frac{\frac{k_{r l}}{v_{l}}}{\frac{k_{r l}}{v_{l}}+\frac{k_{r g}}{v_{g}}} ; \quad \lambda_{g}(s)=1-\lambda_{l}(s) \\
& \mu=\frac{\rho_{l} s+\rho_{g}(1-s)}{\frac{k_{r l}}{v_{l}}+\frac{k_{r g}}{v_{g}}}
\end{aligned}
$$




$$
\begin{aligned}
& \rho_{l} u_{l}=j_{l}+\lambda_{l} \rho u \\
& \rho_{g} u_{g}=-j_{l}+\lambda_{g} \rho u
\end{aligned}
$$

In the DMFC, the anode methanol oxidation reaction and cathode oxygen reduction reaction can be described by the Tafel kinetic equation, given as,

$$
i_{a}=i_{0}^{M e O H} e^{\frac{\alpha_{a} F}{R T} \eta_{a}}
$$

where $i_{0}^{\mathrm{MeOH}}=i_{0, \text { ref }}^{\mathrm{MeOH}}\left(\frac{C_{l}^{\mathrm{MeOH}}}{C_{l, \text { threshold }}^{\mathrm{MeOH}}}\right)^{n}$ and $n= \begin{cases}0 & \text { if } C_{l}^{\mathrm{MeOH}} \geq C_{l, \text { threshold }}^{\mathrm{MeOH}} \\ 1 & \text { if } C_{l}^{\mathrm{MeOH}}<C_{l, \text { threshold }}^{\mathrm{MeOH}}\end{cases}$

$$
i_{c}=i+i_{c}^{\prime}=i_{0, r e f}^{O_{2}}(1-s) e^{-\frac{\alpha_{c} F}{R T} \eta_{c}}
$$

where the cathode current density, $i_{c}$, is in fact made of external current density $i$ and the parasitic current density, $i_{c}^{\prime}$, caused by the methanol crossover.

Thus, anode and cathode overpotentials and cell voltage can be determined as follows,

$$
\begin{aligned}
& \eta_{a}=\frac{R T}{\alpha_{a} F} \ln \left(\frac{i}{i_{0}^{\mathrm{MeOH}}}\right) \\
& \eta_{c}=-\frac{R T}{\alpha_{c} F} \ln \left(\frac{i_{c}}{i_{0, \text { ref }}^{O_{2}}} \frac{1}{1-s}\right) \\
& V_{\text {cell }}=\Delta E^{o}-\eta_{a}+\eta_{c}-i_{a} \frac{H_{m s}}{\kappa}-i_{a} R_{\text {contact }}
\end{aligned}
$$

Such a two-phase model is particularly well suited for the present subtask since it accounts for the realistic species transport and electrochemical reactions of the DMFC.

Boundary conditions

In the liquid-feed DMFC, methanol concentration in the anode channel should decrease along the flow direction due to mass transport into the anode backing layer. Therefore, a linear methanol concentration distribution is assumed along the interface of the anode backing and channel, which can be written as,

$$
\left.C_{l}^{\mathrm{MeOH}}\right|_{y=H}=C_{l, 0}^{\mathrm{MeOH}}\left(1-\frac{1}{\xi_{a}} \frac{X}{L}\right)
$$

where $\xi_{a}$ is the stoichiometric flow ratio of the anode. If $\xi_{a}$ goes to infinity, a constant boundary condition of the methanol concentration results. In this study, stoichiometric number of 2.0 is used for the following simulation. 
Here, constant boundary conditions of liquid water saturation in both anode and cathode boundaries are assumed in the simulation, as shown in the following equations.

$$
\begin{aligned}
& \left.s\right|_{y=H}=0.8 \\
& \left.s\right|_{y=0}=0.05
\end{aligned}
$$

The velocities at both anode backing and cathode backing are assumed as zero,

$$
\left.u\right|_{y=0, H}=0 ;\left.\quad v\right|_{y=0, H}=0
$$

On all other boundary surfaces, no-flow and no-flux conditions are applied; they are,

$$
\left.\frac{\partial p}{\partial x}\right|_{x=0, L}=0,\left.\frac{\partial C_{l}^{M e O H}}{\partial x}\right|_{x=0, L}=0 \text { and }\left.\frac{\partial s}{\partial x}\right|_{x=0, L}=0
$$

Numerical procedure

To numerically solve the foregoing $\mathrm{M}^{2}$ model, general computational fluid dynamics (CFD) technology is adopted. For successful application of CFD techniques, all the equations in the present DMFC model are cast into a general form of convection-diffusion differential equations, i.e.,

$$
\frac{\partial(\varepsilon \Phi)}{\partial t}+\nabla \cdot(u \Phi)=\nabla \cdot\left(\Gamma_{\Phi} \nabla \Phi\right)+S_{\Phi}
$$

where the terms in equation account for accumulation, convection, diffusion and source term of a general variable, $\Phi$, to be solved.

This general differential equation is then discretized by using the control volume-based finite difference method of Patankar [39] and the resulting set of algebraic equations is iteratively solved. The velocity field, existing at the adjacent volumes interface, is calculated in a staggered mesh by using Semi-Implicit Method for Pressure-Linked Equations Revised (SIMPLER) algorithm. Because of the regular geometry of a DMFC, either a uniform or non-uniform grid can theoretically be applied easily in three dimensions. Stringent numerical tests are performed to ensure that the simulation results are independent of the grid size and time step. All the partial differential equations in the form of equation are solved simultaneously, and convergence is considered to be reached when the relative error in each scalar between two consecutive iterations is less than $10^{-6}$. Additionally, the mass balance check is also applied to ensure correct results.

\subsection{Results and Discussion}

Two cases are compared in the study, in Case 1, we simulate the DMFC performance under steady state. The other one, Case 2, is to apply the pulsing methanol feeding strategy to study the transient behavior of the DMFC.

The polarization curves of different initial methanol feeding concentrations are predicted in Figure 3.2.1.68. As a comparison, two-phase transport and single-phase methanol transport effects on the DMFC performance are highlighted in the figure also.

Meanwhile, the predicted polarization curves show great importance of the two-phase transport of the methanol in cell performance. If only the liquid phase transport is considered, a rather low limiting current density of $0.14 \mathrm{~A} / \mathrm{cm}^{2}$ at the $1 \mathrm{M}$ feeding concentration would be expected, as shown 
in Figure 3.2.1.68. Such limiting current density may also be estimated by the analytical numerical calculation,

$$
i_{\lim }=6 F j_{\max }^{\mathrm{MeOH}}=6 F \frac{C_{l}^{\mathrm{MeOH}}}{\frac{H_{b A}}{D_{l, e f f}^{M e O H}}}
$$

Thus, all reported cell current densities higher than $1 \mathrm{~A} / \mathrm{cm}^{2}$ are virtually impossible to sustain by methanol transport through the liquid phase only. Therefore, the gas phase is an important pathway for methanol transport to the reaction surface. The greatly facilitated methanol transport through the gas phase is due to the fact that the diffusion coefficient in gas is nearly four orders of magnitude greater than that in liquid.

Besides the overall performance prediction, the $\mathrm{M}^{2}$ model can provide detailed methanol concentration and liquid water saturation distributions in the porous regions. In Figure 3.2.1.69, the methanol concentration profile for the anode backing and membrane is shown for the average current density of $0.44 \mathrm{~A} / \mathrm{cm}^{2}$ at the initial methanol feeding concentration of $0.8 \mathrm{M}$. From the result, the methanol concentration distribution is determined by the methanol concentration boundary condition at the anode backing boundary. It is evident that some methanol, which does not participate in the anode methanol oxidation reaction, is still able to cross over the membrane under such cell current density. In other words, a parasitic current density due to the crossover methanol would exist in the cathode oxygen reduction reaction. Along the anode catalyst layer, methanol concentration is varied from around $0.3 \mathrm{M}$ to below $0.1 \mathrm{M}$. This indicates the methanol oxidation reaction at the anode catalyst layer is the combination of the zero-order and first-order reactions, according to the local methanol concentration.

Corresponding to the methanol concentration profile, the current density profile along the cell length is clearly shown in Figure 3.2.1.70. The current density is almost flat in the zero-order reaction region, while it decreases quickly in the first-order reaction region. Such current density profile is consistent with the methanol concentration distribution along the anode catalyst, and the current density shown in the overall polarization curve is the average value of local current densities.

Liquid water saturation profiles in the anode backing and cathode backing are shown in Figure 3.2.1.71. Due to the hydrophilic or hydrophobic characteristics of the anode and cathode backing materials, the saturation gradient in these two regions is also quite different. In other words, saturation variation is greater in the anode backing than in the cathode backing layer. Even in the anode backing, the saturation does not remain constant along the cell length, as it shows greater gradient in the beginning of the cell and slightly less at the end. This is due to local current densities. The source/sink term in the saturation governing equation is proportional to the local current density and thus, higher local current density leads to higher local gradient of liquid water saturation. Similarly in the cathode backing, liquid water saturation shows this trend of distribution despite a smaller gradient.

In Case 1, the performance of the DMFC is simulated under the steady state successfully. On the other hand, the two-phase $\mathrm{M}^{2}$ model can also deal with the transient problem of a DMFC. In case 2, the dynamic behavior of the cell voltage in DMFC is numerically simulated using the transient $\mathrm{M}^{2}$ model

Figure 3.2.1.72 [40] shows that the average cell voltage increases when using a pulsing feeding method to input liquid methanol at the concentration of $2 \mathrm{M}$ compared with constant feeding method under the same current loading $100 \mathrm{~mA} / \mathrm{cm}^{2}$. In order to reflect the periodic methanol feeding strategy in the numerical simulation, the boundary condition for the periodically varying concentration of the feeding methanol at the anode backing boundary is introduced as follows, 


$$
\left.C_{l}^{\mathrm{MeOH}}\right|_{y=H}= \begin{cases}4 M & \mathrm{t}<300 \mathrm{~s} \\ 0.5 M & 300 \mathrm{~s} \leq \mathrm{t}<\left(300+\Delta t_{\text {low }}\right) \mathrm{s} \\ 4 M & \left(300+\Delta t_{\text {low }}\right) \mathrm{s} \leq \mathrm{t}<\left(300+\Delta t_{\text {low }}+\Delta t_{\text {high }}\right) \mathrm{s} \\ \ldots & \\ 0.5 M & \left(300+5 \Delta t_{\text {low }}+5 \Delta t_{\text {high }}\right) \mathrm{s} \leq \mathrm{t} \leq 1000 \mathrm{~s}\end{cases}
$$

where the $\Delta t_{\text {low }}$ and $\Delta t_{\text {high }}$ stand for time spans of the low methanol concentration or high concentration at the anode backing layer surface, respectively. Other boundary conditions and initial conditions are listed as those in steady state.

Figure 3.2.1.73 shows the cell voltage jump at the same current loading of $0.1 \mathrm{~A} / \mathrm{cm}^{2}$ according to the pulsing methanol feeding strategy, which is very qualitatively similar to the experimental data. From the figure, the methanol feeding concentration varies between $4 \mathrm{M}$ and $0.5 \mathrm{M}$ with the different time spans as given in the boundary condition function. First, the cell voltage of the DMFC reaches a pseudo steady state during the first 300 seconds under the $4 \mathrm{M}$ methanol feeding concentration at the anode backing layer. Then according to the low methanol concentration of $0.5 \mathrm{M}$ applied, the cell voltage shows a significant recovery from the steady $4 \mathrm{M}$ condition. With another pulse of the higher concentration of methanol introduced, the cell voltage drops again. Finally, when the concentration remains constant at $0.5 \mathrm{M}$, the cell voltage reaches steady state again. Based on this preliminary result, use of such methanol pulsing strategy obviously produces a higher average cell voltage compared to the use of high constant methanol concentration under the same current loading. Therefore, the cell overall performance is also promoted under the same operating current density.

Numerical simulation shows that such methanol periodic feeding strategy provides an alternative to use of a high concentration methanol solution in DMFC applications without loss of the fuel efficiency and cell performance. In addition, the transient DMFC simulation reveals fundamentals of pulse feeding, thus leading to a possibility to optimize the pulse algorithm.

As discussed, the cell voltage jump is theoretically due to the fact that the methanol crossover rate is highly reduced by the pulsing feeding strategy compared to the constant high concentration methanol feeding. Here, the methanol crossover rate, or parasitic current density as a function of the operating time is shown in Figure 3.2.1.74. It is clear that the parasitic current density is higher when high concentration methanol feeding of $4 \mathrm{M}$ is provided. With periodic low concentration methanol feeding, the parasitic current density due to methanol crossover is much reduced. This indicates that the cathode potential is less affected by methanol crossover, which promotes the overall cell voltage.

From the simulation results, it is evident that the amplitude and frequency of the repeated jumpand-fall scheme is controlled by the methanol feeding strategy. The $\mathrm{M}^{2}$ transient model has been proved to be capable of dealing with such cell voltage response phenomena quantitatively, as expected. On the other hand, it may be possible to devise an optimal methanol feeding strategy by numerical simulation to obtain highest usage of methanol and therefore highest cell performance for DMFC applications.

\subsection{Conclusions}

A comprehensive $\mathrm{M}^{2}$ model for DMFCs is developed and several simulations are studied in order to understand the experimental results. It is evident that the $M^{2}$ DMFC model can be successfully applied to a variety of DMFC systems, whether steady state or transient operation.

With the different practical physical parameters and operating conditions implemented in the numerical simulations, the methanol and liquid water distributions in the DMFC can be investigated in detail. The methanol concentration distribution plays a very important role in the local current 
density profile and thus impacts overall performance of the DMFC. The liquid water profile affects the effective methanol transport and oxygen transport in both anode backing and cathode backing layers. These complicated relationships depend strongly on physical parameters and cell operating conditions. In order to produce better performance in DMFC systems, all these relationships must be optimized, including material characteristics and operating conditions. In this respect, the proposed two-phase $\mathrm{M}^{2}$ model is believed to provide insight into the governing physical phenomena and electrochemical kinetics, and thus offers very useful information for the optimization of overall DMFC performance. 


\subsection{NOMENCLATURE}

C

$D$

F

$g$

H

i

$i$

$i_{0}$

$k_{H}$

$k_{r}$

K

$L$

$\dot{m}$

M

$n_{d}$

$p$

$p_{c}$

$r$

$R$

$R_{\text {contact }}$

$S$

$\Delta t$

$u$

$V_{\text {cell }}$

\section{Greek}

$\alpha$

$\alpha_{i}$

$\varepsilon$

$\gamma$

$\eta_{i}$

$\kappa$

$\lambda$ mass fraction, $\mathrm{kg} / \mathrm{kg}$

mass diffusivity, $\mathrm{m}^{2} / \mathrm{s}$

Faraday's constant, $96487 \mathrm{C} / \mathrm{mol}$

gravitational acceleration, $\mathrm{cm} / \mathrm{s}^{2}$

thickness, $\mathrm{m}$

current density, $A / \mathrm{cm}^{2}$

parasitic current density, $A / \mathrm{cm}^{2}$

effective exchange current density, $A / \mathrm{cm}^{2}$

molar flux, $\mathrm{mol} /\left(\mathrm{cm}^{2} \mathrm{~s}\right)$

Henry's law constant

relative permeability

permeability of porous medium, $\mathrm{m}^{2}$

length of the cell, $\mathrm{cm}$

source or sink term in governing equations

molar mass, $\mathrm{kg} / \mathrm{mol}$

electro-osmotic drag coefficient

pressure

capillary pressure

radius of porous medium pores

universal gas constant, $8.314 \mathrm{~J} /(\mathrm{mol} \mathrm{K})$

ohmic contact resistance, $\Omega \mathrm{cm}^{2}$

liquid water saturation

transient time span, $\mathrm{s}$

velocity, $\mathrm{m} / \mathrm{s}$

cell voltage, $\mathrm{V}$

water transport coefficient through the membrane

current transfer coefficient at anode or cathode

porosity of porous medium

advective correction factor

overpotential of anode or cathode, $\mathrm{V}$

ionic conductivity of membrane, $\mathrm{S} / \mathrm{cm}$

water content in membrane 


$\begin{array}{ll}\lambda_{i} & \text { relative mobility of i phase } \\ \mu & \text { viscosity, } \mathrm{kg} /(\mathrm{cm} \mathrm{s}) \\ v & \text { kinetic viscosity, } \mathrm{cm}^{2} / \mathrm{s} \\ \theta & \text { contact angle, }{ }^{\circ} \\ \rho & \text { density, } \mathrm{kg} / \mathrm{m}^{3} \\ \sigma & \text { surface tension, } \mathrm{N} / \mathrm{m} \\ \xi & \text { stoichiometric flow ratio }\end{array}$

\section{Subscript}

a

$b A$

$b C$

$c A$

cC

$c$

channel

cross

eff

g

I

lim

loss

$\max$

mem

$m S$

$m / a$

$m / c$

net

ref

threshold anode

anode backing layer

cathode backing layer

anode catalyst layer

cathode catalyst layer

cathode

channel

cross over through the membrane

effective

gas phase

liquid phase

limitation

loss

maximum

membrane

membrane separator, including catalyst

interface between membrane and anode backing layer

interface between membrane and cathode backing layer

net flux

reference

threshold value

\section{Superscript}

$\mathrm{CO}_{2}$

carbon dioxide

$\mathrm{H}_{2} \mathrm{O}$

water

$\mathrm{MeOH}$

methanol 


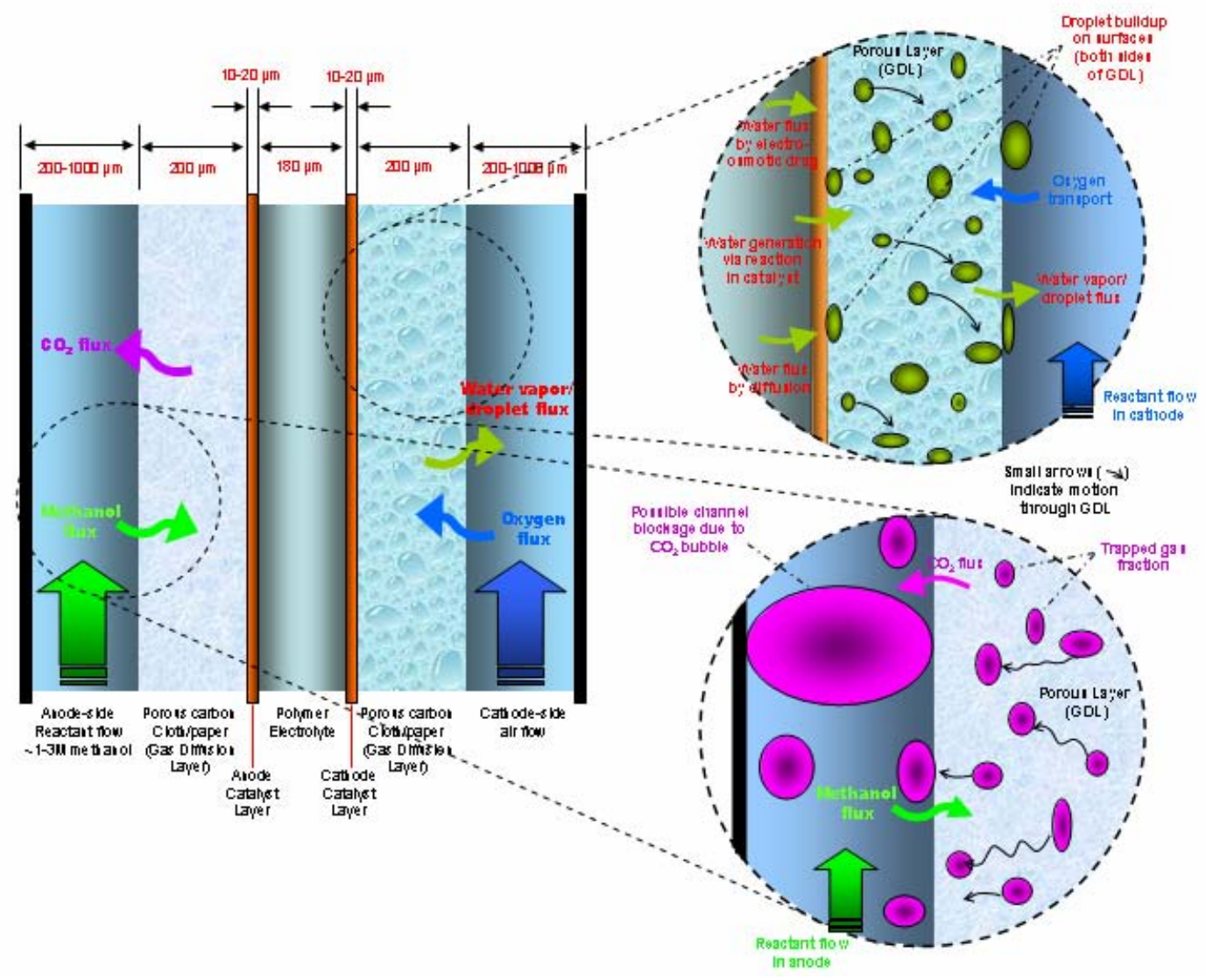

Figure 3.2.1.66 Schematic of methanol, water and carbon dioxide transports in the DMFC. 


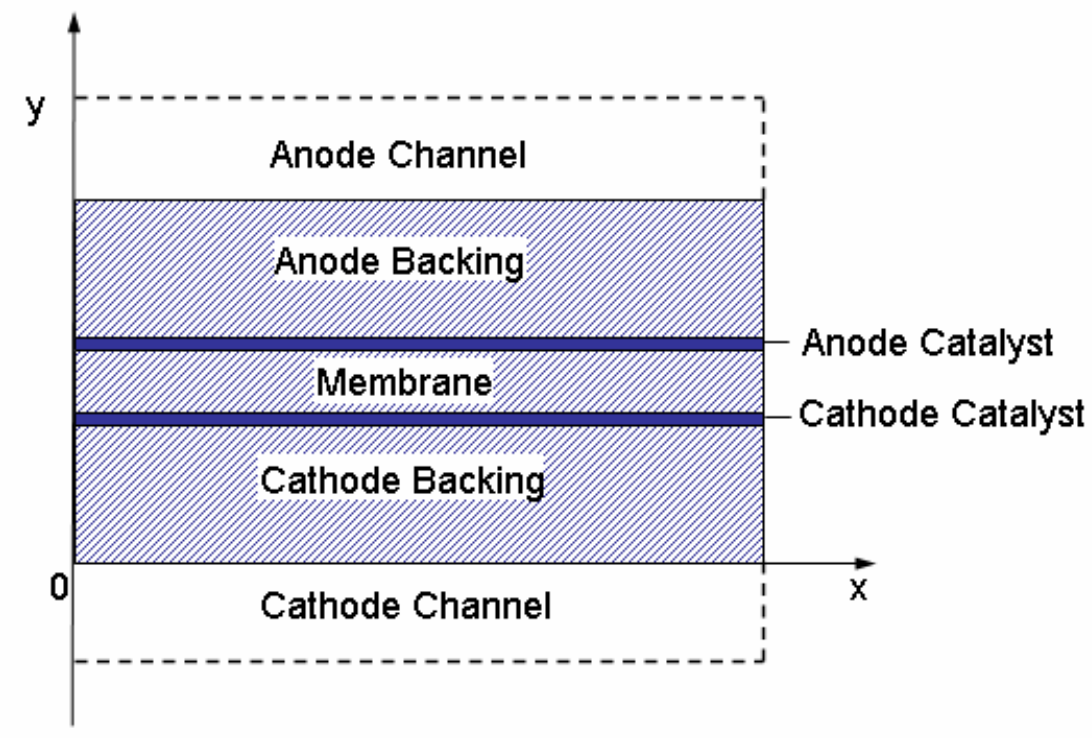

Figure 3.2.1.67 Schematic of a two-dimensional simulation domain for the liquid-feed DMFC and shaded area stands for porous medium which is also numerical domain. 


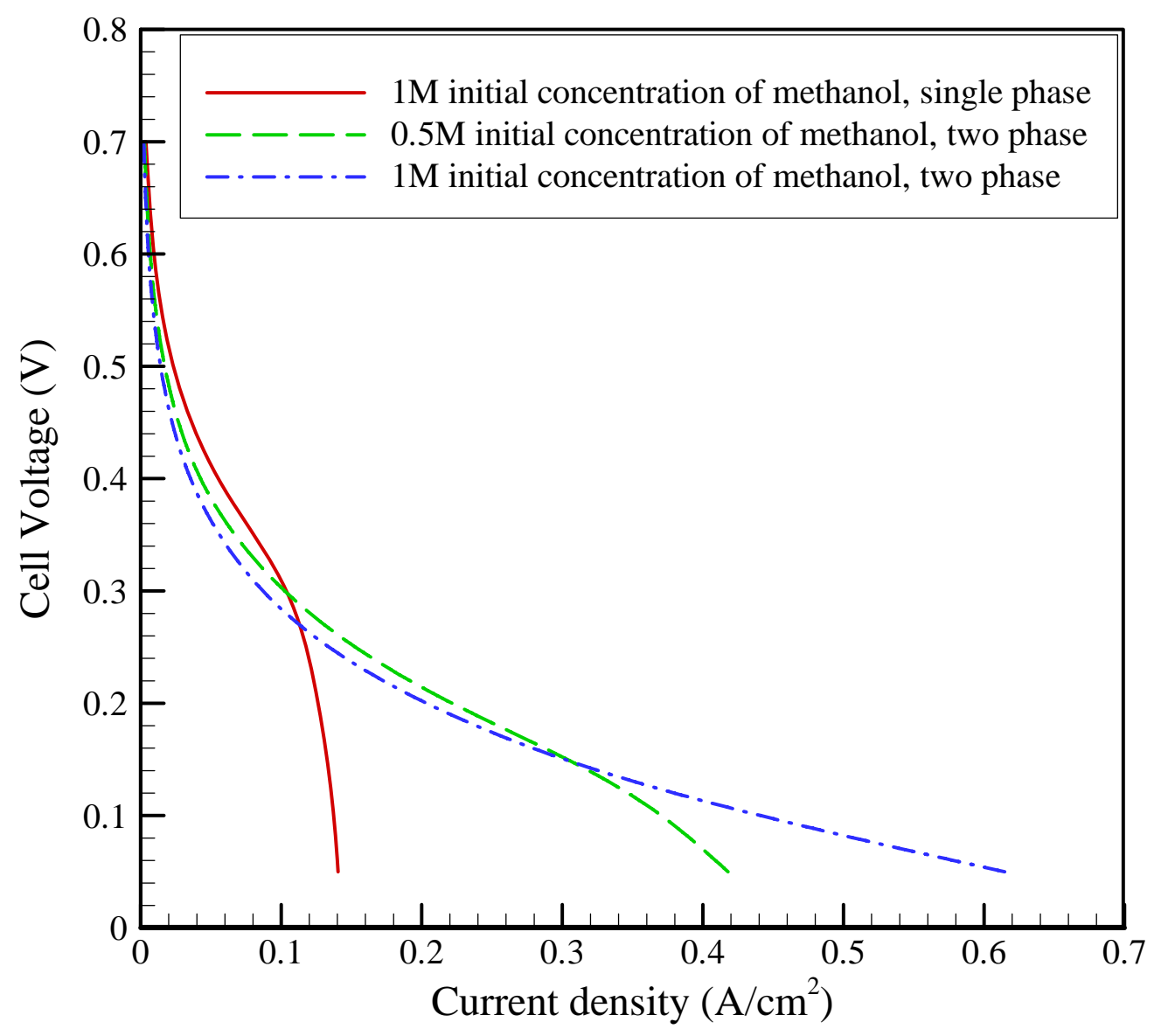

Figure 3.2.1.68 Polarization curve of a liquid-feed DMFC at operating temperature of $25^{\circ} \mathrm{C}$, with different initial methanol feeding concentrations. 


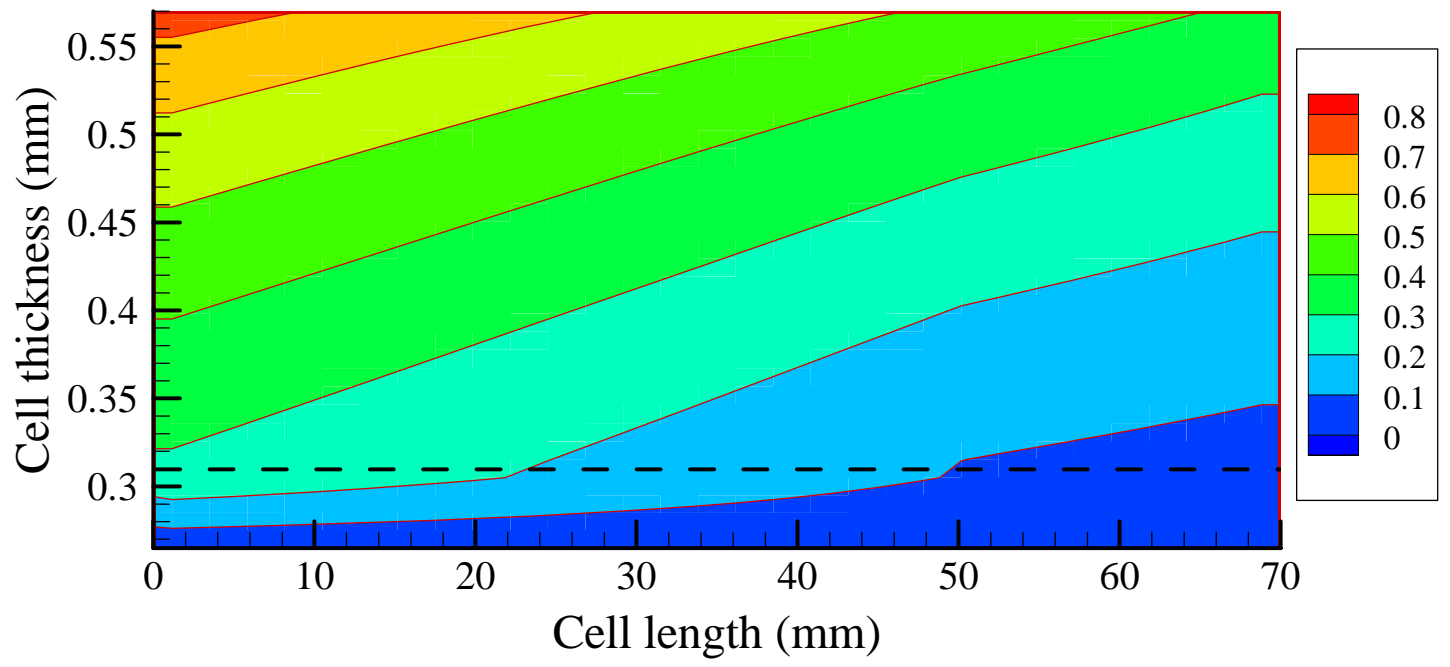

Figure 3.2.1.69 Methanol concentration distribution in the anode backing and membrane of the DMFC at cell voltage of $0.1 \mathrm{~V}$ and initial methanol feeding concentration of $0.8 \mathrm{M}$. 


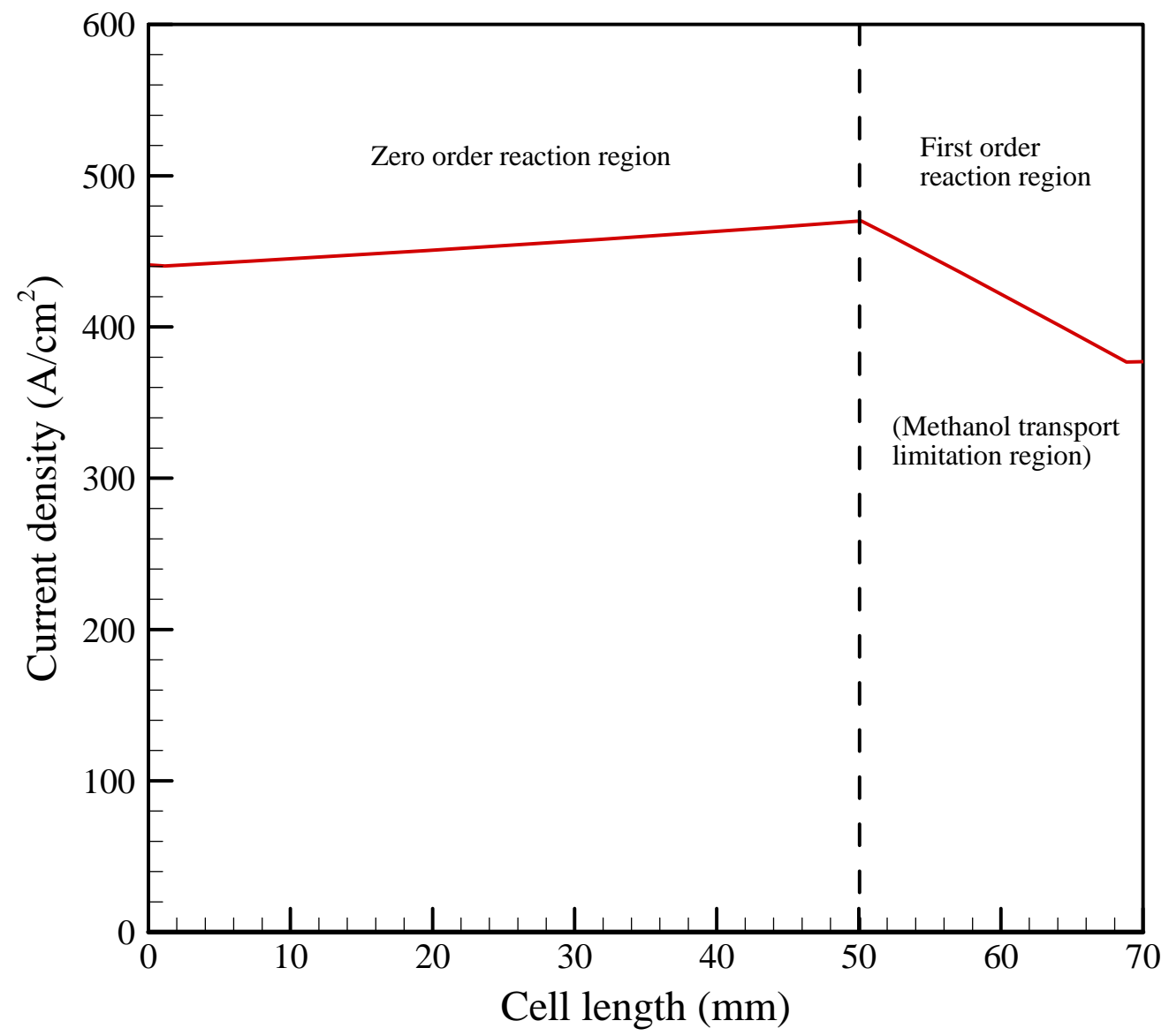

Figure 3.2.1.70 Current density distribution along the cell length for average cell current density of $0.44 \mathrm{~A} / \mathrm{cm}^{2}$, at cell voltage of $0.1 \mathrm{~V}$ and initial methanol feeding concentration of $0.8 \mathrm{M}$. 

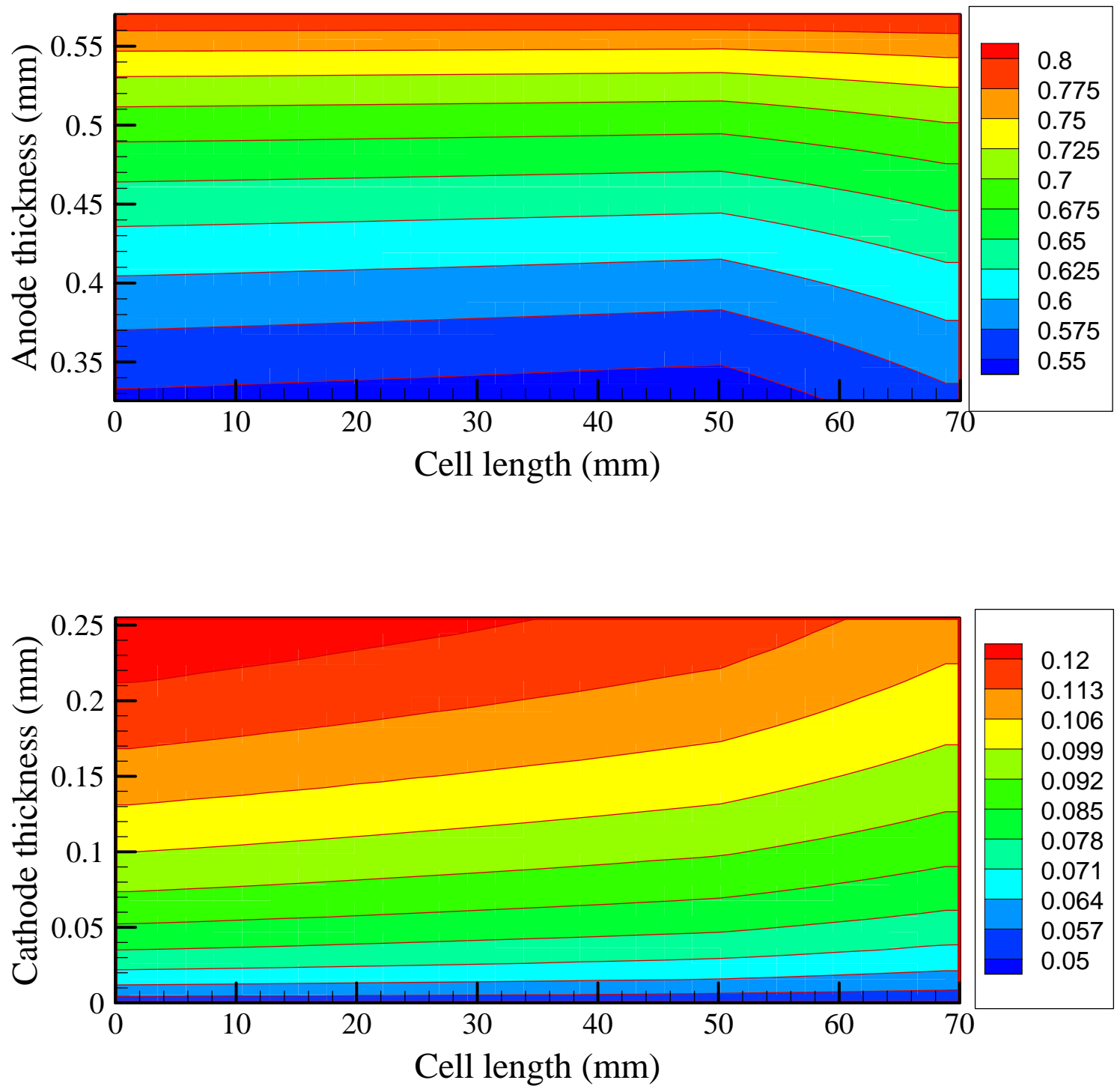

Figure 3.2.1.71 Liquid water saturation distribution in the anode backing and cathode backing separately at cell voltage of $0.1 \mathrm{~V}$ and initial methanol feeding concentration of $0.8 \mathrm{M}$. 


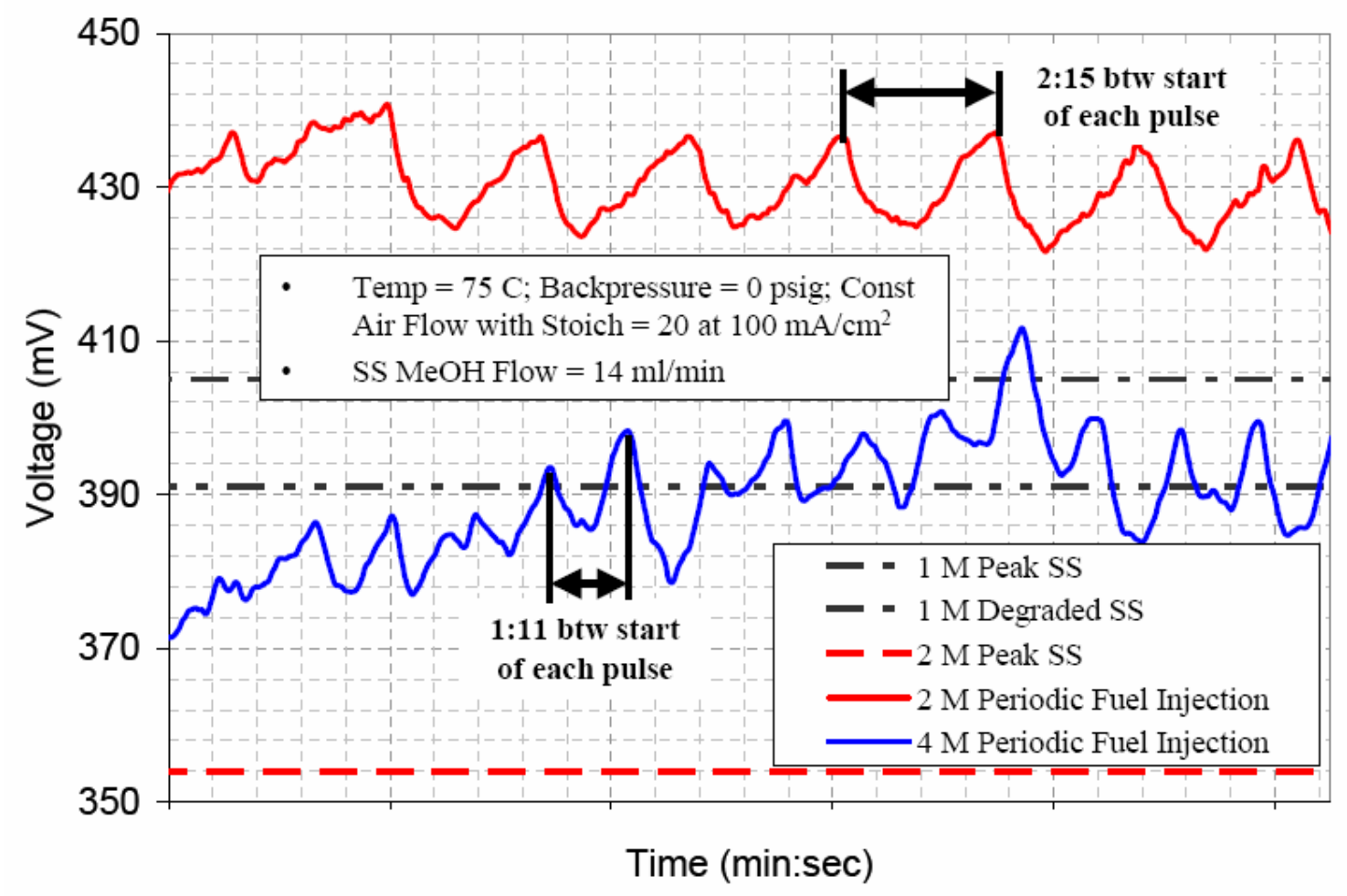

Figure 3.2.1.72 Periodic methanol feeding leads to the average cell voltage promoted under the same current loading of $100 \mathrm{~mA} / \mathrm{cm}^{2}$. 


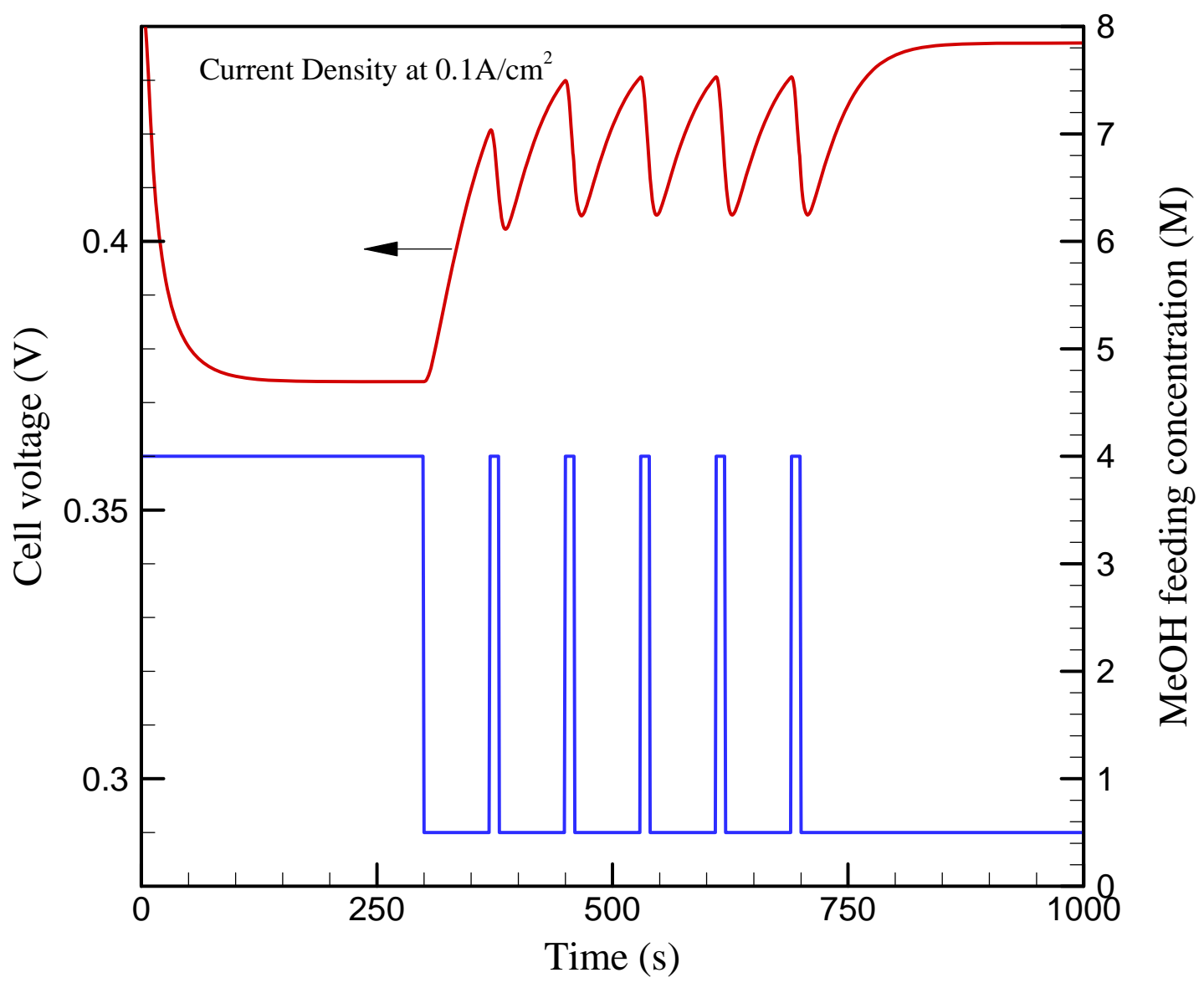

Figure 3.2.1.73 Cell voltage transient response under pulsing methanol feeding strategy using $\mathrm{M}^{2}$ transient model. Current density is kept constant at $0.1 \mathrm{~A} / \mathrm{cm}^{2}$ during the simulation. 


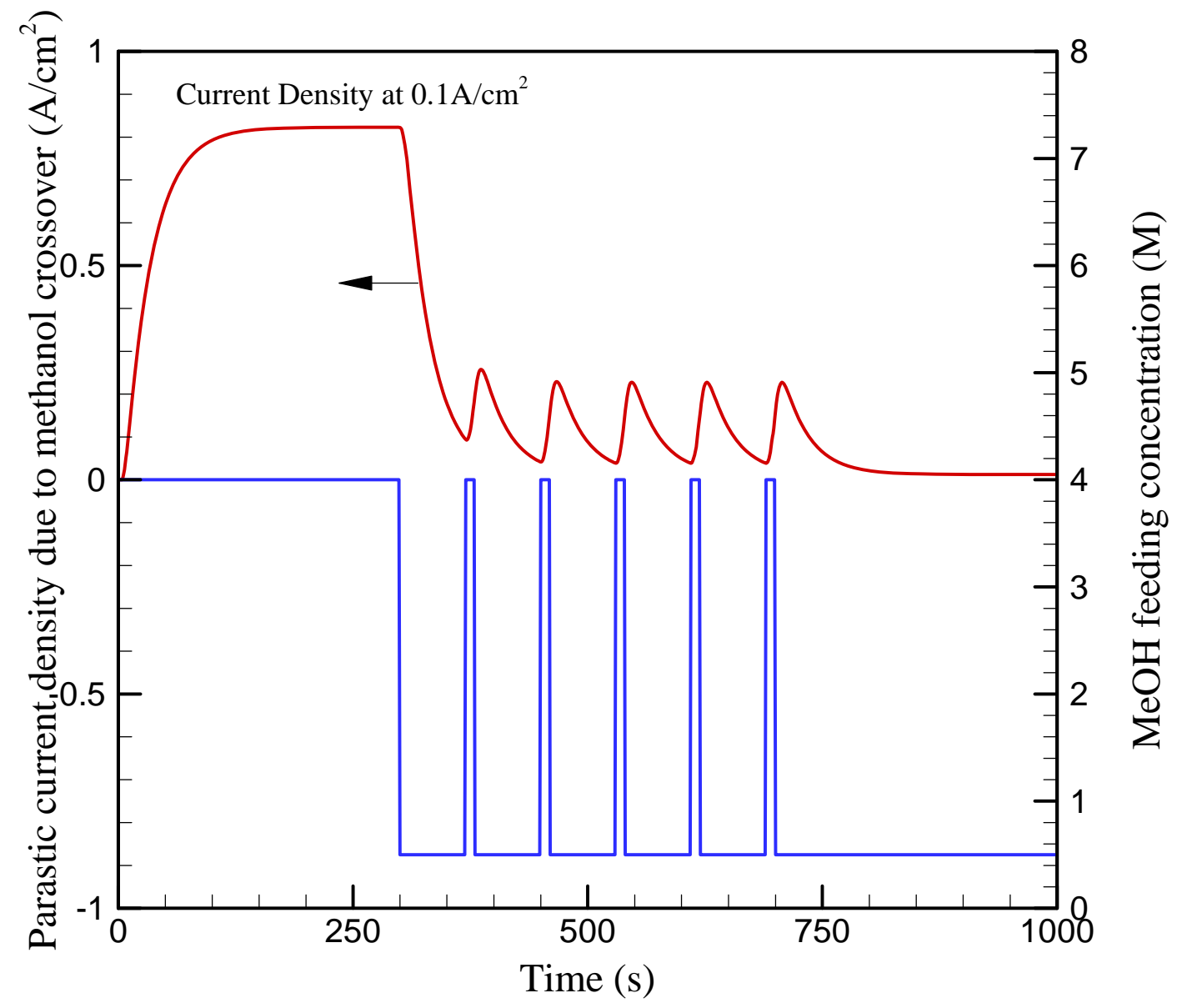

Figure 3.2.1.74 Parasitic current density due to the methanol crossover profile under the pulsing methanol feeding strategy. Current density is kept constant at $0.1 \mathrm{~A} / \mathrm{cm}^{2}$ during the simulation. 
Table 3.2.1.8 Terms in Governing Equations of DMFC Model.

\begin{tabular}{|c|c|c|}
\hline \multicolumn{2}{|l|}{$\dot{m}^{\mathrm{MeOH}}$} & $\dot{m}^{\mathrm{MeOH}}= \begin{cases}-\frac{i / H_{c A}}{6 F} M^{\mathrm{MeOH}} ; & \text { at anode catalyst } \\
-\frac{i_{c}^{\prime} / H_{c C}}{6 F} M^{M e O H} ; & \text { at cathode catalyst }\end{cases}$ \\
\hline \multicolumn{2}{|l|}{$D_{c}$} & $D_{c}=\left\{\begin{array}{cc}\frac{K}{\mu} k_{r l} \nabla p_{c} ; & \text { in backing layer } \\
D_{m e m} ; & \text { in membrane }\end{array}\right.$ \\
\hline \multirow[b]{2}{*}{$\dot{m}^{\mathrm{H}_{2} \mathrm{O}}$} & $\begin{array}{l}\text { Diffusion } \\
\text { Model }\end{array}$ & $\dot{m}^{\mathrm{H}_{2} \mathrm{O}}=\left\{\begin{array}{cl}\left(-M^{\mathrm{H}_{2} \mathrm{O}}-M^{\mathrm{MeOH}}\right)\left(\frac{i / H_{c A}}{6 F}+n_{d}^{\mathrm{H}_{2} \mathrm{O}} \frac{i / H_{c A}}{F}\right) ; & \text { at anode catalyst } \\
i_{c} / H_{c C} \\
M^{\mathrm{H}_{2} \mathrm{O}}\left(\frac{1 / H_{c A}}{2 F}\right) ; & \text { at cathode catalyst }\end{array}\right.$ \\
\hline & $\begin{array}{l}\text { Hydaulic } \\
\text { Model }\end{array}$ & 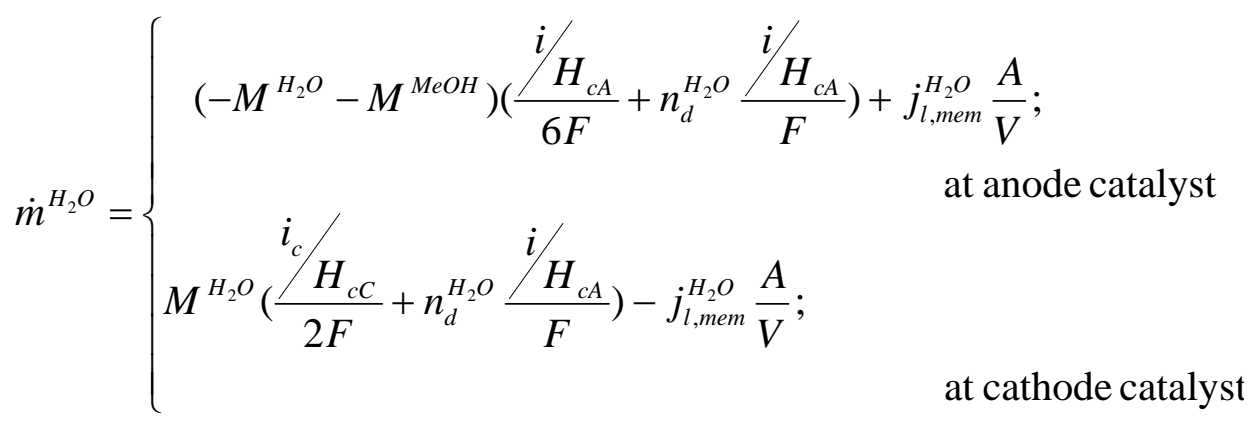 \\
\hline$j_{l, m e m}^{\mathrm{H}_{2} \mathrm{O}}$ & & $J_{l, \text { mem }}^{\text {water }}=\frac{\rho_{\text {mem }} K_{\text {mem }}}{\mu_{\text {mem }} \delta_{\text {mem }}}\left[\frac{2 \sigma_{a} \cos \theta_{a}}{r_{a}} J_{a}(s)-\frac{2 \sigma_{c} \cos \theta_{c}}{r_{c}} J_{c}(s)\right]$ \\
\hline$J(s)$ & & $J(s)= \begin{cases}1.417(1-s)-2.120(1-s)^{2}+1.263(1-s)^{3} & \text { in hydrophilic material } \\
1.417 s-2.120 s^{2}+1.263 s^{3} & \text { in hydrophobic materia }\end{cases}$ \\
\hline
\end{tabular}


Table 3.2.1.9 Geometric Data and Operation Conditions.

\begin{tabular}{l|l|l}
\hline Parameter & Symbol & Value \\
\hline Anode backing thickness & $H_{b A}$ & $0.026 \mathrm{~cm}$ \\
\hline Cathode backing thickness & $H_{b C}$ & $0.026 \mathrm{~cm}$ \\
\hline PEM thickness & $H_{m S}$ & $0.005 \mathrm{~cm}$ \\
\hline Cell length & $L$ & $7 \mathrm{~cm}$ \\
\hline $\begin{array}{l}\text { Permeability of anode backing } \\
\text { layer }\end{array}$ & $K$ & $1 \times 10^{-13} \mathrm{~m}^{2}$ \\
\hline $\begin{array}{l}\text { Permeability of cathode backing } \\
\text { layer }\end{array}$ & $K$ & $1 \times 10^{-13} \mathrm{~m}^{2}$ \\
\hline Porosity of anode backing layer & $\varepsilon_{b A}$ & 0.5 \\
\hline Porosity of cathode backing layer & $\varepsilon_{b C}$ & 0.5 \\
\hline Porosity of membrane & $\varepsilon_{m s}$ & 0.3 \\
\hline Operating temperature & $T$ & $25^{\circ} \mathrm{C}$ \\
\hline $\begin{array}{l}\text { Initial methanol feeding } \\
\text { concentration }\end{array}$ & $C_{l, 0}^{M e O H}$ & $0.5 \sim 1 \mathrm{M}^{2}$ \\
\hline
\end{tabular}


Table 3.2.1.10 Physical Properties.

\begin{tabular}{|c|c|c|}
\hline Parameter & Symbol & Value \\
\hline $\begin{array}{l}\text { Diffusion coefficient of methanol } \\
\text { in liquid phase }\end{array}$ & $D_{l}^{\mathrm{MeOH}}$ & $10^{-5.4163-\frac{999.778}{T}} \mathrm{~m}^{2} / \mathrm{s}$ \\
\hline $\begin{array}{l}\text { Diffusion coefficient of methanol } \\
\text { in gas phase }\end{array}$ & $D_{g}^{\mathrm{MeOH}}$ & $\begin{array}{l}\left(-6.954 \times 10^{-2}+4.5986 \times 10^{-4} T\right. \\
\left.+9.4979 \times 10^{-7} T^{2}\right) \times 10^{-4} \\
\mathrm{~m}^{2} / \mathrm{s}\end{array}$ \\
\hline $\begin{array}{l}\text { Electro-osmotic drag coefficient of } \\
\text { water }\end{array}$ & $n_{d}^{\mathrm{H}_{2} \mathrm{O}}$ & 1 \\
\hline $\begin{array}{l}\text { Electro-osmotic drag coefficient of } \\
\text { methanol }\end{array}$ & $n_{d}^{\mathrm{MeOH}}$ & $n_{d}^{\mathrm{H}_{2} \mathrm{O}} x^{\mathrm{MeOH}}$ \\
\hline Henry's law constant & $k_{H}$ & $k_{H}=\frac{k_{H}^{o} e^{\frac{-\Delta_{\text {soln }} H}{R}\left(\frac{1}{T}-\frac{1}{T^{o}}\right)} R T}{\frac{\rho_{l}}{\rho_{g}}}$ \\
\hline $\begin{array}{l}\text { Henry's law constant in standard } \\
\text { conditions, } T=298.15 \mathrm{~K}\end{array}$ & $k_{H}^{o}$ & 200 M/atm \\
\hline $\begin{array}{l}\text { Enthalpy of solution in Henry' law } \\
\text { constant }\end{array}$ & $\frac{\Delta_{\text {soln }} H}{R}$ & 5200 \\
\hline Viscosity of liquid water & $\mu_{l}$ & $\begin{array}{l}0.458509-5.30474 \times 10^{-3} T \\
+2.31231 \times 10^{-5} T^{2}-4.49461 \times 10^{-8} T^{3} \\
+3.27681 \times 10^{-11} T^{4} \\
\mathrm{~kg} / \mathrm{m} \mathrm{s}\end{array}$ \\
\hline Viscosity of gas & $\mu_{g}$ & $2.03 \times 10^{-5} \mathrm{~kg} / \mathrm{m} \mathrm{s}$ \\
\hline
\end{tabular}


Table 3.2.1.11 Electrochemical Properties.

\begin{tabular}{l|l|l}
\hline Parameter & Symbol & Value \\
\hline Proton conductivity of membrane & $\kappa$ & $0.123 \mathrm{~S} / \mathrm{cm}$ \\
\hline $\begin{array}{l}\text { Anodic transfer coefficient of } \\
\text { anode }\end{array}$ & $\alpha_{a}$ & 0.239 \\
\hline $\begin{array}{l}\text { Cathodic transfer coefficient of } \\
\text { cathode }\end{array}$ & $\alpha_{c}$ & 0.875 \\
\hline $\begin{array}{l}\text { Reference exchange current } \\
\text { density of anode at } 80^{\circ} \mathrm{C}\end{array}$ & $I_{0, \text { ref }, 80 \mathrm{C}}^{\mathrm{MeOH}}$ & $94.25 \mathrm{~A} / \mathrm{m}^{2}$ \\
\hline $\begin{array}{l}\text { Reference exchange current } \\
\text { density of anode }\end{array}$ & $I_{0, \text { ref }}^{\mathrm{MeOH}}$ & $I_{0, \text { ref }, 80 \mathrm{C}}^{\mathrm{MeOH}} e^{\frac{35570}{R}\left(\frac{1}{273+80}-\frac{1}{T}\right)} \mathrm{A} / \mathrm{m}^{2}$ \\
\hline $\begin{array}{l}\text { Reference exchange current } \\
\text { density of cathode at } 80^{\circ} \mathrm{C}\end{array}$ & $I_{0, \text { ref }, 80 \mathrm{C}}^{\mathrm{O}_{2}}$ & $0.04222 \mathrm{~A} / \mathrm{m}^{2}$ \\
\hline $\begin{array}{l}\text { Reference exchange current } \\
\text { density of cathode }\end{array}$ & $I_{0, \text { ref }}^{O_{2}}$ & $I_{0, \text { ref }, 80 \mathrm{C}}^{\mathrm{O}_{2}}$ \\
\hline
\end{tabular}




\section{Subtask 3.2.1.7 - Study of Anode and Cathode Species as a Function of Operating Conditions and Fuel Composition for Direct Methanol Fuel Cell (13-24 months)}

\subsection{DMFC Transient Characteristics}

Figure 3.2.1.75 defines several of the most obvious features of the voltage response curves, which will be included for characterizing DMFC transience. Perhaps the most recognizable feature of the plots, $V_{\text {under }}$ and $V_{\text {over }}$ describe the magnitude of the voltage under/overshoot past the final steady state value for a step load increase and decrease, respectively. Since it is more interesting to consider the relative magnitude of the minimum/maximum as compared to the steady state value, the calculated parameter that will actually be used in transient analysis is the percent under/overshoot. The percent is obtained by dividing the absolute value of either $\mathrm{V}_{\text {under }}$ or $\mathrm{V}_{\text {over }}$ by the ultimate steady state voltage $\left(\mathrm{V}_{\mathrm{SS} \text {, low }}\right.$ or $\mathrm{V}_{\mathrm{SS} \text {, high, }}$ respectively).

The other parameter shown in the figure is the settling time for the DMFC to reach its steady state value (while it would be more accurate to use the term "relaxation time," the mechanical system terminology is used in order to distinguish this parameter's subscript from the rise time, which is defined later). The time associated with cell voltage arriving within a given percent of a stable lower value after experiencing a step current increase is defined as $T_{s, \text { down. }}$. Similarly, the time associated with cell voltage arriving within a given percent of a stable upper value after experiencing a step current reduction is defined as $T_{\text {s,up }}$.

In addition to these quite noticeable features, Figure 3.2.1.76 defines further features of the transient response. Though more subtle than $\mathrm{V}_{\text {under }} / \mathrm{V}_{\text {over }}$ and $\mathrm{T}_{\mathrm{s}, \mathrm{down}} / \mathrm{T}_{\mathrm{s}, \mathrm{up}}$, these parameters are necessary for rigorous characterization of DMFC transients. The first feature, $T_{r \text {,down }} / T_{r \text {,up }}$, describes the rise or fall time of DMFC voltage. $T_{r, \text { down }}$ is defined as the time for DMFC voltage to fall from an initial stable value to a value as low as the final steady state level associated with an increased load. $T_{r \text {,up }}$ is the time for DMFC voltage to rise from an initial stable value to one as high as the final steady state level associated with a decreased load.

The other feature defined in Figure 3.2.1.76 is the peak time, or the time for the voltage response to reach an extreme value. Specifically, $T_{p \text {,down }}$ is defined as the period between application of an increased load and the time at which cell voltage reaches its minimum value below $\mathrm{V}_{\mathrm{SS} \text {,low. }} \mathrm{T}_{\mathrm{p} \text {,up }}$ is defined as the period between the instant of load reduction and the time at which cell voltage reaches its maximum value above $V_{S S \text {,high. }}$ Characteristic values for all of these defined parameters are given in the following sections for various DMFC transient loading conditions.

Voltage-Scale Parameters - An exhaustive investigation of DMFC transient behavior would require a virtually limitless number of tests over an enormous range of operating conditions and variable current demands. Such testing is outside the scope of this study, which seeks instead to gain a better understanding of transient performance trends. After experimentation with a variety of scenarios, it was decided to collect data at the previously described baseline operating conditions for a specific set of load changes over a stable and repeatable cell performance range. The results of such testing should provide a good representation of generalized DMFC transient characteristics over any stable operating region. Because diffusion-driven crossover plays such a large role in determining transient response and is influenced so strongly by methanol concentration, the testing was repeated for operation on a $2 \mathrm{M}$ solution at an otherwise identical set of operating conditions. Table 3.2.1.12 indicates the seven pairs of current densities selected for conducting the transient testing. Voltage transients were elicited by switching the DMFC current draw between these indicated ranges. Each transient cycle was performed twice in order to obtain average values for each of the transient performance parameters. Next to each current range, the table provides the average final voltage level attained at the end of each transient. The corresponding value on the other half of the table indicates the starting voltage before the transient occurs. The measured steady state voltage values show consistency between the different applied load changes. The largest spread in measurements for like current densities occurs at high load for the poorer performing $2 \mathrm{M}$ testing, and is still only on the order of $+/-6 \mathrm{mV}$. 
Figure 3.2.1.77 provides a graphic comparison of $\mathrm{V}_{\text {under }} / \mathrm{V}_{\text {over }}$ normalized by $\mathrm{V}_{\mathrm{SS}, \text { low }} / \mathrm{V}_{\mathrm{SS} \text {,high }}$. Several general trends for percent under/overshoot may be readily observed from the figure. First, the degree of voltage overshoot is typically larger than the corresponding undershoot for a given current density range. One could interpret from this that the crossover detriment resulting from surplus methanol accumulation during the decline from a voltage peak to $\mathrm{V}_{\mathrm{SS} \text {,high }}$ is greater than the

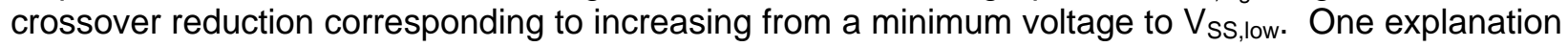
could be that the surplus methanol present at the low load steady state begins to be rapidly consumed at the instant of current application. This leaves the cell with less room for improvement upon reaching its minimum voltage value during the transient. For the case of load removal, the slower methanol diffusion process will not result in an equivalent reduction in potential crossover losses by the time the cell reaches its transient voltage peak.

Further examination of Figure 3.2.1.77 indicates that for large amplitude load reductions the magnitude of voltage overshoots will increase with increasing methanol concentration. Comparing the size of overshoots for different current density ranges suggests a combined positive influence of the relative and absolute magnitude of the load reduction. These observations are consistent with the concept that methanol no longer being used to generate current from the fuel cell will gradually contribute to diffusion-driven crossover. The more substantial the reduction in methanol consumption, the more severe will be the eventual crossover loss. It is similarly logical that increased methanol concentrations will amplify this effect, particularly for situations where its contribution is greatest.

The size of undershoots in Figure 3.2.1.77 also show an increase for larger fractional changes in current density. However, methanol concentration and the application of larger and larger loads from an initial open circuit condition appear to have little effect. The positive influence of relative current density increases on voltage undershoots likely results from the same reasoning used to explain the similar behavior with voltage overshoots. Recalling the previously described damping effect of heightened methanol consumption upon application of an increased load, it is not surprising that the contribution of other similar influences is diminished.

Time-Scale Parameters - The figures in this section describe the time-scale parameters identified as important for transient characterization. Figure 3.2.1.78 presents the rise time, $\mathrm{T}_{\mathrm{r} \text {,down }} / \mathrm{T}_{\mathrm{r} \text {,up }}$, associated with each of the different transient situations. The resolution restriction created by the period between successive voltage measurements limited the precision with which rise time could be determined. However, it is sufficient to say that the voltage rise/drop occurs very quickly (on the order of $0.2 \mathrm{sec}$ for nearly all of the transient situations considered).

For the purposes of fuel cell power electronics, it may be concluded that load changes over a stable cell operating region will result in an almost instantaneous voltage change to levels near the eventual steady state value (corresponding to the new current density). Following this rapid change, the voltage proximity to the final steady state value would remain within the bounds described by the percent under/overshoot limits from the previous section. The one situation where the voltage response seemed to lag slightly was for small load changes to and from open circuit. Though it will be good to be aware of it, this phenomenon will likely have little bearing on fuel cell electronics since the overall voltage differences and power demands are small for such situations.

Figure 3.2.1.79 describes the peak time associated with each of the transient regions. Examination of the figure reveals that $T_{p \text {,down }}$ and $T_{p \text {,up }}$ are both very small for current density changes that occur significantly far from open circuit. The magnitude of $T_{p \text {,down }}$ remains small (on the order of 1-2 seconds or less) for all transient situations. As with rise time, rapid voltage response to an extreme is the expected result of changes in ohmic polarization across the DMFC membrane. Such changes in I-R voltage drop should instantly coincide with adjustments in the current draw through the cell.

For transient regions approaching open circuit, cell voltage adjustments are influenced by changes in kinetic polarization. Although these changes also occur quickly, they will lag slightly 
behind the load perturbation, as reflected in Figure 3.2.1.79. The time lag is greatest for complete current removal to the open circuit condition, where there is no discernable difference in the value of $\mathrm{T}_{\mathrm{p} \text {,up }}$ for different initial levels of loading.

For those sufficiently large durations of $T_{p \text {,up }}$ under complete current removal, there is a discernable decrease in the peak time for increasing methanol concentration. Higher concentration feeds will logically lead to a faster onset of crossover-induced voltage reductions, and hence a faster reversal of the voltage response from rising to falling. As was the case with rise time, a DMFC control engineer should simply be aware of the potential for long peak times, but should have no trouble implementing the fuel cell's power electronics since the long times only occur when the DMFC is completely unloaded.

Figure 3.2.1.80 and Figure 3.2.1.81 provide comparisons of the settling time associated with each of the different transient conditions considered. For this comparison, $T_{\mathrm{s} \text {,down }}$ and $\mathrm{T}_{\mathrm{s} \text {, up }}$ were defined as the time required for the DMFC voltage response to fall within $0.8-1.0 \%$ of $V_{S S \text {,low }}$ and $\mathrm{V}_{\mathrm{SS} \text {,high, }}$ respectively. Figure 3.2.1.80 shows that $\mathrm{T}_{\mathrm{s} \text {,up }}$ can be quite long, up to several minutes in length, for complete current removals. The duration of $\mathrm{T}_{\mathrm{s} \text {,up }}$ under such situations appears to increase with decreasing methanol concentration and with increasing magnitudes of the initial current density. As with the negative relationship observed for $T_{p \text {,up }}$, higher methanol concentrations will tend to hasten the establishment of a steady state diffusion-driven crossover gradient. Returns to stable open circuit levels likely take longer for larger reductions in current density since smaller initial loading conditions already possess a crossover component and so start out closer to the steady state crossover level at open circuit. Not surprisingly, this effect diminishes for higher and higher initial loads as diffusion-driven crossover at these loads also diminishes.

Figure 3.2.1.81 provides a magnification of Figure 3.2.1.80 in order to remove the distorting influence of the large $T_{\mathrm{s} \text {,up }}$ values resulting from complete load removal. Once again, the long settling times for returning to open circuit are of less concern than other trends that can be discerned for various loaded conditions. As with the other time parameters, one trend is that $T_{s, \text { down }}$ is typically faster than $T_{s, u p}$ for a given transient range. This again likely results from the fact that gradual diffusion of surplus methanol across the membrane occurs more slowly than consumption of such a surplus under increased load. Another observation is that the response is fairly rapid at high current densities where the presence of crossover is smallest. The difference between $T_{s, \text { down }}$ and $T_{s \text {,up }}$ is minimized for small changes between finite current densities because the difference in crossover magnitude is similarly small.

Perhaps the most interesting observation from Figure 3.2.1.81 is the reversal in the trend observed at open circuit for increasing methanol concentration. That is, the durations of $T_{s, \text { down }}$ and $\mathrm{T}_{\mathrm{s} \text {,up }}$ appear to positively increase with methanol concentration for changes to load levels significantly greater than zero. It is speculated that increased loading brings cell operation with a 1 $\mathrm{M}$ solution to levels where the diminished presence of crossover allows for a more rapid voltage response. The higher crossover levels still present in the $2 \mathrm{M}$ solution result in a slower relative response. The closer proximity of the response times for the $1 \mathrm{M}$ to $2 \mathrm{M}$ comparison between 20 and $40 \mathrm{~mA} / \mathrm{cm}^{2}$ suggests a threshold level for the trend reversal at a current density very close to open circuit. Only at currents too low to dampen crossover onset will the settling time "benefit" from the ability of concentrated methanol solutions to hasten establishment of steady state crossover. All other situations benefit from minimizing the total crossover amplitude, which can be accomplished in part by reducing methanol concentration.

Having organized these example responses and suggested possible explanations for the results, the next logical step in transient characterization would be to develop a physical model of transient performance. Such an electrochemistry- and mass transport-based model would be able to predict the cell response for a variety of different situations. Further experimentation would then become more useful when used as a tool for model validation. 


\subsection{Periodic Fuel Injection}

Potential Improvement from Flow Interruptions - As described previously, DMFC steady-state performance will include a negative contribution from diffusion-driven methanol crossover, which exists as a result of the stable methanol concentration gradient established across the PEM. DMFC transient response to a step reduction in load illustrates this phenomenon. Following an initial voltage overshoot, cell performance gradually decreases as the elevated concentration gradient stabilizes at the reduced level of cell loading. In a similar fashion, cell performance may be temporarily increased at a constant current draw by reducing the anode methanol concentration. This may be achieved by shutting off the anode inlet, so that as the reaction continues to consume methanol, the solution contained within the chamber becomes increasingly diluted. Figure 3.2.1.82 shows the experimental results of just such an example.

Starting from stable steady-state operation, methanol flow to the cell is shut off. Following some initial small oscillations, the cell voltage then slowly rises a total of $34 \mathrm{mV}$ over the next six minutes. This region indicates a reduction in anode methanol concentration such that crossover is reduced, but catalyst layer reaction kinetics remain relatively unchanged. However, shortly after reaching its peak, cell voltage quickly drops to zero. This is indicative of methanol depletion at the anode catalyst, as is the case for the mass transport limited region of the fuel cell's polarization curve.

Such flow interruption experiments provide insight into the time scales involved and the potential performance improvement associated with cell operation under different current loads for a particular set of operating conditions. Table 3.2.1.13 shows these results for DMFC operation with a $1 \mathrm{M}$ methanol solution. As anticipated intuitively, the time for performance to peak is reduced at higher current densities since methanol consumption occurs more quickly. It is also observed that the potential performance improvement is reduced as current density increases. This is similarly expected, as the increased rate of methanol consumption should reduce the negative impact of unreacted methanol permeation through the membrane.

Another way to view the diminishing performance improvement at an elevated current draw is to characterize the $200 \mathrm{~mA} / \mathrm{cm}^{2}$ loading as closer to the optimal operating current density for a $1 \mathrm{M}$ methanol solution. Conversely, if we are interested in dynamically altering the methanol concentration in the anode, we could instead describe an optimal average anode chamber methanol concentration associated with particular current densities. In considering what concentration to identify as "optimal," the exercise in flow interruption suggests that it is better to err well on the side of too concentrated, as even a slightly insufficient supply of methanol will lead to a rapid decline in cell performance. Before experimenting with periodically reopening methanol flow to the cell, the next section describes development of an analytical guide for selecting such a cyclic operating strategy.

Analytical Model of Periodic Feeding - A simplified one-dimensional model was developed to help prepare for periodic fuel injection experimentation. Analysis focused on the anode diffusion layer, making use of the driving potential established by the difference between the methanol feed concentration $\left(\mathrm{C}_{\mathrm{F}}\right)$ and the concentration at the anode catalyst layer $\left(\mathrm{C}_{\mathrm{CL}}\right)$. The catalyst layer was approximated as an infinitesimally thin interface between the backing layer and the PEM.

Figure 3.2.1.83 shows a schematic of the model with reference to the various modes of methanol flux. Note that as a further simplification, the model neglected transient influences from such phenomena as methanol storage in the backing layer and membrane separator. This and the other reasonable approximations used in developing the model made it easier to obtain a general description of the DMFC's reaction to different feed concentrations. Completion of this general description aided selection of a starting point for experimental investigation of the periodic injection characteristics that would provide the best averaged performance at different steady state operating conditions.

The equations shown in Figure 3.2.1.83 were used to determine the "ideal" steady state methanol feed concentration. Equation 3.2.1.64 in the figure describes the basic mass balance of 
methanol flow into and out of the anode catalyst layer. Equation 3.2.1.65 relates the effective flow rate out of the catalyst layer to easily determined current parameters, where the factor of six accounts for the six electrons transferred during the methanol reaction. Finally, Equation 3.2.1.66 uses the anode backing layer's resistance to methanol diffusion to relate the total flux to the driving potential across the layer. Based on these three equations, a desired value for the methanol feed concentration can be derived from a target catalyst layer concentration and a particular current draw. The following sections will show how the resulting Equation 3.2.1.67 can be used to determine this ideal feed concentration for a particular example.

$$
C_{F, \text { desired }}=C_{C L, \text { desired }}+\frac{L}{D}\left(\frac{i_{\text {cell }}+i_{\text {parasitic }}}{6 F}\right)
$$

Determining Injection Frequency - To provide the ideal feeding strategy at a particular operating state, as determined above, one could simply apply a greater or lesser dilution to the methanol feed stream. It is preferable, however, to simulate $\mathrm{C}_{\mathrm{F} \text {,desired }}$ through use of a single greater concentration of methanol, $\mathrm{C}_{\mathrm{F}}$, by intermittently injecting some volume of the concentrated methanol feed. Figure 3.2.1.84 shows a schematic of the concentration profile within a porous material created when a high concentration feed on the left side of the material is intermittently turned on and off, while the concentration on the right side is kept at a target level below the pulsed concentration.

In Figure 3.2.1.84 (a), the concentrated methanol feed is turned on and off for equal lengths of time. The top portion of the figure shows the evolution of a concentration pulse across the material. In the first phase with the flow turned on, the concentration profile across the diffusion layer begins with an inverse function shape, which tends towards linear the longer flow is left on. After the flow is shut off, the high concentration peak drives fluid diffusion in each direction away from it. This tends to flatten the peak by spreading out the concentration profile, thus raising the concentration in areas of the material initially farther away from the peak. Restarting the concentrated solution flow then limits back diffusion and drives the overall concentration gradient forward.

The bottom portion of Figure 3.2.1.84 (a) shows that the resulting concentration profile from such a uniform feed/interrupt strategy approximates a feed concentration of exactly half the magnitude of the pulsed concentration. The initially steeper profile will be reduced during the length of time the flow is turned off, and the initially flatter profile will be raised during the time the flow is turned on. So, simulation of an average feed concentration much less than half the magnitude of the actual feed concentration requires using a feeding strategy in which the flow is turned on for a shorter period of time than the duration of the flow interruptions. The resulting steady-state concentration profile through a thick diffusion layer is shown in Figure 3.2.1.84 (b). In order to establish such a profile around a given desired feed concentration using an elevated actual feed concentration, Equation 3.21.1.68 may be used to determine the ratio of the time duration that flow should be turned on, $\Delta \mathrm{t}_{\mathrm{on}}$, to the duration of flow interruptions, $\Delta \mathrm{t}_{\text {off. }}$.

$$
\frac{\Delta t_{\text {on }}}{\Delta t_{\text {off }}}=\frac{C_{F, \text { desired }}-0}{C_{F}-C_{F, \text { desired }}}
$$

Transmission Time for a Step Concentration Disturbance - Having determined the appropriate ratio for the ideal feeding strategy, the next step was to obtain an estimate of a desirable time scale for which flow should be turned on and off. To do so, Fick's Law of Diffusion was used to model the length of time it takes for a step concentration disturbance (resulting from establishing flow on one side of the diffusion layer) to affect a concentration change on the other side of the diffusion layer. Figure 3.2.1.85 provides the problem formulation, and Equations 3.2.1.69 - 3.2.1.72 give the 
appropriate partial differential equation from Fick's Law and the assumed boundary and initial conditions.

$$
\begin{aligned}
& \left.\frac{\partial \theta}{\partial t}=D \frac{\partial^{2} \theta}{\partial x^{2}} \quad \text { where } \theta(x, t)=C 9 x, t\right)-C_{F, p u l s e} \\
& \theta(x, 0)=C_{o}-C_{F, p u l s e}=\theta_{o} \\
& \theta(x, 0)=C_{F}-C_{F, p u l s e}=0 \\
& \frac{\partial \theta(0, t)}{\partial t}=0
\end{aligned}
$$

Equation 3.2.1.70 and Figure 3.2.1.85 (a) show the initial condition as a uniform concentration profile across the diffusion layer thickness. This condition was taken as a reasonable approximation of the relatively slight concentration profile desired (as shown by the fairly flat slope of the dashed line in Figure 3.2.1.84 (b)) as compared to the large concentration of the periodically injected solution.

Boundary Conditions - Equations 3.2.1.71 - 3.2.1.72 and Figure 3.2.1.85 (b) demonstrate the selected boundary conditions. The first condition assumes a constant concentration on the backing plate side of the diffusion layer for the duration of the fuel injection, while the second assumes no methanol flux out of the opposite side. As with the initial condition, the relatively flat slope of the desired concentration profile at the catalyst layer justifies the approximation of zero flux out of the diffusion layer. The assumptions in both instances should result in slight underestimation of the time it takes for the step disturbance to produce a significant increase in the catalyst layer concentration, which will be considered when evaluating the simulation results. Figure 3.2.1.86 summarizes that this time period will be used to estimate when fuel delivery should be terminated in order to minimize catalyst layer concentration rise.

Equation 3.2.1.69 may be solved by separation of variables using the separation constant given in Equation 10. Applying the boundary conditions in Equations 3.2.1.71 and 3.2.1.72 to the result gives the solution in Equation 3.2.1.74.

$$
\begin{gathered}
\lambda_{n}=\frac{\pi(2 n+1)}{2 L} \\
\theta(x, t)=\sum_{n=0}^{\infty} a_{n} e^{-D \lambda_{n}^{2} t} \cos \lambda_{n} x
\end{gathered}
$$

The constant, $a_{n}$, is found by applying the initial condition from Equation 3.2.1.70 and recognizing the Fourier cosine series expansion. Equation 3.2.1.26 gives the final result, with concentrations substituted for the solution variable, $\theta$.

$$
C(x, t)=C_{F, \text { pulse }}+\left(C_{o}-C_{F, \text { pulse }}\right) \frac{2}{L} \sum_{n=0}^{\infty}\left(\frac{(-1)^{n}}{\lambda_{n}}\right) e^{-D \lambda_{n}{ }^{2} t} \cos \lambda_{n} x
$$

The following section utilizes this and the other above-derived relationships to perform calculations on an example injection strategy for a representative set of DMFC operating conditions. 


\section{Representative Injection Timing Calculation}

The formulas given in Equations 3.2.1.64 - 3.2.1.66 can be further manipulated by inserting analytical expressions for $i_{\text {cell }}$ from the Butler-Volmer equation and $i_{\text {parasitic }}$ from established DMFC models. Without manipulation, the formulas are well suited to analyze instances where $i_{\text {parasitic }}$ has already been determined for given values of $\mathrm{i}_{\text {cell. }}$. Table 3.2.1.14 describes such a case for a given set of operating conditions, where the approximate area-averaged parasitic current density is given for two different cell current densities.

Use of Equations 3.2.1.64 - 3.2.1.66 demonstrates that the catalyst layer methanol concentration for the high current density, low crossover case is less than half of that for the low current density, high crossover case. It may be safely assumed that a catalyst layer concentration of $0.29 \mathrm{M}$ would be sufficient to satisfy the reaction kinetics of the low current density case, and that such a lowered concentration should reduce crossover to around $5 \mathrm{~mA} / \mathrm{cm}^{2}$ (or even lower since crossover due to electro-osmotic drag should be less than in the high current density case, and crossover due to diffusion should be no different). With these assumed values $\left(\mathrm{C}_{\mathrm{CL} \text {,desired }}=0.29 \mathrm{M}\right.$ and the corresponding value of $i_{\text {parasitic }}=5 \mathrm{~mA} / \mathrm{cm}^{2}$ ), Equation 3.2.1.67 determines a desired effective feed concentration of $C_{F \text {,desired }}=0.5 \mathrm{M}$ for the $i_{\text {cell }}=170 \mathrm{~mA} / \mathrm{cm}^{2}$ case. From equation 3.2.1.68, the given $1 \mathrm{M}$ feed concentration can be used to simulate this value by pulsing it for an equal time on and off. In order to pulse a much larger feed concentration of $10 \mathrm{M}$, the ratio of $\Delta \mathrm{t}_{\mathrm{on}}: \Delta \mathrm{t}_{\text {off }}$ should be 2:19.

Figure 3.2.1.87 shows the catalyst layer concentration response to a $10 \mathrm{M}$ feed concentration pulse as provided by Equation 3.2.1.75. In order to keep the catalyst layer concentration from fluctuating by more than about $0.1 \mathrm{M}$, the injection duration should be limited to roughly 3.2 seconds in length. For operation at $170 \mathrm{~mA} / \mathrm{cm}^{2}$, this results in an overall control strategy of injecting $10 \mathrm{M}$ methanol in 3.2-second intervals with approximately 30 seconds between each injection.

The findings of Sundmacher et al were considered as a first assessment of the validity of the above modeling. Since the model does not distinguish between interrupted and zero-concentration flows, it can be applied to Sundmacher's method of alternating every one minute between $1.5 \mathrm{M}$ methanol and a pure water supply. Using this strategy, Sundmacher reports achieving a sustained $10 \%$ increase in cell voltage when operated at a current density of $50 \mathrm{~mA} / \mathrm{cm}^{2}$. When compared with the findings from the above analysis, such an increase is indeed consistent with that expected if the cell operated at $50 \mathrm{~mA} / \mathrm{cm}^{2}$ on a $0.75 \mathrm{M}$ methanol solution.

Unfortunately, the time scale estimation does not make as good of a comparison, because the much lower feed concentration used in Sundmacher's experiments invalidates the assumptions made in constructing the time scale model. However, it is reasonable that the roughly 60 second time scale that seemed appropriate for transmission of the $1.5 \mathrm{M}$ feed should be reduced when considering the transmission time of a $10 \mathrm{M}$ injection. Recalling that the modeling assumptions most likely led to underestimation of the injection transmission time, a duration somewhat longer than three seconds seems like a logical starting point for experimentation with periodic concentrated fuel injections.

Periodic Injection Experimental Results - Initial attempts at periodic fuel injection operation were unsuccessful using the standard set-up. Computer control over the liquid methanol flow controller proved unable to provide complete flow interruption and unable to give discriminating control over injection variations. Addition of a solenoid valve to the anode inlet line afforded complete shut-off capability, but failed to solve the problem of refined injection control. Unacceptably large voltage oscillations resulted from use of a substantial methanol flow rate (such as from gravity-driven flow through $1 / 4$ " tubing) for the time durations determined using the analysis methods of the previous section. Addition of a flow restriction in series with the solenoid valve enabled more precise control over anode fuel delivery. Following careful tuning of the valve restriction, calibration provided a correlation between the solenoid controller settings, injection timing and duration, and the solution volume delivered for a particular injection duration. 
Response Under Moderate Loading - With the flow restriction in place, injection durations on the order of those predicted by analysis resulted in acceptably small voltage oscillations. Testing began using a $1 \mathrm{M}$ methanol solution, which generally provides the best trade off between limiting crossover at low current densities, while avoiding an unacceptably low mass transport limited current density. Under low $40 \mathrm{~mA} / \mathrm{cm}^{2}$ and moderate $100 \mathrm{~mA} / \mathrm{cm}^{2}$ loading, periodic fuel injection indeed proved able to improve cell performance by reducing the diffusion-driven crossover that exists at such load levels with continuously supplied $1 \mathrm{M}$ feed. Because it is desirable to increase the concentration from this presently preferred level, the cell was next operated using periodic $2 \mathrm{M}$ fuel injection. Figure 3.2.1.88 shows that the optimized $2 \mathrm{M}$ fuel injection strategy at moderate 100 $\mathrm{mA} / \mathrm{cm}^{2}$ loading again results in improved performance over that of constant flow operation using a 1 $M$ methanol solution.

Referencing the jagged shape of the periodic injection performance curve, methanol injection preferably occurs just prior to each peak on the curve. Following a brief upward spike in performance, cell voltage then gradually drops for a period long after the injection valve has reclosed. The minima on the performance curve generally correspond to halfway through the pause between injections. At these points, the methanol concentration gradient across the PEM has reached a maximum, resulting in the largest presence of diffusion-driven crossover. From this point forward the concentration gradient is reduced, as no new methanol enters the cell to replace that being consumed by the current draw. As the cell voltage again approaches a maxima, crossover reaches a minimum, but the catalyst layer methanol concentration begins to near levels low enough to adversely affect the anode reaction kinetics. Before this occurs, methanol is again injected and the cycle begins again.

In order to determine the optimum injection strategy from an initial starting point, the first step is to consider the amplitude of the injection-induced voltage oscillation. It is generally desirable to inject a sufficient quantity of methanol to traverse the length of the anode flow channels, but to keep voltage oscillations to a minimum. It was decided to limit the stable sinusoidal voltage amplitude to roughly $+/-10 \mathrm{mV}$, and so injections creating much larger oscillations than this were reduced in time (and so also in their volume). In this particular experimental set-up, a lower limit of about 5 seconds per injection was found to be the threshold at which injection variations began to affect the stability of the voltage response.

The next step in optimization is to adjust the pause duration between fuel injections. Increasing this time period may result in shifting the average voltage response to an elevated level. This is because a longer pause time will permit an even larger voltage recovery due to diminishing crossover. Increasing the time too much, however, will result in a partial starvation condition at the anode catalyst layer and will instead reduce cell voltage. While continued injections would prevent reduction of cell voltage to zero, entering into such a mass transport limited operation region was found to impose significant voltage reductions, from which cell performance had difficulty recovering.

For determining the ideal periodic $2 \mathrm{M}$ injection strategy for the performance given in Figure 3.2.1.88, the timing was delayed to the point of first starting to show performance loss, and then an ideal period was selected 10-15 seconds shorter than this time. To further increase the achievable fuel energy density, a similar procedure was used to determine the ideal periodic $4 \mathrm{M}$ injection strategy, which is also given in Figure 3.2.1.88. The periodic $4 \mathrm{M}$ injection performance curve is shown gradually increasing from a level where the interrupt pauses had been 25 seconds shorter, and leveling off at a comparable voltage to that obtained from constant flow with a $1 \mathrm{M}$ solution. The performance range shown for $1 \mathrm{M}$ operation reflects the normal span observed after several days of any type of testing.

Response Under High Loading - Practical implementation of a periodically injected concentrated fuel feed will only be possible if operation is also successful at high current densities. It is at these elevated loads that the cell delivers its highest power density. Figure 3.2.1.89 demonstrates optimized periodic $2 \mathrm{M}$ and $4 \mathrm{M}$ fuel injection operation under a current draw of $200 \mathrm{~mA} / \mathrm{cm}^{2}$. In both instances, cell voltage increases from the transient undershoot associated with switching from open 
circuit to $200 \mathrm{~mA} / \mathrm{cm}^{2}$, and reaches levels at or above those obtained from constant $1 \mathrm{M}$ flow operation.

Having demonstrated successful high load operation with a concentrated $4 \mathrm{M}$ methanol feed, it was desired to repeat the test on a membrane having a higher baseline performance. The performance of the membrane used to obtain the results in Figures 3.2.1.88 - 3.2.1.89 began as somewhat below average and declined further as the result of extensive testing. Nevertheless, the significant cost of each membrane necessitated its use for obtaining results data. Fortunately, the data was successfully repeated using a better performing membrane. The results of this testing are shown in Figure 3.2.1.90. Periodic 8-sec, 1-mL injections of $4 \mathrm{M}$ methanol every 1.2 minutes resulted in comparable performance to constant flow of $1 \mathrm{M}$ methanol. Specific performance at 200 $\mathrm{mA} / \mathrm{cm}^{2}$ was about $340 \mathrm{mV}$, which is equivalent to a cell power density of roughly $70 \mathrm{~mW} / \mathrm{cm}^{2}$.

A final comment should be made about the interpretation of Figures 3.2.1.88 - 3.2.1.90. Because the average methanol flow rate is so much smaller under periodic fuel injection as compared to baseline constant flow operation (17 times smaller for the results in Figure 3.2.1.90), it may be tempting to claim much larger increases in DMFC operating range. In practical applications, however, DMFC anode exhaust would likely be recirculated. For comparison purposes, it may be assumed that methanol in excess of that required for stoichiometric reaction can be recaptured from the anode exhaust. This assumption implies identical fuel utilization efficiency regardless of the anode stoichiometry. Since the inefficiencies due to crossover are designed to be identical to constant diluted flow operation for periodic injection of a concentrated fuel solution, increases in fuel energy density may be judged simply on the basis of permissible molar concentration. As complete recovery of unspent fuel would be difficult in reality, periodic injection operation has the potential to benefit even further through its use of a lower anode stoichiometry.

\subsection{Fuel-Grade Methanol Testing}

To the best of this author's knowledge, all DMFC laboratory testing to date has relied upon use of reagent or chemical-grade methanol. In order to become a viable energy carrier for widespread use in direct liquid-feed fuel cells, however, methanol will need to be made widely available and used in a less pure fuel-grade. Such a grade of methanol will be less expensive to produce and deliver, but will have the potential of introducing contaminants to the DMFC anode. Experimental testing was performed with a fuel-grade of methanol referred to as M-100 that is currently available in California for various fuel applications.

\subsection{Comparison to Operation with Chemical-Grade Methanol}

The top thick line in Figure 3.2.1.91 shows the performance of a newly conditioned membrane running on chemical-grade methanol. A comparison test using fuel-grade M-100 performed immediately thereafter resulted in nearly identical performance. This and eight subsequent polarization scans were performed over four days in order evaluate the fuel-grade performance over time. The results are given immediately below the chemical-grade polarization curve in Figure 3.2.1.91. These scans were performed slowly, recording cell voltage at the end of two minutes of steady operation at each of the current densities indicated on the figure.

The data points shown in the figure reflect an average of the voltage values obtained following two minutes of steady operation for both gradually increasing and gradually decreasing cell current density. This was performed in order to exercise the cell for longer periods at a variety of current densities, and to account for the hysteresis effect of increasing vs. decreasing current density. The resulting fuel-grade curves show only slight degradation from the baseline chemical-grade performance.

Because some amount of degradation was observed from the polarization curve comparisons, further testing was desired in order to determine whether the degradation resulted from contaminants in the M-100 or reflected the normal rate of degradation from similar operation using chemical-grade methanol. As a result, an accelerated lifetime test was devised in order to evaluate 
the membrane's durability. The method consisted of applying a $100-\mathrm{mA} / \mathrm{cm}^{2}$ load to the cell for two hours, and then spending 15 minutes to quickly perform a polarization sweep. This cycle was repeated over an entire day of testing, resulting in at least 8-10 hours of constant operation each day.

Figure 3.2.1.92 shows the cell voltage response over a full day of durability testing while operating with chemical-grade methanol. The figure is segmented by the 15-minute periods in which the polarization sweeps were taken. Interestingly, the voltage response during the constant current segments possesses a "saw tooth" shape, which seems to repeat itself after a period of about 40 minutes. Though the reason for this is uncertain, it is expected that the regular saw tooth shape results from slight cyclical variations in the performance of the test stand's variable potentiostat over long periods of constant operation. In spite of the $+/-4 \mathrm{mV}$ noise created by this saw tooth, it is easy to see a general downward trend of about $1.3 \mathrm{mV} / \mathrm{hr}$ over the course of the test.

Figure 3.2.1.93 provides a comparison of durability tests conducted over six different days with M-100 and the durability test conducted with chemical-grade methanol. The six fuel-grade tests show degradation rates between 1.1-1.5 mV/hr, which is consistent with the rate observed for operation on chemical-grade methanol. The tests show a steady decline from one day to the next, with the exception of Day 4 to Day 5, where a $20 \mathrm{mV}$ jump is observed. Between these testing days, the test stand air bottle needed to be replaced, and it is expected that the performance jump may be attributed to this change in air supply. The new air bottle, labeled as "Medical Air," is thought in hindsight to have possessed slightly enhanced oxygen content as compared to the bottles of " $D$ Grade Breathing Air" normally used. The overnight pause in between each of the other tests seems to result in a smaller (5-10 mV) performance recovery. This leads to a combined degradation rate of about $0.9 \mathrm{mV} / \mathrm{hr}$ for the first four tests, and about $1.0 \mathrm{mV} / \mathrm{hr}$ over the three tests performed with medical-grade air.

Note that 3.2.1.91 also includes polarization curve data taken during durability testing. To keep the figure less cluttered, only the first and last polarization curves from each day of testing are displayed. These curves provide accurate bounds of the other curves taken during a particular day of testing. As with the consistent degradation rate of performance at $100 \mathrm{~mA} / \mathrm{cm}^{2}$, the polarization curves reflect a steady rate of decline consistent with that of chemical-grade methanol. Also consistent with the polarization data points is the scatter of durability testing measurements taken at $100 \mathrm{~mA} / \mathrm{cm}^{2}$. The first 40 minutes of measurements for the first durability test and the last 40 minutes of the last test (performed with chemical-grade methanol) are included in Figure 3.2.1.91.

\subsection{Aggravated Effect of Potential Contaminants}

The testing results of the previous section indicate that operation using this particular batch of fuel-grade M-100 has no adverse effect on DMFC performance as compared to chemical-grade methanol operation. The next step in the fuel quality study is to evaluate DMFC sensitivity to increased quantities of contaminants that can be introduced during methanol production. Three particular contaminants with potential to impact DMFC performance were identified from an XCELLSiS. The report found small quantities of chloride, methylene chloride and 2-butanone in an onsite container at a Methanex Corporation production facility, and slightly larger quantities in a dedicated drum at an XCELLSiS location, which was filled at the same methanol production facility. The contaminant concentration levels measured in the XCELLSiS drum were 0.05-ppm chloride, 0.7-ppm methylene chloride and 4.5-ppm 2-butanone.

Figure 3.2.1.94 provides a performance degradation comparison using the same durability test scheme described previously. The comparison was performed with a fresh membrane to determine the impact of potential contaminants added to M-100 in much larger concentrations than those actually expected. The first test was performed with chemical-grade methanol and exhibited a sharp performance drop at $100 \mathrm{~mA} / \mathrm{cm}^{2}$ over the first two hours of operation. This decline likely resulted from the fact that this was the first time the cell had been loaded for such an extensive period of time 
since achieving peak performance. Over the following 10 hours of operation with chemical-grade methanol, the cell exhibited a steady $1.8 \mathrm{mV} / \mathrm{hr}$ decline.

The following four tests used unmodified fuel-grade M-100, and M-100 with elevated levels of each of the three selected contaminants (with a different contaminant added for each test). These experiments displayed degradation rates between $1.4-1.9 \mathrm{mV} / \mathrm{hr}$, comparable to the $1.8 \mathrm{mV} / \mathrm{hr}$ rate of the chemical grade test. For the 2-butanone contamination testing, the concentration in M-100 was increased from the reference value of $4.5 \mathrm{ppm}$ to $450 \mathrm{ppm}$. A similar 100-fold increase was used for the chloride contaminant testing, increasing from 0.05 to $5 \mathrm{ppm}$ (the contaminating chloride solution was prepared with ACS Reagent Grade Sodium Chloride in ACS Reagent Grade Water). A 500 -fold increase was used for the methylene chloride testing, from 0.7 to $350 \mathrm{ppm}$, so that the required volume from a container of pure methylene chloride would be more easily measured.

A final observation about the results of Figure 3.2.1.94 is that the cell voltage response from one day of testing to the next exhibits a greater recovery than was observed in Figure 3.2.1.93. It is hypothesized that the increased recovery results from the superior performance of the new membrane used in the second set of tests. With its higher initial performance and less degraded performance at the start of durability testing, the newer membrane likely possessed a greater aptitude to bounce back from performance declines. Regardless, the test results using this membrane show no performance loss and no escalation in the rate of performance degradation from using elevated levels of the three tested contaminants.

To verify that performance remains unaffected over the full range of cell current densities, Figure 3.2.1.95 shows the polarization curves obtained during the durability testing of Figure 3.2.1.94. The comparison figure only contains the first and last polarization curves taken during each day of testing. These curves again provide accurate bounds of the other curves taken during each day. The figure shows a significant amount of overlap in performance range from one day to the next, with a slight steady overall downward decline in performance. Note that the only aberration is the very first chemical-grade performance curve, which corresponds with the point on Figure 3.2.1.94 prior to the rapid performance decline just after the start of testing. In summary, Figure 3.2.1.95 demonstrates no significant increase in single-day performance degradation from one day to the next, and no significant drop in performance corresponding to the addition of a particular contaminant. It is concluded that DMFC performance should remain unaffected by contamination from 2-butanone, methylene chloride and chloride in concentrations up to 100 times larger than those currently found in methanol samples produced by Methanex Corp. 
Table 3.2.1.12 Current density (i) ranges for transient performance testing, and the resulting steady state voltage levels. Operating conditions: Temperature $=75 \mathrm{C}$; Air stoichiometry $=20$ at $100 \mathrm{~mA} / \mathrm{cm}^{2}$; Backpressure $=0 \mathrm{psig}$; Indicated methanol concentration with constant flow rate $=14 \mathrm{~mL} / \mathrm{min}$.

\begin{tabular}{|c|c|c|c|c|c|}
\hline \multicolumn{3}{|c|}{ I ncreasing Load } & \multicolumn{3}{|c|}{ Decreasing Load } \\
\hline \multirow{2}{*}{$\begin{array}{l}\text { Change in } i \\
\left(\mathrm{~mA} / \mathrm{cm}^{\wedge} 2\right)\end{array}$} & \multicolumn{2}{|c|}{ Final SS Voltage (mV) } & \multirow{2}{*}{$\begin{array}{l}\text { Change in i } \\
\left(\mathrm{mA} / \mathrm{cm}^{\wedge} 2\right)\end{array}$} & \multicolumn{2}{|c|}{ Final SS Voltage (mV) } \\
\hline & 1 M Test & $2 \mathrm{M}$ Test & & $1 \mathrm{M}$ Test & $2 \mathrm{M}$ Test \\
\hline $20-40$ & 505 & 452 & $40-20$ & 541 & 488 \\
\hline $100-120$ & 414 & 358 & $120-100$ & 433 & 378 \\
\hline $200-220$ & 316 & 261 & $220-200$ & 334 & 281 \\
\hline $100-200$ & 331 & 279 & $200-100$ & 435 & 384 \\
\hline $0-20$ & 541 & 489 & $20-0$ & 668 & 589 \\
\hline $0-100$ & 428 & 371 & $100-0$ & 674 & 584 \\
\hline $0-200$ & 323 & 268 & $200-0$ & 672 & 583 \\
\hline
\end{tabular}


Table 3.2.1.13 Comparison of performance improvement for interrupted $1 \mathrm{M}$ methanol flow. Operating conditions: Temp $=75 \mathrm{C}$, Air stoich $=20$ at 100 $\mathrm{mA} / \mathrm{cm}^{2}$, Backpressure $=0$ psig. Reported rise values incorporate a diminished contribution of voltage spikes near the mass transport limited condition.

\begin{tabular}{|c|c|c|c|c|}
\hline $\begin{array}{c}\text { Current } \\
\text { Density } \\
\left(\mathrm{mA} / \mathrm{cm}^{2}\right)\end{array}$ & \multirow{2}{*}{$\begin{array}{c}\text { SS Voltage } \\
(\mathrm{mV})\end{array}$} & \multicolumn{2}{|c|}{ Voltage Rise } & \multirow{2}{*}{$\begin{array}{c}\text { Time to Peak } \\
(\mathrm{min})\end{array}$} \\
\cline { 3 - 4 } & & $(\mathrm{mV})$ & $(\%)$ & \\
\hline 40 & 472 & 47 & 10.0 & 8.0 \\
\hline 100 & 388 & 34 & 8.8 & 5.9 \\
\hline 200 & 242 & 21 & 8.7 & 3.9 \\
\hline
\end{tabular}

Table 3.2.1.14 Cell characteristics at two operating points.

\begin{tabular}{|c|c|c|c|}
\hline \multirow{4}{*}{$\begin{array}{c}\text { Cell } \\
\text { Operating } \\
\text { Parameters }\end{array}$} & $\mathrm{C}_{\mathrm{F}}$ & \multicolumn{2}{|c|}{$1 \mathrm{M}$} \\
\cline { 2 - 4 } & $\mathrm{D}$ & \multicolumn{2}{|c|}{$1.78^{*} 10^{\wedge}-9 \mathrm{~m}^{2} / \mathrm{s}$} \\
\cline { 2 - 4 } & $\mathrm{L}$ & \multicolumn{2}{|c|}{$0.003 \mathrm{~m}$} \\
\cline { 2 - 4 } & $i_{\text {cell }}$ & $720 \mathrm{~mA} / \mathrm{cm}^{2}$ & $170 \mathrm{~mA} / \mathrm{cm}^{2}$ \\
\hline Given Result & $i_{\text {parasitic }}$ & $5 \mathrm{~mA} / \mathrm{cm}^{2}$ & $23 \mathrm{~mA} / \mathrm{cm}^{2}$ \\
\hline \multirow{2}{*}{$\begin{array}{c}\text { Calculated } \\
\text { Results }\end{array}$} & $\dot{n}_{\text {diffusion }}$ & $1.33^{*} 10^{\wedge}-6 \mathrm{~mol} /\left(\mathrm{cm}^{2} * \mathrm{~s}\right)$ & $6.91 * 10^{\wedge}-7 \mathrm{~mol} /\left(\mathrm{cm}^{2} * \mathrm{~s}\right)$ \\
\cline { 2 - 4 } & $\mathrm{C}_{\mathrm{CL}}$ & $0.29 \mathrm{M}$ & $0.63 \mathrm{M}$ \\
\hline
\end{tabular}




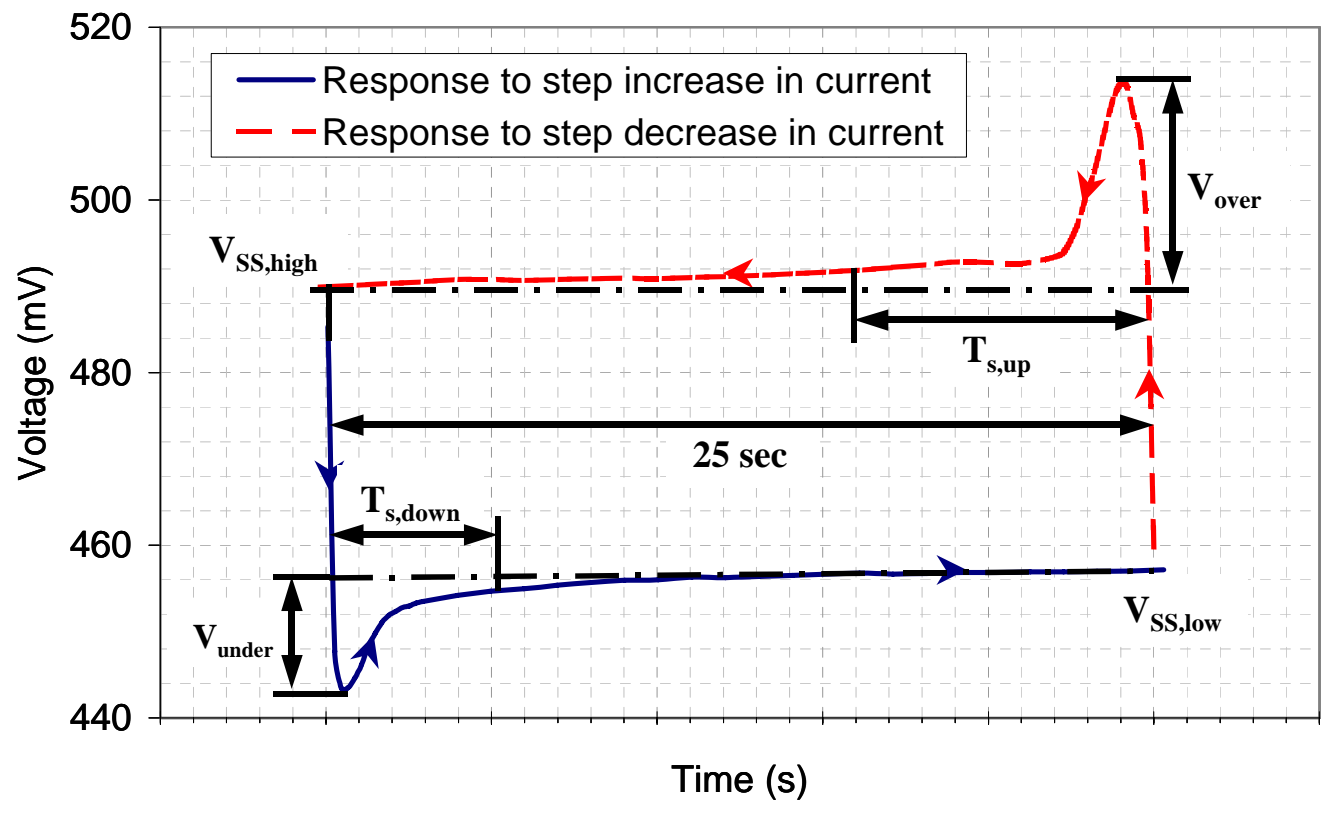

Figure 3.2.1.75 Definition of transient response characteristics using an example where cell load is switched between constant 40 and $60 \mathrm{~mA} / \mathrm{cm}^{2}$ current draws. Operating conditions: Temperature $=75 \mathrm{C}$; Const air stoichiometry $=20$; Backpressure $=0$ psig; $1 \mathrm{M}$ methanol flow $=14 \mathrm{~mL} / \mathrm{min}$ (stoichiometry $=27$ at $100 \mathrm{~mA} / \mathrm{cm}^{2}$ ).

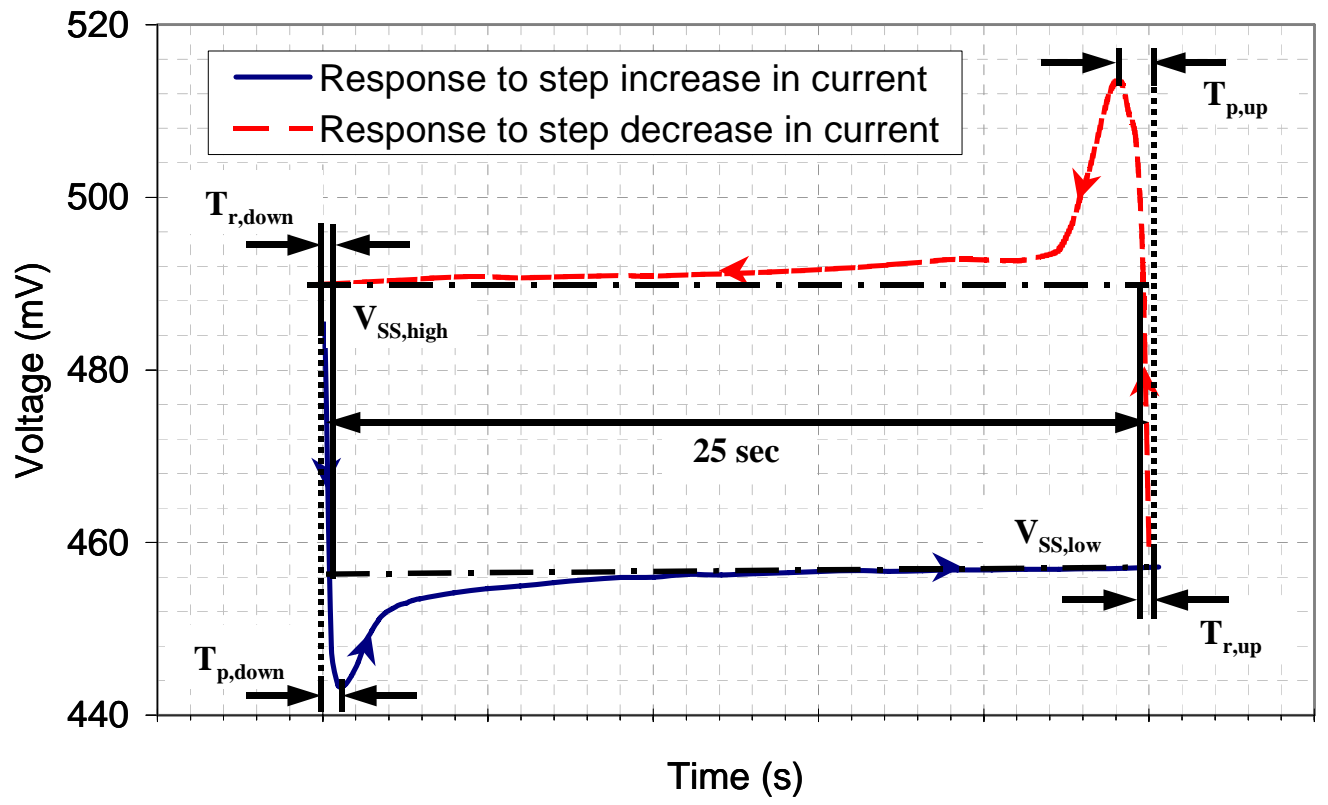

Figure 3.2.1.76 Additional definitions of transient characteristics using the same example from Figure 3.2.1.75. 


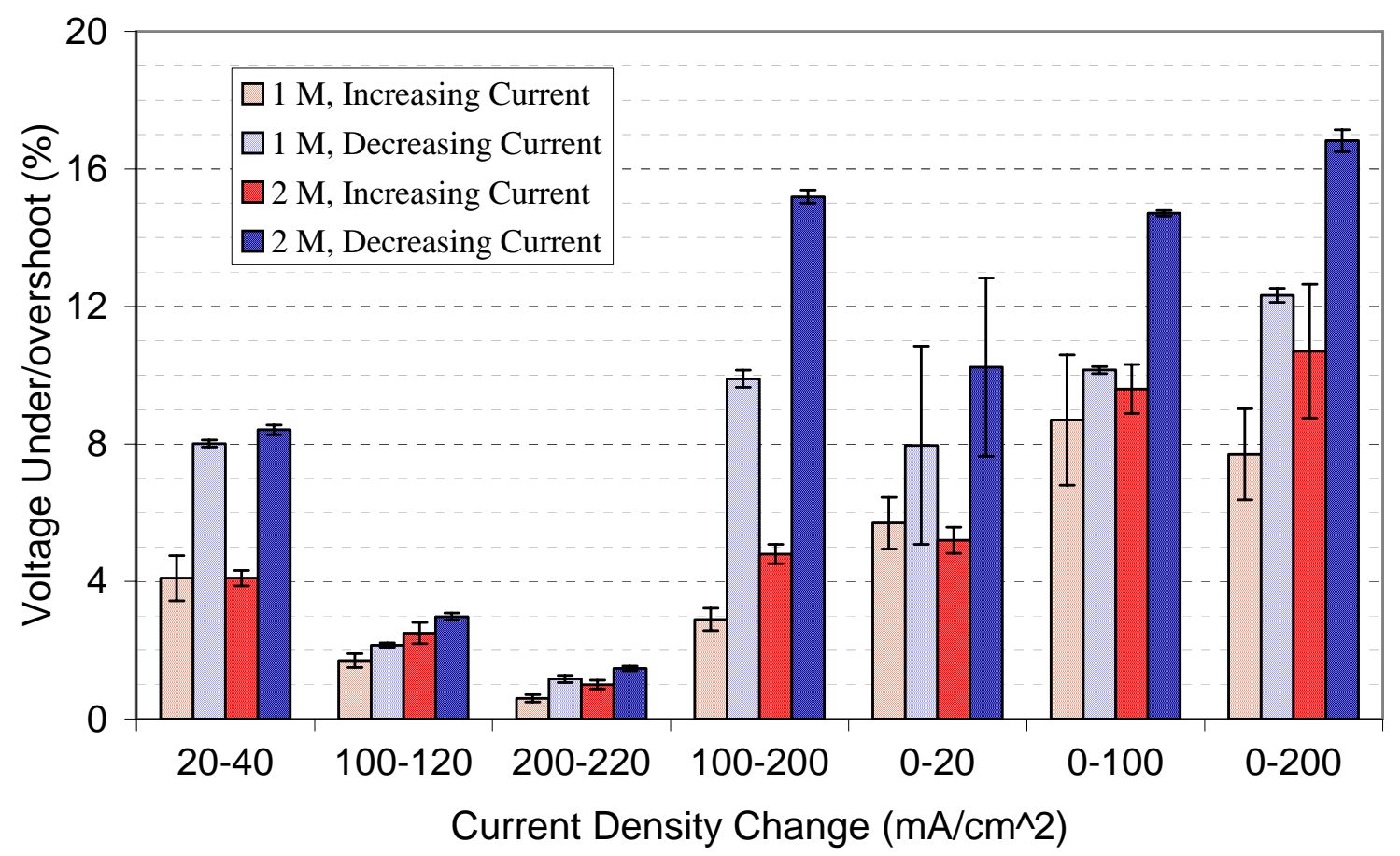

Figure 3.2.1.77 Percent voltage under/overshoot for the transient conditions given in Table 3.2.1 12.

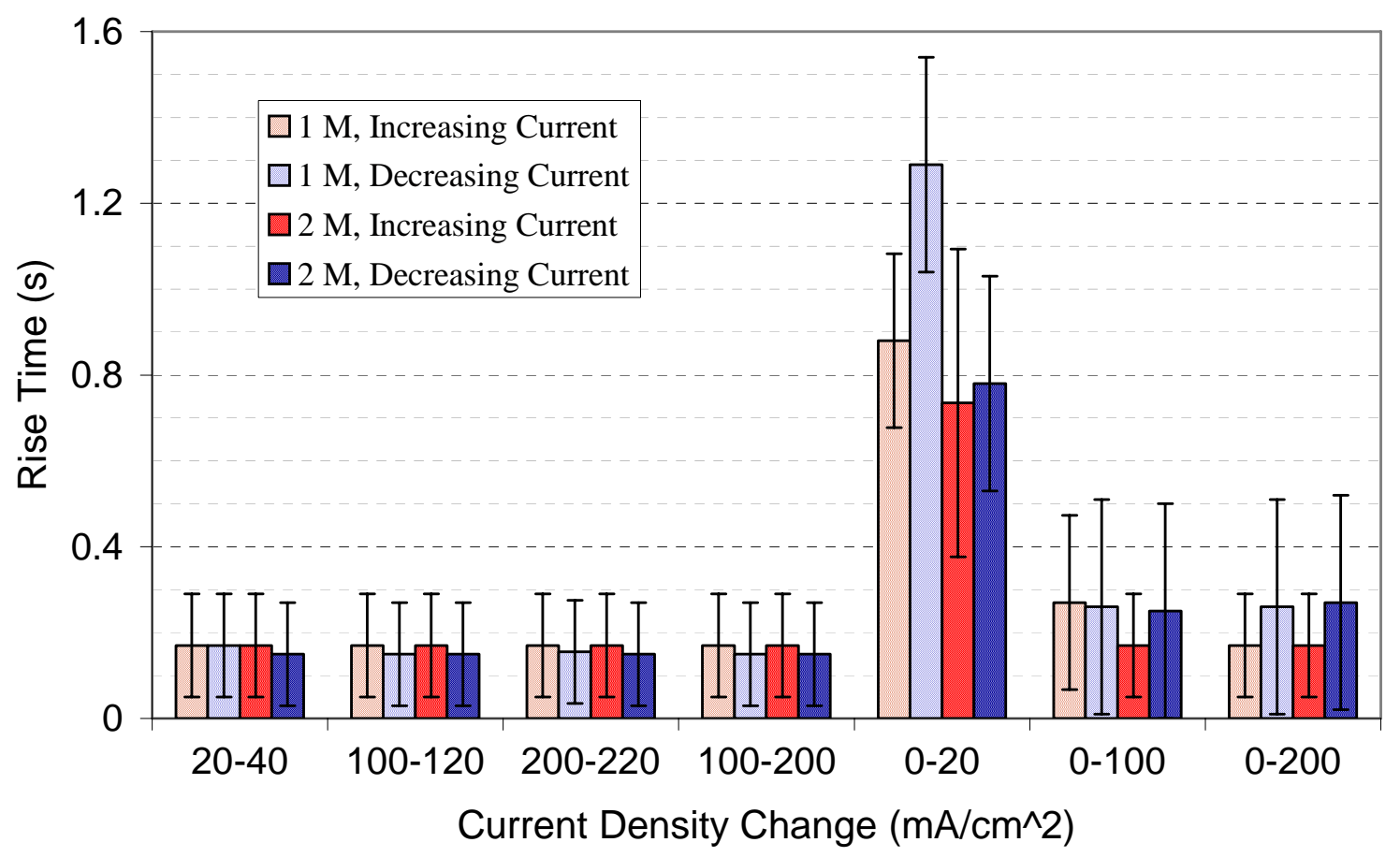

Figure 3.2.1.78 Rise time comparison for the transient conditions given in Table 3.2.1.12. 


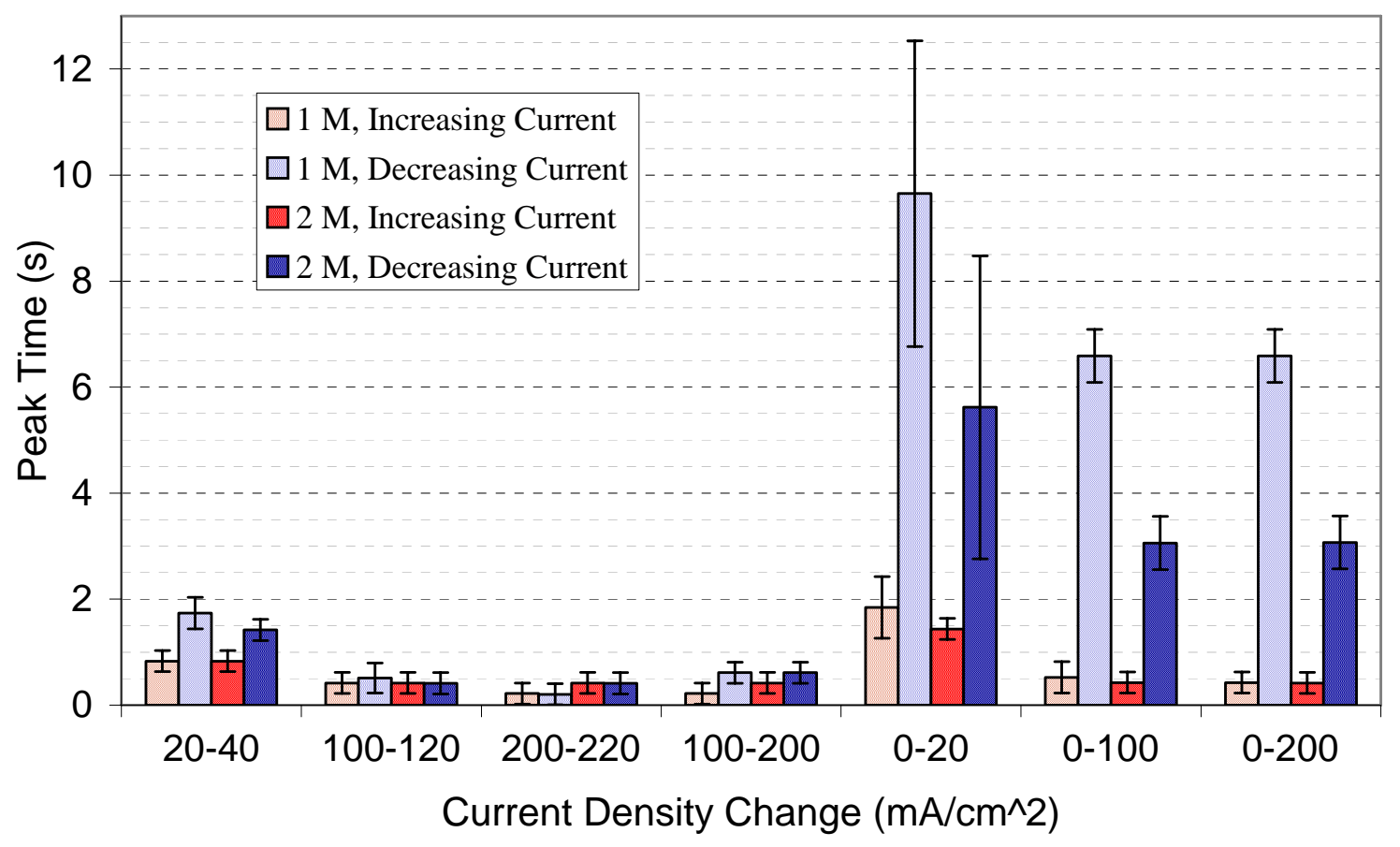

Figure 3.2.1.79 Peak time comparison for the transient conditions given in Table 3.2.1.12.

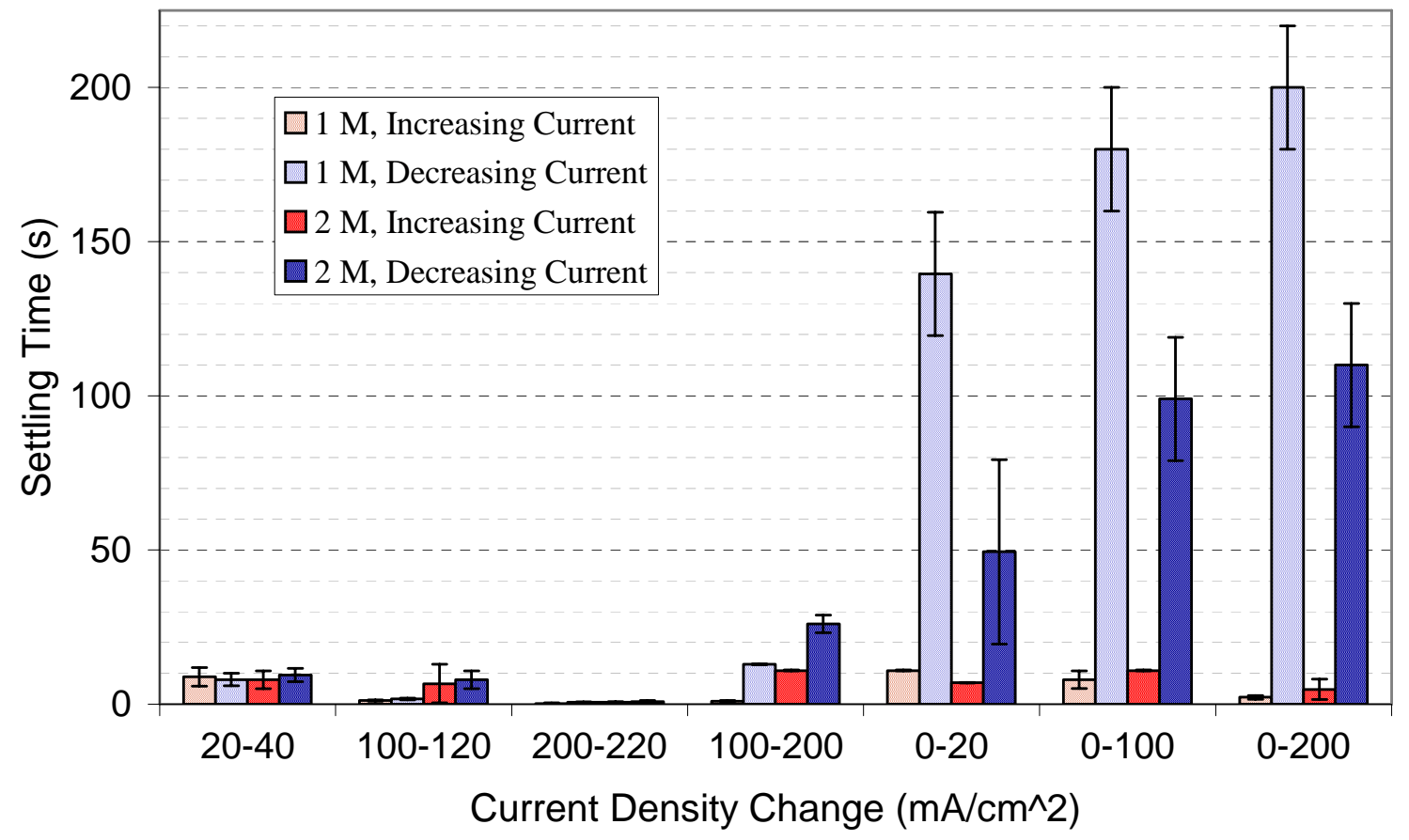

Figure 3.2.1.80 Settling time comparison for the transient conditions given in Table 3.2.1.12. 


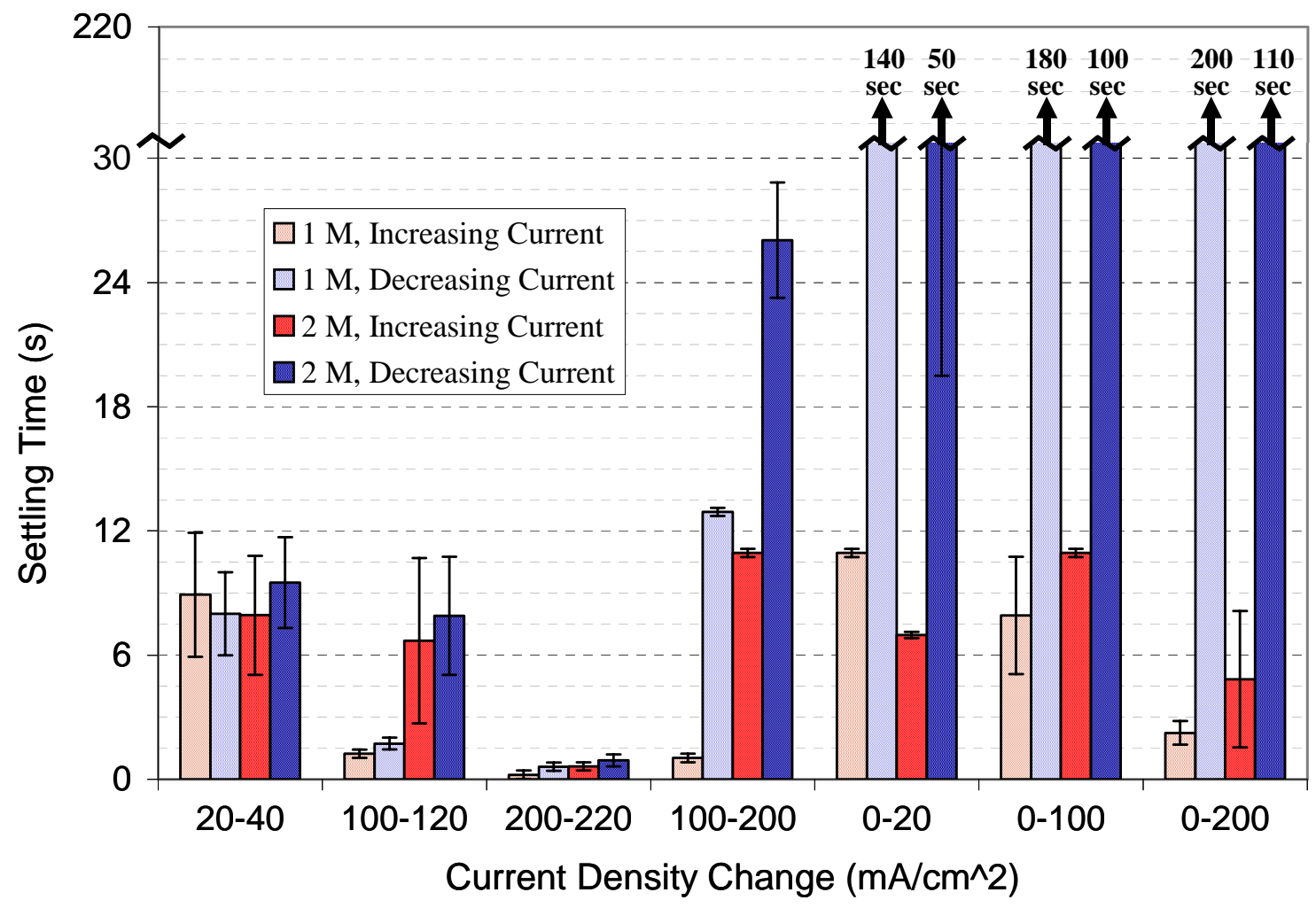

Figure 3.2.1.81 Magnified comparison of the settling time associated with the transient conditions given in Table 3.2.1.12.

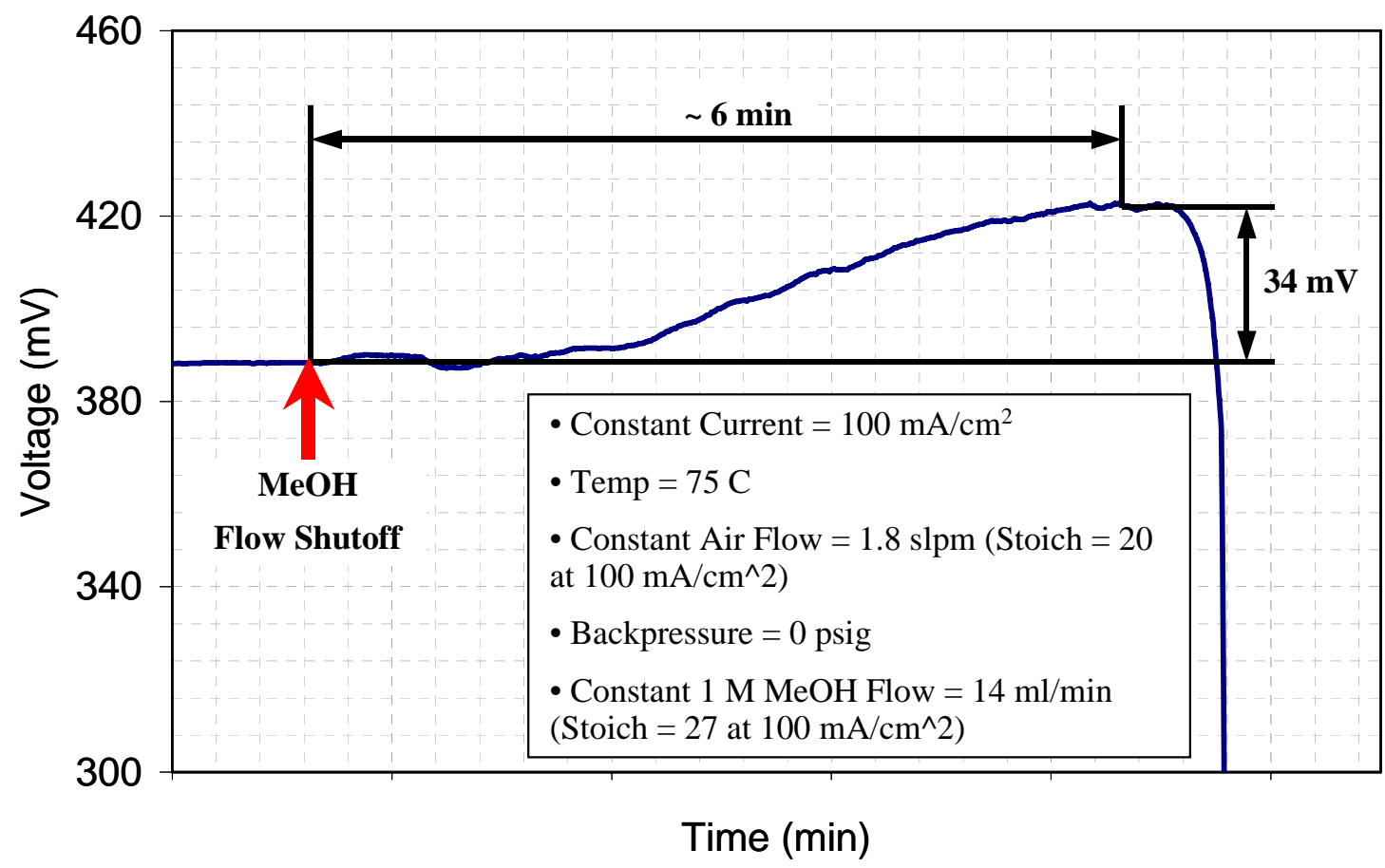

Figure 3.2.1.82 Voltage response to methanol flow shut-off. 


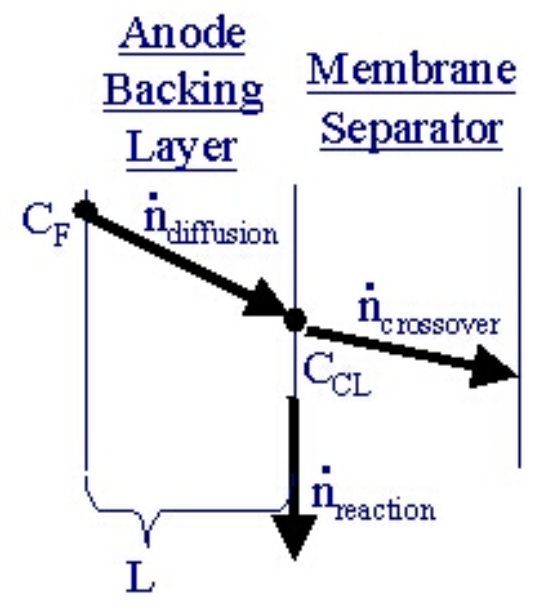

$$
\begin{aligned}
& \dot{n}_{\text {diffusion }}=\dot{n}_{\text {reaction }}+\dot{n}_{\text {crossover }} \\
& \dot{n}_{\text {reaction }}+\dot{n}_{\text {crossover }}=\frac{i_{\text {cell }}+\dot{i}_{\text {parasitic }}}{6 F} \\
& \dot{n}_{\text {diffusion }}=D \frac{C_{F}-C_{C L}}{L}
\end{aligned}
$$

Figure 3.2.1.83 1-D model and governing methanol flux equations.

\section{$\frac{\text { Pulsing }}{\text { On }} \underline{\text { Pulsing Off }} \frac{\text { Pulsing }}{\text { On }}$}

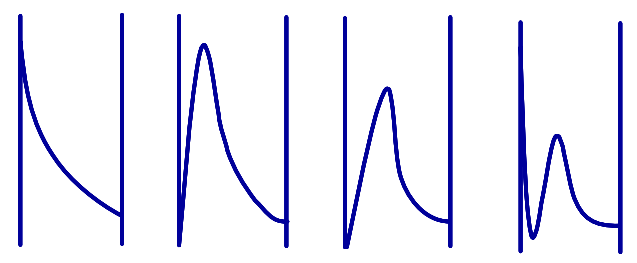

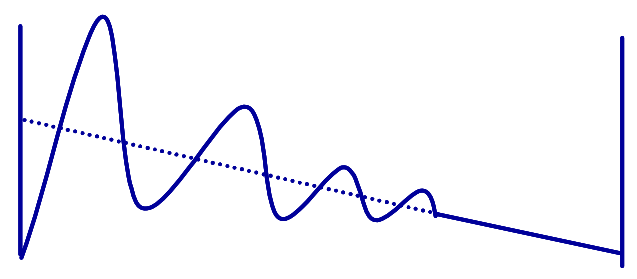

(a)

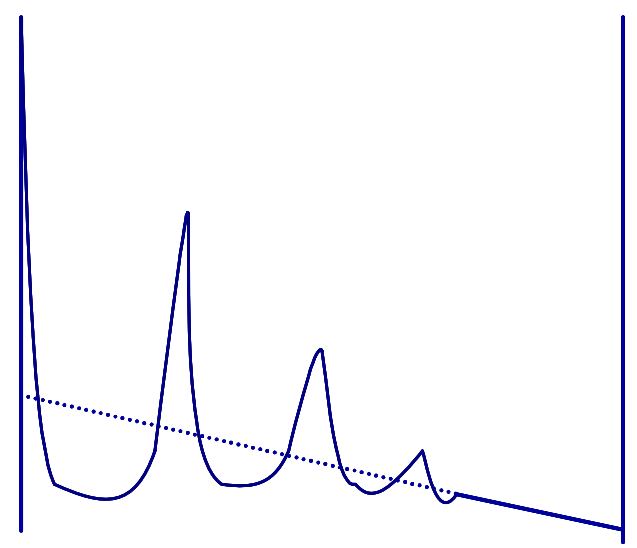

(b)

Figure 3.2.1.84 Diffusion layer concentration profiles for (a) uniform step and (b) nonuniform step methanol pulsing. 


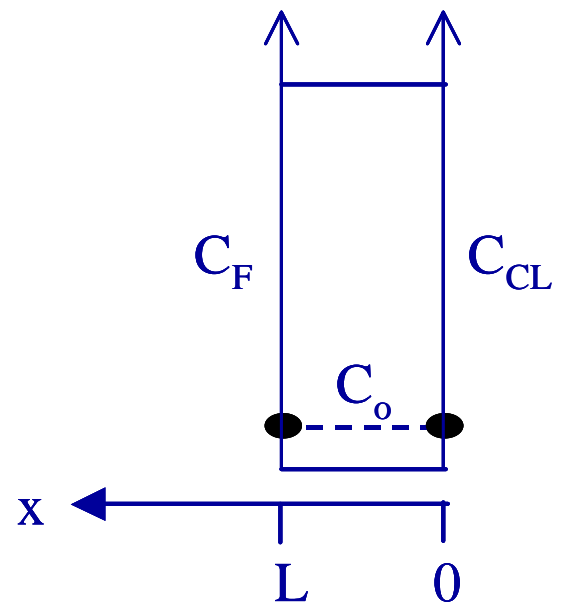

(a)

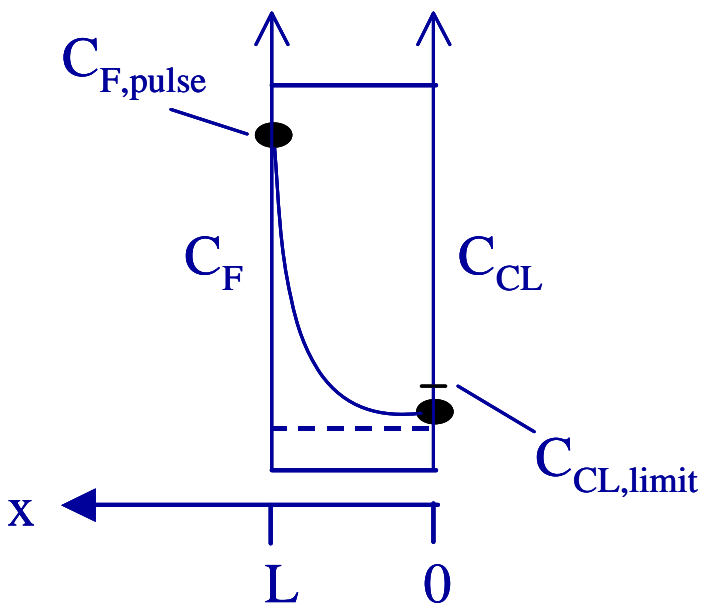

(b)

Figure 3.2.1.85 Problem formulation for determining transmission time of a step concentration disturbance. Figure used to indicate the (a) initial condition and (b).

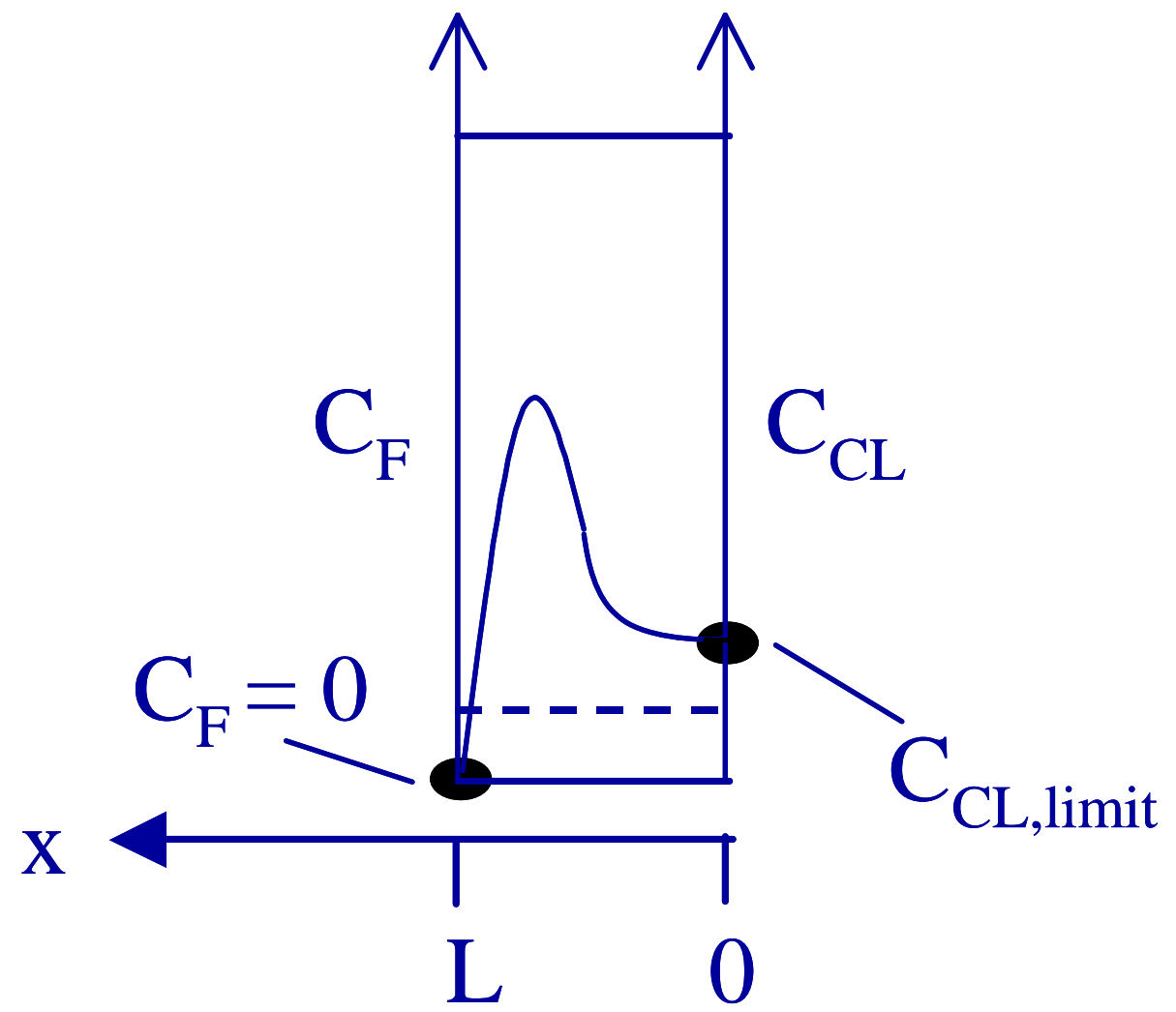

Figure 3.2.1.86 Simulation objective: determine the time it takes for the catalyst layer concentrating to reach a selected limit. Methanol feed should be shut off after this time period in order to prevent the catalyst layer concentration from significantly exceeding this limit. 


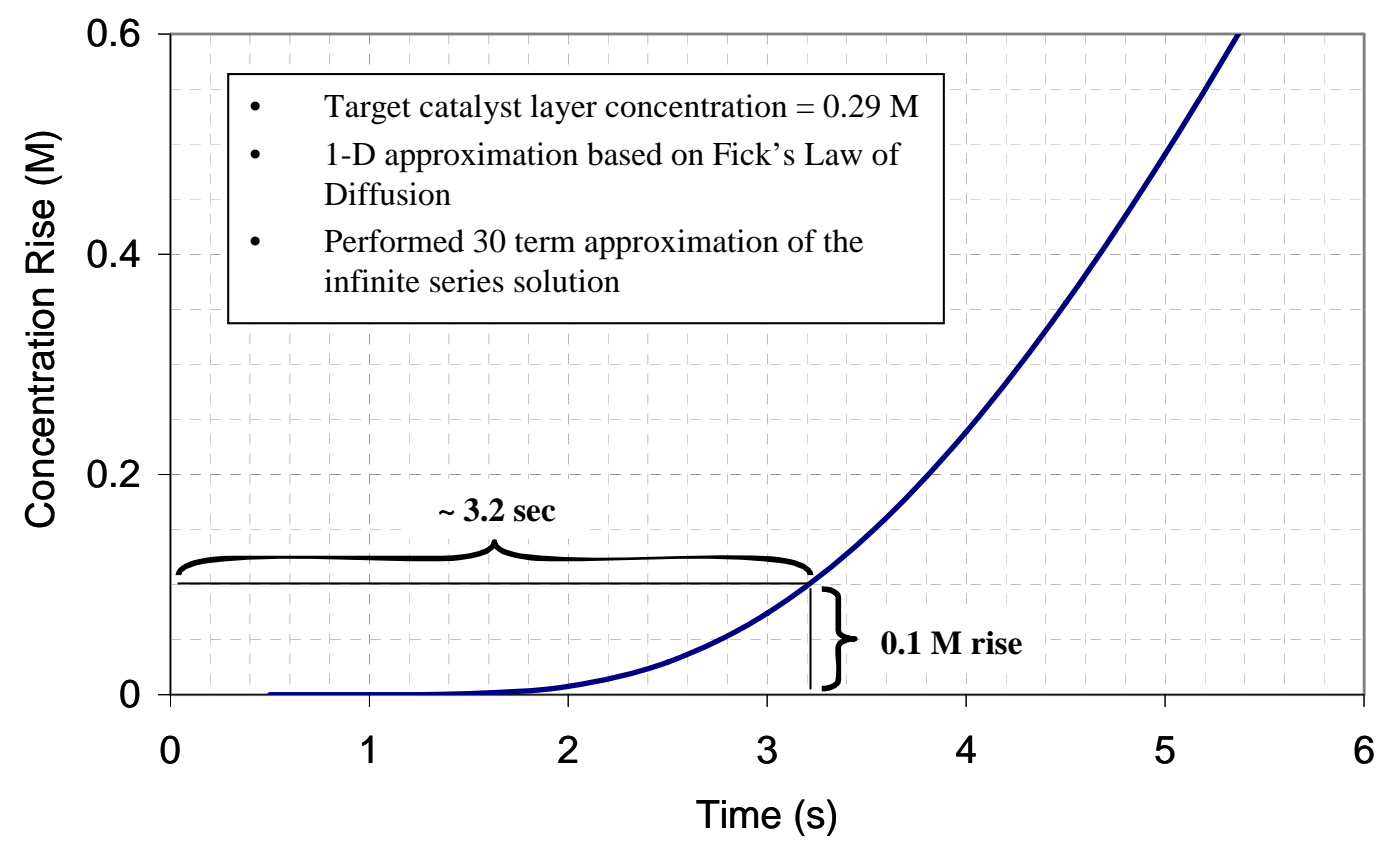

Figure 3.2.1.87 Theoretical time response of catalyst layer concentration to a $10 \mathrm{M}$ step impulse.

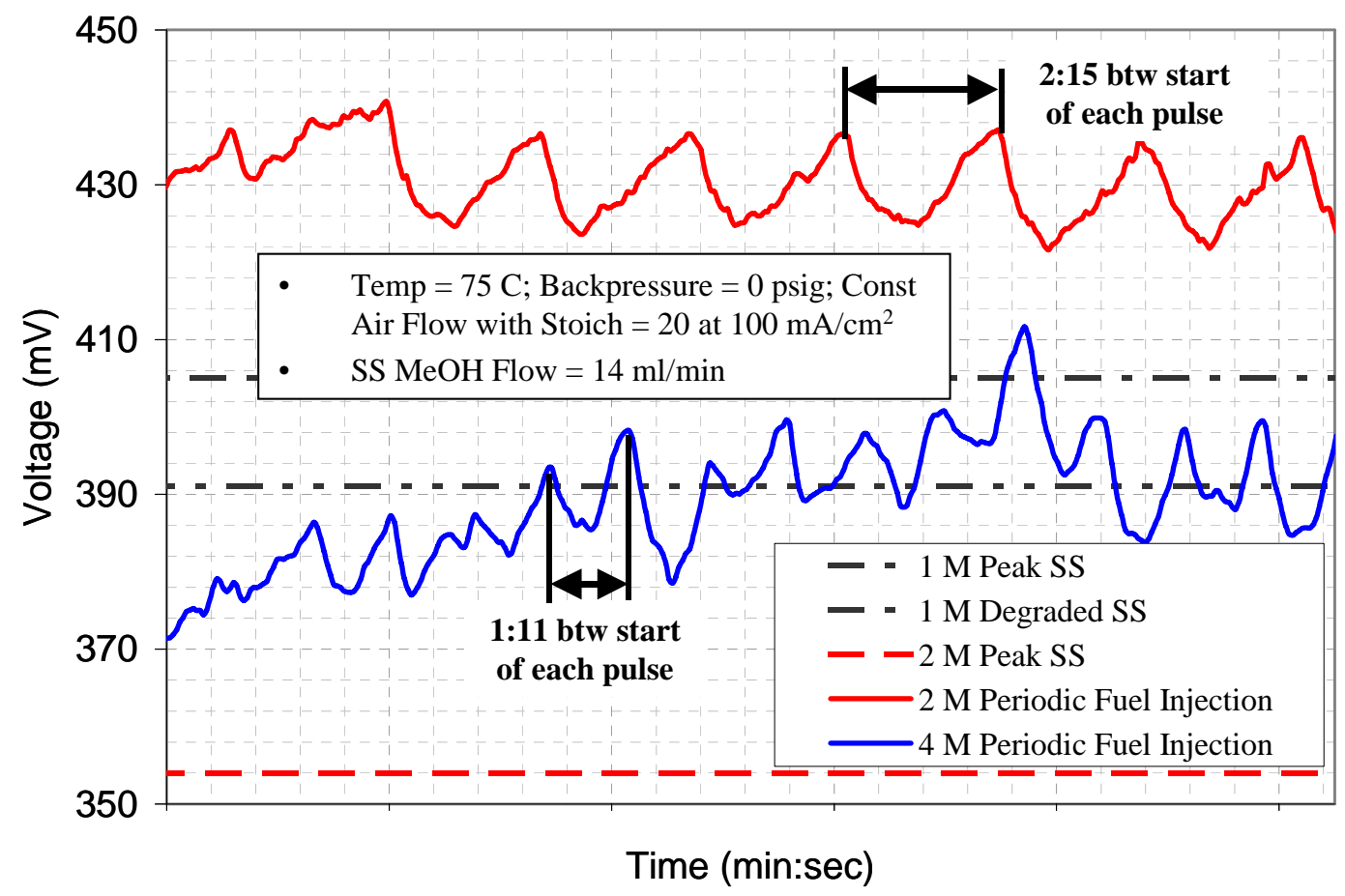

Figure 3.2.1.88 Cell voltage under $100 \mathrm{~mA} / \mathrm{cm}^{2}$ loading. Periodic $2 \mathrm{M}$ fuel delivery (performed first): pause $\sim 2.1 \mathrm{~min}$ between each $10 \mathrm{sec}, 1.2 \mathrm{ml}$ fuel injection. Periodic 4 $\mathrm{M}$ fuel delivery (later testing days): pause $\sim 1.1 \mathrm{~min}$ between each $6 \mathrm{sec}, 0.7$ $\mathrm{ml}$ fuel injection. Peak SS performance measured before periodic injection testing. Degraded SS performance measured after several days of testing, and consistent with normal rate of degradation. 


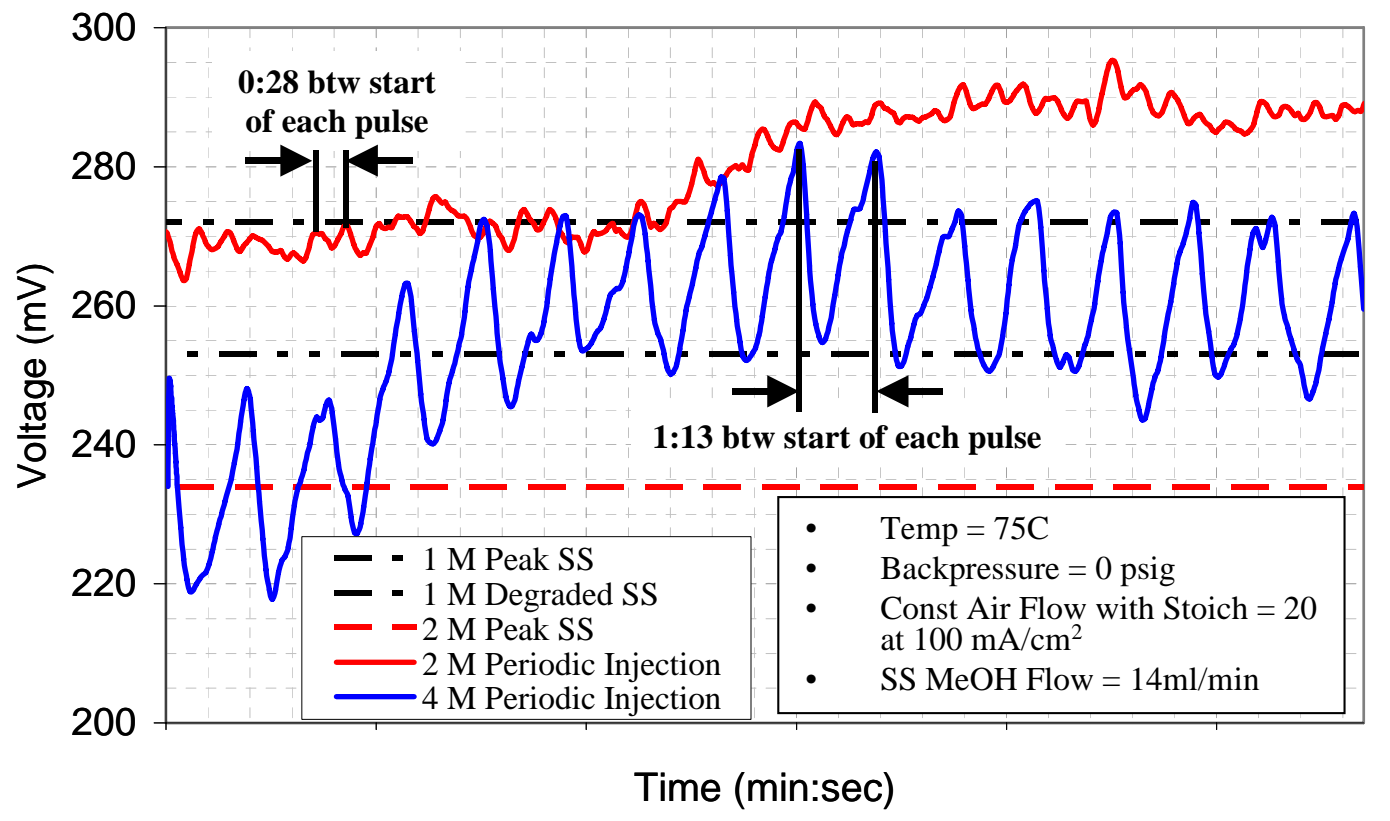

Figure 3.2.1.89 Cell voltage under $200 \mathrm{~mA} / \mathrm{cm}^{2}$ loading. Periodic $2 \mathrm{M}$ fuel delivery (performed first): pause $\sim 18 \mathrm{sec}$ between each $10 \mathrm{sec}, 1.2 \mathrm{ml}$ fuel injection. Periodic $4 \mathrm{M}$ fuel delivery (later testing days): pause $\sim 1.1 \mathrm{~min}$ between each $8 \mathrm{sec}, 1.0 \mathrm{ml}$ fuel injection. Peak SS performance measured before periodic injection testing. Degraded SS performance measured after several days of testing, and consistent with normal rate of degradation.

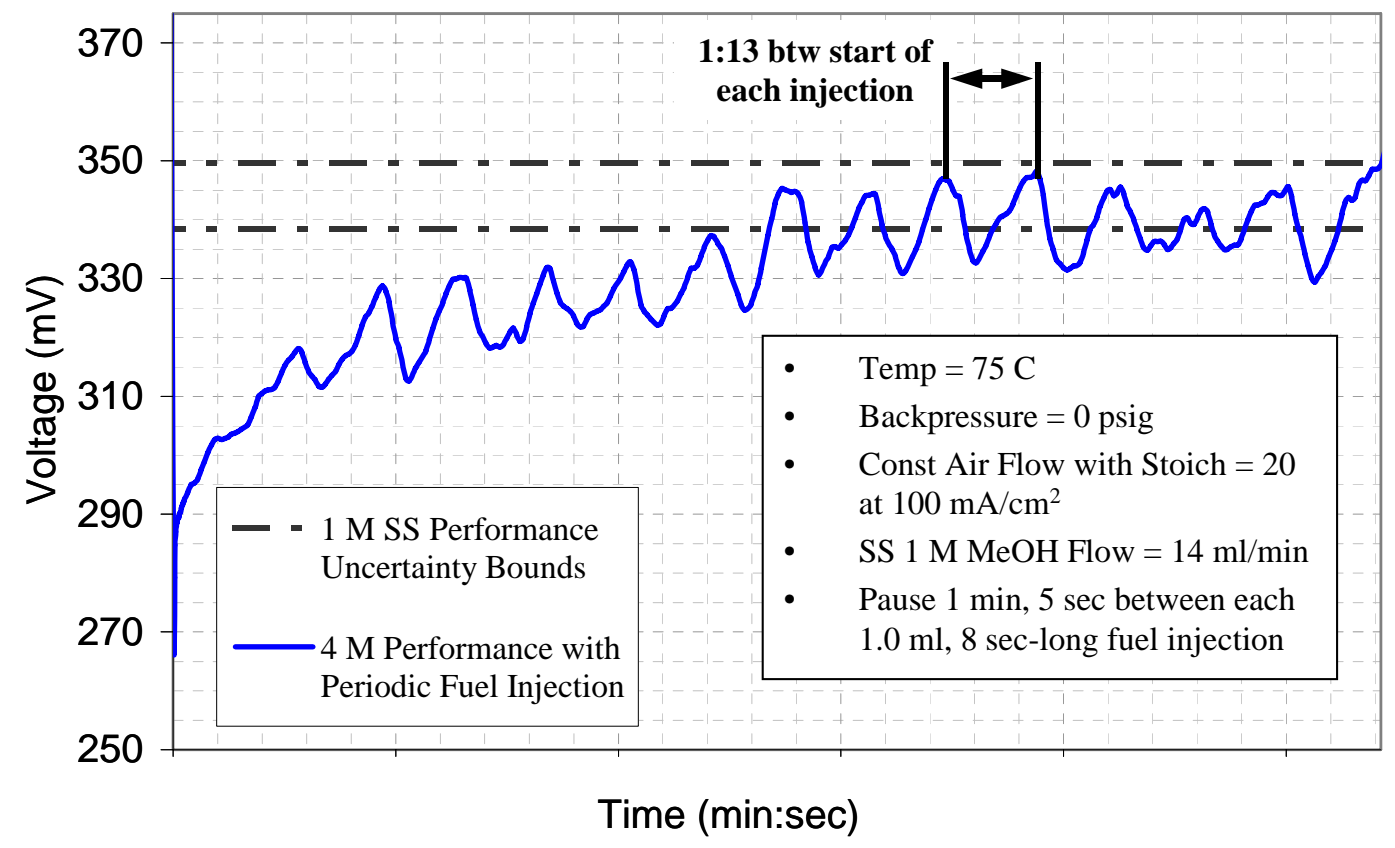

Figure 3.2.1.90 Periodic 4 M fuel injection performance with a fresh membrane under 200 $\mathrm{mA} / \mathrm{cm}^{2}$ loading. Performance matches that of constant $1 \mathrm{M}$ methanol flow, allowing for a quadrupling of the fuel energy density. 


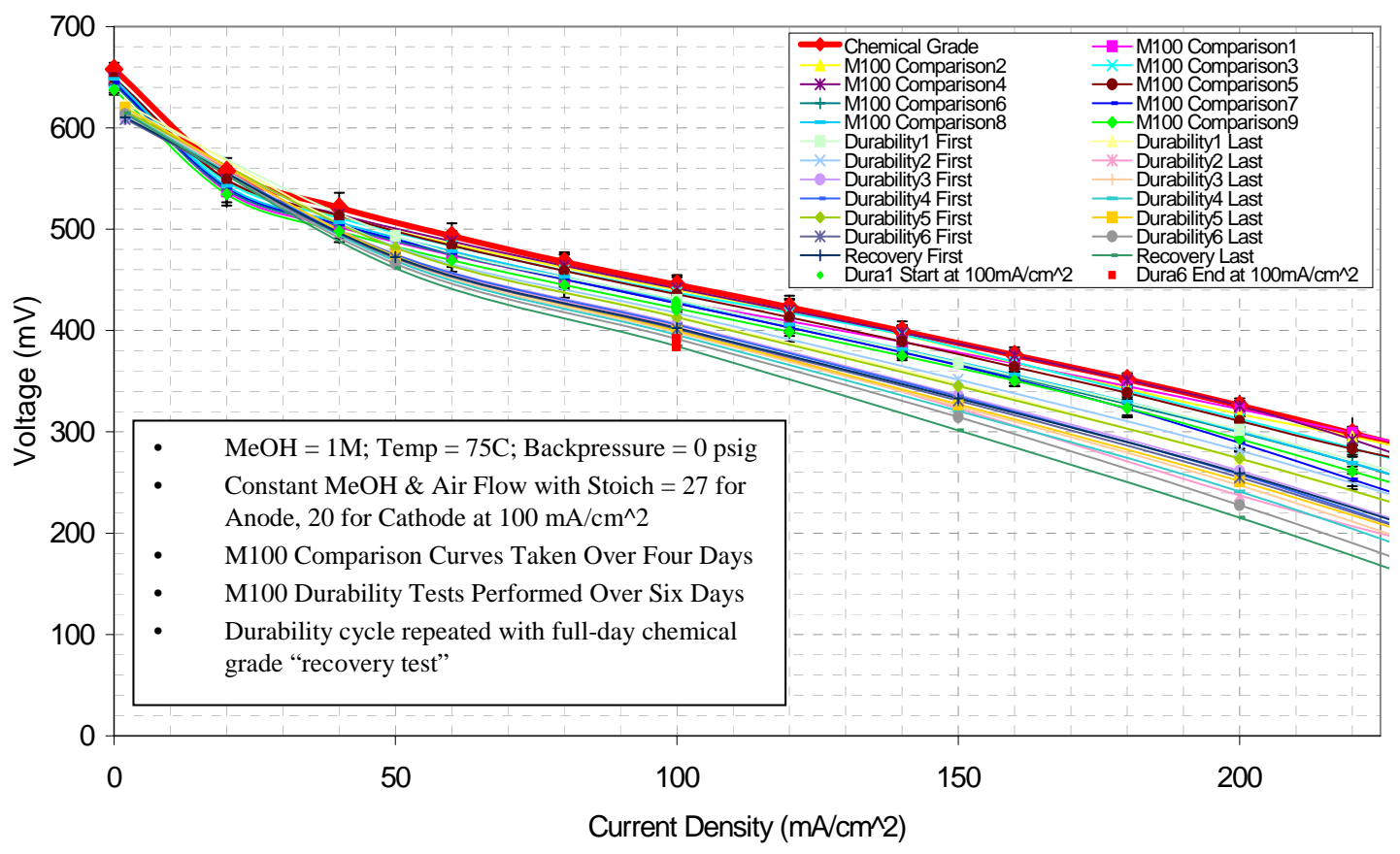

Figure 3.2.1.91 Fuel-grade methanol performance comparison. Durability test description: draw a constant $100 \mathrm{~mA} / \mathrm{cm}^{2}$ during full day test, interrupting for 15 min every two hours to take a polarization sweep. First and last polarization curve given for each full day. Data at $100 \mathrm{~mA} / \mathrm{cm}^{2}$ also given for first $40 \mathrm{~min}$ of the first M100 durability test and last 40 min of the last durability test.

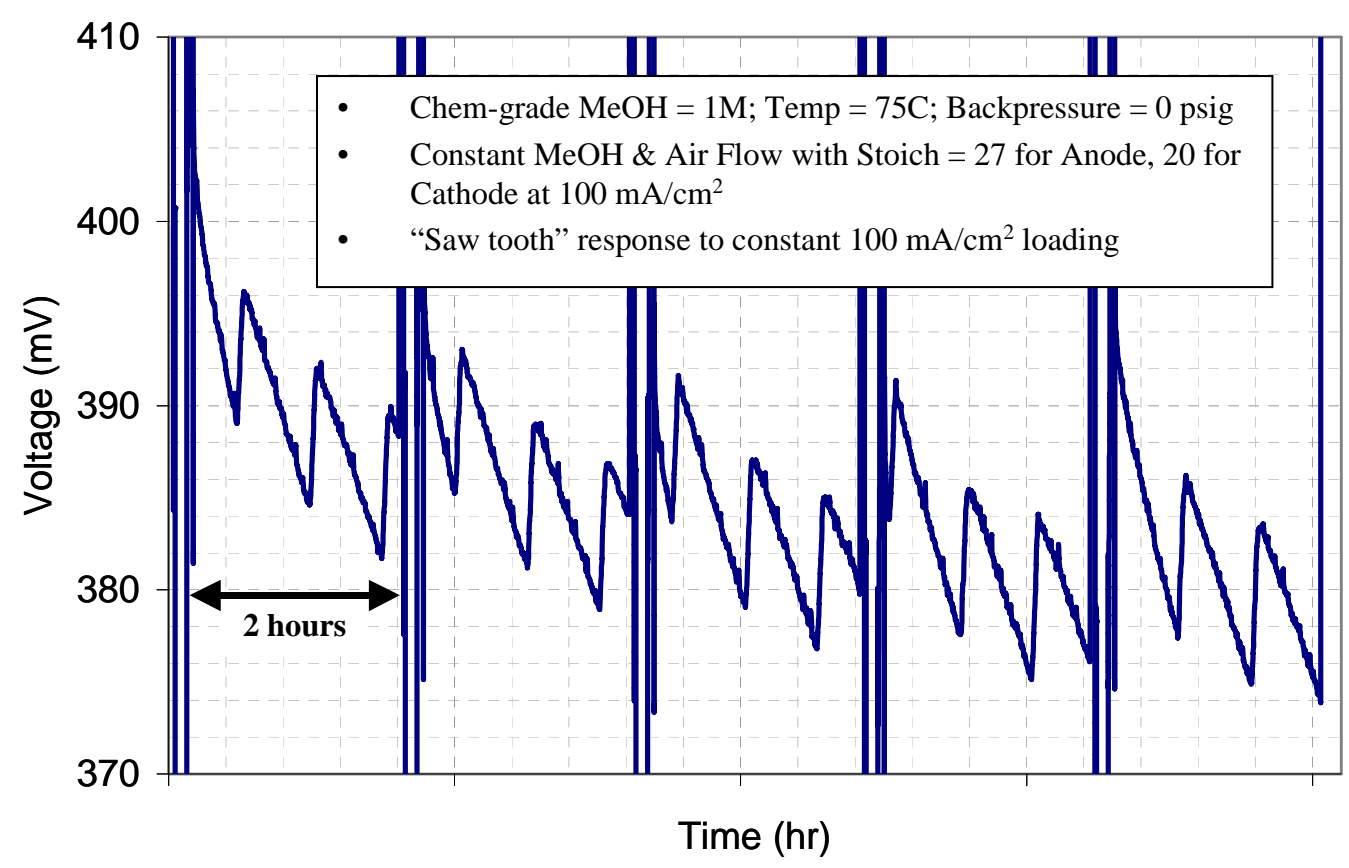

Figure 3.2.1.92 Accelerated lifetime test with chemical-grade methanol. 


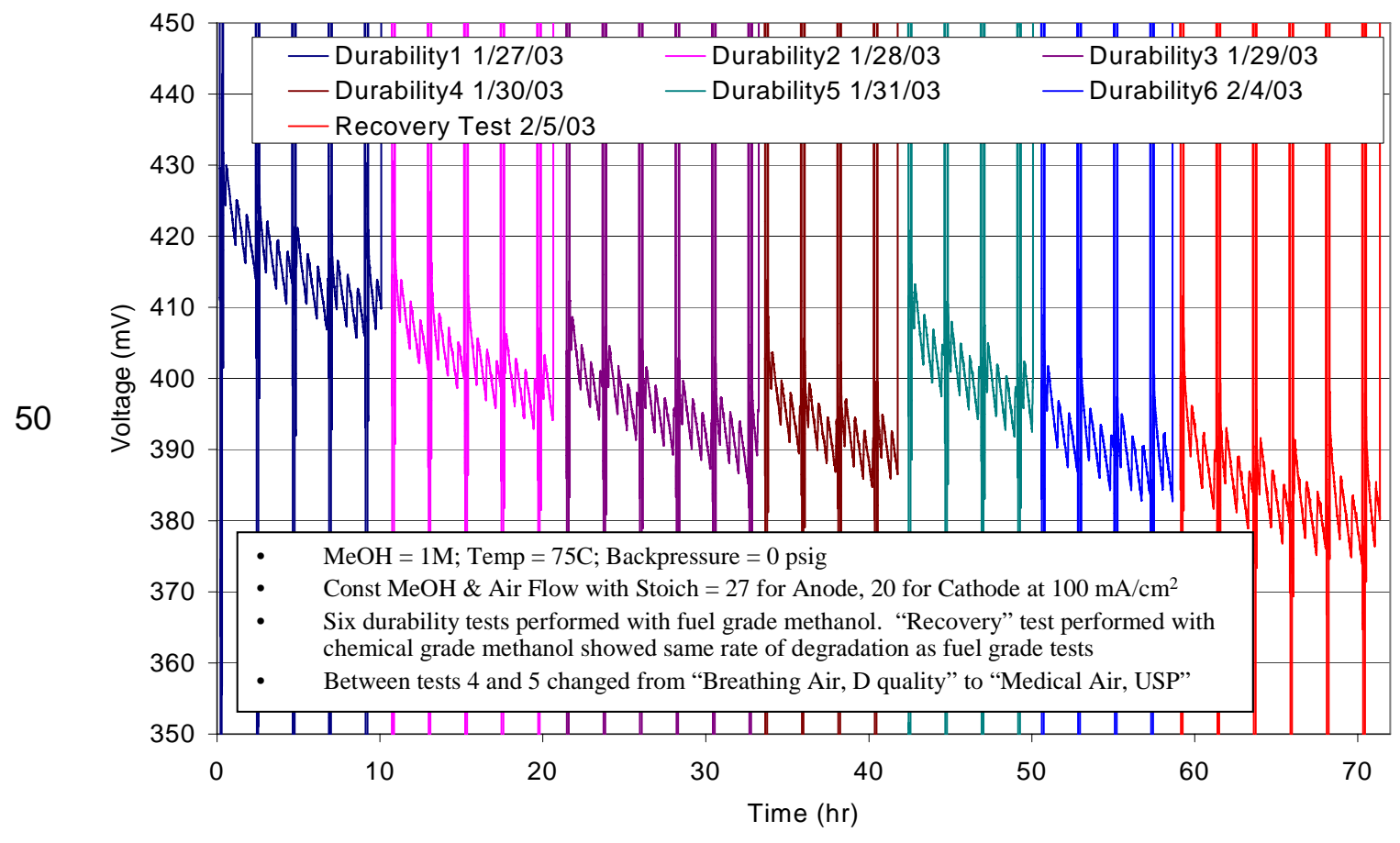

Figure 3.2.1.93 Performance degradation rate comparison. Saw tooth lines give performance under $100-\mathrm{mA} / \mathrm{cm} 2$ loading.

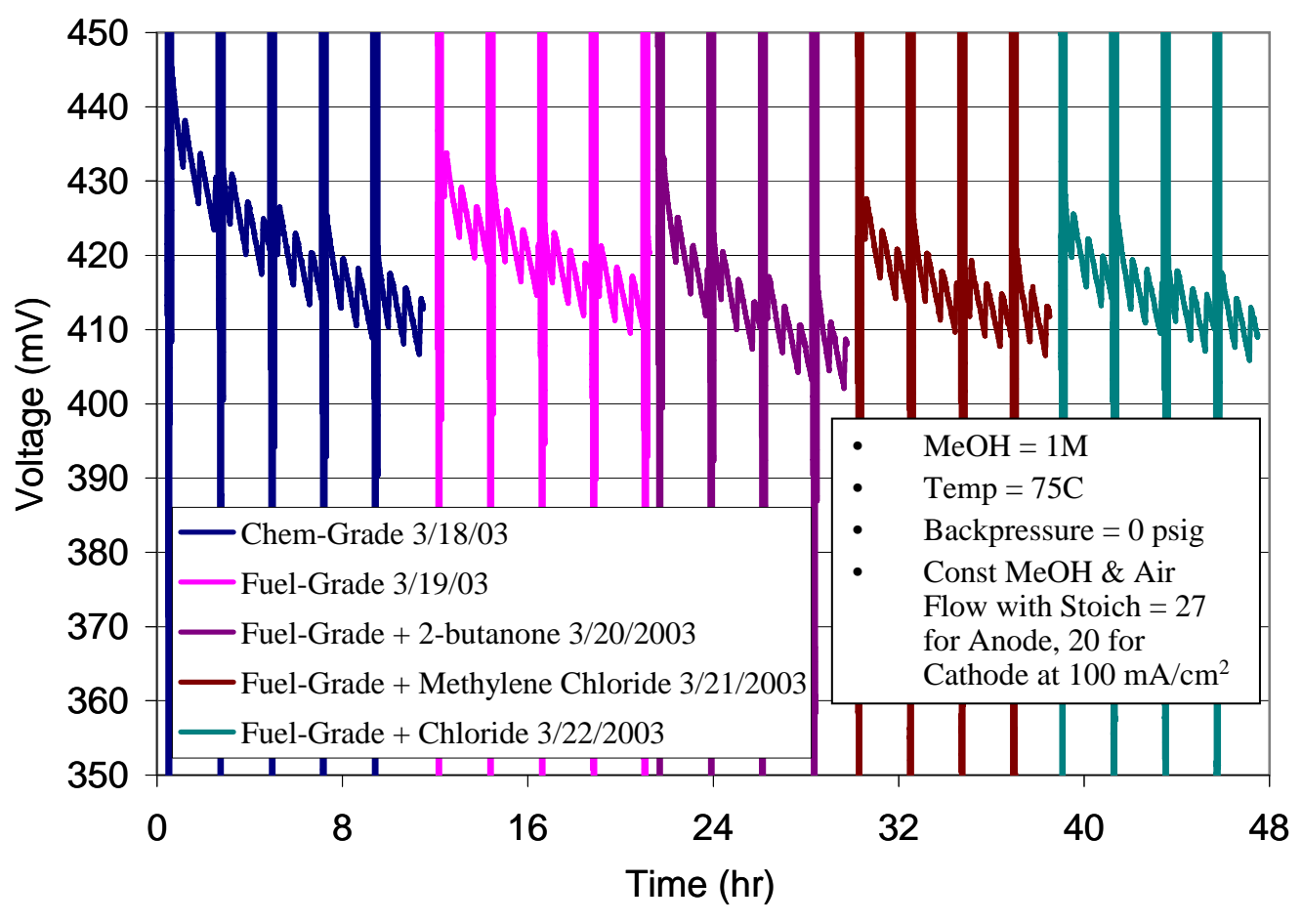

Figure 3.2.1.94 Durability testing with added contaminants. Added contaminant concentration to pure M-100 for indicated tests: 2-butanone $=450 \mathrm{ppm}$; methylene chloride $=350 \mathrm{ppm}$; chloride $=5 \mathrm{ppm}$. Saw tooth lines give performance under 100$\mathrm{mA} / \mathrm{cm} 2$ loading. 


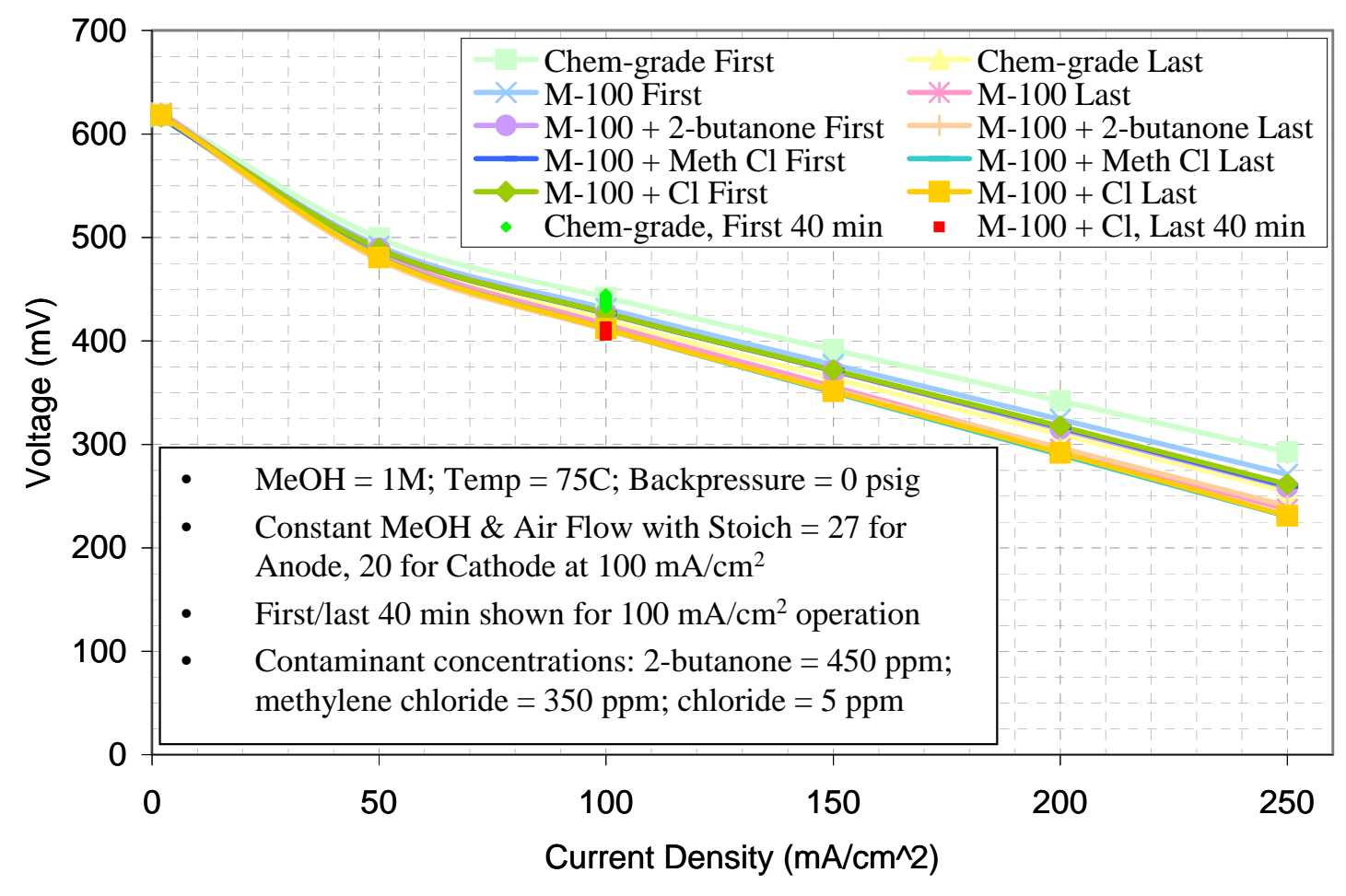

Figure 3.2.1.95 Polarization curve comparison from contaminant addition durability testing. 


\section{Subtask 3.2.1.8 - Comparison of Direct and Indirect Methanol Fuel Cell Efficiency and Optimization (24-27 months)}

\subsection{Introduction}

The development of an integrated methanol reformer and fuel cell system, as outlined in Subtask 3.2.1.4, and a direct methanol fuel cell system, as outlined in Subtask 3.2.1.5, opens up many additional possibilities. Most notably, the ability to conduct system-wide comparisons between the methanol reforming system (IDMFC) and the direct methanol fuel cell (DMFC) exists. Unlike the IDMFC, which requires a methanol reformer to generate hydrogen, the DMFC utilizes dilute liquid methanol directly in a PEM fuel cell. As noted earlier, the voltaic efficiency of current DMFC technology is very low. However, the DMFC may be preferred due to variations between IDMFC and DMFC system size, weight, complexity, and cost.

A DMFC was integrated into the same fuel cell test station as the IDMFC system (Gonder, 2003). A study comparing the efficiency of the two methods, direct and indirect use of methanol, was then undertaken using methanol as the base feedstock for both systems. Because the requirements for efficiency, size, and complexity for various applications differ greatly, the two methanol fuel cell systems were compared at three different power levels: $20 \mathrm{~W}$ for portable power, $5 \mathrm{~kW}$ for auxiliary power, and $80 \mathrm{~kW}$ for automotive applications. Considering the complexities and efficiencies of both electrochemical methods for generating power from methanol, this comparative study will determine the usefulness of both systems for all three power applications.

It is important to note that, depending on the application, the total system efficiency may include additional losses not examined here. For example, in portable applications, direct current (DC) power is desirable. However, for stationary power applications, this DC power would need to be inverted to alternating current $(A C)$, thus introducing another source of efficiency reductions. In automotive applications, the DC power would need to be translated into rotary motion (usually through the use of an inverter and electric motor), which would also introduce sources for power losses. In addition, the portable and auxiliary power calculations do not include the production efficiency of methanol, which may vary depending on the base fuel (i.e. natural gas) and the process for converting this base fuel into methanol. For modern combined reforming systems, the efficiency in converting the higher heating value of natural gas into methanol is only $72 \%$ (Allard, 2000). However, the comparison presented here is valid for determining efficient paths for conversion of methanol into DC power.

\subsection{Experimental Conditions and Methods of Comparison}

For this comparison, the DMFC was run at $75^{\circ} \mathrm{C}$ and atmospheric pressure. It utilized a 1 molar methanol solution with an anode stoichiometry of 27 and cathode stoichiometry of 20 . These conditions were found give peak performance in previous work (Gonder, 2003). The IDMFC was run at $80^{\circ} \mathrm{C}$ and $3 \mathrm{~atm}$ (30 psig) of pressure. It utilized a methanol reformer and $10 \%$ anode air injection to compensate for the $\mathrm{CO}$ poisoning effect. The cell polarization curves for both systems are shown in Figure 3.2.1.96, whereas the power density curves are shown in Figure 3.2.1.97. As shown in Figure 3.2.1.97, the DMFC system has far less peak power density per unit cell area than the IDMFC system. Thus, to generate equal quantities of power, the DMFC would need to be sized much larger. Also, the DMFC reaches its peak power a much lower cell voltage than the IDMFC.

In determining the feasibility of the two systems for different applications, cost is one factor. Although a complete cost comparison between the two systems would be extremely difficult, a platinum catalyst cost analysis is relatively easy. For this analysis, a platinum cost of $\$ 30$ per gram is utilized. The historic cost of platinum is shown in Figure 3.2.1.98 (Johnson Matthey Inc, 2004). Platinum catalyst costs for the three different applications are presented in the sections below. Additionally, for certain applications, size is an additional consideration. The IDMFC system requires the use of a reformer, which does not occupy a trivial amount of space. Finally, for automotive applications, the overall efficiency under dynamic conditions (i.e., with frequent load transients) 
becomes important. Thus, in addition to cost calculations, simulation results for the efficiency of the two different systems under automotive conditions are presented.

Portable Power ( 20W) - Portable electronics, such as cell phones and notebook computers, require a long-lasting electrical supply. These devices' power supplies put a premium on energy density and low weight. For these applications, an output of $20 \mathrm{~W}$ was chosen to cover the entire range of power supplies desired for portable electronics. Based on the DMFC and IDMFC power curves in Figure 3.2.1.97, it is possible to calculate the minimum active cell area needed to generate $20 \mathrm{~W}$. For the DMFC, with its low peak power density of $66 \mathrm{~mW} / \mathrm{cm}^{2}$, approximately $300 \mathrm{~cm}^{2}$ of active cell area would be required to generate $20 \mathrm{~W}$ of DC power. For the IDMFC, the required cell area would be roughly $35 \mathrm{~cm}^{2}$ based on a peak power density of $571 \mathrm{~mW} / \mathrm{cm}^{2}$. Despite the DMFC having a much larger cell area, the overall system is far simpler than the IDMFC. For portable power applications, the integration of a compressor, high temperature oxidative steam reformer, and air injection system in such a small space would be prohibitively difficult.

Table 3.2.1.16 shows the cost of platinum for both the DMFC and IDMFC at the 20W power level. This is based on a projected platinum cost of $\$ 30$ per gram (Figure 3.2.1.98). The costs in Table 3.2.1.16 were established using the MEA platinum loadings and peak power densities achieved in this study. As shown, the DMFC's platinum cost DMFC would be roughly $\$ 55$, as compared to a cost of $\$ 0.53$ for the IDMFC. Despite the DMFC's much higher catalyst costs, it is still desirable over the IDMFC system for portable applications. As mentioned earlier, integration of an IDMFC system at such a small scale would be extremely challenging. Although a platinum cost of $\$ 55$ for the DMFC system may appear high, it is not prohibitively high when compared to cost of current high energy density lithium ion notebook computer and portable electronics batteries.

Auxiliary Power ( $\sim 5 \mathrm{~kW})$ - Auxiliary power applications are those requiring a small, fuel efficient, and cost effective method for generating small quantities of electricity. A small internal combustion engine mated to a generator often takes up this role. By contrast with portable power applications, where the foremost concern is size and simplicity, in auxiliary power systems, energy efficiency and cost are of increasing importance. Therefore, the IDMFC and DMFC systems were compared for both cost and efficiency in converting methanol into power. As mentioned earlier, a fuel cell stack generates DC power. Unlike portable power applications, auxiliary power applications often require AC power. Thus, when comparing the efficiency numbers presented here to those of an internal combustion engine/ AC generator system, the efficiency in inverting the fuel cell's DC power to AC must be included. However, in this study, we are concerned with comparing one fuel cell system to another. Therefore, the efficiency in converting methanol to DC power will suffice.

Figure 3.2.1.99 shows the IDMFC system's power density and raw conversion efficiency. This raw conversion efficiency includes the reformer and cell efficiencies (parasitic losses are ignored). As shown, the efficiency varies depending on the cell current draw. A similar chart for the DMFC system is shown in Figure 3.2.1.100. For both the DMFC and IDMFC systems, the cell efficiencies are compared at the peak power density location along the polarization curves shown in Figures 3.2.1.99 and 3.2.1.100. These DMFC and IDMFC systems efficiencies are $1.95 \%$ and $25.90 \%$ respectively.

Table 3.2.1.17 shows the total efficiency for both systems. The "Conversion Efficiency" represents the actual measured cell power output divided by the power available in the methanol feed stream to each system. This is efficiency obtained from Figures 3.2.1.99 and 3.2.1.100. The "Current System Efficiency" listed in Table 3.2.1.17 represents the inclusion of projected parasitic losses for both systems in the efficiency calculation. As shown, the DMFC system was only 1.75\% efficient in converting methanol to electricity. This is in sharp contrast to the IDMFC system, which was 21.23\% efficient. However, looking at the breakdown of losses given in Table 3.2.1.17, it is clear that low efficiency is the result of low DMFC fuel utilization. This low fuel utilization is due the DMFC running at a high anode stoichiometry of 27 . In practical applications, the remaining methanol, not reacted in the fuel cell, would be simply re-circulated back into the system. During recirculation, a small amount of pure methanol would be added to maintain a constant concentration 
level. Therefore, a much higher practical DMFC efficiency than $1.75 \%$ is possible due to increased fuel utilization. For the IDMFC system, an anode stoichiometry of 1.5 was used. This led to an IDMFC fuel utilization efficiency of only $66.67 \%$. Like the DMFC, in practical applications, this number would be nearly $90 \%$. Thus, for both systems, a projected efficiency employing a realistic fuel utilization figure is also given at the bottom of Table 3.2.1.17. For both systems, projected efficiencies in the mid to high $20 \%$ range are easily possible. The IDMFC resulted in a slightly higher efficiency than the DMFC, with an overall effectiveness of $28.67 \%$ in converting methanol to electricity.

Mizsey and co-workers calculated a possible efficiency of $38.9 \%$ for a methanol reforming fuel cell system (Mizsey, 2001); however, these researchers assumed a high cell voltaic efficiency of $50 \%$, as opposed to $40.54 \%$ measured in this study. Mizsey et al. also estimate parasitic loses as only $13 \%$, whereas the current investigation used 18\%. Advancements in MEA technology and reduced parasitic loses can make these higher efficiency numbers reported by Mizsey et al. achievable. On the DMFC side, improvements in membrane technology can push these numbers higher as well. For the current study, it is interesting to note that the two very different systems are surprisingly close in terms of overall possible efficiency in converting methanol to electricity.

Unlike portable power applications, auxiliary power applications can afford the space necessary for IDMFC subsystems. Considering this, and the roughly equal efficiencies in generating electricity from methanol for the two systems, it appears that either would be suited for auxiliary power applications. However, the two systems vary greatly in terms of platinum costs. According to Table 3.2.1.16, $\$ 132$ of platinum is needed for the IDMFC system. However, to generate $5 \mathrm{~kW}$ of power, over $\$ 13,000$ of platinum is needed for the DMFC system. For portable power applications, high cost per unit power can be tolerated. However, as power requirements increase, the cost per unit power becomes increasing stringent. Over $\$ 13,000$ in catalysts costs alone would make a $5 \mathrm{~kW}$ DMFC auxiliary power system far too expensive. Considering this, an IDMFC is seen as favorable for auxiliary power applications despite the comparable system efficiencies.

Automotive Power ( 80kW) - Automotive power applications have many analogous constraints as portable and auxiliary power applications. Size, weight, efficiency, and cost are all of major concern. However, unlike portable power applications, size and weight constraints are far less stringent. As mentioned previously, as power levels increase, the acceptable cost per unit power generally becomes lower. Thus, at the $80 \mathrm{~kW}$ level, cost becomes an extremely important factor. In order to be competitive with the internal combustion engine, current DOE research goals set a target mass production cost of $\$ 35 / \mathrm{kW}$ for fuel cell in 2010 (U. S. DOE, 2002). Of this $\$ 35 / \mathrm{kW}$, the DOE sets a platinum loading target for hydrogen fuel cells of $0.2 \mathrm{mg} / \mathrm{cm}^{2}$, or $\$ 6 / \mathrm{kW}$ based on current precious metal prices. According to Table 3.2.1.16, the platinum cost per kilowatt is $\$ 2,727$ and $\$ 26$ for the DMFC and IDMFC systems respectively. Thus, while the current IDMFC system requires a little over a 4 fold decrease in platinum loading to be competitive, the DMFC system requires over a 450 fold decrease in catalyst loading. In terms of overall platinum cost for an $80 \mathrm{~kW}$ system, the current DMFC and IDMFC systems are estimated at \$218,182 and \$2,102 respectively, whereas DOE goals, based on $\$ 6 / \mathrm{kW}$, yield a $\$ 480$ target cost.

Despite efficiencies of $23.71 \%$ measured here, and over $30 \%$ reported in the literature (Moore, 2000 and Moore et al., 1999), the outrageously high cost of platinum for a DMFC system makes it unattractive for automotive applications. Based on this platinum cost analysis, the IDMFC has an extremely clear advantage over the DMFC system for automotive applications. However, knowing this fact does not lead to any information concerning the efficiency of an IDMFC system in automotive applications. The auxiliary power analysis results, shown in Table 3.2.1.17, illustrate the efficiency of an IDMFC system in generating steady state DC power from a methanol feedstock. However, this does not indicate the IDMFC's efficiency in automotive applications, where frequent load transients exist. Although a hybrid IDMFC/battery system could be envisioned to somewhat reduce the drive cycle load transients, and load following IDMFC system is considered here. To that end, a simulation of IDMFC performance in automotive applications at the $80 \mathrm{~kW}$ level was 
developed in a Simulink ${ }^{\circledR}$ programming environment. Simulink ${ }^{\circledR}$ was chosen because of its ability to easily and accurately model dynamic systems. The complete Simulink ${ }^{\circledR}$ model is presented in Appendix D.

Using the experimental data taken, fuel cell and reformer performance maps were integrated into Simulink ${ }^{\circledR}$. A simulated vehicle with a fuel cell engine power plant was run through a Federal Test Procedure (FTP) cycle. The specific cycle chosen was the FTP-75, which is used to measure the tailpipe emissions of light duty vehicles in the United States. This cycle, which emulates mild city driving, is approximately 11 miles long, takes just over 31 minutes complete, and has an average vehicle speed of $21.2 \mathrm{mph}$. The top speed in the cycle is $56.7 \mathrm{mph}$. The cycle's speed trace is shown in Figure 3.2.1.101. Vehicle parameters were chosen to emulate a 4 passenger sedan of approximately 4.5 meters (15 ft) in length. The vehicle was given a drag coefficient of 0.35 , a frontal area of $2 \mathrm{~m}^{2}$, a rolling resistance coefficient of 0.015 , and a weight of $2500 \mathrm{lbs}$. This weight is considered the "rolling chassis" weight, and includes the chassis, electric motors, and drivetrain, but does not include the fuel cell power plant. The 2010 DOE target for a combined fuel cell stack and fuel processing system is $325 \mathrm{~W} / \mathrm{kg}$ (U. S. DOE, 2002). Utilizing this for an 80kW (107 hp) system, the total vehicle weight arrives at $3041 \mathrm{lbs}$. At $28.4 \mathrm{lbs} / \mathrm{hp}$, this vehicle is by no means a sports car. However, it has roughly the same weight-to-power ratio as a fully charged Honda Insight Hybrid, which can complete a zero to $60 \mathrm{mph}$ run in just under 11 seconds.

All critical vehicle and fuel cell specifications are given in Table 3.2.1.18. Inverter/motor and drivetrain efficiencies were the same as those used in previous studies (Mizsey, 2001). The methanol reformer efficiency was obtained from the study outlined in section 3.2.1.4. Based on the literature, a fuel utilization efficiency of $90 \%$ and parasitic loss of $18 \%$ were assumed (Larminie et al., 2000). An upstream efficiency of $72 \%$, for generating methanol fuel from natural gas, was used for the well-to-tank efficiency analysis (Allard, 2000). The vehicle's fuel cell stack is based on the reformer fed cell performance, at 30psig, from section 3.2.1.4.

The power required to drive the FTP-75 cycle, for the simulated vehicle, is shown in Figure 3.2.1.102. As shown, just over $30 \mathrm{~kW}$ is required to maintain the city cycle's speed-time profile. Therefore, an $80 \mathrm{~kW}$ methanol reforming fuel cell power plant is of sufficient power. Figure 3.2.1.103 shows the voltage of an individual cell in the stack. As shown by the relatively shallow drops, the fuel cell power plant is sufficient in size to prevent the cell from reaching extremes of low cell voltage during this city cycle. These shallow voltage drops help in maintaining a high cell voltaic efficiency. Figure 3.2.1.104 illustrates the cell current density during the drive cycle. Knowing the cell efficiency during the drive cycle, and the additional efficiency losses outlined in Table 3.2.1.18, the instantaneous well-to-wheel efficiency can be calculated. This efficiency includes all losses incurred from initial generation of methanol from natural gas, to actually moving the vehicle through a drive cycle. This efficiency is illustrated in Figure 3.2.1.105. As shown, during the entire cycle, the efficiency varies between $20 \%$ and $24 \%$. The average cumulative efficiency, as measured from the cycle's commencement, is shown in Figure 3.2.1.106. The simulation revealed a total well-to-wheel efficiency, at the FTP-75 cycle's conclusion, of $22.3 \%$. Obviously, this is the result of the many steps involved in energy transfer: converting natural gas to methanol, reforming methanol to hydrogen, generating DC power from this hydrogen using a fuel cell, inverting DC power to AC, converting AC power to mechanical motion, and transmitting this mechanical motion down the driveline of a vehicle.

To put this well-to-wheel efficiency in perspective, Figure 3.2.1.107 is presented. The well-towheel efficiency for several different vehicle configurations, from four different studies, is presented. As illustrated, both the current study and the study of Mizsey et al. yield well-to-wheel efficiencies for the methanol reforming FCV in the low $20 \%$ range. While this is a marked improvement over the conventional gasoline internal combustion engine (ICE), it is only slightly competitive over current diesel ICE technology. Furthermore, the methanol reforming FCV is inferior to hybrid gasoline, hybrid diesel, and direct hydrogen FCV technology. In particular, the direct hydrogen hybrid FCV shows very high well-to-wheel efficiencies. It is clear from this analysis that while the IDMFC system 
shows great promise in certain applications, for automotive power, considerable improvements are essential to be competitive and cost effective against other vehicle technologies. 
Table 3.2.1.15 Operating Conditions for the DMFC and IDMFC

DMFC

Pressure

Temperature

Anode Humidification

Cathode Humidification

Anode Stoichiometry

Cathode Stoichiometry

Membrane Electrode Assembly

Total Platinum Loading

Methanol Solution

Strength

Notes:
0 psig

$75^{\circ} \mathrm{C}$

N/A

$0 \%$

27

20

Lynntech 115 with

Carbon Cloth GDL

$6 \mathrm{mg} / \mathrm{cm}^{2}$

$1 \mathrm{M}$
IDMFC

30 psig

Cell: $80^{\circ} \mathrm{C}$

Reformer: $230^{\circ} \mathrm{C}$

CO Clean-up: $150^{\circ} \mathrm{C}$

Direct from Reformer

$0 \%$

1.5

2.5

Gore MEA with Carbon Paper GDL

$0.5 \mathrm{mg} / \mathrm{cm}^{2}$

$15.2 \mathrm{M}$

Requires an air supply to reformer and 10\% anode air injection 
Table 3.2.1.16 Cost comparison for both systems various power levels

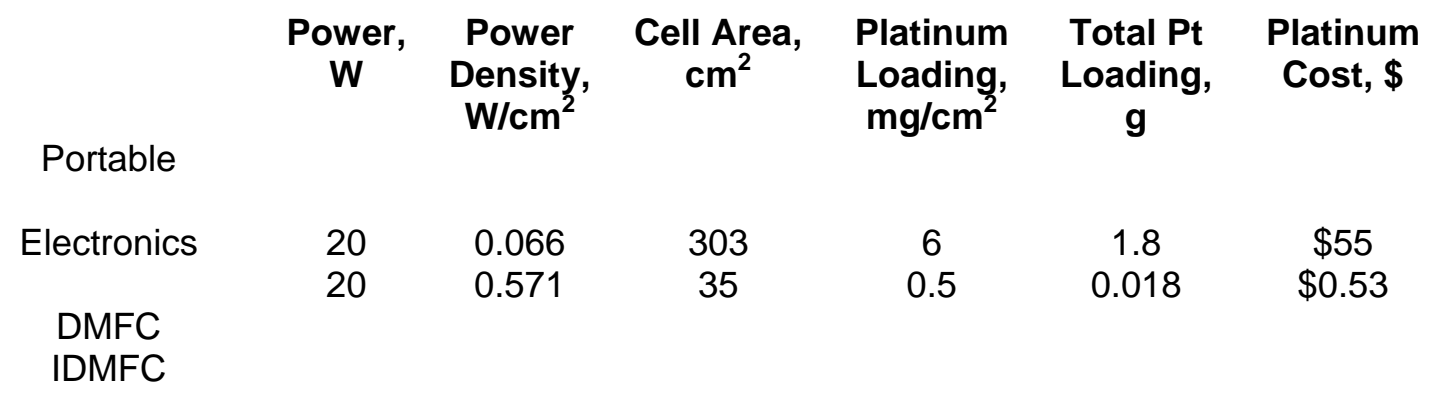

Auxiliary Power

$\begin{array}{ccccccc}\text { DMFC } & 5,000 & 0.066 & 75,758 & 6 & 454.5 & \$ 13,636 \\ \text { IDMFC } & 5,000 & 0.571 & 8,757 & 0.5 & 4.4 & \$ 131\end{array}$

$\begin{array}{ccccccc}\text { Automotive } & 80,000 & 0.066 & 1,212,121 & 6 & 7,273 & \$ 218,182 \\ \text { DMFC } & 80,000 & 0.571 & 140,105 & 0.5 & 70 & \$ 2,102 \\ \text { IDMFC } & & & & & & \\ & & & & & & \\ & & & & & & \\ \text { Per } \boldsymbol{k W} & 1,000 & 0.066 & 15,152 & 6 & 91 & \$ 2,727 \\ \text { DMFC } & 1,000 & 0.571 & 1,751 & 0.5 & 0.88 & \$ 26 \\ \text { IDMFC } & & & & & & \end{array}$

*Based on a platinum cost of $\$ 30$ per gram. 
Table 3.2.1.17 System efficiency comparisons: Methanol to DC Electric Power

DMFC IDMFC

Methanol Feed

Methanol Feed

Total Peak Cell Power

Conversion Efficiency

Current System Efficiency

(including projected parasitic losses)

Efficiency Breakdown:

Cell Voltaic Efficiency

Fuel Utilization

Reformer Efficiency

Parasitic Efficiency

\section{Possible System Efficiency}

(assuming $\mathrm{MeOH}$ fuel recirculation for the DMFC, and $90 \%$ utilization for the IDMFC)

$\begin{array}{cc}0.566 \mathrm{ml} / \mathrm{min} & 0.369 \mathrm{ml} / \mathrm{min} \\ 169.3 \mathrm{~W} & 110 \mathrm{~W} \\ 3.3 \mathrm{~W} & 28.6 \mathrm{~W} \\ & \\ 1.95 \% & 25.90 \% \\ & \\ 1.75 \% & 21.23 \% \\ & \\ 26.35 & \\ 7.4 \% & 40.54 \% \\ \text { N/A } & 66.67 \% \\ 90.0 \% & 95.83 \% \\ & 82.0 \%\end{array}$

$23.71 \%$

$28.67 \%$ 
Table 3.2.1.18 Vehicle specifications for IDMFC automobile

$\begin{array}{ll}\text { Vehicle mass } & 1382 \mathrm{~kg} \\ \text { Frontal Area } & 1.5 \mathrm{~m}^{2} \\ \text { Coefficient of Drag } & 0.35 \\ \text { Rolling Resistance } & 0.015 \\ \text { Fuel Cell Stack } & \\ \quad \text { Number of Cells } & 350 \\ \quad \text { Active Area per Cell } & 400 \mathrm{~cm}^{2} \\ \text { Pressure } & 30 \mathrm{psig} \\ \text { Anode Air Injection } & 10 \% \\ \quad \text { Peak Power Density } & 0.571 \mathrm{~W} / \mathrm{cm}^{2} \\ \text { Gross Peak Power } & 80 \mathrm{~kW} \\ \text { Reformer Efficiency } & 95.8 \% \\ \text { Drivetrain Efficiency } & 83.6 \% \\ \text { Inverter/Motor Efficiency } & 92 \% \\ \text { Fuel Utilization } & 90 \% \\ \text { Parasitic Losses } & 18 \% \\ \text { Well-to-Tank Efficiency } & 72 \%\end{array}$




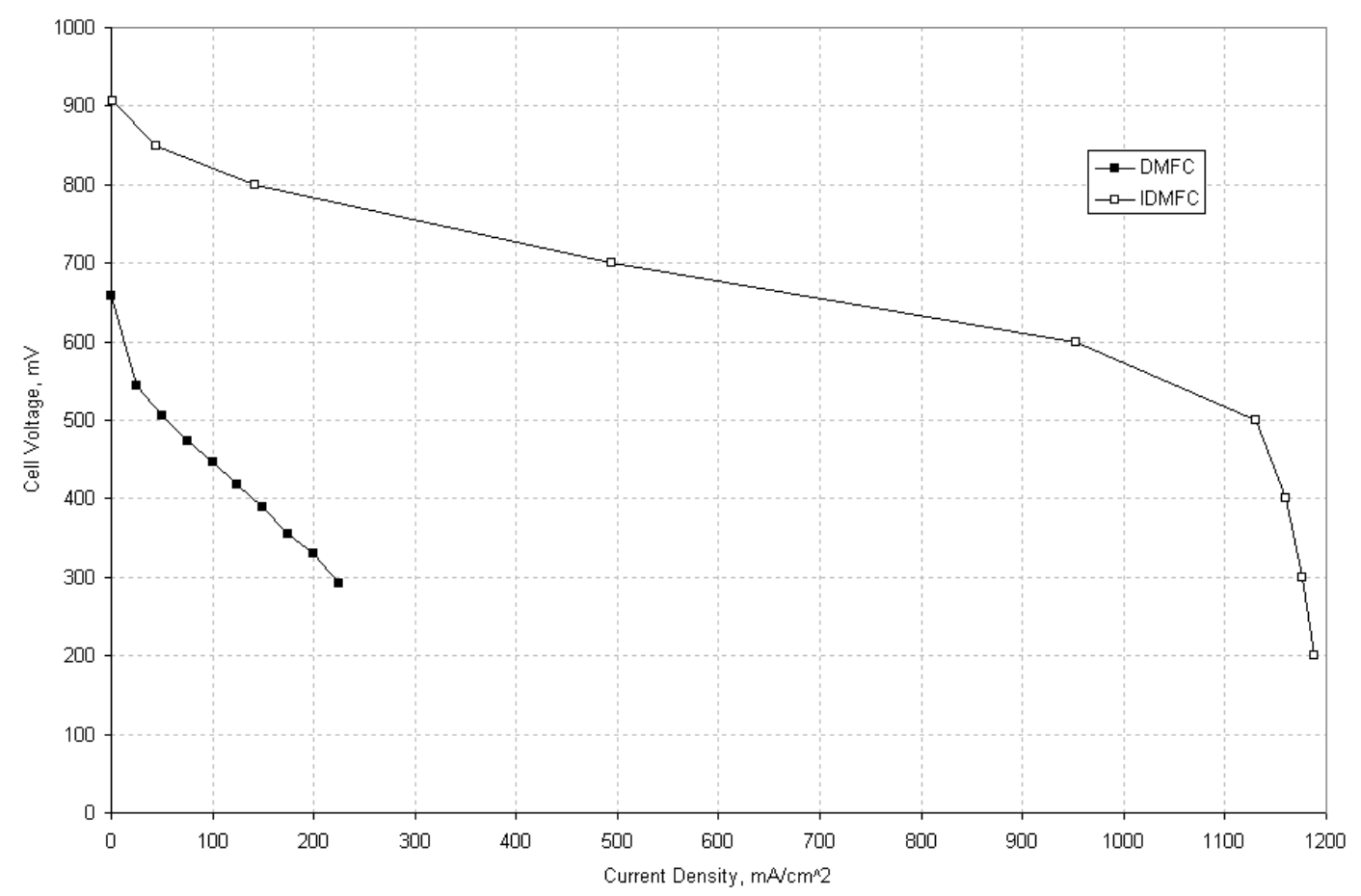

Figure 3.2.1.96 Comparison of the cell polarization curves for the direct (DMFC) and indirect (IDMFC) fuel cell systems

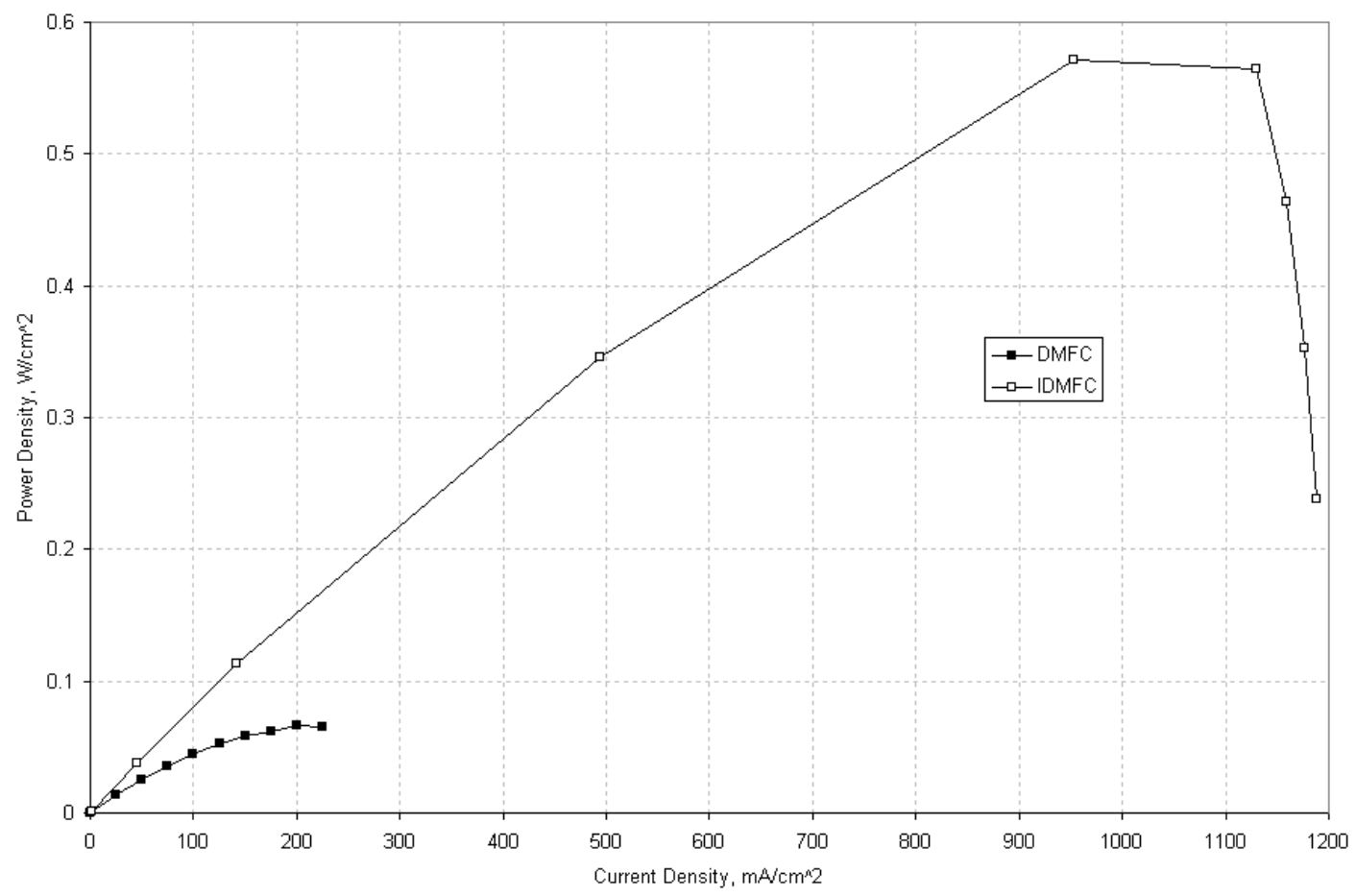

Figure 3.2.1.97 Comparison of the cell power density curves for the direct (DMFC) and indirect (IDMFC) fuel cell systems. 


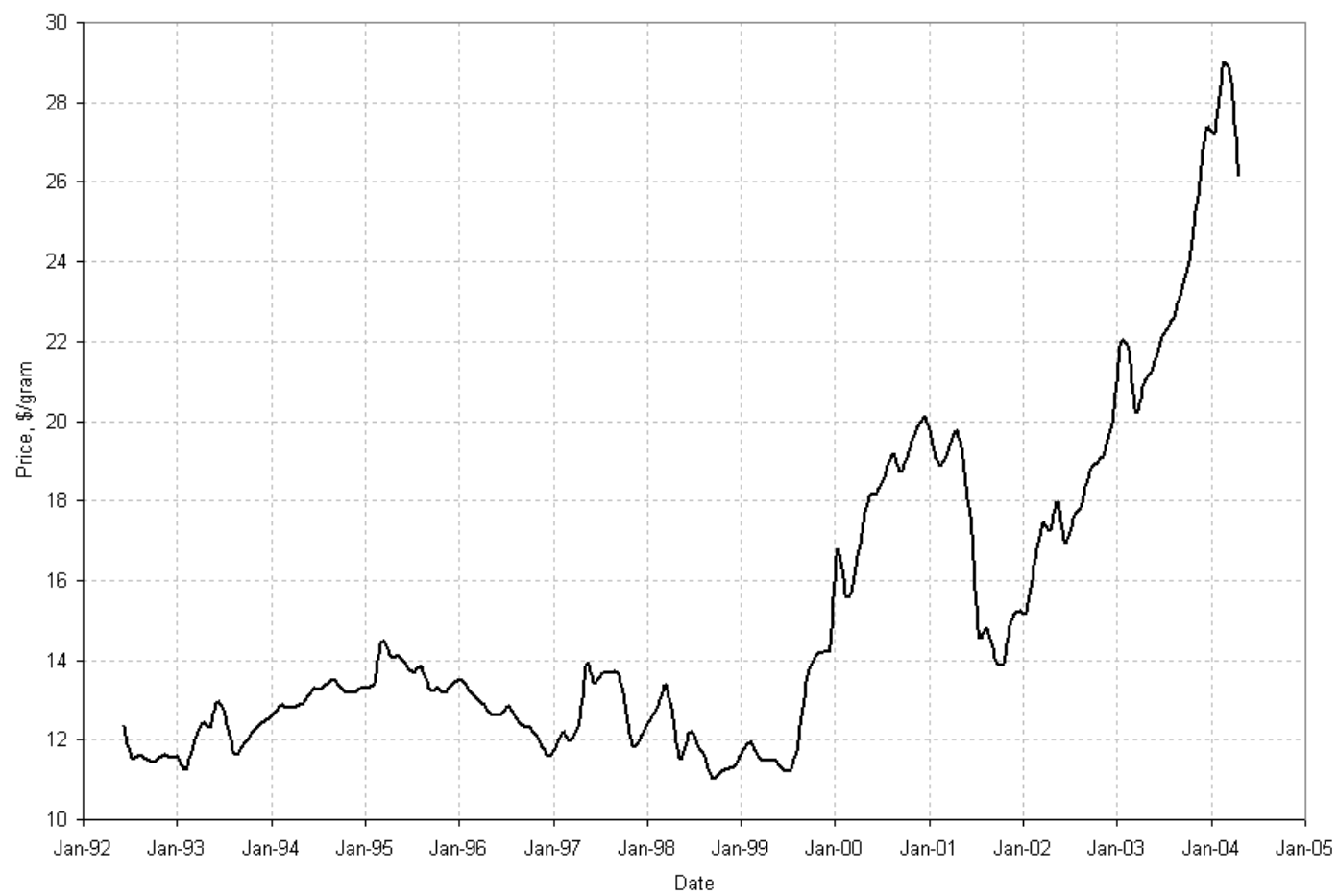

Figure 3.2.1.98 Historic cost of platinum

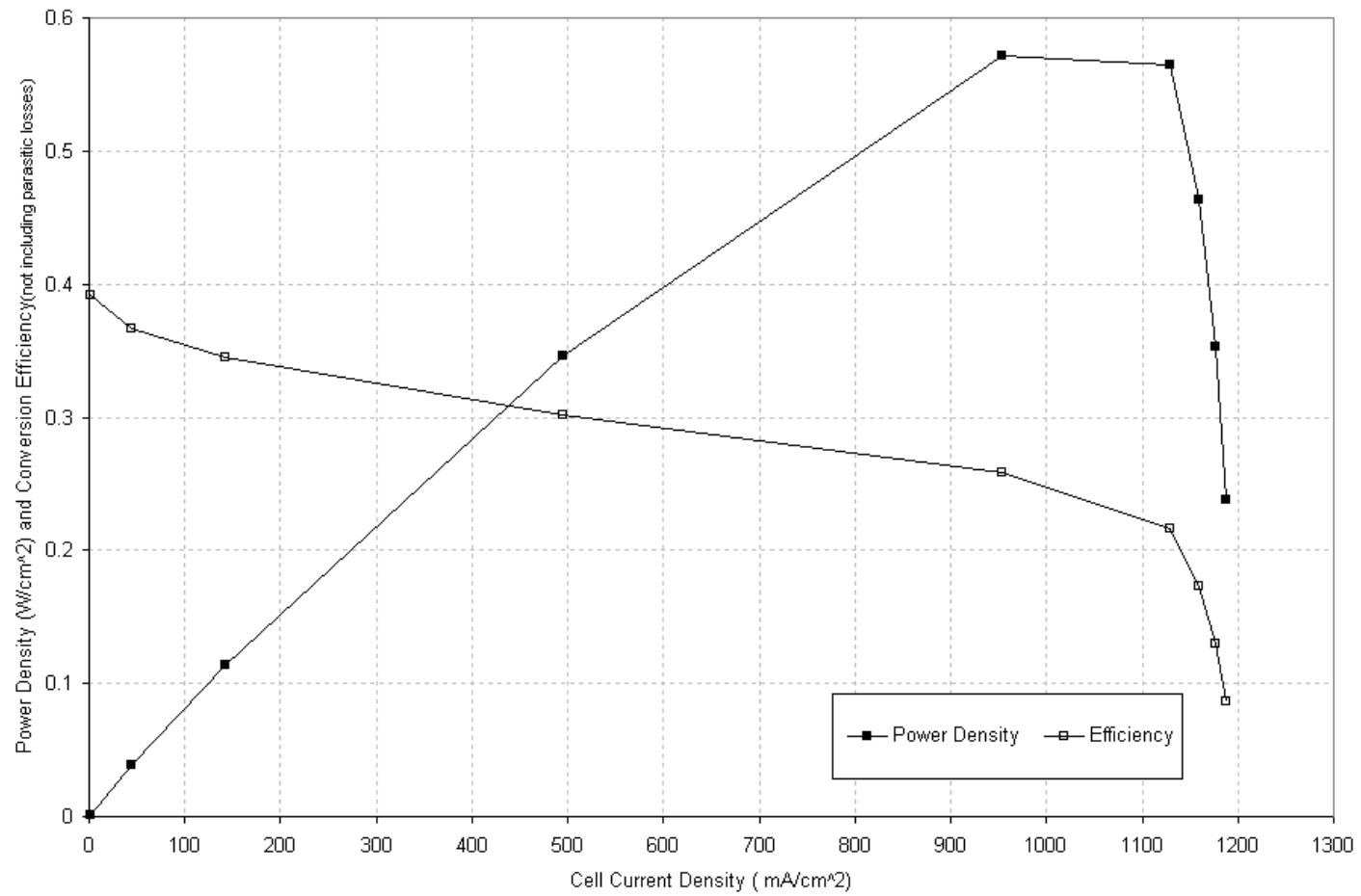

Figure 3.2.1.99 Power density and efficiency (not including parasitic losses) for the indirect methanol fuel cell system (IDMFC) across the entire polarization curve 


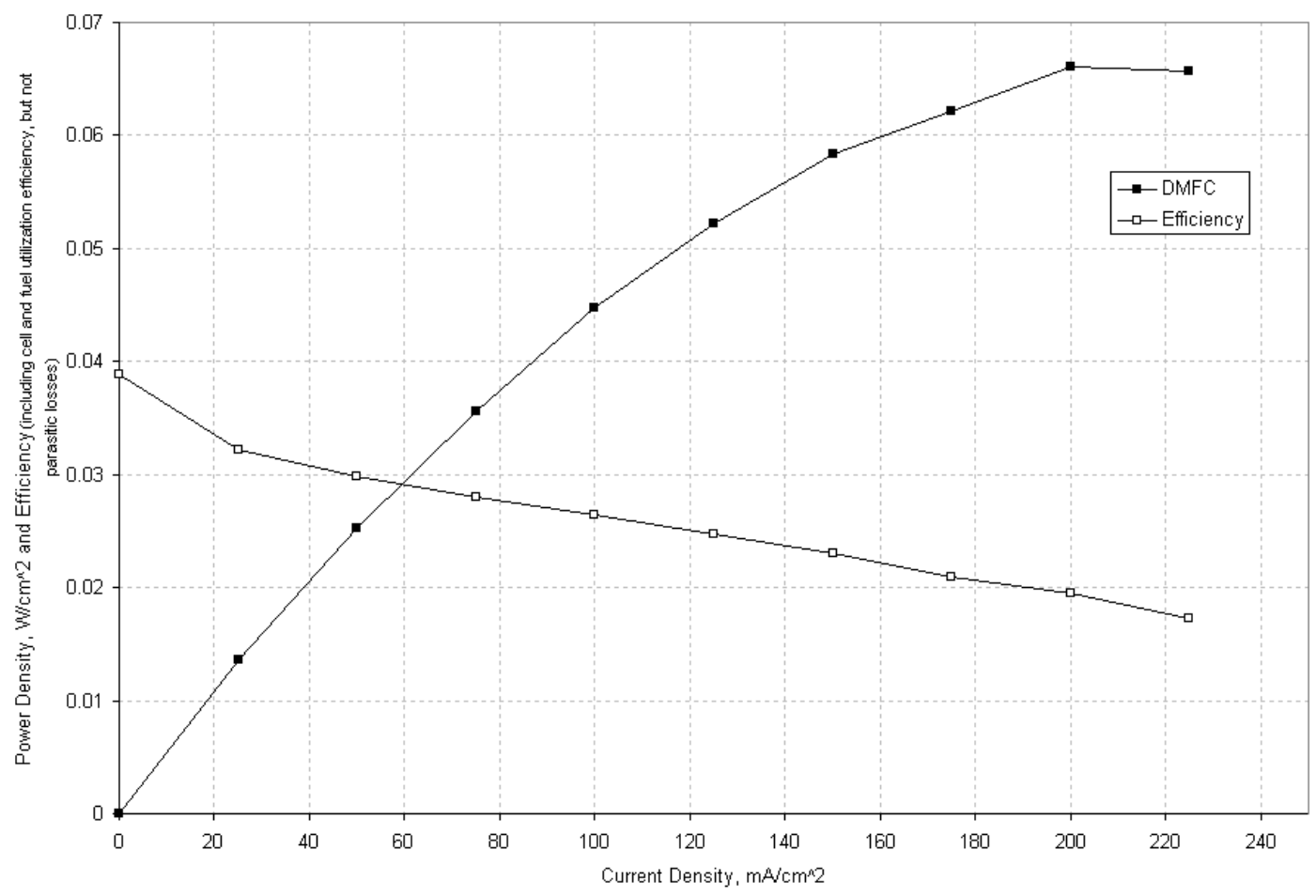

Figure 3.2.1.100 Power density and efficiency (not including parasitic losses) for the direct methanol fuel cell system (DMFC) across the entire polarization curve

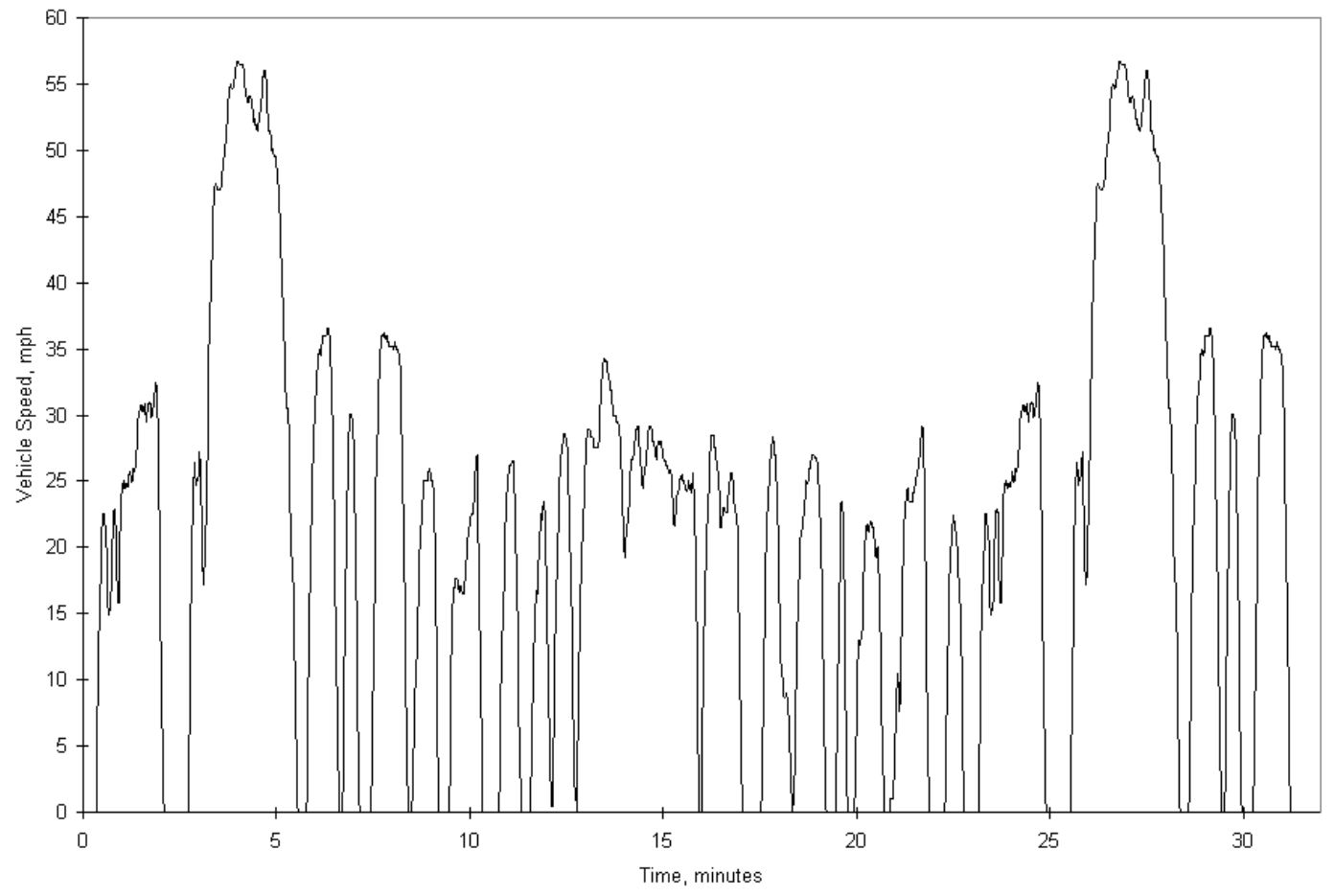

Figure 3.2.1.101 FTP-75 Driving Cycle 


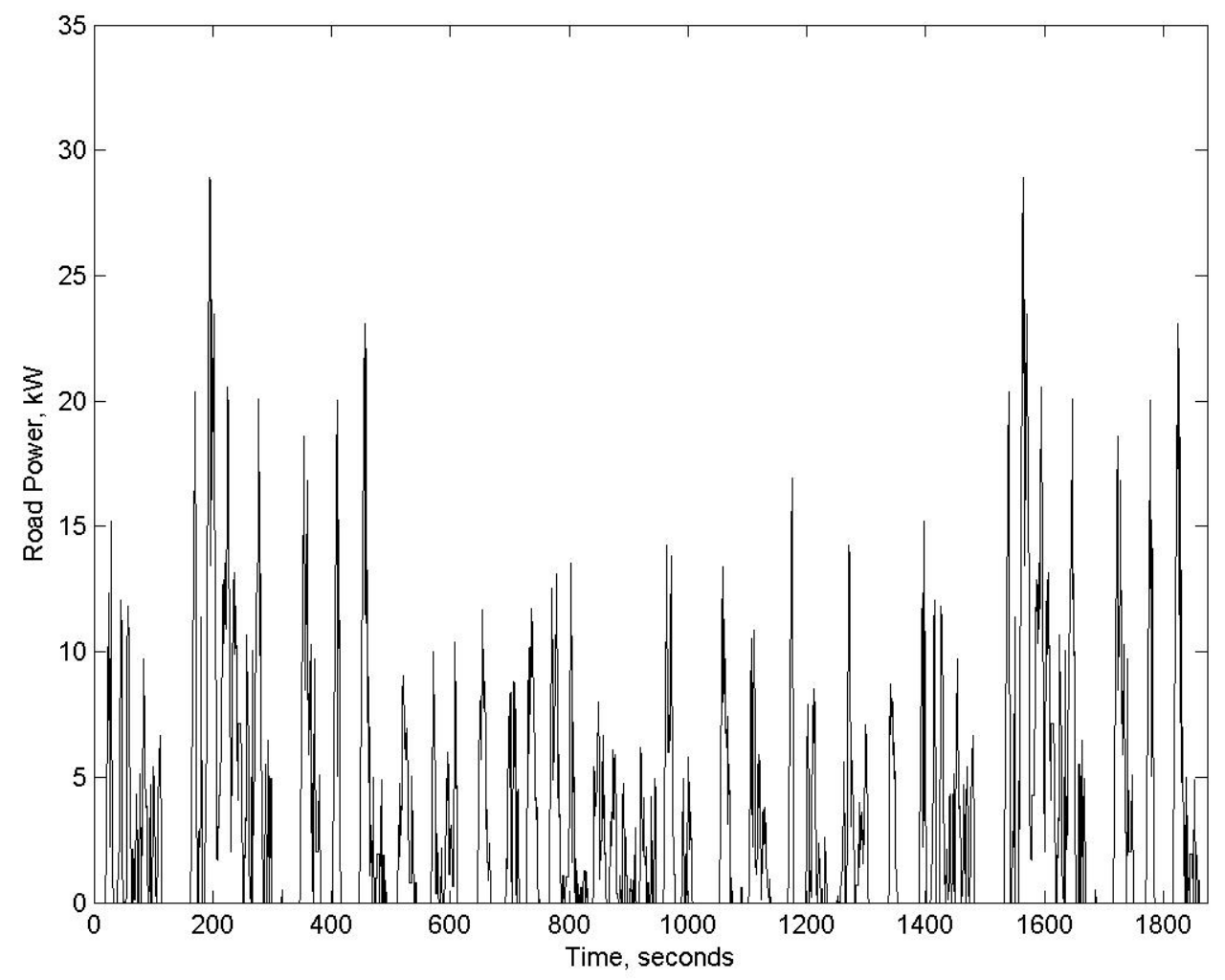

Figure 3.2.1.102 Vehicle power requirements during the FTP-75 driving cycle

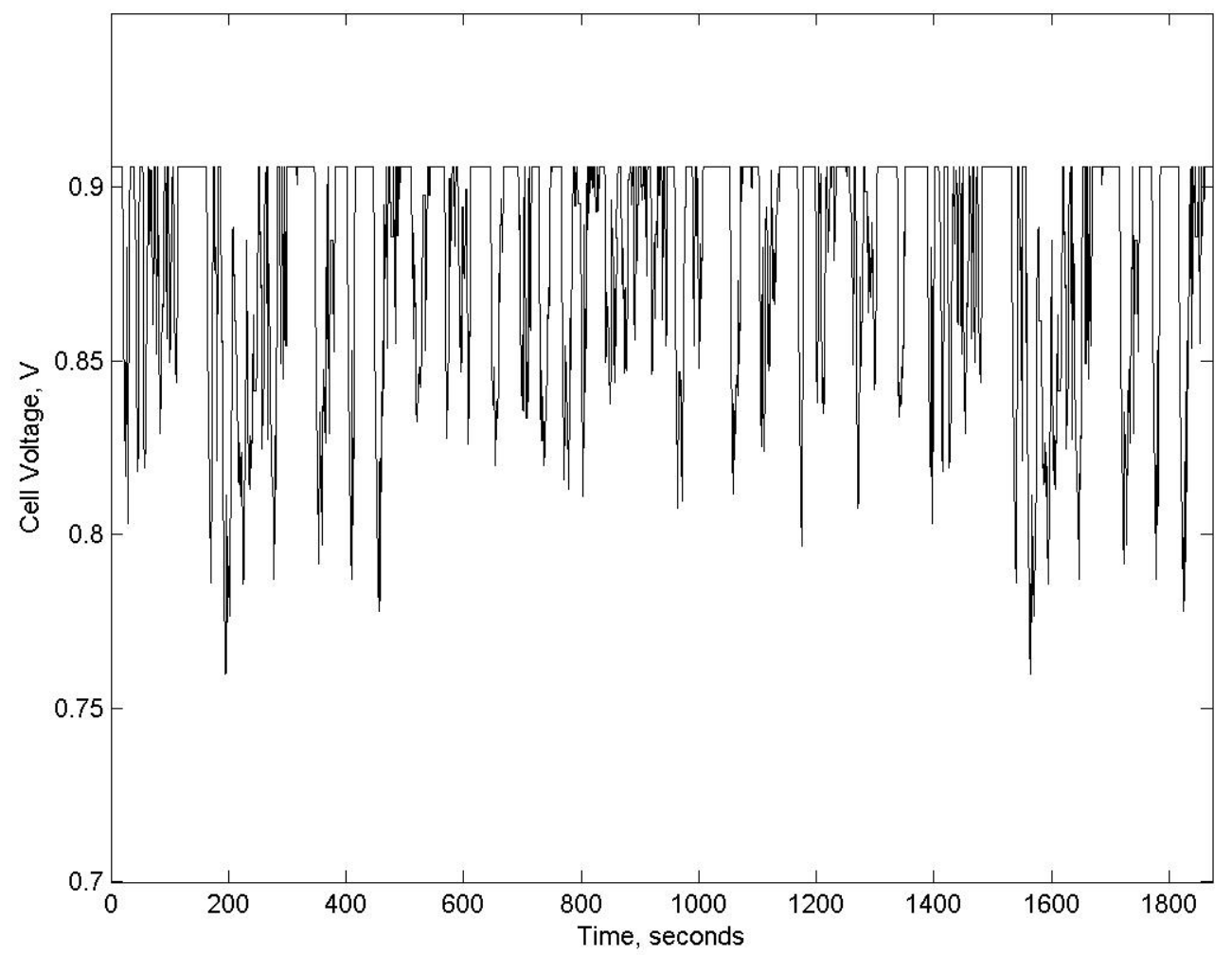

Figure 3.2.1.103 Cell voltage during drive cycle 


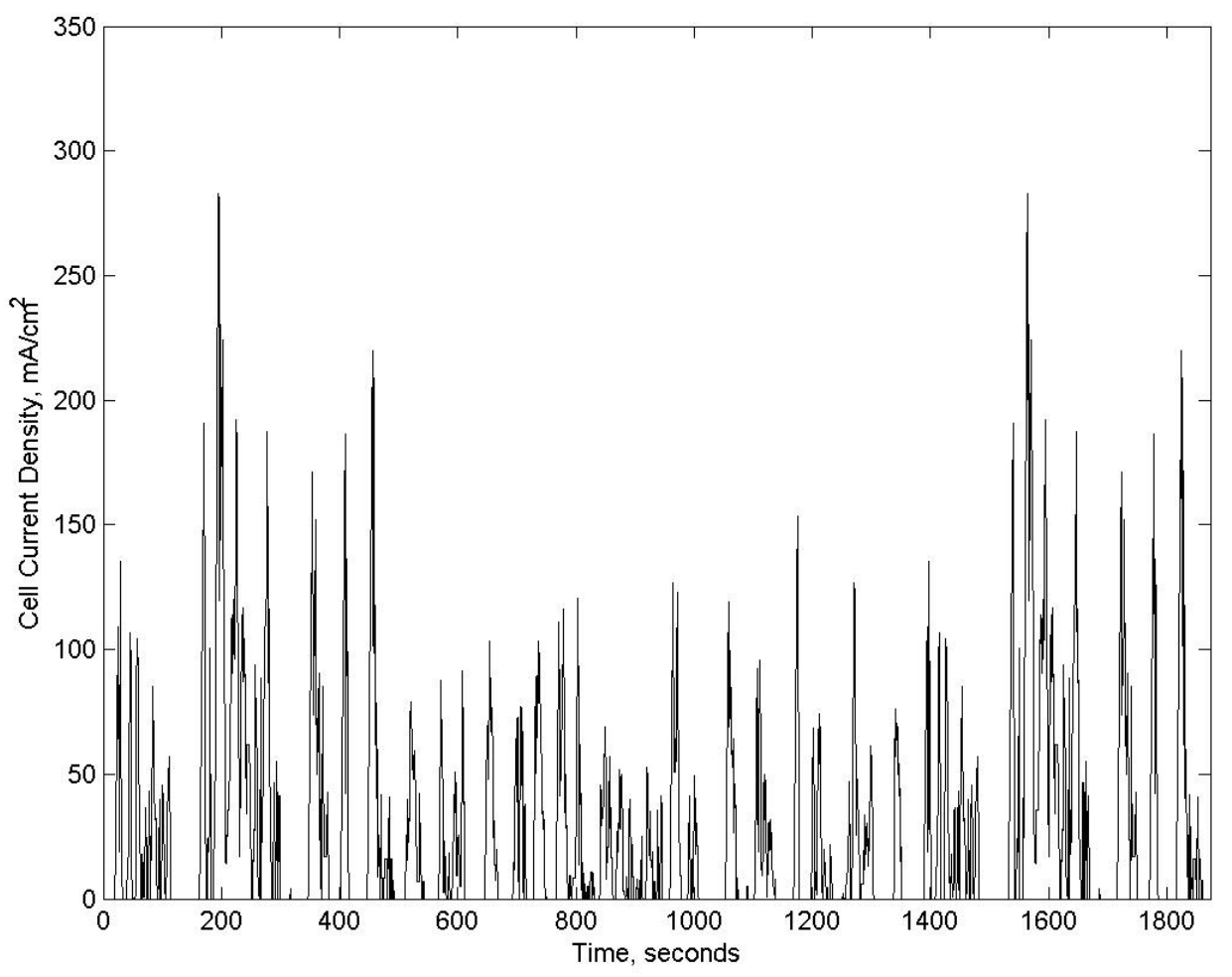

Figure 3.2.1.104 Cell current density during drive cycle

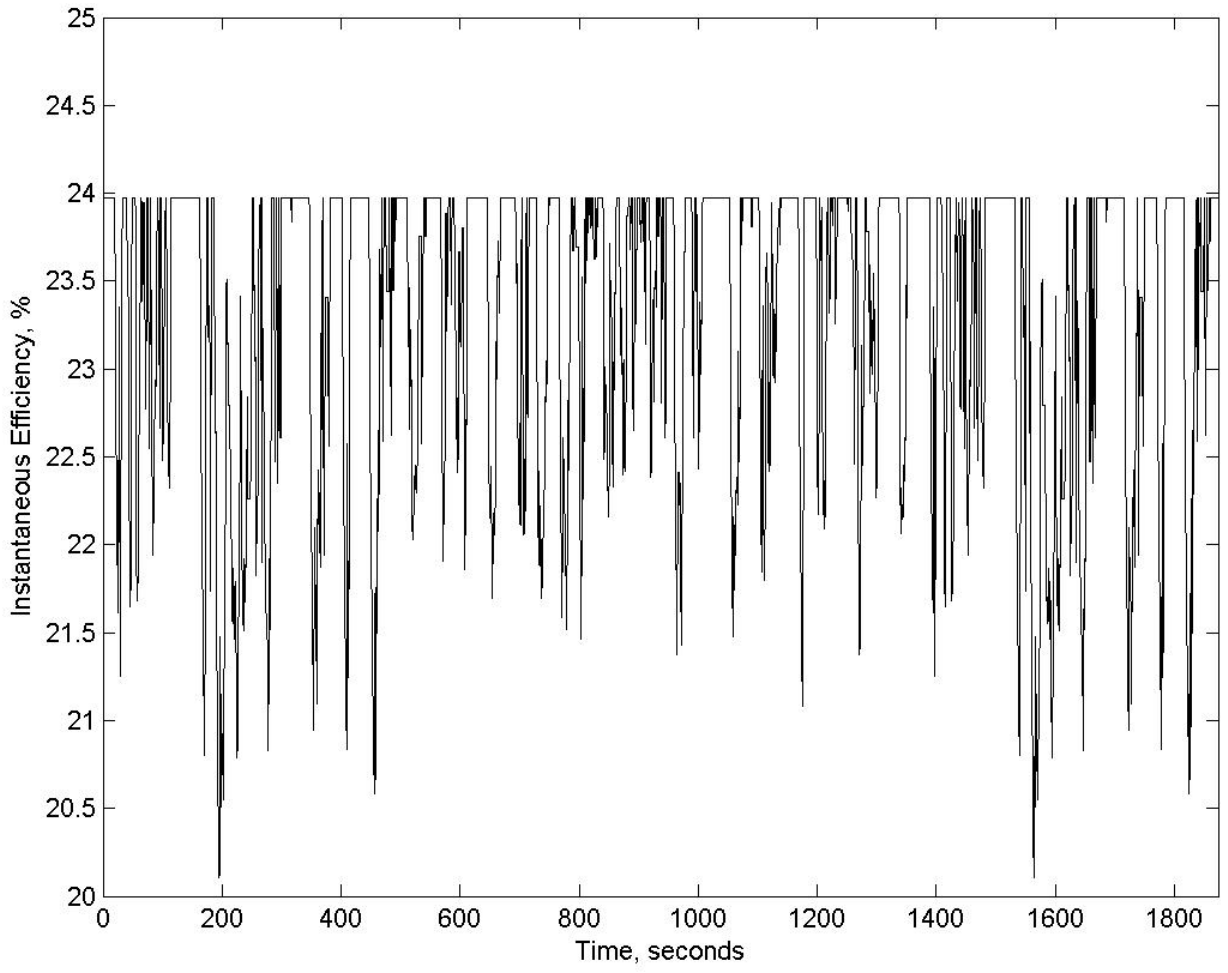

Figure 3.2.1.105 Instantaneous well-to-wheel efficiency during drive cycle 


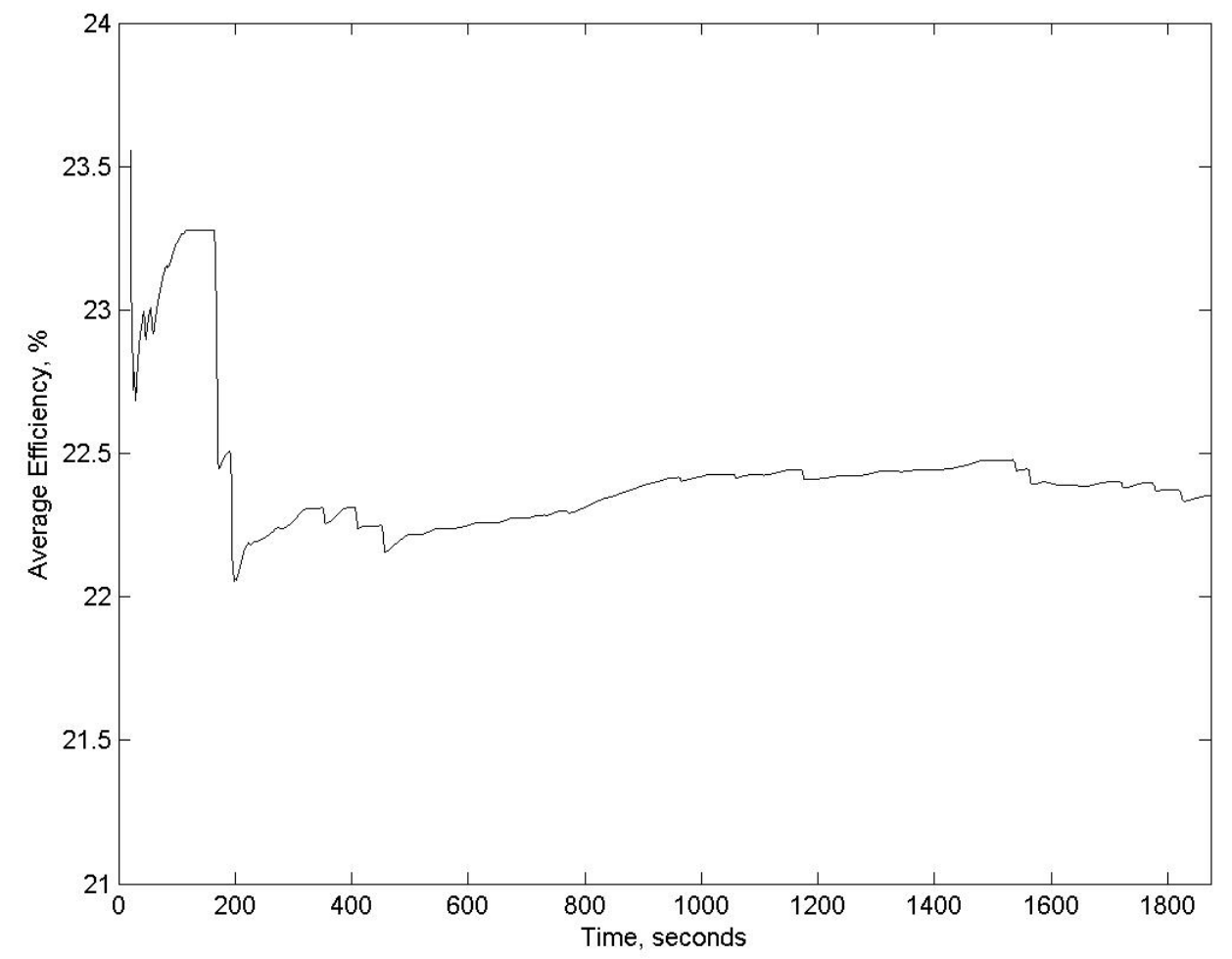

Figure 3.2.1.106 Cumulative well-to-wheel efficiency during drive cycle

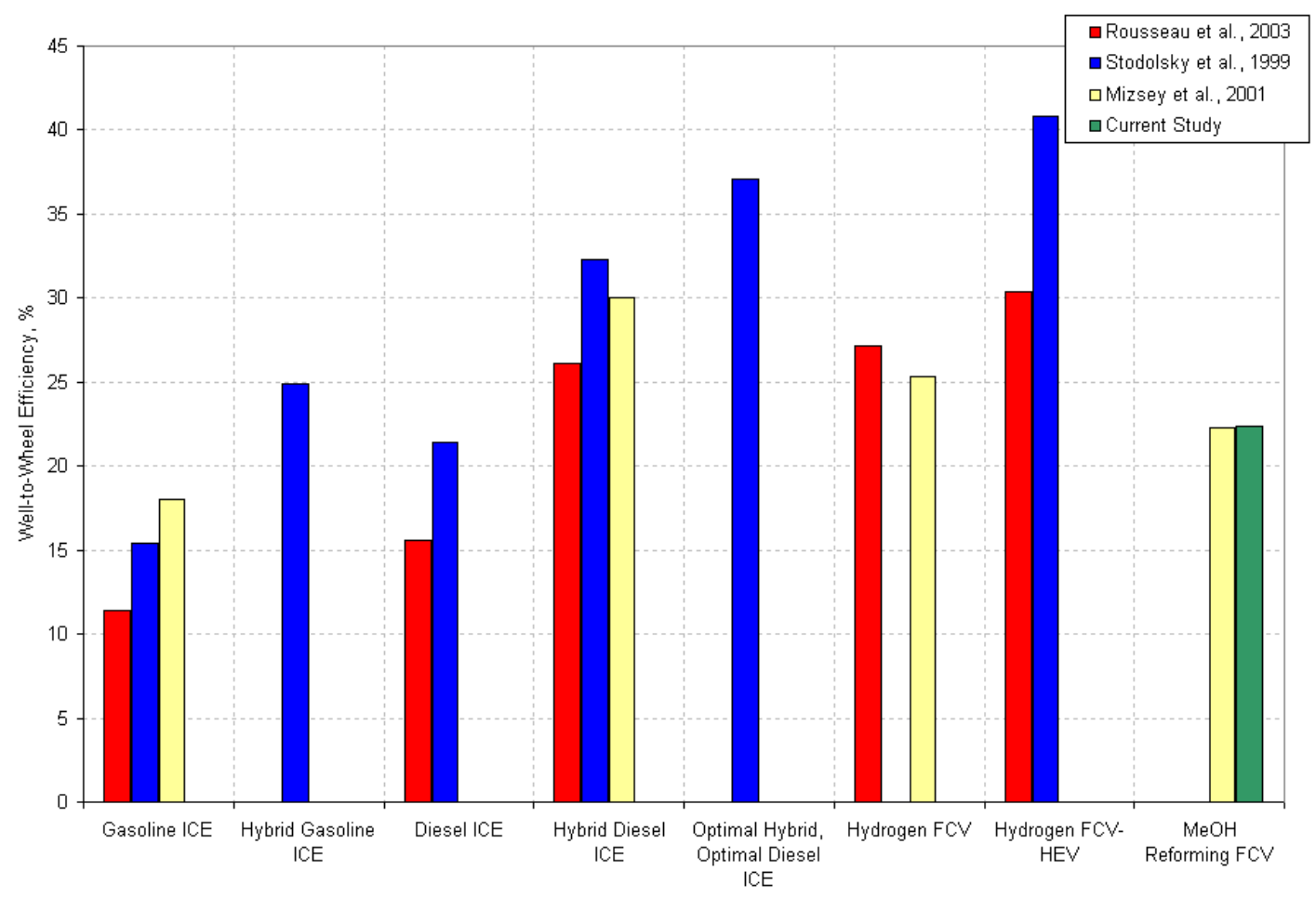

Figure 3.2.1.107 Comparison of well-to-wheel efficiencies from various studies 


\subsubsection{References}

1. D. M. Bernardi and M. W. Verbrugge, J. Electrochem. Soc., 139 (1992) 2477-2491.

2. T. E. Springer, T. A. Zawodinski, and S. Gottesfeld, J. Electrochem. Soc., 136 (1991) 23342341.

3. T. E. Springer, M. S. Wilson, and S. Gottesfeld, J. Electrochem. Soc., 140 (1993) 3513-3527.

4. T. F. Fuller and J. Newman, J. Electrochem. Soc., 140 (1993) 1218-1225.

5. T. V. Nguyen and R. E. White, J. Electrochem. Soc., 140 (1993) 2178-2187.

6. T. Berning, D. M. Lu, and N. Djilali, J. Power Sources, 106 (2002) 284-294.

7. S. Dutta, S. Shimpalee, and J.W. Van Zee, J. Appl. Electrochem., 30 (2000) 135-146.

8. S. Dutta, S. Shimpalee, and J.W. Van Zee, Int. J. of Heat and Mass Transfer, 44 (2001) 20292042.

9. S. Um, C. Y. Wang, and K. S. Chen, J. Electrochem. Soc., 147 (2000) 4485-4493.

10. S. Um and C. Y. Wang, in Proc. of the ASME Heat Transfer Division, Orlando, FL. 1 (2000) 19.

11. S. Um and C. Y. Wang, J. of Power Sources, 125 (2004) 40-51.

12. H. Meng and C. Y. Wang, 2004, Chemical Engineering Science, in press.

13. H. Meng and C. Y. Wang, J. Electrochem. Soc., 151 (2004) A358- A367.

14. S. V. Patankar, Numerical Heat Transfer and Fluid Flow, Hemisphere Publishing Corp., New York, 1980.

15. S. Motupally, A. J. Becker, and J. W. Weidner, J. Electrochem. Soc., 147 (2000) 3171-3177.

16. T. A. Zawodzinski, J. Davey, J. Valerio, and S. Gottesfeld, Electrochim. Acta, 40 (1995) 297302.

17. A. C. West and T. F. Fuller, J. of Applied Electrochemistry, 26 (1996) 557.

18. R. B. Bird, W. E. Stewart, and E. N. Lightfood, Transport Phenomena, John Wiley \& Sons, New York, 1960.

19. F. P. Incropera and D. P. DeWitt, Fundamentals of Heat and Mass Transfer, John Wiley \& Sons, New York, 1996.

20. J.C. Amphlett, R.F. Mann, B.A. Peppley, P.R. Roberge, and A. Rodrigues, J. Power Sources, 61 (1996) 183.

21. J.C. Amphlett, E.H.de Olivera, R.F. Mann, P.R. Roberge, A. Rodrigues, and J.P. Salvador, J. Power Sources, 65 (1997) 173.

22. M. Ceraolo, C. Miulli, and A. Pozio, J. Power Sources, 113 (2003) 131.

23. I.J. Ong and J. Newman, J. Electrochem. Soc.,146 (12) (1999) 4360.

24. R.I. Issa, J.Comp. Phys., 62 (1986) 40.

25. J. Larminie and A. Dicks, Fuel Cell Systems Explained, John Wiley \&Sons, LTD, Chichester, England, (2000)

26. M. J. Moran and H. N. Shapiro, Fundamentals of Engineering thermodynamics, John Wiley \& Sons, Inc, New York, (1999).

27. S. F. Baxter, V. S. Battaglia and R. E. White, "Methanol fuel cell model: anode", Journal of electrochemical Society, 146, 437 (1999). 
28. A. A. Kulikovsky, J. Divisek and A. A. Kornyshev, "Two-dimensional simulation of direct methanol fuel cell -- a new (embedded) type of current collector", Journal of the Electrochemical Society, 147, 953 (2000).

29. A. A. Kulikovsky, "Two-dimensional numerical modeling of a direct methanol fuel cell", Journal of Applied Electrochemistry, 30, 1005 (2000).

30. K. Scott, P. Argyropoulos and K. Sundmacher, "A model for the liquid feed direct methanol fuel cell", Journal of Electroanalytical Chemistry, 477, 97 (1999).

31. P. Argyropoulos, K. Scott and W. M. Taama, "Hydrodynamic modeling of direct methanol liquid feed fuel cell stacks", Journal of Applied Electrochemistry, 30, 899 (2000).

32. Z. H. Wang, C. Y. Wang and K. S. Chen, "Two-phase flow and transport in the air cathode of proton exchange membrane fuel cells", Journal of Power Sources, 94, 40 (2001).

33. C. Y. Wang and P. Cheng, Advances in Heat Transfer, 30, 93 (1997).

34. Z. H. Wang and C. Y. Wang, "Mathematical modeling of liquid-feed direct methanol fuel cells", Journal of Electrochemical Society, 150, A508 (2003).

35. P. Argyropoulos, K. Scott and W. M. Taama, "Dynamic response of the direct methanol fuel cell under variable load conditions", Journal of Power Sources, 87, 153, (2000).

36. A. Simoglou, P. Argyropoulos, E. B. Martin, K. Scott, A. J. Morris and W. M. Taama, "Dynamic modeling of the voltage response of direct methanol fuel cells and stacks Part I: Model development and validation", Chemical Engineering Science, 56, 6761, (2001).

37. A. Simoglou, P. Argyropoulos, E. B. Martin, K. Scott, A. J. Morris and W. M. Taama, "Dynamic modeling of the voltage response of direct methanol fuel cells and stacks Part II: Feasibility study of model-based scale-up and scale-down", Chemical Engineering Science, 56, 6773, (2001).

38. K. Sundmacher, T. Schulta, S. Zhou, K. Scott, M. Ginkel and E. D. Gilles, "Dynamics of the direct methanol fuel cell (DMFC): experiments and model-based analysis", Chemical Engineering Science, 56, 333, (2001).

39. S. V. Patankar, Numerical Heat Transfer and Fluid Flow, Hemisphere, Washington D.C., (1980).

40. J. D. Gonder, "Direct methanol fuel cells for automotive applications: experimental analysis of transient characteristics, periodic fuel injection and fuel quality requirements", Master Thesis, Penn State Univeristy, (2003).

41. Johnson Matthey Inc., http://www.platinum.matthey.com/, 2004.

42. Mizsey, P., Newson, E., 2001, Comparison of different vehicle power trains, Journal of Power Sources, 102, 205.

43. Moore, R., Direct Methanol Fuel Cells for Automotive Power Systems, Society of Automotive Engineers, 2000-01-0012.

44. Moore, R., Gottesfeld, S., Zelenay, P., A Comparison Between Direct-Methanol and DirectHydrogen Fuel Cell Vehicles, Society of Automotive Engineers, 1999-01-2914.

45. Rousseau, A., Ahluwahlia, R., Deville, B., Zhang, Q., Well-to-Wheels Analysis of Advanced SUV Fuel Cell Vehicles, Society of Automotive Engineers, 2003-01-0415.

46. Stodolsky, F., Gains, L., Marshall, C., An, F., Eberhardt, J., 1999, Total Fuel Cycle Impacts of Advanced Vehicles, Society of Automotive Engineers, 1999-01-0322.

47. U.S. Department of Energy, 2002 Annual Progress Report, Hydrogen, Fuel Cells, and Infrastructure Technologies Program, Office of Transportation Technology, 2002. 


\section{Subtask 3.2 Indirect and Direct Methanol Fuel Cell Testing}

Subtask 3.2.2 Methanol Reformer 


\section{Subtask 3.2.2 - Methanol Reformer}

\section{Subtask 3.2.2.1 - Catalyst Review and Selection for Screening, Configuration of Reactor for Catalyst Studies (0-6 months)}

\subsection{Introduction}

The production of hydrogen-rich gas from methanol is a catalytic reaction process. The catalysts used in the converting play a critical role. In order to prepare the basic and necessary experimental approach for the next step, in this subtask, the objectives are to search the catalyst and set up the reactor system.

\subsection{Catalyst Review}

Because the project management excludes exploratory catalyst formulation and testing with laboratory-prepared catalysts in UCF project, the commercial catalysts searching is only way to get available catalysts for the next step.

The methanol reforming reactions are reversible reactions. Therefore, the commercially available catalysts that are designed for water-gas-shift reactions in stationary plants and that are designed for methanol synthesis can also used for methanol steam reforming. The following Table 3.2.2.1 lists the commercial catalysts used for methanol reforming and water gas shift reaction.

Table 3.2.2.1 Commercial catalysts used for methanol reforming

\begin{tabular}{|c|c|c|}
\hline Supplier & Catalyst ID & Memo \\
\hline ICI Katalco & $\begin{array}{l}\text { 83-3 } \\
\text { Low temp shift for } \\
\text { process gas from } \\
\text { high-temp shift }\end{array}$ & $\begin{array}{c}\mathrm{Cu}, \mathrm{Zn}, \mathrm{Al}_{2} \mathrm{O}_{3} \\
\text { For } \mathrm{CO} \text { conv to produce } \mathrm{CO} \text {-free gas } \\
\text { Pellet form, } 84-87 \mathrm{lbs} / \mathrm{cu} \mathrm{ft} \text {. }\end{array}$ \\
\hline ICI Katalco & $\begin{array}{c}83-5 \\
\text { Interim temp CO shift } \\
\text { conv }\end{array}$ & $\begin{array}{c}\mathrm{Cu}, \mathrm{Zn}, \mathrm{Al}_{2} \mathrm{O}_{3} \\
\text { For } \mathrm{CO} \text { conv to produce } \mathrm{CO} \text {-free gas } \\
\text { Pellet form, } 81 \mathrm{lbs} / \mathrm{cu} \mathrm{ft} \text {. }\end{array}$ \\
\hline United Catalysts & $\begin{array}{c}\text { C18 HC } \\
\text { Low-temp shift conv }\end{array}$ & $\begin{array}{l}\text { Cu-based } \\
\text { For CO conv of process gas } \\
\text { Tablet form, } 80-85 \mathrm{lbs} / \mathrm{cu} \mathrm{ft} \text {. }\end{array}$ \\
\hline United Catalysts & $\begin{array}{c}\text { C18 HCS } \\
\text { Low-temp shift conv }\end{array}$ & $\begin{array}{l}\text { Cu-based } \\
\text { For CO conv of process gas } \\
\text { Tablet form, } 75-80 \mathrm{lbs} / \mathrm{cu} \mathrm{ft} \text {. }\end{array}$ \\
\hline United Catalyst Inc. & T-2650, LTS & Cu-based \\
\hline Sud-Chemie, Inc & $\begin{array}{c}\text { C14-2-01, C14-4GG, } \\
\text { DAN }\end{array}$ & Cu-based [?] \\
\hline Sud-Chemie, Inc & C18-7-01, C18G & Cu-based \\
\hline Sud-Chemie, Inc & C18 HA & Cu-based \\
\hline Sud-Chemie, Inc & C18 HAlm & Cu-based \\
\hline $\begin{array}{l}\text { NexTech Materials } \\
\text { Inc. }\end{array}$ & $\mathrm{Pt} / \mathrm{CeO}_{2}$ & $\begin{array}{c}\mathrm{Pt} / \mathrm{CeO}_{2} \\
\text { For WGS, non-pyrophoric; } \\
\text { Could be used for wash-coating }\end{array}$ \\
\hline
\end{tabular}




\begin{tabular}{|c|c|c|}
\hline Synetix & KATALCO 51-2 & $\mathrm{CuO}: \mathrm{Al}_{2} \mathrm{O}_{3}: \mathrm{ZnO}[62: 13: 25]$ \\
\hline Synetix & KATALCO51-7 & $\mathrm{CuO}: \mathrm{Al}_{2} \mathrm{O}_{3}: \mathrm{ZnO}: \mathrm{MgO}[62: 11: 26: 1]$ \\
\hline Synetix & KATALCO51-8 & $\mathrm{CuO}: \mathrm{Al}_{2} \mathrm{O}_{3}: \mathrm{ZnO}: \mathrm{MgO}[64: 10: 24: 2]$ \\
\hline Haldor Topsoe & $\begin{array}{l}\text { LK-821-2 } \\
\text { Low temp CO conv, } \\
\text { sulfur resistant+high } \\
\text { act., long life }\end{array}$ & $\begin{array}{l}\mathrm{Cu}, \mathrm{Zn}, \mathrm{Al} \text { Oxide } \\
\text { For CO conv of high-temp shift effluent, } \\
\text { containing } 0.1-0.3 \% \mathrm{CO} \text { gas. } \\
\text { Cylindrical form, } 62 \mathrm{lbs} / \mathrm{cu} \mathrm{ft} .\end{array}$ \\
\hline Haldor Topsoe & $\begin{array}{l}\text { LSK } \\
\text { Low temp shift } \\
\text { [chlorine guard } \\
\text { catalyst?] }\end{array}$ & $\begin{array}{l}\mathrm{Cu}, \mathrm{Zn}, \mathrm{Cr} \text { Oxide } \\
\text { For CO conv of high-temp shift effluent, } \\
\text { containing } 0.1-0.3 \% \mathrm{CO} \text { gas. } \\
\text { Cylindrical form, } 62 \mathrm{lbs} / \mathrm{cu} \mathrm{ft} .\end{array}$ \\
\hline BASF & K3-110, KM-10 & $\mathrm{CuO}: \mathrm{Al}_{2} \mathrm{O}_{3}: \mathrm{ZnO}[40: 40: 20]$ \\
\hline Exxon Chemical & $\mathrm{N} / \mathrm{A}$ & Zn/Ca/Si-Al [US Pat. 6,057,261] \\
\hline Haldor Topsoe & $\mathrm{N} / \mathrm{A}$ & Cu-based \\
\hline $\begin{array}{l}\text { NexTech Materials } \\
\text { Inc }\end{array}$ & TMC-1, TMC-2 & Carbide-based catalyst \\
\hline
\end{tabular}

\subsection{Catalysts Selected for Testing in UCF Project}

Cu-based catalysts:

- Synetix

- Sud-Chemie

- Sud-Chemie

- Sud-Chemie
83-3

C18-7-01

C18HA

C18HALM
$\mathrm{Cu}-\mathrm{ZnO}-\mathrm{Al} 2 \mathrm{O} 3$

$\mathrm{Cu}-\mathrm{ZnO}-\mathrm{Al} 2 \mathrm{O} 3$

$\mathrm{Cu}-\mathrm{ZnO}-\mathrm{Al} 2 \mathrm{O} 3$

$\mathrm{Cu}-\mathrm{ZnO}-\mathrm{Al} 2 \mathrm{O} 3$

Noble metal catalysts:

- Pressure Chemical Co. Pt/Al2O3 catalysts (5 wt\% Pt)

- Engelhard

$\mathrm{Pt} / \mathrm{Al} 2 \mathrm{O} 3$ catalysts $(1 \mathrm{wt} \% \mathrm{Pt}, 0.5 \mathrm{wt} \% \mathrm{Pt})$

\subsection{Configuration of Reactor}

A continuous fixed-bed flow reactor was set up for catalyst studies. A details of the reactor system is described later.

\subsection{CO-clean-up of reformed methanol}

When testing the reformed methanol fuel, it is necessary to decrease the carbon monoxide content in the exit gas. One reason for this necessary decrease in $\mathrm{CO}$ output is that it has been found that as the CO concentration increase, so do the voltage losses in the fuel cell[Springer et al., 2001] even at values as low as 10-100 ppm. This effect can be seen in Figure 3.2.2.1. The presence of $\mathrm{CO}$ in the feed gas causes irreversible poisoning of the catalyst in the electrodes [Larminie and Dicks, 2000], which will not only contribute to cell voltage losses, but also limit the life of the fuel cell.

In order to reduce the CO content in the feed gas to a tolerable level (less than $10 \mathrm{ppm}$ ), it is necessary to find a more active and more effective catalyst [Song, 2002]. Two reactions that 
contribute to CO clean-up and need improved catalysts are the water-gas-shift (WGS) ${ }^{1}$ and preferential oxidation $(\mathrm{PrOx})^{2}$ reactions. These reactions are represented in equations 3.2.2.1 and 3.2.2.2, respectively. While the oxygen-assisted WGS reaction is the combination of these two reactions, listed in equation 3.2.2.3.

$$
\begin{aligned}
& \mathrm{CO}+\mathrm{H}_{2} \mathrm{O} \rightarrow \mathrm{CO}_{2}+\mathrm{H}_{2} \\
& \mathrm{CO}+1 / 2 \mathrm{O}_{2} \rightarrow \mathrm{CO}_{2} \\
& 2 \mathrm{CO}+\mathrm{H}_{2} \mathrm{O}+1 / 2 \mathrm{O}_{2} \rightarrow 2 \mathrm{CO}_{2}+\mathrm{H}_{2}
\end{aligned}
$$

The objective of the present investigation was to test commercial catalysts for high activity for the low temperature Oxygen-assisted WGS reaction for on-board fuel cell applications. This is to help reduce the steps needed for $\mathrm{CO}$ conversion, thus reducing the space requirement and cost of the fuel cell system, as seen in Figure 3.2.2.2 below.

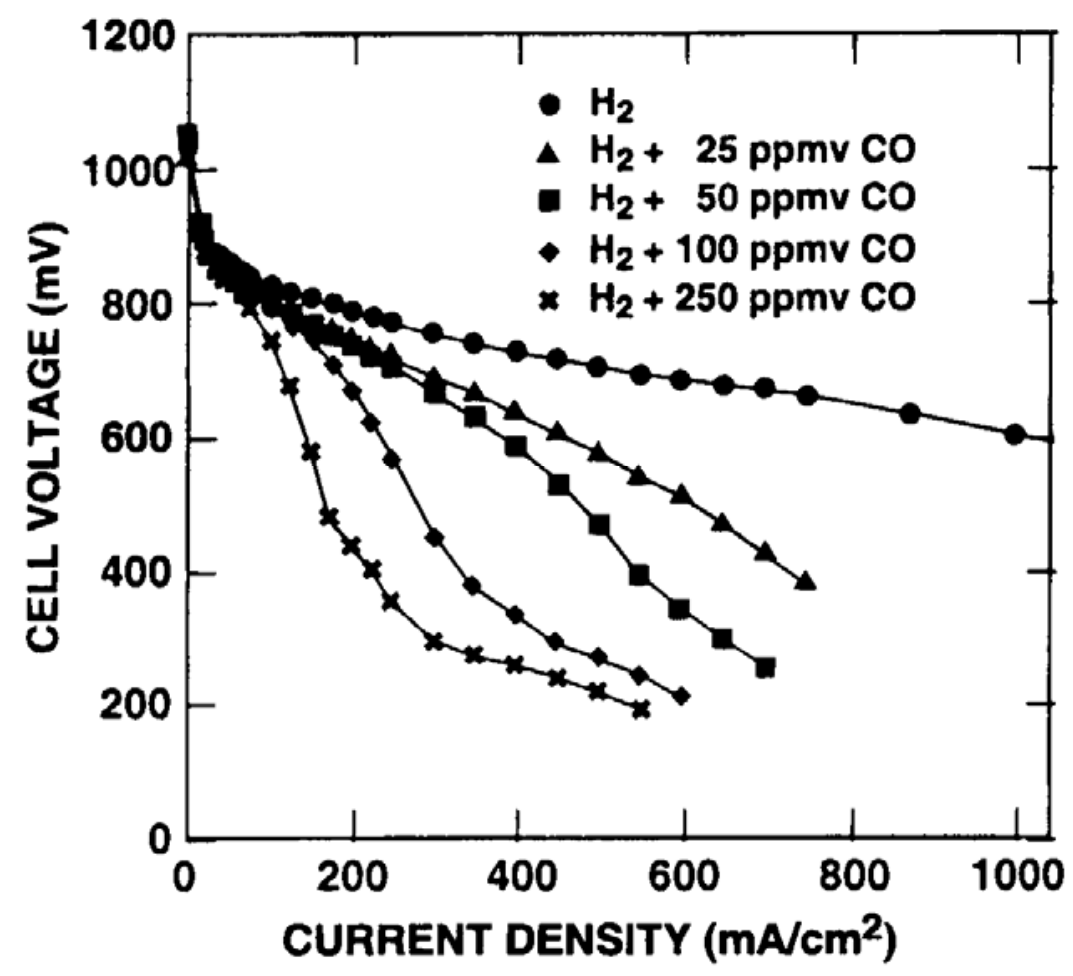

Figure 3.2.2.1 Effect of CO on PEMFC performance [Springer et al., 2001]

${ }^{1} \Delta \mathrm{H}^{\mathrm{o}}=-41.1 \mathrm{~kJ} / \mathrm{mol} \quad \Delta \mathrm{G}^{\mathrm{o}}=-28.6 \mathrm{~kJ} / \mathrm{mol}$

${ }^{2} \Delta \mathrm{H}^{\mathrm{o}}=-241.8 \mathrm{~kJ} / \mathrm{mol} \quad \Delta \mathrm{G}^{\mathrm{o}}=-228.6 \mathrm{~kJ} / \mathrm{mol}$ 


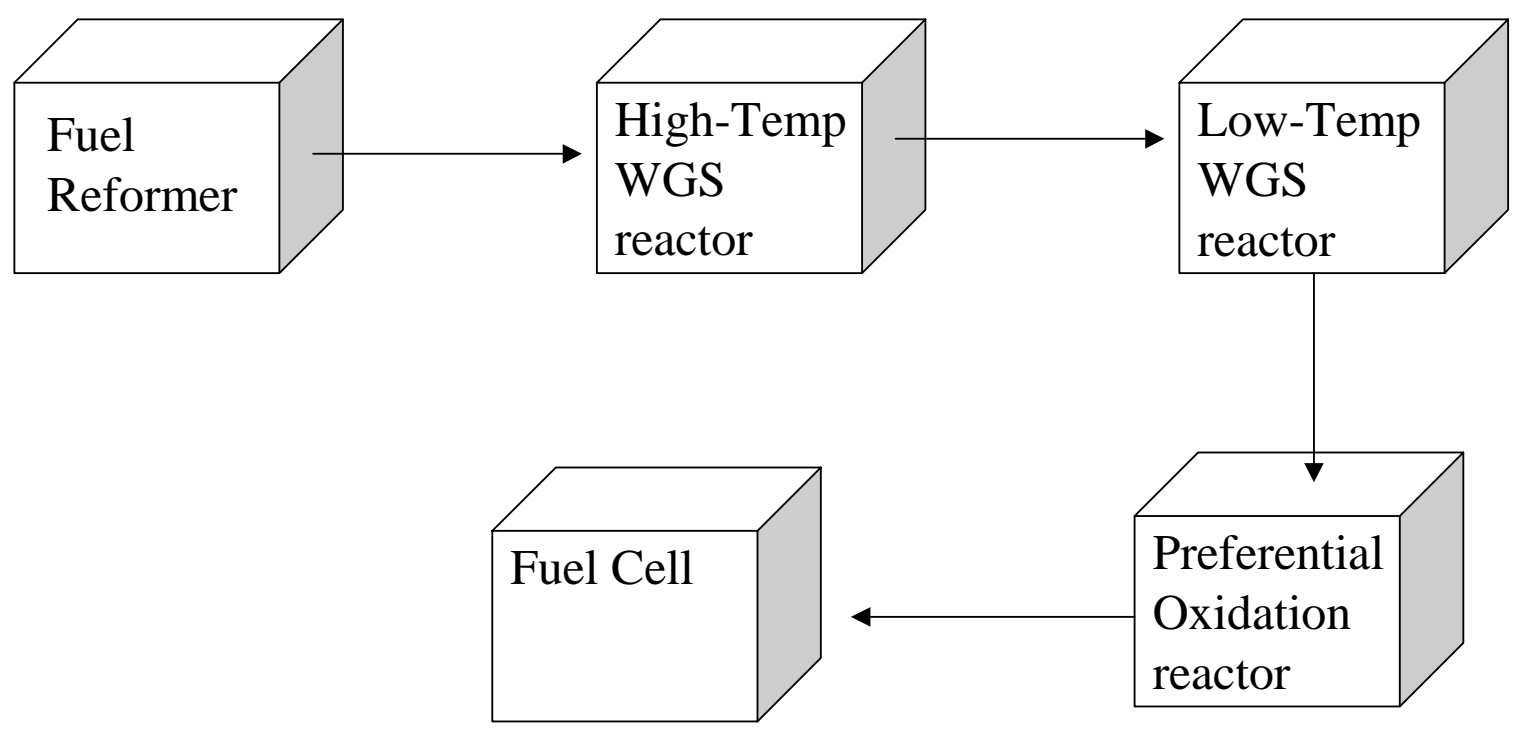

Figure 3.2.2.2 Diagram of the current set-up necessary to remove CO from the feed gas in a hydrocarbon of alcohol-based fuel cell system 
Subtask 3.2.2.2 - Screening Experiments for Catalysts and Process Conditions (7-18 months)

\subsection{Introduction}

Screen the selected catalysts for methanol reforming and comparatively examine them under the conditions selected based literature survey ((different temperatures, ratio of $\mathrm{O}_{2}$ (air)/methanol and water/methanol ratio, flow rate(space velocity)). In this subtask, the objectives are clarifying the effect of catalyst type and reaction conditions on methanol steam reforming and oxidative steam reforming, further optimizing the reaction conditions and achieving the higher hydrogen production and elimination of carbon monoxide yield.

\subsection{Experimental- Reaction Conditions}

Four kinds of commercial copper zinc alumina catalysts and two kinds of platinum catalysts are used in this work. Some features of $\mathrm{Cu} / \mathrm{Zn} / \mathrm{Al}$ catalysts are given in Table 3.2.2.2.

Table 3.2.2.2 Commercial Cu/Zn/Al catalysts and their chemical and physical properties

\begin{tabular}{|c|c|c|c|c|}
\hline Catalyst ID & $83-3$ & C18-7-01 & C18 HA & C18HALM \\
\hline Supplier & Synetix & Sud-Chemie & Sud-Chemie & Sud-Chemie \\
\hline Surface Area, $\mathrm{m}^{2} / \mathrm{g}$ & 75 & $60 \pm 20$ & $60 \pm 20$ & $60 \pm 20$ \\
\hline Bulk Density, Ibs/ft & 86 & $80 \pm 5$ & $67 \pm 5$ & $67 \pm 5$ \\
\hline \multicolumn{5}{|c|}{ Chemical composition (weight \%) } \\
\hline $\mathrm{CuO}$ & 51 & $42 \pm 2.0$ & $58 \pm 3.0$ & $58 \pm 3.0$ \\
\hline $\mathrm{ZnO}$ & 31 & $47 \pm 3.0$ & $31 \pm 2.0$ & $31 \pm 2.0$ \\
\hline $\mathrm{Al}_{2} \mathrm{O}_{3}$ & balance & $10 \pm 2.5$ & $11 \pm 1.5$ & $11 \pm 1.5$ \\
\hline $\mathrm{C}(\mathrm{graphite})$ & & $2-3$ & $1.5-2.5$ & $1.5-2.5$ \\
\hline
\end{tabular}

Two kinds of Platinum commercial catalysts are listed:

- Pressure Chemical Co.

$\mathrm{Pt} / \mathrm{Al}_{2} \mathrm{O}_{3}$ catalysts $(5 \mathrm{wt} \% \mathrm{Pt})$

- Engelhard

$\mathrm{Pt} / \mathrm{Al}_{2} \mathrm{O}_{3}$ catalysts $(1 \mathrm{wt} \% \mathrm{Pt}, 0.5 \mathrm{wt} \% \mathrm{Pt})$

\subsubsection{Methanol Reforming Conditions}

We also prepared hybrid catalysts and two-layers catalysts. Hybrid catalyst was derived from $\mathrm{C} 18 \mathrm{HA}$ and $\mathrm{Pt} / \mathrm{Al}_{2} \mathrm{O}_{3}$. $1 \mathrm{~g}$ of $\mathrm{Pt} / \mathrm{Al}_{2} \mathrm{O}_{3}$ mechanically mixed with $3 \mathrm{~g}$ of $\mathrm{C} 18 \mathrm{HA}$. Two-layer catalysts refer

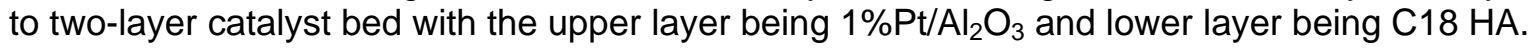

The methanol reforming experiments were preformed in a continuous fixed-bed flow reactor. The schematic of reaction system is shown in the Figure 3.2.2.3.

The stainless steel reactor tube is $61 \mathrm{~cm}$ (24 inches) in length, has an internal diameter of approximately $0.94 \mathrm{~cm}$ (0.37 inches), and has a wall thickness of approximately $0.17 \mathrm{~cm}(0.065$ inches). It is house in tubular electric furnace (Applied Test Systems, Series 3210) capable of heating to $600^{\circ}$. Reactor temperature was monitored and controlled by a digital control system (Applied Test System, Series XT-16). 
An HPLC pump (ISCO Syringe Pump 500) was used to measure $( \pm 0.01 \mathrm{ml} / \mathrm{min})$ and pump the methanol water liquid feedstock into the reactor. The HPLC-grade methanol (99.9\%) was obtained from Aldrich Chemical Company, and the water used in this study was deionized. The feedstock liquid was pre-mixed using methanol and deionized water according methanol to water mole ratio (1:1.4), the corresponding mass composition is $56 \% \mathrm{MeOH}, 44 \% \mathrm{H}_{2} \mathrm{O}$. Four channel Brooks mass flow controller (5850 TR) calibrated for $0-1000 \mathrm{ml} / \mathrm{min}$ were used to control all gases. All gases used were ultra pure level.

The temperature of the reactor and catalyst bed were monitored and maintained using K-type Omega thermocouples respectively. Figure 3.2.2.3 shows the location of the internal thermocouple and catalyst bed.

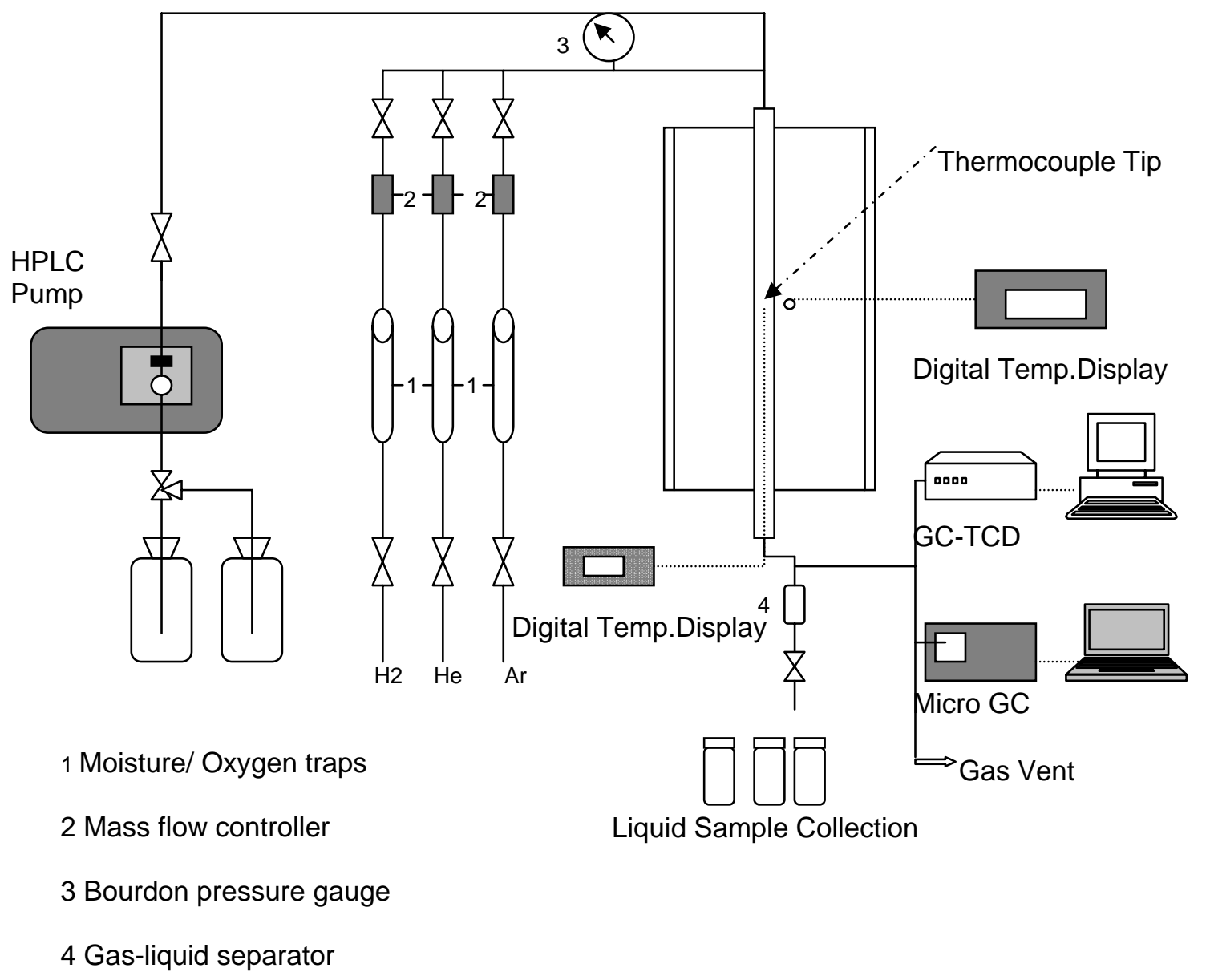

Figure 3.2.2.3 Schematic of a fixed-bed reaction system 


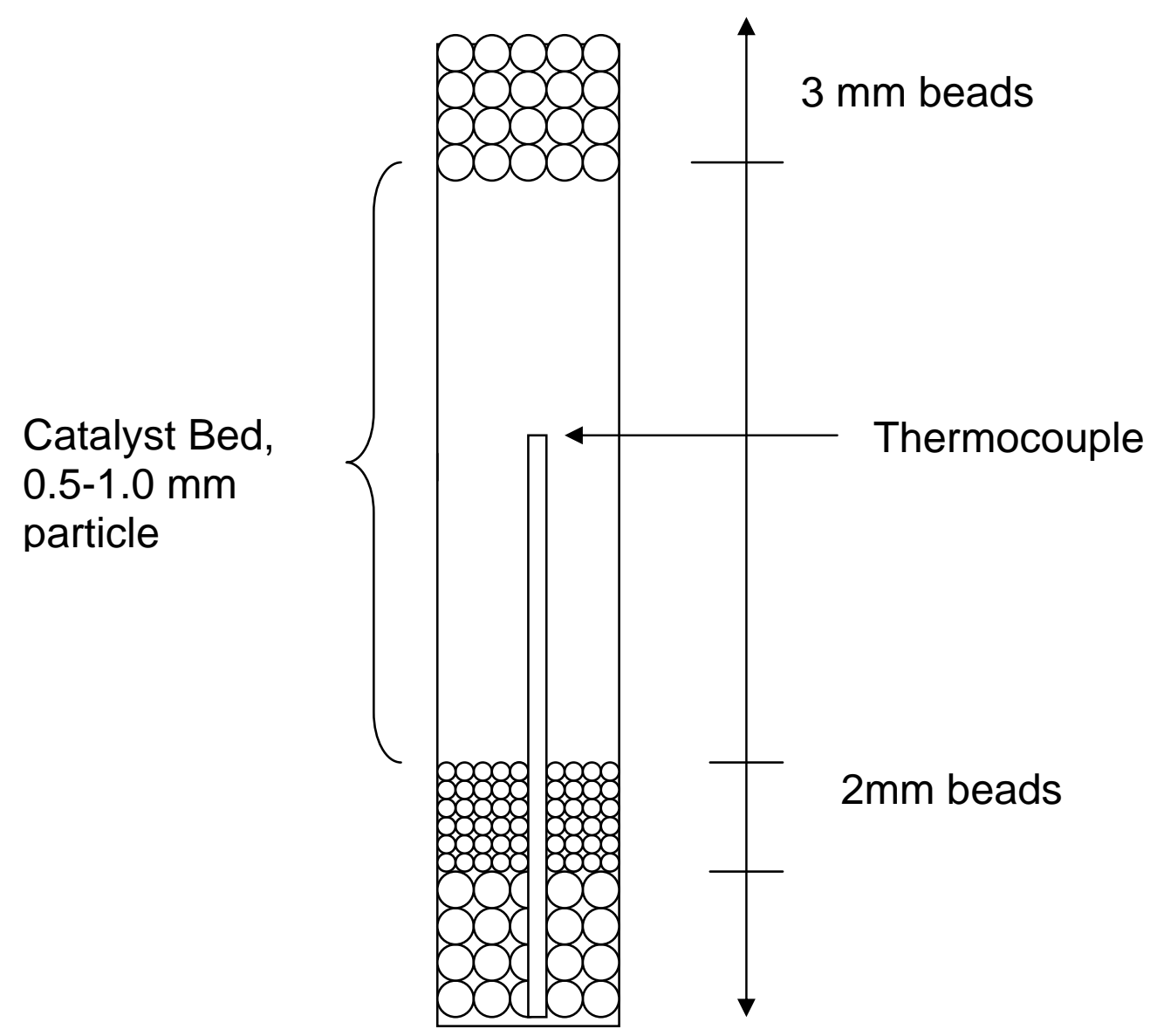

Figure 3.2.2.4 Reactor internal thermocouple, catalyst bed and borosilicate beads

Methanol reforming reaction conditions used in this project are summarized in below. All catalysts were reduced in situ before reforming.

Catalyst Reduction Conditions

Temperature Ramp

Time at Max. Temperature

Hydrogen Flow Rate

Reforming Reaction Conditions

Temperature

Liquid Weight Hourly Space Velocity (WHSV)

$\mathrm{MeOH}: \mathrm{H}_{2} \mathrm{O}$ (mole ratio)

Catalyst Particle Size

Catalyst Loading

Carrier gas $25-325^{\circ} \mathrm{C} @ 2^{\circ} \mathrm{C} / \mathrm{min}$

$0.5 \mathrm{~h}$

$15 \mathrm{ml} / \mathrm{min}$

$180^{\circ} \mathrm{C}-275^{\circ} \mathrm{C}$

$1: 1.4$

0.5-1.0 mm (18-35 mesh)

$0.3 \mathrm{~g}$

$30-80 \mathrm{ml} / \mathrm{min}$

In the beginning of this study, a stainless steel condenser kept at $0^{\circ} \mathrm{C}$ was used to separate the liquid products from gaseous outlet stream. The gas products were analyzed on-line by GC-TCD (SRI8610C 6"SIL GEL/3" MOL SIEVE column), Helium as carrier. The liquid collected once every 
hour (mainly water and noncreative methanol) was analyzed quantitatively on a Hewlett Packard (HP) 5890II GC equipped with a capillary column (Restek XTI-5) and FID detector, and operated in the split-injection mode, at $40^{\circ} \mathrm{C}$ column temperature. Ethanol was used as an internal standard.

In January 2002, the condenser was removed and all of outlet stream of reaction products were analyzed quantitatively by two on-line GC SRI 8610C and Agilent 3000 Micro GC. Agilent Micro GC is equipped with MOL sieve5 and plot $\mathrm{Q}$ column and TCD detector.

\subsection{Water-gas-shift (WGS)}

The WGS reaction was performed at $210^{\circ} \mathrm{C}$ in a down-flow fixed-bed stainless steel reactor using $0.5 \mathrm{~mL}$ of the catalyst (commercial catalyst particle size $=1000-500 \mu \mathrm{m}$ ). C18-7-01 was chosen as the commercial $\mathrm{CuO} / \mathrm{ZnO} / \mathrm{Al}_{2} \mathrm{O}_{3}$ catalyst (obtained from SudChemie) because it exhibited better performance than other commercial catalysts[Gu and Song, 2003]. The weight used in each sample run was $0.48 \mathrm{~g}$, or $0.5 \mathrm{~mL}$, for $\mathrm{Cu} / \mathrm{ZnO} / \mathrm{Al}_{2} \mathrm{O}_{3}$ catalyst. The experimental conditions consisted of using an initial CO concentration of $2000 \mathrm{ppmv}$, and the space velocity of 12,000 $\mathrm{h}^{-1}$ (dry basis). The gas mixture $0.5 \% \mathrm{CO}$, and $25 \% \mathrm{CO}_{2}$ in $\mathrm{Ar}$ was used to prepare the feed gas. The feed gas compositions used in the WGS reaction over the catalysts were $0.2 \% \mathrm{CO}, 10 \% \mathrm{CO}_{2}, 20 \% \mathrm{H}_{2} \mathrm{O}$, and the balance was Ar gas. This used a flow rate of $40 \mathrm{~mL} / \mathrm{min}$ of the $0.5 \% \mathrm{CO}, 25 \% \mathrm{CO}_{2}$ balance Ar gas mixture, $60 \mathrm{~mL} / \mathrm{min} \mathrm{Ar}$ or $\mathrm{H}_{2}$, and $0.15 \mathrm{~mL} / \mathrm{min} \mathrm{H}_{2} \mathrm{O}(\mathrm{l})$. This initial $\mathrm{CO}$ concentration was chosen based on the output feed of a methanol reformer used in parallel work[Gu and Song, 2003]. The effluent of the reactor was analyzed on-line using an Agilent 3000A MicroGC equipped with thermal conductivity detectors with a $\mathrm{CO}$ detection limit of $<5 \mathrm{ppm}$. Prior to the reaction, the catalyst was reduced in situ at $225^{\circ} \mathrm{C}$ for $\mathrm{Cu}-\mathrm{Pd}$ catalysts and $300^{\circ} \mathrm{C}$ for $\mathrm{Cu}-\mathrm{ZnO} / \mathrm{Al}_{2} \mathrm{O}_{3}$ for $3 \mathrm{~h}$ in $\mathrm{H}_{2}$ gas (flow rate: $15 \mathrm{~mL} / \mathrm{min}$ ). The surface of the unreduced commercial catalyst appears in Figure 3.2.2.5 below.

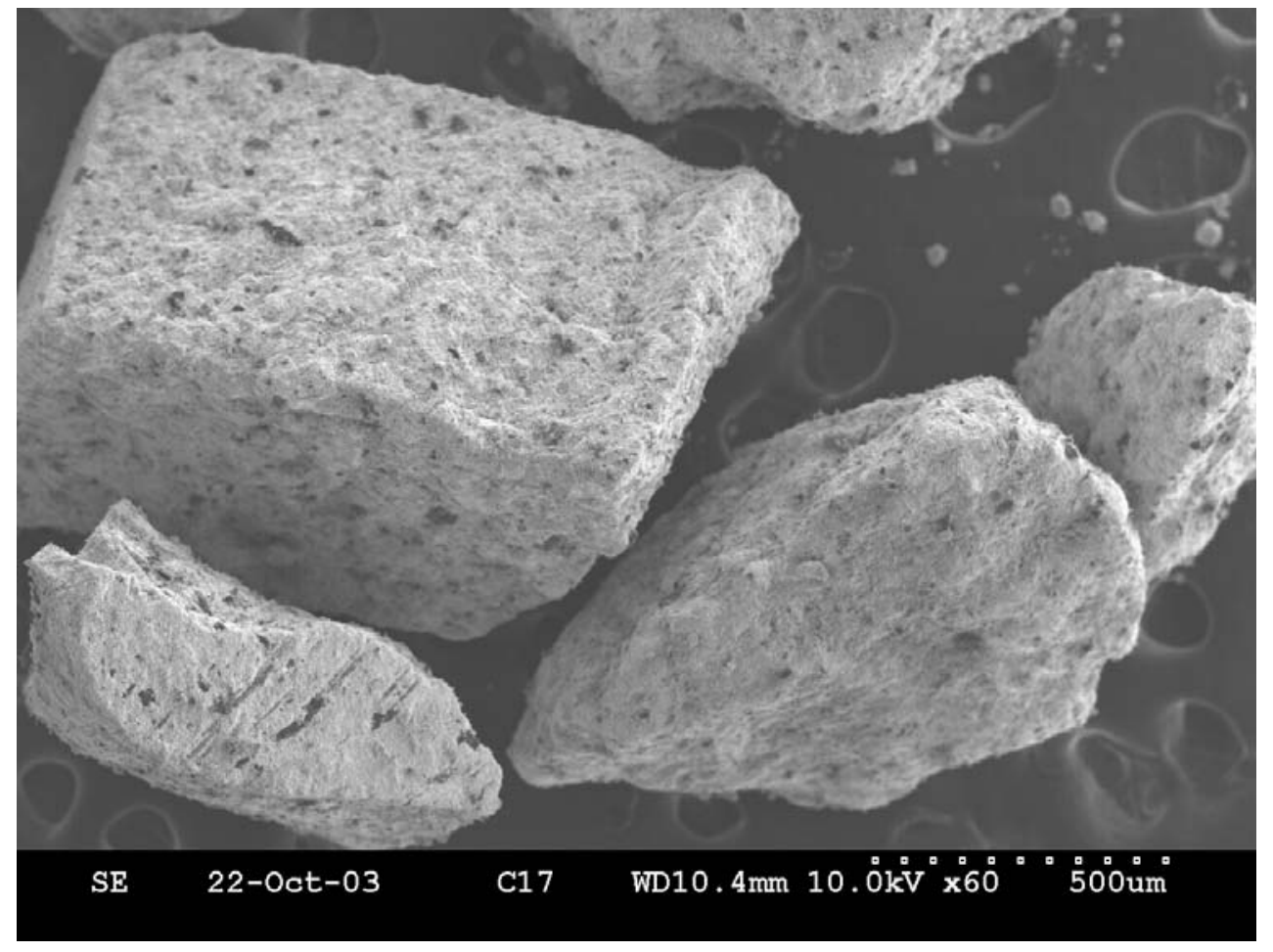

Figure 3.2.2.5 SEM image of $\mathrm{CuO} / \mathrm{ZnO} / \mathrm{Al}_{2} \mathrm{O}_{3}$ (C18-7-01) catalyst particles before reduction or reaction 


\subsection{Preferential Oxidation}

Prior to the reaction, the $\mathrm{Pt} / \mathrm{Al}_{2} \mathrm{O}_{3}$ commercial catalyst was reduced in situ at $300^{\circ} \mathrm{C}$ for $3 \mathrm{~h}$ in $\mathrm{H}_{2}$

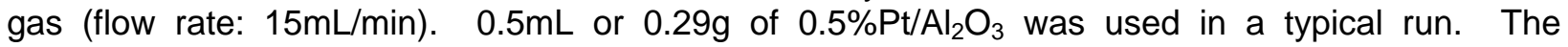
experimental conditions consisted of using an initial CO concentration of $2000 \mathrm{ppmv}$, and the space velocity of $12,000 \mathrm{~h}^{-1}$ (dry basis). Flow rates of $40 \mathrm{~mL} / \mathrm{min}$ of the $0.5 \% \mathrm{CO}, 25 \% \mathrm{CO}_{2}$ balance $\operatorname{Ar}$ gas mixture, $1.6 \mathrm{~mL} / \mathrm{min}$ air, and $58.4 \% \mathrm{Ar}$ or $\mathrm{H}_{2}$ were used. The gas compositions used in the WGS reaction over the catalysts were $0.2 \% \mathrm{CO}, 10 \% \mathrm{CO}_{2}$, and the balance was Ar gas. The effluent of the reactor was analyzed on-line using an Agilent 3000 A MicroGC equipped with thermal conductivity detectors, as described previously. The surface morphology of unreduced, unreacted $0.5 \% \mathrm{Pt} / \mathrm{Al}_{2} \mathrm{O}_{3}$ can be seen in Figure 3.2.2.6 below. The surface is slightly rough, but uniform in characteristics.

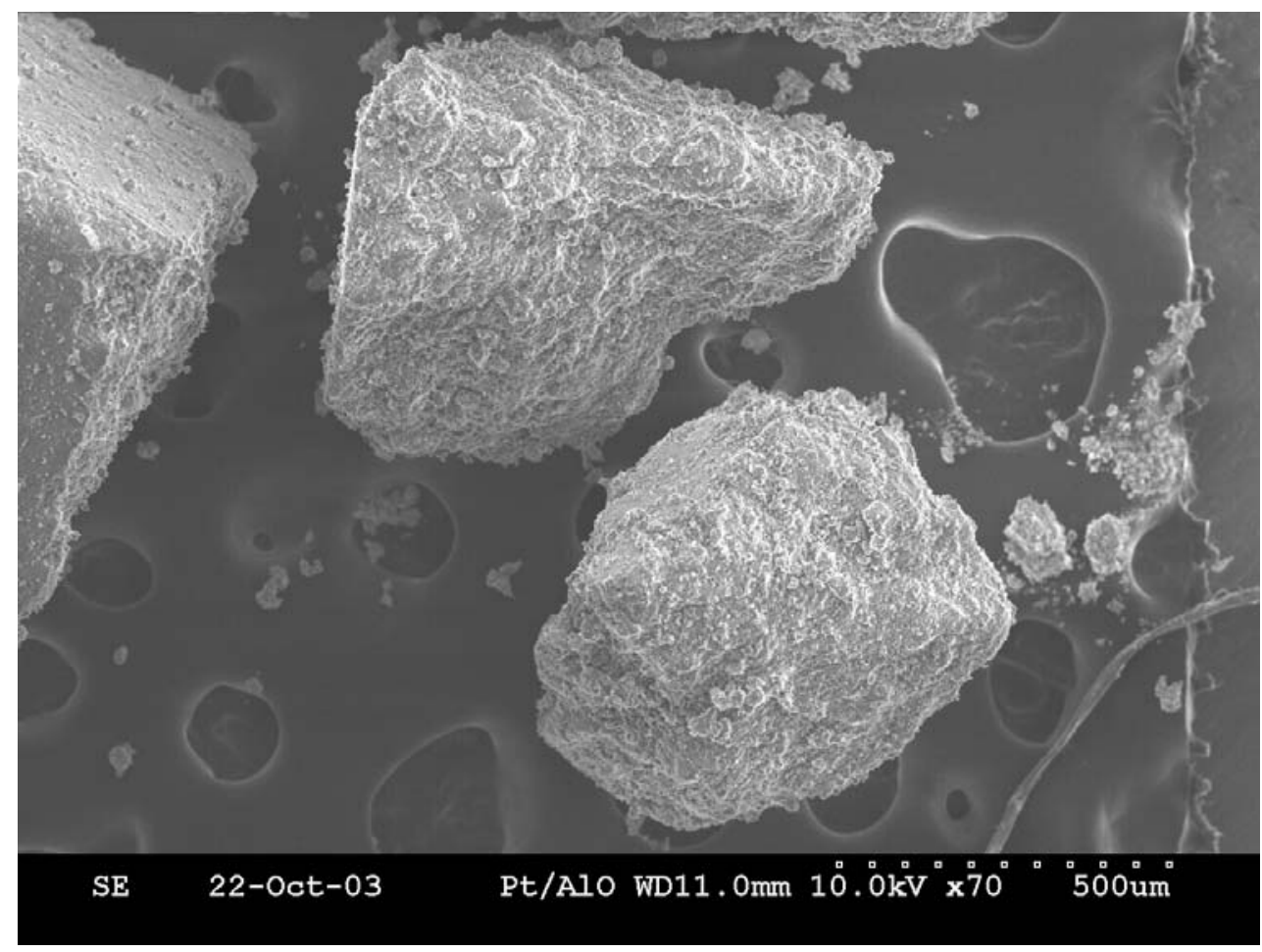

Figure 3.2.2.6 SEM image of unreduced, unreacted $0.5 \% \mathrm{Pt} / \mathrm{Al}_{2} \mathrm{O}_{3}$

\subsubsection{6 $\mathrm{O}_{2}$-assisted water-gas-shift}

In the $\mathrm{O}_{2}$-assisted WGS reaction, $1.6 \% \mathrm{O}_{2}$ in the form of air was also added to the feed making the overall gas composition $0.2 \% \mathrm{CO}, 1.6 \% \mathrm{O}_{2}$ (air), $10 \% \mathrm{CO}_{2}, 20 \% \mathrm{H}_{2} \mathrm{O}$ and the balance was $\mathrm{Ar}$ gas. The dry space velocity remained at $12,000 \mathrm{~h}^{-1}$. Flow rates of $40 \mathrm{~mL} / \mathrm{min}$ of the $0.5 \% \mathrm{CO}$, $25 \% \mathrm{CO}_{2}$ balance Ar gas mixture, $1.6 \mathrm{~mL} / \mathrm{min}$ air, $58.4 \% \mathrm{Ar}$ or $\mathrm{H}_{2}$, and $0.15 \mathrm{~mL} / \mathrm{min}_{2} \mathrm{H}_{(\mathrm{l})}$ were used. Prior to the reaction, the catalyst was reduced in situ at $225^{\circ} \mathrm{C}$ for Cu-Pd catalysts and $300^{\circ} \mathrm{C}$ for $\mathrm{Cu}$ $\mathrm{ZnO} / \mathrm{Al}_{2} \mathrm{O}_{3}, 0.5 \% \mathrm{Pt} / \mathrm{Al}_{2} \mathrm{O}_{3}$ combination for $3 \mathrm{~h}$ in $\mathrm{H}_{2}$ gas (flow rate: $15 \mathrm{~mL} / \mathrm{min}$ ). The effluent of the reactor was analyzed on-line using an Agilent 3000 A MicroGC equipped with thermal conductivity detectors. The CO detection limit is 5 ppm. 


\subsection{Results and Discussion}

\subsection{Effect of Reforming Temperature}

Methanol steam reforming was conducted over four kinds of $\mathrm{Cu} / \mathrm{Zn} / \mathrm{Al}$ catalysts at $180^{\circ} \mathrm{C}$ $275^{\circ} \mathrm{C}$. The catalyst activity in terms of methanol conversion is listed in Table 3.2.2.3.

Table 3.2.2.3 Catalyst activity at different temperature $\left(180-275^{\circ} \mathrm{C}\right)$

\begin{tabular}{c|c|c|c|c}
\hline \multirow{2}{*}{ Temperature } & \multicolumn{4}{|c}{ Methanol conversion (mol \%) } \\
\cline { 2 - 5 } & $83-3$ & C18-7-01 & C18HA & C18HALM \\
\hline $180^{\circ} \mathrm{C}$ & 39.66 & 40.35 & 32.52 & 34.27 \\
\hline $210^{\circ} \mathrm{C}$ & 64.8 & 72.84 & 77.79 & 55.34 \\
\hline $230^{\circ} \mathrm{C}$ & 93.61 & 98.14 & 97.34 & 95.91 \\
\hline $275^{\circ} \mathrm{C}$ & 100 & 100 & 100 & 100 \\
\hline
\end{tabular}

As the reaction temperature increased, the activity of catalysts is increased. When the reaction temperature reached $230^{\circ} \mathrm{C}$, all four kinds of $\mathrm{Cu} / \mathrm{Zn} / \mathrm{Al}$ commercial catalysts showed similar high activity ( $\geq 90 \%)$. Particularly, methanol conversion over the Sud Chemie catalysts was higher than $95 \%$. At $275^{\circ} \mathrm{C}$ methanol is totally converted over any one of the four commercial catalysts.

The Hydrogen concentration of products from the methanol reforming over four commercial catalysts are shown in Figure 3.2.2.7, Figure 3.2.2.8, Figure 3.2.2.9, and Figure 3.2.2.10.

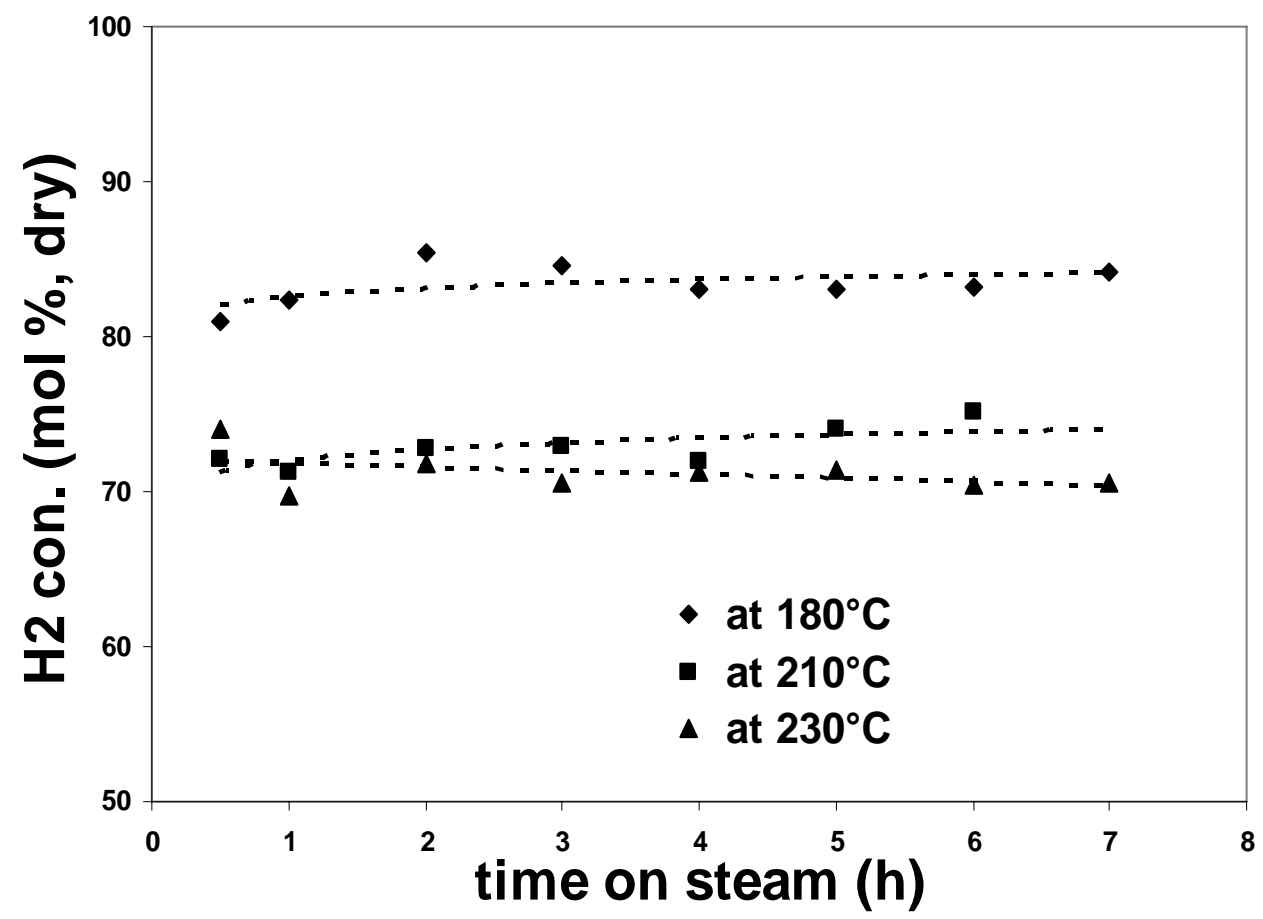

Figure 3.2.2.7 Yield of $\mathrm{H}_{2}$ over Syntix 83-3 at different temperatures 


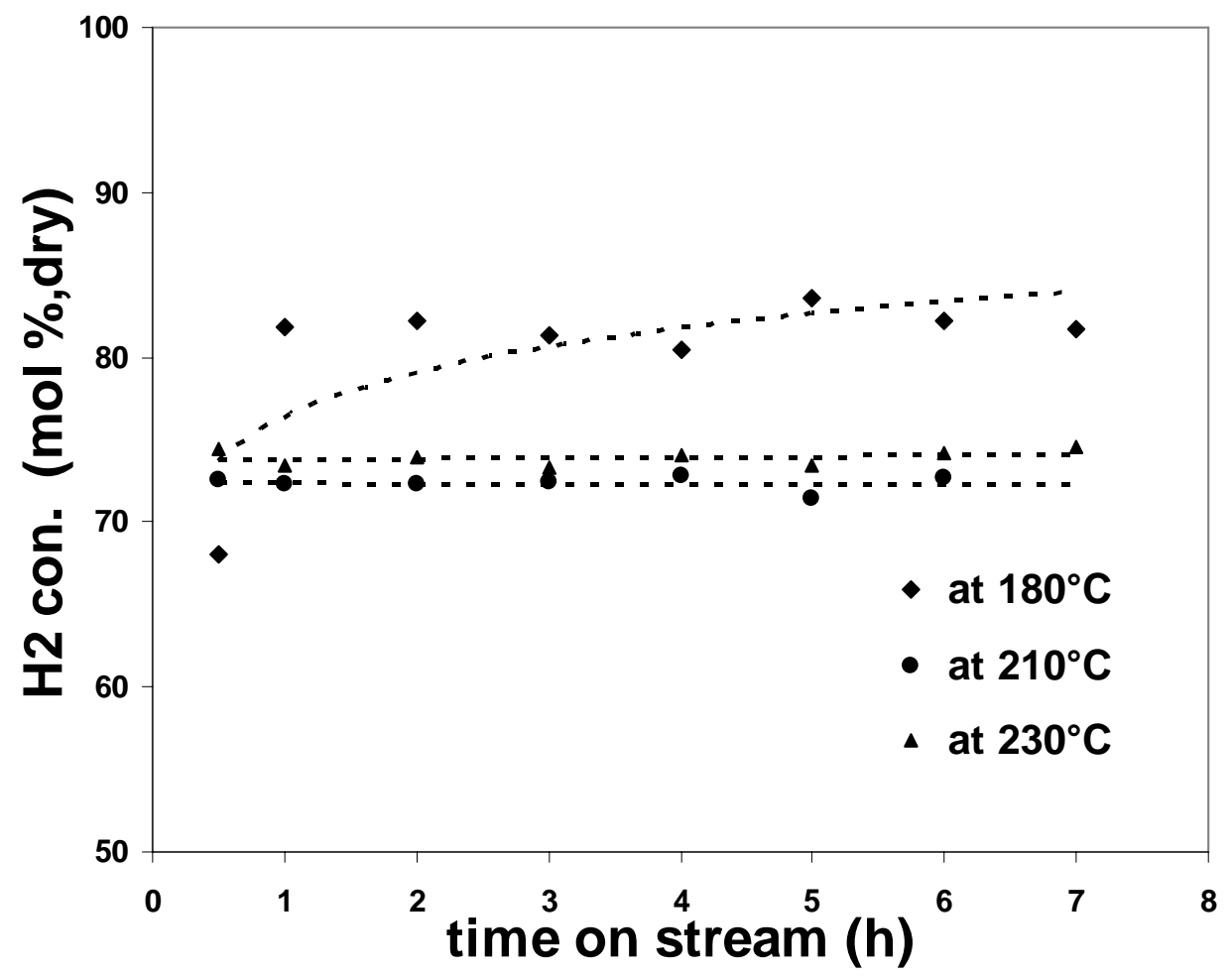

Figure 3.2.2.8 Yield of $\mathrm{H}_{2}$ over Sud-Chemie C18-7-01 at different temperatures

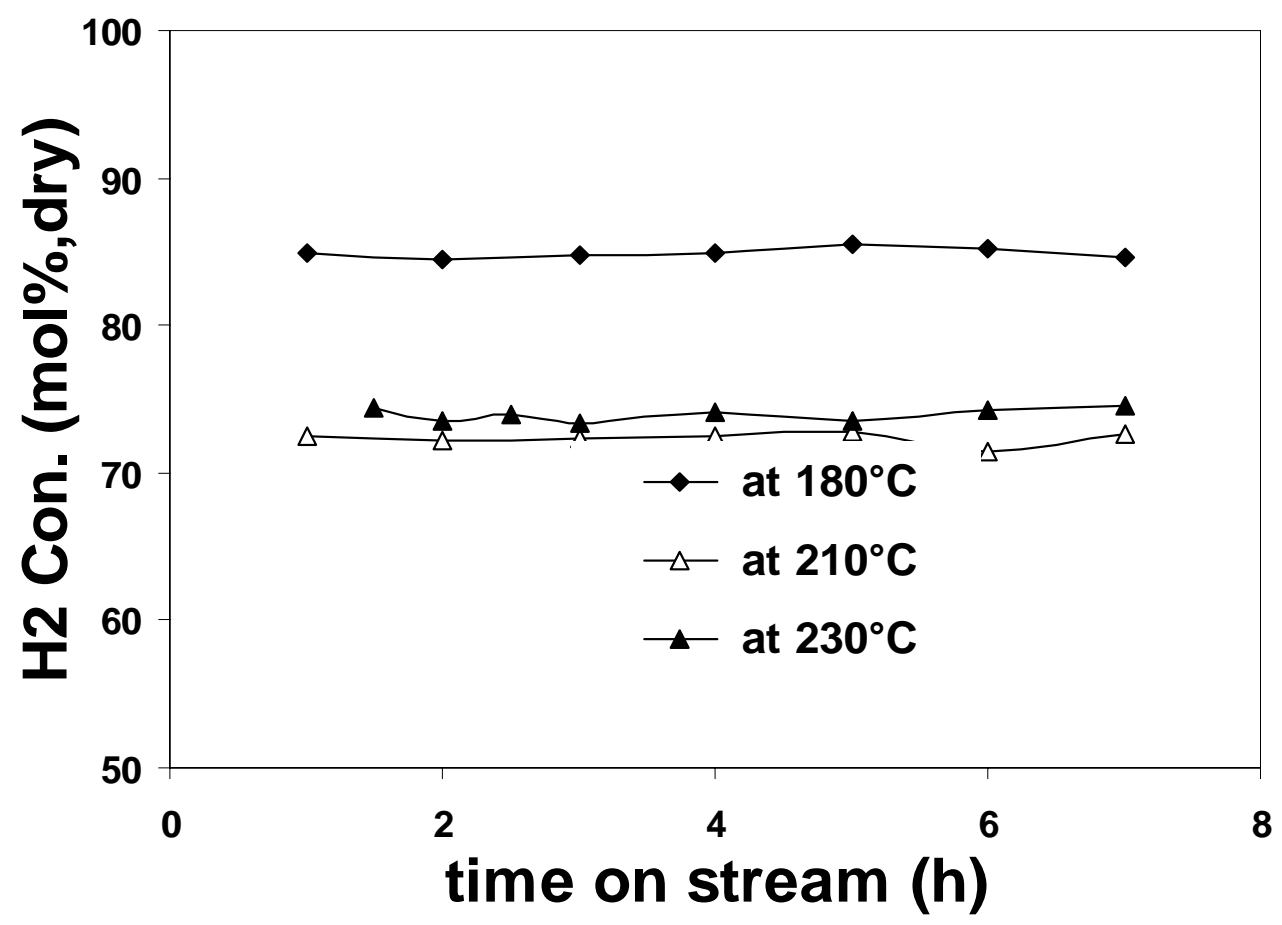

Figure 3.2.2.9 Yield of $\mathrm{H}_{2}$ over Sud-Chemie C18HALM at different temperatures 


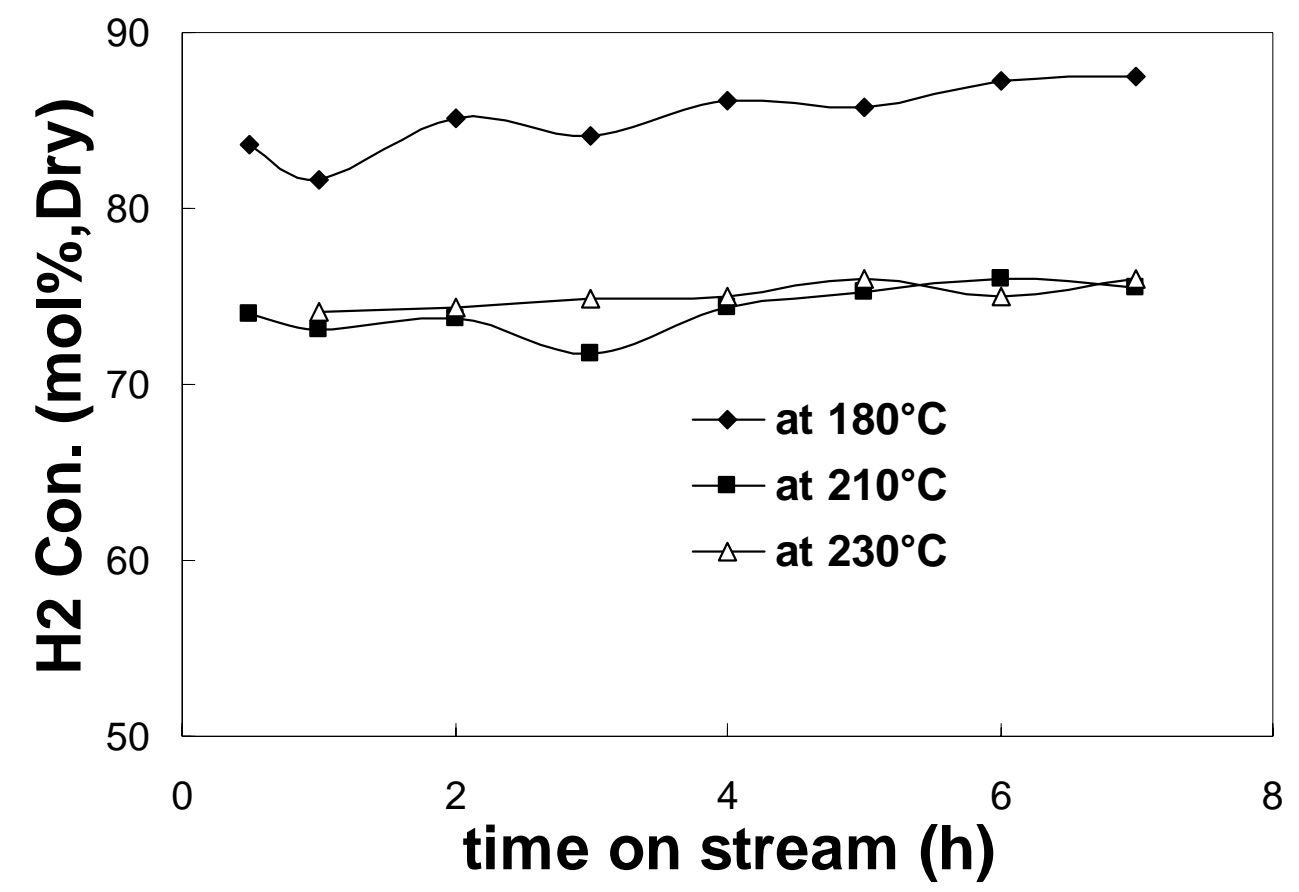

Figure 3.2.2.10 Yield of $\mathrm{H}_{2}$ over Sud-Chemie C18HA at different temperatures

The $\mathrm{CO}_{2}$ concentration shows in Figure 3.2.2.11, Figure 3.2.2.12, Figure 3.2.2.13, and Figure 3.2.2.14.

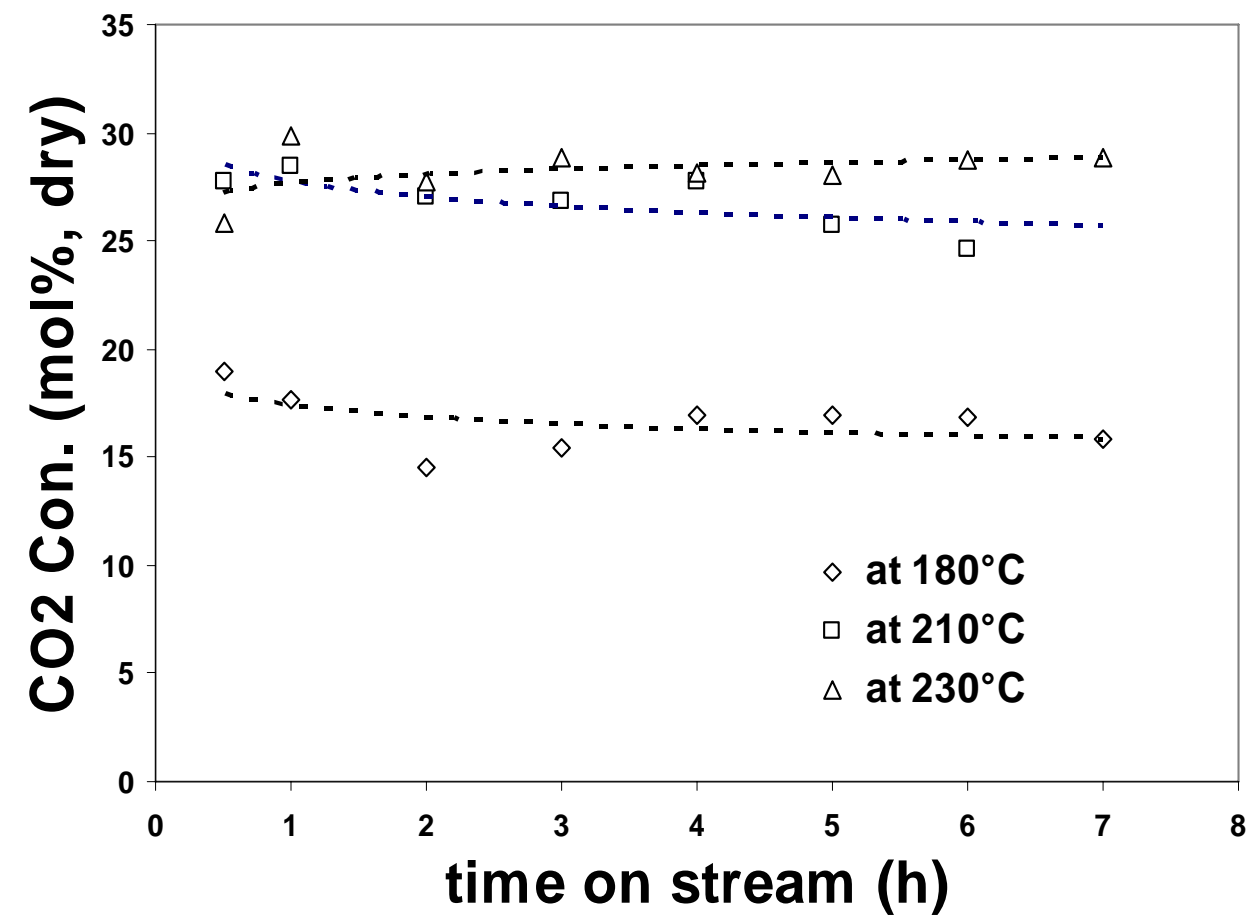

Figure 3.2.2.11 Yield of $\mathrm{CO}_{2}$ over Syntix 83-3 at different temperatures 


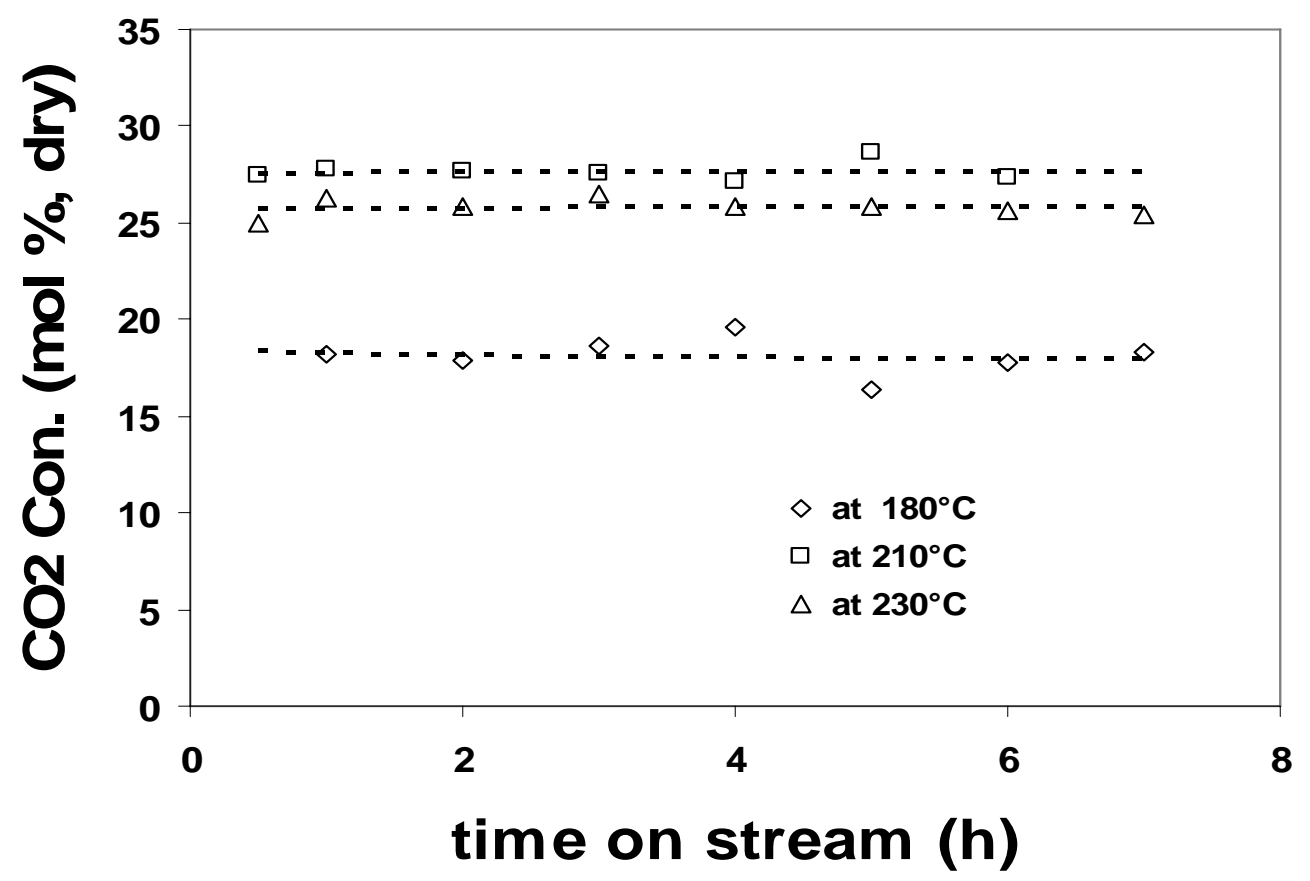

Figure 3.2.2.12 Yield of $\mathrm{CO}_{2}$ over Sud-Chemie C18-7-01 at different temperatures

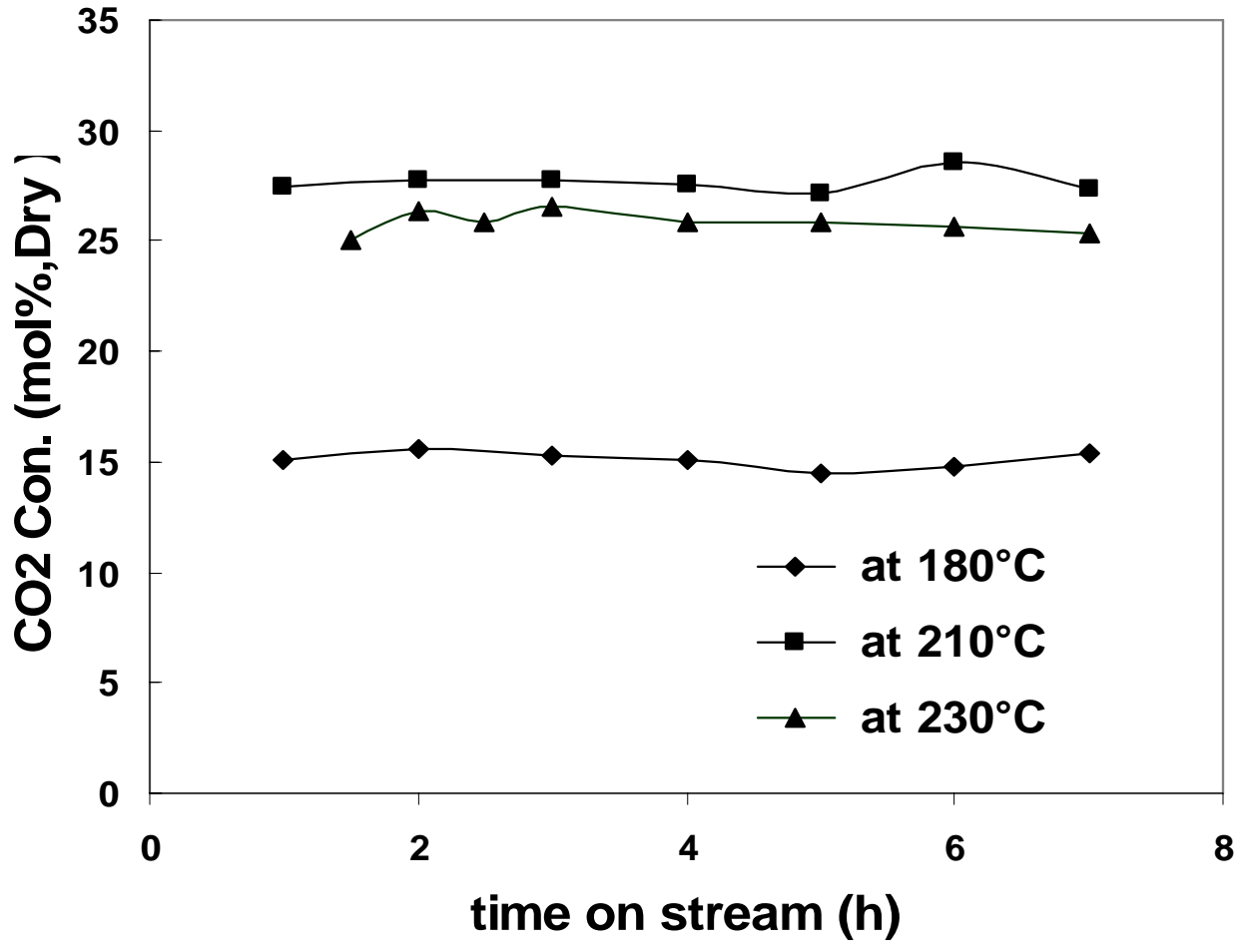

Figure 3.2.2.13 Yield of $\mathrm{CO}_{2}$ over Sud-Chemie C18-HALM at different temperatures 


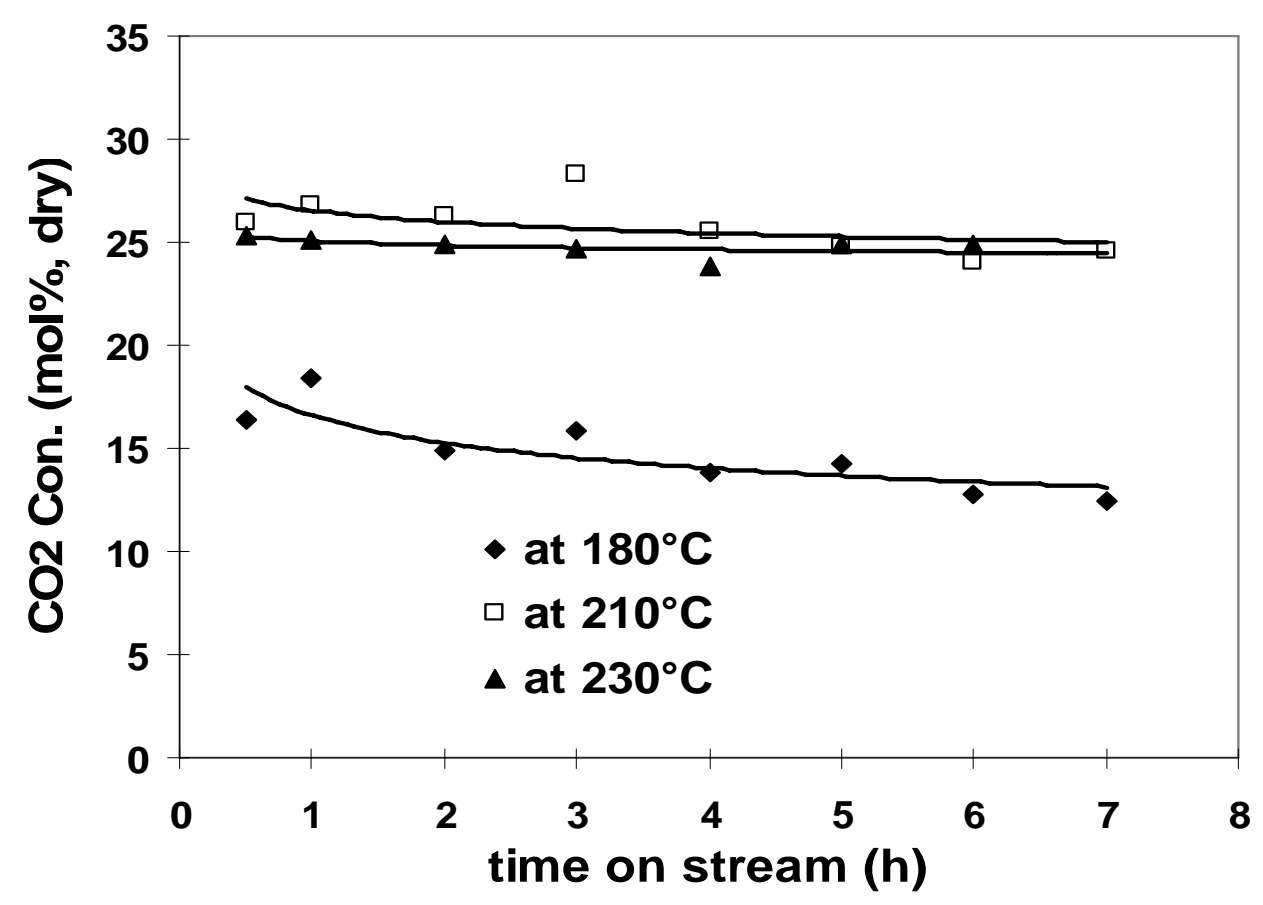

Figure 3.2.2.14 Yield of $\mathrm{CO}_{2}$ over Sud-Chemie $\mathrm{C} 18 \mathrm{HA}$ at different temperatures

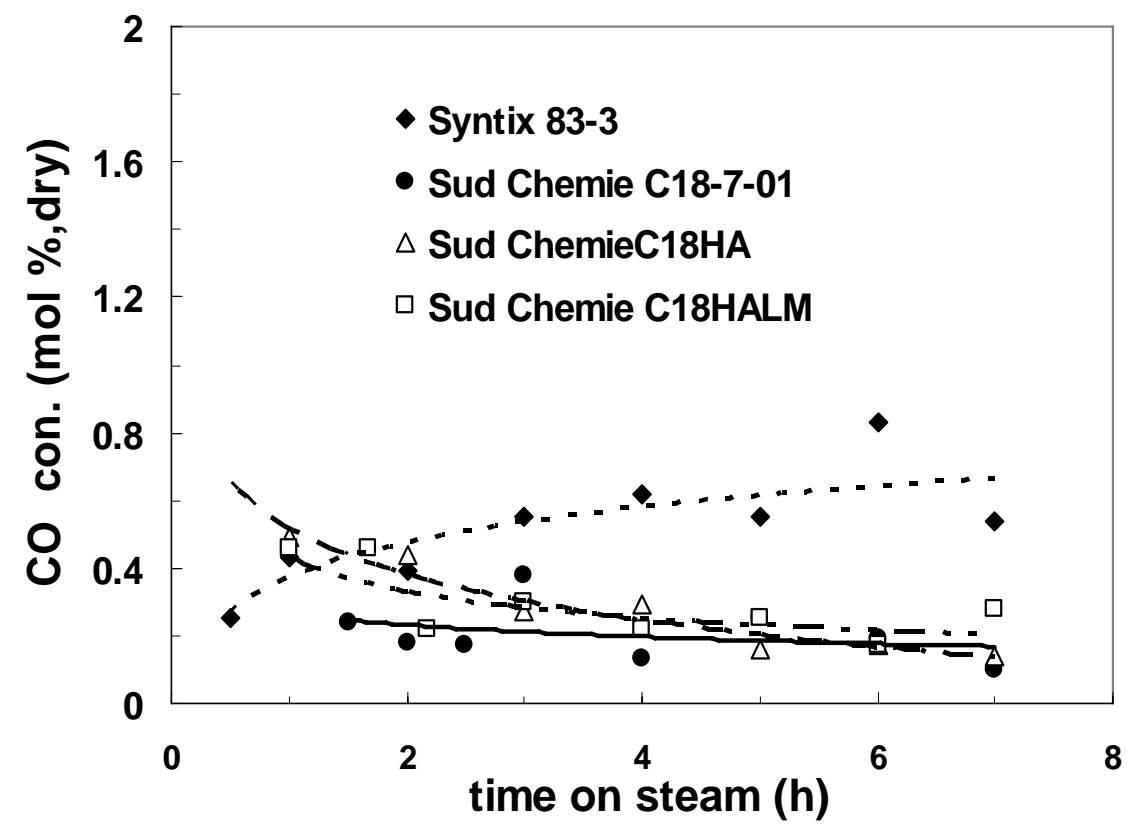

Figure 3.2.2.15 Yield of $\mathrm{CO}$ at $230^{\circ} \mathrm{C}$ over different commercial catalysts at $230^{\circ} \mathrm{C}$

In terms of $\mathrm{H}_{2}$ and $\mathrm{CO}_{2}$ concentration in the outlet stream, we can see when reaction temperature is low $\left(180^{\circ} \mathrm{C}\right.$ ), $\mathrm{H}_{2}$ selectivity is very high (over $80 \%$ ), and $\mathrm{CO}_{2}$ selectivity is lower than $20 \%$. With increasing reaction temperature, $\mathrm{H}_{2}$ selectivity decreases and $\mathrm{CO}_{2}$ selectivity increases.

The interesting aspect of methanol steam reforming is that $\mathrm{CO}$ formation also changes as a function of reaction temperature. With the temperature decreasing from $275^{\circ} \mathrm{C}$ to $180^{\circ} \mathrm{C}$, the $\mathrm{CO}$ concentration in the products decrease from about $1.5 \%$ to about $0.05 \%$. Because water gas shift 
reaction is endothermic reaction, low temperature favors the conversion of $\mathrm{CO}$ into $\mathrm{CO}_{2}$. As shown in Figure 3.2.2.15, the $\mathrm{CO}$ concentration changed with the time on steam over four $\mathrm{Cu} / \mathrm{Zn} / \mathrm{Al}$ commercial catalysts at $230^{\circ} \mathrm{C}$.

In terms of methanol conversion (Catalytic Activity), yield of $\mathrm{H}_{2}$ and yield of $\mathrm{CO}$ over four commercial catalysts at $230^{\circ} \mathrm{C}$, the catalysts $\mathrm{C} 18 \mathrm{HA}$ and $\mathrm{C} 18-7-01$ from Sud-Chemie achieved the best performance. Methanol conversion was >95\%; $\mathrm{H}_{2}$ yield was $70 \sim 75 \%, \mathrm{CO}_{2}$ yield was 30 25\%; $\mathrm{CO}$ yield was less than $0.5 \%$. Therefore, $230^{\circ} \mathrm{C}$ was chosen as the suitable reaction temperature.

\subsection{Effect of Carrier Gas}

Methanol steam reforming over $\mathrm{C} 18 \mathrm{HA}$ and $\mathrm{C} 18-7-01$ at $210^{\circ} \mathrm{C}$ in different flow rates of gas was conducted to investigate the effect of carrier gas on reactions. Other reaction conditions were the same as the before.

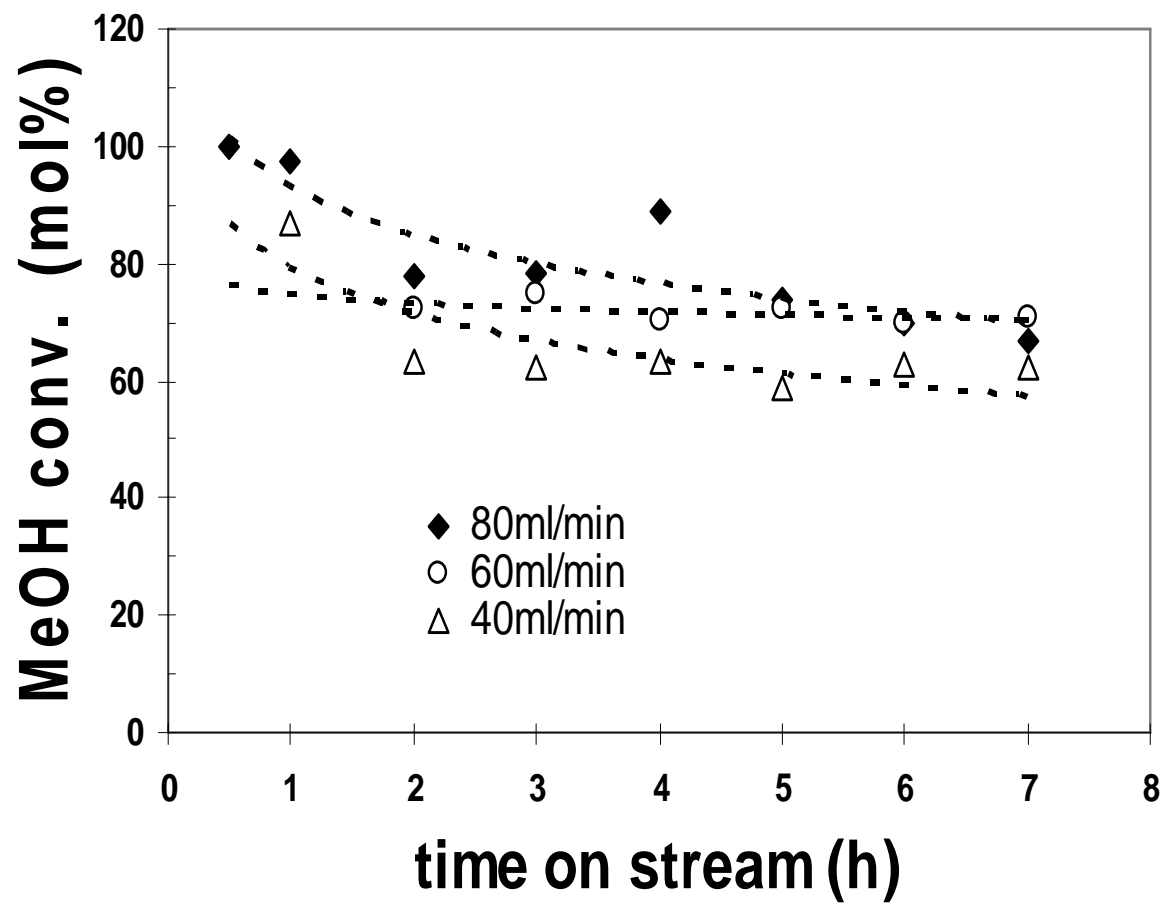

Figure 3.2.2.16 Methanol conversion with different He carrier gas flow rate over $\mathrm{C} 18 \mathrm{HA}$ at $210^{\circ} \mathrm{C}$

The methanol conversion is shown in Figure 3.2.2.16 and Figure 3.2.2.17. Typically, with the decrease of carrier gas flow rate, the average residence time becomes longer. It is possible that more reactant species were adsorbed on active site of catalyst, which allows for increase interaction among reactant species; those may result to increasing conversion of methanol. On other hand, methanol decomposition and steam reforming are endothermic. When gas flow rate is down, the heat transfer rate also is reduced, and that will suppress the endothermic reaction. The result is to reduce the methanol conversion. From the results shown in Figure 3.2.2.16 and Figure 3.2.2.17, when gas flow rate is changed between $80 \mathrm{ml} / \mathrm{min}-60 \mathrm{ml} / \mathrm{min}$ range, the methanol conversion increases with a decrease of carrier gas flow; during the carrier gas $60 \mathrm{ml} / \mathrm{min}-80 \mathrm{ml} / \mathrm{min}$ range, heat transfer dominates the reaction process, the methanol conversion decreases with carrier gas decrease. 


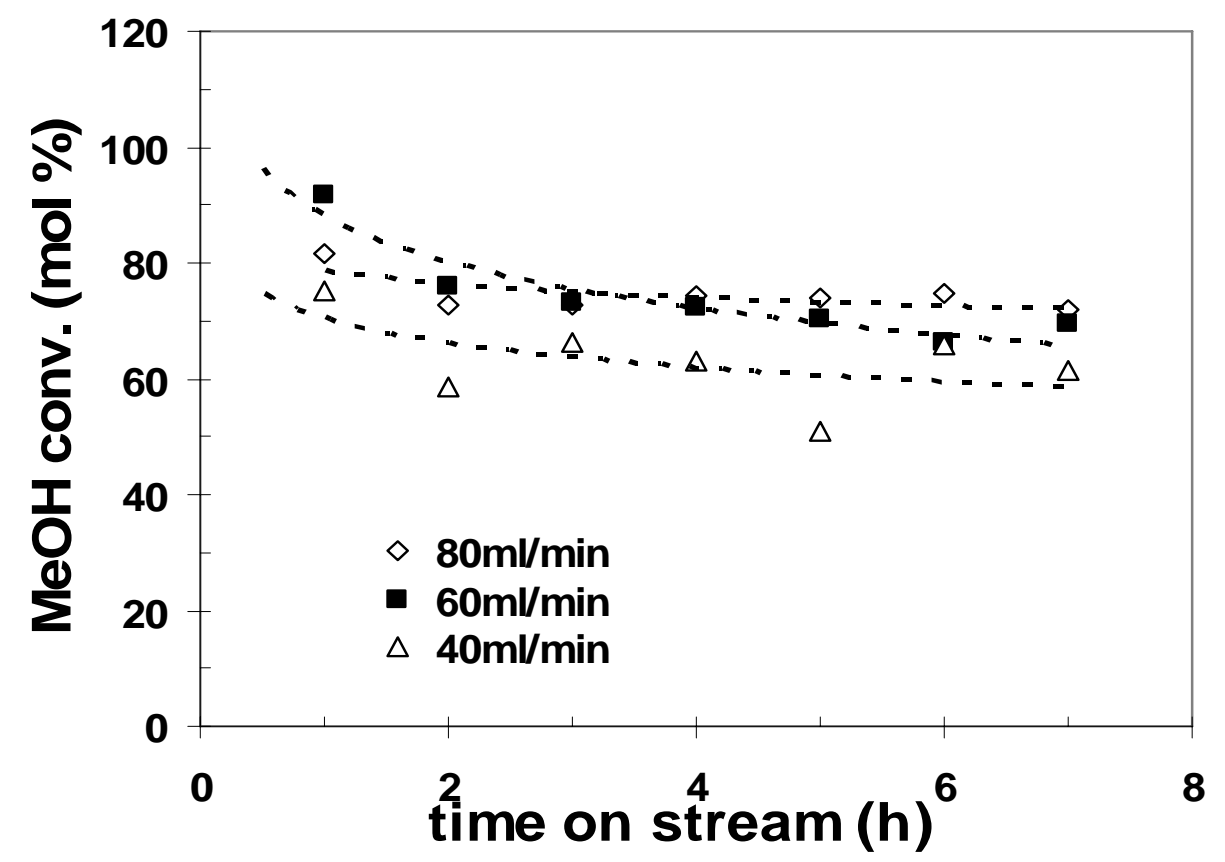

Figure 3.2.2.17 Methanol conversion with different He carrier gas flow rate over C18$7-01$ at $210^{\circ} \mathrm{C}$

\subsection{Effect of Methanol Feed Flow Rate (Space Velocity)}

Methanol steam reforming was carried out under reaction temperature $210^{\circ} \mathrm{C}$ over $\mathrm{C} 18-\mathrm{HA}$, feed flow rate rang is $0.02 \mathrm{ml} / \mathrm{min}$ to $0.05 \mathrm{ml} / \mathrm{min}$, other reaction conditions are the same as before . The methanol conversion over C18HA shows in Figure 3.2.2.18.

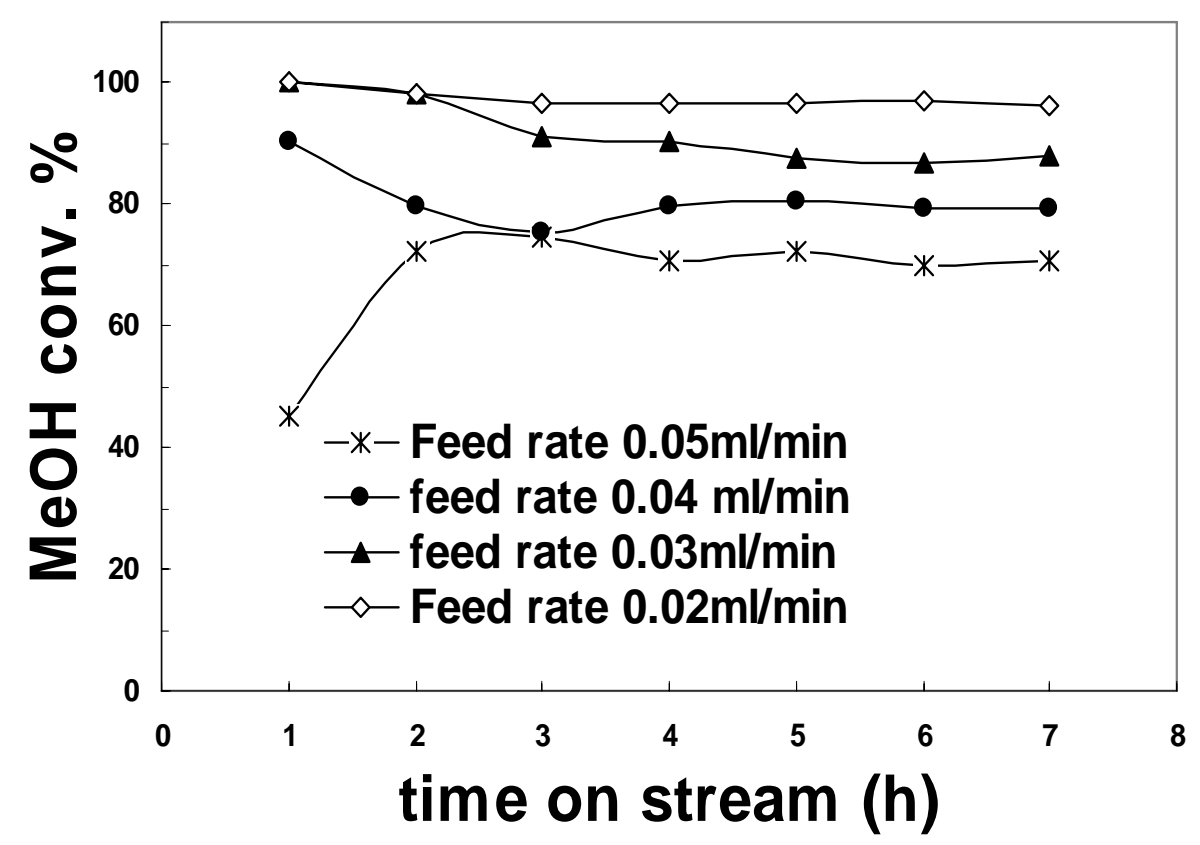

Figure 3.2.2.18 Methanol conversion with different feed flow rate over $\mathrm{C} 18 \mathrm{HA}$ at $210^{\circ} \mathrm{C}$ 
From Figure 3.2.2.18, it can be seen that over catalyst C18-HA, methanol conversion decreases with feed flow rate increase. when feed rate is $0.02 \mathrm{ml} / \mathrm{min}$ (space velocity $3.476 \mathrm{~h}^{-1}$, methanol can almost be fully converted into hydrogen and $\mathrm{CO} 2$. In order to achieve the high methanol conversion with less catalyst cost, the efficient hydrogen production should be controlled in feed rate rang $0.03 \mathrm{ml} / \mathrm{min}-0.04 \mathrm{ml} / \mathrm{min}$.

\subsection{Methanol Steam Reforming over Hybrid and Noble Metal}

Methanol steam reforming was tested over 5\% $\mathrm{Pt}_{2} / \mathrm{Al}_{2} \mathrm{O}_{3}-\mathrm{C} 18 \mathrm{HA}$ hybrid and 5\%Pt.Al2O3 at $230^{\circ} \mathrm{C}$. The comparison of methanol conversion and $\mathrm{CO}$ formation after 3 hours time on steam are shown in Figure 3.2.2.19 and Figure 3.2.2.22, respectively.

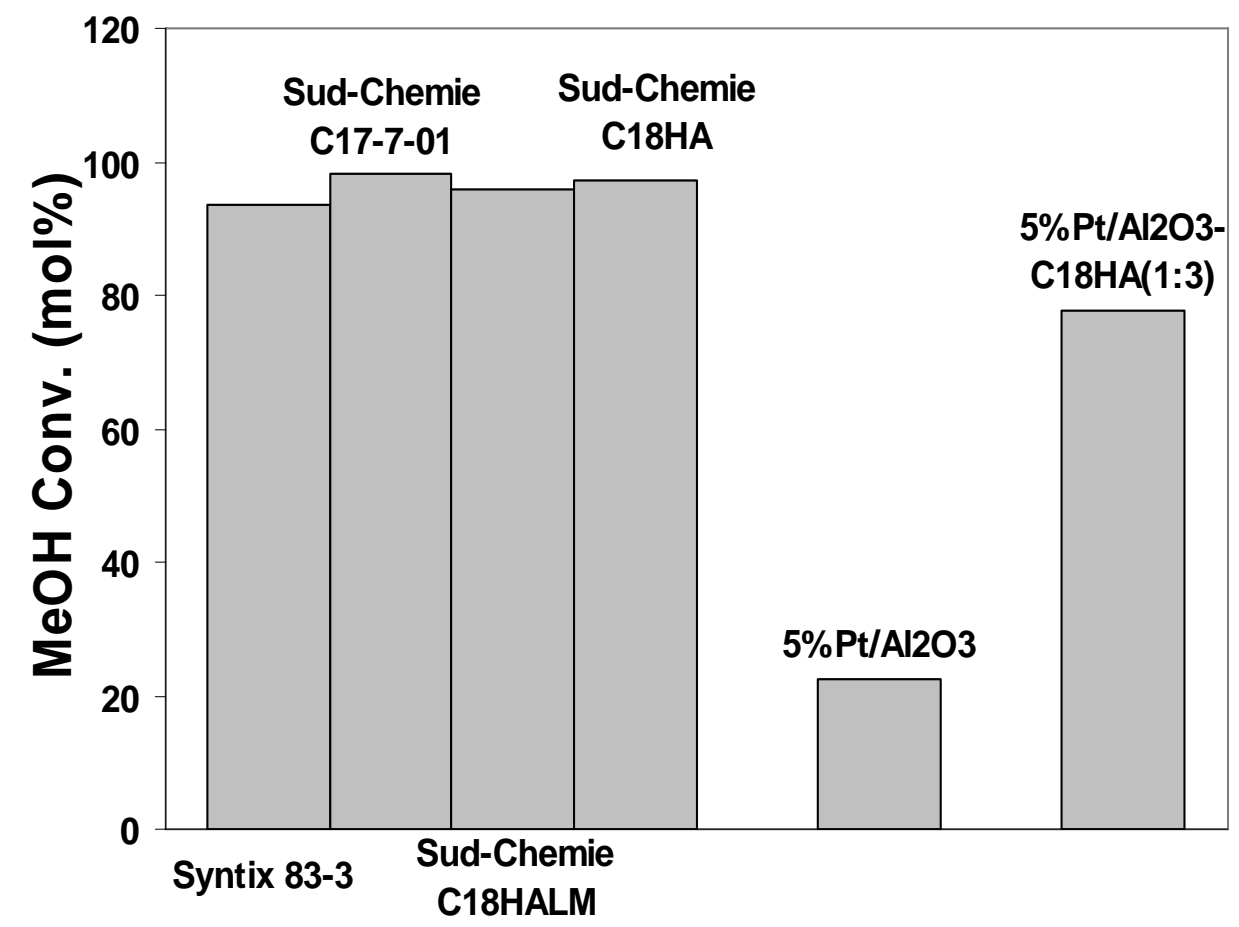

Figure 3.2.2.19 Comparison of conversion of methanol steam reforming over different catalysts at $230^{\circ} \mathrm{C}\left(\mathrm{WHSV} 5.2 \mathrm{~h}^{-1}\right.$, time on stream $2 \mathrm{~h}$ )

It can be seen that the Platinum catalyst has a very low activity for low-temperature methanol steam reforming. According to the yield of $\mathrm{CO}$ over $5 \% \mathrm{Pt}_{\mathrm{Al}} \mathrm{O}_{3}$ and Hybrid catalyst, Pt dose not seem to have the ability to remove $\mathrm{CO}$ under the reaction conditions employed. Cu-based catalysts have better reactivity than $\mathrm{Pt}$ catalysts, and the $\mathrm{C} 18 \mathrm{HA}$ gave the lowest $\mathrm{CO}$ concentration in the gaseous products. For $\mathrm{CO}$, the lower concentration is desired because the $\mathrm{CO}$ in final products needs to be lower than 30ppm. 


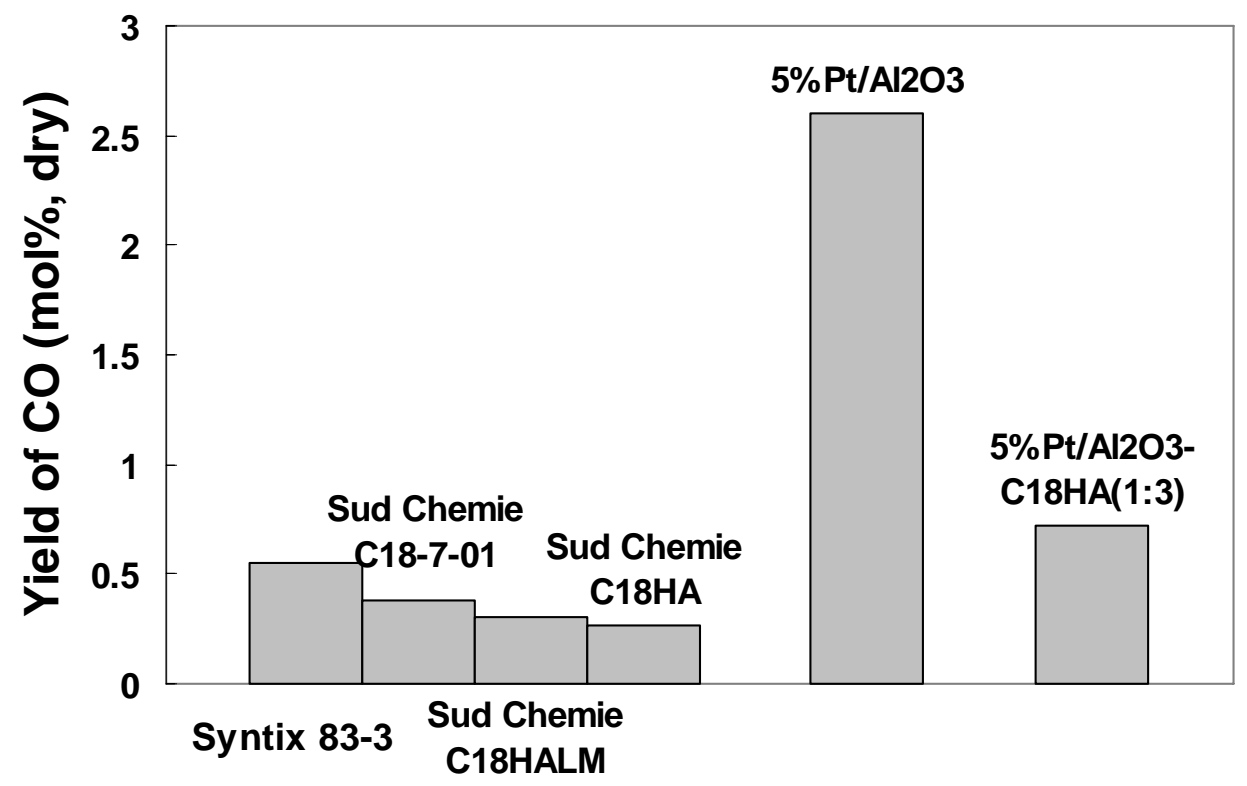

Figure 3.2.2.20 Comparison yield of $\mathrm{CO}$ of methanol reforming over different catalysts at $230^{\circ} \mathrm{C}\left(\mathrm{WHSV} 5.2 \mathrm{~h}^{-1}\right.$, time on stream $\left.2 \mathrm{~h}\right)$

\subsection{2.}

Although steam reforming can produce more hydrogen than oxidative steam reforming, the endothermic nature of steam reforming limits the application of on-board. The main advantage of oxidative steam reforming is that the heat produced by methanol oxidation can be used to drive methanol steam reforming. Air is a practical oxidant for on-board applications. In order to obtain the optimal oxidative steam reforming reaction conditions, the experiments were conducted over $\mathrm{C} 18 \mathrm{HA}$ with $\mathrm{O}_{2} / \mathrm{CH}_{3} \mathrm{OH}$ ratio from $0.1 \sim 0.5$. There is no carrier gas for oxidative steam reforming. For zero air case, carrier gas Ar is employed and the Argon flow rate is the same as the amount of nitrogen in air when the $\mathrm{O}_{2} / \mathrm{CH}_{3} \mathrm{OH}$ ratio is 0.3 . The nitrogen in the air is considered as a carrier gas.

The methanol conversion, $\mathrm{H}_{2}$ and $\mathrm{CO}$ formation of methanol oxidative steam reforming at $230^{\circ} \mathrm{C}$ over $\mathrm{C} 18 \mathrm{HA}$ with $\mathrm{O}_{2} / \mathrm{CH}_{3} \mathrm{OH}$ ratio range 0 0.5 are shown in Table 3.2.2.4.

Table 3.2.2.4 Oxidative Steam Reforming of Methanol over C18HA Catalyst at $230^{\circ} \mathrm{C}$

\begin{tabular}{|c|c|c|c|}
\hline $\mathrm{O}_{2} / \mathrm{CH}_{3} \mathrm{OH}$ ratio & $\begin{array}{c}\mathrm{CH}_{3} \mathrm{OH} \\
\text { conversion }\end{array}$ & $\mathrm{CO}$ yield (ppm) & $\mathrm{H}_{2}$ Yield (mol \%) \\
\hline $0^{*}$ & 60.8 & 848 & 70.4 \\
\hline 0.1 & 74.6 & 2602 & 66.6 \\
\hline 0.2 & 86.9 & 3125 & 69.2 \\
\hline 0.3 & 97.4 & 3371 & 54.4 \\
\hline 0.5 & 98.4 & 3642 & 49.4 \\
\hline
\end{tabular}

* Carrier gas Ar is employed and the Argon flow rate is the same as the amount of nitrogen in air which the $\mathrm{O}_{2} / \mathrm{CH}_{3} \mathrm{OH}$ ratio is 0.3 . 
As the $\mathrm{O}_{2} / \mathrm{CH}_{3} \mathrm{OH}$ ratio increases, the methanol conversion increases. This should be related to oxidation. Methanol partial oxidation produces less hydrogen than methanol steam reforming in terms the methanol reaction Therefore the hydrogen concentration in the product stream is reduced. Meanwhile the methanol partial oxidation produces a slightly more carbon monoxide. Considering of the selectivity of hydrogen and methanol conversion, the optimal $\mathrm{O}_{2} / \mathrm{CH}_{3} \mathrm{OH}$ ratio was determined to be about 0.3 .

\subsection{Water-Gas-Shift Reaction Optimization}

SudChemie's commercial C18-7-01 was chosen as the $\mathrm{CuO} / \mathrm{ZnO}_{\mathrm{AA}} \mathrm{O}_{3}$ water-gas-shift catalyst from preliminary test of three commercial catalysts. The composition of the catalysts is $42 \mathrm{wt} \% \mathrm{CuO}$, $47 \mathrm{wt} \% \mathrm{ZnO}$, and $11 \mathrm{wt} \% \mathrm{Al}_{2} \mathrm{O}_{3}$ as reported by the manufacturer. The first step in catalyst testing was optimization of experimental conditions. A reduction temperature of $300^{\circ} \mathrm{C}$ was chosen based on the temperature-programmed-reduction (TPR) curve as seen in Figure 2.2.2.21. The TPR was run at $10^{\circ} \mathrm{C} / \mathrm{min}$ with a $5 \% \mathrm{H}_{2} / \mathrm{Ar}$ air flow of $25 \mathrm{ml} / \mathrm{min}$.

The reaction temperature was varied over a range from $120-240^{\circ} \mathrm{C}$ in $30^{\circ} \mathrm{C}$ intervals to determine its effect on carbon monoxide (CO) conversion. The results are shown in Figure 3.2.2.22. It can be seen that the CO conversion drastically rises between 150 and $210^{\circ} \mathrm{C}$, where the conversion levels then reach a plateau. Based on this data a reaction temperature of $210^{\circ} \mathrm{C}$ was chosen. This temperature is consistent with reaction temperatures used by Hadden et al. for $\mathrm{Cu} / \mathrm{ZnO} / \mathrm{Al}_{2} \mathrm{O}_{3}$ catalysts with a copper content between 38 and $61 \mathrm{wt} \%$ [Hadden et al., 1995] and Vanden Bussche and Froment for a commercial $\mathrm{Cu} / \mathrm{ZnO} / \mathrm{Al}_{2} \mathrm{O}_{3}$ catalyst [Vanden Bussche and Froment, 1996].

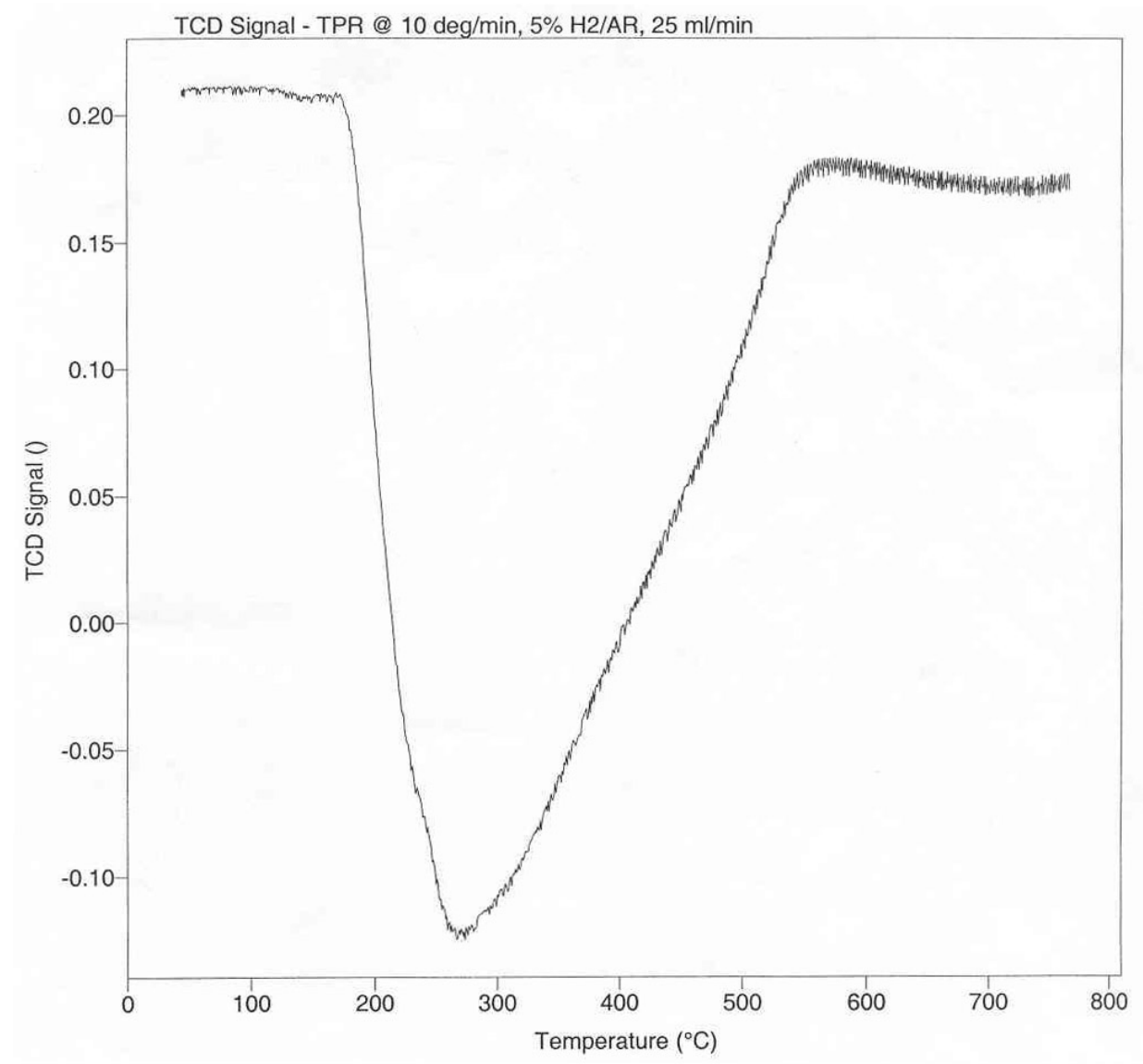

Figure 3.2.2.21: TPR of $\mathrm{CuO} / \mathrm{ZnO} / \mathrm{Al}_{2} \mathrm{O}_{3}(\mathrm{C} 18-7-01)$ using $5 \% \mathrm{H}_{2}$ in $\mathrm{Ar}$ 


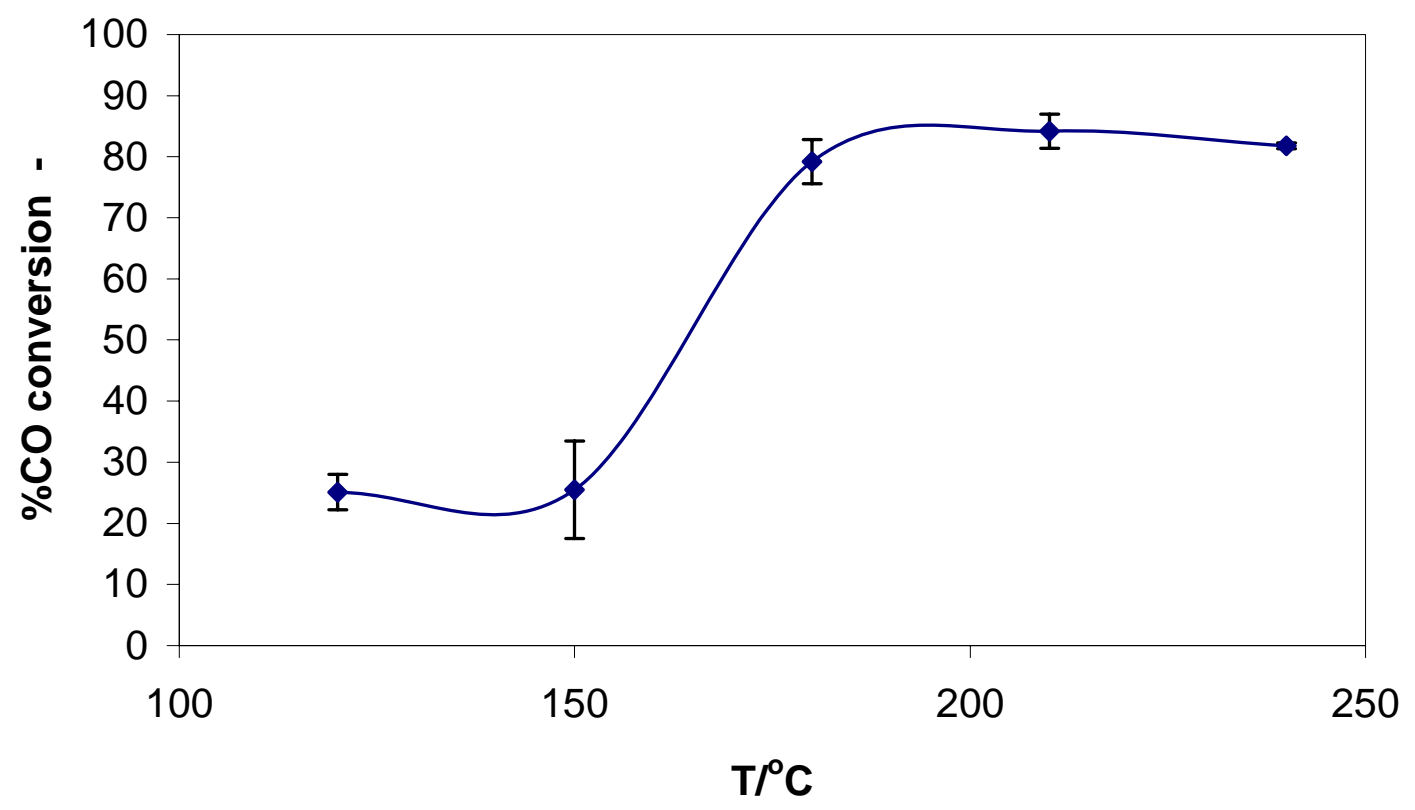

Figure 3.2.2.22 Effect of reaction temperature on CO conversion of 2000ppm over $\mathrm{CuO} / \mathrm{ZnO} / \mathrm{Al}_{2} \mathrm{O}_{3}$ catalyst, $\mathrm{SV}=12,000 \mathrm{~h}^{-1}$ at hour 4

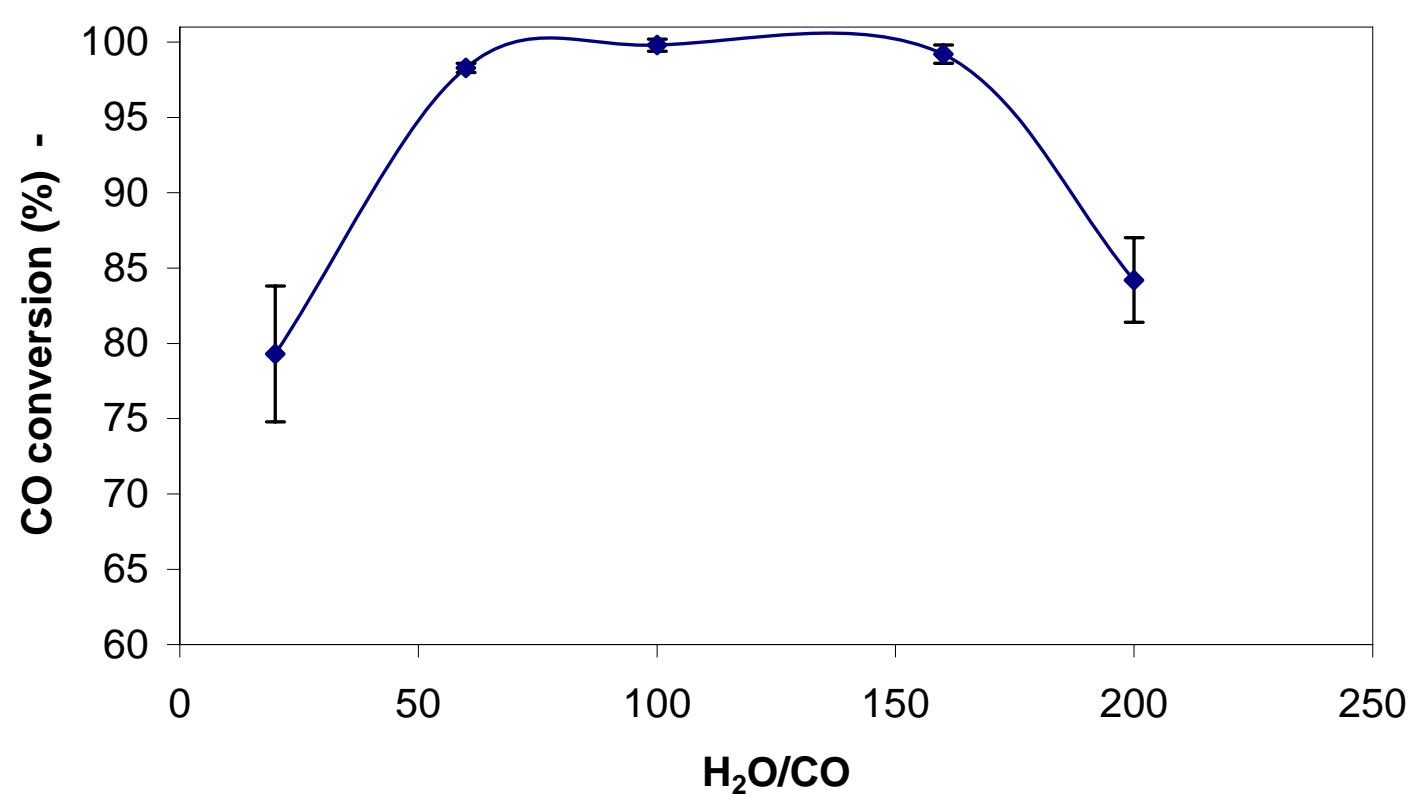

Figure 3.2.2.23 Effects of water to CO ratio on CO conversion of $2000 \mathrm{ppm}, \mathrm{T}=210^{\circ} \mathrm{C}$, $\mathrm{SV}=12,00 \mathrm{~h}^{-1}$ at $\mathrm{hr} 4$

After temperature optimization the effect of the water to carbon monoxide ratio was examined. It was found that optimum performance occurred when there was between 100 and 170 water molecules for every $\mathrm{CO}$ molecule. Based on this evidence a $\mathrm{H}_{2} \mathrm{O}(\mathrm{g})$ to $\mathrm{CO}$ ratio of 100 was chosen for all further testing. A graphical representation of these results can be found in Figure 3.2.2.23 below.

The dry space velocity was found to have a large effect on the performance of the commercial $\mathrm{CuO} / \mathrm{ZnO} / \mathrm{Al}_{2} \mathrm{O}_{3}$ catalyst. At low space velocities the CO conversion approached $28.8 \%$ at $6000 \mathrm{~h}^{-1}$ 
and slowly increased reaching a peak of $99.8 \%$ conversion at $12,000 \mathrm{~h}^{-1}$. The CO conversion then dropped to $87.8 \%$ at $16,000 \mathrm{~h}^{-1}$. All subsequent tests were run at $12,000 \mathrm{~h}^{-1}$ dry space velocity. Although, it is important to note that the maximum space velocity is well below the DOE target of $30,000 \mathrm{~h}^{-1}$ [Thompson et al., 2002]. After reaction optimization of SudChemie's C18-7-01, a conversion of $99.8 \%$ or a remainder of $4 \mathrm{ppm}$ of carbon monoxide was achieved. This exceeds the target of $<10$ ppm CO level that is preferred for use in PEM fuel cells.

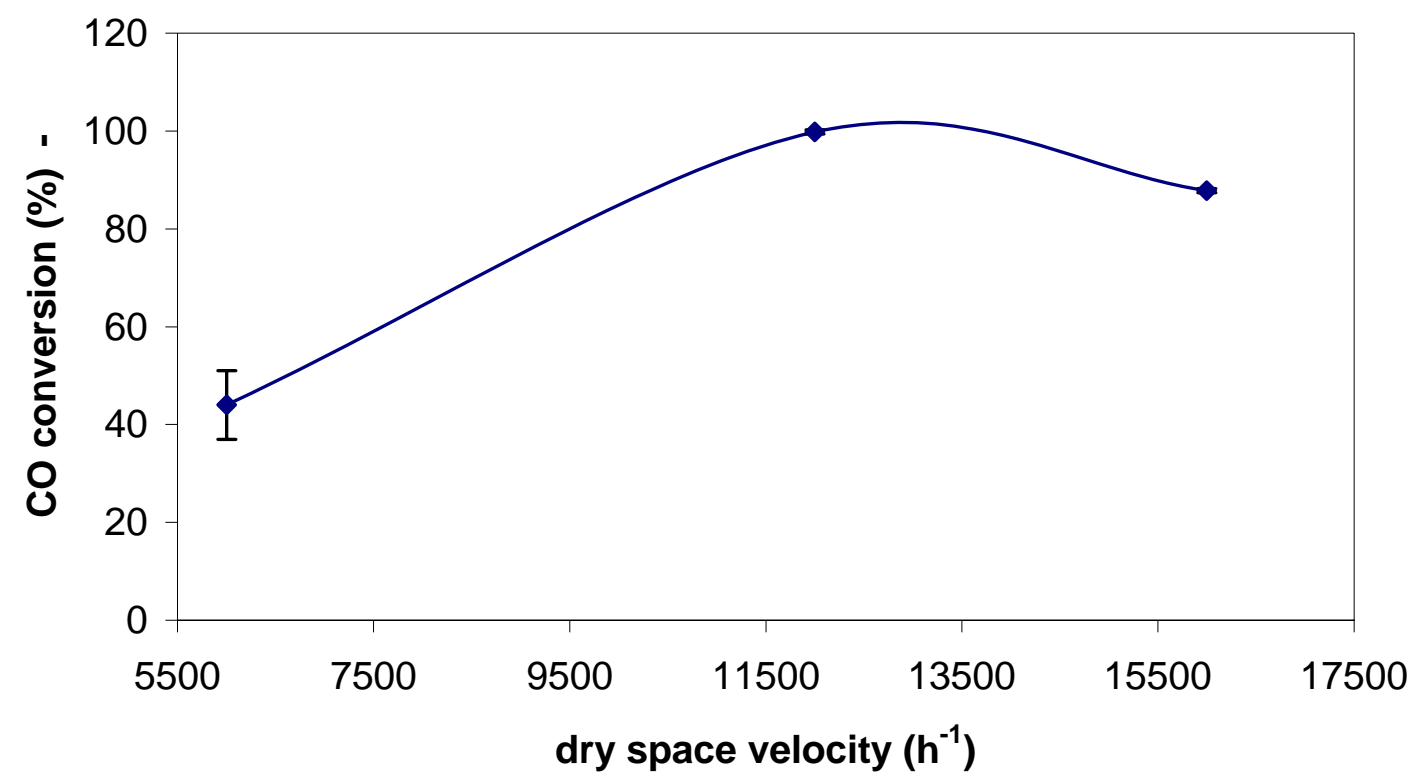

Figure 3.2.2.24 Effects of dry space velocity on CO conversion of 2000ppm, $\mathrm{T}=210^{\circ} \mathrm{C}$ at hour 4

\subsection{Preferential Oxidation}

Two different $\mathrm{Pt} / \mathrm{Al}_{2} \mathrm{O}_{3}$ commercial catalysts $(1 \% \mathrm{Pt}$ and $0.5 \% \mathrm{Pt})$ from Aldrich were tested under preferential oxidation conditions of $1.6 \% \mathrm{O}_{2}, 0.2 \% \mathrm{CO}$, and $10 \% \mathrm{CO}_{2}$, balance Argon gas. Each catalyst achieved $100 \% \mathrm{CO}$ conversion. $0.5 \% \mathrm{Pt} / \mathrm{Al}_{2} \mathrm{O}_{3}$ was then chosen as the preferred catalyst because of reduced commercial costs. Due to constraints on the current system, a $\mathrm{CO} / \mathrm{O}_{2}$ ratio below the $1 / 8$ achieved with $1.6 \% \mathrm{O}_{2}$ in the system feed was unable to be obtained. This is due to the gas mixtures used and the total possible out put of the mass flow controllers. It is important to note that by using only the preferential oxidation reaction, researchers have been able to achieve CO conversion using $\mathrm{CO} / \mathrm{O}_{2}$ ratios as low as $1 / 0.5$ [Kahlich et al., 1997].

\subsection{Oxygen Assisted Water-Gas-Shift Reaction}

After optimization of the individual water-gas-shift and preferential oxidation reactions, the two commercial catalysts were then combined in various ratios as the gas feed was set to combine the two reactions: $1.6 \% \mathrm{O}_{2}, 0.2 \% \mathrm{CO}, 10 \% \mathrm{CO}_{2}$, balance Argon with the addition of $20 \mathrm{~mL} / \mathrm{min} \mathrm{H}_{2} \mathrm{O}(\mathrm{g})$. This was done so that the benefits of both reaction types can be utilized. The great oxidative properties of the precious metal catalyst are used, along with the lower cost water-gas-shift catalyst that also generates additional $\mathrm{H}_{2}$ in the feed stream. As seen in Figure 3.2.2.25 below, where $\mathrm{x}$ is the percentage of $0.5 \% \mathrm{Pt} / \mathrm{Al}_{2} \mathrm{O}_{3}$ and $100-\mathrm{x}$ is the percentage of $\mathrm{C} 18-7-01$, the reaction conversions do not become consistant until $55 \% \mathrm{Pt} / \mathrm{Al}_{2} \mathrm{O}_{3}$ is used, achieving $99.9 \% \mathrm{CO}$ conversion. At all ratios above $55 \% \mathrm{Pt}_{\mathrm{Al}} \mathrm{O}_{3}$, conversion was $100 \%$. The oscillating behavior at less than $55 \% \mathrm{Pt} / \mathrm{Al}_{2} \mathrm{O}_{3}$ was seen in two separate 6 hour tests and are reproducible. It is possible that this is observed because $\mathrm{H}_{2}$ generated by the $\mathrm{Cu} / \mathrm{ZnO} / \mathrm{Al} 2 \mathrm{O} 3$ catalyst is being reoxidized by the $\mathrm{Pt}$ catalyst. 
It is startling to note that the performance of $60 \% \mathrm{Pt}^{-} \mathrm{Al}_{2} \mathrm{O}_{3}-40 \% \mathrm{C} 18-7-01$ drops to $49.3 \%$ (or $1014 \mathrm{ppm} \mathrm{CO}$ remaining) when $58.4 \% \mathrm{H}_{2}$ is added into the feed steam in place of Argon. A nominal amount of additional $\mathrm{H}_{2}$ gas was generated from the reaction, suggesting that the preferential oxidation reaction and the $0.5 \% \mathrm{Pt}_{/} \mathrm{Al}_{2} \mathrm{O}_{3}$ catalyst do the bulk of the carbon monoxide conversion.

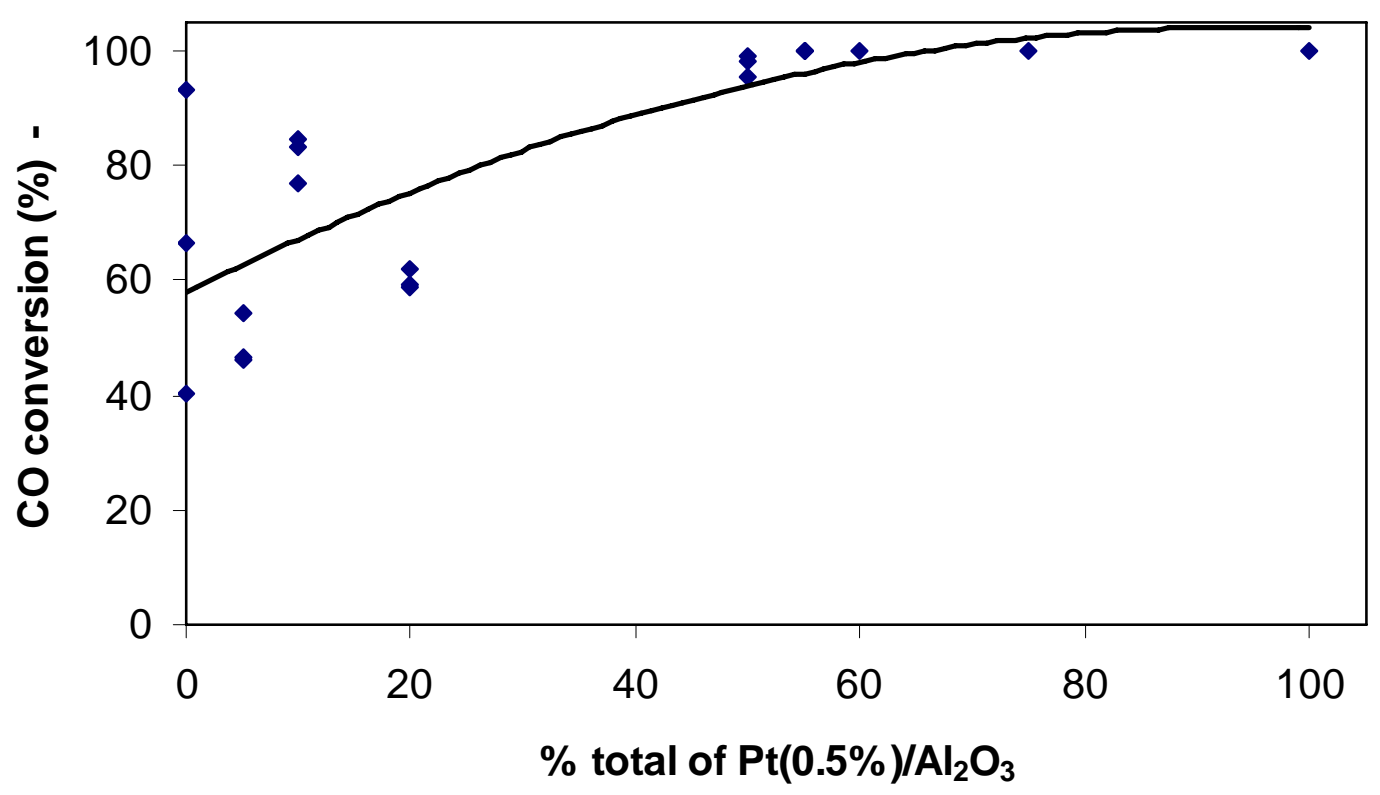

Figure 3.2.2.25 Ratio testing of (x)0.5\% $\mathrm{Pt}_{\mathrm{Al}} \mathrm{O}_{3}$ and $(100-\mathrm{x}) \mathrm{CuO} / \mathrm{ZnO}_{\mathrm{Al}} \mathrm{O}_{3}(\mathrm{C} 18-7-$ 01 ), where $T=210^{\circ} \mathrm{C}, S V=12,00 \mathrm{~h}^{-1}$ at hour 4

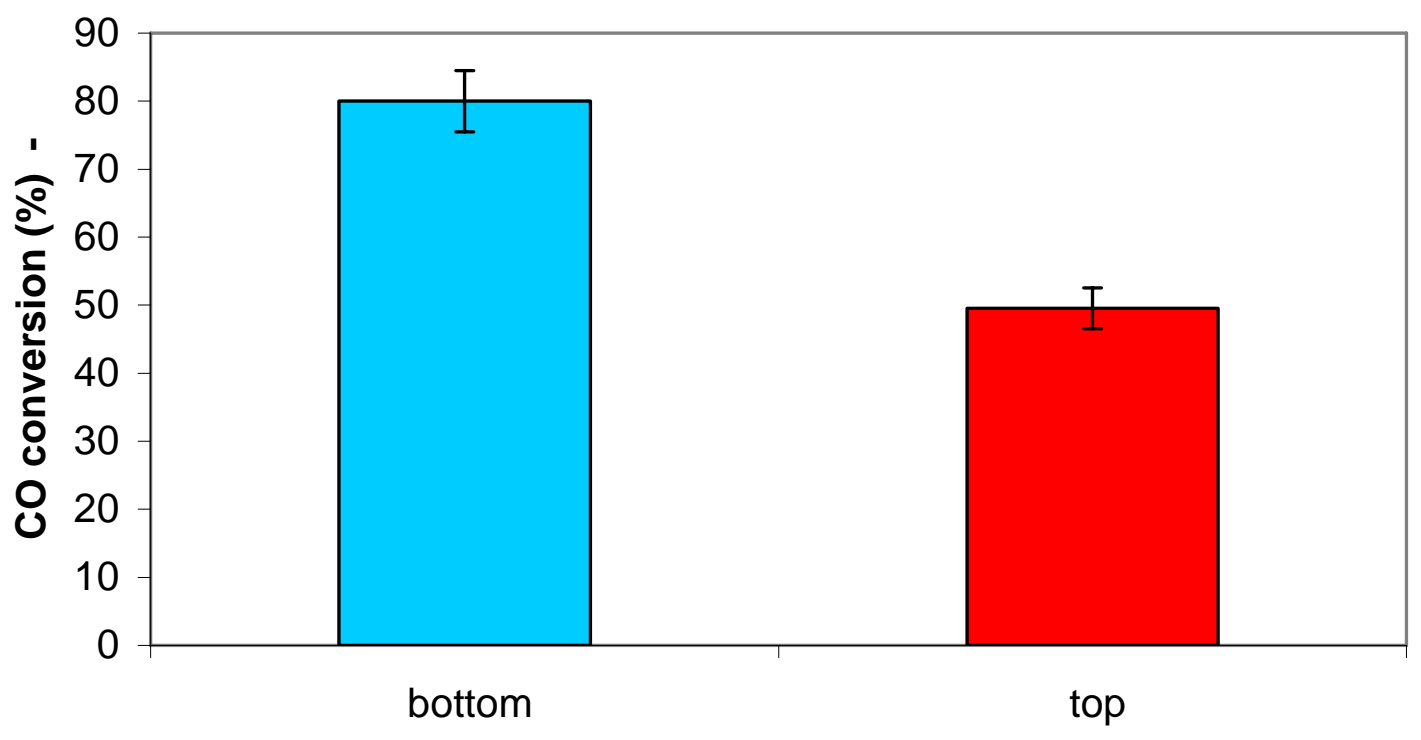

$\mathrm{Pt} / \mathrm{Al}_{2} \mathrm{O}_{3}$ position in bed

Figure 3.2.2.26 Effect of $\mathrm{Pt} / \mathrm{Al}_{2} \mathrm{O}_{3}$ catalyst position in the bed of $10 \% \mathrm{Pt} / \mathrm{Al}_{2} \mathrm{O}_{3}-90 \%$ $\mathrm{CuO} / \mathrm{ZnO} / \mathrm{Al}_{2} \mathrm{O}_{3}$ when converting 2000ppm of $\mathrm{CO}$ in the $\mathrm{O}_{2}+$ WGS reaction at $210^{\circ} \mathrm{C}$ and $\mathrm{SV}=12,000 \mathrm{~h}^{-1}$ at hour 4 
When testing the ratios of commercial catalyst, $10 \% \mathrm{Pt} / \mathrm{Al}_{2} \mathrm{O}_{3}$ and $90 \% \mathrm{CuO} / \mathrm{ZnO} / \mathrm{Al}_{2} \mathrm{O}_{3}$ were tested to see if the bed position of the catalysts effected performance. It was found that the $\mathrm{CO}$ conversion levels largely depended on the position of the catalyst in the fixed bed system. When the $\mathrm{Pt}$ catalyst was on top of the $\mathrm{CuO} / \mathrm{ZnO} / \mathrm{Al}_{2} \mathrm{O}_{3}$ catalyst, conversion levels dropped to $59.6 \%$. Alternately, when the Pt catalyst was placed below, conversion increased to $81.5 \%$. This may be because the oxidation reaction is much faster than the water-gas-shift reaction. Having the WGS catalyst on the top of the bed better allows the catalyst to perform the conversion, while having the faster PrOx reaction convert any CO missed by the WGS reaction.

\subsection{Conclusions}

1. Our preliminary results indicated that $\mathrm{Cu} / \mathrm{Zn} / \mathrm{Al}$ catalysts have high activity for lowtemperature steam reforming and oxidative steam reforming of methanol. As the reaction temperature increased, the activity of catalysts is increased. When the reaction temperature reached $275^{\circ} \mathrm{C}$, methanol is totally converted over any one of the four commercial catalysts. But CO formation can be significantly different. Lower temperature also helps to minimize CO formation. Sud-Chemie catalysts are superior to Synetix, and Sud-Chemie C18HA and C187-01 have the best performance according the methanol conversion and CO concentration in reformate gas. Pt catalysts are not effective for methanol reforming.

2. At the optimal reaction conditions: $230^{\circ} \mathrm{C}$ reforming temperature ; $\mathrm{O}_{2} / \mathrm{CH}_{3} \mathrm{OH}$ ratio as 0.3; WHSV as $5.2 \mathrm{~h}^{-1}$; methanol water mole ratio as 1:1.4, methanol oxidative steam reforming over commercial catalyst $\mathrm{C} 18 \mathrm{HA}$ has high methanol conversion (>97\%) and low CO concentration in products stream (<0.5\%) and Hydrogen concentration is about $55 \%$.

3. It has also been seen that a combination of commercial water-gas-shift and preferential oxidation catalysts can effectively reduce the $\mathrm{CO}$ outlet concentration of reformed gas. It has also been determined that the bed position of the catalysts can play a large role in the CO conversion levels that are achieved. 


\section{Subtask 3.2.2.3 - Catalyst Selection and Configuration in a Prototype Reformer (19-24}

months)

\subsection{Introduction}

For the methanol reformer applied for on board PEM fuel cell, the size and weight limitation of reformer is strict. In order to achieve more efficient reforming of methanol for hydrogen production for on board fuel cell applications, a new reactor configuration was studied for methanol reforming. Catalysts selecting of methanol reforming over the simulator of integrated methanol reformer was conducted.

\subsection{Design Concept of Integrated Methanol Reforming}

A two zones reactor which one zone is for methanol reforming and another is for CO clean up was designed. Schematic diagram of conceptual design is shown at Figure 3.2.2.27.

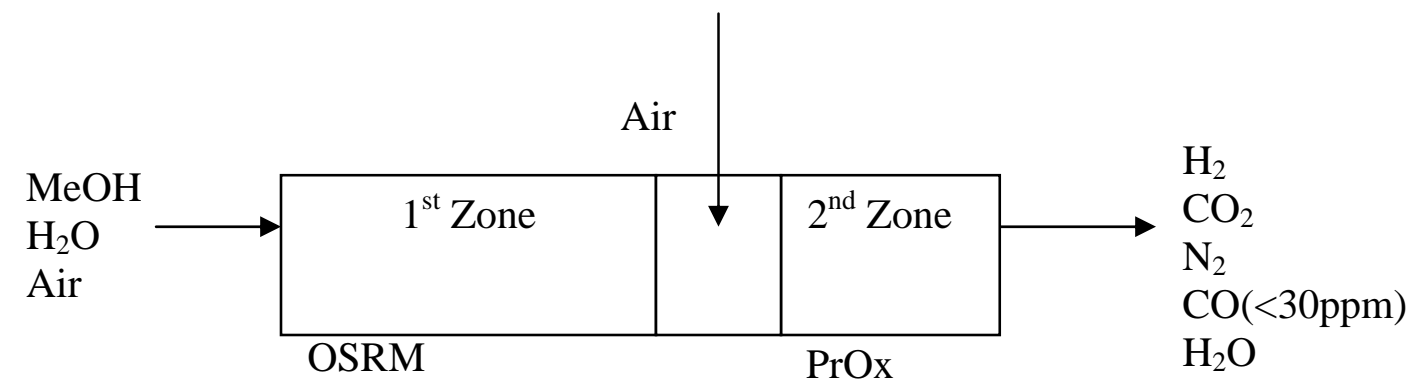

Figure 3.2.2.27 Scheme of integrated methanol reformer

\subsection{Experimental, Results and Discussion}

\subsection{Catalysts selection for $1^{\text {st }}$ Zone}

$\mathrm{C} 18 \mathrm{HA}$, hybrid catalyst and two-layers catalyst are the candidates for $1^{\text {st }}$ Zone methanol oxidative steam reforming. The hybrid catalyst is the mechanical mixture of $1 \% \mathrm{Pt} / \mathrm{Al}_{2} \mathrm{O}_{3}$ and $\mathrm{C} 18 \mathrm{HA}$. In the two-layer catalyst bed, the upper layer is $1 \% \mathrm{Pt} / \mathrm{Al}_{2} \mathrm{O}_{3}$ and lower layer is C18HA. For both kinds of catalyst, weight ratio of $\mathrm{Pt} / \mathrm{Al}_{2} \mathrm{O}_{3}$ to $\mathrm{C} 18 \mathrm{HA}$ is $1: 3$. The oxidative steam reforming experiment was conducted under the optimal reaction conditions:

Reforming temperature is $230^{\circ} \mathrm{C}$;

Liquid feed $\left(\mathrm{H}_{2} \mathrm{O} / \mathrm{CH}_{3} \mathrm{OH}=1.4 \mathrm{~mol}\right.$ ratio $): 0.03 \mathrm{ml} / \mathrm{min}$;

WHSV (weight hourly space velocity) $: 5.2 \mathrm{~h}^{-1}$;

Catalyst loading : $0.3 \mathrm{~g}$;

No carrier gas.

The methanol conversion, hydrogen and $\mathrm{CO}$ concentration in the products were shown in Figure 3.2.2.28, Figure 3.2.2.29, and Figure 3.2.2.30.

Initially, adding or mixing $\mathrm{Pt} / \mathrm{Al} 2 \mathrm{O} 3$ with $\mathrm{Cu} / \mathrm{Zn} / \mathrm{Al}$, we expect the Pt has a high oxidation activity, the heat produced by oxidation to start steam reforming. The experimental results are shown in the Figure 3.2.2.28, Figure 3.2.2.29, and Figure 3.2.2.30. However the catalysts of hybrid and two-layer catalysts have less activity than $\mathrm{C} 18 \mathrm{HA}$ at $230 \mathrm{C}$ for oxidative steam reforming, and the $\mathrm{H}_{2}$ selectivity and $\mathrm{CO}$ yield also reveal the $\mathrm{C} 18 \mathrm{HA}$ is better. Considering the $\mathrm{CO}$ yield, $\mathrm{Pt}$ has much high oxidation activity. But the methanol conversion didn't increase correspondingly. The possible reason is that the heat is not transferred to the steam reforming active site efficiently. On other hand, the oxidation heat make the temperature on some site surface of catalysts overheat, thus result to the catalyst 
lose activity. Therefore, for methanol oxidative steam reforming at $230{ }^{\circ} \mathrm{C}$ without carrier gas, the catalyst C18HA is better choice.

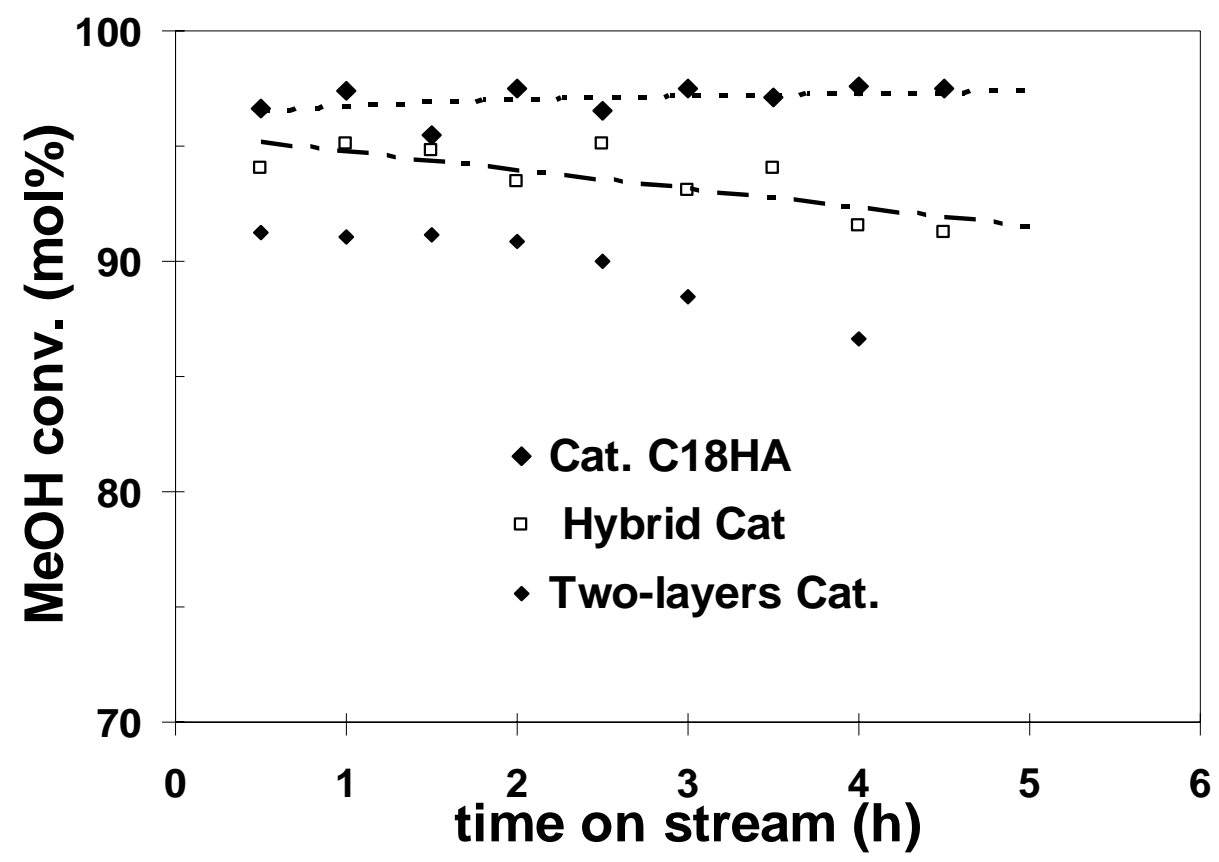

Figure 3.2.2.28 Comparison of the catalytic activity for oxidative steam methanol reforming at $230^{\circ} \mathrm{C}$

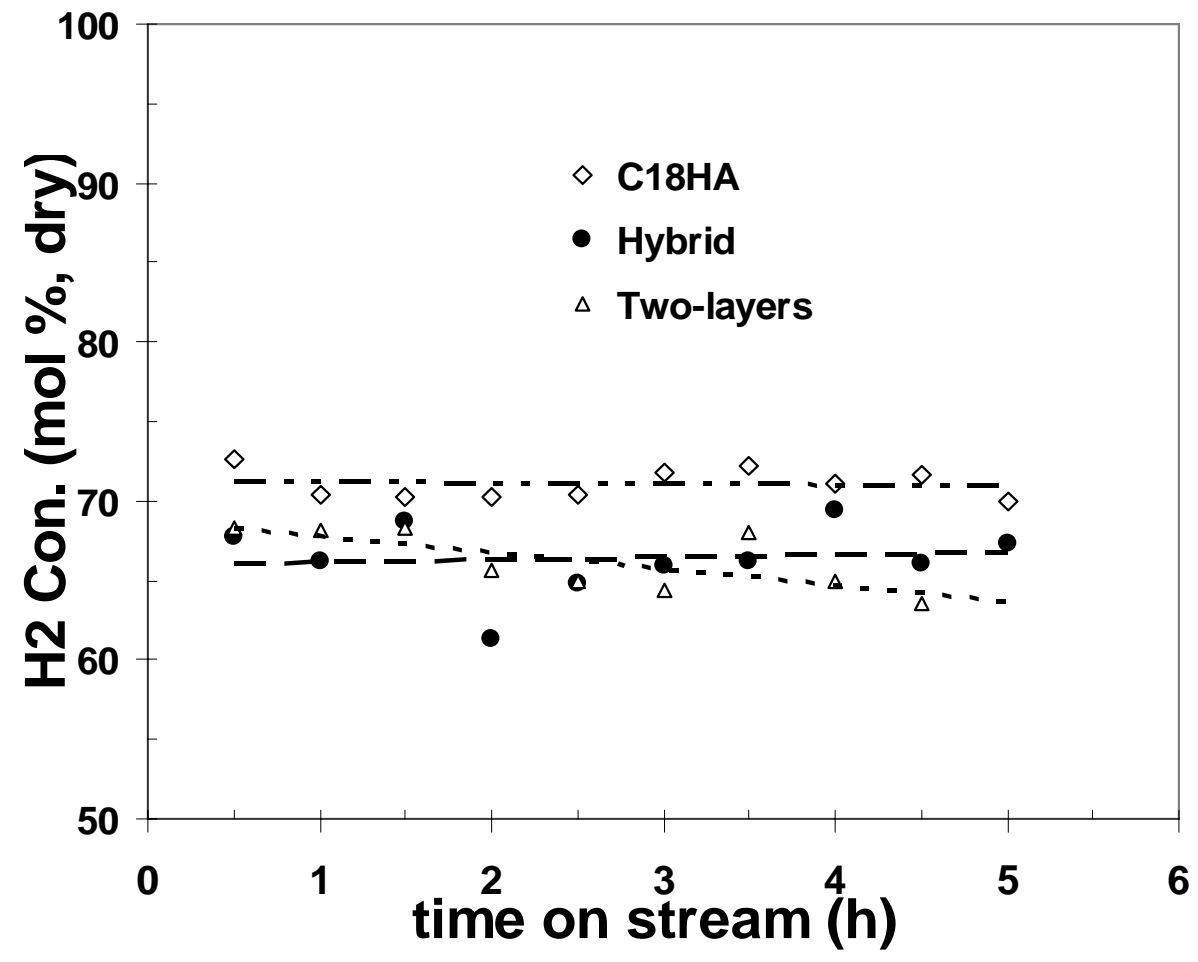

Figure 3.2.2.29 Comparison of $\mathrm{H}_{2}$ selectivity of oxidative steam reforming at $230^{\circ} \mathrm{C}$ 


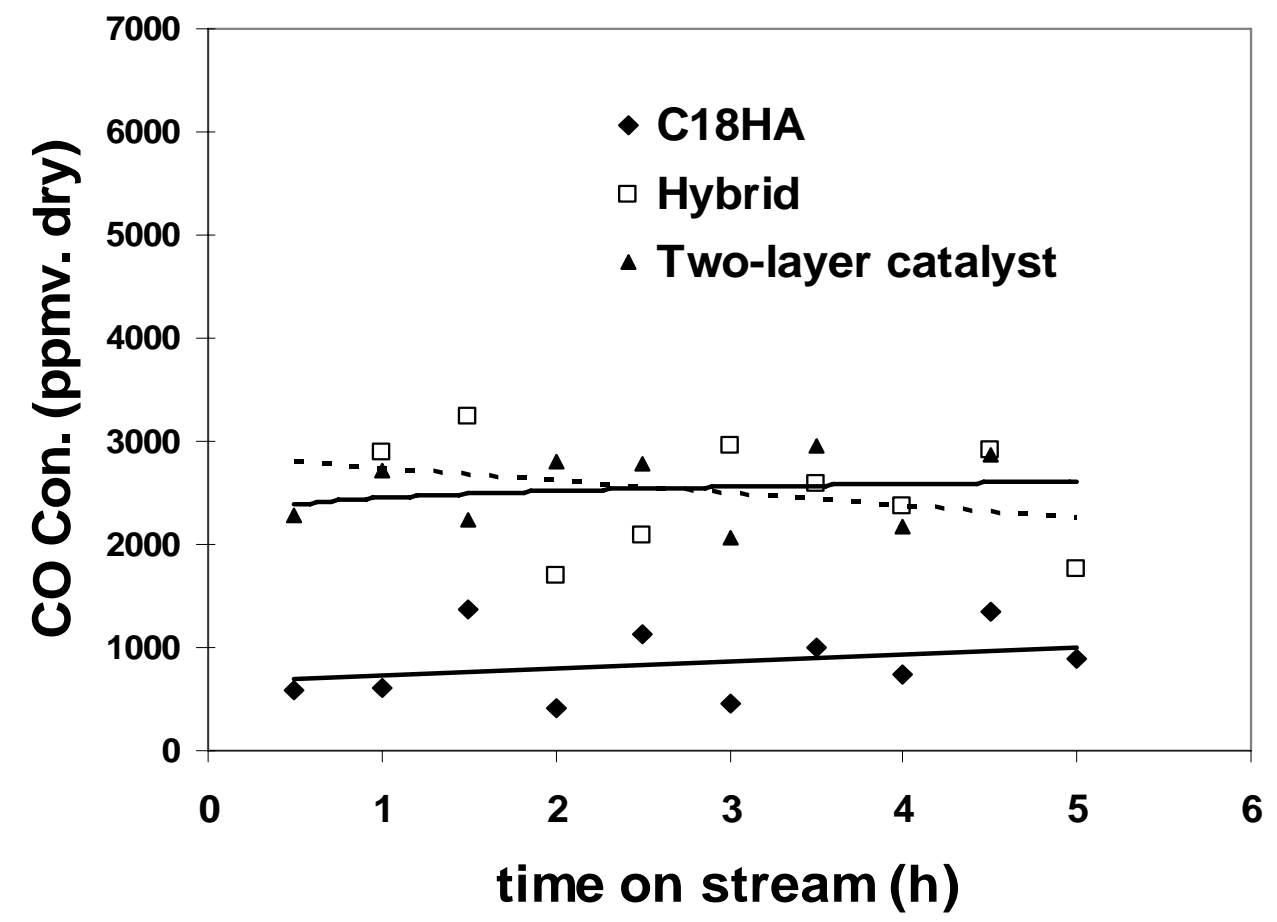

Figure 3.2.2.30 Comparison of $\mathrm{CO}$ formation of oxidative steam reforming at $230^{\circ} \mathrm{C}$

\subsection{Methanol Oxidative Reforming in $1^{\text {st }}$ Zone and CO clean up in $2^{\text {nd }}$ Zone}

In the first zone oxidative steam reforming is conducted under optimized reaction conditions discussed previously and over $\mathrm{C} 18 \mathrm{HA}$. The second zone is for $\mathrm{CO}$ preferential oxidation. The CO preferential oxidation temperature is about $150^{\circ} \mathrm{C}$, in the air ratio range $0.11-0.53$, the catalyst is $1 \% \mathrm{Pt} \mathrm{Al}_{2} \mathrm{O}_{3}$, the hydrogen and $\mathrm{CO}$ concentration in outlet gas and methanol conversion are listed in the Table 3.2.2.5

Table 3.2.2.5 Methanol conversion and $\mathrm{H}_{2}$, CO composition over integrated reformer

\begin{tabular}{|c|c|c|c|}
\hline Air ratio* & $\begin{array}{c}\text { Methanol } \\
\text { conversion } \\
(\text { mol\%) }\end{array}$ & $\begin{array}{c}\mathrm{H}_{2} \text { Yield } \\
\text { (mol \% Dry) }\end{array}$ & $\begin{array}{c}\text { co Yield } \\
\text { (ppm Dry) }\end{array}$ \\
\hline 0.11 & 92.0 & 63.9 & 1330 \\
\hline 0.12 & 96.3 & 57.2 & 477 \\
\hline 0.15 & 96.4 & 55.1 & 215 \\
\hline 0.39 & 94.1 & 56.0 & 139 \\
\hline 0.47 & 95.3 & 55.4 & 102 \\
\hline 0.53 & 96.8 & 52.4 & 31 \\
\hline
\end{tabular}

* Air ratio is the air amount fed to the 2nd Zone to the air amount fed to 1st Zone

When the air ratio is about 0.5 , the CO concentration in outlet steam is about 30ppm. The result reveals the conceptual design of reformer for fuel cell is feasible. No more further CO removal after reforming, the new two zones in one staged integrated reformer has the compact advantage. 


\subsection{Conclusions}

One new integrated methanol reformer was designed. The two zone reformer with one for reforming and another for $\mathrm{CO}$ clean up has simple and compact features. The methanol reforming over the two zone integrated reformer which $1^{\text {st }}$ Zone is at $230^{\circ} \mathrm{C}$ over $\mathrm{C} 18 \mathrm{HA}$ and $2^{\text {nd }}$ zone is at $150^{\circ} \mathrm{C}$ over $1 \% \mathrm{Pt} / \mathrm{Al}_{2} \mathrm{O}_{3}$ reveals the final $\mathrm{CO}$ concentration in outlet stream is able to reach about 30ppm. 


\section{Subtask 3.2.2.4 - Comparison of Fixed-bed Catalyst and Monolith Catalyst Core in a Prototype}

Reformer (24-27 months)

\subsection{Introduction}

The monolith was widely used as high surface area and small pressure drop. The comparison of fixed-bed catalyst and Monolith Catalyst Core in the reformer is conducted in this subtask.

\subsection{Experimental}

The monolith used is 1 inch long and Mask Diameter $0.389 \mathrm{in}$. The C18HA is milled to form fine powder and mix with water to form slurry. The piece of monolith was dipped into an aqueous slurry of catalyst $\mathrm{C} 18 \mathrm{HA}$, then dried and calcinated. And repeated another 2 times. The total catalyst loading is $0.08 \mathrm{~g}$. The methanol reforming conditions are employed as the same as optimal reforming conditions discussed before.

\subsection{Results and Discussion}

When methanol steam reforming over that monolith was tested, feed flow rate $0.03 \mathrm{ml} / \mathrm{min}$ (water I $\mathrm{MeOH}=1.42 \mathrm{~mol}$ ratio), methanol conversion just about $20 \%$. That result is not surprised. Catalyst loading on monolith $(0.08 \mathrm{~g})$ is about a quart of the packed catalyst $(0.3 \mathrm{~g})$. but the volume of the monolith core is almost twice of $0.3 \mathrm{~g}(0.50-1 \mathrm{~mm}$ particle size).

\subsection{Conclusions}

Current monolith loading method is not suitable to loading catalyst for hydrogen production for on board fuel cell application. Improving the monolith loading is necessary. 


\subsubsection{References}

$\mathrm{Gu}$, W. and C. Song (2003). "Hydrogen Production from Intergrated Methanol Reforming ove Cu-ZnO/Al2O3 and Pt/Al2O3 Catalysts for PEM Fuel Cells." Am. Chem. Soc. Fuel Chem Division Prepr 48(2): 804-807.

Hadden, R. A., P. J. Lambert and C. Ranson (1995). "Relationship between the copper surface area and the activity of $\mathrm{CuO} / \mathrm{ZnO} / \mathrm{Al}_{2} \mathrm{O}_{3}$ water-gas shift catalysts." Applied Catalysis A: General 122: L1-L4.

Kahlich, M. J., H. A. Gasteiger and R. J. Behm (1997). "Kinetics of the Selective CO Oxidation in H2-Rich Gas on Pt/Al2O3." Journal of Catalysis 171(1): 93-105.

Kahlich, M. J., H. A. Gasteiger and R. J. Behm (1999). "Kinetics of the selective lowtemperature oxidation of $\mathrm{CO}$ in H2-Rich gas over Au/alpha-Fe2O3." Journal of Catalysis 182: 430-440.

Larminie, J. and A. Dicks (2000). Fuel Cell Systems Explained. New York, NY, John Wiley \& Sons.

Song, C. S. (2002). "Fuel processing for low-temperature and high-temperature fuel cells Challenges, and opportunities for sustainable development in the 21st century." Catalysis Today 77(1-2): 17-49.

Springer, T. E., T. Rockward, T. A. Zawodzinski and S. Gottesfeld (2001). "Model for Polymer Electrolyte Fuel Cell Operation on Reformate Feed." Journal of The Electrochemical Society 148(1): A11-A23.

Thompson, L., N. Garland and W. Smith (2002). Hydrogen, Fuel Cells, and Infrastructure: FY 2002 Progress Report, Department of Energy: 360-363.

Vanden Bussche, K. M. and G. F. Froment (1996). "A Steady-State Kinetic Model for Methanol Synthesis and Water Gas Shift Reaction on a Commercial Cu/ZnO/Al2O3 Catalyst." Journal of Catalysis 161: 1-10. 
Subtask 3.3 Compression Ignition Engine Studies 


\section{Experimental}

\subsection{Compression Ignition Engine Studies}

\subsubsection{Engine Setup for Baseline Test}

TEST ENGINE - Experiments were conducted with a Cummins 5.9L, turbocharged, water cooled, six-cylinder, 4-valves per cylinder direct injection diesel engine. The experimental system consisted of an engine, dynamometer, controller, combustion analysis instrumentation, and emissions analyzers. The engine was fitted with an electronic control module (ECM) that monitors engine performance and controls different events automatically, especially the start of injection (SOI), injection timing advancement or retardation. Figure 3.3.1 presents a diagram of the Cummins 5.9L ISB turbodiesel engine and test cell instrumentation. Specifications of the test engine are shown in Table 3.3.1. The engine uses a Bosch VP-44 type rotary distributor fuel pump. The injectors have 7 holes and a 152 deg spray cone angle. A Leeds \& Northrup "Micromax" data acquisition and control system was used to log the real-time engine speed, torque and power, as well as, exhaust, lubricating oil and coolant temperatures and intake air mass flow.

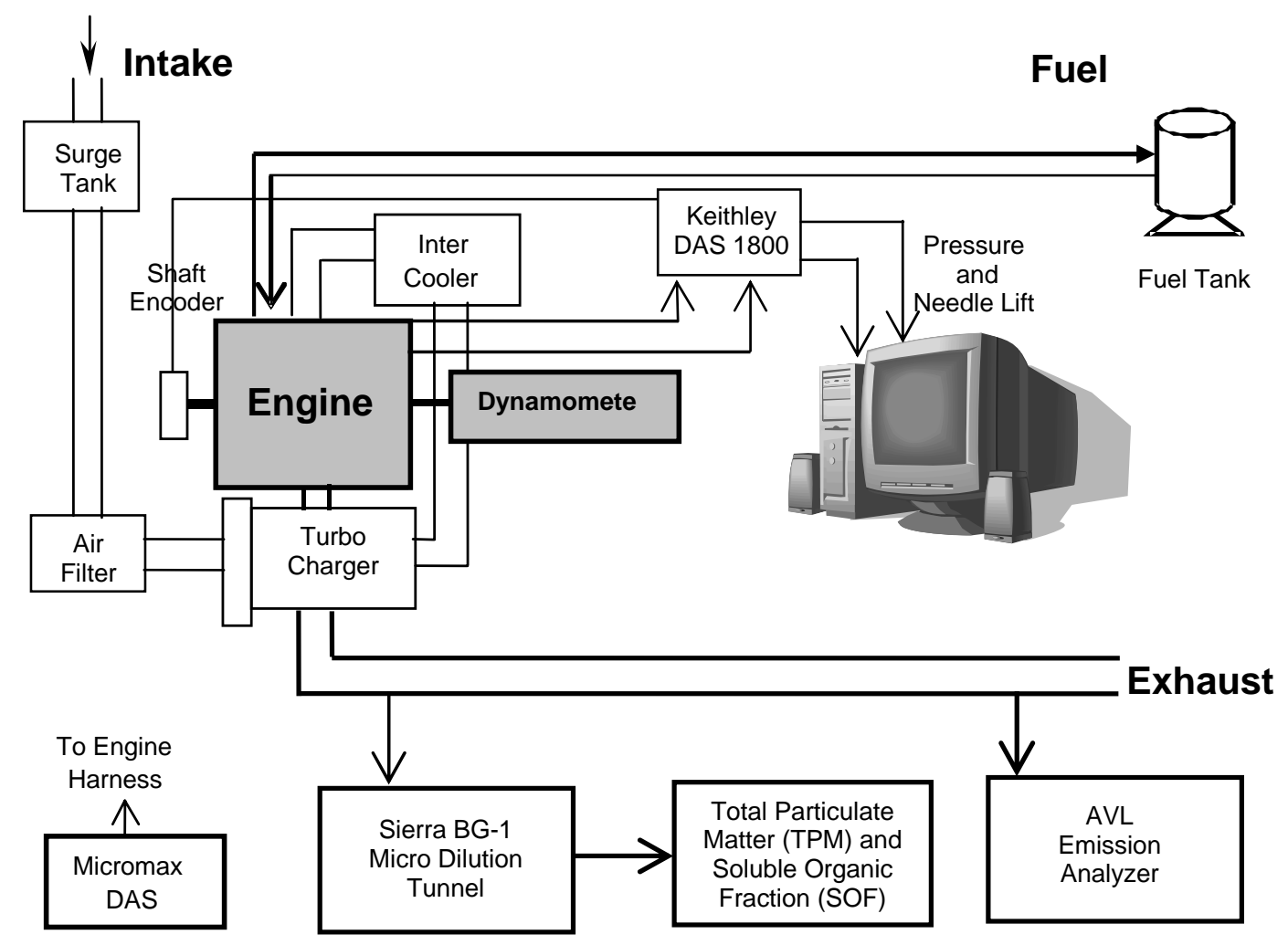

Figure 3.3.1 Schematic diagram of the experimental system for baseline testing

The fuel consumption was monitored using a Sartorious model EA60EDE-IOUR precision scale, with an accuracy of \pm 2 grams. Cylinder pressure was measured using Kistler piezoelectric pressure transducer model 6067B (Figure 3.3.2). A Hall-effect proximity sensor, installed by Wolff Controls Corporation, was used to measure needle-lift in the injector (Figure 3.3.3). Cylinder number six was considered for cylinder pressure and needle lift data. An AVL 364 shaft encoder installed on the engine crankshaft, along with a Keithley DAS 1800 data acquisition board enabled 0.1 CA degree resolution acquisition of these signals. 
Table 3.3.1 Specifications of the test engine

\begin{tabular}{|c|c|}
\hline Engine & Six-cylinder DI Diesel, MY 2000 \\
Advertised Power & $235 \mathrm{hp} @ 2700$ RPM \\
Bore & $102 \mathrm{~mm}$ \\
Stroke & $120 \mathrm{~mm}$ \\
Compression Ratio & 16.3 \\
Displacement & $5.9 \mathrm{~L}$ \\
Injection System & $\begin{array}{c}\text { Bosch VP-44 Rotary Distributor Pump, } \\
\text { Injector 7 holes, 152 deg cone angle }\end{array}$ \\
Swirl Ratio & 2.45 \\
Aspiration & Turbocharged \\
\hline
\end{tabular}

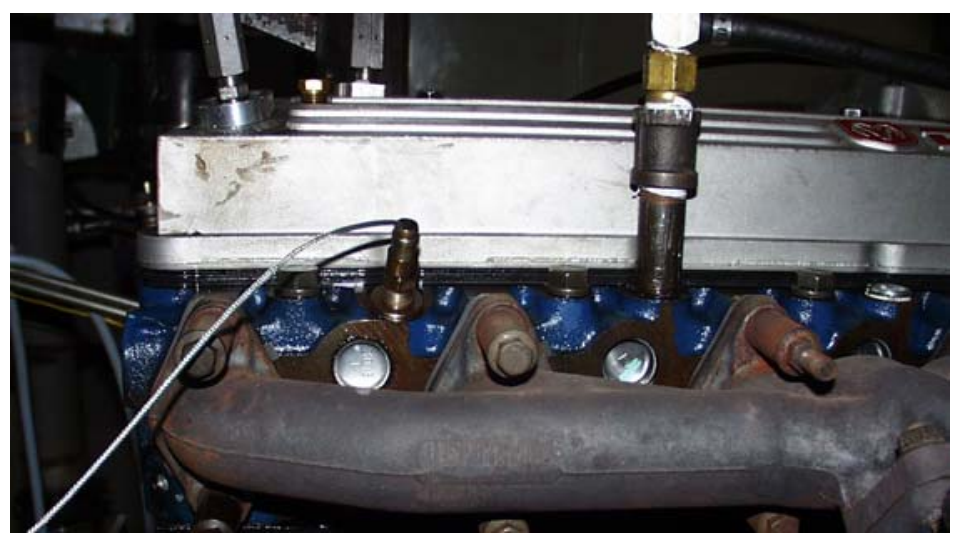

Figure 3.3.2 Piezoelectric cylinder pressure transducer

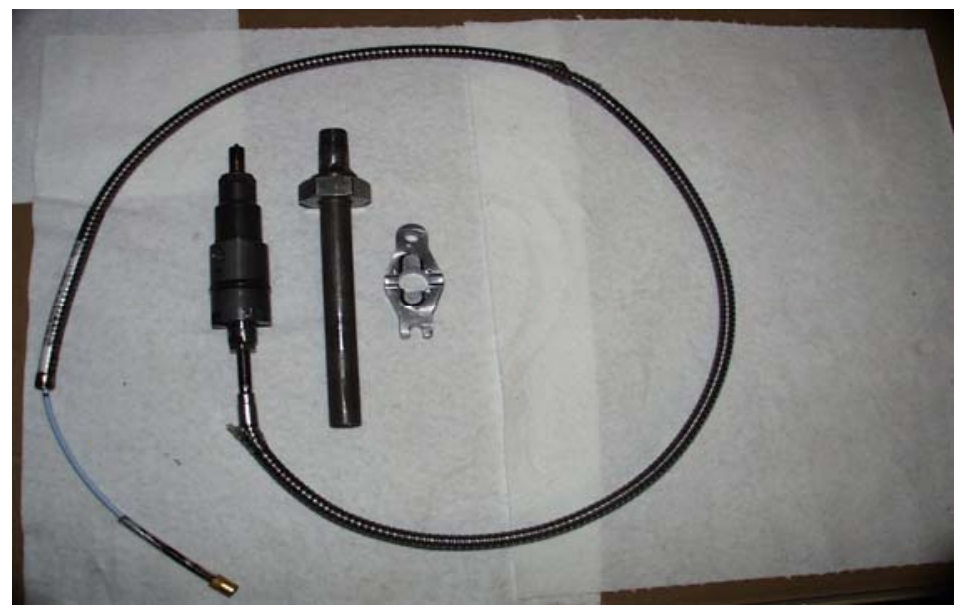

Figure 3.3.3 Hall-effect proximity sensor for measuring needle lift 
TEST CYCLES - For the engine testing, the base and biodiesel blended fuels were evaluated using the AVL 8-Mode test protocol [1]. The engine operating conditions were calculated based on the rated peak torque, power and speed of the engine. Figure 3.3.4 and Table 3.3.2 indicate the test matrix utilized for engine evaluations. The performance of the test engine is shown in Figure 3.3.5. Before measurements were obtained, the engine was warmed up for more than an hour at idle to bring the engine coolant temperature to roughly $90{ }^{\circ} \mathrm{C}$.

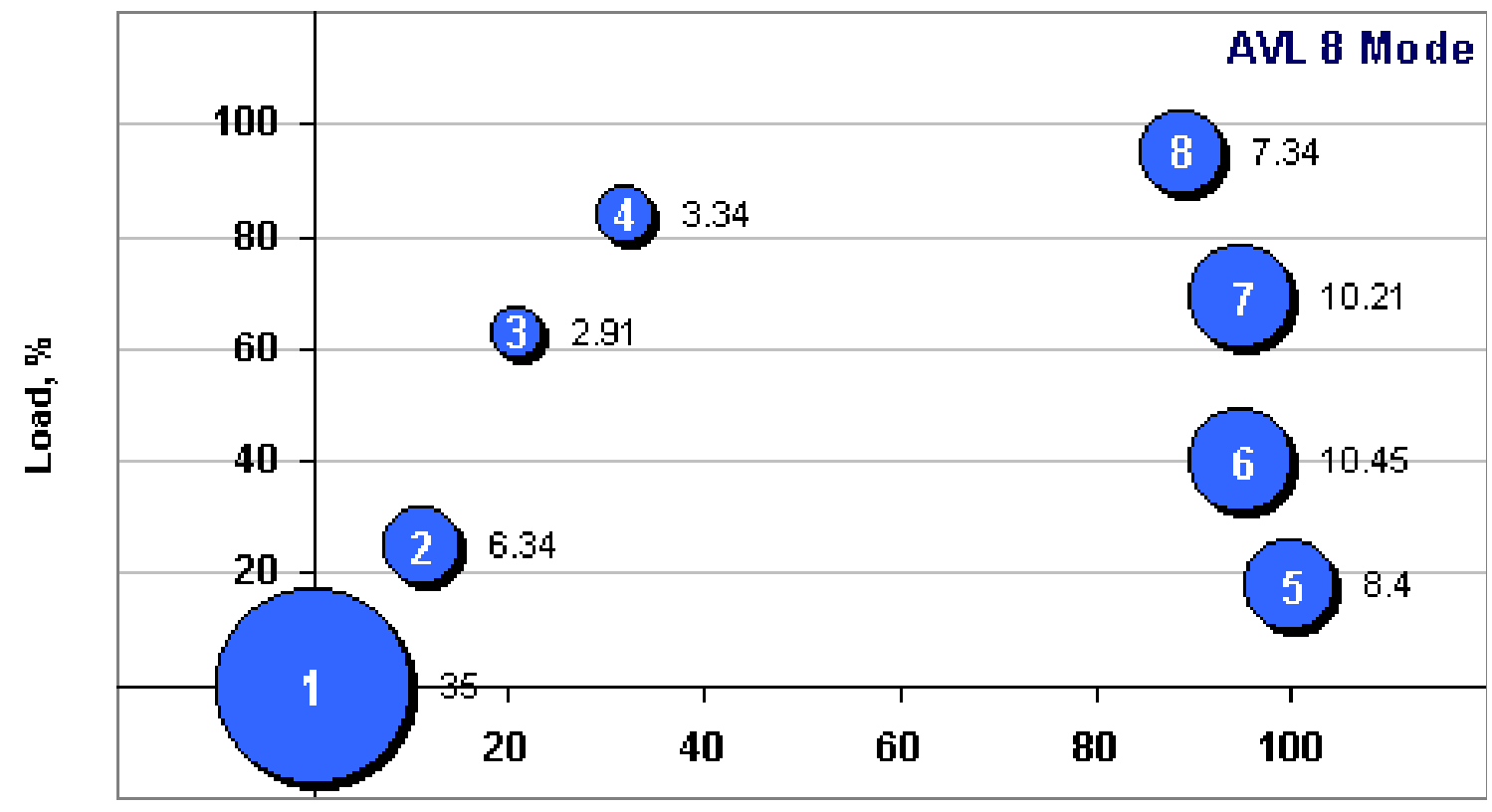

Speed, \%

Figure 3.3.4 Speed and load points for AVL 8-Mode test protocol

Table 3.3.2 AVL 8-Mode test protocol

\begin{tabular}{|c|c|c|c|}
\hline Mode & RPM & Torque (ft-lb) & Weighting Factor \\
\hline 1 & 800 & No load & 0.35 \\
\hline 2 & 1025 & 77 & 0.0634 \\
\hline 3 & 1199 & 252 & 0.0291 \\
\hline 4 & 1408 & 378 & 0.0334 \\
\hline 5 & 2700 & 80 & 0.084 \\
\hline 6 & 2605 & 178 & 0.1045 \\
\hline 7 & 2605 & 307 & 0.1021 \\
\hline 8 & 2491 & 426 & 0.0734 \\
\hline
\end{tabular}




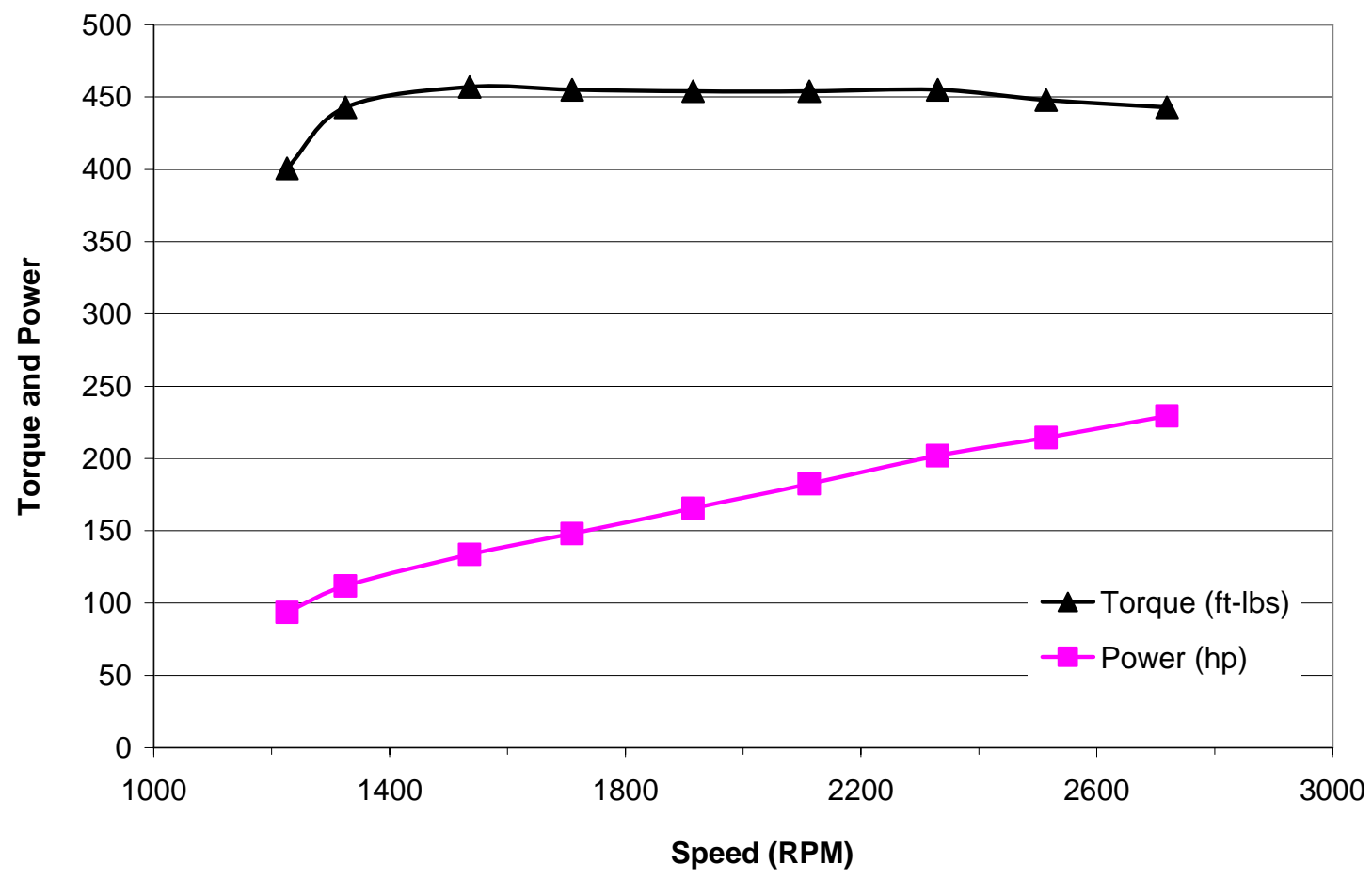

Figure 3.3.5 Performance of the test engine

PARTICULATE \& GASEOUS EMISSIONS - For particulate mass emissions, PM samples were obtained for each mode over the complete AVL 8-Mode test protocol. Exhaust gas was sampled via a Sierra Instruments BG-1 mini-dilution tunnel with constant dilution air/sample flow ratio of 10:1 and total flow of 100 (liters/min). These settings were chosen in order to maintain the filter temperatures below the EPA specification of $52{ }^{\circ} \mathrm{C}$. During these experiments, filter temperatures sometime exceeded $45^{\circ} \mathrm{C}$ under the highest operating mode. Particulate collection occurred on the Pallflex 90 $\mathrm{mm}$ filters with conditioning in an environmental chamber at $25{ }^{\circ} \mathrm{C}$ and $45 \%$ relative humidity before and after sampling.

The PM filters were further chemically analyzed for soluble organic fraction (SOF) and soot. The exposed PM filters which underwent a Soxhlet pre-extraction were again extracted with dichloromethane $\left(\mathrm{CH}_{2} \mathrm{Cl}_{2}\right)$. The extracted filters were then reconditioned in humidity chamber. Measurement of the soluble organic fraction (SOF) of the particulate matter is performed by weighing the sample filter before and after solvent extraction using dichloromethane.

Gaseous emissions were measured using an AVL CEB II emissions analyzer. Undiluted exhaust gas was collected via a heated sample line, which was maintained at $190^{\circ} \mathrm{C}$. 


\subsubsection{In-cylinder Imaging with Videoscope}

Experiments were conducted with a Cummins 5.9L, turbocharged, six-cylinder, 4-stroke direct injection diesel engine. The experimental system consisted of an engine, dynamometer, controller, combustion analysis instrumentation, emissions analyzers and an AVL 513D engine videoscope. The engine was fitted with an electronic control module (ECM) that monitors engine performance and controls different events automatically, especially the start of injection (SOI), injection timing advancement or retardation, etc. Figure 3.3.6 presents a diagram of the Cummins 5.9L ISB turbodiesel engine and test cell instrumentation. Specifications of the test engine are shown in Table 3.3.1. The engine was used a Bosch VP-44 type rotary distributor fuel pump. The injectors have 7 holes and a 152 deg spray cone angle.

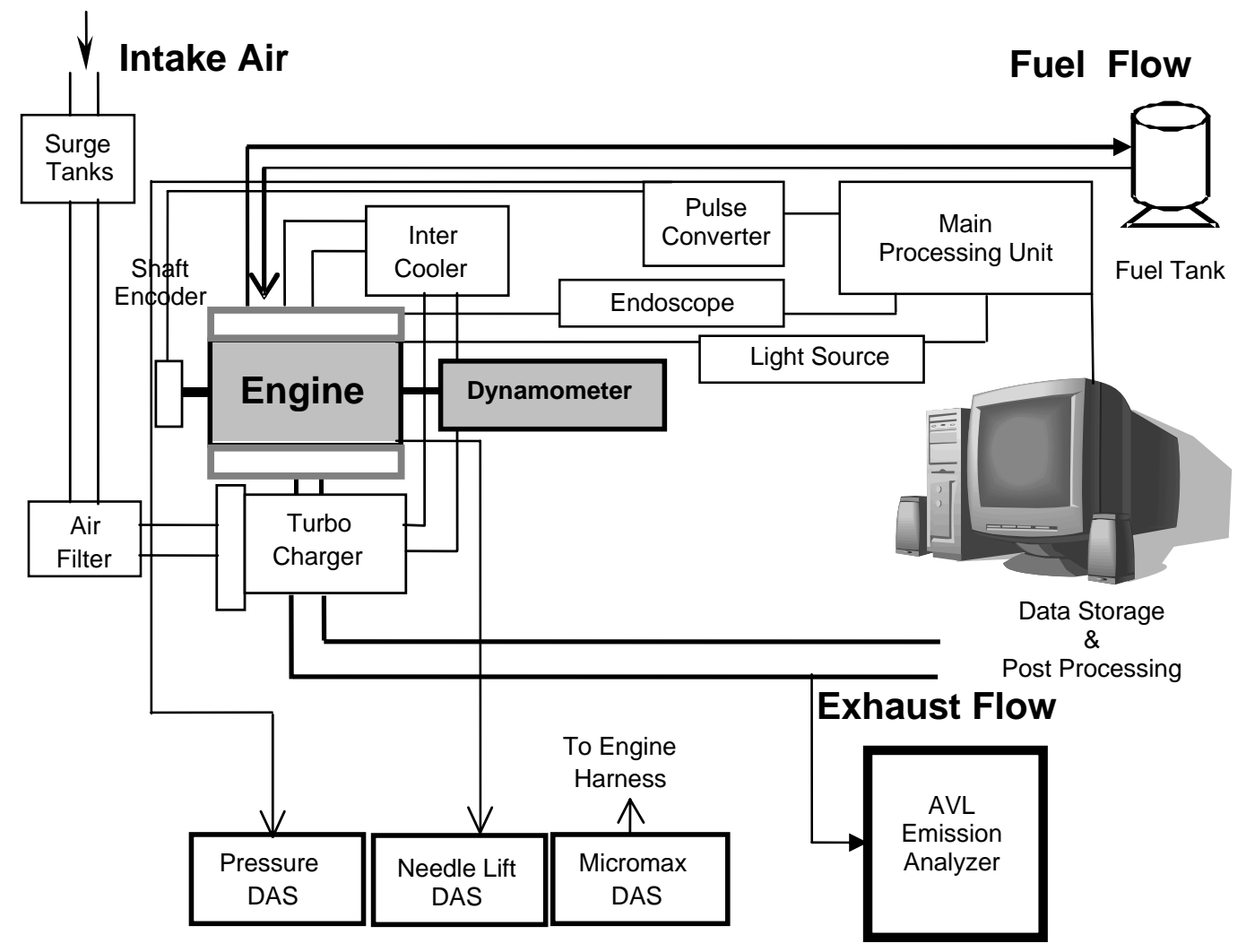

Figure 3.3.6 Schematic diagram of the experimental system

Engine cylinder number six was selected for optical access and the cylinder head modified accordingly. An AVL 513D videoscope was used for capturing images of spray and combustion [2]. Optical access to the combustion chamber was prepared by installing two small windows in the cylinder head. The windows permit access for an external light source through one and an endoscope through the other. Figure 3.3.7 shows how light source and endoscope are mounted in the engine. The windows installed into the cylinder head were designed to withstand the high temperatures and pressures prevailing within the combustion chamber and to stay clean under engine running condition since the deposition of soot particles on the window surface would reduce visibility. However, it was not possible to operate the engine for a long time before soot particles started to deposit on the surface. Because the endoscope needs cooling to keep its maximum operating temperature below $110^{\circ} \mathrm{C}$, soot particles deposited onto the cold window surface due to thermophoresis. Figure 3.3.8 shows the various windows, illumination tips and endoscopes that could be used for capturing spray and combustion images at different viewing angles. 


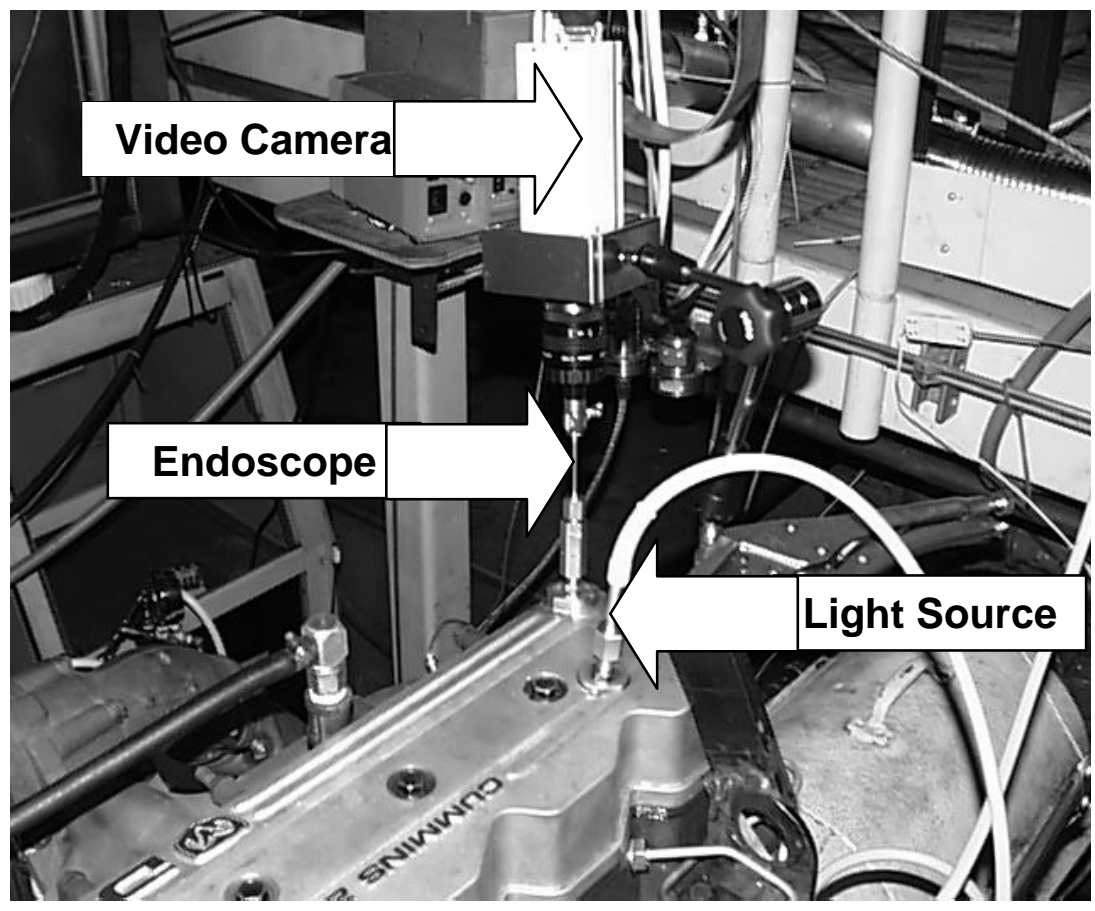

Figure 3.3.7 Endoscope and light source installed on the Cummins 5.9L test engine

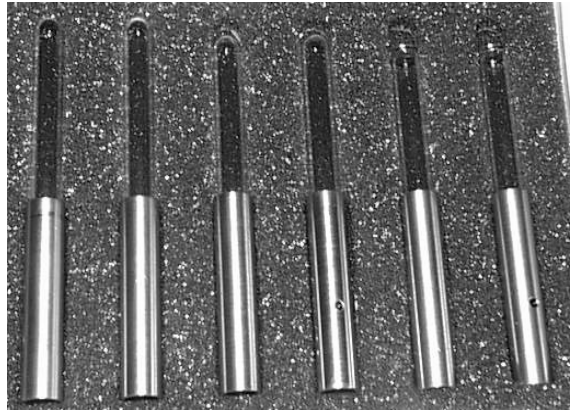

(a)

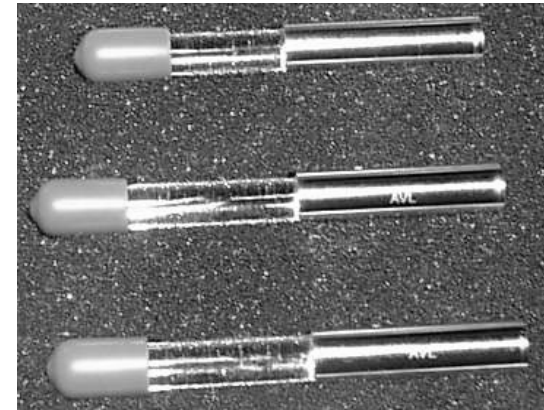

(b)

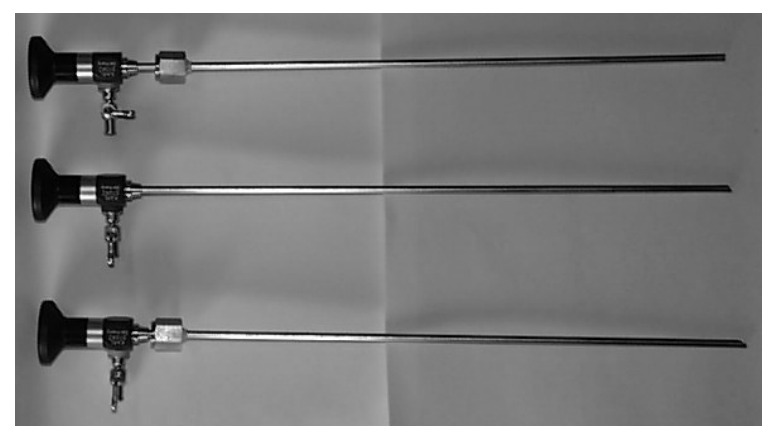

(c)

Figure 3.3 .8 (a) 0,30 and 70 degree glass windows (b) 0,30 and 70 degree illumination tips (C) 0, 30 and 60 degree endoscopes 
Figure 3.3.9 presents a typical endoscope view of the combustion chamber of cylinder number six and it was taken with a 60 degree oblique endoscope. Figure 3.3.10 represents a sketch of the geometric relationship between the fuel injector and videoscope probes. Note that the viewing angle of all the endoscopes was 80 degrees. The depth of field was from $1 \mathrm{~mm}$ beyond the lens to infinity and therefore a sharp picture of the combustion chamber was obtained without any focus adjustment.

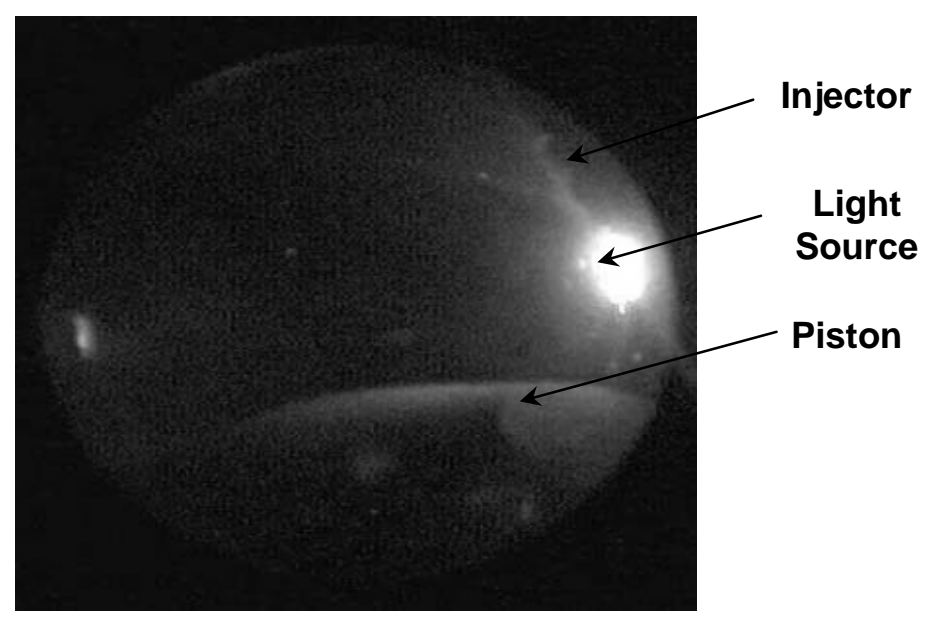

Figure 3.3.9 Combustion chamber image through endoscope

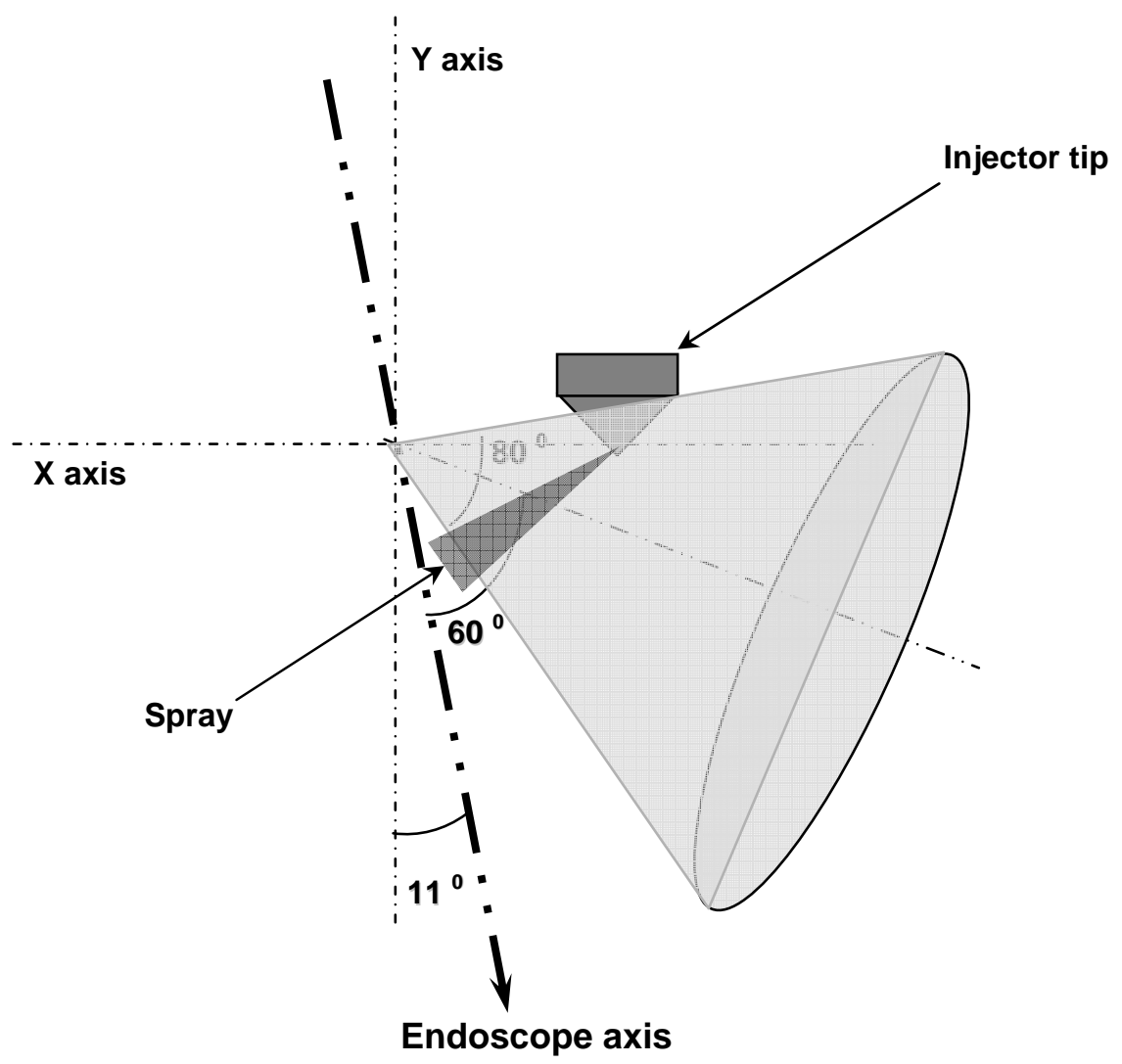

Figure 3.3.10 Sketch of endoscope view angle 
The videoscope system is an integrated triggering and digital imaging system. The triggering system was operated with an AVL 364 angle encoder mounted on the engine crankshaft, enabling 0.1 CA degree resolution. A xenon bulb was used to illuminate the cylinder with a flash duration of $30 \mu \mathrm{s}$, and a radiometric light output of $328 \mathrm{~mJ}$ per flash. The image exposure duration was $62 \mu \mathrm{s}$. This videoscope system was only able to take one image per power cycle. Therefore, the images rely on cycle to cycle repeatability. However, it was not possible to take several images at a particular crank angle position to average out any cycle to cycle variability. Because of the rapid rate of window fouling inside the engine cylinder and the images are obstructed before there is time to capture all the images to perform cycle to cycle averaging. Figure 3.3.11 shows an example of soot deposition on the glass window and illumination tip. Experiments for a particular crank angle range were repeated several times with the same fuel and only the best series of images (in terms of clean images) are presented in this analysis. The AVL videoscope system includes post-processing software for image processing and analysis, which was used to obtain the data presented here.

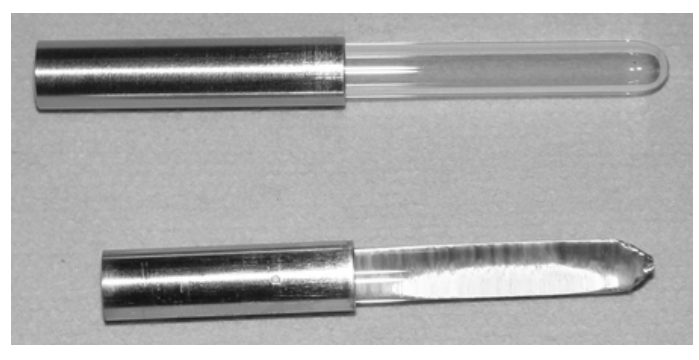

(a)

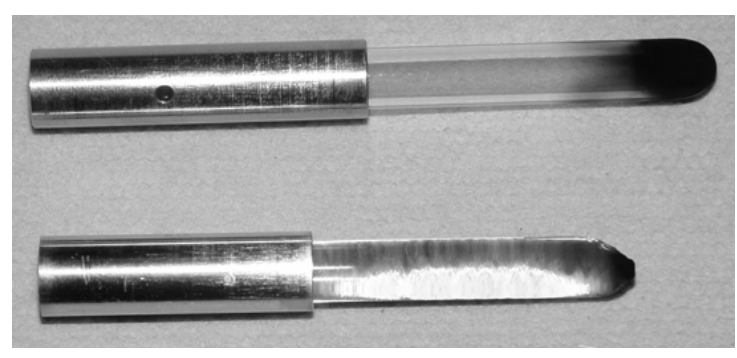

(b)

Figure 3.3.11 (a) Fresh window and illumination tip (b) soot deposition during incylinder observation

Tests were performed at a steady state condition of $10 \%$ rated load ( $40 \mathrm{ft}-\mathrm{lbs}$ torque) and a constant speed of $1800 \mathrm{rpm}$. An extended 30 minutes warm-up period at idle was used to bring the engine coolant roughly 90 deg celsius. Then, the engine was shut down and the endoscope and light source were installed in the cylinder number six. After connecting all optical instruments, the engine was re-started and operated under automatic control. The control system was programmed so as to reach the desired speed and load in less than 10 seconds. Once the engine reached the desired speed and load, the spray and combustion images were taken and saved into the AVL high speed data acquisition system. Simultaneously, cylinder pressure and needle lift data were recorded for combustion and heat release analysis. A Leeds \& Northrup "Micromax" data acquisition system logged the real-time engine speed, torque and power, lubricating oil and coolant temperatures, as well as, exhaust emissions via an AVL CEB II emissions analyzer. 


\subsubsection{Diesel Particulate Filter}

\subsubsection{Test Engine and DPF system}

For this test, a highly instrumented 6-cylinder Cummins ISB 5.9L DI turbodiesel engine, connected to a 250 HP capacity eddy current dynamometer, was used to produce different exhaust temperature conditions by means of precise load control. Table 3.3.1 contains the engine specifications. The engine has been heavily instrumented with a 0.1 crank angle resolution crank shaft encoder, a cylinder pressure sensor and a needle lift sensor.

The Diesel Particulate Filter system used in this work is a catalyzed diesel particulate filter (DPF) as shown in Figure 3.3.12. In this figure, the relevant instrumentation including differential pressure and temperature measurement is shown. First, an indirect way for measuring the onset of soot oxidation was chosen by measuring pressure difference across the DPF. Differential pressure across the DPF was measured using a Viatran differential pressure transducer(Model \#118) with maximum range of 100 inch of $\mathrm{H}_{2} \mathrm{O}$. Absolute pressure prior to DPF was also measured with a Viatran pressure transducer(Model \#118). Another important experimental parameter was the temperature difference across the DPF which can indicate a thermal runaway during the course of regeneration. These temperatures were logged with the Micromax data acquisition system every 1 second. For the high temperature regeneration test where faster burning takes place, another data acquisition system was used to collect gaseous emissions, temperature and pressure drop across the DPF system at a much faster rate $(\sim 0.1 \mathrm{sec})$. By using two high temperature resistant exhaust valves, a bypass and a DPF loading and regeneration mode were alternately achieved. After the bypass valves, the DPF was located 2 meters away from the exhaust manifold with exhaust pipes well insulated by appropriate material for avoiding any temperature loss to the ambient.

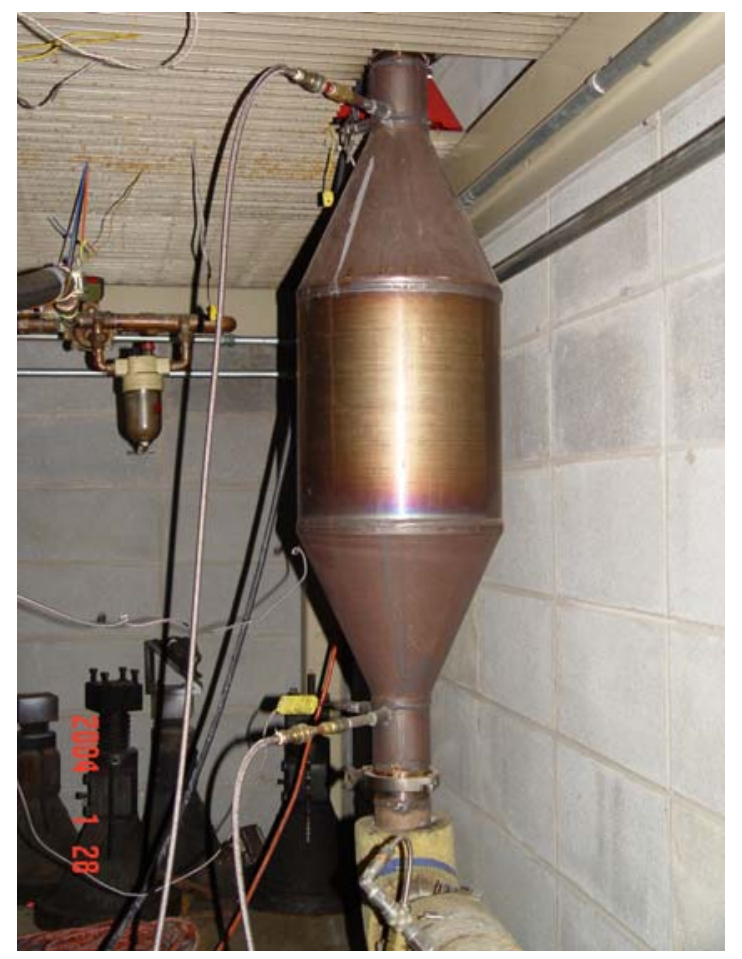

Figure 3.3.12 External view of the diesel particulate filter used in this experiment

The detailed flow schematic inside the catalyzed DPF is shown in Figure 3.3.13, displaying what the catalyzed DPF looks like and how it works. Due to alternately plugged channels, a particle laden exhaust is forced through the porous substrate allowing surface filtration. Therefore, intermittent 
removal through in-situ oxidation, called the regeneration process, is necessary. One of the several methods is to enhance oxidation rates by impregnating platinum catalyst on substrate. Otherwise, large pressure drop arising from continuous particle build up degrades engine performance and fuel economy. Due to the nonselective oxidation of platinum catalyst, several reaction pathways are possible over the Pt catalyzed substrate. At low temperature around $300{ }^{\circ} \mathrm{C}$, catalytic $\mathrm{NO}$ oxidation and subsequent soot- $\mathrm{NO}_{2}$ reaction are known to be the primary reactions. Based on the understanding of these recycled reactions, the main mechanism by which different fuels affect regeneration is through internal $\mathrm{NO}_{2}$ production from the $\mathrm{NO}$ oxidation reaction and particulate oxidation by the soot $\mathrm{NO}_{2}$ reaction. This diesel particulate filter (DPF) is a wall flow cordreite element with platinum coating that was supplied by Engelhard Corporation and was canned by Tenneco Company. The geometric and physical information about the DPF is as follows. The cordreite element is 11.25 inch diameter and 14 inch long. The cell density is 100 cells per square inch (cpsi) of frontal area with 0.017 inch wall thickness. This cordreite substrate material has a nominal average pore size of 10 microns and a porosity of $50 \%$.

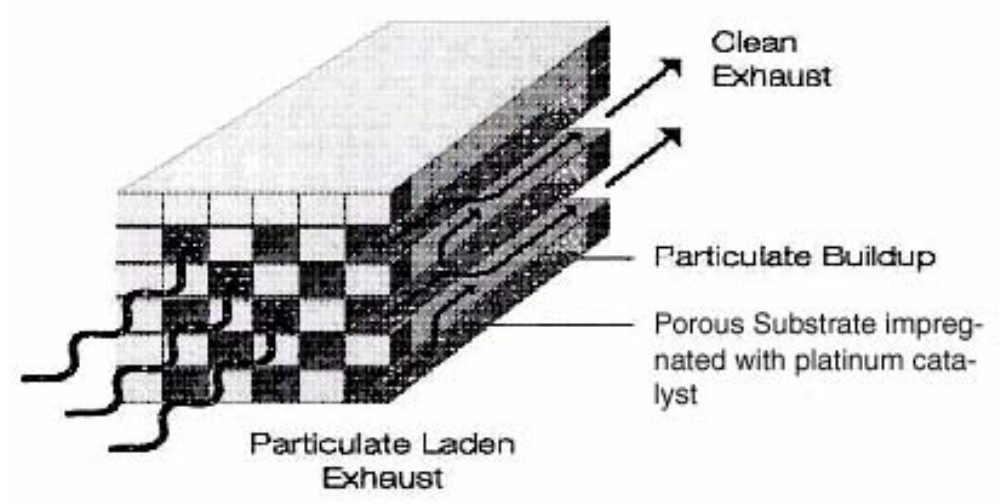

Figure 3.3.13 Close-up inside view of the catalyzed diesel particulate filter used in this study

\subsubsection{Test Cycles and Conditions}

For assessing fuel formulation effects on DPF regeneration in terms of the onset of regeneration temperature or reaction rate, it is essential to control the DPF inlet temperature under engine bench condition where undisturbed soot deposits exist. For this purpose, after exposing the DPF to extremely high temperature $\left(500{ }^{\circ} \mathrm{C}\right)$ for cleaning any residual particulate, the DPF was loaded with particulate matter by letting comparatively cold exhaust gases flow $\left(270^{\circ} \mathrm{C}\right)$ until approximately 80 mbar pressure drop is reached (corresponding to a particulate build-up of about $7.5 \mathrm{~g} / \mathrm{liter}$ ). Then, exhaust temperature is increased from 200 to $480{ }^{\circ} \mathrm{C}$ with approximately $30{ }^{\circ} \mathrm{C}$ increment by means of PID controlled load change, thereby resulting in 10 different temperature points. In response to simultaneous throttle and torque control, speed and torque are stabilized within one and half minutes. Thus, the DPF inlet temperature was also very stable at each step as shown in Figure 3.3.14. The means of comparison for the impact of fuel composition is the break even temperature. It is well known that this is a simple and indirect way to represent the ignition temperature between various fuel-produced particulate [3]. The achievement of flat pressure drop reveals a balance temperature between particulate deposition and oxidation. The temperature at which the slope of pressure drop is equal to zero indicates the self-regeneration point of the trap. Two types of regeneration test were performed with the same DPF and engine bench. First, a low temperature test served to examine the overall regeneration features in terms of onset of regeneration temperature, while a high temperature test served to examine the characteristics of regeneration at high elevated temperature. 


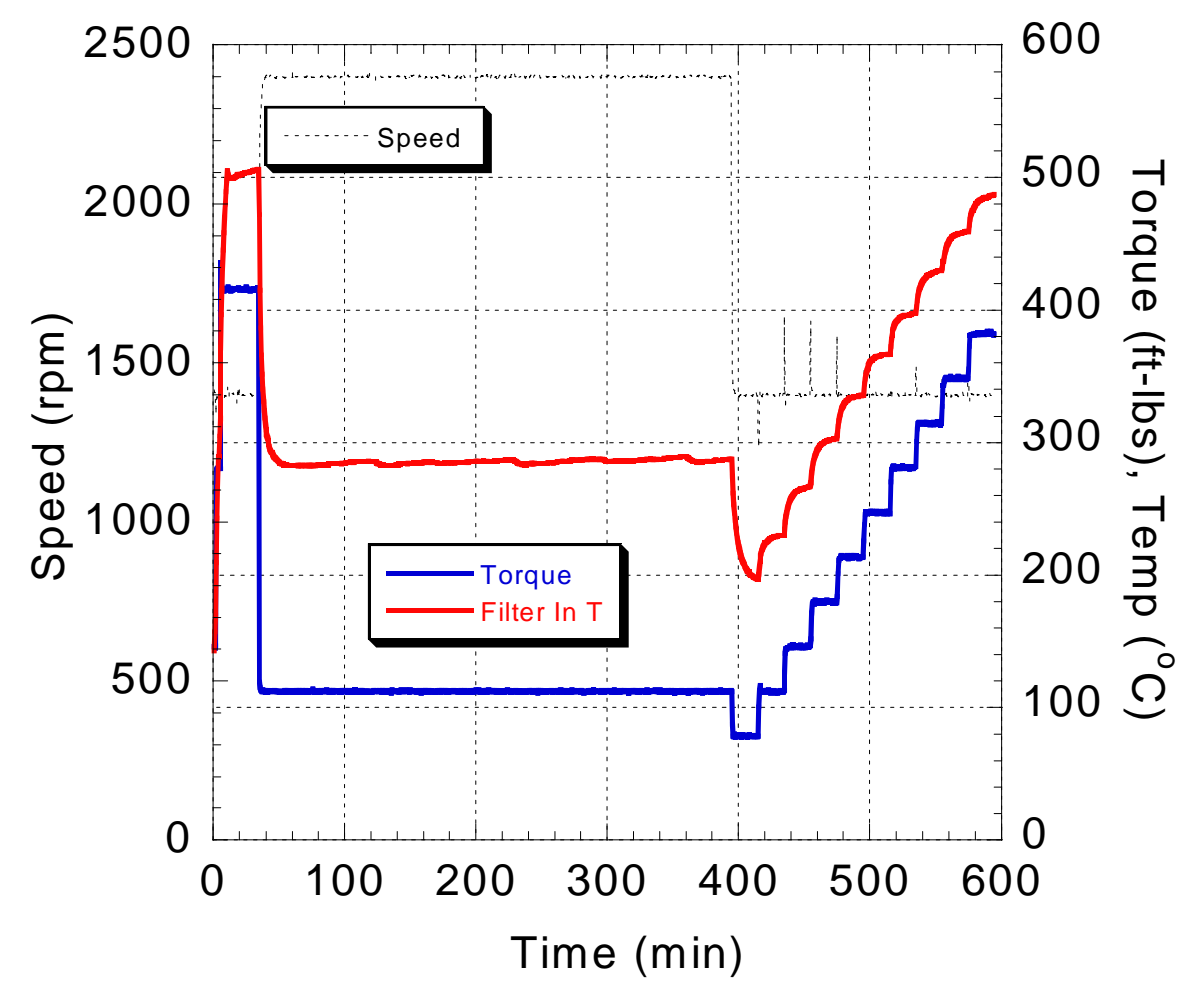

Figure 3.3.14 Torque control for DPF system showing regeneration test cycles starting from 200 to $480{ }^{\circ} \mathrm{C}$

\subsubsection{Test Fuels}

Among the fuels tested up to this point and listed in Table 3.1.3.1 through 3.1.3.3, BP15 and BP325 fuel represent two base fuels that are mainly differentiated by fuel sulfur content. For example, BP15 fuel (sometimes referred to as ULSD) contains $15 \mathrm{wt}$ ppm sulfur and BP325 fuel (sometimes referred to as LSD) contains $325 \mathrm{wt}$ ppm sulfur. BP15/B20 and BP325/B20 represent biodiesel $20 \mathrm{wt} \%$ blends in each base fuel. Therefore, B20 blends are characterized by $20 \%$ reduction in fuel sulfur and approximately $2 \%$ oxygen content relative to the base fuel. From this selection of fuel, the effects of two main fuel formulation changes on regeneration of the catalyzed DPF can be examined. One is decreasing sulfur content in the fuel and the other is blending biodiesel into the base diesel fuel.

\subsubsection{PM Mass and Composition Measurement}

For PM mass determination between different particulate samples, bulk samples were collected on glass fiber filters from diluted exhaust gas via a mini-dilution tunnel (Sierra Instruments BG-1). Further composition analysis was performed using two different instruments. With a Soxhlet extraction method, the mass difference between the unextracted filter and extracted filter via dichloromethane (DCM) extraction was attributed to the SOF fraction of the particulate. With a thermal oxidation technique, $\mathrm{CO}_{2}$ generation between $300 \sim 450{ }^{\circ} \mathrm{C}$ in a thermal carbon analyzer (\#RP5100) was attributed to heavy hydrocarbon fraction of the particulate matter, which is believed to result from unburned fuel. To further clarify the fuel sulfur effect on internal $\mathrm{NO}_{2}$ production, online measurement for sulfate or sulfuric acid $\left(\mathrm{H}_{2} \mathrm{SO}_{4}\right)$ was made by measuring the downstream particulate emission with online PM mass analyzer, called TEOM1105. Whenever necessary, an elemental composition was made for different particulate samples via Energy Dispersive X-ray Spectroscopy (EDXS) technique attached to low resolution transmission electron microscopy (TEM), a Phillips model $420 \mathrm{~T}$. 


\subsubsection{Gaseous Emissions}

The change in gas composition was monitored via an AVL CEB analyzer through sampling ports located upstream and downstream of the DPF. The measurement of both $\mathrm{NO}$ and $\mathrm{NO}_{2}$ is available to determine the internal $\mathrm{NO}_{2}$ production or $\mathrm{NO}$ conversion occurring over the DPF in competition with soot- $\mathrm{NO}_{2}$ reaction. Meanwhile measurement of $\mathrm{CO}_{2}$ and $\mathrm{CO}$ is used as a supplementary measurement for pressure drop for determining onset of regeneration temperature. The $\mathrm{CO}_{2}$ concentration can be used to obtain the instantaneous rate of particulate mass loss along with consideration of the flowrate through a carbon balance calculation.

\subsubsection{Soot Reactivity Study}

PM Sampling and Preparation - A highly instrumented 6-cylinder Cummins ISB 5.9L DI turbodiesel engine, connected to a $250 \mathrm{HP}$ eddy current dynamometer, was used to produce different particulate samples at a fixed engine operating condition (2700 rpm and $25 \%$ load of peak). This condition is the same as the DPF loading condition where exhaust temperature is about $280{ }^{\circ} \mathrm{C}$. The engine has been heavily instrumented with a 0.1 crank angle resolution crank shaft encoder, a cylinder pressure sensor and a needle lift sensor. The engine and dynamometer are operated through an automated control system. To isolate any effect of cylinder temperature history from possible changes in soot nanostructure due to differences in the fuels, the time evolution of incylinder mean temperature was obtained through cylinder pressure trace analysis, along with consideration of injection timing and cylinder geometry. Four test fuels were considered as described in an earlier section. For a Temperature Programmed Oxidation (TPO) test, bulk samples were collected in quartz filters from diluted exhaust gas via a mini-dilution tunnel (Sierra Instruments BG1). Then, the filter was crushed into a powder and $10 \mathrm{mg}$ of the powder was evenly deposited into the sample pan in the furnace. For high-resolution transmission electron microscopy (HRTEM) imaging, thermophoretic sampling was used to capture PM from the raw exhaust. For imaging of the partially oxidized samples, an acoustic suspension in ethanol was used to disperse the sample into transmission electron microscopy (TEM) carbon grid.

Particulate Reactivity - The TPO is examined in two different laboratory reactors as a means of evaluating the differences in reactivity of the soot samples. All particulate samples were treated by 30 minutes heating at $500{ }^{\circ} \mathrm{C}$ under inert gas (i.e. argon) in the TGA to eliminate the soluble organic fraction (SOF). Then, samples were subjected to slow heating to obtain the burning rate of each sample on both DSC (TA2920) and TGA (PE-TGA7). This pretreatment for SOF removal has been reported to yield the same effect as post extraction with dichloromethane $\left(\mathrm{CH}_{2} \mathrm{Cl}_{2}\right)$ [4]. Ignition temperature was used to determine the oxidation reactivity of the samples. From the mass loss curve from the TGA, ignition temperature is determined as the temperature at which soot starts oxidizing at an appreciable rate. A detection of heat release by DSC was used as a supplement to gauge the ignition temperature of different particulate samples [5]. In this DSC configuration, the ignition temperature is determined by thermal runaway that is controlled by competition between heat of combustion and heat loss to gas flow.

Soot Nanostructure Imaging - Structural properties of the diesel particulates were obtained by electron beam probes. Among several characterization techniques to detect the degree of crystallinity of graphene layer, a bright field image method by HRTEM was employed on a field emission JOEL 2010F operated on $200 \mathrm{kV}$, with a point to point resolution of $0.23 \mathrm{~nm}$. In bright field image mode, graphene layer segments are observed as the dark lines blocking/scattering the incident electron beam, thereby creating a dark image on the screen. A thin isolated particle deposited a perforated carbon film is used to obtain the sharp phase contrast while minimizing the interference with the condensable fraction and the grid substrate, since the existence of adsorbed hydrocarbon may block the high contrast imaging of the carbon-rich dry soot.

Soot Structure Measurements - Electron Energy Loss Spectroscopy (EELS), Raman Spectroscopy and X-Ray Diffraction (XRD) were applied to soot samples to quantify the degree of crystallinity and disorder in the soot. In EELS spectra, excitations of the core 1s electrons of a 
carbon atom can produce a characteristic $\mathrm{K}$ edge, denoted by a sharp threshold at energies on the order of $285 \mathrm{eV}$, superimposed on a smoothly decreasing background. It is known that relative ratio of the $\pi$ peak at $285 \mathrm{eV}$ to the $\pi+\sigma$ peak at $293 \mathrm{eV}$ is related to the degree of graphitization and aromatization, as the $\pi$ graphitic peak is more pronounced due to the popularity of shared $\pi$ electrons in the long range and more graphitized layers. As long as this technique is complemented by Raman measurements as done in this study, this technique can provide valuable information about the degree of graphitization of the graphene layers of soot particles. However, great caution should be taken to account for the graphitic peak's angle dependence when quantitative intensity ratio is compared. Whether incident electron beam is directed either perpendicular to or parallel to the basal plane may be important for material with preferential orientation in one direction, but for soot samples with concentric arrangement and therefore no preferential azimuth orientation, this angle dependence can be ruled out for interpreting the relative intensity of the graphitic peak to other carbon peaks. In this study, electron energy-loss spectra (EELS) was obtained with an Enfina 2000 spectrometer attached to the JOEL 2010F. The lens conditions were defined in TEM-diffraction mode as a probe size of $100 \mathrm{~nm}$, with a convergence angle of $11 \mathrm{mrad}$ and a collection angle of 13 $\mathrm{mrad}$. The energy resolution (defined by the full width at half maximum of zero loss peak) of the energy loss spectra is $1.2 \mathrm{eV}$ and is acquired at a dispersion of $0.2 \mathrm{eV}$ per channel for carbon core loss spectra and $0.5 \mathrm{eV}$ for both carbon and oxygen core loss spectra, respectively. These spectra were then background subtracted by fitting the pre-edge backgrounds with a power-law function available in processing software called "Gatan AutoPeels". The elemental content (i.e., carbon and oxygen) of particulate samples was also measured and quantified by EELS and energy dispersive $x$ ray spectrometry (EDXS). Characteristic X-rays are produced and detected in an X-ray detector permitting elemental analysis. A beryllium double-tilt holder was used to reduce the production of spurious X-rays. This spectra is known to be sensitive to low concentrations with minimum detection limits on the order of $0.1 \%$.

To overcome HRTEM limitations associated with probing nanoscale areas, micro Raman spectroscopy was used with probe size of microscale area (i.e., $1 \mu \mathrm{m}$ ) in this study. Raman spectra was collected using a triple-grating Micro-Raman spectrometer (JY Horiba, Model T64000) equipped with a confocal microscope (Olympus $\mathrm{BH}-2$ ) and a CCD detector. The scattering was excited using an argon ion laser $(514.53 \mathrm{~nm})$, and the power measured at the sample was $1 \mathrm{~mW}$. This state-ofthe-art instrument with a multichannel (CCD) detector consists of three monochromators in which the first two monochromators (filter stage) can be coupled additively or subtractively. In the additive mode there is a large gain in the resolution at the expense of bandpass scanned and throughput. In the subtractive mode, it is especially good for working close to the laser line with the multichannel detector. This spectrometer with triple monochromator (focal length $640 \mathrm{~mm}$ and focal speed $\mathrm{f} / 7.5$ ) is equipped with holographic gratings (1800 lines $/ \mathrm{mm})$. This instrument can be used both in micro, as well as, macro scattering geometry. In the micro-Raman arrangement, the laser is focused onto the sample using a microscope objective $(100 x, 50 x$ or $10 x)$ and the scattered light is collected by the same objective collected in a backscattering configuration (180 degree). A confocal aperture in the path of the scattered beam provides a spatial resolution of $\sim 1 \mu \mathrm{m}$. The microscope is equipped with a motorized XY stage for the precise positioning and selection of the sample area. A typical acquisition time is between 40 min and 1 hour per sample during CCD detection. The spectral resolution is 1 cm-1.

The stacking order of the graphene layer along the c-axis was measured by an x-ray diffraction (XRD) technique. Like Raman spectra, it can provide supporting evidence of structure from a microscale area by irradiating a large area of at least $8 \times 8 \mathrm{~mm}^{2}$, while soot nanostructure imaging sometimes fails to obtain a representative image at operator's prejudiced discretion. For this study, a Scintag 3 was used with a Cu Ka radiation (1.54 $\AA$ ) source by spreading a sample (10 mg of soot powder) into a platinum holder without using either petrolatum or alcohol adhesive. This machine had high temperature control capability to monitor XRD pattern of soot samples oxidized at different times (initial, 30min and 120 minutes) of $500{ }^{\circ} \mathrm{C}$. This machine was configured in vertical BraggBrentano pseudo focusing geometry, while the detector and sample mount was scanned in step 
mode every 0.04 second from 10 to 70 of $2 \theta$. Angle calibration was always done before sample run in order to ensure proper angle resolution. The XRD patterns were further analyzed for deducing the structural parameters such as the interlayer spacing, $d_{002}$, stacking height of crystallite, $L_{c}$ and lateral size of crystallite, $L_{a}$, using the classical Scherrer method. XRD pattern is affected by crystallite size and strain, but it is assumed that the broadening is only due to crystallite size for a calculation with Scherrer method.

Soot Surface Property Characterization - The chemical state of the oxygen bonded to carbon atoms in the soot samples was characterized by Fourier Transform Infra Red (FTIR) spectroscopy. Spectral band assignments of the surface oxides are based on the well established IR databases. For example, the $1740 \mathrm{~cm}^{-1}$ band can be assigned to $\mathrm{C}=\mathrm{O}$ stretching in carboxylic, lactone and ketone acid groups. The $1620 \mathrm{~cm}^{-1}$ band, that is the most characteristic in all carbons, can be assigned to $\mathrm{C}=\mathrm{C}$ stretching of aromatic system in conjugation with $\mathrm{C}=\mathrm{O}$. The weak and broad band centered on $1250 \mathrm{~cm}^{-1}$ was ascribed to C-O stretching mode in ethers, esters and phenolic compounds. Before making pellets, all particulate samples and potassium bromide $(\mathrm{KBr})$ powder (product number:22186-4), purchased from Sigma Aldrich as 99\% FTIR grade, were dried under vacuum at $150{ }^{\circ} \mathrm{C}$ overnight to eliminate moisture to which the IR beam is sensitive and were stored in sealed desiccator box to prevent further contamination. By using a pressing machine, $1 \mathrm{mg}$ of each sample was diluted with $\mathrm{KBr}$ by ratio of 300 to 1 to make pellets with $8 \mathrm{~mm}$ diameter. An IR Spectrometer (Biorad FTS45) equipped without a microscope was used with an MCT detector. The spectra were obtained with a scan rate of $8 \mathrm{hz}$ and spectral resolution of $2 \mathrm{~cm}^{-1}$ to provide results that were averaged one over 400 scans. This machine was operated primarily in the absorption mode in which the beam is passed through an infrared-transport material such as $\mathrm{KBr}$ with which soot samples were mixed. Using this technique, it is often difficult to observe spectral detail in the region above $2900 \mathrm{~cm}^{-1}$ that can provide information on $\mathrm{C}-\mathrm{H}$ stretching in aliphatic group at $2950 \mathrm{~cm}^{-}$ ${ }^{1}$ and in aromatic group at $3060 \mathrm{~cm}^{-1}$ or $\mathrm{O}-\mathrm{H}$ stretching in carboxylic acid groups at $3450 \mathrm{~cm}^{-1}$. Therefore, most of identification was focused on the spectral region between $1200 \mathrm{~cm}^{-1}$ and $2000 \mathrm{~cm}$ ${ }^{-1}$, since oxygen surface groups bonded to surface carbons are of major interest in this study. The relative ratio of intensity of the spectrum at $1740 \mathrm{~cm}^{-1}$ and $1620 \mathrm{~cm}^{-1}$ was used to determine the relative presence of oxygen groups.

The pore size distribution versus total surface area was determined using an Accelerated Surface Area and Porosimetry System (ASAP 2000) from Micromeritics Corporation. The quantity of gas adsorbed onto or desorbed from soot samples at some equilibrium vapor pressure was measured by the static volumetric method. As adsorption or desorption occurs, the pressure in the sample changes until equilibrium is established. The quantity of gas adsorbed or desorbed at the equilibrium pressure is the difference between the amount of gas admitted or removed and the amount required to fill the space around the adsorbent. First, any micropores inside the primary particle are quickly filled, then the free surface becomes completely covered and finally, larger meso pores such as voids or gaps between primary particles are filled. This instrument has the capability of measuring adsorbed or desorbed volumes of nitrogen at relative pressures in the range 0.001 to slightly under 1.0. The volume-pressure data can be reduced into BET surface area (single and multipoint), Langmuir surface area, adsorption and desorption isotherms, pore size and surface area distributions, micropore volume and surface area using t-plots, total pore volume and average pore diameter. A sample of $10 \mathrm{mg}$ contained in an evacuated tube is typically cooled to cryogenic temperature and then exposed to nitrogen $\left(\mathrm{N}_{2}\right)$ at a series of precisely controlled pressures. With each incremental pressure increase, the number of gas molecules adsorbed on the surface increases. The pressure at which adsorption equilibrium occurs is measured and the universal gas law is applied to determine the quantity of gas adsorbed. As adsorption proceeds, the thickness of the adsorbed film increases. The process may continue to the point of bulk condensation of the analysis gas. Then, the desorption process may begin in which pressure systematically is reduced resulting in liberation of the adsorbed molecules. As with the adsorption process, the changing quantity of gas on the solid surface is quantified. Analysis of the isotherms yields information about 
the pore size distribution of soot samples that have a wide range of pore size from micropore (0.5 3 $\mathrm{nm})$ to mesopore $(30 \sim 50 \mathrm{~nm})$ between the primary particles. 


\subsubsection{Cold Flow Simulation of Urea Injector}

\subsubsection{Objective}

A twin fluid external atomizer from Spraying Systems Co. (Cincinnati, OH, USA), was selected for aqueous urea spray injection. But, it was necessary to examine its spray characteristics. Concentration of urea vapor should be uniform at all points in the cross sectional plane of the exhaust pipe, so that there are no lean pockets of urea in the exhaust. This would ensure that urea is mixed uniformly with exhaust $\mathrm{NO}_{x}$. A uniform distribution eliminates a possibility of bypassing reaction due to lack of contact between $\mathrm{NO}_{\mathrm{x}}$ and urea, leading to unreacted ammonia emissions (ammonia slip).

\subsubsection{Procedure}

A cold flow exhaust system operated at the same Reynolds number as the engine exhaust system was fabricated to simulate exhaust flow at room temperature. The exhaust pipe in the engine setup is 3" inside diameter stainless steel pipe. For the flow simulation experiment, a transparent pipe of 3" inside diameter was selected and the atomizer was fitted into the pipe to permit injection along the center line of the pipe. Exhaust was simulated by providing air at atmospheric pressure.

In the engine setup, the urea evaporates due to the high exhaust temperature. But the cold flow experiment was performed at room temperature. Therefore, it was not possible to use aqueous urea itself. Hence a simulant fluid was needed which would be liquid under pressure and would evaporate at room temperature and atmospheric pressure. Such a liquid would actually simulate urea in the hot exhaust. The mass flow rates (and not the volumetric flow rates) of simulant-air system were kept the same as the urea-air system. This would nullify the density difference between the simulant and aqueous urea. Other physical properties were matched as described in Table 3.3.3.

\subsubsection{Simulant Selection}

It is required to have a liquid with high vapor pressure at low temperature. Again, the following criteria are adopted to select the simulant:

- Surface tension of the liquid should be near to urea so that penetration characteristics can be maintained similar

- Viscosity of the liquid should be similar because viscosity affects the Reynolds number of the liquid flow field and the atomization process

- Molecular weight of both liquid should be similar

It was discovered that liquid n-butane satisfies the above criteria as shown in Table 3.3.3. It is evident from Table 3.3.3 that apart from mass density, all other physical properties of liquid n-butane and aqueous urea are closely matched. Therefore, liquid n-butane was selected as the simulant fluid.

Table 3.3.3 Comparison of urea and liquid n-butane [6]

\begin{tabular}{|c|c|c|}
\hline Property & Urea & Liquid n-butane \\
\hline Molecular Weight & 60 & 58 \\
\hline Density (Kg/m3) & 1000 & 578 \\
\hline Dynamic Viscosity (N/m $\left.{ }^{2}-\mathrm{s}\right) @ 300 \mathrm{~K}$ & 0.0015 & 0.0022 \\
\hline Surface Tension (Kg/s $\left.{ }^{2}\right) @ 300 \mathrm{~K}$ & 0.02 & 0.0116 \\
\hline Boiling Temperature (K) & NA & 273 \\
\hline
\end{tabular}




\subsubsection{Data Acquisition Procedure}

The maximum vapor pressure available from the liquefied butane supply tank was 23 psi or 8.5 psig. The maximum air supply pressure available was 75 psia. For a twin fluid atomizer, four variables define the flow condition. These are air flow rate $\left(Q_{a}\right)$, liquid flow rate $\left(Q_{l}\right)$, air pressure $\left(P_{a}\right)$ and vapor pressure $\left(P_{l}\right)$. In this system of variables, $Q_{a}$ and $Q_{l}$ are dependent upon $P_{a}$ and $P_{l}$. The dependence of $Q_{a}$ and $Q_{\text {, }}$ on $P_{a}$ is known as it was supplied by the manufacturer in the form of performance data. But the liquid pressure available from the n-butane supply tank was 8.5 psig whereas the performance data is available only for $10,20,30,40$ and 60 psig liquid pressures. This data is given in Figure 3.3.15.

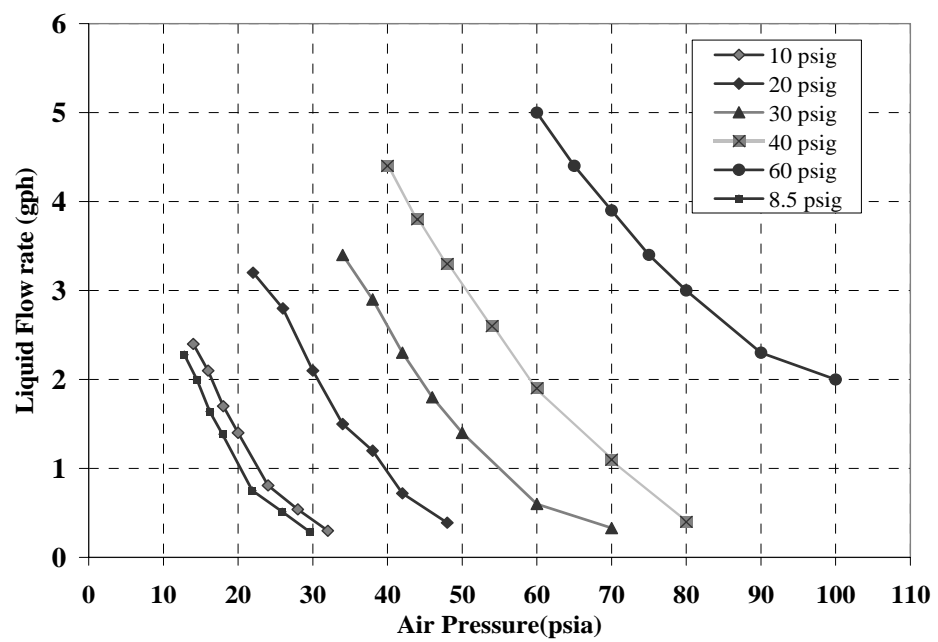

Figure 3.3.15 Air assisted atomizer performance shown as liquid flow rate (gph) versus air supply pressure (psia) for various liquid supply pressures

Since the functional relationship between liquid flow rate and air pressure is continuous (Figure 3.3.15), it is possible to perform a linear interpolation to predict performance data at 8.5 psig liquid pressure. Therefore, liquid flow rates and required atomizing air flow rates were determined at 8.5 psig liquid pressure as shown in Figure 3.3.16.

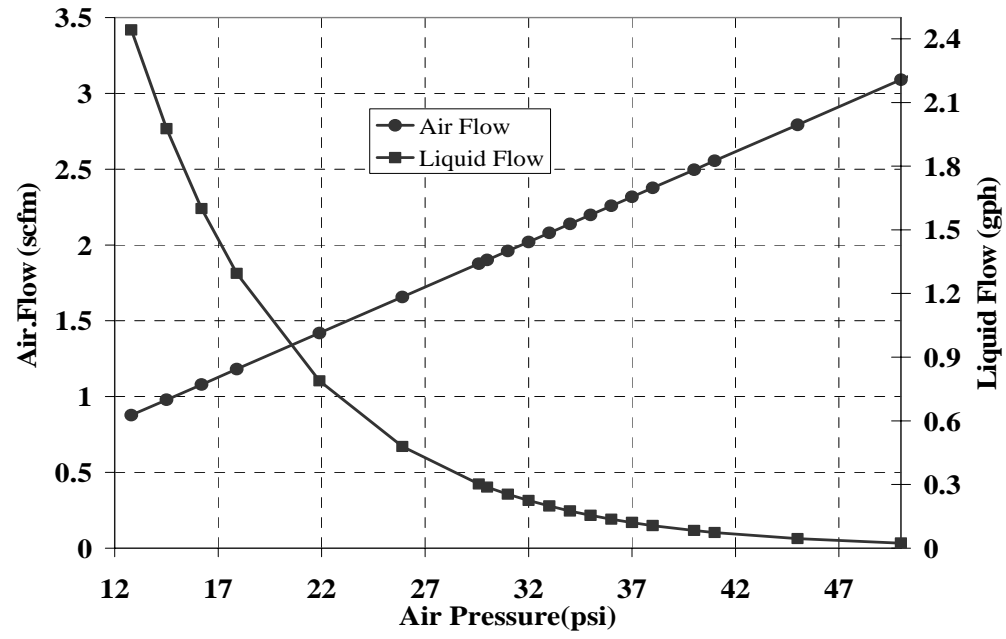

Figure 3.3.16 Air assisted atomizer performance at 8.5 psig liquid pressure 


\subsubsection{Experimental Set Up}

Different liquid-air flow rates were obtained by controlling air pressure. In order to increase the liquid flow rate, air pressure is decreased. Mass flow meters were used to measure liquid and air flow rates. A blower was used to supply air into the transparent pipe to simulate exhaust. At an axial distance of 3 feet from the atomizer mounting, an iso-kinetic sampling probe with a 2-D precision positioning stage mounting was positioned such that it was possible to move the probe along the radius of the cross sectional plane of the pipe. This probe was connected to a hydrocarbon analyzer (HFID) which could measure the amount of butane. By moving the probe across the pipe, the butane-air mixture at different points $10 \mathrm{~mm}$ apart could be sampled by the probe and analyzed by the HFID. The background butane concentration was measured at all of these equidistant points and subtracted from the sample data to correct for the background hydrocarbon concentration. The schematic of the experimental setup is shown in Figure 3.3.17. The air assisted atomizer fitting is shown in Figure 3.3.18. The experimental details are shown in Figure 3.3.19.

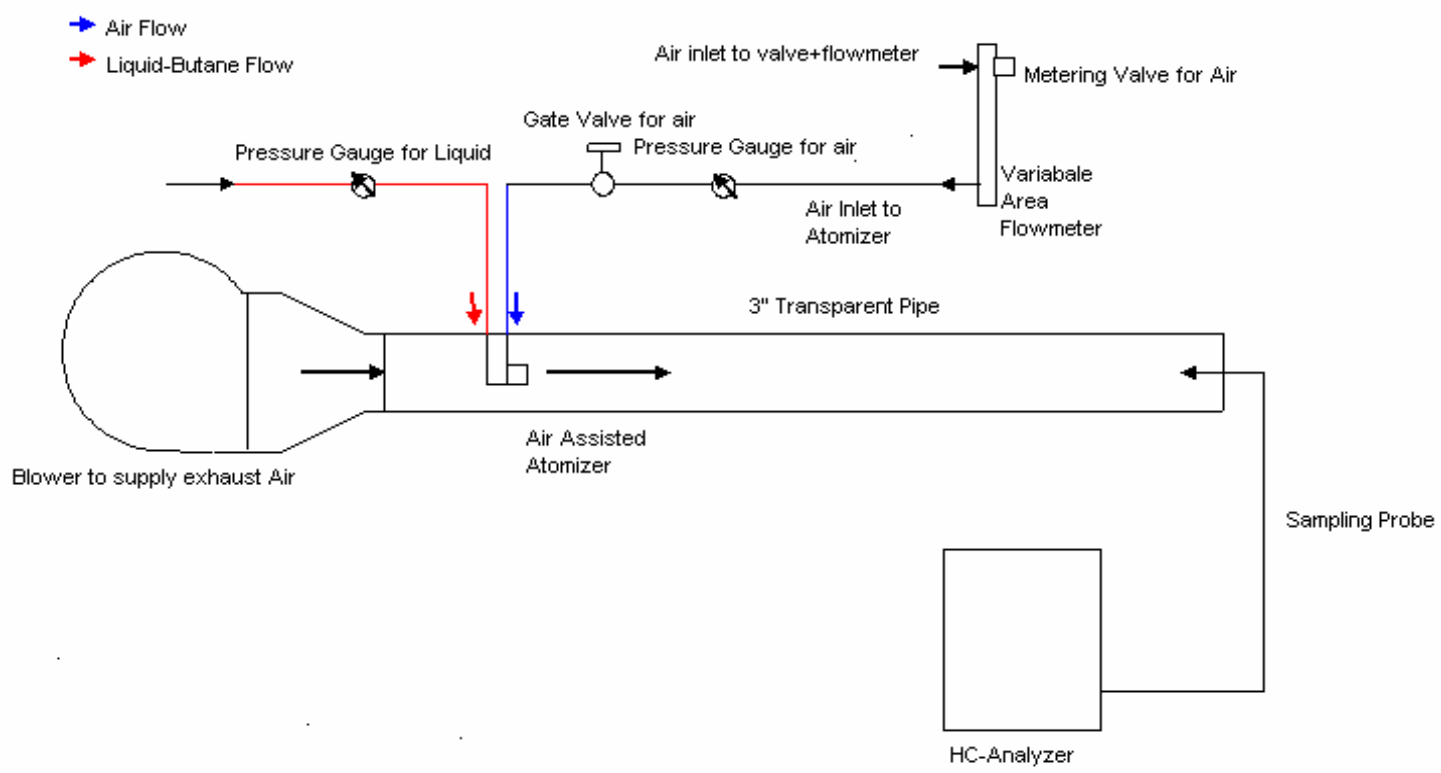

Figure 3.3.17 Schematic of cold flow simulation experimental setup

Air Supply line

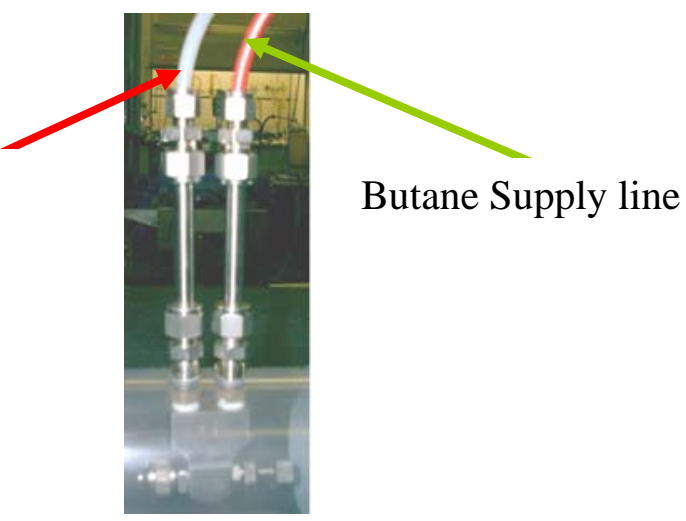

Figure 3.3.18 Air assisted atomizer fitting in the transparent pipe 

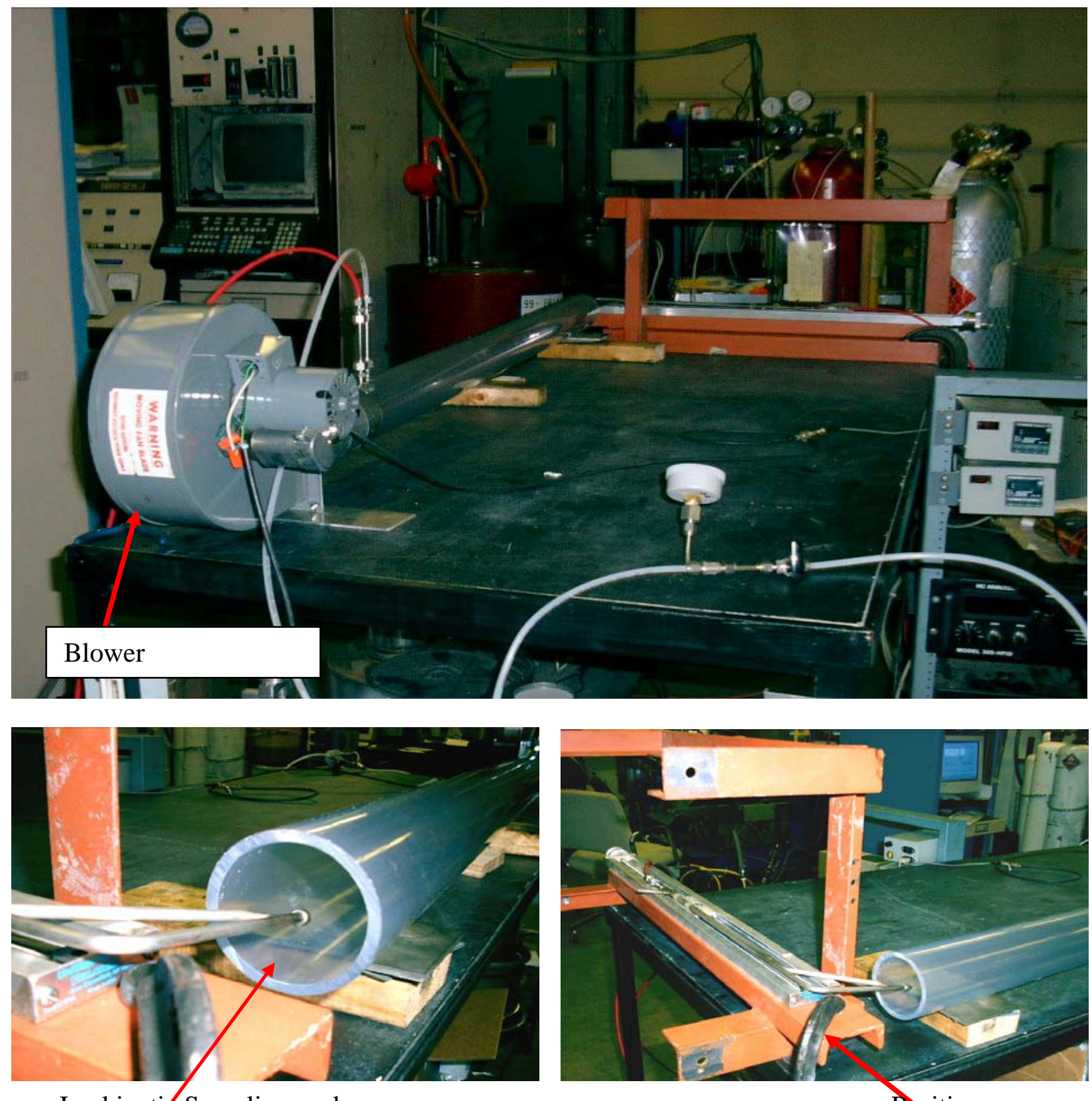

Iso-kinetic Sampling probe

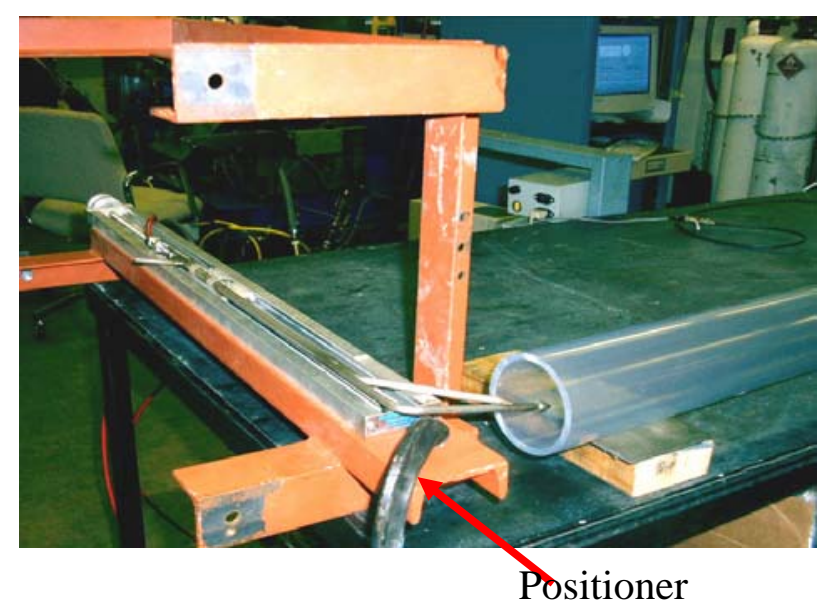

Figure 3.3.19 Experimental details of cold flow simulation test

\subsubsection{HFID}

A California Analytical Instruments Heated Total Hydrocarbon Analyzer Model 300 HFID was used for the cold flow simulation test to measure butane concentration. It contains an adjustable heated oven $\left(60\right.$ to $200^{\circ} \mathrm{C}$ ) which contains a heated pump and a burner in which a small flame is elevated and sustained by regulated flows of air and either pure hydrogen or a 40/60 mixture of hydrogen and helium. 


\subsubsection{Experimental Set up for Engine Testing with Urea-SCR}

This section describes the equipment used for engine testing of urea-SCR system, the experimental setup, data acquisition and experimental procedures. The urea-SCR system consists of two catalytic reactors placed in series downstream of a catalyzed diesel particulate filter.

\subsubsection{Thermocouples}

A single thermocouple (Figure 3.3.20) was used to measure the temperature at the inlet and outlet for each SCR reactor. The thermocouples were quick disconnect thermocouples with miniature connectors from Omega, Inc., K-type, 1/20" thick, 18" long with inconel sheaths. Inconel as a sheath material was chosen so that the thermocouples were not affected by the acidic environment created by the ammonia formed during urea decomposition.

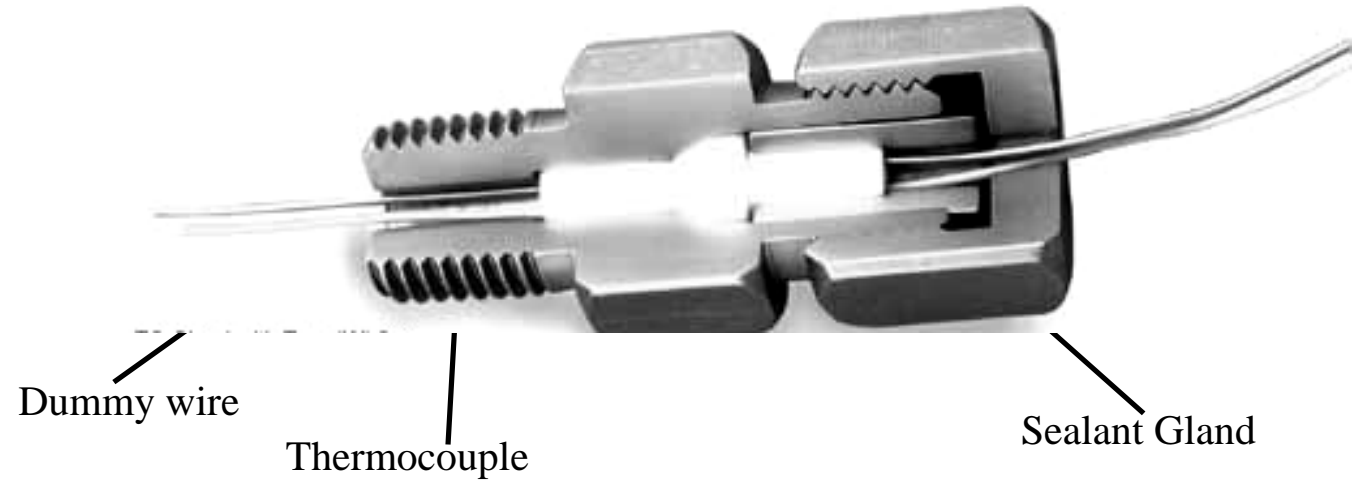

Figure 3.3.20 Thermocouple fitting [7]

The thermocouples were fitted with a Conax "Buffalo" fitting that has sealing glands. Conax Buffalo technologies' "soft sealant" enables easy assembly of the sealing gland by simply inserting the wire or probe and torquing the gland cap. Replaceable sealants permit repeated use of the stainless steel fitting for easy installation and service in the field. The sealant material used for the experiment was "Lava" which can sustain temperatures from $-185^{\circ} \mathrm{C}$ to $+870^{\circ} \mathrm{C}$. Since only one thermocouple was being used at a position, a dummy wire was fit into the sealant gland (Figure 3.3.20).

\subsubsection{Insulation}

The exhaust pipe and all the components along the exhaust piping were insulated to minimize heat loss. The insulating material was glass wool of 1 " thickness. All the valves, tees and couplings were also covered with insulation by custom made mineral wool pipe and tube insulation.

\subsubsection{Plumbing}

Piping of stainless steel 316, 3" diameter and 0.5" wall thickness was used for the exhaust system. The exhaust pipe coming from the manifold of the engine was split into a main exhaust flow going directly to vent and a bypass which passed through the after-treatment devices. The exhaust flow path could be selected with high temperature cast iron flanged gate valves. Two additional valves allowed the exhaust to be routed through the diesel particulate filter or through the diesel particulate filter and the SCR reactors. Figure 3.3.21 shows schematic diagrams of the exhaust system and urea setup. Figure 3.3.22 shows a photograph of the SCR reactor mounting and other hardware.

The urea-injection system was located between valve - 4 and SCR Reactor - I. The air-assisted atomizer for urea injection was fitted in the wall of the exhaust pipe at a distance of 3 feet from the inlet of SCR reactor - I. The distance between the atomizer and the first reactor was determined by calculating the longitudinal distance traveled by $50 \mu \mathrm{m}$ diameter droplet before completely evaporating, so that only vapor enters the SCR reactor. Also this gives the urea time to uniformly mix 
with the exhaust, thereby eliminating any chance of lean-urea pockets being formed, based upon the observations from the cold flow simulation experiment.

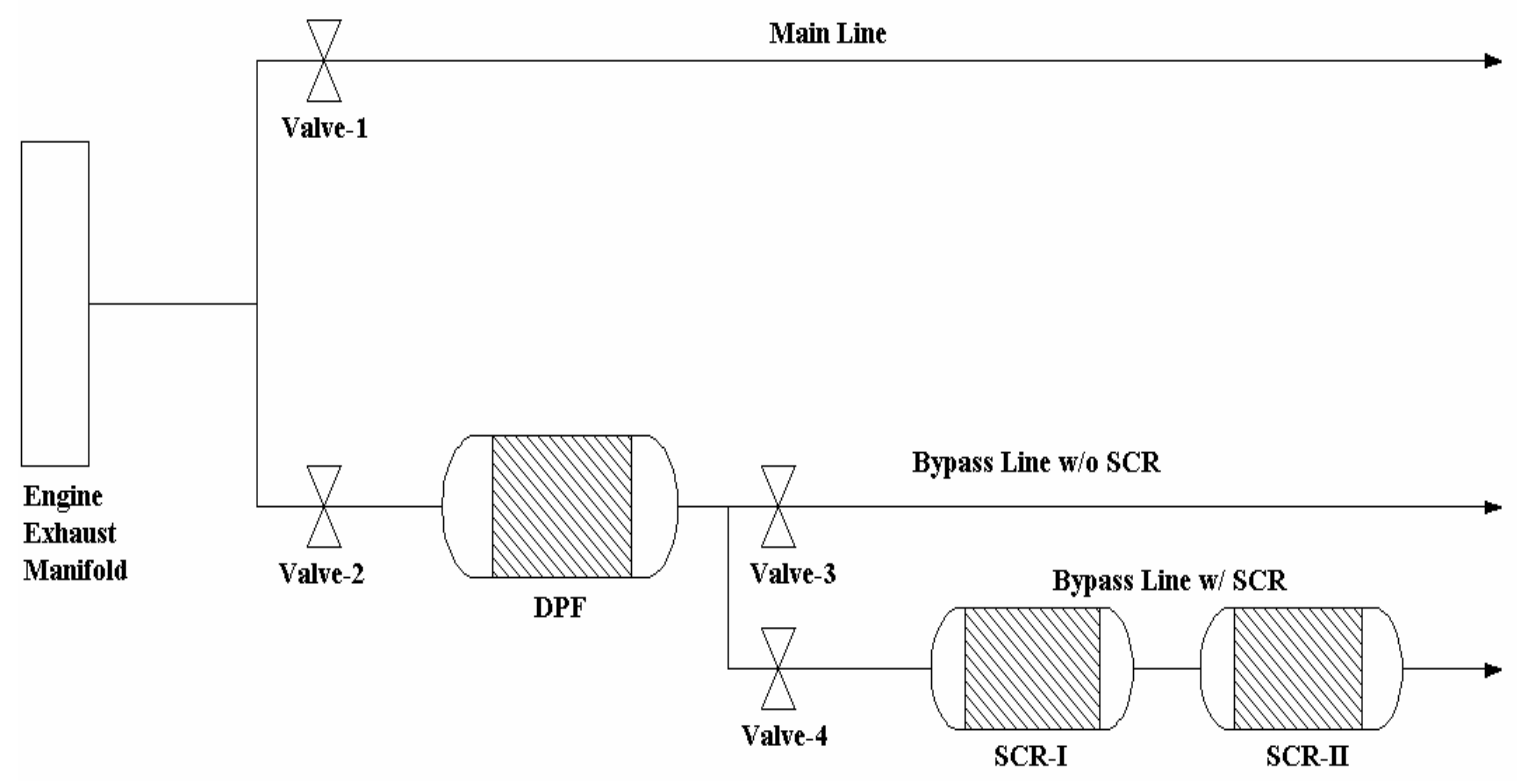

(a)

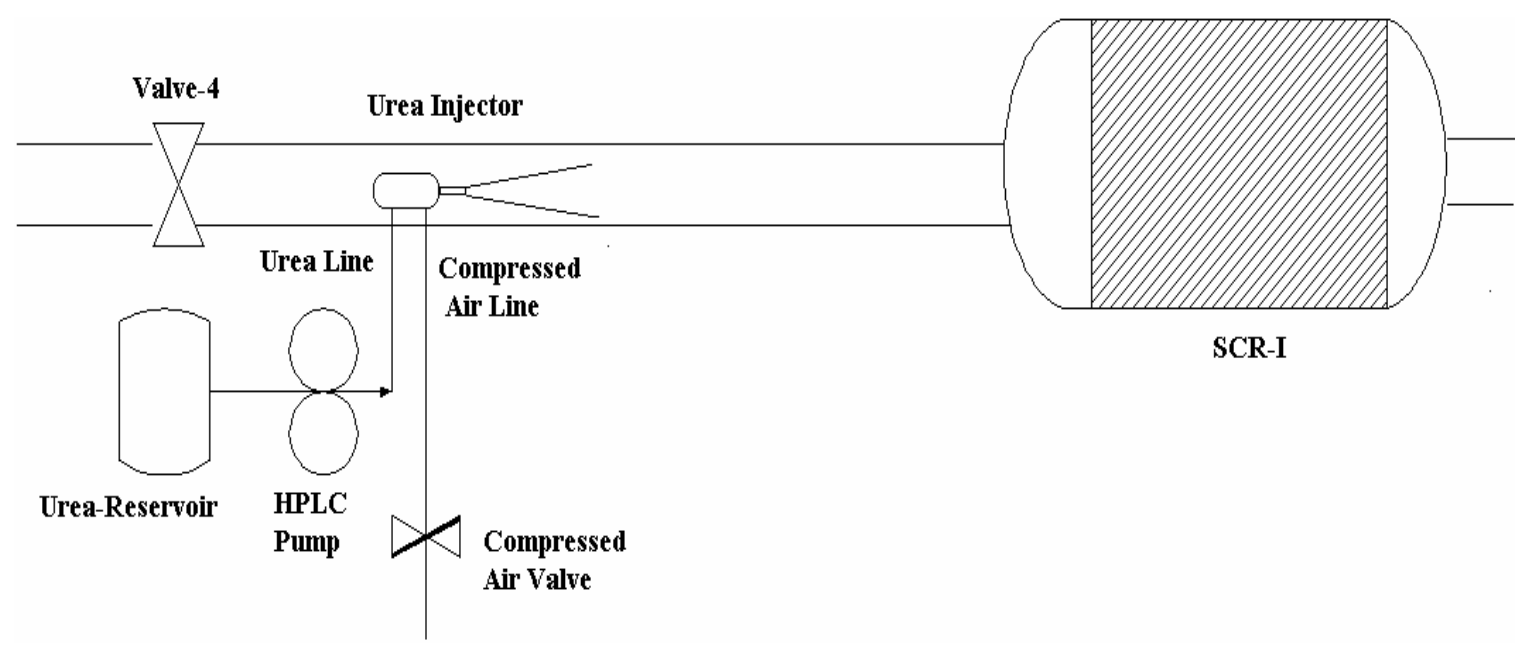

(b)

Figure 3.3.21 Schematic of (a) experimental set up (b) urea-supply system 


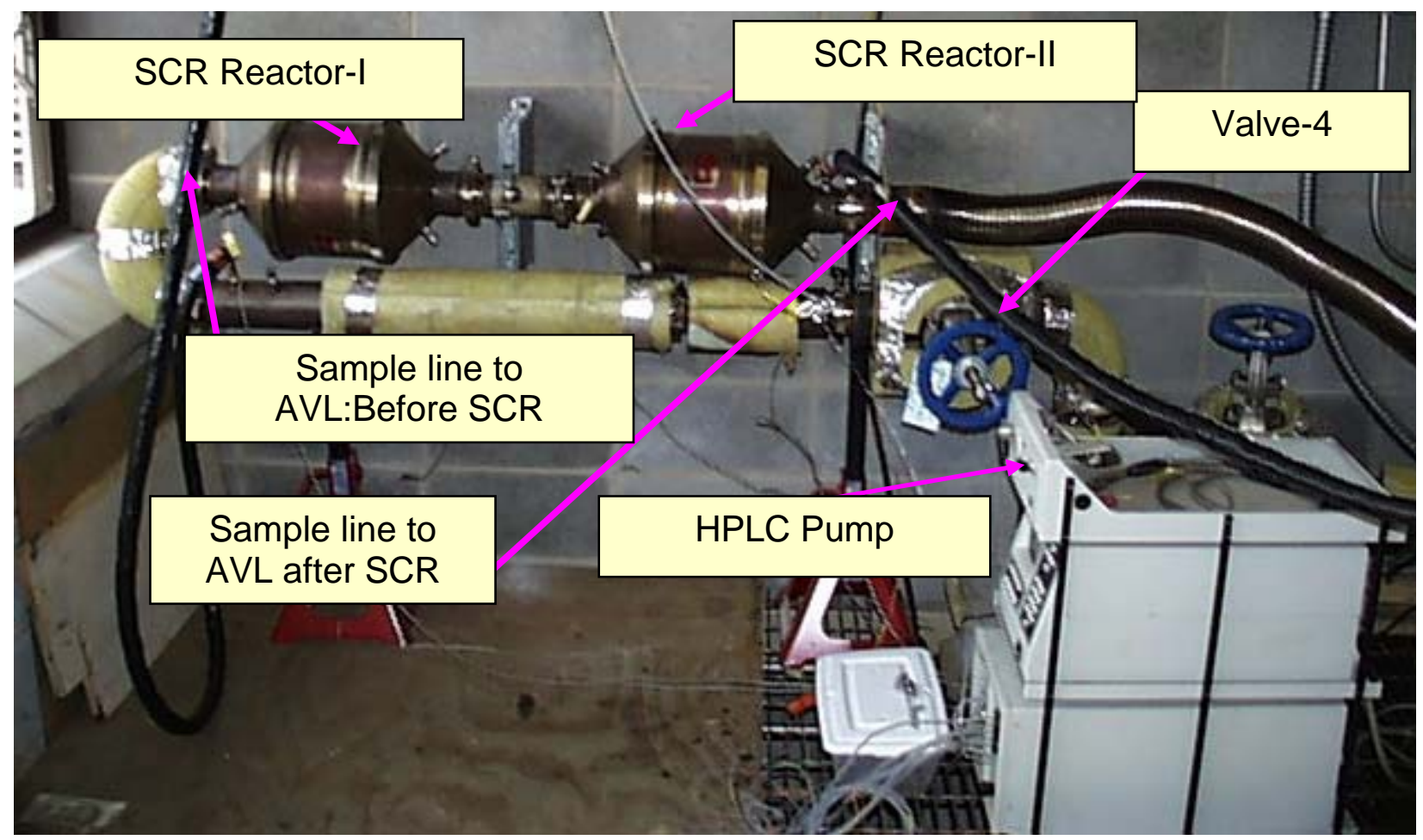

Figure 3.3.22 Experimental setup of the urea-SCR $\mathrm{NO}_{x}$ control system

\subsubsection{SCR Reactors}

The two SCR reactors were supplied by Engelhard Corporation. They were used in series for the experiment. The SCR catalyst volume was 6 liters in total or 3 liters for each reactor. The catalyst was supported on a honeycomb with cell density of $450 \mathrm{cpsi}$. The length of each reactor was 22" and diameter was 9.5".

\subsubsection{Procedures for Emissions Testing}

The objective during testing was to create a map of urea-flow rate vs. engine load and speed. Therefore, it was vital to know the exhaust parameters (catalyst temperature, engine out emissions) and $\mathrm{NO}_{x}$ reduction efficiency of the catalyst as functions of temperature, urea-supply, $\mathrm{NH}_{3}$ slip and emissions of harmful by-products. Therefore, engine testing was performed with two approaches:

\section{AVL 8-mode testing for baseline emissions}

2. Ramp cycle constant engine speed testing for urea-SCR performance

AVL 8-mode test cycle - The AVL 8-Mode test is a steady-state engine test procedure, designed to closely correlate with the exhaust emission results over the US FTP heavy-duty engine transient cycle [8]. The test involves 8 steady state modes. The composite value is calculated by applying weighting factors on the modal results. The sequential engine operating points are as shown in Figure 3.3.4 and Table 3.3.2. These operating points were determined for the Cummins ISB 5.9L turbodiesel test engine based upon the specification data in Table 3.3.1. The performance of the test engine is shown in Figure 3.3.5.

Ramp test cycle - Another test cycle was designed for catalyst characterization as a function of exhaust temperature. The engine speed was fixed at $1400 \mathrm{rpm}$ and engine load was increased gradually. The engine exhaust temperature increased linearly as load was increased thereby increasing the catalyst temperature (Figure 3.3.15). Unlike the AVL 8-mode test cycle, the constant speed test does not provide complete engine mapping. But the SCR-performance is a strong 
function of catalyst temperature and is dependent on engine exhaust temperature, which in turn is a function of engine speed and load. The operating points for the ramp test cycle are listed in Table 3.3.4. The performance of test engine over the ramp test cycle is shown in Figure 3.3.23.

Table 3.3.4 Engine operating points for ramp test cycle

\begin{tabular}{ccccc} 
Mode \# & \multicolumn{3}{c}{ Ramp Test Cycle } \\
1 & Engine RPM & Load (lb-ft) & \% Load & Time (min) \\
2 & 1400 & 146.19 & 31.90 & 70 \\
3 & 1400 & 179.88 & 39.36 & 70 \\
4 & 1400 & 214.17 & 46.86 & 70 \\
5 & 1400 & 247.43 & 54.14 & 70 \\
6 & 1400 & 281.21 & 61.53 & 70 \\
7 & 1400 & 314.92 & 68.91 & 70 \\
8 & 1400 & 348.72 & 76.30 & 70
\end{tabular}

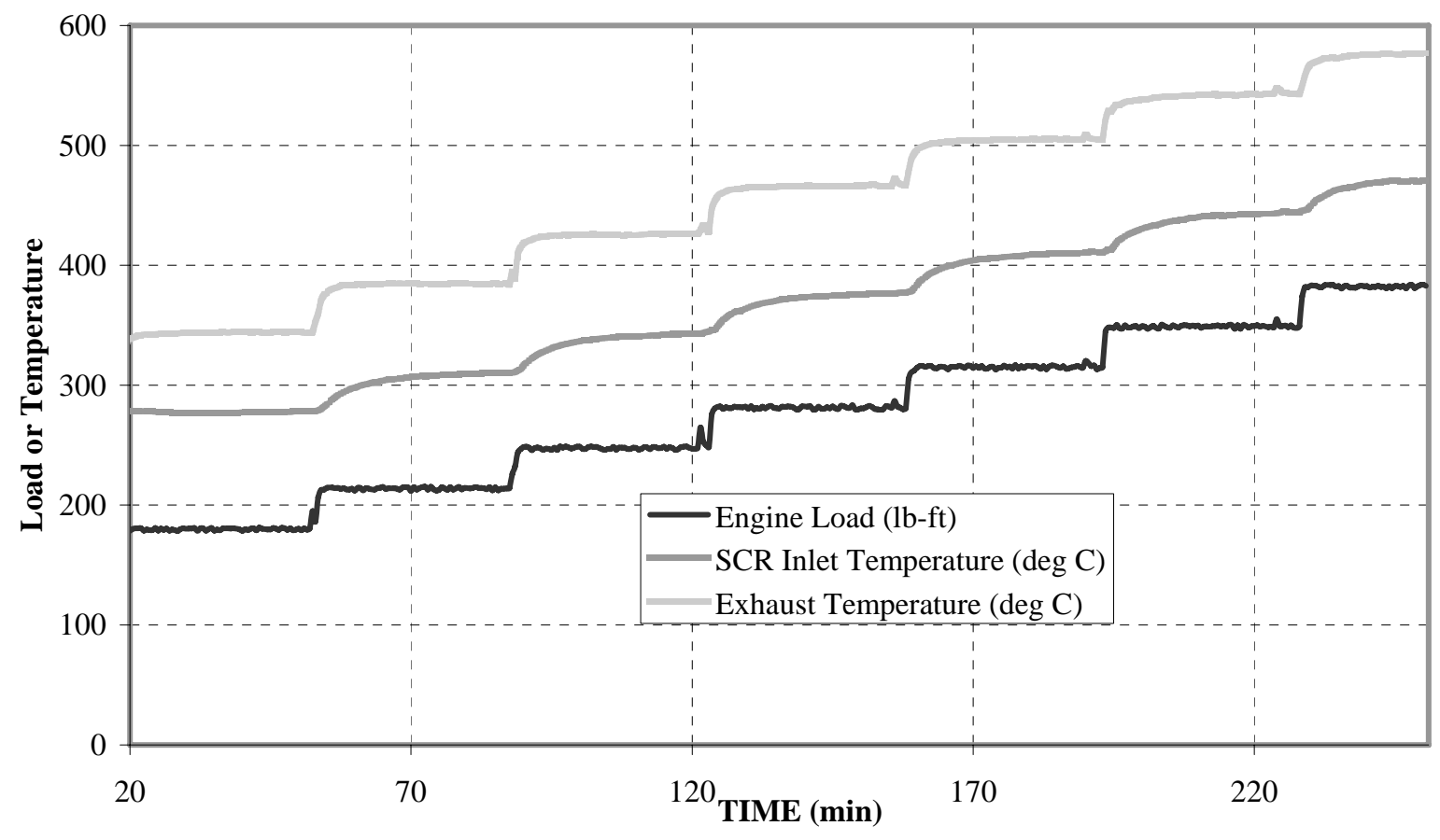

Figure 3.3.23 Cummins ISB performance over ramp test cycle

Fuel Blending - Fuel blends of diesel from British petroleum and biodiesel from World Energy (Chelsea, MA, USA), were prepared by mixing manually in a reservoir while measuring with an Ohaus Explorer balance with a resolution of $\pm 5 \mathrm{gm}$. Fuel blends of $20 \%$ biodiesel $(\mathrm{w} / \mathrm{w})$ with low sulfur diesel (BP15) and high sulfur diesel (BP 325) were prepared for emissions testing. The properties of fuels used are tabulated in Table 3.1.3.1 through Table 3.1.3.3. 
Engine Control and Data Acquisition - The engine control and data acquisition were accomplished with a Leeds and Northrup Micromax II system. Engine speed and load, fuel and air consumption, engine emissions and relevant temperatures are logged by the Micromax. The engine rpm is an analog input and engine load and power are pseudo point inputs. A pseudo point is a data point whose value is derived from other values and relationships. All thermocouples were connected to a junction box which fed the temperature data to the Micromax. Mass air flow rate is also a pseudo point input and is determined using as analog inputs differential pressure, exhaust temperature and inlet air pressure. The function is as follows:

$$
\text { Mass air flow rate }=\text { FACTOR } 1 \times \sqrt{\frac{d P \text { INPUT } \times(\text { Pressure Input }+1.47)}{(\text { Temperature Input }+459)}}
$$

Emissions data from all the analyzers on an AVL CEB II emissions analyzer bench are obtained via an analog output to 37 pin D-type connector and this is fed to the Micromax. Although the AVL bench is capable of taking 10 data points in a second, the Micromax can store only one data point per 30 seconds.

Fuel consumption was measured with a fuel reservoir placed on a weighing scale with a serial port. The scale communicates with a Labview program on a Pentium III computer for determining fuel flow rate in kilograms per hour. The Pentium computer feeds this fuel consumption signal to Micromax.

Other data such as engine coolant temperature, oil pan temperature, dynamometer pan temperature, exhaust gauge pressure, oil pressure were monitored with pressure transducers and thermocouples to monitor engine operation. Intake air temperature (air going into the combustion chamber) was maintained at $40 \mathrm{deg} \mathrm{C}$ at all engine operating conditions using a water-cooled intercooler. The data was saved on the Micromax hard disc and was subsequently downloaded to a floppy for analysis.

Determination of Urea Flow Rate - Decomposition and hydrolysis of urea takes place via the following reactions $\mathrm{R}-3.3 .1-\mathrm{R}-3.3 .3$ :

$$
\begin{aligned}
& \mathrm{NH}_{2} \mathrm{CONH}_{2} \rightarrow \mathrm{NH}_{3}+\mathrm{HNCO} \text { R-3.3.1 } \\
& \mathrm{HNCO}+\mathrm{H}_{2} \mathrm{O} \rightarrow \mathrm{NH}_{3}+\mathrm{CO}_{2} \quad \text { R-3.3.2 } \\
& \mathrm{NH}_{2} \mathrm{CONH}_{2}+\mathrm{H}_{2} \mathrm{O} \rightarrow 2 \mathrm{NH}_{3}+\mathrm{CO}_{2} \quad \text { R-3.3.3 }
\end{aligned}
$$

An analysis of the ammonia yield per unit urea shows that one kmol urea gives $2 \mathrm{kmol}$ of ammonia. The molecular weights of urea and ammonia are $60 \mathrm{~kg} / \mathrm{kmol}$ and $17 \mathrm{~kg} / \mathrm{kmol}$, respectively. Therefore, 1.765 kilogram of urea would give 1 kilogram of ammonia upon hydrolysis.

Ammonia reduces $\mathrm{NO}$ by the following reaction $\mathrm{R}-3.3 .4$ :

$$
4 \mathrm{NO}+4 \mathrm{NH}_{3}+\mathrm{O}_{2} \rightarrow 4 \mathrm{~N}_{2}+6 \mathrm{H}_{2} \mathrm{O}
$$

According to above reaction, one $\mathrm{kmol}$ of $\mathrm{NO}$ requires one $\mathrm{kmol}$ of ammonia. The molecular weights of nitric oxide (NO) and ammonia $\left(\mathrm{NH}_{3}\right)$ are $30 \mathrm{~kg} / \mathrm{kmol}$ and $17 \mathrm{~kg} / \mathrm{kmol}$ respectively. Therefore, 1 kilogram of NO requires 0.567 kilogram of ammonia which is equivalent to 1.008 kilogram of aqueous urea supply. Since a $32 \%(\mathrm{w} / \mathrm{w})$ urea-water solution in water was used, one $\mathrm{kg}$ urea solution gives 0.32 kilogram urea and 1.008 kilogram urea supply requires 3.127 kilogram urea solution.

Therefore, 1 kilogram of NO requires 3.125 kilogram of $32 \%(w / w)$ urea solution for complete reduction. The $\mathrm{NO}_{x}$ consists of $\mathrm{NO}$ and $\mathrm{NO}_{2}$. A baseline emissions study over the AVL 8-mode cycle with all four fuels shows that in diesel exhaust from this engine, $\mathrm{NO}_{\mathrm{x}}$ consists mainly of $\mathrm{NO}$ as shown in Figure 3.3.24 (a - d). So, the amount of urea supply is calculated based on the assumption that $\mathrm{NO}_{\mathrm{x}}$ is only NO. Therefore, $3.125 \mathrm{~kg}$ of urea is supplied per $\mathrm{kg}$ of $\mathrm{NO}_{\mathrm{x}}$. This ratio is called the stoichiometric urea flow rate. If the urea flow rate is higher than this ratio, e.g. 1.4 kilogram of urea is 
supplied per kilogram of $\mathrm{NO}_{\mathrm{x}}$ in exhaust, then this case is called urea rich supply. If urea flow rate is smaller than this ratio $(0.75 \times)$, then this case is called urea lean supply.

Other reactions may be as follows:

$$
\mathrm{CO}\left(\mathrm{NH}_{2}\right)_{2}+6 \mathrm{NO} \rightarrow 5 \mathrm{~N}_{2}+2 \mathrm{CO}_{2}+4 \mathrm{H}_{2} \mathrm{O}
$$

In reaction R-3.3.5, $60 \mathrm{~kg}$ urea is required for the complete removal of $6 \mathrm{kmol}$ or $180 \mathrm{~kg}$ of NO which means $1 \mathrm{~kg}$ NO requires $0.333 \mathrm{~kg}$ Urea.

$$
\mathrm{HNCO}+6 \mathrm{NO} \rightarrow 5 \mathrm{~N}_{2}+4 \mathrm{CO}_{2}+2 \mathrm{H}_{2} \mathrm{O}
$$

Isocyanuric acid (HNCO) is an intermediate product formed by the decomposition of urea. For 1 $\mathrm{kg}$ of $\mathrm{HNCO}, 1.395 \mathrm{~kg}$ of urea is required. Also in reaction R-3.3.6, $43 \mathrm{~kg} \mathrm{HNCO}$ is required for the complete removal of $6 \times 30 \mathrm{~kg} N O$ which means $1 \mathrm{~kg} \mathrm{NO}$ requires $0.239 \mathrm{~kg} \mathrm{HNCO}$, which in turns requires $0.333 \mathrm{~kg}$ of urea.

Therefore, any of the above reactions would require $1.04 \mathrm{~kg} \mathrm{32 \% (w/w)} \mathrm{urea} \mathrm{solution} \mathrm{supply} \mathrm{per}$ $\mathrm{kg}$ of NO produced. But any reactions other than R-3.3.4 are reported as being very slow [9] and thus R-3.3.4 dominates. The urea solution was supplied as per reaction R-3.3.4.

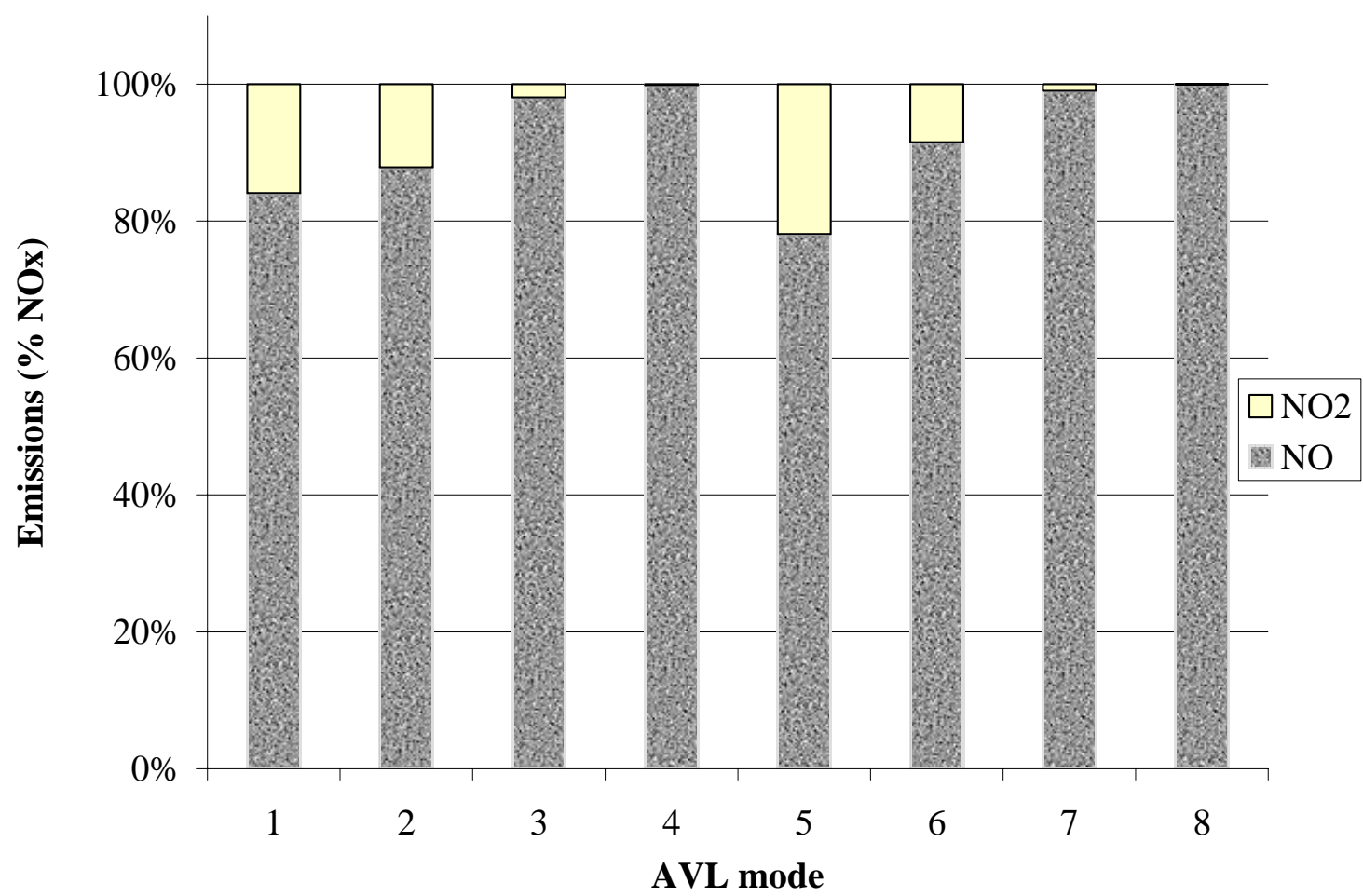

Figure 3.3.24 (a) $\mathrm{NO}_{x}$ structure in AVL 8-Mode emissions test with BP15 fuel 


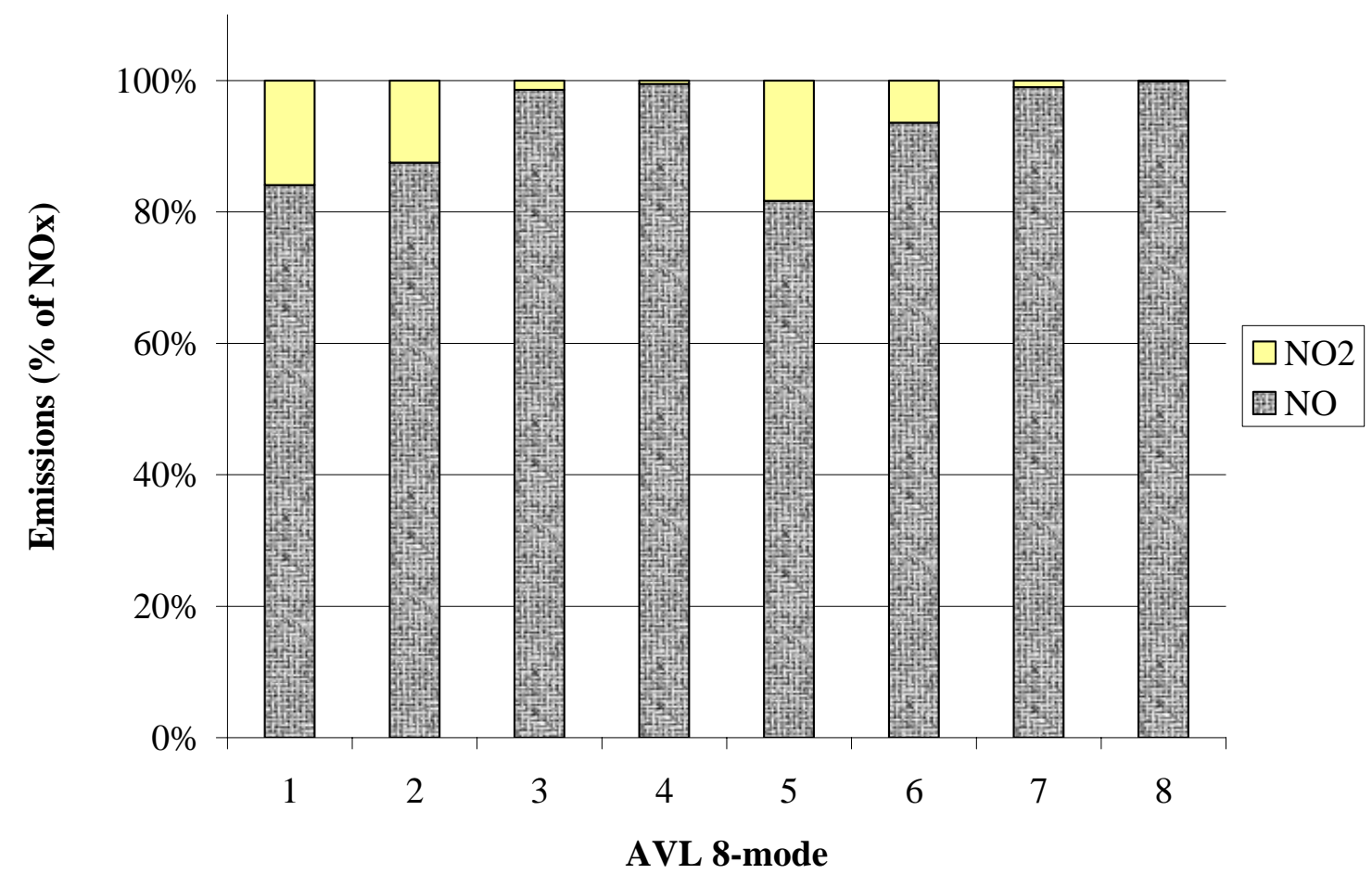

Figure 3.3.24 (b) $\mathrm{NO}_{x}$ structure in AVL 8-Mode emissions test with BP325 fuel

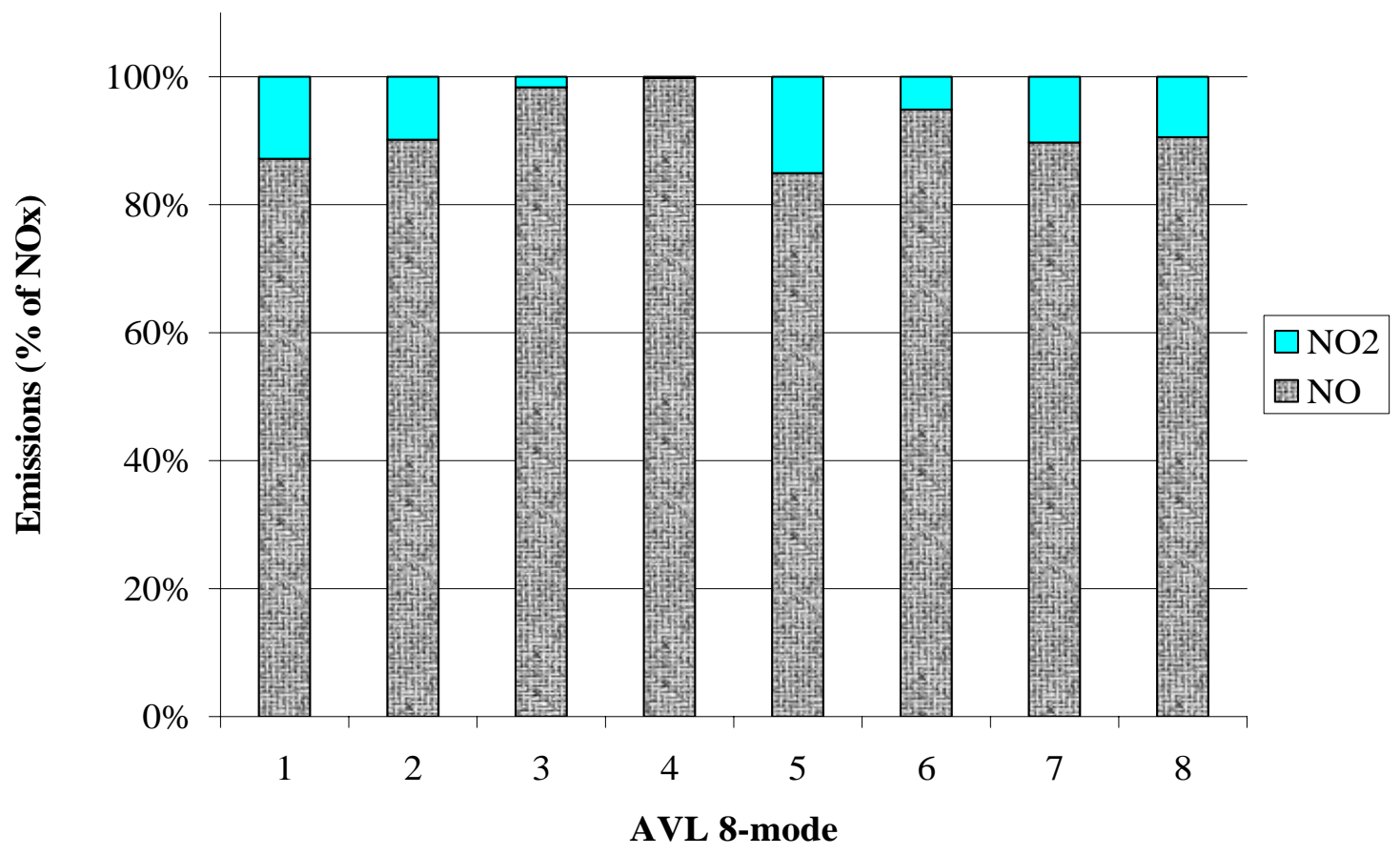

Figure 3.3.24 (c) $\mathrm{NO}_{x}$ structure in AVL 8-Mode emissions test with B20-BP15 fuel 


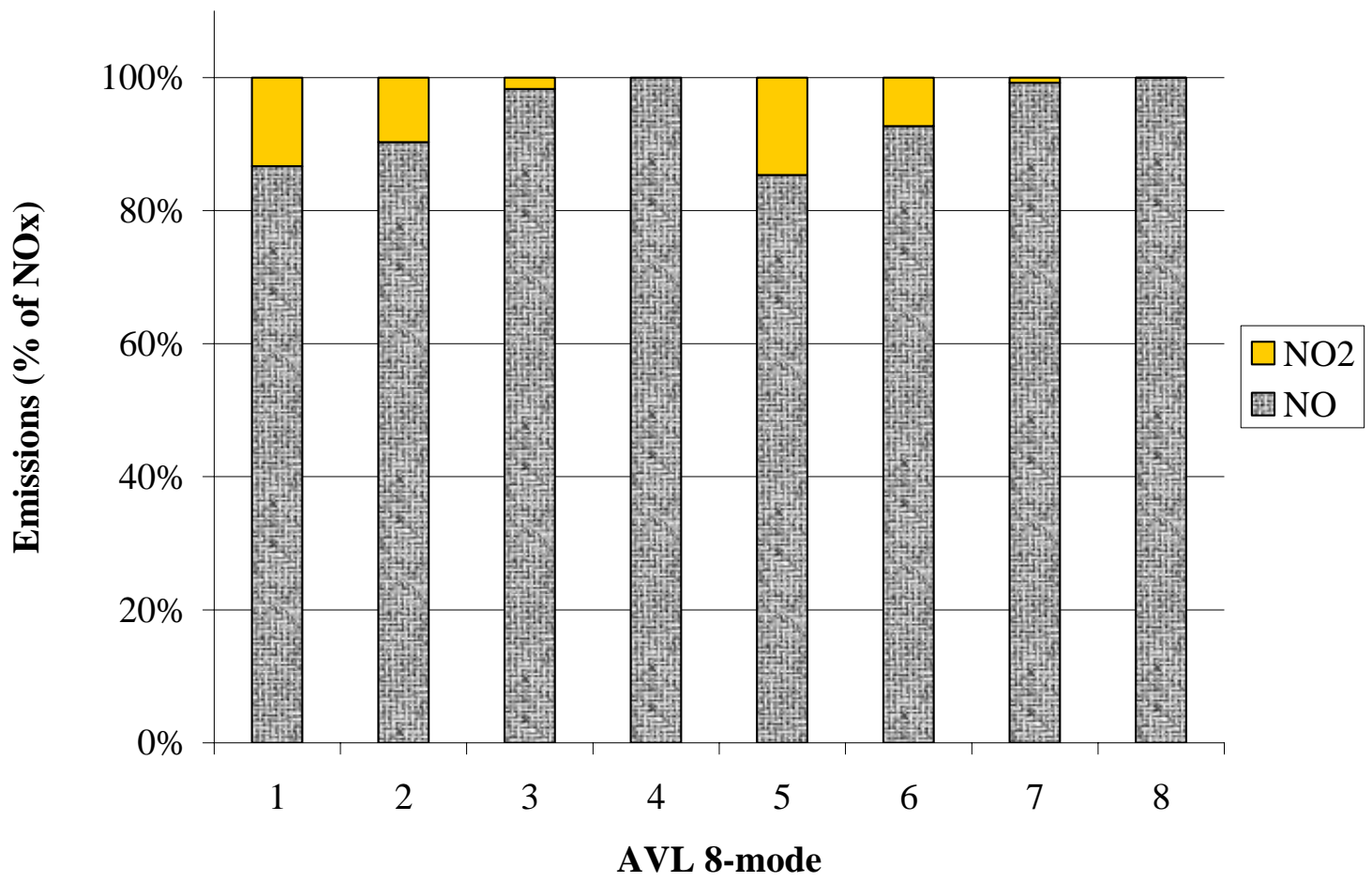

Figure 3.3.24 (d) $\mathrm{NO}_{x}$ structure in AVL 8-Mode emissions test with B20-BP325 fuel

Therefore,

Urea supply rate $(\mathrm{kg} / \mathrm{hr})=3.125 \mathrm{NO}_{\mathrm{x}}$ flow rate $(\mathrm{kg} / \mathrm{hr})$

The density of $32 \%$ Urea solution was measured at room temperature as $1.127 \mathrm{~kg} / \mathrm{m}^{3}$. It was supplied to the air-assisted atomizer using a Waters Prep LC 4000 pump. The urea mass flow rate was monitored using an Ohaus balance with $\pm 0.1 \mathrm{gm}$ resolution and a stop watch with 0.1 second resolution. Properties of urea used in the present work are listed in Table 3.3.5.

Table 3.3.5 Properties of urea used in present work [10]

Specific Gravity

Flashpoint

Appearance

Solubility in water

$\%$ Volatalies (by volume)

Incompatibility

Reaction with water
1.335

Non-flammable

White perils or granules

67 gm/100 gm Water @ 32 deg F

0

Strong oxidizing agents. Prolonged contact may cause oxidation of unprotected materials

none 


\subsubsection{Emissions Analysis and Supplementary Equipment}

AVL CEB-II - An AVL CEB-II raw emissions analyzer bench was used for online measurement of gaseous emissions at both the inlet and outlet of the SCR reactors. The gaseous emissions were sampled through heated samples lines kept at a temperature of 190 deg C. The CEB-II consists of different analyzers for different gaseous species, as shown in Table 3.3.6.

Table 3.3.6 List of analyzers on AVL emissions bench

\section{Gaseous Species}

CO: Carbon Monoxide

$\mathrm{CO}_{2}$ : Carbon Dioxide

$\mathrm{NO}_{\mathrm{x}}$ : Nitrogen Oxides

THC: Total Hydrocarbon

$\mathrm{O}_{2}$ : Oxygen

\section{Analyzer}

NDIR: Non Dispersive Infrared

NDIR: Non Dispersive Infrared

CLD: Chemiluminescence Detector

FID: Flame Ionization Detector

PMA: Paramagnetic Analyzer

FTIR - Fourier Transform Infrared Spectrometry was used to quantify inlet and outlet gases to the SCR reactor specifically ammonia and nitrous oxide. FTIR spectrometry, in conjunction with the 2.1 MHz Pentium 4 computer is capable of providing a real time online quantitative analysis of the gas phase sample. It was the only available instrument capable of quantifying ammonia and nitrous oxide.

In FTIR spectrometry, IR radiation is passed through a sample gas. Some of the IR radiation is absorbed by various species present in the gaseous sample and some is transmitted. The resulting spectrum represents the molecular absorption and transmission, creating a molecular signature of the sample. An IR spectrum of a particular gaseous species corresponds to the frequencies of vibrations between the bonds of atoms present in the species. Since each material is a unique combination of atoms, all molecular structures produce different spectrums which represent the evidence of their presence in the sample. Location of peaks at these characteristic frequencies indicates presence of these species in the gaseous sample. The size of peaks in the spectrum is a direct indication of the amount of material present. Therefore, by analyzing the spectrum, qualitative and quantitative analysis of sample can be performed.

The FTIR is equipped with the liquid nitrogen cooled MCT (Mercury Cadmium Telluride) detector which can detect in the far-infrared region as well as the near infrared regions. Other experimental parameters were set as following:

Beam splitter: $\mathrm{KBr}$

Source: IR

Spectral Range: $4000-650 \mathrm{~m}^{-1}$

Bench: 2 meter cell

Temperature: $135^{\circ} \mathrm{C}$

Pressure: $680 \mathrm{~mm} \mathrm{Hg}$

FTIR Calibration - Before quantitative analysis was done, the FTIR was calibrated for each of the gaseous species that it measured and a method was created for each species respectively. Calibration was done by flowing a known concentration of the gaseous species through the spectrometer with nitrogen as the background gas. Since a wide range of concentrations was expected in the sample, it was divided into narrower ranges and more than one method was created for each concentration range. 


\section{Method Creation Example:}

A sample having known concentration of a species with balance nitrogen gas is flown into the FTIR cell. This sample creates a spectrum and it is saved. After this, another sample is flown that has concentration increased by a fixed number. Several such samples of the same species are flown with concentration increasing by a fixed number till the maximum concentration within the range is attained.

Each sample of calibration gas creates a spectrum and these were used to create a calibration curve using Quantpad version 2.0 software. The correction coefficients for the calibration curve were obtained using same software. The \% error in cases of all methods thus created was below $1 \%$. The calibration curve thus created is saved as a method for that species and for the concentration range. This calibration curve was used directly while analyzing the emission spectrum using another software OMNIC version 1.5. The following is the list of methods for different species and concentration ranges used for ammonia analysis is given in Table 3.3.7.

Table 3.3.7 List of methods for ammonia analysis

$\begin{array}{cc}\text { Species } & \text { Range } \\ \mathrm{NH}_{3} \text { LOW } & 0-50 \mathrm{ppm} \\ \mathrm{NH}_{3} \text { MID } & 100-500 \mathrm{ppm} \\ \mathrm{NH}_{3} \mathrm{HIGH} & 600-1000 \mathrm{ppm}\end{array}$

Sampling and Analysis - A heated sample line was used for ammonia measurement to prevent ammonia dissolution into the condensed water in the sample line. Owing to the high solubility of ammonia, water extraction from the sample was circumvented by using a heated NOx analyzer so that stripping of moisture from the gas sample was unnecessary. The temperature of heated sample line was set at $180^{\circ} \mathrm{C}$. For every sample, the spectrum was collected five times and the concentration was averaged.

HPLC pump - A Waters Prep LC 4000 was used to supply urea through the air-assisted atomizer. It is a High Performance Liquid Chromatography solvent delivery pump. It is equipped with $500 \mu \mathrm{L}$ total head volume. Therefore, it can deliver flow rates from $0 \mathrm{ml} / \mathrm{min}$ to $150 \mathrm{ml} / \mathrm{min}$. The pump can produce maximum supply pressures as high as 4000 psig. This pump delivers the input flow rate irrespective of the supply pressure as long as that is below 4000 psig. There is a feedback control loop incorporated in this system. It monitors the flow rate and if the flow resistance is higher, it increases the supply pressure. Also it has a pressure sensor which sends an error signal if pressure goes beyond 4000 psig. 


\section{Results and Discussion}

\section{Subtask 3.3.6 - Engine Evaluation of Low Sulfur and Ultra Low Sulfur Diesel Fuel}

Experiments were conducted in the Cummins 5.9I ISB engine with the two base fuels, a low sulfur diesel fuel BP325, and an ultra low sulfur diesel fuel BP15. In addition two 20 wt.\% biodiesel blends with BP325 and BP15 were considered in these tests. For the engine testing, each fuel was evaluated using the AVL 8-Mode test protocol. Biodiesel blended fuels are considered to compare their performance and emissions reduction potential with the base fuels. During the engine tests, the data acquisition and analytical instruments were used to monitor engine operating conditions such as, temperatures, intake air flow, turbo boost pressure, fuel consumption, particulate matter, gaseous emissions, in-cylinder pressure and injector needle lift. From each test mode, all the gaseous emissions were recorded over one hour period. Based on the power output for each test mode, the gaseous emissions were calculated on brake-specific basis, as well as, on a mass emission rate per unit fuel consumption.

\subsubsection{Engine Performance}

For each test mode, fuel consumption was recorded over a five minute period as the difference in fuel tank weight. Based on power output for each test mode, brake-specific fuel consumption (BSFC) was calculated and is presented in Figure 3.3.25. Mode 1 is omitted from Figure 3.3.25, since there is no net power output and BSFC cannot be calculated. A comparable brake-specific fuel consumption is observed with BP325 and BP15. The trend is for specific fuel consumption to increase with biodiesel blends, which is consistent with their lower heating value compared to the base fuels as shown in Table 3.3.8.

Table 3.3.8 Calorific value of base and blended fuels

\begin{tabular}{|c|c|}
\hline Tested Fuels & Calorific Value, BTU/lb \\
\hline BP325 & 18486 \\
\hline BP15 & 18516 \\
\hline B20-BP325 & 18101 \\
\hline B20-BP15 & 18122 \\
\hline
\end{tabular}

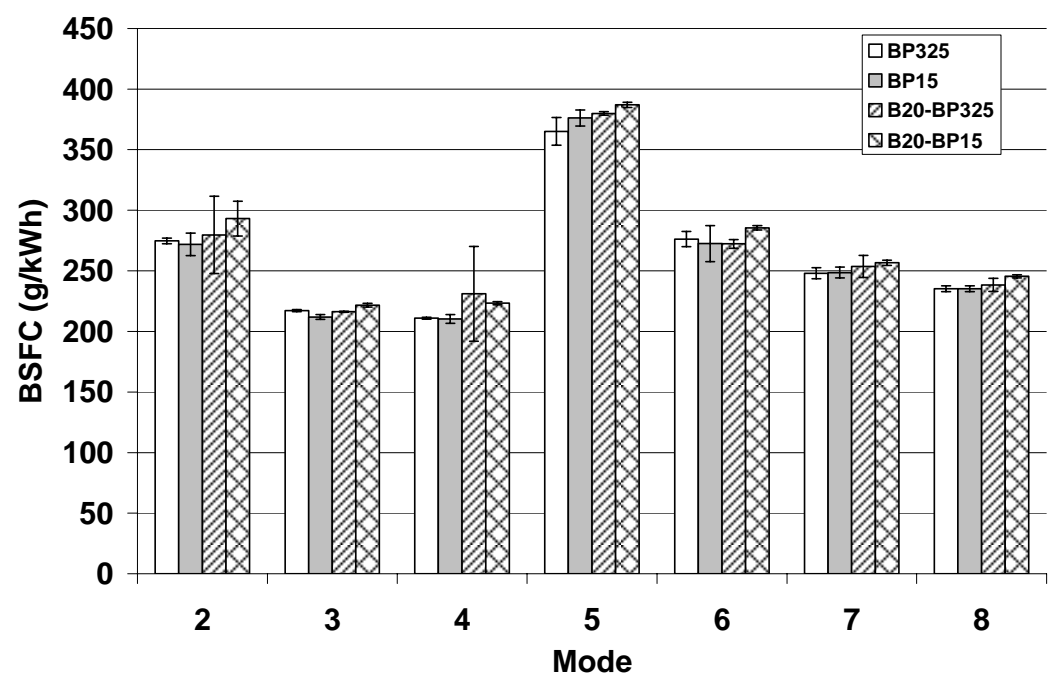

Figure 3.3.25 Brake-specific fuel consumption 
For the base fuels and blends evaluated in this study, the combustion process was monitored using in-cylinder pressure trace analysis. Also, a needle lift sensor was used to monitor dynamic behavior of the start of injection and end of injection events. Rate of heat release (ROHR) was calculated using in-cylinder pressure trace data. Figure 3.3.26 through 3.3.29 show needle lift and rate of heat release results at Modes 2, 4, 6 and 8, respectively.

Among the AVL 8-Modes, only four modes are selected here, two are low load at low (Mode 2) and high speed (Mode 6), and the other two are high load at low (Mode 4) and high speed (Mode 8). Rate of heat release and needle lift were plotted as a function of crank angle relative to top dead center (TDC). In addition to the dynamic start and end of injection, needle lift data also shows fuel injection duration. Changing engine operating conditions from Mode 2 to Mode 4 shows needle lift duration changes, indicating a longer injection duration with Mode 4. A similar trend is present between Modes 6 and 8. It should be noted that the present study was conducted with an electronically controlled fuel injection system so that injection timing is dictated by the protocols in the ECM. Therefore, change in injection timing is observed from the needle lift data as shown in Figures 3.3.26 through 3.3.29. For this engine's calibration, injection timing varied with load.

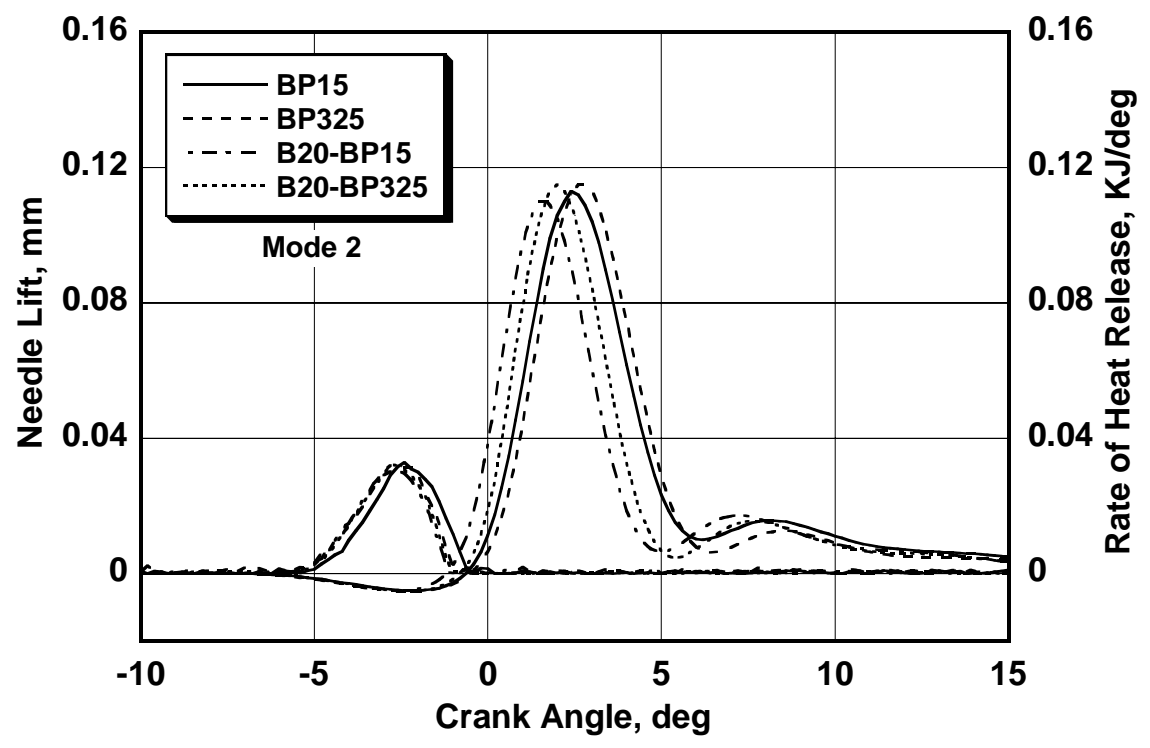

Figure 3.3.26 Needle lift and rate of heat release at mode 2

Comparing the start of injection event among the fuels, Figures 3.3.26 through 3.3.29 show that start of injection varies with the fuel. This behavior is more prominent at high load condition (Figure 3.3.27 and 3.3.29) rather than at low load (Figure 3.3.26 and 3.3.28). Table 3.3.9 shows the specific start of injection timing among the fuels. The density of BP325 is higher than BP15 and blending 20 wt.\% biodiesel into base fuels will increase density of the B20-BP15 and B20-BP325 blends. Among the fuels, BP15 has the lowest density while B20-BP325 has the highest density. An enlarged view of needle lift at mode 8 is shown in Figure 3.3.30, where the B20-BP325 blend showed the earliest start of injection among the fuels. After B20-BP325, the start of injection occurred in the order of B20-BP15, BP325, and BP15. The start of injection occurred in the order of density of the fuels: the higher the density of the fuel, the earlier the start of injection. The B20-BP325 blend showed almost 1.0 crank angle degree (CAD) advanced injection timing compared to BP15. The BP325 fuel also yielded an advanced injection compared to the BP15 fuel. Many researchers, including Szybist et al. [11] observed advanced injection timing with biodiesel blended fuels. However, it is difficult to compare directly with the result of Szybist et al., since their engine was a single cylinder with mechanically controlled injection timing. Boehman et al. also showed advanced injection timing with 
B-20 and B-100 compared to base diesel fuel [12]. It is necessary to mention here that despite the electronic control of start of injection, fuel injection timing changed with density.

Table 3.3.9 Comparison of start of injection timing

\begin{tabular}{|c|c|c|c|c|}
\cline { 2 - 5 } & \multicolumn{4}{|c|}{$\begin{array}{c}\text { Start of Injection Timing } \\
\text { (Degree Before Top Dead Center) }\end{array}$} \\
\cline { 2 - 5 } & Mode 2 & Mode 4 & Mode 6 & Mode 8 \\
\hline BP15 & 4.5 & 4.9 & 0.2 & 2.6 \\
\hline BP325 & 4.9 & 5.2 & 0.6 & 3.1 \\
\hline B20-BP15 & 4.8 & 5.3 & 0.3 & 2.9 \\
\hline B20-BP325 & 4.7 & 5.1 & 0.8 & 3.3 \\
\hline
\end{tabular}

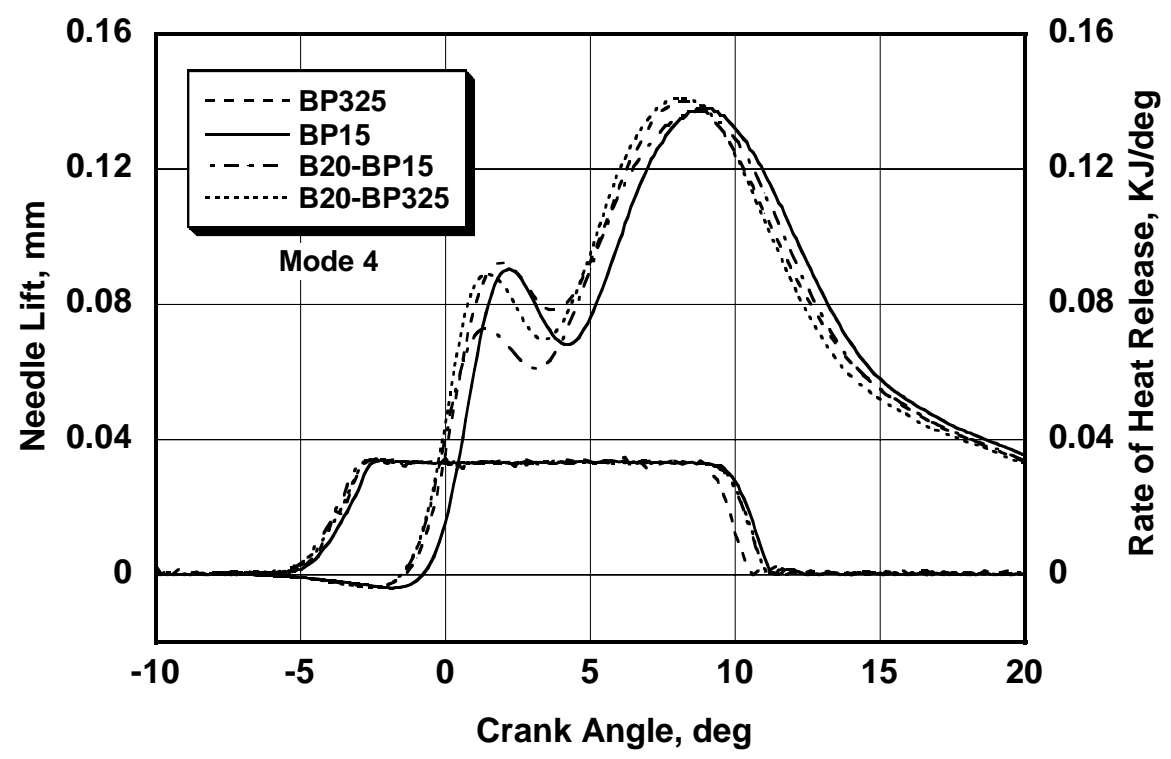

Figure 3.3.27 Needle lift and rate of heat release at mode 3

Boehman et al. observed a good correlation between the density of different fuels and their bulk modulus [12]. Bulk modulus increased with increasing fuel density. Therefore, it seems that the advanced injection timing with biodiesel blends and BP-325 is consistent with the reported results and arises from an increased fuel density and bulk modulus of compressibility [11]. Details of the bulk modulus and injection timing issue can also be found in the section subtask 3.1.3.

This early start of injection or late start of injection has a great effect on engine-out exhaust emissions. An early start of injection can lead to increase $\mathrm{NO}_{x}$ emissions. Biodiesel blends having an early start of injection can increase $\mathrm{NO}_{x}$ emissions compared to base fuels [13]. Similarly, the early start of injection with BP325 increases $\mathrm{NO}_{x}$ emissions relative to BP15. Note that the start of injection is not the only reason for higher $\mathrm{NO}_{x}$ emissions. Some other fuel properties are also related to $\mathrm{NO}_{x}$ emissions, for example, cetane number [14]. The change in $\mathrm{NO}_{x}$ emissions due to the variation of cetane number can be explained with rate of heat release analysis of the fuels. 


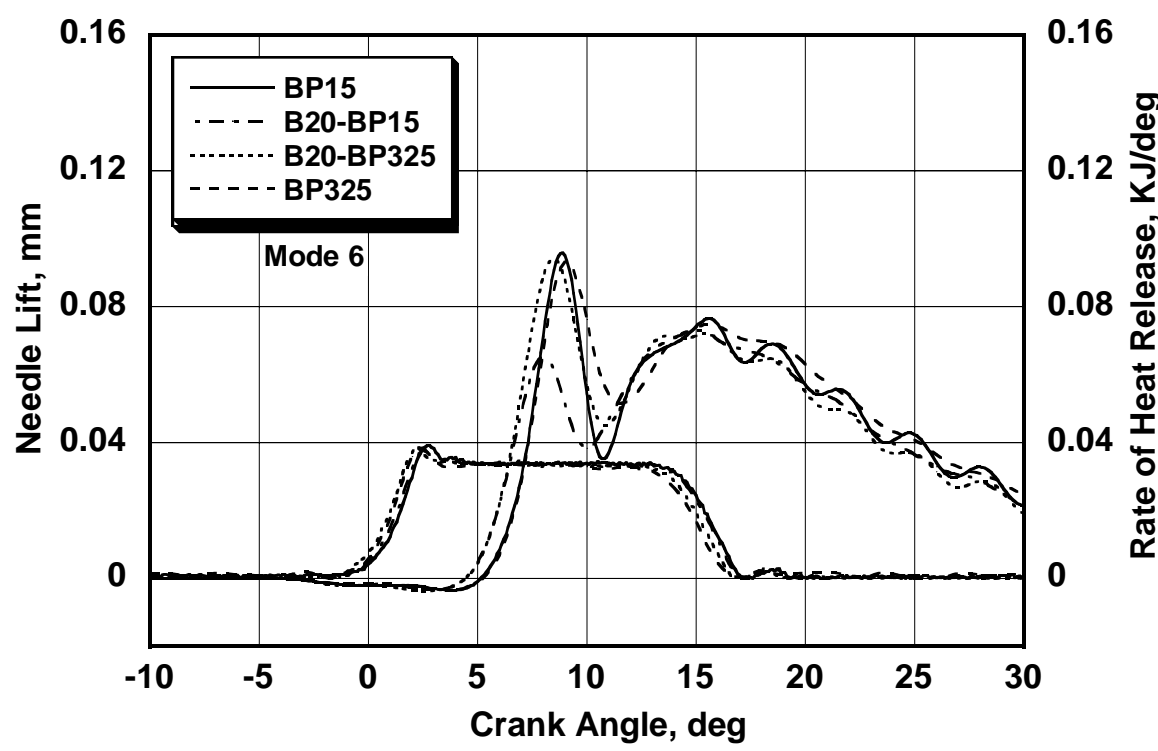

Figure 3.3.28 Needle lift and rate of heat release at mode 6

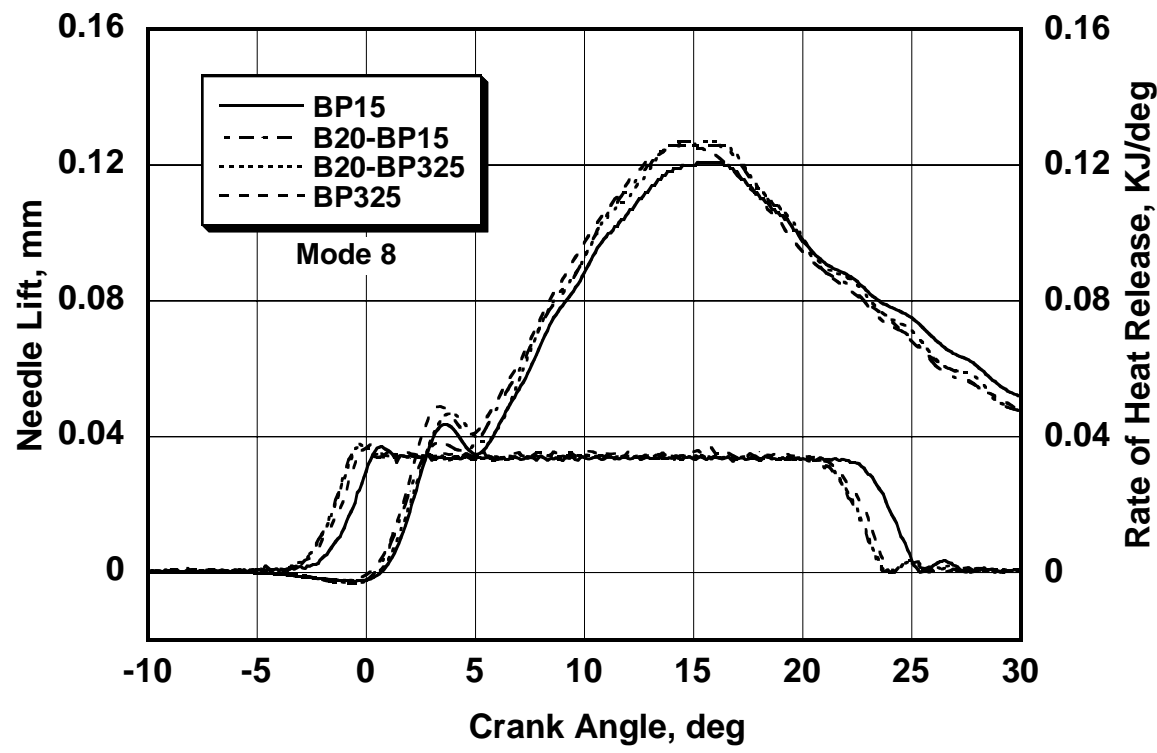

Figure 3.3.29 Needle lift and rate of heat release at mode 8

As shown in Table 3.1.3.1, the BP325 shows the lowest cetane number and biodiesel blended B20-BP15 fuel shows the highest cetane number among the fuels. An increase in the paraffinic content of the fuel increases cetane number and a high content of aromatics impairs the ignition quality and lowers the cetane number. An increase in cetane number results in a reduction of the ignition delay period and reduces the amount of premixed combustion [15].

At low load condition, rate of heat release analysis indicates that the majority of the combustion is premixed. At high load, diffusion burning dominates the combustion process. The early start of heat release with the biodiesel blends is explained by the early start of injection and the cetane number of the fuels. The biodiesel blended fuels show a lower premixed burn peak compared to their respective base fuel due to the increase of cetane number of the blend from blending biodiesel 
into the base fuel. The highest premixed burn peak is observed with BP325. This result is consistent with cetane number of the test fuels, since the highest premixed burn peak among the fuels is for BP325, which has the lowest cetane number.

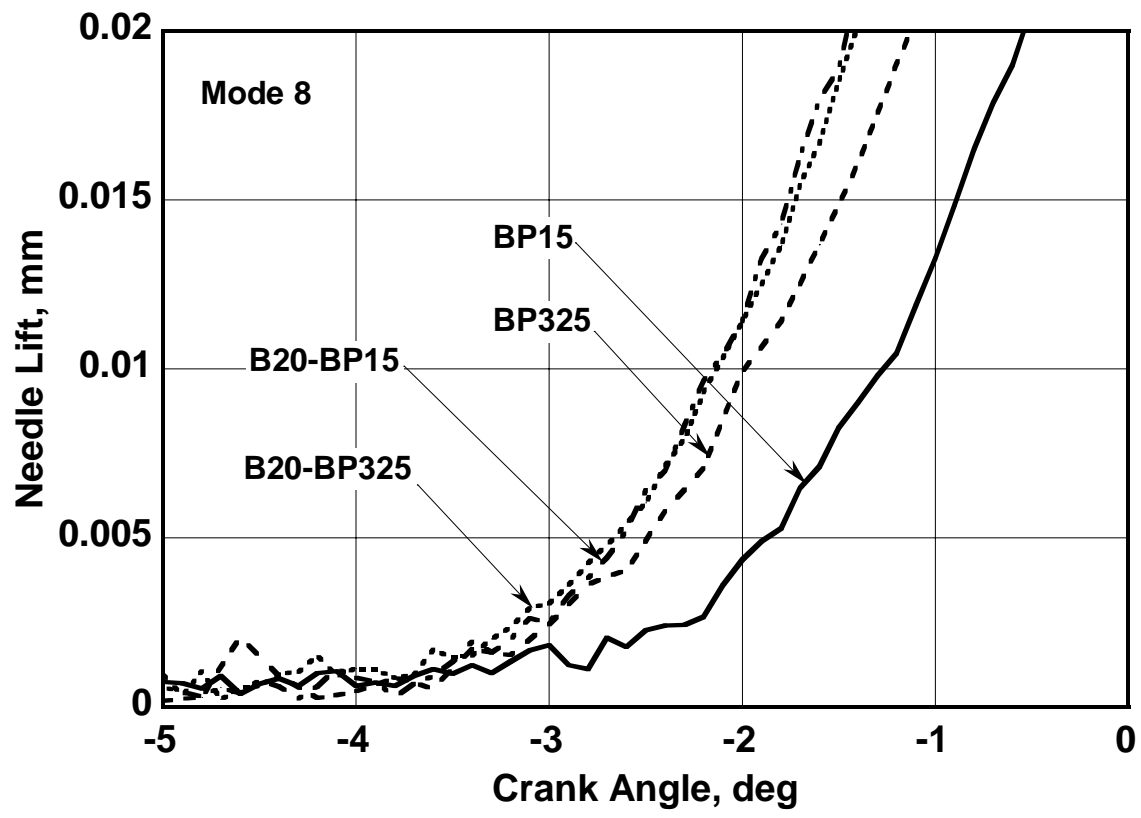

Figure 3.3.30 Enlarged view of needle lift at mode 8

Kidoguchi et al. carried out an experiment with a DI diesel engine by varying the cetane number and aromatic content of the fuel independently [16]. Fuels with the same aromatic content and reduced cetane number indicated longer ignition delay and higher initial heat release, resulting in lower PM emissions and increased $\mathrm{NO}_{\mathrm{X}}$ at high load conditions. On the other hand, higher cetane number produced large amounts of PM due to the longer combustion duration. At low load, low cetane number fuel showed high total hydrocarbon emissions due to the over-lean mixture caused by the long ignition delay which produced incomplete combustion.

Diesel fuel properties have significant effects on start of injection, start of combustion, and premixed and diffusion burn peaks, which impact engine performance and tailpipe exhaust emissions. Sometimes it is very difficult to isolate the effects of one property from another, since the properties of diesel fuels are interrelated. Blending biodiesel into base diesel fuels increases density and cetane number at the same time. As explained earlier, the higher the density, the earlier the start of injection, resulting in higher $\mathrm{NO}_{x}$ emissions. One would expect higher cetane number fuel would show lower $\mathrm{NO}_{x}$ emissions. Therefore, in the case of biodiesel blends, the final $\mathrm{NO}_{x}$ emissions must depend on the resultant effects of the change in density and cetane number. BP15 has lower density and higher cetane number compared to BP325. $\mathrm{NO}_{x}$ emissions with ultra low sulfur diesel fuel would decrease due to the retarded start of injection and lower premixed burn peak.

\subsubsection{Exhaust Emissions}

Figure 3.3.31 shows $\mathrm{NO}_{x}$ emissions in grams per kilogram of fuel consumed provides a means of examining all 8 test modes. Figure 3.3.32 shows the brake-specific $\mathrm{NO}_{\mathrm{x}}$ emissions with all the fuels excluding Mode 1.

In general, $\mathrm{NO}_{x}$ emissions decrease with increasing load for all the test fuels on a brake specific of fuel mass basis. Other than Mode 4 and Mode 7, NOx emissions decrease with BP15 compared to BP325. One reason might be due to the early start of injection with BP325 compared to BP15. The cetane number of BP15 is higher than BP325, which in turn produces a lower premixed burn 
peak with BP15 compared to BP325. Therefore, average cylinder temperature with BP15 is lower than BP325, which contributes to the lower NOx emissions with BP15. Biodiesel blended fuels B20BP325 and B20-BP15 show a NO emissions increase from their respective base fuels [17]. This increase in $\mathrm{NO}_{x}$ emissions with blends is due to the early start of fuel injection event with biodiesel blends compared to the base diesel fuels.

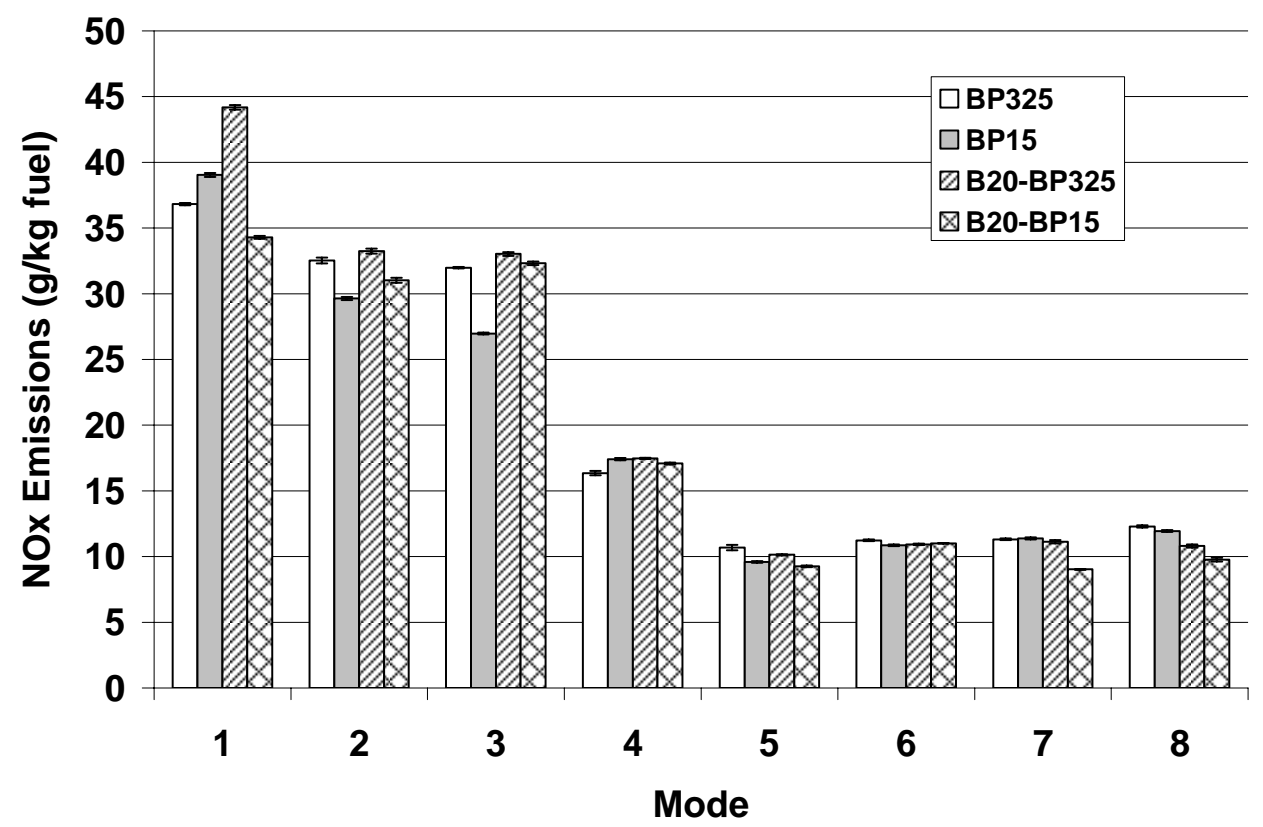

Figure 3.3.31 $\mathrm{NO}_{\mathrm{x}}$ emissions per unit fuel consumed

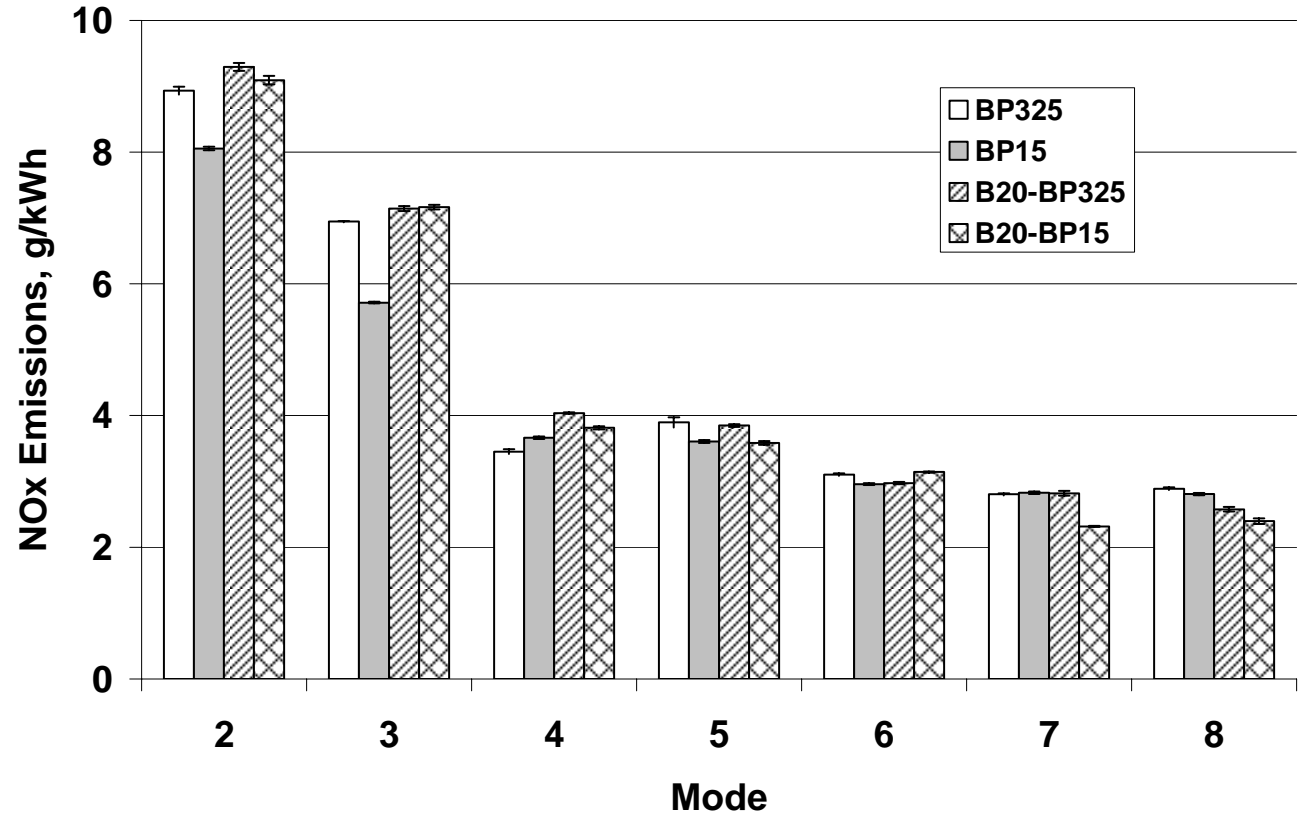

Figure 3.3.32 Brake specific $\mathrm{NO}_{x}$ emissions 
Due to the complex multiphase nature of diesel combustion, some fuels may be exhausted without burning, which leads to unburned hydrocarbon (HC) emissions. The main reason for hydrocarbon emissions is purported to be over-rich or over-lean mixtures inside the engine cylinder [18]. Figure 3.3.33 shows HC emissions in grams per kilogram of fuel consumed. Figure 3.3.34 presents 8-Mode brake-specific total hydrocarbon emissions observed with the four test fuels. In general, $\mathrm{HC}$ emissions decrease with increasing load in both the low speed and high speed modes. With a few exceptions, HC emissions generally trend downwards for the biodiesel blended fuels compared to their respective base fuels. There is no clear general trend of $\mathrm{HC}$ emissions between BP15 and BP325 fuels.

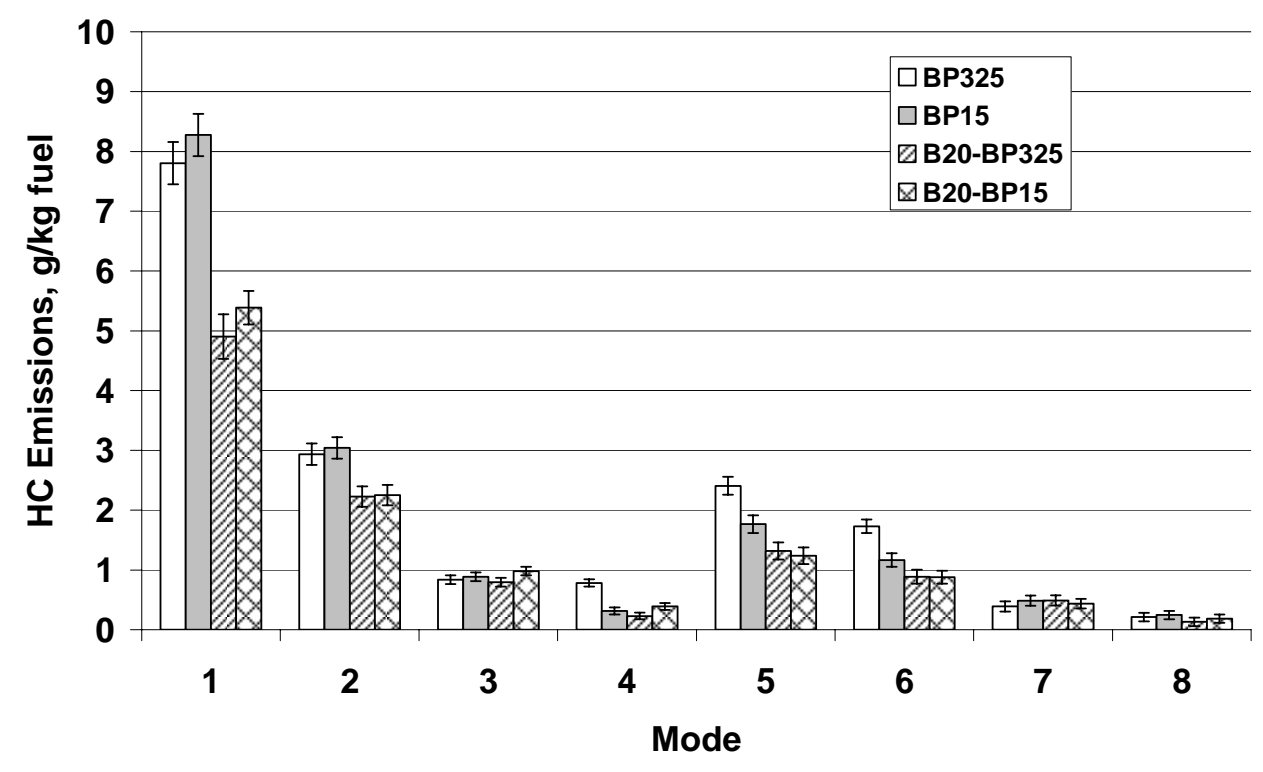

Figure 3.3.33 HC emissions per unit fuel consumed

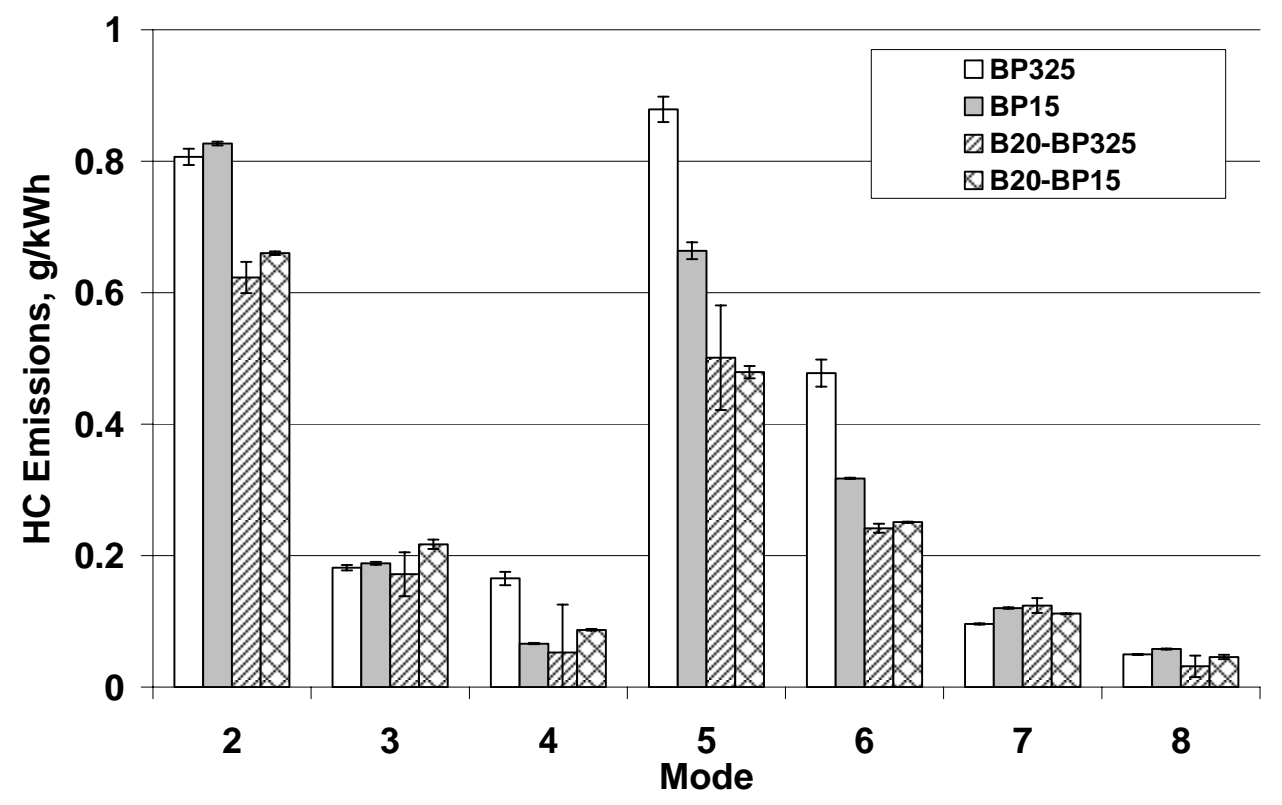

Figure 3.3.34 Brake specific HC emissions 
Carbon monoxide (CO) emissions are a direct result of incomplete combustion. Figure 3.3.35 presents $\mathrm{CO}$ emissions in grams per kilogram of fuel consumed. Figure 3.3.36 shows that brakespecific CO emissions decrease with BP15 compared to BP325. In general, lower CO emissions are observed with the biodiesel blended fuels compared to their respective base diesel fuels. Generally, $\mathrm{CO}$ emissions are high at low load conditions, go downward at medium load conditions and then upward at high load conditions.

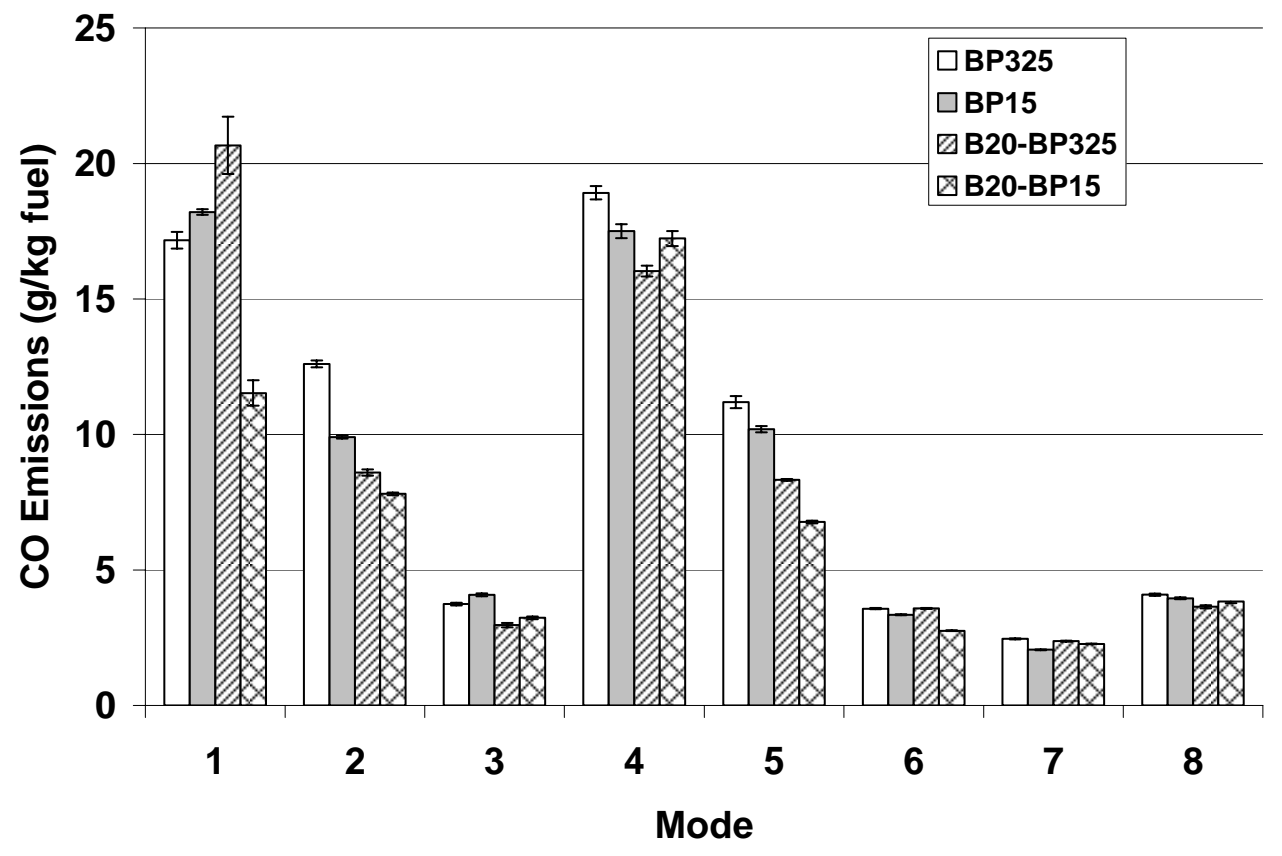

Figure 3.3.35 CO emissions per unit fuel consumed

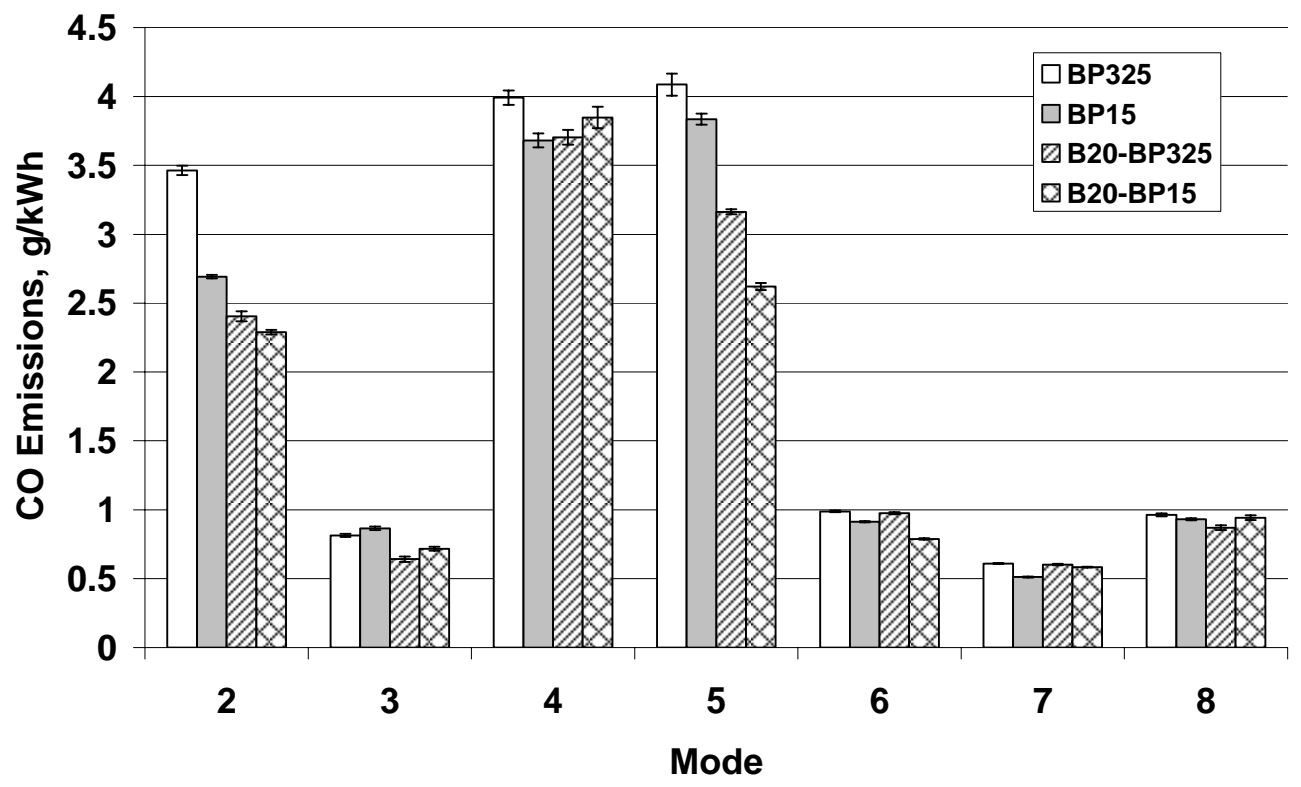

Figure 3.3.36 Brake specific CO emissions 
Engine design and operating conditions such as pressure, temperature, injection timing and compression ratio influence particulate matter (PM) formation by affecting both the size and time/temperature history of PM formation and PM oxidation regions in the combustion chamber. Design and operating conditions impact the more fundamental parameters, which were identified as being important in PM formation/oxidation in laboratory studies. The complexity of the diesel engine can make it unsuitable to study the fundamental PM formation process inside the engine cylinder, due to high temperature, pressure and highly reactive intermediate species. Particulate matter emissions generally arise from pyrolysis of hydrocarbon fuels. Sometimes engine oil also contributes significantly to PM emissions [18].

Figure 3.3.37 shows PM emissions in grams per unit fuel burned, while Figure 3.3.38 presents brake-specific PM emissions observed with each of the test fuels. With a couple of exceptions at low speed, BP15 diesel fuel shows lower PM emissions compared to BP325 diesel fuel. The higher PM emissions with BP325 fuel might be due to the higher sulfur content compared to BP15 fuel. Biodiesel blended with low sulfur diesel B20-BP325 fuel produces lower PM emissions compared to low sulfur diesel BP325 fuel. However, no concrete trends are observed with biodiesel blended with ultra low sulfur diesel B20-BP15 fuel when compared to base BP15 fuel. Some of the modes show an increase in PM emissions and the rest of the modes show a decrease in PM emissions. With the exception of Mode 4, the biodiesel blend B20-BP15 shows higher PM emissions compared to biodiesel blend B20-BP325.

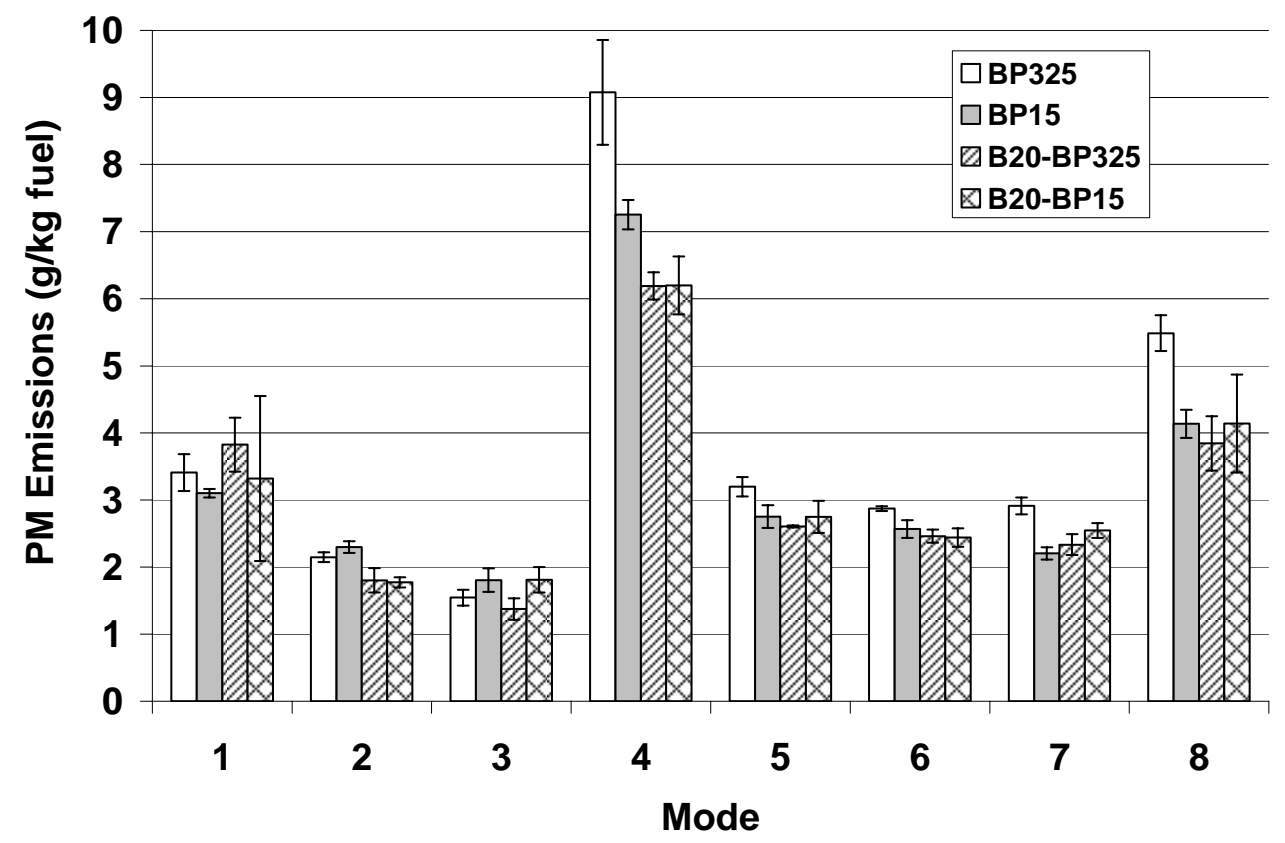

Figure 3.3.37 PM emissions per unit fuel consumed

To understand sulfate mass contribution to the PM mass emissions, a simple calculation was performed with Mode 4. Assuming that fuel sulfur is completely converted to $\mathrm{SO}_{4}$, the estimated mass fraction yield of hydrated sulfate can be calculated by the following equation:

$$
\text { Ysulfate }=\text { Ysulfur }{ }^{\star} \text { MWsulfate/MWsulfur }
$$

Table 3.3.10 shows calculated result of percent sulfate difference with BP325 relative to the other three fuels. The highest sulfate difference is observed between BP325 and BP15, whereas the lowest sulfate difference is observed between BP325 and B20-BP325. Therefore, fuel sulfur plays an important role to the PM mass emissions. 
Table 3.3.10 Sulfate mass contribution to the PM mass emissions

\begin{tabular}{|c|c|c|c|c|c|c|}
\hline Fuel & $\begin{array}{c}\text { Ysulfur } \\
\text { ( } \mathbf{\mu g / g} \text { fuel) }\end{array}$ & $\begin{array}{c}\text { Ysulfate } \\
\text { (mg/g fuel) }\end{array}$ & $\begin{array}{c}\text { Total PM } \\
\text { Mode 4 } \\
\text { (mg/g fuel) }\end{array}$ & $\begin{array}{c}\text { Difference } \\
\text { in Ysulfate } \\
\text { (mg/g fuel) }\end{array}$ & $\begin{array}{c}\text { Difference } \\
\text { in Total } \\
\text { PM } \\
\text { (mg/g fuel) }\end{array}$ & $\begin{array}{c}\text { \% Sulfate } \\
\text { Difference }\end{array}$ \\
\hline BP325 & 322 & 0.99 & 9.00 & - & - & - \\
\hline BP15 & 15 & 0.05 & 7.20 & 0.94 & 1.80 & 52 \\
\hline B20-BP15 & 13 & 0.04 & 6.20 & 0.95 & 2.80 & 34 \\
\hline B20-BP325 & 252 & 0.77 & 6.20 & 0.22 & 2.80 & 8 \\
\hline
\end{tabular}

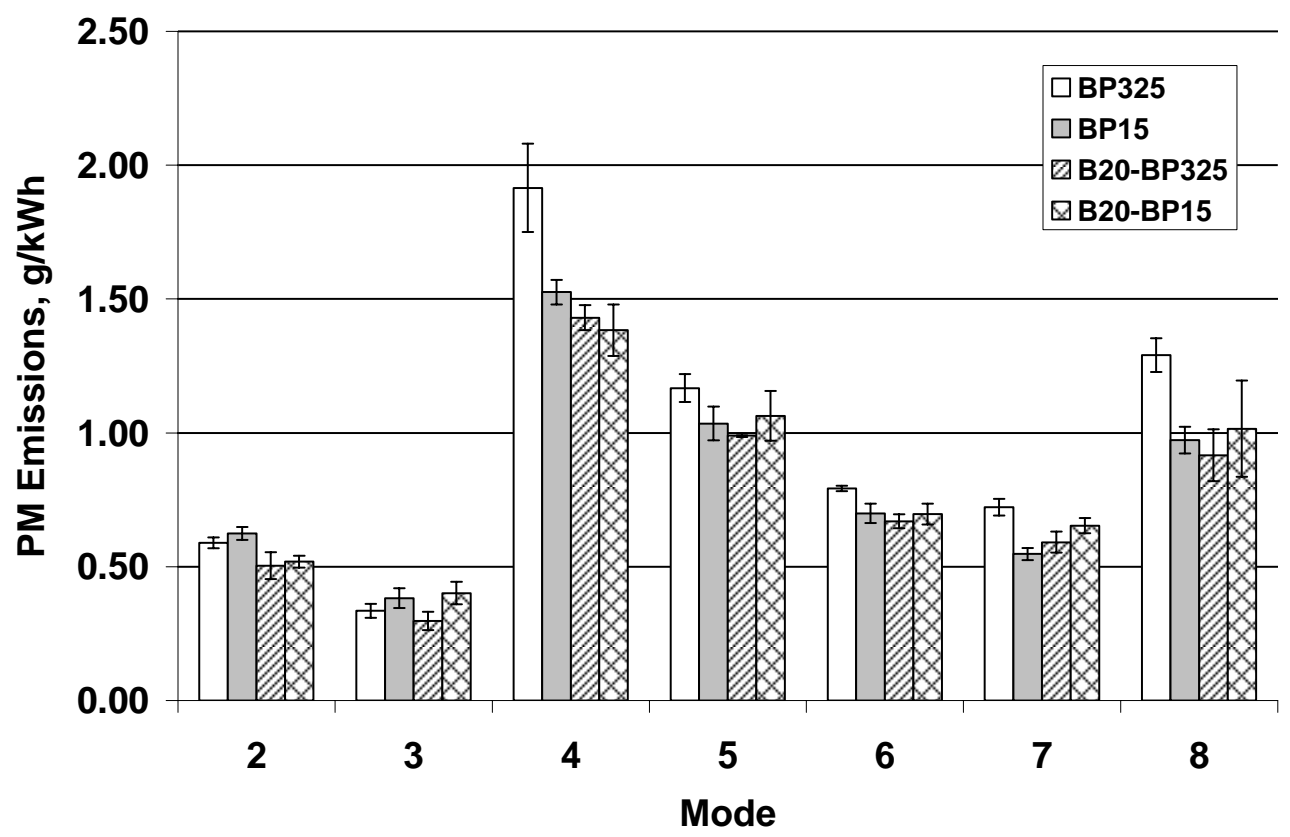

Figure 3.3.38 Brake-specific PM emissions

One possible reason for higher PM emissions might be due to the cetane number of the biodiesel blend of ultra low sulfur diesel fuel is high and reduces the premixed burn. Soluble organic fraction (SOF) of the particulate mass emissions presented in Figure 3.3.39 might be another reason. Literature results showed that SOF emissions increase for biodiesel and their blends [17]. With a few exceptions, B20-BP15 shows higher SOF emissions compared to BP15. Except Mode 6, lower SOF emissions are observed with B20-BP325 compared to BP325. Between biodiesel blends, almost all the modes show higher SOF emissions for B20-BP15. The higher SOF emissions might be the reason for higher PM emissions with B20-BP15 compared to B20-BP325. However, it is not possible to explain the reason behind the different trend of SOF emissions of the blends compared to their base fuels. May be fuel properties have some effect on SOF emissions especially density, viscosity, spray penetration and mixing. Fuel density increases the injection rate linearly, reduces injection duration and, as a result, increases total injected mass. Changes in fuel density do not alter spray angle noticeably. However, spray penetration changes due to the change in fuel density. Higher viscosity fuels tend to produce larger drop diameter, which might have significant influence 
on evaporation characteristics, resulting in changes in the combustion process. Similarly, change in boiling point changes liquid fuel penetration inside the engine cylinder. Since the energy required to evaporate the fuel is supplied by the entrainment of the surrounding air, lower volatility fuels require more time to vaporize, and liquid length penetration increases. The variation in liquid phase fuel penetration due to the change in boiling point for a given engine and operating condition could have a significant effect on engine performance and emissions. Therefore, further investigation is necessary to find out more information regarding SOF emissions with biodiesel blends.

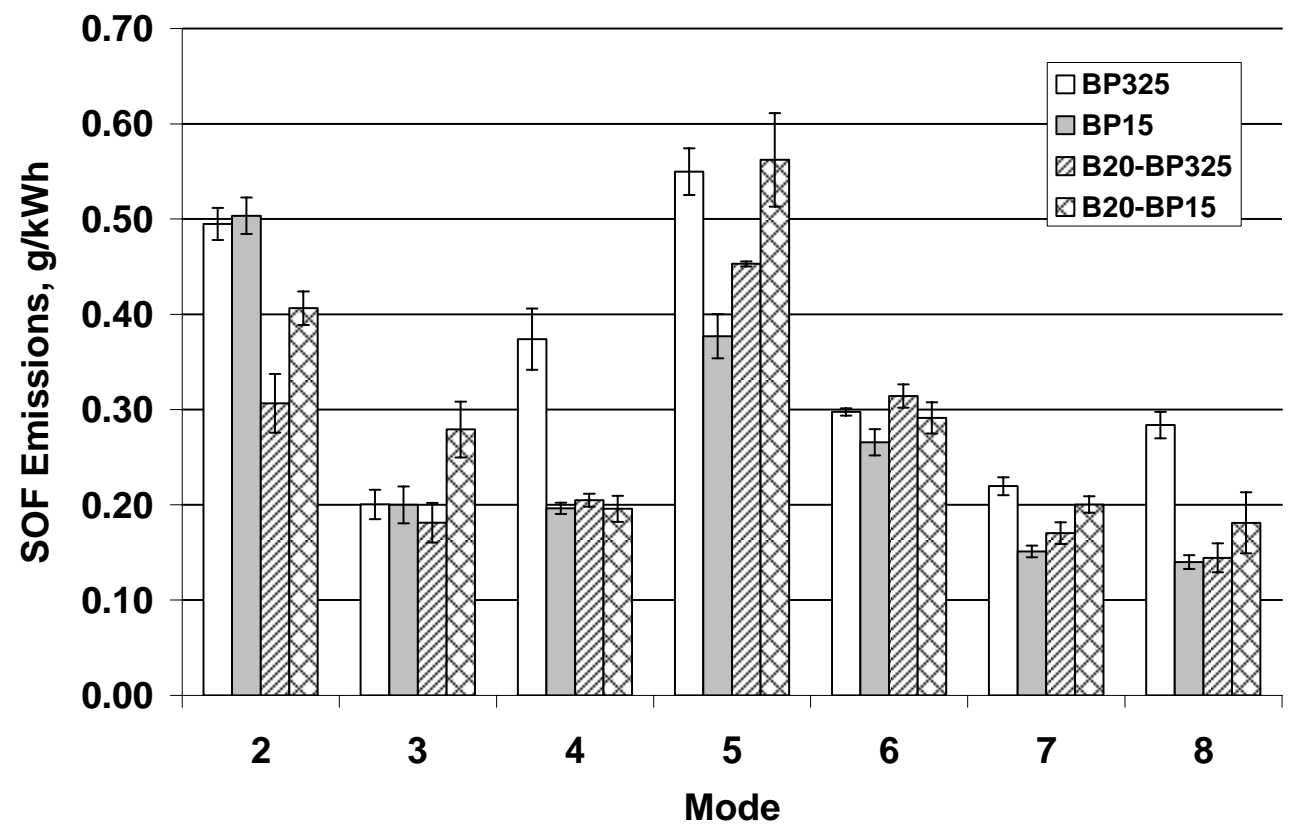

Figure 3.3.39 Brake-specific SOF emissions

Figure 3.3.40 presents the weighted, mode-averaged $\mathrm{CO}, \mathrm{NO}_{\mathrm{x}}, \mathrm{PM}$ and $\mathrm{HC}$ emissions for each of the fuels. All the mode-averaged emissions are the highest with BP325 fuel. A considerable amount of PM reduction has been observed with BP15 compared to BP325. BP15 reduced NO by $5 \%$ relative to $\mathrm{BP} 325$. With the exception of $\mathrm{NO}_{x}$, all emissions are reduced with the biodiesel blend B20-BP325 fuel compared to its base BP325 fuel. However, these two fuels show comparable $\mathrm{NO}_{x}$ emissions. Biodiesel blended with ultra low sulfur B20-BP15 fuel shows that PM emissions increase slightly and gaseous emissions decrease considerably when compared to its base BP15 fuel. In general, both the ultra low sulfur diesel fuel and the biodiesel blends reduce gaseous and PM emissions, however more reduction is necessary from the standpoint of achieving future emissions regulations.

The government and industry conducted a comprehensive study called the "Diesel Emission Control-Sulfur Effects (DECSE)", regarding the impact of diesel fuel sulfur levels on emission control systems [9]. Increasing fuel sulfur from 3 to $350 \mathrm{ppm}$ produced an essentially linear 29\% increase in baseline PM emissions. However, no significant changes in gas phase emissions were observed. As mentioned earlier, a 20\% reduction of PM is observed with BP15 compared to BP325, which is fairly consistent with the DECSE result.

On December 21, 2000 the EPA signed emission standards for model year 2007 and later heavy-duty highway engines (the California ARB adopted virtually identical 2007 heavy-duty engine standards in October 2001). The rule includes emission standards, and diesel fuel regulation. The emissions standard of $\mathrm{PM}$ and $\mathrm{NO}_{\mathrm{x}}$ are $0.0134 \mathrm{~g} / \mathrm{kwh}$ and $0.268 \mathrm{~g} / \mathrm{kwh}$, respectively, which are also presented in Figure 3.3.40. The diesel fuel regulation limits the sulfur content in on-highway diesel 
fuel to $15 \mathrm{ppm}$ wt.\%, down from the previous $500 \mathrm{ppm}$. Refineries will be required to start producing the 15 ppm sulfur fuel beginning June 1, 2006.

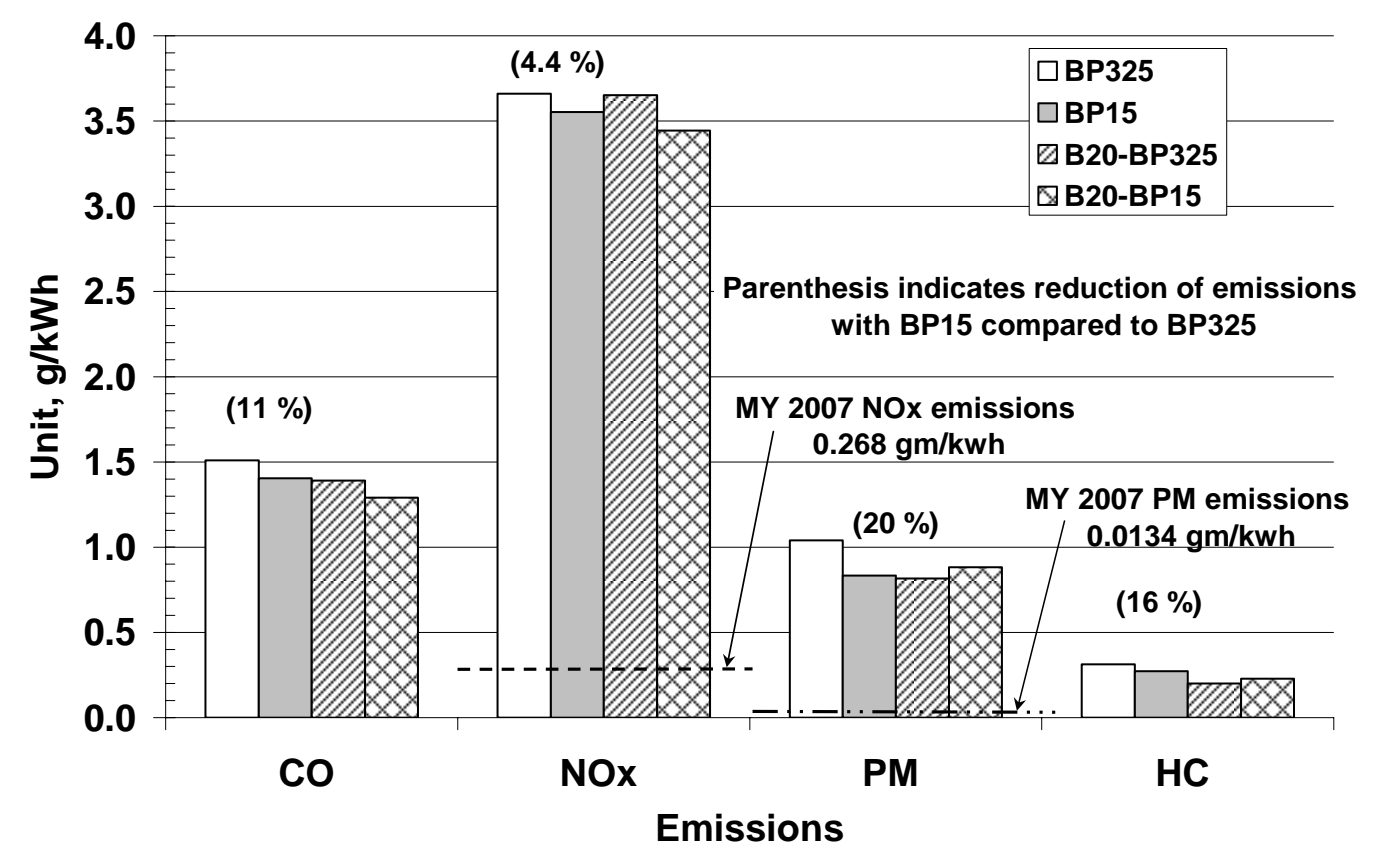

Figure 3.3.40 Weighted mode average emissions

Figure 3.3.40 shows that particulate and $\mathrm{NO}_{x}$ emissions with BP15 fuel are $0.833 \mathrm{~g} / \mathrm{kwh}$ and $3.55 \mathrm{~g} / \mathrm{kwh}$, respectively, which are much higher than the model year 2007 emissions standard. This means that more than $90 \%$ reduction of $\mathrm{PM}$ and $\mathrm{NO}_{\mathrm{X}}$ are necessary to achieve stringent MY2007 emissions standard.

Fuel sulfur has significant effects on diesel particulate filters (DPF) and the PM reduction efficiency of a DPF drops with increased fuel sulfur content. Particulate matter emissions increased downstream of the DPF when 350 ppm level sulfur fuel is used. Fuels with less than 150 ppm sulfur content were required to obtain any reduction in total PM after the DPF [19]. At high exhaust gas temperature and steady state modes, increased sulphate $\left(\mathrm{SO}_{4}\right)$ emissions occurred from engines with diesel oxidation catalysts and lean $\mathrm{NO}_{x}$ catalysts when higher sulfur level fuels (150 to 350 ppm) were used [20]. Diesel fuel with low sulfur level like BP15 is essential to permit adequate performance of exhaust aftertreatment systems.

In general, 20 wt.\% biodiesel (B20) tends to increase $\mathrm{NO}_{x}$ emissions compared base diesel fuel in heavy duty engines [17]. However, biodiesel or biodiesel blends result in dramatically reduced PM emissions relative to base diesel fuel [17]. Reported results show changes in PM emissions between 2 and 25 percent. $\mathrm{NO}_{x}$ emissions mainly increase around 3\%, although sometimes opposite behavior is also reported in the literature [17]. Figure 3.3.40 shows comparable $\mathrm{NO}_{\mathrm{x}}$ emissions between BP325 and B20-BP325, while 3\% NOx reduction is observed with B20-BP15 blend relative to $\mathrm{BP} 15$. This $3 \% \mathrm{NO}_{x}$ reduction with $\mathrm{B} 20-\mathrm{BP} 15$ blend could be explained by the $\mathrm{NO}_{\mathrm{X}}$ emissions with Mode by Mode results presented earlier in Figure 3.3.33. Mode 5 shows comparable $\mathrm{NO}_{x}$ emissions with B20-BP15 and BP15 fuels. $\mathrm{NO}_{x}$ emissions decrease at Mode 7 and Mode 8 with $\mathrm{B} 20-\mathrm{BP} 15$, while the rest of the modes show higher $\mathrm{NO}_{x}$ emissions. The majority of the modes show higher $\mathrm{NO}_{x}$ emissions with $\mathrm{B} 20-\mathrm{BP} 15$, however weighted mode average $\mathrm{NO}_{x}$ emissions are lower, which indicates that the weighting factor has a great influence on weighted mode average results. Modes 7 and 8 have higher $\mathrm{NO}_{x}$ emissions and the high weighting factor of these two modes make the average $\mathrm{NO}_{x}$ emissions higher. 
Biodiesel blend B20-BP325 shows 27\% PM reduction compared to BP325 and 6\% PM emissions increase with B20-BP15 compared to BP15. It seems that the $\mathrm{NO}_{x}$ and PM emissions with B20-BP325 are consistent with the reported results. Almost all the reported results with B20 blends are blended with number 2 diesel fuel [17]. Therefore, it is not possible to compare results of B20-BP15 with other published results, at least at this time. Figure 3.3.39 shows higher SOF emissions with B20-BP15 compared to its base fuel, as well as, the other biodiesel blend. It is necessary to find out the reason behind the higher SOF emissions. Also it is necessary to check the performance of aftertreatment devices with biodiesel blends. Recent results have shown that low temperature diesel particulate filter regeneration was observed with B20-BP325 [21]. However, more research is necessary with biodiesel blends especially, B20-BP15 to find out the reason behind the higher PM emissions.

\subsubsection{Conclusions}

Experiments were conducted with two base fuels consisting of a low sulfur diesel fuel BP325 and an ultra low sulfur diesel fuel BP15 and 20 wt.\% biodiesel blends with the base fuels. All the tests were performed under AVL 8-Mode tests protocol and observation of engine performance and emissions can be summarized as follows:

1. Weighted mode average emissions show that all the gaseous and PM emissions are reduced with ultra low sulfur diesel BP15 fuel. Blending biodiesel provides further reduction in emissions.

2. Comparable specific fuel consumption is observed with the base fuels and higher specific fuel consumption is observed with the biodiesel blends.

3. US 2006 ultra low sulfur diesel fuel BP15 has emissions reduction potential, however, more reduction is necessary to attain future emissions standards. Therefore, ultra low sulfur diesel fuel along with emissions reduction technology clearly is necessary to attain stringent future emission regulations. 


\subsubsection{Spray and Combustion Visualization}

The EPA has proposed an ultra low sulfur diesel fuel beginning in 2006. The introduction of ultra low sulfur diesel fuel should lead to reduced particulate emissions. Also, sulfur sensitive exhaust gas aftertreatment may be used to reduce other emissions from the exhaust gas. It is well established that diesel fuel properties have significant effects on engine performance and exhaust emissions. However, there are differences in sensitivity to fuel property effects between older model engines and later model engines. Sometimes it is very difficult to isolate the effects of one property from another, since the properties of diesel fuels are interrelated. Blending of oxygenates, biodiesel and FT to a base diesel fuel is a means of reducing tailpipe exhaust emissions. Blending of fuels may change the properties of the base fuel such as density, viscosity, flash point, distillation temperature, cetane number, etc. and these properties strongly affect spray formation and combustion. In this study, the effects of the properties of oxygenated fuel blends have been investigated by in-cylinder visualization of spray and combustion.

\subsubsection{Test Fuels}

In the course of this study, different kinds of fuels have been tested for in-cylinder spray and combustion visualization. The physical properties of some of the fuels of interest are presented in Table 3.3.11. A low sulfur diesel fuel (BP-325) with $325 \mathrm{ppm}$ of sulfur and an ultra low sulfur diesel fuel (BP-15) with $15 \mathrm{ppm}$ of sulfur are considered as base fuels. B-100 represents commercially available neat biodiesel. The B-20 is a blend of $80 \mathrm{wt} \%$ BP-15 and $20 \mathrm{wt} . \%$ of B-100. Diglyme is an oxygenated fuel and in this study a blend of diglyme and BP-15 fuel has been included. A neat Fischer Tropsch diesel (FT-100) and its blends with biodiesel and BP-15 fuels have been used in this study. Other than neat diglyme, FT-100 has the highest cetane number among the fuels. The neat Fischer Tropsch or FT-100 has the lowest density among the fuels. The viscosity of FT-100 is higher than the base BP-15 and BP-325 fuels.

Table 3.3.11 Fuel properties of the base diesel and blended fuels

\begin{tabular}{|c|c|c|c|c|c|c|}
\hline Properties & BP-15 & BP-325 & B-20 & B-100 & FT-100 & Diglyme \\
\hline Cetane Number & 50.5 & 48.4 & 52.5 & 55 & 83 & $112-130$ \\
\hline Density, gm/cm & 0.837 & 0.843 & 0.846 & 0.866 & 0.79 & 0.937 \\
\hline Viscosity @ 40 C, cSt & 2.48 & 2.46 & 2.73 & 3.56 & 2.5 & \\
\hline Flash Point, C & 63 & 63 & 66 & $>200$ & 74 & 70 \\
\hline IBP, C & 167.4 & 180 & 171.9 & 331 & 203 & 162 \\
\hline Calorific Value, Btu/lb & 18219 & 18486 & 17773 & 15993 & & 13044 \\
\hline Sulfur Content, wt\% & 0.0015 & 0.0322 & 0.0013 & 0 & $<0.0002$ & 0 \\
\hline Aromatic Content, wt\% & 21.2 & 23.1 & $<21.2$ & 0 & & 0 \\
\hline
\end{tabular}

\subsubsection{Results and Discussion}

The following is a qualitative and quantitative analysis of the spray and combustion characteristics of low sulfur diesel, ultra low sulfur diesel fuel, blends with biodiesel and diglyme, and FT-100 and its blends. It should be noted that the present study was conducted in a Cummins 5.9l ISB engine with an electronically controlled fuel injection system so that injection timing is dictated by the protocols in the ECM. For all the results presented here, the engine was operated at $10 \%$ of rated load (45 ft-lbs) at a constant speed of $1800 \mathrm{rpm}$. 


\subsection{Fuels Blends at $\mathbf{2 0}$ wt.\% of Oxygenated and Biodiesel}

Three types of fuels were considered to perform these experiments. An ultra low (BP-15) sulfur diesel fuel with $15 \mathrm{ppm}$ sulfur was considered for the base fuel and two other fuels were prepared by blending with biodiesel and diglyme. The $20 \mathrm{wt} . \%$ biodiesel blended with ultra low sulfur diesel fuel will be referred to as B-20 and the 20 wt.\% diglyme blended with ultra low sulfur diesel fuel will be referred to as 0-20. Table 3.3.11 shows some properties of the base and blended fuels.

Figure 3.3.41 shows spray images with 0.1 crank angle degree (CAD) resolution and depicts the start of injection (SOI) with BP-15 ultra low sulfur diesel fuel and blends with biodiesel and diglyme. Both the B-20 and O-20 blends consist of 20 wt.\% addition of biodiesel and diglyme, respectively into the base ultra low sulfur diesel fuel. For the O-20 and B-20 blends, the injection event starts at the same time but at 0.2 CAD advanced injection timing compared to the base diesel fuel. Many researchers, including Szybist et al. [11] observed advanced injection timing with biodiesel blended fuels. Boehman et al. also showed advanced injection timing with B-20 and B-100 compared to base diesel fuel [12]. Consistent with the literature, they concluded that the higher bulk modulus of compressibility of biodiesel and biodiesel blends led to advanced injection timing.

Boehman et al. observed a good correlation between the density of different fuels and their bulk modulus [12]. Bulk modulus increased with increasing fuel density. Table 3.3.9 shows the properties of the fuels used in this experiment. The density of B-20 is higher than the base fuel, BP-15, and the density of pure diglyme is 0.937 [22]. The density of pure biodiesel is lower than pure dyglyme and the density of $\mathrm{O}-20$ blended diglyme will be higher than the B-20. Therefore, the advanced injection timing with $\mathrm{O}-20$ and $\mathrm{B}-20$ is consistent with reported results and arises from an increased fuel density and bulk modulus of compressibility relative to the base diesel fuel [11].

Spray penetration with all the fuels can also be observed in Figure 3.3.41. The $0-20$ fuel showed the least penetration compared to B-20 and BP-15 and this change in penetration is due to volatility of the fuels, as well as the cylinder air temperature, density, etc. When the density and temperature of the cylinder gases are the same, then the spray penetration of the fuel depends on the distillation range of the fuel. Canaan et al. reported that a high boiling point or low volatility fuel showed the maximum liquid length penetration [23]. Higgins et al. concluded that the variations of thermodynamic properties of a fuel could change the penetration at a given operating condition [24]. Blending biodiesel and diglyme to the base fuel should change the volatility or initial boiling point (IBP) temperature of the fuel. From Table 3.3.11, the biodiesel blend showed the highest IBP compared to the base diesel fuel. Desantes et al. concluded that an increase in fuel density increased the injection rate linearly, injection duration by a power of $1 / 2$ and, as a result, total injected mass by a power of $3 / 2$. Changes in fuel density did not alter spray angle noticeably. Modified spray penetration was observed due to the change of fuel density [25]. From the spray images shown in Figure 3.3.41, it seems that the spray angle in the present study did not vary with fuel composition, although it is very difficult to quantitatively assess the change in spray angle among the fuels.

Figure 3.3.42 shows the end of injection (EOI) with BP-15, B-20 and O-20 fuels. Both B-20 and O-20 show an earlier EOI compared to the BP-15 base diesel fuel. Injection duration with B-20 is 7.1 CAD, whereas injection duration with $0-20$ is 7.3 CAD and BP-15 is 7.5 CAD. This decrease in injection duration might also be an effect of the density variation among the test fuels, as shown in Table 3.3.11.

In the experimental configuration of the imaging system, it was not possible to see all of the combustion chamber within the engine due to limitations of optical access. Since the test engine is a four valves per cylinder, commercial engine, it has very limited space for optical access. It was not possible to observe the leading edge of the spray or the initiation of combustion at the tip or leading edge of the spray during the premixed phase. Start of combustion was determined by identifying the crank angle position when there was visible flame at the edge or at the periphery of the spray. 


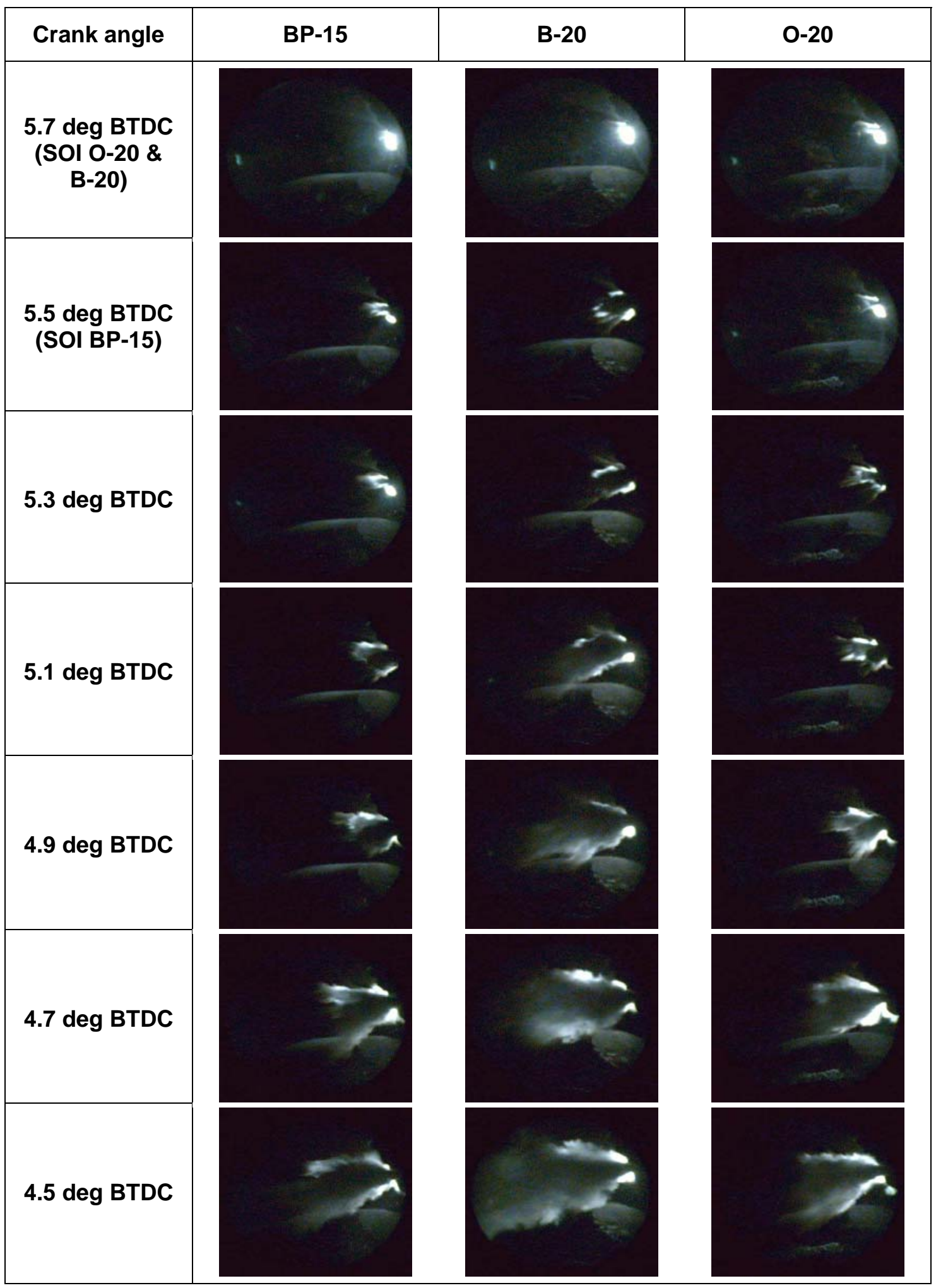

Figure 3.3.41 Start of injection with ultra low sulfur diesel and $20 \mathrm{wt} \%$ blends with biodiesel (B-20) and diglyme (O-20) 


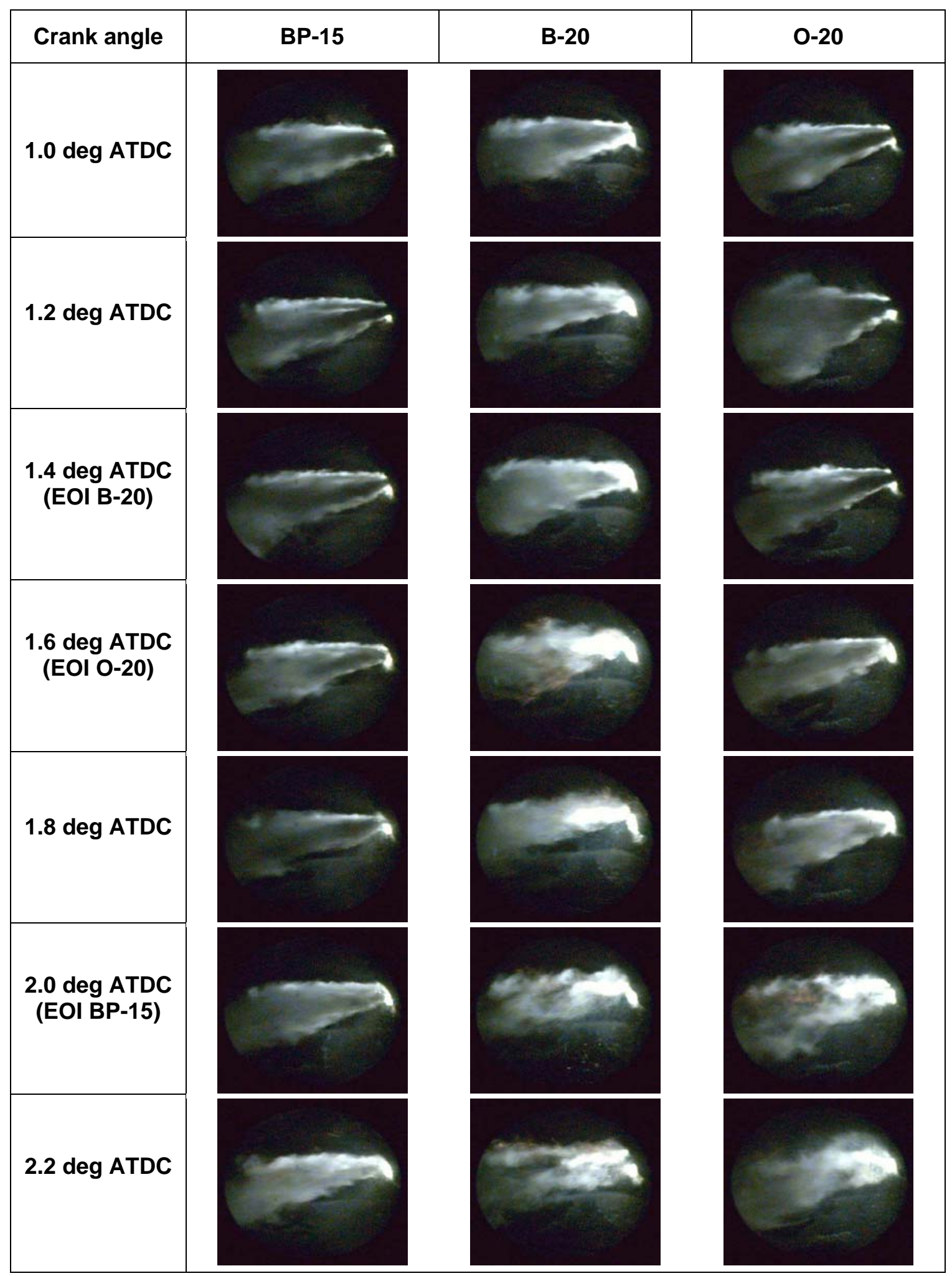

Figure 3.3.42 End of injection with ultra low sulfur diesel and blends with $20 \mathrm{wt} \%$ biodiesel (B-20) and diglyme (O-20) 


\begin{tabular}{|c|c|c|c|}
\hline Crank angle & BP-15 & B-20 & $0-20$ \\
\hline $\begin{array}{c}1.0 \mathrm{deg} \\
\text { ATDC }\end{array}$ & & & \\
\hline $\begin{array}{c}1.3 \mathrm{deg} \\
\text { ATDC } \\
\text { (SOC 0-20 } \\
\text { ID } 7.0 \mathrm{deg} \text { ) }\end{array}$ & & & \\
\hline $\begin{array}{c}1.6 \mathrm{deg} \\
\text { ATDC } \\
\text { (SOC B-20 } \\
\text { ID } 7.3 \mathrm{deg} \text { ) }\end{array}$ & & & \\
\hline $\begin{array}{c}1.9 \mathrm{deg} \\
\text { ATDC }\end{array}$ & & & \\
\hline $\begin{array}{c}2.2 \mathrm{deg} \\
\text { ATDC } \\
\text { (SOC BP-15 } \\
\text { ID } 7.7 \mathrm{deg} \text { ) }\end{array}$ & & & \\
\hline $\begin{array}{c}2.5 \mathrm{deg} \\
\text { ATDC }\end{array}$ & & & \\
\hline $\begin{array}{c}2.8 \mathrm{deg} \\
\text { ATDC }\end{array}$ & & & \\
\hline
\end{tabular}

Figure 3.3.43 Start of combustion with ultra low sulfur diesel fuel and blends with 20 $\mathrm{wt} \%$ biodiesel (B-20) and diglyme (O-20) 
Figure 3.3.43 presents start of combustion (SOC) measurements for the fuels used in this experiment. Start of combustion with B-20 occurs at 1.6 deg after top dead center (ATDC), whereas SOC for O-20 occurs at $1.3 \mathrm{deg}$ ATDC and BP-15 at 2.2 deg ATDC. Ignition delays (ID) for O-20, B20 and BP-15 fuels are 7.0, 7.3 and 7.7 CAD, respectively. Differences in ignition delay among the fuels are due to the cetane number of the fuels. The higher the cetane number, the shorter the ignition delay will be. An increase in the paraffinic content of the fuel increases cetane number and a high content of aromatics impairs the ignition quality and lowers the cetane number. An increase in cetane number results in a reduction of the ignition delay period and reduces the amount of premixed combustion [15]. Because the cetane number of pure dyglyme is about 112-130 [3], 0-20 should have the highest cetane number while B-20 has a lower cetane number than O-20 and BP-15 has the lowest amongst the test fuels as shown in Table 3.3.11. Figure 3.3.43 also shows the ignition delays among the fuels. Consistent with the cetane number of the test fuels, O-20 has the highest cetane number and has the shortest ignition delay.

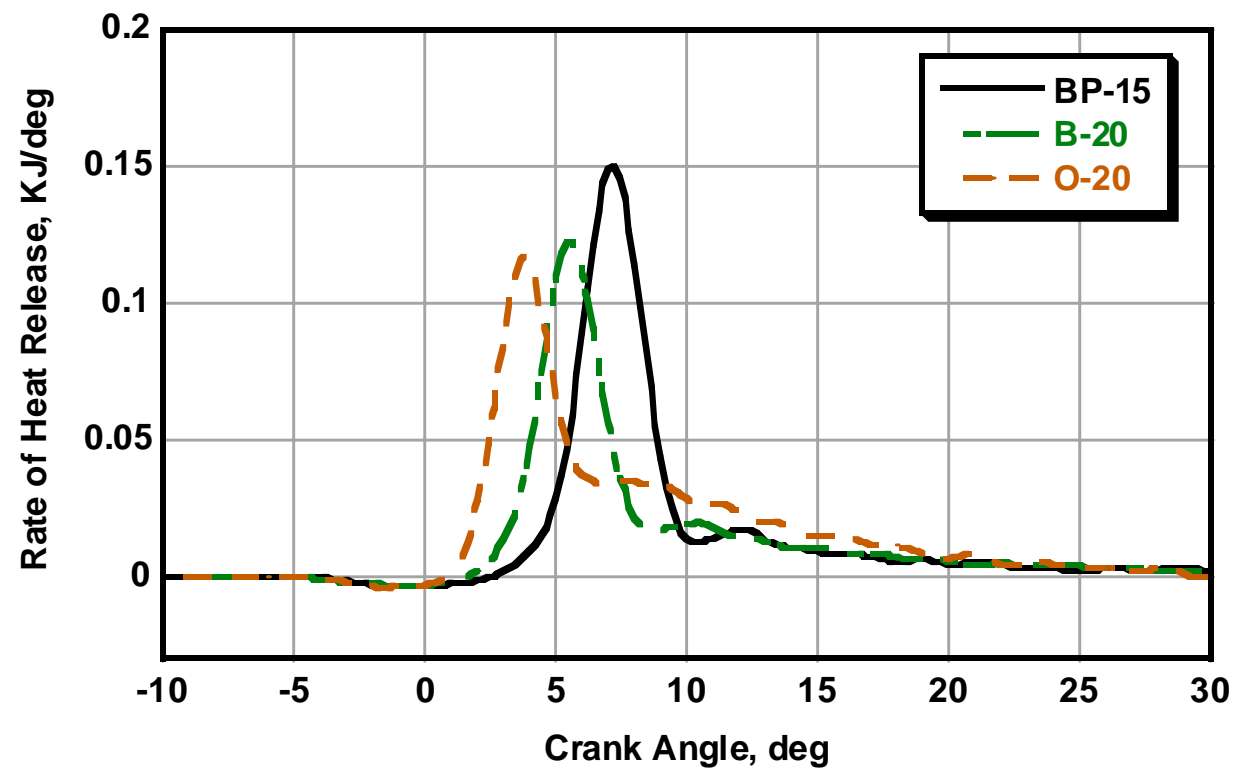

Figure 3.3.44 Rate of heat release analysis with BP-15, B-20 and 0-20 test fuels

Figure 3.3.44 shows rate of heat release (ROHR) analysis of the fuels used in these experiments. The early start of the heat release with $\mathrm{O}-20$ and $\mathrm{B}-20$ is explained by the early start of injection and the cetane number of the fuels. The lowest premixed burn peak is observed with $0-20$, while for B-20 the premixed burn peak is higher and with BP-15 it is the highest. This result is consistent with the cetane number of the test fuels, since the lowest premixed burn peak among the fuels is for $\mathrm{O}-20$, which has the highest cetane number. One big difference between the combustion images and ROHR analysis is the start of combustion, assuming that the start of combustion is indicated by the CAD when the ROHR curve moves from negative to positive value. In that case, most of the test fuels show that the start of combustion occurs before TDC, whereas the combustion images show combustion starts after TDC. This might be because the viewing window with the endoscope was only $60-70 \%$ of the combustion chamber and it was not possible to observe the leading edge of the spray. Premixed combustion initiation mainly occurs at the leading edge or far end of the diesel spray [26, 27]. Therefore, the start of combustion observed through the endoscope may not be as accurate as the heat release calculation.

Figure 3.3.45 presents different combustion events of all the fuels starting from TDC to 20 deg ATDC at an interval of 2.0 CAD. Figure 3.3.45 mainly shows the evolution of the spray and combustion for one of the seven spray jets of the fuel injector for each of the three fuels. The bright spot on the right of the images behind the injector tip is the light source that was used to illuminate 
the spray. The images of the spray and combustion were at a light load condition. Therefore, combustion was mainly controlled by the premixed burning phase. The ROHR analysis also indicated that the majority of the combustion was during the premixed burn (Figure 3.3.44). While both the B-20 and O-20 blends contain fuel oxygen, it is difficult to distinguish between the spray flames of B-20, O-20 and the base diesel fuel. Also, the flames with oxygen present in the fuel were still luminous, unlike the observations by Beatrice et al. of non-luminous flames with oxygenates [28]. However, the fuel oxygen content with $\mathrm{B}-20$ is $2.2 \mathrm{wt} . \% \mathrm{O}_{2}$ and with $\mathrm{O}-20$ is 7.16 wt. $\% \mathrm{O}_{2}$. This is much lower than the $38 \mathrm{wt} . \%$ threshold for "smokeless" combustion identified by Miyamoto et al. [29, 30]. The O-20 blend shows a high burning rate compared to B-20 and the base diesel fuel (Figure 3.3.44), which may be because the presence of oxygen in the fuel led to a high burning rate, as observed by Beatrice and co-workers [28].

\begin{tabular}{|c|c|c|c|c|c|c|c|c|c|c|c|}
\hline \multirow{2}{*}{ Fuel } & \multirow{2}{*}{ TDC } & \multicolumn{10}{|c|}{ Degree after TDC } \\
\hline & & $2^{\circ}$ & $4^{\circ}$ & $6^{\circ}$ & $8^{\circ}$ & $10^{\circ}$ & $12^{\circ}$ & $14^{\circ}$ & $16^{\circ}$ & $18^{\circ}$ & $20^{\circ}$ \\
\hline $\begin{array}{c}\text { BP- } \\
15\end{array}$ & & & & & & & & & & & \\
\hline B-20 & 7 & 0 & & & & & & & & 3 & $x^{3}$ \\
\hline $0-20$ & & & & & & & & & & & \\
\hline
\end{tabular}

Figure 3.3.45 Combustion images from TDC to 20 deg ATDC of the combustion process with 2.0 CAD interval 


\subsection{Neat and 20 wt.\% Biodiesel Blend}

Figure 3.3.46 shows spray images with 0.1 crank angle degrees (CAD) resolution and depicts the start of injection (SOI) with BP-15, B-20 and B-100. For B-100, the injection event starts 0.4 CAD earlier compared to the base diesel fuel whereas, B-20 shows 0.2 CAD earlier injection compared to the base fuel. The density of B-100 is higher than the base fuel, BP-15 and the density of B-20 blended biodiesel will be higher than the BP-15. Therefore, the advanced injection timing with B-20 and B-100 is consistent with reported results and arises from an increased fuel density and bulk modulus of compressibility relative to the base diesel fuel [31].

\begin{tabular}{|c|c|c|c|c|c|c|c|}
\hline $\begin{array}{l}\text { Crank } \\
\text { angle } \\
\text { Fuel }\end{array}$ & $\begin{array}{l}6.1 \mathrm{deg} \\
\text { BTDC }\end{array}$ & $\begin{array}{c}5.9 \mathrm{deg} \\
\text { BTDC } \\
\text { SOI B-100 }\end{array}$ & $\begin{array}{c}5.7 \mathrm{deg} \\
\text { BTDC } \\
\text { SOI B-20 }\end{array}$ & $\begin{array}{c}5.5 \mathrm{deg} \\
\text { BTDC } \\
\text { SOI BP-15 }\end{array}$ & $\begin{array}{c}5.3 \mathrm{deg} \\
\text { BTDC }\end{array}$ & $\begin{array}{c}5.1 \mathrm{deg} \\
\text { BTDC }\end{array}$ & $\begin{array}{c}4.9 \mathrm{deg} \\
\text { BTDC }\end{array}$ \\
\hline BP-15 & & 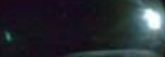 & stat & 8 & 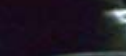 & & \\
\hline B-20 & a & 0 & 0 & $\therefore$ & 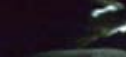 & & \\
\hline B-100 & & 8 & 8 & 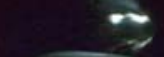 & 4 & & \\
\hline
\end{tabular}

Figure 3.3.46 Start of injection with ultra low sulfur diesel (BP-15), neat biodiesel and B-20 blend

Figure 3.3.47 shows the end of injection (EOI) with BP-15, B-20 and B-100 fuels. Both B-20 and B-100 show an earlier EOI compared to the BP-15 base diesel fuel. Injection duration (Inj D) with B20 is 7.1 CAD, whereas injection duration with B-100 is 7.3 CAD and BP-15 is 7.5 CAD. This decrease in injection duration might be an effect of the density variation and the variation in calorific value among the test fuels.

Figure 3.3.48 shows ROHR analysis of the fuels used in these experiments. The early start of the heat release with B-100 is explained by the early start of injection and the cetane number of the fuel. All the fuels show comparable premixed burn peak and the majority of the combustion occurs during the premixed phase. The start of combustion is indicated by the CAD when the ROHR curve moves from negative to positive value. In that case, most of the test fuels show that the start of combustion occurs before TDC, whereas the combustion images (Figure 3.3.49) show visible flame (VF) after TDC. This might be because the start of premixed combustion is flameless [32] and the viewing window with the endoscope was only $60-70 \%$ of the combustion chamber and it was not possible to observe the leading edge of the spray. Therefore, the start of combustion observed through the endoscope is not as accurate as the heat release calculation. Figure 3.3 .50 presents different combustion events for all the fuels starting from TDC to $30 \mathrm{deg}$ ATDC at an interval of 3.0 CAD. The images of the spray and combustion are at a light load condition. Therefore, combustion is mainly controlled by the premixed burning phase. Although both B-20 and B-100 contain fuel oxygen, it is difficult to distinguish between the spray flames of B-20, B-100 and the base diesel fuel. 


\begin{tabular}{|c|c|c|c|c|c|c|c|}
\hline $\begin{array}{l}\text { Crank } \\
\text { angle } \\
\text { Fuel }\end{array}$ & $\begin{array}{c}1.0 \mathrm{deg} \\
\text { ATDC }\end{array}$ & $\begin{array}{c}1.2 \mathrm{deg} \\
\text { ATDC } \\
\text { EOI B-100 }\end{array}$ & $\begin{array}{c}1.4 \mathrm{deg} \\
\text { ATDC } \\
\text { EOI B-20 }\end{array}$ & $\begin{array}{l}1.6 \mathrm{deg} \\
\text { ATDC }\end{array}$ & $\begin{array}{c}1.8 \mathrm{deg} \\
\text { ATDC }\end{array}$ & $\begin{array}{c}2.0 \mathrm{deg} \\
\text { ATDC } \\
\text { EOI BP-15 }\end{array}$ & $\begin{array}{c}2.2 \mathrm{deg} \\
\text { ATDC }\end{array}$ \\
\hline $\begin{array}{c}\text { BP-15 } \\
\operatorname{Inj} D 7.5^{\circ}\end{array}$ & & $=$ & & & & & \\
\hline $\begin{array}{c}\text { B-20 } \\
\text { Inj } D 7.1^{\circ}\end{array}$ & & & & & & & \\
\hline $\begin{array}{c}B-100 \\
\text { Inj D } 7.3^{\circ}\end{array}$ & (I) & & 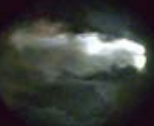 & & & & \\
\hline
\end{tabular}

Figure 3.3.47 End of injection with ultra low sulfur diesel (BP-15), neat biodiesel and B-20 blend

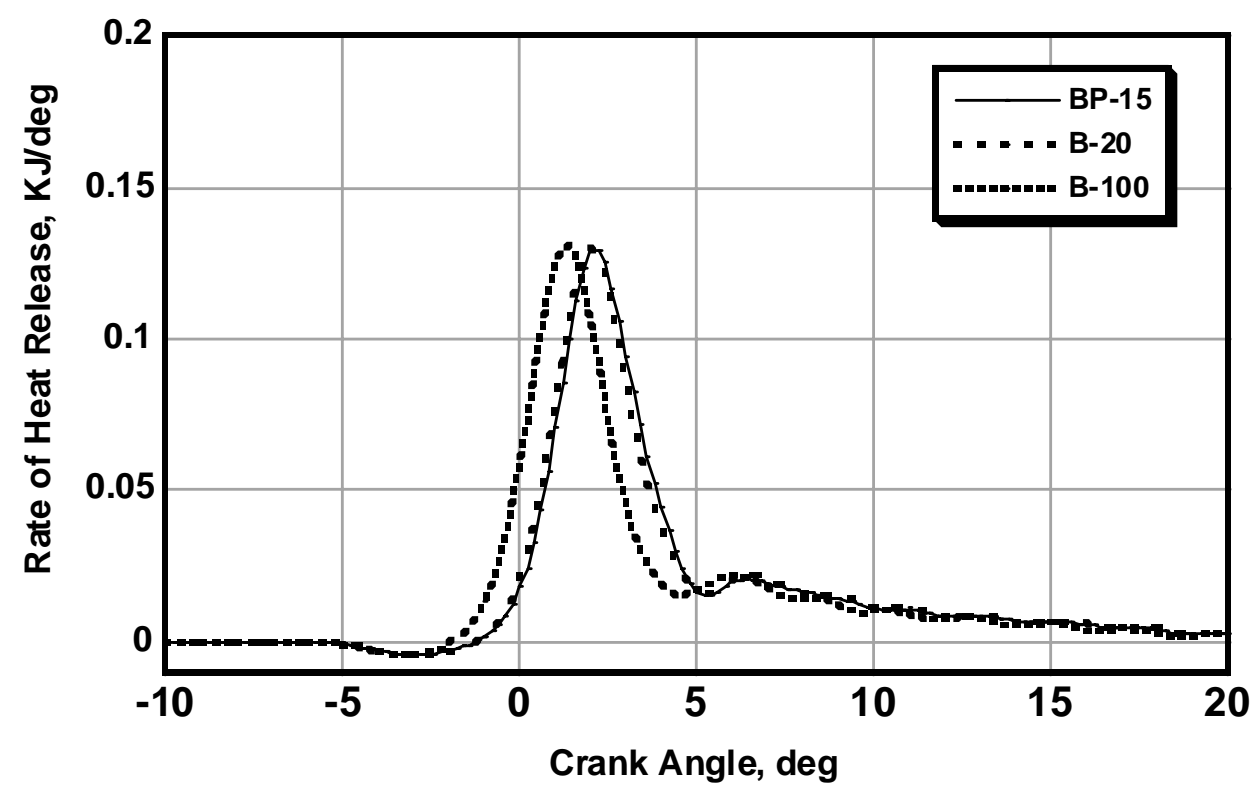

Figure 3.3.48 Rate of heat release analysis with BP-15, B-20 and B-100 test fuels 


\begin{tabular}{|c|c|c|c|c|c|c|c|}
\hline $\begin{array}{l}\text { Crank } \\
\text { angle } \\
\text { Fuel }\end{array}$ & $\begin{array}{c}0.7 \mathrm{deg} \\
\text { ATDC }\end{array}$ & $\begin{array}{c}1.0 \mathrm{deg} \\
\text { ATDC } \\
\text { VF B-100 }\end{array}$ & $\begin{array}{l}1.3 \mathrm{deg} \\
\text { ATDC }\end{array}$ & $\begin{array}{c}1.6 \mathrm{deg} \\
\text { ATDC } \\
\text { VF B-20 }\end{array}$ & $\begin{array}{c}1.9 \mathrm{deg} \\
\text { ATDC }\end{array}$ & $\begin{array}{c}2.2 \mathrm{deg} \\
\text { ATDC } \\
\text { VF BP-15 }\end{array}$ & $\begin{array}{c}2.5 \mathrm{deg} \\
\text { ATDC }\end{array}$ \\
\hline BP-15 & & & & & & & \\
\hline B-20 & & & & & & & \\
\hline B-100 & & & & & & & \\
\hline
\end{tabular}

Figure 3.3.49 Start of combustion with ultra low sulfur diesel (BP-15), neat biodiesel and $\mathrm{B}-20$ blend

\begin{tabular}{|c|c|c|c|c|c|c|c|c|c|c|c|}
\hline \multirow{2}{*}{$\begin{array}{l}\text { Crank } \\
\text { angle }\end{array}$} & \multirow{2}{*}{ TDC } & \multicolumn{10}{|c|}{ Degree after TDC } \\
\hline & & 3 & 6 & 9 & 12 & 15 & 18 & 21 & 24 & 27 & 30 \\
\hline BP-15 & & & & & & & & & & & \\
\hline B-20 & & & & & & & s & & & & \\
\hline B-100 & & & & & & & & & & & \\
\hline
\end{tabular}

Figure 3.3.50 Combustion images from TDC to $30 \mathrm{deg}$ ATDC of the combustion process with 3.0 CAD intervals 


\subsubsection{Base and Biodiesel Blends}

Six types of fuels were considered to perform these experiments. A low sulfur diesel fuel (BP325) with $325 \mathrm{ppm}$ sulfur, an ultra low (BP-15) sulfur diesel fuel with $15 \mathrm{ppm}$ sulfur and four other fuels were prepared by blending with biodiesel. The ultra low sulfur diesel fuel was considered as base fuel for blending with biodiesel. The $20 \mathrm{wt} \%$ biodiesel blended with base fuel will be referred to as B-20 and the $40 \mathrm{wt} \%$ biodiesel blended with base fuel will be referred to as B-40. Similarly, B-60 and B-80 were also prepared to perform experiments. Table 3.3.11 shows some properties of the fuels used in these experiments.

Figure 3.3.51 shows spray images at 0.1 crank angle degrees (CAD) resolution and the start of injection (SOI) with BP-325 low sulfur diesel fuel, BP-15 ultra low sulfur diesel fuel and blends with biodiesel. The blends of B-20, B-40, B-60 and B-80 consist of 20, 40, 60 and $80 \mathrm{wt} \%$ addition of biodiesel, respectively into the base ultra low sulfur diesel fuel. The B-80 blend showed earliest start of injection among the fuels. After that, the start of injection event occurred in the order of B-60, B40, B-20 and base BP-15 fuel. It seems that the start of injection occurred in the order of concentration of biodiesel in the blend, the higher the concentration of biodiesel in the blend earlier the start of injection. The B-80 blend showed 0.8 CAD advanced injection timing compared to base BP-15 diesel fuel. The low sulfur BP-325 diesel fuel yielded 0.6 CAD advanced injection compared to ultra low sulfur BP-15 diesel fuel. The density of B-100 is higher than the base fuel, BP-15, and the density of low sulfur diesel fuel BP-325. The density of blends will be increased according to the concentration of biodiesel in the blends. Therefore, it seems that the advanced injection timing with biodiesel blends and BP-325 is consistent with the reported results and arises from an increased fuel density and bulk modulus of compressibility [11].

Spray penetration with all the fuels can be observed in Figure 3.3.52. Irrespective of actual crank angle position, the first column shows start of injection images and the rest show images after the start of injection with 0.2 CAD interval. The BP-325 showed higher penetration compared to BP15. All the biodiesel blends other than B-20 showed higher penetration compared to base BP-15. However, this comparison may not be suitable when considering start of injection timing, because the observed start of injection in CAD with all the fuels used in this experiment was different. There was almost 1 CAD difference between the start of injection with BP-15 and B-80. In general, the change in penetration is due to volatility of the fuels, as well as, the cylinder air temperature, density, etc. When the density and temperature of the cylinder gases are the same, then the spray penetration of the fuel depends on the distillation range of the fuel. Canaan et al. reported that a high boiling point or low volatility fuel showed the maximum liquid length penetration [23]. Higgins et al. concluded that the variations of thermodynamic properties of a fuel could change the penetration at a given operating condition [24]. Blending biodiesel to the base fuel should change the volatility or initial boiling point (IBP) temperature of the fuel. From Table 3.3.11, biodiesel showed highest IBP compared to base diesel fuel.

Figure 3.3.53 shows the end of injection (EOI) with all the fuels used in these experiments. B-60 shows the earliest EOI among the fuels. After that, EOI occurred with B-20 and B-40, B-80 and BP325 and last of all BP-15 base diesel fuel. B-20 shows the shortest injection duration (Inj. D), while $\mathrm{B}-80$ shows the longest injection duration among the tested fuels. Injection duration with B-20 is 7.1 CAD, while B-80 shows 7.9 CAD injection duration, whereas base BP-15 fuel shows 7.5 CAD. These changes in injection duration might be an effect of the density variation and the variation in calorific value among the test fuels as shown in Table 3.3.11.

Figure 3.3.54 shows rate of heat release (ROHR) analysis of the fuels used in this experiment. The early start of rate of heat release with blends is explained by the early start of injection and the cetane number of the fuels. All the blends and their base fuels show comparable premixed burn peaks and the highest premixed burn peak is observed with BP-325. This result is consistent with the cetane number of the test fuels, since the highest premixed burn peak among the fuels is for BP325 , which has the lowest cetane number. Also it might not be possible to observe the 


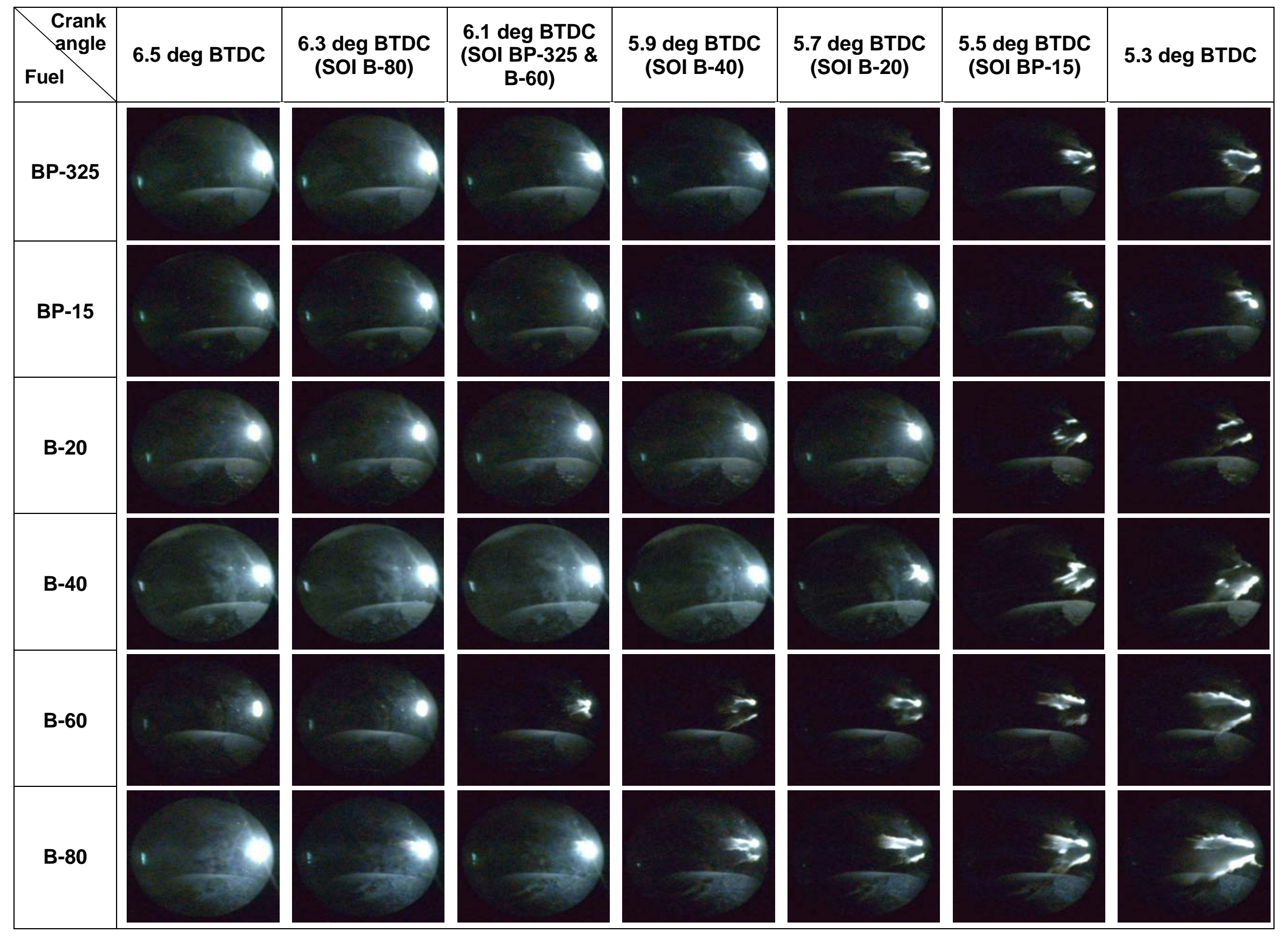

Figure 3.3.51 Start of injection with low sulfur diesel (BP-325), ultra low sulfur diesel (BP-15) and its blends with biodiesel 


\begin{tabular}{|c|c|c|c|c|c|c|c|}
\hline \multirow{2}{*}{ Fuel } & \multirow{2}{*}{$\begin{array}{c}\text { Start of } \\
\text { Injection }\end{array}$} & \multicolumn{6}{|c|}{ Degree After Start of Injection } \\
\hline & & 0.2 CAD & 0.4 CAD & $0.6 \mathrm{CAD}$ & $0.8 \mathrm{CAD}$ & $1.0 \mathrm{CAD}$ & 1.2 CAD \\
\hline BP-325 & & & & & & & \\
\hline BP-15 & & & & & & & \\
\hline B-20 & & & & & & & \\
\hline B-40 & & & & & & & \\
\hline B-60 & & & & & & & \\
\hline B-80 & & & & & & & \\
\hline
\end{tabular}

Figure 3.3.52 Spray penetration with low sulfur diesel (BP-325), ultra low sulfur diesel (BP-15) and biodiesel blends 


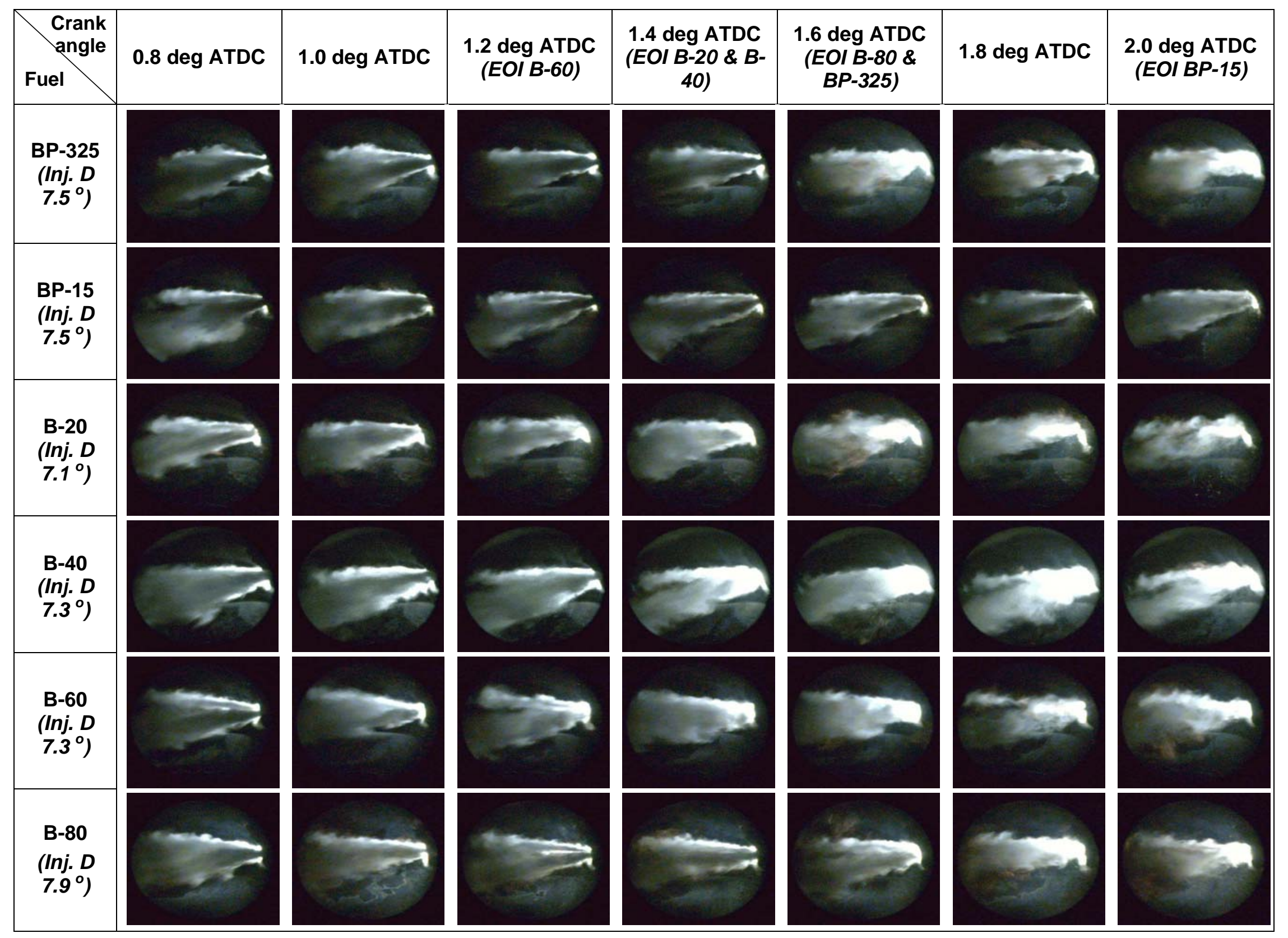

Figure 3.3.53 End of injection with low sulfur diesel (BP-325), ultra low sulfur diesel (BP-15) and its blends with biodiesel 


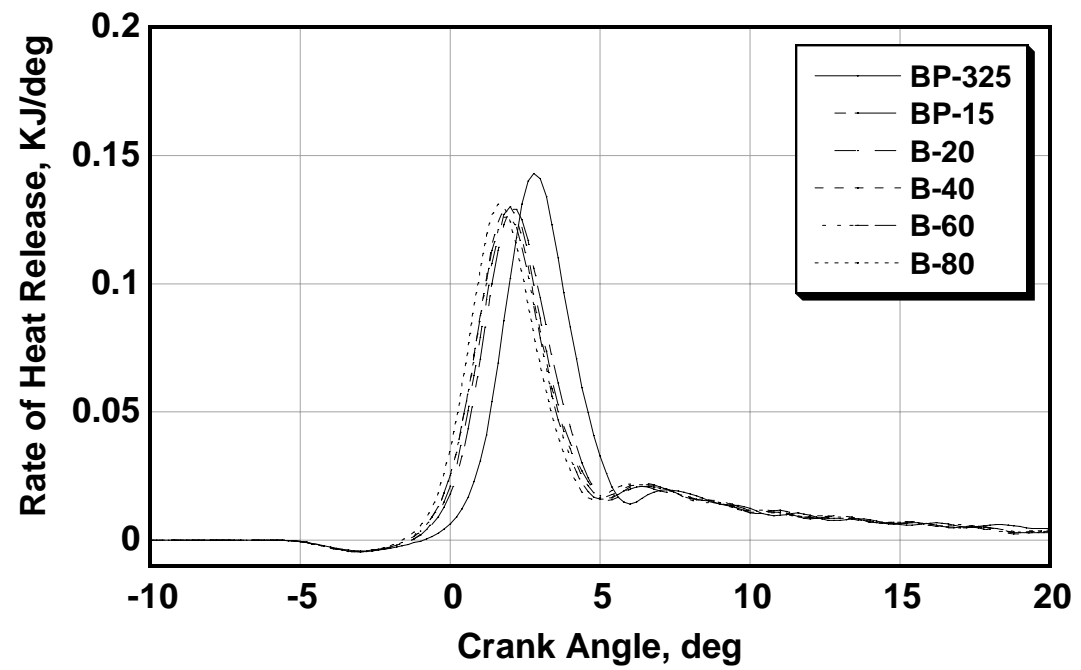

Figure 3.3.54 Rate of heat release analysis with BP-325, BP-15, B-20, B-40, B-60 and $\mathrm{B}-80$ test fuels

initiation of combustion through the endoscope because initiation of premixed combustion is flameless. Therefore, considering the luminous flame as an indicator for start of combustion is not as accurate as ROHR analysis.

\subsection{General Gaseous Emissions}

Table 3.3.12 presents general information on engine out exhaust emissions. Table 3.3.12 shows that $\mathrm{NO}_{x}$ emissions increase with BP-325 compared to BP-15. It seems that the advanced injection with $\mathrm{BP}-325$ compared to the BP-15 is the main reason for higher $\mathrm{NO}_{x}$ emissions. Also premixed burn peak with the BP-325 is higher than the BP-15 and for a higher premixed burn peak, the average cylinder temperature will be higher and as a consequence $\mathrm{NO}_{x}$ emissions will be higher. Similarly, the higher $\mathrm{NO}_{x}$ emissions with the biodiesel blended fuels compared to the base BP-15 fuel is due to the advanced injection with blended fuels compared to BP-15. Among the fuels, O-20 shows the lowest $\mathrm{NO}_{x}$ emissions. The premixed combustion peak with $\mathrm{O}-20$ is lower than for the other two fuels (Figure 3.3.44), while B-20 has a higher premixed combustion peak and the base diesel fuel has the highest premixed burn peak.

Table 3.3.12 Comparison of emissions of all the fuels

\begin{tabular}{|c|c|c|c|c|c|c|}
\hline Fuel & $\begin{array}{c}\mathrm{CO}_{2} \\
\text { Vol \% }\end{array}$ & $\begin{array}{c}\text { CO } \\
\text { PPM }\end{array}$ & $\begin{array}{c}\text { THC } \\
\text { PPM }\end{array}$ & $\begin{array}{c}\mathrm{NO}_{x} \\
\text { PPM }\end{array}$ & $\begin{array}{c}\text { NO } \\
\text { PPM }\end{array}$ & $\begin{array}{c}\mathbf{O}_{2} \\
\text { Vol \% }\end{array}$ \\
\hline BP-15 & 2.88 & 228 & 84 & 383 & 321 & 16.8 \\
\hline BP-325 & 2.84 & 296 & 108 & 405 & 330 & 16.9 \\
\hline B-20 & 2.89 & 215 & 74 & 380 & 320 & 16.8 \\
\hline B-40 & 2.89 & 212 & 69 & 387 & 326 & 16.8 \\
\hline B-60 & 2.89 & 215 & 61 & 387 & 326 & 16.8 \\
\hline B-80 & 2.93 & 208 & 51 & 397 & 337 & 16.8 \\
\hline B-100 & 2.94 & 217 & 31 & 407 & 347 & 16.8 \\
\hline O-20 & 2.88 & 151 & 75 & 337 & 288 & 16.9 \\
\hline
\end{tabular}




\subsection{Fisher Tropsch and Blends}

Fischer-Tropsch (FT) diesel is a synthetic fuel with high cetane number, low aromatic content and ultra low sulfur concentration compared to conventional diesel fuel, making it suitable for ultra clean diesel combustion. The density of FT diesel fuel is typically lower than that of conventional diesel fuel. Six types of fuels were considered to perform these experiments. A low sulfur diesel fuel (BP-325) with 325 ppm sulfur, an ultra low (BP-15) sulfur diesel fuel with 15 ppm sulfur, a 20 wt.\% biodiesel (B-20) blended with BP-15, a neat FT (FT-100), a 20 wt.\% biodiesel (FT-80 B-20) blended with FT-100 and a 80 wt.\% BP-15 was (FT-20 BP15-80) blended with FT-100. Table 3.3.11 shows properties of the base diesel fuels, FT-100 and some other blends used in these experiments.

Figure 3.3.55 shows spray images at 0.1 crank angle degrees (CAD) resolution and the start of injection (SOI) with BP-325 low sulfur diesel fuel, BP-15 ultra low sulfur diesel fuel, B-20, FT-100 and blends with FT. The BP-325 blend showed the earliest start of injection among the fuels. The low sulfur BP-325 diesel fuel yielded 0.6 CAD advanced injection compared to ultra low sulfur BP-15 diesel fuel. The start of injection event was retarded with FT-100 and its blends compared to the base diesel fuels and B-20 blend. FT-100 and FT-80 B-20 blend showed identical SOI at 5.3 deg. BTDC and both showed a 0.8 CAD retarded SOI compared to BP-325 low sulfur diesel fuel while a 0.2 CAD retarded SOI was observed compared to BP-15 ultra low sulfur diesel fuel. Among FT-100 and its blends, a 0.2 CAD advanced start of injection occurred with the FT-20 BP15-80 blend compared to FT-100 and the FT-80 B-20 blend. The change in start of injection timing among the fuels might be due to the density differences of the fuels. The engine used in these experiments is a commercial engine fitted with an electronic control module designed to compensate injection timing according to the fuel properties such as density, calorific value, etc. The effects of density variation on start of injection timing might be more prominent with a mechanically controlled fuel injection system.

Spray penetration with all the fuels can be observed in Figure 3.3.56. Irrespective of actual crank angle position, the first column shows start of injection images and the rest show images after the start of injection with 0.2 CAD interval. The spray penetration between the base fuels and B-20 can be found in the earlier studies. Compared to all the fuels used in this study B-20 showed the highest penetration. However, this comparison may not be suitable when considering start of injection timing in CAD, since the observed start of injection of all the fuels did not happen at the same time in terms of CAD (Figure 3.3.55). Therefore, the length of penetration might change with cylinder pressure, temperature and finally the volatility of the fuels. Another difference between the base and FT-100 and its blends is spray pattern. Soon after the start of injection with FT-100 and its blends, it seems that the initial spray angle is wider than the base and B-20 fuel blend. From the spray images as shown in Figure 3.3.56, it seems that the spray angle in the present study did not vary with fuel composition, although it is very difficult to quantitatively assess the change in spray angle among the fuels.

Figure 3.3.57 shows the end of injection (EOI) with all the fuels used in these experiments. B-20 shows the earliest EOI among the fuels, after that EOI occurs with FT-100 and its blends and last of all BP-15, BP-325 base diesel fuels. Injection duration with B-20 is 7.1 CAD, while FT-100 and its blends show 7.3 CAD, whereas base BP-15 and BP-325 fuels show 7.5 CAD. This change in injection duration might be an effect of the density variation and the variation in calorific value among the test fuels as shown in Table 3.3.11. 


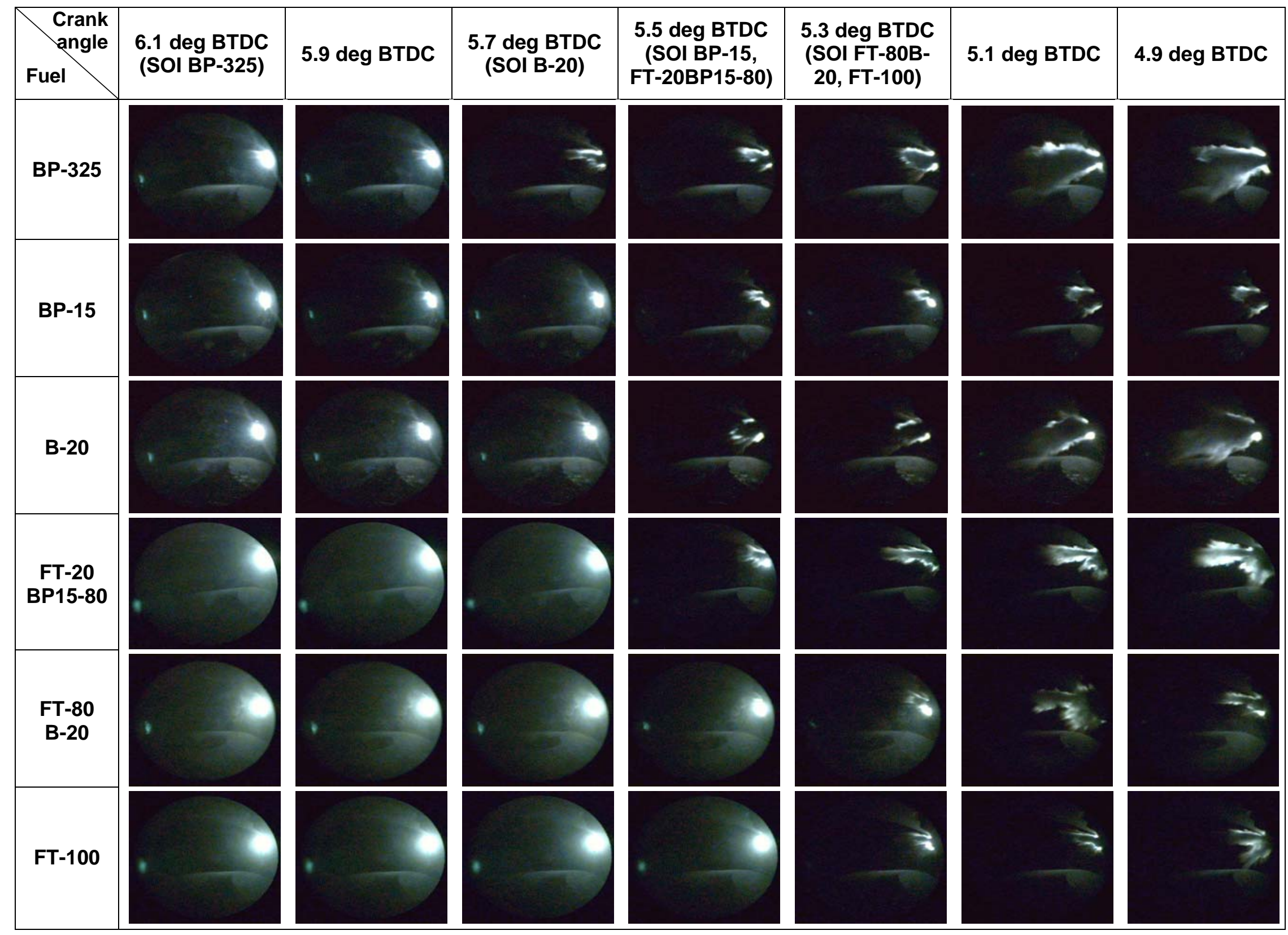

Figure 3.3.55 Start of injection with low sulfur diesel (BP-325), ultra low sulfur diesel (BP-15), FT and its blends 


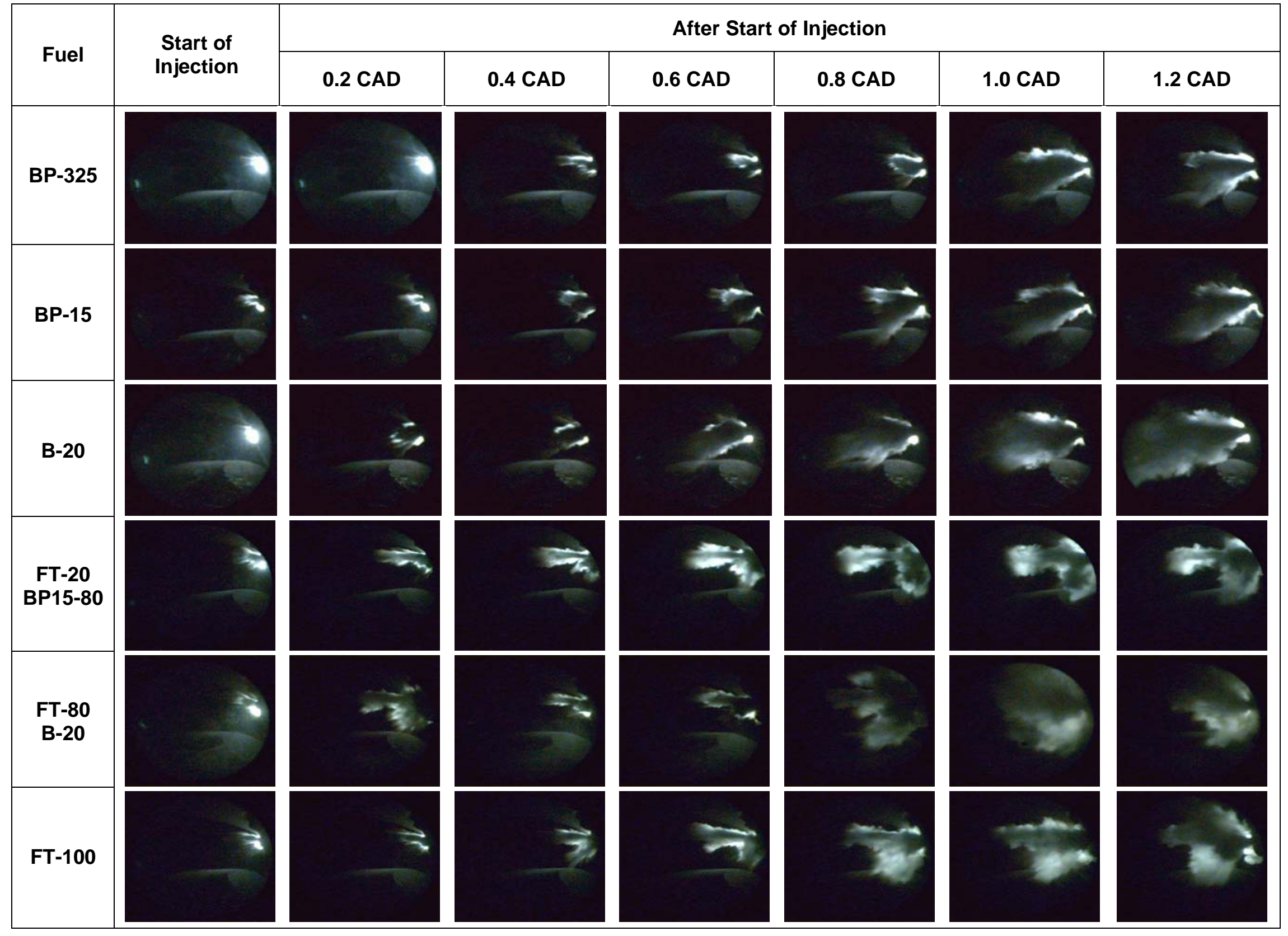

Figure 3.3.56 Spray penetration with low sulfur diesel (BP-325), ultra low sulfur diesel (BP-15), FT and its blends 


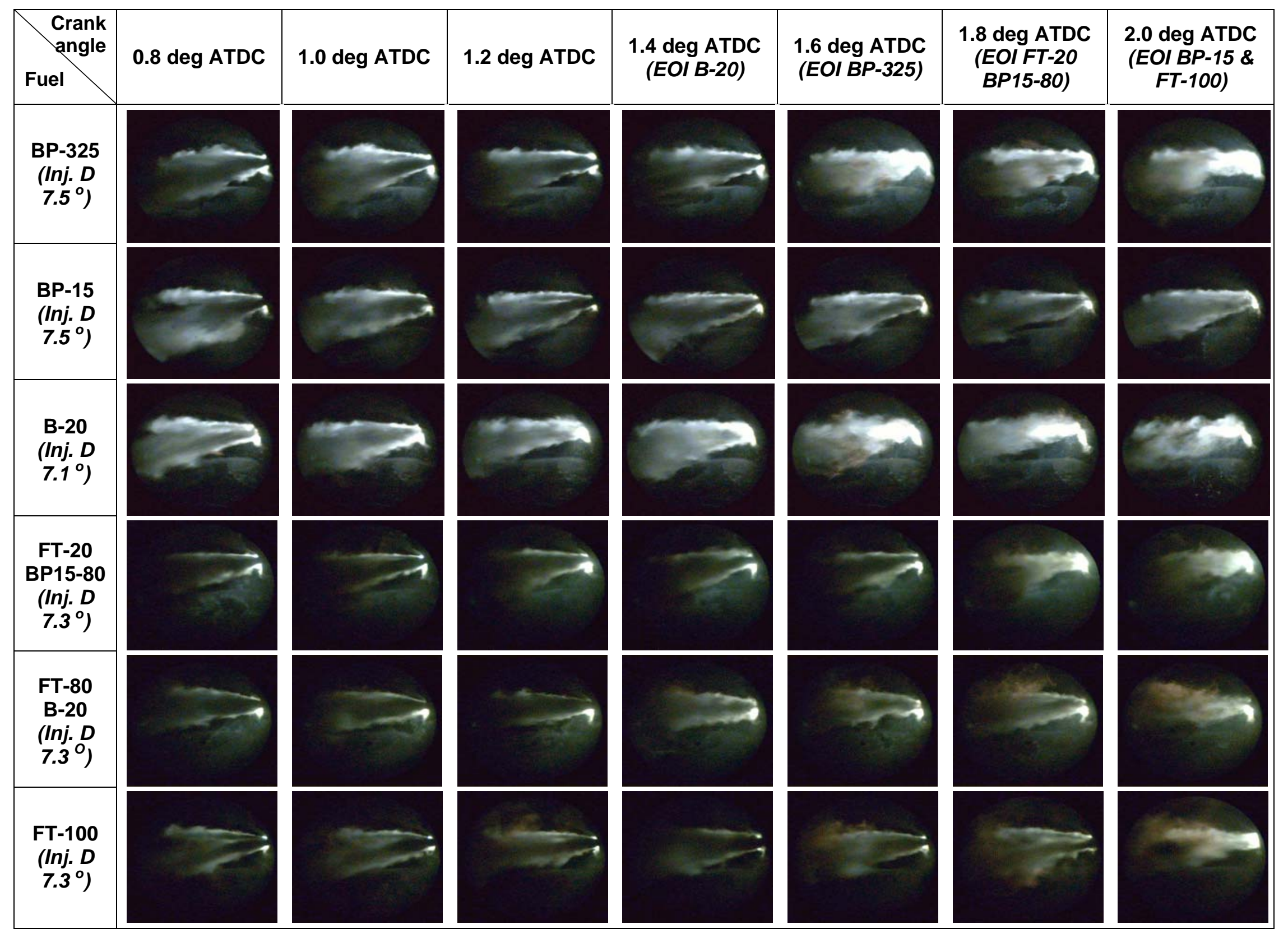

Figure 3.3.57 End of injection with low sulfur diesel (BP-325), ultra low sulfur diesel (BP-15), FT and its blends 
Figure 3.3.58 shows ROHR analysis of the fuels used in these experiments. The start of combustion is indicated by the CAD when the ROHR curve moves from negative to positive value. It seems that the early start of the heat release with FT-100 and FT-80 B-20 is explained by the cetane number of the fuel, however, the start of injection with these two fuels was delayed relative to the other fuels. Among FT-100 and its blends and BP-15, the highest premixed burn peak is observed with the base BP-15 fuel, which is consistent to the cetane number of the fuels as shown in Table 3.3.11. In general, it seems that the $\mathrm{NO}_{x}$ emissions with FT-100 and FT-80 B-20 might be decreased due to the lower premixed burn peak with these two fuels. However, this statement may not be true at high load conditions. Figure 3.3.59 presents different combustion events for all the fuels starting from TDC to $30 \mathrm{deg}$ ATDC at an interval of 3.0 CAD. The images of the spray and combustion are at a light load condition. Therefore, combustion is mainly controlled by the premixed burning phase. The ROHR analysis also indicated that the majority of the combustion was during the premixed burn (Figure 3.3.58).

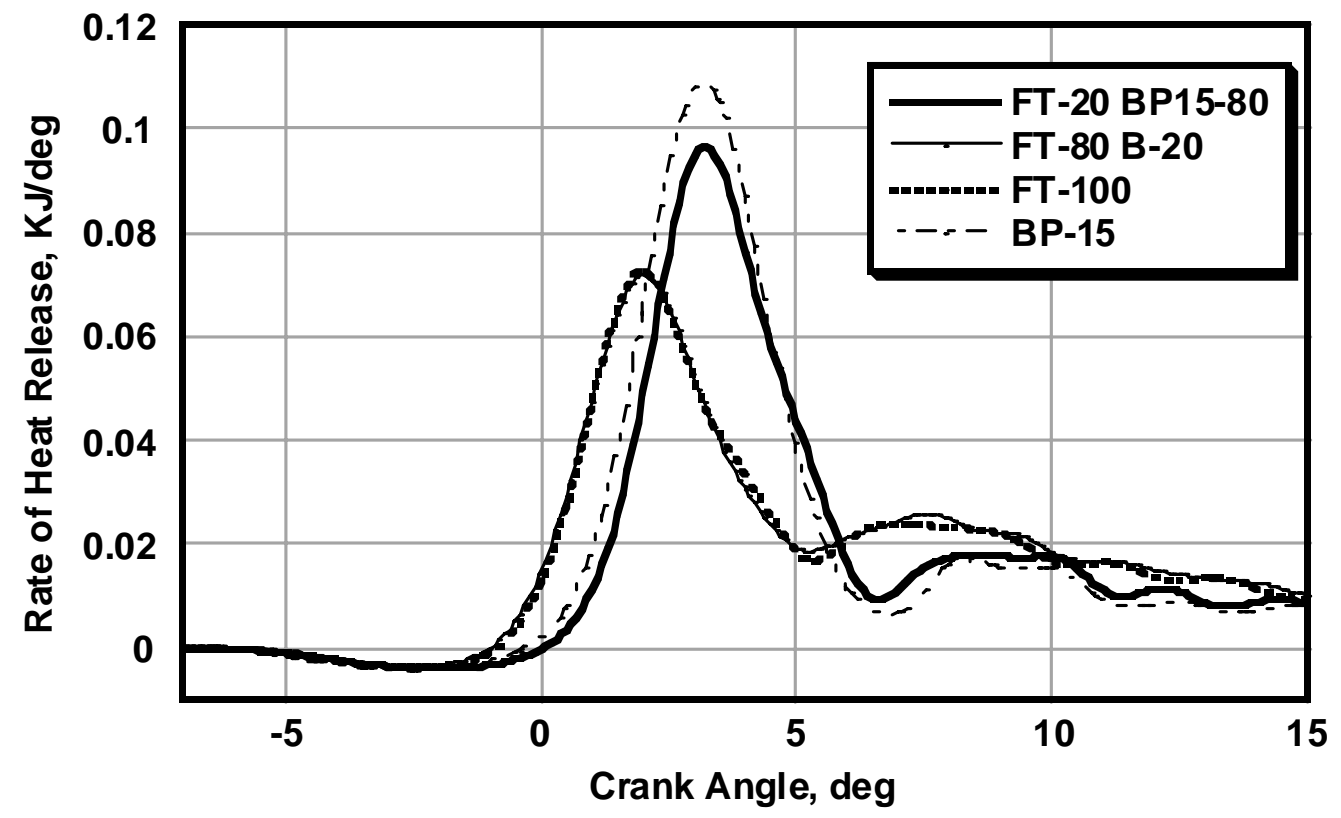

Figure 3.3.58 Rate of heat release analysis with BP-325, BP-15, B-20, FT-20 BP15$80, \mathrm{FT}-80 \mathrm{~B}-20$ and FT-100 test fuels 


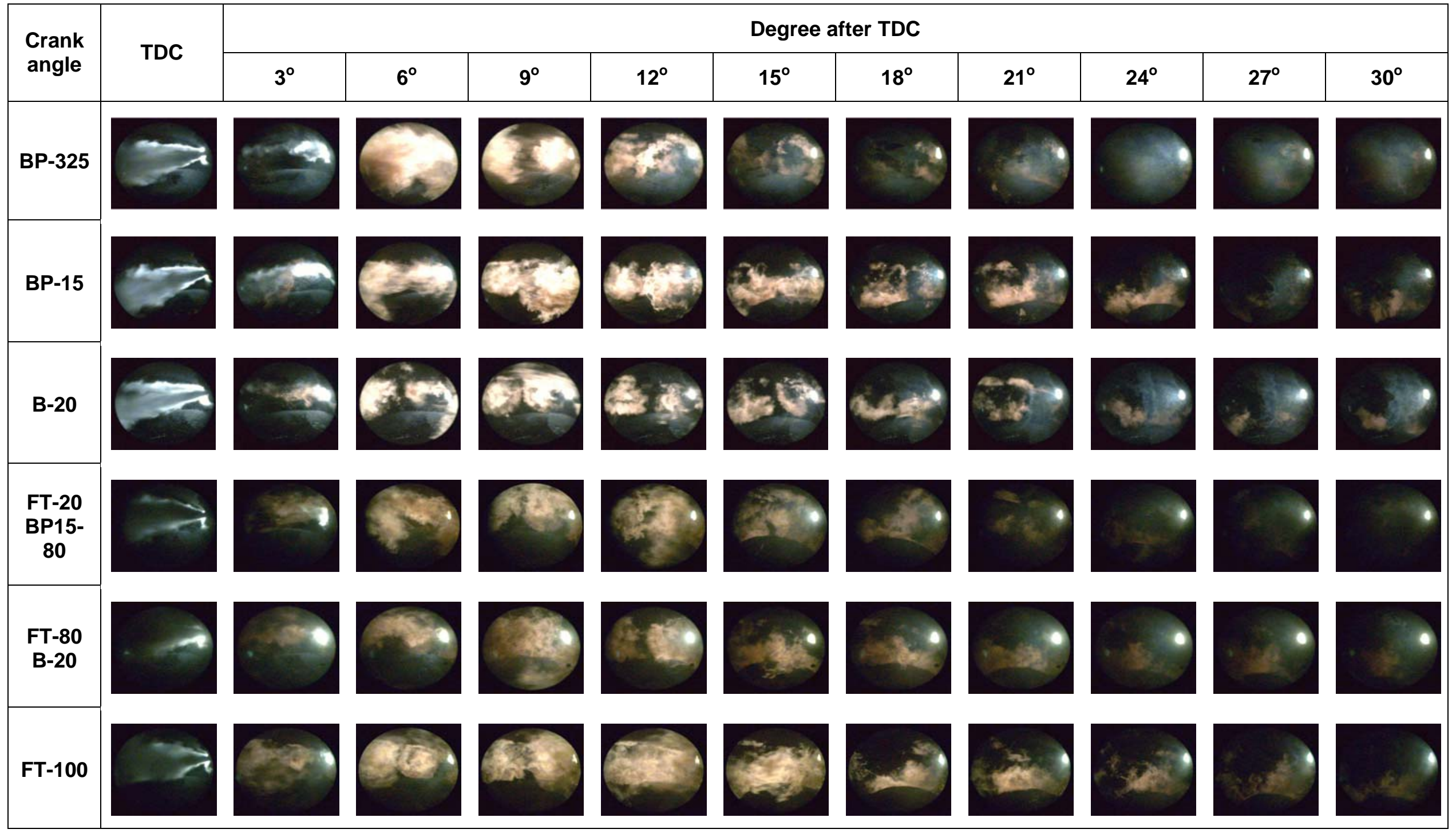

Figure 3.3.59 Combustion images from TDC to $30 \mathrm{deg}$ ATDC of the combustion process with 3.0 CAD interval 


\subsubsection{Summary}

Experiments were conducted with base BP-325 and BP-15 diesel fuels, an oxygenated blend, FT-100 and its blends and some biodiesel blends with BP-15. In-cylinder visualization of spray and combustion was performed with these test fuels with 0.1 crank angle degree resolution. Findings from the present study can be summarized as follows:

1. For both the B-20 and O-20 blended fuels, the start of injection event occurs at the same time. A 0.2 deg crank angle advance of fuel injection timing is observed with the blended fuels relative to the base BP-15 diesel fuel. Among the test fuels, the lowest premixed burn peak is observed with the O-20 blend, after that with the B-20 blend and the highest is with base diesel fuel. This trend is consistent with the cetane number of the test fuels, wherein the highest cetane number fuel should show the lowest premixed burn peak. The 0-20 blend has the highest cetane number compared to B-20 and the base diesel fuel.

2. For the biodiesel blended fuels, the start of injection event occurs earlier compared to the base fuel. Almost one deg crank angle advance of fuel injection timing is observed with the B-80 blended fuel relative to the base diesel fuel. Among the biodiesel blends, B-20 shows the earliest end of injection, while B-80 shows the longest injection duration.

3. The start of injection event was retarded with FT-100 and its blends compared to the base diesel fuels and B-20 blend. The FT-100 and FT-80 B-20 blend show identical start of injection and 0.2 CAD retarded SOI compared to base BP-15 fuel. Among the FT-100 and its blends and BP-15, the highest premixed burn peak is observed with the base BP-15 fuel, which is consistent with the cetane number of the fuels.

4. The change in start of injection event and injection duration might be an effect of the density variation and the variation in calorific value among the test fuels. 


\subsubsection{Diesel Particulate Filter}

\subsubsection{Introduction}

The development of regenerative diesel particulate filters (DPF) requires fundamental information about how the properties of the collected soot and its interaction with the catalyst on the DPF surface affect the filter regeneration to achieve a regeneration temperature below $250 \sim 300{ }^{\circ} \mathrm{C}$. The main movement towards this goal is to develop novel catalysts with high reactivity at low temperature that either maximize the yield of the more effective agents such as $\mathrm{NO}_{2}$ or that catalytically react with soot or adsorbed hydrocarbon by providing the intimate solid-solid contact and thereby better oxygen transfer to the soot surface. In some cases, the regeneration temperature is substantially determined by this catalyst activity depending on the corresponding oxidation mechanism, reaction temperature and fuel composition (e.g., sulfur content).

Other pathways to enhancement of regeneration may be possible by altering the surface, compositional and structural properties of soot deposits. Compared to screening efforts for better catalysts, research on this subject of the reactivity of diesel particulate has not been extensive. However, when different fuels are tested on the same catalytic DPF filter as in this study, this variation in particulate reactivity may be large enough to affect the filter regeneration apart from catalyst reactivity. Initial particulate matter properties such as crystallite size, orientation and its population are known to determine the reactivity with various oxidants from other carbon science studies. Therefore, the variation of these properties should be characterized to interprete the reactivity data obtained from in-situ engine bench oxidation tests and well- controlled laboratory oxidation tests.

In this study, fuels of different sulfur content including Fischer-Tropsch(F-T) diesel and biodiesel are considered to reduce the regeneration temperature of a catalytic DPF, since both F-T and biodiesel have no sulfur content that can inhibit catalyst activity. Furthermore, biodiesel is known to suppress soot and increase the soluble organic fraction (SOF) in particulate matter due to its high oxygen content and its distinct property effects on in-cylinder combustion. Thus, biodiesel and biodiesel fuel blends are good candidates to explore the effects of soot nanostructure and SOF content on particulate reactivity during oxidation on the catalytic surface of a DPF.

\subsubsection{Motivation and Objective}

Among several approaches to improve the regeneration behavior of catalyzed DPF in the literature, the impact on regeneration temperature of non-petroleum based alternative fuels such as Fischer-Tropsch fuel (F-Tdiesel), and renewable vegetable oil and animal fat based fuel (Biodiesel) remains to be seen. The fuel sulfur level is believed to ultimately affect or even determine the onset temperature of regeneration. This is attributed to enhancement of catalyst activity by reducing $\mathrm{SO}_{2}$ inhibition over active sites of Pt catalyst, which in turn enables reuse of NO within the catalyzed DPF $[20,33]$.

However, to determine whether this fuel sulfur effect is dominant or other effects are inadvertently masked, the following question must be answered about the difference in regeneration characteristics for alternative fuels. "Are there inherent differences in oxidative reactivity of particulate matter produced from different fuels?" To answer this question, a better understanding of the physico-chemical properties of particulate and its effect on reactivity is needed. Despite reported correlation between reactivity and crystalline phase of carbon blacks [34,35], applicability to diesel soot and its derivatives with non-traditional fuels remains to be determined. Also, there is little information about the relative importance of surface groups, related to the chemical properties of the carbon, and active edge sites, mainly related to the crystalline properties on soot reactivity toward oxidants at low temperature [36, 37].

The purpose of this research is to better understand the differences in the regeneration process, which provides the context for the following hypothesis. The difference in particulate oxidation in the catalytic DPF for alternative diesel fuels is a result of three different mechanisms. The first 
mechanism is an internal reactive species production (i.e, $\mathrm{NO}_{2}$ ), caused mainly by differences in sulfur content of fuel. The second mechanism is through differences in particulate reactivity such as the availability of active edge sites, which relates purely to its structural properties such as the graphene layer size and arrangement for subsequent $\mathrm{O}_{2}$ chemisorption and any possible change during the course of oxidation. The third difference has to do with the surface functional groups bonded to carbon atoms and hydrocarbons condensed onto the particulates, which can interact with the oxidation catalyst or directly react with oxidizers in either promoting or inhibiting manner.

\subsubsection{Experimental Strategies}

As mentioned earlier, regeneration characteristics alone can be deceiving because of the change in exhaust gas conditions, namely, internal $\mathrm{NO}_{2}$ production (i.e., oxidation of $\mathrm{NO}$ by the catalyst impregnated in or upstream of the DPF) and inlet NO concentration, that different fuels cause. So, in addition to engine bench tests of DPF regeneration, soot reactivity experiments are performed with the intention to decouple the effects of particulate reactivity from fuel sulfur effects on regeneration. This research will focus on two of the most commonly used alternative diesel fuels, biodiesel and FT diesel, and blends of each these fuels at $20 \mathrm{wt} \%$ with two baseline diesel fuels. During each experiment, action items are pursued as follows.

During Engine Bench Test of DPF Regeneration:

$\checkmark \quad$ Identify regeneration characteristics between different fuels in terms of onset temperature of regeneration and particulate oxidation rate on a catalyzed particulate filter.

$\checkmark \quad$ Calculate nominal oxidation rate constant between different fuel-derived particulates through the measurement of $\mathrm{NO}_{2}$ production across the catalyst and PM oxidation rate.

$\checkmark \quad$ Determine difference in reaction rate constant that can represent a variation in intrinsic particulate reactivity between different fuels, due to elimination of $\mathrm{NO}_{2}$ dependency and, in turn, fuel sulfur effects on catalyst activity related to the first mechanism.

During Soot Reactivity Study:

$\checkmark \quad$ Verify the second mechanism relevant to the intrinsic reactivity of particulate via an independent oxidation test and microscopy characterization.

$\checkmark \quad$ Characterize the initial soot structure produced by various fuels via microscopy.

$\checkmark \quad$ Perform oxidation tests of soot samples via TGA/DSC with two different oxidants.

During Characterization of Adsorbed Hydrocarbon or Surface Functional Group on Particulates:

$\checkmark \quad$ Characterize the variation in adsorbed heavy hydrocarbon via TEM micrograph and PM composition analysis.

$\checkmark \quad$ Characterize the surface functional groups by FTIR, XPS and EELS/STEM technique.

$\checkmark \quad$ Independent oxidation test will not be included in present research for determining its interaction with the oxidation catalyst coated on the DPF and its relative contribution on regeneration temperature postulated as the third mechanism.

\subsection{Engine Bench Test of DPF Regeneration}

During the low temperature regeneration test, the regeneration temperature (referred to as onset temperature of in situ oxidation) is determined by the point where the slope of pressure drop goes to zero. Based on this definition, ultra low sulfur and its B20 blend lower the regeneration temperature by $27{ }^{\circ} \mathrm{C}$ compared to low sulfur fuel fuel as shown in Figure 3.3.60. Figure 3.3.61 shows that this shift in regeneration temperature is coincident with shift in DPF inlet temperature for maximum $\mathrm{NO}_{2}$ production. Therefore, it suggests that more internal $\mathrm{NO}_{2}$ production is the dominant mechanism to lower regeneration temperature at least for different sulfur containing base fuels. Online sulfate measurement in Figure 3.3.62 clearly supported this sulfur effect as the dominant 
mechanism for this reduction in regeneration onset temperature. Although no effort to measure the gas-phase $\mathrm{SO}_{2}$ conversion to $\mathrm{SO}_{3}$ across DPF was made, ththe online sulfate measurement provides evidence that a dramatic $\mathrm{SO}_{2}$ oxidation competes with $\mathrm{NO}$ oxidation across catalytic surface of DPF. From the comparison between ultra low sulfur fuel and low sulfur fuel, there is no detectable sulfuric acid formation for ultra low sulfur fuel, implying that a decrease in fuel sulfur content can lead to enhanced $\mathrm{NO}_{2}$ generation capability of the catalyst by avoiding the competition with $\mathrm{SO}_{2}$ oxidation. In summary, with decreasing sulfur content in the fuel, it is apparent that the catalyst produces more $\mathrm{NO}_{2}$ due to reduced $\mathrm{SO}_{2}$ inhibition, leading to an overall reactivity increase, while particulate reactivity remains constant.

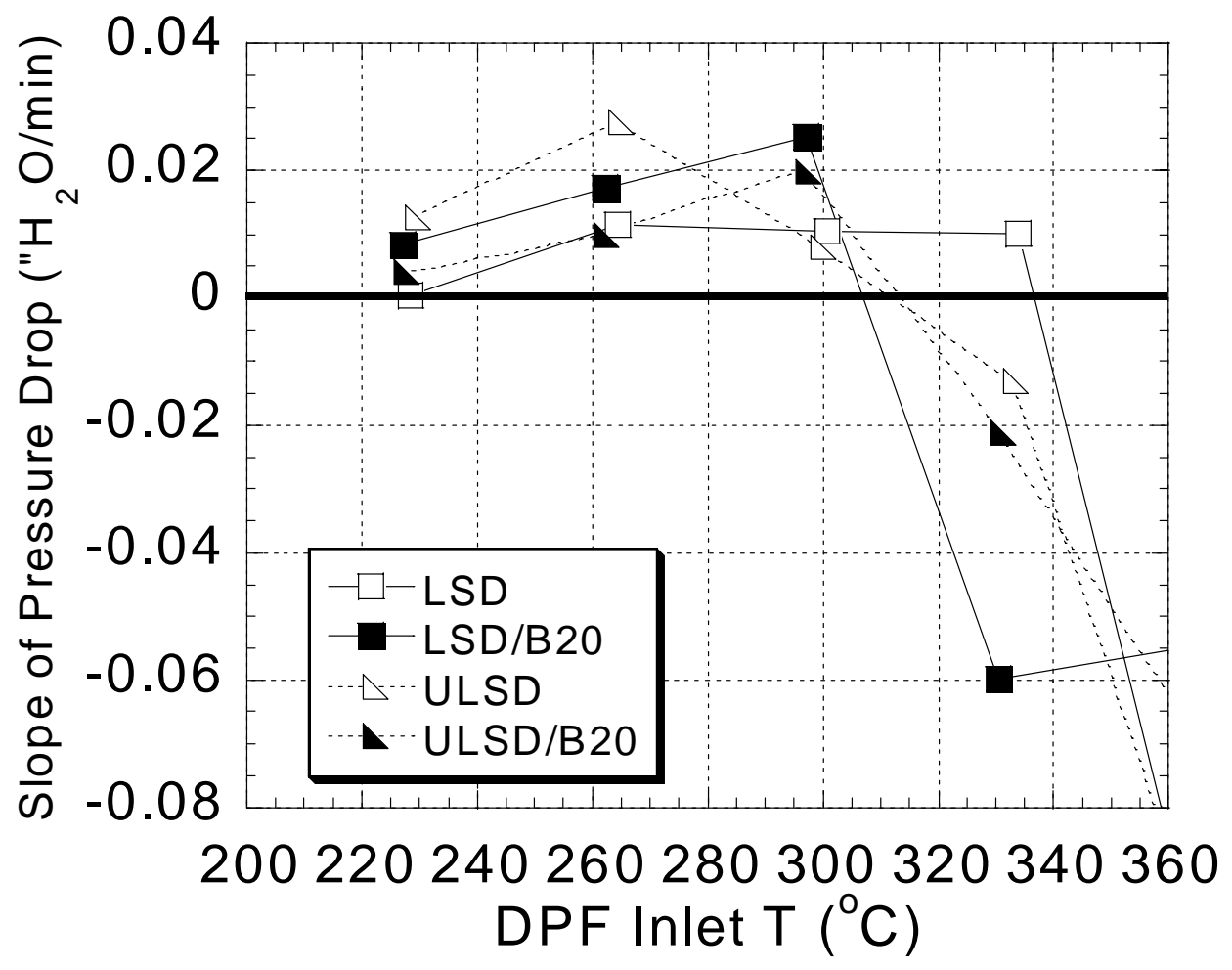

Figure 3.3.60 Filter temperature versus slope of the pressure drop, indicating the break even temperature for the various test fuels

The high temperature regeneration test is accomplished by direct temperature ramping from the PM loading condition $\left(-280^{\circ} \mathrm{C}\right)$ to an elevated temperature condition $\left(-480{ }^{\circ} \mathrm{C}\right)$. As shown in Figure 3.3.63, ultra low sulfur fuel has two times faster oxidation rate than low sulfur fuel, which is similar to that of the low sulfur/B20 blend. This faster oxidation is accompanied by higher $\mathrm{NO}_{2}$ production (or recovery) in Figure 3.3.64. Again, this obsrervation reconfirms the significant role of internal $\mathrm{NO}_{2}$ production in the engine bench test to affect the regeneration process. An interesting observation was that a low sulfur diesel/B20 blend provided the lowest regeneration temperature and yielded comparable oxidation rate with ultra low sulfur fuel, despite the rather modest $20 \%$ reduction in fuel sulfur due to blending with biodiesel.

From the key observations obtained from both the low and high temperature DPF regeneration tests, two kinds of fuel formulation effects are evident. First, reducing fuel sulfur content (BP15) leads to increased oxidation rate with no change in activation energy relative to the base fuel (BP325), indicating that the sole effect of sulfur on catalyst behavior is inhibition of internal $\mathrm{NO}_{2}$ production. Secondly, increasing biodiesel addition also leads to increase oxidation rate with modest decrease in activation energy, relative to the base fuel (BP325), indicating an enhancement 
of the reactivity of the particulate itself, through both an enhancement of the reactivity of the dry soot fraction and an increase in reactive soluble compounds on the particulate. Therefore, the first mechanism related to internal $\mathrm{NO}_{2}$ production is the predominant mechanism to explain the difference in particulate oxidation between the two base fuels arising from the difference in sulfur content.

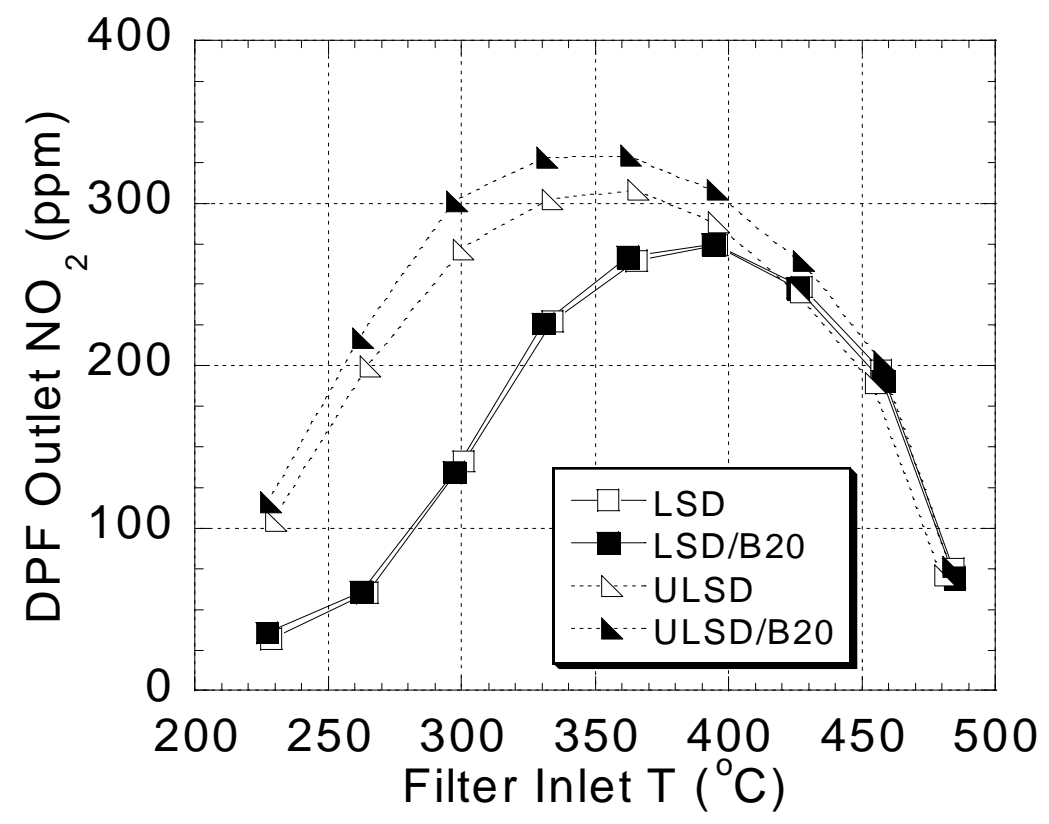

Figure 3.3.61 Variation in outlet $\mathrm{NO}_{2}$ generated across the DPF during the filter regeneration process

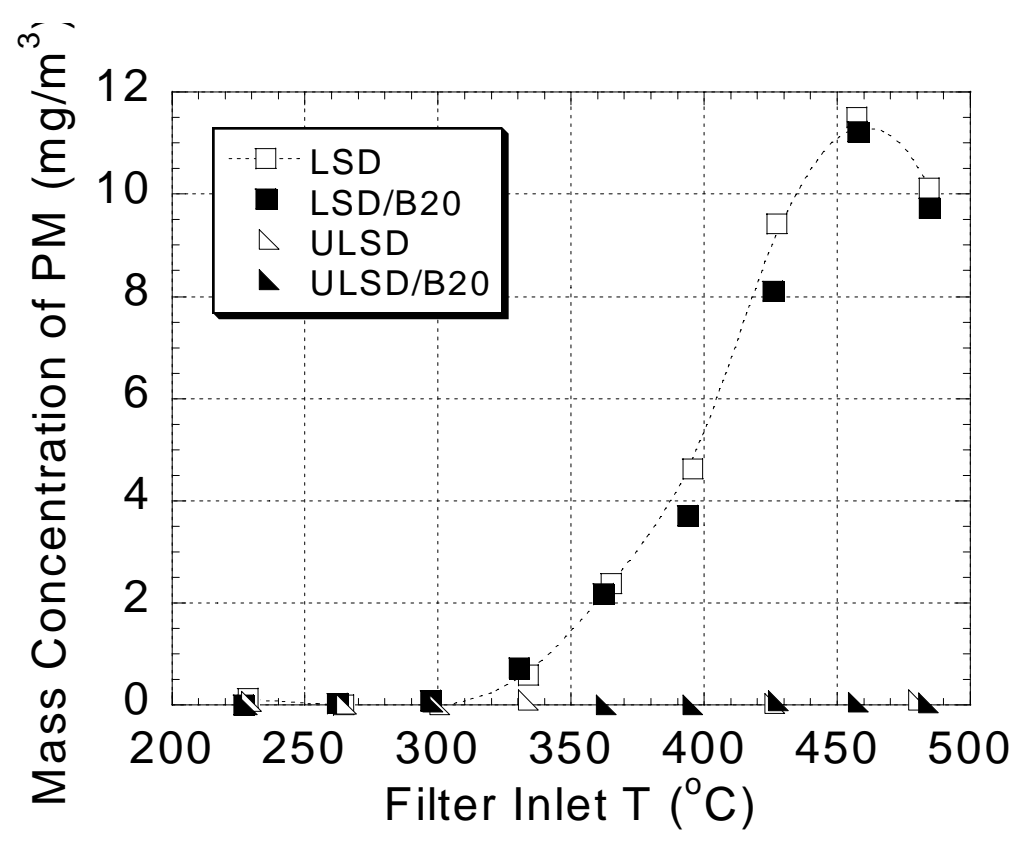

Figure 3.3.62 Variation in outlet PM generated across the DPF during the filter regeneration process 


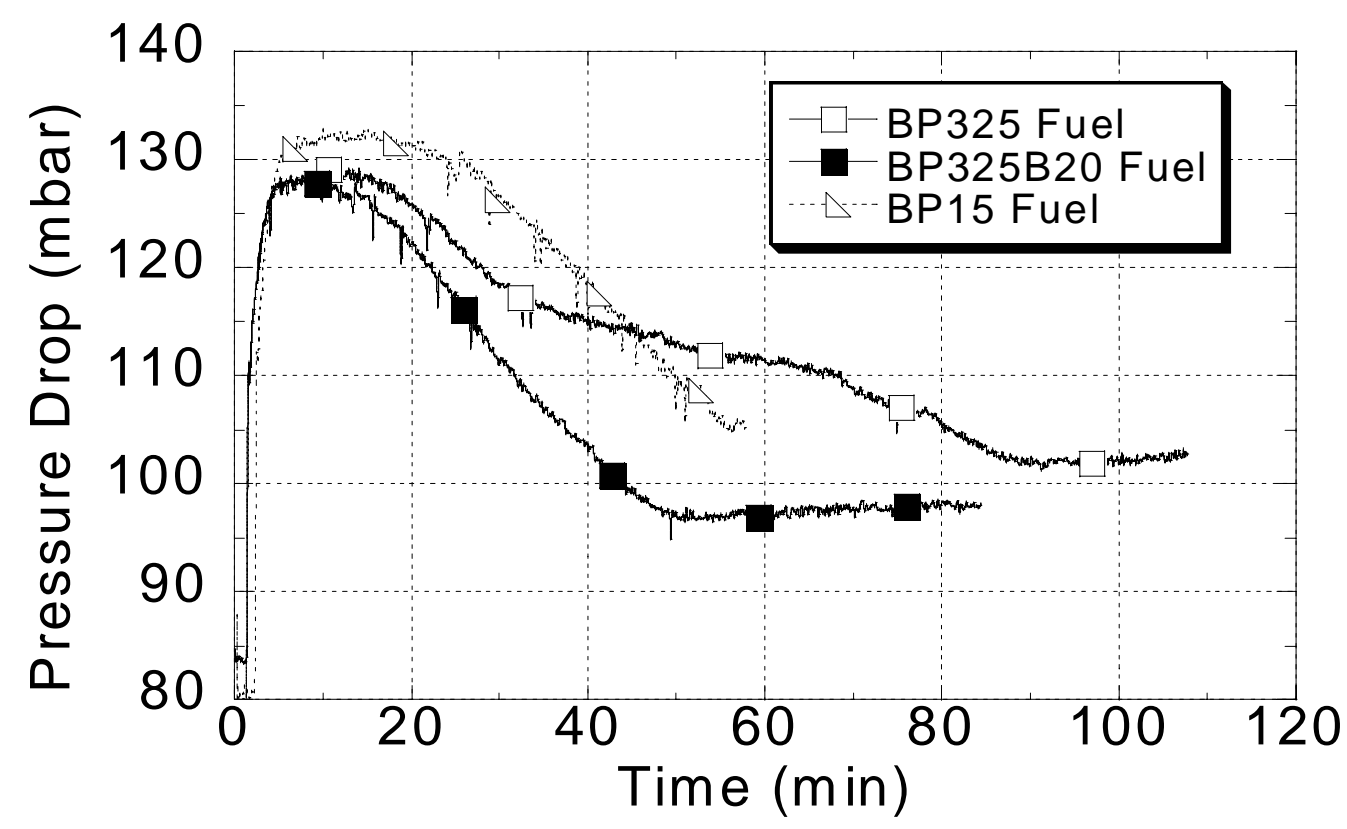

Figure 3.3.63 Variation in regeneration rate during high temperature regeneration progress

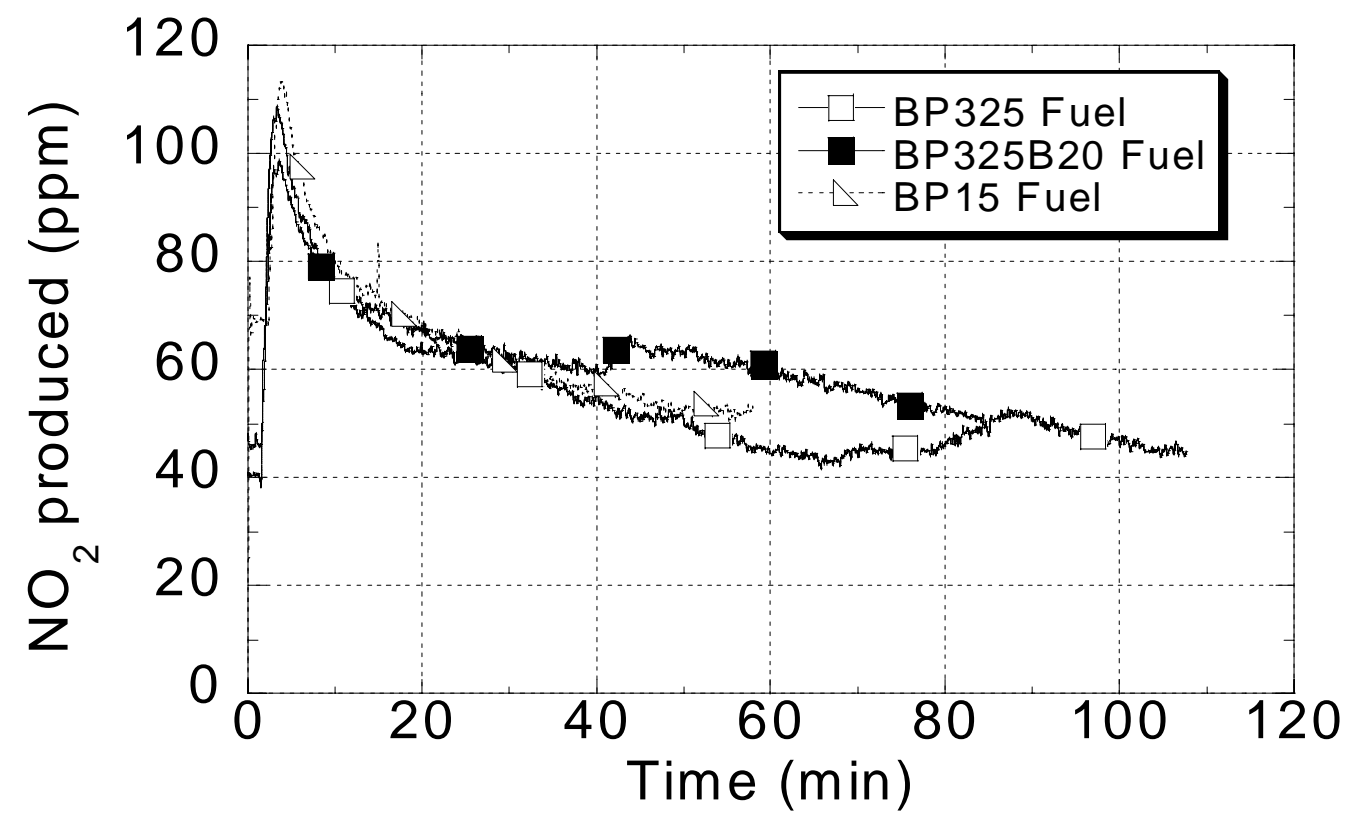

Figure 3.3.64 Variation in $\mathrm{NO}_{2}$ produced during high temperature regeneration progress

\subsection{Soot Reactivity Experiment}

The second test was a soot reactivity experiment with the intention to isolate the effect of variations in the reactivity of the dry soot fraction arising from variations in soot nanostructure. Separately, results on the variation in adsorbed heavy hydrocarbon fraction with biodiesel addition provide indications of the effect of catalytic hydrocarbon oxidation. Figure 3.3.65 (a) compares mass loss curve from thermo gravimetric analysis (TGA) while Figure 3.3.65 (b) compares heat release curves from differential scanning calorimetry (DSC), both of which indicate the differences in the ignition temperature of the soot samples. Compared to normal diesel soot, both B20 soots exhibit a lower ignition temperature by $40 \sim 50{ }^{\circ} \mathrm{C}$ in both the burning rate curve from the DSC and the mass 
reduction curve from the TGA. Results from HRTEM imaging are shown in Figures 3.3.66 (a)-(f). The Figures 3.3.66 (a) and (b) compare the soot nanostructure for the BP325 and its BP325B20. The Figures 3.3.66 (c) - (f) compare the soot nanostructure for BP15 and BP15B20 at two different oxidation stages, shown in terms of burn off time.

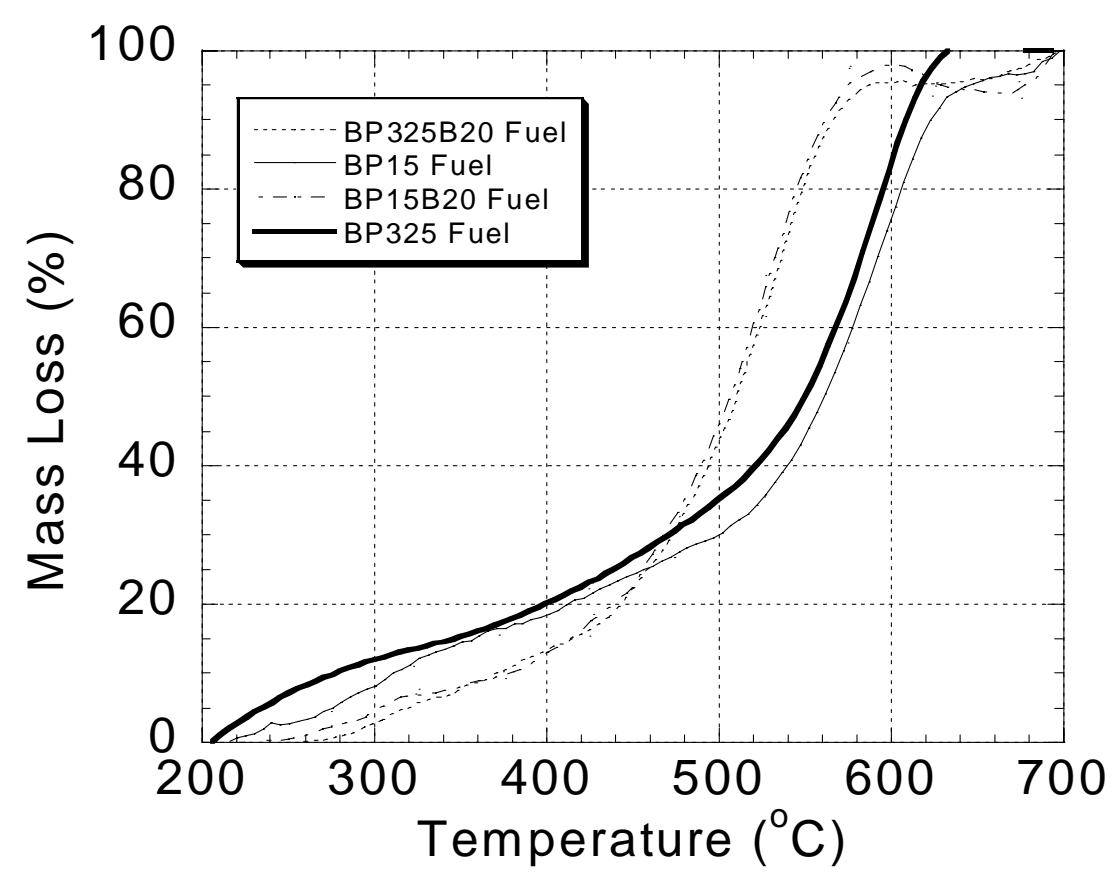

(a)

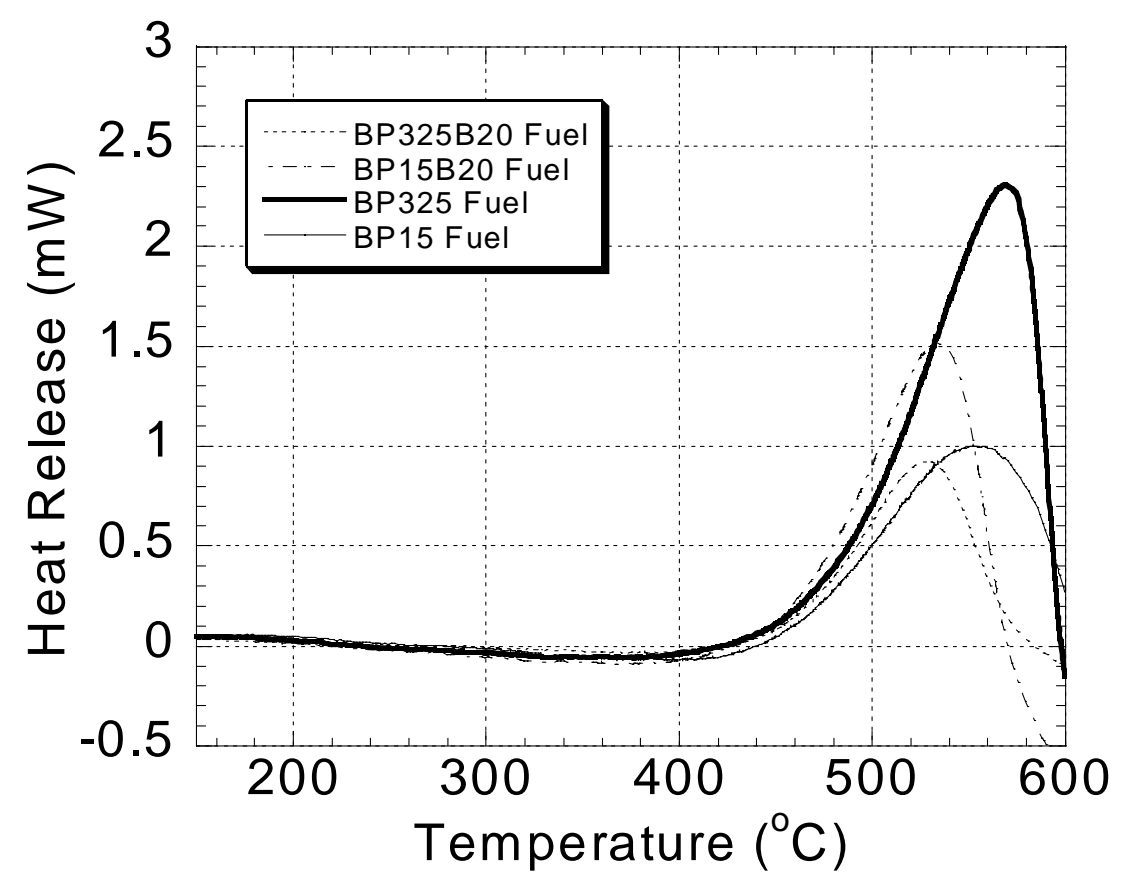

(b)

Figure 3.3.65 (a) Mass reduction TGA curve of pretreated samples under 21\% oxygen; (b) DSC burning rate of pretreated samples under 21\% oxygen. Treated sample is prepared by 30 minutes heating at $500{ }^{\circ} \mathrm{C}$ under inert argon. 


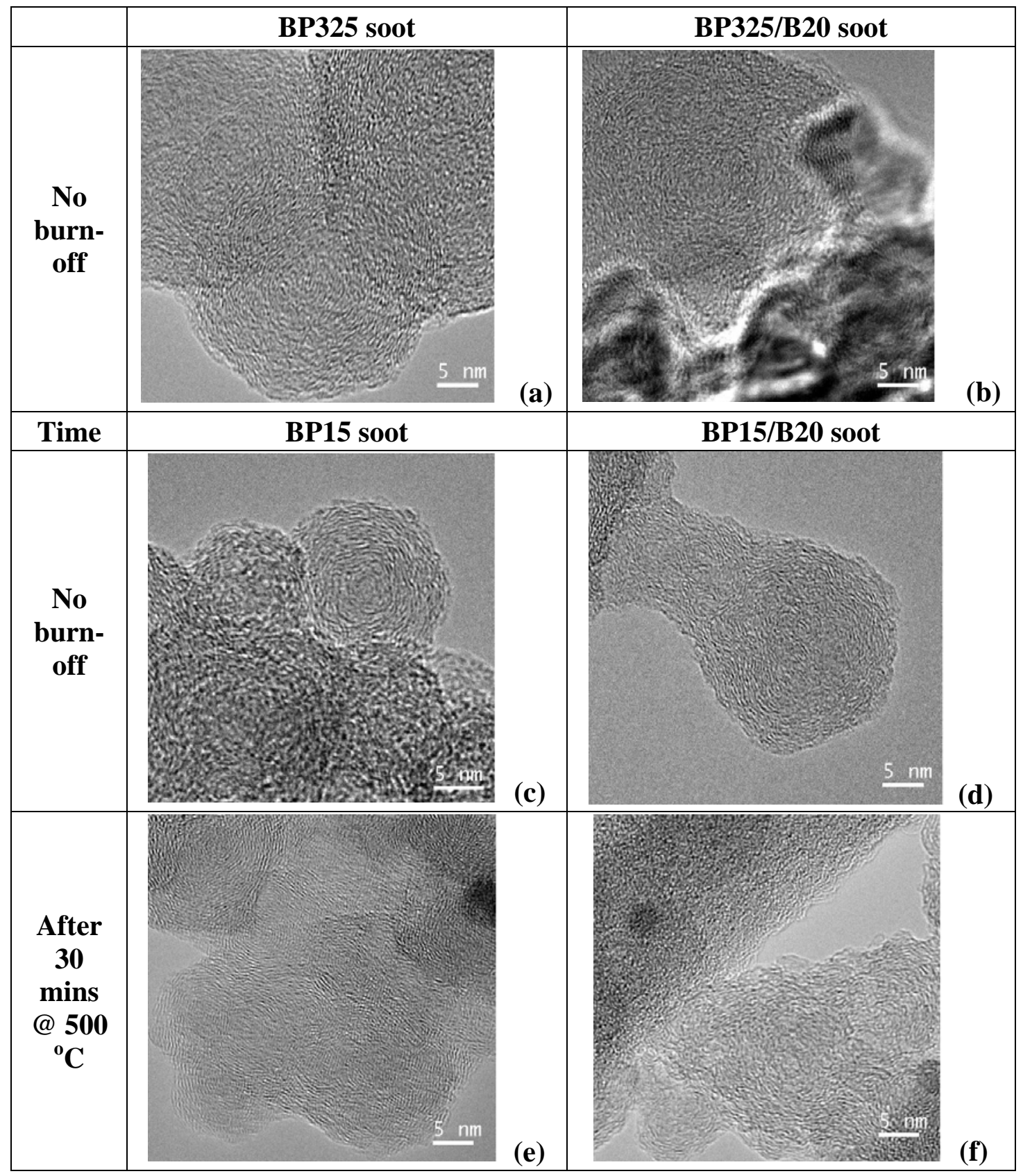

Figure 3.3.66 HRTEM images of diesel soot from (a) BP325 (b) BP325B20 (c) BP15 (d) BP15B20 (e) BP15 after 30 minutes of oxidation in air at $500{ }^{\circ} \mathrm{C}$ and (f) BP15B20 after 30 minutes of oxidation in air at $500{ }^{\circ} \mathrm{C}$

From comparison between BP325 and BP325B20 soot at the initial stage (no burn-off), a more amorphous and disordered arrangement of short-range graphene segments is apparent for the BP325B20 soot. In contrast, BP325 diesel soot possesses the typical the shell-core structure in which graphene layers are oriented parallel to the external outer surface, but are randomly oriented in a central core. From the comparison between BP15 soot and BP15B20 soot at the initial stage (no burn-off), the extent of ordering becomes more distinct. Within this primary particle from the BP15B20 soot, wrinkled or curved crystallites with many misalignments relative to each other and 
structural defects are more pronounced. The more reactive edge site carbon, which is more prevalent with short-range amorphous arrangement of the crystallites, is known to be more vulnerable to oxidative attack due to greater accessibility and electronic affinity for $\mathrm{O}_{2}$ chemisorption $[34,35]$. Consistent with this understanding of the relationship between structure and oxidative activity, BP15B20 soot indeed leads to higher reactivity compared to the BP15 soot partly due to differences in soot nanostructure.

The partially oxidized samples show in Figures 3.3.66 (e) and (f) display nanostructural changes after exposure to $500^{\circ} \mathrm{C}$ for 30 minutes. The BP15 soot, that has initially a shell-core structure, remains untouched or slightly graphitized, indicating slow surface burning progression during the course of oxidation. In contrast, for the BP15B20 soot, porous and ragged layers have developed, indicating a faster burning through either internal burning or stripping of the outer crystallite structure. Although few if any studies have compared the microstructural variations during oxidation for soots derived from different fuels, the observations in this work are consistent with the reported progression of soot oxidation wherein more surface area was developed through opening of micropores by removal of adsorbed hydrocarbon, followed by pre-graphitization before the outer crystallite is stripped away at greater extent of burn-off [38, 39]. Consistent with the quantitative measures in Figure 3.3.65, this qualitative comparison of nanostructure between the partially oxidized samples supports a significant difference in reactivity.

Figure 3.3.67 shows TEM images of whole particulates. Due to the low resolution of this TEM, these images are just used to characterize major morphological changes such as particle size and the degree of aggregation. From the comparison between BP325 soot and its BP325B20 soot shown in Figures 3.3.67 (a) and (b), a modest morphological change in BP325B20 particulate is apparent showing the greater presence of condensable products adsorbed onto the primary particle surfaces. For BP15 and BP15B20 soots, a similar difference is discernable in Figure 3.3.67 (c) and (d). This presence of adsorbed heavy hydrocarbon and its increase with B20 addition is supported by two separate composition results. As seen in Table 3.3.13 (a) and (b), a 4 5\% increase in SOF content from each base soot, measured by Soxhlet DCM extraction and gravimetric analysis, was consistent with 5 6\% increase in heavy organic carbon fraction $\left(300 \sim 450{ }^{\circ} \mathrm{C}\right.$ range) measured by thermal carbon analyzer. This shift with biodiesel addition may be favorable for promoting catalytic hydrocarbon reaction during catalyzed DPF regeneration, depending on the soot loading conditions, exhaust temperature and hydrocarbon species concentration.

Table 3.3.13 Composition of particulates measured

\begin{tabular}{|c|c|c|c|}
\hline Particulates & PM emissions & $\begin{array}{c}\text { SOF contents } \\
(\%)\end{array}$ & $\begin{array}{c}\text { Dry soot Reduction (\%) } \\
\text { relative BP325 }\end{array}$ \\
\hline BP325 & 29.4 & 52.4 & - \\
\hline BP325-B20 & 25.1 & 57.6 & 24 \\
\hline BP15 & 26.6 & 57.8 & 20 \\
\hline BP15-B20 & 27.8 & 61.1 & 23 \\
\hline
\end{tabular}

(a) Soxhlet extraction and gravimetrics

\begin{tabular}{|c|c|c|c|c|}
\hline Fuels & $\begin{array}{c}\text { Organic } \\
\text { Carbon } \\
\left(150 \sim 300^{\circ} \mathrm{C}\right)\end{array}$ & $\begin{array}{c}\text { Organic } \\
\text { Carbon } \\
\left(300 \sim 450^{\circ} \mathrm{C}\right)\end{array}$ & $\begin{array}{c}\text { Element } \\
\text { Carbon } \\
\left(450 \sim 750^{\circ} \mathrm{C}\right)\end{array}$ & $\begin{array}{c}\text { EC Reduction } \\
(\%) \text { relative } \\
\text { BP325 }\end{array}$ \\
\hline BP325 & 23 & 42 & 35 & - \\
\hline BP325-B20 & 32 & 48 & 20 & 42 \\
\hline BP15 & 32 & 48 & 20 & 42 \\
\hline BP15-B20 & 27 & 53 & 20 & 42 \\
\hline
\end{tabular}

(b) Thermal Carbon Analyzer 


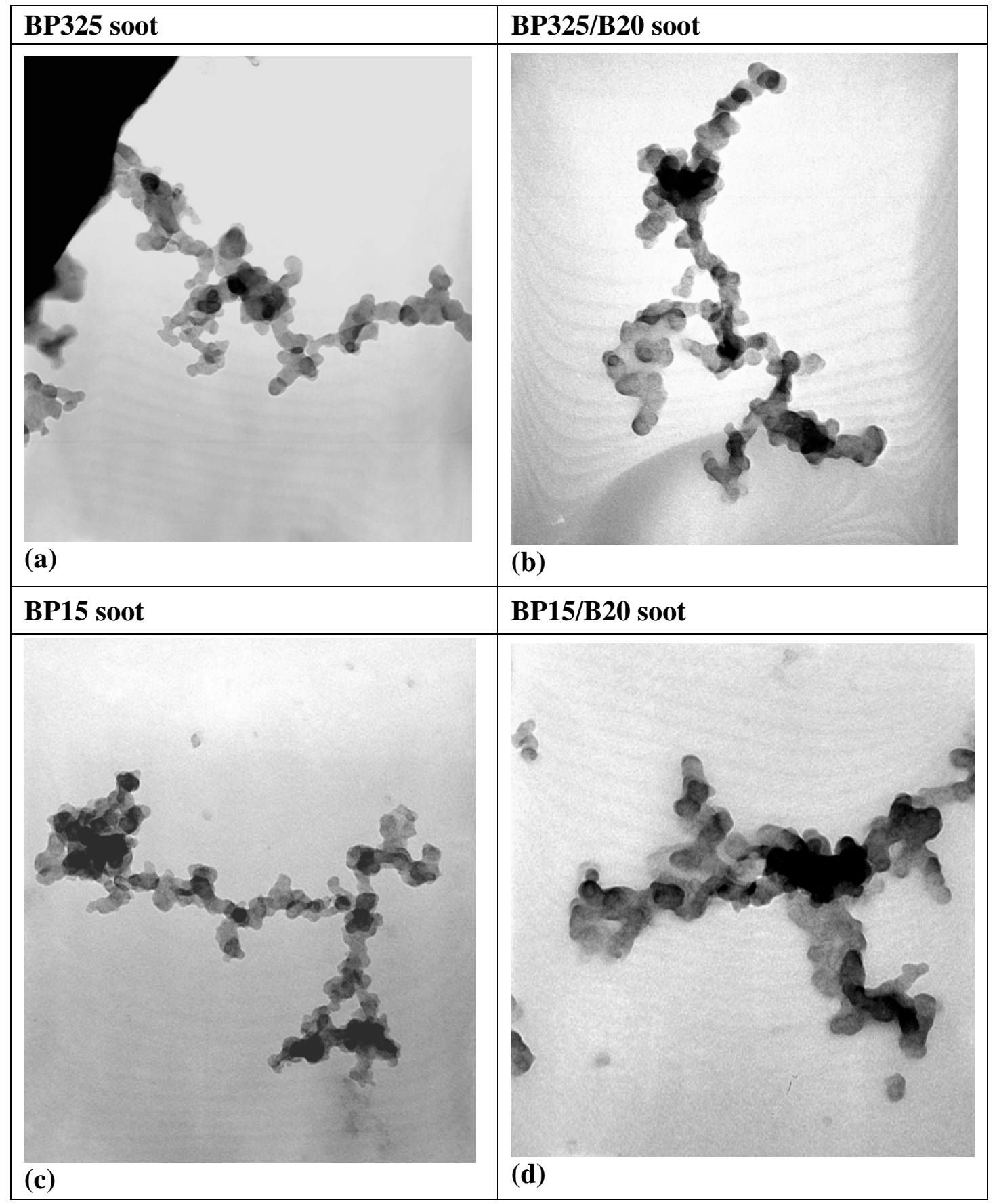

Figure 3.3.67 TEM images of diesel and its B20 soot at 105,000 magnification

From this soot reactivity experiment, two important fuel formulation effects on soot nanostructure are evident. With reducing fuel sulfur content (BP15), a lack of difference in nanostructure and morphology is apparent between soots from fuels with different sulfur content and leads to no difference reactivity being observed in DSC/TGA tests. With increasing biodiesel addition, a more amorphous arrangement of short-range graphene layers is responsible for the higher observed reactivity of the dry soot. In addition, modest morphological change supports an increase in heavy hydrocarbon fraction observed in the composition results. This raises an intriguing 
issue of the possible significance of the third mechanism related to catalytic oxidation of hydrocarbons adsorbed on to soot surfaces, which is recommended as a follow-up experiment.

\subsubsection{Summary}

From these two experiments, overall conclusions can be drawn as follows:

$\checkmark \quad$ Enhanced regeneration with decreasing fuel sulfur is due to the sole effect of reduced sulfur inhibition on catalyst activity, with no difference in intrinsic particulate reactivity.

$\checkmark \quad$ B20 addition exhibits the lowest activation energy suggesting a high intrinsic particulate reactivity that is confirmed by soot reactivity test.

$\checkmark \quad$ More short-range, amorphous structure in B20 soot is in part responsible for its enhanced particulate reactivity. 


\subsubsection{Impact of Alternative Fuels on Soot Properties and DPF Regeneration}

In this section we delve deeper into the impacts of diesel fuel formulation on the regeneration process in a catalyzed diesel particulate filter. The results in Section 3.3.8 form a preliminary investigation of the effects of biodiesel blending of DPF regeneration. This section expands the consideration to include neat Fischer Tropsch Diesel Fuel and neat biodiesel, FT100 and B100, respectively.

\subsubsection{Performance of DPF Regeneration}

During an engine bench test, two kinds of regeneration were employed. From low temperature regeneration tests, the break even temperature (BET) was determined by following the slope in the variation of pressure drop with time as exhaust temperature increases. For the tests presented here, results were obtained for ULSD, B20 and B100. In the practical operation of DPF, this BET represents an exhaust temperature at which DPF regeneration commences and decreasing this temperature is very important to minimize active regeneration. As shown in Figure 3.3.68 (a), the BET temperature decreased by $30^{\circ} \mathrm{C}$ with B100 compared to ULSD. This shift in BET temperature was coincident with a $30{ }^{\circ} \mathrm{C}$ shift in DPF inlet temperature where maximum $\mathrm{NO}_{2}$ is produced over the DPF with B100 in Figure 3.3.68 (b). Therefore, this correlation suggests that internal $\mathrm{NO}_{2}$ production is one of the mechanisms by which neat biodiesel (B100) lowers the BET temperature due to the absence of fuel sulfur in B100. The profile of $\mathrm{NO}_{2}$ production over temperature and inhibitive effect of

sulfur dioxide is similar with a result from flow reactor experiment [40].

From the high temperature regeneration tests, a plot of pressure drop versus time shows a variation in pressure drop between the 4 different fuels. As biodiesel content increases in Figure 3.3.69 (a) from B20 to B100, a fast regeneration happens that is also accompanied by an increase in $\mathrm{NO}_{2}$ production as seen in Figure 3.3.69 (b). This confirms the role of internal $\mathrm{NO}_{2}$ production in the DPF regeneration process. Despite of the absence of fuel sulfur, FT exhibits an unexpected behavior in that it yields the slowest regeneration and the least $\mathrm{NO}_{2}$ production. The explanation for this can be found in two additional measurements shown in Figure 3.3.70 (a) and (b). A $30{ }^{\circ} \mathrm{C}$ increase in exhaust temperature and a reduced inlet NO concentration prior to the DPF contribute to a reduction in $\mathrm{NO}_{2}$ production, thereby leading to suppression of DPF regeneration. In the case of $\mathrm{B} 100$, factors that affect catalyst activity such as the absence of sulfur, a $30^{\circ} \mathrm{C}$ decrease in DPF inlet temperature and a higher inlet NO concentration together contribute to enhanced DPF regeneration. Of course, we can speculate that an enhanced particulate reactivity for the B100 soot accounts for this difference in regeneration behavior, but other effects such as SOF content could not be factored out from this test.

The combustion characteristics in Figure 4-15 provide an insight on how the engine responds to different fuels and how much this would change tailpipe conditions prior to the DPF. These measurements were obtained at the DPF loading condition of $2400 \mathrm{rpm}$ and $115 \mathrm{ft}$-lbs torque. Needle lift measurements in Figure 4-15 (a) show that FT retards injection timing by 2 crank angle degrees (CAD) relative to ULSD, while B100 advances injection timing by about 1 crank angle degree (CAD) relative to ULSD. The heat release rate analysis in Figure 4-15 (b) shows that FT ignites at a similar timing as B100 despite the retarded injection timing for neat FT, probably due to the high cetane number of the paraffinic FT fuel. This shift in injection and ignition timing can create a significant variation in in-cylinder mean temperature and time history as shown in Figure 4-15 (c). For example, B100 is exposed to much higher temperature at longer residence time compared to ULSD and FT. Therefore, this difference in diesel combustion characteristics is a source of the previously identified variation in tailpipe conditions, as well as, possible variation in diesel particulate properties that will be shown. 


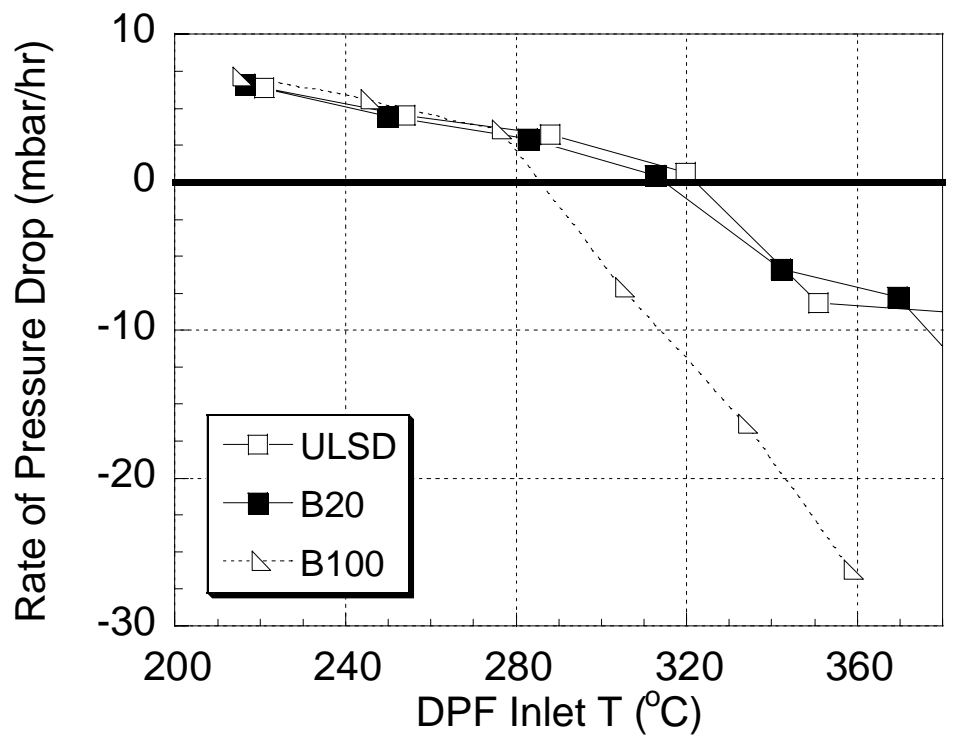

(a)

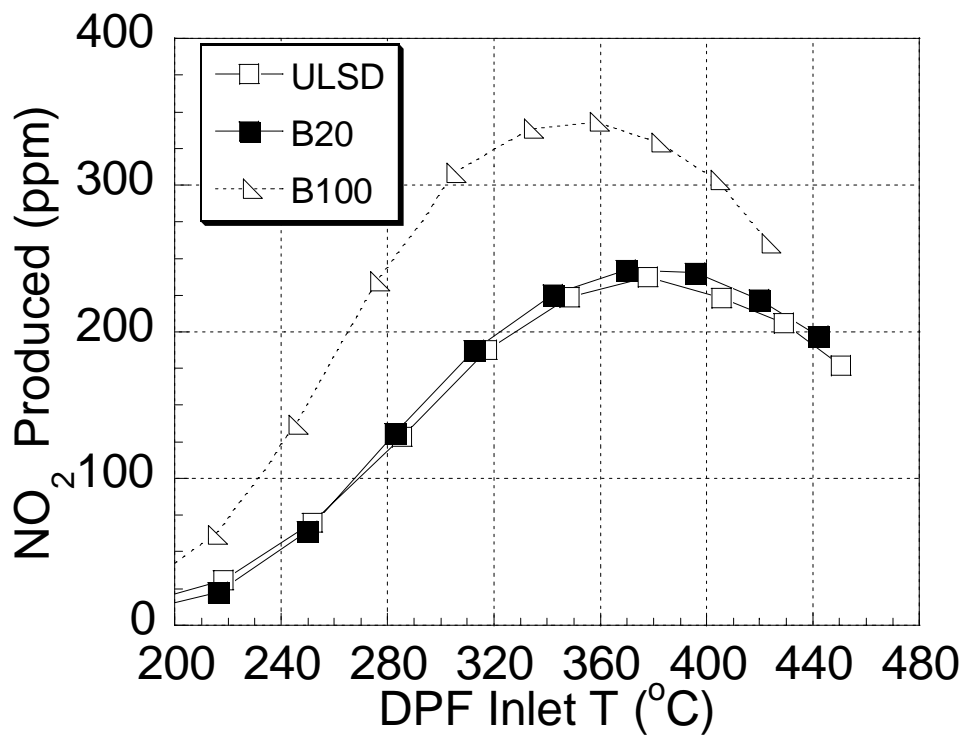

(b)

Figure 3.3.68 (a) Variation in BET Temperature indicating $30{ }^{\circ} \mathrm{C}$ BET temperature decrease with $\mathrm{B} 100$ fuel relative to ULSD fuel, (b) Variation in DPF outlet $\mathrm{NO}_{2}$ indicating $30{ }^{\circ} \mathrm{C}$ shift of temperature where maximum $\mathrm{NO}_{2}$ is produced over DPF with B100 relative to ULSD fuel. 


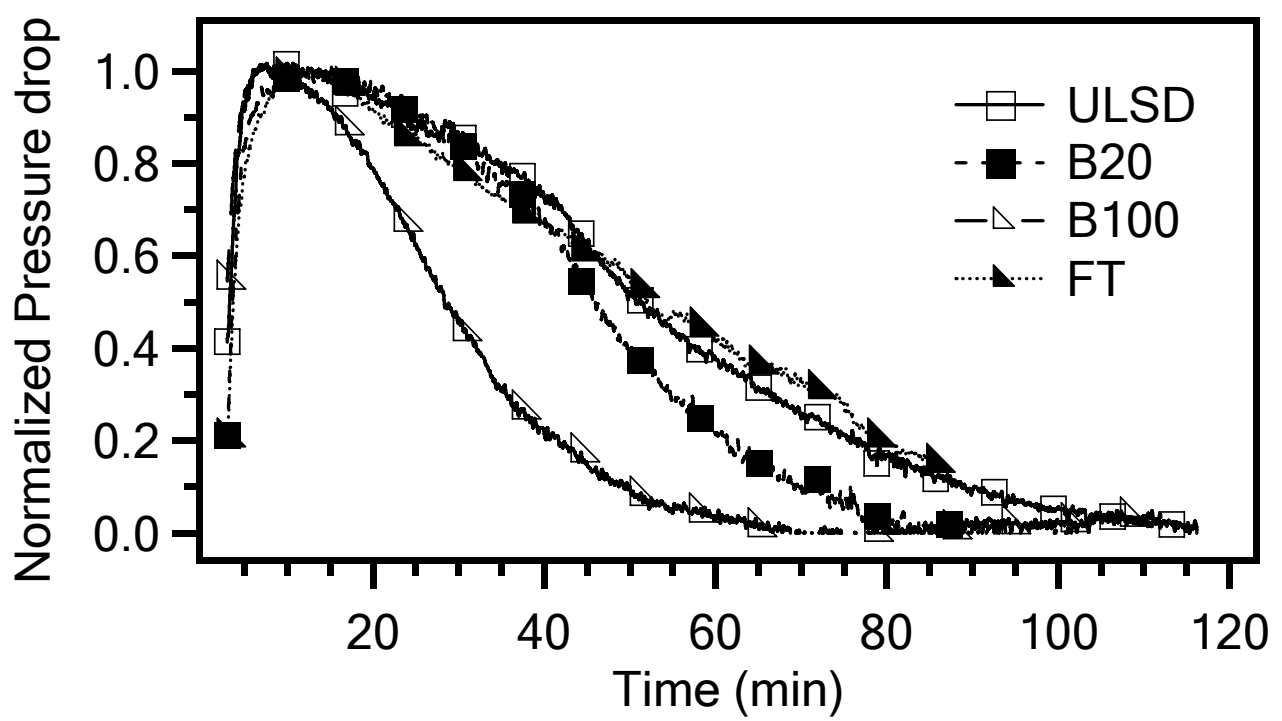

(a)

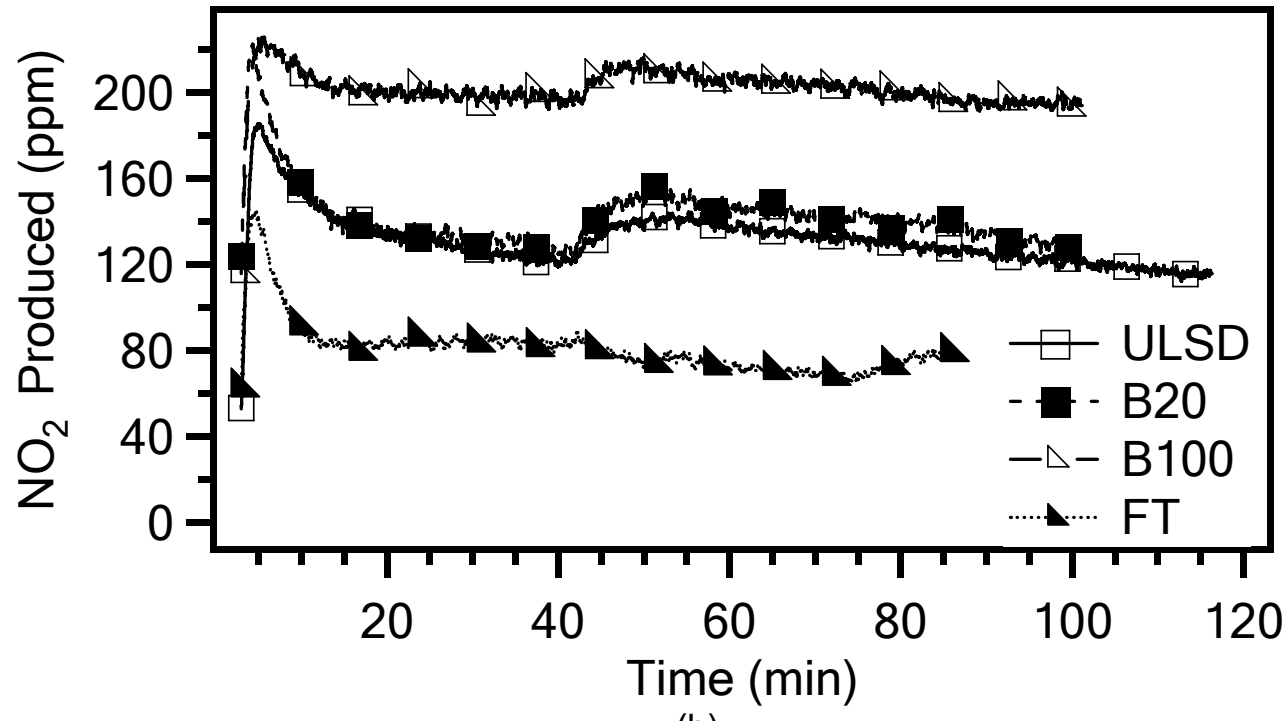

(b)

Figure 3.3.69 (a) Variation in pressure drop based oxidation rate, (b) internal $\mathrm{NO}_{2}$ production over DPF during high temperature regeneration period. 


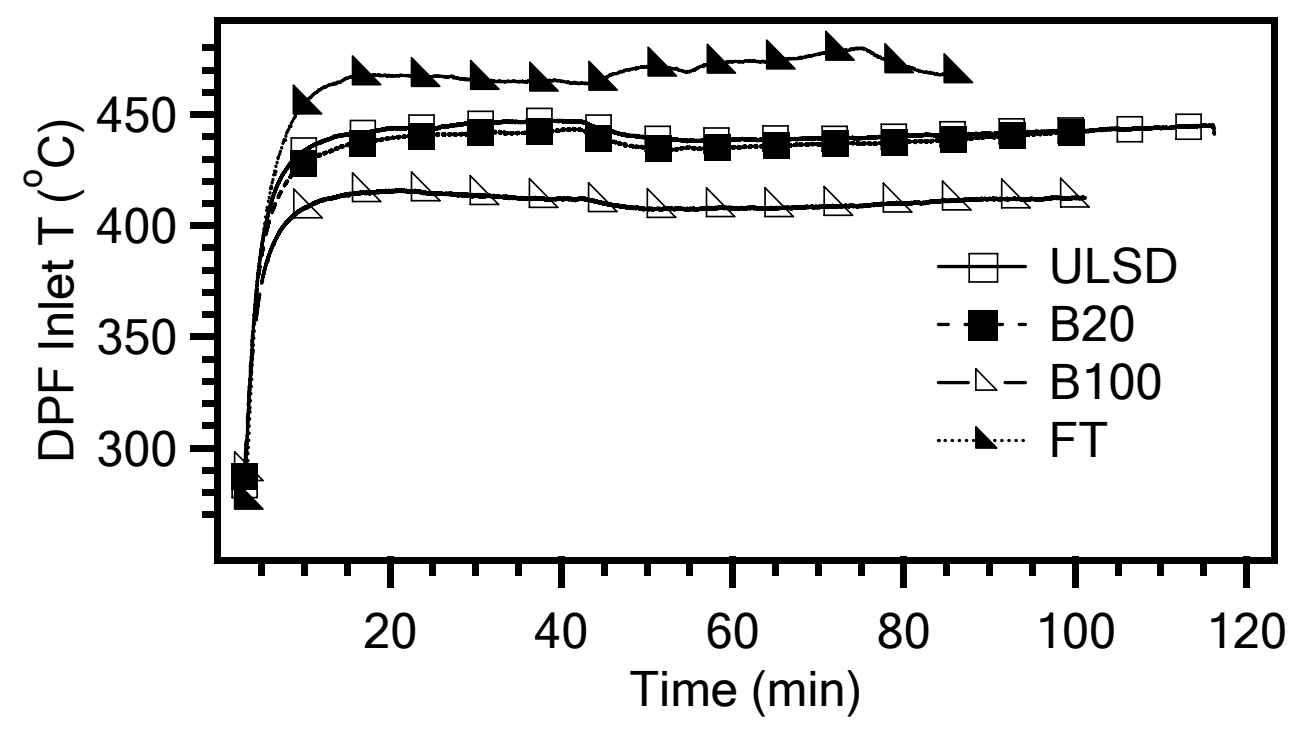

(a)

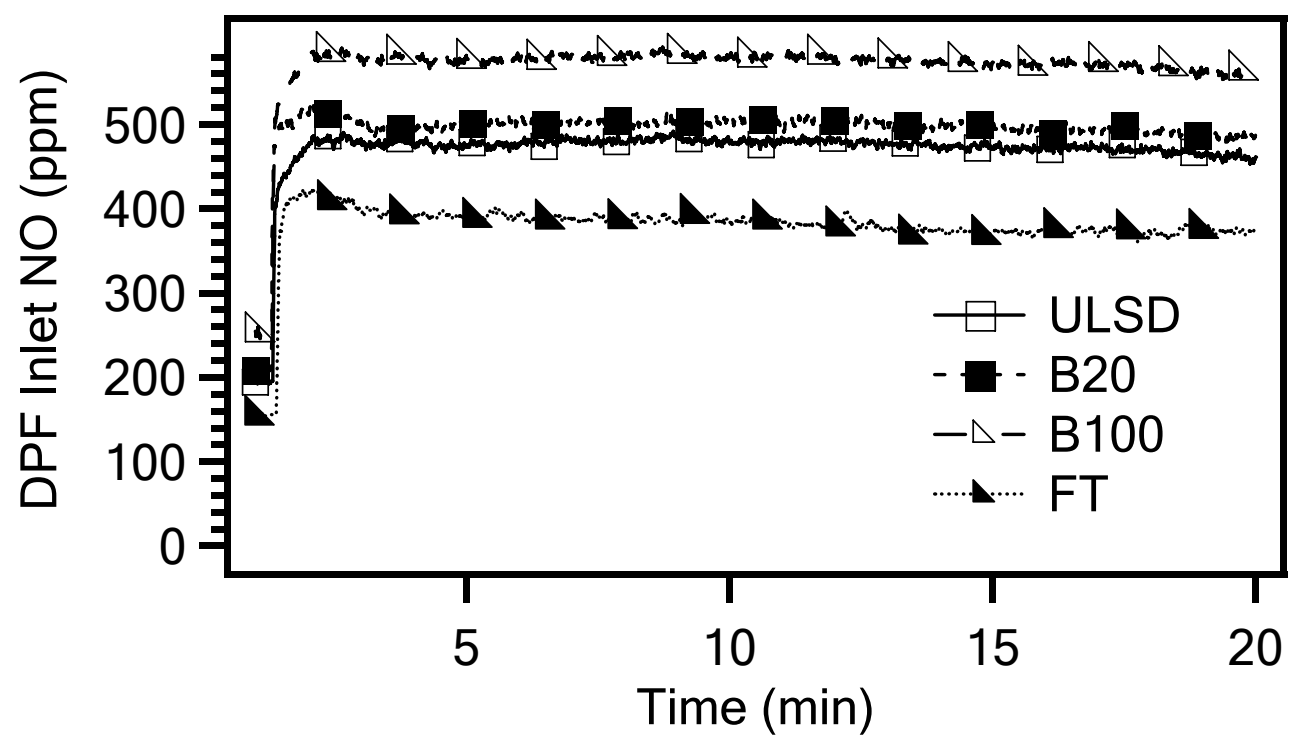

(b)

Figure 3.3.70 (a) DPF inlet temperature, (b) inlet NO concentration during high temperature regeneration period

From this comparison of DPF regeneration behavior between these fuels, enhanced regeneration with B100 is observed in terms of both rate and BET temperature regardless of whether this comes from particulate reactivity or catalyst activity, which is sensitive to temperature, inlet NO and fuel sulfur prior to the DPF. Second, this difference in oxidation rate of the DPF soot cake, based upon pressure drop measurements here, will be reproduced in mass based oxidation rate measurements from TGA as will be presented in the next section. Again, since particulate reactivity was masked by catalyst activity, thermogravimetric analysis of soot sample is used to assess differences in particulate reactivity. 


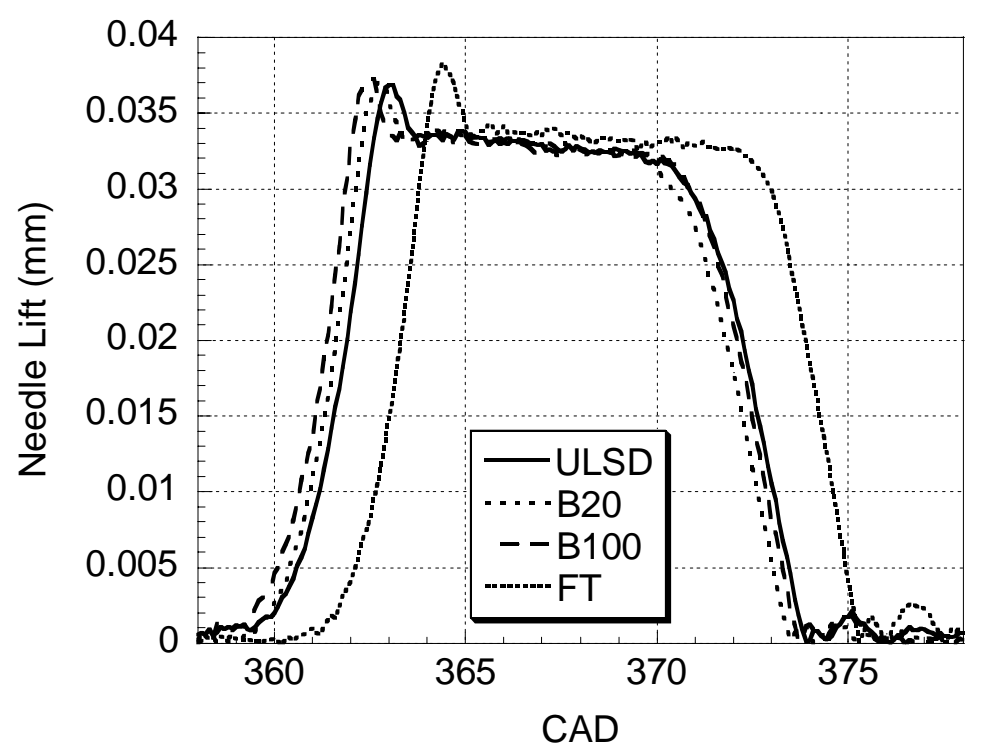

(a)

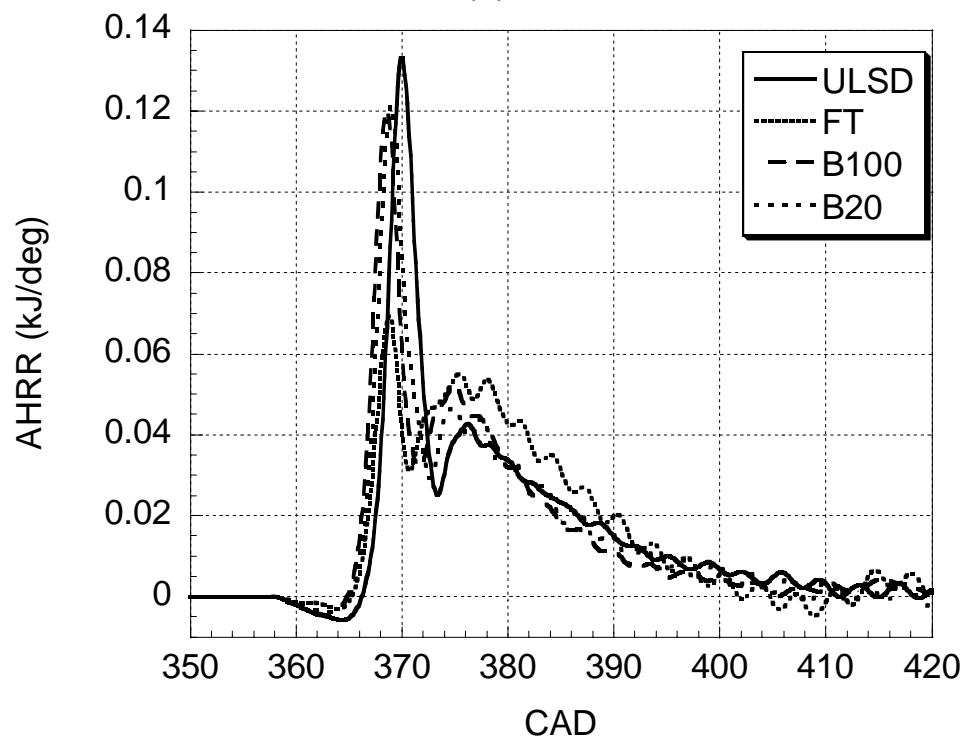

(b) 


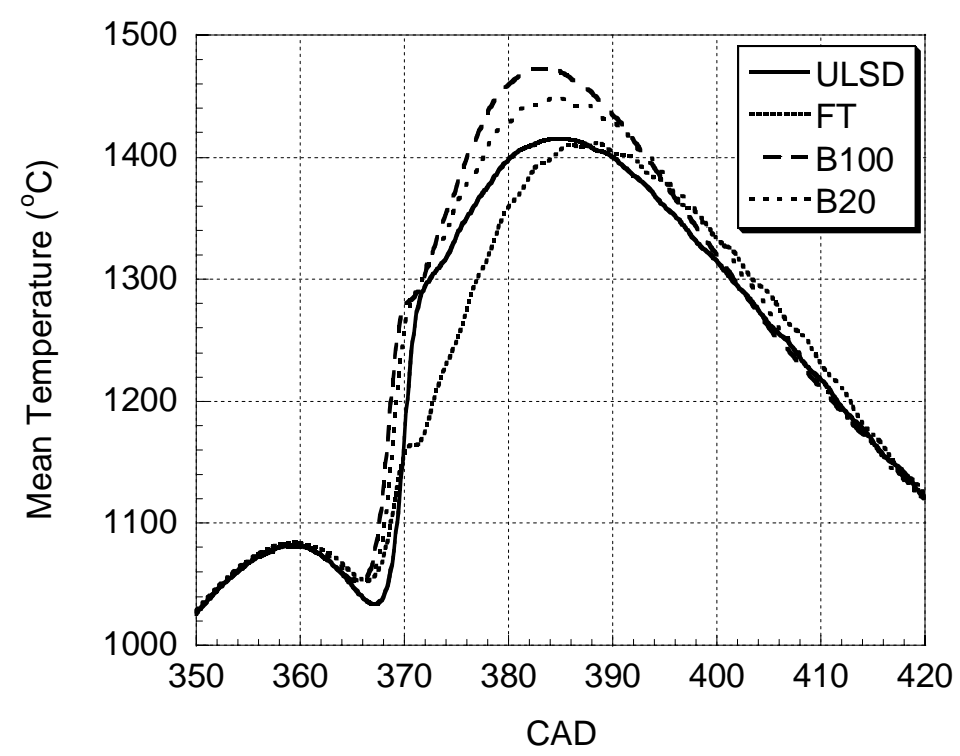

(c)

Figure 3.3.71 Engine responses at particulate loading condition, (a) injection timing (b) heat release, (c) temperature and time history prior to regeneration period indicating a longer residence time at high temperature that B100 soot is exposed to than ULSD and FT.

\subsubsection{Particulate Reactivity and Properties}

\subsection{Mass Based Oxidation Rate}

For this TGA test, all soot samples were collected on filter media at the same engine condition as was used for DPF loading, so that the results represent the soot cake on the DPF substrate in the regeneration experiments. Prior to oxidation, the soot samples were always pretreated at $500{ }^{\circ} \mathrm{C}$ in inert argon gas to drive off the volatile matter, such as adsorbed hydrocarbons. As shown in Figure 3.3.72 (a), oxidation at $500{ }^{\circ} \mathrm{C}$ shows B100 soot exhibits the fastest oxidation on a mass basis with B20, ULSD and FT soot in order of oxidation rate. Variation in furnace temperature was not noticeable between the different soot samples, as shown in the same Figure 3.3.72 (a). To ensure that volatile matter did not affect the mass loss measurements, an additional test was performed in which more severe pretreatment of the samples at $900{ }^{\circ} \mathrm{C}$ was followed by oxidation at $500{ }^{\circ} \mathrm{C}$. The results in Figure 3.3.72 (b) show that, despite a slight difference, the rank of oxidation rate between the different soot samples was unchanged. To confirm that kinetically controlled oxidation occurred in the flow configuration of the TGA $[41,42,43]$, two samples which have 2 times difference in mass (and therefore thickness) were loaded and run at $500{ }^{\circ} \mathrm{C}$. Comparison of the results shows identical mass profiles between the two cases and thereby implies that no boundary layer resistance for oxygen transfer to the soot layer occurred on the bottom of the furnace pan. Nonetheless, sweeping the flowrate over a broad range would be a better means to justify this dominance particularly for the TGA configuration used in this study. At elevated temperatures of $600{ }^{\circ} \mathrm{C}$ in Figure 3.3 .72 (c) and $700{ }^{\circ} \mathrm{C}$ in Figure 3.3.72 (d), a significant difference between FT and B100 soot remains. By using time to reach the desired burnoff extent for each sample at $500{ }^{\circ} \mathrm{C}$, oxidized samples at 20,40 and $75 \%$ burnoff were prepared for additional analysis by Raman and HRTEM imaging. 

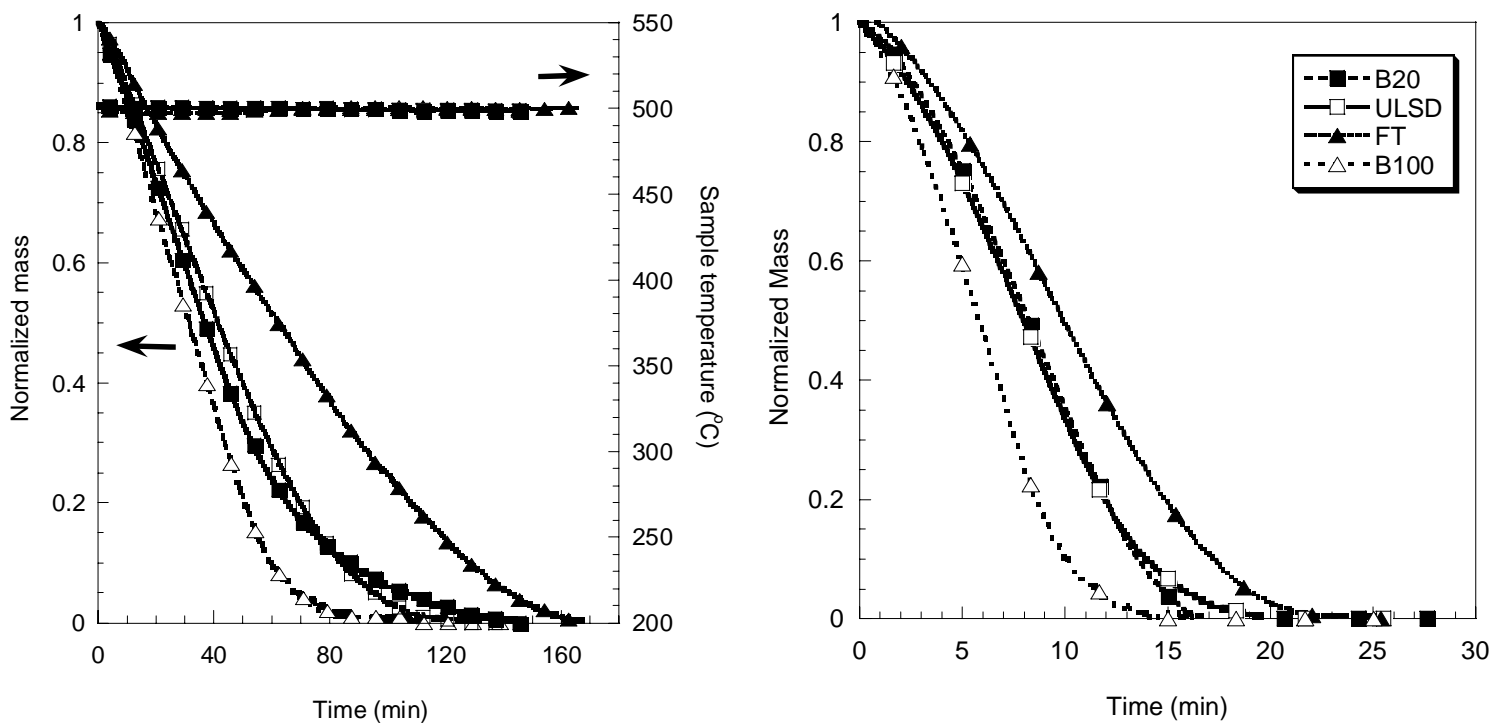

(a)

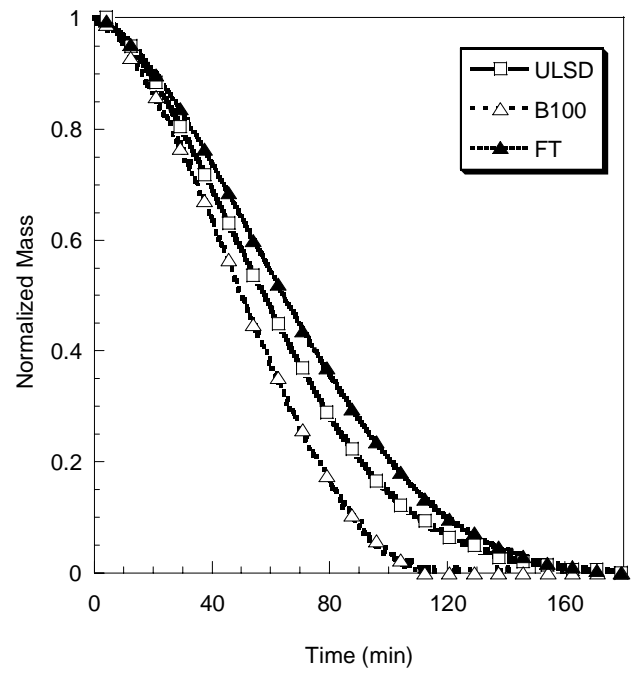

(b)

(c)

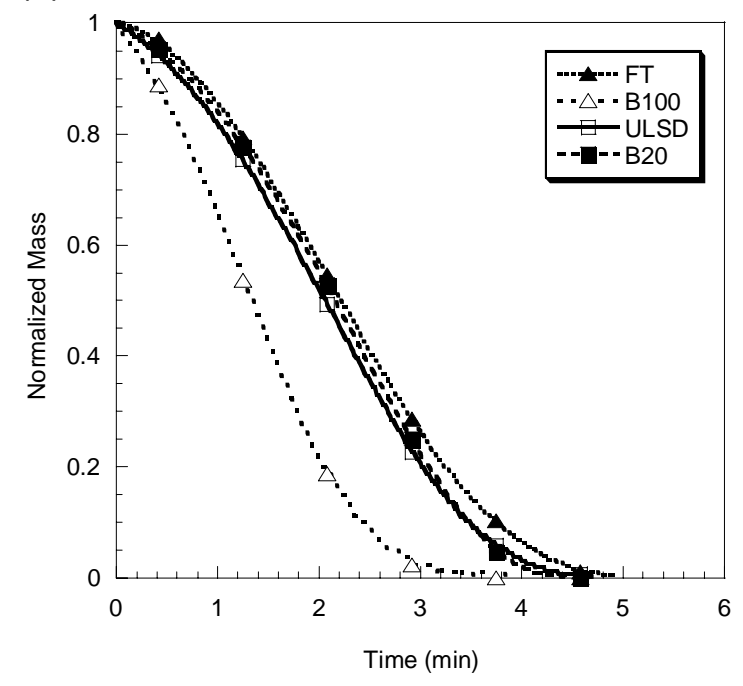

(d)

Figure 3.3.72 Mass based oxidation rate at isothermal conditions of (a) 500, (c) 600, (d) $700{ }^{\circ} \mathrm{C}$ after mildly pretreated under $500{ }^{\circ} \mathrm{C}$ of inert gas, (b) oxidation at the same $500{ }^{\circ} \mathrm{C}$ as (a) after severe pretreatment at $900{ }^{\circ} \mathrm{C}$; ULSD soot ( $\left.\square\right)$, B20 $\operatorname{soot}(\mathbf{a})$, $\mathrm{B} 100 \operatorname{soot}(\triangle), \mathrm{FT} \operatorname{soot}(\boldsymbol{\Delta})$.

Based on these TGA curves measured under isothermal conditions, theoretical analysis was performed to extract rate constants at each temperature. These rate constants will be related to initial structure parameters and changes in the structure parameters measured by structural characterization in the next section. With simplified rate expressions of carbon oxidation, the following expression can be transformed into a mass rate law for the first order oxidative removal of diesel soot with $\mathrm{O}_{2}$ :

$$
\frac{d m_{c}}{m_{c}}=-k_{c} \cdot p_{O_{2}}^{1} \cdot d t
$$

where $\quad k_{\mathrm{c}}$ is apparent rate constant 


\section{$p_{\mathrm{O} 2}$ is partial pressure of $\mathrm{O}_{2}$}

It is interesting that Eqn. 3.3.1 represents a first-order rate law, because $k_{\mathrm{c}}(\mathrm{T})$ and $\mathrm{p}_{\mathrm{O} 2}$ are assumed to be independent of time. Integration yields:

$$
\frac{m_{C}}{m_{C, 0}}=\exp ^{-k_{C} \cdot p_{O_{2}}^{1} \cdot\left(t-t_{0}\right)}
$$

From Eqn. 3.3.2, it is clear that determination of the exponent in the exponential function can yield a rate constant. As illustrated in Figure 3.3.73 (a), this determination was made by exponential fitting. Curve fitting software was used to fit an exponential function to each TGA mass curve. This calculation shows that $\mathrm{B} 100$ soot has 5 times higher oxidation rate constant than FT soot at $500{ }^{\circ} \mathrm{C}$ in Table 3.3.14. It is worthwhile to note that graphite has much lower oxidation rate constant than the soot samples by two orders of magnitude.

After extracting each rate constant at three different temperatures and plotting against temperature in Figure 3.3.73 (b), apparent kinetic parameters such as frequency factor $\left(A_{f}\right)$ and activation energy $(E a)$ were extracted by linear fitting over three temperature points.

$$
k_{c}=A_{f} \cdot \exp \left(-\frac{E_{a}}{R_{u} T}\right) \quad\left[\mathrm{Pa}^{-1} \cdot \mathrm{sec}^{-1}\right]
$$

Comparison in Table 3.3.14 shows no significant difference in both frequency factor and activation energy. For example, differences in activation energy of about $33 \mathrm{~kJ} / \mathrm{mol}$ between FT soot and B100 soot may not be statistically significant due to the experimental error of $\pm 10 \mathrm{~kJ} / \mathrm{mol}$ associated with the TGA measurement. In addition, it should be noted that using only three temperature points may not give reliable and accurate kinetics parameters and that more data points should be added to improve a confidence of linear fitting. However, more detailed experiments to determining kinetic parameters related to soot ignition temperature were not performed. Rather, the rate constant measured at $500{ }^{\circ} \mathrm{C}$ is simply related to the initial structure parameters and the changes in structure parameters measured by structural characterization in the next section. The $\log k_{c}$ at $500{ }^{\circ} \mathrm{C}$, normalized to $10 \mathrm{kPa}$ pressure of oxygen, is also provided in Table 3.3.14 for the comparison with those available in the literature. Our range is in the same order of magnitude with others (i.e. between -3.3 and -4.0 ) in this temperature $[44,45,46,47,48,49]$ as excerpted from ref.[50]. An order of magnitude lower rate (i.e. between -4.5 and -5.0 ) than our range was reported for oxidation at $500{ }^{\circ} \mathrm{C}$ in the prior studies [51,52] as excerpted from ref. [53]. 


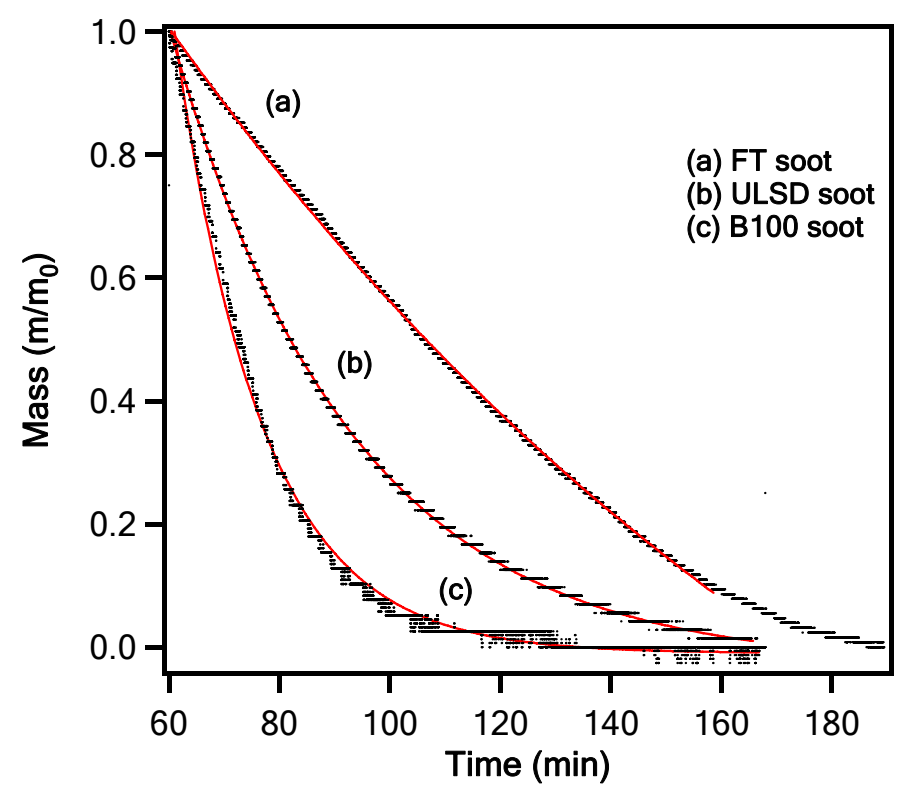

(a)

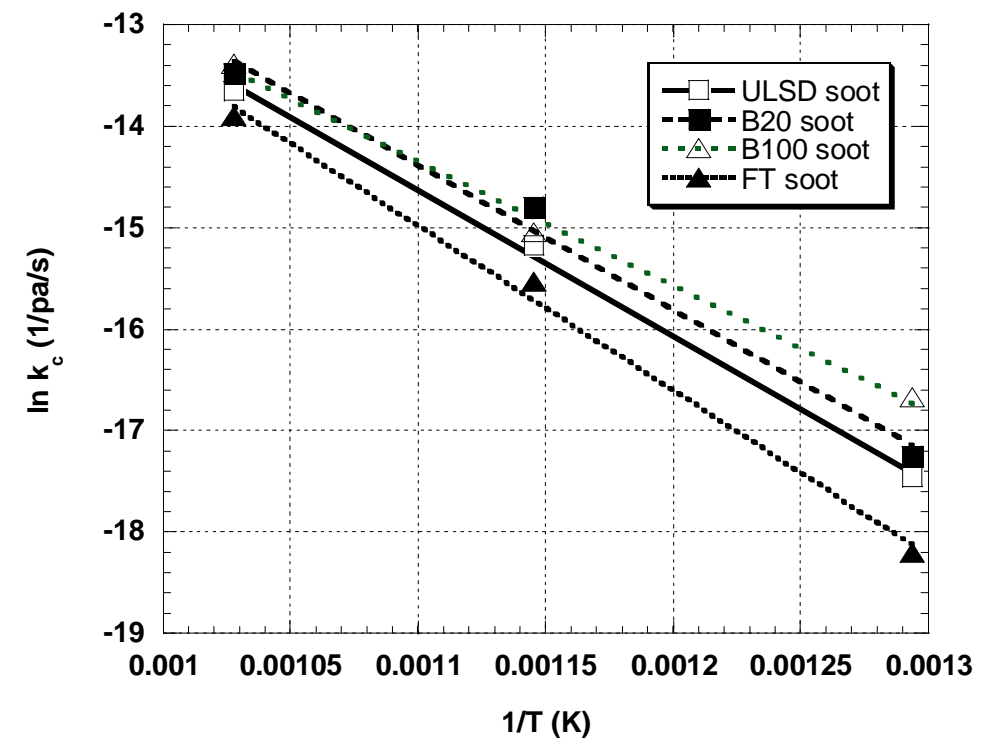

(b)

Figure 3.3.73 (a) Exponential curve fit (straight line) to raw curve (dotted line) at $500^{\circ} \mathrm{C}$, (b) Arrhenius plot of apparent rate constant of soot-air reaction, reduced from isothermal oxidation data measured at 3 different temperatures. 
Table 3.3.14 Comparison of kinetic parameters for all soot samples

\begin{tabular}{|c|c|c|c|c|}
\hline Soot & $\begin{array}{c}\text { Frequency } \\
\text { Factor, } \mathrm{A}_{\mathrm{f}} \\
\left(\mathrm{Pa}^{-1} \mathrm{sec}^{-1}\right)\end{array}$ & $\begin{array}{c}\text { Activation } \\
\text { Energy,Ea } \\
(\mathrm{kJ} / \mathrm{mol})\end{array}$ & $\begin{array}{c}\text { Rate Constant, } k_{c} \\
\text { at } 500{ }^{\circ} \mathrm{C} \\
(1 / \mathrm{Pa} / \mathrm{sec})\end{array}$ & $\begin{array}{c}\log k_{c}(1 / \mathrm{sec}) \\
\text { at } 10 \mathrm{kPa}\end{array}$ \\
\hline ULSD & 3.24 & 119.5 & $2.6 \times 10^{-8}$ & -3.58 \\
\hline B20 & 3.69 & 118.6 & $3.2 \times 10^{-8}$ & -3.49 \\
\hline B100 & 0.44 & 102.3 & $5.7 \times 10^{-8}$ & -3.24 \\
\hline FT & 18.23 & 135.1 & $1.2 \times 10^{-8}$ & -3.91 \\
\hline
\end{tabular}

In order to check differences in ignition temperature for all of the soot samples, temperature programmed oxidation (TPO) was performed using TGA. As shown in Figure 3.3.74, the TPO measurements show no significant difference in ignition temperature between all the samples. For instances, B100 shows a lower ignition temperature than ULSD and B20 soot by only $10{ }^{\circ} \mathrm{C}$, while FT soot has higher ignition temperature than ULSD soot by only $5{ }^{\circ} \mathrm{C}$. This difference is not statistically significant. Furthermore, this similarity in ignition behavior is consistent with negligible difference in activation energy determined from isothermal TGA.

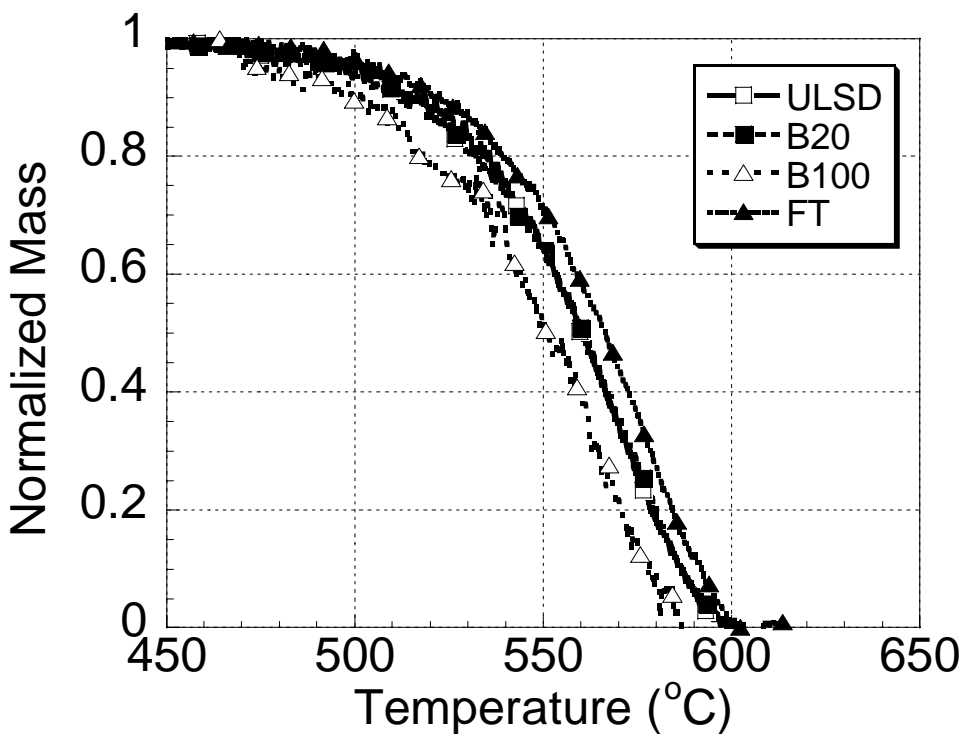

Figure 3.3.74 Mass reduction TGA curve for soot samples obtained from various test fuels. 


\subsection{Initial Nanostructure}

As the first structural parameter considered, initial soot nanostructure such as graphene layer size, curvature and arrangement was visualized by HRTEM imaging. Unlike other samples, these were collected on TEM grids via thermophoretic sampling. Comparison of Figure 3.3.75 (a) through (d) shows a typical shell-core structure for both FT and B100 soots, where long-range layers are concentrically arranged along the periphery and short layers are amorphously arranged inside the core [54]. There is slightly less order for ULSD and an extremely amorphous arrangement of short range and defective layers for B20 soot. Fullerene like soot was not observed for any samples even though some portion of the soot generated from flames $[55,56]$ and the latest diesel engines $[57,58]$ have often been reported to exhibit a fullerenic structure in HRTEM imaging.

To overcome the limitation of HRTEM imaging associated with probing a nanoscale area, Raman spectra were measured with irradiation probe size of $1 \mu \mathrm{m}$. All samples have a defect band called the "D" band at $1354 \mathrm{~cm}^{-1}$ and a graphitic band called the " $G$ " band at $1598 \mathrm{~cm}^{-}$Special focus is placed on the relative $D$ band to $G$ band intensity, which is related to the size and (physical and chemical) defects in the basal plane of individual graphene layers $[59,60]$. For quantification of the $I_{d} / I_{g}$ ratio, raw spectra for each sample were normalized to the intensity of the $G$ band and then curve-fit with a multipeak Lorentzian function available in the curve fitting software. Finally, fitted curves were deconvoluted into three individual curves for display, as shown in Figure 3.3.76. The parameters such as height and band width determined for each peak were used to obtain the $I_{d} / I_{g}$ ratio by using the expression in Eqn. 3.3.4. For validation of the Raman measurement, graphite was used as reference material which has a D band at $1354 \mathrm{~cm}^{-1}$ and $G$ band at $1583 \mathrm{~cm}^{-1}$ and for which the $\mathrm{G}$ band is shifted slightly compared to the $1598 \mathrm{~cm}^{-1} \mathrm{G}$ band of the soot samples. This gives the lowest $I_{d} / I_{g}$ ratio of 0.37 for graphite, indicating a long range and straight nature for the graphene layers in graphite.

$$
\begin{aligned}
& I=A+\frac{B_{0}}{\left(x-x_{0}\right)^{2}+\Gamma_{0}^{2}}+\frac{B_{1}}{\left(x-x_{1}\right)^{2}+\Gamma_{1}^{2}}+\ldots \ldots . . \\
& \text { where } \quad A \text { : Background, } \quad B \text { : height, } \quad x_{0} \text { :peak position, } \Gamma_{0}: \text { FWHM } \\
& \text { so, } \quad I_{0}=\frac{B_{0}}{\Gamma_{0}^{2}}, \quad I_{1}=\frac{B_{1}}{\Gamma_{1}^{2}}
\end{aligned}
$$

For the soot samples, the $I_{d} / I_{g}$ increases from the lowest number of 1.08 for B100 soot, to 1.18 for FT and to 1.20 for ULSD soot, indicating a trend to a less ordered structure that has smaller size layers and more defective layers. This structural variation is similar to that observed in the HRTEM images. But, this difference is within an experimental error of \pm 0.05 , implying statistically insignificant variation between B100, ULSD and FT soot. In contrast, the qualitative impression for B20 soot which has the least graphitic structure in the HRTEM image is clearly supported by the highest $I_{d} / I_{g}$ ratio of 1.28 in the Raman spectra.

As the second structural parameter measurement, the number of stacking of graphene layers along $\mathrm{c}$ axis is measured by 002 peak via XRD and further quantified in the manner described in the Experimental section. Figure 3.3.77 shows an increase in stacking order for both B100 and FT soot compared to ULSD and B20 soot. This range between 10 14 for all the samples is much higher than that of 4.6 5.8, which was reported for diesel soot [61] and paraffinic hydrocarbon soot $[62,63]$, while this is still lesser than 14 for a diesel soot found in ref. [64]. A strain effect may be one source of this deviation since it is more likely to skew the XRD pattern as described in ref. $[65,66]$. Nonetheless, this range may be not only consistent with the observations in HRTEM images, but relative differences between soot samples from XRD results are also discernable in the HRTEM images. For 
a better consistency, 1.3 was chosen as the scherrer constant rather than 0.9 that has been invariably used for many carbonaceous materials [67].

In relating these initial parameters to the oxidation rate, there is no correlation found. For example, the similar structural parameters for FT and B100 soot do not help to explain the significant 5 fold difference in oxidation rate. Second, if this initial structure is the only factor governing the oxidation rate, then B20 soot with its short, amorphous, less stacked tendency should have the fastest oxidation rate, yet it does not. Therefore, this suggests that there is no definitive impact of initial nanostructure on soot oxidation rate. This observation differs from what Vander Wal and Tomasek demonstrated $[37,68]$.
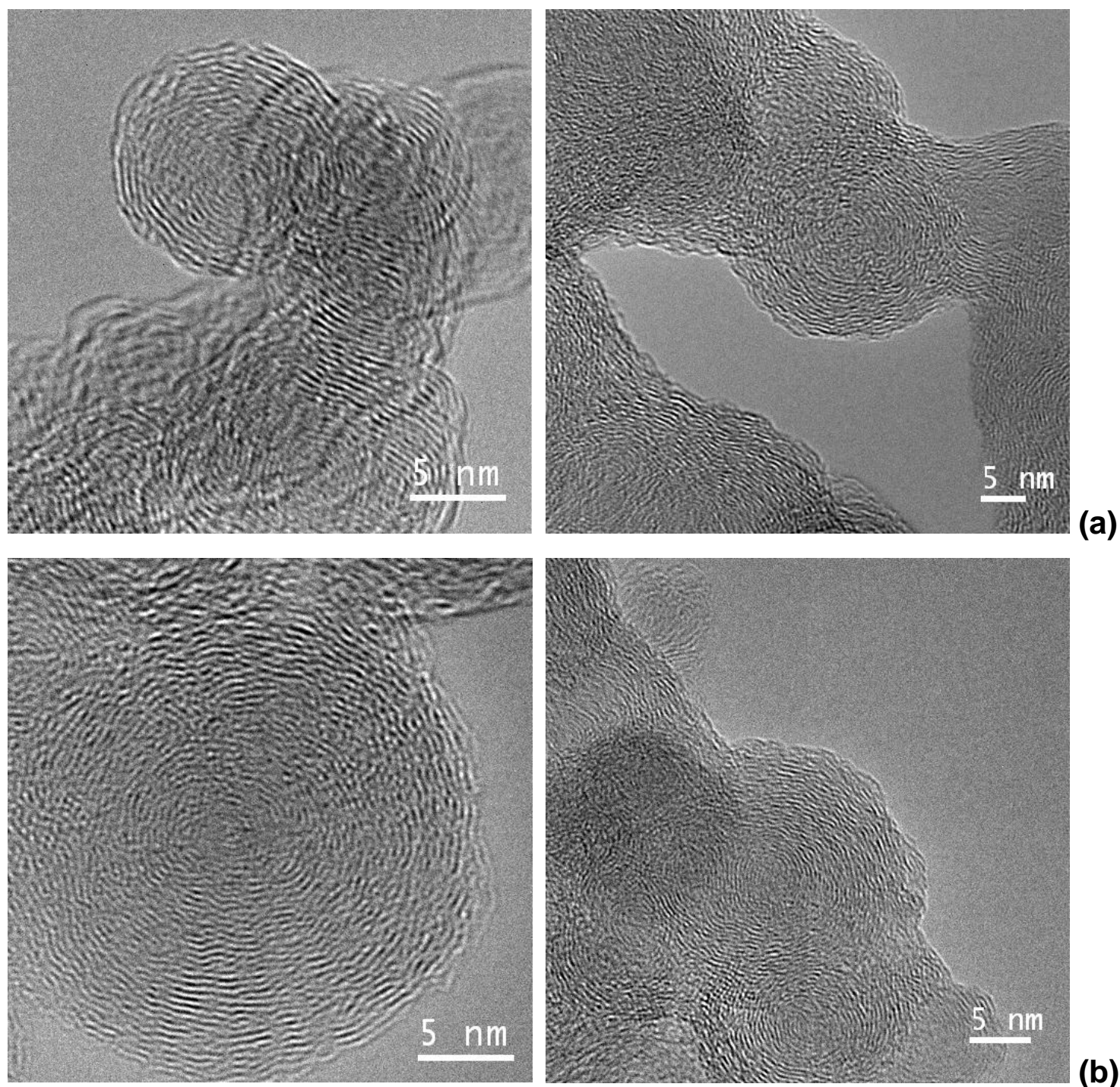

(b) 

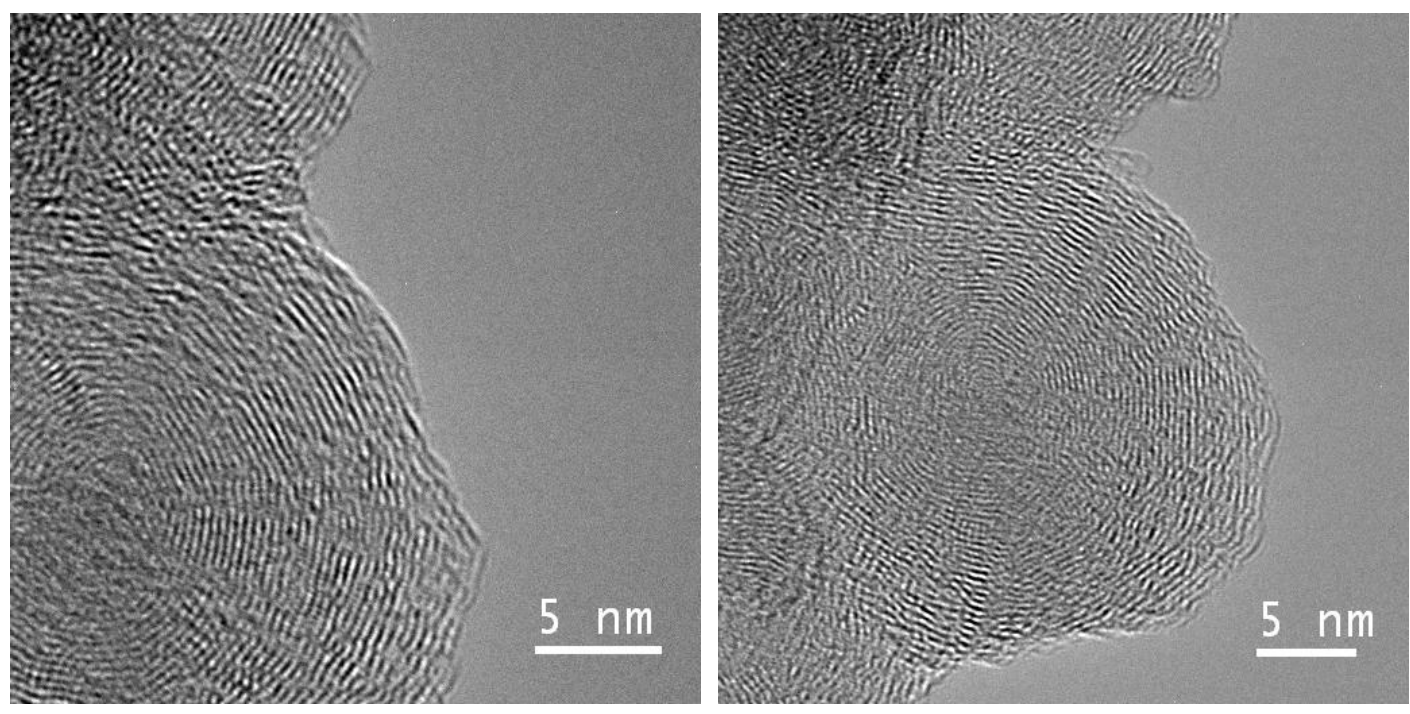

(c)
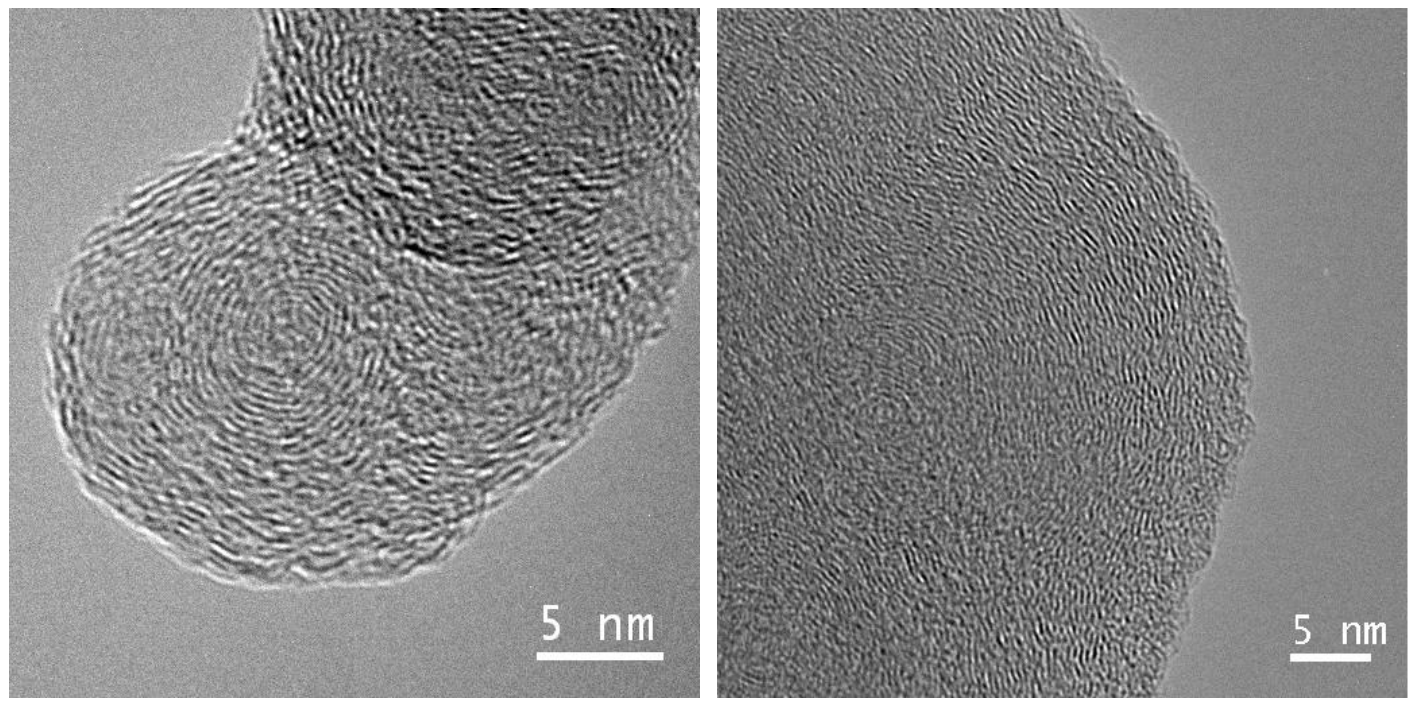

(d)

Figure 3.3.75 HRTEM imaging between various soot samples (a) B100; (b) FT; (c) ULSD; (d) B20 soot, indicating no significant variation in initial nanostructure between B100, FT and ULSD soot while extremely amorphous arrangement of short range and defective layer for B20 soot. 


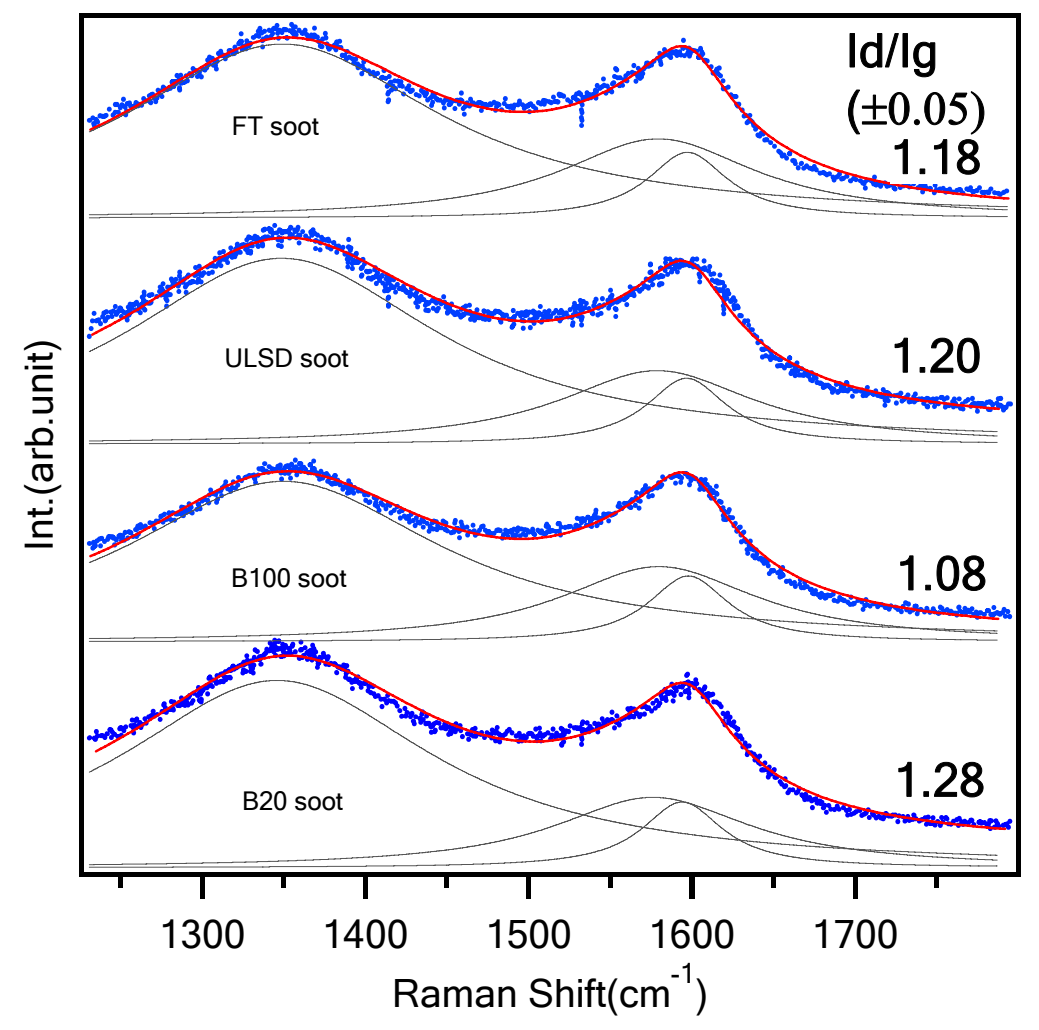

\begin{tabular}{|c|c|c|c|}
\hline Samples & D band $\left(\mathrm{cm}^{-1}\right)$ & $\mathrm{G}$ band $\left(\mathrm{cm}^{-1}\right)$ & $\mathrm{I}_{\mathrm{d}} / \mathrm{I}_{\mathrm{g}}$ \\
\hline B100 & 1354 & 1598 & 1.08 \\
\hline FT & 1354 & 1598 & 1.18 \\
\hline ULSD & 1354 & 1598 & 1.20 \\
\hline B20 & 1354 & 1598 & 1.28 \\
\hline
\end{tabular}

Figure 3.3.76 Micro-Raman Spectra for all samples of initial stage 


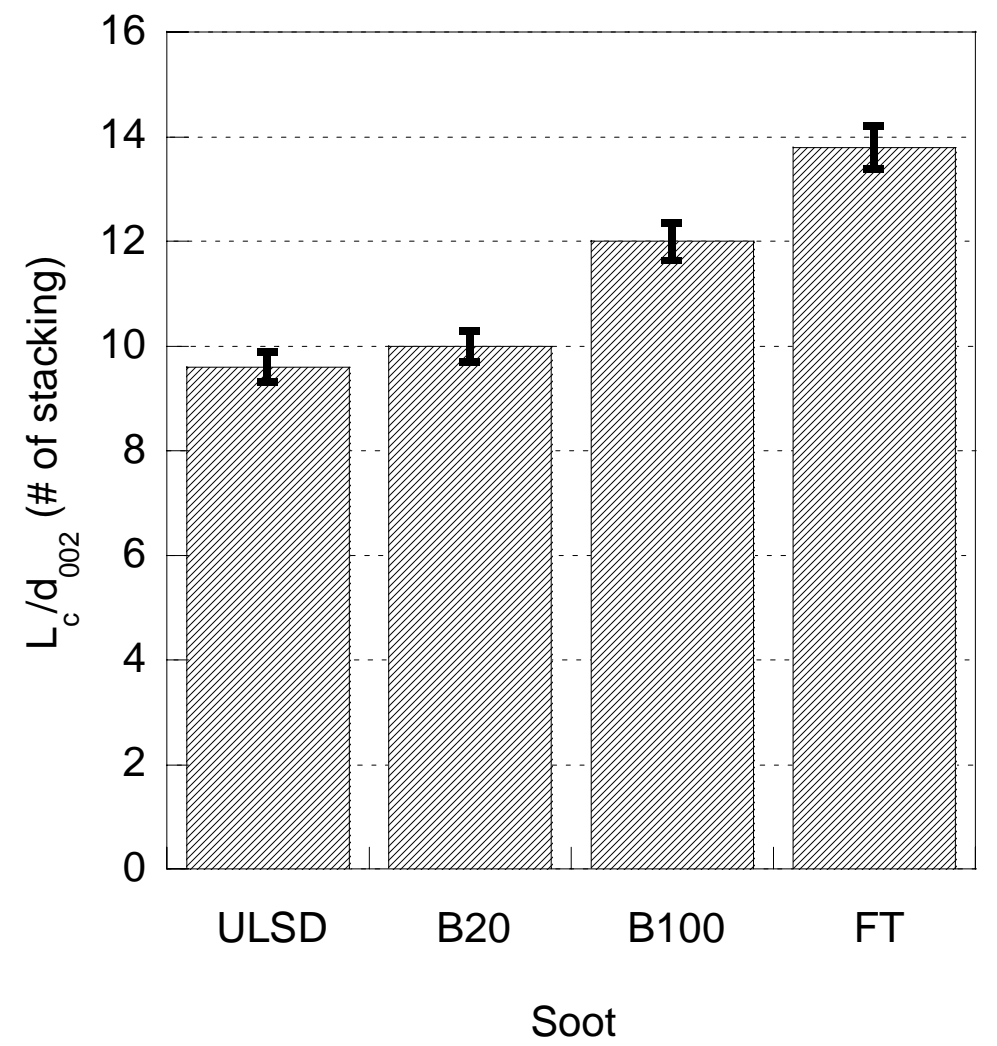

Figure 3.3.77 002 peak of XRD indicating higher stacking order for both B100 and FT soot than ULSD and B20 soot.

\subsection{Structural Changes During Early Oxidation}

Continuing to find important factor that govern oxidative reactivity, the structural changes after the $30 \mathrm{~min}$ of oxidation were investigated. Consideration was restricted to two soot samples, B100 and FT soots, which exhibit a large difference in oxidation rate. From the HRTEM images in Figure 3.3.78, comparison of the initial FT soot (a) and oxidized FT soot (b) indicates little structural change especially at the outer periphery, as revealed by only $5 \%$ defect band increase in the Raman spectra in Figure 3.3.80 (a). Comparison of the initial B100 soot in Figure 3.3.79 (a) and the oxidized B100 soot in (b) indicates drastic structural changes, as revealed by a $60 \%$ defect band increase in the Raman spectra in Figure 3.3.80 (b). This clearly indicates B100 soot's tendency toward a less ordered arrangement with short and defective graphene layers during the early stage of oxidation. 

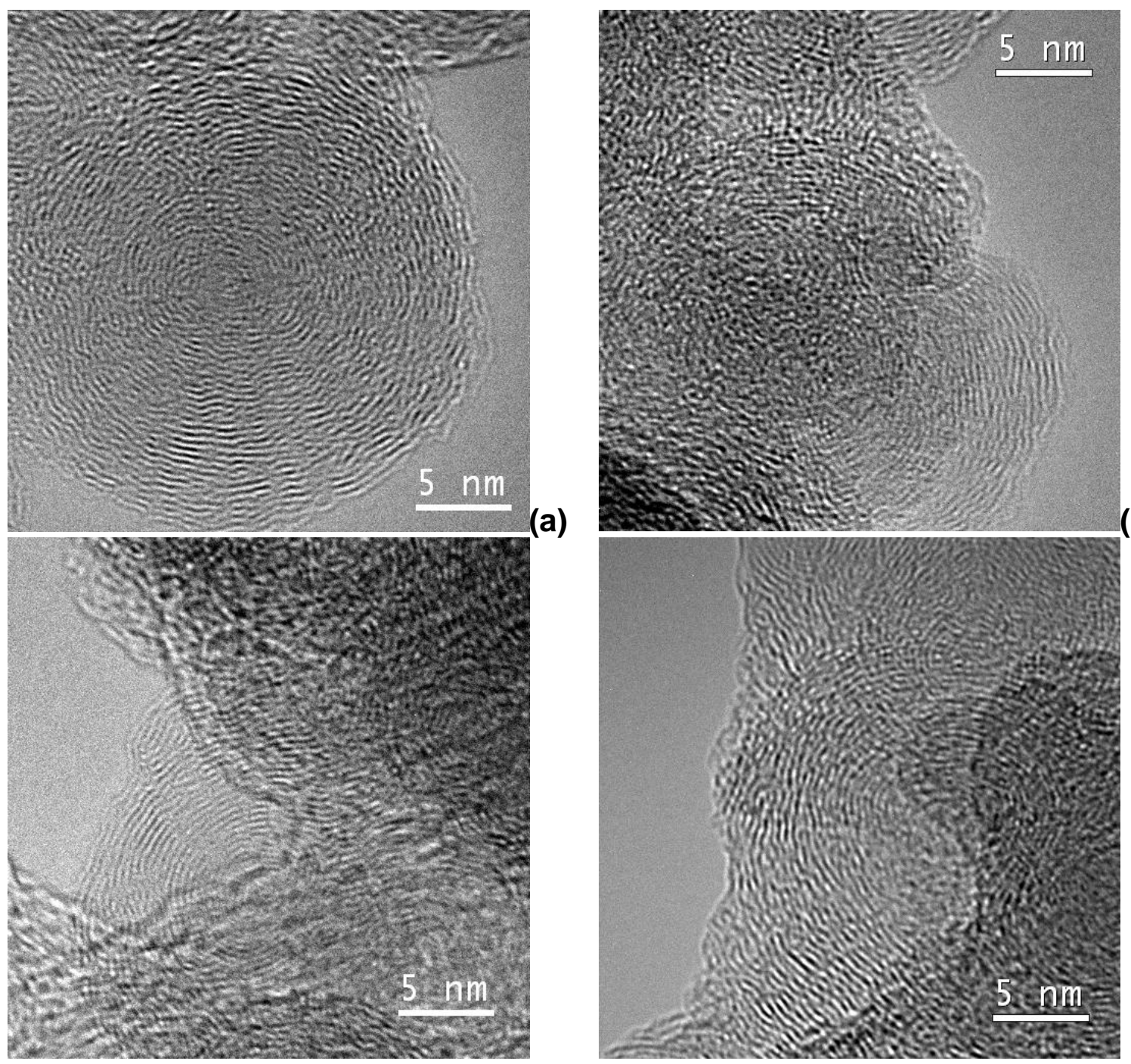

(b)
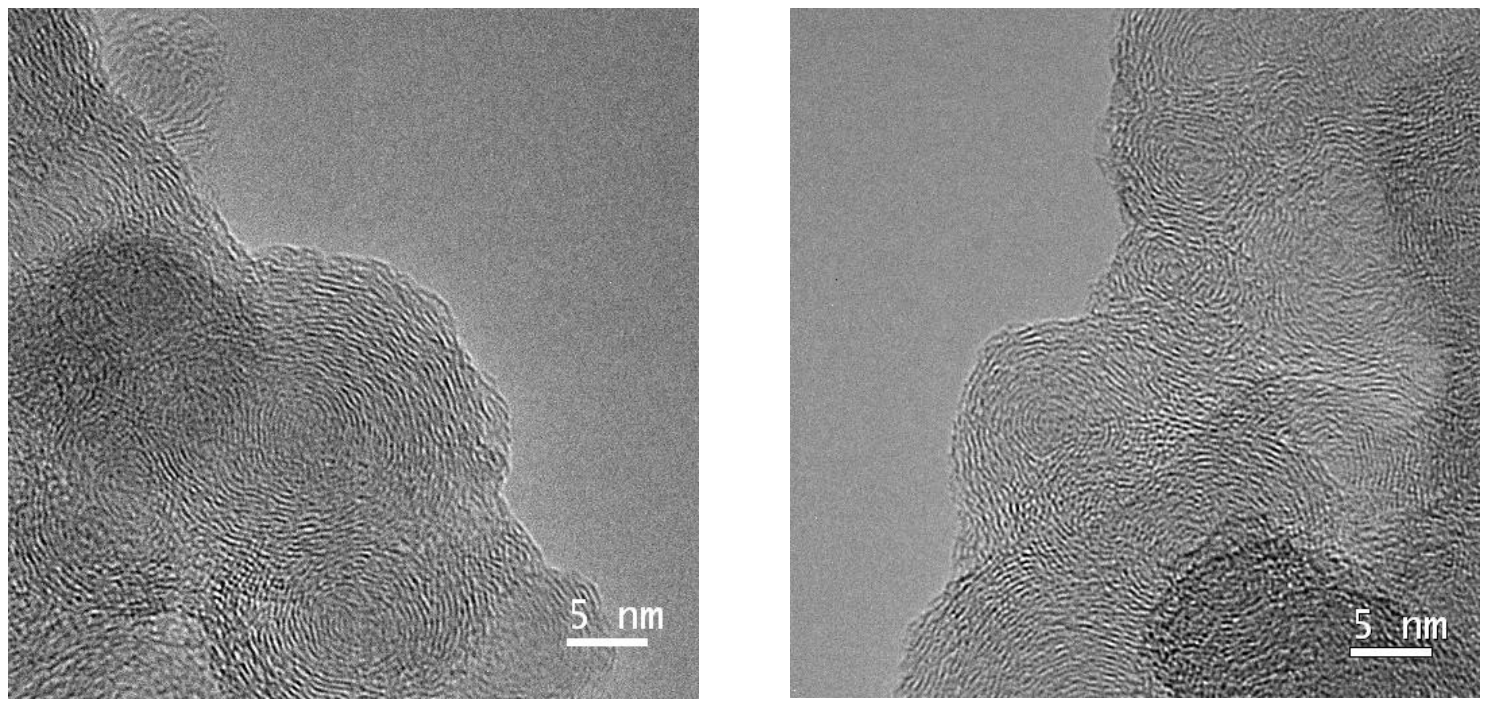

Figure 3.3.78 Comparison of (a) initial FT soot; (b) oxidized FT after 30 min oxidation (20 wt\% burn off), indicating little structural change especially at outer periphery 

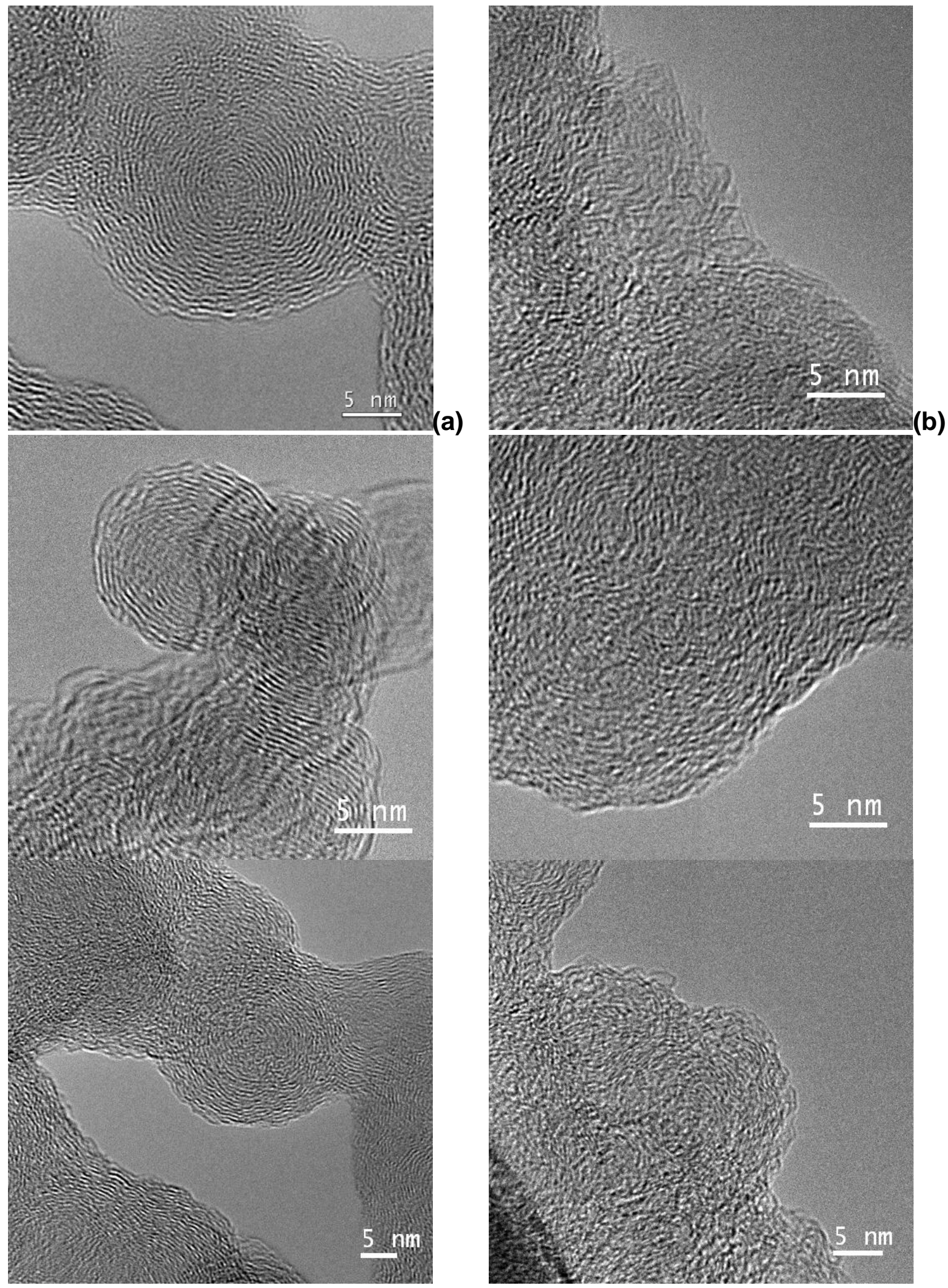

Figure 3.3.79 Comparison of (a) initial B100 soot; (b) oxidized B100 after 30 min oxidation (40 wt\% burn off), indicating a drastic structural change in B100 soot 


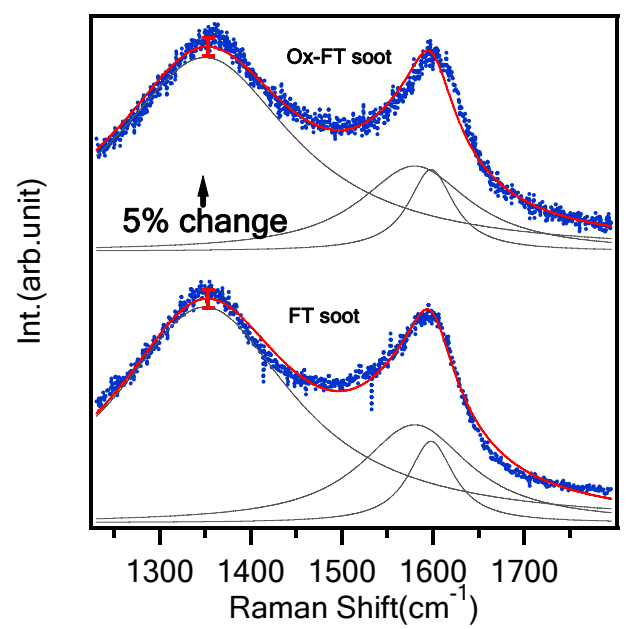

(a)

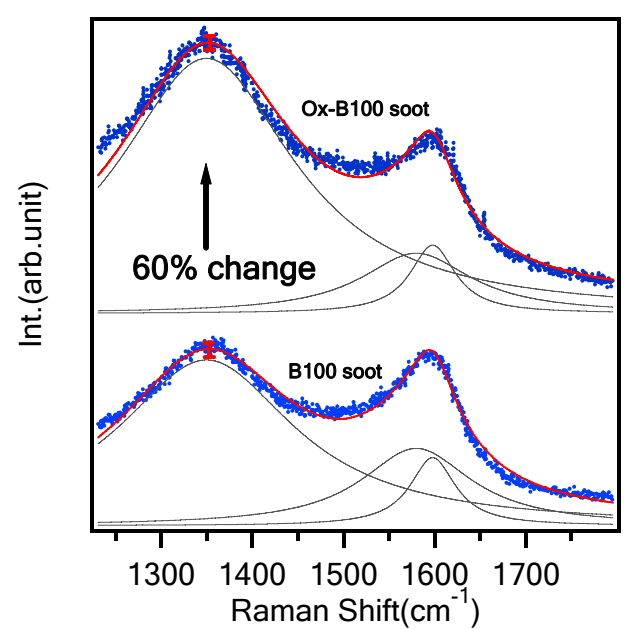

(b)

Figure 3.3.80 Defect band change of Raman Spectra indicating (a) only 5\% change for FT soot (b) a drastic change of $60 \%$ in inner structure for B100 soot

In electron energy loss spectra (EELS), excitation of core 1s electrons of carbon atoms can produce two peaks, a $\pi$ graphitic peak at $285 \mathrm{eV}$ and a $\pi+\sigma$ peak at $293 \mathrm{eV}$ seen in Figure 3.3.81 (a). The presence of the $\pi$ graphitic peak and the relative ratio of the $\pi$ peak to the other peak is related to the degree of graphitization, since the $\pi$ peak is more pronounced due to the popularity of shared $\pi$ electrons for carbons within a long-range graphitized layer. The EELS measurement comparison in Figure 3.3.81 (a) shows the prominent presence of a graphitic peak for the oxidized FT soot and its absence for the oxidized B100 soot. This behavior of the oxidized FT soot is also supported by another peak, called the $\pi-\pi$ shoulder, in the zero and low loss spectra between zero and $50 \mathrm{eV}$ on the far left hand of the Figure 3.3.81 (a), since the disappearance of this peak is observed for oxidized B100 soot. The percentage change of the relative ratio of these two peaks in Figure 3.3 .81 (b) shows only a $2 \%$ change for FT soot and a $26 \%$ change for B100 soot, confirming the previously indicated far greater structural change in B100 soot during early oxidation.

Another comparison of the 002 diffraction contrast images between the two oxidized samples provides further evidence of the previously indicated far greater structural change for B100 soot. From the bright field (BF) image constructed by phase contrast in the left column of Figure 3.3.82 lectron beam was aligned to produce the corresponding 002 dark field (DF) image in right column of the same figure, which is constructed by diffraction contrast. Although comparison of the BF image did not show a significant difference in morphology, a comparison of the DF image with diffraction pattern (DP) inset reveals a slight difference in the spot intensity inside the primary particle and the intensity of outer two rings (i.e.,100 and 110 diffraction) from the DP between the two samples. Oxidized FT soot in (a) still has a quite bright spot inside the primary particle, while a much less bright spot is apparent for the oxidized B100 soot in (b) This observation is additional evidence of a greater inner structural change for B100 soot during oxidation. The weaker intensity is related to the presence of turbostratic structure and imperfect arrangement of the graphene layers in the direction normal to the graphene layers. It is believed that inner structure change can easily lead to a prevalence of this arrangement during oxidation. This difference in intensity of the DF image is similar to observations of differences in spot intensity between ordered and less ordered phases of mesophase materials, such as petroleum pitch during a carbonization process $[69,70,71]$.

However, the observed difference may not truly reflect information about the stacking order of the graphene layers with neighboring layers, since sample thickness is another parameter that can contribute to spot intensity [72]. In the present case, no attempt to control sample thickness for the 
two samples was made. In addition, great care should be taken to keep both the incident beam intensity irradiated and the exposure time the same for all samples. Otherwise, any difference in both intensity of the DP rings and the DP image can be attributed to differences in the operation of the TEM. For this reason, the DP image and its corresponding 002 DF image technique may not be the best method to determine the degree of arrangement of the graphene layers between the soot samples unless the above two parameters that affect spot intensity are properly controlled.
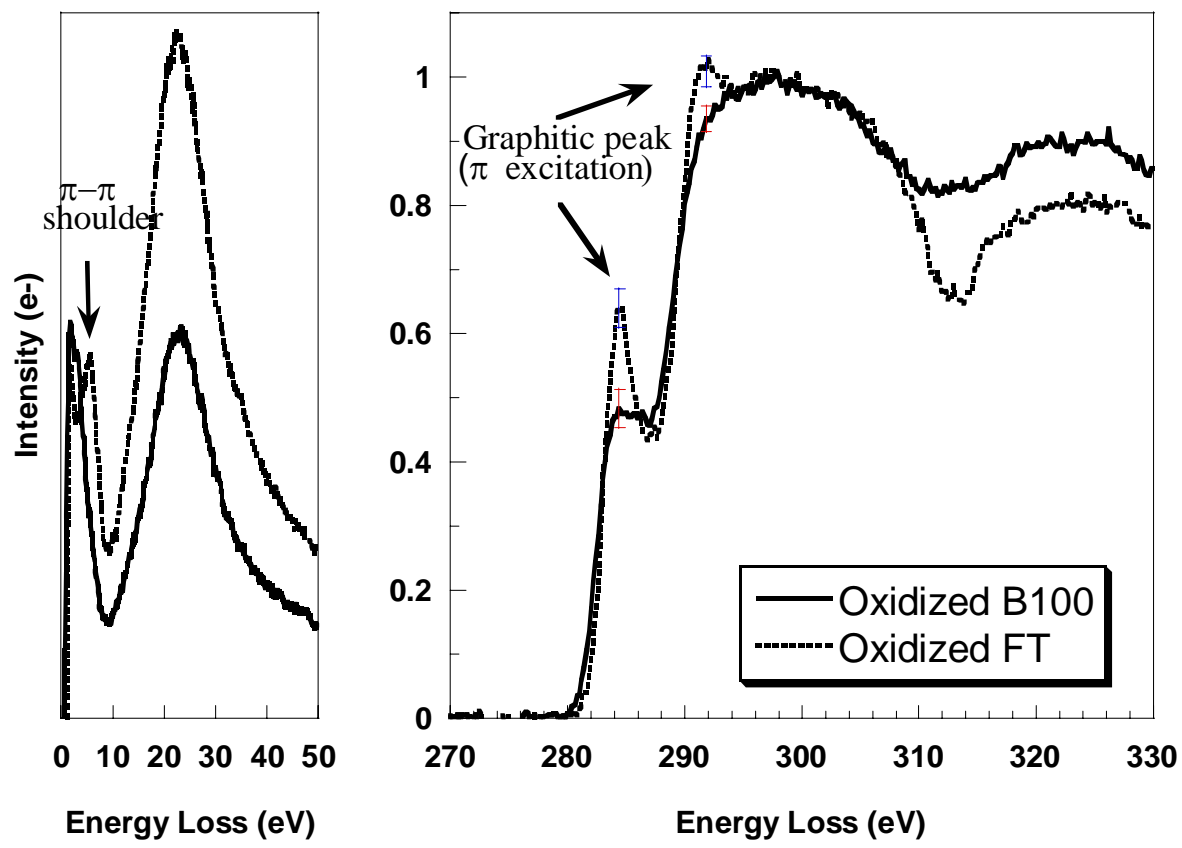

(a)

\begin{tabular}{|c|c|c|c|}
\hline Soot & Before & After & \%Change \\
\hline FT & 0.642 & $0.610( \pm 0.03)$ & -2 \\
\hline B100 & 0.650 & $0.489( \pm 0.03)$ & -26 \\
\hline
\end{tabular}

(b)

Figure 3.3.81 $\mathrm{I}_{\pi} / \mathrm{I}_{\sigma}$ peak ratio of EELS indicating graphitic peak absence in B100 oxidized soot (a) and its greater structure change than FT soot in (b) 

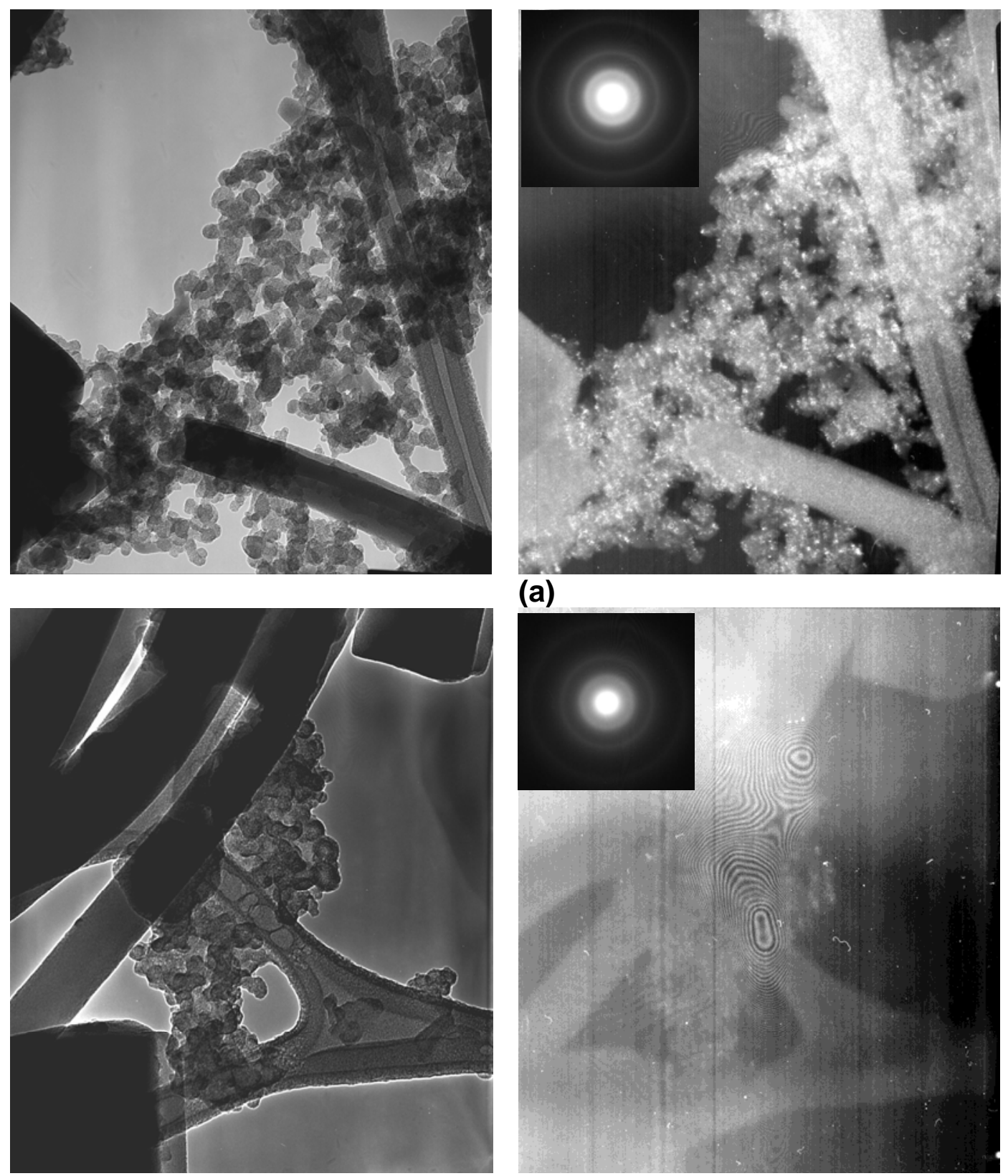

(b)

Figure 3.3.82 Comparison of BF (phase contrast) in left and 002 DF image (diffraction contrast) in right (a) oxidized FT at $30 \mathrm{~min}$ of $500{ }^{\circ} \mathrm{C}$, (b) oxidized B100 at 30 min of $500{ }^{\circ} \mathrm{C}$, indicating much lesser bright spot in oxidized B100 soot associated with a greater structure change of B100 soot.

Motivated by these finding about the B100 and FT soot samples, the oxidation rate was further correlated with the \%change of two of the structural parameters for all four soot samples. First, Figure 3.3.83 (a) presents Raman spectra obtained for all soot samples after oxidation for 30 minutes. From these raw spectra, the $\mathrm{I}_{\mathrm{d}} / \mathrm{I}_{\mathrm{g}}$ ratio was determined in the same manner as for the initial samples and is summarized in Figure 3.3.83 (b). Then, the \% change of this ratio was plotted against oxidation rate for all the soot samples in Figure 3.3.83 (c). By inference from the linear correlation between the rate constant and the \%change of $\mathrm{I}_{\mathrm{d}} / \mathrm{I}_{\mathrm{g}}$ ratio, soot that becomes easily disordered such as B100 soot is likely to display an enhanced oxidation rate. 
Layer size $\left(L_{a}\right)$ was also predicted by using an empirical relation between $I_{d} / l_{g}$ and layer size that fit to various carbon materials by Tuinstra et al. [73].

$$
L_{a}=C \cdot \frac{1}{\frac{I_{d}}{I_{g}}} \quad \text { where } C \sim 4.4 \mathrm{~nm}
$$

Results for the initial and oxidized samples are given in Table 3.3.15. For the initial samples, the difference of La (about $0.2 \mathrm{~nm}$ ) between B100, ULSD and FT soot is not significant, as was already observed in the HRTEM images. The average La over these three samples is $3.9 \mathrm{~nm}$, which lies between the highest length of $5.5 \mathrm{~nm}$ reported by Lee et al. [74] and the smallest length of $2.2 \mathrm{~nm}$ reported by Ighiguro [38]. For oxidized samples, a difference of La $(1.16 \mathrm{~nm})$ especially between oxidized FT soot and oxidized B100 soot is similar to the variation in the corresponding HRTEM images. As mentioned before, the 100 or 110 peak from XRD can give a complementary information about this layer size (La), but it was impossible to separate the 100 peak for the soot samples from the much stronger 200 peak for the platinum sample holder used in the hot stage XRD.

Figure 3.3.84 (a) illustrates the example of B20 soot for which XRD profiles were obtained at three different times during oxidation (i.e. initial, $30 \mathrm{~min}$ and $120 \mathrm{~min}$ ). Figure 3.3.84 (a) shows that the position of the 002 peak is shifted to a higher angle as oxidation proceeds. This shift to a higher angle can be interpreted as a trend toward narrower 002 layer spacing $\left(d_{002}\right)$, since $d$ spacing is inversely proportional to the diffraction angle $\left(\lambda=2 d \cdot \sin \left(\theta_{p}\right)\right)$ from XRD theory, called Bragg's law $[75,66]$. This shift was observed for all the samples except for B100 soot. From this raw spectra, curve fitted spectra were determined using curve fit software as shown in Figure 3.3.84 (b) through (e) and fitting parameters such as the 002 peak position and the full width at half magnitude (FWHM) were extracted. Unlike other samples, B100 could not give any signal for the 002 peak even at 30 min oxidation due to the faster oxidation observed in the TGA experiment. Therefore, this observation clearly supports the enhanced oxidation behavior of B100 soot with the various oxidation apparatus such as TGA. This also confirms the amorphous arrangement of B100 soot observed in the HRTEM image.

Using these parameters, the crystallite size $\left(L_{c}\right)$ was calculated through the empirical Scherrer expression available in the literature.

$$
L_{c}=\frac{A_{s} \cdot \lambda}{\varpi \cdot \cos \left(\theta_{p}\right)}
$$

where $A_{s}$ : constant(1.31), $\lambda$ : wave length (1.54 $\AA$ ), $\theta_{p}$ : 002 peak position, $\omega$ : FWHM

As summarized in Figure 3.3.85 (a), this shows a general trend of increasing crystallite size, except for B100 soot, during early oxidation from initial to 30 minutes. This is consistent with other's observations on structural ordering in the direction normal to the graphene layer $[76,65,77]$. By dividing the crystallite size $\left(\mathrm{L}_{c}\right)$ by the layer spacing $\left(\mathrm{d}_{002}\right)$, the number of stacking of the graphene layers in the direction normal to the graphene layers was determined. Then, the \% change of the number of stacking order during 30 minute oxidation was plotted against the oxidation rate for all the soot samples and is shown in Figure 3.3.85 (b). Inferred from the exponential correlation from the rate constant and the \%change of stacking order, soot that is less stacked such as B100 soot is likely to have a higher oxidation rate. 


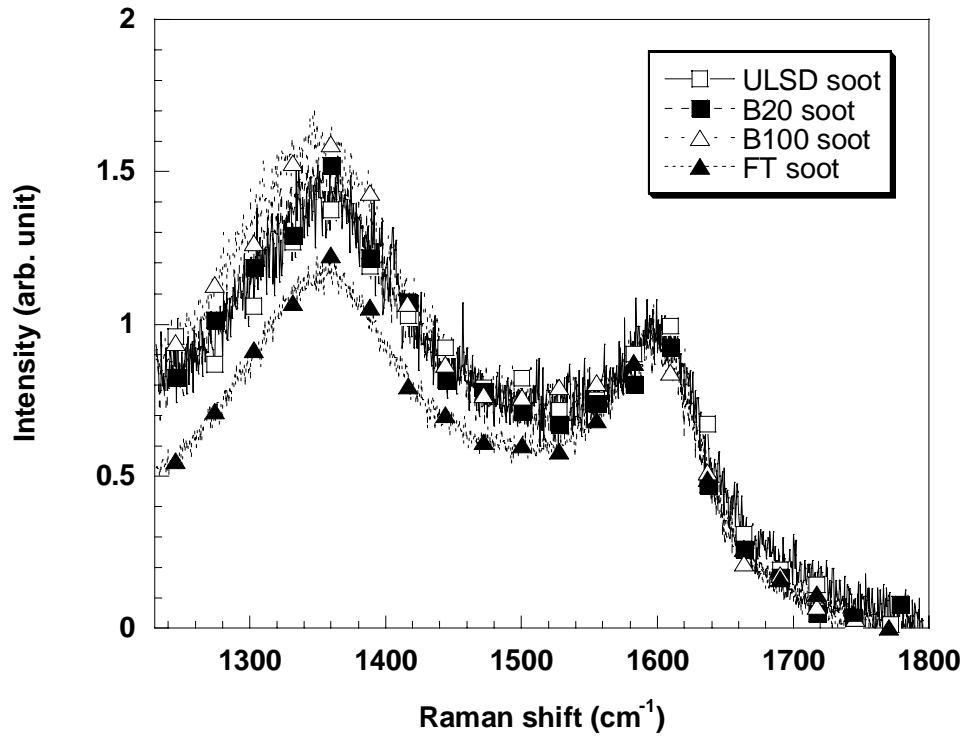

(a)

\begin{tabular}{|c|c|c|c|c|}
\hline Sample & $\mathrm{I}_{\mathrm{d}} / \mathrm{I}_{\mathrm{g}}$ Before & $\mathrm{I}_{\mathrm{d}} / \mathrm{I}_{\mathrm{g}}$ After & $\begin{array}{c}\text { Change }(\%) \\
\text { to disorder }\end{array}$ & $\begin{array}{c}\text { Rate constant at } \\
500{ }^{\circ} \mathrm{C}(1 / \mathrm{Pa} / \mathrm{s})\end{array}$ \\
\hline ULSD soot & 1.11 & 1.36 & 23 & $2.6 \mathrm{E}-08$ \\
\hline B20 soot & 1.18 & 1.53 & 30 & $3.2 \mathrm{E}-08$ \\
\hline B100 soot & 1.06 & 1.69 & 60 & $5.7 \mathrm{E}-08$ \\
\hline FT soot & 1.12 & 1.17 & 5 & $1.2 \mathrm{E}-08$ \\
\hline
\end{tabular}

(b)

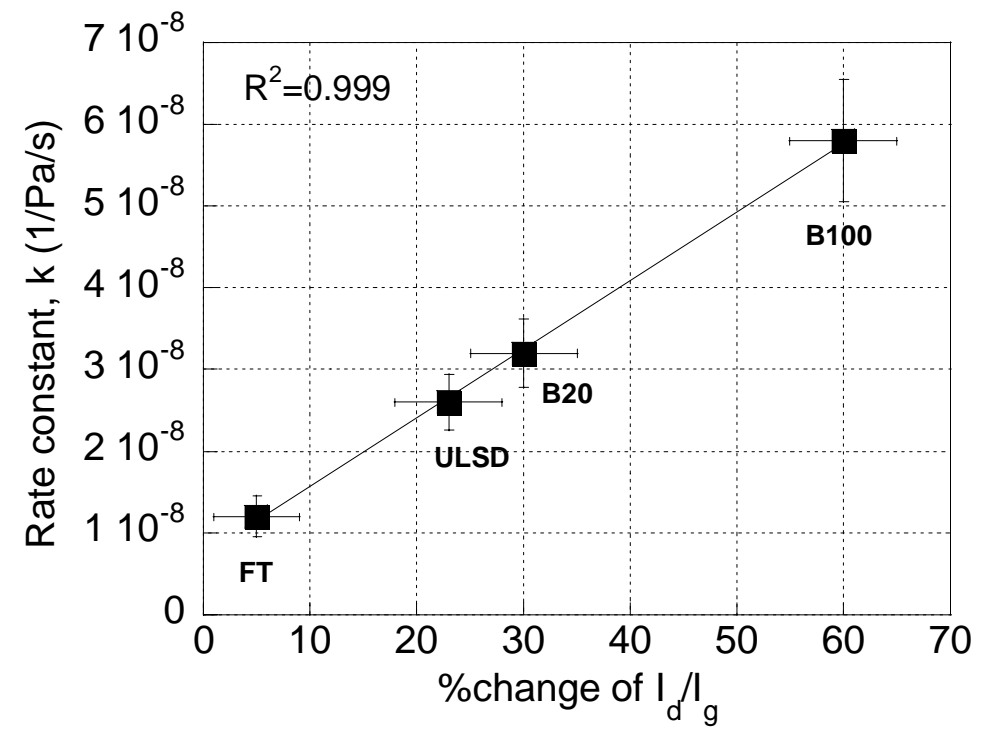

(c)

Figure 3.3.83(a) Raman spectra after 30 min oxidized at $500{ }^{\circ} \mathrm{C}$, (b) Calculation of $\mathrm{I}_{\mathrm{d}} / \mathrm{lg}$ ratio, (c) correlation between rate constant and \%change to disorder, indicating soot that becomes easily disordered such as B100 soot is likely to enhance an oxidation 
Table 3.3.15 Prediction of graphene layer size (La)

\begin{tabular}{|c|c|c|c|c|}
\hline Sample & $I_{d} / I_{g}$ Before & $\begin{array}{c}\text { La (nm) } \\
\text { Before }\end{array}$ & $I_{d} / I_{g}$ After & La (nm) After \\
\hline ULSD soot & 1.11 & 3.96 & 1.36 & 3.24 \\
\hline B20 soot & 1.18 & 3.73 & 1.53 & 2.88 \\
\hline B100 soot & 1.06 & 4.15 & 1.69 & 2.60 \\
\hline FT soot & 1.12 & 3.93 & 1.17 & 3.76 \\
\hline
\end{tabular}

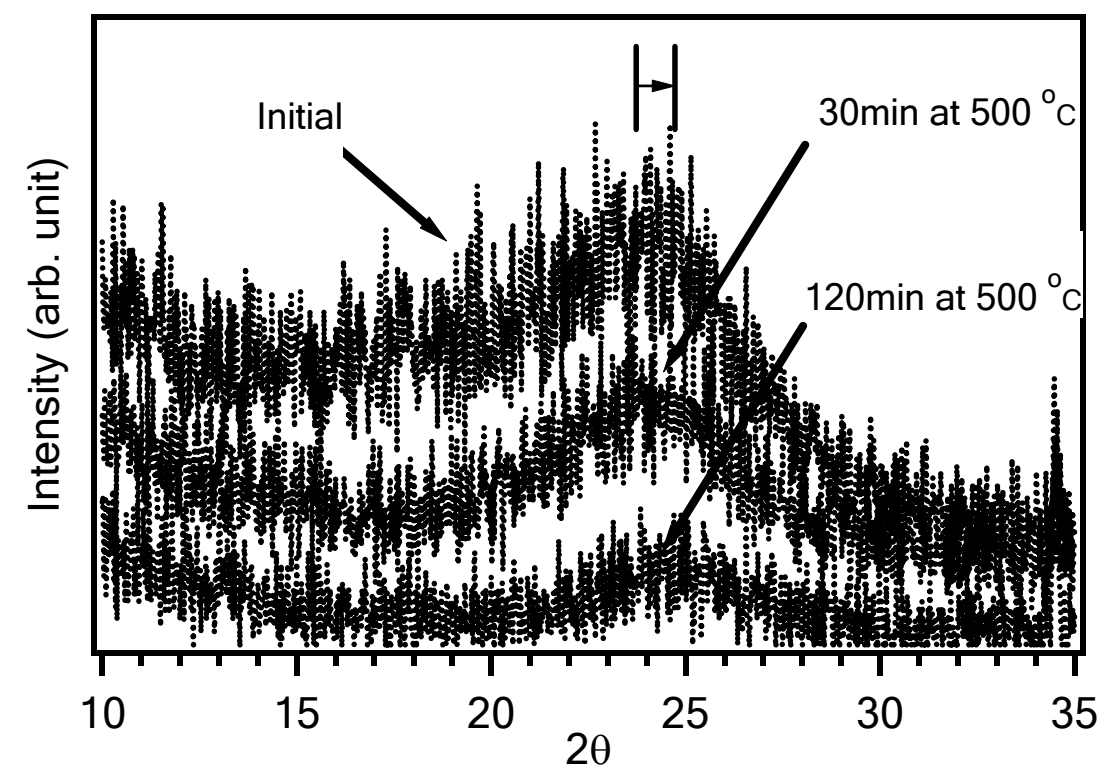

(a) 


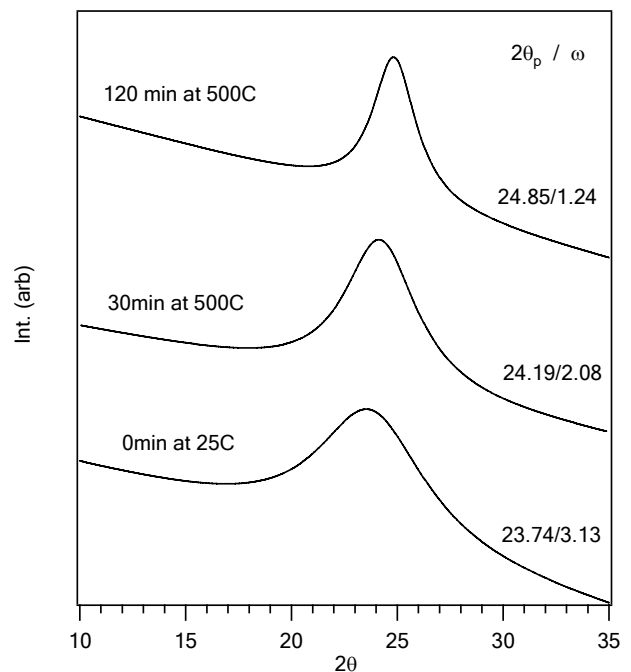

(b)

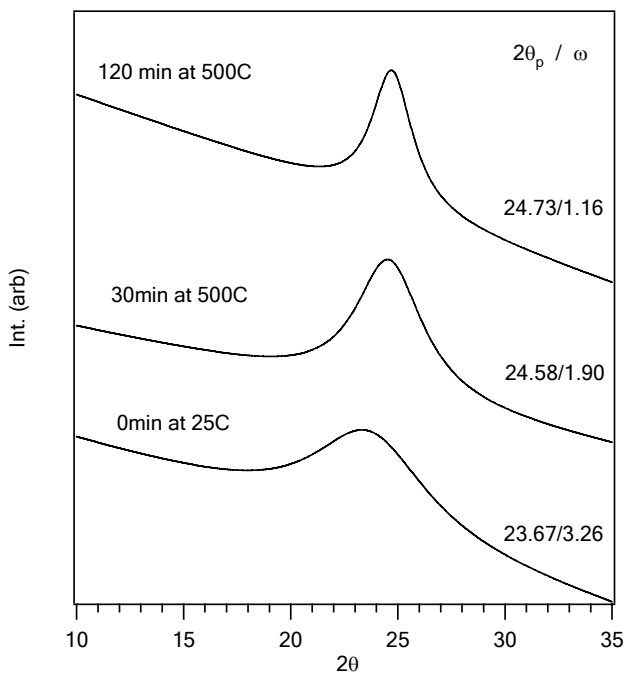

(d)

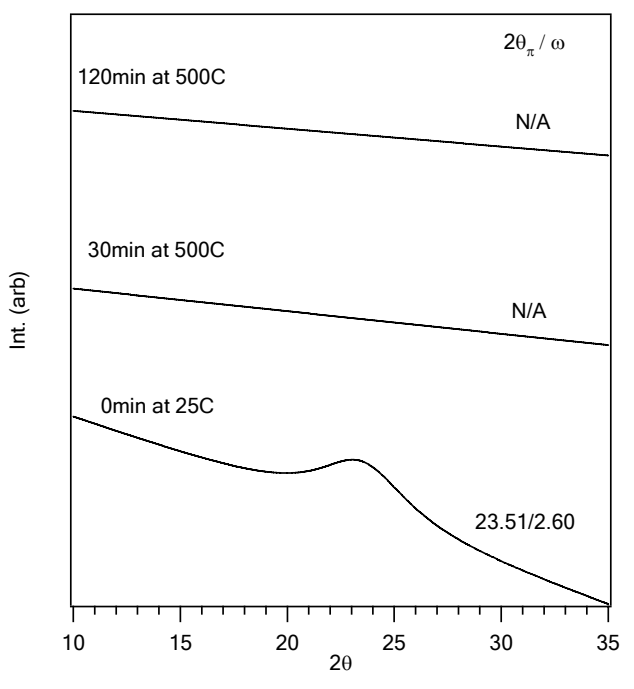

(c)

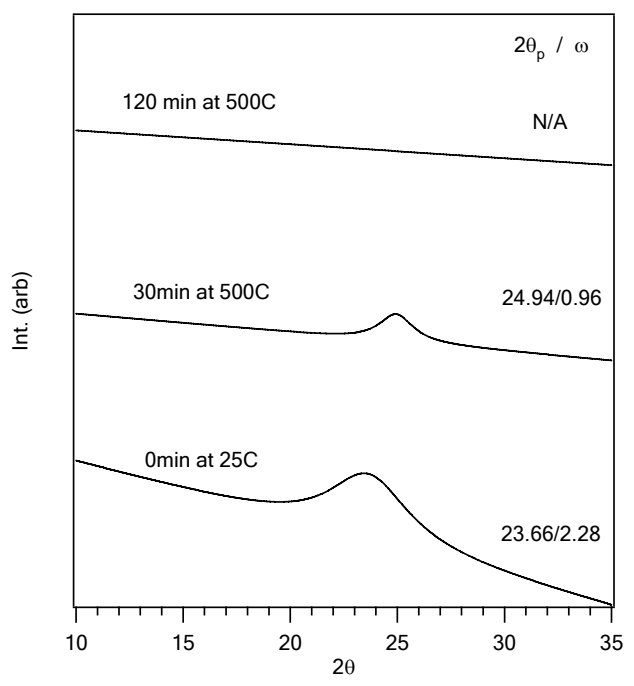

(e)

Figure 3.3.84 (a) Example of raw XRD profile for B20 soot at 3 different times of oxidation, multi-Lorentzian fits for (b) B20 soot, (c) B100 soot, (d) ULSD soot, (e) FT soot. 


\begin{tabular}{|l|l|l|l|}
\hline Sample & $\begin{array}{l}\text { Initial } \\
\text { Lc }(\mathrm{nm})\end{array}$ & $\begin{array}{l}\text { ox30min } \\
\text { Lc (nm) }\end{array}$ & $\begin{array}{l}\text { Rate constant at } \\
500^{\circ} \mathrm{C}(1 / \mathrm{s} / \mathrm{Pa})\end{array}$ \\
\hline ULSD & 2.4 & 4.2 & $2.6 \mathrm{E}-08$ \\
\hline B20 & 2.5 & 3.9 & $3.2 \mathrm{E}-08$ \\
\hline B100 & 3.1 & N/A & $5.7 \mathrm{E}-08$ \\
\hline FT & 3.5 & 8.4 & $1.2 \mathrm{E}-08$ \\
\hline
\end{tabular}

(a)

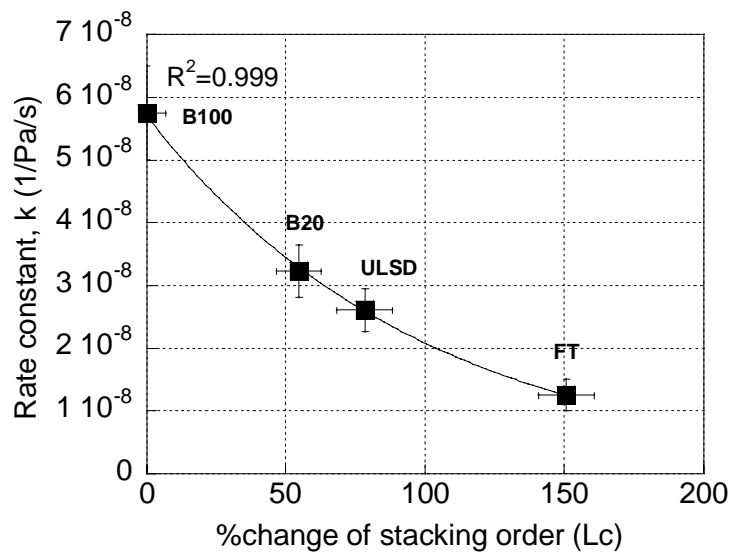

(b)

Figure 3.3.85 (a) Calculation of crystallite size, indicating an increase of thickness (LC) in the direction normal to graphene layer during an early oxidation (b) correlation between rate constant and \% change of number of stacking order

\subsection{Surface Based Oxidation Rate}

Without considering surface burning by which the ordered outer shell is removed and the inner amorphous rich core is left during early oxidation period, an increase in the defect band that was observed for all of the soot samples could not be explained. Therefore, another step in explaining the differences in oxidative behavior between the soot samples is to check whether surface burning is dominant during this early burnoff.

TEM images taken at $105,000 \times$ magnification were used to examine the change of the average diameter of the primary particles and the fractal dimension during the early oxidation. For more accurate and quantitative information, size distributions were statistically analyzed to calculate the instantaneous surface area-based oxidation rate at 30min. For this purpose, at least 400 primary particles were counted over at least 5 different areas to ensure a statistically significant result using image analysis software called "Digital Micrograph 3.0" [78]. Similar calculations were reported in other work $[62,79,80]$. TEM images and their size distributions in Figure 3.3.86 (a)-(d) and Figure 3.3.87 (a)-(d) show an abrupt diameter change of $4.0 \mathrm{~nm}$ from the initial to the oxidized state for B100 soot, while only $0.9 \mathrm{~nm}$ change for FT soot. It is noteworthy to mention that B100 soot has a larger mean diameter of $30.7 \mathrm{~nm}$ than FT soot of $28.1 \mathrm{~nm}$ at the initial stage. It should be noted that initial samples were colleted on TEM grids via thermophoretic sampling, while oxidized samples were collected on filter media. Then, they were carefully analyzed by TGA oxidation and then dispersed on TEM grids. 


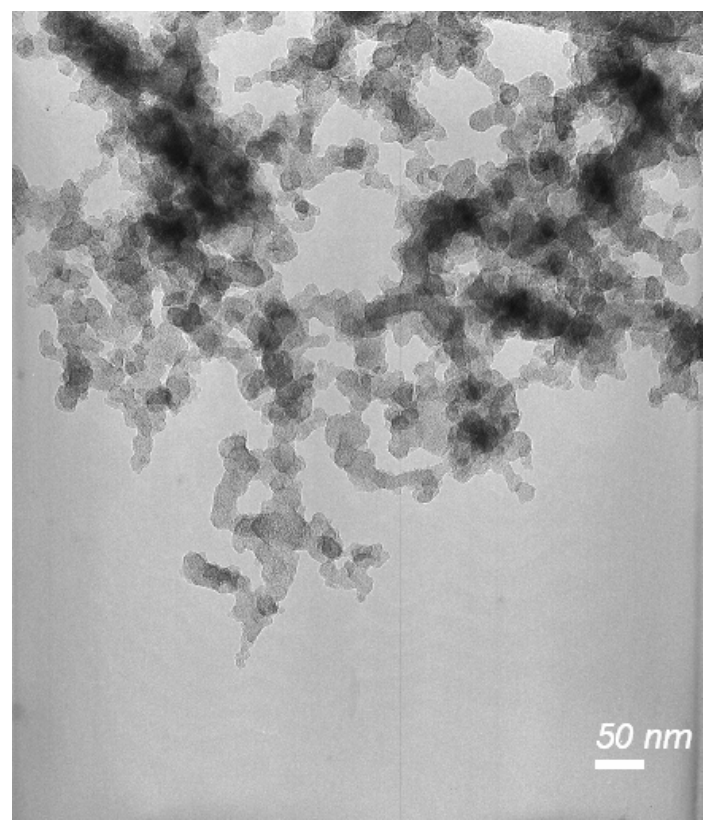

(a)

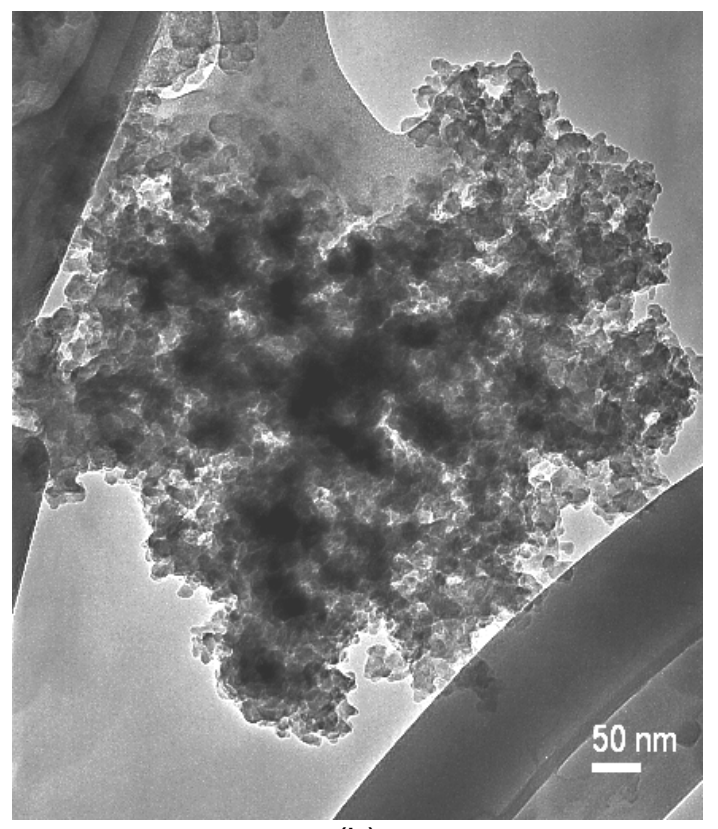

(b)

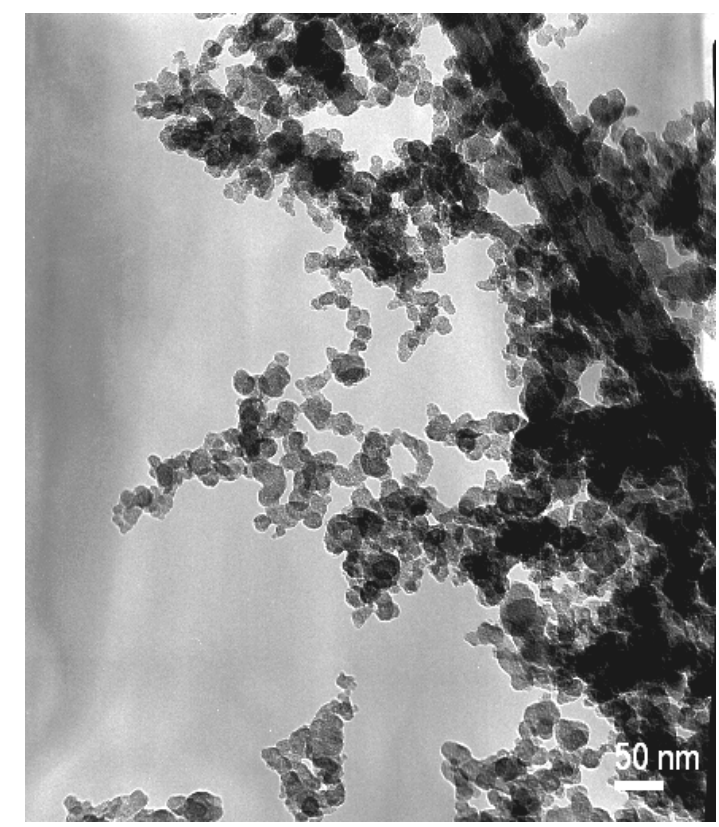

(c)

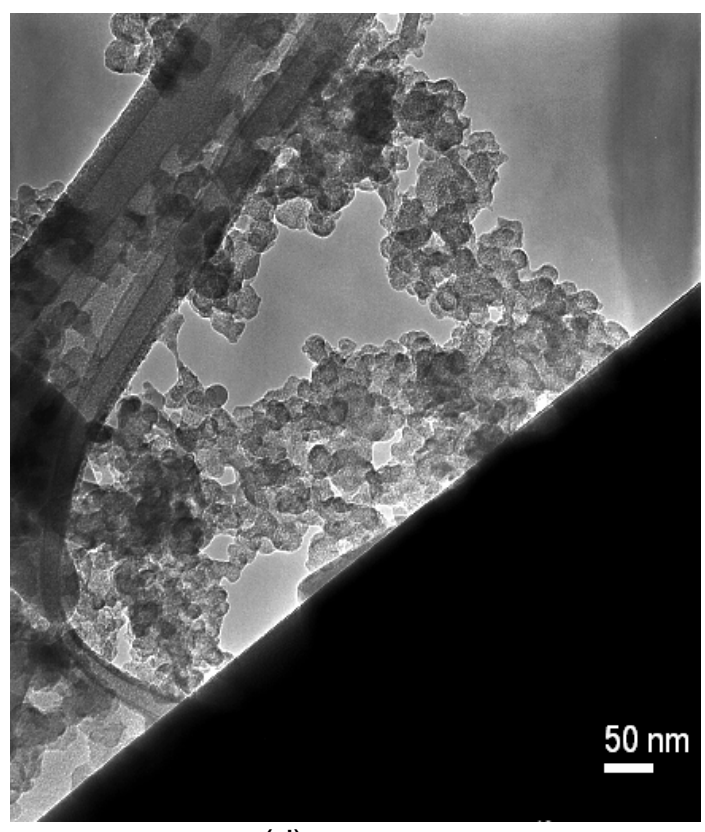

(d)

Figure 3.3.86 Morphology and diameter change after 30min burn off, (a) B100 soot at initial, (b) B100 oxidized at $30 \mathrm{~min}$ of $500{ }^{\circ} \mathrm{C}$, (c) FT soot at initial, (d) FT oxidized at $30 \mathrm{~min}$ of $500{ }^{\circ} \mathrm{C}$ 


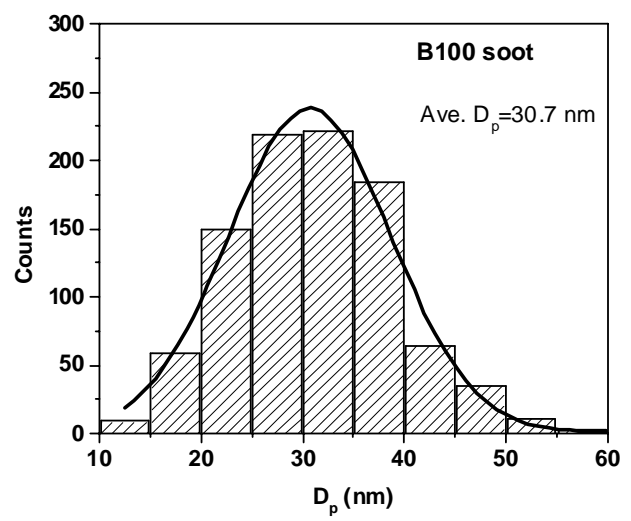

(a)

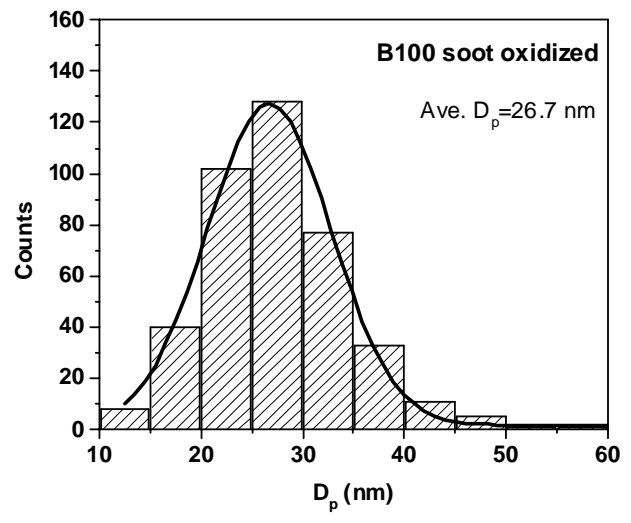

(b)

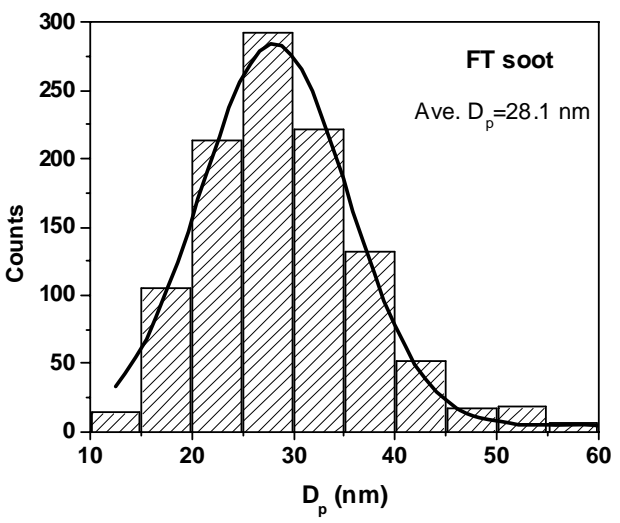

(c)

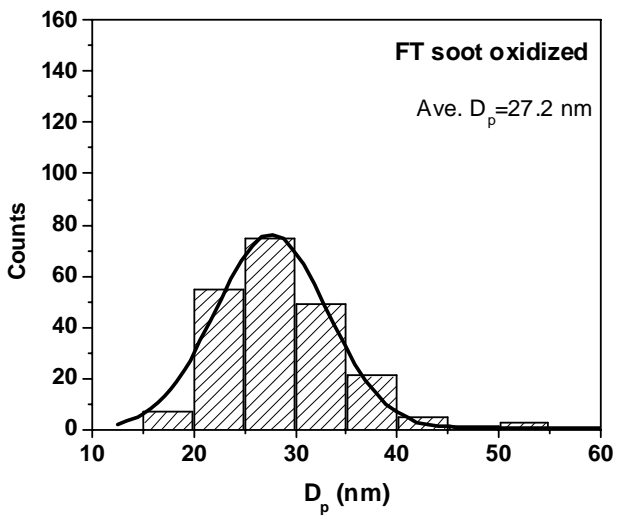

(d)

Figure 3.3.87 Size distributions for two extreme soot samples between initial and oxidation state (a) B100 soot at initial, Std: $\pm 0.29 \mathrm{~nm}$, (b) B100 oxidized at 30min of $500{ }^{\circ} \mathrm{C}$, Std: $\pm 0.16 \mathrm{~nm}$, (c) FT soot at initial, Std: $\pm 0.24 \mathrm{~nm}$, (d) FT oxidized at $30 \mathrm{~min}$ of $500{ }^{\circ} \mathrm{C}$, Std: $\pm 0.29 \mathrm{~nm}$.

With the size determination and using Eqn. 3.3.7, a surface area-based oxidation rate was calculated wherein surface burning is assumed to take place. Density and initial surface area were assumed by choosing values from the literature $[37,53]$. This oxidation rate was converted to a mass basis for comparison with the mass-based oxidation rate measured by TGA in Table 3.3.16. If there is a discrepancy between the mass-based oxidation rate and surface area-based oxidation rate, the difference can be attributed to the presence of internal burning during the early stage of oxidation. It should be noted that the mass-based oxidation rate measured on the TGA is an integrated rate, while the surface area-based oxidation in this calculation is an instantaneous oxidation rate at 30 $\min$. 


$$
\begin{aligned}
& \omega=\frac{\rho \cdot r_{0}}{\Delta t}\left(1-\frac{r_{t}}{r_{0}}\right)=\frac{1}{A_{t}} \cdot \frac{d m}{d t \cdot m}, \quad \text { Assume, } \quad \rho=1500 \quad \mathrm{~kg} / \mathrm{m}^{3} \\
& A_{0}=150 \quad \mathrm{~m}^{2} / \mathrm{g} \\
& A_{t}=A_{0} \cdot \frac{r_{0}}{r_{t}} \\
& \Delta t=1800^{t} \sec
\end{aligned}
$$

Comparison in Figure 3.3.88 shows a close agreement between surface area-based and massbased rates for each soot validating the dominance of surface burning during the early stage oxidation. This surface burning by which the ordered outer shell is removed and inner amorphous rich core is left during this early oxidation period can explain the increase in the defect band observed for all the soot samples. Second, the surface area-based oxidation rate still captures the 5 times higher oxidation rate for B100 soot than for FT soot. This suggests that mass loss is mostly coming from a diameter change through surface burning (i.e. outer shell removal). But we still have

\begin{tabular}{|c|c|c|c|c|c|c|c|}
\hline \multirow[b]{2}{*}{ Sample } & \multicolumn{5}{|c|}{$\begin{array}{l}\text { Surface based } \\
\text { oxidation rate (based on shrink core model) }\end{array}$} & \multicolumn{2}{|c|}{ Mass based oxidation rate } \\
\hline & $\begin{array}{l}r_{0} \\
(\mathrm{~nm})\end{array}$ & $\begin{array}{l}r_{t} \\
(n m)\end{array}$ & $\begin{array}{l}\omega \\
\left(\mathrm{kg} / \mathrm{m}^{2} \mathrm{~s}\right)\end{array}$ & $\begin{array}{l}\mathrm{dm} / \mathrm{dt} / \mathrm{m} \\
(1 / \mathrm{s})\end{array}$ & \begin{tabular}{|l} 
ratio \\
relative to \\
FT
\end{tabular} & $\begin{array}{l}\mathrm{dm} / \mathrm{dt} / \mathrm{m} \\
(1 / \mathrm{s})\end{array}$ & $\begin{array}{l}\text { ratio } \\
\text { relative to } \mathrm{FT}\end{array}$ \\
\hline B100 soot & 30.7 & 26.7 & 3.3E-9 & $1.20 \mathrm{E}-3$ & 4.9 & $1.20 \mathrm{E}-3$ & 4.8 \\
\hline FT soot & 28.1 & 27.2 & 7.5E-10 & 2.43E-4 & - & 2.52E-4 & - \\
\hline
\end{tabular}
the remaining question: "under surface burning, why did B100 soot undergo such severe structural change even though it had largely the same initial nanostructure as FT soot ?".

Table 3.3.16 Calculation of surface area based oxidation rate

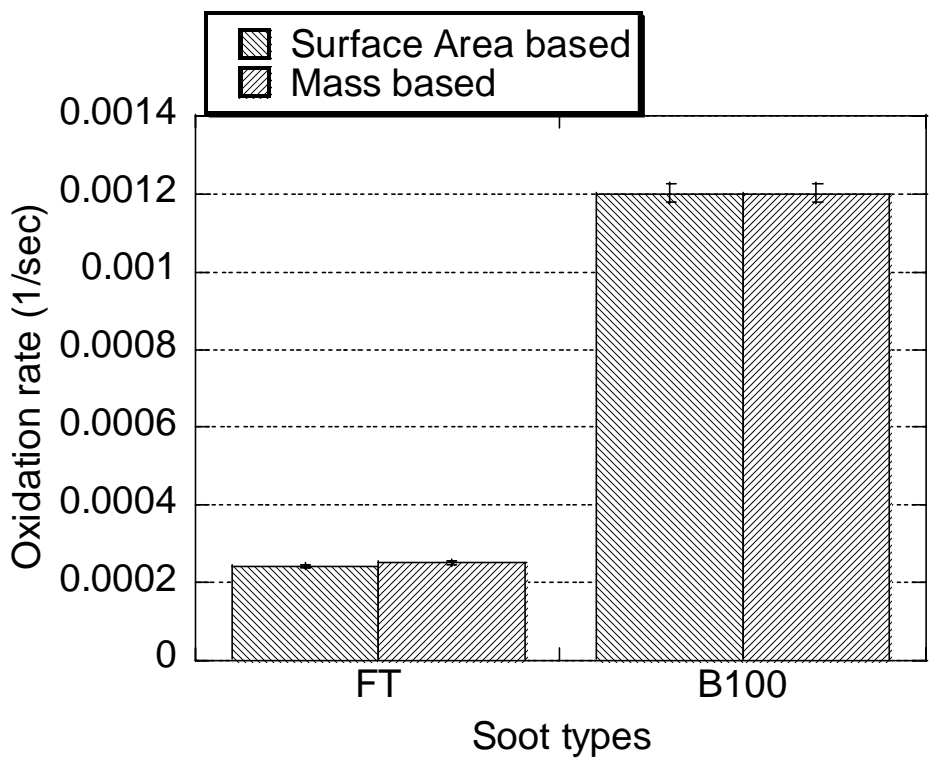

Figure 3.3.88 Comparison of surface area based and mass based oxidation rate 


\subsection{Initial Oxygen Groups}

To answer this question regarding the higher oxidation rate for B100 soot, the difference in the surface oxygen groups was measured by Fourier Transform Infra Red (FTIR) spectroscopy. Since the initial nanostructure of the FT and B100 soots is similar, the significant difference in both oxidation rate and extent of structure change to $30 \mathrm{~min}$ may be induced by surface reactivity related to an initial presence of surface oxygen groups.

On the FTIR spectra in Figure 3.3.89 (a), all samples have four peaks including an aromatic peak at 1620, carboxyl and lactone peaks at 1740 and other minor groups at 1480 and $1380 \mathrm{~cm}^{-1}$, respectively. Comparison shows that more surface oxygen groups are present in the B100 soot, while the FT soot has the least indication of oxygen groups. The ratio of the carboxyl peak and the aromatic peak was further used to determine the relative presence of oxygen groups. Good correlation between the oxidation rate and the relative ratio in Figure 3.3.89 (b) suggests that the differences in internal structure change and its resultant impact on the oxidation rate arises from the difference in surface oxygen groups.

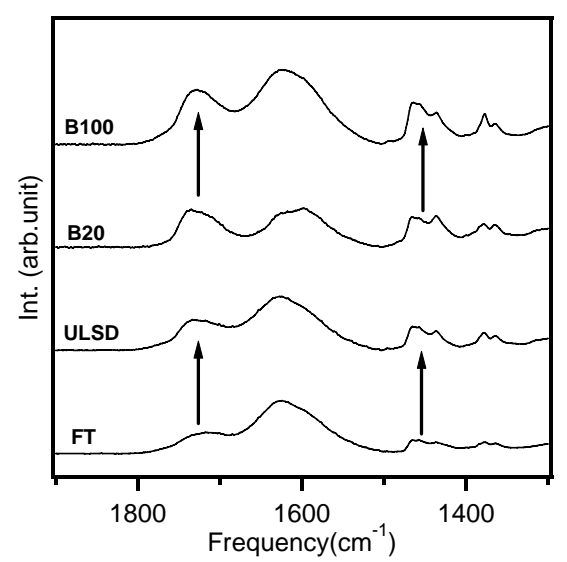

(a)

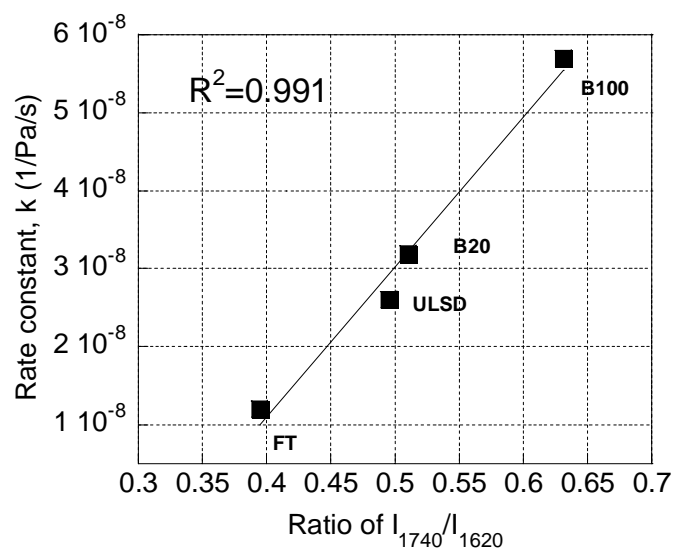

(b)

Figure 3.3.89 (a) Variation in surface oxygen group of FTIR spectra indicating a higher presence of oxygen group in B100 soot rather than FT soot (b) Correlation between oxidation rate and ratio of two IR spectra peaks suggesting a difference in oxidation rate of soots with similar nanostructure (previously revealed) is from the difference in surface oxygen groups.

For biodiesel (B100) soot, the devolatilization of surface oxygen groups bonded at the edge sites provides nascent reactive sites for continuing oxidation via attack by air on the edge sites. Therefore, the presence of surface oxygen functionality may facilitate surface burning that occurs progressively from outermost periphery. This can result in appreciable diameter change by which the inner amorphous core is left. This change in structure can explain the greater structure change of B100 soot observed in Raman, EELS and HRTEM. In contrast, the lower content of oxygen groups in the FT soot is unlikely to create reactive sites during devolatilization and oxidation, leading to lesser structure change and slower oxidation.

As shown in Table 3.3.17, PM composition via soxhlet extraction shows a gradual increase in soluble organic fraction (SOF) with biodiesel addition. However, this content is believed not to affect particulate reactivity since most of the SOF was removed during pre-treatment before oxidation via TGA. Inferred from similar shell-core structure of the B100 and FT soot samples, any difference in initial pore structure is unlikely. However, the secondary effect of SOF on pore structure development during devolatilization and early oxidation should be investigated. 
The pore size distribution for measuring internal surface area was determined from $\mathrm{N}_{2}$ adsorption isotherms obtained at $77 \mathrm{~K}$. Comparison between initial and 30 minute oxidation was made only for B100 soot since other samples could not give a reliable result due to limited amount of soot samples. For instance, a $10 \mathrm{mg}$ sample was insufficient to increase the sensitivity of the pressure measurement associated with the pore size distribution measurement. Although comparison between the soot samples from the various fuels was not made and it is important to explain difference in oxidation rate, two observations for single sample can be made from the results in Figure 3.3.90. During oxidation, the micropore portion of $1 \sim 3 \mathrm{~nm}$ inside the primary particles is increased, implying an increase in internal pores during this period, which is consistent with other's observations $[81,45,53,82]$. This implies the simultaneous contribution of micropore development with structural change even under the surface burning dominance of the early stage oxidation, but it is not conclusive as to which one is more important or precedent to govern oxidation rate. Hurt et al. demonstrated that gasification induced particle shrinkage is important in pore structure evolution during gasification and can therefore be expected to affect gasification rates [83].

Mesopores of 20 25 $\mathrm{nm}$ between the aggregates are decreased, implying a trend toward a more compact shape with a higher fractal number. This increase can support the appearance of more agglomerated and compact morphology of B100 soot after 30 min oxidation observed in the TEM image of Figure 3.3.90 (b). This may reduce the void or gap between the primary particles of the aggregates. A similar increase in the fractal number of the soot samples up to a certain burn off level of oxidation was also observed with SAXS measurements by Kandas et al. [81]. Similar agglomerated behavior was also observed during combustion of biomass by Ohman et al. [84]

Table 3.3.17 PM composition via Soxhlet extraction

\begin{tabular}{|c|c|c|}
\hline Fuels & $\begin{array}{c}\text { SOF content } \\
(\%)\end{array}$ & Dry soot reduction (\%) relative ULSD \\
\hline ULSD & 57.8 & - \\
\hline B20 & 61.1 & 4 \\
\hline B100 & 70.6 & 20 \\
\hline FT & 49.2 & 2 \\
\hline
\end{tabular}




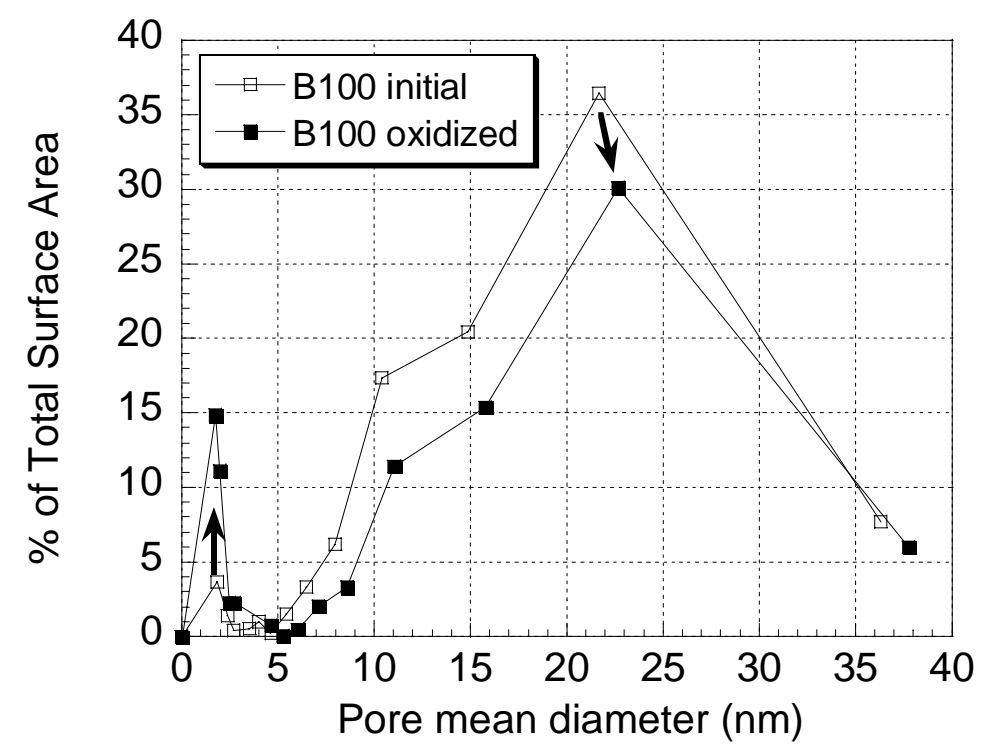

Figure 3.3.90 Pore size distribution for measuring an internal surface area only for B100 soot, determined from N2 adsorption isotherms obtained at $77 \mathrm{~K}$

From a comparison of particulate reactivity and structure between various soot samples, the important findings are as follows.

- There is no definitive impact of initial nanostructure on oxidation rate.

- Under the surface burning dominance of the early stage oxidation, the degree of internal structural change has a strong influence on the oxidation rate.

- The relative amount of initial oxygen groups is an important factor governing the oxidation rate.

- Tailoring surface reactivity of diesel soot can ease the regeneration of DPF and its interval.

\subsubsection{Thermal Oxidation Process}

Although an important factor governing the oxidation rate especially between FT soot and B100 soot has been identified, continued investigation is warranted into whether this factor would affect the complete oxidation process, particularly at later stage in this experiment.

\subsection{B100 Soot}

First, TEM images taken at low magnification in Figure 3.3.91 (a) show a different morphology for drastically oxidized B100 soot at $75 \%$ burn off compared to B100 soot at initial and 40\% burnoff conditions. It appears that individual primary particles have become hollow inside due to the appearance of donut shapes or capsules formed at the outer boundary. HRTEM images at both $500,000 \times$ in (c) and $800,000 \times$ magnification in Figure 3.3.91 (d) show that this particle is indeed hollow inside with long and straight outer graphene layers. Further coalescence of multiple particles is also present due to the appearance of multi-walled carbon nanotubes (MWCNT). This observation clearly indicates another transition to internal burning of the primary particles, leaving a graphitic outside and hollow inside, and further coalescence of multiple particles. It is worth noting that the time when B100 soot reached $75 \%$ burn off is only 50 minutes. 
By using refined images that are magnified and further processed from the raw images with DM3 software in Figure 3.3.91 (e), fringe length analysis was performed and confirmed this transitional trend, starting from median 002 lattice fringe of $2.8 \mathrm{~nm}$ for the initial soot, to shortened range of $1.3 \mathrm{~nm}$ at $40 \%$ burnoff and then transformed to the longest length of $4.5 \mathrm{~nm}$ at $75 \%$ burnoff as shown in Figure 3.3.91 (f). Customized image analysis software was also used to calculate fringe length distributions in other work $[85,39,86]$. A change in intensity of two outer rings such as 100 and 110 peak from diffraction pattern in Figure 3.3.91 (g) shows a transition from intermediate at initial, to turbostratic at $40 \%$ burnoff and finally to perfect and graphitic arrangement along the c-axis at $75 \%$ burnoff due to their brightest and strongest intensity. As shown in Figure 3.3.92, the presence of long and straight layers at $75 \%$ burnoff leads to $20 \%$ decrease in defect band of Raman spectra relative to $40 \%$ burn off. Since a strain associated with the remaining curvature features still contributes to the defect band through an asymmetry effect [87], the degree of decrease in the defect band is not as large as expected. This can also produce a prominent presence of a graphitic peak and a significant increase in its intensity relative to the other peaks in the EELS spectra.

From this observation, an oxidation model for B100 soot can be proposed as seen in Figure 3.3.93. B100 soot seems to experience a fast and capsule type oxidation through internal burning to become hollow inside. Eventually it leads to a long range and more ordered flat layer arrangement in the outer shell, where further coalescence takes place. A tentative explanation can be offered about why this transition may occur. From initial to $40 \%$ burnoff, surface burning is dominant for the amorphous rich sections of the soot during which time micropores get easily opened. This simultaneous contribution of micropore development with structural change, even with the surface burning dominance of this period, was observed by surface area and porosity measurements in the previous section. Once micropores are fully penetrated, the soot becomes hollow inside due to the more reactive internal carbon through internal burning. Significant mass loss is likely to take place during this internal burning stage, thereby leading to fast oxidation. After that, physical factors such as an increase in layer mobility arising from reduced cross-linking and minimization of strain energy arising from the hollowing out of the soot $[88,86,89,90]$ can lead to layer rearrangement and coalescence where the wavy layers become much flatter and longer. Heat transfer from inside to outer periphery associated with exothermic oxidation may be another driving force for layer rearrangement.

Similar internal burning behavior was observed during oxidation of carbon black by Heckman et al. [91]. They showed the difference in oxidation rate between several carbon blacks produced from different synthesis conditions and the dependence on burning mode. For example, thermal carbon black that was oxidized at $450{ }^{\circ} \mathrm{C}$ in $50 \% \mathrm{O}_{2}$ had a strong tendency to burn from the inside out, forming "capsules". They have also reported a further coalescence of two particles since "cell walls" between two particles disappeared at a later stage. In contrast, the mode and rate of oxidative attack on graphitized thermal black were strikingly different. This particle was likely to burn from the outside in through surface burning and resulted in the slowest oxidation. Even after 64 hours, oxidation had not reached an advanced stage resulting in much slower burning. No studies on oxidation rate and its dependence on burning mode have been made specifically for diesel soot and its derivatives.

The presence of hollow particles was also observed during the laser heating of soot samples by Vander Wal and Choi [92]. They attributed this behavior to a thermal annealing mechanism by which outer layers become graphitic, which then is followed by densification leading to a central void. The annealing behavior was observed only when soot samples were oxidized at much higher temperature above $700{ }^{\circ} \mathrm{C}[93,94]$ or during the later stage of oxidation $[95,96]$. Various researchers have attributed a loss in particulate reactivity under either condition to thermal annealing behavior. Amazingly, the layer rearrangement observed with B100 soot is associated with an enhancement of particulate reactivity that provides supporting evidence for Heckman's findings on the dependence of the oxidation rate on the burning mode.

Recently, the behavior of DPF regeneration using a biodiesel fuel was evaluated in a vehicle test and on a diesel engine bench $[97,98]$. Thermal regeneration was achieved with air by using 
batch heating with electric power. The result showed biodiesel greatly reduces the interval of active regeneration compared to that of the base diesel fuel, implying an enhancement of regeneration. However, the mechanism by which biodiesel enhances regeneration was attributed to the residual impurity of potassium methoxide $\left(\mathrm{CH}_{3} \mathrm{OK}\right)$ acting as an oxidation catalyst from the biodiesel fuel, since a catalyst $(\mathrm{KOH})$ was used in the transesterification process of biodiesel production. Along with oxygen content of the B100 in this study, the catalyst impurities in B100 should be considered for their effect on particulate reactivity even though no signature from potassium on any of the soot samples was detected by EELS or EDXS, which was probably due to the amount of potassium being below the lower detection limit of the apparatus. However, the presence of this catalyst still can't explain the appearance of internal burning with B100 soot, since the metal oxide is mostly coated on the outermost surface and catalytic oxidation proceeds from the outside in [99].

The diameter change of the primary particles in Figure 3.3.91 (b) shows that B100 soot undergoes a change of $7.0 \mathrm{~nm}$ from initial to $75 \%$ burnoff which is the same as the $7.0 \mathrm{~nm}$ change observed by Ishiguro [38]. Due to the appearance of long range and coalesced particles at $75 \%$ burnoff, the shortest width along either side was assumed to be the diameter as a first approximation. Between $40 \%$ and $75 \%$ burnoff, no significant change in morphology is observed, implying no further increase in fractal number after $40 \%$ burnoff. 

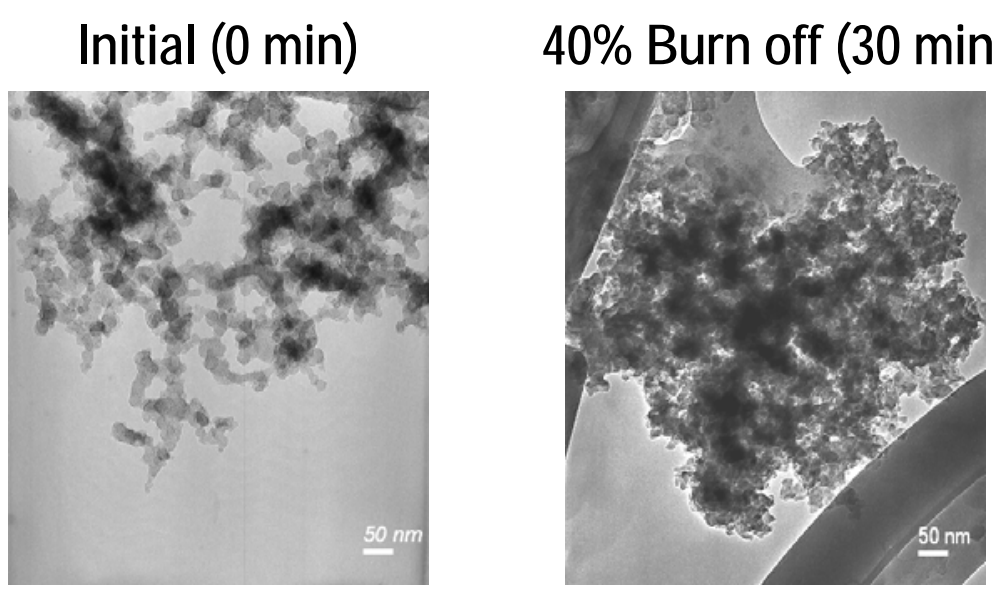

75\% Burn off (50 min)

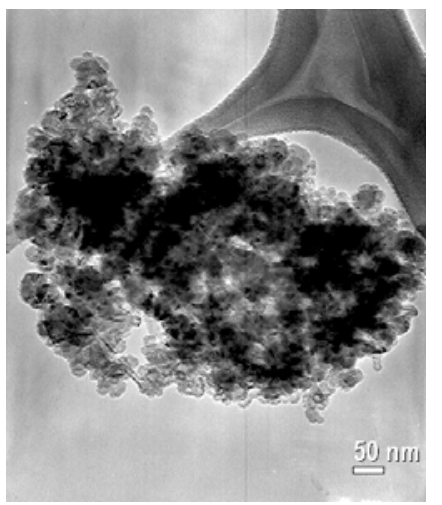

(a)
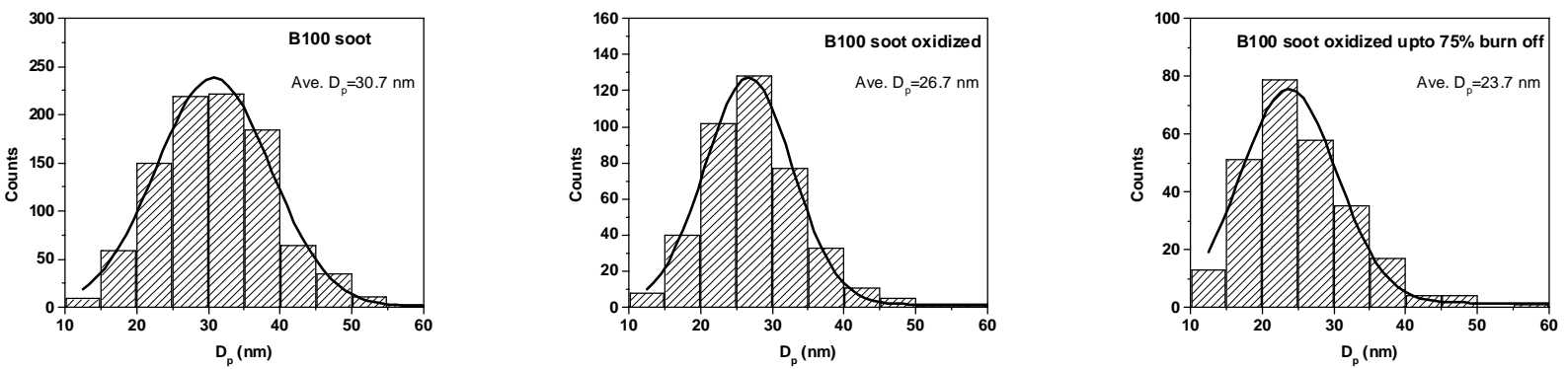

(b)
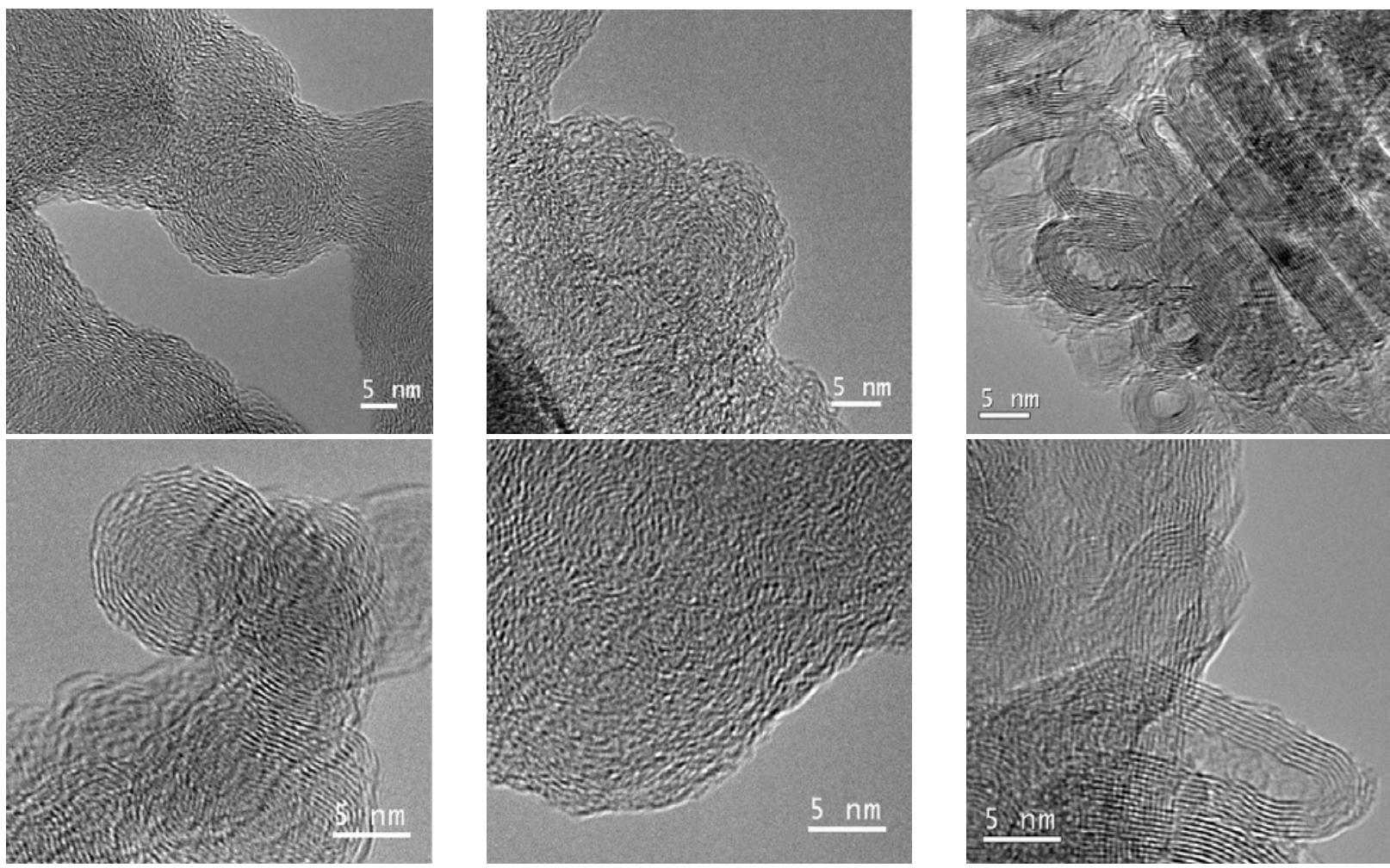

(c)
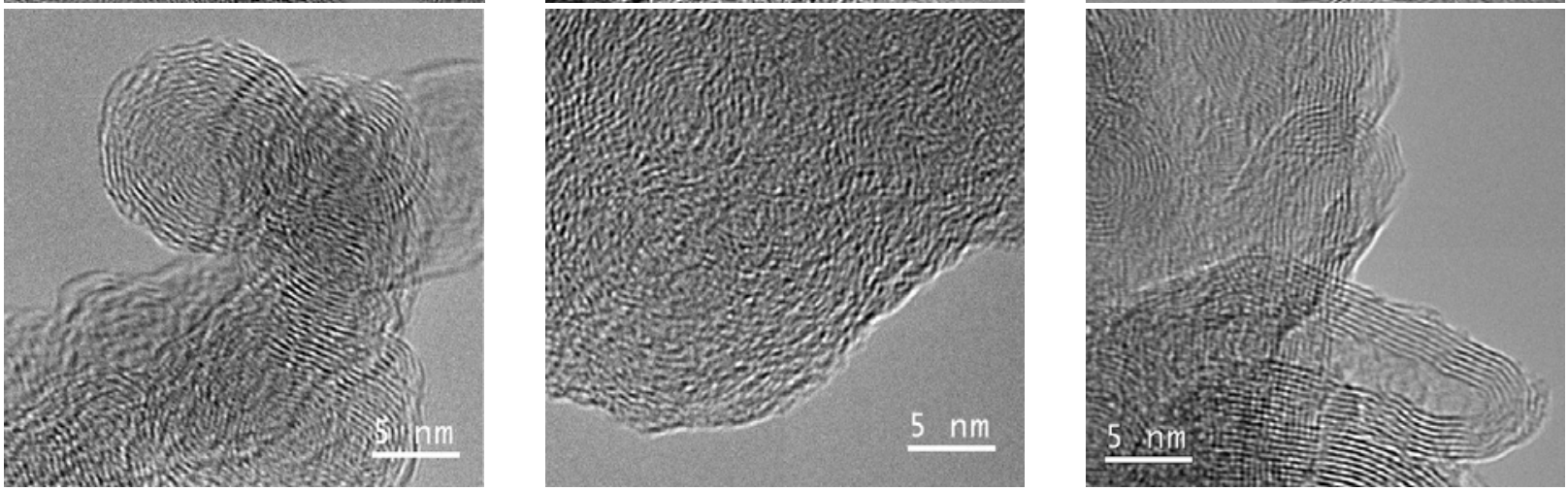

(d) 

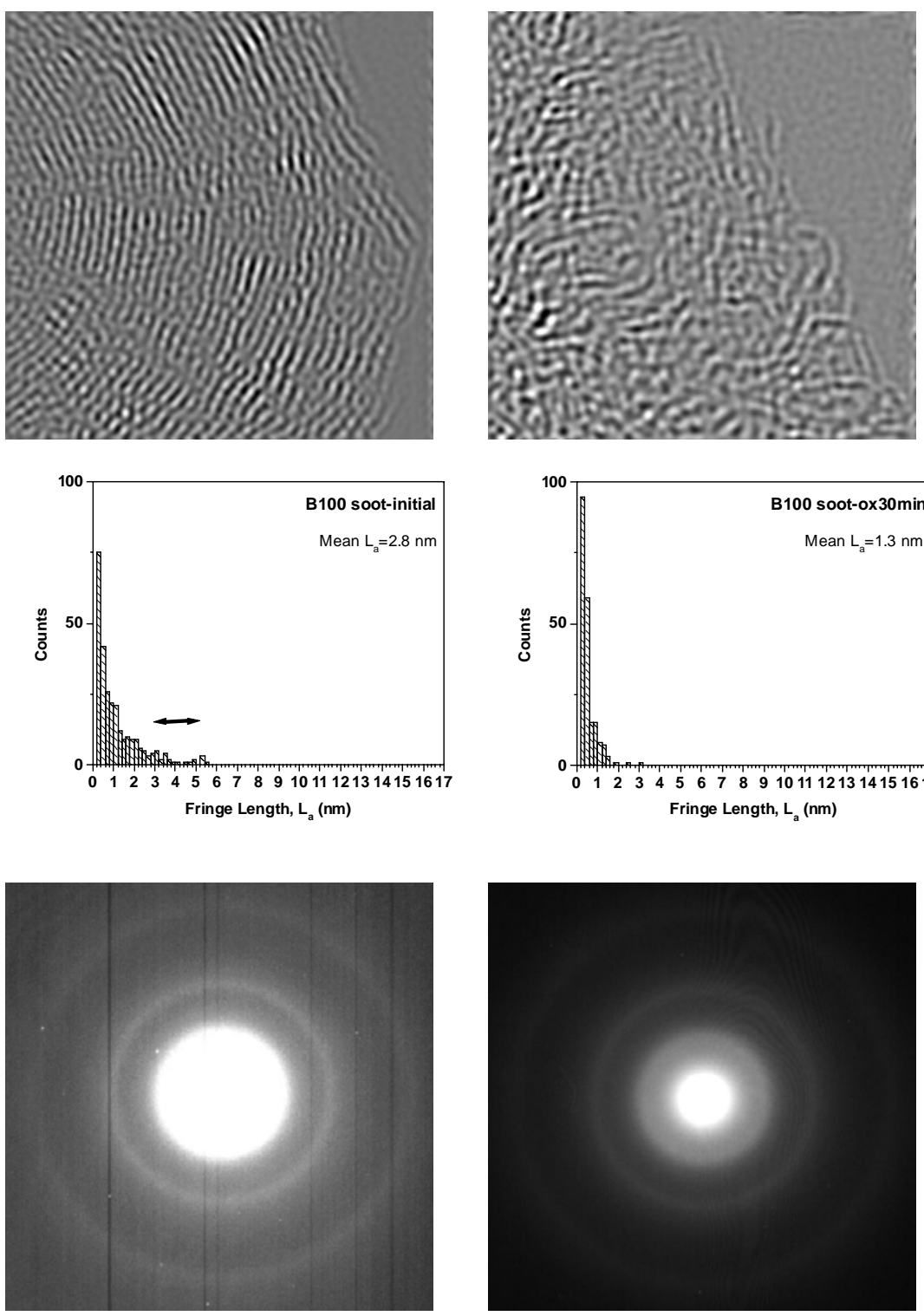

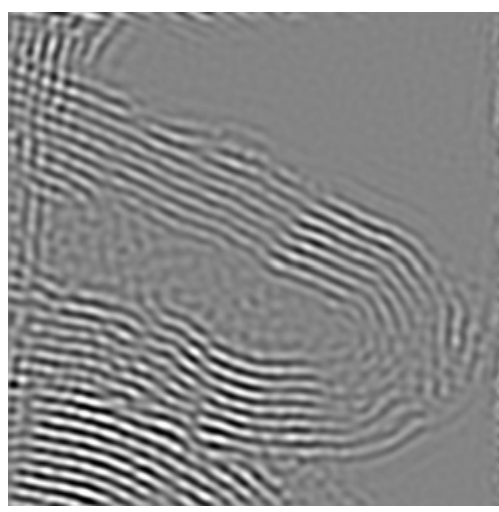

(e)

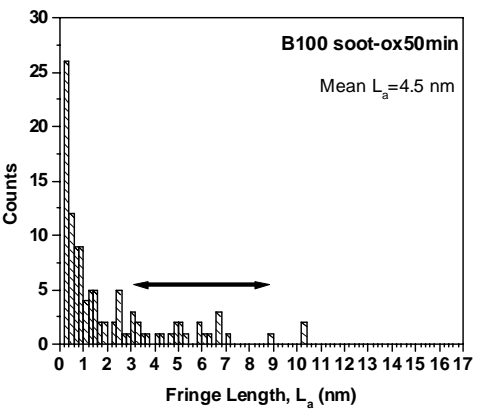

(f)

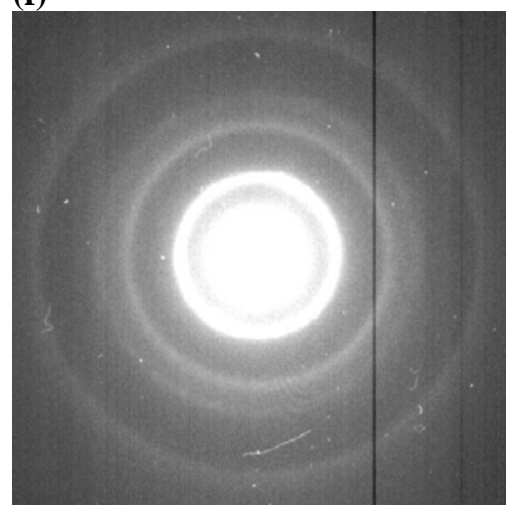

(g)

Figure 3.3.91 TEM image(a) and its size distribution(b), HRTEM images at 500k(c), and $800 \mathrm{k}(\mathrm{d})$, Fringe length analysis $(\mathrm{e}, \mathrm{f})$ and diffraction pattern $(\mathrm{g})$ at three different burn off stage of B100 soot, indicating a transition to internal burning and further coalescence at $75 \%$ burn off. 


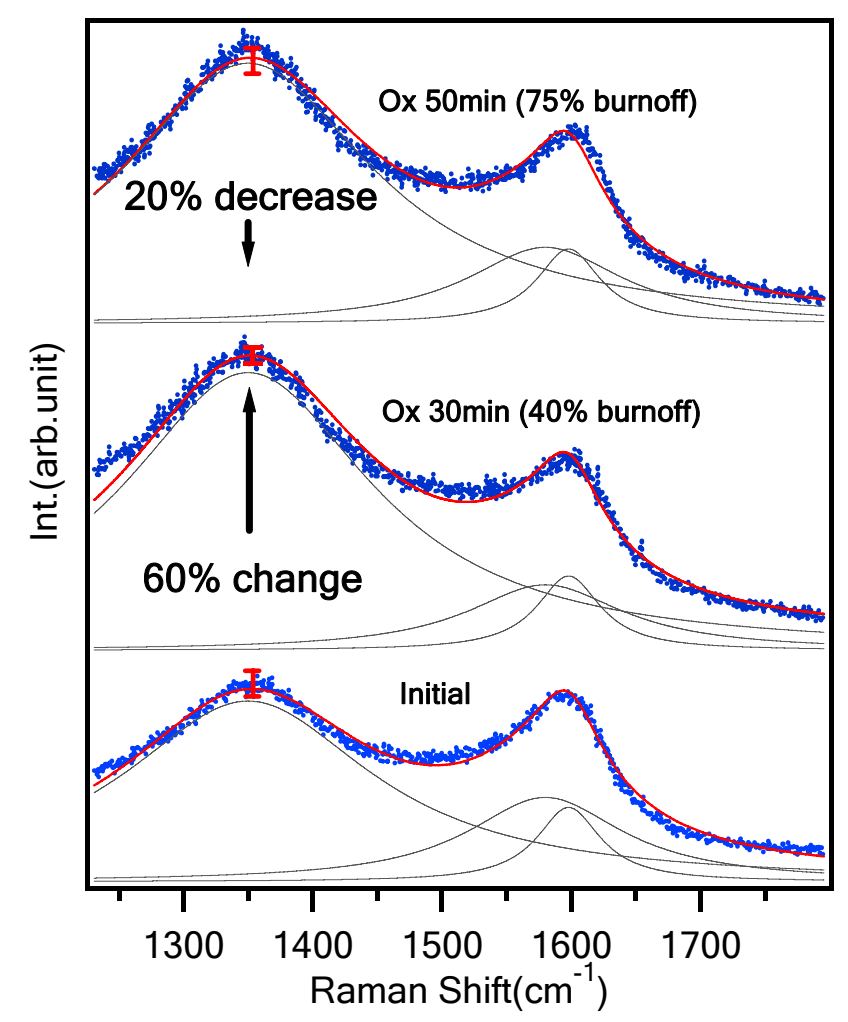

(a)

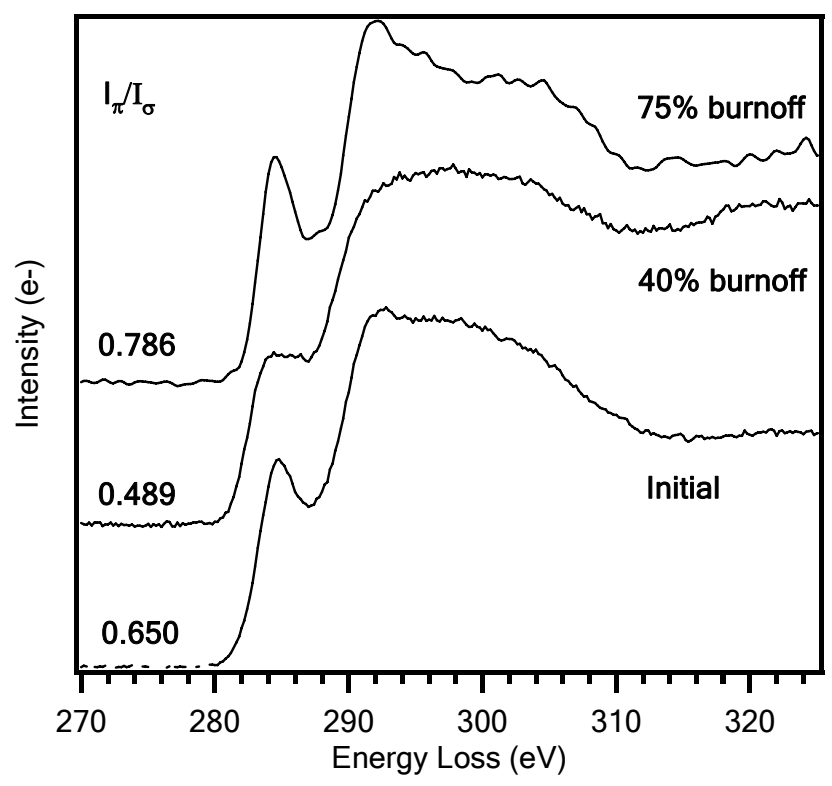

(b)

Figure 3.3.92 (a) Raman spectra, (b) EELS spectra, supporting a presence of long and straight layer for B100 soot oxidized at $75 \%$ burn off compared to $40 \%$ burnoff. 


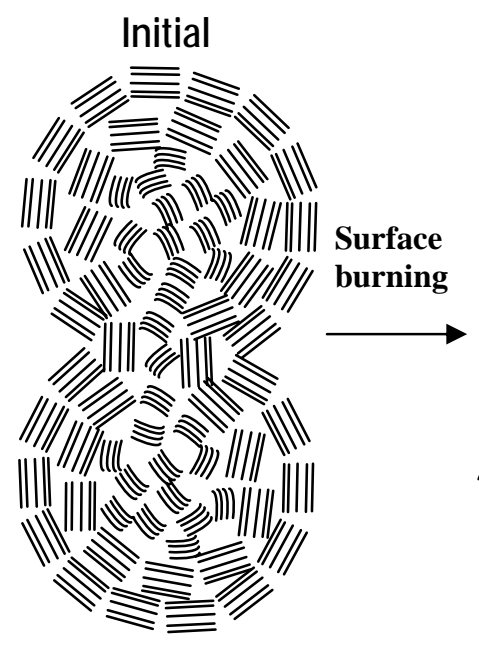

For simplicity, ignore crosslinking in this shell-core structure

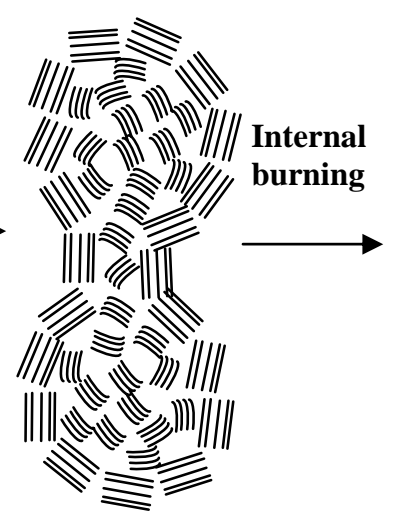

Once micro pore is fully penetrated, central hollow
$75 \%$ burnoff

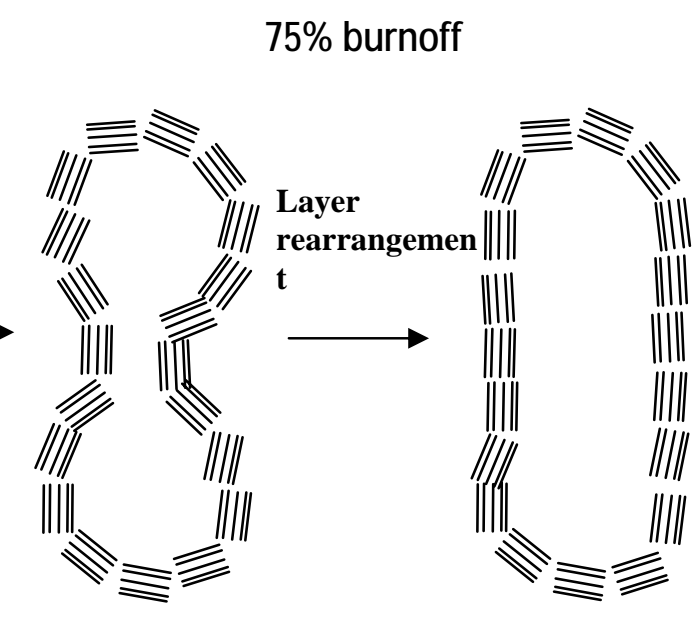

Further coalescence, due to physical factor such as increase in layer mobility and minimizing a strain energy

Figure 3.3.93 Simplified oxidation progression model for B100 soot.

\subsection{FT Soot}

For a comparison with B100 soot, the oxidation behavior of FT soot, which had slowest oxidation rate, is presented here. As shown in Figure 3.3.94 (a), low magnification TEM images of oxidized FT soot at $75 \%$ burnoff does not show a clear difference in morphology compared to B100 soot at the same level of burnoff. However, HRTEM images at $500 \mathrm{k}$ in Figure 3.3 .94 (c) and $800 \mathrm{k}$ in Figure 3.3.94 (d) show wavy and much shorter layers than for B100 soot at the same $75 \%$ burn off, indicating a lesser degree of internal burning and layer rearrangement. It should be noted that the time of 105 min required to reach this burnoff for FT soot is twice as long as that for B100 soot. In Figure 3.3.94 (e)-(f), the same fringe length analysis as performed for B100 soot was employed for FT soot, indicating no significant change in fringe length from initial to $75 \%$ burnoff. FT soot at $75 \%$ burnoff still has a shorter mean fringe length $(2.1 \mathrm{~nm})$ than for B100 soot $(4.5 \mathrm{~nm})$ at the same burnoff.

The gradual increase in the defect band in the Raman spectra in Figure 3.3.95 (a) and the gradual decrease in the ratio of the graphitic peak to the other peaks in Figure 3.3.95 (b) clearly supports the tendency toward a more disordered state during oxidation. Therefore, unlike B100 soot, FT soot has a slow and progressive shrinking core-type oxidation with less indication of internal burning even up to $75 \%$ burn off, thereby resulting in less layer rearrangement than B100 soot, as seen in Figure 3.3.96. This lesser extent of internal burning is believed to result in less layer rearrangement and coalescence where the wavy layer remains unchanged. Due to the reduced internal burning, abrupt mass loss is unlikely to take place, thereby leading to a mild and slow oxidation, unlike as was observed for B100 soot. As shown in Figure 3.3.97, a comparison of 002 diffraction contrast images between B100 soot in Figure 3.3.97 (a) and FT soot in Figure 3.3.97 (b) indicates the prevalence of more hollowed out particles with B100 soot compared to FT soot at the same $75 \%$ burnoff. As pointed out in the experimental section, the 002 diffraction contrast technique may be not suitable for determining differences in the arrangement of graphene layers for initial soot samples with either random or concentric arrangements. Unless high resolution a TEM instrument 
that supports operation of diffraction contrast is used, the bright spots from the 002 diffraction of samples under low magnification TEM will overlap each other, preventing proper information. However, when soot samples have either a preferential arrangement of graphene layers (i.e., with respect to one direction) or differences in internal hollowness as in this comparison, this technique is a great help to investigate this behavior.

Finally, diameter change of the primary particles in Figure 3.3 .94 (b) shows that FT soot undergoes a total change of $7.5 \mathrm{~nm}$ from initial to $75 \%$ burnoff. Therefore, the difference of total diameter change between B100 soot and FT soot is $0.5 \mathrm{~nm}$, while the maximum statistical error for the size distribution measurement was $\pm 0.25 \mathrm{~nm}$. 

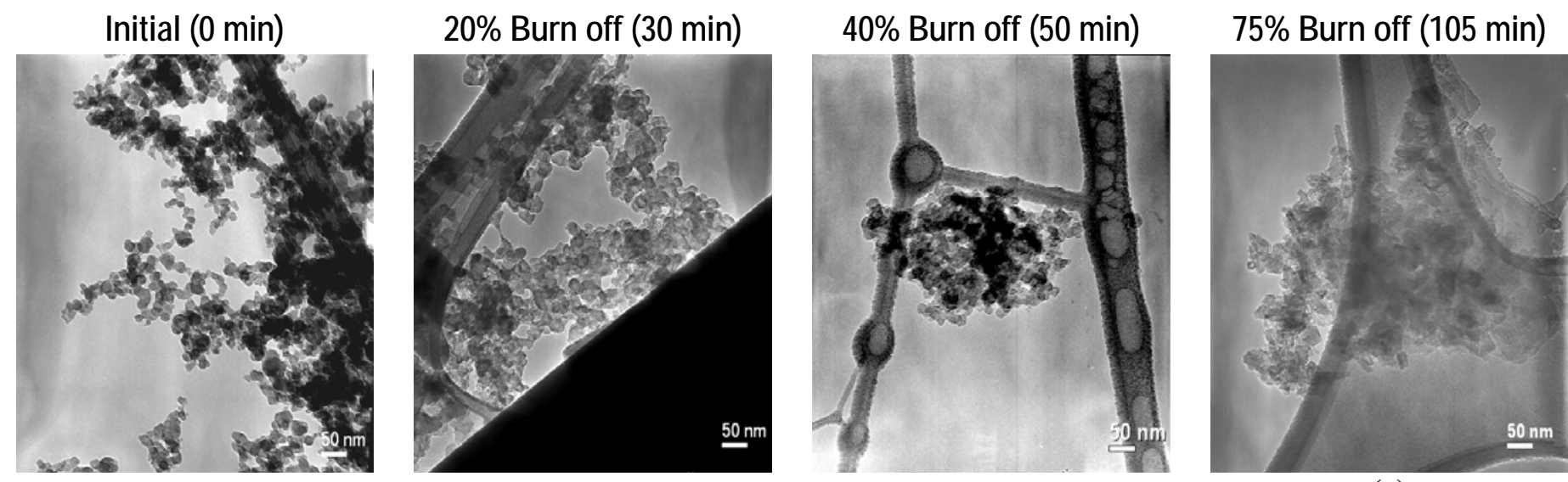

(a)
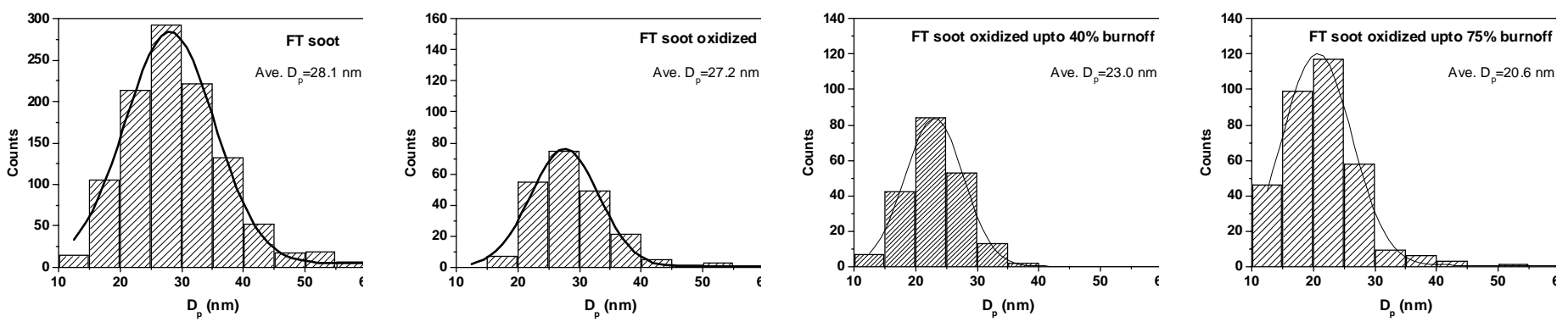

(b)
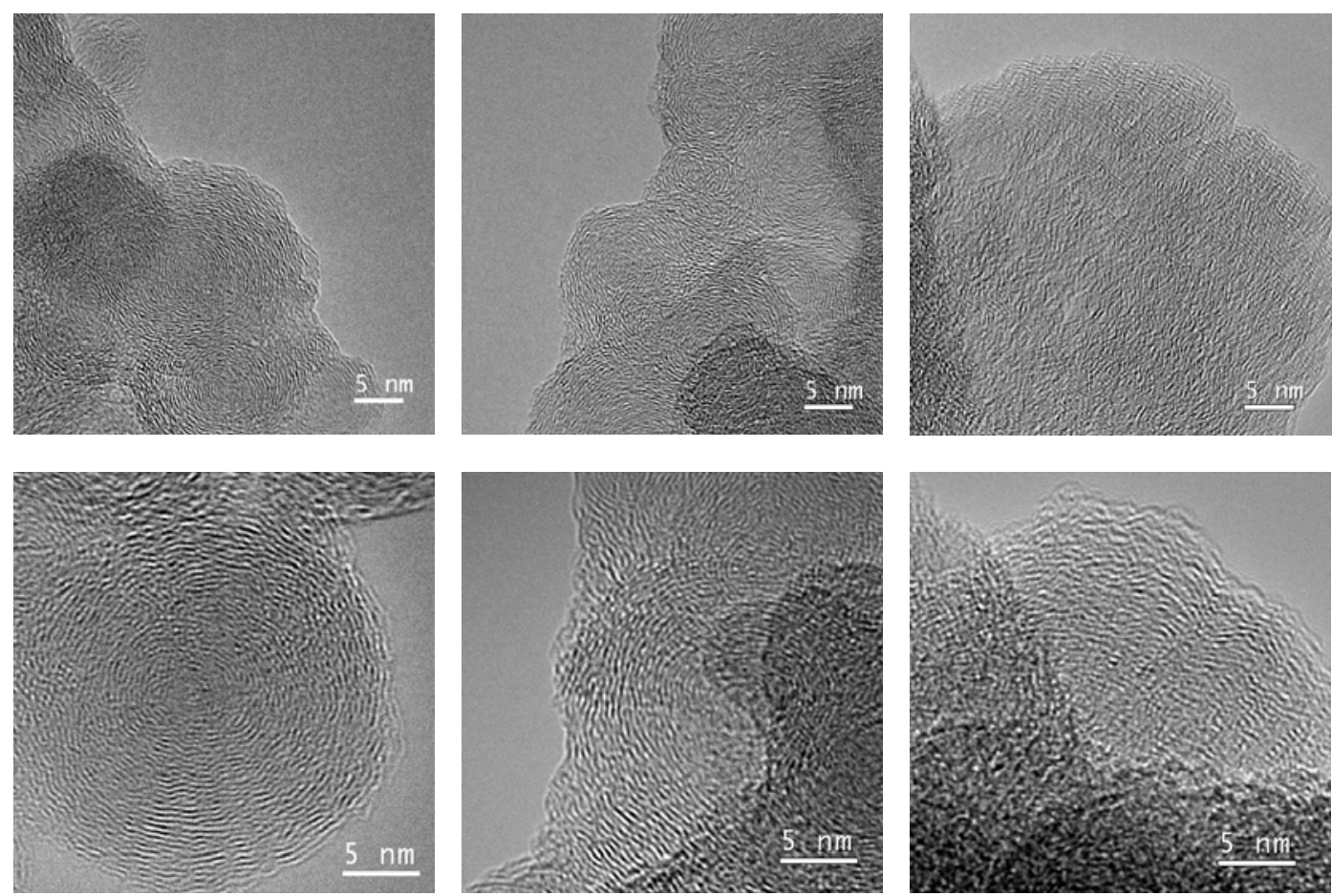

\section{(c)}

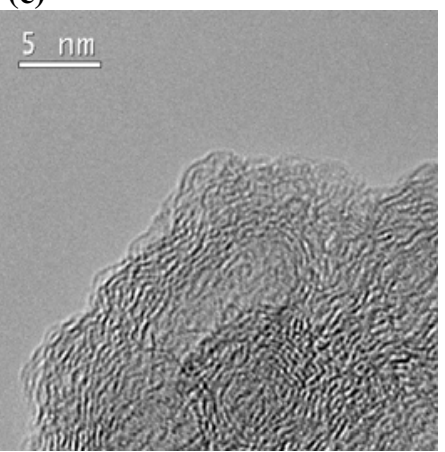

(d) 

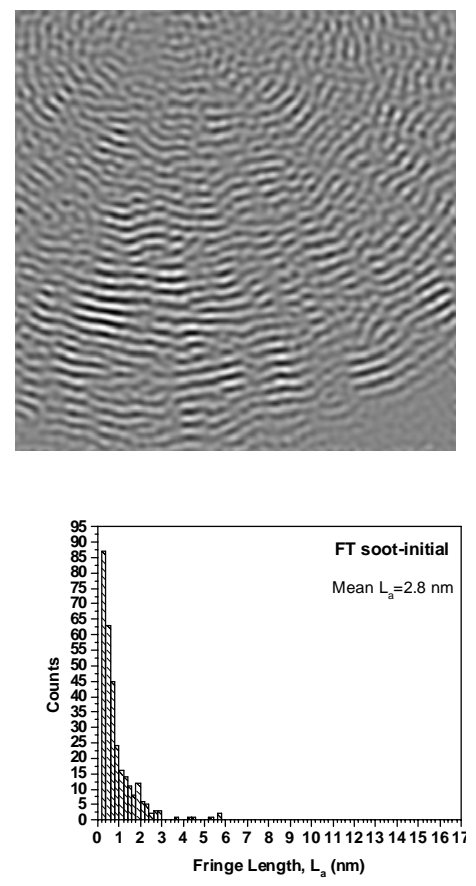
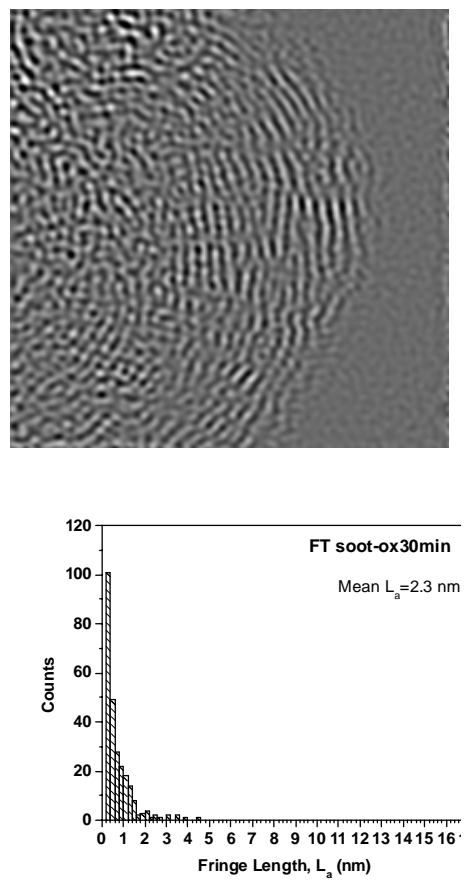
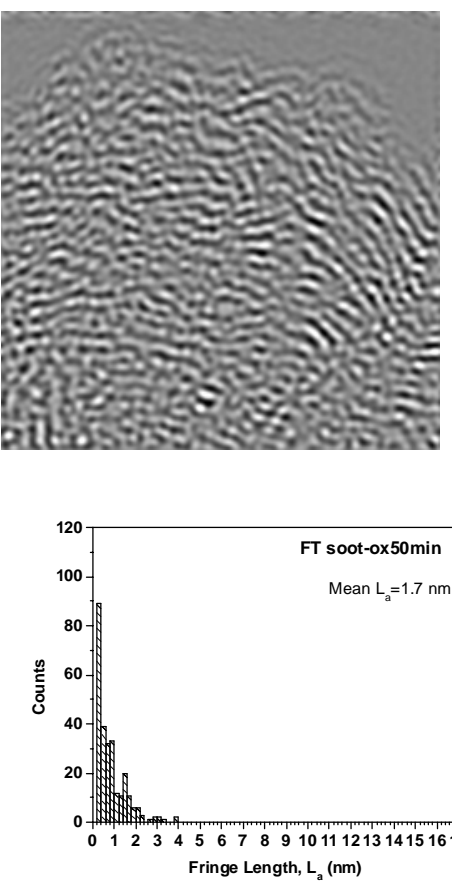

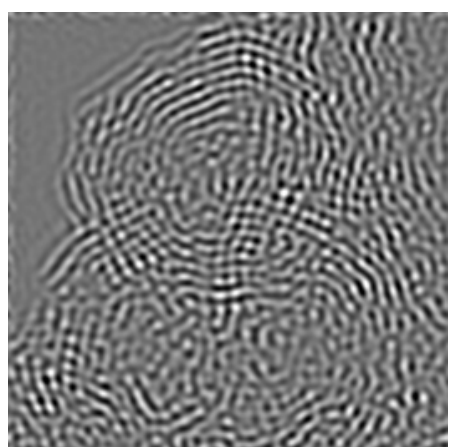

(e)

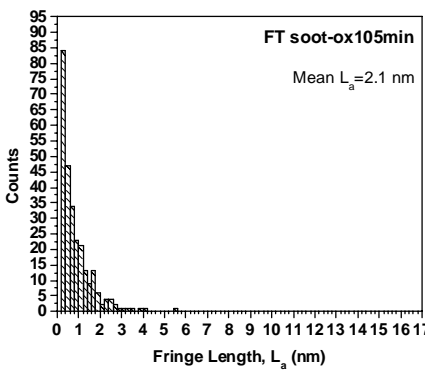

(f)

Figure 3.3.94 TEM image(a) and its size distribution(b), HRTEM images at 500k(c), and $800 \mathrm{k}(\mathrm{d})$, Fringe length analysis(e,f) at three different burn off stages for FT soot 


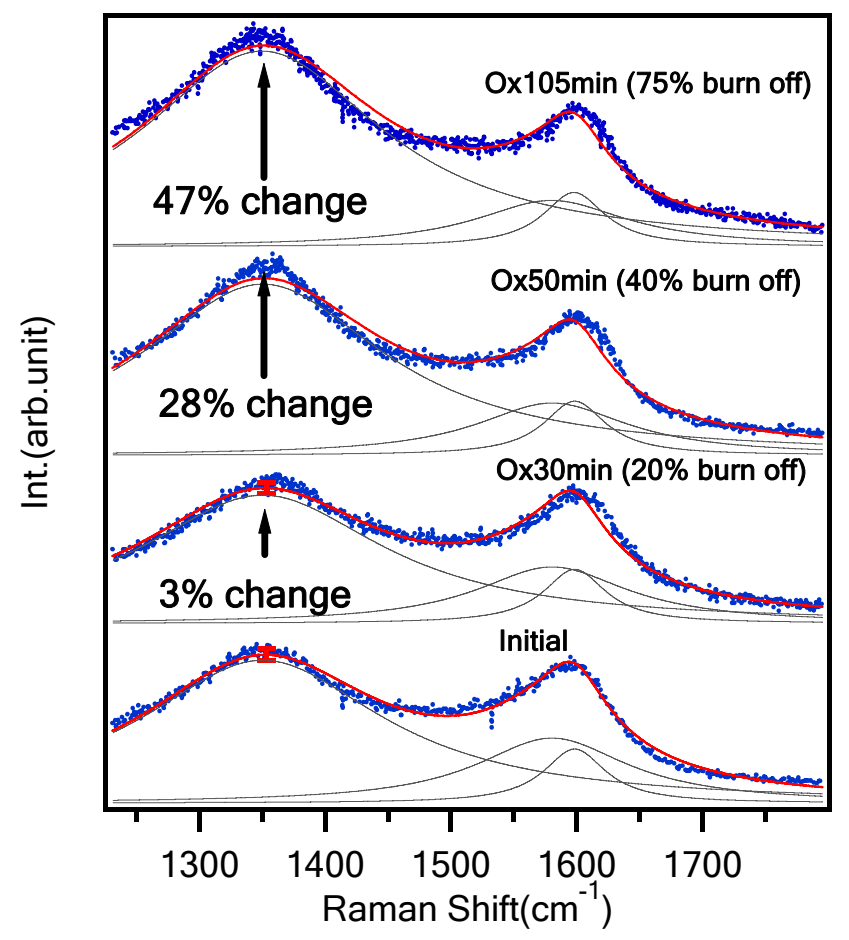

(a)

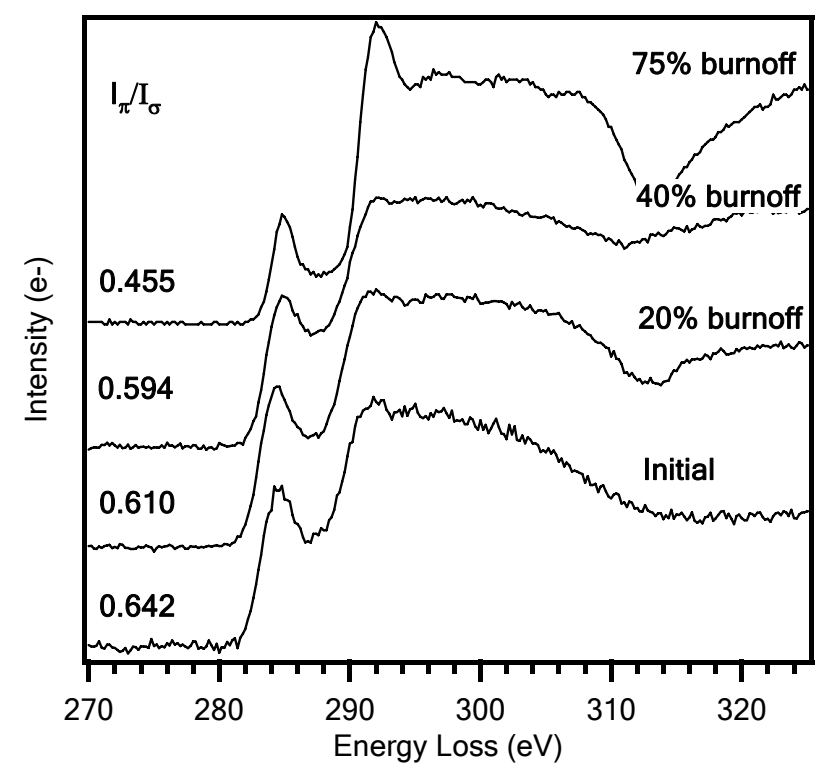

(b)

Figure 3.3.95 (a) Raman spectra, (b) EELS spectra, supporting a continuous tendency toward disordered state during an oxidation for FT soot 


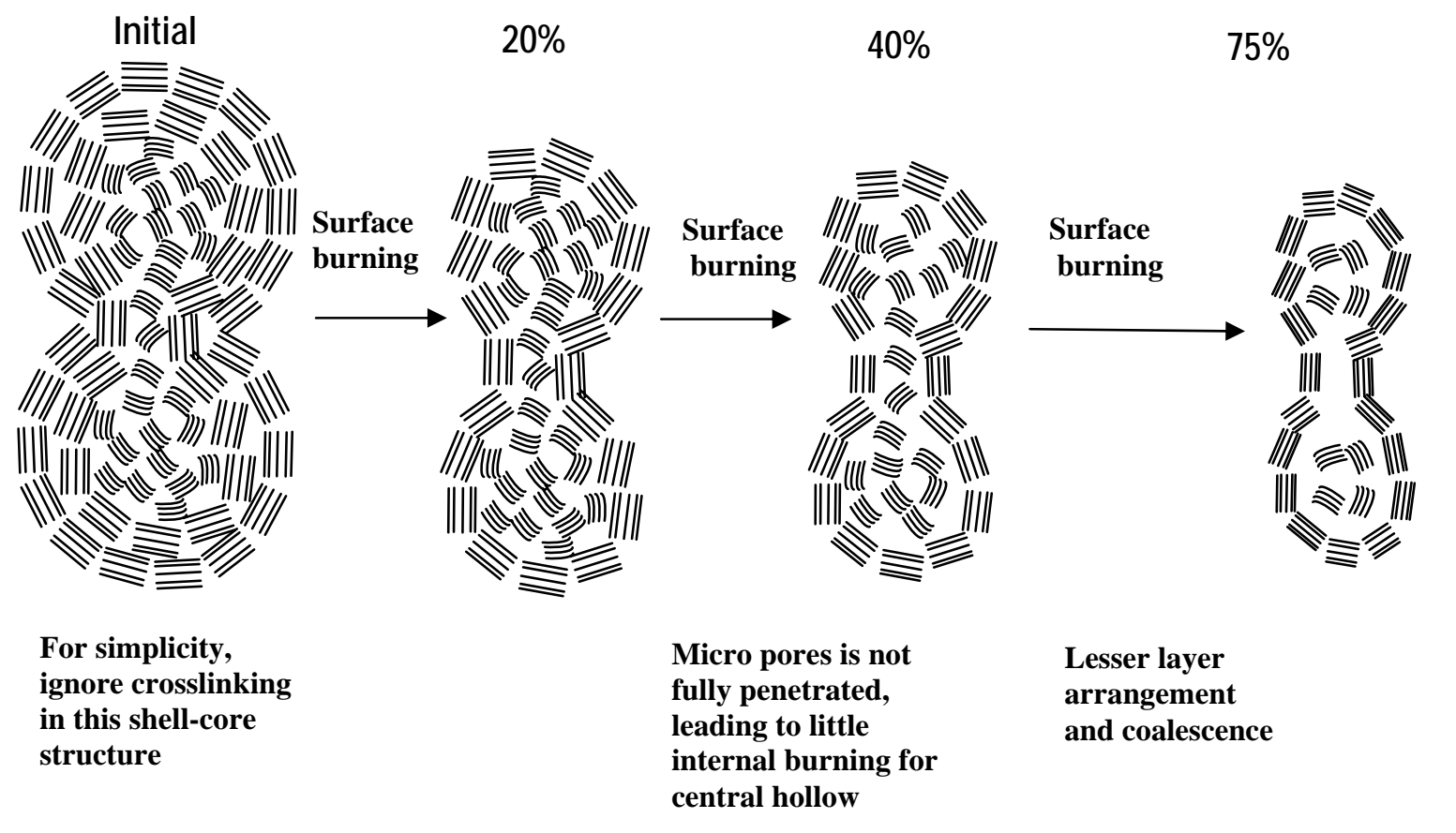

Figure 3.3.96 Simplified oxidation progression model for FT soot, indicating progressive shrinking core type oxidation with lesser indication of internal burning and layer rearrangement even up to $75 \%$ burn off than B100 soot 
BF image
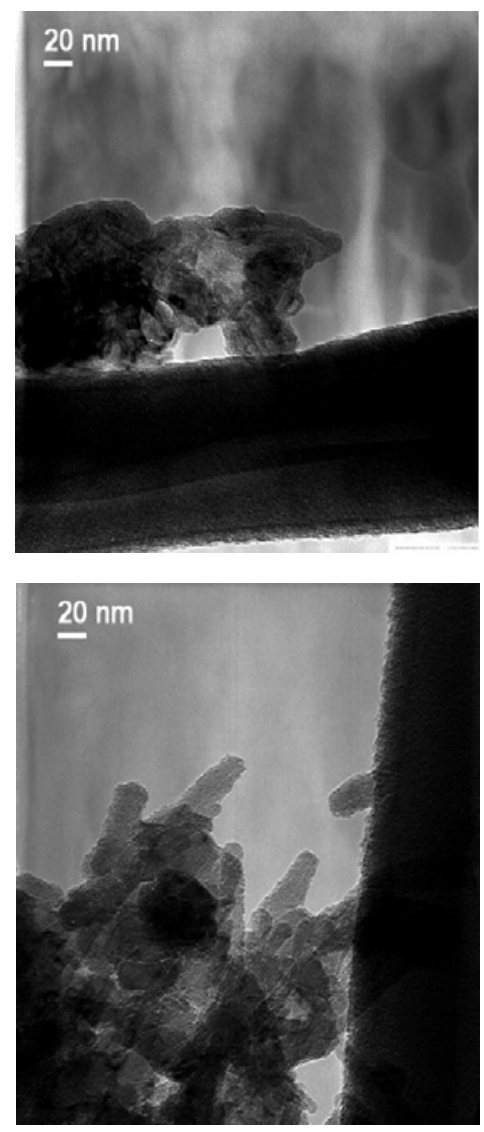

DF image

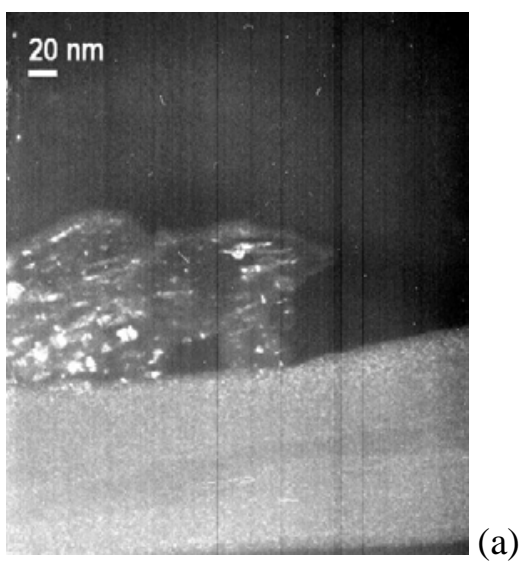

\section{$\underline{20} \mathrm{~nm}$}

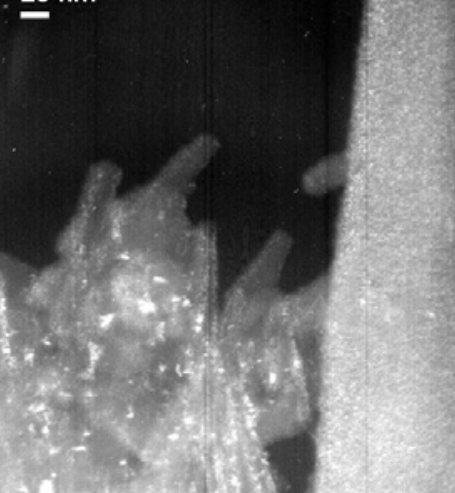

(b)

Figure 3.3.97 Comparison of 002 diffraction contrast images taken at 230,000 magnifications indicating a prevalence of more hollow inside particle with B100 soot(a) compared to FT soot(b) at the same $75 \%$ burnoff. 


\subsection{Comparison of Burning Modes}

From the size distributions at different burnoff levels that were described earlier, the diameter change for the B100 and FT soot samples is summarized in Table 3.3.18. This diameter change for both B100 and FT soots was plotted against extent of burnoff in Figure 3.3.98 (a) and was compared with the two burning modes described in the literature. The straight line represents a diameter change that is theoretically predicted by assuming the surface burning regime, while the dotted line represents diameter change that was experimentally determined with several porous carbon materials including diesel soot under a burning regime where the internal burning rate is 10 times higher than that for surface burning $[38,100,53,101]$. The relation between diameter change and burn off can be expressed as below for each burning mode.

$$
\begin{array}{ll}
\text { Surface burning mode } & \frac{d}{d_{0}}=(1-x)^{\frac{1}{3}} \\
10 \text { to } 1 \text { Internal burning mode } & \frac{d}{d_{0}}=(1-x)^{\frac{1}{6}}
\end{array}
$$

The soot samples from this study fit well between the two burning regimes, but a deviation from surface burning to internal burning is apparent after $40 \mathrm{wt} \%$ burnoff. It is apparent that FT soot is likely to remain in the surface burning regime to some extent, whereas B100 soot is more likely to transition to internal burning. Therefore, the rate of oxidation depends on the burning mode (i.e., how fast internal burning occurs). For a more accurate determination of burning modes, the density or surface area should be supplemented as a function of burnoff and compared with available expressions from the literature $[100,102]$.

Oxygen content was measured and quantified by EELS and is plotted against burnoff as shown in Figure 3.3.98 (b). At the initial stage, twice much oxygen content is indicated for B100 soot than for FT soot, supporting a higher presence of surface oxygen groups with B100 soot by FTIR. This initial oxygen content ranging from 5 to $10 \%$ is reasonable since the oxygen content between 5 and $10 \%$ was reported for soot samples measured with different apparatus including a dedicated EDXS $[103,53,104]$. However, it should be noted that initial samples for EELS measurement still contain oxygen from both SOF and non-SOF portions of the particulates since particulates on the TEM grid were used. In contrast, the oxidized samples are believed to have no contribution of the SOF portion to their measured oxygen content due to the pretreatment prior to TGA oxidation. For a fair comparison, it is recommended to measure the oxygen content for an initial sample after SOF removal. In addition, an identification of where this oxygen is incorporated (i.e., bonded at edges, inside the basal plane or adsorbed on outer surfaces) would give supporting evidence on how initial oxygen groups influence structural change and thereby affect reactivity. Identifying a local distribution of oxygen content in STEM mode and a comparison between surface-sensitive spectra (i.e., XPS) and bulk volume-sensitive spectra (FTIR or EELS) are recommended to further examine this mechanism.

After $40 \%$ burnoff, B100 soot has a more abrupt consumption of oxygen content than FT soot, supporting a rigorous internal burning and layer arrangement with B100 soot. During the oxidation or gasification of carbon, a similar trend of oxygen consumption was also observed [105]. Since an unstable oxygen complex is quickly formed and consumed during oxidation $[106,107,108]$, the net oxygen content is likely to decrease during the graphitization process where each layer can rearrange with neighboring layers $[69,71]$. 
Table 3.3.18 Summary of diameter change as a function of wt $\%$ burn off

\begin{tabular}{|l|l|l|}
\hline $\begin{array}{l}\text { Burn } \\
\text { off }(x)\end{array}$ & $\begin{array}{l}\text { B100 } \\
\left(d / d_{0}\right)\end{array}$ & $\begin{array}{l}F T \\
\left(d / d_{0}\right)\end{array}$ \\
\hline 0 & 1 & 1 \\
\hline 0.2 & 0.902 & 0.967 \\
\hline 0.4 & 0.869 & 0.818 \\
\hline 0.75 & 0.771 & 0.733 \\
\hline
\end{tabular}

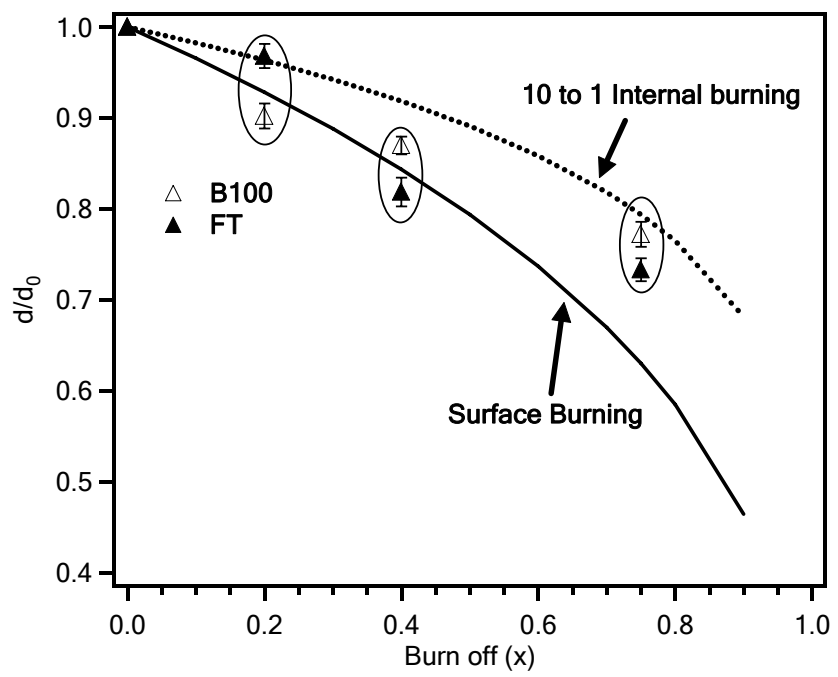

(a)

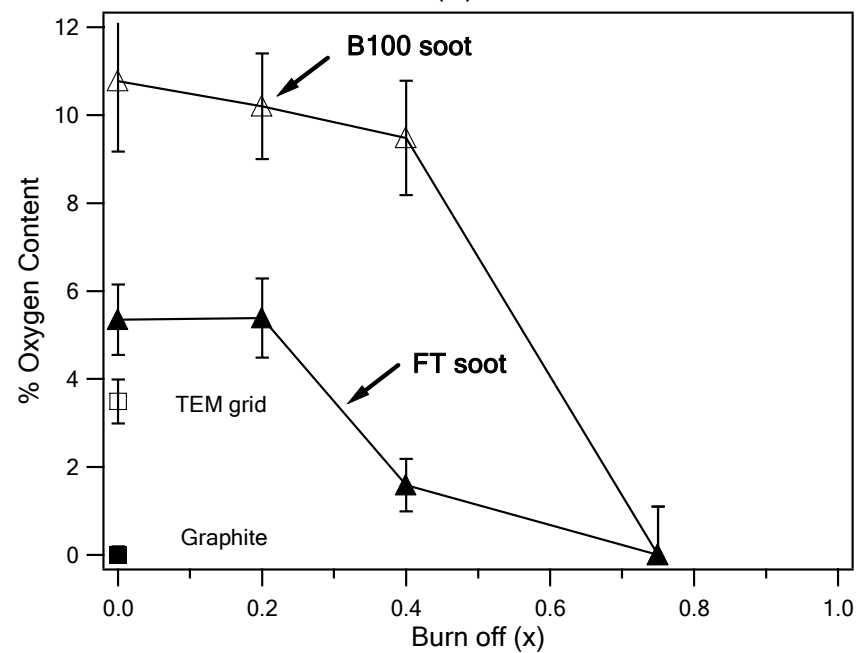

(b)

Figure 3.3.98 (a) Diameter change for two soot samples as function of burn off indicating a transition from surface burning to internal burning after $40 \mathrm{wt} \%$ burn off, (b) Oxygen content as function of burn off indicating higher oxygen at initial stage and more abrupt oxygen consumption after $40 \%$ burnoff in B100 soot. 
Sarofim and co-workers observed a transition from surface area around 40 50\% burnoff with $\mathrm{CO}_{2}$ surface area measurements during oxidation [81]. As shown in Figure 3.3.99, the $\mathrm{CO}_{2}$ surface area increased until 40 50\% conversion was reached. Thereafter, the $\mathrm{CO}_{2}$ surface area was relatively constant with conversion for the NIST soot, but rapidly decreased for the NEU soot. This fall off behavior of the NEU soot after a certain burnoff level may be related to the observation made here regarding the general transition from surface burning to internal burning/layer rearrangement after $40 \%$ burnoff. Once the layer rearrangement proceeds further, a more closed shell that is hollow inside is likely to be formed. This structure is not likely to allow any gases such as $\mathrm{CO}_{2}$ to penetrate inside, thereby resulting in a loss of internal surface area and possible loss in particulate reactivity at later stages of oxidation $[95,96]$.

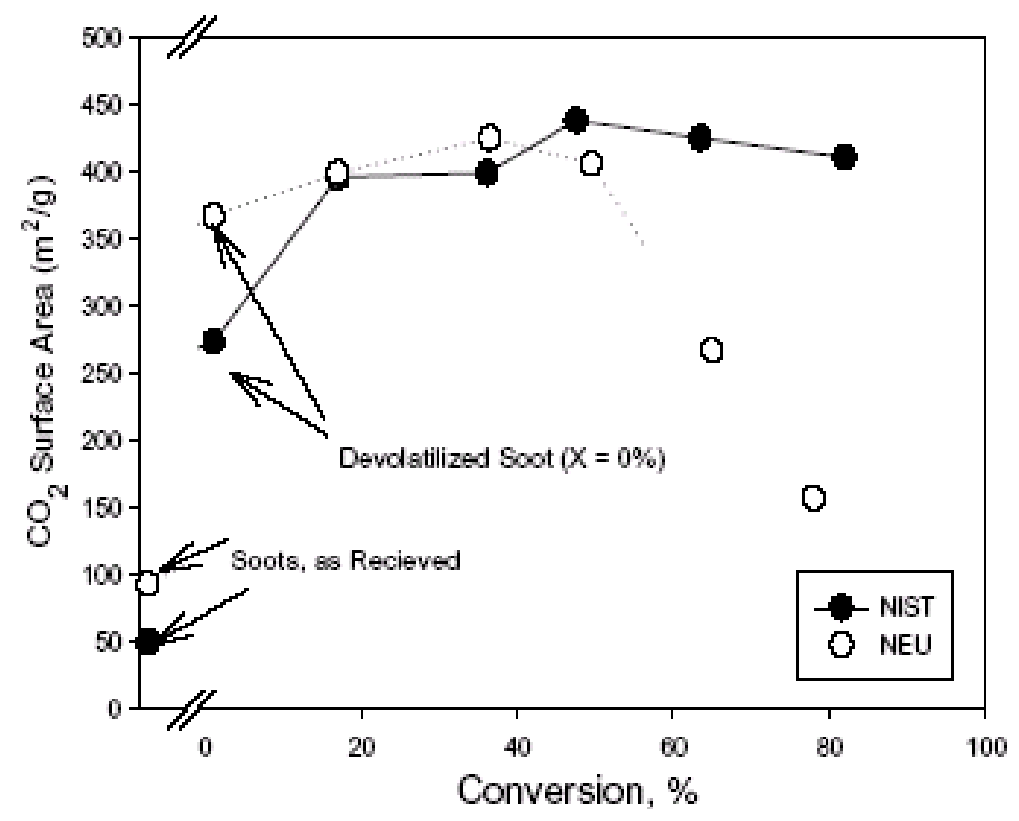

Figure 3.3.99 Surface area evolution during an oxidation for two soot samples, NIST represents soot sample with high volatile content, while NEUsoot has low volatile content, respectively [81].

A graphitized structure of severely oxidized soot provides some implications related to diesel engine application. From key results on the liquid adsorption behavior of soot samples $[103,109,110]$, loss in porosity or edge sites may minimize oil consumption through reduced adsorption of lubricant oil on the soot surface in engines with EGR control. Despite the negligible contribution due to small amount of soot remaining after regeneration, this may be source of adverse plugging of the pores and resultant degradation via a change in permeability of the deposited soot on the DPF substrate and should be controlled to minimize degradation of performance and increase in difficulty during regeneration.

In summary for these last experiments, B100 soot results in capsule-type oxidation through internal burning, leading to a more ordered layering via rearrangement. In contrast, FT soot displays surface burning and less degree of layer rearrangement than B100 soot, even at $75 \%$ burnoff. Early dramatic changes in the inner structure and subsequent hollowing out of the soot are crucial factors that enhance oxidation. Surface reactivity involved in the early stage oxidation also seems to be responsible for the layer rearrangement at later stage of oxidation. 


\subsubsection{Evaluation of Selective Catalytic Reduction of $\mathrm{NO}_{\mathrm{x}}$}

\subsubsection{Introduction}

Nitrogen oxides are formed by oxidation of nitrogen at high temperatures. Such conditions are available in the combustion chamber of an internal combustion engine especially at higher power conditions. Nitrogen oxides are comprised of nitric oxide (NO), nitrogen dioxide $\left(\mathrm{NO}_{2}\right)$, and nitrous oxide $\left(\mathrm{N}_{2} \mathrm{O}\right)$. These gases are popularly known as $\mathrm{NO}_{x}$ and are harmful to the environment.

Emissions of nitrogen oxides discharged into the atmosphere from the burning of fossil fuels have significant adverse effects on human health and the environment, contributing substantially to the formation of ozone, acid deposition, eutrophication of water bodies, inhalable fine particles, and visibility degradation. However, the most deleterious effect is caused as $\mathrm{NO}_{x}$ reacts with hydrocarbons, ozone and light to produce smog. In addition, nitrous oxide $\left(\mathrm{N}_{2} \mathrm{O}\right.$, also a greenhouse gas) reacts with water to produce acid which causes corrosion problems and acid rain. Substantial, additional regional $\mathrm{NO}_{x}$ reductions from current levels are likely to be necessary to address these problems. Electric utilities are a major contributor to $\mathrm{NO}_{\mathrm{x}}$ emissions nationwide along with motor vehicles. Approximately 90 percent of electric utility $\mathrm{NO}_{x}$ comes from coal-fired power plants, while approximately $36 \%$ of $\mathrm{NO}_{\mathrm{x}}$ from the transportation sector comes from diesel vehicles [111].

Therefore, it is essential to curb these emissions from internal combustion engines. Over the past decade, a number of researchers have developed and tested emission control techniques for $\mathrm{NO}_{\mathrm{x}}$ emissions from diesel engines. The target for accepted $\mathrm{NO}_{x}$ emissions in $\mathrm{U}$. $\mathrm{S}$. has been tightened over time by the U. S. Environment Protection Agency (EPA). Between 1997 and 2000, the EPA set new Federal emission standards for on-road diesel vehicles that will dramatically reduce allowable $\mathrm{NO}_{x}$ and particulate matter (PM) emissions. Under these new standards, model year 2004 (MY2004) $\mathrm{NO}_{x}$ emissions from on-road heavy-duty diesel engines will be half those required under MY1998 standards (2.5 g/KW-hr in MY2004) Starting with MY2007, new on-road heavy-duty diesel engines will need to achieve PM levels and phased-in $\mathrm{NO}_{x}$ (starting from 2007 , ending in 2010) that are only $10 \%$ of MY2004 levels [111]. As a result, diesel engine and vehicle manufacturers will need to implement exhaust after-treatment control devices to meet the MY2007 and later (MY2007+) requirements. These standards will be implemented in conjunction with federal ultra low-sulfur diesel (<15-ppm sulfur) production requirements, facilitating the introduction of low-emission technologies that would otherwise be compromised by high sulfur levels in the diesel engine exhaust. Nitrous oxide $\left(\mathrm{N}_{2} \mathrm{O}\right)$ is not regulated however. The $\mathrm{NO}_{x}$ regulation is as described in Figures 3.3.100 and 3.3.101.

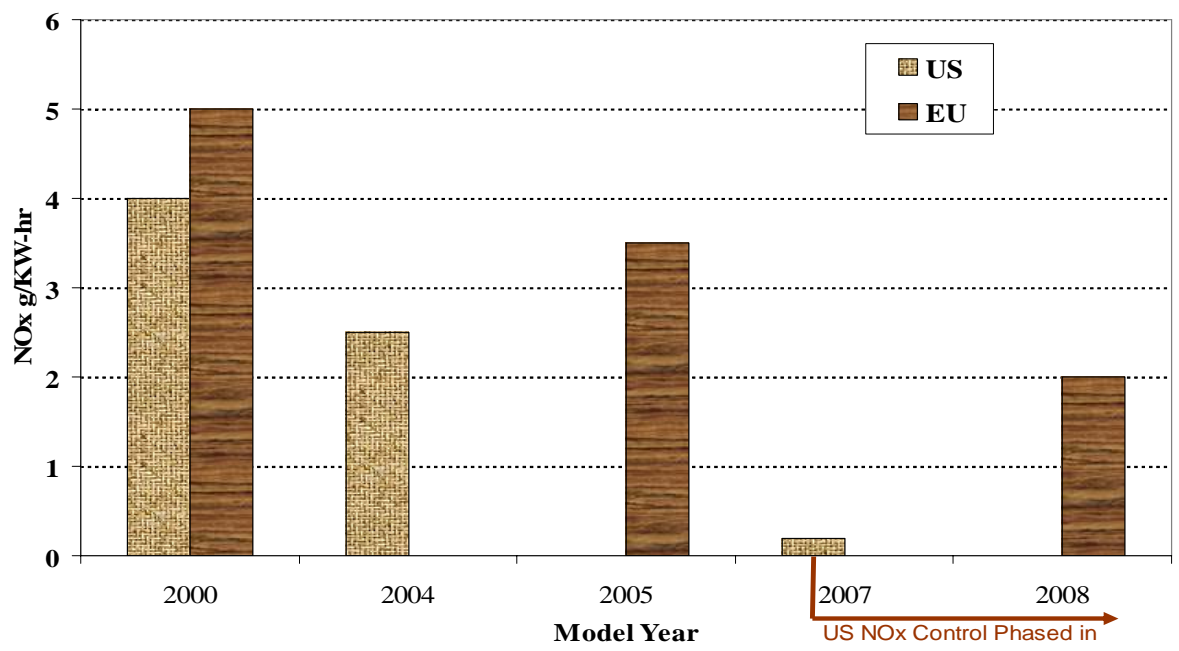

Figure 3.3.100 United States and European Union emissions regulations [111] 
There are successful strategies to deal with $\mathrm{NO}_{x}$ emissions from gasoline engine exhausts and coal-fired utility boilers. Three-way catalysts (for oxidation of $\mathrm{HC} \& \mathrm{CO}$ and reduction of $\mathrm{NO}_{\mathrm{x}}$ ) are successful at reducing emissions from gasoline engine exhausts, but they do not work for diesel engines. Excess oxygen in raw diesel exhaust inhibits the $\mathrm{NO}_{x}$ reduction reaction in the conventional three-way automotive catalyst. Also, the lean nature of diesel engine combustion results in less $\mathrm{CO}$ and $\mathrm{HC}$ emissions but low exhaust temperature. The high efficiency of diesel engines relative to gasoline-powered engines has motivated ongoing research on $\mathrm{NO}_{\mathrm{x}}$ emission control strategies for diesel engines.

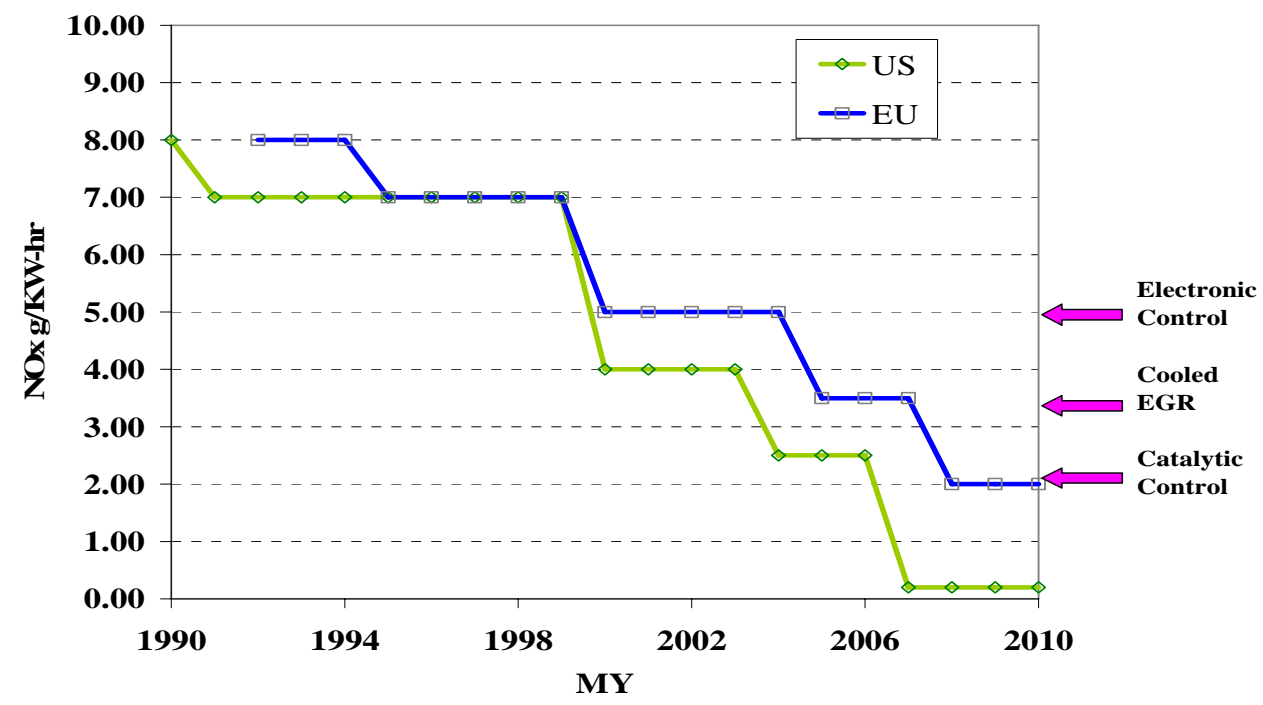

Figure 3.3.101 Trends in $\mathrm{NO}_{\mathrm{x}}$ reduction technology [111]

\subsection{Catalyst Fundamentals}

A catalyst is a substance which can increase the rate of a chemical reaction (i.e., molecules converted per unit time) while itself not undergoing any permanent change. Heterogeneous catalysts supported on high surface area porous oxides are used in emission control applications. The overall catalytic conversion in a heterogeneous catalyst is composed of several sub-processes which involve chemical reaction, bulk mass transfer and pore diffusion. Catalytic processes controlled by reaction kinetics can be modeled using the Arrhenius equation. Catalytic conversions in the mass transfer controlled region can be estimated using mass transfer correlations developed for monolithic catalyst supports. Even though catalysts are not consumed in the reaction, they can undergo gradual deterioration due to thermal deactivation and poisoning [112].

\subsection{Catalyst Selectivity}

The catalyst influences reaction selectivity by preferentially lowering the activation energy for a particular step in the reaction sequence and increasing the rate at which this step proceeds. Selectivity is an issue for many reactions in which multiple reaction pathways can occur in parallel. For example in reactions R-3.3.1, for the partial oxidation of ethylene over a $\mathrm{V}_{2} \mathrm{O}_{5}$ catalyst, the reaction pathway leading to the formation of the aldehyde product is favored because it has a lower activation energy than the complete combustion to $\mathrm{CO}_{2}$ and $\mathrm{H}_{2} \mathrm{O}$ as shown in R-3.3.2. For the reaction, using $\mathrm{Pt}$, the opposite is true. It is the job of the catalyst to reduce the activation energy of the reaction that will yield the desirable product [112].

$$
\begin{aligned}
& \mathrm{C}_{2} \mathrm{H}_{4}+0.5 \mathrm{O}_{2} \rightarrow \mathrm{CH}_{3} \mathrm{CH}=\mathrm{O} \\
& \mathrm{C}_{2} \mathrm{H}_{4}+3 \mathrm{O}_{2} \rightarrow 2 \mathrm{CO}_{2}+2 \mathrm{H}_{2} \mathrm{O}
\end{aligned}
$$




\subsection{Cellular Monolith Substrates}

Cellular monoliths have replaced pellet shaped catalyst supports and have become the standard substrate for emission control catalysts. Monoliths can be either ceramic extrusions or corrugated metal foil assemblies. Each type is typically coated with an intermediate layer of inorganic oxides, called washcoat, in order to provide the high surface area required for effective gas-solid content [112].

Extruded ceramic monolithic honeycombs are the standard catalyst substrates for emission control catalysts. Cordierite $\left(2 \mathrm{MgO} \cdot 2 \mathrm{Al}_{2} \mathrm{O}_{3} \cdot 5 \mathrm{SiO}_{2}\right)$, a synthetic ceramic material of very low thermal expansion coefficient, is the most commonly used material. Raw materials such as kaolin, talc, alumina, aluminum hydroxide, and silica are blended into a paste and extruded and calcined. It is possible to produce sizes up to about 11 inches in diameter and 7 inches long, with cell densities from 9 to 600 cells per square inch (cpsi) [112].

Metallic monolithic catalyst supports consist of thin metal foils made of ferrite iron-chromiumaluminum alloys of high thermal durability. The foils are corrugated to produce the honeycomb channels, typically resulting in a sinusoidal cell shape. Many substrate designs have been developed, featuring interchanged corrugated and flat foils or only corrugated foils, which can be wound or stacked in layers [112].

\subsection{Catalytic Coating and Materials}

Emission control catalysts are usually manufactured by applying a washcoat onto catalyst supports. The washcoated parts are then impregnated with precious metal catalyst. The washcoat is a porous, base metal oxide layer which is applied to the substrates from acidified aqueous slurry, dried and calcined. The internal surface of washcoat and walls of pores are covered by $\mathrm{OH}$ - species which represent sites upon which one can physically or chemically bond a catalytic species [112].

Aluminum oxide is the most common washcoat material. Other materials, used either as catalyst carriers or as promoters and stabilizers, include silicon oxide, cerium dioxide, titanium dioxide, zirconium oxide, and zeolites. Rare earth metals like $\mathrm{Ba}$, $\mathrm{La}$, etc are also good catalyst carriers. A carrier is usually a high surface area inorganic material containing a complex pore structure into which catalytic materials such as $\mathrm{Pt}, \mathrm{Pd}$, and $\mathrm{V}_{2} \mathrm{O}_{5}$ are deposited. Alumina is by far the most common carrier used in commercial environmental applications. But it is highly reactive with $\mathrm{SO}_{3}$ and forms compounds that alter the internal surface of the carrier resulting in catalyst deactivation. In contrast, $\mathrm{SiO}_{2}$ and $\mathrm{TiO}_{2}$ are inert towards sulfate formation. $\mathrm{TiO}_{2}$ is a preferred surface carrier for vanadia in catalytic reduction of $\mathrm{NO}_{\mathrm{x}}$. Zeolites are naturally occurring or synthetic crystalline aluminosilicates with well defined crystalline structure and pore size. The $\mathrm{Al}_{2} \mathrm{O}_{3}$ and $\mathrm{SiO}_{2}$ are bound in a tetrahedral structure with each Al and Si cation bonded to four oxygen anions. In turn each $\mathrm{O}^{-2}$ is bonded to either $\mathrm{Si}^{+4}$ or $\mathrm{Al}^{+3}$ in an arrangement similar to Figure 3.3.102 [112].<smiles>CO[Si](O)(O)O[Al](O)O[Si](O)(O)O[Si](O)(O)OC</smiles>

Figure 3.3.102 Typical zeolite structure [112]

\subsection{Catalytic Converters}

Ceramic catalyst cores are wrapped in mounting mats and packaged into steel housings. Specially developed materials and technologies allow the design and construction of extremely durable catalytic converters. The most commonly used mounting mats, called intumescing mats, contain vermiculite which expands under high temperatures to provide high mounting pressures. 
Among the three known converter canning technologies, which include clamshell, tourniquet and stuffing, the tourniquet technology provides the most robust converter design. In each of the technologies, the converter shell geometry has to provide the required mounting density for the mat. The design of converter inlet and outlet headers or cones affects the gas flow distribution and pressure drop. In applications with space limitations, catalysts can be placed inside catalytic mufflers [112].

\subsection{Catalyst Light-off}

Catalyst light-off marks the transition from kinetically controlled to diffusion-limited reaction on the catalyst. So light-off temperature and light-off axial position (i.e., the time to reach light-off during a transient experiment) in the cell are two indicators of this transition. At the light-off temperature, light-off takes place at some axial position along the catalyst. A lower catalyst light-off temperature means that the catalyst can reach light-off while the incoming exhaust gas temperature is still low. A short light-off time means the converter distributes the energy from the catalytic reaction rapidly and reaches a fully warmed state quickly. The light-off temperature is largely set by the catalyst/washcoat formulation, while the light-off time is dependent on the thermo-physical properties of the substrate as well as the catalyst formulation. The light-off time decreases as the catalyst loading is increased. Light-off times for converters are obtained through transient, warm-up tests. Light-off temperatures, in contrast, are measured in steady or quasi-steady experiments [112].

The process of light-off is a complex heat and mass transfer interaction within the converter, combining the effects of heat transfer to and from the exhaust gas and the variation of catalyst activity with surface temperature and surface concentration. Light-off in an automotive exhaust gas reactor is characterized by steep gradients in surface temperature and in reactant concentration. These steep gradients make it virtually impossible to characterize the reaction rates in the normal, adiabatic mode of converter operation. This difficulty has led many to study catalyst behavior in controlled micro-reactors. During a cold start, the reactions on the cold catalytic surface are kinetically controlled. Heat release from these reactions warms the catalytic surface and accelerates the reaction rates. Reaction rates increase until they reach their limiting values, which are set by diffusion of the reactants to the catalyst [112].

\subsection{Dual Site Mechanism}

The stoichiometric equation does not tell us how the chemical transformation takes place at the molecular level, unless it represents an elementary step. The rate-limiting steps can be classified into two categories: 1. Langmuir-Hinshelwood mechanism assumes a reaction between two adsorbed species, and 2. the Eley-Rideal mechanism assumes a reaction between an adsorbed species and a gas phase species. The Langmuir-Hinshelwood mechanism is referred to as the "dual site" mechanism [112].

\subsection{Sulfur and Catalytic Converters}

The impact of sulphur on catalytic converters is an issue of special concern. Sulphur is highly reactive with the precious metals used on the active surface of the catalyst. This limits the efficiency of the device because sulphur reduces the active surface area of the catalyst. Sulphur can also delay the operation of the catalyst, retarding its light-off temperature especially in cold start conditions. According to Robert Searles of the catalyst-makers industry association AECC (Association for Emissions Control by Catalyst), "one tank full of high sulphur fuel will immediately degrade the catalyst performance" [113]. Fortunately, such effects can be reversed with low sulphur fuel; correspondingly it is clear that, for the future, lower sulphur levels will be needed to improve catalyst performance.

This is becoming even more important as regulators around the world introduce ever more stringent vehicle emission regulations. According to both AECC and the ACEA (the European Car Makers Association), lower $\mathrm{NO}_{\mathrm{x}}$ levels for diesel engines will require sulphur levels as low as 15 
ppm. These engines will need advanced $\mathrm{DeNO}_{\mathrm{x}}$ catalyst technologies (currently under development) which will only work effectively with very low sulphur content [113].

\subsubsection{2 $\mathrm{NO}_{\mathrm{x}}$ Reduction Technologies}

There have been a number of efforts for developing $\mathrm{NO}_{\mathrm{x}}$ control strategies, ranging from combustion chamber modifications to tail pipe emission control. Typically, there exists a trade off between $\mathrm{NO}_{\mathrm{x}}$ and $\mathrm{PM}$ whereby decreasing one will increase the other. Therefore, the popular approach has been to reduce PM by in-cylinder processes and control $\mathrm{NO}_{x}$ by after-treatment devices. Among $\mathrm{NO}_{x}$ after-treatment devices, use of catalytic technology has been the dominant one. Lean $\mathrm{NO}_{x}$ catalysts, SCR-Catalysts, $\mathrm{NO}_{x}$ adsorber catalyst and non-thermal plasma aftertreatment techniques have been the main options for future $\mathrm{NO}_{x}$ reduction technology, shown in Figure 3.3.103. A comparison of their performance is shown in Table 3.3.19.

Table 3.3.19 Reduction efficiency of available $\mathrm{NO}_{\mathrm{x}}$ reduction technologies [114]

\begin{tabular}{|c|c|c|c|c|c|}
\hline \multirow[t]{2}{*}{ Technology } & \multicolumn{4}{|c|}{ Performance Range (Reduction Efficiency \%) } & \multirow{2}{*}{$\begin{array}{c}\text { Commercial } \\
\text { Availability }\end{array}$} \\
\hline & $\mathrm{NO}_{\mathrm{x}}$ & $\mathrm{CO}$ & $\mathrm{HC}$ & PM & \\
\hline $\begin{array}{l}\text { Lean } \mathrm{NO}_{\mathrm{x}} \\
\text { Catalysts }\end{array}$ & $25-50$ & 70 & 70 & $\sim 30$ & 2000 \\
\hline $\begin{array}{c}\mathrm{NO}_{\mathrm{x}} \\
\text { adsorber }\end{array}$ & $50-70$ & 70 & 70 & 30 & 2004 \\
\hline $\begin{array}{l}\text { Plasma } / \mathrm{NO}_{\mathrm{x}} \\
\text { Treatment }\end{array}$ & 65 & 50 & 50 & $\sim 30$ & $<2004$ \\
\hline $\begin{array}{l}\text { Compact } \\
\text { Urea SCR }\end{array}$ & 90 & 70 & 70 & 30 & 2004 \\
\hline
\end{tabular}

\subsection{Lean $\mathrm{NO}_{x}$ Catalysts}

Catalysts that selectively promote the reduction of $\mathrm{NO}_{x}$ by hydrocarbons have been termed lean $\mathrm{NO}_{x}$ catalysts (LNC) or DeNO ${ }_{x}$ catalysts. This technique utilizes the components of exhaust gases (unburned hydrocarbons and carbon monoxide) or injection of reductant species to selectively reduce $\mathrm{NO}_{\mathrm{x}}$ over a catalyst site. In this process, hydrocarbons react with $\mathrm{NO}_{x}$, rather than with $\mathrm{O}_{2}$ to form nitrogen. Assuming that a single hydrocarbon species of the formula $\mathrm{C}_{m} \mathrm{H}_{n}$ reacts with NO, the following equation R-3.3.3 describes the chemical reaction:

$$
\mathrm{C}_{\mathrm{m}} \mathrm{H}_{\mathrm{n}}+(2 \mathrm{~m}+1 / 2 \mathrm{n}) \mathrm{NO} \rightarrow(\mathrm{m}+1 / 4 \mathrm{n}) \mathrm{N}_{2}+\mathrm{m} \mathrm{CO}_{2}+1 / 2 \mathrm{n} \mathrm{H}_{2} \mathrm{O}
$$

A competitive reaction R-3.3.4, oxidation of hydrocarbon, also takes place as follows:

$$
\mathrm{C}_{\mathrm{m}} \mathrm{H}_{\mathrm{n}}+(\mathrm{m}+1 / 4 \mathrm{n}) \mathrm{O}_{2} \rightarrow \mathrm{mCO}_{2}+1 / 2 \mathrm{nH}_{2} \mathrm{O}
$$

Lean $\mathrm{NO}_{\mathrm{x}}$ catalysts have to be optimized to selectively promote the desired reaction (with $\mathrm{NO}_{\mathrm{x}}$ ) over undesired reaction with oxygen. Numerous catalysts systems, both precious and base metal based, have been reported to exhibit lean $\mathrm{NO}_{x}$ reduction activity. Some of these formulations are listed in Table 3.3.20. 


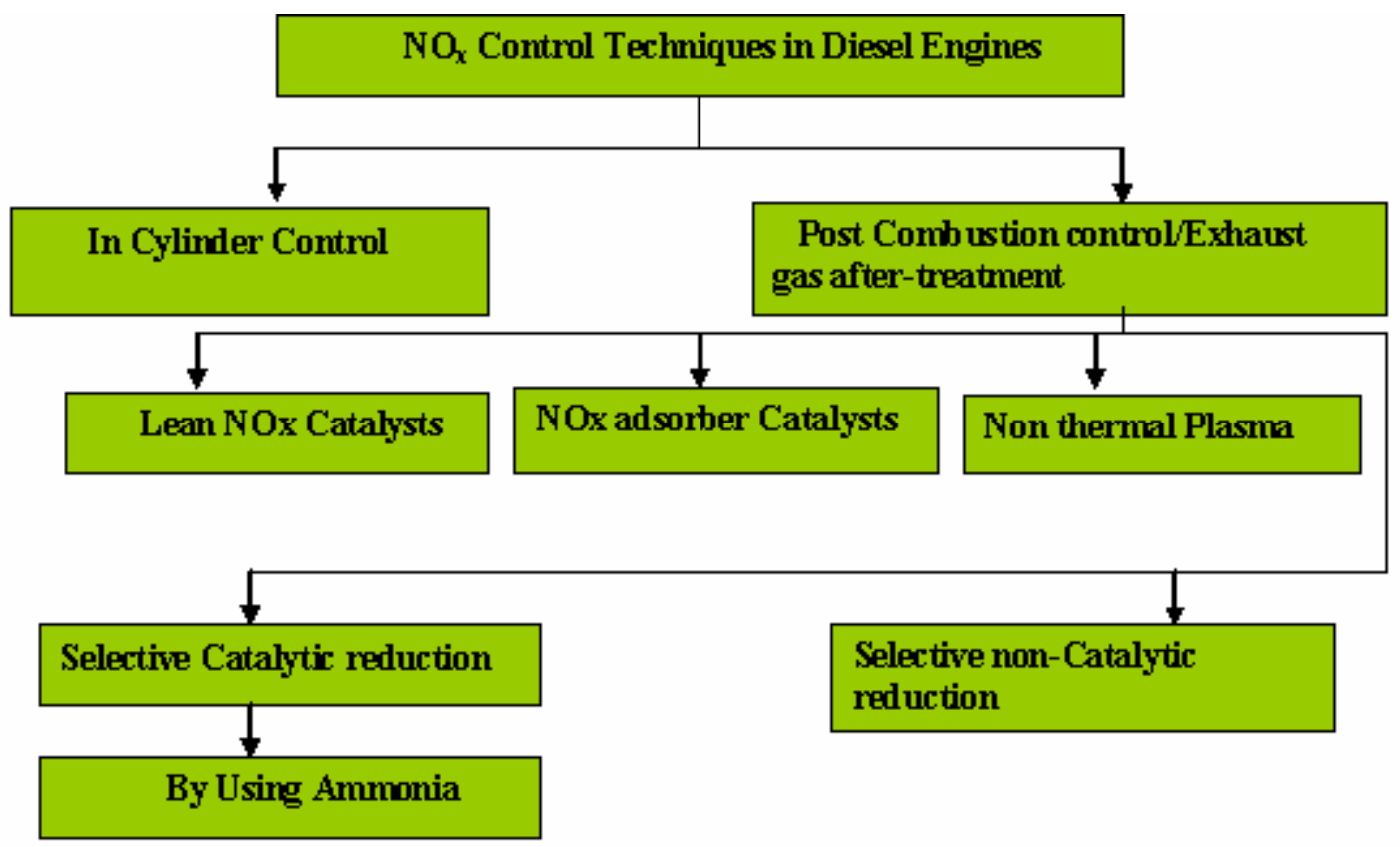

\section{By Using Hydrocarbon}

Figure 3.3.103 Layout of available $\mathrm{NO}_{\mathrm{x}}$ reduction technologies

Table 3.3.20 Catalyst formulations of lean $\mathrm{NO}_{x}$ catalysts [115]

\begin{tabular}{|c|c|}
\hline Washcoat & Metal \\
\hline Zeolite-Based & $\mathrm{Cu}, \mathrm{Pt}, \mathrm{Mn}, \mathrm{Fe}, \mathrm{Co}, \mathrm{Ni}, \mathrm{Zn}, \mathrm{Ag}, \mathrm{Ce}, \mathrm{Ga}$ \\
\hline Alumina Based & $\begin{array}{l}\mathrm{Pt}, \mathrm{Pd}, \mathrm{Rh}, \mathrm{Ir}, \mathrm{Ru}, \mathrm{Pt}-\mathrm{Rh}, \mathrm{Pt}-\mathrm{W}, \mathrm{V}, \mathrm{Cr}, \mathrm{Mn} \text {, } \\
\text { Fe, Co, Ni, Cu, Zn, Ag }\end{array}$ \\
\hline Silica-Alumina & $\mathrm{Co}, \mathrm{Cu}$ \\
\hline \multicolumn{2}{|l|}{ Titania, sulfated titania } \\
\hline Zirconia, sulfated zirconia & \\
\hline
\end{tabular}

Some very optimistic results were published initially using a variety of catalysts. But, the multitude of systems under development proved that the catalysts were far from being perfect. Some of the reported laboratory conversion efficiencies and their corresponding temperatures are listed in Table 3.3.21 [116].

Out of the catalysts listed above, only two groups of catalyst systems have been identified as most promising for the reduction of $\mathrm{NO}_{\mathrm{x}}$ with hydrocarbons:

- Copper exchanged zeolite ZSM5 catalyst, which is active at high temperatures, and 
- Platinum/alumina catalyst, exhibiting low temperature activity.

Both catalysts have narrow operating temperature windows, resulting in only a limited $\mathrm{NO}_{\mathrm{x}}$ reduction efficiency ranging between $50-60 \%$ [115].

Table 3.3.21 Performance of different catalyst materials [116]

\begin{tabular}{|c|c|c|c|}
\hline Catalyst & Peak NO $_{\mathbf{x}}$ Conversion (\%) & Temperature ${ }^{\circ}$ C) & Reducing Agent \\
\hline Cu-ZSM & 60 & 400 & $\mathrm{C}_{2} \mathrm{H}_{4}$ \\
\hline H-Mordenite & 62 & 400 & $\mathrm{C}_{2} \mathrm{H}_{8}$ \\
\hline Ga-Ferrite & 100 & 600 & $\mathrm{C}_{3} \mathrm{H}_{8}$ \\
\hline Ga-ZSM & 100 & 500 & $\mathrm{C}_{2} \mathrm{H}_{6}$ \\
\hline $\mathrm{SnO}_{2}$ & 67 & 400 & $\mathrm{C}_{2} \mathrm{H}_{4}$ \\
\hline $\mathrm{Ag}-\mathrm{Al}_{2} \mathrm{O}_{3}$ & 80 & 400 & $\mathrm{C}_{2} \mathrm{H}_{6}$ \\
\hline
\end{tabular}

In a final report by Diesel Emission Control -Sulfur Effects (DECSE) Program on "Diesel Oxidation Catalysts and Lean- $\mathrm{NO}_{x}$ Catalysts" [117], the following conclusions are made about lean $\mathrm{NO}_{\mathrm{x}}$ catalysts:

- Both low temperature (LT) and high temperature (HT) lean-NO $\mathrm{NO}_{\mathrm{x}}$ catalysts possess a narrow operating temperature window.

- With the limited $\mathrm{NO}_{\mathrm{x}}$ reduction efficiency ( $\left.20 \%\right)$, the lean- $\mathrm{NO}_{\mathrm{x}}$ technologies will not be capable of addressing the stringent EPA diesel emissions regulation for Model Year 2007 and beyond. However, lean- $\mathrm{NO}_{\mathrm{x}}$ catalysts could still have the opportunity to address EPA Model Year 2004 emissions regulations for both light-duty (LD) and heavy-duty (HD) diesel engines. For LD engines, low temperature (LT) lean- $N \mathrm{O}_{\mathrm{x}}$ catalysts can be used. For HD engines, both LT and high temperature (HT) lean- $\mathrm{NO}_{\mathrm{x}}$ catalysts have to be applied simultaneously to broaden the operating temperature window.

- A diesel oxidation catalyst (DOC) might be required for $\mathrm{HC}$ clean up when the active lean- $\mathrm{NO}_{\mathrm{x}}\left(\right.$ or De-NO${ }_{\mathrm{x}}$ ) approach is implemented.

- For high temperature or HD diesel applications, the sulfate making issue with both LT and $\mathrm{HT}$ lean- $\mathrm{NO}_{\mathrm{x}}$ catalysts needs to be properly addressed. The EPA Model Year 2004 emissions certification regulation requires the supplemental test cycle (OICA-13) along with not-to exceed zones for both $\mathrm{NO}_{\mathrm{x}}$ and $\mathrm{PM}$ emissions. Federal certification fuel ( $350-p p m$ sulfur) or California certification fuel ( $200-p p m)$ will have to be used for meeting the EPA 2004 emissions regulation.

- The HC slippage issue, especially with active $\mathrm{HT}$ lean- $\mathrm{NO}_{\mathrm{x}}$ catalysts, has to be alleviated. Beginning in 2004, $\mathrm{HC}$ emissions will be as critical as $\mathrm{NO}_{x}$ emissions according to the EPA regulations. Inefficient use of supplemental hydrocarbon impairs catalyst performance and increases the fuel penalty.

- The effect of thermal and sulfur aging (up to 250 hours in this study) on performance of the LT lean- $\mathrm{NO}_{x}$ catalyst was noticeable in two areas. Even though the NOx reduction efficiency was maintained, the $\mathrm{PM}$ emissions and $\mathrm{HC}$ slippage rate was 
substantially increased. This could be a potential problem for LD diesel applications using high sulfur fuels.

- The hydro-thermal durability of a base metal - zeolite type $\mathrm{HT}$ lean- $\mathrm{NO}_{\mathrm{x}}$ catalyst has been a critical issue to blocking its use in the field. If necessary and whenever applicable, further study is needed to investigate ways to improve HT lean- $\mathrm{NO}_{\mathrm{x}}$ catalyst durability.

\subsection{2 $\mathrm{NO}_{\mathrm{x}}$ Adsorber Catalysts}

Unlike catalysts, which continuously convert $\mathrm{NO}_{x}$ to $\mathrm{N}_{2}, \mathrm{NO}_{x}$ adsorbers are materials which store $\mathrm{NO}_{\mathrm{x}}$ under lean conditions and release and catalytically reduce the stored $\mathrm{NO}_{\mathrm{x}}$ under rich conditions. $\mathrm{NO}, \mathrm{NO}_{2}$ and excessive $\mathrm{O}_{2}$ in the diesel exhaust are adsorbed on the catalyst sites which are incorporated into the catalyst washcoat during lean engine operation, where oxidation of NO to $\mathrm{NO}_{2}$ takes place as shown in Figure 3.3.104. After the adsorber capacity is saturated, a reductant in the form of hydrocarbon fuel or hydrogen is supplied then for desorption or regeneration as shown in Figure 3.3.105 [118]. It reduces $\mathrm{NO}_{x}$ on the catalysts site to nitrogen. Following reaction R-3.3.5 - R3.3.8 represent the sorption process and reaction $\mathrm{R}-3.3 .9-\mathrm{R}-3.3 .10$ represent the regeneration process.

(1) Sorption Period: Oxidation/Capture Occurs

$$
\begin{aligned}
& 2 \mathrm{NO}+\mathrm{O}_{2}+\mathrm{Pt}+\mathrm{K}_{2} \mathrm{CO}_{3} \rightarrow \mathrm{KNO}_{2}+\mathrm{KNO}_{3}+\mathrm{Pt}+\mathrm{CO}_{2} \\
& 2 \mathrm{NO}_{2}+\mathrm{K}_{2} \mathrm{CO}_{3} \rightarrow \mathrm{KNO}_{2}+\mathrm{KNO}_{3}+\mathrm{CO}_{2} \\
& 2 \mathrm{NO}_{2}+1 / 2 \mathrm{O}_{2}+\mathrm{K}_{2} \mathrm{CO}_{3} \rightarrow 2 \mathrm{KNO}_{3}+\mathrm{CO}_{2} \\
& 3 \mathrm{NO}_{2}+\mathrm{K}_{2} \mathrm{CO}_{3} \rightarrow 2 \mathrm{KNO}_{3}+\mathrm{CO}_{2}+\mathrm{NO}
\end{aligned}
$$

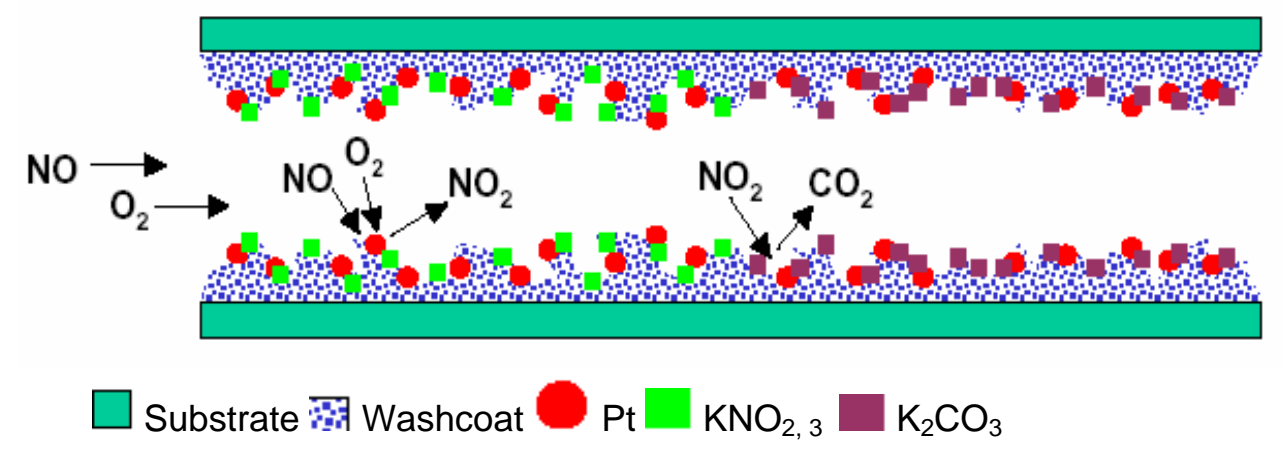

Figure 3.3.104 $\mathrm{NO}_{\mathrm{x}}$ adsorber catalysts: Sorption period [45]

\section{(2) Regeneration Period: Reduction/Reactivation}

Reduction with Hydrogen [Efficient at Temperatures as Low as $150^{\circ} \mathrm{C}$ ]:

$$
\begin{aligned}
& \mathrm{KNO}_{2}+\mathrm{KNO}_{3}+\mathrm{Pt}+4 \mathrm{H}_{2}+\mathrm{CO}_{2} \rightarrow 2 \mathrm{KOH}+\mathrm{N}_{2}+\mathrm{CO}_{2}+\mathrm{Pt}+3 \mathrm{H}_{2} \mathrm{O} \rightarrow \\
& \mathrm{K}_{2} \mathrm{CO}_{3}+\mathrm{N}_{2}+4 \mathrm{H}_{2} \mathrm{O}+\mathrm{Pt}
\end{aligned}
$$

Reduction with Hydrocarbons [Efficiency Dependent on Light-Off]:

$$
\begin{aligned}
& \mathrm{KNO}_{2}+\mathrm{KNO}_{3}+\mathrm{Pt}+\mathrm{HC} \rightarrow 2 \mathrm{KOH}+\mathrm{N}_{2}+\mathrm{CO}_{2}+\mathrm{Pt}+\mathrm{H}_{2} \mathrm{O} \rightarrow \\
& \mathrm{K}_{2} \mathrm{CO}_{3}+\mathrm{N}_{2}+2 \mathrm{H} \mathrm{O}+\mathrm{Pt}
\end{aligned}
$$

Among their merits $\mathrm{NO}_{\mathrm{x}}$ adsorber catalysts have a wide operating temperature window and thermal stability consistent with diesel applications. $\mathrm{NO}_{x}$ adsorber catalysts are capable of providing $\mathrm{NO}_{x}$ conversions in excess of $90 \%$ over much of the operating range, although, they have some shortcomings. The fuel intended for adsorber regeneration is wasted if it reacts with $\mathrm{O}_{2}$ instead of 
with $\mathrm{NO}_{\mathrm{x}}$. Also, the heat generated by excessive combustion may induce thermal desorption of $\mathrm{NO}_{\mathrm{x}}$. Apart from these issues, $\mathrm{NO}_{\mathrm{x}}$ adsorbers are vulnerable to sulfur poisoning due to use of noble metal catalysts and the potassium and barium adsorption materials [118].

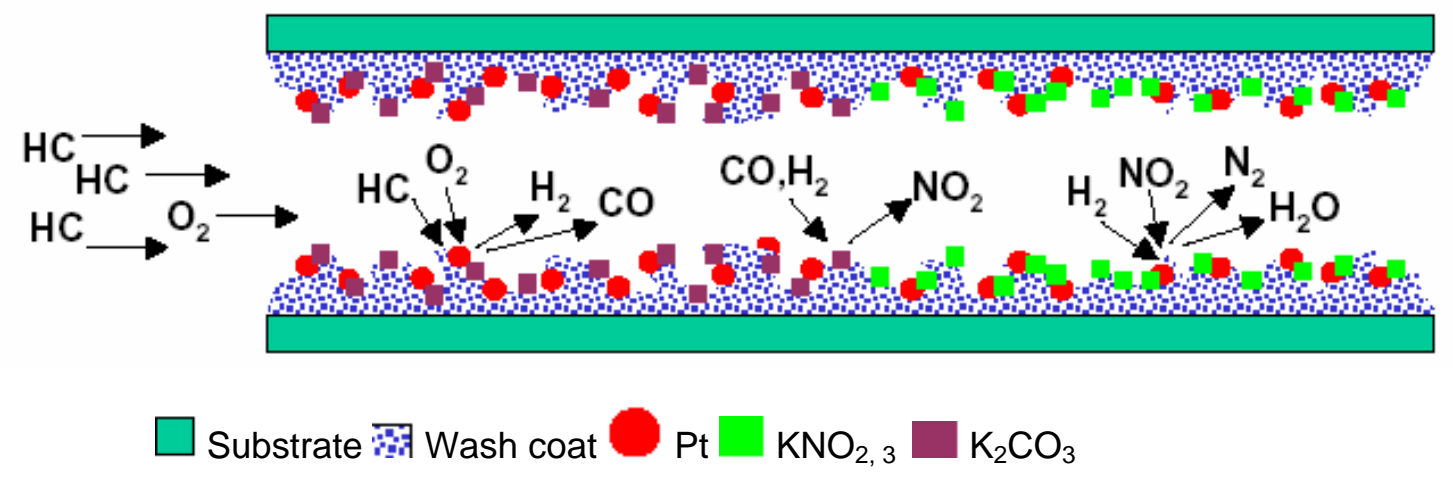

Figure 3.3.105 $\mathrm{NO}_{\mathrm{x}}$ adsorber catalysts: Regeneration period [45]

\subsection{Non-thermal Plasma After-treatment}

Application of plasma or plasma-catalyst hybrid systems is a relatively new approach to aftertreatment, which has the potential for treatment of both oxides of nitrogen and particulate emissions. Many applications of non-thermal plasma (NTP) have been developed [119 - 122] and treatment of diesel engine exhausts has been proposed [120]. The primary focus of recent plasma aftertreatment studies has been upon the removal of $\mathrm{NO}_{x}$ and it has been shown that by combining plasmas with catalysts it is possible to chemically reduce $\mathrm{NO}_{\mathrm{x}}$. A section of NTP reactor is shown in Figure 3.3.106.

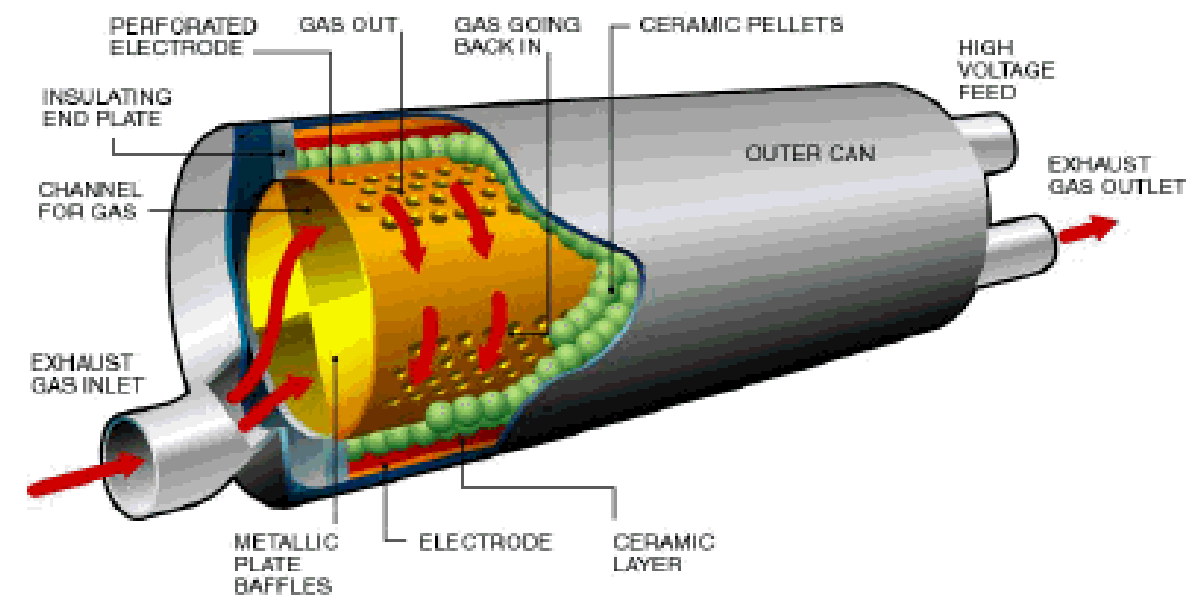

Figure 3.3.106 Section of NTP reactor [123]

In the NTP reactor, energetic electrons and free radicals are created that collide with stable molecules in the exhaust gas stream. The required energy is provided by a high-voltage power supply. This high voltage, and the corresponding high electric field, is applied to a criss-cross structure of electrodes. This is shown in Figure 3.3.107. As the exhaust gas flows between the electrodes (\#1), the applied field breaks down the gas, creating a partially ionized plasma.

At atmospheric pressures, this breakdown results in a multitude of current filaments, referred to as micro-discharges (\#2). Because of the short duration of the discharges, the electrons and heavy particles do not thermally equilibrate; the temperature of the electrons, $\mathrm{e}^{\star}$, is generally on the order 
of 3-8 eV, while the bulk gas (heavy particles) temperature remains approximately constant. The relatively large collision cross-section between 3-8 eV electrons and most molecules, $\mathrm{m}$, leads to collisions between these energetic electrons and atoms/molecules, resulting in the formation of excited atomic/molecular states and other highly reactive species, RS (\#3) [124].

After a discharge extinguishes, the created reactive species collide with other species, causing chemical reactions that convert hazardous compounds into benign, easy to capture, or simpler compounds, SC (\#4). For the destruction of $\mathrm{NO}$, the energetic electrons collide and split the molecular oxygen into atomic oxygen. While a portion of the NO is reduced to molecular nitrogen and oxygen, a majority is oxidized through direct and secondary reaction with the atomic oxygen into nitrogen dioxide $\left(\mathrm{NO}_{2}\right)$. The $\mathrm{NO}_{2}$ can then be removed from the gas by a conventional wet scrubber. The potential advantages of NTP technology include tolerance to sulfur and wide operating temperature window [124].

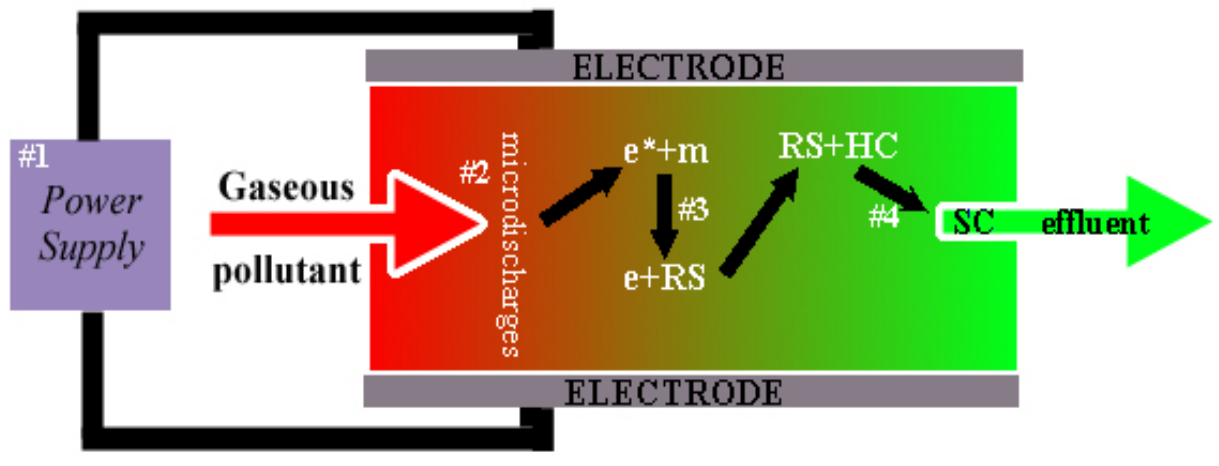

Figure 3.3.107 Physics of NTP reactor [124]

The plasma alone is ineffective in reducing $\mathrm{NO}_{\mathrm{x}}$, since oxidation reactions dominate during plasma discharges in lean exhaust. Combined plasma-catalyst systems, however, have been shown to enhance the catalyst selectivity and $\mathrm{NO}_{x}$ removal efficiency. Non-thermal plasma reactors can be also designed as diesel particulate matter reducing devices. Plasma technologies still require a significant improvement in their consumption of electrical energy and in other areas to be commercially available.

\subsection{Selective Catalytic Reduction (SCR)}

Selective catalytic reduction (SCR) is further classified into different groups based on the reductant used. Research has been done using hydrocarbons (alkanes, alkenes, alcohols, and alkalines), hydrogen, carbon monoxide and ammonia. It is only from early 1990s that urea has been used as a reducing agent. Use of urea instead of ammonia was motivated by the fact that ammonia is toxic while urea is harmless. An aqueous urea solution is used to provide ammonia, as well as, to minimize handling and storage problems. At 160 deg C, urea hydrolysis takes place and ammonia is released. So, indirectly, ammonia enters the catalytic reactor and acts as a reducing agent. One molecule of urea yields two molecules of ammonia by a two stage decomposition process.

\subsection{1 $\mathrm{NO}_{\mathrm{x}}$ Reduction using Hydrocarbons}

This technique received attention due to the presence of hydrocarbons in the diesel engine exhaust. There were various catalysts and reductants combinations that have shown potential. Selective reduction of nitric oxide (NO) using methane has been shown over metal exchanges ZSM5 zeolites $[125,126]$ and rare-earth oxides [127]. Supported platinum catalysts have been shown to be very effective for SCR of NO by hydrocarbons [128].

Hydrocarbons such as ethylene, propane, propene and butylenes have reasonable selectivity towards NO reduction in presence of oxygen. With the hydrocarbon SCR system, NO conversion 
achieves a maximum at the temperature at which complete hydrocarbon conversion occurs [129]. Selectivity towards NO reduction is high if both the NO and hydrocarbons have close to the same light off temperature. In most hydrocarbon SCR systems, the peak NO conversion window is very narrow. A comparison of $\mathrm{NO}$ conversion efficiency of various hydrocarbons over a $5 \% \mathrm{Ag} / \mathrm{Al}_{2} \mathrm{O}_{3} / \mathrm{sol}$ gel is given in Figure 3.3.108. It was concluded that presence of $\mathrm{NO}_{2}$ has a negative impact on $\mathrm{NO}$ conversion efficiency. Also, long term sulfur dioxide $\left(\mathrm{SO}_{2}\right)$ and water $\left(\mathrm{H}_{2} \mathrm{O}\right)$ exposure results in low NO conversion efficiency [130].

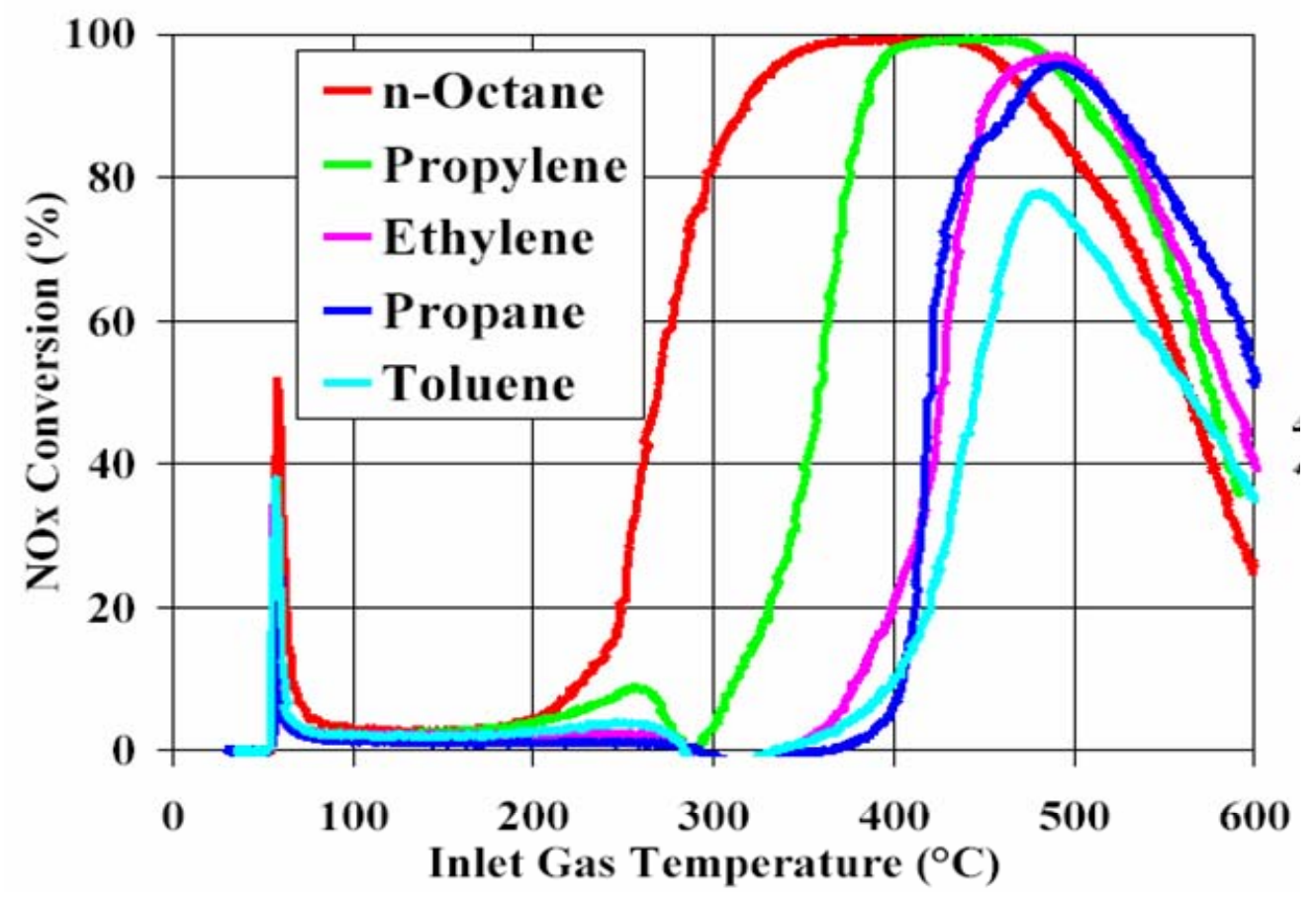

Figure 3.3.108 Performance of hydrocarbon SCR with various hydrocarbons

(5\% Ag/Alumina/Sol-gel, catalyst mass $=1.00$ grams, Flow rate $=4,000 \mathrm{cc} / \mathrm{min}$, Ramp rate $\left.=10^{\circ} \mathrm{C} / \mathrm{min}\right)[130]$

\subsection{2 $\mathrm{NO}_{\mathrm{x}}$ Reduction using Urea and Ammonia}

\subsection{1 Urea}

In the SCR process, water solutions of urea are injected into the process gas stream. At temperatures above $160^{\circ} \mathrm{C}$ urea starts to decompose and hydrolyze according to the following reactions $\mathrm{R}-3.3 .11$ and $\mathrm{R}-3.3 .12$ :

$$
\begin{aligned}
& \mathrm{CO}\left(\mathrm{NH}_{2}\right)_{2} \rightarrow 2 \cdot \mathrm{NH}_{2}+\mathrm{CO} \\
& \mathrm{CO}\left(\mathrm{NH}_{2}\right)_{2}+\mathrm{H}_{2} \mathrm{O} \rightarrow 2 \mathrm{NH}_{3}+\mathrm{CO}_{2}
\end{aligned}
$$

The thermal decomposition, reaction R-3.3.11, is confirmed by evidence of formation of CO during SCR processes with urea $[131,132]$. The $\bullet \mathrm{NH}_{2}$ radical can then react with $\mathrm{NO}$ as reaction R3.3.13:

$$
\text { - } \mathrm{NH}_{2}+\mathrm{NO} \rightarrow \mathrm{N}_{2}+\mathrm{H}_{2} \mathrm{O}
$$

Along with hydrolysis of urea, thermal decomposition of urea would also take place that would liberate $\mathrm{HNCO}$. By hydrolysis of $\mathrm{HNCO}$ over SCR catalyst, $\mathrm{NH}_{3}$ would be liberated according to reaction R-3.3.14 and R-3.3.15 [133]. Though liberation of $\mathrm{NH}_{3}$ is faster than the SCR reaction, this would contribute to the delayed liberation of ammonia. In fact all of the three reactions would contribute to delay. 


\subsection{2 Ammonia}

Several chemical reactions which occur in the ammonia SCR system are expressed by reactions R-3.3.16 to R-3.3.20. All of these processes represent desirable reactions which reduce $\mathrm{NO}_{x}$ to molecular nitrogen. Reaction R-3.3.17 is the dominant reaction mechanism.

$$
\begin{aligned}
& 6 \mathrm{NO}+4 \mathrm{NH}_{3} \rightarrow 5 \mathrm{~N}_{2}+6 \mathrm{H}_{2} \mathrm{O} \\
& 4 \mathrm{NO}+4 \mathrm{NH}_{3}+\mathrm{O}_{2} \rightarrow 4 \mathrm{~N}_{2}+6 \mathrm{H}_{2} \mathrm{O} \\
& 6 \mathrm{NO}_{2}+8 \mathrm{NH}_{3} \rightarrow 7 \mathrm{~N}_{2}+12 \mathrm{H}_{2} \mathrm{O} \\
& 2 \mathrm{NO}_{2}+4 \mathrm{NH}_{3}+\mathrm{O}_{2} \rightarrow 3 \mathrm{~N}_{2}+6 \mathrm{H}_{2} \mathrm{O} \\
& \mathrm{NO}+\mathrm{NO}_{2}+2 \mathrm{NH}_{3} \rightarrow 2 \mathrm{~N}_{2}+3 \mathrm{H}_{2} \mathrm{O}
\end{aligned}
$$

Kiovsky et al. [134] observed that $\mathrm{NO}$ requires the presence of $\mathrm{O}_{2}$ in order to be reduced while $\mathrm{NO}_{2}$ does not. Moreover, increasing the $\mathrm{NO}_{2} / \mathrm{NO}$ ratio in the reactant stream increases the rate of $\mathrm{NO}_{\mathrm{x}}$ reduction by $\mathrm{NH}_{3}$. Thus they concluded that $\mathrm{NO}_{2}$ is a reactive intermediate and that differences in SCR activity over zeolites are due to different rates at which the catalysts oxidize $\mathrm{NO}$ to $\mathrm{NO}_{2}$.

Table 3.3.22 Specification of aqueous urea for SCR applications [135]

$\begin{array}{cc}\text { Property } & \text { Value } \\ \text { Name } & \text { Aqueous urea solution } \\ \text { CAS \# } & 57-13-6 \\ \text { Chemical formula } & \left(\mathrm{NH}_{2}\right)_{2} \mathrm{CO} \cdot \mathrm{H}_{2} \mathrm{O} \\ \text { Molecular weight (anh. urea) } & 60.06 \mathrm{~kg} / \mathrm{kmole} \\ \text { Urea content } & 32.5+/-0.5 \% \\ \text { Density at } 15^{\circ} \mathrm{C} & 1085 \mathrm{~kg} / \mathrm{m}^{3} \\ \text { pH } & 9-11 \\ \text { Appearance } & \text { Colorless } \\ \text { Point of crystallization } & -11^{\circ} \mathrm{C} \\ \text { Alkalinity as } \mathrm{NH}_{3} & \text { Max. } 0.4 \% \\ \text { Carbon as } \mathrm{CO}_{2} & \text { Max. } 0.4 \% \\ \text { Biuret } & \text { Max. } 0.4 \% \\ \text { Calcium } & \text { Max. } 1 \mathrm{mg} / \mathrm{dm}^{3}\end{array}$

Koebel et al. [133] performed model gas experiments over vanadium and titanium based catalysts where test gas contained $5 \% \mathrm{H}_{2} \mathrm{O}, 10 \% \mathrm{O}_{2}$ and varying amounts of $\mathrm{NH}_{3}$, balance $\mathrm{N}_{2}$. They concluded that the reaction involving oxygen would be predominant reaction. The reactions not involving oxygen would be slower. Also, the reaction rate with equimolar amounts of $\mathrm{NO}$ and $\mathrm{NO}_{2}$ is much faster than that of the main reaction. They determined that only $21 \% \mathrm{NO}_{\mathrm{x}}$ reduction was obtained (approximately) with pure $\mathrm{NO}$ but $93 \%$ with the $\mathrm{NO}-\mathrm{NO}_{2}$ mixture. Therefore, reactions R3.3.17 for $\mathrm{NO}$ and $\mathrm{R}-3.3 .19$ - 3.3.20 for $\mathrm{NO}_{2}$ are the dominant reactions. 
Undesirable processes occurring in SCR systems include several competitive, nonselective reactions with oxygen, which are abundant in the system. These reactions can either produce secondary emissions or, at best, unproductively consume ammonia. Several groups have researched on different catalyst formulations for ammonia oxidation. Chen and Yang [136] compared three formulations of $\mathrm{V}_{2} \mathrm{O}_{5} / \mathrm{TiO}_{2}$ catalyst and concluded that the high temperature fall-off of selective reduction activity is caused by the oxidation of $\mathrm{NH}_{3}$. They determined that as temperature increased from $350 \mathrm{deg} C$ to $425 \mathrm{deg} C$, the amount of NO produced by ammonia oxidation increased most for a $5 \% \mathrm{~V}_{2} \mathrm{O}_{5} / \mathrm{TiO}_{2}$ catalyst. Ozkan et al. [137] performed nitrogen isotope labeling experiments and concluded that up to $47 \%$ of the ammonia is consumed through direct oxidation over $\mathrm{V}_{2} \mathrm{O}_{5}$, although the ammonia consumption due to direct oxidation seemed to decrease in the presence of NO. They recommended that the activity and selectivity of the SCR reactions above 300 deg $C$ should be considered in conjunction with oxidation of ammonia. Komatsu et al. [138] examined SCR with ammonia over $\mathrm{Cu}^{2+}$-exchanged zeolites and concluded that the oxidation of ammonia with oxygen occurs concomitantly with the $\mathrm{NO}_{x}$ reduction at temperatures above $573 \mathrm{~K}$. Lietti et al. [139] studied $\mathrm{V}_{2} \mathrm{O}_{5}-\mathrm{MoO}_{3} / \mathrm{TiO}_{2} \mathrm{SCR}$ catalysts and they observed a decrease in the NO conversion and $\mathrm{N}_{2}$ selectivity at high temperatures under SCR conditions and attributed that to the occurrence of the $\mathrm{NH}_{3}$ oxidation reaction. They determined that the onset of the ammonia oxidation reaction is evident at high temperatures if compared to that of the SCR reaction (520 vs. $420 \mathrm{~K}$ ), and is significantly shifted at higher temperatures by water that strongly inhibits the $\mathrm{NH}_{3}$ oxidation reaction. Koebel et al. [133] also confirmed that at still higher temperatures, ammonia may be oxidized to NO, thus limiting maximum $\mathrm{NO}_{\mathrm{x}}$ conversion.

Partial oxidation of ammonia, given by reactions R-3.3.21 and R-3.3.22, may produce nitrous oxide $\left(\mathrm{N}_{2} \mathrm{O}\right)$ or molecular nitrogen, respectively. Complete oxidation of ammonia, expressed by reaction $\mathrm{R}-3.3 .23$, generates nitric oxide (NO).

$$
\begin{aligned}
& 2 \mathrm{NH}_{3}+2 \mathrm{O}_{2} \rightarrow \mathrm{N}_{2} \mathrm{O}+3 \mathrm{H}_{2} \mathrm{O} \\
& 4 \mathrm{NH}_{3}+3 \mathrm{O}_{2} \rightarrow 2 \mathrm{~N}_{2}+6 \mathrm{H}_{2} \mathrm{O} \\
& 4 \mathrm{NH}_{3}+5 \mathrm{O}_{2} \rightarrow 4 \mathrm{NO}+6 \mathrm{H}_{2} \mathrm{O}
\end{aligned}
$$

Ozkan et al. [137] clearly ruled out the possibility of $\mathrm{N}_{2} \mathrm{O}$ formation from two $\mathrm{NO}$ molecules. However, based upon the total amount of nitrous oxide produced over a 12 min period over two different $\mathrm{V}_{2} \mathrm{O}_{5}$ catalysts formulations, they concluded that up to $16 \%$ of $\mathrm{N}_{2} \mathrm{O}$ formed is from ammonia oxidation reactions. The remaining nitrous oxide, i.e. $84 \%$, was produced from an ammonia molecule reacting with one $\mathrm{NO}$ molecule. It is reported that ammonia reduces the $\mathrm{V}_{2} \mathrm{O}_{5}$ surface resulting in the production of $\mathrm{N}_{2} \mathrm{O}$. It is also reported that molecular nitrogen is formed from ammonia oxidation reactions. Komatsu et al. [138] reported that in the case of the reduction of nitric oxide with ammonia on $\mathrm{Cu}-\mathrm{Z}$, the amounts of $\mathrm{N}_{2} \mathrm{O}$ and $\mathrm{NO}_{2}$ formed were negligible. The lack of $\mathrm{N}_{2} \mathrm{O}$ formation was in contrast with the results obtained with platinum foil catalysts where $\mathrm{N}_{2} / \mathrm{N}_{2} \mathrm{O}$ ratio of about 2 was observed at $573 \mathrm{~K}$ from a reactant mixture of $\mathrm{NO}, \mathrm{NH}_{3}$, and $\mathrm{O}_{2}$. Lettie et al. [139] observed large amounts of $\mathrm{N}_{2} \mathrm{O}$ at temperatures above $670 \mathrm{~K}$. Marangozis [140] did not detect $\mathrm{NO}_{2}$ in the product gas stream, but small amounts of $\mathrm{N}_{2} \mathrm{O}$ were observed. Thus, it was suggested that $\mathrm{N}_{2} \mathrm{O}$ formation from adsorbed $\mathrm{NO}$ and adsorbed $\mathrm{O}_{2}$ could be the rate-limiting step. Koebel et al. [133] suggested that at higher temperatures, ( $>400 \mathrm{deg} \mathrm{C}$ ), the commonly used catalysts based on $\mathrm{TiO}_{2}-\mathrm{WO}_{3}-\mathrm{V}_{2} \mathrm{O}_{5}$ tend to form nitrous-oxide.

At low temperatures, below about $100-200^{\circ} \mathrm{C}$, ammonia can also react with $\mathrm{NO}_{2}$ producing explosive ammonium nitrate $\left(\mathrm{NH}_{4} \mathrm{NO}_{3}\right)$ shown in reaction $\mathrm{R}-3.3 .24$ :

$$
2 \mathrm{NH}_{3}+2 \mathrm{NO}_{2}+\mathrm{H}_{2} \mathrm{O} \rightarrow \mathrm{NH}_{4} \mathrm{NO}_{3}+\mathrm{NH}_{4} \mathrm{NO}_{2}
$$

The reaction $\mathrm{R}-3.3 .24$ can be avoided by making sure that the temperature never falls below about $200^{\circ} \mathrm{C}$. The tendency for $\mathrm{NH}_{4} \mathrm{NO}_{3}$ formation can also be minimized by supplying into the gas stream less than the precise amount of $\mathrm{NH}_{3}$ necessary for the stoichiometric reaction with $\mathrm{NO}_{\mathrm{x}}(1$ to 1 molar ratio). 
When high sulfur fuel is used, the $\mathrm{SO}_{2}$ in diesel exhaust can be oxidized to $\mathrm{SO}_{3}$ with the following formation of $\mathrm{H}_{2} \mathrm{SO}_{4}$ upon reaction with $\mathrm{H}_{2} \mathrm{O}$. These reactions are the same as those occurring in the diesel oxidation catalyst [141]. In another reaction, $\mathrm{NH}_{3}$ combines with $\mathrm{SO}_{3}$ to form $\left(\mathrm{NH}_{4}\right)_{2} \mathrm{SO}_{4}$ and $\mathrm{NH}_{4} \mathrm{HSO}_{4}$, reactions R-3.3.25 and R-3.3.26, which deposit on and foul the catalyst and downstream piping and equipment. At low exhaust temperatures, generally below $250^{\circ} \mathrm{C}$, the fouling by ammonium sulfate may lead to a deactivation of the SCR catalyst [141].

$$
\begin{aligned}
& \mathrm{NH}_{3}+\mathrm{SO}_{3}+\mathrm{H}_{2} \mathrm{O} \rightarrow \mathrm{NH}_{4} \mathrm{HSO}_{4} \\
& 2 \mathrm{NH}_{3}+\mathrm{SO}_{3}+\mathrm{H}_{2} \mathrm{O} \rightarrow\left(\mathrm{NH}_{4}\right)_{2} \mathrm{SO}_{4}
\end{aligned}
$$

\subsection{Development of Urea-SCR}

The first mobile SCR $\mathrm{NO}_{x}$ control systems were installed on marine applications. Large sizes and steady-state operation of marine units, similar to stationary diesel engines, make the adaptation of stationary SCR technology straightforward. The first SCR units were installed in 1989 and 1990 on two Korean 30,000 metric ton carriers [142]. The ship operator was seeking a permit from the Bay Area Air Quality Management District (BAAQMD) to allow the reduced-emission ships in its docks. Both ships were powered by MAN B\&W 2-stroke $8 \mathrm{MW}$ diesel engines. The ships were equipped with an ammonia SCR system designed for $92 \% \mathrm{NO}_{x}$ reduction. The SCR reactor included a by-pass system. Exhaust gases were passed through the reactor only when the ships were sailing in waters subject to $\mathrm{NO}_{\mathrm{x}}$ emission regulations.

In 1992 the ferry "Aurora of Helsingborg" that shuttled between Sweden and Denmark was equipped with a urea SCR system [143]. The engine was $2.4 \mathrm{MW}$ Wartsila, type 6R32E. The reactor included three layers of monolithic extruded SCR catalysts and one layer of an oxidation catalyst. The fuel had a sulfur content of $0.24 \mathrm{wt} \%$. The emissions measurements were made on board during routine ferry operation, at approximately constant service conditions and two different loads. The $\mathrm{NO}_{\mathrm{x}}$ was reduced by $96.5 \%$ at full load and $95 \%$ at part load. The ammonia slip was 8.2 and 2.9 ppm, respectively. Nitrous oxide emissions were detected between 4.9 and 5.8 ppm.

Hug et al. [144] conducted one of the early studies on urea-SCR in mobile applications. They employed an extruded T-W-V (i.e., titanium-tungsten-vanadium) type catalytic converter. It was a mixed oxide type in which $\mathrm{V}_{2} \mathrm{O}_{5}$ is the catalyst, titanium oxide the carrier material and tungsten oxide, as well as, other metallic oxides function as promoters. They investigated $\mathrm{NO}_{\mathrm{x}}$ conversion efficiency as a function of space velocity, temperature and mixing rate. They achieved conversion rates over $95 \%$ at a mean operating temperature of $380{ }^{\circ} \mathrm{C}$ and space velocity of roughly $20,000 \mathrm{1} / \mathrm{hr}$. The ammonia slip did not exceed $30 \mathrm{ppm}$. They observed formation of ammonium sulfate at temperatures under $250^{\circ} \mathrm{C}$ on the catalytic converter. This was a major problem and choked the converter after 20 hours of operation. They used an oxidation catalyst after SCR to counteract CO formation during the SCR process by decomposition of HC. The oxidation catalyst simultaneously enabled reduction of $\mathrm{HC}$ and residual ammonia.

Havenith et al. [145] developed a compact SCR DeNO system for heavy duty diesel engines suitable for transient operation and capable of meeting EURO-4 NO $\mathrm{N}_{x}$ regulations. The SCR system used was a base metal catalyst while the oxidation catalyst used platinum on alumina washcoat. Both catalysts featured $400 \mathrm{cpsi}$ ceramic monoliths as substrates. They tested the SCR reactor on a turbocharged and inter-cooled truck engine (315 KW@ $2000 \mathrm{rpm})$. They evaluated the performance of the $\mathrm{DeNO}_{x}$ catalyst systems with respect to $\mathrm{NH}_{3}$ slippage and $\mathrm{N}_{2} \mathrm{O}$ formation. They used a heat shielded air blast nozzle for injection of a 40\% aqueous urea solution at a location about 1 meter upstream of the catalysts. They achieved an average $\mathrm{NO}_{x}$ reduction of $73 \%$ for a steady state cycle and $60 \%$ for the transient test cycle. These results were obtained with a urea- $\mathrm{NO}_{\mathrm{x}}$ steady state ratio of $8 \%$ below stoichiometric. They stopped urea injection below $300{ }^{\circ} \mathrm{C}$ as the oxidation catalyst would be ineffective in oxidizing ammonia, increasing the risk of ammonia slippage. They did not get sulfate formation over the SCR catalyst. Ammonia slip was $11 \mathrm{mg} / \mathrm{KWh}$ and $\mathrm{N}_{2} \mathrm{O}$ emissions were $0.28 \mathrm{~g} / \mathrm{KWh}$. This $\mathrm{N}_{2} \mathrm{O}$ emission is substantial and is approximately 10 times greater than normal. They recommended removal of the oxidation catalyst and testing for improving $\mathrm{NO}_{\mathrm{x}}$ conversion. 
Chandler et al. [146] used an oxidation catalyst for $\mathrm{HC}$ and $\mathrm{CO}$ removal, a particulate filter for PM, SCR catalyst for $\mathrm{NO}_{x}$ and an ammonia oxidation catalyst for ammonia slip. With this integrated system they could achieve ammonia slip as low as $15 \mathrm{ppm}$ and $\mathrm{NO}_{\mathrm{x}}$ reduction up to $92 \%$. They used 15 ppm and 3 ppm sulfur fuels for their tests.

Miller et al. [147] demonstrated a prototype urea-SCR system using a $200 \mathrm{cpsi}$ catalyst on a 12litre heavy duty (HD) diesel engine. Injection timing was changed in order to better suit the application of urea-SCR system. This group conducted two phases of testing. The first phase included cell tests using a new compact SCR catalyst and an engine calibration optimized for lower $\mathrm{NO}_{\mathrm{x}}$. They used an electrically controlled urea dosing unit. They could reduce $\mathrm{NO}_{\mathrm{x}}$ by $55.6 \%$ during the European stationary cycle (ESC) test, $70.5 \%$ during the cold US-transient cycle and $85.6 \%$ during the hot US-transient cycle. Carbon monoxide (CO) increased by $28.3 \%$ in cold US-transient cycle and $37.5 \%$ in hot US-transient cycle. The second phase included application on a class-8 highway truck. The overall $\mathrm{NO}_{\mathrm{x}}$ reduction achieved was $68 \%$, on average.

Gieshoff et al. [148] studied the function and application of the pre-oxidation, hydrolysis and SCR catalysts individually and as a combined system for urea SCR both in model gas and engine bench tests. Using the basic system and a non-optimized urea injection strategy, $45 \% \mathrm{NO}_{\mathrm{x}}$ conversion was achieved in the ESC engine test. Adding a pre-oxidation catalyst significantly improved the $\mathrm{NO}_{x}$ conversion in the low temperature region of the engine mapping. $\mathrm{NO}_{\mathrm{x}}$ conversions over $75 \%$ were achieved in the ESC test using the improved system. With a $50 \%$ reduced SCR catalyst volume, a NO conversion of over $65 \%$ still could be achieved. The catalysts that were used consisted of coated $400 \mathrm{cpsi}$ metallic substrates. The volume of the SCR catalyst was varied between 4.6 and $9.2 \mathrm{~L}$.

Most development projects aimed at adapting SCR technology to diesel powered truck and car engines have been conducted in Europe. In a project sponsored by the Netherlands Ministry of Environment, a 12 liter heavy-duty diesel engine equipped with an urea SCR catalyst system was tested under both steady-state and transient conditions [145, 149]. In another study by FEV and Ford, a urea SCR system was tested on a 2.5 liter light-duty diesel engine [150].

Siemens has been developing an automotive SCR system termed "SiNOx". Reported demonstration programs involved bench testing, chassis dynamometer tests, and vehicle road tests with a number of heavy-duty trucks which were operated by trucking companies under normal service conditions [151]. A prototype of the Siemens system has also been tested on a heavy-duty truck on US highways [147].

Choi et al. [152] tested $\mathrm{Pt} / \mathrm{Al}_{2} \mathrm{O}_{3}+\mathrm{V}_{2} \mathrm{O}_{5} / \mathrm{TiO}_{2}$ and $\mathrm{Cu} /$ Mordenite $+\mathrm{Pt} / \mathrm{Al}_{2} \mathrm{O}_{3}$ to broaden the temperature window for catalyst activity. They utilized closed loop control for urea-injection. They concluded that a $\mathrm{Pt} / \mathrm{Al}_{2} \mathrm{O}_{3}+\mathrm{V}_{2} \mathrm{O}_{5} / \mathrm{TiO}_{2}$ combination catalyst system has a broadened temperature window. It achieved more than $50 \% \mathrm{NO}_{\mathrm{x}}$ conversion efficiency over a range from $300 \mathrm{C}$ to $375 \mathrm{C}$. They also discovered that maximum $\mathrm{NO}_{x}$ conversions were obtained at certain injection rates and if the injection rates were higher than this value, $\mathrm{NO}_{\mathrm{x}}$ conversion decreased to zero. They also concluded that injection frequency was proportional to $\mathrm{NO}_{\mathrm{x}}$ conversion below $350 \mathrm{C}$. Above this temperature more urea injection negatively affected $\mathrm{NO}_{\mathrm{x}}$ conversion.

Gieshoff et al. [153] demonstrated the $\mathrm{NO}_{x}$ reduction potential of ion exchanged synthetic zeolite, its impact of $\mathrm{NO}_{2}$ on the $\mathrm{NO}_{x}$ conversion, its aging behavior and its applicability on passenger cars and SUVs. Gieshoff reported overall $\mathrm{NO}_{x}$ reduction in the ESC cycle to be $70 \%$. Model gas experiments showed that in the presence of $\mathrm{NO}_{2}$, the $\mathrm{NO}_{\mathrm{x}}$ conversion increased considerably but $\mathrm{N}_{2} \mathrm{O}$ emissions also increased by the same degree. Levels of $\mathrm{NO}_{2}$ above $50 \%$ of the total $\mathrm{NO}_{\mathrm{x}}$ concentration led to a decreased selectivity. They used low sulfur diesel fuel for bench experiments. They used a pre-oxidation catalyst, as well.

Farshchi et al. [154] tested an extruded homogeneous monolithic catalyst consisting of titanium oxide, vanadium penta-oxide and tungsten oxide $\left(\mathrm{TiO}_{2}-\mathrm{V}_{2} \mathrm{O}_{5}-\mathrm{WO}_{3}\right)$ without additional coating. It had a cell density of $200 \mathrm{cpsi}$ and volume of $45 \mathrm{~L}$. They did not use hydrolysis or oxidation catalysts. 
They reported $74 \% \mathrm{NO}_{x}$ reduction over the FTP cycle with negligible effect on $\mathrm{CO}_{2}$ and fuel economy.

Gabrielsson et al. [155] tested one OEM urea-SCR silencer, comprised of a silencer with built-in catalyst. The test results showed $85 \% \mathrm{NO}_{\mathrm{x}}$ reduction over the European Transient Cycle (ETC) with negligible ammonia slip. They studied $\mathrm{NO}_{x}$ reduction and $\mathrm{NH}_{3}$ slip as a function of injected $\mathrm{NH}_{3}$. They reported $99.7 \% \mathrm{NO}_{\mathrm{x}}$ reduction with overdosing of urea but this resulted in ammonia slip of 100 ppm on average.

Krijnsen et al. [156] tested a catalytic deSoot-deNO $\mathrm{N}_{\mathrm{x}}$ system, comprising $\mathrm{Pt}$ and Ce fuel additives, a Pt impregnated wall-flow monolith soot filter and a vanadia-type monolithic $\mathrm{NH}_{3}$-SCR catalyst. They reported $\mathrm{NO}_{x}$ conversion ranging from $40 \%$ to $73 \%$ at a $\mathrm{NH}_{3} / \mathrm{NO}$ ratio of 0.9 . The maximum $\mathrm{NO}_{x}$ conversion was obtained at $400 \mathrm{C}$.

\subsection{Catalyst Selection}

Diesel aftertreatment catalysts need to be active, i.e., show significant $\mathrm{NO}_{\mathrm{x}}$ conversion efficiency, for a wide temperature window due to the exhaust temperatures across the diesel duty cycle. Engine exhaust temperatures range from $100 \mathrm{deg} C$ to $450 \mathrm{deg} C$. The Pt catalyst technology is not applicable for the exhaust temperature region above $250 \mathrm{deg} C$, because of its poor selectivity for $\mathrm{NO}_{\mathrm{x}}$ reduction at the higher temperature. So base metal catalysts have been used. Figure 3.3.109 shows a comparison of the operating temperature ranges for various catalyst technologies available for SCR $\mathrm{NO}_{x}$ control. At higher temperatures (>250 deg C), $\mathrm{V}_{2} \mathrm{O}_{5} / \mathrm{Al}_{2} \mathrm{O}_{3}$ was used first but due to selectivity of $\mathrm{Al}_{2} \mathrm{O}_{3}$ towards sulfur, it was replaced by a non-sulfating carrier. The $\mathrm{V}_{2} \mathrm{O}_{5} / \mathrm{TiO}_{2}$ formulation then became the catalyst of choice. These catalysts function at higher temperatures and over a broader range than Pt based catalysts [112] (see Figure 3.3.109). Quite recently, zeolite based catalysts have been developed for this function at higher temperature. Therefore, the dosing rate of urea should not only be governed by the actual mass flow of $\mathrm{NO}_{\mathrm{x}}$, but should also take into account the catalyst activity at the catalyst operating temperature. It was observed that during fast increase in load during the diesel test, a considerable ammonia peak is obtained if the dosage of urea is increased abruptly with load. Much better results are obtained if the knowledge of the catalyst activity as a function of catalyst temperature is taken into account.

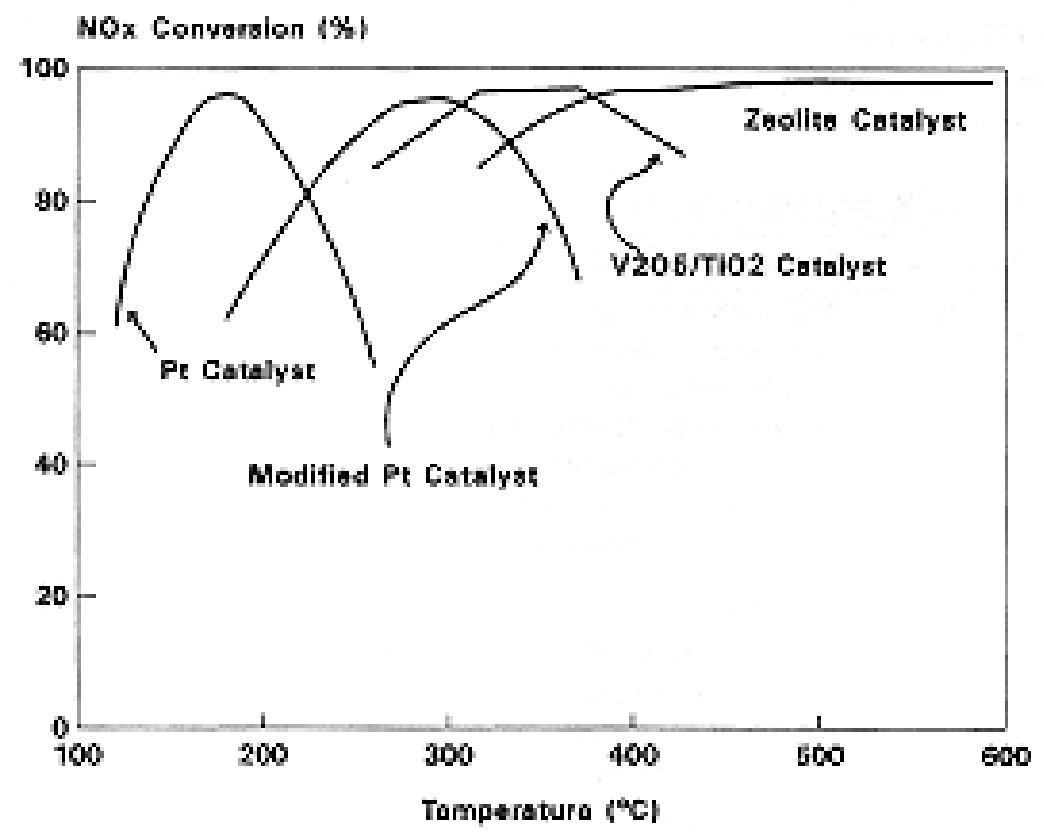

Figure 3.3.109 Operating temperature windows for different catalyst formulations [112] 
Komatsu et al. [138], in their kinetic studies of the reduction of NO with ammonia on $\mathrm{Cu}^{2+}$ exchanged zeolites concluded that the amounts of $\mathrm{N}_{2} \mathrm{O}$ and $\mathrm{NO}_{2}$ formed were negligible. They determined that the presence of oxygen enhanced the activity, while $\mathrm{H}_{2} \mathrm{O}$ and $\mathrm{SO}_{2}$ had poisoning effects on Cu-NaY catalyst. They obtained linear relations for all the catalysts, which confirm that the SCR of nitric oxide in the presence of oxygen with ammonia is first order with respect to the concentration of nitric oxide under their reaction conditions.

\subsection{Summary}

The urea-SCR system with different catalyst formulations has been evaluated for performance on both steady and transient test cycles. The key observations can be summarized as follows:

1. The urea-SCR system has been evaluated with urea rich and lean supply and several researchers have reported an increase in $\mathrm{NO}_{x}$ reduction efficiency [154 - 156].

2. Some researchers have demonstrated $\mathrm{N}_{2} \mathrm{O}$ formation $[139,140]$ whereas some have clearly ruled out the possibility of $\mathrm{N}_{2} \mathrm{O}$ formation $[137,138]$.

3. Several research groups have demonstrated that ammonia oxidation over SCR catalyst limits the $\mathrm{NO}_{x}$ conversion efficiency of urea-SCR system [133, 136, 137, 139]

4. Ammonia slip has been minimized by using an oxidation catalyst after the urea-SCR catalyst system by some groups [144 - 146].

5. Some researchers have suggested that presence of $\mathrm{NO}_{2}$ improves the $\mathrm{NO}_{\mathrm{x}}$ reduction efficiency of urea-SCR system [133, 153]. 


\subsubsection{Objectives}

The primary objective of this research is to examine the effect of fuel sulfur on $\mathrm{NO}_{\mathrm{x}}$ reduction efficiency of urea-SCR $\mathrm{NO}_{x}$ control system. Sulfur competes with other species for active sites on the catalyst surface. Selectivity of most catalyst materials is greater toward sulfur than any other substance. Biodiesel typically does not have any sulfur content. Therefore by blending it with conventional low and ultra low sulfur diesel fuels, a very low sulfur fuel is prepared. This was performed with $20 \%$ biodiesel blends (w/w) with low sulfur diesel (325 ppm S) and ultra low sulfur diesel (15 ppm S). It is worthwhile to know if moving from low sulfur diesel to ultra low sulfur diesel has any incremental benefits on $\mathrm{NO}_{x}$ reduction efficiency of the urea-SCR technique following work of a similar nature performed during the Diesel Emission Control - Sulfur Effects (DECSE) program.

The second objective has been to examine the effect of $\mathrm{NO}_{2}$ on ammonia consumption. In the present study, before entering the SCR reactors, the engine exhaust passes through a diesel particulate filter (DPF) which is impregnated with an oxidation catalyst. The DPF oxidizes some NO into $\mathrm{NO}_{2}$. The ratio of $\mathrm{NO}_{2}$ and $\mathrm{NO}$ is different from the engine-out exhaust. Some researchers [60, 61 ] have suggested that a reaction involving $\mathrm{NO}_{2}$ would be faster than the one with $\mathrm{NO}$ over a SCR catalyst. Therefore it is important to assess SCR catalyst activity for variations in $\mathrm{NO}_{2}$.

The third objective is to determine the optimum urea supply rate with engine operating conditions. Koebel et al. [133] have recommended that along with $\mathrm{NO}_{\mathrm{x}}$ flow rate in the exhaust, urea dosing rate should be a function of catalyst activity which is determined by catalyst temperature. In addition to $\mathrm{NO}_{x}$ reduction efficiency, the urea-SCR system is examined for ammonia slip (unreacted ammonia) and the emissions of nitrous oxide $\left(\mathrm{N}_{2} \mathrm{O}\right)$, which may be formed during reaction between $\mathrm{NO} / \mathrm{NO}_{2}$ and $\mathrm{NH}_{3}$. There is a difference of opinion as reported in the literature regarding these issues $[133,137,139]$. Also, the conclusions vary with different catalyst materials. The question to be answered is if urea dosage is increased, would the $\mathrm{NO}_{\mathrm{x}}$ reduction increase due to availability of more ammonia and how would this affect the unreacted ammonia emissions? Therefore, an optimum urea dosing strategy would be developed based on minimization of ammonia slip, catalyst activity, $\mathrm{NO}_{\mathrm{x}}$ flow rate and $\mathrm{NO}_{2}$ percentage of the total $\mathrm{NO}_{\mathrm{x}}$. 


\subsubsection{Results of Cold Flow Simulation of Urea SCR}

A cross sectional plane of pipe is shown in Figure 3.3.110. The results show that butane concentration does not vary much along the $x$ - and $y$-axes [Figures 3.3.111 - 3.3.112]. The maximum variation is $7.39 \%$. The concentration profile remains uniform as butane flow rate is increased [Figure 3.3.113]. Because the time averaged concentration is uniform across the pipe, the air-assisted atomizer was judged to be capable of effective urea injection.

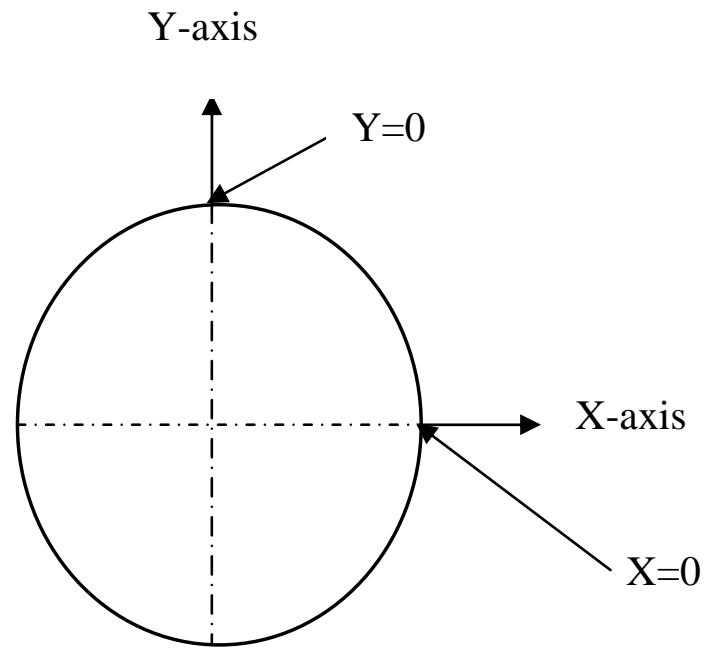

Figure 3.3.110 Cross sectional plane of pipe

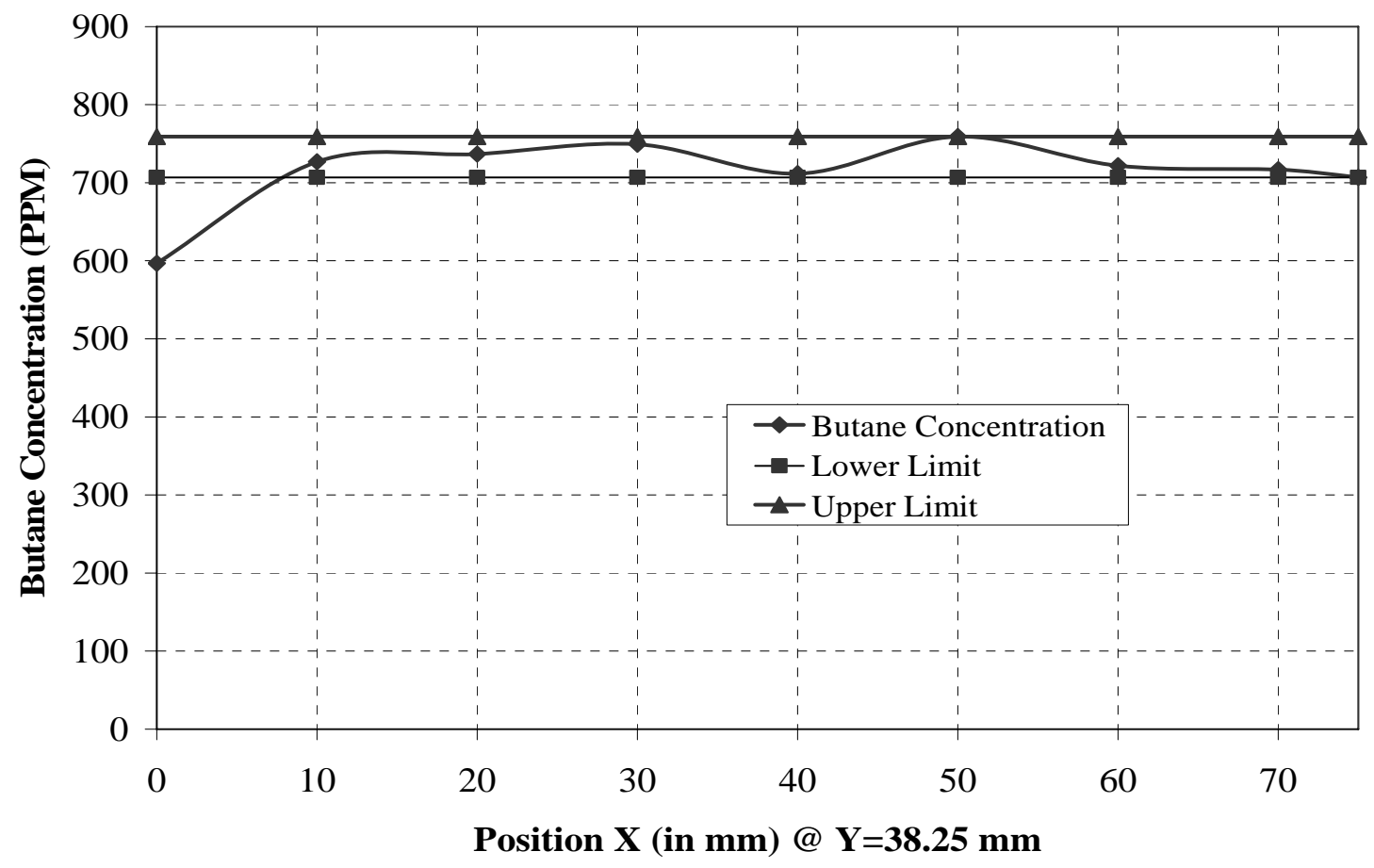

Figure 3.3.111 Concentration distributions along the $\mathrm{x}$-axis 


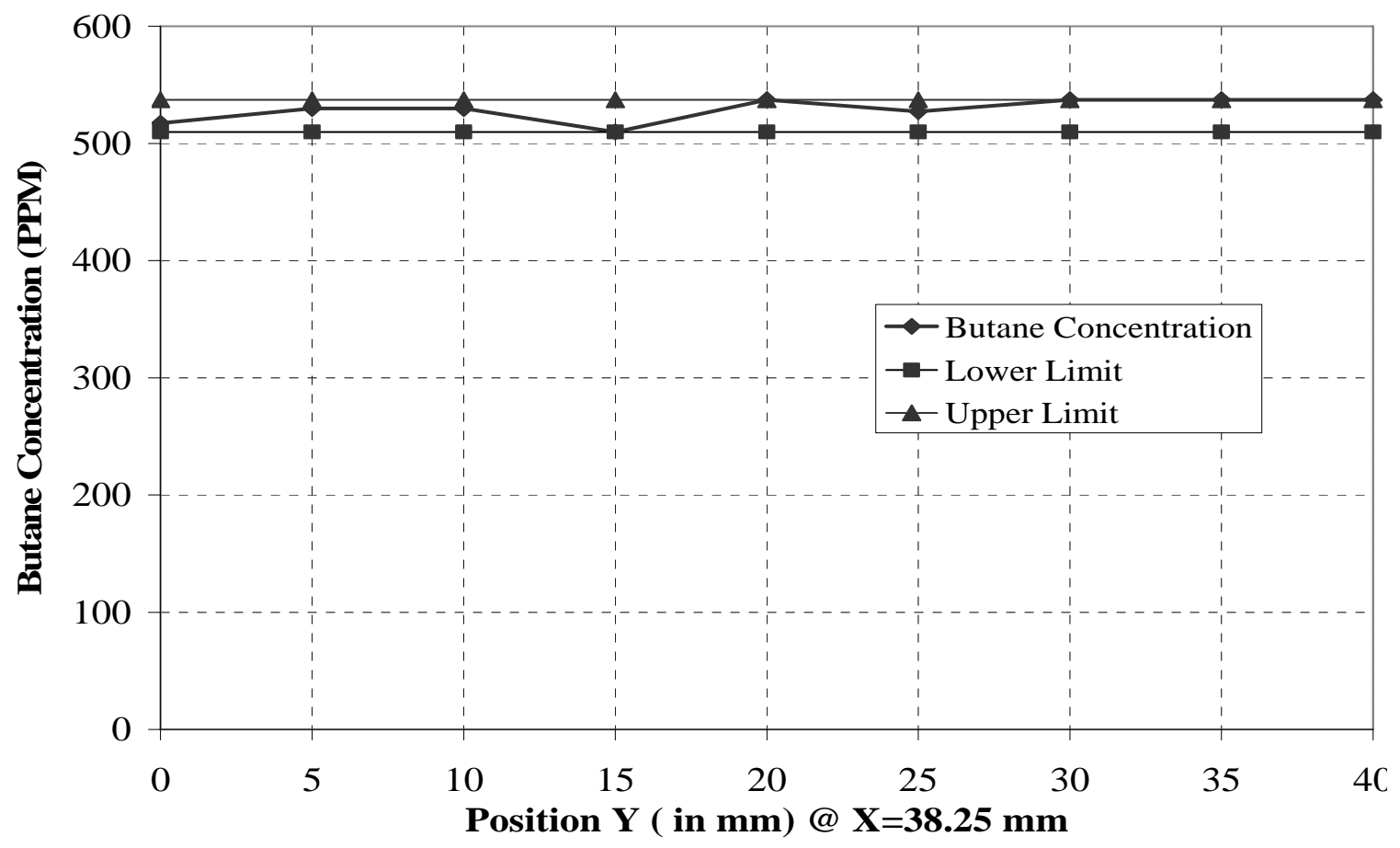

Figure 3.3.112 Concentration distributions along the y-axis

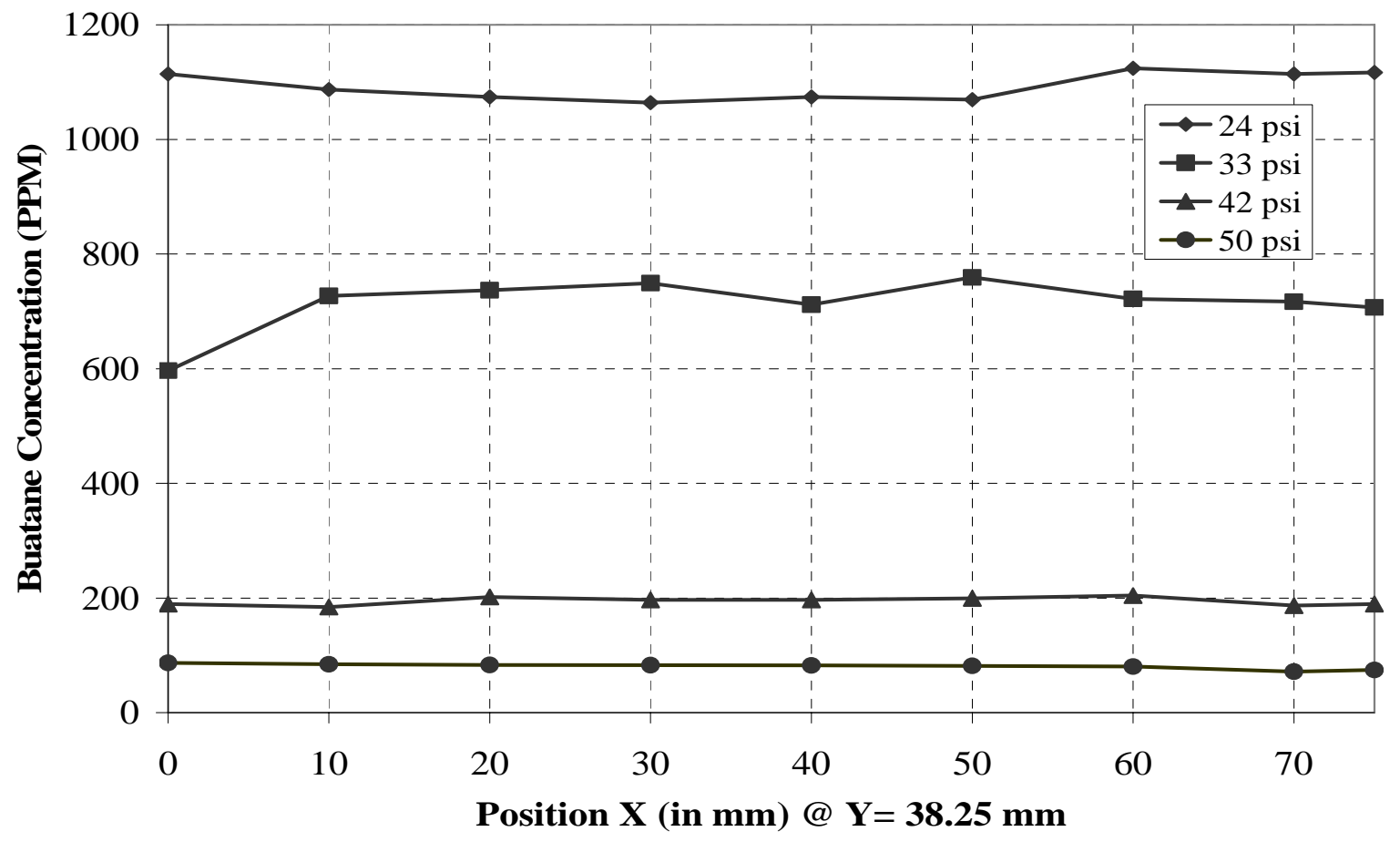

Figure 3.3.113 Concentration distribution along $\mathrm{x}$-axis at different butane flow rates 


\subsubsection{Results and Analysis of SCR}

The urea-SCR system was examined via several experiments. The catalyst activity was compared for low and ultra low sulfur diesel fuels and their blends $(20 \%(\mathrm{w} / \mathrm{w}))$ with biodiesel. In addition, the system was examined for optimum urea dosage (peak $\mathrm{NO}_{\mathrm{x}}$ reduction and minimum unreacted ammonia defined as ammonia slip) for all four fuels. This was accomplished by varying the urea dosing rate while operating the engine over a load ramp cycle for each fuel. For each condition (engine load-urea dosage rate-fuel), the FTIR spectrum was collected and examined for the presence of $\mathrm{NH}_{3}$ and $\mathrm{N}_{2} \mathrm{O}$. In addition, the analysis of the experimental results shows the role of $\mathrm{NO}_{2}$ in the reaction kinetics of the urea-SCR catalyst. It was possible to observe the role of $\mathrm{NO}_{2}$ due to the catalyzed for filtering diesel particulate (DPF) filter upstream of the SCR catalyst. This catalyzed DPF reactor oxidizes nitric oxide (NO) in the engine-out emissions to $\mathrm{NO}_{2}$ and uses $\mathrm{NO}_{2}$ to oxidize particulate matter (PM). But depending on the catalyst temperature and PM accumulation, the $\mathrm{NO}_{2}$ generation and consumption varies. Therefore, the net $\mathrm{NO}_{2}$ in the exhaust that enters SCR catalyst can be significantly higher than the baseline engine out emissions as shown in Figures 3.3.24 (a-d). This phenomenon provided an excellent opportunity to examine the relative selectivity of the SCR catalyst for both nitrogen oxides, $\mathrm{NO}$ and $\mathrm{NO}_{2}$, as well as, to observe the reaction kinetics of $\mathrm{NH}_{3}$ with $\mathrm{NO}_{2}$ over this catalyst. The results show that urea dosage rate should be a function of $\mathrm{NO}_{2} / \mathrm{NO}_{x}$ also.

\subsection{Baseline Emissions with different fuels}

A comparison of baseline (before entering the SCR catalyst and after DPF catalyst) NO, NO and $\mathrm{NO}_{2}$ emissions is displayed in Figures 3.3.114 - 3.3.116. It shows that biodiesel blends have less $\mathrm{NO}_{\mathrm{x}}$ at higher loads than high and low sulfur diesels. B20-BP15 gives the least $\mathrm{NO}_{\mathrm{x}}$ at all loads with average of $5 \%$ difference from BP15. Both BP325 and BP15 give comparable $\mathrm{NO}_{2}$ at all loads and their $20 \%(\mathrm{w} / \mathrm{w})$ biodiesel blends give less $\mathrm{NO}_{2}$ than the base fuels but similar amounts with each other at all loads. The uncertainty levels are higher in the case of $\mathrm{NO}_{2}$ than $\mathrm{NO}_{\mathrm{x}}$.

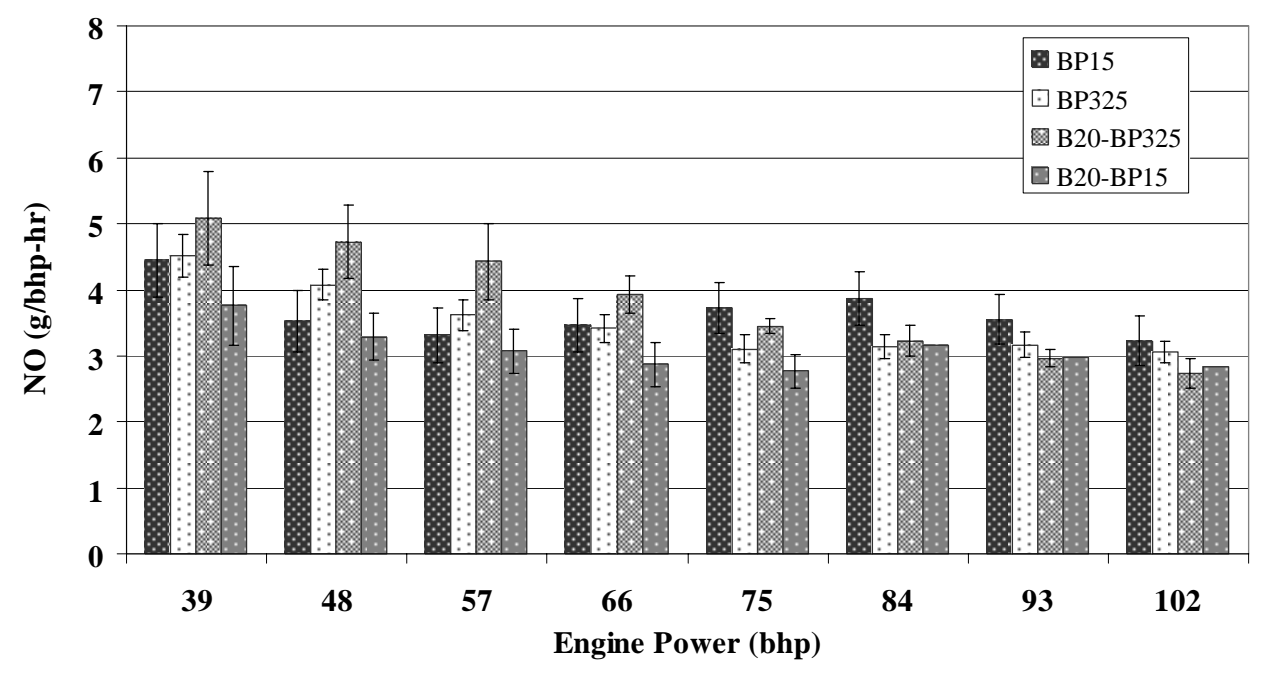

Figure 3.3.114 Baseline nitric oxide emissions (g/bhp-hr) over ramp cycle 


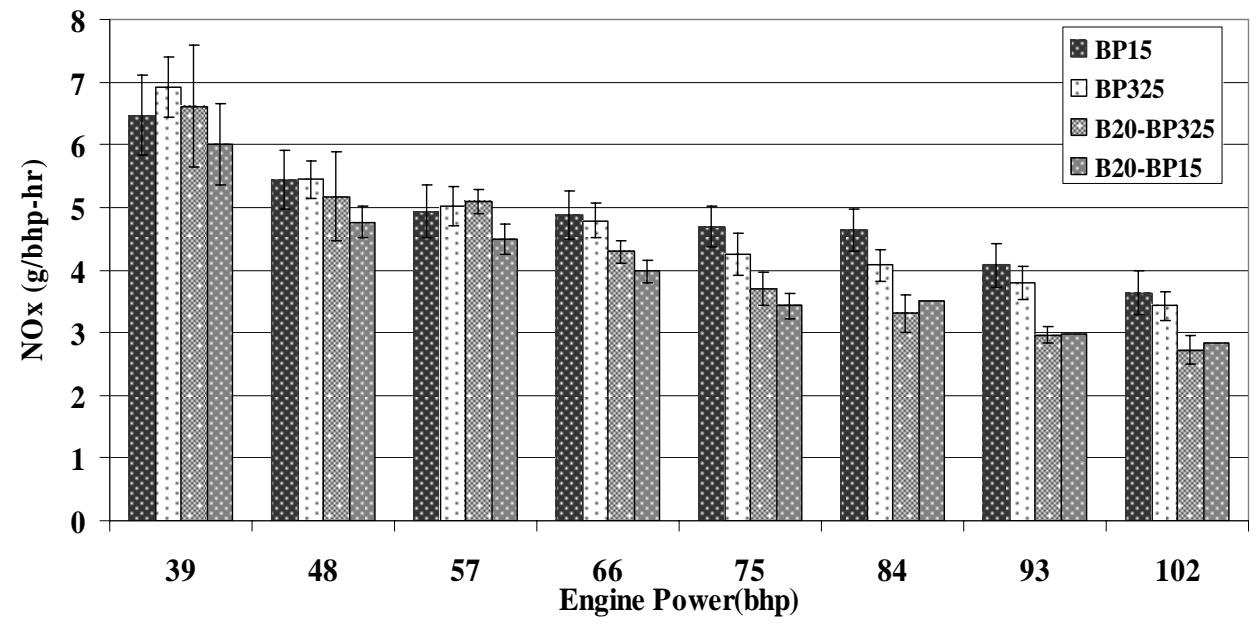

Figure 3.3.115 Baseline nitrogen oxide emissions $\left(\mathrm{NO}_{\mathrm{x}}\right)$ over ramp cycle

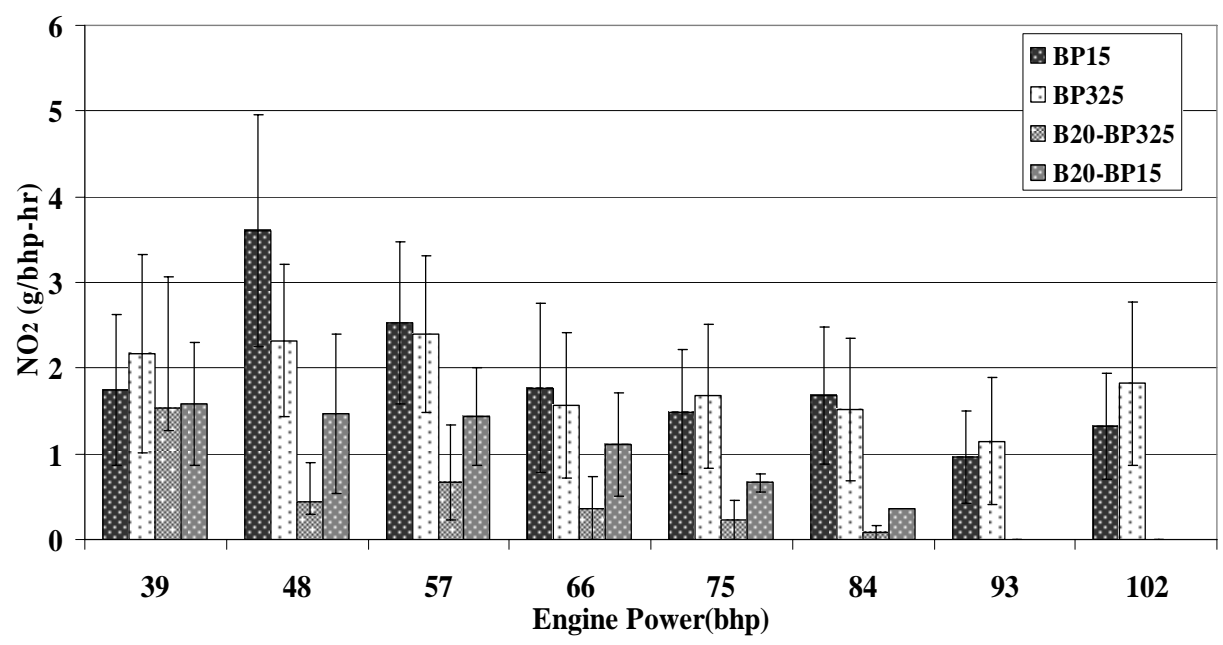

Figure 3.3.116 Baseline nitrogen dioxide emissions (g/bhp-hr) over ramp cycle 


\subsection{Peak $\mathrm{NO}_{\mathrm{x}}$ Reduction}

The comparison of peak \% $\mathrm{NO}_{\mathrm{x}}$ conversion for all four fuels is shown in Figure 3.3.117. The catalyst gives similar performance within experimental and statistical uncertainty for all four fuels. At 283 deg C catalyst temperature, the SCR system gives $92 \% \pm 2.5 \%$ NOx conversion and above this temperature, it reaches its peak performance.

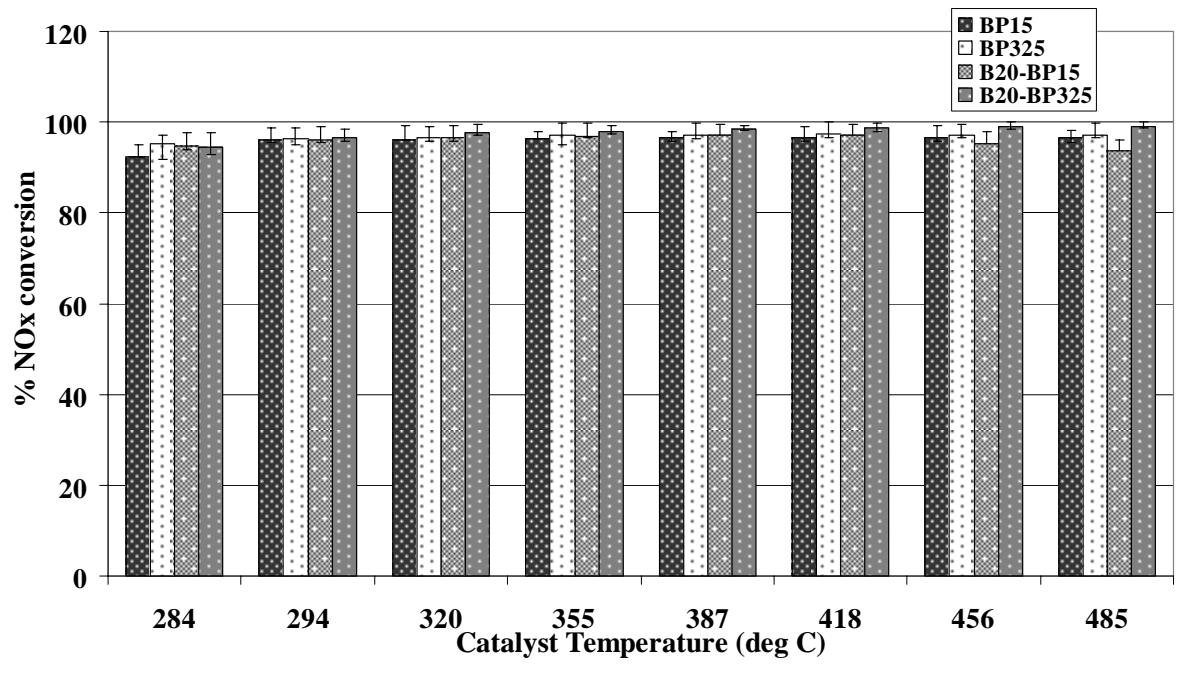

Figure 3.3.117 Comparison of peak $\mathrm{NO}_{x}$ reduction efficiency of catalyst with different fuels

\subsection{Effect of Urea Dosing on $\mathrm{NO}_{\mathrm{x}}$ Reduction}

Effect of urea dosing on $\mathrm{NO}_{\mathrm{x}}$ reduction has been shown in Figures 3.3.118 - 3.3.121 for all four fuels. With BP15 and BP325 fuels, four urea dosing rates were examined (Figures 3.3.118 3.3.119) whereas with biodiesel blends only three urea dosing rates were examined (Figures 3.3.120 $-3.3 .121)$.

In Figure 3.3.118, results for BP15 fuel show that from catalyst temperature 282 deg $\mathrm{C}$ to 361 deg $\mathrm{C}, \mathrm{NO}_{\mathrm{x}}$ reduction reached peak value for $0.75 \mathrm{NH}_{3} / \mathrm{NO}_{\mathrm{x}}, 1.0 \mathrm{NH}_{3} / \mathrm{NO}_{\mathrm{x}}$ and $1.4 \mathrm{NH}_{3} / \mathrm{NO}_{\mathrm{x}}$, but $0.65 \mathrm{NH}_{3} / \mathrm{NO}_{\mathrm{x}}$ gives $13 \%$ less than the peak value. From 395 deg $\mathrm{C}$ to 494 deg $\mathrm{C}, 1.0 \mathrm{NH}_{3} / \mathrm{NO}_{\mathrm{x}}$ and $1.4 \mathrm{NH}_{3} / \mathrm{NO}_{x}$ still give peak value but $0.75 \mathrm{NH}_{3} / \mathrm{NO}_{x}$ shows $6 \%$ less than peak performance. However, $0.65 \mathrm{NH}_{3} / \mathrm{NO}_{x}$ gives $20 \%$ less than peak performance but always above $65 \%$.

In Figure 3.3.119, results for BP325 fuel show that from catalyst temperature 281 deg $\mathrm{C}$ to 470 deg $\mathrm{C}, \mathrm{NO}_{\mathrm{x}}$ reduction reached peak value for $0.75 \mathrm{NH}_{3} / \mathrm{NO}_{\mathrm{x}}, 1.0 \mathrm{NH}_{3} / \mathrm{NO}_{\mathrm{x}}$ and $1.4 \mathrm{NH}_{3} / \mathrm{NO}_{\mathrm{x}}$ but $0.65 \mathrm{NH}_{3} / \mathrm{NO}_{x}$ gives $11 \%$ less than peak value. Only at 504 deg $\mathrm{C}$ catalyst temperature $\mathrm{NO}_{\mathrm{x}}$ reduction reached peak value for $1.0 \mathrm{NH}_{3} / \mathrm{NO}_{x}$ and $1.4 \mathrm{NH}_{3} / \mathrm{NO}_{\mathrm{x}}$ but $0.75 \mathrm{NH}_{3} / \mathrm{NO}_{x}$ gives $19 \%$ less than peak value. Again, $0.65 \mathrm{NH}_{3} / \mathrm{NO}_{x}$ always give more than $65 \% \mathrm{NO}_{\mathrm{x}}$ conversion.

In Figure 3.3.120, results for B20-BP15 fuel show that from catalyst temperature 265 deg C to 370 deg $\mathrm{C}, \mathrm{NO}_{\mathrm{x}}$ reduction reached peak value for $0.75 \mathrm{NH}_{3} / \mathrm{NO}_{\mathrm{x}}, 1.0 \mathrm{NH}_{3} / \mathrm{NO}_{\mathrm{x}}$ and $1.4 \mathrm{NH}_{3} / \mathrm{NO}_{\mathrm{x}}$ From 406 deg $\mathrm{C}$ to 502 deg $\mathrm{C}$ catalyst temperature $\mathrm{NO}_{\mathrm{x}}$ reduction reached peak value for 1.0 $\mathrm{NH}_{3} / \mathrm{NO}_{x}$ and $1.4 \mathrm{NH}_{3} / \mathrm{NO}_{\mathrm{x}}$ but $0.75 \mathrm{NH}_{3} / \mathrm{NO}_{\mathrm{x}}$ gives $11 \%$ less than peak value but always give more than $75 \% \mathrm{NO}_{x}$ conversion.

In Figure 3.3.121, results for B20-BP325 fuel show that from catalyst temperature 275 deg C to 319 deg $\mathrm{C}, \mathrm{NO}_{\mathrm{x}}$ reduction reached peak value for $0.75 \mathrm{NH}_{3} / \mathrm{NO}_{\mathrm{x}}, 1.0 \mathrm{NH}_{3} / \mathrm{NO}_{\mathrm{x}}$ and $1.4 \mathrm{NH}_{3} / \mathrm{NO}_{\mathrm{x}}$ From 355 deg $\mathrm{C}$ to 482 deg $\mathrm{C}$ catalyst temperature $\mathrm{NO}_{\mathrm{x}}$ reduction reached peak value for 1.0 $\mathrm{NH}_{3} / \mathrm{NO}_{x}$ and $1.4 \mathrm{NH}_{3} / \mathrm{NO}_{\mathrm{x}}$ but $0.75 \mathrm{NH}_{3} / \mathrm{NO}_{x}$ gives $18 \%$ less than peak value but always gives more than $75 \% \mathrm{NO}_{\mathrm{x}}$ conversion. 


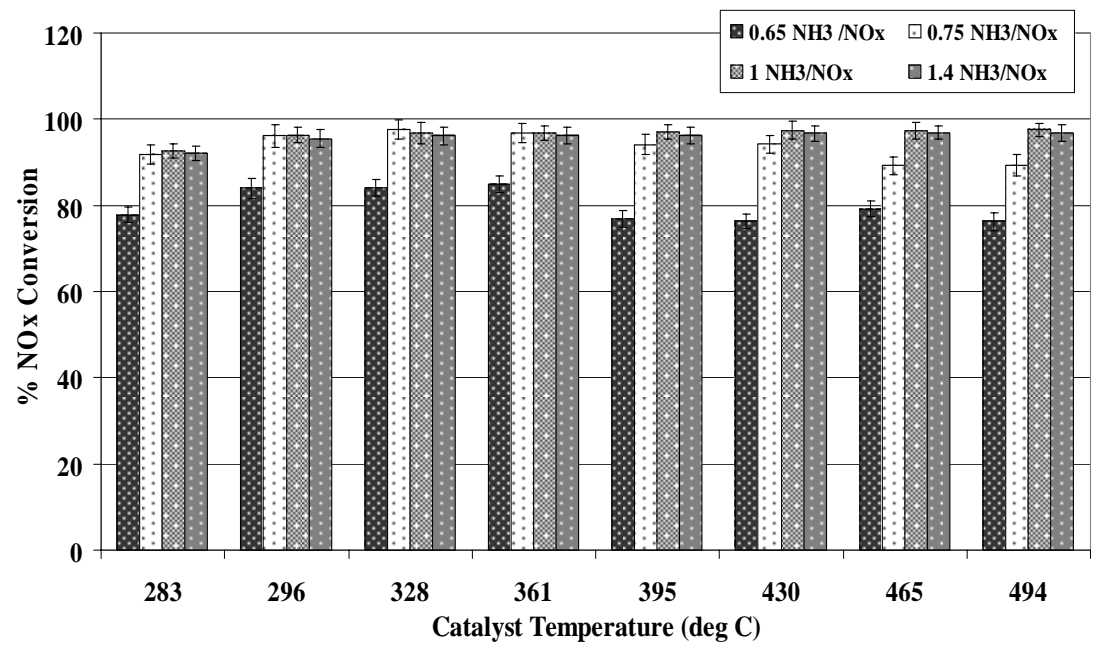

Figure 3.3.118 $\mathrm{NO}_{x}$ Reduction efficiency of catalyst at varying urea dosage for BP15 fuel

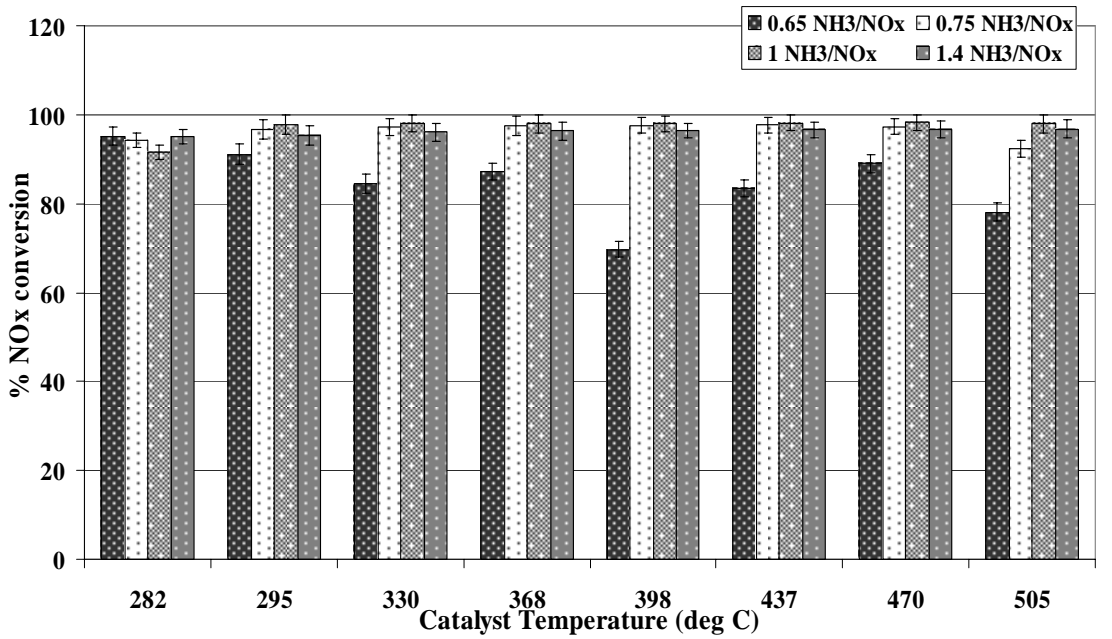

Figure 3.3.119 $\mathrm{NO}_{\mathrm{x}}$ Reduction efficiency of catalyst at varying urea dosage for BP325 fuel

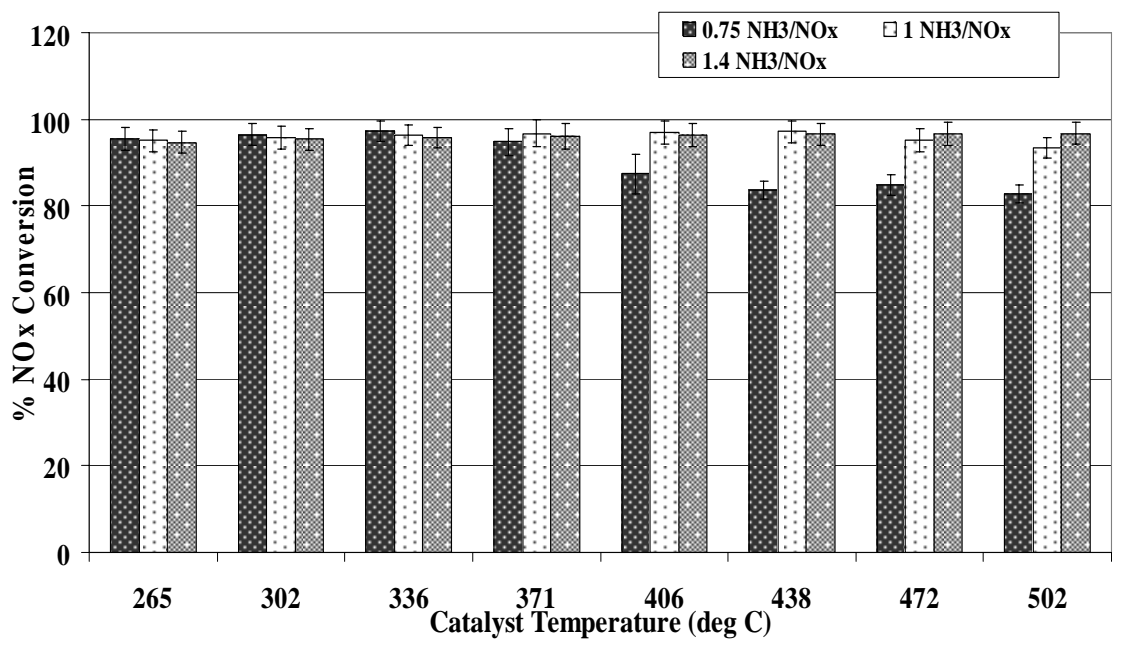

Figure 3.3.120 $\mathrm{NO}_{\mathrm{x}}$ reduction efficiency of catalyst at varying urea dosage for B20-BP15 fuel 


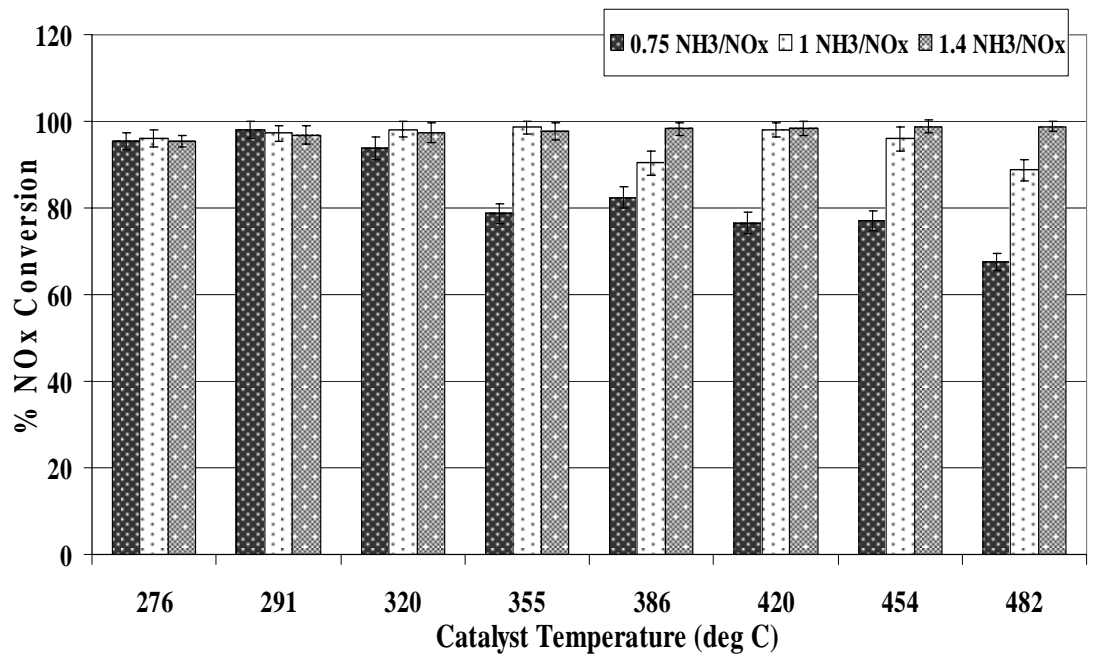

Figure 3.3.121 NO Reduction efficiency of catalyst at varying urea dosage for B20-BP325 fuel

\subsection{Effect of Urea Dosing on $\mathrm{NH}_{3}$ Slip}

Effect of urea dosing on $\mathrm{NH}_{3}$ slip (ppm) normalized to the $\mathrm{NO}_{\mathrm{x}}$ concentration (ppm) at the inlet to the SCR is shown in Figures 3.3.122 - 3.3.125. For both BP15 and BP325 fuels, 0.65 $\mathrm{NH}_{3} / \mathrm{NO}_{x}$ gives zero $\mathrm{NH}_{3}$ slip at all catalyst temperatures. For all four fuels, $1.4 \mathrm{NH}_{3} / \mathrm{NO}_{x}$ gives $100 \%$ higher $\mathrm{NH}_{3}$ slip/NO $\mathrm{NO}_{\mathrm{x}}$ inlet than $1.0 \mathrm{NH}_{3} / \mathrm{NO}_{\mathrm{x}}$. For all four fuels $0.75 \mathrm{NH}_{3} / \mathrm{NO}_{\mathrm{x}}$ gives near zero ammonia slip at higher catalyst temperatures when it gives less than peak $\mathrm{NO}_{\mathrm{x}}$ conversion.

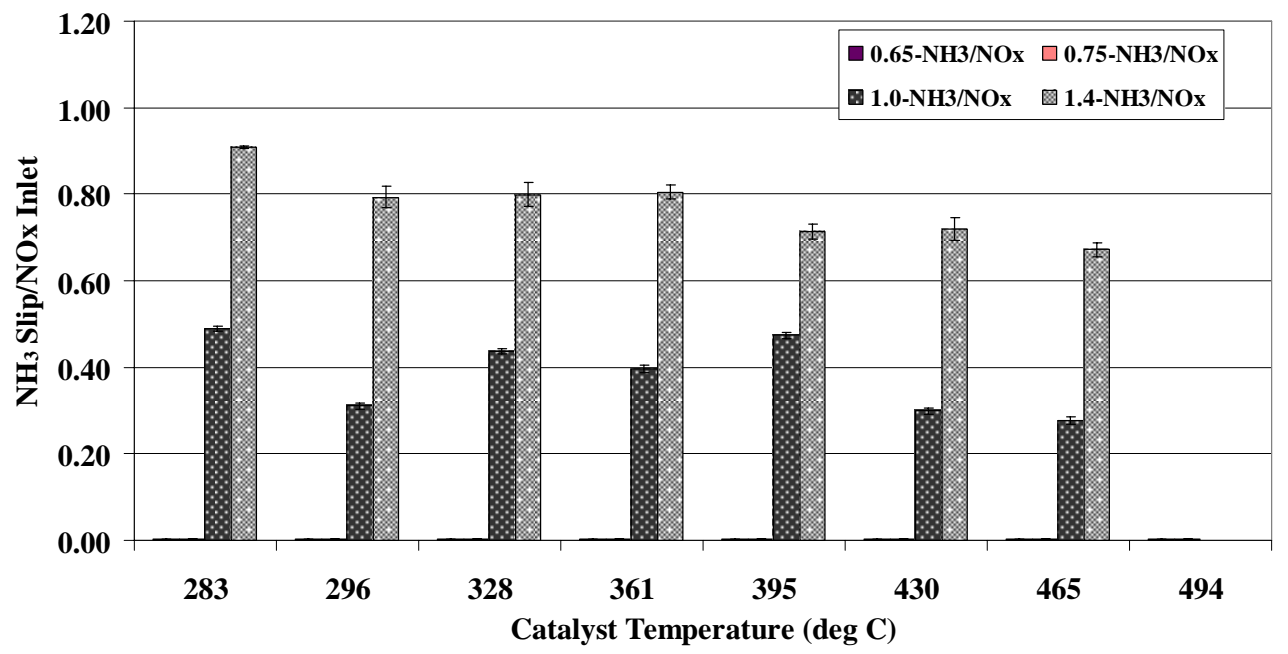

Figure 3.3.122 Ammonia slip as a function of catalyst temperature with varying urea dosage for BP15 fuel $\left(\mathrm{NH}_{3}\right.$ slip and $\mathrm{NO}_{x}$ inlet are in $\left.\mathrm{ppm}\right)$ 


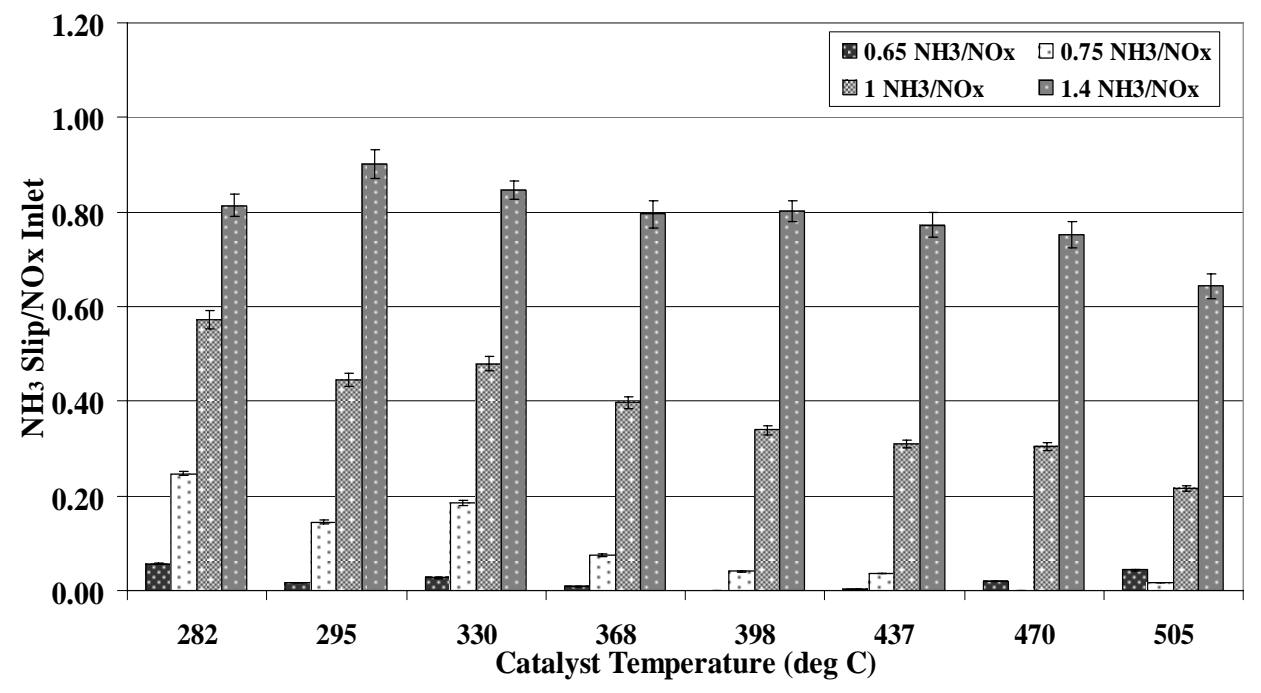

Figure 3.3.123 Ammonia slip as a function of catalyst temperature with varying urea dosage for BP325 fuel $\left(\mathrm{NH}_{3}\right.$ slip and $\mathrm{NO}_{x}$ inlet are in $\left.\mathrm{ppm}\right)$

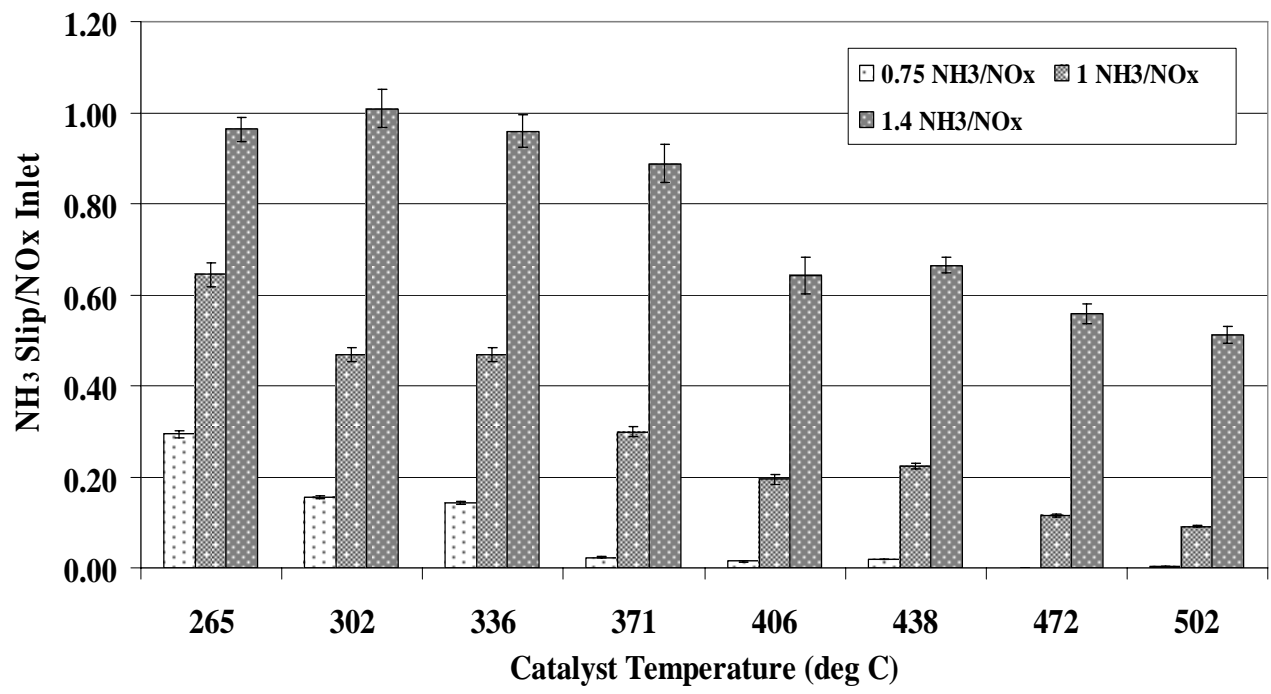

Figure 3.3.124 Ammonia slip as a function of catalyst temperature with varying urea dosage for B20-BP15 fuel $\left(\mathrm{NH}_{3}\right.$ slip and $\mathrm{NO}_{x}$ inlet are in ppm)

Occurrence of ammonia slip shows that no ammonia oxidation takes place over the SCR catalyst. However, several researchers have predicted the possibility of ammonia oxidation and subsequent fall-off of $\mathrm{NO}_{x}$ reduction efficiency [136 - 138]. Some of the observations were made over vanadium based catalysts where ammonia oxidation occurred over a temperature range of $300-450$ deg $C[136,137]$. Lietti et al. [139] suggested that ammonia oxidation shifts to higher temperature in the presence of water. Therefore, the absence of ammonia oxidation may be attributed to presence of water in exhaust. 


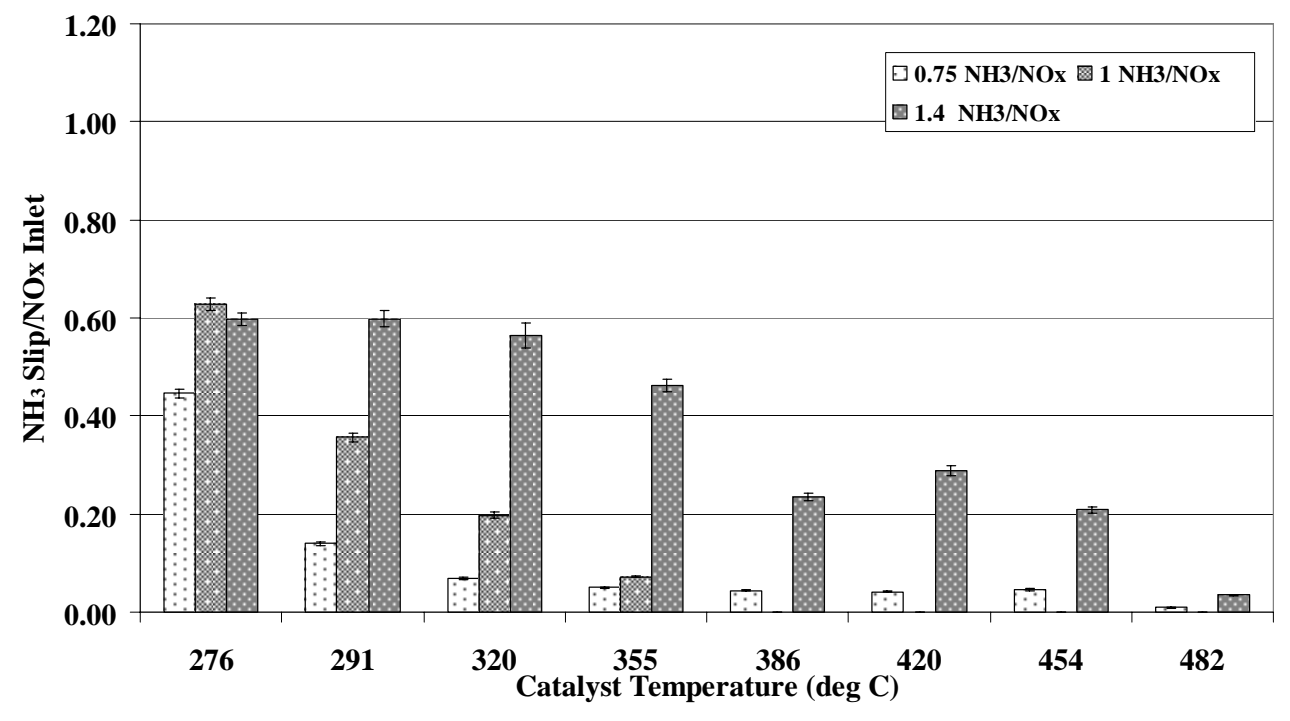

Figure 3.3.125 Ammonia slip as a function of catalyst temperature with varying urea dosage for $\mathrm{B} 20-\mathrm{BP} 325$ fuel $\left(\mathrm{NH}_{3}\right.$ slip and $\mathrm{NO}_{x}$ linlet are in $\left.\mathrm{ppm}\right)$

\subsection{Effect of $\mathrm{NO}_{2}$ on $\mathrm{NH}_{3}$ Consumption}

The results for testing with lean urea dosage, for the four test fuels show an effect of fuel composition, but the question arises of whether this difference is due to the sensitivity of SCR catalyst towards fuel properties or if there is some other factor which is different between the test fuels. It is hypothesized that in all cases of testing with lean urea dosing, $\mathrm{NO}_{2}$ content in the $\mathrm{NO}_{\mathrm{x}}$ entering the SCR system was different which caused the performance at lean urea dosage to be different. To verify this, Figures 3.3.126 - 3.3.130 were plotted. These Figures compare $\mathrm{NH}_{3}$ Consumed/ $\mathrm{NO}_{\mathrm{x}}$ Inlet (both in ppm) and $\mathrm{NO}_{2}$ Inlet/ $\mathrm{NO}_{\mathrm{x}}$ Inlet (both in ppm) with catalyst temperature.

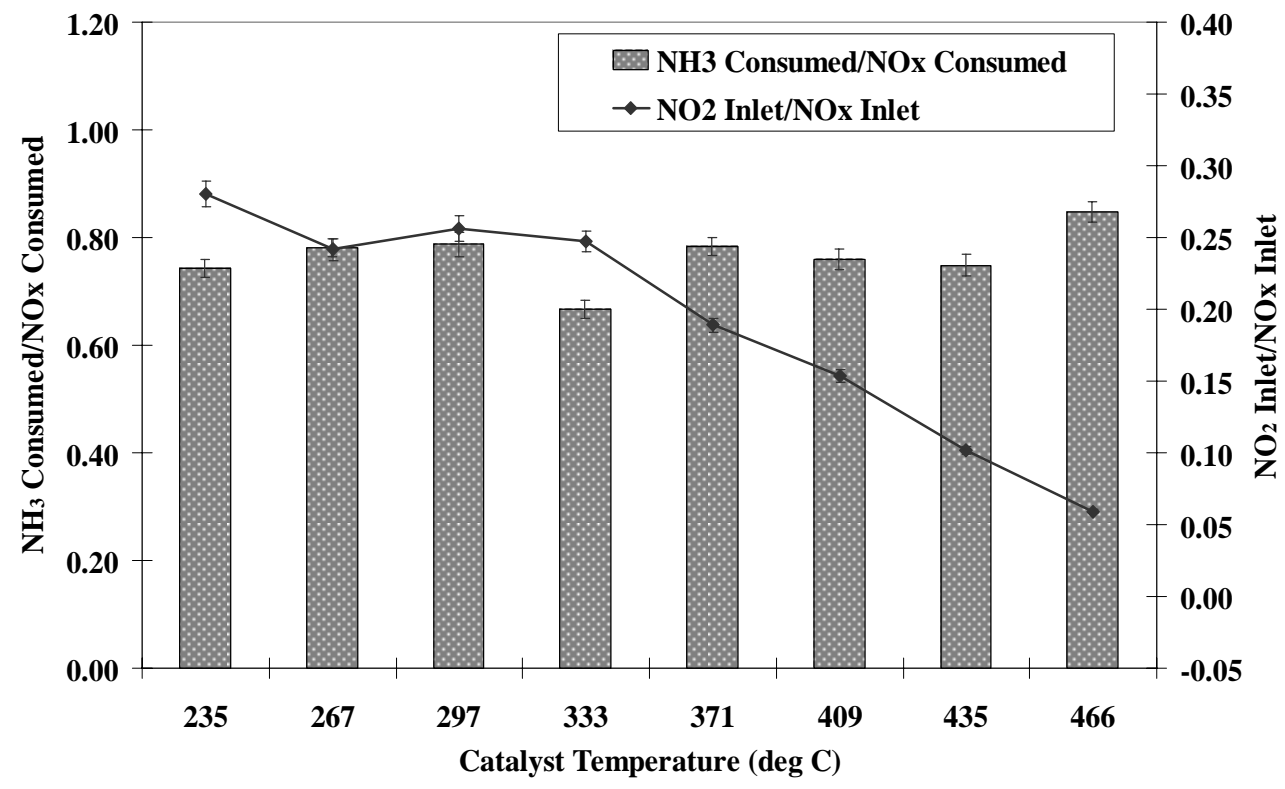

Figure 3.3.126 Ammonia consumption as a function of $\mathrm{NO}_{2}$ inlet for $\mathrm{BP} 15$ fuel 


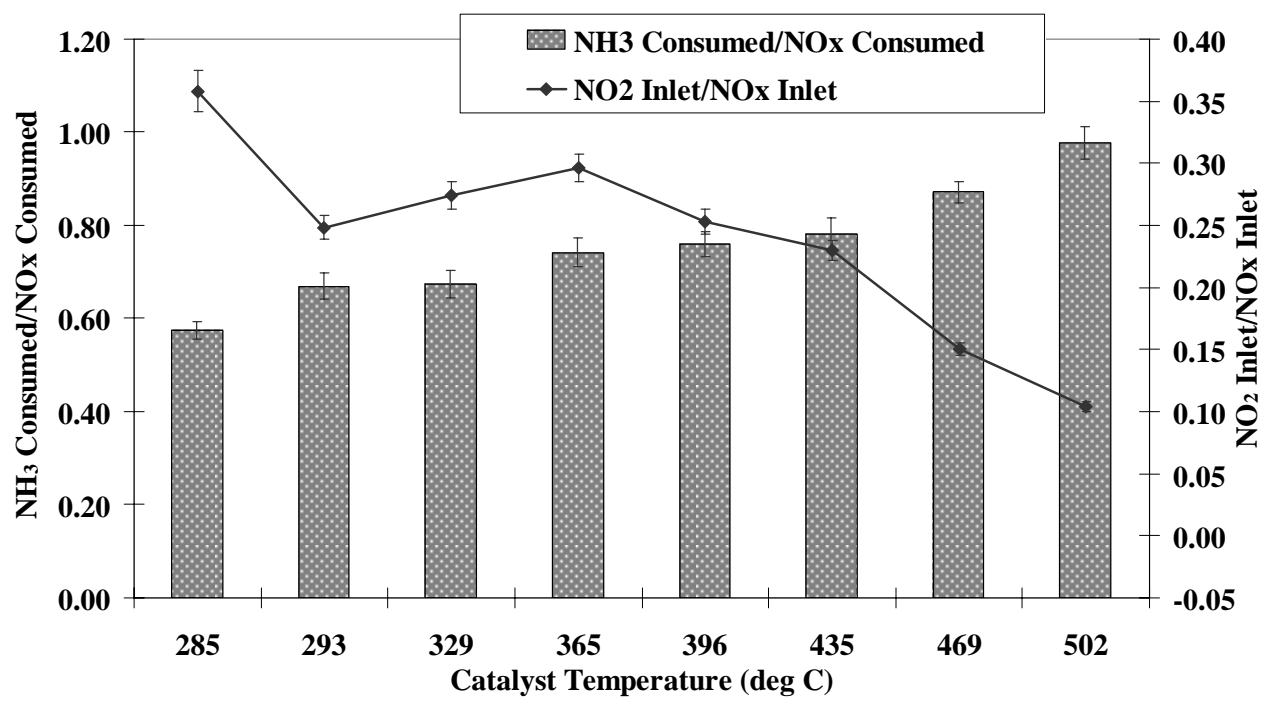

Figure 3.3.127 Ammonia consumption as a function of $\mathrm{NO}_{2}$ inlet for $\mathrm{BP} 325$ fuel

$\left(\mathrm{NH}_{3}\right.$ consumed and $\mathrm{NO}_{\mathrm{x}}$ consumed are in $\left.\mathrm{ppm}\right)$

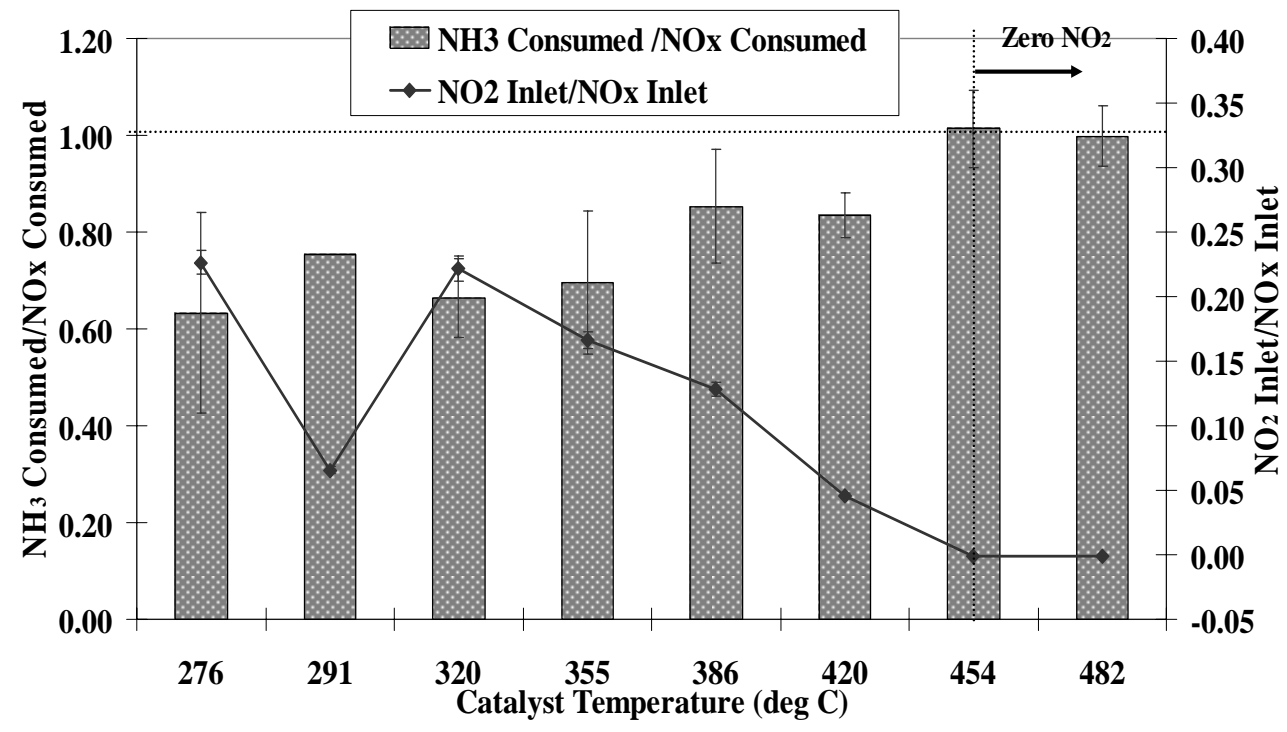

Figure 3.3.128 Ammonia consumption as a function of $\mathrm{NO}_{2}$ inlet for $\mathrm{B} 20-\mathrm{BP} 325$ fuel

For the same fuel B20-BP325, in two separate experiments, (Figures 3.3.128 - 3.3.129) since $\mathrm{NO}_{2}$ Inlet $/ \mathrm{NO}_{\mathrm{x}}$ Inlet is different, $\mathrm{NH}_{3}$ Consumed/NO Inlet is different. Therefore, this difference is not due to fuel properties. For the same test conditions, if $\mathrm{NO}_{2}$ is higher in one condition, $\mathrm{NH}_{3}$ Consumed/NO Inlet is less in this condition than in the other same load, but different $\mathrm{NO}_{2}$, condition (Figures 3.3.126 - 3.3.128). Another observation is that $\mathrm{NH}_{3}$ Consumed/NO $\mathrm{NO}_{\mathrm{x}}$ Inlet is always less than 1 as long as $\mathrm{NO}_{2}$ Inlet $/ \mathrm{NO}_{x}$ Inlet is non-zero. It approaches 1 as shown in Figures 3.3.126 3.3.127 and it is 1 while $\mathrm{NO}_{2}$ Inlet $/ \mathrm{NO}_{\mathrm{x}}$ Inlet is zero as shown in Figures 3.3.128 - 3.3.130.

These results prove that $\mathrm{NO}_{2}$ plays a significant role in the SCR efficiency. In the literature, there have been some suggestions about the significance of $\mathrm{NO}_{2}$ in SCR activity. [133, 134]. Section 3.3.10.3.6 further elaborates the relative selectivity of $\mathrm{NO}_{2}$ and $\mathrm{NO}$. 


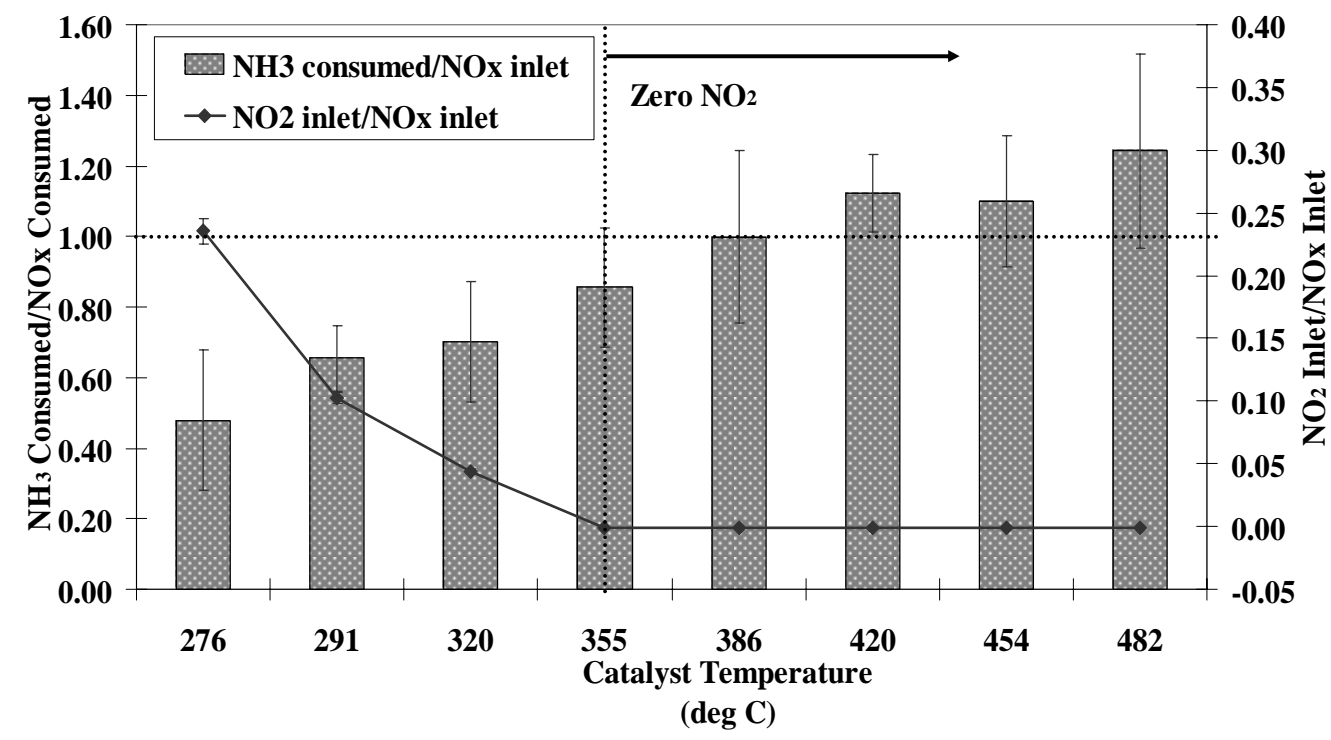

Figure 3.3.129 Ammonia consumption as a function of $\mathrm{NO}_{2}$ inlet for $\mathrm{B} 20-\mathrm{BP} 325$ fuel

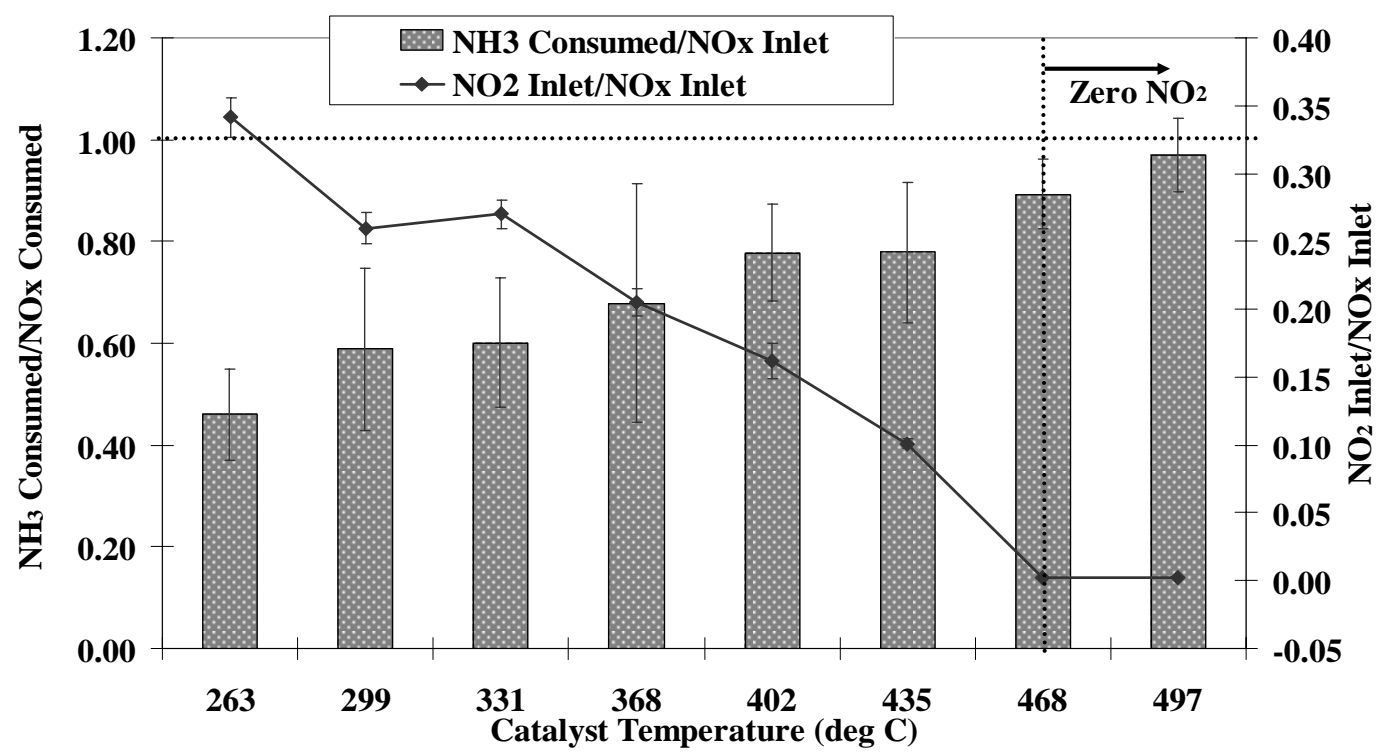

Figure 3.3.130 Ammonia consumption as a function of $\mathrm{NO}_{2}$ inlet for $\mathrm{B} 20-\mathrm{BP} 15$ fuel

\subsection{Comparison of selectivity for $\mathrm{NO}$ and $\mathrm{NO}_{2}$}

This observation stresses upon the significant role of $\mathrm{NO}_{2}$ in the SCR catalysis. Therefore, selectivity of SCR catalyst for $\mathrm{NO}_{2}$ and $\mathrm{NO}$ was compared for BP15 and BP325 fuels. It is shown in Figures 3.3.131 - 3.3.132. These plots clearly show that $\mathrm{NO}_{2} \%$ conversion is always $100 \% \pm 2.5 \%$. This complete $\mathrm{NO}_{2}$ conversion is more evident at lower catalyst temperature with $0.65 \mathrm{NH}_{3} / \mathrm{NO}_{\mathrm{x}}$. At this urea dosage, $\mathrm{NO}_{2} \%$ conversion is $100 \% \pm 2.5 \%$, whereas $\mathrm{NO} \%$ conversion is $65 \% \pm 2.5 \%$. Therefore, it can be concluded that the SCR catalyst prefers a reaction involving $\mathrm{NO}_{2}$ over a reaction with $\mathrm{NO}$ alone although a possibility of $\mathrm{NO}_{2}$ conversion into $\mathrm{NO}$ can not be denied. This result is consistent with the results obtained in model gas experiments by Koebel [133] and Kiovsky [134]. 


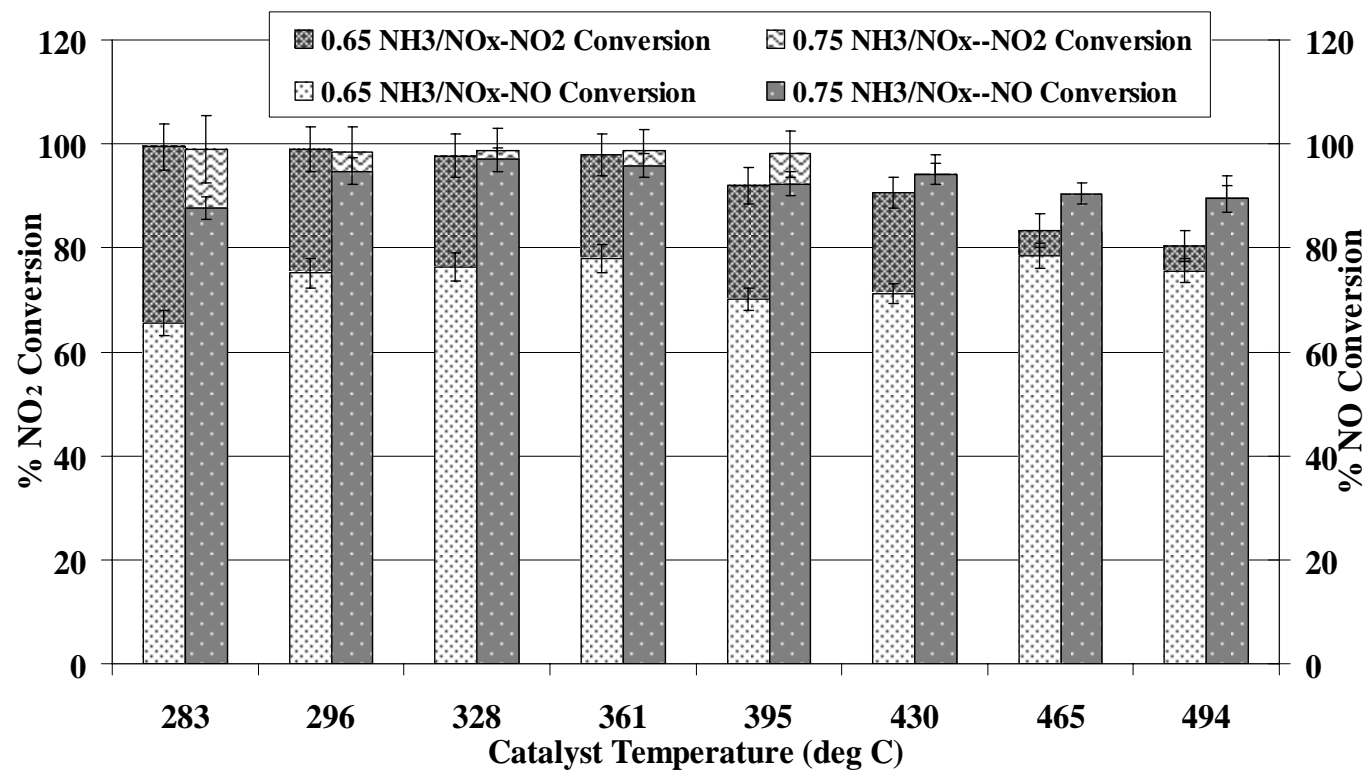

Figure 3.3.131 Comparison of $\% \mathrm{NO}_{2}$ conversion and \% $\mathrm{NO}$ conversion over $0.65 \mathrm{NH}_{3} / \mathrm{NO}_{\mathrm{x}}$ and $0.75 \mathrm{NH}_{3} / \mathrm{NO}_{\mathrm{x}}$ urea dosing rates for BP15 fuel

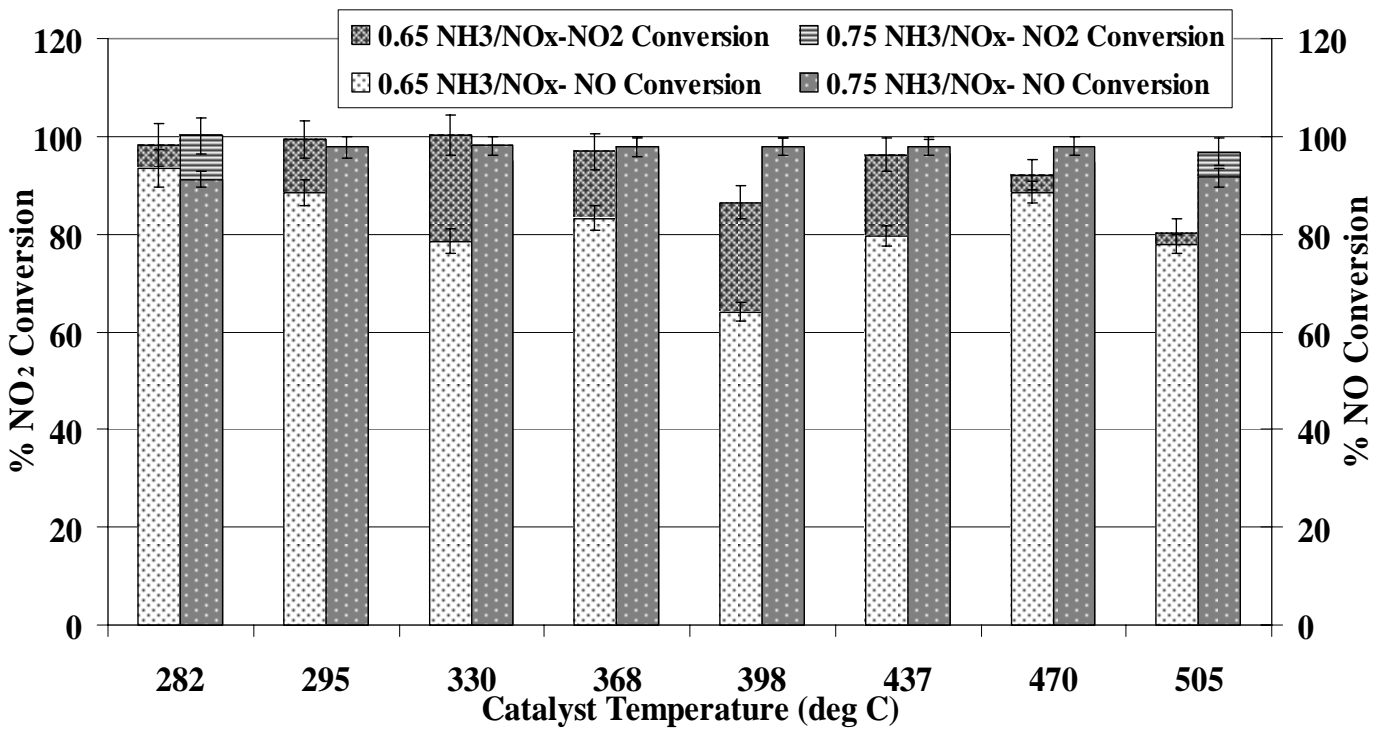

Figure 3.3.132 Comparison of $\% \mathrm{NO}_{2}$ conversion and \% NO conversion over $0.65 \mathrm{NH}_{3} / \mathrm{NO}_{\mathrm{x}}$ and $0.75 \mathrm{NH}_{3} / \mathrm{NO}_{x}$ urea dosing rates for BP325 fuel

\subsubsection{7 $\mathrm{NH}_{3}$ Consumption/ $\mathrm{NO}_{2}$ Inlet at Different Urea Dosing}

Figures 3.3.133 - 3.3.132 further show the $\mathrm{NH}_{3}$ consumption (ppm) per unit $\mathrm{NO}_{2}$ inlet (ppm) for three of the test fuels, BP 15, BP325 and B20-BP15, respectively. This ratio increases as $\mathrm{NO}_{2}$ decreases. These figures show that at lower $\mathrm{NH}_{3}$ Consumed/NO $\mathrm{NO}_{2}$ Inlet, i.e., at higher $\mathrm{NO}_{2}$ content in the $\mathrm{NO}_{\mathrm{x}}$ inlet to the SCR system, there is no difference between lean and rich urea dosing rates. But as $\mathrm{NH}_{3}$ Consumed/ $\mathrm{NO}_{2}$ Inlet increases, i.e., $\mathrm{NO}_{2}$ content in the $\mathrm{NO}_{x}$ inlet to SCR system decreases, there is a clear difference between $0.65 \mathrm{NH}_{3} / \mathrm{NO}_{\mathrm{x}}, 0.75 \mathrm{NH}_{3} / \mathrm{NO}_{\mathrm{x}}$ and $1.0 \mathrm{NH}_{3} / \mathrm{NO}_{\mathrm{x}}$ dosing rates. One rich urea dosage, i.e., $1.4 \mathrm{NH}_{3} / \mathrm{NO}_{x}$ produces the same results as for $1.0 \mathrm{NH}_{3} / \mathrm{NO}_{\mathrm{x}}$. These results show that at lower catalyst temperatures when $\mathrm{NO}_{2}$ is higher, the urea lean dosing rate produces the 
best results, whereas as catalyst temperature goes up and $\mathrm{NO}_{2}$ starts decreasing, optimum performance approaches the stoichiometric urea dosing rate. Most importantly, this result shows that the rich urea dosing rates do not produce any benefits. This observation is contrary to several research works that have shown some advantage with rich urea dosage [144, 146 - 148]. This difference is attributed to different experimental configurations wherein in the present work a DPF was used upstream SCR reactor. This setup resulted in significant amounts of $\mathrm{NO}_{2}$ in the exhaust inlet to the SCR reactors thereby producing different results and shedding light on the impact of enhanced exhaust $\mathrm{NO}_{2}$.

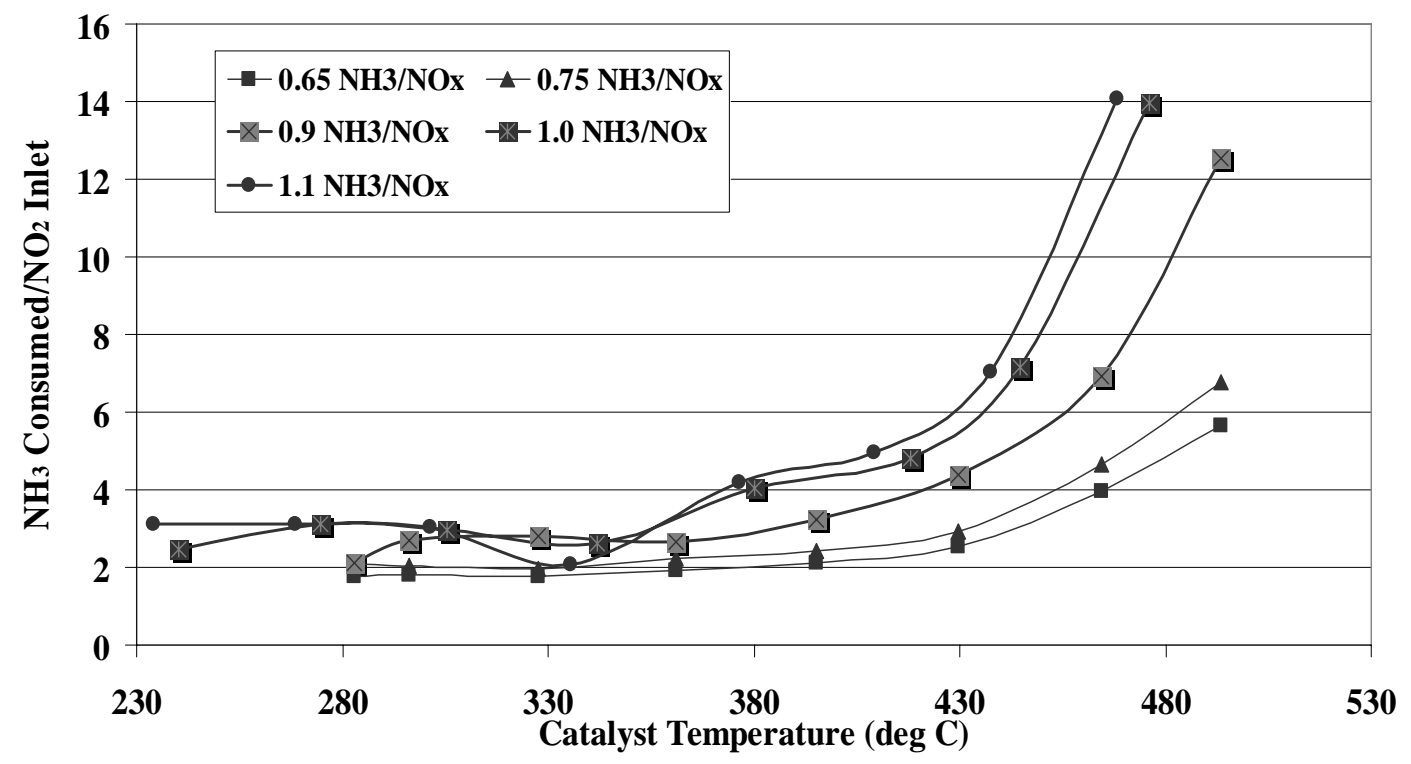

Figure 3.3.133 Comparison of $\mathrm{NH}_{3}$ consumption as a function of $\mathrm{NO}_{2}$ inlet for different urea dosing rates for BP15 fuel

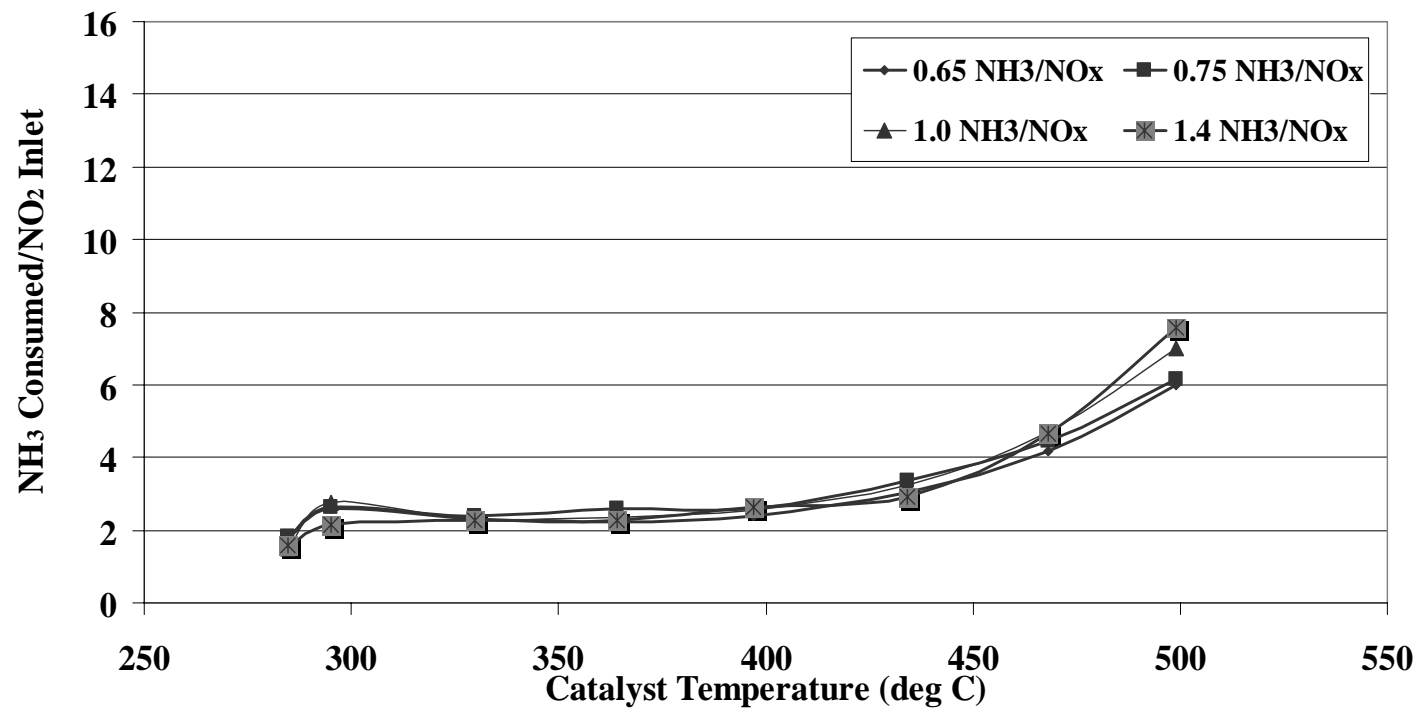

Figure 3.3.134 Comparison of $\mathrm{NH}_{3}$ consumption as a function of $\mathrm{NO}_{2}$ inlet for different Urea dosing rates for BP325 fuel 


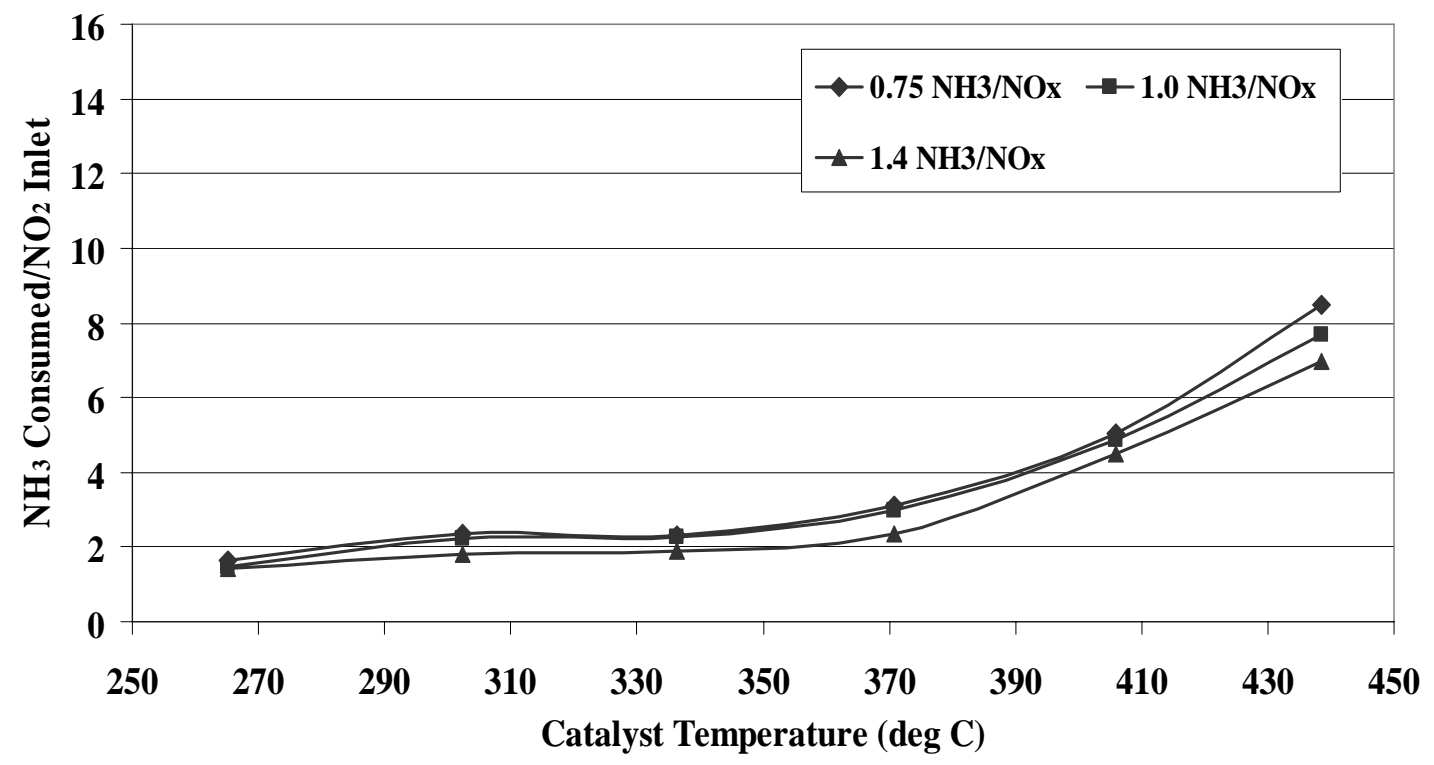

Figure 3.3.135 Comparison of $\mathrm{NH}_{3}$ consumption as a function of $\mathrm{NO}_{2}$ inlet for different urea dosing rates for $\mathrm{B} 20-\mathrm{BP} 15$ fuel

\subsection{Presence of $\mathrm{N}_{2} \mathrm{O}$}

Finally, Figures 3.3.136 - 3.3.139 show FTIR spectra of the SCR-out exhaust superimposed with the standard spectra of $\mathrm{N}_{2} \mathrm{O}$. The spectra show no trace of (less than $0.001 \%$ ) $\mathrm{N}_{2} \mathrm{O}$ in SCR-out emissions.

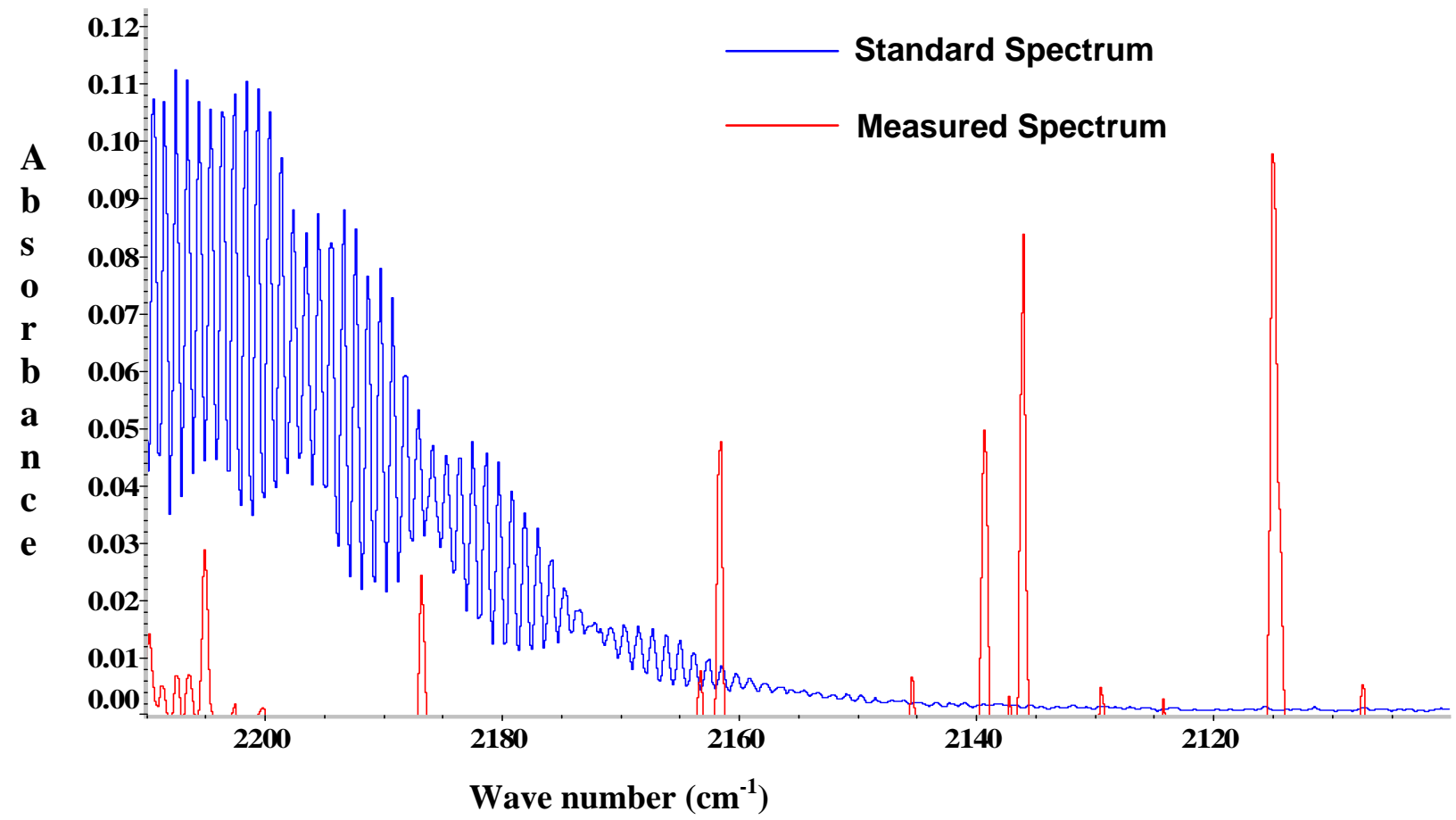

Figure 3.3.136 FTIR spectra of SCR-out exhaust at $1400 \mathrm{rpm}$ and $380 \mathrm{lb}$-ft load for BP15 fuel at $\mathrm{NH}_{3} / \mathrm{NO}$ ratio 0.75 
These results are also contrary to the results obtained by Ozkan et al. [137], Lietti et al. [139], Marangozis et al. [140], and Koebel [133]. Komatsu et al. [138] did not observe any $\mathrm{N}_{2} \mathrm{O}$ in the case of the reduction of nitric oxide with ammonia on $\mathrm{Cu}-\mathrm{Z}$. In another experiment over platinum foil catalysts, Komatsu et al., found $\mathrm{N}_{2} / \mathrm{N}_{2} \mathrm{O}$ ratio of about 2 at $573 \mathrm{~K}$. Therefore, the results obtained in this work can be attributed to differences in catalyst formulation.

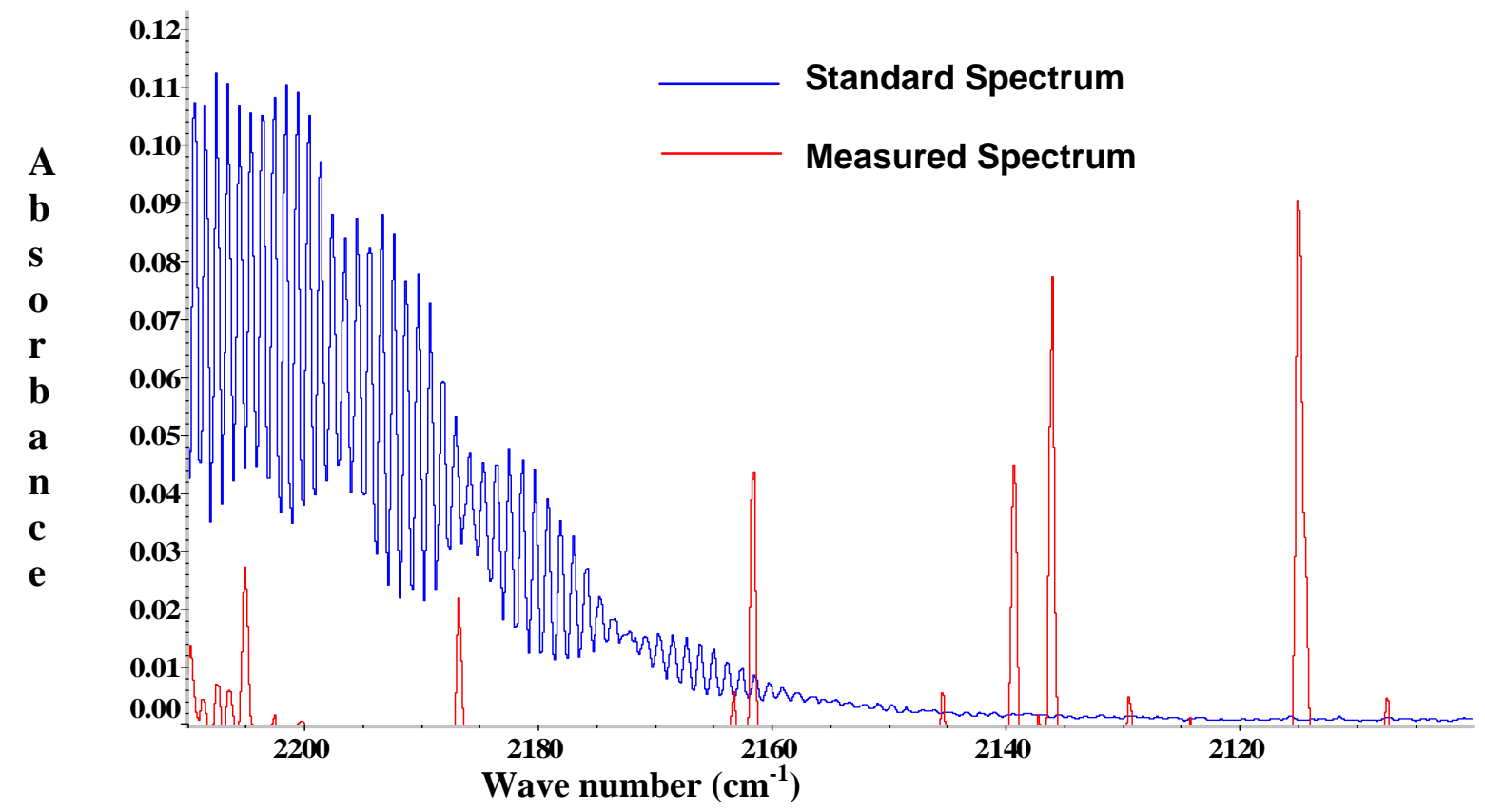

Figure 3.3.137 FTIR spectra of SCR-out exhaust at $1400 \mathrm{rpm}$ and $380 \mathrm{lb}$-ft load for BP15 fuel at $\mathrm{NH}_{3} / \mathrm{NO}$ ratio 0.75

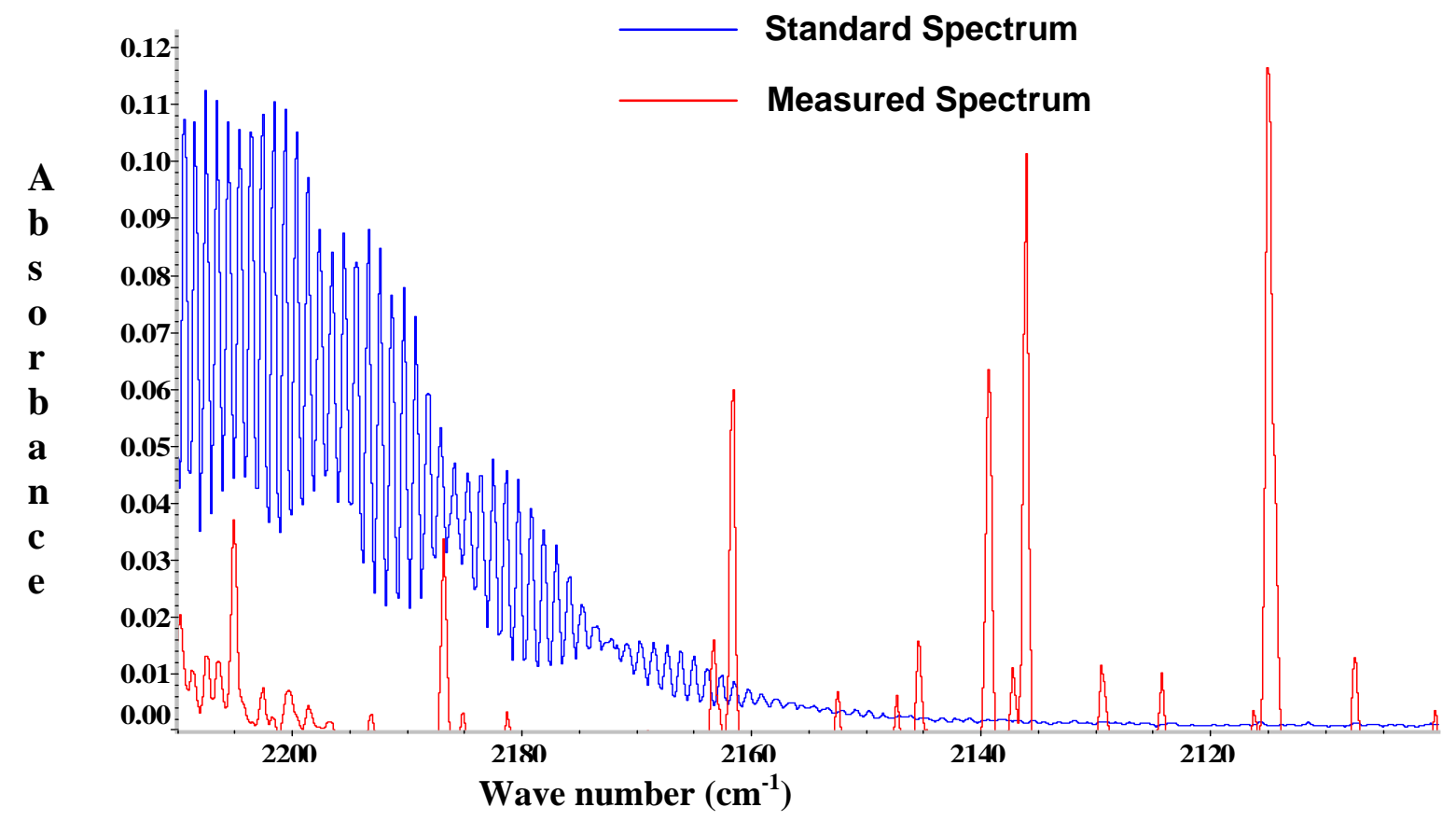

Figure 3.3.138 FTIR spectra of SCR-out exhaust at $1400 \mathrm{rpm}$ and $380 \mathrm{lb}-\mathrm{ft}$ load for B20BP15 fuel at $\mathrm{NH}_{3} / \mathrm{NO}$ ratio 0.75 


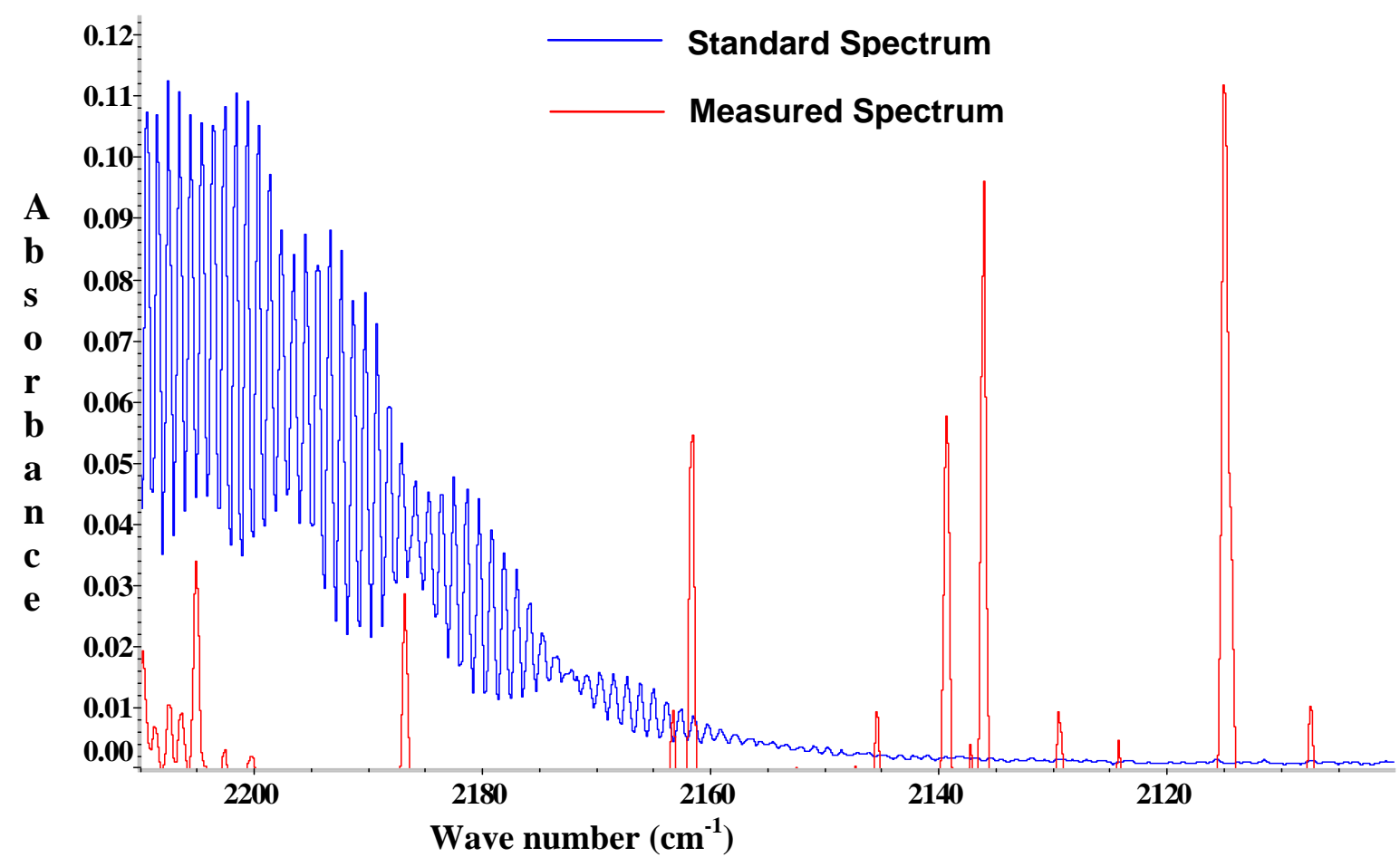

Figure 3.3.139 FTIR spectra of SCR-out exhaust at $1400 \mathrm{rpm}$ and $380 \mathrm{lb}-\mathrm{ft}$ load for B20BP325 fuel at $\mathrm{NH}_{3} / \mathrm{NO}$ ratio 0.75

\subsubsection{Conclusions}

The primary focus of this research was to examine the effect of fuel sulfur on $\mathrm{NO}_{x}$ reduction efficiency of urea- SCR system and to determine the effect of urea dosing rate on $\mathrm{NO}_{\mathrm{x}}$ reduction efficiency and $\mathrm{NH}_{3}$ slip. Due to an oxidizing DPF filter before the urea-SCR reactor, the composition of $\mathrm{NO}_{x}$ going into the urea-SCR reactor changed. The DPF reactor oxidized some of $\mathrm{NO}$ into $\mathrm{NO}_{2}$, making it a major constituent in the $\mathrm{NO}_{x}$ inlet to the urea-SCR reactor. So the urea- SCR system was characterized for $\mathrm{NO}_{x}$ reduction efficiency, urea dosing rate and $\mathrm{NH}_{3}$ slip with four test fuels, i.e., BP15, BP325 and their $20 \% \mathrm{w} / \mathrm{w}$ blends with biodiesel, in the exhaust with enhanced $\mathrm{NO}_{2}$. Specifically, the following observations can be made:

1. The SCR catalyst activity is not affected directly by fuel sulfur.

2. $\mathrm{NO}_{\mathrm{x}}$ reduction cannot be increased by increasing $\mathrm{NH}_{3}$ (urea) supply due to the limitations of catalyst activity.

3. The SCR catalyst is more selective for $\mathrm{NO}_{2}$ than $\mathrm{NO}$ in the $\mathrm{NO}_{x}$ reduction reaction.

4. Catalytic activity for $\mathrm{NO}_{2}$ is higher than $\mathrm{NO}$ at lower temperatures (below 300 deg $\mathrm{C}$ ).

5. The reaction involving $\mathrm{NO}_{2}$ requires less than 1 mole of $\mathrm{NH}_{3}$ per mole of $\mathrm{NO}_{\mathrm{x}}$. But it is not possible to determine the exact number of moles of $\mathrm{NO}$ and $\mathrm{NO}_{2}$ taking part in some reactions with $\mathrm{NH}_{3}$ from this experiment.

6. The SCR out emissions do not have any traces of $\mathrm{N}_{2} \mathrm{O}$. So, while $\mathrm{N}_{2} \mathrm{O}$ may be formed as an intermediate transient product, it is certainly not the final product for the catalyst formulation in this work.

These observations highlight the role of $\mathrm{NO}_{2}$ in the urea-SCR reaction mechanism. So, while making an optimum urea dosing strategy, i.e., maximum $\mathrm{NO}_{\mathrm{x}}$ conversion efficiency and minimum 
(zero) $\mathrm{NH}_{3}$ slip, it is important to map $\mathrm{NO}_{2}$ as well as $\mathrm{NO}$. The greater catalyst selectivity of $\mathrm{NO}_{2}$ in comparison with $\mathrm{NO}$ is in agreement with suggestions by Koebel et al. [133]. The $\mathrm{NO}_{2}$ content in the $\mathrm{NO}_{\mathrm{x}}$ inlet to the SCR reactor depends upon the DPF activity, which is affected by the fuel sulfur content and temperature. So, it can be concluded that in this work, the fuel sulfur content indirectly affects the urea-SCR catalyst performance through DPF. It would be better to operate in the operating range when the DPF is most active as it would produce more $\mathrm{NO}_{2}$ that requires less ammonia than the NO.

\subsubsection{Suggestions for Future Work}

The results presented here demonstrate the role of $\mathrm{NO}_{2}$ in the reaction kinetics of urea SCR catalysis. But the engine testing does not provide exact information about the reaction pathways. There are two questions concerning the reaction involving $\mathrm{NO}_{2}$ :

1. The first question would be to identify the key elementary reaction(s) and whether it involves $\mathrm{NO}$ also. If it does, what is the molar ratio of $\mathrm{NO}, \mathrm{NO}_{2}$ and $\mathrm{NH}_{3}$ in this reaction. Also, is there only one such reaction or a series of reactions?

2. The second question would be to investigate the kinetics of these reaction(s) (rate(s) of reaction, activation energy, etc). This information would provide the complete picture of SCR catalysis and could be accomplished by model gas experiments on a small prototype catalytic reactor.

This work does not include the catalyst activity and impact of $\mathrm{NO}_{2}$ at lower catalyst temperature. Therefore, an effort should be made to understand low temperature behavior of the SCR catalysis process. 


\subsubsection{Evaluation of Performance and Emissions of GTL Diesel Fuel}

\subsubsection{Introduction}

During the course of this research program, the availability of GTL diesel fuel was limited. Not until near the end of the project were sufficient quantities of GTL diesel available to permit extension combustion and emissions studies in the Cummins ISB test engine. However, by the summer of 2005, barrel quantities of GTL diesel became available and a program of combustion, performance, emissions and emission control experiments were undertaken. This section summarizes the observations of the operation of the Cummins ISB engine on GTL diesel fuel.

\subsubsection{2 - Engine Evaluation of FT Diesel Fuel}

Fischer Tropsch (FT100) diesel fuel (referred to as Batch \#2 in Table 3.1.3.5) was evaluated with a commercial Cummins 5.9L ISB engine. Two base fuels, a low sulfur diesel fuel BP325, and an ultra low sulfur diesel fuel BP15 were tested and their detailed performance was reported in the earlier sections. In addition two other blends were also tested, a 20 vol.\% biodiesel blended with FT (FT80B20) and a 20 vol.\% BP15 blended with FT (FT80BP15-20) for comparative analysis.

\subsubsection{Engine Performance}

For the engine testing, each fuel was evaluated using the AVL 8-Mode test protocol. It was not possible to operate mode 8 with all the fuels especially with FT100 and blends due to the density and calorific value of the fuel. All the test conditions were the same as in the baseline test procedure. Based on the power output for each test mode, the gaseous emissions were calculated on brakespecific basis, as well as, on a mass emission rate per unit fuel consumption.

\subsection{Fuel consumption}

For the engine testing, the base, FT100 and blended fuels were evaluated using the AVL 8Mode test protocol. The engine operating conditions were calculated based on the rated peak torque, power and speed of the engine. For each test mode, fuel consumption was recorded over a five minute period as the difference in fuel tank weight. Fuel consumption per unit time is shown in Figure 3.3.140. Based on the power output for each test mode, brake-specific fuel consumption (BSFC) was calculated and is presented in Figure 3.3.140. The calorific value of each of the base fuels, FT100 and their blends were evaluated and are shown in Table 3.3.23. An increase in calorific value is observed with the FT100 compared to its base diesel fuel.

Table 3.3.23 Calorific value and other properties of base, FT100 and blended fuels

\begin{tabular}{|c|c|c|c|}
\hline Tested Fuels & Calorific Value, BTU/lb & Density, gm/CC & Cetane \# IQT \\
\hline BP325 & 18486 & 0.84 & 43.95 \\
\hline BP15 & 18516 & 0.83 & 47.24 \\
\hline FT100 & 18941 & 0.78 & 74.41 \\
\hline FT80B20 & 18318 & 0.80 & 69.53 \\
\hline FT80BP15-20 & 18798 & 0.79 & 70.07 \\
\hline
\end{tabular}

Mode 1 is omitted from Figure 3.3.141, since there is no net power output and BSFC cannot be calculated. A comparable brake-specific fuel consumption is observed with BP325 and BP15. With a few exceptions consistent BSFC was observed with the FT and their blends. The trend is for specific 
fuel consumption to decrease with FT100, which is consistent with its higher heating value compared to the base fuels as shown in Table 3.3.23.

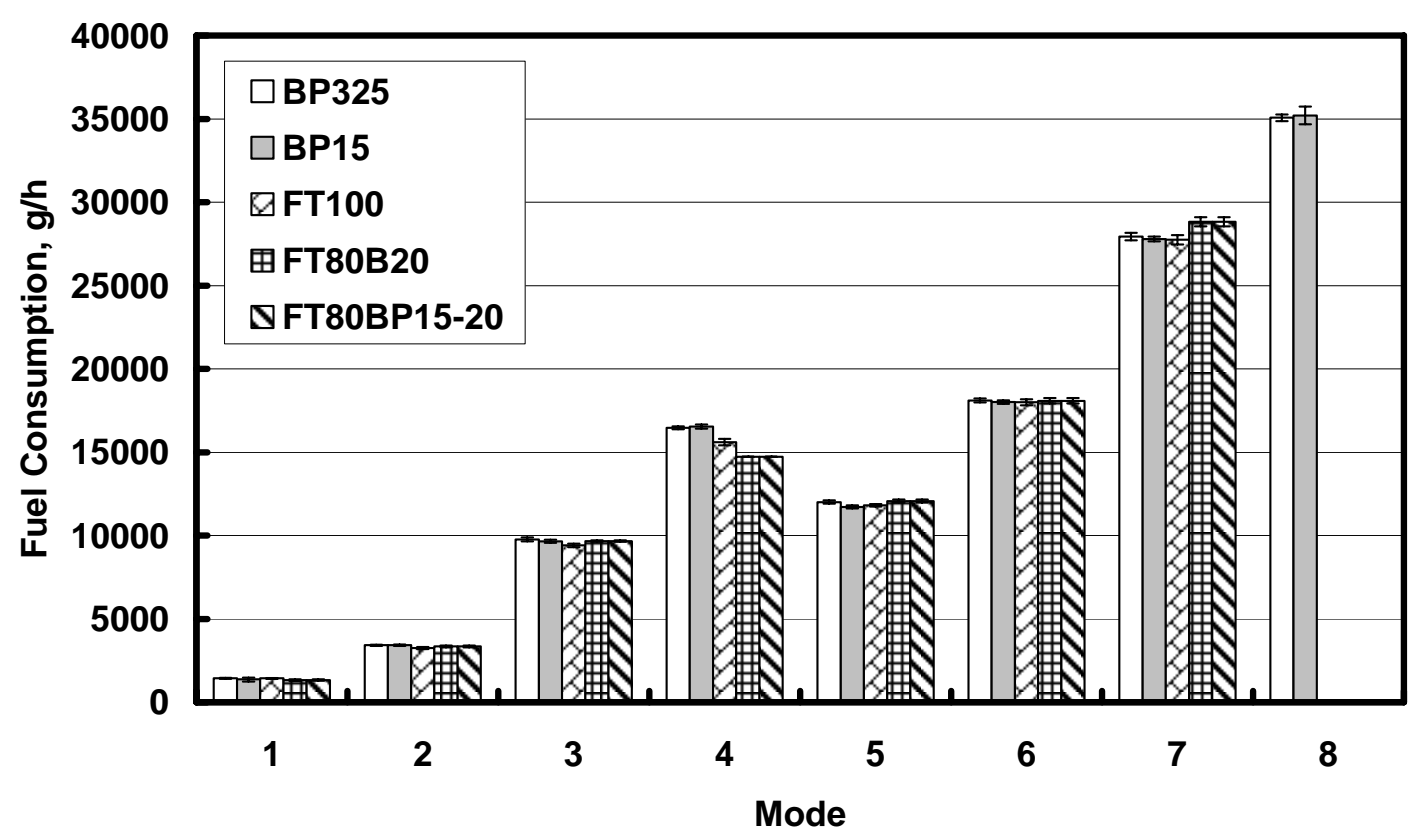

Figure 3.3.140 Fuel consumption per unit time

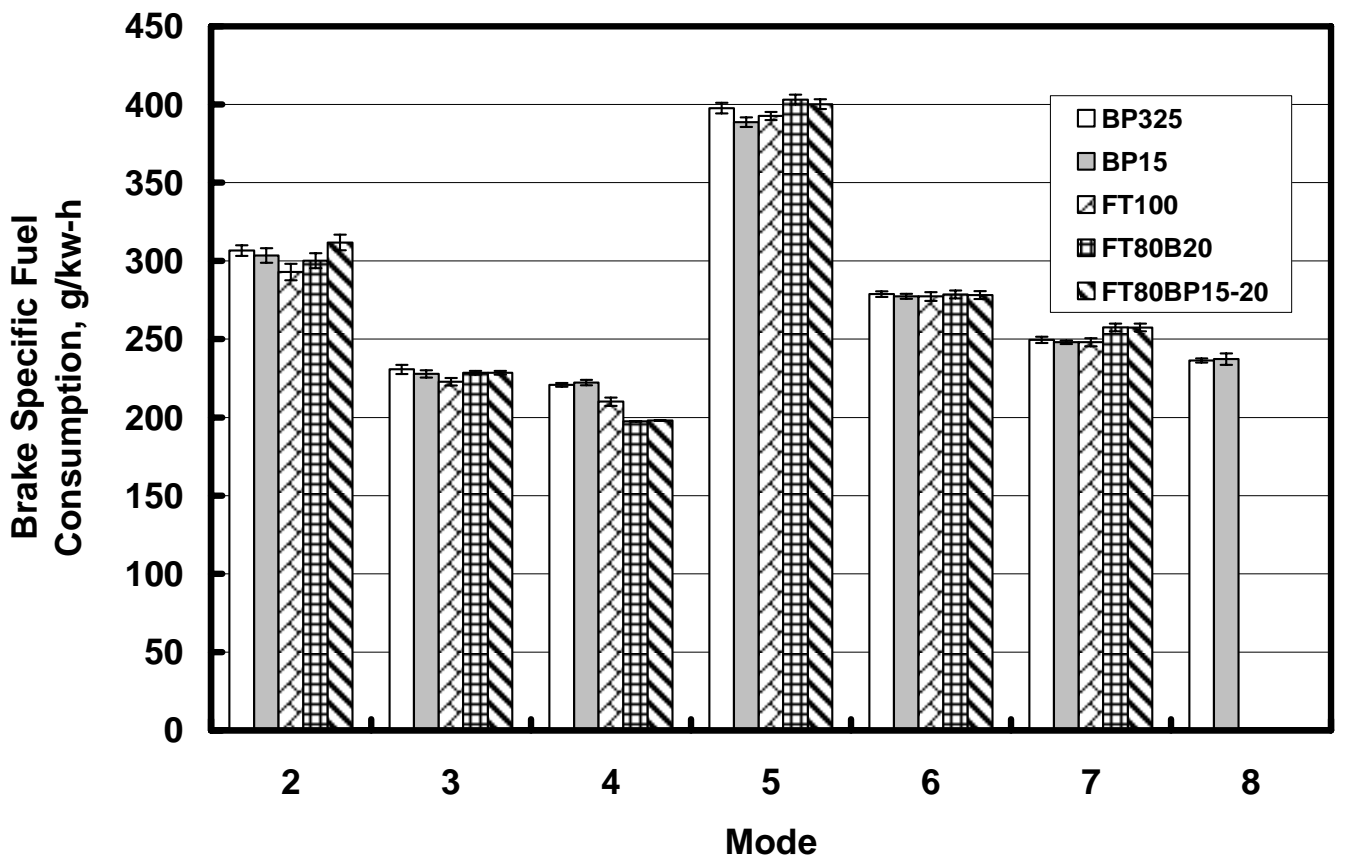

Figure 3.3.141 Brake-specific fuel consumption 


\subsection{Engine Combustion}

For the base fuels, FT100 and blends evaluated in this study, the combustion process was monitored using in-cylinder pressure trace analysis. Also, a needle lift sensor was used to monitor dynamic behavior of the start of injection and end of injection events. Rate of heat release (ROHR) was calculated using in-cylinder pressure trace data.

\subsection{Needle Lift}

Among the AVL 8-Mode tests as a basis, only four modes (M2, M4, M5 and M7) are selected here to understand and compare the start of injection and its effect on ROHR. Figures 3.3.142 and 3.3.143 present injector needle lift data as a function of crank angle. In addition to the dynamic start and end of injection, needle lift data also shows the fuel injection duration. Changing engine operating conditions from Mode 2 to Mode 4 yields needle lift duration changes, indicating a longer injection duration with Mode 4. A similar trend is present between Modes 5 and 7. It should be noted that the present study was conducted with an electronically controlled fuel injection system so that injection timing is dictated by the protocols in the ECM. Therefore, changes in injection timing are observed from the needle lift data as shown in Figures 3.3.142 through 3.3.143. For this engine's calibration, injection timing varied with load.

Comparing the start of injection event among the fuels, Figures 3.3.142 through 3.3.143 show that the start of injection event changes with the fuel. This behavior is more prominent at high load conditions (M4 and M7) rather than at low load (M2 and M5). Table 3.3.24 shows the specific start of injection timing among the fuels. Blending 20 vol.\% biodiesel and 20 vol.\% BP15 with pure FT will increase the density of the blend. Among the fuels, FT100 has the lowest density while BP325 has the highest density. An enlarged view of needle lift at mode 4 is shown in Figure 3.3.144, where the BP325 shows the earliest start of injection among the fuels. After BP325, the start of injection occurred in the order of BP15, FT80B20, FT80Bp15-20 and FT100. The start of injection occurred in the order of density and bulk modulus of compressibility of the fuels: the higher the density of the fuel, the earlier the start of injection.

The BP325 showed an average of almost 1.0 CAD advanced injection timing compared to FT100. The BP325 fuel also yielded an advanced injection compared to the BP15 fuel. It is necessary to mention here that despite the electronic control of start of injection, fuel injection timing changed with density.

This variation in start of injection has a great effect on engine combustion and engine-out exhaust emissions. An early start of injection can lead to increased $\mathrm{NO}_{x}$ emissions. Previous studies with base and biodiesel blends confirmed that the biodiesel blends have an early start of injection and can increase $\mathrm{NO}_{x}$ emissions compared to base fuels. Similarly, the early start of injection with BP325 increases $\mathrm{NO}_{x}$ emissions relative to BP15. Note that the start of injection is not the only reason for higher $\mathrm{NO}_{x}$ emissions. Some other fuel properties are also related to $\mathrm{NO}_{x}$ emissions, for example, cetane number. The change in $\mathrm{NO}_{x}$ emissions due to the variation of cetane number can be explained with rate of heat release analysis of the fuels. 


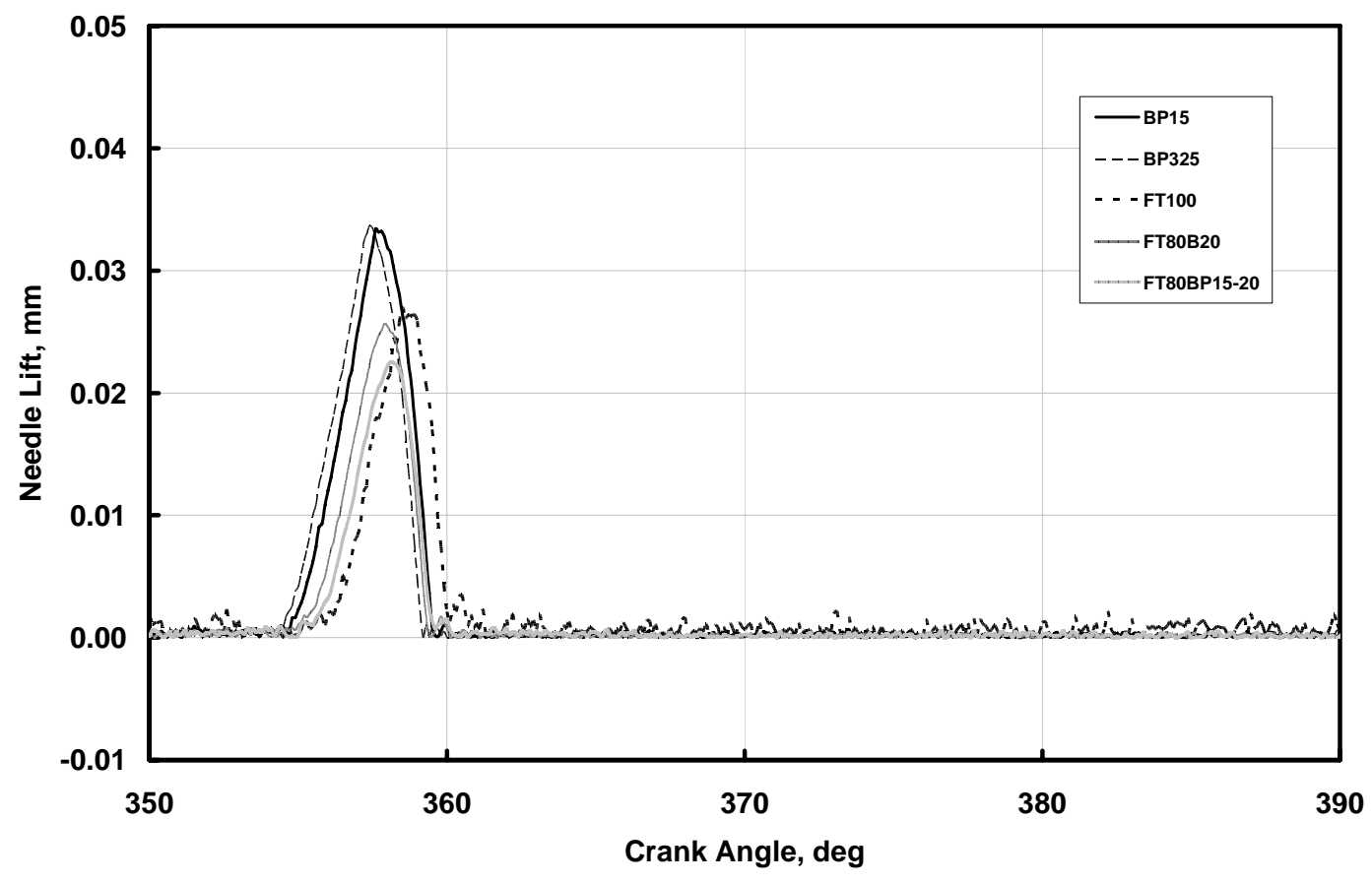

(a)

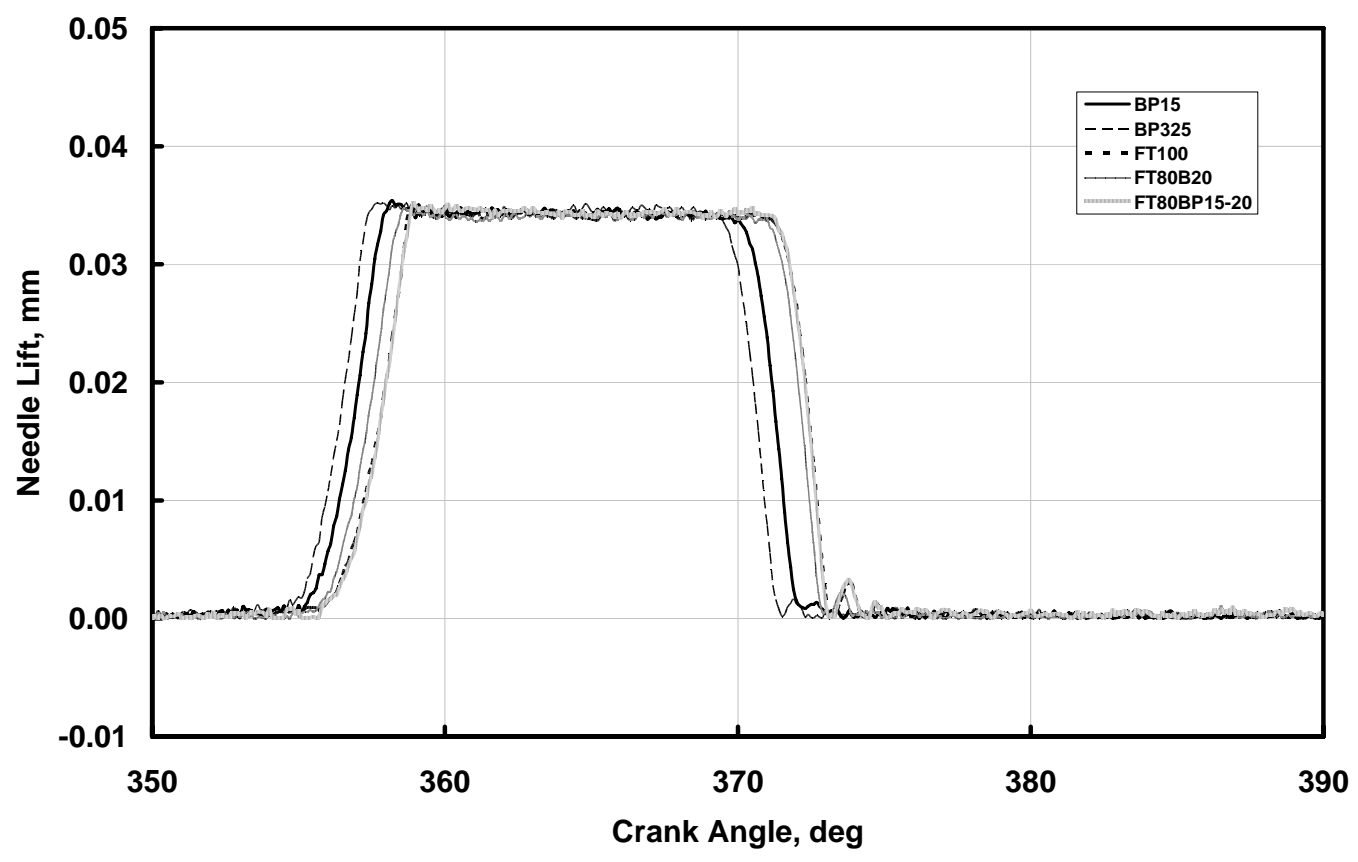

(b)

Figure 3.3.142 Injector needle lift at (a) M2, and (b) M4 


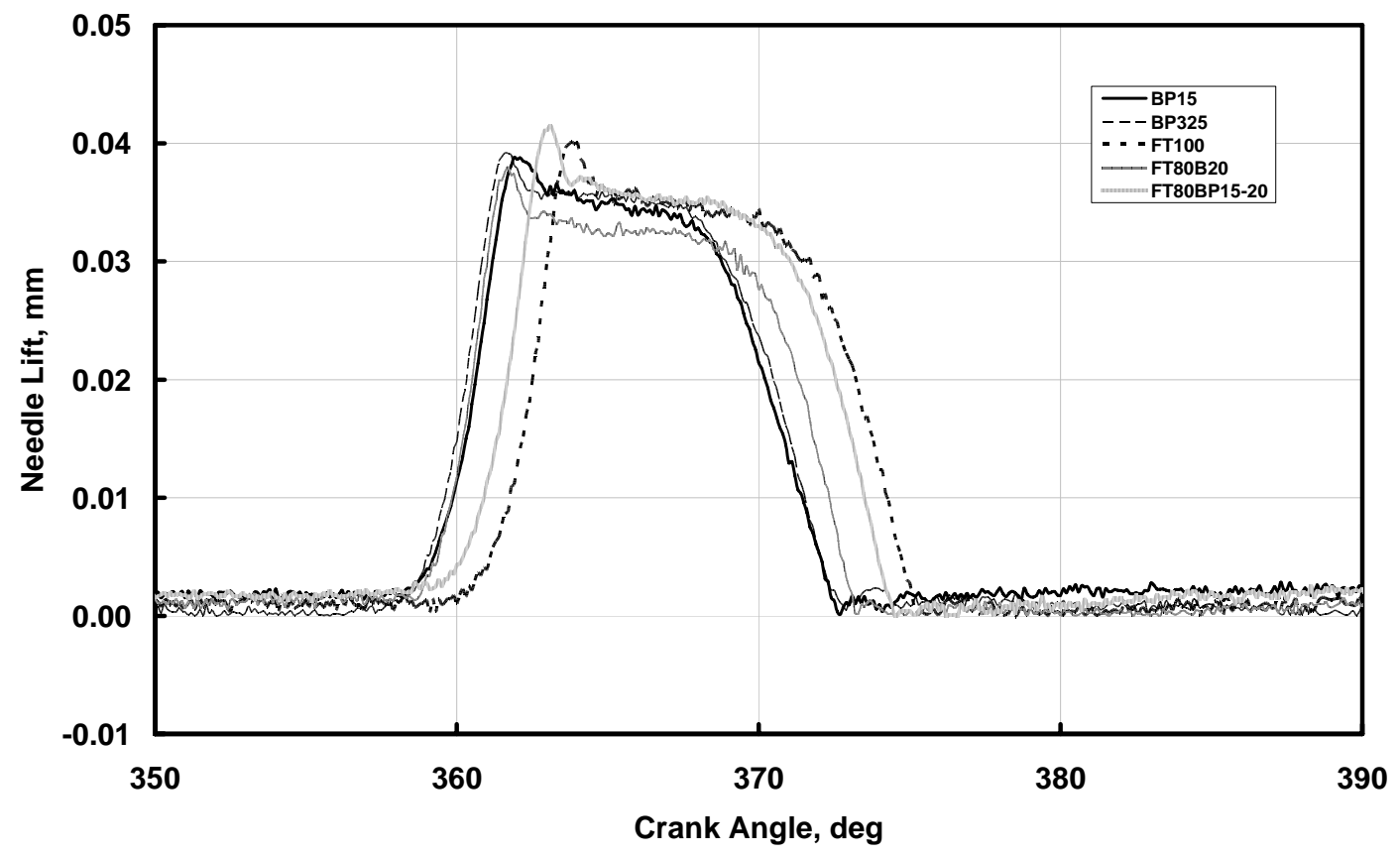

(a)

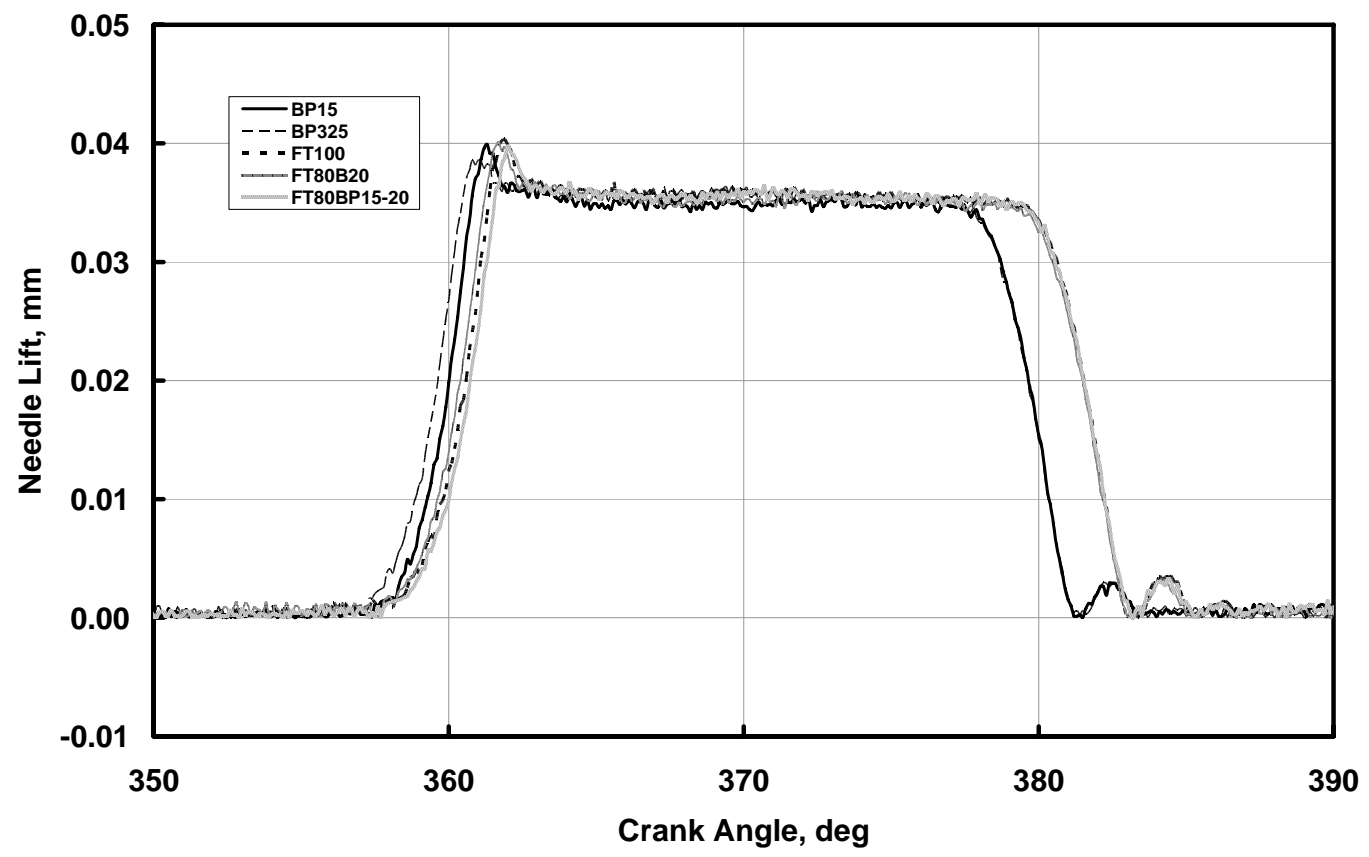

(b)

Figure 3.3.143 Injector needle lift at (a) M5, and (b) M7 


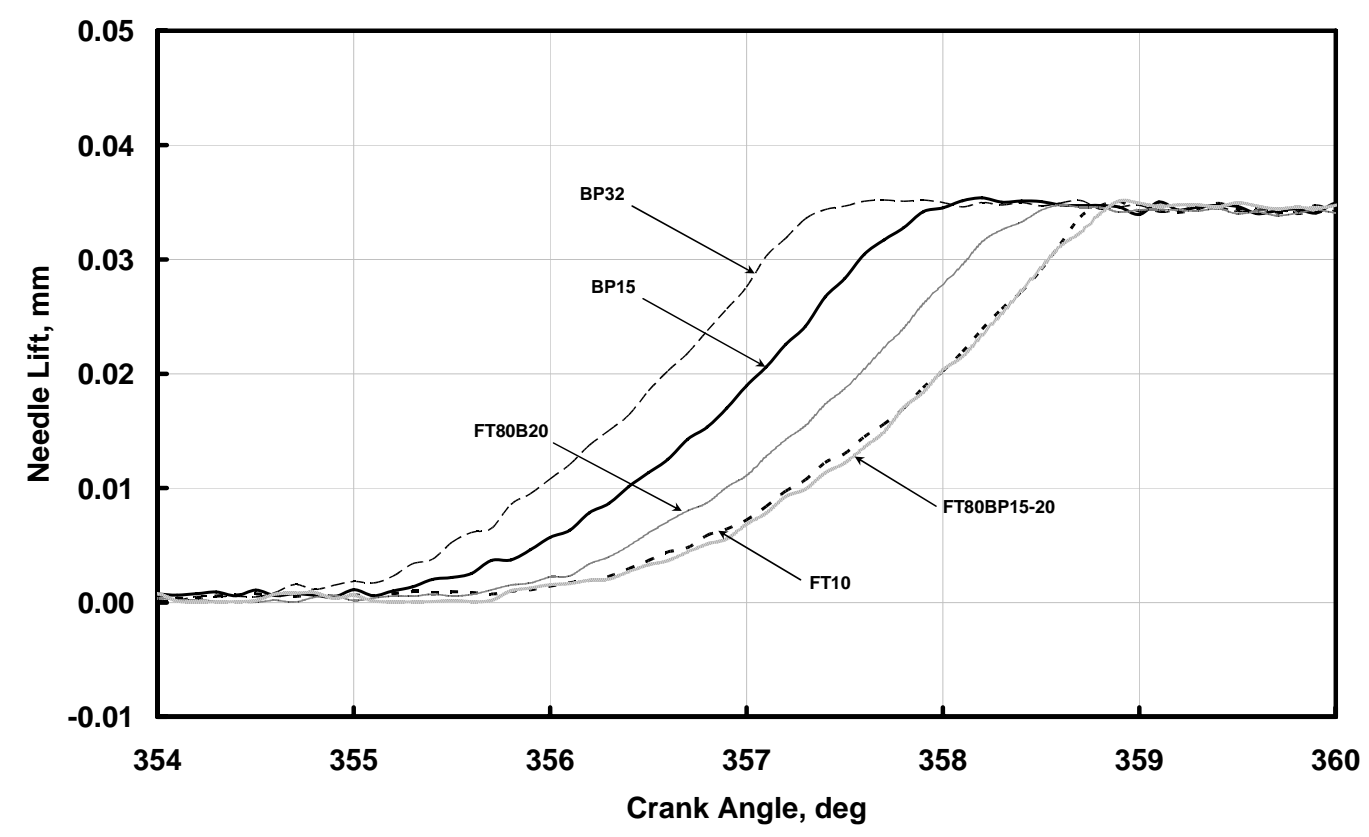

Figure 3.3.144 Enlarged injector needle lift at M4

Table 3.3.24 Comparison of start of injection timing

\begin{tabular}{|c|c|c|c|c|}
\hline \multirow{2}{*}{ Timing } & \multicolumn{5}{|c|}{$\begin{array}{c}\text { Start of Injection } \\
\text { (Degree Before Top Dead Center) }\end{array}$} \\
\hline Mode & $\mathbf{2}$ & $\mathbf{4}$ & $\mathbf{5}$ & $\mathbf{7}$ \\
\hline BP325 & 5.4 & 5.3 & 1.7 & 2.7 \\
\hline BP15 & 5.2 & 4.8 & 1.8 & 2.5 \\
\hline FT80B20 & 5.0 & 4.3 & 1.3 & 2.2 \\
\hline FT80-BP15-20 & 4.9 & 4.2 & 1.0 & 2.1 \\
\hline FT100 & 4.8 & 4.1 & 1.0 & 1.8 \\
\hline $\begin{array}{c}\text { Difference } \\
\text { BP325 - FT100 }\end{array}$ & 0.6 CAD & 1.2 CAD & 0.7 CAD & 0.9 CAD \\
\hline Average & \multicolumn{5}{|c|}{0.85 CAD } \\
\hline
\end{tabular}




\subsection{Cylinder Pressure}

Plots of cylinder pressure as a function of crank angle are presented in Figures 3.3.145 and 3.3.146. Two low load points $M 1$ and $M 2$ and a high load point M4 are shown in these figures. During operation with FT100 and its blends, the engine was not stable at idle or at low load conditions. At M1 and M2, lower peak cylinder pressure is observed with the FT100 and its blends compared to base BP15 or BP325 fuels. This unstable engine operation might be due to the weak combustion of the fuels as shown in Figures 3.3.145 and 3.3.146, which is a direct consequence of the delayed and weakened injection process. Mode 4, a low speed-high load condition, shows that there is a peak cylinder pressure difference between the fuels. However, that pressure difference is lower than the idle or low load conditions.

It was possible to operate the engine across M1 to M7 of the AVL 8-mode test protocol. The engine was rather stable at high load conditions with FT100 and its blends. However, it was not possible to operate the engine at M8, which represents nearly maximum speed and load. The test engine was calibrated with regular \#2 diesel fuel. To get better results with the FT100 and to operate at rated load condition, the engine needs to be calibrated for optimum performance.

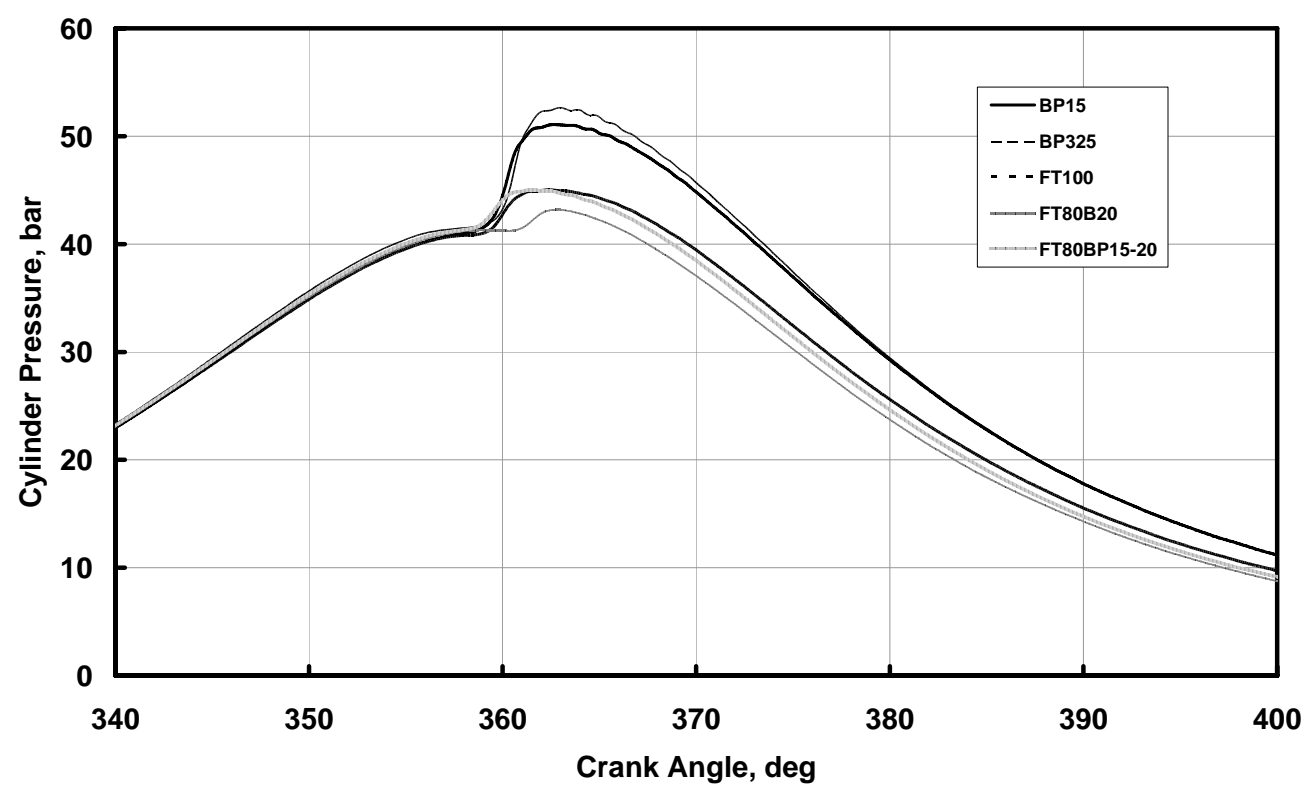

Figure 3.3.145 Cylinder pressure time histories at M1 


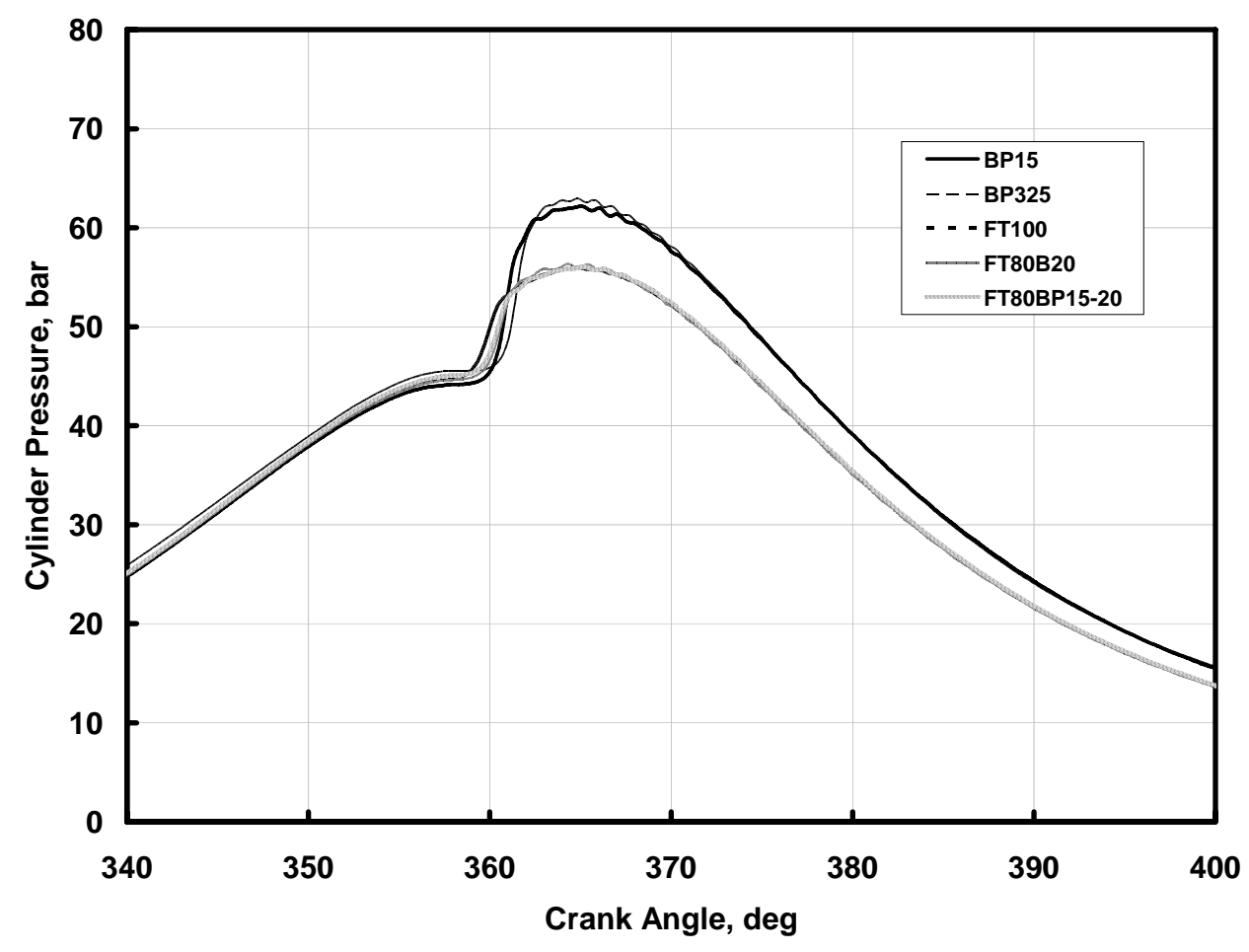

(a)

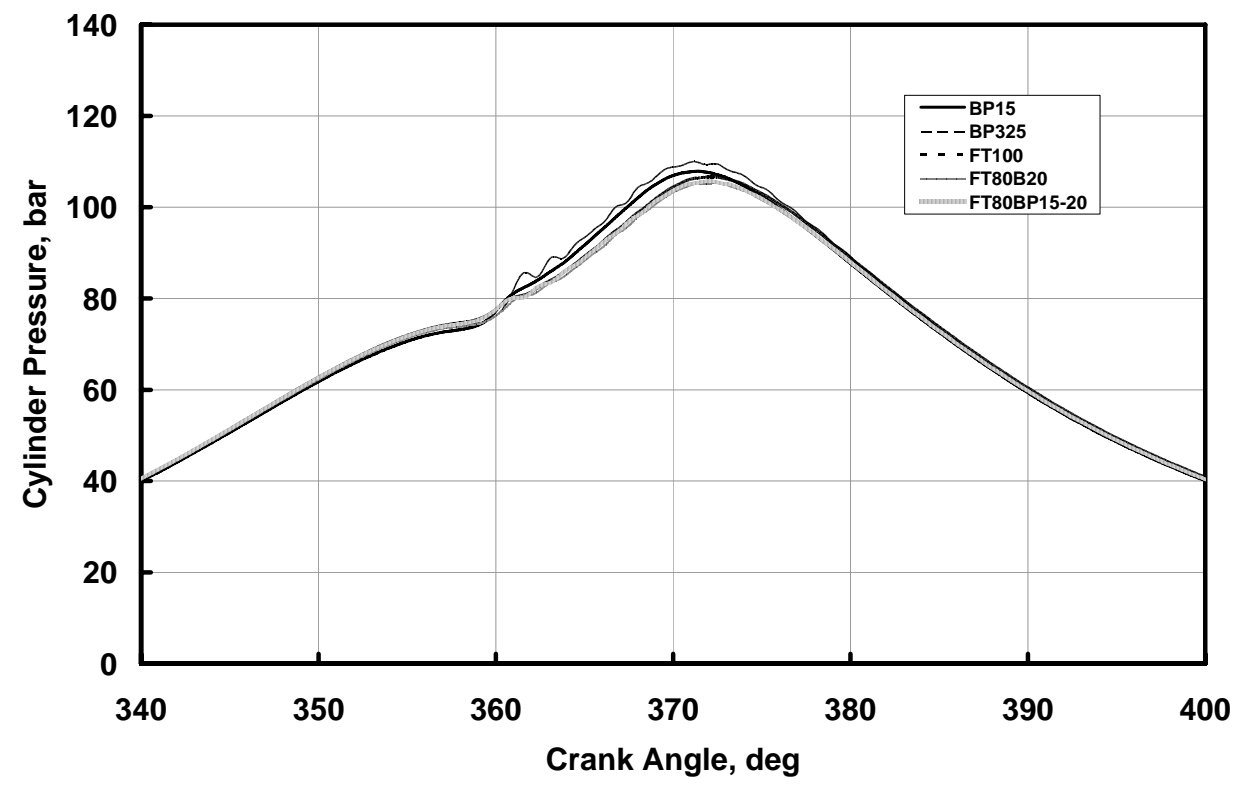

(b)

Figure 3.3.146 Cylinder pressure time histories at (a) M2 and (b) M4 


\subsection{Rate of Heat Release}

As shown in Table 3.3.23, BP325 has the lowest cetane number and FT100 has the highest cetane number among the fuels. An increase in the paraffinic content of the fuel increases cetane number and a high content of aromatics impairs the ignition quality and lowers the cetane number. An increase in cetane number results in a reduction of the ignition delay period and reduces the amount of premixed combustion.

Figures 3.3.147 - 3.3.149 present the rate of heat release at M2 \& M4, M5 \& M7 and an enlarged view at M4, respectively. At low load (M2 and M5) conditions, the rate of heat release analysis indicates that the majority of the combustion is premixed. At high load (M4 and M7), diffusion burning dominates the combustion process. The FT100 and its blends show a lower premixed burn peak compared to the base fuel due to the higher cetane number of the FT100 and its blends. The highest premixed burn peak is observed with BP325. This result is consistent with the cetane number of the test fuels, since the highest premixed burn peak among the fuels is for BP325, which has the lowest cetane number.

However, the start of combustion does not occur in the order of cetane number of the fuels since the start of injection event happened in the order of the density of the fuels. Table 3.3.23 shows that the highest density fuel BP325 does not have the highest cetane number. Among the fuels, rate of heat release curves show that the start of combustion occurs last for BP325 despite the earlier start of injection with BP325. The start of combustion depends on multiple parameters of the fuel and in-cylinder conditions of the engine.

Generally, low cetane fuel shows a longer ignition delay and higher initial heat release, resulting in lower PM emissions and increased $\mathrm{NO}_{x}$ at high load conditions. On the other hand, higher cetane number fuel produces large amounts of PM due to the longer combustion duration. Diesel fuel properties have significant effects on start of injection, start of combustion, and premixed and diffusion burn peaks, which impact engine performance and tailpipe exhaust emissions. Sometimes it is very difficult to isolate the effects of one property from another, since the properties of diesel fuels are interrelated. 


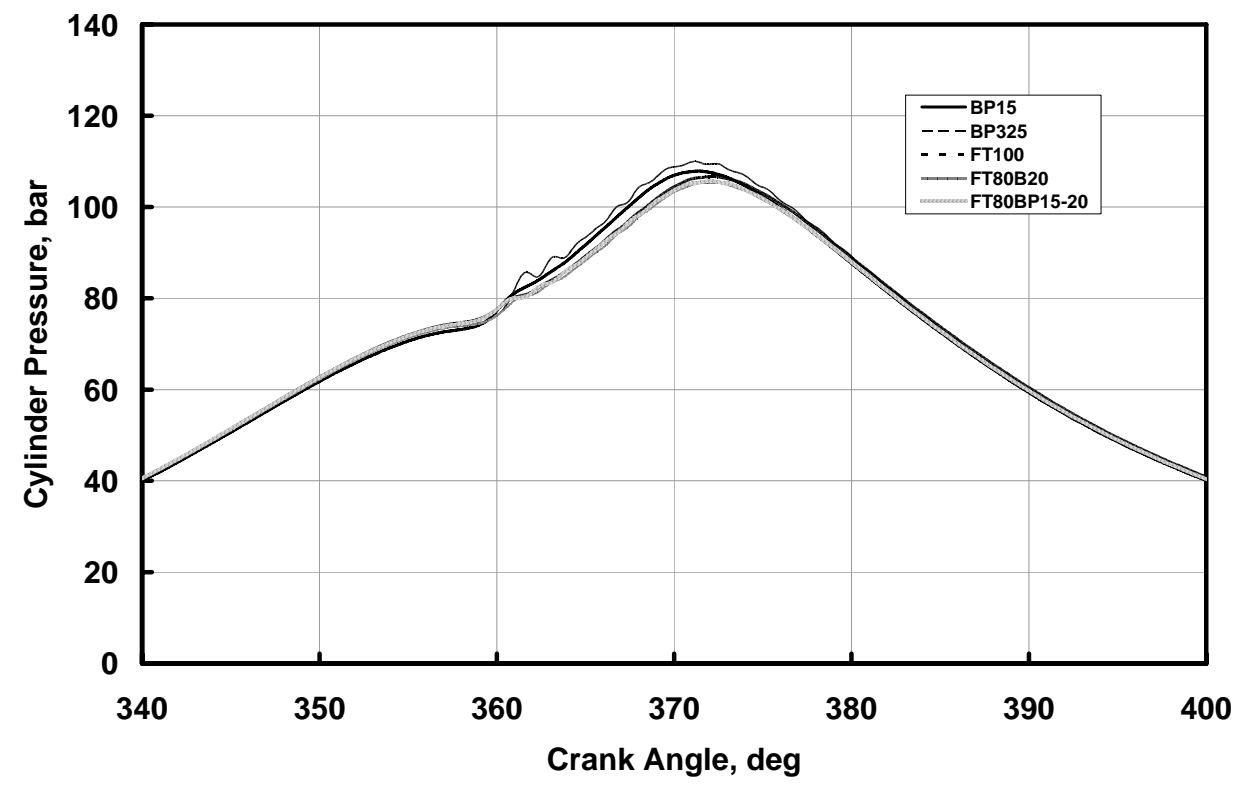

(a)

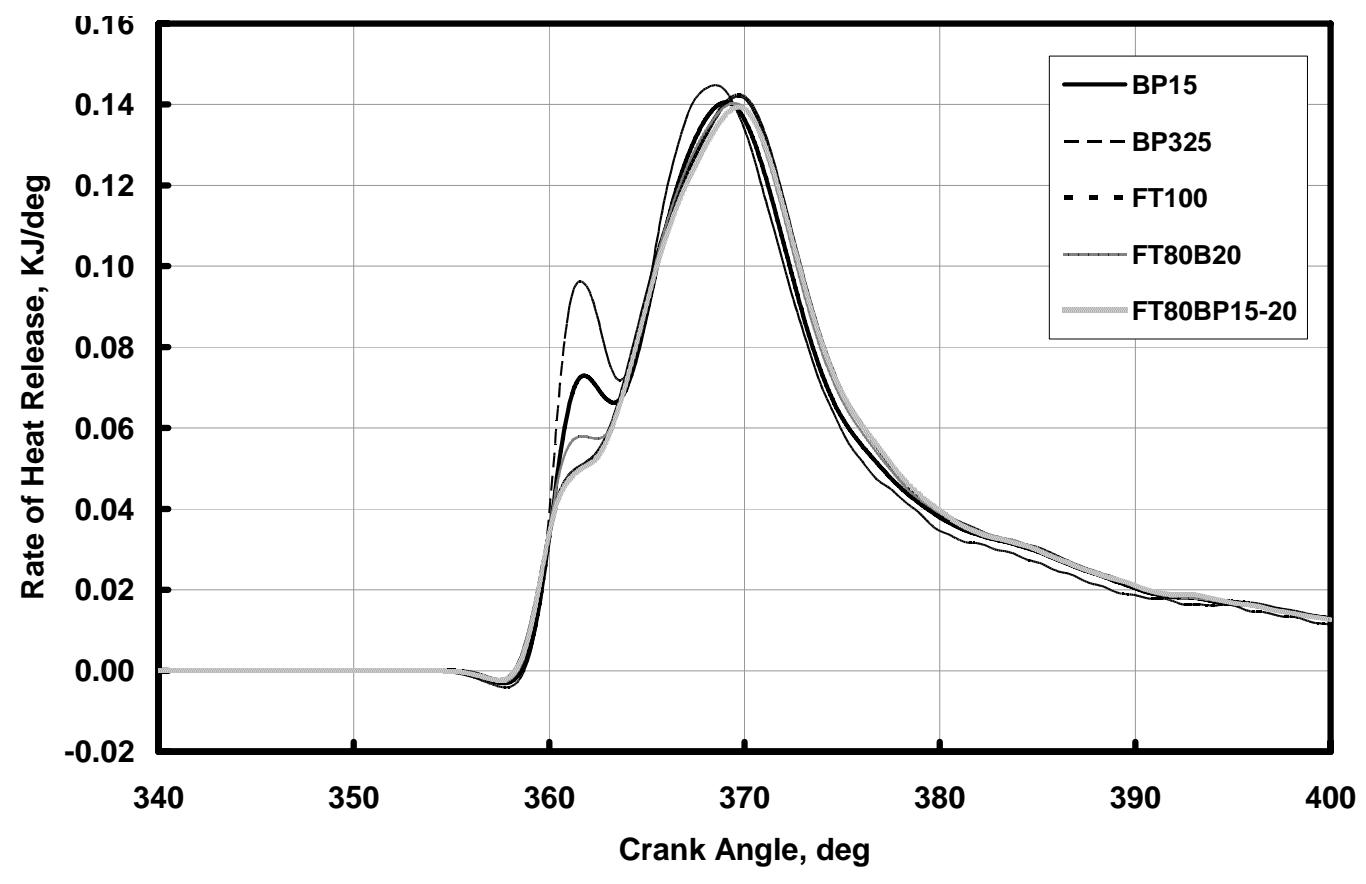

(b)

Figure 3.3.147 Rate of heat release at (a) M2 and (b) M4 


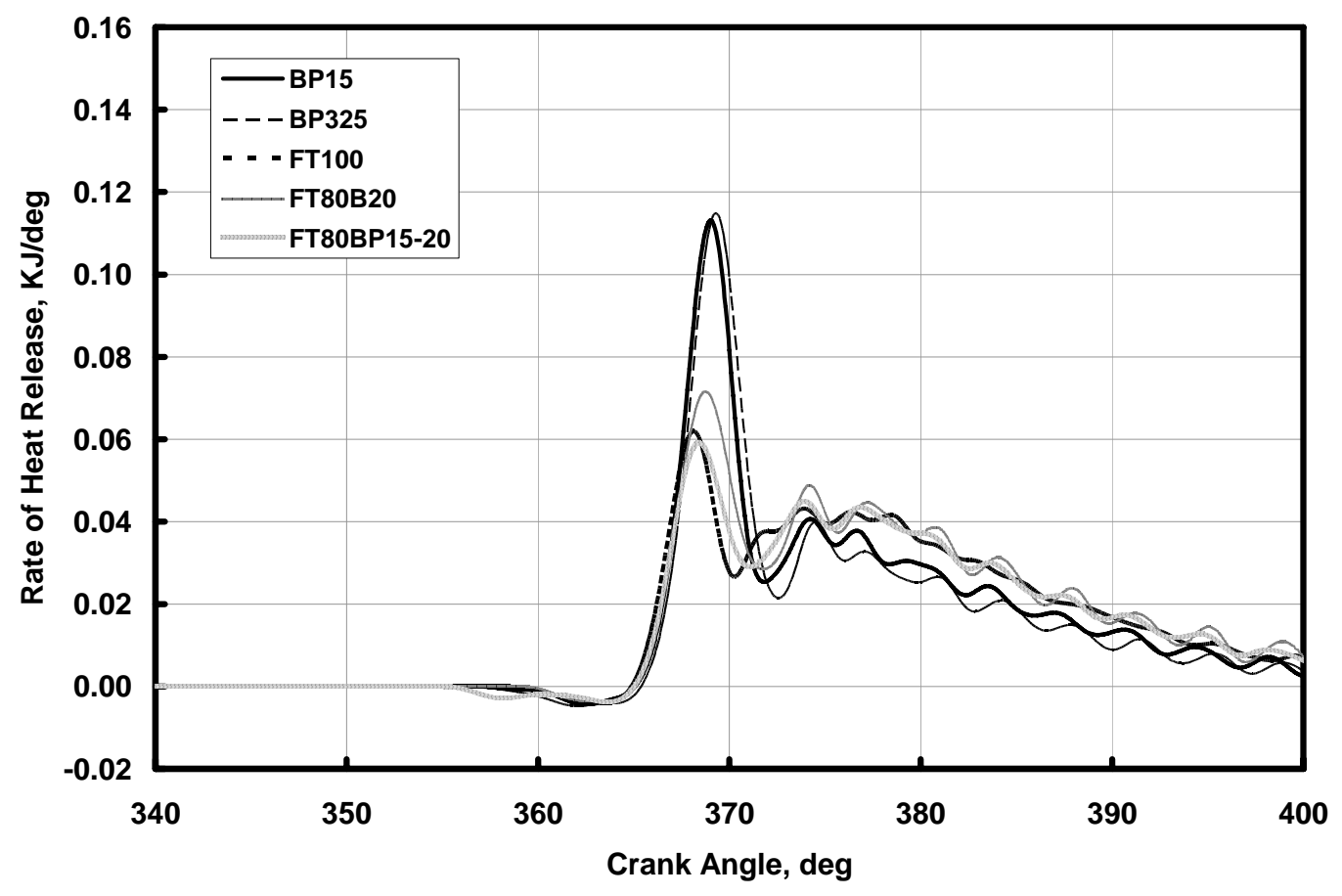

(a)

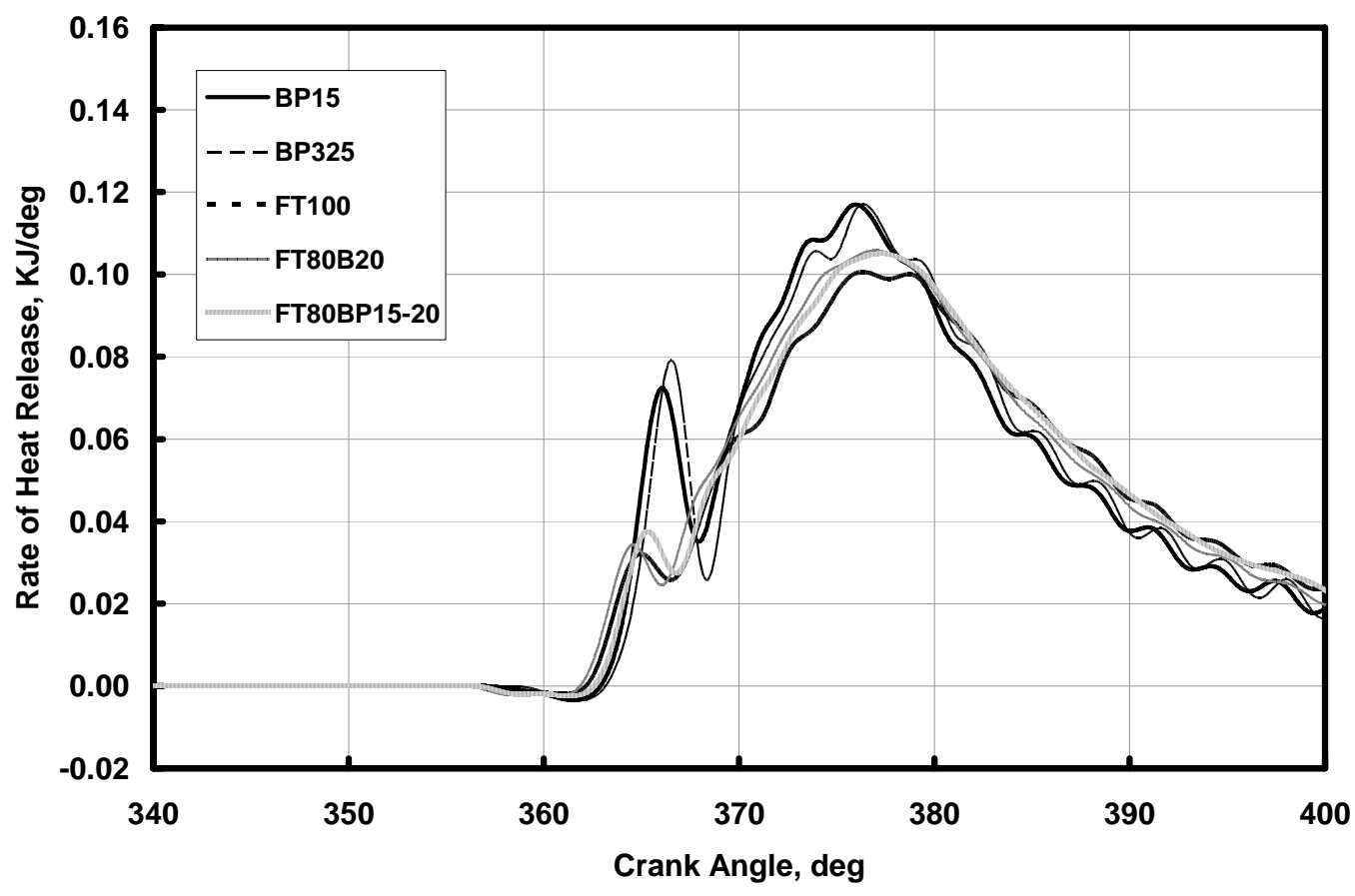

(b)

Figure 3.3.148 Rate of heat release at (a) M5 and (b) M7 


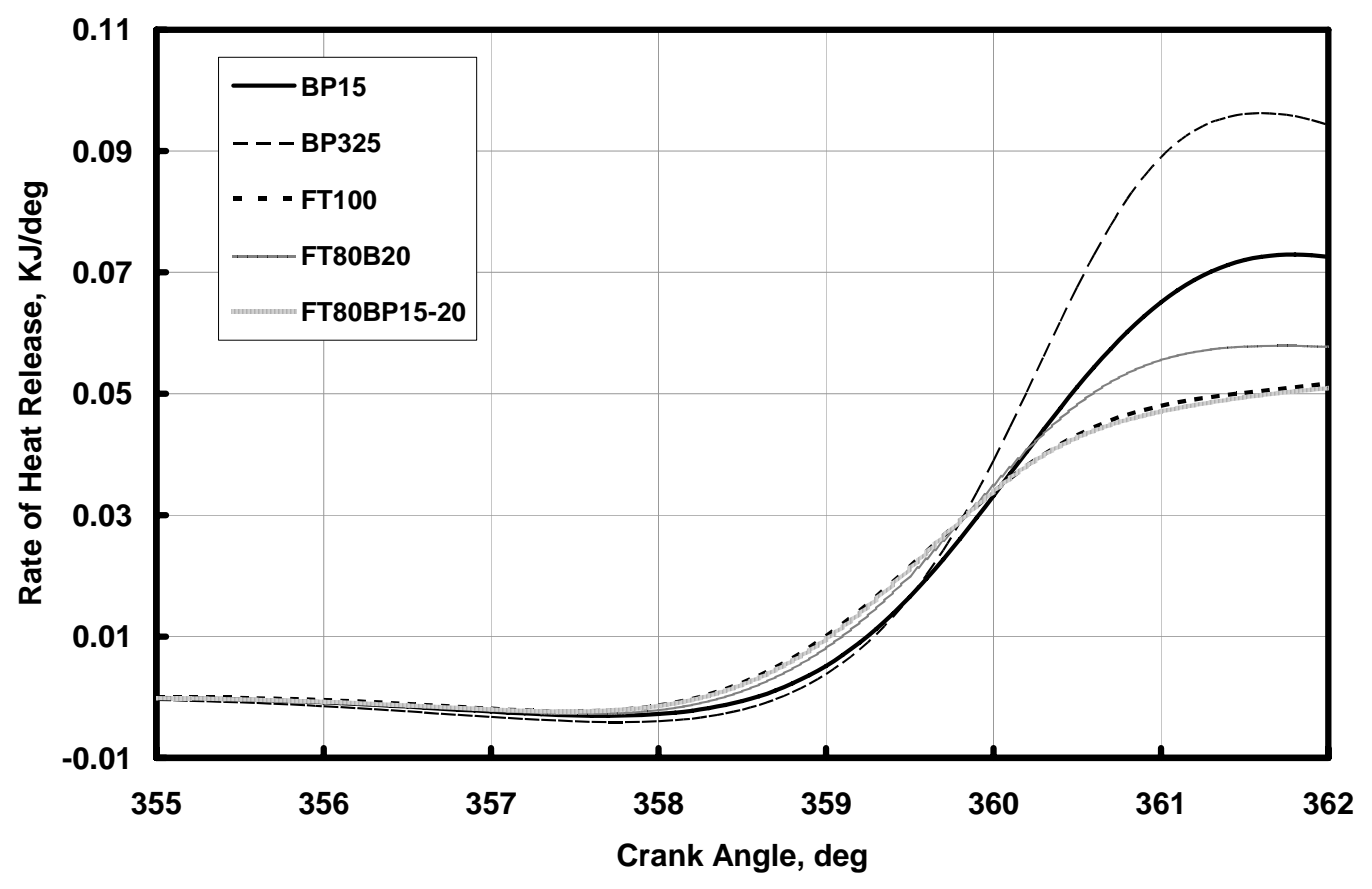

Figure 3.3.149 Enlarge rate of heat release at M4

\subsubsection{Exhaust Emissions}

Figure 3.3.150 shows $\mathrm{NO}_{x}$ emissions in grams per kilogram of fuel consumed and provides a means of examining all 8 test modes. Figure 3.3.151 shows the brake-specific $\mathrm{NO}_{x}$ emissions with all the fuels excluding Mode 1 . In general, $\mathrm{NO}_{x}$ emissions decrease with increasing load for all the test fuels on a brake specific or fuel mass basis. Other than Mode $6, \mathrm{NO}_{\mathrm{x}}$ emissions decrease with BP15 compared to BP325. One reason might be due to the early start of injection with BP325 compared to BP15. The cetane number of BP15 is higher than BP325, which in turn produces a lower premixed burn peak for BP15 compared to BP325. Therefore, average cylinder temperature with BP15 is lower than for BP325, which contributes to the lower $\mathrm{NO}_{x}$ emissions with BP15. The FT100 shows the lowest $\mathrm{NO}_{x}$ emissions among the fuels, which may be due to the high cetane number and late start of injection of FT100. However, blends of FT100 show a NOx emissions increase relative to FT100. This increase in $\mathrm{NO}_{x}$ emissions with the blends is due to the early start of fuel injection event, as well as, the lower cetane number of the blends compared to FT100. 


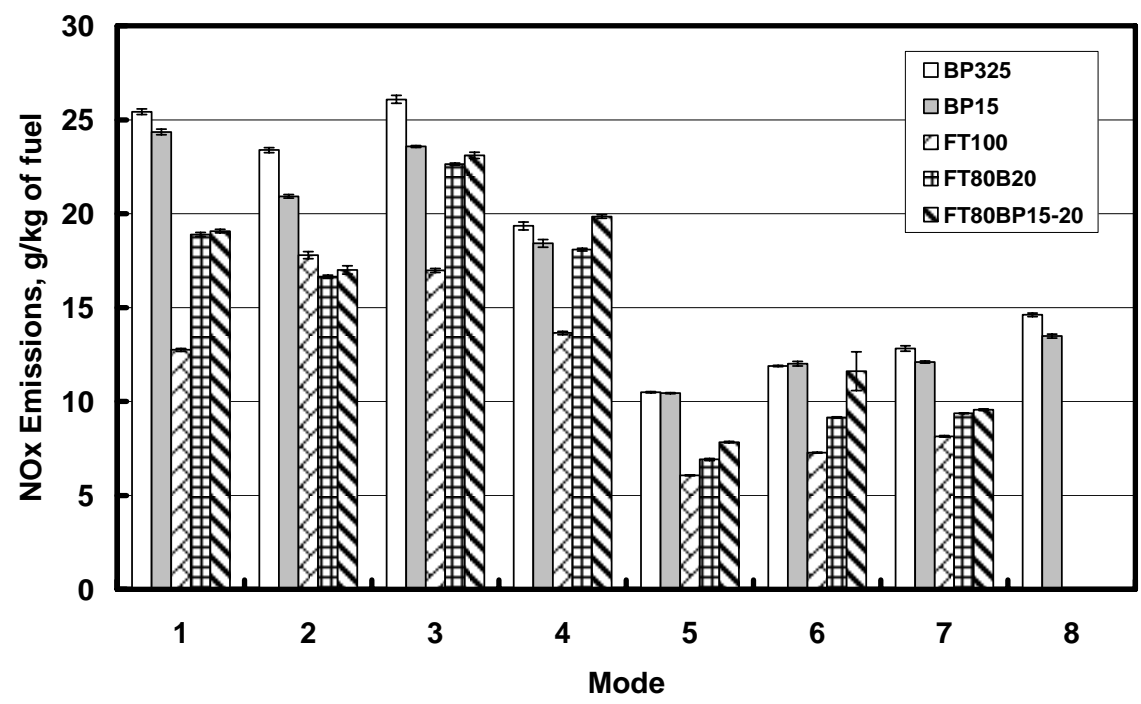

Figure 3.3.150 $\mathrm{NO}_{\mathrm{X}}$ emissions per unit fuel consumed

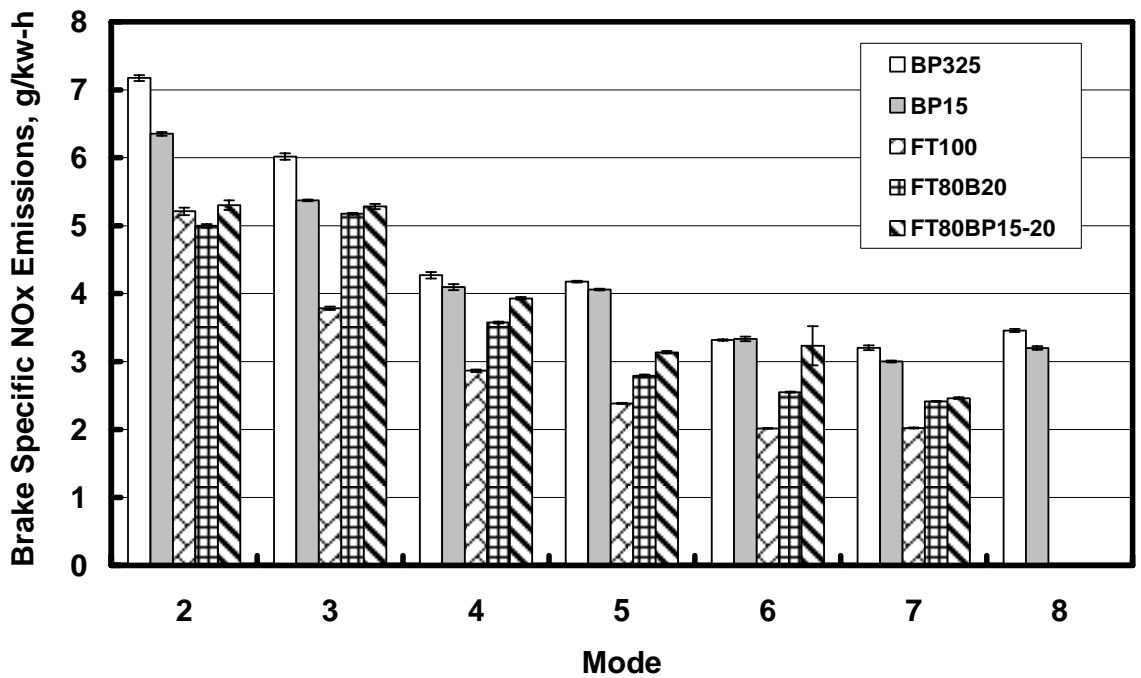

Figure 3.3.151 Brake specific $\mathrm{NO}_{x}$ emissions

Figure 3.3.152 shows HC emissions in grams per kilogram of fuel consumed. Figure 3.3.153 presents 8-Mode brake-specific total hydrocarbon emissions observed with the four test fuels. In general, $\mathrm{HC}$ emissions decrease with increasing load in both the low speed and high speed modes. Except for M7, HC emissions with BP15 are lower than for BP325 fuel. The FT100 shows the lowest $\mathrm{HC}$ emissions among the fuels. With a few exceptions, $\mathrm{HC}$ emissions generally trend downwards for 
the FT100 compared to the blends. The general trend between the two FT blends is higher HC emissions with FT80BP15-20 compared to FT80B20.

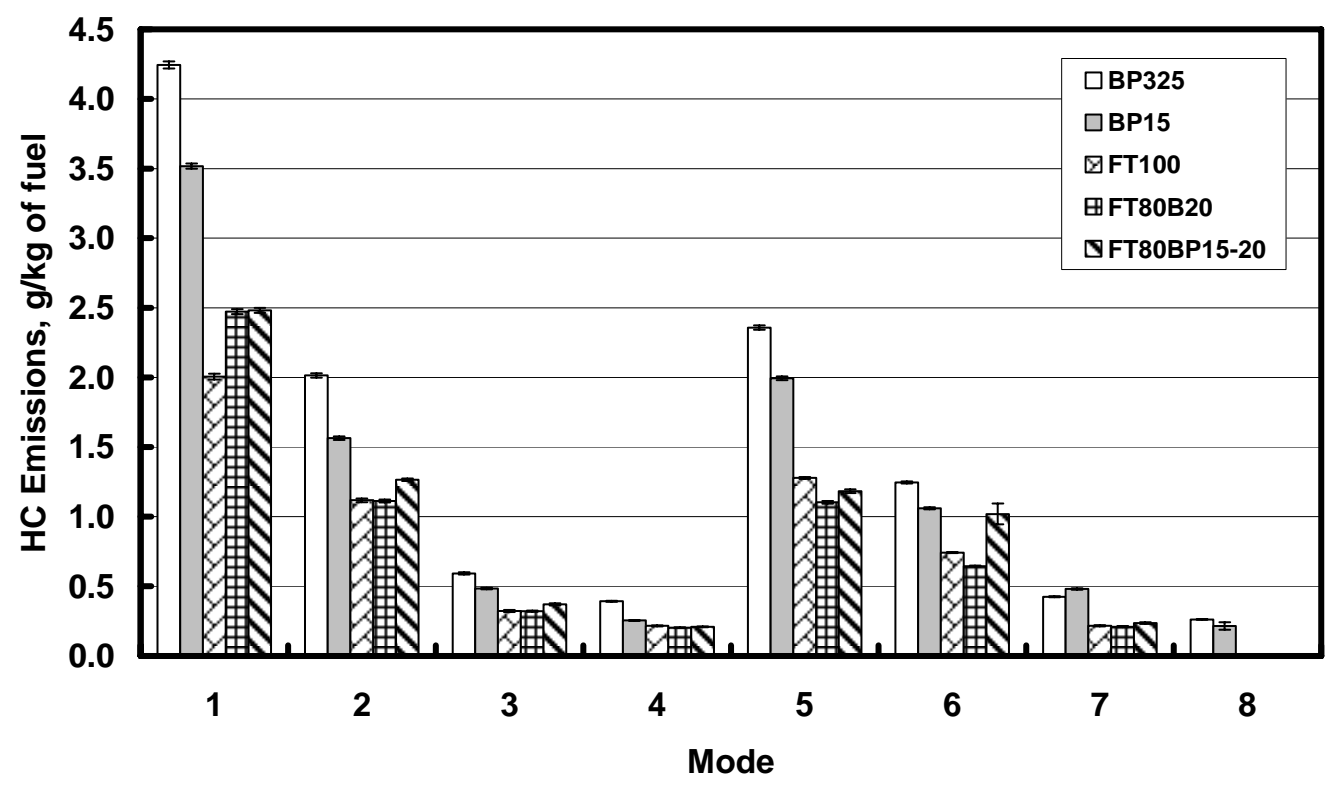

Figure 3.3.152 HC emissions per unit fuel consumed

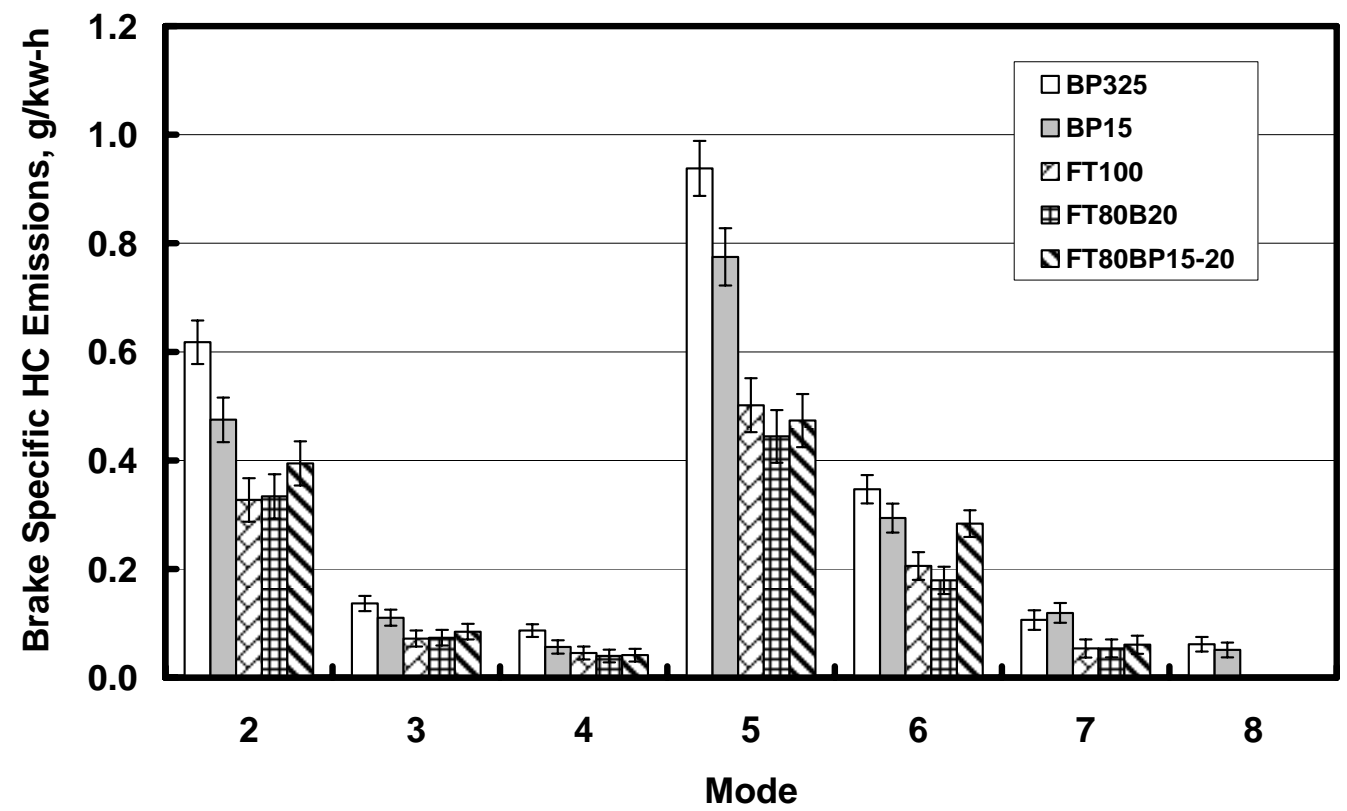

Figure 3.3.153 Brake specific HC emissions 
Carbon monoxide (CO) emissions are a direct result of incomplete combustion. Figure 3.3.154 presents $\mathrm{CO}$ emissions in grams per kilogram of fuel consumed. Figure 3.3.155 shows that except for M4, brake-specific CO emissions decrease with BP15 compared to BP325. In general, lower CO emissions are observed with the FT100 and its blends compared to the base BP15 and BP325 diesel fuels. Generally, CO emissions are high at low load conditions, go downward at medium load conditions and then upward at high load conditions.

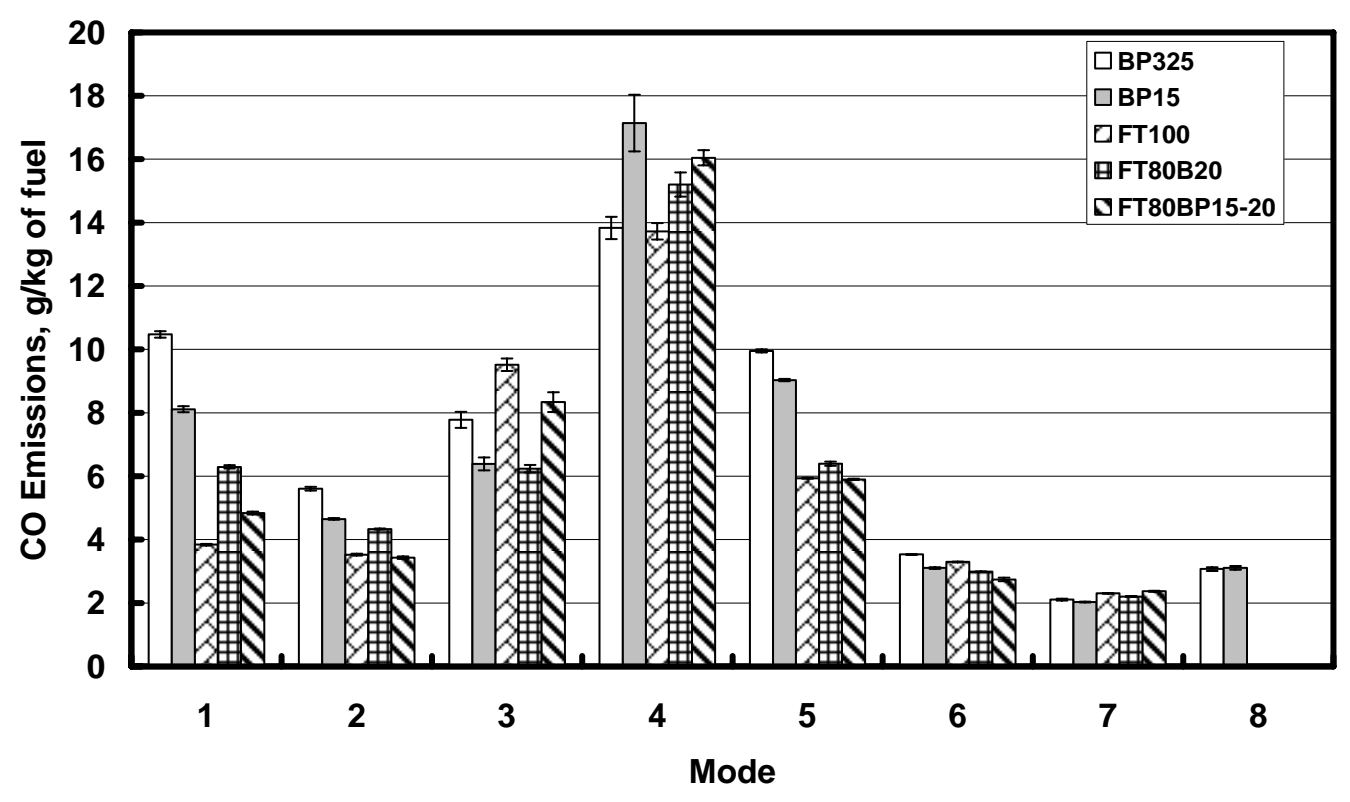

Figure 3.3.154 CO emissions per unit fuel consumed

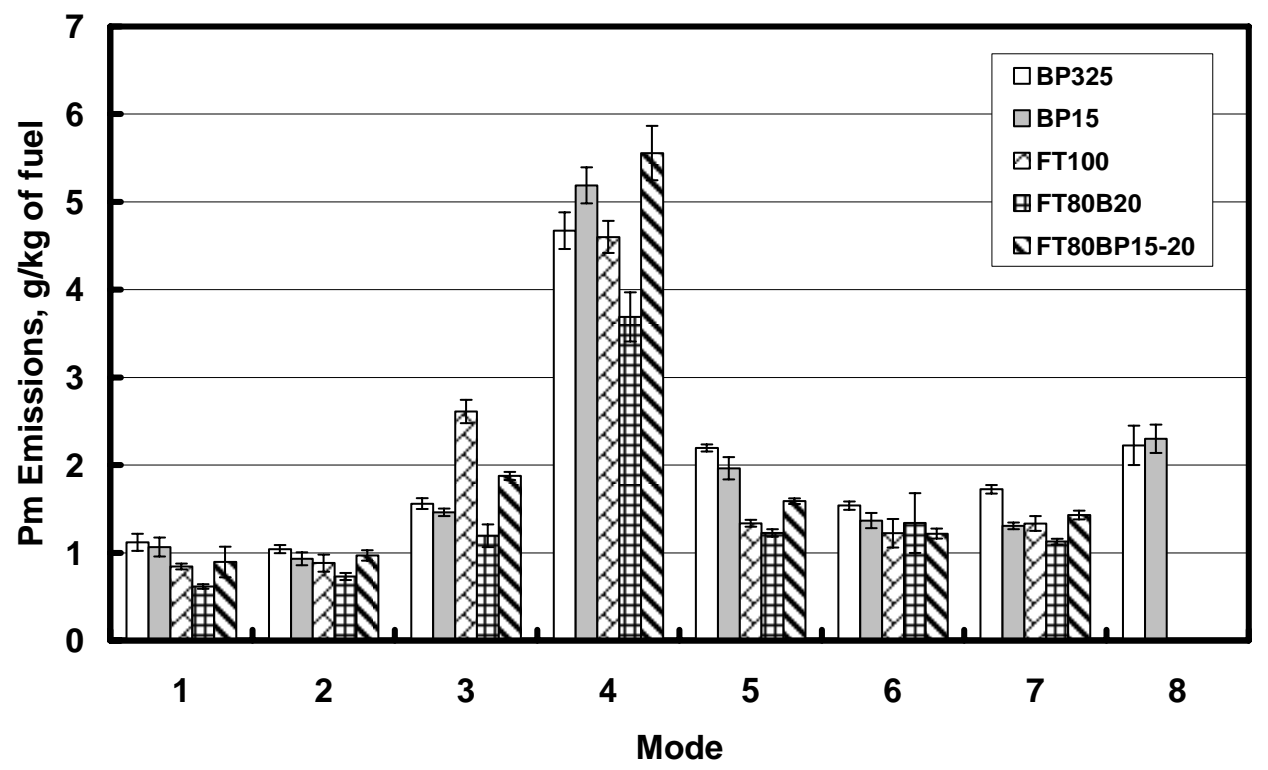

Figure 3.3.155 Brake specific CO emissions 
Figure 3.3.156 shows PM emissions in grams per unit fuel burned, while Figure 3.3.157 presents brake-specific PM emissions observed with each of the test fuels. With a couple of exceptions at high load, BP15 diesel fuel shows lower PM emissions compared to BP325 diesel fuel. The higher PM emissions with BP325 fuel might be due to the higher sulfur content compared to BP15 fuel. Except for M3, FT100 shows lower PM emissions compared to base BP15 and BP325 diesel fuel. The lowest specific PM emissions are observed with biodiesel blended FT (FT80B20). With a few exceptions, FT80BP15-20 blend shows higher PM emissions compared to FT100 and the FT80B20 blend.

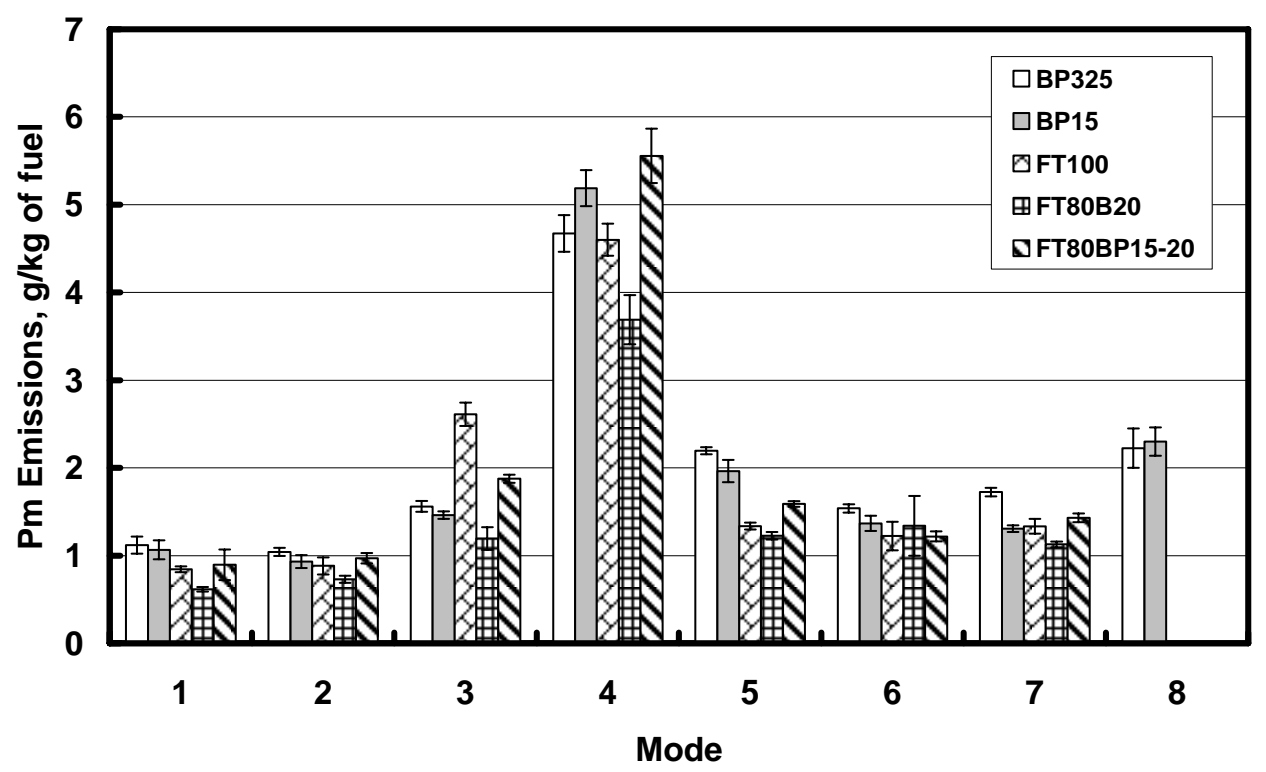

Figure 3.3.156 PM emissions per unit fuel consumed

Soluble organic fraction (SOF) of the particulate mass emissions are presented in Figure 3.3.158. Except for M8, BP325 shows higher SOF emissions compared to BP15. With a few exceptions, the lowest SOF emissions are observed with FT100. However, trends between the FT blends are inconclusive. It is not possible to explain the reason behind the different trend of SOF emissions of the blends compared to FT100. It may be that fuel properties have some effect on SOF emissions especially density, viscosity, spray penetration and mixing. The degraded fuel injection behavior with the FT100 and its blends may also contribute to increased SOF due to degraded combustion. Some of the possible fuel properties effects on PM emissions have already been discussed in the earlier baseline fuel evaluation section. Further investigation is necessary to find out more information regarding SOF emissions with FT and blends. 


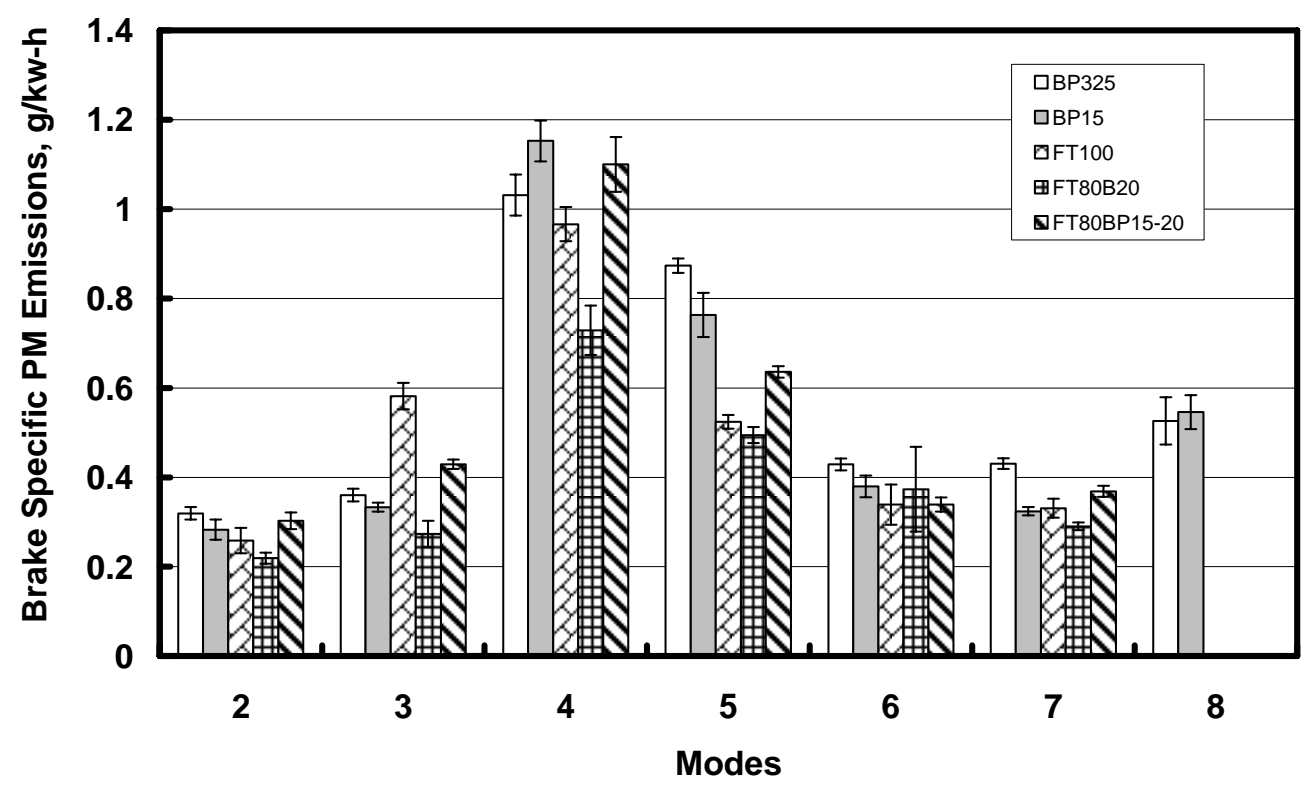

Figure 3.3.157 Brake-specific PM emissions

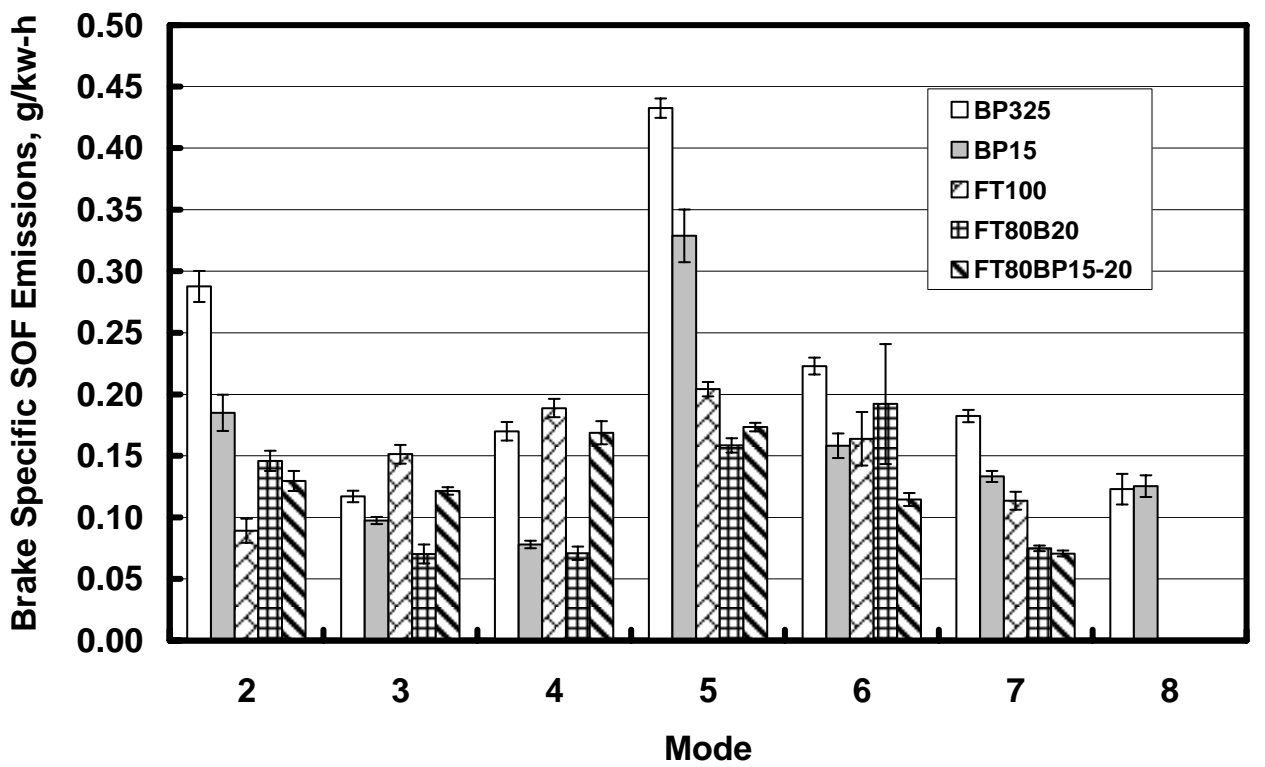

Figure 3.3.158 Brake-specific SOF emissions

\subsubsection{DPF Tests with GTL Diesel Fuel: Break Even Temperature Measurement}

As described in Sections 3.3.3, 3.3.8 and 3.3.9, a progression of fuels were examined for their impact on the behavior of a catalyzed diesel particulate filter. Some testing involved the measurement of the "break even temperature" (BET), which roughly represents the temperature at which oxidation and deposition of the particulate are balanced, and some testing involved a high 
temperature particulate burn off from the trap by rapidly shifting the engine to a high load after the trap was loaded with particulate. While the high temperature regeneration was performed with GTL diesel fuel (see Section 3.3.9), there was not a sufficient quantity of GTL diesel available to perform the break even temperature test, which requires a substantial quantity of fuel. The BET tests require both an extended "filling stage" and a gradual stepwise change in load to find the point at which exhaust temperature is just sufficient to achieve BET. Thus, it was not until the last 6 months of the project that a BET test could be attempted with GTL diesel.

As described in this section, the batch of GTL diesel used in 2005 led to operational problems with the Cummins ISB engine. These problems interfered with the performance of the BET test, because the difficulty that the engine had with idle operation and lighter load operation translated into unstable operation during the load ramp stage of the BET test and often caused the engine to stall. Engine stall during the BET test is highly undesirable because it invalidates the experiment and requires that the entire procedure, including the 6 hour trap filling stage, be repeated. The inconsistency of engine operation on this batch of GTL diesel thus led to great difficulty in obtaining BET measurements.

As shown in Figure 3.3.159, when the engine was operating under the BET test protocol, the peridodic increases in load led to an engine stall prior to completion of the load ramp. This same phenomenon was repeated twice, costing a substantial quantity of GTL diesel fuel. At that point, we began detailed technical discussion with Cummins Engine Company about ways to alter the engine programming settings to circumvent the stall problem. These discussions are ongoing and we expect to perform follow up experiments with new programming settings in 2006. We have requested support from the Pennsylvania Energy Development Authority within the Pennsyvlania Department of Environmental Protection for an extended study of GTL diesel effects in commercial engines.

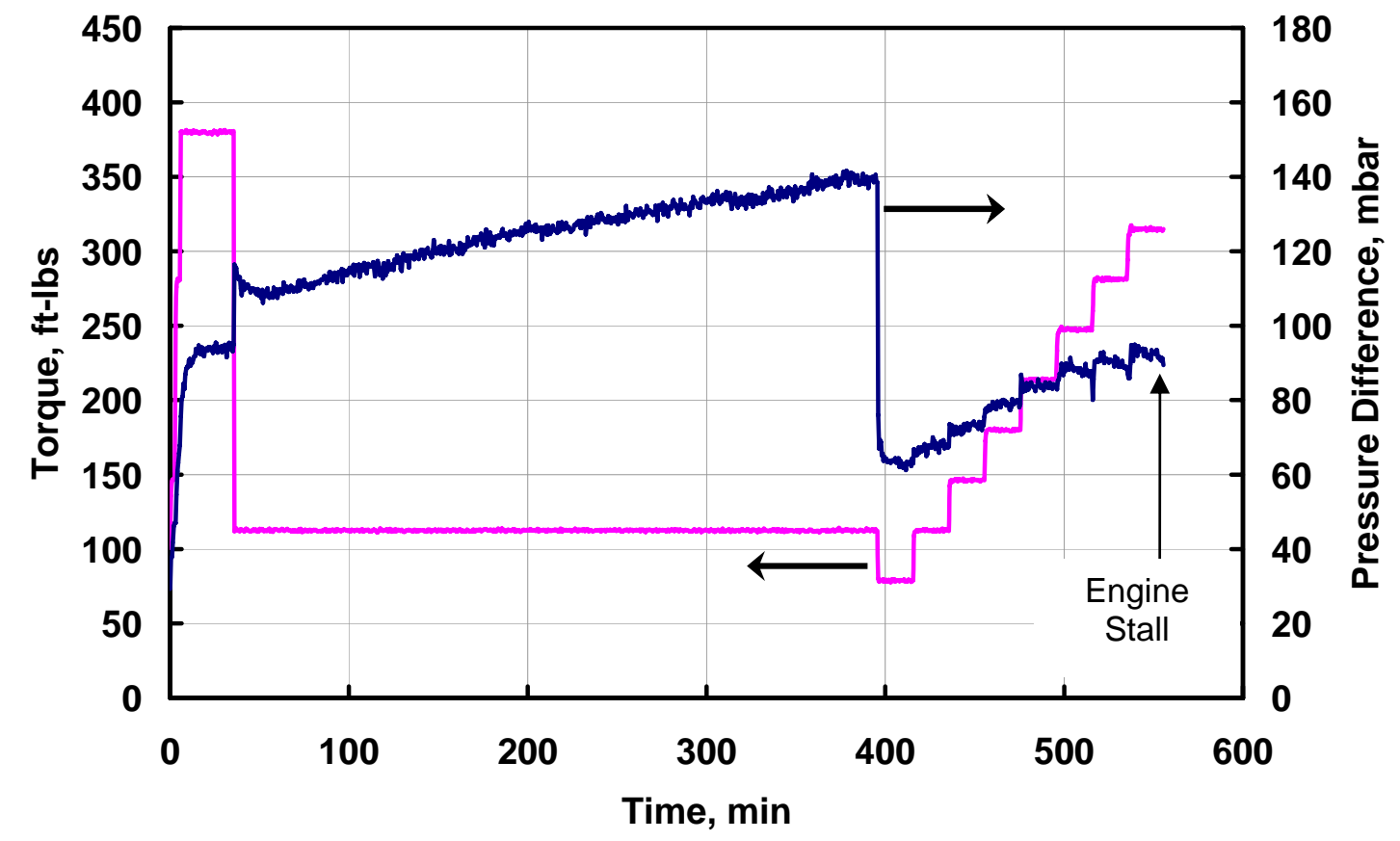

Figure 3.3.159 Time history of pressure drop across the diesel particulate filter and engine load during an attempted BET measurement with neat GTL diesel fuel, test failed due to engine stall during the load ramp 


\subsubsection{Conclusions and Future Work}

All the tests were performed under AVL 8-Mode tests protocol and observation of engine performance and emissions can be summarized as follows:

1. The Cummins ISB test engine is not stable at idle or light load with FT100 or with the blends due to weak combustion arising from underfueling at certain engine conditions. This underfueling is a direct consequence of the compressibility of the fuel, which is related to the formulation of the GTL diesel fuel (batch \#2). The engine needs to be calibrated for stable operation for FT100 and its blends, which will require changes in injection timing and quantity to offset the sluggish start of injection.

2. Specific fuel consumption seems lower with the FT100 compared to base BP15 and BP325 fuels.

3. Among the fuels tested, almost all the regulated emissions are lower with FT100. It has emissions reduction potential, however, more reduction is necessary to attain future emissions standards.

The observations in Section 3.3.11 provide substantial motivation for continuing studies of the relationship between GTL diesel fuel formulation and the performance of GTL diesel fuel in practical fuel injection systems. This should include consideration of PLN type fuel injection systems, such as on the MY2000 build Cummins ISB test engine used in these studies and engines with advanced common rail fuel injection systems. 


\subsubsection{References}

1. Fleisch, T., McCarthy, C., Basu, A., Udovich, C., Charbonneau, P., Slodowske, W., Mikkelsen, S., and McCandless, J., "A New Clean Diesel Technology: Demonstration of ULEV Emissions on a Navistar Diesel Engine Fueled With Dimethyl Ether", SAE Paper 950061, 1995.

2. Werlberger, P., and Cartellieri, W. P., "Fuel Injection and Combustion Phenomena in a High Speed DI Diesel Engine Observed by Means of Endoscopic High Speed Photography", SAE Technical Paper 870097, 1987.

3. Marsh, H., "Kinetics and catalysis of carbon gasification", in: Introduction to Carbon Science, p.107-152, Butterworths, London, 1989.

4. Smith, D.M. and Chughtai, A.R., "Surface structure and reactivity of black carbon", Colloids and Surfaces, Vol. 105, p.47-77, 1995.

5. Boehm, H.P., "Some Aspects of the surface chemistry of carbon blacks and other carbons", Carbon, Vol.32, p.759-769, 1994.

6. http://www.airliquide.com/en/business/products/gases/gasdata/index.asp?Gas/D=8.

7. Conax Buffalo website: www.conaxbuffalo.com.

8. Cummins engines website: www.cummins.org.

9. Koebel, M., Elsener, M., Kleemann, M. “Urea-SCR: A Promising technique to reduce NOx emissions from automotive diesel engines" Paul Scherrer Insitute, $\mathrm{CH}-5232$ Villigen PSI, Switzerland.

10. Material Safety and Data Sheet, J.R.D.Mondt Company, PA.

11. Szybist, J. P., and Boehman, A. L., "Behavoir of a Diesel Injection System with Biodiesel Fuel", SAE Paper 2003-01-1039, 2003.

12. Boehman, A. L., Szybist, J., P., Dave, M., and Shirish, B., "The Impact of the Bulk Modulus of Diesel Fuels on Fuel Injection Timing", submitted Energy \& Fuels for publication, 2004.

13. McCormick, R. L., Graboski, M. S., Alleman, T. L., and Herring, A. M., "Impact of Biodiesel Source Material and Chemical Structure on Emissions of Criteria Pollutants from a HeavyDuty Engine", Journal of Environmental Science and Technology, 35 (9), 1742-1147, 2001.

14. Atkinson, C. M., Thompson, G. J., Traver, M. L., and Clark, N. N., "In-Cylinder combustion pressure characteristics of Fischer-Tropsch and conventional diesel fuels in a heavy duty Cl engine", SAE Paper 1999-01-1472, 1999.

15. Lee, R., Hobbs, C. H., and Pedley, J. F., "Fuel Quality Impact on Heavy Duty Diesel Emissions: A literature Review", SAE Paper 982649, 1998.

16. Kidoguchi, Y., Miwa, K., and Yang, C., "Effects of fuel properties on combustion and emission characteristics of a direct-injection diesel engine", SAE Paper 2000-01-1851, 2000.

17. Graboski, M. S., and McCormick, R. L., "Combustion of Fat and Vegetable Oil Derived Fuels in Diesel Engines", Prog. Energy Combustion Science, Vol. 24 P. 125-164, 1998.

18. Heywood, J. B., "Internal Combustion Engine Fundamentals", McGrow-Hill International Editions, ISBN0-07-100499-8, 1988.

19. http://www.ott.doe.gov/decse/pdfs/decserpt.pdf, Diesel Emission Control - Sulfur Effects (DECSE) Program, Final Report: Diesel Oxidation Catalysts and Lean-NO $\mathrm{N}_{\mathrm{X}}$ Catalysts June 2001, Sponsored by: The U. S. Department of Energy. 
20. http://www.ott.doe.gov/decse/pdfs/interim4.pdf, Diesel Emission Control - Sulfur Effects (DECSE) Program, Final Report: Diesel particulate filters - Final report, January 2000, Sponsored by: The U. S. Department of Energy.

21. Boehman, A., Song, J., Alam, M., and Zello, V., "Fuel Formulation Effects on Diesel Particulate Filter Regeneration", Am. Chem. Soc., Div. Fuel Chem. 48 (2), 2003.

22. Giacomo, N. D., Beatrice, C., and Bertoli, C., "Diesel Combustion Improvements by the Us of Oxygenated Synthetic Fuels", SAE Technical Paper 972972, 1997.

23. Canaan, R. E., Dec, J. E., Green, R. M., and Daly, D. T., "The Influence of Fuel Volatility on the Liquid-Phase Fuel Penetration in a Heavy-Duty D. I. Diesel Engine", SAE Technical Paper 980510, 1998.

24. Higgins, B. S., Mueller, C. J., and Siebers, D. L., "Measurements of Fuel Effects on LiquidPhase Penetration in DI Sprays", SAE Technical Paper 1999-01-0519, 1999.

25. Arregle, J. M., Desantes, J. M., and Pastor, J. V., "Influence of the Fuel Characteristics on the Injection Process in a D. I. Diesel Engine", SAE Technical Paper 980802, 1998.

26. Flynn, P. F., Durrett, R. P., Hunter, G. L., Loye, A. Z., Akinyemi, O. C., Dec, J. E., and Westbrook, C. K., "Diesel Combustion: An Integrated View Combining Laser Diagnostics, Chemical Kinetics, and Empirical Validation", SAE Technical Paper 1999-01-0509, 1999.

27. Alam, M., Goto, S., Sugiyama, K., Kajiwara, M., Mori, M., Motohashi, M., and Oyama, K., "Performance and Emissions of a DI Diesel Engine Operated with LPG and Ignition Improving Additives", SAE Technical Paper 2001-01-3680, 2001.

28. Beatrice, C., Bertoli, C., and Giacomo, N. D., "New Findings on Combustion Behavior of Oxygenated Synthetic Diesel Fuels", Combustion Sci. and Tech., 1998, 137, 31-50.

29. Nabi, M. N., Minami, M., Ogawa, H., and Miyamoto, N., "Ultra Low Emission and High Performance Diesel Combustion with Highly Oxygenated Fuel", SAE Technical Paper 2000-01-0231, 2000.

30. Ogawa, H., Nabi, M. N., Minami, M., Miyamoto, N., and Bong-Seock, K., "Ultra Low Emissions and High Performance Diesel Combustion with a Combination of High EGR, Three-way Catalyst, and a Highly Oxygenated Fuel, Dimethoxy Methane (DMM)", SAE Technical Paper 2000-01-1819, 2000.

31. Tow, C., and Reitz, R. D., "Reducing Particulate and NOx Emissions by Using Multiple Injections in a Heavy Duty D. I. Diesel Engine", SAE Technical Paper 940897, 1994.

32. Ishiyama, T., Shioji, M., Ihara, T., and Katsuura, A., "Modeling and Experiments on Ignition of Fuel Sprays Considering the Interaction Between Fuel-Air Mixing and Chemical Reactions", SAE Technical Paper 2003-01-1071, 2003.

33. Stratakis, G.A. and Stamatelos, A.M., "Thermogravimetric analysis of soot emitted by a modern diesel engine run on catalyst-doped fuel", Comb. and Flame, Vol. 132, p.157-169, 2003.

34. Neeft, J.P.A., Nijhuis, X., Smakman, E., Makkee, M. and Moulijn, J.A., "Kinetics of the oxidation of diesel soot", Fuel, Vol. 76, p.1129-1136, 1997.

35. Allanson, R., Blakeman P.G., Cooper, B.J., Howard, H., Silcock, P.J. and Walker, A.P., "Optimizing the Low Temperature Performance and Regeneration Efficiency of the Continuously Regenerating Diesel Particulate Filter(CR-DPF) System", SAE 2002-01-0428, 2002.

36. Stanmore, B.R., Brilhac, J.F. and Gilot, P.,"The oxidation of soot: A review of experiments, mechanisms and models", Carbon, Vol. 39, p.2247-2268, 2001. 
37. Vander Wal, R.L. and Tomasek, A.J.,"Soot Oxidation: Dependence upon initial nanostructure", Comb. and Flame, Vol. 132, 2003.

38. Ishiguro, T., Suzuki, N., Fujitani, Y. and Morimoto, H., "Microstructural Changes of Diesel Soot During Oxidation", Comb. and Flame, Vol.85, p 1-6, 1991.

39. Palotas, A.B., Rainey, L.C., Sarofim, A.F., Sande, J.B.V., Ciambelli, P.,"Effect of Oxidation on the Microstructure of Carbon Blacks", Energy and Fuels, Vol. 10, p.254-259, 1996.

40. Despres, J., Koebel, M., Elsener, M. and Wokaun, A., "Investigation of oxidation of NO over platinum catalyst," PSI scientific report 2001, Vol. 5, p.64-65, 2002.

41. Brilhac, J.F., Bensouda, Gilot, P., Brillard, A. and Stanmore, B.R., "Experimental and theoretical study of oxygen diffusion with packed beds of carbon black," Carbon, Vol. 38, p.1011-1019, 2000.

42. Gilot, P., Brillard, A. and Stanmore, B.R., "Geometric effects on mass transfer during thermogravimetric analysis : Application to reactivity of diesel soot," Combustion and Flame, Vol. 102, p.471-480, 1995.

43. Turns, S.R., An Introduction to Combustion: Concepts and Applications, $1^{\text {st }}$ edition, McGraw Hill, Inc., 1996.

44. Otto, K., Sieg, M.H., Zinbo, M. and Bartosiewicz, L.,"The oxidation of soot deposits from diesel engines", SAE paper No. 800336, 1980.

45. Ahlstrom, A.F. and Odenbrand, C.U.I., "Combustion characteristics of soot deposits from diesel engines," Carbon, Vol.27, No.3, p.475-483, 1989.

46. Neeft, J.P.A., Nijhuis, X., Smakman, E., Makkee, M. and Moulijn, J.A., "Kinetics of the oxidation of diesel soot," Fuel, Vol. 76, p.1129-1136, 1997.

47. Miyamoto, N., Hou, Z. and Ogawa, H., "Catalytic effects of metallic fuel additives on oxidation characteristics of trapped diesel soot," SAE paper No.881224, 1988.

48. De Soete, G., "Catalysis of soot combustion by metal oxides," Western States Section Meeting, The Combustion Institute, March, 1988.

49. Du, Z., Sarofim, A.F. and Longwell, J.P., "Activation energy distribution in temperature programmed desorption: Modeling and application to the soot-oxygen system," Energy and Fuels, Vol. 4, p.296-302, 1990.

50. Jung, H.J., Kittelson, D.B. and Zachariah, M.R., "Kinetics and visualization of soot oxidation using transmission electron microscopy," Combustion and Flame, Vol. 136, p.445-456, 2004.

51. Smith, I.W., "The intrinsic reactivity of carbons to oxygen," Fuel, Vol.57, p.409-420, 1978.

52. Stanmore, B.R., Brilhac, J.F. and Gilot, P., "The ignition and combustion of cerium doped diesel soot," SAE paper No.1999-01-0115, 1999.

53. Stanmore, B.R., Brilhac, J.F. and Gilot, P., "The oxidation of soot: A review of experiments, mechanisms and models," Carbon, Vol. 39, p.2247-2268, 2001.

54. Marsh, P.A.,"Quantitative micrography of carbon black microstructure," Carbon, Vol.9, p.797-805, 1971.

55. Zhu, W., Miser, D.E., Chan, G. and Hajaligol, M.R.,"Characterization of combustion fullerene soot, $\mathrm{C}_{60}$ and mixed fullerene," Carbon, Vol.42, p.1463-1471, 2004.

56. Goel, A., Howard, J.B. and Sande, J.B., "Size analysis of single fullerene molecules by electron microscopy," Carbon, Vol. 42, Issue 10, p.1907-1915, 2004. 
57. Su, D.S., Jentoft, R.E., Müller, J.O., Rothe, D., Jacob, E. and Schlögl, R., "Microstructure and oxidation behavior of Euro IV diesel engine soot: a comparative study with synthetic model soot substances", Catalysis Today, Vol. 90, p.127-132, 2004.

58. Müller, J.-O., Su, D.S., Jentoft, R.E., Kröhnert, J., Jentoft, F.C. and Schlögl, R., "Morphology-controlled reactivity of carbonaceous materials towards oxidation", Catalysis Today, Vol. 102 103, p.259-265, 2005.

59. Dresselhaus, M.S., "Graphite fibers and filaments," Springer Series in Materials Science, Vol. 5, 1988.

60. Dresselhaus, M.S., Dresselhaus, G., Pimenta, M.A., Eklund, P.C., Analytical Applications of Raman Spectroscopy, Michael J. Pelletier Eds., Blackwell Science; Chap. 9, 1999.

61. Ebert, L.B. and Scanlon, J.C., "Combustion tube soot from a diesel fuel/air mixture: issues in structure and reactivity," Energy \& Fuels, Vol. 2, p.438-445, 1988.

62. Munoz, R. and Charalampopoulos, T.T., "Evolution of compositional and structural properties of soot in premixed alkane flames," Twenty-Seventh Symposium on Combustion, , p.1471-1479, 1998.

63. McEnally, C.S. and Pfefferle, L.D.,"Comparison of non-fuel hydrocarbon concentrations measured in coflowing nonpremixed flames fueled with small hydrocarbons," Combustion and Flame, Vol. 117, p.362-372, 1999.

64. Babu, V.S., Farinash, L. and Seehra, M.S., "Carbon in diesel particulate matter: Structure, microwave adsorption and oxidation," Journal of Material Research, Vol. 10, No.5, 1995.

65. Feng, B., Bhatia, S.K. and Barry, J.C., "Structural ordering of coal char and its impact on reactivity during heat treatment", Carbon, Vol. 40, p.481-496, 2002.

66. Shi, H, Reimers, J.N. and Dahn, J.R., "Structure-refinement program for disordered carbons," Journal of Applied Crystallography, Vol. 26, p.827-836, 1993.

67. Chen, H.X., and Dobbins, R.A., "Crytallogenesis of particles formed in hydrocarbon combustion," Combustion Science and Technology, Vol. 159, p.109-128, 2000.

68. Vander Wal, R.L. and Tomasek, A.J., "Soot Nanostructure: Dependence upon synthesis conditions", Combustion and Flame, Volume 136, Issues 1-2, p.129-140, 2004

69. Oberlin, A., "High resolution tem images of carbonization and graphitization," Chemistry and Physics of Carbon, Vol.22, p.1-143, 1989.

70. Oberlin, A., "Application of dark-field electron microscopy to carbon study," Carbon, Vol. 17, p.7-20, 1979.

71. Oberlin, A., "Carbonization and graphitization," Carbon, Vol.22, p.521-541, 1984.

72. William, D.B. and Carter, C.B., Transmission Electron Microscopy: A Textbook for Material Science, Plenum Press, 1996.

73. Tuinstra, F. and Koenig, "Raman spectrum of graphite," Journal of Chemical Physics, Vol. 53, No. 3, p.1126-1130, 1970.

74. Lee, K.Y., "An investigation of particulate morphology, microstructures and fractal geometry for a diesel engine-simulating combustor," SAE paper No. 2004-01-3044, 2004.

75. Klug, H.P., and Alexander, L.E., X-ray Diffraction Procedure For Polycrystalline and Amorphous materials, Wiley and Sons, New York, 1974.

76. Hurt RH, Sarofim AF, Longwell JP., "Gasification-induced densification of carbons: from soot to form coke", Combustion and Flame, Vol.95, p.430-432, 1993. 
77. Palotas, A.B., Rainey, L.C., Feldermann, C.J. and Sarofim, A.F., "Soot morphology: an application of image analysis in high resolution transmistion electron microscopy," Microscopy Research and Technique, Vol.33, p.266-278, 1996.

78. Digital Micrograph 3.4 User's Guide, Gatan, Inc., 1999.

79. Jung, H.J., Kittelson, D.B. and Zachariah, M.R., "Kinetics and visualization of soot oxidation using transmission electron microscopy," Combustion and Flame, Vol. 136, p.445-456, 2004.

80. Lee, K.Y., "An investigation of particulate morphology, microstructures and fractal geometry for a diesel engine-simulating combustor," SAE paper No. 2004-01-3044, 2004.

81. Kandas, A.W., Senel, I.G., Levendis, Y. and Sarofim, A.F., "Soot surface area evolution during air oxidation as evaluated by small angle $\mathrm{X}$-ray scattering and $\mathrm{CO}_{2}$ adsorption", Carbon, Vol.43, p.241-251, 2005.

82. Feng, B. and Bhatia, S.K., "Variation of the pore structure of coal chars during gasification," Carbon, Vol. 41, p.507-523, 2003.

83. Hurt, R.H., Duder, D.R., Longwell, J.P. and Sarofim, A.F., "The phenomenon of gasification-induced carbon densification and its influence on pore structure evolution," Carbon, Vol.26, No.4, p.433-449, 1988.

84. Ohman, M., Pommer, L. and Nordin, A., "Bed agglomeration characteristics and mechanisms during gasification and combustion of biomass fuels," Energy \& Fuels, Vol. 19, p.1742-1748, 2005.

85. Vander Wal, R.L., Tomasek, A.J., Berger, G.M., Street, K., Hull, D.R. and Thompson, W.K., "Soot nanostructure: Definition, quantification and implications," presentation at the 2004 DOE Diesel Engine Emissions Reduction Conference, August 29-September 2, 2004, Coronado, California.

86. Shim, H.S., Hurt, R.H. and Yang, N.Y.C, "A methodology for analysis of 002 lattice fringe images and its application to combustion-derived carbons," Carbon, Vol.38, p.29-45, 2000.

87. Dresselhaus, M.S., "Graphite fibers and filaments," Springer Series in Materials Science, Vol. 5, 1988.

88. Hurt, R.H., Crawford, G.P. and Shim, H.S., "Equilibrium nanostructure of primary soot particles," Proceedings of the Combustion Institute, Vol. 28, p.2539-2546, 2000.

89. Inagaki, M., "Discussion of the formation of nanometric texture in spherical carbon bodies," Carbon, Vol. 35, No.5, p. 711-713, 1997.

90. Hurt, R.H. and Hu, Y., "Thermodynamics of carbonaceous mesophase," Carbon, Vol.37, p.281-292, 1999.

91. Heckman, F.A. and Harling, D.F., "Progressive oxidation of selected particles of carbon black: Further evidence for a new microstructural model", Rubber Chemistry Technology, Vol. 37, p.1245-1254, 1964.

92. Vander Wal, R.L. and Choi, M.Y., "Pulsed laser heating of soot: Morphological changes," Carbon, Vol. 37, p.231-239, 1999.

93. Marcuccilli F., Gilot, P., Stanmore, B. and Prado, G., "Experimental and theoretical study on diesel soot reactivity," Nineteenth Symposium on Combustion, p.1045-1065, 1982.

94. Fang, H.L. and Lance, M.J., "Influence of soot surface changes on DPF regeneration," SAE paper No.2004-01-3043, 2004. 
95. Hurt, R.H. and Davis, K.A., "Near-extinction and final burnout in coal combustion", Twenty Fifth Symposium on Combustion, p.561-568, 1994.

96. Hurt, R.H., Sun, J.K. and Lunden, M., "A kinetic model of carbon burn out in pulverized coal combustion", Combustion and Flame, Vol. 113, p.181-197, 1998.

97. Yamane, K., Asakawa, T., Numao, H. and Komori, M., "Characteristics of DPF for diesel engine fueled with biodiesel fuel-first report: Self-regeneration behavior on vehicle road test and engine bench rig test," SAE paper No.2004-01-1883, 2004.

98. Yamane, K., Asakawa, T., Numao, H. and Komori, M., "Characteristics of DPF for diesel engine fueled with biodiesel fuel-second report: Exhaust gas emission characteristics at self-regeneration of DPF," SAE paper No.2005-01-2198, 2005.

99. Song, J.H. and Boehman, A.L., "Role of fuel borne catalyst in diesel particulate oxidation characteristics," submitted to Combustion and Flame, 2005.

100. Hurt RH, Sarofim AF, Longwell JP., "Gasification-induced densification of carbons: from soot to form coke", Combustion and Flame, Vol.95, p.430-432, 1993.

101. Essenhigh, R.H., "Influence of initial particle density on reaction mode of porous carbon particles," Combustion and Flame, Vol. 99, p.269-279, 1994.

102. Essenhigh, R.H., "Influence of initial particle density on reaction mode of porous carbon particles," Combustion and Flame, Vol. 99, p.269-279, 1994.

103. Popovicheva, O.B., Persiantseva, N.M., Kuznetsov, B.V., Rakhmanova, T.A., Shonija, N.K., Suzanne, J. and Ferry, D., "Microstructure and water adsorbability of aircraft combustor soots and kerosene flame soots : Toward aircraft-generated soot laboratory surrogate", Journal of Physics and Chemistry A., Vol. 107, p.10046-10054, 2003.

104. Lindheimer, E.G., Lindheimer, A.,Lagerge, A. and Partyka, S., "Surface characterization of diesel engine soot inferred from physico-chemical methods," Colloids and Surfaces A, Vol. 233, p.79-86, 2004.

105. Wornat, M.J., Hurt, R.H., Yang, N.Y.C., "Structural and compositional transformations of biomass chars during combustion", Combustion and Flame, Vol. 100, p 131-143, 1995.

106. Laine, N.R., Vastola, F.J. and Walker, Jr., P.L., "The role of the surface complex in the carbon-oxygen reaction," Proceedings of the Fifth Conference on Carbon, p.211-217, 1961.

107. Bansal, R.C., Vastola, F.J. and Walker Jr., P.L., "Studies on ultra clean carbon surfaces," Journal of Colloid and Interface Science, Vol. 32, p.187-194, 1970.

108. Puri, B.R., "Surface complexes on carbons," Physics and Chemistry of Carbon, p.191-282, 2003.

109. Ghzaouli, E.I., Lindheimer, M., Lindheimer, A., Lagerge, S. and Partyka, S., "Surface characterization of diesel engine soot inferred from physico-chemical methods," Colloids and Surfaces A, Vol. 233, p.79-86, 2004.

110. Popovitcheva, O.B., Persiantseva, N.M., Trukhin, M.E., Rulev, G.B., Shonija, N.K., Yu, Y., Buriko, A.M., Starik, B., Ferry, D. and Suzanne, J., "Experimental characterization of aircraft combustor soot : Microstructure, surface area, porosity and water adsorption," Phys. Chem. Chem. Phys., Vol. 2, p.4421-4426, 2000.

111. Stone, Richard, "Introduction to Internal Combustion Engines" $3^{\text {rd }}$ edition, Society of Automotive Engineers: Warandale, PA, 1999.

112. Heck, Ronald M. and Farrauto, Robert J, "Catalytic Air Pollution Control, Commercial Technology", First Edition ISBN 0-442-01782-0. 
113. www.fia.com/Automotive/Automotive/ spring\%201997/p4.html

114. www.dieselnet.com

115. Truex T. J., 1994, "Lean NOx Catalysis", SAE Catalysts and Emission Control TOPTEC, MI, September, 1994.

116. Smedler, G., "Diesel Catalysts for Europe Beyond 1996", Automotive Engineering, October 1995, pg. 41.

117. Diesel Emission Control -Sulfur Effects (DECSE) Program "Final Report: Diesel Oxidation Catalysts and Lean-NOx Catalysts", June 2001.

118. Parks, J., Watson, A., Campbell, G., Epling, B. Campbell, L., "NOx Adsorber Catalysts: Sorption, Regeneration, and DeSulfation", DOE Workshop, National Transportation Research Center, Knoxville, TN, May 7-8, 2001.

119. Eliasson, B., and Kogelschatz, K., "Non-equilibrium volume plasma chemical processing", IEEE Trans. Plasma Sci., 19,1063 (1991).

120. Penetrante, B.M., and Schulthesis, S.E., (Eds.), " Non-Thermal Plasma Techniques for Pollution Control: Part A: Overview, Fundamentals and Supporting Technologies, and Part B: Electron Beam and Electrical Discharge Processing", NATO ASI Series, Series G: Ecological Sciences, Vol. 34, Part B, Springer- Verlag, 1993.

121. Carlow, J.S., King, R., McAdams, R., Jorgensen, N., and Winterbottom, F., "The removal of gaseous pollutants in the flue-gas from the Chineham, UK Municipal solid waste incinerator using pulsed corona technology", First International Symposium on Incineration and Flue Gas Treatment Technologies", Sheffield UK (1997).

122. Hall, S., "From Lab to Reality, Plasma Engineering for Pollution Control", p. 139 - 144 in Proceedings of the 1997 DEER Workshop.

123. Thomas, S. E., Martin, A. R., Raybone, D., James T., Shawcross, J. T., Ka Lok Ng Beech P., Whitehead, J.C. "Non-Thermal Plasma Aftertreatment of Particulates ,Theoretical Limits and Impact on Reactor Design", SAE Spring Fuels and Lubes Conference Paris, 19-22 June 2000.

124. Ecozone website: http://www.ecozone.co.il/plasma.htm

125. Li, Y., and Armor, J. N., "Catalytic combustion of methane over palladium exchanged zeolites", Applied Catalysis B: Environmental, Volume 3, Issue 4, 24 May 1994, Pages 275282.

126. Burch, R. and Scire, S. "Selective catalytic reduction of nitric oxide with ethane and methane on some metal exchanged ZSM-5 zeolites", Applied Catalysis B: Environmental, Volume 3, Issue 4, 24 May 1994, Pages 295-318.

127. Zhang, X., Walters, A. B., and Vannice, M. A., "NO reduction by $\mathrm{CH}_{4}$ over rare earth oxides", Catalysis Today, Volume 27, Issues 1-2, 29 January 1996, Pages 41-47.

128. Cho B. K., "Nitric Oxide Reduction by Hydrocarbons over Cu-ZSM-5 Monolith Catalyst under Lean Conditions: Steady-State Kinetics", Journal of Catalysis, Volume 142, Issue 2, August 1993, Pages 418-429.

129. Iwamoto, M., Yahiro, H., Shin, H. K., Watanabe, M., Guo, J., Konno, M., Chikahisa T., and Murayama, T., "Performance and durability of Pt-MFI zeolite catalyst for selective reduction of nitrogen monoxide in actual diesel engine exhaust", Applied Catalysis B: Environmental, Volume 5, Issues 1-2, 31 December 1994, Pages L1-L16.

130. Cavataio, J. and Gulari, E., "Selective Catalytic Reduction of NOx Over Silver and Platinum Alumina Catalysts", CLEERS Workshop, May 2, 2002. 
131. Held W., 1990. "Catalytic NOx Reduction in Net Oxidizing Exhaust Gas", SAE 900496.

132. Hug H.T., Mayer, A., Hartenstein, A., "Exhaust Gas after Treatment: Combining Urea-SCR, Oxidation Catalysis and Traps", SAE 930363.

133. Koebel, M., Elsener, M., Kleemann, M. "Urea-SCR: A Promising technique to reduce NOx emissions from automotive diesel engines" Paul Scherrer Insitute, $\mathrm{CH}-5232$ Villigen PSI, Switzerland.

134. Kiovsky, J.R.,Koradia,P.B., and Lim, C.T., I.E.C Prod. Res. Dev. 19, 218 (1980).

135. http://www.jtbaker.com/msds/u4725.htm.

136. Chen, J.P., Yang, R.T., "Selective Catalytic Reduction of $\mathrm{NO}$ with $\mathrm{NH}_{3}$ on $\mathrm{SO}^{-2}{ }_{4} / \mathrm{TiO}_{2}$ Super acid Catalyst" pp. 277-288 (doi:10.1006/jcat.1993.1023).

137. Ozkan, U.S., Cai, Y.P., Kumthekar, M.W., "Investigation of the Reaction Pathways in Selective Catalytic Reduction of $\mathrm{NO}$ with $\mathrm{NH}_{3}$ over $\mathrm{V}_{2} \mathrm{O}_{5}$ Catalysts: Isotopic Labeling Studies Using ${ }^{18} \mathrm{O}_{2},{ }^{15} \mathrm{NH}_{3},{ }^{15} \mathrm{NO}$, and ${ }^{15} \mathrm{~N}^{18} \mathrm{O}^{\prime}$ pp. 390-403 (doi:10.1006/jcat.1994.1306).

138. Komatsu, T., Nunokawa, M., Moon, I.S., Takahara, T., Namba, S., Yashima, T., "Kinetic Studies of Reduction of Nitric Oxide with Ammonia on Cu2+-Exchanged Zeolites" pp. 427437 (doi:10.1006/jcat.1994.1229).

139. Lietti, L. Nova, I., Ramis, G., Dall'Acqua, L., Busca, G., Giamello, E., Forzatti, P., Bregani, F., "Characterization and Reactivity of V2O5-MoO3/TiO2 De-NOx SCR Catalysts" Journal of Catalysis, Vol. 187, No. 2, Oct 1999, pp. 419-435 (doi: 10.1006/jcat.1999.2603).

140. Marangozis, J., Industrial Eng. Chem. Res. 31, 987 (1992).

141. Lepperhoff G., Schommers J., 1988. "Verhalten von SCR-Katalysatoren im dieselmotorischen Abgas", MTZ, 49, pg. 1.

142. Gibson J., Groene O., 1991. "Selective Catalytic Reduction on Marine Diesel Engines", Automotive Engineering, October 1991, pg. 18-22.

143. Hug, H. T., "Off-Highway Exhaust Gas After-Treatment: Combining Urea-SCR, Oxidation Catalysis and Traps", SAE 930363.

144. Hug H.T., Mayer, A., Hartenstein, A., "Exhaust Gas after Treatment: Combining Urea-SCR, Oxidation Catalysis and Traps", SAE 930363.

145. Havenith C., "Development of a Urea DeNO ${ }_{x}$ Catalyst Concept for European Ultra-Low Emission Heavy-Duty Diesel Engines", SAE 952652.

146. Chandler G.R., "An Integrated SCR and Contiuously Regenerating Trap System to Meet Future $\mathrm{NO}_{x}$ and PM Legislation", SAE 2000-01-0188.

147. Miller W.R., Klein, J.T., Mueller, R., Doelling,W., and Zuerbig, Jeurgen, "The Development of Urea-SCR Technology for US Heavy Duty Trucks", SAE 2000-01-0190.

148. Gieshoff J., Sindlinger, A. S., Spurk, P. C., and Tillaart, J.A.A.V., "Improved SCR Systems for Heavy Duty Applications", SAE 2000-01-0189.

149. Havenith C., Verbeek R.P., 1997. "Transient Performance of a Urea DeNOx Catalyst for Low Emissions Heavy-Duty Diesel Engines", SAE 970185.

150. Lueders H., 1995. "An Urea Lean NOx Catalyst System for Light Duty Diesel Vehicles", SAE 952493.

151. Fritz N., "On-Road Demonstration of NOx Emission Control for Diesel Trucks with SiNO Urea SCR System", SAE 1999-01-0111. 
152. Choi Sung-Mu, Kim Seok-Jae, Youn Young-Kee, Yeo Gwon-Koo, “Development of UreaSCR System for Light Duty passenger car", SAE 2001-01-0519.

153. Gieshoff, J., Pfeifer, M., Schafer-Sindlinger, A., Spurk, P.C., "Advanced Urea SCR Catalysts for Automotive Applications", SAE 2001-01-0514.

154. Farshchi, M., Brodrick, C.J., Dwyer, H.A., "Dynamometer testing of heavy duty diesel engine equipped with a Urea-SCR system", SAE 2001-01-0516.

155. Par Gabrielsson Peter Schoubye Ioannis Gekas Svend Frederiksen Soren Mikkelsen, "Combined Silencers and Urea-SCR Systems for Heavy-Duty Diesel Vehicles for OEM and Retrofit Markets", 2001-01-0517.

156. Krijnsen, H.C., Bertin, S.S., Makkee, M., Van den Bleek, C.M., Calis, H.P.A., " Bench Scale Demonstration of an Integrated Desoot-DeNOx System", SAE 2001-01-0515. 


\section{List of Publications}

The following is a list of conference papers and journal publications that have been prepared based upon the work supported under this Cooperative Agreement.

\section{Conference Papers}

1. Acharya, R., M. Alam and A. L. Boehman. Fuel and System Interaction Effects on Urea-SCR Control of NOx in Diesel Exhaust Aftertreatment. Submitted to Society of Automotive Engineers for presentation at the 2006 SAE International Congress and Exposition.

2. Alam, M., J. Song and A. Boehman. In-cylinder Combustion Visualization of Ultra Low Sulfur, Neat Biodiesel and Biodiesel Blended Fuels. In ACS Fuel Chemistry Division Preprints, 50(1), 412-414 (2005).

3. Boehman, A.L., J. P. Szybist, J. Song, V. Zello, M. Alam, K. Miller. Combustion Characterization of GTL Diesel Fuel. In ACS Fuel Chemistry Division Preprints, 49(2), 714716 (2004).

4. Song, J., M. Alam, A. L. Boehman and K. Miller. Characterization of Diesel and Biodiesel Soot. In ACS Fuel Chemistry Division Preprints, 49(2), 767-769 (2004).

5. Boehman, A., J. Song, M. Alam, V. Zello and K. Miller. Fuel Formulation Effects on Diesel Particulate Filter Regeneration. In ACS Fuel Chemistry Division Preprints, 48(2), 634-635 (2003).

6. Song, J., M. Alam, V. Zello, A.L. Boehman, B. Bishop and F. Walton. Fuel Sulfur Effect on Membrane Coated Diesel Particulate Filter. Society of Automotive Engineers Technical Paper No. 2002-01-2788. Presented at the SAE Powertrain \& Fluid Systems Conference \& Exhibition, San Diego, CA, October 2002.

7. Szybist, J.P. and A.L. Boehman. Auto-Ignition Behavior of Methyl Decanoate. In ACS Fuel Chemistry Division Preprints, 50(2), 730-731 (2005).

8. Boehman, A.L., J. P. Szybist, J. Song, V. Zello, M. Alam, K. Miller. Combustion Characterization of GTL Diesel Fuel. In ACS Fuel Chemistry Division Preprints, 49(2), 714716 (2004).

9. Szybist J., D. Morris, A.L. Boehman and E. Esen. Diesel Fuel Formulation Effects on Injection Timing and Emissions. In ACS Fuel Chemistry Division Preprints, 48(1), 428-429 (2003).

10. C.Y. Wang, Computational fuel cell research at Penn State," invited talk at NASA SOFC Workshop, NASA - Glenn Research Center, April 2003.

11. U. Pasaogullari and C.Y. Wang, Flooding prediction in polymer electrolyte fuel cells, $203^{\text {rd }}$ Electrochemical Soc. Meeting, Paris, France, April 2003.

12. X.G. Yang, N. Burke, Q.L. Dong, M.M. Mench and C.Y. Wang, Simultaneous measurement of current and species distributions in polymer electrolyte fuel cells, $203^{\text {rd }}$ Electrochemical Soc. Meeting, Paris, France, April 2003.

13. H. Meng and C.Y. Wang, Large-scale modeling of PEM fuel cells by parallel computations, $203^{\text {rd }}$ Electrochemical Soc. Meeting, Paris, France, April 2003.

14. C.Y. Wang, Transport issues in polymer electrolyte fuel cells, in Proc of Heat Transfer $75^{\text {th }}$ Celebration, Purdue University, April 2003.

15. C.Y. Wang, Micro- and meso-scale phenomena in polymer electrolyte fuel cells, invited talk at Nanotech 2003, San Francisco, Feb. 2003. 
16. Gu, W., J.-P. Shen and C. Song. Hydrogen Production from Integrated Methanol Reforming over Cu-ZnO/Al $\mathrm{O}_{3}$ and $\mathrm{Pt} / \mathrm{Al}_{2} \mathrm{O}_{3}$ Catalysts for PEM Fuel Cells. Am. Chem. Soc. Div. Fuel Chem. Prepr., 2003, 48 (2), 804-807.

\section{Journal Articles and Book Chapters}

1. Boehman, A.L., J. Song, and M. Alam. Impact of Biodiesel Blending on Diesel Soot and the Regeneration of Particulate Filters. Energy \& Fuels, 19, 1857-1864 (2005).

2. Alam, M., J. Song, R. Acharya A. Boehman and K. Miller. Combustion and Emissions Performance of Low Sulfur, Ultra Low Sulfur and Biodiesel Blends in a DI Diesel Engine. Society of Automotive Engineers Technical Paper No. 2004-01-3024. SAE Transactions: Journal of Fuels and Lubricants, 113:4, 1986-1997 (2004).

3. Szybist, J. P., A.L. Boehman, J.D. Taylor and R.L. McCormick. Evaluation of Formulation Strategies to Eliminate the Biodiesel NOx Effect. Fuel Processing Technology, 86, 11091126 (2005).

4. Szybist, J. P., S.R. Kirby and A.L. Boehman. NOx Emissions of Alternative Diesel Fuels: A Comparative Analysis of Biodiesel and FT Diesel. Energy \& Fuels, 19, 1484-1492 (2005).

5. Boehman, A.L., D. Morris, J. Szybist and E. Esen. The Impact of Bulk Modulus of Diesel Fuels on Fuel Injection Timing. Energy \& Fuels, 18, 1877-1882 (2004).

6. C.Y. Wang, "Two-phase flow and transport in polymer electrolyte fuel cells," in Handbook of Fuel Cells, eds. by W. Vielstich, A. Lamm, and H. Gasteiger, Wiley-VCH, 2003, pp.337-348.

7. C.Y. Wang, "Fundamental Models for Fuel Cell Engineering," Chemical Reviews, Vol.104, pp.4727-4766, 2004.

8. G. Lu and C.Y. Wang, "Two-phase microfluidics, heat and mass transport in direct methanol fuel cells," Chapter 9 in Transport Phenomena in Fuel Cells, Eds. B. Sunder and M. Faghri, WIT Press, pp.317-358 (2005).

9. C. Lim and C.Y. Wang, Development of high-power electrodes for a liquid-feed direct methanol fuel cell, J of Power Sources, Vol.113, pp.145-150, 2003.

10. Z.H. Wang and C.Y. Wang, Mathematical modeling of liquid-feed direct methanol fuel cells, J of Electrochem. Soc., Vol.150, pp.A508-A519, 2003.

11. M.M. Mench, C.Y. Wang and M. Ishikawa, In-situ current distribution measurements in polymer electrolyte fuel cells, J of Electrochem. Soc., Vol.150, pp.A1052-A1059, 2003.

12. M.M. Mench, Q.L. Dong, C.Y. Wang, In-situ water distribution measurements in a polymer electrolyte fuel cell, J of Power Sources, Vol.124, pp.90-98, 2003.

13. H. Meng and C.Y. Wang, Large-scale simulation of polymer electrolyte fuel cells by parallel computing, Chemical Engineering Science, Vol.59, 3331-3343, 2004.

14. H. Meng and C.Y. Wang, Electron transport in polymer electrolyte fuel cells, J. Electrochem. Soc., Vol.151, pp.A358-A367, 2004.

15. K.K. Bhatia and C.Y. Wang, Transient carbon monoxide poisoning of a polymer electrolyte fuel cell operating on diluted hydrogen feed, Electrochim. Acta, Vol.49, pp.2333-2341, 2004.

16. C. Lim and C.Y. Wang, Effects of hydrophobic polymer content in GDL on power performance of a PEM fuel cell, Electrochim. Acta, Vol.49, pp.4149-4156, 2004.

17. Y. Wang and C.Y. Wang, Modeling polymer electrolyte fuel cells with large density and velocity changes, J. Electrochem. Soc., Vol.152, pp.A445-A453, 2005. 
18. Y. Wang and C.Y. Wang, Simulation of flow and transport phenomena in a polymer electrolyte fuel cell under low-humidity operation, J. Power Sources, Vol.147, pp.148-161, 2005.

19. Y. Wang and C.Y. Wang, Transient analysis of polymer electrolyte fuel cells, Electrochimica Acta, Vol.50, 1307-1315, 2005.

Journal Articles in Preparation or Submitted

1. Alam. M., J. Song, V. Zello, and A.L. Boehman. Spray and Combustion Visualization of a Direct Injection Diesel Engine Operated with Various Fuel Blends. Submitted to the International Journal of Engine Research (2005).

2. Szybist, J. P., A.L. Boehman, H. Koga and D.C. Haworth. Premixed Ignition Behavior of Alternative Diesel Fuel-Relevant Compounds in a Motored Engine Experiment. Submitted to Combustion \& Flame (2005).

3. Song, J., M. Alam and A.L. Boehman. Impact of Alternative Fuels on Soot Properties and DPF Regeneration. In preparation for submission to Combustion Science and Technology (2006).

\section{Patents}

Jeffrey Gonder and C.Y. Wang, Method of using concentrated fuel in direct methanol fuel cells by periodic anode injection, Provisional U.S. Patent 60/462,720, April 2003.

David Morris, André L. Boehman and Etop Esen. Invention Conception Record submitted to ConocoPhillips under DOE Contract \#DE-FC26-01NT41098 on "Biodiesel - Paraffinic Fuel Blend Ratios to Offset the Biodiesel NOx Effect," 2004.

\section{Theses}

Jeffrey Gonder, "Direct Methanol Fuel Cells for Automotive Applications: Experimental Analysis of transient characteristics, periodic fuel injection and fuel quality requirements," (M.S.) (M.S.)

Ragini Acharya, "Impact of Ultra Clean Fuel on Selective Catalytic Reduction of NOx with Urea,"

Weidong $\mathrm{Gu}$, "New Processing Scheme of $\mathrm{MeOH}$ Reforming for Hydrogen Production for Proton-Exchange Membrane Fuel Cell Application," (M.S.) (Ph.D.)

James Szybist, "Fuel Composition Impacts on Processes in Compression Ignition Engines,"

Juhun Song, "Effect of Fuel Formulation on Soot Properties and Regeneration of Diesel Particulate Filters," (Ph.D.)

Krishan Bhatia, "Study of a Methanol Reforming Polymer Electrolyte Fuel Cell System," (Ph.D.) 


\section{Acknowledgement}

The authors wish to thank ConocoPhillips for its support of this work and Doug Smith, Kirk Miller, Etop Esen, Rafael Espinoza, Keith Lawson, Ed Casey, Jim Rockwell and Steven McDonald of ConocoPhillips for their support and technical guidance. We gratefully acknowledge financial support of this project by the U.S. Department of Energy and Alternative Fuel Incentive Grant program of the Pennsylvania Department of Environmental Protection. The authors would like to thank Edward Lyford-Pike and John Wright of Cummins Engine Co., Inc., Howard Hess of Johnson-Matthey and Joseph Patchett of Engelhard Corporation for their support and technical assistance. We would also like to acknowledge our appreciation of Farley Fisher of the National Science Foundation for his support for the purchase of the Videoscope system (NSF Grant No. CTS-0079073).

This paper was written with support of the U.S. Department of Energy under Cooperative Agreement No. DE-FC26-01NT41098. The Government reserves for itself and others acting on its behalf a royalty-free, nonexclusive, irrevocable, worldwide license for Governmental purposes to publish, distribute, translate, duplicate, exhibit, and perform this copyrighted paper.

This material was prepared with the support of the Pennsylvania Department of Environmental Protection. Any opinions, findings, conclusions, or recommendations expressed herein are those of the author(s) and do not necessarily reflect the views of the DEP. 


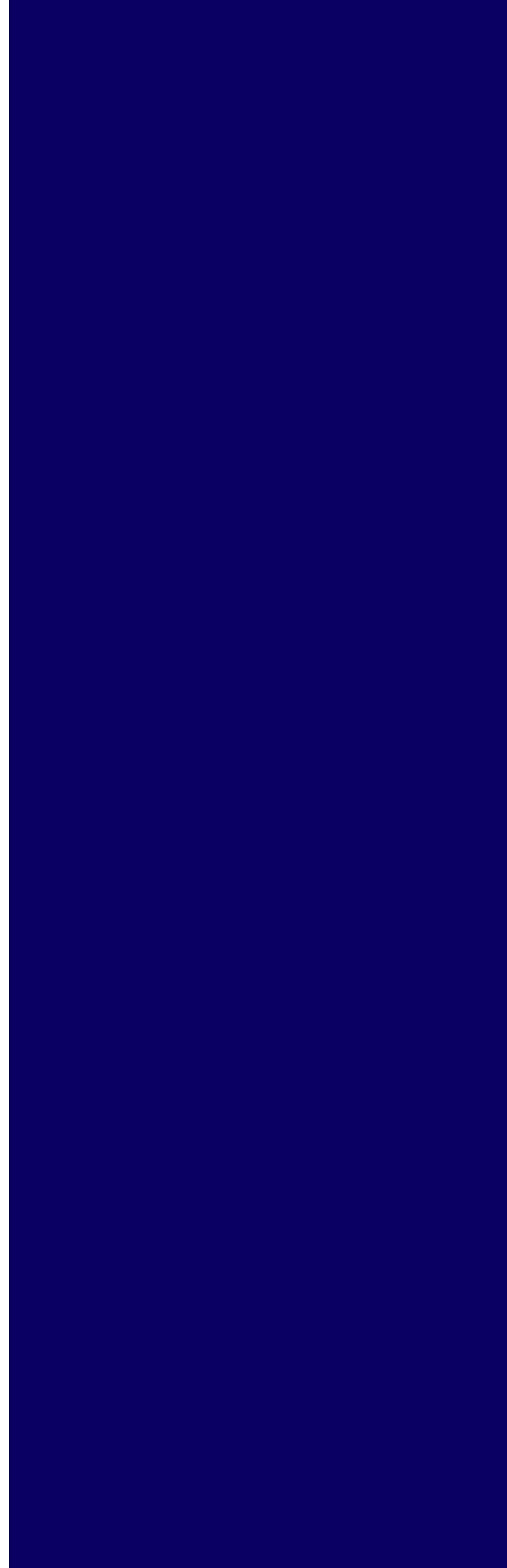

